\title{
BASIN CHARACTERISTICS AND STREAMFLOW STATISTICS \\ IN ARIZONA AS OF 1989
}

U.S. GEOLOGICAL SURVEY

Water-Resources Investigations Report 91-4041

Prepared in cooperation with the

ARIZONA DEPARTMENT OF WATER RESOURCES and FLOOD CONTROL DISTRICT OF MARICOPA COUNTY 


\section{U.S. DEPARTMENT OF THE INTERIOR}

MANUEL LUJAN, Jr., Secretary

U.S. GEOLOGICAL SURVEY

Dallas L. Peck, Director

For additional information write to:

District Chief

U.S. Geological Survey 375 South Euclid Avenue Tucson, Arizona 85719
Copies of this report can be purchased from:

U,S. Geological Survey

Books and Open-File Reports Section Federal Center, Box 25425

Denver, Colorado 80225 
Abstract................................ 1

Introduction $\ldots \ldots \ldots \ldots \ldots \ldots \ldots \ldots \ldots \ldots \ldots \ldots \ldots \ldots \ldots \ldots \ldots \ldots \ldots$

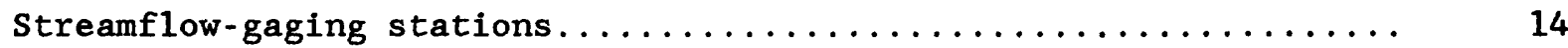

Continuous-record gaging stations................. 14

Partial-record gaging stations................... 14

Streamflow records and basin characteristics............... 14

statistical summaries......................... 16

Discharge................................. 17

Selected references............................. 18

Streamflow data............................. 21

\section{ILLUSTRATIONS}

Figure 1. Map showing location of continuous streamflow-record gaging stations in Arizona as of $1989 \ldots \ldots \ldots \ldots \ldots$

2. Map showing location of partial streamflow-record gaging stations in Arizona as of 1989

TABLES

Page

Table 1. Period of record for streamflow-gaging stations included in the compilation. 


\section{CONVERSION FACTORS AND VERTICAL DATUM}

\section{Multiply}

inch (in.)

foot $(f t)$

mile (mi)

square mile $\left(\mathrm{mi}^{2}\right)$

acre-foot (acre-ft)

cubic foot per second $\left(f t^{3} / s\right)$
By

25.40

0.3048

1.609

2.590

0.001233

0.02832
To obtain

millimeter

meter

kilometer

square kilometer

cubic hectometer

cubic meter per second

Sea leve1: In this report "sea level" refers to the National Geodetic Vertical Datum of 1929 (NGVD of 1929)-A geodetic datum derived from a general adjustment of the first-order level nets of both the United States and Canada, formerly called "Sea Level Datum of 1929". 
BASIN CHARACTERISTICS AND STREAMFLOW STATISTICS IN ARIZONA AS OF 1989

By

J.M. Garrett and D.J. Gellenbeck

\begin{abstract}
Streamflow and statistical data are given for 138 continuousrecord streamflow-gaging stations and 176 partial-record gaging stations in Arizona. Data are presented for active and discontinued stations that have unregulated flow or partly regulated flow and at least 10 years of record. Data for continuous-record gaging stations include (1) annual peak discharges; (2) selected basin and climatic characteristics; and (3) statistical summaries of mean and annual discharges, magnitude and probability of annual low and high flows, flow duration, and magnitude and probability of annual peak flows. Mean annual discharge and mean monthly discharge are shown for each continuous-record gaging station. Data for partial-record gaging stations include (1) annual peak discharges, (2) basin and climatic characteristics, and (3) magnitude and probability of annual peak flows. Annual peak discharge is shown for each gaging station.
\end{abstract}

\title{
INTRODUCTION
}

To appraise the water resources of Arizona, definition of streamflow at selected locations is essential. To answer this need, the U.S. Geological Survey collects data at hundreds of continuous-record gaging stations and partial-record gaging stations throughout Arizona.

The primary purpose of this report is to expand and update an earlier report, "Statistical Summaries of Arizona Streamflow Data" (Anderson and White, 1979). This study was done in cooperation with the Arizona Department of Water Resources and the Flood Control District of Maricopa County. The report includes data from the files of the U.S. Geological Survey for continuous-record gaging stations and partial-record gaging stations through 1989. Streamflow data are presented in downstream order for 138 continuous-record gaging stations (fig. 1) and for 176 partialrecord gaging stations ( $f$ ig. 2). Data are included for active and discontined gaging stations that have at least 10 years of record (table 1 ).

Location, drainage area, and remarks are given for each streamflow-gaging station. Data for continuous-record gaging stations include (1) annual peak discharges; (2) selected basin and climatic characteristics; and (3) statistical summaries of mean and annual discharges, magnitude and probability of annual low and high flows, flow duration, and magnitude and probability of annual peak flows. Mean annual discharge and mean monthly discharge are shown for each continuous-record gaging station. Data for partial-record gaging stations include (1) annual peak discharges, (2) basin and climatic characteristics, and (3) magnitude and probability of annual peak flows. Annual peak discharge is shown for each station in the report. 


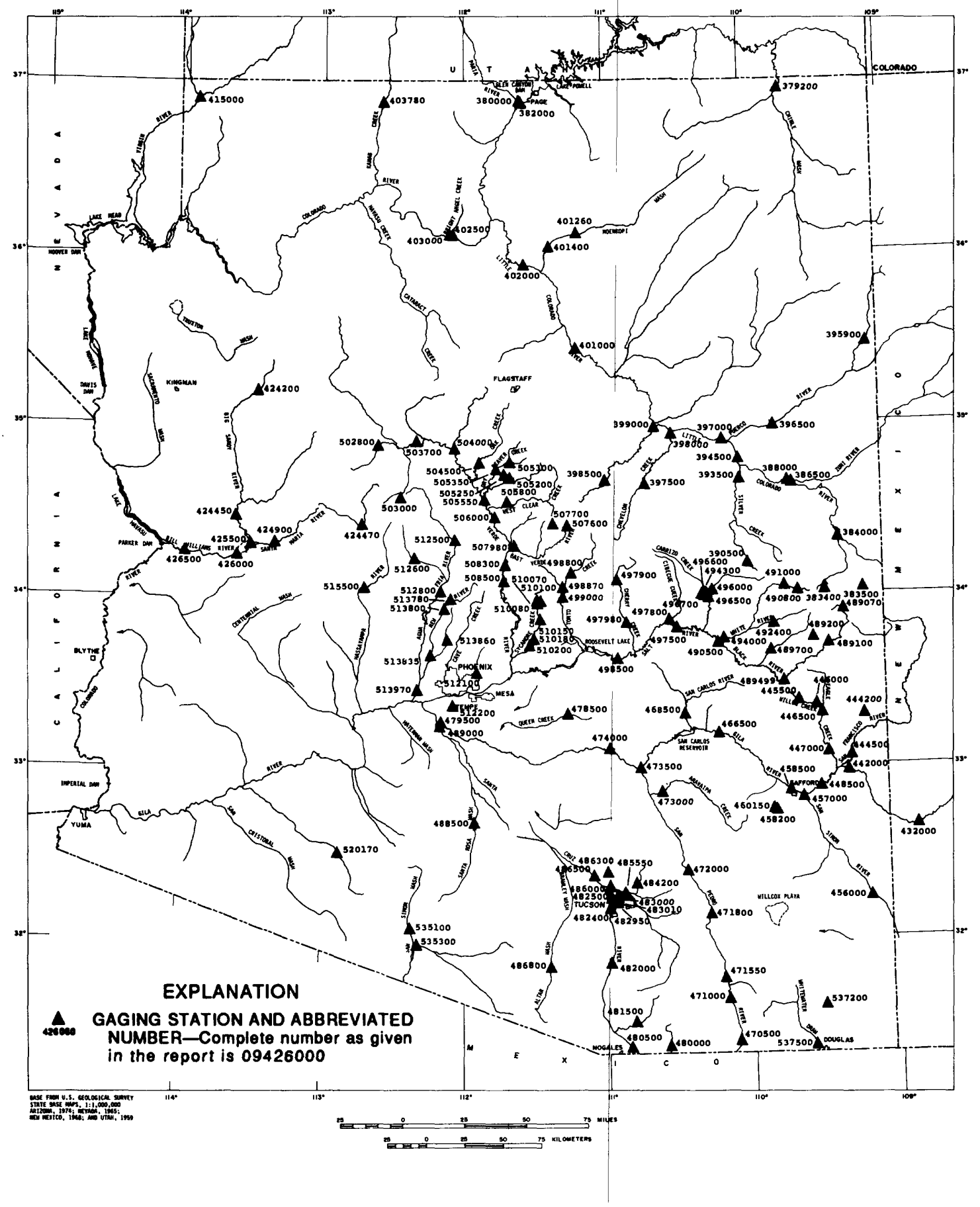

Figure 1.--Location of continuous-gaging stations. 


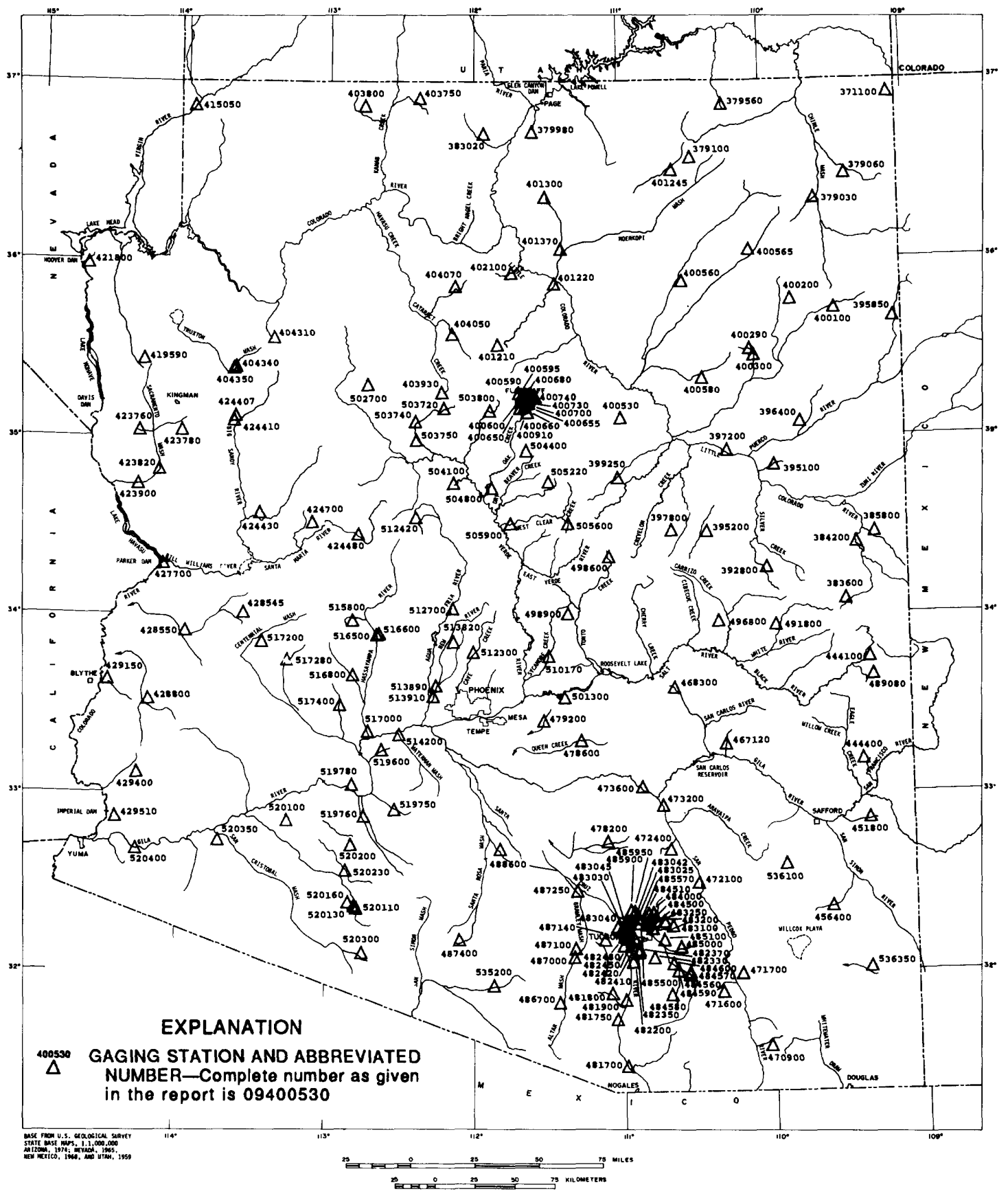

Figure 2.--Location of crest-stage gages. 
Table 1.--Period of record for streamflow-gaging stations included in the compilation

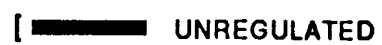

PERIOD OF RECORD
תפEGULATED

STATION

NUMBER

\section{PARTLY REGULATED ]}

GAGING STATION

PAGE

NUMBER

\section{寅 잉}

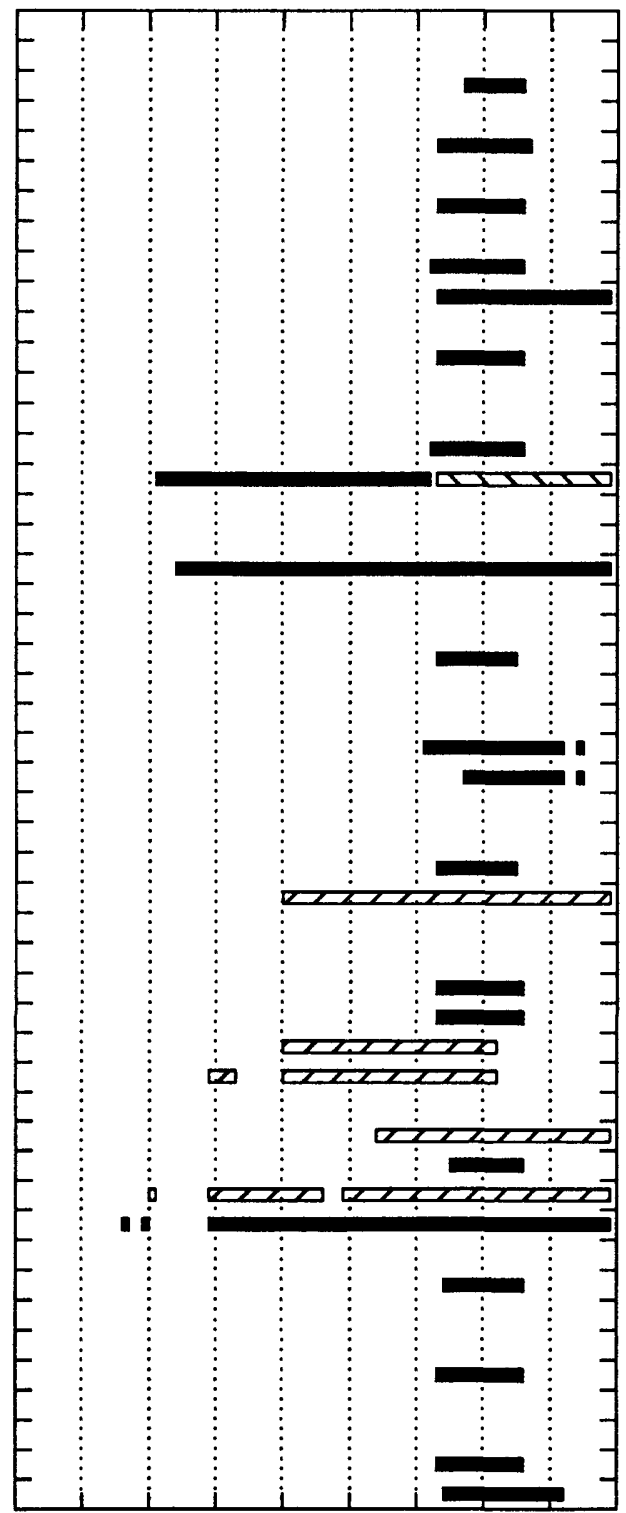

09371100

09379030

09379060

09379100

09379200

09379560

09379980

09380000

09382000

09383020

09383400

09383500

09383600

09384000

09384200

09385800

09386500

09388000

09390500

09392800

09393500

09394500

09395100

09395200

09395850

09395900
COLORADO RIVER BASIN

Colorodo River:

SAN JUAN RIVER BASIN

Son Juon River:

Teec Nos Pos Wosh neor Teec Nos Pos 23

Chinle Wosh:

Block Mountain Wosh near Chinle

Lukochukai Creek:

Lukochukoi Creek tributory neor Lukochukoi Loguno Creek:

Long House Wosh neor Koyento 26

Chinle Creek near Mexican Woter 27

Oljeto Wash:

El Copitan Wosh neor Koyento

JACK BENCH WASH BASIN

Jack Bench Wash:

Jock Bench Wosh tributory near Page

Colorodo River ot Lees Ferry

PARIA RIVER BASIN

Porio River:

Porio River ot Lees Ferry

HOUSE ROCK WASH BASIN

House Rock Wosh:

House Rock Wosh tributory near Morble Conyon

LITTLE COLORADO RIVER BASIN

Little Colorodo River:

Little Colorodo River at Greer

Nutrioso Creek above Nelson Reservoir near Springerville

Hall Creek:

Fish Creek neor Eogor

Little Colorado River obove Lyman Lake, near St Johns

Lyman Reservoir:

Lymon Reservoir tributory near St Johns

Little Colorodo River tributary near St Johns

Little Colorodo River above Zuni River near Hunt

Little Colorado River neor Hunt

Silver Creek:

Show Low Creek near Lakeside

Long Lake tributary near Show Low

Silver Creek near Snow floke

Little Colorodo River at Woodruff

Corr Loke Drow:

Corr Lake Draw tributary near Holbrook

Woshboord Creek:

Phoenix Park Wosh (closed bosin)

Decker Wosh near Snowflake

Puerco River:

Block Creek:

Block Creek tributory neor Window Rock

Black Creek neor Lupton
24 


\section{Table 1.--Period of record for streamflow-gaging stations included in the compilation--Continued}

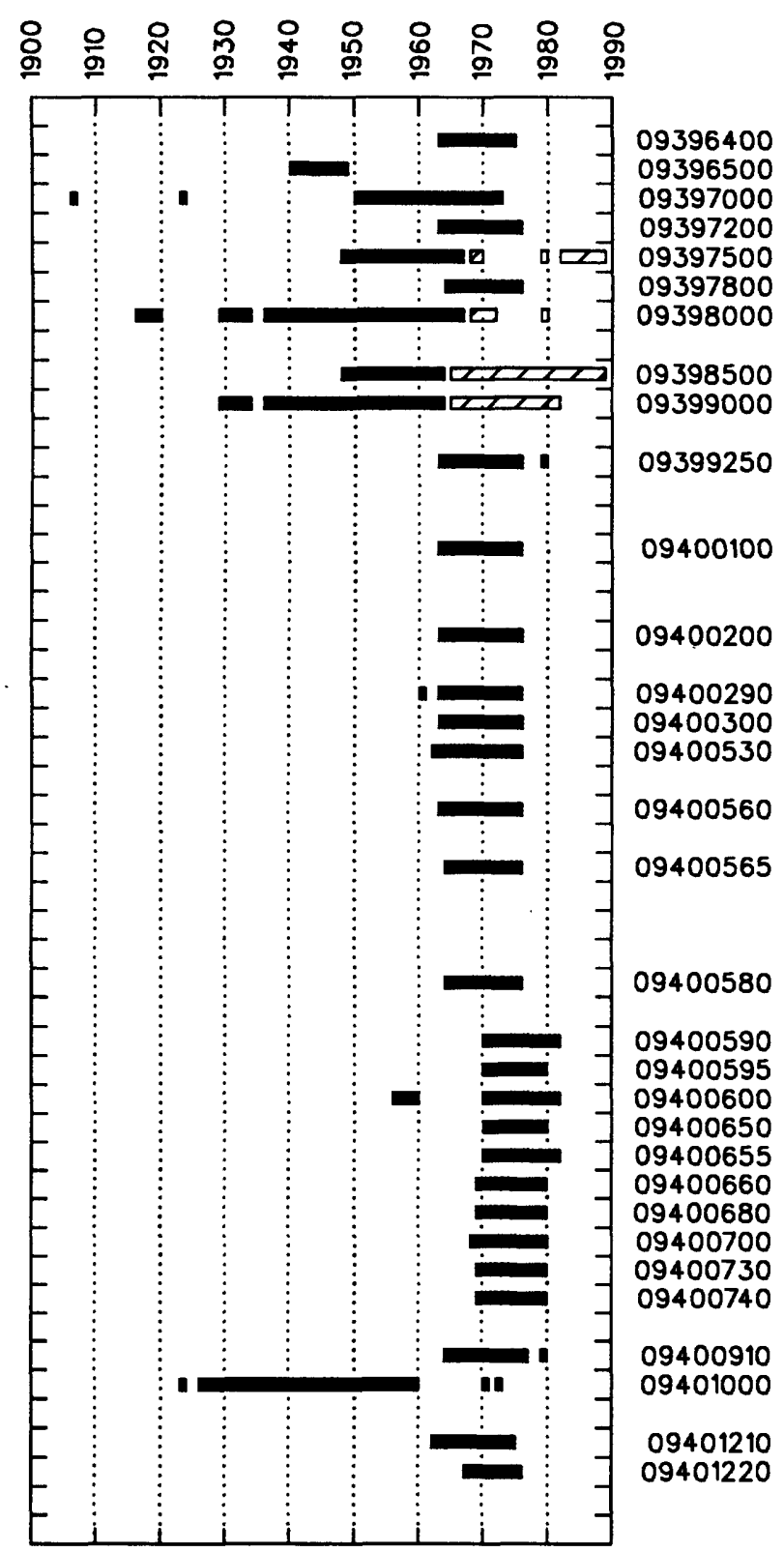

Colorado River--Continued

Little Colorado River Bosin--Continued

Puerco River Bosin--Continued

Dead Wosh:

Dead Wosh tributory neor Holbrook

Puerco River near Adamano

Little Colorodo River ot Holbrook

Penzonce Wosh neor Joseph City

Chevelon Fork below Wildcot Conyon, near Winslow

Brookbonk Conyon near Heber

Chevelon Creek near Winslow

Eost Clear Creek (heod of Cleor Creek):

Cleor Creek below Willow Creek, neor Winslow

Cleor Creek neor Winslow

Jocks Canyon Creek (head of Solt Creek):

Jocks Conyon tributory No.2 near Winslow

Cottonwood Wosh:

Gonodo Wosh (heod of Pueblo Colorodo Wash):

Gonodo Wosh tributory neor Gonado

Pueblo Colorado Wash:

Steomboat Wosh:

Steomboot Wosh tributary near Gonodo

Teshbito Wosh:

Teshbito Wosh tributary neor Holbrook

Teshbito Wosh neor Holbrook

Cow Conyon (meter Wash) near Winslow

Oraibi Wosh:

Oraibi Wash triburary near Oraibi

Polocco Wosh:

Polacco Wosh tributrory near Chinle

Corn Wosh:

Whe Yol Do Soh Wosh:

Dilkon Wosh:

Costle Butte Wosh neor Winslow 102

Conyon Dioblo:

Rio De Flog ot Hidden Hollow Rd ot Flagstaff 103

Schultz Conyon ot Flogstoff

Rio De Flog ot Flogstoff

Sinclair Wosh ot Flogstoff

Rio De Flog ot 140 ot Flogstoff

Bow And Arrow Wosh ot Flogstoff

Switzer Conyon ot Flogstoff

Switzer Conyon tributory ot Flagstaff

Lockett Fonning Diversion ot Flogstaff

Horenberg Wosh ot Flogstoff

Walnut Creek:

Foy Canyon neor Flagstoff

Little Colorado River ot Grond Falls

Cedar Wosh:

Slate Mountain Wash near Flagstaff

Cedor Wosh neor Comeron

Moenkopi Wosh:

Shonto Wash: 


\section{Table 1.--Period of record for streamflow-gaging stations included in the compilation--Continued}

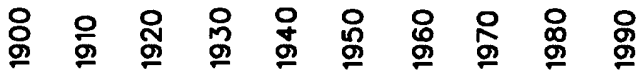

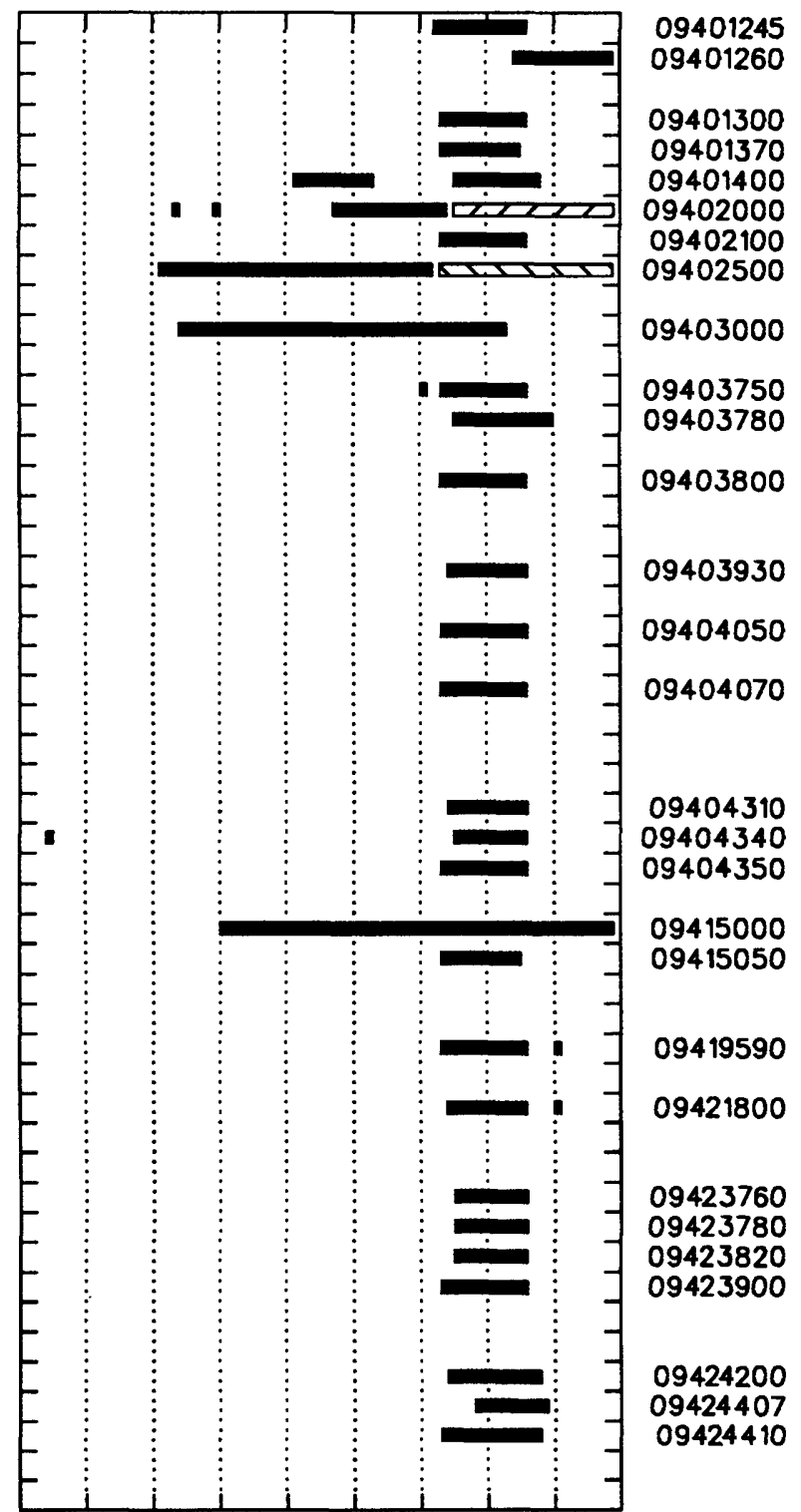

Colorado River--Continued

Little Colorodo River Bosin--Continued

Cedor Wosh--Continued

Moenkopi Wosh--Continued Klethla Valley tributory neor Koyento 119

Moenkopi Wosh ot Moenkopi Homblin Wosh:

Hamblin Wosh tributary near Cedar Ridge $\quad 123$

Homblin Wosh tributory No.2 near Tubo City 124

Moenkopi Wosh neor Tubo City 125

Little Colorado River neor Comeron 128

Forest Boundory Wosh near Comeron 132

Colorado River near Grand Canyon 133

BRIGHT ANGEL CREEK BASIN

Bright Angel Creek neor Grand Conyon 136

KANAB CREEK BASIN

Sogebrush Drow neor Fredonio 140

Kanob Creek neor Fredonio 141

Bitter Seeps Wosh:

Bitter Seeps Wosh tributory neor Fredonio 144

HAVASU CREEK BASIN

Cotoroct Creek (heod of Hovasu Creek):

West Catoract Creek near Willioms

Spring Volley Wosh:

Spring Valley Wosh tributory near Williams $\quad 146$

Red Horse Wosh:

Little Red Horse Wosh neor Grand Conyon

HUALAPAI WASH BASIN

Truxton Wosh (head of Hualapai Wosh):

Yompai Canyon:

Yompai Conyon tributary neor Peach Springs $\quad 148$

Truxton Wosh of Volentine

Volentine Wosh ot Volentine

VIRGIN RIVER BASIN

Virgin River ot Littlefield

Big Bend Wosh tributory neor Littlefield

DETRITAL WASH BASIN

Detrital Wosh:

Detrital Wosh tributory near Chloride

Eldorado Valley

Ringbolt Wash near Hoover Dam

SACRAMENTO WASH BASIN

Socromento Wosh:

Little Meodow Creek near Ootmon 158

Woinut Creek neor Kingmon 159

Socromento Wosh neor Yucco 160

Socramento Wosh tributory near Topock 161

BILL WILLIAMS RIVER BASIN

Big Sondy River (heod of Bill Willioms River):

Willow Creek neor Kingmon

McGorrys Wosh neor Kingmon

Big Sondy River tributory neor Kingman

Burro Creek:

Koiser Spring Conyon: 


\section{Table 1.--Period of record for streamflow-gaging stations included in the compilation--Continued}

PERIOD OF RECORD

STATION

NUMBER

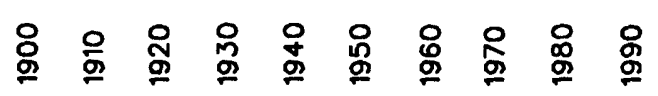

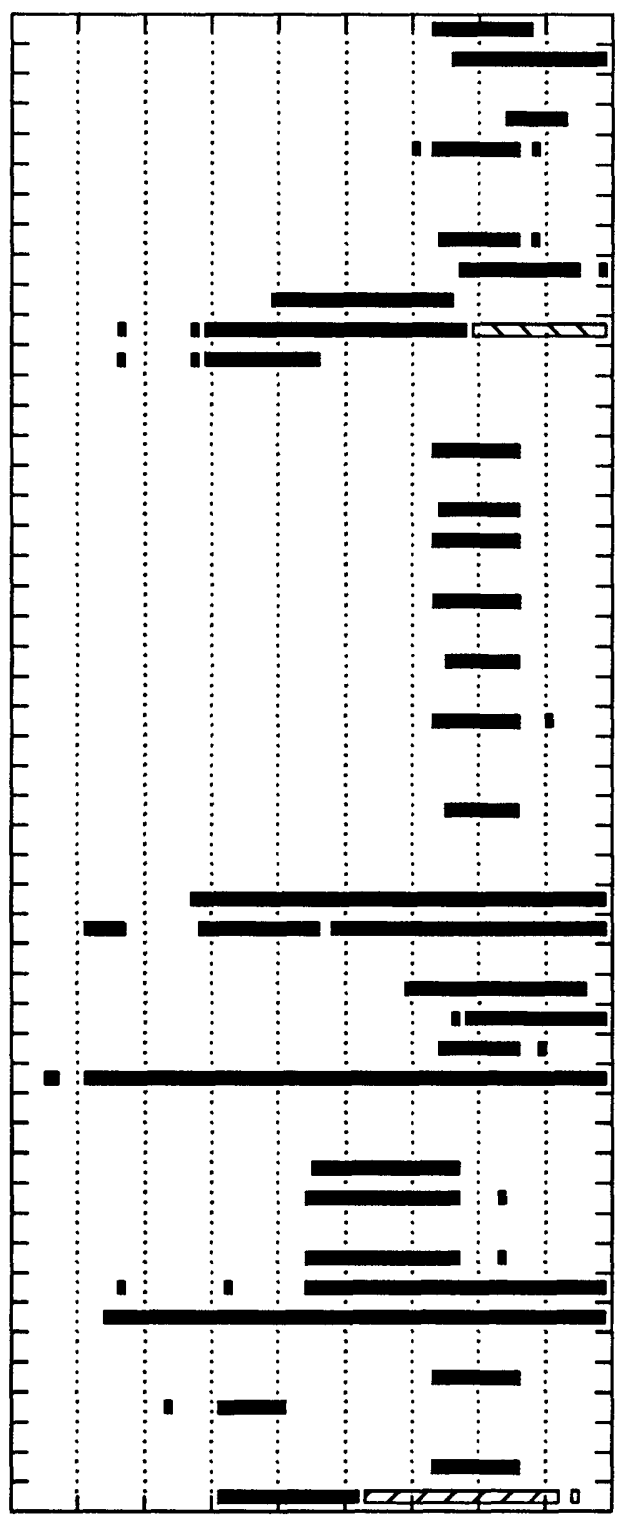

09424430 09424450

09424470

09424480

09424700

09424900

09425500

09426000

09426500

09427700

09428545

09428550

09428800

09429150

09429400

09429510

09432000

09442000

09444100

09444200

09444400

09444500

09445500

09446000

09446500

09447000

09448500

09451800

09456000

09456400 09457000
Colorodo River--Continued

Big Sondy River--Continued

Burro Creek--Continued

Koiser Spring Conyon--Continued

Koiser Spring Conyon tributory neor Wikieup $\quad 167$

Big Sondy River neor Wikieup 168

Kirklond Creek (heod of Sonto Morio River):

Kirklond Creek neor Kirkland

Ash Creek near Kirkland

171

Sonto Morio River:

Iron Spring Wosh:

Iron Spring Wosh tributory neor Bagdod 173

Sonto Mario River near Bogdod 174

Sonto Morio River near Alomo $\quad 177$

Bill Willioms River below Alomo Dom 180

Bill Willioms River ot Planet 183

TRIBUTARIES AND OIVERSIONS BETWEEN PARKER DAM

AND PALO VERDE DAM

Monkeys Heod Wosh neor Porker

Cunninghom Wosh:

Cunninghom Wosh tributory neor Wenden $\quad 187$

Bouse Wosh tributory neor Bouse $\quad 188$

Tyson Wosh:

Tyson Wosh neor Quortzsite

189

TRIBUTARIES BETWEEN PALO VERDE DAM AND IMPERIAL DAM

Creosote Wosh neor Ehrenberg

Indion Wash:

Indion Wosh tributory neor Yumo

TRIBUTARIES BETWEEN IMPERIAL DAM AND GILA RIVER

Mittry Loke:

Mittry Loke tributory near Yumo

GILA RIVER BASIN

Gilo River:

Gila River below Blue Creek, neor Virden NM 193

Gila River near Clifton

Son Froncisco River:

Compbell Blue Creek neor Alpine 199

Blue River near Clifton 200

Chose Creek near Clifton 203

Son Francisco River at Clifton 204

Eogle Creek:

Willow Creek:

Willow Creek neor Point of Pines neor Morenci 208

Willow Creek near Double Circle Ronch neor Morenci

190

191

192

93

04

Eogle Creek neor Double Circle Rnch neor Morenci 214

Eogle Creek obove Pumping Plont near Morenci $\quad 217$

Gila River at Head of Sofford Volley near Solomon 220

Tollgate Wash (head of Yuma Wash):

Tollgote Wosh tributory neor Clifton 224

Son Simon River neor Son Simon 225

Porks Lake Bosin:

Gold Gulch neor Bowie

226

Son Simon River neor Solomon 


\section{Table 1.--Period of record for streamflow-gaging stations included in the compilation--Continued}

PERIOD OF RECORD

STATION

NUMBER
GAGING STATION

PAGE

NUMBER

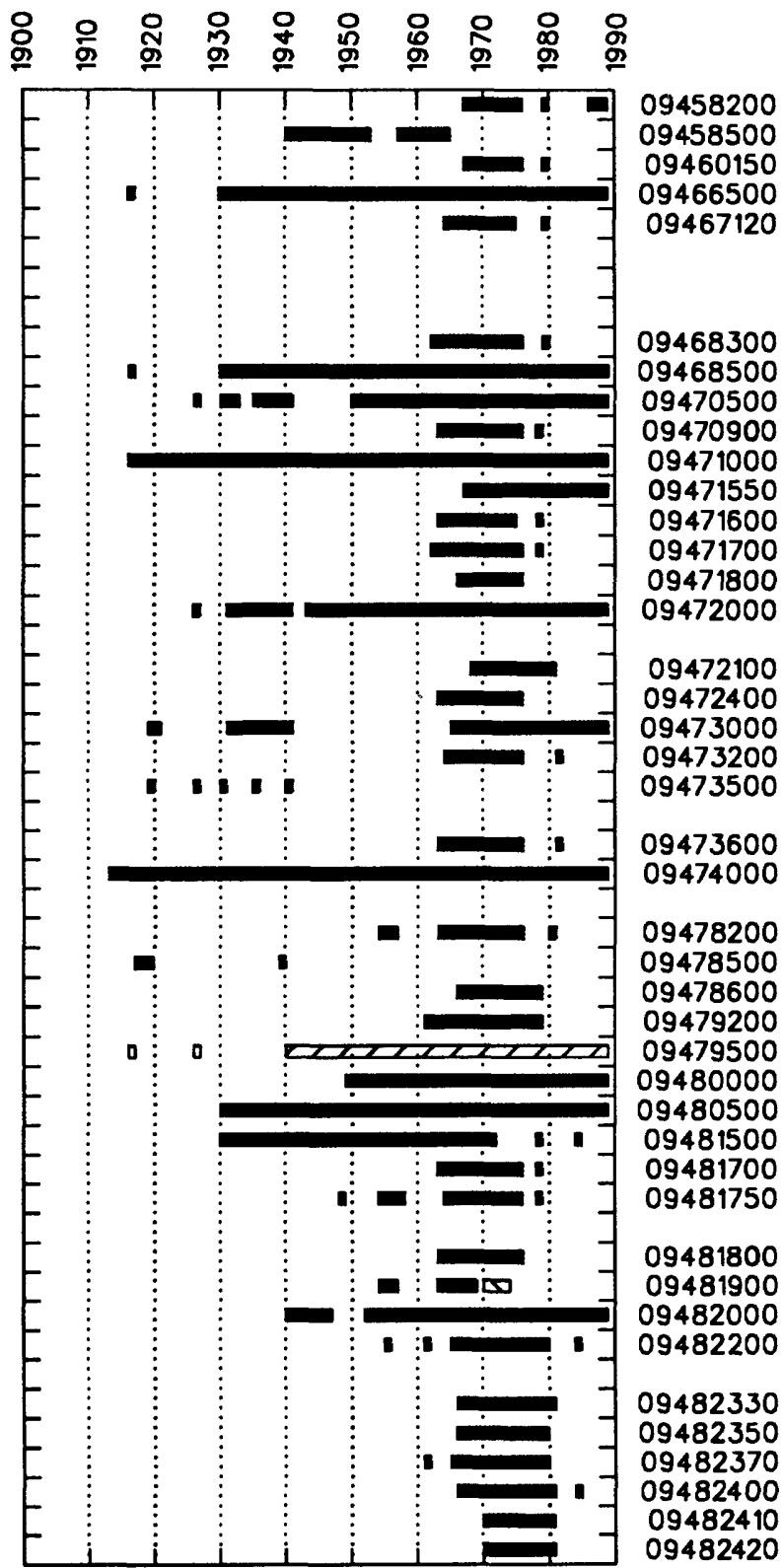

Colorodo River--Continued

Gilo River Bosin--Continued

Deadman Creek neor Sofford

Gila River at Sof ford

Frye Creek neor Thatcher

Gilo River of Colvo

Solt Creek neor Peridot

Son Corlos River:

Sycomore Creek:

Sevenmile Wosh:

Sevenmile Wosh tributory neor Glabe

Son Corlos River neor Peridot

Son Pedro River at Polominos

Son Pedro River ot Chorleston 249

Son Pedro River neor Tombstone 253

Conary Wosh near Benson 256

Fenner Wash near Benson 257

Son Pedro River neor Bensan 258

Son Pedro River neor Redington 261

Peck Conyon:

Peck Canyon tributory neor Redington 264

Mammath Wosh near Mammath 265

Arovoipo Creek neor Mommath 266

Green Lontern Wosh neor Winkelmon 269

Son Pedro River at Winkelmon 270

Tom O'shonter Wosh neor Hayden 273

Gilo River ot Kelvin 274

Mcclellon Wash:

Durhom Wosh neor Florence

277

Queen Creek ot Whitlow Domsite neor Superior $\quad 278$

Queen Creek tributory No.3 ot Whitlow Dom 281

Queen Creek tributory at Apoche Junction 282

Gilo River neor Loveen

Sonto Cruz River neor Lochiel

Sonto Cruz River near Nogoles 290

Sonoito Creek neor Potogonia 293

Colobosas Conyon neor Nogoles 296

Sopori Wosh at Amodo 297

Demetrie Wosh:

Demetrie Wosh tributary near Continental 298

Ocotillo Wosh neor Continental 299

Sonto Cruz River ot Continental 300

Floto Wosh neor Sohuorito 303

South Fork Airport Wosh:

Pumping Wosh near Voil

304

305

306

307

310 


\section{Table 1.--Period of record for streamflow-gaging stations included in the compilation--Continued}

PERIOD OF RECORD
STATION

NUMBER
PAGE

NUMBER

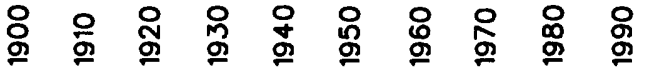

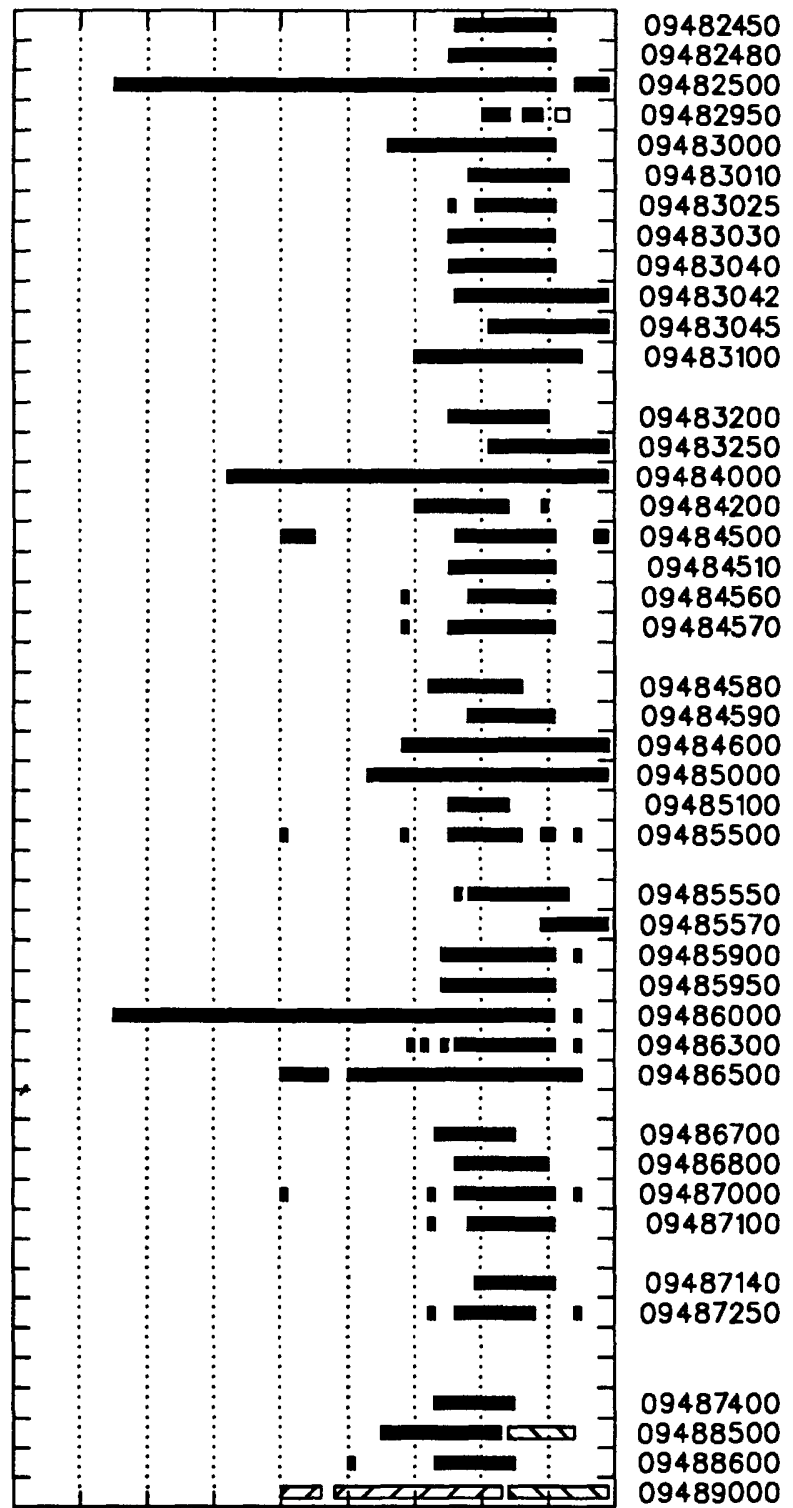

Colorodo River--Contínued

Gilo River Bosin--Continued

Sonto Cruz River--Continued

West Bronch Sonto Cruz River at Tucson $\quad 312$

Big Wash at Tucson 313

Santo Cruz River ot Tucson 314

Roilroad Wosh ot Tucson 317

Tucson Arroyo ot Vine Ave ot Tucson 318

High School Wosh ot Tucson 321

Silvercroft Wosh ot Tucson 324

Anklom Wosh ot Tucson $\quad 325$

West Speedwoy Wosh near Tucson 326

Cemetery Wosh ot Tucson 327

Flowing Wells Wosh ot Tucson 328

Tonque Verde Creek neor Tucson 329

Aguo Caliente Wosh:

Agua Coliente Wosh tributary neor Tucson 332

Rob Wosh ot Tucson 333

Sobino Creek neor Tucson $\quad 334$

Bear Creek near Tucson 337

Tonque Verde Creek ot Tucson 340

Ventono Conyon Wosh neor Tucson 341

Cienega Creek neor Pontono 342

Mescal Arroyo near Pantono 343

Pantono Wosh:

Borrel Conyon neor Sonaito 344

Dovidson Conyon Wosh near Voil $\quad-345$

Pontono Wosh neor Vail 346

Rincon Creek neor Tucson $\quad 349$

Soguora Corners Wosh neor Tucson 352

Pontono Wosh neor Tucson 353

Rillito Creek:

Arcodio Wosh ot Tucson $\quad 354$

Alamo Wosh at Tucson $\quad 355$

Pimo Wosh neor Tucson 356

Geronimo Wosh near Tucson $\quad 357$

Rillito Creek neor Tucson 358

Conodo Del Oro neor Tucson 361

Sonto Cruz River ot Cortaro 364

Altor Wosh (heod of Los Robles Wosh):
Chiltepines Wosh neor Sosobe

Altor Wosh near Three Points 368

Browley Wosh neor Three Points 369

Little Browley Wosh near Three Points 370

Browley Wosh tributory:

Son Jooquin Wosh near Tucson 371

Los Robles Wosh neor Marano 372

Sonto Roso Wosh:

Quijotoo Wosh:

Quijotoo Wosh tributory near Quijotoo 373

Sonto Roso Wash neor Vaivo Vo 374

Silver Reef Wosh neor Coso Grande 375

Sonto Cruz River near Loveen 376 


\section{Table 1.--Period of record for streamflow-gaging stations included in the compilation--Continued}

PAGE NUMBER

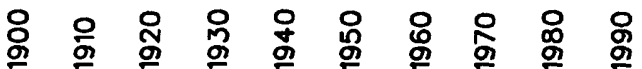

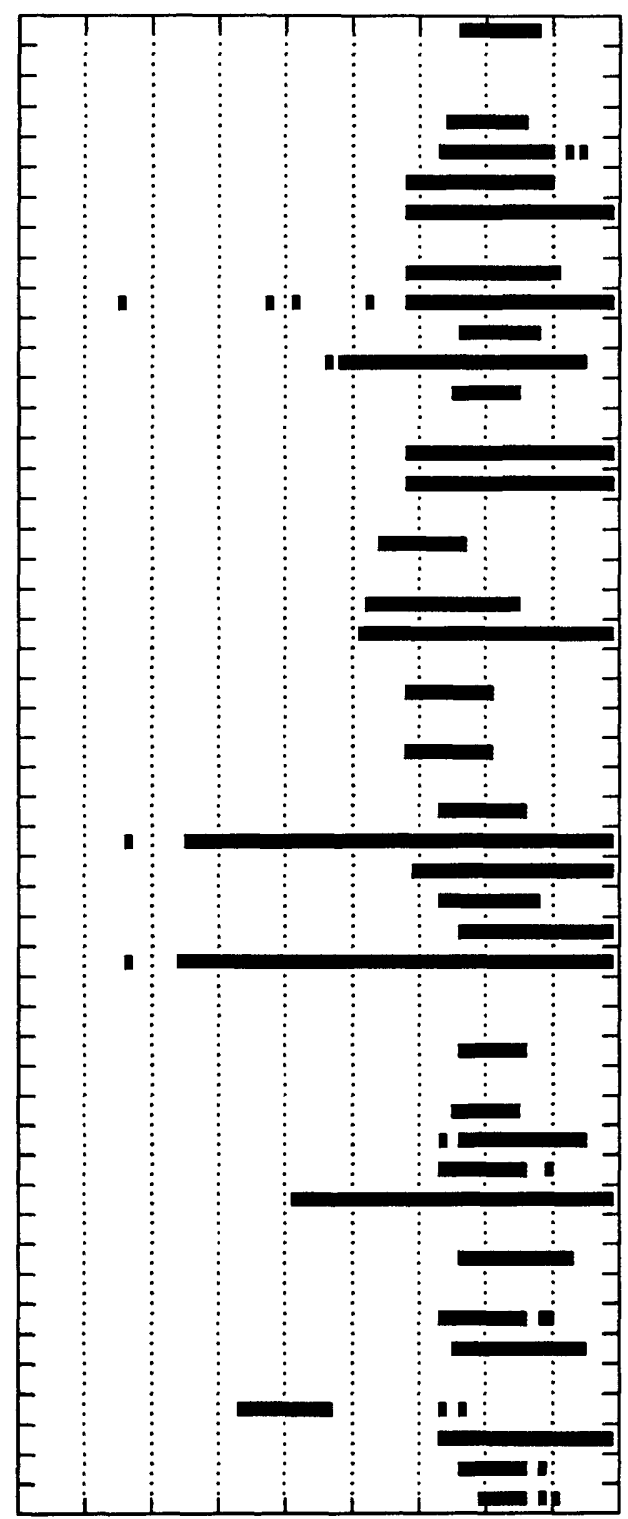

09489070

09489080

09489100

09489200

09489499

09489700

09490500

09490800

09491000

09491800

09492400

09494000

09494300

09496000

09496500

09496600

09496700

09496800

09497500

09497800

09497900

09497980

09498500

09498600

09498800

09498870

09498900

09499000

09501300

09502700

09502800

09503000

09503700

09503720

09503740
Colorodo River--Continued

Gilo River--Continued

North Fork of East Fork Black River near Alpine

Black River:

Beover Creek:

Honnogan Creek neor Hannogan Meadow 382

Block River neor Moverick 383

Pacheto Creek at Maverick 386

Black River obove Willow Creek Diversion, neor Point of Pines

Big Bonito Creek near Fort Apoche 392

Black River near Fort Apache

North Fork White River neor Greer

North Fork White River near McNory

North Fork White River tributary near Whiteriver

Eost Fork White River near Fort Apoche

White River near Fort Apache

Solt River:

Corrizo Creek above Corduroy Creek, near Show Low

Corduroy Creek near mouth near Show Low

Carrizo Creek neor Show Low

Corrizo Creek tributory:

Cibecue 1 tributory Corrizo Creek, neor Show Low

Cibecue 2 tributary Corrizo Creek, near Show Low

Corrizo Creek tributary near Show Low

Solt River near Chrysotile

Cibecue Creek near Chrysotile

Cherry Creek neor Young

Cherry Creek neor Globe

Solt River neor Roosevelt

Tonto Creek:

Christopher Creek:

Christopher Creek tributory near Kohl's Ronch

Tonto Creek neor Gisela

Rye Creek near Gisela

Gold Creek neor Payson

Tonto Creek above Gun Creek neor Roosevelt

Tor tillo Creek:

Tor tilla Creek at Tortilla Flat

Big Chino Wosh (head of Verde Volley):

Crookton Wosh neor Seligmon

Williomson Valley Wash near Paulden

Verde River:

Granite Creek neor Prescott

Verde River near Paulden

Hell Canyon neor Willioms

Hell Canyon tributary Near Ash Fork
395

398

401

404

405

408

411

414

417

420

423

426

427

430

433

436

439

443

444

447

450

451

454

455

456

459

462

465

466 


\section{Table 1.--Period of record for streamflow-gaging stations included in the compilation--Continued}

PERIOD OF RECORD

STATION

NUMBER
PAGE

NUMBER

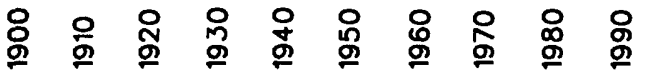

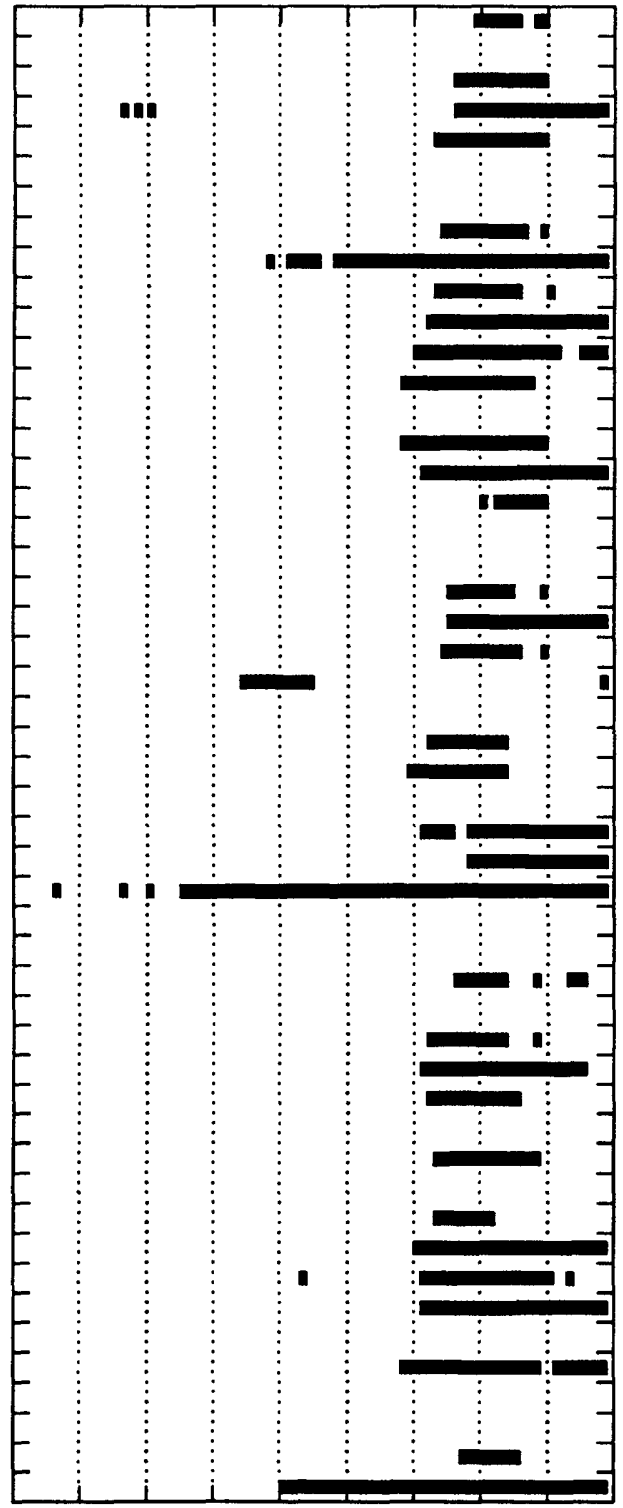

09503750

09503800

09504000

09504100

09504400

09504500

09504800

09505200

09505220

09505250

09505300

09505350

09505550

09505600

09505800

09505900

09506000

09507600

09507700

09507980

09508300

09508500

09510070

09510080

09510100

09510150

09510170

09510180

09510200

09512100

09512200

09512300

09512420

09512500
Colorodo River--Continued

Gilo River Bosin--Continued

Solt River--Continued

Verde River--Continued

Limestone Conyon neor Poulden

Sycamore Creek:

Volunteer Wosh near Bellemont 468

Verde River neor Clorkdole $\quad 469$

Hull Conyon neor Jerome 472

Ook Creek:

Munds Canyon:

Munds Conyon tributory neor Sedono 473

Ook Creek near Cornville 474

Oak Creek tributory neor Cornville $\quad 478$

Wet Beover Creek neor Rimrock 479

Rocky Gulch neor Rimrock 482

Red Tonk Draw neor Rimrock 483

Dry Beover Creek:

Rattlesnake Conyon neor Rimrock 486 Dry Beover Creek neor Rimrock 489

Verde River below Comp Verde 492

Clover Creek (heod of West Cleor Creek): Forty Four Conyon:

Dirty Neck Conyon neor Clints Well 493

West Cleor Creek neor Comp Verde 494

Cottonwood Wosh neor Comp Verde $\quad 497$

Verde River neor Comp Verde 498

Eost Verde River:

Eost Verde River neor Pine 501

Webber Creek obover West Fork Webber Creek. neor Pine

Eost Verde River neor Childs

Wet Bottom Creek neor Childs

Verde River below Tongle Creek, obove Horseshoe Dam

Verde River tributory:

West Fork Sycomore Creek obove McForlond Canyon, near Sunflower

West Fork Sycomore Creek neor Sunflower

Eost Fork Sycomore Creek neor Sunflower

Sycomore Creek neor Sunflower

Pine Creek:

Comp Creek neor Sunflower

Mesquite Wosh:

Rock Creek neor Sunflower

Sycoll

Sosh ot Scottsdole 535

Solt River tributory in South Mountoin Pork, Phoenix

Cove Creek neor Cove Creek

Aguo Fria River:

Lynx Creek:

Lynx Creek tributory neor Prescott

Aguo Frio River near Moyer
536

541
542

518

524

527

530

31

535

540 


\section{Table 1.--Period of record for streamflow-gaging stations included in the compilation--Continued}

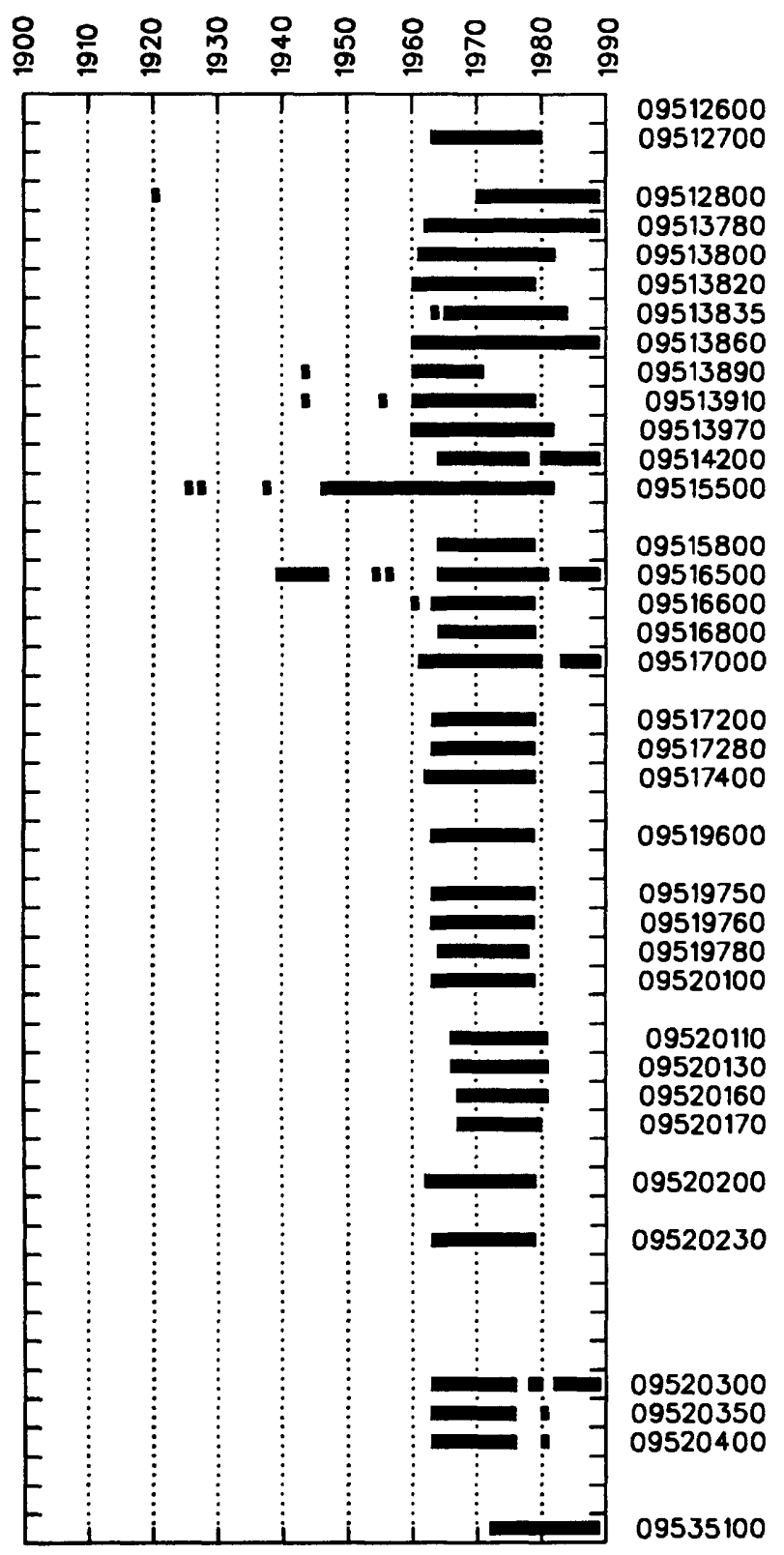

Colorodo River--Continued

Gila River Bosin--Continued

Aquo Frio River--Continued

Turkey Creek neor Cleotor

Agua Frio River tributory No.2 neor Rock Springs

Aguo Frio River neor Rock Springs

政 $\quad 549$

New River neor Rock Springs 552

New River ot New River $\quad 555$

Deadmon Wosh neor New River 558

New River ot Bell Rood, neor Peorio 559

Skunk Creek neor Phoenix 562

New River ot Peorio 565

New River near Glendale $\quad 566$

Agua Frio River ot Avondale 567

Wotermon Wash neor Buckeye 570

Hossoyompo River at Box domsite near Wickenburg 571

Sols Wosh:

Hor tmon Wosh neor Wickenburg 574

Hossoyompo River neor Morristown 575

Ox Wosh neor Morristown 576

Jock Robbit Wosh neor Tonopoh 577

Hossoyompo River neor Arlington $\quad 578$

Centennial Wosh:

Centenniol Wosh tributory neor Wenden 579

Tiger Wosh near Aguilo $\quad 580$

Winters Wosh neor Tonopoh 581

Roinbow Wosh:

Roinbow Wosh tributory neor Buckeye 582

Sond Tonk Wosh:

Bender Wosh near Gila Bend 583

Soucedo Wosh neor Gila Bend 584

Windmill Wosh neor Gilo Bend 585

Military Wosh neor Sentinel 586

Rio Cornez (heod of Ten Mile Wosh):

Dorby Arroyo neor Ajo $\quad 588$

Gibson Arroyo ot Ajo $\quad 589$

Rio Cornez neor Ajo 590

Ten Mile Wosh tributory:

Block Gop Wosh near Ajo 593

Midwoy Wosh:

Crater Ronge Wosh neor Ajo 594

Son Cristobal Wosh

Growler Wosh:

Cherioni Wosh:

Alamo Wosh:

Alama Wosh tributory near Ajo 595

Mohowk Poss Wosh ot Mohowk 596

Ligurto Wosh ot Ligur to $\quad 597$

RIO SONOYTA BASIN

SAN SIMON WASH BASIN

San Simon Wash neor Pisinima 598 
Table 1.--Period of record for streamflow-gaging stations included in the compilation--Continued

PERIOD OF RECORD

STATION

NUMBER
GAGING STATION

PAGE

NUMBER

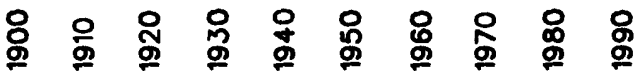

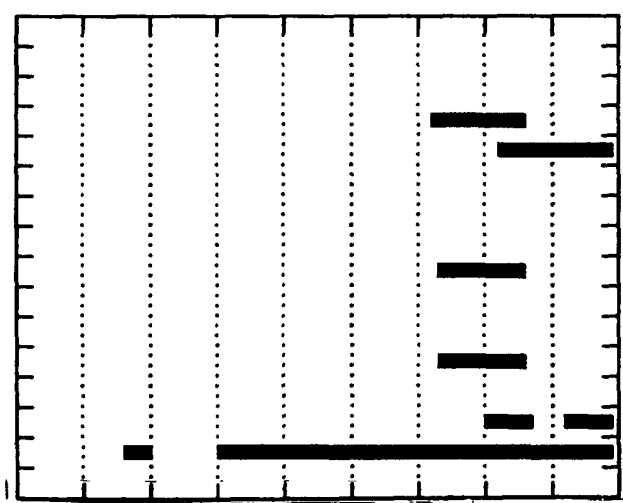

Rio Sonoyto--Continued

Son Simon Wosh Bosin--Continued

Vomori Wosh:

Gu Oidak Wash:

Sells Wash:

Little Tucson Wosh ot Sells $\quad 601$

09535200

09535300

Vomori Wosh at Kom Vo

SULPHUR SPRING VALLEY

WILLCOX PLAYA BASIN (closed bosin)

Pitchfork Conyon:

Pitchfork Canyon tributary neor Fort Grant Pinery Creek:

Bonito Conyon:

Surprise Canyon near Dos Cobezos

602

09536100

09536350

09537200

09537500
WHITEWATER DRAW BASIN

Leslie Creek neor MCNeal

Whitewater Draw neor Douglas
605

606

607

610 


\section{STREAMFLOW-GAGING STATIONS}

Gaging stations provide data that can be used in an appraisal of the State's surface-water resources. The U.S. Geological Survey began collecting streamflow data in Arizona in 1888. Since 1912, the Geological Survey has conducted a data-collection program in cooperation with the State of Arizona and has operated continuous-record gaging stations and partial-record gaging stations in cooperation with Federal, State, and local agencies. Gaging stations are installed at sites where streamflow data are required for management of water resources. Because of the similarities of natural streamflow among streams, the information collected at gaging stations that have natural flow are useful at the gaged site and at nearby ungaged sites.

\section{Continuous-Record Gaging Stations}

At continuous-record gaging stations, instruments are installed to sense and record the water-surface elevation in the stream. Using discharge measurements made at various stages and other observations of flow, a stagedischarge rating is determined for the range of streamflow measurements. This rating enables mean daily discharge to be calculated for the defined time-weighted range in the stage of the stream.

\section{Partial-Record Gaging Stations}

Partial-record gaging stations can be continuous-record gaging stations for which only the annual maximum discharge is computed or crest-stage gaging stations or a combination of the two. A crest-stage gage records the maximum peak stage. The peak discharge for each maximum recorded stage is determined from a stage-discharge rating determined for each site. Peak-flow data generally are collected for use in the design of safe and economical bridges and culverts.

The U.S. Geological Survey operated a statewide network of partial-record gaging stations during 1963-75 in a cooperative program with the Arizona Department of Transportation and the Federal Highway Administration. Data collected in this program also were used in a statewide flood-frequency analysis (Roeske, 1978).

\section{STREAMFLOW RECORDS AND BASIN CHARACTERISTICS}

A station description, annual peak discharges, and basin and climatic characteristics are provided for each gaging station in this report. The station description includes location, drainage area (the area of a stream basin upstream from the gaging station), and remarks. The location and drainage area generally are obtained from 1:24,000 topographic maps. Annual peak discharge is the maximum instantaneous discharge that occurs in a water year (October 1 through September 30). The annual peak 
discharges also include historical data (peaks that occurred before, during, or after the systematic records), paleoflood data (flood data that uses geologic evidence to estimate discharges), date of the discharge, and discharge codes.

Basin and climatic characteristics were calculated for streamflow-gaging stations with unregulated or partly regulated flow (flow affected to an unknown degree by regulation or diversion). The characteristics include main channel slope, stream length, mean basin elevation, forested area, soil index, mean annual precipitation, and rainfall intensities. These characteristics were determined using the following criteria (U.S. Geological Survey, 1977).

Main-channel slope, in feet per mile, is an index of the slope of the main channel and is computed from the difference in streambed elevation at points that are 10 and 85 percent of the distance along the main channel from the gaging station to the basin divide. The main-channel slope is computed by the equation:

where

$$
S_{c}=\frac{\left(E_{85}-E_{10}\right)}{0.75 L_{c}}
$$

$S_{c}=$ main-channel slope, in feet per mile;

$E_{85}=$ elevation at 85 -percent point of main-channel distance, in feet;

$E_{10}=$ elevation at 10 -percent point of main channel distance, in feet; and

$L_{c}=$ length of main channel from the gage to the basin divide, in miles.

Stream length, in miles, is the length of the main channe1, $L$, from the gaging station to the basin divide. The main channel is chosen at each bifurcation by following the fork that has the largest drainage area.

Mean basin elevation, in feet, is the average distance above sea level of representative points in the basin. Mean basin elevation is computed as the arithmetic average of the elevation of 50 to 100 points at the intersections of equally spaced grid lines superimposed on a map of the basin.

Forested area, in percent, is the portion of drainage area shown as forested on topographic maps. Forested area is computed as the ratio of the area shown as covered by forests to the total drainage times 100 percent. Areas were measured by planimeter. 
Soil index, in inches, is a numerical index proportional to the long-term infiltration rate. The soil index was calculated by applying a grid system to a soils map (U.S. Soil Conservation Service, 1969) that had the drainage basin delineated on the map.

Mean annual precipitation, in inches, is the normal annual precipitation that falls on the drainage basin. Mean annual precipitation is determined by outlining the drainage basin on a normal annual precipitation map (University of Arizona, 1965), summing the products of the planimetered subareas and their midrange precipitation value, and dividing by total area.

Rainfall intensities, in inches for a 24-hour storm period with recurrence intervals of 2 years and 50 years, are determined by outlining the drainage basin on a precipitation map (U.S. Weather Bureau, 1967), summing the products of the planimetered subareas and their midrange precipitation value, and dividing by total area.

\section{STATISTICAL SUMMARIES}

Statistical summaries of streamflow data computed from daily mean values of flow and instantaneous peak flows are presented for the continuous-record gaging stations. Only recurrence intervals for instantaneous peak flows are presented for the partial-record gaging stations. The statistical summaries for equivalent periods of record contain analyses of mean monthly and annual discharges, magnitude and probability of annual low and high flows, magnitude and probability of instantaneous high flows (flood frequency), and percentage of time that a given daily mean flow was equaled or exceeded. Records from two or more sites are combined into one equivalent record. Nonequivalent record normally means that the amount of low flow was different because of recent upstream diversions, increased infiltration between the old gage site and present gage site, and increased spring flow between past and present gage sites. Normally the high flows and annual peak discharges are considered equivalent. Recurrence intervals equal to more than twice the period of record are flagged as unreliable. All recurrence intervals may be flagged for some stations where flood-frequency relations are unreliable. Except for magnitude and probability of instantaneous peak flow, values of the streamflow statistics are computed from data collected during a water year that had a daily mean flow value for each day of the year. Streamflow statistics are calculated on the basis of a water year, which begins on October 1 and ends on September 30; however, the magnitude and probability of annual low-flow statistics are calculated on the basis of a climatic year, which begins on April 1 and ends on March 31.

Low-flow magnitude and probability were calculated for 1 -, 3-, $7-, 14-, 30-, 60-, 90-, 120-$, and 183-day periods. High-flow magnitude 
and probability were calculated for 1-, 3-, 7-, 15-, 30-, 60-, and 90day periods. These statistics indicate the nonexceedance probability for low flows and exceedance probability for high flows that have 2-, 5-, 10-, 25-, 50-, and 100-year recurrence intervals. Discharges in the low-flow magnitude and probability were adjusted graphically when computer-generated values in the 50- and 100-year recurrence intervals were unacceptable.

Instantaneous peak-flow magnitudes were calculated from observed peak-flow record using the log-Pearson Type III frequency distribution for the 2-, 5-, 10-, 25-, 50-, and 100-year recurrence intervals. The analyses followed the guidelines of the U.S. Water Resources Council (1981b), and historical flood information, no-flow years, and outliers were treated according to the guidelines. Statistics show stationarity in peak-flow records for Arizona (H.W. Hjalmarson, hydrologist, U.S. Geological Survey, oral commun., 1989). The probability of a flood exceeding a given discharge is the same in the last year of record as it was in the first.

Flood-frequency relations are shown for unregulated or partly regulated streamflow stations, that is, stations at which flow is affected to an unknown degree by regulation or diversion. Since 1963, the flow of the Colorado River has been regulated by Lake Powell; since 1929, flow of the Gila River below Coolidge Dam has been regulated largely by major reservoirs on the Gila River and several of its principal tributaries. Peak-flow magnitudes for station data prior to regulation are published in Anderson and White (1979). Relation of discharge to miles, below Coolidge Dam adjusted to remove the regulated condition prior to 1975 below the dam on the Gila River for selected recurrence intervals, is published in Roeske (1978). Several methods for estimating magnitude and frequency of floods in Arizona were described by Patterson and Somers (1966), Roeske (1978), Eychaner (1984), and Hill and others (1988).

Duration of daily mean discharge is described in terms of percentage of time a given daily mean discharge was equaled or exceeded. Discharges were calculated for the $1,5,10,15,20,30,40,50,60,70,80$, $90,95,98,99,99.5$, and 99.9 percentiles.

\section{DISCHARGE}

Annual peak discharge, mean annual discharge, and mean monthly discharge are shown for all continuous-record gaging stations. Annual peak discharge is shown for partial-record gaging stations. Cumulative departure from the mean is shown for selected long-term gaging stations or hydrologic bench-mark stations.

Annual means are shown for some stations for years in which daily values are not available but monthly or annual means have been estimated. The median value line is shown when applicable. Median discharge is published when it is consistently (about two-thirds of the time) less than 90 percent of the mean (Novak, 1985). Mean monthly discharge is based on period of equivalent record; maximum, mean, and minimum mean monthly discharges by months are shown. Periods when monthly means were estimated are not included. The trend of the lines on the graphs showing accumulated departures from the annual mean for the period of record indicates wet and 
dry periods; downward trends indicate below-normal means, and upward trends indicate above-normal means.

\section{SELECTED REFERENCES}

Anderson, T.W., and White, N.D., 1979, Statistical summaries of Arizona streamflow data: U.S. Geological Survey Water-Resources Investigations $79-5,416 \mathrm{p}$.

Boner, F.C., Garrett, W.B., and Konieczki, A.D., 1989, Water-resources data for Arizona, water year 1988: U.S. Geological Survey Water-Resources Data Report AZ-88-1, 391 p.

Boner, F.C., Garrett, W.B., Konieczki, A.D., and Smith, C.F., 1990, Water-resources data for Arizona, water year 1989: U.S. Geological Survey Water-Resources Data Report AZ-89-1, 396 p.

Ely, L.L., and Baker, V.R., 1985, Reconstructing paleoflood hydrology with slackwater deposits: Verde River, Arizona, Physical Geography, v. 6 , no. 2 , p. 103-126.

Eychaner, J.H., 1984, Estimation of magnitude and frequency of floods in Pima County, Arizona, with comparisons of alternate methods: U.S. Geological Survey Water-Resources Investigations Report 84-4142, $69 \mathrm{p}$.

Hill, G.W., Hales, T.A., and Aldridge, B.N., 1988, Flood hydrology near Flagstaff, Arizona: U.S. Geological Survey Water-Resources Investigations Report 87-4210, 31 p.

National Oceanic and Atmospheric Administration, 1933-86, Climatological data annual summary, Arizona, 1877-1986: Asheville, North Carolina, National Climatic Data Center, v. 1-90, no. 13, published annually.

Novak, C.E., 1985, WRD data report preparation guide: U.S. Geological Survey report, $199 \mathrm{p}$.

O'Connor, J.E., Fuller, J.E., and Baker, V.R., 1986, Late Holocene flooding within the Salt River basin, central Arizona: Tucson, University of Arizona, Department of Geosciences, 84 p.

Partridge, J.B., and Baker, V.R., 1987, Paleoflood hydrology of the Salt River, Arizona: Earth Surface Processes and Landforms, v. 12, p. $109-125$.

Patterson, J.L., and Somers, W.P., 1966, Magnitude and frequency of floods in the United States-Part 9, Colorado River basin: U.S. Geological Survey Water-Supply Paper 1683, 475 p.

Rantz, S.E., and others, $1982 a$, Measurement and computation of streamflow-Volume 1 . Measurement of stage and discharge: U.S. Geological Survey Water-Supply Paper 2175, 284 p. 
1982b, Measurement and computation of streamflow-Volume 2 . Computation of discharge: U.S. Geological Survey Water-Supply Paper 2175, 347 p.

Roberts, L.K., 1987 , Paleohydrologic reconstruction, hydraulics, and frequency-magnitude relationships of large flood events along Aravaipa Creek, Arizona: Tucson, University of Arizona, master's thesis, $63 \mathrm{p}$.

Roeske, R.H., 1978, Methods for estimating the magnitude and frequency of floods in Arizona: Arizona Department of Transportation Report ADOT-RS-115(121), 82 p.

Sellers, W.D., Hill, R.H., and Sanderson-Rae, Margaret, eds., 1985, Arizona climate-The first hundred years: Tucson, University of Arizona Press, $143 \mathrm{p}$.

University of Arizona, 1965, Normal annual precipitation-Normal MaySeptember precipitation-1931-1960, State of Arizona: Tucson, University of Arizona map, scale 1:500,000.

U.S. Geological Survey, 1954, Compilation of records of surface waters of the United States through September 1950, Part 9, Colorado River basin: U.S. Geological Survey Water-Supply Paper 1313, $749 \mathrm{p}$.

1963-64a, Surface-water records of Arizona: U.S. Geological Survey report (published annually).

1964, Compilation of records of surface waters of the United States, October 1950 to September 1960, Part 9, Colorado River basin: U.S. Geological Survey Water-Supply Paper 1733, 586 p.

1965-74a, Water resources data for Arizona-Part 1, Surfacewater records: U.S. Geological Survey Water-Resources Data Report (published annually).

1975-81, Water-resources data for Arizona, water years 1975-81: U.S. Geological Survey Water-Resources Data Reports AZ-75-1 to AZ-81-1, (published annually).

1977, National handbook of recommended methods for water-data acquisition: U.S. Geological Survey, Office of Water Data Coordination, 2 volumes.

U.S. Soil Conservation Service, 1969, Generalized hydrologic soil map-Arizona: U.S. Soll Conservation Service map report, scale $1: 1,000,000$.

U.S. Water Resources Council, 1981, Guidelines for determining flood flow frequency: U.S. Water Resources Council Bulletin 17B, $183 \mathrm{p}$. (Errata corrections included through March 1982.)

U.S. Weather Bureau, 1967, Arizona 50-year 24-hour precipitation: U.S. Weather Bureau map. 
White, N.D., and Garrett, W.B., 1984, Water-resources data for Arizona, water year 1982: U.S. Geological Survey Water-Resources Data Report AZ-82-1, $343 \mathrm{p}$.

1986, Water-resources data for Arizona, water year 1983: U.S . Geological Survey Water-Resources Data Report AZ-83-1, 343 p.

1987, Water-resources data for Arizona, water year 1984: U.S. Geological Survey Water-Resources Data Report AZ-84-1, 343 p.

1988, Water-resources data for Arizona, water year 1985: U.S. Geological Survey Water-Resources Data Report AZ-85-1, 343 p.

Wilson, R.P., and Garrett, W.B., 1988, Water-resources data for Arizona, water year 1986: U.S. Geological Survey Water-Resources Data Report AZ-86-1, 341 p.

1989, Water-resources data for Arizona, water year 1987: U.S. Geologica1 Survey Water-Resources Data Report AZ-87-1, 385 p. 


\section{STREAMFLOW DATA}

Abbreviations used in the table of annual peak discharges are given below:

\begin{tabular}{|c|c|}
\hline$M D$ & Maximum daily average. \\
\hline ES & Discharge is an estimate. \\
\hline$L T$ & Discharge is less than indicated value. \\
\hline$U R$ & $\begin{array}{l}\text { Discharge is affected to unknown degree by } \\
\text { regulation or diversion. }\end{array}$ \\
\hline$K R$ & $\begin{array}{l}\text { Discharge is affected by regulation or } \\
\text { diversion. }\end{array}$ \\
\hline$H P$ & $\begin{array}{l}\text { Discharge is an isolated historic peak; not } \\
\text { part of the systematic record. }\end{array}$ \\
\hline$P F$ & $\begin{array}{l}\text { Discharge is a paleoflood peak; not part of } \\
\text { the systematic record. }\end{array}$ \\
\hline$C$ & $\begin{array}{l}\text { A11 or part of the record is affected by } \\
\text { urbanization. }\end{array}$ \\
\hline$D F$ & Discharge is affected by dam failure. \\
\hline
\end{tabular}




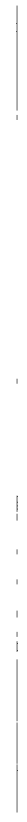

- 
09371100 Teec Nos Pos Wash near Teec Nos Pos, AZ

LOCATION.--Lat 36.55'58", long 109.06'35", in WEX sec.27, T.41 N., R.30 E., Apeche County, Hydrologic Unit 14080201, at U.S. Highway 160 (renumbered), 1.5 mi northwest of Teec Nos Pos Trading Post.

DRAIMAGE AREA. $--16.0 \mathrm{mi}^{2}$.

\section{ANMUAL PEAK DISCHARGE}

\begin{tabular}{|c|c|c|c|}
\hline $\begin{array}{l}\text { WATER } \\
\text { YEAR }\end{array}$ & DATE & 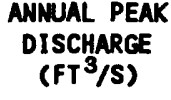 & $\begin{array}{l}\text { DISCHARGE } \\
\text { CODES }\end{array}$ \\
\hline $\begin{array}{l}1967 \\
1968 \\
1969 \\
1970 \\
1971 \\
1972 \\
1973 \\
1974 \\
1975 \\
1976\end{array}$ & $\begin{array}{l}00-00-67 \\
08-01-68 \\
07-18-69 \\
09-12-70 \\
08-00-71 \\
09-06-72 \\
10-19-72 \\
07-22-74 \\
09-00-75 \\
00-00-76\end{array}$ & $\begin{array}{r}750 \\
400 \\
580 \\
1,350 \\
500 \\
810 \\
770 \\
100 \\
450 \\
300\end{array}$ & ES \\
\hline
\end{tabular}

Magnitude and PROBABILITY OF instantaneOUS PEAK flOH BASED ON PERIOD OF RECORD 1967-76

DISCHARGE, IN FT ${ }^{3} / \mathrm{S}$, FOR INDICATED RECURRENCE INTERVAL IN YEARS, AND EXCEEDANCE PROBABILITY, IN PERCENT

\begin{tabular}{|c|c|c|c|c|c|}
\hline $\begin{array}{c}2 \\
50 \%\end{array}$ & $\underset{20 \%}{5}$ & $\begin{array}{r}10 \\
10 \%\end{array}$ & $\begin{array}{l}25 \nmid \\
4 \%\end{array}$ & $\begin{array}{l}50 f \\
2 x\end{array}$ & $\begin{array}{c}100 \nmid \\
1 \%\end{array}$ \\
\hline 557 & 841 & 1,050 & 1,320 & 1,530 & 1,760 \\
\hline $\begin{array}{l}\text { WEIGHTED } \\
\text { MEAN } \\
\text { STANDARD }\end{array}$ & $\begin{array}{l}\text { SKEW } \\
\text { DEV. }\end{array}$ & $\begin{array}{l}\text { LOGS) }= \\
\text { LOGS) }= \\
(\text { OGS) }=\end{array}$ & $\begin{array}{l}0.03 \\
2.75 \\
0.21\end{array}$ & & \\
\hline
\end{tabular}

+ Reliability of values in colum is uncertain, and potential errors are large.

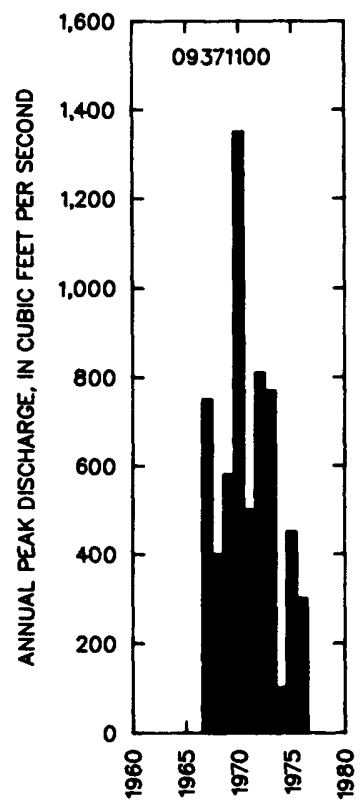

BASIN CHARACTERISTICS

\begin{tabular}{|c|c|c|c|c|c|c|c|}
\hline \multirow{2}{*}{$\begin{array}{c}\text { MAIN } \\
\text { CHANNEL } \\
\text { SLOPE } \\
\text { (FT/MI) }\end{array}$} & \multirow[b]{2}{*}{$\begin{array}{l}\text { STREAM } \\
\text { LENGTH } \\
\text { (MI) }\end{array}$} & \multirow{2}{*}{$\begin{array}{l}\text { MEAN } \\
\text { BASIN } \\
\text { ELEVA- } \\
\text { TION } \\
\text { (FT) }\end{array}$} & \multirow[b]{2}{*}{$\begin{array}{l}\text { FORESTED } \\
\text { AREA } \\
\text { (PERCENT) }\end{array}$} & \multirow[b]{2}{*}{$\begin{array}{l}\text { SOIL } \\
\text { INDEX }\end{array}$} & \multirow{2}{*}{$\begin{array}{l}\text { MEAN } \\
\text { ANMUAL } \\
\text { PRECIPI- } \\
\text { TAT ION } \\
\text { (IN) }\end{array}$} & \multicolumn{2}{|c|}{ RAIMFALL INTEUSITY, 24-HOUR } \\
\hline & & & & & & $\begin{array}{l}\text { 2-YEAR } \\
\text { (IN) }\end{array}$ & $\begin{array}{l}\text { 50-YEAR } \\
\text { (IN) }\end{array}$ \\
\hline 411 & 11.2 & 7,600 & 80.0 & 2.0 & 16.5 & 1.4 & 2.9 \\
\hline
\end{tabular}


09379030 BLACK MOUNTAIN WASH MEAR CHIMLE, AZ

LOCATION.--Lat 36'20'00", I ong 109'37'25", Apache County, Hydrologic Unit 14080204, at State Highway 63, $1 \mathrm{mi}$ south of Many Farms, and 13 mi north of Chinle.

DRAIMACE AREA. $--80.7 \mathrm{mi}^{2}$.

ANIUAL PEAK DISCHARGE

\begin{tabular}{ccc}
$\begin{array}{c}\text { WATER } \\
\text { YEAR }\end{array}$ & DATE & $\begin{array}{c}\text { ANMUAL PEAK } \\
\text { DISCHARGE } \\
\text { (FT } 3 \text { /S) }\end{array}$ \\
\hline 1963 & $08-06-63$ & 737 \\
1964 & $08-13-64$ & 1,500 \\
1965 & $08-02-65$ & 238 \\
1966 & $07-31-66$ & 610 \\
1967 & $08-00-67$ & 360 \\
1968 & $08-01-68$ & 1,560 \\
1969 & $08-03-69$ & 422 \\
1970 & $08-20-70$ & 1,020 \\
1971 & $08-00-71$ & 2,180 \\
1972 & $08-00-72$ & 900 \\
1973 & $10-19-72$ & 1,040 \\
1974 & $07-00-74$ & 140 \\
1975 & $08-20-75$ & 110 \\
1976 & $00-00-76$ & 1,900 \\
1977 & $08-17-77$ & 3,100 \\
\hline$\ldots$
\end{tabular}

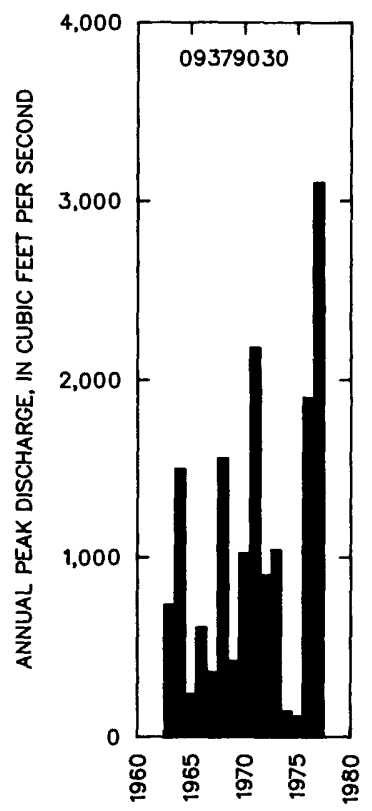

magNitUde AND PROBABILITY OF INSTANTANEOUS PEAK FLON BASED ON PERIOD OF RECORD 1963-77

DISCHARGE, IN $\mathrm{FT}^{3} / \mathrm{S}$, FOR INDICATED RECURRENCE INTERVAL IN YEARS, AND EXCEEDANCE PROBABILITY, IN PERCENT

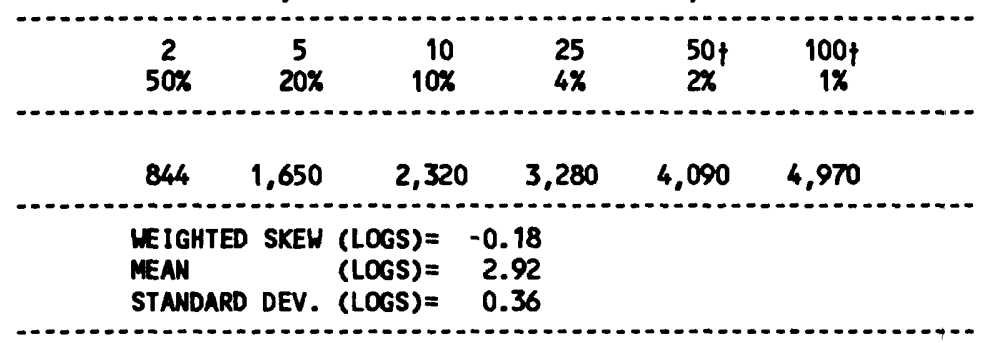

f Reliability of values in column is uncertain, and potential errors are large.

BASIN CHARACTERISTICS

\begin{tabular}{|c|c|c|c|c|c|c|c|}
\hline MAIN & & & & & & RAINFALL II & SITY, 24-HOUR \\
\hline $\begin{array}{l}\text { CHANNEL } \\
\text { SLOPE } \\
\text { (FT/MI) }\end{array}$ & $\begin{array}{l}\text { LENGTH } \\
\text { (MI) }\end{array}$ & $\begin{array}{l}\text { ELEVA- } \\
\text { TION } \\
\text { (FT) }\end{array}$ & $\begin{array}{l}\text { AREA } \\
\text { (PERCENT) }\end{array}$ & $\begin{array}{l}\text { SOIL } \\
\text { INDEX }\end{array}$ & $\begin{array}{l}\text { TATION } \\
\text { (IN) }\end{array}$ & $\begin{array}{c}\text { 2-YEAR } \\
\text { (IN) }\end{array}$ & $\begin{array}{c}\text { 50-YEAR } \\
\text { (IN) }\end{array}$ \\
\hline 46.2 & 14.4 & 5,920 & 2.1 & 3.0 & 10.9 & 1.3 & 2.7 \\
\hline
\end{tabular}


09379060 LUKACHUKAI CREEK TRIBUTARY NEAR LUKACHUKAI, AZ

LOCATION.--Lat 36.28'10", long 109.24'20", Apache County, Hydrologic Unit 14080204, at Navajo Highway 12 , $6.8 \mathrm{mi}$ southeast of Round Rock, and $10 \mathrm{mi}$ northwest of Lukachukai.

DRAINAGE AREA. $--1.37 \mathrm{mi}^{2}$.

ANMUAL PEAK DISCHARGE

\begin{tabular}{cccc}
$\begin{array}{c}\text { MATER } \\
\text { YEAR }\end{array}$ & DATE & $\begin{array}{c}\text { ANMUAL PEAK } \\
\text { DISCHARGE } \\
\text { (FT } 3 / \text { S) }\end{array}$ & $\begin{array}{c}\text { DISCHARGE } \\
\text { COOES }\end{array}$ \\
\hline 1963 & $08-31-63$ & 15 & \\
1964 & $07-31-64$ & 33 & \\
1965 & $01-06-65$ & 227 & \\
1966 & $07-31-66$ & 10 & ES \\
1967 & $00-00-67$ & 0 & \\
1968 & $08-00-68$ & 30 & \\
1969 & $07-18-69$ & 49 & \\
1970 & $10-04-69$ & 36 & \\
1971 & $08-00-71$ & 3.0 & ES \\
1972 & $00-00-72$ & 0 & \\
1973 & $00-00-73$ & 20 & \\
1974 & $02-21-74$ & 10 & \\
1975 & $00-00-75$ & 1.0 & ES \\
1976 & $00-00-76$ & 43 &
\end{tabular}

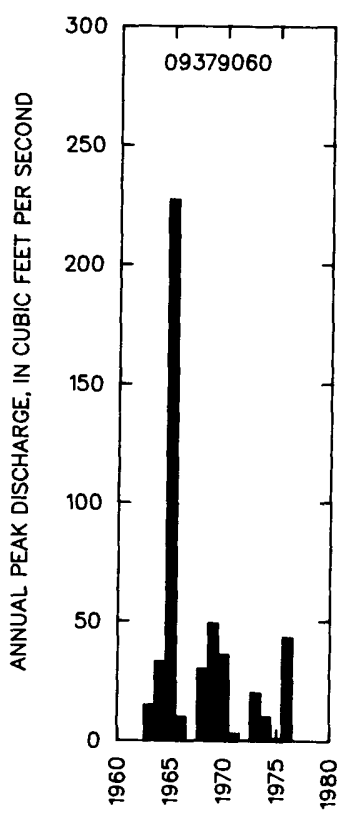

MAGNITUDE AND PROBABILITY OF INSTANTANEOUS PEAK FLOW BASED ON PERIOD OF RECORD 1963-76

DISCHARGE, IN $\mathrm{FT}^{3} / \mathrm{S}$, FOR INDICATED RECURRENCE INTERVAL IN YEARS, AND EXCEEDANCE PROBABILITY, IN PERCENT

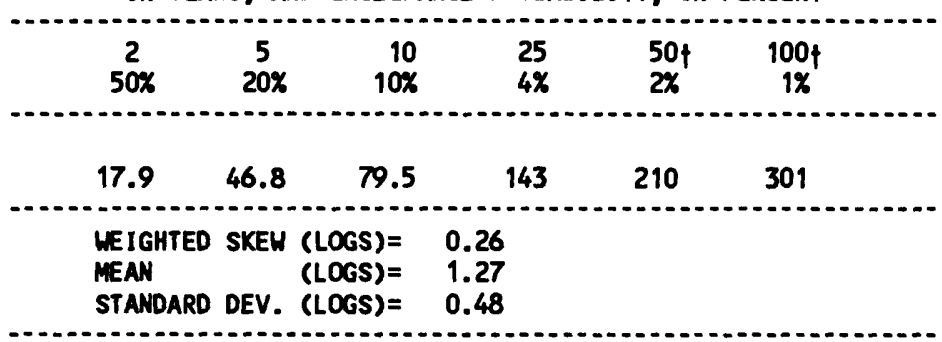

f Reliability of values in column is uncertain, and potential errors are large.

BASIN CHARACTERISTICS

\begin{tabular}{|c|c|c|c|c|c|c|c|}
\hline \multirow{2}{*}{$\begin{array}{l}\text { MAIN } \\
\text { CHANNEL } \\
\text { SLOPE } \\
\text { (FT/MI) }\end{array}$} & \multirow[b]{2}{*}{$\begin{array}{c}\text { STREAM } \\
\text { LENGTH } \\
\text { (MI) }\end{array}$} & \multirow{2}{*}{$\begin{array}{l}\text { MEAN } \\
\text { BASIN } \\
\text { ELEVA- } \\
\text { TION } \\
\text { (FT) }\end{array}$} & \multirow[b]{2}{*}{$\begin{array}{l}\text { FORESTED } \\
\text { AREA } \\
\text { (PERCENT) }\end{array}$} & \multirow[b]{2}{*}{$\begin{array}{l}\text { SOIL } \\
\text { INDEX }\end{array}$} & \multirow{2}{*}{$\begin{array}{l}\text { MEAN } \\
\text { ANNUAL } \\
\text { PRECIPI - } \\
\text { TATION } \\
\text { (IN) }\end{array}$} & \multicolumn{2}{|c|}{ RAINFALL INTENSITY, 24-HOUR } \\
\hline & & & & & & $\begin{array}{l}\text { 2-YEAR } \\
\text { (IN) }\end{array}$ & $\begin{array}{l}\text { 50-YEAR } \\
\text { (IN) }\end{array}$ \\
\hline 72.2 & 2.4 & 5,820 & 0.0 & 3.0 & 9.8 & 1.2 & 2.63 \\
\hline
\end{tabular}


LOCATION.--Lat 36 34'02", long 110'29'17", Navajo County, Hydrologic Unit 15020018, at U.S. Highway 160, $17 \mathrm{mi}$ southwest of Kayenta.

DRAINAGE AREA. $--1.38 \mathrm{mi}^{2}$.

ANIUAL PEAK DISCHARGE

\begin{tabular}{cccc}
$\begin{array}{c}\text { HATER } \\
\text { YEAR }\end{array}$ & DATE & $\begin{array}{c}\text { ANNUAL PEAK } \\
\text { DISCHARGE } \\
\text { (FT } 3 / \text { S) }\end{array}$ & $\begin{array}{c}\text { DISCHAREE } \\
\text { CCOES }\end{array}$ \\
\hline 1962 & $00-00-62$ & 960 & \\
1963 & $08-06-63$ & 548 & \\
1964 & $07-31-64$ & 1,150 & \\
1965 & $00-00-65$ & 0 & \\
1966 & $08-31-66$ & 1,120 & \\
1967 & $07-30-67$ & 2,060 & \\
1968 & $08-00-68$ & 96 & \\
1969 & $08-03-69$ & 5.0 & ES \\
1970 & $09-05-70$ & 480 & \\
1971 & $08-00-71$ & 590 & \\
1972 & $00-00-72$ & 10 & ES \\
1973 & $10-19-72$ & 150 & \\
1974 & $07-00-74$ & 123 & \\
1975 & $09-08-75$ & 960 & \\
1976 & $00-00-76$ & 1.0 & ES \\
\hline
\end{tabular}

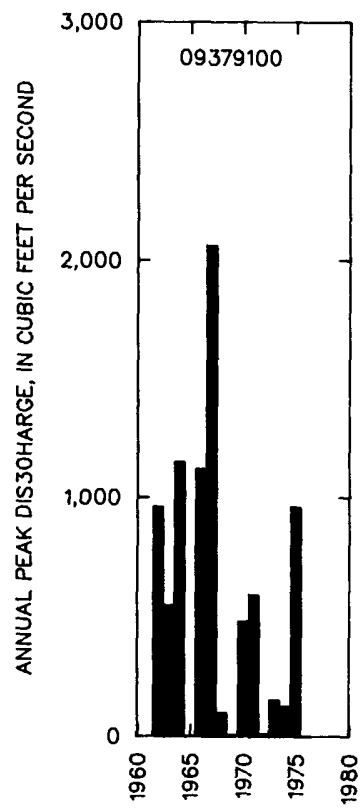

MAGNITUDE AND PROBABILITY OF INSTANTANEOUS PEAK FLOW BASED ON PERIOD OF RECORD 1962-76

DISCHARGE, IN $\mathrm{FT}^{3} / \mathrm{S}$, FOR INDICATED RECURRENCE INTERVAL IN YEARS, ND EXCEEDANCE PROBABILITY, IN PERCENT

\begin{tabular}{|c|c|c|c|c|c|}
\hline $\begin{array}{r}2 \psi \\
50 \%\end{array}$ & $\begin{array}{c}5 \phi \\
20 \%\end{array}$ & $\begin{array}{c}10 \nmid \\
10 \%\end{array}$ & $\begin{array}{l}25 \uparrow \\
4 x\end{array}$ & $\begin{array}{l}50\} \\
2 x\end{array}$ & $\begin{array}{c}100 \nmid \\
1 \%\end{array}$ \\
\hline 304 & 1,000 & 1,760 & 3,100 & 4,380 & 5,880 \\
\hline $\begin{array}{l}\text { WEIGH } \\
\text { MEAN } \\
\text { STAND }\end{array}$ & $\begin{array}{l}\text { SKEW } \\
\text { DEV. }\end{array}$ & $\begin{array}{l}(x S)= \\
(G S)= \\
(G S)=\end{array}$ & $\begin{array}{r}-0.40 \\
2.44 \\
0.66\end{array}$ & & \\
\hline
\end{tabular}

+ Reliability of values in column is uncertain, and potential errors are large.

BASIN CHARACTERISTICS

\begin{tabular}{|c|c|c|c|c|c|c|c|}
\hline \multirow{2}{*}{$\begin{array}{l}\text { MAIN } \\
\text { CHANNEL } \\
\text { SLOPE } \\
\text { (FT/MI) }\end{array}$} & \multirow[b]{2}{*}{$\begin{array}{c}\text { STREAM } \\
\text { LENGTH } \\
\text { (MI) }\end{array}$} & \multirow{2}{*}{$\begin{array}{l}\text { MEAN } \\
\text { BASIN } \\
\text { ELEVA- } \\
\text { TION } \\
\text { (FT) }\end{array}$} & \multirow[b]{2}{*}{$\begin{array}{l}\text { FORESTED } \\
\text { AREA } \\
\text { (PERCENT) }\end{array}$} & \multirow[b]{2}{*}{$\begin{array}{l}\text { SOIL } \\
\text { INDEX }\end{array}$} & \multirow{2}{*}{$\begin{array}{l}\text { MEAN } \\
\text { ANNUAL } \\
\text { PRECIPI- } \\
\text { TATION } \\
\text { (IN) }\end{array}$} & \multicolumn{2}{|c|}{ RAINFALL INTENSITY, 24-HOUR } \\
\hline & & & & & & $\begin{array}{c}\text { 2-YEAR } \\
\text { (IN) }\end{array}$ & $\begin{array}{l}\text { 50-YEAR } \\
\text { (IN) }\end{array}$ \\
\hline 236 & 1.1 & 6,920 & 57.0 & 3.0 & 12.0 & 1.4 & 2.9 \\
\hline
\end{tabular}


09379200 CHINLE CREEK NEAR MEXICAN UATER, AZ

LOCATION.--Lat 36.56'38", long 109.42'36", in sec.19, T.41 N., R.25 E. (unsurveyed), Apache County, Hydrologic Unit 1400204, in Navajo Indian Reservation, on right bank $150 \mathrm{ft}$ upstrean from bridge on U.S. Highway $160,3 \mathrm{mi}$ upstream from Walker Creek, $4 \mathrm{mi}$ southwest of Mexican Water, $5 \mathrm{mi}$ downstream from confluence of Chinle Wash and Laguna Creek, and 6 mi upstream from Arizona-Utah State line.

DRAIMACE AREA. $--3,650 \mathrm{mi}^{2}$.

REMARKS. --Many Farms Reservoir, above 25 mi upstream, was built in 1939 with an original capacity of 25,000 acre-ft and provides off-channel storage for irrigation of about 1,600 acres.

ANNUAL PEAK DISCHARGE

\begin{tabular}{|c|c|c|c|}
\hline $\begin{array}{l}\text { WATER } \\
\text { YEAR }\end{array}$ & DATE & $\begin{array}{c}\text { ANNUAL PEAK } \\
\text { DISCHARGE } \\
\left(\mathrm{FT}^{3} / \mathrm{S}\right)\end{array}$ & $\begin{array}{l}\text { DISCHARGE } \\
\text { COOES }\end{array}$ \\
\hline $\begin{array}{l}1963 \\
1964 \\
1965 \\
1966 \\
1967 \\
1968 \\
1969 \\
1970 \\
1971 \\
1972 \\
1973 \\
1974 \\
1975 \\
1976 \\
1977 \\
1978 \\
1979 \\
1980 \\
1981 \\
1982 \\
1983 \\
1984 \\
1985 \\
1986 \\
1987 \\
1988 \\
1989\end{array}$ & $\begin{array}{l}00-00-63 \\
08-01-64 \\
05-15-65 \\
12-24-65 \\
08-10-67 \\
08-08-68 \\
01-15-69 \\
09-07-70 \\
08-23-71 \\
08-28-72 \\
10-20-72 \\
03-02-74 \\
07-13-75 \\
09-25-76 \\
08-19-77 \\
07-18-78 \\
11-12-78 \\
09-10-80 \\
07-14-81 \\
08-24-82 \\
07-28-83 \\
07-24-84 \\
04-30-85 \\
09-09-86 \\
11-19-86 \\
11-06-87 \\
08-19-89\end{array}$ & $\begin{array}{r}2,070 \\
3,280 \\
732 \\
650 \\
1,230 \\
1,040 \\
590 \\
19,880 \\
1,050 \\
850 \\
984 \\
646 \\
3,680 \\
1,620 \\
7,120 \\
751 \\
1,390 \\
1,630 \\
3,270 \\
12,000 \\
3,650 \\
7,500 \\
4,914 \\
1,720 \\
5,800 \\
2,900 \\
2,940\end{array}$ & $\begin{array}{l}\text { ES } \\
\text { ES }\end{array}$ \\
\hline
\end{tabular}

1Highest since 1950 .

BASIN CHARACTERISTICS

\begin{tabular}{|c|c|c|c|c|c|c|c|}
\hline MAIN & & $\begin{array}{l}\text { MEAN } \\
\text { BASIN }\end{array}$ & & & $\begin{array}{c}\text { MEAN } \\
\text { ANNUAL }\end{array}$ & RAINFALL II & SITY, 24-HOUR \\
\hline $\begin{array}{c}\text { CHANNEL } \\
\text { SLOPE } \\
\text { (FT/MI) }\end{array}$ & $\begin{array}{c}\text { STREAM } \\
\text { LENGTH } \\
\text { (MI) }\end{array}$ & $\begin{array}{l}\text { ELEVA- } \\
\text { TION } \\
\text { (FT) }\end{array}$ & $\begin{array}{l}\text { FORESTED } \\
\text { AREA } \\
\text { (PERCENT) }\end{array}$ & $\begin{array}{l}\text { SOIL } \\
\text { INDEX }\end{array}$ & $\begin{array}{l}\text { PRECIPI - } \\
\text { TATION } \\
\text { (IN) }\end{array}$ & $\begin{array}{l}\text { 2-YEAR } \\
\text { (IN) }\end{array}$ & $\begin{array}{l}\text { 50-YEAR } \\
\text { (IN) }\end{array}$ \\
\hline 12.3 & 86.8 & 6,260 & 24.0 & 3.0 & 10.9 & 1.3 & 2.7 \\
\hline
\end{tabular}


MEAN MONTHLY AND ANMUAL DISCHARGES 1965-78, 1980-89

\begin{tabular}{|c|c|c|c|c|c|c|}
\hline MONTH & $\begin{array}{l}\operatorname{MAXIMUM} \\
\left(F^{3} / S\right)\end{array}$ & $\begin{array}{l}\text { MINIMUM } \\
\left(F T^{3} / S\right)\end{array}$ & $\begin{array}{c}\text { MEAN } \\
\left(F T^{3} / S\right)\end{array}$ & $\begin{array}{l}\text { STAN- } \\
\text { DARD } \\
\text { DEVIA- } \\
\text { TION } \\
\text { (FT } 3 / S)\end{array}$ & $\begin{array}{l}\text { COEFFI - } \\
\text { CIENT OF } \\
\text { VARI - } \\
\text { ATION }\end{array}$ & $\begin{array}{c}\text { PERCENT } \\
\text { OF } \\
\text { ANNUAL } \\
\text { RUNOFF }\end{array}$ \\
\hline $\begin{array}{l}\text { OCTOBER } \\
\text { NOVEMBER } \\
\text { DECEMBER } \\
\text { JANUARY } \\
\text { FEBRUARY } \\
\text { MARCH } \\
\text { APRIL } \\
\text { MAY } \\
\text { JUNE } \\
\text { JULY } \\
\text { AUGUST } \\
\text { SEPTEMBER }\end{array}$ & $\begin{array}{r}142 \\
144 \\
41 \\
71 \\
169 \\
215 \\
402 \\
294 \\
73 \\
129 \\
501 \\
342\end{array}$ & $\begin{array}{l}0.90 \\
3.4 \\
1.1 \\
1.6 \\
2.4 \\
0.67 \\
0.73 \\
0.26 \\
0.00 \\
0.36 \\
0.00 \\
0.65\end{array}$ & $\begin{array}{l}25 \\
17 \\
9.5 \\
14 \\
28 \\
29 \\
69 \\
58 \\
7.1 \\
28 \\
64 \\
43\end{array}$ & $\begin{array}{r}33 \\
31 \\
10 \\
17 \\
47 \\
50 \\
104 \\
88 \\
19 \\
33 \\
109 \\
79\end{array}$ & $\begin{array}{l}1.3 \\
1.8 \\
1.0 \\
1.3 \\
1.6 \\
1.7 \\
1.5 \\
1.5 \\
2.7 \\
1.2 \\
1.7 \\
1.8\end{array}$ & $\begin{array}{r}6.5 \\
4.4 \\
2.4 \\
3.5 \\
7.2 \\
7.4 \\
17.5 \\
14.9 \\
1.8 \\
7.0 \\
16.4 \\
11.0\end{array}$ \\
\hline INNUAL & 94 & 4.5 & 33 & 28 & 0.85 & 100 \\
\hline
\end{tabular}

MAGNITLDE AND PROBABILITY OF INSTANTANEOUS PEAK FLOH BASED ON PERIOD OF RECORD 1963-89

DISCHARGE, IN $\mathrm{FT}^{3} / \mathrm{S}$, FOR INDICATED RECURRENCE INTERVAL IN YEARS, AND EXCEEDANCE PROBABILITY, IN PERCENT

\begin{tabular}{|c|c|c|c|c|c|}
\hline$\stackrel{2}{50 x}$ & $\underset{20 \%}{5}$ & $\begin{array}{r}10 \\
10 \%\end{array}$ & $\begin{array}{l}25 \\
4 \%\end{array}$ & $\begin{array}{l}50 \\
2 \%\end{array}$ & $\begin{array}{c}100 \nmid \\
1 \%\end{array}$ \\
\hline 2,060 & 4.450 & 6,650 & 10,200 & 13,500 & 17,300 \\
\hline $\begin{array}{l}\text { MEIGHTED } \\
\text { MEAN } \\
\text { STANDARD }\end{array}$ & $\begin{array}{l}\text { SKEW } \\
\text { DEV. }\end{array}$ & $\begin{array}{l}(\operatorname{LOGS})= \\
(\text { LOGS })= \\
(\text { LOGS })=\end{array}$ & $\begin{array}{l}0.00 \\
3.31 \\
0.40\end{array}$ & & \\
\hline
\end{tabular}

MAGNITUDE AND PROBABILITY OF ANNUAL LOW FLOW BASED ON PERIOD OF RECORD 1966-78, 1981-89

\begin{tabular}{|c|c|c|c|c|c|c|}
\hline \multirow{2}{*}{$\begin{array}{l}\text { PERIQD } \\
\text { (COH- } \\
\text { SECH- } \\
\text { TIVE } \\
\text { DAYS) }\end{array}$} & \multicolumn{6}{|c|}{$\begin{array}{l}\text { DISCHARGE, IN FT } 3 / 5, \text { FOR INDICATED } \\
\text { RECURRENCE INTERVAL, IN YEARS, AND } \\
\text { NON-EXCEEDANCE PROBABILITY, IN PERCENT }\end{array}$} \\
\hline & $\begin{array}{c}2 \\
50 \%\end{array}$ & $\begin{array}{c}5 \\
20 \%\end{array}$ & $\begin{array}{l}10 \\
10 \%\end{array}$ & $\begin{array}{l}20 \\
5 \%\end{array}$ & $\begin{array}{l}50 \psi \\
2 \%\end{array}$ & $\begin{array}{l}100 \dagger \\
1 \%\end{array}$ \\
\hline 1 & & & & & & \\
\hline $\begin{array}{r}14 \\
30 \\
60 \\
90 \\
120 \\
183\end{array}$ & $\begin{array}{l}0.00 \\
0.00 \\
0.74 \\
2.4 \\
4.6 \\
8.2\end{array}$ & $\begin{array}{l}0.00 \\
0.00 \\
0.20 \\
0.92 \\
2.4 \\
4.3\end{array}$ & $\begin{array}{l}0.00 \\
0.00 \\
0.09 \\
0.55 \\
1.9 \\
3.2\end{array}$ & $\begin{array}{l}0.00 \\
0.00 \\
0.05 \\
0.35 \\
1.5 \\
2.6\end{array}$ & $\begin{array}{l}0.00 \\
0.00 \\
0.02 \\
0.21 \\
1.3 \\
2.1\end{array}$ & $\begin{array}{l}0.00 \\
0.00 \\
0.01 \\
0.10 \\
1.1 \\
1.8\end{array}$ \\
\hline
\end{tabular}

MAGNITLDE AND PROBABILITY OF ANNUAL HIGH FLOW BASED ON PERIOD OF RECORD 1965-78, 1980-89

\begin{tabular}{|c|c|c|c|c|c|c|}
\hline \multirow{2}{*}{$\begin{array}{l}\text { PERIOD } \\
\text { (CON- } \\
\text { SEWU- } \\
\text { TIVE } \\
\text { DAYS) }\end{array}$} & & \multicolumn{5}{|c|}{$\begin{array}{l}\text { DISCHARGE, IN } \mathrm{FT}^{3} / \mathrm{S} \text {, FOR INDICATED } \\
\text { RECURRENCE INTERVAL, IN YEARS, AND } \\
\text { EXCEEDANCE PROBABILITY, IN PERCENT }\end{array}$} \\
\hline & $\begin{array}{c}2 \\
50 \%\end{array}$ & $\begin{array}{c}5 \\
20 \%\end{array}$ & $\begin{array}{l}10 \\
10 x\end{array}$ & $\begin{array}{l}25 \\
4 \%\end{array}$ & $\begin{array}{l}50 \dagger \\
2 \%\end{array}$ & $\underset{1 \%}{100} \uparrow$ \\
\hline $\begin{array}{c}1 \\
3 \\
7 \\
15 \\
30 \\
60 \\
90\end{array}$ & $\begin{array}{r}797 \\
511 \\
287 \\
180 \\
120 \\
70 \\
55\end{array}$ & $\begin{array}{r}1,830 \\
1,100 \\
591 \\
368 \\
259 \\
159 \\
125\end{array}$ & $\begin{array}{r}2,920 \\
1,680 \\
879 \\
537 \\
388 \\
246 \\
194\end{array}$ & $\begin{array}{r}4,950 \\
2,690 \\
1,360 \\
806 \\
600 \\
396 \\
315\end{array}$ & $\begin{array}{r}7,080 \\
3,690 \\
1,820 \\
1,050 \\
796 \\
541 \\
433\end{array}$ & $\begin{array}{r}9,860 \\
4,940 \\
2,380 \\
1,330 \\
1,030 \\
718 \\
579\end{array}$ \\
\hline
\end{tabular}

DURATION TABLE OF DAILY MEAN FLON FOR PERICD OF RECORD 1965-78, 1980-89

DISCHARGE, IN FT $3 / 5$, WHICH WAS EQUALED OR EXCEEDED FOR INDICATED PERCENT OF TIME

\begin{tabular}{|c|c|c|c|c|c|c|c|c|c|c|c|c|c|c|c|c|}
\hline $1 \%$ & $5 \%$ & $10 \%$ & $15 \%$ & $20 \%$ & $30 \%$ & $40 \%$ & $50 \%$ & $60 \%$ & $70 \%$ & $80 \%$ & $90 \%$ & $95 \%$ & $98 \%$ & $99 \%$ & $99.5 \%$ & $99.9 \%$ \\
\hline 516 & 169 & 71 & 33 & 17 & 8.2 & 4.9 & 3.6 & 2.3 & 1.3 & 0.62 & 0.00 & 0.00 & 0.00 & 0.00 & 0.00 & 0.00 \\
\hline
\end{tabular}

\footnotetext{
† Reliability of values in colum is uncertain, and potential errors are large.
} 
SAN JUAN RIVER BASIN

09379200 CHINLE CREEK NEAR MEXICAN MATER, AZ--CONTINUED
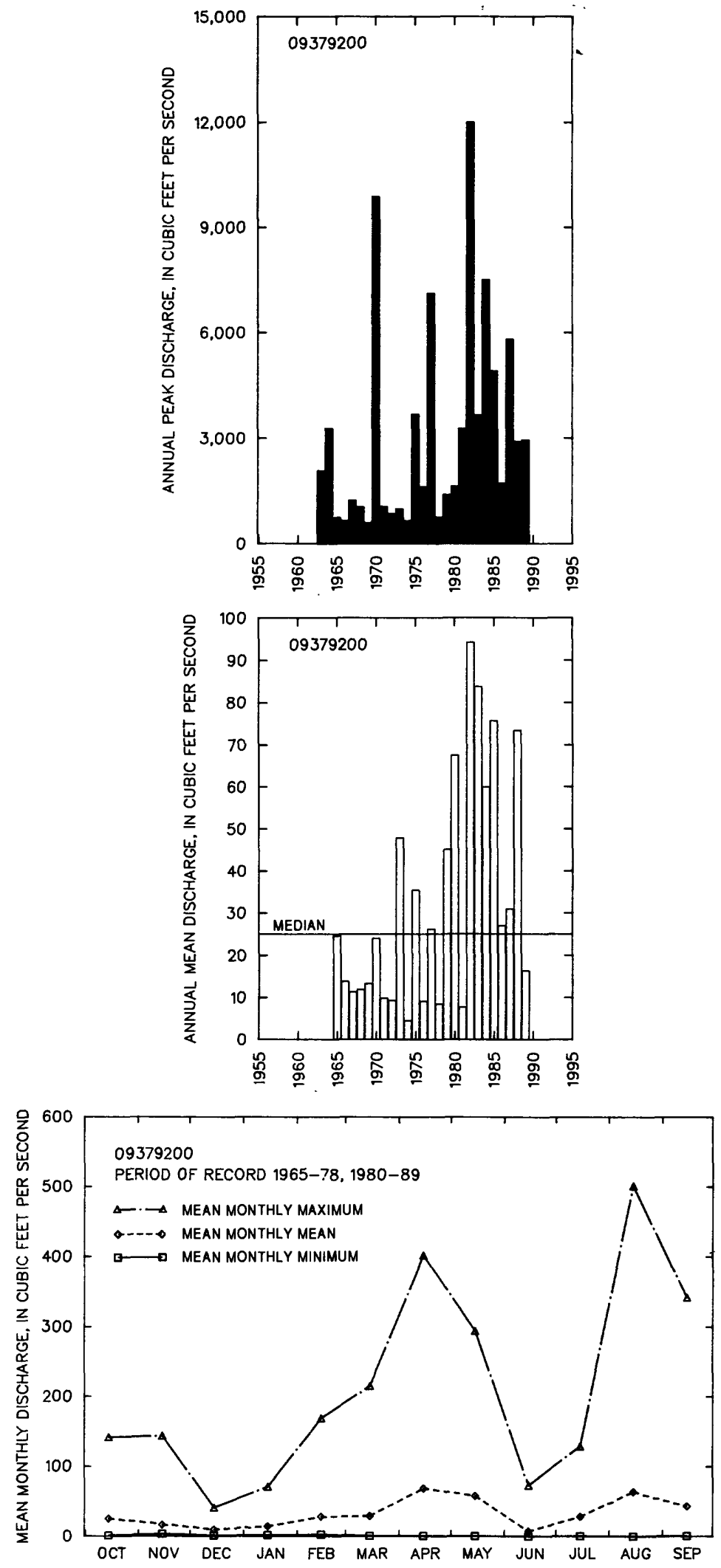
LOCATION.--Lat 36.51'32", Long 110'15'55", Navajo County, Hydrologic Unit 14080205, at U.S. Highway 163, 12 mi north of Kayenta.

ORAINAGE AREA. $--5.88 \mathrm{mi}^{2}$.

ANNUAL PEAK DISCHARGE

\begin{tabular}{lcc}
$\begin{array}{l}\text { MATER } \\
\text { YEAR }\end{array}$ & DATE & $\begin{array}{c}\text { ANNUAL PEAK } \\
\text { DISCHARGE } \\
\text { (FT } 3 / \text { S) }\end{array}$ \\
\hline 1963 & $08-30-63$ & 663 \\
1964 & $07-31-64$ & 181 \\
1965 & $08-02-65$ & 278 \\
1966 & $10-16-65$ & 185 \\
1967 & $09-00-67$ & 638 \\
1968 & $00-00-68$ & 1,225 \\
1969 & $10-04-68$ & 335 \\
1970 & $10-11-69$ & 390 \\
1971 & $08-26-71$ & 2,340 \\
1972 & $00-00-72$ & 1,320 \\
1973 & $10-19-72$ & 750 \\
1974 & $07-20-74$ & 145 \\
1975 & $07-00-75$ & 530 \\
1976 & $00-00-76$ & 301 \\
\hline
\end{tabular}

MAGNITUDE AND PROBABILITY OF INSTANTANEOUS PEAK FLON BASED ON PERIOD OF RECORD 1963-76

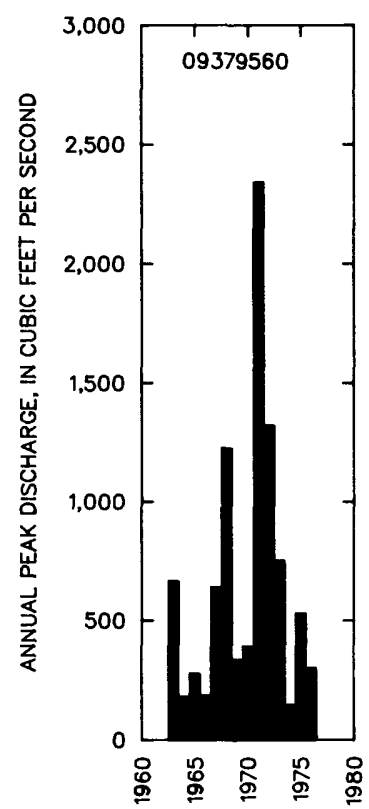

DISCHARGE, IN $\mathrm{FT}^{3} / \mathrm{S}$, FOR INDICATED RECURRENCE INTERVAL IN YEARS, AND EXCEEDANCE PROBABILITY, IN PERCENT

\begin{tabular}{|c|c|c|c|c|c|}
\hline $\begin{array}{c}2 \\
50 \%\end{array}$ & $\begin{array}{c}5 \\
20 \%\end{array}$ & $\begin{array}{r}10 \\
10 \%\end{array}$ & $\begin{array}{l}25 \\
4 \%\end{array}$ & $\begin{array}{l}50 \dagger \\
2 \%\end{array}$ & $\begin{array}{l}100 \dagger \\
1 \%\end{array}$ \\
\hline 470 & 952 & 1,390 & 2,100 & 2,760 & 3,530 \\
\hline $\begin{array}{l}\text { WEIGHTED } \\
\text { MEAN } \\
\text { STANDARD }\end{array}$ & $\begin{array}{l}\text { SKEW } \\
\text { DEV. }\end{array}$ & $\begin{array}{l}\text { LOGS) }= \\
\text { LOGS) }= \\
\text { LOGS) }=\end{array}$ & $\begin{array}{l}0.14 \\
2.68 \\
0.36\end{array}$ & & \\
\hline
\end{tabular}

f Reliability of values in column is uncertain, and potential errors are large.

BASIN CHARACTERISTICS

\begin{tabular}{|c|c|c|c|c|c|c|c|}
\hline MAIN & & $\begin{array}{l}\text { MEAN } \\
\text { BASIN }\end{array}$ & & & $\begin{array}{c}\text { MEAN } \\
\text { ANNUAL }\end{array}$ & RAINFALL IN & SITY, 24-HOUR \\
\hline $\begin{array}{l}\text { CHANNEL } \\
\text { SLOPE } \\
\text { (FT/MI) }\end{array}$ & $\begin{array}{l}\text { STREAM } \\
\text { LENGTH } \\
\text { (MI) }\end{array}$ & $\begin{array}{l}\text { ELEVA- } \\
\text { TION } \\
\text { (FT) }\end{array}$ & $\begin{array}{l}\text { FORESTED } \\
\text { AREA } \\
\text { (PERCENT) }\end{array}$ & $\begin{array}{l}\text { SOIL } \\
\text { INDEX }\end{array}$ & $\begin{array}{l}\text { PRECIPI- } \\
\text { TATION } \\
\text { (IN) }\end{array}$ & $\begin{array}{c}\text { 2-YEAR } \\
\text { (IN) }\end{array}$ & $\begin{array}{l}\text { 50-YEAR } \\
\text { (IN) }\end{array}$ \\
\hline 78.4 & 3.4 & 5,690 & 8.0 & 3.0 & 9.0 & 1.2 & 2.4 \\
\hline
\end{tabular}


09379980 JACK BENCH WASH TRIBUTARY NEAR PAGE, AZ

LOCATION.--Lat 36'42'50", Long 111'35'30", Coconino County, Hydrologic Unit 14070006, at U.S. Highway 89, $17 \mathrm{mi}$ south of Page.

DRAIMAGE AREA. $--0.98 \mathrm{mi}^{2}$.

ANNUAL PEAK DISCHARGE

\begin{tabular}{|c|c|c|c|}
\hline $\begin{array}{l}\text { WATER } \\
\text { YEAR }\end{array}$ & DATE & $\begin{array}{l}\text { ANNUAL PEAK } \\
\text { DISCHARGE } \\
\left(F^{3} / S\right)\end{array}$ & $\begin{array}{l}\text { DISCHARGE } \\
\text { COOES }\end{array}$ \\
\hline $\begin{array}{l}1962 \\
1963 \\
1964 \\
1965 \\
1966 \\
1967 \\
1968 \\
1969 \\
1970 \\
1971 \\
1972 \\
1973 \\
1974 \\
1975 \\
1976\end{array}$ & $\begin{array}{l}00-00-62 \\
00-00-63 \\
08-29-64 \\
00-00-65 \\
00-00-66 \\
07-16-67 \\
00-00-68 \\
00-00-69 \\
00-00-70 \\
00-00-71 \\
06-22-72 \\
00-00-73 \\
11-00-73 \\
00-00-75 \\
00-00-76\end{array}$ & $\begin{array}{c}200 \\
2.0 \\
1.0 \\
0 \\
0 \\
128 \\
0 \\
0 \\
0 \\
2.0 \\
10 \\
10 \\
125 \\
1.0 \\
99\end{array}$ & $\begin{array}{l}\text { LT } \\
\text { LT } \\
\text { LT } \\
\text { LT }\end{array}$ \\
\hline
\end{tabular}

MAGNITUDE AND PROBABILITY OF INSTANTANEOUS PEAK FLOW BASED ON PERIOD OF RECORD 1962-76

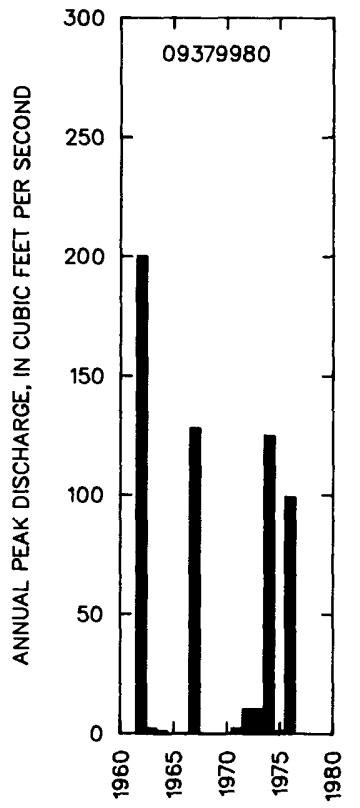

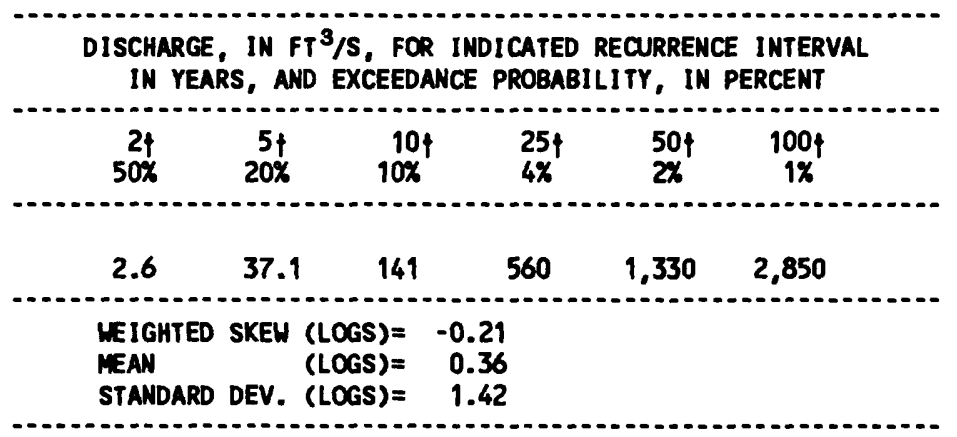

f Reliability of values in colum is uncertain, and potential errors are large.

BASIN CHARACTERISTICS

\begin{tabular}{|c|c|c|c|c|c|c|c|}
\hline \multirow{2}{*}{$\begin{array}{l}\text { MAIN } \\
\text { CHANNEL } \\
\text { SLOPE } \\
\text { (FT/MI) }\end{array}$} & \multirow[b]{2}{*}{$\begin{array}{c}\text { STREAM } \\
\text { LENGTH } \\
\text { (MI) }\end{array}$} & \multirow{2}{*}{$\begin{array}{l}\text { MEAN } \\
\text { BASIN } \\
\text { ELEVA- } \\
\text { TION } \\
\text { (FT) }\end{array}$} & \multirow[b]{2}{*}{$\begin{array}{l}\text { FORESTED } \\
\text { AREA } \\
\text { (PERCENT) }\end{array}$} & \multirow[b]{2}{*}{$\begin{array}{l}\text { SOIL } \\
\text { INDEX }\end{array}$} & \multirow{2}{*}{$\begin{array}{l}\text { MEAN } \\
\text { ANNUAL } \\
\text { PRECIPI- } \\
\text { TATION } \\
\text { (IN) }\end{array}$} & \multicolumn{2}{|c|}{ RAINFALL INTENSITY, 24-HOUR } \\
\hline & & & & & & $\begin{array}{c}\text { 2-YEAR } \\
\text { (IN) }\end{array}$ & $\begin{array}{l}\text { 50-YEAR } \\
\text { (IN) }\end{array}$ \\
\hline 133 & 2.6 & 6,180 & 22.0 & 3.0 & 8.8 & 1.3 & 2.7 \\
\hline
\end{tabular}


09380000 COLORADO RIVER AT LEES FERRY, AZ (National stream-qual ity account ing network)

LOCATION.--Lat 36.51'53", long 111.35'15", in NEKSEK sec.13, T.40 N., R.7 E., Coconino County, Hydrologic Unit 14070006, in Mavajo Indian Reservation, on left bank at head of Marble Gorge at Lees Ferry, just upstream from Paria River, $16 \mathrm{mi}$ downstream from Glen Camyon Dam, $28 \mathrm{mi}$ downstream from Utah-Arizona State line, and $61.5 \mathrm{mi}$ upstream from Little Colorado River.

DRAIMACE AREA. $--111,800 \mathrm{mi}^{2}$, approximately, including $3,959 \mathrm{mi}^{2}$ in Great Divide basin in southern Wyoming which is noncontributing.

REMARKS.--Flow regulated since Mar. 13, 1963, by Lake Powell, 16 mi upstream. Many diversions above Lake Powell for irrigation, municipal, and industrial use. No diversions or inflow between Lake Powell and the gage.

ANIUAL PEAK OISCHARGE

\begin{tabular}{|c|c|c|c|c|c|c|c|}
\hline $\begin{array}{l}\text { WATER } \\
\text { YEAR }\end{array}$ & DATE & $\begin{array}{l}\text { ANNUAL PEAK } \\
\text { OISCHARGE } \\
\left(\mathrm{FT}^{3} / \mathrm{S}\right)\end{array}$ & $\begin{array}{l}\text { DISCHARGE } \\
\text { CODES }\end{array}$ & $\begin{array}{l}\text { WATER } \\
\text { YEAR }\end{array}$ & DATE & $\begin{array}{l}\text { ANNUAL PEAK } \\
\text { DISCHARGE } \\
\left(\mathrm{FT}^{3} / \mathrm{S}\right)\end{array}$ & $\begin{array}{l}\text { DISCHARGE } \\
\text { CODES }\end{array}$ \\
\hline $\begin{array}{l}1884 \\
1921 \\
1922 \\
1923 \\
1924 \\
1925 \\
1926 \\
1927 \\
1928 \\
1929 \\
1930 \\
1931 \\
1932 \\
1933 \\
1934 \\
1935 \\
1936 \\
1937 \\
1938 \\
1939 \\
1940 \\
1941 \\
1942 \\
1943 \\
1944 \\
1945 \\
1946 \\
1947 \\
1948 \\
1949 \\
1950 \\
1951 \\
1952 \\
1953 \\
1954\end{array}$ & $\begin{array}{l}07-07-84 \\
06-18-21 \\
05-31-22 \\
05-31-23 \\
06-17-24 \\
06-03-25 \\
05-29-26 \\
07-01-27 \\
06-03-28 \\
05-29-29 \\
06-03-30 \\
05-21-31 \\
05-26-32 \\
06-05-33 \\
05-16-34 \\
06-19-35 \\
05-23-36 \\
05-20-37 \\
06-08-38 \\
05-26-39 \\
05-18-40 \\
05-17-41 \\
05-30-42 \\
06-05-43 \\
05-19-44 \\
05-17-45 \\
06-14-46 \\
05-13-47 \\
05-25-48 \\
06-22-49 \\
06-06-50 \\
06-01-51 \\
06-12-52 \\
06-17-53 \\
05-26-54\end{array}$ & $\begin{array}{r}300,000 \\
220,000 \\
116,000 \\
98,300 \\
76,200 \\
54,900 \\
86,500 \\
127,000 \\
115,000 \\
114,000 \\
73,300 \\
34,600 \\
102,000 \\
82,700 \\
25,300 \\
105,000 \\
76,300 \\
84,800 \\
101,000 \\
49,700 \\
47,200 \\
120,000 \\
92,800 \\
68,600 \\
94,400 \\
64,400 \\
50,400 \\
80,400 \\
92,400 \\
119,000 \\
60,600 \\
67,300 \\
123,000 \\
69,600 \\
34,300\end{array}$ & ES, HP & $\begin{array}{l}1955 \\
1956 \\
1957 \\
1958 \\
1959 \\
1960 \\
1961 \\
1962 \\
1963 \\
1964 \\
1965 \\
1966 \\
1967 \\
1968 \\
1969 \\
1970 \\
1971 \\
1972 \\
1973 \\
1974 \\
1975 \\
1976 \\
1977 \\
1978 \\
1979 \\
1980 \\
1981 \\
1982 \\
1983 \\
1984 \\
1985 \\
1986 \\
1987 \\
1988 \\
1989\end{array}$ & $\begin{array}{l}06-13-55 \\
06-06-56 \\
06-12-57 \\
06-01-58 \\
06-19-59 \\
06-08-60 \\
06-05-61 \\
05-16-62 \\
10-21-62 \\
04-28-64 \\
06-15-65 \\
05-03-66 \\
04-19-67 \\
07-19-68 \\
08-28-69 \\
08-26-70 \\
04-05-71 \\
07-12-72 \\
03-28-73 \\
01-02-74 \\
05-07-75 \\
05-19-76 \\
09-07-77 \\
01-23-78 \\
01-29-79 \\
06-24-80 \\
07-20-81 \\
05-25-82 \\
06-29-83 \\
08-12-84 \\
06-02-85 \\
05-13-86 \\
12-03-86 \\
07-28-88 \\
08-28-89\end{array}$ & $\begin{array}{r}35,600 \\
69,600 \\
126,000 \\
105,600 \\
38,900 \\
46,700 \\
40,200 \\
85,000 \\
19,200 \\
20,200 \\
60,200 \\
21,100 \\
22,500 \\
26,800 \\
26,100 \\
27,300 \\
28,700 \\
30,600 \\
31,000 \\
27,700 \\
28,400 \\
27,100 \\
29,000 \\
28,400 \\
28,600 \\
44,800 \\
25,900 \\
29,700 \\
97,300 \\
58,200 \\
47,900 \\
53,200 \\
31,500 \\
27,100 \\
28,400\end{array}$ & $\begin{array}{l}\text { KR } \\
\text { KR } \\
\text { KR } \\
\text { KR } \\
\text { KR } \\
\text { KR } \\
\text { KR } \\
\text { KR } \\
\text { KR } \\
\text { KR } \\
\text { KR } \\
\text { KR } \\
\text { KR } \\
\text { KR } \\
\text { KR } \\
\text { KR } \\
\text { KR } \\
\text { KR } \\
\text { KR } \\
\text { KR } \\
\text { KR } \\
\text { KR } \\
\text { KR } \\
\text { KR } \\
\text { KR } \\
\text { KR } \\
\text { KR }\end{array}$ \\
\hline
\end{tabular}


09380000 COLORADO RIVER AT LEES FERRY, AZ---Cont inued

MEAN MONTHLY AND ANNUAL DISCHARGES 1964-89

\begin{tabular}{|c|c|c|c|c|c|c|}
\hline MONTH & $\begin{array}{l}\operatorname{MAXIMN} \\
\left(F^{3} / S\right)\end{array}$ & $\begin{array}{l}\text { MINIMUM } \\
\left(\mathrm{FT}^{3} / \mathrm{S}\right)\end{array}$ & $\begin{array}{c}\text { MEAN } \\
\left(F T^{3 / S}\right)\end{array}$ & $\begin{array}{l}\text { STAN- } \\
\text { DARD } \\
\text { DEVIA- } \\
\text { TION } \\
\left(F T^{3} / S\right)\end{array}$ & $\begin{array}{l}\text { COEFFI - } \\
\text { CIENT OF } \\
\text { VARI - } \\
\text { ATION }\end{array}$ & $\begin{array}{c}\text { PERCENT } \\
\text { OF } \\
\text { ANNUAL } \\
\text { RUNOFF }\end{array}$ \\
\hline $\begin{array}{l}\text { OCTOBER } \\
\text { NOVEMBER } \\
\text { DECEMBER } \\
\text { JANUARY } \\
\text { FEBRUARY } \\
\text { MARCH } \\
\text { APRIL } \\
\text { MAY } \\
\text { JUNE } \\
\text { JULY } \\
\text { AUGUST } \\
\text { SEPTEMBER }\end{array}$ & $\begin{array}{l}25,600 \\
24,800 \\
25,000 \\
26,300 \\
26,700 \\
24,800 \\
29,100 \\
44,800 \\
55,700 \\
54,800 \\
29,800 \\
27,100\end{array}$ & $\begin{array}{l}1,000 \\
1,000 \\
1,020 \\
1,150 \\
4,010 \\
3,320 \\
2,750 \\
3,340 \\
1,000 \\
977 \\
2,840 \\
2,630\end{array}$ & $\begin{array}{l}10,700 \\
11,800 \\
12,400 \\
13,600 \\
12,000 \\
11,200 \\
14,000 \\
16,400 \\
18,500 \\
17,100 \\
16,300 \\
14,500\end{array}$ & $\begin{array}{r}\mathbf{5}, 000 \\
\mathbf{5}, 390 \\
\mathbf{5}, \mathbf{5 4 0} \\
\mathbf{5}, 560 \\
\mathbf{5}, 530 \\
\mathbf{5}, 270 \\
6,530 \\
10,800 \\
13,000 \\
10,200 \\
\mathbf{5}, 980 \\
\mathbf{5 , 6 6 0}\end{array}$ & $\begin{array}{l}0.47 \\
0.46 \\
0.45 \\
0.41 \\
0.46 \\
0.47 \\
0.47 \\
0.66 \\
0.70 \\
0.60 \\
0.37 \\
0.39\end{array}$ & $\begin{array}{r}6.4 \\
7.0 \\
7.4 \\
8.0 \\
7.1 \\
6.6 \\
8.3 \\
9.7 \\
11.0 \\
10.1 \\
9.7 \\
8.6\end{array}$ \\
\hline NNUAL & 28,200 & 3,330 & 14,000 & 5,600 & 0.40 & 100 \\
\hline
\end{tabular}

MAGNITUDE AND PROBABILITY OF ANNUAL LOW FLOW BASED ON PERIOD OF RECORD 1965-89

\begin{tabular}{|c|c|c|c|c|c|c|}
\hline \multirow{2}{*}{$\begin{array}{l}\text { PERIOD } \\
\text { (CON- } \\
\text { SECU- } \\
\text { TIVE } \\
\text { DAYS) }\end{array}$} & \multicolumn{6}{|c|}{$\begin{array}{l}\text { DISCHARGE, IN FT } 3 / 5 \text {, FOR INDICATED } \\
\text { RECURRENCE INTERVAL, IN YEARS, AND } \\
\text { NON-EXCEEDANCE PROBAB ILITY, IN PERCENT }\end{array}$} \\
\hline & $\begin{array}{c}2 \\
50 \%\end{array}$ & $\begin{array}{c}5 \\
20 \%\end{array}$ & $\begin{array}{l}10 \\
10 \%\end{array}$ & $\begin{array}{l}20 \\
5 \%\end{array}$ & $\begin{array}{l}50 \\
2 \%\end{array}$ & $\begin{array}{l}100 \uparrow \\
1 \%\end{array}$ \\
\hline $\begin{array}{r}1 \\
3 \\
7 \\
14 \\
30 \\
60 \\
90 \\
120 \\
183\end{array}$ & $\begin{array}{r}2,440 \\
3,710^{\circ} \\
5,110 \\
6,390 \\
7,830 \\
9,660 \\
11,100 \\
11,500 \\
12,100\end{array}$ & $\begin{array}{l}1,470 \\
1,960 \\
2,760 \\
3,500 \\
4,520 \\
5,650 \\
6,500 \\
7,220 \\
8,070\end{array}$ & $\begin{array}{l}1,110 \\
1,330 \\
1,880 \\
2,370 \\
3,110 \\
3,790 \\
4,320 \\
5,160 \\
6,160\end{array}$ & $\begin{array}{r}882 \\
1,040 \pm \\
1,320 \\
1,640 \\
2,170 \\
2,550 \\
2,860 \\
3,710 \\
4,770\end{array}$ & $\begin{array}{r}676 \\
770 \pm \\
859 \\
1,040 \\
1,380 \\
1,520 \\
1,650 \\
2,420 \\
3,440\end{array}$ & $\begin{array}{c}565 \\
580 \pm \\
629 \\
743 \\
982 \\
1,020 \\
1,090 \\
1,760 \\
2,710\end{array}$ \\
\hline
\end{tabular}

MAGNITUDE AND PROBABILITY OF ANNUAL HIGH FLOW BASED ON PERIOD OF RECORD 1964-89

\begin{tabular}{|c|c|c|c|c|c|c|}
\hline \multirow{2}{*}{$\begin{array}{l}\text { PERIOD } \\
\text { (CON- } \\
\text { SECU- } \\
\text { TIVE } \\
\text { DAYS) }\end{array}$} & & \multicolumn{5}{|c|}{$\begin{array}{l}\text { DISCHARGE, IN FT } 3 / 5 \text {, FOR INDICATED } \\
\text { RECURRENCE INTERVAL, IN YEARS, AND } \\
\text { EXCEEDANCE PROBABILITY, IN PERCENT }\end{array}$} \\
\hline & $\stackrel{2}{2}$ & $\begin{array}{c}5 \\
20 \%\end{array}$ & $\begin{array}{l}10 \\
10 \%\end{array}$ & $\begin{array}{l}25 \\
4 \%\end{array}$ & $\begin{array}{l}50 \\
2 \%\end{array}$ & $\begin{array}{c}100 \nmid \\
1 \%\end{array}$ \\
\hline $\begin{array}{r}1 \\
3 \\
7 \\
15 \\
30 \\
60 \\
90\end{array}$ & $\begin{array}{l}24,300 \\
23,400 \\
22,100 \\
21,000 \\
19,800 \\
18,500 \\
17,400\end{array}$ & $\begin{array}{l}35,800 \\
34,900 \\
33,600 \\
32,000 \\
30,300 \\
27,500 \\
25,400\end{array}$ & $\begin{array}{l}47,000 \\
45,900 \\
44,700 \\
42,400 \\
40,000 \\
35,600 \\
32,200\end{array}$ & $\begin{array}{l}66,300 \\
64,900 \\
64,000 \\
60,100 \\
56,100 \\
48,700 \\
42,600\end{array}$ & $\begin{array}{l}85,600 \\
83,600 \\
83,200 \\
77,500 \\
71,700 \\
61,000 \\
51,900\end{array}$ & $\begin{array}{l}110 \\
107 \\
108\end{array}$ \\
\hline
\end{tabular}

DURATION TABLE OF DAILY MEAN FLOW FOR PERIOD OF RECORD $1964-89$ DISCHARGE, IN FT 3/S, WHICH WAS EQUALED OR EXCEEDED FOR INDICATED PERCENT OF TIME

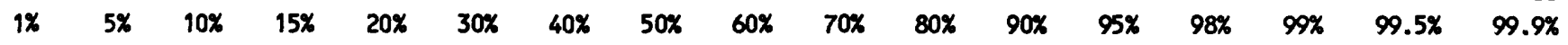

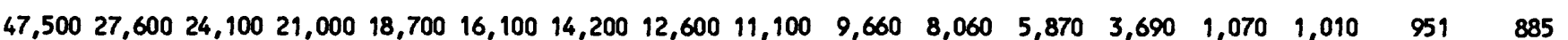

$\uparrow$ Reliability of values in colum is uncertain, and potential errors are large.

\pm Adjusted. 
09380000 COLORADO RIVER AT LEES FERRY, AZ--CONTINUED
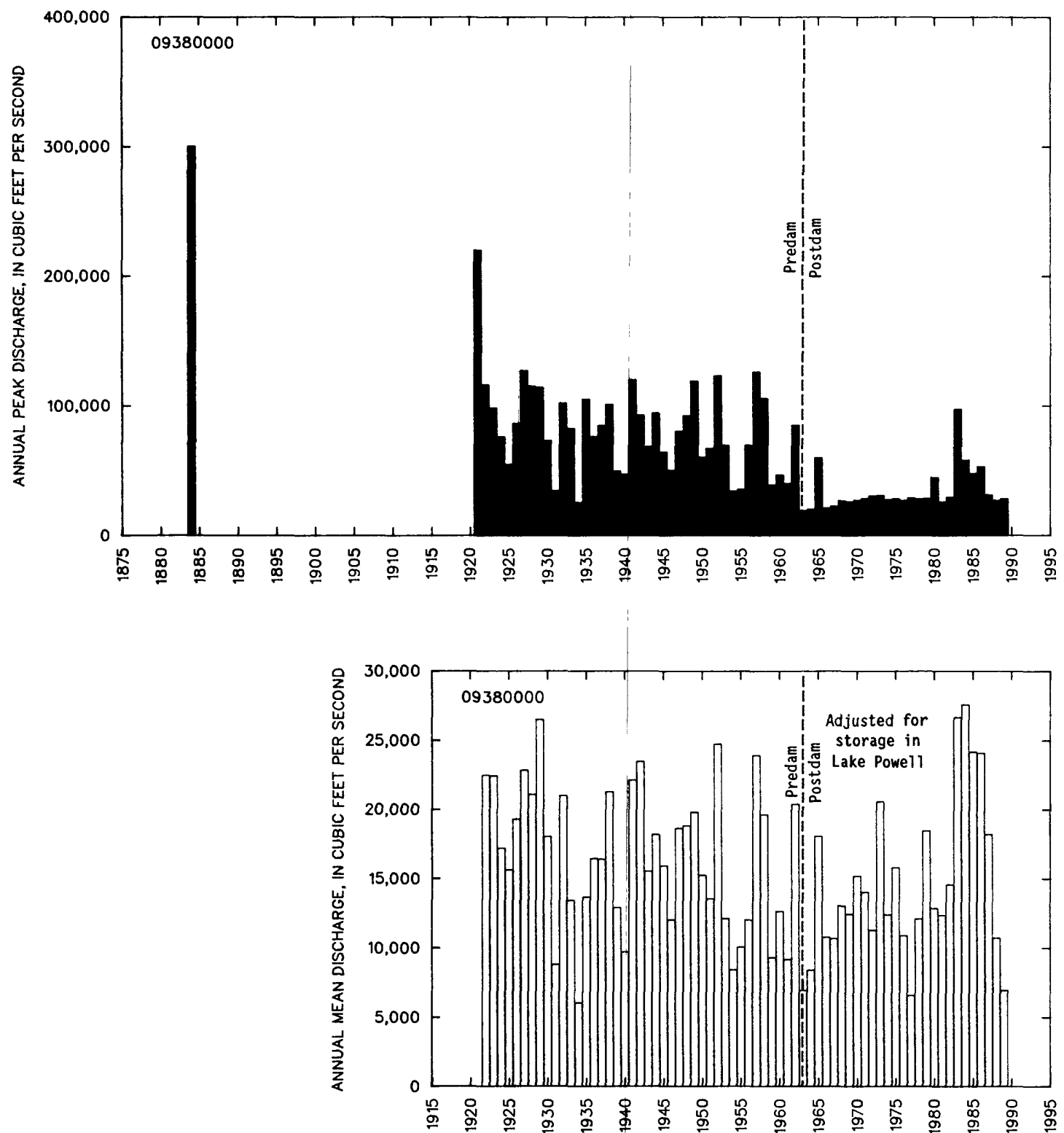
09380000 COLORADO RIVER AT LEES FERRY, AZ--CONTINUED
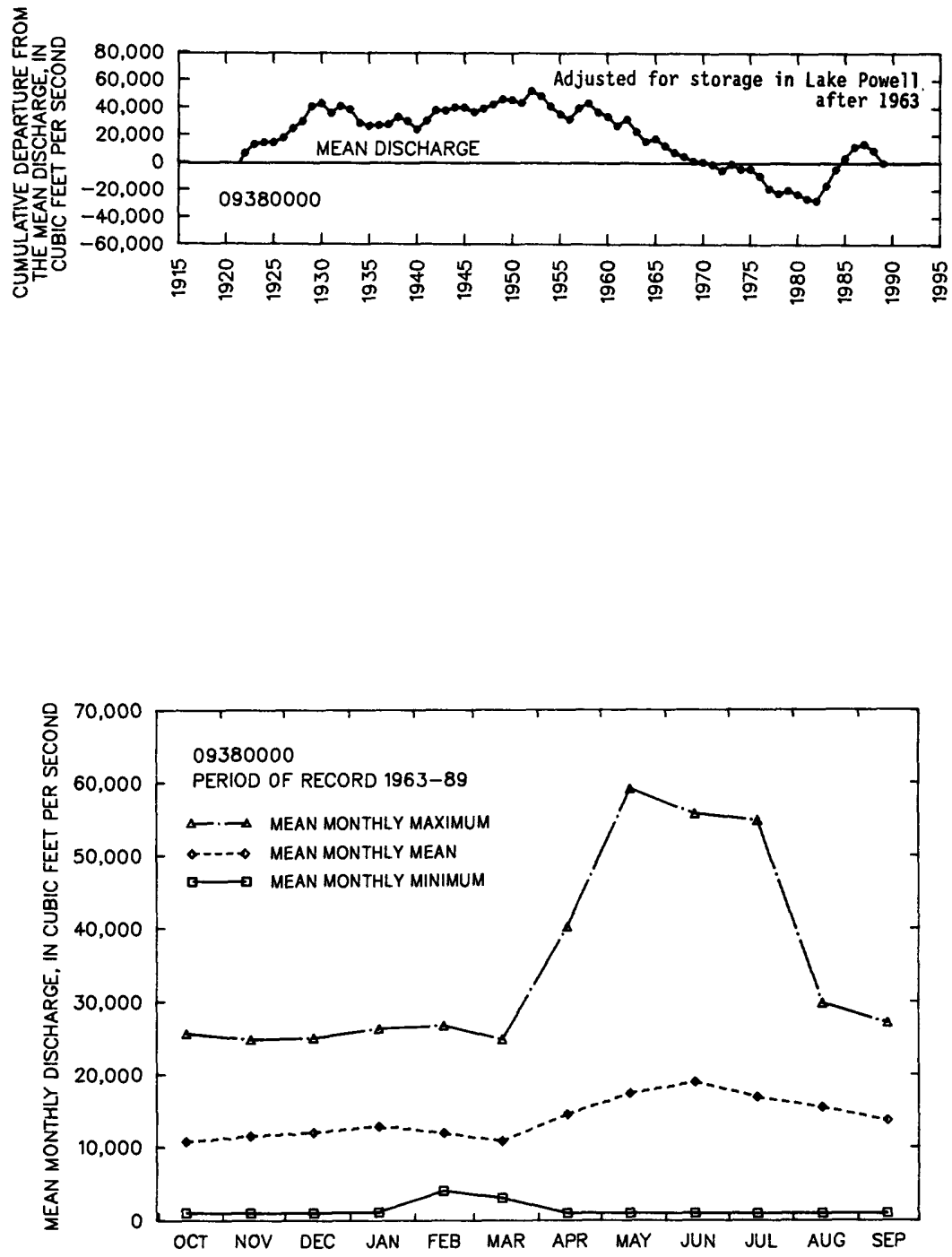
LOCATION.--Lat 36.52'20", Long 111'35'3", in WWHEK sec.13, T.40 N., R.7 E., Coconino County, Hydrologic Unit 14070007, on left bank 0.6 mi northwest of Lees Ferry, and 1.1 mi upstream from mouth.

DRAIMAGE AREA. $--1,410 \mathrm{mi}^{2}$.

REMARKS.--Diversions above station for irrigation of about 3,300 acres, mostly in southern Utah.

ANNUAL PEAK DISCHARGE

\begin{tabular}{|c|c|c|c|c|c|c|c|}
\hline $\begin{array}{l}\text { WATER } \\
\text { YEAR }\end{array}$ & DATE & $\begin{array}{c}\text { ANNUAL PEAK } \\
\text { DISCHARGE } \\
\text { (FT } 3 / S)\end{array}$ & $\begin{array}{l}\text { DISCHARGE } \\
\text { CODES }\end{array}$ & $\begin{array}{l}\text { WATER } \\
\text { YEAR }\end{array}$ & DATE & $\begin{array}{c}\text { ANNUAL PEAK } \\
\text { DISCHARGE } \\
\left(F^{3} / S\right)\end{array}$ & $\begin{array}{l}\text { DISCHARGE } \\
\text { CODES }\end{array}$ \\
\hline $\begin{array}{l}1924 \\
1925 \\
1926 \\
1927 \\
1928 \\
1929 \\
1930 \\
1931 \\
1932 \\
1933 \\
1934 \\
1935 \\
1936 \\
1937 \\
1938 \\
1939 \\
1940 \\
1941 \\
1942 \\
1943 \\
1944 \\
1945 \\
1946 \\
1947 \\
1948 \\
1949 \\
1950 \\
1951 \\
1952 \\
1953 \\
1954 \\
1955 \\
1956\end{array}$ & $\begin{array}{l}09-10-24 \\
09-19-25 \\
10-05-25 \\
09-13-27 \\
07-16-28 \\
08-02-29 \\
08-11-30 \\
11-18-30 \\
08-28-32 \\
08-22-33 \\
08-29-34 \\
09-01-35 \\
07-11-36 \\
08-29-37 \\
03-03-38 \\
09-13-39 \\
09-06-40 \\
07-24-41 \\
10-28-41 \\
08-22-43 \\
10-19-43 \\
09-03-45 \\
07-25-46 \\
08-22-47 \\
08-05-48 \\
09-29-49 \\
07-19-50 \\
08-04-51 \\
09-22-52 \\
08-27-53 \\
09-12-54 \\
08-17-55 \\
08-17-56\end{array}$ & $\begin{array}{r}4,330 \\
4,800 \\
16,100 \\
14,300 \\
2,960 \\
12,000 \\
7,150 \\
2,190 \\
10,500 \\
3,660 \\
8,400 \\
2,700 \\
8,700 \\
3,720 \\
7,440 \\
9,800 \\
14,000 \\
7,500 \\
1,680 \\
4,680 \\
8,400 \\
3,290 \\
4,980 \\
7,650 \\
6,150 \\
3,410 \\
1,340 \\
4,480 \\
1,830 \\
6,400 \\
3,980 \\
3,010 \\
1,420\end{array}$ & & $\begin{array}{l}1957 \\
1958 \\
1959 \\
1960 \\
1961 \\
1962 \\
1963 \\
1964 \\
1965 \\
1966 \\
1967 \\
1968 \\
1969 \\
1970 \\
1971 \\
1972 \\
1973 \\
1974 \\
1975 \\
1976 \\
1977 \\
1978 \\
1979 \\
1980 \\
1981 \\
1982 \\
1983 \\
1984 \\
1985 \\
1986 \\
1987 \\
1988 \\
1989\end{array}$ & $\begin{array}{l}08-22-57 \\
09-12-58 \\
08-19-59 \\
06-07-60 \\
08-04-61 \\
09-21-62 \\
09-01-63 \\
08-12-64 \\
09-06-65 \\
11-23-65 \\
12-07-66 \\
07-27-68 \\
01-26-69 \\
08-20-70 \\
08-26-71 \\
06-22-72 \\
10-19-72 \\
07-23-74 \\
07-30-75 \\
02-09-76 \\
08-17-77 \\
03-05-78 \\
11-03-78 \\
09-09-80 \\
08-14-81 \\
10-03-81 \\
07-25-83 \\
08-07-84 \\
08-07-85 \\
07-15-86 \\
08-08-87 \\
11-06-87 \\
08-11-89\end{array}$ & $\begin{array}{r}3,310 \\
11,500 \\
5,370 \\
370 \\
8,040 \\
2,830 \\
7,150 \\
2,360 \\
1,220 \\
2,140 \\
3,500 \\
4,090 \\
2,570 \\
3,010 \\
1,880 \\
4,750 \\
5,530 \\
520 \\
3,680 \\
718 \\
2,070 \\
1,270 \\
2,890 \\
8,520 \\
2,110 \\
2,400 \\
2,950 \\
1,880 \\
416 \\
3,520 \\
1,990 \\
910 \\
1,240\end{array}$ & ES \\
\hline
\end{tabular}

BASIN CHARACTERISTICS

\begin{tabular}{|c|c|c|c|c|c|c|c|}
\hline MAIN & & $\begin{array}{l}\text { MEAN } \\
\text { BASIN }\end{array}$ & & & $\begin{array}{c}\text { MEAN } \\
\text { ANNUAL }\end{array}$ & RAINFALL II & SITY, 24-HOUR \\
\hline $\begin{array}{l}\text { CHANNEL } \\
\text { SLOPE } \\
\text { (FT/MI) }\end{array}$ & $\begin{array}{l}\text { STREAM } \\
\text { LENGTH } \\
\text { (MI) }\end{array}$ & $\begin{array}{l}\text { ELEVA- } \\
\text { TION } \\
\text { (FT) }\end{array}$ & $\begin{array}{l}\text { FORESTED } \\
\text { AREA } \\
\text { (PERCENT) }\end{array}$ & $\begin{array}{l}\text { SOIL } \\
\text { INDEX }\end{array}$ & $\begin{array}{l}\text { PRECIPI - } \\
\text { TATION } \\
\text { (IN) }\end{array}$ & $\begin{array}{c}\text { 2-YEAR } \\
\text { (IN) }\end{array}$ & $\begin{array}{c}\text { 50-YEAR } \\
\text { (IN) }\end{array}$ \\
\hline 43.0 & 78.0 & 6,150 & 73.0 & 3.0 & 12.0 & 1.4 & 3.0 \\
\hline
\end{tabular}


09382000 PARIA RIVER AT LEES FERRY, AZ--Continued

MEAN MONTHLY AND ANNUAL DISCHARGES 1924-89

\begin{tabular}{|c|c|c|c|c|c|c|}
\hline MONTH & $\begin{array}{l}\operatorname{MAXIMU} \\
\left(\mathrm{FT}^{3} / \mathrm{S}\right)\end{array}$ & $\begin{array}{l}\text { MINIMUM } \\
\left(F T^{3} / S\right)\end{array}$ & $\begin{array}{c}\text { MEAN } \\
\left(F T^{3} / S\right)\end{array}$ & $\begin{array}{l}\text { STAN- } \\
\text { DARD } \\
\text { DEVIA- } \\
\text { TION } \\
\left(F T^{3} / S\right)\end{array}$ & $\begin{array}{l}\text { COEFFI - } \\
\text { CIENT OF } \\
\text { VARI - } \\
\text { ATION }\end{array}$ & $\begin{array}{c}\text { PERCENT } \\
\text { OF } \\
\text { ANNUAL } \\
\text { RUNOFF }\end{array}$ \\
\hline $\begin{array}{l}\text { OCTOBER } \\
\text { NOVEMBER } \\
\text { DECEMBER } \\
\text { JANUARY } \\
\text { FEBRUARY } \\
\text { MARCH } \\
\text { APRIL } \\
\text { MAY } \\
\text { JUNE } \\
\text { JULY } \\
\text { AUGUST } \\
\text { SEPTEMBER }\end{array}$ & $\begin{array}{r}288 \\
123 \\
69 \\
97 \\
242 \\
216 \\
93 \\
52 \\
58 \\
172 \\
237 \\
424\end{array}$ & $\begin{array}{c}6.0 \\
11 \\
8.8 \\
8.0 \\
16 \\
8.9 \\
4.9 \\
2.0 \\
2.0 \\
2.3 \\
4.5 \\
4.2\end{array}$ & $\begin{array}{l}30 \\
24 \\
22 \\
22 \\
38 \\
38 \\
21 \\
10 \\
7.2 \\
26 \\
58 \\
55\end{array}$ & $\begin{array}{l}43 \\
19 \\
9.9 \\
12 \\
33 \\
36 \\
19 \\
9.4 \\
9.5 \\
29 \\
51 \\
83\end{array}$ & $\begin{array}{l}1.4 \\
0.77 \\
0.46 \\
0.54 \\
0.86 \\
0.95 \\
0.91 \\
0.92 \\
1.3 \\
1.1 \\
0.87 \\
1.5\end{array}$ & $\begin{array}{r}8.6 \\
6.9 \\
6.1 \\
6.3 \\
10.8 \\
10.8 \\
6.0 \\
2.9 \\
2.0 \\
7.4 \\
16.5 \\
15.6\end{array}$ \\
\hline NNUAL & 65 & 11 & 29 & 12 & 0.40 & 100 \\
\hline
\end{tabular}

MAGNITUDE AND PROBABILITY OF INSTANTANEQUS PEAK FLON BASED ON PERIOD OF RECORD 1924-89

DISCHARGE, IN $\mathrm{FT}^{3} / \mathrm{S}$, FOR INDICATED RECURRENCE INTERVAL IN YEARS, AND EXCEEDANCE PROBABILITY, IN PERCENT

\begin{tabular}{lccccc}
2 & 5 & 10 & 25 & 50 & 100 \\
$50 \%$ & $20 \%$ & $10 \%$ & $4 \%$ & $2 \%$ & $1 \%$ \\
3,700 & 6,790 & 9,360 & 13,200 & 16,500 & 20,200 \\
\hline WEIGHTED SKEW (LOGS) & & 0.04 & & \\
MEAN & (LOGS) & $=3.57$ & & \\
STANDARD DEV. (LOGS) & $=0.31$
\end{tabular}

MAENITUDE AND PROBABILITY OF ANNUAL LON FLOW BASED ON PERIOD OF RECORD 1925-89

\begin{tabular}{|c|c|c|c|c|c|c|}
\hline \multirow{2}{*}{$\begin{array}{l}\text { PERIOD } \\
\text { (CON- - } \\
\text { SECU- } \\
\text { TIVE } \\
\text { DAYS) }\end{array}$} & \multicolumn{6}{|c|}{$\begin{array}{l}\text { DISCHARGE, IN FT } 3 / S \text {, FOR INDICATED } \\
\text { RECURRENCE INTERVAL, IN YEARS, AND } \\
\text { NON-EXCEEDANCE PROBABILITY, IN PERCENT }\end{array}$} \\
\hline & $\stackrel{2}{2}$ & $\begin{array}{c}5 \\
20 \%\end{array}$ & $\begin{array}{l}10 \\
10 \%\end{array}$ & $\begin{array}{l}20 \\
5 \%\end{array}$ & $\begin{array}{l}50 \\
2 \%\end{array}$ & $\begin{array}{l}100 \\
1 \%\end{array}$ \\
\hline $\begin{array}{r}1 \\
3 \\
7 \\
14 \\
30 \\
60 \\
90 \\
120 \\
183\end{array}$ & $\begin{array}{c}2.4 \\
2.7 \\
2.9 \\
3.1 \\
3.4 \\
4.3 \\
6.4 \\
11 \\
19\end{array}$ & $\begin{array}{r}1.8 \\
2.0 \\
2.3 \\
2.5 \\
2.8 \\
3.4 \\
4.4 \\
7.2 \\
13\end{array}$ & $\begin{array}{r}1.5 \\
1.7 \\
1.9 \\
2.2 \\
2.5 \\
3.1 \\
3.8 \\
5.7 \\
10\end{array}$ & $\begin{array}{l}1.2 \\
1.5 \\
1.7 \\
2.0 \\
2.3 \\
2.8 \\
3.3 \\
4.6 \\
8.5\end{array}$ & $\begin{array}{l}1.0 \\
1.2 \\
1.4 \\
1.8 \\
2.2 \\
2.7 \\
2.9 \\
3.6 \\
6.8\end{array}$ & $\begin{array}{l}0.89 \\
1.0 \\
1.2 \\
1.7 \\
2.1 \\
2.6 \\
2.7 \\
3.1 \\
5.8\end{array}$ \\
\hline
\end{tabular}

MAGNITLOE AND PROBABILITY OF ANNUAL HIGH FLOH BASED ON PERIOD OF RECORD 1924-89

\begin{tabular}{|c|c|c|c|c|c|c|}
\hline \multirow{2}{*}{$\begin{array}{l}\text { PERIOD } \\
\text { (CON- } \\
\text { SECU- } \\
\text { TIVE } \\
\text { DAYS) }\end{array}$} & \multicolumn{6}{|c|}{$\begin{array}{l}\text { DISCHARGE, IN } \mathrm{FT}^{3} / \mathrm{S} \text {, FOR INDICATED } \\
\text { RECURRENCE INTERVAL, IN YEARS, AND } \\
\text { EXCEEDANCE PROBABILITY, IN PERCENT }\end{array}$} \\
\hline & $\begin{array}{c}2 \\
50 x\end{array}$ & $\begin{array}{c}5 \\
20 \%\end{array}$ & $\begin{array}{l}10 \\
10 x\end{array}$ & $\begin{array}{l}25 \\
4 \%\end{array}$ & $\begin{array}{l}50 \\
2 \%\end{array}$ & $\begin{array}{r}100 \\
1 \%\end{array}$ \\
\hline $\begin{array}{r}1 \\
3 \\
7 \\
15 \\
30 \\
60 \\
90\end{array}$ & $\begin{array}{r}824 \\
423 \\
229 \\
139 \\
94 \\
64 \\
50\end{array}$ & $\begin{array}{r}1,790 \\
892 \\
458 \\
262 \\
168 \\
108 \\
80\end{array}$ & $\begin{array}{r}2,760 \\
1,360 \\
680 \\
376 \\
232 \\
145 \\
106\end{array}$ & $\begin{array}{r}4,450 \\
2,190 \\
1,060 \\
563 \\
332 \\
202 \\
145\end{array}$ & $\begin{array}{r}6,130 \\
3,010 \\
1,440 \\
740 \\
423 \\
252 \\
178\end{array}$ & $\begin{array}{r}8,220 \\
4,060 \\
1,900 \\
954 \\
529 \\
311 \\
217\end{array}$ \\
\hline
\end{tabular}

DURATION TABLE OF DAILY MEAN FLOW FOR PERIOD OF RECORD 1924-89 DISCHARGE, IN FT $3 / \mathrm{S}$, WHICH WAS EQUALED OR EXCEEDED FOR INDICATED PERCENT OF TIME

$1 \% \quad 5 \% \quad 10 \% \quad 15 \% \quad 20 \% \quad 30 \% \quad 40 \% \quad 50 \% \quad 60 \% \quad 70 \% \quad 80 \% \quad 90 \% \quad 95 \% \quad 98 \% \quad 99 \% \quad 99.5 \% \quad 99.9 \%$

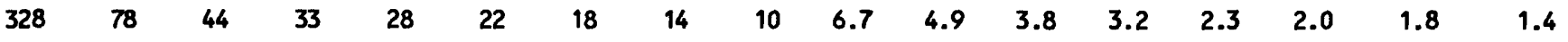


PARIA RIVER BASIN

09382000 PARIA RIVER AT LEES FERRY, AZ--CONTINUEd
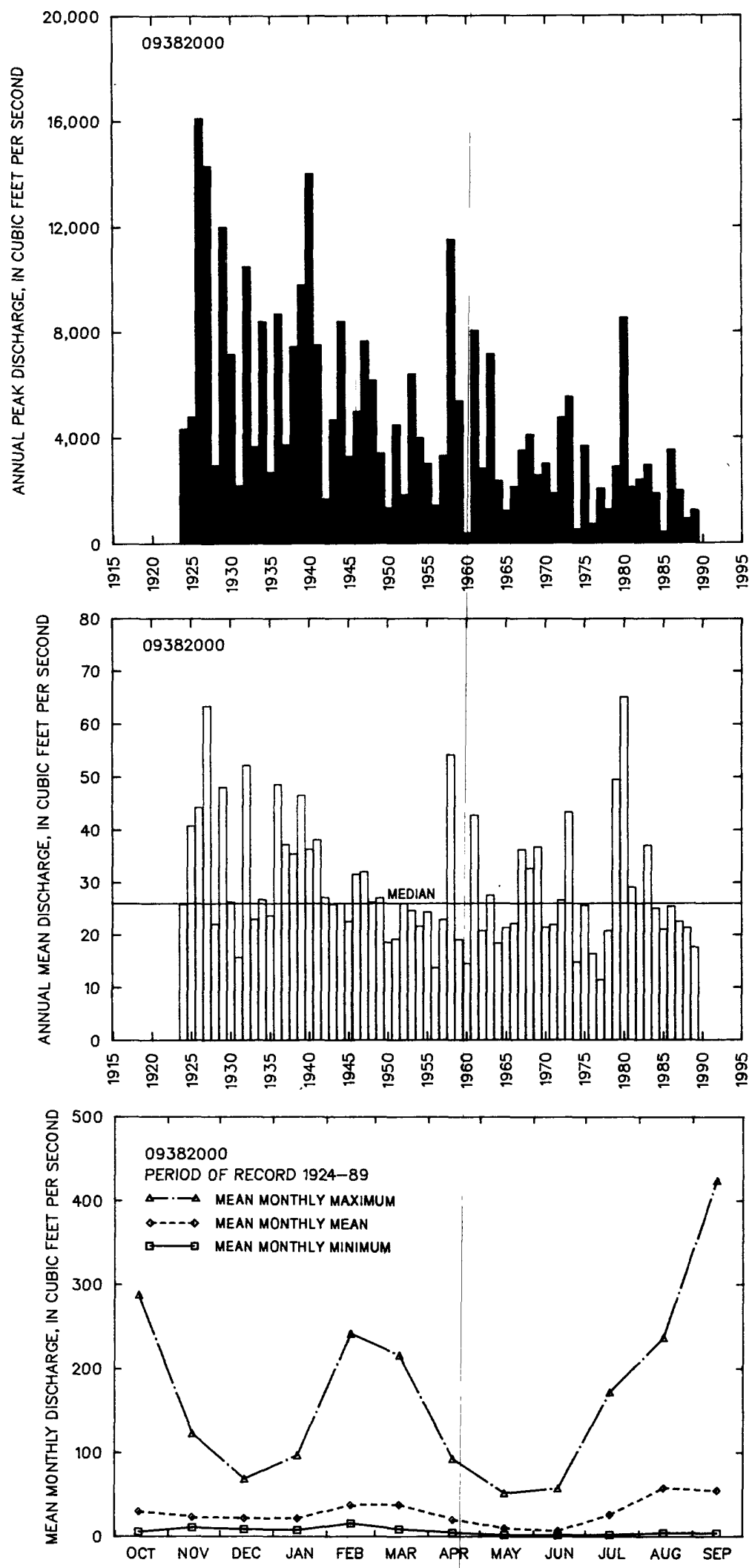
09383020 HOUSE ROCK WASH TRIBUTARY MEAR MARBLE CANYON, AZ

LOCATION.-- Lat 36'42'05", long 111'55'45", in SEKSEK sec.11, T.38 N., R.4 E., Coconino County, Hydrologic Unit 15010001, at U.S. Highway 89 Al ternate, 21 mi southwest of Marble Canyon Post Office.

DRAINAGE AREA. $--3.54 \mathrm{mi}^{2}$.

ANNUAL PEAK DISCHARGE

\begin{tabular}{lccc}
$\begin{array}{c}\text { WATER } \\
\text { YEAR }\end{array}$ & DATE & $\begin{array}{c}\text { ANNUAL PEAK } \\
\text { DISCHARGE } \\
\text { (FT } 3 / 5)\end{array}$ & $\begin{array}{c}\text { DISCHARGE } \\
\text { CODES }\end{array}$ \\
\hline 1963 & $09-04-63$ & 11,610 & HP \\
1963 & 10 & LT \\
1964 & $09-13-64$ & 50 & ES \\
1965 & $00-00-65$ & 10 & LT \\
1966 & $00-00-66$ & 5.0 & LT \\
1967 & $07-28-67$ & 24 & \\
1968 & $00-00-68$ & 39 & \\
1969 & $07-27-69$ & 19 & \\
1970 & $07-23-70$ & 100 & ES \\
1971 & $08-07-71$ & 58 & \\
1972 & $06-22-72$ & 80 & \\
1973 & $10-19-72$ & 197 & \\
1974 & $11-04-73$ & 5.0 & LT \\
1975 & $00-00-75$ & 5.0 & LT
\end{tabular}

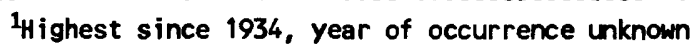

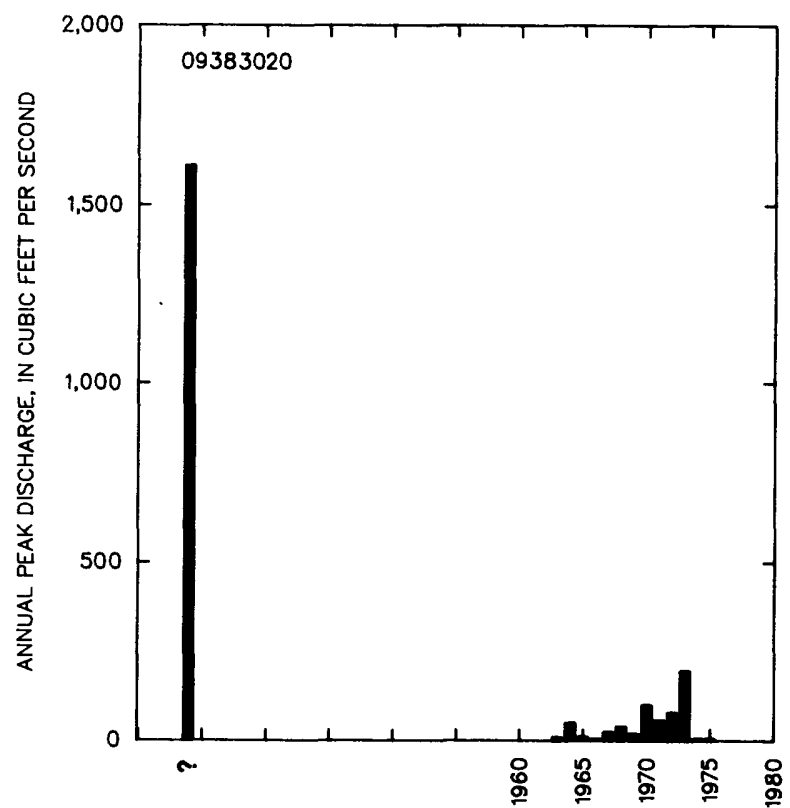

MAGNITUDE AND PROBABILITY OF INSTANTANEOUS PEAK FLOW BASED ON PERIOD OF RECORD 1934, 1963-75

DISCHARGE, IN $\mathrm{FT}^{3} / \mathrm{S}$, FOR INDICATED RECURRENCE INTERVAL IN YEARS, AND EXCEEDANCE PROBABILITY, IN PERCENT

\begin{tabular}{cccccc}
2 & 5 & 10 & 25 & 50 & $100 \uparrow$ \\
$50 \%$ & $20 \%$ & $10 \%$ & $4 \%$ & $2 \%$ & $1 \%$ \\
24.7 & 81.8 & 161 & 342 & 569 & 913 \\
\hline WEIGHTED SKEW (LOGS) & & 0.37 & & \\
MEAN & (LOGS) & 1.43 & & \\
STANDARD DEV. (LOGS) & $=0.59$
\end{tabular}

$\uparrow$ Reliability of values in column is uncertain, and potential errors are large.

BASIN CHARACTERISTICS

\begin{tabular}{|c|c|c|c|c|c|c|c|}
\hline \multirow{2}{*}{$\begin{array}{l}\text { MAIN } \\
\text { CHANNEL } \\
\text { SLOPE } \\
\text { (FT/MI) }\end{array}$} & \multirow[b]{2}{*}{$\begin{array}{l}\text { STREAM } \\
\text { LENGTH } \\
\text { (MI) }\end{array}$} & \multirow{2}{*}{$\begin{array}{l}\text { MEAN } \\
\text { BASIN } \\
\text { ELEVA- } \\
\text { TION } \\
\text { (FT) }\end{array}$} & \multirow[b]{2}{*}{$\begin{array}{l}\text { FORESTED } \\
\text { AREA } \\
\text { (PERCENT) }\end{array}$} & \multirow[b]{2}{*}{$\begin{array}{l}\text { SOIL } \\
\text { INDEX }\end{array}$} & \multirow{2}{*}{$\begin{array}{l}\text { MEAN } \\
\text { ANNUAL } \\
\text { PRECIPI- } \\
\text { TATION } \\
\text { (IN) }\end{array}$} & \multicolumn{2}{|c|}{ RAINFALL INTENSITY, 24-HOUR } \\
\hline & & & & & & $\begin{array}{c}\text { 2-YEAR } \\
\text { (IN) }\end{array}$ & $\begin{array}{c}\text { 50-YEAR } \\
\text { (IN) }\end{array}$ \\
\hline 209 & 3.7 & 5,290 & 2.3 & 3.0 & 9.6 & 1.5 & 3.2 \\
\hline
\end{tabular}


09383400 LITTLE COLORADO RIVER AT GREER, AZ

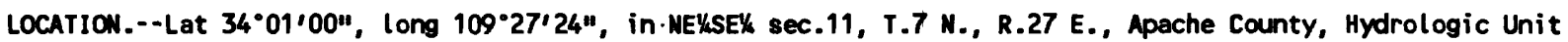
15020001 , in Apache-Sitgreaves National Forest, on upstream side of right abutment of culverts on State Highway 373, at Greer, $0.1 \mathrm{mi}$ downstream from Filler ditch.

DRAINAGE AREA. $--29.1 \mathrm{mi}^{2}$.

REMARKS. --filler ditch diverts about 1,700 acre-ft/yr from river $0.1 \mathrm{mi}$ above station.

ANNUAL PEAK DISCHARGE

\begin{tabular}{|c|c|c|c|}
\hline $\begin{array}{l}\text { WATER } \\
\text { YEAR }\end{array}$ & DATE & $\begin{array}{l}\text { ANIUUAL PEAK } \\
\text { DISCHARGE } \\
\left(F^{3} / S\right)\end{array}$ & $\begin{array}{l}\text { DISCHARGE } \\
\text { CODES }\end{array}$ \\
\hline $\begin{array}{l}1961 \\
1962 \\
1963 \\
1964 \\
1965 \\
1966 \\
1967 \\
1968 \\
1969 \\
1970 \\
1971 \\
1972 \\
1973 \\
1974 \\
1975 \\
1976 \\
1977 \\
1978 \\
1979 \\
1980 \\
1981 \\
1982 \\
1984\end{array}$ & $\begin{array}{l}04-05-61 \\
04-15-62 \\
03-28-63 \\
04-12-64 \\
04-22-65 \\
04-03-66 \\
08-11-67 \\
04-15-68 \\
09-08-69 \\
09-06-70 \\
08-29-71 \\
10-24-71 \\
10-20-72 \\
03-30-74 \\
04-26-75 \\
04-10-76 \\
04-09-77 \\
04-07-78 \\
04-26-79 \\
04-22-80 \\
04-10-81 \\
04-12-82 \\
10-02-83\end{array}$ & $\begin{array}{r}76 \\
277 \\
108 \\
135 \\
355 \\
326 \\
216 \\
316 \\
414 \\
112 \\
42 \\
108 \\
615 \\
45 \\
231 \\
97 \\
174 \\
78 \\
247 \\
221 \\
100 \\
212 \\
444\end{array}$ & HP \\
\hline
\end{tabular}

BASIN CHARACTERISTICS

\begin{tabular}{|c|c|c|c|c|c|c|c|}
\hline \multirow{2}{*}{$\begin{array}{l}\text { MAIN } \\
\text { CHANNEL } \\
\text { SLOPE } \\
\text { (FT/MI) }\end{array}$} & \multirow[b]{2}{*}{$\begin{array}{c}\text { STREAM } \\
\text { LENGTH } \\
\text { (MI) }\end{array}$} & \multirow{2}{*}{$\begin{array}{l}\text { MEAN } \\
\text { BASIN } \\
\text { ELEVA- } \\
\text { TION } \\
\text { (FT) }\end{array}$} & \multirow[b]{2}{*}{$\begin{array}{l}\text { FORESTED } \\
\text { AREA } \\
\text { (PERCENT) }\end{array}$} & \multirow[b]{2}{*}{$\begin{array}{l}\text { SOIL } \\
\text { INDEX }\end{array}$} & \multirow{2}{*}{$\begin{array}{l}\text { MEAN } \\
\text { ANNUAL } \\
\text { PRECIPI- } \\
\text { TATION } \\
\text { (IN) }\end{array}$} & \multicolumn{2}{|c|}{ RAINFALL INTENSITY, 24-HOUR } \\
\hline & & & & & & $\begin{array}{c}\text { 2-YEAR } \\
\text { (IN) }\end{array}$ & $\begin{array}{l}\text { 50-YEAR } \\
\text { (IN) }\end{array}$ \\
\hline 180 & 10.4 & 9,400 & 69.0 & 2.9 & 31.2 & 2.8 & 5.1 \\
\hline
\end{tabular}


09383400 LITTLE COLORADO RIVER AT GREER, AZ--Cont inued

MEAN MONTHLY AND ANNUAL DISCHARGES 1961-82

\begin{tabular}{|c|c|c|c|c|c|c|}
\hline MONTH & $\begin{array}{l}\operatorname{MAX}[\operatorname{MUM} \\
\left(F T^{3} / S\right)\end{array}$ & $\begin{array}{l}\text { MINIMUM } \\
\left(\mathrm{FT}^{3} / \mathrm{S}\right)\end{array}$ & $\begin{array}{c}\text { MEAN } \\
\left(F T^{3} / S\right)\end{array}$ & $\begin{array}{l}\text { STAN- } \\
\text { DARD } \\
\text { DEVIA- } \\
\text { TION } \\
\text { (FT'/S) }\end{array}$ & $\begin{array}{l}\text { COEFFI- } \\
\text { CIENT OF } \\
\text { VARI - } \\
\text { ATION }\end{array}$ & $\begin{array}{c}\text { PERCENT } \\
\text { OF } \\
\text { ANNUAL } \\
\text { RUNOFF }\end{array}$ \\
\hline $\begin{array}{l}\text { OCTOBER } \\
\text { NOVEMBER } \\
\text { DECEMBER } \\
\text { JANUARY } \\
\text { FEBRUARY } \\
\text { MARCH } \\
\text { APRIL } \\
\text { MAY } \\
\text { JUNE } \\
\text { JULY } \\
\text { AUGUST } \\
\text { SEPTEMBER }\end{array}$ & $\begin{array}{r}35 \\
11 \\
15 \\
18 \\
17 \\
26 \\
107 \\
163 \\
96 \\
28 \\
54 \\
37\end{array}$ & $\begin{array}{l}0.64 \\
0.99 \\
1.6 \\
2.3 \\
2.8 \\
3.5 \\
7.4 \\
7.3 \\
6.4 \\
5.9 \\
5.7 \\
5.0\end{array}$ & $\begin{array}{l}5.9 \\
4.4 \\
5.6 \\
6.2 \\
7.2 \\
9.7 \\
43 \\
41 \\
26 \\
13 \\
14 \\
11\end{array}$ & $\begin{array}{c}7.3 \\
2.7 \\
3.3 \\
3.2 \\
3.3 \\
5.0 \\
30 \\
37 \\
24 \\
6.7 \\
9.9 \\
7.4\end{array}$ & $\begin{array}{l}1.2 \\
0.61 \\
0.59 \\
0.51 \\
0.47 \\
0.51 \\
0.70 \\
0.89 \\
0.91 \\
0.51 \\
0.69 \\
0.67\end{array}$ & $\begin{array}{r}3.2 \\
2.4 \\
3.0 \\
3.3 \\
3.8 \\
5.2 \\
22.8 \\
22.0 \\
13.9 \\
7.0 \\
7.7 \\
5.9\end{array}$ \\
\hline ANNUAL & 38 & 6.0 & 16 & 8.3 & 0.53 & 100 \\
\hline
\end{tabular}

MAGNITUDE AND PROBABILITY OF INSTANTANEOUS PEAK FLOW BASED ON PERICD OF RECORD 1961-82, 1984

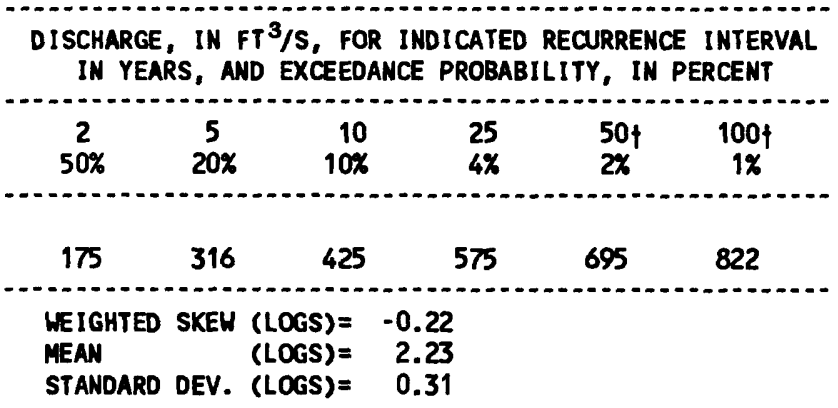

MAGNITLDE AND PROBABILITY OF ANNUAL LON FLON BASED ON PERIOD OF RECORD 1962-82

\begin{tabular}{|c|c|c|c|c|c|c|}
\hline \multirow{2}{*}{$\begin{array}{l}\text { PERIOD } \\
\text { (CON- } \\
\text { SECU- } \\
\text { TIVE } \\
\text { DAYS) }\end{array}$} & \multicolumn{6}{|c|}{$\begin{array}{l}\text { DISCHARGE, IN FT } 3 / S \text {, FOR INDICATED } \\
\text { RECURRENCE INTERVAL, IN YEARS, AND } \\
\text { MON-EXCEEDANCE PROBABILITY, IN PERCENT }\end{array}$} \\
\hline & $\begin{array}{c}2 \\
50 \%\end{array}$ & $\begin{array}{c}5 \\
20 \%\end{array}$ & $\begin{array}{l}10 \\
10 \%\end{array}$ & $\begin{array}{l}20 \\
5 \%\end{array}$ & $\begin{array}{l}50 \dagger \\
2 \%\end{array}$ & $\begin{array}{l}100 t \\
1 \%\end{array}$ \\
\hline $\begin{array}{r}1 \\
3 \\
7 \\
14 \\
30 \\
60 \\
90 \\
120 \\
183\end{array}$ & $\begin{array}{l}2.0 \\
2.2 \\
2.3 \\
2.5 \\
2.5 \\
3.0 \\
3.6 \\
4.4\end{array}$ & $\begin{array}{l}0.99 \\
1.1 \\
1.1 \\
1.2 \\
1.4 \\
1.8 \\
2.3 \\
3.1 \\
4.2\end{array}$ & $\begin{array}{l}0.57 \\
0.61 \\
0.63 \\
0.66 \\
0.96 \\
1.3 \\
1.8 \\
2.6 \\
3.6\end{array}$ & $\begin{array}{l}0.32 \\
0.34 \\
0.34 \\
0.36 \\
0.69 \\
1.0 \\
1.5 \\
2.2 \\
3.2\end{array}$ & $\begin{array}{l}0.15 \\
0.15 \\
0.15 \\
0.16 \\
0.46 \\
0.77 \\
1.2 \\
1.8 \\
2.8\end{array}$ & $\begin{array}{l}0.08 \\
0.08 \\
0.08 \\
0.08 \\
0.35 \\
0.63 \\
0.98 \\
1.5 \\
2.6\end{array}$ \\
\hline
\end{tabular}

MAGNITLDE AND PROBABILITY OF ANNUAL HIGH FLON BASED ON PERIOD OF RECORD 1961-82

\begin{tabular}{|c|c|c|c|c|c|c|}
\hline \multirow{2}{*}{$\begin{array}{l}\text { PERIOD } \\
\text { (CON- } \\
\text { SECU- } \\
\text { TIVE } \\
\text { DAYS) }\end{array}$} & \multicolumn{6}{|c|}{$\begin{array}{l}\text { DISCHARGE, IN } \mathrm{FT}^{3} / \mathrm{S} \text {, FOR INDICATED } \\
\text { RECURRENCE INTERVAL, IN YEARS, AND } \\
\text { EXCEEDANCE PROBABILITY, IN PERCENT }\end{array}$} \\
\hline & 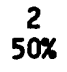 & $\begin{array}{c}5 \\
20 \%\end{array}$ & $\begin{array}{l}10 \\
10 \%\end{array}$ & $\begin{array}{l}25 \\
4 \%\end{array}$ & $\begin{array}{l}50 \dagger \\
2 \%\end{array}$ & $\underset{1 \%}{100 \dagger}$ \\
\hline $\begin{array}{r}1 \\
3 \\
7 \\
15 \\
30 \\
60 \\
90\end{array}$ & $\begin{array}{l}95 \\
82 \\
68 \\
55 \\
45 \\
37 \\
31\end{array}$ & $\begin{array}{r}164 \\
146 \\
124 \\
105 \\
87 \\
70 \\
57\end{array}$ & $\begin{array}{r}213 \\
193 \\
167 \\
147 \\
121 \\
97 \\
78\end{array}$ & $\begin{array}{l}277 \\
255 \\
227 \\
208 \\
172 \\
137 \\
109\end{array}$ & $\begin{array}{l}325 \\
303 \\
275 \\
259 \\
215 \\
169 \\
134\end{array}$ & $\begin{array}{l}374 \\
352 \\
325 \\
315 \\
262 \\
205 \\
162\end{array}$ \\
\hline
\end{tabular}

DURATION TABLE OF DAILY MEAN FLON FOR PERIOD OF RECORD 1961-82

DISCHARGE, IN FT $3 / \mathrm{S}$, HHICH WAS EQUALED OR EXCEEDED FOR INDICATED PERCENT OF TIME

\begin{tabular}{|c|c|c|c|c|c|c|c|c|c|c|c|c|c|c|c|c|}
\hline $1 \%$ & $5 \%$ & $10 \%$ & $15 \%$ & $20 \%$ & $30 \%$ & $40 \%$ & $50 x$ & $60 x$ & $70 \%$ & $80 \%$ & $90 \%$ & $95 \%$ & $98 \%$ & $99 \%$ & $99.5 \%$ & $99.9 \%$ \\
\hline 133 & 58 & 36 & 26 & 20 & 13 & 10 & 8.2 & 6.8 & 5.5 & 4.1 & 2.7 & 1.8 & 1.3 & 0.96 & 0.73 & 0.1 \\
\hline
\end{tabular}

† Reliability of values in colum is uncertain, and potential errors are large. 

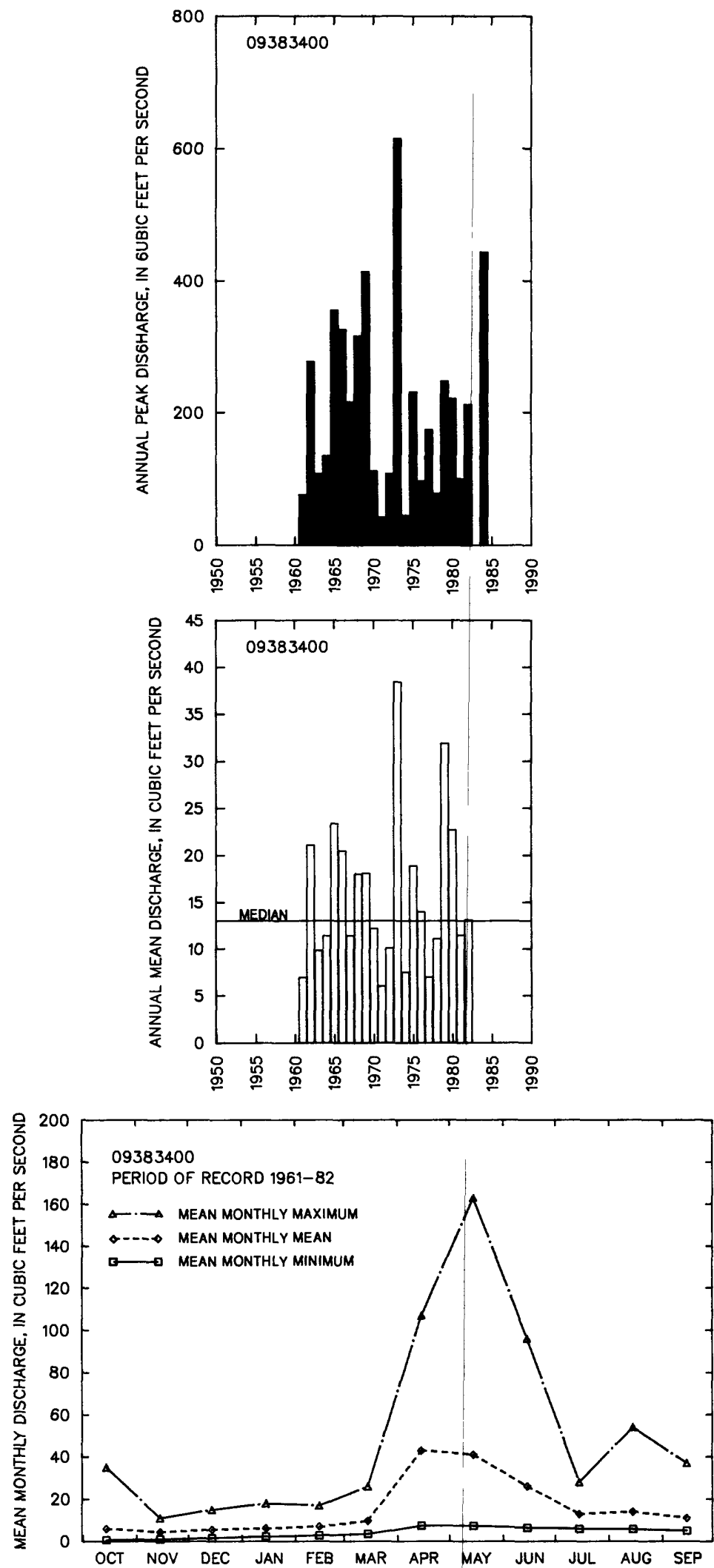
09383500 MUTRIOSO CREEK ABOVE NELSON RESERVOIR, NEAR SPRINGERVILLE, AZ

LOCATION.--Lat 34.01'49", long 109.11'09", in NEKSWK sec.4, T.7 N., R.30 E., Apache County, Hydrologic Unit 15020001, in Apache-Sitgreaves National Forest, on right bank 2.4 mi upstream from dam on Nelson Reservoir and $9 \mathrm{mi}$ southeast of Springerville.

DRAINAGE AREA. $--83.3 \mathrm{mi}^{2}$.

ANNUAL PEAK DISChARGE

\begin{tabular}{cccc}
$\begin{array}{c}\text { WATER } \\
\text { YEAR }\end{array}$ & DATE & $\begin{array}{c}\text { ANIWAL PEAK } \\
\text { DISCHARGE } \\
\text { (FT } 3 / \text { S })\end{array}$ & $\begin{array}{c}\text { DISCHARGE } \\
\text { COCES }\end{array}$ \\
\hline 1967 & $09-05-67$ & 126 & \\
1968 & $04-15-68$ & 121 & \\
1969 & $09-08-69$ & 133 & \\
1970 & $04-11-70$ & 30 & \\
1971 & $09-01-71$ & 291 & \\
1972 & $10-25-71$ & 67 & \\
1973 & $04-28-73$ & 439 & \\
1974 & $03-31-74$ & 7.1 & \\
1975 & $04-25-75$ & 142 & \\
1976 & $04-05-76$ & 41 & \\
1977 & $09-03-77$ & 90 & \\
1978 & $03-31-78$ & 88 & \\
1979 & $12-18-78$ & 462 & \\
1980 & $04-21-80$ & 174 & \\
1981 & $04-10-81$ & 29 & \\
1982 & $04-13-82$ & 37 & \\
1984 & $10-02-83$ & 700 & \\
\hline
\end{tabular}

BASIN CHARACTERISTICS

\begin{tabular}{|c|c|c|c|c|c|c|c|}
\hline \multirow{2}{*}{$\begin{array}{c}\text { MAIN } \\
\text { CHANNEL } \\
\text { SLOPE } \\
\text { (FT/MI) }\end{array}$} & \multirow[b]{2}{*}{$\begin{array}{l}\text { STREAM } \\
\text { LENGTH } \\
\text { (MI) }\end{array}$} & \multirow{2}{*}{$\begin{array}{l}\text { MEAN } \\
\text { BASIN } \\
\text { ELEVA- } \\
\text { TION } \\
\text { (FT) }\end{array}$} & \multirow[b]{2}{*}{$\begin{array}{l}\text { FORESTED } \\
\text { AREA } \\
\text { (PERCENT) }\end{array}$} & \multirow[b]{2}{*}{$\begin{array}{l}\text { SOIL } \\
\text { INDEX }\end{array}$} & \multirow{2}{*}{$\begin{array}{l}\text { MEAN } \\
\text { ANNUAL } \\
\text { PRECIPI- } \\
\text { TATION } \\
\text { (IN) }\end{array}$} & \multicolumn{2}{|c|}{ RAINFALL INTENSITY, 24-HOUR } \\
\hline & & & & & & $\begin{array}{c}\text { 2-YEAR } \\
\text { (IN) }\end{array}$ & $\begin{array}{l}\text { 50-YEAR } \\
\text { (IN) }\end{array}$ \\
\hline 78.0 & 12.6 & 8,550 & 75.0 & 3.0 & 20.0 & 1.7 & 3.4 \\
\hline
\end{tabular}


09383500 nUTRIOSO CREeK ABOVE MELSON RESERVOIR, MEAR SPRINGerVILLE, AZ--Cont inued

MEAN MONTHLY AND ANNUAL DISCHARGES $1968-82$

\begin{tabular}{|c|c|c|c|c|c|c|}
\hline MONTH & $\begin{array}{l}\text { MAXIMUM } \\
\left(F T^{3} / S\right)\end{array}$ & $\begin{array}{l}\text { MINIMUM } \\
\left.\text { (FT }^{3} / S\right)\end{array}$ & $\begin{array}{c}\text { MEAN } \\
\left(F T^{3} / S\right)\end{array}$ & $\begin{array}{l}\text { STAN- } \\
\text { DARD } \\
\text { DEVIA- } \\
\text { TION } \\
\text { (FT } 3 / S)\end{array}$ & $\begin{array}{l}\text { COEFFI- } \\
\text { CIENT OF } \\
\text { VARI - } \\
\text { ATION }\end{array}$ & $\begin{array}{c}\text { PERCENT } \\
\text { OF } \\
\text { ANNUAL } \\
\text { RUNOFF }\end{array}$ \\
\hline $\begin{array}{l}\text { OCTOBER } \\
\text { NOVEMBER } \\
\text { DECEMBER } \\
\text { JANUARY } \\
\text { FEBRUARY } \\
\text { MARCH } \\
\text { APRIL } \\
\text { MAY } \\
\text { JUNE } \\
\text { JULY } \\
\text { AUGUST } \\
\text { SEPTEMBER }\end{array}$ & $\begin{array}{c}16 \\
6.4 \\
26 \\
9.5 \\
16 \\
32 \\
106 \\
117 \\
12 \\
7.1 \\
5.0 \\
11\end{array}$ & $\begin{array}{l}0.00 \\
0.20 \\
0.15 \\
0.17 \\
0.23 \\
0.39 \\
0.20 \\
0.12 \\
0.01 \\
0.00 \\
0.00 \\
0.00\end{array}$ & $\begin{array}{l}2.4 \\
1.7 \\
2.8 \\
2.2 \\
3.9 \\
9.1 \\
28 \\
15 \\
2.0 \\
0.93 \\
1.2 \\
1.8\end{array}$ & $\begin{array}{l}4.3 \\
2.1 \\
6.6 \\
2.7 \\
4.3 \\
9.0 \\
35 \\
30 \\
3.7 \\
1.8 \\
1.3 \\
2.8\end{array}$ & $\begin{array}{l}1.8 \\
1.2 \\
2.3 \\
1.2 \\
1.1 \\
0.99 \\
1.2 \\
2.0 \\
1.8 \\
1.9 \\
1.1 \\
1.6\end{array}$ & $\begin{array}{r}3.3 \\
2.4 \\
4.0 \\
3.1 \\
5.5 \\
12.8 \\
39.8 \\
20.8 \\
2.9 \\
1.3 \\
1.6 \\
2.5\end{array}$ \\
\hline NWU & 25 & 0.56 & 5.9 & 7.1 & 1.2 & 100 \\
\hline
\end{tabular}

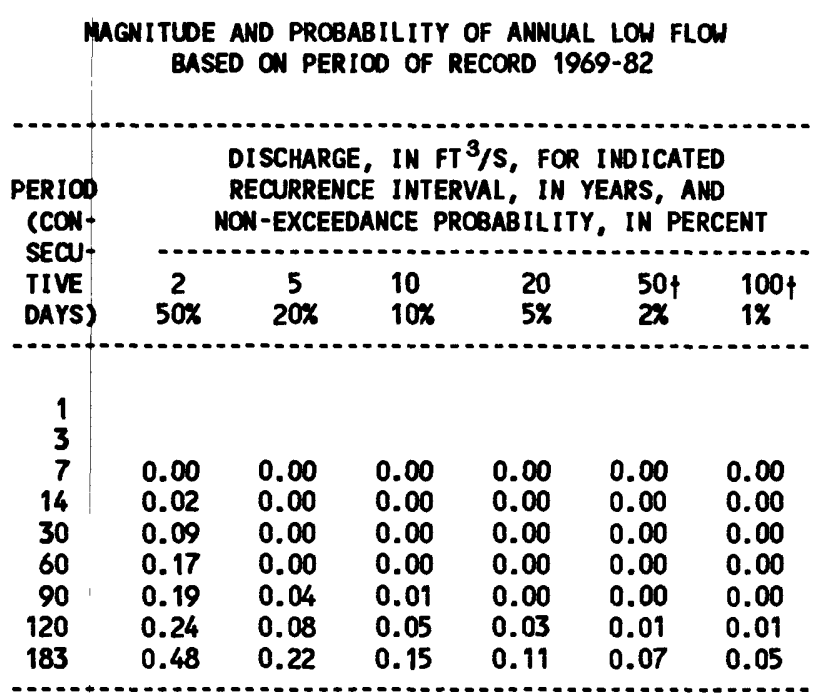

MGNITLDE AND PROBABILITY OF ANMUAL HIGH FLOH BASED ON PERIOD OF RECORD 1968-82

\begin{tabular}{|c|c|c|c|c|c|c|}
\hline \multirow{2}{*}{$\begin{array}{l}\text { PERIOD } \\
\text { (CON- } \\
\text { SECU- } \\
\text { TIVE } \\
\text { DAYS) }\end{array}$} & \multicolumn{6}{|c|}{$\begin{array}{l}\text { DISCHARGE, IN } \mathrm{FT}^{3} / \mathrm{S} \text {, FOR INDICATED } \\
\text { RECURRENCE INTERVAL, IN YEARS, AND } \\
\text { EXCEEDANCE PROBABILITY, IN PERCENT }\end{array}$} \\
\hline & $\stackrel{2}{2}$ & $\begin{array}{c}5 \\
20 \%\end{array}$ & $\begin{array}{l}10 \\
10 \%\end{array}$ & $\begin{array}{l}25 \\
4 x\end{array}$ & $\begin{array}{l}50 \dagger \\
2 x\end{array}$ & $\begin{array}{c}100 \dagger \\
1 \%\end{array}$ \\
\hline $\begin{array}{c}1 \\
3 \\
7 \\
15 \\
30 \\
60 \\
90\end{array}$ & $\begin{array}{c}52 \\
40 \\
30 \\
23 \\
17 \\
11 \\
8.8\end{array}$ & $\begin{array}{r}122 \\
99 \\
81 \\
67 \\
50 \\
34 \\
27\end{array}$ & $\begin{array}{r}183 \\
160 \\
138 \\
118 \\
91 \\
63 \\
48\end{array}$ & $\begin{array}{r}276 \\
264 \\
247 \\
223 \\
178 \\
122 \\
91\end{array}$ & $\begin{array}{l}354 \\
364 \\
361 \\
339 \\
277 \\
189 \\
137\end{array}$ & $\begin{array}{l}439 \\
486 \\
512 \\
497 \\
417 \\
283 \\
200\end{array}$ \\
\hline
\end{tabular}

DURATION TABLE OF DAILY MEAN FLON FOR PERIOD OF RECORD 1968-82

DISCHARGE, IN FT $3 / \mathrm{s}$, WHICH WAS EQUALED OR EXCEEDED FOR INDICATED PERCENT OF TIME

\begin{tabular}{|c|c|c|c|c|c|c|c|c|c|c|c|c|c|c|c|c|}
\hline $1 \%$ & $5 \%$ & $10 \%$ & $15 \%$ & $20 \%$ & $30 \%$ & $40 \%$ & $50 \%$ & $60 \%$ & $70 x$ & $80 \%$ & $90 \%$ & $95 \%$ & $98 \%$ & $99 \%$ & $99.5 \%$ & $99.9 \%$ \\
\hline 100 & 29 & 14 & 7.9 & 4.9 & 2.4 & 1.2 & 0.68 & 0.44 & 0.28 & 0.18 & 0.05 & 0.00 & 0.00 & 0.00 & 0.00 & 0.00 \\
\hline
\end{tabular}

\footnotetext{
$\uparrow$ Reliability of values in column is uncertain, and potential errors are large.
} 
09383500 NUTRIOSO CREEK ABOVE NELSON RESERVOIR, NEAR SPRINGERVILLE, AZ--CONTINUED
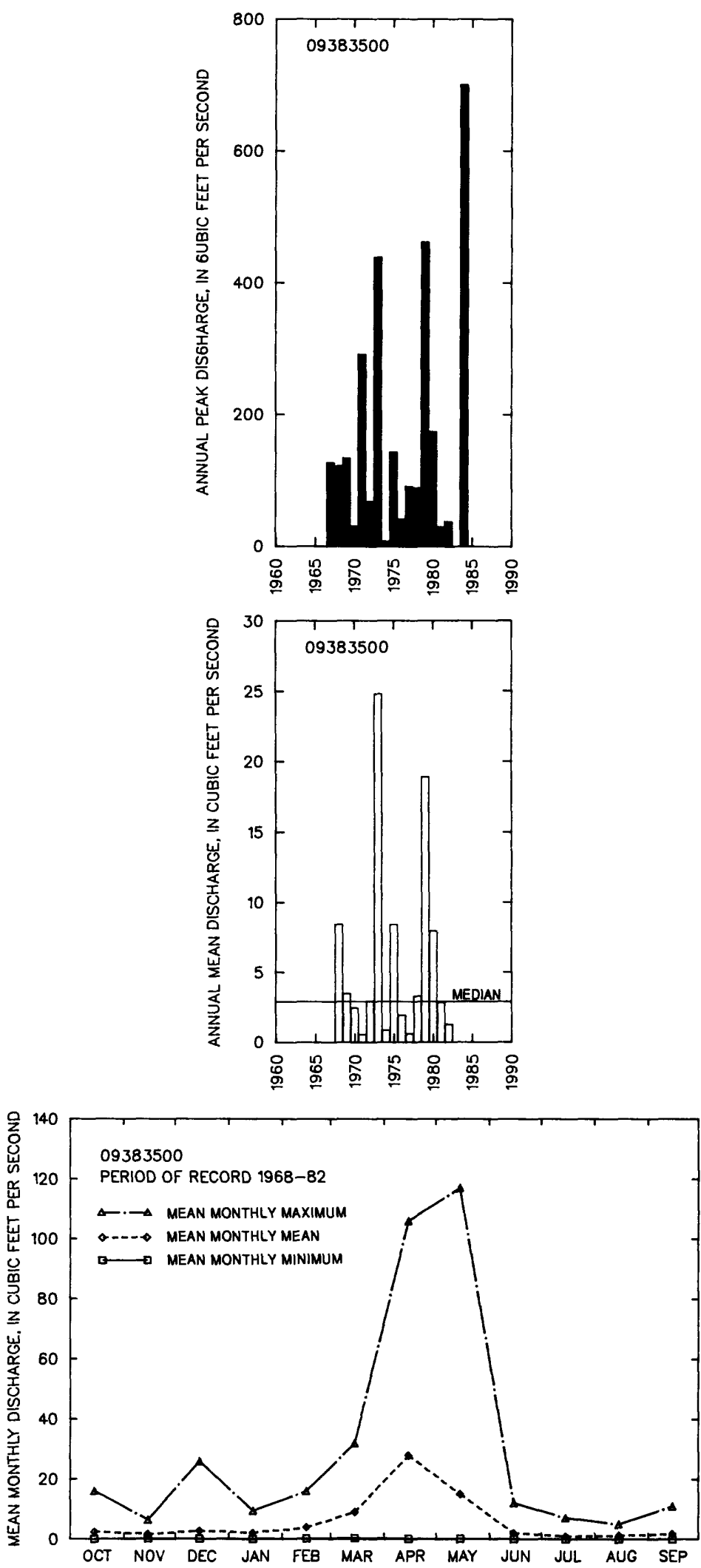
LOCATION.--Lat 34'04'35", Long 109.27'45", in SWMNEX sec.23, T.8 N., R.27 E., Apache County, Hydrologic Unit 15020001 , at State Highway $73,10.5$ mi west of Eagar.

DRAINAGE AREA. $--16.9 \mathrm{mi}^{2}$, of which $2.5 \mathrm{mi}^{2}$ is noncontributing.

aniuUal peak discharge

\begin{tabular}{cccc}
$\begin{array}{c}\text { UATER } \\
\text { YEAR }\end{array}$ & DATE & $\begin{array}{c}\text { ANNUAL PEAK } \\
\text { DISCHARGE } \\
\text { (FT } 3 / \text { S) }\end{array}$ & $\begin{array}{c}\text { DISCHARGE } \\
\text { CODES }\end{array}$ \\
\hline 1963 & $08-21-63$ & 168 & \\
1964 & $08-01-64$ & 236 & \\
1965 & $07-25-65$ & 81 & \\
1966 & $04-03-66$ & 48 & \\
1967 & $09-05-67$ & 139 & \\
1968 & $00-00-68$ & 45 & \\
1969 & $09-08-69$ & 215 & \\
1970 & $00-00-70$ & 3.0 & ES \\
1971 & $00-00-71$ & 3.0 & LT \\
1972 & $00-00-72$ & 0 & \\
1973 & $04-00-73$ & 153 & \\
1974 & $00-00-74$ & 3.0 & ES \\
1975 & $09-07-75$ & 81 &
\end{tabular}

MAGNITUDE AND PROBABILITY OF INSTANTANEOUS PEAK FLON BASED ON PERIOD OF RECORD 1963-75

DISCHARGE, IN $\mathrm{FT}^{3} / \mathrm{S}$, FOR INDICATED RECURRENCE INTERVAL IN YEARS, AND EXCEEDANCE PROBABILITY, IN PERCENT

\begin{tabular}{|c|c|c|c|c|c|}
\hline $\begin{array}{c}2 \\
50 \%\end{array}$ & $\begin{array}{c}5 \\
20 \%\end{array}$ & $\begin{array}{r}10 \\
10 \%\end{array}$ & $\begin{array}{l}25 \\
4 \%\end{array}$ & $\begin{array}{l}50 \dagger \\
2 x\end{array}$ & $\begin{array}{c}100 \\
1 \%\end{array}$ \\
\hline 74.5 & 159 & 227 & 325 & 403 & 485 \\
\hline $\begin{array}{l}\text { WEIGI } \\
\text { MEAN } \\
\text { STAND }\end{array}$ & $\begin{array}{l}\text { SKEW } \\
\text { DEV. }\end{array}$ & $\begin{array}{l}(\text { LOGS })= \\
(\text { LOGS })= \\
(\text { LOGS })=\end{array}$ & $\begin{array}{r}-0.42 \\
1.84 \\
0.42\end{array}$ & & \\
\hline
\end{tabular}

+ Reliability of values in column is uncertain, and potential errors are large.

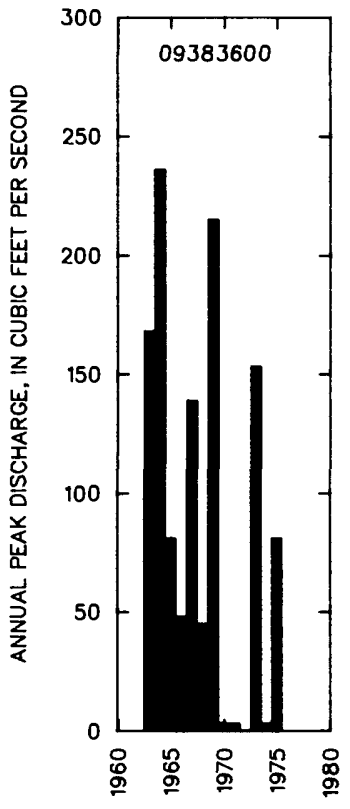

BASIN CHARACTERISTICS

\begin{tabular}{|c|c|c|c|c|c|c|c|}
\hline MAIN & & $\begin{array}{l}\text { MEAN } \\
\text { BASIN }\end{array}$ & & & $\begin{array}{l}\text { MEAN } \\
\text { ANMUAL }\end{array}$ & RAINFALL II & SITY, 24-HOUR \\
\hline $\begin{array}{l}\text { CHANNEL } \\
\text { SLOPE } \\
\text { (FT/MI) }\end{array}$ & $\begin{array}{l}\text { STREAM } \\
\text { LENGTH } \\
\text { (MI) }\end{array}$ & $\begin{array}{l}\text { ELEVA- } \\
\text { TION } \\
\text { (FT) }\end{array}$ & $\begin{array}{l}\text { FORESTED } \\
\text { AREA } \\
\text { (PERCENT) }\end{array}$ & $\begin{array}{l}\text { SOIL } \\
\text { INDEX }\end{array}$ & $\begin{array}{l}\text { PRECIPI- } \\
\text { TATION } \\
\text { (IN) }\end{array}$ & $\begin{array}{c}\text { 2-YEAR } \\
\text { (IN) }\end{array}$ & $\begin{array}{l}\text { 50-YEAR } \\
\text { (IN) }\end{array}$ \\
\hline 164 & 8.1 & 9,160 & 38.0 & 3.0 & 26.1 & 1.8 & 4.2 \\
\hline
\end{tabular}


09384000 LitTLe COlorado RIVER above LMMAN LAKE, NEAR ST. JOHNS, aZ

LOCATION.-- Lat 34.18/52", long 109.21/42", in SW/2SEK sec.27, T.11 N., R.28 E., Apache County, Hydrologic Unit 15020001, on left bank 0.75 mi downstream from Coyote Creek, 6 mi upstream from Lyman Dam, and $15 \mathrm{mi}$ south of St. Johns. Prior to December 7, 1976, at site 0.4 mi downstream.

DRAIMAGE AREA. --706 $\mathrm{mi}^{2}$, of which $250 \mathrm{mi}^{2}$ is noncontributing.

REMARKS. - - Flow regulated by many small reservoirs-combined capacity, about 15,500 acre-ft. Diversions for irrigation of about 6,700 acres above station.

ANWUAL PEAK DISCHARGE

\begin{tabular}{|c|c|c|c|c|c|c|c|}
\hline $\begin{array}{l}\text { WATER } \\
\text { YEAR }\end{array}$ & DATE & $\begin{array}{c}\text { ANNUAL PEAK } \\
\text { DISCHARGE } \\
\left(\mathrm{FT}^{3} / \mathrm{S}\right)\end{array}$ & $\begin{array}{l}\text { DISCHARGE } \\
\text { COOES }\end{array}$ & $\begin{array}{l}\text { WATER } \\
\text { YEAR }\end{array}$ & DATE & $\begin{array}{c}\text { ANNUAL PEAK } \\
\text { DISCHARGE } \\
\left(F^{3} / S\right)\end{array}$ & $\begin{array}{l}\text { DISCHARGE } \\
\text { CODES }\end{array}$ \\
\hline $\begin{array}{l}1940 \\
1941 \\
1942 \\
1943 \\
1944 \\
1945 \\
1946 \\
1947 \\
1948 \\
1949 \\
1950 \\
1951 \\
1952 \\
1953 \\
1954 \\
1955 \\
1956 \\
1957 \\
1958 \\
1959 \\
1960 \\
1961 \\
1962 \\
1963 \\
1964\end{array}$ & $\begin{array}{l}07-25-40 \\
07-23-41 \\
08-10-42 \\
08-22-43 \\
08-15-44 \\
08-11-45 \\
08-04-46 \\
08-22-47 \\
04-17-48 \\
08-02-49 \\
07-18-50 \\
08-02-51 \\
08-28-52 \\
08-10-53 \\
08-05-54 \\
08-23-55 \\
08-18-56 \\
08-27-57 \\
04-23-58 \\
08-08-59 \\
03-30-60 \\
08-11-61 \\
04-16-62 \\
08-26-63 \\
07-31-64\end{array}$ & $\begin{array}{r}116,000 \\
2,520 \\
379 \\
2,360 \\
3,400 \\
740 \\
6,000 \\
1,620 \\
732 \\
1,000 \\
181 \\
3,200 \\
1,570 \\
229 \\
1,390 \\
2,990 \\
206 \\
2,850 \\
1,120 \\
1,340 \\
323 \\
619 \\
736 \\
733 \\
1,160\end{array}$ & $\begin{array}{l}\text { HP } \\
\text { UR } \\
\text { UR } \\
\text { UR } \\
\text { UR } \\
\text { UR } \\
\text { UR } \\
\text { UR } \\
\text { UR } \\
\text { UR } \\
\text { UR } \\
\text { UR } \\
\text { UR } \\
\text { UR } \\
\text { UR } \\
\text { UR } \\
\text { UR } \\
\text { UR } \\
\text { UR } \\
\text { UR } \\
\text { UR } \\
\text { UR } \\
\text { UR } \\
\text { UR } \\
\text { UR }\end{array}$ & $\begin{array}{l}1965 \\
1966 \\
1967 \\
1968 \\
1969 \\
1970 \\
1971 \\
1972 \\
1973 \\
1974 \\
1975 \\
1976 \\
1977 \\
1978 \\
1979 \\
1980 \\
1981 \\
1982 \\
1983 \\
1984 \\
1985 \\
1986 \\
1987 \\
1988 \\
1989\end{array}$ & $\begin{array}{l}04-23-65 \\
04-04-66 \\
07-27-67 \\
04-16-68 \\
07-26-69 \\
04-09-70 \\
09-09-71 \\
08-29-72 \\
04-29-73 \\
08-04-74 \\
09-12-75 \\
04-09-76 \\
08-21-77 \\
08-01-78 \\
04-00-79 \\
04-23-80 \\
08-01-81 \\
08-29-82 \\
08-03-83 \\
10-02-83 \\
03-13-85 \\
08-26-86 \\
04-20-87 \\
09-01-88 \\
07-28-89\end{array}$ & $\begin{array}{r}527 \\
658 \\
4,850 \\
460 \\
764 \\
120 \\
229 \\
225 \\
1,180 \\
3,240 \\
1,600 \\
170 \\
389 \\
389 \\
1,500 \\
840 \\
618 \\
260 \\
1,340 \\
2,330 \\
695 \\
292 \\
1,090 \\
414 \\
165\end{array}$ & $\begin{array}{l}\text { UR } \\
\text { UR } \\
\text { UR } \\
\text { UR } \\
\text { UR } \\
\text { UR } \\
\text { UR } \\
\text { UR } \\
\text { UR } \\
\text { UR } \\
\text { UR } \\
\text { UR } \\
\text { UR } \\
\text { UR } \\
\text { UR } \\
\text { UR } \\
\text { UR } \\
\text { UR } \\
\text { UR } \\
\text { UR } \\
\text { UR } \\
\text { UR } \\
\text { UR } \\
\text { UR } \\
\text { UR }\end{array}$ \\
\hline
\end{tabular}

$\mathcal{I}_{\text {Highest since } 1900 .}$

BASIN CHARACTERISTICS

\begin{tabular}{|c|c|c|c|c|c|c|c|}
\hline MAIN & & $\begin{array}{r}\text { MEAN } \\
\text { BASIN }\end{array}$ & & & $\begin{array}{c}\text { MEAN } \\
\text { ANNUAL }\end{array}$ & RAINFALL I & SITY, 24-HOUR \\
\hline $\begin{array}{l}\text { CHANNEL } \\
\text { SLOPE } \\
\text { (FT/MI) }\end{array}$ & $\begin{array}{l}\text { STREAM } \\
\text { LENGTH } \\
\text { (MI) }\end{array}$ & $\begin{array}{l}\text { ELEVA- } \\
\text { TION } \\
\text { (FT) }\end{array}$ & $\begin{array}{l}\text { FORESTED } \\
\text { AREA } \\
\text { (PERCENT) }\end{array}$ & $\begin{array}{l}\text { SOIL } \\
\text { INDEX }\end{array}$ & $\begin{array}{l}\text { PRECIPI- } \\
\text { TATION } \\
\text { (IN) }\end{array}$ & $\begin{array}{c}\text { 2-YEAR } \\
\text { (IN) }\end{array}$ & $\begin{array}{c}\text { 50-YEAR } \\
\text { (IN) }\end{array}$ \\
\hline 89.5 & 41.7 & 7,760 & 39.0 & 2.93 & 20.0 & 1.6 & 3.3 \\
\hline
\end{tabular}


MEAN MONTHLY AND ANNUAL DISCHARGES 1941-89

\begin{tabular}{|c|c|c|c|c|c|c|}
\hline MONTH & $\begin{array}{l}\max I \min _{\left(\mathrm{FT}^{3} / \mathrm{S}\right)}\end{array}$ & $\begin{array}{l}\text { MINIMUM } \\
\left(\mathrm{FT}^{3} / \mathrm{S}\right)\end{array}$ & $\begin{array}{c}\text { MEAN } \\
\left(\mathrm{FT}^{\mathbf{3}} / \mathrm{S}\right)\end{array}$ & $\begin{array}{l}\text { STAN- } \\
\text { DARD } \\
\text { DEVIA- } \\
\text { TIOM } \\
\left(F^{3}{ }^{3} / S\right)\end{array}$ & $\begin{array}{l}\text { COEFFI- } \\
\text { CIENT OF } \\
\text { VARI- } \\
\text { ATIOW }\end{array}$ & $\begin{array}{c}\text { PERCENT } \\
\text { OF } \\
\text { ANNUAL } \\
\text { RUNOFF }\end{array}$ \\
\hline $\begin{array}{l}\text { OCTOBER } \\
\text { NOVEMBER } \\
\text { DECEMBER } \\
\text { JANUARY } \\
\text { FEBRUARY } \\
\text { MARCH } \\
\text { APRIL } \\
\text { MAY } \\
\text { JUNE } \\
\text { JULY } \\
\text { AUGUST } \\
\text { SEPTEMBER }\end{array}$ & $\begin{array}{r}213 \\
38 \\
47 \\
39 \\
43 \\
182 \\
397 \\
374 \\
95 \\
40 \\
143 \\
105\end{array}$ & $\begin{array}{l}0.07 \\
0.32 \\
0.83 \\
2.1 \\
2.8 \\
2.5 \\
1.3 \\
0.73 \\
0.01 \\
0.00 \\
0.83 \\
0.02\end{array}$ & $\begin{array}{c}11 \\
8.3 \\
11 \\
11 \\
13 \\
31 \\
101 \\
41 \\
10 \\
11 \\
25 \\
13\end{array}$ & $\begin{array}{c}30 \\
8.0 \\
10 \\
8.3 \\
8.7 \\
35 \\
110 \\
74 \\
18 \\
9.9 \\
29 \\
20\end{array}$ & $\begin{array}{l}2.8 \\
0.97 \\
0.95 \\
0.73 \\
0.65 \\
1.1 \\
1.1 \\
1.8 \\
1.7 \\
0.93 \\
1.2 \\
1.5\end{array}$ & $\begin{array}{r}3.8 \\
2.9 \\
3.8 \\
4.0 \\
4.7 \\
10.7 \\
35.2 \\
14.3 \\
3.7 \\
3.7 \\
8.7 \\
4.6\end{array}$ \\
\hline ANMUAL & 72 & 2.9 & 24 & 18 & 0.77 & 100 \\
\hline
\end{tabular}

MAGNITUDE AND PROBABILITY OF INSTANTANEOUS PEAK FLOW BASED ON PERIOD OF RECORD 1940-89

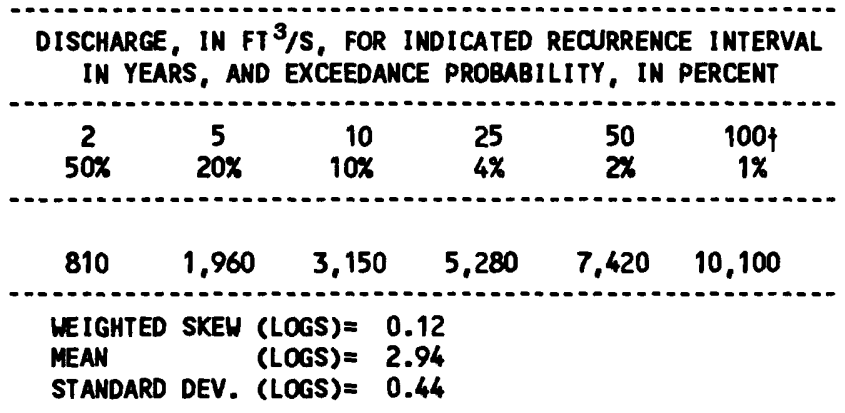

MAGNITUDE AND PROBABILITY OF ANNUAL LOW FLOW BASED ON PERIOD OF RECORD 1941-89

\begin{tabular}{|c|c|c|c|c|c|c|}
\hline \multirow{2}{*}{$\begin{array}{l}\text { PERIOD } \\
\text { (CON- } \\
\text { SECU- } \\
\text { TIVE } \\
\text { DAYS) }\end{array}$} & \multicolumn{6}{|c|}{$\begin{array}{l}\text { DISCHARGE, IN } \mathrm{FT}^{3} / \mathrm{S} \text {, FOR INDICATED } \\
\text { RECURRENCE INTERVAL, IN YEARS, AND } \\
\text { NON-EXCEEDANCE PROBABILITY, IN PERCENT }\end{array}$} \\
\hline & $\begin{array}{c}2 \\
50 \%\end{array}$ & $\begin{array}{c}5 \\
20 \%\end{array}$ & $\begin{array}{l}10 \\
10 \%\end{array}$ & $\begin{array}{l}20 \\
5 \%\end{array}$ & $\begin{array}{l}50 \\
2 \%\end{array}$ & $\begin{array}{l}100 \dagger \\
1 \%\end{array}$ \\
\hline $\begin{array}{r}1 \\
3 \\
7 \\
14 \\
30 \\
60 \\
90 \\
120 \\
183\end{array}$ & $\begin{array}{l}0.00 \\
0.00 \\
0.00 \\
0.00 \\
0.00 \\
2.4 \\
3.2 \\
4.6 \\
6.4\end{array}$ & $\begin{array}{l}0.00 \\
0.00 \\
0.00 \\
0.00 \\
0.00 \\
0.80 \\
1.3 \\
2.2 \\
3.2\end{array}$ & $\begin{array}{l}0.00 \\
0.00 \\
0.00 \\
0.00 \\
0.00 \\
0.40 \\
0.80 \\
1.4 \\
2.2\end{array}$ & $\begin{array}{l}0.00 \\
0.00 \\
0.00 \\
0.00 \\
0.00 \\
0.21 \\
0.50 \\
0.91 \\
1.6\end{array}$ & $\begin{array}{l}0.00 \\
0.00 \\
0.00 \\
0.00 \\
0.00 \\
0.09 \\
0.29 \\
0.55 \\
1.1\end{array}$ & $\begin{array}{l}0.0 \\
0.0 \\
0.0 \\
0.0 \\
0.0 \\
0.05 \\
0.20 \\
0.39 \\
0.84\end{array}$ \\
\hline
\end{tabular}

MMGNITUDE AND PROBABILITY OF ANNUAL HIGH FLOW BASED ON PERIOD OF RECORD 1941-89

\begin{tabular}{|c|c|c|c|c|c|c|}
\hline \multirow{2}{*}{$\begin{array}{l}\text { PERIOD } \\
\text { (CON- } \\
\text { SECU } \\
\text { TIVE } \\
\text { DAYS) }\end{array}$} & & \multicolumn{5}{|c|}{$\begin{array}{l}\text { DISCHARGE, IN FT }{ }^{3} / S \text {, FOR INDICATED } \\
\text { RECURRENCE INTERVAL, IN YEARS, AND } \\
\text { EXCEEDANCE PROBABILITY, IN PERCENT }\end{array}$} \\
\hline & $\begin{array}{c}2 \\
50 \%\end{array}$ & $\begin{array}{c}5 \\
20 x\end{array}$ & $\begin{array}{l}10 \\
10 \%\end{array}$ & $\begin{array}{l}25 \\
4 \%\end{array}$ & $\begin{array}{l}50 \\
2 \%\end{array}$ & $\begin{array}{c}100 \nmid \\
1 \%\end{array}$ \\
\hline $\begin{array}{r}1 \\
3 \\
7 \\
15 \\
30 \\
60 \\
90\end{array}$ & $\begin{array}{r}283 \\
222 \\
177 \\
130 \\
90 \\
58 \\
43\end{array}$ & $\begin{array}{l}600 \\
505 \\
411 \\
308 \\
216 \\
138 \\
101\end{array}$ & $\begin{array}{l}866 \\
751 \\
617 \\
472 \\
333 \\
213 \\
156\end{array}$ & $\begin{array}{r}1,250 \\
1,120 \\
928 \\
730 \\
520 \\
336 \\
244\end{array}$ & $\begin{array}{r}1,580 \\
1,430 \\
1,190 \\
958 \\
686 \\
448 \\
326\end{array}$ & $\begin{array}{r}1,920 \\
1,770 \\
1,480 \\
1,210 \\
876 \\
579 \\
421\end{array}$ \\
\hline
\end{tabular}

DURATION TABLE OF DAILY MEAN FLON FOR PERIOD OF RECORD 1941-89

DISCHARGE, IN $\mathrm{FT}^{3} / \mathrm{S}$, WHICH WAS EQUALED OR EXCEEDED FOR INDICATED PERCENT OF TIME

\begin{tabular}{|c|c|c|c|c|c|c|c|c|c|c|c|c|c|c|c|c|}
\hline $1 \%$ & $5 \%$ & $10 \%$ & $15 \%$ & $20 \%$ & $30 \%$ & $40 \%$ & $50 \%$ & $60 \%$ & $70 \%$ & $80 \%$ & $90 \%$ & $95 \%$ & $98 \%$ & $99 \%$ & $99.5 \%$ & $99.9 \%$ \\
\hline 350 & 96 & 47 & 31 & 23 & 14 & 9.9 & 7.3 & 5.6 & 4.1 & 2.6 & 1.3 & 0.62 & 0.10 & 0.00 & 0.00 & 0.0 \\
\hline
\end{tabular}

I Reliability of values in colum is uncertain, and potential errors are large. 
09384000 . LITTLE COLORAdO RIVER ABOVE LyMAN LAKE, MEAR ST. JOHMS, AZ--CONTIMUed
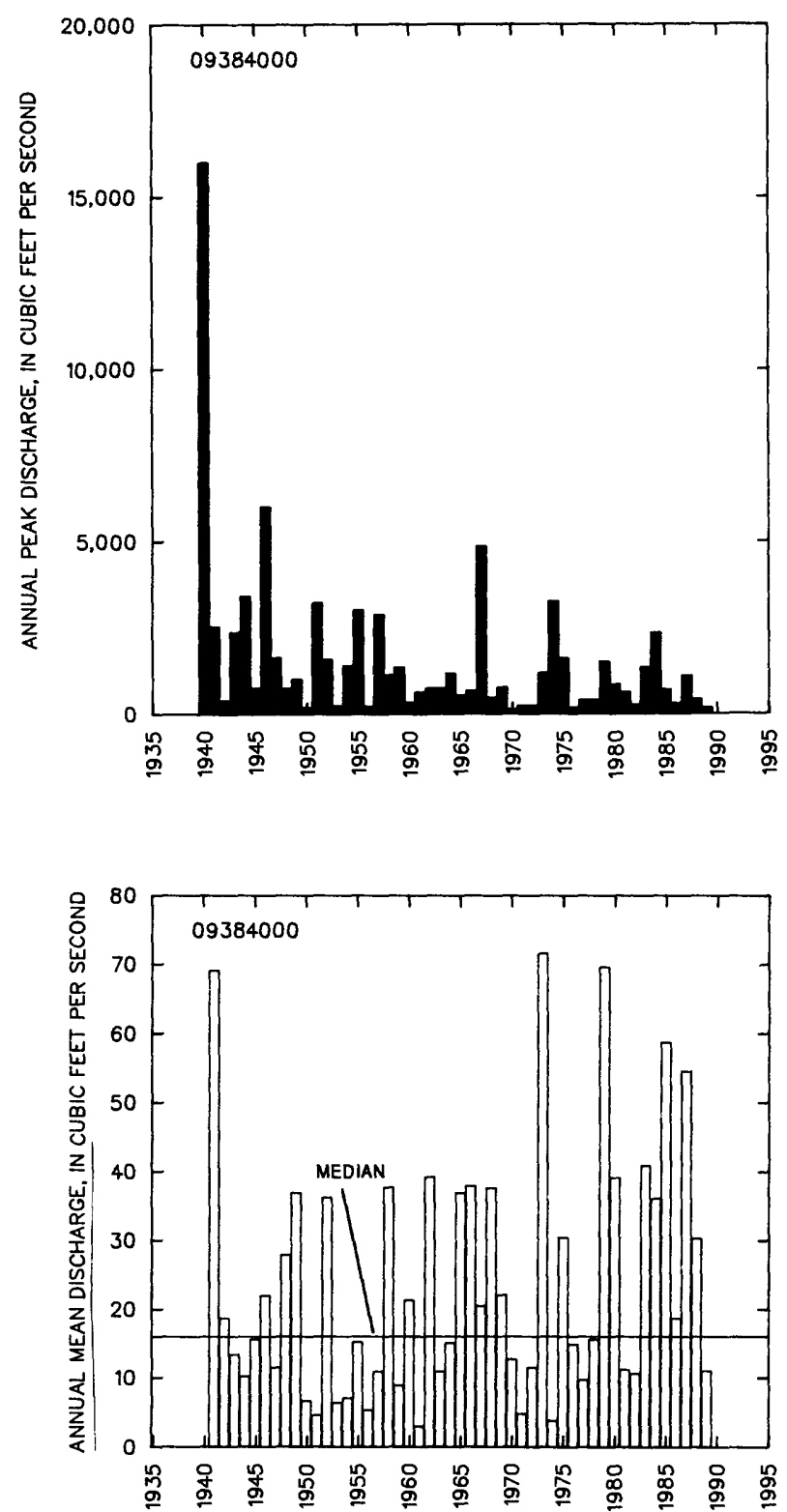
09384000 LITTLE COLORADO RIVER ABOVE LYMAN LAKE, NEAR ST. JOHNS, AZ--CONTINUED
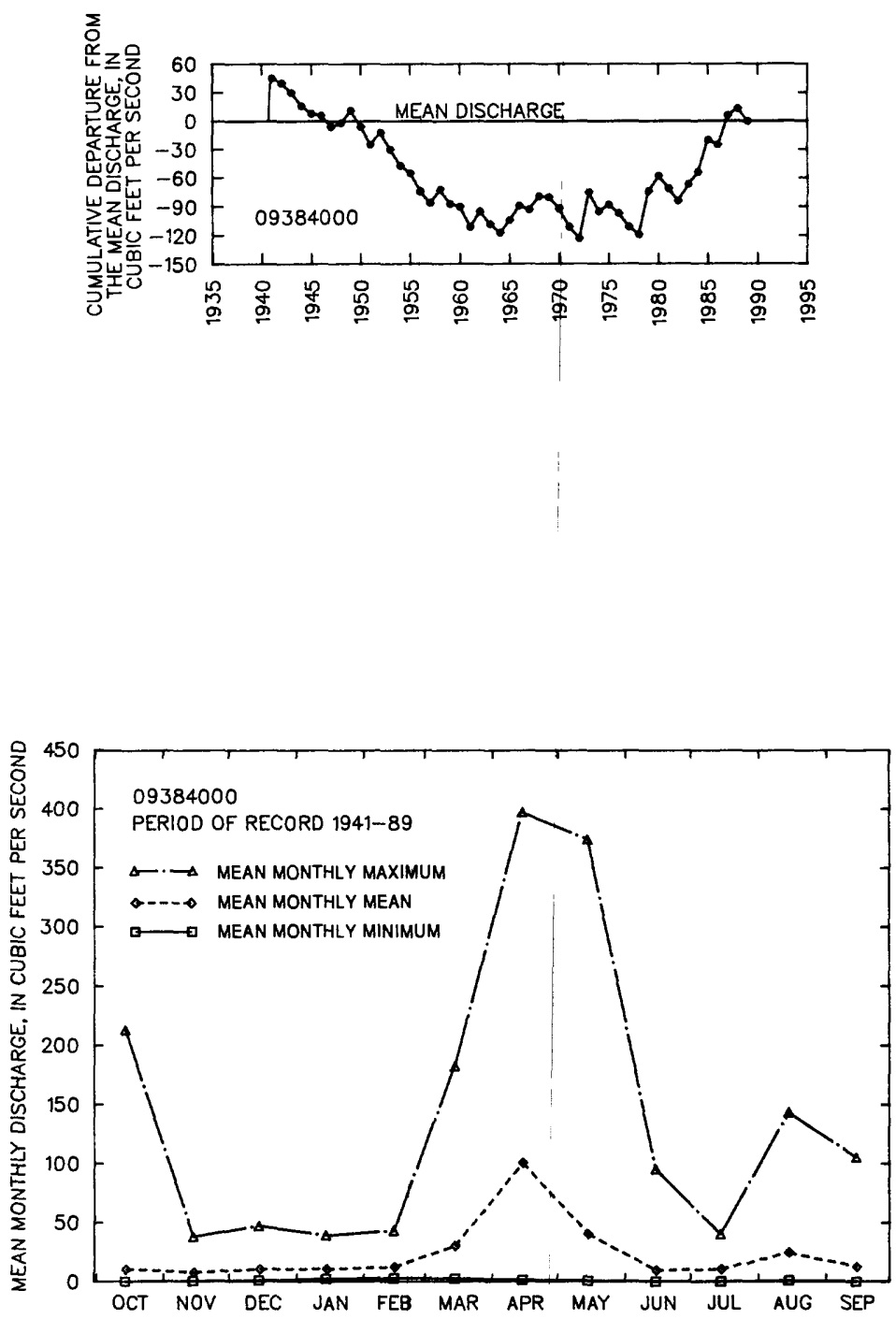
09384200 LYMAN RESERVOIR TRIBUTARY MEAR ST. JOHNS, AZ

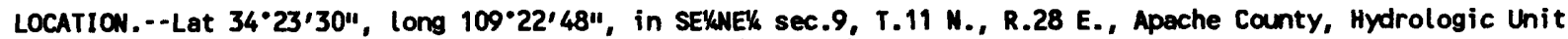
15020002 , at Lyman Reservoir Road, $10 \mathrm{mi}$ south of St. Johns.

DRAINAGE AREA. $--0.24 \mathrm{mi}^{2}$.

ANMUAL PEAK DISCHARGE

\begin{tabular}{cccc}
$\begin{array}{c}\text { WATER } \\
\text { YEAR }\end{array}$ & DATE & $\begin{array}{c}\text { ANNUAL PEAK } \\
\text { DISCHARGE } \\
\text { (FT } 3 / \text { S) }\end{array}$ & $\begin{array}{c}\text { DISCHARGE } \\
\text { CODES }\end{array}$ \\
\hline 1963 & $08-26-63$ & 101 & \\
1964 & $08-11-64$ & 53 & \\
1965 & $08-02-65$ & 42 & \\
1966 & $09-30-66$ & 52 & \\
1967 & $00-00-67$ & 48 & \\
1968 & $00-00-68$ & 1.0 & LT \\
1969 & $09-00-69$ & 7.0 & \\
1970 & $07-20-70$ & 33 & \\
1971 & $08-00-71$ & 60 & \\
1972 & $07-24-72$ & 64 & \\
1973 & $07-00-73$ & 5.0 & \\
1974 & $00-00-74$ & 0 & \\
1975 & $09-06-75$ & 3.0 & ES \\
1976 & $00-00-76$ & 60 & \\
\hline
\end{tabular}

MAGNITUDE AND PROBABILITY OF INSTANTANEOUS PEAK FLON BASED ON PERIOD OF RECORD 1963-76

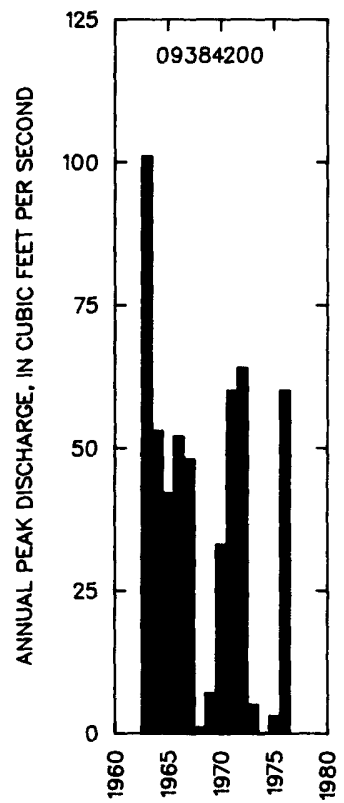

DISCHARGE, IN $\mathrm{FT}^{3} / \mathrm{S}$, FOR INDICATED RECURRENCE INTERVAL

IN YEARS, AND EXCEEDANCE PROBABILITY, IN PERCENT

\begin{tabular}{|c|c|c|c|c|c|}
\hline $\begin{array}{c}2 \\
50 \%\end{array}$ & $\begin{array}{c}5 \\
20 \%\end{array}$ & $\begin{array}{r}10 \\
10 \%\end{array}$ & $\begin{array}{l}25 \\
4 \%\end{array}$ & $\begin{array}{l}50 \nmid \\
2 \%\end{array}$ & $\begin{array}{c}100\} \\
1 \%\end{array}$ \\
\hline 42.8 & 62 & 74.9 & 91.4 & 104 & 116 \\
\hline $\begin{array}{l}\text { WEIGHTED } \\
\text { MEAN } \\
\text { STANDARD }\end{array}$ & $\begin{array}{l}\text { SKEW } \\
\text { DEV. }\end{array}$ & $\begin{array}{l}(\text { LOGS })= \\
(\text { LOGS) }= \\
(L O G S)=\end{array}$ & $\begin{array}{r}-0.11 \\
1.63 \\
0.20\end{array}$ & & \\
\hline
\end{tabular}

t Reliability of values in column is uncertain, and potential errors are large.

\section{BASIN CHARACTERISTICS}

\begin{tabular}{|c|c|c|c|c|c|c|c|}
\hline \multirow{2}{*}{$\begin{array}{l}\text { MAIN } \\
\text { CHANNEL } \\
\text { SLOPE } \\
\text { (FT/MI) }\end{array}$} & \multirow[b]{2}{*}{$\begin{array}{c}\text { STREAM } \\
\text { LENGTH } \\
\text { (MI) }\end{array}$} & \multirow{2}{*}{$\begin{array}{l}\text { MEAN } \\
\text { BASIN } \\
\text { ELEVA- } \\
\text { TION } \\
\text { (FT) }\end{array}$} & \multirow[b]{2}{*}{$\begin{array}{l}\text { FORESTED } \\
\text { AREA } \\
\text { (PERCENT) }\end{array}$} & \multirow[b]{2}{*}{$\begin{array}{l}\text { SOIL } \\
\text { INDEX }\end{array}$} & \multirow{2}{*}{$\begin{array}{l}\text { MEAN } \\
\text { ANNULL } \\
\text { PRECIPI- } \\
\text { TATION } \\
\text { (IN) }\end{array}$} & \multicolumn{2}{|c|}{ RAINFALL INTENSITY, 24-HOUR } \\
\hline & & & & & & $\begin{array}{c}\text { 2-YEAR } \\
\text { (IN) }\end{array}$ & $\begin{array}{l}\text { 50-YEAR } \\
\text { (IN) }\end{array}$ \\
\hline 267 & 1.0 & 6,100 & 58.0 & 3.0 & 11.6 & 1.55 & 3.3 \\
\hline
\end{tabular}


09385800 LITTLE COLORADO RIVER TRIBUTARY NEAR ST. JOHNS, AZ

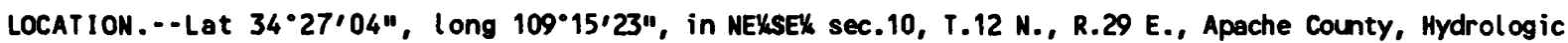
Unit 15020002, at county road, $7 \mathrm{mi}$ southeast of St. Johns.

DRAIMAGE AREA. $--0.35 \mathrm{mi}^{2}$.

ANHUAL PEAK DISCHARge

\begin{tabular}{lcc}
$\begin{array}{c}\text { HATER } \\
\text { YEAR }\end{array}$ & DATE & $\begin{array}{c}\text { ANNUAL PEAK } \\
\text { DISCHARGE } \\
\text { (FT 3/S) }\end{array}$ \\
\hline 1963 & $08-00-63$ & 48 \\
1964 & $08-27-64$ & 18 \\
1965 & $09-04-65$ & 326 \\
1966 & $08-30-66$ & 16 \\
1967 & $00-00-67$ & 300 \\
1968 & $08-00-68$ & 118 \\
1969 & $07-00-69$ & 165 \\
1970 & $10-21-69$ & 24 \\
1971 & $08-00-71$ & 40 \\
1972 & $12-26-71$ & 61 \\
1973 & $07-00-73$ & 42 \\
1974 & $00-00-74$ & 0 \\
1975 & $07-29-75$ & 29 \\
1976 & $08-00-76$ & 57 \\
$\ldots \ldots$
\end{tabular}

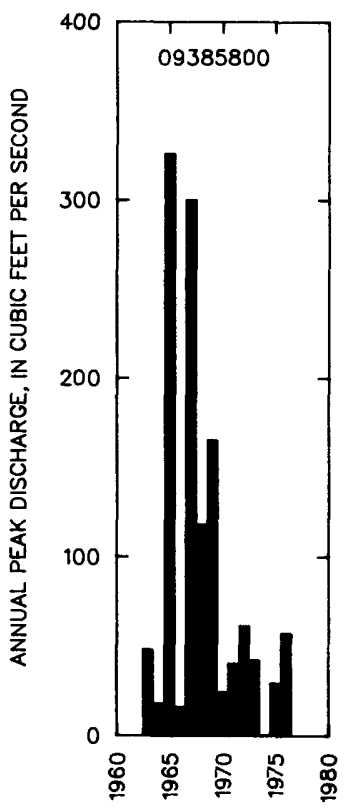

MAGNITUDE AND PROBABILITY OF INSTANTANEOUS PEAK FLOW BASED ON PERIOD OF RECORD 1963-76

DISCHARGE, IN $\mathrm{FT}^{3} / \mathrm{S}$, FOR INDICATED RECURRENCE INTERVAL IN YEARS, AND EXCEEDANCE PROBABILITY, IN PERCENT

\begin{tabular}{|c|c|c|c|c|c|}
\hline$\stackrel{2}{20 \%}$ & $\begin{array}{c}5 \\
20 x\end{array}$ & $\begin{array}{r}10 \\
10 \%\end{array}$ & $\begin{array}{l}25 \\
4 \%\end{array}$ & $\begin{array}{l}50 \dagger \\
2 x\end{array}$ & $\begin{array}{r}100 \\
1 \%\end{array}$ \\
\hline 52 & 127 & 206 & 348 & 491 & 672 \\
\hline $\begin{array}{l}\text { WEIGHTED } \\
\text { MEAN } \\
\text { STANDARD }\end{array}$ & $\begin{array}{l}\text { SKEW } \\
\text { DEV. }\end{array}$ & $\begin{array}{l}(\text { LOGS })= \\
(\text { LOGS })= \\
(\text { LOGS })=\end{array}$ & $\begin{array}{l}0.13 \\
1.73 \\
0.46\end{array}$ & & \\
\hline
\end{tabular}

t Reliability of values in column is uncertain, and potential errors are large.

\section{BASIN CHARACTERISTICS}

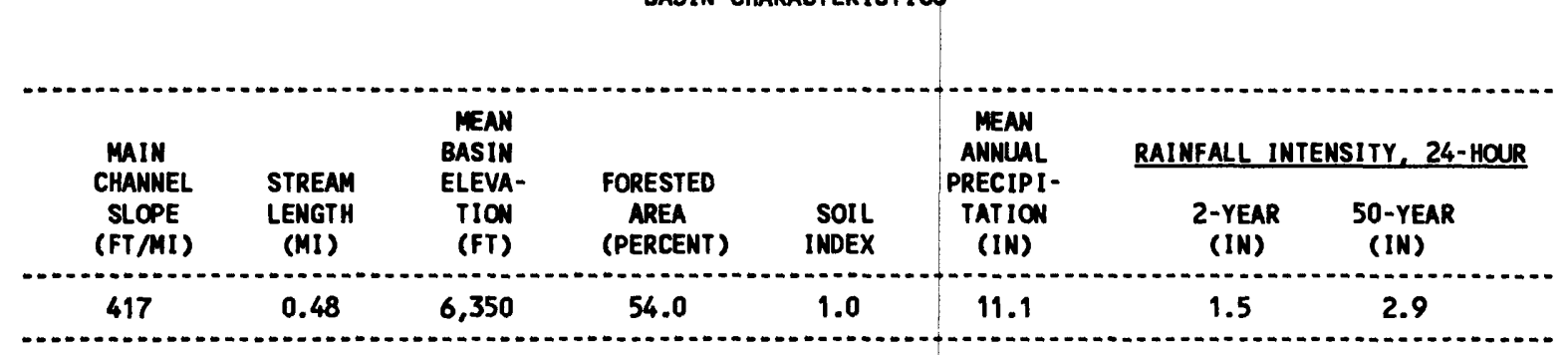


09386500 LITTLE COLORADO RIVER ABONE ZUNI RIVER, MEAR HUNT, AZ

LOCATION.--Lat 34.38'30", long 109.40'35", in SWANWk sec.2, T.14 N., R.25 E. (unsurveyed), Apache County, Hydrologic Unit 15020002, on right bank $500 \mathrm{ft}$ upstream from Zuni River and 3.6 mi northwest of Hunt.

DRAINAGE AREA. $--3,741 \mathrm{mi}^{2}$, of which $184 \mathrm{mi}^{2}$ is noncontributing.

REMARKS.--Diversions for irrigation of about 11,000 acres above station. Considerable regulation by many reservoirs (combined capacity about 50,000 acre-ft), the largest of which is Lyman Lake, 40 mi upstream.

ANMUAL PEAK DISCHARGE

\begin{tabular}{|c|c|c|c|c|c|c|c|}
\hline $\begin{array}{l}\text { WATER } \\
\text { YEAR }\end{array}$ & DATE & $\begin{array}{c}\text { ANMUAL PENK } \\
\text { DISCHARGE } \\
\text { (FT } 3 / S \text { ) }\end{array}$ & $\begin{array}{l}\text { DISCHARGE } \\
\text { CODES }\end{array}$ & $\begin{array}{l}\text { WATER } \\
\text { YEAR }\end{array}$ & DATE & $\begin{array}{c}\text { ANMUAL PEAK } \\
\text { DISCHARGE } \\
\text { (FT } 3 / S)\end{array}$ & $\begin{array}{l}\text { DISCHARGE } \\
\text { CODES }\end{array}$ \\
\hline $\begin{array}{l}1940 \\
1941 \\
1942 \\
1943 \\
1944 \\
1945 \\
1946 \\
1947 \\
1948 \\
1949 \\
1950 \\
1951 \\
1952 \\
1953 \\
1954 \\
1955 \\
1956\end{array}$ & $\begin{array}{l}07-26-40 \\
05-11-41 \\
10-07-41 \\
09-25-43 \\
09-26-44 \\
08-13-45 \\
08-04-46 \\
08-04-47 \\
09-17-48 \\
08-10-49 \\
07-07-50 \\
08-28-51 \\
07-27-52 \\
07-27-53 \\
07-26-54 \\
08-24-55 \\
02-19-56\end{array}$ & $\begin{array}{r}577 \\
516 \\
37 \\
11 \\
101 \\
1.100 \\
745 \\
301 \\
75 \\
478 \\
140 \\
70 \\
67 \\
62 \\
136 \\
831 \\
37\end{array}$ & $\begin{array}{l}\text { UR } \\
\text { UR } \\
\text { UR } \\
\text { UR } \\
\text { UR } \\
\text { UR } \\
\text { UR } \\
\text { UR } \\
\text { UR } \\
\text { UR } \\
\text { UR } \\
\text { UR } \\
\text { UR } \\
\text { UR } \\
\text { UR } \\
\text { UR } \\
\text { UR }\end{array}$ & $\begin{array}{l}1957 \\
1958 \\
1959 \\
1960 \\
1961 \\
1962 \\
1963 \\
1964 \\
1965 \\
1966 \\
1967 \\
1968 \\
1969 \\
1970 \\
1971 \\
1972\end{array}$ & $\begin{array}{l}09-01-57 \\
08-21-58 \\
08-11-59 \\
10-30-59 \\
09-11-61 \\
01-31-62 \\
09-04-63 \\
08-09-64 \\
09-08-65 \\
09-14-66 \\
08-01-67 \\
08-07-68 \\
07-23-69 \\
08-16-70 \\
09-03-71 \\
10-01-71\end{array}$ & $\begin{array}{c}476 \\
1,020 \\
130 \\
38 \\
2.6 \\
10 \\
34 \\
233 \\
194 \\
56 \\
176 \\
179 \\
747 \\
52 \\
1,310 \\
552\end{array}$ & $\begin{array}{c}\text { UR } \\
\text { UR } \\
\text { UR } \\
\text { UR } \\
\text { UR } \\
\text { UR,LT } \\
\text { UR } \\
\text { UR } \\
\text { UR } \\
\text { UR } \\
\text { UR } \\
\text { UR } \\
\text { UR } \\
\text { UR } \\
\text { UR,DF } \\
\text { UR }\end{array}$ \\
\hline
\end{tabular}

BASIN CHARACTERISTICS

\begin{tabular}{|c|c|c|c|c|c|c|c|}
\hline \multirow{2}{*}{$\begin{array}{c}\text { MAIN } \\
\text { CHANNEL } \\
\text { SLOPE } \\
\text { (FT/MI) }\end{array}$} & \multirow[b]{2}{*}{$\begin{array}{l}\text { STREAM } \\
\text { LENGTH } \\
\text { (MI) }\end{array}$} & \multirow{2}{*}{$\begin{array}{l}\text { MEAN } \\
\text { BASIN } \\
\text { ELEVA- } \\
\text { TION } \\
\text { (FT) }\end{array}$} & \multirow[b]{2}{*}{$\begin{array}{l}\text { FORESTED } \\
\text { AREA } \\
\text { (PERCENT) }\end{array}$} & \multirow[b]{2}{*}{$\begin{array}{l}\text { SOIL } \\
\text { INDEX }\end{array}$} & \multirow{2}{*}{$\begin{array}{l}\text { MEAN } \\
\text { ANNUAL } \\
\text { PRECIPI- } \\
\text { TATION } \\
\text { (IN) }\end{array}$} & \multicolumn{2}{|c|}{ RAINFALL INTEMSITY, 24-HOUR } \\
\hline & & & & & & $\begin{array}{c}\text { 2-YEAR } \\
\text { (IN) }\end{array}$ & $\begin{array}{c}\text { 50-YEAR } \\
\text { (IN) }\end{array}$ \\
\hline 40.2 & 87.9 & 7,160 & 25.0 & 2.9 & 14.6 & 1.5 & 3.1 \\
\hline
\end{tabular}


09386500 LITTLE COLORADO RIVER ABOVE ZUNI RIVER, MEAR HUNT, AZ--Cont inued

MEAN MONTHLY AND ANNUAL DISCHARGES 1941-72

\begin{tabular}{|c|c|c|c|c|c|c|}
\hline MONTH & $\begin{array}{l}\left.\operatorname{Max} \operatorname{IImUN}^{3} / \mathrm{S}\right) \\
\left(\mathrm{FT}^{3} / \mathrm{S}\right)\end{array}$ & $\begin{array}{l}\text { MINIIMUN } \\
\left(\mathrm{FT}^{3} / \mathrm{S}\right)\end{array}$ & $\begin{array}{c}\text { MEAN } \\
\left(\mathrm{FT}^{3} / \mathrm{S}\right)\end{array}$ & $\begin{array}{l}\text { STAN- } \\
\text { DARD } \\
\text { DEVIA- } \\
\text { TION } \\
\text { (FT }{ }^{3} / S \text { S) }\end{array}$ & $\begin{array}{l}\text { COEFFI - } \\
\text { CIENT OF } \\
\text { VARI - } \\
\text { ATION }\end{array}$ & $\begin{array}{c}\text { PERCENT } \\
\text { OF } \\
\text { ANNUAL } \\
\text { RUNOFF }\end{array}$ \\
\hline $\begin{array}{l}\text { OCTOBER } \\
\text { NOVEMBER } \\
\text { DECEMBER } \\
\text { JANUARY } \\
\text { FEBRUARY } \\
\text { MARCH } \\
\text { APRIL } \\
\text { MAY } \\
\text { JUNE } \\
\text { JULY } \\
\text { AUGUST } \\
\text { SEPTEMBER }\end{array}$ & $\begin{array}{c}41 \\
9.3 \\
16 \\
15 \\
14 \\
29 \\
10 \\
148 \\
7.6 \\
20 \\
338 \\
71\end{array}$ & $\begin{array}{l}0.00 \\
0.00 \\
0.00 \\
0.00 \\
0.00 \\
0.00 \\
0.00 \\
0.00 \\
0.00 \\
0.00 \\
0.00 \\
0.00\end{array}$ & $\begin{array}{c}3.3 \\
2.0 \\
3.2 \\
3.8 \\
3.8 \\
2.9 \\
1.2 \\
5.0 \\
0.44 \\
1.7 \\
25 \\
9.2\end{array}$ & $\begin{array}{l}7.9 \\
2.7 \\
3.8 \\
4.1 \\
4.2 \\
5.5 \\
2.5 \\
26 \\
1.3 \\
3.9 \\
64 \\
17\end{array}$ & $\begin{array}{l}2.4 \\
1.3 \\
1.2 \\
1.1 \\
1.1 \\
1.9 \\
2.1 \\
5.2 \\
3.0 \\
2.3 \\
2.6 \\
1.9\end{array}$ & $\begin{array}{l}5.4 \\
3.3 \\
5.2 \\
6.1 \\
6.1 \\
4.8 \\
2.0 \\
8.2 \\
0.7 \\
2.8 \\
40.6 \\
14.9\end{array}$ \\
\hline ANNUAL & 30 & 0.01 & 5.2 & 6.3 & 1.2 & 100 \\
\hline
\end{tabular}

MAGITUDE AND PROBABILITY OF ANNUAL LOW FLON BASED ON PERIOD OF RECORD 1941-72

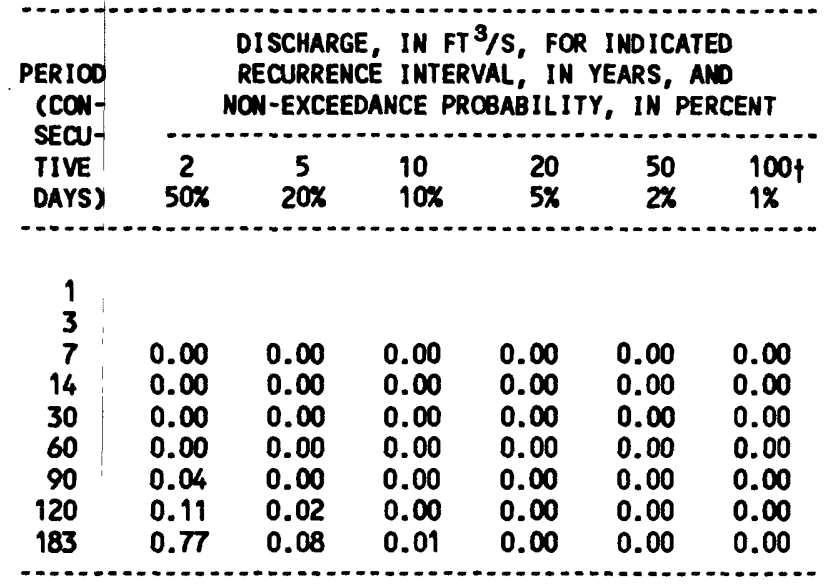

magitUde AND PROBABILITY OF INSTANTANEOUS PEAK FLON BASED ON PERIOD OF RECORD 1940-72

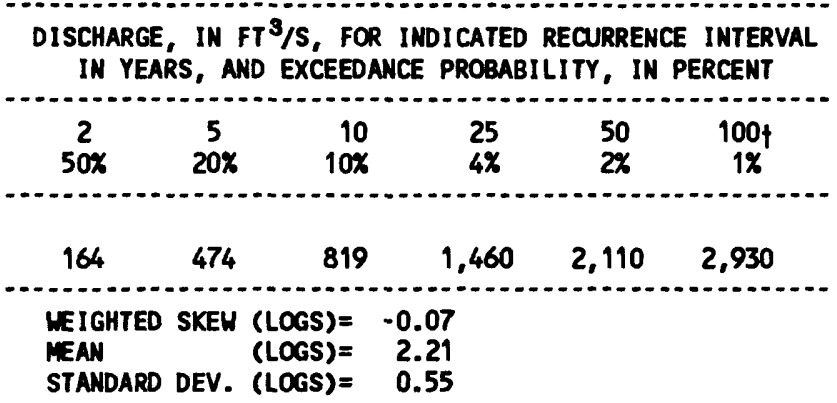

MAGNITLDE AND PROBABILITY OF ANNUAL HIGH FLON BASED ON PERIOD OF RECORD 1941-72

\begin{tabular}{|c|c|c|c|c|c|c|}
\hline \multirow{2}{*}{$\begin{array}{l}\text { PERIOD } \\
\text { (CON- } \\
\text { SECU } \\
\text { TIVE } \\
\text { DAYS) }\end{array}$} & \multicolumn{6}{|c|}{$\begin{array}{l}\text { DISCHARGE, IN } \mathrm{FT}^{3} / \mathrm{S}, \text { FOR INDICATED } \\
\text { RECURRENCE INTERVAL, IN YEARS, AND } \\
\text { EXCEEDANCE PROBABILITY, IN PERCENT }\end{array}$} \\
\hline & $\stackrel{2}{20 \%}$ & $\begin{array}{c}5 \\
20 x\end{array}$ & $\begin{array}{l}10 \\
10 \%\end{array}$ & $\begin{array}{l}25 \\
4 \%\end{array}$ & $\begin{array}{l}50 \\
2 \%\end{array}$ & $\begin{array}{c}100 \dagger \\
1 \%\end{array}$ \\
\hline $\begin{array}{c}1 \\
3 \\
7 \\
15 \\
30 \\
60 \\
90\end{array}$ & $\begin{array}{c}63 \\
46 \\
32 \\
22 \\
15 \\
10 \\
7.9\end{array}$ & $\begin{array}{r}276 \\
213 \\
147 \\
98 \\
61 \\
39 \\
29\end{array}$ & $\begin{array}{r}550 \\
439 \\
303 \\
194 \\
116 \\
68 \\
49\end{array}$ & $\begin{array}{r}1,080 \\
903 \\
617 \\
373 \\
209 \\
111 \\
75\end{array}$ & $\begin{array}{r}1,630 \\
1,400 \\
949 \\
546 \\
294 \\
145 \\
94\end{array}$ & $\begin{array}{r}2,300 \\
2,030 \\
1,370 \\
751 \\
387 \\
177 \\
112\end{array}$ \\
\hline
\end{tabular}

DURATION TABLE OF DAILY MEAN FLOW FOR PERIOD OF RECORD 1941-72 DISCHARGE, IN FT $3 / 5$, WHICH WAS EQUALED OR EXCEEDED FOR INDICATED PERCENT OF TIME

\begin{tabular}{|c|c|c|c|c|c|c|c|c|c|c|c|c|c|c|c|c|}
\hline $1 \%$ & $5 \%$ & $10 \%$ & $15 \%$ & $20 \%$ & $30 \%$ & $40 \%$ & $50 \%$ & $60 \%$ & $70 \%$ & $80 x$ & $90 \%$ & $95 \%$ & $98 \%$ & $99 \%$ & $99.5 \%$ & $99.9 \%$ \\
\hline 89 & 13 & 8.2 & 6.2 & 4.0 & 1.5 & 0.63 & 0.19 & 0.09 & 0.00 & 0.00 & 0.00 & 0.00 & 0.00 & 0.00 & 0.00 & 0.0 \\
\hline
\end{tabular}

$\uparrow$ Reliability of values in colum is uncertain, and potential errors are large. 
LITTLE COLORADO RIVER BASIN

09386500 LITTLE COLORADO RIVER ABOVE ZUNI RIVER, NEAR HUNT, AZ--CONTIMUED
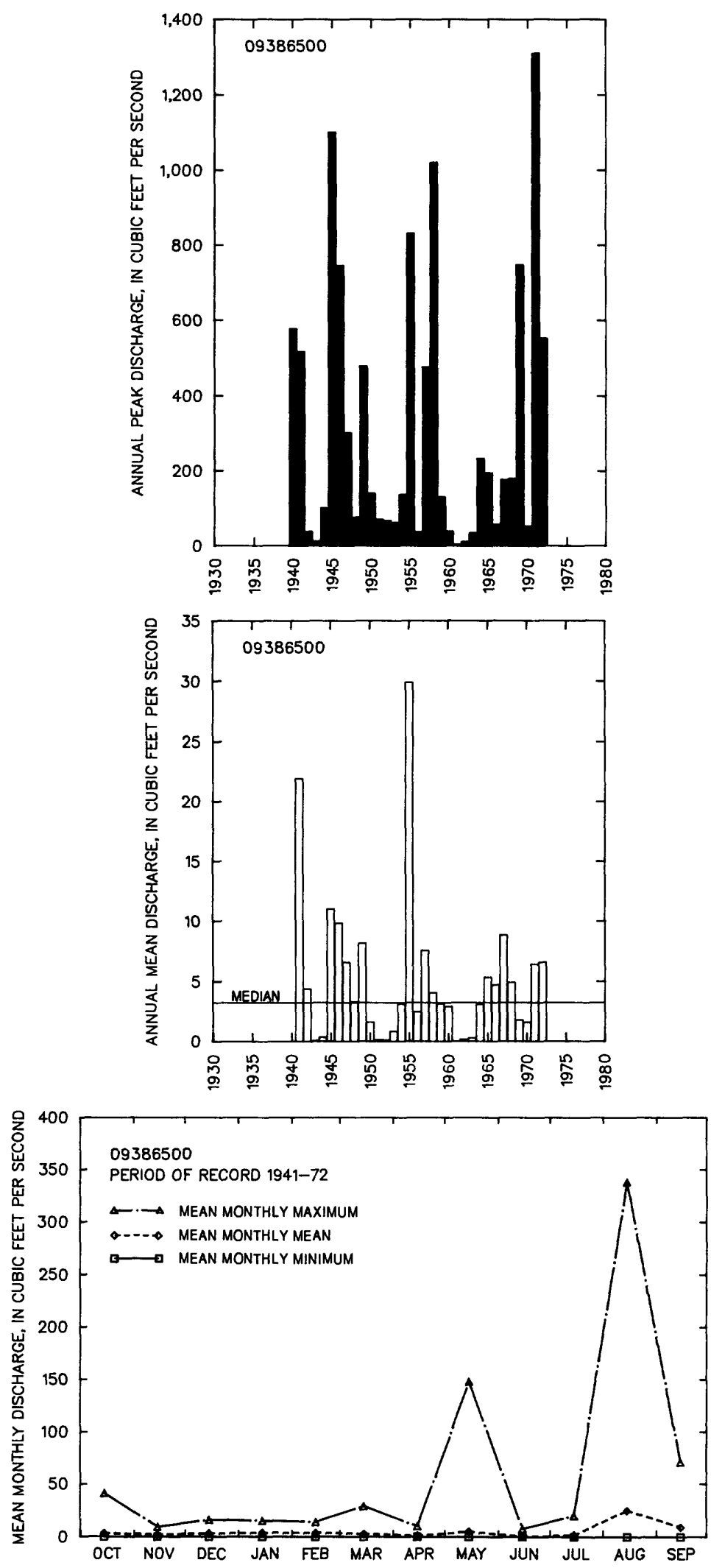


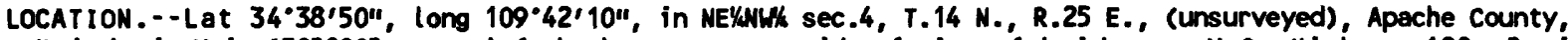
Hydrologic Unit 15020002, near left bank on upstrean side of pier of bridge on U.S. Highway $180,2 \mathrm{mi}$ downstream from Zuni River and 5 mi northwest of Hunt.

DRAINAGE AREA. $--6,383 \mathrm{mi}^{2}$, of which $210 \mathrm{mi}^{2}$ is noncontributing.

REMARKS.--Diversions for irrigation above station of about 14,000 acres. Considerable regulation by many reservoirs (combined capacity, about 59,000 acre-ft).

ANNUAL PEAK DISCHARGE

\begin{tabular}{|c|c|c|c|c|c|c|c|}
\hline $\begin{array}{l}\text { WATER } \\
\text { YEAR }\end{array}$ & DATE & $\begin{array}{c}\text { ANNUAL PEAK } \\
\text { DISCHARGE } \\
\left.\text { (FT }{ }^{3} / \mathrm{S}\right)\end{array}$ & $\begin{array}{l}\text { DISCHARGE } \\
\text { COOES }\end{array}$ & $\begin{array}{l}\text { WATER } \\
\text { YEAR }\end{array}$ & DATE & $\begin{array}{l}\text { ANNUAL PEAK } \\
\text { DISCHARGE } \\
\left.\text { (FT }{ }^{3} / \mathrm{S}\right)\end{array}$ & $\begin{array}{l}\text { DISCHARGE } \\
\text { CODES }\end{array}$ \\
\hline $\begin{array}{l}1929 \\
1930 \\
1931 \\
1932 \\
1933 \\
1940 \\
1941 \\
1942 \\
1943 \\
1944 \\
1945 \\
1946 \\
1947 \\
1948 \\
1949 \\
1950 \\
1951 \\
1952 \\
1953\end{array}$ & $\begin{array}{l}07-28-29 \\
08-07-30 \\
08-05-31 \\
08-29-32 \\
07-24-33 \\
07-26-40 \\
07-25-41 \\
10-04-41 \\
08-11-43 \\
09-30-44 \\
08-13-45 \\
08-05-46 \\
08-23-47 \\
10-14-47 \\
08-09-49 \\
07-24-50 \\
08-28-51 \\
09-22-52 \\
07-18-53\end{array}$ & $\begin{array}{r}8,000 \\
965 \\
3,600 \\
1,200 \\
3,600 \\
2,110 \\
1,560 \\
725 \\
508 \\
451 \\
1,590 \\
2,390 \\
1,290 \\
925 \\
4,050 \\
119 \\
531 \\
395 \\
42\end{array}$ & $\begin{array}{l}\text { UR } \\
\text { UR } \\
\text { UR } \\
\text { UR } \\
\text { UR } \\
\text { UR } \\
\text { UR } \\
\text { UR } \\
\text { UR } \\
\text { UR } \\
\text { UR } \\
\text { UR } \\
\text { UR } \\
\text { UR } \\
\text { UR } \\
\text { UR } \\
\text { UR } \\
\text { UR } \\
\text { UR }\end{array}$ & $\begin{array}{l}1954 \\
1955 \\
1956 \\
1957 \\
1958 \\
1959 \\
1960 \\
1961 \\
1962 \\
1963 \\
1964 \\
1965 \\
1966 \\
1967 \\
1968 \\
1969 \\
1970 \\
1971 \\
1972\end{array}$ & $\begin{array}{l}07-26-54 \\
08-08-55 \\
07-22-56 \\
09-01-57 \\
08-21-58 \\
08-04-59 \\
10-30-59 \\
08-15-61 \\
10-31-61 \\
08-21-63 \\
08-04-64 \\
09-04-65 \\
08-15-66 \\
08-14-67 \\
08-04-68 \\
07-24-69 \\
08-17-70 \\
09-03-71 \\
10-01-71\end{array}$ & $\begin{array}{r}214 \\
2,550 \\
145 \\
882 \\
1,400 \\
235 \\
453 \\
272 \\
112 \\
232 \\
580 \\
545 \\
570 \\
748 \\
1,140 \\
2,360 \\
378 \\
1,900 \\
1,230\end{array}$ & $\begin{array}{l}\text { UR } \\
\text { UR } \\
\text { UR } \\
\text { UR } \\
\text { UR } \\
\text { UR } \\
\text { UR } \\
\text { UR } \\
\text { UR } \\
\text { UR } \\
\text { UR } \\
\text { UR } \\
\text { UR } \\
\text { UR } \\
\text { UR } \\
\text { UR } \\
\text { UR } \\
\text { UR } \\
\text { UR }\end{array}$ \\
\hline
\end{tabular}

BASIN CHARACTERISTICS

\begin{tabular}{|c|c|c|c|c|c|c|c|}
\hline MAIN & & & & & & RAINFALL II & SITY, 24-HOUR \\
\hline $\begin{array}{l}\text { CHANHEL } \\
\text { SLOPE } \\
\text { (FT/MI) }\end{array}$ & $\begin{array}{l}\text { LENGTH } \\
\text { (MI) }\end{array}$ & $\begin{array}{l}\text { ELEVA- } \\
\text { TION } \\
\text { (FT) }\end{array}$ & $\begin{array}{l}\text { AREA } \\
\text { (PERCENT) }\end{array}$ & $\begin{array}{l}\text { SOIL } \\
\text { INDEX }\end{array}$ & $\begin{array}{l}\text { TATION } \\
\text { (IN) }\end{array}$ & $\begin{array}{c}\text { 2-YEAR } \\
\text { (IN) }\end{array}$ & $\begin{array}{l}\text { 50-YEAR } \\
\text { (IN) }\end{array}$ \\
\hline 37.6 & 90.4 & 7,060 & 27.0 & 2.9 & 13.4 & 1.4 & 2.8 \\
\hline
\end{tabular}


09388000 LITTLE COLORADO RIVER NEAR HUNT, AZ--Continued

MEAN MONTHLY AND ANMUAL DISCHARGES 1930-33, 1941-72

\begin{tabular}{|c|c|c|c|c|c|c|}
\hline MONTH & $\begin{array}{l}\operatorname{MAXIMUM} \\
\left(F^{3} / S\right)\end{array}$ & $\begin{array}{l}\text { MINIMUM } \\
\left(F T^{3} / S\right)\end{array}$ & $\begin{array}{c}\text { MEAN } \\
\left(F T^{3} / S\right)\end{array}$ & $\begin{array}{l}\text { STAN- } \\
\text { DARD } \\
\text { DEVIA- } \\
\text { TIOU } \\
\left(\mathrm{FT}^{3} / \mathrm{S}\right)\end{array}$ & $\begin{array}{l}\text { COEFFI- } \\
\text { CIENT OF } \\
\text { VARI - } \\
\text { ATION }\end{array}$ & $\begin{array}{c}\text { PERCENT } \\
\text { OF } \\
\text { ANNUAL } \\
\text { RUNOFF }\end{array}$ \\
\hline $\begin{array}{l}\text { OCTOBER } \\
\text { NOVEMBER } \\
\text { DECEMBER } \\
\text { JANUARY } \\
\text { FEBRUARY } \\
\text { MARCH } \\
\text { APRIL } \\
\text { MAY } \\
\text { JUNE } \\
\text { JULY } \\
\text { AUGUST } \\
\text { SEPTEMBER }\end{array}$ & $\begin{array}{c}105 \\
10 \\
20 \\
33 \\
149 \\
223 \\
315 \\
239 \\
9.1 \\
68 \\
524 \\
170\end{array}$ & $\begin{array}{l}0.00 \\
0.00 \\
0.00 \\
0.00 \\
0.00 \\
0.00 \\
0.00 \\
0.00 \\
0.00 \\
0.00 \\
0.00 \\
0.00\end{array}$ & $\begin{array}{c}11 \\
3.1 \\
4.2 \\
5.4 \\
9.1 \\
14 \\
16 \\
7.6 \\
0.93 \\
11 \\
63 \\
27\end{array}$ & $\begin{array}{c}24 \\
3.3 \\
4.6 \\
6.7 \\
25 \\
47 \\
59 \\
40 \\
1.8 \\
17 \\
105 \\
42\end{array}$ & $\begin{array}{l}2.1 \\
1.0 \\
1.1 \\
1.2 \\
2.7 \\
3.3 \\
3.7 \\
5.3 \\
1.9 \\
1.6 \\
1.7 \\
1.6\end{array}$ & $\begin{array}{l}6.6 \\
1.8 \\
2.4 \\
3.2 \\
5.3 \\
8.3 \\
9.1 \\
4.4 \\
0.5 \\
6.4 \\
36.4 \\
15.5\end{array}$ \\
\hline NNUAL & 79 & 0.44 & 14 & 18 & 1.2 & 100 \\
\hline
\end{tabular}

MAGNITUDE AND PROBABILITY OF INSTANTANEOUS PEAK FLON BASED ON PERIOD OF RECORD 1929-33, 1940-72

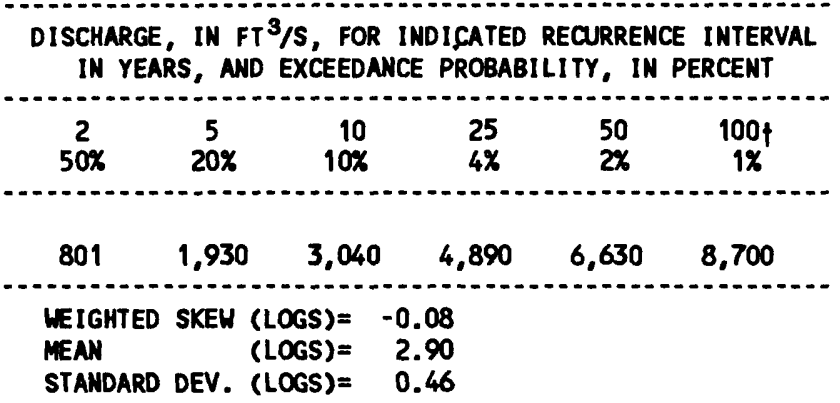

MAGNITUDE AND PROBABILITY OF ANNUAL LOW FLON BASED ON PERIDO OF RECORD 1931-33, 1941-72

\begin{tabular}{|c|c|c|c|c|c|c|}
\hline \multirow{2}{*}{$\begin{array}{l}\text { PERIOD } \\
\text { (CON- } \\
\text { SECU- } \\
\text { TIVE } \\
\text { DAYS) }\end{array}$} & \multicolumn{6}{|c|}{$\begin{array}{l}\text { DISCHARGE, IN FT } 3 / 5 \text {, FOR INDICATED } \\
\text { RECURRENCE INTERVAL, IN YEARS, AND } \\
\text { NOW-EXCEEDANCE PROBABILITY, IN PERCENT }\end{array}$} \\
\hline & $\begin{array}{c}2 \\
50 \%\end{array}$ & $\begin{array}{c}5 \\
20 \%\end{array}$ & $\begin{array}{l}10 \\
10 \%\end{array}$ & $\begin{array}{l}20 \\
5 \%\end{array}$ & $\begin{array}{l}50 \\
2 \%\end{array}$ & $\begin{array}{l}100 \dagger \\
1 \%\end{array}$ \\
\hline $\begin{array}{r}1 \\
3 \\
7 \\
14 \\
30 \\
60 \\
90 \\
120 \\
183\end{array}$ & $\begin{array}{l}0.00 \\
0.00 \\
0.00 \\
0.00 \\
0.00 \\
0.10 \\
0.19 \\
0.70 \\
2.4\end{array}$ & $\begin{array}{l}0.00 \\
0.00 \\
0.00 \\
0.00 \\
0.00 \\
0.00 \\
0.00 \\
0.09 \\
0.47\end{array}$ & $\begin{array}{l}0.00 \\
0.00 \\
0.00 \\
0.00 \\
0.00 \\
0.00 \\
0.00 \\
0.01 \\
0.15\end{array}$ & $\begin{array}{l}0.00 \\
0.00 \\
0.00 \\
0.00 \\
0.00 \\
0.00 \\
0.00 \\
0.00 \\
0.00\end{array}$ & $\begin{array}{l}0.00 \\
0.00 \\
0.00 \\
0.00 \\
0.00 \\
0.00 \\
0.00 \\
0.00 \\
0.00\end{array}$ & $\begin{array}{l}0.00 \\
0.00 \\
0.00 \\
0.00 \\
0.00 \\
0.00 \\
0.00 \\
0.00 \\
0.00\end{array}$ \\
\hline
\end{tabular}

MAGNITUDE AND PROBABILITY OF ANNUAL HIGH FLOH BASED ON PERIOD OF RECORD 1930-33, 1941-72

\begin{tabular}{|c|c|c|c|c|c|c|}
\hline \multirow{2}{*}{$\begin{array}{l}\text { PERIOD } \\
\text { (CON- } \\
\text { SECU- } \\
\text { TIVE } \\
\text { DAYS) }\end{array}$} & \multicolumn{6}{|c|}{$\begin{array}{l}\text { DISCHARGE, IN } \mathrm{FT}^{3} / \mathrm{S} \text {, FOR INDICATED } \\
\text { RECURRENCE INTERVAL, IN YEARS, AND } \\
\text { EXCEEDANCE PROBABILITY, IN PERCENT }\end{array}$} \\
\hline & $\stackrel{2}{50 \%}$ & $\begin{array}{c}5 \\
20 \%\end{array}$ & $\begin{array}{l}10 \\
10 \%\end{array}$ & $\begin{array}{l}25 \\
4 \%\end{array}$ & $\begin{array}{l}50 \\
2 \%\end{array}$ & $\begin{array}{c}100 \dagger \\
1 \%\end{array}$ \\
\hline $\begin{array}{r}1 \\
3 \\
7 \\
15 \\
30 \\
60 \\
90\end{array}$ & $\begin{array}{r}374 \\
229 \\
132 \\
77 \\
47 \\
30 \\
22\end{array}$ & $\begin{array}{r}904 \\
600 \\
373 \\
230 \\
146 \\
95 \\
68\end{array}$ & $\begin{array}{r}1,320 \\
922 \\
603 \\
392 \\
258 \\
170 \\
122\end{array}$ & $\begin{array}{r}1,870 \\
1,380 \\
962 \\
670 \\
466 \\
314 \\
223\end{array}$ & $\begin{array}{r}2,270 \\
1,740 \\
1,270 \\
932 \\
677 \\
463 \\
328\end{array}$ & $\begin{array}{r}2,660 \\
2,110 \\
1,610 \\
1,240 \\
941 \\
653 \\
462\end{array}$ \\
\hline
\end{tabular}

DURATION TABLE OF DAILY MEAN FLON FOR PERICD OF RECORD 1930-33, 1941-72

DISCHARGE, IN FT $3 / 5$, WHICH WAS EQUALED OR EXCEEDED FOR INDICATED PERCENT OF TIME

\begin{tabular}{|c|c|c|c|c|c|c|c|c|c|c|c|c|c|c|c|c|}
\hline $1 \%$ & $5 \%$ & $10 \%$ & $15 \%$ & $20 \%$ & $30 \%$ & $40 \%$ & $50 \%$ & $60 \%$ & $70 \%$ & $80 \%$ & $90 \%$ & $95 \%$ & $98 \%$ & $99 \%$ & $99.5 \%$ & $99.9 \%$ \\
\hline 347 & 49 & 16 & 10 & 7.7 & 3.3 & 1.5 & 0.67 & 0.23 & 0.11 & 0.00 & 0.00 & 0.00 & 0.00 & 0.00 & 0.00 & 0.00 \\
\hline
\end{tabular}

† Reliability of values in column is uncertain, and potential errors are large. 
LITTLE COLORADO RIVER BASIN

09388000 LITTLE COLORADO RIVER NR HUNT, AZ--CONTINUED
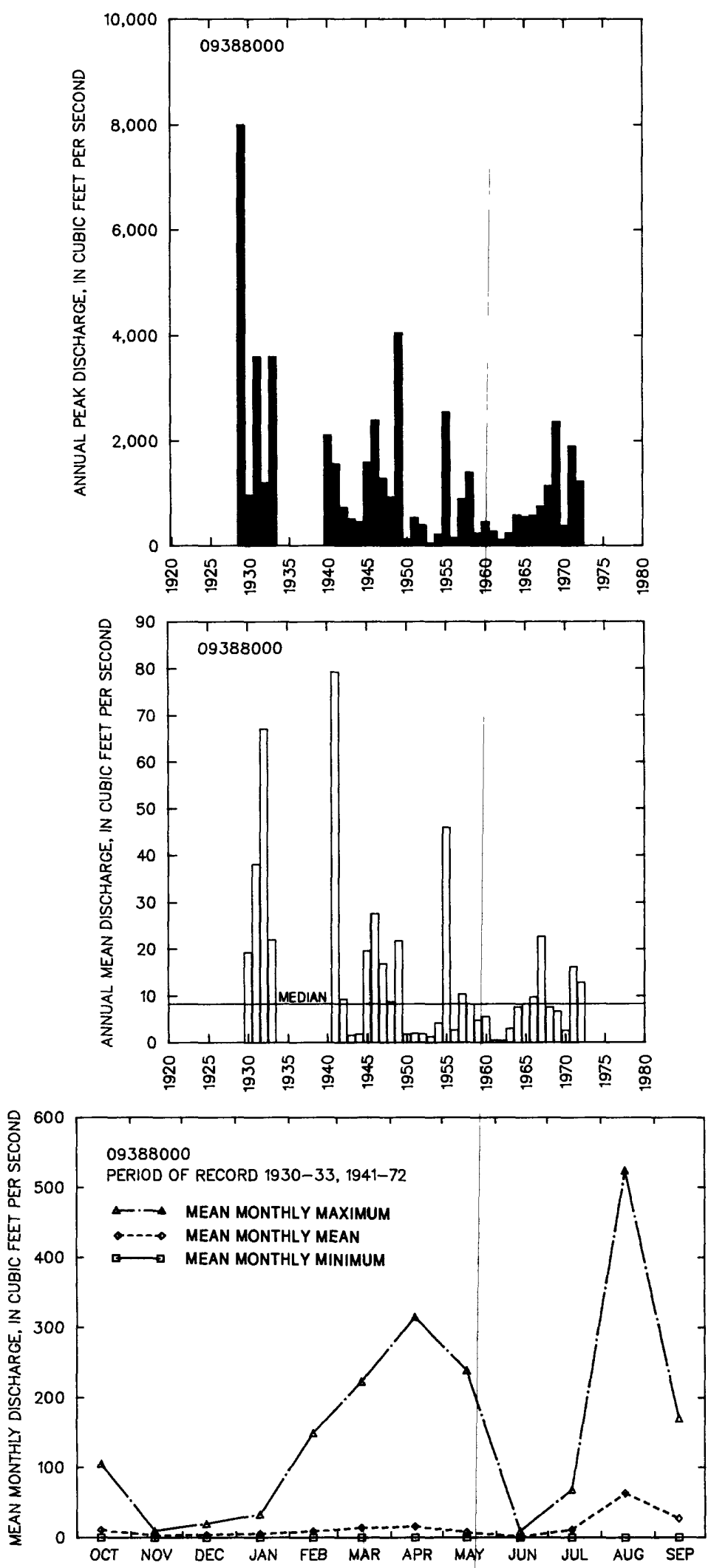
09390500 SHOW LOH CREEK NEAR LAKESIDE, AZ

LOCATION.-- Lat 34'10'46", long 109'59'14", in SWHWh sec.14, T.9 N., R.22 E., Navajo County, Hydrologic Unit 15020005, on left bank 1 mi upstrean from pumping plant on Show Low Lake, 1.9 mi northwest of Lakeside, 2.2 mi upstream from Jaques Dam, and 6 mi southeast of Show Low.

DRAIMAGE AREA. $--68.6 \mathrm{mi}^{2}$.

REMARKS. --Record shows inflow to Show Low Lake. Flow partly regulated by several small reservoirs, largest of which are Rainbow Lake and Scott Reservoir, combined capacity, 2,400 acre-ft. Diversions for irrigation of about 250 acres above station.

aNMUAL PEAK DISCHARge

\begin{tabular}{|c|c|c|c|c|c|c|c|}
\hline $\begin{array}{l}\text { WATER } \\
\text { YEAR }\end{array}$ & DATE & $\begin{array}{c}\text { ANNUAL PEAK } \\
\text { DISCHARGE } \\
\left.\text { (FT }{ }^{3} / \mathrm{S}\right)\end{array}$ & $\begin{array}{l}\text { DISCHARGE } \\
\text { COOES }\end{array}$ & $\begin{array}{l}\text { WATER } \\
\text { YEAR }\end{array}$ & DATE & $\begin{array}{c}\text { ANNUAL PEAK } \\
\text { DISCHARGE } \\
\text { (FT } 3 / \mathrm{S})\end{array}$ & $\begin{array}{l}\text { DISCHARGE } \\
\text { COOES }\end{array}$ \\
\hline $\begin{array}{l}1954 \\
1955 \\
1956 \\
1957 \\
1958 \\
1959 \\
1960 \\
1961 \\
1962 \\
1963 \\
1964 \\
1965 \\
1966 \\
1967 \\
1968 \\
1969 \\
1970 \\
1971\end{array}$ & $\begin{array}{l}03-23-54 \\
08-27-55 \\
07-31-56 \\
02-09-57 \\
03-22-58 \\
08-28-59 \\
03-08-60 \\
04-01-61 \\
02-13-62 \\
02-22-63 \\
04-10-64 \\
01-07-65 \\
12-30-65 \\
08-02-67 \\
02-25-68 \\
03-19-69 \\
04-21-70 \\
08-10-71\end{array}$ & $\begin{array}{r}2,040 \\
273 \\
103 \\
56 \\
867 \\
45 \\
487 \\
27 \\
930 \\
64 \\
30 \\
2,430 \\
3,880 \\
42 \\
345 \\
395 \\
30 \\
219\end{array}$ & $\begin{array}{l}\text { UR } \\
\text { UR } \\
\text { UR } \\
\text { UR } \\
\text { UR } \\
\text { UR } \\
\text { UR } \\
\text { UR } \\
\text { UR } \\
\text { UR } \\
\text { UR } \\
\text { UR } \\
\text { UR } \\
\text { UR } \\
\text { UR } \\
\text { UR } \\
\text { UR } \\
\text { UR }\end{array}$ & $\begin{array}{l}1972 \\
1973 \\
1974 \\
1975 \\
1976 \\
1977 \\
1978 \\
1979 \\
1980 \\
1981 \\
1982 \\
1983 \\
1984 \\
1985 \\
1986 \\
1987 \\
1988 \\
1989\end{array}$ & $\begin{array}{l}12-26-71 \\
05-05-73 \\
03-21-74 \\
03-09-75 \\
04-20-76 \\
04-08-77 \\
03-01-78 \\
12-18-78 \\
02-15-80 \\
03-30-81 \\
03-13-82 \\
03-30-83 \\
10-02-83 \\
12-27-84 \\
02-16-86 \\
03-09-87 \\
08-31-88 \\
02-27-89\end{array}$ & $\begin{array}{r}5,450 \\
1,400 \\
60 \\
405 \\
632 \\
35 \\
2,750 \\
5,550 \\
1,860 \\
31 \\
575 \\
442 \\
683 \\
5,430 \\
345 \\
500 \\
890 \\
92\end{array}$ & $\begin{array}{l}\text { UR } \\
\text { UR } \\
\text { UR } \\
\text { UR } \\
\text { UR } \\
\text { UR } \\
\text { UR } \\
\text { UR } \\
\text { UR } \\
\text { UR } \\
\text { UR } \\
\text { UR } \\
\text { UR } \\
\text { UR } \\
\text { UR } \\
\text { UR } \\
\text { UR } \\
\text { UR }\end{array}$ \\
\hline
\end{tabular}

BASIN CHARACTERISTICS

\begin{tabular}{|c|c|c|c|c|c|c|c|}
\hline \multirow{2}{*}{$\begin{array}{l}\text { MAIN } \\
\text { CHANNEL } \\
\text { SLOPE } \\
\text { (FT/MI) }\end{array}$} & \multirow[b]{2}{*}{$\begin{array}{c}\text { STREAM } \\
\text { LENGTH } \\
\text { (MI) }\end{array}$} & \multirow{2}{*}{$\begin{array}{l}\text { MEAN } \\
\text { BASIN } \\
\text { ELEVA- } \\
\text { TION } \\
\text { (FT) }\end{array}$} & \multirow[b]{2}{*}{$\begin{array}{l}\text { FORESTED } \\
\text { AREA } \\
\text { (PERCENT) }\end{array}$} & \multirow[b]{2}{*}{$\begin{array}{l}\text { SOIL } \\
\text { INDEX }\end{array}$} & \multirow{2}{*}{$\begin{array}{c}\text { MEAN } \\
\text { ANNUAL } \\
\text { PRECIPI- } \\
\text { TATION } \\
\text { (IN) }\end{array}$} & \multicolumn{2}{|c|}{ RAINFALL INTENSITY, 24-HOUR } \\
\hline & & & & & & $\begin{array}{c}\text { 2-YEAR } \\
\text { (IN) }\end{array}$ & $\begin{array}{l}\text { 50-YEAR } \\
\text { (IN) }\end{array}$ \\
\hline 7.2 & 21.0 & 7,320 & 85.0 & 3.0 & 23.7 & 2.2 & 4.6 \\
\hline
\end{tabular}


MEAN MONTHLY AND ANNUAL DISCHARGES 1954-89

\begin{tabular}{|c|c|c|c|c|c|c|}
\hline MONTH & $\begin{array}{l}\operatorname{MAXIMMM} \\
\left(F T^{3} / S\right)\end{array}$ & $\begin{array}{l}\text { MINIMUM } \\
\left(F^{3} / S\right)\end{array}$ & $\begin{array}{c}\text { MEAN } \\
\left(F T^{3} / S\right)\end{array}$ & $\begin{array}{l}\text { STAN- } \\
\text { DARD } \\
\text { DEVIA- } \\
\text { TION } \\
\text { (FT } 3 / S \text { ) }\end{array}$ & $\begin{array}{l}\text { COEFFI- } \\
\text { CIENT OF } \\
\text { VARI- } \\
\text { ATION }\end{array}$ & $\begin{array}{c}\text { PERCENT } \\
\text { OF } \\
\text { ANNUAL } \\
\text { RUNOFF }\end{array}$ \\
\hline $\begin{array}{l}\text { OCTOBER } \\
\text { NOVEMBER } \\
\text { DECEMBER } \\
\text { JANUARY } \\
\text { FEBRUARY } \\
\text { MARCH } \\
\text { APRIL } \\
\text { MAY } \\
\text { JUNE } \\
\text { JULY } \\
\text { AUGUST } \\
\text { SEPTEEMER }\end{array}$ & $\begin{array}{r}57 \\
54 \\
285 \\
60 \\
225 \\
189 \\
197 \\
72 \\
11 \\
11 \\
20 \\
19\end{array}$ & $\begin{array}{l}0.73 \\
0.29 \\
0.20 \\
0.10 \\
0.19 \\
0.87 \\
0.97 \\
1.7 \\
2.2 \\
1.1 \\
1.4 \\
1.3\end{array}$ & $\begin{array}{l}6.8 \\
5.6 \\
25 \\
10 \\
30 \\
47 \\
22 \\
7.5 \\
6.4 \\
6.2 \\
5.4 \\
5.2\end{array}$ & $\begin{array}{l}12 \\
10 \\
61 \\
14 \\
45 \\
50 \\
36 \\
12 \\
1.9 \\
2.3 \\
3.4 \\
3.2\end{array}$ & $\begin{array}{l}1.8 \\
1.9 \\
2.4 \\
1.4 \\
1.5 \\
1.0 \\
1.6 \\
1.5 \\
0.31 \\
0.37 \\
0.62 \\
0.61\end{array}$ & $\begin{array}{r}3.9 \\
3.1 \\
14.1 \\
5.7 \\
16.9 \\
26.5 \\
12.5 \\
4.2 \\
3.6 \\
3.5 \\
3.0 \\
2.9\end{array}$ \\
\hline ANNUAL & 57 & 2.6 & 15 & 13 & 0.91 & 100 \\
\hline
\end{tabular}

MAGNITUDE AND PROBABILITY OF INSTANTANEOUS PEAK FLON BASED ON PERIOD OF RECORD 1954-89

\begin{tabular}{|c|c|c|c|c|c|}
\hline $\begin{array}{c}2 \\
50 x\end{array}$ & $\begin{array}{c}5 \\
20 \%\end{array}$ & $\begin{array}{r}10 \\
10 \%\end{array}$ & $\begin{array}{l}25 \\
4 \%\end{array}$ & $\begin{array}{l}50 \\
2 \%\end{array}$ & $\begin{array}{c}100 \dagger \\
1 \%\end{array}$ \\
\hline 474 & 1,540 & 2,830 & 5,360 & 8,060 & 11,600 \\
\hline $\begin{array}{l}\text { WEIGH } \\
\text { MEAN } \\
\text { STAND }\end{array}$ & $\begin{array}{l}\text { SKEW } \\
\text { DEV. }\end{array}$ & $\begin{array}{l}(G S)=-( \\
(G S)= \\
(G S)=\end{array}$ & & & \\
\hline
\end{tabular}

MAGNITLDE AND PROBABILITY OF ANMUAL LOW FLOW BASED ON PERICD OF RECORD 1955-89

\begin{tabular}{|c|c|c|c|c|c|c|}
\hline \multirow{2}{*}{$\begin{array}{l}\text { PERICO } \\
\text { (CON- } \\
\text { SECU- } \\
\text { TIVE } \\
\text { DAYS) }\end{array}$} & \multicolumn{6}{|c|}{$\begin{array}{l}\text { DISCHARGE, IN FT } 3 / \mathrm{S} \text {, FOR INDICATED } \\
\text { RECURRENCE INTERVAL, IN YEARS, AND } \\
\text { NON-EXCEEDANCE PROBAB ILITY, IN PERCENT }\end{array}$} \\
\hline & $\begin{array}{c}2 \\
50 \%\end{array}$ & $\begin{array}{c}5 \\
20 \%\end{array}$ & $\begin{array}{l}10 \\
10 \%\end{array}$ & $\begin{array}{l}20 \\
5 \%\end{array}$ & $\begin{array}{l}50 \\
2 \%\end{array}$ & $\begin{array}{l}100 \dagger \\
1 \%\end{array}$ \\
\hline $\begin{array}{r}1 \\
3 \\
7 \\
14 \\
30 \\
60 \\
90 \\
120 \\
183\end{array}$ & $\begin{array}{l}0.00 \\
0.00 \\
0.00 \\
0.75 \\
1.1 \\
1.5 \\
1.9 \\
2.3 \\
3.2\end{array}$ & $\begin{array}{l}0.00 \\
0.00 \\
0.00 \\
0.20 \\
0.38 \\
0.59 \\
0.88 \\
1.2 \\
1.9\end{array}$ & $\begin{array}{l}0.00 \\
0.00 \\
0.00 \\
0.09 \\
0.21 \\
0.34 \\
0.58 \\
0.83 \\
1.4\end{array}$ & $\begin{array}{l}0.00 \\
0.00 \\
0.00 \\
0.04 \\
0.12 \\
0.21 \\
0.40 \\
0.60 \\
1.2\end{array}$ & $\begin{array}{l}0.00 \\
0.00 \\
0.00 \\
0.02 \\
0.07 \\
0.12 \\
0.26 \\
0.42 \\
0.88\end{array}$ & $\begin{array}{l}0.00 \\
0.00 \\
0.00 \\
0.01 \\
0.04 \\
0.08 \\
0.19 \\
0.32 \\
0.74\end{array}$ \\
\hline
\end{tabular}

MAGNITLDE AND PROBABILITY OF ANMUAL HIGH FLOW BASED ON PERIOD OF RECORD 1954-89

\begin{tabular}{|c|c|c|c|c|c|c|}
\hline \multirow{2}{*}{$\begin{array}{l}\text { PERIOO } \\
\text { (CON- } \\
\text { SECU- } \\
\text { TIVE } \\
\text { DAYS) }\end{array}$} & & \multicolumn{5}{|c|}{$\begin{array}{l}\text { DISCHARGE, IN } \mathrm{FT}^{3} / \mathrm{S} \text {, FOR INDICATED } \\
\text { RECURRENCE INTTERVAL, IN YEARS, AND } \\
\text { EXCEEDANCE PROBABILITY, IN PERCENT }\end{array}$} \\
\hline & $\stackrel{2}{50 \%}$ & $\begin{array}{c}5 \\
20 \%\end{array}$ & $\begin{array}{l}10 \\
10 \%\end{array}$ & $\begin{array}{l}25 \\
4 \%\end{array}$ & $\begin{array}{l}50 \\
2 \%\end{array}$ & $\begin{array}{c}100 \dagger \\
1 \%\end{array}$ \\
\hline $\begin{array}{r}1 \\
3 \\
7 \\
15 \\
30 \\
60 \\
90\end{array}$ & $\begin{array}{r}188 \\
135 \\
93 \\
62 \\
43 \\
30 \\
24\end{array}$ & $\begin{array}{r}748 \\
491 \\
313 \\
190 \\
122 \\
79 \\
63\end{array}$ & $\begin{array}{r}1.560 \\
957 \\
584 \\
334 \\
207 \\
129 \\
103\end{array}$ & $\begin{array}{r}3,440 \\
1,940 \\
1,120 \\
601 \\
358 \\
217 \\
175\end{array}$ & $\begin{array}{r}5,760 \\
3,060 \\
1,700 \\
870 \\
507 \\
304 \\
248\end{array}$ & $\begin{array}{r}9,190 \\
4,590 \\
2,450 \\
1,210 \\
690 \\
410 \\
338\end{array}$ \\
\hline
\end{tabular}

DURATION TABLE OF DAILY MEAN FLON FOR PERICD OF RECORD 1954-89

DISCHARGE, IN FT $3 / 5$, WHICH WAS EQUALED OR EXCEEDED FOR INDICATED PERCENT OF TIME

\begin{tabular}{|lllllllllllllllll}
$1 \%$ & $5 \%$ & $10 \%$ & $15 \%$ & $20 \%$ & $30 \%$ & $40 \%$ & $50 \%$ & $60 \%$ & $70 \%$ & $80 \%$ & $90 \%$ & $95 \%$ & $98 \%$ & $99 \%$ & $99.5 \%$ & $99.9 \%$ \\
\hline 202 & 57 & 21 & 13 & 9.5 & 7.5 & 5.9 & 4.7 & 3.6 & 2.6 & 1.6 & 0.79 & 0.40 & 0.20 & 0.11 & 0.08 & 0.00
\end{tabular}

$\uparrow$ Reliability of values in column is uncertain, and potential errors are large. 
LITTLE COLORADO RIVER BASIN

09390500 SHOW LOW CREEK NEAR LAKESIDE, AZ--CONTIMUED
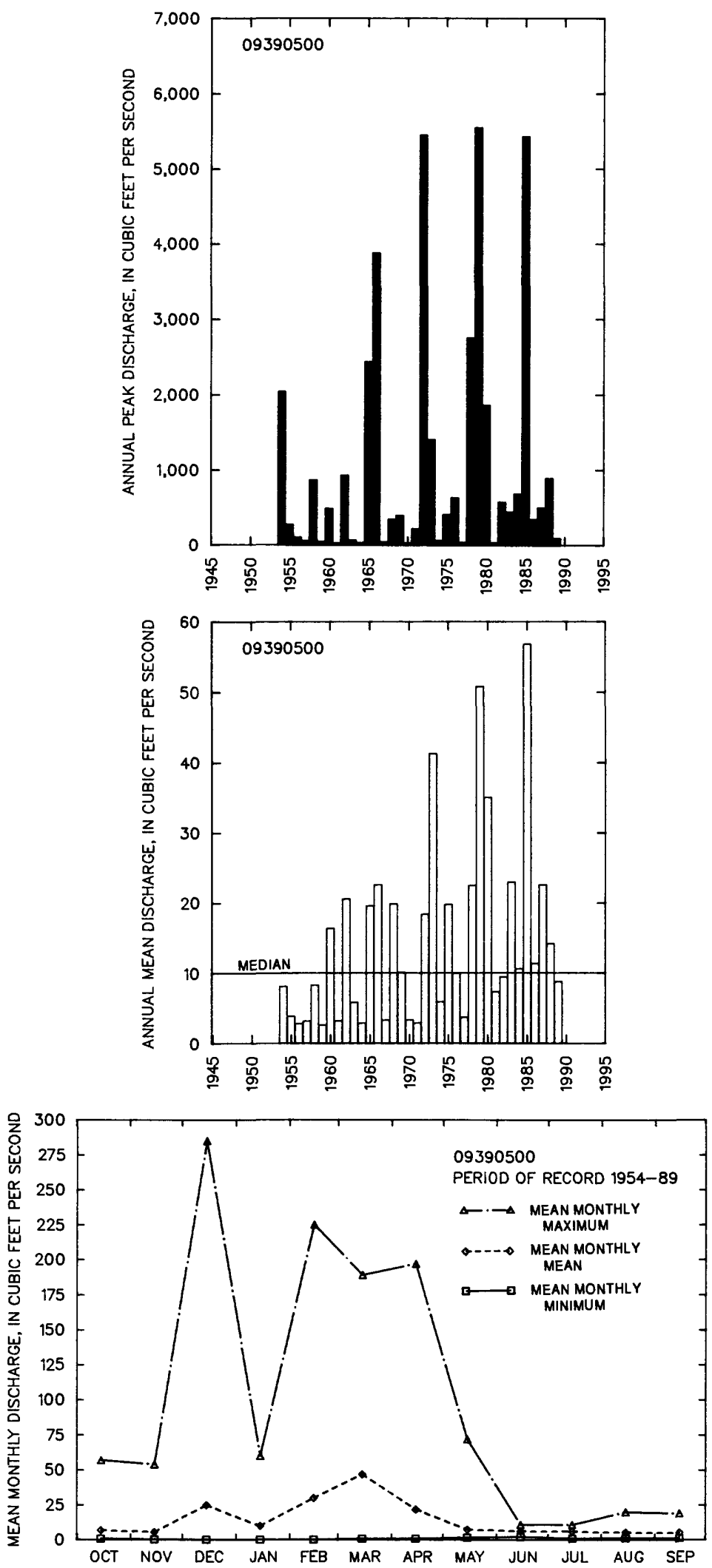
09392800 LONG LAKE TRIBUTARY NEAR SHOW LOW, AZ

LOCATION.--Lat 34'15'40", long 109'59'41", in MWKSEX sec.15, T.10 N., R.22 E., Mavajo County, Hydrologic Unit 15020005, at U.S. Highway 60, $1 \mathrm{mi}$ east of Show Low.

ORAINACE AREA. $--5.22 \mathrm{mi}^{2}$.

ANIUAL PEAK DISCHARGE

\begin{tabular}{|c|c|c|c|}
\hline $\begin{array}{l}\text { WATER } \\
\text { YEAR }\end{array}$ & DATE & $\begin{array}{c}\text { ANNUAL PEAK } \\
\text { DISCHARGE } \\
\text { (FT } 3 / \mathrm{S})\end{array}$ & $\begin{array}{l}\text { DISCHARCE } \\
\text { COOES }\end{array}$ \\
\hline $\begin{array}{l}1965 \\
1966 \\
1967 \\
1968 \\
1969 \\
1970 \\
1971 \\
1972 \\
1973 \\
1974 \\
1975 \\
1976\end{array}$ & $\begin{array}{l}01 / 07 / 65 \\
12 / 30 / 65 \\
00 / 00 / 67 \\
02 / 00 / 68 \\
03 / 19 / 69 \\
00 / 00 / 70 \\
00 / 00 / 71 \\
12 / 26 / 71 \\
10 / 19 / 72 \\
00 / 00 / 74 \\
00 / 00 / 75 \\
00 / 00 / 76\end{array}$ & $\begin{array}{r}231 \\
298 \\
0 \\
100 \\
30 \\
0 \\
0 \\
530 \\
140 \\
0 \\
0 \\
20\end{array}$ & LT \\
\hline
\end{tabular}

MAGNITUDE AND PROBABILITY OF INSTANTANEOUS PEAK FLOW BASED ON PERICD OF RECORD 1965-76

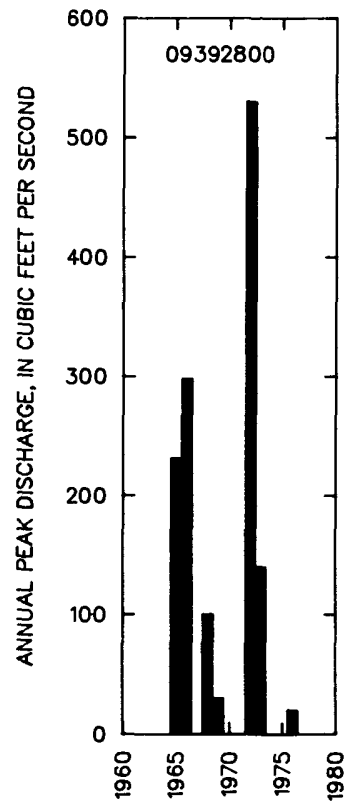

DISCHARGE, IN $\mathrm{FT}^{3} / \mathrm{S}$, FOR INOICATED RECURRENCE INTERVAL IN YEARS, AND EXCEEDANCE PROBABILITY, IN PERCENT

\begin{tabular}{|c|c|c|c|c|c|}
\hline $\begin{array}{c}2 \\
50 \%\end{array}$ & $\underset{20 \%}{5}$ & $\begin{array}{r}10 \\
10 \%\end{array}$ & $\begin{array}{l}25 \dagger \\
4 \%\end{array}$ & $\begin{array}{l}50 \dagger \\
2 \%\end{array}$ & $\begin{array}{c}100 \dagger \\
1 \%\end{array}$ \\
\hline 23.4 & 195 & 524 & 1,380 & 2,460 & 4,030 \\
\hline $\begin{array}{l}\text { WEIGHTED } \\
\text { MEAN } \\
\text { STANDARD }\end{array}$ & $\begin{array}{l}\text { SKEW } \\
\text { DEV. }\end{array}$ & $\begin{array}{l}(\operatorname{LOSS})= \\
(\operatorname{LOGS})= \\
(\operatorname{LOGS})=\end{array}$ & $\begin{array}{r}-0.49 \\
1.27 \\
1.19\end{array}$ & & \\
\hline
\end{tabular}

+ Reliability of values in colum is uncertain, and potential errors are large.

BASIN CHARACTERISTICS

\begin{tabular}{|c|c|c|c|c|c|c|c|}
\hline MAIN & & $\begin{array}{l}\text { MEAN } \\
\text { BASIN }\end{array}$ & & & $\begin{array}{c}\text { MEAN } \\
\text { ANNUAL }\end{array}$ & RAINFALL II & ISITY, 24-HOUR \\
\hline $\begin{array}{l}\text { CHANNEL } \\
\text { SLOPE } \\
\text { (FT/MI) }\end{array}$ & $\begin{array}{c}\text { STREAM } \\
\text { LENGTH } \\
\text { (MI) }\end{array}$ & $\begin{array}{l}\text { ELEVA- } \\
\text { TION } \\
\text { (FT) }\end{array}$ & $\begin{array}{l}\text { FORESTED } \\
\text { AREA } \\
\text { (PERCENT) }\end{array}$ & $\begin{array}{l}\text { SOIL } \\
\text { INDEX }\end{array}$ & $\begin{array}{l}\text { PRECIPI- } \\
\text { TATION } \\
\text { (IN) }\end{array}$ & $\begin{array}{c}\text { 2-YEAR } \\
\text { (IN) }\end{array}$ & $\begin{array}{l}\text { 50-YEAR } \\
\text { (IN) }\end{array}$ \\
\hline 133 & 4.0 & 6,700 & 66.0 & 3.0 & 13.5 & 1.8 & 3.9 \\
\hline
\end{tabular}


09393500 SILVER CREEK NEAR SNOWFLAKE, AZ

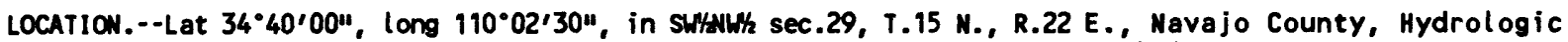
Unit 15020005, on left bank 6 mi upstream from mouth and 11 mi north of Snowflake.

DRAINAGE AREA.--925 $\mathrm{mi}^{2}$, of which $79 \mathrm{mi}^{2}$ is noncontributing.

REMARKS.--Diversions for irrigation above station of about 6,600 acres. Flow regulated by several reservoirs-combined capacity, about 13,700 acre-ft, excluding Lone Pine Reservoir, but including 6,176 acre-ft in Show Low Lake.

ANIUAL PEAK DISCHARGE

\begin{tabular}{|c|c|c|c|c|c|c|c|}
\hline $\begin{array}{l}\text { WATER } \\
\text { YEAR }\end{array}$ & DATE & $\begin{array}{c}\text { ANNUAL PEAK } \\
\text { DISCHARGE } \\
\text { (FT } 3 / S \text { ) }\end{array}$ & $\begin{array}{l}\text { DISCHARGE } \\
\text { CODES }\end{array}$ & $\begin{array}{l}\text { WATER } \\
\text { YEAR }\end{array}$ & DATE & $\begin{array}{c}\text { ANNUAL PEAK } \\
\text { DISCHARGE } \\
\left(F^{3} / S\right)\end{array}$ & $\begin{array}{l}\text { DISCHARGE } \\
\text { CODES }\end{array}$ \\
\hline $\begin{array}{l}1920 \\
1929 \\
1930 \\
1931 \\
1932 \\
1933 \\
1934 \\
1935 \\
1936 \\
1937 \\
1938 \\
1939 \\
1940 \\
1941 \\
1942 \\
1943 \\
1944 \\
1945 \\
1946 \\
1949 \\
1950 \\
1951 \\
1952 \\
1953 \\
1954 \\
1955 \\
1956 \\
1957 \\
1958 \\
1959\end{array}$ & $\begin{array}{l}12-05-19 \\
07-21-29 \\
08-11-30 \\
09-06-31 \\
02-09-32 \\
09-10-33 \\
00-00-34 \\
09-27-35 \\
07-25-36 \\
02-07-37 \\
08-08-38 \\
08-29-39 \\
07-26-40 \\
03-15-41 \\
10-03-41 \\
08-31-43 \\
08-25-44 \\
08-11-45 \\
09-19-46 \\
01-13-49 \\
07-07-50 \\
08-28-51 \\
01-19-52 \\
07-16-53 \\
09-02-54 \\
08-06-55 \\
06-29-56 \\
08-05-57 \\
09-08-58 \\
07-05-59\end{array}$ & $\begin{array}{r}25,000 \\
110,500 \\
3,000 \\
2,850 \\
9,900 \\
4,600 \\
2,000 \\
2,820 \\
4,300 \\
4,300 \\
3,100 \\
1,460 \\
11,000 \\
3,700 \\
932 \\
3,120 \\
416 \\
3,230 \\
1,680 \\
2,900 \\
1,160 \\
3,780 \\
10,100 \\
1,060 \\
7,670 \\
4,980 \\
3,620 \\
1,910 \\
4,340 \\
630\end{array}$ & $\begin{array}{c}\text { ES,UR, HP } \\
\text { UR } \\
\text { UR } \\
\text { UR } \\
\text { UR } \\
\text { UR } \\
\text { ES,UR } \\
\text { UR } \\
\text { UR } \\
\text { UR } \\
\text { UR } \\
\text { UR } \\
\text { UR } \\
\text { UR } \\
\text { UR } \\
\text { UR } \\
\text { UR } \\
\text { UR } \\
\text { UR } \\
\text { UR } \\
\text { UR } \\
\text { UR } \\
\text { UR } \\
\text { UR } \\
\text { UR } \\
\text { UR } \\
\text { UR } \\
\text { UR } \\
\text { UR } \\
\text { UR }\end{array}$ & $\begin{array}{l}1960 \\
1961 \\
1962 \\
1963 \\
1964 \\
1965 \\
1966 \\
1967 \\
1968 \\
1969 \\
1970 \\
1971 \\
1972 \\
1973 \\
1974 \\
1975 \\
1976 \\
1977 \\
1978 \\
1979 \\
1980 \\
1981 \\
1982 \\
1983 \\
1984 \\
1985 \\
1986 \\
1987 \\
1988 \\
1989\end{array}$ & $\begin{array}{l}12-25-59 \\
08-17-61 \\
02-13-62 \\
08-21-63 \\
07-31-64 \\
01-08-65 \\
12-30-65 \\
07-29-67 \\
08-05-68 \\
07-24-69 \\
09-06-70 \\
09-30-71 \\
12-26-71 \\
10-20-72 \\
09-22-74 \\
10-29-74 \\
02-10-76 \\
08-04-77 \\
03-01-78 \\
12-19-78 \\
02-20-80 \\
07-15-81 \\
08-12-82 \\
09-29-83 \\
08-23-84 \\
12-27-84 \\
08-28-86 \\
08-06-87 \\
02-03-88 \\
07-23-89\end{array}$ & $\begin{array}{r}2,120 \\
1,300 \\
1,030 \\
5,860 \\
6,090 \\
1,260 \\
6,800 \\
4,070 \\
3,890 \\
3,150 \\
1,690 \\
4,470 \\
4,780 \\
3,260 \\
558 \\
990 \\
2,540 \\
1,840 \\
4,160 \\
7,700 \\
4,460 \\
907 \\
5,090 \\
1,510 \\
3,160 \\
5,840 \\
409 \\
1,820 \\
737 \\
1,020\end{array}$ & $\begin{array}{l}\text { UR } \\
\text { UR } \\
\text { UR } \\
\text { UR } \\
\text { UR } \\
\text { UR } \\
\text { UR } \\
\text { UR } \\
\text { UR } \\
\text { UR } \\
\text { UR } \\
\text { UR } \\
\text { UR } \\
\text { UR } \\
\text { UR } \\
\text { UR } \\
\text { UR } \\
\text { UR } \\
\text { UR } \\
\text { UR } \\
\text { UR } \\
\text { UR } \\
\text { UR } \\
\text { UR } \\
\text { UR } \\
\text { UR } \\
\text { UR } \\
\text { UR } \\
\text { UR } \\
\text { UR }\end{array}$ \\
\hline
\end{tabular}

1 Highest since 1923.

\section{BASIN CHARACTERISTICS}

\begin{tabular}{|c|c|c|c|c|c|c|c|}
\hline \multirow{2}{*}{$\begin{array}{l}\text { MAIN } \\
\text { CHANNEL } \\
\text { SLOPE } \\
\text { (FT/MI) }\end{array}$} & \multirow[b]{2}{*}{$\begin{array}{l}\text { STREAM } \\
\text { LENGTH } \\
\text { (MI) }\end{array}$} & \multirow{2}{*}{$\begin{array}{l}\text { MEAN } \\
\text { BASIN } \\
\text { ELEVA- } \\
\text { TION } \\
\text { (FT) }\end{array}$} & \multirow[b]{2}{*}{$\begin{array}{l}\text { FORESTED } \\
\text { AREA } \\
\text { (PERCENT) }\end{array}$} & \multirow[b]{2}{*}{$\begin{array}{l}\text { SOIL } \\
\text { INDEX }\end{array}$} & \multirow{2}{*}{$\begin{array}{l}\text { MEAN } \\
\text { ANNUAL } \\
\text { PRECIPI- } \\
\text { TATION } \\
\text { (IN) }\end{array}$} & \multicolumn{2}{|c|}{ RAINFALL INTENSITY, 24-HOUR } \\
\hline & & & & & & $\begin{array}{c}\text { 2-YEAR } \\
\text { (IN) }\end{array}$ & $\begin{array}{c}\text { 50-YEAR } \\
\text { (IN) }\end{array}$ \\
\hline 35.0 & 53.3 & 6,400 & 53.0 & 3.0 & 16.7 & 1.8 & 3.8 \\
\hline
\end{tabular}


MEAN MONTHLY AND ANMUAL DISCHARGES 1951-89

\begin{tabular}{|c|c|c|c|c|c|c|}
\hline MONTH & $\begin{array}{l}\operatorname{MAXIMUN} \\
(F T 3 / S)\end{array}$ & $\begin{array}{l}\text { MINIIMUM } \\
\left(F^{3} / S\right)\end{array}$ & $\begin{array}{c}\text { MEAN } \\
\left(F^{3} / S\right)\end{array}$ & $\begin{array}{l}\text { STAN- } \\
\text { DARD } \\
\text { DEVIA- } \\
\text { TION } \\
\left(F^{3} / S\right)\end{array}$ & $\begin{array}{l}\text { COEFFI- } \\
\text { CIENT OF } \\
\text { VARI - } \\
\text { ATION }\end{array}$ & $\begin{array}{c}\text { PERCENT } \\
\text { OF } \\
\text { ANNUAL } \\
\text { RUNOFF }\end{array}$ \\
\hline $\begin{array}{l}\text { OCTOBER } \\
\text { NOVEMBER } \\
\text { DECEMBER } \\
\text { JANUARY } \\
\text { FEBRUARY } \\
\text { MARCH } \\
\text { APRIL } \\
\text { MAY } \\
\text { JUNE } \\
\text { JULY } \\
\text { AUGUST } \\
\text { SEPTEMBER }\end{array}$ & $\begin{array}{r}89 \\
109 \\
276 \\
457 \\
468 \\
195 \\
212 \\
71 \\
27 \\
67 \\
119 \\
173\end{array}$ & $\begin{array}{l}0.70 \\
0.82 \\
1.0 \\
0.88 \\
0.57 \\
0.15 \\
0.20 \\
0.96 \\
0.30 \\
0.86 \\
2.8 \\
0.59\end{array}$ & $\begin{array}{l}13 \\
8.5 \\
25 \\
27 \\
28 \\
32 \\
11 \\
4.9 \\
4.1 \\
16 \\
31 \\
21\end{array}$ & $\begin{array}{l}19 \\
19 \\
55 \\
78 \\
77 \\
52 \\
34 \\
11 \\
5.6 \\
17 \\
29 \\
33\end{array}$ & $\begin{array}{l}1.5 \\
2.3 \\
2.2 \\
2.9 \\
2.8 \\
1.6 \\
3.1 \\
2.3 \\
1.3 \\
1.0 \\
0.95 \\
1.5\end{array}$ & $\begin{array}{r}5.7 \\
3.8 \\
11.2 \\
12.3 \\
12.6 \\
14.3 \\
5.1 \\
2.2 \\
1.9 \\
7.3 \\
14.0 \\
9.5\end{array}$ \\
\hline ANNU & 69 & 3.1 & 18 & 17 & 0.91 & 100 \\
\hline
\end{tabular}

MAGNITUDE AND PROBABILITY OF ANNUAL LON FLON BASED ON PERIOD OF RECORD 1952-89

\begin{tabular}{|c|c|c|c|c|c|c|}
\hline \multirow{2}{*}{$\begin{array}{l}\text { PERIOD } \\
\text { (CON- } \\
\text { SECU- } \\
\text { TIVE } \\
\text { DAYS) }\end{array}$} & \multicolumn{6}{|c|}{$\begin{array}{l}\text { DISCHARGE, IN FT } 3 / \text { /S, FOR INDICATED } \\
\text { RECURRENCE INTERVAL, IN YEARS, AND } \\
\text { NON-EXCEEDANCE PROBABILITY, IN PERCENT }\end{array}$} \\
\hline & $\begin{array}{c}2 \\
50 x\end{array}$ & $\begin{array}{c}5 \\
20 \%\end{array}$ & $\begin{array}{l}10 \\
10 \%\end{array}$ & $\begin{array}{l}20 \\
5 \%\end{array}$ & $\begin{array}{l}50 \\
2 \%\end{array}$ & $\begin{array}{l}100 \dagger \\
1 \%\end{array}$ \\
\hline $\begin{array}{r}1 \\
3 \\
7 \\
14 \\
30 \\
60 \\
90 \\
120 \\
183\end{array}$ & $\begin{array}{l}0.00 \\
0.00 \\
0.00 \\
0.00 \\
0.59 \\
1.2 \\
1.7 \\
2.5 \\
4.7\end{array}$ & $\begin{array}{l}0.00 \\
0.00 \\
0.00 \\
0.00 \\
0.32 \\
0.82 \\
1.2 \\
1.7 \\
2.7\end{array}$ & $\begin{array}{l}0.00 \\
0.00 \\
0.00 \\
0.00 \\
0.23 \\
0.68 \\
0.99 \\
1.4 \\
2.2\end{array}$ & $\begin{array}{l}0.00 \\
0.00 \\
0.00 \\
0.00 \\
0.17 \\
0.60 \\
0.87 \\
1.2 \\
1.8\end{array}$ & $\begin{array}{l}0.00 \\
0.00 \\
0.00 \\
0.00 \\
0.12 \\
0.51 \\
0.77 \\
1.0 \\
1.6\end{array}$ & $\begin{array}{l}0.00 \\
0.00 \\
0.00 \\
0.00 \\
0.09 \\
0.46 \\
0.71 \\
0.92 \\
1.4\end{array}$ \\
\hline
\end{tabular}

MAGNITLOE AND PROBABILITY OF ANNUAL HIGH FLOW BASED ON PERIOD OF RECORD 1951-89

\begin{tabular}{|c|c|c|c|c|c|c|}
\hline $\begin{array}{l}\text { PERIOO } \\
\text { (CON- }\end{array}$ & & $\begin{array}{l}\text { DISCHA } \\
\text { RECURR } \\
\text { EXCEED }\end{array}$ & $\begin{array}{l}\text { IN } \\
\text { E INT } \\
\text { E PRO }\end{array}$ & $\begin{array}{l}3 / S, \\
\text { VAL, II } \\
\text { BILITY }\end{array}$ & $\begin{array}{l}\text { YEARS, } \\
\text { IN PER }\end{array}$ & \\
\hline $\begin{array}{l}\text { TIVE } \\
\text { DAYS) }\end{array}$ & $\begin{array}{c}2 \\
50 \%\end{array}$ & $\begin{array}{c}5 \\
20 \%\end{array}$ & $\begin{array}{l}10 \\
10 \%\end{array}$ & $\begin{array}{l}25 \\
4 \%\end{array}$ & $\begin{array}{l}50 \\
2 \%\end{array}$ & $\begin{array}{c}100 \dagger \\
1 \%\end{array}$ \\
\hline $\begin{array}{r}1 \\
3 \\
7 \\
15 \\
30 \\
60 \\
90\end{array}$ & $\begin{array}{r}672 \\
348 \\
191 \\
111 \\
72 \\
46 \\
34\end{array}$ & $\begin{array}{r}1,660 \\
876 \\
467 \\
264 \\
164 \\
102 \\
76\end{array}$ & $\begin{array}{r}2,620 \\
1,440 \\
751 \\
419 \\
252 \\
155 \\
118\end{array}$ & $\begin{array}{r}4,210 \\
2,460 \\
1,260 \\
690 \\
401 \\
243 \\
190\end{array}$ & $\begin{array}{r}5,680 \\
3,490 \\
1,760 \\
957 \\
542 \\
326 \\
261\end{array}$ & $\begin{array}{r}7,410 \\
4,810 \\
2,390 \\
1,290 \\
711 \\
425 \\
348\end{array}$ \\
\hline
\end{tabular}

DURATION TABLE OF DAILY MEAN FLON FOR PERIOD OF RECORD 1951-89

DISCHARGE, IN FT $3 / \mathrm{S}$, HHICH HAS EQUALED OR EXCEEDED FOR INDICATED PERCENT OF TIME

\begin{tabular}{|c|c|c|c|c|c|c|c|c|c|c|c|c|c|c|c|c|}
\hline $1 \%$ & $5 \%$ & $10 \%$ & $15 \%$ & $20 \%$ & $30 \%$ & $40 \%$ & $50 \%$ & $60 \%$ & $70 \%$ & $80 \%$ & $90 \%$ & $95 \%$ & $98 \%$ & $99 \%$ & $99.5 \%$ & $99.9 \%$ \\
\hline 290 & 67 & 26 & 14 & 9.0 & 5.5 & 4.1 & 3.1 & 2.3 & 1.7 & 1.1 & 0.63 & 0.33 & 0.10 & 0.01 & 0.00 & 0.00 \\
\hline
\end{tabular}

$f$ Reliability of values in colum is uncertain, and potential errors are large. 
LITTLE COLORADO RIVER BASIN

09393500 SILVER CREEK NEAR SNOWFLAKE, AZ--CONTINUEd
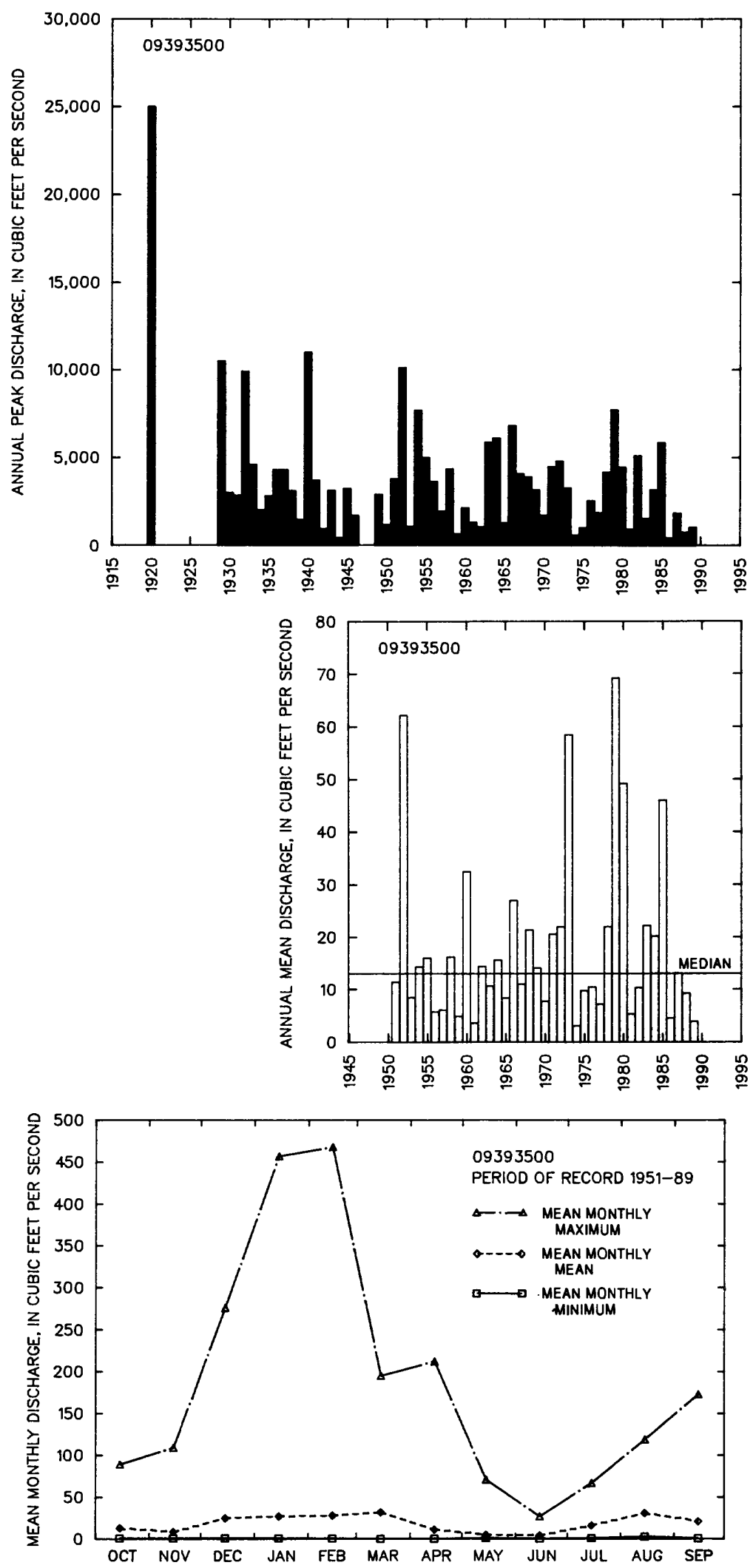
09394500 LITTLE COLORADO RIVER AT WOODRUFF, AZ

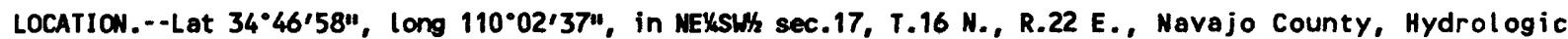
Unit 15020002, on left bank at abandoned county road bridge in Woodruff, 3.7 mi downstream from silver Creek.

DRAINAGE AREA. - - $8,072 \mathrm{mi}^{2}$, of which $297 \mathrm{mi}^{2}$ is noncontributing.

REMARKS.--Diversions above station for irrigation of about 22,000 acres including a pump installation $1,000 \mathrm{ft}$ upstream installed in spring of 1973. Some regulation by reservoirs above station; conbinad capacity, about 73,000 acre-ft, excluding Lone Pine Reservoir.

ANNUAL PEAK DISCHARGE

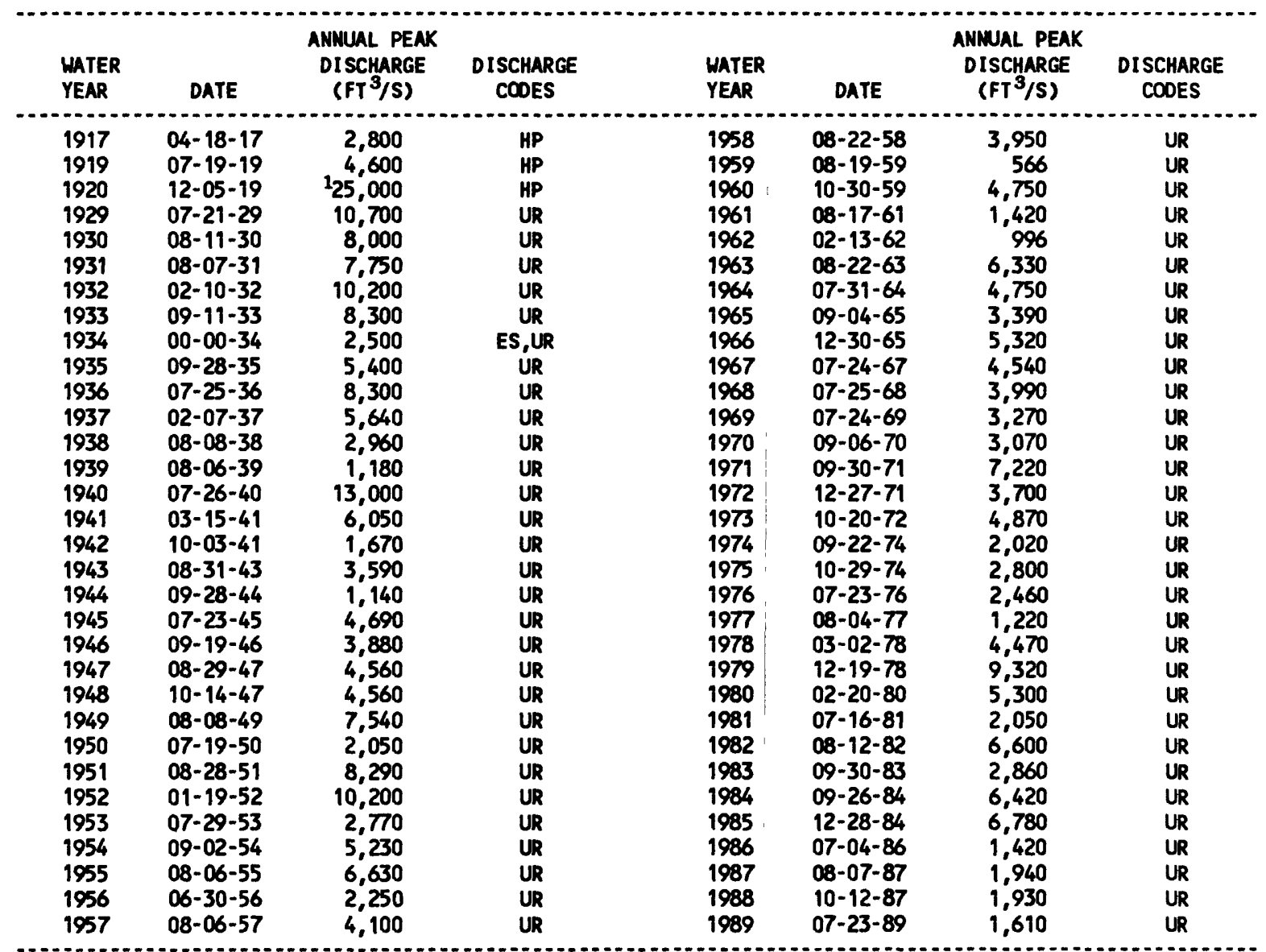

1Highest since 1917.

BASIN CHARACTERISTICS

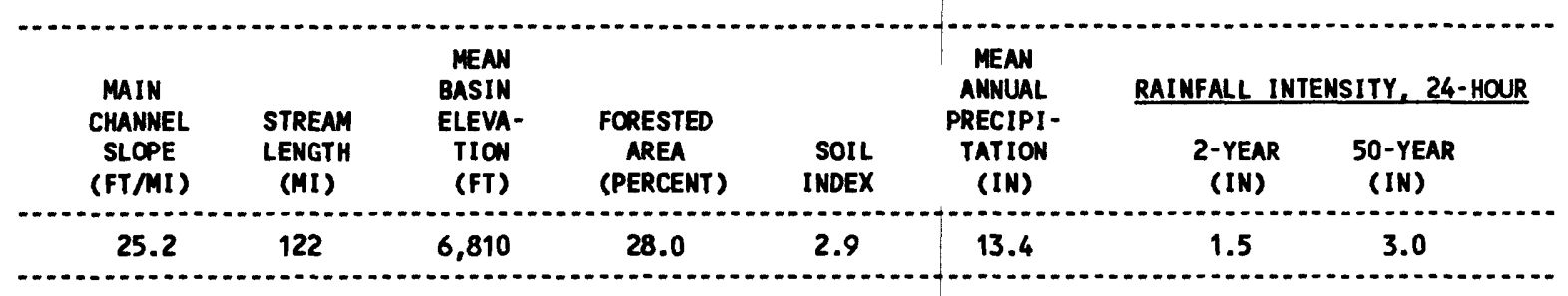


09394500 LITTLE COLORADO RIVER AT WOODRUFF, AZ--Continued

meAN MONTHLY AND ANNUAL DISChARGES 1906, 1930-33, 1936-89

\begin{tabular}{|c|c|c|c|c|c|c|}
\hline MONTH & $\begin{array}{l}\operatorname{MAx} \operatorname{Im} M \\
\left(F T^{3} / S\right)\end{array}$ & $\begin{array}{l}\text { MINIMUM } \\
\left(F^{3} / S\right)\end{array}$ & $\begin{array}{c}\text { MEAN } \\
\left(F T^{3} / S\right)\end{array}$ & $\begin{array}{c}\text { STAN- } \\
\text { DARD } \\
\text { DEVIA- } \\
\text { TION } \\
\left.\text { (FT }{ }^{3} / S\right)\end{array}$ & $\begin{array}{l}\text { COEFFI- } \\
\text { CIENT OF } \\
\text { VARI- } \\
\text { ATION }\end{array}$ & $\begin{array}{c}\text { PERCENT } \\
\text { OF } \\
\text { ANNUAL } \\
\text { RUNOFF }\end{array}$ \\
\hline $\begin{array}{l}\text { OCTOBER } \\
\text { NOVEMBER } \\
\text { DECEMBER } \\
\text { JANUARY } \\
\text { FEBRUARY } \\
\text { MARCH } \\
\text { APRIL } \\
\text { MAY } \\
\text { JUNE } \\
\text { JULY } \\
\text { AUGUST } \\
\text { SEPTEMBER }\end{array}$ & $\begin{array}{r}301 \\
543 \\
349 \\
488 \\
827 \\
610 \\
414 \\
488 \\
88 \\
238 \\
951 \\
611\end{array}$ & $\begin{array}{l}1.0 \\
3.0 \\
2.3 \\
3.8 \\
2.6 \\
2.7 \\
0.00 \\
0.00 \\
0.00 \\
0.53 \\
3.6 \\
0.71\end{array}$ & $\begin{array}{c}43 \\
26 \\
28 \\
36 \\
56 \\
76 \\
45 \\
24 \\
7.4 \\
62 \\
143 \\
78\end{array}$ & $\begin{array}{r}66 \\
75 \\
55 \\
71 \\
127 \\
126 \\
91 \\
72 \\
13 \\
60 \\
163 \\
106\end{array}$ & $\begin{array}{l}1.5 \\
2.9 \\
1.9 \\
2.0 \\
2.3 \\
1.7 \\
2.0 \\
3.1 \\
1.8 \\
0.98 \\
1.2 \\
1.3\end{array}$ & $\begin{array}{r}6.8 \\
4.2 \\
4.6 \\
5.7 \\
9.0 \\
12.2 \\
7.2 \\
3.8 \\
1.2 \\
9.9 \\
22.8 \\
12.5\end{array}$ \\
\hline ANMCLAL & 161 & 9.6 & 52 & 39 & 0.74 & 100 \\
\hline
\end{tabular}

MAGNITUDE AND PROBABILITY OF INSTANTAMEOUS PEAK FLOW BASED ON PERIOD OF RECORD 1917, 1919-20, 1929-89

\begin{tabular}{|c|c|c|c|c|c|}
\hline $\begin{array}{c}2 \\
50 \%\end{array}$ & $\begin{array}{c}5 \\
20 \%\end{array}$ & $\begin{array}{r}10 \\
10 \%\end{array}$ & $\begin{array}{l}25 \\
4 \%\end{array}$ & $\begin{array}{l}50 \\
2 \%\end{array}$ & $\begin{array}{r}100 \\
1 \%\end{array}$ \\
\hline 4,180 & 6,970 & 9,160 & 12,300 & 15,100 & 17,900 \\
\hline $\begin{array}{l}\text { NEIGHTED } \\
\text { MEAN } \\
\text { STANDARD }\end{array}$ & $\begin{array}{l}\text { SKEH } \\
\text { DEV. }\end{array}$ & $\begin{array}{l}(\text { LOGS })= \\
(\text { LOGS) }= \\
(\text { LOGS) }=\end{array}$ & $\begin{array}{l}0.12 \\
3.62 \\
0.26\end{array}$ & & \\
\hline
\end{tabular}

MAGNITLDE AND PROBABILITY OF ANNUAL LOW FLOW BASED ON PERIOD OF RECORD 1907, 1931-33, 1937-89

\begin{tabular}{|c|c|c|c|c|c|c|}
\hline \multirow{2}{*}{$\begin{array}{l}\text { PERIOD } \\
\text { (CON- } \\
\text { SECU- } \\
\text { TIVE } \\
\text { DAYS) }\end{array}$} & \multicolumn{6}{|c|}{$\begin{array}{l}\text { DISCHARGE, IN FT } 3 / S \text {, FOR INDICATED } \\
\text { RECURRENCE INTERVAL, IN YEARS, AND } \\
\text { NON-EXCEEDANCE PROBABILITY, IN PERCENT }\end{array}$} \\
\hline & $\stackrel{2}{2}$ & $\begin{array}{c}5 \\
20 \%\end{array}$ & $\begin{array}{l}10 \\
10 \%\end{array}$ & $\begin{array}{l}20 \\
5 \%\end{array}$ & $\begin{array}{l}50 \\
2 \%\end{array}$ & $\begin{array}{l}100 \\
1 \%\end{array}$ \\
\hline $\begin{array}{r}1 \\
3 \\
7 \\
14 \\
30 \\
60 \\
90 \\
120 \\
183\end{array}$ & $\begin{array}{l}0.00 \\
0.00 \\
0.00 \\
0.00 \\
0.00 \\
0.00 \\
0.00 \\
8.1 \\
15\end{array}$ & $\begin{array}{l}0.00 \\
0.00 \\
0.00 \\
0.00 \\
0.00 \\
0.00 \\
0.00 \\
4.9 \\
7.9\end{array}$ & $\begin{array}{l}0.00 \\
0.00 \\
0.00 \\
0.00 \\
0.00 \\
0.00 \\
0.00 \\
3.9 \\
6.0\end{array}$ & $\begin{array}{l}0.00 \\
0.00 \\
0.00 \\
0.00 \\
0.00 \\
0.00 \\
0.00 \\
3.4 \\
5.0\end{array}$ & $\begin{array}{l}0.00 \\
0.00 \\
0.00 \\
0.00 \\
0.00 \\
0.00 \\
0.00 \\
2.9 \\
4.1\end{array}$ & $\begin{array}{l}0.00 \\
0.00 \\
0.00 \\
0.00 \\
0.00 \\
0.00 \\
0.00 \\
2.6 \\
3.6\end{array}$ \\
\hline
\end{tabular}

MAGNITLOE AND PROBABILITY OF ANNUAL HIGH FLOW BASED ON PERIOD OF RECORD 1906, 1930-33, 1936-89

\begin{tabular}{|c|c|c|c|c|c|c|}
\hline $\begin{array}{c}\text { PERIOD } \\
\text { CCON- } \\
\text { SECU- }\end{array}$ & & $\begin{array}{l}\text { DISCHAR } \\
\text { RECURRE } \\
\text { EXCEED }\end{array}$ & $\begin{array}{l}\text { E, IN } \\
\text { CE INT } \\
\text { CE PRO }\end{array}$ & $\begin{array}{l}\text { 3/S, FC } \\
\text { VAL, II } \\
\text { BILITY. }\end{array}$ & $\begin{array}{l}\text { INDIC } \\
\text { YEARS, } \\
\text { IN PER }\end{array}$ & $\begin{array}{l}\text { ND } \\
\text { NT }\end{array}$ \\
\hline $\begin{array}{l}\text { TIVE } \\
\text { DAYS) }\end{array}$ & $\begin{array}{c}2 \\
50 \%\end{array}$ & $\begin{array}{c}5 \\
20 \%\end{array}$ & $\begin{array}{l}10 \\
10 \%\end{array}$ & $\begin{array}{l}25 \\
4 \%\end{array}$ & $\begin{array}{l}50 \\
2 \%\end{array}$ & $\begin{array}{r}100 \\
1 \%\end{array}$ \\
\hline $\begin{array}{r}1 \\
3 \\
7 \\
15 \\
30 \\
60 \\
90\end{array}$ & $\begin{array}{r}1,870 \\
1,040 \\
581 \\
348 \\
227 \\
149 \\
111\end{array}$ & $\begin{array}{r}3,630 \\
2,080 \\
1,120 \\
659 \\
432 \\
291 \\
219\end{array}$ & $\begin{array}{r}4,940 \\
2,890 \\
1,530 \\
892 \\
591 \\
405 \\
308\end{array}$ & $\begin{array}{r}6,690 \\
4,000 \\
2,080 \\
1,200 \\
813 \\
568 \\
436\end{array}$ & $\begin{array}{r}8,030 \\
4,880 \\
2,490 \\
1,450 \\
991 \\
701 \\
543\end{array}$ & $\begin{array}{r}9,370 \\
5,790 \\
2,910 \\
1,690 \\
1,180 \\
842 \\
658\end{array}$ \\
\hline
\end{tabular}

DURATION TABLE OF DAILY MEAN FLOW FOR PERIOD OF RECORD 1906, 1930-33, 1936-89

DISCHARGE, IN $\mathrm{FT}^{3} / \mathrm{S}$, WHICH WAS EQUALED OR EXCEEDED FOR INDICATED PERCENT OF TIME

\begin{tabular}{|c|c|c|c|c|c|c|c|c|c|c|c|c|c|c|c|c|}
\hline $1 \%$ & $5 \%$ & $10 \%$ & $15 \%$ & $20 \%$ & $30 \%$ & $40 \%$ & $50 \%$ & $60 \%$ & $70 \%$ & $80 \%$ & $90 \%$ & $95 \%$ & $98 \%$ & $99 \%$ & $99.5 \%$ & $99.9 \%$ \\
\hline 812 & 235 & 102 & 53 & 33 & 16 & 11 & 7.6 & 5.9 & 4.6 & 3.2 & 1.2 & 0.22 & 0.00 & 0.00 & 0.00 & 0.00 \\
\hline
\end{tabular}

† Reliability of values in column is uncertain, and potential errors are large. 
09394500 LITTLE COLORADO RIVER AT WOODRUFF, AZ--CONTINUED
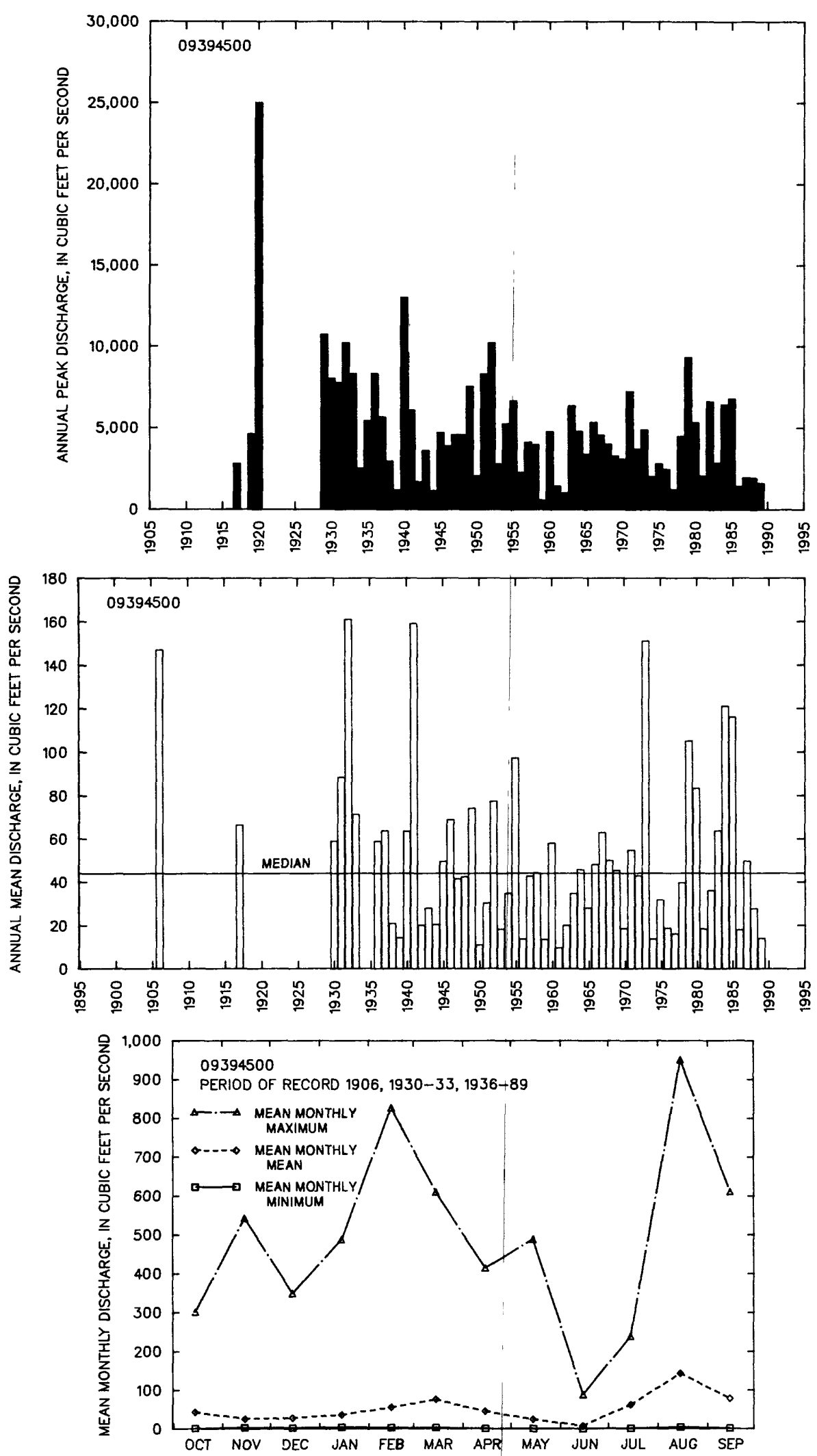
09395100 CARR LAKE DRAW TRIBUTARY NEAR HOLBROOK, AZ

LOCATION.-- Lat 34'50'05", long 109'56'00", in SEKSEK sec.30, T.17 N., R.23 E., Navajo County, Hydrologic Unit 15020002, at (former) U.S. Highway 180, 14 mi southeast of Holbrook.

DRAINAGE AREA. $--1.28 \mathrm{mi}^{2}$.

ANNUAL PEAK DISCHARGE

\begin{tabular}{ccc}
$\begin{array}{c}\text { WATER } \\
\text { YEAR }\end{array}$ & DATE & $\begin{array}{c}\text { ANNUAL PEAK } \\
\text { DISCHARGE } \\
\text { (FT } 3 / \text { S) }\end{array}$ \\
\hline 1964 & $07-28-64$ & 129 \\
1965 & $00-00-65$ & 0 \\
1966 & $08-12-66$ & 140 \\
1967 & $00-00-67$ & 35 \\
1968 & $08-00-68$ & 102 \\
1969 & $09-05-69$ & 39 \\
1970 & $09-06-70$ & 52 \\
1971 & $09-29-71$ & 45 \\
1972 & $00-00-72$ & 0 \\
1973 & $00-00-73$ & 5.0 \\
1974 & $00-00-74$ & 0 \\
1975 & $10-29-74$ & 4.0 \\
1976 & $09-00-76$ & 1.0 \\
$\ldots$
\end{tabular}

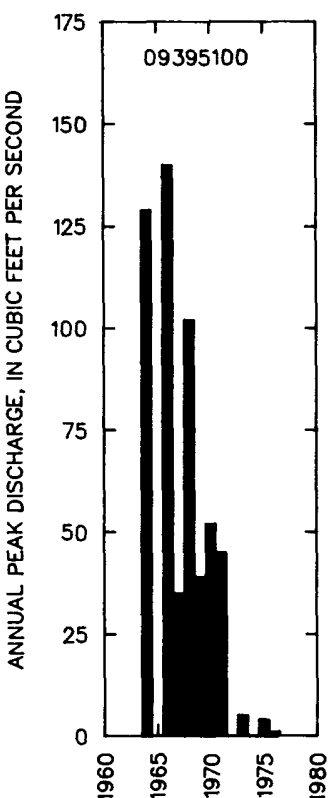

MAGNITUDE AND PROBABILITY OF INSTANTANEOUS PEAK FLON BASED ON PERIOD OF RECORD $1964-76$

DISCHARGE, IN $\mathrm{FT}^{3} / \mathrm{S}$, FOR INDICATED RECURRENCE INTERVAL

IN YEARS, AND EXCEEDANCE PROBABILITY, IN PERCENT

\begin{tabular}{|c|c|c|c|c|c|}
\hline $\begin{array}{r}2 \dagger \\
50 \%\end{array}$ & $\begin{array}{r}5 \dagger \\
20 \%\end{array}$ & $\begin{array}{r}10 \\
10 \%\end{array}$ & $\begin{array}{l}25 \dagger \\
4 \%\end{array}$ & $\begin{array}{l}50 \dagger \\
2 \%\end{array}$ & $\begin{array}{c}100 \dagger \\
1 \%\end{array}$ \\
\hline 27 & 73.8 & 120 & 196 & 266 & 345 \\
\hline $\begin{array}{l}\text { WE IGHTED } \\
\text { MEAN } \\
\text { STANDARD }\end{array}$ & $\begin{array}{l}\text { SKEW } \\
\text { DEV. }\end{array}$ & $\begin{array}{l}(\text { LOGS })= \\
(\text { LOGS })= \\
(\text { LOGS })=\end{array}$ & $\begin{array}{r}-0.34 \\
1.40 \\
0.55\end{array}$ & & \\
\hline
\end{tabular}

$\uparrow$ Reliability of values in colum is uncertain, and potential errors are large.

BASIN CHARACTERISTICS

\begin{tabular}{|c|c|c|c|c|c|c|c|}
\hline MAIN & & $\begin{array}{r}\text { MEAN } \\
\text { BASIN }\end{array}$ & & & & RAINFALL I & SITY, 24-HOUR \\
\hline $\begin{array}{l}\text { CHANNEL } \\
\text { SLOPE } \\
\text { (FT/MI) }\end{array}$ & $\begin{array}{l}\text { STREAM } \\
\text { LENGTH } \\
\text { (MI) }\end{array}$ & $\begin{array}{l}\text { ELEVA- } \\
\text { TION } \\
\text { (FT) }\end{array}$ & $\begin{array}{l}\text { FORESTED } \\
\text { AREA } \\
\text { (PERCENT) }\end{array}$ & $\begin{array}{l}\text { SOIL } \\
\text { INDEX }\end{array}$ & $\begin{array}{l}\text { PRECIPI- } \\
\text { TAT ION } \\
\text { (IN) }\end{array}$ & $\begin{array}{c}\text { 2-YEAR } \\
\text { (IN) }\end{array}$ & $\begin{array}{c}\text { 50-YEAR } \\
\text { (IN) }\end{array}$ \\
\hline 103 & 2.4 & 5,420 & 0.0 & 3.0 & 7.8 & 1.3 & 2.9 \\
\hline
\end{tabular}


LOCATION.--Lat 34'27'40", Long 110.24'15", in SWK sec.2, T.12 N., R.18 E., Navajo County, Hydrologic Unit 15020008, at State Highway $277,19 \mathrm{mi}$ west of Snowflake.

DRAINAGE AREA. $--16.5 \mathrm{mi}^{2}$.

ANIUAL PEAK DISCHARgE

\begin{tabular}{|c|c|c|c|}
\hline $\begin{array}{l}\text { WATER } \\
\text { YEAR }\end{array}$ & DATE & $\begin{array}{c}\text { ANNUAL PEAK } \\
\text { DISCHARGE } \\
\text { (FT } 3 / \mathrm{S})\end{array}$ & $\begin{array}{l}\text { DISCHARGE } \\
\text { CODES }\end{array}$ \\
\hline $\begin{array}{l}1963 \\
1964 \\
1965 \\
1966 \\
1967 \\
1968 \\
1969 \\
1970 \\
1971 \\
1972 \\
1973 \\
1974 \\
1975 \\
1976\end{array}$ & $\begin{array}{l}08-31-63 \\
08-02-64 \\
01-07-65 \\
12-30-65 \\
08-00-67 \\
02-00-68 \\
08-00-69 \\
00-00-70 \\
08-04-71 \\
12-26-71 \\
10-19-72 \\
00-00-74 \\
09-00-75 \\
02-09-76\end{array}$ & $\begin{array}{c}0.5 \\
74 \\
135 \\
1.170 \\
152 \\
60 \\
2.0 \\
0.5 \\
349 \\
\text { (1) } \\
\text { (1) } \\
0 \\
1.5 \\
\text { (1) }\end{array}$ & $\begin{array}{l}\text { LT } \\
\text { ES }\end{array}$ \\
\hline
\end{tabular}

Discharge unknown.

MAGNITUDE AND PROBABILITY OF INSTANTANEOUS PEAK FLON BASED ON PERICD OF RECORD

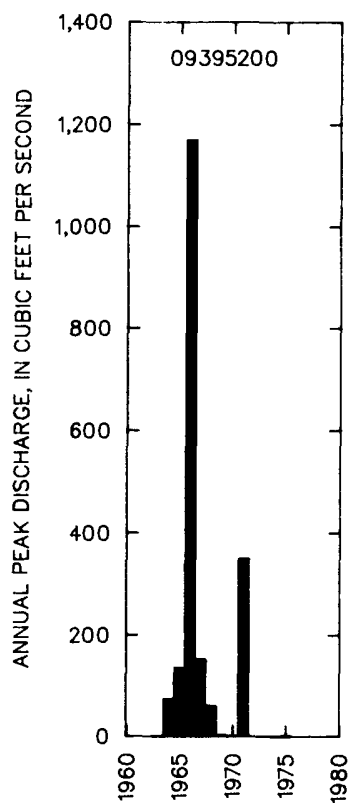

DISCHARGE, IN $\mathrm{FT}^{3} / \mathrm{S}$, FOR INDICATED RECURRENCE INTERVAL IN YEARS, AND EXCEEDANCE PROBABILITY, IN PERCENT

\begin{tabular}{|c|c|c|c|c|c|}
\hline$\stackrel{2}{50 \%}$ & $\begin{array}{c}5 \\
20 \%\end{array}$ & $\begin{array}{r}10 \\
10 \%\end{array}$ & $\begin{array}{l}25 \\
4 \%\end{array}$ & $\begin{array}{l}50 \\
2 x\end{array}$ & $\begin{array}{r}100 \\
1 \%\end{array}$ \\
\hline$\cdots$ &.- & ... & $\ldots$ & $\cdots$ & $\cdots$ \\
\hline $\begin{array}{l}\text { WEIGHTED } \\
\text { MEAN } \\
\text { STANDARD }\end{array}$ & $\begin{array}{l}\text { SKEH } \\
\text { DEV. }\end{array}$ & $\begin{array}{l}(\text { LOGS })= \\
(\text { LOGS })= \\
(L O G S)=\end{array}$ & $\cdots$ & & \\
\hline
\end{tabular}

BASIN CHARACTERISTICS

\begin{tabular}{|c|c|c|c|c|c|c|c|}
\hline MAIN & & $\begin{array}{l}\text { MEAN } \\
\text { BASIN }\end{array}$ & & & $\begin{array}{c}\text { MEAN } \\
\text { ANMUAL }\end{array}$ & RAIMFALL II & SITY, 24-HOUR \\
\hline $\begin{array}{l}\text { CHANMEL } \\
\text { SLOPE } \\
\text { (FT/MI) }\end{array}$ & $\begin{array}{c}\text { STREAM } \\
\text { LENGTH } \\
\text { (MI) }\end{array}$ & $\begin{array}{l}\text { ELEVA- } \\
\text { TION } \\
\text { (FT) }\end{array}$ & $\begin{array}{l}\text { FORESTED } \\
\text { AREA } \\
\text { (PERCENT) }\end{array}$ & $\begin{array}{r}\text { SOIL } \\
\text { INDEX }\end{array}$ & $\begin{array}{l}\text { PRECIPI- } \\
\text { TATION } \\
\text { (IN) }\end{array}$ & $\begin{array}{c}\text { 2-YEAR } \\
\text { (IN) }\end{array}$ & $\begin{array}{l}50-\text { YEAR } \\
\text { (IN) }\end{array}$ \\
\hline 31.1 & 14.9 & 6,660 & 97.0 & 3.0 & 20.0 & 1.9 & 3.6 \\
\hline
\end{tabular}


09395850 BLACK CREEK TRIBUTARY NEAR WINDOW ROCK, AZ

LOCATION.--Lat 35'39'15", long 109॰05'20", in SEK sec.13, T.26 N., R.30 E., Apache County, Hydrologic Unit 15020006, at Navajo Highway 21, $0.2 \mathrm{mi}$ south of State Highway 264 , and $2.75 \mathrm{mi}$ southwest of Hindow Rock.

DRAINAGE AREA. $-0.33 \mathrm{mi}^{2}$.

ANNUAL PEAK DISCHARGE

\begin{tabular}{ccc}
$\begin{array}{c}\text { WATER } \\
\text { YEAR }\end{array}$ & DATE & $\begin{array}{c}\text { ANNUAL PEAK } \\
\text { DISCHARGE } \\
\text { (FT } 3 / \text { S) }\end{array}$ \\
\hline 1963 & $08-30-63$ & 134 \\
1964 & $08-13-64$ & 145 \\
1965 & $07-27-65$ & 125 \\
1966 & $08-01-66$ & 12 \\
1967 & $08-00-67$ & 141 \\
1968 & $08-06-68$ & 171 \\
1969 & $08-00-69$ & 134 \\
1970 & $08-07-70$ & 102 \\
1971 & $08-27-71$ & 55 \\
1972 & $09-00-72$ & 124 \\
1973 & $08-00-73$ & 106 \\
1974 & $08-05-74$ & 109 \\
1975 & $07-11-75$ & 156 \\
1976 & $00-00-76$ & 81 \\
$\ldots$
\end{tabular}

MAGNITUDE AND PROBABILITY OF INSTANTANEOUS PEAK FLON BASED ON PERIOD OF RECORD

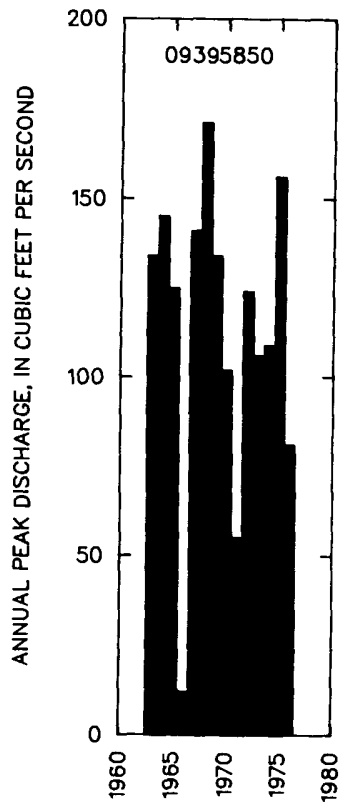

DISCHARGE, IN $\mathrm{FT}^{3} / \mathrm{S}$, FOR INDICATED RECURRENCE INTERVAL IN YEARS, AND EXCEEDANCE PROBABILITY, IN PERCENT

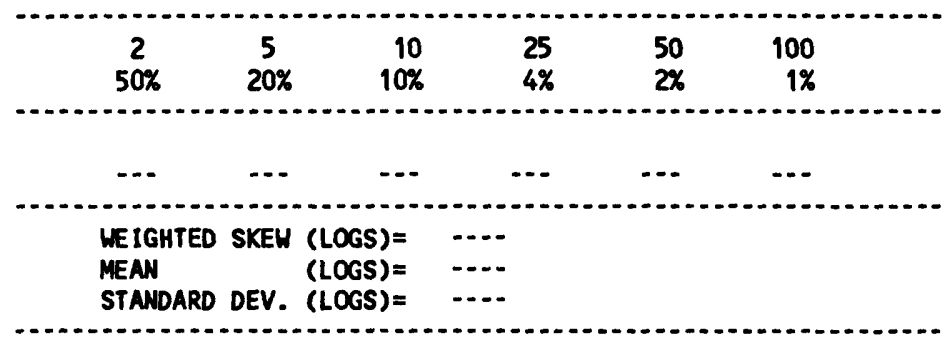

BASIN CHARACTERISTICS

\begin{tabular}{|c|c|c|c|c|c|c|c|}
\hline \multirow{2}{*}{$\begin{array}{c}\text { MAIN } \\
\text { CHANNEL } \\
\text { SLOPE } \\
\text { (FT/MI) }\end{array}$} & \multirow[b]{2}{*}{$\begin{array}{l}\text { STREAM } \\
\text { LENGTH } \\
\text { (MI) }\end{array}$} & \multirow{2}{*}{$\begin{array}{l}\text { MEAN } \\
\text { BASIN } \\
\text { ELEVA- } \\
\text { TION } \\
\text { (FT) }\end{array}$} & \multirow[b]{2}{*}{$\begin{array}{l}\text { FORESTED } \\
\text { AREA } \\
\text { (PERCENT) }\end{array}$} & \multirow[b]{2}{*}{$\begin{array}{l}\text { SOIL } \\
\text { INDEX }\end{array}$} & \multirow{2}{*}{$\begin{array}{l}\text { MEAN } \\
\text { ANNUAL } \\
\text { PRECIPI- } \\
\text { TATION } \\
\text { (IN) }\end{array}$} & \multicolumn{2}{|c|}{ RAINFALL INTENSITY, 24-HOUR } \\
\hline & & & & & & $\begin{array}{c}\text { 2-YEAR } \\
\text { (IN) }\end{array}$ & $\begin{array}{c}\text { 50-YEAR } \\
\text { (IN) }\end{array}$ \\
\hline 53.3 & 0.75 & 6,830 & 0.0 & 1.0 & 14.1 & 1.2 & 2.6 \\
\hline
\end{tabular}


LOCATION.--Lat 35'27'09", long 109.07'30", in SEYNEK sec.26, T.24 N., R.30 E., Apache County, Hydrologic Unit 15020006, in Navajo Indian Reservation, on downstream end of center bridge pier on State Highway 166 , $7 \mathrm{mi}$ upstream from West Fork, and $8 \mathrm{mi}$ northwest of Lupton, and $16 \mathrm{mi}$ south of Window Rock.

DRAIMACE AREA. $--494 \mathrm{mi}^{2}$, of which $0.56 \mathrm{mi}^{2}$ is noncontributing.

REMARKS.--Red Lake, near headwaters $35 \mathrm{mi}$ upstream, was built in 1954, with capacity of 9,700 acre-ft, but silting may have reduced this amount.

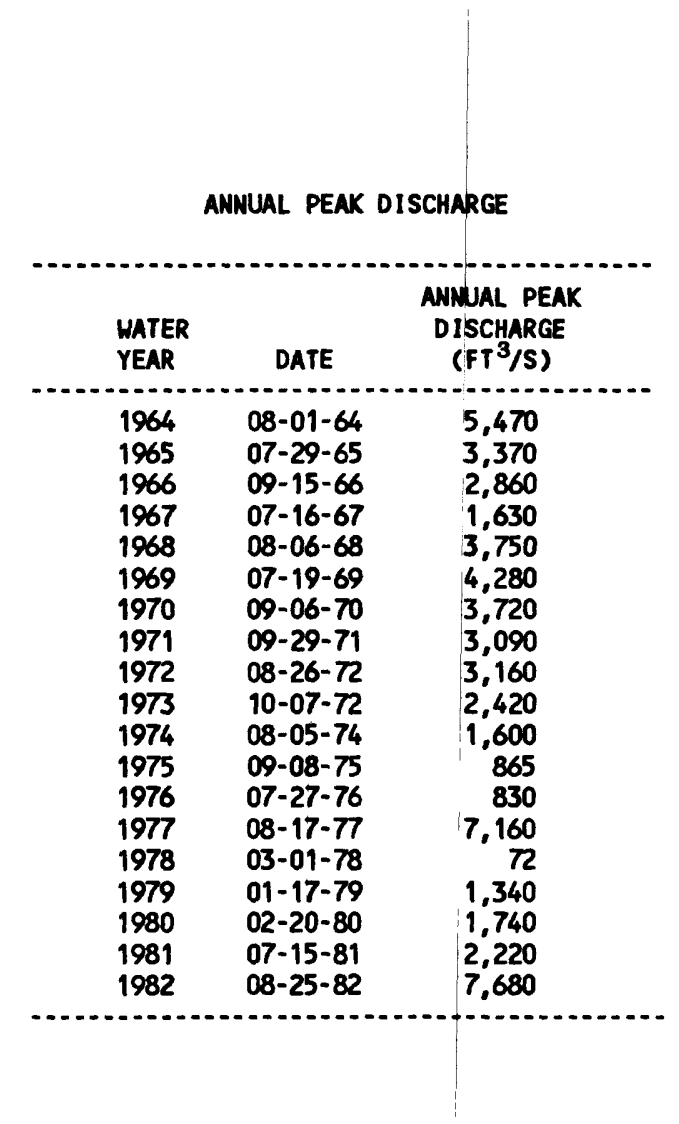

BASIN CHARACTERISTICS

\begin{tabular}{|c|c|c|c|c|c|c|c|}
\hline \multirow{2}{*}{$\begin{array}{c}\text { MAIN } \\
\text { CHANNEL } \\
\text { SLOPE } \\
\text { (FT/MI) }\end{array}$} & \multirow[b]{2}{*}{$\begin{array}{c}\text { STREAM } \\
\text { LENGTH } \\
\text { (MI) }\end{array}$} & \multirow{2}{*}{$\begin{array}{l}\text { MEAN } \\
\text { BASIN } \\
\text { ELEVA- } \\
\text { TION } \\
\text { (FT) }\end{array}$} & \multirow[b]{2}{*}{$\begin{array}{l}\text { FORESTED } \\
\text { AREA } \\
\text { (PERCENT) }\end{array}$} & \multirow[b]{2}{*}{$\begin{array}{l}\text { SOIL } \\
\text { INDEX }\end{array}$} & \multirow{2}{*}{$\begin{array}{l}\text { MEAN } \\
\text { ANNUAL } \\
\text { PRECIPI- } \\
\text { TATION } \\
\text { (IN) }\end{array}$} & \multicolumn{2}{|c|}{ RAINFALL INTENSITY, 24-HOUR } \\
\hline & & & & & & $\begin{array}{c}\text { 2-YEAR } \\
\text { (IN) }\end{array}$ & $\begin{array}{c}\text { 50-YEAR } \\
\text { (IN) }\end{array}$ \\
\hline 11.2 & 47.6 & 7,500 & 50.0 & 2.0 & 15.8 & 1.4 & 2.6 \\
\hline
\end{tabular}


09395900 BLACK CREEK MEAR LUPTON, AZ--Continued

MEAN MONTHLY AND ANMUAL DISCHARGES 1965-72, 1975-78, 1980-82

\begin{tabular}{|c|c|c|c|c|c|c|}
\hline MONTH & $\begin{array}{l}\operatorname{MAX} I M M \\
\left(F T^{3} / S\right)\end{array}$ & $\begin{array}{l}\operatorname{MINIMUM} \\
\left(F T^{3} / S\right)\end{array}$ & $\begin{array}{c}\text { MEAN } \\
\left(F^{3} / S\right)\end{array}$ & $\begin{array}{l}\text { STAN- } \\
\text { DARD } \\
\text { DEVIA- } \\
\text { TION } \\
\text { (FT } 3 / 5)\end{array}$ & $\begin{array}{l}\text { COEFFI - } \\
\text { CIENT OF } \\
\text { VARI - } \\
\text { ATION }\end{array}$ & $\begin{array}{c}\text { PERCENT } \\
\text { OF } \\
\text { ANNUAL } \\
\text { RUNOFF }\end{array}$ \\
\hline $\begin{array}{l}\text { OCTOBER } \\
\text { NOVEMBER } \\
\text { DECEMBER } \\
\text { JANUARY } \\
\text { FEBRUARY } \\
\text { MARCH } \\
\text { APRIL } \\
\text { MAY } \\
\text { JUNE } \\
\text { JULY } \\
\text { AUCUST } \\
\text { SEPTEMBER }\end{array}$ & $\begin{array}{c}12 \\
4.8 \\
11 \\
13 \\
75 \\
27 \\
57 \\
14 \\
9.4 \\
81 \\
124 \\
53\end{array}$ & $\begin{array}{l}0.00 \\
0.00 \\
0.02 \\
0.03 \\
0.18 \\
0.00 \\
0.00 \\
0.00 \\
0.00 \\
0.03 \\
0.23 \\
0.00\end{array}$ & $\begin{array}{c}2.5 \\
0.86 \\
1.8 \\
2.5 \\
12 \\
8.3 \\
8.0 \\
1.6 \\
0.71 \\
15 \\
29 \\
14\end{array}$ & $\begin{array}{c}4.4 \\
1.2 \\
2.8 \\
3.3 \\
22 \\
9.2 \\
16 \\
3.4 \\
2.4 \\
21 \\
34 \\
16\end{array}$ & $\begin{array}{l}1.7 \\
1.4 \\
1.6 \\
1.3 \\
1.8 \\
1.1 \\
2.0 \\
2.2 \\
3.4 \\
1.4 \\
1.2 \\
1.1\end{array}$ & $\begin{array}{r}2.6 \\
0.9 \\
1.9 \\
2.6 \\
12.6 \\
8.6 \\
8.3 \\
1.7 \\
0.7 \\
15.8 \\
29.9 \\
14.5\end{array}$ \\
\hline NNUAL & 19 & 0.71 & 8.0 & 5.7 & 0.70 & 100 \\
\hline
\end{tabular}

MAGNITUDE AND PROBABILITY OF INSTANTANEOUS PEAK FLOW BASED ON PERIOD OF RECORD 1964-82

DISCHARGE, IN $\mathrm{FT}^{3} / \mathrm{S}$, FOR INDICATED RECURRENCE INTERVAL IN YEARS, AND EXCEEDANCE PROBABILITY, IN PERCENT

\begin{tabular}{lccccc}
2 & 5 & 10 & 25 & $\begin{array}{c}50 \\
20\end{array}$ & $\begin{array}{c}100 \uparrow \\
1 \%\end{array}$ \\
$50 \%$ & $20 \%$ & $10 \%$ & $4 \%$ & $2 \%$ & \\
2,550 & 4,440 & 5,880 & 7,880 & 9,480 & 11,200 \\
\hline WEIGHTED SKEW (LOGS) & $=$ & -0.15 & & \\
MEAN & (LOGS) & 3.40 & & \\
STANDARD DEV. (LOGS) & $=0.29$
\end{tabular}

MAGNITLOE AND PROBABILITY OF ANNUAL LOW FLOW BASED ON PERIOD OF RECORD 1966-72, 1976-78, 1981-82

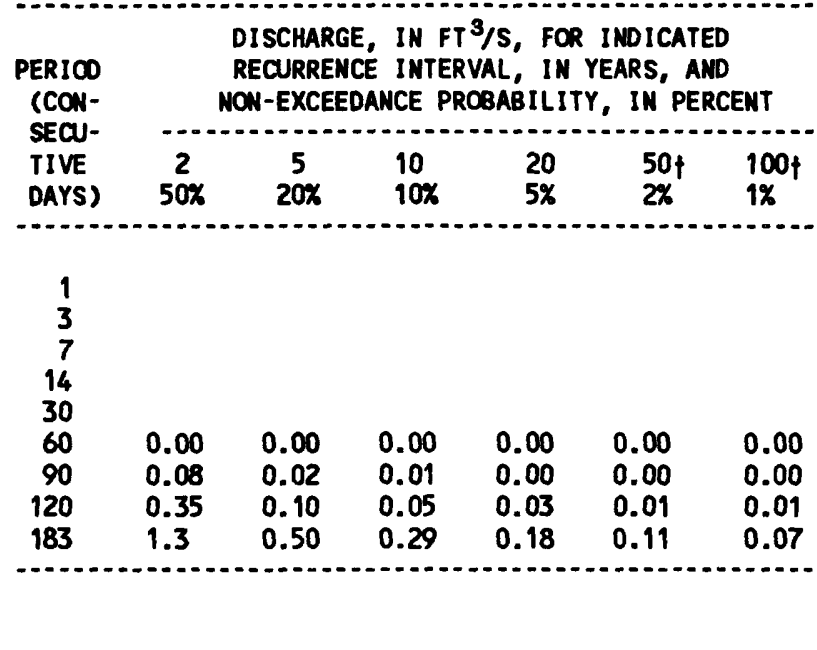

MAGNITUDE AND PROBABILITY OF ANNUAL HIGH FLON BASED ON PERIOD OF RECORD 1965-72, 1975-78, 1980-82

\begin{tabular}{|c|c|c|c|c|c|c|}
\hline \multirow{2}{*}{$\begin{array}{l}\text { PERIOD } \\
\text { (CON- } \\
\text { SECU- } \\
\text { TIVE } \\
\text { DAYS) }\end{array}$} & & \multicolumn{5}{|c|}{$\begin{array}{l}\text { DISCHARGE, IN } \mathrm{FT}^{3} / \mathrm{S} \text {, FOR INDICATED } \\
\text { RECURRENCE INTERVAL, IN YEARS, AND } \\
\text { EXCEEDANCE PROBABILITY, IN PERCENT }\end{array}$} \\
\hline & $\begin{array}{c}2 \\
50 \%\end{array}$ & $\begin{array}{c}5 \\
20 \%\end{array}$ & $\begin{array}{l}10 \\
10 \%\end{array}$ & $\begin{array}{l}25 \\
4 \%\end{array}$ & $\begin{array}{l}50 \dagger \\
2 \%\end{array}$ & ${ }_{1 \%}^{100}+$ \\
\hline $\begin{array}{r}1 \\
3 \\
7 \\
15 \\
30 \\
60 \\
90\end{array}$ & $\begin{array}{r}455 \\
224 \\
123 \\
69 \\
41 \\
26 \\
19\end{array}$ & $\begin{array}{r}912 \\
477 \\
254 \\
140 \\
83 \\
54 \\
39\end{array}$ & $\begin{array}{r}1,190 \\
668 \\
348 \\
189 \\
115 \\
74 \\
53\end{array}$ & $\begin{array}{r}1,490 \\
917 \\
463 \\
249 \\
155 \\
100 \\
70\end{array}$ & $\begin{array}{r}1,670 \\
1,100 \\
545 \\
291 \\
185 \\
119 \\
82\end{array}$ & $\begin{array}{r}1,810 \\
1,280 \\
620 \\
330 \\
214 \\
136 \\
94\end{array}$ \\
\hline
\end{tabular}

DURATION TABLE OF DAILY MEAN FLOW FOR PERIOD OF RECORD 1965-72, 1975-78, 1980-82 DISCHARGE, IN FT $3 / 5$, WHICH WAS EQUALED OR EXCEEDED FOR INDICATED PERCENT OF TIME

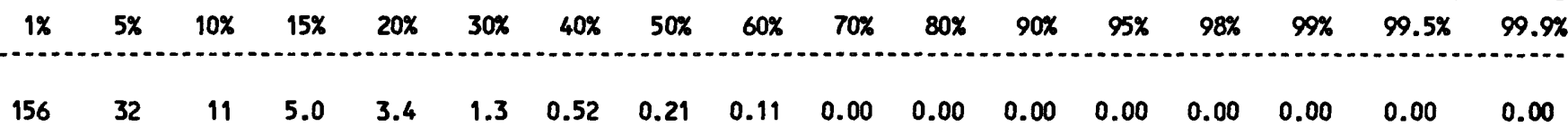

† Reliability of values in column is uncertain, and potential errors are large. 

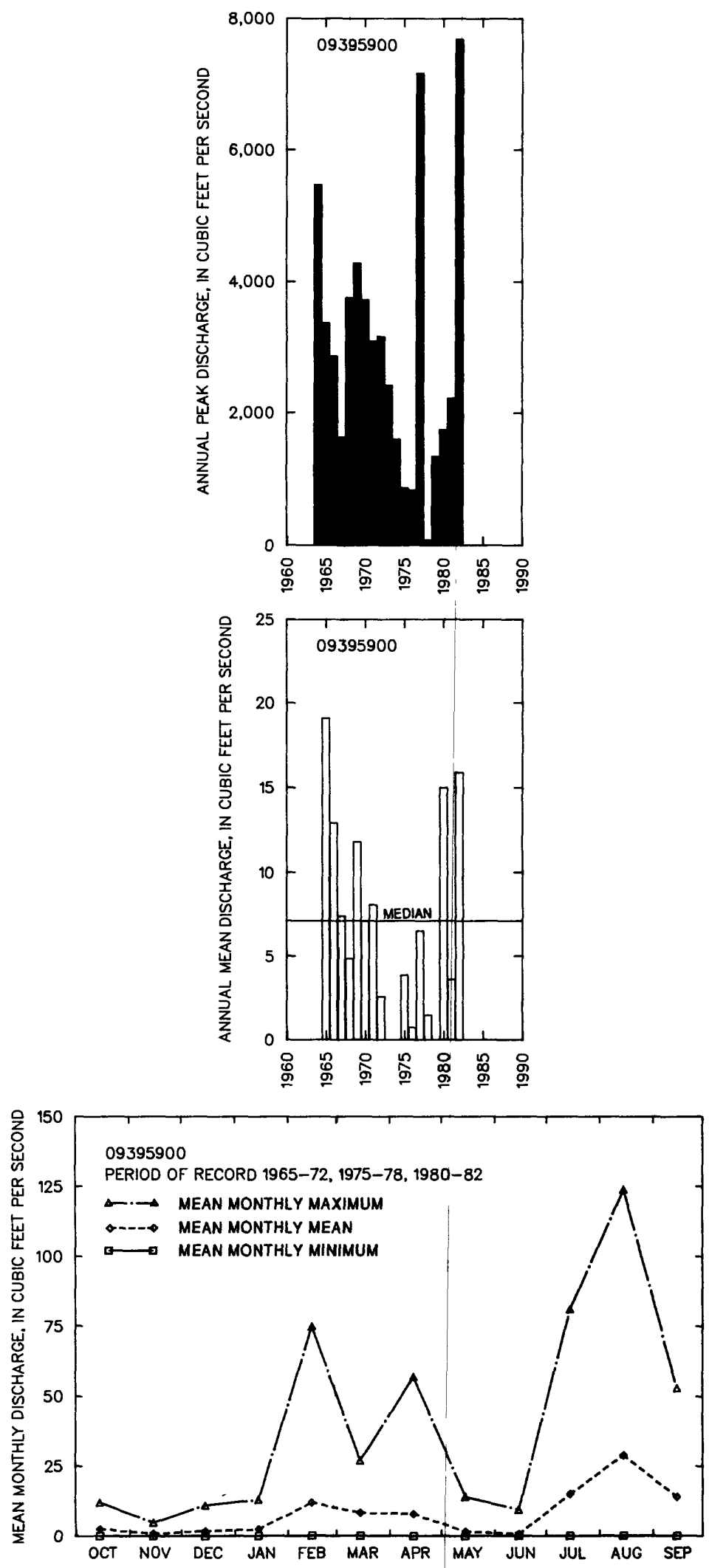
09396400 DEAD WASH TRIBUTARY NEAR HOLBROOK, AZ

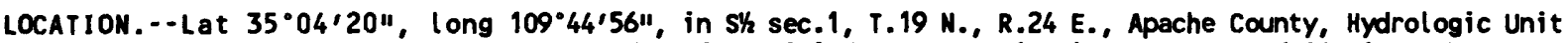
15020007, at U.S. Highway 66 , near east edge of Petrified Forest National Monument, and 26 mi northeast of Holbrook.

DRAINAGE AREA. $--1.22 \mathrm{mi}^{2}$.

ANNUAL PEAK DISCHARGE

\begin{tabular}{|c|c|c|c|}
\hline $\begin{array}{l}\text { MATER } \\
\text { YEAR }\end{array}$ & DATE & $\begin{array}{c}\text { ANNUAL PEAK } \\
\text { DISCHARGE } \\
\left(\mathrm{FT}^{3} / \mathrm{S}\right)\end{array}$ & $\begin{array}{l}\text { DISCHARGE } \\
\text { CODES }\end{array}$ \\
\hline $\begin{array}{l}1963 \\
1964 \\
1965 \\
1966 \\
1967 \\
1968 \\
1969 \\
1970 \\
1971 \\
1972 \\
1973 \\
1974 \\
1975\end{array}$ & $\begin{array}{l}09-00-63 \\
08-12-64 \\
09-04-65 \\
12-21-65 \\
08-00-67 \\
03-00-68 \\
10-03-68 \\
09-05-70 \\
08-23-71 \\
09-09-72 \\
10-19-72 \\
07-00-74 \\
10-29-74\end{array}$ & $\begin{array}{r}210 \\
130 \\
307 \\
142 \\
743 \\
73 \\
94 \\
340 \\
526 \\
377 \\
180 \\
30 \\
138\end{array}$ & ES \\
\hline
\end{tabular}

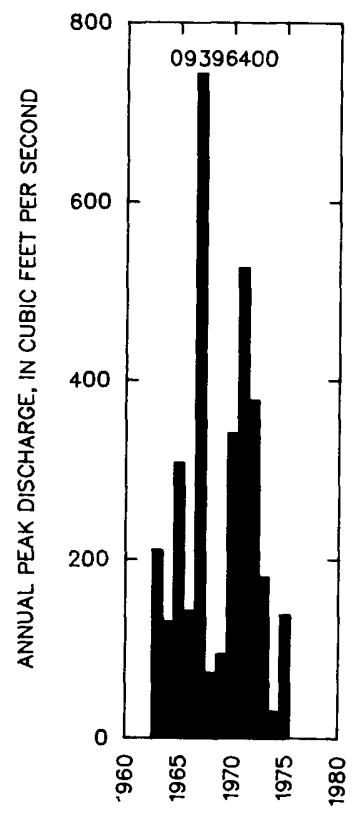

MAGNITUDE AND PROBABILITY OF INSTANTANEOUS PEAK FLON BASED ON PERIOD OF RECORD 1963-75

DISCHARGE, IN FT $3 / 5$, FOR INDICATED RECURRENCE INTERVAL IN YEARS, AND EXCEEDANCE PROBABILITY, IN PERCENT

\begin{tabular}{|c|c|c|c|c|c|}
\hline$\stackrel{2}{50 \%}$ & $\begin{array}{c}5 \\
20 x\end{array}$ & $\begin{array}{r}10 \\
10 \%\end{array}$ & $\begin{array}{l}25 \\
4 \%\end{array}$ & $\begin{array}{l}50 \dagger \\
2 \%\end{array}$ & $\begin{array}{c}100 \dagger \\
1 \%\end{array}$ \\
\hline 198 & 374 & 522 & 745 & 938 & 1,150 \\
\hline $\begin{array}{l}\text { WEIGHTED } \\
\text { MEAN } \\
\text { STANDARD }\end{array}$ & $\begin{array}{l}\text { SKEH } \\
\text { DEV. }\end{array}$ & $\begin{array}{l}(\text { LOGS })= \\
(\text { LOGS) }= \\
(\text { LOGS })=\end{array}$ & $\begin{array}{l}0.01 \\
2.30 \\
0.33\end{array}$ & & \\
\hline
\end{tabular}

$\uparrow$ Reliability of values in colum is uncertain, and potential errors are large.

BASIN CHARACTERISTICS

\begin{tabular}{|c|c|c|c|c|c|c|c|}
\hline \multirow{3}{*}{$\begin{array}{l}\text { MAIN } \\
\text { CHANNEL } \\
\text { SLOPE } \\
\text { (FT/MI) }\end{array}$} & \multicolumn{3}{|c|}{ MEAN } & \multicolumn{3}{|c|}{ MEAN } & \multirow[b]{2}{*}{ 24-HOUR } \\
\hline & & BASIN & & & ANNUAL & RAINFALL II & \\
\hline & $\begin{array}{l}\text { STREAM } \\
\text { LENGTH } \\
\text { (MI) }\end{array}$ & $\begin{array}{l}\text { ELEVA- } \\
\text { TION } \\
\text { (FT) }\end{array}$ & $\begin{array}{l}\text { FORESTED } \\
\text { AREA } \\
\text { (PERCENT) }\end{array}$ & $\begin{array}{l}\text { SOIL } \\
\text { INDEX }\end{array}$ & $\begin{array}{l}\text { PRECIPI - } \\
\text { TATION } \\
\text { (IN) }\end{array}$ & $\begin{array}{c}\text { 2-YEAR } \\
\text { (IN) }\end{array}$ & $\begin{array}{c}\text { 50-YEAR } \\
\text { (IN) }\end{array}$ \\
\hline 60.0 & 1.8 & 5,740 & 0.0 & 3.0 & 7.9 & 1.3 & 2.6 \\
\hline
\end{tabular}




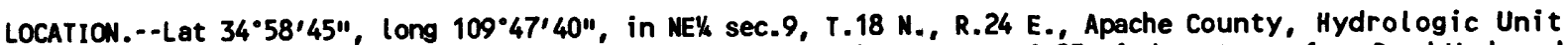
15020007 , at highway bridge in Petrified Forest National Monument, 0.25 mi downstream from Dead Wash and $1.5 \mathrm{mi}$ east of Adamana.

DRAINAGE AREA. $--2,654 \mathrm{mi}^{2}$, of which $50.5 \mathrm{mi}^{2}$ is noncontributing.

ANMUAL PEAK DISCHARGE

\begin{tabular}{|c|c|c|}
\hline $\begin{array}{l}\text { WATER } \\
\text { YEAR }\end{array}$ & DATE & $\begin{array}{l}\text { ANNUAL PEAK } \\
\text { DISCHARGE } \\
\left.\text { (FT }{ }^{3} / \mathrm{S}\right)\end{array}$ \\
\hline $\begin{array}{l}1940 \\
1941 \\
1942 \\
1943 \\
1944 \\
1945 \\
1946 \\
1947 \\
1948 \\
1949\end{array}$ & $\begin{array}{l}08-23-40 \\
09-29-41 \\
10-04-41 \\
09-26-43 \\
09-26-44 \\
02-03-45 \\
08-12-46 \\
08-10-47 \\
10-14-47 \\
08-08-49\end{array}$ & $\begin{array}{r}7,500 \\
22,600 \\
19,400 \\
4,800 \\
4,700 \\
5,740 \\
30,000 \\
22,000 \\
17,100 \\
8,040\end{array}$ \\
\hline
\end{tabular}

MAGNITUDE AND PROBABILITY OF INSTANTANEOUS PEAK FLOW BASED ON PERIOD OF RECORD 1940-49

DISCHARGE, IN $\mathrm{FT}^{3} / \mathrm{S}$, FOR INDICATED RECURRENCE INTERVAL IN YEARS, AND EXCEEDANCE PROBABILITY, IN PERCENT

\begin{tabular}{|c|c|c|c|c|c|}
\hline $\begin{array}{r}2 \dagger \\
50 \%\end{array}$ & $\begin{array}{r}5 f \\
20 \%\end{array}$ & $\begin{array}{c}10 \dagger \\
10 \%\end{array}$ & $\begin{array}{l}25 \uparrow \\
4 \%\end{array}$ & $\begin{array}{l}50 \nmid \\
2 \%\end{array}$ & $\begin{array}{c}100 \nmid \\
1 \%\end{array}$ \\
\hline 11,500 & 20,900 & 28,400 & 39,200 & 48,200 & 57,900 \\
\hline $\begin{array}{l}\text { WEIGH } \\
\text { MEAN } \\
\text { STAND }\end{array}$ & & $\begin{array}{l}.0(S)= \\
.0(S)= \\
.0(S)=\end{array}$ & & & \\
\hline
\end{tabular}

† Reliability of values in column is uncertain, and potential errors are large.

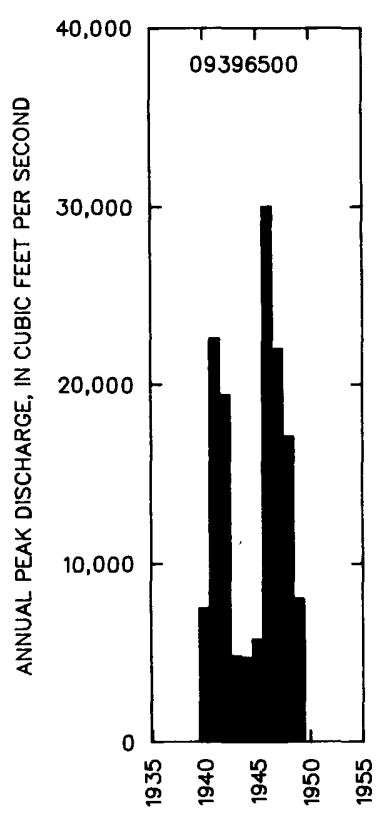

BASIN CHARACTERISTICS

\begin{tabular}{|c|c|c|c|c|c|c|c|}
\hline MAIN & & $\begin{array}{l}\text { MEAN } \\
\text { BASIN }\end{array}$ & & & & \multicolumn{2}{|c|}{ RAINFALL INTENSITY, 24-HOUR } \\
\hline $\begin{array}{l}\text { CHANNEL } \\
\text { SLOPE } \\
\text { (FT/MI) }\end{array}$ & $\begin{array}{c}\text { STREAM } \\
\text { LENGTH } \\
\text { (MI) }\end{array}$ & $\begin{array}{l}\text { ELEVA- } \\
\text { TION } \\
\text { (FT) }\end{array}$ & $\begin{array}{l}\text { FORESTED } \\
\text { AREA } \\
\text { (PERCENT) }\end{array}$ & $\begin{array}{l}\text { SOIL } \\
\text { INDEX }\end{array}$ & $\begin{array}{l}\text { PRECIPI - } \\
\text { TATION } \\
\text { (IN) }\end{array}$ & $\begin{array}{l}\text { 2-YEAR } \\
\text { (IN) }\end{array}$ & $\begin{array}{l}\text { 50-YEAR } \\
\text { (IN) }\end{array}$ \\
\hline 15.7 & 115 & 6,730 & 29.0 & 2.8 & 12.6 & 1.4 & 2.7 \\
\hline
\end{tabular}


09397000 LITTLE COLORADO RIVER AT HOLBROOK, AZ

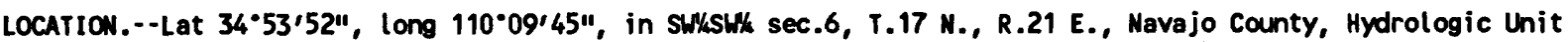
15020008, near right bank on downstream side of bridge on U.S. Highway 180 at Holbrook, 2.3 mi downstream from Puerco River.

DRAINACE AREA. $--11,462 \mathrm{mi}^{2}$, of which $347 \mathrm{mi}^{2}$ is noncontributing.

ANMUAL PEAK DISCHARGE

\begin{tabular}{|c|c|c|c|}
\hline $\begin{array}{l}\text { WATER } \\
\text { YEAR }\end{array}$ & DATE & $\begin{array}{c}\text { ANNUAL PEAK } \\
\text { DISCHARGE } \\
\text { (FT } 3 / S)\end{array}$ & $\begin{array}{l}\text { DISCHARCE } \\
\text { CODES }\end{array}$ \\
\hline $\begin{array}{l}1906 \\
1923 \\
1950 \\
1951 \\
1952 \\
1953 \\
1954 \\
1955 \\
1956 \\
1957 \\
1958 \\
1959 \\
1960 \\
1961 \\
1962 \\
1963 \\
1964 \\
1965 \\
1966 \\
1967 \\
1968 \\
1969 \\
1970 \\
1971 \\
1972 \\
1973\end{array}$ & $\begin{array}{l}11-27-05 \\
09-19-23 \\
07-19-50 \\
08-28-51 \\
01-19-52 \\
07-29-53 \\
07-22-54 \\
08-17-55 \\
06-30-56 \\
08-05-57 \\
09-14-58 \\
08-06-59 \\
10-29-59 \\
08-16-61 \\
10-31-61 \\
08-31-63 \\
09-09-64 \\
07-25-65 \\
08-13-66 \\
08-12-67 \\
08-12-68 \\
10-04-68 \\
09-06-70 \\
08-21-71 \\
10-01-71 \\
10-20-72\end{array}$ & $\begin{array}{r}20,200 \\
160,000 \\
2,960 \\
8,700 \\
8,400 \\
6,030 \\
10,800 \\
10,500 \\
4,210 \\
21,800 \\
7,000 \\
6,300 \\
11,400 \\
4,160 \\
4,010 \\
9,370 \\
15,100 \\
14,800 \\
10,400 \\
14,100 \\
21,000 \\
24,200 \\
19,700 \\
13,200 \\
20,300 \\
15,000\end{array}$ & $\begin{array}{l}\text { HP } \\
\text { HP }\end{array}$ \\
\hline
\end{tabular}

Highest since 1870 .

BASIN CHARACTERISTICS

\begin{tabular}{|c|c|c|c|c|c|c|c|}
\hline \multirow{4}{*}{$\begin{array}{c}\text { MAIN } \\
\text { CHANNEL } \\
\text { SLOPE } \\
\text { (FT/MI) }\end{array}$} & \multirow{4}{*}{$\begin{array}{l}\text { STREAM } \\
\text { LENGTH } \\
\text { (MI) }\end{array}$} & \multirow{4}{*}{$\begin{array}{l}\text { MEAN } \\
\text { BASIN } \\
\text { ELEVA- } \\
\text { TION } \\
\text { (FT) }\end{array}$} & \multirow{4}{*}{$\begin{array}{l}\text { FORESTED } \\
\text { AREA } \\
\text { (PERCENT) }\end{array}$} & \multirow{3}{*}{\multicolumn{2}{|c|}{$\begin{array}{c}\text { MEAN } \\
\text { ANNUAL } \\
\text { PRECIPI - }\end{array}$}} & \multirow{2}{*}{\multicolumn{2}{|c|}{ RAINFALL INTENSITY, 24-HOUR }} \\
\hline & & & & & & & \\
\hline & & & & & & & \\
\hline & & & & $\begin{array}{l}\text { SOIL } \\
\text { INDEX }\end{array}$ & $\begin{array}{l}\text { TATION } \\
\text { (IN) }\end{array}$ & $\begin{array}{c}\text { 2-YEAR } \\
\text { (IN) }\end{array}$ & $\begin{array}{l}\text { 50-YEAR } \\
\text { (IN) }\end{array}$ \\
\hline 21.9 & 134 & 6,730 & 27.0 & 2.8 & 13.0 & 1.4 & 2.9 \\
\hline
\end{tabular}


MEAN MONTHLY AND ANMUAL DISCHARGES 1906, 1950-73

\begin{tabular}{|c|c|c|c|c|c|c|}
\hline MONTH & $\begin{array}{l}\operatorname{MAXIMN} \\
\left(F^{3} / S\right)\end{array}$ & $\begin{array}{l}\text { MINIMUM } \\
\text { (FT } 3 / S)\end{array}$ & $\begin{array}{c}\text { MEAN } \\
\left(F T^{3} / S\right)\end{array}$ & $\begin{array}{l}\text { STAN- } \\
\text { DARD } \\
\text { DEVIA- } \\
\text { TION } \\
\text { (FT3/S) }\end{array}$ & $\begin{array}{l}\text { COEFFI - } \\
\text { CIENT OF } \\
\text { VARI - } \\
\text { ATION }\end{array}$ & $\begin{array}{c}\text { PERCENT } \\
\text { OF } \\
\text { ANNUAL } \\
\text { RUNOFF }\end{array}$ \\
\hline $\begin{array}{l}\text { OCTOBER } \\
\text { NOVEMBER } \\
\text { DECEMBER } \\
\text { JANUARY } \\
\text { FEBRUARY } \\
\text { MARCH } \\
\text { APRIL } \\
\text { MAY } \\
\text { JUNE } \\
\text { JULY } \\
\text { AUGUST } \\
\text { SEPTEMBER }\end{array}$ & $\begin{array}{r}939 \\
1,160 \\
529 \\
565 \\
312 \\
1,270 \\
1,020 \\
600 \\
161 \\
638 \\
2,130 \\
1,000\end{array}$ & $\begin{array}{l}2.4 \\
4.4 \\
3.9 \\
3.2 \\
2.8 \\
3.4 \\
2.3 \\
1.3 \\
0.37 \\
2.4 \\
4.5 \\
2.3\end{array}$ & $\begin{array}{r}138 \\
75 \\
51 \\
105 \\
58 \\
112 \\
64 \\
32 \\
19 \\
157 \\
537 \\
240\end{array}$ & $\begin{array}{r}231 \\
229 \\
110 \\
178 \\
81 \\
272 \\
206 \\
119 \\
33 \\
190 \\
606 \\
285\end{array}$ & $\begin{array}{l}1.7 \\
3.1 \\
2.1 \\
1.7 \\
1.4 \\
2.4 \\
3.2 \\
3.7 \\
1.8 \\
1.2 \\
1.1 \\
1.2\end{array}$ & $\begin{array}{l}8.7 \\
4.7 \\
3.2 \\
6.6 \\
3.6 \\
7.1 \\
4.1 \\
2.0 \\
1.2 \\
9.9 \\
33.8 \\
15.1\end{array}$ \\
\hline NNUAL & 350 & 20 & 133 & 87 & 0.65 & 100 \\
\hline
\end{tabular}

MAGNITUDE AND PROBABILITY OF INSTANTANEOUS PEAK FLOH BASED ON PERICD OF RECORD 1906, 1923, 1950-73

DISCHARGE, IN $\mathrm{FT}^{3} / \mathrm{S}$, FOR INDICATED RECURRENCE INTERVAL IN YEARS, AND EXCEEDANCE PROBABILITY, IN PERCENT

$\begin{array}{lccccc}2 & 5 & 10 & 25 & 50 \dagger & 100 \dagger \\ 50 \% & 20 \% & 10 \% & 4 \% & 2 \% & 1 \% \\ 11,000 & 17,000 & 21,400 & 27,400 & 32,100 & 37,200\end{array}$

MAGNITUDE AND PROBABILITY OF ANNUAL LON FLON BASED ON PERICD OF RECORD 1906-07, 1951-74

\begin{tabular}{|c|c|c|c|c|c|c|}
\hline \multirow{2}{*}{$\begin{array}{l}\text { PERIOD } \\
\text { (CON- } \\
\text { SECU- } \\
\text { TIVE } \\
\text { DAYS) }\end{array}$} & \multicolumn{6}{|c|}{$\begin{array}{l}\text { DISCHARGE, IN } F^{3} / S \text {, FOR INDICATED } \\
\text { RECURRENCE INTERVAL, IN YEARS, AND } \\
\text { NON-EXCEEDANCE PROBABILITY, IN PERCENT }\end{array}$} \\
\hline & $\begin{array}{c}2 \\
50 \%\end{array}$ & $\begin{array}{c}5 \\
20 \%\end{array}$ & $\begin{array}{l}10 \\
10 \%\end{array}$ & $\begin{array}{l}20 \\
5 \%\end{array}$ & $\begin{array}{l}50 \\
2 \%\end{array}$ & $\begin{array}{l}100 \dagger \\
18\end{array}$ \\
\hline $\begin{array}{r}1 \\
3 \\
7 \\
14 \\
30 \\
60 \\
90 \\
120 \\
183\end{array}$ & $\begin{array}{c}0.38 \\
0.61 \\
1.1 \\
1.7 \\
2.4 \\
3.0 \\
5.1 \\
10 \\
28\end{array}$ & $\begin{array}{c}0.07 \\
0.16 \\
0.35 \\
0.75 \\
1.0 \\
1.8 \\
2.6 \\
5.0 \\
12\end{array}$ & $\begin{array}{l}0.00 \\
0.04 \\
0.15 \\
0.44 \\
0.68 \\
1.5 \\
1.9 \\
3.8 \\
7.9\end{array}$ & $\begin{array}{l}0.00 \\
0.00 \\
0.04 \\
0.28 \\
0.47 \\
1.3 \\
1.5 \\
3.1 \\
5.7\end{array}$ & $\begin{array}{l}0.00 \\
0.00 \\
0.00 \\
0.15 \\
0.31 \\
1.2 \\
1.2 \\
2.6 \\
4.1\end{array}$ & $\begin{array}{l}0.00 \\
0.00 \\
0.00 \\
0.10 \\
0.23 \\
1.1 \\
1.1 \\
2.3 \\
3.2\end{array}$ \\
\hline
\end{tabular}

MAGNITLDE AND PROBABILITY OF ANNUAL HIGH FLOW BASED ON PERICD OF RECORD 1906, 1950-73

\begin{tabular}{|c|c|c|c|c|c|c|}
\hline \multirow{2}{*}{$\begin{array}{l}\text { PERIOD } \\
\text { (CON- } \\
\text { SECU- } \\
\text { TIVE } \\
\text { DAYS) }\end{array}$} & \multicolumn{6}{|c|}{$\begin{array}{l}\text { DISCHARGE, IN } \mathrm{FT}^{3} / \mathrm{S} \text {, FOR INDICATED } \\
\text { RECURRENCE INTERVAL, IN YEARS, AND } \\
\text { EXCEEDANCE PROBABILITY, IN PERCENT }\end{array}$} \\
\hline & $\stackrel{2}{50 \%}$ & $\underset{20 \%}{5}$ & $\begin{array}{l}10 \\
10 \%\end{array}$ & $\begin{array}{l}25 \\
4 \%\end{array}$ & $\begin{array}{l}50 \\
2 x\end{array}$ & $\begin{array}{c}100 \dagger \\
1 \%\end{array}$ \\
\hline $\begin{array}{r}1 \\
3 \\
7 \\
15 \\
30 \\
60 \\
90\end{array}$ & $\begin{array}{r}5,460 \\
3,290 \\
1,850 \\
1,110 \\
717 \\
457 \\
329\end{array}$ & $\begin{array}{r}10,600 \\
6,030 \\
3,350 \\
2,030 \\
1,310 \\
875 \\
625\end{array}$ & $\begin{array}{r}14,600 \\
7,820 \\
4,320 \\
2,670 \\
1,720 \\
1,180 \\
841\end{array}$ & $\begin{array}{r}19,800 \\
9,940 \\
5,440 \\
3,480 \\
2,230 \\
1,580 \\
1,120\end{array}$ & $\begin{array}{r}23,900 \\
11,400 \\
6,180 \\
4,070 \\
2,610 \\
1,890 \\
1,340\end{array}$ & $\begin{array}{r}28,000 \\
12,700 \\
6,850 \\
4,640 \\
2,960 \\
2,190 \\
1,540\end{array}$ \\
\hline
\end{tabular}

DURATION TABLE OF DAILY MEAN FLON FOR PERIOD OF RECORD 1906, 1950-73

DISCHARGE, IN FT $3 / 5$, WHICH WAS EQUALED OR EXCEEDED FOR INDICATED PERCENT OF TIME

\begin{tabular}{|c|c|c|c|c|c|c|c|c|c|c|c|c|c|c|c|c|}
\hline $1 \%$ & $5 \%$ & $10 \%$ & $15 \%$ & $20 \%$ & $30 \%$ & $40 \%$ & $50 \%$ & $60 \%$ & $70 \%$ & $80 \%$ & $90 \%$ & $95 \%$ & $98 \%$ & $99 \%$ & $99.5 \%$ & $99.9 \%$ \\
\hline 460 & 588 & 191 & 93 & 49 & 19 & 12 & 9.2 & 7.1 & 5.3 & 3.7 & 2.2 & 1.3 & 0.70 & 0.41 & 0.18 & .00 \\
\hline
\end{tabular}

$\uparrow$ Reliability of values in column is uncertain, and potential errors are large. 
09397000 LITTLE COLORADO RIVER AT HOLBROOK, AZ--CONTINUED
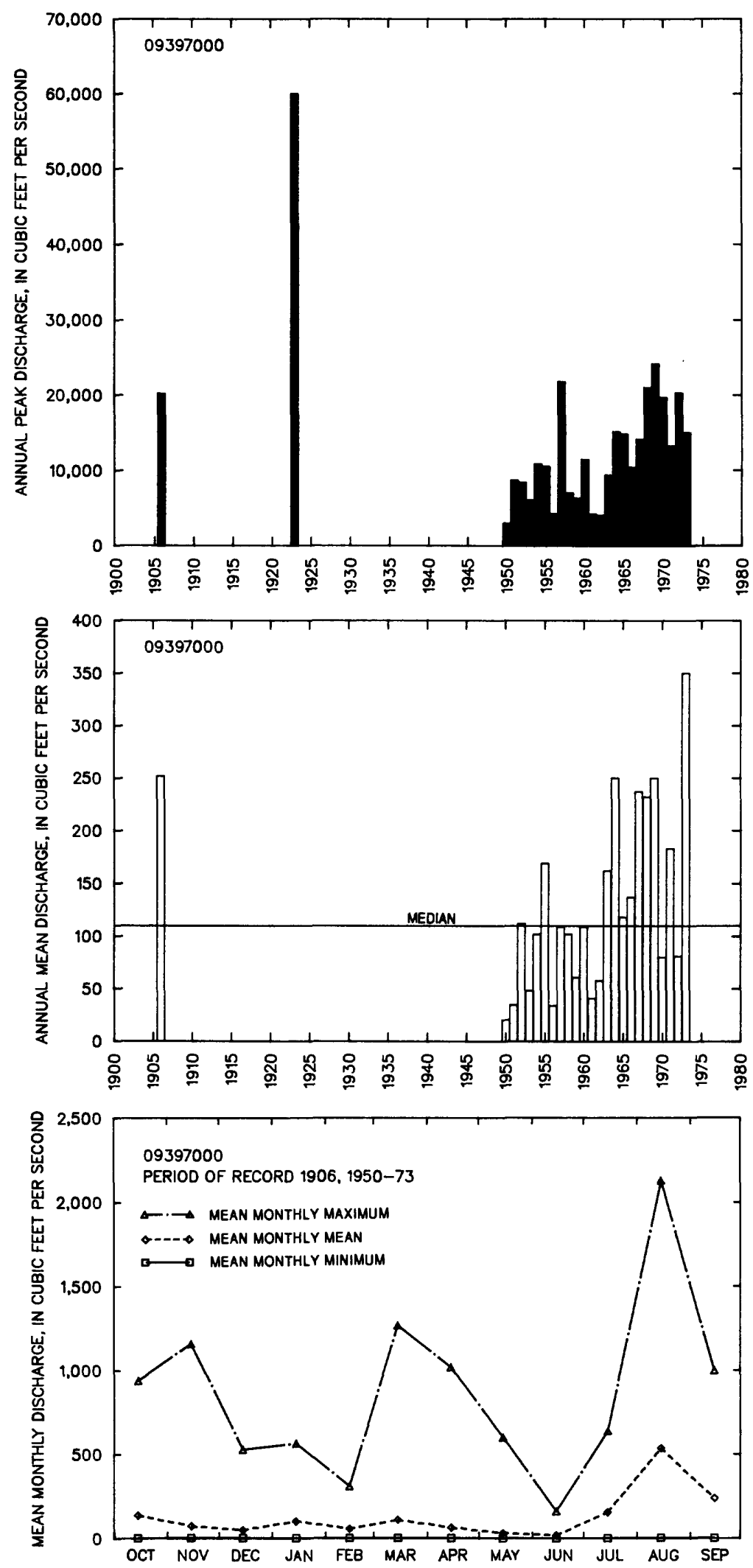
LOCATION.--Lat 34'55'08", long 110'15'13", in NEK sec.31, T.18 N., R.20 E., Navajo County, Hydrologic Unit 15020008, at U.S. Highway $66,5.6 \mathrm{mi}$ southeast of Joseph City.

DRAIMAGE AREA. $--0.17 \mathrm{mi}^{2}$.

\section{ANMUAL PEAK DISCHARGE}

\begin{tabular}{cccc}
$\begin{array}{c}\text { WATER } \\
\text { YEAR }\end{array}$ & $\begin{array}{c}\text { DATE } \\
\text { ANMUAL PEAK } \\
\text { DISCHARGE } \\
\text { (FT } 3 / \text { S })\end{array}$ & $\begin{array}{c}\text { DISCHARGE } \\
\text { CODES }\end{array}$ \\
\hline 1963 & $08-30-63$ & 106 & \\
1964 & $09-09-64$ & 120 & \\
1965 & $00-00-65$ & 3.0 & ES \\
1966 & $08-09-66$ & 36 & \\
1967 & $08-05-67$ & 116 & \\
1968 & $00-00-68$ & 0 & \\
1969 & $07-24-69$ & 1.0 & LT \\
1970 & $09-06-70$ & 95 & \\
1971 & $09-02-71$ & 24 & \\
1972 & $08-13-72$ & 40 & \\
1973 & $10-19-72$ & 5.0 & \\
1974 & $08-00-74$ & 20 & ES \\
1975 & $09-00-75$ & 35 & \\
1976 & $00-00-76$ & 96 &
\end{tabular}

MAGNI TUDE AND PROBABILITY OF INSTANTANEOUS PEAK FLON BASED ON PERIOD OF RECORD 1963-76

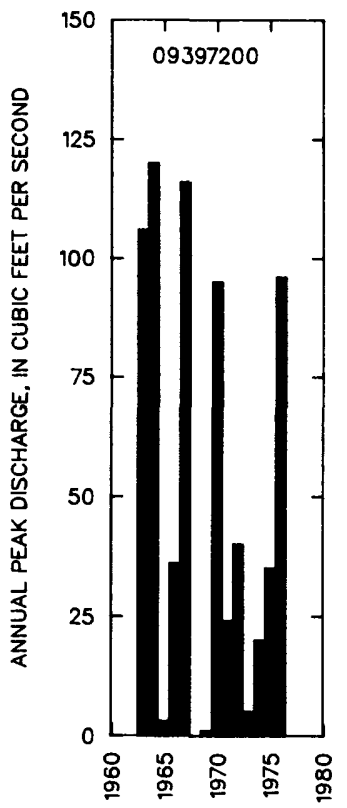

DISCHARGE, IN $\mathrm{FT}^{3} / \mathrm{S}$, FOR INDICATED RECURRENCE INTERVAL

IN YEARS, AND EXCEEDANCE PROBABILITY, IN PERCENT

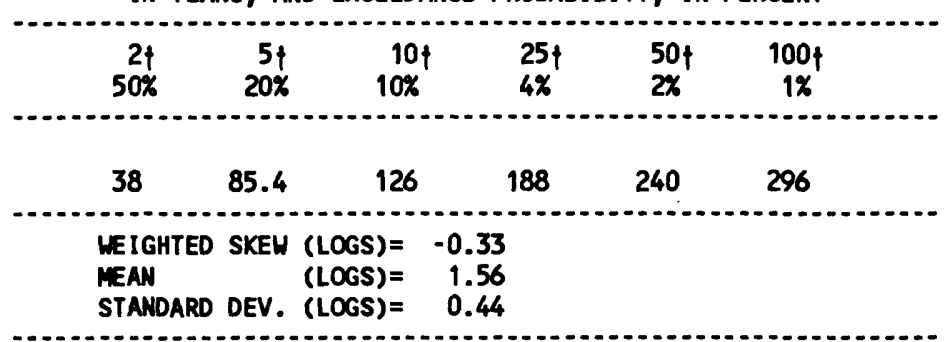

t Reliability of values in column is uncertain, and potential errors are large.

BASIN CHARACTERISTICS

\begin{tabular}{|c|c|c|c|c|c|c|c|}
\hline \multirow{3}{*}{$\begin{array}{l}\text { MAIN } \\
\text { CHANNEL } \\
\text { SLOPE } \\
\text { (FT/MI) }\end{array}$} & \multirow[b]{3}{*}{$\begin{array}{l}\text { STREAM } \\
\text { LENGTH } \\
\text { (MI) }\end{array}$} & \multirow{3}{*}{$\begin{array}{l}\text { MEAN } \\
\text { BASIN } \\
\text { ELEVA- } \\
\text { TION } \\
\text { (FT) }\end{array}$} & \multirow[b]{3}{*}{$\begin{array}{l}\text { FORESTED } \\
\text { AREA } \\
\text { (PERCENT) }\end{array}$} & \multirow[b]{3}{*}{$\begin{array}{c}\text { SOIL } \\
\text { INDEX }\end{array}$} & \multirow{3}{*}{$\begin{array}{l}\text { MEAN } \\
\text { ANNUAL } \\
\text { PRECIPI- } \\
\text { TATION } \\
\text { (IN) }\end{array}$} & \multirow{2}{*}{\multicolumn{2}{|c|}{ RAINFALL INTENSITY, 24-HOUR }} \\
\hline & & & & & & & \\
\hline & & & & & & $\begin{array}{c}\text { 2-YEAR } \\
\text { (IN) }\end{array}$ & $\begin{array}{l}\text { 50-YEAR } \\
\text { (IN) }\end{array}$ \\
\hline 237 & 0.45 & 5,150 & 0.0 & 3.0 & 7.8 & 1.2 & 2.6 \\
\hline
\end{tabular}


09397500 CHEVELON CREEK BELON WILDCAT CANYON, NEAR WINSLOW, AZ

LOCATION. - - Lat 34.38'11", Long 110.42'49", in SWK sec.36, T.15 N., R.15 E., Navajo County, Hydrologic Unit 15020010, on right benk $0.4 \mathrm{mi}$ downstream from Wildcat Canyon and $25 \mathrm{mi}$ south of Winslow.

DRAIMAGE AREA. $--271 \mathrm{mi}^{2}$.

REMARKS.--Storage and regulation by Chevelon Canyon Lake (capacity, 6, 193 acre-ft) 17 mi upstream since June 1967. No diversion above station.

ANNUAL PEAK DISCHARGE

\begin{tabular}{|c|c|c|c|c|c|c|c|}
\hline $\begin{array}{l}\text { WATER } \\
\text { YEAR }\end{array}$ & DATE & $\begin{array}{c}\text { ANNUAL PEAK } \\
\text { DISCHARGE } \\
\text { (FT } 3 / S \text { ) }\end{array}$ & $\begin{array}{l}\text { DISCHARGE } \\
\text { CODES }\end{array}$ & $\begin{array}{l}\text { WATER } \\
\text { YEAR }\end{array}$ & DATE & $\begin{array}{l}\text { ANNUAL PEAK } \\
\text { DISCHARGE } \\
\left(F^{3} / S\right)\end{array}$ & $\begin{array}{l}\text { DISCHARGE } \\
\text { CODES }\end{array}$ \\
\hline $\begin{array}{l}1948 \\
1949 \\
1950 \\
1951 \\
1952 \\
1953 \\
1954 \\
1955 \\
1956 \\
1957 \\
1958 \\
1959 \\
1960 \\
1961 \\
1962 \\
1963\end{array}$ & $\begin{array}{l}04-12-48 \\
04-14-49 \\
02-28-50 \\
08-29-51 \\
01-18-52 \\
03-11-53 \\
03-23-54 \\
08-23-55 \\
03-06-56 \\
01-09-57 \\
09-28-58 \\
10-06-58 \\
12-25-59 \\
04-04-61 \\
02-13-62 \\
08-27-63\end{array}$ & $\begin{array}{r}931 \\
1,290 \\
726 \\
8,940 \\
19,800 \\
653 \\
7,500 \\
631 \\
227 \\
11,300 \\
4,080 \\
479 \\
2,630 \\
476 \\
1,920 \\
950\end{array}$ & & $\begin{array}{l}1964 \\
1965 \\
1966 \\
1967 \\
1968 \\
1969 \\
1970 \\
1979 \\
1982 \\
1983 \\
1984 \\
1985 \\
1986 \\
1987 \\
1988 \\
1989\end{array}$ & $\begin{array}{l}04-12-64 \\
01-07-65 \\
12-30-65 \\
12-07-66 \\
04-02-68 \\
01-26-69 \\
09-05-70 \\
12-18-78 \\
03-12-82 \\
04-01-83 \\
12-27-83 \\
12-28-84 \\
11-26-85 \\
03-14-87 \\
02-27-88 \\
03-10-89\end{array}$ & $\begin{array}{r}1,240 \\
9,100 \\
9,560 \\
9,920 \\
1,600 \\
6,340 \\
11,100 \\
119,900 \\
6,440 \\
1,950 \\
2,360 \\
5,250 \\
3,490 \\
417 \\
1,170 \\
525\end{array}$ & $\begin{array}{l}\text { UR } \\
\text { UR } \\
\text { UR } \\
\text { HP }\end{array}$ \\
\hline
\end{tabular}

Highest since 1929.

\section{BASIN CHARACTERISTICS}

\begin{tabular}{|c|c|c|c|c|c|c|c|}
\hline \multirow{3}{*}{$\begin{array}{l}\text { MAIN } \\
\text { CHANNEL } \\
\text { SLOPE } \\
\text { (FT/MI) }\end{array}$} & \multirow[b]{3}{*}{$\begin{array}{l}\text { STREAM } \\
\text { LENGTH } \\
\text { (MI) }\end{array}$} & \multirow{3}{*}{$\begin{array}{l}\text { MEAN } \\
\text { BASIN } \\
\text { ELEVA- } \\
\text { TION } \\
\text { (FT) }\end{array}$} & \multirow[b]{3}{*}{$\begin{array}{l}\text { FORESTED } \\
\text { AREA } \\
\text { (PERCENT) }\end{array}$} & \multirow[b]{3}{*}{$\begin{array}{l}\text { SOIL } \\
\text { INDEX }\end{array}$} & \multirow{3}{*}{$\begin{array}{l}\text { MEAN } \\
\text { ANNUAL } \\
\text { PRECIPI- } \\
\text { TATION } \\
\text { (IN) }\end{array}$} & \multirow{2}{*}{\multicolumn{2}{|c|}{ RAINFALL INTENSITY, 24-HOUR }} \\
\hline & & & & & & & \\
\hline & & & & & & $\begin{array}{c}\text { 2-YEAR } \\
\text { (IN) }\end{array}$ & $\begin{array}{c}\text { 50-YEAR } \\
\text { (IN) }\end{array}$ \\
\hline 54.4 & 39.2 & 7,030 & 99.0 & 3.0 & 24.0 & 2.5 & 4.6 \\
\hline
\end{tabular}


MEAN MONTHLY AND ANNUAL DISCHARGES $1948-70$

\begin{tabular}{|c|c|c|c|c|c|c|}
\hline MONTH & $\begin{array}{l}\operatorname{MAX} I_{3} \operatorname{Mn} \\
\left(F T^{3} / S\right)\end{array}$ & $\begin{array}{l}\operatorname{MINIMUN} \\
\left(F T^{3} / S\right)\end{array}$ & $\begin{array}{c}\text { MEAN } \\
\left(F T^{3} / S\right)\end{array}$ & $\begin{array}{l}\text { STAN- } \\
\text { DARD } \\
\text { DEVIA- } \\
\text { TION } \\
\text { (FT'/S) }\end{array}$ & $\begin{array}{l}\text { COEFFI- } \\
\text { CIENT OF } \\
\text { VARI - } \\
\text { ATION }\end{array}$ & $\begin{array}{c}\text { PERCENT } \\
\text { OF } \\
\text { ANNUAL } \\
\text { RUNOFF }\end{array}$ \\
\hline $\begin{array}{l}\text { OCTOBER } \\
\text { NOVEMBER } \\
\text { DECEMBER } \\
\text { JANUARY } \\
\text { FEBRUARY } \\
\text { MARCH } \\
\text { APRIL } \\
\text { MAY } \\
\text { JUNE } \\
\text { JULY } \\
\text { AUGUST } \\
\text { SEPTEMBER }\end{array}$ & $\begin{array}{c}46 \\
108 \\
320 \\
523 \\
308 \\
473 \\
658 \\
47 \\
1.7 \\
4.4 \\
205 \\
210\end{array}$ & $\begin{array}{c}0.00 \\
0.00 \\
0.00 \\
0.00 \\
0.00 \\
31 \\
5.3 \\
0.00 \\
0.00 \\
0.00 \\
0.00 \\
0.00\end{array}$ & $\begin{array}{c}2.7 \\
9.2 \\
46 \\
96 \\
64 \\
164 \\
166 \\
11 \\
0.09 \\
0.29 \\
18 \\
19\end{array}$ & $\begin{array}{c}9.7 \\
24 \\
88 \\
172 \\
80 \\
119 \\
182 \\
16 \\
0.35 \\
1.0 \\
47 \\
51\end{array}$ & $\begin{array}{l}3.5 \\
2.7 \\
1.9 \\
1.8 \\
1.3 \\
0.73 \\
1.1 \\
1.4 \\
3.9 \\
3.4 \\
2.7 \\
2.7\end{array}$ & $\begin{array}{r}0.5 \\
1.5 \\
7.8 \\
16.1 \\
10.7 \\
27.6 \\
27.9 \\
1.9 \\
0.0 \\
0.0 \\
2.9 \\
3.2\end{array}$ \\
\hline NMUAL & IS2 & 15 & 50 & 33 & 0.66 & 100 \\
\hline
\end{tabular}

MAGNITUDE AND PROBABILITY OF INSTANTANEQUS PEAK FLON BASED ON PERIOD OF RECORD 1948-67, 1968-70, 1979, 1982-89

\begin{tabular}{|c|c|c|c|c|c|}
\hline$\stackrel{2}{20 x}$ & $\begin{array}{c}5 \\
20 \%\end{array}$ & $\begin{array}{r}10 \\
10 \%\end{array}$ & $\begin{array}{l}25 \\
4 \%\end{array}$ & $\begin{array}{l}50 \\
2 \%\end{array}$ & $\begin{array}{c}100 \dagger \\
1 \%\end{array}$ \\
\hline 2,360 & 6,680 & 11,500 & 20,300 & 29,400 & 41,000 \\
\hline $\begin{array}{l}\text { WEIGHT } \\
\text { MEAN } \\
\text { STANDA }\end{array}$ & $\begin{array}{l}\text { SKEH } \\
\text { DEV. }\end{array}$ & $\begin{array}{l}\text { LOGS) }= \\
\text { LOGS) }= \\
\text { LOGS) }=\end{array}$ & $\begin{array}{l}0.03 \\
3.37 \\
0.54\end{array}$ & & \\
\hline
\end{tabular}

MAGNITUDE AND PROBABILITY OF ANNUAL LON FLON BASED ON PERIOD OF RECORD 1949-70

\begin{tabular}{|c|c|c|c|c|c|c|}
\hline $\begin{array}{l}\text { PERIOD } \\
\text { (CON- } \\
\text { SECU- }\end{array}$ & & $\begin{array}{l}\text { ISCHAI } \\
\text { ECURR } \\
\text { N-EXC } \\
-\end{array}$ & $\begin{array}{l}\text { IN F } \\
\text { ENCE } \\
\text { ANTE } \\
\text { A }\end{array}$ & $\begin{array}{l}\text { /S, FC } \\
\text { AL, II } \\
\text { BAB IL } \\
0\end{array}$ & $\begin{array}{l}\text { INDICA } \\
\text { EARS, } \\
\text { IN P }\end{array}$ & CENT \\
\hline $\begin{array}{l}\text { TIVE } \\
\text { DAYS) }\end{array}$ & $\stackrel{2}{50 \%}$ & $\begin{array}{c}5 \\
20 \%\end{array}$ & $\begin{array}{l}10 \\
10 \%\end{array}$ & $\begin{array}{l}20 \\
5 \%\end{array}$ & $\begin{array}{l}50 \nmid \\
2 \%\end{array}$ & $\begin{array}{l}100 \dagger \\
1 \%\end{array}$ \\
\hline $\begin{array}{r}1 \\
3 \\
7 \\
14 \\
30 \\
60\end{array}$ & & & & & & \\
\hline $\begin{array}{r}90 \\
120 \\
183\end{array}$ & $\begin{array}{l}0.00 \\
0.00 \\
0.22\end{array}$ & $\begin{array}{l}0.00 \\
0.00 \\
0.00\end{array}$ & $\begin{array}{l}0.00 \\
0.00 \\
0.00\end{array}$ & $\begin{array}{l}0.00 \\
0.00 \\
0.00\end{array}$ & $\begin{array}{l}0.00 \\
0.00 \\
0.00\end{array}$ & $\begin{array}{l}0.00 \\
0.00 \\
0.00\end{array}$ \\
\hline
\end{tabular}

MAGNITUDE AND PROBABILITY OF ANNUAL HIGH FLOW BASED ON PERIOD OF RECORD 1948-70

\begin{tabular}{|c|c|c|c|c|c|c|}
\hline $\begin{array}{c}\text { PERIOD } \\
\text { (CON- } \\
\text { CENI- }\end{array}$ & & $\begin{array}{l}\text { DISCHA } \\
\text { RECURRE } \\
\text { EXCEED } \\
\end{array}$ & $\begin{array}{l}\text { E, IN } \\
\text { CE INTE } \\
\text { CE PRO } \\
\end{array}$ & $\begin{array}{l}\Gamma^{3} / S, F \\
\text { ZVAL, } 11 \\
\text { ABILITY }\end{array}$ & $\begin{array}{l}\text { R INDIC } \\
\text { YEARS, } \\
\text { IN PERC }\end{array}$ & $\begin{array}{l}\text { TED } \\
\text { AND } \\
\text { ENT } \\
. . .\end{array}$ \\
\hline $\begin{array}{l}\text { TIVE } \\
\text { DAYSD }\end{array}$ & $\stackrel{2}{50 \%}$ & $\begin{array}{c}5 \\
20 \%\end{array}$ & $\begin{array}{l}10 \\
10 \%\end{array}$ & $\begin{array}{l}25 \\
4 \%\end{array}$ & $\begin{array}{l}50\} \\
2 \%\end{array}$ & $\underset{1 \%}{100 \dagger}$ \\
\hline $\begin{array}{r}1 \\
3 \\
7 \\
15 \\
30 \\
60 \\
90\end{array}$ & $\begin{array}{r}1,400 \\
979 \\
670 \\
448 \\
297 \\
175 \\
131\end{array}$ & $\begin{array}{r}3,640 \\
2,170 \\
1,250 \\
741 \\
480 \\
303 \\
239\end{array}$ & $\begin{array}{r}5,980 \\
3,230 \\
1,640 \\
912 \\
591 \\
395 \\
320\end{array}$ & $\begin{array}{r}10,100 \\
4,870 \\
2,120 \\
1,100 \\
716 \\
516 \\
430\end{array}$ & $\begin{array}{r}14,200 \\
6,310 \\
2,460 \\
1,210 \\
798 \\
607 \\
517\end{array}$ & $\begin{array}{r}19,300 \\
7,930 \\
2,770 \\
1,310 \\
870 \\
700 \\
607\end{array}$ \\
\hline
\end{tabular}

DURATION TABLE OF DAILY MEAN FLON FOR PERIOD OF RECORD 1948-70 DISCHARGE, IN FT $3 / \mathrm{S}$, WHICH WAS EQUALED OR EXCEEDED FOR INDICATED PERCENT OF TIME

\begin{tabular}{|c|c|c|c|c|c|c|c|c|c|c|c|c|c|c|c|c|}
\hline $1 \%$ & $5 \%$ & $10 \%$ & $15 \%$ & $20 \%$ & $30 \%$ & $40 \%$ & $50 \%$ & $60 \%$ & $70 \%$ & $80 \%$ & $90 \%$ & $95 \%$ & $98 \%$ & $99 \%$ & $99.5 \%$ & $99.9 \%$ \\
\hline 774 & 253 & 106 & 65 & 37 & 8.4 & 0.78 & 0.00 & 0.00 & 0.00 & 0.00 & 0.00 & 0.00 & 0.00 & 0.00 & 0.00 & 0.00 \\
\hline
\end{tabular}


LITTLE COLORADO RIVER BASIN

09397500 CHEVELON CREEK BELOW WILDCAT CANYON, NEAR WINSLOW, AZ--CONTINUED
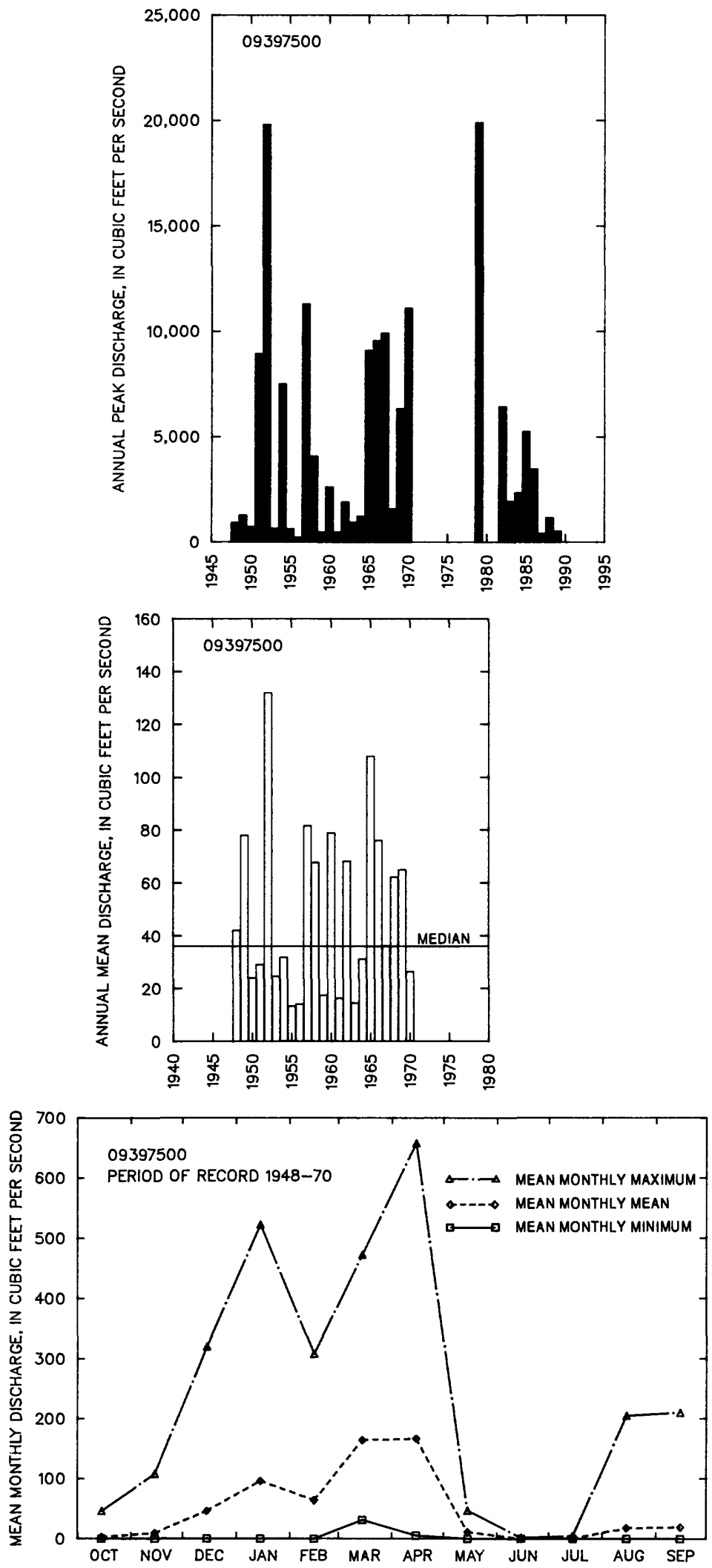


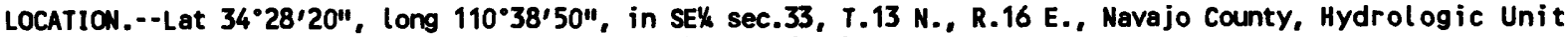
15020010, at Heber-Winslow Road, 4 miles northwest of Heber.

DRAINAGE AREA. $--27.9 \mathrm{mi}^{2}$.

ANMUAL PEAK DISCHARGE

\begin{tabular}{|c|c|c|c|}
\hline $\begin{array}{l}\text { WATER } \\
\text { YEAR }\end{array}$ & DATE & $\begin{array}{c}\text { ANNUAL PEAK } \\
\text { DISCHARGE } \\
\left(\mathrm{FT}^{3} / \mathrm{S}\right)\end{array}$ & $\begin{array}{l}\text { DISCHARGE } \\
\text { COOES }\end{array}$ \\
\hline $\begin{array}{l}1964 \\
1965 \\
1966 \\
1967 \\
1968 \\
1969 \\
1970 \\
1971 \\
1972 \\
1973 \\
1974 \\
1975 \\
1976\end{array}$ & $\begin{array}{l}08-00-64 \\
01-07-65 \\
12-30-65 \\
12-07-66 \\
02-00-68 \\
03-00-69 \\
09-05-70 \\
09-29-71 \\
07-16-72 \\
10-19-72 \\
07-15-74 \\
08-11-75 \\
02-09-76\end{array}$ & $\begin{array}{c}666 \\
139 \\
310 \\
140 \\
10 \\
32 \\
335 \\
78 \\
200 \\
390 \\
1.0 \\
2.0 \\
165\end{array}$ & $\begin{array}{l}\text { LT } \\
\text { ES }\end{array}$ \\
\hline
\end{tabular}

MAGNITUDE AND PROBABILITY OF INSTANTANEOUS PEAK FLOW BASED ON PERIOD OF RECORD 1964-76

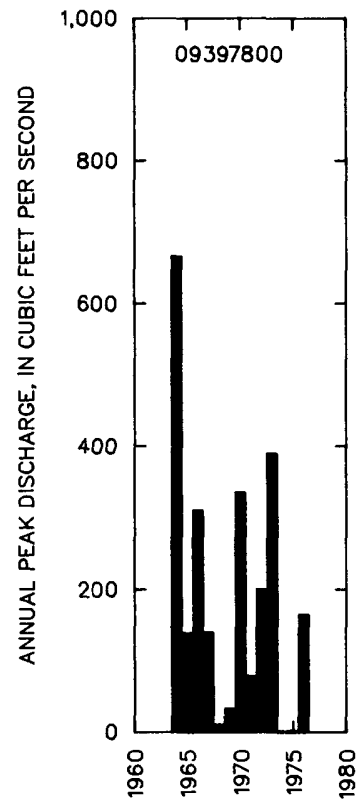

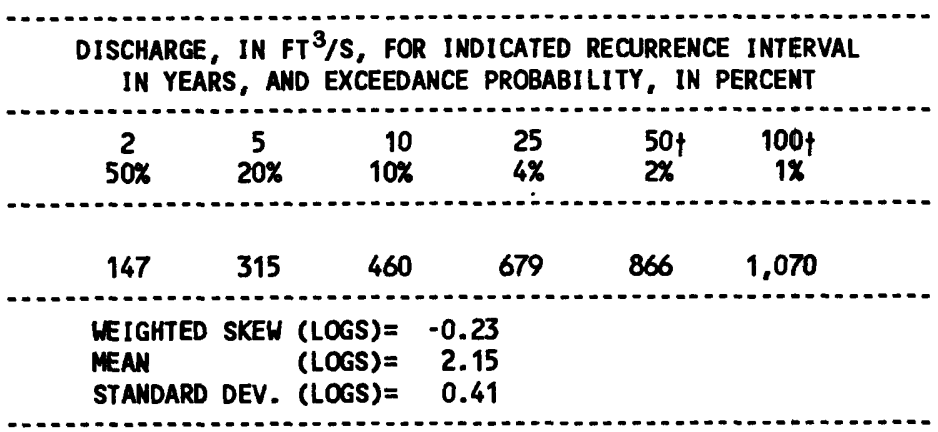

f Reliability of values in column is uncertain, and potential errors are large.

BASIN CHARACTERISTICS

\begin{tabular}{|c|c|c|c|c|c|c|c|}
\hline MAIN & & $\begin{array}{r}\text { MEAN } \\
\text { BASIN }\end{array}$ & & & $\begin{array}{l}\text { MEAN } \\
\text { ANNUAL }\end{array}$ & RAINFALL I & SITY, 24-HOUR \\
\hline $\begin{array}{l}\text { CHANNEL } \\
\text { SLOPE } \\
\text { (FT/MI) }\end{array}$ & $\begin{array}{c}\text { STREAM } \\
\text { LENGTH } \\
\text { (MI) }\end{array}$ & $\begin{array}{l}\text { ELEVA- } \\
\text { TION } \\
\text { (FT) }\end{array}$ & $\begin{array}{l}\text { FORESTED } \\
\text { AREA } \\
\text { (PERCENT) }\end{array}$ & $\begin{array}{l}\text { SOIL } \\
\text { INDEX }\end{array}$ & $\begin{array}{l}\text { PRECIPI - } \\
\text { TATION } \\
\text { (IN) }\end{array}$ & $\begin{array}{c}\text { 2-YEAR } \\
\text { (IN) }\end{array}$ & $\begin{array}{l}\text { 50-YEAR } \\
\text { (IN) }\end{array}$ \\
\hline 65.5 & 11.6 & 6,950 & 99.0 & 3.0 & 22.1 & 2.3 & 5.0 \\
\hline
\end{tabular}


09398000 CHEVELON CREEK NEAR HINSLON, AZ

LOCATION.--Lat 34.55'35", long 110.31'51", in SEKSWK sec.27, T.18 N., R.17 E., Navajo County, Hydrologic Unit 15020010, on right bank 3 mi upstream from mouth and 12 mi southeast of Winslow.

DRAINAGE AREA.-- $785 \mathrm{mi}^{2}$, of which $3.9 \mathrm{mi}^{2}$ is noncontributing.

REMARKS.--Storage and regulation by Chevelon Canyon Lake (capacity, 6,193 acre-ft) 57 mi upstream since June 1967. No known diversion above station. Chevelon Canal diverts 2 mi downstream from station for irrigation.

ANMUAL PEAK DISCHARGE

\begin{tabular}{|c|c|c|c|c|c|c|c|}
\hline $\begin{array}{l}\text { WATER } \\
\text { YEAR }\end{array}$ & DATE & $\begin{array}{c}\text { ANNUAL PEAK } \\
\text { DISCHARGE } \\
\text { (FT } 3 / \mathrm{S})\end{array}$ & $\begin{array}{l}\text { DISCHARGE } \\
\text { COOES }\end{array}$ & $\begin{array}{l}\text { WATER } \\
\text { YEAR }\end{array}$ & DATE & $\begin{array}{l}\text { ANNUAL PEAK } \\
\text { DISCHARGE } \\
\left(F^{3} / \mathrm{S}\right)\end{array}$ & $\begin{array}{l}\text { DISCHARGE } \\
\text { COOES }\end{array}$ \\
\hline $\begin{array}{l}1916 \\
1917 \\
1918 \\
1919 \\
1920 \\
1929 \\
1930 \\
1931 \\
1932 \\
1933 \\
1934 \\
1936 \\
1937 \\
1938 \\
1939 \\
1940 \\
1941 \\
1942 \\
1943 \\
1944 \\
1945 \\
1946 \\
1947 \\
1948 \\
1949\end{array}$ & $\begin{array}{l}01-19-16 \\
04-24-17 \\
03-13-18 \\
04-01-19 \\
12-05-19 \\
04-04-29 \\
03-27-30 \\
03-19-31 \\
02-10-32 \\
09-20-33 \\
00-00-34 \\
04-12-36 \\
02-08-37 \\
03-04-38 \\
08-03-39 \\
07-25-40 \\
03-15-41 \\
04-06-42 \\
03-11-43 \\
04-06-44 \\
08-04-45 \\
09-20-46 \\
08-04-47 \\
04-13-48 \\
04-14-49\end{array}$ & $\begin{array}{r}9,500 \\
1,300 \\
6,200 \\
1,110 \\
9,000 \\
16,100 \\
519 \\
548 \\
3,100 \\
1,060 \\
2,700 \\
1,350 \\
1,820 \\
9,400 \\
2,410 \\
1,180 \\
1,630 \\
985 \\
1,330 \\
1,180 \\
2,620 \\
892 \\
2,460 \\
825 \\
1,150\end{array}$ & & $\begin{array}{l}1950 \\
1951 \\
1952 \\
1953 \\
1954 \\
1955 \\
1956 \\
1957 \\
1958 \\
1959 \\
1960 \\
1961 \\
1962 \\
1963 \\
1964 \\
1965 \\
1966 \\
1967 \\
1968 \\
1969 \\
1970 \\
1971 \\
1972 \\
1979\end{array}$ & $\begin{array}{l}03-01-50 \\
08-30-51 \\
01-19-52 \\
03-12-53 \\
03-23-54 \\
06-13-55 \\
07-23-56 \\
01-09-57 \\
09-28-58 \\
08-14-59 \\
12-26-59 \\
07-30-61 \\
02-13-62 \\
08-21-63 \\
08-01-64 \\
01-08-65 \\
12-31-65 \\
12-07-66 \\
04-02-68 \\
01-26-69 \\
09-06-70 \\
08-24-71 \\
12-27-71 \\
12-18-78\end{array}$ & $\begin{array}{r}616 \\
7,200 \\
25,300 \\
650 \\
5,730 \\
1,800 \\
562 \\
8,680 \\
2,140 \\
1,320 \\
2,640 \\
500 \\
1,540 \\
1,620 \\
1,680 \\
13,100 \\
13,300 \\
8,890 \\
1,640 \\
5,120 \\
8,020 \\
4,150 \\
9,040 \\
133,600\end{array}$ & $\begin{array}{c}\text { UR } \\
\text { UR } \\
\text { UR } \\
\text { UR } \\
\text { UR } \\
\text { UR, HP }\end{array}$ \\
\hline
\end{tabular}

IHighest since 1923.

BASIN CHARACTERISTICS

\begin{tabular}{|c|c|c|c|c|c|c|c|}
\hline \multirow{2}{*}{$\begin{array}{l}\text { MAIN } \\
\text { CHANNEL } \\
\text { SLOPE } \\
\text { (FT/MI) }\end{array}$} & \multirow[b]{2}{*}{$\begin{array}{l}\text { STREAM } \\
\text { LENGTH } \\
\text { (MI) }\end{array}$} & \multirow{2}{*}{$\begin{array}{l}\text { MEAN } \\
\text { BASIN } \\
\text { ELEVA- } \\
\text { TION } \\
\text { (FT) }\end{array}$} & \multirow[b]{2}{*}{$\begin{array}{l}\text { FORESTED } \\
\text { AREA } \\
\text { (PERCENT) }\end{array}$} & \multirow[b]{2}{*}{$\begin{array}{l}\text { SOIL } \\
\text { INDEX }\end{array}$} & \multirow{2}{*}{$\begin{array}{l}\text { MEAN } \\
\text { ANNUAL } \\
\text { PRECIPI- } \\
\text { TATION } \\
\text { (IN) }\end{array}$} & \multicolumn{2}{|c|}{ RAINFALL INTENSITY, 24-HOUR } \\
\hline & & & & & & $\begin{array}{l}\text { 2-YEAR } \\
\text { (IN) }\end{array}$ & $\begin{array}{l}\text { 50-YEAR } \\
\text { (IN) }\end{array}$ \\
\hline 27.7 & 77.1 & 6,440 & 70.0 & 3.0 & 18.4 & 2.1 & 4.2 \\
\hline
\end{tabular}


MEAN MONTHLY AND ANNUAL DISCHARGES 1917-19, 1930-33, 1936-72

\begin{tabular}{|c|c|c|c|c|c|c|}
\hline MONTH & $\begin{array}{l}\operatorname{MAXIIMM} \\
\left(F T^{3} / S\right)\end{array}$ & $\begin{array}{l}\text { MINIMUM } \\
\left(F T^{3} / S\right)\end{array}$ & $\begin{array}{c}\text { MEAN } \\
\left(\mathrm{FT}^{3} / \mathrm{S}\right)\end{array}$ & $\begin{array}{l}\text { STAN- } \\
\text { DARD } \\
\text { DEVIA- } \\
\text { TION } \\
\left(F^{3} / S\right)\end{array}$ & $\begin{array}{l}\text { COEFFI- } \\
\text { CIENT OF } \\
\text { VARI - } \\
\text { ATION }\end{array}$ & $\begin{array}{c}\text { PERCENT } \\
\text { OF } \\
\text { ANNUAL } \\
\text { RUNOFF }\end{array}$ \\
\hline $\begin{array}{l}\text { OCTOBER } \\
\text { NOVEMBER } \\
\text { DECEMBER } \\
\text { JANUARY } \\
\text { FEBRUARY } \\
\text { MARCH } \\
\text { APRIL } \\
\text { MAY } \\
\text { JUNE } \\
\text { JULY } \\
\text { AUGUST } \\
\text { SEPTEMBER }\end{array}$ & $\begin{array}{r}247 \\
137 \\
347 \\
663 \\
338 \\
527 \\
733 \\
211 \\
21 \\
25 \\
171 \\
182\end{array}$ & $\begin{array}{l}3.1 \\
2.7 \\
2.8 \\
2.6 \\
2.7 \\
3.5 \\
3.9 \\
2.2 \\
2.1 \\
3.0 \\
2.9 \\
2.5\end{array}$ & $\begin{array}{c}12 \\
14 \\
37 \\
58 \\
64 \\
171 \\
181 \\
23 \\
5.1 \\
7.1 \\
18 \\
15\end{array}$ & $\begin{array}{c}37 \\
26 \\
76 \\
135 \\
89 \\
138 \\
188 \\
39 \\
3.1 \\
4.1 \\
32 \\
31\end{array}$ & $\begin{array}{l}3.1 \\
1.9 \\
2.1 \\
2.3 \\
1.4 \\
0.80 \\
1.0 \\
1.7 \\
0.61 \\
0.57 \\
1.8 \\
2.0\end{array}$ & $\begin{array}{r}2.0 \\
2.3 \\
6.1 \\
9.6 \\
10.6 \\
28.2 \\
29.9 \\
3.7 \\
0.8 \\
1.2 \\
3.0 \\
2.5\end{array}$ \\
\hline ANNUAL & 145 & 7.7 & 50 & 32 & 0.63 & 100 \\
\hline
\end{tabular}

MAGNITUDE AND PROBABILITY OF INSTANTANEOUS PEAK FLON BASED ON PERICD OF RECORD 1916-20, 1929-34, 1936-67, 1968-72

\begin{tabular}{|c|c|c|c|c|c|}
\hline $\begin{array}{c}2 \\
50 \%\end{array}$ & $\begin{array}{c}5 \\
20 \%\end{array}$ & $\begin{array}{r}10 \\
10 \%\end{array}$ & $\begin{array}{l}25 \\
4 \%\end{array}$ & $\begin{array}{l}50 \\
2 \%\end{array}$ & $\begin{array}{c}100 \dagger \\
1 \%\end{array}$ \\
\hline 2,360 & 5,860 & 9,670 & 16,800 & 24,200 & 33,800 \\
\hline $\begin{array}{l}\text { WEIGHTED } \\
\text { MEAN } \\
\text { STANDARD }\end{array}$ & $\begin{array}{l}\text { SKEW } \\
\text { DEV. }\end{array}$ & $\begin{array}{l}(\text { LOGS })= \\
(\text { LOGS })= \\
(L O G S)=\end{array}$ & $\begin{array}{l}.24 \\
.39 \\
.46\end{array}$ & & \\
\hline
\end{tabular}

MAGNITUDE AND PROBABILITY OF ANNUAL LON FLON BASED ON PERICD OF RECORD 1918-19, 1930-33, 1937-72

\begin{tabular}{|c|c|c|c|c|c|c|}
\hline \multirow{2}{*}{$\begin{array}{l}\text { PERIOD } \\
\text { (CON- } \\
\text { SECU- } \\
\text { TIVE } \\
\text { DAYS) }\end{array}$} & \multicolumn{6}{|c|}{$\begin{array}{l}\text { DISCHARGE, IN } \mathrm{FT}^{3} / \mathrm{S} \text {, FOR INDICATED } \\
\text { RECURRENCE INTERVAL, IN YEARS, AND } \\
\text { NON-EXCEEDANCE PROBABILITY, IN PERCENT }\end{array}$} \\
\hline & $\begin{array}{c}2 \\
50 \%\end{array}$ & $\begin{array}{c}5 \\
20 x\end{array}$ & $\begin{array}{l}10 \\
10 x\end{array}$ & $\begin{array}{l}20 \\
5 \%\end{array}$ & $\begin{array}{l}50 \\
2 \%\end{array}$ & $\begin{array}{l}100 \dagger \\
\mathbf{1 \%}\end{array}$ \\
\hline $\begin{array}{r}1 \\
3 \\
7 \\
14 \\
30 \\
60 \\
90 \\
120 \\
183\end{array}$ & $\begin{array}{l}2.1 \\
2.3 \\
2.6 \\
2.8 \\
3.2 \\
3.7 \\
4.0 \\
4.1 \\
5.1\end{array}$ & $\begin{array}{l}1.5 \\
1.7 \\
2.0 \\
2.3 \\
2.7 \\
3.2 \\
3.3 \\
3.5 \\
3.9\end{array}$ & $\begin{array}{l}1.2 \\
1.4 \\
1.7 \\
2.0 \\
2.5 \\
2.9 \\
3.0 \\
3.4 \\
3.6\end{array}$ & $\begin{array}{l}0.94 \\
1.2 \\
1.5 \\
1.9 \\
2.3 \\
2.7 \\
2.8 \\
3.3 \\
3.4\end{array}$ & $\begin{array}{l}0.72 \\
0.95 \\
1.3 \\
1.7 \\
2.1 \\
2.5 \\
2.5 \\
3.3 \\
3.3\end{array}$ & $\begin{array}{l}0.60 \\
0.82 \\
1.2 \\
1.5 \\
2.0 \\
2.3 \\
2.4 \\
3.3 \\
3.3\end{array}$ \\
\hline
\end{tabular}

MAGNITLOE AND PROBABILITY OF ANNUAL HIGH FLOW BASED ON PERIOD OF RECORD 1917-19, 1930-33, 1936-72

\begin{tabular}{|c|c|c|c|c|c|c|}
\hline \multirow{2}{*}{$\begin{array}{l}\text { PERIOD } \\
\text { (CON- } \\
\text { SECU- } \\
\text { TIVE } \\
\text { DAYS) }\end{array}$} & \multicolumn{6}{|c|}{$\begin{array}{l}\text { DISCHARGE, IN } \mathrm{FT}^{3} / \mathrm{S}, \text { FOR INDICATED } \\
\text { RECURRENCE INTERVAL, IN YEARS, AND } \\
\text { EXCEEDANCE PROBABILITY, IN PERCENT }\end{array}$} \\
\hline & $\stackrel{2}{2}$ & $\underset{20 x}{5}$ & $\begin{array}{l}10 \\
10 x\end{array}$ & $\begin{array}{l}25 \\
4 \%\end{array}$ & $\begin{array}{l}50 \\
2 \%\end{array}$ & ${ }_{1 \%}^{100 \nmid}$ \\
\hline $\begin{array}{r}1 \\
3 \\
7 \\
15 \\
30 \\
60 \\
90\end{array}$ & $\begin{array}{r}1,040 \\
830 \\
629 \\
449 \\
304 \\
188 \\
140\end{array}$ & $\begin{array}{r}2,430 \\
1,650 \\
1,090 \\
703 \\
479 \\
317 \\
246\end{array}$ & $\begin{array}{r}3,950 \\
2,370 \\
1,390 \\
843 \\
575 \\
401 \\
319\end{array}$ & $\begin{array}{r}6,880 \\
3,490 \\
1,760 \\
989 \\
674 \\
502 \\
411\end{array}$ & $\begin{array}{r}10,000 \\
4,480 \\
2,010 \\
1,080 \\
734 \\
572 \\
478\end{array}$ & $\begin{array}{r}14,300 \\
5,630 \\
2,260 \\
1,150 \\
783 \\
637 \\
543\end{array}$ \\
\hline
\end{tabular}

DURATION TABLE OF DAILY MEAN FLON FOR PERICD OF RECORD 1917-19, 1930-33, 1936-72

DISCHARGE, IN FT $3 / 5$, WHICH WAS EQUALED OR EXCEEDED FOR INDICATED PERCENT OF TIME

\begin{tabular}{|c|c|c|c|c|c|c|c|c|c|c|c|c|c|c|c|c|}
\hline $1 \%$ & $5 \%$ & $10 \%$ & $15 \%$ & $20 \%$ & $30 \%$ & $40 \%$ & $50 \%$ & $60 \%$ & $70 \%$ & $80 \%$ & $90 \%$ & $95 \%$ & $98 \%$ & $99 \%$ & $99.5 \%$ & $99.9 \%$ \\
\hline 768 & 267 & 113 & 60 & 33 & 9.0 & 5.6 & 5.1 & 4.7 & 4.3 & 3.8 & 3.3 & 3.0 & 2.1 & 1.8 & 1.7 & 1.1 \\
\hline
\end{tabular}

$\uparrow$ Reliability of values in column is uncertain, and potential errors are large. 
09398000 CHEVELON CREEK NEAR WINSLOW, AZ--CONTINUED
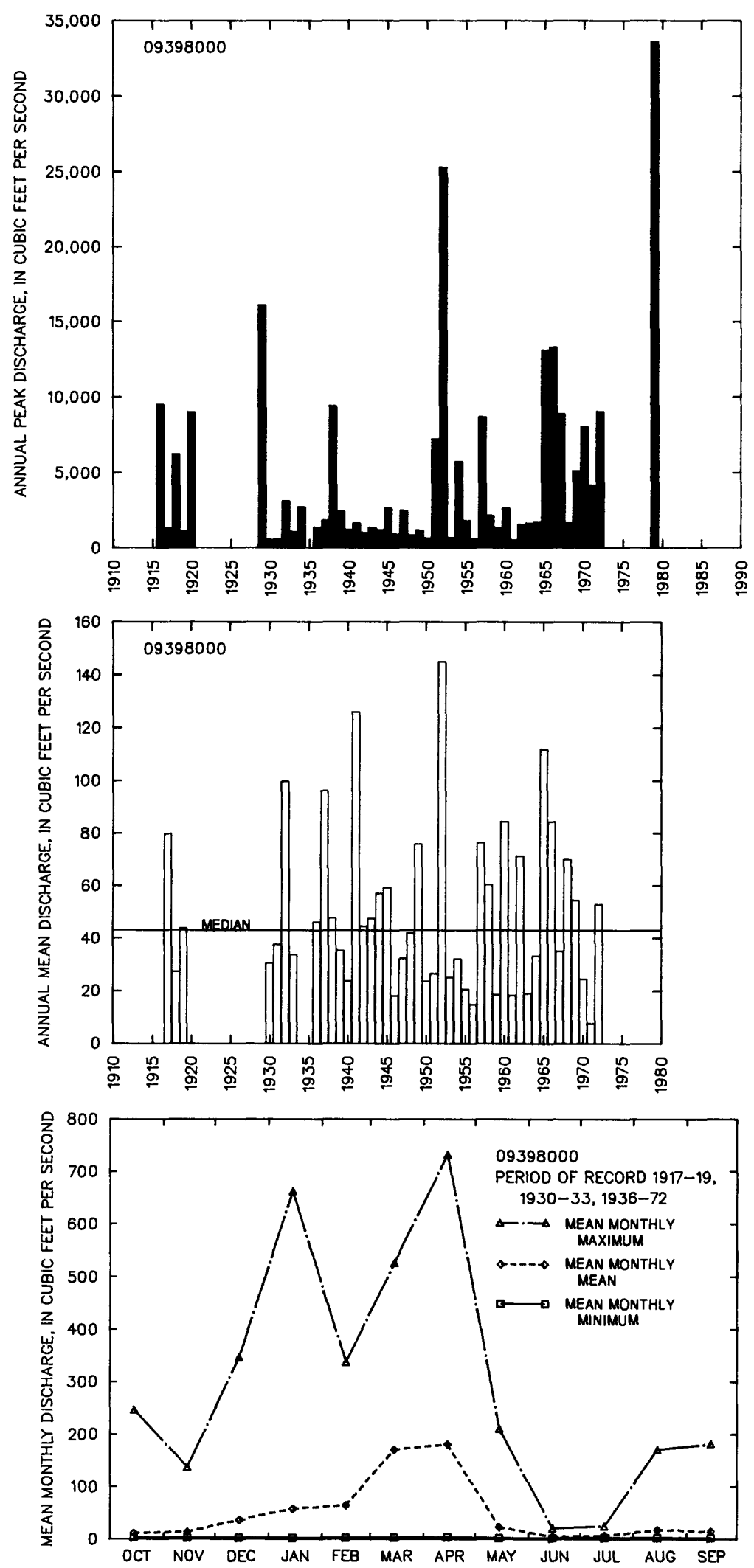


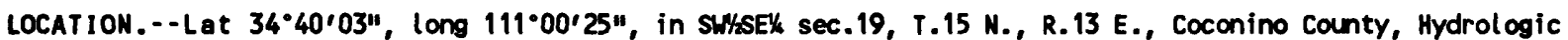
Unit 15020008, in Apache-sitgreaves National Forest, on right bank 2 mi downstream from Willow Creek and $30 \mathrm{mi}$ southwest of Winslow.

DRAIMAGE AREA. $--317 \mathrm{mi}^{2}$.

REMARKS.--Flow is partially controlled by Blue Ridge Reservoir (usable capacity, 15,000 acre-ft) about $20 \mathrm{mi}$ upstream. Diversion to East Verde River from Blue Ridge Reservoir.

ANMUAL PEAK DISCHARGE

\begin{tabular}{|c|c|c|c|c|c|c|c|}
\hline $\begin{array}{l}\text { WATER } \\
\text { YEAR }\end{array}$ & DATE & $\begin{array}{c}\text { ANNUAL PEAK } \\
\text { DISCHARGE } \\
\text { (FT } 3 / \mathrm{S})\end{array}$ & $\begin{array}{l}\text { DISCHARGE } \\
\text { COOES }\end{array}$ & $\begin{array}{l}\text { WATER } \\
\text { YEAR }\end{array}$ & DATE & $\begin{array}{l}\text { ANNUAL PEAK } \\
\text { DISCHARCE } \\
\left(\mathrm{FT}^{3} / \mathrm{S}\right)\end{array}$ & $\begin{array}{l}\text { DISCHARGE } \\
\text { CODES }\end{array}$ \\
\hline $\begin{array}{l}1948 \\
1949 \\
1950 \\
1951 \\
1952 \\
1953 \\
1954 \\
1955 \\
1956 \\
1957 \\
1958 \\
1959 \\
1960 \\
1961 \\
1962 \\
1963 \\
1964 \\
1965 \\
1966 \\
1967 \\
1968\end{array}$ & $\begin{array}{l}04-12-48 \\
04-15-49 \\
02-28-50 \\
08-29-51 \\
01-18-52 \\
03-11-53 \\
03-23-54 \\
06-14-55 \\
03-26-56 \\
01-10-57 \\
03-22-58 \\
08-20-59 \\
12-25-59 \\
04-05-61 \\
02-13-62 \\
02-11-63 \\
04-16-64 \\
01-07-65 \\
12-30-65 \\
12-07-66 \\
04-02-68\end{array}$ & $\begin{array}{r}1,810 \\
1,990 \\
1,090 \\
8,090 \\
16,400 \\
497 \\
5,730 \\
1,220 \\
198 \\
8,880 \\
2,920 \\
296 \\
2,770 \\
1,080 \\
2,240 \\
1,403 \\
1,210 \\
5,600 \\
13,100 \\
9,970 \\
1,840\end{array}$ & $\begin{array}{l}\text { UR } \\
\text { UR } \\
\text { UR } \\
\text { UR }\end{array}$ & $\begin{array}{l}1969 \\
1970 \\
1971 \\
1972 \\
1973 \\
1974 \\
1975 \\
1976 \\
1977 \\
1978 \\
1979 \\
1980 \\
1981 \\
1982 \\
1983 \\
1984 \\
1985 \\
1986 \\
1987 \\
1988 \\
1989\end{array}$ & $\begin{array}{l}01-26-69 \\
09-06-70 \\
08-27-71 \\
12-26-71 \\
10-20-72 \\
03-21-74 \\
04-26-75 \\
02-09-76 \\
04-09-77 \\
03-01-78 \\
12-18-78 \\
02-20-80 \\
04-08-81 \\
03-12-82 \\
04-25-83 \\
12-27-83 \\
03-12-85 \\
11-26-85 \\
04-12-87 \\
11-01-87 \\
03-11-89\end{array}$ & $\begin{array}{r}5,550 \\
15,800 \\
1,180 \\
5,840 \\
8,190 \\
589 \\
920 \\
4,170 \\
353 \\
10,500 \\
1,79,700 \\
8,140 \\
250 \\
5,230 \\
2,020 \\
2,130 \\
4,750 \\
2,570 \\
1,070 \\
1,270 \\
602\end{array}$ & $\begin{array}{l}\text { UR } \\
\text { UR } \\
\text { UR } \\
\text { UR } \\
\text { UR } \\
\text { UR } \\
\text { UR } \\
\text { UR } \\
\text { UR } \\
\text { UR } \\
\text { UR } \\
\text { UR } \\
\text { UR } \\
\text { UR } \\
\text { UR } \\
\text { UR } \\
\text { UR } \\
\text { UR } \\
\text { UR } \\
\text { UR } \\
\text { UR }\end{array}$ \\
\hline
\end{tabular}

IHighest since 1939.

BASIN CHARACTERISTICS

\begin{tabular}{|c|c|c|c|c|c|c|c|}
\hline \multicolumn{5}{|c|}{ MEAN } & \multirow{3}{*}{$\begin{array}{l}\text { MEAN } \\
\text { ANNUAL } \\
\text { PRECIPI- } \\
\text { TATION } \\
\text { (IN) }\end{array}$} & & \\
\hline MAIN & & BASIN & & & & \multicolumn{2}{|c|}{ RAINFALL INTENSITY, 24-HOUR } \\
\hline $\begin{array}{l}\text { SLOPE } \\
\text { (FT/MI) }\end{array}$ & $\begin{array}{l}\text { LENGTH } \\
\text { (MI) }\end{array}$ & $\begin{array}{l}\text { TION } \\
\text { (FT) }\end{array}$ & $\begin{array}{l}\text { AREA } \\
\text { (PERCENT) }\end{array}$ & $\begin{array}{l}\text { SOIL } \\
\text { INDEX }\end{array}$ & & $\begin{array}{l}\text { 2-YEAR } \\
\text { (IN) }\end{array}$ & $\begin{array}{l}\text { 50-YEAR } \\
\text { (IN) }\end{array}$ \\
\hline 26.0 & 41.0 & 7,100 & 100 & 3.0 & 25.8 & 2.6 & 4.7 \\
\hline
\end{tabular}


09398500 CLEAR CREEK BELON HILLON CREEK, NEAR HINSLON, AZ--Continued

MEAN MONTHLY AND ANNUAL DISChARGES 1948-89

\begin{tabular}{|c|c|c|c|c|c|c|}
\hline MONTH & $\begin{array}{l}\operatorname{Max} I \operatorname{MN} \\
(\mathrm{FT} 3 / \mathrm{S})\end{array}$ & $\begin{array}{l}\text { MINIMUM } \\
\left(\mathrm{FT}^{3} / \mathrm{S}\right)\end{array}$ & $\begin{array}{c}\text { MEAN } \\
\left(F^{3} / S\right)\end{array}$ & $\begin{array}{c}\text { STAN- } \\
\text { DARO } \\
\text { DEVIA- } \\
\text { TION } \\
\text { (FT } 3 / S)\end{array}$ & $\begin{array}{l}\text { COEFFI- } \\
\text { CIENT OF } \\
\text { VARI - } \\
\text { ATION }\end{array}$ & $\begin{array}{c}\text { PERCENT } \\
\text { OF } \\
\text { ANNUAL } \\
\text { RUNOFF }\end{array}$ \\
\hline $\begin{array}{l}\text { OCTOBER } \\
\text { NOVEMBER } \\
\text { DECEMBER } \\
\text { JANUARY } \\
\text { FEBRUARY } \\
\text { MARCH } \\
\text { APRIL } \\
\text { MAY } \\
\text { JUNE } \\
\text { JULY } \\
\text { AUGUST } \\
\text { SEPTEMBER }\end{array}$ & $\begin{array}{c}359 \\
202 \\
720 \\
576 \\
721 \\
1,250 \\
1,330 \\
1,050 \\
39 \\
4.3 \\
228 \\
218\end{array}$ & $\begin{array}{l}0.00 \\
0.00 \\
0.00 \\
0.00 \\
0.00 \\
4.0 \\
0.00 \\
0.00 \\
0.00 \\
0.00 \\
0.00 \\
0.00\end{array}$ & $\begin{array}{c}17 \\
25 \\
75 \\
63 \\
92 \\
260 \\
369 \\
78 \\
1.4 \\
0.26 \\
16 \\
11\end{array}$ & $\begin{array}{c}62 \\
51 \\
150 \\
131 \\
140 \\
255 \\
372 \\
180 \\
6.1 \\
0.90 \\
48 \\
41\end{array}$ & $\begin{array}{l}3.6 \\
2.0 \\
2.0 \\
2.1 \\
1.5 \\
0.98 \\
1.0 \\
2.3 \\
4.3 \\
3.5 \\
3.0 \\
3.6\end{array}$ & $\begin{array}{r}1.7 \\
2.5 \\
7.4 \\
6.3 \\
9.1 \\
25.8 \\
36.6 \\
7.7 \\
0.1 \\
0.0 \\
1.6 \\
1.1\end{array}$ \\
\hline ANMUAL & 279 & 9.0 & 84 & 68 & 0.81 & 100 \\
\hline
\end{tabular}

MAGNITUDE AND PROBABILITY OF INSTANTANEOUS PEAK FLOH BASED ON PERIOD OF RECORD $1948-89$

DISCHARGE, IN FT $3 / 5$, FOR INDICATED RECURRENCE INTERVAL IN YEARS, AND EXCEEDANCE PROBABILITY, IN PERCENT

\begin{tabular}{lccccc}
2 & 5 & 10 & 25 & 50 & 1004 \\
$50 \%$ & $20 \%$ & $10 \%$ & $4 \%$ & $2 \%$ & $1 \%$ \\
2,680 & 6,740 & 10,800 & 17,400 & 23,700 & 31,100 \\
\hline MEIGHTED SKEU (LOGS) & $=0.15$ & & \\
MEAN & (LOGS) & $=3.41$ \\
STANDARD DEV. (LOGS) & $=0.49$
\end{tabular}

MAGNITLDE AND PROBABILITY OF ANNUAL LON FLON BASED ON PERIOD OF RECORD 1949-89

\begin{tabular}{|c|c|c|c|c|c|c|}
\hline \multirow{2}{*}{$\begin{array}{l}\text { PERIOD } \\
\text { (CON- } \\
\text { SECU- } \\
\text { TIVE } \\
\text { DAYS) }\end{array}$} & \multicolumn{6}{|c|}{$\begin{array}{l}\text { DISCHARGE, IN } F^{3} / S \text {, FOR INDICATED } \\
\text { RECURRENCE INTERVAL, IN YEARS, AND } \\
\text { NON-EXCEEDANCE PROBABILITY, IN PERCENT }\end{array}$} \\
\hline & $\begin{array}{c}2 \\
50 \%\end{array}$ & $\begin{array}{c}5 \\
20 \%\end{array}$ & $\begin{array}{l}10 \\
10 \%\end{array}$ & $\begin{array}{l}20 \\
5 \%\end{array}$ & $\begin{array}{l}50 \\
2 \%\end{array}$ & $\begin{array}{l}100 \dagger \\
1 \%\end{array}$ \\
\hline $\begin{array}{r}1 \\
3 \\
7 \\
14 \\
30 \\
60\end{array}$ & & & ${ }^{\prime}$ & & & \\
\hline $\begin{array}{r}90 \\
120 \\
183\end{array}$ & $\begin{array}{l}0.00 \\
0.00 \\
0.00\end{array}$ & $\begin{array}{l}0.00 \\
0.00 \\
0.00\end{array}$ & $\begin{array}{l}0.00 \\
0.00 \\
0.00\end{array}$ & $\begin{array}{l}0.00 \\
0.00 \\
0.00\end{array}$ & $\begin{array}{l}0.00 \\
0.00 \\
0.00\end{array}$ & $\begin{array}{l}0.00 \\
0.00 \\
0.00\end{array}$ \\
\hline
\end{tabular}

MAGNITUDE AND PROBABILITY OF ANNUAL HIGH FLON BASED ON PERIOD OF RECORD 1948-89

\begin{tabular}{|c|c|c|c|c|c|c|}
\hline \multirow{2}{*}{$\begin{array}{l}\text { PERIOD } \\
\text { (CON- } \\
\text { SECU- } \\
\text { TIVE } \\
\text { DAYS) }\end{array}$} & \multicolumn{6}{|c|}{$\begin{array}{l}\text { DISCHARGE, IN FT } 3 / S \text {, FOR INDICATED } \\
\text { RECURRENCE INTERVAL, IN YEARS, AND } \\
\text { EXCEEDANCE PROBABILITY, IN PERCENT }\end{array}$} \\
\hline & $\begin{array}{c}2 \\
50 \%\end{array}$ & $\begin{array}{c}5 \\
20 \%\end{array}$ & $\begin{array}{l}10 \\
10 x\end{array}$ & $\begin{array}{l}25 \\
4 \%\end{array}$ & $\begin{array}{l}50 \\
2 \%\end{array}$ & $\begin{array}{c}100 \dagger \\
1 \%\end{array}$ \\
\hline $\begin{array}{r}1 \\
3 \\
7 \\
15 \\
30 \\
60 \\
90\end{array}$ & $\begin{array}{r}1.630 \\
1.250 \\
911 \\
614 \\
426 \\
271 \\
206\end{array}$ & $\begin{array}{r}3,780 \\
2,610 \\
1,680 \\
1,110 \\
824 \\
547 \\
428\end{array}$ & $\begin{array}{r}5,680 \\
3,660 \\
2,190 \\
1,460 \\
1,140 \\
776 \\
614\end{array}$ & $\begin{array}{r}8,530 \\
5,070 \\
2,810 \\
1,890 \\
1,580 \\
1,110 \\
887\end{array}$ & $\begin{array}{r}10,900 \\
6,150 \\
3,230 \\
2,210 \\
1,940 \\
1,390 \\
1,120\end{array}$ & $\begin{array}{r}13,600 \\
7,230 \\
3,620 \\
2,510 \\
2,310 \\
1,700 \\
1,360\end{array}$ \\
\hline
\end{tabular}

DURATION TABLE OF DAILY MEAN FLON FOR PERIOD OF RECORD $1948-89$

DISCHARGE, IN FT $3 / 5$, HHICH WAS EQUALED OR EXCEEDED FOR INDICATED PERCENT OF TIME

\begin{tabular}{|c|c|c|c|c|c|c|c|c|c|c|c|c|c|c|c|c|}
\hline $1 \%$ & $5 \%$ & $10 \%$ & $15 \%$ & $20 \%$ & $30 \%$ & $40 \%$ & $50 \%$ & $60 \%$ & $70 x$ & $80 \%$ & $90 \%$ & $95 \%$ & $98 \%$ & $99 \%$ & $99.5 \%$ & $99.9 \%$ \\
\hline $37 \pi$ & 495 & 191 & 102 & 61 & 16 & 2.2 & 0.00 & 0.00 & 0.00 & 0.00 & 0.00 & 0.00 & 0.00 & 0.00 & 0.00 & 0.0 \\
\hline
\end{tabular}

f Reliability of values in colum is uncertain, and potential errors are large. 

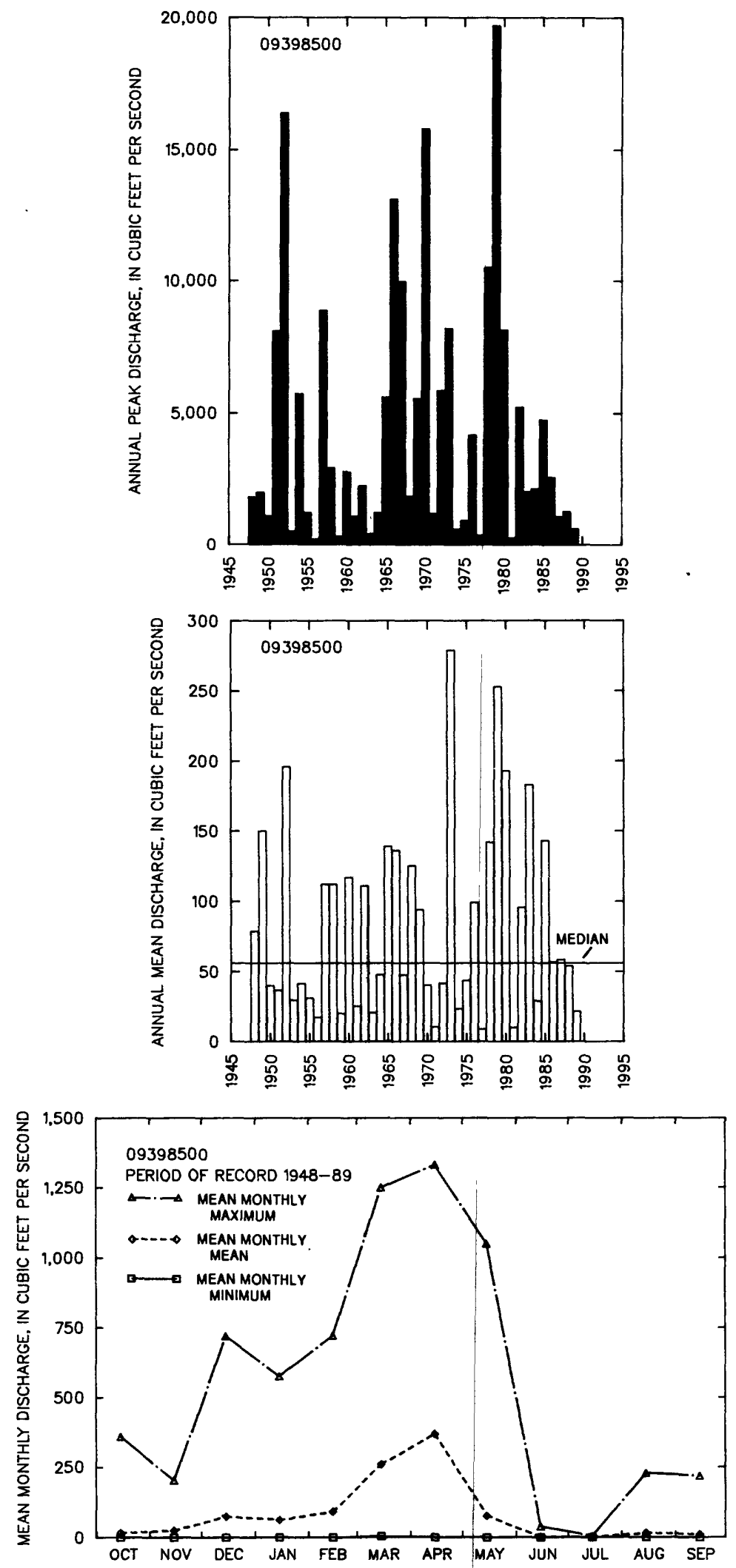
09399000 CLEAR CREEK NEAR HINSLOW, AZ

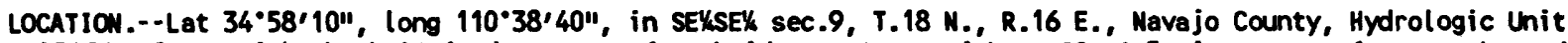
15020008 , on right bank $10 \mathrm{ft}$ downstream from bridge on State Highway $99,1.5 \mathrm{mi}$ upstream from mouth, and 5 mi southeast of Winslow.

DRAIMAGE AREA. $--621 \mathrm{mi}^{2}$.

REMARKS.--Records show discharge over spillway and through outlet tube. Prior to Nov. 20, 1982, records show discharge over dam but do not show leakage through dam. Storage in and diversion from Blue Ridge Reservoir near Pine, about 50 mi upstream, since December 1964.

ANIUAL PEAK DISCHARGE

\begin{tabular}{|c|c|c|c|c|c|c|c|}
\hline $\begin{array}{l}\text { WATER } \\
\text { YEAR }\end{array}$ & DATE & $\begin{array}{c}\text { ANNUAL PEAK } \\
\text { DISCHARGE } \\
\left(\mathrm{FT}^{3} / \mathrm{S}\right)\end{array}$ & $\begin{array}{l}\text { DISCHARCE } \\
\text { CODES }\end{array}$ & $\begin{array}{l}\text { WATER } \\
\text { YEAR }\end{array}$ & DATE & $\begin{array}{l}\text { ANNUAL PEAK } \\
\text { DISCHARGE } \\
\left(\mathrm{FT}^{3} / \mathrm{S}\right)\end{array}$ & $\begin{array}{l}\text { DISCHARGE } \\
\text { COOES }\end{array}$ \\
\hline $\begin{array}{l}1929 \\
1930 \\
1931 \\
1932 \\
1933 \\
1934 \\
1936 \\
1937 \\
1938 \\
1939 \\
1940 \\
1941 \\
1942 \\
1943 \\
1944 \\
1945 \\
1946 \\
1947 \\
1948 \\
1949 \\
1950 \\
1951 \\
1952 \\
1953 \\
1954 \\
1955\end{array}$ & $\begin{array}{l}04-04-29 \\
04-10-30 \\
03-24-31 \\
02-10-32 \\
04-05-33 \\
00-00-34 \\
04-14-36 \\
03-17-37 \\
03-04-38 \\
04-04-39 \\
08-15-40 \\
03-15-41 \\
04-06-42 \\
03-11-43 \\
04-08-44 \\
04-22-45 \\
09-20-46 \\
11-25-46 \\
04-13-48 \\
04-16-49 \\
03-01-50 \\
08-30-51 \\
01-19-52 \\
08-27-53 \\
03-24-54 \\
08-25-55\end{array}$ & $\begin{array}{r}50,000 \\
1,080 \\
850 \\
6,100 \\
780 \\
6,300 \\
1,680 \\
2,790 \\
26,200 \\
1,500 \\
1,840 \\
3,300 \\
1,940 \\
1,500 \\
1,500 \\
2,230 \\
1,100 \\
1,740 \\
1,810 \\
1,970 \\
1,000 \\
8,530 \\
22,500 \\
6995 \\
5,800 \\
1,080\end{array}$ & & $\begin{array}{l}1956 \\
1957 \\
1958 \\
1959 \\
1960 \\
1961 \\
1962 \\
1963 \\
1964 \\
1965 \\
1966 \\
1967 \\
1968 \\
1969 \\
1970 \\
1971 \\
1972 \\
1973 \\
1974 \\
1975 \\
1976 \\
1977 \\
1978 \\
1979 \\
1980 \\
1982\end{array}$ & $\begin{array}{l}03-27-56 \\
01-11-57 \\
03-23-58 \\
10-01-58 \\
12-26-59 \\
04-06-61 \\
02-13-62 \\
09-02-63 \\
04-17-64 \\
01-08-65 \\
12-30-65 \\
12-07-66 \\
04-02-68 \\
01-26-69 \\
09-06-70 \\
08-05-71 \\
12-27-71 \\
10-20-72 \\
03-22-74 \\
09-12-75 \\
02-10-76 \\
04-10-77 \\
03-01-78 \\
12-19-78 \\
02-20-80 \\
04-09-82\end{array}$ & $\begin{array}{r}173 \\
9,150 \\
2,920 \\
542 \\
2,440 \\
925 \\
2,330 \\
881 \\
1,060 \\
5,930 \\
18,500 \\
12,500 \\
1,840 \\
5,700 \\
9,650 \\
1,460 \\
5,480 \\
9,350 \\
538 \\
3,940 \\
2,120 \\
372 \\
12,900 \\
36,300 \\
10,800 \\
570\end{array}$ & $\begin{array}{l}\text { UR } \\
\text { UR } \\
\text { UR } \\
\text { UR } \\
\text { UR } \\
\text { UR } \\
\text { UR } \\
\text { UR } \\
\text { UR } \\
\text { UR } \\
\text { UR } \\
\text { UR } \\
\text { UR } \\
\text { UR } \\
\text { UR } \\
\text { UR } \\
\text { UR }\end{array}$ \\
\hline
\end{tabular}

BASIN CHARACTERISTICS

\begin{tabular}{|c|c|c|c|c|c|c|c|}
\hline \multirow{3}{*}{$\begin{array}{c}\text { MAIN } \\
\text { CHANNEL } \\
\text { SLOPE } \\
\text { (FT/MI) }\end{array}$} & \multirow[b]{3}{*}{$\begin{array}{l}\text { STREAM } \\
\text { LENGTH } \\
\text { (MI) }\end{array}$} & \multirow{3}{*}{$\begin{array}{l}\text { MEAN } \\
\text { BASIN } \\
\text { ELEVA- } \\
\text { TION } \\
\text { (FT) }\end{array}$} & \multirow[b]{3}{*}{$\begin{array}{l}\text { FORESTED } \\
\text { AREA } \\
\text { (PERCENT) }\end{array}$} & \multirow{2}{*}{\multicolumn{2}{|c|}{$\begin{array}{c}\text { MEAN } \\
\text { ANNUAL } \\
\text { PRECIPI- }\end{array}$}} & \multirow{2}{*}{\multicolumn{2}{|c|}{ RAINFALL INTENSITY, 24-HOUR }} \\
\hline & & & & & & & \\
\hline & & & & $\begin{array}{l}\text { SOIL } \\
\text { INDEX }\end{array}$ & $\begin{array}{l}\text { TATION } \\
\text { (IN) }\end{array}$ & $\begin{array}{c}\text { 2-YEAR } \\
\text { (IN) }\end{array}$ & $\begin{array}{c}\text { 50-YEAR } \\
\text { (IN) }\end{array}$ \\
\hline 24.1 & 85.9 & 6,500 & 66.0 & 3.0 & 18.7 & 2.1 & 4.0 \\
\hline
\end{tabular}


MEAN MONTHLY AND ANMUAL DISChARGES 1930-33, 1936-78, 1980-82

\begin{tabular}{|c|c|c|c|c|c|c|}
\hline MONTH & $\begin{array}{l}\operatorname{MAX} \operatorname{IIMN}_{(\mathrm{M})} \\
(\mathrm{FT} / \mathrm{S})\end{array}$ & $\begin{array}{l}\text { MINIMUM } \\
\left(F T^{3} / S\right)\end{array}$ & $\begin{array}{c}\text { MEAN } \\
\left(F T^{3} / S\right)\end{array}$ & $\begin{array}{l}\text { STAN- } \\
\text { DARD } \\
\text { DEVIA- } \\
\text { TION } \\
\left(F^{3} / S\right)\end{array}$ & $\begin{array}{l}\text { COEFFI- } \\
\text { CIENT OF } \\
\text { VARI - } \\
\text { ATION }\end{array}$ & $\begin{array}{c}\text { PERCENT } \\
\text { OF } \\
\text { ANNUAL } \\
\text { RUNOFF }\end{array}$ \\
\hline $\begin{array}{l}\text { OCTOBER } \\
\text { NOVEMBER } \\
\text { DECEMBER } \\
\text { JANUARY } \\
\text { FEBRUARY } \\
\text { MARCH } \\
\text { APRIL } \\
\text { MAY } \\
\text { JUNE } \\
\text { JULY } \\
\text { AUGUST } \\
\text { SEPTEMBER }\end{array}$ & $\begin{array}{r}348 \\
174 \\
480 \\
784 \\
780 \\
1,250 \\
1,290 \\
1,090 \\
25 \\
18 \\
207 \\
192\end{array}$ & $\begin{array}{l}0.00 \\
0.00 \\
0.00 \\
0.00 \\
0.00 \\
0.00 \\
0.00 \\
0.00 \\
0.00 \\
0.00 \\
0.00 \\
0.00\end{array}$ & $\begin{array}{c}13 \\
15 \\
38 \\
54 \\
87 \\
256 \\
372 \\
93 \\
1.5 \\
1.7 \\
11 \\
12\end{array}$ & $\begin{array}{c}52 \\
34 \\
98 \\
142 \\
162 \\
277 \\
344 \\
190 \\
4.0 \\
3.3 \\
37 \\
34\end{array}$ & $\begin{array}{l}4.2 \\
2.3 \\
2.6 \\
2.6 \\
1.9 \\
1.1 \\
0.92 \\
2.1 \\
2.7 \\
2.0 \\
3.3 \\
2.9\end{array}$ & $\begin{array}{r}1.3 \\
1.6 \\
4.0 \\
5.7 \\
9.1 \\
26.8 \\
39.0 \\
9.7 \\
0.2 \\
0.2 \\
1.2 \\
1.2\end{array}$ \\
\hline ANNUAL & 271 & 6.5 & 79 & 65 & 0.82 & 100 \\
\hline
\end{tabular}

MAENITUDE AND PROBABILITY OF ANMUAL LON FLON BASED ON PERIDD OF RECORD 1930-33, 1937-78, 1980-82

\begin{tabular}{|c|c|c|c|c|c|c|}
\hline \multirow{2}{*}{$\begin{array}{l}\text { PERIOD } \\
\text { (CON- } \\
\text { SECU- } \\
\text { TIVE } \\
\text { DAYS) }\end{array}$} & \multicolumn{6}{|c|}{$\begin{array}{l}\text { DISCHARGE, IN } \mathrm{FT}^{3} / \mathrm{S}, \text { FOR INDICATED } \\
\text { RECURRENCE INTERVAL, IN YEARS, AND } \\
\text { NON-EXCEEDANCE PROBAB ILITY, IN PERCENT }\end{array}$} \\
\hline & $\begin{array}{c}2 \\
50 \%\end{array}$ & $\begin{array}{c}5 \\
20 \%\end{array}$ & $\begin{array}{l}10 \\
10 \%\end{array}$ & $\begin{array}{l}20 \\
5 \%\end{array}$ & $\begin{array}{l}50 \\
2 \%\end{array}$ & $\begin{array}{l}100 \dagger \\
1 \%\end{array}$ \\
\hline $\begin{array}{r}1 \\
3 \\
7 \\
14 \\
30 \\
60 \\
90 \\
120 \\
183\end{array}$ & $\begin{array}{l}0.00 \\
0.00 \\
0.00 \\
0.00 \\
0.00 \\
0.00 \\
0.04 \\
0.36 \\
0.84\end{array}$ & $\begin{array}{l}0.00 \\
0.00 \\
0.00 \\
0.00 \\
0.00 \\
0.00 \\
0.00 \\
0.00 \\
0.05\end{array}$ & $\begin{array}{l}0.00 \\
0.00 \\
0.00 \\
0.00 \\
0.00 \\
0.00 \\
0.00 \\
0.00 \\
0.00\end{array}$ & $\begin{array}{l}0.00 \\
0.00 \\
0.00 \\
0.00 \\
0.00 \\
0.00 \\
0.00 \\
0.00 \\
0.00\end{array}$ & $\begin{array}{l}0.00 \\
0.00 \\
0.00 \\
0.00 \\
0.00 \\
0.00 \\
0.00 \\
0.00 \\
0.00\end{array}$ & $\begin{array}{l}0.00 \\
0.00 \\
0.00 \\
0.00 \\
0.00 \\
0.00 \\
0.00 \\
0.00 \\
0.00\end{array}$ \\
\hline
\end{tabular}

MMGITUDE AND PROBABILITY OF ANNUAL HIGH FLOW BASED ON PERIDO OF RECORD 1930-33, 1936-78, 1980-82

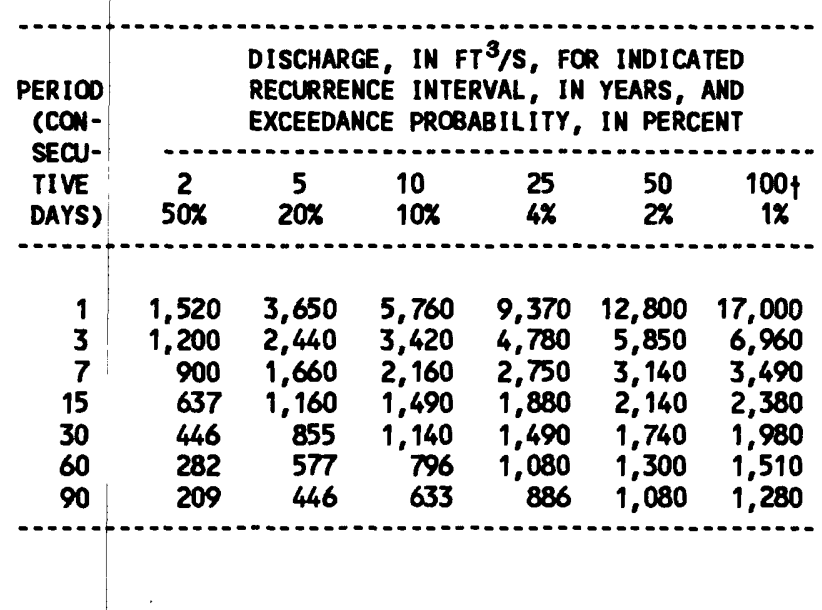

MAGNITUDE AND PROBABILITY OF INSTANTANEOUS PEAK FLON BASED ON PERIOD OF RECORD 1929-34, 1936-64, 1965-82

\begin{tabular}{|c|c|c|c|c|c|}
\hline$\stackrel{2}{2}$ & $\begin{array}{c}5 \\
20 \%\end{array}$ & $\begin{array}{r}10 \\
10 \%\end{array}$ & $\begin{array}{l}25 \\
4 \%\end{array}$ & $\begin{array}{l}50 \\
2 \%\end{array}$ & $\begin{array}{r}100 \\
1 \%\end{array}$ \\
\hline 2,620 & 7,530 & 13,600 & 26,100 & 40,600 & 60,900 \\
\hline $\begin{array}{l}\text { WEIGHTED } \\
\text { MEAN } \\
\text { STANDARD }\end{array}$ & $\begin{array}{l}\text { SKEW } \\
\text { DEV. }\end{array}$ & $\begin{array}{l}\text { LOGS }= \\
\text { LOGS }= \\
\text { LOGS }=\end{array}$ & $\begin{array}{l}.32 \\
.45 \\
.52\end{array}$ & & \\
\hline
\end{tabular}

DURATION TABLE OF DAILY MEAN FLOW FOR PERID OF RECORD 1930-33, 1936-78, 1980-82

DISCHARGE, IN $\mathrm{FT}^{3} / \mathrm{s}$, WHICH WAS EQUALED OR EXCEEDED FOR INDICATED PERCENT OF TIME

\begin{tabular}{|c|c|c|c|c|c|c|c|c|c|c|c|c|c|c|c|c|}
\hline 1,320 & 482 & 199 & 89 & 42 & 7.0 & 2.1 & 0.96 & 0.20 & 0.00 & 0.00 & 0.00 & 0.00 & 0.00 & 0.00 & 0.00 & 0.00 \\
\hline
\end{tabular}

f Reliability of values in column is uncertain, and potential errors are large. 
09399000 Clear CREex nEAR HINSLOW, AZ--COntImued
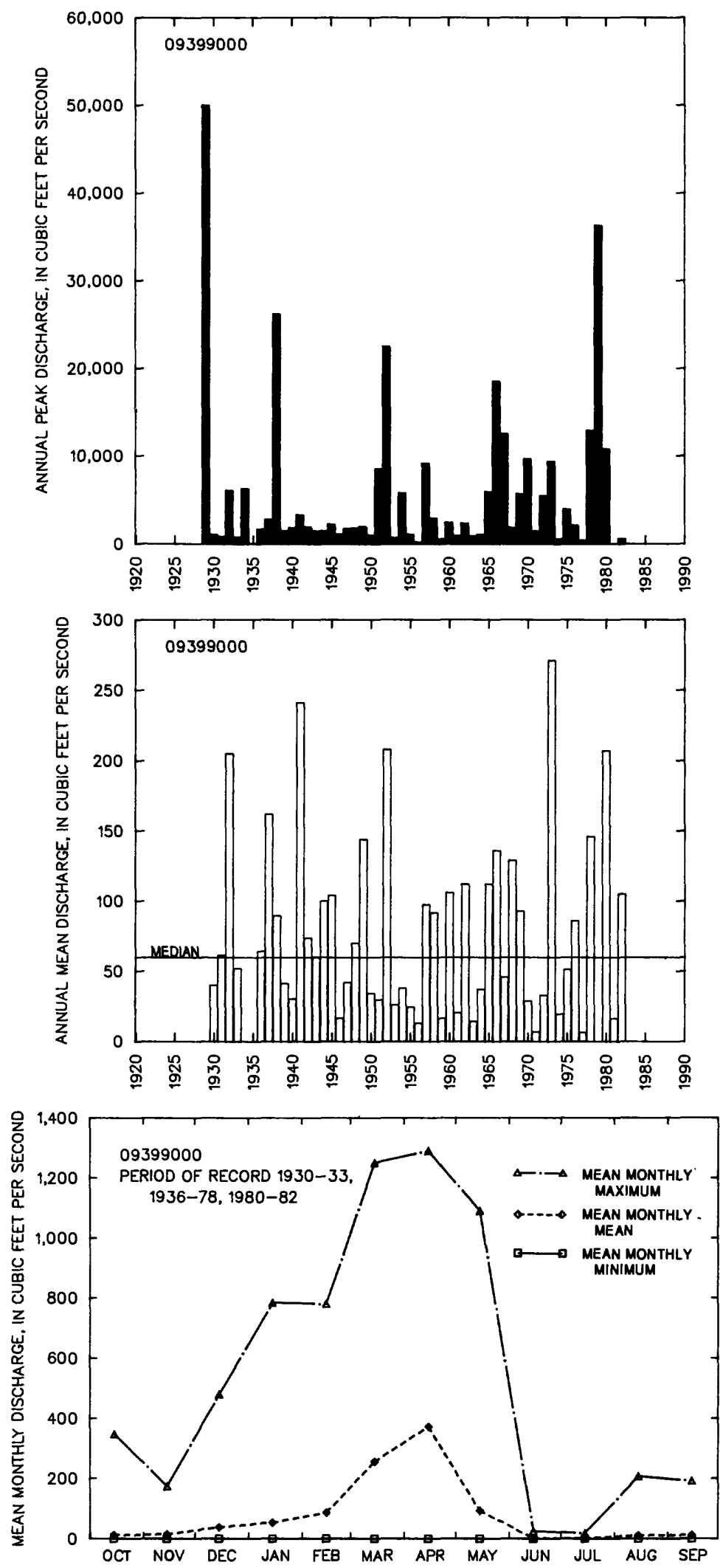


\section{LITTLE COLORADO RIVER BASIN}

09399250 JACKS CANYON TRIBUTARY NO. 2 NEAR MINSLOW, AZ

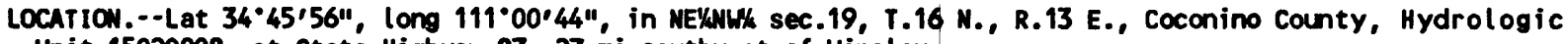
Unit 15020008, at State Highway 87,27 mi southwest of Winslow.

DRAIMAGE AREA. $--31.8 \mathrm{mi}^{2}$.

ANMUAL PEAK DISCHARGE

\begin{tabular}{|c|c|c|c|}
\hline $\begin{array}{l}\text { WATER } \\
\text { YEAR }\end{array}$ & DATE & $\begin{array}{c}\text { ANNUAL PEAK } \\
\text { DISCHARGE } \\
\text { (FT } 3 / \mathrm{S})\end{array}$ & $\begin{array}{l}\text { DISCHARGE } \\
\text { COOES }\end{array}$ \\
\hline $\begin{array}{l}1963 \\
1964 \\
1965 \\
1966 \\
1967 \\
1968 \\
1969 \\
1970 \\
1971 \\
1972 \\
1973 \\
1974 \\
1975 \\
1976 \\
1979\end{array}$ & $\begin{array}{l}08-21-63 \\
00-00-64 \\
07-10-65 \\
00-00-66 \\
00-00-67 \\
00-00-68 \\
00-00-69 \\
00-00-70 \\
07-00-71 \\
00-00-72 \\
10-00-72 \\
00-00-74 \\
00-00-75 \\
00-00-76 \\
12-18-78\end{array}$ & $\begin{array}{r}9,330 \\
0 \\
544 \\
0 \\
0 \\
0 \\
0 \\
0 \\
67 \\
0 \\
2.0 \\
0 \\
0 \\
11) \\
267\end{array}$ & HP \\
\hline
\end{tabular}

MagnitLDe AND PROBABILITY OF INSTANTANEOUS PEAK FLON BASED ON PERIOD OF RECORD

DISCHARGE, IN $\mathrm{FT}^{3} / \mathrm{S}$, FOR INDICATED RECURRENCE INTERVAL IN YEARS, AND EXCEEDANCE PROBABILITY, IN PERCENT

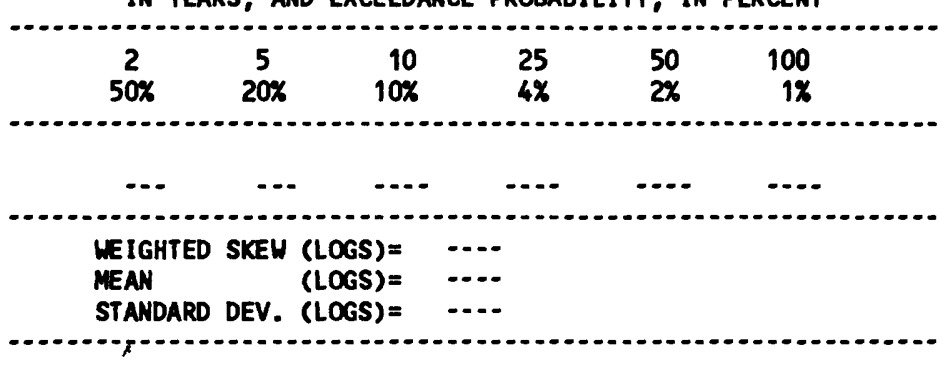

\section{BASIN CHARACTERISTICS}

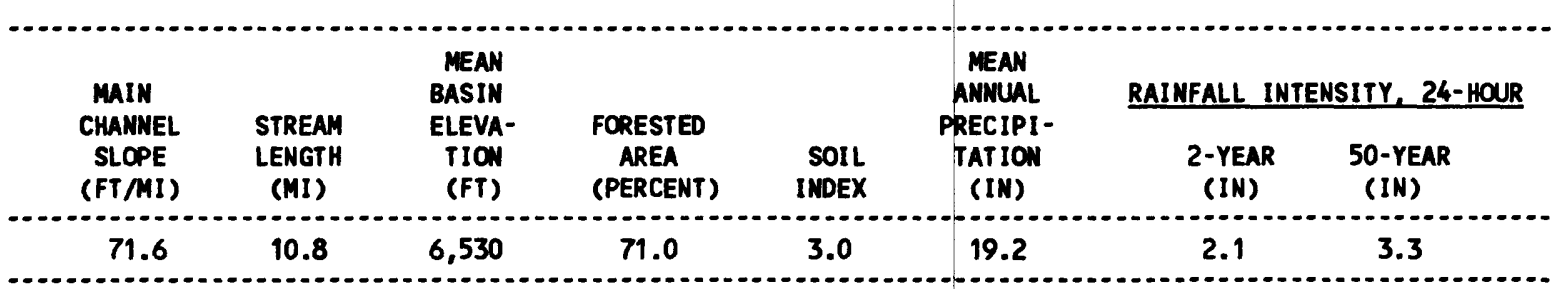

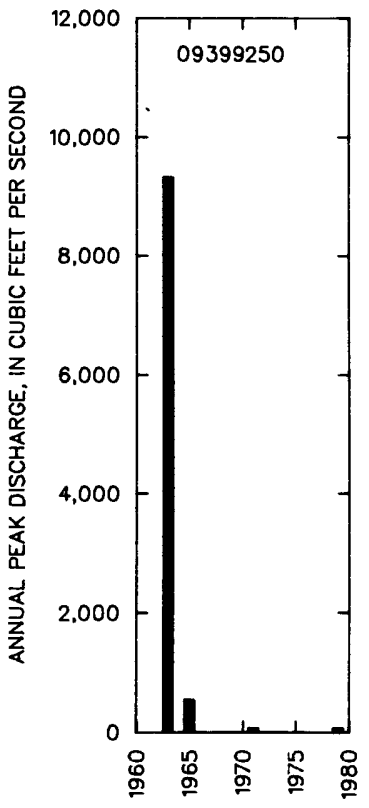


09400100 GANADO WASH TRIBUTARY NEAR GANADO, AZ

LOCAtion.--Lat 35'42'40", Long 109'29'50", Apache County, Hydrologic Unit 15020011, at state Highway 264, $2.4 \mathrm{mi}$ east of Ganado.

DRAINAGE AREA. $--7.85 \mathrm{mi}^{2}$.

ANMUAL PEAK DISCHARGE

\begin{tabular}{cccc}
$\begin{array}{l}\text { UATER } \\
\text { YEAR }\end{array}$ & DATE & $\begin{array}{c}\text { ANMUALL PEAK } \\
\text { DISCHARGE } \\
\text { (FT } 3 / \text { S) }\end{array}$ & $\begin{array}{c}\text { DISCHARGE } \\
\text { CODES }\end{array}$ \\
\hline 1963 & $08-09-63$ & 231 & \\
1964 & $08-26-64$ & 620 & \\
1965 & $07-17-65$ & 1,680 & \\
1966 & $00-00-66$ & 150 & \\
1967 & $09-00-67$ & 456 & \\
1968 & $00-00-68$ & 280 & \\
1969 & $07-26-69$ & 10 & ES \\
1970 & $09-06-70$ & 1.0 & ES \\
1971 & $08-30-71$ & 35 & ES \\
1972 & $06-00-72$ & 2.0 & \\
1973 & $00-00-73$ & 287 & \\
1974 & $07-16-74$ & 548 & \\
1975 & $07-12-75$ & 418 & \\
1976 & $00-00-76$ & 0 &
\end{tabular}

MAGNI TUDE AND PROBABILITY OF INSTANTANEOUS PEAK FLOW BASED ON PERICD OF RECORD 1963-76

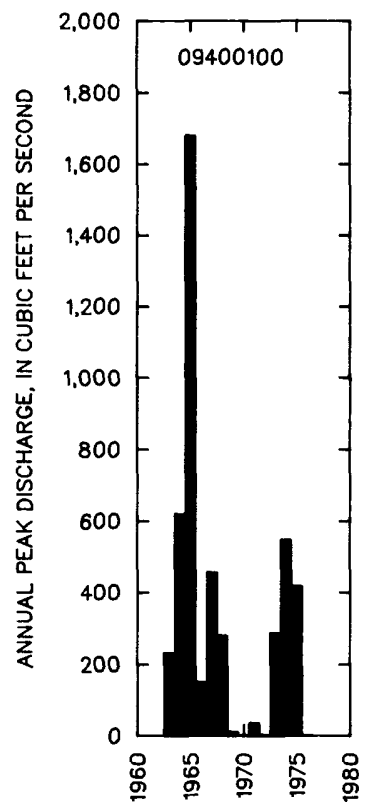

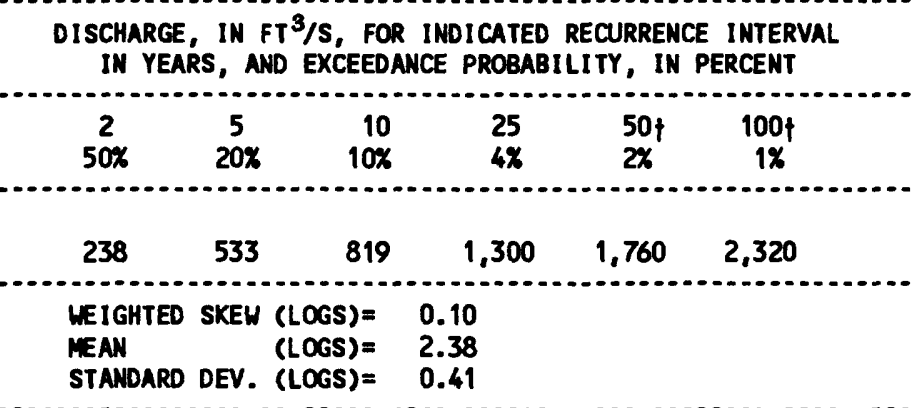

+ Reliability of values in colum is uncertain, and potential errors are large.

BASIN CHARACTERISTICS

\begin{tabular}{|c|c|c|c|c|c|c|c|}
\hline \multirow{2}{*}{$\begin{array}{l}\text { MAIN } \\
\text { CHANNEL } \\
\text { SLOPE } \\
\text { (FT/MI) }\end{array}$} & \multirow[b]{2}{*}{$\begin{array}{l}\text { STREAM } \\
\text { LENGTH } \\
\text { (MI) }\end{array}$} & \multirow{2}{*}{$\begin{array}{l}\text { MEAN } \\
\text { BASIN } \\
\text { ELEVA- } \\
\text { TION } \\
\text { (FT) }\end{array}$} & \multirow[b]{2}{*}{$\begin{array}{l}\text { FORESTED } \\
\text { AREA } \\
\text { (PERCENT) }\end{array}$} & \multirow[b]{2}{*}{$\begin{array}{l}\text { SOIL } \\
\text { IMDEX }\end{array}$} & \multirow{2}{*}{$\begin{array}{l}\text { MEAN } \\
\text { ANNUAL } \\
\text { PRECIPI- } \\
\text { TATION } \\
\text { (IN) }\end{array}$} & \multicolumn{2}{|c|}{ RAINFALL INTENSITY, 24-HOUR } \\
\hline & & & & & & $\begin{array}{c}\text { 2-YEAR } \\
\text { (IN) }\end{array}$ & $\begin{array}{c}\text { 50-YEAR } \\
\text { (IN) }\end{array}$ \\
\hline 55.5 & 4.1 & 6,770 & 6.8 & 3.0 & 11.8 & 1.4 & 2.9 \\
\hline
\end{tabular}


LOCATION.--Lat 35'45'50", Long 109'48'00", Apache County, Hydrologic Unit 15020011, at State Highway 264, $15 \mathrm{mi}$ west of Ganado.

DRAIMAGE AREA. $--0.32 \mathrm{mi}^{2}$.

ANNUAL PEAK DISCHARGE

\begin{tabular}{ccc}
$\begin{array}{c}\text { MATER } \\
\text { YEAR }\end{array}$ & DATE & $\begin{array}{c}\text { ANNUAL PEAK } \\
\text { DISCHARGE } \\
\text { (FT } 3 \text { /S) }\end{array}$ \\
\hline 1963 & $09-00-63$ & 1.0 \\
1964 & $08-13-64$ & 383 \\
1965 & $09-00-65$ & 1.0 \\
1966 & $08-00-66$ & 35 \\
1967 & $09-06-67$ & 5.0 \\
1968 & $08-00-68$ & 130 \\
1969 & $07-19-69$ & 49 \\
1970 & $09-05-70$ & 360 \\
1971 & $10-02-70$ & 55 \\
1972 & $06-00-72$ & 35 \\
1973 & $10-19-72$ & 380 \\
1974 & $08-00-74$ & 5.0 \\
1975 & $09-07-75$ & 28 \\
$\ldots$
\end{tabular}

MAGNITUDE AND PROBABILITY OF INSTANTANEOUS PEAK FLOM BASED ON PERIOD OF RECORD 1963-76

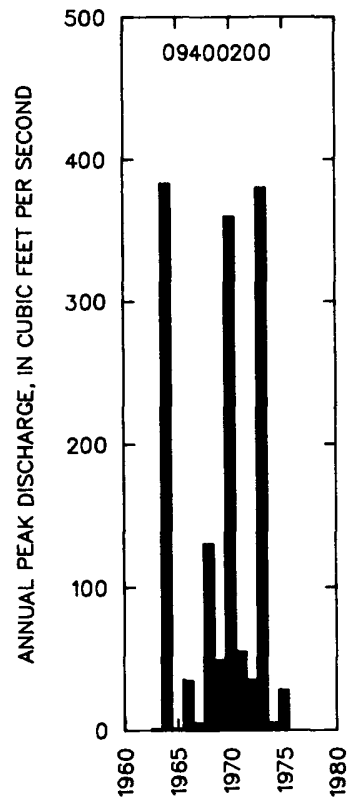

DISCHARGE, IN $\mathrm{FT}^{3} / \mathrm{S}$, FOR INDICATED RECURRENCE INTERVAL IN YEARS, AND EXCEEDANCE PROBABILITY, IN PERCENT

\begin{tabular}{|c|c|c|c|c|c|}
\hline $\begin{array}{r}2 \phi \\
50 \%\end{array}$ & $\begin{array}{r}5 \dagger \\
20 \%\end{array}$ & $\begin{array}{c}10\} \\
10 \%\end{array}$ & $\begin{array}{l}25 \nmid \\
4 x\end{array}$ & $\begin{array}{l}50 \uparrow \\
2 \%\end{array}$ & $\begin{array}{c}100\} \\
1 \%\end{array}$ \\
\hline 46.6 & 167 & 322 & 648 & 1,020 & 1,520 \\
\hline $\begin{array}{l}\text { MEIGI } \\
\text { MEAN } \\
\text { STAND }\end{array}$ & $\begin{array}{l}\text { SKEW } \\
\text { DEV. }\end{array}$ & $\begin{array}{l}(\text { LOGS })= \\
(\text { LOGS) }= \\
(\text { LOGS })=\end{array}$ & $\begin{array}{r}-0.04 \\
1.66 \\
0.66\end{array}$ & & \\
\hline
\end{tabular}

t Reliability of values in colum is uncertain, and potential errors are large.

\section{BASIN CHARACTERISTICS}

\begin{tabular}{|c|c|c|c|c|c|c|c|}
\hline \multirow{2}{*}{$\begin{array}{l}\text { MAIN } \\
\text { CHANNEL } \\
\text { SLOPE } \\
\text { (FT/MI) }\end{array}$} & \multirow[b]{2}{*}{$\begin{array}{l}\text { STREAM } \\
\text { LENGTH } \\
\text { (MI) }\end{array}$} & \multirow{2}{*}{$\begin{array}{l}\text { MEAN } \\
\text { BASIN } \\
\text { ELEVA- } \\
\text { TION } \\
\text { (FT) }\end{array}$} & \multirow[b]{2}{*}{$\begin{array}{l}\text { FORESTED } \\
\text { AREA } \\
\text { (PERCENT) }\end{array}$} & \multirow[b]{2}{*}{$\begin{array}{l}\text { SOIL } \\
\text { INDEX }\end{array}$} & \multirow{2}{*}{$\begin{array}{l}\text { MEAN } \\
\text { ANNUAL } \\
\text { PRECIPI- } \\
\text { TATION } \\
\text { (IN) }\end{array}$} & \multicolumn{2}{|c|}{ RAINFALL INTENSITY, 24-HOUR } \\
\hline & & & & & & $\begin{array}{c}\text { 2-YEAR } \\
\text { (IN) }\end{array}$ & $\begin{array}{c}\text { 50-YEAR } \\
\text { (IN) }\end{array}$ \\
\hline 100 & 1.1 & 6,750 & 72.0 & 1.0 & 12.1 & 1.5 & 2.9 \\
\hline
\end{tabular}


09400290 TESHBITO WASH TRIBUTARY NEAR HOLBROOK, AZ

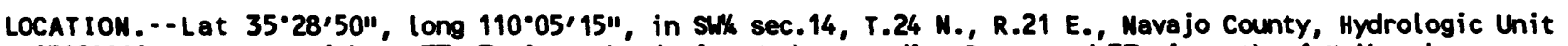
15020011, at State Highway 77, 7 mi north of Bita Hochee Tradino Post, and 37 mi north of Holbrook.

DRAIMAGE AREA. $--20.0 \mathrm{mi}^{2}$, of which $10.7 \mathrm{mi}^{2}$ is noncontributino.

\section{ANIUAL PEAK DISCHARGE}

\begin{tabular}{cccc}
$\begin{array}{c}\text { WATER } \\
\text { YEAR }\end{array}$ & DATE & $\begin{array}{c}\text { ANNUAL PEAK } \\
\text { DISCHARGE } \\
\text { (FT } 3 / \text { S) }\end{array}$ & $\begin{array}{c}\text { DISCHARGE } \\
\text { CODES }\end{array}$ \\
\hline 1960 & $00-00-60$ & $\left({ }^{1}\right)$ & HP \\
1963 & $00-00-63$ & 700 & \\
1964 & $08-00-64$ & 870 & \\
1965 & $07-00-65$ & 787 & \\
1966 & $08-01-66$ & 100 & \\
1967 & $08-30-67$ & 600 & \\
1968 & $08-11-68$ & 61 & \\
1969 & $09-12-69$ & 640 & \\
1970 & $09-05-70$ & 890 & \\
1971 & $08-31-71$ & 660 & \\
1972 & $09-00-72$ & 30 & \\
1973 & $10-19-72$ & 740 & \\
1974 & $08-00-74$ & 370 & \\
1975 & $07-15-75$ & 330 & \\
1976 & $00-00-76$ & 160 &
\end{tabular}

Discharge unknown.

MAGNITUDE AND PROBABILITY Of INSTANTANEOUS PEAK FLOM BASED ON PERIOD OF RECORD 1963-76

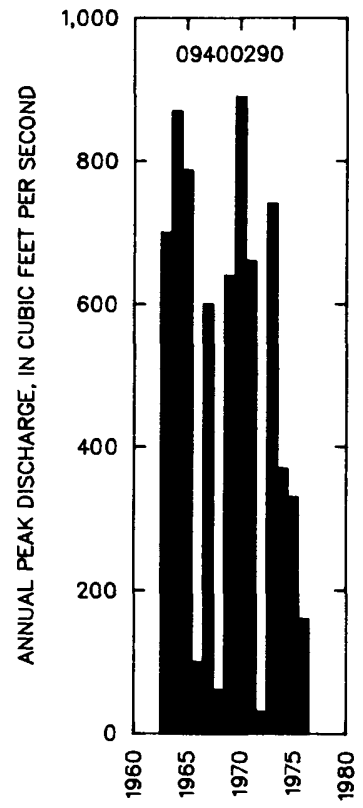

DISCHARGE, IN $\mathrm{FT}^{3} / \mathrm{S}$, FOR INDICATED RECURRENCE INTERVAL

IN YEARS, AND EXCEEDANCE PROBABILITY, IN PERCENT

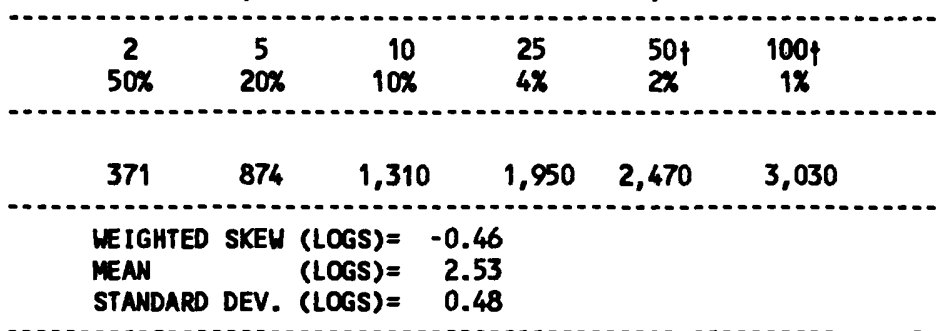

$\uparrow$ Reliability of values in colum is uncertain, and potential errors are large.

BASIN CHARACTERISTICS

\begin{tabular}{|c|c|c|c|c|c|c|c|}
\hline \multirow{4}{*}{$\begin{array}{l}\text { MAIN } \\
\text { CHANNEL } \\
\text { SLOPE } \\
\text { (FT/MI) }\end{array}$} & \multirow{4}{*}{$\begin{array}{c}\text { STREAM } \\
\text { LENGTH } \\
\text { (MI) }\end{array}$} & \multirow{4}{*}{$\begin{array}{l}\text { MEAN } \\
\text { BASIN } \\
\text { ELEVA- } \\
\text { TION } \\
\text { (FT) }\end{array}$} & \multirow{4}{*}{$\begin{array}{l}\text { FORESTED } \\
\text { AREA } \\
\text { (PERCENT) }\end{array}$} & \multirow[b]{4}{*}{$\begin{array}{l}\text { SOIL } \\
\text { INDEXX }\end{array}$} & \multirow{3}{*}{$\begin{array}{c}\text { MEAN } \\
\text { ANNUAL } \\
\text { PRECIPI- }\end{array}$} & \multirow{2}{*}{\multicolumn{2}{|c|}{ RAINFALL INTENSITY, 24-HOUR }} \\
\hline & & & & & & & \\
\hline & & & & & & & \\
\hline & & & & & $\begin{array}{l}\text { TATION } \\
\text { (IN) }\end{array}$ & $\begin{array}{l}\text { 2-YEAR } \\
\text { (IN) }\end{array}$ & $\begin{array}{c}\text { 50-YEAR } \\
\text { (IN) }\end{array}$ \\
\hline 93.7 & 6.4 & 6,420 & 43.0 & 3.0 & 8.2 & 1.3 & 2.9 \\
\hline
\end{tabular}




\section{LITTLE COLORADO RIVER BASIN}

09400300 TESHBITO MASH NEAR HOLBROOK, AZ

LOCATION.--Lat 35'26'55", long 110'04'05", in WH sec.36, T.24 N., R.21 E., Navajo County, Hydrologic Unit 15020011, at State Highway 77, 4.0 miles north of Bita Hochee Trading Post, 35 miles nor th of Holbrook.

DRAINAGE AREA. $--60.3 \mathrm{mi}^{2}$, of which $10.7 \mathrm{mi}^{2}$ is noncontributing.

ANNUAL PEAK DISCharge

\begin{tabular}{ccc}
$\begin{array}{c}\text { HATER } \\
\text { YEAR }\end{array}$ & DATE & $\begin{array}{c}\text { ANNUAL PEAK } \\
\text { DISCHHARGE } \\
\text { (FT } 3 / \text { SEC) }\end{array}$ \\
\hline 1963 & $09 / 06 / 63$ & 1,220 \\
1964 & $08 / 13 / 64$ & 514 \\
1965 & $07 / 20 / 65$ & 374 \\
1966 & $08 / 01 / 66$ & 1,080 \\
1967 & $00 / 00 / 67$ & 1,580 \\
1968 & $08 / 11 / 68$ & 540 \\
1969 & $09 / 12 / 69$ & 550 \\
1970 & $09 / 05 / 70$ & 950 \\
1971 & $08 / 00 / 71$ & 1,280 \\
1972 & $00 / 00 / 72$ & 68 \\
1973 & $10 / 19 / 72$ & 628 \\
1974 & $08 / 00 / 74$ & 256 \\
1975 & $07 / 15 / 75$ & 700 \\
1976 & $00 / 00 / 76$ & 100 \\
$\ldots$
\end{tabular}

MAGNITUDE AND PROBABILITY OF INSTANTANEOUS PEAK FLOU BASED ON PERIOD OF RECORD 1963-76

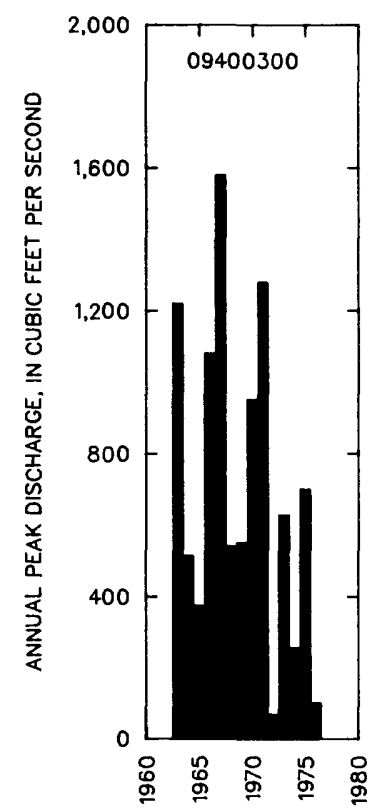

DISCHARGE, IN FT 3 /S, FOR INDICATED RECURRENCE INTERVAL IN YEARS, AND EXCEEDANCE PROBABILITY, IN PERCENT

\begin{tabular}{|c|c|c|c|c|c|}
\hline $\begin{array}{c}2 \\
50 \%\end{array}$ & $\begin{array}{c}5 \\
20 \%\end{array}$ & $\begin{array}{r}10 \\
10 \%\end{array}$ & $\begin{array}{l}25 \\
4 \%\end{array}$ & $\begin{array}{l}50 \dagger \\
2 \%\end{array}$ & $\begin{array}{c}100 \nmid \\
1 \%\end{array}$ \\
\hline 653 & 1,050 & 1,340 & 1,720 & 2,020 & 2,320 \\
\hline $\begin{array}{l}\text { WE IGHTED } \\
\text { MEAN } \\
\text { STANDARD }\end{array}$ & $\begin{array}{l}\text { SKEW } \\
\text { DEV. }\end{array}$ & $\begin{array}{l}(L O G S)= \\
(L O G S)= \\
(L O G S)=\end{array}$ & $\begin{array}{r}-0.14 \\
2.81 \\
0.25\end{array}$ & & \\
\hline
\end{tabular}

† Reliability of values in column is uncertain, and potential errors are large.

\section{BASIN CHARACTERISTICS}

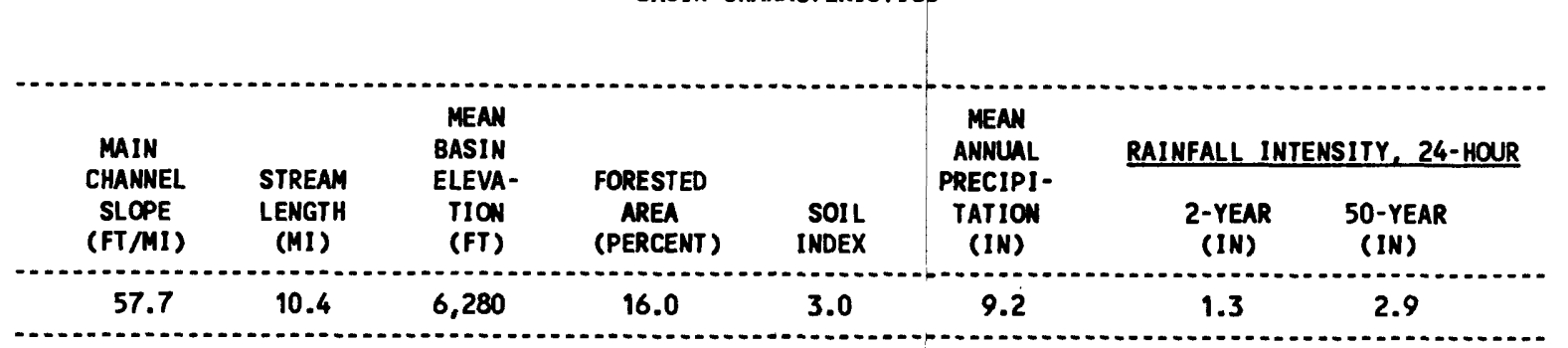


09400530 CON CANYOW MEAR HINSLOW, AZ

LOCATION.--Lat 35'06'00", Long 110.59'15", in SWK sec.29, T.20 N., R.13E., Coconino County, Hydrologic Unit 15020008 , at U.S. Highway 66,17 mi west of Winslow.

DRAIMAGE AREA. --7.53 $\mathrm{mi}^{2}$, of wich $3.96 \mathrm{mi}^{2}$ is noncontributing.

ANNUAL PEAK DISCHARGE

\begin{tabular}{cccc}
$\begin{array}{l}\text { UATER } \\
\text { YEAR }\end{array}$ & DATE & $\begin{array}{c}\text { ANMUAL PEAK } \\
\text { DISCHARGE } \\
\text { (FT } 3 / \text { S })\end{array}$ & $\begin{array}{c}\text { DISCHARGE } \\
\text { CODES }\end{array}$ \\
\hline 1962 & $00-00-62$ & 90 & ES \\
1963 & $08-30-63$ & 140 & \\
1964 & $07-30-64$ & 253 & \\
1965 & $00-00-65$ & 0 & \\
1966 & $00-00-66$ & 0.1 & LT \\
1967 & $00-00-67$ & 192 & \\
1968 & $00-00-68$ & 82 & \\
1969 & $12-02-68$ & 1.0 & LT \\
1970 & $00-00-70$ & 55 & \\
1971 & $08-00-71$ & 102 & \\
1972 & $07-16-72$ & 20 & \\
1973 & $10-00-72$ & 61 & \\
1974 & $00-00-74$ & 0 & \\
1975 & $09-18-75$ & 8.0 & \\
1976 & $00-00-76$ & 122 & \\
\hline
\end{tabular}

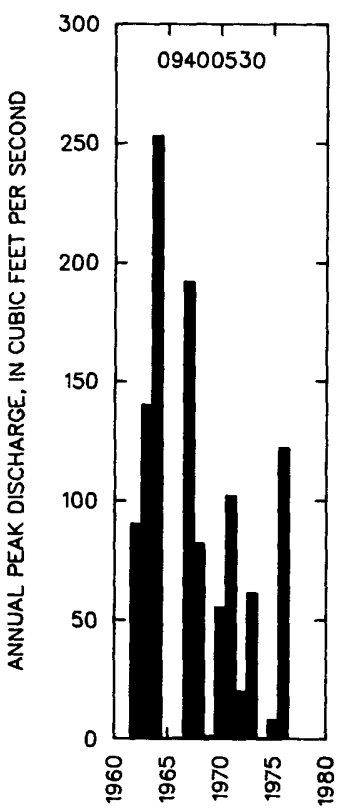

MAGNI TUDE AND PROBABILITY OF INSTANTANEOUS PEAK FLON BASED ON PERIOD OF RECORD 1962-76

DISCHARCE; IN FT $3 / \mathrm{S}$, FOR INDICATED RECURRENCE INTERVAL IN YEARS, AND EXCEEDANCE PROBABILITY, IN PERCENT

\begin{tabular}{|c|c|c|c|c|c|}
\hline $\begin{array}{c}2 \\
50 \%\end{array}$ & $\begin{array}{c}5 \\
20 \%\end{array}$ & $\begin{array}{r}10 \\
10 \%\end{array}$ & $\begin{array}{l}25 \\
4 \%\end{array}$ & $\begin{array}{l}50 \nmid \\
2 \%\end{array}$ & $\begin{array}{c}100 \\
1 \%\end{array}$ \\
\hline 64.8 & 129 & 181 & 257 & 319 & 387 \\
\hline $\begin{array}{l}\text { WEIGH } \\
\text { MEAN } \\
\text { STAND }\end{array}$ & & $\begin{array}{l}5)= \\
5)= \\
5)=\end{array}$ & & & \\
\hline
\end{tabular}

+ Reliability of values in column is uncertain, and potential errors are large.

BASIN CHARACTERISTICS

\begin{tabular}{|c|c|c|c|c|c|c|c|}
\hline MAIN & & $\begin{array}{l}\text { MEAN } \\
\text { BASIN }\end{array}$ & & & $\begin{array}{l}\text { MEAN } \\
\text { ANNUAL }\end{array}$ & RAINFALL II & ISITY, 24-HOUR \\
\hline $\begin{array}{l}\text { CHANNEL } \\
\text { SLOPE } \\
\text { (FT/MI) }\end{array}$ & $\begin{array}{l}\text { STREAM } \\
\text { LENGTH } \\
\text { (MI) }\end{array}$ & $\begin{array}{l}\text { ELEVA- } \\
\text { TION } \\
\text { (FT) }\end{array}$ & $\begin{array}{l}\text { FORESTED } \\
\text { AREA } \\
\text { (PERCENT) }\end{array}$ & $\begin{array}{l}\text { SOIL } \\
\text { INDEX }\end{array}$ & $\begin{array}{l}\text { PRECIPI- } \\
\text { TATION } \\
\text { (IN) }\end{array}$ & $\begin{array}{c}\text { 2-YEAR } \\
\text { (IN) }\end{array}$ & $\begin{array}{c}\text { 50-YEAR } \\
\text { (IN) }\end{array}$ \\
\hline 61.8 & 4.1 & 5,380 & 0.0 & 3.0 & 10.0 & 1.4 & 2.9 \\
\hline
\end{tabular}


LOCATION.-- Lat 35'52'20", Long 110'33'20", in SWk sec.31, T.29 N., R.17 E., Navajo County, Hydrologic Unit 15020012, at State Highway $264,3.5$ mi east of Oraibi.

DRAIMACE AREA. - - $1.78 \mathrm{mi}^{2}$.

anIuAl peak discharge

\begin{tabular}{|c|c|c|c|}
\hline $\begin{array}{l}\text { MATER } \\
\text { YEAR }\end{array}$ & DATE & $\begin{array}{l}\text { AMNUAL PEAK } \\
\text { DISCHARGE } \\
\text { (FT } 3 / \mathrm{S})\end{array}$ & $\begin{array}{l}\text { DISCHARGE } \\
\text { CODES }\end{array}$ \\
\hline $\begin{array}{l}1963 \\
1964 \\
1965 \\
1966 \\
1967 \\
1968 \\
1969 \\
1970 \\
1971 \\
1972 \\
1973 \\
1974 \\
1975 \\
1976\end{array}$ & $\begin{array}{l}08-00-63 \\
07-31-64 \\
09-19-65 \\
00-00-66 \\
00-00-67 \\
00-00-68 \\
07-19-69 \\
09-05-70 \\
00-00-71 \\
07-00-72 \\
10-19-72 \\
07-19-74 \\
09-07-75 \\
00-00-76\end{array}$ & $\begin{array}{c}96 \\
142 \\
383 \\
112 \\
65 \\
7.0 \\
135 \\
382 \\
305 \\
20 \\
310 \\
90 \\
100 \\
1.0\end{array}$ & ES \\
\hline
\end{tabular}

MAGNITUDE AMD PROBABILITY OF INSTANTANEOUS PEAK FLON BASED ON PERIOO OF RECORD 1963-76

DISCHARGE, IN $\mathrm{FT}^{3} / \mathrm{S}$, FOR INDICATED RECURRENCE INTERVAL IN YEARS, NDD EXCEEDANCE PROBABILITY, IN PERCENT

+ Reliability of values in colum is uncertain, and potential errors are large.

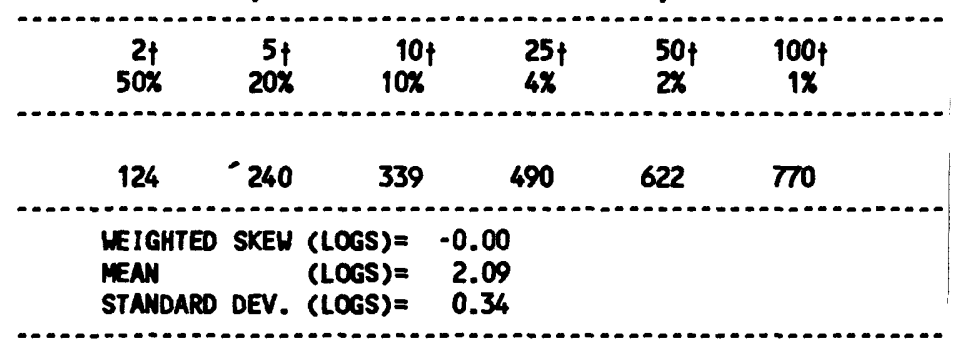

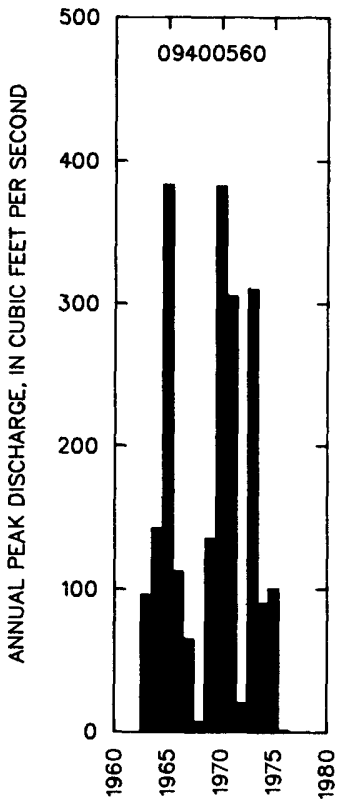

BASIN CHARACTERISTICS

\begin{tabular}{|c|c|c|c|c|c|c|c|}
\hline MAIN & & $\begin{array}{c}\text { MEAN } \\
\text { BASIN }\end{array}$ & & & $\begin{array}{c}\text { MEAN } \\
\text { ANNUAL }\end{array}$ & RAINFALL II & SITY, 24-HOUR \\
\hline $\begin{array}{l}\text { CHANNEL } \\
\text { SLOPE } \\
\text { (FT/MI) }\end{array}$ & $\begin{array}{c}\text { STREAM } \\
\text { LENGTH } \\
\text { (MI) }\end{array}$ & $\begin{array}{l}\text { ELEVA- } \\
\text { TION } \\
\text { (FT) }\end{array}$ & $\begin{array}{l}\text { FORESTED } \\
\text { AREA } \\
\text { (PERCENT) }\end{array}$ & $\begin{array}{l}\text { SOIL } \\
\text { INDEX }\end{array}$ & $\begin{array}{l}\text { PRECIPI- } \\
\text { TATION } \\
\text { (IN) }\end{array}$ & $\begin{array}{c}\text { 2-YEAR } \\
\text { (IN) }\end{array}$ & $\begin{array}{l}\text { 50-YEAR } \\
\text { (IN) }\end{array}$ \\
\hline 105.0 & 2.0 & 6,020 & 38.0 & 3.0 & 10.2 & 1.3 & 2.8 \\
\hline
\end{tabular}


09400565 POLACCA MASH TRIBUTARY MEAR CHIMLE, AZ

LOCATION.--Lat 36.02'50", Long 110.04'50", Navajo County, Hydrologic Unit 15020013, at Navajo Highway No. 4, 9 mi east of Pinon, and 31 mi southwest of chinle.

DRAINAGE AREA. $--6.45 \mathrm{mi}^{2}$.

ANMUAL PEAK DISCHARGE

\begin{tabular}{cccc}
$\begin{array}{c}\text { WATER } \\
\text { YEAR }\end{array}$ & DATE & $\begin{array}{c}\text { ANMUAL PEAK } \\
\text { DISCHARGE } \\
\text { (FT } 3 / \text { S) }\end{array}$ & $\begin{array}{c}\text { DISCHARGE } \\
\text { CODES }\end{array}$ \\
\hline 1964 & $09-20-64$ & 7.0 & ES \\
1965 & $09-19-65$ & 247 & \\
1966 & $00-00-66$ & 43 & \\
1967 & $09-00-67$ & 295 & \\
1968 & $08-00-68$ & 20 & \\
1969 & $09-11-69$ & 485 & \\
1970 & $00-00-70$ & 275 & \\
1971 & $08-26-71$ & 610 & \\
1972 & $00-00-72$ & 540 & \\
1973 & $10-19-72$ & 940 & \\
1974 & $07-21-74$ & 900 & \\
1975 & $09-07-75$ & 1,130 & \\
1976 & $00-00-76$ & 180 & \\
\hline
\end{tabular}

MAGMITUDE AND PROBABILITY OF INSTANTANEOUS PEAK FLOA BASED ON PERIOD OF RECORD 1964-76

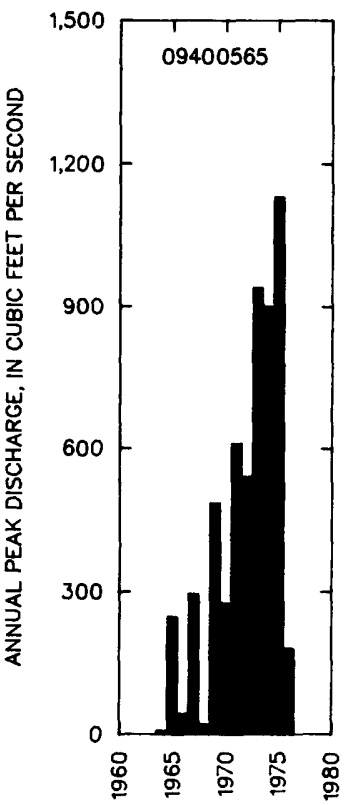

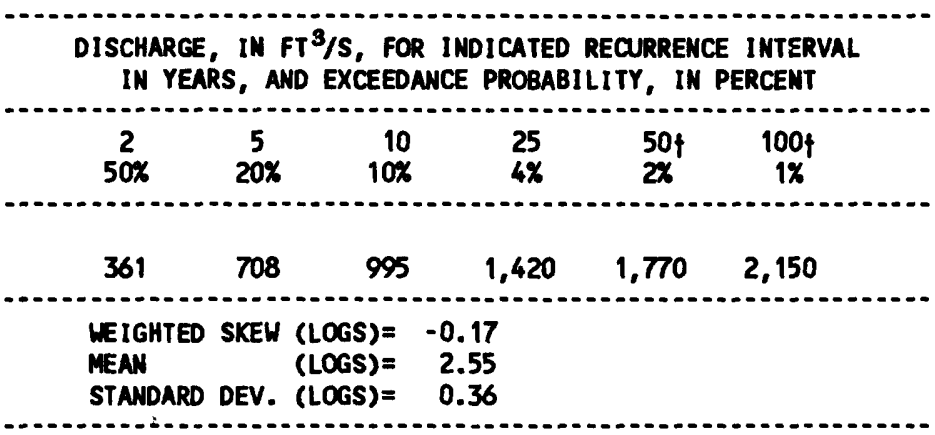

f Reliability of values in colum is uncertain, and potential errors are large.

\section{BASIN CHARACTERISTICS}

\begin{tabular}{|c|c|c|c|c|c|c|c|}
\hline \multirow{2}{*}{$\begin{array}{l}\text { MAIN } \\
\text { CHANNEL } \\
\text { SLOPE } \\
\text { (FT/MI) }\end{array}$} & \multirow[b]{2}{*}{$\begin{array}{c}\text { STREAM } \\
\text { LENGTH } \\
\text { (MI) }\end{array}$} & \multirow{2}{*}{$\begin{array}{l}\text { MEAN } \\
\text { BASIN } \\
\text { ELEVA- } \\
\text { TION } \\
\text { (FT) }\end{array}$} & \multirow[b]{2}{*}{$\begin{array}{l}\text { FORESTED } \\
\text { AREA } \\
\text { (PERCENT) }\end{array}$} & \multirow[b]{2}{*}{$\begin{array}{l}\text { SOIL } \\
\text { INDEX }\end{array}$} & \multirow{2}{*}{$\begin{array}{l}\text { MEAN } \\
\text { ANNUAL } \\
\text { PRECIPI- } \\
\text { TATION } \\
\text { (IN) }\end{array}$} & \multicolumn{2}{|c|}{ RAINFALL INTENSITY, 24-HOUR } \\
\hline & & & & & & $\begin{array}{c}\text { 2-YEAR } \\
\text { (IN) }\end{array}$ & $\begin{array}{l}\text { 50-YEAR } \\
\text { (IN) }\end{array}$ \\
\hline 160 & 5.7 & 6,890 & 78.0 & 1.0 & 12.3 & 1.5 & 2.9 \\
\hline
\end{tabular}


LOCATION.--Lat 35'19'30", long 110.25'20", in sWk sec.10, T.22 N., R.18 E., Navajo County, Hydrologic Unit 15020014, at State Highway 87, 26 mi northeast of Winslow.

DRAINAGE AREA. $--5.57 \mathrm{mi}^{2}$.

ANIUAL PEAK DISCHARGE

\begin{tabular}{|c|c|c|c|}
\hline $\begin{array}{l}\text { WATER } \\
\text { YEAR }\end{array}$ & DATE & $\begin{array}{c}\text { ANNUAL PEAK } \\
\text { DISCHARGE } \\
\text { (FT } 3 / \mathrm{S})\end{array}$ & $\begin{array}{l}\text { DISCHARGE } \\
\text { COOES }\end{array}$ \\
\hline $\begin{array}{l}1964 \\
1965 \\
1966 \\
1967 \\
1968 \\
1969 \\
1970 \\
1971 \\
1972 \\
1973 \\
1974 \\
1975 \\
1976\end{array}$ & $\begin{array}{l}09-09-64 \\
07-00-65 \\
00-00-66 \\
00-00-67 \\
00-00-68 \\
10-04-68 \\
09-05-70 \\
08-00-71 \\
09-18-72 \\
10-19-72 \\
07-17-74 \\
07-15-75 \\
00-00-76\end{array}$ & $\begin{array}{c}101 \\
707 \\
5.0 \\
0 \\
0 \\
1.0 \\
117 \\
127 \\
280 \\
215 \\
2.0 \\
860 \\
58\end{array}$ & LT \\
\hline
\end{tabular}

MAGNITUDE AND PROBABILITY OF INSTANTANEOUS PEAK FLOW BASED ON PERIOD OF RECORD 1964-76

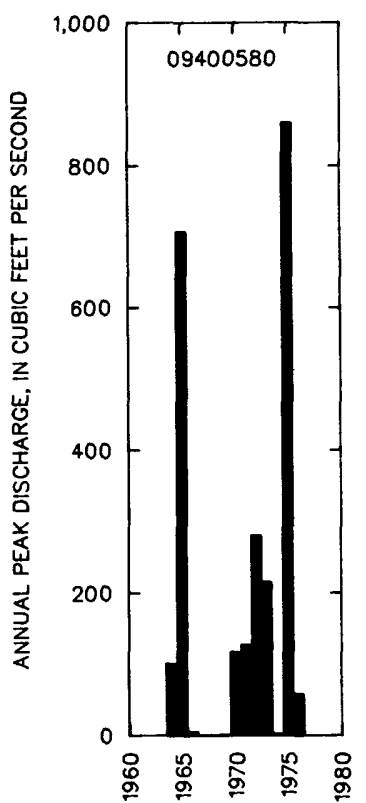

DISCHARGE, IN $\mathrm{FT}^{3} / \mathrm{S}$, FOR INDICATED RECURRENCE INTERVAL IN YEARS, AND EXCEEDANCE PROBABILITY, IN PERCENT

\begin{tabular}{|c|c|c|c|c|c|}
\hline $\begin{array}{c}2 \\
50 \%\end{array}$ & $\begin{array}{c}5 \\
20 \%\end{array}$ & $\begin{array}{r}10 \\
10 \%\end{array}$ & $\begin{array}{l}25 \\
4 \%\end{array}$ & $\begin{array}{l}50 \dagger \\
2 x\end{array}$ & $\begin{array}{c}100 \dagger \\
1 \%\end{array}$ \\
\hline 86 & 289 & 536 & 1,020 & 1,540 & 2,220 \\
\hline $\begin{array}{l}\text { MEIGHTED } \\
\text { MEAN } \\
\text { STANDARD }\end{array}$ & SKEW & $\begin{array}{l}(\text { LOGS })= \\
(\text { LOGS })= \\
(\text { LOGS })=\end{array}$ & $\begin{array}{r}-0.12 \\
1.92 \\
0.64\end{array}$ & & \\
\hline
\end{tabular}

f Reliability of values in column is uncertain, and potential errors are large.

BASIN CHARACTERISTICS

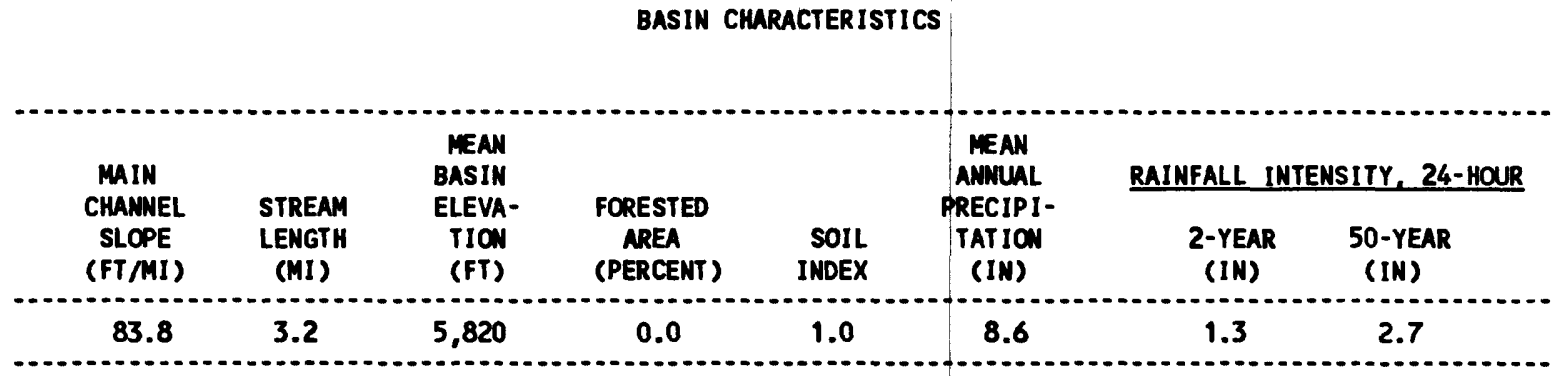


09400590 RIO DE FLAG AT HIDDEN HOLLOU ROAD, AT FLAGSTAFF, AZ

LOCATION.--Lat 35'14'31", Long 111'41'02", in SWKSWk sec.32, T.22 N., R.7 E., Coconino County, Hydrologic Unit 15020015, at Hidden Hollow Road, $1.4 \mathrm{mi}$ northwest of the Museum of Northern Arizona, and $3.4 \mathrm{mi}$ northwest of downtown flagstaff.

DRAIMAGE AREA. $--31.5 \mathrm{mi}^{2}$.

ANIUAL PEAK DISCHARGE

\begin{tabular}{|c|c|c|c|}
\hline $\begin{array}{l}\text { WATER } \\
\text { YENR }\end{array}$ & DATE & $\begin{array}{l}\text { ANNUAL PEAK } \\
\text { DISCHARGE } \\
\text { (FT } 3 / S)\end{array}$ & $\begin{array}{l}\text { DISCHARGE } \\
\text { CODES }\end{array}$ \\
\hline $\begin{array}{l}1970 \\
1971 \\
1972 \\
1973 \\
1974 \\
1975 \\
1976 \\
1977 \\
1978 \\
1979 \\
1980 \\
1981 \\
1982\end{array}$ & $\begin{array}{l}08-03-70 \\
08-00-71 \\
12-26-71 \\
04-28-73 \\
00-00-74 \\
00-00-75 \\
00-00-76 \\
00-00-77 \\
04-00-78 \\
05-00-79 \\
02-20-80 \\
00-00-81 \\
03-12-82\end{array}$ & $\begin{array}{c}2.0 \\
0.1 \\
11 \\
153 \\
0 \\
0 \\
1.0 \\
1.0 \\
144 \\
93 \\
110 \\
1.0 \\
133\end{array}$ & $\begin{array}{l}\text { ES } \\
\text { LT }\end{array}$ \\
\hline
\end{tabular}

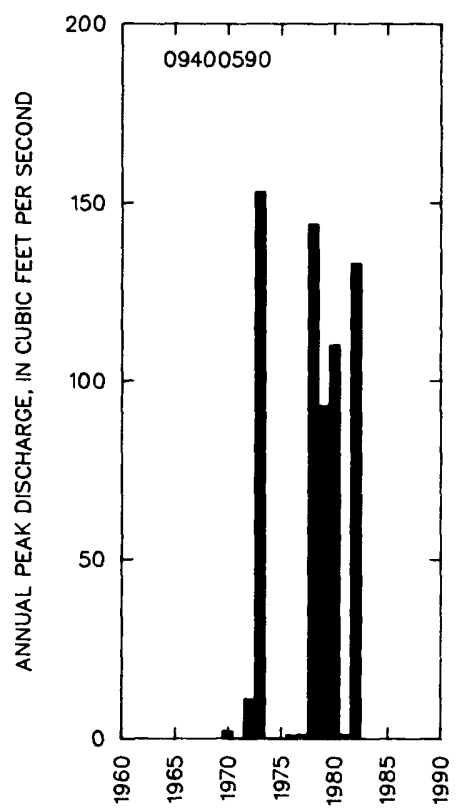

MAGNITUDE AND PROBABILITY OF INSTANTANEOUS PEAK FLOH BASED ON PERIOD OF RECORD

DISCHARGE, IN $\mathrm{FT}^{3} / \mathrm{S}$, FOR INDICATED RECURRENCE INTERVAL IN YEARS, AND EXCEEDANCE PROBABILITY, IN PERCENT

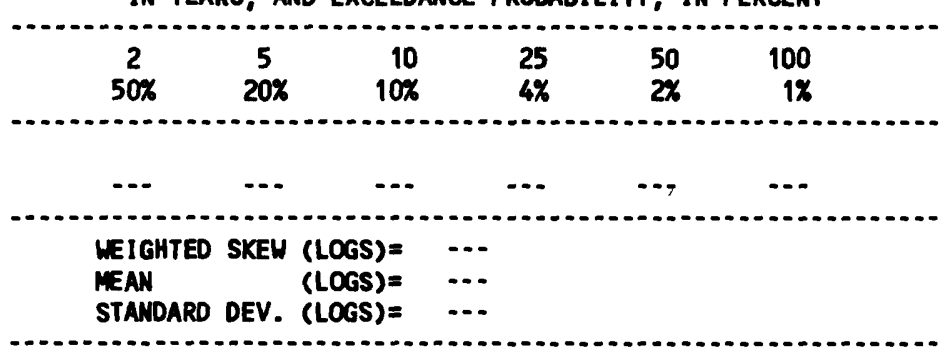

BASIN CHARACTERISTICS

\begin{tabular}{|c|c|c|c|c|c|c|c|}
\hline MAIN & & $\begin{array}{l}\text { MEAN } \\
\text { BASIN }\end{array}$ & & & $\begin{array}{c}\text { MEAN } \\
\text { ANNUAL }\end{array}$ & RAINFALL II & SITY, 24-HOUR \\
\hline $\begin{array}{l}\text { CHANNEL } \\
\text { SLOPE } \\
\text { (FT/MI) }\end{array}$ & $\begin{array}{l}\text { STREAM } \\
\text { LENGTH } \\
\text { (MI) }\end{array}$ & $\begin{array}{l}\text { ELEVA- } \\
\text { TION } \\
\text { (FT) }\end{array}$ & $\begin{array}{l}\text { FORESTED } \\
\text { AREA } \\
\text { (PERCENT) }\end{array}$ & $\begin{array}{l}\text { SOIL } \\
\text { INDEX }\end{array}$ & $\begin{array}{l}\text { PRECIPI- } \\
\text { TATION } \\
\text { (IN) }\end{array}$ & $\begin{array}{c}\text { 2-YEAR } \\
\text { (IN) }\end{array}$ & $\begin{array}{l}\text { 50-YEAR } \\
\text { (IN) }\end{array}$ \\
\hline 129 & 8.1 & 8,130 & 78.0 & 3.0 & 25.4 & 2.3 & 4.5 \\
\hline
\end{tabular}


LOCATION.- - Lat 35*13'37", long 111'39'29w, in SEYSWK sec.4, T.21 N., R.7 E., Coconino County, Hydrologic Unit 15020015, at U.S. Highway 180, $0.6 \mathrm{mi}$ south of the Museum of Northern Arizona in Flagstaff.

DRAIMAGE AREA. $--6.09 \mathrm{mi}^{2}$.

ANIUAL PEAK DISCMARGE

\begin{tabular}{lccc}
$\begin{array}{c}\text { WATER } \\
\text { YEAR }\end{array}$ & DATE & $\begin{array}{c}\text { ANWUAL PEAK } \\
\text { DISCHARGE } \\
\text { (FT } 3 / \text { S) }\end{array}$ & $\begin{array}{c}\text { DISCHARCE } \\
\text { CCDES }\end{array}$ \\
\hline 1970 & $00-00-70$ & 0 & \\
1971 & $00-00-71$ & 0 & \\
1972 & $00-00-72$ & 0 & \\
1973 & $04-28-73$ & 48 & \\
1974 & $00-00-74$ & 0 & \\
1975 & $00-00-75$ & 0 & \\
1976 & $00-00-76$ & 0 & \\
1977 & $00-00-77$ & 3.0 & \\
1978 & $07-06-78$ & 17 & \\
1979 & $03-00-79$ & 41 & \\
1980 & $03-00-80$ & 35 & \\
$\ldots$
\end{tabular}

MAGNITUDE AND PROBABILITY OF INSTANTANEOUS PEAK FLOW BASED ON PERIOO OF RECORD

DISCHARCE, IN $\mathrm{FT}^{3} / \mathrm{S}$, FOR INDICATED RECURRENCE INTERVAL IN YEARS, AND EXCEEDANCE PROBABILITY, IN PERCENT

\begin{tabular}{|c|c|c|c|c|c|}
\hline $\begin{array}{c}2 \\
50 \%\end{array}$ & $\begin{array}{c}5 \\
20 \%\end{array}$ & $\begin{array}{r}10 \\
10 \%\end{array}$ & $\begin{array}{l}25 \\
4 x\end{array}$ & $\begin{array}{l}50 \\
2 \%\end{array}$ & $\begin{array}{r}100 \\
1 \%\end{array}$ \\
\hline$\cdots$ & $\cdots$ & $\cdots$ & $\cdots$ & $\cdots$ & $\cdots$ \\
\hline $\begin{array}{l}\text { WEIGHTED } \\
\text { MEAN } \\
\text { STANDARD }\end{array}$ & DEV. & $\begin{array}{l}(\text { LOGS })= \\
(\text { LOGS) }= \\
(\text { LOGS }=\end{array}$ & $\cdots$ & & \\
\hline
\end{tabular}

BASIN CHARACTERISTICS

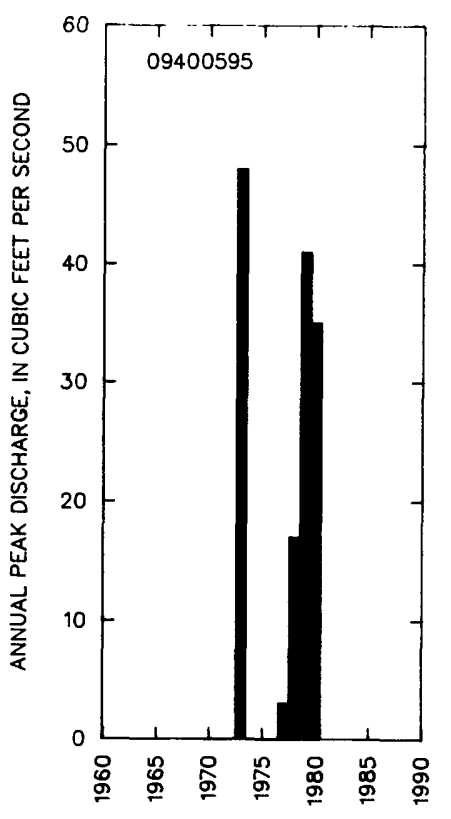


09400600 RIO DE fLAG AT FLAGSTAFF, AZ

LOCATION.--Lat 35.13'18", long 111.39'24", in MNANEK sec.9, T.21 N., R.7 E., Coconino County, Hydrologic Unit 15020015, at west side of Crescent Drive in Flagstaff.

DRAINAGE AREA. $--51.0 \mathrm{mi}^{2}$.

AMIUUAL PEAK DISCHARGE

\begin{tabular}{cccc}
$\begin{array}{c}\text { WATER } \\
\text { YEAR }\end{array}$ & $\begin{array}{c}\text { DATE } \\
\text { DNMUAL PEAK } \\
\text { DISCHARGE } \\
\text { (FT } 3 / \text { S })\end{array}$ & $\begin{array}{c}\text { DISCHARGE } \\
\text { COOES }\end{array}$ \\
\hline 1956 & $00-00-56$ & 0 & $C$ \\
1957 & $00-00-57$ & 0 & $C$ \\
1958 & $04-20-58$ & 56 & $C$ \\
1959 & $00-00-59$ & 0 & $C$ \\
1960 & $03-24-60$ & 11 & $C$ \\
1970 & $08-03-70$ & 10 & ES,C \\
1971 & $09-30-71$ & 10 & LT,C \\
1972 & $00-00-72$ & 0 & $C$ \\
1973 & $04-28-73$ & 235 & $C$ \\
1974 & $04-03-74$ & 3.0 & LT,C \\
1975 & $04-00-75$ & 10 & ES,C \\
1976 & $02-09-76$ & 35 & $C$ \\
1977 & $05-15-77$ & 8.5 & KR,C \\
1978 & $04-00-78$ & 128 & $C$ \\
1979 & $05-00-79$ & 90 & $C$ \\
1980 & $07-00-80$ & 104 & $C$ \\
1981 & $04-00-81$ & 14 & ES,C \\
1982 & $03-12-82$ & 240 & $C$ \\
\hline
\end{tabular}

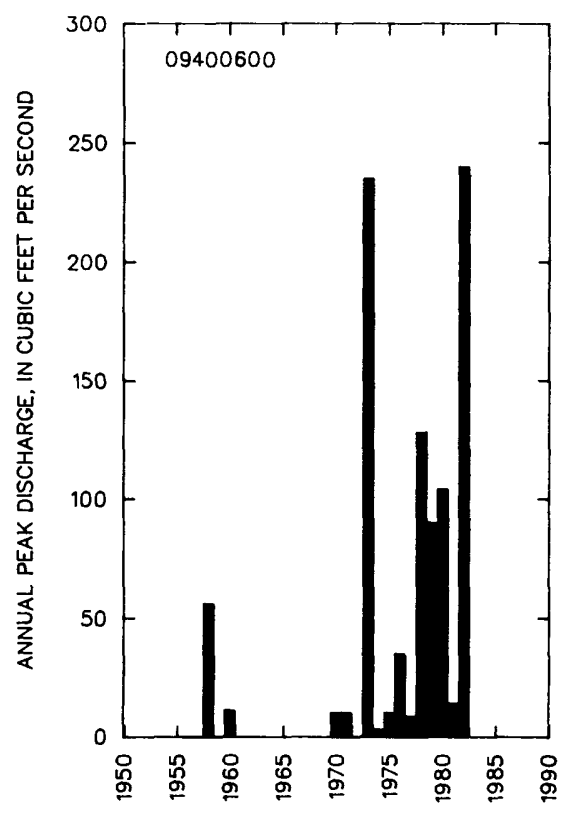

MAGNITUDE AND PROBABILITY OF INSTANTAMEOUS PEAK FLOW BASED ON PERIOD OF RECORD 1956-60, 1970-82

DISCHARGE, IN $\mathrm{FT}^{3} / \mathrm{S}$, FOR INDICATED RECURRENCE INTERVAL IN YEARS, AND EXCEEDANCE PROBABILITY, IN PERCENT

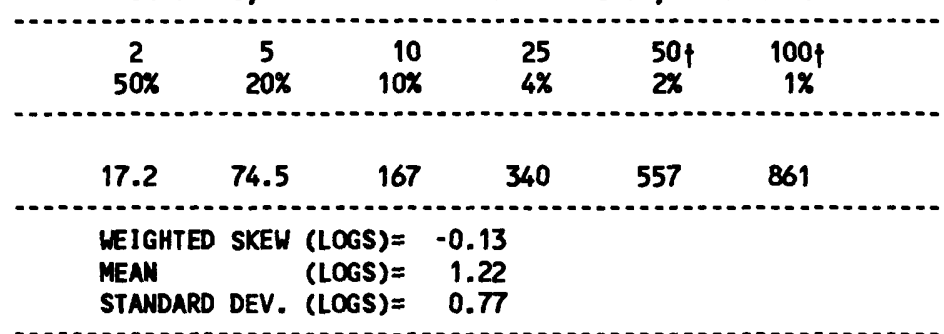

+ Reliability of values in column is uncertain, and potential errors are large.

BASIN CHARACTERISTICS

\begin{tabular}{|c|c|c|c|c|c|c|c|}
\hline \multirow{2}{*}{$\begin{array}{l}\text { MAIN } \\
\text { CHANNEL } \\
\text { SLOPE } \\
\text { (FT/MI) }\end{array}$} & \multirow[b]{2}{*}{$\begin{array}{l}\text { STREAM } \\
\text { LENGTH } \\
\text { (MI) }\end{array}$} & \multirow{2}{*}{$\begin{array}{l}\text { MEAN } \\
\text { BASIN } \\
\text { ELEVA- } \\
\text { TION } \\
\text { (FT) }\end{array}$} & \multirow[b]{2}{*}{$\begin{array}{l}\text { FORESTED } \\
\text { AREA } \\
\text { (PERCENT) }\end{array}$} & \multirow[b]{2}{*}{$\begin{array}{l}\text { SOIL } \\
\text { INDEX }\end{array}$} & \multirow{2}{*}{$\begin{array}{l}\text { MEAN } \\
\text { ANNUAL } \\
\text { PRECIPI- } \\
\text { TATION } \\
\text { (IN) }\end{array}$} & \multicolumn{2}{|c|}{ RAINFALL INTENSITY, 24-HOUR } \\
\hline & & & & & & $\begin{array}{c}\text { 2-YEAR } \\
\text { (IN) }\end{array}$ & $\begin{array}{l}\text { 50-YEAR } \\
\text { (IN) }\end{array}$ \\
\hline 106 & 10.8 & 8,050 & 76.0 & 3.0 & 25.3 & 2.2 & 4.3 \\
\hline
\end{tabular}


LOCATION.--Lat 35.09150", L ong $1111^{\circ} 401481$, in MMANM sec.32, T.21 N., R.7 E., Coconino County, at Holmes Avenue in the cormunity of Palmerville at Flagstaff.

DRAIMAGE AREA. $--8.11 \mathrm{mi}^{2}$.

ANIUUAL PEAK DISCHARGE

\begin{tabular}{|c|c|c|c|}
\hline $\begin{array}{l}\text { WATER } \\
\text { YEAR }\end{array}$ & DATE & $\begin{array}{l}\text { ANMUAL PEAK } \\
\text { DISCHARGE } \\
\left(\mathrm{FT}^{3} / \mathrm{S}\right)\end{array}$ & $\begin{array}{l}\text { DISCHARGE } \\
\text { CCOES }\end{array}$ \\
\hline $\begin{array}{l}1970 \\
1971 \\
1972 \\
1973 \\
1974 \\
1975 \\
1976 \\
1977 \\
1978 \\
1979 \\
1980\end{array}$ & $\begin{array}{l}09-05-70 \\
07-21-71 \\
12-28-71 \\
10-19-72 \\
08-01-74 \\
10-30-74 \\
04-00-76 \\
08-09-77 \\
02-28-78 \\
12-18-78 \\
02-20-80\end{array}$ & $\begin{array}{c}1401 \\
62 \\
105 \\
135 \\
1.0 \\
74 \\
44 \\
23 \\
37 \\
295 \\
70\end{array}$ & LT \\
\hline
\end{tabular}

Highest since 1944 .

MAGNITUDE AND PROBABILITY OF INSTANTANEOUS PEAK FLON BASED ON PERICO OF RECORD 1970-80

DISCHARGE, IN $\mathrm{FT}^{3} / \mathrm{S}$, FOR INDICATED RECURRENCE INTERVAL

IN YEARS, AND EXCEEDANCE PROBABILITY, IN PERCENT

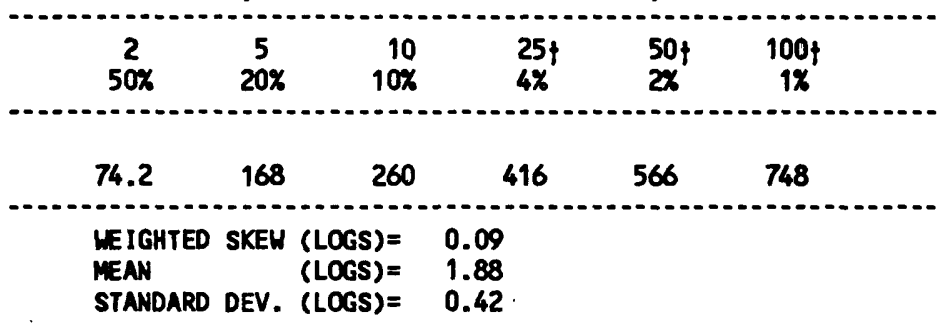

t Reliability of values in column is uncertain, and potential errors are large.

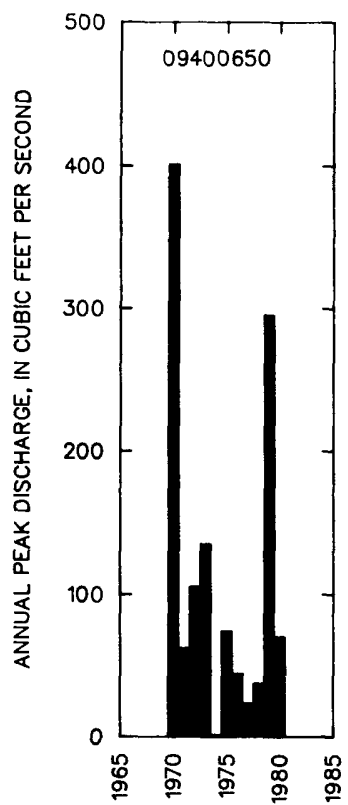

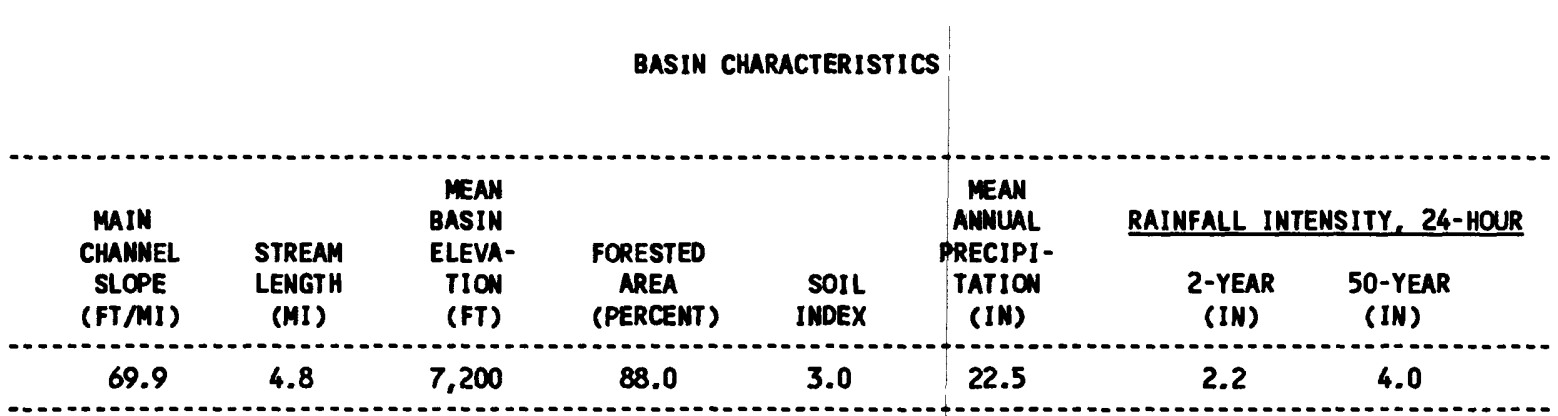




\section{RIO DE FLAG AT INTERSTATE 40 AT FLAGSTAFF, AZ}

LOCATION.--Lat 35'11'04", long 111'37'56", in SEKSEK sec.22, T.21 N., R.7 E., Coconino County, Hydrologic Unit 15020015, on left bank $80 \mathrm{ft}$ upstream from bridge for eastbound lanes of Interstate 40, in Flagstaff.

DRAINAGE AREA. $--82.4 \mathrm{mi}^{2}$.

ANIUAL PEAK DISCHARGE

\begin{tabular}{|c|c|c|c|}
\hline $\begin{array}{l}\text { WATER } \\
\text { YEAR }\end{array}$ & DATE & $\begin{array}{c}\text { ANMUAL PEAK } \\
\text { DISCHARGE } \\
\text { (FT } 3 / \mathrm{S})\end{array}$ & $\begin{array}{l}\text { DISCHARGE } \\
\text { CODES }\end{array}$ \\
\hline $\begin{array}{l}1970 \\
1971 \\
1972 \\
1973 \\
1974 \\
1975 \\
1976 \\
1977 \\
1978 \\
1979 \\
1980 \\
1981 \\
1982\end{array}$ & $\begin{array}{l}09-05-70 \\
07-21-71 \\
12-28-71 \\
04-25-73 \\
00-00-74 \\
10-30-74 \\
02-09-76 \\
00-00-77 \\
02-28-78 \\
12-19-78 \\
02-20-80 \\
04-00-81 \\
03-12-82\end{array}$ & $\begin{array}{c}350 \\
50 \\
100 \\
1300 \\
0 \\
70 \\
134 \\
3.0 \\
153 \\
421 \\
165 \\
150 \\
370\end{array}$ & $\begin{array}{c}E S, C \\
E S, C \\
E S, C \\
C \\
E S, C \\
C \\
L T, \\
C \\
C \\
C \\
E S, C \\
C\end{array}$ \\
\hline
\end{tabular}

Highest since 1938.

MAGNITUDE AND PROBABILITY OF INSTANTANEQUS PEAK FLOW BASED ON PERIOD OF RECORD

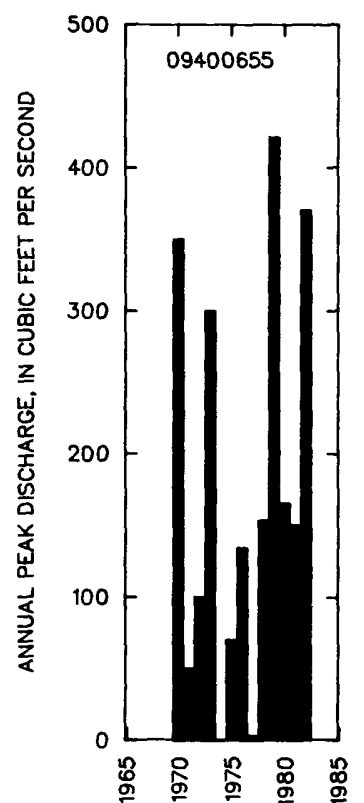

DISCHARGE, IN $\mathrm{FT}^{3} / \mathrm{S}$, FOR INDICATED RECURRENCE INTERVAL IN YEARS, AND EXCEEDANCE PROBABILITY, IN PERCENT

\begin{tabular}{|c|c|c|c|c|c|}
\hline $\begin{array}{c}2 \\
50 \%\end{array}$ & $\begin{array}{c}5 \\
20 \%\end{array}$ & $\begin{array}{r}10 \\
10 \%\end{array}$ & $\begin{array}{l}25 \\
4 \%\end{array}$ & $\begin{array}{l}50 \\
2 \%\end{array}$ & $\begin{array}{r}100 \\
1 \%\end{array}$ \\
\hline$\cdots$ & $-\cdot$ & -... & -... & $\cdots$ & $\cdots$ \\
\hline $\begin{array}{l}\text { WEIGHTED } \\
\text { MEAN } \\
\text { STANDARD }\end{array}$ & $\begin{array}{l}\text { SKEW } \\
\text { DEV. }\end{array}$ & $\begin{array}{l}(\text { LOGS })= \\
(\text { LOGS) }= \\
(\text { LOGS }=\end{array}$ & $\ldots$ & & \\
\hline
\end{tabular}

BASIN CHARACTERISTICS

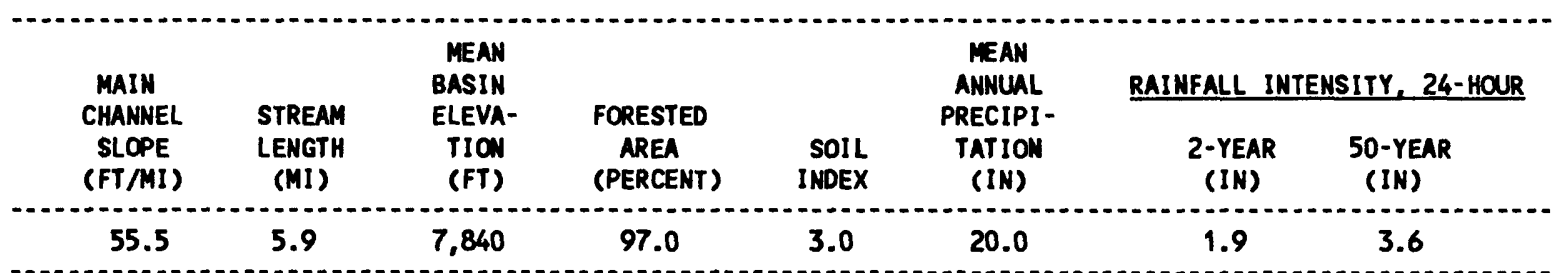




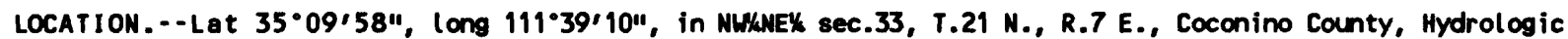
Unit 15020015, at Zuni Road in Flagstaff.

DRAINAGE AREA. $--2.06 \mathrm{mi}^{2}$.

MNUUAL PEAK DISCHARGE

\begin{tabular}{cccc}
$\begin{array}{c}\text { WATER } \\
\text { YEAR }\end{array}$ & DATE & $\begin{array}{c}\text { ANNUAL PEAK } \\
\text { DISCHARGE } \\
\text { (FT } 3 / \text { S) }\end{array}$ & $\begin{array}{c}\text { DISCHAREE } \\
\text { CCDES }\end{array}$ \\
\hline 1969 & $00-00-69$ & 45 & C \\
1970 & $09-05-70$ & 42 & C \\
1971 & $08-15-71$ & 73 & C \\
1972 & $12-28-71$ & 26 & C \\
1973 & $00-00-73$ & 10 & LT,C \\
1974 & $08-02-74$ & 12 & C \\
1975 & $00-00-75$ & 13 & C \\
1976 & $07-00-76$ & 7 & ES,C \\
1977 & $08-09-77$ & 24 & C \\
1978 & $10-06-77$ & 20 & C \\
1979 & $11-11-78$ & 17 & C \\
1980 & $02-18-80$ & 40 & ES,C \\
\hline
\end{tabular}

MAGNITUDE AND PROBABILITY OF INSTANTANEOUS PEAK FLON BASED ON PERIOD OF RECORD 1969-80

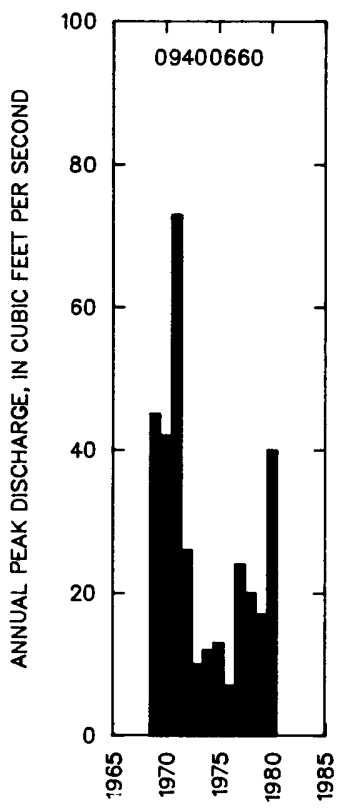

DISCHARCE, IN $\mathrm{FT}^{3} / \mathrm{S}$, FOR INDICATED RECURRENCE INTERVAL IN YEARS, AND EXCEEDNICE PROBABILITY, IN PERCENT

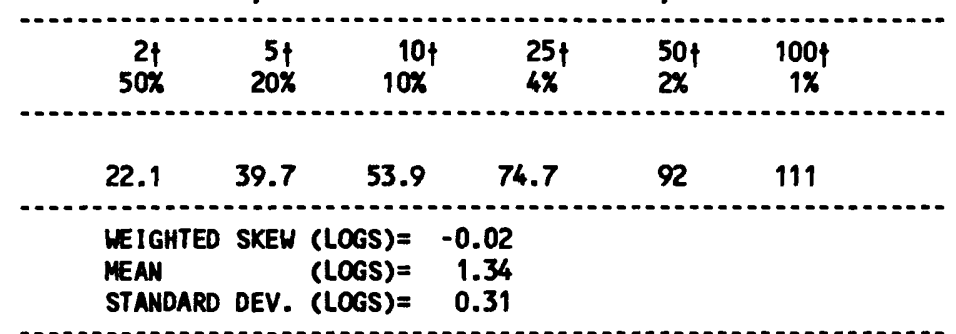

$\uparrow$ Reliability of values in colum is uncertain, and potential errors are large.

\section{BASIN CHARACTERISTICS}

\begin{tabular}{|c|c|c|c|c|c|c|c|}
\hline \multirow{2}{*}{$\begin{array}{l}\text { MAIN } \\
\text { CHANNEL } \\
\text { SLOPE } \\
\text { (FT/MI) }\end{array}$} & \multirow[b]{2}{*}{$\begin{array}{c}\text { STREAM } \\
\text { LENGTH } \\
\text { (MI) }\end{array}$} & \multirow{2}{*}{$\begin{array}{l}\text { MEAN } \\
\text { BASIN } \\
\text { ELEVA- } \\
\text { TION } \\
\text { (FT) }\end{array}$} & \multirow[b]{2}{*}{$\begin{array}{l}\text { FORESTED } \\
\text { AREA } \\
\text { (PERCENT) }\end{array}$} & \multirow[b]{2}{*}{$\begin{array}{c}\text { SOIL } \\
\text { INDEX }\end{array}$} & \multirow{2}{*}{$\begin{array}{l}\text { MEN } \\
\text { ANNUAL } \\
\text { PRECIPI- } \\
\text { TATION } \\
\text { (IN) }\end{array}$} & \multicolumn{2}{|c|}{ RAINFALL INTENSITY, 24-HOUR } \\
\hline & & & & & & $\begin{array}{c}\text { 2-YEAR } \\
\text { (IN) }\end{array}$ & $\begin{array}{c}\text { 50-YEAR } \\
\text { (IN) }\end{array}$ \\
\hline 46.5 & 2.9 & 6,990 & 75.0 & 3.0 & 19.4 & 2.0 & 4.0 \\
\hline
\end{tabular}


09400680 SHITZER CANYON AT FLAGSTAFF, AZ

LOCATION.--Lat 35'12'44", Long 111'38'21", in SwKSEK sec.10, T.21 N., R.7 E., Coconino County, Hydrologic Unit 15020015, at Turquoise and Oak Streets in Flagstaff.

DRAINACE AREA. $-1.87 \mathrm{mi}^{2}$.

ANNUAL PEAK DISCHARGE

\begin{tabular}{ccc}
$\begin{array}{c}\text { UATER } \\
\text { YEAR }\end{array}$ & DATE & $\begin{array}{c}\text { ANMUAL PEAK } \\
\text { DISCHARGE } \\
\text { (FT } 3 / \text { S) }\end{array}$ \\
\hline 1969 & $09-12-69$ & 112 \\
1970 & $09-05-70$ & 61 \\
1971 & $08-03-71$ & 12 \\
1972 & $12-28-71$ & 15 \\
1973 & $04-13-73$ & 79 \\
1974 & $08-10-74$ & 18 \\
1975 & $09-00-75$ & 10 \\
1976 & $02-09-76$ & 51 \\
1977 & $07-22-77$ & 5 \\
1978 & $02-28-78$ & 90 \\
1979 & $12-18-78$ & 135 \\
1980 & $02-19-80$ & 107 \\
$\ldots$
\end{tabular}

MAGNITUDE ANO PROBABILITY OF INSTANTANEOUS PEAK FLOW BASED ON PERIOD OF RECORD 1969-80

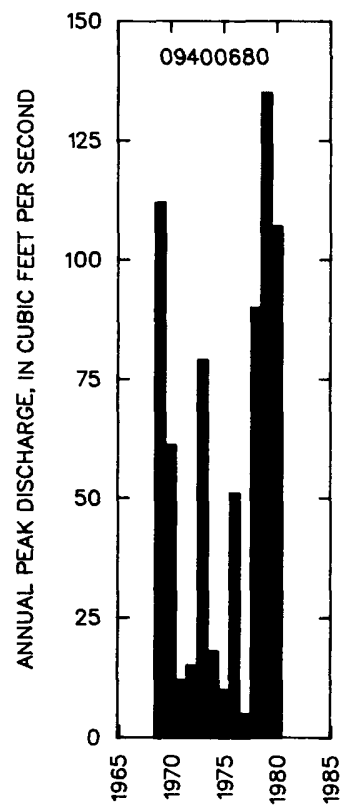

DISCHARGE, IN $\mathrm{FT}^{3} / \mathrm{S}$, FOR IMDICATED RECURREMCE INTERVAL

IN YEARS, AND EXCEEDANCE PROBABILITY, IN PERCENT

\begin{tabular}{|c|c|c|c|c|c|}
\hline $\begin{array}{c}2 \\
50 \%\end{array}$ & $\begin{array}{c}5 \\
20 \%\end{array}$ & $\begin{array}{r}10 \\
10 \%\end{array}$ & $\begin{array}{l}25 f \\
4 \%\end{array}$ & $\begin{array}{l}50\} \\
2 \%\end{array}$ & $\begin{array}{c}100 \nmid \\
1 \%\end{array}$ \\
\hline 38.4 & 95.9 & 151 & 240 & 321 & 413 \\
\hline $\begin{array}{l}\text { ME IGHTED } \\
\text { MEAN } \\
\text { STANDARD }\end{array}$ & $\begin{array}{l}\text { SKEH } \\
\text { DEV. }\end{array}$ & $\begin{array}{l}(\text { LOGS })= \\
(\text { LOGS) }= \\
(\text { LOGS) }=\end{array}$ & $\begin{array}{r}-0.25 \\
1.56 \\
0.49\end{array}$ & & \\
\hline
\end{tabular}

+ Reliability of values in colum is uncertain, and potential errors are large.

BASIN CHARACTERISTICS

\begin{tabular}{|c|c|c|c|c|c|c|c|}
\hline \multirow{2}{*}{$\begin{array}{l}\text { MAIN } \\
\text { CHANNEL } \\
\text { SLOPE } \\
\text { (FT/MI) }\end{array}$} & \multirow[b]{2}{*}{$\begin{array}{l}\text { STREAM } \\
\text { LENGTH } \\
\text { (MI) }\end{array}$} & \multirow{2}{*}{$\begin{array}{l}\text { MEAN } \\
\text { BASIN } \\
\text { ELEVA- } \\
\text { TION } \\
\text { (FT) }\end{array}$} & \multirow[b]{2}{*}{$\begin{array}{l}\text { FORESTED } \\
\text { AREA } \\
\text { (PERCENT) }\end{array}$} & \multirow[b]{2}{*}{$\begin{array}{r}\text { SOIL } \\
\text { IMDEX }\end{array}$} & \multirow{2}{*}{$\begin{array}{l}\text { MEAN } \\
\text { ANNUAL } \\
\text { PRECIPI- } \\
\text { TATION } \\
\text { (IN) }\end{array}$} & \multicolumn{2}{|c|}{ RAINFALL INTENSITY, 24-HOUR } \\
\hline & & & & & & $\begin{array}{l}\text { 2-YEAR } \\
\text { (IN) }\end{array}$ & $\begin{array}{l}\text { 50-YEAR } \\
\text { (IN) }\end{array}$ \\
\hline 375 & 2.4 & 7,130 & 45.0 & 3.0 & 19.9 & 2.0 & 4.0 \\
\hline
\end{tabular}


LOCATION.--Lat 35'12'03", long 111'36'46", in NEKSEK sec.14, T.21 N. , R.7 E., Coconino County, Hydrologic Unit 15020015, at gravel road $500 \mathrm{ft}$ upstream from interstate 40, and one-quarter mile downstream from U.S. Highway 66 in Flagstaff.

DRAINAGE AREA. --7.02 $\mathrm{mi}^{2}$, of which $2.50 \mathrm{mi}^{2}$ is noncontributing.

ANMUAL PEAK DISCHARGE

\begin{tabular}{|c|c|c|c|}
\hline $\begin{array}{l}\text { WATER } \\
\text { YEAR }\end{array}$ & DATE & $\begin{array}{l}\text { ANNUAL PEAK } \\
\text { DISCHARGE } \\
\text { (FT } 3 / S \text { ) }\end{array}$ & $\begin{array}{l}\text { DISCHARGE } \\
\text { CODES }\end{array}$ \\
\hline $\begin{array}{l}1968 \\
1969 \\
1970 \\
1971 \\
1972 \\
1973 \\
1974 \\
1975 \\
1976 \\
1977 \\
1978 \\
1979 \\
1980\end{array}$ & $\begin{array}{l}08-02-68 \\
09-12-69 \\
09-05-70 \\
08-03-71 \\
12-28-71 \\
07-16-73 \\
08-06-74 \\
07-16-75 \\
02-09-76 \\
08-09-77 \\
07-15-78 \\
08-12-79 \\
02-19-80\end{array}$ & $\begin{array}{r}262 \\
70 \\
178 \\
42 \\
15 \\
73 \\
100 \\
65 \\
45 \\
47 \\
76 \\
103 \\
84\end{array}$ & $\begin{array}{l}c \\
c \\
c \\
C \\
c \\
C \\
c \\
c \\
C \\
C \\
c \\
c \\
C\end{array}$ \\
\hline
\end{tabular}

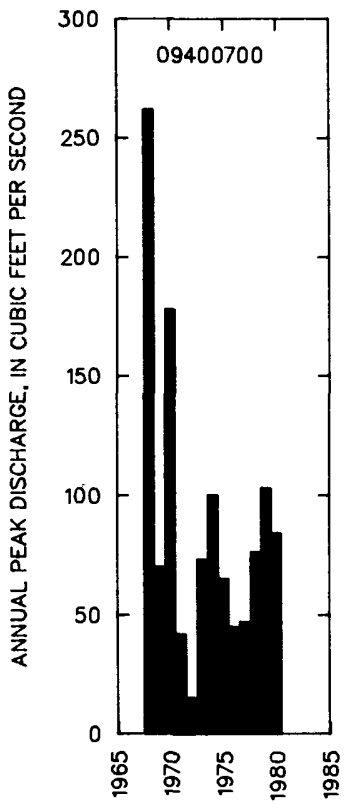

MAGNITUDE AND PROBABILITY OF INSTANTANEOUS PEAK FLOW BASED ON PERIOD OF RECORD 1968-80

DISCHARGE, IN FT $3 / 5$, FOR INDICATED RECURRENCE INTERVAL IN YEARS, AND EXCEEDANCE PROBABILITY, IN PERCENT

\begin{tabular}{|c|c|c|c|c|c|}
\hline $\begin{array}{c}2 \uparrow \\
50 \%\end{array}$ & $\begin{array}{r}5 \dagger \\
20 \%\end{array}$ & $\begin{array}{c}10 \dagger \\
10 \%\end{array}$ & $\begin{array}{l}25 \dagger \\
4 \%\end{array}$ & $\begin{array}{l}50 \dagger \\
2 \%\end{array}$ & $\begin{array}{c}100 \uparrow \\
1 \%\end{array}$ \\
\hline 75.2 & 124 & 163 & 221 & 271 & 326 \\
\hline $\begin{array}{l}\text { WEIGHTED } \\
\text { MEAN } \\
\text { STANDARD }\end{array}$ & $\begin{array}{l}\text { SKEW } \\
\text { DEV. }\end{array}$ & $\begin{array}{l}(\text { LOGS })= \\
(\text { LOGS })= \\
(\text { LOGS })=\end{array}$ & $\begin{array}{l}0.28 \\
1.89 \\
0.25\end{array}$ & & \\
\hline
\end{tabular}

$\uparrow$ Reliability of values in column is uncertain, and potential errors are large.

BASIN CHARACTERISTICS

\begin{tabular}{|c|c|c|c|c|c|c|c|}
\hline \multirow{2}{*}{$\begin{array}{l}\text { MAIN } \\
\text { CHANHEL } \\
\text { SLOPE } \\
\text { (FT/MI) }\end{array}$} & \multirow[b]{2}{*}{$\begin{array}{c}\text { STREAM } \\
\text { LENGTH } \\
\text { (MI) }\end{array}$} & \multirow{2}{*}{$\begin{array}{l}\text { MEAN } \\
\text { BASIN } \\
\text { ELEVA- } \\
\text { TION } \\
\text { (FT) }\end{array}$} & \multirow[b]{2}{*}{$\begin{array}{l}\text { FORESTED } \\
\text { AREA } \\
\text { (PERCENT) }\end{array}$} & \multirow[b]{2}{*}{$\begin{array}{l}\text { SOIL } \\
\text { INDEX }\end{array}$} & \multirow{2}{*}{$\begin{array}{l}\text { MEAN } \\
\text { ANMUAL } \\
\text { PRECIPI- } \\
\text { TATION } \\
\text { (IN) }\end{array}$} & \multicolumn{2}{|c|}{ RAINFALL INTENSITY, 24-HOUR } \\
\hline & & & & & & $\begin{array}{l}\text { 2-YEAR } \\
\text { (IN) }\end{array}$ & $\begin{array}{l}\text { 50-YEAR } \\
\text { (IN) }\end{array}$ \\
\hline 267 & 4.1 & 6,950 & 78.0 & 3.0 & 20.0 & 2.0 & 4.0 \\
\hline
\end{tabular}


09400730 LOCKETT FANNING DIVERSION AT FLAGSTAFF, AZ

LOCATION.-- Lat 35'13'19", long 111'35'58", in NWANEK sec.12, T.21 N., R.7 E., Coconino County, Hydrologic Unit 15020015, at Linda Vista Drive in Flagstaff.

DRAINAGE AREA. $--1.05 \mathrm{mi}^{2}$.

ANNUAL PEAK DISCHARGE

\begin{tabular}{|c|c|c|c|}
\hline $\begin{array}{l}\text { WATER } \\
\text { YEAR }\end{array}$ & DATE & $\begin{array}{l}\text { ANNUAL PEAK } \\
\text { DISCHARGE } \\
\text { (FT } 3 / \mathrm{S})\end{array}$ & $\begin{array}{l}\text { DISCHARGE } \\
\text { CODES }\end{array}$ \\
\hline $\begin{array}{l}1969 \\
1970 \\
1971 \\
1972 \\
1973 \\
1974 \\
1975 \\
1976 \\
1977 \\
1978 \\
1979 \\
1980\end{array}$ & $\begin{array}{l}09-12-69 \\
09-05-70 \\
08-22-71 \\
00-00-72 \\
07-16-73 \\
08-06-74 \\
00-00-75 \\
07-14-76 \\
08-09-77 \\
07-26-78 \\
12-18-78 \\
00-00-80\end{array}$ & $\begin{array}{c}85 \\
65 \\
66 \\
0 \\
17 \\
2.0 \\
0 \\
46 \\
1.0 \\
54 \\
46 \\
0\end{array}$ & $\begin{array}{l}\text { ES } \\
\text { ES }\end{array}$ \\
\hline
\end{tabular}

MAGNITUDE AND PROBABILITY OF INSTANTANEOUS PEAK FLOW BASED ON PERIOD OF RECORD $1969-80$

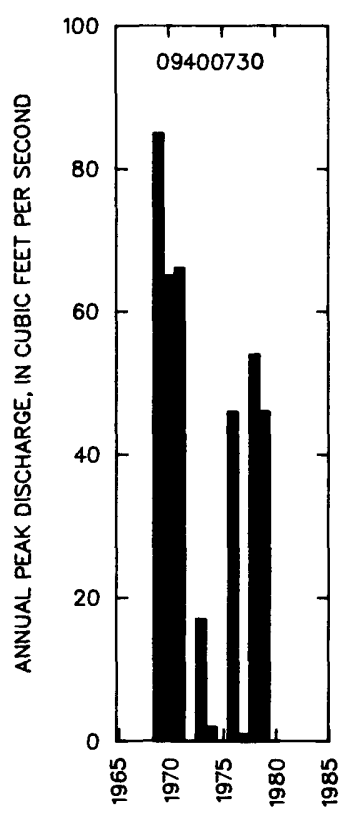

DISCHARGE, IN FT $3 / 5$, FOR INDICATED RECURRENCE INTERVAL

IN YEARS, AND EXCEEDANCE PROBABILITY, IN PERCENT

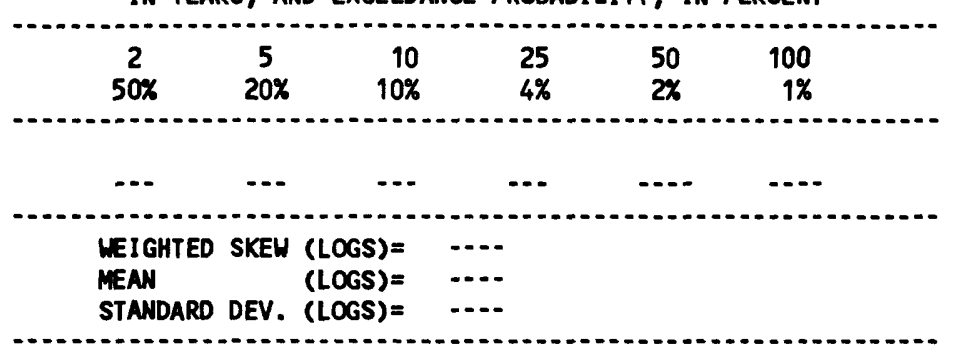

BASIN CHARACTERISTICS

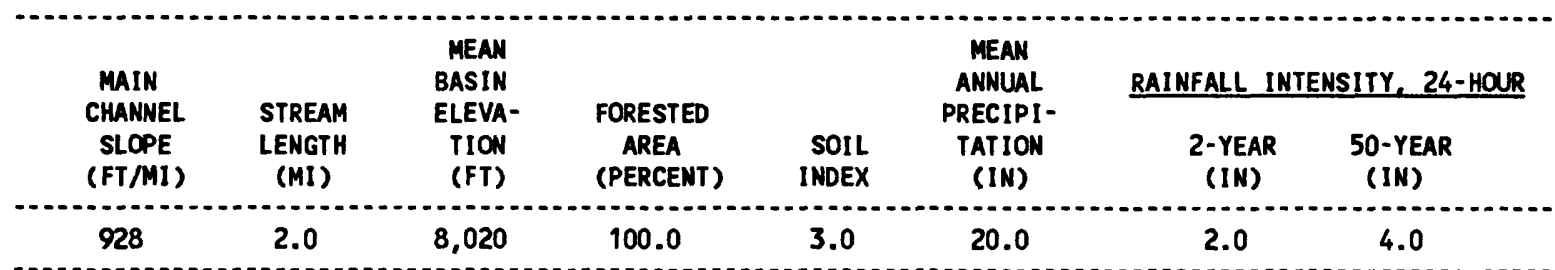


LOCATION.--Lat 35'13'09", Long 111'35'16", in SEKNWK sec.7, T.21 N., R.8 E., Coconino County, Hydrologic Unit 15020015, at Atchison, Topeka, and Santa Fe railroad tracks at the east edge of Flagstaff.

DRAINAGE AREA. $--2.41 \mathrm{mi}^{2}$.

ANNUAL PEAK DISCHARGE

\begin{tabular}{cccc}
$\begin{array}{c}\text { WATER } \\
\text { YEAR }\end{array}$ & DATE & $\begin{array}{c}\text { ANNUAL PEAK } \\
\text { DISCHARGE } \\
\text { (FT 3/S) }\end{array}$ & $\begin{array}{c}\text { DISCHARGE } \\
\text { CODES }\end{array}$ \\
\hline 1969 & $09-12-69$ & 183 & C \\
1970 & $09-05-70$ & 146 & C \\
1971 & $08-19-71$ & 74 & C \\
1972 & $07-24-72$ & 30 & C \\
1973 & $07-00-73$ & 25 & ES,C \\
1974 & $08-06-74$ & 120 & C \\
1975 & $09-00-75$ & 24 & C \\
1976 & $07-13-76$ & 85 & C \\
1977 & $08-09-77$ & 44 & C \\
1978 & $02-28-78$ & 42 & C \\
1979 & $02-17-79$ & 57 & C \\
1980 & $07-00-80$ & 57 & C \\
$\ldots$
\end{tabular}

MAGNI TUDE AND PROBABILITY OF INSTANTANEOUS PEAK FLON BASED ON PERIOD OF RECORD 1969-80

DISCHARGE, IN FT $3 / 5$, FOR INDICATED RECURRENCE INTERVAL IN YEARS, AND EXCEEDANCE PROBABILITY, IN PERCENT

\begin{tabular}{|c|c|c|c|c|c|}
\hline $\begin{array}{r}2 \dagger \\
50 \%\end{array}$ & $\begin{array}{r}5 \nmid \\
20 \%\end{array}$ & $\begin{array}{c}10 \dagger \\
10 \%\end{array}$ & $\begin{array}{l}25 \dagger \\
4 \%\end{array}$ & $\begin{array}{l}50 \dagger \\
2 \%\end{array}$ & $\begin{array}{c}100 \nmid \\
1 \%\end{array}$ \\
\hline 60.2 & 107 & 144 & 198 & 243 & 293 \\
\hline $\begin{array}{l}\text { WEIGHTED } \\
\text { MEAN } \\
\text { STANDARD }\end{array}$ & $\begin{array}{l}\text { SKEW } \\
\text { DEV. }\end{array}$ & $\begin{array}{l}(\text { LOGS })= \\
(\text { LOGS })= \\
(\text { LOGS })=\end{array}$ & $\begin{array}{r}-0.02 \\
1.78 \\
0.30\end{array}$ & & \\
\hline
\end{tabular}

+ Reliability of values in column is uncertain, and potential errors are large.

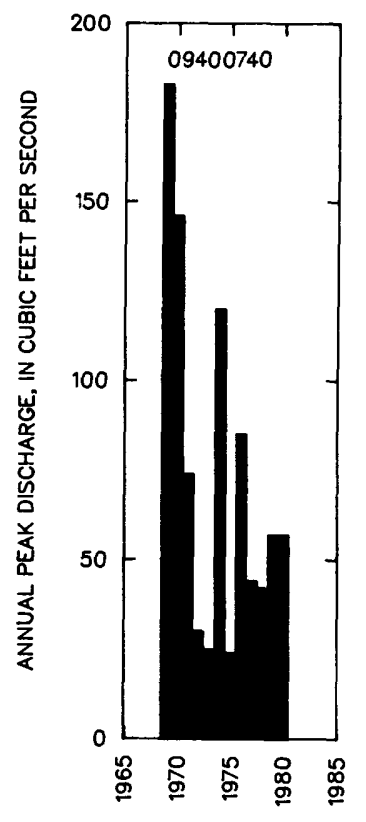

BASIN CHARACTERISTICS

\begin{tabular}{|c|c|c|c|c|c|c|c|}
\hline MAIN & & $\begin{array}{l}\text { MEAN } \\
\text { BASIN }\end{array}$ & & & $\begin{array}{c}\text { MEAN } \\
\text { ANNUAL }\end{array}$ & RAINFALL II & SITY, 24-HOQR \\
\hline $\begin{array}{l}\text { CHANNEL } \\
\text { SLOPE } \\
\text { (FT/MI) }\end{array}$ & $\begin{array}{l}\text { STREAM } \\
\text { LENGTH } \\
\text { (MI) }\end{array}$ & $\begin{array}{l}\text { ELEVA- } \\
\text { TION } \\
\text { (FT) }\end{array}$ & $\begin{array}{l}\text { FORESTED } \\
\text { AREA } \\
\text { (PERCENT) }\end{array}$ & $\begin{array}{l}\text { SOIL } \\
\text { INDEX }\end{array}$ & $\begin{array}{l}\text { PRECIPI - } \\
\text { TATION } \\
\text { (IN) }\end{array}$ & $\begin{array}{c}\text { 2-YEAR } \\
\text { (IN) }\end{array}$ & $\begin{array}{c}\text { 50-YEAR } \\
\text { (IN) }\end{array}$ \\
\hline 594 & 3.1 & 7,570 & 91.0 & 3.0 & 20.1 & 2.0 & 4.0 \\
\hline
\end{tabular}




\section{0 faY CANYON NEAR FLAGSTAFF, AZ}

LOCATION.--Lat 35.08'06", Long 111'37'48", in NW/NWK sec.11, T.20 N., R.7 E., Cococino County, Hydrologic Unit 15020015; at Lake Mary Road within corporate limits of Flagstaff.

DRAIMAGE AREA. $--3.28 \mathrm{mi}^{2}$.

ANWUAL PEAK DISCHARGE

\begin{tabular}{cccc}
$\begin{array}{c}\text { WATER } \\
\text { YEAR }\end{array}$ & DATE & $\begin{array}{c}\text { ANNUAL PEAK } \\
\text { DISCHARGE } \\
\text { (FT } 3 / \text { S })\end{array}$ & $\begin{array}{c}\text { DISCHARGE } \\
\text { CODES }\end{array}$ \\
\hline 1964 & $00-00-64$ & 0.3 & LT \\
1965 & $09-18-65$ & 9.0 & \\
1966 & $12-30-65$ & 87 & \\
1967 & $00-00-67$ & 10 & LT \\
1968 & $04-00-68$ & 4.0 & \\
1969 & $01-25-69$ & 10 & LT \\
1970 & $09-05-70$ & 3.0 & ES \\
1971 & $08-15-71$ & 2.0 & ES \\
1972 & $10-24-71$ & 31 & \\
1973 & $10-00-72$ & 10 & ES \\
1974 & $08-06-74$ & 3.0 & LT \\
1975 & $09-00-75$ & 1.0 & LT \\
1976 & $00-00-76$ & 10 & ES \\
1977 & $08-09-77$ & 18 & \\
1979 & $00-00-79$ & 70 & \\
1980 & $02-19-80$ & 29 &
\end{tabular}

MAGNI TUDE AND PROBABILITY OF INSTANTANEOUS PEAK FLOU BASED ON PERIOD OF RECORD 1964-77, 1979-80

DISCHARGE, IN FT $3 / 5$, FOR INDICATED RECURRENCE INTERVAL IN YEARS, AND EXCEEDANCE PROBABILITY, IN PERCENT

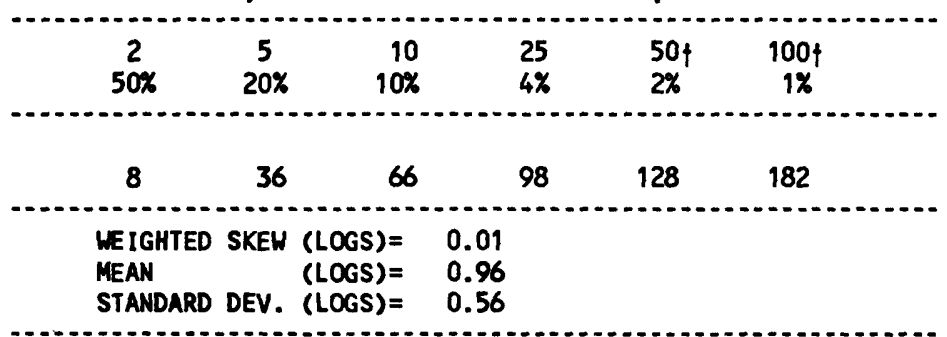

t Reliability of values in column is uncertain, and potential errors are large.

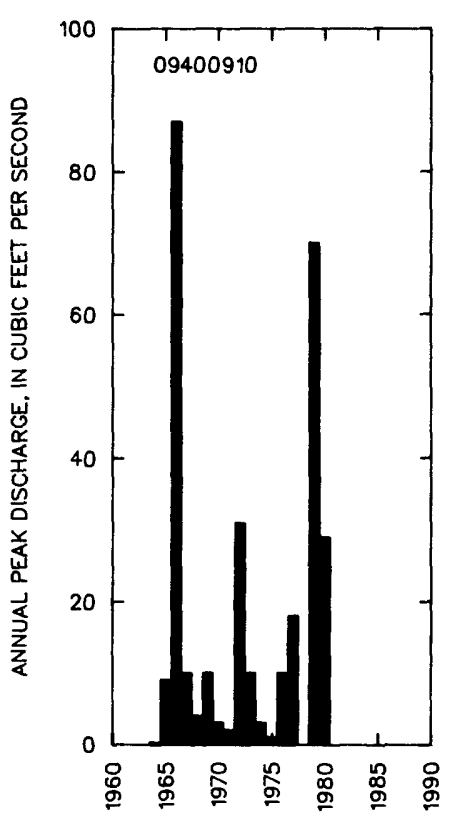

BASIN CHARACTERISTICS

\begin{tabular}{|c|c|c|c|c|c|c|c|}
\hline \multirow{3}{*}{$\begin{array}{l}\text { MAIN } \\
\text { CHANNEL } \\
\text { SLOPE } \\
\text { (FT/MI) }\end{array}$} & \multicolumn{3}{|c|}{ MEAN } & \multicolumn{3}{|c|}{ MEAN } & \multirow[b]{2}{*}{ 24-HOQR } \\
\hline & & BASIN & & & ANNUAL & RAINFALL II & \\
\hline & $\begin{array}{c}\text { STREAM } \\
\text { LENGTH } \\
\text { (MI) }\end{array}$ & $\begin{array}{l}\text { ELEVA- } \\
\text { TION } \\
\text { (FT) }\end{array}$ & $\begin{array}{l}\text { FORESTED } \\
\text { AREA } \\
\text { (PERCENT) }\end{array}$ & $\begin{array}{l}\text { SOIL } \\
\text { INDEX }\end{array}$ & $\begin{array}{l}\text { PRECIPI - } \\
\text { TAT ION } \\
\text { (IN) }\end{array}$ & $\begin{array}{c}\text { 2-YEAR } \\
\text { (IN) }\end{array}$ & $\begin{array}{l}\text { 50-YEAR } \\
\text { (IN) }\end{array}$ \\
\hline 72.2 & 2.4 & 7,000 & 73.0 & 3.0 & 19.6 & 2.1 & 4.1 \\
\hline
\end{tabular}


114

\section{LITTLE COLORADO RIVER BASIN}

09401000 LITTLE COLORADO RIVER AT GRAND FALLS, AZ

LOCATION.--Lat $35^{\circ} 26^{\prime}$, long $111^{\circ} 12^{\prime}$, in T.24 N., R.11 E., Coconino County, Hydrologic Unit 15020016, on left bank 1,000 ft downstream from Grand Falls on Navajo Indian Reservation, 4.5 mi upstream from DInnebito Wash, $30 \mathrm{mi}$ northeast of Flagstaff, and $96 \mathrm{mi}$ upstream from mouth.

DRAINAGE AREA. --21,068 $\mathrm{mi}^{2}$, of which $368 \mathrm{mi}^{2}$ is noncontributing.

REMARKS.--Some regulation by reservoirs on headwaters (combined capacity, about 71,000 acre-ft in 1950, not including Lone Pine Reservoir or Lake Mary).

ANNUAL PEAK DISCHARGE

\begin{tabular}{|c|c|c|c|c|c|c|c|}
\hline \multicolumn{4}{|c|}{ ANNUAL PEAK } & & \multicolumn{3}{|c|}{ ANNUAL PEAK } \\
\hline $\begin{array}{l}\text { WATER } \\
\text { YEAR }\end{array}$ & DATE & $\begin{array}{c}\text { DISCHARGE } \\
\left(\mathrm{FT}^{3} / \mathrm{S}\right)\end{array}$ & $\begin{array}{l}\text { DISCHARGE } \\
\text { COOES }\end{array}$ & $\begin{array}{l}\text { WATER } \\
\text { YEAR }\end{array}$ & DATE & $\begin{array}{c}\text { DISCHARGE } \\
\left(\mathrm{FT}^{3} / \mathrm{S}\right)\end{array}$ & $\begin{array}{l}\text { DISCHARGE } \\
\text { COOES }\end{array}$ \\
\hline $\begin{array}{l}1923 \\
1926 \\
1927 \\
1928 \\
1929 \\
1930 \\
1931 \\
1932 \\
1933 \\
1934 \\
1935 \\
1936 \\
1937 \\
1938 \\
1939 \\
1940 \\
1941 \\
1942 \\
1943\end{array}$ & $\begin{array}{l}09-19-23 \\
09-27-26 \\
06-28-27 \\
02-07-28 \\
04-05-29 \\
07-19-30 \\
08-01-31 \\
02-10-32 \\
09-12-33 \\
10-07-33 \\
04-10-35 \\
08-06-36 \\
02-09-37 \\
03-05-38 \\
04-05-39 \\
07-27-40 \\
03-15-41 \\
10-04-41 \\
09-28-43\end{array}$ & $\begin{array}{r}120,000 \\
27,800 \\
28,800 \\
2,, 140 \\
50,500 \\
13,700 \\
6,530 \\
31,000 \\
7,500 \\
4,920 \\
7,350 \\
5,430 \\
21,800 \\
38,000 \\
6,680 \\
20,100 \\
17,000 \\
8,760 \\
3,900\end{array}$ & HP & $\begin{array}{l}1944 \\
1945 \\
1946 \\
1947 \\
1948 \\
1949 \\
1950 \\
1951 \\
1952 \\
1953 \\
1954 \\
1955 \\
1956 \\
1957 \\
1958 \\
1959 \\
1960 \\
1970 \\
1972\end{array}$ & $\begin{array}{l}09-29-44 \\
08-12-45 \\
09-19-46 \\
08-24-47 \\
10-16-47 \\
08-09-49 \\
07-18-50 \\
08-30-51 \\
01-20-52 \\
07-31-53 \\
03-25-54 \\
06-15-55 \\
08-17-56 \\
01-12-57 \\
08-23-58 \\
08-07-59 \\
11-01-59 \\
09-06-70 \\
10-03-71\end{array}$ & $\begin{array}{r}5,320 \\
4,650 \\
12,900 \\
10,600 \\
12,400 \\
10,400 \\
3,500 \\
10,200 \\
26,100 \\
4,140 \\
7,450 \\
9,020 \\
2,320 \\
8,390 \\
4,560 \\
3,080 \\
7,960 \\
11,400 \\
13,200\end{array}$ & $\begin{array}{l}\text { KR, HP } \\
\text { KR, HP }\end{array}$ \\
\hline
\end{tabular}

$1_{\text {Highest since } 1870 .}$

BASIN CHARACTERISTICS

\begin{tabular}{|c|c|c|c|c|c|c|c|}
\hline \multirow{2}{*}{$\begin{array}{l}\text { MAIN } \\
\text { CHANNEL } \\
\text { SLOPE } \\
\text { (FT/MI) }\end{array}$} & \multirow[b]{2}{*}{$\begin{array}{c}\text { STREAM } \\
\text { LENGTH } \\
\text { (MI) }\end{array}$} & \multirow{2}{*}{$\begin{array}{l}\text { MEAN } \\
\text { BASIN } \\
\text { ELEVA- } \\
\text { TION } \\
\text { (FT) }\end{array}$} & \multirow[b]{2}{*}{$\begin{array}{l}\text { FORESTED } \\
\text { AREA } \\
\text { (PERCENT) }\end{array}$} & \multirow[b]{2}{*}{$\begin{array}{l}\text { SOIL } \\
\text { INDEX }\end{array}$} & \multirow{2}{*}{$\begin{array}{l}\text { MEAN } \\
\text { ANNUAL } \\
\text { PRECIPI- } \\
\text { TATION } \\
\text { (IN) }\end{array}$} & \multicolumn{2}{|c|}{ RAINFALL INTENSITY, 24-HOUR } \\
\hline & & & & & & $\begin{array}{c}\text { 2-YEAR } \\
\text { (IN) }\end{array}$ & $\begin{array}{l}\text { 50-YEAR } \\
\text { (IN) }\end{array}$ \\
\hline 10.5 & 234 & 6,440 & 33.0 & 2.7 & 12.9 & 1.5 & 2.9 \\
\hline
\end{tabular}


09401000 LITTLE COLORADO RIVER AT GRAND FALLS, AZ--Continued

MEAN MONTHLY AND ANMLAL DISCHARGES 1927-49, 1951, 1954-59

\begin{tabular}{|c|c|c|c|c|c|c|}
\hline MONTH & $\begin{array}{l}\operatorname{MAXIMMN} \\
\left(F T^{3} / S\right)\end{array}$ & $\begin{array}{l}\operatorname{MINIMUN} \\
\left(F T^{3} / S\right)\end{array}$ & $\begin{array}{c}\text { MEAN } \\
\left(F T^{3} / S\right)\end{array}$ & $\begin{array}{l}\text { STAN- } \\
\text { DARD } \\
\text { DEVIA- } \\
\text { TION } \\
\text { (FT } 3 / S)\end{array}$ & $\begin{array}{l}\text { COEFFI - } \\
\text { CIENT OF } \\
\text { VARI - } \\
\text { ATION }\end{array}$ & $\begin{array}{c}\text { PERCENT } \\
\text { OF } \\
\text { ANNUAL } \\
\text { RUNOFF }\end{array}$ \\
\hline $\begin{array}{l}\text { OCTOBER } \\
\text { NOVEMBER } \\
\text { DECEMBER } \\
\text { JANUARY } \\
\text { FEBRUARY } \\
\text { MARCH } \\
\text { APRIL } \\
\text { MAY } \\
\text { JUNE } \\
\text { JULY } \\
\text { AUGUST } \\
\text { SEPTEMBER }\end{array}$ & $\begin{array}{r}927 \\
287 \\
468 \\
922 \\
2,670 \\
2,390 \\
2,610 \\
1,410 \\
622 \\
1,580 \\
1,990 \\
1,940\end{array}$ & $\begin{array}{l}0.00 \\
0.00 \\
0.00 \\
0.00 \\
0.00 \\
4.1 \\
8.8 \\
0.00 \\
0.00 \\
0.00 \\
0.00 \\
0.00\end{array}$ & $\begin{array}{r}127 \\
41 \\
34 \\
94 \\
349 \\
647 \\
642 \\
106 \\
34 \\
181 \\
531 \\
337\end{array}$ & $\begin{array}{r}242 \\
75 \\
87 \\
212 \\
643 \\
679 \\
657 \\
265 \\
124 \\
327 \\
487 \\
448\end{array}$ & $\begin{array}{l}1.9 \\
1.8 \\
2.6 \\
2.3 \\
1.8 \\
1.0 \\
1.0 \\
2.5 \\
3.6 \\
1.8 \\
0.92 \\
1.3\end{array}$ & $\begin{array}{r}4.1 \\
1.3 \\
1.1 \\
3.0 \\
11.2 \\
20.7 \\
20.5 \\
3.4 \\
1.1 \\
5.8 \\
17.0 \\
10.8\end{array}$ \\
\hline ANNUAL & 811 & 26 & 260 & 191 & 0.74 & 100 \\
\hline
\end{tabular}

MAGNITLDE AND PROBABILITY OF INSTANTANEOUS PEAK FLOW BASED ON PERICD OF RECORD 1923, 1926-60

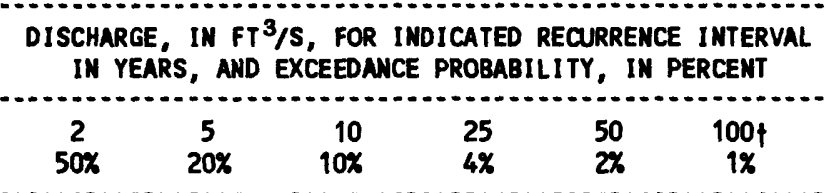

$9,140 \quad 18,700 \quad 28,000 \quad 44,300 \quad 60,400 \quad 80,600$

WEIGHTED SKEW (LOGS) $=0.42$

MEAN (LOGS) $=3.99$

STANDARD DEV. (LOGS) $=0.35$
MAGNITLDE AND PROBABILITY OF ANNUAL LON FLON BASED ON PERIOD OF RECORD 1927-49, 1955-60

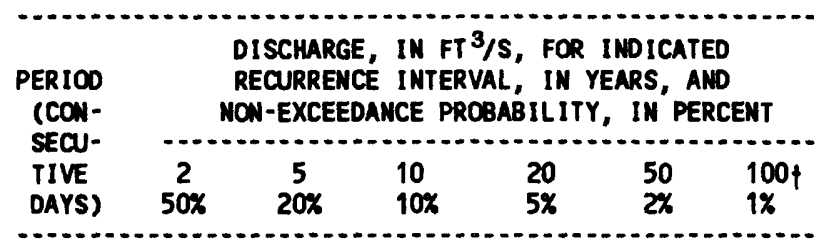

$\begin{array}{rrrrrrrr}1 & & & & & & \\ 3 & & & & & & \\ 7 & & & & & & \\ 14 & & & & & & \\ 30 & & & & & & \\ 60 & 0.00 & 0.00 & 0.00 & 0.00 & 0.00 & 0.00 \\ 90 & 0.62 & 0.00 & 0.00 & 0.00 & 0.00 & 0.00 \\ 120 & 7.0 & 1.2 & 0.00 & 0.00 & 0.00 & 0.00 \\ 183 & 58 & 22 & 13 & 8.1 & 4.7 & 3.3\end{array}$

MAGNITLDE AND PROBABILITY OF ANNUAL HIGH FLON BASED ON PERICD OF RECORD 1927-49, 1951, 1954-59

\begin{tabular}{|c|c|c|c|c|c|c|}
\hline \multirow{2}{*}{$\begin{array}{l}\text { PERICD } \\
\text { (CON- } \\
\text { SECU- } \\
\text { TIVE } \\
\text { DAYS) }\end{array}$} & \multicolumn{6}{|c|}{$\begin{array}{l}\text { DISCHARGE, IN } \mathrm{FT}^{3} / \mathrm{S} \text {, FOR INDICATED } \\
\text { RECURRENCE INTERVAL, IN YEARS, AND } \\
\text { EXCEEDANCE PROBABILITY, IN PERCENT }\end{array}$} \\
\hline & $\begin{array}{c}2 \\
50 \%\end{array}$ & $\begin{array}{c}5 \\
20 \%\end{array}$ & $\begin{array}{l}10 \\
10 \%\end{array}$ & $\begin{array}{l}25 \\
4 \%\end{array}$ & $\begin{array}{l}50 \\
2 \%\end{array}$ & $\begin{array}{c}100 \dagger \\
1 \%\end{array}$ \\
\hline $\begin{array}{l}1 \\
3 \\
7 \\
15 \\
30 \\
60 \\
90\end{array}$ & $\begin{array}{r}5,510 \\
3,950 \\
2,600 \\
1,860 \\
1,250 \\
815 \\
587\end{array}$ & $\begin{array}{r}10,400 \\
7,150 \\
4,310 \\
2,830 \\
1,950 \\
1,390 \\
1,050\end{array}$ & $\begin{array}{r}14,500 \\
9,670 \\
5,420 \\
3,300 \\
2,320 \\
1,770 \\
1,380\end{array}$ & $\begin{array}{r}20,600 \\
13,300 \\
6,750 \\
3,730 \\
2,690 \\
2,250 \\
1,820\end{array}$ & $\begin{array}{r}25,900 \\
16,200 \\
7,680 \\
3,950 \\
2,910 \\
2,580 \\
2,150\end{array}$ & $\begin{array}{r}31,700 \\
19,300 \\
8,560 \\
4,120 \\
3,090 \\
2,910 \\
2,490\end{array}$ \\
\hline
\end{tabular}

DURATION TABLE OF DAILY MEAN FLOW FOR PERIOD OF RECORD 1927-49, 1951, 1954-59

DISCHARGE, IN FT $3 / \mathrm{S}$, WHICH HAS EQUALED OR EXCEEDED FOR INDICATED PERCENT OF TIME

\begin{tabular}{|c|c|c|c|c|c|c|c|c|c|c|c|c|c|c|c|c|}
\hline $1 \%$ & $5 \%$ & $10 \%$ & $15 \%$ & $20 \%$ & $30 \%$ & $40 \%$ & $50 \%$ & $60 \%$ & $70 \%$ & $80 \%$ & $90 \%$ & $95 \%$ & $98 \%$ & $99 \%$ & $99.5 \%$ & $99.9 \%$ \\
\hline 3,530 & 1,440 & 730 & 413 & 229 & 84 & 27 & 9.3 & 1.0 & 0.00 & 0.00 & 0.00 & 0.00 & 0.00 & 0.00 & 0.00 & 0.00 \\
\hline
\end{tabular}

I Reliability of values in column is uncertain, and potential errors are large. 
09401000 LITTLE COLORADO RIVER AT GRAND FALLS, AZ--CONTIMUED
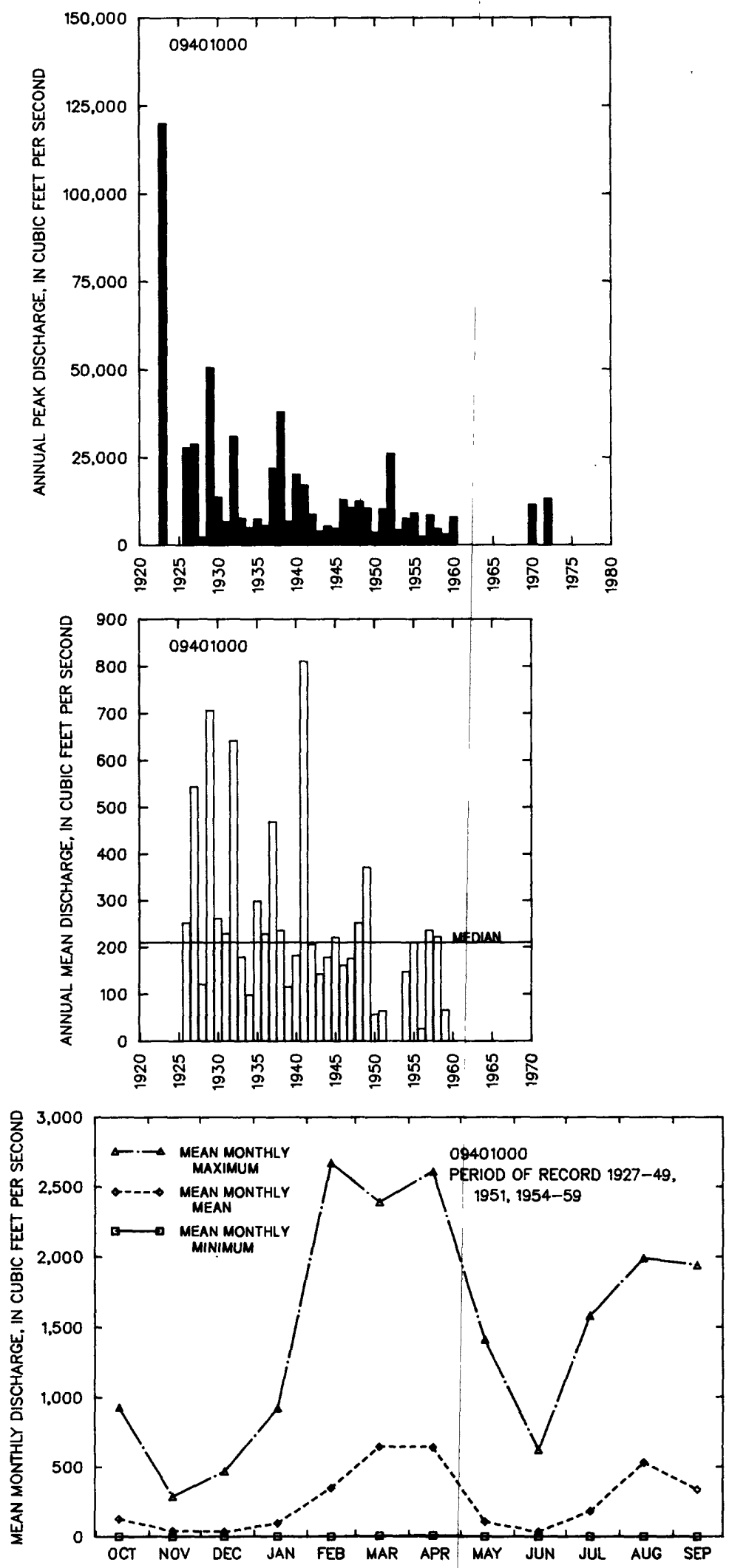
09401210 SLATE MOUNTAIN WASH NEAR FLAGSTAFF, AZ

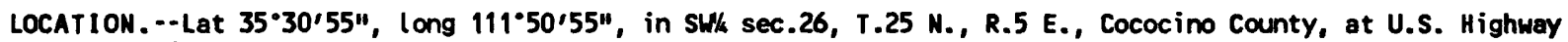
$180,24 \mathrm{mi}$ nor thwest of Flagstaff.

DRAIMAGE AREA. $--5.43 \mathrm{mi}^{2}$.

ANIUAL PEAK DISCHARGE

\begin{tabular}{|c|c|c|c|}
\hline $\begin{array}{l}\text { WATER } \\
\text { YEAR }\end{array}$ & DATE & $\begin{array}{c}\text { ANNUAL PEAK } \\
\text { DISCHARGE } \\
\text { (FT } 3 / \mathrm{S})\end{array}$ & $\begin{array}{l}\text { DISCHARGE } \\
\text { CODES }\end{array}$ \\
\hline $\begin{array}{l}1962 \\
1963 \\
1964 \\
1965 \\
1966 \\
1967 \\
1968 \\
1969 \\
1970 \\
1971 \\
1972 \\
1973 \\
1974 \\
1975\end{array}$ & $\begin{array}{l}00-00-62 \\
00-00-63 \\
00-00-64 \\
10-00-64 \\
12-31-65 \\
00-00-67 \\
00-00-68 \\
08-00-69 \\
00-00-70 \\
00-00-71 \\
06-06-72 \\
04-00-73 \\
00-00-74 \\
00-00-75\end{array}$ & $\begin{array}{l}77 \\
0 \\
0 \\
5.0 \\
37 \\
66 \\
0 \\
1.0 \\
13 \\
0 \\
40 \\
88 \\
0 \\
0\end{array}$ & LT \\
\hline
\end{tabular}

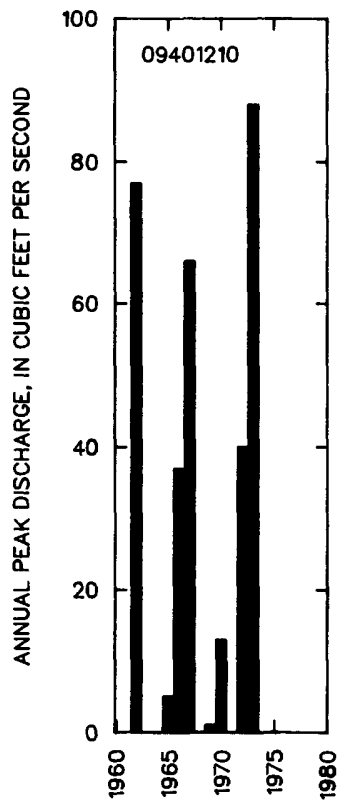

MAGNITUDE AND PROBABILITY OF INSTANTANEOUS PEAK FLON BASED ON PERIOD OF RECORD

DISCHARGE, IN $\mathrm{FT}^{3} / \mathrm{S}$, FOR INDICATED RECURRENCE INTERVAL IN YEARS, AND EXCEEDANCE PROBABILITY, IN PERCENT

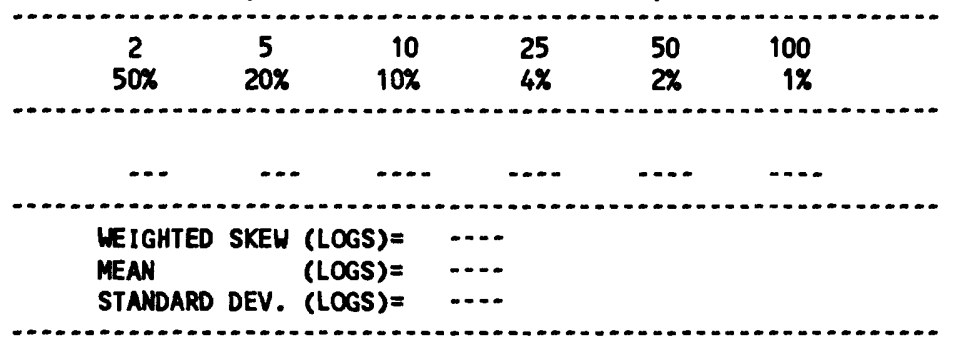

BASIN CHARACTERISTICS

\begin{tabular}{|c|c|c|c|c|c|c|c|}
\hline \multirow{2}{*}{$\begin{array}{l}\text { MAIN } \\
\text { CHANNEL } \\
\text { SLOPE } \\
\text { (FT/MI) }\end{array}$} & \multirow[b]{2}{*}{$\begin{array}{c}\text { STREAM } \\
\text { LENGTH } \\
\text { (MI) }\end{array}$} & \multirow{2}{*}{$\begin{array}{l}\text { MEAN } \\
\text { BASIN } \\
\text { ELEVA- } \\
\text { TION } \\
\text { (FT) }\end{array}$} & \multirow[b]{2}{*}{$\begin{array}{l}\text { FORESTED } \\
\text { AREA } \\
\text { (PERCENT) }\end{array}$} & \multirow[b]{2}{*}{$\begin{array}{l}\text { SOIL } \\
\text { INDEX }\end{array}$} & \multirow{2}{*}{$\begin{array}{l}\text { MEAN } \\
\text { ANNUAL } \\
\text { PRECIPI- } \\
\text { TATION } \\
\text { (IN) }\end{array}$} & \multicolumn{2}{|c|}{ RAINFALL INTENSITY, 24-HOUR } \\
\hline & & & & & & $\begin{array}{c}\text { 2-YEAR } \\
\text { (IN) }\end{array}$ & $\begin{array}{l}\text { 50-YEAR } \\
\text { (IN) }\end{array}$ \\
\hline 46.4 & 9.8 & 7,350 & 60.0 & 3.0 & 19.7 & 2.1 & 3.8 \\
\hline
\end{tabular}


LOCATION.--Lat 35'51'31", long 111'26'32", in NW/AWK sec.33, T.29 N., R.9 E., Coconino County, Hydrologic Unit 15020016 downstream from State Highway 64 at the Tappan Spring, and 1 mi west of the intersection of State Highway 64 and U.S. Highway 89.

DRAINAGE AREA. $--579 \mathrm{mi}^{2}$.

ANNUAL PEAK DISCHARGE

\begin{tabular}{|c|c|c|c|}
\hline $\begin{array}{l}\text { WATER } \\
\text { YEAR }\end{array}$ & DATE & $\begin{array}{l}\text { ANNUAL PEAK } \\
\text { DISCHARGE } \\
\left(\mathrm{FT}^{3} / \mathrm{S}\right)\end{array}$ & $\begin{array}{l}\text { DISCHARGE } \\
\text { CODES }\end{array}$ \\
\hline $\begin{array}{l}1967 \\
1968 \\
1969 \\
1970 \\
1971 \\
1972 \\
1973 \\
1974 \\
1975 \\
1976\end{array}$ & $\begin{array}{l}00-00-67 \\
07-00-68 \\
09-11-69 \\
09-05-70 \\
09-29-71 \\
07-18-72 \\
10-19-72 \\
09-05-74 \\
09-00-75 \\
00-00-76\end{array}$ & $\begin{array}{r}4,400 \\
880 \\
10,400 \\
50 \\
7,900 \\
440 \\
1,950 \\
50 \\
1,490 \\
1,400\end{array}$ & ES \\
\hline
\end{tabular}

MAGNITUDE AND PROBABILITY OF INSTANTANEOUS PEAK FLOH BASED ON PERIOD OF RECORD 1967-76

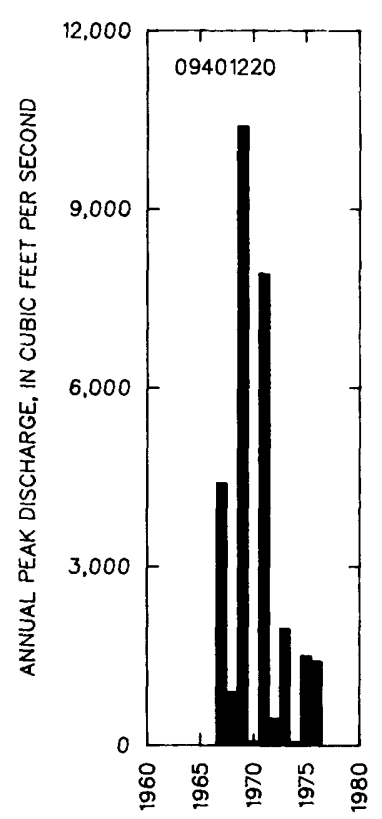

DISCHARGE, IN $\mathrm{FT}^{3} / \mathrm{S}$, FOR INDICATED RECURRENCE INTERVAL IN YEARS, AND EXCEEDANCE PROBABILITY, IN PERCENT

\begin{tabular}{|c|c|c|c|c|c|}
\hline $\begin{array}{c}2 \\
50 \%\end{array}$ & $\begin{array}{c}5 \\
20 \%\end{array}$ & $\begin{array}{r}10 \\
10 \%\end{array}$ & $\begin{array}{l}25 \dagger \\
4 \%\end{array}$ & $\begin{array}{l}50 \dagger \\
2 \%\end{array}$ & $\begin{array}{c}100 \dagger \\
1 \%\end{array}$ \\
\hline 1,510 & 4,550 & 8,040 & 14,600 & 21,400 & 30,200 \\
\hline $\begin{array}{l}\text { WEIGHTED } \\
\text { MEAN } \\
\text { STANDARD }\end{array}$ & $\begin{array}{l}\text { SKEW } \\
\text { DEV. }\end{array}$ & $\begin{array}{l}\text { OGS) }= \\
\text { OGS) }= \\
\text { OGS) }=\end{array}$ & $\begin{array}{r}-0.08 \\
3.17 \\
0.58\end{array}$ & & \\
\hline
\end{tabular}

$\uparrow$ Reliability of values in column is uncertain, and potential errors are large.

BASIN CHARACTERISTICS

\begin{tabular}{|c|c|c|c|c|c|c|c|}
\hline MAIN & & $\begin{array}{r}\text { MEAN } \\
\text { BASIN }\end{array}$ & & & $\begin{array}{c}\text { MEAN } \\
\text { ANNUAL }\end{array}$ & RAINFALL I & SITY, 24-HOUR \\
\hline $\begin{array}{l}\text { CHANNEL } \\
\text { SLOPE } \\
\text { (FT/MI) }\end{array}$ & $\begin{array}{c}\text { STREAM } \\
\text { LENGTH } \\
\text { (MI) }\end{array}$ & $\begin{array}{l}\text { ELEVA- } \\
\text { TION } \\
\text { (FT) }\end{array}$ & $\begin{array}{l}\text { FORESTED } \\
\text { AREA } \\
\text { (PERCENT) }\end{array}$ & $\begin{array}{c}\text { SOIL } \\
\text { INDEX }\end{array}$ & $\begin{array}{l}\text { PRECIPI- } \\
\text { TATION } \\
\text { (IN) }\end{array}$ & $\begin{array}{c}\text { 2-YEAR } \\
\text { (IN) }\end{array}$ & $\begin{array}{l}\text { 50-YEAR } \\
\text { (IN) }\end{array}$ \\
\hline 123 & 32.4 & 6,430 & 37.0 & 3.0 & 13.7 & 1.7 & 3.1 \\
\hline
\end{tabular}


09401245 KLETHLA VALLEY TRIBUTARY MEAR KAYENTA, AZ

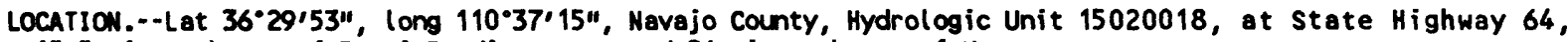
$15.5 \mathrm{mi}$ southwest of Tsegi Trading Post, and $26 \mathrm{mi}$ southwest of Kayenta.

DRAINAGE AREA. $--0.79 \mathrm{mi}^{2}$.

ANMUAL PEAK DISCHARGE

\begin{tabular}{cccc}
$\begin{array}{c}\text { WATER } \\
\text { YEAR }\end{array}$ & DATE & $\begin{array}{c}\text { ANNUAL PEAK } \\
\text { DISCHARGE } \\
\text { (FT } 3 / \text { S) }\end{array}$ & $\begin{array}{c}\text { DISCHARGE } \\
\text { CODES }\end{array}$ \\
\hline 1962 & $00-00-62$ & 175 & \\
1963 & $08-06-63$ & 109 & \\
1964 & $08-00-64$ & 128 & \\
1965 & $00-00-65$ & 23 & \\
1966 & $11-23-65$ & 12 & LT \\
1967 & $07-30-67$ & 80 & \\
1968 & $07-25-68$ & 195 & \\
1969 & $09-00-69$ & 94 & \\
1970 & $09-05-70$ & 137 & \\
1971 & $08-00-71$ & 290 & \\
1972 & $09-02-72$ & 250 & \\
1973 & $10-00-72$ & 225 & \\
1974 & $07-22-74$ & 114 & \\
1975 & $07-11-75$ & 57 & \\
1976 & $00-00-76$ & 0.3 & ES \\
$\ldots$
\end{tabular}

MAGNITUDE AND PROBABILITY OF INSTANTANEOUS PEAK FLON BASED ON PERIOD OF RECORD 1962-76

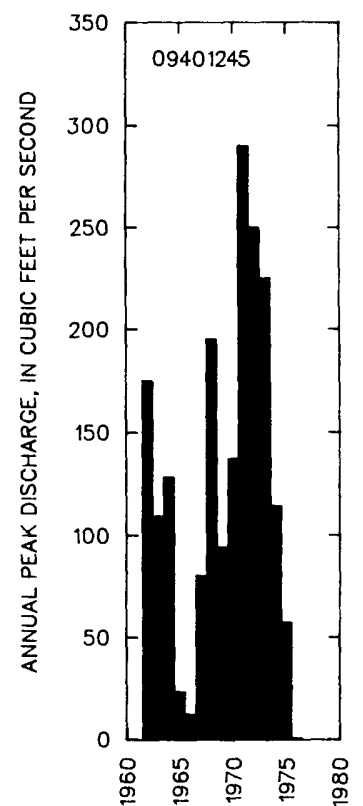

DISCHARGE, IN FT $3 / S$, FOR INDICATED RECURRENCE INTERVAL IN YEARS, AND EXCEEDANCE PROBABILITY, IN PERCENT

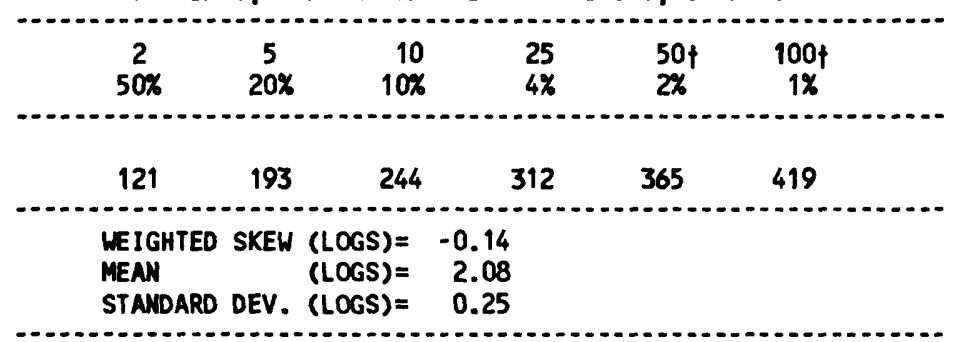

f Reliability of values in column is uncertain, and potential errors are large.

BASIN CHARACTERISTICS

\begin{tabular}{|c|c|c|c|c|c|c|c|}
\hline \multirow{2}{*}{$\begin{array}{l}\text { MAIN } \\
\text { CHANNEL } \\
\text { SLOPE } \\
\text { (FT/MI) }\end{array}$} & \multirow[b]{2}{*}{$\begin{array}{l}\text { STREAM } \\
\text { LENGTH } \\
\text { (MI) }\end{array}$} & \multirow{2}{*}{$\begin{array}{l}\text { MEAN } \\
\text { BASIN } \\
\text { ELEVA- } \\
\text { TION } \\
\text { (FT) }\end{array}$} & \multirow[b]{2}{*}{$\begin{array}{l}\text { FORESTED } \\
\text { AREA } \\
\text { (PERCENT) }\end{array}$} & \multirow[b]{2}{*}{$\begin{array}{l}\text { SOIL } \\
\text { INDEX }\end{array}$} & \multirow{2}{*}{$\begin{array}{l}\text { MEAN } \\
\text { ANNUAL } \\
\text { PRECIPI- } \\
\text { TATION } \\
\text { (IN) }\end{array}$} & \multicolumn{2}{|c|}{ RAINFALL INTENSITY, 24-HOUR } \\
\hline & & & & & & $\begin{array}{c}\text { 2-YEAR } \\
\text { (IN) }\end{array}$ & $\begin{array}{l}\text { 50-YEAR } \\
\text { (IN) }\end{array}$ \\
\hline 87.7 & 2.3 & 6,730 & 21.0 & 3.0 & 10.2 & 1.3 & 2.8 \\
\hline
\end{tabular}




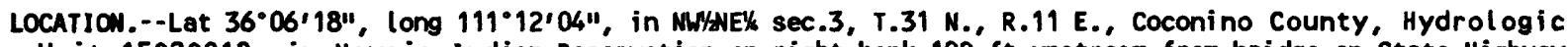
Unit 15020018, in Navajo Indian Reservation on right bank $100 \mathrm{ft}$ upstream from bridge on State Highway 264, $1.3 \mathrm{mi}$ southeast of Moenkopi, $2.5 \mathrm{mi}$ downstream from former gaging station 09401250, and 12.5 $\mathrm{mi}$ dounstream from Begashibito Wash.

DRAINACE AREA.--1,629 $\mathrm{mi}^{2}$, including all closed basins entirely within the drainage area.

ANNUAL PEAK DISCHARGE

\begin{tabular}{|c|c|c|}
\hline $\begin{array}{l}\text { WATER } \\
\text { YEAR }\end{array}$ & DATE & $\begin{array}{l}\text { ANNUAL PEAK } \\
\text { DISCHARGE } \\
\left(\mathrm{FT}^{3} / \mathrm{S}\right)\end{array}$ \\
\hline $\begin{array}{l}1974 \\
1975 \\
1976 \\
1977 \\
1978 \\
1979 \\
1980 \\
1981 \\
1982 \\
1983 \\
1984 \\
1985 \\
1986 \\
1987 \\
1988 \\
1989\end{array}$ & $\begin{array}{l}07-19-74 \\
09-13-75 \\
09-25-76 \\
07-21-77 \\
09-25-78 \\
11-12-78 \\
09-10-80 \\
07-14-81 \\
10-02-81 \\
09-30-83 \\
08-18-84 \\
09-12-85 \\
09-09-86 \\
08-24-87 \\
08-27-88 \\
08-01-89\end{array}$ & $\begin{array}{r}2,340 \\
2,380 \\
5,420 \\
4,120 \\
262 \\
330 \\
1,740 \\
4,640 \\
8,010 \\
10,100 \\
9,030 \\
520 \\
7,970 \\
3,990 \\
7,280 \\
3,380\end{array}$ \\
\hline
\end{tabular}

BASIN CHARACTERISTICS

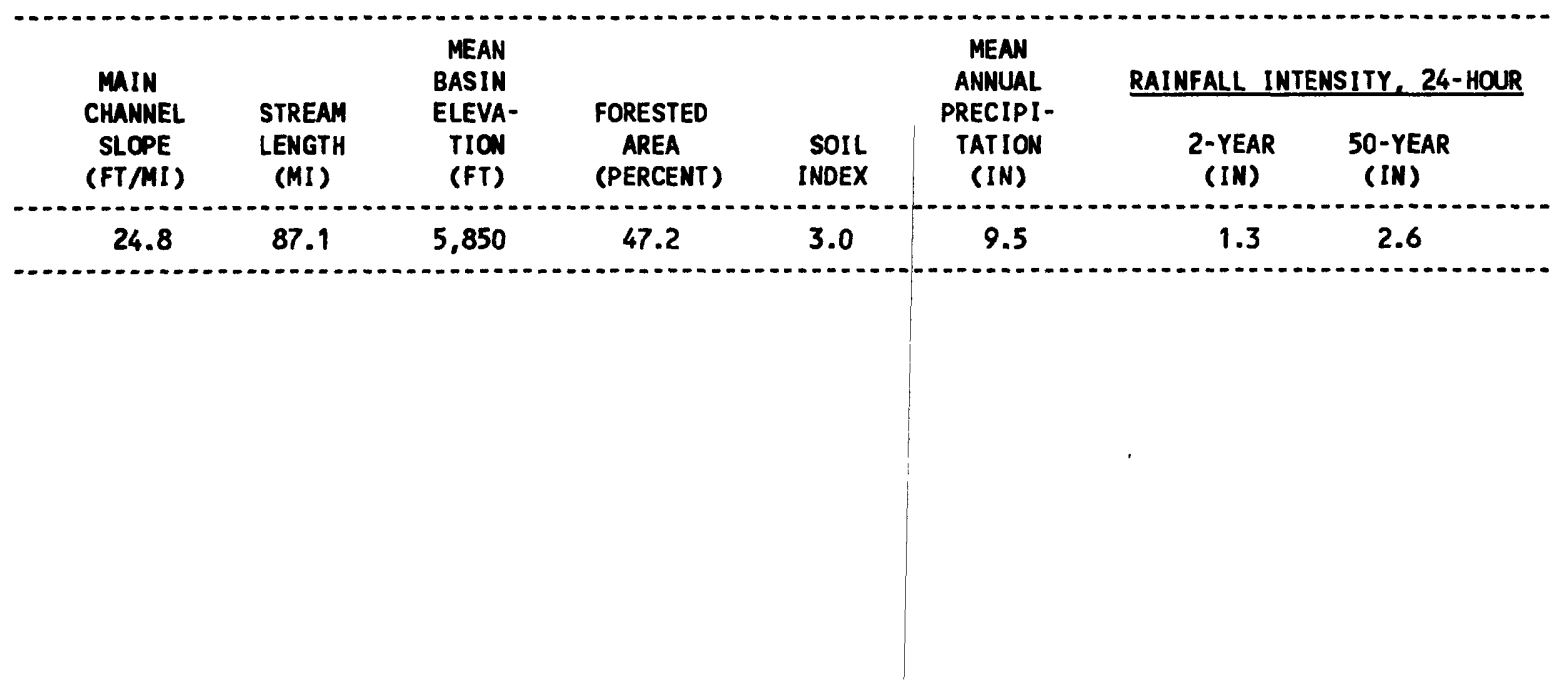


09401260 MOENKOPI MASH AT MOENKOPI, AZ--Continued

MEAN MONTHLY AMD ANMUAL DISCHARGES $1977-89$

\begin{tabular}{|c|c|c|c|c|c|c|}
\hline MONTH & $\begin{array}{l}\operatorname{MAXIMUM} \\
\left(F T^{3} / S\right)\end{array}$ & $\begin{array}{l}\text { MINIMMN } \\
\left(F T^{3} / S\right)\end{array}$ & $\begin{array}{c}\text { MEAN } \\
\left(F T^{3} / S\right)\end{array}$ & $\begin{array}{l}\text { STAN- } \\
\text { DARD } \\
\text { DEVIA- } \\
\text { TION } \\
\left(F^{3} / S\right)\end{array}$ & $\begin{array}{l}\text { COEFF I- } \\
\text { CIENT OF } \\
\text { VARI - } \\
\text { ATION }\end{array}$ & $\begin{array}{c}\text { PERCENT } \\
\text { OF } \\
\text { ANNUAL } \\
\text { RUNOFF }\end{array}$ \\
\hline $\begin{array}{l}\text { OCTOBER } \\
\text { MOVEMBER } \\
\text { DECEMBER } \\
\text { JANUARY } \\
\text { FEBRUARY } \\
\text { MARCH } \\
\text { APRIL } \\
\text { MAY } \\
\text { JUNE } \\
\text { JULY } \\
\text { AUGUST } \\
\text { SEPTEMBER }\end{array}$ & $\begin{array}{c}82 \\
71 \\
14 \\
9.2 \\
29 \\
10 \\
8.5 \\
11 \\
11 \\
92 \\
129 \\
134\end{array}$ & $\begin{array}{l}0.25 \\
1.1 \\
0.62 \\
2.0 \\
2.2 \\
2.0 \\
1.0 \\
0.31 \\
0.00 \\
0.00 \\
0.00 \\
0.00\end{array}$ & $\begin{array}{l}11 \\
9.9 \\
4.1 \\
4.3 \\
7.4 \\
3.8 \\
2.5 \\
1.9 \\
0.90 \\
17 \\
34 \\
32\end{array}$ & $\begin{array}{l}22 \\
19 \\
3.2 \\
2.1 \\
8.0 \\
2.2 \\
1.9 \\
2.7 \\
2.9 \\
28 \\
37 \\
38\end{array}$ & $\begin{array}{l}2.0 \\
1.9 \\
0.78 \\
0.48 \\
1.1 \\
0.57 \\
0.76 \\
1.4 \\
3.3 \\
1.6 \\
1.1 \\
1.2\end{array}$ & $\begin{array}{r}8.5 \\
7.7 \\
3.2 \\
3.4 \\
5.8 \\
3.0 \\
1.9 \\
1.5 \\
0.7 \\
13.4 \\
26.4 \\
24.7\end{array}$ \\
\hline ANNUAL & 19 & 2.2 & 11 & 6.0 & 0.56 & 100 \\
\hline
\end{tabular}

MAGMITUDE AND PROBABILITY OF INSTANTANEOUS PEAK FLON BASED ON PERIOD OF RECORD 1974-89

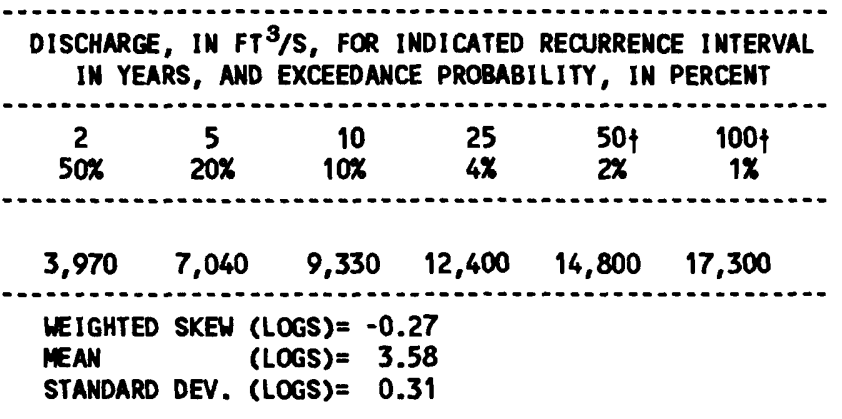

MAGNITUDE AND PROBABILITY OF ANMUAL LON FLON BASED ON PERIOD OF RECORD 1978-89

\begin{tabular}{|c|c|c|c|c|c|c|}
\hline \multirow{2}{*}{$\begin{array}{l}\text { PERIOD } \\
\text { (CON- } \\
\text { SECU- } \\
\text { TIVE } \\
\text { DAYS) }\end{array}$} & \multicolumn{6}{|c|}{$\begin{array}{l}\text { DISCHARGE, IN FT } 3 / S \text {, FOR INDICATED } \\
\text { RECURRENCE INTERVAL, IN YEARS, AND } \\
\text { NON-EXCEEDANCE PROBABILITY, IN PERCENT }\end{array}$} \\
\hline & $\begin{array}{c}2 \\
50 \%\end{array}$ & $\begin{array}{c}5 \\
20 \%\end{array}$ & $\begin{array}{l}10 \\
10 \%\end{array}$ & $\begin{array}{l}20 \\
5 \%\end{array}$ & $\begin{array}{l}50 \dagger \\
2 \%\end{array}$ & $\begin{array}{l}100 \nmid \\
1 \%\end{array}$ \\
\hline $\begin{array}{r}1 \\
3 \\
7 \\
14\end{array}$ & & & & & & \\
\hline $\begin{array}{r}30 \\
60 \\
90 \\
120 \\
183\end{array}$ & $\begin{array}{l}0.00 \\
0.00 \\
0.67 \\
1.8 \\
3.5\end{array}$ & $\begin{array}{l}0.00 \\
0.00 \\
0.39 \\
0.77 \\
1.6\end{array}$ & $\begin{array}{l}0.00 \\
0.00 \\
0.30 \\
0.44 \\
1.0\end{array}$ & $\begin{array}{l}0.00 \\
0.00 \\
0.24 \\
0.27 \\
0.72\end{array}$ & $\begin{array}{l}0.00 \\
0.00 \\
0.19 \\
0.15 \\
0.49\end{array}$ & $\begin{array}{l}0.00 \\
0.00 \\
0.16 \\
0.09 \\
0.38\end{array}$ \\
\hline
\end{tabular}

MAGNITLDE AND PROBABILITY OF ANMUAL HIGH FLOH BASED ON PERIOD OF RECORD 1977-89

\begin{tabular}{|c|c|c|c|c|c|c|}
\hline \multirow{2}{*}{$\begin{array}{l}\text { PERIOD } \\
\text { (CON- } \\
\text { SECU- } \\
\text { TIVE } \\
\text { DAYS) }\end{array}$} & \multicolumn{6}{|c|}{$\begin{array}{l}\text { DISCHARGE, IN } \mathrm{FT}^{3} / \mathrm{S} \text {, FOR INDICATED } \\
\text { RECURRENCE INTERVAL, IN YEARS, AND } \\
\text { EXCEEDANCE PROBABILITY, IN PERCEWT }\end{array}$} \\
\hline & $\begin{array}{c}2 \\
50 \%\end{array}$ & $\begin{array}{c}5 \\
20 \%\end{array}$ & $\begin{array}{l}10 \\
10 \%\end{array}$ & $\begin{array}{l}25 \\
4 \%\end{array}$ & $\begin{array}{l}50 f \\
2 x\end{array}$ & $\begin{array}{c}100\} \\
1 \%\end{array}$ \\
\hline $\begin{array}{r}1 \\
3 \\
7 \\
15 \\
30 \\
60 \\
90\end{array}$ & $\begin{array}{r}766 \\
406 \\
198 \\
104 \\
61 \\
34 \\
25\end{array}$ & $\begin{array}{r}1,830 \\
844 \\
397 \\
209 \\
114 \\
66 \\
48\end{array}$ & $\begin{array}{r}2,750 \\
1,140 \\
521 \\
276 \\
145 \\
89 \\
64\end{array}$ & $\begin{array}{r}4,080 \\
1,480 \\
653 \\
351 \\
179 \\
117 \\
83\end{array}$ & $\begin{array}{r}5,170 \\
1,710 \\
734 \\
398 \\
199 \\
138 \\
98\end{array}$ & $\begin{array}{r}6,310 \\
1,910 \\
800 \\
438 \\
215 \\
158 \\
111\end{array}$ \\
\hline
\end{tabular}

DURATION TABLE OF DAILY MEAN FLOU FOR PERIOD OF RECORD 1977-89

DISCHARGE, IN $\mathrm{FT}^{3} / \mathrm{S}$, WHICH WAS EQUALED OR EXCEEDED FOR INDICATED PERCENT OF TIME

\begin{tabular}{|c|c|c|c|c|c|c|c|c|c|c|c|c|c|c|c|c|}
\hline $1 \%$ & $5 \%$ & $10 \%$ & $15 \%$ & $20 \%$ & $30 \%$ & $40 \%$ & $50 \%$ & $60 \%$ & $70 x$ & $80 \%$ & $90 \%$ & $95 \%$ & $98 \%$ & $99 \%$ & $99.5 \%$ & $99.9 x$ \\
\hline 173 & 20 & 8.0 & 5.3 & 4.3 & 3.2 & 2.5 & 2.1 & 1.5 & 0.77 & 0.12 & 0.00 & 0.00 & 0.00 & 0.00 & 0.00 & 0.00 \\
\hline
\end{tabular}

$\uparrow$ Reliability of values in column is uncertain, and potential errors are large. 
09401260 MOENKOPI WASH AT MOENKOPI, AZ--CONTINUED
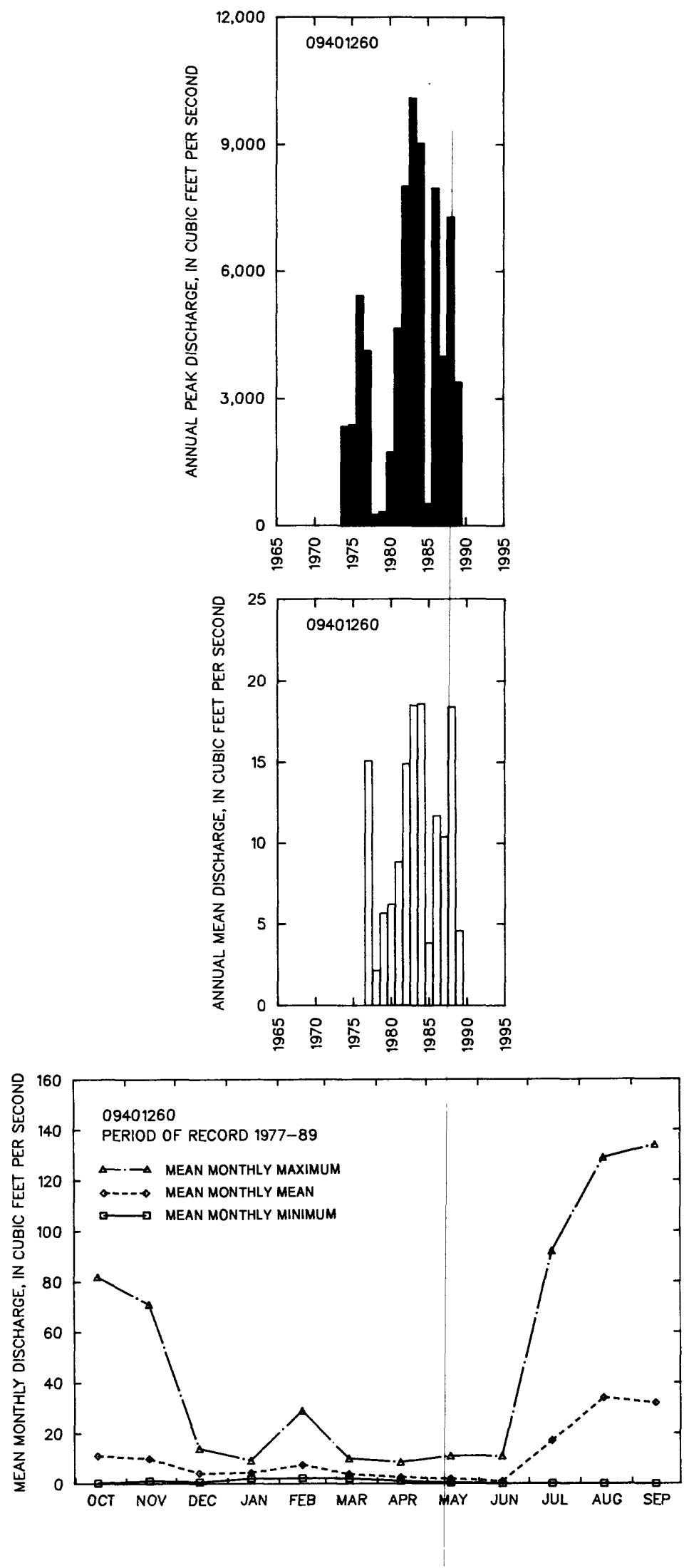
09401300 HAMBLIN WASH TRIBUTARY NEAR CEDAR RIDGE, AZ

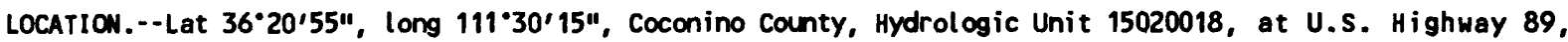
$3.3 \mathrm{mi}$ south of Cedar Ridge.

DRAINAGE AREA. $--0.10 \mathrm{mi}^{2}$.

ANNUAL PEAK DISCHARGE

\begin{tabular}{cccc}
$\begin{array}{c}\text { WATER } \\
\text { YEAR }\end{array}$ & DATE & $\begin{array}{c}\text { ANNUAL PEAK } \\
\text { DISCHARGE } \\
\text { (FT } 3 / \text { S) }\end{array}$ & $\begin{array}{c}\text { DISCHARGE } \\
\text { CODES }\end{array}$ \\
\hline 1963 & $09-07-63$ & 21 & \\
1964 & $00-00-64$ & 0.3 & ES \\
1965 & $00-00-65$ & 1.0 & LT \\
1966 & $07-30-66$ & 15 & \\
1967 & $09-25-67$ & 26 & \\
1968 & $00-00-68$ & 0 & \\
1969 & $09-11-69$ & 25 & \\
1970 & $00-00-70$ & 0 & \\
1971 & $00-00-71$ & 0 & \\
1972 & $00-00-72$ & 0 & \\
1973 & $10-19-72$ & 37 & \\
1974 & $00-00-74$ & 0 & \\
1975 & $09-08-75$ & 12 & \\
1976 & $00-00-76$ & 110 & \\
$\ldots$ & &
\end{tabular}

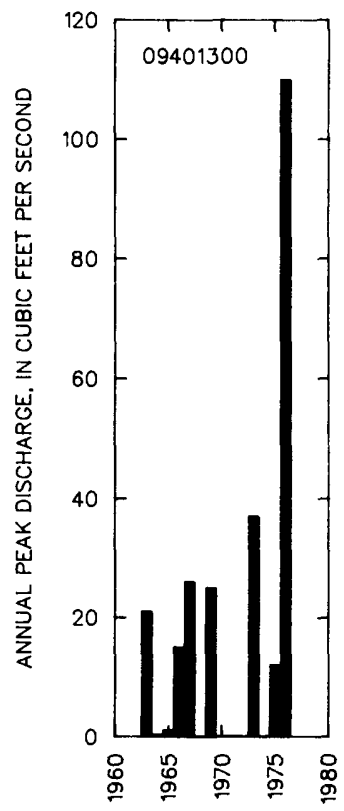

MAGNITUDE AND PROBABILITY OF INSTANTANEOUS PEAK FLON BASED ON PERIOD OF RECORD 1963-76

DISCHARGE, IN FT $3 / 5$, FOR INDICATED RECURRENCE INTERVAL

IN YEARS, AND EXCEEDANCE PROBABILITY, IN PERCENT

\begin{tabular}{|c|c|c|c|c|c|}
\hline $\begin{array}{r}2 \dagger \\
50 \%\end{array}$ & $\begin{array}{r}5 \dagger \\
20 \%\end{array}$ & $\begin{array}{r}10 \\
10 \%\end{array}$ & $\begin{array}{l}25 \dagger \\
4 \%\end{array}$ & $\begin{array}{l}50 \dagger \\
2 \%\end{array}$ & $\begin{array}{c}100 \dagger \\
1 \%\end{array}$ \\
\hline 1.7 & 37.3 & 156 & 638 & 1,480 & 3,040 \\
\hline $\begin{array}{l}\text { WEIGHTED } \\
\text { MEAN } \\
\text { STANDARD }\end{array}$ & $\begin{array}{l}\text { SKEW } \\
\text { DEV. }\end{array}$ & $\begin{array}{l}(\text { LOGS })= \\
(\text { LOGS) }= \\
(\text { LOGS }=\end{array}$ & $\begin{array}{r}-0.48 \\
0.11 \\
1.71\end{array}$ & & \\
\hline
\end{tabular}

$\uparrow$ Reliability of values in column is uncertain, and potential errors are large.

BASIN CHARACTERISTICS

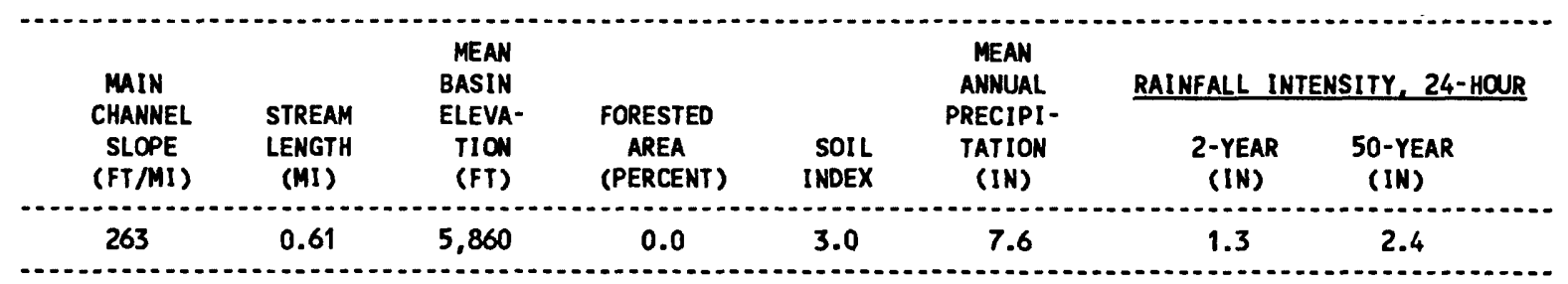


LOCATION.--Lat 36'03'20", Long 111'23'35", Coconino County, Hydrologic Unit 15020018, at U.S. Highway 89, 10 mi west of Tuba City.

DRAIMAGE AREA. $--2.16 \mathrm{mi}^{2}$.

ANNUAL PEAK DISCHARGE

\begin{tabular}{cccc}
$\begin{array}{c}\text { HATER } \\
\text { YEAR }\end{array}$ & DATE & $\begin{array}{c}\text { ANNUAL PEAK } \\
\text { DISCHARGE } \\
\text { (FT } 3 / \text { S })\end{array}$ & $\begin{array}{c}\text { DISCHARGE } \\
\text { CODES }\end{array}$ \\
\hline 1963 & $00-00-63$ & 10 & LT \\
1964 & $00-00-64$ & 268 & \\
1965 & $00-00-65$ & 0 & \\
1966 & $10-16-65$ & 7.0 & ES \\
1967 & $12-06-66$ & 0.5 & ES \\
1968 & $08-07-68$ & 285 & \\
1969 & $09-11-69$ & 5.0 & LT \\
1970 & $10-21-69$ & 5.0 & LT \\
1971 & $07-00-71$ & 14 & ES \\
1972 & $07-18-72$ & 5.0 & LT \\
1973 & $10-19-72$ & 350 & \\
1974 & $00-00-74$ & 0 & \\
1975 & $09-00-75$ & 7.0 & ES \\
$\ldots$ & & &
\end{tabular}

Magnitude AND PROBABILITY OF INSTANTANEOUS PEAK FLON BASED ON PERIOD OF RECORD

DISCHARGE, IN $\mathrm{FT}^{3} / \mathrm{S}$, FOR INDICATED RECURRENCE INTERVAL IN YEARS, AND EXCEEDANCE PROBABILITY, IN PERCENT

\begin{tabular}{|c|c|c|c|c|c|}
\hline $\begin{array}{c}2 \\
50 \%\end{array}$ & $\begin{array}{c}5 \\
20 \%\end{array}$ & $\begin{array}{r}10 \\
10 \%\end{array}$ & $\begin{array}{l}25 \\
4 \%\end{array}$ & $\begin{array}{l}50 \\
2 \%\end{array}$ & $\begin{array}{r}100 \\
1 \%\end{array}$ \\
\hline -. & $\cdots$ & -... & $\cdots$ & .... & $\ldots$ \\
\hline $\begin{array}{l}\text { WEIGHTED } \\
\text { MEAN } \\
\text { STANDARD }\end{array}$ & $\begin{array}{l}\text { SKEH } \\
\text { DEV. }\end{array}$ & $\begin{array}{l}(\text { LOGS })= \\
(\text { LOGS })= \\
(\text { LOGS })=\end{array}$ & $\ldots$ & & \\
\hline
\end{tabular}

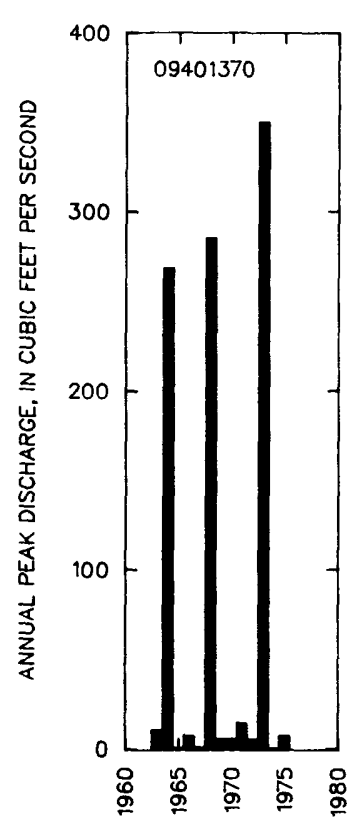

BASIN CHARACTERISTICS

\begin{tabular}{|c|c|c|c|c|c|c|c|}
\hline \multicolumn{8}{|c|}{ BASIN CHARACTERISTICS } \\
\hline MAIN & & $\begin{array}{r}\text { MEAN } \\
\text { BASIN }\end{array}$ & & & $\begin{array}{l}\text { MEAN } \\
\text { ANNUAL }\end{array}$ & RAINFALL I & SITY, 24-HOUR \\
\hline $\begin{array}{l}\text { CHANNEL } \\
\text { SLOPE } \\
\text { (FT/MI) }\end{array}$ & $\begin{array}{l}\text { STREAM } \\
\text { LENGTH } \\
\text { (MI) }\end{array}$ & $\begin{array}{l}\text { ELEVA- } \\
\text { TION } \\
\text { (FT) }\end{array}$ & $\begin{array}{l}\text { FORESTED } \\
\text { AREA } \\
\text { (PERCENT) }\end{array}$ & $\begin{array}{l}\text { SOIL } \\
\text { INDEXX }\end{array}$ & $\begin{array}{l}\text { PRECIPI - } \\
\text { TATION } \\
\text { (IN) }\end{array}$ & $\begin{array}{l}\text { 2-YEAR } \\
\text { (IN) }\end{array}$ & $\begin{array}{c}\text { 50-YEAR } \\
\text { (IN) }\end{array}$ \\
\hline 348 & 2.3 & 4,670 & 0.0 & 3.0 & 6.0 & 1.2 & 2.5 \\
\hline
\end{tabular}


09401400 MOENKOPI WASH MEAR TUBA CITY, AZ

LOCATION.--Lat 36.01'25", long $111^{\circ} 23^{\prime} 48^{\prime \prime}$, in sec.35, T.31 N., R.9 E. (unsurveyed), Coconino County, Hydrologic Unit 15020018, on Navajo Indian Reservation, on downstream side of bridge on U.S. Highway 89, 3,500 ft downstream from Hambl in Wash, $11 \mathrm{mi}$ upstream from mouth, and 12 mi southwest of Tuba City.

DRAINAGE AREA. $--2,492 \mathrm{mi}^{2}$, including all closed basins entirely with in the drainage area.

REMARKS.--Diversions above station for irrigation of about 500 acres.

ANNUAL PEAK DISCHARGE

\begin{tabular}{|c|c|c|c|c|c|}
\hline $\begin{array}{l}\text { WATER } \\
\text { YEAR }\end{array}$ & DATE & $\begin{array}{l}\text { ANNUAL PEAK } \\
\text { DISCHARGE } \\
\text { (FT } 3 / S \text { ) }\end{array}$ & $\begin{array}{l}\text { WATER } \\
\text { YEAR }\end{array}$ & DATE & $\begin{array}{l}\text { ANNUAL PEAK } \\
\text { DISCHARGE } \\
\text { (FT } 3 / \mathrm{S})\end{array}$ \\
\hline $\begin{array}{l}1941 \\
1942 \\
1943 \\
1944 \\
1945 \\
1946 \\
1947 \\
1948 \\
1949 \\
1950 \\
1951 \\
1952 \\
1953 \\
1965\end{array}$ & $\begin{array}{l}08-16-41 \\
10-13-41 \\
08-17-43 \\
09-27-44 \\
08-01-45 \\
08-12-46 \\
08-17-47 \\
10-13-47 \\
08-09-49 \\
07-25-50 \\
09-30-51 \\
09-21-52 \\
07-30-53 \\
07-30-65\end{array}$ & $\begin{array}{r}5,240 \\
7,000 \\
7,150 \\
964 \\
6,290 \\
3,910 \\
2,860 \\
6,980 \\
2,210 \\
2,890 \\
5,000 \\
10,000 \\
5,700 \\
2,960\end{array}$ & $\begin{array}{l}1966 \\
1967 \\
1968 \\
1969 \\
1970 \\
1971 \\
1972 \\
1973 \\
1974 \\
1975 \\
1976 \\
1977 \\
1978\end{array}$ & $\begin{array}{l}07-29-66 \\
09-08-67 \\
08-12-68 \\
07-29-69 \\
09-06-70 \\
08-26-71 \\
08-27-72 \\
10-19-72 \\
07-19-74 \\
07-15-75 \\
09-25-76 \\
07-23-77 \\
06-28-78\end{array}$ & $\begin{array}{r}742 \\
3,790 \\
3,120 \\
1,900 \\
4,990 \\
5,410 \\
2,510 \\
12,100 \\
1,840 \\
1,200 \\
3,990 \\
3,360 \\
1,710\end{array}$ \\
\hline
\end{tabular}

\section{BASIN CHARACTERISTICS}

\begin{tabular}{|c|c|c|c|c|c|c|c|}
\hline \multirow{2}{*}{$\begin{array}{l}\text { MAIN } \\
\text { CHANNEL } \\
\text { SLOPE } \\
\text { (FT/MI) }\end{array}$} & \multirow[b]{2}{*}{$\begin{array}{l}\text { STREAM } \\
\text { LENGTH } \\
\text { (MI) }\end{array}$} & \multirow{2}{*}{$\begin{array}{l}\text { MEAN } \\
\text { BASIN } \\
\text { ELEVA- } \\
\text { TION } \\
\text { (FT) }\end{array}$} & \multirow[b]{2}{*}{$\begin{array}{l}\text { FORESTED } \\
\text { AREA } \\
\text { (PERCENT) }\end{array}$} & \multirow[b]{2}{*}{$\begin{array}{l}\text { SOIL } \\
\text { INDEX }\end{array}$} & \multirow{2}{*}{$\begin{array}{l}\text { MEAN } \\
\text { ANNUAL } \\
\text { PRECIPI- } \\
\text { TATION } \\
\text { (IN) }\end{array}$} & \multicolumn{2}{|c|}{ RAINFALL INTENSITY, 24-HOUR } \\
\hline & & & & & & $\begin{array}{c}\text { 2-YEAR } \\
\text { (IN) }\end{array}$ & $\begin{array}{l}\text { 50-YEAR } \\
\text { (IN) }\end{array}$ \\
\hline 27.2 & 88.3 & 5,820 & 37.0 & 2.7 & 8.7 & 1.3 & 2.5 \\
\hline
\end{tabular}


MEAN MONTHLY AND ANNUAL DISCHARGES 1941-53, 1966-78

\begin{tabular}{|c|c|c|c|c|c|c|}
\hline MONTH & $\begin{array}{l}\operatorname{Max} \ln _{3} M \\
\left(F^{3} / S\right)\end{array}$ & $\begin{array}{l}\text { MINIIMUN } \\
\left(\mathrm{FT}^{3} / \mathrm{S}\right)\end{array}$ & $\begin{array}{c}\text { MEAN } \\
\left(F T^{3} / S\right)\end{array}$ & $\begin{array}{l}\text { STAN- } \\
\text { DARO } \\
\text { DEVIA- } \\
\text { TION } \\
\text { (FT } \text { FTS }^{3}\end{array}$ & $\begin{array}{l}\text { COEFFI- } \\
\text { CIENT OF } \\
\text { VARI - } \\
\text { ATION }\end{array}$ & $\begin{array}{c}\text { PERCENT } \\
\text { OF } \\
\text { AINUAL } \\
\text { RUNOFF }\end{array}$ \\
\hline $\begin{array}{l}\text { OCTOBER } \\
\text { MOVEMBER } \\
\text { DECEMBER } \\
\text { JANUARY } \\
\text { FEBRUARY } \\
\text { MARCH } \\
\text { APRIL } \\
\text { MAY } \\
\text { JUNE } \\
\text { JULY } \\
\text { AUGUST } \\
\text { SEPTEMBER }\end{array}$ & $\begin{array}{c}686 \\
7.9 \\
20 \\
18 \\
25 \\
17 \\
14 \\
1.1 \\
12 \\
174 \\
226 \\
191\end{array}$ & $\begin{array}{l}0.00 \\
0.33 \\
0.70 \\
1.0 \\
0.80 \\
0.43 \\
0.00 \\
0.00 \\
0.00 \\
0.00 \\
0.69 \\
0.00\end{array}$ & $\begin{array}{l}53 \\
3.2 \\
5.0 \\
4.9 \\
5.1 \\
4.1 \\
1.4 \\
0.22 \\
1.1 \\
26 \\
48 \\
30\end{array}$ & $\begin{array}{l}141 \\
1.6 \\
4.1 \\
3.7 \\
5.6 \\
4.0 \\
3.2 \\
0.34 \\
2.9 \\
39 \\
57 \\
47\end{array}$ & $\begin{array}{l}2.7 \\
0.50 \\
0.83 \\
0.75 \\
1.1 \\
0.96 \\
2.2 \\
1.6 \\
2.7 \\
1.5 \\
1.2 \\
1.6\end{array}$ & $\begin{array}{r}29.0 \\
1.8 \\
2.8 \\
2.7 \\
2.8 \\
2.3 \\
0.8 \\
0.1 \\
0.6 \\
14.3 \\
26.5 \\
16.3\end{array}$ \\
\hline ANNUAL & 62 & 3.1 & 15 & 12 & 0.81 & 100 \\
\hline
\end{tabular}

MAGNITUDE AND PROBABILITY OF INSTANTANEOUS PEAK FLOW BASED ON PERIOO OF RECORD 1941-53, 1965-78

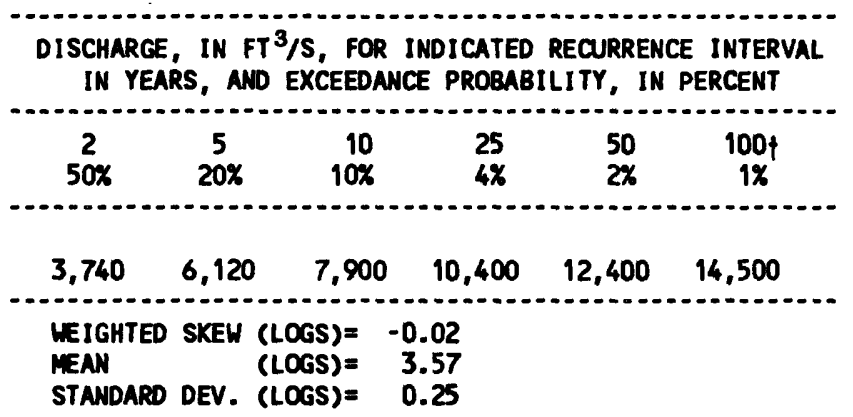

MAGNITUDE AND PROBABILITY OF ANMUAL LON FLON BASED ON PERICD OF RECORD 1942-53, 1966-78

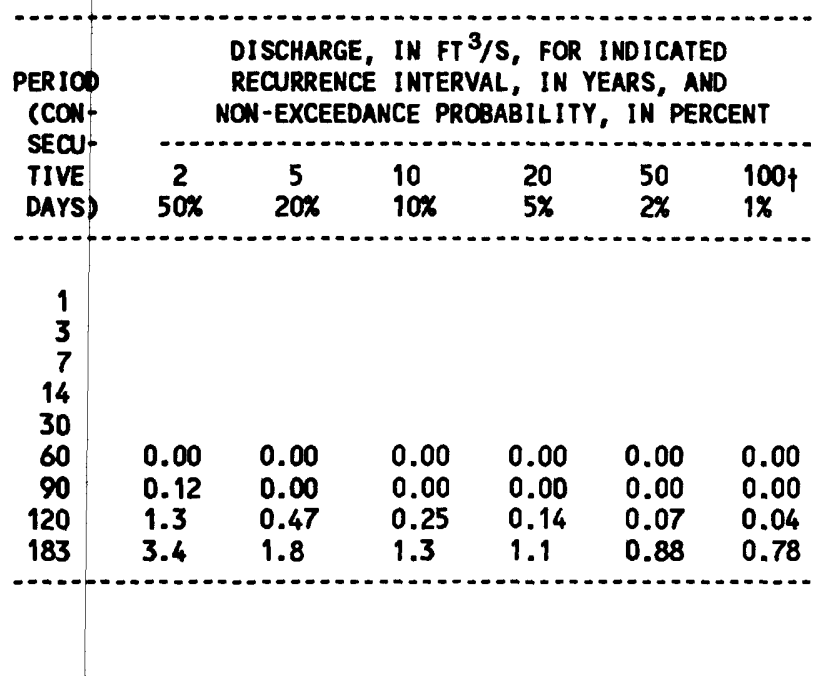

MAGNITUDE AND PROBABILITY OF ANNUAL HIGH FLON BASED ON PERICD OF RECORD 1941-53, 1966-78

\begin{tabular}{|c|c|c|c|c|c|c|}
\hline \multirow{2}{*}{$\begin{array}{l}\text { PERICD } \\
\text { (CON- } \\
\text { SECU- } \\
\text { TIVE } \\
\text { DAYS) }\end{array}$} & \multicolumn{6}{|c|}{$\begin{array}{l}\text { DISCHARCE, IN } \mathrm{FT}^{3} / \mathrm{S} \text {, FOR INDICATED } \\
\text { RECURRENCE INTERVAL, IN YEARS, AND } \\
\text { EXCEEDANCE PROBABILITY, IN PERCENT }\end{array}$} \\
\hline & $\begin{array}{c}2 \\
50 \%\end{array}$ & $\begin{array}{c}5 \\
20 \%\end{array}$ & $\begin{array}{l}10 \\
10 \%\end{array}$ & $\begin{array}{l}25 \\
4 \%\end{array}$ & $\begin{array}{l}50 \\
2 \%\end{array}$ & $\begin{array}{c}100 \dagger \\
1 \%\end{array}$ \\
\hline $\begin{array}{r}1 \\
3 \\
7 \\
15 \\
30 \\
60 \\
90\end{array}$ & $\begin{array}{r}1,030 \\
513 \\
272 \\
146 \\
88 \\
51 \\
36\end{array}$ & $\begin{array}{r}2,330 \\
1,170 \\
607 \\
341 \\
199 \\
112 \\
77\end{array}$ & $\begin{array}{r}3,400 \\
1,760 \\
890 \\
514 \\
295 \\
165 \\
111\end{array}$ & $\begin{array}{r}4,910 \\
2,670 \\
1,310 \\
777 \\
435 \\
242 \\
160\end{array}$ & $\begin{array}{r}6,100 \\
3,450 \\
1,650 \\
1,000 \\
551 \\
306 \\
201\end{array}$ & $\begin{array}{r}7,330 \\
4,330 \\
2,020 \\
1,250 \\
675 \\
375 \\
244\end{array}$ \\
\hline
\end{tabular}

DURATION TABLE OF DAILY MEAN FLON FOR PERIOD OF RECORD 1941-53, 1966-78

DISCHARGE, IN FT 33 , WHICH WAS EQUALED OR EXCEEDED FOR INDICATED PERCENT OF TIME

\begin{tabular}{|c|c|c|c|c|c|c|c|c|c|c|c|c|c|c|c|c|}
\hline $1 \%$ & $5 \%$ & $10 \%$ & $15 \%$ & $20 \%$ & $30 x$ & $40 \%$ & $50 \%$ & $60 \%$ & $70 \%$ & $80 \%$ & $90 \%$ & $95 \%$ & $98 \%$ & $99 \%$ & $99.5 \%$ & $99.9 \%$ \\
\hline 306 & 29 & 9.5 & 5.3 & 4.4 & 3.2 & 2.3 & 1.3 & 0.38 & 0.00 & 0.00 & 0.00 & 0.00 & 0.00 & 0.00 & 0.00 & 0.00 \\
\hline
\end{tabular}

† Reliability of values in column is uncertain, and potential errors are large. 
LITTLE COLORADO RIVER BASIN

09401400 MOENKOPI WASH NEAR TUBA CITY, AZ--CONTIMUED
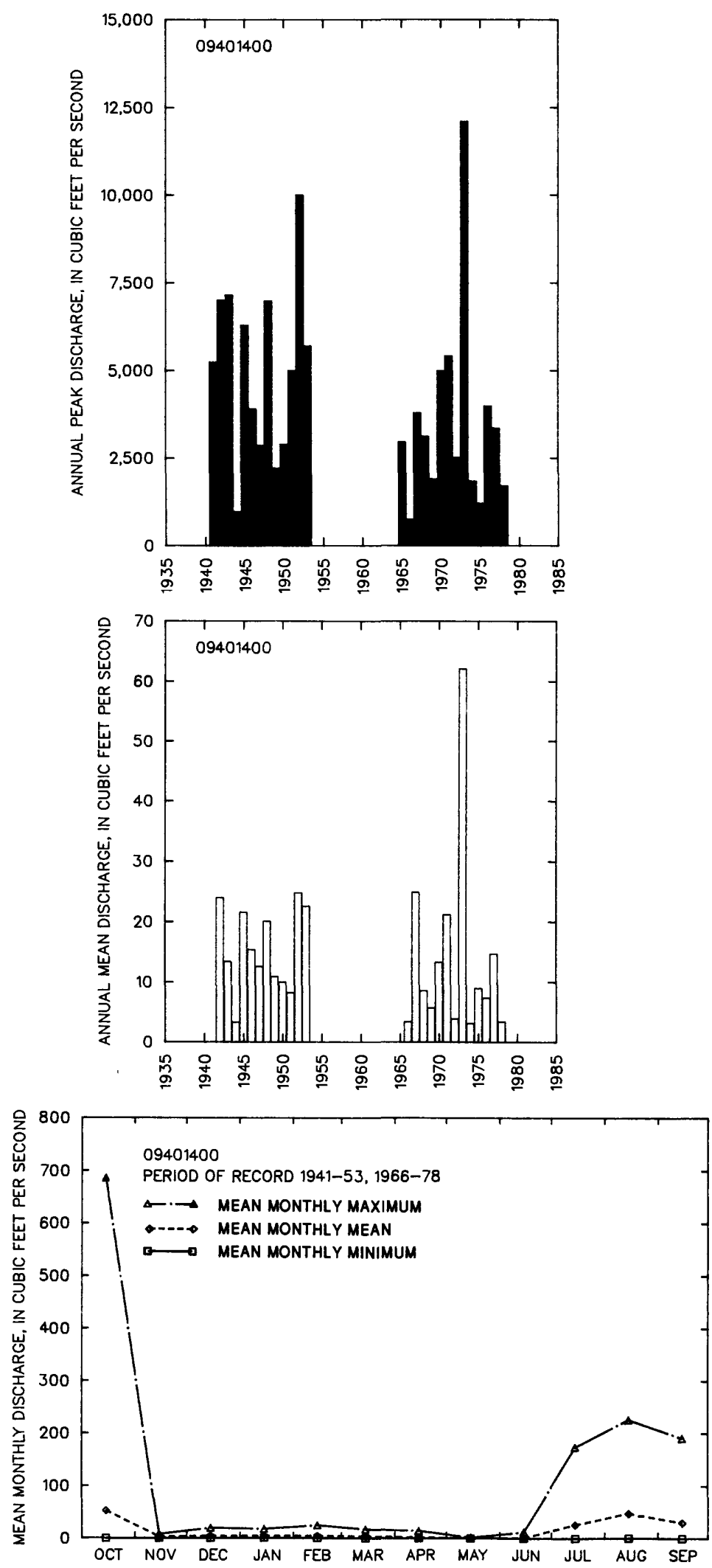
LOCATION.-- Lat 35.55'35", long $111^{\circ} 34^{\prime} 00^{\prime \prime}$, in NW/2 sec.5, T.29 N., R.8 E. (unsurveyed), Coconino County, Hydrologic Unit 15020016, in Navajo Indian Reservation, on left bank 3 mi downstream from Coconino damsite, $9.5 \mathrm{mi}$ downstream from Moenkopi Wash, $9.5 \mathrm{mi}$ northwest of Cameron, and $45 \mathrm{mi}$ upstream from mouth.

DRAIMAGE AREA. $--26,459 \mathrm{mi}^{2}$, of which $368 \mathrm{mi}^{2}$ is noncontributing.

REMARKS.--Diversions above station for irrigation of about 32,000 acres. Some regulation by reservoirs above station (combined capacity of principal reservoirs, about 127,000 acre-ft).

ANNUAL PEAK DISCHARGE

\begin{tabular}{|c|c|c|c|c|c|c|c|}
\hline $\begin{array}{l}\text { WATER } \\
\text { YEAR }\end{array}$ & DATE & $\begin{array}{c}\text { ANNUAL PEAK } \\
\text { DISCHARGE } \\
\text { (FT } 3 / S)\end{array}$ & $\begin{array}{l}\text { DISCHARGE } \\
\text { CODES }\end{array}$ & $\begin{array}{l}\text { WATER } \\
\text { YEAR }\end{array}$ & DATE & $\begin{array}{l}\text { ANNUAL PEAK } \\
\text { DISCHARGE } \\
\left(\mathrm{FT}^{3} / \mathrm{S}\right)\end{array}$ & $\begin{array}{l}\text { DISCHARGE } \\
\text { CODES }\end{array}$ \\
\hline $\begin{array}{l}1923 \\
1929 \\
1947 \\
1948 \\
1949 \\
1950 \\
1951 \\
1952 \\
1953 \\
1954 \\
1955 \\
1956 \\
1957 \\
1958 \\
1959 \\
1960 \\
1961 \\
1962 \\
1963 \\
1964 \\
1965 \\
1966 \\
1967\end{array}$ & $\begin{array}{l}09-20-23 \\
04-06-29 \\
08-09-47 \\
10-14-47 \\
08-09-49 \\
07-18-50 \\
08-30-51 \\
01-21-52 \\
07-30-53 \\
03-25-54 \\
06-13-55 \\
08-17-56 \\
01-12-57 \\
10-14-57 \\
08-07-59 \\
11-02-59 \\
09-09-61 \\
02-17-62 \\
09-01-63 \\
08-02-64 \\
01-11-65 \\
01-03-66 \\
09-08-67\end{array}$ & $\begin{array}{r}120,000 \\
250,000 \\
21,900 \\
18,600 \\
12,400 \\
4,340 \\
11,700 \\
24,900 \\
6,230 \\
7,070 \\
8,990 \\
6,650 \\
8,060 \\
4,840 \\
4,600 \\
6,620 \\
2,600 \\
3,470 \\
7,680 \\
8,540 \\
6,770 \\
9,100 \\
7,580\end{array}$ & $\begin{array}{l}\text { ES, HP } \\
\text { ES,HP }\end{array}$ & $\begin{array}{l}1968 \\
1969 \\
1970 \\
1971 \\
1972 \\
1973 \\
1974 \\
1975 \\
1976 \\
1977 \\
1978 \\
1979 \\
1980 \\
1981 \\
1982 \\
1983 \\
1984 \\
1985 \\
1986 \\
1987 \\
1988 \\
1989\end{array}$ & $\begin{array}{l}08-12-68 \\
09-11-69 \\
09-07-70 \\
08-27-71 \\
07-18-72 \\
10-19-72 \\
00-00-74 \\
11-01-74 \\
09-25-76 \\
08-20-77 \\
03-06-78 \\
12-23-78 \\
02-20-80 \\
09-23-81 \\
10-02-81 \\
09-30-83 \\
08-26-84 \\
03-16-85 \\
11-30-85 \\
01-30-87 \\
11-01-87 \\
08-19-89\end{array}$ & $\begin{array}{r}5,600 \\
11,600 \\
12,600 \\
7,290 \\
9,250 \\
22,400 \\
1,590 \\
4,100 \\
3,870 \\
3,300 \\
9,540 \\
17,800 \\
12,400 \\
5,100 \\
8,320 \\
10,600 \\
12,400 \\
6,030 \\
6,530 \\
6,730 \\
12,600 \\
12,800\end{array}$ & $\begin{array}{l}\text { UR } \\
\text { UR } \\
\text { UR } \\
\text { UR } \\
\text { UR } \\
\text { UR } \\
\text { UR } \\
\text { UR } \\
\text { UR } \\
\text { UR } \\
\text { UR } \\
\text { UR } \\
\text { UR } \\
\text { UR } \\
\text { UR } \\
\text { UR } \\
\text { UR } \\
\text { UR } \\
\text { UR } \\
\text { UR } \\
\text { UR } \\
\text { UR }\end{array}$ \\
\hline
\end{tabular}

Highest since 1870.

2 Highest since 1923.

BASIN CHARACTERISTICS

\begin{tabular}{|c|c|c|c|c|c|c|c|}
\hline \multirow{2}{*}{$\begin{array}{l}\text { MAIN } \\
\text { CHANNEL } \\
\text { SLOPE } \\
\text { (FT/MI) }\end{array}$} & \multirow[b]{2}{*}{$\begin{array}{l}\text { STREAM } \\
\text { LENGTH } \\
\text { (MI) }\end{array}$} & \multirow{2}{*}{$\begin{array}{l}\text { MEAN } \\
\text { BASIN } \\
\text { ELEVA- } \\
\text { TION } \\
\text { (FT) }\end{array}$} & \multirow[b]{2}{*}{$\begin{array}{l}\text { FORESTED } \\
\text { AREA } \\
\text { (PERCENT) }\end{array}$} & \multirow[b]{2}{*}{$\begin{array}{l}\text { SOIL } \\
\text { INDEX }\end{array}$} & \multirow{2}{*}{$\begin{array}{l}\text { MEAN } \\
\text { ANNUAL } \\
\text { PRECIPI- } \\
\text { TATION } \\
\text { (IN) }\end{array}$} & \multicolumn{2}{|c|}{ RAINFALL INTENSITY, 24-HOUR } \\
\hline & & & & & & $\begin{array}{c}\text { 2-YEAR } \\
\text { (IN) }\end{array}$ & $\begin{array}{c}\text { 50-YEAR } \\
\text { (IN) }\end{array}$ \\
\hline 7.48 & 285 & 6,300 & 32.0 & 2.7 & 12.2 & 1.5 & 2.8 \\
\hline
\end{tabular}


09402000 LITTLE COLORADO RIVER MEAR CAMERON, AZ--Continued

MEAN MONTHLY aNd ANMUAL DISCHARGES 1948-89

\begin{tabular}{|c|c|c|c|c|c|c|}
\hline MONTH & $\begin{array}{l}\text { MAXIMUM } \\
\left(F^{3} / S\right)\end{array}$ & $\begin{array}{l}\text { MINIMUM } \\
\left(\mathrm{FT}^{3} / \mathrm{S}\right)\end{array}$ & $\begin{array}{c}\text { MEAN } \\
\left(F T^{3} / S\right)\end{array}$ & $\begin{array}{l}\text { STAN- } \\
\text { DARD } \\
\text { DEVIA- } \\
\text { TION } \\
\left(\mathrm{FT}^{3} / \mathrm{S}\right)\end{array}$ & $\begin{array}{l}\text { COEFFI- } \\
\text { CIENT OF } \\
\text { VARI - } \\
\text { ATION }\end{array}$ & $\begin{array}{c}\text { PERCENT } \\
\text { OF } \\
\text { ANNUAL } \\
\text { RUNOFF }\end{array}$ \\
\hline $\begin{array}{l}\text { OCTOBER } \\
\text { NOVEMBER } \\
\text { DECEMBER } \\
\text { JANUARY } \\
\text { FEBRUARY } \\
\text { MARCH } \\
\text { APRIL } \\
\text { MAY } \\
\text { JUNE } \\
\text { JULY } \\
\text { AUGUST } \\
\text { SEPTEMBER }\end{array}$ & $\begin{array}{r}4,190 \\
753 \\
1,690 \\
2,030 \\
2,110 \\
1,870 \\
3,970 \\
2,880 \\
595 \\
616 \\
2,260 . \\
832\end{array}$ & $\begin{array}{l}0.00 \\
0.00 \\
0.00 \\
0.00 \\
0.00 \\
0.00 \\
0.00 \\
0.00 \\
0.00 \\
0.00 \\
0.00 \\
0.00\end{array}$ & $\begin{array}{r}245 \\
82 \\
114 \\
172 \\
228 \\
466 \\
640 \\
154 \\
19 \\
120 \\
412 \\
226\end{array}$ & $\begin{array}{l}684 \\
172 \\
284 \\
361 . \\
382 \\
545 \\
843 \\
460 \\
92 \\
139 \\
490 \\
233\end{array}$ & $\begin{array}{l}2.8 \\
2.1 \\
2.5 \\
2.1 \\
1.7 \\
1.2 \\
1.3 \\
3.0 \\
4.9 \\
1.2 \\
1.2 \\
1.0\end{array}$ & $\begin{array}{r}8.5 \\
2.9 \\
4.0 \\
6.0 \\
7.9 \\
16.2 \\
22.3 \\
5.3 \\
0.7 \\
4.2 \\
14.3 \\
7.9\end{array}$ \\
\hline ANNUAL & 1,130 & 27 & 240 & 197 & 0.82 & 100 \\
\hline
\end{tabular}

MAGNITUDE AND PROBABILITY OF INSTANTANEOUS PEAK FLOW BASED ON PERIOD OF RECORD 1947-64, 1965-89

DISCHARGE, IN $\mathrm{FT}^{3} / \mathrm{S}$, FOR INDICATED RECURRENCE INTERVAL IN YEARS, AND EXCEEDANCE PROBABILITY, IN PERCENT

\begin{tabular}{lccccc}
2 & 5 & 10 & 25 & 50 & $100 \uparrow$ \\
$50 \%$ & $20 \%$ & $10 \%$ & $4 \%$ & $2 \%$ & $1 \%$ \\
8,000 & 12,600 & 16,000 & 20,800 & 24,700 & 28,900 \\
\hline WEIGHTED SKEH (LOGS) & $=0.12$ & & \\
MEAN & (LOGS) & 3.91 \\
STANDARD DEV. (LOGS) & $=0.23$
\end{tabular}

MAGNITUDE AND PROBABILITY OF ANNUAL LOW FLOW BASED ON PERIOD OF RECORD 1949-89

\begin{tabular}{|c|c|c|c|c|c|c|}
\hline \multirow{2}{*}{$\begin{array}{l}\text { PERIOD } \\
\text { (CON- } \\
\text { SECU- } \\
\text { TIVE } \\
\text { DAYS) }\end{array}$} & \multicolumn{6}{|c|}{$\begin{array}{l}\text { DISCHARGE, IN FT } 3 / S \text {, FOR INDICATED } \\
\text { RECURRENCE INTERVAL, IN YEARS, AND } \\
\text { NON-EXCEEDANCE PROBABILITY, IN PERCENT }\end{array}$} \\
\hline & $\begin{array}{c}2 \\
50 \%\end{array}$ & $\begin{array}{c}5 \\
20 \%\end{array}$ & $\begin{array}{l}10 \\
10 \%\end{array}$ & $\begin{array}{l}20 \\
5 \%\end{array}$ & $\begin{array}{l}50 \\
2 \%\end{array}$ & $\begin{array}{l}100 \dagger \\
1 \%\end{array}$ \\
\hline $\begin{array}{r}1 \\
3 \\
7 \\
14 \\
30 \\
60 \\
90 \\
120 \\
183\end{array}$ & $\begin{array}{r}0.00 \\
0.00 \\
0.00 \\
44\end{array}$ & $\begin{array}{l}0.00 \\
0.00 \\
0.00 \\
9.4\end{array}$ & $\begin{array}{l}0.00 \\
0.00 \\
0.00 \\
3.5\end{array}$ & $\begin{array}{l}0.00 \\
0.00 \\
0.00 \\
1.4\end{array}$ & $\begin{array}{l}0.00 \\
0.00 \\
0.00 \\
0.44\end{array}$ & $\begin{array}{l}0.00 \\
0.00 \\
0.00 \\
0.19\end{array}$ \\
\hline
\end{tabular}

MAGNITUDE AND PROBABILITY OF ANNLAL HIGH FLOW BASED ON PERIOD OF RECORD 1948-89

\begin{tabular}{|c|c|c|c|c|c|c|}
\hline $\begin{array}{l}\text { PERIOD } \\
\text { CCON- } \\
\text { CECI- }\end{array}$ & & $\begin{array}{l}\text { DISCHA } \\
\text { RECURRE } \\
\text { EXCEED }\end{array}$ & $\begin{array}{l}\text { GE, IN } \\
\text { NCE INT } \\
\text { NCE PRO }\end{array}$ & $\begin{array}{l}3 / S, F 0 \\
\text { VAL, II } \\
\text { BILITY, }\end{array}$ & $\begin{array}{l}\text { YEA } \\
\text { IN }\end{array}$ & $\begin{array}{l}\text { TED } \\
\text { AND } \\
\text { ENT }\end{array}$ \\
\hline $\begin{array}{l}\text { TIVE } \\
\text { DAYS) }\end{array}$ & $\stackrel{2}{50 \%}$ & $\begin{array}{c}5 \\
20 \%\end{array}$ & $\begin{array}{l}10 \\
10 \%\end{array}$ & $\begin{array}{l}25 \\
4 \%\end{array}$ & $\begin{array}{l}50 \\
2 \%\end{array}$ & $\begin{array}{c}100 \dagger \\
1 \%\end{array}$ \\
\hline $\begin{array}{r}1 \\
3 \\
7 \\
15 \\
30 \\
60 \\
90\end{array}$ & $\begin{array}{r}4,510 \\
3,430 \\
2,280 \\
1,480 \\
1,010 \\
666 \\
517\end{array}$ & $\begin{array}{r}7,880 \\
6,160 \\
4,010 \\
2,520 \\
1,810 \\
1,240 \\
989\end{array}$ & $\begin{array}{r}10,400 \\
8,260 \\
5,290 \\
3,230 \\
2,380 \\
1,660 \\
1,330\end{array}$ & $\begin{array}{r}13,900 \\
11,200 \\
6,990 \\
4,090 \\
3,140 \\
2,210 \\
1,780\end{array}$ & $\begin{array}{r}16,600 \\
13,500 \\
8,310 \\
4,710 \\
3,710 \\
2,630 \\
2,120\end{array}$ & $\begin{array}{r}19,500 \\
16,000 \\
9,660 \\
5,300 \\
4,290 \\
3,050 \\
2,450\end{array}$ \\
\hline
\end{tabular}

DURATION TABLE OF DAILY MEAN FLON FOR PERIO0 OF RECORD 1948-89

DISCHARGE, IN FT $3 / 5$, HHICH WAS EQUALED OR EXCEEDED FOR INDICATED PERCENT OF TIME

\begin{tabular}{|c|c|c|c|c|c|c|c|c|c|c|c|c|c|c|c|c|}
\hline 18 & $5 \%$ & $10 \%$ & $15 \%$ & $20 \%$ & $30 \%$ & $40 \%$ & $50 \%$ & $60 \%$ & $70 \%$ & $80 \%$ & $90 \%$ & $95 \%$ & $98 \%$ & $99 \%$ & $99.5 \%$ & $99.9 \%$ \\
\hline 630 & 1,390 & 675 & 373 & 199 & 67 & 19 & 3.1 & 0.29 & 0.00 & 0.00 & 0.00 & 0.00 & 0.00 & 0.00 & 0.00 & 0.00 \\
\hline
\end{tabular}

† Reliability of values in colum is uncertain, and potential errors are large. 
09402000 LITTLE COLORADO RIVER NEAR CAMERON, AZ--CONTIMUED
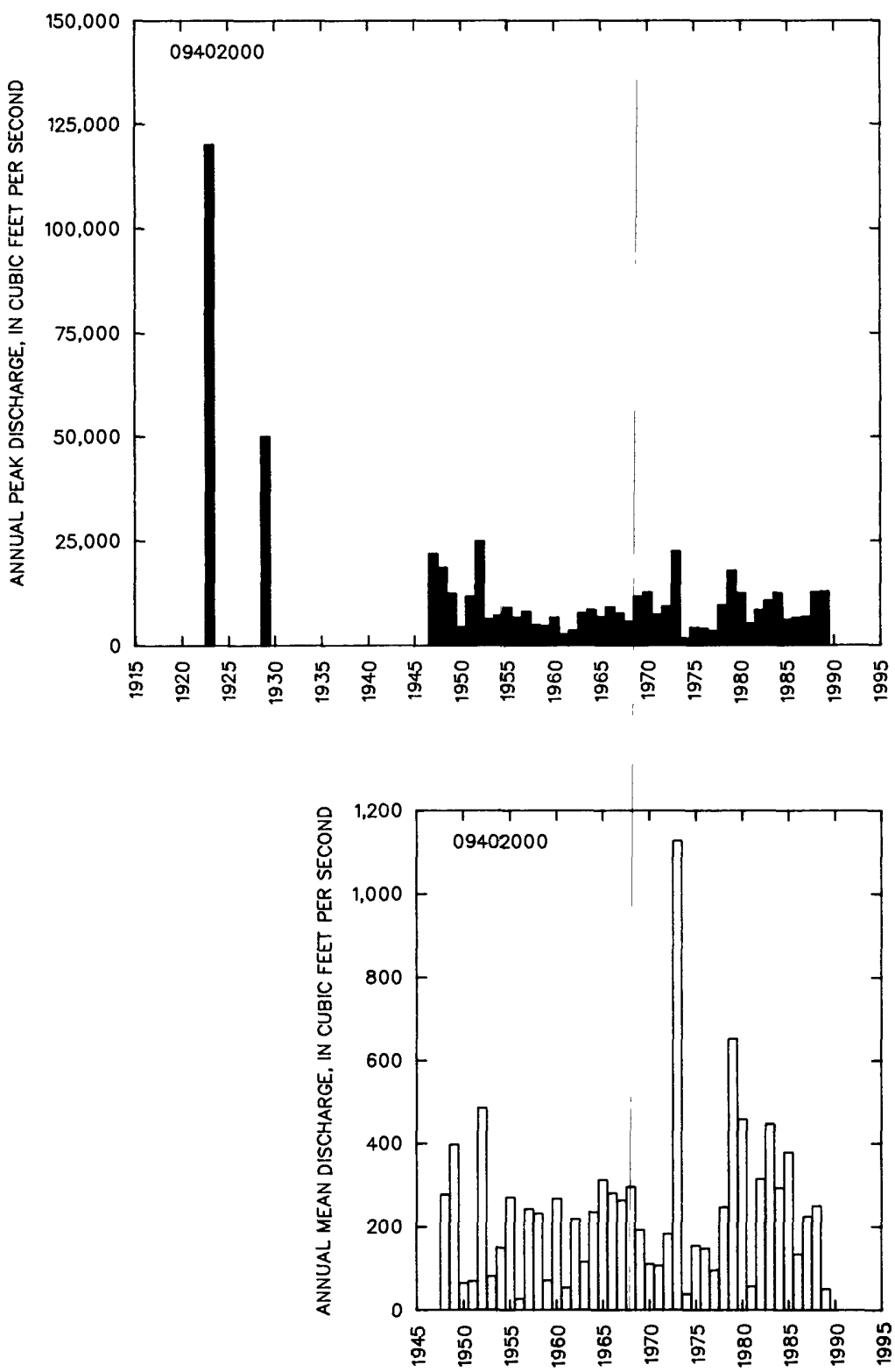
09402000 LITTLE COLORADO RIVER NEAR CAMERON, AZ--CONTIMUED
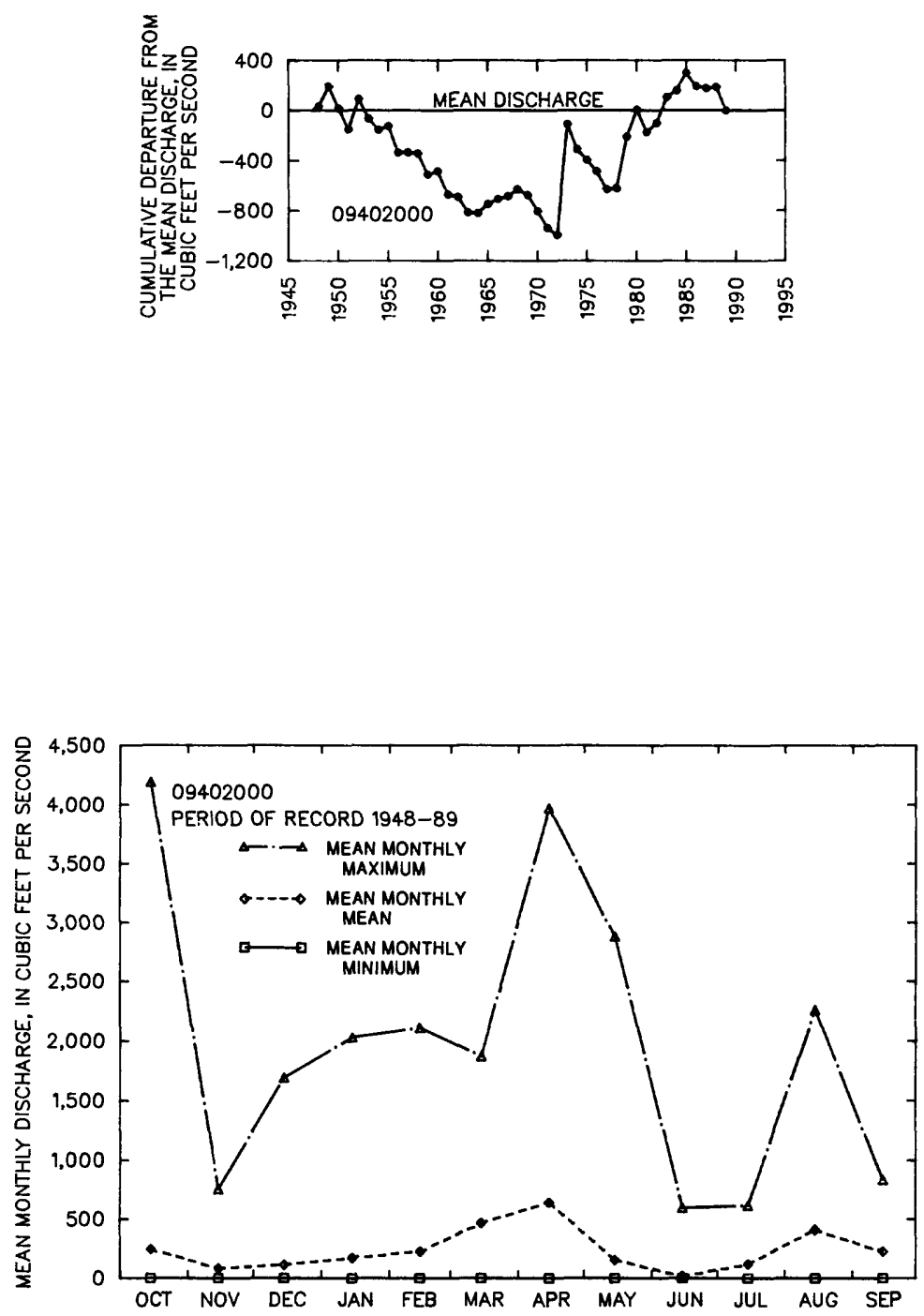
LOCATION.--Lat 35'55'25", long 111'44'15", in MEKSWK sec.3, T.29 N., R.6 E.., Coconino County, Hydrologic Unit 15020016, at State Híghway 64, $0.6 \mathrm{mi}$ inside eastern boundary of Kaibab National Forest, and $18 \mathrm{mi}$ west of Cameron.

DRAIMAGE AREA. $-0.72 \mathrm{mi}^{2}$.

ANMUAL PEAK DISCHARGE

\begin{tabular}{cccc}
$\begin{array}{c}\text { MATER } \\
\text { YEAR }\end{array}$ & DATE & $\begin{array}{c}\text { ANNUAL PEAK } \\
\text { DISCHARGE } \\
\text { (FT } 3 / \text { S) }\end{array}$ & $\begin{array}{c}\text { DISCHARGE } \\
\text { COOES }\end{array}$ \\
\hline 1963 & $00-00-63$ & 0 & \\
1964 & $00-00-64$ & 0 & \\
1965 & $00-00-65$ & 0 & \\
1966 & $00-00-66$ & 1.0 & LT \\
1967 & $00-00-67$ & 12 & \\
1968 & $00-00-68$ & 0 & \\
1969 & $09-11-69$ & 115 & \\
1970 & $08-00-70$ & 3.0 & \\
1971 & $00-00-71$ & 0 & \\
1972 & $07-18-72$ & 1.0 & ES \\
1973 & $00-00-73$ & 0 & \\
1974 & $00-00-74$ & 0 & \\
1975 & $00-00-75$ & 0 & \\
1976 & $00-00-76$ & 0.5 & ES \\
$\ldots$
\end{tabular}

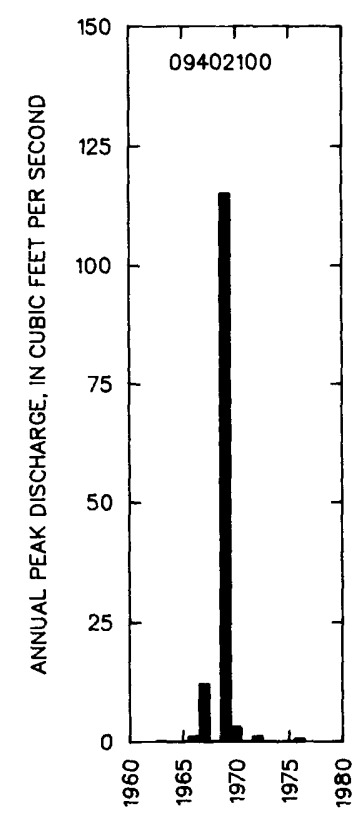

MAGNITUDE AND PROBABILITY OF INSTANTANEOUS PEAK FLOW BASED ON PERIOD OF RECORD

DISCHARGE, IN $F T^{3} / \mathrm{S}$, FOR INDICATED RECURRENCE INTERVAL IN YEARS, AND EXCEEDANCE PROBABILITY, IN PERCENT

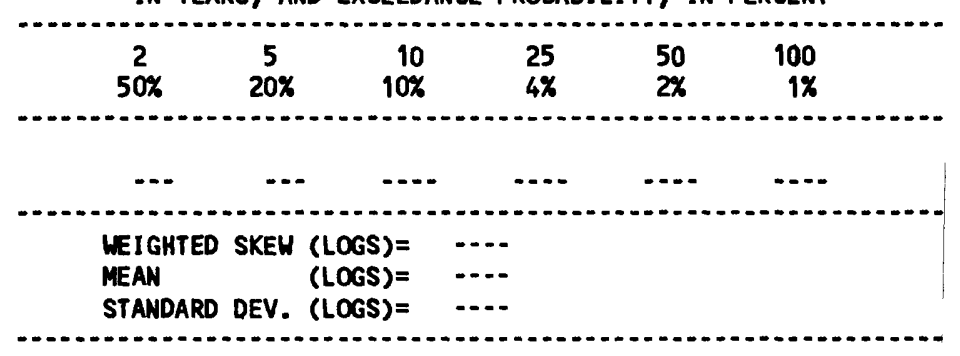

BASIN CHARACTERISTICS

\begin{tabular}{|c|c|c|c|c|c|c|c|}
\hline MAIN & & $\begin{array}{l}\text { MEAN } \\
\text { BASIN }\end{array}$ & & & $\begin{array}{c}\text { MEAN } \\
\text { ANMUAL }\end{array}$ & RAINFALL IN & SITY, 24-HOUR \\
\hline $\begin{array}{l}\text { CHANNEL } \\
\text { SLOPE } \\
\text { (FT/MI) }\end{array}$ & $\begin{array}{c}\text { STREAM } \\
\text { LENGTH } \\
\text { (MI) }\end{array}$ & $\begin{array}{l}\text { ELEVA- } \\
\text { TION } \\
\text { (FT) }\end{array}$ & $\begin{array}{l}\text { FORESTED } \\
\text { AREA } \\
\text { (PERCENT) }\end{array}$ & $\begin{array}{l}\text { SOIL } \\
\text { INDEX }\end{array}$ & $\begin{array}{l}\text { PRECIPI- } \\
\text { TATION } \\
\text { (IN) }\end{array}$ & $\begin{array}{c}\text { 2-YEAR } \\
\text { (IN) }\end{array}$ & $\begin{array}{l}\text { 50-YEAR } \\
\text { (IN) }\end{array}$ \\
\hline 167 & 1.6 & 6,810 & 94.0 & 3.0 & 11.9 & 1.4 & 3.2 \\
\hline
\end{tabular}


09402500 COLORADO RIVER NEAR GRAND CANYON, AZ

LOCATION. - - Lat 36.06.05", long 112.05'08", in sec.5, T.31 N., R.3 E. (unsurveyed), Coconino County, Hydrologic Unit 15010001, in Grand Canyon National Park, on left bank 0.2 mi upstream from Kaibab Bridge, $0.4 \mathrm{mi}$ upstream from Bright Angel Creek, $4.5 \mathrm{mi}$ northeast of village of Grand Canyon, $26 \mathrm{mi}$ downstream from Little Colorado River, and 267 mi upstream from Hoover Dam.

DRAINAGE AREA.--141,600 $\mathrm{mi}^{2}$ approximately, including 3,959 $\mathrm{mi}^{2}$ in Great Divide bas in in southern Wyoming which is noncontributing.

REMARKS.--Flow completely regulated by Lake Powell, 104 mi upstream, since Mar. 13, 1963. (See elsewhere in this report.) Many diversions above station for irrigation, municipal, and industrial uses.

ANMUAL PEAK DISCHARGE

\begin{tabular}{|c|c|c|c|c|c|c|c|}
\hline $\begin{array}{l}\text { WATER } \\
\text { YEAR }\end{array}$ & DATE & $\begin{array}{c}\text { ANNUAL PEAK } \\
\text { DISCHARGE } \\
\text { (FT } 3 / S)\end{array}$ & $\begin{array}{l}\text { DISCHARGE } \\
\text { CODES }\end{array}$ & $\begin{array}{l}\text { WATER } \\
\text { YEAR }\end{array}$ & DATE & $\begin{array}{l}\text { ANNUAL PEA } \\
\text { DISCHARGE } \\
\left(\mathrm{FT}^{3} / \mathrm{S}\right)\end{array}$ & $\begin{array}{l}\text { DISCHARGE } \\
\text { CODES }\end{array}$ \\
\hline $\begin{array}{l}1884 \\
1921 \\
1922 \\
1923 \\
1924 \\
1925 \\
1926 \\
1927 \\
1928 \\
1929 \\
1930 \\
1931 \\
1932 \\
1933 \\
1934 \\
1935 \\
1936 \\
1937 \\
1938 \\
1939 \\
1940 \\
1941 \\
1942 \\
1943 \\
1944 \\
1945 \\
1946 \\
1947 \\
1948 \\
1949 \\
1950 \\
1951 \\
1952 \\
1953 \\
1954\end{array}$ & $\begin{array}{l}07-08-84 \\
06-19-21 \\
06-01-22 \\
09-19-23 \\
06-18-24 \\
06-03-25 \\
05-29-26 \\
07-02-27 \\
06-03-28 \\
05-29-29 \\
06-04-30 \\
05-22-31 \\
05-26-32 \\
06-05-33 \\
05-17-34 \\
06-19-35 \\
05-24-36 \\
05-21-37 \\
06-08-38 \\
05-26-39 \\
05-18-40 \\
05-17-41 \\
05-31-42 \\
06-06-43 \\
05-20-44 \\
05-17-45 \\
06-14-46 \\
05-14-47 \\
05-26-48 \\
06-22-49 \\
06-06-50 \\
06-01-51 \\
06-12-52 \\
06-17-53 \\
05-27-54\end{array}$ & $\begin{array}{r}300,000 \\
220,000 \\
115,000 \\
112,000 \\
74,000 \\
53,700 \\
85,600 \\
127,000 \\
115,000 \\
111,000 \\
71,000 \\
34,600 \\
102,000 \\
81,500 \\
25,500 \\
105,000 \\
76,300 \\
85,300 \\
100,000 \\
49,000 \\
46,800 \\
120,000 \\
91,800 \\
66,800 \\
93,400 \\
63,300 \\
50,100 \\
80,100 \\
89,800 \\
112,000 \\
58,400 \\
63,700 \\
122,000 \\
68,500 \\
32,800\end{array}$ & $\begin{array}{c}\text { ES, HP } \\
\text { ES }\end{array}$ & $\begin{array}{l}1955 \\
1956 \\
1957 \\
1958 \\
1959 \\
1960 \\
1961 \\
1962 \\
1963 \\
1964 \\
1965 \\
1966 \\
1967 \\
1968 \\
1969 \\
1970 \\
1971 \\
1972 \\
1973 \\
1974 \\
1975 \\
1976 \\
1977 \\
1978 \\
1979 \\
1980 \\
1981 \\
1982 \\
1983 \\
1984 \\
1985 \\
1986 \\
1987 \\
1988 \\
1989\end{array}$ & $\begin{array}{l}06-14-55 \\
06-06-56 \\
06-13-57 \\
06-02-58 \\
06-19-59 \\
06-10-60 \\
06-06-61 \\
05-17-62 \\
10-22-62 \\
04-29-64 \\
06-15-65 \\
05-04-66 \\
09-09-67 \\
07-20-68 \\
09-12-69 \\
08-27-70 \\
08-24-71 \\
05-26-72 \\
04-19-73 \\
08-21-74 \\
07-30-75 \\
05-20-76 \\
08-19-77 \\
09-09-78 \\
12-23-78 \\
06-24-80 \\
07-30-81 \\
08-28-82 \\
06-29-83 \\
08-13-84 \\
06-02-85 \\
05-31-86 \\
01-31-87 \\
07-29-88 \\
08-19-89\end{array}$ & $\begin{array}{r}40,400 \\
67,200 \\
125,000 \\
107,700 \\
38,300 \\
46,300 \\
39,800 \\
85,600 \\
20,700 \\
19,700 \\
58,400 \\
21,300 \\
23,900 \\
26,800 \\
30,800 \\
27,600 \\
33,400 \\
29,500 \\
38,300 \\
28,200 \\
28,900 \\
27,700 \\
32,100 \\
29,400 \\
38,600 \\
45,000 \\
25,400 \\
27,900 \\
96,200 \\
47,600 \\
47,400 \\
53,500 \\
31,600 \\
25,500 \\
31,300\end{array}$ & $\begin{array}{l}K R \\
K R \\
K R \\
K R \\
K R \\
K R \\
K R \\
K R \\
K R \\
K R \\
K R \\
K R \\
K R \\
K R \\
K R \\
K R \\
K R \\
K R \\
K R \\
K R \\
K R \\
K R \\
K R \\
K R \\
K R \\
\text { KR } \\
K R \\
K R\end{array}$ \\
\hline
\end{tabular}


MEAN MONTHLY AND ANNUAL DISCHARGES 1964-89

\begin{tabular}{|c|c|c|c|c|c|c|}
\hline MONTH & $\begin{array}{l}\operatorname{Max} \operatorname{limuM}_{3} \\
\left(F T^{3} / S\right)\end{array}$ & $\begin{array}{l}\text { MINIMUM } \\
\left(\mathrm{FT}^{3} / \mathrm{S}\right)\end{array}$ & $\begin{array}{c}\text { MEAN } \\
\left.\text { (FT }{ }^{3} / S\right)\end{array}$ & $\begin{array}{l}\text { STAN- } \\
\text { DARD } \\
\text { DEVIA- } \\
\text { TION } \\
\left(F^{3} / S\right)\end{array}$ & $\begin{array}{l}\text { COEFFI - } \\
\text { CIENT OF } \\
\text { VARI - } \\
\text { ATION }\end{array}$ & $\begin{array}{c}\text { PERCENT } \\
\text { OF } \\
\text { ANNUAL } \\
\text { RUNOFF }\end{array}$ \\
\hline $\begin{array}{l}\text { OCTOBER } \\
\text { NOVEMBER } \\
\text { DECEMBER } \\
\text { JANUARY } \\
\text { FEBRUARY } \\
\text { MARCH } \\
\text { APRIL } \\
\text { MAY } \\
\text { JUNE } \\
\text { JULY } \\
\text { AUGUST } \\
\text { SEPTEMBER }\end{array}$ & $\begin{array}{l}26,300 \\
25,000 \\
25,200 \\
26,300 \\
27,200 \\
25,800 \\
32,200 \\
44,800 \\
55,900 \\
55,600 \\
29,700 \\
27,900\end{array}$ & $\begin{array}{l}1,260 \\
1,280 \\
1,260 \\
1,280 \\
4,260 \\
5,170 \\
3,180 \\
3,580 \\
1,290 \\
1,370 \\
4,660 \\
3,200\end{array}$ & $\begin{array}{l}11,300 \\
12,200 \\
13,000 \\
14,000 \\
12,700 \\
11,900 \\
14,800 \\
16,800 \\
18,700 \\
17,300 \\
16,900 \\
15,000\end{array}$ & $\begin{array}{r}5,060 \\
5,310 \\
5,610 \\
5,520 \\
5,600 \\
5,410 \\
6,850 \\
10,600 \\
12,900 \\
10,200 \\
5,770 \\
5,590\end{array}$ & $\begin{array}{l}0.45 \\
0.44 \\
0.43 \\
0.39 \\
0.44 \\
0.45 \\
0.46 \\
0.63 \\
0.69 \\
0.59 \\
0.34 \\
0.37\end{array}$ & $\begin{array}{r}6.5 \\
7.0 \\
7.4 \\
8.0 \\
7.3 \\
6.8 \\
8.5 \\
9.6 \\
10.7 \\
9.9 \\
9.7 \\
8.6\end{array}$ \\
\hline ANNU & 00 & .760 & 14,500 & 5,560 & 0.38 & 100 \\
\hline
\end{tabular}

MAGNITUDE AMD PROBABILITY OF INSTANTANEOUS PEAK FLOW BASED ON PERIOD OF RECORD

DISCHARGE, IN $\mathrm{FT}^{3} / \mathrm{S}$, FOR INDICATED RECURRENCE INTERVAL IN YEARS, AND EXCEEDANCE PROBABILITY, IN PERCENT

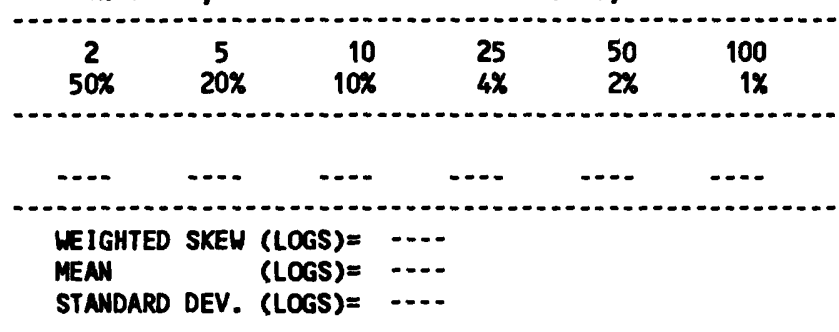

MAGNITUDE AND PROBABILITY OF ANMUAL LOM FLON BASED ON PER IOD OF RECORD 1965-89

\begin{tabular}{|c|c|c|c|c|c|c|}
\hline \multirow{2}{*}{$\begin{array}{l}\text { PER IOD } \\
\text { (CON- } \\
\text { SECU } \\
\text { TIVE } \\
\text { DAYS }\end{array}$} & \multicolumn{6}{|c|}{$\begin{array}{l}\text { DISCHARGE, IN FT } 3 / S \text {, FOR INDICATED } \\
\text { RECURRENCE INTERVAL, IN YEARS, AND } \\
\text { NON-EXCEEDANCE PROBABILITY, IN PERCENT }\end{array}$} \\
\hline & $\begin{array}{c}2 \\
50 \%\end{array}$ & $\begin{array}{c}5 \\
20 \%\end{array}$ & $\begin{array}{l}10 \\
10 \%\end{array}$ & $\begin{array}{l}20 \\
5 \%\end{array}$ & $\begin{array}{l}50 \\
2 \%\end{array}$ & $\begin{array}{l}100 \nmid \\
1 \%\end{array}$ \\
\hline $\begin{array}{r}1 \\
3 \\
7 \\
14 \\
30 \\
60 \\
90 \\
120 \\
183\end{array}$ & $\begin{array}{r}3,290 \\
4,490 \\
5,830 \\
7,090 \\
8,560 \\
10,200 \\
11,200 \\
11,600 \\
12,400\end{array}$ & $\begin{array}{l}2,080 \\
2,700 \\
3,500 \\
4,260 \\
5,160 \\
6,120 \\
6,890 \\
7,660 \\
8,580\end{array}$ & $\begin{array}{l}1,620 \\
2,000 \\
2,570 \\
3,080 \\
3,670 \\
4,240 \\
4,930 \\
5,860 \\
6,820\end{array}$ & $\begin{array}{l}1,300 \\
1,540 \\
1,930 \\
2,290 \\
2,650 \\
2,960 \\
3,570 \\
4,570 \\
5,520\end{array}$ & $\begin{array}{l}1,020 \\
1,120 \\
1,370 \\
1,580 \\
1,760 \\
1,860 \\
2,360 \\
3,340 \\
4,250\end{array}$ & $\begin{array}{r}857 \\
891 \\
1,070 \\
1,210 \\
1,300 \\
1,310 \\
1,730 \\
2,660 \\
3,520\end{array}$ \\
\hline
\end{tabular}

MAGNITUDE AND PROBABILITY OF ANNUAL HIGH FLOW BASED ON PERIOD OF RECORD 1964-89

\begin{tabular}{|c|c|c|c|c|c|c|}
\hline \multirow{2}{*}{$\begin{array}{l}\text { PERICD } \\
\text { (CON- } \\
\text { SECU- } \\
\text { TIVE } \\
\text { DAYS) }\end{array}$} & & \multicolumn{5}{|c|}{$\begin{array}{l}\text { DISCHARGE, IN } \mathrm{FT}^{3} / \mathrm{S} \text {, FOR INDICATED } \\
\text { RECURRENCE INTERVAL, IN YEARS, AND } \\
\text { EXCEEDANCE PROBABILITY, IN PERCENT }\end{array}$} \\
\hline & $\begin{array}{c}2 \\
50 \%\end{array}$ & $\begin{array}{c}5 \\
20 \%\end{array}$ & $\begin{array}{l}10 \\
10 \%\end{array}$ & $\begin{array}{l}25 \\
4 \%\end{array}$ & $\begin{array}{l}50 \\
2 \%\end{array}$ & $\begin{array}{c}100 \dagger \\
1 \%\end{array}$ \\
\hline $\begin{array}{r}1 \\
3 \\
7 \\
15 \\
30 \\
60 \\
90\end{array}$ & $\begin{array}{l}25,600 \\
24,500 \\
22,800 \\
21,500 \\
20,400 \\
19,100 \\
17,900\end{array}$ & $\begin{array}{l}37,400 \\
36,300 \\
34,500 \\
32,600 \\
30,800 \\
28,100 \\
25,900\end{array}$ & $\begin{array}{l}48,300 \\
47,100 \\
45,500 \\
42,900 \\
40,400 \\
36,000 \\
32,500\end{array}$ & $\begin{array}{l}66,600 \\
65,300 \\
64,400 \\
60,200 \\
56,100 \\
48,700 \\
42,500\end{array}$ & $\begin{array}{l}84,100 \\
82,700 \\
82,800 \\
77,100 \\
71,200 \\
60,400 \\
51,300\end{array}$ & $\begin{array}{r}106,000 \\
104,000 \\
106,000 \\
98,000 \\
89,600 \\
74,300 \\
61,400\end{array}$ \\
\hline
\end{tabular}

DURATION TABLE OF DAILY MEAN FLON FOR PERIOD OF RECORD 1964-89

DISCHARGE, IN FT $3 / 5$, WHICH WAS EQUALED OR EXCEEDED FOR INDICATED PERCENT OF TIME

\begin{tabular}{|c|c|c|c|c|c|c|c|c|c|c|c|c|c|c|c|c|}
\hline $1 \%$ & $5 \%$ & $10 \%$ & $15 \%$ & $20 \%$ & $30 \%$ & $40 \%$ & $50 \%$ & $60 \%$ & $70 \%$ & $80 \%$ & $90 \%$ & $95 \%$ & $98 \%$ & $99 \%$ & $99.5 \%$ & $99.9 \%$ \\
\hline 6,400 & 28,800 & 24,9 & 21. & 19,500 & 16,6 & 14 & 12 & 11 & 100 & 8,530 & 6,380 & 4,150 & 1,460 & 1,250 & 1,220 & 1,19 \\
\hline
\end{tabular}

† Reliability of values in column is uncertain, and potential errors are large. 
COLORADO RIVER MAIN STEM

09402500 COLORADO RIVER NEAR GRAND CANYON, AZ--CONTIMUED
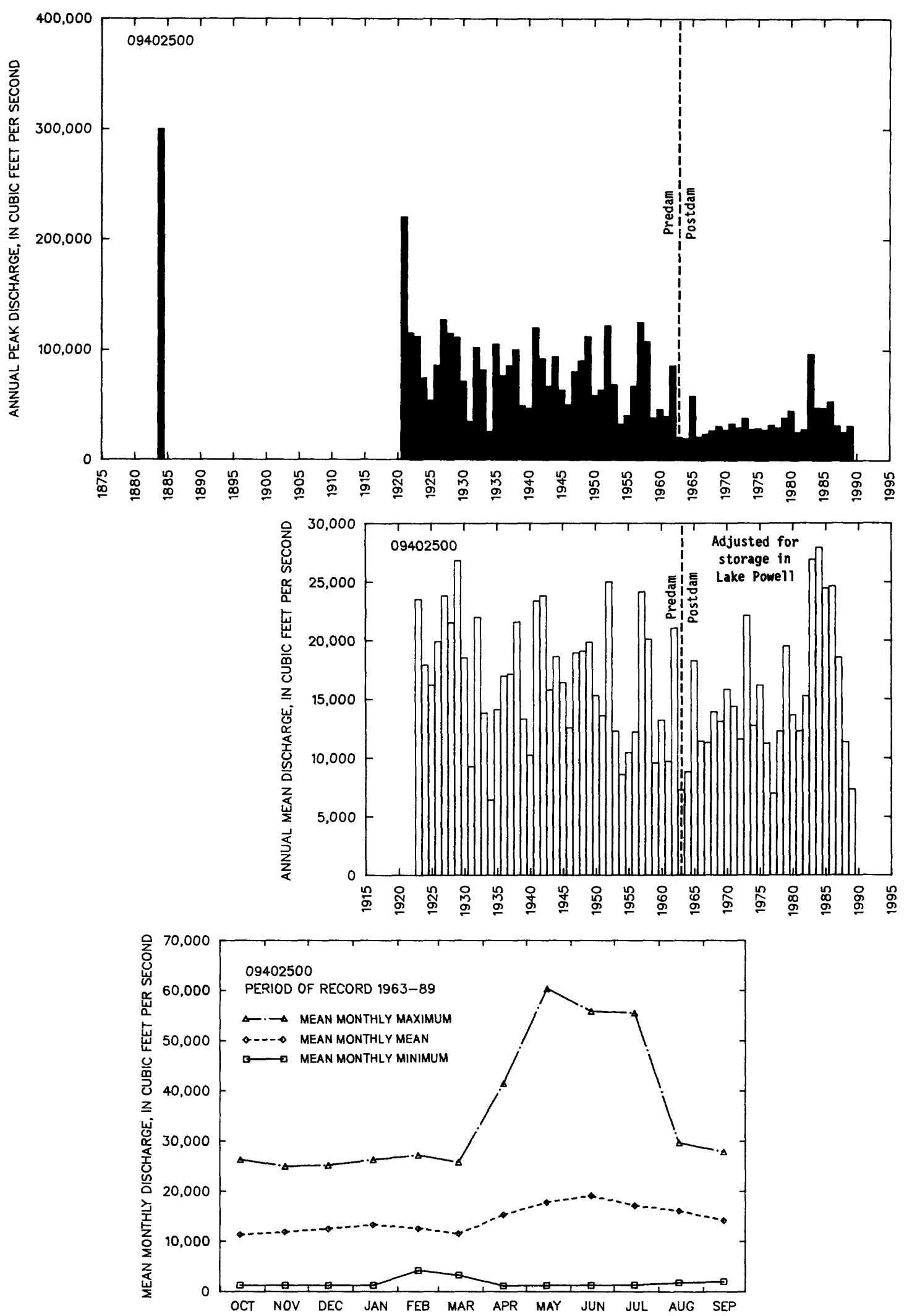


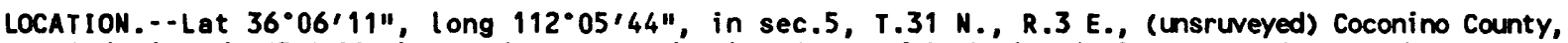
Hydrologic Unit 1501001, in Grand Canyon National Park, on right bank $0.4 \mathrm{mi}$ upstream from mouth and $4 \mathrm{mi}$ northeast of Grand Canyon.

DRAINAGE AREA. - - $101 \mathrm{mi}^{2}$.

\begin{tabular}{|c|c|c|c|c|c|c|c|}
\hline $\begin{array}{l}\text { WATER } \\
\text { YEAR }\end{array}$ & DATE & $\begin{array}{c}\text { ANNUAL PEAK } \\
\text { DISCHARGE } \\
\text { (FT } 3 / S)\end{array}$ & $\begin{array}{l}\text { DISCHARGE } \\
\text { COOES }\end{array}$ & $\begin{array}{l}\text { WATER } \\
\text { YEAR }\end{array}$ & DATE & $\begin{array}{l}\text { ANNUAL PEAK } \\
\text { DISCHARGE } \\
\left(F^{3} / S\right)\end{array}$ & $\begin{array}{l}\text { DISCHARGE } \\
\text { CODES }\end{array}$ \\
\hline $\begin{array}{l}1924 \\
1925 \\
1926 \\
1927 \\
1928 \\
1929 \\
1930 \\
1931 \\
1932 \\
1933 \\
1934 \\
1935 \\
1936 \\
1937 \\
1938 \\
1939 \\
1940 \\
1941 \\
1942 \\
1943 \\
1944 \\
1945 \\
1946 \\
1947 \\
1948\end{array}$ & $\begin{array}{l}09-10-24 \\
09-17-25 \\
07-27-26 \\
09-16-27 \\
05-03-28 \\
07-10-29 \\
02-23-30 \\
06-25-31 \\
02-09-32 \\
08-07-33 \\
10-09-33 \\
07-20-35 \\
08-19-36 \\
07-29-37 \\
04-21-38 \\
09-06-39 \\
08-24-40 \\
05-13-41 \\
04-23-42 \\
04-23-43 \\
05-15-44 \\
07-30-45 \\
07-22-46 \\
08-27-47 \\
08-11-48\end{array}$ & $\begin{array}{r}530 \\
122 \\
1,000 \\
1,000 \\
187 \\
173 \\
113 \\
45 \\
500 \\
186 \\
250 \\
270 \\
4,400 \\
2,000 \\
575 \\
270 \\
602 \\
848 \\
264 \\
426 \\
199 \\
297 \\
840 \\
310 \\
1,900\end{array}$ & & $\begin{array}{l}1949 \\
1950 \\
1951 \\
1952 \\
1953 \\
1954 \\
1955 \\
1956 \\
1957 \\
1958 \\
1959 \\
1960 \\
1961 \\
1962 \\
1963 \\
1964 \\
1965 \\
1966 \\
1967 \\
1968 \\
1969 \\
1970 \\
1971 \\
1972 \\
1973\end{array}$ & $\begin{array}{l}04-28-49 \\
10-18-49 \\
08-29-51 \\
05-05-52 \\
08-27-53 \\
03-23-54 \\
06-13-55 \\
01-27-56 \\
08-05-57 \\
08-22-58 \\
08-11-59 \\
06-06-60 \\
08-30-61 \\
02-08-62 \\
08-17-63 \\
08-26-64 \\
08-15-65 \\
11-23-65 \\
12-06-66 \\
07-07-68 \\
01-25-69 \\
03-01-70 \\
07-19-71 \\
07-25-72 \\
05-12-73\end{array}$ & $\begin{array}{r}206 \\
197 \\
193 \\
672 \\
930 \\
446 \\
103 \\
77 \\
1,770 \\
900 \\
660 \\
240 \\
266 \\
240 \\
855 \\
353 \\
788 \\
484 \\
4,000 \\
240 \\
930 \\
1,180 \\
2,300 \\
126 \\
578\end{array}$ & ES \\
\hline
\end{tabular}

BASIN CHARACTERISTICS

\begin{tabular}{|c|c|c|c|c|c|c|c|}
\hline MAIN & & $\begin{array}{l}\text { MEAN } \\
\text { BASIN }\end{array}$ & & & $\begin{array}{c}\text { MEAN } \\
\text { ANNUAL }\end{array}$ & RAINFALL II & SITY, 24-HOUR \\
\hline $\begin{array}{l}\text { CHANNEL } \\
\text { SLOPE } \\
\text { (FT/MI) }\end{array}$ & $\begin{array}{c}\text { STREAM } \\
\text { LENGTH } \\
\text { (MI) }\end{array}$ & $\begin{array}{l}\text { ELEVA- } \\
\text { TION } \\
\text { (FT) }\end{array}$ & $\begin{array}{l}\text { FORESTED } \\
\text { AREA } \\
\text { (PERCENT) }\end{array}$ & $\begin{array}{l}\text { SOIL } \\
\text { INDEX }\end{array}$ & $\begin{array}{l}\text { PRECIPI - } \\
\text { TATION } \\
\text { (IN) }\end{array}$ & $\begin{array}{c}\text { 2-YEAR } \\
\text { (IN) }\end{array}$ & $\begin{array}{l}\text { 50-YEAR } \\
\text { (IN) }\end{array}$ \\
\hline 421.0 & 17.6 & 7,390 & 53.0 & 2.2 & 19.8 & 2.5 & 4.3 \\
\hline
\end{tabular}


MEAN MONTHLY AND ANMUAL DISCHARGES $1924-73$

\begin{tabular}{|c|c|c|c|c|c|c|}
\hline MONTH & $\begin{array}{l}\operatorname{MAX} I \operatorname{Im} M \\
\left(F T^{3} / S\right)\end{array}$ & $\begin{array}{l}\operatorname{MINIMM} \\
\left(F^{3} / S\right)\end{array}$ & $\begin{array}{c}\text { MEAN } \\
\left(F T^{3} / S\right)\end{array}$ & $\begin{array}{l}\text { STAN- } \\
\text { DARD } \\
\text { DEVIA- } \\
\text { TION } \\
\text { (FT } 3 / S)\end{array}$ & $\begin{array}{l}\text { COEFFI - } \\
\text { CIENT OF } \\
\text { VARI - } \\
\text { ATION }\end{array}$ & $\begin{array}{c}\text { PERCENT } \\
\text { OF } \\
\text { ANNUAL } \\
\text { RUNOFF }\end{array}$ \\
\hline $\begin{array}{l}\text { OCTOBER } \\
\text { NONEMBER } \\
\text { DECEMBER } \\
\text { JANUARY } \\
\text { FEBRUARY } \\
\text { MARCH } \\
\text { APRIL } \\
\text { MAY } \\
\text { JUNE } \\
\text { JULY } \\
\text { AUGUST } \\
\text { SEPTEMBER }\end{array}$ & $\begin{array}{r}34 \\
34 \\
181 \\
33 \\
51 \\
64 \\
217 \\
501 \\
131 \\
44 \\
41 \\
45\end{array}$ & $\begin{array}{l}15 \\
15 \\
16 \\
16 \\
16 \\
16 \\
15 \\
14 \\
14 \\
13 \\
13 \\
14\end{array}$ & $\begin{array}{r}21 \\
21 \\
25 \\
22 \\
24 \\
27 \\
77 \\
103 \\
34 \\
23 \\
22 \\
21\end{array}$ & $\begin{array}{c}4.1 \\
4.2 \\
23 \\
4.0 \\
7.6 \\
9.8 \\
51 \\
106 \\
23 \\
5.8 \\
4.7 \\
5.6\end{array}$ & $\begin{array}{l}0.20 \\
0.20 \\
0.90 \\
0.18 \\
0.31 \\
0.36 \\
0.66 \\
1.0 \\
0.67 \\
0.25 \\
0.21 \\
0.26\end{array}$ & $\begin{array}{r}5.0 \\
5.1 \\
6.0 \\
5.3 \\
5.8 \\
6.5 \\
18.3 \\
24.4 \\
8.0 \\
5.5 \\
5.2 \\
5.1\end{array}$ \\
\hline ANNUAL & 89 & 15 & 35 & 15 & 0.44 & 100 \\
\hline
\end{tabular}

MAGNITUDE AND PROBABILITY OF INSTANTANEOUS PEAK FLOU BASED ON PERIOD OF RECORD 1924-73

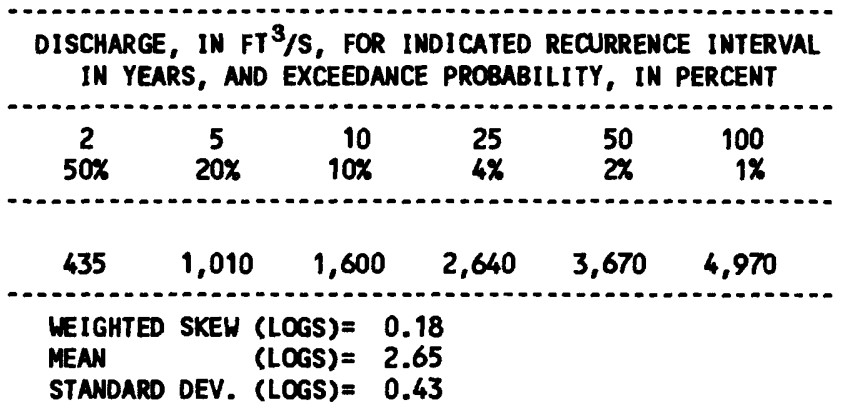

MACNITLDE AND PROBABILITY OF ANNUAL LON FLON BASED ON PERIOD OF RECORD 1925-74

\begin{tabular}{|c|c|c|c|c|c|c|}
\hline \multirow{2}{*}{$\begin{array}{l}\text { PERIOD } \\
\text { (CON- } \\
\text { SECU- } \\
\text { TIVE } \\
\text { DAYS) }\end{array}$} & \multicolumn{6}{|c|}{$\begin{array}{l}\text { DISCHARGE, IN FT } 3 / 5 \text {, FOR INDICATED } \\
\text { RECURRENCE INTERVAL, IN YEARS, AND } \\
\text { NON-EXCEEDANCE PROBABILITY, IN PERCENT }\end{array}$} \\
\hline & $\stackrel{2}{20 \%}$ & $\begin{array}{c}5 \\
20 \%\end{array}$ & $\begin{array}{l}10 \\
10 \%\end{array}$ & $\begin{array}{l}20 \\
5 \%\end{array}$ & $\begin{array}{l}50 \\
2 \%\end{array}$ & $\begin{array}{l}100 \uparrow \\
1 \%\end{array}$ \\
\hline $\begin{array}{r}1 \\
3 \\
7 \\
14 \\
30 \\
60 \\
90 \\
120 \\
183\end{array}$ & $\begin{array}{l}17 \\
17 \\
17 \\
18 \\
18 \\
19 \\
19 \\
20 \\
20\end{array}$ & $\begin{array}{l}14 \\
14 \\
15 \\
15 \\
16 \\
16 \\
17 \\
17 \\
18\end{array}$ & $\begin{array}{l}13 \\
13 \\
13 \\
14 \\
15 \\
15 \\
16 \\
16 \\
16\end{array}$ & $\begin{array}{l}12 \\
12 \\
12 \\
13 \\
14 \\
14 \\
15 \\
15 \\
15\end{array}$ & $\begin{array}{l}11 \\
11 \\
12 \\
12 \\
13 \\
13 \\
14 \\
14 \\
14\end{array}$ & $\begin{array}{l}11 \\
11 \\
11 \\
12 \\
12 \\
13 \\
13 \\
13 \\
14\end{array}$ \\
\hline
\end{tabular}

MAGNITLDE AND PROBABILITY OF ANNUAL HIGH FLOW BASED ON PERIOD OF RECORD 1924-73

\begin{tabular}{|c|c|c|c|c|c|c|}
\hline \multirow{2}{*}{$\begin{array}{l}\text { PERIOD } \\
\text { (CON- } \\
\text { SECU- } \\
\text { TIVE } \\
\text { DAYS) }\end{array}$} & \multicolumn{6}{|c|}{$\begin{array}{l}\text { DISCHARGE, IN } \mathrm{FT}^{3} / \mathrm{S} \text {, FOR INDICATED } \\
\text { RECURRENCE INTERVAL, IN YEARS, AND } \\
\text { EXCEEDANCE PROBABILITY, IN PERCENT }\end{array}$} \\
\hline & $\begin{array}{c}2 \\
50 \%\end{array}$ & $\begin{array}{c}5 \\
20 \%\end{array}$ & $\begin{array}{l}10 \\
10 \%\end{array}$ & $\begin{array}{l}25 \\
4 x\end{array}$ & $\begin{array}{l}50 \\
2 \%\end{array}$ & $\begin{array}{c}100 \dagger \\
1 \%\end{array}$ \\
\hline $\begin{array}{r}1 \\
3 \\
7 \\
15 \\
30 \\
60 \\
90\end{array}$ & $\begin{array}{r}148 \\
137 \\
126 \\
112 \\
94 \\
72 \\
58\end{array}$ & $\begin{array}{l}339 \\
309 \\
281 \\
242 \\
195 \\
138 \\
104\end{array}$ & $\begin{array}{l}539 \\
476 \\
424 \\
360 \\
284 \\
194 \\
143\end{array}$ & $\begin{array}{l}907 \\
760 \\
654 \\
546 \\
422 \\
281 \\
203\end{array}$ & $\begin{array}{r}1,290 \\
1,030 \\
863 \\
712 \\
544 \\
357 \\
256\end{array}$ & $\begin{array}{r}1,780 \\
1,360 \\
1,110 \\
902 \\
681 \\
444 \\
315\end{array}$ \\
\hline
\end{tabular}

DURATION TABLE OF DAILY MEAN FLON FOR PERIOD OF RECORD 1924-73 DISCHARGE, IN FT $3 / 5$, HHICH WAS EQUALED OR EXCEEDED FOR INDICATED PERCENT OF TIME

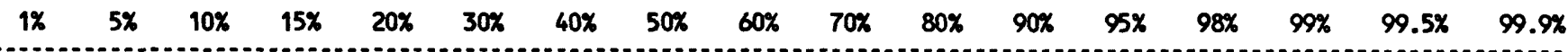

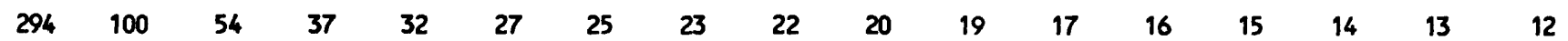


09403000 BRIGHT ANGEL CREEK NEAR grand CANYON, AZ--Continued
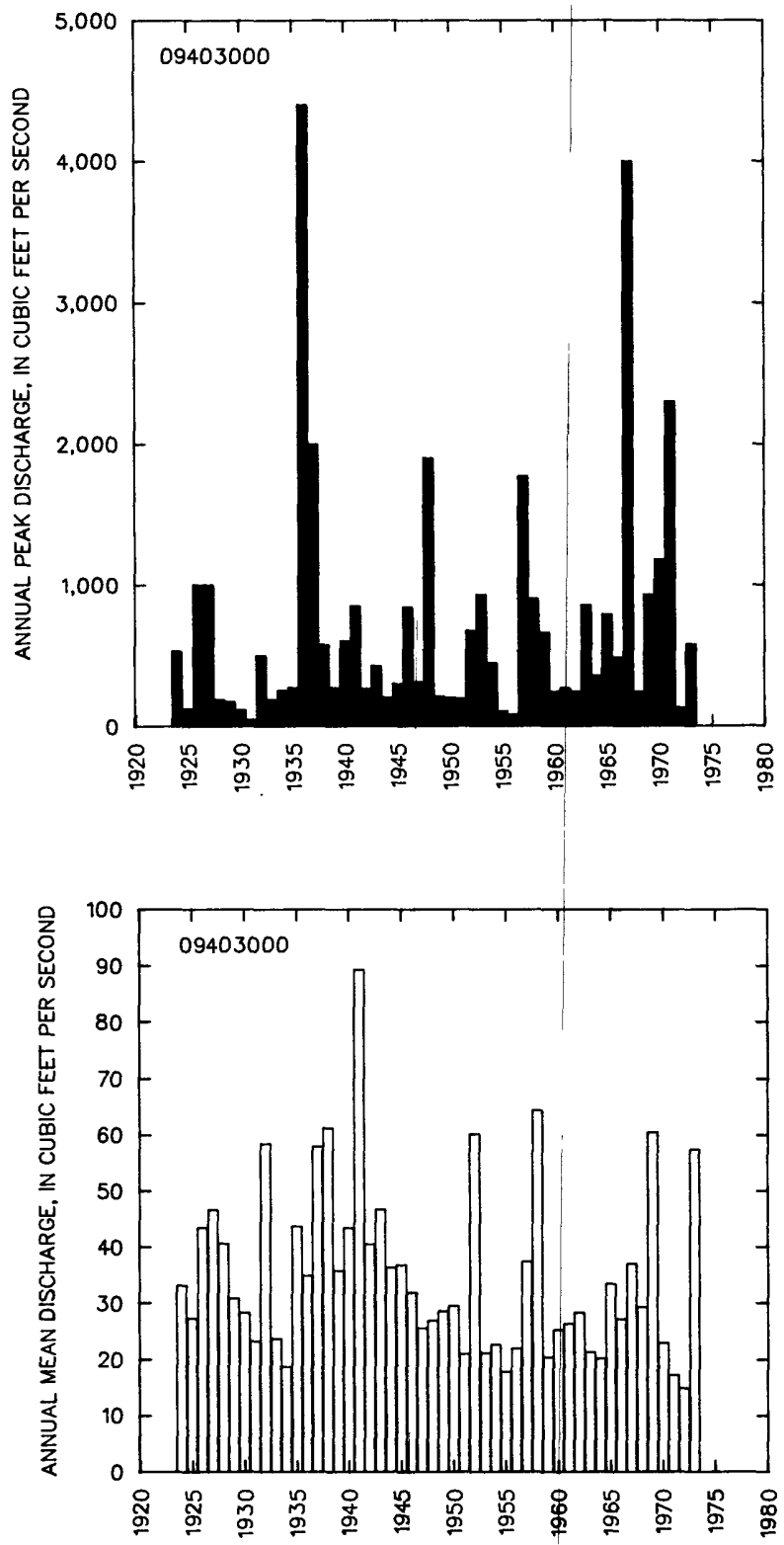
09403000 BRIGHT NGEL CREEK MEAR GRAND CANYON, AZ--CONTINUED
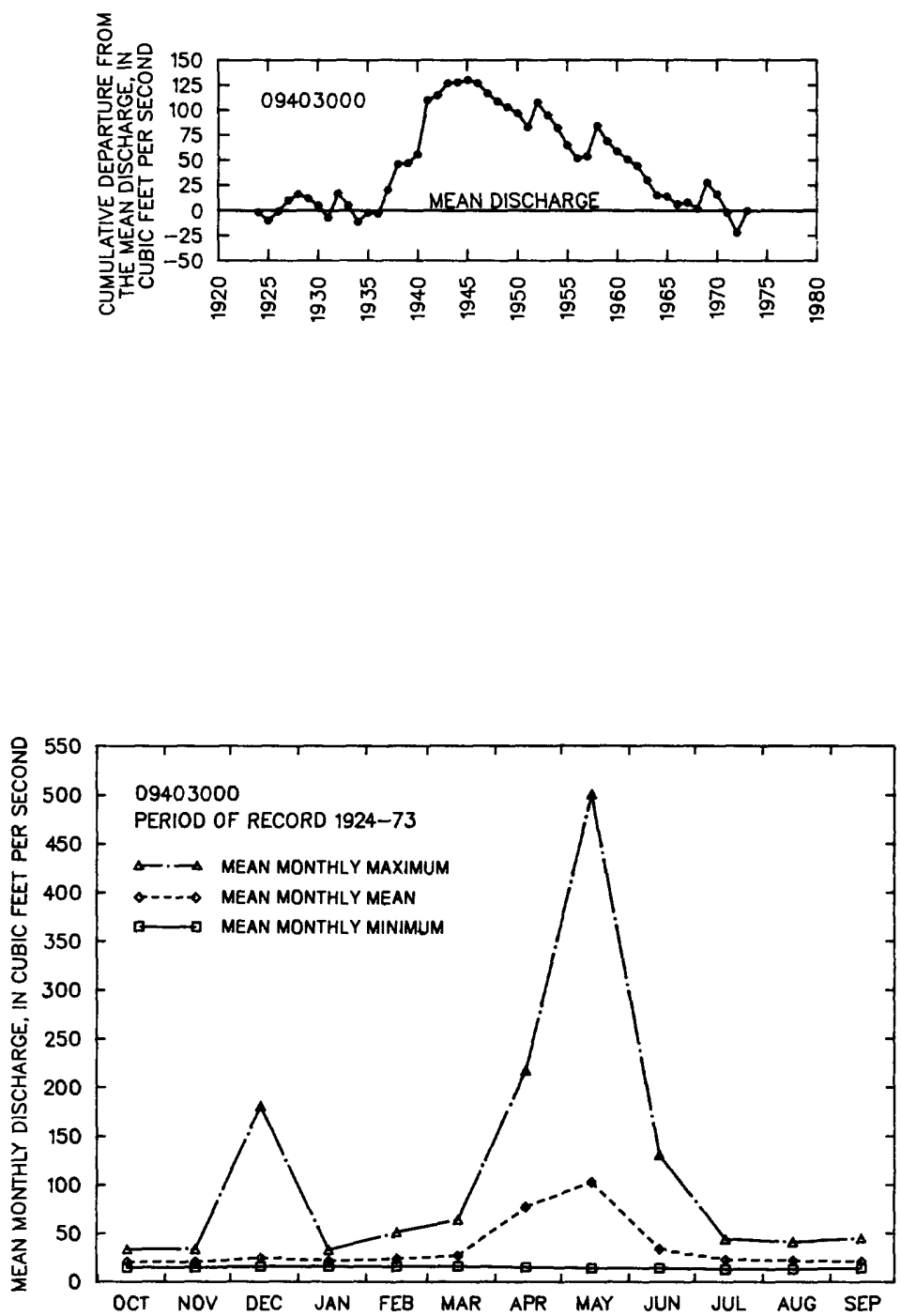


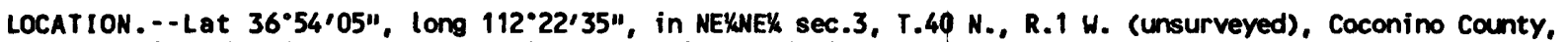
Hydrologic Unit 1501003, at U.S. Highway 89 Alt., $9.5 \mathrm{mi}$ east of Fredonia.

DRAIMAGE AREA. $--0.68 \mathrm{mi}^{2}$.

ANIUAL PEAK DISCHARGE

\begin{tabular}{cccc}
$\begin{array}{c}\text { UATER } \\
\text { YEAR }\end{array}$ & DATE & $\begin{array}{c}\text { AMNUAL PEAK } \\
\text { DISCHARGE } \\
\text { (FT } 3 / \text { S) }\end{array}$ & $\begin{array}{c}\text { DISCHARGE } \\
\text { CODES }\end{array}$ \\
\hline 1960 & $00-00-60$ & 150 & HP \\
1963 & $08-30-63$ & 50 & ES \\
1964 & $07-14-64$ & 35 & ES \\
1965 & $00-00-65$ & 0 & \\
1966 & $00-00-66$ & 0 & \\
1967 & $00-00-67$ & 0 & \\
1968 & $00-00-68$ & 0 & \\
1969 & $00-00-69$ & 0 & \\
1970 & $00-00-70$ & 0 & \\
1971 & $02-00-71$ & 16 & ES \\
1972 & $06-22-72$ & 20 & ES \\
1973 & $10-19-72$ & 5.0 & ES \\
1974 & $00-00-74$ & 0 & \\
1975 & $08-21-75$ & 10 & LT \\
1976 & $00-00-76$ & 0.1 & \\
\hline
\end{tabular}

magnitude aND PROBABILITY OF INSTANTANEOUS PEAK FLON BASED ON PERIOD OF RECORD

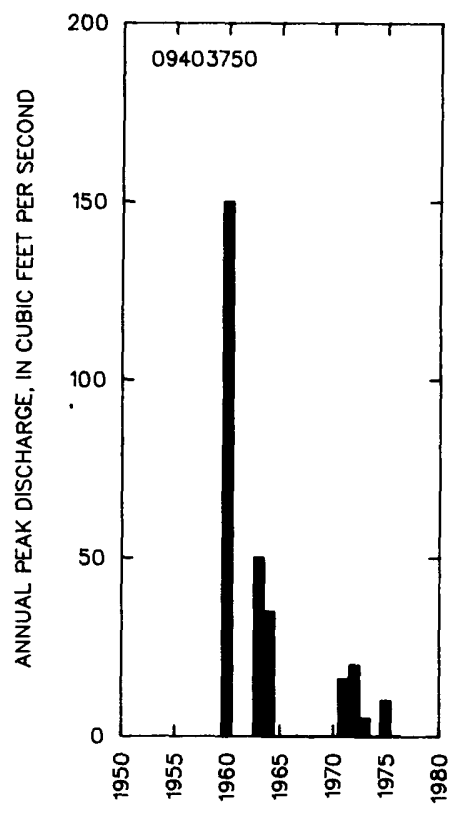

DISCHARGE, IN $\mathrm{FT}^{3} / \mathrm{S}$, FOR IMDICATED RECURRENCE INTERVAL IN YEARS, AND EXCEEDANCE PROBABILITY, IN PERCENT

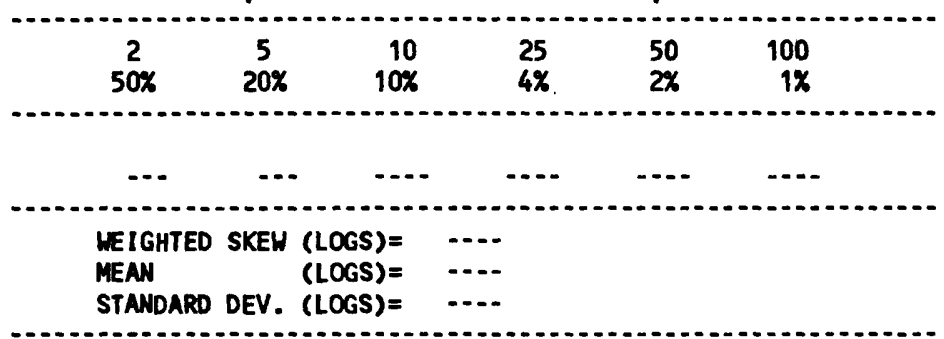

BASIN CHARACTERISTICS

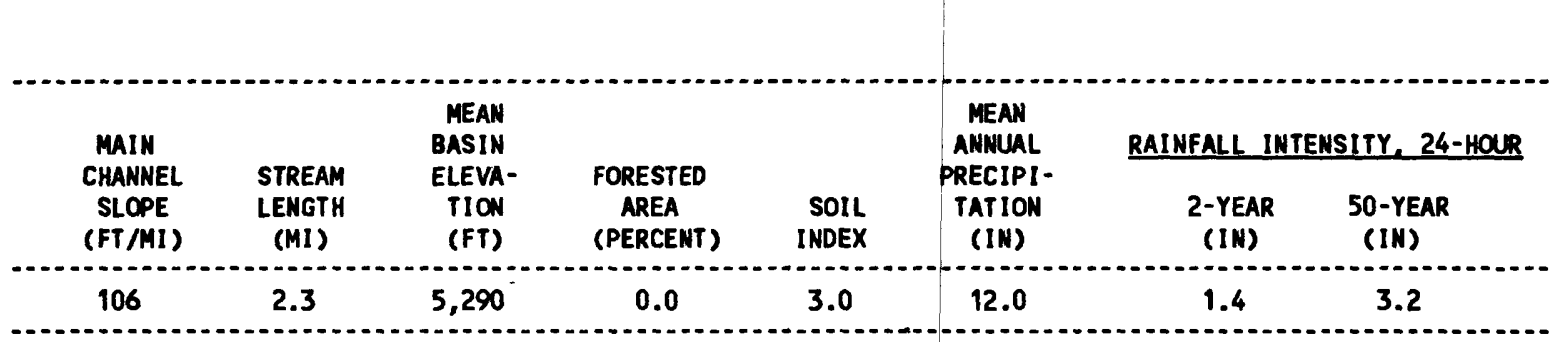


09403780 KANAB CREEK NEAR FREDONIA, AZ

LOCATION.--Lat 36.51'50", long 112.34'45", in SEK sec.14, T.40 N., R.3 W. (unsurveyed), Coconino Canty, Hydrologic Unit 15010003, in Kaibab Indian Reservation, at Nagles Crossing, on left bank 0.2 mi downstream from Johnson Wash and $6.5 \mathrm{mi}$ southwest of Fredonia.

DRAIMAGE AREA. $--1,085 \mathrm{mi}^{2}$.

REMARKS.--Diversions upstream for irrigation of about 1,400 acres in Utah and 800 acres in Arizona in 1967.

ANNUAL PEAK DISCHARGE

\begin{tabular}{|c|c|c|c|}
\hline $\begin{array}{l}\text { WATER } \\
\text { YEAR }\end{array}$ & DATE & $\begin{array}{c}\text { ANNUAL PEAK } \\
\text { DISCHARGE } \\
\left(F^{3} / \mathrm{S}\right)\end{array}$ & $\begin{array}{l}\text { DISCHARGE } \\
\text { COOES }\end{array}$ \\
\hline $\begin{array}{l}1550 \\
1964 \\
1965 \\
1966 \\
1967 \\
1968 \\
1969 \\
1970 \\
1971 \\
1972 \\
1973 \\
1974 \\
1975 \\
1976 \\
1977 \\
1978 \\
1979 \\
1980\end{array}$ & $\begin{array}{l}00-00-50 \\
08-13-65 \\
04-18-65 \\
03-08-66 \\
12-07-66 \\
07-31-68 \\
07-23-69 \\
08-18-70 \\
08-18-71 \\
09-19-72 \\
04-14-73 \\
07-23-74 \\
07-13-75 \\
09-25-76 \\
07-23-77 \\
04-11-78 \\
02-14-79 \\
02-20-80\end{array}$ & $\begin{array}{r}1,000 \\
(2) \\
250 \\
668 \\
2,960 \\
1,130 \\
1,330 \\
4,630 \\
1,340 \\
1,680 \\
660 \\
84 \\
603 \\
410 \\
435 \\
460 \\
2,020 \\
957\end{array}$ & ES,PF \\
\hline
\end{tabular}

BASIN CHARACTERISTICS

\begin{tabular}{|c|c|c|c|c|c|c|c|}
\hline \multirow{3}{*}{$\begin{array}{l}\text { MAIN } \\
\text { CHANNEL } \\
\text { SLOPE } \\
\text { (FT/MI) }\end{array}$} & \multirow[b]{3}{*}{$\begin{array}{c}\text { STREAM } \\
\text { LENGTH } \\
\text { (MI) }\end{array}$} & \multirow{3}{*}{$\begin{array}{l}\text { MEAN } \\
\text { BASIN } \\
\text { ELEVA- } \\
\text { TION } \\
\text { (FT) }\end{array}$} & \multirow[b]{3}{*}{$\begin{array}{l}\text { FORESTED } \\
\text { AREA } \\
\text { (PERCENT) }\end{array}$} & \multirow{2}{*}{\multicolumn{2}{|c|}{$\begin{array}{l}\text { MEAN } \\
\text { ANNUAL } \\
\text { PRECIPI- }\end{array}$}} & \multirow{2}{*}{\multicolumn{2}{|c|}{ RAINFALL INTENSITY, 24-HOUR }} \\
\hline & & & & & & & \\
\hline & & & & $\begin{array}{l}\text { SOIL } \\
\text { INDEX }\end{array}$ & $\begin{array}{l}\text { PRECIPI- } \\
\text { TATION } \\
\text { (IN) }\end{array}$ & $\begin{array}{c}\text { 2-YEAR } \\
\text { (IN) }\end{array}$ & $\begin{array}{l}\text { 50-YEAR } \\
\text { (IN) }\end{array}$ \\
\hline 56.4 & 49.6 & 6,100 & 60.0 & 3.0 & 12.0 & 1.5 & 3.0 \\
\hline
\end{tabular}


MEAN MONTHLY AND AMNUAL DISCHARGES $1964-80$

\begin{tabular}{|c|c|c|c|c|c|c|}
\hline MONTH & $\begin{array}{l}\operatorname{MAXIMM} \\
\left(F^{3} / S\right)\end{array}$ & $\begin{array}{l}\text { MINIMUM } \\
\left(F^{3} / S\right)\end{array}$ & $\begin{array}{c}\text { MEAN } \\
\left(F T^{3} / S\right)\end{array}$ & $\begin{array}{l}\text { STAN- } \\
\text { DARD } \\
\text { DEVIA- } \\
\text { TION } \\
\left(F T^{3} / S\right)\end{array}$ & $\begin{array}{l}\text { COEFFI- } \\
\text { CIENT OF } \\
\text { VARI - } \\
\text { ATION }\end{array}$ & $\begin{array}{c}\text { PERCENT } \\
\text { OF } \\
\text { ANNUAL } \\
\text { RUNOFF }\end{array}$ \\
\hline $\begin{array}{l}\text { OCTOBER } \\
\text { NOVEMBER } \\
\text { OECEMBER } \\
\text { JANUARY } \\
\text { FEBRUARY } \\
\text { MARCH } \\
\text { APRIL } \\
\text { MAY } \\
\text { JUNE } \\
\text { JULY } \\
\text { AUGUST } \\
\text { SEPTEMBER }\end{array}$ & $\begin{array}{l}19 \\
16 \\
58 \\
30 \\
49 \\
90 \\
80 \\
6.5 \\
0.77 \\
20 \\
48 \\
29\end{array}$ & $\begin{array}{l}0.00 \\
0.00 \\
0.00 \\
0.00 \\
0.00 \\
0.00 \\
0.00 \\
0.00 \\
0.00 \\
0.00 \\
0.00 \\
0.00\end{array}$ & $\begin{array}{c}1.8 \\
2.2 \\
7.3 \\
5.9 \\
9.9 \\
17 \\
21 \\
0.71 \\
0.05 \\
3.5 \\
7.6 \\
4.8\end{array}$ & $\begin{array}{c}4.6 \\
5.1 \\
15 \\
8.2 \\
14 \\
24 \\
30 \\
1.6 \\
0.19 \\
6.4 \\
14 \\
8.6\end{array}$ & $\begin{array}{l}2.6 \\
2.3 \\
2.0 \\
1.4 \\
1.5 \\
1.5 \\
1.4 \\
2.3 \\
3.5 \\
1.8 \\
1.9 \\
1.8\end{array}$ & $\begin{array}{r}2.2 \\
2.7 \\
8.9 \\
7.2 \\
12.2 \\
20.5 \\
25.8 \\
0.9 \\
0.1 \\
4.3 \\
9.4 \\
5.9\end{array}$ \\
\hline NWUAL & 18 & 0.78 & 6.8 & 5.2 & 0.77 & 100 \\
\hline
\end{tabular}

MAGNITUDE AND PROBABILITY OF INSTANTANEQUS PEAK FLON BASED ON PERIOD OF RECORD 1550, 1965-80

DISCHARGE, IN $\mathrm{FT}^{3} / \mathrm{S}$, FOR INDICATED RECURRENCE INTERVAL IN YEARS, AND EXCEEDANCE PROBABILITY, IN PERCENT

$\begin{array}{lccccc}52 & 5 & 10 & 25 & \begin{array}{c}50 \\ 2 \%\end{array} & \begin{array}{c}100\} \\ 1 \%\end{array} \\ 50 \% & 20 \% & 10 \% & 4 \% & & \\ 875 & 1,760 & 2,610 & 4,050 & 5,440 & 7,140\end{array}$

MACNITUDE ANO PROBABILITY OF ANNUAL LOW FLON BASED ON PERIOD OF RECORD 1965-80

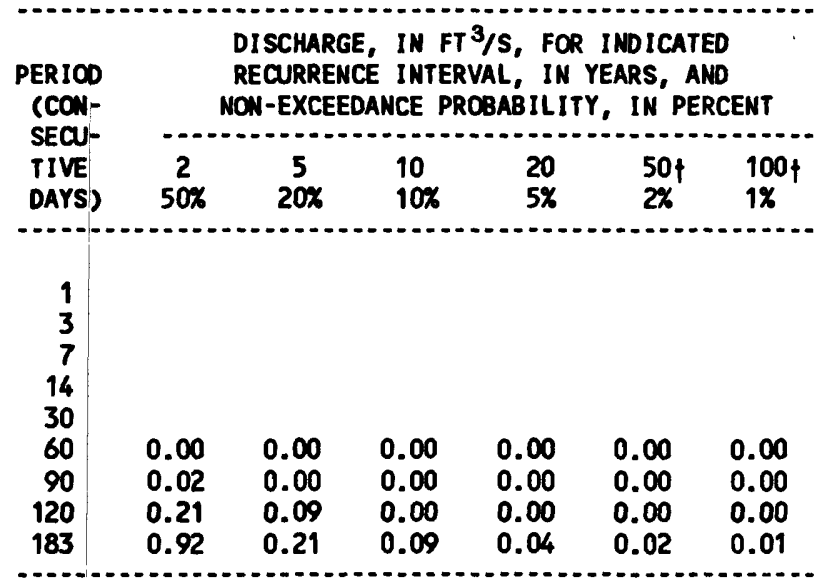

MAGNITUDE AND PROBABILITY OF ANNUAL HIGH FLOW BASED ON PERIOD OF RECORD 1964-80

\begin{tabular}{|c|c|c|c|c|c|c|}
\hline \multirow{2}{*}{$\begin{array}{l}\text { PERIOD } \\
\text { (CON- } \\
\text { SECU- } \\
\text { TIVE } \\
\text { DAY\$) }\end{array}$} & \multicolumn{6}{|c|}{$\begin{array}{l}\text { DISCHARGE, IN FT } 3 / S \text {, FOR INDICATED } \\
\text { RECURRENCE INTERVAL, IN YEARS, AND } \\
\text { EXCEEDANCE PROBABILITY, IN PERCENT }\end{array}$} \\
\hline & $\stackrel{2}{2}$ & $\begin{array}{c}5 \\
20 \%\end{array}$ & $\begin{array}{l}10 \\
10 \%\end{array}$ & $\begin{array}{l}25 \\
4 \%\end{array}$ & $\begin{array}{l}50 \phi \\
2 \%\end{array}$ & $\underset{1 \%}{100 \phi}$ \\
\hline $\begin{array}{l}1 \\
3 \\
7 \\
15 \\
30 \\
60 \\
90\end{array}$ & $\begin{array}{r}223 \\
139 \\
85 \\
50 \\
32 \\
19 \\
14\end{array}$ & $\begin{array}{r}482 \\
290 \\
179 \\
116 \\
74 \\
46 \\
35\end{array}$ & $\begin{array}{r}679 \\
397 \\
244 \\
166 \\
108 \\
67 \\
53\end{array}$ & $\begin{array}{r}936 \\
529 \\
319 \\
232 \\
154 \\
97 \\
78\end{array}$ & $\begin{array}{r}1,130 \\
620 \\
369 \\
280 \\
188 \\
119 \\
99\end{array}$ & $\begin{array}{r}1,310 \\
704 \\
414 \\
327 \\
221 \\
142 \\
121\end{array}$ \\
\hline
\end{tabular}

OURATION TABLE OF DAILY MEAN FLON FOR PERIOD OF RECORD 1964-80

DISCMARGE, IN $\mathrm{FT}^{3} / \mathrm{S}$, WHICH WAS EQUALED OR EXCEEDED FOR INDICATED PERCENT OF TIME

\begin{tabular}{|c|c|c|c|c|c|c|c|c|c|c|c|c|c|c|c|c|}
\hline $1 \%$ & $5 \%$ & $10 \%$ & $15 \%$ & $20 \%$ & $30 \%$ & $40 \%$ & $50 \%$ & $60 \%$ & $70 x$ & $80 \%$ & $90 \%$ & $95 \%$ & $98 \%$ & $99 \%$ & $99.5 x$ & $99.9 \%$ \\
\hline 146 & 28 & 11 & 5.5 & 2.9 & 0.69 & 0.10 & 0.01 & 0.01 & 0.00 & 0.00 & 0.00 & 0.00 & 0.00 & 0.00 & 0.00 & 0.00 \\
\hline
\end{tabular}

† Reliability of values in colum is uncertain, and potential errors are large. 
KANAB CREEK BASIN

09403780 KANAB CREEK NEAR FREDONIA, AZ--CONTINUED
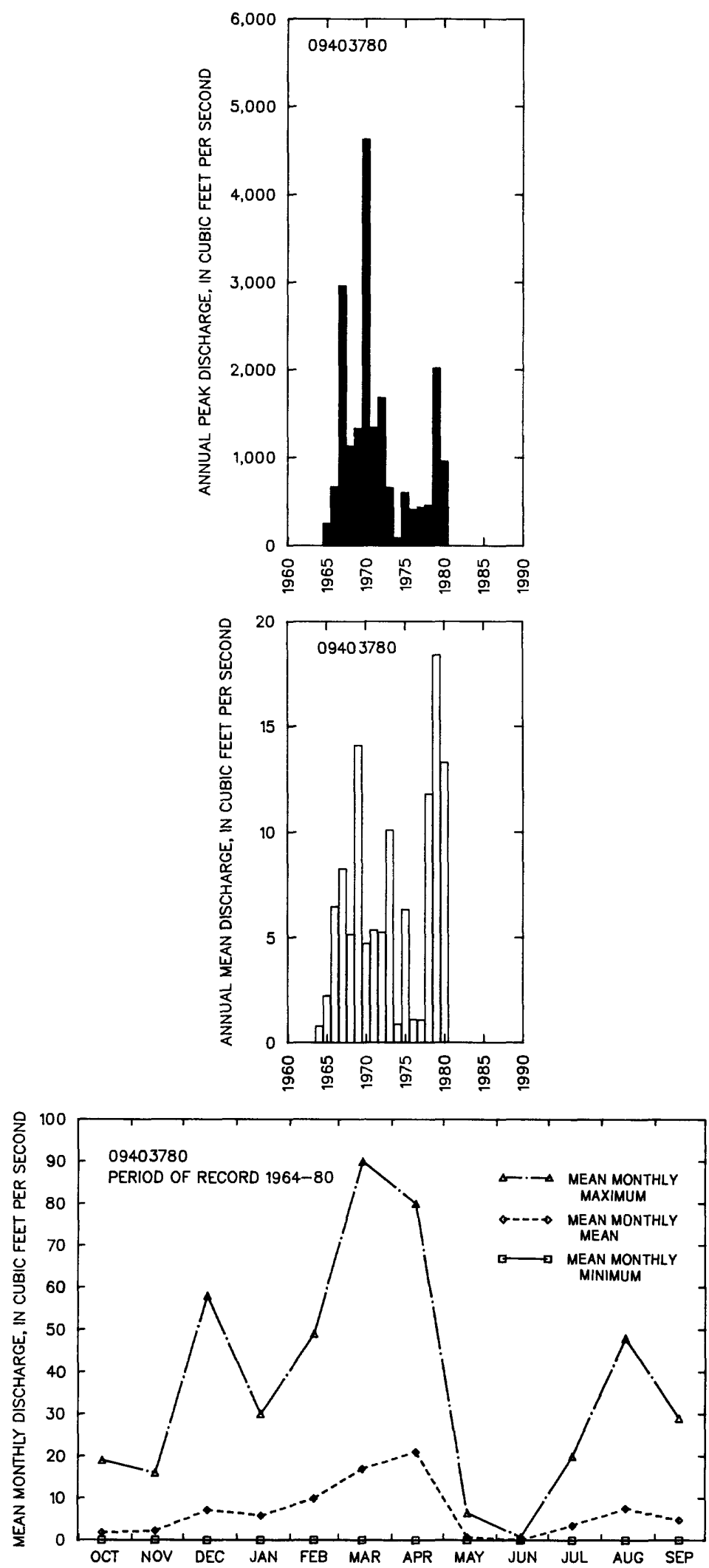
09403800 BITTER SEEPS WASH TRIB MEAR FREDONIA, AZ

LOCATION. --Lat 36.51'25", long 112.45'30", in MEK sec.19, T.40 N., R.4 W., Mohave County, at State Highway 389, 1 mi west of Pipe Spring National Monument, and 14 mi southwest of Fredonia.

DRAIMAGE AREA. $--2.85 \mathrm{mi}^{2}$.

ANMUAL PEAK DISCHARGE

\begin{tabular}{lccc}
$\begin{array}{l}\text { WATER } \\
\text { YEAR }\end{array}$ & DATE & $\begin{array}{c}\text { ANNUAL PEAK } \\
\text { DISCHARGE } \\
\text { (FT } 3 / \text { S })\end{array}$ & $\begin{array}{c}\text { DISCHARGE } \\
\text { COOES }\end{array}$ \\
\hline 1963 & $08-30-63$ & 622 & \\
1964 & $07-24-64$ & 736 & \\
1965 & $00-00-65$ & 0 & \\
1966 & $00-00-66$ & 0 & \\
1967 & $09-23-67$ & 55 & \\
1968 & $07-31-68$ & 57 & \\
1969 & $08-29-69$ & 137 & \\
1970 & $08-18-70$ & 670 & \\
1971 & $08-23-71$ & 1,950 & \\
1972 & $09-20-72$ & 50 & \\
1973 & $10-19-72$ & 30 & \\
1974 & $00-00-74$ & 0 & \\
1975 & $07-08-75$ & 1,050 & \\
1976 & $00-00-76$ & 165 & \\
$\ldots$
\end{tabular}

MAGNITUDE AND PROBABILITY OF INSTANTANEOUS PEAK FLOW BASED ON PERIOD OF RECORD 1963-76

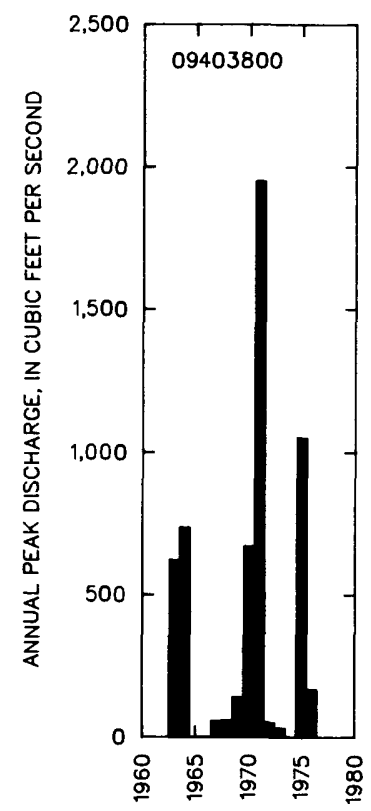

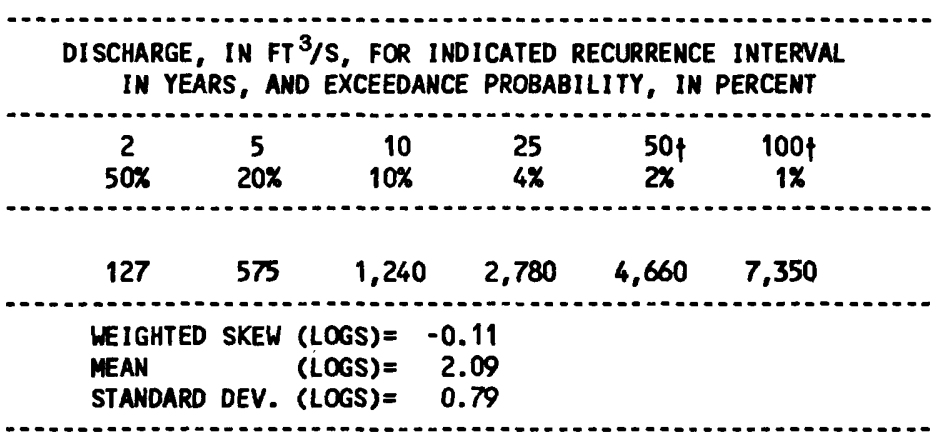

+ Reliability of values in column is uncertain, and potential errors are large.

\section{BASIN CHARACTERISTICS}

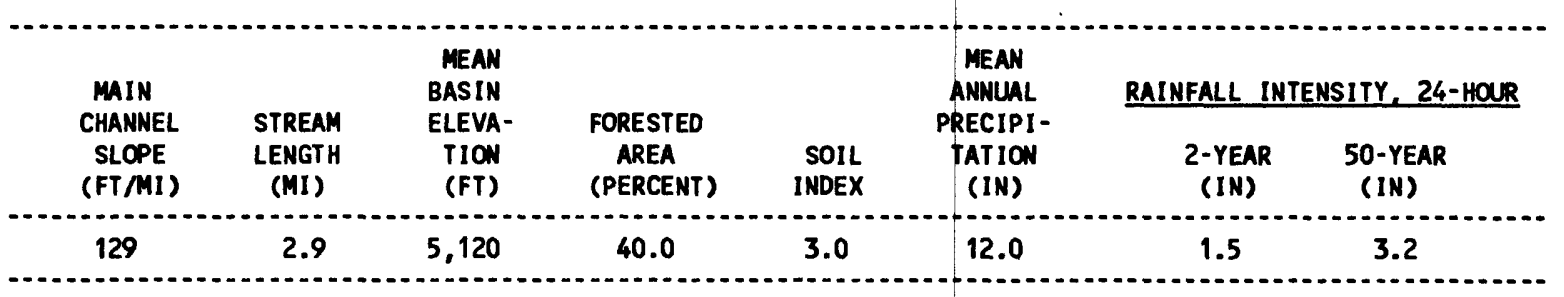


09403930 WEST CATARACT CREEK NEAR HILLIAMS, AZ

LOCATION.--Lat $35^{\circ} 14^{\prime} 52^{\prime \prime}$, long $112^{\circ} 13^{\prime} 2^{\prime \prime}$, in NHK sec.31, T.22 N., R.2 E., Coconino County, Hydrologic Unit 15010004 , at Country Club Road, $0.25 \mathrm{mi}$ above Cataract Lake, and 1 mi west of Williams city limits.

DRAINAGE AREA. $--3.18 \mathrm{mi}^{2}$.

ANNUAL PEAK DISCHARGE

\begin{tabular}{|c|c|c|c|}
\hline $\begin{array}{l}\text { WATER } \\
\text { YEAR }\end{array}$ & DATE & $\begin{array}{c}\text { ANNUAL PEAK } \\
\text { DISCHARGE } \\
\text { (FT } 3 / \mathrm{S})\end{array}$ & $\begin{array}{l}\text { DISCHARGE } \\
\text { CODES }\end{array}$ \\
\hline $\begin{array}{l}1964 \\
1965 \\
1966 \\
1967 \\
1968 \\
1969 \\
1970 \\
1971 \\
1972 \\
1973 \\
1974 \\
1975 \\
1976\end{array}$ & $\begin{array}{l}08-26-64 \\
04-00-65 \\
11-25-65 \\
12-06-66 \\
00-00-68 \\
03-00-69 \\
00-00-70 \\
00-00-71 \\
12-26-71 \\
10-00-72 \\
07-00-74 \\
04-00-75 \\
00-00-76\end{array}$ & $\begin{array}{c}21 \\
99 \\
122 \\
151 \\
12 \\
36 \\
5.0 \\
4.0 \\
60 \\
96 \\
1.0 \\
2.0 \\
88\end{array}$ & LT \\
\hline
\end{tabular}

MAGNITUDE AND PROBABILITY OF INSTANTANEQUS PEAK FLON BASED ON PERIOD OF RECORD 1964-76

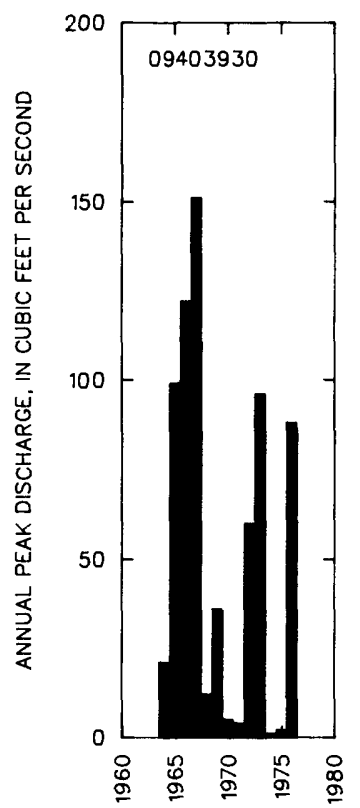

DISCHARGE, IN $\mathrm{FT}^{3} / \mathrm{S}$, FOR INDICATED RECURRENCE INTERVAL IN YEARS, AND EXCEEDANCE PROBABILITY, IN PERCENT

\begin{tabular}{cccccc}
2 & 5 & 10 & 25 & $50 \dagger$ & $100 \nmid$ \\
$50 \%$ & $20 \%$ & $10 \%$ & $4 \%$ & $2 \%$ & $1 \%$ \\
26.2 & 96.4 & 181 & 342 & 505 & 708 \\
\hline WEIGHTED SKEW (LOGS) & -0.34 & & \\
MEAN & & & \\
(LOGS) & 1.38 & & \\
STAMDARD DEV. (LOGS) & 0.71
\end{tabular}

$\uparrow$ Reliability of values in column is uncertain, and potential errors are large.

BASIN CHARACTERISTICS

\begin{tabular}{|c|c|c|c|c|c|c|c|}
\hline MAIN & & $\begin{array}{l}\text { MEAN } \\
\text { BASIN }\end{array}$ & & & $\begin{array}{c}\text { MEAN } \\
\text { ANNUAL }\end{array}$ & RAINFALL II & SITY, 24-HOUR \\
\hline $\begin{array}{l}\text { CHANNEL } \\
\text { SLOPE } \\
\text { (FT/MI) }\end{array}$ & $\begin{array}{c}\text { STREAM } \\
\text { LENGTH } \\
\text { (MI) }\end{array}$ & $\begin{array}{l}\text { ELEVA- } \\
\text { TION } \\
\text { (FT) }\end{array}$ & $\begin{array}{l}\text { FORESTED } \\
\text { AREA } \\
\text { (PERCENT) }\end{array}$ & $\begin{array}{l}\text { SOIL } \\
\text { INDEX }\end{array}$ & $\begin{array}{l}\text { PRECIPI- } \\
\text { TATION } \\
\text { (IN) }\end{array}$ & $\begin{array}{l}\text { 2-YEAR } \\
\text { (IN) }\end{array}$ & $\begin{array}{l}\text { 50-YEAR } \\
\text { (IN) }\end{array}$ \\
\hline 465 & 3.9 & 7,190 & 82.0 & 3.0 & 23.5 & 2.0 & 4.2 \\
\hline
\end{tabular}




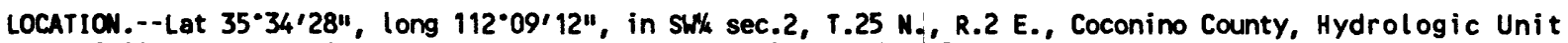
15010004 , at State Highway $64,6 \mathrm{mi}$ southeast of Valle, and $22.5 \mathrm{mi}$ north of Williams.

DRAINAGE AREA. $--5.00 \mathrm{mi}^{2}$, of which $1.07 \mathrm{mi}^{2}$ is noncontributing.

ANIUAL PEAK DISCHARGE

\begin{tabular}{cccc}
$\begin{array}{c}\text { WATER } \\
\text { YEAR }\end{array}$ & DATE & $\begin{array}{c}\text { ANNUAL PEAK } \\
\text { DISCHARGE } \\
\text { (FT }{ }^{3} / \mathrm{S} \text { ) }\end{array}$ & $\begin{array}{c}\text { DISCHARGE } \\
\text { CODES }\end{array}$ \\
\hline 1963 & $08-24-63$ & 100 & \\
1964 & $07-00-64$ & 25 & ES \\
1965 & $09-06-65$ & 35 & ES \\
1966 & $00-00-66$ & 20 & ES \\
1967 & $00-00-67$ & 98 & \\
1968 & $00-00-68$ & 190 & \\
1969 & $00-00-69$ & 1.0 & ES \\
1970 & $07-22-70$ & 30 & ES \\
1971 & $00-00-71$ & 1.0 & LT \\
1972 & $07-17-72$ & 8.0 & LT \\
1973 & $00-00-73$ & 1.0 & LT \\
1974 & $00-00-74$ & 0 & \\
1975 & $00-00-75$ & 0 & \\
1976 & $09-26-76$ & 32 & \\
\hline & & &
\end{tabular}

MAGNITUDE AND PROBABILITY OF INSTANTANEOUS PEAK FLOH BASED ON PERIOD OF RECORD 1963-76

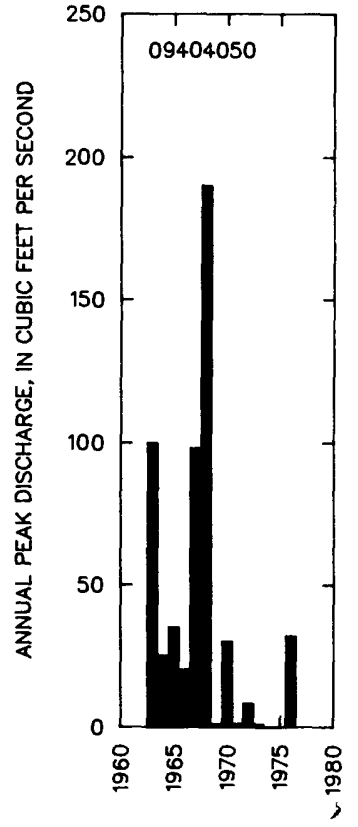

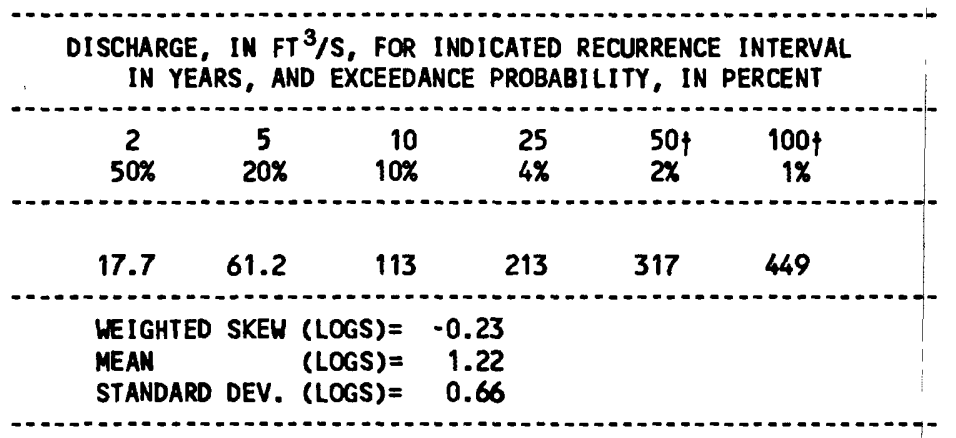

† Reliability of values in column is uncertain, and potential errors are large.

\section{BASIN CHARACTERISTICS}

\begin{tabular}{|c|c|c|c|c|c|c|c|}
\hline MAIN & & $\begin{array}{l}\text { MEAN } \\
\text { BASIN }\end{array}$ & & & & RAINFALL II & SITY, 24-HOUR \\
\hline $\begin{array}{l}\text { CHANNEL } \\
\text { SLOPE } \\
\text { (FT/MI) }\end{array}$ & $\begin{array}{c}\text { STREAM } \\
\text { LENGTH } \\
\text { (MI) }\end{array}$ & $\begin{array}{l}\text { ELEVA- } \\
\text { TION } \\
\text { (FT) }\end{array}$ & $\begin{array}{l}\text { FORESTED } \\
\text { AREA } \\
\text { (PERCENT) }\end{array}$ & $\begin{array}{l}\text { SOIL } \\
\text { INDEX }\end{array}$ & $\begin{array}{l}\text { PRECIPI- } \\
\text { TATION } \\
\text { (IN) }\end{array}$ & $\begin{array}{c}\text { 2-YEAR } \\
\text { (IN) }\end{array}$ & $\begin{array}{l}\text { 50-YEAR } \\
\text { (IN) }\end{array}$ \\
\hline 40.5 & 2.4 & 6,750 & 9.2 & 3.0 & 12.2 & 1.5 & 3.3 \\
\hline
\end{tabular}


09404070 LITTLE RED HORSE WASH MEAR GRAND CANYON, AZ

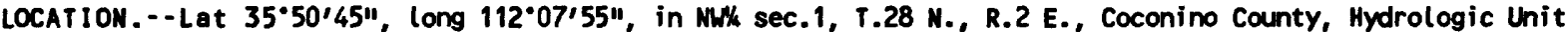
15010004, at State Highway 64, $0.1 \mathrm{mi}$ south of road to Old Grand Canyon airport, and $15 \mathrm{mi}$ south of Grand Canyon village.

DRAINAGE AREA. $--21.8 \mathrm{mi}^{2}$.

ANNUAL PEAK DISCHARGE

$\begin{array}{ccc}\begin{array}{c}\text { UATER } \\ \text { YEAR }\end{array} & \text { DATE } & \begin{array}{c}\text { ANNUAL PEAK } \\ \text { DISCHARGE } \\ \text { (FT } 3 / \text { S) }\end{array} \text { DISCHARGE } \\ \text { COOES }\end{array}$

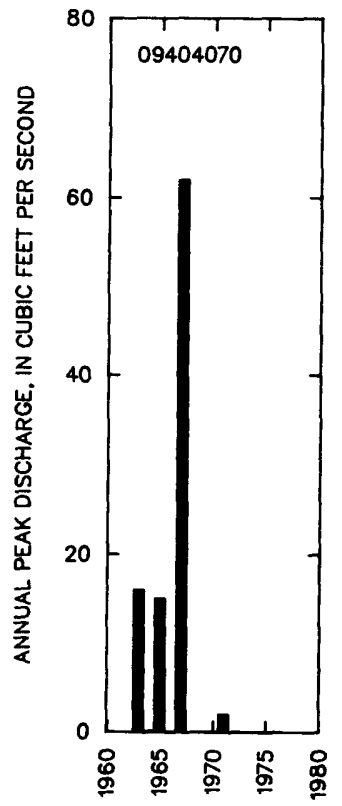

MAGNITUDE AND PROBABILITY OF INSTANTANEOUS PEAK FLOW BASED ON PERIOD OF RECORD

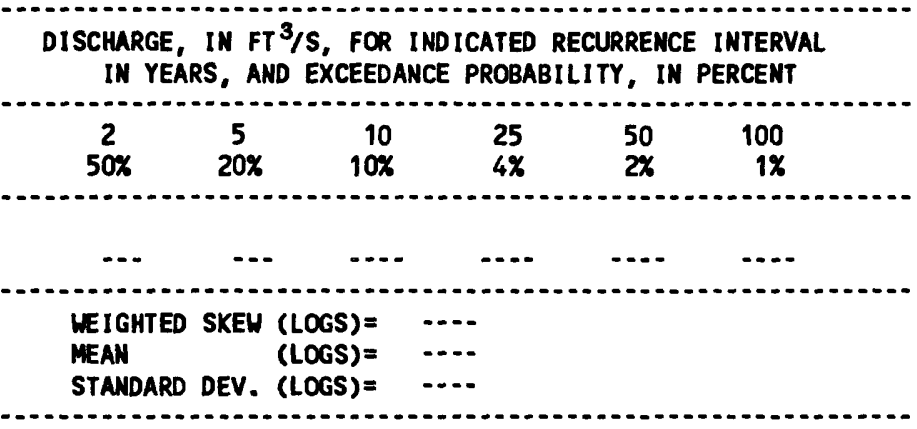

BASIN CHARACTERISTICS

\begin{tabular}{|c|c|c|c|c|c|c|c|}
\hline \multirow{3}{*}{$\begin{array}{l}\text { MAIN } \\
\text { CHANNEL } \\
\text { SLOPE } \\
\text { (FT/MI) }\end{array}$} & \multirow[b]{3}{*}{$\begin{array}{l}\text { STREAM } \\
\text { LENGTH } \\
\text { (MI) }\end{array}$} & \multirow{3}{*}{$\begin{array}{c}\text { MEAN } \\
\text { BASIN } \\
\text { ELEVA- } \\
\text { TION } \\
\text { (FT) }\end{array}$} & \multirow[b]{3}{*}{$\begin{array}{l}\text { FORESTED } \\
\text { AREA } \\
\text { (PERCENT) }\end{array}$} & \multirow[b]{3}{*}{$\begin{array}{l}\text { SOIL } \\
\text { INDEX }\end{array}$} & \multirow{3}{*}{$\begin{array}{l}\text { MEAN } \\
\text { ANNUAL } \\
\text { PRECIPI- } \\
\text { TATION } \\
\text { (IN) }\end{array}$} & \multirow{2}{*}{\multicolumn{2}{|c|}{ RAINFALL INTENSITY, 24-HOUR }} \\
\hline & & & & & & & \\
\hline & & & & & & $\begin{array}{l}\text { 2-YEAR } \\
\text { (IN) }\end{array}$ & $\begin{array}{l}\text { 50-YEAR } \\
\text { (IN) }\end{array}$ \\
\hline 56.9 & 9.6 & 6,780 & 87.0 & 3.0 & 13.2 & 1.7 & 3.3 \\
\hline
\end{tabular}


LOCATION.-- Lat 35'33'07", long 113.23'17", in SEMNWK sec.18, T.25 N., R.10 W., Mohave County, Hydrologic Unit 15010002, at U.S. Highway 66, 2.8 mi northeast of the Peach Springs Post Office.

DRAIMAGE AREA. $-0.20 \mathrm{mi}^{2}$.

AMNUAL PEAK DISCHARGE

\begin{tabular}{|c|c|c|c|}
\hline $\begin{array}{l}\text { WATER } \\
\text { YEAR }\end{array}$ & DATE & $\begin{array}{l}\text { ANNUAL PEAK } \\
\text { DISCHARGE } \\
\left(\mathrm{FT}^{3} / \mathrm{S}\right)\end{array}$ & $\begin{array}{l}\text { DISCHARGE } \\
\text { CODES }\end{array}$ \\
\hline $\begin{array}{l}1964 \\
1965 \\
1966 \\
1967 \\
1968 \\
1969 \\
1970 \\
1971 \\
1972 \\
1973 \\
1974 \\
1975 \\
1976\end{array}$ & $\begin{array}{l}00-00-64 \\
00-00-65 \\
07-30-66 \\
09-03-67 \\
08-04-68 \\
07-29-69 \\
07-00-70 \\
08-10-71 \\
08-12-72 \\
00-00-73 \\
07-21-74 \\
07-06-75 \\
00-00-76\end{array}$ & $\begin{array}{c}0 \\
0 \\
177 \\
17 \\
19 \\
6.0 \\
27 \\
21 \\
27 \\
0 \\
25 \\
25 \\
5.0\end{array}$ & ES \\
\hline
\end{tabular}

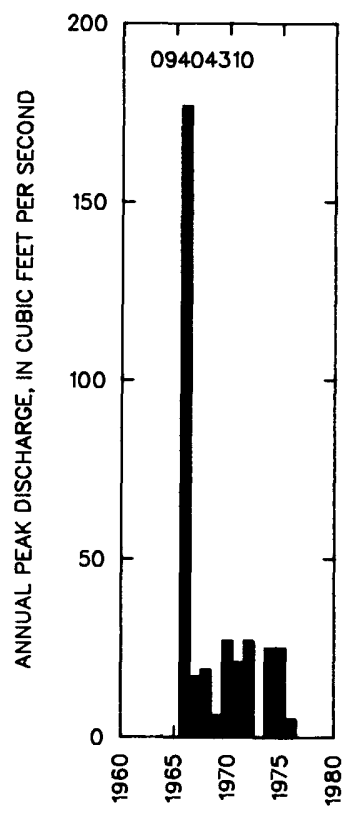

MAGNITUDE AND PROBABILITY OF INSTANTANEOUS PEAK FLOH BASED ON PERIOD OF RECORD 1964-76

DISCHARGE, IN $\mathrm{FT}^{3} / \mathrm{S}$, FOR INDICATED RECURRENCE INTERVAL IN YEARS, AND EXCEEDANCE PROBABILITY, IN PERCENT

\begin{tabular}{|c|c|c|c|c|c|}
\hline $\begin{array}{c}2 \nmid \\
50 \%\end{array}$ & $\begin{array}{r}5 \dagger \\
20 \%\end{array}$ & $\begin{array}{c}10 \dagger \\
10 \%\end{array}$ & $\begin{array}{l}25 \dagger \\
4 \%\end{array}$ & $\begin{array}{l}50 \dagger \\
2 \%\end{array}$ & $\begin{array}{c}100 \dagger \\
1 \%\end{array}$ \\
\hline 13.8 & 37.2 & 63.5 & 114 & 167 & 237 \\
\hline $\begin{array}{l}\text { WEIGHTED } \\
\text { MEAN } \\
\text { STANDARD }\end{array}$ & $\begin{array}{l}\text { SKEH } \\
\text { DEV. }\end{array}$ & $\begin{array}{l}(L O G S)= \\
\text { (LOGS)= } \\
(L O G S)=\end{array}$ & $\begin{array}{l}0.16 \\
1.15 \\
0.50\end{array}$ & & \\
\hline
\end{tabular}

$\uparrow$ Reliability of values in column is uncertain, and potential errors are large.

BASIN CHARACTERISTICS

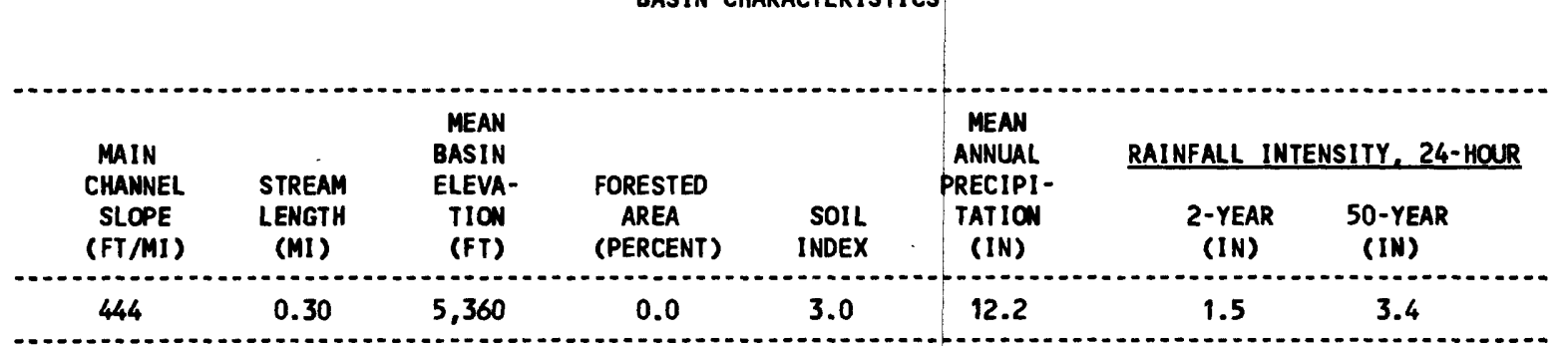


09404340 TRUXTON WASH AT VALENTINE, AZ

LOCATION.-- Lat 35'23'10", Long 113'39'20", in SEK sec.10, T.23 N., R.13 H., Mohave County, Hydrologic Unit 15010007, in Hualapai Indian Reservation, at Valentine.

DRAIMAGE AREA. $--370 \mathrm{mi}^{2}$.

\section{ANNUAL PEAK DISCHARGE}

\begin{tabular}{cccc}
$\begin{array}{c}\text { WATER } \\
\text { YEAR }\end{array}$ & DATE & $\begin{array}{c}\text { ANNUAL PEAK } \\
\text { DISCHARGE } \\
\text { (FT } 3 / \text { S) }\end{array}$ & $\begin{array}{c}\text { DISCHARGE } \\
\text { CODES }\end{array}$ \\
\hline 1904 & $07-30-04$ & 149,000 & ES,HP \\
1965 & $07-29-65$ & 250 & \\
1966 & $08-18-66$ & 1,960 & \\
1967 & $09-15-67$ & 1,640 & \\
1968 & $08-04-68$ & 8,760 & \\
1969 & $07-19-69$ & 900 & \\
1970 & $07-22-70$ & 2,650 & \\
1971 & $08-21-71$ & 1,130 & \\
1972 & $09-19-72$ & 40 & \\
1973 & $07-08-73$ & 380 & \\
1974 & $07-20-74$ & 6,500 & \\
1975 & $00-00-75$ & 1,400 & \\
1976 & $00-00-76$ & 5.0 & ES \\
$\ldots$
\end{tabular}

Highest since 1898.

MAGNITUDE AND PROBABILITY OF INSTANTANEOUS PEAK FLOW BASED ON PERIOD OF RECORD 1904, 1965-76

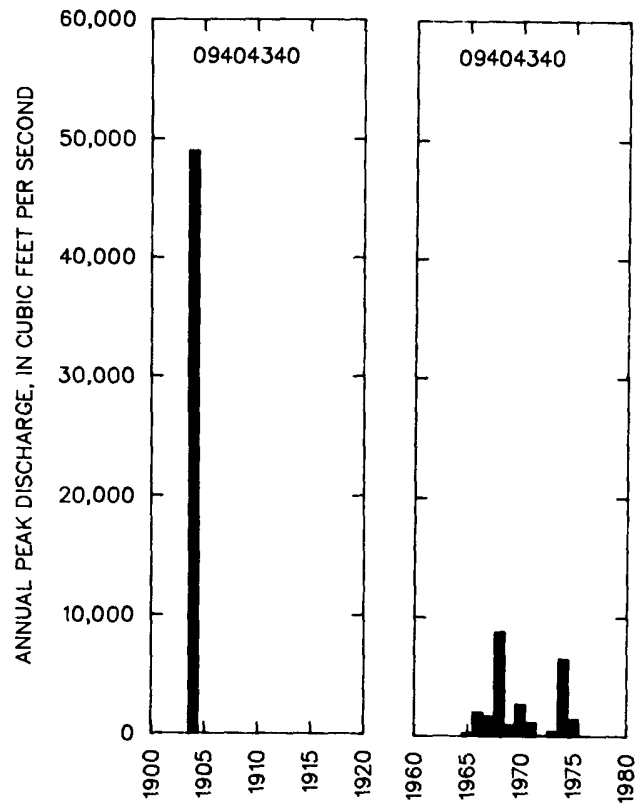

DISCHARGE, IN FT $3 / 5$, FOR INDICATED RECURRENCE INTERVAL IN YEARS, AND EXCEEDANCE PROBABILITY, IN PERCENT

\begin{tabular}{|c|c|c|c|c|c|}
\hline $\begin{array}{c}2 f \\
50 \%\end{array}$ & $\begin{array}{r}5 \dagger \\
20 \%\end{array}$ & $\begin{array}{c}10 \dagger \\
10 \%\end{array}$ & $\begin{array}{l}25 \uparrow \\
4 \%\end{array}$ & $\begin{array}{l}50 \dagger \\
2 \%\end{array}$ & $\begin{array}{c}100 \dagger \\
1 \%\end{array}$ \\
\hline 1,150 & 3,510 & 6,330 & 12,000 & 18,100 & 26,300 \\
\hline $\begin{array}{l}\text { VEIGHTED } \\
\text { MEAN } \\
\text { STANDARD }\end{array}$ & $\begin{array}{l}\text { SKEW } \\
\text { DEV. }\end{array}$ & $\begin{array}{l}(\text { LOGS })= \\
(\text { LOGS })= \\
(\text { LOGS })=\end{array}$ & $\begin{array}{l}0.06 \\
3.07 \\
0.57\end{array}$ & & \\
\hline
\end{tabular}

$\uparrow$ Reliability of values in column is uncertain, and potential errors are large.

BASIN CHARACTERISTICS

\begin{tabular}{|c|c|c|c|c|c|c|c|}
\hline \multirow{3}{*}{$\begin{array}{c}\text { MAIN } \\
\text { CHANNEL } \\
\text { SLOPE } \\
\text { (FT/MI) }\end{array}$} & \multirow[b]{3}{*}{$\begin{array}{l}\text { STREAM } \\
\text { LENGTH } \\
\text { (MI) }\end{array}$} & \multirow{3}{*}{$\begin{array}{l}\text { MEAN } \\
\text { BASIN } \\
\text { ELEVA- } \\
\text { TION } \\
\text { (FT) }\end{array}$} & \multirow[b]{3}{*}{$\begin{array}{l}\text { FORESTED } \\
\text { AREA } \\
\text { (PERCENT) }\end{array}$} & \multirow[b]{3}{*}{$\begin{array}{l}\text { SOIL } \\
\text { INDEX }\end{array}$} & \multirow{3}{*}{$\begin{array}{l}\text { MEAN } \\
\text { ANNUAL } \\
\text { PRECIPI- } \\
\text { TATION } \\
\text { (IN) }\end{array}$} & \multirow{2}{*}{\multicolumn{2}{|c|}{ RAINFALL INTENSITY, 24-HOUR }} \\
\hline & & & & & & & \\
\hline & & & & & & $\begin{array}{c}\text { 2-YEAR } \\
\text { (IN) }\end{array}$ & $\begin{array}{c}\text { 50-YEAR } \\
\text { (IN) }\end{array}$ \\
\hline 57.0 & 30.4 & 4,630 & 72.0 & 2.0 & 12.1 & 1.5 & 3.5 \\
\hline
\end{tabular}


LOCATION.-- Lat 35'23'00", long $113^{\circ} 39^{\prime} 45^{\prime \prime}$, in NHK sec.15, T.23, R.13 H., Mohave County, Hydrologic Unit 15010007, at U.S. Highway $66,0.3 \mathrm{mi}$ southwest of Valent ine.

DRAIMAGE AREA. $--3.15 \mathrm{mi}^{2}$

\section{ANNUAL PEAK DISCHARGE}

\begin{tabular}{cccc}
$\begin{array}{c}\text { MATER } \\
\text { YEAR }\end{array}$ & DATE & $\begin{array}{c}\text { ANNUAL PEAK } \\
\text { DISCHARGE } \\
\text { (FT } 3 / \text { S) }\end{array}$ & $\begin{array}{c}\text { DISCHARGE } \\
\text { CODES }\end{array}$ \\
\hline 1963 & $00-00-63$ & 0 & \\
1964 & $08-00-64$ & 5.0 & ES \\
1965 & $10-17-64$ & 20 & ES \\
1966 & $12-09-65$ & 4.0 & ES \\
1967 & $08-20-67$ & 3,800 & \\
1968 & $08-04-68$ & 50 & ES \\
1969 & $07-29-69$ & 2.0 & LT \\
1970 & $07-00-70$ & 30 & ES \\
1971 & $00-00-71$ & 15 & ES \\
1972 & $08-12-72$ & 2,800 & \\
1973 & $03-12-73$ & 25 & ES \\
1974 & $00-00-74$ & 0 & \\
1975 & $00-00-75$ & 1.0 & ES \\
1976 & $00-00-76$ & 10 & LT \\
$\ldots$
\end{tabular}

MAGNITUDE AND PROBABILITY OF INSTANTANEOUS PEAK FLOW BASED ON PERIOD OF RECORD 1963-76

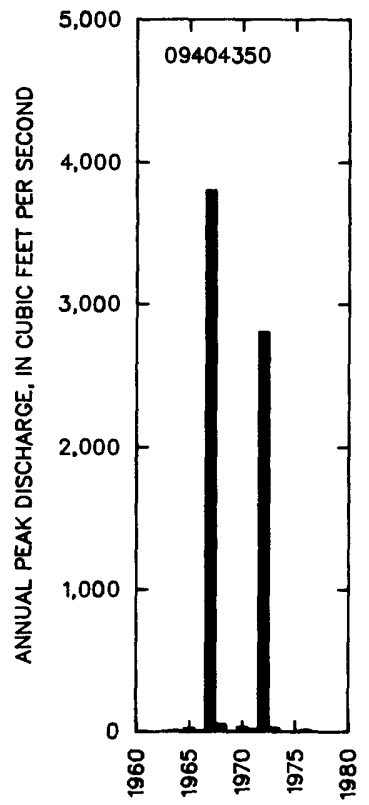

DISCHARGE, IN $\mathrm{FT}^{3}$ /S, FOR INDICATED RECURRENCE INTERVAL IN YEARS, AND EXCEEDANCE PROBABILITY, IN PERCENT

\begin{tabular}{|c|c|c|c|c|c|}
\hline $\begin{array}{c}2 \dagger \\
50 \%\end{array}$ & $\begin{array}{r}5 \dagger \\
20 \%\end{array}$ & $\begin{array}{c}10 \dagger \\
10 \%\end{array}$ & $\begin{array}{l}25 \nmid \\
4 \%\end{array}$ & $\begin{array}{l}50\} \\
2 x\end{array}$ & $\begin{array}{c}100 \gamma \\
18\end{array}$ \\
\hline 12.7 & 142 & 552 & 2,540 & 7,090 & 18,400 \\
\hline $\begin{array}{l}\text { VEIGH } \\
\text { MEAN } \\
\text { STANO }\end{array}$ & $\begin{array}{l}\text { SKEW } \\
\text { DEV. }\end{array}$ & $\begin{array}{l}(\text { LOGS })= \\
(\text { LOGS) }= \\
(\text { LOGS }=\end{array}$ & $\begin{array}{l}0.37 \\
1.18 \\
1.19\end{array}$ & & \\
\hline
\end{tabular}

$\uparrow$ Reliability of values in colum is uncertain, and potential errors are large.

BASIN CHARACTERISTICS

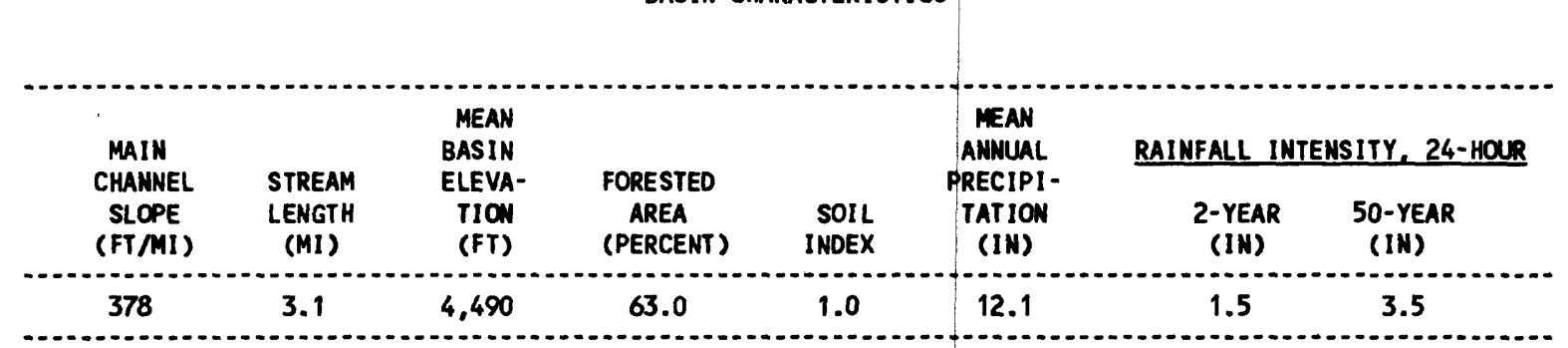


09415000 VIRGIN RIVER AT LITTLEFIELD, $A Z$

LOCATION.--Lat 36'53'30", long 113.55'25", in SW/2SWh sec.4, T.40 N., R.15 W., Mohave County, Hydrologic Unit 15010010, on right bank 0.5 mi downstream from Beaver Dam Wash, $0.4 \mathrm{mi}$ upstream from Littlefield, and $36 \mathrm{mi}$ upstream from waterline of Lake Mead at altitude 1,22l ft. National Geodetic Vertical Datum of 1929.

DRAIMAGE AREA. $--5,090 \mathrm{mi}^{2}$, approximately.

ANMUAL PEAK DISCHARGE

\begin{tabular}{|c|c|c|c|c|c|c|c|}
\hline $\begin{array}{l}\text { WATER } \\
\text { YEAR }\end{array}$ & DATE & $\begin{array}{l}\text { ANNUAL PEAK } \\
\text { DISCHARGE } \\
\left(F^{3} / S\right)\end{array}$ & $\begin{array}{l}\text { DISCHARGE } \\
\text { CODES }\end{array}$ & $\begin{array}{l}\text { WATER } \\
\text { YEAR }\end{array}$ & DATE & $\begin{array}{l}\text { ANNUAL PEAK } \\
\text { DISCHARGE } \\
\left(\mathrm{FT}^{3} / \mathrm{S}\right)\end{array}$ & $\begin{array}{l}\text { DISCHARGE } \\
\text { CODES }\end{array}$ \\
\hline $\begin{array}{l}1930 \\
1931 \\
1932 \\
1933 \\
1934 \\
1935 \\
1936 \\
1937 \\
1938 \\
1939 \\
1940 \\
1941 \\
1942 \\
1943 \\
1944 \\
1945 \\
1946 \\
1947 \\
1948 \\
1949 \\
1950 \\
1951 \\
1952 \\
1953 \\
1954 \\
1955 \\
1956 \\
1957 \\
1958 \\
1959\end{array}$ & $\begin{array}{l}08-09-30 \\
11-18-30 \\
08-27-32 \\
05-01-33 \\
12-14-33 \\
08-16-35 \\
07-10-36 \\
02-07-37 \\
03-03-38 \\
09-12-39 \\
09-18-40 \\
03-02-41 \\
10-13-41 \\
03-11-43 \\
05-09-44 \\
02-03-45 \\
08-12-46 \\
10-29-46 \\
09-16-48 \\
09-10-49 \\
07-18-50 \\
08-04-51 \\
12-30-51 \\
08-27-53 \\
08-04-54 \\
08-25-55 \\
01-27-56 \\
08-21-57 \\
03-17-58 \\
08-19-59\end{array}$ & $\begin{array}{r}6,500 \\
3,000 \\
18,000 \\
1,500 \\
1,220 \\
1,900 \\
2,710 \\
1,440 \\
22,000 \\
13,000 \\
11,000 \\
6,000 \\
3,740 \\
2,660 \\
1,900 \\
4,170 \\
5,010 \\
9,400 \\
1,090 \\
2,290 \\
3,450 \\
12,000 \\
7,170 \\
5,490 \\
6,020 \\
19,800 \\
2,460 \\
3,950 \\
7,180 \\
3,490\end{array}$ & & $\begin{array}{l}1960 \\
1961 \\
1962 \\
1963 \\
1964 \\
1965 \\
1966 \\
1967 \\
1968 \\
1969 \\
1970 \\
1971 \\
1972 \\
1973 \\
1974 \\
1975 \\
1976 \\
1977 \\
1978 \\
1979 \\
1980 \\
1981 \\
1982 \\
1983 \\
1984 \\
1985 \\
1986 \\
1987 \\
1988 \\
1989\end{array}$ & $\begin{array}{l}11-03-59 \\
09-18-61 \\
02-12-62 \\
09-14-63 \\
08-14-64 \\
09-06-65 \\
12-30-65 \\
12-06-66 \\
08-08-68 \\
01-26-69 \\
07-22-70 \\
08-15-71 \\
12-25-71 \\
05-11-73 \\
09-05-74 \\
07-30-75 \\
02-09-76 \\
10-02-76 \\
03-02-78 \\
03-28-79 \\
02-20-80 \\
07-16-81 \\
09-27-82 \\
12-01-82 \\
07-23-84 \\
04-11-85 \\
11-30-85 \\
07-21-87 \\
08-03-88 \\
01-01-89\end{array}$ & $\begin{array}{r}2,320 \\
10,900 \\
5,380 \\
4,720 \\
6,300 \\
4,040 \\
5,490 \\
35,200 \\
2,180 \\
21,400 \\
8,960 \\
6,140 \\
8,180 \\
3,740 \\
5,840 \\
5,910 \\
5,180 \\
7,140 \\
22,000 \\
4,440 \\
10,380 \\
2,260 \\
4,840 \\
6,200 \\
4,940 \\
1,260 \\
1,970 \\
5,690 \\
8,280 \\
61,000\end{array}$ & $\begin{array}{l}\text { ES } \\
\text { DF }\end{array}$ \\
\hline
\end{tabular}

\section{BASIN CHARACTERISTICS}

\begin{tabular}{|c|c|c|c|c|c|c|c|}
\hline MaIN & & $\begin{array}{l}\text { MEAN } \\
\text { BASIN }\end{array}$ & & & $\begin{array}{l}\text { MEAN } \\
\text { ANNUAL }\end{array}$ & RAINFALL IN & SITY, 24-HOUR \\
\hline $\begin{array}{l}\text { CHANNEL } \\
\text { SLOPE } \\
\text { (FT/MI) }\end{array}$ & $\begin{array}{c}\text { STREAM } \\
\text { LENGTH } \\
\text { (MI) }\end{array}$ & $\begin{array}{l}\text { ELEVA- } \\
\text { TION } \\
\text { (FT) }\end{array}$ & $\begin{array}{l}\text { FORESTED } \\
\text { AREA } \\
\text { (PERCENT) }\end{array}$ & $\begin{array}{l}\text { SOIL } \\
\text { INDEX }\end{array}$ & $\begin{array}{l}\text { PRECIPI - } \\
\text { TATION } \\
\text { (IN) }\end{array}$ & $\begin{array}{c}\text { 2-YEAR } \\
\text { (IN) }\end{array}$ & $\begin{array}{c}\text { 50-YEAR } \\
\text { (IN) }\end{array}$ \\
\hline 38.4 & 112 & 5,500 & 50.0 & 3.0 & 16.0 & 1.8 & 3.4 \\
\hline
\end{tabular}


MEAN MONTHLY AND ANNUAL DISCHARGES 1930-89

\begin{tabular}{|c|c|c|c|c|c|c|}
\hline MONTH & $\begin{array}{l}\text { MAXIMUM } \\
\left(F T^{3} / S\right)\end{array}$ & $\begin{array}{l}\operatorname{MINIMUN} \\
\left(\mathrm{FT}^{3} / \mathrm{S}\right)\end{array}$ & $\begin{array}{c}\text { MEAN } \\
\left(F T^{3} / S\right)\end{array}$ & $\begin{array}{l}\text { STAN- } \\
\text { DARD } \\
\text { DEVIA- } \\
\text { TIQN } \\
\text { (FT } / S)\end{array}$ & $\begin{array}{l}\text { COEFFI - } \\
\text { CIENT OF } \\
\text { VARI - } \\
\text { ATION }\end{array}$ & $\begin{array}{c}\text { PERCENT } \\
\text { OF } \\
\text { ANNUAL } \\
\text { RUNOFF }\end{array}$ \\
\hline $\begin{array}{l}\text { OCTOBER } \\
\text { NOVEMBER } \\
\text { DECEMBER } \\
\text { JANUARY } \\
\text { FEBRUARY } \\
\text { MARCH } \\
\text { APRIL } \\
\text { MAY } \\
\text { JUNE } \\
\text { JULY } \\
\text { AUGUST } \\
\text { SEPTEMBER }\end{array}$ & $\begin{array}{r}602 \\
552 \\
1,250 \\
775 \\
2,330 \\
1,710 \\
1,390 \\
2,120 \\
1,120 \\
381 \\
976 \\
737\end{array}$ & $\begin{array}{r}53 \\
102 \\
111 \\
108 \\
119 \\
85 \\
62 \\
55 \\
47 \\
52 \\
50 \\
53\end{array}$ & $\begin{array}{l}147 \\
193 \\
230 \\
232 \\
315 \\
349 \\
416 \\
427 \\
137 \\
109 \\
188 \\
148\end{array}$ & $\begin{array}{r}92 \\
80 \\
153 \\
110 \\
321 \\
344 \\
374 \\
515 \\
159 \\
73 \\
175 \\
133\end{array}$ & $\begin{array}{l}0.63 \\
0.41 \\
0.67 \\
0.47 \\
1.0 \\
0.99 \\
0.90 \\
1.2 \\
1.2 \\
0.67 \\
0.93 \\
0.90\end{array}$ & $\begin{array}{r}5.1 \\
6.7 \\
7.9 \\
8.0 \\
10.9 \\
12.1 \\
14.4 \\
14.8 \\
4.7 \\
3.8 \\
6.5 \\
5.1\end{array}$ \\
\hline NHUAL & 697 & 108 & 240 & 132 & 0.55 & 100 \\
\hline
\end{tabular}

MAGNITUDE AND PROBABILITY OF INSTANTANEOUS PEAK FLON BASED ON PERIOD OF RECORD 1930-89

DISCHARGE, IN $\mathrm{FT}^{3} / \mathrm{S}$, FOR INDICATED RECURRENCE INTERVAL IN YEARS, AND EXCEEDANCE PROBABILITY, IN PERCENT

\begin{tabular}{lccccc}
2 & 5 & 10 & 25 & 50 & 100 \\
$50 \%$ & $20 \%$ & $10 \%$ & $4 \%$ & $2 \%$ & $1 \%$ \\
5,070 & 10,600 & 16,000 & 25,400 & 34,600 & 46,000 \\
\hline WEIGHTED SKEW (LOGS) & $=0.32$ & & \\
MEAN & (LOGS) & 3.72 & & \\
STANDARD DEV. (LOGS) & $=0.37$ & &
\end{tabular}

MAGNITLDE AND PROBABILITY OF ANNUAL LON FLON BASED ON PERIOD OF RECORD 1931-89

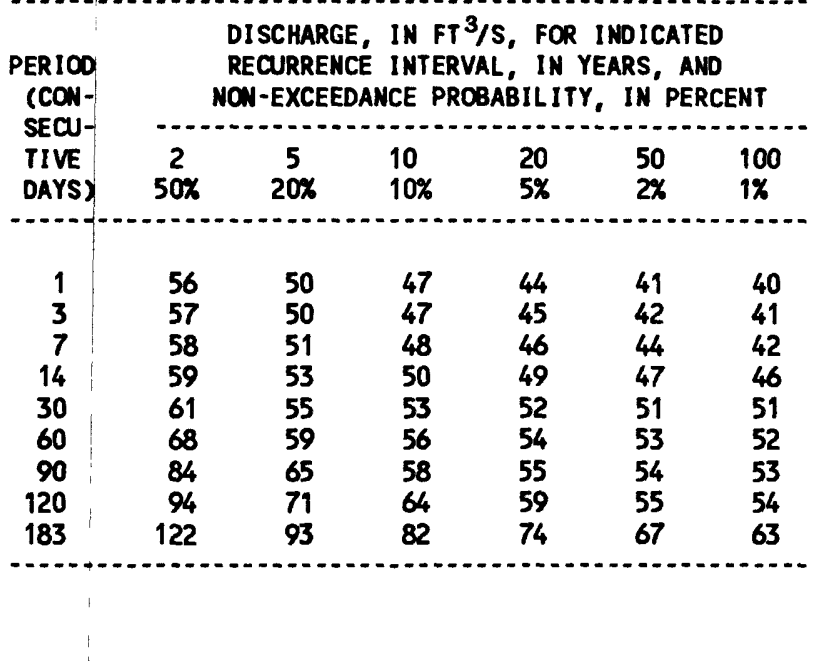

MAGNITUDE AND PROBABILITY OF ANNUAL HIGH FLOW BASED ON PERIOD OF RECORD 1930-89

\begin{tabular}{|c|c|c|c|c|c|c|}
\hline \multirow{2}{*}{$\begin{array}{l}\text { PERIOD } \\
\text { (CON- } \\
\text { SECU } \\
\text { TIVE } \\
\text { DAYS) }\end{array}$} & & \multicolumn{5}{|c|}{$\begin{array}{l}\text { DISCHARGE, IN } \mathrm{FT}^{3} / \mathrm{S} \text {, FOR INDICATED } \\
\text { RECURRENCE INTERVAL, IN YEARS, AND } \\
\text { EXCEEDANCE PROBABILITY, IN PERCENT }\end{array}$} \\
\hline & $\begin{array}{c}2 \\
50 \%\end{array}$ & $\begin{array}{c}5 \\
20 \%\end{array}$ & $\begin{array}{l}10 \\
10 \%\end{array}$ & $\begin{array}{l}25 \\
4 \%\end{array}$ & $\begin{array}{l}50 \\
2 \%\end{array}$ & $\begin{array}{r}100 \\
1 \%\end{array}$ \\
\hline $\begin{array}{r}1 \\
3 \\
7 \\
15 \\
30 \\
60 \\
90\end{array}$ & $\begin{array}{r}2,190 \\
1,380 \\
924 \\
676 \\
518 \\
404 \\
352\end{array}$ & $\begin{array}{r}4,470 \\
2,820 \\
1,850 \\
1,300 \\
968 \\
743 \\
636\end{array}$ & $\begin{array}{r}6,910 \\
4,390 \\
2,810 \\
1,910 \\
1,400 \\
1,070 \\
907\end{array}$ & $\begin{array}{r}11,500 \\
7,430 \\
4,570 \\
2,980 \\
2,120 \\
1,620 \\
1,370\end{array}$ & $\begin{array}{r}16,500 \\
10,800 \\
6,400 \\
4,040 \\
2,830 \\
2,160 \\
1,830\end{array}$ & $\begin{array}{r}23,200 \\
15,400 \\
8,800 \\
5,380 \\
3,720 \\
2,840 \\
2,410\end{array}$ \\
\hline
\end{tabular}

DURATION TABLE OF DAILY MEAN FLON FOR PERIOD OF RECORD 1930-89 DISCHARGE, IN FT $3 / 5$, WHICH WAS EQUALED OR EXCEEDED FOR INDICATED PERCENT OF TIME

\begin{tabular}{|c|c|c|c|c|c|c|c|c|c|c|c|c|c|c|c|c|}
\hline $1 \%$ & $5 \%$ & $10 \%$ & $15 x$ & $20 \%$ & $30 \%$ & $40 x$ & $50 \%$ & $60 \%$ & $70 \%$ & $80 \%$ & $90 \%$ & $95 \%$ & $98 \%$ & $99 \%$ & $99.5 \%$ & $99.9 \%$ \\
\hline 1,870 & 760 & 428 & 319 & 270 & 216 & 180 & 149 & 115 & 84 & 68 & 60 & 56 & 51 & 49 & 48 & 42 \\
\hline
\end{tabular}


09415000 VIRGIN RIVER AT LITTLEFIELD, AZ--CONTIMUEd
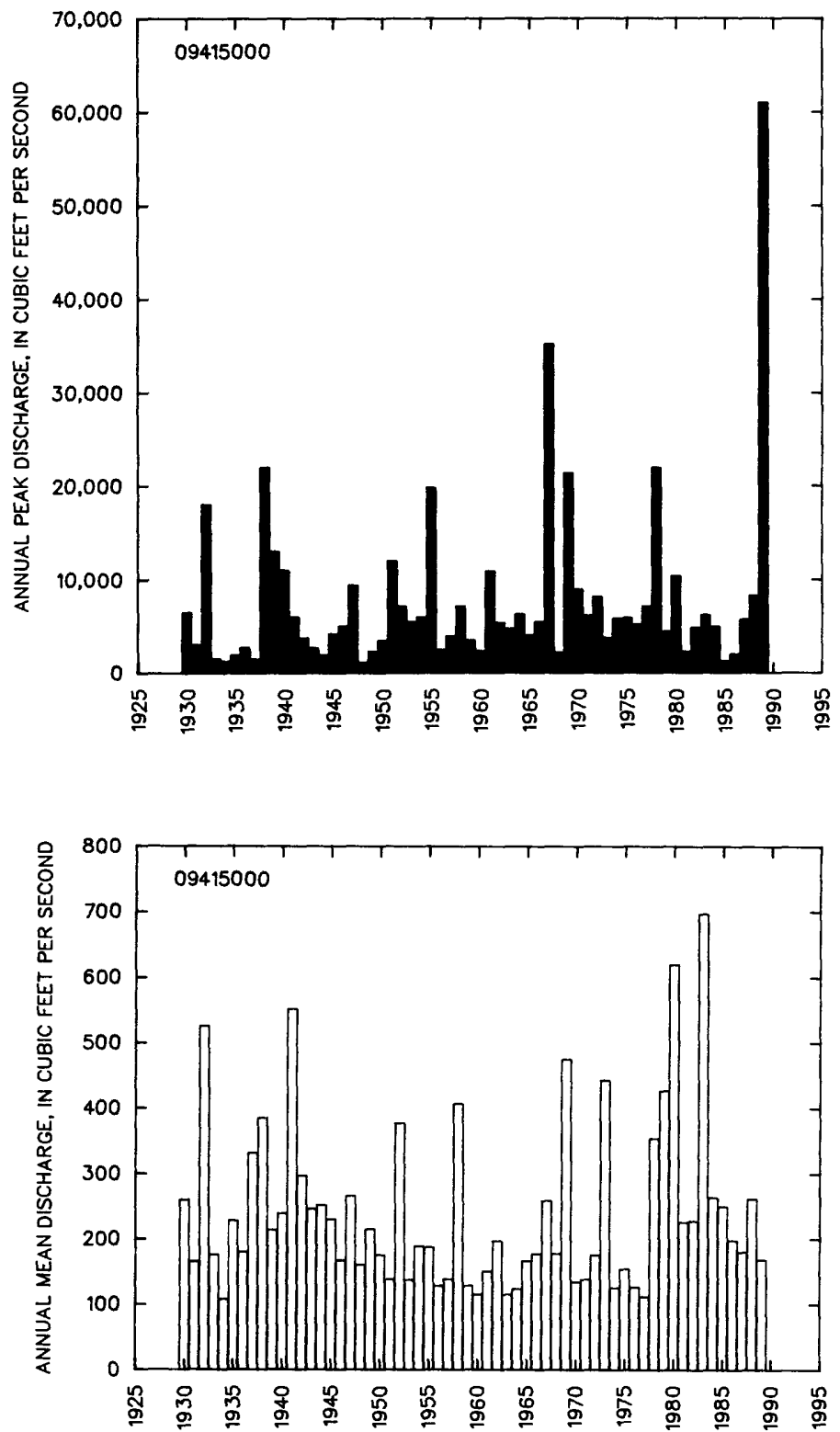
09415000 VIRGIN RIVER AT LITTLEFIELD, AZ--CONTINUED
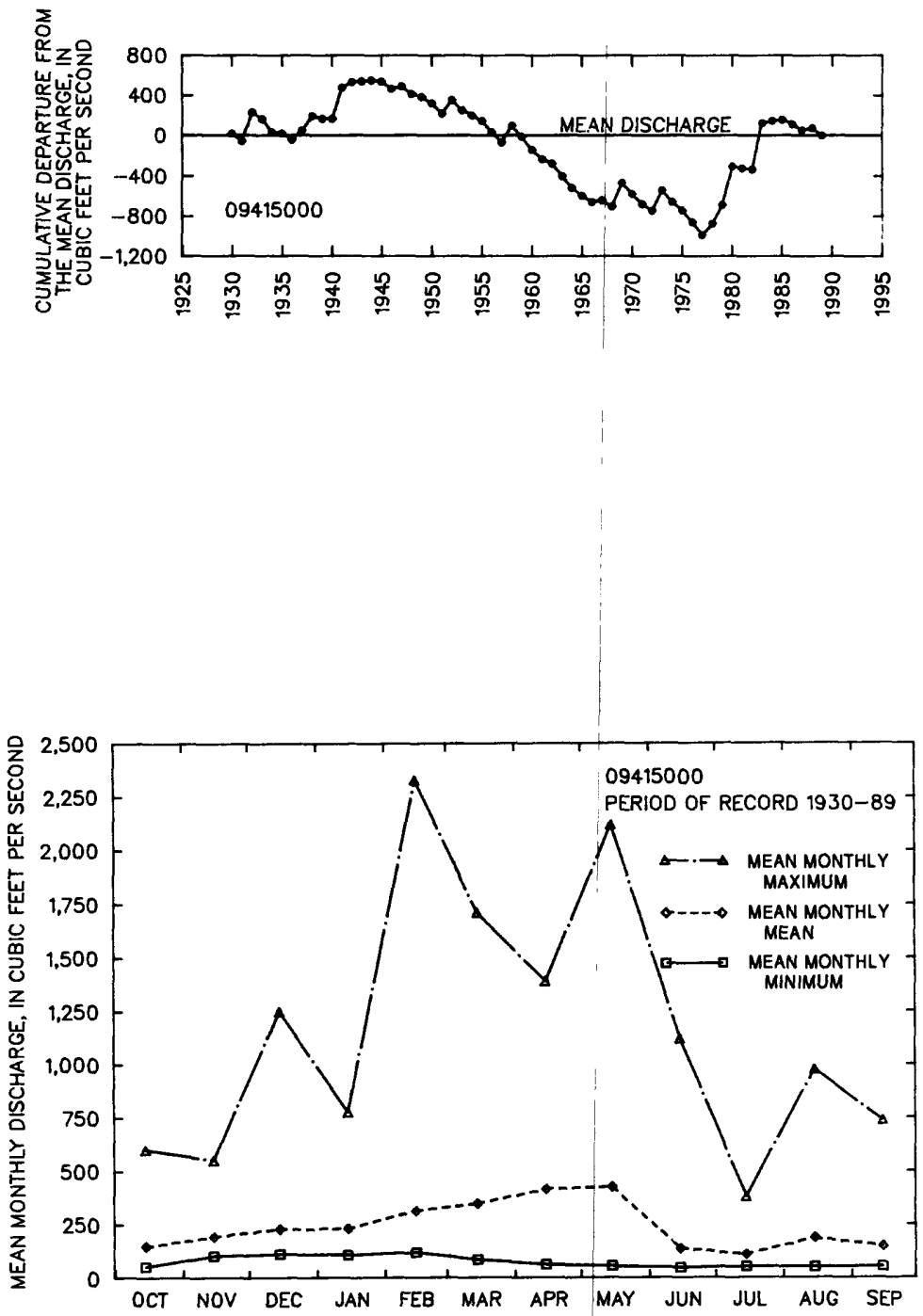
09415050 BIG BEND WASH TRIBUTARY NEAR LITTLEFIELD, AZ

LOCATION. - - Lat 36'51'45", long 113'58'05", in SE\% sec.13, T.40 N., R.16 W., Mohave County, Hydrologic Unit 15010010 , at U.S. Highway $91,2.7 \mathrm{mi}$ southwest of Littlefield.

DRAINAGE AREA. $--7.27 \mathrm{mi}^{2}$.

ANNAUL PEAK DISCHARGE

\begin{tabular}{cccc}
$\begin{array}{c}\text { MATER } \\
\text { YEAR }\end{array}$ & DATE & $\begin{array}{c}\text { ANNUAL PEAK } \\
\text { DISCHARGE } \\
\text { (FT } 3 / \text { S) }\end{array}$ & $\begin{array}{c}\text { DISCHARGE } \\
\text { CODES }\end{array}$ \\
\hline 1963 & $09-18-63$ & 248 & \\
1964 & $07-00-64$ & 1.5 & ES \\
1965 & $08-00-65$ & 3.0 & ES \\
1966 & $11-23-65$ & 2.0 & ES \\
1967 & $12-06-66$ & 2.0 & ES \\
1968 & $00-00-68$ & 0.1 & LT \\
1969 & $00-00-69$ & 0 & \\
1970 & $00-00-70$ & 250 & \\
1971 & $00-00-71$ & 0 & \\
1972 & $09-19-72$ & 160 & \\
1973 & $10-09-72$ & 10 & ES \\
1974 & $00-00-74$ & 0 & LT \\
1975 & $11-00-74$ & 1.0 & \\
$\ldots$ & &
\end{tabular}

MAGNITUDE AND PROBABILITY OF INSTANTANEOUS PEAK FLOW BASED ON PERIOD OF RECORD 1963-75

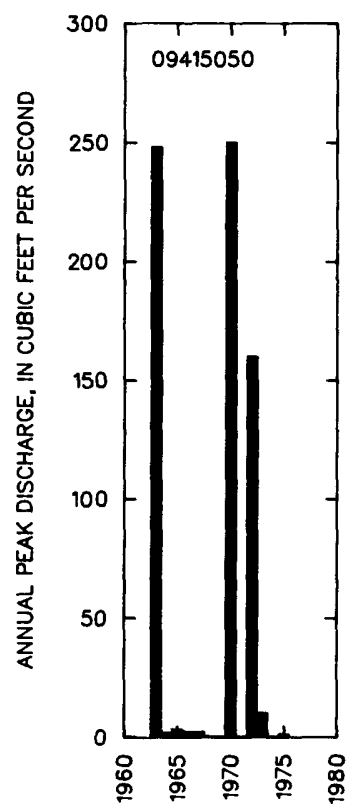

DISCHARGE, IN FT $3 / 5$, FOR INDICATED RECURRENCE INTERVAL IN YEARS, AND EXCEEDANCE PROBABILITY, IN PERCENT

\begin{tabular}{|c|c|c|c|c|c|}
\hline $\begin{array}{r}2 \dagger \\
50 \%\end{array}$ & $\begin{array}{r}5 \dagger \\
20 \%\end{array}$ & $\begin{array}{c}10 \nmid \\
10 \%\end{array}$ & $\begin{array}{l}25 \dagger \\
4 \%\end{array}$ & $\begin{array}{l}50 \dagger \\
2 \chi\end{array}$ & $\begin{array}{c}100 \dagger \\
1 \%\end{array}$ \\
\hline 1.7 & 32.8 & 152 & 759 & 2,120 & 5,300 \\
\hline $\begin{array}{l}\text { MEIGHTED } \\
\text { MEAN } \\
\text { STANDARD }\end{array}$ & $\begin{array}{l}\text { SKEW } \\
\text { DEV. }\end{array}$ & $\begin{array}{l}(\text { LOGS })= \\
(\text { LOGS })= \\
(\text { LOGS })=\end{array}$ & $\begin{array}{r}-0.09 \\
0.20 \\
1.56\end{array}$ & & \\
\hline
\end{tabular}

f Reliability of values in column is uncertain, and potential errors are large.

BASIN CHARACTERISTICS

\begin{tabular}{|c|c|c|c|c|c|c|c|}
\hline MAIN & & $\begin{array}{l}\text { MEAN } \\
\text { BASIN }\end{array}$ & & & $\begin{array}{c}\text { MEAN } \\
\text { ANNUAL }\end{array}$ & RAINFALL II & SITY, 24-HOUR \\
\hline $\begin{array}{l}\text { CHANNEL } \\
\text { SLOPE } \\
\text { (FT/MI) }\end{array}$ & $\begin{array}{l}\text { STREAM } \\
\text { LENGTH } \\
\text { (MI) }\end{array}$ & $\begin{array}{l}\text { ELEVA- } \\
\text { TION } \\
\text { (FT) }\end{array}$ & $\begin{array}{l}\text { FORESTED } \\
\text { AREA } \\
\text { (PERCENT) }\end{array}$ & $\begin{array}{l}\text { SOIL } \\
\text { INDEX }\end{array}$ & $\begin{array}{l}\text { PRECIPI- } \\
\text { TATION } \\
\text { (IN) }\end{array}$ & $\begin{array}{c}\text { 2-YEAR } \\
\text { (IN) }\end{array}$ & $\begin{array}{l}\text { 50-YEAR } \\
\text { (IN) }\end{array}$ \\
\hline 55.8 & 7.4 & 2,240 & 0.0 & 3.0 & 7.6 & 1.5 & 3.6 \\
\hline
\end{tabular}


09419590 DETRITAL WASH TRIBUTARY NEAR CHLORIDE, AZ

LOCATION.--Lat 35॰25'55", long 114'17'05", in NWk sec.35, T.24 N., R.19 W., Mohave County, Hydrologic Unit 15010014 , at U.S. Highway $93,5.5 \mathrm{mi}$ northwest of Chloride.

DRAINAGE AREA. $--1.23 \mathrm{mi}^{2}$.

ANNUAL PEAK DISCHARGE

\begin{tabular}{|c|c|c|c|}
\hline $\begin{array}{l}\text { WATER } \\
\text { YEAR }\end{array}$ & DATE & $\begin{array}{c}\text { ANNUAL PEA } \\
\text { DISCHARGE } \\
\left(F^{3} / S\right)\end{array}$ & $\begin{array}{l}\text { DI SCHARGE } \\
\text { CODES }\end{array}$ \\
\hline $\begin{array}{l}1963 \\
1964 \\
1965 \\
1966 \\
1967 \\
1968 \\
1969 \\
1970 \\
1971 \\
1972 \\
1973 \\
1974 \\
1975 \\
1976 \\
1980\end{array}$ & $\begin{array}{l}09-17-63 \\
08-12-64 \\
04-03-65 \\
08-16-66 \\
09-00-67 \\
00-00-68 \\
07-27-69 \\
00-00-70 \\
08-12-71 \\
09-19-72 \\
00-00-73 \\
07-21-74 \\
00-00-75 \\
09-10-76 \\
00-00-80\end{array}$ & $\begin{array}{c}25 \\
50 \\
0.2 \\
73 \\
117 \\
20 \\
42 \\
0 \\
470 \\
92 \\
0 \\
46 \\
0 \\
460 \\
130\end{array}$ & $\begin{array}{l}\text { ES } \\
\text { ES } \\
\text { ES }\end{array}$ \\
\hline
\end{tabular}

IHighest since 1976.

MAGNITUDE AND PROBABILITY OF INSTANTANEQUS PEAK FLON BASED ON PERICD OF RECORD 1963-76, 1980

DISCHARGE, IN $\mathrm{FT}^{3} / \mathrm{S}$, FOR INDICATED RECURRENCE INTERVAL

IN YEARS, AND EXCEEDANCE PROBABILITY, IN PERCENT

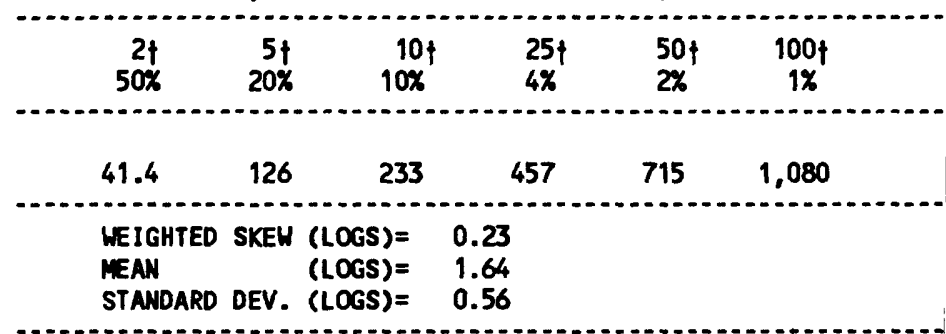

f Reliability of values in colum is uncertain, and potential errors are large.

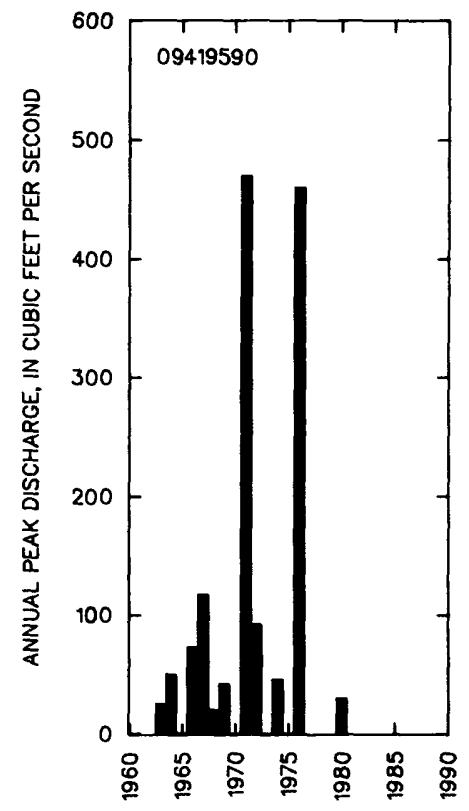

BASIN CHARACTERISTICS

\begin{tabular}{|c|c|c|c|c|c|c|c|}
\hline & & MEAN & & & MEAN & & \\
\hline MAIN & & BASIN & & & ANNUAL & RAINFALL II & SITY, 24-HOUR \\
\hline $\begin{array}{l}\text { CHANNEL } \\
\text { SLOPE } \\
\text { (FT/MI) }\end{array}$ & $\begin{array}{c}\text { STREAM } \\
\text { LENGTH } \\
\text { (MI) }\end{array}$ & $\begin{array}{l}\text { ELEVA- } \\
\text { TION } \\
\text { (FT) }\end{array}$ & $\begin{array}{l}\text { FORESTED } \\
\text { AREA } \\
\text { (PERCENT) }\end{array}$ & $\begin{array}{l}\text { SOIL } \\
\text { INDEX }\end{array}$ & $\begin{array}{l}\text { PRECIPI- } \\
\text { TATION } \\
\text { (IN) }\end{array}$ & $\begin{array}{c}\text { 2-YEAR } \\
\text { (IN) }\end{array}$ & $\begin{array}{c}\text { 50-YEAR } \\
\text { (IN) }\end{array}$ \\
\hline 200 & 2.4 & 3,710 & 0.0 & 3.0 & 10.1 & 1.4 & 3.6 \\
\hline
\end{tabular}


09421800 RINGBOLT WASH NEAR HOOVER DAM, AZ

LOCATION.--Lat 35'58'05", long $114^{\circ} 411^{\prime} 00^{\prime \prime}$, in SW' sec.19, T.30 N., R.22 W., Mohave County, Hydrologic Unit 15030101, at U.S. Highway $93,5.9 \mathrm{mi}$ southeast of Hoover Dam.

DRAINAGE AREA. $--1.21 \mathrm{mi}^{2}$.

ANNUAL PEAK DISCHARGE

\begin{tabular}{|c|c|c|c|}
\hline $\begin{array}{l}\text { WATER } \\
\text { YEAR }\end{array}$ & DATE & $\begin{array}{c}\text { ANNUAL PEAK } \\
\text { DISCHARGE } \\
\left(\mathrm{FT}^{3} / \mathrm{S}\right)\end{array}$ & $\begin{array}{l}\text { DISCHARGE } \\
\text { CODES }\end{array}$ \\
\hline $\begin{array}{l}1964 \\
1965 \\
1966 \\
1967 \\
1968 \\
1969 \\
1970 \\
1971 \\
1972 \\
1973 \\
1974 \\
1975 \\
1976 \\
1980\end{array}$ & $\begin{array}{l}00-00-64 \\
04-03-65 \\
12-00-65 \\
08-00-67 \\
00-00-68 \\
00-00-69 \\
08-00-70 \\
00-00-71 \\
00-00-72 \\
00-00-73 \\
07-19-74 \\
08-19-75 \\
09-08-76 \\
00-00-80\end{array}$ & $\begin{array}{c}0 \\
1.0 \\
1.0 \\
2.0 \\
0 \\
10 \\
1.0 \\
16 \\
0 \\
0 \\
1.0 \\
250 \\
310 \\
1125\end{array}$ & $\begin{array}{l}\text { ES } \\
\text { ES } \\
\text { ES } \\
\text { ES } \\
\text { ES } \\
\text { ES }\end{array}$ \\
\hline
\end{tabular}

Highest since 1976.

MAGNITUDE AND PROBABILITY OF INSTANTANEOUS PEAK FLOW BASED ON PERIOD OF RECORD

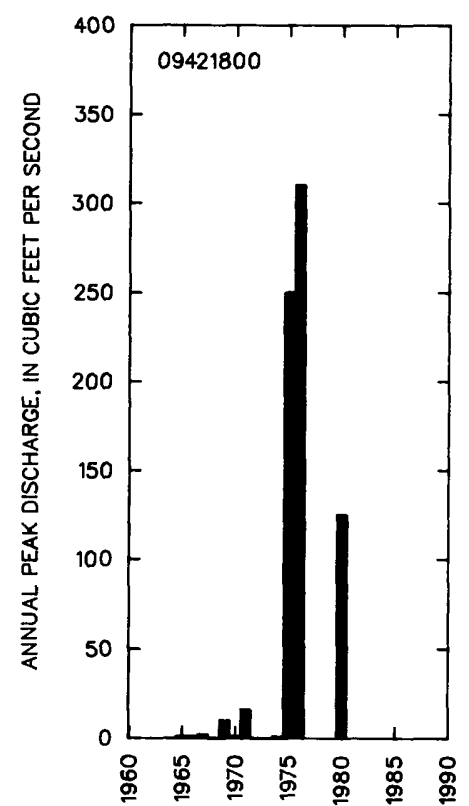

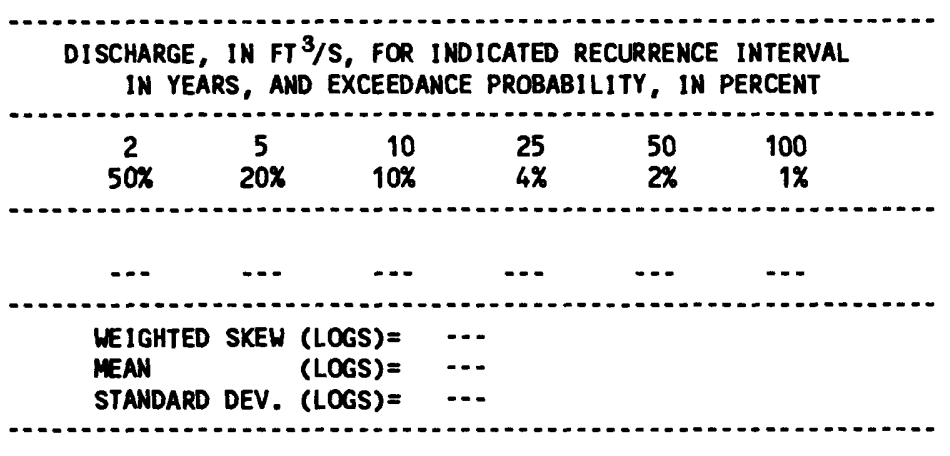

\section{BASIN CHARACTERISTICS}

\begin{tabular}{|c|c|c|c|c|c|c|c|}
\hline \multicolumn{5}{|c|}{ MEAN } & \multirow{2}{*}{$\begin{array}{c}\text { MEAN } \\
\text { ANNUAL } \\
\text { PRECIPI - }\end{array}$} & \multirow{2}{*}{\multicolumn{2}{|c|}{ RAINFALL INTENSITY, 24-HOUR }} \\
\hline MAIN & & BASIN & & & & & \\
\hline $\begin{array}{l}\text { CHANNEL } \\
\text { SLOPE } \\
\text { (FT/M1) }\end{array}$ & $\begin{array}{c}\text { STREAM } \\
\text { LENGTH } \\
\text { (MI) }\end{array}$ & $\begin{array}{c}\text { ELEVA- } \\
\text { TION } \\
\text { (FT) }\end{array}$ & $\begin{array}{l}\text { FORESTED } \\
\text { AREA } \\
\text { (PERCENT) }\end{array}$ & $\begin{array}{l}\text { SOIL } \\
\text { INDEX }\end{array}$ & $\begin{array}{l}\text { PRECIPI - } \\
\text { TATION } \\
\text { (IN) }\end{array}$ & $\begin{array}{l}\text { 2-YEAR } \\
\text { (IN) }\end{array}$ & $\begin{array}{l}\text { 50-YEAR } \\
\text { (IN) }\end{array}$ \\
\hline 428 & 3.0 & 2,590 & 0.0 & 1.0 & 5.8 & 1.4 & 3.6 \\
\hline
\end{tabular}


09423760 LITTLE MEADON CREEK NEAR OATMAN, AZ

LOCATION.--Lat 35'01'50", long 114'18'30", in NEKSWK sec.16, T.19 N., R.19 H., Mohave County, Hydrologic Unit 15030103, at Eds Camp, $4 \mathrm{mi}$ east of Oatman, and $19 \mathrm{mi}$ southwest of Kingman.

DRAINAGE AREA. $--8.47 \mathrm{mi}^{2}$.

ANNUAL PEAK DISCHARGE

\begin{tabular}{cccc}
$\begin{array}{c}\text { MATER } \\
\text { YEAR }\end{array}$ & DATE & $\begin{array}{c}\text { ANNUAL PEAK } \\
\text { DISCHARGE } \\
\text { (FT } 3 / \text { S })\end{array}$ & $\begin{array}{c}\text { DISCHARGE } \\
\text { CODES }\end{array}$ \\
\hline 1965 & $04-00-65$ & 10 & LT \\
1966 & $12-09-65$ & 20 & ES \\
1967 & $08-06-67$ & 0.5 & ES \\
1968 & $00-00-68$ & 0 & \\
1969 & $00-00-69$ & 0 & \\
1970 & $08-00-70$ & 869 & \\
1971 & $08-12-71$ & 50 & ES \\
1972 & $09-00-72$ & 50 & ES \\
1973 & $11-00-72$ & 600 & ES \\
1974 & $07-19-74$ & 182 & \\
1975 & $00-00-75$ & 0 & \\
1976 & $02-08-76$ & 105 & \\
\hline
\end{tabular}

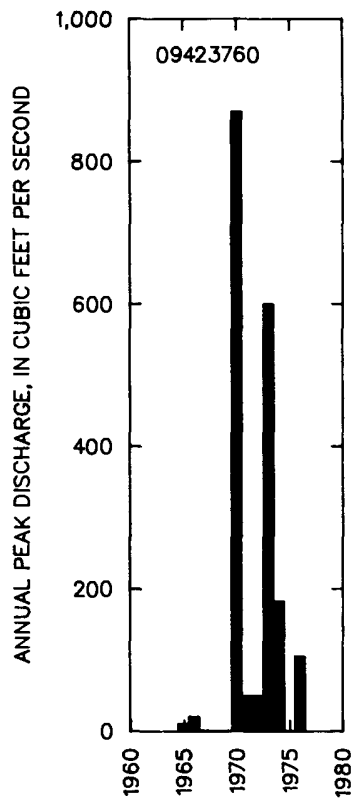

MAGNI TUDE AND PROBABILITY OF INSTANTANEOUS PEAK FLOH BASED ON PERIOD OF RECORD $1965-76$

DISCHARGE, IN $\mathrm{FT}^{3} / \mathrm{S}$, FOR INDICATED RECURRENCE INTERVAL IN YEARS, AND EXCEEDANCE PROBABILITY, IN PERCENT

\begin{tabular}{|c|c|c|c|c|c|}
\hline $\begin{array}{r}2 \dagger \\
50 \%\end{array}$ & $\begin{array}{r}5 \dagger \\
20 \%\end{array}$ & $\begin{array}{r}10 \\
10 \%\end{array}$ & $\begin{array}{l}25 \dagger \\
4 \%\end{array}$ & $\begin{array}{l}50 \dagger \\
2 \%\end{array}$ & $\begin{array}{c}100 \\
1 \%\end{array}$ \\
\hline 28.7 & 194 & 508 & 1,390 & 2,610 & 4,590 \\
\hline $\begin{array}{l}\text { WEIGHTED } \\
\text { MEAN } \\
\text { STANDARD }\end{array}$ & $\begin{array}{l}\text { SKEW } \\
\text { DEV. }\end{array}$ & $\begin{array}{l}(L O G S)= \\
(L O G S)= \\
(L O G S)=\end{array}$ & $\begin{array}{r}-0.16 \\
1.43 \\
1.01\end{array}$ & & \\
\hline
\end{tabular}

$\uparrow$ Reliability of values in column is uncertain, and potential errors are large.

BASIN CHARACTERISTICS

\begin{tabular}{|c|c|c|c|c|c|c|c|}
\hline \multirow{2}{*}{$\begin{array}{l}\text { MAIN } \\
\text { CHANNEL } \\
\text { SLOPE } \\
\text { (FT/MI) }\end{array}$} & \multirow[b]{2}{*}{$\begin{array}{c}\text { STREAM } \\
\text { LENGTH } \\
\text { (MI) }\end{array}$} & \multirow{2}{*}{$\begin{array}{l}\text { MEAN } \\
\text { BASIN } \\
\text { ELEVA- } \\
\text { TION } \\
\text { (FT) }\end{array}$} & \multirow[b]{2}{*}{$\begin{array}{l}\text { FORESTED } \\
\text { AREA } \\
\text { (PERCENT) }\end{array}$} & \multirow[b]{2}{*}{$\begin{array}{l}\text { SOIL } \\
\text { INDEX }\end{array}$} & \multirow{2}{*}{$\begin{array}{l}\text { MEAN } \\
\text { ANNUAL } \\
\text { PRECIPI- } \\
\text { TATION } \\
\text { (IN) }\end{array}$} & \multicolumn{2}{|c|}{ RAINFALL INTENSITY, 24-HOUR } \\
\hline & & & & & & $\begin{array}{c}\text { 2-YEAR } \\
\text { (IN) }\end{array}$ & $\begin{array}{c}\text { 50-YEAR } \\
\text { (IN) }\end{array}$ \\
\hline 241 & 3.8 & 3,400 & 0.0 & 1.0 & 12.0 & 1.6 & 3.9 \\
\hline
\end{tabular}


09423780 HALNUT CREEK NEAR KINGMAN, AZ

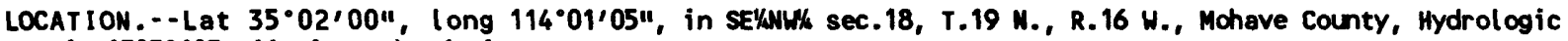
Unit 15030103, $11 \mathrm{mi}$ south of Kingman.

DRAINAGE AREA. $--31.3 \mathrm{mi}^{2}$.

ANNUAL PEAK DISCHARGE

\begin{tabular}{cccc}
$\begin{array}{c}\text { WATER } \\
\text { YEAR }\end{array}$ & DATE & $\begin{array}{c}\text { ANNUAL PEAK } \\
\text { DISCHARGE } \\
\text { (FT } 3 / \text { S) }\end{array}$ & $\begin{array}{c}\text { DISCHARGE } \\
\text { COOES }\end{array}$ \\
\hline 1965 & $08-00-65$ & 152 & \\
1966 & $07-20-66$ & 288 & \\
1967 & $00-00-67$ & 228 & \\
1968 & $00-00-68$ & 289 & \\
1969 & $09-13-69$ & 2.0 & LT \\
1970 & $08-15-70$ & 290 & \\
1971 & $08-12-71$ & 715 & \\
1972 & $06-06-72$ & 235 & \\
1973 & $07-00-73$ & 425 & \\
1974 & $09-00-74$ & 360 & \\
1975 & $00-00-75$ & 0 & \\
1976 & $00-00-76$ & 60 & ES \\
\hline
\end{tabular}

MAGNITUDE AND PROBABILITY OF INSTANTANEOUS PEAK FLOH BASED ON PERIOD OF RECORD 1965-76

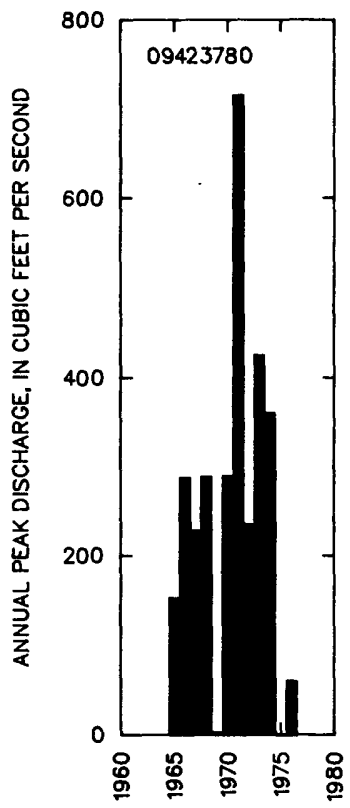

DISCHARGE, IN FT $3 / 5$, FOR INDICATED RECURRENCE INTERVAL

IN YEARS, AND EXCEEDANCE PROBABILITY, IN PERCENT

\begin{tabular}{|c|c|c|c|c|c|}
\hline $\begin{array}{r}2 \nmid \\
50 \%\end{array}$ & $\begin{array}{r}5 \dagger \\
20 \%\end{array}$ & $\begin{array}{c}10 \dagger \\
10 \%\end{array}$ & $\begin{array}{l}25 \dagger \\
4 \%\end{array}$ & $\begin{array}{l}50 \uparrow \\
2 \%\end{array}$ & $\begin{array}{c}100 \nmid \\
1 \%\end{array}$ \\
\hline 247 & 389 & 496 & 644 & 764 & 892 \\
\hline $\begin{array}{l}\text { IEIGHTED } \\
\text { MEAN } \\
\text { STANDARD }\end{array}$ & $\begin{array}{l}\text { SKEW } \\
\text { DEV. }\end{array}$ & $\begin{array}{l}(\operatorname{LOGS})= \\
(L O G S)= \\
(L O G S)=\end{array}$ & $\begin{array}{l}0.08 \\
2.40 \\
0.23\end{array}$ & & \\
\hline
\end{tabular}

f Reliability of values in column is uncertain, and potential errors are large.

BASIN CHARACTERISTICS

\begin{tabular}{|c|c|c|c|c|c|c|c|}
\hline \multirow{2}{*}{$\begin{array}{l}\text { MAIN } \\
\text { CHANNEL } \\
\text { SLOPE } \\
\text { (FT/MI) }\end{array}$} & \multirow[b]{2}{*}{$\begin{array}{c}\text { STREAM } \\
\text { LENGTH } \\
\text { (MI) }\end{array}$} & \multirow{2}{*}{$\begin{array}{l}\text { MEAN } \\
\text { BASIN } \\
\text { ELEVA- } \\
\text { TION } \\
\text { (FT) }\end{array}$} & \multirow[b]{2}{*}{$\begin{array}{l}\text { FORESTED } \\
\text { AREA } \\
\text { (PERCENT) }\end{array}$} & \multirow[b]{2}{*}{$\begin{array}{l}\text { SOIL } \\
\text { INDEX }\end{array}$} & \multirow{2}{*}{$\begin{array}{l}\text { MEAN } \\
\text { ANNUAL } \\
\text { PRECIPI- } \\
\text { TAT ION } \\
\text { (IN) }\end{array}$} & \multicolumn{2}{|c|}{ RAINFALL INTENSITY, 24-HOUR } \\
\hline & & & & & & $\begin{array}{c}\text { 2-YEAR } \\
\text { (IN) }\end{array}$ & $\begin{array}{l}\text { 50-YEAR } \\
\text { (IN) }\end{array}$ \\
\hline 255 & 9.3 & 5,040 & 50.0 & 1.0 & 13.9 & 1.8 & 4.0 \\
\hline
\end{tabular}




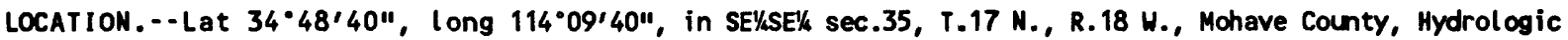
Unit 15030103, at. Santa Fe Railroad bridge, 5 mi south of Yucca.

DRAINAGE AREA. $--787 \mathrm{mi}^{2}$.

ANNUAL PEAK DISCHARGE

\begin{tabular}{|c|c|c|}
\hline $\begin{array}{l}\text { WATER } \\
\text { YEAR }\end{array}$ & DATE & $\begin{array}{c}\text { ANNUAL PEAK } \\
\text { DISCHARGE } \\
\text { (FT } 3 / \mathrm{S})\end{array}$ \\
\hline $\begin{array}{l}1965 \\
1966 \\
1967 \\
1968 \\
1969 \\
1970 \\
1971 \\
1972 \\
1973 \\
1974 \\
1975 \\
1976\end{array}$ & $\begin{array}{l}00-00-65 \\
12-09-65 \\
09-00-67 \\
07-00-68 \\
09-16-69 \\
00-00-70 \\
08-12-71 \\
06-00-72 \\
11-16-72 \\
07-19-74 \\
00-00-75 \\
09-25-76\end{array}$ & $\begin{array}{r}0 \\
2,060 \\
800 \\
520 \\
8,030 \\
3,000 \\
13,000 \\
3,010 \\
5,200 \\
4,260 \\
0 \\
2,100\end{array}$ \\
\hline
\end{tabular}

MAGNI TUDE AND PROBABILITY OF INSTANTANEQUS PEAK FLOW BASED ON PERIOD OF RECORD 1965-76

DISCHARGE, IN $\mathrm{FT}^{3} / \mathrm{S}$, FOR INDICATED RECURRENCE INTERVAL IN YEARS, AND EXCEEDANCE PROBABILITY, IN PERCENT

\begin{tabular}{|c|c|c|c|c|c|}
\hline $\begin{array}{r}2 \dagger \\
50 \%\end{array}$ & $\begin{array}{c}5 \dagger \\
20 \%\end{array}$ & $\begin{array}{c}10 \uparrow \\
10 \%\end{array}$ & $\begin{array}{l}25 \dagger \\
4 \%\end{array}$ & $\begin{array}{l}50 \nmid \\
2 \%\end{array}$ & $\begin{array}{c}100 \nmid \\
1 \%\end{array}$ \\
\hline 2,640 & 5,540 & 8,200 & 12,500 & 16,500 & 21,200 \\
\hline $\begin{array}{l}\text { WEIGHTED } \\
\text { MEAN } \\
\text { STANDARD }\end{array}$ & $\begin{array}{l}\text { SKEW } \\
\text { DEV. }\end{array}$ & $\begin{array}{l}\text { OGS) }= \\
\text { OGS) }= \\
\text { OGS) }=\end{array}$ & $\begin{array}{l}07 \\
43 \\
38\end{array}$ & & \\
\hline
\end{tabular}

† Reliability of values in column is uncertain, and potential errors are large.

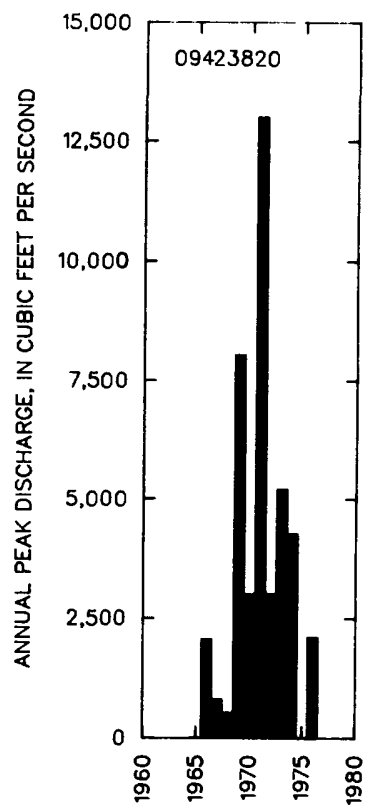

BASIN CHARACTERISTICS

\begin{tabular}{|c|c|c|c|c|c|c|c|}
\hline \multirow{4}{*}{$\begin{array}{l}\text { MAIN } \\
\text { CHANNEL } \\
\text { SLOPE } \\
\text { (FT/MI) }\end{array}$} & \multirow{4}{*}{$\begin{array}{l}\text { STREAM } \\
\text { LENGTH } \\
\text { (MI) }\end{array}$} & \multirow{4}{*}{$\begin{array}{l}\text { MEAN } \\
\text { BASIN } \\
\text { ELEVA- } \\
\text { TION } \\
\text { (FT) }\end{array}$} & \multirow{4}{*}{$\begin{array}{l}\text { FORESTED } \\
\text { AREA } \\
\text { (PERCENT) }\end{array}$} & \multirow[b]{4}{*}{$\begin{array}{l}\text { SOIL } \\
\text { INDEX }\end{array}$} & \multirow{4}{*}{$\begin{array}{l}\text { MEAN } \\
\text { ANNUAL } \\
\text { PRECIPI- } \\
\text { TATION } \\
\text { (IN) }\end{array}$} & \multirow{2}{*}{\multicolumn{2}{|c|}{ RAINFALL INTENSITY, 24-HOUR }} \\
\hline & & & & & & & \\
\hline & & & & & & & \\
\hline & & & & & & $\begin{array}{c}\text { 2-YEAR } \\
\text { (IN) }\end{array}$ & $\begin{array}{l}\text { 50-YEAR } \\
\text { (IN) }\end{array}$ \\
\hline 45.2 & 48.4 & 3,400 & 6.4 & 2.5 & 10.1 & 1.6 & 3.7 \\
\hline
\end{tabular}


09423900 SACRAMENTO WASH TRIBUTARY NEAR TOPOCK, $A Z$

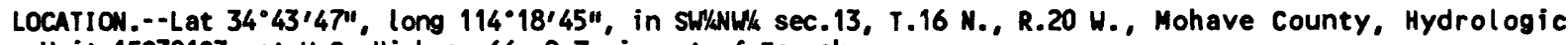
Unit 15030103, at U.S. Highway $66,9.7 \mathrm{mi}$ east of Topock.

DRAINAGE AREA. $--14.7 \mathrm{mi}^{2}$.

ANNUAL PEAK DISCHARGE

\begin{tabular}{|c|c|c|c|}
\hline $\begin{array}{l}\text { WATER } \\
\text { YEAR }\end{array}$ & DATE & $\begin{array}{l}\text { ANNUAL PEAK } \\
\text { DISCHARGE } \\
\left(\mathrm{FT}^{3} / \mathrm{S}\right)\end{array}$ & $\begin{array}{l}\text { DISCHARGE } \\
\text { COOES }\end{array}$ \\
\hline $\begin{array}{l}1963 \\
1964 \\
1965 \\
1966 \\
1967 \\
1968 \\
1969 \\
1970 \\
1971 \\
1972 \\
1973 \\
1974 \\
1975 \\
1976\end{array}$ & $\begin{array}{l}08-00-63 \\
07-26-64 \\
08-10-65 \\
12-09-65 \\
00-00-67 \\
11-21-67 \\
07-17-69 \\
08-00-70 \\
08-00-71 \\
00-00-72 \\
10-00-72 \\
01-00-74 \\
00-00-75 \\
09-10-76\end{array}$ & $\begin{array}{c}70 \\
128 \\
10 \\
20 \\
0 \\
10 \\
430 \\
15 \\
320 \\
500 \\
240 \\
1.0 \\
0 \\
1,030\end{array}$ & $\begin{array}{l}\text { ES } \\
\text { ES } \\
\text { LT } \\
\text { ES } \\
\text { ES } \\
\text { ES } \\
\text { ES }\end{array}$ \\
\hline
\end{tabular}

MAGNITUDE AND PROBABILITY OF INSTANTANEOUS PEAK FLOH BASED ON PERIOD OF RECORD 1963-76

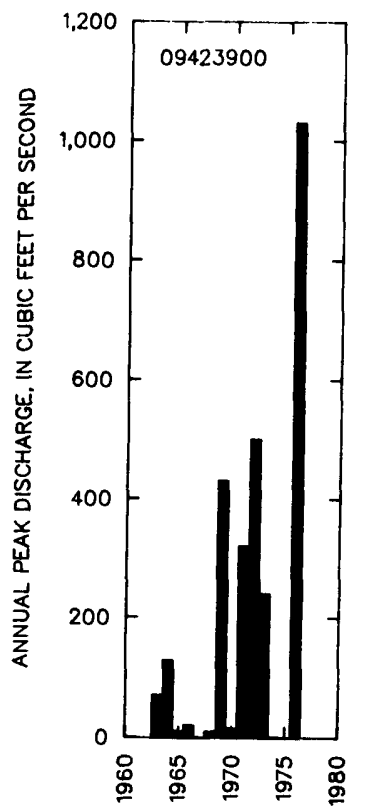

DISCHARGE, IN FT $3 / 5$, FOR INDICATED RECURRENCE INTERVAL IN YEARS, AND EXCEEDANCE PROBABILITY, IN PERCENT

\begin{tabular}{|c|c|c|c|c|c|}
\hline $\begin{array}{r}2 \dagger \\
50 \%\end{array}$ & $\begin{array}{r}5 \dagger \\
20 \%\end{array}$ & $\begin{array}{c}10 \\
10 \%\end{array}$ & $\begin{array}{l}25 \dagger \\
4 \%\end{array}$ & $\begin{array}{l}50 \dagger \\
2 \%\end{array}$ & $\begin{array}{c}100 \dagger \\
1 \%\end{array}$ \\
\hline 48.7 & 291 & 710 & 1,780 & 3,180 & 5,290 \\
\hline $\begin{array}{l}\text { WEIGHTED } \\
\text { MEAN } \\
\text { STANDARD }\end{array}$ & $\begin{array}{l}\text { SKEH } \\
\text { DEV. }\end{array}$ & $\begin{array}{l}(\text { LOGS })= \\
(\text { LOGS })= \\
(\text { LOGS })=\end{array}$ & $\begin{array}{r}-0.20 \\
1.66 \\
0.95\end{array}$ & & \\
\hline
\end{tabular}

$\uparrow$ Reliability of values in column is uncertain, and potential errors are large.

BASIN CHARACTERISTICS

\begin{tabular}{|c|c|c|c|c|c|c|c|}
\hline \multirow{3}{*}{$\begin{array}{l}\text { MAIN } \\
\text { CHANNEL } \\
\text { SLOPE } \\
\text { (FTMI) }\end{array}$} & \multirow[b]{3}{*}{$\begin{array}{c}\text { STREAM } \\
\text { LENGTH } \\
\text { (MI) }\end{array}$} & \multirow{3}{*}{$\begin{array}{l}\text { MEAN } \\
\text { BASIN } \\
\text { ELEVA- } \\
\text { TION } \\
\text { (FT) }\end{array}$} & \multirow[b]{3}{*}{$\begin{array}{l}\text { FORESTED } \\
\text { AREA } \\
\text { (PERCENT) }\end{array}$} & \multirow{2}{*}{\multicolumn{2}{|c|}{$\begin{array}{c}\text { MEAN } \\
\text { ANNUAL } \\
\text { PRECIPI- }\end{array}$}} & \multirow{2}{*}{\multicolumn{2}{|c|}{ RAINFALL INTENSITY, 24-HOUR }} \\
\hline & & & & & & & \\
\hline & & & & $\begin{array}{l}\text { SOIL } \\
\text { INDEX }\end{array}$ & $\begin{array}{l}\text { PRECIPI- } \\
\text { TAT ION } \\
\text { (IN) }\end{array}$ & $\begin{array}{c}\text { 2-YEAR } \\
\text { (IN) }\end{array}$ & $\begin{array}{l}\text { 50-YEAR } \\
\text { (IN) }\end{array}$ \\
\hline 98.2 & 7.6 & 1,450 & 0.0 & 3.0 & 6.2 & 1.5 & 3.6 \\
\hline
\end{tabular}


09424200 WILLON CREEK (COTTONWOOO WASH NO, 1) NEAR KINGMAN, AZ

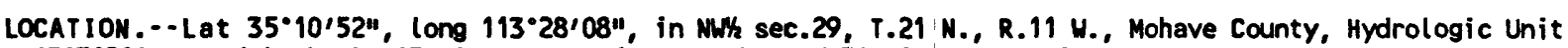
15030201, on right bank, $13 \mathrm{mi}$ upstream from mouth, and 34 mi east of Kingman.

DRAIMACE AREA. $--143 \mathrm{mi}^{2}$.

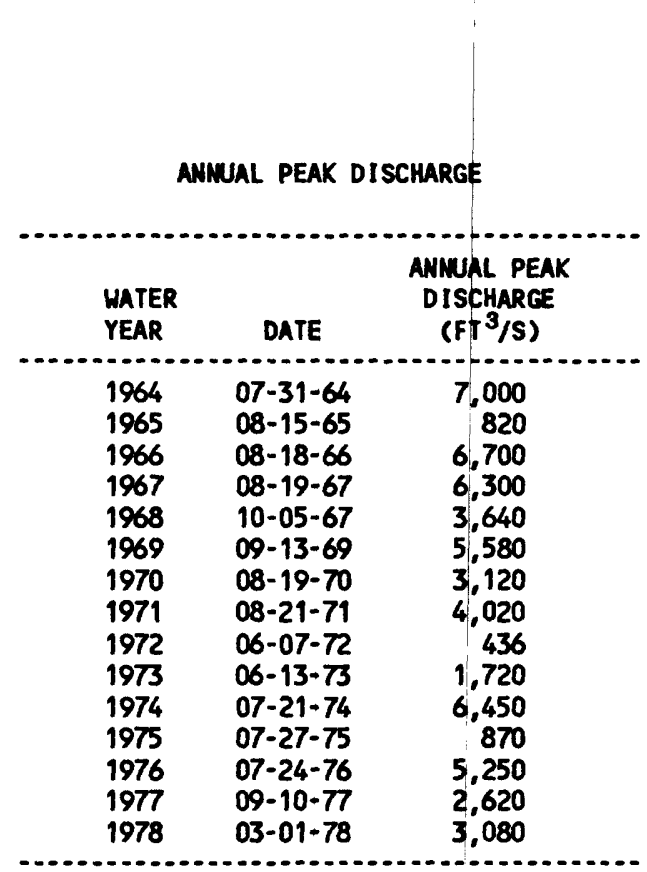

BASIN CHARACTERISTICS

\begin{tabular}{|c|c|c|c|c|c|c|c|}
\hline MAIN & & $\begin{array}{l}\text { MEAN } \\
\text { BASIN }\end{array}$ & & & $\begin{array}{c}\text { MEAN } \\
\text { ANNUAL }\end{array}$ & RAINFALL II & SITY, 24-HOUR \\
\hline $\begin{array}{l}\text { CHANNEL } \\
\text { SLOPE } \\
\text { (FT/MI) }\end{array}$ & $\begin{array}{c}\text { STREAM } \\
\text { LENGTH } \\
\text { (MI) }\end{array}$ & $\begin{array}{l}\text { ELEVA- } \\
\text { TION } \\
\text { (FT) }\end{array}$ & $\begin{array}{l}\text { FORESTED } \\
\text { AREA } \\
\text { (PERCENT) }\end{array}$ & $\begin{array}{l}\text { SOIL } \\
\text { INDEX }\end{array}$ & $\begin{array}{l}\text { PRECIPI- } \\
\text { TATION } \\
\text { (IN) }\end{array}$ & $\begin{array}{c}\text { 2-YEAR } \\
\text { (IN) }\end{array}$ & $\begin{array}{l}\text { 50-YEAR } \\
\text { (IN) }\end{array}$ \\
\hline 67.0 & 17.6 & 5,350 & 90.0 & 1.0 & 14.0 & 1.7 & 3.6 \\
\hline
\end{tabular}


09424200 HILLOW CREEK (COTTONWOOD MASH 1) NEAR KINGMAN, AZ--Cont inued

MEAN MONTHLY AND ANNUAL DISCHARGES 1965-78

\begin{tabular}{|c|c|c|c|c|c|c|}
\hline MONTH & $\begin{array}{l}\operatorname{Max} \operatorname{Im}_{3} \\
(\mathrm{FT} / \mathrm{S})\end{array}$ & $\begin{array}{l}\operatorname{MINIMUN} \\
\left(F T^{3} / S\right)\end{array}$ & $\begin{array}{c}\text { MEAN } \\
\left(F T^{3} / S\right)\end{array}$ & $\begin{array}{l}\text { STAN- } \\
\text { DARD } \\
\text { DEVIA- } \\
\text { TION } \\
\left(F^{3} / S\right)\end{array}$ & $\begin{array}{l}\text { COEFF I- } \\
\text { CIENT OF } \\
\text { VARI - } \\
\text { ATION }\end{array}$ & $\begin{array}{c}\text { PERCENT } \\
\text { OF } \\
\text { ANNUAL } \\
\text { RUNOFF }\end{array}$ \\
\hline $\begin{array}{l}\text { OCTOBER } \\
\text { NOVEMBER } \\
\text { DECEMBER } \\
\text { JANUARY } \\
\text { FEBRUARY } \\
\text { MARCH } \\
\text { APRIL } \\
\text { MAY } \\
\text { JUNE } \\
\text { JULY } \\
\text { AUGUST } \\
\text { SEPTEMBER }\end{array}$ & $\begin{array}{c}7.8 \\
2.0 \\
38 \\
6.6 \\
82 \\
88 \\
18 \\
1.3 \\
4.2 \\
21 \\
32 \\
31\end{array}$ & $\begin{array}{l}0.27 \\
0.65 \\
0.68 \\
0.61 \\
0.91 \\
0.51 \\
0.15 \\
0.18 \\
0.10 \\
0.13 \\
0.21 \\
0.20\end{array}$ & $\begin{array}{c}1.4 \\
1.1 \\
4.3 \\
1.7 \\
8.8 \\
10 \\
2.4 \\
0.74 \\
0.94 \\
5.1 \\
12 \\
7.6\end{array}$ & $\begin{array}{l}1.9 \\
0.38 \\
10 \\
1.5 \\
22 \\
24 \\
4.7 \\
0.33 \\
1.1 \\
6.3 \\
11 \\
11\end{array}$ & $\begin{array}{l}1.3 \\
0.35 \\
2.3 \\
0.86 \\
2.4 \\
2.3 \\
1.9 \\
0.45 \\
1.2 \\
1.3 \\
0.99 \\
1.5\end{array}$ & $\begin{array}{r}2.5 \\
1.9 \\
7.7 \\
3.1 \\
15.7 \\
18.7 \\
4.3 \\
1.3 \\
1.7 \\
9.0 \\
20.7 \\
13.4\end{array}$ \\
\hline ANNUAL & 11 & 0.86 & 4.7 & 3.4 & 0.72 & 100 \\
\hline
\end{tabular}

MAGNITUDE AND PROBABILITY OF INSTANTANEOUS PEAK FLOW BASED ON PERIOD OF RECORD 1964-78

DISCHAREE, IN $\mathrm{FT}^{3} / \mathrm{S}$, FOR INDICATED RECURRENCE INTERVAL IN YEARS, AND EXCEEDANCE PROBABILITY, IN PERCENT

\begin{tabular}{lccccc}
2 & 5 & 10 & 25 & $50 \dagger$ & $100 \dagger$ \\
$50 \%$ & $20 \%$ & $10 \%$ & $4 \%$ & $2 \%$ & $1 \%$ \\
3,690 & 5,860 & 7,310 & 9,110 & 10,400 & 11,700 \\
\hline WEIGHTED SKEW (LOGS) & $=$ & -0.40 & & \\
MEAN & (LOGS) & 3.55 & & \\
STANDARD DEV. (LOGS) & $=0.25$ & &
\end{tabular}

MAGNITLDE AND PROBABILITY OF ANNUAL LON FLON BASED ON PERIOD OF RECORD 1965-78

\begin{tabular}{|c|c|c|c|c|c|c|}
\hline \multirow{2}{*}{$\begin{array}{l}\text { PERIOD } \\
\text { (CON- } \\
\text { SECU- } \\
\text { TIVE } \\
\text { DAYS) }\end{array}$} & \multicolumn{6}{|c|}{$\begin{array}{l}\text { DISCHARGE, IN } \mathrm{FT}^{3} / \mathrm{S}, \text { FOR INDICATED } \\
\text { RECURRENCE INTERVAL, IN YEARS, AND } \\
\text { NON-EXCEEDANCE PROBABILITY, IN PERCENT }\end{array}$} \\
\hline & $\begin{array}{c}2 \\
50 \%\end{array}$ & $\begin{array}{c}5 \\
20 \%\end{array}$ & $\begin{array}{l}10 \\
10 \%\end{array}$ & $\begin{array}{l}20 \\
5 \%\end{array}$ & $\begin{array}{l}50 \dagger \\
2 \%\end{array}$ & $\begin{array}{l}100 \dagger \\
1 \%\end{array}$ \\
\hline $\begin{array}{r}1 \\
3 \\
7 \\
14 \\
30 \\
60 \\
90 \\
120 \\
183\end{array}$ & $\begin{array}{l}0.27 \\
0.29 \\
0.30 \\
0.31 \\
0.34 \\
0.49 \\
0.54 \\
0.81 \\
1.2\end{array}$ & $\begin{array}{l}0.13 \\
0.14 \\
0.14 \\
0.14 \\
0.16 \\
0.25 \\
0.29 \\
0.50 \\
0.82\end{array}$ & $\begin{array}{l}0.09 \\
0.09 \\
0.10 \\
0.09 \\
0.10 \\
0.16 \\
0.20 \\
0.37 \\
0.69\end{array}$ & $\begin{array}{l}0.06 \\
0.07 \\
0.07 \\
0.07 \\
0.07 \\
0.11 \\
0.14 \\
0.28 \\
0.61\end{array}$ & $\begin{array}{l}0.04 \\
0.05 \\
0.05 \\
0.05 \\
0.05 \\
0.07 \\
0.09 \\
0.20 \\
0.54\end{array}$ & $\begin{array}{l}0.03 \\
0.04 \\
0.03 \\
0.03 \\
0.03 \\
0.05 \\
0.07 \\
0.15 \\
0.50\end{array}$ \\
\hline
\end{tabular}

MAGNITLDE AND PROBABILITY OF ANNUAL HIGH FLON BASED ON PERIOD OF RECORD 1965-78

\begin{tabular}{|c|c|c|c|c|c|c|}
\hline $\begin{array}{l}\text { PERIOO } \\
\text { (CON- }\end{array}$ & & $\begin{array}{l}\text { ISCH } \\
\text { XECUR } \\
\text { XCEE }\end{array}$ & $\begin{array}{ll}E, & \text { IN } \\
\text { CE } & \text { INT } \\
\text { CE } & \text { PRO }\end{array}$ & $\begin{array}{l}3 / S, \\
\text { VAL, II } \\
\text { BILITY }\end{array}$ & $\begin{array}{l}\text { YEARS } \\
\text { IN PE }\end{array}$ & \\
\hline $\begin{array}{l}\text { TIVE } \\
\text { DAYS) }\end{array}$ & $\begin{array}{c}2 \\
50 x\end{array}$ & $\begin{array}{c}5 \\
20 x\end{array}$ & $\begin{array}{l}10 \\
10 \%\end{array}$ & $\begin{array}{l}25 \\
4 \%\end{array}$ & $\begin{array}{l}50 \dagger \\
2 \%\end{array}$ & $\begin{array}{c}100 \nmid \\
1 \%\end{array}$ \\
\hline $\begin{array}{r}1 \\
3 \\
7 \\
15 \\
30 \\
60 \\
90\end{array}$ & $\begin{array}{c}298 \\
143 \\
76 \\
42 \\
24 \\
14 \\
9.3\end{array}$ & $\begin{array}{r}697 \\
322 \\
175 \\
93 \\
52 \\
29 \\
20\end{array}$ & $\begin{array}{r}1,060 \\
469 \\
254 \\
131 \\
73 \\
41 \\
28\end{array}$ & $\begin{array}{r}1,640 \\
679 \\
363 \\
179 \\
99 \\
55 \\
38\end{array}$ & $\begin{array}{r}2,160 \\
848 \\
447 \\
213 \\
118 \\
65 \\
46\end{array}$ & $\begin{array}{r}2,740 \\
1,020 \\
532 \\
246 \\
135 \\
75 \\
53\end{array}$ \\
\hline
\end{tabular}

DURATION TABLE OF DAILY MEAN FLON FOR PERIOD OF RECORD 1965-78

DISCHARGE, IN $\mathrm{FT}^{3} / \mathrm{S}$, WHICH MAS EQUALED OR EXCEEDED FOR INDICATED PERCENT OF TIME

\begin{tabular}{|c|c|c|c|c|c|c|c|c|c|c|c|c|c|c|c|c|}
\hline $1 \%$ & $5 \%$ & $10 \%$ & $15 \%$ & $20 \%$ & $30 \%$ & $40 \%$ & $50 \%$ & $60 \%$ & $70 \%$ & $80 \%$ & $90 \%$ & $95 \%$ & $98 \%$ & $99 \%$ & $99.5 \%$ & $99.9 \%$ \\
\hline 86 & 3.8 & 1.6 & 1.5 & 1.4 & 1.2 & 1.1 & 0.94 & 0.80 & 0.66 & 0.50 & 0.23 & 0.18 & 0.11 & 0.11 & 0.10 & 0.10 \\
\hline
\end{tabular}


BILL WILLIAMS RIVER BASIM

09424200 WILLOW CREEK (COTTONWOOD WASH 1) NEAR KINGMAN, RZ--CONTINUED
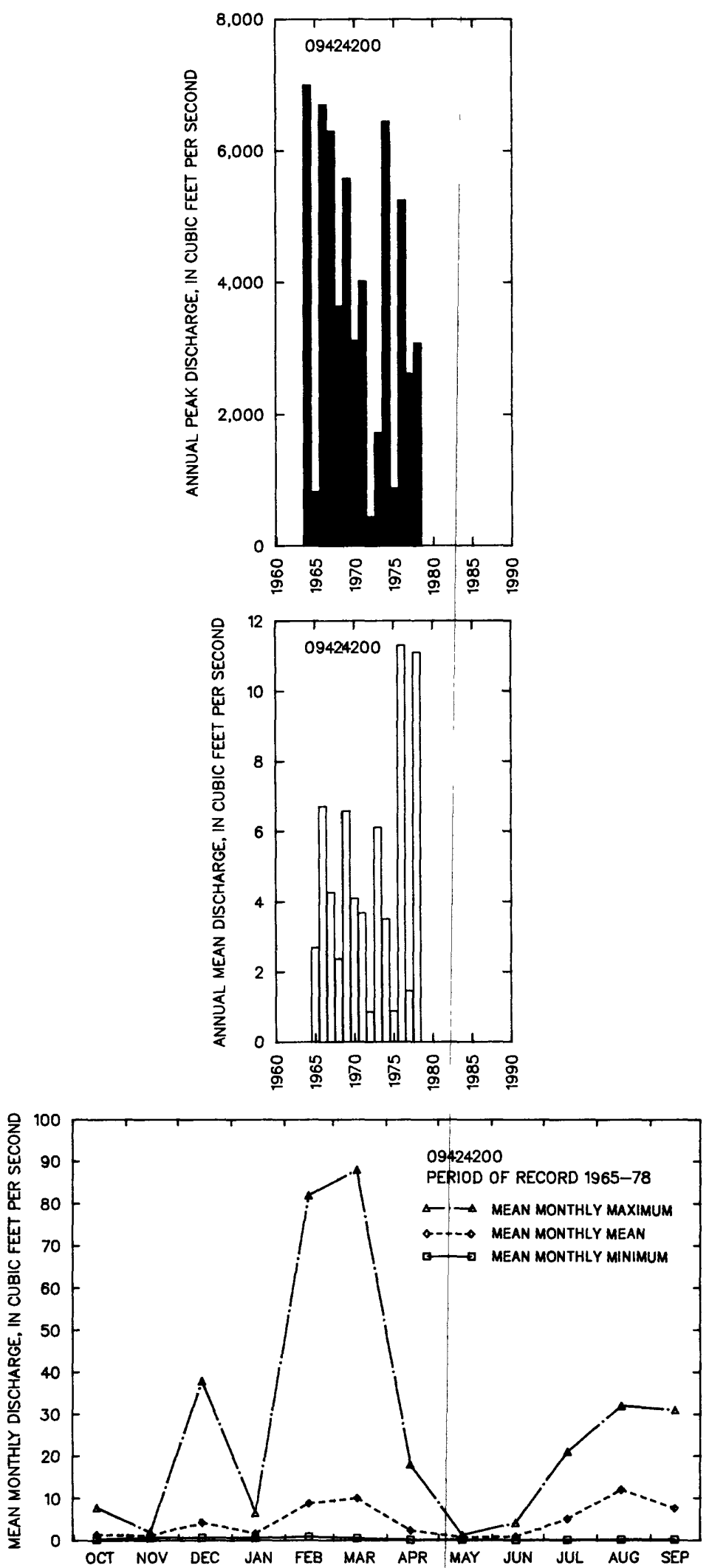


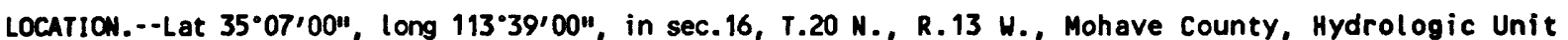
15030201, on U.S. Highway $93,1.2 \mathrm{mi}$ north of junction of U.S. Highway 93 and Hackberry Road, and $23 \mathrm{mi}$ southeast of Kingman.
\end{abstract}

DRAIMAGE AREA. $--13.5 \mathrm{mi}^{2}$

ANMUAL PEAK DISCHARGE

\begin{tabular}{|c|c|c|c|}
\hline $\begin{array}{l}\text { WATER } \\
\text { YEAR }\end{array}$ & DATE & $\begin{array}{c}\text { ANNUAL PEAK } \\
\text { DISCHARGE } \\
\left(\mathrm{FT}^{3} / \mathrm{S}\right)\end{array}$ & $\begin{array}{l}\text { DI SCHARGE } \\
\text { COOES }\end{array}$ \\
\hline $\begin{array}{l}1968 \\
1969 \\
1970 \\
1971 \\
1972 \\
1973 \\
1974 \\
1975 \\
1976 \\
1977 \\
1978 \\
1979\end{array}$ & $\begin{array}{l}08-04-68 \\
00-00-69 \\
08-00-70 \\
07-00-71 \\
09-19-72 \\
00-00-73 \\
00-00-74 \\
10-29-74 \\
00-00-76 \\
00-00-77 \\
00-00-78 \\
00-00-79\end{array}$ & $\begin{array}{r}20 \\
0 \\
400 \\
40 \\
1,000 \\
150 \\
0 \\
2 \\
20 \\
25 \\
25 \\
25\end{array}$ & $\begin{array}{l}\text { ES } \\
\text { LT } \\
\text { LT } \\
\text { LT } \\
\text { LT }\end{array}$ \\
\hline
\end{tabular}

MAGNITUDE AND PROBABILITY OF INSTANTANEOUS PEAK FLOW BASED ON PERIOD OF RECORD 1968-79

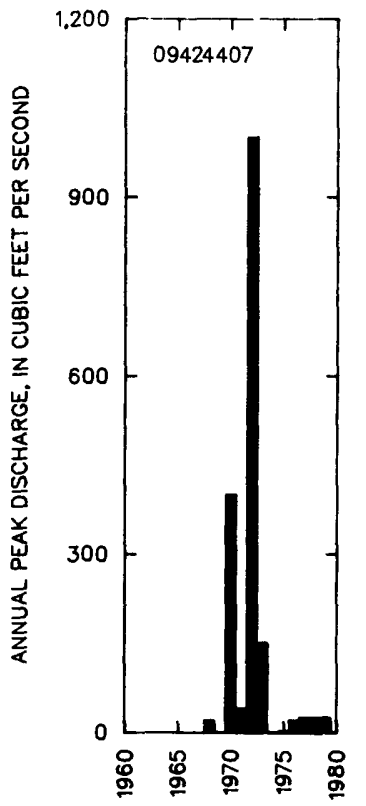

DISCHARGE, IN $\mathrm{FT}^{3} / \mathrm{S}$, FOR INDICATED RECURRENCE INTERVAL IN YEARS, AND EXCEEDANCE PROBABILITY, IN PERCENT

\begin{tabular}{|c|c|c|c|c|c|}
\hline $\begin{array}{c}2 \dagger \\
50 \%\end{array}$ & $\begin{array}{r}5 \dagger \\
20 \%\end{array}$ & $\begin{array}{c}10 \dagger \\
10 \%\end{array}$ & $\begin{array}{l}25 \dagger \\
4 \%\end{array}$ & $\begin{array}{l}50 \dagger \\
2 \%\end{array}$ & $\begin{array}{c}100\} \\
1 \%\end{array}$ \\
\hline 26.9 & 150 & 369 & 963 & 1,790 & 3,130 \\
\hline $\begin{array}{l}\text { WEIGHTED } \\
\text { MEAN } \\
\text { STANDARD }\end{array}$ & $\begin{array}{l}\text { SKEH } \\
\text { DEV. }\end{array}$ & $\begin{array}{l}(\text { LOGS })= \\
(\text { LOGS) }= \\
(\text { LOGS })=\end{array}$ & $\begin{array}{l}0.00 \\
1.43 \\
0.89\end{array}$ & & \\
\hline
\end{tabular}

+ Reliability of values in colum is uncertain, and potential errors are large.

BASIN CHARACTERISTICS

\begin{tabular}{|c|c|c|c|c|c|c|c|}
\hline \multirow{2}{*}{$\begin{array}{l}\text { MAIN } \\
\text { CHANNEL } \\
\text { SLOPE } \\
\text { (FT/MI) }\end{array}$} & \multirow[b]{2}{*}{$\begin{array}{c}\text { STREAM } \\
\text { LENGTH } \\
\text { (MI) }\end{array}$} & \multirow{2}{*}{$\begin{array}{l}\text { MEAN } \\
\text { BASIN } \\
\text { ELEVA- } \\
\text { TION } \\
\text { (FT) }\end{array}$} & \multirow[b]{2}{*}{$\begin{array}{l}\text { FORESTED } \\
\text { AREA } \\
\text { (PERCENT) }\end{array}$} & \multirow[b]{2}{*}{$\begin{array}{l}\text { SOIL } \\
\text { INDEX }\end{array}$} & \multirow{2}{*}{$\begin{array}{l}\text { MEAN } \\
\text { ANNUAL } \\
\text { PRECIPI- } \\
\text { TATION } \\
\text { (IN) }\end{array}$} & \multicolumn{2}{|c|}{ RAINFALL INTENSITY, 24-HOUR } \\
\hline & & & & & & $\begin{array}{l}\text { 2-YEAR } \\
\text { (IN) }\end{array}$ & $\begin{array}{l}\text { 50-YEAR } \\
\text { (IN) }\end{array}$ \\
\hline 203 & 12.1 & 4,610 & 40.0 & 3.0 & 12.0 & 1.5 & 3.7 \\
\hline
\end{tabular}


09424410 BIG SANDY RIVER TRIBUTARY NEAR KINGHAN, AZ

LOCATION.--Lat 35'05'30", long 113'39'30", in NEK sec.28, T.20 N., R.13 W., Mohave County, Hydrologic Unit 15030201 , at U.S. Highway 93,21 mi southeast of Kingman.

DRAINAGE AREA. $--1.99 \mathrm{mi}^{2}$

ANNUAL PEAK DISCHARGE

\begin{tabular}{|c|c|c|c|}
\hline $\begin{array}{l}\text { WATER } \\
\text { YEAR }\end{array}$ & DATE & $\begin{array}{l}\text { ANNUAL PEAK } \\
\text { DISCHARGE } \\
\left(\mathrm{FT}^{3} / \mathrm{S}\right)\end{array}$ & $\begin{array}{l}\text { DI SCHARGE } \\
\text { COOES }\end{array}$ \\
\hline $\begin{array}{l}1963 \\
1964 \\
1965 \\
1966 \\
1967 \\
1968 \\
1969 \\
1970 \\
1971 \\
1972 \\
1973 \\
1974 \\
1975 \\
1976 \\
1977 \\
1978\end{array}$ & $\begin{array}{l}08-00-63 \\
08-02-64 \\
08-29-65 \\
07-30-66 \\
12-06-66 \\
08-04-68 \\
07-18-69 \\
08-00-70 \\
08-00-71 \\
09-19-72 \\
08-00-73 \\
00-00-74 \\
11-02-74 \\
02-09-76 \\
00-00-77 \\
03-01-78\end{array}$ & $\begin{array}{c}10 \\
353 \\
100 \\
10 \\
5.0 \\
1.0 \\
5.0 \\
30 \\
25 \\
210 \\
220 \\
0 \\
10 \\
7.0 \\
25 \\
25\end{array}$ & $\begin{array}{l}\text { ES } \\
\text { ES } \\
\text { ES } \\
\text { LT } \\
\text { ES } \\
\text { ES } \\
\text { ES } \\
\text { ES }\end{array}$ \\
\hline
\end{tabular}

MAGNITUDE AND PROBABILITY OF INSTANTANEOUS PEAK FLON BASED ON PERIOD OF RECORD 1963-78

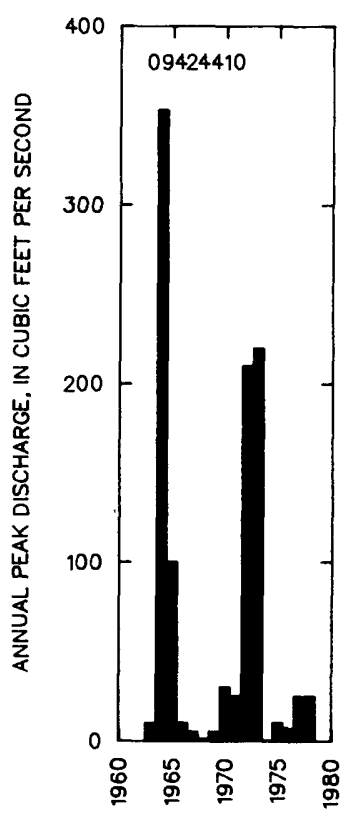

DISCHARGE, IN $\mathrm{FT}^{3} / \mathrm{S}$, FOR INDICATED RECURRENCE INTERVAL IN YEARS, AND EXCEEDANCE PROBABILITY, IN PERCENT

\begin{tabular}{|c|c|c|c|c|c|}
\hline $\begin{array}{c}2 \\
50 \%\end{array}$ & $\begin{array}{c}5 \\
20 \%\end{array}$ & $\begin{array}{r}10 \\
10 \%\end{array}$ & $\begin{array}{l}25 \uparrow \\
4 \%\end{array}$ & $\begin{array}{l}50 \dagger \\
2 \%\end{array}$ & $\begin{array}{c}100 \dagger \\
1 \%\end{array}$ \\
\hline 18.6 & 80.2 & 173 & 394 & 672 & 1,090 \\
\hline $\begin{array}{l}\text { WEIGHTED } \\
\text { MEAN } \\
\text { STANDARD }\end{array}$ & $\begin{array}{l}\text { SKEW } \\
\text { DEV. }\end{array}$ & $\begin{array}{l}(\text { LOGS })= \\
(\text { LOGS) }= \\
(\text { LOGS }=\end{array}$ & $\begin{array}{l}0.03 \\
1.27 \\
0.75\end{array}$ & & \\
\hline
\end{tabular}

Reliability of values in column is uncertain, and potential errors are large.

BASIN CHARACTERISTICS

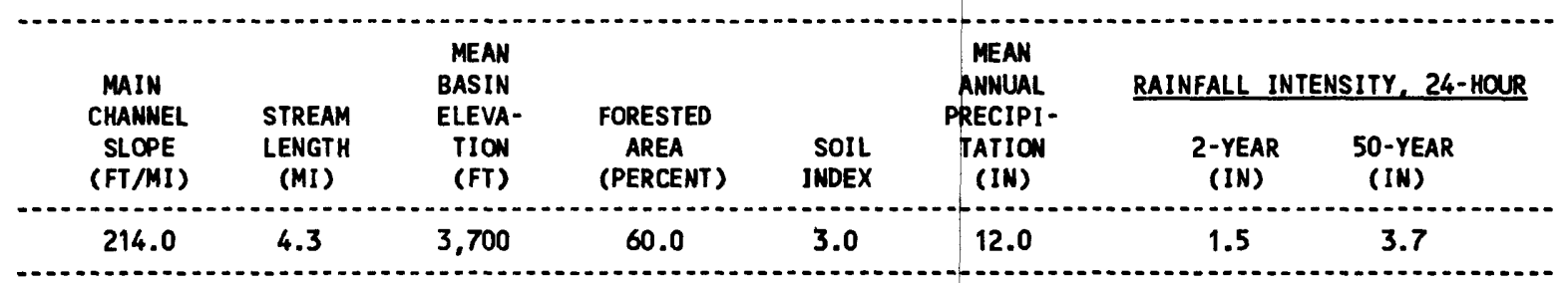


09424430 KAISER SPRING CANYON TRIBUTARY NEAR UIKIELP, AZ

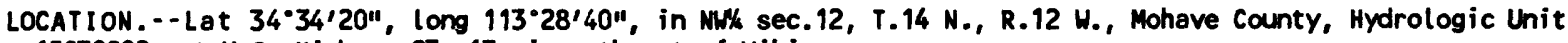
15030202 , at U.S. Highway 93,13 mi southeast of Wikieup.

DRAIMAGE AREA. $--1.7 \mathrm{mi}^{2}$

ANNUAL PEAK DISCHARCE

\begin{tabular}{cccc}
$\begin{array}{c}\text { WATER } \\
\text { YEAR }\end{array}$ & DATE & $\begin{array}{c}\text { ANNUAL PEAK } \\
\text { DISCHARGE } \\
\text { (FT } 3 / \text { S })\end{array}$ & $\begin{array}{c}\text { DISCHARGE } \\
\text { CODES }\end{array}$ \\
\hline 1963 & $08-22-63$ & 1,310 & \\
1964 & $08-02-64$ & 290 & \\
1965 & $00-00-65$ & 50 & LT \\
1966 & $12-10-65$ & 90 & \\
1967 & $00-00-67$ & 50 & LT \\
1968 & $08-04-68$ & 2.0 & ES \\
1969 & $00-00-69$ & 0 & \\
1970 & $08-00-70$ & 50 & ES \\
1971 & $08-19-71$ & 510 & \\
1972 & $00-00-72$ & 0 & \\
1973 & $05-31-73$ & 250 & ES \\
1974 & $09-00-74$ & 50 & ES \\
1975 & $00-00-75$ & 0 & \\
1976 & $00-00-76$ & 0 & LT \\
1977 & $00-00-77$ & 30 & ES \\
1978 & $00-00-78$ & 30 &
\end{tabular}

MAGNITUDE AND PROBABILITY OF INSTANTANEOUS PEAK FLOW BASED ON PERIOD OF RECORD 1963-78

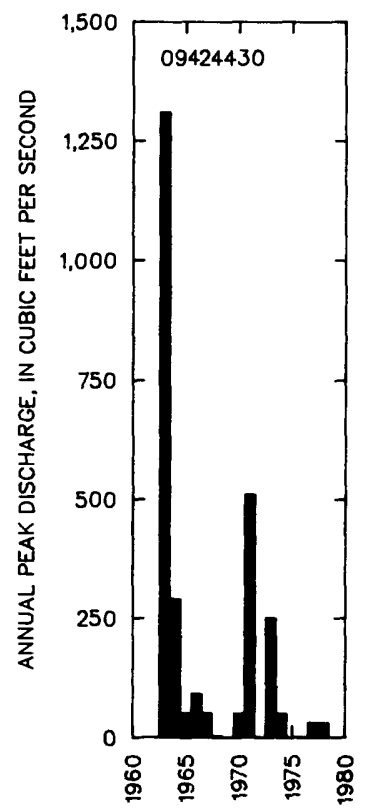

DISCHARGE, IN $\mathrm{FT}^{3} / \mathrm{S}$, FOR INDICATED RECURRENCE INTERVAL IN YEARS, AND EXCEEDANCE PROBABILITY, IN PERCENT

\begin{tabular}{|c|c|c|c|c|c|}
\hline $\begin{array}{r}2 \uparrow \\
50 \%\end{array}$ & $\begin{array}{r}5 \dagger \\
20 \%\end{array}$ & $\begin{array}{c}10 \dagger \\
10 \%\end{array}$ & $\begin{array}{l}25 \dagger \\
4 \%\end{array}$ & $\begin{array}{l}50 \dagger \\
2 \%\end{array}$ & $\begin{array}{c}100 \dagger \\
1 \%\end{array}$ \\
\hline 49.2 & 196 & 413 & 933 & 1,600 & 2,610 \\
\hline $\begin{array}{l}\text { WE IGHTED } \\
\text { MEAN } \\
\text { STANDARD }\end{array}$ & $\begin{array}{l}\text { SKEW } \\
\text { DEV. }\end{array}$ & $\begin{array}{l}(\text { LOGS })= \\
(\text { LOGS) }= \\
(\text { LOGS) }=\end{array}$ & $\begin{array}{l}0.17 \\
1.71 \\
0.70\end{array}$ & & \\
\hline
\end{tabular}

$\uparrow$ Reliability of values in column is uncertain, and potential errors are large.

BASIN CHARACTERISTICS

\begin{tabular}{|c|c|c|c|c|c|c|c|}
\hline \multirow{2}{*}{$\begin{array}{l}\text { MAIN } \\
\text { CHANNEL } \\
\text { SLOPE } \\
\text { (FT/MI) }\end{array}$} & \multirow[b]{2}{*}{$\begin{array}{c}\text { STREAM } \\
\text { LENGTH } \\
\text { (MI) }\end{array}$} & \multirow{2}{*}{$\begin{array}{l}\text { MEAN } \\
\text { BASIN } \\
\text { ELEVA- } \\
\text { TION } \\
\text { (FT) }\end{array}$} & \multirow[b]{2}{*}{$\begin{array}{l}\text { FORESTED } \\
\text { AREA } \\
\text { (PERCENT) }\end{array}$} & \multirow[b]{2}{*}{$\begin{array}{l}\text { SOIL } \\
\text { INDEX }\end{array}$} & \multirow{2}{*}{$\begin{array}{l}\text { MEAN } \\
\text { ANNUAL } \\
\text { PRECIPI- } \\
\text { TATION } \\
\text { (IN) }\end{array}$} & \multicolumn{2}{|c|}{ RAINFALL INTENSITY, 24-HOUR } \\
\hline & & & & & & $\begin{array}{c}\text { 2-YEAR } \\
\text { (IN) }\end{array}$ & $\begin{array}{l}\text { 50-YEAR } \\
\text { (IN) }\end{array}$ \\
\hline 615 & 1.3 & 3,520 & 0.0 & 1.0 & 11.2 & 1.7 & 3.9 \\
\hline
\end{tabular}


LOCATION.--Lat 34'27'45", long 113'37'25", in SE\% sec.16, T.13 N., R.13 H., Mohave County, Hydrologic Unit 15030201, on left bank 7 mi downstream from Burro Creek, 15 mi upstream from confluence with Santa Maria River, and 17 mi south of Wikieup.

DRAIMACE AREA. $--2,742 \mathrm{mi}^{2}$, of wich $10.1 \mathrm{mi}^{2}$ is noncontribut ing.

REMARKS.--Diversions above station for irrigation of about 3,800 acres, mostly by pumping from ground water.

ANMUAL PEAK DISCHARGE

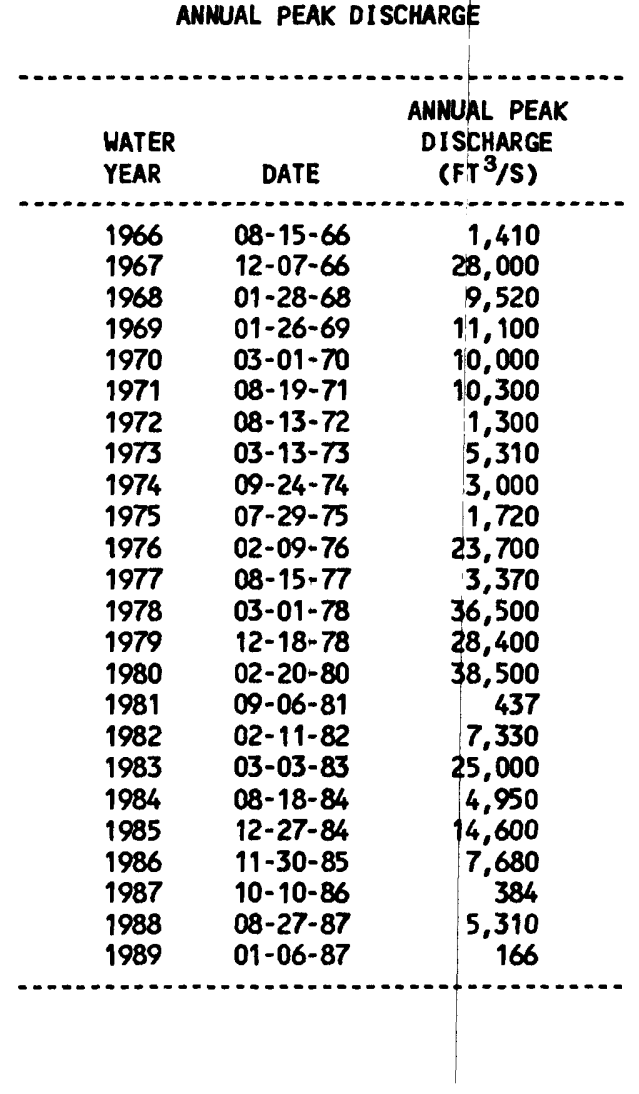

BASIN CHARACTERISTICS

\begin{tabular}{|c|c|c|c|c|c|c|c|}
\hline MAIN & & $\begin{array}{l}\text { MEAN } \\
\text { BASIN }\end{array}$ & & & & RAINFALL I & SITY, 24-HOUR \\
\hline $\begin{array}{l}\text { CHANNEL } \\
\text { SLOPE } \\
\text { (FT/MI) }\end{array}$ & $\begin{array}{l}\text { STREAM } \\
\text { LENGTH } \\
\text { (MI) }\end{array}$ & $\begin{array}{l}\text { ELEVA- } \\
\text { TION } \\
\text { (FT) }\end{array}$ & $\begin{array}{l}\text { FORESTED } \\
\text { AREA } \\
\text { (PERCENT) }\end{array}$ & $\begin{array}{l}\text { SOIL } \\
\text { INDEX }\end{array}$ & $\begin{array}{l}\text { PRECIPI- } \\
\text { TAT ION } \\
\text { (IN) }\end{array}$ & $\begin{array}{c}\text { 2-YEAR } \\
\text { (IN) }\end{array}$ & $\begin{array}{c}\text { 50-YEAR } \\
\text { (IN) }\end{array}$ \\
\hline 41.9 & 58.8 & 4,490 & 46.0 & 1.7 & 14.2 & 1.8 & 4.1 \\
\hline
\end{tabular}


BILL HILLIAMS RIVER BASIN

09424450 BIG SANDY RIVER MEAR WIKIEUP, AZ--Continued

MEAN MONTHLY AND ANMUAL DISCHARGES $1967-89$

\begin{tabular}{|c|c|c|c|c|c|c|}
\hline MONTH & $\begin{array}{l}\operatorname{MAX} \operatorname{IIMM}^{3} \\
\left(\mathrm{FT}^{3} / \mathrm{S}\right)\end{array}$ & $\begin{array}{l}\text { MINIMUN } \\
\left(F T^{3} / S\right)\end{array}$ & $\begin{array}{c}\text { MEAN } \\
\left(F T^{3} / S\right)\end{array}$ & $\begin{array}{l}\text { STAN- } \\
\text { DARD } \\
\text { DEVIA- } \\
\text { TION } \\
\left(F T^{3} / S\right)\end{array}$ & $\begin{array}{l}\text { COEFFI - } \\
\text { CIENT OF } \\
\text { VARI - } \\
\text { ATION }\end{array}$ & $\begin{array}{c}\text { PERCENT } \\
\text { OF } \\
\text { ANNUAL } \\
\text { RUNOFF }\end{array}$ \\
\hline $\begin{array}{l}\text { OCTOBER } \\
\text { NOVEMBER } \\
\text { OECEMBER } \\
\text { JANUARY } \\
\text { FEBRUARY } \\
\text { MARCH } \\
\text { APRIL } \\
\text { MAY } \\
\text { JUNE } \\
\text { JULY } \\
\text { AUGUST } \\
\text { SEPTEMBER }\end{array}$ & $\begin{array}{r}100 \\
252 \\
737 \\
821 \\
2,750 \\
1,940 \\
153 \\
36 \\
14 \\
17 \\
178 \\
226\end{array}$ & $\begin{array}{l}2.7 \\
3.1 \\
2.8 \\
4.2 \\
3.9 \\
4.6 \\
3.6 \\
2.7 \\
2.1 \\
1.9 \\
2.7 \\
2.8\end{array}$ & $\begin{array}{c}12 \\
28 \\
107 \\
119 \\
297 \\
304 \\
35 \\
9.1 \\
5.3 \\
5.3 \\
28 \\
21\end{array}$ & $\begin{array}{c}24 \\
60 \\
208 \\
209 \\
615 \\
512 \\
43 \\
8.2 \\
2.8 \\
3.2 \\
48 \\
46\end{array}$ & $\begin{array}{l}1.9 \\
2.1 \\
2.0 \\
1.8 \\
2.1 \\
1.7 \\
1.3 \\
0.91 \\
0.54 \\
0.61 \\
1.7 \\
2.2\end{array}$ & $\begin{array}{r}1.3 \\
2.9 \\
11.0 \\
12.2 \\
30.6 \\
31.3 \\
3.6 \\
0.9 \\
0.5 \\
0.5 \\
2.9 \\
2.2\end{array}$ \\
\hline INUA & 320 & 4.5 & 80 & 91 & 1.1 & 100 \\
\hline
\end{tabular}

MAGNITUDE AND PROBABILITY OF INSTANTANEOUS PEAK FLOW BASED ON PERIOD OF RECORD 1966-89

DISCHARGE, IN $\mathrm{FT}^{3} / \mathrm{S}$, FOR INDICATED RECURRENCE INTERVAL IN YEARS, AND EXCEEDANCE PROBABILITY, IN PERCENT

\begin{tabular}{lccccc}
2 & 5 & 10 & 25 & 50 & $100\}$ \\
$50 \%$ & $20 \%$ & $10 \%$ & $4 \%$ & $2 \%$ & $1 \%$ \\
7,710 & 18,500 & 28,700 & 45,200 & 60,200 & 77,400 \\
\hline WEIGHTED SKEW (LOGS) & $=-0.19$ & & \\
MEAN & (LOGS) & $=3.87$ \\
STANDARD DEV. (LOGS) & $=0.46$
\end{tabular}

MAGNITUDE AND PROBABILITY OF ANNUAL LOW FLOW BASED ON PERIOD OF RECORD 1967-89

\begin{tabular}{|c|c|c|c|c|c|c|}
\hline \multirow{2}{*}{$\begin{array}{l}\text { PERIOD } \\
\text { (CON- } \\
\text { SECU- } \\
\text { TIVE } \\
\text { DAYS) }\end{array}$} & \multicolumn{6}{|c|}{$\begin{array}{l}\text { DISCHARGE, IN } \mathrm{FT}^{3} / \mathrm{S} \text {, FOR INDICATED } \\
\text { RECURRENCE INTERVAL, IN YEARS, AND } \\
\text { NON-EXCEEDANCE PROBABILITY, IN PERCENT }\end{array}$} \\
\hline & $\begin{array}{c}2 \\
50 \%\end{array}$ & $\begin{array}{c}5 \\
20 \%\end{array}$ & $\begin{array}{l}10 \\
10 \%\end{array}$ & $\begin{array}{l}20 \\
5 \%\end{array}$ & $\begin{array}{l}50 \uparrow \\
2 \%\end{array}$ & $\begin{array}{l}100 t \\
1 \%\end{array}$ \\
\hline $\begin{array}{r}1 \\
3 \\
7 \\
14 \\
30 \\
60 \\
90 \\
120 \\
183\end{array}$ & $\begin{array}{l}2.7 \\
2.8 \\
2.9 \\
3.1 \\
3.4 \\
3.9 \\
4.2 \\
4.5 \\
5.9\end{array}$ & $\begin{array}{l}2.0 \\
2.1 \\
2.3 \\
2.4 \\
2.6 \\
3.0 \\
3.3 \\
3.5 \\
4.1\end{array}$ & $\begin{array}{l}1.7 \\
1.8 \\
1.9 \\
2.1 \\
2.2 \\
2.6 \\
2.8 \\
3.1 \\
3.6\end{array}$ & $\begin{array}{l}1.5 \\
1.5 \\
1.7 \\
1.8 \\
1.9 \\
2.2 \\
2.5 \\
2.7 \\
3.4\end{array}$ & $\begin{array}{l}1.3 \\
1.3 \\
1.4 \\
1.6 \\
1.6 \\
1.9 \\
2.1 \\
2.4 \\
3.2\end{array}$ & $\begin{array}{l}1.1 \\
1.2 \\
1.3 \\
1.4 \\
1.5 \\
1.7 \\
1.9 \\
2.2 \\
3.2\end{array}$ \\
\hline
\end{tabular}

MAGNITUDE AND PROBABILITY OF ANNUAL HIGH FLOW BASED ON PERIOD OF RECORD 1967-89

\begin{tabular}{|c|c|c|c|c|c|c|}
\hline \multirow{2}{*}{$\begin{array}{l}\text { PERIOD } \\
\text { (CON- } \\
\text { SECU- } \\
\text { TIVE } \\
\text { DAYS) }\end{array}$} & \multicolumn{6}{|c|}{$\begin{array}{l}\text { DISCHARGE, IN } \mathrm{FT}^{3} / \mathrm{S} \text {, FOR INDICATED } \\
\text { RECURRENCE INTERVAL, IN YEARS, AND } \\
\text { EXCEEDANCE PROBABILITY, IN PERCENT }\end{array}$} \\
\hline & $\begin{array}{c}2 \\
50 \%\end{array}$ & $\begin{array}{c}5 \\
20 \%\end{array}$ & $\begin{array}{l}10 \\
10 \%\end{array}$ & $\begin{array}{l}25 \\
4 \%\end{array}$ & $\begin{array}{l}50 \dagger \\
2 \%\end{array}$ & $\begin{array}{c}100 \dagger \\
1 \%\end{array}$ \\
\hline $\begin{array}{l}1 \\
3 \\
7 \\
15 \\
30 \\
60 \\
90\end{array}$ & $\begin{array}{r}1,950 \\
1,120 \\
665 \\
389 \\
234 \\
149 \\
108\end{array}$ & $\begin{array}{r}8,230 \\
4,800 \\
2,860 \\
1,640 \\
960 \\
581 \\
414\end{array}$ & $\begin{array}{r}16,400 \\
9,690 \\
5,800 \\
3,290 \\
1,910 \\
1,130 \\
803\end{array}$ & $\begin{array}{r}32,400 \\
19,600 \\
11,800 \\
6,630 \\
3,820 \\
2,200 \\
1,580\end{array}$ & $\begin{array}{r}49,200 \\
30,200 \\
18,300 \\
10,200 \\
5,860 \\
3,320 \\
2,410\end{array}$ & $\begin{array}{r}70,300 \\
43,700 \\
26,700 \\
14,800 \\
8,510 \\
4,750 \\
3,480\end{array}$ \\
\hline
\end{tabular}

DURATION TABLE OF DAILY MEAN FLON FOR PERIOD OF RECORD 1967-89 DISCHARGE, IN FT $3 / \mathrm{S}$, WHICH WAS EQUALED OR EXCEEDED FOR INDICATED PERCENT OF TIME

\begin{tabular}{|c|c|c|c|c|c|c|c|c|c|c|c|c|c|c|c|c|}
\hline $1 \%$ & $5 \%$ & $10 \%$ & $15 \%$ & $20 \%$ & $30 \%$ & $40 \%$ & $50 \%$ & $60 \%$ & $70 \%$ & $80 \%$ & $90 \%$ & $95 \%$ & $98 \%$ & $99 \%$ & $99.5 \%$ & $99.9 \%$ \\
\hline 1,580 & 196 & 61 & 30 & 19 & 9.5 & 6.7 & 5.5 & 4.9 & 4.4 & 3.9 & 3.2 & 2.7 & 2.3 & 2.0 & 1.8 & 1.5 \\
\hline
\end{tabular}

$\uparrow$ Reliability of values in colum is uncertain, and potential errors are large. 
09424450 BIG SANDY RIVER NEAR WIKIEUP, AZ--CONTINUED
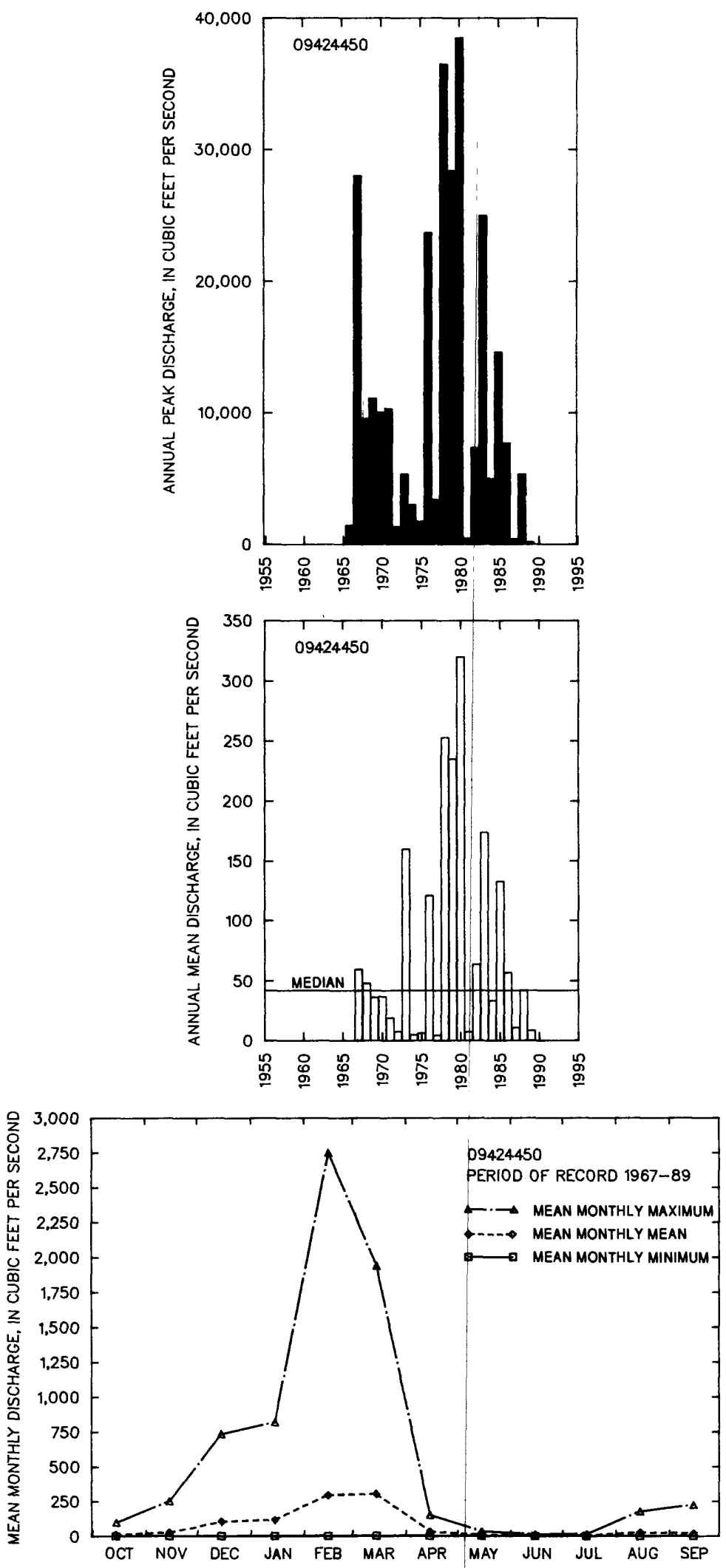
09424470 KIRKLAND CREEK NEAR KIRKLAND, AZ

LOCATION.--Lat 34'23'38", Long $112^{\circ} 43^{\prime} 19^{\prime \prime}$, in SW/2 sec.7, T.12 N., R.4 W., Yavapai County, Hydrologic Unit 15030203, on right bank $1.3 \mathrm{mi}$ upstream from Skull Valley Wash and $1.7 \mathrm{mi}$ southwest of $\mathrm{Kirkland}$.

DRAINAGE AREA. $--109 \mathrm{mi}^{2}$.

ANNUAL PEAK DISCHARGE

\begin{tabular}{lcc}
$\begin{array}{c}\text { WATER } \\
\text { YEAR }\end{array}$ & DATE & $\begin{array}{c}\text { ANNUAL PEAK } \\
\text { DISCHARGE } \\
\text { (FT }{ }^{3} / \mathrm{S} \text { ) }\end{array}$ \\
\hline 1974 & $08-02-74$ & 615 \\
1975 & $07-28-75$ & 776 \\
1976 & $02-09-76$ & 2,710 \\
1977 & $10-23-76$ & 328 \\
1978 & $03-01-78$ & 7,890 \\
1979 & $11-11-78$ & 10,300 \\
1980 & $02-19-80$ & 8,440 \\
1981 & $07-11-81$ & 706 \\
1982 & $03-15-82$ & 520 \\
1983 & $03-03-83$ & 2,980 \\
\hline
\end{tabular}

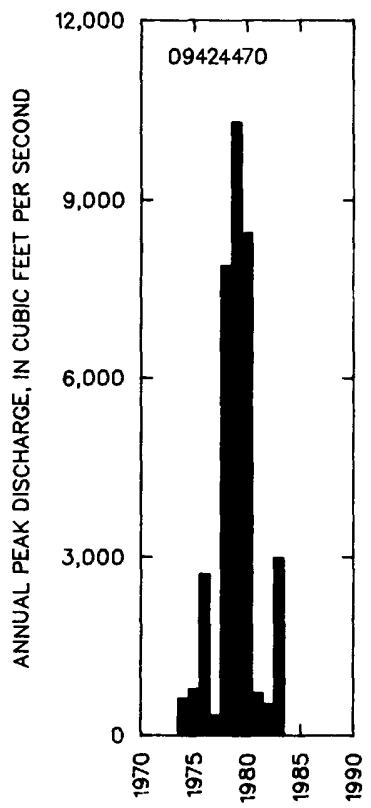

DISCHARGE, IN $\mathrm{FT}^{3} / \mathrm{S}$, FOR INDICATED RECURRENCE INTERVAL IN YEARS, AND EXCEEDANCE PROBABILITY, IN PERCENT

MAGNITUDE AND PROBABILITY OF INSTANTANEOUS PEAK FLOW BASED ON PERIOD OF RECORD

$\begin{array}{llllll}2 & 5 & 10 & 25 & 50 & 100\end{array}$

$\begin{array}{llllll}50 \% & 20 \% & 10 \% & 4 \% & 2 \% & 1 \%\end{array}$

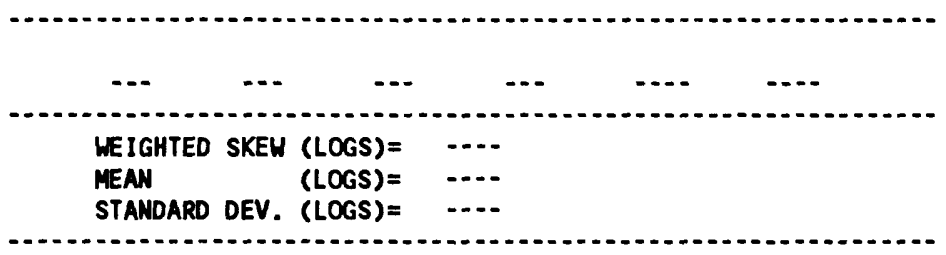

BASIN CHARACTERISTICS

\begin{tabular}{|c|c|c|c|c|c|c|c|}
\hline \multirow{2}{*}{$\begin{array}{l}\text { MAIN } \\
\text { CHANNEL } \\
\text { SLOPE } \\
\text { (FT } / M I)\end{array}$} & \multirow[b]{2}{*}{$\begin{array}{c}\text { STREAM } \\
\text { LENGTH } \\
\text { (MI) }\end{array}$} & \multirow{2}{*}{$\begin{array}{l}\text { MEAN } \\
\text { BASIN } \\
\text { ELEVA- } \\
\text { TION } \\
\text { (FT) }\end{array}$} & \multirow[b]{2}{*}{$\begin{array}{l}\text { FORESTED } \\
\text { AREA } \\
\text { (PERCENT) }\end{array}$} & \multicolumn{2}{|r|}{$\begin{array}{c}\text { MEAN } \\
\text { ANNUAL } \\
\text { PRECIPI- }\end{array}$} & \multicolumn{2}{|c|}{ RAINFALL INTENSITY, 24-HOUR } \\
\hline & & & & $\begin{array}{l}\text { SOIL } \\
\text { INDEX }\end{array}$ & $\begin{array}{l}\text { PRECIPI - } \\
\text { TATION } \\
\text { (IN) }\end{array}$ & $\begin{array}{c}\text { 2-YEAR } \\
\text { (IN) }\end{array}$ & $\begin{array}{c}\text { 50-YEAR } \\
\text { (IN) }\end{array}$ \\
\hline 40.5 & 23 & 4,665 & 72.0 & 1.0 & 18.4 & 1.4 & 4.4 \\
\hline
\end{tabular}




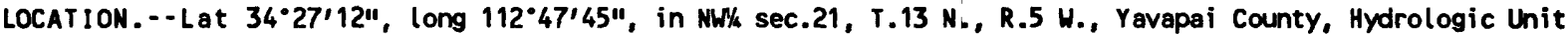
15030203, at State Highway $96,5.5$ mi west of Kirkland.

DRAINAGE AREA. $--6.95 \mathrm{mi}^{2}$

ANNUAL PEAK DISCHARGE

\begin{tabular}{cccc}
$\begin{array}{c}\text { WATER } \\
\text { YEAR }\end{array}$ & DATE & $\begin{array}{c}\text { ANNUAL PEAK } \\
\text { DISCHARGE } \\
\text { (FT } 3 / \text { S })\end{array}$ & $\begin{array}{c}\text { DISCHARGE } \\
\text { CODES }\end{array}$ \\
\hline 1960 & $00-00-60$ & 4,000 & HP \\
1963 & $08-20-63$ & 109 & \\
1964 & $09-13-64$ & 1,020 & \\
1965 & $09-03-65$ & 140 & \\
1966 & $12-10-65$ & 230 & \\
1967 & $07-15-67$ & 225 & \\
1968 & $08-12-68$ & 140 & \\
1969 & $08-19-69$ & 250 & \\
1970 & $08-00-70$ & 15 & ES \\
1971 & $08-19-71$ & 300 & ES \\
1972 & $08-13-72$ & 20 & \\
1973 & $10-07-72$ & 60 & ES \\
1974 & $00-00-74$ & 15 & ES \\
1975 & $11-02-74$ & 20 & ES \\
1976 & $09-25-76$ & 240 & \\
1978 & $03-01-78$ & 300 & \\
1979 & $12-18-78$ & 205 & \\
\hline$\ldots . . \ldots$ & &
\end{tabular}

MAGNI TUDE AND PROBABILITY OF INSTANTANEQUS PEAK FLOW BASED ON PERIOD OF RECORD 1960, 1963-76, 1979

DISCHARGE, IN $\mathrm{FT}^{3} / \mathrm{S}$, FOR INDICATED RECURRENCE INTERVAL IN YEARS, ANO EXCEEDANCE PROBABILITY, IN PERCENT

\begin{tabular}{|c|c|c|c|c|c|}
\hline $\begin{array}{c}2 \\
50 \%\end{array}$ & $\begin{array}{c}5 \\
20 \%\end{array}$ & $\begin{array}{r}10 \\
10 \%\end{array}$ & $\begin{array}{l}25 \\
4 \%\end{array}$ & $\begin{array}{l}50 \dagger \\
2 \%\end{array}$ & $\begin{array}{c}100 \nmid \\
1 \%\end{array}$ \\
\hline 133 & 459 & 882 & 1,780 & 2,810 & 4,250 \\
\hline $\begin{array}{l}\text { WEIGHTED } \\
\text { MEAN } \\
\text { STANDARD }\end{array}$ & $\begin{array}{l}\text { SKEH } \\
\text { DEV. }\end{array}$ & $\begin{array}{l}(\text { LOGS })= \\
(\text { LOGS })= \\
(\text { LOGS })=\end{array}$ & $\begin{array}{l}0.05 \\
2.13 \\
0.63\end{array}$ & & \\
\hline
\end{tabular}

$\uparrow$ Reliability of values in column is uncertain, and potential errors are large.

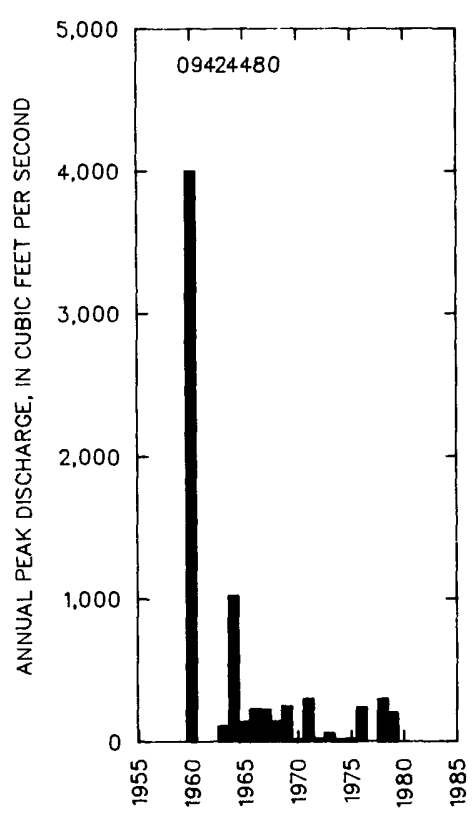

BASIN CHARACTERISTICS

\begin{tabular}{|c|c|c|c|c|c|c|c|}
\hline & & MEAN & & & MEAN & & \\
\hline MAIN & & BASIN & & & ANNUAL & RAINFALL I & SITY, 24-HOUR \\
\hline $\begin{array}{l}\text { CHANNEL } \\
\text { SLOPE } \\
\text { (FT } / \text { MI) }\end{array}$ & $\begin{array}{c}\text { STREAM } \\
\text { LENGTH } \\
\text { (MI) }\end{array}$ & $\begin{array}{l}\text { ELEVA- } \\
\text { TION } \\
\text { (FT) }\end{array}$ & $\begin{array}{l}\text { FORESTED } \\
\text { AREA } \\
\text { (PERCENT) }\end{array}$ & $\begin{array}{l}\text { SOIL } \\
\text { INDEX }\end{array}$ & $\begin{array}{l}\text { PRECIPI - } \\
\text { TATION } \\
\text { (IN) }\end{array}$ & $\begin{array}{c}\text { 2-YEAR } \\
\text { (IN) }\end{array}$ & $\begin{array}{c}\text { 50-YEAR } \\
\text { (IN) }\end{array}$ \\
\hline 278.0 & 5.3 & 4,680 & 1.4 & 1.0 & 10.4 & 1.9 & 4.0 \\
\hline
\end{tabular}


09424700 IRON SPRING WASH TRIBUTARY NEAR BAGDAD, AZ

LOCATION.-- Lat 34'31'20", long 113.06'43", in NEYSEK sec.29, T.14 N., R.8 H., Yavapai County, Hydrologic Unit 15030203, at State Highway $96,6.6 \mathrm{mi}$ southeast of Bagdad.

DRAIMAGE AREA. $--0.64 \mathrm{mi}^{2}$.

\section{ANMUAL PEAK DISCHARGE}

\begin{tabular}{|c|c|c|c|}
\hline $\begin{array}{l}\text { WATER } \\
\text { YEAR }\end{array}$ & DATE & $\begin{array}{l}\text { ANNUAL PEAK } \\
\text { DISCHARGE } \\
\left(F^{3} / S\right)\end{array}$ & $\begin{array}{l}\text { DISCHARGE } \\
\text { COOES }\end{array}$ \\
\hline $\begin{array}{l}1964 \\
1965 \\
1966 \\
1967 \\
1968 \\
1969 \\
1970 \\
1971 \\
1972 \\
1973 \\
1974 \\
1975 \\
1976 \\
1978 \\
1979\end{array}$ & $\begin{array}{l}09-25-64 \\
04-04-65 \\
11-23-65 \\
12-06-66 \\
08-12-68 \\
01-14-69 \\
08-12-70 \\
08-00-71 \\
08-00-72 \\
10-00-72 \\
08-05-74 \\
11-02-74 \\
02-06-76 \\
03-01-78 \\
00-00-79\end{array}$ & $\begin{array}{c}150 \\
10 \\
65 \\
10 \\
85 \\
5.0 \\
6.0 \\
0.6 \\
0.5 \\
25 \\
4.0 \\
1.0 \\
9.0 \\
180 \\
125\end{array}$ & $\begin{array}{l}\text { ES } \\
\text { ES } \\
\text { ES } \\
\text { ES } \\
\text { ES } \\
\text { ES }\end{array}$ \\
\hline
\end{tabular}

MAGNITUDE AND PROBABILITY OF INSTANTANEOUS PEAK FLOW BASED ON PERIOD OF RECORD 1964-76, 1978-79

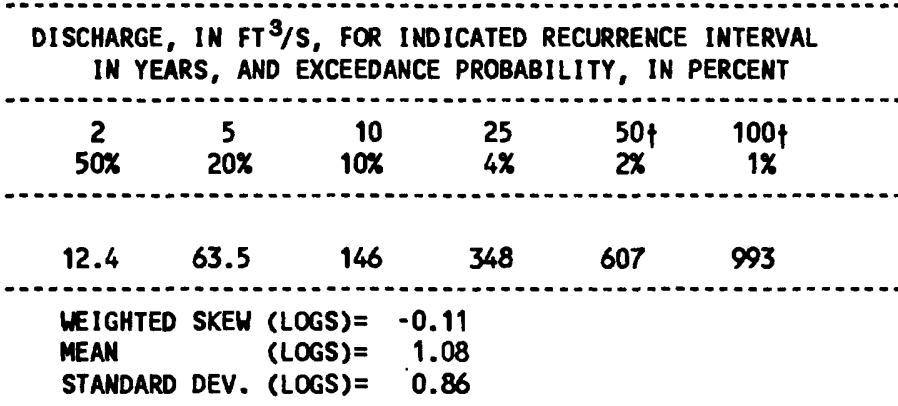

f Reliability of values in column is uncertain, and potential errors are large.

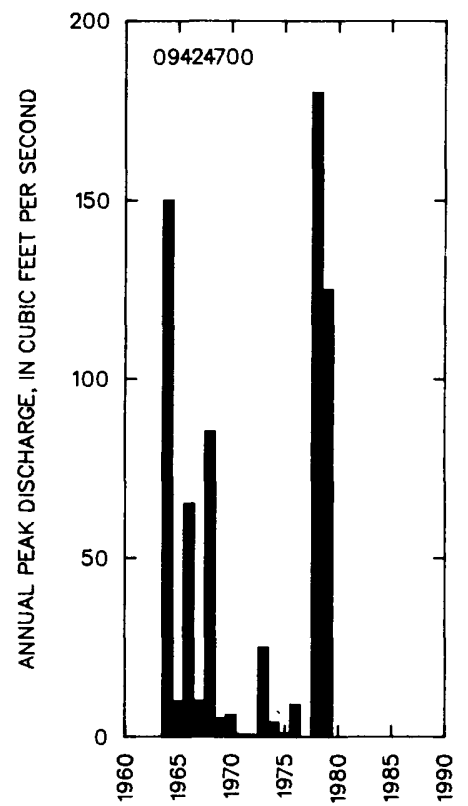

BASIN CHARACTERISTICS

\begin{tabular}{|c|c|c|c|c|c|c|c|}
\hline MAIN & & $\begin{array}{r}\text { MEAN } \\
\text { BASIN }\end{array}$ & & & $\begin{array}{l}\text { MEAN } \\
\text { ANNUAL }\end{array}$ & RAINFALL II & SITY, 24 -HOUR \\
\hline $\begin{array}{l}\text { CHANNEL } \\
\text { SLOPE } \\
\text { (FT/MI) }\end{array}$ & $\begin{array}{c}\text { STREAM } \\
\text { LENGTH } \\
\text { (MI) }\end{array}$ & $\begin{array}{l}\text { ELEVA- } \\
\text { TION } \\
\text { (FT) }\end{array}$ & $\begin{array}{l}\text { FORESTED } \\
\text { AREA } \\
\text { (PERCENT) }\end{array}$ & $\begin{array}{l}\text { SOIL } \\
\text { INDEX }\end{array}$ & $\begin{array}{l}\text { PRECIPI- } \\
\text { TATION } \\
\text { (IN) }\end{array}$ & $\begin{array}{c}\text { 2-YEAR } \\
\text { (IN) }\end{array}$ & $\begin{array}{l}\text { 50-YEAR } \\
\text { (IN) }\end{array}$ \\
\hline 431 & 2.6 & 3,470 & 0.0 & 1.0 & 12.1 & 1.9 & 4.0 \\
\hline
\end{tabular}


LOCATION.--Lat 34'18'21", Long 113.20'47", in SEK sec.12, T.11 N., R.11 W., Mohave County, Hydrologic Unit 15030203, on $r i g h t$ bank $4.0 \mathrm{mi}$ east of Palmerita Ranch, $12 \mathrm{mi}$ upstream from confluence with Big Sandy River, and $21 \mathrm{mi}$ southwest of Bagdad.

DRAIMAGE AREA. $--1,128 \mathrm{mi}^{2}$.

REMARKS.--Diversions above station for irrigation of about 5,300 acres, most of which is by pumping from ground water.

ANMUAL PEAK DISCHAREE

\begin{tabular}{|c|c|c|c|}
\hline $\begin{array}{l}\text { HATER } \\
\text { YEAR }\end{array}$ & DATE & $\begin{array}{c}\text { ANIWAL PEAK } \\
\text { DISCHARGE } \\
\left.\text { (FT }{ }^{3} / \mathrm{S}\right)\end{array}$ & $\begin{array}{l}\text { DISCHARGE } \\
\text { CODES }\end{array}$ \\
\hline $\begin{array}{l}1967 \\
1968 \\
1969 \\
1970 \\
1971 \\
1972 \\
1973 \\
1974 \\
1975 \\
1976 \\
1977 \\
1978 \\
1979 \\
1980 \\
1981 \\
1982 \\
1983 \\
1984 \\
1985 \\
1989\end{array}$ & $\begin{array}{l}12-07-66 \\
01-28-68 \\
01-26-69 \\
03-03-70 \\
08-25-71 \\
08-13-72 \\
10-19-72 \\
08-05-74 \\
07-29-75 \\
02-09-76 \\
09-11-77 \\
03-01-78 \\
12-18-78 \\
01-30-80 \\
03-06-81 \\
02-11-82 \\
09-24-83 \\
08-17-84 \\
02-10-85 \\
02-06-89\end{array}$ & $\begin{array}{r}13,500 \\
6,500 \\
7,200 \\
1,420 \\
2,940 \\
1,350 \\
11,000 \\
600 \\
1,890 \\
11,800 \\
1,500 \\
23,100 \\
17,200 \\
19,800 \\
191 \\
6,750 \\
15,200 \\
5,450 \\
10,400 \\
394\end{array}$ & ES \\
\hline
\end{tabular}

BASIN CHARACTERISTICS

\begin{tabular}{|c|c|c|c|c|c|c|c|}
\hline \multirow{2}{*}{$\begin{array}{c}\text { MAIN } \\
\text { CHANNEL } \\
\text { SLOPE } \\
\text { (FTMI) }\end{array}$} & \multirow[b]{2}{*}{$\begin{array}{l}\text { STREAM } \\
\text { LENGTH } \\
\text { (MI) }\end{array}$} & \multirow{2}{*}{$\begin{array}{l}\text { MEAN } \\
\text { BASIN } \\
\text { ELEVA- } \\
\text { TION } \\
\text { (FT) }\end{array}$} & \multirow[b]{2}{*}{$\begin{array}{l}\text { FORESTED } \\
\text { AREA } \\
\text { (PERCENT) }\end{array}$} & \multirow[b]{2}{*}{$\begin{array}{l}\text { SOIL } \\
\text { INDEX }\end{array}$} & \multirow{2}{*}{$\begin{array}{l}\text { MEAN } \\
\text { ANNUAL } \\
\text { PRECIPI- } \\
\text { TATION } \\
\text { (IN) }\end{array}$} & \multicolumn{2}{|c|}{ RAINFALL INTENSITY, 24-HOUR } \\
\hline & & & & & & $\begin{array}{l}\text { 2-YEAR } \\
\text { (IN) }\end{array}$ & $\begin{array}{c}\text { 50-YEAR } \\
\text { (IN) }\end{array}$ \\
\hline 91.9 & 46.4 & 4,010 & 1.0 & 1.7 & 14.0 & 1.9 & 3.5 \\
\hline
\end{tabular}


MEAN MONTHLY AND ANMUAL DISCHARGES 1967-85, 1989

\begin{tabular}{|c|c|c|c|c|c|c|}
\hline MONTH - & $\begin{array}{l}\operatorname{MAXIMUN} \\
\left(\mathrm{FT}^{3} / \mathrm{S}\right)\end{array}$ & $\begin{array}{l}\text { MINIMUM } \\
\left(F^{3} / S\right)\end{array}$ & $\begin{array}{c}\text { MEAN } \\
\left(\mathrm{FT}^{3} / \mathrm{S}\right)\end{array}$ & $\begin{array}{l}\text { STAN- } \\
\text { DARD } \\
\text { DEVIA- } \\
\text { TION } \\
\left(F^{3} / S\right)\end{array}$ & $\begin{array}{l}\text { COEFFI - } \\
\text { CIENT OF } \\
\text { VARI - } \\
\text { ATION }\end{array}$ & $\begin{array}{c}\text { PERCENT } \\
\text { OF } \\
\text { ANNUAL } \\
\text { RUNOFF }\end{array}$ \\
\hline $\begin{array}{l}\text { OCTOBER } \\
\text { NOVEMBER } \\
\text { DECEMBER } \\
\text { JANUARY } \\
\text { FEBRUARY } \\
\text { MARCH } \\
\text { APRIL } \\
\text { MAY } \\
\text { JUNE } \\
\text { JULY } \\
\text { AUGUST } \\
\text { SEPTEMBER }\end{array}$ & $\begin{array}{c}505 \\
392 \\
461 \\
936 \\
1,520 \\
1,040 \\
204 \\
33 \\
16 \\
6.7 \\
150 \\
355\end{array}$ & $\begin{array}{l}0.00 \\
0.00 \\
0.00 \\
0.00 \\
0.00 \\
0.00 \\
0.00 \\
0.00 \\
0.00 \\
0.00 \\
0.00 \\
0.00\end{array}$ & $\begin{array}{c}33 \\
30 \\
108 \\
119 \\
243 \\
239 \\
34 \\
6.6 \\
1.8 \\
0.57 \\
13 \\
21\end{array}$ & $\begin{array}{c}115 \\
93 \\
167 \\
228 \\
376 \\
377 \\
55 \\
10 \\
4.6 \\
1.7 \\
34 \\
80\end{array}$ & $\begin{array}{l}3.5 \\
3.1 \\
1.5 \\
1.9 \\
1.5 \\
1.6 \\
1.6 \\
1.5 \\
2.6 \\
3.0 \\
2.6 \\
3.7\end{array}$ & $\begin{array}{r}3.8 \\
3.6 \\
12.7 \\
14.0 \\
28.6 \\
28.1 \\
4.0 \\
0.8 \\
0.2 \\
0.1 \\
1.6 \\
2.5\end{array}$ \\
\hline NNUA & 232 & 0.56 & 70 & 81 & 1.2 & 100 \\
\hline
\end{tabular}

MAGNITLDE AND PROBABILITY OF INSTANTANEQUS PEAK FLOW BASED ON PERIOD OF RECORD 1967-89

\begin{tabular}{cccccc}
$\begin{array}{c}\text { DISCHARGE, IN FT } \\
\text { IN YS, FOR INDICATED RECURRENCE INTERVAL }\end{array}$ \\
\hline 2 & 5 & 10 & 25 & $50 \dagger$ & $\begin{array}{c}100 \dagger \\
1 \%\end{array}$ \\
$50 \%$ & $20 \%$ & $10 \%$ & $4 \%$ & $2 \%$ & $1 \%$ \\
\hline 6,670 & 13,400 & 18,600 & 26,000 & 31,800 & 37,900
\end{tabular}

WEIGHTED SKEW (LOGS) $=-0.39$

MEAN (LOGS) $=3.80$

STANDARD DEV. (LOGS) $=0.38$
MAGNITLDE AND PROBABILITY OF ANNUAL LOW FLOW BASED ON PERIOD OF RECORD 1968-85

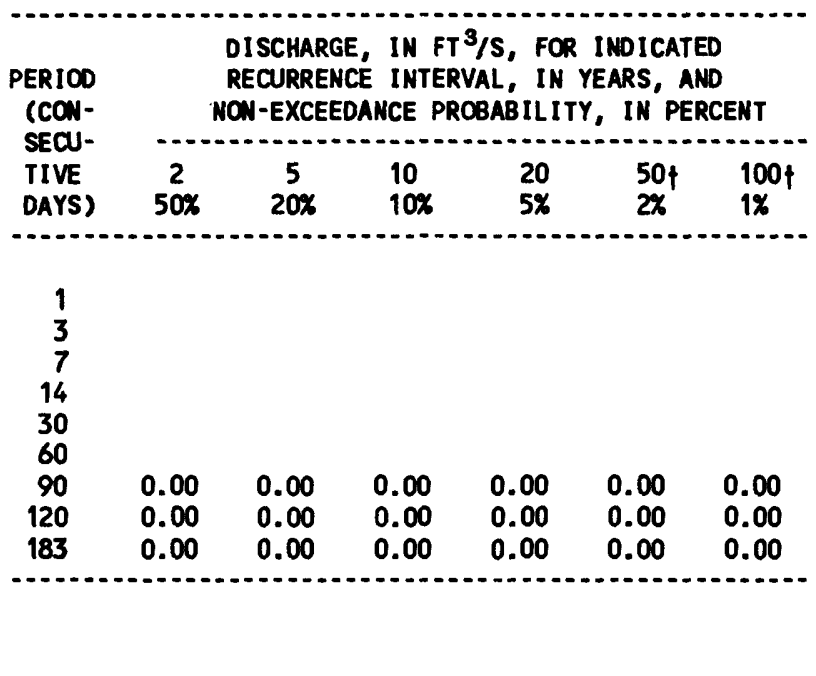

MAGNITLDE AND PROBABILITY OF ANNUAL HIGH FLON BASED OW PERIOD OF RECORD 1967-85, 1989

\begin{tabular}{|c|c|c|c|c|c|c|}
\hline \multirow{2}{*}{$\begin{array}{l}\text { PERIOD } \\
\text { (CON- } \\
\text { SECU- } \\
\text { TIVE } \\
\text { DAYS) }\end{array}$} & \multicolumn{6}{|c|}{$\begin{array}{l}\text { DISCHARGE, IN FT } 3 / S \text {, FOR INDICATED } \\
\text { RECURRENCE INTERVAL, IN YEARS, AND } \\
\text { EXCEEDANCE PROBABILITY, IN PERCENT }\end{array}$} \\
\hline & $\begin{array}{c}2 \\
50 \%\end{array}$ & $\begin{array}{c}5 \\
20 \%\end{array}$ & $\begin{array}{l}10 \\
10 \%\end{array}$ & $\begin{array}{l}25 \\
4 \%\end{array}$ & $\begin{array}{l}50 \nmid \\
2 \%\end{array}$ & $\underset{1 \%}{100 \nmid}$ \\
\hline $\begin{array}{r}1 \\
3 \\
7 \\
15 \\
30 \\
60 \\
90\end{array}$ & $\begin{array}{r}1,520 \\
871 \\
516 \\
290 \\
170 \\
109 \\
80\end{array}$ & $\begin{array}{r}5,250 \\
3,240 \\
2,030 \\
1,240 \\
770 \\
527 \\
396\end{array}$ & $\begin{array}{r}9,480 \\
6,050 \\
3,880 \\
2,470 \\
1,570 \\
1,100 \\
827\end{array}$ & $\begin{array}{r}17,000 \\
11,200 \\
7,360 \\
4,890 \\
3,150 \\
2,240 \\
1,690\end{array}$ & $\begin{array}{r}24,300 \\
16,400 \\
10,800 \\
7,380 \\
4,810 \\
3,440 \\
2,600\end{array}$ & $\begin{array}{r}33,000 \\
22,600 \\
15,100 \\
10,500 \\
6,890 \\
4,950 \\
3,730\end{array}$ \\
\hline
\end{tabular}

DURATION TABLE OF DAILY MEAN FLON FOR PERIOD OF RECORD 1967-85, 1989 DISCHARGE, IN FT $3 / \mathrm{S}$, WHICH WAS EQUALED OR EXCEEDED FOR INDICATED PERCENT OF TIME

\begin{tabular}{|c|c|c|c|c|c|c|c|c|c|c|c|c|c|c|c|c|}
\hline $1 \%$ & $5 \%$ & $10 \%$ & $15 \%$ & $20 \%$ & $30 \%$ & $40 \%$ & $50 \%$ & $60 \%$ & $70 \%$ & $80 \%$ & $90 \%$ & $95 \%$ & $98 \%$ & $99 \%$ & $99.5 \%$ & $99.9 \%$ \\
\hline 780 & 248 & 76 & 32 & 18 & 0.59 & 0.00 & 0.00 & 0.00 & 0.00 & 0.00 & 0.00 & 0.00 & 0.00 & 0.00 & 0.00 & 0.00 \\
\hline
\end{tabular}

† Reliability of values in column is uncertain, and potential errors are large. 
BILL MILLIAMS RIVER BASIM

09424900 SANTA MARIA RIVER NEAR BAGDAD, AZ--CONTINUED
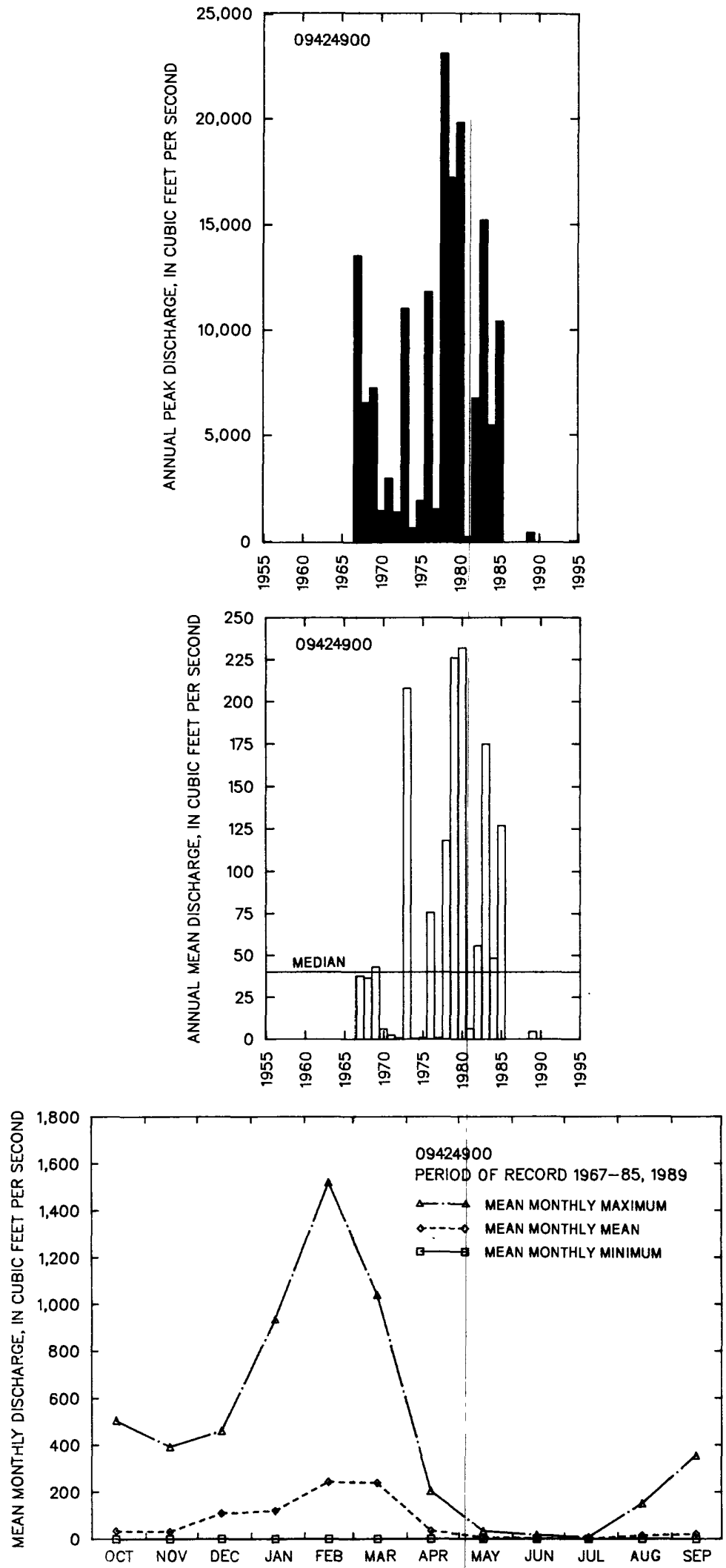
09425500 SANTA MARIA RIVER NEAR ALAMO, AZ

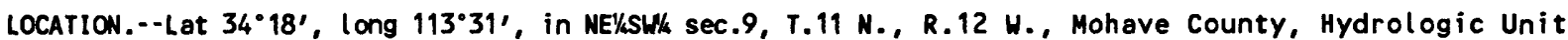
15030204, on $r i g h t$ bank $0.5 \mathrm{mi}$ upstream from confluence with Big Sandy River and $5.25 \mathrm{mi}$ upstream from Alamo.

DRAINAGE AREA. $--1,439 \mathrm{mi}^{2}$.

ANNUAL PEAK DISCHARGE

\begin{tabular}{|c|c|c|c|c|c|}
\hline $\begin{array}{l}\text { WATER } \\
\text { YEAR }\end{array}$ & DATE & $\begin{array}{l}\text { ANNUAL PEAK } \\
\text { OISCHARGE } \\
\text { (FT } 3 / \mathrm{S})\end{array}$ & $\begin{array}{l}\text { WATER } \\
\text { YEAR }\end{array}$ & DATE & $\begin{array}{l}\text { ANNUAL PEAK } \\
\text { DISCHARGE } \\
\text { (FT } 3 / \mathrm{S})\end{array}$ \\
\hline $\begin{array}{l}1939 \\
1940 \\
1941 \\
1942 \\
1943 \\
1944 \\
1945 \\
1946 \\
1947 \\
1948 \\
1949 \\
1950 \\
1951 \\
1952\end{array}$ & $\begin{array}{l}09-06-39 \\
09-17-40 \\
03-14-41 \\
01-14-42 \\
08-04-43 \\
02-24-44 \\
03-26-45 \\
07-24-46 \\
09-19-47 \\
08-05-48 \\
02-25-49 \\
10-18-49 \\
08-29-51 \\
12-31-51\end{array}$ & $\begin{array}{r}22,300 \\
262 \\
20,600 \\
91 \\
544 \\
6,000 \\
1,530 \\
1,170 \\
1,610 \\
1,520 \\
1,100 \\
1,570 \\
33,600 \\
8,020\end{array}$ & $\begin{array}{l}1953 \\
1954 \\
1955 \\
1956 \\
1957 \\
1958 \\
1959 \\
1960 \\
1961 \\
1962 \\
1963 \\
1964 \\
1965 \\
1966\end{array}$ & $\begin{array}{l}08-28-53 \\
03-23-54 \\
08-18-55 \\
07-24-56 \\
08-20-57 \\
03-22-58 \\
08-03-59 \\
12-26-59 \\
08-30-61 \\
09-27-62 \\
08-23-63 \\
08-02-64 \\
04-04-65 \\
12-30-65\end{array}$ & $\begin{array}{r}560 \\
16,000 \\
7,180 \\
107 \\
2,050 \\
7,870 \\
2,940 \\
3,220 \\
1,720 \\
3,800 \\
4,240 \\
22,500 \\
4,100 \\
15,900\end{array}$ \\
\hline
\end{tabular}

BASIN CHARACTERISTICS

\begin{tabular}{|c|c|c|c|c|c|c|c|}
\hline \multirow{3}{*}{$\begin{array}{l}\text { MAIN } \\
\text { CHANNEL } \\
\text { SLOPE } \\
\text { (FT/MI) }\end{array}$} & \multirow[b]{3}{*}{$\begin{array}{c}\text { STREAM } \\
\text { LENGTH } \\
\text { (MI) }\end{array}$} & \multirow{3}{*}{$\begin{array}{l}\text { MEAN } \\
\text { BASIN } \\
\text { ELEVA- } \\
\text { TION } \\
\text { (FT) }\end{array}$} & \multirow[b]{3}{*}{$\begin{array}{l}\text { FORESTED } \\
\text { AREA } \\
\text { (PERCENT) }\end{array}$} & \multirow[b]{3}{*}{$\begin{array}{l}\text { SOIL } \\
\text { INDEX }\end{array}$} & \multirow{3}{*}{$\begin{array}{l}\text { MEAN } \\
\text { ANNUALL } \\
\text { PRECIPI- } \\
\text { TATION } \\
\text { (IN) }\end{array}$} & \multirow{2}{*}{\multicolumn{2}{|c|}{ RAINFALL INTENSITY, 24-HOUR }} \\
\hline & & & & & & & \\
\hline & & & & & & $\begin{array}{l}\text { 2-YEAR } \\
\text { (IN) }\end{array}$ & $\begin{array}{l}\text { 50-YEAR } \\
\text { (IN) }\end{array}$ \\
\hline 46.5 & 81.7 & 3,650 & 0.9 & 1.7 & 14.4 & 1.9 & 4.0 \\
\hline
\end{tabular}


MEAN MONTHLY AND ANNUAL DISCHARGES 1941-65

\begin{tabular}{|c|c|c|c|c|c|c|}
\hline MONTH & $\begin{array}{l}\operatorname{MAXIMUM} \\
\left(\mathrm{FT}^{3} / \mathrm{S}\right)\end{array}$ & $\begin{array}{l}\operatorname{MINIMUM} \\
\left(F T^{3} / S\right)\end{array}$ & $\begin{array}{c}\text { MEAN } \\
\left(\mathrm{FT}^{3} / \mathrm{S}\right)\end{array}$ & $\begin{array}{l}\text { STAN- } \\
\text { DARD } \\
\text { DEVIA- } \\
\text { TION } \\
\text { (FT } / S)\end{array}$ & $\begin{array}{l}\text { COEFFI - } \\
\text { CIENT OF } \\
\text { VARI - } \\
\text { ATION }\end{array}$ & $\begin{array}{c}\text { PERCENT } \\
\text { OF } \\
\text { ANNUAL } \\
\text { RUNOFF }\end{array}$ \\
\hline $\begin{array}{l}\text { OCTOBER } \\
\text { NOVEMBER } \\
\text { DECEMBER } \\
\text { JANUARY } \\
\text { FEBRUARY } \\
\text { MARCH } \\
\text { APRIL } \\
\text { MAY } \\
\text { JUNE } \\
\text { JULY } \\
\text { AUGUST } \\
\text { SEPTEMBER }\end{array}$ & $\begin{array}{r}34 \\
13 \\
228 \\
160 \\
397 \\
1,070 \\
880 \\
34 \\
38 \\
38 \\
624 \\
257\end{array}$ & $\begin{array}{l}0.55 \\
0.92 \\
2.1 \\
2.7 \\
1.9 \\
3.3 \\
2.6 \\
1.4 \\
0.79 \\
0.60 \\
0.74 \\
0.53\end{array}$ & $\begin{array}{c}6.4 \\
3.9 \\
20 \\
20 \\
47 \\
129 \\
65 \\
4.8 \\
3.4 \\
3.4 \\
50 \\
19\end{array}$ & $\begin{array}{c}9.2 \\
3.3 \\
50 \\
39 \\
101 \\
259 \\
199 \\
7.1 \\
7.3 \\
7.2 \\
131 \\
52\end{array}$ & $\begin{array}{l}1.4 \\
0.85 \\
2.5 \\
1.9 \\
2.2 \\
2.0 \\
3.1 \\
1.5 \\
2.2 \\
2.1 \\
2.7 \\
2.8\end{array}$ & $\begin{array}{r}1.7 \\
1.0 \\
5.5 \\
5.4 \\
12.6 \\
34.6 \\
17.6 \\
1.3 \\
0.9 \\
0.9 \\
13.4 \\
5.1\end{array}$ \\
\hline ANNUAL & 255 & 2.4 & 31 & 52 & 1.7 & 100 \\
\hline
\end{tabular}

MAGNITUdE AND PROBABILITY OF INSTANTANEOUS PEAK FLON BASED ON PERIOD OF RECORD 1939-66

DISCHARGE, IN FT $3 / S$, FOR INDICATED RECURRENCE INTERVAL IN YEARS, AND EXCEEDANCE PROBABILITY, IN PERCENT

$\begin{array}{cccccc}2 & 5 & 10 & 25 & 50 & 100 \dagger \\ 50 \% & 20 \% & 10 \% & 4 \% & 2 \% & 1 \%\end{array}$

$3,260 \quad 9,870 \quad 17,600 \quad 32,600 \quad 48,600 \quad 69,600$
WEIGHTED SKEW (LOGS) $=0.00$
MEAN
STANDARD DEV. (LOGS) $=3.51$
LOGS) $=0.57$

MAGNITLDE AND PROBABILITY OF ANNUAL LOW FLOW BASED ON PERIOD OF RECORD 1941-66

\begin{tabular}{|c|c|c|c|c|c|c|}
\hline \multirow{2}{*}{$\begin{array}{l}\text { PERIOD } \\
\text { (CON- } \\
\text { SECU- } \\
\text { TIVE } \\
\text { DAYS) }\end{array}$} & \multicolumn{6}{|c|}{$\begin{array}{l}\text { DISCHARGE, IN } \mathrm{FT}^{3} / \mathrm{S} \text {, FOR INDICATED } \\
\text { RECURRENCE INTERVAL, IN YEARS, AND } \\
\text { NON-EXCEEDANCE PROBABILITY, IN PERCENT }\end{array}$} \\
\hline & $\stackrel{2}{50 x}$ & $\underset{20 \%}{5}$ & $\begin{array}{l}10 \\
10 \%\end{array}$ & $\begin{array}{l}20 \\
5 \%\end{array}$ & $\begin{array}{l}50 \\
2 \%\end{array}$ & $\begin{array}{l}100 \dagger \\
1 \%\end{array}$ \\
\hline $\begin{array}{r}1 \\
3 \\
7 \\
14 \\
30 \\
60 \\
90 \\
120 \\
183\end{array}$ & $\begin{array}{l}0.71 \\
0.77 \\
0.88 \\
0.95 \\
1.0 \\
1.3 \\
1.5 \\
1.7 \\
2.7\end{array}$ & $\begin{array}{l}0.34 \\
0.38 \\
0.45 \\
0.52 \\
0.68 \\
0.92 \\
1.0 \\
1.2 \\
1.7\end{array}$ & $\begin{array}{l}0.22 \\
0.25 \\
0.30 \\
0.37 \\
0.54 \\
0.76 \\
0.89 \\
1.1 \\
1.5\end{array}$ & $\begin{array}{l}0.15 \\
0.17 \\
0.20 \\
0.26 \\
0.44 \\
0.65 \\
0.78 \\
0.94 \\
1.4\end{array}$ & $\begin{array}{l}0.09 \\
0.11 \\
0.13 \\
0.18 \\
0.35 \\
0.55 \\
0.68 \\
0.83 \\
1.3\end{array}$ & $\begin{array}{l}0.07 \\
0.08 \\
0.09 \\
0.13 \\
0.30 \\
0.48 \\
0.62 \\
0.77 \\
1.3\end{array}$ \\
\hline
\end{tabular}

MAGNITUDE AND PROBABILITY OF ANNUAL HIGH FLOW BASED ON PERIOD OF RECORD 1941-65

\begin{tabular}{|c|c|c|c|c|c|c|}
\hline \multirow{2}{*}{$\begin{array}{l}\text { PERIOD } \\
\text { (CON- } \\
\text { SECU- } \\
\text { TIVE } \\
\text { DAYS) }\end{array}$} & & \multicolumn{5}{|c|}{$\begin{array}{l}\text { DISCHARGE, IN } \mathrm{FT}^{3} / \mathrm{S} \text {, FOR INDICATED } \\
\text { RECURRENCE INTERVAL, IN YEARS, AND } \\
\text { EXCEEDANCE PROBABILITY, IN PERCENT }\end{array}$} \\
\hline & $\begin{array}{c}2 \\
50 \%\end{array}$ & $\underset{20 \%}{5}$ & $\begin{array}{l}10 \\
10 \%\end{array}$ & $\begin{array}{l}25 \\
4 \%\end{array}$ & $\begin{array}{l}50 \\
2 \%\end{array}$ & $\begin{array}{c}100 \dagger \\
1 \%\end{array}$ \\
\hline $\begin{array}{r}1 \\
3 \\
7 \\
15 \\
30 \\
60 \\
90\end{array}$ & $\begin{array}{r}633 \\
359 \\
200 \\
126 \\
78 \\
48 \\
36\end{array}$ & $\begin{array}{r}2,810 \\
1,550 \\
871 \\
537 \\
318 \\
186 \\
133\end{array}$ & $\begin{array}{r}5,930 \\
3,260 \\
1,860 \\
1,140 \\
672 \\
386 \\
271\end{array}$ & $\begin{array}{r}12,800 \\
7,040 \\
4,170 \\
2,560 \\
1,500 \\
855 \\
591\end{array}$ & $\begin{array}{r}20,700 \\
11,500 \\
6,980 \\
4,300 \\
2,530 \\
1,440 \\
991\end{array}$ & $\begin{array}{r}31,600 \\
17,600 \\
11,100 \\
6,850 \\
4,060 \\
2,320 \\
1,590\end{array}$ \\
\hline
\end{tabular}

DURATION TABLE OF DAILY MEAN FLON FOR PERIDO OF RECORD 1941-65

DISCHARGE, IN FT $3 / \mathrm{S}$, WHICH WAS EQUALED OR EXCEEDED FOR INDICATED PERCENT OF TIME

\begin{tabular}{|c|c|c|c|c|c|c|c|c|c|c|c|c|c|c|c|c|}
\hline $1 \%$ & $5 \%$ & $10 \%$ & $15 \%$ & $20 \%$ & $30 \%$ & $40 \%$ & $50 \%$ & $60 \%$ & $70 \%$ & $80 \%$ & $90 \%$ & $95 \%$ & $98 \%$ & $99 \%$ & $99.5 \%$ & $99.9 \%$ \\
\hline 662 & 49 & 13 & 7.9 & 6.0 & 4.6 & 3.7 & 2.9 & 2.3 & 2.0 & 1.6 & 1.1 & 0.84 & 0.56 & 0.46 & 0.41 & 0.21 \\
\hline
\end{tabular}

† Reliability of values in column is uncertain, and potential errors are large. 
BILL WILLIAMS RIVER BASIN

09425500 SANTA MARIA RIVER NEAR ALAMO, AZ--CONTIMUEd
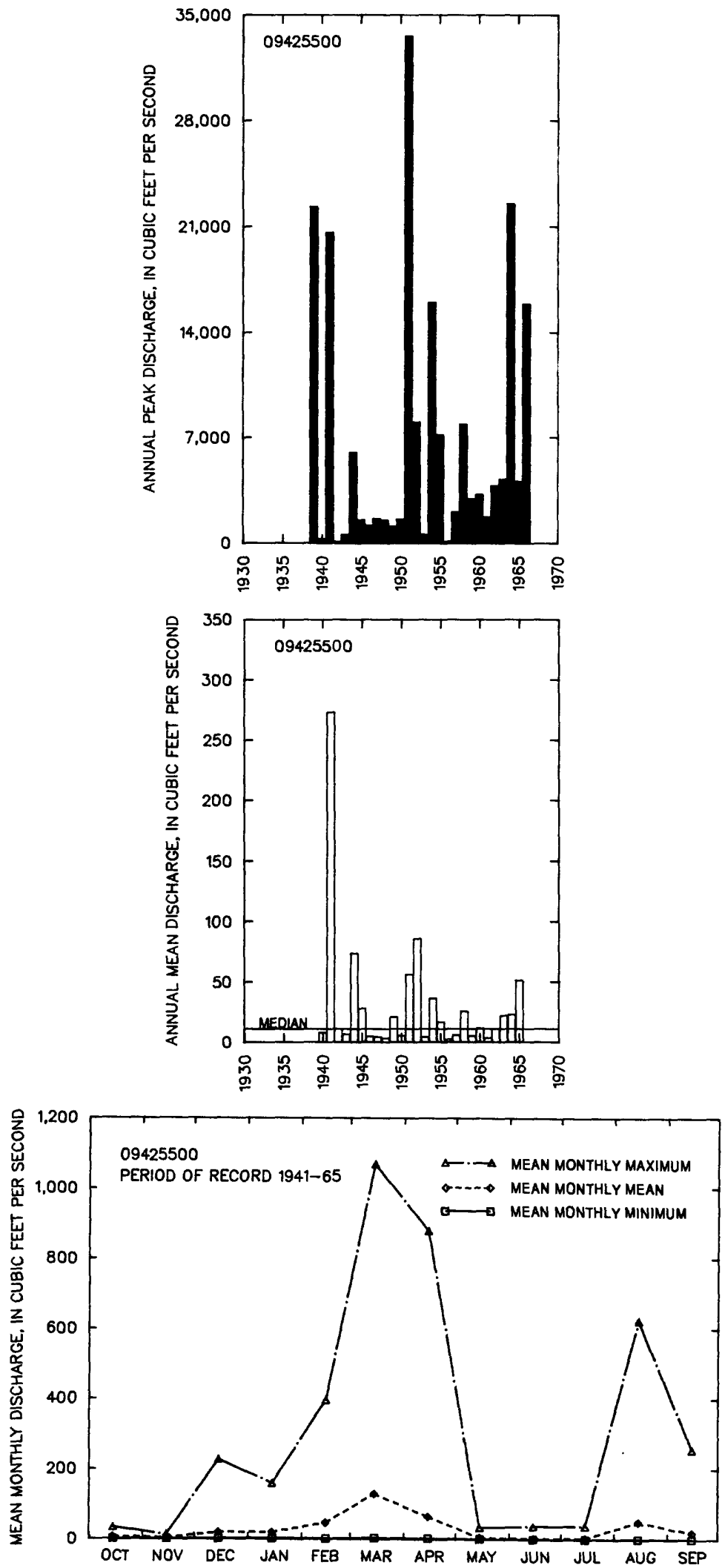


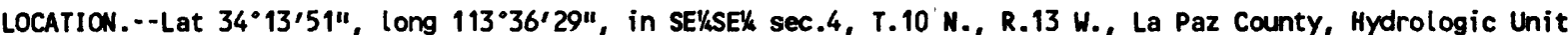
15030204, on left bank $0.6 \mathrm{mi}$ downstream from Alamo Dam, $3.7 \mathrm{mi}$ downstream from Bullard Wash, and $8 \mathrm{mi}$ downstream from confluence of Santa Maria and Big Sandy Rivers.

DRAIMAGE AREA. $-4,633 \mathrm{mi}^{2}$, of which $10.1 \mathrm{mi}^{2}$ is noncontributing and $400 \mathrm{mi}^{2}$ is below confluence of Santa Maria and Big Sandy Rivers.

REMARKS.--Diversions above station for irrigation of about 9,100 acres, mostly by pumping from ground water. Flow regulated by Alamo Lake, beginning Mar. 2, 1969. Temporary storage and slight regulation of releases through uncontrolled rectangular conduit through Alamo Dam June 23, 1968, to Mar. 27, 1969. Alamo Lake is formed by an earthfill and rockfill dam, completed in 1968. Total capacity of lake is 1,043,000 acre-ft. See table below for monthend contents.

\begin{tabular}{|c|c|c|c|c|c|c|c|}
\hline $\begin{array}{l}\text { WATER } \\
\text { YEAR }\end{array}$ & DATE & $\begin{array}{c}\text { ANNUAL PEAK } \\
\text { DISCHARGE } \\
\left(\mathrm{FT}^{3} / \mathrm{S}\right)\end{array}$ & $\begin{array}{l}\text { DISCHARGE } \\
\text { COOES }\end{array}$ & $\begin{array}{l}\text { WATER } \\
\text { YEAR }\end{array}$ & DATE & $\begin{array}{l}\text { ANNUAL PEAK } \\
\text { DISCHARGE } \\
\left(F^{3} / S\right)\end{array}$ & $\begin{array}{l}\text { DISCHARGE } \\
\text { CODES }\end{array}$ \\
\hline $\begin{array}{l}1891 \\
1916 \\
1927 \\
1929 \\
1930 \\
1931 \\
1932 \\
1933 \\
1934 \\
1935 \\
1936 \\
1937 \\
1938 \\
1939 \\
1940 \\
1941 \\
1942 \\
1943 \\
1944 \\
1945 \\
1946 \\
1947 \\
1948 \\
1949 \\
1950 \\
1951 \\
1952 \\
1953 \\
1954 \\
1955 \\
1956 \\
1957\end{array}$ & $\begin{array}{l}02-21-91 \\
01-19-16 \\
02-16-27 \\
09-04-29 \\
09-08-30 \\
08-05-31 \\
02-09-32 \\
03-04-33 \\
08-29-34 \\
02-07-35 \\
08-09-36 \\
02-07-37 \\
03-04-38 \\
09-06-39 \\
02-03-40 \\
03-14-41 \\
01-14-42 \\
03-05-43 \\
02-24-44 \\
03-16-45 \\
07-25-46 \\
12-28-46 \\
08-05-48 \\
02-25-49 \\
09-06-50 \\
08-29-51 \\
12-31-51 \\
08-28-53 \\
03-23-54 \\
08-23-55 \\
07-24-56 \\
08-20-57\end{array}$ & $\begin{array}{r}1200,000 \\
175,000 \\
125,000 \\
35,000 \\
90,000 \\
100,000 \\
60,000 \\
150 \\
2,000 \\
20,000 \\
4,000 \\
105,000 \\
70,000 \\
86,000 \\
2,700 \\
46,000 \\
407 \\
2,480 \\
11,000 \\
7,380 \\
972 \\
7,230 \\
2,070 \\
2,900 \\
1,850 \\
65,100 \\
37,600 \\
193 \\
34,700 \\
4,610 \\
162 \\
12,100\end{array}$ & $\begin{array}{c}\text { HP } \\
\text { ES, HP } \\
\text { ES,HP } \\
\text { ES } \\
\text { ES } \\
\text { ES } \\
\text { ES } \\
\text { ES } \\
\text { ES } \\
\text { ES } \\
\text { ES } \\
\text { ES }\end{array}$ & $\begin{array}{l}1958 \\
1959 \\
1960 \\
1961 \\
1962 \\
1963 \\
1964 \\
1965 \\
1966 \\
1967 \\
1968 \\
1969 \\
1970 \\
1971 \\
1972 \\
1973 \\
1974 \\
1975 \\
1976 \\
1977 \\
1978 \\
1979 \\
1980 \\
1981 \\
1982 \\
1983 \\
1984 \\
1985 \\
1986 \\
1987 \\
1988 \\
1989\end{array}$ & $\begin{array}{l}03-22-58 \\
08-18-59 \\
12-26-59 \\
09-13-61 \\
02-13-62 \\
08-22-63 \\
08-02-64 \\
04-10-65 \\
12-10-65 \\
12-07-66 \\
01-28-68 \\
01-26-69 \\
03-03-70 \\
08-30-71 \\
12-29-71 \\
03-16-73 \\
03-11-74 \\
04-04-75 \\
02-19-76 \\
12-08-76 \\
03-04-78 \\
09-30-79 \\
03-22-80 \\
10-11-80 \\
03-12-82 \\
03-30-83 \\
03-14-84 \\
03-21-85 \\
10-15-85 \\
10-01-86 \\
09-03-88 \\
10-04-88\end{array}$ & $\begin{array}{r}13,000 \\
2,900 \\
3,420 \\
1,630 \\
8,400 \\
10,300 \\
25,600 \\
12,300 \\
41,900 \\
38,900 \\
16,000 \\
4,950 \\
2,240 \\
732 \\
108 \\
2,150 \\
13 \\
27 \\
418 \\
60 \\
286 \\
652 \\
3,400 \\
1,100 \\
25 \\
1,930 \\
2,000 \\
2,000 \\
379 \\
300 \\
328 \\
54\end{array}$ & $\begin{array}{c}E S \\
K R \\
K R \\
K R \\
M D, K R \\
M D, K R \\
M D, K R \\
M D, K R \\
M D, K R \\
M D, K R \\
M D, K R \\
M D, K R \\
M D, K R \\
M D, K R \\
\text { KR } \\
M D, K R \\
M D, K R \\
M D, K R \\
M D, K R \\
M D, K R \\
M D, K R \\
M D, K R\end{array}$ \\
\hline
\end{tabular}

Highest since 1861 .

BASIN CHARACTERISTIOS

\begin{tabular}{|c|c|c|c|c|c|c|c|}
\hline MAIN & & $\begin{array}{l}\text { MEAN } \\
\text { BASIN }\end{array}$ & & & $\begin{array}{l}\text { MEAN } \\
\text { ANNUAL }\end{array}$ & RAINFALL If & SITY, 24-HOQR \\
\hline $\begin{array}{l}\text { CHANNEL } \\
\text { SLOPE } \\
\text { (FT/MI) }\end{array}$ & $\begin{array}{l}\text { STREAM } \\
\text { LENGTH } \\
\text { (MI) }\end{array}$ & $\begin{array}{l}\text { ELEVA- } \\
\text { TION } \\
\text { (FT) }\end{array}$ & $\begin{array}{l}\text { FORESTED } \\
\text { AREA } \\
\text { (PERCENT) }\end{array}$ & $\begin{array}{l}\text { SOIL } \\
\text { INDEX }\end{array}$ & $\begin{array}{l}\text { PRECIPI- } \\
\text { TATION } \\
\text { (IN) }\end{array}$ & $\begin{array}{c}\text { 2-YEAR } \\
\text { (IN) }\end{array}$ & $\begin{array}{l}\text { 50-YEAR } \\
\text { (IN) }\end{array}$ \\
\hline 42.6 & 125 & 4,120 & 28.0 & 1.7 & 13.7 & 1.8 & 3.9 \\
\hline
\end{tabular}


BILL WILLIAMS RIVER BASIN

09426000 BILL WILLIAMS RIVER BELOU ALAMO DAM, AZ--continued

MEAN MONTHLY AND ANNUAL DISCHARGES 1970-89

\begin{tabular}{|c|c|c|c|c|c|c|}
\hline MONTH & $\begin{array}{l}\operatorname{Max} I \min \\
\left(F^{3} / S\right)\end{array}$ & $\begin{array}{l}\text { MINIMUM } \\
\left(F^{3} / S\right)\end{array}$ & $\begin{array}{c}\text { MEAN } \\
\left(F T^{3} / S\right)\end{array}$ & $\begin{array}{l}\text { STAN- } \\
\text { DARD } \\
\text { DEVIA- } \\
\text { TION } \\
\left(F^{3} / S\right)\end{array}$ & $\begin{array}{l}\text { COEFFI- } \\
\text { CIENT OF } \\
\text { VARI - } \\
\text { ATION }\end{array}$ & $\begin{array}{c}\text { PERCENT } \\
\text { OF } \\
\text { ANNUAL } \\
\text { RUNOFF }\end{array}$ \\
\hline $\begin{array}{l}\text { OCTOBER } \\
\text { NOVEMBER } \\
\text { DECEMBER } \\
\text { JANUARY } \\
\text { FEBRUARY } \\
\text { MARCH } \\
\text { APRIL } \\
\text { MAY } \\
\text { JUNE } \\
\text { JULY } \\
\text { AUGUST } \\
\text { SEPTEMBER }\end{array}$ & $\begin{array}{r}456 \\
505 \\
606 \\
354 \\
970 \\
3,080 \\
562 \\
719 \\
494 \\
1,420 \\
912 \\
1,110\end{array}$ & $\begin{array}{l}0.00 \\
0.00 \\
1.3 \\
1.5 \\
2.7 \\
5.0 \\
2.1 \\
0.00 \\
0.00 \\
0.00 \\
0.63 \\
0.05\end{array}$ & $\begin{array}{r}99 \\
72 \\
76 \\
49 \\
157 \\
516 \\
110 \\
86 \\
64 \\
131 \\
129 \\
142\end{array}$ & $\begin{array}{r}154 \\
131 \\
152 \\
89 \\
251 \\
811 \\
158 \\
184 \\
128 \\
324 \\
227 \\
258\end{array}$ & $\begin{array}{l}1.5 \\
1.8 \\
2.0 \\
1.8 \\
1.6 \\
1.6 \\
1.4 \\
2.1 \\
2.0 \\
2.5 \\
1.8 \\
1.8\end{array}$ & $\begin{array}{r}6.1 \\
4.4 \\
4.7 \\
3.0 \\
9.6 \\
31.7 \\
6.7 \\
5.3 \\
3.9 \\
8.0 \\
7.9 \\
8.7\end{array}$ \\
\hline ANMUAL & 888 & 2.1 & 136 & 203 & 1.5 & 100 \\
\hline
\end{tabular}

\section{MAGNITUDE AND PROBABILITY OF INSTANTANEOUS PEAK FLON} BASED ON PERIOD OF RECORD

DISCHARGE, IN $\mathrm{FT}^{3} / \mathrm{S}$, FOR INDICATED RECURRENCE INTERVAL IN YEARS, AND EXCEEDANCE PROBABILITY, IN PERCENT

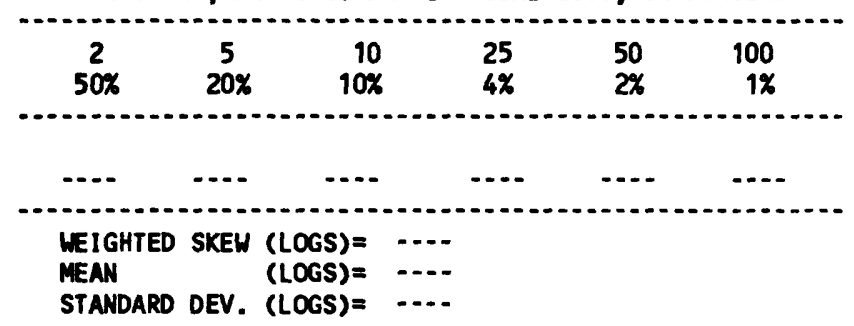

MAGNITUDE AND PROBABILITY OF ANNUAL LON FLON BASED ON PERIOD OF RECORD 1971-89

\begin{tabular}{|c|c|c|c|c|c|c|}
\hline \multirow{2}{*}{$\begin{array}{l}\text { PERIOD } \\
\text { (CON- } \\
\text { SECU- } \\
\text { TIVE } \\
\text { DAYS) }\end{array}$} & \multicolumn{6}{|c|}{$\begin{array}{l}\text { DISCHARGE, IN FT3/S, FOR INDICATED } \\
\text { RECURRENCE INTERVAL, IN YEARS, AND } \\
\text { NON-EXCEEDANCE PROBABILITY, IN PERCENT }\end{array}$} \\
\hline & $\begin{array}{c}2 \\
50 \%\end{array}$ & $\begin{array}{c}5 \\
20 \%\end{array}$ & $\begin{array}{l}10 \\
10 \%\end{array}$ & $\begin{array}{l}20 \\
5 \%\end{array}$ & $\begin{array}{l}50 \dagger \\
2 \%\end{array}$ & $\begin{array}{l}100 \uparrow \\
1 \%\end{array}$ \\
\hline $\begin{array}{r}1 \\
3 \\
7 \\
14 \\
30 \\
60 \\
90 \\
120 \\
183\end{array}$ & $\begin{array}{l}0.00 \\
0.00 \\
0.00 \\
0.00 \\
0.00 \\
0.00 \\
0.00 \\
6.6 \\
16\end{array}$ & $\begin{array}{l}0.00 \\
0.00 \\
0.00 \\
0.00 \\
0.00 \\
0.00 \\
0.00 \\
1.1 \\
3.5\end{array}$ & $\begin{array}{l}0.00 \\
0.00 \\
0.00 \\
0.00 \\
0.00 \\
0.00 \\
0.00 \\
0.43 \\
1.5\end{array}$ & $\begin{array}{l}0.00 \\
0.00 \\
0.00 \\
0.00 \\
0.00 \\
0.00 \\
0.06 \\
0.19 \\
0.76\end{array}$ & $\begin{array}{l}0.00 \\
0.00 \\
0.00 \\
0.00 \\
0.00 \\
0.00 \\
0.40 \\
0.08 \\
0.33\end{array}$ & $\begin{array}{l}1.0 \\
1.1 \\
1.6 \\
2.0 \\
3.1 \\
4.4 \\
5.2 \\
0.04 \\
0.19\end{array}$ \\
\hline
\end{tabular}

MAGNITLDE AND PROBABILITY OF ANNUAL HIGH FLOW BASED ON PERIOD OF RECORD 1970-89

\begin{tabular}{|c|c|c|c|c|c|c|}
\hline \multirow{2}{*}{$\begin{array}{l}\text { PERIOD } \\
\text { (CON- } \\
\text { SECU- } \\
\text { TIVE } \\
\text { DAYS) }\end{array}$} & & \multicolumn{5}{|c|}{$\begin{array}{l}\text { DISCHARGE, IN } \mathrm{FT}^{3} / \mathrm{S} \text {, FOR INDICATED } \\
\text { RECURRENCE INTERVAL, IN YEARS, AND } \\
\text { EXCEEDANCE PROBABILITY, IN PERCENT }\end{array}$} \\
\hline & $\begin{array}{c}2 \\
50 \%\end{array}$ & $\begin{array}{c}5 \\
20 \%\end{array}$ & $\begin{array}{l}10 \\
10 \%\end{array}$ & $\begin{array}{l}25 \\
4 \%\end{array}$ & $\begin{array}{l}50 \psi \\
2 \%\end{array}$ & $\begin{array}{c}100 \uparrow \\
1 \%\end{array}$ \\
\hline $\begin{array}{r}1 \\
3 \\
7 \\
15 \\
30 \\
60 \\
90\end{array}$ & $\begin{array}{l}401 \\
385 \\
343 \\
278 \\
210 \\
151 \\
121\end{array}$ & $\begin{array}{r}1,490 \\
1,460 \\
1,350 \\
1,190 \\
921 \\
618 \\
473\end{array}$ & $\begin{array}{r}2,740 \\
2,700 \\
2,550 \\
2,370 \\
1,880 \\
1,220 \\
913\end{array}$ & $\begin{array}{l}4,970 \\
4,930 \\
4,770 \\
4,710 \\
3,870 \\
2,400 \\
1,770\end{array}$ & $\begin{array}{l}7,080 \\
7,060 \\
6,940 \\
7,160 \\
6,030 \\
3,630 \\
2,660\end{array}$ & $\begin{array}{r}9,550 \\
9,560 \\
9,540 \\
10,300 \\
8,850 \\
5,200 \\
3,780\end{array}$ \\
\hline
\end{tabular}

DURATION TABLE OF DAILY MEAN FLON FOR PERIOD OF RECORD 1970-89

DISCHARGE, IN $\mathrm{FT}^{3} / \mathrm{S}$, HHICH WAS EQUALED OR EXCEEDED FOR INDICATED PERCENT OF TIME

\begin{tabular}{|c|c|c|c|c|c|c|c|c|c|c|c|c|c|c|c|c|}
\hline $1 \%$ & $5 \%$ & $10 \%$ & $15 \%$ & $20 \%$ & $30 \%$ & $40 \%$ & $50 \%$ & $60 \%$ & $70 \%$ & $80 \%$ & $90 \%$ & $95 \%$ & $98 \%$ & $99 \%$ & $99.5 \%$ & $99.9 \%$ \\
\hline .000 & 667 & 424 & 289 & 143 & 40 & 15 & 13 & 11 & 8.3 & 4.4 & 0.51 & 0.00 & 0.00 & 0.00 & 0.00 & 0.00 \\
\hline
\end{tabular}

f Reliability of values in column is uncertain, and potential errors are large. 
BILL WILLIAMS RIVER BASIM

09426000 BILL WILLIAMS RIVER BELOW ALANO DAM, AZ--'CONTIMUED
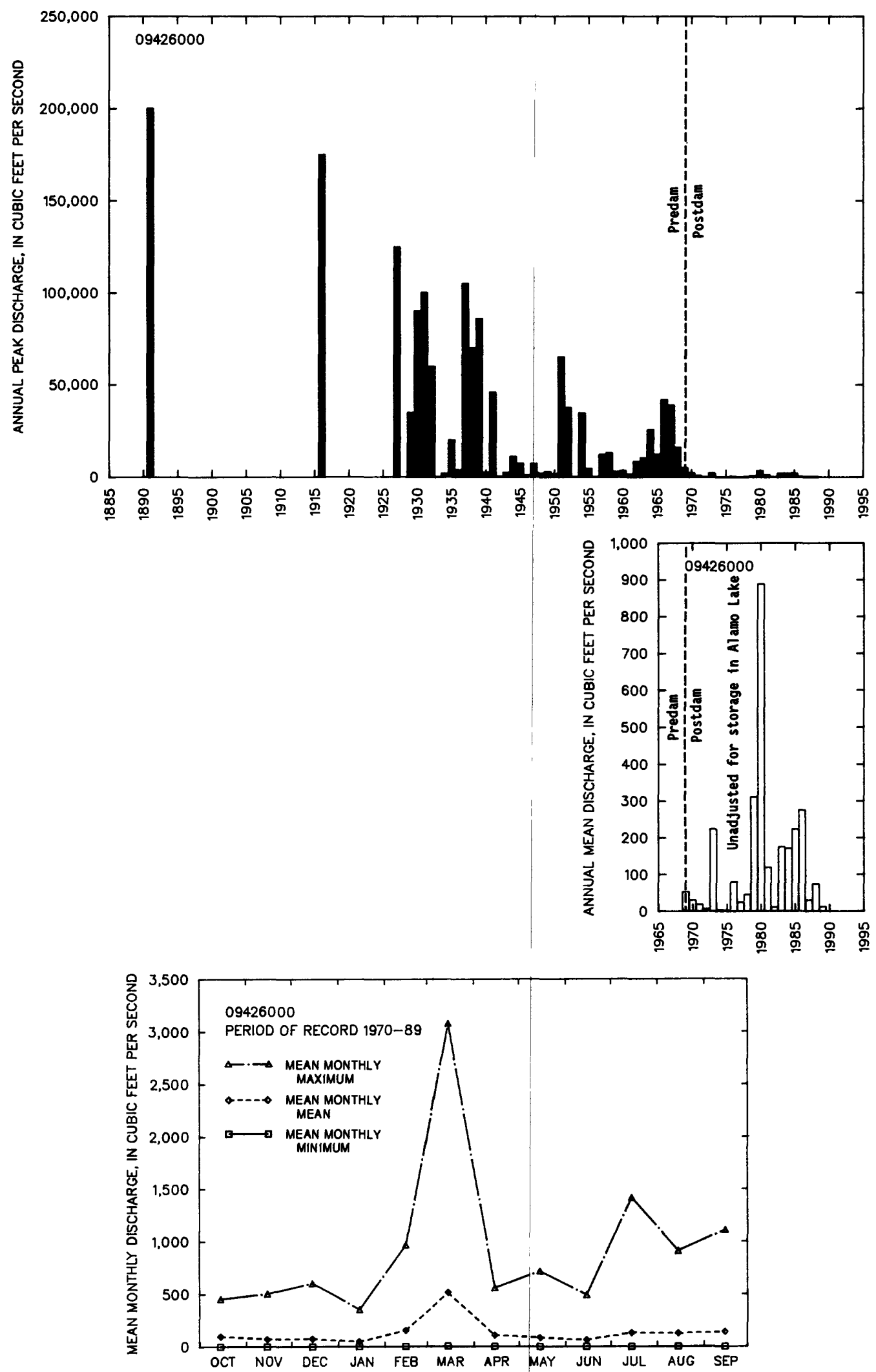
09426500 BILL WILLIIAM RIVER AT PLANET, AZ

LOCATION.-- Lat 34*15'23", Long 113.58'41", in NEK sec.36, T.11 N., R.17 W. Yuma County, Hydrologic Unit 15030204, $1 \mathrm{mi}$ west of Planet and $6 \mathrm{mi}$ upstream from water line of Havasu Lake at elevation $450 \mathrm{ft}$ above mean sea level.

DRAINAGE AREA. $--5,054 \mathrm{mi}^{2}$, of which $10.1 \mathrm{mi}^{2}$ is noncontributing.

ANNUAL PEAK DISCHARGE

\begin{tabular}{|c|c|c|c|}
\hline $\begin{array}{l}\text { WATER } \\
\text { YEAR }\end{array}$ & DATE & $\begin{array}{c}\text { ANNUAL PEAK } \\
\text { DISCHARGE } \\
\text { (FT } 3 / \mathrm{S})\end{array}$ & $\begin{array}{l}\text { DISCHARGE } \\
\text { CODES }\end{array}$ \\
\hline $\begin{array}{l}1891 \\
1916 \\
1927 \\
1929 \\
1930 \\
1931 \\
1932 \\
1933 \\
1934 \\
1935 \\
1936 \\
1937 \\
1938 \\
1939 \\
1940 \\
1941 \\
1942 \\
1943 \\
1944 \\
1945 \\
1946\end{array}$ & $\begin{array}{l}02-21-91 \\
01-19-16 \\
02-16-27 \\
09-04-29 \\
09-08-30 \\
08-05-31 \\
02-09-32 \\
03-04-33 \\
08-29-34 \\
02-07-35 \\
08-09-36 \\
02-07-37 \\
03-04-38 \\
09-07-39 \\
02-03-40 \\
03-02-41 \\
01-15-42 \\
03-05-43 \\
02-24-44 \\
03-16-45 \\
07-22-46\end{array}$ & $\begin{array}{r}200,000 \\
175,000 \\
125,000 \\
25,000 \\
64,000 \\
80,000 \\
51,000 \\
107 \\
1,470 \\
15,900 \\
2,900 \\
92,500 \\
61,000 \\
73,000 \\
2,600 \\
42,600 \\
300 \\
1,580 \\
10,800 \\
4,520 \\
328\end{array}$ & $\begin{array}{l}\text { HP } \\
\text { HP } \\
\text { HP }\end{array}$ \\
\hline
\end{tabular}

BASIN CHARACTERISTICS

\begin{tabular}{|c|c|c|c|c|c|c|c|}
\hline \multirow{2}{*}{$\begin{array}{l}\text { MAIN } \\
\text { CHANNEL } \\
\text { SLOPE } \\
\text { (FT/MI) }\end{array}$} & \multirow[b]{2}{*}{$\begin{array}{c}\text { STREAM } \\
\text { LENGTH } \\
\text { (MI) }\end{array}$} & \multirow{2}{*}{$\begin{array}{l}\text { MEAN } \\
\text { BASIN } \\
\text { ELEVA- } \\
\text { TION } \\
\text { (FT) }\end{array}$} & \multirow[b]{2}{*}{$\begin{array}{l}\text { FORESTED } \\
\text { AREA } \\
\text { (PERCENT) }\end{array}$} & \multicolumn{2}{|r|}{$\begin{array}{c}\text { MEAN } \\
\text { ANNUAL } \\
\text { PRECIPI - }\end{array}$} & \multicolumn{2}{|c|}{ RAINFALL INTENSITY, 24-HOUR } \\
\hline & & & & $\begin{array}{l}\text { SOIL } \\
\text { INDEX }\end{array}$ & $\begin{array}{l}\text { PRECIPI- } \\
\text { TAT ION } \\
\text { (IN) }\end{array}$ & $\begin{array}{l}\text { 2-YEAR } \\
\text { (IN) }\end{array}$ & $\begin{array}{c}\text { 50-YEAR } \\
\text { (IN) }\end{array}$ \\
\hline 38.6 & 152 & 3,900 & 26.0 & 1.7 & 13.2 & 1.8 & 3.9 \\
\hline
\end{tabular}


MEAN MONTHLY AND ANHUAL DISCHARGES 1915, 1929-46

\begin{tabular}{|c|c|c|c|c|c|c|}
\hline MONTH & $\begin{array}{l}\operatorname{MAXIMNM} \\
\left(F T^{3} / S\right)\end{array}$ & $\begin{array}{l}\text { MINIMUN } \\
\left(F T^{3} / S\right)\end{array}$ & $\begin{array}{c}\text { MEAN } \\
\left(F^{3} / S\right)\end{array}$ & $\begin{array}{l}\text { STAN- } \\
\text { DARD } \\
\text { DEVIA- } \\
\text { TION } \\
\left(F T^{3} / S\right)\end{array}$ & $\begin{array}{l}\text { COEFFI- } \\
\text { CIENT OF } \\
\text { VARI- } \\
\text { ATION }\end{array}$ & $\begin{array}{c}\text { PERCENT } \\
\text { OF } \\
\text { ANNUAL } \\
\text { RUNOFF }\end{array}$ \\
\hline $\begin{array}{l}\text { OCTOBER } \\
\text { NOVEMBER } \\
\text { DECEMBER } \\
\text { JANUARY } \\
\text { FEBRUARY } \\
\text { MARCH } \\
\text { APRIL } \\
\text { MAY } \\
\text { JUNE } \\
\text { JULY } \\
\text { AUGUST } \\
\text { SEPTEMBER }\end{array}$ & $\begin{array}{r}46 \\
26 \\
659 \\
445 \\
4,680 \\
2,780 \\
1,830 \\
122 \\
95 \\
80 \\
1,180 \\
3,660\end{array}$ & $\begin{array}{l}9.2 \\
10 \\
13 \\
13 \\
13 \\
13 \\
12 \\
11 \\
11 \\
9.5 \\
14 \\
13\end{array}$ & $\begin{array}{r}21 \\
19 \\
68 \\
78 \\
687 \\
425 \\
121 \\
28 \\
21 \\
22 \\
93 \\
276\end{array}$ & $\begin{array}{c}8.5 \\
3.8 \\
150 \\
125 \\
1.320 \\
730 \\
414 \\
29 \\
18 \\
15 \\
264 \\
832\end{array}$ & $\begin{array}{l}0.40 \\
0.20 \\
2.2 \\
1.6 \\
1.9 \\
1.7 \\
3.4 \\
1.0 \\
0.86 \\
0.70 \\
2.8 \\
3.0\end{array}$ & $\begin{array}{r}1.1 \\
1.0 \\
3.7 \\
4.2 \\
36.9 \\
22.9 \\
6.5 \\
1.5 \\
1.1 \\
1.2 \\
5.0 \\
14.8\end{array}$ \\
\hline NNUAL & 603 & 16 & 152 & 164 & 1.1 & 100 \\
\hline
\end{tabular}

MAGNITUDE AND PROBABILITY OF INSTANTAMEQUS PEAK FLOW BASED ON PERIOD OF RECORD

DISCHARGE, IN FT $3 / 5$, FOR INDICATED RECURRENCE INTERVAL IN YEARS, AND EXCEEDANCE PROBABILITY, IN PERCENT

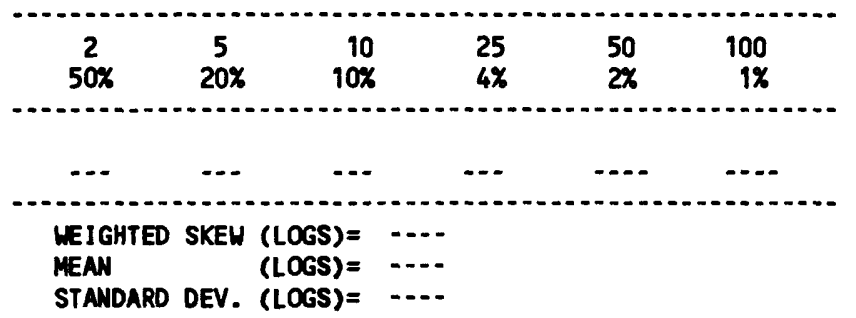

MAGITUDE AND PROBABILITY OF ANMUAL LOW FLOW BASED ON PERIOD OF RECORD 1930-46

\begin{tabular}{|c|c|c|c|c|c|c|}
\hline \multirow{2}{*}{$\begin{array}{l}\text { PERIOD } \\
\text { (CON- } \\
\text { SECU- } \\
\text { TIVE } \\
\text { DAYS) }\end{array}$} & \multicolumn{6}{|c|}{$\begin{array}{l}\text { DISCHARGE, IN FT }{ }^{3} / \mathrm{S} \text {, FOR INDICATED } \\
\text { RECURRENCE INTERVAL, IN YEARS, AND } \\
\text { NON-EXCEEDANCE PROBABILITY, IN PERCENT }\end{array}$} \\
\hline & $\begin{array}{c}2 \\
50 \%\end{array}$ & $\begin{array}{c}5 \\
20 \%\end{array}$ & $\begin{array}{l}10 \\
10 \%\end{array}$ & $\begin{array}{l}20 \\
5 \%\end{array}$ & $\begin{array}{l}50 \gamma \\
2 \%\end{array}$ & $\begin{array}{l}100 f \\
1 \%\end{array}$ \\
\hline $\begin{array}{r}1 \\
3 \\
7 \\
14 \\
30 \\
60 \\
90 \\
120 \\
183\end{array}$ & $\begin{array}{l}12 \\
13 \\
14 \\
14 \\
15 \\
16 \\
17 \\
17 \\
23\end{array}$ & $\begin{array}{l}10 \\
10 \\
11 \\
12 \\
13 \\
13 \\
14 \\
14 \\
15\end{array}$ & $\begin{array}{c}9.3 \\
9.4 \\
10 \\
11 \\
11 \\
12 \\
12 \\
13 \\
13\end{array}$ & $\begin{array}{c}8.6 \\
8.7 \\
9.3 \\
9.6 \\
10 \\
11 \\
11 \\
12 \\
12\end{array}$ & $\begin{array}{l}7.8 \\
7.9 \\
8.2 \\
8.6 \\
8.9 \\
9.3 \\
9.7 \\
12 \\
12\end{array}$ & $\begin{array}{r}7.3 \\
7.4 \\
7.5 \\
7.9 \\
8.1 \\
8.4 \\
8.9 \\
11 \\
11\end{array}$ \\
\hline
\end{tabular}

MAGNITLDE AND PROBABILITY OF ANMUAL HIGH FLOW BASED ON PERIOD OF RECORD 1915, 1929-46

\begin{tabular}{|c|c|c|c|c|c|c|}
\hline \multirow{2}{*}{$\begin{array}{l}\text { PERIOD } \\
\text { (CON- } \\
\text { SECU- } \\
\text { TIVE } \\
\text { DAYS }\end{array}$} & \multicolumn{6}{|c|}{$\begin{array}{l}\text { DISCHARGE, IN } \mathrm{FT}^{3} / \mathrm{S} \text {, FOR INDICATED } \\
\text { RECURRENCE INTERVAL, IN YEARS, AND } \\
\text { EXCEEDANCE PROBABILITY, IN PERCENT }\end{array}$} \\
\hline & $\begin{array}{c}2 \\
50 \%\end{array}$ & $\begin{array}{c}5 \\
20 \%\end{array}$ & $\begin{array}{l}10 \\
10 \%\end{array}$ & $\begin{array}{l}25 \\
4 \%\end{array}$ & $\begin{array}{l}50 \dagger \\
2 x\end{array}$ & $\underset{1 \%}{100+}$ \\
\hline $\begin{array}{r}1 \\
3 \\
7 \\
15 \\
30 \\
60 \\
90\end{array}$ & $\begin{array}{r}4,220 \\
2,560 \\
1,440 \\
937 \\
584 \\
333 \\
237\end{array}$ & $\begin{array}{r}19,600 \\
11,200 \\
5,730 \\
3,680 \\
2,220 \\
1,200 \\
813\end{array}$ & $\begin{array}{r}39,200 \\
22,000 \\
10,800 \\
6,920 \\
4,160 \\
2,240 \\
1,500\end{array}$ & $\begin{array}{r}75,900 \\
42,100 \\
19,700 \\
12,700 \\
7,700 \\
4,210 \\
2,810\end{array}$ & $\begin{array}{r}112,000 \\
61,800 \\
28,100 \\
18,300 \\
11,200 \\
6,200 \\
4,160\end{array}$ & $\begin{array}{r}154 \\
85 \\
37 \\
24 \\
15\end{array}$ \\
\hline
\end{tabular}

DURATION TABLE OF DAILY MEAN FLOW FOR PERIOD OF RECORD 1915, 1929-46 DISCHARGE, IN FT $3 / \mathrm{s}$, HHICH WAS EQUALED OR EXCEEDED FOR INDICATED PERCENT OF TIME

\begin{tabular}{|c|c|c|c|c|c|c|c|c|c|c|c|c|c|c|c|c|}
\hline $1 x$ & $5 \%$ & $10 \%$ & $15 \%$ & $20 \%$ & $30 \%$ & $40 \%$ & $50 \%$ & $60 \%$ & $70 \%$ & $80 \%$ & $90 \%$ & $95 \%$ & $98 \%$ & $99 \%$ & $99.5 \%$ & $99.9 \%$ \\
\hline 3,030 & 275 & 82 & 39 & 28 & 23 & 21 & 20 & 18 & 17 & 15 & 13 & 12 & 10 & 10 & 9.0 & 8.2 \\
\hline
\end{tabular}

$\uparrow$ Reliability of values in column is uncertain, and potential errors are large. 
BILL WILLIAMS RIVER BASIN

09426500 BILl WILLIAMS RIVER AT PLANET, AZ--CONTINUEd
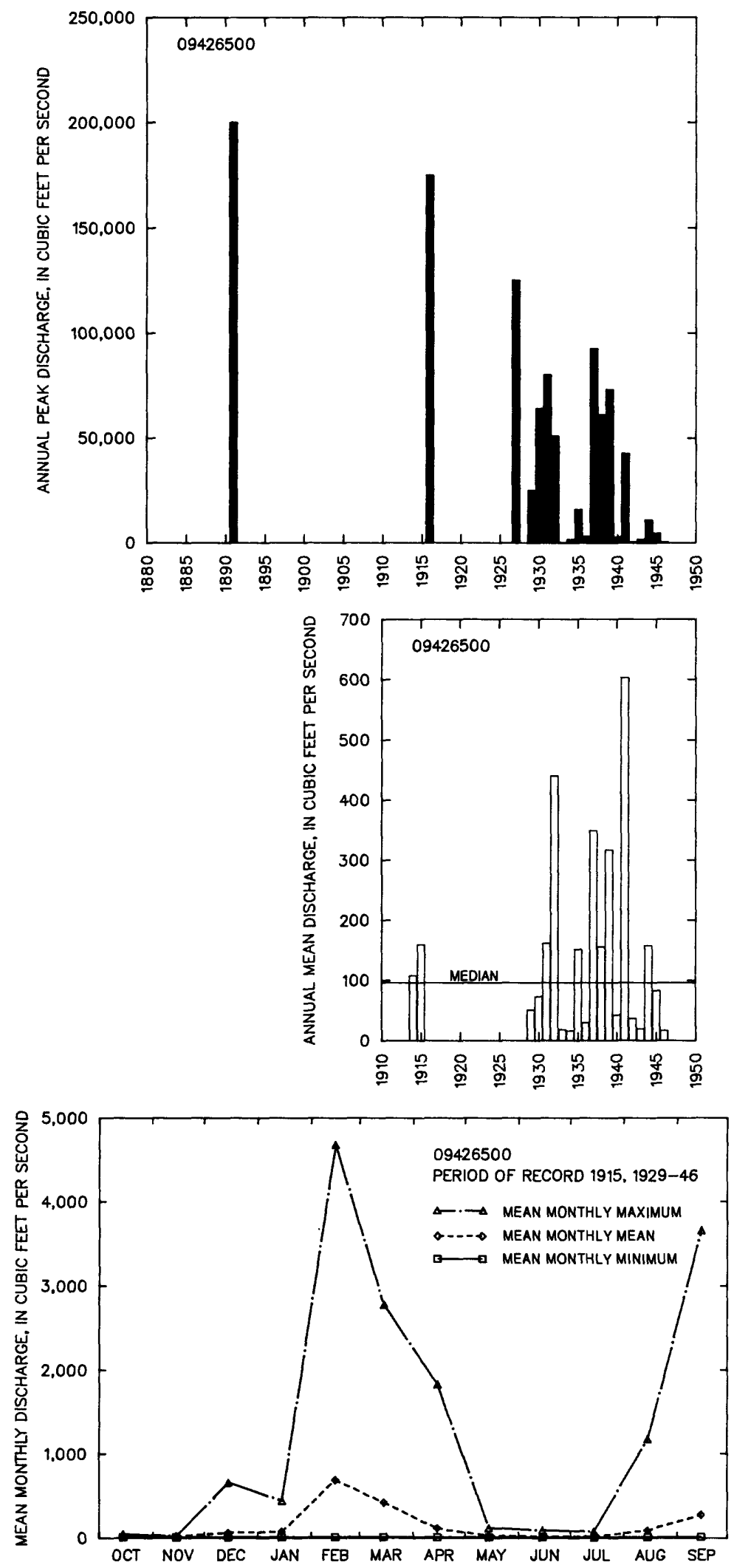


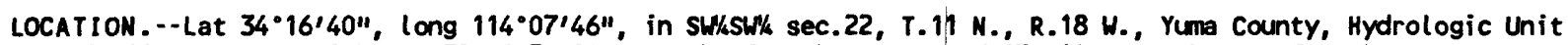
15030104, at State Highway 172, 1.5 mi les south of Parker Dam, and 13 mi les northeast of Parker.

DRAINAGE AREA. $--1.84 \mathrm{mi}^{2}$.

ANNUAL PEAK DISCHARGE

\begin{tabular}{lccc}
$\begin{array}{l}\text { WATER } \\
\text { YEAR }\end{array}$ & DATE & $\begin{array}{c}\text { ANNUAL PEAK } \\
\text { DISCHARGE } \\
\text { (FT } 3 / \text { S) }\end{array}$ & $\begin{array}{c}\text { DISCHARGE } \\
\text { CODES }\end{array}$ \\
\hline 1963 & $08-16-63$ & 10 & ES \\
1964 & $00-00-64$ & 0 & \\
1965 & $00-00-65$ & 0 & \\
1966 & $12-09-65$ & 12 & \\
1967 & $09-00-67$ & 103 & \\
1968 & $08-13-68$ & 320 & \\
1969 & $10-03-68$ & 12 & \\
1970 & $03-01-70$ & 35 & \\
1971 & $00-00-71$ & 265 & \\
1972 & $09-18-72$ & 5.0 & ES \\
1973 & $11-16-72$ & 60 & \\
1974 & $00-00-74$ & 0 & \\
1975 & $08-00-75$ & 0.5 & LT \\
1976 & $09-25-76$ & 160 &
\end{tabular}

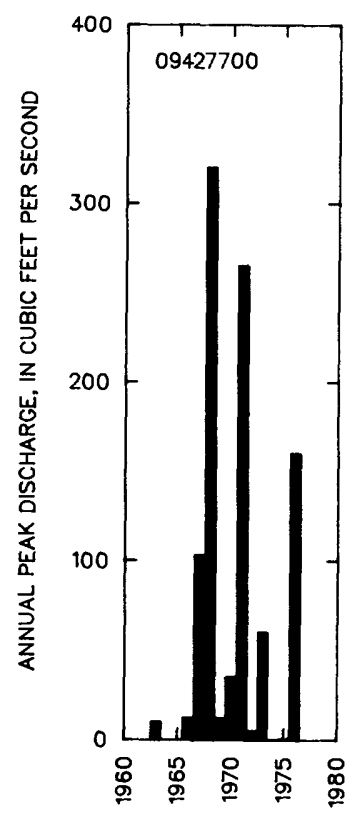

MAGNITUDE AND PROBABILITY OF INSTANTANEOUS PEAK FLOW BASED ON PERIOD OF RECORD 1963-76

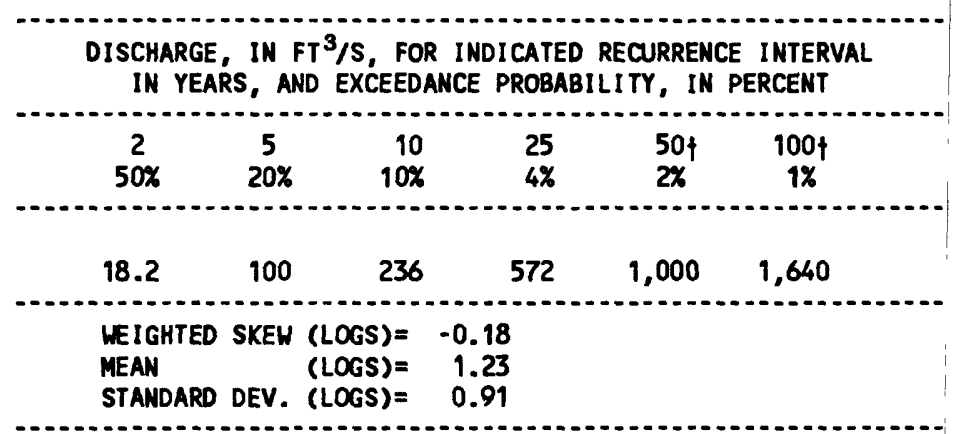

$\uparrow$ Reliability of values in column is uncertain, and potential errors are large.

\section{BASIN CHARACTERISTICS}

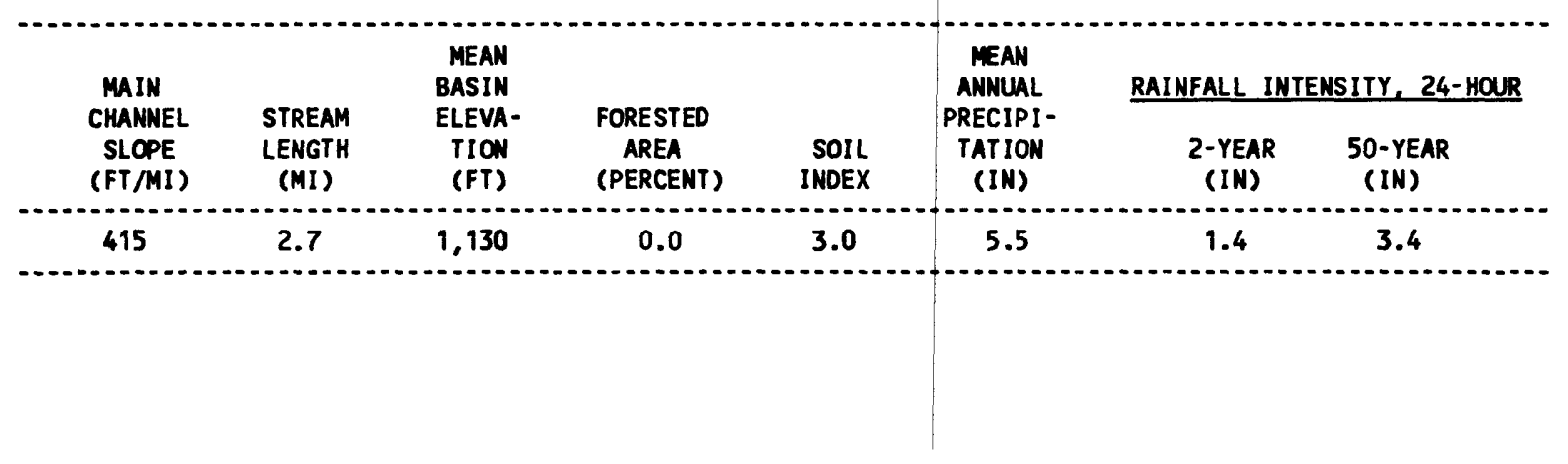


09428545 CUNNINGHAM WASH TRIBUTARY NEAR WENDEN, AZ

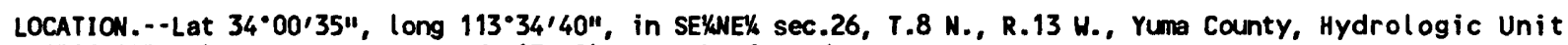
15030105, Al amo Dam access road, 13 miles north of Wenden.

DRAINAGE AREA. $--0.77 \mathrm{mi}^{2}$.

ANMUAL PEAK DISCHARGE

\begin{tabular}{|c|c|c|c|}
\hline $\begin{array}{l}\text { WATER } \\
\text { YEAR }\end{array}$ & DATE & $\begin{array}{l}\text { ANNUAL PEAK } \\
\text { D1 SCHARGE } \\
\left(\mathrm{FT}^{3} / \mathrm{S}\right)\end{array}$ & $\begin{array}{l}\text { DISCHARGE } \\
\text { CODES }\end{array}$ \\
\hline $\begin{array}{l}1964 \\
1965 \\
1966 \\
1967 \\
1968 \\
1969 \\
1970 \\
1971 \\
1972 \\
1973 \\
1974 \\
1975 \\
1976\end{array}$ & $\begin{array}{l}08-02-64 \\
04-04-65 \\
08-18-66 \\
08-20-67 \\
08-06-68 \\
08-00-69 \\
08-10-70 \\
00-00-71 \\
09-17-72 \\
10-06-72 \\
07-20-74 \\
07-25-75 \\
09-25-76\end{array}$ & $\begin{array}{c}173 \\
5.0 \\
46 \\
155 \\
88 \\
15 \\
80 \\
68 \\
12 \\
31 \\
85 \\
0.4 \\
48\end{array}$ & | ES \\
\hline
\end{tabular}

MAGNI TUDE AND PROBABILITY OF INSTANTANEOUS PEAK FLOW BASED ON PERICO OF RECORD 1964-76

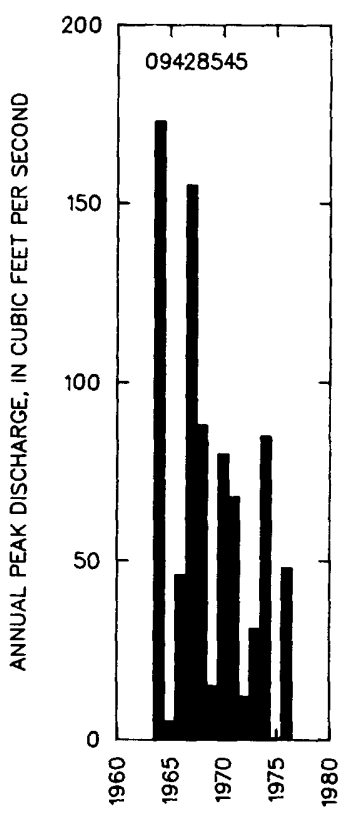

DISCHARGE, IN $\mathrm{FT}^{3} / \mathrm{S}$, FOR INDICATED RECURRENCE INTERVAL IN YEARS, AND EXCEEDANCE PROBABILITY, IN PERCENT

\begin{tabular}{|c|c|c|c|c|c|}
\hline$\stackrel{2}{50 \%}$ & $\begin{array}{c}5 \\
20 \%\end{array}$ & $\begin{array}{r}10 \\
10 \%\end{array}$ & $\begin{array}{l}25 \\
4 \%\end{array}$ & $\begin{array}{l}50 \dagger \\
2 \%\end{array}$ & $\begin{array}{c}100 \\
1 \%\end{array}$ \\
\hline 52.1 & 101 & 140 & 198 & 245 & 296 \\
\hline $\begin{array}{l}\text { MEIGHTED } \\
\text { MEAN } \\
\text { STANDARD }\end{array}$ & $\begin{array}{l}\text { SKEW } \\
\text { DEV. }\end{array}$ & $\begin{array}{l}(\text { LOGS })= \\
(\text { LOGS) }= \\
(\text { LOGS }=\end{array}$ & $\begin{array}{r}-0.19 \\
1.71 \\
0.35\end{array}$ & & \\
\hline
\end{tabular}

$\uparrow$ Reliability of values in column is uncertain, and potential errors are large.

BASIN CHARACTERISTICS

\begin{tabular}{|c|c|c|c|c|c|c|c|}
\hline MAIN & & $\begin{array}{l}\text { MEAN } \\
\text { BASIN }\end{array}$ & & & $\begin{array}{c}\text { MEAN } \\
\text { ANNUAL }\end{array}$ & RAINFALL II & SITY, 24-HOUR \\
\hline $\begin{array}{l}\text { CHANNEL } \\
\text { SLOPE } \\
\text { (FT/MI) }\end{array}$ & $\begin{array}{l}\text { STREAM } \\
\text { LENGTH } \\
\text { (MI) }\end{array}$ & $\begin{array}{l}\text { ELEVA- } \\
\text { TION } \\
\text { (FT) }\end{array}$ & $\begin{array}{l}\text { FORESTED } \\
\text { AREA } \\
\text { (PERCENT) }\end{array}$ & $\begin{array}{l}\text { SOIL } \\
\text { IMDEX }\end{array}$ & $\begin{array}{l}\text { PRECIPI- } \\
\text { TATION } \\
\text { (IN) }\end{array}$ & $\begin{array}{c}\text { 2-YEAR } \\
\text { (IN) }\end{array}$ & $\begin{array}{c}\text { 50-YEAR } \\
\text { (IN) }\end{array}$ \\
\hline 365 & 1.8 & 2,330 & 0.0 & 3.0 & 8.1 & 1.6 & 3.8 \\
\hline
\end{tabular}




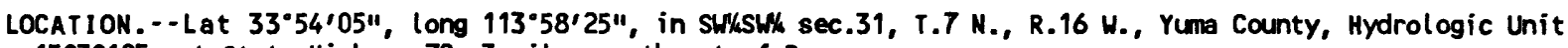
15030105, at State Highway 72,3 miles southeast of Bouse.

DRAINAGE AREA. $--14.6 \mathrm{mi}^{2}$.

\section{ANNUAL PEAK DISCHARGE}

\begin{tabular}{|c|c|c|c|}
\hline $\begin{array}{l}\text { WATER } \\
\text { YEAR }\end{array}$ & DATE & $\begin{array}{c}\text { ANNUAL PEAK } \\
\text { DISCHARGE } \\
\left(\mathrm{FT}^{3} / \mathrm{S}\right)\end{array}$ & $\begin{array}{l}\text { DISCHARGE } \\
\text { COOES }\end{array}$ \\
\hline $\begin{array}{l}1963 \\
1964 \\
1965 \\
1966 \\
1967 \\
1968 \\
1969 \\
1970 \\
1971 \\
1972 \\
1973 \\
1974 \\
1975 \\
1976\end{array}$ & $\begin{array}{l}09-17-63 \\
10-18-63 \\
04-03-65 \\
09-20-66 \\
10-04-66 \\
08-03-68 \\
08-08-69 \\
08-02-70 \\
08-10-71 \\
09-17-72 \\
08-16-73 \\
08-03-74 \\
07-29-75 \\
09-25-76\end{array}$ & $\begin{array}{r}248 \\
75 \\
20 \\
678 \\
170 \\
180 \\
890 \\
1,000 \\
2,920 \\
76 \\
390 \\
120 \\
828 \\
1,500\end{array}$ & ES \\
\hline
\end{tabular}

MAGNI TUDE AND PROBABILITY OF INSTANTANEOUS PEAK FLOW BASED ON PERIOD OF RECORD 1963-76

DISCHARGE, IN $\mathrm{FT}^{3} / \mathrm{S}$, FOR INDICATED RECURRENCE INTERVAL IN YEARS, AND EXCEEDANCE PROBABILITY, IN PERCENT

$\begin{array}{cccccc}2 & 5 & 10 & 25 & 50 \uparrow & 100 \dagger \\ 50 \% & 20 \% & 10 \% & 4 \% & 2 \% & 1 \% \\ 344 & 998 & 1,730 & 3,070 & 4,440 & 6,170\end{array}$

WEIGHTED SKEW (LOGS) $=-0.08$

MEAN (LOGS) $=2.53$

STANDARD DEV. (LOGS) $=0.56$

† Reliability of values in column is uncertain, and potential errors are large.

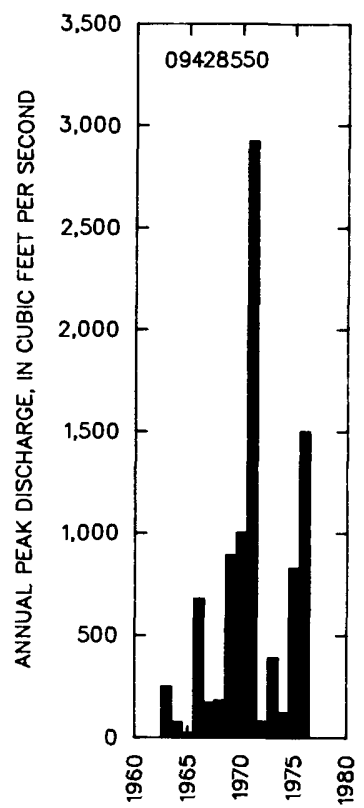


09428800 TYSON WASH TRIBUTARY NEAR QUARTZSITE, AZ

LOCATION.--Lat 33.30'45", long 114.13'00", in SWK SEC. 15, T.2 N., R.19 W., Yuma County, Hydrologic Unit 15030106, at U.S. Highway $95,10.7$ miles south of Quartzsite.

DRAIMAGE AREA. $-13.7 \mathrm{mi}^{2}$, contributing drainage area not determined.

ANNUAL PEAK DISCHARGE

\begin{tabular}{cccc}
$\begin{array}{c}\text { WATER } \\
\text { YEAR }\end{array}$ & DATE & $\begin{array}{c}\text { ANNUAL PEAK } \\
\text { DISCHARGE } \\
\text { (FT } 3 / \text { S })\end{array}$ & $\begin{array}{c}\text { DISCHARGE } \\
\text { CODES }\end{array}$ \\
\hline 1963 & $09-17-63$ & 554 & \\
1964 & $08-01-64$ & 55 & \\
1965 & $08-19-65$ & 503 & \\
1966 & $09-13-66$ & 510 & \\
1967 & $10-04-66$ & 535 & \\
1968 & $07-05-68$ & 740 & \\
1969 & $09-13-69$ & 120 & \\
1970 & $08-00-70$ & 365 & \\
1971 & $08-19-71$ & 300 & \\
1972 & $08-08-72$ & 5.0 & \\
1973 & $08-04-73$ & 300 & \\
1974 & $08-03-74$ & 980 & \\
1975 & $09-07-75$ & 80 & \\
1976 & $09-25-76$ & 1,950 & \\
\hline
\end{tabular}

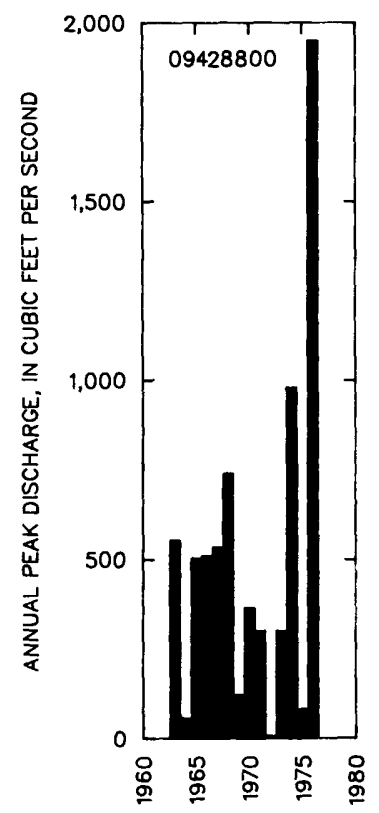

MAGNI TUDE AND PROBABILITY OF INSTANTANEOUS PEAK FLOW BASED ON PERIOD OF RECORD

DISCHARGE, IN $\mathrm{FT}^{3} / \mathrm{S}$, FOR INDICATED RECURRENCE INTERVAL IN YEARS, AND EXCEEDANCE PROBABILITY, IN PERCENT

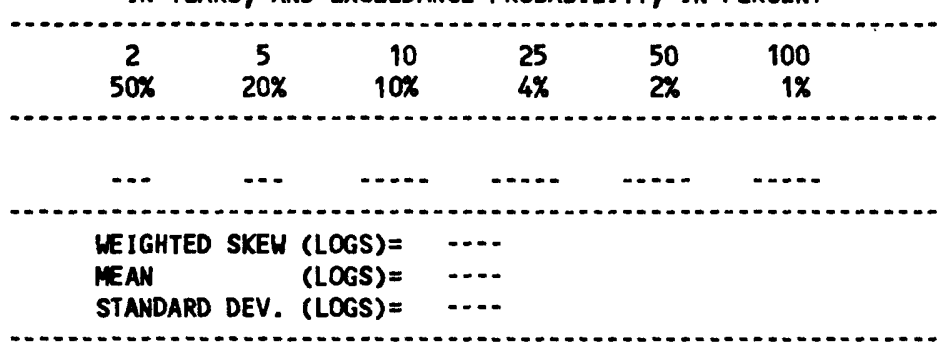

BASIN CHARACTERISTICS

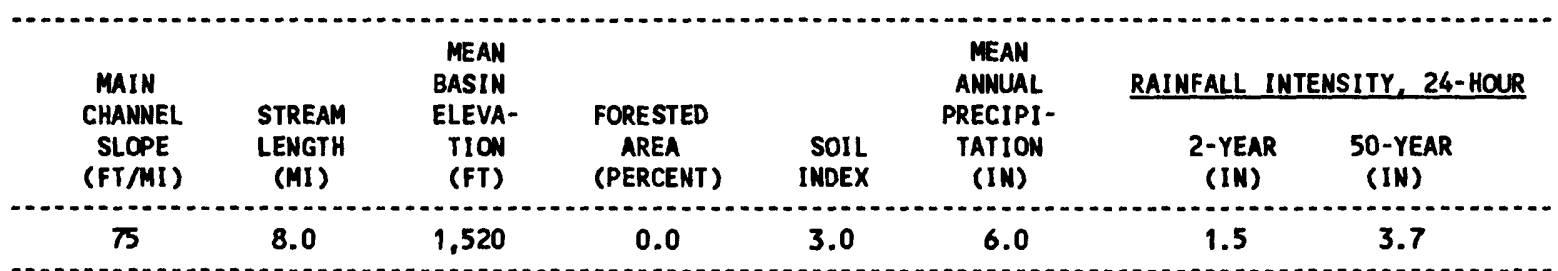


LOCATION.--Lat 33'37'15", long $114^{\circ} 29 \cdot 41^{\prime \prime}$, in NEK sec.2, T.3 N., R.22 H., Yuma County, Hydrologic Unit 15030104, at Parker Valley Road, 2.5 miles northeast of Ehrenberg, and 6 miles northeast of Blythe, California.

DRAINAGE AREA. $--1.98 \mathrm{mi}^{2}$.

ANNUAL PEAK DISCHARGE

\begin{tabular}{cccc}
$\begin{array}{c}\text { WATER } \\
\text { YEAR }\end{array}$ & DATE & $\begin{array}{c}\text { ANNUAL PEAK } \\
\text { DISCHARGE } \\
\text { (FT } 3 / \text { S) }\end{array}$ & $\begin{array}{c}\text { DISCHARGE } \\
\text { CODES }\end{array}$ \\
\hline 1965 & $08-16-65$ & 259 & \\
1966 & $12-09-65$ & 265 & \\
1967 & $08-14-67$ & 98 & \\
1968 & $07-06-68$ & 43 & \\
1969 & $07-17-69$ & 65 & \\
1970 & $02-28-70$ & 34 & \\
1971 & $08-10-71$ & 580 & \\
1972 & $08-08-72$ & 72 & \\
1973 & $08-16-73$ & 125 & \\
1974 & $08-00-74$ & 5.0 & \\
1975 & $09-16-75$ & 28 & \\
1976 & $09-25-76$ & 325 & \\
$\ldots$
\end{tabular}

MAGNI TUDE AND PROBABILITY OF INSTANTANE OUS PEAK FLOM BASED ON PERIOD OF RECORD 1965-76

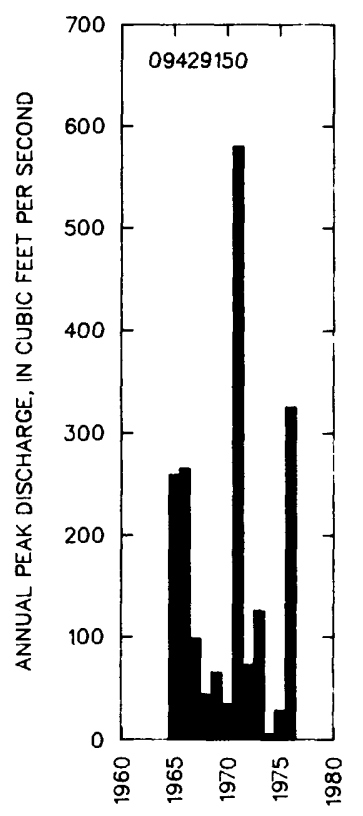

DISCHARGE, IN $\mathrm{FT}^{3} / \mathrm{S}$, FOR INDICATED RECU RRENCE INTERVAL IN YEARS, AND EXCEEDANCE PROBABILITY , IN PERCENT

\begin{tabular}{|c|c|c|c|c|c|}
\hline$\stackrel{2}{2}$ & $\begin{array}{c}5 \\
20 \%\end{array}$ & $\begin{array}{r}10 \\
10 \%\end{array}$ & $\begin{array}{l}25 \nmid \\
4 \%\end{array}$ & $\begin{array}{l}50 \dagger \\
2 \%\end{array}$ & $\begin{array}{c}100 \dagger \\
1 \%\end{array}$ \\
\hline 95.6 & 239 & 390 & 660 & 932 & 1,270 \\
\hline $\begin{array}{l}\text { WEIGHTED } \\
\text { MEAN } \\
\text { STANDARD }\end{array}$ & $\begin{array}{l}\text { SKEW } \\
\text { DEV. }\end{array}$ & $\begin{array}{l}(\text { LOGS })= \\
(\text { LOGS })= \\
(\text { LOGS })=\end{array}$ & $\begin{array}{l}0.09 \\
1.99 \\
0.47\end{array}$ & & \\
\hline
\end{tabular}

+ Reliability of values in column is uncertain, and potential errors are large.

BASIN CHARACTERISTICS

\begin{tabular}{|c|c|c|c|c|c|c|c|}
\hline MAIN & & $\begin{array}{l}\text { MEAN } \\
\text { BASIN }\end{array}$ & & & $\begin{array}{c}\text { MEAN } \\
\text { ANNUAL }\end{array}$ & RAINFALL II & SITY, 24-HOUR \\
\hline $\begin{array}{l}\text { CHANNEL } \\
\text { SLOPE } \\
\text { (FT/MI) }\end{array}$ & $\begin{array}{c}\text { STREAM } \\
\text { LENGTH } \\
\text { (MI) }\end{array}$ & $\begin{array}{c}\text { ELEVA- } \\
\text { TION } \\
\text { (FT) }\end{array}$ & $\begin{array}{l}\text { FORESTED } \\
\text { AREA } \\
\text { (PERCENT) }\end{array}$ & $\begin{array}{l}\text { SOIL } \\
\text { INDEX }\end{array}$ & $\begin{array}{l}\text { PRECIPI - } \\
\text { TATION } \\
\text { (IN) }\end{array}$ & $\begin{array}{c}\text { 2-YEAR } \\
\text { (IN) }\end{array}$ & $\begin{array}{l}\text { 50-YEAR } \\
\text { (IN) }\end{array}$ \\
\hline 95.2 & 4.2 & 509.0 & 0.0 & 3.0 & 5.5 & 1.2 & 3.3 \\
\hline
\end{tabular}


LOCATION.--Lat 33.06'33", long 114'17'41", in NHK sec.2, T.4 S., R.20 W. (unsurveyed), Yuma County, Hydrologic Unit 15030104, at U.S. Highway 95,33 miles northeast of Dome.

DRAINAGE AREA. $--2.56 \mathrm{mi}^{2}$.

ANNUAL PEAK DISCHARGE

\begin{tabular}{cccc}
$\begin{array}{l}\text { MATER } \\
\text { YEAR }\end{array}$ & DATE & $\begin{array}{c}\text { ANNUAL PEAK } \\
\text { DISCHARGE } \\
\text { (FT 3/S) }\end{array}$ & $\begin{array}{c}\text { DISCHARGE } \\
\text { COEES }\end{array}$ \\
\hline 1963 & $09-17-63$ & 72 & \\
1964 & $10-18-63$ & 24 & \\
1965 & $04-03-65$ & 37 & \\
1966 & $09-13-66$ & 90 & \\
1967 & $10-03-66$ & 24 & \\
1968 & $11-00-67$ & 50 & \\
1969 & $09-06-69$ & 43 & \\
1970 & $03-01-70$ & 36 & \\
1971 & $09-29-71$ & 45 & \\
1972 & $08-00-72$ & 29 & \\
1973 & $10-06-72$ & 37 & \\
1974 & $07-21-74$ & 57 & \\
1975 & $00-00-75$ & 40 & \\
1976 & $09-25-76$ & 61 & \\
1980 & $00-00-80$ & 198 & \\
\hline
\end{tabular}

Highest since 1976.

MAGNITUDE AND PROBABILITY OF INSTANTANEOUS PEAK FLOW BASED ON PERIOD OF RECORD 1963-76, 1980

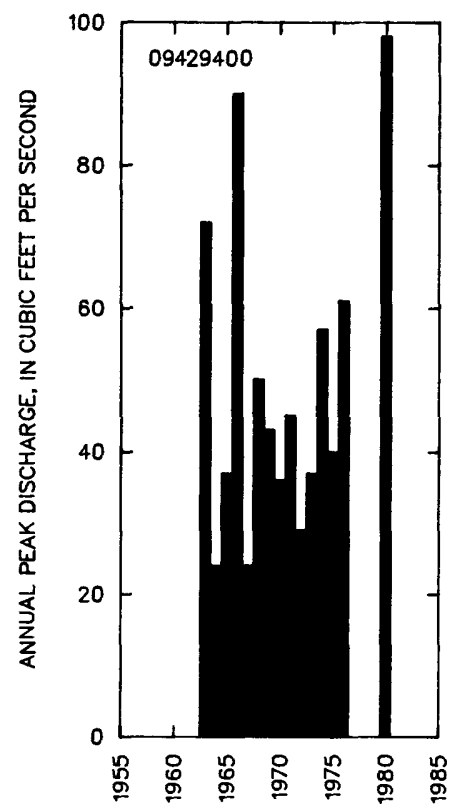

DISCHARGE, IN $F T^{3} / S$, FOR INDICATED RECURRENCE INTERVAL IN YEARS, AND EXCEEDANCE PROBABILITY, IN PERCENT

\begin{tabular}{cccccc}
2 & 5 & 10 & 25 & $50 \%$ & $100 \dagger$ \\
$50 \%$ & $20 \%$ & $10 \%$ & $4 \%$ & $2 \%$ & $1 \%$ \\
44.7 & 64.8 & 79.3 & 99 & 115 & 131 \\
\hline MEIGHTED SKEW (LOGS) & & 0.19 & & \\
MEAN & (LOGS) & 1.66 & & \\
STANDARD DEV. (LOGS) & $=0.19$ & &
\end{tabular}

+ Reliability of values in column is uncertain, and potential errors are large.

BASIN CHARACTERISTICS

\begin{tabular}{|c|c|c|c|c|c|c|c|}
\hline MAIN & & $\begin{array}{c}\text { MEAN } \\
\text { BASIN }\end{array}$ & & & $\begin{array}{c}\text { MEAN } \\
\text { ANNUAL }\end{array}$ & RAINFALL IN & SITY, 24-HOUR \\
\hline $\begin{array}{l}\text { CHANNEL } \\
\text { SLOPE } \\
\text { (FT/MI) }\end{array}$ & $\begin{array}{l}\text { STREAM } \\
\text { LENGTH } \\
\text { (MI) }\end{array}$ & $\begin{array}{l}\text { ELEVA- } \\
\text { TION } \\
\text { (FT) }\end{array}$ & $\begin{array}{l}\text { FORESTED } \\
\text { AREA } \\
\text { (PERCENT) }\end{array}$ & $\begin{array}{l}\text { SOIL } \\
\text { INDEX }\end{array}$ & $\begin{array}{l}\text { PRECIPI- } \\
\text { TATION } \\
\text { (IN) }\end{array}$ & $\begin{array}{c}\text { 2-YEAR } \\
\text { (IN) }\end{array}$ & $\begin{array}{l}\text { 50-YEAR } \\
\text { (IN) }\end{array}$ \\
\hline 66.7 & 5.0 & 1,190 & 0.0 & 3.0 & 5.5 & 1.5 & 3.7 \\
\hline
\end{tabular}




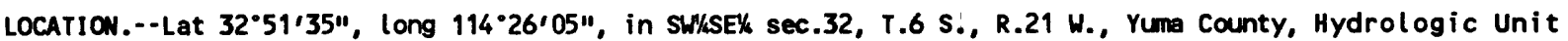
15030107, at Yuma Test Station, 14.5 miles northeast of Yuma.

DRAINAGE AREA. $--0.30 \mathrm{mi}^{2}$.

ANMUAL PEAK DISCHARGE

\begin{tabular}{cccc}
$\begin{array}{c}\text { WATER } \\
\text { YEAR }\end{array}$ & DATE & $\begin{array}{c}\text { ANMUAL PEAK } \\
\text { DISCHARGE } \\
\text { (FT } 3 / \text { S })\end{array}$ & $\begin{array}{c}\text { DISCHARGE } \\
\text { CODES }\end{array}$ \\
\hline 1965 & $04-03-65$ & 1.0 & LT \\
1966 & $12-09-65$ & 50 & \\
1967 & $09-02-67$ & 42 & \\
1968 & $02-12-68$ & 48 & \\
1969 & $01-14-69$ & 3.0 & \\
1970 & $03-01-70$ & 22 & \\
1971 & $09-29-71$ & 45 & \\
1972 & $06-06-72$ & 55 & \\
1973 & $08-16-73$ & 165 & \\
1974 & $00-00-74$ & 0 & \\
1975 & $00-00-75$ & 0 & \\
1976 & $09-24-76$ & 10 & \\
\hline
\end{tabular}

MAGNITUDE AND PROBABILITY OF INSTANTANEOUS PEAK FLON BASED ON PERIOD RECORD 1965-76

DISCHARGE, IN $\mathrm{FT}^{3} / \mathrm{S}$, FOR INDICATED RECURRENCE INTERVAL IN YEARS, AND EXCEEDANCE PROBABILITY, IN PERCENT

\begin{tabular}{|c|c|c|c|c|c|}
\hline $\begin{array}{r}2 \dagger \\
50 \%\end{array}$ & $\begin{array}{r}5 \dagger \\
20 \%\end{array}$ & $\begin{array}{c}10 \nmid \\
10 \%\end{array}$ & $\begin{array}{l}25 \uparrow \\
4 \%\end{array}$ & $\begin{array}{l}50 \uparrow \\
2 \%\end{array}$ & $\begin{array}{c}100 \nmid \\
1 \%\end{array}$ \\
\hline 22 & 62.8 & 106 & 182 & 256 & 346 \\
\hline $\begin{array}{l}\text { WEIGHTED } \\
\text { MEAN } \\
\text { STANDARD }\end{array}$ & $\begin{array}{l}\text { SKEW } \\
\text { DEV. }\end{array}$ & $\begin{array}{l}(\text { LOGS })= \\
(\text { LOGS })= \\
(\text { LOGS })=\end{array}$ & $\begin{array}{r}-0.19 \\
1.33 \\
0.56\end{array}$ & & \\
\hline
\end{tabular}

t Reliability of values in column is uncertain, and potential errors are large.

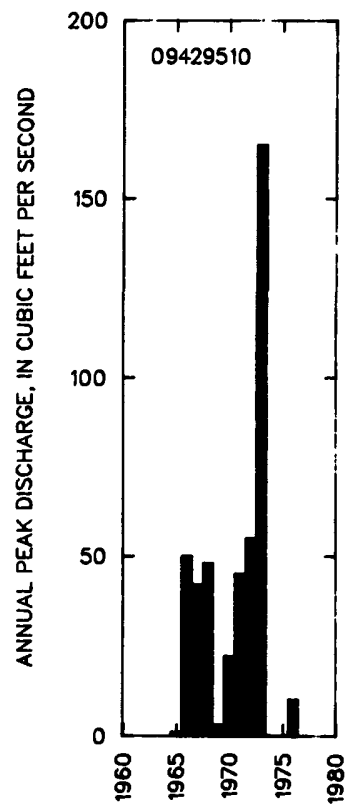

BASIN CHARACTERISTICS

\begin{tabular}{|c|c|c|c|c|c|c|c|}
\hline \multirow{3}{*}{$\begin{array}{l}\text { MAIN } \\
\text { CHANNEL } \\
\text { SLOPE } \\
\text { (FT/MI) }\end{array}$} & \multicolumn{3}{|c|}{ MEAN } & \multicolumn{3}{|c|}{ MEAN } & \multirow[b]{2}{*}{ ITY, 24-HOUR } \\
\hline & & BASIN & & & ANNUAL & RAINFALL IN & \\
\hline & $\begin{array}{l}\text { STREAM } \\
\text { LENGTH } \\
\text { (MI) }\end{array}$ & $\begin{array}{l}\text { ELEVA- } \\
\text { TION } \\
\text { (FT) }\end{array}$ & $\begin{array}{l}\text { FORESTED } \\
\text { AREA } \\
\text { (PERCENT) }\end{array}$ & $\begin{array}{l}\text { SOIL } \\
\text { INDEX }\end{array}$ & $\begin{array}{l}\text { PRECIPI- } \\
\text { TATION } \\
\text { (IN) }\end{array}$ & $\begin{array}{c}\text { 2-YEAR } \\
\text { (IN) }\end{array}$ & $\begin{array}{l}\text { 50-YEAR } \\
\text { (IN) }\end{array}$ \\
\hline 122 & 0.98 & 346.0 & 0.0 & 3.0 & 4.2 & 1.3 & 3.6 \\
\hline
\end{tabular}


09432000 GILA RIVER BELOW BLUE CREeK, NEAR VIRDEN, NM

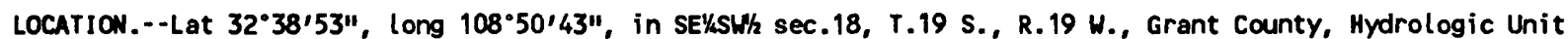
15040002, on left bank at head of canyon, $1.4 \mathrm{mi}$ downstream from Blue Creek, $10 \mathrm{mi}$ east of virden, and 16 mi upstream from New Mexico-Arizona State line.

DRAINAGE AREA. - -3,203 $\mathrm{mi}^{2}$, excluding Animas River basin.

REMARKS.-Station is above all Duncan Valley diversions. Diversions for irrigation of about 6,200 acres above station.

ANNUAL PEAK DISCHARGE

\begin{tabular}{|c|c|c|c|c|c|}
\hline $\begin{array}{l}\text { WATER } \\
\text { YEAR }\end{array}$ & DATE & $\begin{array}{l}\text { ANNUAL PEAK } \\
\text { DISCHARGE } \\
\left(\mathrm{FT}^{3} / \mathrm{S}\right)\end{array}$ & $\begin{array}{l}\text { WATER } \\
\text { YEAR }\end{array}$ & DATE & $\begin{array}{c}\text { ANNUAL PEAK } \\
\text { DISCHARGE } \\
\left(\mathrm{FT}^{3} / \mathrm{S}\right)\end{array}$ \\
\hline $\begin{array}{l}1927 \\
1928 \\
1929 \\
1930 \\
1931 \\
1932 \\
1933 \\
1934 \\
1935 \\
1936 \\
1937 \\
1938 \\
1939 \\
1940 \\
1941 \\
1942 \\
1943 \\
1944 \\
1945 \\
1946 \\
1947 \\
1948 \\
1949 \\
1950 \\
1951 \\
1952 \\
1953 \\
1954 \\
1955 \\
1956 \\
1957 \\
1958\end{array}$ & $\begin{array}{l}07-04-27 \\
07-26-28 \\
07-30-29 \\
08-11-30 \\
08-03-31 \\
07-30-32 \\
09-08-33 \\
08-26-34 \\
09-27-35 \\
06-11-36 \\
02-17-37 \\
08-31-38 \\
09-16-39 \\
09-06-40 \\
09-29-41 \\
09-13-42 \\
09-27-43 \\
08-19-44 \\
08-11-45 \\
10-08-45 \\
08-22-47 \\
08-12-48 \\
01-14-49 \\
09-24-50 \\
08-28-51 \\
01-19-52 \\
08-21-53 \\
08-21-54 \\
07-28-55 \\
08-13-56 \\
08-05-57 \\
03-23-58\end{array}$ & $\begin{array}{r}1,800 \\
1,630 \\
5,700 \\
7,400 \\
8,000 \\
6,800 \\
5,650 \\
8,920 \\
8,600 \\
3,600 \\
9,070 \\
6,400 \\
1,630 \\
11,000 \\
141,700 \\
3,140 \\
1,600 \\
4,010 \\
5,370 \\
10,600 \\
3,400 \\
2,240 \\
15,600 \\
2,190 \\
4440 \\
6,100 \\
3,330 \\
6,670 \\
5,280 \\
2,660 \\
6,710 \\
4,550\end{array}$ & $\begin{array}{l}1959 \\
1960 \\
1961 \\
1962 \\
1963 \\
1964 \\
1965 \\
1966 \\
1967 \\
1968 \\
1969 \\
1970 \\
1971 \\
1972 \\
1973 \\
1974 \\
1975 \\
1976 \\
1977 \\
1978 \\
1979 \\
1980 \\
1981 \\
1982 \\
1983 \\
1984 \\
1985 \\
1986 \\
1987 \\
1988 \\
1989\end{array}$ & $\begin{array}{l}08-13-59 \\
01-12-60 \\
08-15-61 \\
09-26-62 \\
08-31-63 \\
07-25-64 \\
07-24-65 \\
12-23-65 \\
08-12-67 \\
02-15-68 \\
09-02-69 \\
09-19-70 \\
09-18-71 \\
10-26-71 \\
10-20-72 \\
08-04-74 \\
09-08-75 \\
09-15-76 \\
08-13-77 \\
03-03-78 \\
12-19-78 \\
09-10-80 \\
08-18-81 \\
10-02-81 \\
02-04-83 \\
10-02-83 \\
12-28-84 \\
10-11-85 \\
08-11-87 \\
09-22-88 \\
07-30-89\end{array}$ & $\begin{array}{r}16,400 \\
5,220 \\
1,920 \\
3,920 \\
7,320 \\
4,480 \\
2,540 \\
10,900 \\
11,500 \\
2,920 \\
1,790 \\
1,130 \\
3,730 \\
5,700 \\
27,200 \\
7,560 \\
7,720 \\
3,700 \\
4,450 \\
7,800 \\
58,700 \\
4,300 \\
1,890 \\
3,680 \\
5,870 \\
15,500 \\
37,000 \\
6,670 \\
2,680 \\
9,000 \\
696\end{array}$ \\
\hline
\end{tabular}

$1_{H i g h e s t}$ since 1891.

\section{BASIN CHARACTERISTICS}

\begin{tabular}{|c|c|c|c|c|c|c|c|}
\hline MAIN & & $\begin{array}{l}\text { MEAN } \\
\text { BASIN }\end{array}$ & & & $\begin{array}{l}\text { MEAN } \\
\text { ANNUAL }\end{array}$ & RAINFALL I & SITY, 24-HOUR \\
\hline $\begin{array}{c}\text { CHANNEL } \\
\text { SLOPE } \\
\text { (FT/MI) }\end{array}$ & $\begin{array}{c}\text { STREAM } \\
\text { LENGTH } \\
\text { (MI) }\end{array}$ & $\begin{array}{l}\text { ELEVA- } \\
\text { TION } \\
\text { (FT) }\end{array}$ & $\begin{array}{l}\text { FORESTED } \\
\text { AREA } \\
\text { (PERCENT) }\end{array}$ & $\begin{array}{l}\text { SOIL } \\
\text { INDEX }\end{array}$ & $\begin{array}{l}\text { PRECIPI - } \\
\text { TATION } \\
\text { (IN) }\end{array}$ & $\begin{array}{c}\text { 2-YEAR } \\
\text { (IN) }\end{array}$ & $\begin{array}{l}\text { 50-YEAR } \\
\text { (IN) }\end{array}$ \\
\hline 35.8 & 115 & 6,690 & 54.0 & 3.0 & 16.2 & 1.6 & 3.3 \\
\hline
\end{tabular}


MEAN MONTHLY AND ANNUAL DISCHARGES 1928-78, 1981-89

\begin{tabular}{|c|c|c|c|c|c|c|}
\hline MONTH & $\begin{array}{l}\text { MAXIMUM } \\
\left(F^{3} / S\right)\end{array}$ & $\begin{array}{l}\text { MINIMUM } \\
\left(F^{3} / S\right)\end{array}$ & $\begin{array}{c}\text { MEAN } \\
\left(F^{3} / S\right)\end{array}$ & $\begin{array}{l}\text { STAN- } \\
\text { DARD } \\
\text { DEVIA- } \\
\text { TION } \\
\left(F T^{3} / S\right)\end{array}$ & $\begin{array}{l}\text { COEFFI- } \\
\text { CIENT OF } \\
\text { VARI - } \\
\text { ATION }\end{array}$ & $\begin{array}{c}\text { PERCENT } \\
\text { OF } \\
\text { ANNUAL } \\
\text { RUNOFF }\end{array}$ \\
\hline $\begin{array}{l}\text { OCTOBER } \\
\text { NOVEMBER } \\
\text { DECEMBER } \\
\text { JANUARY } \\
\text { FEBRUARY } \\
\text { MARCH } \\
\text { APRIL } \\
\text { MAY } \\
\text { JUNE } \\
\text { JULY } \\
\text { AUGUST } \\
\text { SEPTEMBER }\end{array}$ & $\begin{array}{r}1,670 \\
520 \\
1,800 \\
1,390 \\
1,280 \\
1,460 \\
1,140 \\
907 \\
183 \\
366 \\
1,160 \\
1,510\end{array}$ & $\begin{array}{l}5.4 \\
35 \\
48 \\
64 \\
61 \\
45 \\
28 \\
14 \\
4.4 \\
4.9 \\
9.4 \\
4.9\end{array}$ & $\begin{array}{r}170 \\
107 \\
186 \\
209 \\
293 \\
387 \\
255 \\
141 \\
45 \\
81 \\
221 \\
194\end{array}$ & $\begin{array}{r}295 \\
72 \\
276 \\
256 \\
315 \\
418 \\
257 \\
163 \\
42 \\
64 \\
225 \\
283\end{array}$ & $\begin{array}{l}1.7 \\
0.67 \\
1.5 \\
1.2 \\
1.1 \\
1.1 \\
1.0 \\
1.2 \\
0.93 \\
0.78 \\
1.0 \\
1.5\end{array}$ & $\begin{array}{r}7.4 \\
4.7 \\
8.1 \\
9.1 \\
12.8 \\
16.9 \\
11.1 \\
6.2 \\
2.0 \\
3.5 \\
9.7 \\
8.5\end{array}$ \\
\hline NNUAL & 640 & 43 & 190 & 136 & 0.71 & 100 \\
\hline
\end{tabular}

MAGNITUDE AND PROBABILITY OF INSTANTANEOUS PEAK FLON BASED ON PERIOD OF RECORD $1927-89$

DISCHARGE, IN FT $3 / 5$, FOR INDICATED RECURRENCE INTERVAL IN YEARS, AND EXCEEDANCE PROBABILITY, IN PERCENT

\begin{tabular}{|c|c|c|c|c|c|}
\hline $\begin{array}{c}2 \\
50 \%\end{array}$ & $\begin{array}{c}5 \\
20 \%\end{array}$ & $\begin{array}{r}10 \\
10 \%\end{array}$ & $\begin{array}{l}25 \\
4 \%\end{array}$ & $\begin{array}{l}50 \\
2 \%\end{array}$ & $\begin{array}{r}100 \\
1 \%\end{array}$ \\
\hline 4,980 & 10,400 & 15,200 & 22,900 & 29,900 & 37,900 \\
\hline $\begin{array}{l}\text { WE IGHTEI } \\
\text { MEAN } \\
\text { STANDARI }\end{array}$ & $\begin{array}{l}\text { SKEW } \\
\text { DEV. }\end{array}$ & $\begin{array}{l}\text { LOGS) }= \\
\text { LOGS) }= \\
\text { LOGS) }=\end{array}$ & $\begin{array}{l}00 \\
70 \\
38\end{array}$ & & \\
\hline
\end{tabular}

MAGNITLDE AND PROBABILITY OF ANNUAL LON FLON BASED ON PERIOD OF RECORD 1929-78, 1981-89

\begin{tabular}{|c|c|c|c|c|c|c|}
\hline \multirow{2}{*}{$\begin{array}{l}\text { PERICD } \\
\text { (CON- } \\
\text { SECU- } \\
\text { TIVE } \\
\text { DAYS) }\end{array}$} & \multicolumn{6}{|c|}{$\begin{array}{l}\text { DISCHARGE, IN FT } 3 / 5 \text {, FOR IND ICATED } \\
\text { RECURRENCE INTERVAL, IN YEARS, AND } \\
\text { NON-EXCEEDANCE PROBABILITY, IN PERCENT }\end{array}$} \\
\hline & 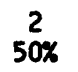 & $\begin{array}{c}5 \\
20 \%\end{array}$ & $\begin{array}{l}10 \\
10 \%\end{array}$ & $\begin{array}{l}20 \\
5 \%\end{array}$ & $\begin{array}{l}50 \\
2 \%\end{array}$ & $\begin{array}{l}100 \\
1 \%\end{array}$ \\
\hline $\begin{array}{r}1 \\
3 \\
7 \\
14 \\
30 \\
60 \\
90 \\
120 \\
183\end{array}$ & $\begin{array}{c}6.5 \\
6.9 \\
7.9 \\
10 \\
17 \\
32 \\
45 \\
61 \\
91\end{array}$ & $\begin{array}{c}3.1 \\
3.4 \\
3.8 \\
4.7 \\
7.4 \\
16 \\
24 \\
34 \\
54\end{array}$ & $\begin{array}{c}2.2 \\
2.4 \\
2.7 \\
3.2 \\
4.7 \\
11 \\
17 \\
24 \\
40\end{array}$ & $\begin{array}{c}1.7 \\
1.8 \\
2.0 \\
2.3 \\
3.3 \\
7.4 \\
12 \\
17 \\
30\end{array}$ & $\begin{array}{r}1.2 \\
1.3 \\
1.5 \\
1.5 \\
2.1 \\
4.8 \\
8.4 \\
11 \\
22\end{array}$ & $\begin{array}{c}1.0 \\
1.1 \\
1.2 \\
1.2 \\
1.6 \\
3.5 \\
6.4 \\
8.3 \\
17\end{array}$ \\
\hline
\end{tabular}

MAGNITUDE AND PROBABILITY OF ANNUAL HIGH FLOW BASED ON PERIOD OF RECORD 1928-78, 1981-89

\begin{tabular}{|c|c|c|c|c|c|c|}
\hline \multirow{2}{*}{$\begin{array}{l}\text { PERIOD } \\
\text { (CON- } \\
\text { SECU- } \\
\text { TIVE } \\
\text { DAYS) }\end{array}$} & \multicolumn{6}{|c|}{$\begin{array}{l}\text { DISCHARGE, IN FT } 3 / S \text {, FOR INDICATED } \\
\text { RECURRENCE INTERVAL, IN YEARS, AND } \\
\text { EXCEEDANCE PROBABILITY, IN PERCENT }\end{array}$} \\
\hline & $\stackrel{2}{50 \%}$ & $\begin{array}{c}5 \\
20 \%\end{array}$ & $\begin{array}{l}10 \\
10 \%\end{array}$ & $\begin{array}{l}25 \\
4 \%\end{array}$ & $\begin{array}{l}50 \\
2 \%\end{array}$ & $\begin{array}{r}100 \\
1 \%\end{array}$ \\
\hline $\begin{array}{l}1 \\
3 \\
7 \\
15 \\
30 \\
60 \\
90\end{array}$ & $\begin{array}{r}1,910 \\
1,370 \\
965 \\
704 \\
523 \\
364 \\
295\end{array}$ & $\begin{array}{r}4,830 \\
3,300 \\
2,130 \\
1,440 \\
1,010 \\
706 \\
580\end{array}$ & $\begin{array}{r}8,000 \\
5,300 \\
3,230 \\
2,100 \\
1,410 \\
1,000 \\
840\end{array}$ & $\begin{array}{r}13,900 \\
8,890 \\
5,080 \\
3,110 \\
2,000 \\
1,460 \\
1,260\end{array}$ & $\begin{array}{r}20,000 \\
12,500 \\
6,810 \\
4,010 \\
2,500 \\
1,870 \\
1,650\end{array}$ & $\begin{array}{r}27,900 \\
17,000 \\
8,890 \\
5,040 \\
3,050 \\
2,340 \\
2,120\end{array}$ \\
\hline
\end{tabular}

DURATION TABLE OF DAILY MEAN FLON FOR PERIOD OF RECORD 1928-78, 1981-89

DISCHARGE, IN $\mathrm{FT}^{3} / \mathrm{S}$, WHICH WAS EQUALED OR EXCEEDED FOR INDICATED PERCENT OF TIME

\begin{tabular}{|c|c|c|c|c|c|c|c|c|c|c|c|c|c|c|c|c|}
\hline $1 \%$ & $5 \%$ & $10 \%$ & $15 \%$ & $20 \%$ & $30 \%$ & $40 \%$ & $50 \%$ & $60 \%$ & $70 x$ & $80 \%$ & $90 \%$ & $95 \%$ & $98 \%$ & $99 \%$ & $99.5 \%$ & $99.9 \%$ \\
\hline 1,760 & 684 & 404 & 284 & 214 & 146 & 110 & 91 & 77 & 61 & 43 & 21 & $c^{*} 5$ & 4.4 & 3.3 & 2.8 & 2.0 \\
\hline
\end{tabular}


GILA RIVER BASIN

09432000 GILA RIVER BELOW BLUE CREEK, NEAR VIRDEN, MM--CONTINUED
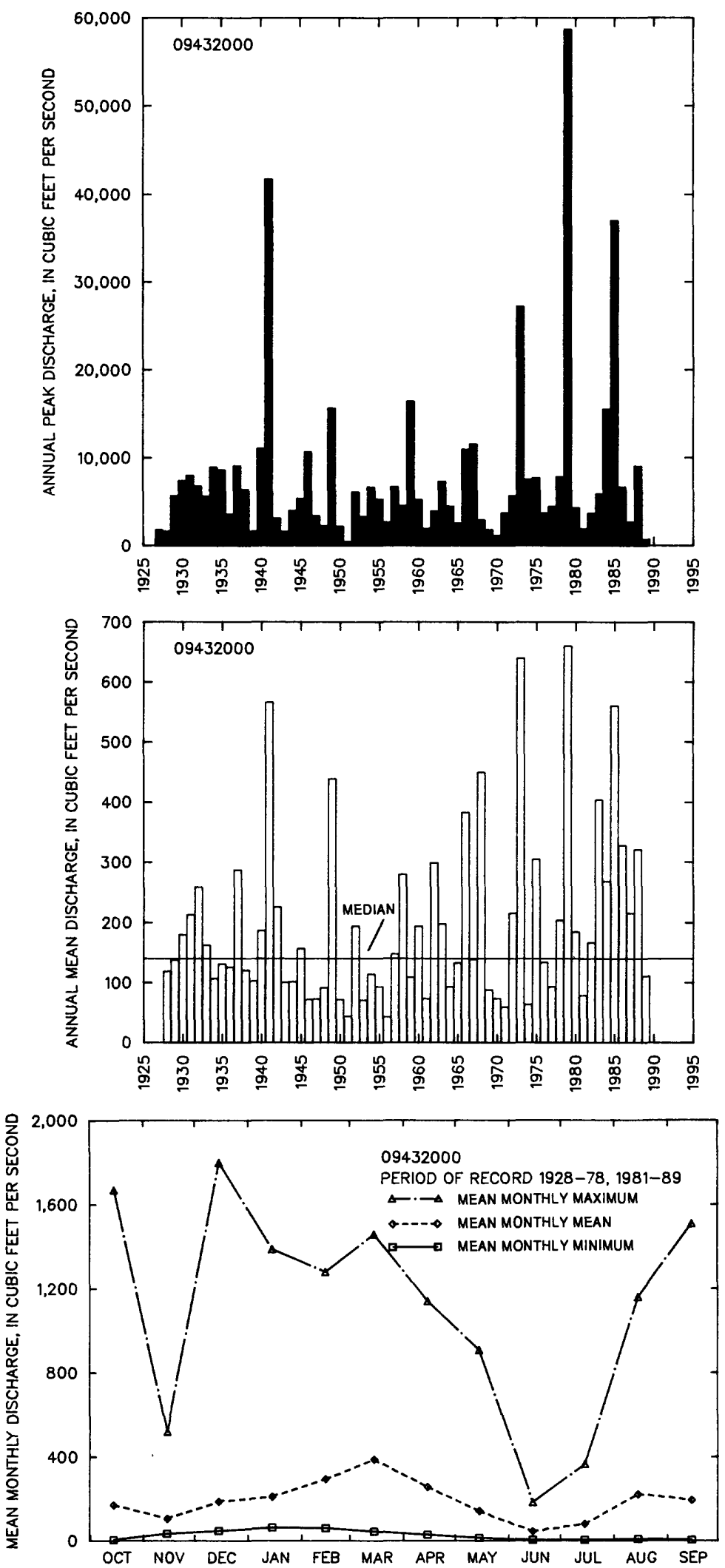
LOCATION.--Lat $32^{\circ} 57^{\prime} 57^{\prime \prime}$, Long 109*18'35", in NEKSEY sec.25, T.5 S., R.29 E., Greenlee County, Hydrologic Unit 15040002, on right bank $60 \mathrm{ft}$ upstream from bridge on county road, 6 mi upstream from San Francisco River, and 6 mi south of clifton.

DRAIMAGE AREA. $--4,010 \mathrm{mi}^{2}$.

REMARKS.--Diversions for irrigation of about 14,300 acres above station. Station is below all Duncan Valley diversions.

\section{ANNUAL PEAK DISCHARGE}

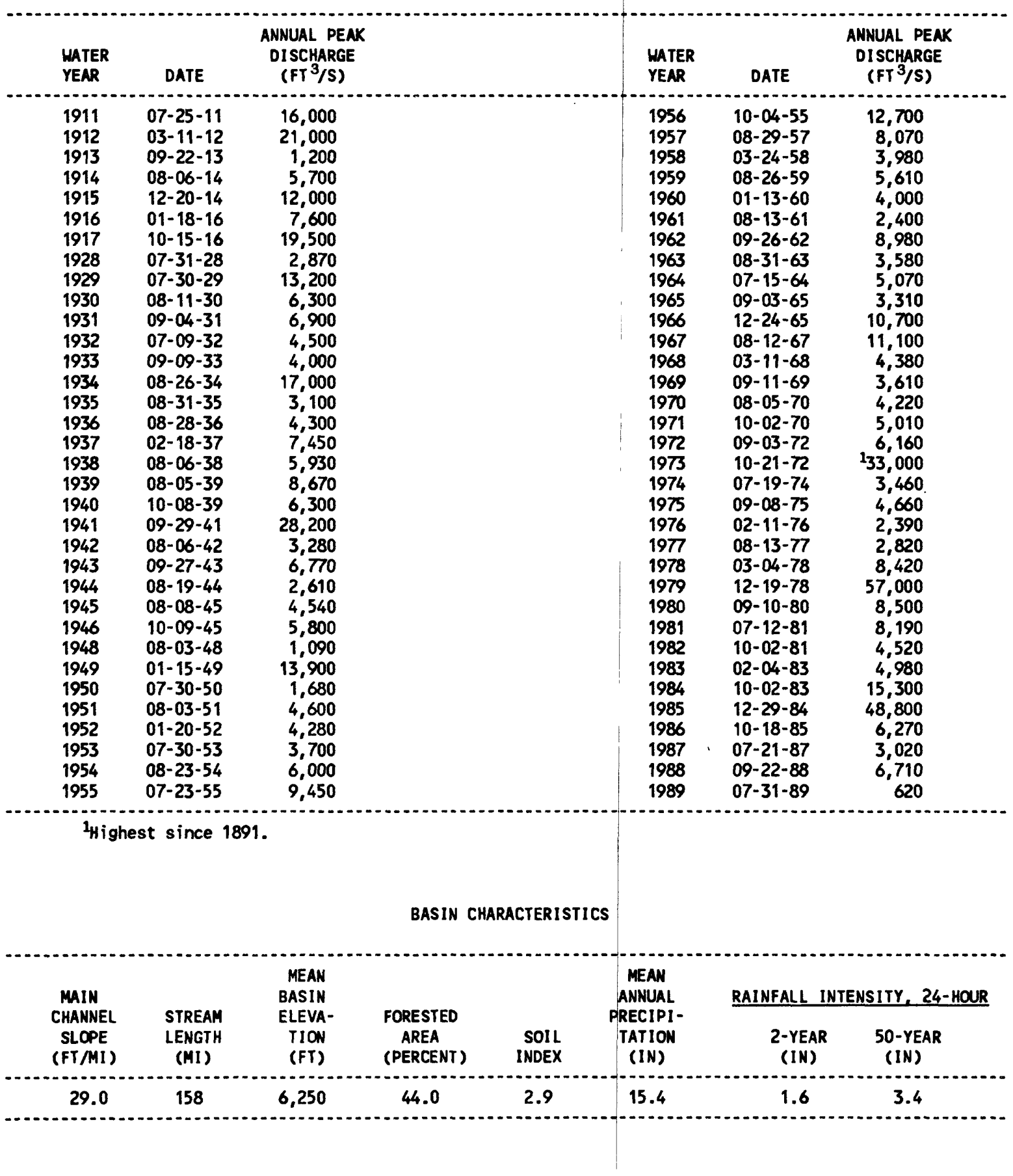


09442000 GILA RIVER NEAR CLIFTOW, AZ--Continued

MEAN MONTHLY AND ANMUAL DISCHARGES 1912-17, 1929-33, 1936-46, 1949-89 MAGNITUDE AND PROBABILITY OF ANNLAL LOW FLOW BASED ON PERIOD OF RECORD 1912-18, 1929-33, 1937-47, 1950-89

\begin{tabular}{|c|c|c|c|c|c|c|}
\hline MONTH & 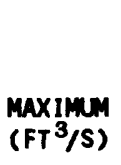 & $\begin{array}{l}\operatorname{MINIMUM} \\
\left(\mathrm{FT}^{3} / \mathrm{S}\right)\end{array}$ & $\begin{array}{c}\text { MEAN } \\
\left(\mathrm{FT}^{3} / \mathrm{S}\right)\end{array}$ & $\begin{array}{l}\text { STAN- } \\
\text { DARD } \\
\text { DEVIA- } \\
\text { TION } \\
\left(\text { FT }^{3} / S\right)\end{array}$ & $\begin{array}{l}\text { COEFFI - } \\
\text { CIENT OF } \\
\text { VARI- } \\
\text { ATION }\end{array}$ & $\begin{array}{c}\text { PERCENT } \\
\text { OF } \\
\text { ANMUAL } \\
\text { RUNOFF }\end{array}$ \\
\hline $\begin{array}{l}\text { OCTOBER } \\
\text { MOVEMBER } \\
\text { DECEMBER } \\
\text { JANUARY } \\
\text { FEBRUARY } \\
\text { MARCH } \\
\text { APRIL } \\
\text { MAY } \\
\text { JUNE } \\
\text { JULY } \\
\text { AUGUST } \\
\text { SEPTEMBER }\end{array}$ & $\begin{array}{r}1,750 \\
564 \\
2,390 \\
1,360 \\
1,670 \\
1,770 \\
1,690 \\
874 \\
171 \\
934 \\
898 \\
1,210\end{array}$ & $\begin{array}{c}8.7 \\
11 \\
17 \\
43 \\
24 \\
21 \\
12 \\
12 \\
9.4 \\
13 \\
17 \\
8.2\end{array}$ & $\begin{array}{r}194 \\
111 \\
237 \\
258 \\
324 \\
396 \\
249 \\
121 \\
41 \\
121 \\
234 \\
191\end{array}$ & $\begin{array}{r}336 \\
106 \\
458 \\
329 \\
367 \\
437 \\
303 \\
158 \\
38 \\
167 \\
217 \\
230\end{array}$ & $\begin{array}{l}1.7 \\
0.95 \\
1.9 \\
1.3 \\
1.1 \\
1.1 \\
1.2 \\
1.3 \\
0.93 \\
1.4 \\
0.93 \\
1.2\end{array}$ & $\begin{array}{r}7.8 \\
4.5 \\
9.6 \\
10.4 \\
13.1 \\
16.0 \\
10.0 \\
4.9 \\
1.7 \\
4.9 \\
9.4 \\
7.7\end{array}$ \\
\hline ANMUAL & 930 & 43 & 206 & 167 & 0.81 & 100 \\
\hline
\end{tabular}

\begin{tabular}{|c|c|c|c|c|c|c|}
\hline \multirow{2}{*}{$\begin{array}{l}\text { PERIOD } \\
\text { (CON- } \\
\text { SECU- } \\
\text { TIVE } \\
\text { DAYS) }\end{array}$} & \multicolumn{6}{|c|}{$\begin{array}{l}\text { DISCHARGE, IN FT }{ }^{3} / \mathrm{S} \text {, FOR INDICATED } \\
\text { RECURRENCE INTERVAL, IN YEARS, AND } \\
\text { NON-EXCEEDANCE PROBABILITY, IN PERCENT }\end{array}$} \\
\hline & $\stackrel{2}{20 \%}$ & $\begin{array}{c}5 \\
20 \%\end{array}$ & $\begin{array}{l}10 \\
10 \%\end{array}$ & $\begin{array}{l}20 \\
5 \%\end{array}$ & $\begin{array}{l}50 \\
2 \%\end{array}$ & $\begin{array}{l}100 \\
1 \%\end{array}$ \\
\hline $\begin{array}{r}1 \\
3 \\
7 \\
14 \\
30 \\
60 \\
90 \\
120 \\
183\end{array}$ & $\begin{array}{l}14 \\
15 \\
15 \\
17 \\
20 \\
26 \\
37 \\
53 \\
85\end{array}$ & $\begin{array}{l}8.9 \\
9.4 \\
10 \\
11 \\
13 \\
16 \\
21 \\
31 \\
50\end{array}$ & $\begin{array}{c}6.9 \\
7.4 \\
8.3 \\
9.2 \\
10 \\
12 \\
16 \\
23 \\
38\end{array}$ & $\begin{array}{c}5.5 \\
6.1 \\
7.0 \\
7.8 \\
8.8 \\
10 \\
12 \\
18 \\
30\end{array}$ & $\begin{array}{r}4.3 \\
4.8 \\
5.8 \\
6.4 \\
7.3 \\
8.2 \\
9.1 \\
14 \\
23\end{array}$ & $\begin{array}{r}3.6 \\
4.1 \\
5.1 \\
5.7 \\
6.4 \\
7.1 \\
7.5 \\
11 \\
20\end{array}$ \\
\hline
\end{tabular}

MAGNITUDE AND PROBABILITY OF INSTANTANEOUS PEAK FLOW BASED ON PERICD OF RECORD 1911-17, 1928-46, 1948-89

DISCHARGE, IN $\mathrm{FT}^{3} / \mathrm{S}$, FOR INDICATED RECURRENCE INTERVAL IN YEARS, AND EXCEEDANCE PROBABILITY, IN PERCENT

$\begin{array}{lccccc}2 & 5 & 10 & 25 & 50 & 100 \\ 50 \% & 20 \% & 10 \% & 4 \% & 2 \% & 1 \% \\ 5,940 & 11,500 & 16,800 & 26,100 & 35,400 & 47,000\end{array}$

MAGNITUDE AND PROBABILITY OF ANNUAL HIGH FLOW BASED ON PERIOD OF RECORD 1912-17, 1929-33, 1936-46, 1949-89

\begin{tabular}{|c|c|c|c|c|c|c|}
\hline \multirow{2}{*}{$\begin{array}{l}\text { PERIOD } \\
\text { (CON- } \\
\text { SECU- } \\
\text { TIVE } \\
\text { DAYS) }\end{array}$} & \multicolumn{6}{|c|}{$\begin{array}{l}\text { DISCHARGE, IN } \mathrm{FT}^{3} / \mathrm{S} \text {, FOR INDICATED } \\
\text { RECURRENCE INTERVAL, IN YEARS, AND } \\
\text { EXCEEDANCE PROBABILITY, IN PERCENT }\end{array}$} \\
\hline & $\stackrel{2}{50 \%}$ & $\begin{array}{c}5 \\
20 \%\end{array}$ & $\begin{array}{l}10 \\
10 x\end{array}$ & $\begin{array}{l}25 \\
4 \%\end{array}$ & $\begin{array}{l}50 \\
2 \%\end{array}$ & $\begin{array}{r}100 \\
1 \%\end{array}$ \\
\hline $\begin{array}{r}1 \\
3 \\
7 \\
15 \\
30 \\
60 \\
90\end{array}$ & $\begin{array}{r}2,680 \\
1,780 \\
1,190 \\
823 \\
586 \\
410 \\
325\end{array}$ & $\begin{array}{r}6,160 \\
4,050 \\
2,580 \\
1,700 \\
1,160 \\
819 \\
663\end{array}$ & $\begin{array}{r}9,830 \\
6,340 \\
3,920 \\
2,490 \\
1,640 \\
1,170 \\
968\end{array}$ & $\begin{array}{r}16,600 \\
10,400 \\
6,180 \\
3,730 \\
2,330 \\
1,700 \\
1,460\end{array}$ & $\begin{array}{r}23,500 \\
14,400 \\
8,330 \\
4,850 \\
2,910 \\
2,150 \\
1,900\end{array}$ & $\begin{array}{r}32,500 \\
19,500 \\
10,900 \\
6,130 \\
3,540 \\
2,660 \\
2,420\end{array}$ \\
\hline
\end{tabular}

DURATION TABLE OF DAILY MEAN FLON FOR PERIOD OF RECORD 1912-17, 1929-33, 1936-46, 1949-89

DISCHARGE, IN FT $3 / \mathrm{S}$, WHICH WAS EQUALED OR EXCEEDED FOR INDICATED PERCENT OF TIME

\begin{tabular}{|c|c|c|c|c|c|c|c|c|c|c|c|c|c|c|c|c|}
\hline $1 \%$ & $5 \%$ & $10 \%$ & $15 \%$ & $20 \%$ & $30 \%$ & $40 \%$ & $50 \%$ & $60 \%$ & $70 \%$ & $80 \%$ & $90 \%$ & $95 \%$ & $98 \%$ & $99 \%$ & $99.5 \%$ & $99.9 \%$ \\
\hline 2,010 & 818 & 455 & 313 & 230 & 146 & 103 & 80 & 62 & 44 & 28 & 18 & 13 & 10 & 9.0 & 8.3 & 6.5 \\
\hline
\end{tabular}


09442000 GILA RIVER NEAR CLIFTON, AZ--CONTINUEd
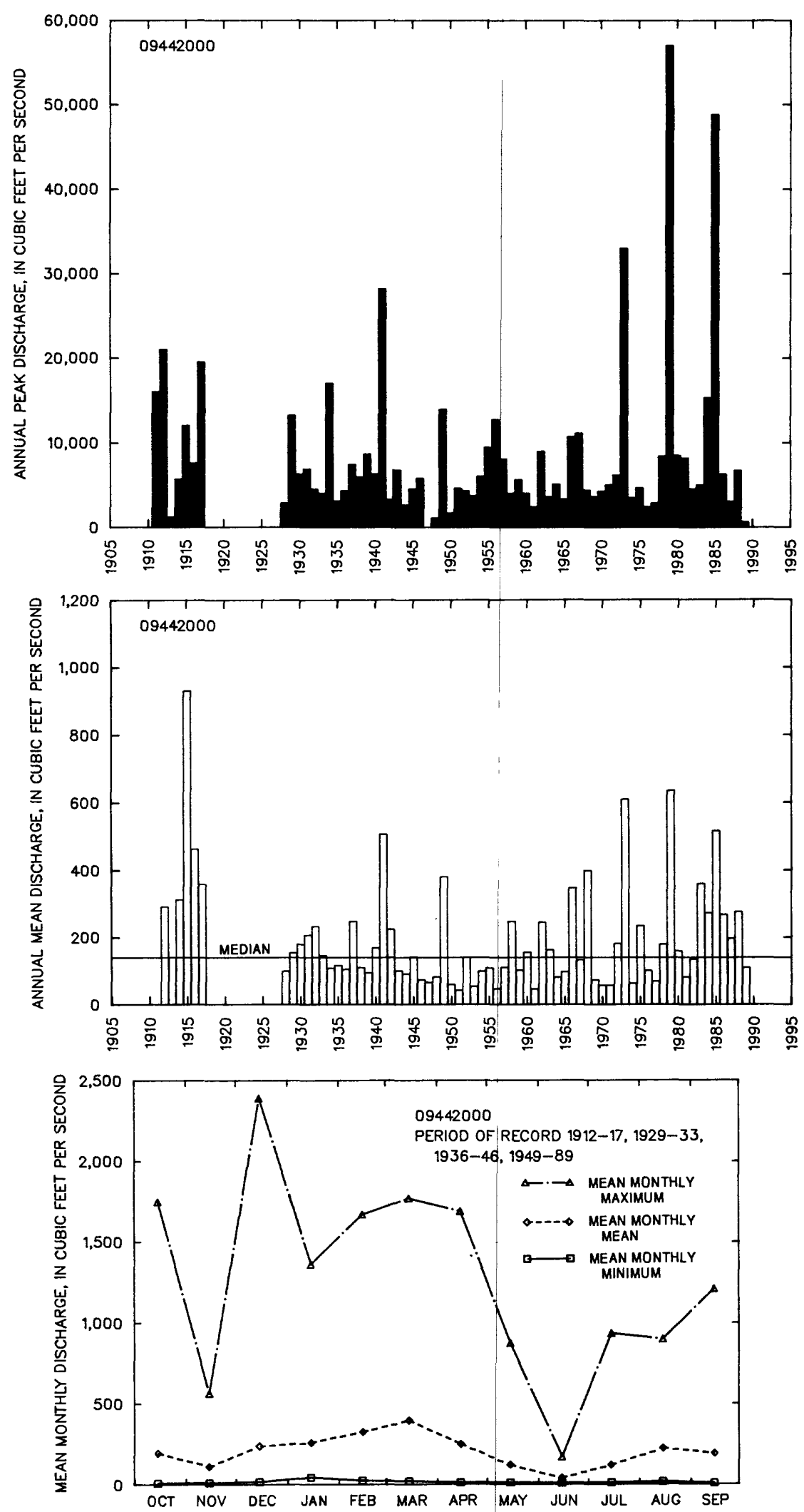
09444100 CAMPBELL BLUE CREEK NEAR ALPINE, AZ

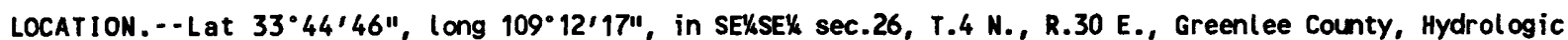
Unit 15040004, Apache National forest, $2.5 \mathrm{mi}$ upstream from Coleman Creek, and 8 mi southwest of Alpine.

DRAINAGE AREA. $--11.6 \mathrm{mi}^{2}$.

REMARKS.--Discharges furnished by U.S. Forest Service, Rocky Mountain Forest and Range Experimental Station.

ANNUAL PEAK DISCHARCE

\begin{tabular}{|c|c|c|c|c|c|}
\hline $\begin{array}{l}\text { WATER } \\
\text { YEAR }\end{array}$ & DATE & $\begin{array}{c}\text { ANNUAL PEAK } \\
\text { OISCHARGE } \\
\left(\mathrm{FT}^{3} / \mathrm{S}\right)\end{array}$ & $\begin{array}{l}\text { WATER } \\
\text { YEAR }\end{array}$ & DATE & $\begin{array}{c}\text { ANNUAL PEAK } \\
\text { OISCHARGE } \\
\left(\mathrm{FT}^{3} / \mathrm{S}\right)\end{array}$ \\
\hline $\begin{array}{l}1959 \\
1960 \\
1961 \\
1962 \\
1963 \\
1964 \\
1965 \\
1966 \\
1967 \\
1968 \\
1969 \\
1970 \\
1971 \\
1972 \\
1973 \\
1974\end{array}$ & $\begin{array}{l}10-13-58 \\
03-12-60 \\
08-23-61 \\
01-05-62 \\
08-25-63 \\
08-10-64 \\
01-07-65 \\
03-18-66 \\
07-31-67 \\
04-01-68 \\
03-28-69 \\
03-15-70 \\
09-08-71 \\
10-26-71 \\
10-20-72 \\
03-20-74\end{array}$ & $\begin{array}{c}8.2 \\
41 \\
32 \\
61 \\
132 \\
48 \\
33 \\
123 \\
17 \\
35 \\
37 \\
9.6 \\
3.3 \\
23 \\
342 \\
3.7\end{array}$ & $\begin{array}{l}1975 \\
1976 \\
1977 \\
1978 \\
1979 \\
1980 \\
1981 \\
1982 \\
1983 \\
1984 \\
1985 \\
1986 \\
1987 \\
1988 \\
1989\end{array}$ & $\begin{array}{l}03-08-75 \\
02-10-76 \\
04-08-77 \\
03-22-78 \\
12-18-78 \\
04-10-80 \\
08-01-81 \\
03-12-82 \\
03-31-83 \\
10-02-83 \\
03-12-85 \\
03-26-86 \\
11-18-86 \\
08-31-88 \\
03-08-89\end{array}$ & $\begin{array}{c}71 \\
13.6 \\
4.2 \\
58.5 \\
255 \\
53.3 \\
34 \\
43 \\
84 \\
619 \\
204 \\
29.9 \\
53.3 \\
54.3 \\
12.3\end{array}$ \\
\hline
\end{tabular}

MAGNITUDE ANO PROBABILITY OF INSTANTANEOUS PEAK FLOW BASED ON PERIOD OF RECORD 1959-89

OISCHARGE, IN $\mathrm{FT}^{3} / \mathrm{S}$, FOR INDICATED RECURRENCE INTERVAL IN YEARS, AND EXCEEDANCE PROBABILITY, IN PERCENT

\begin{tabular}{cccccc}
2 & 5 & 10 & 25 & 50 & $100 \%$ \\
$50 \%$ & $20 \%$ & $10 \%$ & $4 \%$ & $2 \%$ & $1 \%$ \\
42 & 108 & 181 & 321 & 470 & 667 \\
\hline WEIGHTED SKEH (LOGS) & & 0.24 & & \\
MEAN & (LOGS) & 1.64 & & \\
STANDARD DEV. (LOGS) & $=0.47$ &
\end{tabular}

$\uparrow$ Reliability of values in column is uncertain, and potential errors are large.

BASIN CHARACTERISTICS

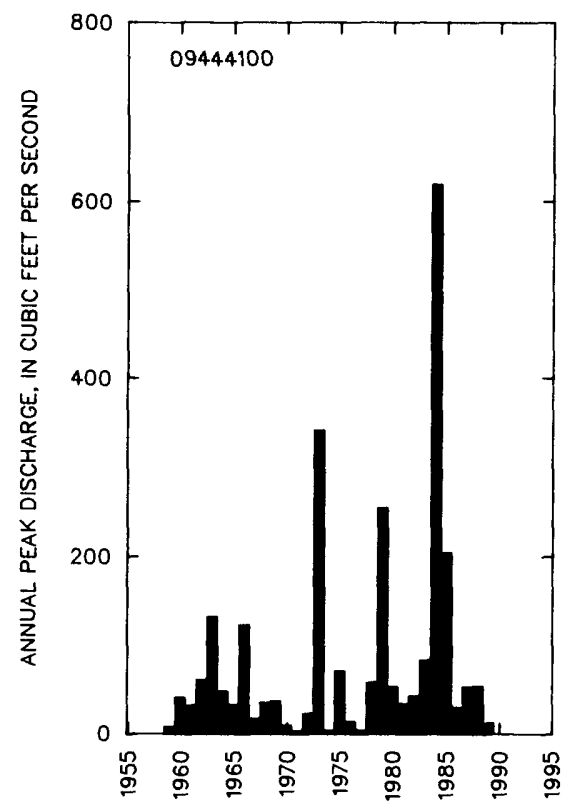

\begin{tabular}{|c|c|c|c|c|c|c|c|}
\hline \multirow{4}{*}{$\begin{array}{l}\text { MAIN } \\
\text { CHANNEL } \\
\text { SLOPE } \\
\text { (FT/MI) }\end{array}$} & \multirow{4}{*}{$\begin{array}{c}\text { STREAM } \\
\text { LENGTH } \\
\text { (MI) }\end{array}$} & \multirow{4}{*}{$\begin{array}{l}\text { MEAN } \\
\text { BASIN } \\
\text { ELEVA- } \\
\text { TION } \\
\text { (FT) }\end{array}$} & \multirow{4}{*}{$\begin{array}{l}\text { FORESTED } \\
\text { AREA } \\
\text { (PERCENT) }\end{array}$} & \multirow[b]{4}{*}{$\begin{array}{l}\text { SOIL } \\
\text { INDEX }\end{array}$} & \multirow{4}{*}{$\begin{array}{l}\text { MEAN } \\
\text { ANNUAL } \\
\text { PRECIPI- } \\
\text { TATION } \\
\text { (IN) }\end{array}$} & \multirow{2}{*}{\multicolumn{2}{|c|}{ RAINFALL INTENSITY, 24-HOUR }} \\
\hline & & & & & & & \\
\hline & & & & & & & \\
\hline & & & & & & $\begin{array}{c}\text { 2-YEAR } \\
\text { (IN) }\end{array}$ & $\begin{array}{l}\text { 50-YEAR } \\
\text { (IN) }\end{array}$ \\
\hline 90.2 & 8.9 & 8,300 & 91.0 & 3.0 & 20.0 & 2.2 & 4.0 \\
\hline
\end{tabular}


LOCATION.--Lat 33・17'27", long 109・11'44", in sec.6, T.2 S., R.31 E. (unsurveyed), Greenlee County, Hydrologic Unit 15040004, in Apache National Forest, on right bank $0.1 \mathrm{mi}$ downstream from county road crossing, $0.9 \mathrm{mi}$ upstream from Clear Creek, $8 \mathrm{mi}$ upstream from mouth, and $17 \mathrm{mi}$ northeast of $\mathrm{Clifton}$.

DRAIMAGE AREA. $--506 \mathrm{mi}^{2}$.

ANNUAL PEAK DISCHARGE

\begin{tabular}{|c|c|c|}
\hline $\begin{array}{l}\text { WATER } \\
\text { YEAR }\end{array}$ & DATE & $\begin{array}{c}\text { ANNUAL PEAK } \\
\text { DISCHARGE } \\
\left(\mathrm{FT}^{3} / \mathrm{S}\right)\end{array}$ \\
\hline $\begin{array}{l}1966 \\
1968 \\
1969 \\
1970 \\
1971 \\
1972 \\
1973 \\
1974 \\
1975 \\
1976 \\
1977 \\
1978 \\
1979 \\
1980 \\
1981 \\
1982 \\
1983 \\
1984 \\
1985 \\
1986 \\
1987 \\
1988 \\
1989\end{array}$ & $\begin{array}{l}12-30-65 \\
08-09-68 \\
08-07-69 \\
07-28-70 \\
10-03-70 \\
10-25-71 \\
10-20-72 \\
08-23-74 \\
09-08-75 \\
02-10-76 \\
08-19-77 \\
03-02-78 \\
11-24-78 \\
02-15-80 \\
08-07-81 \\
08-14-82 \\
07-27-83 \\
10-01-83 \\
12-28-84 \\
07-16-86 \\
07-30-87 \\
08-31-88 \\
09-22-89\end{array}$ & $\begin{array}{r}9,380 \\
6,290 \\
1,360 \\
1,180 \\
4,240 \\
2,520 \\
130,000 \\
2,380 \\
25,500 \\
2,550 \\
1,570 \\
3,660 \\
14,700 \\
5,570 \\
1,910 \\
2,620 \\
2,040 \\
24,300 \\
7,630 \\
2,040 \\
2,910 \\
6,410 \\
1,380\end{array}$ \\
\hline
\end{tabular}

BASIN CHARACTERISTICS

\begin{tabular}{|c|c|c|c|c|c|c|c|}
\hline MAIN & & $\begin{array}{l}\text { MEAN } \\
\text { BASIN }\end{array}$ & & & & RAINFALL I & SITY, 24-HOUR \\
\hline $\begin{array}{l}\text { CHANNEL } \\
\text { SLOPE } \\
\text { (FT/MI) }\end{array}$ & $\begin{array}{c}\text { STREAM } \\
\text { LENGTH } \\
\text { (MI) }\end{array}$ & $\begin{array}{l}\text { ELEVA- } \\
\text { TION } \\
\text { (FI) }\end{array}$ & $\begin{array}{l}\text { FORESTED } \\
\text { AREA } \\
\text { (PERCENT) }\end{array}$ & $\begin{array}{l}\text { SOIL } \\
\text { INDEX }\end{array}$ & $\begin{array}{l}\text { PRECIPI - } \\
\text { TATION } \\
\text { (IN) }\end{array}$ & $\begin{array}{c}\text { 2-YEAR } \\
\text { (IN) }\end{array}$ & $\begin{array}{l}\text { 50-YEAR } \\
\text { (IN) }\end{array}$ \\
\hline 65.3 & 40.8 & 6,910 & 85.0 & 3.0 & 20.7 & 1.8 & 3.6 \\
\hline
\end{tabular}


09444200 BLUE RIVER NEAR CLIFTON, AZ--Continued

MEAN MONTHLY AND ANNUAL DISCHARGES 1969-89

\begin{tabular}{|c|c|c|c|c|c|c|}
\hline MONTH & $\begin{array}{l}\operatorname{MAX} \operatorname{IIMN}_{3} \\
\left(\mathrm{FT}^{3} / \mathrm{S}\right)\end{array}$ & $\begin{array}{l}\text { MINIMUM } \\
\left(\mathrm{FT}^{3} / \mathrm{S}\right)\end{array}$ & $\begin{array}{c}\text { MEAN } \\
\left(F T^{3} / S\right)\end{array}$ & $\begin{array}{l}\text { STAN- } \\
\text { DARD } \\
\text { DEVIA- } \\
\text { TION } \\
\text { (FT } 3 / S)\end{array}$ & $\begin{array}{l}\text { COEFF 1- } \\
\text { CIENT OF } \\
\text { VARI - } \\
\text { ATION }\end{array}$ & $\begin{array}{c}\text { PERCENT } \\
\text { OF } \\
\text { ANNUAL } \\
\text { RUNOFF }\end{array}$ \\
\hline $\begin{array}{l}\text { OCTOBER } \\
\text { NOVEMBER } \\
\text { DECEMBER } \\
\text { JANUARY } \\
\text { FEBRUARY } \\
\text { MARCH } \\
\text { APRIL } \\
\text { MAY } \\
\text { JUNE } \\
\text { JULY } \\
\text { AUGUST } \\
\text { SEPTEMBER }\end{array}$ & $\begin{array}{r}1,030 \\
443 \\
616 \\
569 \\
707 \\
584 \\
488 \\
338 \\
46 \\
71 \\
108 \\
366\end{array}$ & $\begin{array}{l}2.6 \\
3.9 \\
3.7 \\
5.4 \\
8.0 \\
8.9 \\
6.7 \\
4.9 \\
2.9 \\
7.6 \\
8.7 \\
7.4\end{array}$ & $\begin{array}{r}108 \\
47 \\
89 \\
74 \\
124 \\
171 \\
132 \\
63 \\
13 \\
25 \\
37 \\
48\end{array}$ & $\begin{array}{r}260 \\
95 \\
161 \\
128 \\
172 \\
182 \\
150 \\
82 \\
12 \\
17 \\
23 \\
82\end{array}$ & $\begin{array}{l}2.4 \\
2.0 \\
1.8 \\
1.7 \\
1.4 \\
1.1 \\
1.1 \\
1.3 \\
0.91 \\
0.67 \\
0.63 \\
1.7\end{array}$ & $\begin{array}{r}11.6 \\
5.1 \\
9.5 \\
7.9 \\
13.3 \\
18.3 \\
14.2 \\
6.7 \\
1.4 \\
2.7 \\
4.0 \\
5.2\end{array}$ \\
\hline ANNUAL & 243 & 10 & 78 & 74 & 0.95 & 100 \\
\hline
\end{tabular}

MAGNITUDE AND PROBABILITY OF INSTANTANEOUS PEAK FLOW BASED ON PERIOD OF RECORD 1966, 1968-89

DISCHARGE, IN $\mathrm{FT}^{3} / \mathrm{S}$, FOR INDICATED RECURRENCE INTERVAL IN YEARS, AND EXCEEDANCE PROBABILITY, IN PERCENT

\begin{tabular}{lccccc}
2 & 5 & 10 & 25 & $50 \dagger$ & $100 \dagger$ \\
$50 \%$ & $20 \%$ & $10 \%$ & $4 \%$ & $2 \%$ & $1 \%$ \\
4,000 & 9,760 & 15,800 & 26,800 & 38,000 & 52,300 \\
\hline WEIGHTED SKEW (LOGS) & & 0.17 & & \\
MEAN & (LOGS) & 3.61 \\
STANDARD DEV. (LOGS) & $=0.45$
\end{tabular}

MAGNITUDE AND PROBABILITY OF ANNUAL LOW FLOH BASED ON PERIOD OF RECORD 1969-89

\begin{tabular}{|c|c|c|c|c|c|c|}
\hline \multirow{2}{*}{$\begin{array}{l}\text { PERIOD } \\
\text { (CON- } \\
\text { SECU- } \\
\text { TIVE } \\
\text { DAYS) }\end{array}$} & \multicolumn{6}{|c|}{$\begin{array}{l}\text { DISCHARGE, IN } \mathrm{FT}^{3} / \mathrm{S} \text {, FOR INDICATED } \\
\text { RECURRENCE INTERVAL, IN YEARS, AND } \\
\text { NON-EXCEEDANCE PROBABILITY, IN PERCENT }\end{array}$} \\
\hline & $\begin{array}{c}2 \\
50 \%\end{array}$ & $\begin{array}{c}5 \\
20 \%\end{array}$ & $\begin{array}{l}10 \\
10 x\end{array}$ & $\begin{array}{l}20 \\
5 \%\end{array}$ & $\begin{array}{l}50 \dagger \\
2 \%\end{array}$ & $\begin{array}{l}100 \dagger \\
1 \%\end{array}$ \\
\hline $\begin{array}{r}1 \\
3 \\
7 \\
14 \\
30 \\
60 \\
90 \\
120 \\
183\end{array}$ & $\begin{array}{c}3.5 \\
3.6 \\
3.9 \\
4.4 \\
5.3 \\
7.4 \\
10 \\
13 \\
17\end{array}$ & $\begin{array}{r}2.3 \\
2.3 \\
2.6 \\
3.0 \\
3.6 \\
5.0 \\
6.3 \\
7.9 \\
11\end{array}$ & $\begin{array}{l}1.8 \\
1.8 \\
2.1 \\
2.4 \\
3.0 \\
4.2 \\
5.0 \\
6.0 \\
9.4\end{array}$ & $\begin{array}{l}1.5 \\
1.5 \\
1.8 \\
2.1 \\
2.6 \\
3.7 \\
4.2 \\
4.8 \\
8.6\end{array}$ & $\begin{array}{l}1.2 \\
1.2 \\
1.5 \\
1.7 \\
2.2 \\
3.3 \\
3.5 \\
3.8 \\
8.0\end{array}$ & $\begin{array}{l}1.1 \\
1.1 \\
1.3 \\
1.5 \\
2.0 \\
3.1 \\
3.1 \\
3.2 \\
7.8\end{array}$ \\
\hline
\end{tabular}

MAGNITUDE AND PROBABILITY OF ANNUAL HIGH FLOW BASED ON PERIOD OF RECORD $1969-89$

\begin{tabular}{|c|c|c|c|c|c|c|}
\hline \multirow{2}{*}{$\begin{array}{l}\text { PERIOD } \\
\text { (CON- } \\
\text { SECU- } \\
\text { TIVE } \\
\text { DAYS) }\end{array}$} & & \multicolumn{5}{|c|}{$\begin{array}{l}\text { DISCHARGE, IN } \mathrm{FT}^{3} / \mathrm{S} \text {, FOR INDICATED } \\
\text { RECURRENCE INTERVAL, IN YEARS, AND } \\
\text { EXCEEDANCE PROBABILITY, IN PERCENT }\end{array}$} \\
\hline & $\begin{array}{c}2 \\
50 \%\end{array}$ & $\begin{array}{c}5 \\
20 \%\end{array}$ & $\begin{array}{l}10 \\
10 \%\end{array}$ & $\begin{array}{l}25 \\
4 \%\end{array}$ & $\begin{array}{l}50 \dagger \\
2 \%\end{array}$ & $\begin{array}{c}100 \dagger \\
1 \%\end{array}$ \\
\hline $\begin{array}{r}1 \\
3 \\
7 \\
15 \\
30 \\
60 \\
90\end{array}$ & $\begin{array}{l}918 \\
564 \\
370 \\
255 \\
176 \\
126 \\
107\end{array}$ & $\begin{array}{r}3,460 \\
2,090 \\
1,240 \\
754 \\
483 \\
330 \\
278\end{array}$ & $\begin{array}{r}7,050 \\
4,230 \\
2,330 \\
1,320 \\
816 \\
545 \\
457\end{array}$ & $\begin{array}{r}15,300 \\
9,100 \\
4,580 \\
2,380 \\
1,420 \\
931 \\
774\end{array}$ & $\begin{array}{r}25,400 \\
15,000 \\
7,100 \\
3,470 \\
2,040 \\
1,320 \\
1,090\end{array}$ & $\begin{array}{r}40,400 \\
23,800 \\
10,500 \\
4,860 \\
2,810 \\
1,790 \\
1,470\end{array}$ \\
\hline
\end{tabular}

DURATION TABLE OF DAILY MEAN FLOW FOR PERIOD OF RECORD 1969-89 DISCHARGE, IN FT $3 / \mathrm{S}$, HHICH WAS EQUALED OR EXCEEDED FOR INDICATED PERCENT OF TIME

\begin{tabular}{|c|c|c|c|c|c|c|c|c|c|c|c|c|c|c|c|c|}
\hline $1 \%$ & $5 \%$ & $10 \%$ & $15 \%$ & $20 \%$ & $30 x$ & $40 \%$ & $50 \%$ & $60 \%$ & $70 x$ & $80 \%$ & $90 x$ & $95 \%$ & $98 \%$ & $99 \%$ & $99.5 \%$ & $99.9 \%$ \\
\hline 713 & 334 & 182 & 108 & 74 & 44 & 31 & 22 & 15 & 11 & 8.0 & 5.3 & 4.0 & 3.2 & 2.7 & 2.4 & 1.8 \\
\hline
\end{tabular}

f Reliability of values in colum is uncertain, and potential errors are large. 
09444200 BLUE RIVER NEAR CLIfTON, AZ--CONTImued
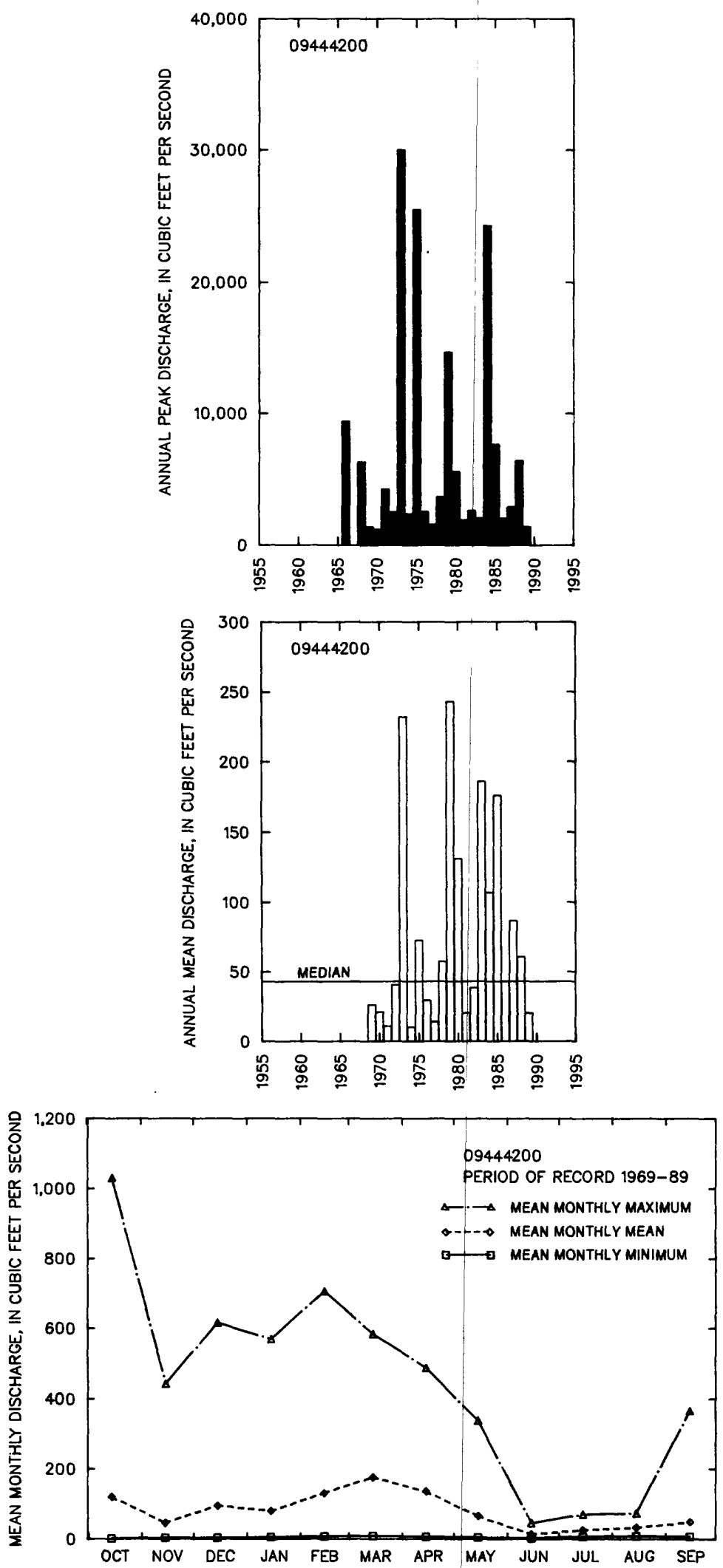
09444400 CHASE CREEK NEAR CLIFTON, AZ

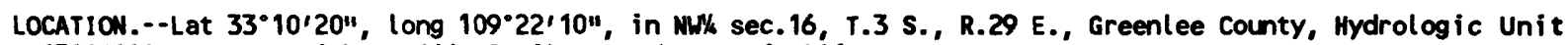
15040004 , at U.S. Highway 666,9 miles northwest of Clifton.

DRAINAGE AREA. $--1.37 \mathrm{mi}^{2}$.

ANNUAL PEAK DISCHARGE

\begin{tabular}{cccc}
$\begin{array}{c}\text { WATER } \\
\text { YEAR }\end{array}$ & DATE & $\begin{array}{c}\text { ANNUAL PEAK } \\
\text { DISCHARGE } \\
\text { (FT } 3 / \text { S) }\end{array}$ & $\begin{array}{c}\text { DISCHARGE } \\
\text { CODES }\end{array}$ \\
\hline 1964 & $07-25-64$ & 600 & ES \\
1965 & $00-00-65$ & 0 & \\
1966 & $12-22-65$ & 29 & \\
1967 & $08-12-67$ & 400 & \\
1968 & $00-00-68$ & 1.0 & ES \\
1969 & $00-00-69$ & 0 & \\
1970 & $08-06-70$ & 1.0 & LT \\
1971 & $00-00-71$ & 0 & \\
1972 & $00-00-72$ & 0 & \\
1973 & $10-19-72$ & 150 & \\
1974 & $00-00-74$ & 0 & \\
1975 & $09-09-75$ & 22 & HT \\
1976 & $00-00-76$ & 10 & \\
1979 & $12-18-78$ & 172.0 & \\
$\ldots$
\end{tabular}

$\mathbf{1}_{\text {Highest since } 1973 .}$

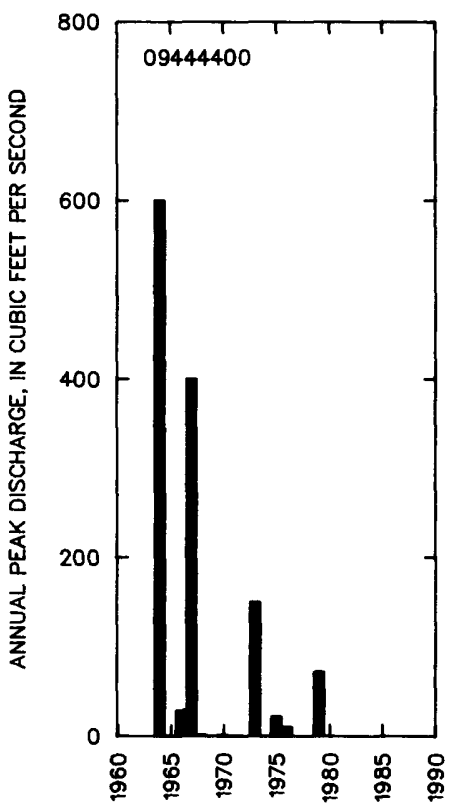

MAGNITUDE AND PROBABILITY OF INSTANTANEOUS PEAK FLOW BASED ON PERIOD OF RECORD

DISCHARGE, IN $\mathrm{FT}^{3} / \mathrm{S}$, FOR INDICATED RECURRENCE INTERVAL

IN YEARS, AND EXCEEDANCE PROBABILITY, IN PERCENT

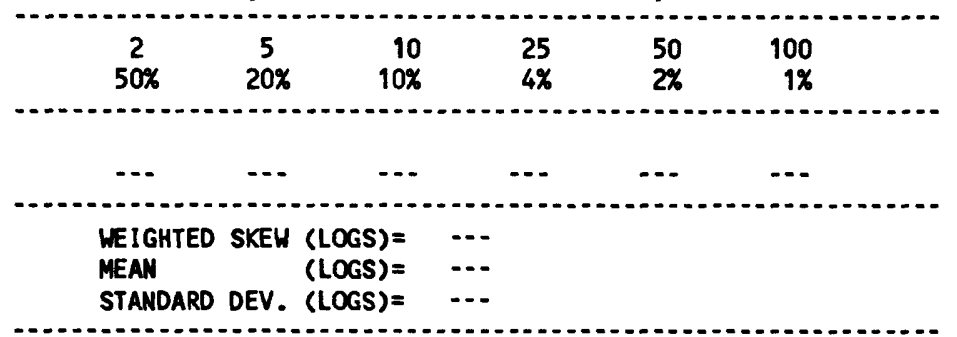

BASIN CHARACTERISTICS

\begin{tabular}{|c|c|c|c|c|c|c|c|}
\hline \multirow{2}{*}{$\begin{array}{l}\text { MAIN } \\
\text { CHANNEL } \\
\text { SLOPE } \\
\text { (FT/MI) }\end{array}$} & \multirow[b]{2}{*}{$\begin{array}{l}\text { STREAM } \\
\text { LENGTH } \\
\text { (MI) }\end{array}$} & \multirow{2}{*}{$\begin{array}{l}\text { MEAN } \\
\text { BASIN } \\
\text { ELEVA- } \\
\text { TION } \\
\text { (FT) }\end{array}$} & \multirow[b]{2}{*}{$\begin{array}{l}\text { FORESTED } \\
\text { AREA } \\
\text { (PERCENT) }\end{array}$} & \multirow[b]{2}{*}{$\begin{array}{l}\text { SOIL } \\
\text { INDEX }\end{array}$} & \multirow{2}{*}{$\begin{array}{c}\text { MEAN } \\
\text { ANNUAL } \\
\text { PRECIPI- } \\
\text { TATION } \\
\text { (IN) }\end{array}$} & \multicolumn{2}{|c|}{ RAINFALL INTENSITY, 24-HOQR } \\
\hline & & & & & & $\begin{array}{l}\text { 2-YEAR } \\
\text { (IN) }\end{array}$ & $\begin{array}{c}\text { 50-YEAR } \\
\text { (IN) }\end{array}$ \\
\hline 363 & 2.5 & 6,840 & 98.0 & 1.0 & 20.0 & 2.2 & 4.0 \\
\hline
\end{tabular}




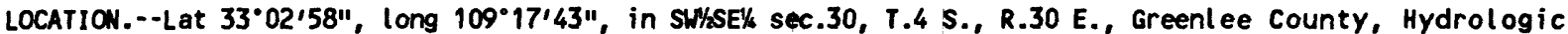
Unit 15040004, on downstream side of $r$ ight pier at Railroad Boulevard Bridge (U.S. Highway 666 ), at Clifton, $9.9 \mathrm{mi}$ upstream from mouth.

DRAINAGE AREA. - -2,765 $\mathrm{mi}^{2}$, of which $2.01 \mathrm{mi}^{2}$ is noncontributing. REMARKS.--Diversions for mining, municipal use, and for irrigation of about 2,700 acres above station.

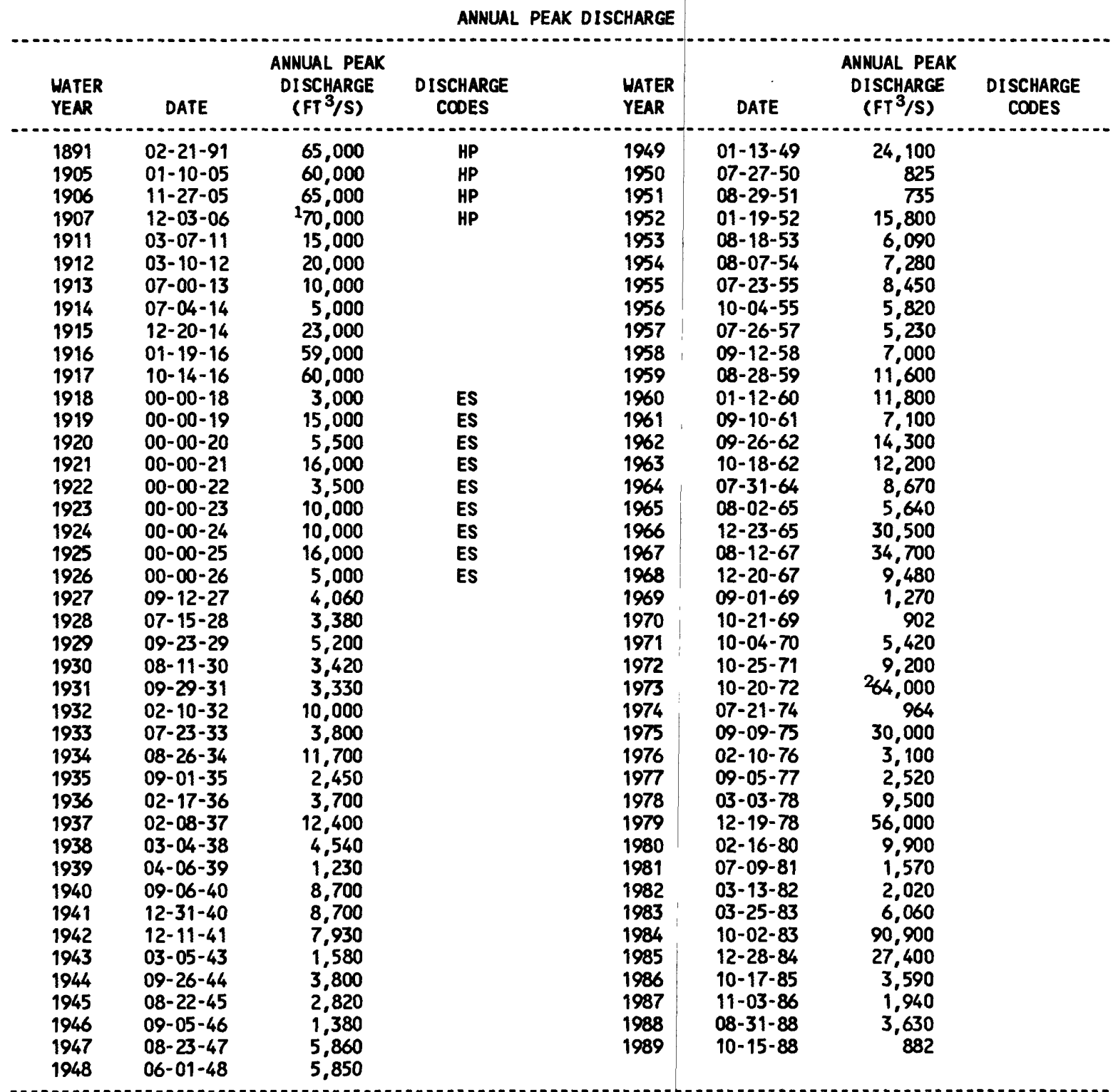

1 Highest since 1870 .

$2 \mathrm{Highest}$ since 1907 .

BASIN CHARACTERISTICS

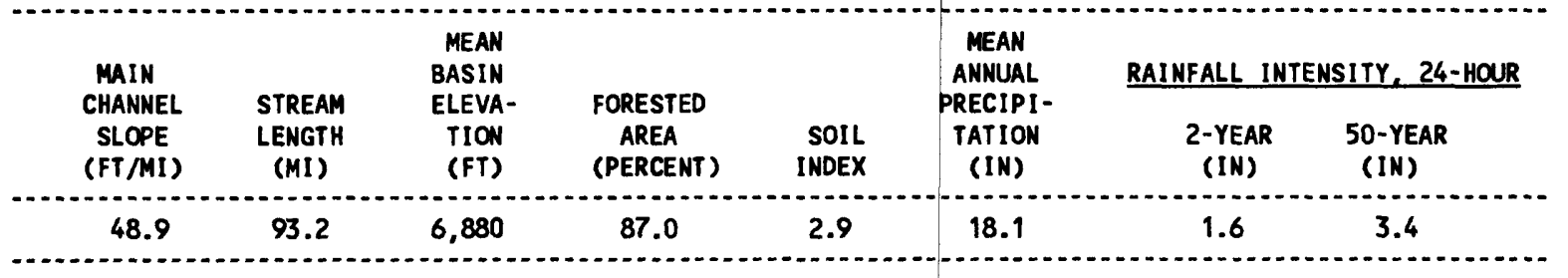




\begin{tabular}{|c|c|c|c|c|c|c|}
\hline MONTH & $\begin{array}{l}\operatorname{MAX} \operatorname{IMMN}_{(\mathrm{M}} \\
\left(\mathrm{FT}^{3} / \mathrm{S}\right)\end{array}$ & $\begin{array}{l}\text { MININUN } \\
\left(F T^{3} / S\right)\end{array}$ & $\begin{array}{c}\text { MEAN } \\
\left(F T^{3} / S\right)\end{array}$ & $\begin{array}{l}\text { STAN- } \\
\text { DARD } \\
\text { DEVIA- } \\
\text { TION } \\
\text { (FT3/S) }\end{array}$ & $\begin{array}{l}\text { COEFFI - } \\
\text { CIENT OF } \\
\text { VARI - } \\
\text { ATION }\end{array}$ & $\begin{array}{c}\text { PERCENT } \\
\text { OF } \\
\text { ANNUAL } \\
\text { RUNOFF }\end{array}$ \\
\hline $\begin{array}{l}\text { OCTOBER } \\
\text { NOVEMBER } \\
\text { DECEMBER } \\
\text { JANUARY } \\
\text { FEBRUARY } \\
\text { MARCH } \\
\text { APRIL } \\
\text { MAY } \\
\text { JUNE } \\
\text { JULY } \\
\text { AUGUST } \\
\text { SEPTEMBER }\end{array}$ & $\begin{array}{r}4,290 \\
1,450 \\
2,450 \\
1,590 \\
1,630 \\
2,140 \\
2,250 \\
1,240 \\
178 \\
657 \\
1,360 \\
816\end{array}$ & $\begin{array}{l}23 \\
28 \\
34 \\
37 \\
39 \\
44 \\
36 \\
24 \\
11 \\
29 \\
41 \\
22\end{array}$ & $\begin{array}{l}246 \\
116 \\
255 \\
240 \\
314 \\
418 \\
328 \\
155 \\
53 \\
107 \\
204 \\
149\end{array}$ & $\begin{array}{r}656 \\
183 \\
501 \\
357 \\
403 \\
480 \\
417 \\
201 \\
36 \\
100 \\
210 \\
145\end{array}$ & $\begin{array}{l}2.7 \\
1.6 \\
2.0 \\
1.5 \\
1.3 \\
1.2 \\
1.3 \\
1.3 \\
0.68 \\
0.93 \\
1.0 \\
0.98\end{array}$ & $\begin{array}{r}9.5 \\
4.5 \\
9.9 \\
9.3 \\
12.2 \\
16.2 \\
12.7 \\
6.0 \\
2.1 \\
4.1 \\
7.9 \\
5.8\end{array}$ \\
\hline ANNUAL & 937 & 42 & 215 & 190 & 0.88 & 100 \\
\hline
\end{tabular}

\begin{tabular}{|c|c|c|c|c|c|c|}
\hline \multirow{2}{*}{$\begin{array}{c}\text { PERIOD } \\
\text { (CON- }- \\
\text { SECU- } \\
\text { TIVE } \\
\text { DAYS) }\end{array}$} & \multicolumn{6}{|c|}{$\begin{array}{l}\text { DISCHARGE, IN FT } 3 / S \text {, FOR INDICATED } \\
\text { RECURRENCE INTERVAL, IN YEARS, AND } \\
\text { NON-EXCEEDANCE PROBABILITY, IN PERCENT }\end{array}$} \\
\hline & $\begin{array}{c}2 \\
50 \%\end{array}$ & $\begin{array}{c}5 \\
20 \%\end{array}$ & $\begin{array}{l}10 \\
10 \%\end{array}$ & $\begin{array}{l}20 \\
5 \%\end{array}$ & $\begin{array}{l}50 \\
2 \%\end{array}$ & $\begin{array}{l}100 \\
1 \%\end{array}$ \\
\hline $\begin{array}{r}1 \\
3 \\
7 \\
14 \\
30 \\
60 \\
90 \\
120 \\
183\end{array}$ & $\begin{array}{l}21 \\
22 \\
24 \\
27 \\
32 \\
40 \\
49 \\
57 \\
75\end{array}$ & $\begin{array}{l}14 \\
15 \\
17 \\
19 \\
23 \\
28 \\
34 \\
41 \\
51\end{array}$ & $\begin{array}{l}11 \\
12 \\
14 \\
16 \\
19 \\
24 \\
29 \\
35 \\
44\end{array}$ & $\begin{array}{l}9.3 \\
11 \\
12 \\
14 \\
16 \\
20 \\
25 \\
32 \\
39\end{array}$ & $\begin{array}{l}7.6 \\
8.8 \\
10 \\
12 \\
14 \\
17 \\
22 \\
28 \\
35\end{array}$ & $\begin{array}{c}6.6 \\
7.8 \\
9.0 \\
10 \\
12 \\
16 \\
20 \\
27 \\
33\end{array}$ \\
\hline
\end{tabular}

MAGNITLDE AND PROBABILITY OF ANNUAL HIGH FLOW BASED ON PERIOD OF RECORD 1914-15, 1917, 1928-33, 1936-89

\begin{tabular}{|c|c|c|c|c|c|c|}
\hline \multirow{2}{*}{$\begin{array}{l}\text { PERIOD } \\
\text { (CON- } \\
\text { SECU- } \\
\text { TIVE } \\
\text { DAYS) }\end{array}$} & \multicolumn{6}{|c|}{$\begin{array}{l}\text { DISCHARGE, IN FT } 3 / S \text {, FOR INDICATED } \\
\text { RECURRENCE INTERVAL, IN YEARS, AND } \\
\text { EXCEEDANCE PROBABILITY, IN PERCENT }\end{array}$} \\
\hline & $\stackrel{2}{2}$ & $\begin{array}{c}5 \\
20 \%\end{array}$ & $\begin{array}{l}10 \\
10 \%\end{array}$ & $\begin{array}{l}25 \\
4 \%\end{array}$ & $\begin{array}{l}50 \\
2 \%\end{array}$ & $\begin{array}{r}100 \\
1 \%\end{array}$ \\
\hline $\begin{array}{r}1 \\
3 \\
7 \\
15 \\
30 \\
60 \\
90\end{array}$ & $\begin{array}{r}2,480 \\
1,620 \\
1,070 \\
728 \\
522 \\
376 \\
303\end{array}$ & $\begin{array}{r}7,600 \\
4,700 \\
2,850 \\
1,840 \\
1,240 \\
857 \\
699\end{array}$ & $\begin{array}{r}14,100 \\
8,480 \\
4,910 \\
3,050 \\
1,970 \\
1,340 \\
1,100\end{array}$ & $\begin{array}{r}27,900 \\
16,300 \\
8,990 \\
5,340 \\
3,300 \\
2,170 \\
1,820\end{array}$ & $\begin{array}{r}44,100 \\
25,200 \\
13,500 \\
7,750 \\
4,620 \\
2,980 \\
2,540\end{array}$ & $\begin{array}{r}67, \\
37, \\
19, \\
10, \\
6,3 \\
3,5 \\
3,4\end{array}$ \\
\hline
\end{tabular}

DURATION TABLE OF DAILY MEAN FLOW FOR PERIOD OF RECORD 1914-15, 1917, 1928-33, 1936-89

DISCHARGE, IN FT $3 / 5$, WHICH WAS EQUALED OR EXCEEDED FOR INDICATED PERCENT OF TIME

\begin{tabular}{|c|c|c|c|c|c|c|c|c|c|c|c|c|c|c|c|c|}
\hline $1 \%$ & $5 \%$ & $10 \%$ & $15 \%$ & $20 \%$ & $30 \%$ & $40 \%$ & $50 \%$ & $60 \%$ & $70 \%$ & $80 \%$ & $90 \%$ & $95 \%$ & $98 \%$ & $99 \%$ & $99.5 \%$ & $99.9 \%$ \\
\hline 2,120 & 771 & 417 & 278 & 208 & 136 & 98 & 76 & 63 & 54 & 45 & 34 & 27 & 20 & 18 & 15 & 10 \\
\hline
\end{tabular}


09444500 SAN FRANCISCO RIVER AT CLIFTON, AZ--CONTINUED
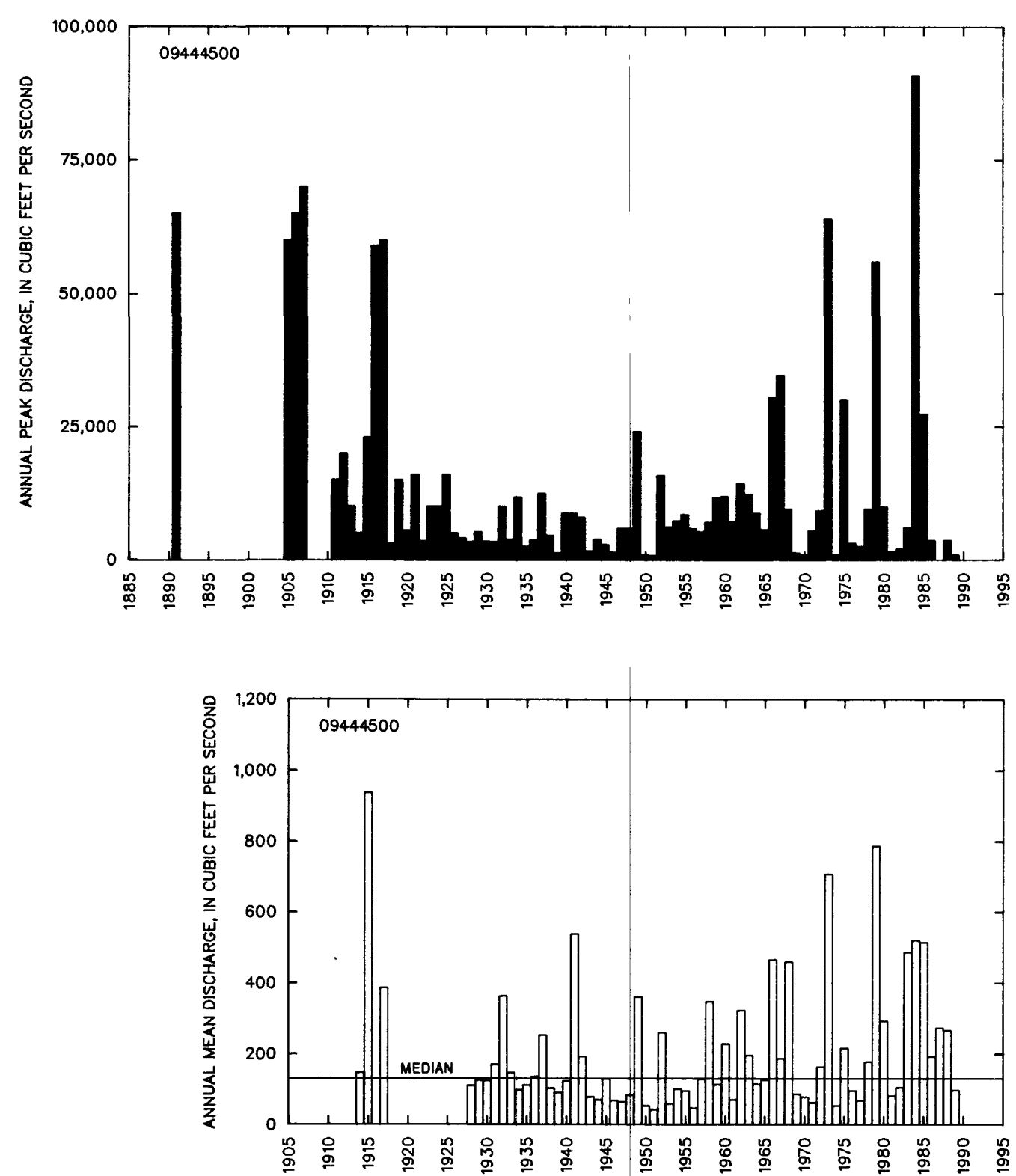
09444500 SAN FRANCISCO RIVER AT CLIFTON, AZ--CONTIMUED
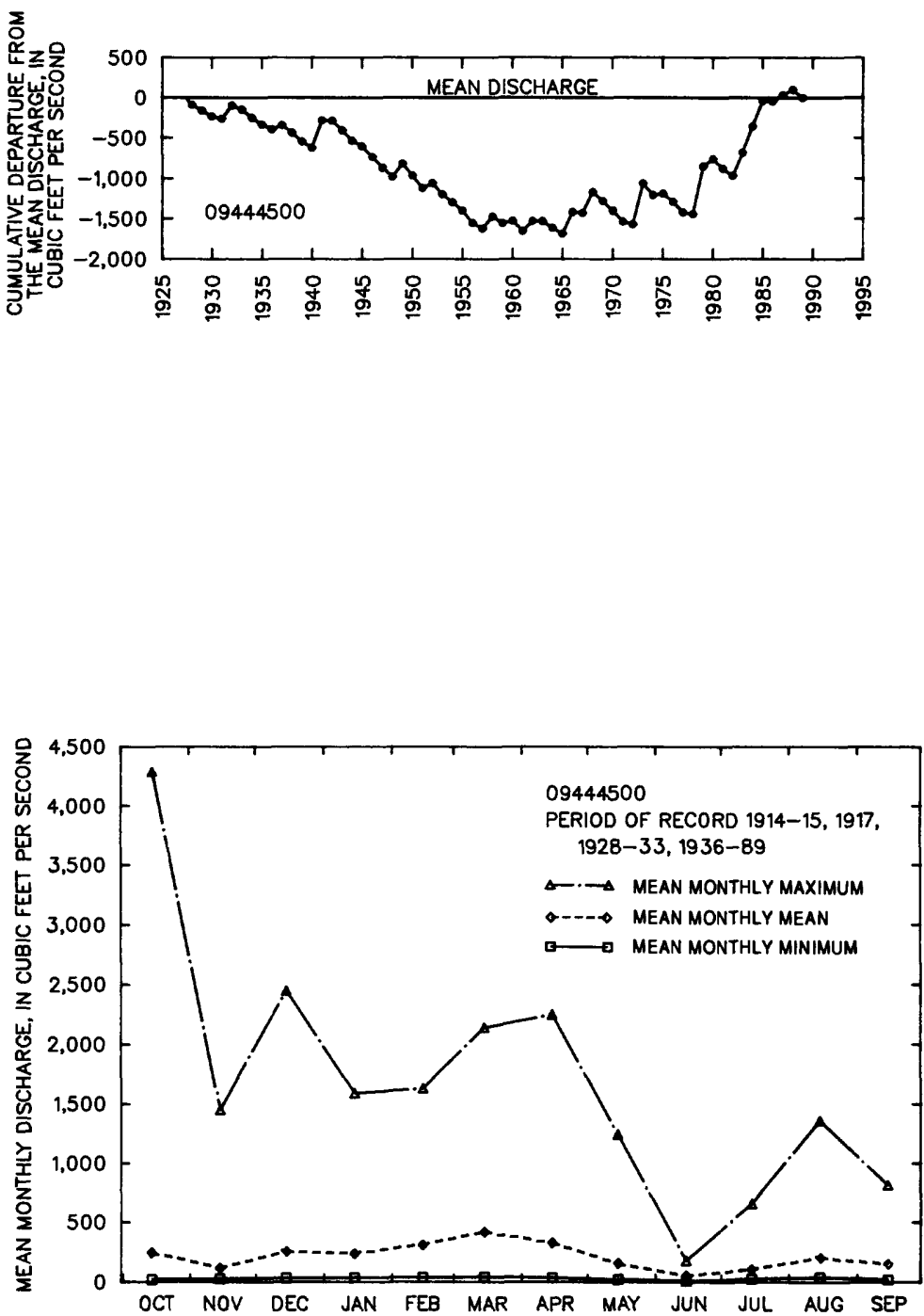
09445500 HILLON CREEK NEAR POINT OF PINES, MEAR MORENCI, AZ

LOCATION.--Lat 33.22'45", long 109.39'00", in NWK sec.2, T.1 S., R.26 E. Graham County, Hydrologic Unit 15040005, (unsurveyed), in San Carlos Indian Reservation, on right bank at head of Box Canyon, 4 mi east of Point of Pines, $10 \mathrm{mi}$ west of Double Circle Ranch, and $23 \mathrm{mi}$ northwest of Morenci.

DRAINAGE AREA. $-102 \mathrm{mi}^{2}$.

ANNUAL PEAK DISCHARGE

\begin{tabular}{|c|c|c|}
\hline $\begin{array}{l}\text { WATER } \\
\text { YEAR }\end{array}$ & DATE & $\begin{array}{c}\text { ANMUAL PEAK } \\
\text { DISCHARGE } \\
\text { (FT } 3 / S)\end{array}$ \\
\hline $\begin{array}{l}1945 \\
1946 \\
1947 \\
1948 \\
1949 \\
1950 \\
1951 \\
1952 \\
1953 \\
1954 \\
1955 \\
1956 \\
1957 \\
1958 \\
1959 \\
1960 \\
1961 \\
1962 \\
1963 \\
1964 \\
1965 \\
1966 \\
1967\end{array}$ & $\begin{array}{l}03-26-45 \\
07-10-46 \\
08-12-47 \\
08-20-48 \\
01-13-49 \\
07-01-50 \\
08-05-51 \\
01-13-52 \\
07-08-53 \\
03-23-54 \\
08-10-55 \\
10-02-55 \\
08-24-57 \\
03-22-58 \\
08-01-59 \\
01-11-60 \\
08-17-61 \\
01-24-62 \\
08-21-63 \\
07-22-64 \\
01-07-65 \\
12-30-65 \\
09-04-67\end{array}$ & $\begin{array}{r}178 \\
1,390 \\
935 \\
428 \\
744 \\
37 \\
878 \\
2,590 \\
378 \\
1,410 \\
1,140 \\
440 \\
459 \\
727 \\
1,920 \\
1,140 \\
245 \\
195 \\
825 \\
435 \\
294 \\
3,710 \\
895\end{array}$ \\
\hline
\end{tabular}

BASIN CHARACTERISTICS

\begin{tabular}{|c|c|c|c|c|c|c|c|}
\hline \multirow{3}{*}{$\begin{array}{l}\text { MAIN } \\
\text { CHANNEL } \\
\text { SLOPE } \\
\text { (FT/MI) }\end{array}$} & \multicolumn{3}{|c|}{ MEAN } & \multicolumn{3}{|c|}{ MEAN } & \multirow[b]{2}{*}{ 24-HOUR } \\
\hline & & BASIN & & & ANNUAL & RAINFALL Il & \\
\hline & $\begin{array}{l}\text { STREAM } \\
\text { LENGTH } \\
\text { (MI) }\end{array}$ & $\begin{array}{l}\text { ELEVA- } \\
\text { TION } \\
\text { (FT) }\end{array}$ & $\begin{array}{l}\text { FORESTED } \\
\text { AREA } \\
\text { (PERCENT) }\end{array}$ & $\begin{array}{l}\text { SOIL } \\
\text { INDEX }\end{array}$ & $\begin{array}{l}\text { PRECIPI - } \\
\text { TATION } \\
\text { (IN) }\end{array}$ & $\begin{array}{c}\text { 2-YEAR } \\
\text { (IN) }\end{array}$ & $\begin{array}{c}\text { 50-YEAR } \\
\text { (IN) }\end{array}$ \\
\hline 73.0 & 18.3 & 6,340 & 59.0 & 3.0 & 19.8 & 2.0 & 4.0 \\
\hline
\end{tabular}


09445500 HILLOW CREEK NEAR POINT OF PINES, NEAR MORENCI, AZ--Continued

MEAN MONTHLY AND ANNUAL DISCHARGES 1945-67

\begin{tabular}{|c|c|c|c|c|c|c|}
\hline MONTH & $\begin{array}{l}\operatorname{MAXIIMN} \\
\left(F T^{3} / S\right)\end{array}$ & $\begin{array}{l}\text { MINIMUN } \\
\left(F T^{3} / S\right)\end{array}$ & $\begin{array}{c}\text { MEAH } \\
\left(F T^{3} / S\right)\end{array}$ & $\begin{array}{l}\text { STAN- } \\
\text { DARO } \\
\text { DEVIA- } \\
\text { TION } \\
\text { (FT } 3 / S)\end{array}$ & $\begin{array}{l}\text { COEFF I- } \\
\text { CIENT OF } \\
\text { VARI - } \\
\text { ATION }\end{array}$ & $\begin{array}{c}\text { PERCENT } \\
\text { OF } \\
\text { ANNUAL } \\
\text { RUNOFF }\end{array}$ \\
\hline $\begin{array}{l}\text { OCTOBER } \\
\text { NOVEMBER } \\
\text { DECEMBER } \\
\text { JANUARY } \\
\text { FEBRUARY } \\
\text { MARCH } \\
\text { APRIL } \\
\text { MAY } \\
\text { JUNE } \\
\text { JULY } \\
\text { AUGUST } \\
\text { SEPTEMBER }\end{array}$ & $\begin{array}{r}21 \\
17 \\
157 \\
103 \\
33 \\
76 \\
21 \\
19 \\
22 \\
25 \\
35 \\
19\end{array}$ & $\begin{array}{l}0.00 \\
0.00 \\
0.00 \\
0.00 \\
0.00 \\
0.00 \\
0.00 \\
0.00 \\
0.00 \\
0.06 \\
4.1 \\
0.00\end{array}$ & $\begin{array}{l}9.6 \\
6.8 \\
11 \\
12 \\
6.1 \\
17 \\
13 \\
12 \\
12 \\
12 \\
15 \\
11\end{array}$ & $\begin{array}{l}6.6 \\
5.7 \\
32 \\
25 \\
10 \\
18 \\
5.6 \\
4.8 \\
5.9 \\
6.0 \\
6.2 \\
6.0\end{array}$ & $\begin{array}{l}0.69 \\
0.84 \\
2.9 \\
2.1 \\
1.6 \\
1.1 \\
0.44 \\
0.41 \\
0.49 \\
0.50 \\
0.42 \\
0.55\end{array}$ & $\begin{array}{r}7.0 \\
5.0 \\
8.1 \\
8.6 \\
4.5 \\
12.4 \\
9.3 \\
8.7 \\
8.8 \\
8.7 \\
10.9 \\
7.9\end{array}$ \\
\hline ANNUAL & 32 & 1.0 & 11 & 6.3 & 0.55 & 100 \\
\hline
\end{tabular}

MAGNITUDE AND PROBABILITY OF INSTANTANEOUS PEAK FLOW BASED ON PERICD OF RECORD 1945-67

DISCHARGE, IN $\mathrm{FT}^{3} / \mathrm{S}$, FOR INDICATED RECURRENCE INTERVAL IN YEARS, AND EXCEEDANCE PROBABILITY, IN PERCENT

\begin{tabular}{|c|c|c|c|c|c|}
\hline$\stackrel{2}{2}$ & $\underset{20 \%}{5}$ & $\begin{array}{r}10 \\
10 \%\end{array}$ & $\begin{array}{l}25 \\
4 \%\end{array}$ & $\begin{array}{l}50\} \\
2 \%\end{array}$ & $\begin{array}{c}100 \dagger \\
1 \%\end{array}$ \\
\hline 678 & 1,370 & 1,970 & 2,890 & 3,710 & 4,620 \\
\hline $\begin{array}{l}\text { WEIGHTED } \\
\text { MEAN } \\
\text { STANDARD }\end{array}$ & $\begin{array}{l}\text { SKEH } \\
\text { DEV. }\end{array}$ & $\begin{array}{l}\text { OGS) }= \\
(O G S)= \\
\text { OGS) }=\end{array}$ & $\begin{array}{r}-0.04 \\
2.83 \\
0.36\end{array}$ & & \\
\hline
\end{tabular}

MAGNITLDE AND PROBABILITY OF ANNUAL LOW FLOH BASED ON PERICD OF RECORD 1946-67

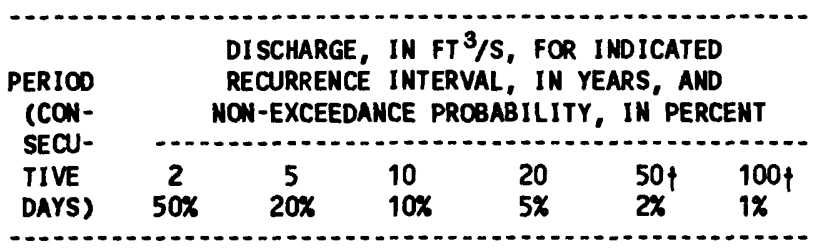

MAGNITLDE AND PROBABILITY OF ANNUAL HIGH FLOW BASED ON PERIOD OF RECORD 1945-67

\begin{tabular}{|c|c|c|c|c|c|c|}
\hline \multirow{2}{*}{$\begin{array}{l}\text { PERIOD } \\
\text { (CON- } \\
\text { SECU- } \\
\text { TIVE } \\
\text { DAYS) }\end{array}$} & \multicolumn{6}{|c|}{$\begin{array}{l}\text { DISCHARGE, IN } \mathrm{FT}^{3} / \mathrm{S} \text {, FOR INDICATED } \\
\text { RECURRENCE INTERVAL, IN YEARS, AND } \\
\text { EXCEEDANCE PROBABILITY, IN PERCENT }\end{array}$} \\
\hline & $\underset{50 \%}{2}$ & $\begin{array}{c}5 \\
20 \%\end{array}$ & $\begin{array}{l}10 \\
10 \%\end{array}$ & $\begin{array}{l}25 \\
4 \%\end{array}$ & $\begin{array}{l}50 \dagger \\
2 x\end{array}$ & $\underset{10}{100} \uparrow$ \\
\hline $\begin{array}{r}1 \\
3 \\
7 \\
15 \\
30 \\
60 \\
90\end{array}$ & $\begin{array}{r}108 \\
63 \\
45 \\
32 \\
25 \\
20 \\
19\end{array}$ & $\begin{array}{r}357 \\
187 \\
115 \\
72 \\
50 \\
36 \\
32\end{array}$ & $\begin{array}{r}710 \\
360 \\
206 \\
120 \\
77 \\
50 \\
42\end{array}$ & $\begin{array}{r}1,560 \\
772 \\
409 \\
225 \\
131 \\
71 \\
55\end{array}$ & $\begin{array}{r}2,660 \\
1,310 \\
662 \\
351 \\
191 \\
91 \\
66\end{array}$ & $\begin{array}{r}4,380 \\
2,170 \\
1,050 \\
540 \\
275 \\
113 \\
78\end{array}$ \\
\hline
\end{tabular}

DURATION TABLE OF DAILY MEAN FLON FOR PERICO OF RECORD 1945-67

DISCHARGE, IN $\mathrm{FT}^{3} / \mathrm{S}$, WHICH WAS EQUALED OR EXCEEDED FOR INDICATED PERCENT OF TIME

\begin{tabular}{|c|c|c|c|c|c|c|c|c|c|c|c|c|c|c|c|c|}
\hline $1 \%$ & $5 \%$ & $10 \%$ & $15 \%$ & $20 \%$ & $30 \%$ & $40 \%$ & $50 \%$ & $60 \%$ & $70 \%$ & $80 \%$ & $90 \%$ & $95 \%$ & $98 \%$ & $99 \%$ & $99.5 \%$ & $99.9 \%$ \\
\hline 66 & 24 & 20 & 18 & 17 & 15 & 13 & 10 & 6.3 & 0.49 & 0.07 & 0.04 & 0.02 & 0.01 & 0.00 & 0.00 & 0.00 \\
\hline
\end{tabular}

† Reliability of values in colum is uncertain, and potential errors are large. 
GILA RIVER BASIN

09445500 WILLOW CREEK NEAR POINT OF PINES, NEAR MORENCI, AZ--CONTINUEd
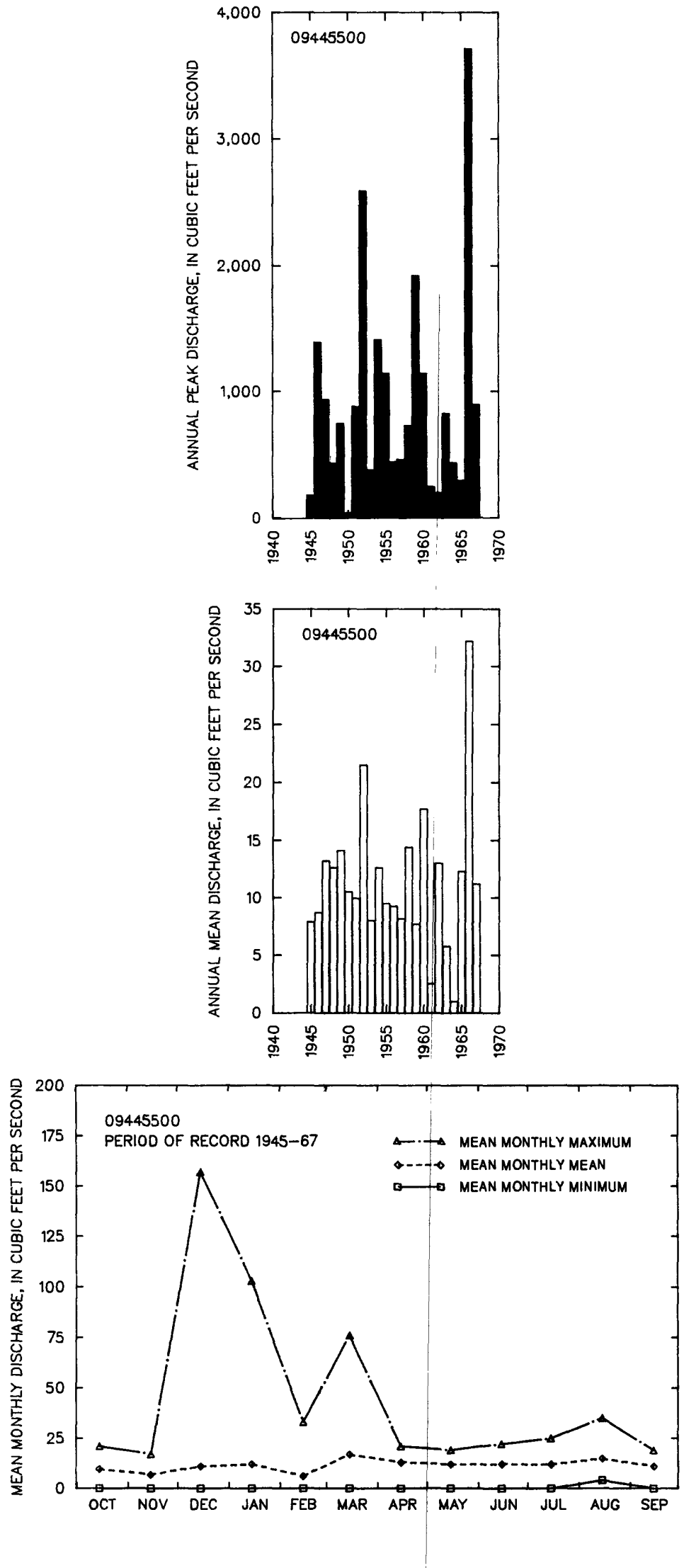
09446000 HILLOW CREEK NEAR DQUBLE CIRCLE RANCH, NEAR MORENCI, AZ

LOCATION.--Lat 33॰21'15", long 109'31'30", in NEK sec.13, T.1 S., R.27 E. Graham County, Hydrologic Unit 15040005, (unsurveyed), in San Carlos Indian Reservation, on left bank 1 mi upstream from lower end of Box Canyon, $2.25 \mathrm{mi}$ northwest of Double Circle Ranch, $2.5 \mathrm{mi}$ upstrean from mouth, an $19 \mathrm{mi}$ northwest of Morenci.

DRAIMAGE AREA. $--149 \mathrm{mi}^{2}$.

ANNUAL PEAK DISCHARGE

\begin{tabular}{|c|c|c|c|c|c|c|c|}
\hline $\begin{array}{l}\text { WATER } \\
\text { YEAR }\end{array}$ & DATE & $\begin{array}{c}\text { ANNUAL PEAK } \\
\text { DISCHARGE } \\
\left(\mathrm{FT}^{3} / \mathrm{S}\right)\end{array}$ & $\begin{array}{l}\text { DISCHARGE } \\
\text { CODES }\end{array}$ & $\begin{array}{l}\text { WATER } \\
\text { YEAR }\end{array}$ & DATE & $\begin{array}{c}\text { ANNUAL PEAK } \\
\text { DISCHARGE } \\
\left(\mathrm{FT}^{3} / \mathrm{S}\right)\end{array}$ & $\begin{array}{l}\text { DISCHARGE } \\
\text { CODES }\end{array}$ \\
\hline $\begin{array}{l}1944 \\
1945 \\
1946 \\
1947 \\
1948 \\
1949 \\
1950 \\
1951 \\
1952 \\
1953 \\
1954 \\
1955 \\
1956\end{array}$ & $\begin{array}{l}09-28-44 \\
03-27-45 \\
07-10-46 \\
07-22-47 \\
08-20-48 \\
01-13-49 \\
12-11-49 \\
08-05-51 \\
01-13-52 \\
07-08-53 \\
03-23-54 \\
08-06-55 \\
10-03-55\end{array}$ & $\begin{array}{r}1,100 \\
134 \\
1,240 \\
629 \\
164 \\
2,010 \\
28 \\
1,370 \\
4,230 \\
202 \\
1,610 \\
2,840 \\
122\end{array}$ & & $\begin{array}{l}1957 \\
1958 \\
1959 \\
1960 \\
1961 \\
1962 \\
1963 \\
1964 \\
1965 \\
1966 \\
1967 \\
1973\end{array}$ & $\begin{array}{l}08-24-57 \\
03-22-58 \\
08-01-59 \\
01-11-60 \\
09-11-61 \\
01-25-62 \\
08-22-63 \\
07-31-64 \\
08-01-65 \\
12-30-65 \\
07-24-67 \\
10-20-72\end{array}$ & $\begin{array}{r}630 \\
1,640 \\
3,520 \\
2,380 \\
950 \\
378 \\
1,020 \\
2,040 \\
4,880 \\
7,500 \\
1,750 \\
16,500\end{array}$ & $\mathrm{KR}, \mathrm{HP}$ \\
\hline
\end{tabular}

Highest since 1944.

BASIN CHARACTERISTICS

\begin{tabular}{|c|c|c|c|c|c|c|c|}
\hline \multirow{2}{*}{$\begin{array}{c}\text { MIIN } \\
\text { CHANNEL } \\
\text { SLOPE } \\
\text { (FT/MI) }\end{array}$} & \multirow[b]{2}{*}{$\begin{array}{l}\text { STREAM } \\
\text { LENGTH } \\
\text { (MI) }\end{array}$} & \multirow{2}{*}{$\begin{array}{l}\text { MEAN } \\
\text { BASIN } \\
\text { ELEVA- } \\
\text { TION } \\
\text { (FT) }\end{array}$} & \multirow[b]{2}{*}{$\begin{array}{l}\text { FORESTED } \\
\text { AREA } \\
\text { (PERCENT) }\end{array}$} & \multirow[b]{2}{*}{$\begin{array}{l}\text { SOIL } \\
\text { INDEX }\end{array}$} & \multirow{2}{*}{$\begin{array}{l}\text { MEAN } \\
\text { ANNUAL } \\
\text { PRECIPI- } \\
\text { TATION } \\
\text { (IN) }\end{array}$} & \multicolumn{2}{|c|}{ RAINFALL INTEMSITY, 24-HOUR } \\
\hline & & & & & & $\begin{array}{l}\text { 2-YEAR } \\
\text { (IN) }\end{array}$ & $\begin{array}{l}\text { 50-YEAR } \\
\text { (IN) }\end{array}$ \\
\hline 77.7 & 27.5 & 6,310 & 63.0 & 3.0 & 19.2 & 2.0 & 3.9 \\
\hline
\end{tabular}


MEAN MONTHLY AND ANNUAL DISCHARGES 1945-67

\begin{tabular}{|c|c|c|c|c|c|c|}
\hline MONTH & $\begin{array}{l}\operatorname{MAXIMMN} \\
\left(\mathrm{FT} \mathrm{T}^{3} / \mathrm{S}\right)\end{array}$ & $\begin{array}{l}\operatorname{MINIMUM} \\
\left(\mathrm{FT}^{3} / \mathrm{S}\right)\end{array}$ & $\begin{array}{c}\text { MEAN } \\
\left(F T^{3} / S\right)\end{array}$ & $\begin{array}{l}\text { STAN- } \\
\text { DARD } \\
\text { DEVIA- } \\
\text { TION } \\
\text { (FT } 3 / S)\end{array}$ & $\begin{array}{l}\text { COEFFI- } \\
\text { CIENT OF } \\
\text { VARI - } \\
\text { ATION }\end{array}$ & $\begin{array}{c}\text { PERCENT } \\
\text { OF } \\
\text { ANNUAL } \\
\text { RUNOFF }\end{array}$ \\
\hline $\begin{array}{l}\text { OCTOBER } \\
\text { NONEMBER } \\
\text { DECEMBER } \\
\text { JANUARY } \\
\text { FEBRUARY } \\
\text { MARCH } \\
\text { APRIL } \\
\text { MAY } \\
\text { JUNE } \\
\text { JULY } \\
\text { AUGUST } \\
\text { SEPTEMBER }\end{array}$ & $\begin{array}{r}22 \\
19 \\
273 \\
163 \\
36 \\
103 \\
23 \\
19 \\
20 \\
24 \\
55 \\
20\end{array}$ & $\begin{array}{l}0.84 \\
0.86 \\
0.93 \\
0.90 \\
0.86 \\
0.79 \\
0.76 \\
0.59 \\
0.03 \\
0.40 \\
6.3 \\
0.43\end{array}$ & $\begin{array}{l}10 \\
8.1 \\
18 \\
19 \\
7.9 \\
19 \\
13 \\
12 \\
11 \\
13 \\
19 \\
11\end{array}$ & $\begin{array}{l}6.1 \\
5.6 \\
56 \\
40 \\
11 \\
23 \\
5.4 \\
4.8 \\
5.7 \\
5.6 \\
9.8 \\
5.4\end{array}$ & $\begin{array}{l}0.61 \\
0.69 \\
3.1 \\
2.1 \\
1.4 \\
1.2 \\
0.41 \\
0.42 \\
0.51 \\
0.44 \\
0.52 \\
0.48\end{array}$ & $\begin{array}{r}6.3 \\
5.0 \\
11.2 \\
11.8 \\
4.9 \\
11.8 \\
8.3 \\
7.2 \\
7.0 \\
7.9 \\
11.6 \\
7.0\end{array}$ \\
\hline ANNUAL & 42 & 2.8 & 13 & 8.3 & 0.62 & 100 \\
\hline
\end{tabular}

MAGNITLDE AND PROBABILITY OF INSTANTANEOUS PEAK FLOH BASED ON PERIOD OF RECORD 1944-67, 1973

DISCHARGE, IN $\mathrm{FT}^{3} / \mathrm{S}$, FOR INDICATED RECURRENCE INTERVAL IN YEARS, AND EXCEEDANCE PROBABILITY, IN PERCENT

$\begin{array}{lccccc}2 & 5 & 10 & 25 & 50 \dagger & \begin{array}{l}100 \dagger \\ 2 \%\end{array} \\ 50 \% & 20 \% & 10 \% & 4 \% & & \\ 1 \%\end{array}$

MACNITUDE AND PROBABILITY OF ANNUAL LOW FLON BASED ON PERIOD OF RECORD 1946-67

\begin{tabular}{|c|c|c|c|c|c|c|}
\hline \multirow{2}{*}{$\begin{array}{l}\text { PERIOO } \\
\text { (CON- } \\
\text { SECU. } \\
\text { TIVE } \\
\text { DAYS) }\end{array}$} & \multicolumn{6}{|c|}{$\begin{array}{l}\text { DISCHARGE, IN } \mathrm{FT}^{3} / \mathrm{S} \text {, FOR INDICATED } \\
\text { RECURRENCE INTERVAL, IN YEARS, AND } \\
\text { NON-EXCEEDANCE PROBABILITY, IN PERCENT }\end{array}$} \\
\hline & $\begin{array}{c}2 \\
50 \%\end{array}$ & $\begin{array}{c}5 \\
20 \%\end{array}$ & $\begin{array}{l}10 \\
10 \%\end{array}$ & $\begin{array}{l}20 \\
5 \%\end{array}$ & $\begin{array}{l}50 \dagger \\
2 \%\end{array}$ & $\begin{array}{l}100 \dagger \\
1 \%\end{array}$ \\
\hline $\begin{array}{r}1 \\
3 \\
7 \\
14 \\
30 \\
60 \\
90 \\
120 \\
183\end{array}$ & $\begin{array}{l}0.71 \\
0.77 \\
0.87 \\
0.87 \\
1.0 \\
1.4 \\
1.9 \\
3.0 \\
6.8\end{array}$ & $\begin{array}{l}0.19 \\
0.22 \\
0.28 \\
0.32 \\
0.46 \\
0.59 \\
0.94 \\
1.7 \\
3.8\end{array}$ & $\begin{array}{l}0.02 \\
0.02 \\
0.05 \\
0.10 \\
0.24 \\
0.37 \\
0.69 \\
1.2 \\
2.7\end{array}$ & $\begin{array}{l}0.00 \\
0.00 \\
0.00 \\
0.00 \\
0.00 \\
0.25 \\
0.54 \\
0.97 \\
2.0\end{array}$ & $\begin{array}{l}0.00 \\
0.00 \\
0.00 \\
0.00 \\
0.00 \\
0.16 \\
0.43 \\
0.76 \\
1.3\end{array}$ & $\begin{array}{l}0.00 \\
0.00 \\
0.00 \\
0.00 \\
0.00 \\
0.12 \\
0.37 \\
0.65 \\
1.0\end{array}$ \\
\hline
\end{tabular}

MAGNITLOE AND PROBABILITY OF ANNUAL HIGH FLOW BASED ON PERIOO OF RECORD 1945-67

\begin{tabular}{|c|c|c|c|c|c|c|}
\hline \multirow{2}{*}{$\begin{array}{l}\text { PERIOD } \\
\text { (CON- } \\
\text { SECU- } \\
\text { TIVE } \\
\text { DAYSS) }\end{array}$} & \multicolumn{6}{|c|}{$\begin{array}{l}\text { DISCHARGE, IN } \mathrm{FT}^{3} / \mathrm{S} \text {, FOR INDICATED } \\
\text { RECURRENCE INTERVAL, IN YEARS, AND } \\
\text { EXCEEDANCE PROBABILITY, IN PERCENT }\end{array}$} \\
\hline & $\begin{array}{c}2 \\
50 \%\end{array}$ & $\begin{array}{c}5 \\
20 \%\end{array}$ & $\begin{array}{l}10 \\
10 \%\end{array}$ & $\begin{array}{l}25 \\
4 \%\end{array}$ & $\begin{array}{l}50 \dagger \\
2 \%\end{array}$ & $\begin{array}{c}100 \dagger \\
1 \%\end{array}$ \\
\hline $\begin{array}{r}1 \\
3 \\
7 \\
15 \\
30 \\
60 \\
90\end{array}$ & $\begin{array}{r}181 \\
96 \\
63 \\
42 \\
31 \\
23 \\
20\end{array}$ & $\begin{array}{r}593 \\
300 \\
176 \\
106 \\
68 \\
45 \\
37\end{array}$ & $\begin{array}{r}1,150 \\
582 \\
326 \\
188 \\
114 \\
68 \\
54\end{array}$ & $\begin{array}{r}2,400 \\
1,250 \\
668 \\
374 \\
210 \\
112 \\
83\end{array}$ & $\begin{array}{r}3,930 \\
2,100 \\
1,100 \\
610 \\
326 \\
158 \\
113\end{array}$ & $\begin{array}{r}6,200 \\
3,430 \\
1,760 \\
975 \\
499 \\
222 \\
150\end{array}$ \\
\hline
\end{tabular}

DURATION TABLE OF DAILY MEAN FLON FOR PERIOD OF RECORD 1945-67

DISCHARGE, IN FT $3 / \mathrm{s}$, WHICH WAS EQUALED OR EXCEEDED FOR INDICATED PERCENT OF TIME

\begin{tabular}{|c|c|c|c|c|c|c|c|c|c|c|c|c|c|c|c|c|}
\hline $1 \%$ & $5 \%$ & $10 \%$ & $15 \%$ & $20 \%$ & $30 \%$ & $40 \%$ & $50 \%$ & $60 \%$ & $70 \%$ & $80 \%$ & $90 \%$ & $95 \%$ & $98 \%$ & $99 \%$ & $99.5 \%$ & $99.9 \%$ \\
\hline 83 & 26 & 21 & 18 & 16 & 14 & 12 & 10 & 7.3 & 2.9 & 1.4 & 0.97 & 0.67 & 0.27 & 0.00 & 0.00 & 0.00 \\
\hline
\end{tabular}

† Reliability of values in column is uncertain, and potential errors are large. 
GILA RIVER BASIN

09446000 WILLOW CREEK NEAR DOUBLE CIRCLE RANCH, NEAR MORENCI, AZ--CONTINUEd
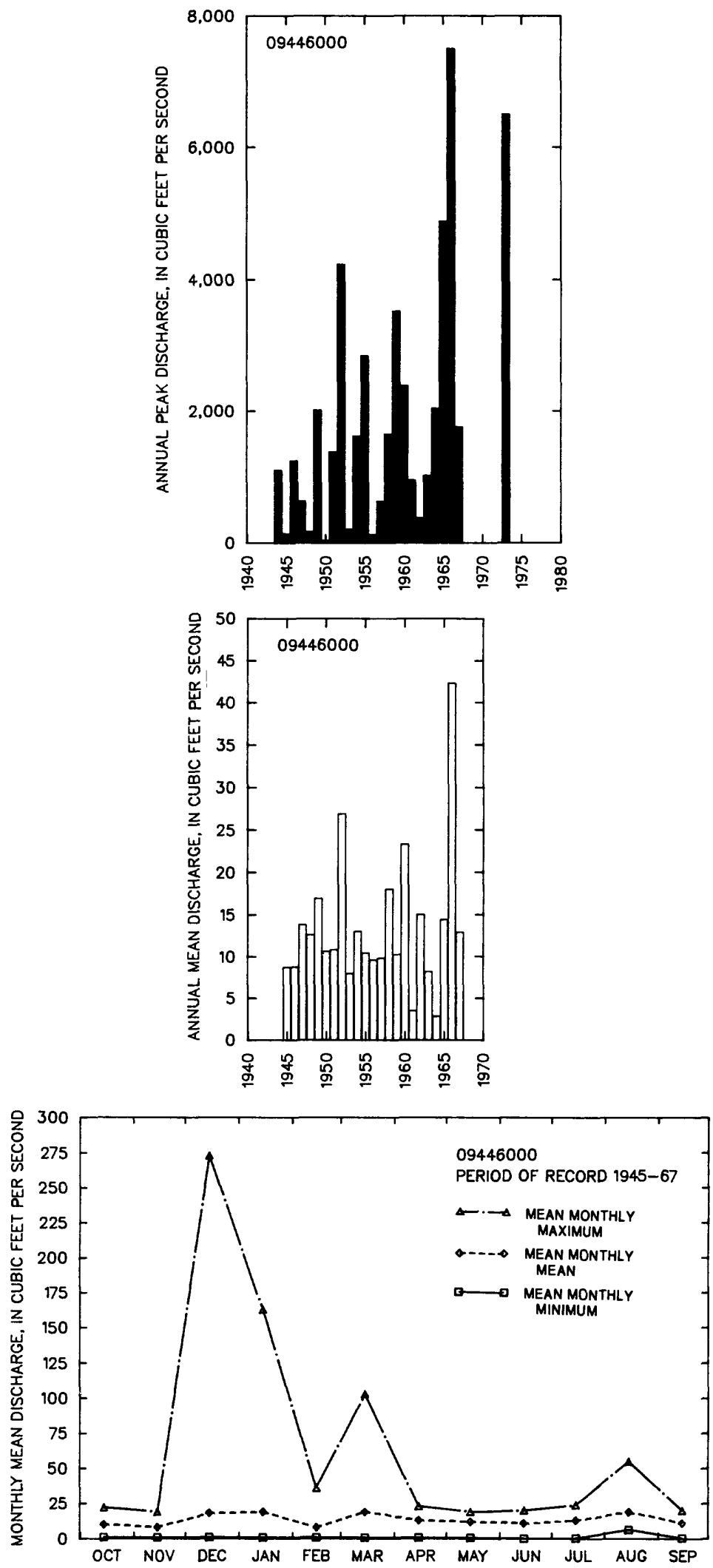


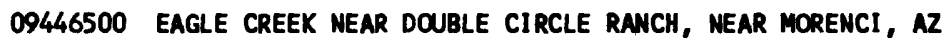

LOCATION.--Lat 33.18'00", long 109.29'30", in SWK sec.32, T.1 S., R.28 E. Graham County, Hydrologic Unit 15040005, (unsurveyed), on left bank $0.5 \mathrm{mi}$ upstream from head of Box Canyon, $2.75 \mathrm{mi}$ downstream from Willow Creek, $3.25 \mathrm{mi}$ downstream from Double Circle Ranch, and $17 \mathrm{mi}$ northwest of Morenci.

DRAIMAGE AREA. $--377 \mathrm{mi}^{2}$.

ANMUAL PEAK DISCHARGE

\begin{tabular}{|c|c|c|c|c|c|c|c|}
\hline $\begin{array}{l}\text { WATER } \\
\text { YEAR }\end{array}$ & DATE & $\begin{array}{c}\text { ANNUAL PEAK } \\
\text { DISCHARGE } \\
\left(\mathrm{FT}^{3} / \mathrm{S}\right)\end{array}$ & $\begin{array}{l}\text { DISCHARGE } \\
\text { COOES }\end{array}$ & $\begin{array}{l}\text { WATER } \\
\text { YEAR }\end{array}$ & DATE & $\begin{array}{l}\text { NMUAL PEAK } \\
\text { DISCHARGE } \\
\left(\mathrm{FT}^{3} / \mathrm{S}\right)\end{array}$ & $\begin{array}{l}\text { DISCHARGE } \\
\text { CODES }\end{array}$ \\
\hline $\begin{array}{l}1944 \\
1945 \\
1946 \\
1947 \\
1948 \\
1949 \\
1950 \\
1951 \\
1952 \\
1953 \\
1954 \\
1955 \\
1956\end{array}$ & $\begin{array}{l}09-11-44 \\
08-06-45 \\
07-10-46 \\
08-25-47 \\
08-21-48 \\
01-13-49 \\
07-28-50 \\
08-28-51 \\
01-13-52 \\
08-01-53 \\
08-24-54 \\
08-21-55 \\
07-31-56\end{array}$ & $\begin{array}{r}2,400 \\
798 \\
1,160 \\
2,070 \\
135 \\
2,400 \\
874 \\
1,470 \\
7,000 \\
456 \\
4,380 \\
2,680 \\
1,410\end{array}$ & & $\begin{array}{l}1957 \\
1958 \\
1959 \\
1960 \\
1961 \\
1962 \\
1963 \\
1964 \\
1965 \\
1966 \\
1967 \\
1973\end{array}$ & $\begin{array}{l}08-01-57 \\
09-10-58 \\
08-01-59 \\
01-12-60 \\
09-11-61 \\
01-25-62 \\
08-21-63 \\
09-10-64 \\
08-01-65 \\
12-30-65 \\
08-11-67 \\
10-20-72\end{array}$ & $\begin{array}{r}1,610 \\
7,270 \\
3,200 \\
4,990 \\
2,470 \\
612 \\
3,920 \\
6,390 \\
3,510 \\
13,600 \\
6,000 \\
130,000\end{array}$ & HP \\
\hline
\end{tabular}

BASIN CHARACTERISTICS

\begin{tabular}{|c|c|c|c|c|c|c|c|}
\hline MAIN & & $\begin{array}{l}\text { MEAN } \\
\text { BASIN }\end{array}$ & & & $\begin{array}{c}\text { MEAN } \\
\text { ANNUAL }\end{array}$ & RAIAFALL I & SITY, 24-HOQR \\
\hline $\begin{array}{l}\text { CHANNEL } \\
\text { SLOPE } \\
\text { (FT/MI) }\end{array}$ & $\begin{array}{l}\text { STREAM } \\
\text { LENGTH } \\
\text { (MI) }\end{array}$ & $\begin{array}{c}\text { ELEVA- } \\
\text { TION } \\
\text { (FT) }\end{array}$ & $\begin{array}{l}\text { FORESTED } \\
\text { AREA } \\
\text { (PERCENT) }\end{array}$ & $\begin{array}{l}\text { SOIL } \\
\text { INDEX }\end{array}$ & $\begin{array}{l}\text { PRECIPI- } \\
\text { TATION } \\
\text { (IN) }\end{array}$ & $\begin{array}{c}\text { 2-YEAR } \\
\text { (IN) }\end{array}$ & $\begin{array}{l}\text { 50-YEAR } \\
\text { (IN) }\end{array}$ \\
\hline 100 & 29.2 & 6,410 & 75.0 & 3.0 & 20.0 & 2.0 & 3.9 \\
\hline
\end{tabular}


GILA RIVER BASIN

09446500 EAGLE CREEK NEAR DOUBLE CIRCLE RANCH, NEAR MOREMCI, AZ--Continued

MEAN MONTHLY AND ANMUAL DISCHARGES 1945-67

\begin{tabular}{|c|c|c|c|c|c|c|}
\hline MONTH & $\begin{array}{l}\text { MAXIMUN } \\
\left(F T^{3} / S\right)\end{array}$ & $\begin{array}{l}\text { MINIMUM } \\
\left(F^{3} / S\right)\end{array}$ & $\begin{array}{c}\text { MEAN } \\
\left(F^{3} / S\right)\end{array}$ & $\begin{array}{l}\text { STAN- } \\
\text { DARD } \\
\text { OEVIA- } \\
\text { TION } \\
\text { (FT } 3 \text { /S) }\end{array}$ & $\begin{array}{l}\text { COEFFI- } \\
\text { CIENT OF } \\
\text { VARI - } \\
\text { ATION }\end{array}$ & $\begin{array}{c}\text { PERCENT } \\
\text { OF } \\
\text { ANMUAL } \\
\text { RUNOFF }\end{array}$ \\
\hline $\begin{array}{l}\text { OCTOBER } \\
\text { NOVEMBER } \\
\text { OECEMBER } \\
\text { JANUARY } \\
\text { FEBRUARY } \\
\text { MARCH } \\
\text { APRIL } \\
\text { MAY } \\
\text { JUNE } \\
\text { JULY } \\
\text { AUGUST } \\
\text { SEPTEMBER }\end{array}$ & $\begin{array}{r}33 \\
22 \\
502 \\
310 \\
101 \\
213 \\
89 \\
25 \\
25 \\
36 \\
93 \\
42\end{array}$ & $\begin{array}{l}5.7 \\
5.2 \\
4.7 \\
4.7 \\
4.1 \\
5.9 \\
4.3 \\
5.3 \\
3.7 \\
13 \\
13 \\
11\end{array}$ & $\begin{array}{l}18 \\
14 \\
36 \\
41 \\
22 \\
41 \\
27 \\
18 \\
16 \\
21 \\
38 \\
20\end{array}$ & $\begin{array}{c}5.9 \\
5.3 \\
103 \\
76 \\
27 \\
48 \\
18 \\
4.3 \\
4.6 \\
6.3 \\
25 \\
8.8\end{array}$ & $\begin{array}{l}0.33 \\
0.38 \\
2.9 \\
1.8 \\
1.2 \\
1.2 \\
0.64 \\
0.24 \\
0.30 \\
0.30 \\
0.66 \\
0.45\end{array}$ & $\begin{array}{r}5.7 \\
4.5 \\
11.6 \\
13.3 \\
7.1 \\
13.1 \\
8.9 \\
5.7 \\
5.0 \\
6.7 \\
12.1 \\
6.4\end{array}$ \\
\hline ANNUAL & 81 & 11 & 26 & 16 & 0.62 & 100 \\
\hline
\end{tabular}

MAGNI TUDE AND PROBABILITY OF INSTANTANEOUS PEAK FLOW BASED ON PERIOD OF RECORD 1944-67, 1973

DISCHARGE, IN FT $3 / S$, FOR INDICATED RECURRENCE INTERVAL

IN YEARS, AND EXCEEDANCE PROBABILITY, IN PERCENT

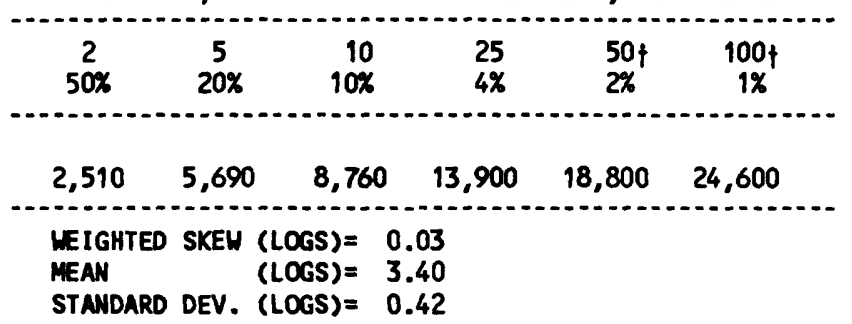

MAGNITLDE AND PROBABILITY OF ANNUAL LOW FLOW BASED ON PERIOD OF RECORD 1946-67

\begin{tabular}{|c|c|c|c|c|c|c|}
\hline \multirow{2}{*}{$\begin{array}{l}\text { PERIOD } \\
\text { (CON- } \\
\text { SECU- } \\
\text { TIVE } \\
\text { DAYS) }\end{array}$} & \multicolumn{6}{|c|}{$\begin{array}{l}\text { DISCHARGE, IN FT } 3 / S \text {, FOR INDICATED } \\
\text { RECURRENCE INTERVAL, IN YEARS, AND } \\
\text { NON-EXCEEDANCE PROBABILITY, IN PERCENT }\end{array}$} \\
\hline & $\begin{array}{c}2 \\
50 \%\end{array}$ & $\begin{array}{c}5 \\
20 \%\end{array}$ & $\begin{array}{l}10 \\
10 \%\end{array}$ & $\begin{array}{l}20 \\
5 \%\end{array}$ & $\begin{array}{l}50 \dagger \\
2 \%\end{array}$ & $\begin{array}{l}100+ \\
1 \%\end{array}$ \\
\hline $\begin{array}{r}1 \\
3 \\
7 \\
14 \\
30 \\
60 \\
90 \\
120 \\
183\end{array}$ & $\begin{array}{r}4.1 \\
4.2 \\
4.4 \\
5.1 \\
5.8 \\
6.8 \\
7.5 \\
9.1 \\
12\end{array}$ & $\begin{array}{l}3.1 \\
3.1 \\
3.3 \\
3.9 \\
4.5 \\
5.0 \\
5.4 \\
6.6 \\
9.4\end{array}$ & $\begin{array}{l}2.7 \\
2.7 \\
2.9 \\
3.4 \\
4.0 \\
4.4 \\
4.6 \\
5.6 \\
8.2\end{array}$ & $\begin{array}{l}2.3 \\
2.4 \\
2.6 \\
3.1 \\
3.8 \\
3.9 \\
4.1 \\
5.0 \\
7.3\end{array}$ & $\begin{array}{l}2.0 \\
2.1 \\
2.3 \\
2.8 \\
3.5 \\
3.6 \\
3.6 \\
4.3 \\
6.5\end{array}$ & $\begin{array}{l}1.9 \\
1.9 \\
2.2 \\
2.7 \\
3.4 \\
3.3 \\
3.4 \\
3.9 \\
6.0\end{array}$ \\
\hline
\end{tabular}

MAGNITLDE AND PROBABILITY OF ANNUAL HIGH FLOW BASED ON PERIOD OF RECORD 1945-67

\begin{tabular}{|c|c|c|c|c|c|c|}
\hline \multirow{2}{*}{$\begin{array}{l}\text { PERIOD } \\
\text { (CON- } \\
\text { SECU- } \\
\text { TIVE } \\
\text { DAYS) }\end{array}$} & & \multicolumn{5}{|c|}{$\begin{array}{l}\text { DISCHARGE, IN } \mathrm{FT}^{3} / \mathrm{S} \text {, FOR INDICATED } \\
\text { RECURRENCE INTERVAL, IN YEARS, AND } \\
\text { EXCEEDANCE PROBABILITY, IN PERCENT }\end{array}$} \\
\hline & $\stackrel{2}{50 x}$ & $\begin{array}{c}5 \\
20 \%\end{array}$ & $\begin{array}{l}10 \\
10 \%\end{array}$ & $\begin{array}{l}25 \\
4 \%\end{array}$ & $\begin{array}{l}50\} \\
2 \%\end{array}$ & $\begin{array}{c}100 \dagger \\
1 \%\end{array}$ \\
\hline $\begin{array}{c}1 \\
3 \\
7 \\
15 \\
30 \\
60 \\
90\end{array}$ & $\begin{array}{r}290 \\
181 \\
121 \\
85 \\
65 \\
48 \\
39\end{array}$ & $\begin{array}{r}908 \\
532 \\
326 \\
215 \\
147 \\
97 \\
75\end{array}$ & $\begin{array}{r}1,780 \\
1,000 \\
584 \\
376 \\
238 \\
147 \\
113\end{array}$ & $\begin{array}{r}3,850 \\
2,090 \\
1,140 \\
719 \\
415 \\
238 \\
182\end{array}$ & $\begin{array}{r}6,550 \\
3,460 \\
1,810 \\
1,130 \\
608 \\
332 \\
254\end{array}$ & $\begin{array}{r}10,800 \\
5,550 \\
2,790 \\
1,720 \\
871 \\
454 \\
349\end{array}$ \\
\hline
\end{tabular}

DURATION TABLE OF DAILY MEAN FLON FOR PERIOD OF RECORD 1945-67

DISCHARGE, IN FT $3 / 5$, WHICH WAS EQUALED OR EXCEEDED FOR INDICATED PERCENT OF TIME

\begin{tabular}{|c|c|c|c|c|c|c|c|c|c|c|c|c|c|c|c|c|}
\hline $1 \%$ & $5 \%$ & $10 \%$ & $15 \%$ & $20 \%$ & $30 \%$ & $40 \%$ & $50 \%$ & $60 \%$ & $70 x$ & $80 \%$ & $90 \%$ & $95 \%$ & $98 \%$ & $99 \%$ & $99.5 \%$ & $99.9 \%$ \\
\hline 193 & 70 & 38 & 27 & 24 & 20 & 18 & 16 & 14 & 11 & 7.9 & 5.6 & 4.9 & 4.2 & 3.8 & 2.9 & 2.4 \\
\hline
\end{tabular}

f Reliability of values in column is uncertain, and potential errors are large. 
GILA RIVER BASIN

09446500 EAGLE CREEK NEAR DOUBLE CIRCLE RANCH, NEAR MORENCI, AZ--CONTINUEd
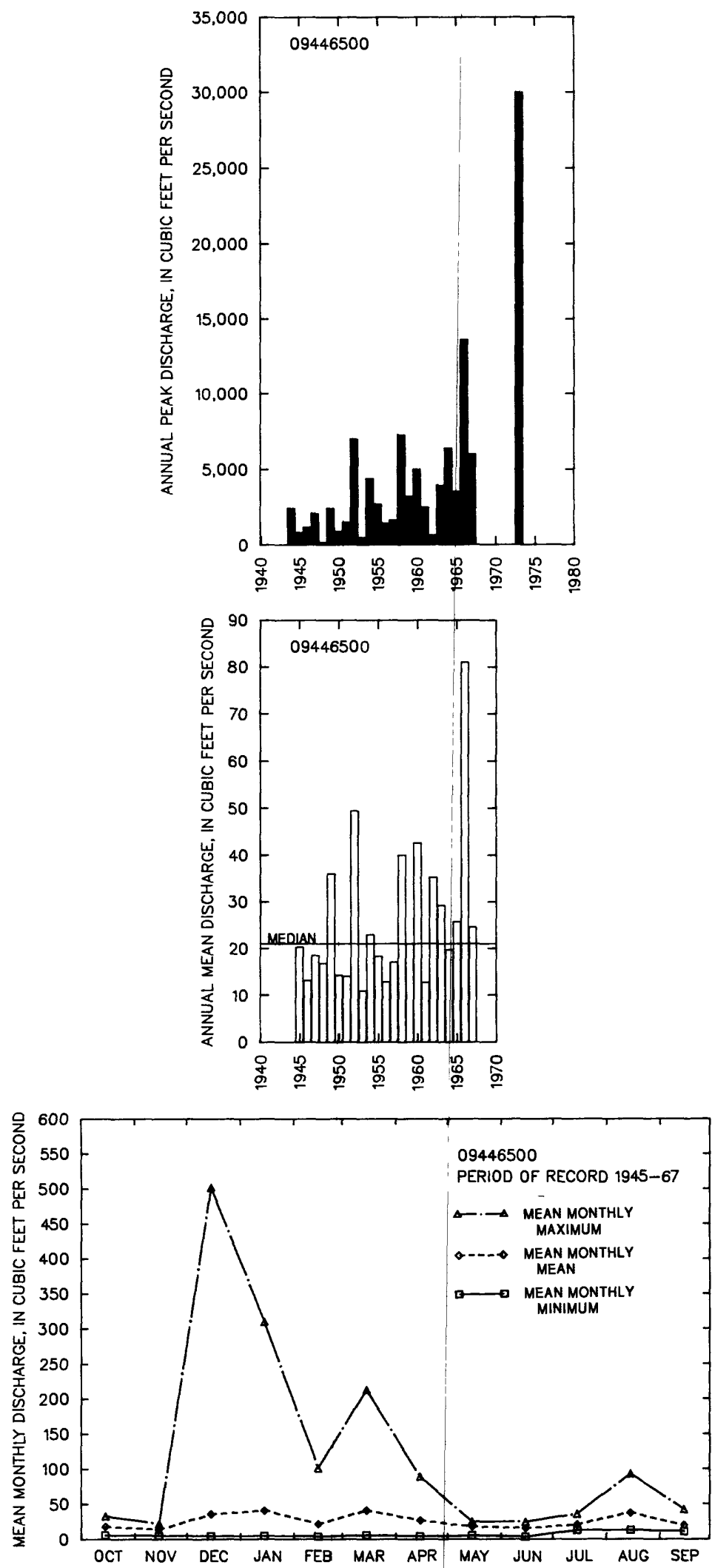
09447000 eAgle CREeK above PUMPIng PLANT, NeAR MORENCI, AZ

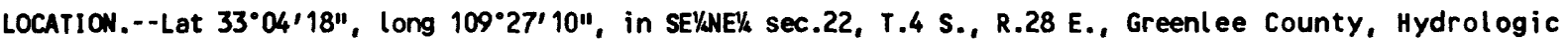
Unit 15040005, on left bank 3 mi upstream from Phelps Dodge Corp. pumping plant, 5 mi west of Morenci, and 13 mi upstream from mouth.

DRAINAGE AREA. - -613 mi2.

REMARKS.--Diversions above station for irrigation of about 500 acres, mostly above Willow Creek.

ANNUAL PEAK DISCHARGE

\begin{tabular}{|c|c|c|c|c|c|c|c|}
\hline $\begin{array}{l}\text { WATER } \\
\text { YEAR }\end{array}$ & DATE & $\begin{array}{c}\text { ANNUAL PEAK } \\
\text { DISCHARGE } \\
\left(\mathrm{FT}^{3} / \mathrm{S}\right)\end{array}$ & $\begin{array}{l}\text { DISCHARGE } \\
\text { COOES }\end{array}$ & $\begin{array}{l}\text { WATER } \\
\text { YEAR }\end{array}$ & DATE & $\begin{array}{c}\text { ANNUAL PEAK } \\
\text { DISCHARGE } \\
\left(\mathrm{FT}^{3} / \mathrm{S}\right)\end{array}$ & $\begin{array}{l}\text { DISCHARGE } \\
\text { CODES }\end{array}$ \\
\hline $\begin{array}{l}1916 \\
1932 \\
1944 \\
1945 \\
1946 \\
1947 \\
1948 \\
1949 \\
1950 \\
1951 \\
1952 \\
1953 \\
1954 \\
1955 \\
1956 \\
1957 \\
1958 \\
1959 \\
1960 \\
1961 \\
1962 \\
1963 \\
1964 \\
1965\end{array}$ & $\begin{array}{l}01-18-16 \\
02-10-32 \\
00-00-44 \\
08-11-45 \\
08-07-46 \\
08-08-47 \\
08-05-48 \\
01-13-49 \\
07-28-50 \\
08-28-51 \\
01-14-52 \\
07-25-53 \\
07-22-54 \\
08-06-55 \\
07-30-56 \\
07-26-57 \\
09-10-58 \\
08-17-59 \\
01-12-60 \\
09-12-61 \\
07-18-62 \\
08-30-63 \\
07-15-64 \\
08-01-65\end{array}$ & $\begin{array}{r}36,000 \\
13,000 \\
7,500 \\
433 \\
384 \\
710 \\
300 \\
2,500 \\
470 \\
1,260 \\
5,340 \\
2,780 \\
4,930 \\
3,260 \\
452 \\
4,210 \\
6,150 \\
4,780 \\
5,350 \\
1,210 \\
1,850 \\
6,150 \\
8,620 \\
3,080\end{array}$ & $\begin{array}{c}\text { ES, HP } \\
\text { HP }\end{array}$ & $\begin{array}{l}1966 \\
1967 \\
1968 \\
1969 \\
1970 \\
1971 \\
1972 \\
1973 \\
1974 \\
1975 \\
1976 \\
1977 \\
1978 \\
1979 \\
1980 \\
1981 \\
1982 \\
1983 \\
1984 \\
1985 \\
1986 \\
1987 \\
1988 \\
1989\end{array}$ & $\begin{array}{c}12-30-65 \\
08-12-67 \\
12-20-67 \\
07-25-69 \\
07-23-70 \\
08-22-71 \\
07-16-72 \\
10-19-72 \\
08-03-74 \\
09-09-75 \\
07-29-76 \\
07-31-77 \\
03-02-78 \\
12-18-78 \\
02-15-80 \\
08-07-81 \\
08-23-82 \\
03-25-83 \\
10-02-83 \\
12-28-84 \\
10-17-85 \\
11-03-86 \\
08-15-88 \\
08-18-89\end{array}$ & $\begin{array}{r}21,000 \\
7,650 \\
3,300 \\
250 \\
560 \\
1,680 \\
6,650 \\
14,000 \\
630 \\
1,550 \\
2,250 \\
2,190 \\
3,900 \\
24,500 \\
9,000 \\
3,380 \\
1,720 \\
6,210 \\
136,400 \\
8,400 \\
1,030 \\
1,990 \\
3,770 \\
97\end{array}$ & \\
\hline
\end{tabular}

$1_{H \text { ighest since } 1916 .}$

BASIN CHARACTERISTICS

\begin{tabular}{|c|c|c|c|c|c|c|c|}
\hline \multirow{2}{*}{$\begin{array}{l}\text { MAIN } \\
\text { CHANNEL } \\
\text { SLOPE } \\
\text { (FT/MI) }\end{array}$} & \multirow[b]{2}{*}{$\begin{array}{c}\text { STREAM } \\
\text { LENGTH } \\
\text { (MI) }\end{array}$} & \multirow{2}{*}{$\begin{array}{l}\text { MEAN } \\
\text { BASIN } \\
\text { ELEVA- } \\
\text { TION } \\
\text { (FT) }\end{array}$} & \multirow[b]{2}{*}{$\begin{array}{l}\text { FORESTED } \\
\text { AREA } \\
\text { (PERCENT) }\end{array}$} & \multirow[b]{2}{*}{$\begin{array}{l}\text { SOIL } \\
\text { INDEX }\end{array}$} & \multirow{2}{*}{$\begin{array}{l}\text { MEAN } \\
\text { ANNUAL } \\
\text { PRECIPI- } \\
\text { TATION } \\
\text { (IN) }\end{array}$} & \multicolumn{2}{|c|}{ RAINFALL INTENSITY, 24-HOUR } \\
\hline & & & & & & $\begin{array}{c}\text { 2-YEAR } \\
\text { (IN) }\end{array}$ & $\begin{array}{c}\text { 50-YEAR } \\
\text { (IN) }\end{array}$ \\
\hline 60.9 & 52.5 & 6,060 & 64.0 & 2.8 & 19.2 & 2.0 & 3.8 \\
\hline
\end{tabular}


MEAN MONTHLY AND ANMUAL DISCHARGES $1945-89$

\begin{tabular}{|c|c|c|c|c|c|c|}
\hline MONTH & $\begin{array}{l}\left.\operatorname{MAX} \operatorname{IMMM}_{(\mathrm{MT}} / \mathrm{S}\right) \\
\left(\mathrm{F}^{2}\right.\end{array}$ & $\begin{array}{l}\text { MINIMUM } \\
\left.\text { (FT }{ }^{3} / S\right)\end{array}$ & $\begin{array}{c}\text { MEAN } \\
\left(F T^{3} / S\right)\end{array}$ & $\begin{array}{l}\text { STAN- } \\
\text { DARD } \\
\text { DEVIA- } \\
\text { TION } \\
\text { (FT } 3 / S)\end{array}$ & $\begin{array}{l}\text { COEFFI- } \\
\text { CIENT OF } \\
\text { VARI - } \\
\text { ATION }\end{array}$ & $\begin{array}{c}\text { PERCENT } \\
\text { OF } \\
\text { ANNUAL } \\
\text { RUNOFF }\end{array}$ \\
\hline $\begin{array}{l}\text { OCTOBER } \\
\text { NOVEMBER } \\
\text { DECEMBER } \\
\text { JANUARY } \\
\text { FEBRUARY } \\
\text { MARCH } \\
\text { APRIL } \\
\text { MAY } \\
\text { JUNE } \\
\text { JULY } \\
\text { AUGUST } \\
\text { SEPTEMBER }\end{array}$ & $\begin{array}{r}1,170 \\
228 \\
884 \\
1,080 \\
989 \\
700 \\
214 \\
81 \\
40 \\
98 \\
203 \\
114\end{array}$ & $\begin{array}{l}13 \\
10 \\
11 \\
11 \\
11 \\
14 \\
11 \\
9.2 \\
5.3 \\
16 \\
19 \\
13\end{array}$ & $\begin{array}{l}65 \\
33 \\
86 \\
92 \\
94 \\
96 \\
50 \\
31 \\
23 \\
37 \\
56 \\
33\end{array}$ & $\begin{array}{c}176 \\
34 \\
170 \\
179 \\
174 \\
131 \\
40 \\
15 \\
8.4 \\
18 \\
41 \\
18\end{array}$ & $\begin{array}{l}2.7 \\
1.0 \\
2.0 \\
1.9 \\
1.9 \\
1.4 \\
0.79 \\
0.50 \\
0.37 \\
0.48 \\
0.73 \\
0.55\end{array}$ & $\begin{array}{r}9.3 \\
4.8 \\
12.4 \\
13.2 \\
13.4 \\
13.8 \\
7.2 \\
4.4 \\
3.3 \\
5.4 \\
8.0 \\
4.8\end{array}$ \\
\hline ANNUAL & 239 & 17 & 58 & 49 & 0.85 & 100 \\
\hline
\end{tabular}

MAGNITUDE AND PROBABILITY OF INSTANTANEOUS PEAK FLOH BASED ON PERICD OF RECORD $1944-89$

DISCHARGE, IN $\mathrm{FT}^{3} / \mathrm{S}$, FOR INDICATED RECURRENCE INTERVAL

IN YEARS, AND EXCEEDANCE PROBABILITY, IN PERCENT

\begin{tabular}{lccccc}
2 & 5 & 10 & 25 & 50 & $100 \uparrow$ \\
$50 \%$ & $20 \%$ & $10 \%$ & $4 \%$ & $2 \%$ & $1 \%$ \\
2,770 & 7,310 & 11,900 & 19,500 & 26,300 & 34,200 \\
\hline MEIGHTED SKEH (LOGS) & $=-0.34$ & & \\
MEAN & (LOGS) & 3.39 \\
STANDARD DEV. (LOGS) & $=0.55$
\end{tabular}

DURATION TABLE OF DAILY MEAN FLON FOR PERIOD OF RECORD 1945-89
MAGUITUDE AND PROBABILITY OF ANNUAL LOW FLOW BASED ON PERIOD OF RECORD $1945-89$

\begin{tabular}{|c|c|c|c|c|c|c|}
\hline \multirow{2}{*}{$\begin{array}{l}\text { PERIOD } \\
\text { (CON- } \\
\text { SECU- } \\
\text { TIVE } \\
\text { DAYS) }\end{array}$} & \multicolumn{6}{|c|}{$\begin{array}{l}\text { DISCHARGE, IN FT }{ }^{3} / S \text {, FOR INDICATED } \\
\text { RECURRENCE INTERVAL, IN YEARS, AND } \\
\text { NON-EXCEEDANCE PROBABILITY, IN PERCENT }\end{array}$} \\
\hline & $\begin{array}{c}2 \\
50 \%\end{array}$ & $\begin{array}{c}5 \\
20 \%\end{array}$ & $\begin{array}{l}10 \\
10 \%\end{array}$ & $\begin{array}{l}20 \\
5 \%\end{array}$ & $\begin{array}{l}50 \\
2 \%\end{array}$ & $\begin{array}{l}100 \uparrow \\
1 \%\end{array}$ \\
\hline \begin{tabular}{r|}
1 \\
3 \\
7 \\
14 \\
30 \\
60 \\
90 \\
120 \\
183
\end{tabular} & $\begin{array}{l}11 \\
12 \\
13 \\
14 \\
16 \\
18 \\
19 \\
21 \\
25\end{array}$ & $\begin{array}{c}6.8 \\
7.2 \\
7.9 \\
9.2 \\
11 \\
12 \\
13 \\
15 \\
19\end{array}$ & $\begin{array}{c}5.2 \\
5.4 \\
6.0 \\
7.1 \\
8.5 \\
10 \\
11 \\
13 \\
16\end{array}$ & $\begin{array}{r}4.1 \\
4.3 \\
4.7 \\
5.6 \\
6.9 \\
8.5 \\
9.5 \\
11 \\
15\end{array}$ & $\begin{array}{r}3.0 \\
3.2 \\
3.6 \\
4.3 \\
5.3 \\
7.0 \\
8.0 \\
9.5 \\
13\end{array}$ & 12 \\
\hline
\end{tabular}

MAGNITLDE AND PROBABILITY OF ANNUAL HIGH FLOM BASED ON PERIOD OF RECORD $1945-89$

\begin{tabular}{|c|c|c|c|c|c|c|}
\hline \multirow{2}{*}{$\begin{array}{l}\text { PERIOD } \\
\text { (CON- } \\
\text { SECU- } \\
\text { TIVE } \\
\text { DAYS) }\end{array}$} & \multicolumn{6}{|c|}{$\begin{array}{l}\text { DISCHARGE, IN } \mathrm{FT}^{3} / \mathrm{S} \text {, FOR INDICATED } \\
\text { RECURRENCE INTERVAL, IN YEARS, AND } \\
\text { EXCEEDANCE PROBABILITY, IN PERCENT }\end{array}$} \\
\hline & $\stackrel{2}{50 \%}$ & $\begin{array}{c}5 \\
20 \%\end{array}$ & $\begin{array}{l}10 \\
10 \%\end{array}$ & $\begin{array}{l}25 \\
4 \%\end{array}$ & $\begin{array}{l}50 \\
2 \%\end{array}$ & $\begin{array}{c}100 \dagger \\
1 \%\end{array}$ \\
\hline $\begin{array}{l}1 \\
3 \\
7 \\
15 \\
30 \\
60 \\
90\end{array}$ & $\begin{array}{r}652 \\
393 \\
250 \\
169 \\
125 \\
91 \\
74\end{array}$ & $\begin{array}{r}2,330 \\
1,380 \\
814 \\
498 \\
330 \\
224 \\
175\end{array}$ & $\begin{array}{r}4,660 \\
2,800 \\
1,600 \\
933 \\
580 \\
381 \\
293\end{array}$ & $\begin{array}{r}9,940 \\
6,230 \\
3,470 \\
1,910 \\
1,110 \\
707 \\
532\end{array}$ & $\begin{array}{r}16,400 \\
10,700 \\
5,870 \\
3,120 \\
1,720 \\
1,080 \\
804\end{array}$ & $\begin{array}{r}25,900 \\
17,600 \\
9,580 \\
4,950 \\
2,600 \\
1,620 \\
1,190\end{array}$ \\
\hline
\end{tabular}

DISCHARGE, IN FT 33 , WHICH HAS EQUALED OR EXCEEDED FOR INDICATED PERCENT OF TIME

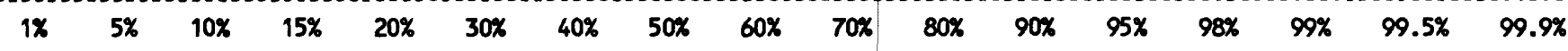

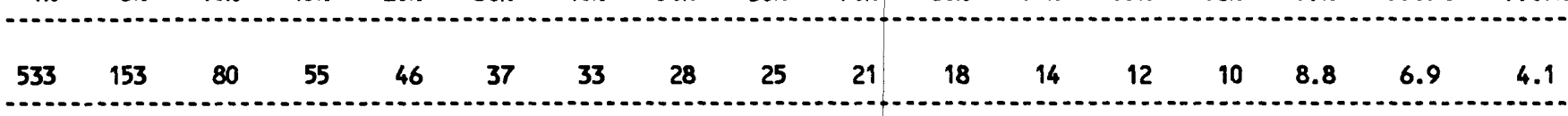

f Reliability of values in colum is uncertain, and potential errors are large. 
09447000 EAgle CREEK ABOVE PUAPING PLANT, MEAR MORENCI, AZ--CONtIMUED
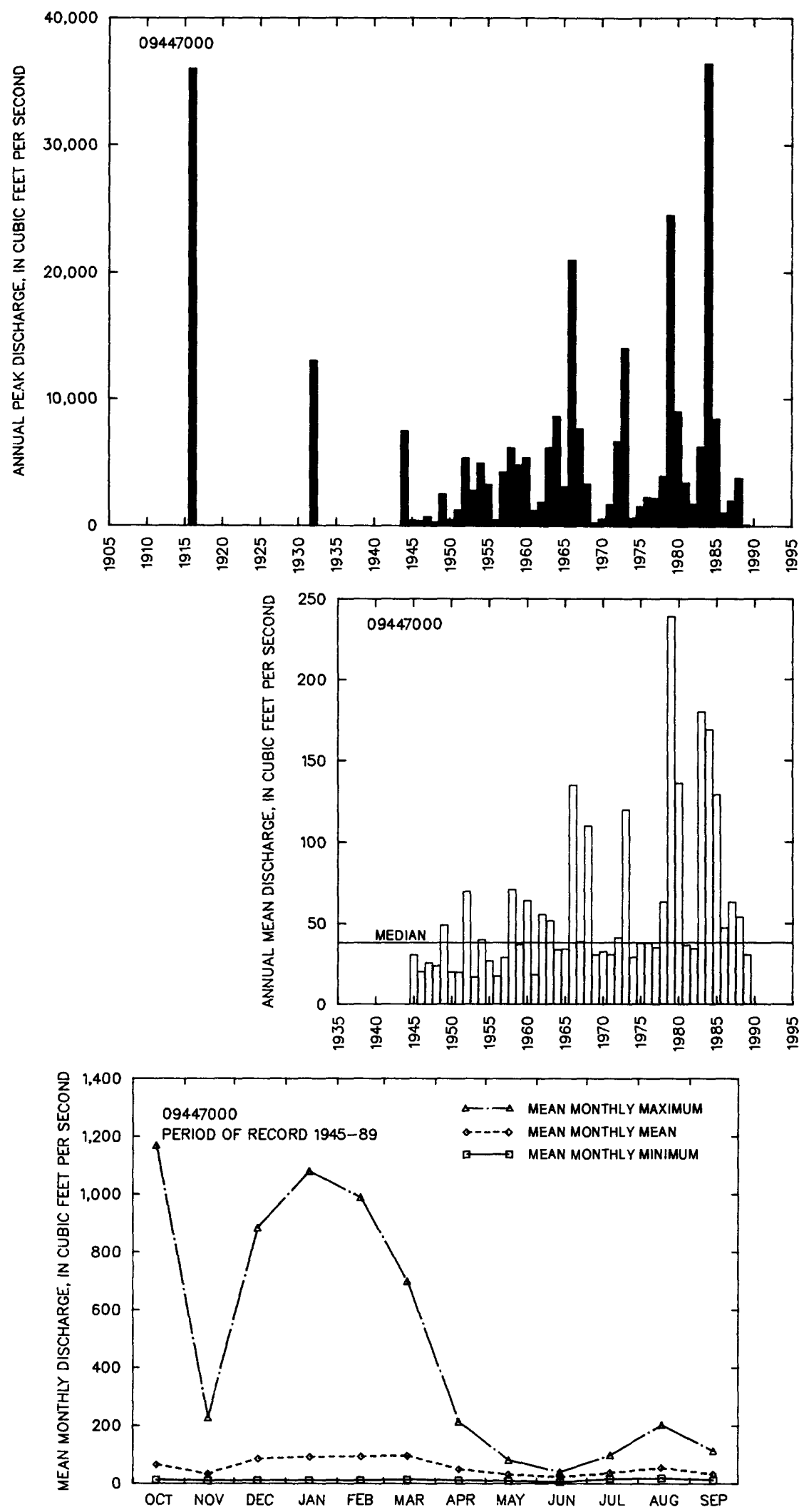


\section{GILA RIVER BASIN}

09448500 GILA RIVER AT HEAD OF SAFFORd VALLEY, NEAR SOLOMON, AZ

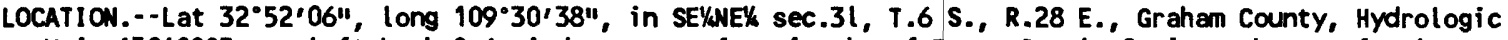
Unit 15040005, on left bank 0.6 mi downstream from intake of Brown Canal, 8 mi northeast of Solomon, and $17 \mathrm{mi}$ downstream from San Francisco River. Records include flow of Brown Canal, which is measured 2,000 ft downstream from intake.

DRAINAGE AREA. $--7,896 \mathrm{mi}^{2}$.

ANNUAL PEAK DISCHARGE

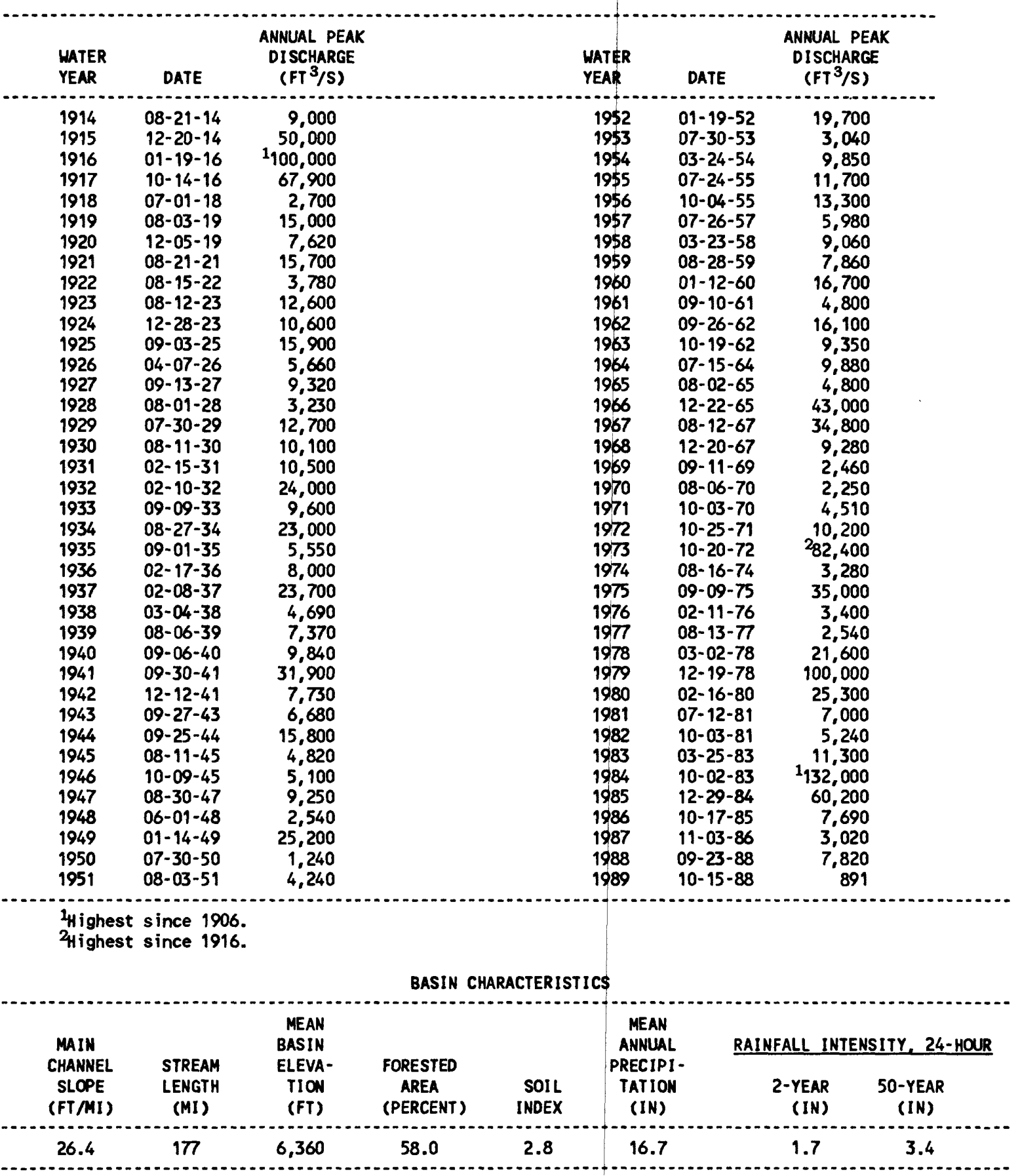


09448500 GILA RIVER AT HEAD OF SAFFORD VALLEY, NEAR SOLOMON, AZ--Cont inued

MEAN MONTHLY AND ANNUAL DISCHARGES 1921-33, 1936-89

\begin{tabular}{|c|c|c|c|c|c|c|}
\hline MONTH & $\begin{array}{l}\operatorname{MAX} \lim _{(\mathrm{M}} \\
(\mathrm{FT} / \mathrm{S})\end{array}$ & $\begin{array}{l}\text { MINIMUM } \\
\left(F T^{3} / S\right)\end{array}$ & $\begin{array}{c}\text { MEAN } \\
\left(F T^{3} / S\right)\end{array}$ & $\begin{array}{l}\text { STAN- } \\
\text { DARD } \\
\text { DEVIA- } \\
\text { TION } \\
\text { (FT } 3 / S)\end{array}$ & $\begin{array}{l}\text { COEFFI - } \\
\text { CIENT OF } \\
\text { VARI - } \\
\text { ATION }\end{array}$ & $\begin{array}{c}\text { PERCENT } \\
\text { OF } \\
\text { ANNUAL } \\
\text { RUNOFF }\end{array}$ \\
\hline $\begin{array}{l}\text { OCTOBER } \\
\text { NOVEMBER } \\
\text { DECEMBER } \\
\text { JANUARY } \\
\text { FEBRUARY } \\
\text { MARCH } \\
\text { APRIL } \\
\text { MAY } \\
\text { JUNE } \\
\text { JULY } \\
\text { AUGUST } \\
\text { SEPTEMBER }\end{array}$ & $\begin{array}{r}7,450 \\
2,230 \\
5,800 \\
3,370 \\
3,870 \\
3,380 \\
2,780 \\
2,040 \\
388 \\
735 \\
2,500 \\
2,080\end{array}$ & $\begin{array}{r}40 \\
49 \\
60 \\
93 \\
103 \\
82 \\
64 \\
38 \\
20 \\
44 \\
66 \\
36\end{array}$ & $\begin{array}{l}403 \\
240 \\
494 \\
490 \\
680 \\
801 \\
568 \\
291 \\
100 \\
218 \\
528 \\
392\end{array}$ & $\begin{array}{r}1,060 \\
286 \\
928 \\
682 \\
875 \\
913 \\
618 \\
364 \\
77 \\
152 \\
525 \\
399\end{array}$ & $\begin{array}{l}2.6 \\
1.2 \\
1.9 \\
1.4 \\
1.3 \\
1.1 \\
1.1 \\
1.3 \\
0.77 \\
0.70 \\
0.99 \\
1.0\end{array}$ & $\begin{array}{r}7.7 \\
4.6 \\
9.5 \\
9.4 \\
13.1 \\
15.4 \\
10.9 \\
5.6 \\
1.9 \\
4.2 \\
10.2 \\
7.5\end{array}$ \\
\hline AMMUAL & 1,680 & 101 & 433 & 334 & 0.77 & 100 \\
\hline
\end{tabular}

MAGNI TUDE AND PROBABILITY OF INSTANTANEOUS PEAK FLOW BASED ON PERIOD OF RECORD $1914-89$

DISCHARGE, IN $\mathrm{FT}^{3} / \mathrm{S}$, FOR INDICATED RECURRENCE INTERVAL IN YEARS, AND EXCEEDANCE PROBABILITY, IN PERCENT

\begin{tabular}{lccccc}
2 & 5 & 10 & 25 & 50 & 100 \\
$50 \%$ & $20 \%$ & $10 \%$ & $4 \%$ & $2 \%$ & $1 \%$ \\
9,400 & 22,900 & 38,000 & 66,900 & 98,000 & 140,000 \\
\hline MEIGHTED SKEW (LOGS) & $=0.38$ & & \\
MEAN & (LOGS) & 4.00 \\
STANDARD DEV. (LOGS) & $=0.44$ & &
\end{tabular}

DURATION TABLE OF DAILY MEAN FLOW FOR PERIDO OF RECORD 1921-33, 1936-89
MAGNITLDE AND PROBABILITY OF ANNUAL LOW FLOH BASED ON PERICD OF RECORD 1922-33, 1937-89

\begin{tabular}{|c|c|c|c|c|c|c|}
\hline \multirow{2}{*}{$\begin{array}{l}\text { PERICD } \\
\text { (CON- } \\
\text { SECU- } \\
\text { TIVE } \\
\text { DAYS) }\end{array}$} & \multicolumn{6}{|c|}{$\begin{array}{l}\text { DISCHARGE, IN } \mathrm{FT}^{3} / \mathrm{S} \text {, FOR INDICATED } \\
\text { RECURRENCE INTERVAL, IN YEARS, AND } \\
\text { NOW-EXCEEDANCE PROBABILITY, IN PERCENT }\end{array}$} \\
\hline & $\begin{array}{c}2 \\
50 \%\end{array}$ & $\begin{array}{c}5 \\
20 \%\end{array}$ & $\begin{array}{l}10 \\
10 x\end{array}$ & $\begin{array}{l}20 \\
5 \%\end{array}$ & $\begin{array}{l}50 \\
2 \%\end{array}$ & $\begin{array}{l}100 \\
1 \%\end{array}$ \\
\hline $\begin{array}{r}1 \\
3 \\
7 \\
14 \\
30 \\
60 \\
90 \\
120 \\
183 .\end{array}$ & $\begin{array}{r}40 \\
41 \\
44 \\
48 \\
57 \\
75 \\
98 \\
128 \\
176\end{array}$ & $\begin{array}{r}26 \\
27 \\
29 \\
32 \\
38 \\
50 \\
64 \\
87 \\
118\end{array}$ & $\begin{array}{l}21 \\
22 \\
24 \\
27 \\
31 \\
40 \\
52 \\
71 \\
99\end{array}$ & $\begin{array}{l}17 \\
18 \\
20 \\
23 \\
26 \\
34 \\
44 \\
59 \\
86\end{array}$ & $\begin{array}{l}14 \\
15 \\
17 \\
19 \\
22 \\
28 \\
36 \\
48 \\
74\end{array}$ & $\begin{array}{l}12 \\
13 \\
15 \\
17 \\
19 \\
25 \\
32 \\
42 \\
68\end{array}$ \\
\hline
\end{tabular}

MAGNITLDE AND PROBABILITY OF ANNUAL HIGH FLOW BASED ON PERICD OF RECORD 1921-33, 1936-89

\begin{tabular}{|c|c|c|c|c|c|c|}
\hline $\begin{array}{l}\text { PERIOD } \\
\text { (CON- } \\
\text { SECU- }\end{array}$ & & $\begin{array}{l}\text { DISCHAR } \\
\text { RECURRE } \\
\text { EXCEED }\end{array}$ & $\begin{array}{l}\text { GE, IN } \\
\text { NCE INT } \\
\text { NCE PRO }\end{array}$ & $\begin{array}{l}3 / S \text {, } \\
V A L\end{array}$ & YEAR & $\begin{array}{l}\text { TED } \\
\text { AND } \\
\text { ENT }\end{array}$ \\
\hline $\begin{array}{l}\text { TIVE } \\
\text { DAYS) }\end{array}$ & $\stackrel{2}{50 x}$ & $\begin{array}{c}5 \\
20 \%\end{array}$ & $\begin{array}{l}10 \\
10 \%\end{array}$ & $\begin{array}{l}25 \\
4 \%\end{array}$ & $\begin{array}{l}50 \\
2 \%\end{array}$ & $\begin{array}{r}100 \\
1 \%\end{array}$ \\
\hline $\begin{array}{r}1 \\
3 \\
7 \\
15 \\
30 \\
60 \\
90\end{array}$ & $\begin{array}{r}4,680 \\
3,340 \\
2,300 \\
1,640 \\
1,190 \\
853 \\
678\end{array}$ & $\begin{array}{r}12,300 \\
8,500 \\
5,450 \\
3,630 \\
2,480 \\
1,750 \\
1,410\end{array}$ & $\begin{array}{r}21,200 \\
14,300 \\
8,790 \\
5,570 \\
3,670 \\
2,550 \\
2,090\end{array}$ & $\begin{array}{r}39,000 \\
25,700 \\
14,900 \\
8,880 \\
5,610 \\
3,840 \\
3,200\end{array}$ & $\begin{array}{r}58,800 \\
38,200 \\
21,200 \\
12,100 \\
7,390 \\
5,000 \\
4,230\end{array}$ & $\begin{array}{r}86,200 \\
55,000 \\
29,400 \\
16,000 \\
9,500 \\
6,350 \\
5,470\end{array}$ \\
\hline
\end{tabular}

DISCHARGE, IN FT $3 / 5$, WHICH WAS EQUALED OR EXCEEDED FOR INDICATED PERCENT OF TIME

\begin{tabular}{|c|c|c|c|c|c|c|c|c|c|c|c|c|c|c|c|c|}
\hline $1 \%$ & $5 \%$ & $10 \%$ & $15 \%$ & $20 \%$ & $30 \%$ & $40 \%$ & $50 \%$ & $60 \%$ & $70 \%$ & $80 \%$ & $90 \%$ & $95 \%$ & $98 \%$ & $99 \%$ & $99.5 \%$ & $99.9 \%$ \\
\hline 70 & 1,630 & 932 & 607 & 456 & $2 \%$ & 214 & 174 & 144 & 117 & 91 & 62 & 47 & 35 & 29 & 25 & 18 \\
\hline
\end{tabular}


09448500 GILA RIVER AT HEAD OF SAFFORD VALLEY, NEAR SOLOMON, AZ--CONTINUED
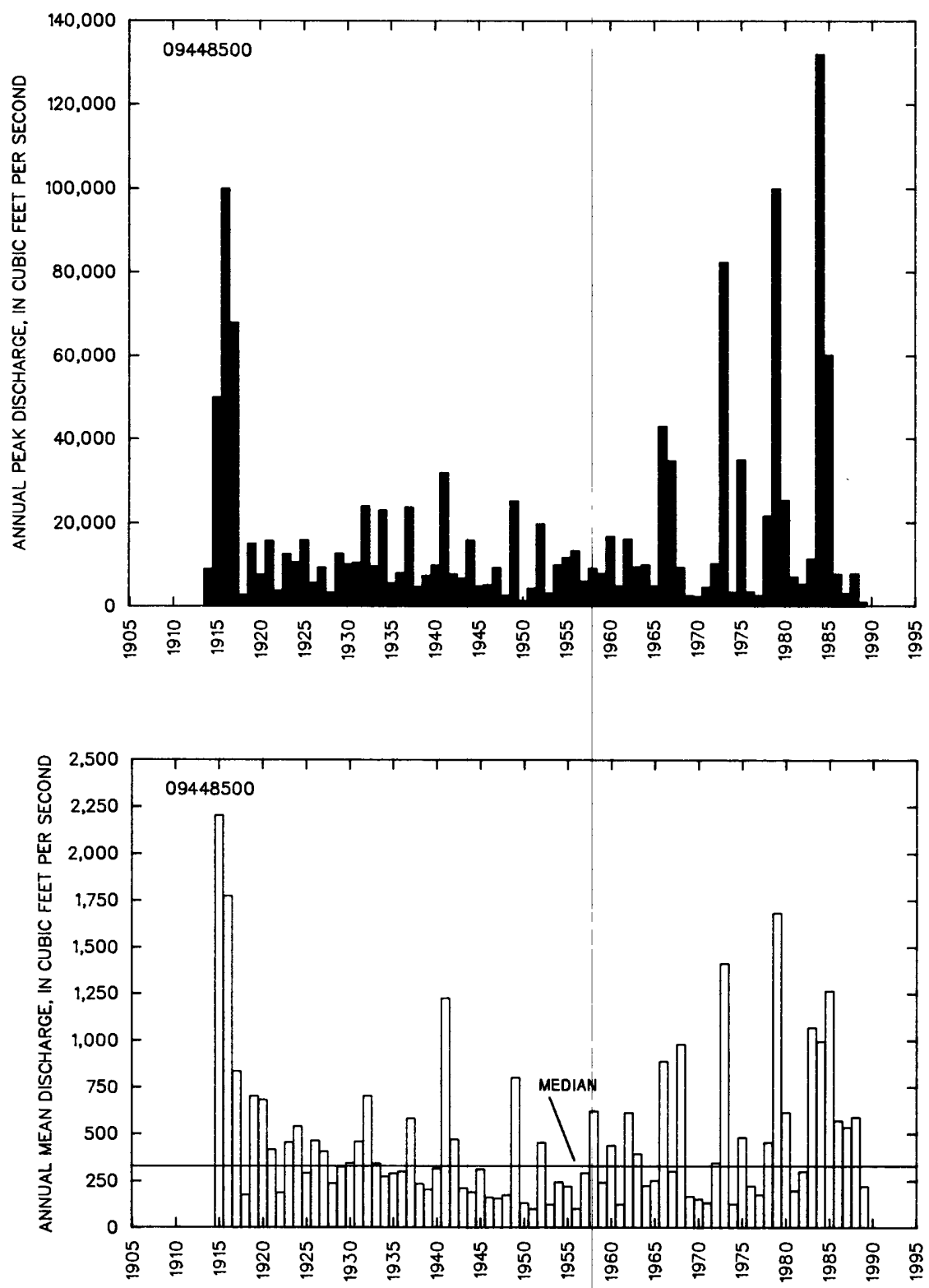
09448500 GILA RIVER AT HEAD OF SAFFORD VALLEY, NEAR SOLOMON, AZ--CONTIMUED
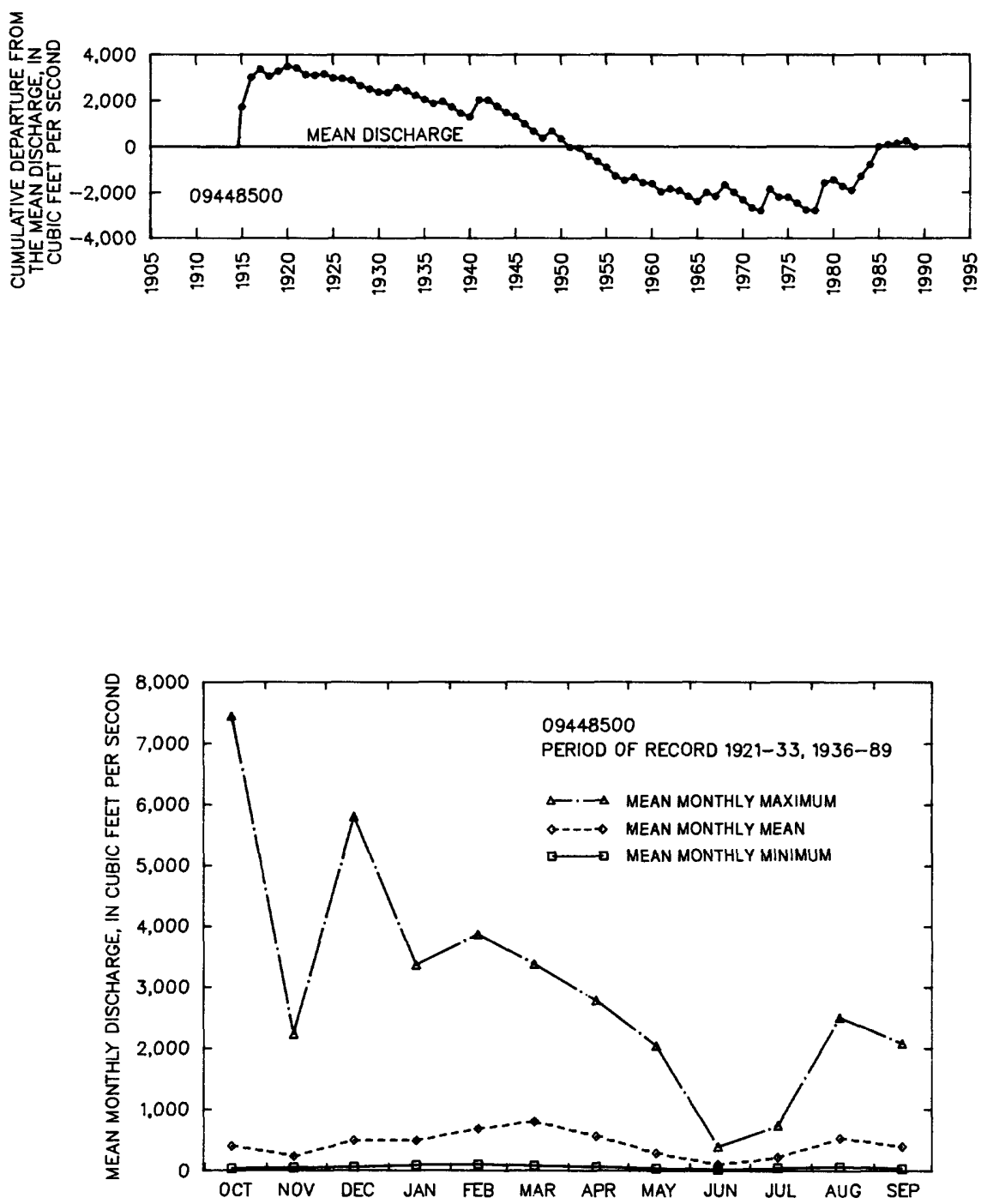
09451800 TOLLGATE WASH TRIBUTARY NEAR CLIFTON, AZ

LOCATION.--Lat 32.51'00", long 109'20'15", in SWk sec.1, T.7 S., R.29 E., Graham County, Hydrologic Unit 15040005, at U.S. Highway 666 , at Graham-Greenlee County line 14 miles south of Clifton.

DRAINAGE AREA. - - $0.12 \mathrm{mi}^{2}$.

ANNUAL PEAK DISCHARGE

\begin{tabular}{lccc}
$\begin{array}{l}\text { WATER } \\
\text { YEAR }\end{array}$ & DATE & $\begin{array}{c}\text { ANNUAL PEAK } \\
\text { DISCHARGE } \\
\text { (FT } 3 / \text { S })\end{array}$ & $\begin{array}{c}\text { DISCHARGE } \\
\text { CODES }\end{array}$ \\
\hline 1963 & $07-19-63$ & 62 & \\
1964 & $00-00-64$ & 29 & \\
1965 & $09-03-65$ & 10 & \\
1966 & $09-15-66$ & 34 & \\
1967 & $00-00-67$ & 0 & \\
1968 & $00-00-68$ & 0 & \\
1969 & $00-00-69$ & 0 & \\
1970 & $00-00-70$ & 0 & \\
1971 & $10-02-70$ & 15 & \\
1972 & $00-00-72$ & 8.0 & \\
1973 & $10-19-72$ & 63 & \\
1974 & $08-23-74$ & 56 & \\
1975 & $07-24-75$ & 22 & \\
1976 & $00-00-76$ & 0 &
\end{tabular}

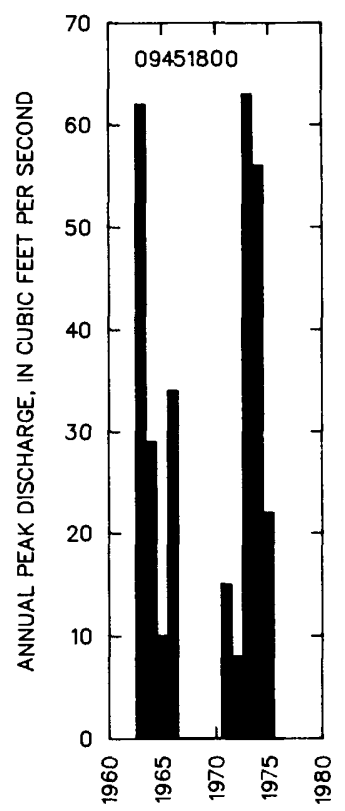

MAGNITUDE AND PROBABILITY OF INSTANTANEOUS PEAK FLON BASED ON PERIOD OF RECORD 1963-76

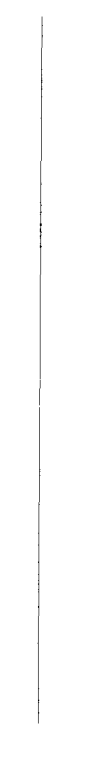


09456000 SAN SIMON RIVER NEAR SAN SIMON, AZ

LOCATION.--Lat 32'13'30", long 109'10'30", in SWK sec.10, T.14 S., R.31 E., Cochise County, Hydrologic Unit $15040006,4.5 \mathrm{mi}$ southeast of San Simon.

DRAINAGE AREA. $--814 \mathrm{mi}^{2}$.

ANMUAL PEAK DISCHARGE

\begin{tabular}{lccc}
$\begin{array}{l}\text { WATER } \\
\text { YEAR }\end{array}$ & DATE & $\begin{array}{c}\text { ANMUAL PEAK } \\
\text { DISCHARGE } \\
\text { (FT }{ }^{3} / \text { /S) }\end{array}$ & $\begin{array}{c}\text { DISCHARGE } \\
\text { CODES }\end{array}$ \\
\hline 1923 & $07-21-23$ & 5,350 & HP \\
1931 & $08-10-31$ & 4,500 & \\
1932 & $07-25-32$ & 1,250 & \\
1933 & $08-04-33$ & 1,550 & \\
1934 & $08-00-34$ & 4,550 & \\
1935 & $08-28-35$ & 5,020 & \\
1936 & $08-18-36$ & 4,190 & \\
1937 & $08-09-37$ & 548 & \\
1938 & $06-29-38$ & 2,280 & \\
1939 & $08-13-39$ & 2,840 & \\
1940 & $06-29-40$ & 4,280 & \\
1941 & $08-15-41$ & 1,870 & \\
\hline
\end{tabular}

MAGNITUDE AND PROBABILITY OF INSTANTANEOUS PEAK FLOW BASED ON PERIOD OF RECORD 1923, 1931-41

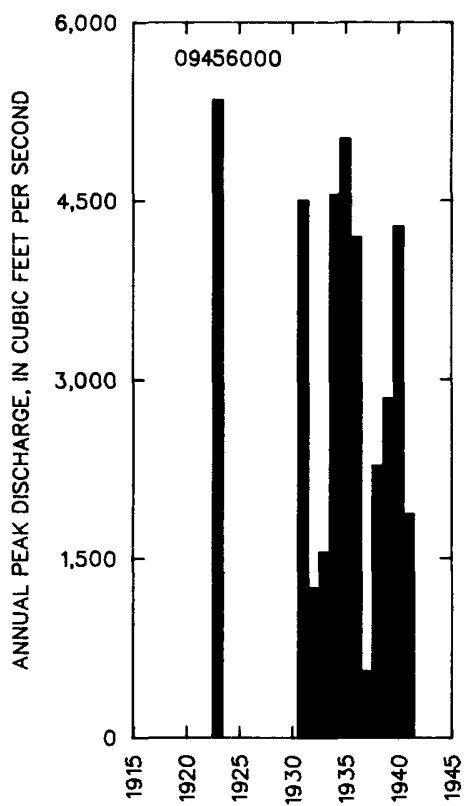

DISCHARGE, IN $\mathrm{FT}^{3} / \mathrm{S}$, FOR INDICATED RECURRENCE INTERVAL IN YEARS, AND EXCEEDANCE PROBABILITY, IN PERCENT

\begin{tabular}{|c|c|c|c|c|c|}
\hline $\begin{array}{c}2 \\
50 \%\end{array}$ & $\begin{array}{c}5 \\
20 \%\end{array}$ & $\begin{array}{r}10 \\
10 \%\end{array}$ & $\begin{array}{l}25 t \\
4 \%\end{array}$ & $\begin{array}{l}50 \uparrow \\
2 \%\end{array}$ & $\begin{array}{c}100 t \\
1 \%\end{array}$ \\
\hline 2,920 & 4,520 & 5,570 & 6,860 & 7,770 & 8,660 \\
\hline $\begin{array}{l}\text { WEIGHT } \\
\text { MEAN } \\
\text { STANDA }\end{array}$ & DEV. & $\begin{array}{l}(\mathbf{G S})=- \\
(\mathbf{G S})= \\
(\mathbf{G S})=\end{array}$ & & & \\
\hline
\end{tabular}

$\uparrow$ Reliability of values in column is uncertain, and potential errors are large.

\section{BASIN CHARACTERISTICS}

\begin{tabular}{|c|c|c|c|c|c|c|c|}
\hline MAIN & & $\begin{array}{r}\text { MEAN } \\
\text { BASIN }\end{array}$ & & & $\begin{array}{c}\text { MEAN } \\
\text { ANNUAL }\end{array}$ & RAINFALL II & SITY, 24-HOUR \\
\hline $\begin{array}{l}\text { CHANNEL } \\
\text { SLOPE } \\
\text { (FT/MI) }\end{array}$ & $\begin{array}{c}\text { STREAM } \\
\text { LENGTH } \\
\text { (MI) }\end{array}$ & $\begin{array}{l}\text { ELEVA- } \\
\text { TION } \\
\text { (FT) }\end{array}$ & $\begin{array}{l}\text { FORESTED } \\
\text { AREA } \\
\text { (PERCENT) }\end{array}$ & $\begin{array}{l}\text { SOIL } \\
\text { INDEX }\end{array}$ & $\begin{array}{l}\text { PRECIPI - } \\
\text { TATION } \\
\text { (IN) }\end{array}$ & $\begin{array}{c}\text { 2-YEAR } \\
\text { (IN) }\end{array}$ & $\begin{array}{c}\text { 50-YEAR } \\
\text { (IN) }\end{array}$ \\
\hline 23.8 & 64.6 & 4,830 & 23.0 & 2.3 & 14.9 & 1.9 & 3.6 \\
\hline
\end{tabular}


09456400 GOLD GULCH NEAR BONIE, AZ

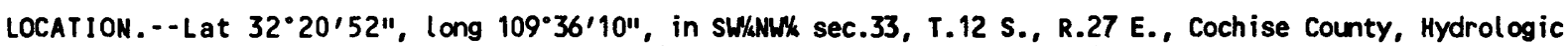
Unit 15040006, $100 \mathrm{ft}$ upstream from State Highway 86, 7 miles west of Bowie.

DRAINAGE AREA. - - $15.0 \mathrm{mi}^{2}$.

ANNUAL PEAK DISCHARGE

\begin{tabular}{cccc}
$\begin{array}{c}\text { WATER } \\
\text { YEAR }\end{array}$ & DATE & $\begin{array}{c}\text { ANNUAL PEAK } \\
\text { DISCHARGE } \\
\text { (FT } 3 / \text { S) }\end{array}$ & $\begin{array}{c}\text { DISCHARGE } \\
\text { CODES }\end{array}$ \\
\hline 1963 & $08-23-63$ & 420 & \\
1964 & $08-18-64$ & 1,180 & \\
1965 & $08-29-65$ & 1,770 & \\
1966 & $08-07-66$ & 450 & ES \\
1967 & $07-07-67$ & 640 & \\
1968 & $12-20-67$ & 1,740 & \\
1969 & $09-11-69$ & 520 & \\
1970 & $07-20-70$ & 150 & ES \\
1971 & $08-18-71$ & 2,550 & \\
1972 & $00-00-72$ & 90 & LT \\
1973 & $10-00-72$ & 400 & \\
1974 & $08-24-74$ & 147 & \\
1975 & $07-22-75$ & 630 & \\
1976 & $00-00-76$ & 225 & \\
\hline$\ldots \ldots$ & &
\end{tabular}

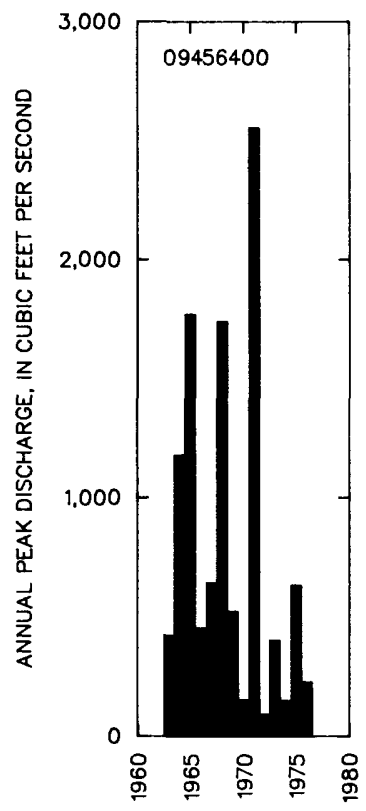

MAGNITUDE AND PROBABILITY OF INSTANTANEOUS PEAK FLOU BASED ON PERIOD OF RECORD 1963-76

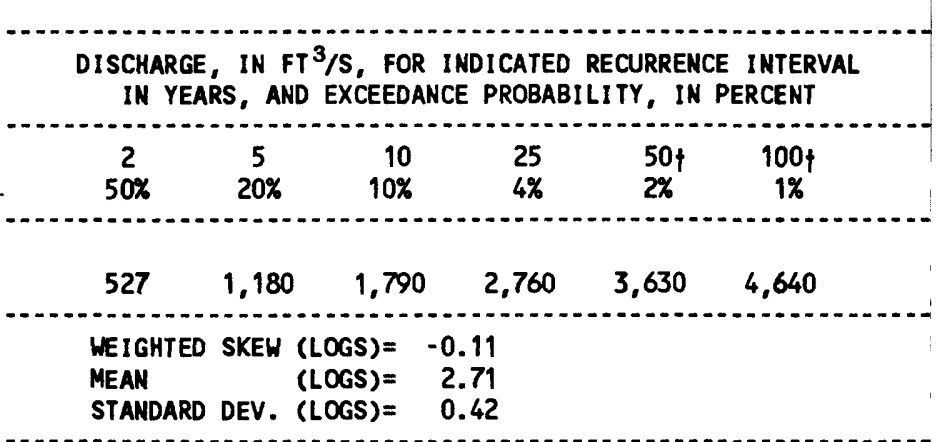

$\uparrow$ Reliability of values in colum is uncertain, and potential errors are large.

\section{BASIN CHARACTERISTICS}

\begin{tabular}{|c|c|c|c|c|c|c|c|}
\hline & & MEAN & & & MEAN & & \\
\hline MAIN & & BASIN & & & ANNUAL & RAINFALL II & SITY, 24-HOUR \\
\hline $\begin{array}{l}\text { CHANNEL } \\
\text { SLOPE } \\
\text { (FT/MI) }\end{array}$ & $\begin{array}{c}\text { STREAM } \\
\text { LENGTH } \\
\text { (MI) }\end{array}$ & $\begin{array}{l}\text { ELEVA- } \\
\text { TION } \\
\text { (FT) }\end{array}$ & $\begin{array}{l}\text { FORESTED } \\
\text { AREA } \\
\text { (PERCENT) }\end{array}$ & $\begin{array}{l}\text { SOIL } \\
\text { INDEX }\end{array}$ & $\begin{array}{l}\text { PRECIPI - } \\
\text { TATION } \\
\text { (IN) }\end{array}$ & $\begin{array}{l}\text { 2-YEAR } \\
\text { (IN) }\end{array}$ & $\begin{array}{l}\text { 50-YEAR } \\
\text { (IN) }\end{array}$ \\
\hline 201 & 9.6 & 5,170 & 0.0 & 2.0 & 10.9 & 1.8 & 4.4 \\
\hline
\end{tabular}


09457000 SAN SIMON RIVER NEAR SOLOMON, AZ

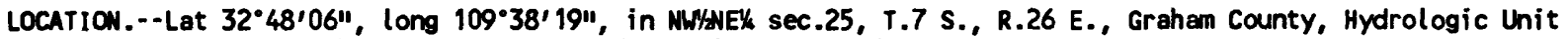
$15040006,1.0 \mathrm{mi}$ southwest of Solomon and $2.2 \mathrm{mi}$ upstream from mouth.

DRAINAGE AREA. $--2,192 \mathrm{mi}^{2}$.

REMARKS.--Records do not include waste water passing station from San Jose Canal, which diverts from Gila River. Irrigation of about 34,000 acres above station, mostly by pumping from ground water. Floodflows are partly regulated by flood-control detention structures on main stream and tributaries; combined maximum capacity in excess of 10,500 acre-ft.

ANNUAL PEAK DISCHARGE

\begin{tabular}{|c|c|c|c|c|c|c|c|}
\hline $\begin{array}{l}\text { MATER } \\
\text { YEAR }\end{array}$ & DATE & $\begin{array}{c}\text { ANNUAL PEAK } \\
\text { DISCHARGE } \\
\left(F^{3} / S\right)\end{array}$ & $\begin{array}{l}\text { DISCHARGE } \\
\text { CODES }\end{array}$ & $\begin{array}{l}\text { WATER } \\
\text { YEAR }\end{array}$ & DATE & $\begin{array}{c}\text { ANNUAL PEAK } \\
\text { DISCHARGE } \\
\left(F^{3} / \mathrm{S}\right)\end{array}$ & $\begin{array}{l}\text { DISCHARGE } \\
\text { CODES }\end{array}$ \\
\hline $\begin{array}{l}1931 \\
1932 \\
1933 \\
1934 \\
1935 \\
1936 \\
1937 \\
1938 \\
1939 \\
1940 \\
1941 \\
1942 \\
1943 \\
1944 \\
1945 \\
1946 \\
1947 \\
1948 \\
1949 \\
1950 \\
1951 \\
1952 \\
1953 \\
1954 \\
1955 \\
1956 \\
1957\end{array}$ & $\begin{array}{l}08-09-31 \\
07-30-32 \\
07-16-33 \\
08-00-34 \\
08-01-35 \\
09-10-36 \\
08-21-37 \\
07-12-38 \\
08-14-39 \\
09-05-40 \\
08-17-41 \\
09-11-42 \\
08-15-43 \\
09-25-44 \\
08-10-45 \\
08-30-46 \\
06-18-47 \\
08-06-48 \\
08-08-49 \\
09-18-50 \\
08-02-51 \\
08-17-52 \\
07-07-53 \\
09-12-54 \\
07-30-55 \\
10-04-55 \\
08-30-57\end{array}$ & $\begin{array}{r}127,500 \\
8,800 \\
4,000 \\
11,500 \\
12,000 \\
10,600 \\
2,370 \\
4,500 \\
2,140 \\
6,080 \\
13,000 \\
5,000 \\
6,430 \\
5,900 \\
7,350 \\
4,820 \\
2,700 \\
5,880 \\
8,100 \\
2,060 \\
7,390 \\
5,100 \\
3,970 \\
6,980 \\
6,400 \\
1,520 \\
8,950\end{array}$ & $\begin{array}{l}\text { UR } \\
\text { UR } \\
\text { UR } \\
\text { UR } \\
\text { UR }\end{array}$ & $\begin{array}{l}1958 \\
1959 \\
1960 \\
1961 \\
1962 \\
1963 \\
1964 \\
1965 \\
1966 \\
1967 \\
1968 \\
1969 \\
1970 \\
1971 \\
1972 \\
1973 \\
1974 \\
1975 \\
1976 \\
1977 \\
1978 \\
1979 \\
1980 \\
1981 \\
1982 \\
1984\end{array}$ & $\begin{array}{l}08-16-58 \\
08-23-59 \\
09-09-60 \\
08-22-61 \\
09-26-62 \\
08-26-63 \\
07-14-64 \\
08-29-65 \\
09-15-66 \\
08-12-67 \\
07-02-68 \\
07-10-69 \\
08-17-70 \\
09-23-71 \\
08-26-72 \\
10-19-72 \\
08-15-74 \\
09-08-75 \\
09-24-76 \\
08-22-77 \\
07-22-78 \\
08-14-79 \\
08-13-80 \\
09-17-81 \\
07-26-82 \\
10-02-83\end{array}$ & $\begin{array}{r}4,250 \\
4,610 \\
3,260 \\
7,750 \\
3,970 \\
5,170 \\
5,800 \\
4,880 \\
2,250 \\
5,570 \\
3,870 \\
2,310 \\
1,010 \\
3,310 \\
4,570 \\
1,820 \\
4,840 \\
3,690 \\
3,070 \\
3,010 \\
1,630 \\
4,370 \\
484 \\
3,560 \\
4,430 \\
5,500\end{array}$ & $\begin{array}{l}\text { UR } \\
\text { UR } \\
\text { UR } \\
\text { UR } \\
\text { UR } \\
\text { UR } \\
\text { UR } \\
\text { UR } \\
\text { UR } \\
\text { UR } \\
\text { UR } \\
\text { UR } \\
\text { UR } \\
\text { UR } \\
\text { UR } \\
\text { UR } \\
\text { UR } \\
\text { UR } \\
\text { UR } \\
\text { UR } \\
\text { UR } \\
\text { UR } \\
\text { UR } \\
\text { UR } \\
\text { UR } \\
\text { UR, HP }\end{array}$ \\
\hline
\end{tabular}

Highest since 1880 .

\section{BASIN CHARACTERISTICS}

\begin{tabular}{|c|c|c|c|c|c|c|c|}
\hline \multirow{2}{*}{$\begin{array}{l}\text { MAIN } \\
\text { CHANNEL } \\
\text { SLOPE } \\
\text { (FT/MI) }\end{array}$} & \multirow[b]{2}{*}{$\begin{array}{l}\text { STREAM } \\
\text { LENGTH } \\
\text { (MI) }\end{array}$} & \multirow{2}{*}{$\begin{array}{c}\text { MEAN } \\
\text { BASIN } \\
\text { ELEVA- } \\
\text { TION } \\
\text { (FT) }\end{array}$} & \multirow[b]{2}{*}{$\begin{array}{l}\text { FORESTED } \\
\text { AREA } \\
\text { (PERCENT) }\end{array}$} & \multirow[b]{2}{*}{$\begin{array}{l}\text { SOIL } \\
\text { INDEX }\end{array}$} & \multirow{2}{*}{$\begin{array}{l}\text { MEAN } \\
\text { ANNUAL } \\
\text { PRECIPI- } \\
\text { TATION } \\
\text { (IN) }\end{array}$} & \multicolumn{2}{|c|}{ RAINFALL INTENSITY, 24-HOUR } \\
\hline & & & & & & $\begin{array}{l}\text { 2-YEAR } \\
\text { (IN) }\end{array}$ & $\begin{array}{l}\text { 50-YEAR } \\
\text { (IN) }\end{array}$ \\
\hline 14.6 & 119 & 4,270 & 11.0 & 2.3 & 12.2 & 1.8 & 3.4 \\
\hline
\end{tabular}




\section{GILA RIVER BASIN}

09457000 SAN SIMON RIVER NEAR SOLOMON, AZ--Cont inued

MEAN MONTHLY AND ANMUAL DISCHARGES 1932, 1936-82

\begin{tabular}{|c|c|c|c|c|c|c|}
\hline MONTH & $\begin{array}{l}\operatorname{MAx} \lim _{3} \\
\left(F T^{3} / S\right)\end{array}$ & $\begin{array}{l}\text { MINIIMUM } \\
\left(F T^{3} / S\right)\end{array}$ & $\begin{array}{c}\text { MEAN } \\
\left(F T^{3} / S\right)\end{array}$ & $\begin{array}{l}\text { STAN- } \\
\text { DARD } \\
\text { DEVIA- } \\
\text { TION } \\
\left(\mathrm{FT}^{3} / \mathrm{S}\right)\end{array}$ & $\begin{array}{l}\text { COEFFI - } \\
\text { CIENT OF } \\
\text { VARI - } \\
\text { ATION }\end{array}$ & $\begin{array}{c}\text { PERCENT } \\
\text { OF } \\
\text { ANNUAL } \\
\text { RUNOFF }\end{array}$ \\
\hline $\begin{array}{l}\text { OCTOBER } \\
\text { NOVEMBER } \\
\text { DECEMBER } \\
\text { JANUARY } \\
\text { FEBRUARY } \\
\text { MARCH } \\
\text { APRIL } \\
\text { MAY } \\
\text { JUNE } \\
\text { JULY } \\
\text { AUGUST } \\
\text { SEPTEMBER }\end{array}$ & $\begin{array}{c}71 \\
8.0 \\
25 \\
8.0 \\
14 \\
5.5 \\
15 \\
11 \\
20 \\
274 \\
328 \\
176\end{array}$ & $\begin{array}{l}0.00 \\
0.00 \\
0.00 \\
0.00 \\
0.00 \\
0.00 \\
0.00 \\
0.00 \\
0.00 \\
0.00 \\
0.00 \\
0.00\end{array}$ & $\begin{array}{l}8.8 \\
0.65 \\
1.1 \\
0.45 \\
0.86 \\
0.20 \\
0.52 \\
0.44 \\
1.6 \\
32 \\
68 \\
24\end{array}$ & $\begin{array}{l}17 \\
1.9 \\
4.1 \\
1.6 \\
3.0 \\
0.85 \\
2.5 \\
1.7 \\
4.1 \\
44 \\
74 \\
32\end{array}$ & $\begin{array}{l}1.9 \\
2.9 \\
3.6 \\
3.5 \\
3.4 \\
4.4 \\
4.8 \\
3.9 \\
2.6 \\
1.4 \\
1.1 \\
1.4\end{array}$ & $\begin{array}{l}6.3 \\
0.5 \\
0.8 \\
0.3 \\
0.6 \\
0.1 \\
0.4 \\
0.3 \\
1.2 \\
23.0 \\
49.1 \\
17.3\end{array}$ \\
\hline AMNUAL & 38 & 1.4 & 12 & 8.8 & 0.75 & 100 \\
\hline
\end{tabular}

Magkitude AND PROBability of INSTANTANEQUS PEAK FLOW BASED ON PERICD OF RECORD 1931-82, 1984

DISCHARGE, IN $\mathrm{FT}^{3} / \mathrm{S}$, FOR INDICATED RECURRENCE INTERVAL IN YEARS, AND EXCEEDANCE PROBABILITY, IN PERCENT

\begin{tabular}{|c|c|c|c|c|c|}
\hline $\begin{array}{c}2 \\
50 \%\end{array}$ & $\begin{array}{c}5 \\
20 \%\end{array}$ & $\begin{array}{r}10 \\
10 \%\end{array}$ & $\begin{array}{l}25 \\
4 \%\end{array}$ & $\begin{array}{l}50 \\
2 \%\end{array}$ & $\begin{array}{r}100 \\
1 \%\end{array}$ \\
\hline 4,520 & 7,250 & 9,320 & 12,200 & 14,500 & 17,000 \\
\hline $\begin{array}{l}\text { WEIGHTED } \\
\text { MEAN } \\
\text { STANDARD }\end{array}$ & $\begin{array}{l}\text { SKEW } \\
\text { DEV. }\end{array}$ & $\begin{array}{l}(\text { LOGS })= \\
(\text { LOGS) }= \\
(\text { LOGS })=\end{array}$ & $\begin{array}{l}05 \\
66 \\
24\end{array}$ & & \\
\hline
\end{tabular}

MAGNITUDE AND PROBABILITY OF ANNUAL LOW FLOW BASED ON PERIOD OF RECORD 1937-82

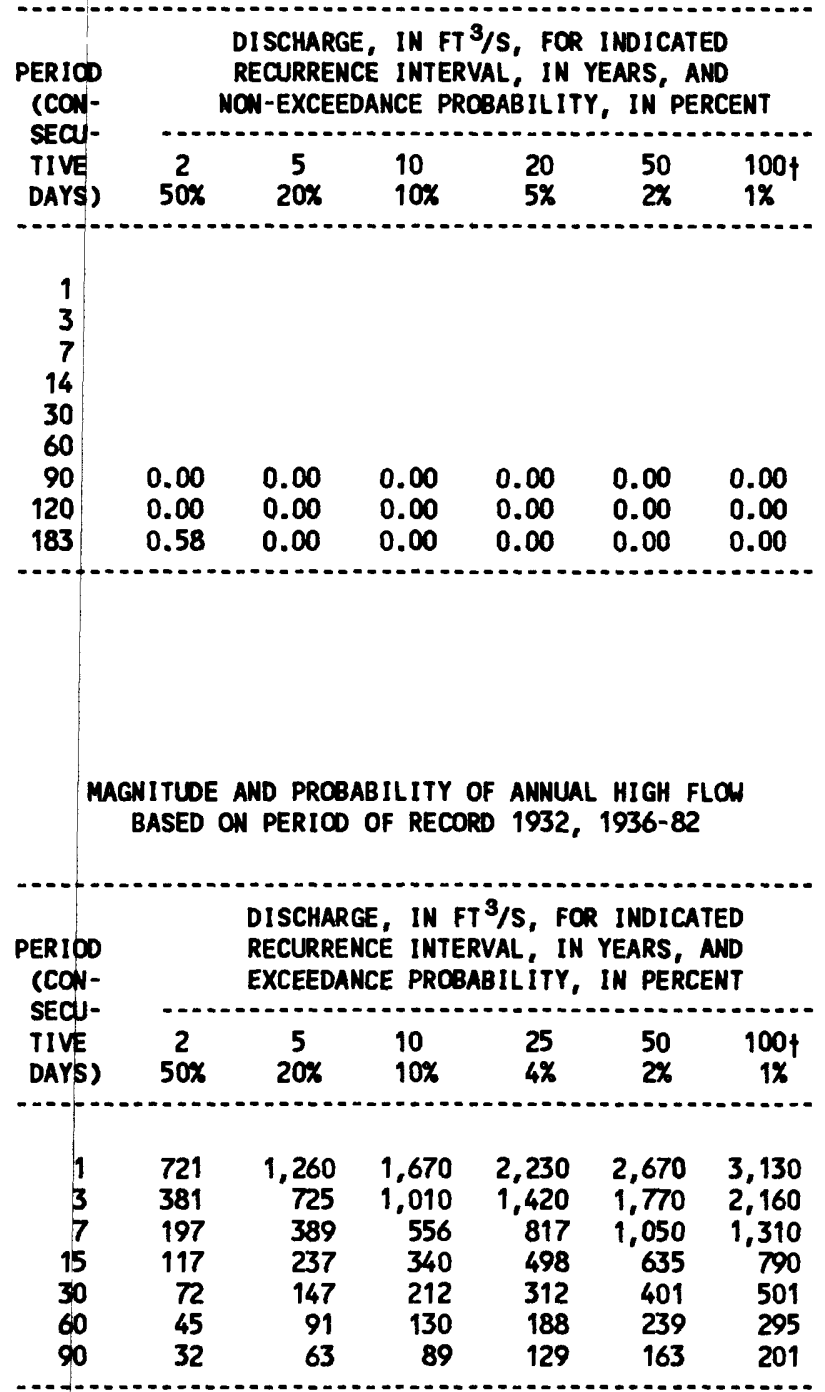

DURATION TABLE OF DAILY MEAN FLOH FOR PERICO OF RECORD 1932, 1936-82

DISCHARGE, IN FT $3 / \mathrm{S}$, WHICH WAS EQUALED OR EXCEEDED FOR INDICATED PERCENT OF TIME

$1 \% \quad 5 \% \quad 10 \% \quad 15 \% \quad 20 \% \quad 30 \% \quad 40 \% \quad 50 \% \quad 60 \% \quad 70 \% \quad 80 \% \quad 90 \% \quad 95 \% \quad 98 \% \quad 99 \% \quad 99.5 \% \quad 99.9 \%$

$\begin{array}{lllllllllllllllll}329 & 25 & 0.21 & 0.00 & 0.00 & 0.00 & 0.00 & 0.00 & 0.00 & 0.00 & 0.00 & 0.00 & 0.00 & 0.00 & 0.00 & 0.00 & 0.00\end{array}$ 
GILA RIVER BASIN

09457000 SAN SIMON RIVER NEAR SOLOMON, AZ--CONTINUED
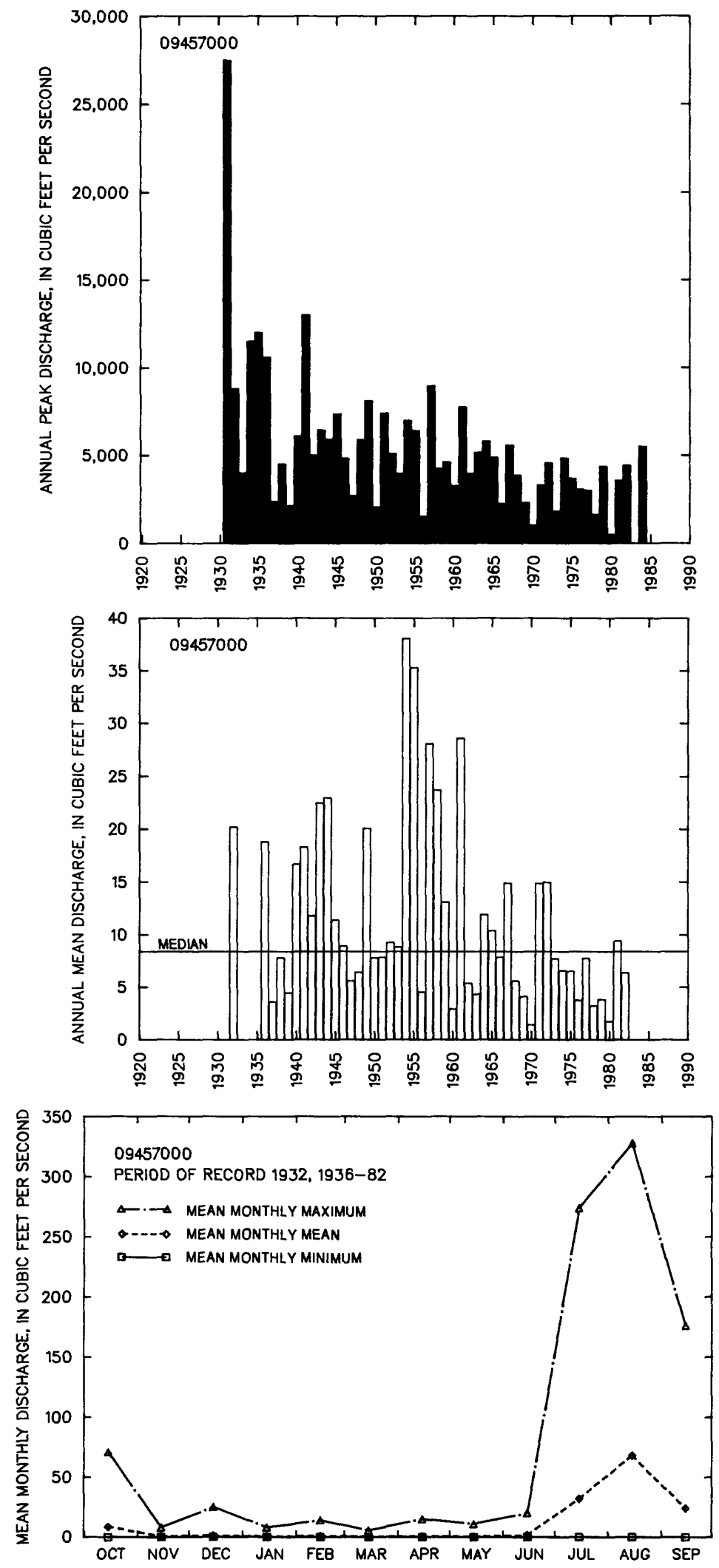


\section{GILA RIVER BASIN \\ 09458200 DEADMAN CREEK NEAR SAFFORD, AZ}

LOCATION.--Lat 32*43'59", long 109.48'57", in SWk sec.17, T.8 S., R.25 E. (unsurveyed), Graham County, Hydrologic Unit 1504005, in Coronado National Forest, on left benk 9 mi southwest of Safford.

DRAINAGE ARA. $--4.99 \mathrm{mi}^{2}$.

ANNUAL PEAK DISCHARGE

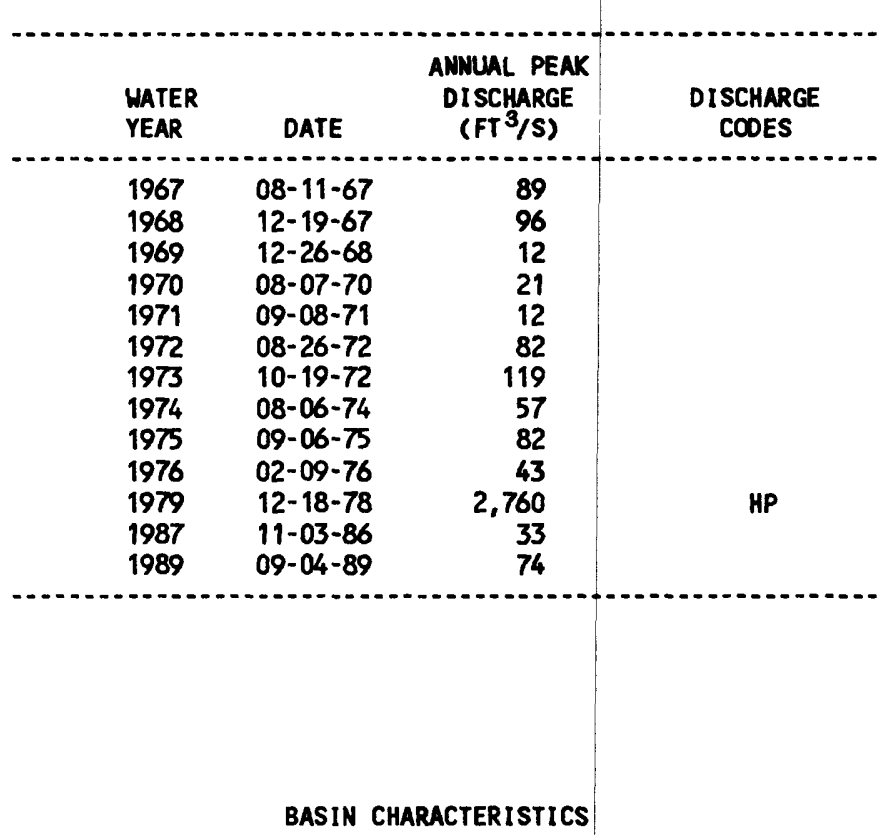

\begin{tabular}{|c|c|c|c|c|c|c|c|}
\hline & & MEAN & & & MEAN & & \\
\hline MAIN & & BASIN & & & ANNUAL & RAINFALL & SITY, 24-HOUR \\
\hline $\begin{array}{l}\text { CHANNEL } \\
\text { SLOPE } \\
\text { (FT/MI) }\end{array}$ & $\begin{array}{c}\text { STREAM } \\
\text { LENGTH } \\
\text { (MI) }\end{array}$ & $\begin{array}{l}\text { ELEVA- } \\
\text { TION } \\
\text { (FT) }\end{array}$ & $\begin{array}{l}\text { FORESTED } \\
\text { AREA } \\
\text { (PERCENT) }\end{array}$ & $\begin{array}{l}\text { SOIL } \\
\text { INDEXX }\end{array}$ & $\begin{array}{l}\text { PRECIPI- } \\
\text { TATION } \\
\text { (IN) }\end{array}$ & $\begin{array}{c}\text { 2-YEAR } \\
\text { (IN) }\end{array}$ & $\begin{array}{c}\text { 50-YEAR } \\
\text { (IN) }\end{array}$ \\
\hline 1,100 & 4.1 & 7,520 & 48.0 & 1.0 & 25.0 & 1.9 & 3.8 \\
\hline
\end{tabular}


GILA RIVER BASIN

09458200 DEADMAN CREEK NEAR SAFFORD, AZ--Continued

MEAN MONTHLY AND ANNUAL DISCHARGES 1968-76, 1987, 1989

\begin{tabular}{|c|c|c|c|c|c|c|}
\hline MONTH & $\begin{array}{l}\operatorname{MAXIMUM} \\
\left(F^{3} / S\right)\end{array}$ & $\begin{array}{l}\text { MINIMM } \\
\left(F^{3} / S\right)\end{array}$ & $\begin{array}{c}\text { MEAN } \\
\left(F T^{3} / S\right)\end{array}$ & $\begin{array}{l}\text { STAN- } \\
\text { DARO } \\
\text { DEVIA- } \\
\text { TION } \\
\text { (FT } 3 / S)\end{array}$ & $\begin{array}{l}\text { COEFFI- } \\
\text { CIENT OF } \\
\text { VARI - } \\
\text { ATION }\end{array}$ & $\begin{array}{c}\text { PERCENT } \\
\text { OF } \\
\text { ANNUAL } \\
\text { RUNOFF }\end{array}$ \\
\hline $\begin{array}{l}\text { OCTOBER } \\
\text { NOVEMBER } \\
\text { DECEMBER } \\
\text { JANUARY } \\
\text { FEBRUARY } \\
\text { MARCH } \\
\text { APRIL } \\
\text { MAY } \\
\text { JUNE } \\
\text { JULY } \\
\text { AUGUST } \\
\text { SEPTEMBER }\end{array}$ & $\begin{array}{l}4.1 \\
3.3 \\
4.5 \\
2.9 \\
7.1 \\
7.0 \\
6.6 \\
13 \\
4.0 \\
0.73 \\
1.3 \\
6.0\end{array}$ & $\begin{array}{l}0.00 \\
0.08 \\
0.13 \\
0.15 \\
0.14 \\
0.12 \\
0.13 \\
0.03 \\
0.00 \\
0.00 \\
0.00 \\
0.03\end{array}$ & $\begin{array}{l}0.96 \\
0.80 \\
1.3 \\
0.94 \\
1.7 \\
2.1 \\
2.2 \\
3.3 \\
1.1 \\
0.26 \\
0.34 \\
0.84\end{array}$ & $\begin{array}{l}1.3 \\
1.0 \\
1.5 \\
0.83 \\
2.2 \\
2.4 \\
2.4 \\
3.8 \\
1.4 \\
0.27 \\
0.49 \\
1.7\end{array}$ & $\begin{array}{l}1.3 \\
1.3 \\
1.2 \\
0.88 \\
1.3 \\
1.1 \\
1.1 \\
1.2 \\
1.3 \\
1.1 \\
1.4 \\
2.1\end{array}$ & $\begin{array}{r}6.0 \\
5.0 \\
8.1 \\
5.9 \\
10.4 \\
13.3 \\
14.2 \\
20.9 \\
6.9 \\
1.6 \\
2.2 \\
5.3\end{array}$ \\
\hline INUAL & 3.7 & 0.11 & 1.3 & 1.2 & 0.93 & 100 \\
\hline
\end{tabular}

MAGNITUDE AND PROBABILITY OF INSTANTANEOUS PEAK FLON BASED ON YEARS OF RECORD

DISCHARGE, IN FT $3 / 5$, FOR INDICATED RECURRENCE INTERVAL IN YEARS, AND EXCEEDANCE PROBABILITY, IN PERCENT

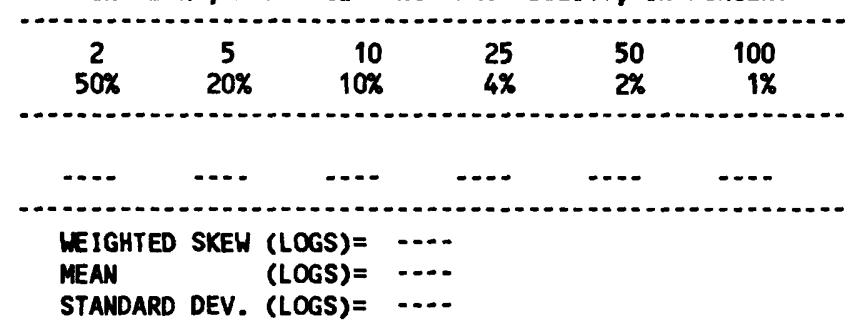

MAGNITUEE AND PROBABILITY OF ANNUAL LON FLOW BASED ON PERIDO OF RECORD 1968-76, 1988

\begin{tabular}{|c|c|c|c|c|c|c|}
\hline \multirow{2}{*}{$\begin{array}{l}\text { PERIOD } \\
\text { (CON- } \\
\text { SECU- } \\
\text { TIVE } \\
\text { DAYS) }\end{array}$} & \multicolumn{6}{|c|}{$\begin{array}{l}\text { DISCHARGE, IN } \mathrm{FT}^{3} / \mathrm{S} \text {, FOR INDICATED } \\
\text { RECURRENCE INTERVAL, IN YEARS, AND } \\
\text { NOW-EXCEEDANCE PROBABILITY, IN PERCENT }\end{array}$} \\
\hline & $\stackrel{2}{20 \%}$ & $\begin{array}{c}5 \\
20 \%\end{array}$ & $\begin{array}{l}10 \\
10 \%\end{array}$ & $\begin{array}{l}20 \phi \\
5 \%\end{array}$ & $\begin{array}{l}50 \dagger \\
2 \%\end{array}$ & $\begin{array}{l}100 \dagger \\
1 \%\end{array}$ \\
\hline $\begin{array}{r}1 \\
3 \\
7 \\
14 \\
30 \\
60 \\
90 \\
120 \\
183\end{array}$ & $\begin{array}{l}0.00 \\
0.00 \\
0.00 \\
0.00 \\
0.00 \\
0.00 \\
0.00 \\
0.00 \\
0.23\end{array}$ & $\begin{array}{l}0.00 \\
0.00 \\
0.00 \\
0.00 \\
0.00 \\
0.00 \\
0.00 \\
0.00 \\
0.11\end{array}$ & $\begin{array}{l}0.00 \\
0.00 \\
0.00 \\
0.00 \\
0.00 \\
0.00 \\
0.00 \\
0.00 \\
0.07\end{array}$ & $\begin{array}{l}0.00 \\
0.00 \\
0.00 \\
0.00 \\
0.00 \\
0.00 \\
0.00 \\
0.00 \\
0.05\end{array}$ & $\begin{array}{l}0.00 \\
0.00 \\
0.00 \\
0.00 \\
0.00 \\
0.00 \\
0.03 \\
0.07 \\
0.03\end{array}$ & $\begin{array}{l}0.00 \\
0.00 \\
0.00 \\
0.00 \\
0.00 \\
0.04 \\
0.08 \\
0.15 \\
0.02\end{array}$ \\
\hline
\end{tabular}

MAGNITLOE AND PROBABILITY OF ANNUAL HIGH FLON BASED ON PERICO OF RECORD 1968-76, 1987, 1989

\begin{tabular}{|c|c|c|c|c|c|c|}
\hline \multirow{2}{*}{$\begin{array}{l}\text { PERICD } \\
\text { (CON- } \\
\text { SECU- } \\
\text { TIVE } \\
\text { DAYS) }\end{array}$} & \multicolumn{6}{|c|}{$\begin{array}{l}\text { DISCHARGE, IN } \mathrm{FT}^{3} / \mathrm{S}, \text { FOR INDICATED } \\
\text { RECURRENCE INTERVAL, IN YEARS, AND } \\
\text { EXCEEDANCE PROBABILITY, IN PERCENT }\end{array}$} \\
\hline & $\begin{array}{c}2 \\
50 \%\end{array}$ & $\begin{array}{c}5 \\
20 \%\end{array}$ & $\begin{array}{l}10 \\
10 \%\end{array}$ & $\begin{array}{l}25 \dagger \\
4 \%\end{array}$ & $\begin{array}{l}50 \uparrow \\
2 \%\end{array}$ & $\begin{array}{c}100 \dagger \\
1 \%\end{array}$ \\
\hline $\begin{array}{r}1 \\
3 \\
7 \\
15 \\
30 \\
60 \\
90\end{array}$ & $\begin{array}{l}16 \\
10 \\
6.9 \\
4.8 \\
3.3 \\
2.3 \\
2.0\end{array}$ & $\begin{array}{l}34 \\
24 \\
16 \\
11 \\
7.7 \\
5.4 \\
4.9\end{array}$ & $\begin{array}{c}44 \\
32 \\
22 \\
15 \\
11 \\
7.9 \\
7.3\end{array}$ & $\begin{array}{l}53 \\
42 \\
28 \\
20 \\
15 \\
12 \\
11\end{array}$ & $\begin{array}{l}58 \\
48 \\
32 \\
23 \\
18 \\
14 \\
14\end{array}$ & $\begin{array}{l}62 \\
53 \\
36 \\
26 \\
21 \\
17 \\
17\end{array}$ \\
\hline
\end{tabular}

DURATION TABLE OF DAILY MEAN FLON FOR PERIOD OF RECORD 1968-76, 1987, 1989

DISCHARGE, IN FT $3 / 5$, WHICH WAS EQUALED OR EXCEEDED FOR INDICATED PERCENT OF TIME

\begin{tabular}{|c|c|c|c|c|c|c|c|c|c|c|c|c|c|c|c|c|}
\hline $1 \%$ & $5 \%$ & $10 \%$ & $15 \%$ & $20 \%$ & $30 \%$ & $40 \%$ & $50 \%$ & $60 \%$ & $70 \%$ & $80 \%$ & $90 \%$ & $95 \%$ & $98 \%$ & $99 \%$ & $99.5 \%$ & $99.9 \%$ \\
\hline 14 & 6.1 & 3.9 & 2.5 & 1.8 & 0.86 & 0.55 & 0.37 & 0.26 & 0.17 & 0.12 & 0.00 & 0.00 & 0.00 & 0.00 & 0.00 & 0.00 \\
\hline
\end{tabular}

$\uparrow$ Reliability of values in column is uncertain, and potential errors are large. 
GILA RIVER BASIN

09458200 DEADMAN CREEK NEAR SAFFORD, AZ--CONTIMUED
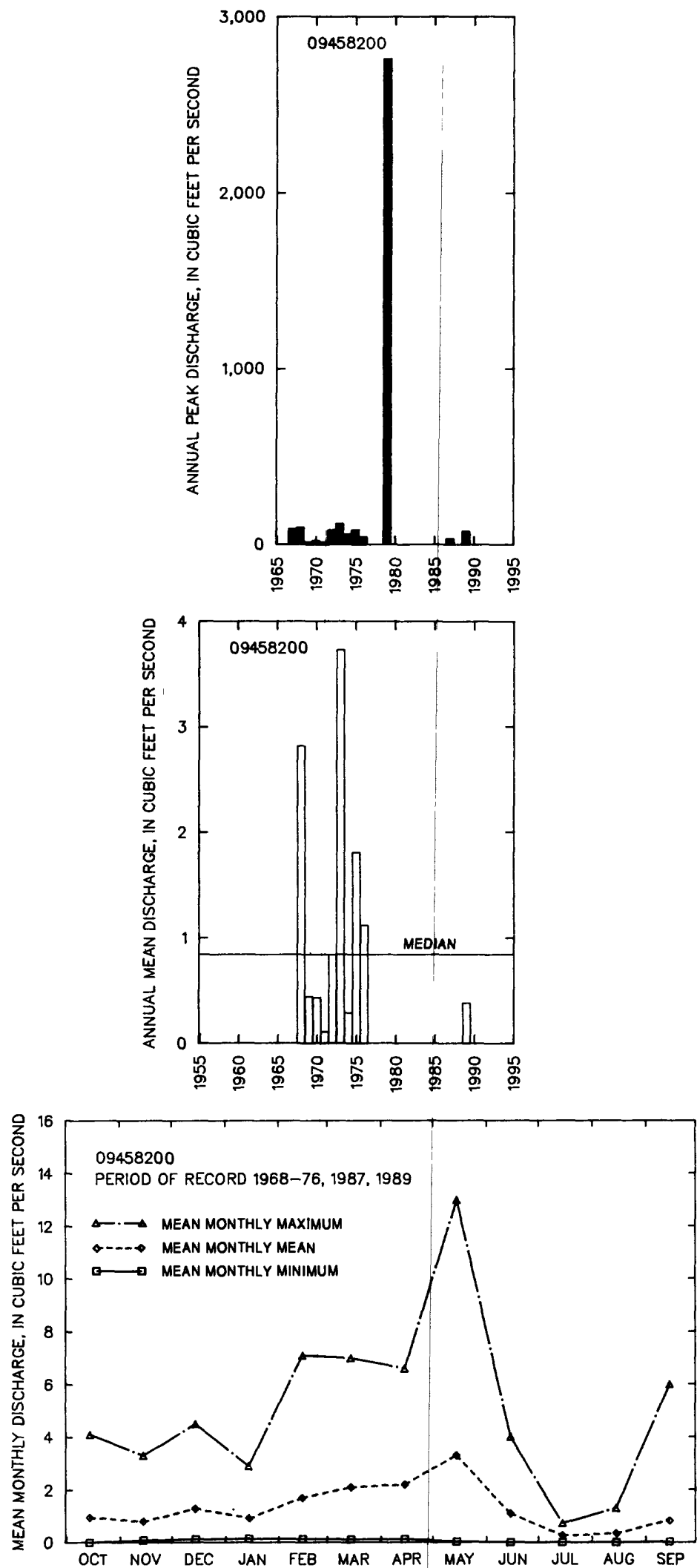


\section{GILA RIVER AT SAFFORD, AZ}

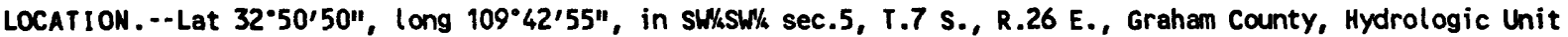
15040005, on downstream side of highway bridge $1 \mathrm{mi}$ north of Safford and 4.5 mi downstream from San Simon River.

DRAIMAGE AREA. $--10,459 \mathrm{mi}^{2}$.

\section{ANNUAL PEAK DISCHARGE}

\begin{tabular}{|c|c|c|c|c|c|}
\hline $\begin{array}{l}\text { WATER } \\
\text { YEAR }\end{array}$ & DATE & $\begin{array}{c}\text { ANNUAL PEAK } \\
\text { DISCHARGE } \\
\left(\mathrm{FT}^{3} / \mathrm{S}\right)\end{array}$ & $\begin{array}{l}\text { WATER } \\
\text { YEAR }\end{array}$ & DATE & $\begin{array}{l}\text { ANNUAL PEAK } \\
\text { DISCHARGE } \\
\left(\mathrm{FT}^{3} / \mathrm{S}\right)\end{array}$ \\
\hline $\begin{array}{l}1940 \\
1941 \\
1942 \\
1943 \\
1944 \\
1945 \\
1946 \\
1947 \\
1948 \\
1949 \\
1950 \\
1951\end{array}$ & $\begin{array}{l}09-06-40 \\
09-30-41 \\
12-12-41 \\
09-27-43 \\
09-26-44 \\
08-03-45 \\
10-09-45 \\
08-31-47 \\
08-07-48 \\
01-14-49 \\
07-30-50 \\
08-03-51\end{array}$ & $\begin{array}{r}8,600 \\
33,000 \\
7,800 \\
5,780 \\
13,600 \\
5,320 \\
6,340 \\
4,600 \\
6,090 \\
23,900 \\
1,860 \\
6,390\end{array}$ & $\begin{array}{l}1952 \\
1953 \\
1957 \\
1958 \\
1959 \\
1960 \\
1961 \\
1962 \\
1963 \\
1964 \\
1965\end{array}$ & $\begin{array}{l}01-19-52 \\
07-07-53 \\
08-31-57 \\
09-13-58 \\
08-28-59 \\
01-12-60 \\
08-22-61 \\
09-27-62 \\
10-19-62 \\
07-15-64 \\
08-29-65\end{array}$ & $\begin{array}{r}15,700 \\
2,670 \\
10,300 \\
9,660 \\
6,810 \\
15,400 \\
6,990 \\
16,200 \\
7,460 \\
7,330 \\
4,900\end{array}$ \\
\hline
\end{tabular}

BASIN CHARACTERISTICS

\begin{tabular}{|c|c|c|c|c|c|c|c|}
\hline \multirow{2}{*}{$\begin{array}{l}\text { MAIN } \\
\text { CHANNEL } \\
\text { SLOPE } \\
\text { (FT/MI) }\end{array}$} & \multirow[b]{2}{*}{$\begin{array}{l}\text { STREAM } \\
\text { LENGTH } \\
\text { (MI) }\end{array}$} & \multirow{2}{*}{$\begin{array}{l}\text { MEAN } \\
\text { BASIN } \\
\text { ELEVA- } \\
\text { TION } \\
\text { (FT) }\end{array}$} & \multirow[b]{2}{*}{$\begin{array}{l}\text { FORESTED } \\
\text { AREA } \\
\text { (PERCENT) }\end{array}$} & \multirow[b]{2}{*}{$\begin{array}{l}\text { SOIL } \\
\text { INDEX }\end{array}$} & \multirow{2}{*}{$\begin{array}{l}\text { MEAN } \\
\text { ANNUAL } \\
\text { PRECIPI- } \\
\text { TATION } \\
\text { (IN) }\end{array}$} & \multicolumn{2}{|c|}{ RAINFALL INTENSITY, 24-HOUR } \\
\hline & & & & & & $\begin{array}{c}\text { 2-YEAR } \\
\text { (IN) }\end{array}$ & $\begin{array}{l}\text { 50-YEAR } \\
\text { (IN) }\end{array}$ \\
\hline 23.6 & 186 & 5,830 & 46.0 & 2.6 & 15.6 & 1.7 & 3.4 \\
\hline
\end{tabular}


MEAN MONTHLY AND ANMUAL DISCHARGES 1941-46, 1957-65

\begin{tabular}{|c|c|c|c|c|c|c|}
\hline MONTH & $\begin{array}{l}\operatorname{MAX} \operatorname{IIMM}_{3} \\
\left(\mathrm{FT}^{3} / \mathrm{S}\right)\end{array}$ & $\begin{array}{l}\operatorname{MINIMMM} \\
\left(\mathrm{FT}^{3} / \mathrm{S}\right)\end{array}$ & $\begin{array}{c}\text { MEAN } \\
\left(\mathrm{FT}^{3} / \mathrm{S}\right)\end{array}$ & $\begin{array}{l}\text { STAN- } \\
\text { DARD } \\
\text { DEVIA- } \\
\text { TION } \\
\text { (FT3/S) }\end{array}$ & $\begin{array}{l}\text { COEFFI- } \\
\text { CIENT OF } \\
\text { VARI - } \\
\text { ATION }\end{array}$ & $\begin{array}{c}\text { PERCENT } \\
\text { OF } \\
\text { ANNUAL } \\
\text { RUNOFF }\end{array}$ \\
\hline $\begin{array}{l}\text { OCTOBER } \\
\text { NOVEMBER } \\
\text { DECEMBER } \\
\text { JANUARY } \\
\text { FEBRUARY } \\
\text { MARCH } \\
\text { APRIL } \\
\text { MAY } \\
\text { JUNE } \\
\text { JULY } \\
\text { AUGUST } \\
\text { SEPTEMBER }\end{array}$ & $\begin{array}{r}1,180 \\
403 \\
1,400 \\
2,040 \\
2,170 \\
2,660 \\
1,680 \\
1,560 \\
130 \\
442 \\
1,660 \\
1,180\end{array}$ & $\begin{array}{l}0.16 \\
0.28 \\
1.3 \\
74 \\
27 \\
13 \\
4.7 \\
0.13 \\
0.00 \\
5.6 \\
11 \\
16\end{array}$ & $\begin{array}{l}194 \\
139 \\
288 \\
445 \\
458 \\
491 \\
337 \\
154 \\
15 \\
94 \\
428 \\
380\end{array}$ & $\begin{array}{r}292 \\
128 \\
423 \\
574 \\
640 \\
796 \\
533 \\
393 \\
33 \\
115 \\
417 \\
332\end{array}$ & $\begin{array}{l}1.5 \\
0.92 \\
1.5 \\
1.3 \\
1.4 \\
1.6 \\
1.6 \\
2.6 \\
2.2 \\
1.2 \\
0.98 \\
0.87\end{array}$ & $\begin{array}{r}5.7 \\
4.1 \\
8.4 \\
13.0 \\
13.4 \\
14.3 \\
9.8 \\
4.5 \\
0.4 \\
2.7 \\
12.5 \\
11.1\end{array}$ \\
\hline ANNUAL & 1,120 & 87 & 284 & 263 & 0.92 & 100 \\
\hline
\end{tabular}

MAGNITUDE AND PROBABILITY OF INSTANTANEOUS PEAK FLON BASED ON PERICD OF RECORD 1940-53, 1957-65

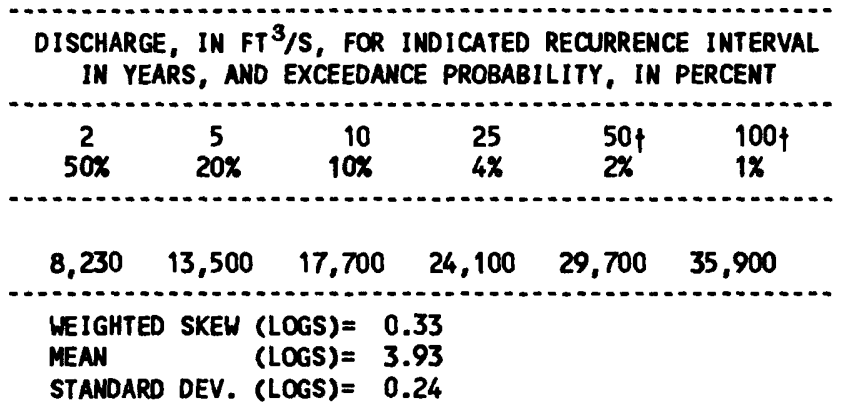

MAGITUDE AND PROBABILITY OF ANNUAL LOW FLON BASED ON PERICD OF RECORD 1942-47, 1958-65

\begin{tabular}{|c|c|c|c|c|c|c|}
\hline \multirow{2}{*}{$\begin{array}{l}\text { PERIOD } \\
\text { (CON- } \\
\text { SECU- } \\
\text { TIVE } \\
\text { DAYS) }\end{array}$} & \multicolumn{6}{|c|}{$\begin{array}{l}\text { DISCHARGE, IN } \mathrm{FT}^{3} / \mathrm{S}, \text { FOR INDICATED } \\
\text { RECURRENCE INTERVAL, IN YEARS, AND } \\
\text { NON-EXCEEDANCE PROBABILITY, IN PERCENT }\end{array}$} \\
\hline & $\begin{array}{c}2 \\
50 x\end{array}$ & $\begin{array}{c}5 \\
20 x\end{array}$ & $\begin{array}{l}10 \\
10 x\end{array}$ & $\begin{array}{l}20 \\
5 \%\end{array}$ & $\begin{array}{l}50 \uparrow \\
2 \%\end{array}$ & $\begin{array}{l}100 \dagger \\
1 \%\end{array}$ \\
\hline $\begin{array}{r}1 \\
3 \\
7 \\
14 \\
30 \\
60 \\
90 \\
120 \\
183\end{array}$ & $\begin{array}{c}0.00 \\
0.00 \\
0.01 \\
0.51 \\
4.3 \\
14 \\
36 \\
116\end{array}$ & $\begin{array}{l}0.00 \\
0.00 \\
0.00 \\
0.00 \\
0.75 \\
5.2 \\
19 \\
57\end{array}$ & $\begin{array}{c}0.00 \\
0.00 \\
0.00 \\
0.00 \\
0.27 \\
3.4 \\
14 \\
38\end{array}$ & $\begin{array}{c}0.00 \\
0.00 \\
0.00 \\
0.00 \\
0.11 \\
2.4 \\
11 \\
26\end{array}$ & $\begin{array}{l}0.00 \\
0.00 \\
0.00 \\
0.00 \\
0.04 \\
1.7 \\
8.3 \\
17\end{array}$ & $\begin{array}{l}0.00 \\
0.00 \\
0.00 \\
0.00 \\
0.02 \\
1.3 \\
7.0 \\
13\end{array}$ \\
\hline
\end{tabular}

MAGNITLDE AND PROBABILITY OF ANNUAL HIGH FLOW BASED ON PERICD OF RECORD 1941-46, 1957-65

\begin{tabular}{|c|c|c|c|c|c|c|}
\hline \multirow{2}{*}{$\begin{array}{l}\text { PERIOD } \\
\text { (CON- } \\
\text { SECU- } \\
\text { TIVE } \\
\text { DAYS) }\end{array}$} & & \multicolumn{5}{|c|}{$\begin{array}{l}\text { DISCHARGE, IN } \mathrm{FT}^{3} / \mathrm{S} \text {, FOR INDICATED } \\
\text { RECURRENCE INTERVAL, IN YEARS, AND } \\
\text { EXCEEDANCE PROBABILITY, IN PERCENT }\end{array}$} \\
\hline & $\begin{array}{c}2 \\
50 \%\end{array}$ & $\begin{array}{c}5 \\
20 x\end{array}$ & $\begin{array}{l}10 \\
10 \%\end{array}$ & $\begin{array}{l}25 \\
4 \%\end{array}$ & $\begin{array}{l}50 \dagger \\
2 \%\end{array}$ & $\begin{array}{c}100 \dagger \\
1 \%\end{array}$ \\
\hline $\begin{array}{r}1 \\
3 \\
7 \\
15 \\
30 \\
60 \\
90\end{array}$ & $\begin{array}{r}4,090 \\
2,900 \\
1,940 \\
1,310 \\
873 \\
610 \\
479\end{array}$ & $\begin{array}{r}7,800 \\
5,340 \\
3,490 \\
2,390 \\
1,640 \\
1,180 \\
967\end{array}$ & $\begin{array}{r}11,500 \\
7,490 \\
4,700 \\
3,250 \\
2,290 \\
1,700 \\
1,440\end{array}$ & $\begin{array}{r}17,900 \\
10,900 \\
6,440 \\
4,500 \\
3,300 \\
2,560 \\
2,250\end{array}$ & $\begin{array}{r}24,400 \\
14,000 \\
7,870 \\
5,540 \\
4,190 \\
3,380 \\
3,050\end{array}$ & $\begin{array}{r}32,600 \\
17,700 \\
9,400 \\
6,660 \\
5,210 \\
4,360 \\
4,030\end{array}$ \\
\hline
\end{tabular}

DURATION TABLE OF DAILY MEAN FLON FOR PERICD OF RECORD 1941-46, 1957-65

DISCHARGE, IN FT $3 / 5$, WHICH WAS EQUALED OR EXCEEDED FOR INDICATED PERCENT OF TIME

\begin{tabular}{|ccccccccccccccccc}
$1 \%$ & $5 \%$ & $10 \%$ & $15 \%$ & $20 \%$ & $30 \%$ & $40 \%$ & $50 \%$ & $60 \%$ & $70 \%$ & $80 \%$ & $90 \%$ & $95 \%$ & $98 \%$ & $99 \%$ & $99.5 \%$ & $99.9 \%$ \\
\hline 3,480 & 1,360 & 694 & 442 & 322 & 176 & 103 & 66 & 40 & 21 & 7.9 & 0.52 & 0.00 & 0.00 & 0.00 & 0.00 & 0.00
\end{tabular}

+ Reliability of values in column is uncertain, and potential errors are large. 
GILA RIVER BASIN

09458500 GILA RIVER AT SAFFORD, AZ--CONTIMUED
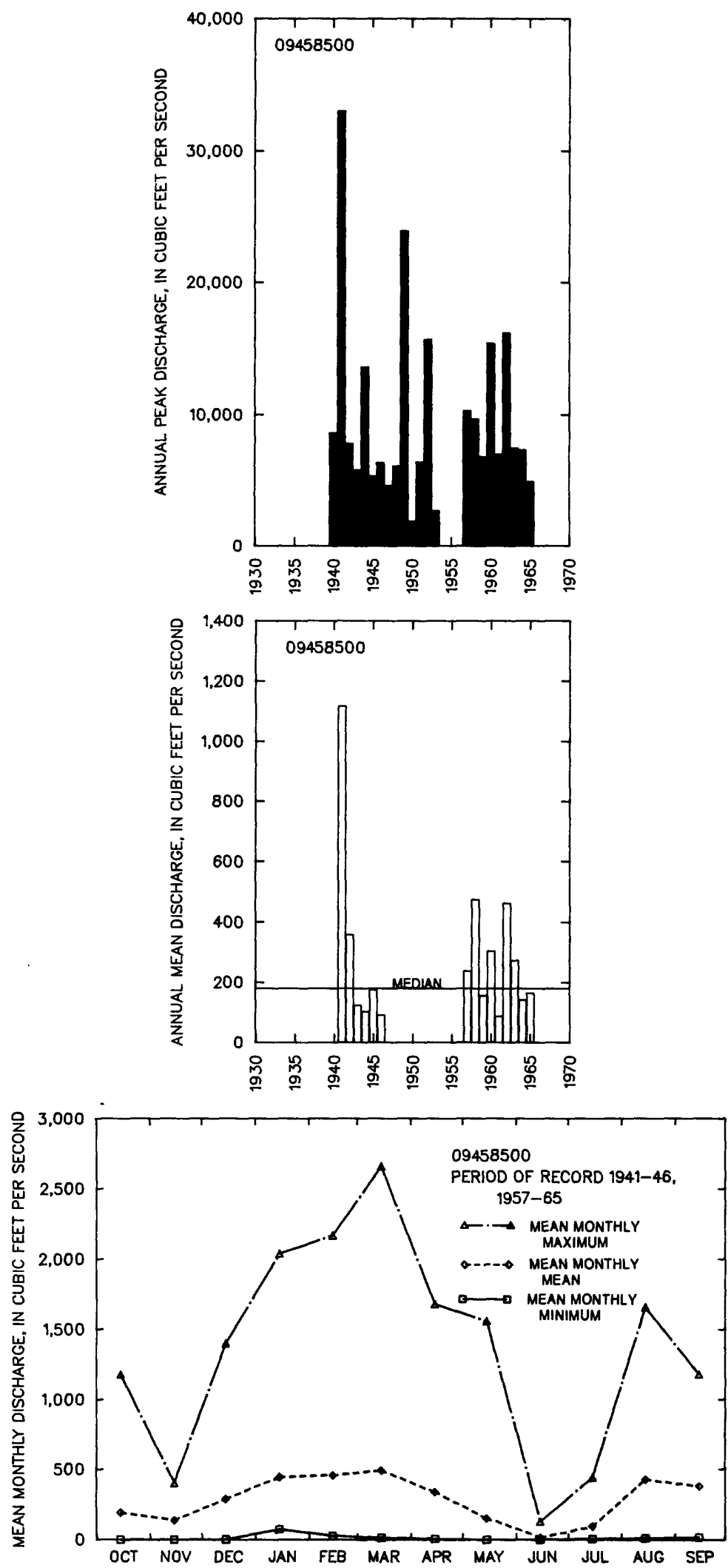
LOCATION.--Lat 32.44'32", long 109'50'24", in NEK seC.13, T.8 S., R.24 E. (unsurveyed), Graham County, Hydrologic Unit 15040005, in Coronado National Forest, on right bank and 9 mi southwest of Thatcher.

DRAINAGE AREA. - -3.91 $\mathrm{mi}^{2}$.

ANMUAL PEAK DISCHARGE

\begin{tabular}{cccc}
$\begin{array}{c}\text { WATER } \\
\text { YEAR }\end{array}$ & DATE & $\begin{array}{c}\text { ANNUAL PEAK } \\
\text { DISCHARGE } \\
\text { (FT }{ }^{3} / \mathrm{S} \text { ) }\end{array}$ & $\begin{array}{c}\text { DISCHARGE } \\
\text { CODES }\end{array}$ \\
\hline 1967 & $08-11-67$ & 2.2 & \\
1968 & $05-29-68$ & 17 & \\
1969 & $05-23-69$ & 3.2 & \\
1970 & $09-06-70$ & 30 & \\
1971 & $10-03-70$ & 0.8 & \\
1972 & $10-24-71$ & 36 & \\
1973 & $10-19-72$ & 51 & \\
1974 & $08-06-74$ & 42 & \\
1975 & $09-06-75$ & 96 & \\
1976 & $02-09-76$ & 24 & \\
1979 & $12-19-78$ & 2,300 & ES, HP \\
$\ldots$
\end{tabular}

MAGNITUDE AND PROBABILITY OF INSTANTANEQUS PEAK FLOW BASED ON PERIOD OF RECORD

DISCHARGE, IN FT $3 / S$, FOR INDICATED RECURRENCE INTERVAL IN YEARS, AND EXCEEDANCE PROBABILITY, IN PERCENT

$\begin{array}{lrrrrr}2 & 5 & 10 & 25 & 50 & 100\end{array}$

$50 \% \quad 20 \% \quad 10 \% \quad 4 \% \quad 2 \% \quad 1 \%$

WEIGHTED SKEH (LOGS)=

MEAN (LOGS) $=\ldots$

STANDARD DEV. (LOGS) $=\quad \ldots$

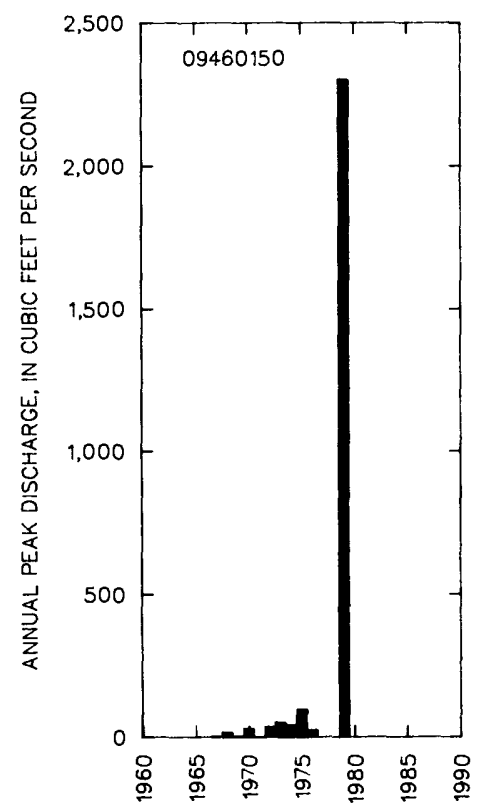

BASIN CHARACTERISTICS

\begin{tabular}{|c|c|c|c|c|c|c|c|}
\hline \multirow{2}{*}{$\begin{array}{c}\text { MAIN } \\
\text { CHANNEL } \\
\text { SLOPE } \\
\text { (FT/MI) }\end{array}$} & \multirow[b]{2}{*}{$\begin{array}{l}\text { STREAM } \\
\text { LENGTH } \\
\text { (MI) }\end{array}$} & \multirow{2}{*}{$\begin{array}{l}\text { MEAN } \\
\text { BASIN } \\
\text { ELEVA- } \\
\text { TION } \\
\text { (FT) }\end{array}$} & \multirow[b]{2}{*}{$\begin{array}{l}\text { FORESTED } \\
\text { AREA } \\
\text { (PERCENT) }\end{array}$} & \multirow[b]{2}{*}{$\begin{array}{l}\text { SOIL } \\
\text { INDEX }\end{array}$} & \multirow{2}{*}{$\begin{array}{l}\text { MEAN } \\
\text { ANNUAL } \\
\text { PRECIPI- } \\
\text { TATION } \\
\text { (IN) }\end{array}$} & \multicolumn{2}{|c|}{ RAINFALL INTENSITY, 24-HOUR } \\
\hline & & & & & & $\begin{array}{c}\text { 2-YEAR } \\
\text { (IN) }\end{array}$ & $\begin{array}{l}\text { 50-YEAR } \\
\text { (IN) }\end{array}$ \\
\hline $1,160.0$ & 4.0 & 8,400 & 79.0 & 1.0 & 25.0 & 2.0 & 4.0 \\
\hline
\end{tabular}


09466500 GILA RIVER AT CALVA, AZ

(National stream-quality accounting network station)

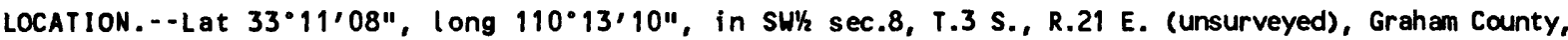
Hydrologic Unit 15040005, in San Carlos Indian Reservation, on Southern Pacific Railroad bridge at head of San Carlos Reservoir, $2.0 \mathrm{mi}$ west of Calva.

DRAINAGE AREA. $--11,470 \mathrm{mi}^{2}$.

REMARKS.--Diversion above station for irrigation of about 69,000 acres, metallurgical treatment of ores, and municipal uses.

ANMUAL PEAK DISCHARGE

\begin{tabular}{|c|c|c|c|c|c|c|c|}
\hline $\begin{array}{l}\text { WATER } \\
\text { YEAR }\end{array}$ & DATE & $\begin{array}{l}\text { ANNUAL PEAK } \\
\text { DISCHARGE } \\
\left(F^{3} / S\right)\end{array}$ & $\begin{array}{l}\text { DISCHARGE } \\
\text { CODES }\end{array}$ & $\begin{array}{l}\text { WATER } \\
\text { YEAR }\end{array}$ & DATE & $\begin{array}{c}\text { ANNUAL PEAK } \\
\text { DISCHARGE } \\
\text { (FT } 3 / \mathrm{S})\end{array}$ & $\begin{array}{l}\text { DISCHARGE } \\
\text { CODES }\end{array}$ \\
\hline $\begin{array}{l}1916 \\
1930 \\
1931 \\
1932 \\
1933 \\
1934 \\
1935 \\
1936 \\
1937 \\
1938 \\
1939 \\
1940 \\
1941 \\
1942 \\
1943 \\
1944 \\
1945 \\
1946 \\
1947 \\
1948 \\
1949 \\
1950 \\
1951 \\
1952 \\
1953 \\
1954 \\
1955 \\
1956 \\
1957 \\
1958 \\
1959\end{array}$ & $\begin{array}{l}01-20-16 \\
07-29-30 \\
08-11-31 \\
02-12-32 \\
09-09-33 \\
08-28-34 \\
07-31-35 \\
09-11-36 \\
02-09-37 \\
03-05-38 \\
08-07-39 \\
10-09-39 \\
01-02-41 \\
10-01-41 \\
09-28-43 \\
09-27-44 \\
08-03-45 \\
10-10-45 \\
08-24-47 \\
08-07-48 \\
01-15-49 \\
07-30-50 \\
08-04-51 \\
01-20-52 \\
07-30-53 \\
03-25-54 \\
08-04-55 \\
10-05-55 \\
09-01-57 \\
03-26-58 \\
08-26-59\end{array}$ & $\begin{array}{r}100,000 \\
9,600 \\
9,900 \\
21,500 \\
6,560 \\
18,000 \\
4,470 \\
6,000 \\
12,800 \\
4,310 \\
4,260 \\
5,620 \\
14,300 \\
27,900 \\
3,710 \\
12,800 \\
3,390 \\
4,680 \\
3,200 \\
2,570 \\
19,400 \\
3,210 \\
2,970 \\
13,200 \\
2,040 \\
4,260 \\
4,950 \\
4,240 \\
4,220 \\
6,700 \\
3,920\end{array}$ & ES, HP & $\begin{array}{l}1960 \\
1961 \\
1962 \\
1963 \\
1964 \\
1965 \\
1966 \\
1967 \\
1968 \\
1969 \\
1970 \\
1971 \\
1972 \\
1973 \\
1974 \\
1975 \\
1976 \\
1977 \\
1978 \\
1979 \\
1980 \\
1981 \\
1982 \\
1983 \\
1984 \\
1985 \\
1986 \\
1987 \\
1988 \\
1989\end{array}$ & $\begin{array}{l}01-14-60 \\
08-23-61 \\
09-29-62 \\
10-20-62 \\
09-26-64 \\
08-14-65 \\
12-24-65 \\
08-13-67 \\
12-21-67 \\
09-14-69 \\
03-03-70 \\
08-22-71 \\
10-28-71 \\
10-20-72 \\
07-20-74 \\
09-10-75 \\
02-12-76 \\
08-15-77 \\
03-04-78 \\
12-19-78 \\
02-16-80 \\
08-02-81 \\
09-12-82 \\
02-06-83 \\
10-03-83 \\
12-29-84 \\
10-18-85 \\
11-04-86 \\
09-24-88 \\
10-16-88\end{array}$ & $\begin{array}{r}9,090 \\
3,080 \\
9,000 \\
3,240 \\
3,060 \\
4,700 \\
39,000 \\
40,000 \\
8,960 \\
1,160 \\
982 \\
7,470 \\
7,160 \\
80,000 \\
1,160 \\
15,800 \\
2,600 \\
6,090 \\
19,000 \\
100,000 \\
20,600 \\
2,200 \\
2,020 \\
10,260 \\
2150,000 \\
53,700 \\
6,720 \\
2,150 \\
7,820 \\
903\end{array}$ & - \\
\hline
\end{tabular}

1Highest since 1906

$2 \mathrm{Highest}$ since 1907 .

BASIN CHARACTERISTICS

\begin{tabular}{|c|c|c|c|c|c|c|c|}
\hline MAIN & & $\begin{array}{r}\text { MEAN } \\
\text { BASIN }\end{array}$ & & & $\begin{array}{l}\text { MEAN } \\
\text { ANNUAL }\end{array}$ & RAINFALL IN & SITY, 24-HOUR \\
\hline $\begin{array}{l}\text { CHANNEL } \\
\text { SLOPE } \\
\text { (FT/MI) }\end{array}$ & $\begin{array}{c}\text { STREAM } \\
\text { LENGTH } \\
\text { (MI) }\end{array}$ & $\begin{array}{l}\text { ELEVA- } \\
\text { TION } \\
\text { (FT) }\end{array}$ & $\begin{array}{l}\text { FORESTED } \\
\text { AREA } \\
\text { (PERCENT) }\end{array}$ & $\begin{array}{l}\text { SOIL } \\
\text { INDEX }\end{array}$ & $\begin{array}{l}\text { PRECIPI - } \\
\text { TATION } \\
\text { (IN) }\end{array}$ & $\begin{array}{c}\text { 2-YEAR } \\
\text { (IN) }\end{array}$ & $\begin{array}{l}\text { 50-YEAR } \\
\text { (IN) }\end{array}$ \\
\hline 20.4 & 225 & 5,650 & 44.0 & 2.6 & 15.5 & 1.7 & 3.5 \\
\hline
\end{tabular}


MEAN MONTHLY AND ANNUAL DISCHARGES $1930-89$

\begin{tabular}{|c|c|c|c|c|c|c|}
\hline MONTH & 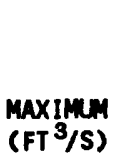 & $\begin{array}{l}\operatorname{MINIMUN} \\
\left(\mathrm{FT}^{3} / \mathrm{S}\right)\end{array}$ & $\begin{array}{c}\text { MEAN } \\
\left(F T^{3} / S\right)\end{array}$ & $\begin{array}{l}\text { STAN- } \\
\text { DARD } \\
\text { DEVIA- } \\
\text { TION } \\
\text { (FT } 3 / S)\end{array}$ & $\begin{array}{l}\text { COEFFI- } \\
\text { CIENT OF } \\
\text { VARI- } \\
\text { ATION }\end{array}$ & $\begin{array}{c}\text { PERCENT } \\
\text { OF } \\
\text { ANNUAL } \\
\text { RUNOFF }\end{array}$ \\
\hline $\begin{array}{l}\text { OCTOBER } \\
\text { NOVEMBER } \\
\text { DECEMBER } \\
\text { JANUARY } \\
\text { FEBRUARY } \\
\text { MARCH } \\
\text { APRIL } \\
\text { MAY } \\
\text { JUNE } \\
\text { JULY } \\
\text { AUGUST } \\
\text { SEPTEMBER }\end{array}$ & $\begin{array}{r}8,490 \\
1,540 \\
5,650 \\
3,580 \\
3,550 \\
2,940 \\
2,330 \\
2,080 \\
292 \\
838 \\
1,660 \\
1,680\end{array}$ & $\begin{array}{l}0.00 \\
0.00 \\
0.00 \\
22 \\
29 \\
10 \\
1.3 \\
1.3 \\
0.00 \\
0.00 \\
0.00 \\
0.00\end{array}$ & $\begin{array}{l}381 \\
172 \\
413 \\
475 \\
633 \\
646 \\
355 \\
179 \\
33 \\
89 \\
329 \\
243\end{array}$ & $\begin{array}{r}1,240 \\
253 \\
921 \\
741 \\
867 \\
868 \\
534 \\
368 \\
63 \\
147 \\
406 \\
331\end{array}$ & $\begin{array}{l}3.3 \\
1.5 \\
2.2 \\
1.6 \\
1.4 \\
1.3 \\
1.5 \\
2.1 \\
1.9 \\
1.7 \\
1.2 \\
1.4\end{array}$ & $\begin{array}{r}9.6 \\
4.4 \\
10.5 \\
12.0 \\
16.0 \\
16.4 \\
9.0 \\
4.5 \\
0.8 \\
2.2 \\
8.3 \\
6.2\end{array}$ \\
\hline ANNUAL & 1,520 & 29 & 328 & 338 & 1.0 & 100 \\
\hline
\end{tabular}

MAGNI TLDE AND PROBABILITY OF INSTANTANEOUS PEAK FLON BASED ON PERIOD OF RECORD 1916, 1930-89

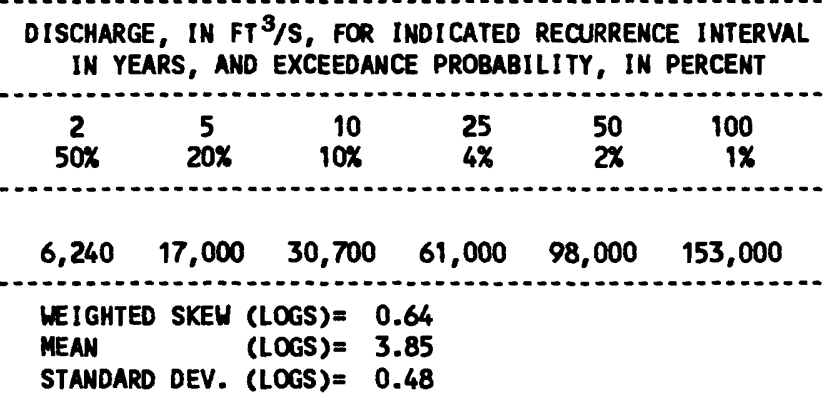

MAGNITLDE AND PROBABILITY OF ANNUAL LOW FLOW BASED ON PERIOD OF RECORD 1931-89

\begin{tabular}{|c|c|c|c|c|c|c|}
\hline \multirow{2}{*}{$\begin{array}{l}\text { PERIOD } \\
\text { (CON- } \\
\text { SECU. } \\
\text { TIVE } \\
\text { DAYS) }\end{array}$} & \multicolumn{6}{|c|}{$\begin{array}{l}\text { DISCHARGE, IN FT } 3 / 5 \text {, FOR INDICATED } \\
\text { RECURRENCE INTERVAL, IN YEARS, AND } \\
\text { NON-EXCEEDANCE PROBABILITY, IN PERCENT }\end{array}$} \\
\hline & $\begin{array}{c}2 \\
50 \%\end{array}$ & $\begin{array}{c}5 \\
20 \%\end{array}$ & $\begin{array}{l}10 \\
10 \%\end{array}$ & $\begin{array}{l}20 \\
5 \%\end{array}$ & $\begin{array}{l}50 \\
2 \%\end{array}$ & $\begin{array}{l}100 \\
1 \%\end{array}$ \\
\hline $\begin{array}{r}1 \\
3 \\
7 \\
14 \\
30 \\
60 \\
90 \\
120 \\
183\end{array}$ & $\begin{array}{c}0.00 \\
0.00 \\
0.00 \\
0.00 \\
0.00 \\
0.00 \\
0.00 \\
0.00 \\
85\end{array}$ & $\begin{array}{l}0.00 \\
0.00 \\
0.00 \\
0.00 \\
0.00 \\
0.00 \\
0.00 \\
0.00 \\
38\end{array}$ & $\begin{array}{l}0.00 \\
0.00 \\
0.00 \\
0.00 \\
0.00 \\
0.00 \\
0.00 \\
0.00 \\
24\end{array}$ & $\begin{array}{c}0.00 \\
0.00 \\
0.00 \\
0.00 \\
0.00 \\
0.00 \\
0.00 \\
0.00 \\
16\end{array}$ & $\begin{array}{c}0.00 \\
0.00 \\
0.00 \\
0.00 \\
0.00 \\
0.00 \\
0.00 \\
0.00 \\
10\end{array}$ & $\begin{array}{l}0.00 \\
0.00 \\
0.00 \\
0.00 \\
0.00 \\
0.00 \\
0.00 \\
0.00 \\
7.8\end{array}$ \\
\hline
\end{tabular}

MAGNITLOE AND PROBABILITY OF ANNUAL HIGH FLON BASED ON PERIOD OF RECORD 1930-89

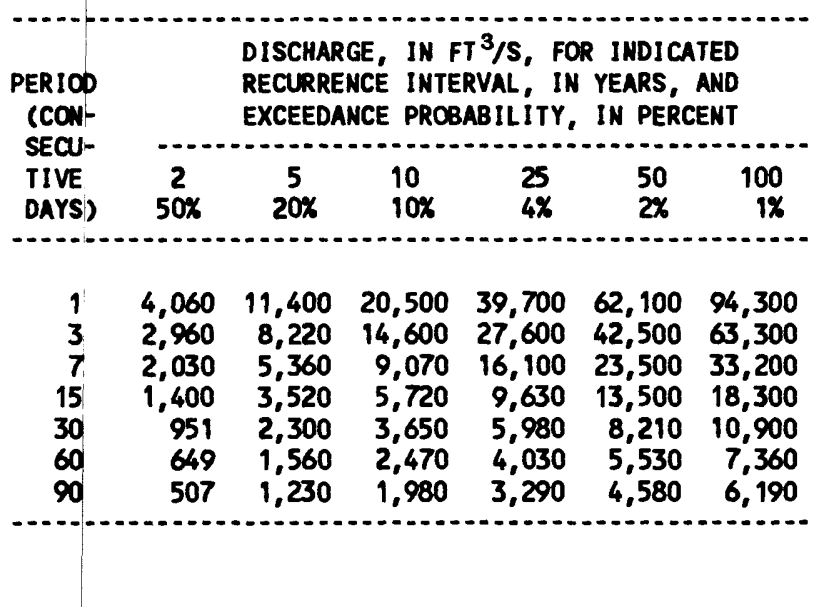

DURATION TABLE OF DAILY MEAN FLON FOR PERIOD OF RECORD 1930-89

\begin{tabular}{|c|c|c|c|c|c|c|c|c|c|c|c|c|c|c|c|c|}
\hline $1 \%$ & $5 \%$ & $10 \%$ & $15 \%$ & $20 \%$ & $30 \%$ & $40 \%$ & $50 \%$ & $60 \%$ & $70 \%$ & $80 \%$ & $90 \%$ & $95 \%$ & $98 \%$ & $99 \%$ & $99.5 \%$ & $99.9 \%$ \\
\hline 910 & 1,540 & 741 & 484 & 341 & 183 & 106 & 66 & 41 & 24 & 11 & 2.0 & 0.00 & 0.00 & 0.00 & 0.00 & 0.00 \\
\hline
\end{tabular}

f Reliability of values in colum is uncertain, and potential errors are large. 
09466500 GILA RIVER AT CALVA, AZ--CONTINUEd
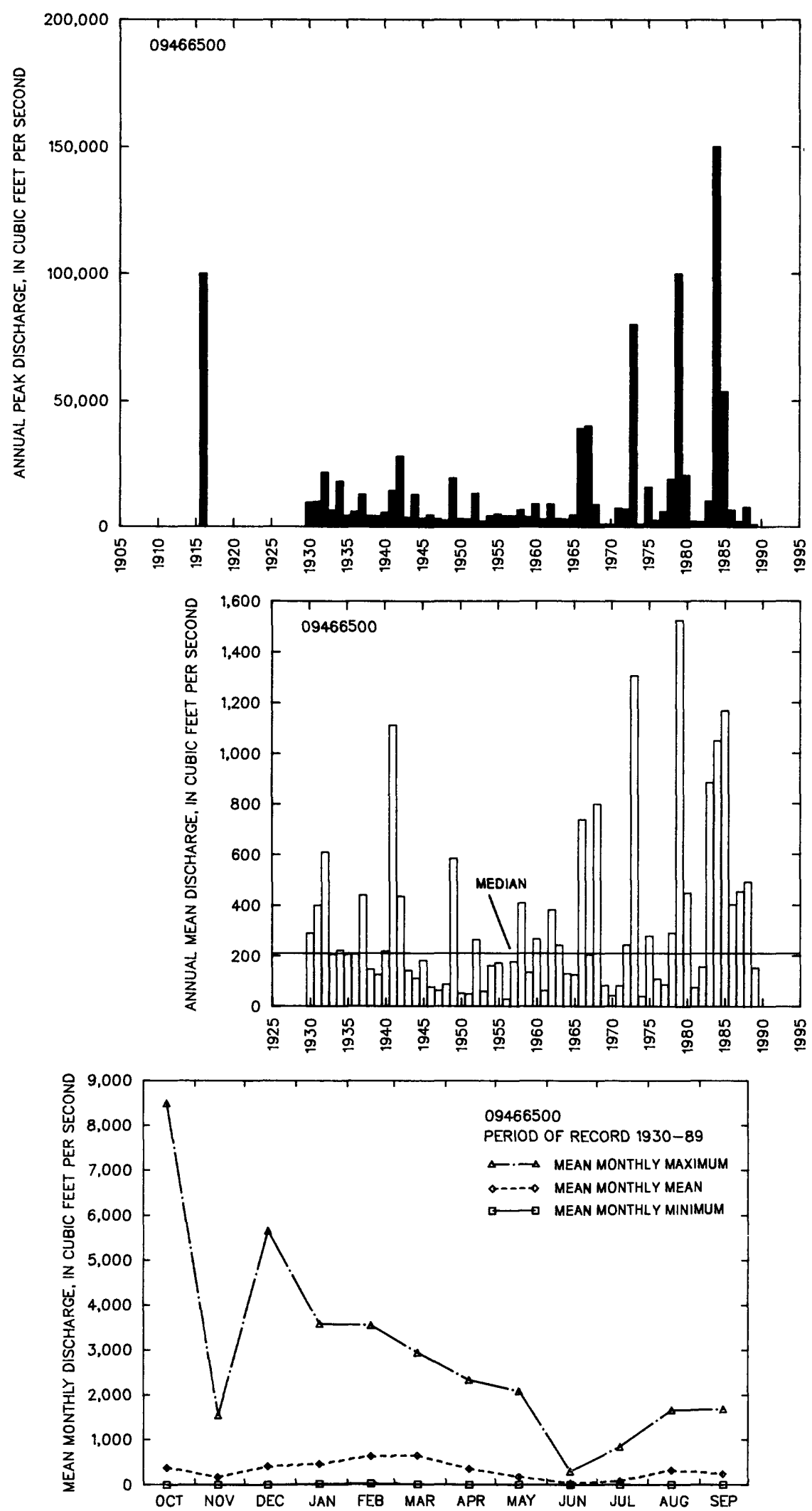
LOCATION. - - Lat $33^{\prime 16} 16^{\prime \prime}$, Iong 110*18'15", Graham County, Hydrologic Unit 15040005, at U.S. Highway 70, 4 miles above mouth, and 9.5 miles southeast of Peridot.

DRAIMAGE AREA.--35.2 $\mathrm{mi}^{2}$, of which $4.9 \mathrm{mi}^{2}$ is noncontributing.

ANMUAL PEAK DISCHARGE

\begin{tabular}{|c|c|c|c|}
\hline $\begin{array}{l}\text { WATER } \\
\text { YEAR }\end{array}$ & DATE & $\begin{array}{l}\text { ANNUAL PEAK } \\
\text { DISCHARGE } \\
\left(\mathrm{FT}^{3} / \mathrm{S}\right)\end{array}$ & $\begin{array}{c}\text { DISCHARGE } \\
\text { COOES }\end{array}$ \\
\hline $\begin{array}{l}1964 \\
1965 \\
1966 \\
1967 \\
1968 \\
1969 \\
1970 \\
1971 \\
1972 \\
1973 \\
1974 \\
1975 \\
1979\end{array}$ & $\begin{array}{l}08-13-64 \\
01-03-65 \\
12-22-65 \\
08-06-67 \\
12-20-67 \\
00-00-69 \\
09-06-70 \\
09-30-71 \\
10-00-71 \\
10-19-72 \\
00-00-74 \\
07-20-75 \\
12-18-78\end{array}$ & $\begin{array}{r}604 \\
17 \\
1,270 \\
1,650 \\
2,500 \\
100 \\
40 \\
2,300 \\
517 \\
3,200 \\
0 \\
880 \\
12,200\end{array}$ & $\begin{array}{l}\text { LT } \\
\text { ES }\end{array}$ \\
\hline
\end{tabular}

Highest since 1975.

MAGNI TUDE AND PROBABILITY OF INSTANTANEOUS PEAK FLOH BASED ON PERIOD OF RECORD 1964-75

DISCHARGE, IN $\mathrm{FT}^{3} / \mathrm{S}$, FOR INDICATED RECURRENCE INTERVAL IN YEARS, AND EXCEEDANCE PROBABILITY, IN PERCENT

\begin{tabular}{cccccc}
2 & 5 & 10 & $25 \dagger$ & $\begin{array}{c}50 \dagger \\
2 \%\end{array}$ & $\begin{array}{c}100 \dagger \\
1 \%\end{array}$ \\
\hline 810 & 1,920 & 2,890 & 4,350 & 5,580 & 6,910
\end{tabular}

WEIGHTED SKEW (LOGS) $=-0.40$

MEAN (LOGS) $=2.88$

STANDARD DEV. $(L O G S)=0.48$

+ Reliability of values in column is uncertain, and potential errors are large.

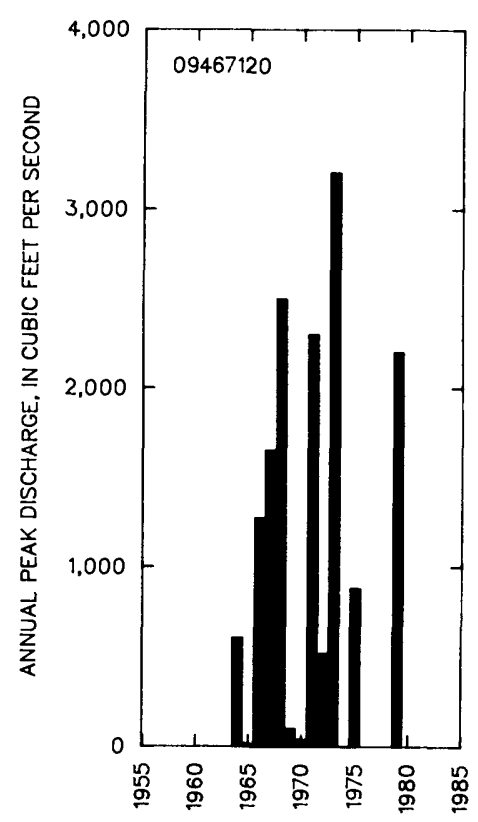

BASIN CHARACTERISTICS

\begin{tabular}{|c|c|c|c|c|c|c|c|}
\hline MAIN & & $\begin{array}{l}\text { MEAN } \\
\text { BASIN }\end{array}$ & & & $\begin{array}{c}\text { MEAN } \\
\text { ANNUAL }\end{array}$ & RAINFALL I & SITY, 24-HOUR \\
\hline $\begin{array}{l}\text { CHANNEL } \\
\text { SLOPE } \\
\text { (FT/MI) }\end{array}$ & $\begin{array}{c}\text { STREAM } \\
\text { LENGTH } \\
\text { (MI) }\end{array}$ & $\begin{array}{l}\text { ELEVA- } \\
\text { TION } \\
\text { (FT) }\end{array}$ & $\begin{array}{l}\text { FORESTED } \\
\text { AREA } \\
\text { (PERCENT) }\end{array}$ & $\begin{array}{l}\text { SOIL } \\
\text { INDEX }\end{array}$ & $\begin{array}{l}\text { PREC IP 1- } \\
\text { TATION } \\
\text { (IN) }\end{array}$ & $\begin{array}{l}\text { 2-YEAR } \\
\text { (IN) }\end{array}$ & $\begin{array}{c}\text { 50-YEAR } \\
\text { (IN) }\end{array}$ \\
\hline 169 & 14.4 & 3,490 & 2.3 & 1.0 & 16.0 & 1.9 & 3.9 \\
\hline
\end{tabular}


09468300 SEVENMILE WASH TRIBUTARY NEAR GLOBE, AZ

LOCATION.--Lat 33"35'10", Long 110.39'00", Gila County, Hydrologic Unit 15040007, at U.S. Highway 60, 0.2 mi south of Sevenmile Wash, and $15 \mathrm{miles}$ northeast of Globe.

DRAINAGE AREA. $--0.83 \mathrm{mi}^{2}$.

ANNUAL PEAK DISCHARGE

\begin{tabular}{|c|c|c|c|}
\hline $\begin{array}{l}\text { WATER } \\
\text { YEAR }\end{array}$ & DATE & $\begin{array}{l}\text { ANHUAL PEAK } \\
\text { DISCHARGE } \\
\text { (FT } 3 / S)\end{array}$ & $\begin{array}{l}\text { DISCHARGE } \\
\text { COOES }\end{array}$ \\
\hline $\begin{array}{l}-. .- \\
1962 \\
1963 \\
1964 \\
1965 \\
1966 \\
1967 \\
1968 \\
1969 \\
1970 \\
1971 \\
1972 \\
1973 \\
1974 \\
1975 \\
1976 \\
1979\end{array}$ & $\begin{array}{l}00-00-62 \\
08-17-63 \\
07-31-64 \\
00-00-65 \\
12-10-65 \\
00-00-67 \\
08-04-68 \\
08-27-69 \\
08-00-70 \\
00-00-71 \\
10-17-71 \\
10-19-72 \\
07-19-74 \\
09-08-75 \\
00-00-76 \\
12-18-78\end{array}$ & $\begin{array}{c}1526 \\
38 \\
22 \\
486 \\
0 \\
30 \\
0 \\
135 \\
35 \\
150 \\
50 \\
5.0 \\
245 \\
4.0 \\
0.1 \\
5.0 \\
2640\end{array}$ & $\begin{array}{l}\text { ES } \\
\text { ES } \\
\text { HP }\end{array}$ \\
\hline
\end{tabular}

1Highest since 1933, year of occurrence unknown. 4 ighest since 1933 .

MAGNITUDE AND PROBABILITY OF INSTANTANEOUS PEAK FLON BASED ON PERIOD OF RECORD 1933, 1962-76, 1979

DISCHARGE, IN $\mathrm{FT}^{3} / \mathrm{S}$, FOR INDICATED RECURRENCE INTERVAL IN YEARS, AND EXCEEDANCE PROBABILITY, IN PERCENT

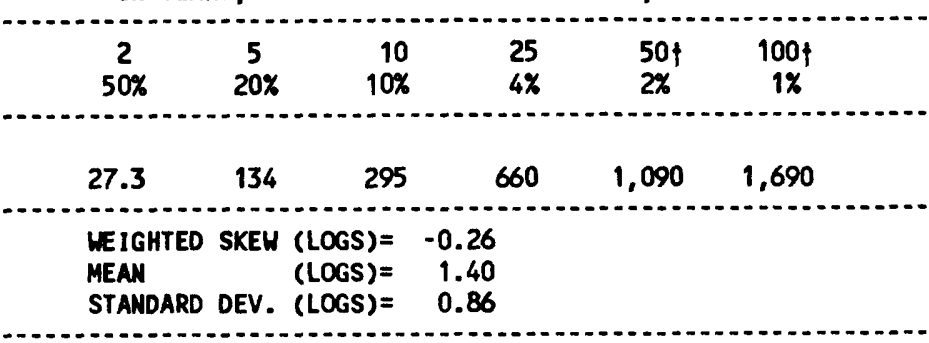

$\uparrow$ Reliability of values in column is uncertain, and potential errors are large.

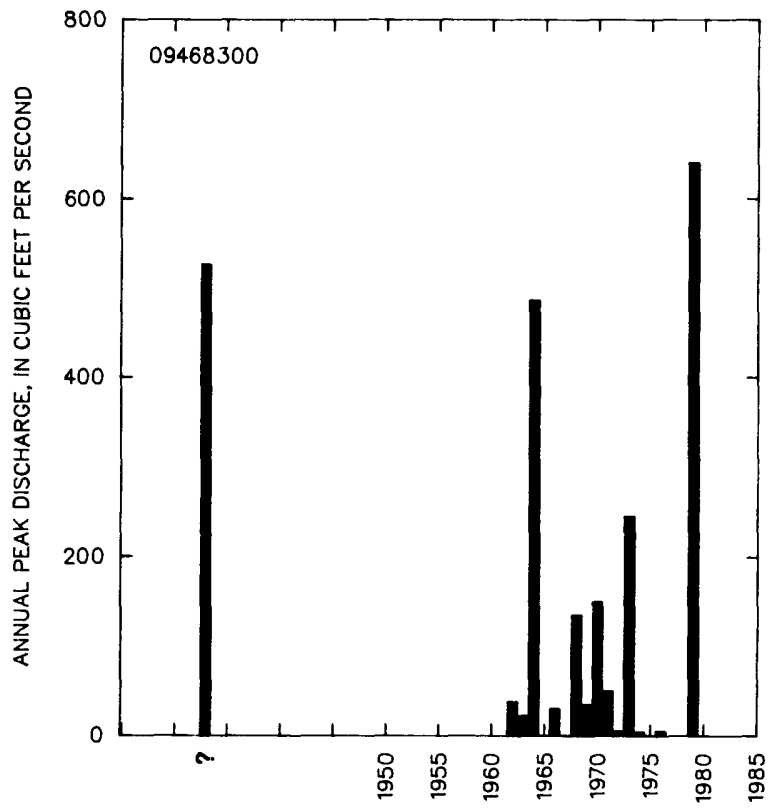

BASIN CHARACTERISTICS

\begin{tabular}{|c|c|c|c|c|c|c|c|}
\hline \multirow{3}{*}{$\begin{array}{l}\text { MAIN } \\
\text { CHANNEL } \\
\text { SLOPE } \\
\text { (FT/MI) }\end{array}$} & \multirow{3}{*}{$\begin{array}{c}\text { STREAM } \\
\text { LENGTH } \\
\text { (MI) }\end{array}$} & \multirow{3}{*}{$\begin{array}{l}\text { MEAN } \\
\text { BASIN } \\
\text { ELEVA- } \\
\text { TION } \\
\text { (FT) }\end{array}$} & \multirow{3}{*}{$\begin{array}{l}\text { FORESTED } \\
\text { AREA } \\
\text { (PERCENT) }\end{array}$} & \multirow[b]{3}{*}{$\begin{array}{l}\text { SOIL } \\
\text { INDEX }\end{array}$} & \multirow{3}{*}{$\begin{array}{l}\text { MEAN } \\
\text { ANNUAL } \\
\text { PRECIPI- } \\
\text { TATION } \\
\text { (IN) }\end{array}$} & \multirow{2}{*}{\multicolumn{2}{|c|}{ RAINFALL INTENSITY, 24-HOUR }} \\
\hline & & & & & & & \\
\hline & & & & & & $\begin{array}{c}\text { 2-YEAR } \\
\text { (IN) }\end{array}$ & $\begin{array}{c}\text { 50-YEAR } \\
\text { (IN) }\end{array}$ \\
\hline 280 & 2.0 & 4,410 & 36.0 & 3.0 & 19.0 & 2.0 & 4.0 \\
\hline
\end{tabular}


09468500 SAN CARLOS RIVER NEAR 'PERIDOT, AZ

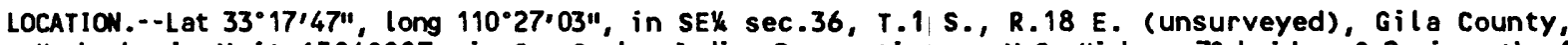
Hydrologic Unit 15040007, in San Carlos Indian Reservation, on U.S. Highway 70 bridge, 0.9 mi south of Peridot.

DRAINAGE AREA. $--1,026 \mathrm{mi}^{2}$.

REMARKS.--Diversions above station for irrigation of about 600 acres. Small inflow from sewage treatment system about $3.6 \mathrm{mi}$ upstream. Flow regulated to some extent since June 15, 1979, by Talkalai Reservoir; capacity of reservoir is about 6,000 acre-ft.

\begin{tabular}{|c|c|c|c|c|c|c|c|}
\hline \multicolumn{8}{|c|}{ ANNUAL PEAK DISCHARGE } \\
\hline $\begin{array}{l}\text { WATER } \\
\text { YEAR }\end{array}$ & DATE & $\begin{array}{l}\text { ANNUAL PEAK } \\
\text { DISCHARGE } \\
\left(\mathrm{FT}^{3} / \mathrm{S}\right)\end{array}$ & $\begin{array}{l}\text { DISCHARGE } \\
\text { CODES }\end{array}$ & $\begin{array}{l}\text { WATER } \\
\text { YEAR }\end{array}$ & DATE & $\begin{array}{c}\text { ANNUAL PEAK } \\
\text { DISCHARGE } \\
\left(\mathrm{FT}^{3} / \mathrm{S}\right)\end{array}$ & $\begin{array}{l}\text { DISCHARGE } \\
\text { CODES }\end{array}$ \\
\hline $\begin{array}{l}1916 \\
1930 \\
1931 \\
1932 \\
1933 \\
1934 \\
1935 \\
1936 \\
1937 \\
1938 \\
1939 \\
1940 \\
1941 \\
1942 \\
1943 \\
1944 \\
1945 \\
1946 \\
1947 \\
1948 \\
1949 \\
1950 \\
1951 \\
1952 \\
1953 \\
1954 \\
1955 \\
1956 \\
1957 \\
1958 \\
1959\end{array}$ & $\begin{array}{l}01-18-16 \\
03-17-30 \\
08-07-31 \\
02-10-32 \\
09-08-33 \\
08-18-34 \\
02-07-35 \\
02-17-36 \\
02-07-37 \\
03-04-38 \\
08-03-39 \\
08-03-40 \\
03-14-41 \\
12-12-41 \\
09-26-43 \\
09-27-44 \\
08-09-45 \\
07-27-46 \\
08-08-47 \\
08-02-48 \\
01-09-49 \\
07-21-50 \\
08-29-51 \\
01-13-52 \\
08-27-53 \\
03-23-54 \\
08-06-55 \\
01-29-56 \\
07-26-57 \\
03-22-58 \\
08-18-59\end{array}$ & $\begin{array}{r}25,000 \\
5,700 \\
7,000 \\
12,000 \\
11,000 \\
8,200 \\
13,800 \\
14,400 \\
29,400 \\
8,640 \\
10,200 \\
6,000 \\
40,600 \\
2,520 \\
5,060 \\
795 \\
3,200 \\
4,530 \\
15,000 \\
2,850 \\
3,260 \\
2,150 \\
2,940 \\
39,200 \\
860 \\
23,500 \\
14,600 \\
9,300 \\
7,310 \\
7,670 \\
2,280\end{array}$ & ES, HP & $\begin{array}{l}1960 \\
1961 \\
1962 \\
1963 \\
1964 \\
1965 \\
1966 \\
1967 \\
1968 \\
1969 \\
1970 \\
1971 \\
1972 \\
1973 \\
1974 \\
1975 \\
1976 \\
1977 \\
1978 \\
1979 \\
1980 \\
1981 \\
1982 \\
1983 \\
1984 \\
1985 \\
1986 \\
1987 \\
1988 \\
1989\end{array}$ & $\begin{array}{l}12-26-59 \\
07-22-61 \\
09-26-62 \\
02-11-63 \\
07-25-64 \\
01-08-65 \\
12-22-65 \\
07-29-67 \\
12-20-67 \\
01-22-69 \\
09-06-70 \\
08-14-71 \\
10-17-71 \\
10-19-72 \\
07-20-74 \\
04-11-75 \\
09-25-76 \\
09-11-77 \\
03-02-78 \\
12-18-78 \\
02-15-80 \\
09-22-81 \\
02-11-82 \\
03-25-83 \\
10-01-83 \\
12-27-84 \\
07-16-86 \\
12-07-86 \\
08-27-88 \\
08-03-89\end{array}$ & $\begin{array}{r}14,300 \\
5,510 \\
4,400 \\
9,740 \\
6,610 \\
1,710 \\
36,300 \\
16,100 \\
32,000 \\
4,580 \\
5,080 \\
7,930 \\
4,970 \\
25,000 \\
7,800 \\
1,960 \\
12,000 \\
5,400 \\
18,600 \\
22,500 \\
12,300 \\
565 \\
6,260 \\
6,260 \\
10,300 \\
4,470 \\
3,240 \\
4,130 \\
3,400 \\
3,160\end{array}$ & \\
\hline
\end{tabular}

\section{BASIN CHARACTERISTICS}

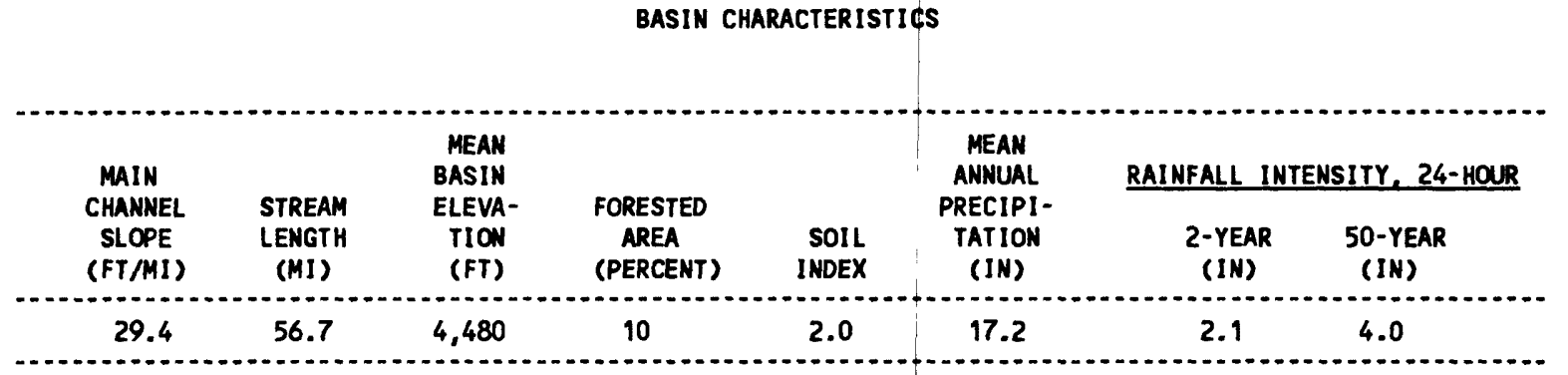


MEAN MONTHLY AND ANNUAL DISCHARGES 1930-89

\begin{tabular}{|c|c|c|c|c|c|c|}
\hline MONTH & 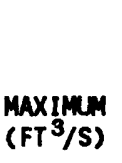 & $\begin{array}{l}\text { MINIMUM } \\
\left(F^{3} / S\right)\end{array}$ & $\begin{array}{c}\text { MEAN } \\
\left(F T^{3} / S\right)\end{array}$ & $\begin{array}{l}\text { STAN- } \\
\text { DARD } \\
\text { DEVIA- } \\
\text { TION } \\
\left(\text { FT }^{\mathbf{3}} / \mathrm{S}\right)\end{array}$ & $\begin{array}{l}\text { COEFFI- } \\
\text { CIENT OF } \\
\text { VARI - } \\
\text { ATION }\end{array}$ & $\begin{array}{c}\text { PERCENT } \\
\text { OF } \\
\text { ANNUAL } \\
\text { RUNOFF }\end{array}$ \\
\hline $\begin{array}{l}\text { OCTOBER } \\
\text { NOVEMBER } \\
\text { OECEMBER } \\
\text { JANUARY } \\
\text { FEBRUARY } \\
\text { MARCH } \\
\text { APRIL } \\
\text { MAY } \\
\text { JUNE } \\
\text { JULY } \\
\text { AUGUST } \\
\text { SEPTEMBER }\end{array}$ & $\begin{array}{r}519 \\
178 \\
1,580 \\
870 \\
1,500 \\
1,260 \\
170 \\
42 \\
18 \\
85 \\
294 \\
166\end{array}$ & $\begin{array}{l}0.20 \\
2.7 \\
5.1 \\
5.8 \\
7.0 \\
4.8 \\
2.2 \\
0.03 \\
0.00 \\
0.00 \\
1.6 \\
0.00\end{array}$ & $\begin{array}{c}32 \\
19 \\
108 \\
91 \\
154 \\
136 \\
22 \\
7.1 \\
3.0 \\
18 \\
52 \\
24\end{array}$ & $\begin{array}{c}88 \\
27 \\
254 \\
153 \\
254 \\
246 \\
31 \\
7.3 \\
3.7 \\
19 \\
57 \\
30\end{array}$ & $\begin{array}{l}2.8 \\
1.4 \\
2.3 \\
1.7 \\
1.7 \\
1.8 \\
1.4 \\
1.0 \\
1.3 \\
1.0 \\
1.1 \\
1.3\end{array}$ & $\begin{array}{r}4.8 \\
2.8 \\
16.3 \\
13.6 \\
23.1 \\
20.4 \\
3.3 \\
1.1 \\
0.4 \\
2.7 \\
7.7 \\
3.6\end{array}$ \\
\hline ANNUAL & 278 & 8.2 & 55 & 55 & 0.99 & 100 \\
\hline
\end{tabular}

MAGNITUDE AND PROBABILITY OF INSTANTANEQUS PEAK FLOW BASED ON PERIOD OF RECORD 1930-89

DISCHARGE, IN $\mathrm{FT}^{3} / \mathrm{S}$, FOR INDICATED RECURRENCE INTERVAL IN YEARS, AND EXCEEDANCE PROBABILITY, IN PERCENT

\begin{tabular}{lccccc}
2 & 5 & 10 & 25 & 50 & 100 \\
$50 \%$ & $20 \%$ & $10 \%$ & $4 \%$ & $2 \%$ & $1 \%$ \\
7,130 & 14,600 & 21,400 & 32,400 & 42,600 & 54,500 \\
\hline WEIGHTED SKEW (LOGS) & $=0.11$ & & \\
MEAN & (LOGS) & $=3.86$ & & \\
STANDARD DEV. (LOGS) & $=0.36$
\end{tabular}

MAGNITUDE ANO PROBABILITY OF ANNUAL LOW FLOW BASED ON PERIOD OF RECORD 1931-89

\begin{tabular}{|c|c|c|c|c|c|c|}
\hline \multirow{2}{*}{$\begin{array}{l}\text { PERIOD } \\
\text { (CON- } \\
\text { SECU- } \\
\text { TIVE } \\
\text { DAYS) }\end{array}$} & \multicolumn{6}{|c|}{$\begin{array}{l}\text { DISCHARGE, IN } \mathrm{FT}^{3} / \mathrm{S}, \text { FOR INDICATED } \\
\text { RECURRENCE INTERVAL, IN YEARS, AND } \\
\text { NON-EXCEEDANCE PROBABILITY, IN PERCENT }\end{array}$} \\
\hline & $\begin{array}{c}2 \\
50 \%\end{array}$ & $\begin{array}{c}5 \\
20 \%\end{array}$ & $\begin{array}{l}10 \\
10 \%\end{array}$ & $\begin{array}{l}20 \\
5 \%\end{array}$ & $\begin{array}{l}50 \\
2 \%\end{array}$ & $\begin{array}{l}100 \\
1 \%\end{array}$ \\
\hline $\begin{array}{r}1 \\
3 \\
7 \\
14 \\
30 \\
60 \\
90 \\
120 \\
183\end{array}$ & $\begin{array}{c}0.00 \\
0.00 \\
0.00 \\
0.00 \\
0.00 \\
0.00 \\
3.3 \\
6.6 \\
12\end{array}$ & $\begin{array}{l}0.00 \\
0.00 \\
0.00 \\
0.00 \\
0.00 \\
0.00 \\
1.5 \\
3.4 \\
6.3\end{array}$ & $\begin{array}{l}0.00 \\
0.00 \\
0.00 \\
0.00 \\
0.00 \\
0.00 \\
0.91 \\
2.3 \\
4.5\end{array}$ & $\begin{array}{l}0.00 \\
0.00 \\
0.00 \\
0.00 \\
0.00 \\
0.00 \\
0.59 \\
1.6 \\
3.3\end{array}$ & $\begin{array}{l}0.00 \\
0.00 \\
0.00 \\
0.00 \\
0.00 \\
0.00 \\
0.36 \\
1.0 \\
2.3\end{array}$ & $\begin{array}{l}0.00 \\
0.00 \\
0.00 \\
0.00 \\
0.00 \\
0.00 \\
0.25 \\
0.77 \\
1.8\end{array}$ \\
\hline
\end{tabular}

MAGNITUDE AND PROBABILITY OF ANNUAL HIGH FLON BASED ON PERIOD OF RECORD $1930-89$

\begin{tabular}{|c|c|c|c|c|c|c|}
\hline \multirow{2}{*}{$\begin{array}{l}\text { PER IOO } \\
\text { (CON- } \\
\text { SECU- } \\
\text { TIVE } \\
\text { DAYS) }\end{array}$} & \multicolumn{6}{|c|}{$\begin{array}{l}\text { DISCHARCE, IN } \text { FT }^{3} / S \text {, FOR INDICATED } \\
\text { RECURRENCE INTERVAL, IN YEARS, AND } \\
\text { EXCEEDANCE PROBABILITY, IN PERCENT }\end{array}$} \\
\hline & $\begin{array}{c}2 \\
50 \%\end{array}$ & $\begin{array}{c}5 \\
20 \%\end{array}$ & $\begin{array}{l}10 \\
10 \%\end{array}$ & $\begin{array}{l}25 \\
4 \%\end{array}$ & $\begin{array}{l}50 \\
2 \%\end{array}$ & $\begin{array}{r}100 \\
1 \%\end{array}$ \\
\hline $\begin{array}{r}1 \\
3 \\
7 \\
15 \\
30 \\
60 \\
90\end{array}$ & $\begin{array}{r}1,740 \\
968 \\
543 \\
319 \\
196 \\
126 \\
93\end{array}$ & $\begin{array}{r}4,810 \\
2,750 \\
1,490 \\
832 \\
496 \\
315 \\
236\end{array}$ & $\begin{array}{r}8,320 \\
4,860 \\
2,580 \\
1,400 \\
821 \\
520 \\
391\end{array}$ & $\begin{array}{r}15,100 \\
9,060 \\
4,700 \\
2,470 \\
1,430 \\
901 \\
680\end{array}$ & $\begin{array}{r}22,300 \\
13,700 \\
6,980 \\
3,580 \\
2,070 \\
1,300 \\
983\end{array}$ & $\begin{array}{c}31, \\
19, \\
10, \\
5, \\
2, \\
1, \\
1,\end{array}$ \\
\hline
\end{tabular}

DURATION TABLE OF DAILY MEAN FLON FOR PERIOD OF RECORD 1930-89 DISCHARGE, IN FT $3 / \mathrm{S}$, HHICH WAS EQUALED OR EXCEEDED FOR INDICATED PERCENT OF TIME

\begin{tabular}{|c|c|c|c|c|c|c|c|c|c|c|c|c|c|c|c|c|}
\hline $1 \%$ & $5 \%$ & $10 \%$ & $15 \%$ & $20 \%$ & $30 \%$ & $40 \%$ & $50 \%$ & $60 \%$ & $70 \%$ & $80 \%$ & $90 \%$ & $95 \%$ & $98 \%$ & $99 \%$ & $99.5 \%$ & $99.9 \%$ \\
\hline & 147 & 64 & 38 & 26 & 16 & 12 & 9.2 & 6.9 & 4.9 & 3.0 & 0.93 & 0.00 & 0.00 & 0.00 & 0.00 & .0 \\
\hline
\end{tabular}


GILA RIVER BASIN

09468500 SAN CARLOS RIVER NEAR PERIDOT, AZ--CONTINUED
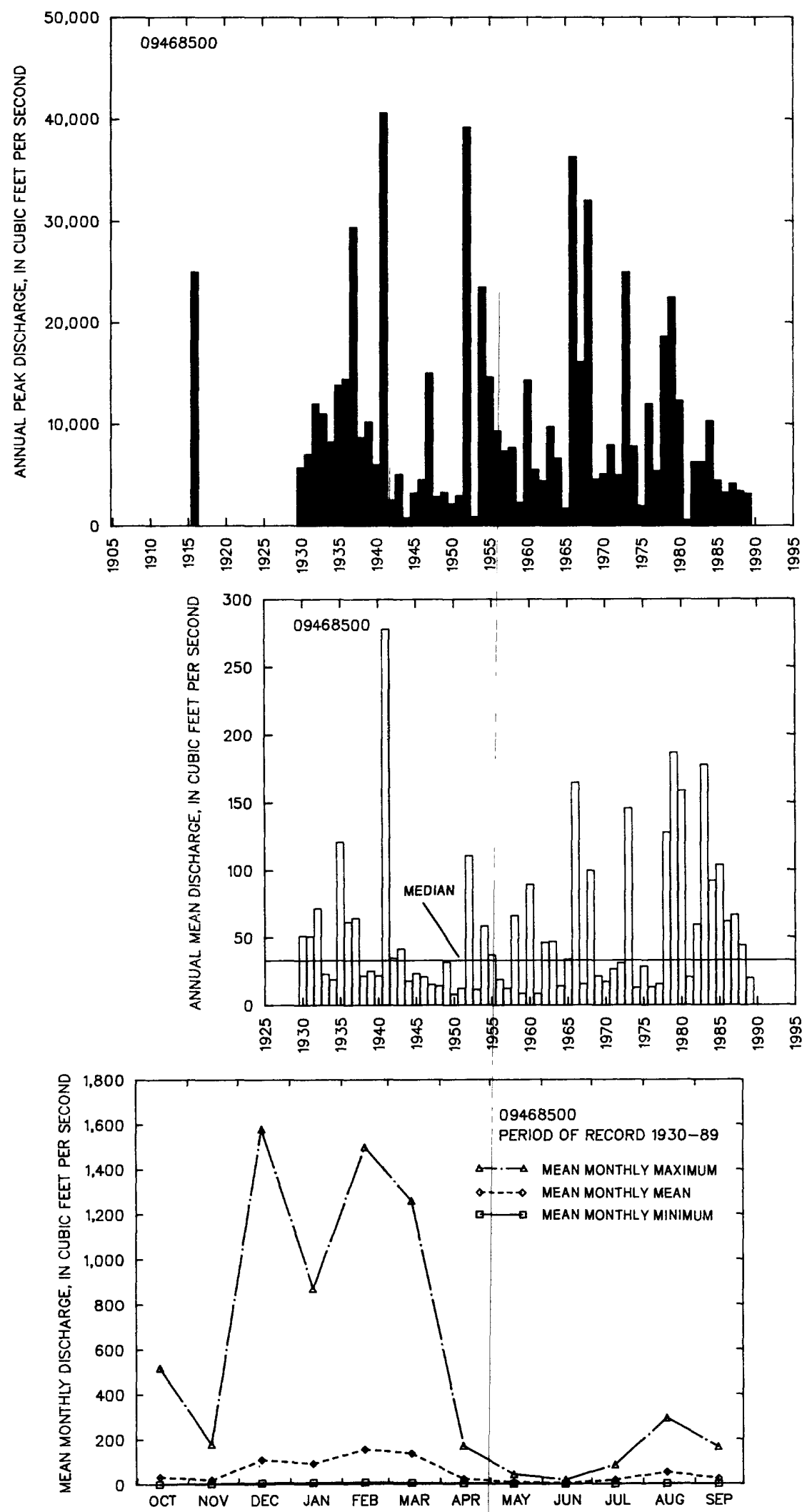
09470500 SAN PEDRo RIVER AT PALOMINAS, AZ

LOCATION.--Lat 31'22'48", long 110.06'38", in SW/2SEK sec.33, T.23 S., R.22 E., Cochise County, Hydrologic Unit 15050202, near left bank on downstream side of pier of bridge on State Highway $92,0.7 \mathrm{mi}$ east of Palominas, 2.5 mi upstream from Green Brush Draw, 4.5 mi downstream from international boundary, and 12 mi southwest of Bisbee.

DRAIMAGe AREA. $-737 \mathrm{mi}^{2}$, of which $649 \mathrm{mi}^{2}$ is in Mexico.

REMARKS.--Small diversions for irrigation of a few hundred acres above station, mostly in Mexico. Records show approximate flow of river at international boundary.

Records furnished by International Boundary and Water Commission 1982-89.

ANNUAL PEAK DISCHARGE

\begin{tabular}{|c|c|c|c|c|c|c|c|}
\hline $\begin{array}{l}\text { WATER } \\
\text { YEAR }\end{array}$ & DATE & $\begin{array}{l}\text { ANNUAL PEAK } \\
\text { DISCHARGE } \\
\left(\mathrm{FT}^{3} / \mathrm{S}\right)\end{array}$ & $\begin{array}{l}\text { DISCHARGE } \\
\text { CODES }\end{array}$ & $\begin{array}{l}\text { WATER } \\
\text { YEAR }\end{array}$ & DATE & $\begin{array}{l}\text { ANNUAL PEAK } \\
\text { DISCHARGE } \\
\left(\mathrm{FT}^{3} / \mathrm{S}\right)\end{array}$ & $\begin{array}{l}\text { DISCHARGE } \\
\text { CODES }\end{array}$ \\
\hline $\begin{array}{l}1926 \\
1930 \\
1931 \\
1932 \\
1933 \\
1935 \\
1936 \\
1937 \\
1938 \\
1939 \\
1940 \\
1941 \\
1950 \\
1951 \\
1952 \\
1953 \\
1954 \\
1955 \\
1956 \\
1957 \\
1958 \\
1959 \\
1960 \\
1961 \\
1962 \\
1963\end{array}$ & $\begin{array}{l}09-28-26 \\
08-07-30 \\
08-08-31 \\
08-09-32 \\
09-19-33 \\
08-14-35 \\
09-10-36 \\
08-20-37 \\
08-07-38 \\
08-06-39 \\
08-14-40 \\
01-28-41 \\
07-05-50 \\
07-02-51 \\
08-16-52 \\
07-07-53 \\
08-14-54 \\
07-31-55 \\
07-17-56 \\
08-20-57 \\
08-05-58 \\
07-27-59 \\
08-16-60 \\
07-29-61 \\
07-26-62 \\
07-27-63\end{array}$ & $\begin{array}{r}(\mathbf{1}) \\
9,400 \\
8,900 \\
6,000 \\
4,700 \\
3,000 \\
13,500 \\
8,090 \\
6,300 \\
7,500 \\
222,000 \\
5,900 \\
6,270 \\
5,710 \\
7,400 \\
11,900 \\
6,510 \\
6,250 \\
4,640 \\
2,540 \\
16,500 \\
13,000 \\
3,410 \\
3,820 \\
4,130 \\
6,340\end{array}$ & HP & $\begin{array}{l}1964 \\
1965 \\
1966 \\
1967 \\
1968 \\
1969 \\
1970 \\
1971 \\
1972 \\
1973 \\
1974 \\
1975 \\
1976 \\
1977 \\
1978 \\
1979 \\
1980 \\
1981 \\
1982 \\
1983 \\
1984 \\
1985 \\
1986 \\
1987 \\
1988 \\
1989\end{array}$ & $\begin{array}{l}08-14-64 \\
07-28-65 \\
07-28-66 \\
07-26-67 \\
12-20-67 \\
07-28-69 \\
08-09-70 \\
08-11-71 \\
08-26-72 \\
10-18-72 \\
07-30-74 \\
09-14-75 \\
07-27-76 \\
07-31-77 \\
10-09-77 \\
01-18-79 \\
08-04-80 \\
07-10-81 \\
09-10-82 \\
02-04-83 \\
10-02-83 \\
12-28-84 \\
08-18-86 \\
08-10-87 \\
09-11-88 \\
08-04-89\end{array}$ & $\begin{array}{r}11,000 \\
4,530 \\
3,610 \\
5,560 \\
6,500 \\
4,000 \\
5,870 \\
6,380 \\
1,830 \\
2,900 \\
7,360 \\
6,840 \\
5,000 \\
3,310 \\
14,500 \\
12,000 \\
2,000 \\
3,360 \\
4,260 \\
1,940 \\
8,180 \\
10,600 \\
4,000 \\
9,978 \\
7,020 \\
1,550\end{array}$ & ES \\
\hline
\end{tabular}

1Highest since 1906; discharge unknown.

$2 \mathrm{Highest}$ since 1927.

BASIN CHARACTERISTICS

\begin{tabular}{|c|c|c|c|c|c|c|c|}
\hline MAIN & & $\begin{array}{r}\text { MEAN } \\
\text { BASIN }\end{array}$ & & & $\begin{array}{c}\text { MEAN } \\
\text { ANNUAL }\end{array}$ & RAINFALL I & SITY, 24-HOUR \\
\hline $\begin{array}{l}\text { CHANNEL } \\
\text { SLOPE } \\
\text { (FT/MI) }\end{array}$ & $\begin{array}{l}\text { STREAM } \\
\text { LENGTH } \\
\text { (MI) }\end{array}$ & $\begin{array}{l}\text { ELEVA- } \\
\text { TION } \\
\text { (FT) }\end{array}$ & $\begin{array}{l}\text { FORESTED } \\
\text { AREA } \\
\text { (PERCENT) }\end{array}$ & $\begin{array}{l}\text { SOIL } \\
\text { INDEX }\end{array}$ & $\begin{array}{l}\text { PRECIPI - } \\
\text { TATION } \\
\text { (IN) }\end{array}$ & $\begin{array}{c}\text { 2-YEAR } \\
\text { (IN) }\end{array}$ & $\begin{array}{c}\text { 50-YEAR } \\
\text { (IN) }\end{array}$ \\
\hline 23.5 & 35.4 & 4,950 & 12.0 & 2.3 & 17.9 & 1.9 & 4.0 \\
\hline
\end{tabular}


MEAN MONTHLY AND ANMUAL DISCHARGeS 1931-33, 1936-40, 1951-81

\begin{tabular}{|c|c|c|c|c|c|c|}
\hline MONTH & $\begin{array}{l}\operatorname{MAXIMUN} \\
\left(F T^{3} / \mathrm{S}\right)\end{array}$ & $\begin{array}{l}\text { MINIMUN } \\
\left(F T^{3} / S\right)\end{array}$ & $\begin{array}{c}\text { MEAN } \\
\left(F^{3} / S\right)\end{array}$ & $\begin{array}{l}\text { STAN- } \\
\text { DARD } \\
\text { DEVIA- } \\
\text { TION } \\
\text { (FT'/S) }\end{array}$ & $\begin{array}{l}\text { COEFFI - } \\
\text { CIENT OF } \\
\text { VARI - } \\
\text { ATION }\end{array}$ & $\begin{array}{c}\text { PERCENT } \\
\text { OF } \\
\text { ANNUAL } \\
\text { RUNOFF }\end{array}$ \\
\hline $\begin{array}{l}\text { OCTOBER } \\
\text { NOVEMBER } \\
\text { DECEMBER } \\
\text { JANUARY } \\
\text { FEBRUARY } \\
\text { MARCH } \\
\text { APRIL } \\
\text { MAY } \\
\text { JUNE } \\
\text { JULY } \\
\text { AUGUST } \\
\text { SEPTEMBER }\end{array}$ & $\begin{array}{c}770 \\
43 \\
414 \\
452 \\
74 \\
76 \\
15 \\
7.0 \\
23 \\
280 \\
591 \\
275\end{array}$ & $\begin{array}{l}0.00 \\
0.00 \\
0.10 \\
0.04 \\
0.07 \\
0.22 \\
0.00 \\
0.00 \\
0.00 \\
3.0 \\
2.7 \\
0.19\end{array}$ & $\begin{array}{c}26 \\
5.0 \\
22 \\
22 \\
11 \\
8.3 \\
2.7 \\
1.2 \\
4.0 \\
89 \\
154 \\
36\end{array}$ & $\begin{array}{c}123 \\
7.8 \\
71 \\
74 \\
16 \\
14 \\
3.1 \\
1.5 \\
6.4 \\
71 \\
167 \\
53\end{array}$ & $\begin{array}{l}4.7 \\
1.5 \\
3.2 \\
3.4 \\
1.5 \\
1.8 \\
1.2 \\
1.2 \\
1.6 \\
0.80 \\
1.1 \\
1.5\end{array}$ & $\begin{array}{r}6.8 \\
1.3 \\
5.9 \\
5.7 \\
2.9 \\
2.2 \\
0.7 \\
0.3 \\
1.0 \\
23.4 \\
40.3 \\
9.4\end{array}$ \\
\hline INNUAL & 93 & 7.1 & 32 & 22 & 0.69 & 100 \\
\hline
\end{tabular}

MAGNITUDE AND PROBABILITY OF INSTANTANEOUS PEAK FLOH BASED ON PERIOO OF RECORD 1926, 1930-33, 1935-41, 1950-89

\begin{tabular}{|c|c|c|c|c|c|}
\hline $\begin{array}{c}2 \\
50 \%\end{array}$ & $\begin{array}{c}5 \\
20 \%\end{array}$ & $\begin{array}{r}10 \\
10 \%\end{array}$ & $\begin{array}{l}25 \\
4 \%\end{array}$ & $\begin{array}{l}50 \\
2 \%\end{array}$ & $\begin{array}{r}100 \\
1 \%\end{array}$ \\
\hline 5,810 & 9,190 & 11,800 & 15,400 & 18,300 & 21,500 \\
\hline $\begin{array}{l}\text { WE IGHTED } \\
\text { MEAN } \\
\text { STANDARD }\end{array}$ & $\begin{array}{l}\text { SKEW } \\
\text { DEV. }\end{array}$ & $\begin{array}{l}(\text { LOGS })= \\
(\text { LOGS) }= \\
(\text { LOGS })=\end{array}$ & $\begin{array}{l}.12 \\
.77 \\
.23\end{array}$ & & \\
\hline
\end{tabular}

MAGNITUDE AND PROBABILITY OF ANNUAL LON FLON BASED ON PERIOD OF RECORD 1932-33, 1937-41, 1952-81

\begin{tabular}{|c|c|c|c|c|c|c|}
\hline \multirow{2}{*}{$\begin{array}{l}\text { PER IOD } \\
\text { (CON- } \\
\text { SECU- } \\
\text { TIVE } \\
\text { DAYS) }\end{array}$} & \multicolumn{6}{|c|}{$\begin{array}{l}\text { DISCHARGE, IN FT } 3 / S \text {, FOR INDICATED } \\
\text { RECURRENCE INTERVAL, IN YEARS, AND } \\
\text { NON-EXCEEDANCE PROBABILITY, IN PERCENT }\end{array}$} \\
\hline & $\stackrel{2}{20 \%}$ & $\begin{array}{c}5 \\
20 \%\end{array}$ & $\begin{array}{l}10 \\
10 \%\end{array}$ & $\begin{array}{l}20 \\
5 \%\end{array}$ & $\begin{array}{l}50 \\
2 \%\end{array}$ & $\begin{array}{l}100 \nmid \\
1 \%\end{array}$ \\
\hline $\begin{array}{r}1 \\
3 \\
7 \\
14 \\
30 \\
60 \\
90 \\
120 \\
183\end{array}$ & $\begin{array}{l}0.00 \\
0.00 \\
0.00 \\
0.02 \\
0.09 \\
0.25 \\
0.55 \\
2.4 \\
3.9\end{array}$ & $\begin{array}{l}0.00 \\
0.00 \\
0.00 \\
0.00 \\
0.00 \\
0.05 \\
0.12 \\
0.69 \\
1.1\end{array}$ & $\begin{array}{l}0.00 \\
0.00 \\
0.00 \\
0.00 \\
0.00 \\
0.00 \\
0.05 \\
0.32 \\
0.54\end{array}$ & $\begin{array}{l}0.00 \\
0.00 \\
0.00 \\
0.00 \\
0.00 \\
0.00 \\
0.03 \\
0.16 \\
0.30\end{array}$ & $\begin{array}{l}0.00 \\
0.00 \\
0.00 \\
0.00 \\
0.00 \\
0.00 \\
0.01 \\
0.07 \\
0.15\end{array}$ & $\begin{array}{l}0.00 \\
0.00 \\
0.00 \\
0.00 \\
0.00 \\
0.00 \\
0.01 \\
0.04 \\
0.09\end{array}$ \\
\hline
\end{tabular}

MAGNITUDE AND PROBABILITY OF ANNUAL HIGH FLOH BASED ON PERIOD OF RECORD 1931-33, 1936-40, 1951-81

\begin{tabular}{|c|c|c|c|c|c|c|}
\hline \multirow{2}{*}{$\begin{array}{l}\text { PERIOD } \\
\text { (CON- }- \\
\text { SECY- } \\
\text { TIVE } \\
\text { DAYS) }\end{array}$} & \multicolumn{6}{|c|}{$\begin{array}{l}\text { DISCHARGE, IN FT } 3 / S \text {, FOR INDICATED } \\
\text { RECURRENCE INTERVAL, IN YEARS, AND } \\
\text { EXCEEDANCE PROBABILITY, IN PERCENT }\end{array}$} \\
\hline & $\begin{array}{c}2 \\
50 \%\end{array}$ & $\begin{array}{c}5 \\
20 \%\end{array}$ & $\begin{array}{l}10 \\
10 \%\end{array}$ & $\begin{array}{l}25 \\
4 \%\end{array}$ & $\begin{array}{l}50 \\
2 \%\end{array}$ & $\underset{1 \%}{100 \uparrow}$ \\
\hline $\begin{array}{c}1 \\
3 \\
7 \\
15 \\
30 \\
60 \\
90\end{array}$ & $\begin{array}{r}1,560 \\
818 \\
473 \\
303 \\
198 \\
127 \\
90\end{array}$ & $\begin{array}{r}3,190 \\
1,670 \\
954 \\
596 \\
379 \\
237 \\
166\end{array}$ & $\begin{array}{r}4,750 \\
2,510 \\
1,400 \\
854 \\
533 \\
327 \\
227\end{array}$ & $\begin{array}{r}7,380 \\
3,990 \\
2,130 \\
1,260 \\
767 \\
457 \\
313\end{array}$ & $\begin{array}{r}9,920 \\
5,460 \\
2,810 \\
1,620 \\
972 \\
567 \\
383\end{array}$ & $\begin{array}{r}13,000 \\
7,320 \\
3,630 \\
2,050 \\
1,200 \\
686 \\
459\end{array}$ \\
\hline
\end{tabular}

DURATION TABLE OF DAILY MEAN FLON FOR PERICD OF RECORD 1931-33, 1936-40, 1951-81

DISCHARGE, IN FT $3 / 5$, WHICH WAS EQUALED OR EXCEEDED FOR INDICATED PERCENT OF TIME

\begin{tabular}{|c|c|c|c|c|c|c|c|c|c|c|c|c|c|c|c|c|}
\hline $1 \%$ & $5 \%$ & $10 \%$ & $15 \%$ & $20 \%$ & $30 \%$ & $40 \%$ & $50 \%$ & $60 \%$ & $70 \%$ & $80 \%$ & $90 \%$ & $95 \%$ & $98 \%$ & $99 \%$ & $99.5 \%$ & $99.9 \%$ \\
\hline 634 & 111 & 35 & 18 & 11 & 6.6 & 4.3 & 2.7 & 1.4 & 0.53 & 0.21 & 0.00 & 0.00 & 0.00 & 0.00 & 0.00 & 0.00 \\
\hline
\end{tabular}

$\uparrow$ Reliability of values in colum is uncertain, and potential errors are large. 
GILA RIVER BASIN

09470500 SAN PEDRo RIVER AT PALOMINAS, AZ--CONTIMUEd
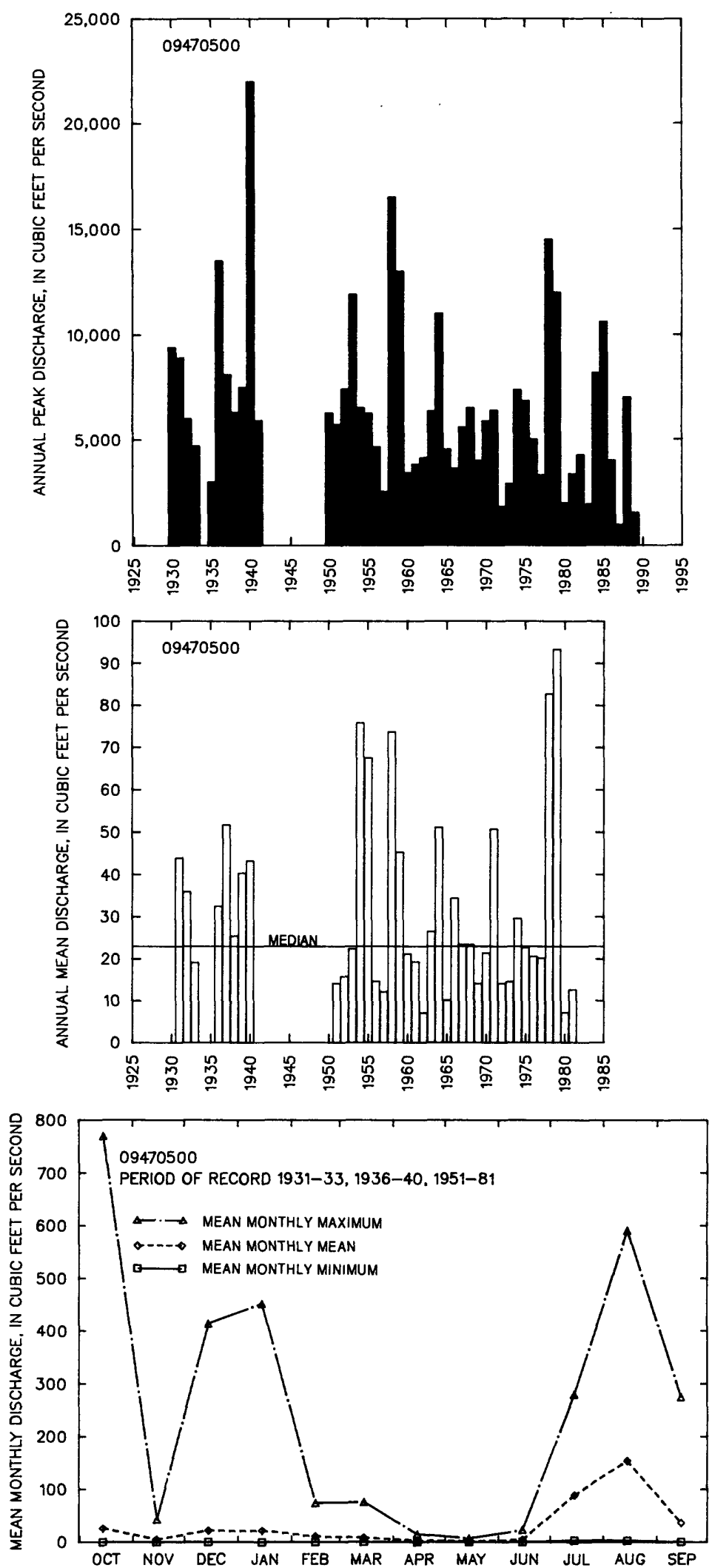
09470900 SAN PEDRO RIVER TRIBUTARY | MEAR BISBEE, AZ

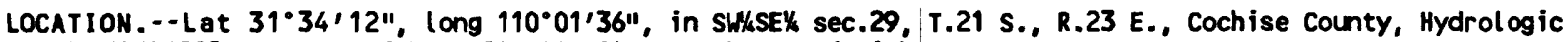
Unit 15050202, at U.S. Highway 80, 11 miles northwest of Bisbee.

DRAIMAGE AREA.--7.12 $\mathrm{mi}^{2}$, of which $1.87 \mathrm{mi}^{2}$ is noncontributing.

ANNUAL PEAK DISCHARGE

\begin{tabular}{cccc}
$\begin{array}{c}\text { WATER } \\
\text { YEAR }\end{array}$ & DATE & $\begin{array}{c}\text { ANNUAL PEAK } \\
\text { DISCHARGE } \\
\text { (FT } 3 / \text { S) }\end{array}$ & $\begin{array}{c}\text { DISCHARGE } \\
\text { CODES }\end{array}$ \\
\hline 1963 & $09-20-63$ & 360 & \\
1964 & $08-10-64$ & 962 & \\
1965 & $09-04-65$ & 1,460 & \\
1966 & $00-00-66$ & 150 & LT \\
1967 & $08-12-67$ & 1,060 & \\
1968 & $07-00-68$ & 400 & \\
1969 & $08-30-69$ & 120 & \\
1970 & $07-28-70$ & 556 & \\
1971 & $07-23-71$ & 780 & \\
1972 & $08-26-72$ & 620 & \\
1973 & $07-00-73$ & 280 & \\
1974 & $00-00-74$ & 1,000 & \\
1975 & $07-24-75$ & 320 & \\
1976 & $00-00-76$ & 60 & \\
1978 & $10-07-77$ & 800 & \\
1979 & $00-00-79$ & 20 & \\
$\ldots$
\end{tabular}

MAGNITUDE AND PROBABILITY OF INSTANTANEOUS PEAK FLOW BASED ON PERIOD OF RECORD 1963-76, 1978-79

DISCHARGE, IN $\mathrm{FT}^{3} / \mathrm{S}$, FOR INDICATED RECURRENCE INTERVAL IN YEARS, AND EXCEEDANCE PROBABILITY, IN PERCENT

\begin{tabular}{|c|c|c|c|c|c|}
\hline $\begin{array}{c}2 \\
50 \%\end{array}$ & $\begin{array}{c}5 \\
20 \%\end{array}$ & $\begin{array}{r}10 \\
10 \%\end{array}$ & $\begin{array}{l}25 \\
4 \%\end{array}$ & $\begin{array}{l}50 \dagger \\
2 \%\end{array}$ & $\begin{array}{c}100 \dagger \\
1 \%\end{array}$ \\
\hline 498 & 885 & 1,170 & 1,550 & 1.840 & 2,140 \\
\hline $\begin{array}{l}\text { WEIGH } \\
\text { MEAN } \\
\text { STAND }\end{array}$ & SKEW & $\begin{array}{l}(\text { LOGS })= \\
(\text { LOGS) }= \\
(\text { LOGS })=\end{array}$ & $\begin{array}{r}-0.34 \\
2.68 \\
0.31\end{array}$ & & \\
\hline
\end{tabular}

t Reliability of values in column is uncertain, and potential errors are large.

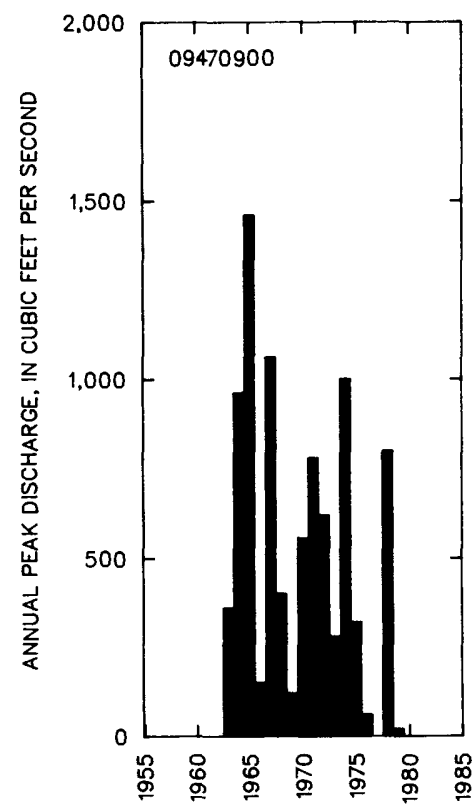


09471000 SAN PEDRO RIVER AT CHARLESTON, AZ

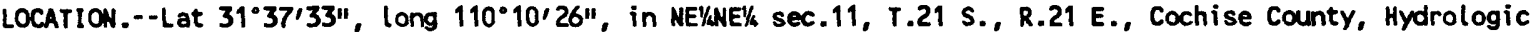
Unit 15050202, in Spanish land grant of San Juan de las Boquillas y Nogales, at downstream side of pier near center of highway bridge, 0.3 mi south of Charleston, $1.5 \mathrm{mi}$ upstream from Charleston damsite, and 9 mi upstream from Babocomari River.

DRAINAGe AREA. $-1,234 \mathrm{mi}^{2}$, of which $696 \mathrm{mi}^{2}$ is in Mexico.

REMARKS. - - Diversions above station, mostly by pumping from ground water, for irrigation of 3,200 acres in 1978, excluding an unknown amount in Mexico. Record shows flow available at Charleston damsite.

ANMUAL PEAK DISCHARGE

\begin{tabular}{|c|c|c|c|c|c|c|c|}
\hline $\begin{array}{l}\text { WATER } \\
\text { YEAR }\end{array}$ & DATE & $\begin{array}{l}\text { ANNUAL PEAK } \\
\text { DI SCHARGE } \\
\left(\mathrm{FT}^{3} / \mathrm{S}\right)\end{array}$ & $\begin{array}{l}\text { DISCHARGE } \\
\text { COOES }\end{array}$ & $\begin{array}{l}\text { WATER } \\
\text { YEAR }\end{array}$ & DATE & $\begin{array}{c}\text { ANNUAL PEAK } \\
\text { DISCHARGE } \\
\left(\mathrm{FT}^{3} / \mathrm{S}\right)\end{array}$ & $\begin{array}{l}\text { DISCHARGE } \\
\text { CODES }\end{array}$ \\
\hline $\begin{array}{l}1916 \\
1917 \\
1918 \\
1919 \\
1920 \\
1921 \\
1922 \\
1923 \\
1924 \\
1925 \\
1926 \\
1927 \\
1928 \\
1929 \\
1930 \\
1931 \\
1932 \\
1933 \\
1934 \\
1935 \\
1936 \\
1937 \\
1938 \\
1939 \\
1940 \\
1941 \\
1942 \\
1943 \\
1944 \\
1945 \\
1946 \\
1947 \\
1948 \\
1949 \\
1950 \\
1951 \\
1952\end{array}$ & $\begin{array}{l}08-16-16 \\
08-12-17 \\
07-01-18 \\
08-16-19 \\
09-05-20 \\
07-19-21 \\
09-09-22 \\
08-12-23 \\
07-24-24 \\
08-06-25 \\
09-28-26 \\
10-09-26 \\
07-15-28 \\
07-29-29 \\
08-07-30 \\
08-09-31 \\
08-09-32 \\
07-22-33 \\
00-00-34 \\
08-28-35 \\
09-11-36 \\
08-20-37 \\
08-07-38 \\
08-07-39 \\
08-13-40 \\
08-16-41 \\
07-24-42 \\
08-09-43 \\
08-18-44 \\
08-09-45 \\
08-04-46 \\
08-09-47 \\
08-03-48 \\
07-24-49 \\
07-06-50 \\
07-02-51 \\
08-17-52\end{array}$ & $\begin{array}{r}7,700 \\
13,000 \\
4,000 \\
25,100 \\
4,500 \\
19,000 \\
3,720 \\
5,200 \\
1,900 \\
11,900 \\
198,000 \\
5,100 \\
3,800 \\
10,400 \\
9,740 \\
24,500 \\
7,000 \\
9,600 \\
5,000 \\
8,600 \\
13,000 \\
9,430 \\
7,450 \\
9,370 \\
31,000 \\
10,800 \\
2,870 \\
8,650 \\
3,430 \\
7,670 \\
12,000 \\
10,100 \\
7,850 \\
6,720 \\
6,070 \\
5,730 \\
7,850\end{array}$ & ES & $\begin{array}{l}1953 \\
1954 \\
1955 \\
1956 \\
1957 \\
1958 \\
1959 \\
1960 \\
1961 \\
1962 \\
1963 \\
1964 \\
1965 \\
1966 \\
1967 \\
1968 \\
1969 \\
1970 \\
1971 \\
1972 \\
1973 \\
1974 \\
1975 \\
1976 \\
1977 \\
1978 \\
1979 \\
1980 \\
1981 \\
1982 \\
1983 \\
1984 \\
1985 \\
1986 \\
1987 \\
1988 \\
1989\end{array}$ & $\begin{array}{l}07-07-53 \\
08-15-54 \\
08-06-55 \\
07-18-56 \\
07-25-57 \\
08-05-58 \\
07-27-59 \\
08-11-60 \\
07-30-61 \\
07-28-62 \\
07-27-63 \\
08-14-64 \\
09-04-65 \\
08-03-66 \\
07-26-67 \\
12-20-67 \\
07-28-69 \\
08-09-70 \\
08-10-71 \\
08-26-72 \\
07-15-73 \\
07-20-74 \\
09-14-75 \\
09-05-76 \\
08-23-77 \\
10-09-77 \\
01-18-79 \\
08-15-80 \\
09-03-81 \\
09-10-82 \\
09-12-83 \\
10-03-83 \\
12-28-84 \\
08-18-86 \\
08-04-87 \\
09-12-88 \\
08-04-89\end{array}$ & $\begin{array}{r}8,590 \\
23,600 \\
14,400 \\
6,550 \\
6,000 \\
8,400 \\
7,480 \\
3,900 \\
3,620 \\
3,580 \\
6,460 \\
7,690 \\
4,180 \\
4,400 \\
6,010 \\
5,050 \\
3,920 \\
4,600 \\
5,920 \\
5,950 \\
3,340 \\
13,100 \\
4,020 \\
3,620 \\
5,200 \\
23,700 \\
11,800 \\
990 \\
3,210 \\
8,800 \\
3,100 \\
8,560 \\
13,000 \\
5,020 \\
3,290 \\
3,640 \\
1,680\end{array}$ & \\
\hline
\end{tabular}

$1_{H \text { ighest since } 1906 .}$

\section{BASIN CHARACTERISTICS}

\begin{tabular}{|c|c|c|c|c|c|c|c|}
\hline \multirow{2}{*}{$\begin{array}{l}\text { MAIN } \\
\text { CHANNEL } \\
\text { SLOPE } \\
\text { (FT/MI) }\end{array}$} & \multicolumn{2}{|r|}{$\begin{array}{l}\text { MEAN } \\
\text { BASIN }\end{array}$} & \multirow[b]{2}{*}{$\begin{array}{l}\text { FORESTED } \\
\text { AREA } \\
\text { (PERCENT) }\end{array}$} & \multicolumn{2}{|r|}{$\begin{array}{c}\text { MEAN } \\
\text { ANNUAL } \\
\text { PRECIPI - }\end{array}$} & \multicolumn{2}{|c|}{ RAINFALL INTENSITY, 24-HOUR } \\
\hline & $\begin{array}{c}\text { STREAM } \\
\text { LENGTH } \\
\text { (MI) }\end{array}$ & $\begin{array}{l}\text { ELEVA- } \\
\text { TION } \\
\text { (FT) }\end{array}$ & & $\begin{array}{l}\text { SOIL } \\
\text { INDEX }\end{array}$ & $\begin{array}{l}\text { PRECIPI - } \\
\text { TATION } \\
\text { (IN) }\end{array}$ & $\begin{array}{c}\text { 2-YEAR } \\
\text { (IN) }\end{array}$ & $\begin{array}{l}\text { 50-YEAR } \\
\text { (IN) }\end{array}$ \\
\hline 18.4 & 56.2 & 4,840 & 12.0 & 2.0 & 16.5 & 1.90 & 3.8 \\
\hline
\end{tabular}




\begin{tabular}{|c|c|c|c|c|c|c|}
\hline MONTH & $\begin{array}{l}\operatorname{MAXIMUN} \\
\left(F T^{3} / S\right)\end{array}$ & $\begin{array}{l}\text { MINIMUM } \\
\left(F T^{3} / S\right)\end{array}$ & $\begin{array}{c}\text { MEAN } \\
\left(F T^{3} / S\right)\end{array}$ & $\begin{array}{l}\text { STAN- } \\
\text { DARD } \\
\text { DEVIA- } \\
\text { TION } \\
\left(\mathrm{FT}^{3} / \mathrm{S}\right)\end{array}$ & $\begin{array}{l}\text { COEFFI - } \\
\text { CIENT OF } \\
\text { VARI - } \\
\text { ATION }\end{array}$ & $\begin{array}{c}\text { PERCENT } \\
\text { OF } \\
\text { ANNUAL } \\
\text { RUNOFF }\end{array}$ \\
\hline $\begin{array}{l}\text { OCTOBER } \\
\text { NOVEMBER } \\
\text { DECEMBER } \\
\text { JANUARY } \\
\text { FEBRUARY } \\
\text { MARCH } \\
\text { APRIL } \\
\text { MAY } \\
\text { JUNE } \\
\text { JULY } \\
\text { AUGUST } \\
\text { SEPTEMBER }\end{array}$ & $\begin{array}{r}1,090 \\
128 \\
1,230 \\
507 \\
217 \\
160 \\
67 \\
37 \\
167 \\
876 \\
968 \\
1,890\end{array}$ & $\begin{array}{c}2.9 \\
5.0 \\
6.0 \\
9.5 \\
7.2 \\
8.1 \\
3.0 \\
2.4 \\
1.3 \\
3.1 \\
10 \\
4.1\end{array}$ & $\begin{array}{c}40 \\
18 \\
50 \\
38 \\
28 \\
24 \\
13 \\
8.6 \\
13 \\
148 \\
233 \\
91\end{array}$ & $\begin{array}{c}133 \\
17 \\
153 \\
68 \\
31 \\
28 \\
9.4 \\
5.5 \\
23 \\
153 \\
228 \\
221\end{array}$ & $\begin{array}{l}3.3 \\
0.93 \\
3.1 \\
1.8 \\
1.1 \\
1.2 \\
0.70 \\
0.64 \\
1.8 \\
1.0 \\
0.98 \\
2.4\end{array}$ & $\begin{array}{l}5.7 \\
2.5 \\
7.1 \\
5.4 \\
3.9 \\
3.4 \\
1.9 \\
1.2 \\
1.9 \\
21.1 \\
33.1 \\
12.9\end{array}$ \\
\hline NMUAL & 206 & 13 & 59 & 38 & 0.63 & 100 \\
\hline
\end{tabular}

\begin{tabular}{|c|c|c|c|c|c|c|}
\hline \multirow{2}{*}{$\begin{array}{l}\text { PERIOD } \\
\text { (CON- } \\
\text { SECU- } \\
\text { TIVE } \\
\text { DAYS) }\end{array}$} & \multicolumn{6}{|c|}{$\begin{array}{l}\text { DISCHARGE, IN FT } 3 / S \text {, FOR INDICATED } \\
\text { RECURRENCE INTERVAL, IN YEARS, AND } \\
\text { NON-EXCEEDANCE PROBAB ILITY, IN PERCENT }\end{array}$} \\
\hline & $\stackrel{2}{50 \%}$ & $\begin{array}{c}5 \\
20 \%\end{array}$ & $\begin{array}{l}10 \\
10 \%\end{array}$ & $\begin{array}{l}20 \\
5 \%\end{array}$ & $\begin{array}{l}50 \\
2 \%\end{array}$ & $\begin{array}{l}100 \\
\mathbf{1 x}\end{array}$ \\
\hline $\begin{array}{r}1 \\
3 \\
7 \\
14 \\
30 \\
60 \\
90 \\
120 \\
183\end{array}$ & $\begin{array}{c}2.0 \\
2.1 \\
2.3 \\
2.6 \\
3.4 \\
4.9 \\
6.9 \\
13 \\
16\end{array}$ & $\begin{array}{r}1.2 \\
1.3 \\
1.5 \\
1.7 \\
2.3 \\
3.4 \\
5.0 \\
9.0 \\
11\end{array}$ & $\begin{array}{l}0.88 \\
0.97 \\
1.1 \\
1.3 \\
1.8 \\
2.9 \\
4.2 \\
7.6 \\
9.1\end{array}$ & $\begin{array}{l}0.69 \\
0.77 \\
0.90 \\
1.1 \\
1.5 \\
2.5 \\
3.7 \\
6.6 \\
8.1\end{array}$ & $\begin{array}{l}0.52 \\
0.58 \\
0.69 \\
0.88 \\
1.2 \\
2.1 \\
3.2 \\
5.8 \\
7.4\end{array}$ & $\begin{array}{l}0.42 \\
0.48 \\
0.58 \\
0.76 \\
1.0 \\
1.9 \\
2.9 \\
5.3 \\
7.1\end{array}$ \\
\hline
\end{tabular}

MAGNITUDE AND PROBABILITY OF INSTANTANEOUS PEAK FLON BASED ON PERIOD OF RECORD 1916-89

\section{DISCHARGE, IN $\mathrm{FT}^{3} / \mathrm{S}$, FOR INDICATED RECURRENCE INTERVAL} IN YEARS, AND EXCEEDANCE PROBABILITY, IN PERCENT

\begin{tabular}{lccccc}
52 & 5 & 10 & 25 & 50 & 100 \\
$50 \%$ & $20 \%$ & $10 \%$ & $4 \%$ & $2 \%$ & $1 \%$ \\
6,600 & 11,900 & 16,900 & 25,500 & 33,800 & 44,000 \\
\hline MEIGHTED SKEW (LOGS) & $=0.65$ & & \\
MEAN & & & \\
(LOGS) & $=3.85$ & & \\
STANDARD DEV. (LOGS) & $=0.28$ &
\end{tabular}

MAGNITUDE AND PROBABILITY OF ANNUAL HIGH FLON BASED ON PERIOD OF RECORD 1905, 1913-26, 1929-33, 1936-89

\begin{tabular}{|c|c|c|c|c|c|c|}
\hline \multirow{2}{*}{$\begin{array}{l}\text { PERIOD } \\
\text { (CON- } \\
\text { SECU- } \\
\text { TIVE } \\
\text { DAYS) }\end{array}$} & \multicolumn{6}{|c|}{$\begin{array}{l}\text { DISCHARGE, IN } \mathrm{FT}^{3} / \mathrm{S} \text {, FOR INDICATED } \\
\text { RECURRENCE INTERVAL, IN YEARS, AND } \\
\text { EXCEEDANCE PROBABILITY, IN PERCENT }\end{array}$} \\
\hline & $\begin{array}{c}2 \\
50 \%\end{array}$ & $\begin{array}{c}5 \\
20 \%\end{array}$ & $\begin{array}{l}10 \\
10 \%\end{array}$ & $\begin{array}{l}25 \\
4 \%\end{array}$ & $\begin{array}{l}50 \\
2 \%\end{array}$ & $\begin{array}{r}100 \\
1 \%\end{array}$ \\
\hline $\begin{array}{l}1 \\
3 \\
7 \\
15 \\
30 \\
60 \\
90\end{array}$ & $\begin{array}{r}1,960 \\
1,080 \\
643 \\
423 \\
289 \\
196 \\
144\end{array}$ & $\begin{array}{r}4,100 \\
2,270 \\
1,340 \\
860 \\
564 \\
364 \\
263\end{array}$ & $\begin{array}{r}6,230 \\
3,510 \\
2,040 \\
1,280 \\
815 \\
505 \\
360\end{array}$ & $\begin{array}{r}9,950 \\
5,760 \\
3,270 \\
2,010 \\
1,220 \\
717 \\
502\end{array}$ & $\begin{array}{r}13,600 \\
8,100 \\
4,500 \\
2,730 \\
1,600 \\
900 \\
623\end{array}$ & $\begin{array}{r}18,300 \\
11,200 \\
6,050 \\
3,620 \\
2,040 \\
1,110 \\
755\end{array}$ \\
\hline
\end{tabular}

DURATION TABLE OF DAILY MEAN FLON FOR PERIDD OF RECORD 1905, 1913-26, 1929-33, 1936-89

DISCHARGE, IN $\mathrm{FT}^{3} / \mathrm{S}$, WHICH WAS EQUALED OR EXCEEDED FOR INDICATED PERCENT OF TIME

\begin{tabular}{|c|c|c|c|c|c|c|c|c|c|c|c|c|c|c|c|c|}
\hline $1 \%$ & $5 \%$ & $10 \%$ & $15 \%$ & $20 \%$ & $30 \%$ & $40 \%$ & $50 \%$ & $60 \%$ & $70 \%$ & $80 \%$ & $90 \%$ & $95 \%$ & $98 \%$ & $99 \%$ & $99.5 \%$ & $99.9 \%$ \\
\hline 947 & 190 & 77 & 45 & 32 & 22 & 17 & 14 & 12 & 9.5 & 6.6 & 3.9 & 2.7 & 1.9 & 1.6 & 1.2 & 0.83 \\
\hline
\end{tabular}


09471000 SAN PEDRO RIVER AT CHARLESTON, AZ--CONTIMUEd
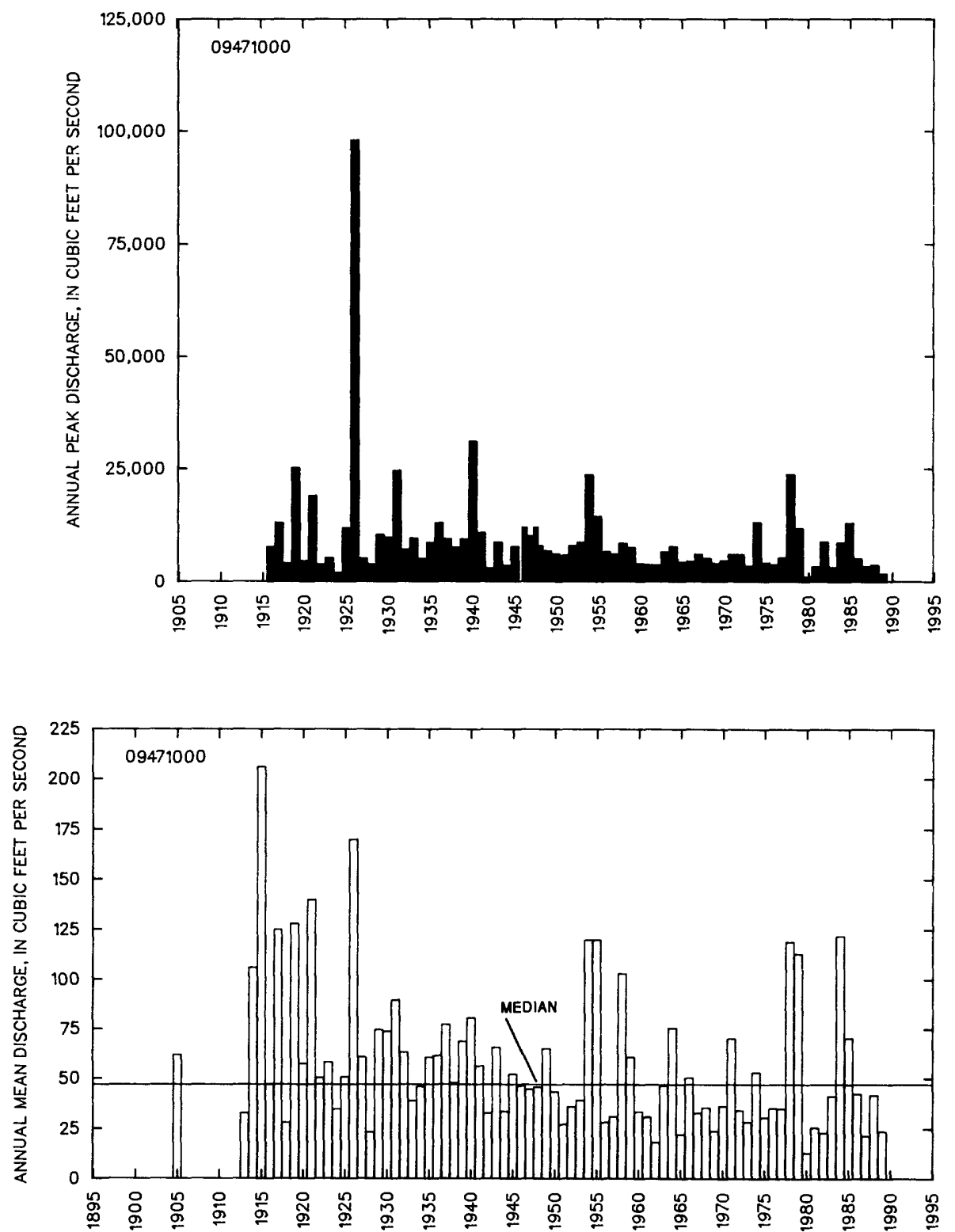
09471000 SAN PEDRO RIVER AT CHARLESTON, AZ--CONTINUED
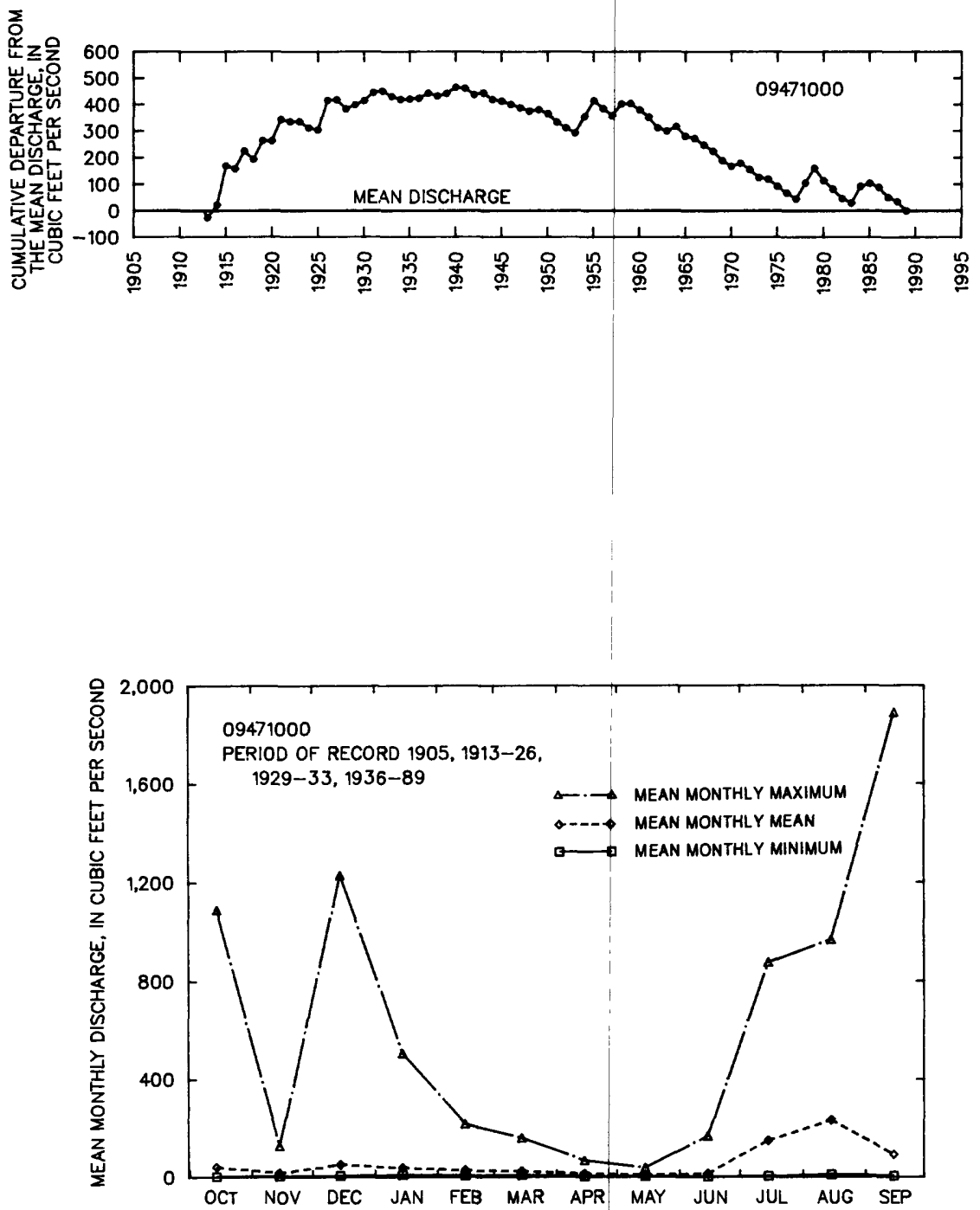
09471550 SAN PEDRO RIVER NEAR TOMBSTONE, AZ

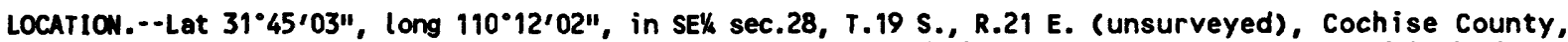
Hydrologic Unit 15050202, in Spanish land grant of San Juan de las Boquillas y Nogales, on right benk 0.5 mi downstream from Willow Wash, 2.6 mi north of Fairbenk, and 8 mi northwest of Tombstone.

DRAIMACE AREA. $-1,730 \mathrm{mi}^{2}$ approximately, of wich $696 \mathrm{mi}^{2}$ is in Mexico.

REMARKS. - Diversions above station, mostly by pumping from ground water, for irrigation of 3,200 acres in 1978, excluding an unknown amount in Mexico.

ANNUAL PEAK DISCHARGE

\begin{tabular}{|c|c|c|}
\hline $\begin{array}{l}\text { WATER } \\
\text { YEAR }\end{array}$ & DATE & $\begin{array}{l}\text { ANNUAL PEAK } \\
\text { DISCHARGE } \\
\text { (FT } 3 / \mathrm{S})\end{array}$ \\
\hline $\begin{array}{l}1967 \\
1968 \\
1969 \\
1970 \\
1971 \\
1972 \\
1973 \\
1974 \\
1975 \\
1976 \\
1977 \\
1978 \\
1979 \\
1980 \\
1981 \\
1982 \\
1983 \\
1984 \\
1985 \\
1986\end{array}$ & $\begin{array}{l}07-26-67 \\
12-20-67 \\
07-28-69 \\
08-03-70 \\
08-10-71 \\
08-12-72 \\
08-21-73 \\
07-20-74 \\
09-14-75 \\
07-27-76 \\
08-23-77 \\
10-09-77 \\
01-18-79 \\
08-15-80 \\
08-01-81 \\
09-10-82 \\
09-10-83 \\
10-02-83 \\
12-28-84 \\
08-18-86\end{array}$ & $\begin{array}{r}7,790 \\
7,340 \\
2,950 \\
5,400 \\
9,220 \\
12,900 \\
1,880 \\
18,500 \\
4,500 \\
8,580 \\
8,900 \\
24,200 \\
10,200 \\
1,400 \\
5,640 \\
6,500 \\
4,720 \\
13,600 \\
10,500 \\
4,410\end{array}$ \\
\hline
\end{tabular}

BASIN CHARACTERISTICS

\begin{tabular}{|c|c|c|c|c|c|c|c|}
\hline \multirow{3}{*}{$\begin{array}{l}\text { MAIN } \\
\text { CHANNEL } \\
\text { SLOPE } \\
\text { (FT/MI) }\end{array}$} & \multirow[b]{3}{*}{$\begin{array}{l}\text { STREAM } \\
\text { LENGTH } \\
\text { (MI) }\end{array}$} & \multirow{3}{*}{$\begin{array}{l}\text { MEAN } \\
\text { BASIN } \\
\text { ELEVA- } \\
\text { TION } \\
\text { (FT) }\end{array}$} & \multirow[b]{3}{*}{$\begin{array}{l}\text { FORESTED } \\
\text { AREA } \\
\text { (PERCENT) }\end{array}$} & \multirow[b]{3}{*}{$\begin{array}{l}\text { SOIL } \\
\text { INDEX }\end{array}$} & \multirow{3}{*}{$\begin{array}{l}\text { MEAN } \\
\text { ANNUAL } \\
\text { PRECIPI- } \\
\text { TATION } \\
\text { (IN) }\end{array}$} & & \\
\hline & & & & & & \multicolumn{2}{|c|}{ RAINFALL INTENSITY, 24-HOUR } \\
\hline & & & & & & $\begin{array}{c}\text { 2-YEAR } \\
\text { (IN) }\end{array}$ & $\begin{array}{l}\text { 50-YEAR } \\
\text { (IN) }\end{array}$ \\
\hline 18.0 & 67.4 & 4,820 & 13.0 & 2.0 & 16.2 & 1.9 & 3.8 \\
\hline
\end{tabular}


MEAN MONTHLY AND ANNUAL DISCHARGES 1968-86

\begin{tabular}{|c|c|c|c|c|c|c|}
\hline MONTH & $\begin{array}{l}\operatorname{MAX} \operatorname{Im} M \\
\left(\mathrm{FT}^{3} / \mathrm{S}\right)\end{array}$ & $\begin{array}{l}\text { MINIMUM } \\
\left(\mathrm{FT}^{3} / \mathrm{S}\right)\end{array}$ & $\begin{array}{c}\text { MEAN } \\
\left(\mathrm{FT}^{3} / \mathrm{S}\right)\end{array}$ & $\begin{array}{l}\text { STAN- } \\
\text { DARD } \\
\text { DEVIA- } \\
\text { TION } \\
\text { (FT } 3 / S)\end{array}$ & $\begin{array}{l}\text { COEFFI- } \\
\text { CIENT OF } \\
\text { VARI - } \\
\text { ATION }\end{array}$ & $\begin{array}{c}\text { PERCENT } \\
\text { OF } \\
\text { ANNUAL } \\
\text { RUNOFF }\end{array}$ \\
\hline $\begin{array}{l}\text { OCTOBER } \\
\text { NOVEMBER } \\
\text { DECEMBER } \\
\text { JANUARY } \\
\text { FEBRUARY } \\
\text { MARCH } \\
\text { APRIL } \\
\text { MAY } \\
\text { JUNE } \\
\text { JULY } \\
\text { AUGUST } \\
\text { SEPTEMBER }\end{array}$ & $\begin{array}{r}998 \\
61 \\
375 \\
450 \\
214 \\
179 \\
44 \\
21 \\
22 \\
369 \\
820 \\
177\end{array}$ & $\begin{array}{l}0.00 \\
2.8 \\
6.4 \\
9.7 \\
9.1 \\
9.1 \\
4.2 \\
1.7 \\
0.00 \\
1.8 \\
15 \\
0.09\end{array}$ & $\begin{array}{c}95 \\
16 \\
63 \\
56 \\
45 \\
37 \\
15 \\
7.9 \\
3.8 \\
104 \\
160 \\
58\end{array}$ & $\begin{array}{c}247 \\
14 \\
112 \\
105 \\
53 \\
42 \\
9.4 \\
4.9 \\
5.8 \\
102 \\
188 \\
56\end{array}$ & $\begin{array}{l}2.6 \\
0.88 \\
1.8 \\
1.9 \\
1.2 \\
1.1 \\
0.63 \\
0.62 \\
1.5 \\
0.98 \\
1.2 \\
0.96\end{array}$ & $\begin{array}{r}14.4 \\
2.4 \\
9.6 \\
8.5 \\
6.7 \\
5.7 \\
2.3 \\
1.2 \\
0.6 \\
15.8 \\
24.1 \\
8.8\end{array}$ \\
\hline ANMUAL & 157 & 13 & 56 & 36 & 0.64 & 100 \\
\hline
\end{tabular}

MAGNITUDE AND PROBABILITY OF INSTANTANEOUS PEAK FLOH BASED ON PERIOD OF RECORD 1967-86

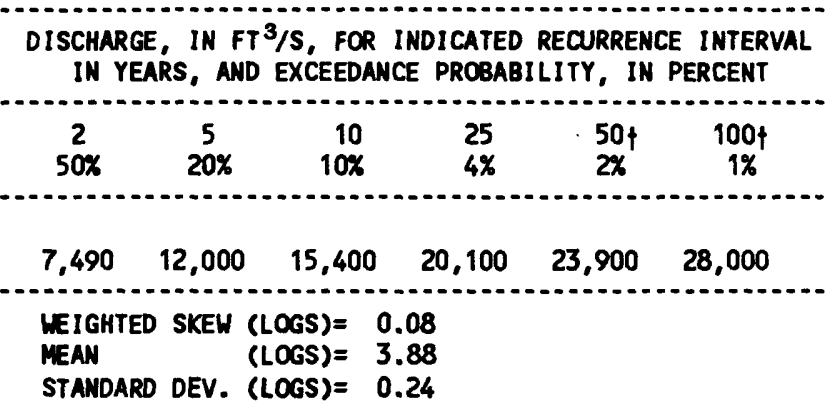

MAGNITLDE AND PROBABILITY OF ANNUAL LOW FLOW BASED ON PERIOD OF RECORD 1969-86

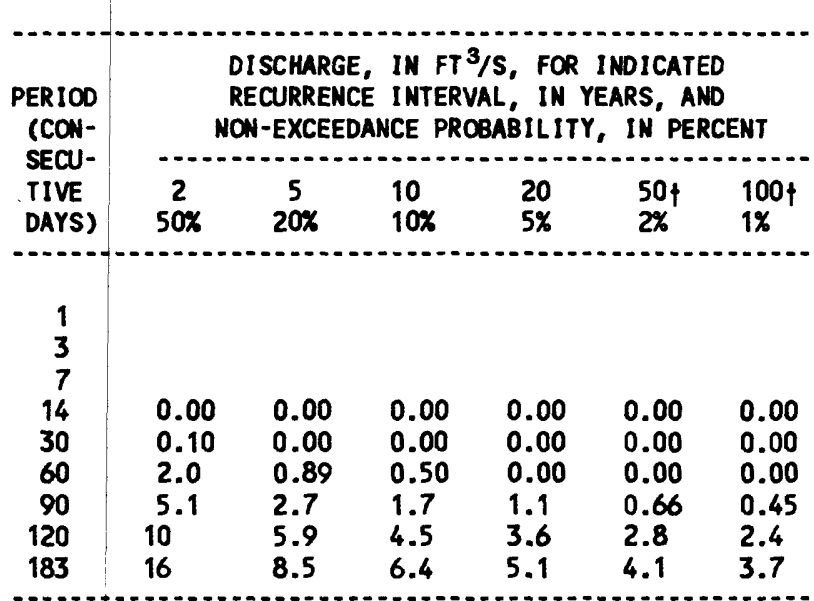

MAGNITLDE AND PROBABILITY OF ANNUAL HIGH FLOH BASED ON PERIOD OF RECORD 1968-86

\begin{tabular}{|c|c|c|c|c|c|c|}
\hline $\begin{array}{l}\text { PERIOD } \\
\text { (CON- }\end{array}$ & & $\begin{array}{l}\text { DISCHA } \\
\text { RECURR } \\
\text { EXCEED }\end{array}$ & $\begin{array}{ll}\vdots & \text { IN } \\
\text { E } & \text { INT } \\
\text { E } & \text { PRO }\end{array}$ & $\begin{array}{l}r^{3} / S, \\
\text { RAL, I } \\
\text { ABILITY }\end{array}$ & $\begin{array}{l}\text { R INDIC } \\
\text { YEARS, } \\
\text { IN PER }\end{array}$ & \\
\hline $\begin{array}{l}\text { TIVE } \\
\text { DAYS) }\end{array}$ & $\begin{array}{c}2 \\
50 \%\end{array}$ & $\begin{array}{c}5 \\
20 \%\end{array}$ & $\begin{array}{l}10 \\
10 \%\end{array}$ & $\begin{array}{l}25 \\
4 \%\end{array}$ & $\begin{array}{l}50 \dagger \\
2 \%\end{array}$ & $\underset{1 \%}{100 \dagger}$ \\
\hline $\begin{array}{r}1 \\
3 \\
7 \\
15 \\
30 \\
60 \\
90\end{array}$ & $\begin{array}{r}1.840 \\
1,120 \\
654 \\
431 \\
285 \\
198 \\
145\end{array}$ & $\begin{array}{r}4,060 \\
2,370 \\
1,320 \\
816 \\
501 \\
332 \\
237\end{array}$ & $\begin{array}{r}6,440 \\
3,670 \\
1,940 \\
1,130 \\
666 \\
420 \\
294\end{array}$ & $\begin{array}{r}10,900 \\
6,030 \\
2,950 \\
1,590 \\
896 \\
527 \\
358\end{array}$ & $\begin{array}{r}15,600 \\
8,470 \\
3,890 \\
1,980 \\
1,080 \\
602 \\
402\end{array}$ & $\begin{array}{r}21,900 \\
11,600 \\
5,020 \\
2,410 \\
1,280 \\
674 \\
441\end{array}$ \\
\hline
\end{tabular}

DURATION TABLE OF DAILY MEAN FLOW FOR PERIOD OF RECORD 1968-86

DISCHARGE, IN FT $3 / \mathrm{S}$, WHICH HAS EQUALED OR EXCEEDED FOR INDICATED PERCENT OF TIME

\begin{tabular}{|c|c|c|c|c|c|c|c|c|c|c|c|c|c|c|c|c|}
\hline $1 \%$ & $5 \%$ & $10 \%$ & $15 \%$ & $20 \%$ & $30 \%$ & $40 \%$ & $50 \%$ & $60 \%$ & $70 \%$ & $80 \%$ & $90 \%$ & $95 \%$ & $98 \%$ & $99 \%$ & $99.5 \%$ & $99.9 \%$ \\
\hline 898 & 182 & 82 & 49 & 36 & 23 & 17 & 13 & 10 & 6.9 & 3.7 & 0.03 & 0.00 & 0.00 & 0.00 & 0.00 & 0.00 \\
\hline
\end{tabular}

$\uparrow$ Reliability of values in colum is uncertain, and potential errors are large. 
GILA RIVER BASIN

09471550 SAN PEDRO RIVER NEAR TOMBSTONE, AZ--CONTINUEd
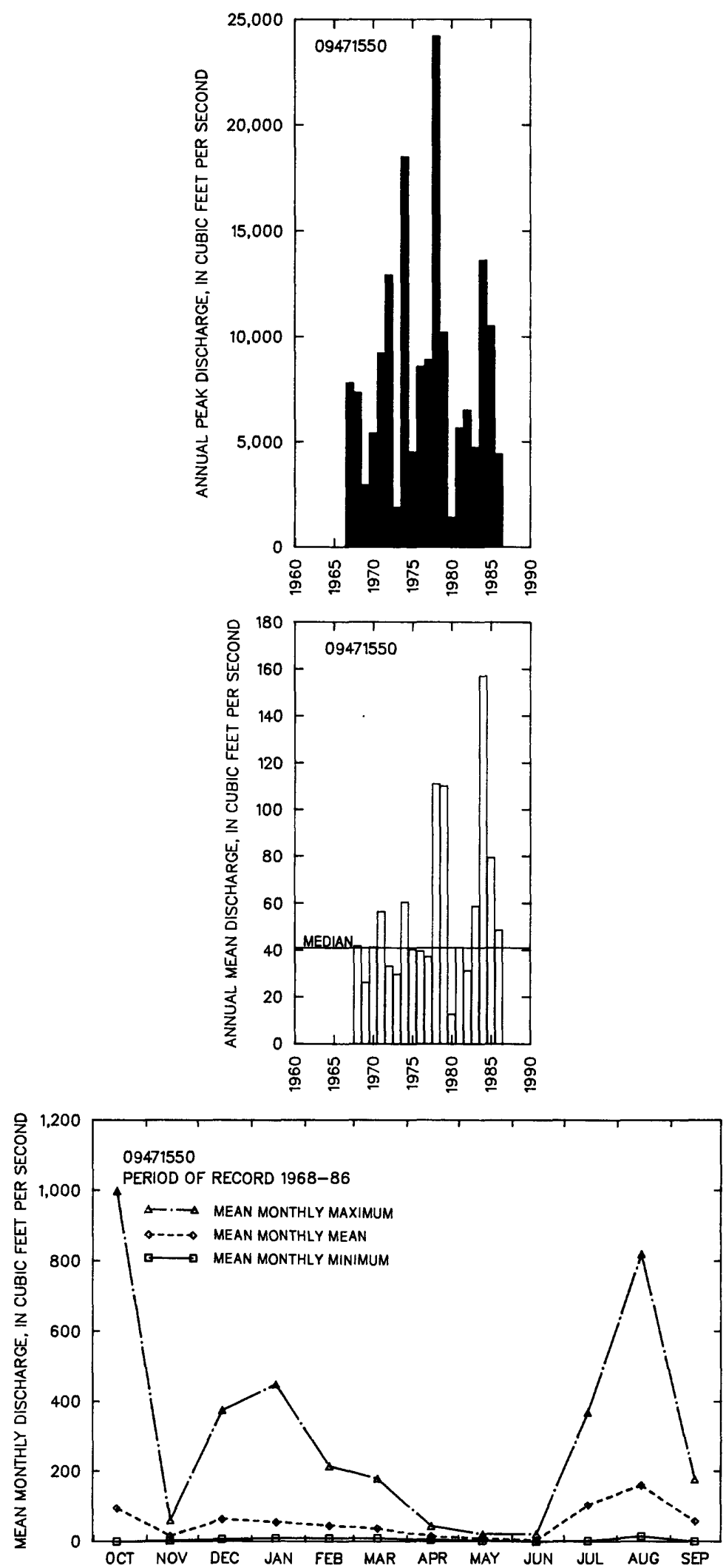
LOCATION.--Lat 31'52'35", Long 110'20'30", in NW/ sec.18, T.18 S., R.20 E., Cochise County, Hydrologic Unit 15050202 , at State Highway $90,6.5$ miles southwest of Benson.

DRAINAGE AREA. $--0.79 \mathrm{mi}^{2}$.

ANNUAL PEAK DISCHARGE

\begin{tabular}{|c|c|c|c|}
\hline $\begin{array}{l}\text { WATER } \\
\text { YEAR }\end{array}$ & DATE & $\begin{array}{l}\text { ANNUAL PEAK } \\
\text { DISCHARGE } \\
\left(\mathrm{FT}^{3} / \mathrm{S}\right)\end{array}$ & $\begin{array}{l}\text { DISCHARGE } \\
\text { COOES }\end{array}$ \\
\hline $\begin{array}{l}1963 \\
1964 \\
1965 \\
1966 \\
1967 \\
1968 \\
1969 \\
1970 \\
1971 \\
1972 \\
1973 \\
1974 \\
1975 \\
1978\end{array}$ & $\begin{array}{l}00-00-63 \\
00-00-64 \\
08-13-65 \\
08-00-66 \\
07-00-67 \\
00-00-68 \\
09-06-69 \\
00-00-70 \\
00-00-71 \\
00-00-72 \\
00-00-73 \\
07-19-74 \\
10-00-74 \\
00-00-78\end{array}$ & $\begin{array}{c}84 \\
2.0 \\
59 \\
20 \\
15 \\
10 \\
2.0 \\
0 \\
0 \\
0 \\
0 \\
2.0 \\
2.0 \\
155\end{array}$ & $\begin{array}{l}\text { ES } \\
\text { ES } \\
\text { ES } \\
\text { LT } \\
\text { ES }\end{array}$ \\
\hline
\end{tabular}

1Highest since 1976.

MAGNITUDE AND PROBABILITY OF INSTANTANEOUS PEAK FLOW BASED ON PERIDO OF RECORD 1963-75, 1978

DISCHARGE, IN $\mathrm{FT}^{3} / \mathrm{S}$, FOR INDICATED RECURRENCE INTERVAL

IN YEARS, AND EXCEEDANCE PROBABILITY, IN PERCENT

\begin{tabular}{|c|c|c|c|c|c|}
\hline $\begin{array}{r}2 \dagger \\
50 \%\end{array}$ & $\begin{array}{r}5 \nmid \\
20 \%\end{array}$ & $\begin{array}{c}10 \uparrow \\
10 \%\end{array}$ & $\begin{array}{l}25 \dagger \\
4 \%\end{array}$ & $\begin{array}{l}50 \dagger \\
2 x\end{array}$ & $\begin{array}{c}100 \dagger \\
1 \%\end{array}$ \\
\hline 4.4 & 24.7 & 58 & 139 & 239 & 385 \\
\hline $\begin{array}{l}\text { WEIGHTED } \\
\text { MEAN } \\
\text { STANDARD }\end{array}$ & $\begin{array}{l}\text { SKEW } \\
\text { DEV. }\end{array}$ & $\begin{array}{l}(L O G S)= \\
(L O G S)= \\
(L O G S)=\end{array}$ & $\begin{array}{r}-0.26 \\
0.60 \\
0.93\end{array}$ & & \\
\hline
\end{tabular}

$\uparrow$ Reliability of values in column is uncertain, and potential errors are large.

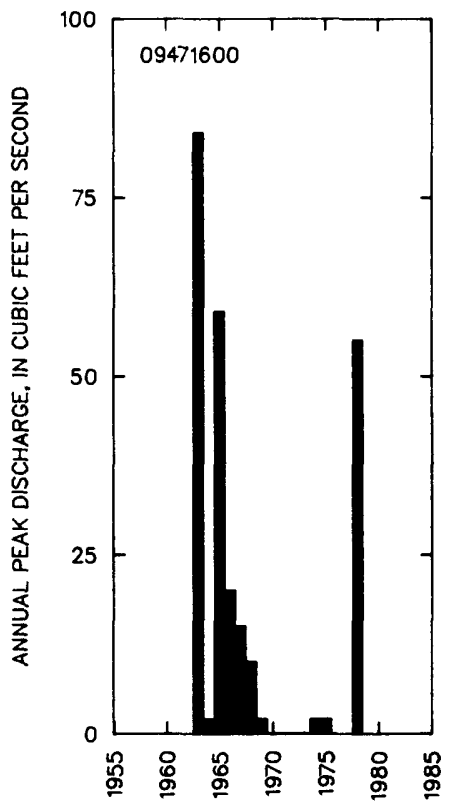

BASIN CHARACTERISTICS

\begin{tabular}{|c|c|c|c|c|c|c|c|}
\hline MAIN & & $\begin{array}{l}\text { MEAN } \\
\text { BASIN }\end{array}$ & & & $\begin{array}{c}\text { MEAN } \\
\text { ANNUAL }\end{array}$ & RAINFALL II & SITY, 24-HOUR \\
\hline $\begin{array}{l}\text { CHANNEL } \\
\text { SLOPE } \\
\text { (FT/MI) }\end{array}$ & $\begin{array}{l}\text { STREAM } \\
\text { LENGTH } \\
\text { (MI) }\end{array}$ & $\begin{array}{l}\text { ELEVA- } \\
\text { TION } \\
\text { (FT) }\end{array}$ & $\begin{array}{l}\text { FORESTED } \\
\text { AREA } \\
\text { (PERCENT) }\end{array}$ & $\begin{array}{l}\text { SOIL } \\
\text { INDEX }\end{array}$ & $\begin{array}{l}\text { PRECIPI- } \\
\text { TATION } \\
\text { (IN) }\end{array}$ & $\begin{array}{c}\text { 2-YEAR } \\
\text { (IN) }\end{array}$ & $\begin{array}{l}\text { 50-YEAR } \\
\text { (IN) }\end{array}$ \\
\hline 472 & 2.6 & 5,240 & 66.0 & 3.0 & 15.0 & 1.7 & 3.9 \\
\hline
\end{tabular}


09471700 FENNER WASH NEAR BENSON, AZ

LOCATION.--Lat 31.58'49", long 110'12'57", in SEMSEX sec.5, T.17 S., R.21 E., Cochise County, Hydrologic Unit 15050202, at Interstate 10,4.3 miles east of Benson.

DRAIMAGE AREA. $--2.71 \mathrm{mi}^{2}$.

ANMUAL PEAK DISCHARGE

\begin{tabular}{cccc}
$\begin{array}{c}\text { WATER } \\
\text { YEAR }\end{array}$ & $\begin{array}{c}\text { DATE } \\
\text { ANNUAL PEAK } \\
\text { DISCHARGE } \\
\text { (FT } 3 / \text { S) }\end{array}$ & $\begin{array}{c}\text { DISCHARCE } \\
\text { COOES }\end{array}$ \\
\hline 1962 & $00-00-62$ & 1950 & \\
1963 & $07-30-63$ & 896 & \\
1964 & $00-00-64$ & 110 & ES \\
1965 & $10-17-64$ & 70 & ES \\
1966 & $08-00-66$ & 300 & ES \\
1967 & $09-24-67$ & 330 & \\
1968 & $10-03-67$ & 27 & \\
1969 & $08-30-69$ & 40 & \\
1970 & $07-00-70$ & 615 & \\
1971 & $08-03-71$ & 250 & \\
1972 & $09-07-72$ & 649 & \\
1973 & $00-00-73$ & 48 & \\
1974 & $07-19-74$ & 225 & \\
1975 & $07-22-75$ & 50 & \\
1976 & $00-00-76$ & 220 & \\
1978 & $00-00-78$ & 2290 & HP \\
\hline 1 & & \\
2 Highest since 1958. & &
\end{tabular}

MAGNITUDE AND PROBABILITY OF INSTANTANEOUS PEAK FLOW BASED ON PERIOD OF OF RECORD 1962-76, 1978

DISCHARGE, IN $\mathrm{FT}^{3} / \mathrm{S}$, FOR INDICATED RECURRENCE INTERVAL IN YEARS, AND EXCEEDANCE PROBABILITY, IN PERCENT

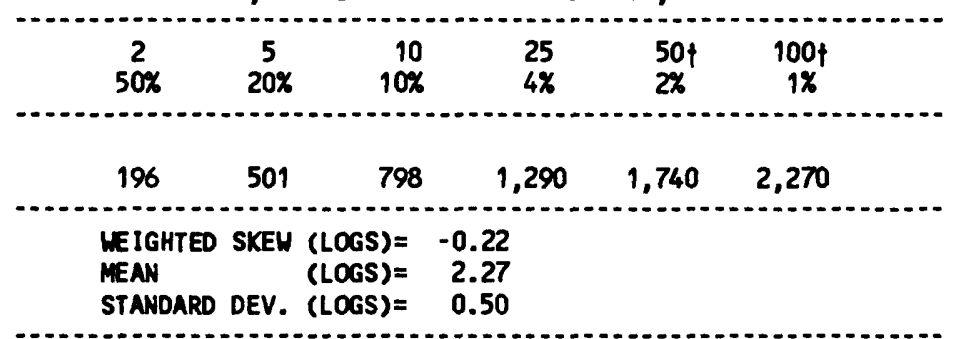

f Reliability of values in column is uncertain, and potential errors are large.

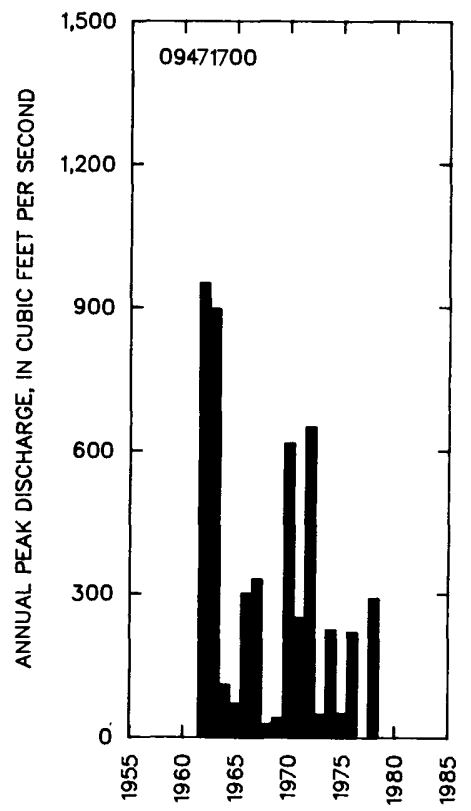

BASIN CHARACTERISTICS

\begin{tabular}{|c|c|c|c|c|c|c|c|}
\hline \multirow{2}{*}{$\begin{array}{l}\text { MAIN } \\
\text { CHANNEL } \\
\text { SLOPE } \\
\text { (FT/MI) }\end{array}$} & \multirow[b]{2}{*}{$\begin{array}{l}\text { STREAM } \\
\text { LENGTH } \\
\text { (MI) }\end{array}$} & \multirow{2}{*}{$\begin{array}{l}\text { MEAN } \\
\text { BASIN } \\
\text { ELEVA- } \\
\text { TION } \\
\text { (FT) }\end{array}$} & \multirow[b]{2}{*}{$\begin{array}{l}\text { FORESTED } \\
\text { AREA } \\
\text { (PERCENT) }\end{array}$} & \multirow[b]{2}{*}{$\begin{array}{l}\text { SOIL } \\
\text { INDEX }\end{array}$} & \multirow{2}{*}{$\begin{array}{l}\text { MEAN } \\
\text { ANNUAL } \\
\text { PRECIPI- } \\
\text { TATION } \\
\text { (IN) }\end{array}$} & \multicolumn{2}{|c|}{ RAINFALL INTENSITY, 24-HOUR } \\
\hline & & & & & & $\begin{array}{l}\text { 2-YEAR } \\
\text { (IN) }\end{array}$ & $\begin{array}{l}\text { 50-YEAR } \\
\text { (IN) }\end{array}$ \\
\hline 93.8 & 5.4 & 4,180 & 0.0 & 1.0 & 12.3 & 1.7 & 4.3 \\
\hline
\end{tabular}


09471800 SAN PEDRO RIVER NEAR BENSON, AZ

LOCATION.---Lat 32.07'35", long 110'17'22", in SWK sec.15, T.15 S., R.20 E., Cochise County, Hydrologic Unit 15050203, on right bank, $6 \mathrm{mi}$ downstream from Tres Alamo Wash, and $11 \mathrm{mi}$ north of Benson.

DRAINAGE AREA. $--2,490 \mid \mathrm{mi}^{2}$ of which $696 \mathrm{mi}^{2}$ is in Mexico.

ANMUAL PEAK DISCHARGE

\begin{tabular}{ccc}
$\begin{array}{c}\text { WATER } \\
\text { YEAR }\end{array}$ & DATE & $\begin{array}{c}\text { ANNUAL PEAK } \\
\text { DISCHARGE } \\
\text { (FT } 3 / 5)\end{array}$ \\
\hline 1966 & $08-06-66$ & 5,470 \\
1967 & $07-26-67$ & 4,560 \\
1968 & $08-10-68$ & 5,900 \\
1969 & $07-28-69$ & 2,640 \\
1970 & $07-20-70$ & 8,200 \\
1971 & $08-11-71$ & 7,390 \\
1972 & $08-26-72$ & 9,800 \\
1973 & $07-16-73$ & 2,140 \\
1974 & $07-20-74$ & 9,520 \\
1975 & $07-23-75$ & 8,920 \\
1976 & $07-28-76$ & 5,110 \\
\hline
\end{tabular}

BASIN CHARACTERISTICS

\begin{tabular}{|c|c|c|c|c|c|c|c|}
\hline \multirow{2}{*}{$\begin{array}{l}\text { MAIN } \\
\text { CHANNEL } \\
\text { SLOPE } \\
\text { (FT/MI) }\end{array}$} & \multirow[b]{2}{*}{$\begin{array}{l}\text { STREAM } \\
\text { LENGTH } \\
\text { (MI) }\end{array}$} & \multirow{2}{*}{$\begin{array}{l}\text { MEAN } \\
\text { BASIN } \\
\text { ELEVA- } \\
\text { TION } \\
\text { (FT) }\end{array}$} & \multirow[b]{2}{*}{$\begin{array}{l}\text { FORESTED } \\
\text { AREA } \\
\text { (PERCENT) }\end{array}$} & \multirow[b]{2}{*}{$\begin{array}{l}\text { SOIL } \\
\text { INDEX }\end{array}$} & \multirow{2}{*}{$\begin{array}{l}\text { MEAN } \\
\text { ANNUAL } \\
\text { PRECIPI- } \\
\text { TATION } \\
\text { (IN) }\end{array}$} & \multicolumn{2}{|c|}{ RAINFALL INTENSITY, 24-HOUR } \\
\hline & & & & & & $\begin{array}{c}\text { 2-YEAR } \\
\text { (IN) }\end{array}$ & $\begin{array}{l}\text { 50-YEAR } \\
\text { (IN) }\end{array}$ \\
\hline 17.3 & 84.0 & 4,800 & 12.0 & 1.9 & 15.6 & 1.9 & 4.4 \\
\hline
\end{tabular}


MEAN MONTHLY AND ANNUAL DISCHARGES $1967-76$

\begin{tabular}{|c|c|c|c|c|c|c|}
\hline MONTH' & $\begin{array}{l}\text { MAXIMUN } \\
\left(F T^{3} / S\right)\end{array}$ & $\begin{array}{l}\text { MINIMUM } \\
\left(\mathrm{FT}^{3} / \mathrm{S}\right)\end{array}$ & $\begin{array}{c}\text { MEAN } \\
\left(\mathrm{FT}^{\mathbf{3}} / \mathrm{S}\right)\end{array}$ & $\begin{array}{l}\text { STAN- } \\
\text { DARD } \\
\text { DEVIA- } \\
\text { TION } \\
\left(\mathrm{FT}^{3} / \mathrm{S}\right)\end{array}$ & $\begin{array}{l}\text { COEFFI- } \\
\text { CIENT OF } \\
\text { VARI - } \\
\text { ATION }\end{array}$ & $\begin{array}{c}\text { PERCENT } \\
\text { OF } \\
\text { ANNUAL } \\
\text { RUNOFF }\end{array}$ \\
\hline $\begin{array}{l}\text { OCTOBER } \\
\text { NOVEMBER } \\
\text { DECEMBER } \\
\text { JANUARY } \\
\text { FEBRUARY } \\
\text { MARCH } \\
\text { APRIL } \\
\text { MAY } \\
\text { JUNE } \\
\text { JULY } \\
\text { AUGUST } \\
\text { SEPTEMBER }\end{array}$ & $\begin{array}{c}71 \\
23 \\
196 \\
28 \\
47 \\
46 \\
0.01 \\
0.08 \\
34 \\
260 \\
555 \\
81\end{array}$ & $\begin{array}{c}0.00 \\
0.00 \\
0.00 \\
0.00 \\
0.00 \\
0.00 \\
0.00 \\
0.00 \\
0.00 \\
11 \\
2.0 \\
0.00\end{array}$ & $\begin{array}{c}8.6 \\
2.3 \\
20 \\
2.8 \\
8.2 \\
8.1 \\
0.00 \\
0.01 \\
4.6 \\
124 \\
165 \\
34\end{array}$ & $\begin{array}{c}22 \\
7.2 \\
62 \\
8.9 \\
18 \\
17 \\
0.00 \\
0.03 \\
11 \\
85 \\
177 \\
25\end{array}$ & $\begin{array}{l}2.6 \\
3.2 \\
3.1 \\
3.1 \\
2.1 \\
2.1 \\
3.2 \\
2.3 \\
2.3 \\
0.68 \\
1.1 \\
0.74\end{array}$ & $\begin{array}{r}2.3 \\
0.6 \\
5.4 \\
0.8 \\
2.2 \\
2.1 \\
0.0 \\
0.0 \\
1.2 \\
32.8 \\
43.6 \\
9.0\end{array}$ \\
\hline ANNUAL & 61 & 15 & 32 & 14 & 0.43 & 100 \\
\hline
\end{tabular}

\section{MAGNITUDE AND PROBABILITY OF INSTANTANEOUS PEAK FLOW} BASED ON PERIOD OF RECORD

DISCHARGE, IN FT $3 / 5$, FOR INDICATED RECURRENCE INTERVAL IN YEARS, AND EXCEEDANCE PROBABILITY, IN PERCENT

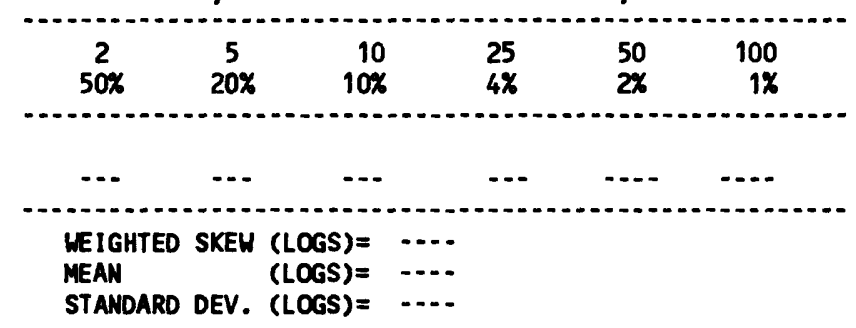

MAGNITLDE AND PROBABILITY OF ANNUAL LON FLON BASED ON PERIOD OF RECORD 1967-76

\begin{tabular}{|c|c|c|c|c|c|c|}
\hline \multirow{2}{*}{$\begin{array}{l}\text { PERIOD } \\
\text { (CON- } \\
\text { SECU- } \\
\text { TIVE } \\
\text { DAYS) }\end{array}$} & \multicolumn{6}{|c|}{$\begin{array}{l}\text { DISCHARGE, IN FT } 3 / \mathrm{S}, \text { FOR INDICATED } \\
\text { RECURRENCE INTERVAL, IN YEARS, AND } \\
\text { NOW-EXCEEDANCE PROBABILITY, IN PERCENT }\end{array}$} \\
\hline & $\begin{array}{c}2 \\
50 \%\end{array}$ & $\begin{array}{c}5 \\
20 \%\end{array}$ & $\begin{array}{l}10 \\
10 \%\end{array}$ & $\begin{array}{l}20 \\
5 \%\end{array}$ & $\begin{array}{l}50 \dagger \\
2 \%\end{array}$ & $\begin{array}{l}100+ \\
1 \%\end{array}$ \\
\hline $\begin{array}{r}1 \\
3 \\
7 \\
14 \\
30 \\
60 \\
90\end{array}$ & & & & & & \\
\hline $\begin{array}{l}120 \\
183\end{array}$ & $\begin{array}{l}0.00 \\
0.20\end{array}$ & $\begin{array}{l}0.00 \\
0.00\end{array}$ & $\begin{array}{l}0.00 \\
0.00\end{array}$ & $\begin{array}{l}0.00 \\
0.00\end{array}$ & $\begin{array}{l}0.00 \\
0.00\end{array}$ & $\begin{array}{l}0.00 \\
0.00\end{array}$ \\
\hline
\end{tabular}

MAGNITUDE AND PROBABILITY OF ANNUAL HIGH FLON BASED ON PERIOD OF RECORD 1967-76

\begin{tabular}{|c|c|c|c|c|c|c|}
\hline \multirow{2}{*}{$\begin{array}{l}\text { PERIOD } \\
\text { (CON- } \\
\text { SECU- } \\
\text { TIVE } \\
\text { DAYS) }\end{array}$} & \multicolumn{6}{|c|}{$\begin{array}{l}\text { DISCHARGE, IN } \mathrm{FT}^{3} / \mathrm{S}, \text { FOR INDICATED } \\
\text { RECURRENCE INTERVAL, IN YEARS, AND } \\
\text { EXCEEDANCE PROBABILITY, IN PERCENT }\end{array}$} \\
\hline & $\begin{array}{c}2 \\
50 \%\end{array}$ & $\begin{array}{c}5 \\
20 \%\end{array}$ & $\begin{array}{l}10 \\
10 \%\end{array}$ & $\begin{array}{l}25 \dagger \\
4 \%\end{array}$ & $\begin{array}{l}50 \dagger \\
2 x\end{array}$ & $\begin{array}{c}100 \dagger \\
1 \%\end{array}$ \\
\hline $\begin{array}{r}1 \\
3 \\
7 \\
15 \\
30 \\
60 \\
90\end{array}$ & $\begin{array}{r}1,970 \\
1,100 \\
608 \\
392 \\
251 \\
153 \\
110\end{array}$ & $\begin{array}{r}2,910 \\
1,620 \\
915 \\
619 \\
414 \\
243 \\
170\end{array}$ & $\begin{array}{r}3,440 \\
1,930 \\
1,100 \\
774 \\
532 \\
302 \\
207\end{array}$ & $\begin{array}{r}4,030 \\
2,260 \\
1,330 \\
974 \\
688 \\
374 \\
250\end{array}$ & $\begin{array}{r}4,400 \\
2,470 \\
1,480 \\
1,120 \\
810 \\
427 \\
279\end{array}$ & $\begin{array}{r}4,730 \\
2,660 \\
1,620 \\
1,270 \\
934 \\
477 \\
306\end{array}$ \\
\hline
\end{tabular}

DURATION TABLE OF DAILY MEAN FLON FOR PERIOD OF RECORD 1967-76

DISCHARGE, IN FT $3 / \mathrm{S}$, WHICH WAS EQUALED OR EXCEEDED FOR INDICATED PERCENT OF TIME

\begin{tabular}{|c|c|c|c|c|c|c|c|c|c|c|c|c|c|c|c|c|}
\hline $1 \%$ & $5 \%$ & $10 \%$ & $15 \%$ & $20 \%$ & $30 \%$ & $40 \%$ & $50 \%$ & $60 \%$ & $70 \%$ & $80 \%$ & $90 \%$ & $95 \%$ & $98 \%$ & $99 \%$ & $99.5 \%$ & $99.9 \%$ \\
\hline 777 & 125 & 41 & 16 & 2.5 & 0.00 & 0.00 & 0.00 & 0.00 & 0.00 & 0.00 & 0.00 & 0.00 & 0.00 & 0.00 & 0.00 & 0.00 \\
\hline
\end{tabular}

$\uparrow$ Reliability of values in column is uncertain, and potential errors are large. 
09471800 SAN PEDRO RIVER NEAR BENSON, AZ--CONTINUEd
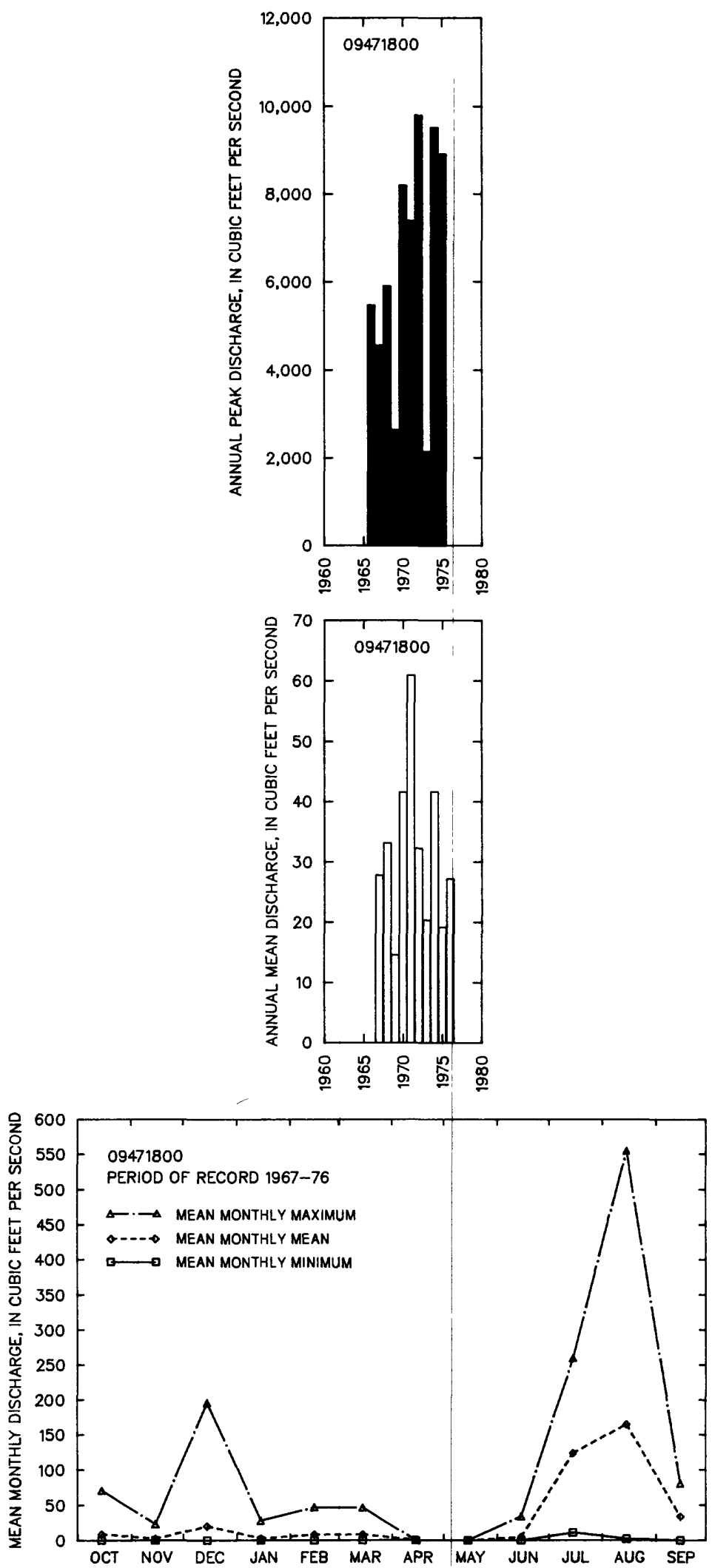


\section{SAN PEDRO RIVER NEAR REDINGTON, AZ}

LOCATION.--Lat 32.22'50", long 110.26'45", in NEMNW/2 sec.19, T.12 S., R.19 E., Cochise County, Hydrologic Unit 15050203, on left bank, 0.3 mi upstream from Cochise-Pima County line, 4.3 mi southeast of Redington, and $30 \mathrm{mi}$ north of Benson.

DRAIMAGE AREA. $--2,927 \mathrm{mi}^{2}$, of which $696 \mathrm{mi}^{2}$ is in Mexico.

REMARKS.--Diversions above station for irrigation of about 10,800 acres in 1978, excluding an unknown amount in Mexico. Diversion above gage into formerly used ditch on right bank was placed in operation in January 1972.

ANNUAL PEAK DISCHARGE

\begin{tabular}{|c|c|c|c|c|c|c|c|}
\hline $\begin{array}{l}\text { WATER } \\
\text { YEAR }\end{array}$ & DATE & $\begin{array}{c}\text { ANNUAL PEAK } \\
\text { DISCHARGE } \\
\text { (FT } 3 / 5)\end{array}$ & $\begin{array}{l}\text { DISCHARGE } \\
\text { CODES }\end{array}$ & $\begin{array}{l}\text { WATER } \\
\text { YEAR }\end{array}$ & DATE & $\begin{array}{c}\text { ANNUAL PEAK } \\
\text { DISCHARGE } \\
\left(F T^{3} / \mathrm{S}\right)\end{array}$ & $\begin{array}{l}\text { DISCHARGE } \\
\text { COOES }\end{array}$ \\
\hline $\begin{array}{l}1926 \\
1931 \\
1932 \\
1933 \\
1934 \\
1935 \\
1936 \\
1937 \\
1938 \\
1939 \\
1940 \\
1941 \\
1943 \\
1944 \\
1945 \\
1946 \\
1947 \\
1948 \\
1949 \\
1950 \\
1951 \\
1952 \\
1953 \\
1954 \\
1955 \\
1956 \\
1957 \\
1958 \\
1959 \\
1960\end{array}$ & $\begin{array}{l}09-28-26 \\
08-10-31 \\
10-02-31 \\
07-23-33 \\
08-04-34 \\
08-24-35 \\
09-11-36 \\
08-30-37 \\
08-05-38 \\
08-02-39 \\
08-14-40 \\
01-29-41 \\
08-09-43 \\
09-24-44 \\
08-10-45 \\
08-04-46 \\
08-08-47 \\
09-26-48 \\
00-00-49 \\
07-30-50 \\
08-02-51 \\
08-16-52 \\
07-07-53 \\
08-01-54 \\
08-07-55 \\
07-30-56 \\
08-18-57 \\
08-17-58 \\
07-27-59 \\
09-05-60\end{array}$ & $\begin{array}{r}190,000 \\
18,000 \\
19,400 \\
13,500 \\
7,400 \\
16,300 \\
10,400 \\
14,100 \\
7,800 \\
9,920 \\
50,000 \\
10,100 \\
7,090 \\
19,000 \\
14,600 \\
9,000 \\
23,000 \\
11,500 \\
10,000 \\
8,800 \\
28,600 \\
4,470 \\
7,290 \\
18,500 \\
18,800 \\
3,160 \\
9,300 \\
10,800 \\
8,580 \\
1,980\end{array}$ & $\begin{array}{c}\text { ES, HP } \\
\text { ES } \\
\text { ES } \\
\text { ES } \\
\text { ES } \\
\text { ES } \\
\text { ES } \\
\text { ES } \\
\text { ES } \\
\text { ES } \\
\text { ES } \\
\text { ES }\end{array}$ & $\begin{array}{l}1961 \\
1962 \\
1963 \\
1964 \\
1965 \\
1966 \\
1967 \\
1968 \\
1969 \\
1970 \\
1971 \\
1972 \\
1973 \\
1974 \\
1975 \\
1976 \\
1977 \\
1978 \\
1979 \\
1980 \\
1981 \\
1982 \\
1983 \\
1984 \\
1985 \\
1986 \\
1987 \\
1988 \\
1989\end{array}$ & $\begin{array}{l}07-30-61 \\
07-28-62 \\
08-26-63 \\
08-15-64 \\
08-14-65 \\
07-29-66 \\
09-25-67 \\
12-20-67 \\
08-07-69 \\
07-21-70 \\
08-11-71 \\
08-27-72 \\
10-19-72 \\
07-20-74 \\
07-23-75 \\
07-28-76 \\
08-24-77 \\
10-10-77 \\
01-18-79 \\
08-14-80 \\
07-29-81 \\
09-11-82 \\
09-28-83 \\
10-02-83 \\
12-29-84 \\
08-18-86 \\
08-22-87 \\
09-12-88 \\
10-20-88\end{array}$ & $\begin{array}{r}3,800 \\
2,050 \\
5,530 \\
6,070 \\
2,140 \\
5,890 \\
7,800 \\
5,000 \\
2,480 \\
8,490 \\
8,600 \\
11,400 \\
1,680 \\
12,100 \\
8,030 \\
6,550 \\
1,980 \\
23,000 \\
10,800 \\
3392 \\
3,460 \\
7,190 \\
6,880 \\
25,400 \\
7,000 \\
2,140 \\
410 \\
1,020 \\
2,210\end{array}$ & \\
\hline
\end{tabular}

IHighest since 1906.

BASIN CHARACTERISTICS

\begin{tabular}{|c|c|c|c|c|c|c|c|}
\hline \multirow{2}{*}{$\begin{array}{l}\text { MAIN } \\
\text { CHANNEL } \\
\text { SLOPE } \\
\text { (FT/MI) }\end{array}$} & \multirow[b]{2}{*}{$\begin{array}{c}\text { STREAM } \\
\text { LENGTH } \\
\text { (MI) }\end{array}$} & \multirow{2}{*}{$\begin{array}{l}\text { MEAN } \\
\text { BASIN } \\
\text { ELEVA- } \\
\text { TION } \\
\text { (FT) }\end{array}$} & \multirow[b]{2}{*}{$\begin{array}{l}\text { FORESTED } \\
\text { AREA } \\
\text { (PERCENT) }\end{array}$} & \multirow[b]{2}{*}{$\begin{array}{l}\text { SOIL } \\
\text { INDEX }\end{array}$} & \multirow{2}{*}{$\begin{array}{l}\text { MEAN } \\
\text { ANNUAL } \\
\text { PRECIPI- } \\
\text { TAT ION } \\
\text { (IN) }\end{array}$} & \multicolumn{2}{|c|}{ RAINFALL INTENSITY, 24-HOUR } \\
\hline & & & & & & $\begin{array}{c}\text { 2-YEAR } \\
\text { (IN) }\end{array}$ & $\begin{array}{c}\text { 50-YEAR } \\
\text { (IN) }\end{array}$ \\
\hline 15.3 & 124 & 4,660 & 13.0 & 1.8 & 15.5 & 1.9 & 3.7 \\
\hline
\end{tabular}


MEAN MONTHLY AND ANNUAL DISCHARGES 1944-46, 1951-89

\begin{tabular}{|c|c|c|c|c|c|c|}
\hline MONTH & $\begin{array}{l}\operatorname{MAXIMUN} \\
\left(F T^{3} / S\right)\end{array}$ & $\begin{array}{l}\text { MINIMUM } \\
\left(F T^{3} / S\right)\end{array}$ & $\begin{array}{c}\text { MEAN } \\
\left(F T^{3} / S\right)\end{array}$ & $\begin{array}{l}\text { STAN- } \\
\text { DARD } \\
\text { DEVIA- } \\
\text { TION } \\
\text { (FT } 3 / S)\end{array}$ & $\begin{array}{l}\text { COEFFI - } \\
\text { CIENT OF } \\
\text { VARI - } \\
\text { ATION }\end{array}$ & $\begin{array}{c}\text { PERCENT } \\
\text { OF } \\
\text { ANNUAL } \\
\text { RUNOFF }\end{array}$ \\
\hline $\begin{array}{l}\text { OCTOBER } \\
\text { NOVEMBER } \\
\text { DECEMBER } \\
\text { JANUARY } \\
\text { FEBRUARY } \\
\text { MARCH } \\
\text { APRIL } \\
\text { MAY } \\
\text { JUNE } \\
\text { JULY } \\
\text { AUGUST } \\
\text { SEPTEMBER }\end{array}$ & $\begin{array}{r}939 \\
41 \\
532 \\
749 \\
223 \\
193 \\
59 \\
19 \\
26 \\
621 \\
1,480 \\
367\end{array}$ & $\begin{array}{l}0.00 \\
0.00 \\
0.00 \\
0.00 \\
0.00 \\
0.00 \\
0.00 \\
0.00 \\
0.00 \\
0.47 \\
0.37 \\
0.17\end{array}$ & $\begin{array}{c}51 \\
3.7 \\
36 \\
33 \\
22 \\
16 \\
4.0 \\
1.4 \\
1.8 \\
103 \\
215 \\
50\end{array}$ & $\begin{array}{c}186 \\
8.7 \\
106 \\
120 \\
50 \\
36 \\
10 \\
4.0 \\
4.7 \\
119 \\
292 \\
74\end{array}$ & $\begin{array}{l}3.7 \\
2.3 \\
3.0 \\
3.6 \\
2.2 \\
2.2 \\
2.6 \\
2.8 \\
2.6 \\
1.2 \\
1.4 \\
1.5\end{array}$ & $\begin{array}{r}9.4 \\
0.7 \\
6.7 \\
6.2 \\
4.2 \\
3.1 \\
0.7 \\
0.3 \\
0.3 \\
19.1 \\
40.0 \\
9.4\end{array}$ \\
\hline ANNUAL & 179 & 3.1 & 45 & 42 & 0.92 & 100 \\
\hline
\end{tabular}

MAGNITUDE AND PROBABILITY OF INSTANTANEOUS PEAK FLON BASED ON PERICD OF RECORD 1926, 1931-41, 1943-89

DISCHARGE, IN FT $3 / 5$, FOR INDICATED RECURRENCE INTERVAL IN YEARS, AND EXCEEDANCE PROBABILITY, IN PERCENT

\begin{tabular}{lccccc}
2 & 5 & 10 & 25 & 50 & 100 \\
$50 \%$ & $20 \%$ & $10 \%$ & $4 \%$ & $2 \%$ & $1 \%$ \\
\hline 7,800 & 16,100 & 23,100 & 33,800 & 43,000 & 53,200 \\
\hline WEIGHTED SKEW (LOGS) & -0.16 & & \\
MEAN & (LOGS) & 3.88 & & \\
STANDARD DEV. (LOGS) & $=0.38$
\end{tabular}

DURATION TABLE OF DAILY MEAN FLOW FOR PERIOD OF RECORD 1944-46, 1951-89
MAENITLDE AND PROBABILITY OF ANMUAL LON FLON BASED ON PERIOD OF RECORD 1945-47, 1952-89

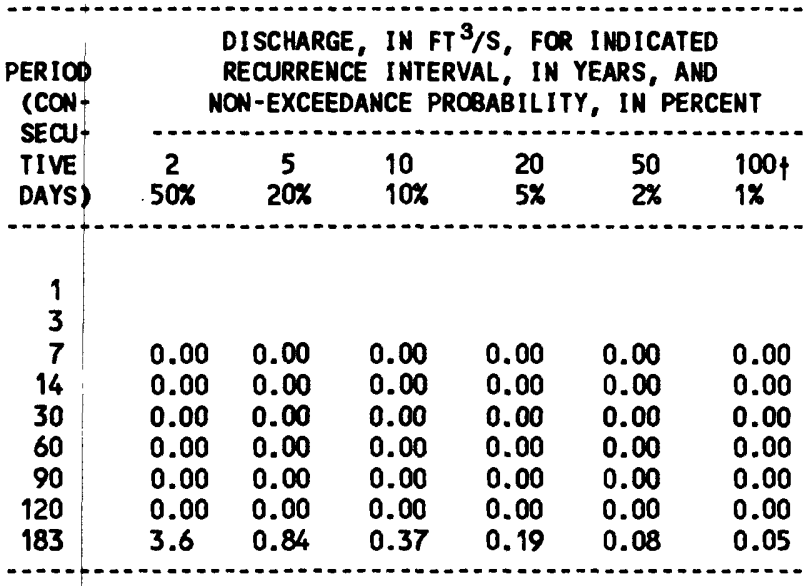

MAGNITUDE AND PROBABILITY OF ANNUAL HIGH FLON BASED ON PERICD OF RECORD 1944-46, 1951-89

\begin{tabular}{|c|c|c|c|c|c|c|}
\hline $\begin{array}{l}\text { ERIOD } \\
\text { (CON- } \\
\text { SECU- }\end{array}$ & & \multicolumn{5}{|c|}{$\begin{array}{l}\text { DISCHARGE, IN } \mathrm{FT}^{3} / \mathrm{S}, \text { FOR INDICATED } \\
\text { RECURRENCE INTERVAL, IN YEARS, AND } \\
\text { EXCEEDANCE PROBABILITY, IN PERCENT }\end{array}$} \\
\hline $\begin{array}{l}\text { TIVE } \\
\text { DAYS) }\end{array}$ & $\begin{array}{c}2 \\
50 \%\end{array}$ & $\begin{array}{c}5 \\
20 \%\end{array}$ & $\begin{array}{l}10 \\
10 \%\end{array}$ & $\begin{array}{l}25 \\
4 \%\end{array}$ & $\begin{array}{l}50 \\
2 \%\end{array}$ & \\
\hline $\begin{array}{r}1 \\
3 \\
7 \\
15 \\
30 \\
60 \\
90\end{array}$ & $\begin{array}{r}1,940 \\
1,120 \\
614 \\
402 \\
257 \\
161 \\
113\end{array}$ & $\begin{array}{r}4,240 \\
2,480 \\
1,360 \\
866 \\
553 \\
343 \\
239\end{array}$ & $\begin{array}{r}6,000 \\
3,560 \\
1,970 \\
1,230 \\
796 \\
492 \\
341\end{array}$ & $\begin{array}{r}8,300 \\
5,050 \\
2,820 \\
1,720 \\
1,140 \\
704 \\
484\end{array}$ & $\begin{array}{r}10,000 \\
6,200 \\
3,500 \\
2,100 \\
1,420 \\
875 \\
597\end{array}$ & $\begin{array}{r}11 . \\
7 \\
4\end{array}$ \\
\hline
\end{tabular}

DISCHARGE, IN FT $3 / 5$, WHICH WAS EQUALED OR EXCEEDED FOR INDICATED PERCENT OF TIME

\begin{tabular}{|c|c|c|c|c|c|c|c|c|c|c|c|c|c|c|c|c|}
\hline $1 \%$ & $5 \%$ & $10 \%$ & $15 \%$ & $20 \%$ & $30 \%$ & $40 \%$ & $50 \%$ & $60 \%$ & $70 \%$ & $80 \%$ & $90 \%$ & $95 \%$ & $98 \%$ & $99 \%$ & $99.5 \%$ & $99.9 \%$ \\
\hline 968 & 177 & 55 & 26 & 13 & 3.6 & 1.5 & 0.63 & 0.29 & 0.00 & 0.00 & 0.00 & 0.00 & 0.00 & 0.00 & 0.00 & 0.00 \\
\hline
\end{tabular}

$\uparrow$ Reliability of values in colum is uncertain, and potential errors are large. 
GILA RIVER BASIN

09472000 SAN PEDRO RIVER MEAR REDINGTON, AZ--CONTINUEd
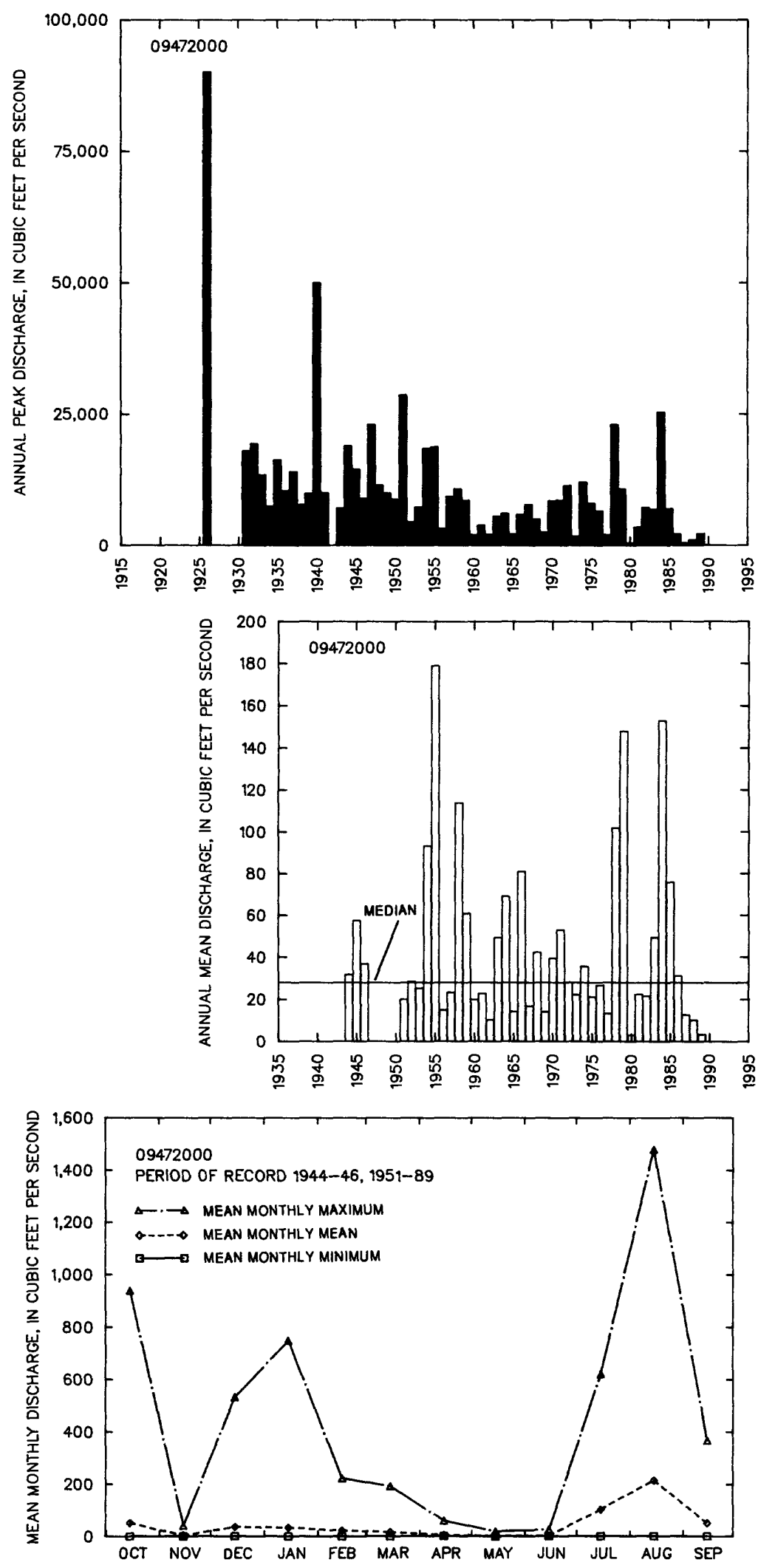


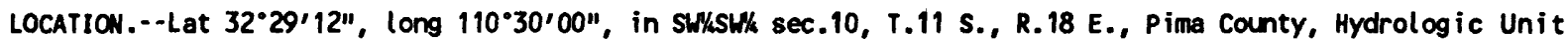
15050203, on left bank 0.2 mi upstream from mouth and 4 miles north of Redington.

DRAINAGE AREA. $--8.02 \mathrm{mi}^{2}$.

ANNUAL PEAK DISCHARge

\begin{tabular}{lccc}
$\begin{array}{l}\text { WATER } \\
\text { YEAR }\end{array}$ & DATE & $\begin{array}{c}\text { ANNUAL PEAK } \\
\text { DISCHARGE } \\
\text { (FT } 3 / \text { S) }\end{array}$ & $\begin{array}{c}\text { DISCHARGE } \\
\text { COOES }\end{array}$ \\
\hline 1968 & $08-09-68$ & 650 & \\
1969 & $08-28-69$ & 150 & \\
1970 & $08-14-70$ & 73 & \\
1971 & $07-29-71$ & 442 & \\
1972 & $08-12-72$ & 4,340 & \\
1973 & $10-00-72$ & 10 & \\
1974 & $00-00-74$ & 120 & \\
1975 & $10-00-74$ & 70 & \\
1976 & $07-19-76$ & 110 & \\
1977 & $08-14-77$ & 58 & \\
1978 & $10-07-77$ & 69 & \\
1979 & $08-07-79$ & 94 & \\
1980 & $08-11-80$ & 51 & \\
1981 & $07-20-81$ & 100 & \\
\hline
\end{tabular}

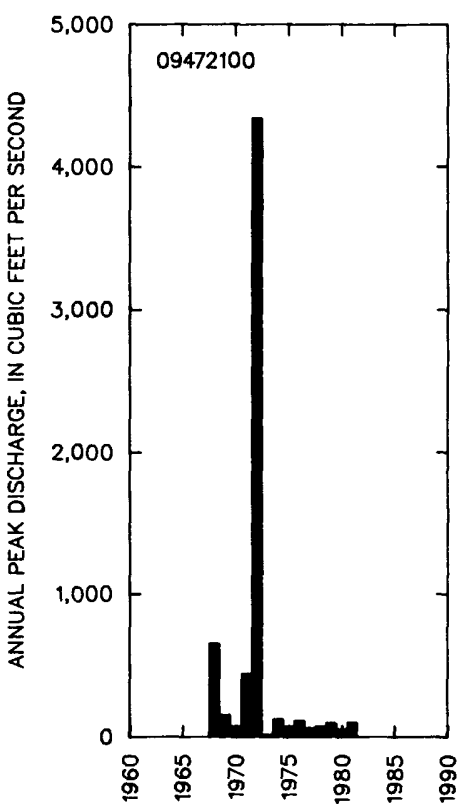

MAGNITUDE AND PROBABILITY OF INSTANTANEOUS PEAK FLOW BASED ON PERIOD OF RECORD 1968-81

DISCHARGE, IN $\mathrm{FT}^{3} / \mathrm{S}$, FOR INDICATED RECURRENCE INTERVAL IN YEARS, AND EXCEEDANCE PROBABILITY, IN PERCENT

\begin{tabular}{|cccccc}
2 & 5 & 10 & 25 & $50 \uparrow$ & $100 \dagger$ \\
$50 \%$ & $20 \%$ & $10 \%$ & $4 \%$ & $2 \%$ & $1 \%$ \\
118 & 402 & 793 & 1,680 & 2,780 & 4,410 \\
\hline MEIGHTED SKEW (LOGS) & & 0.27 & & \\
MEAN & (LOGS) & 2.10 & & \\
STANDARD DEV. (LOGS) & 0.61
\end{tabular}

+ Reliability of values in column is uncertain, and potential errors are large.

BASIN CHARACTERISTICS

\begin{tabular}{|c|c|c|c|c|c|c|c|}
\hline MAIN & & $\begin{array}{l}\text { MEAN } \\
\text { BASIN }\end{array}$ & & & & RAINFALL I & SITY, 24-HOUR \\
\hline $\begin{array}{l}\text { CHANNEL } \\
\text { SLOPE } \\
\text { (FT/MI) }\end{array}$ & $\begin{array}{c}\text { STREAM } \\
\text { LENGTH } \\
\text { (MI) }\end{array}$ & $\begin{array}{l}\text { ELEVA- } \\
\text { TION } \\
\text { (FT) }\end{array}$ & $\begin{array}{l}\text { FORESTED } \\
\text { AREA } \\
\text { (PERCENT) }\end{array}$ & $\begin{array}{l}\text { SOIL } \\
\text { INDEX }\end{array}$ & $\begin{array}{l}\text { PRECIPI- } \\
\text { TATION } \\
\text { (IN) }\end{array}$ & $\begin{array}{c}\text { 2-YEAR } \\
\text { (IN) }\end{array}$ & $\begin{array}{c}\text { 50-YEAR } \\
\text { (IN) }\end{array}$ \\
\hline 146 & 9.3 & 3,680 & 0.0 & 1.0 & 11.7 & 1.7 & 3.9 \\
\hline
\end{tabular}


09472400 MAMMOTH WASH NEAR MAMMOTH, AZ

LOCATION.-- Lat 32.40'35", long 110.41'05", in SW/ sec.2, T.9 S., R.16 E., Pinal County, Hydrologic Unit 15050203, at State Highway 76, 3 miles southwest of Marmoth.

DRAINAGE AREA. $--2.40 \mathrm{mi}^{2}$.

ANNUAL PEAK DISCHARGE

\begin{tabular}{cccc}
$\begin{array}{c}\text { WATER } \\
\text { YEAR }\end{array}$ & DATE & $\begin{array}{c}\text { ANNUAL PEAK } \\
\text { DISCHARGE } \\
\text { (FT } 3 / \text { S) }\end{array}$ & $\begin{array}{c}\text { DISCHARGE } \\
\text { COOES }\end{array}$ \\
\hline 1963 & $00-00-63$ & 1,290 & HP \\
1964 & $00-00-64$ & 736 & \\
1965 & $07-16-65$ & 300 & ES \\
1966 & $12-10-65$ & 10 & LT \\
1967 & $07-17-67$ & 510 & \\
1968 & $08-26-68$ & 100 & \\
1969 & $09-05-69$ & 12 & ES \\
1970 & $03-03-70$ & 1.0 & LT \\
1971 & $09-29-71$ & 240 & \\
1972 & $12-00-71$ & 15 & \\
1973 & $08-05-73$ & 1,060 & \\
1974 & $09-00-74$ & 236 & \\
1975 & $08-13-75$ & 40 & ES \\
1976 & $00-00-76$ & 260 & \\
\hline & & 13,200 &
\end{tabular}

$1_{H i g h e s t}$ since 1956 , year of occurrence unknown.

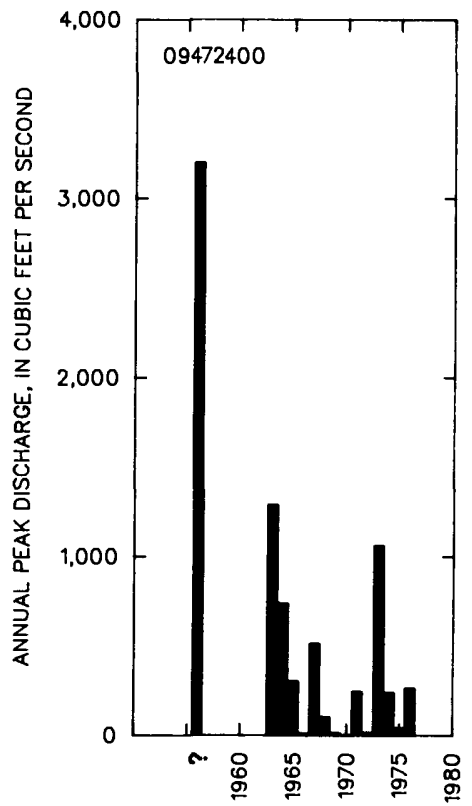

MAGNITUDE AND PROBABILITY OF INSTANTANEOUS PEAK FLOW BASED ON PER IOD OF RECORD 1956, 1963-76

DISCHARGE, IN $\mathrm{FT}^{3} / \mathrm{S}$, FOR INDICATED RECURRENCE INTERVAL

IN YEARS, AND EXCEEDANCE PROBABILITY, IN PERCENT

\begin{tabular}{|c|c|c|c|c|c|}
\hline $\begin{array}{c}2 \\
50 \%\end{array}$ & $\begin{array}{c}5 \\
20 \%\end{array}$ & $\begin{array}{r}10 \\
10 \%\end{array}$ & $\begin{array}{l}25 \\
4 \%\end{array}$ & $\begin{array}{l}50 \uparrow \\
2 \%\end{array}$ & $\begin{array}{c}100 \nmid \\
1 \%\end{array}$ \\
\hline 167 & 752 & 1,540 & 3,130 & 4,810 & 6,960 \\
\hline $\begin{array}{l}\text { WEIGHTED } \\
\text { MEAN } \\
\text { STANDARD }\end{array}$ & $\begin{array}{l}\text { SKEW } \\
\text { DEV. }\end{array}$ & $\begin{array}{l}(L O G S)= \\
(L O G S)= \\
(L O G S)=\end{array}$ & $\begin{array}{r}-0.42 \\
2.16 \\
0.83\end{array}$ & & \\
\hline
\end{tabular}

$\uparrow$ Reliability of values in column is uncertain, and potential errors are large.

BASIN CHARACTERISTICS

\begin{tabular}{|c|c|c|c|c|c|c|c|}
\hline \multirow{3}{*}{$\begin{array}{l}\text { MAIN } \\
\text { CHANNEL } \\
\text { SLOPE } \\
\text { (FT/MI) }\end{array}$} & \multirow{2}{*}{\multicolumn{2}{|c|}{$\begin{array}{l}\text { MEAN } \\
\text { BASIN }\end{array}$}} & \multicolumn{5}{|c|}{ MEAN } \\
\hline & & & & & ANNUAL & RAINFALL II & SITY, 24-HOUR \\
\hline & $\begin{array}{c}\text { STREAM } \\
\text { LENGTH } \\
\text { (MI) }\end{array}$ & $\begin{array}{l}\text { ELEVA- } \\
\text { TION } \\
\text { (FT) }\end{array}$ & $\begin{array}{l}\text { FORESTED } \\
\text { AREA } \\
\text { (PERCENT) }\end{array}$ & $\begin{array}{l}\text { SOIL } \\
\text { INDEX }\end{array}$ & $\begin{array}{l}\text { PRECIPI - } \\
\text { TATION } \\
\text { (IN) }\end{array}$ & $\begin{array}{c}\text { 2-YEAR } \\
\text { (IN) }\end{array}$ & $\begin{array}{c}\text { 50-YEAR } \\
\text { (IN) }\end{array}$ \\
\hline 181 & 4.2 & 3,700 & 0.0 & 1.0 & 13.8 & 1.8 & 4.1 \\
\hline
\end{tabular}


09473000 ARAVAIPA CREEK NEAR MAMMOTH, AZ

LOCATION.--Lat 32.50'37", long 110.37'09", in MANWH sec.9, T.7 S., R.17 E., Pinal County, Hydrologic Unit 15050203, on right bank $6 \mathrm{mi}$ upstream from mouth and 9 mi north of Manmoth.

DRAIMAGE AREA. $--537 \mathrm{mi}^{2}$.

REMARKS. --Diversions for irrigation of several hundred acres above station.

ANIUAL PEAK DISCHARGE

\begin{tabular}{|c|c|c|c|c|c|c|c|}
\hline $\begin{array}{l}\text { WATER } \\
\text { YEAR }\end{array}$ & DATE & $\begin{array}{l}\text { ANNUAL PEAK } \\
\text { DISCHARGE } \\
\text { (FT } 3 / S \text { ) }\end{array}$ & $\begin{array}{l}\text { DISCHARGE } \\
\text { CODES }\end{array}$ & $\begin{array}{l}\text { WATER } \\
\text { YEAR }\end{array}$ & DATE & $\begin{array}{l}\text { ANMUAL PEAK } \\
\text { DISCHARGE } \\
\left(\mathrm{FT}^{3} / \mathrm{S}\right)\end{array}$ & $\begin{array}{l}\text { DISCHARGE } \\
\text { CODES }\end{array}$ \\
\hline $\begin{array}{l}1919 \\
1920 \\
1921 \\
1931 \\
1932 \\
1933 \\
1934 \\
1935 \\
1936 \\
1937 \\
1938 \\
1939 \\
1940 \\
1941 \\
1965 \\
1966 \\
1967 \\
1968 \\
1969 \\
1970\end{array}$ & $\begin{array}{l}08-02-19 \\
01-05-20 \\
07-31-21 \\
08-20-31 \\
10-01-31 \\
07-23-33 \\
07-20-34 \\
08-15-35 \\
07-25-36 \\
02-07-37 \\
03-04-38 \\
08-05-39 \\
09-21-40 \\
12-31-40 \\
09-03-65 \\
12-22-65 \\
09-25-67 \\
12-17-67 \\
08-29-69 \\
03-03-70\end{array}$ & $\begin{array}{r}20,000 \\
7,400 \\
12,600 \\
4,700 \\
6,300 \\
9,340 \\
3,100 \\
10,200 \\
6,500 \\
3,380 \\
3,600 \\
6,450 \\
5,480 \\
9,600 \\
4,480 \\
6,340 \\
2,340 \\
15,300 \\
1,800 \\
5,560\end{array}$ & & $\begin{array}{l}1971 \\
1972 \\
1973 \\
1974 \\
1975 \\
1976 \\
1977 \\
1978 \\
1979 \\
1980 \\
1981 \\
1982 \\
1983 \\
1984 \\
1985 \\
1986 \\
1987 \\
1988 \\
1989\end{array}$ & $\begin{array}{l}08-21-71 \\
09-10-72 \\
10-19-72 \\
08-02-74 \\
10-22-74 \\
08-23-76 \\
07-12-77 \\
08-01-78 \\
12-18-78 \\
02-15-80 \\
08-10-81 \\
08-12-82 \\
03-19-83 \\
10-01-83 \\
12-12-84 \\
03-14-86 \\
10-12-86 \\
07-31-88 \\
09-03-89\end{array}$ & $\begin{array}{r}1,780 \\
1,830 \\
8,200 \\
2,100 \\
836 \\
1,120 \\
2,560 \\
5,100 \\
16,200 \\
2,460 \\
2,460 \\
1,620 \\
3,920 \\
170,800 \\
1,330 \\
1,060 \\
1,320 \\
1,040 \\
3,610\end{array}$ & \\
\hline
\end{tabular}

IHighest in 1100 years based on Roberts (1987).

\begin{tabular}{|c|c|c|c|c|c|c|c|}
\hline \multicolumn{8}{|c|}{ BASIN CHARACTERISTICS } \\
\hline MAIN & & $\begin{array}{l}\text { MEAN } \\
\text { BASIN }\end{array}$ & & & $\begin{array}{c}\text { MEAN } \\
\text { ANNUAL }\end{array}$ & RAINFALL II & ISITY, 24-HOUR \\
\hline $\begin{array}{l}\text { CHANNEL } \\
\text { SLOPE } \\
\text { (FT/MI) }\end{array}$ & $\begin{array}{c}\text { STREAM } \\
\text { LENGTH } \\
\text { (MI) }\end{array}$ & $\begin{array}{l}\text { ELEVA- } \\
\text { TION } \\
\text { (FT) }\end{array}$ & $\begin{array}{l}\text { FORESTED } \\
\text { AREA } \\
\text { (PERCENT) }\end{array}$ & $\begin{array}{l}\text { SOIL } \\
\text { INDEX }\end{array}$ & $\begin{array}{l}\text { PRECIPI- } \\
\text { TATION } \\
\text { (IN) }\end{array}$ & $\begin{array}{c}\text { 2-YEAR } \\
\text { (IN) }\end{array}$ & $\begin{array}{l}\text { 50-YEAR } \\
\text { (IN) }\end{array}$ \\
\hline 45.7 & 55.4 & 4,530 & 24.0 & 2.0 & 16.2 & 2.0 & 4.0 \\
\hline
\end{tabular}


09473000 ARAVAIPA CREEK NEAR MAMHOTH, AZ--Continued

MEAN MONTHLY AND ANNUAL DISCHARGES 1932-40, 1942, 1967-89

\begin{tabular}{|c|c|c|c|c|c|c|}
\hline MONTH' & $\begin{array}{l}\operatorname{Max} I M U M \\
\left(F T^{3} / S\right)\end{array}$ & $\begin{array}{l}\text { MINIMUM } \\
\left(F T^{3} / S\right)\end{array}$ & $\begin{array}{c}\text { MEAN } \\
\left(F T^{3} / S\right)\end{array}$ & $\begin{array}{l}\text { STAN- } \\
\text { DARD } \\
\text { DEVIA- } \\
\text { TION } \\
\left(F^{3} / S\right)\end{array}$ & $\begin{array}{l}\text { COEFFI- } \\
\text { CIENT OF } \\
\text { VARI- } \\
\text { ATION }\end{array}$ & $\begin{array}{c}\text { PERCENT } \\
\text { OF } \\
\text { ANNUAL } \\
\text { RUNOFF }\end{array}$ \\
\hline $\begin{array}{l}\text { OCTOBER } \\
\text { NOVEMBER } \\
\text { DECEMBER } \\
\text { JANUARY } \\
\text { FEBRUARY } \\
\text { MARCH } \\
\text { APRIL } \\
\text { MAY } \\
\text { JUNE } \\
\text { JULY } \\
\text { AUGUST } \\
\text { SEPTEMBER }\end{array}$ & $\begin{array}{r}1,100 \\
91 \\
474 \\
230 \\
215 \\
311 \\
47 \\
45 \\
40 \\
115 \\
133 \\
56\end{array}$ & $\begin{array}{c}6.2 \\
8.7 \\
9.7 \\
10 \\
11 \\
9.5 \\
7.2 \\
4.3 \\
1.9 \\
7.1 \\
7.8 \\
5.4\end{array}$ & $\begin{array}{l}59 \\
23 \\
48 \\
37 \\
59 \\
54 \\
19 \\
14 \\
12 \\
24 \\
32 \\
25\end{array}$ & $\begin{array}{c}190 \\
17 \\
85 \\
41 \\
58 \\
66 \\
11 \\
9.4 \\
9.6 \\
23 \\
26 \\
14\end{array}$ & $\begin{array}{l}3.2 \\
0.75 \\
1.8 \\
1.1 \\
0.98 \\
1.2 \\
0.58 \\
0.69 \\
0.83 \\
0.92 \\
0.79 \\
0.54\end{array}$ & $\begin{array}{r}14.6 \\
5.6 \\
11.8 \\
9.1 \\
14.5 \\
13.3 \\
4.6 \\
3.4 \\
2.9 \\
6.1 \\
8.0 \\
6.2\end{array}$ \\
\hline ANNUAL & 140 & 9.6 & 34 & 27 & 0.81 & 100 \\
\hline
\end{tabular}

MAGNITLDE AND PROBABILITY OF INSTANTANEOUS PEAK FLOH BASED ON PERIOD OF RE'CORD 888, 1919-21, 1931-41, 1965-89

DISCHARGE, IN $\mathrm{FT}^{3} / \mathrm{S}$, FOR INDICATED RECURRENCE INTERVAL IN YEARS, AND EXCEEDANCE PROBABILITY, IN PERCENT

\begin{tabular}{lcccccc}
2 & 5 & 10 & 25 & 50 & $100 \dagger$ \\
$50 \%$ & $20 \%$ & $10 \%$ & $4 \%$ & $2 \%$ & $1 \%$ \\
3,790 & 7,720 & 11,300 & 17,000 & 22,100 & 28,200 \\
\hline WEIGHTED SKEW (LOGS) & $=0.07$ & & \\
MEAN & $\begin{array}{l}\text { (LOGS) } \\
\text { STANDARD DEV. (LOGS) }\end{array}$ & 3.58 & 0.36 & &
\end{tabular}

MAGNITLDE AND PROBABILJTY OF ANMUAL LOW FLOW BASED ON PERIOD OF RECORD 1933-41, 1968-89

\begin{tabular}{|c|c|c|c|c|c|c|}
\hline $\begin{array}{l}\text { PERIOD } \\
\text { (CON- } \\
\text { SECU- }\end{array}$ & & $\begin{array}{l}\text { SCHAR } \\
\text { CURRE } \\
\text { I-EXCE }\end{array}$ & $\begin{array}{l}\text { IN } \\
\text { INT } \\
\text { INCE }\end{array}$ & ABILI & $\begin{array}{l}\text { DICATE } \\
\text { RS, A } \\
\text { IN PE }\end{array}$ & \\
\hline $\begin{array}{l}\text { TIVE } \\
\text { DAYS) }\end{array}$ & $\begin{array}{c}2 \\
50 \%\end{array}$ & $\begin{array}{c}5 \\
20 \%\end{array}$ & $\begin{array}{l}10 \\
10 \%\end{array}$ & $\begin{array}{l}20 \\
5 \%\end{array}$ & $\begin{array}{l}50 \\
2 x\end{array}$ & $\begin{array}{l}1004 \\
1 \%\end{array}$ \\
\hline $\begin{array}{r}1 \\
3 \\
7 \\
14 \\
30 \\
60 \\
90 \\
120 \\
183\end{array}$ & $\begin{array}{c}3.1 \\
3.4 \\
3.8 \\
4.4 \\
5.7 \\
7.4 \\
9.5 \\
12 \\
17\end{array}$ & $\begin{array}{r}1.3 \\
1.5 \\
1.7 \\
2.2 \\
3.1 \\
4.4 \\
6.1 \\
8.5 \\
12\end{array}$ & $\begin{array}{c}0.87 \\
0.98 \\
1.2 \\
1.6 \\
2.3 \\
3.4 \\
4.9 \\
7.3 \\
11\end{array}$ & $\begin{array}{l}0.63 \\
0.70 \\
0.84 \\
1.2 \\
1.8 \\
2.8 \\
4.2 \\
6.4 \\
9.5\end{array}$ & $\begin{array}{l}0.44 \\
0.49 \\
0.59 \\
0.92 \\
1.4 \\
2.2 \\
3.5 \\
5.7 \\
8.4\end{array}$ & $\begin{array}{l}0.34 \\
0.38 \\
0.48 \\
0.78 \\
1.2 \\
2.0 \\
3.2 \\
5.3 \\
7.9\end{array}$ \\
\hline
\end{tabular}

MAGNITUDE AND PROBABILITY OF ANMUAL HIGH FLOW BASED ON PERIOD OF RECORD 1932-40, 1942, 1967-89

\begin{tabular}{|c|c|c|c|c|c|c|}
\hline $\begin{array}{l}\text { PERIOD } \\
\text { (CON- }\end{array}$ & & $\begin{array}{l}\text { DISCHA } \\
\text { RECURRE } \\
\text { EXCEEDI }\end{array}$ & $\begin{array}{l}\text { E, IN } \\
\text { CE INTI } \\
\text { CE PRO }\end{array}$ & $\begin{array}{l}\text { 3/S, FO } \\
\text { VAL, IN } \\
\text { BILITY, }\end{array}$ & $\begin{array}{l}\text { R INDICA } \\
\text { YEARS, } \\
\text { IN PERC }\end{array}$ & $\begin{array}{l}\text { TED } \\
\text { AND } \\
\text { ENT }\end{array}$ \\
\hline $\begin{array}{l}\text { TIVE } \\
\text { DAYS) }\end{array}$ & $\begin{array}{c}2 \\
50 x\end{array}$ & $\begin{array}{c}5 \\
20 x\end{array}$ & $\begin{array}{l}10 \\
10 \%\end{array}$ & $\begin{array}{l}25 \\
4 \%\end{array}$ & $\begin{array}{l}50 \\
2 x\end{array}$ & $\underset{1 \%}{100 \dagger}$ \\
\hline $\begin{array}{r}1 \\
3 \\
7 \\
15 \\
30 \\
60 \\
90\end{array}$ & $\begin{array}{r}634 \\
346 \\
205 \\
123 \\
80 \\
55 \\
45\end{array}$ & $\begin{array}{r}1,780 \\
1,010 \\
557 \\
306 \\
186 \\
123 \\
97\end{array}$ & $\begin{array}{r}3,310 \\
1,910 \\
1,000 \\
527 \\
307 \\
200 \\
154\end{array}$ & $\begin{array}{l}6,790 \\
4,070 \\
1,970 \\
992 \\
551 \\
356 \\
263\end{array}$ & $\begin{array}{r}11,200 \\
6,890 \\
3,130 \\
1,540 \\
825 \\
531 \\
382\end{array}$ & $\begin{array}{r}18,000 \\
11,300 \\
4,850 \\
2,320 \\
1,210 \\
778 \\
544\end{array}$ \\
\hline
\end{tabular}

DURATION TABLE OF DAILY MEAN FLON FOR PERICD OF RECORD 1932-40, 1942, 1967-89

DISCHARGE, IN FT $3 / 5$, WHICH WAS EQUALED OR EXCEEDED FOR INDICATED PERCENT OF TIME

\begin{tabular}{|c|c|c|c|c|c|c|c|c|c|c|c|c|c|c|c|c|}
\hline $1 \%$ & $5 \%$ & $10 \%$ & $15 \%$ & $20 \%$ & $30 \%$ & $40 \%$ & $50 \%$ & $60 \%$ & $70 \%$ & $80 \%$ & $90 \%$ & $95 \%$ & $98 \%$ & $99 \%$ & $99.5 \%$ & $99.9 \%$ \\
\hline 329 & 80 & 46 & 34 & 30 & 23 & 18 & 15 & 13 & 11 & 8.3 & 5.4 & 3.9 & 2.6 & 2.1 & 1.4 & .8 \\
\hline
\end{tabular}

$\uparrow$ Reliability of values in colum is uncertain, and potential errors are large. 
09473000 ARAVAIPA CREEK NEAR MAMNOTH, AZ--CONTINUEd
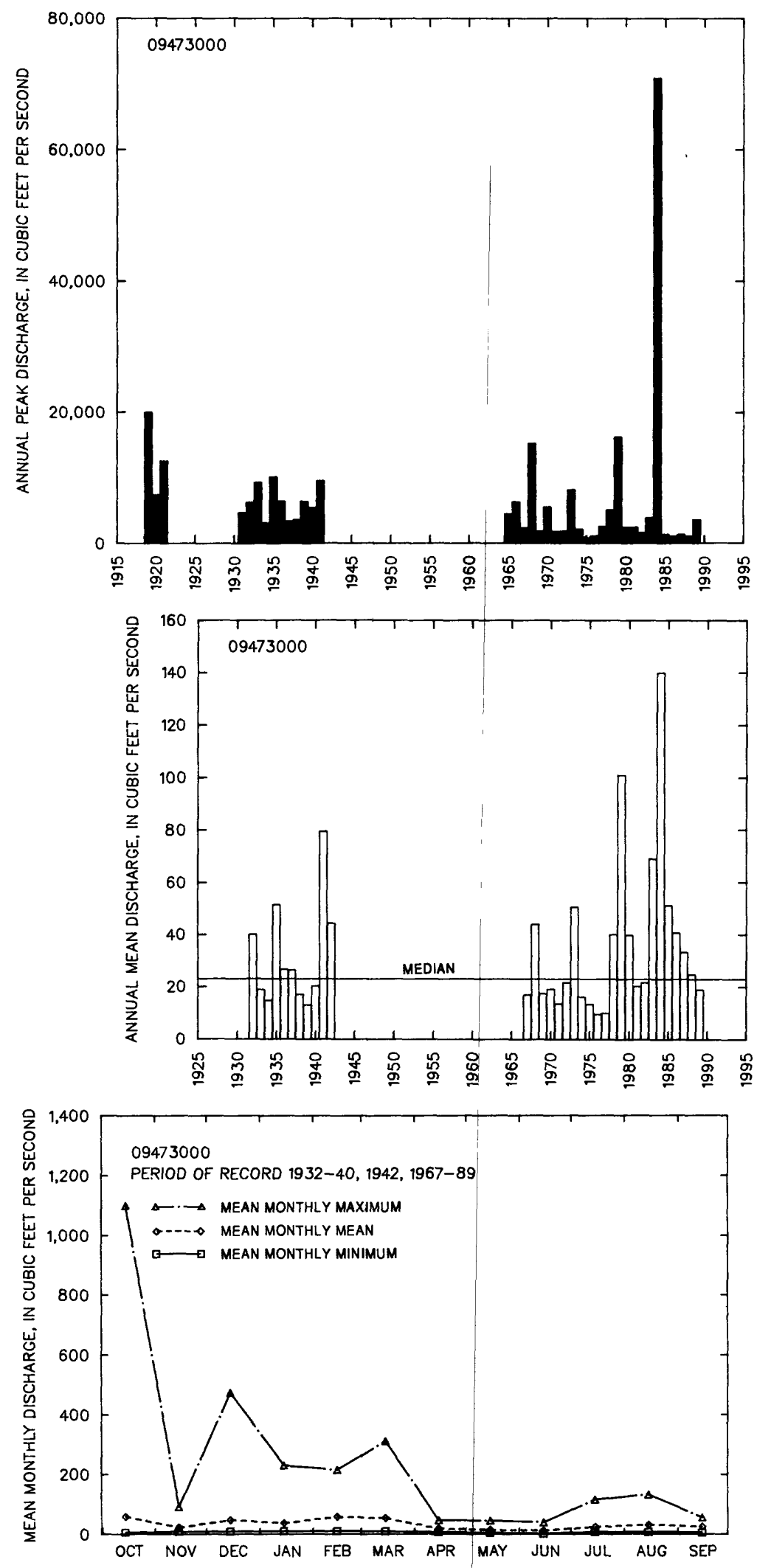
09473200 GREEN LANTERN WASH NEAR WINKELMAN, AZ

LOCATION.--Lat 32.55'30", long 110.43'35", in NEYSEK sec.8, T.6 S., R.16 E., Pinal County, Hydrologic Unit 15050203, at State Highway 77,5 miles southeast of Winkelman.

DRAINAGE AREA. $--3.63 \mathrm{mi}^{2}$.

ANNUAL PEAK DISCHARGE

\begin{tabular}{lccc}
$\begin{array}{l}\text { UATER } \\
\text { YEAR }\end{array}$ & DATE & $\begin{array}{c}\text { ANNUAL PEAK } \\
\text { DISCHARGE } \\
\text { (FT } 3 / \text { S) }\end{array}$ & $\begin{array}{c}\text { DISCHARGE } \\
\text { CODES }\end{array}$ \\
\hline 1964 & $08-00-64$ & 1,060 & \\
1965 & $07-23-65$ & 200 & ES \\
1966 & $09-13-66$ & 900 & \\
1967 & $07-17-67$ & 2,650 & \\
1968 & $08-03-68$ & 1,960 & \\
1969 & $08-29-69$ & 15 & ES \\
1970 & $08-16-70$ & 250 & ES \\
1971 & $09-30-71$ & 600 & \\
1972 & $08-12-72$ & 170 & \\
1973 & $10-00-72$ & 440 & \\
1974 & $07-00-74$ & 100 & \\
1975 & $09-00-75$ & 1,200 & ES \\
1976 & $09-25-76$ & 13,700 & HP \\
1981 & $05-01-81$ & 13,700 &
\end{tabular}

IHighest since 1964 .

MAGNITUDE AND PROBABILITY OF INSTANTANEOUS PEAK FLOW BASED ON PERIOD OF RECORD 1964-76, 1981

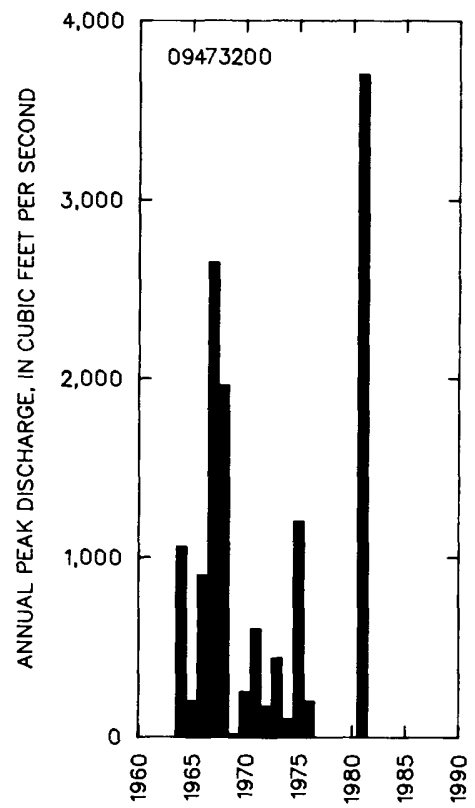

ISCHARGE, IN $\mathrm{FT}^{3} / \mathrm{S}$, FOR IND!CATED RECURRENCE INTERVAL IN YEARS, AND EXCEEDANCE PROBABILITY, IN PERCENT

\begin{tabular}{|c|c|c|c|c|c|}
\hline $\begin{array}{c}2 \\
50 \%\end{array}$ & $\begin{array}{c}5 \\
20 \%\end{array}$ & $\begin{array}{r}10 \\
10 \%\end{array}$ & $\begin{array}{l}25 \\
4 \%\end{array}$ & $\begin{array}{l}50+ \\
2 \%\end{array}$ & $\begin{array}{c}100 \dagger \\
1 \%\end{array}$ \\
\hline 509 & 1,380 & 2,290 & 3,920 & 5,520 & 7,490 \\
\hline $\begin{array}{l}\text { WEIGHTED } \\
\text { MEAN } \\
\text { STANDARD }\end{array}$ & $\begin{array}{l}\text { SKEW } \\
\text { DEV. }\end{array}$ & $\begin{array}{l}\text { LOGS) }= \\
\text { LOGS) }= \\
\text { LOGS) }=\end{array}$ & $\begin{array}{r}-0.09 \\
2.70 \\
0.52\end{array}$ & & \\
\hline
\end{tabular}

+ Reliability of values in column is uncertain, and potential errors are large.

BASIN CHARACTERISTICS

\begin{tabular}{|c|c|c|c|c|c|c|c|}
\hline MAIN & & $\begin{array}{r}\text { MEAN } \\
\text { BASIN }\end{array}$ & & & $\begin{array}{c}\text { MEAN } \\
\text { ANNUAL }\end{array}$ & RAINFALL II & SITY, 24-HOUR \\
\hline $\begin{array}{l}\text { CHANNEL } \\
\text { SLLPE } \\
\text { (FT/MI) }\end{array}$ & $\begin{array}{l}\text { STREAM } \\
\text { LENGTH } \\
\text { (MI) }\end{array}$ & $\begin{array}{l}\text { ELEVA- } \\
\text { TION } \\
\text { (FT) }\end{array}$ & $\begin{array}{l}\text { FORESTED } \\
\text { AREA } \\
\text { (PERCENT) }\end{array}$ & $\begin{array}{l}\text { SOIL } \\
\text { INDEX }\end{array}$ & $\begin{array}{l}\text { PRECIPI - } \\
\text { TATION } \\
\text { (IN) }\end{array}$ & $\begin{array}{c}\text { 2-YEAR } \\
\text { (IN) }\end{array}$ & $\begin{array}{l}\text { 50-YEAR } \\
\text { (IN) }\end{array}$ \\
\hline 189 & 4.8 & 2,590 & 0.0 & 1.0 & 14.0 & 1.9 & 4.1 \\
\hline
\end{tabular}


LOCATION.--Lat 32.58'38", long 110'46'11", in SEYSWK sec.24, T.5 S., R.15 E., Pinal County, Hydrologic Unit 15050203, on right bank 0.7 mi south of Winkelman, and $1.0 \mathrm{mi}$ upstream from mouth.

DRAINAGE AREA. $--4,453 \mathrm{mi}^{2}$.

AMIUJAL PEAK DISCHARGE

\begin{tabular}{|c|c|c|c|c|c|c|c|}
\hline $\begin{array}{l}\text { WATER } \\
\text { YEAR }\end{array}$ & DATE & $\begin{array}{c}\text { ANNUAL PEAK } \\
\text { DISCHARGE } \\
\text { (FT } 3 / 5)\end{array}$ & $\begin{array}{l}\text { DISCHARGE } \\
\text { CODES }\end{array}$ & $\begin{array}{l}\text { WATER } \\
\text { YEAR }\end{array}$ & DATE & $\begin{array}{c}\text { ANNUAL PEAK } \\
\text { DISCHARGE } \\
\text { (FT } 3 / \mathrm{S})\end{array}$ & $\begin{array}{l}\text { DISCHARGE } \\
\text { CODES }\end{array}$ \\
\hline $\begin{array}{l}1919 \\
1926 \\
1930 \\
1935 \\
1940 \\
1963 \\
1964 \\
1965 \\
1966 \\
1967 \\
1968 \\
1969 \\
1970 \\
1971\end{array}$ & $\begin{array}{l}08-13-19 \\
09-28-26 \\
08-08-30 \\
08-28-35 \\
08-14-40 \\
02-12-63 \\
08-15-64 \\
09-03-65 \\
12-22-65 \\
09-24-67 \\
12-20-67 \\
12-26-68 \\
03-03-70 \\
08-19-71\end{array}$ & $\begin{array}{r}120,000 \\
285,000 \\
325,000 \\
420,000 \\
545,000 \\
5,220 \\
6,460 \\
4,080 \\
16,800 \\
3,640 \\
15,000 \\
2,060 \\
6,340 \\
10,500\end{array}$ & $\begin{array}{l}\text { ES, HP } \\
\text { ES, HP } \\
\text { ES, HP } \\
\text { ES, HP } \\
\text { ES, HP }\end{array}$ & $\begin{array}{l}1972 \\
1973 \\
1974 \\
1975 \\
1976 \\
1977 \\
1978 \\
1979 \\
1980 \\
1981 \\
1982 \\
1983 \\
1984\end{array}$ & $\begin{array}{l}08-27-72 \\
10-20-72 \\
07-21-74 \\
07-23-75 \\
07-28-76 \\
09-11-77 \\
10-10-77 \\
12-18-78 \\
02-15-80 \\
07-19-81 \\
09-12-82 \\
01-30-83 \\
10-01-83\end{array}$ & $\begin{array}{r}4,130 \\
13,300 \\
6,620 \\
5,050 \\
4,300 \\
4,900 \\
16,000 \\
18,000 \\
2,900 \\
3,800 \\
4,950 \\
6,730 \\
2135,000\end{array}$ & ES \\
\hline
\end{tabular}

$1_{\text {Highest since } 1917 .}$

$2 \mathrm{Highest}$ since 1906.

3ighest since 1927.

Highest since 1931.

$5_{H i g h e s t}$ since 1927.

BASIN CHARACTERISTICS

\begin{tabular}{|c|c|c|c|c|c|c|c|}
\hline MAIN & & $\begin{array}{l}\text { MEAN } \\
\text { BASIN }\end{array}$ & & & $\begin{array}{c}\text { MEAN } \\
\text { ANNUAL }\end{array}$ & RAINFALL II & SITY, 24-HOUR \\
\hline $\begin{array}{l}\text { CHANNEL } \\
\text { SLOPE } \\
\text { (FT/MI) }\end{array}$ & $\begin{array}{l}\text { STREAM } \\
\text { LENGTH } \\
\text { (MI) }\end{array}$ & $\begin{array}{l}\text { ELEVA- } \\
\text { TION } \\
\text { (FT) }\end{array}$ & $\begin{array}{l}\text { FORESTED } \\
\text { AREA } \\
\text { (PERCENT) }\end{array}$ & $\begin{array}{l}\text { SOIL } \\
\text { INDEX }\end{array}$ & $\begin{array}{l}\text { PRECIPI - } \\
\text { TATION } \\
\text { (IN) }\end{array}$ & $\begin{array}{c}\text { 2-YEAR } \\
\text { (IN) }\end{array}$ & $\begin{array}{c}\text { 50-YEAR } \\
\text { (IN) }\end{array}$ \\
\hline 18.0 & 176 & 4,520 & 15.0 & 1.7 & 15.3 & 1.9 & 3.8 \\
\hline
\end{tabular}


GILA RIVER BASIN

09473500 SAN PEDRO RIVER AT HINKELMAN, AZ--Continued

MEAN MONTHLY AND ANNUAL DISCHARGES 1967-78

\begin{tabular}{|c|c|c|c|c|c|c|}
\hline MONTH & $\begin{array}{l}\operatorname{MAXIMUM} \\
\left(F^{3} / S\right)\end{array}$ & $\begin{array}{l}\text { MINIMUM } \\
\left(\mathrm{FT}^{3} / \mathrm{S}\right)\end{array}$ & $\begin{array}{c}\text { MEAN } \\
\text { (FT } 3 / S)\end{array}$ & $\begin{array}{l}\text { STAN- } \\
\text { DARD } \\
\text { DEVIA- } \\
\text { TION } \\
\text { (FT } 3 / S)\end{array}$ & $\begin{array}{l}\text { COEFFI - } \\
\text { CIENT OF } \\
\text { VARI - } \\
\text { ATION }\end{array}$ & $\begin{array}{c}\text { PERCENT } \\
\text { OF } \\
\text { ANNUAL } \\
\text { RUNOFF }\end{array}$ \\
\hline $\begin{array}{l}\text { OCTOBER } \\
\text { NOVEMBER } \\
\text { DECEMBER } \\
\text { JANUARY } \\
\text { FEBRUARY } \\
\text { MARCH } \\
\text { APRIL } \\
\text { MAY } \\
\text { JUNE } \\
\text { JULY } \\
\text { AUGUST } \\
\text { SEPTEMBER }\end{array}$ & $\begin{array}{c}565 \\
25 \\
538 \\
48 \\
206 \\
459 \\
35 \\
7.2 \\
16 \\
184 \\
586 \\
81\end{array}$ & $\begin{array}{c}0.00 \\
0.01 \\
0.34 \\
2.3 \\
0.76 \\
0.00 \\
0.00 \\
0.00 \\
0.00 \\
10 \\
3.4 \\
0.13\end{array}$ & $\begin{array}{c}80 \\
6.9 \\
55 \\
15 \\
43 \\
74 \\
8.2 \\
1.6 \\
2.3 \\
66 \\
134 \\
39\end{array}$ & $\begin{array}{c}174 \\
7.6 \\
153 \\
17 \\
73 \\
133 \\
11 \\
2.2 \\
5.4 \\
59 \\
156 \\
27\end{array}$ & $\begin{array}{l}2.2 \\
1.1 \\
2.8 \\
1.1 \\
1.7 \\
1.8 \\
1.4 \\
1.4 \\
2.3 \\
0.89 \\
1.2 \\
0.68\end{array}$ & $\begin{array}{r}15.2 \\
1.3 \\
10.5 \\
2.9 \\
8.1 \\
14.1 \\
1.6 \\
0.3 \\
0.4 \\
12.5 \\
25.6 \\
7.5\end{array}$ \\
\hline NNUAL & 104 & 13 & 44 & 30 & 0.67 & 100 \\
\hline
\end{tabular}

MAGNITUDE AND PROBABILITY OF INSTANTANEOUS PEAK FLOH BASED ON PERIOD OF RECORD 1963-84

DISCHARGE, IN FT $3 / 5$, FOR INDICATED RECURRENCE INTERVAL IN YEARS, AND EXCEEDANCE PROBABILITY, IN PERCENT

\begin{tabular}{lccccc}
2 & 5 & 10 & 25 & $50 \dagger$ & $100 \uparrow$ \\
$50 \%$ & $20 \%$ & $10 \%$ & $4 \%$ & $2 \%$ & $1 \%$ \\
6,390 & 12,800 & 19,500 & 31,600 & 44,300 & 60,900 \\
\hline MEIGHTED SKEW (LOGS) & $=0.68$ & & \\
MEAN & (LOGS) & $=3.84$ & & \\
STANDARD DEV. (LOGS) & $=0.33$
\end{tabular}

MACNITUDE AND PROBABILITY OF ANNUAL LON FLOW BASED ON PERIOD OF RECORD 1967-78

\begin{tabular}{|c|c|c|c|c|c|c|}
\hline $\begin{array}{l}\text { PERIOD } \\
\text { (CON- } \\
\text { SECU- }\end{array}$ & & $\begin{array}{l}\text { ISCHAR } \\
\text { ECURRE } \\
\text { N-EXCE }\end{array}$ & $\begin{array}{l}\text { IN } \\
\text { INT } \\
\text { INCE } \\
\end{array}$ & $\begin{array}{l}\text { S, ro } \\
\text { L, IN } \\
\text { ABILII } \\
. . . .\end{array}$ & $\begin{array}{l}\text { ARS, } \\
\text { IN PE }\end{array}$ & \\
\hline $\begin{array}{l}\text { TIVE } \\
\text { DAYS) }\end{array}$ & $\begin{array}{c}2 \\
50 \%\end{array}$ & $\begin{array}{c}5 \\
20 \%\end{array}$ & $\begin{array}{l}10 \\
10 \%\end{array}$ & $\begin{array}{l}20 \\
5 \%\end{array}$ & $\begin{array}{l}50 \uparrow \\
2 \%\end{array}$ & $\begin{array}{l}100\} \\
1 \%\end{array}$ \\
\hline $\begin{array}{r}1 \\
3 \\
7 \\
14 \\
30 \\
60 \\
90 \\
120 \\
183\end{array}$ & $\begin{array}{l}0.02 \\
0.49 \\
4.9 \\
9.4\end{array}$ & $\begin{array}{l}0.00 \\
0.05 \\
1.6 \\
2.6\end{array}$ & $\begin{array}{l}0.00 \\
0.00 \\
0.82 \\
1.2\end{array}$ & $\begin{array}{l}0.00 \\
0.00 \\
0.46 \\
0.63\end{array}$ & $\begin{array}{l}0.00 \\
0.00 \\
0.23 \\
0.29\end{array}$ & $\begin{array}{l}0.00 \\
0.00 \\
0.14 \\
0.17\end{array}$ \\
\hline
\end{tabular}

MAGNITLDE AND PROBABILITY OF ANMUAL HIGH FLOW BASED ON PERIOD OF RECORD 1967-78

\begin{tabular}{|c|c|c|c|c|c|c|}
\hline \multirow{2}{*}{$\begin{array}{l}\text { PERIOD } \\
\text { (CON- } \\
\text { SECU- } \\
\text { TIVE } \\
\text { DAYS) }\end{array}$} & \multicolumn{6}{|c|}{$\begin{array}{l}\text { DISCHARGE, IN FT } 3 / S \text {, FOR INDICATED } \\
\text { RECURRENCE INTERVAL, IN YEARS, AND } \\
\text { EXCEEDANCE PROBABILITY, IN PERCENT }\end{array}$} \\
\hline & $\begin{array}{c}2 \\
50 \%\end{array}$ & $\begin{array}{c}5 \\
20 \%\end{array}$ & $\begin{array}{l}10 \\
10 \%\end{array}$ & $\begin{array}{l}25 \dagger \\
4 \%\end{array}$ & $\begin{array}{l}50 \nmid \\
2 \%\end{array}$ & $\begin{array}{c}100 \dagger \\
1 \%\end{array}$ \\
\hline $\begin{array}{r}1 \\
3 \\
7 \\
15 \\
30 \\
60 \\
90\end{array}$ & $\begin{array}{r}2,000 \\
1,130 \\
587 \\
362 \\
236 \\
147 \\
105\end{array}$ & $\begin{array}{r}4,460 \\
2,380 \\
1,230 \\
715 \\
425 \\
244 \\
173\end{array}$ & $\begin{array}{r}7,020 \\
3,650 \\
1,880 \\
1,040 \\
578 \\
323 \\
228\end{array}$ & $\begin{array}{r}11,700 \\
5,950 \\
3,050 \\
1,590 \\
802 \\
439 \\
309\end{array}$ & $\begin{array}{r}16,600 \\
8,290 \\
4,230 \\
2,100 \\
993 \\
539 \\
379\end{array}$ & $\begin{array}{r}22,900 \\
11,300 \\
5,750 \\
2,720 \\
1,200 \\
650 \\
456\end{array}$ \\
\hline
\end{tabular}

DURATION TABLE OF DAILY MEAN FLOW FOR PERIOD OF RECORD 1967-78

DISCHARGE, IN FT $3 / 5$, WHICH WAS EQUALED OR EXCEEDED FOR INDICATED PERCENT OF TIME

\begin{tabular}{|c|c|c|c|c|c|c|c|c|c|c|c|c|c|c|c|c|}
\hline $1 \%$ & $5 \%$ & $10 \%$ & $15 \%$ & $20 \%$ & $30 x$ & $40 \%$ & $50 x$ & $60 \%$ & $70 \%$ & $80 \%$ & $90 \%$ & $95 \%$ & $98 \%$ & $99 \%$ & $99.5 \%$ & $99.9 \%$ \\
\hline 810 & 148 & 52 & 28 & 20 & 10 & 5.5 & 3.1 & 1.5 & 0.25 & 0.00 & 0.00 & 0.00 & 0.00 & 0.00 & 0.00 & 0.00 \\
\hline
\end{tabular}

$\uparrow$ Reliability of values in colum is uncertain, and potential errors are large. 
09473500 SAN PEDRo RIVER AT WINKELMAN, AZ--COntImUed
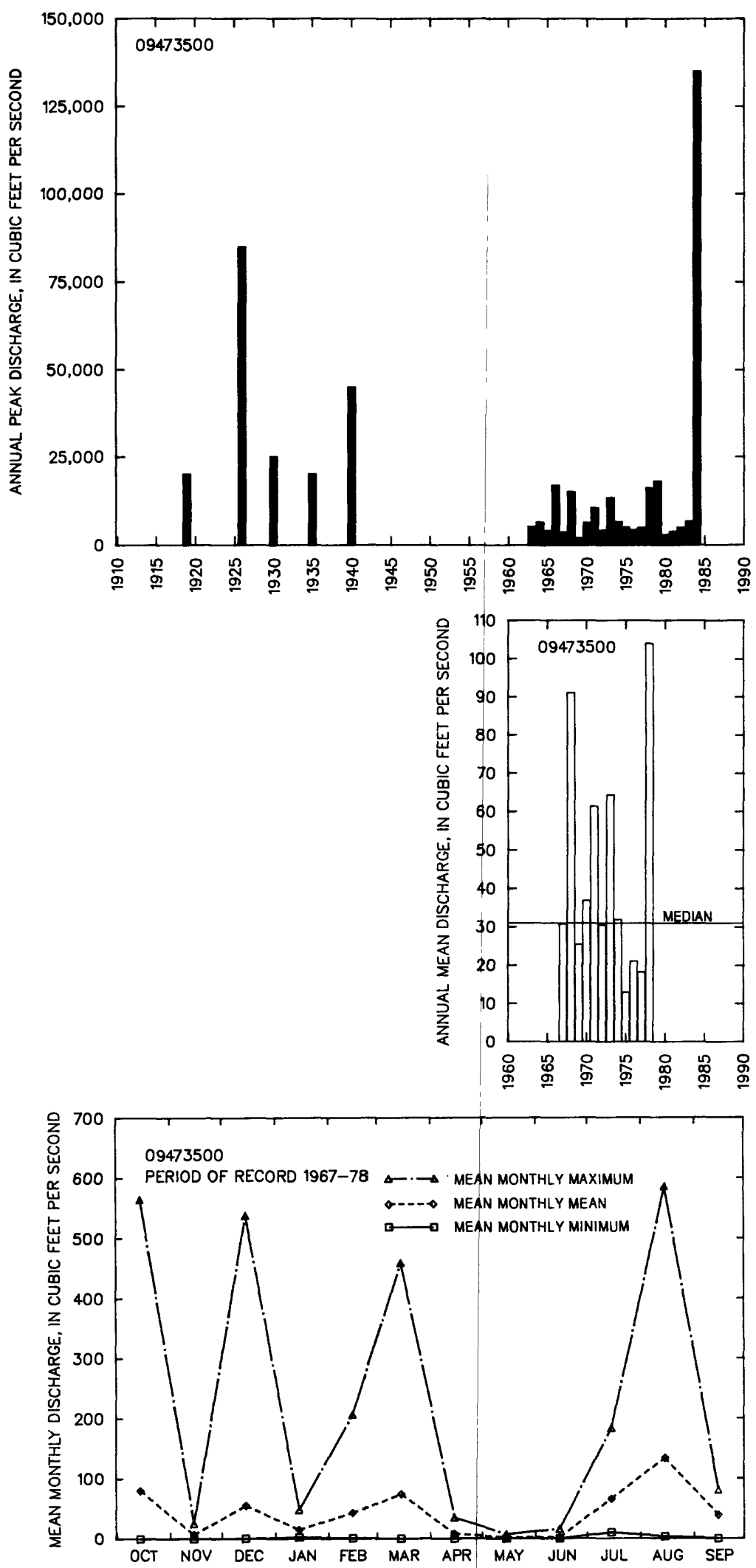
09473600 TAM O'SHANTER WASH NEAR HAYDEN, AZ

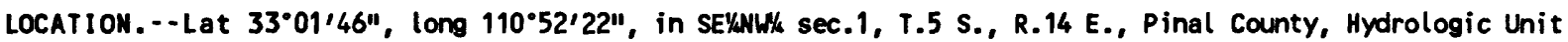
15050100, at State Highway 177,6 mi les west of Hayden.

DRAIHAGE AREA. $--4.37 \mathrm{mi}^{2}$.

ANMUAL PEAK DISCHARGE

\begin{tabular}{|c|c|c|c|}
\hline $\begin{array}{l}\text { MATER } \\
\text { YEAR }\end{array}$ & DATE & $\begin{array}{c}\text { ANNUAL PEAK } \\
\text { DISCHARGE } \\
\text { (FT } 3 / S)\end{array}$ & $\begin{array}{l}\text { DISCHARGE } \\
\text { CODES }\end{array}$ \\
\hline $\begin{array}{l}1963 \\
1964 \\
1965 \\
1966 \\
1967 \\
1968 \\
1969 \\
1970 \\
1971 \\
1972 \\
1973 \\
1974 \\
1975 \\
1976 \\
1981\end{array}$ & $\begin{array}{l}08-00-63 \\
00-00-64 \\
07-00-65 \\
09-13-66 \\
07-22-67 \\
08-03-68 \\
00-00-69 \\
03-03-70 \\
09-30-71 \\
09-02-72 \\
05-31-73 \\
08-02-74 \\
09-13-75 \\
00-00-76 \\
00-00-81\end{array}$ & $\begin{array}{c}322 \\
305 \\
412 \\
399 \\
445 \\
460 \\
0 \\
180 \\
410 \\
260 \\
615 \\
1,570 \\
360 \\
5.0 \\
1690\end{array}$ & HP \\
\hline
\end{tabular}

$\mathcal{I H}_{\text {Highest since } 1974 .}$

MAGNITUDE AND PROBABILITY OF INSTANTANEOUS PEAK FLON BASED ON PERIOD OF RECORD 1963-76, 1981

DISCHARGE, IN $\mathrm{FT}^{3} / \mathrm{S}$, FOR INDICATED RECURRENCE INTERVAL IN YEARS, AND EXCEEDANCE PROBABILITY, IN PERCENT

\begin{tabular}{lccccc}
2 & 5 & 10 & 25 & $50 \dagger$ & $100 \dagger$ \\
$50 \%$ & $20 \%$ & $10 \%$ & $4 \%$ & $2 \%$ & $1 \%$ \\
368 & 586 & 759 & 1,010 & 1,220 & 1,460 \\
\hline WEIGHTED SKEW (LOGS) & & 0.28 & & \\
MEAN & $\quad$ (LOGS) & 2.58 & & \\
STANDARD DEV. (LOGS) & $=0.23$ & &
\end{tabular}

$\uparrow$ Reliability of values in column is uncertain, and potential errors are large.

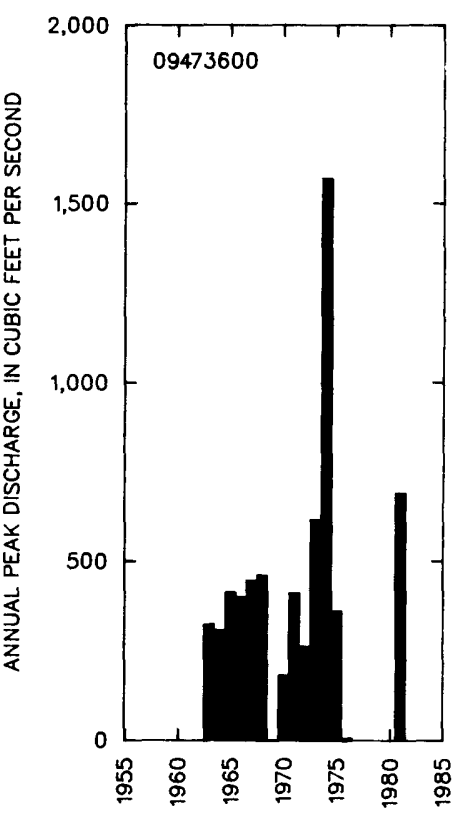




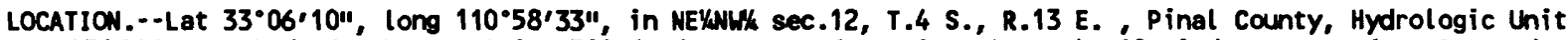
15050100, on left bank at Kelvin, $500 \mathrm{ft}$ dounstream from Mineral Creek, 18 mi downstream from San Pedro River, and $19 \mathrm{mi}$ upstream from Ashurst-Hayden Dam.

DRAINAGE AREA. - - 18,011 $\mathrm{mi}^{2}$, of which $5,125 \mathrm{mi}^{2}$ is below Coolidge'Dam.

REMARKS. --Annual peak discharges are for unregulated flow.

ANNUAL PEAK -DISCHARGE

\begin{tabular}{|c|c|c|c|c|c|c|c|}
\hline $\begin{array}{l}\text { WATER } \\
\text { YEAR }\end{array}$ & DATE & $\begin{array}{c}\text { ANNUAL PEAK } \\
\text { DISCHARGE } \\
\left(\mathrm{FT}^{3} / \mathrm{S}\right)\end{array}$ & $\begin{array}{l}\text { DISCHARGE } \\
\text { CCOES }\end{array}$ & $\begin{array}{l}\text { WATER } \\
\text { YEAR }\end{array}$ & DATE & $\begin{array}{c}\text { ANIUALL PEAK } \\
\text { DISCHARGE } \\
\left(\mathrm{FT}^{3} / \mathrm{S}\right)\end{array}$ & $\begin{array}{l}\text { DISCHARGE } \\
\text { CODES }\end{array}$ \\
\hline $\begin{array}{l}1913 \\
1914 \\
1915 \\
1916 \\
1917 \\
1918 \\
1919 \\
1920 \\
1921 \\
1922 \\
1923 \\
1924 \\
1925 \\
1926 \\
1927 \\
1928 \\
1929 \\
1930 \\
1931 \\
1932 \\
1933 \\
1934 \\
1935 \\
1936 \\
1937 \\
1938 \\
1939 \\
1940 \\
1941 \\
1942 \\
1943 \\
1944 \\
1945 \\
1946 \\
1947 \\
1948 \\
1949 \\
1950 \\
1951\end{array}$ & $\begin{array}{l}00-00-13 \\
09-21-14 \\
12-24-14 \\
01-20-16 \\
08-13-17 \\
08-06-18 \\
08-03-19 \\
12-05-19 \\
07-31-21 \\
07-26-22 \\
07-14-23 \\
08-03-24 \\
08-06-25 \\
09-28-26 \\
09-12-27 \\
08-02-28 \\
09-24-29 \\
08-08-30 \\
08-30-31 \\
10-02-31 \\
07-24-33 \\
08-23-34 \\
08-29-35 \\
09-11-36 \\
08-21-37 \\
08-05-38 \\
08-07-39 \\
08-14-40 \\
12-31-40 \\
08-09-42 \\
09-26-43 \\
08-09-44 \\
08-10-45 \\
08-05-46 \\
08-08-47 \\
08-03-48 \\
09-15-49 \\
07-30-50 \\
08-03-51\end{array}$ & $\begin{array}{r}4,000 \\
17,600 \\
30,000 \\
100,000 \\
20,000 \\
10,000 \\
18,000 \\
15,000 \\
15,000 \\
7,400 \\
11,400 \\
2,000 \\
6,200 \\
81,000 \\
3,000 \\
11,800 \\
11,400 \\
42,600 \\
28,100 \\
12,800 \\
8,100 \\
6,750 \\
21,000 \\
12,100 \\
10,100 \\
5,630 \\
9,320 \\
38,000 \\
23,300 \\
2,600 \\
6,100 \\
28,000 \\
9,200 \\
6,440 \\
10,000 \\
5,800 \\
5,600 \\
6,800 \\
13,100\end{array}$ & $\begin{array}{l}\text { ES } \\
\text { ES } \\
\text { ES } \\
\text { ES } \\
\text { ES } \\
\text { ES } \\
\\
\text { ES }\end{array}$ & \begin{tabular}{l|}
1952 \\
1953 \\
1954 \\
1955 \\
1956 \\
1957 \\
1958 \\
1959 \\
1960 \\
1961 \\
1962 \\
1963 \\
1964 \\
1965 \\
1966 \\
1967 \\
1968 \\
1969 \\
1970 \\
1971 \\
1972 \\
1973 \\
1974 \\
1975 \\
1976 \\
1977 \\
1978 \\
1979 \\
1980 \\
1981 \\
1982 \\
1983 \\
1984 \\
1985 \\
1986 \\
1987 \\
1988 \\
1989
\end{tabular} & $\begin{array}{l}01-14-52 \\
07-07-53 \\
08-05-54 \\
08-08-55 \\
08-17-56 \\
08-19-57 \\
08-06-58 \\
08-17-59 \\
12-26-59 \\
07-22-61 \\
12-16-61 \\
02-12-63 \\
08-15-64 \\
08-17-65 \\
12-23-65 \\
09-24-67 \\
12-20-67 \\
01-22-69 \\
03-03-70 \\
08-20-71 \\
10-01-71 \\
10-20-72 \\
08-02-74 \\
07-23-75 \\
07-28-76 \\
09-11-77 \\
10-11-77 \\
12-19-78 \\
02-15-80 \\
08-01-81 \\
09-12-82 \\
03-19-83 \\
10-02-83 \\
12-30-84 \\
03-18-86 \\
08-04-87 \\
07-25-88 \\
07-24-89\end{array}$ & $\begin{array}{r}5,430 \\
4,210 \\
17,800 \\
9,860 \\
1,800 \\
4,300 \\
5,000 \\
5,930 \\
11,200 \\
9,600 \\
4,910 \\
5,880 \\
4,150 \\
4,980 \\
26,200 \\
3,900 \\
27,600 \\
5,000 \\
6,400 \\
3,120 \\
3,930 \\
10,300 \\
3,880 \\
2,000 \\
2,340 \\
2,220 \\
16,100 \\
27,000 \\
6,950 \\
3,320 \\
3,530 \\
4,490 \\
100,000 \\
6,150 \\
4,270 \\
1,670 \\
4,080 \\
1,720\end{array}$ & ES \\
\hline
\end{tabular}

BASIN CHARACTERISTICS

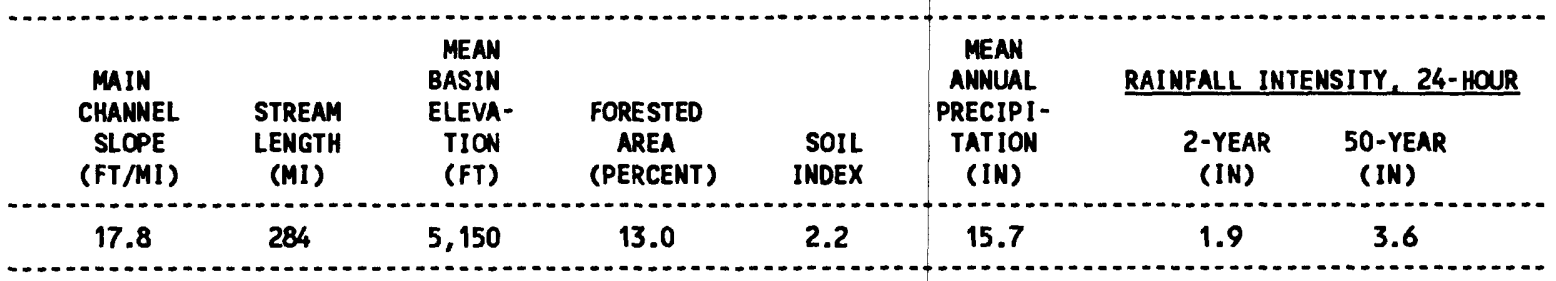


09474000 GILA RIVER AT KELVIN, AZ--Continued

MEAN MONTHLY AND ANNUAL DISCHARGES 1929-89

\begin{tabular}{|c|c|c|c|c|c|c|}
\hline MONTH & $\begin{array}{l}\left.\operatorname{MAX} \operatorname{IMMN}_{(\mathrm{M}}{ }^{3} / \mathrm{S}\right)\end{array}$ & $\begin{array}{l}\text { MINIMUN } \\
\left(\mathrm{FT}^{3} / \mathrm{S}\right)\end{array}$ & $\begin{array}{c}\text { MEAN } \\
\left(F T^{3} / S\right)\end{array}$ & $\begin{array}{l}\text { STAN- } \\
\text { DARD } \\
\text { DEVIA- } \\
\text { TION } \\
\text { (FT'/S) }\end{array}$ & $\begin{array}{l}\text { COEFFI - } \\
\text { CIENT OF } \\
\text { VARI - } \\
\text { ATION }\end{array}$ & $\begin{array}{c}\text { PERCENT } \\
\text { OF } \\
\text { ANNUAL } \\
\text { RUNOFF }\end{array}$ \\
\hline $\begin{array}{l}\text { OCTCBER } \\
\text { NOVEMBER } \\
\text { DECEMBER } \\
\text { JANUARY } \\
\text { FEBRUARY } \\
\text { MARCH } \\
\text { APRIL } \\
\text { MAY } \\
\text { JUNE } \\
\text { JULY } \\
\text { AUGUST } \\
\text { SEPTEMBER }\end{array}$ & $\begin{array}{r}4,370 \\
752 \\
1,690 \\
2,000 \\
2,900 \\
3,330 \\
1,210 \\
1,110 \\
1,200 \\
1,430 \\
1,570 \\
923\end{array}$ & $\begin{array}{c}1.0 \\
3.1 \\
7.1 \\
9.3 \\
22 \\
38 \\
9.2 \\
2.5 \\
0.46 \\
2.7 \\
43 \\
2.1\end{array}$ & $\begin{array}{l}251 \\
130 \\
300 \\
241 \\
338 \\
549 \\
448 \\
421 \\
507 \\
654 \\
797 \\
459\end{array}$ & $\begin{array}{l}553 \\
124 \\
384 \\
366 \\
399 \\
509 \\
255 \\
269 \\
347 \\
390 \\
374 \\
229\end{array}$ & $\begin{array}{l}2.2 \\
0.96 \\
1.3 \\
1.5 \\
1.2 \\
0.93 \\
0.57 \\
0.64 \\
0.68 \\
0.60 \\
0.47 \\
0.50\end{array}$ & $\begin{array}{r}4.9 \\
2.5 \\
5.9 \\
4.7 \\
6.6 \\
10.8 \\
8.8 \\
8.3 \\
10.0 \\
12.8 \\
15.6 \\
9.0\end{array}$ \\
\hline NNUA & 1,280 & 78 & 426 & 253 & 0.59 & 100 \\
\hline
\end{tabular}

MAGNitLDE AND PROBABILITY OF INSTANTANEOUS PEAK FLOW BASED ON PERIOD OF RECORD

DISCHARGE, IN $\mathrm{FT}^{3} / \mathrm{S}$, FOR INDICATED RECURRENCE INTERVAL IN YEARS, AND EXCEEDANCE PROBABILITY, IN PERCENT

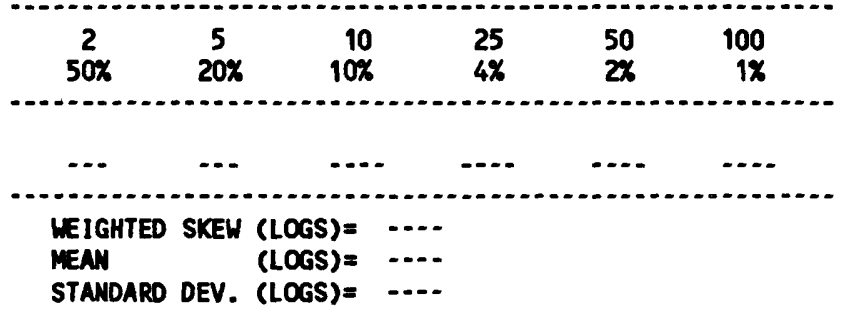

MAGNITLDE AND PROBABILITY OF ANNUAL LON FLON BASED ON PERIOD OF RECORD 1930-89

\begin{tabular}{|c|c|c|c|c|c|c|}
\hline \multirow{2}{*}{$\begin{array}{l}\text { PERICO } \\
\text { (CON- } \\
\text { SECU- } \\
\text { TIVE } \\
\text { DAYS) }\end{array}$} & \multicolumn{6}{|c|}{$\begin{array}{l}\text { DISCHARGE, IN FT } 3 / S \text {, FOR INDICATED } \\
\text { RECURRENCE INTERVAL, IN YEARS, AND } \\
\text { NOW-EXCEEDANCE PROBABILITY, IN PERCENT }\end{array}$} \\
\hline & $\begin{array}{c}2 \\
50 \%\end{array}$ & $\begin{array}{c}5 \\
20 \%\end{array}$ & $\begin{array}{l}10 \\
10 \%\end{array}$ & $\begin{array}{l}20 \\
5 \%\end{array}$ & $\begin{array}{l}50 \\
2 x\end{array}$ & $\begin{array}{l}100 \\
1 \%\end{array}$ \\
\hline $\begin{array}{r}1 \\
3 \\
7 \\
14 \\
30 \\
60 \\
90 \\
120 \\
183\end{array}$ & $\begin{array}{r}19 \\
20 \\
22 \\
25 \\
35 \\
69 \\
104 \\
135 \\
218\end{array}$ & $\begin{array}{c}3.1 \\
3.3 \\
3.6 \\
4.5 \\
6.4 \\
16 \\
30 \\
52 \\
108\end{array}$ & $\begin{array}{l}0.97 \\
1.0 \\
1.2 \\
1.5 \\
2.2 \\
6.1 \\
13 \\
27 \\
66\end{array}$ & $\begin{array}{c}0.33 \\
0.35 \\
0.40 \\
0.57 \\
0.79 \\
2.4 \\
5.9 \\
14 \\
41\end{array}$ & $\begin{array}{l}0.08 \\
0.09 \\
0.11 \\
0.17 \\
0.22 \\
0.76 \\
2.2 \\
6.3 \\
22\end{array}$ & $\begin{array}{c}0.03 \\
0.03 \\
0.04 \\
0.07 \\
0.09 \\
0.33 \\
1.0 \\
3.4 \\
14\end{array}$ \\
\hline
\end{tabular}

MAGNITLOE AND PROBABILITY OF ANNUAL HIGH FLOW BASED ON PERIOD OF RECORD 1929-89

\begin{tabular}{|c|c|c|c|c|c|c|}
\hline \multirow{2}{*}{$\begin{array}{l}\text { PERIOD } \\
\text { (CON- } \\
\text { SECU- } \\
\text { TIVE } \\
\text { DAYS) }\end{array}$} & & \multicolumn{5}{|c|}{$\begin{array}{l}\text { DISCHARGE, IN FT }{ }^{3} / S \text {, FOR INDICATED } \\
\text { RECURRENCE INTERVAL, IN YEARS, AND } \\
\text { EXCEEDANCE PROBABILITY, IN PERCENT }\end{array}$} \\
\hline & $\begin{array}{c}2 \\
50 \%\end{array}$ & $\begin{array}{c}5 \\
20 \%\end{array}$ & $\begin{array}{l}10 \\
10 \%\end{array}$ & $\begin{array}{l}25 \\
4 x\end{array}$ & $\begin{array}{l}50 \\
2 \%\end{array}$ & $\begin{array}{r}100 \\
1 \%\end{array}$ \\
\hline $\begin{array}{l}1 \\
3 \\
7 \\
15 \\
30 \\
60 \\
90\end{array}$ & $\begin{array}{r}3,270 \\
2,100 \\
1,400 \\
1,040 \\
865 \\
732 \\
653\end{array}$ & $\begin{array}{l}7,080 \\
4,190 \\
2,600 \\
1,820 \\
1,430 \\
1,190 \\
1,090\end{array}$ & $\begin{array}{r}11,300 \\
6,360 \\
3,750 \\
2,520 \\
1,880 \\
1,530 \\
1,390\end{array}$ & $\begin{array}{r}19,400 \\
10,400 \\
5,730 \\
3,630 \\
2,540 \\
2,010 \\
1,790\end{array}$ & $\begin{array}{r}28,200 \\
14,600 \\
7,670 \\
4,660 \\
3,110 \\
2,390 \\
2,090\end{array}$ & $\begin{array}{r}40,400 \\
20,300 \\
10,100 \\
5,870 \\
3,750 \\
2,790 \\
2,390\end{array}$ \\
\hline
\end{tabular}

DURATION TABLE OF DAILY MEAN FLON FOR PERIOD OF RECORD 1929-89

DISCHARGE, IN FT $3 / 5$, WHICH WAS EQUALED OR EXCEEDED FOR INDICATED PERCENT OF TIME

\begin{tabular}{|c|c|c|c|c|c|c|c|c|c|c|c|c|c|c|c|c|}
\hline $1 \%$ & $5 \%$ & $10 x$ & $15 \%$ & $20 \%$ & $30 \%$ & $40 \%$ & $50 \%$ & $60 \%$ & $70 \%$ & $80 \%$ & $90 \%$ & $95 \%$ & $98 \%$ & $99 \%$ & $99.5 \%$ & $99.9 \%$ \\
\hline, 530 & 1,220 & 965 & 791 & 678 & 516 & 382 & 282 & 203 & 141 & 85 & 30 & 10 & 1.8 & 0.83 & 0.57 & 0.1 \\
\hline
\end{tabular}


GILA RIVER BASIN

09474000 GILA RIVER AT KELVIN AZ--CONTINUED
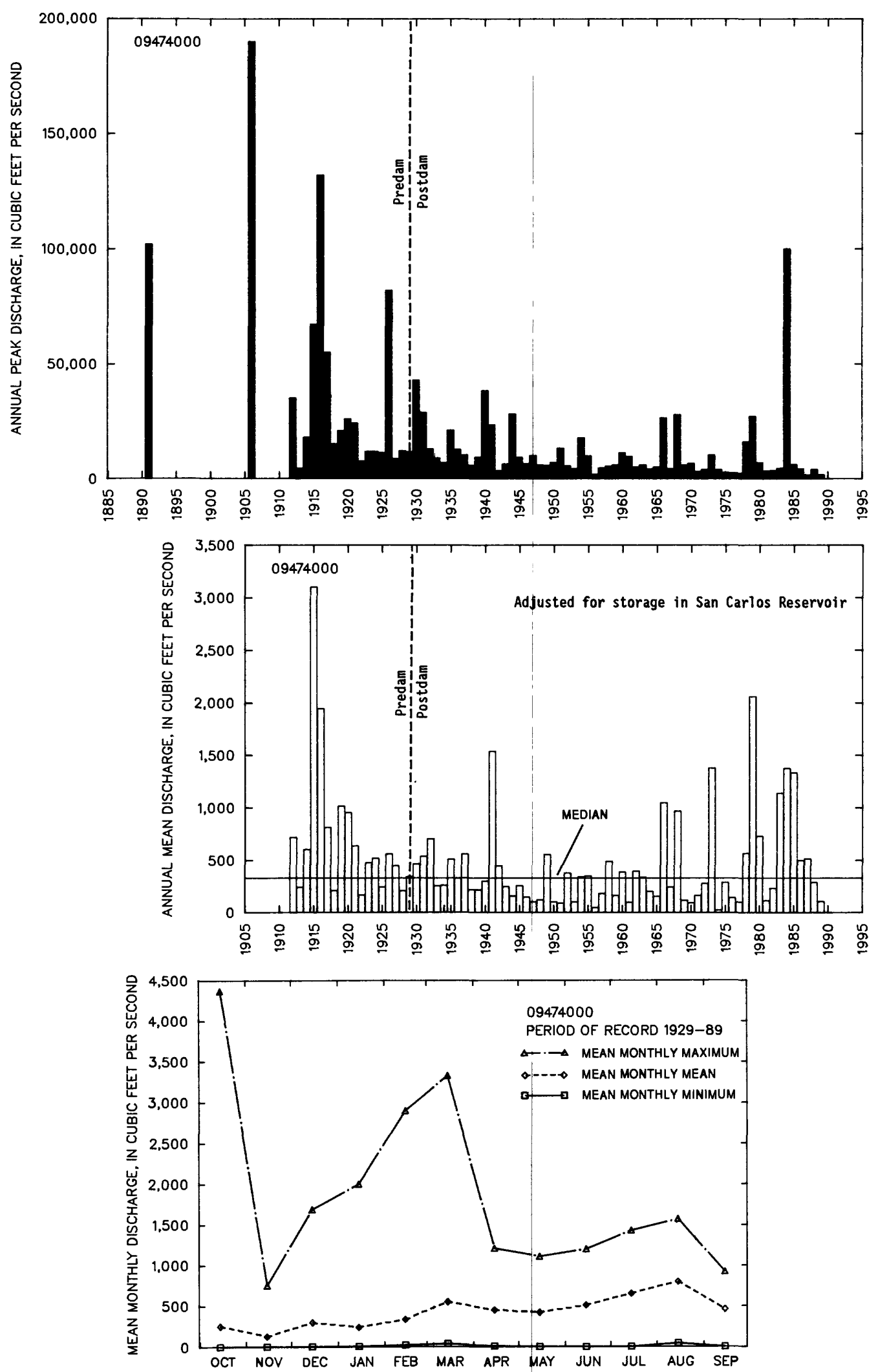
09478200 DURHAM WASH NEAR FLORENCE, AZ

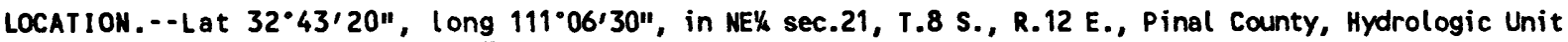
15050100 , at U.S. Highway 80,27 miles southeast of Florence.

DRAINAGE AREA. $--15.6 \mathrm{mi}^{2}$.

ANMUAL PEAK DISCHARGE

\begin{tabular}{|c|c|c|c|}
\hline $\begin{array}{l}\text { WATER } \\
\text { YEAR }\end{array}$ & DATE & $\begin{array}{l}\text { ANNUAL PEAK } \\
\text { DISCHARGE } \\
\text { (FT } 3 / \mathrm{S})\end{array}$ & $\begin{array}{l}\text { DISCHARGE } \\
\text { CODES }\end{array}$ \\
\hline $\begin{array}{l}1954 \\
1955 \\
1956 \\
1957 \\
1963 \\
1964 \\
1965 \\
1966 \\
1967 \\
1968 \\
1969 \\
1970 \\
1971 \\
1972 \\
1973 \\
1974 \\
1975 \\
1976 \\
1980\end{array}$ & $\begin{array}{l}07-20-54 \\
08-00-55 \\
07-00-56 \\
00-00-57 \\
09-01-63 \\
09-14-64 \\
09-08-65 \\
12-00-65 \\
09-25-67 \\
00-00-68 \\
00-00-69 \\
08-00-70 \\
08-20-71 \\
06-00-72 \\
10-19-72 \\
08-02-74 \\
09-13-75 \\
09-25-76 \\
07-00-80\end{array}$ & $\begin{array}{r}3,340 \\
1,000 \\
100 \\
2,700 \\
1,080 \\
1,790 \\
40 \\
50 \\
230 \\
500 \\
310 \\
290 \\
23,500 \\
1,450 \\
100 \\
550 \\
570 \\
1,100 \\
3500\end{array}$ & $\begin{array}{l}\text { ES } \\
\text { ES }\end{array}$ \\
\hline
\end{tabular}

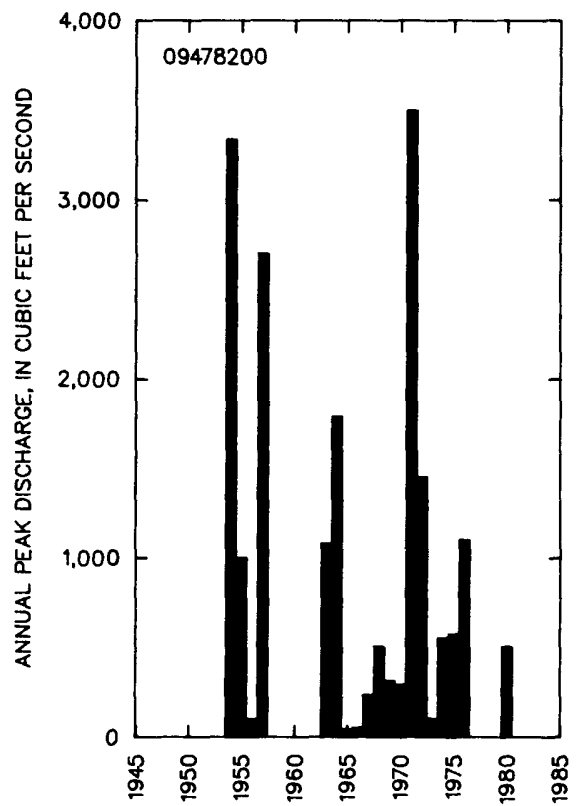

1Highest since 1957 .

2 Highest since 1954 .

3ighest since 1976 .

MAGNITUDE AND PROBABILITY OF INSTANTANEOUS PEAK FLOW BASED ON PERIOD OF RECORD 1954-57, 1963-76, 1980

DISCHARGE, IN $\mathrm{FT}^{3} / \mathrm{S}$, FOR INDICATED RECURRENCE INTERVAL IN YEARS, AND EXCEEDANCE PROBABILITY, IN PERCENT

\begin{tabular}{|c|c|c|c|c|c|}
\hline$\stackrel{2}{50 \%}$ & $\begin{array}{c}5 \\
20 \%\end{array}$ & $\begin{array}{r}10 \\
10 \%\end{array}$ & $\begin{array}{l}25 \\
4 \%\end{array}$ & $\begin{array}{l}50 \dagger \\
2 \%\end{array}$ & $\begin{array}{c}100 \dagger \\
1 \%\end{array}$ \\
\hline 561 & 1,320 & 2,050 & 3,260 & 4,390 & 5,710 \\
\hline $\begin{array}{l}\text { WEIGHTED } \\
\text { MEAN } \\
\text { STANDARD }\end{array}$ & $\begin{array}{l}\text { SKEW } \\
\text { DEV. }\end{array}$ & $\begin{array}{l}(\text { LOGS })= \\
(\text { LOGS })= \\
(\text { LOGS })=\end{array}$ & $\begin{array}{r}-0.08 \\
2.74 \\
0.45\end{array}$ & & \\
\hline
\end{tabular}

$\uparrow$ Reliability of values in colum is uncertain, and potential errors are large.

\section{BASIN CHARACTERISTICS}

\begin{tabular}{|c|c|c|c|c|c|c|c|}
\hline \multirow{2}{*}{$\begin{array}{l}\text { MAIN } \\
\text { CHANNEL } \\
\text { SLOPE } \\
\text { (FT/MI) }\end{array}$} & \multirow[b]{2}{*}{$\begin{array}{l}\text { STREAM } \\
\text { LENGTH } \\
\text { (MI) }\end{array}$} & \multirow{2}{*}{$\begin{array}{l}\text { MEAN } \\
\text { BASIN } \\
\text { ELEVA- } \\
\text { TION } \\
\text { (FT) }\end{array}$} & \multirow[b]{2}{*}{$\begin{array}{l}\text { FORESTED } \\
\text { AREA } \\
\text { (PERCENT) }\end{array}$} & \multirow[b]{2}{*}{$\begin{array}{l}\text { SOIL } \\
\text { INDEX }\end{array}$} & $\begin{array}{c}\text { MEAN } \\
\text { ANNUAL } \\
\text { PRECIPI- }\end{array}$ & \multicolumn{2}{|c|}{ RAINFALL INTENSITY, 24-HOUR } \\
\hline & & & & & $\begin{array}{l}\text { PRECIPI- } \\
\text { TATION } \\
\text { (IN) }\end{array}$ & $\begin{array}{l}\text { 2-YEAR } \\
\text { (IN) }\end{array}$ & $\begin{array}{l}\text { 50-YEAR } \\
\text { (IN) }\end{array}$ \\
\hline 143 & 11.0 & $3 ; 670$ & 0.0 & 3.0 & 12.1 & 1.9 & 4.3 \\
\hline
\end{tabular}


09478500 QUEEN CREEK AT WHITLON DAMSITE, NEAR SUPERIOR, AZ

LOCATION.--Lat 33'17'55", long 111'16'25", in NWHSE sec.36, T.1 S., R.10 E., Pinal County, Hydrologic Unit 15050100, at thitlow damsite, 2.5 mi upstream from thitlow Canyon, 4 mi northeast of Florence Junction, and $10 \mathrm{mi}$ west of superior.

DRAINAGE AREA. $--144 \mathrm{mi}^{2}$.'

ANNUAL PEAK DISCHARGE

\begin{tabular}{|c|c|c|c|}
\hline $\begin{array}{l}\text { WATER } \\
\text { YEAR }\end{array}$ & DATE & $\begin{array}{l}\text { ANNUAL PEAK } \\
\text { DISCHARGE } \\
\text { (FT } 3 / S)\end{array}$ & $\begin{array}{l}\text { DISCHARGE } \\
\text { CODES }\end{array}$ \\
\hline $\begin{array}{l}1917 \\
1918 \\
1919 \\
1920 \\
1939 \\
1948 \\
1949 \\
1950 \\
1951 \\
1952 \\
1953 \\
1954 \\
1955 \\
1956 \\
1957 \\
1958 \\
1959\end{array}$ & $\begin{array}{l}05-20-17 \\
08-05-18 \\
08-01-19 \\
02-20-20 \\
08-06-39 \\
07-21-48 \\
07-22-49 \\
07-18-50 \\
08-03-51 \\
01-18-52 \\
07-29-53 \\
08-19-54 \\
08-03-55 \\
08-17-56 \\
08-19-57 \\
03-22-58 \\
08-17-59\end{array}$ & $\begin{array}{r}2,800 \\
5,000 \\
10,000 \\
750 \\
13,200 \\
676 \\
2,630 \\
5,100 \\
1,510 \\
1,170 \\
1,780 \\
42,900 \\
5,430 \\
4,100 \\
8,260 \\
3,970 \\
30,000\end{array}$ & ES \\
\hline
\end{tabular}

BASIN CHARACTERISTICS

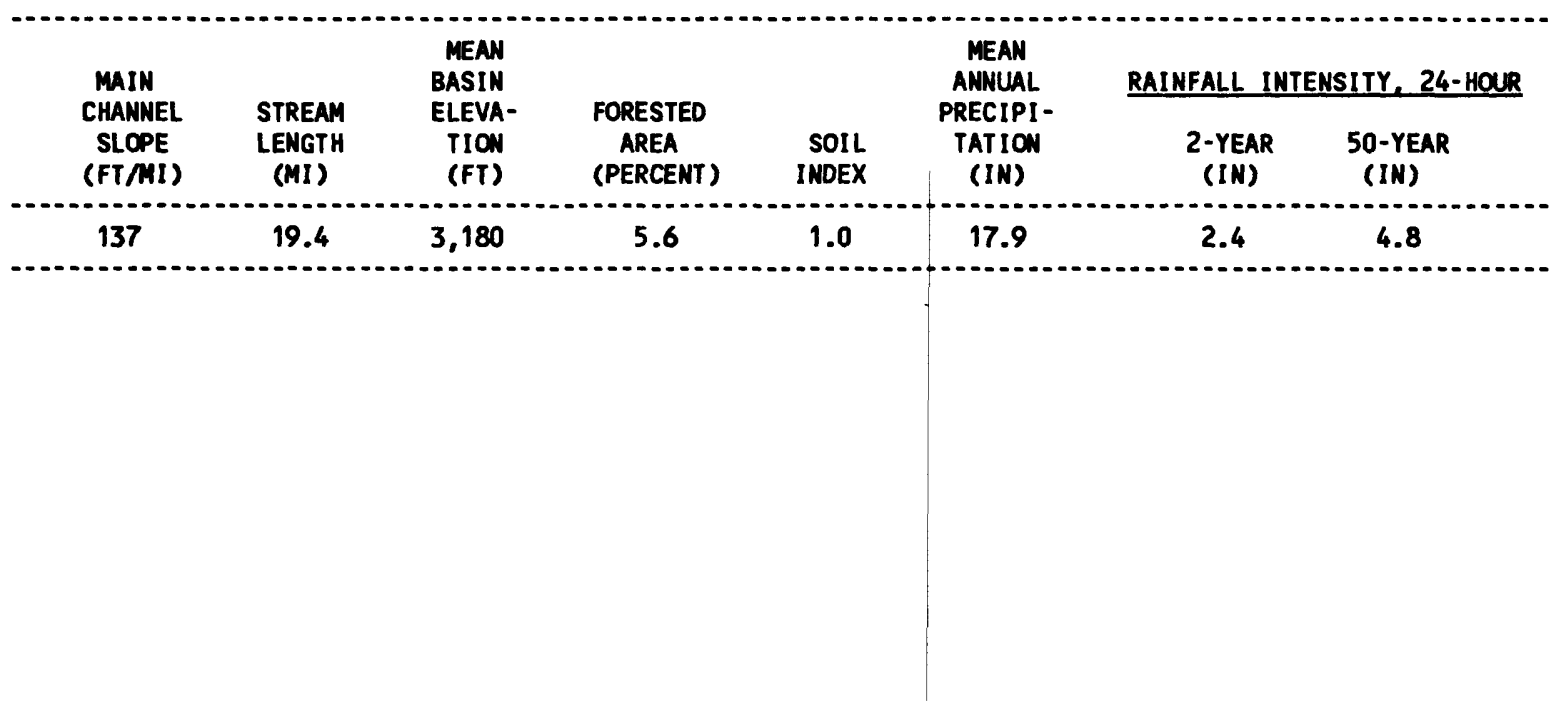


09478500 QUEEN CREEK AT WHITLOW DAMSITE MEAR SUPERIOR, AZ--Continued

MEAN MONTHLY AND ANMUAL DISCHARGES $1949-58$

\begin{tabular}{|c|c|c|c|c|c|c|}
\hline MONTH & 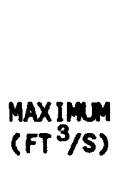 & $\begin{array}{l}\text { MINIMUM } \\
\left(F T^{3} / S\right)\end{array}$ & $\begin{array}{c}\text { MEAN } \\
\left(F T^{3} / S\right)\end{array}$ & $\begin{array}{c}\text { STAN- } \\
\text { DARO } \\
\text { DEVIA- } \\
\text { TION } \\
\text { (FT } 3 / S)\end{array}$ & $\begin{array}{l}\text { COEFFI - } \\
\text { CIENT OF } \\
\text { VARI - } \\
\text { ATION }\end{array}$ & $\begin{array}{c}\text { PERCENT } \\
\text { OF } \\
\text { ANNUAL } \\
\text { RUNOFF }\end{array}$ \\
\hline $\begin{array}{l}\text { OCTOBER } \\
\text { NOVEMBER } \\
\text { DECEMBER } \\
\text { JANUARY } \\
\text { FEBRUARY } \\
\text { MARCH } \\
\text { APRIL } \\
\text { MAY } \\
\text { JUNE } \\
\text { JULY } \\
\text { AUGUST } \\
\text { SEPTEMBER }\end{array}$ & $\begin{array}{c}8.5 \\
3.8 \\
13 \\
17 \\
4.4 \\
50 \\
8.9 \\
2.4 \\
10 \\
19 \\
106 \\
2.8\end{array}$ & $\begin{array}{l}0.00 \\
0.00 \\
0.00 \\
0.00 \\
0.00 \\
0.00 \\
0.00 \\
0.00 \\
0.00 \\
0.30 \\
0.03 \\
0.00\end{array}$ & $\begin{array}{l}1.1 \\
0.61 \\
2.0 \\
3.8 \\
0.65 \\
13 \\
1.7 \\
0.55 \\
1.4 \\
5.6 \\
18 \\
0.75\end{array}$ & $\begin{array}{c}2.7 \\
1.2 \\
4.0 \\
5.1 \\
1.4 \\
18 \\
3.3 \\
0.87 \\
3.2 \\
6.8 \\
32 \\
1.2\end{array}$ & $\begin{array}{l}2.4 \\
2.0 \\
2.0 \\
1.4 \\
2.1 \\
1.4 \\
2.0 \\
1.6 \\
2.2 \\
1.2 \\
1.8 \\
1.6\end{array}$ & $\begin{array}{r}2.3 \\
1.2 \\
4.1 \\
7.7 \\
1.3 \\
25.6 \\
3.5 \\
1.1 \\
2.9 \\
11.4 \\
37.4 \\
1.5\end{array}$ \\
\hline NMUAL & 14 & 1.3 & 4.1 & 3.7 & 0.89 & 100 \\
\hline
\end{tabular}

MAGNITUDE AND PROBABILITY OF INSTANTAMEOUS PEAK FLOW BASED ON PERIOD OF RECORD 1917-20, 1939, 1948-59

DISCHARGE, IN $\mathrm{FT}^{3} / \mathrm{S}$, FOR INDICATED RECURREMCE INTERVAL IN YEARS, AND EXCEEDANCE PROBABILITY, IN PERCENT

\begin{tabular}{lccccc}
2 & 5 & 10 & 25 & $50 \dagger$ & $100 \dagger$ \\
$50 \%$ & $20 \%$ & $10 \%$ & $4 \%$ & $2 \%$ & $1 \%$ \\
3,630 & 8,850 & 14,300 & 24,000 & 33,800 & 46,100 \\
\hline MEIGHTED SKEW (LOGS) & $=0.13$ & & \\
MEAN & (LOGS) & 3.57 \\
STANDARD DEV. (LOGS) & $=0.45$
\end{tabular}

MAGNITUDE AND PROBABILITY OF ANNUAL LOH FLOM BASED ON PERIOD OF RECORD 1950-58

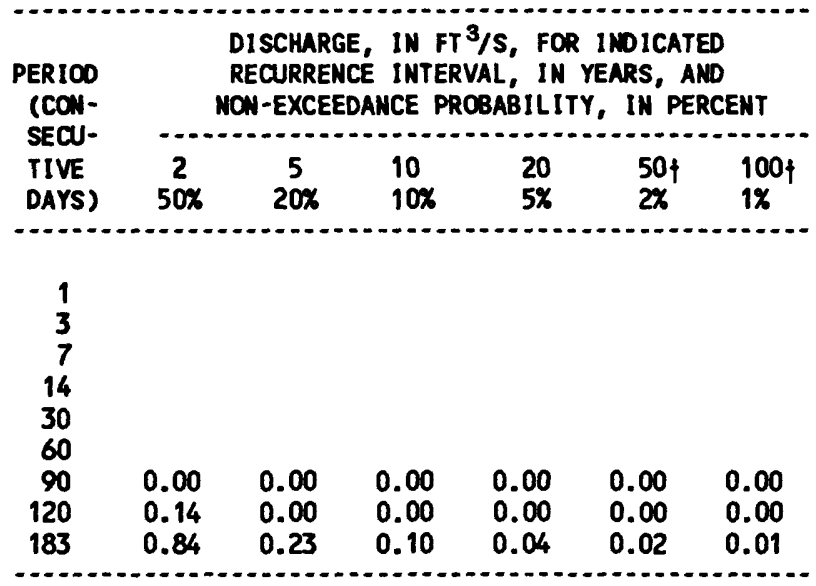

MAGNITLOE AND PROBABILITY OF ANNUAL HIGH FLON BASED ON PERIOD OF RECORD 1949-58

\begin{tabular}{|c|c|c|c|c|c|c|}
\hline \multirow{2}{*}{$\begin{array}{l}\text { PERIOD } \\
\text { (CON- } \\
\text { SECU- } \\
\text { TIVE } \\
\text { DAYS) }\end{array}$} & \multicolumn{6}{|c|}{$\begin{array}{l}\text { DISCHARGE, IN FT } 3 / S \text {, FOR INDICATED } \\
\text { RECURRENCE INTERVAL, IN YEARS, AND } \\
\text { EXCEEDANCE PROBABILITY, IN PERCENT }\end{array}$} \\
\hline & $\begin{array}{c}2 \\
50 \%\end{array}$ & $\begin{array}{c}5 \\
20 \%\end{array}$ & $\begin{array}{l}10 \\
10 \%\end{array}$ & $\begin{array}{l}25 \\
4 \%\end{array}$ & $\begin{array}{l}50 \dagger \\
22\end{array}$ & $\begin{array}{c}100 \dagger \\
1 \%\end{array}$ \\
\hline $\begin{array}{r}1 \\
3 \\
7 \\
15 \\
30 \\
60 \\
90\end{array}$ & $\begin{array}{c}297 \\
122 \\
60 \\
35 \\
22 \\
12 \\
9.1\end{array}$ & $\begin{array}{r}670 \\
266 \\
129 \\
76 \\
43 \\
24 \\
18\end{array}$ & $\begin{array}{r}1,150 \\
436 \\
205 \\
118 \\
65 \\
35 \\
27\end{array}$ & $\begin{array}{r}2,250 \\
792 \\
354 \\
195 \\
103 \\
53 \\
40\end{array}$ & $\begin{array}{r}3,650 \\
1,210 \\
518 \\
274 \\
142 \\
71 \\
54\end{array}$ & $\begin{array}{r}5,860 \\
1,830 \\
745 \\
376 \\
193 \\
93 \\
69\end{array}$ \\
\hline
\end{tabular}

DURATION TABLE OF DALLY MEAN FLOW FOR PERIOD OF RECORD 1949-58

DISCHARGE, IN FT $3 / \mathrm{S}$, WHICH WAS EQUALED OR EXCEEDED FOR INDICATED PERCENT OF TIME

\begin{tabular}{|c|c|c|c|c|c|c|c|c|c|c|c|c|c|c|c|c|}
\hline $1 \%$ & $5 \%$ & $10 \%$ & $15 \%$ & $20 \%$ & $30 \%$ & $40 \%$ & $50 \%$ & $60 \%$ & $70 \%$ & $80 \%$ & $90 \%$ & $95 \%$ & $98 \%$ & $99 \%$ & $99.5 \%$ & $99.9 \%$ \\
\hline 88 & 3.3 & 1.7 & 0.96 & 0.53 & 0.19 & 0.00 & 0.00 & 0.00 & 0.00 & 0.00 & 0.00 & 0.00 & 0.00 & 0.00 & 0.00 & 0.00 \\
\hline
\end{tabular}

i Reliability of values in column is uncertain, and potential errors are large. 
09478500 QUEEN CREEK AT WHITLOW DANSITE, NEAR SUPERIOR, AZ--CONTINUED
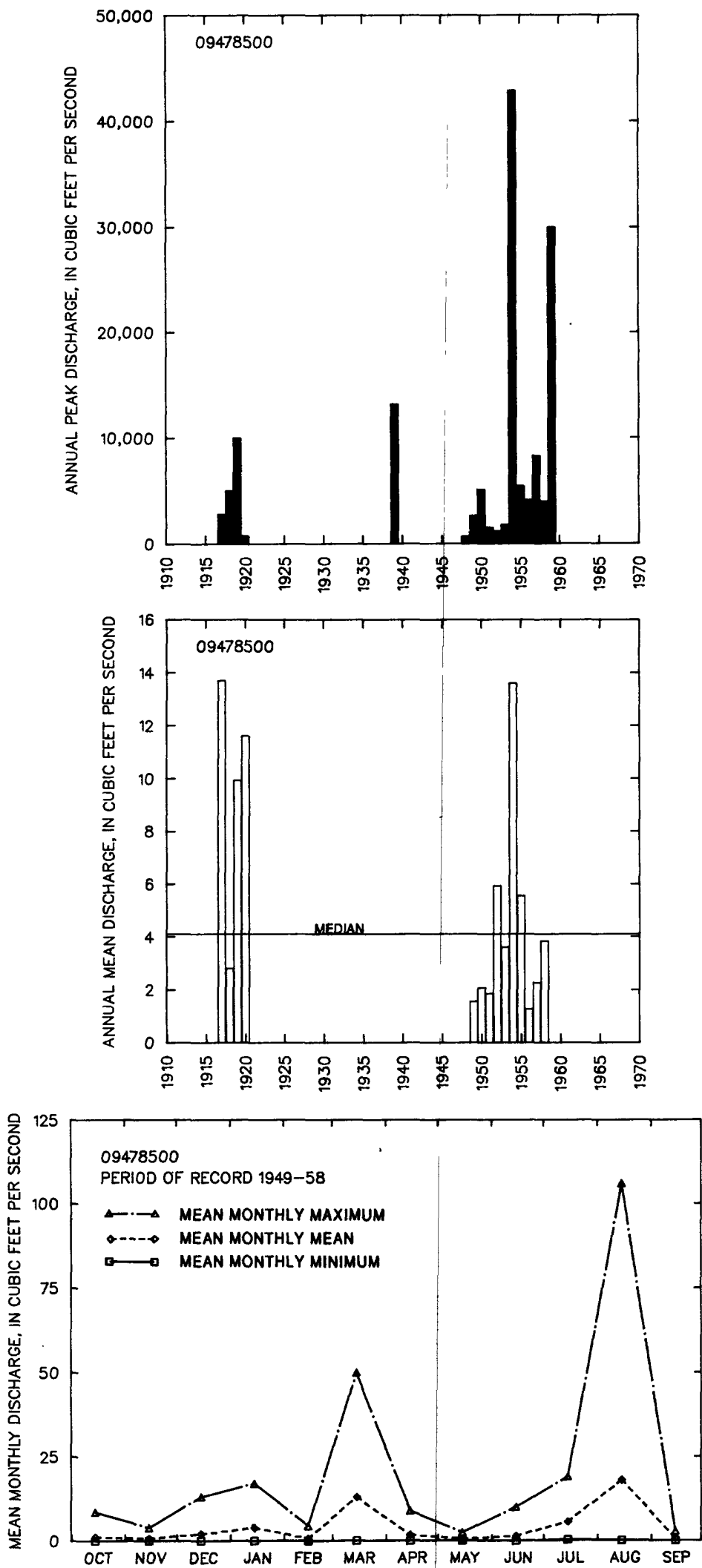
09478600 QUEEN CREEK TRIBUTARY NO. 3 AT WHITLON DAM, AZ

LOCATION.--Lat 33'17'30", long 111'16'50", in Nh sec.1, T.2 S., R.10 E.., Pinal County, Hydrologic Unit $15050100,0.5 \mathrm{mi}$ south of Whitlow Dam, and 4.5 miles northeast of Florence Junction.

DRAIMAGE AREA. $--0.37 \mathrm{mi}^{2}$.

ANMUAL PEAK DISCHARGE

\begin{tabular}{|c|c|c|c|}
\hline $\begin{array}{l}\text { WATER } \\
\text { YEAR }\end{array}$ & DATE & $\begin{array}{l}\text { ANNUAL PEAK } \\
\text { DISCHARGE } \\
\text { (FT } 3 / S)\end{array}$ & $\begin{array}{l}\text { DISCHARGE } \\
\text { COOES }\end{array}$ \\
\hline $\begin{array}{l}1966 \\
1967 \\
1968 \\
1969 \\
1970 \\
1971 \\
1972 \\
1973 \\
1974 \\
1975 \\
1976 \\
1977 \\
1978 \\
1979\end{array}$ & $\begin{array}{l}09-13-66 \\
08-00-67 \\
08-00-68 \\
09-16-69 \\
08-09-70 \\
08-00-71 \\
08-00-72 \\
10-19-72 \\
00-00-74 \\
09-05-75 \\
04-16-76 \\
10-23-76 \\
03-02-78 \\
12-18-78\end{array}$ & $\begin{array}{c}280 \\
110 \\
95 \\
85 \\
64 \\
63 \\
44 \\
80 \\
0 \\
35 \\
4.0 \\
115 \\
240 \\
5.0\end{array}$ & ES \\
\hline
\end{tabular}

MAGNITUDE AND PROBABILITY OF INSTANTANEOUS PEAK FLOH BASED ON PERIOD OF RECORD 1966-79

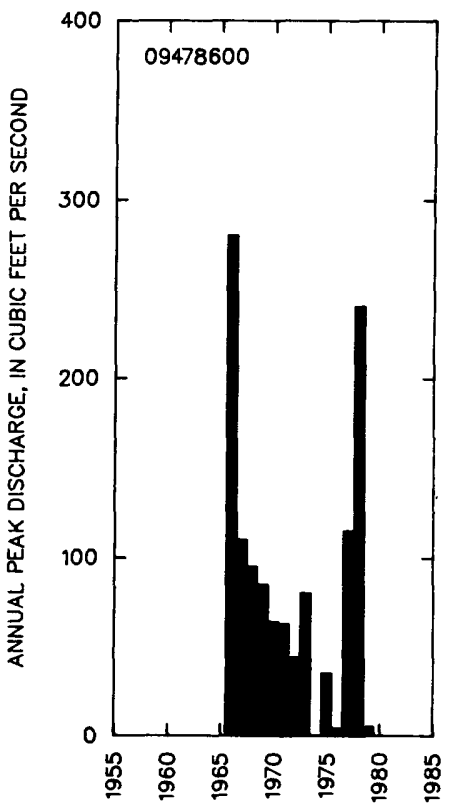

DISCHARGE, IN $\mathrm{FT}^{3} / \mathrm{S}$, FOR INDICATED RECURRENCE INTERVAL

IN YEARS, AND EXCEEDANCE PROBABILITY, IN PERCENT

\begin{tabular}{|c|c|c|c|c|c|}
\hline $\begin{array}{r}2 \dagger \\
50 \%\end{array}$ & $\begin{array}{r}5 \dagger \\
20 \%\end{array}$ & $\begin{array}{c}10 \dagger \\
10 \%\end{array}$ & $\begin{array}{l}25 \dagger \\
4 \%\end{array}$ & $\begin{array}{l}50 \dagger \\
2 \%\end{array}$ & $\begin{array}{c}100 \dagger \\
1 \%\end{array}$ \\
\hline 71.3 & 135 & 189 & 270 & 339 & 417 \\
\hline $\begin{array}{l}\text { WEIGHTED } \\
\text { MEAN } \\
\text { STANDARD }\end{array}$ & $\begin{array}{l}\text { SKEW } \\
\text { DEV. }\end{array}$ & $\begin{array}{l}(\text { LOGS })= \\
(\text { LOGS })= \\
(\text { LOGS })=\end{array}$ & $\begin{array}{r}-0.00 \\
1.85 \\
0.33\end{array}$ & & \\
\hline
\end{tabular}

f Reliability of values in column is uncertain, and potential errors are large.

BASIN CHARACTERISTICS

\begin{tabular}{|c|c|c|c|c|c|c|c|}
\hline \multirow{2}{*}{$\begin{array}{l}\text { MAIN } \\
\text { CHANNEL } \\
\text { SLOPE } \\
\text { (FT/MI) }\end{array}$} & \multirow[b]{2}{*}{$\begin{array}{c}\text { STREAM } \\
\text { LENGTH } \\
\text { (MI) }\end{array}$} & \multirow{2}{*}{$\begin{array}{l}\text { MEAN } \\
\text { BASIN } \\
\text { ELEVA- } \\
\text { TION } \\
\text { (FT) }\end{array}$} & \multirow[b]{2}{*}{$\begin{array}{l}\text { FORESTED } \\
\text { AREA } \\
\text { (PERCENT) }\end{array}$} & \multirow[b]{2}{*}{$\begin{array}{l}\text { SOIL } \\
\text { INDEX }\end{array}$} & \multirow{2}{*}{$\begin{array}{l}\text { MEAN } \\
\text { ANNUAL } \\
\text { PRECIPI - } \\
\text { TATION } \\
\text { (IN) }\end{array}$} & \multicolumn{2}{|c|}{ RAINFALL INTENSITY, 24-HOUR } \\
\hline & & & & & & $\begin{array}{c}\text { 2-YEAR } \\
\text { (IN) }\end{array}$ & $\begin{array}{l}\text { 50-YEAR } \\
\text { (IN) }\end{array}$ \\
\hline 187 & 1.1 & 2,320 & 0.0 & 1.0 & 12.0 & 1.8 & 3.9 \\
\hline
\end{tabular}




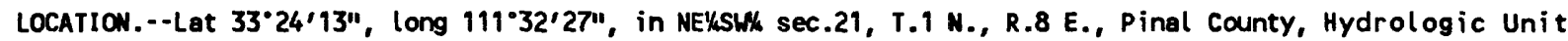
15050100 , at eastbound lane of U.S. Highway $60,0.6 \mathrm{mi}$ southeast of Apache Junction.

DRAIMAGE AREA. $-0.51 \mathrm{mi}^{2}$.

ANNUAL PEAK DISCHARGE

\begin{tabular}{lcc}
$\begin{array}{l}\text { WATER } \\
\text { YEAR }\end{array}$ & DATE & $\begin{array}{c}\text { ANNUAL PEAK } \\
\text { DISCHARGE } \\
\text { (FT } 3 / \text { S) }\end{array}$ \\
\hline 1961 & $08-18-61$ & 179 \\
1962 & $11-21-61$ & 39 \\
1963 & $08-17-63$ & 46 \\
1964 & $09-14-64$ & 74 \\
1965 & $08-17-65$ & 1.7 \\
1966 & $08-30-66$ & 126 \\
1967 & $07-11-67$ & 42 \\
1968 & $08-03-68$ & 70 \\
1969 & $09-16-69$ & 19 \\
1970 & $09-05-70$ & 137 \\
1971 & $09-30-71$ & 262 \\
1972 & $00-00-72$ & 0 \\
1973 & $10-18-72$ & 109 \\
1974 & $07-07-74$ & 22 \\
1975 & $09-05-75$ & 54 \\
1976 & $07-24-76$ & 176 \\
1977 & $00-00-77$ & 0 \\
1978 & $00-00-78$ & 0 \\
1979 & $00-00-79$ & 0 \\
\hline$\ldots \ldots$ & $0 . \ldots 19$
\end{tabular}

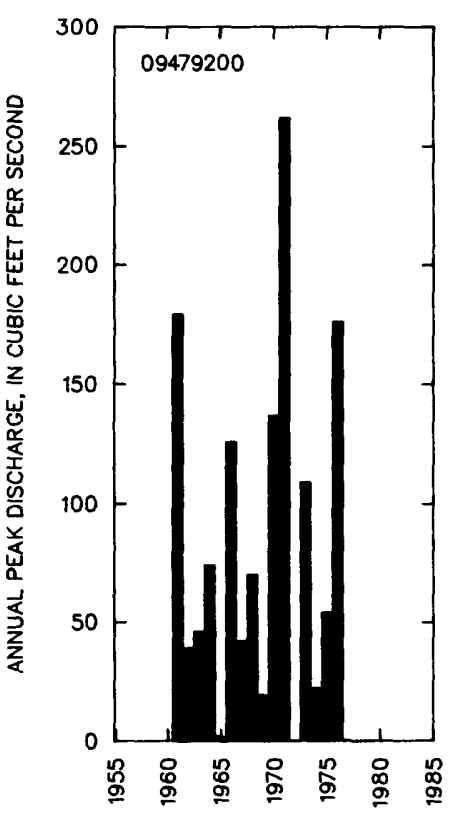

MAGNITUDE AND PROBABILITY OF INSTANTANEOUS PEAK FLOW BASED ON PERIOD OF RECORD 1961-79

DISCHARGE, IN FT $3 / 5$, FOR INDICATED RECURRENCE INTERVAL

IN YEARS, AND EXCEEDANCE PROBABILITY, IN PERCENT

\begin{tabular}{|c|c|c|c|c|c|}
\hline $\begin{array}{c}2 \nmid \\
50 \%\end{array}$ & $\begin{array}{r}5 \dagger \\
20 \%\end{array}$ & $\begin{array}{r}10 \\
10 \%\end{array}$ & $\begin{array}{l}25 \dagger \\
4 \%\end{array}$ & $\begin{array}{l}50 \dagger \\
2 \%\end{array}$ & $\begin{array}{c}100 \dagger \\
1 \%\end{array}$ \\
\hline 52.5 & 120 & 179 & 269 & 346 & 431 \\
\hline $\begin{array}{l}\text { WEIGH } \\
\text { MEAN } \\
\text { STAND }\end{array}$ & SKEH & $\begin{array}{l}(\text { LOGS })= \\
(\text { LOGS) }= \\
(\text { LOGS) }=\end{array}$ & $\begin{array}{r}-0.31 \\
1.70 \\
0.45\end{array}$ & & \\
\hline
\end{tabular}

$\uparrow$ Reliability of values in column is uncertain, and potential errors are large.

BASIN CHARACTERISTICS

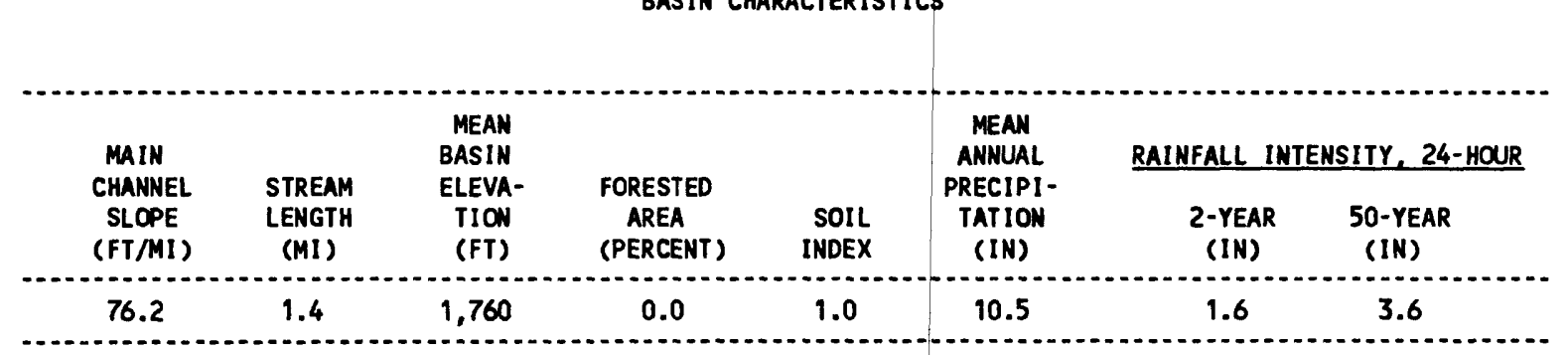


09479500 gILA RIVER MEAR LAVEen, AZ

LOCATION.-- Lat 33.15'25", long 112.09'59", in SW/NWh sec.16, T.2 S., R.2 E., Pinal County, Hydrologic Unit 15050100, in Gila River Indian Reservation, on left abutment of highway bridge, 2.1 mi upstream from Santa Cruz River, $2.6 \mathrm{mi}$ south of Komatke, and $7.3 \mathrm{mi}$ south of Laveen.

DRAINAGE AREA. $--20,615 \mathrm{mi}^{2}$, of which $696 \mathrm{mi}^{2}$ is in Mexico.

REMARKS.--Records include flow over dam and in overflow channel. Large diversions above station for irrigation. Most low flow is waste water from irrigated lands and from Chandler, Arizona treatment plant (1979-83). Flow partly regulated by storage in San Carlos Reservoir. (See elsewhere in this report.)

\section{ANNUAL PEAK DISCHARGE}

\begin{tabular}{|c|c|c|c|c|c|c|c|}
\hline $\begin{array}{l}\text { WATER } \\
\text { YEAR }\end{array}$ & DATE & $\begin{array}{l}\text { ANNUAL PEAK } \\
\text { DISCHARGE } \\
\text { (FT } 3 / 5)\end{array}$ & $\begin{array}{l}\text { DISCHARGE } \\
\text { CODES }\end{array}$ & $\begin{array}{l}\text { WATER } \\
\text { YEAR }\end{array}$ & DATE & $\begin{array}{l}\text { ANNUAL PEAK } \\
\text { DISCHARGE } \\
\text { (FT } 3 / 5)^{3} / S \text { ) }\end{array}$ & $\begin{array}{l}\text { DISCHARGE } \\
\text { CODES }\end{array}$ \\
\hline $\begin{array}{l}1916 \\
1926 \\
1940 \\
1941 \\
1942 \\
1943 \\
1944 \\
1945 \\
1946 \\
1948 \\
1949 \\
1950 \\
1951 \\
1952 \\
1953 \\
1954 \\
1955 \\
1956 \\
1957 \\
1958 \\
1959 \\
1960 \\
1961 \\
1962 \\
1963 \\
1964\end{array}$ & $\begin{array}{l}01-20-16 \\
09-28-26 \\
08-17-40 \\
01-02-41 \\
12-12-41 \\
09-27-43 \\
08-11-44 \\
08-13-45 \\
09-20-46 \\
08-05-48 \\
08-10-49 \\
08-02-50 \\
08-29-51 \\
01-20-52 \\
07-31-53 \\
08-08-54 \\
08-24-55 \\
01-31-56 \\
08-20-57 \\
08-19-58 \\
08-19-59 \\
01-14-60 \\
08-25-61 \\
12-18-61 \\
02-14-63 \\
08-17-64\end{array}$ & $\begin{array}{r}165,000 \\
240,000 \\
8,740 \\
11,900 \\
1,170 \\
1,570 \\
1,330 \\
2,800 \\
1,260 \\
1,430 \\
1,250 \\
1,500 \\
1,210 \\
1,070 \\
565 \\
4,510 \\
3,230 \\
46 \\
446 \\
995 \\
934 \\
1,760 \\
655 \\
1,020 \\
798 \\
996\end{array}$ & $\begin{array}{c}\text { ES, HP } \\
\text { ES, HP } \\
\text { UR } \\
\text { UR } \\
\text { UR } \\
\text { UR } \\
\text { UR } \\
\text { UR } \\
\text { UR } \\
\text { UR } \\
\text { UR } \\
\text { UR } \\
\text { UR } \\
\text { UR } \\
\text { UR } \\
\text { UR } \\
\text { UR } \\
\text { UR } \\
\text { UR } \\
\text { UR } \\
\text { UR } \\
\text { UR } \\
\text { UR } \\
\text { UR } \\
\text { UR } \\
\text { UR }\end{array}$ & $\begin{array}{l}1965 \\
1966 \\
1967 \\
1968 \\
1969 \\
1970 \\
1971 \\
1972 \\
1973 \\
1974 \\
1975 \\
1976 \\
1977 \\
1978 \\
1979 \\
1980 \\
1981 \\
1982 \\
1983 \\
1984 \\
1985 \\
1986 \\
1987 \\
1988 \\
1989\end{array}$ & $\begin{array}{l}02-09-65 \\
12-26-65 \\
09-28-67 \\
12-23-67 \\
00-00-69 \\
03-05-70 \\
08-23-71 \\
10-03-71 \\
10-23-72 \\
08-07-74 \\
11-02-74 \\
09-25-76 \\
10-22-76 \\
10-13-77 \\
12-21-78 \\
02-23-80 \\
03-03-81 \\
09-15-82 \\
02-09-83 \\
10-04-83 \\
01-11-85 \\
12-10-85 \\
02-25-87 \\
12-18-87 \\
01-05-89\end{array}$ & $\begin{array}{r}85 \\
10,900 \\
350 \\
5,890 \\
0 \\
178 \\
1,130 \\
544 \\
1,500 \\
1,220 \\
19 \\
397 \\
430 \\
6,360 \\
9,720 \\
545 \\
20 \\
194 \\
385 \\
35,000 \\
2,080 \\
10 \\
7.1 \\
16 \\
12\end{array}$ & $\begin{array}{c}\text { UR } \\
\text { UR } \\
\text { UR } \\
\text { UR } \\
\text { UR } \\
\text { UR } \\
\text { UR } \\
\text { UR } \\
\text { UR } \\
\text { UR } \\
\text { UR } \\
\text { UR } \\
\text { UR } \\
\text { UR } \\
\text { UR } \\
\text { UR } \\
\text { MD,U } \\
\text { MD,U } \\
\text { UR } \\
\text { UR } \\
\text { MD,U } \\
\text { UR } \\
\text { UR } \\
\text { UR } \\
\text { UR }\end{array}$ \\
\hline
\end{tabular}

1Highest since 1907.

$2 \mathrm{Highest}$ since 1916. 


\section{GILA RIVER BASIN}

09479500 GILA RIVER NEAR LAVEEN, AZ--Continued

MEAN MONTHLY AND ANNUAL DISCHARGES 1941-46, 1949-89

\begin{tabular}{|c|c|c|c|c|c|c|}
\hline MONTH & $\begin{array}{l}\left.\operatorname{MAX} \operatorname{IMUMA}_{(\mathrm{FT}}{ }^{3} / \mathrm{S}\right) \\
\end{array}$ & $\begin{array}{l}\text { MINIIMUM } \\
\left(\mathrm{FT}^{3} / \mathrm{S}\right)\end{array}$ & $\begin{array}{c}\text { MEAN } \\
\left(F^{3} / S\right)\end{array}$ & $\begin{array}{l}\text { STAN- } \\
\text { DARD } \\
\text { DEVIA- } \\
\text { TION } \\
\text { (FT } 3 / S \text { ) }\end{array}$ & $\begin{array}{l}\text { COEFFI- } \\
\text { CIENT OF } \\
\text { VARI - } \\
\text { ATION }\end{array}$ & $\begin{array}{c}\text { PERCENT } \\
\text { OF } \\
\text { ANNUAL } \\
\text { RUNOFF }\end{array}$ \\
\hline $\begin{array}{l}\text { OCTOBER } \\
\text { NOVEMBER } \\
\text { DECEMBER } \\
\text { JANUARY } \\
\text { FEBRUARY } \\
\text { MARCH } \\
\text { APRIL } \\
\text { MAY } \\
\text { JUNE } \\
\text { JULY } \\
\text { AUGUST } \\
\text { SEPTEMBER }\end{array}$ & $\begin{array}{r}2,660 \\
182 \\
518 \\
1,100 \\
1,300 \\
1,060 \\
98 \\
26 \\
12 \\
249 \\
895 \\
106\end{array}$ & $\begin{array}{l}0.00 \\
0.00 \\
0.00 \\
0.00 \\
0.00 \\
0.00 \\
0.00 \\
0.00 \\
0.00 \\
0.00 \\
0.00 \\
0.00\end{array}$ & $\begin{array}{l}66 \\
9.3 \\
43 \\
70 \\
58 \\
52 \\
6.5 \\
2.0 \\
1.1 \\
15 \\
67 \\
15\end{array}$ & $\begin{array}{c}388 \\
29 \\
115 \\
210 \\
201 \\
176 \\
18 \\
4.6 \\
2.4 \\
41 \\
160 \\
26\end{array}$ & $\begin{array}{l}5.9 \\
3.1 \\
2.7 \\
3.0 \\
3.5 \\
3.4 \\
2.7 \\
2.3 \\
2.1 \\
2.7 \\
2.4 \\
1.8\end{array}$ & $\begin{array}{r}16.3 \\
2.3 \\
10.6 \\
17.2 \\
14.4 \\
12.9 \\
1.6 \\
0.5 \\
0.3 \\
3.7 \\
16.6 \\
3.6\end{array}$ \\
\hline NNUAL & 285 & 0.00 & 34 & 64 & 1.9 & 100 \\
\hline
\end{tabular}

MAGNI TUDE AND PROBABILITY OF INSTANTANEOUS PEAK FLON BASED ON PERIOD OF RECORD

DISCHARGE, IN $\mathrm{FT}^{3} / \mathrm{S}$, FOR INDICATED RECURRENCE INTERVAL IN YEARS, AND EXCEEDANCE PROBABILITY, IN PERCENT

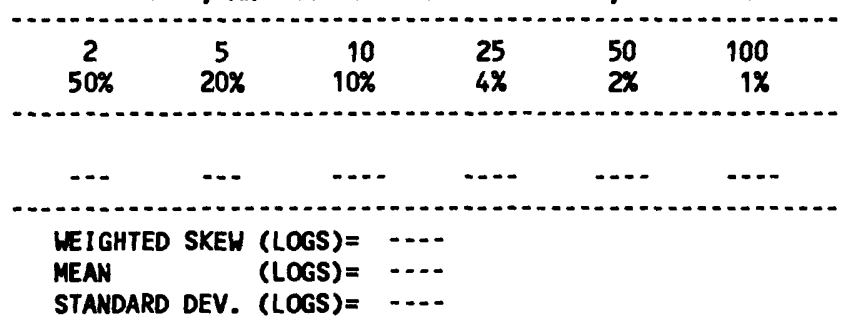

MAGNITUDE AND PROBABILITY OF ANNUAL LON FLON BASED ON PERIOD OF RECORD 1941-46, 1949-89

\begin{tabular}{|c|c|c|c|c|c|c|}
\hline \multirow{2}{*}{$\begin{array}{l}\text { PERIOD } \\
\text { (CON- } \\
\text { SECU- } \\
\text { TIVE } \\
\text { DAYS) }\end{array}$} & \multicolumn{6}{|c|}{$\begin{array}{l}\text { DISCHARGE, IN FT } 3 / S \text {, FOR INDICATED } \\
\text { RECURRENCE INTERVAL, IN YEARS, AND } \\
\text { NON-EXCEEDANCE PROBABILITY, IN PERCENT }\end{array}$} \\
\hline & $\begin{array}{c}2 \\
50 \%\end{array}$ & $\begin{array}{c}5 \\
20 \%\end{array}$ & $\begin{array}{l}10 \\
10 \%\end{array}$ & $\begin{array}{l}20 \\
5 \%\end{array}$ & $\begin{array}{l}50 \\
2 \%\end{array}$ & $\begin{array}{l}100 \dagger \\
\mathbf{1 x}\end{array}$ \\
\hline $\begin{array}{r}1 \\
3 \\
7 \\
14 \\
30 \\
60 \\
90 \\
120 \\
183\end{array}$ & $\begin{array}{l}0.00 \\
0.00 \\
0.00 \\
0.00 \\
0.00 \\
0.00 \\
0.00 \\
0.00 \\
0.00\end{array}$ & $\begin{array}{l}0.00 \\
0.00 \\
0.00 \\
0.00 \\
0.00 \\
0.00 \\
0.00 \\
0.00 \\
0.00\end{array}$ & $\begin{array}{l}0.00 \\
0.00 \\
0.00 \\
0.00 \\
0.00 \\
0.00 \\
0.00 \\
0.00 \\
0.00\end{array}$ & $\begin{array}{l}0.00 \\
0.00 \\
0.00 \\
0.00 \\
0.00 \\
0.00 \\
0.00 \\
0.00 \\
0.00\end{array}$ & $\begin{array}{l}0.00 \\
0.00 \\
0.00 \\
0.00 \\
0.00 \\
0.00 \\
0.00 \\
0.00 \\
0.00\end{array}$ & $\begin{array}{l}0.00 \\
0.00 \\
0.00 \\
0.00 \\
0.00 \\
0.00 \\
0.00 \\
0.00 \\
0.00\end{array}$ \\
\hline
\end{tabular}

MAGNITUDE AND PROBABILITY OF ANNUAL HIGH FLON BASED ON PERIOD OF RECORD 1941-46, 1949-89

\begin{tabular}{|c|c|c|c|c|c|c|}
\hline \multirow{2}{*}{$\begin{array}{l}\text { PERIOD } \\
\text { (CON- } \\
\text { SECU- } \\
\text { TIVE } \\
\text { DAYS) }\end{array}$} & \multicolumn{6}{|c|}{$\begin{array}{l}\text { DISCHARGE, IN FT } 3 / S \text {, FOR INDICATED } \\
\text { RECURRENCE INTERVAL, IN YEARS, AND } \\
\text { EXCEEDANCE PROBABILITY, IN PERCENT }\end{array}$} \\
\hline & $\begin{array}{c}2 \\
50 \%\end{array}$ & $\underset{20 \%}{5}$ & $\begin{array}{l}10 \\
10 \%\end{array}$ & $\begin{array}{l}25 \\
4 \%\end{array}$ & $\begin{array}{l}50 \\
2 \%\end{array}$ & $\underset{1 \%}{100} \uparrow$ \\
\hline $\begin{array}{l}1 \\
3 \\
7 \\
15 \\
30 \\
60 \\
90\end{array}$ & $\begin{array}{r}546 \\
344 \\
185 \\
100 \\
62 \\
36 \\
25\end{array}$ & $\begin{array}{r}2,500 \\
1,650 \\
943 \\
542 \\
348 \\
210 \\
151\end{array}$ & $\begin{array}{r}4,850 \\
3,270 \\
1,920 \\
1,150 \\
748 \\
459 \\
338\end{array}$ & $\begin{array}{r}8,970 \\
6,150 \\
3,710 \\
2,310 \\
1,530 \\
957 \\
726\end{array}$ & $\begin{array}{r}12,800 \\
8,830 \\
5,410 \\
3,470 \\
2,320 \\
1,470 \\
1,140\end{array}$ & $\begin{array}{r}17,100 \\
11,900 \\
7,370 \\
4,870 \\
3,270 \\
2,090 \\
1,660\end{array}$ \\
\hline
\end{tabular}

DURATION TABLE OF DAILY MEAN FLON FOR PERICD OF RECORD 1941-46, 1949-89

DISCHARGE, IN FT $3 / 5$, WHICH WAS EQUALED OR EXCEEDED FOR INDICATED PERCENT OF TIME

\begin{tabular}{|c|c|c|c|c|c|c|c|c|c|c|c|c|c|c|c|c|}
\hline 869 & 48 & 17 & 9.3 & 6.1 & 2.4 & 0.09 & 0.00 & 0.00 & 0.00 & 0.00 & 0.00 & 0.00 & 0.00 & 0.00 & 0.00 & 0.00 \\
\hline
\end{tabular}

† Reliability of values in column is uncertain, and potential errors are large. 
GILA RIVER BASIN

09479500 GILA RIVER NEAR LAVEEN, AZ--CONTIMUEo
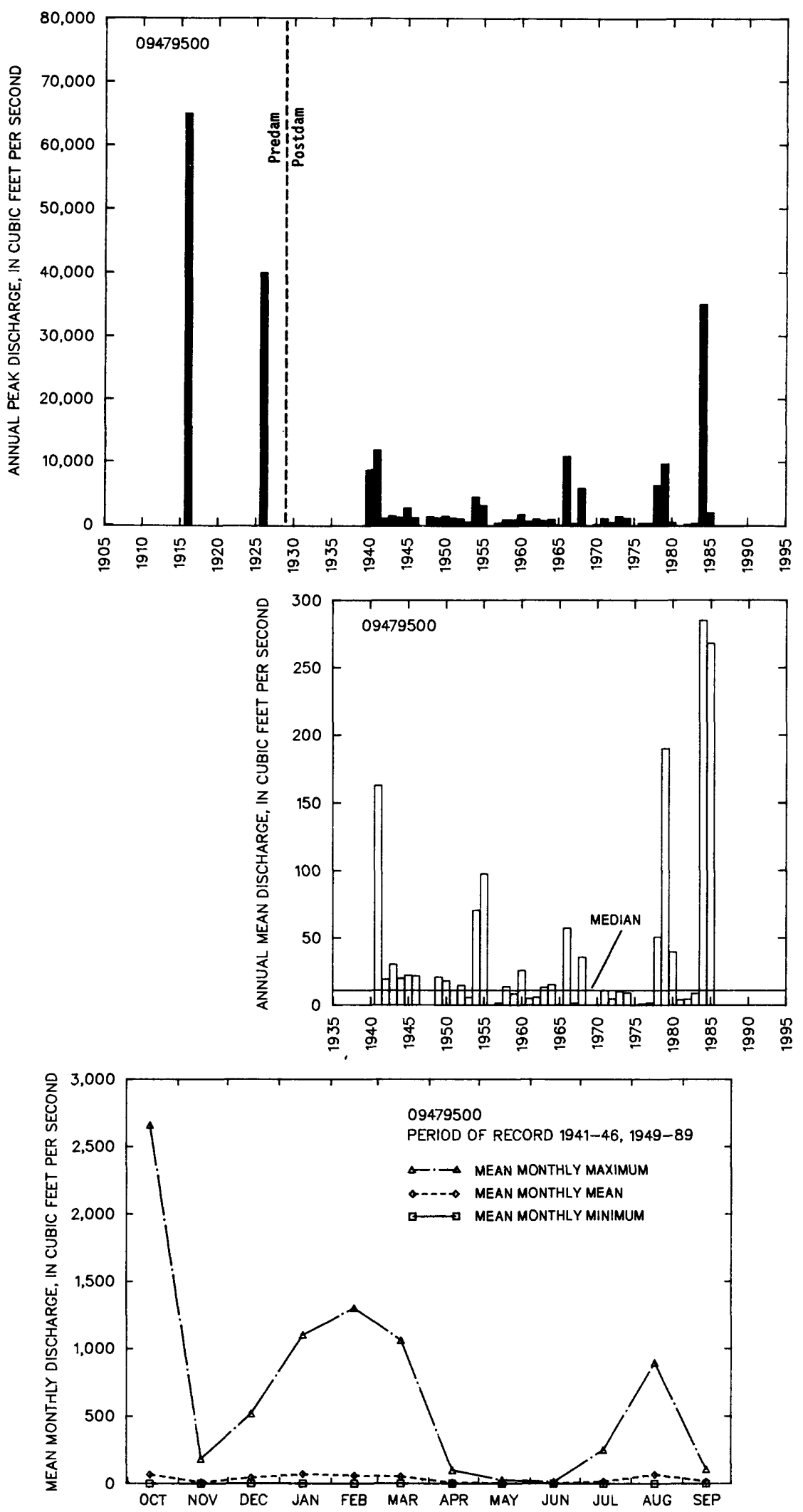
09480000 SANTA CRUZ RIVER NEAR LOCHIEL, AZ

LOCATION.--Lat 31'21'19", long 110.35'20", in SW; sec.11, T.24 S., R.17 E. (unsurveyed), Santa Cruz County, Hydrologic Unit 15050301, on southern border of Spanish land grant of San Rafael, near left bank on downstream side of pier of bridge on county road, $1.7 \mathrm{mi}$ upstream from international boundary and $2.5 \mathrm{mi}$ northeast of Lochiel.

DRAINAGE AREA. $--82.2 \mathrm{mi}^{2}$.

REMARKS.-Small diversions for irrigation of 200 acres above station, mostly by pumping from ground water.

ANMUAL PEAK DISCHARGE

\begin{tabular}{|c|c|c|c|c|}
\hline $\begin{array}{l}\text { WATER } \\
\text { YEAR }\end{array}$ & $\begin{array}{cc} & \text { ANNUAL PEAK } \\
& \text { DISCHARGE } \\
\text { DATE } & \left(\mathrm{FT}^{3} / \mathrm{S}\right)\end{array}$ & $\begin{array}{l}\text { WATER } \\
\text { YEAR }\end{array}$ & DATE & $\begin{array}{l}\text { ANNUAL PEAK } \\
\text { DISCHARGE } \\
\left(\mathrm{FT}^{3} / \mathrm{S}\right)\end{array}$ \\
\hline $\begin{array}{l}1949 \\
1950 \\
1951 \\
1952 \\
1953 \\
1954 \\
1955 \\
1956 \\
1957 \\
1958 \\
1959 \\
1960 \\
1961 \\
1962 \\
1963 \\
1964 \\
1965 \\
1966 \\
1967 \\
1968 \\
1969\end{array}$ & $\begin{array}{l}09-13-49 \\
07-30-50 \\
08-02-51 \\
08-16-52 \\
07-14-53 \\
07-22-54 \\
08-06-55 \\
07-17-56 \\
08-09-57 \\
08-07-58 \\
08-14-59 \\
07-30-60 \\
08-08-61 \\
07-29-62 \\
08-25-63 \\
09-09-64 \\
09-12-65 \\
08-18-66 \\
08-03-67 \\
12-20-67 \\
08-05-69\end{array}$ & $\begin{array}{l}1970 \\
1971 \\
1972 \\
1973 \\
1974 \\
1975 \\
1976 \\
1977 \\
1978 \\
1979 \\
1980 \\
1981 \\
1982 \\
1983 \\
1984 \\
1985 \\
1986 \\
1987 \\
1988 \\
1989\end{array}$ & $\begin{array}{l}08-03-70 \\
08-10-71 \\
07-16-72 \\
06-30-73 \\
08-04-74 \\
07-22-75 \\
07-22-76 \\
09-05-77 \\
10-09-77 \\
01-25-79 \\
06-30-80 \\
07-15-81 \\
08-11-82 \\
03-04-83 \\
08-15-84 \\
07-19-85 \\
08-29-86 \\
08-10-87 \\
08-23-88 \\
08-04-89\end{array}$ & $\begin{array}{r}880 \\
2,830 \\
2,070 \\
1,490 \\
1,730 \\
3,330 \\
3,540 \\
1,130 \\
112,000 \\
1,060 \\
406 \\
1,110 \\
2,640 \\
1,120 \\
12,000 \\
850 \\
4,210 \\
291 \\
804 \\
871\end{array}$ \\
\hline
\end{tabular}

$1_{H i g h e s t}$ since 1926.

BASIN CHARACTERISTICS

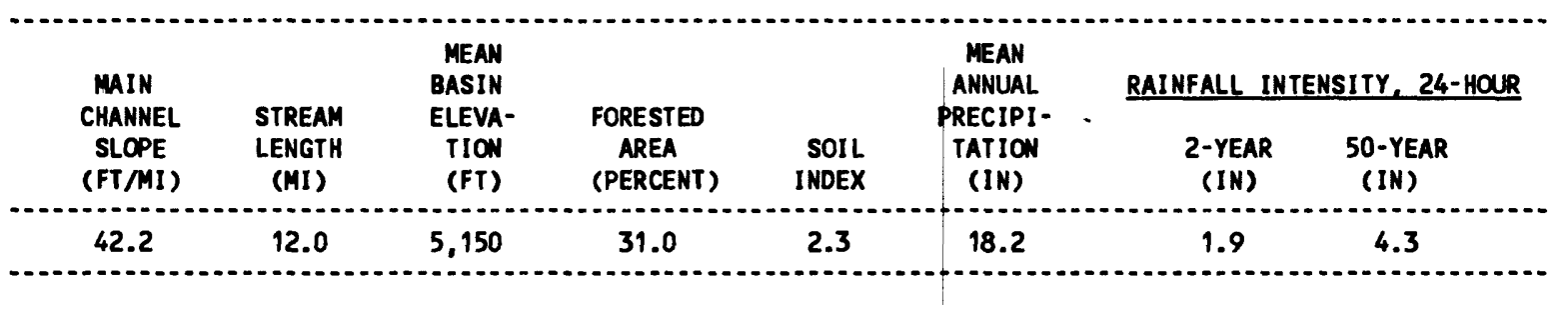


09480000 SANTA CRUZ RIVER NEAR LOCHIEL, AZ--Continued

MEAN MONTHLY AND ANNUAL DISCHARGES 1950-89

\begin{tabular}{|c|c|c|c|c|c|c|}
\hline MONTH & $\begin{array}{l}\operatorname{MAXIMUN} \\
\left(F T^{3} / S\right)\end{array}$ & $\begin{array}{l}\text { MINIMUM } \\
\left(\mathrm{FT}^{3} / \mathrm{S}\right)\end{array}$ & $\begin{array}{c}\text { MEAN } \\
\left(F^{3} / S\right)\end{array}$ & $\begin{array}{l}\text { STAN- } \\
\text { DARD } \\
\text { DEVIA- } \\
\text { TION } \\
\left.\text { (FT }{ }^{3} / S\right)\end{array}$ & $\begin{array}{l}\text { COEFF I - } \\
\text { CIENT OF } \\
\text { VARI - } \\
\text { ATION }\end{array}$ & $\begin{array}{c}\text { PERCENT } \\
\text { OF } \\
\text { ANNUAL } \\
\text { RUNOFF }\end{array}$ \\
\hline $\begin{array}{l}\text { OCTOBER } \\
\text { NOVEMBER } \\
\text { DECEMBER } \\
\text { JANUARY } \\
\text { FEBRUARY } \\
\text { MARCH } \\
\text { APRIL } \\
\text { MAY } \\
\text { JUNE } \\
\text { JULY } \\
\text { AUGUST } \\
\text { SEPTEMBER }\end{array}$ & $\begin{array}{c}77 \\
6.8 \\
18 \\
47 \\
18 \\
34 \\
5.2 \\
2.8 \\
2.8 \\
69 \\
187 \\
44\end{array}$ & $\begin{array}{l}0.00 \\
0.00 \\
0.00 \\
0.02 \\
0.03 \\
0.01 \\
0.00 \\
0.00 \\
0.00 \\
0.03 \\
0.00 \\
0.00\end{array}$ & $\begin{array}{c}5.2 \\
1.1 \\
1.8 \\
2.7 \\
1.7 \\
1.9 \\
0.74 \\
0.39 \\
0.30 \\
8.4 \\
17 \\
5.3\end{array}$ & $\begin{array}{c}17 \\
1.5 \\
3.7 \\
8.3 \\
3.4 \\
5.6 \\
1.2 \\
0.67 \\
0.65 \\
16 \\
38 \\
9.5\end{array}$ & $\begin{array}{l}3.2 \\
1.4 \\
2.0 \\
3.1 \\
2.0 \\
2.9 \\
1.6 \\
1.7 \\
2.2 \\
1.8 \\
2.2 \\
1.8\end{array}$ & $\begin{array}{r}11.1 \\
2.3 \\
3.9 \\
5.7 \\
3.6 \\
4.0 \\
1.6 \\
0.8 \\
0.6 \\
17.8 \\
37.0 \\
11.4\end{array}$ \\
\hline ANNUAL & 29 & 0.31 & 3.9 & 5.3 & 1.3 & 100 \\
\hline
\end{tabular}

MAGNITUDE AND PROBABILITY OF INSTANTANEOUS PEAK FLOH BASED ON PERIOD OF RECORD 1949-89

DISCHARGE, IN FT $3 / 5$, FOR INDICATED RECURRENCE INTERVAL IN YEARS, AND EXCEEDANCE PROBABILITY, IN PERCENT

\begin{tabular}{|c|c|c|c|c|c|}
\hline $\begin{array}{c}2 \\
50 x\end{array}$ & $\begin{array}{c}5 \\
20 \%\end{array}$ & $\begin{array}{r}10 \\
10 x\end{array}$ & $\begin{array}{l}25 \\
4 \%\end{array}$ & $\begin{array}{l}50 \\
2 \%\end{array}$ & $\begin{array}{c}100 \dagger \\
1 \%\end{array}$ \\
\hline 1,460 & 2,950 & 4,330 & 6,590 & 8,700 & 11,200 \\
\hline $\begin{array}{l}\text { WE IGHTED } \\
\text { MEAN } \\
\text { STANDARD }\end{array}$ & $\begin{array}{l}\text { SKEH } \\
\text { DEV. }\end{array}$ & $\begin{array}{l}(\text { LOGS })= \\
(\text { LOGS })= \\
(\text { LOGS })=\end{array}$ & $\begin{array}{l}0.20 \\
3.17 \\
0.35\end{array}$ & & \\
\hline
\end{tabular}

MAGNITLDE AND PROBABILITY OF ANNUAL LON FLON BASED ON PERIOD OF RECORD 1950-89

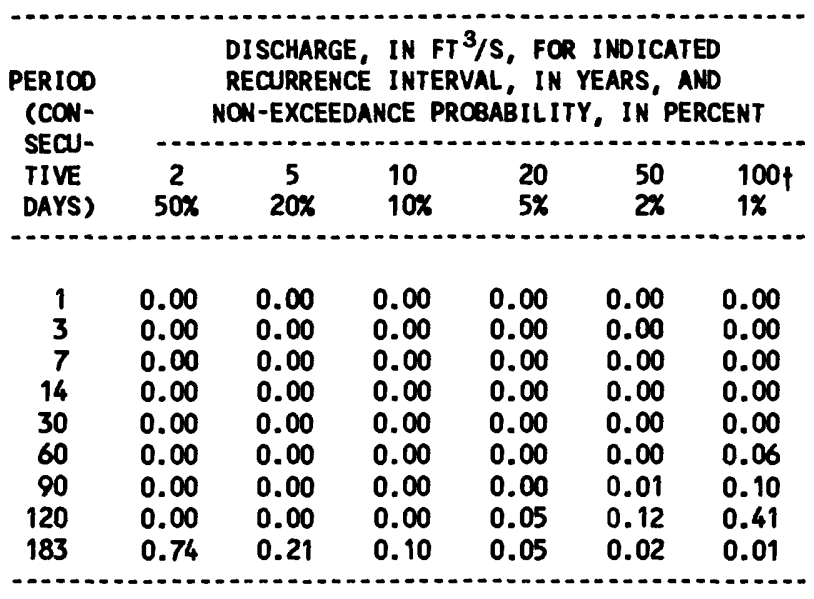

MAGNITLDE AND PROBABILITY OF ANNUAL HIGH FLOH BASED ON PERIOD OF RECORD 1950-89

\begin{tabular}{|c|c|c|c|c|c|c|}
\hline \multirow{2}{*}{$\begin{array}{l}\text { PERIOD } \\
\text { (CON- } \\
\text { SECU- } \\
\text { TIVE } \\
\text { DAYS) }\end{array}$} & \multicolumn{6}{|c|}{$\begin{array}{l}\text { DISCHARGE, IN } \mathrm{FT}^{3} / \mathrm{S} \text {, FOR INDICATED } \\
\text { RECURRENCE INTERVAL, IN YEARS, AND } \\
\text { EXCEEDANCE PROBABILITY, IN PERCENT }\end{array}$} \\
\hline & $\begin{array}{c}2 \\
50 \%\end{array}$ & $\begin{array}{c}5 \\
20 \%\end{array}$ & $\begin{array}{l}10 \\
10 \%\end{array}$ & $\begin{array}{l}25 \\
4 x\end{array}$ & $\begin{array}{l}50 \\
2 \%\end{array}$ & $\begin{array}{c}100 \dagger \\
1 \%\end{array}$ \\
\hline $\begin{array}{r}1 \\
3 \\
7 \\
15 \\
30 \\
60 \\
90\end{array}$ & $\begin{array}{c}170 \\
75 \\
38 \\
22 \\
14 \\
8.7 \\
6.3\end{array}$ & $\begin{array}{r}439 \\
211 \\
114 \\
66 \\
41 \\
25 \\
17\end{array}$ & $\begin{array}{r}661 \\
343 \\
196 \\
115 \\
72 \\
43 \\
30\end{array}$ & $\begin{array}{r}963 \\
553 \\
341 \\
202 \\
130 \\
77 \\
54\end{array}$ & $\begin{array}{r}1,190 \\
735 \\
482 \\
290 \\
190 \\
114 \\
80\end{array}$ & $\begin{array}{r}1,410 \\
937 \\
651 \\
398 \\
267 \\
161 \\
114\end{array}$ \\
\hline
\end{tabular}

DURATION TABLE OF DAILY MEAN FLOU FOR PERIOD OF RECORD 1950-89

DISCHARGE, IN $\mathrm{FT}^{3} / \mathrm{S}$, HHICH HAS EQUALED OR EXCEEDED FOR INDICATED PERCENT OF TIME

\begin{tabular}{|c|c|c|c|c|c|c|c|c|c|c|c|c|c|c|c|c|}
\hline $1 \%$ & $5 \%$ & $10 \%$ & $15 \%$ & $20 \%$ & $30 \%$ & $40 \%$ & $50 \%$ & $60 \%$ & $70 \%$ & $80 \%$ & $90 \%$ & $95 \%$ & $98 \%$ & $99 \%$ & $99.5 \%$ & $99.9 \%$ \\
\hline 59 & 9.1 & 4.3 & 2.5 & 1.6 & 0.95 & 0.64 & 0.45 & 0.30 & 0.20 & 0.10 & 0.00 & 0.00 & 0.00 & 0.00 & 0.00 & 0.00 \\
\hline
\end{tabular}


09480000 SANTA CRUZ RIVER NEAR LOCHIEL, AZ--CONTINUED
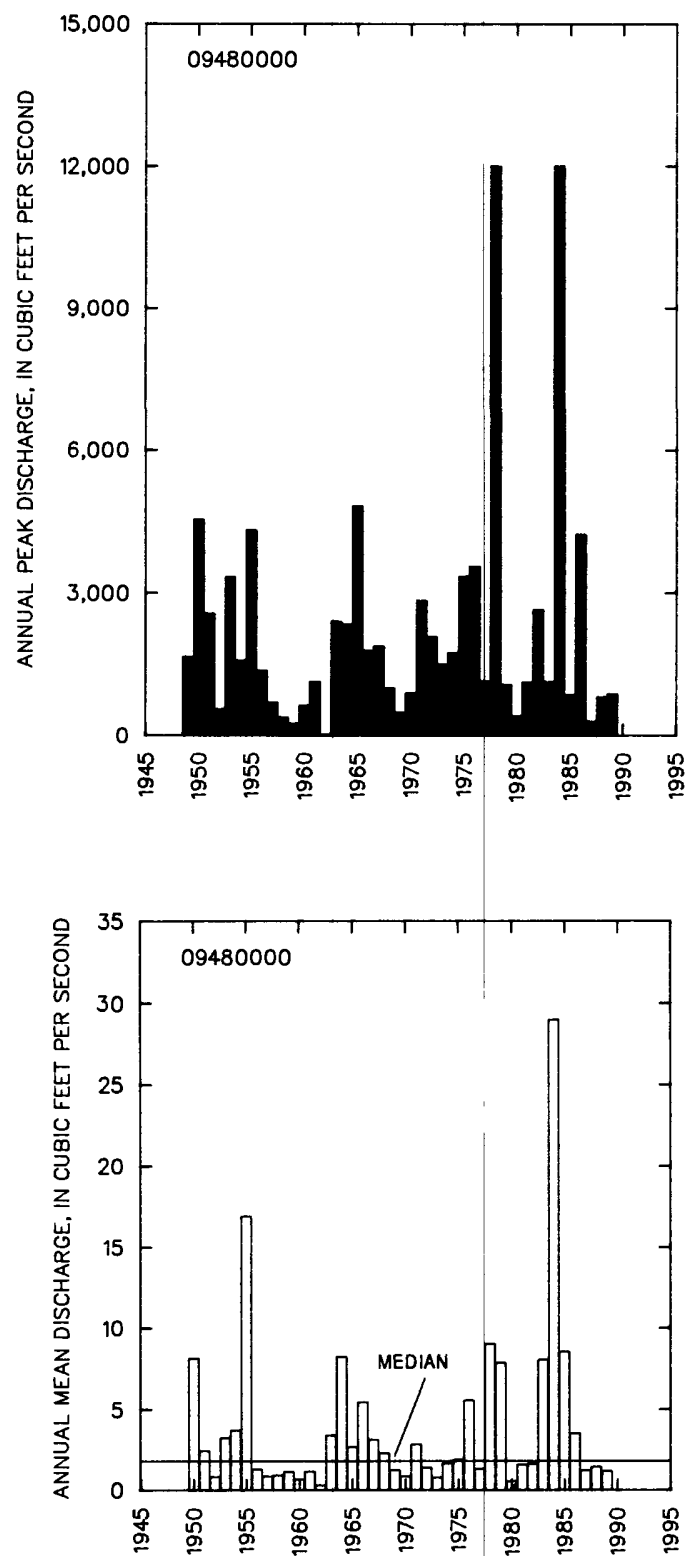
99480000 SANTA CRUZ RIVER MEAR LOCHIEL, AZ--CONTIMUED
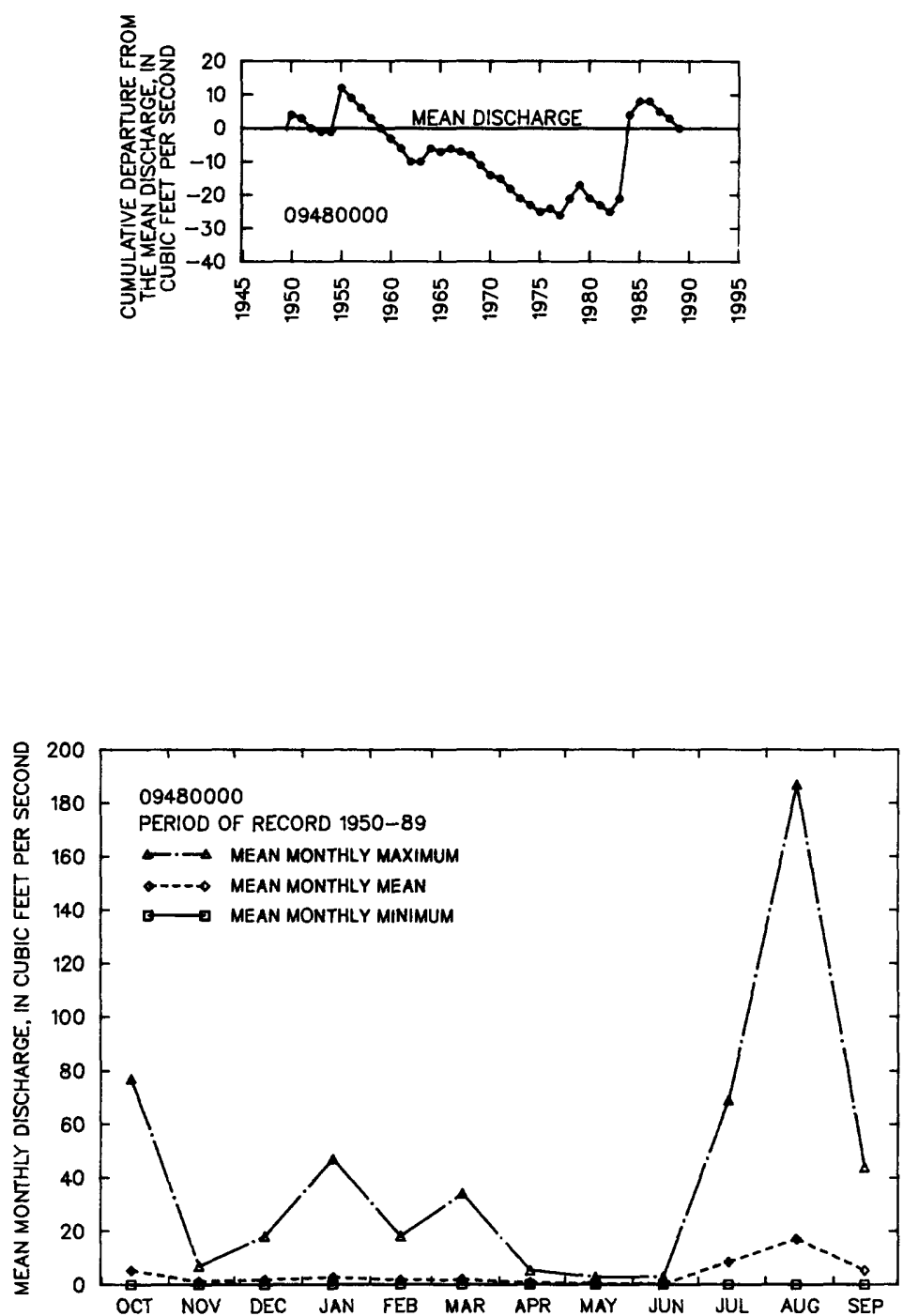
LOCATION.--Lat $31^{\circ} 20^{\prime} 40^{\prime \prime}$, long 110'51'03", in NW/2 sec.18, T.24 S., R.15 E. (unsurveyed), Santa Cruz County, Hydrologic Unit 15050301, in Spanish land grant of Maria Santisima del Carmen, on left bank $0.8 \mathrm{mi}$ dounstream from international boundary and $5.5 \mathrm{mi}$ east of Nogales.

DRAinaGe AREA. $--533 \mathrm{mi}^{2}$, of which $348 \mathrm{mi}^{2}$ is in Mexico.

REMARKS.--Diversions above station of about 4,300 acre-ft-yr for irrigation of about 2,150 acres in Mexico in 1977. Diversion $19 \mathrm{mi}$ upstream for municipal supply of city of Nogales, Sonora, began in 1949; diversion in 1968 totaled 3500 acre-ft-yr.

ANMUAL PEAK DISCHARGE

\begin{tabular}{|c|c|c|c|c|c|}
\hline $\begin{array}{l}\text { WATER } \\
\text { YEAR }\end{array}$ & DATE & $\begin{array}{c}\text { ANNUAL PEAK } \\
\text { DISCHARGE } \\
\left(\mathrm{FT}^{3} / \mathrm{S}\right)\end{array}$ & $\begin{array}{l}\text { WATER } \\
\text { YEAR }\end{array}$ & DATE & $\begin{array}{c}\text { ANNUAL PEAK } \\
\text { DISCHARGE } \\
\text { (FT } 3 / S)\end{array}$ \\
\hline $\begin{array}{l}1930 \\
1931 \\
1932 \\
1933 \\
1934 \\
1935 \\
1936 \\
1937 \\
1938 \\
1939 \\
1940 \\
1941 \\
1942 \\
1943 \\
1944 \\
1945 \\
1946 \\
1947 \\
1948 \\
1949 \\
1950 \\
1951 \\
1952 \\
1953 \\
1954 \\
1955 \\
1956 \\
1957 \\
1958 \\
1959\end{array}$ & $\begin{array}{l}08-07-30 \\
08-04-31 \\
07-08-32 \\
09-19-33 \\
08-00-34 \\
08-31-35 \\
08-09-36 \\
08-16-37 \\
07-28-38 \\
08-13-39 \\
08-04-40 \\
07-21-41 \\
07-08-42 \\
07-30-43 \\
08-15-44 \\
07-30-45 \\
07-26-46 \\
08-29-47 \\
08-01-48 \\
09-14-49 \\
07-20-50 \\
08-03-51 \\
07-29-52 \\
07-14-53 \\
07-10-54 \\
08-20-55 \\
06-28-56 \\
08-18-57 \\
08-13-58 \\
08-06-59\end{array}$ & $\begin{array}{r}5,400 \\
4,150 \\
6,400 \\
1,900 \\
5,900 \\
12,000 \\
4,050 \\
2,400 \\
2,200 \\
7,010 \\
1,800 \\
1,980 \\
8,200 \\
5,300 \\
4,700 \\
3,290 \\
7,200 \\
2,550 \\
3,410 \\
6,350 \\
7,210 \\
3,040 \\
2,330 \\
3,500 \\
10,600 \\
11,100 \\
2,530 \\
1,620 \\
4,000 \\
2,640\end{array}$ & $\begin{array}{l}1960 \\
1961 \\
1962 \\
1963 \\
1964 \\
1965 \\
1966 \\
1967 \\
1968 \\
1969 \\
1970 \\
1971 \\
1972 \\
1973 \\
1974 \\
1975 \\
1976 \\
1977 \\
1978 \\
1979 \\
1980 \\
1981 \\
1982 \\
1983 \\
1984 \\
1985 \\
1986 \\
1987 \\
1988 \\
1989\end{array}$ & $\begin{array}{l}01-11-60 \\
08-15-61 \\
08-19-62 \\
07-10-63 \\
08-14-64 \\
09-13-65 \\
08-20-66 \\
07-27-67 \\
12-20-67 \\
08-02-69 \\
08-16-70 \\
08-20-71 \\
10-24-71 \\
02-22-73 \\
08-01-74 \\
07-22-75 \\
07-22-76 \\
08-18-77 \\
10-09-77 \\
12-18-78 \\
08-09-80 \\
07-29-81 \\
10-02-81 \\
02-04-83 \\
10-02-83 \\
12-27-84 \\
08-30-86 \\
08-10-87 \\
09-12-88 \\
08-16-89\end{array}$ & $\begin{array}{r}2,760 \\
1,640 \\
2,390 \\
4,510 \\
5,630 \\
1,580 \\
4,400 \\
6,310 \\
15,200 \\
4,460 \\
4,100 \\
2,930 \\
738 \\
2,300 \\
17,100 \\
11,400 \\
6,700 \\
6,700 \\
131,000 \\
12,700 \\
1,950 \\
3,220 \\
1,620 \\
6,410 \\
16,200 \\
7,080 \\
2,440 \\
3,560 \\
2,940 \\
663\end{array}$ \\
\hline
\end{tabular}

IHighest since 1892.

\section{BASIN CHARACTERISTICS}

\begin{tabular}{|c|c|c|c|c|c|c|c|}
\hline MAIN & & $\begin{array}{l}\text { MEAN } \\
\text { BASIN }\end{array}$ & & & & RAINFALL II & SITY, 24-HOUR \\
\hline $\begin{array}{l}\text { CHANNEL } \\
\text { SLOPE } \\
\text { (FT/MI) }\end{array}$ & $\begin{array}{l}\text { STREAM } \\
\text { LENGTH } \\
\text { (MI) }\end{array}$ & $\begin{array}{l}\text { ELEVA- } \\
\text { TION } \\
\text { (FT) }\end{array}$ & $\begin{array}{l}\text { FORESTED } \\
\text { AREA } \\
\text { (PERCENT) }\end{array}$ & $\begin{array}{l}\text { SOIL } \\
\text { INDEX }\end{array}$ & $\begin{array}{l}\text { PRECIPI - } \\
\text { TATION } \\
\text { (IN) }\end{array}$ & $\begin{array}{c}\text { 2-YEAR } \\
\text { (IN) }\end{array}$ & $\begin{array}{c}\text { 50-YEAR } \\
\text { (IN) }\end{array}$ \\
\hline 26.0 & 51.2 & 4,850 & 28.0 & 2.1 & 18.7 & 2.0 & 4.3 \\
\hline
\end{tabular}


09480500 SANTA CRUZ RIVER NEAR MOGALES, AZ--Continued

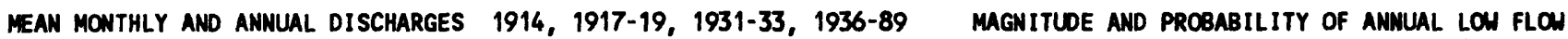
BASED ON PERIOD OF RECORD 1914, 1918-20, 1932-33, 1937-89

\begin{tabular}{|c|c|c|c|c|c|c|}
\hline MONTH & $\begin{array}{l}\operatorname{MAXIMUNA} \\
\left(\mathrm{FT}^{3} / \mathrm{S}\right)\end{array}$ & $\begin{array}{l}\text { MINIMUIM } \\
\left(\mathrm{FT}^{3} / \mathrm{S}\right)\end{array}$ & $\begin{array}{c}\text { MEAN } \\
\left(F T^{3} / S\right)\end{array}$ & $\begin{array}{l}\text { STAN- } \\
\text { DARD } \\
\text { DEVIA- } \\
\text { TION } \\
\left(F^{3} / S\right)\end{array}$ & $\begin{array}{l}\text { COEFF I- } \\
\text { CIENT OF } \\
\text { VARI - } \\
\text { ATION }\end{array}$ & $\begin{array}{c}\text { PERCENT } \\
\text { OF } \\
\text { ANNUAL } \\
\text { RUNOFF }\end{array}$ \\
\hline $\begin{array}{l}\text { OCTOBER } \\
\text { NOVEMBER } \\
\text { DECEMBER } \\
\text { JANUARY } \\
\text { FEBRUARY } \\
\text { MARCH } \\
\text { APRIL } \\
\text { MAY } \\
\text { JUNE } \\
\text { JULY } \\
\text { AUGUST } \\
\text { SEPTEMBER }\end{array}$ & $\begin{array}{r}904 \\
120 \\
542 \\
492 \\
370 \\
318 \\
50 \\
17 \\
24 \\
254 \\
745 \\
159\end{array}$ & $\begin{array}{l}0.00 \\
0.00 \\
0.00 \\
0.00 \\
0.00 \\
0.00 \\
0.00 \\
0.00 \\
0.00 \\
0.00 \\
1.5 \\
0.00\end{array}$ & $\begin{array}{l}27 \\
9.0 \\
38 \\
34 \\
31 \\
22 \\
6.2 \\
1.8 \\
1.3 \\
44 \\
92 \\
28\end{array}$ & $\begin{array}{c}123 \\
18 \\
106 \\
88 \\
67 \\
52 \\
10 \\
3.4 \\
3.9 \\
55 \\
125 \\
37\end{array}$ & $\begin{array}{l}4.5 \\
2.0 \\
2.8 \\
2.6 \\
2.2 \\
2.3 \\
1.6 \\
1.9 \\
2.9 \\
1.3 \\
1.4 \\
1.3\end{array}$ & $\begin{array}{r}8.1 \\
2.7 \\
11.4 \\
10.1 \\
9.2 \\
6.6 \\
1.9 \\
0.5 \\
0.4 \\
13.1 \\
27.6 \\
8.4\end{array}$ \\
\hline ANNUAL & 123 & 3.4 & 28 & 30 & 1.1 & 100 \\
\hline
\end{tabular}

MAGNITUDE AND PROBABILITY OF ANNUAL HIGH FLO BASED ON PERIOD OF RECORD 1914, 1917-19, 1931-33, 1936-89

\begin{tabular}{|c|c|c|c|c|c|c|}
\hline \multirow{2}{*}{$\begin{array}{l}\text { PERIOD } \\
\text { (CON- } \\
\text { SECU- } \\
\text { TIVE } \\
\text { DAYS) }\end{array}$} & \multicolumn{6}{|c|}{$\begin{array}{l}\text { DISCHARGE, IN } \mathrm{FT}^{3} / \mathrm{S}, \text { FOR INDICATED } \\
\text { RECURRENCE INTERVAL, IN YEARS, AND } \\
\text { EXCEEDANCE PROBABILITY, IN PERCENT }\end{array}$} \\
\hline & $\stackrel{2}{50 \%}$ & $\begin{array}{c}5 \\
20 x\end{array}$ & $\begin{array}{l}10 \\
10 \%\end{array}$ & $\begin{array}{l}25 \\
4 \%\end{array}$ & $\begin{array}{l}50 \\
2 \%\end{array}$ & $\begin{array}{r}100 \\
1 \%\end{array}$ \\
\hline $\begin{array}{r}1 \\
3 \\
7 \\
15 \\
30 \\
60 \\
90\end{array}$ & $\begin{array}{r}696 \\
405 \\
250 \\
163 \\
111 \\
73 \\
52\end{array}$ & $\begin{array}{r}1,840 \\
1,080 \\
641 \\
399 \\
262 \\
172 \\
123\end{array}$ & $\begin{array}{r}3,150 \\
1,860 \\
1,070 \\
645 \\
413 \\
272 \\
195\end{array}$ & $\begin{array}{r}5,670 \\
3,380 \\
1,870 \\
1,090 \\
677 \\
447 \\
323\end{array}$ & $\begin{array}{r}8,380 \\
5,020 \\
2,700 \\
1,530 \\
934 \\
617 \\
449\end{array}$ & $\begin{array}{r}12,000 \\
7,240 \\
3,790 \\
2,090 \\
1,250 \\
827 \\
607\end{array}$ \\
\hline
\end{tabular}

DURATION TABLE OF DALLY MEAN FLOW FOR PERIOD OF RECORD 1914, 1917-19, 1931-33, 1936-89 DISCHARGE, IN FT $3 / 5$, WHICH WAS EQUALED OR EXCEEDED FOR INDICATED PERCENT OF TIME

\begin{tabular}{|c|c|c|c|c|c|c|c|c|c|c|c|c|c|c|c|c|}
\hline $1 \%$ & $5 \%$ & $10 \%$ & $15 \%$ & $20 \%$ & $30 \%$ & $40 \%$ & $50 \%$ & $60 \%$ & $70 \%$ & $80 \%$ & $90 \%$ & $95 \%$ & $98 \%$ & $99 \%$ & $99.5 \%$ & $99.9 \%$ \\
\hline 454 & 103 & 43 & 26 & 17 & 8.0 & 5.0 & 3.0 & 1.6 & 0.81 & 0.33 & 0.00 & 0.00 & 0.00 & 0.00 & 0.00 & 0.00 \\
\hline
\end{tabular}


GILA RIVER BASIN

09480500 SANTA CRUZ RIVER MEAR NOGALES, AZ--CONTINUEo
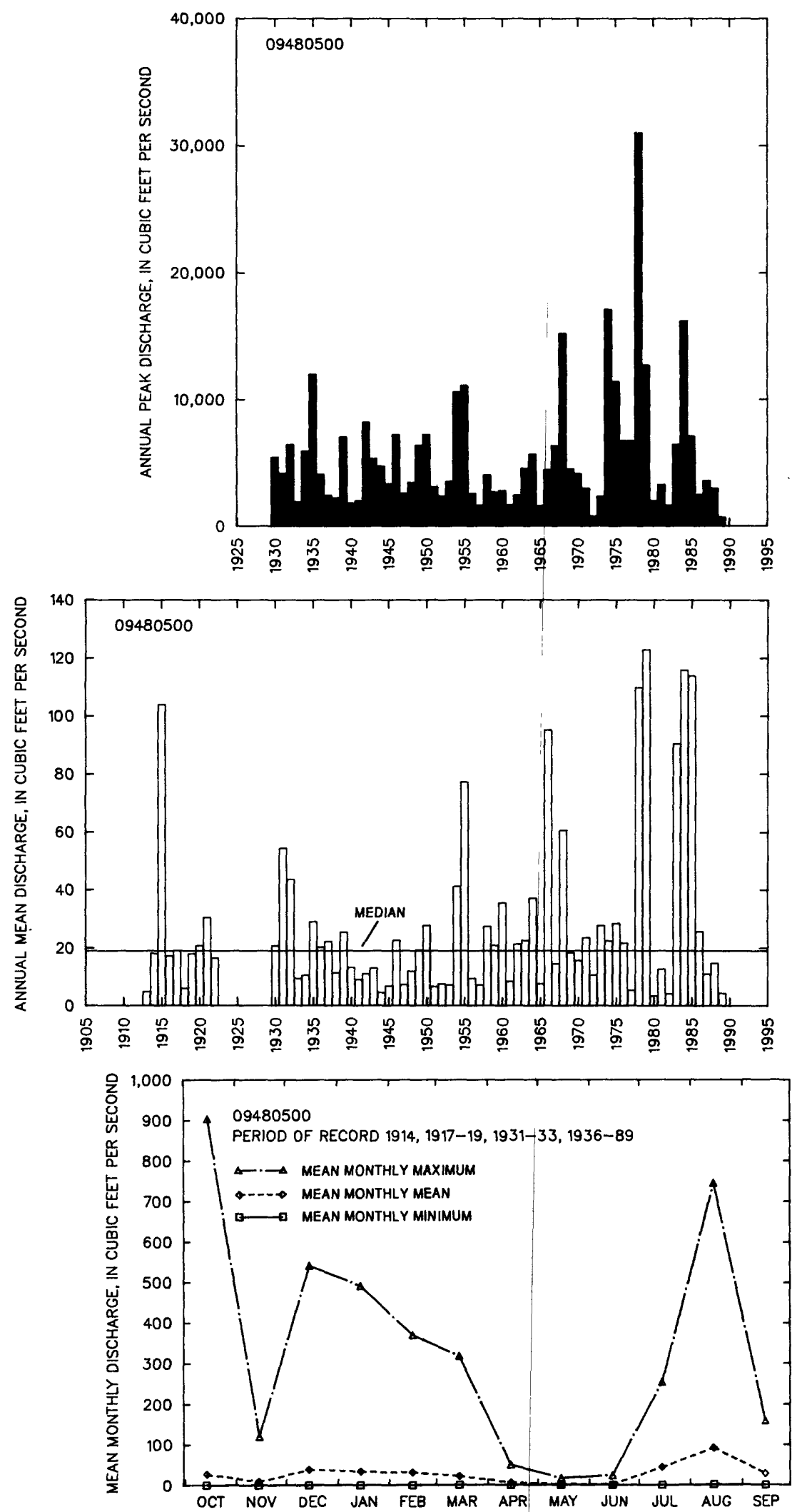
09481500 SONOITA CREEK MEAR PATAGONIA, AZ

LOCATION.--Lat 31'30'00", long 110\%49'00", in SEKSW\% sec.21, T.22 S., R.15 E., Santa Cruz County, Hydrologic Unit 15050301, on left abutment of former railroad bridge, 5 mi downstream from Patagonia.

DRAIMAGE AREA. $--209 \mathrm{mi}^{2}$.

ANNUAL PEAK DISCHARGE

\begin{tabular}{|c|c|c|c|c|c|c|c|}
\hline $\begin{array}{l}\text { WATER } \\
\text { YEAR }\end{array}$ & DATE & $\begin{array}{c}\text { ANNUAL PEAK } \\
\text { DISCHARGE } \\
\left.\text { (FT }{ }^{3} / \mathrm{S}\right)\end{array}$ & $\begin{array}{l}\text { DISCHARGE } \\
\text { COOES }\end{array}$ & $\begin{array}{l}\text { WATER } \\
\text { YEAR }\end{array}$ & DATE & $\begin{array}{l}\text { ANNUAL PEAK } \\
\text { DISCHARGE } \\
\text { (FT } 3 / \mathrm{S} \text { ) }\end{array}$ & $\begin{array}{l}\text { DISCHARGE } \\
\text { COOES }\end{array}$ \\
\hline $\begin{array}{l}1930 \\
1931 \\
1932 \\
1933 \\
1934 \\
1935 \\
1936 \\
1937 \\
1938 \\
1939 \\
1940 \\
1941 \\
1942 \\
1943 \\
1944 \\
1945 \\
1946 \\
1947 \\
1948 \\
1949 \\
1950 \\
1951 \\
1952\end{array}$ & $\begin{array}{l}08-07-30 \\
07-28-31 \\
07-26-32 \\
07-15-33 \\
08-00-34 \\
08-23-35 \\
08-09-36 \\
09-06-37 \\
09-09-38 \\
08-08-39 \\
08-13-40 \\
08-09-41 \\
09-12-42 \\
08-28-43 \\
08-09-44 \\
08-06-45 \\
09-30-46 \\
08-12-47 \\
08-15-48 \\
08-08-49 \\
07-30-50 \\
08-02-51 \\
08-14-52\end{array}$ & $\begin{array}{r}2,600 \\
1,900 \\
1,700 \\
1,050 \\
11,000 \\
4,700 \\
3,600 \\
3,600 \\
3,400 \\
3,300 \\
2,580 \\
2,150 \\
1,000 \\
4,530 \\
6690 \\
3,140 \\
14,000 \\
2,360 \\
4,750 \\
5,790 \\
7,300 \\
5,030 \\
3,630\end{array}$ & & $\begin{array}{l}1953 \\
1954 \\
1955 \\
1956 \\
1957 \\
1958 \\
1959 \\
1960 \\
1961 \\
1962 \\
1963 \\
1964 \\
1965 \\
1966 \\
1967 \\
1968 \\
1969 \\
1970 \\
1971 \\
1972 \\
1978 \\
1984\end{array}$ & $\begin{array}{l}07-14-53 \\
07-20-54 \\
08-12-55 \\
07-19-56 \\
08-02-57 \\
07-05-58 \\
08-24-59 \\
08-13-60 \\
10-09-60 \\
12-15-61 \\
08-26-63 \\
09-10-64 \\
09-08-65 \\
08-18-66 \\
07-03-67 \\
12-20-67 \\
08-24-69 \\
08-03-70 \\
08-11-71 \\
09-09-72 \\
10-09-77 \\
10-02-83\end{array}$ & $\begin{array}{r}2,870 \\
4,670 \\
6,920 \\
780 \\
4,860 \\
5,590 \\
2,310 \\
1,550 \\
2,760 \\
680 \\
4,320 \\
2,640 \\
806 \\
4,120 \\
2,060 \\
5,410 \\
450 \\
622 \\
2,860 \\
368 \\
17,380 \\
216,000\end{array}$ & $\begin{array}{l}\text { HP } \\
\text { HP }\end{array}$ \\
\hline
\end{tabular}

BASIN CHARACTERISTICS

\begin{tabular}{|c|c|c|c|c|c|c|c|}
\hline \multirow{2}{*}{$\begin{array}{l}\text { MAIN } \\
\text { CHANHEL } \\
\text { SLOPE } \\
\text { (FT/MI) }\end{array}$} & \multicolumn{2}{|r|}{$\begin{array}{l}\text { MEAN } \\
\text { BASIN }\end{array}$} & & \multicolumn{2}{|r|}{$\begin{array}{l}\text { MEAN } \\
\text { ANNUAL }\end{array}$} & \multicolumn{2}{|c|}{ RAINFALL INTENSITY, 24-HOUR } \\
\hline & $\begin{array}{l}\text { STREAM } \\
\text { LENGTH } \\
\text { (MI) }\end{array}$ & $\begin{array}{l}\text { ELEVA- } \\
\text { TION } \\
\text { (FT) }\end{array}$ & $\begin{array}{l}\text { FORESTED } \\
\text { AREA } \\
\text { (PERCENT) }\end{array}$ & $\begin{array}{l}\text { SOIL } \\
\text { INDEX }\end{array}$ & $\begin{array}{l}\text { PRECIPI- } \\
\text { TATION } \\
\text { (IN) }\end{array}$ & $\begin{array}{c}\text { 2-YEAR } \\
\text { (IN) }\end{array}$ & $\begin{array}{c}\text { 50-YEAR } \\
\text { (IN) }\end{array}$ \\
\hline 76.7 & 21.7 & 4,800 & 52.0 & 2.0 & 19.3 & 2.0 & 4.1 \\
\hline
\end{tabular}


MEAN MONTHLY AND ANMUAL DISCHARGES 1931-33, 1936-72

\begin{tabular}{|c|c|c|c|c|c|c|}
\hline MONTH & $\begin{array}{l}\operatorname{MAX} \operatorname{IIm}_{(\mathrm{M}} \\
\left(\mathrm{FT}^{3} / \mathrm{S}\right)\end{array}$ & $\begin{array}{l}\text { MINIMUM } \\
\left(F T^{3} / S\right)\end{array}$ & $\begin{array}{c}\text { MEAN } \\
\left(F T^{3} / S\right)\end{array}$ & $\begin{array}{l}\text { STAN- } \\
\text { DARD } \\
\text { DEVIA- } \\
\text { TION } \\
\text { (FT } 3 / S)\end{array}$ & $\begin{array}{l}\text { COEFF I- } \\
\text { CIENT OF } \\
\text { VARI - } \\
\text { ATION }\end{array}$ & $\begin{array}{c}\text { PERCENT } \\
\text { OF } \\
\text { ANNUAL } \\
\text { RUNOFF }\end{array}$ \\
\hline $\begin{array}{l}\text { OCTOBER } \\
\text { NOVEMBER } \\
\text { DECEMBER } \\
\text { JANUARY } \\
\text { FEBRUARY } \\
\text { MARCH } \\
\text { APRIL } \\
\text { MAY } \\
\text { JUNE } \\
\text { JULY } \\
\text { AUGUST } \\
\text { SEPTEMBER }\end{array}$ & $\begin{array}{c}20 \\
18 \\
107 \\
52 \\
96 \\
16 \\
12 \\
10 \\
8.6 \\
112 \\
151 \\
71\end{array}$ & $\begin{array}{l}0.03 \\
0.32 \\
0.99 \\
1.1 \\
0.99 \\
0.87 \\
0.49 \\
0.06 \\
0.00 \\
0.06 \\
1.5 \\
0.05\end{array}$ & $\begin{array}{c}3.9 \\
4.0 \\
10 \\
7.5 \\
9.9 \\
5.5 \\
4.1 \\
2.5 \\
1.6 \\
13 \\
25 \\
9.2\end{array}$ & $\begin{array}{c}3.9 \\
3.3 \\
21 \\
8.9 \\
18 \\
3.3 \\
2.9 \\
2.4 \\
2.1 \\
19 \\
27 \\
13\end{array}$ & $\begin{array}{l}0.99 \\
0.83 \\
2.1 \\
1.2 \\
1.8 \\
0.61 \\
0.70 \\
0.95 \\
1.3 \\
1.4 \\
1.1 \\
1.4\end{array}$ & $\begin{array}{r}4.0 \\
4.1 \\
10.5 \\
7.8 \\
10.2 \\
5.7 \\
4.3 \\
2.6 \\
1.7 \\
13.5 \\
26.1 \\
9.5\end{array}$ \\
\hline NNUAL & 33 & 1.9 & 8.1 & 5.6 & 0.69 & 100 \\
\hline
\end{tabular}

MAGNITLEE AND PROBABILITY OF INSTANTANEOUS PEAK FLON BASED ON PERIOD OF RECORD 1930-72, 1978, 1984

DISCHARGE, IN $\mathrm{FT}^{3} / \mathrm{S}$, FOR INDICATED RECURRENCE INTERVAL IN YEARS, AND EXCEEDANCE PROBABILITY, IN PERCENT

\begin{tabular}{lccccc}
2 & 5 & 10 & 25 & 50 & $100 \dagger$ \\
$50 \%$ & $20 \%$ & $10 \%$ & $4 \%$ & $2 \%$ & $1 \%$ \\
3,130 & 5,360 & 7,190 & 9,950 & 12,300 & 15,100 \\
\hline MEIGHTED SKEN (LOGS) & $=0.22$ & & \\
MEAN & (LOGS) & 3.51 \\
STANDARD DEV. (LOGS) & $=0.27$
\end{tabular}

MAGNITUDE AND PROBABILITY OF ANHUAL LOW FLON BASED ON PERICD OF RECORD 1932-33, 1937-72

\begin{tabular}{|c|c|c|c|c|c|c|}
\hline \multirow{2}{*}{$\begin{array}{l}\text { PERIOD } \\
\text { (CON- } \\
\text { SECU- } \\
\text { TIVE } \\
\text { DAYS) }\end{array}$} & \multicolumn{6}{|c|}{$\begin{array}{l}\text { DISCHARGE, IN FT } 3 / S \text {, FOR INDICATED } \\
\text { RECURRENCE INTERVAL, IN YEARS, AND } \\
\text { NON-EXCEEDANCE PROBABILITY, IN PERCENT }\end{array}$} \\
\hline & $\begin{array}{c}2 \\
50 \%\end{array}$ & $\begin{array}{c}5 \\
20 x\end{array}$ & $\begin{array}{l}10 \\
10 \%\end{array}$ & $\begin{array}{l}20 \\
5 \%\end{array}$ & $\begin{array}{l}50 \\
2 \%\end{array}$ & $\begin{array}{l}100 \dagger \\
1 \%\end{array}$ \\
\hline $\begin{array}{r}1 \\
3 \\
7 \\
14 \\
30 \\
60 \\
90 \\
120 \\
183\end{array}$ & $\begin{array}{l}0.00 \\
0.08 \\
0.11 \\
0.19 \\
0.35 \\
0.70 \\
1.3 \\
2.4 \\
3.8\end{array}$ & $\begin{array}{l}0.00 \\
0.00 \\
0.00 \\
0.00 \\
0.05 \\
0.18 \\
0.52 \\
1.3 \\
2.2\end{array}$ & $\begin{array}{l}0.00 \\
0.00 \\
0.00 \\
0.00 \\
0.00 \\
0.08 \\
0.31 \\
0.97 \\
1.6\end{array}$ & $\begin{array}{l}0.00 \\
0.00 \\
0.00 \\
0.00 \\
0.00 \\
0.03 \\
0.20 \\
0.74 \\
1.2\end{array}$ & $\begin{array}{l}0.00 \\
0.00 \\
0.00 \\
0.00 \\
0.00 \\
0.00 \\
0.12 \\
0.55 \\
0.90\end{array}$ & $\begin{array}{l}0.00 \\
0.00 \\
0.00 \\
0.00 \\
0.00 \\
0.00 \\
0.09 \\
0.45 \\
0.73\end{array}$ \\
\hline
\end{tabular}

MACNITUDE AND PROBABILITY OF ANNUAL HIGH FLOW BASED ON PERICD OF RECORD 1931-33, 1936-72

\begin{tabular}{|c|c|c|c|c|c|c|}
\hline \multirow{2}{*}{$\begin{array}{l}\text { PERIOO } \\
\text { (CON- } \\
\text { SEW- } \\
\text { TIVE } \\
\text { DAYS) }\end{array}$} & \multicolumn{6}{|c|}{$\begin{array}{l}\text { DISCHARGE, IN FT }{ }^{3} / S, \text { FOR INDICATED } \\
\text { RECURRENCE INTERVAL, IN YEARS, AND } \\
\text { EXCEEDANCE PROBABILITY, IN PERCENT }\end{array}$} \\
\hline & $\stackrel{2}{50 x}$ & $\begin{array}{c}5 \\
20 \%\end{array}$ & $\begin{array}{l}10 \\
10 \%\end{array}$ & $\begin{array}{l}25 \\
4 \%\end{array}$ & $\begin{array}{l}50 \\
2 \%\end{array}$ & $\underset{1 \%}{100 \dagger}$ \\
\hline $\begin{array}{l}1 \\
3 \\
7 \\
15 \\
30 \\
60 \\
90\end{array}$ & $\begin{array}{r}277 \\
132 \\
74 \\
44 \\
29 \\
20 \\
15\end{array}$ & $\begin{array}{r}599 \\
285 \\
156 \\
92 \\
59 \\
39 \\
28\end{array}$ & $\begin{array}{r}881 \\
415 \\
225 \\
138 \\
87 \\
54 \\
39\end{array}$ & $\begin{array}{r}1,310 \\
608 \\
329 \\
212 \\
131 \\
79 \\
56\end{array}$ & $\begin{array}{r}1,680 \\
771 \\
418 \\
282 \\
171 \\
100 \\
71\end{array}$ & $\begin{array}{r}2,090 \\
948 \\
516 \\
364 \\
218 \\
124 \\
87\end{array}$ \\
\hline
\end{tabular}

DURATION TABLE OF DAILY MEAN FLON FOR PERIOO OF RECORD 1931-33, 1936-72
DISCHARGE, IN FT $3 / 5$, WHICH WAS EQUALED OR EXCEEDED FOR INDICATED PERCENT OF TIME

\begin{tabular}{|c|c|c|c|c|c|c|c|c|c|c|c|c|c|c|c|c|}
\hline $1 \%$ & $5 \%$ & $10 \%$ & $15 \%$ & $20 \%$ & $30 \%$ & $40 \%$ & $50 \%$ & $60 \%$ & $70 x$ & $80 \%$ & $90 \%$ & $95 \%$ & $98 \%$ & $99 \%$ & $99.5 \%$ & $99.9 \%$ \\
\hline 115 & 19 & 11 & 8.0 & 7.1 & 5.3 & 4.0 & 3.2 & 2.6 & 2.1 & 1.2 & 0.45 & 0.10 & 0.00 & 0.00 & 0.00 & 0.00 \\
\hline
\end{tabular}


GILA RIVER BASIN

09481500 SONOITA CREEK MEAR PATAGONIA, AZ--CONTIMUED
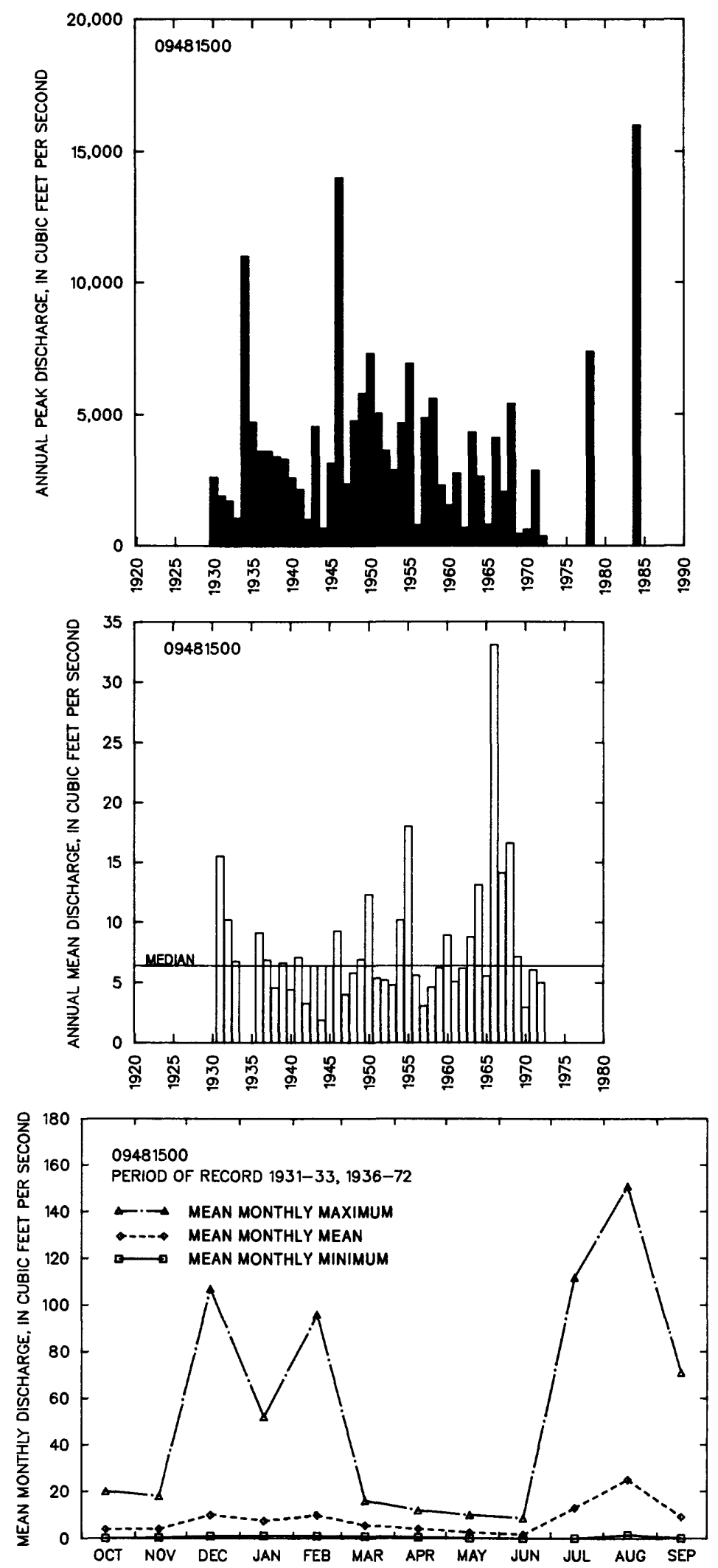


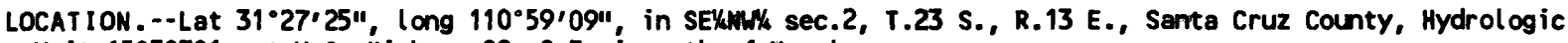
Unit 15050301 , at U.S. Highway $89,8.5 \mathrm{mi}$ north of Mogales.

DRAINAGE AREA. $--10.3 \mathrm{mi}^{2}$.

\section{ANMUAL PEAK DISCHARGE}

\begin{tabular}{cccc}
$\begin{array}{c}\text { WATER } \\
\text { YEAR }\end{array}$ & $\begin{array}{c}\text { DATE } \\
\text { ANNUAL PEAK } \\
\text { DISCHARGE } \\
\text { (FT } 3 / \text { S) }\end{array}$ & $\begin{array}{c}\text { DISCHARGE } \\
\text { CODES }\end{array}$ \\
\hline 1963 & $08-05-63$ & 179 & \\
1964 & $07-00-64$ & 813 & \\
1965 & $07-17-65$ & 263 & \\
1967 & $07-00-67$ & 520 & \\
1968 & $12-20-67$ & 150 & ES \\
1969 & $09-00-69$ & 1,000 & \\
1970 & $08-08-70$ & 50 & \\
1971 & $08-00-71$ & 700 & \\
1972 & $07-24-72$ & 300 & \\
1973 & $10-00-72$ & 80 & \\
1974 & $08-02-74$ & 115 & \\
1975 & $07-00-75$ & 600 & \\
1976 & $00-00-76$ & 220 & HP \\
1978 & $10-09-77$ & 1,200 &
\end{tabular}

MAGNITUDE AND PROBABILITY OF INSTANTANEOUS PEAK FLOW BASED ON PERIOD OF RECORD 1963-76, 1978

DISCHARGE, IN $\mathrm{FT}^{3} / \mathrm{S}$, FOR INDICATED RECURRENCE INTERVAL IN YEARS, AND EXCEEDANCE PROBABILITY, IN PERCENT

\begin{tabular}{|c|c|c|c|c|c|}
\hline $\begin{array}{c}2 \\
50 \%\end{array}$ & $\begin{array}{c}5 \\
20 \%\end{array}$ & $\begin{array}{r}10 \\
10 \%\end{array}$ & $\begin{array}{l}25 \\
4 \%\end{array}$ & $\begin{array}{l}50 \dagger \\
2 \%\end{array}$ & $\begin{array}{c}100 \dagger \\
1 \%\end{array}$ \\
\hline 309 & 691 & 1,030 & 1,560 & 2,020 & 2,540 \\
\hline $\begin{array}{l}\text { WEIGHTED } \\
\text { MEAN } \\
\text { STANDARD }\end{array}$ & $\begin{array}{l}\text { SKEW } \\
\text { DEV. }\end{array}$ & $\begin{array}{l}(\text { LOGS })= \\
(\text { LOGS) }= \\
(\text { LOGS })=\end{array}$ & $\begin{array}{r}-0.21 \\
2.48 \\
0.43\end{array}$ & & \\
\hline
\end{tabular}

f Reliability of values in colum is uncertain, and potential errors are large.

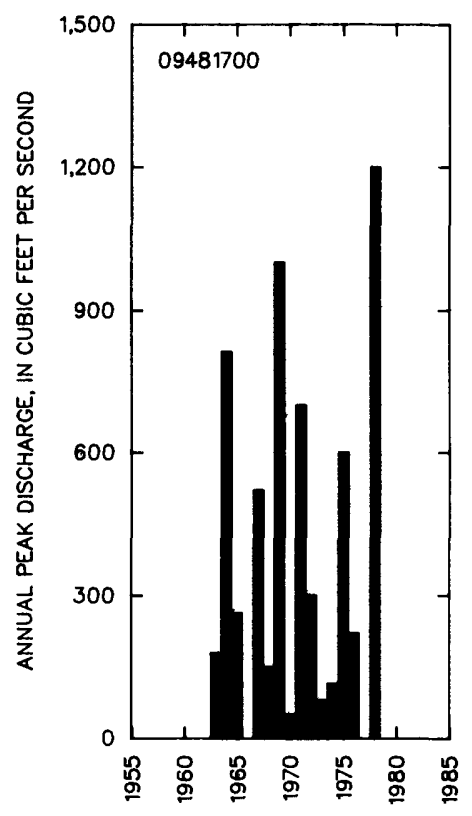

BASIN CHARACTERISTICS

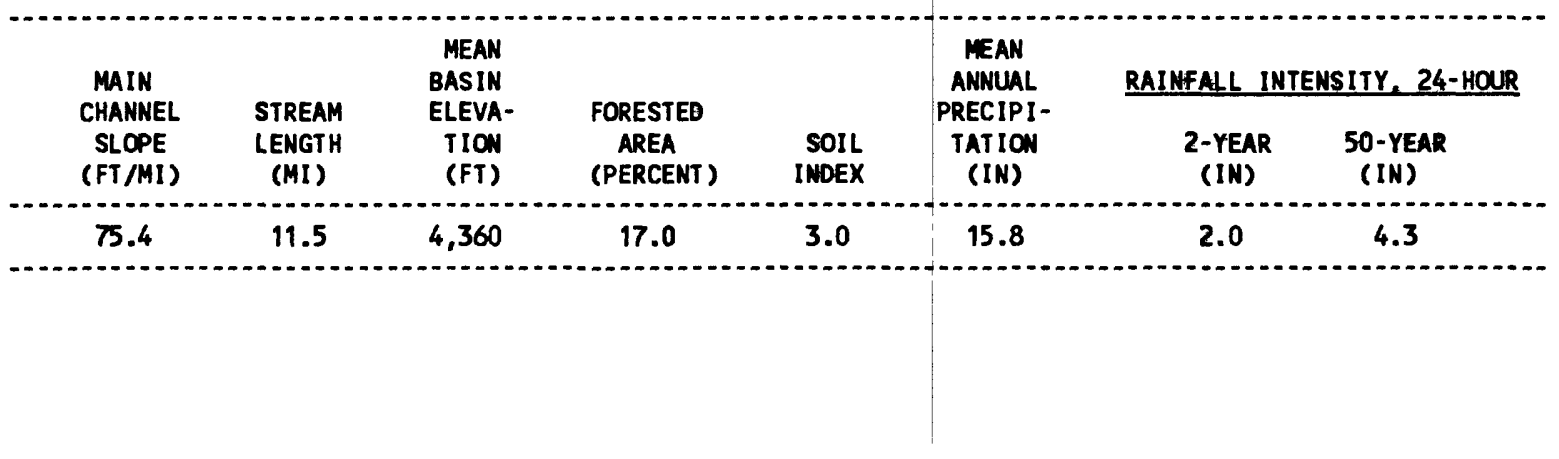


09481750 SOPORI WASH AT AMADO, AZ

LOCATION.--Lat 31'43'25", long 111.03'40", in NEKNEK sec.1, T.20 S., R.12 E., Santa Cruz County, Hydrologic Unit 15050301, $200 \mathrm{ft}$ below bridge on State Highway $89,1.1 \mathrm{mi}$ north of Amado.

DRAIMAGE AREA. $--176 \mathrm{mi}^{2}$.

ANNUAL PEAK DISCHARGE

\begin{tabular}{|c|c|c|c|}
\hline $\begin{array}{l}\text { WATER } \\
\text { YEAR }\end{array}$ & DATE & $\begin{array}{c}\text { ANNUAL PEAK } \\
\text { DISCHARGE } \\
\left(\mathrm{FT}^{3} / \mathrm{S}\right)\end{array}$ & $\begin{array}{l}\text { DISCHARGE } \\
\text { COOES }\end{array}$ \\
\hline $\begin{array}{l}1948 \\
1954 \\
1955 \\
1956 \\
1957 \\
1958 \\
1964 \\
1965 \\
1966 \\
1967 \\
1968 \\
1969 \\
1970 \\
1971 \\
1972 \\
1973 \\
1974 \\
1975 \\
1976 \\
1978\end{array}$ & $\begin{array}{l}08-15-48 \\
00-00-54 \\
08-00-55 \\
00-00-56 \\
00-00-57 \\
00-00-58 \\
09-10-64 \\
00-00-65 \\
12-22-65 \\
00-00-67 \\
00-00-68 \\
00-00-69 \\
09-04-70 \\
09-01-71 \\
07-14-72 \\
07-00-73 \\
07-23-74 \\
08-23-75 \\
09-25-76 \\
10-00-77\end{array}$ & $\begin{array}{r}16,000 \\
6,500 \\
2,700 \\
500 \\
100 \\
18,000 \\
3,800 \\
500 \\
1,500 \\
500 \\
500 \\
500 \\
1,800 \\
2,900 \\
27,300 \\
400 \\
3,900 \\
2,700 \\
2,500 \\
2,300\end{array}$ & $\begin{array}{l}\text { LT } \\
\text { LT } \\
\text { LT }\end{array}$ \\
\hline
\end{tabular}

MAGNITUDE AND PROBABILITY OF INSTANTANEOUS PEAK FLOU BASED ON PERICD OF RECORD 1948, 1954-58, 1964-76, 1978

DISCHARGE, IN $\mathrm{FT}^{3} / \mathrm{S}$, FOR INDICATED RECURRENCE INTERVAL IN YEARS, AND EXCEEDANCE PROBABILITY, IN PERCENT

\begin{tabular}{|c|c|c|c|c|c|}
\hline $\begin{array}{c}2 \\
50 \%\end{array}$ & $\begin{array}{c}5 \\
20 \%\end{array}$ & $\begin{array}{r}10 \\
10 \%\end{array}$ & $\begin{array}{l}25 \\
4 \%\end{array}$ & $\begin{array}{l}50 \dagger \\
2 \%\end{array}$ & $\underset{1 \%}{100}+$ \\
\hline 2,230 & 4,610 & 6,780 & 10,200 & 13,400 & 17,100 \\
\hline $\begin{array}{l}\text { WEIGHTED } \\
\text { MEAN } \\
\text { STANDARD }\end{array}$ & $\begin{array}{l}\text { SKEW } \\
\text { DEV. }\end{array}$ & $\begin{array}{l}(\text { LOGS })= \\
(\text { LOGS }= \\
(\text { LOGS }=\end{array}$ & $\begin{array}{l}0.05 \\
3.35 \\
0.37\end{array}$ & & \\
\hline
\end{tabular}

$\uparrow$ Reliability of values in colum is uncertain, and potential errors are large.

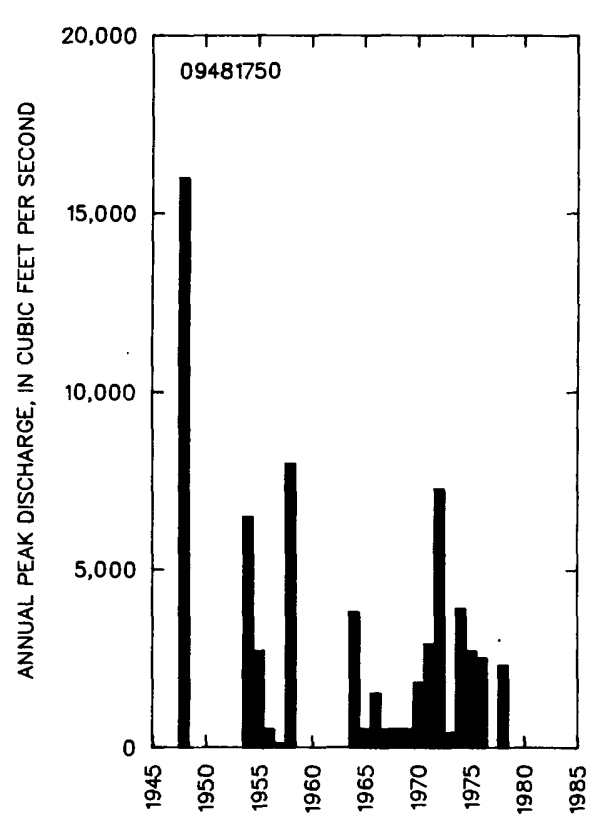

\section{BASIN CHARACTERISTICS}

\begin{tabular}{|c|c|c|c|c|c|c|c|}
\hline \multirow{4}{*}{$\begin{array}{l}\text { MAIN } \\
\text { CHANNEL } \\
\text { SLOPE } \\
\text { (FT/MI) }\end{array}$} & \multirow{4}{*}{$\begin{array}{l}\text { STREAM } \\
\text { LENGTH } \\
\text { (MI) }\end{array}$} & \multirow{4}{*}{$\begin{array}{l}\text { MEAN } \\
\text { BASIN } \\
\text { ELEVA- } \\
\text { TION } \\
\text { (FT) }\end{array}$} & \multirow{4}{*}{$\begin{array}{l}\text { FORESTED } \\
\text { AREA } \\
\text { (PERCENT) }\end{array}$} & \multirow[b]{4}{*}{$\begin{array}{l}\text { SOIL } \\
\text { INDEX }\end{array}$} & \multirow{3}{*}{$\begin{array}{c}\text { MEAN } \\
\text { ANNUAL } \\
\text { PRECIPI- }\end{array}$} & & \\
\hline & & & & & & \multicolumn{2}{|c|}{ RAINFALL INTENSITY, 24-HOUR } \\
\hline & & & & & & & \\
\hline & & & & & $\begin{array}{l}\text { TATION } \\
\text { (IN) }\end{array}$ & $\begin{array}{c}\text { 2-YEAR } \\
\text { (IN) }\end{array}$ & $\begin{array}{c}\text { 50-YEAR } \\
\text { (IN) }\end{array}$ \\
\hline 35.9 & 27.3 & 3,840 & 0.3 & 3.0 & 15.5 & 2.2 & 4.3 \\
\hline
\end{tabular}


09481800 DEMETRIE WASH TRIBUTARY MEAR CONTINENTAL, AZ

LOCATION.--Lat 31'52'15", long 111'05'15", in SWKSEK sec.11, T.18 S., R.12 E., Pima County, Hydrologic Unit 15050301, at Duval Mine Road, 6.5 mi west of Continental.

DRAINAGE AREA. $--0.15 \mathrm{mi}^{2}$.

ANNUAL PEAK DISCHARGE

\begin{tabular}{|c|c|c|c|}
\hline $\begin{array}{l}\text { WATER } \\
\text { YEAR }\end{array}$ & DATE & $\begin{array}{c}\text { ANNUAL PEAK } \\
\text { DISCHARGE } \\
\left(\mathrm{FT}^{3} / \mathrm{S}\right)\end{array}$ & $\begin{array}{l}\text { DISCHARGE } \\
\text { COOES }\end{array}$ \\
\hline $\begin{array}{l}1963 \\
1964 \\
1965 \\
1966 \\
1967 \\
1968 \\
1969 \\
1970 \\
1971 \\
1972 \\
1973 \\
1974 \\
1975 \\
1976\end{array}$ & $\begin{array}{l}08-08-63 \\
00-00-64 \\
10-00-64 \\
00-00-66 \\
07-17-67 \\
12-15-67 \\
09-00-69 \\
08-00-70 \\
07-00-71 \\
00-00-72 \\
07-00-73 \\
00-00-74 \\
09-07-75 \\
09-25-76\end{array}$ & $\begin{array}{c}71 \\
71 \\
17 \\
11 \\
19 \\
10 \\
20 \\
10 \\
4.0 \\
60 \\
17 \\
63 \\
110 \\
36\end{array}$ & ES \\
\hline
\end{tabular}

MAGNITUDE AND PROBABILITY OF INSTANTANEOUS PEAK FLOW BASED ON PERIOD OF RECORD 1963-76

DISCHARGE, IN FT ${ }^{3} / \mathrm{S}$, FOR INDICATED RECURRENCE INTERVAL IN YEARS, AND EXCEEDANCE PROBABILITY, IN PERCENT

\begin{tabular}{|c|c|c|c|c|c|}
\hline 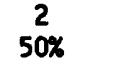 & $\begin{array}{c}5 \\
20 \%\end{array}$ & $\begin{array}{r}10 \\
10 \%\end{array}$ & $\begin{array}{l}25 \\
4 \%\end{array}$ & $\begin{array}{l}50 \dagger \\
2 \%\end{array}$ & $\begin{array}{c}100 \nmid \\
1 \%\end{array}$ \\
\hline 25.6 & 56.9 & 85.2 & 130 & 169 & 214 \\
\hline $\begin{array}{l}\text { WEIGHTED } \\
\text { MEAN } \\
\text { STANDARD }\end{array}$ & $\begin{array}{l}\text { SKEW } \\
\text { DEV. }\end{array}$ & $\begin{array}{l}(\text { LOGS })= \\
(\text { LOGS) }= \\
(\text { LOGS) }=\end{array}$ & $\begin{array}{r}-0.15 \\
1.40 \\
0.42\end{array}$ & & \\
\hline
\end{tabular}

+ Reliability of values in column is uncertain, and potential errors are large.

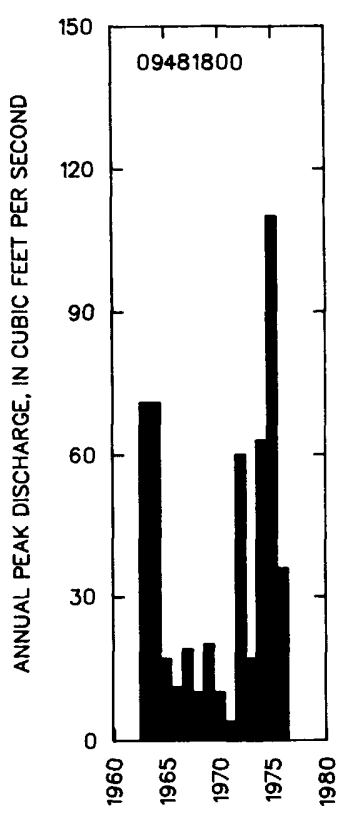

BASIN CHARACTERISTICS

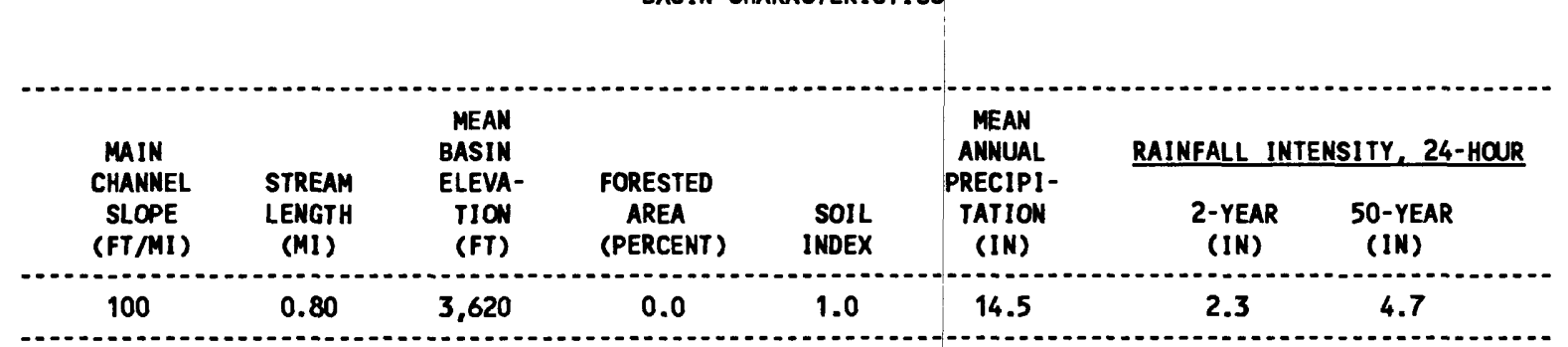


09481900 OCOTILLO WASH NEAR CONTINENTAL, AZ

LOCATION.--Lat 31.50'00", long 111.00'00", in SEK sec.27, T.18 S., R.13E. (unsurveyed), Pima County, Hydrologic Unit 15050301, in Spanish Land Grant of San Ignacio de la Canoa at U.S. Highway $89,1.5 \mathrm{mi}$ southwest of Continental.

DRAIMAGE AREA. --3.60 $\mathrm{mi}^{2}$.

ANNUAL PEAK DISCHARGE

\begin{tabular}{|c|c|c|c|}
\hline $\begin{array}{l}\text { MATER } \\
\text { YEAR }\end{array}$ & DATE & $\begin{array}{c}\text { ANNUAL PEAK } \\
\text { DISCHARGE } \\
\text { (FT } 3 / S)\end{array}$ & $\begin{array}{l}\text { DISCHARGE } \\
\text { CCOES }\end{array}$ \\
\hline $\begin{array}{l}1954 \\
1955 \\
1956 \\
1957 \\
1963 \\
1964 \\
1965 \\
1966 \\
1967 \\
1968 \\
1969 \\
1970 \\
1971 \\
1972 \\
1973 \\
1974\end{array}$ & $\begin{array}{l}07-20-54 \\
00-00-55 \\
00-00-56 \\
00-00-57 \\
08-05-63 \\
07-00-64 \\
00-00-65 \\
00-00-66 \\
00-00-67 \\
12-00-67 \\
00-00-69 \\
00-00-70 \\
08-00-71 \\
00-00-72 \\
00-00-73 \\
00-00-74\end{array}$ & $\begin{array}{r}1,250 \\
200 \\
90 \\
35 \\
11,660 \\
11,840 \\
0 \\
40 \\
20 \\
1.0 \\
0 \\
0 \\
12 \\
0 \\
10 \\
0\end{array}$ & $\begin{array}{c}\text { ES } \\
\text { ES } \\
\text { ES } \\
\\
\\
\text { ES } \\
\text { ES } \\
\text { LT } \\
\text { KR } \\
\text { KR } \\
\text { KR } \\
\text { ES, KR } \\
\text { KR }\end{array}$ \\
\hline
\end{tabular}

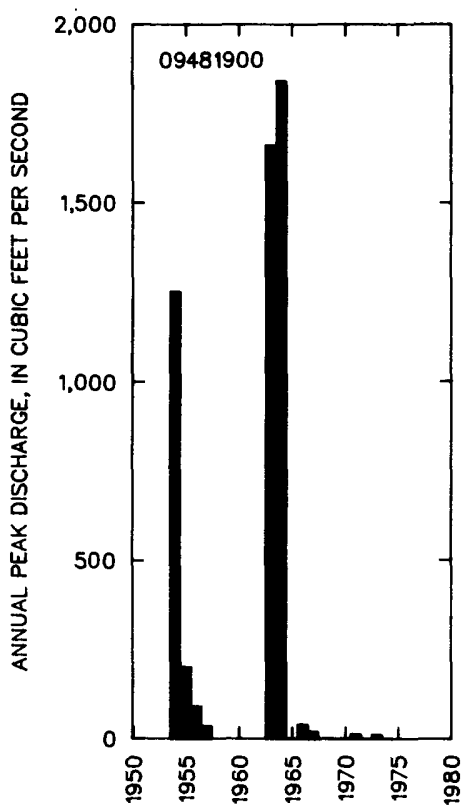

MAGNITUDE AND PROBABILITY OF INSTANTANEOUS PEAK FLOW BASED ON PERIOD OF RECORD

DISCHARGE, IN FT $3 / \mathrm{S}$, FOR INDICATED RECURRENCE INTERVAL IN YEARS, AND EXCEEDANCE PROBABILITY, IN PERCENT

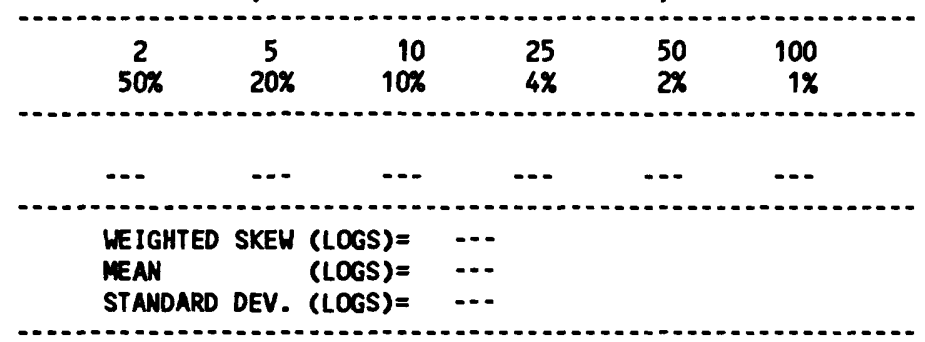

BASIN CHARACTERISTICS

\begin{tabular}{|c|c|c|c|c|c|c|c|}
\hline \multirow{2}{*}{$\begin{array}{l}\text { MAIN } \\
\text { CHANNEL } \\
\text { SLOPE } \\
\text { (FT/MI) }\end{array}$} & \multirow[b]{2}{*}{$\begin{array}{l}\text { STREAM } \\
\text { LENGTH } \\
\text { (MI) }\end{array}$} & \multirow{2}{*}{$\begin{array}{l}\text { MEAN } \\
\text { BASIN } \\
\text { ELEVA- } \\
\text { TION } \\
\text { (FT) }\end{array}$} & \multirow[b]{2}{*}{$\begin{array}{l}\text { FORESTED } \\
\text { AREA } \\
\text { (PERCENT) }\end{array}$} & \multirow[b]{2}{*}{$\begin{array}{l}\text { SOIL } \\
\text { INDEX }\end{array}$} & \multirow{2}{*}{$\begin{array}{l}\text { MEAN } \\
\text { ANNUAL } \\
\text { PRECIPI- } \\
\text { TATION } \\
\text { (IN) }\end{array}$} & \multicolumn{2}{|c|}{ RAINFALL INTENSITY, 24-HOUR } \\
\hline & & & & & & $\begin{array}{c}\text { 2-YEAR } \\
\text { (IN) }\end{array}$ & $\begin{array}{l}\text { 50-YEAR } \\
\text { (IN) }\end{array}$ \\
\hline 106 & 5.99 & 3,280 & 0.0 & 3.0 & 14.1 & 2.1 & 4.6 \\
\hline
\end{tabular}




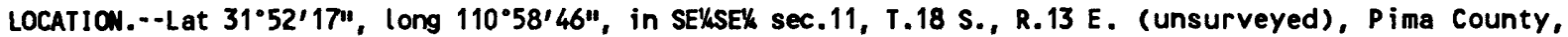
Hydrologic Unit 15050301, in Spanish land grant of San Ignacio de la Canoa, on right bank $0.8 \mathrm{mi}$ northeast of Green Valley Post Office, and $1.5 \mathrm{mi}$ north of Continental. Prior to Feb. 13, 1981, at site 1.5 mi upstream.

DRAINAGE AREA. $--1,682 \mathrm{mi}^{2}$, revised, of which $395 \mathrm{mi}^{2}$ is in Mexico.

REMARKS. - Irrigation above station of about 12,500 acres including about 2,300 acres in Mexico, mostly by pumping from ground water.

\section{ANNUAL PEAK DISCHARGE}

\begin{tabular}{|c|c|c|c|c|c|}
\hline $\begin{array}{l}\text { WATER } \\
\text { YEAR }\end{array}$ & DATE & $\begin{array}{l}\text { WNUAL PEAK } \\
\text { DISCHARGE } \\
\left(\mathrm{FT}^{3} / \mathrm{S}\right)\end{array}$ & $\begin{array}{l}\text { WATER } \\
\text { YEAR }\end{array}$ & DATE & $\begin{array}{l}\text { ANNUAL PEAK } \\
\text { DISCHARGE } \\
\left(F^{3} / S\right)\end{array}$ \\
\hline $\begin{array}{l}1940 \\
1941 \\
1942 \\
1943 \\
1944 \\
1945 \\
1946 \\
1947 \\
1952 \\
1953 \\
1954 \\
1955 \\
1956 \\
1957 \\
1958 \\
1959 \\
1960 \\
1961 \\
1962 \\
1963 \\
1964 \\
1965 \\
1966\end{array}$ & $\begin{array}{l}08-14-40 \\
08-09-41 \\
07-28-42 \\
08-01-43 \\
08-12-44 \\
08-09-45 \\
09-09-46 \\
10-01-46 \\
08-15-52 \\
07-14-53 \\
08-05-54 \\
08-19-55 \\
07-29-56 \\
08-21-57 \\
08-05-58 \\
08-17-59 \\
01-12-60 \\
08-23-61 \\
01-25-62 \\
08-06-63 \\
09-10-64 \\
09-12-65 \\
12-23-65\end{array}$ & $\begin{array}{r}12,100 \\
3,670 \\
2,700 \\
4,000 \\
4,440 \\
7,820 \\
4,120 \\
5,330 \\
1,820 \\
4,910 \\
14,600 \\
17,500 \\
3,090 \\
1,690 \\
5,620 \\
3,900 \\
3,740 \\
4,820 \\
2,480 \\
4,220 \\
14,000 \\
3,370 \\
5,990\end{array}$ & $\begin{array}{l}1967 \\
1968 \\
1969 \\
1970 \\
1971 \\
1972 \\
1973 \\
1974 \\
1975 \\
1976 \\
1977 \\
1978 \\
1979 \\
1980 \\
1981 \\
1982 \\
1983 \\
1984 \\
1985 \\
1986 \\
1987 \\
1988 \\
1989\end{array}$ & $\begin{array}{l}07-27-67 \\
12-20-67 \\
08-05-69 \\
07-20-70 \\
08-20-71 \\
07-14-72 \\
03-14-73 \\
09-03-74 \\
09-01-75 \\
07-12-76 \\
07-18-77 \\
10-09-77 \\
12-18-78 \\
08-25-80 \\
09-05-81 \\
08-15-82 \\
02-04-83 \\
10-02-83 \\
12-28-84 \\
07-16-86 \\
08-05-87 \\
07-28-88 \\
09-03-89\end{array}$ & $\begin{array}{r}3,730 \\
18,000 \\
1,680 \\
3,720 \\
3,270 \\
3,290 \\
2,130 \\
3,450 \\
3,350 \\
3,800 \\
3,290 \\
26,500 \\
16,000 \\
2,360 \\
3,350 \\
2,160 \\
4,800 \\
145,000 \\
11,600 \\
840 \\
340 \\
930 \\
1,200\end{array}$ \\
\hline
\end{tabular}

$1_{H}$ ighest since 1892 .

BASIN CHARACTERISTICS

\begin{tabular}{|c|c|c|c|c|c|c|c|}
\hline \multirow{3}{*}{$\begin{array}{l}\text { MAIN } \\
\text { CHANNEL } \\
\text { SLOPE } \\
\text { (FT/MI) }\end{array}$} & \multirow[b]{3}{*}{$\begin{array}{l}\text { STREAM } \\
\text { LENGTH } \\
\text { (MI) }\end{array}$} & \multirow{3}{*}{$\begin{array}{l}\text { MEAN } \\
\text { BASIN } \\
\text { ELEVA- } \\
\text { TION } \\
\text { (FT) }\end{array}$} & \multirow[b]{3}{*}{$\begin{array}{l}\text { FORESTED } \\
\text { AREA } \\
\text { (PERCENT) }\end{array}$} & \multirow[b]{3}{*}{$\begin{array}{l}\text { SOIL } \\
\text { INDEX }\end{array}$} & \multirow{3}{*}{$\begin{array}{l}\text { MEAN } \\
\text { ANNUAL } \\
\text { PRECIPI- } \\
\text { TAT ION } \\
\text { (IN) }\end{array}$} & \multirow{2}{*}{\multicolumn{2}{|c|}{ RAINFALL INTENSITY, 24-HOUR }} \\
\hline & & & & & & & \\
\hline & & & & & & $\begin{array}{c}\text { 2-YEAR } \\
\text { (IN) }\end{array}$ & $\begin{array}{c}\text { 50-YEAR } \\
\text { (IN) }\end{array}$ \\
\hline 21.0 & 99.2 & 4,350 & 22.0 & 2.0 & 18.1 & 2.1 & 4.3 \\
\hline
\end{tabular}


GILA RIVER BASIN

09482000 SANTA CRUZ RIVER AT CONTINENTAL, AZ--Cont inued

MEAN MONTHLY AND ANMUAL DISCHARGES 1941-46, 1952-80

\begin{tabular}{|c|c|c|c|c|c|c|}
\hline MONTH & $\begin{array}{l}\operatorname{MAXIMUN} \\
\left(F^{3} / S\right)\end{array}$ & $\begin{array}{l}\text { MINIMUN } \\
\left(F^{3} / S\right)\end{array}$ & $\begin{array}{c}\text { MEAN } \\
\left(F T^{3} / S\right)\end{array}$ & $\begin{array}{l}\text { STAN- } \\
\text { DARD } \\
\text { DEVIA- } \\
\text { TION } \\
\text { (FT'/S) }\end{array}$ & $\begin{array}{l}\text { COEFFI - } \\
\text { CIENT OF } \\
\text { VARI - } \\
\text { ATION }\end{array}$ & $\begin{array}{c}\text { PERCENT } \\
\text { OF } \\
\text { ANNUAL } \\
\text { RUNOFF }\end{array}$ \\
\hline $\begin{array}{l}\text { OCTOBER } \\
\text { NOVEMBER } \\
\text { DECEMBER } \\
\text { JANUARY } \\
\text { FEBRUARY } \\
\text { MARCH } \\
\text { APRIL } \\
\text { MAY } \\
\text { JUNE } \\
\text { JULY } \\
\text { AUGUST } \\
\text { SEPTEMBER }\end{array}$ & $\begin{array}{c}755 \\
133 \\
658 \\
565 \\
207 \\
132 \\
0.12 \\
0.00 \\
6.2 \\
227 \\
753 \\
285\end{array}$ & $\begin{array}{l}0.00 \\
0.00 \\
0.00 \\
0.00 \\
0.00 \\
0.00 \\
0.00 \\
0.00 \\
0.00 \\
0.13 \\
0.00 \\
0.00\end{array}$ & $\begin{array}{l}24 \\
3.9 \\
47 \\
24 \\
11 \\
8.5 \\
0.00 \\
0.00 \\
0.44 \\
36 \\
88 \\
19\end{array}$ & $\begin{array}{c}127 \\
22 \\
155 \\
100 \\
38 \\
30 \\
0.02 \\
0.00 \\
1.3 \\
48 \\
147 \\
48\end{array}$ & $\begin{array}{l}5.3 \\
5.7 \\
3.3 \\
4.2 \\
3.4 \\
3.6 \\
5.9 \\
\\
3.0 \\
1.3 \\
1.7 \\
2.5\end{array}$ & $\begin{array}{r}9.1 \\
1.5 \\
18.0 \\
9.1 \\
4.3 \\
3.2 \\
0.0 \\
0.0 \\
0.2 \\
13.7 \\
33.6 \\
7.3\end{array}$ \\
\hline NNUAL & 116 & 0.26 & 22 & 29 & 1.3 & 100 \\
\hline
\end{tabular}

MAGNITUDE AND PROBABILITY OF INSTANTANEOUS PEAK FLOW BASED ON PERIOD OF RECORD 1940-47, 1952-89

DISCHARGE, IN $\mathrm{FT}^{3} / \mathrm{S}$, FOR INDICATED RECURRENCE INTERVAL IN YEARS, AND EXCEEDANCE PROBABILITY, IN PERCENT

\begin{tabular}{lccccc}
2 & 5 & 10 & 25 & 50 & $100 \uparrow$ \\
$50 \%$ & $20 \%$ & $10 \%$ & $4 \%$ & $2 \%$ & $1 \%$ \\
3,980 & 8,140 & 12,300 & 19,600 & 27,000 & 36,500 \\
\hline MEIGHTED SKEW (LOGS) & $=0.48$ & & \\
MEAN & (LOGS) & 3.63 \\
STANDARD DEV. (LOGS) & $=0.35$
\end{tabular}

MAGNITLOE AND PROBABILITY OF ANNUAL LOW FLON BASED ON PERICD OF RECORD 1942-46, 1953-80

\begin{tabular}{|c|c|c|c|c|c|c|}
\hline \multirow{2}{*}{$\begin{array}{l}\text { PERIOD } \\
\text { (CON- } \\
\text { SECU } \\
\text { TIVE } \\
\text { DAYS) }\end{array}$} & \multicolumn{6}{|c|}{$\begin{array}{l}\text { DISCHARGE, IN FT } 3 / S \text {, FOR IND ICATED } \\
\text { RECURRENCE INTERVAL, IN YEARS, AND } \\
\text { NON-EXCEEDANCE PROBABILITY, IN PERCENT }\end{array}$} \\
\hline & $\begin{array}{c}2 \\
50 \%\end{array}$ & $\begin{array}{c}5 \\
20 \%\end{array}$ & $\begin{array}{l}10 \\
10 \%\end{array}$ & $\begin{array}{l}20 \\
5 \%\end{array}$ & $\begin{array}{l}50 \\
2 \%\end{array}$ & $\begin{array}{l}100 \uparrow \\
1 x\end{array}$ \\
\hline $\begin{array}{r}1 \\
3 \\
7 \\
14 \\
30 \\
60 \\
90\end{array}$ & '. & & & & & \\
\hline $\begin{array}{l}120 \\
183\end{array}$ & $\begin{array}{l}0.00 \\
0.06\end{array}$ & $\begin{array}{l}0.00 \\
0.00\end{array}$ & $\begin{array}{l}0.00 \\
0.00\end{array}$ & $\begin{array}{l}0.00 \\
0.00\end{array}$ & $\begin{array}{l}0.00 \\
0.00\end{array}$ & $\begin{array}{l}0.00 \\
0.00\end{array}$ \\
\hline
\end{tabular}

MAGNITLDE AND PROBABILITY OF ANNUAL HIGH FLOW BASED ON PERICD OF RECORD 1941-46, 1952-80

\begin{tabular}{|c|c|c|c|c|c|c|}
\hline \multirow{2}{*}{$\begin{array}{l}\text { PERIOD } \\
\text { (CON- } \\
\text { SECU- } \\
\text { TIVE } \\
\text { DAYS) }\end{array}$} & & \multicolumn{5}{|c|}{$\begin{array}{l}\text { DISCHARGE, IN } \mathrm{FT}^{3} / \mathrm{S} \text {, FOR INDICATED } \\
\text { RECURRENCE INTERVAL, IN YEARS, AND } \\
\text { EXCEEDANCE PROBABILITY, IN PERCENT }\end{array}$} \\
\hline & $\begin{array}{c}2 \\
50 x\end{array}$ & $\begin{array}{c}5 \\
20 \%\end{array}$ & $\begin{array}{l}10 \\
10 \%\end{array}$ & $\begin{array}{l}25 \\
4 \%\end{array}$ & $\begin{array}{l}50 \\
2 \%\end{array}$ & $\begin{array}{c}100 \dagger \\
1 \%\end{array}$ \\
\hline $\begin{array}{r}1 \\
3 \\
7 \\
15 \\
30 \\
60 \\
90\end{array}$ & $\begin{array}{r}936 \\
489 \\
260 \\
158 \\
107 \\
63 \\
44\end{array}$ & $\begin{array}{r}2,790 \\
1,480 \\
788 \\
466 \\
297 \\
174 \\
120\end{array}$ & $\begin{array}{r}4,940 \\
2,630 \\
1,390 \\
799 \\
482 \\
282 \\
196\end{array}$ & $\begin{array}{r}9,080 \\
4,850 \\
2,550 \\
1,390 \\
783 \\
459 \\
320\end{array}$ & $\begin{array}{r}13,500 \\
7,190 \\
3,750 \\
1,970 \\
1,050 \\
616 \\
432\end{array}$ & $\begin{array}{r}19,200 \\
10,200 \\
5,290 \\
2,670 \\
1,350 \\
795 \\
561\end{array}$ \\
\hline
\end{tabular}

DURATION TABLE OF DAILY MEAN FLOW FOR PERIOD OF RECORD 1941-46, 1952-80

DISCHARGE, IN FT $3 / \mathrm{S}$, WHICH WAS EQUALED OR EXCEEDED FOR INDICATED PERCENT OF TIME

\begin{tabular}{|c|c|c|c|c|c|c|c|c|c|c|c|c|c|c|c|c|}
\hline $1 \%$ & $5 \%$ & $10 \%$ & $15 \%$ & $20 \%$ & $30 \%$ & $40 \%$ & $50 \%$ & $60 \%$ & $70 \%$ & $80 \%$ & $90 \%$ & $95 \%$ & $98 \%$ & $99 \%$ & $99.5 \%$ & $99.9 \%$ \\
\hline 525 & 37 & 0.47 & 0.00 & 0.00 & 0.00 & 0.00 & 0.00 & 0.00 & 0.00 & 0.00 & 0.00 & 0.00 & 0.00 & 0.00 & 0.00 & 0.00 \\
\hline
\end{tabular}

\& Reliability of values in colum is uncertain, and potential errors are large. 
GILA RIVER BASIN

09482000 SANTA CRUZ RIVER AT CONTINENTAL, AZ--CONTIMUED
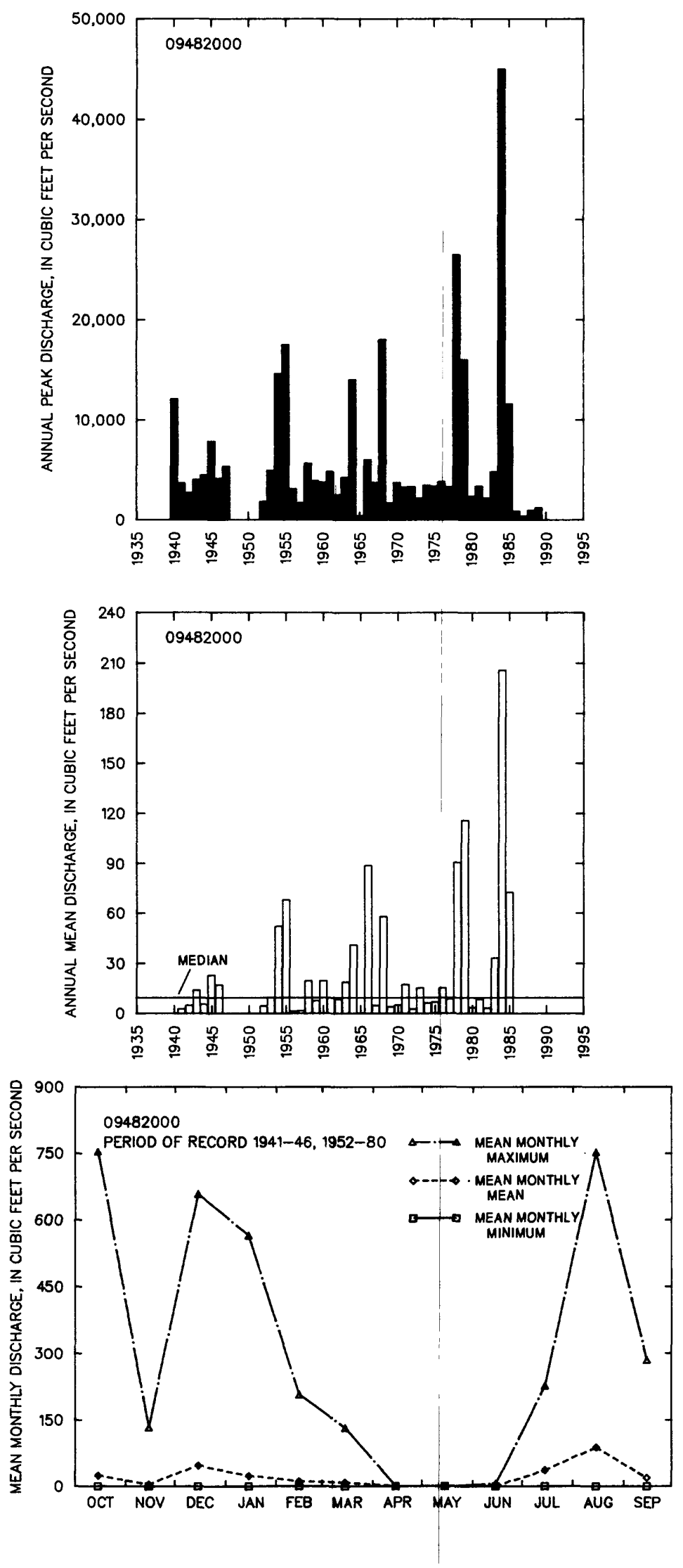
09482200 FLATO MASH MEAR SAHUARITA, AZ

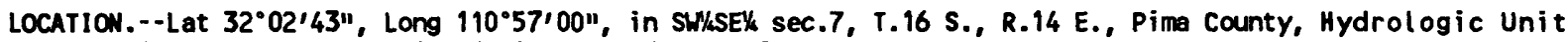
15050301, at U.S. Highway 89, 6 mi north of Sahuarita.

DRAIMAGE AREA.--30.1 $\mathrm{mi}^{2}$ of which $23.4 \mathrm{mi}^{2}$ is noncontribut ing and/or distributary flow.

ANNUAL PEAK DISCHARGE

\begin{tabular}{|c|c|c|c|}
\hline $\begin{array}{l}\text { WATER } \\
\text { YEAR }\end{array}$ & DATE & $\begin{array}{l}\text { ANNUAL PEAK } \\
\text { DISCHARGE } \\
\text { (FT } 3 / \mathrm{S} \text { ) }\end{array}$ & $\begin{array}{l}\text { DISCHARGE } \\
\text { COOES }\end{array}$ \\
\hline $\begin{array}{l}1955 \\
1961 \\
1965 \\
1966 \\
1967 \\
1968 \\
1969 \\
1970 \\
1971 \\
1972 \\
1973 \\
1974 \\
1975 \\
1976 \\
1977 \\
1978 \\
1979 \\
1980 \\
1984\end{array}$ & $\begin{array}{l}00-00-55 \\
00-00-61 \\
08-30-65 \\
08-19-66 \\
07-17-67 \\
02-12-68 \\
08-07-69 \\
07-21-70 \\
08-08-71 \\
09-12-72 \\
10-19-72 \\
07-07-74 \\
09-07-75 \\
09-25-76 \\
07-22-77 \\
08-01-78 \\
08-15-79 \\
08-13-80 \\
10-01-83\end{array}$ & $\begin{array}{r}1 / 4,500 \\
23,500 \\
250 \\
340 \\
307 \\
230 \\
913 \\
1,150 \\
760 \\
365 \\
370 \\
1,170 \\
960 \\
790 \\
390 \\
580 \\
310 \\
271 \\
3820\end{array}$ & $\begin{array}{l}\text { HP } \\
\text { HP }\end{array}$ \\
\hline
\end{tabular}

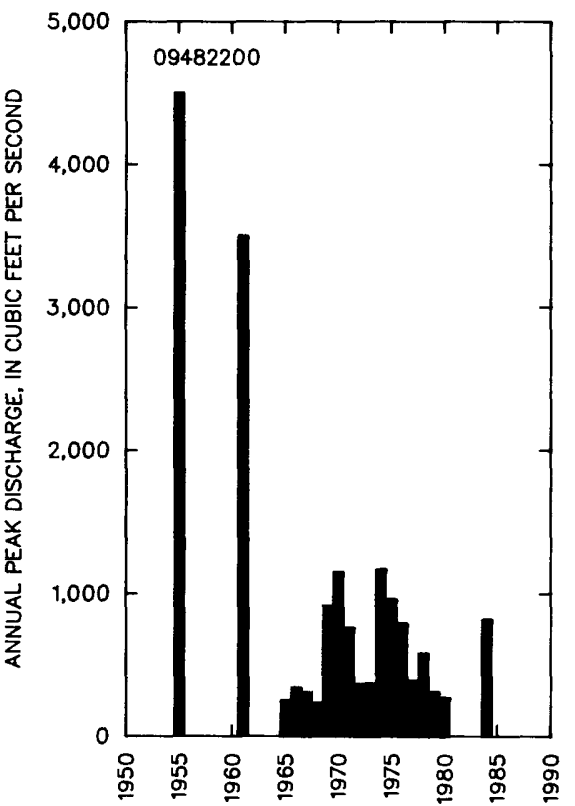

MAGNITUDE AND PROBABILITY OF INSTANTANEOUS PEAK FLOW BASED ON PERIOD OF RECORD

DISCHARGE, IN $\mathrm{FT}^{3} / \mathrm{S}$, FOR INDICATED RECURRENCE INTERVAL IN YEARS, AND EXCEEDANCE PROBABILITY, IN PERCENT

\begin{tabular}{|c|c|c|c|c|c|}
\hline $\begin{array}{c}2 \\
50 \%\end{array}$ & $\begin{array}{c}5 \\
20 \%\end{array}$ & $\begin{array}{r}10 \\
10 \%\end{array}$ & $\begin{array}{l}25 \\
4 \%\end{array}$ & $\begin{array}{l}50 \\
2 \%\end{array}$ & $\begin{array}{r}100 \\
1 \%\end{array}$ \\
\hline-- & -. & $\ldots$ & $\cdots$ & $\ldots$ & $\ldots$ \\
\hline $\begin{array}{l}\text { WEIGHTED } \\
\text { MEAN } \\
\text { STANDARD }\end{array}$ & $\begin{array}{l}\text { SKEW } \\
\text { DEV. }\end{array}$ & $\begin{array}{l}(\text { LOGS })= \\
(\text { LOGS }= \\
(\text { LOGS })=\end{array}$ & $\ldots$ & & \\
\hline
\end{tabular}

BASIN CHARACTERISTICS

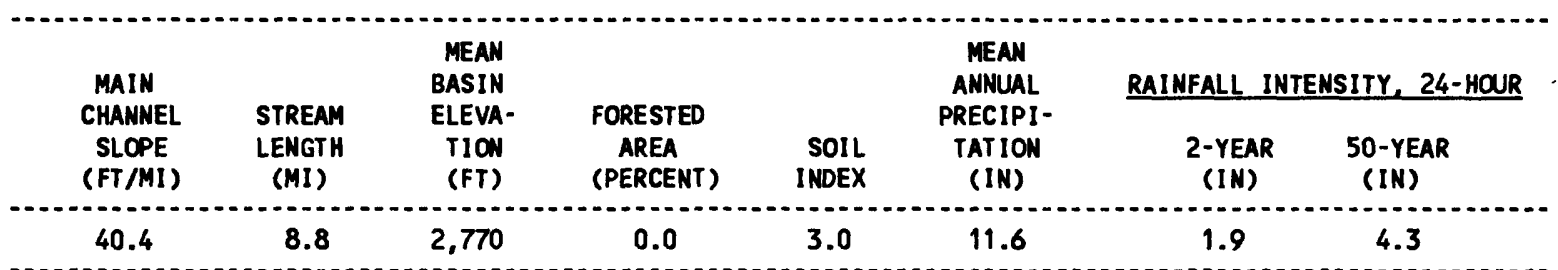


LOCATION.-- Lat $32^{\circ} 04^{\prime} 10^{\prime \prime}$, long $110^{\circ} 48^{\prime} 23^{\prime \prime}$, in SW/2NWk sec.3, T.16 S., R.15 E., Pima County, Hydrologic Unit 15050301, at road to pumping station $1.1 \mathrm{mi}$ south of Interstate 10, and 5.7 mi west of Vail.

DRAINAGE AREA. $--0.81 \mathrm{mi}^{2}$.

ANNUAL PEAK DISCHARGE

\begin{tabular}{ccc}
$\begin{array}{c}\text { HATER } \\
\text { YEAR }\end{array}$ & DATE & $\begin{array}{c}\text { ANNUAL PEAK } \\
\text { DISCHARGE } \\
\text { (FT } 3 / \text { S })\end{array}$ \\
\hline 1966 & $08-16-66$ & 90 \\
1967 & $07-17-67$ & 205 \\
1968 & $00-00-68$ & 135 \\
1969 & $08-07-69$ & 33 \\
1970 & $08-00-70$ & 220 \\
1971 & $07-00-71$ & 337 \\
1972 & $07-17-72$ & 30 \\
1973 & $10-05-72$ & 142 \\
1974 & $07-07-74$ & 210 \\
1975 & $07-00-75$ & 43 \\
1976 & $09-25-76$ & 9.0 \\
1977 & $10-22-76$ & 67 \\
1978 & $10-06-77$ & 90 \\
1979 & $12-18-78$ & 41 \\
1980 & $08-24-80$ & 190 \\
1981 & $07-25-81$ & 195 \\
$\ldots \ldots$
\end{tabular}

MAGNITUDE AND PROBABILITY OF INSTANTANEOUS PEAK FLOU BASED ON PERIOD OF RECORD 1966-81

DISCHARGE, IN FT 3 /S, FOR INDICATED RECURRENCE INTERVAL IN YEARS, AND EXCEEDANCE PROBABILITY, IN PERCENT

\begin{tabular}{|c|c|c|c|c|c|}
\hline $\begin{array}{c}2 \\
50 \%\end{array}$ & $\begin{array}{c}5 \\
20 \%\end{array}$ & $\begin{array}{r}10 \\
10 \%\end{array}$ & $\begin{array}{l}25 \\
4 \%\end{array}$ & $\begin{array}{l}50 \nmid \\
2 \%\end{array}$ & $\begin{array}{c}100 \dagger \\
1 \%\end{array}$ \\
\hline 102 & 198 & 274 & 382 & 469 & 560 \\
\hline $\begin{array}{l}\text { WEIGHTED } \\
\text { MEAN } \\
\text { STANDARD }\end{array}$ & $\begin{array}{l}\text { SKEW } \\
\text { DEV. }\end{array}$ & $\begin{array}{l}(\text { LOGS })= \\
(\text { LOGS) }= \\
(\text { LOGS }=\end{array}$ & $\begin{array}{r}-0.31 \\
1.99 \\
0.36\end{array}$ & & \\
\hline
\end{tabular}

f Reliability of values in colum is uncertain, and potential errors are large.

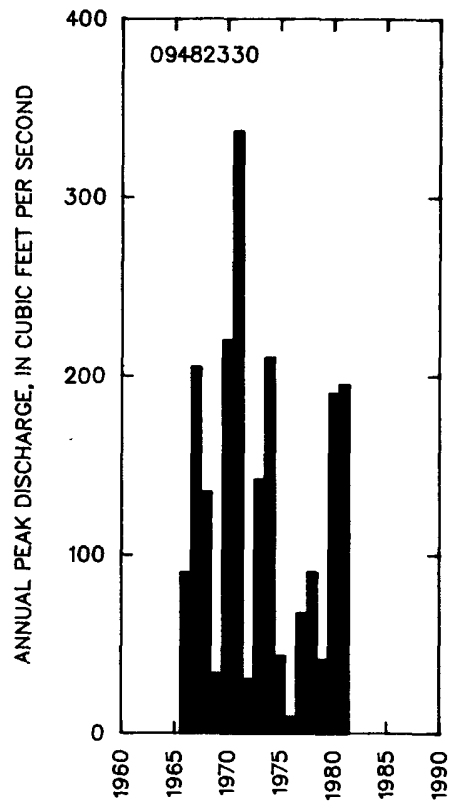


09482350 SOUTH FORK ARIPORT MASH NEAR TUCSON, AZ

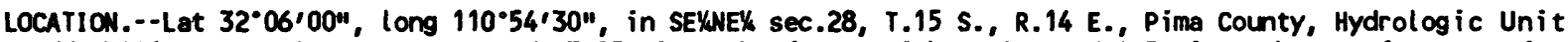
15050301, at Hughes Access Road, $3.25 \mathrm{mi}$ south of U.S. Highway 80 , and $1.5 \mathrm{mi}$ southeast of Tucson city limits.

DRAIMAGE AREA. - -9.78 $\mathrm{mi}^{2}$, of which $5.40 \mathrm{mi}^{2}$ is noncontributing and/or distributary flow.

ANMUAL PEAK DISCHARGE

\begin{tabular}{cccc}
$\begin{array}{c}\text { MATER } \\
\text { YEAR }\end{array}$ & DATE & $\begin{array}{c}\text { AMNUAL PEAK } \\
\text { DISCHARGE } \\
\text { (FT } 3 / \text { S) }\end{array}$ & $\begin{array}{c}\text { DISCHARGE } \\
\text { CODES }\end{array}$ \\
\hline 1966 & $07-28-66$ & 225 & \\
1967 & $07-17-67$ & 450 & \\
1968 & $08-19-68$ & 180 & \\
1969 & $07-28-69$ & 8.0 & \\
1970 & $07-19-70$ & 216 & \\
1971 & $10-02-70$ & 480 & \\
1972 & $08-12-72$ & 180 & \\
1973 & $10-19-72$ & 250 & \\
1974 & $07-08-74$ & 11,890 & \\
1975 & $07-00-75$ & 10 & \\
1976 & $09-25-76$ & 980 & \\
1977 & $01-29-77$ & 69 & \\
1978 & $01-15-78$ & 59 & \\
1979 & $00-00-79$ & 0.0 & \\
1980 & $09-07-80$ & 620 & \\
$\ldots$ & &
\end{tabular}

Highest since 1956.

MAgNITUDE AND PROBABILITY OF INSTANTANEOUS PEAK FLOW BASED ON PERIOD OF RECORD

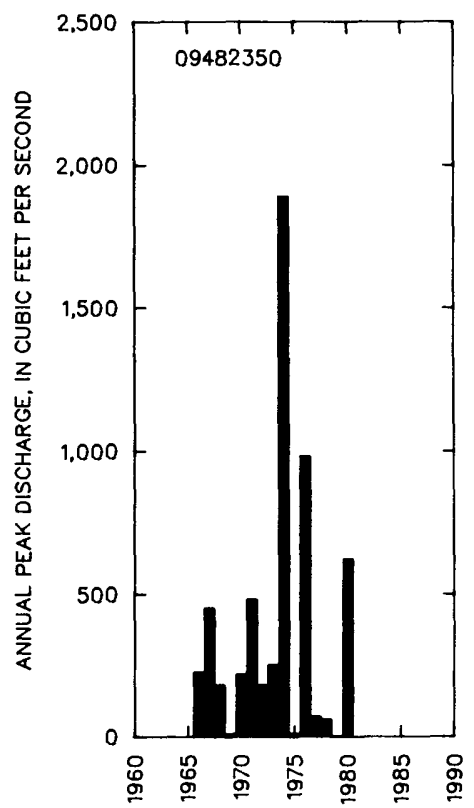

DISCHARGE, IN $\mathrm{FT}^{3} / \mathrm{S}$, FOR INDICATED RECURRENCE INTERVAL IN YEARS, AND EXCEEDANCE PROBABILITY, IN PERCENT

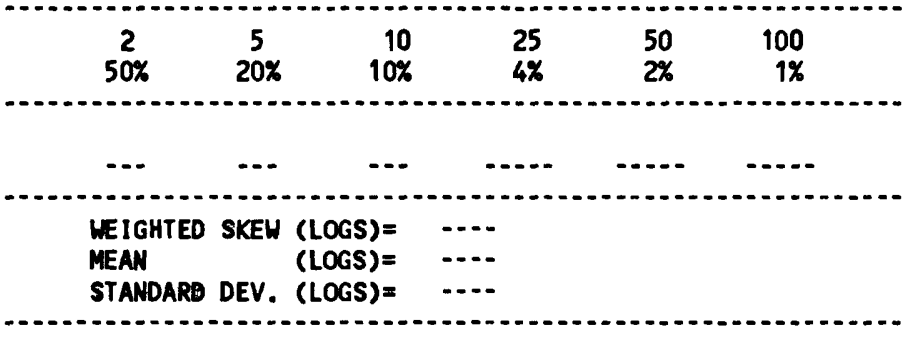

BASIN CHARACTERISTICS

\begin{tabular}{|c|c|c|c|c|c|c|c|}
\hline \multirow{2}{*}{$\begin{array}{l}\text { MAIN } \\
\text { CHANWEL } \\
\text { SLOPE } \\
\text { (FT/MI) }\end{array}$} & \multirow[b]{2}{*}{$\begin{array}{l}\text { STREAM } \\
\text { LENGTH } \\
\text { (MI) }\end{array}$} & \multirow{2}{*}{$\begin{array}{l}\text { MEAN } \\
\text { BASIN } \\
\text { ELEVA- } \\
\text { TION } \\
\text { (FT) }\end{array}$} & \multirow[b]{2}{*}{$\begin{array}{l}\text { FORESTED } \\
\text { AREA } \\
\text { (PERCENT) }\end{array}$} & \multicolumn{2}{|r|}{$\begin{array}{c}\text { MEAN } \\
\text { ANNUAL } \\
\text { PRECIPI - }\end{array}$} & \multicolumn{2}{|c|}{ RAINFALL INTENSITY, 24-HOUR } \\
\hline & & & & $\begin{array}{l}\text { SOIL } \\
\text { INDEX }\end{array}$ & $\begin{array}{l}\text { PRECIPI - } \\
\text { TATION } \\
\text { (IN) }\end{array}$ & $\begin{array}{c}\text { 2-YEAR } \\
\text { (IN) }\end{array}$ & $\begin{array}{c}\text { 50-YEAR } \\
\text { (IN) }\end{array}$ \\
\hline 36.5 & 3.1 & 2,740 & 0.0 & 1.0 & 11.0 & 1.8 & 3.9 \\
\hline
\end{tabular}


09482370 NORTH FORK AIRPORT WASH NEAR TUCSON, AZ

LOCATION.--Lat 32.06'40", long 110.54'30", in NEYSEX sec.21, T.15 S., R.14 E., Pima County, Hydrologic Unit 15050301, at Hughes Access Road, $2.5 \mathrm{mi}$ south of U.S. Highway 80, and $1 \mathrm{mi}$ east of Tucson city limits.

DRAINAGE AREA. $--6.65 \mathrm{mi}^{2}$, of which $1.37 \mathrm{mi}^{2}$ is noncontributing and/or distributary flow.

ANIUAL PEAK DISCHARGE

\begin{tabular}{|c|c|c|c|}
\hline $\begin{array}{l}\text { WATER } \\
\text { YEAR }\end{array}$ & DATE & $\begin{array}{c}\text { ANNUAL PEAK } \\
\text { DISCHARGE } \\
\left(\mathrm{FT}^{3} / \mathrm{S}\right)\end{array}$ & $\begin{array}{l}\text { DISCHARGE } \\
\text { CODES }\end{array}$ \\
\hline $\begin{array}{l}1961 \\
1965 \\
1966 \\
1967 \\
1968 \\
1969 \\
1970 \\
1971 \\
1972 \\
1973 \\
1974 \\
1975 \\
1976 \\
1977 \\
1978 \\
1979 \\
1980\end{array}$ & $\begin{array}{l}08-22-61 \\
00-00-65 \\
07-28-66 \\
07-17-67 \\
08-19-68 \\
09-15-69 \\
07-19-70 \\
10-02-70 \\
08-12-72 \\
10-19-72 \\
07-08-74 \\
07-12-75 \\
09-25-76 \\
11-11-76 \\
01-15-78 \\
00-00-79 \\
09-07-80\end{array}$ & $\begin{array}{r}1_{1}, 350 \\
2650 \\
100 \\
30 \\
370 \\
40 \\
190 \\
450 \\
130 \\
230 \\
1_{1,030} \\
10 \\
700 \\
70 \\
115 \\
0 \\
460\end{array}$ & $\begin{array}{l}\text { HP } \\
\text { ES } \\
\text { ES }\end{array}$ \\
\hline
\end{tabular}

1Highest since 1956.

$2 \mathrm{Highest}$ since 1961 .

MAGNITUDE AND PROBABILITY OF INSTANTANEOUS PEAK FLOW BASED ON PERIOD OF RECORD

DISCHARGE, IN $\mathrm{FT}^{3} / \mathrm{S}$, FOR INDICATED RECURRENCE INTERVAL IN YEARS, AND EXCEEDANCE PROBABILITY, IN PERCENT

\begin{tabular}{|c|c|c|c|c|c|}
\hline$\underset{50 \%}{2}$ & $\begin{array}{c}5 \\
20 \%\end{array}$ & $\begin{array}{r}10 \\
10 \%\end{array}$ & $\begin{array}{l}25 \\
4 \%\end{array}$ & $\begin{array}{l}50 \\
2 x\end{array}$ & $\begin{array}{r}100 \\
1 \%\end{array}$ \\
\hline$\ldots$ & $\ldots$ & $\cdots$ & $\ldots$ & $\ldots$ & $\ldots . .$. \\
\hline $\begin{array}{l}\text { WEIGHTED } \\
\text { MEAN } \\
\text { STANDARD }\end{array}$ & $\begin{array}{l}\text { SKEW } \\
\text { DEV. }\end{array}$ & $\begin{array}{l}(\text { LOGS })= \\
(\text { LOGS })= \\
(\text { LOGS })=\end{array}$ & $\ldots$ & & \\
\hline
\end{tabular}

BASIN CHARACTERISTICS

\begin{tabular}{|c|c|c|c|c|c|c|c|}
\hline MAIN & & $\begin{array}{l}\text { MEAN } \\
\text { BASIN }\end{array}$ & & & $\begin{array}{c}\text { MEAN } \\
\text { ANNUAL }\end{array}$ & RAINFALL II & SITY, 24-HOUR \\
\hline $\begin{array}{l}\text { CHANNEL } \\
\text { SLOPE } \\
\text { (FT/MI) }\end{array}$ & $\begin{array}{l}\text { STREAM } \\
\text { LENGTH } \\
\text { (MI) }\end{array}$ & $\begin{array}{l}\text { ELEVA- } \\
\text { TION } \\
\text { (FT) }\end{array}$ & $\begin{array}{l}\text { FORESTED } \\
\text { AREA } \\
\text { (PERCENT) }\end{array}$ & $\begin{array}{l}\text { SOIL } \\
\text { INDEX }\end{array}$ & $\begin{array}{l}\text { PRECIPI- } \\
\text { TATION } \\
\text { (IN) }\end{array}$ & $\begin{array}{c}\text { 2-YEAR } \\
\text { (IN) }\end{array}$ & $\begin{array}{l}\text { 50-YEAR } \\
\text { (IN) }\end{array}$ \\
\hline 40.6 & 4.6 & 2,780 & 3.0 & 1.0 & 10.8 & 1.8 & 3.9 \\
\hline
\end{tabular}

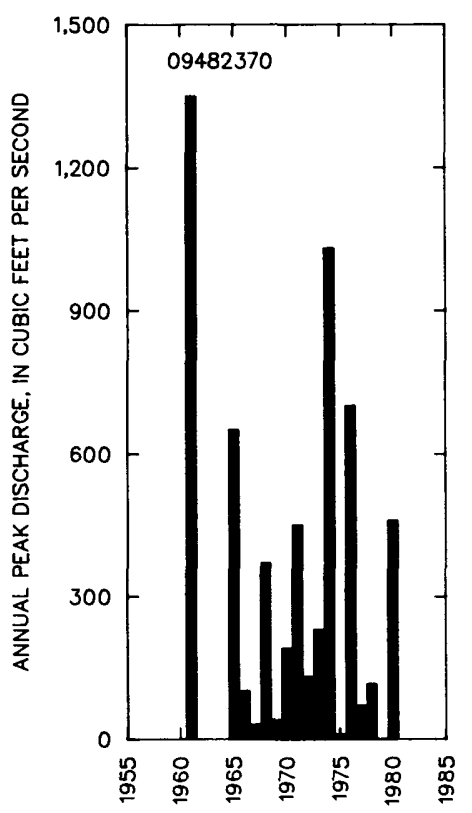


09482400 AIRPORT WASH AT TUCSON, AZ

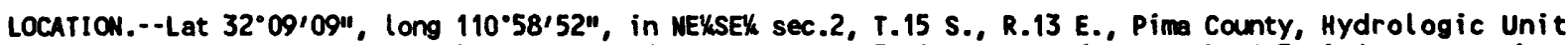
15050301, $25 \mathrm{ft}$ upstream from Santa Clara Avenue, 0.7 mi upstream from mouth, 4.3 mi downstream from confluence of north and south forks of Airport Wash, and $4.9 \mathrm{mi}$ south of city hall in Tucson.

DRAINAGE AREA. $--23.0 \mathrm{mi}^{2}$.

\section{ANNUAL PEAK DISCHAREE}

\begin{tabular}{|c|c|c|c|}
\hline $\begin{array}{l}\text { WATER } \\
\text { YEAR }\end{array}$ & DATE & $\begin{array}{c}\text { ANNUAL PEAK } \\
\text { DISCHARGE } \\
\text { (FT } 3 / S)\end{array}$ & $\begin{array}{l}\text { DISCHAREE } \\
\text { CODES }\end{array}$ \\
\hline $\begin{array}{l}1966 \\
1967 \\
1968 \\
1969 \\
1970 \\
1971 \\
1972 \\
1973 \\
1974 \\
1975 \\
1976 \\
1977 \\
1978 \\
1979 \\
1980 \\
1981 \\
1984\end{array}$ & $\begin{array}{l}09-11-66 \\
07-17-67 \\
08-20-68 \\
08-28-69 \\
07-20-70 \\
10-02-70 \\
07-16-72 \\
10-19-72 \\
07-07-74 \\
07-12-75 \\
09-25-76 \\
09-09-77 \\
09-21-78 \\
10-21-78 \\
09-07-80 \\
07-27-81 \\
10-01-83\end{array}$ & $\begin{array}{l}322 \\
106 \\
385 \\
118 \\
823 \\
549 \\
310 \\
159 \\
689 \\
377 \\
896 \\
304 \\
405 \\
279 \\
378 \\
385 \\
2,900\end{array}$ & $\begin{array}{l}C \\
C \\
C \\
C \\
C \\
C \\
C \\
C \\
C \\
C \\
C \\
C \\
C \\
C \\
C \\
C \\
\text { HP, C }\end{array}$ \\
\hline
\end{tabular}

BASIN CHARACTERISTICS

\begin{tabular}{|c|c|c|c|c|c|c|c|}
\hline \multirow{2}{*}{$\begin{array}{l}\text { MAIN } \\
\text { CHANNEL } \\
\text { SLOPE } \\
\text { (FT/MI) }\end{array}$} & \multirow[b]{2}{*}{$\begin{array}{l}\text { STREAM } \\
\text { LENGTH } \\
\text { (MI) }\end{array}$} & \multirow{2}{*}{$\begin{array}{l}\text { MEAN } \\
\text { BASIN } \\
\text { ELEVA- } \\
\text { TION } \\
\text { (FT) }\end{array}$} & \multirow[b]{2}{*}{$\begin{array}{l}\text { FORESTED } \\
\text { AREA } \\
\text { (PERCENT) }\end{array}$} & \multirow[b]{2}{*}{$\begin{array}{l}\text { SOIL } \\
\text { INDEX }\end{array}$} & \multirow{2}{*}{$\begin{array}{l}\text { MEAN } \\
\text { ANNUAL } \\
\text { PRECIPI- } \\
\text { TATION } \\
\text { (IN) }\end{array}$} & \multicolumn{2}{|c|}{ RAINFALL INTENSITY, 24-HOUR } \\
\hline & & & & & & $\begin{array}{c}\text { 2-YEAR } \\
\text { (IN) }\end{array}$ & $\begin{array}{c}\text { 50-YEAR } \\
\text { (IN) }\end{array}$ \\
\hline 37.0 & 10.8 & 2,700 & 1.1 & 1.0 & 10.8 & 1.8 & 3.9 \\
\hline
\end{tabular}


MEAN MONTHLY AND ANNUAL DISCHARGES 1966-81

\begin{tabular}{|c|c|c|c|c|c|c|}
\hline MONTH & $\begin{array}{l}\operatorname{MAXIMUN} \\
\left(F^{3} / S\right)\end{array}$ & $\begin{array}{l}\text { MINIMUM } \\
\left(F^{3} / S\right)\end{array}$ & $\begin{array}{c}\text { MEAN } \\
\text { (FT } 3 / S)\end{array}$ & $\begin{array}{l}\text { STAN- } \\
\text { DARO } \\
\text { DEVIA- } \\
\text { TION } \\
\text { (FT3/S) }\end{array}$ & $\begin{array}{l}\text { COEFFI- } \\
\text { CIENT OF } \\
\text { VARI - } \\
\text { ATION }\end{array}$ & $\begin{array}{c}\text { PERCENT } \\
\text { OF } \\
\text { ANNUAL } \\
\text { RUNOFF }\end{array}$ \\
\hline $\begin{array}{l}\text { OCTOBER } \\
\text { NONEMBER } \\
\text { DECEMBER } \\
\text { JANUARY } \\
\text { FEBRUARY } \\
\text { MARCH } \\
\text { APRIL } \\
\text { MAY } \\
\text { JUNE } \\
\text { JULY } \\
\text { AUGUST } \\
\text { SEPTEMBER }\end{array}$ & $\begin{array}{l}3.4 \\
0.67 \\
0.97 \\
0.53 \\
1.4 \\
0.41 \\
0.24 \\
0.05 \\
0.19 \\
9.4 \\
3.0 \\
6.0\end{array}$ & $\begin{array}{l}0.00 \\
0.00 \\
0.00 \\
0.00 \\
0.00 \\
0.00 \\
0.00 \\
0.00 \\
0.00 \\
0.00 \\
0.00 \\
0.00\end{array}$ & $\begin{array}{l}0.54 \\
0.10 \\
0.19 \\
0.09 \\
0.13 \\
0.06 \\
0.02 \\
0.00 \\
0.01 \\
1.9 \\
0.81 \\
1.2\end{array}$ & $\begin{array}{l}1.1 \\
0.20 \\
0.32 \\
0.18 \\
0.35 \\
0.12 \\
0.06 \\
0.01 \\
0.05 \\
2.7 \\
0.80 \\
1.8\end{array}$ & $\begin{array}{l}2.0 \\
2.0 \\
1.7 \\
2.0 \\
2.7 \\
1.8 \\
3.0 \\
3.4 \\
3.8 \\
1.4 \\
0.98 \\
1.5\end{array}$ & $\begin{array}{r}10.6 \\
2.0 \\
3.7 \\
1.7 \\
2.6 \\
1.2 \\
0.4 \\
0.1 \\
0.2 \\
38.0 \\
16.0 \\
23.5\end{array}$ \\
\hline ANNUAL & 1.1 & 0.08 & 0.43 & 0.31 & 0.72 & 100 \\
\hline
\end{tabular}

MAGNITUDE AND PROBABILITY OF INSTANTANEOUS PEAK FLON BASED ON PERICO OF RECORD 1966-81, 1984

DISCHARGE, IN FT $3 / 5$, FOR INDICATED RECURRENCE INTERVAL IN YEARS, AND EXCEEDANCE PROBABILITY, IN PERCENT

\begin{tabular}{lccccc}
2 & 5 & 10 & 25 & $50 \dagger$ & $100 \dagger$ \\
$50 \%$ & $20 \%$ & $10 \%$ & $4 \%$ & $2 \%$ & $1 \%$ \\
403 & 666 & 889 & 1,230 & 1,540 & 1,900 \\
\hline WEIGHTED SKEW (LOGS) & $=0.47$ & & \\
MEAN & & & & \\
(LOGS) & $=2.63$ \\
STANDARD DEV. (LOGS) & $=0.25$
\end{tabular}

MAGNITUDE AND PROBABILITY OF ANNUAL LON FLOH BASED ON PERIOD OF RECORD 1967-81

\begin{tabular}{|c|c|c|c|c|c|c|}
\hline \multirow{2}{*}{$\begin{array}{l}\text { PERIOD } \\
\text { (CON- } \\
\text { SECU- } \\
\text { TIVE } \\
\text { DAYS) }\end{array}$} & \multicolumn{6}{|c|}{$\begin{array}{l}\text { DISCHARGE, IN FT } 3 / S \text {, FOR INDICATED } \\
\text { RECURRENCE INTERVAL, IN YEARS, AND } \\
\text { NON-EXCEEDANCE PROBABILITY, IN PERCENT }\end{array}$} \\
\hline & $\begin{array}{c}2 \\
50 \%\end{array}$ & $\begin{array}{c}5 \\
20 \%\end{array}$ & $\begin{array}{l}10 \\
10 \%\end{array}$ & $\begin{array}{l}20 \\
5 \%\end{array}$ & $\begin{array}{l}50 \uparrow \\
2 \%\end{array}$ & $\begin{array}{l}100 \uparrow \\
18\end{array}$ \\
\hline \begin{tabular}{r|}
1 \\
3 \\
7 \\
14 \\
30 \\
60 \\
90
\end{tabular} & & & & & & \\
\hline $\begin{array}{l}120 \\
183\end{array}$ & $\begin{array}{l}0.00 \\
0.11\end{array}$ & $\begin{array}{l}0.00 \\
0.03\end{array}$ & $\begin{array}{l}0.00 \\
0.00\end{array}$ & $\begin{array}{l}0.00 \\
0.00\end{array}$ & $\begin{array}{l}0.00 \\
0.00\end{array}$ & $\begin{array}{l}0.00 \\
0.00\end{array}$ \\
\hline
\end{tabular}

MAGNITUDE AND PROBABILITY OF ANNLAL HIGH FLON BASED ON PERIOD OF RECORD 1966-81

\begin{tabular}{|c|c|c|c|c|c|c|}
\hline \multirow{2}{*}{$\begin{array}{l}\text { PERIOD } \\
\text { (CON- } \\
\text { SECU- } \\
\text { TIVE } \\
\text { DAYS) }\end{array}$} & \multicolumn{6}{|c|}{$\begin{array}{l}\text { DISCHARGE, IN FT } 3 / S \text {, FOR INDICATED } \\
\text { RECURRENCE INTERVAL, IN YEARS, AND } \\
\text { EXCEEDANCE PRCBABILITY, IN PERCENT }\end{array}$} \\
\hline & $\stackrel{2}{50 \%}$ & $\begin{array}{c}5 \\
20 \%\end{array}$ & $\begin{array}{l}10 \\
10 \%\end{array}$ & $\begin{array}{l}25 \\
4 \%\end{array}$ & $\begin{array}{l}50 \nmid \\
2 \%\end{array}$ & $\begin{array}{c}100 \dagger \\
1 \%\end{array}$ \\
\hline $\begin{array}{l}1 \\
3 \\
7 \\
15 \\
30 \\
60 \\
90\end{array}$ & $\begin{array}{l}41 \\
17 \\
7.8 \\
3.9 \\
2.5 \\
1.5 \\
1.0\end{array}$ & $\begin{array}{l}81 \\
38 \\
17 \\
8.7 \\
5.3 \\
3.1 \\
2.1\end{array}$ & $\begin{array}{c}118 \\
58 \\
27 \\
13 \\
7.8 \\
4.6 \\
3.1\end{array}$ & $\begin{array}{c}176 \\
92 \\
42 \\
20 \\
12 \\
7.0 \\
4.6\end{array}$ & $\begin{array}{c}229 \\
124 \\
57 \\
27 \\
15 \\
9.1 \\
6.0\end{array}$ & $\begin{array}{c}291 \\
162 \\
74 \\
35 \\
19 \\
11 \\
7.6\end{array}$ \\
\hline
\end{tabular}

DURATION TABLE OF DAILY MEAN FLON FOR PERIOD OF RECORD 1966-81

DISCHARGE, IN FT $3 / 5$, WHICH WAS EQUALED OR EXCEEDED FOR INDICATED PERCENT OF TIME

\begin{tabular}{|c|c|c|c|c|c|c|c|c|c|c|c|c|c|c|c|c|}
\hline $1 \%$ & $5 \%$ & $10 \%$ & $15 \%$ & $20 \%$ & $30 \%$ & $40 \%$ & $50 \%$ & $60 \%$ & $70 \%$ & $80 \%$ & $90 x$ & $95 \%$ & $98 \%$ & $99 x$ & $99.5 \%$ & $99.9 \%$ \\
\hline 9.3 & 0.18 & 0.00 & 0.00 & 0.00 & 0.00 & 0.00 & 0.00 & 0.00 & 0.00 & 0.00 & 0.00 & 0.00 & 0.00 & 0.00 & 0.00 & .00 \\
\hline
\end{tabular}

$\uparrow$ Reliability of values in column is uncertain, and potential errors are large. 
09482400 AIRPORT MASH AT TUCSON, AZ--CONTIMUED
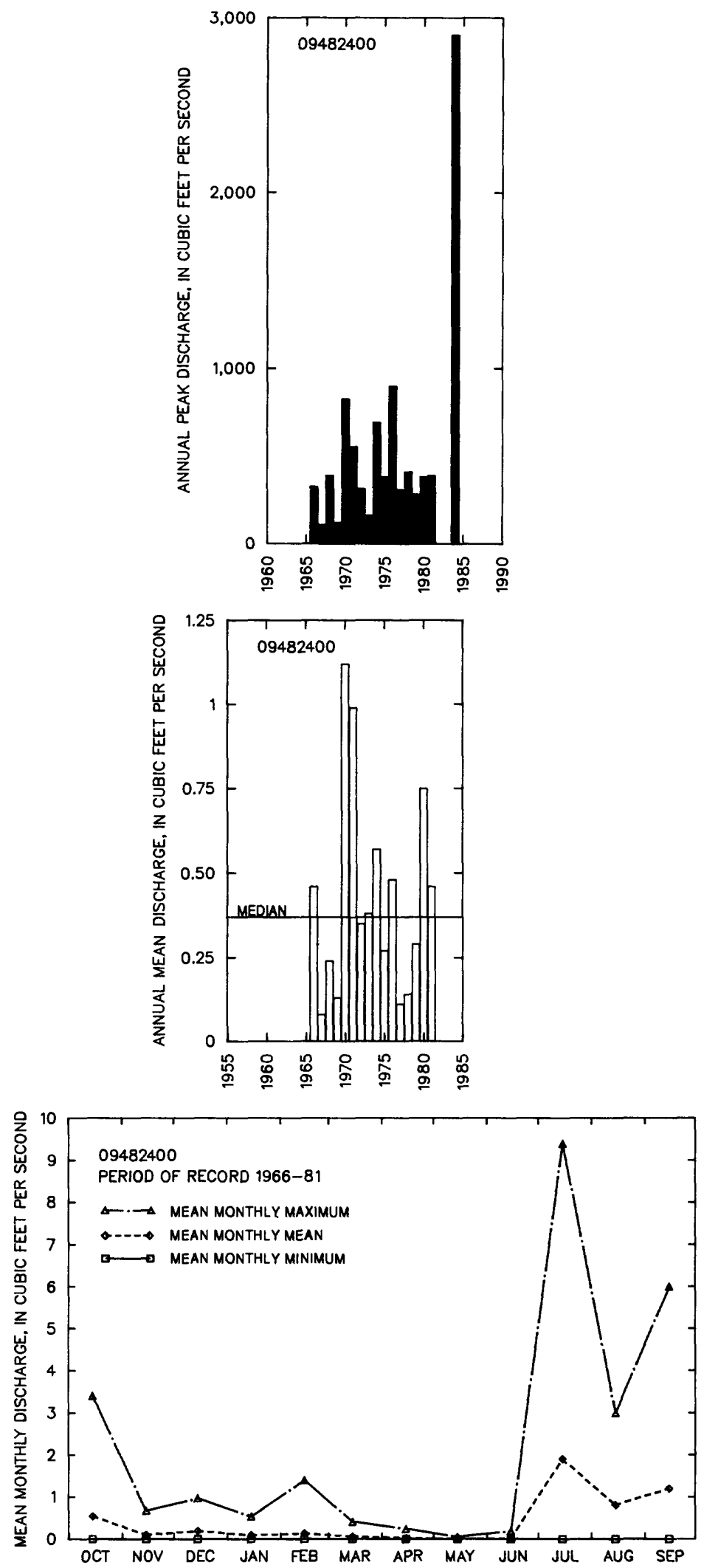
LOCATION.--Lat 32'10'20", long 110.58'35", in SW/AwW sec.36, T.14 S., R.13 E., Pima County, Hydrologic Unit 15050301, at South 12th Avenue, $0.8 \mathrm{mi}$ above mouth in Tucson city limits.

DRAINAGE AREA. $--7.24 \mathrm{mi}^{2}$.

ANMUAL PEAK DISCHARGE

\begin{tabular}{lccc}
$\begin{array}{l}\text { WATER } \\
\text { YEAR }\end{array}$ & DATE & $\begin{array}{c}\text { ANNUAL PEAK } \\
\text { DISCHARGE } \\
\text { (FT } 3 / \text { S) }\end{array}$ & $\begin{array}{c}\text { DISCHARGE } \\
\text { CODES }\end{array}$ \\
\hline 1970 & $07-20-70$ & 898 & $\mathrm{C}$ \\
1971 & $08-19-71$ & 476 & $\mathrm{C}$ \\
1972 & $07-16-72$ & 380 & $\mathrm{C}$ \\
1973 & $07-00-73$ & 97 & $\mathrm{C}$ \\
1974 & $07-21-74$ & 125 & $\mathrm{C}$ \\
1975 & $07-12-75$ & 212 & $\mathrm{C}$ \\
1976 & $00-00-76$ & 300 & $\mathrm{C}$ \\
1977 & $08-15-77$ & 32 & $\mathrm{C}$ \\
1978 & $10-06-77$ & 170 & $\mathrm{C}$ \\
1979 & $08-12-79$ & 320 & $\mathrm{C}$ \\
1980 & $09-07-80$ & 460 & $\mathrm{C}$ \\
1981 & $07-29-81$ & 360 & $\mathrm{C}$ \\
\hline
\end{tabular}

MAGNITUDE AND PROBABILITY OF INSTANTANEOUS PEAK FLOH BASED ON PERIOD OF RECORD 1970-81

DISCHAREE, IN $\mathrm{FT}^{3} / \mathrm{S}$, FOR INDICATED RECURRENCE INTERVAL

IN YEARS, AND EXCEEDANCE PROBABILITY, IN PERCENT

\begin{tabular}{|c|c|c|c|c|c|}
\hline $\begin{array}{c}2 \\
50 \%\end{array}$ & $\begin{array}{c}5 \\
20 \%\end{array}$ & $\begin{array}{r}10 \\
10 \%\end{array}$ & $\begin{array}{l}25 \dagger \\
4 \%\end{array}$ & $\begin{array}{l}50 \uparrow \\
2 \%\end{array}$ & $\begin{array}{c}100 \dagger \\
1 \%\end{array}$ \\
\hline 260 & 441 & 572 & 746 & 880 & 1,020 \\
\hline $\begin{array}{l}\text { WEIGHTED } \\
\text { MEAN } \\
\text { STANDARD }\end{array}$ & $\begin{array}{l}\text { SKEW } \\
\text { DEV. }\end{array}$ & $\begin{array}{l}(\text { LOGS })= \\
(\text { LOGS })= \\
(\text { LOGS })=\end{array}$ & $\begin{array}{r}-0.27 \\
2.40 \\
0.28\end{array}$ & & \\
\hline
\end{tabular}

t Reliability of values in column is uncertain, and potential errors are large.

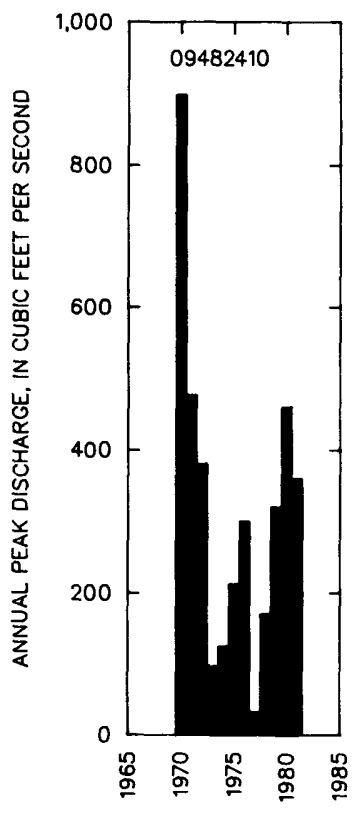

BASIN CHARACTERISTICS

\begin{tabular}{|c|c|c|c|c|c|c|c|}
\hline MAIN & & $\begin{array}{l}\text { MEAN } \\
\text { BASIN }\end{array}$ & & & $\begin{array}{l}\text { MEAN } \\
\text { ANNUAL }\end{array}$ & RAINFALL I & ITY, 24-HOUR \\
\hline $\begin{array}{l}\text { CHANNEL } \\
\text { SLOPE } \\
\text { (FT/MI) }\end{array}$ & $\begin{array}{l}\text { STREAM } \\
\text { LENGTH } \\
\text { (MI) }\end{array}$ & $\begin{array}{l}\text { ELEVA- } \\
\text { TION } \\
\text { (FT) }\end{array}$ & $\begin{array}{l}\text { FORESTED } \\
\text { AREA } \\
\text { (PERCENT) }\end{array}$ & $\begin{array}{l}\text { SOIL } \\
\text { INDEX }\end{array}$ & $\begin{array}{l}\text { PRECIPI- } \\
\text { TATION } \\
\text { (IN) }\end{array}$ & $\begin{array}{c}\text { 2-YEAR } \\
\text { (IN) }\end{array}$ & $\begin{array}{c}\text { 50-YEAR } \\
\text { (IN) }\end{array}$ \\
\hline 33.7 & 7.9 & 2,560 & 0.0 & 1.0 & 10.6 & 1.9 & 4.2 \\
\hline
\end{tabular}




\section{JULIAN WASH AT TUCSON, AZ}

LOCATION.--Lat 32.10'15", long 110.56'25", in SWkNwk sec.32, T.14 S., R.14 E., Pima County, Hydrologic Unit 15050302, 1,600 ft above confluence with Tucson Diversion channel, and $0.5 \mathrm{mi}$ south of Ajo Road in Tucson.

DRAINAGE AREA. $--26.5 \mathrm{mi}^{2}$.

ANNUAL PEAK DISCHARGE

\begin{tabular}{ccc}
$\begin{array}{c}\text { WATER } \\
\text { YEAR }\end{array}$ & DATE & $\begin{array}{c}\text { ANNUAL PEAK } \\
\text { DISCHARGE } \\
\text { (FT } 3 / \text { S })\end{array}$ \\
\hline 1970 & $07-19-70$ & 1,270 \\
1971 & $08-20-71$ & 1,050 \\
1972 & $07-16-72$ & 440 \\
1973 & $10-19-72$ & 330 \\
1974 & $07-07-74$ & 130 \\
1975 & $07-12-75$ & 112 \\
1976 & $09-25-76$ & 1,050 \\
1977 & $09-09-77$ & 680 \\
1978 & $10-06-77$ & 395 \\
1979 & $07-29-79$ & 190 \\
1980 & $09-07-80$ & 435 \\
1981 & $03-02-81$ & 400 \\
$\ldots . \ldots 1$ &
\end{tabular}

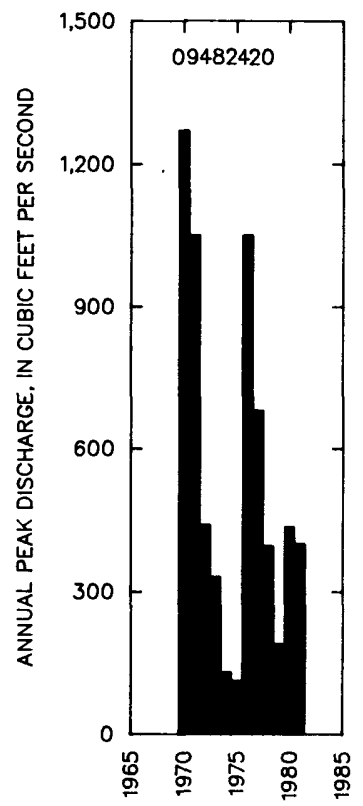

MAGNITUDE AND PROBABILITY OF INSTANTANEQUS PEAK FLOU BASED ON PERIOD OF RECORD 1970-81

DISCHARGE, IN $F T^{3} / S$, FOR INDICATED RECURRENCE INTERVAL

IN YEARS, AND EXCEEDANCE PROBABILITY, IN PERCENT

\begin{tabular}{|c|c|c|c|c|c|}
\hline $\begin{array}{c}2 \\
50 x\end{array}$ & $\begin{array}{c}5 \\
20 \%\end{array}$ & $\begin{array}{r}10 \\
10 \%\end{array}$ & $\begin{array}{l}25 \dagger \\
4 \%\end{array}$ & $\begin{array}{l}50 \uparrow \\
2 \%\end{array}$ & $\begin{array}{c}100 \nmid \\
1 \%\end{array}$ \\
\hline 428 & 817 & 1,130 & 1,570 & 1,930 & 2,310 \\
\hline $\begin{array}{l}\text { WEIGHTED } \\
\text { MEAN } \\
\text { STANDARD }\end{array}$ & SKEH & $\begin{array}{l}(L O G S)= \\
(L O G S)= \\
(L O G S)=\end{array}$ & $\begin{array}{r}-0.22 \\
2.62 \\
0.34\end{array}$ & & \\
\hline
\end{tabular}

† Reliability of values in column is uncertain, and potential errors are large.

BASIN CHARACTERISTICS

\begin{tabular}{|c|c|c|c|c|c|c|c|}
\hline \multirow{2}{*}{$\begin{array}{l}\text { MAIN } \\
\text { CHANNEL } \\
\text { SLOPE } \\
\text { (FT/MI) }\end{array}$} & \multirow[b]{2}{*}{$\begin{array}{l}\text { STREAM } \\
\text { LENGTH } \\
\text { (MI) }\end{array}$} & \multirow{2}{*}{$\begin{array}{l}\text { MEAN } \\
\text { BASIN } \\
\text { ELEVA- } \\
\text { TION } \\
\text { (FT) }\end{array}$} & \multirow[b]{2}{*}{$\begin{array}{l}\text { FORESTED } \\
\text { AREA } \\
\text { (PERCENT) }\end{array}$} & \multicolumn{2}{|r|}{$\begin{array}{c}\text { MEAN } \\
\text { ANNUAL } \\
\text { PRECIPI - }\end{array}$} & \multicolumn{2}{|c|}{ RAINFALL INTENSITY, 24-HOUR } \\
\hline & & & & $\begin{array}{l}\text { SOIL } \\
\text { INDEX }\end{array}$ & $\begin{array}{l}\text { PRECIPI - } \\
\text { TATION } \\
\text { (IN) }\end{array}$ & $\begin{array}{c}\text { 2-YEAR } \\
\text { (IN) }\end{array}$ & $\begin{array}{l}\text { 50-YEAR } \\
\text { (IN) }\end{array}$ \\
\hline 38.9 & 17.3 & 2,900 & 1.9 & 1.0 & 11.0 & 1.7 & 4.0 \\
\hline
\end{tabular}


09482450 WEST BRANCH SANTA CRUZ RIVER AT TUCSON, AZ

LOCATION.--Lat 32'08'00", Long $111^{\circ} 00^{\prime} 30^{\prime \prime}$, in NEKNEK sec.16, T.15 S., R.13 E., Pima County, Hydrologic Unit 15050301, at Valencia Road, $0.4 \mathrm{mi}$ west of Tucson city limits.

DRAINAGE AREA. $--23.6 \mathrm{mi}^{2}$, contributing drainage area not determined.

ANNUAL PEAK DISCHARGE

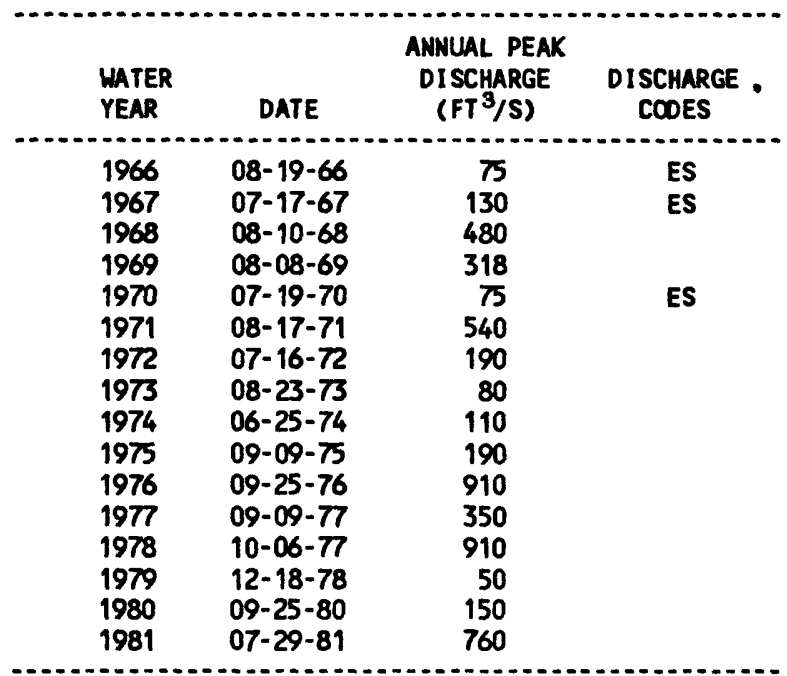

MAGNITUDE AND PROBABILITY OF INSTANTANEOUS PEAK FLOW BASED ON PERIOD OF RECORD

DISCHARGE, IN $\mathrm{FT}^{3} / \mathrm{S}$, FOR INDICATED RECURRENCE INTERVAL IN YEARS, AND EXCEEDANCE PROBABILITY, IN PERCENT

\begin{tabular}{|c|c|c|c|c|c|}
\hline $\begin{array}{c}2 \\
50 \%\end{array}$ & $\begin{array}{c}5 \\
20 \%\end{array}$ & $\begin{array}{r}10 \\
10 \%\end{array}$ & $\begin{array}{l}25 \\
4 \%\end{array}$ & $\begin{array}{l}50 \\
2 \%\end{array}$ & $\begin{array}{r}100 \\
1 \%\end{array}$ \\
\hline$-\cdot$ & $\cdots$ & $\cdots$ & $\cdots$ & ...... & $\cdots$ \\
\hline $\begin{array}{l}\text { WEIGHTED } \\
\text { MEAN } \\
\text { STANDARD }\end{array}$ & DEV. & $\begin{array}{l}(\text { LOGS })= \\
(\text { LOGS) }= \\
(\text { LOGS }=\end{array}$ & - & & \\
\hline
\end{tabular}

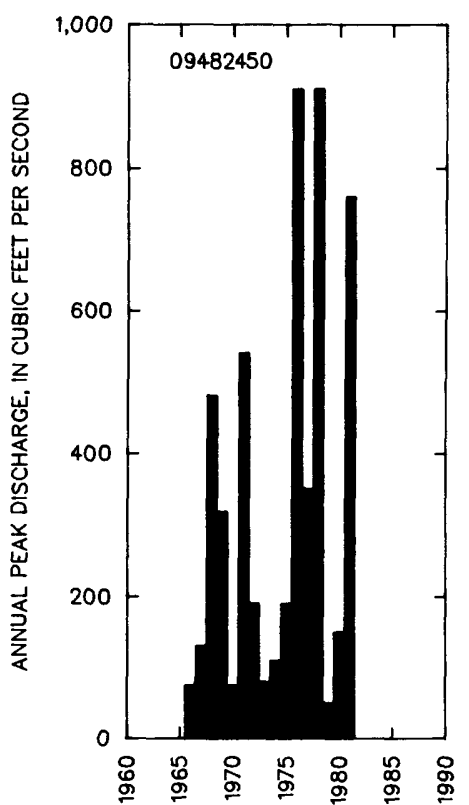

BASIN CHARACTERISTICS

\begin{tabular}{|c|c|c|c|c|c|c|c|}
\hline \multirow{2}{*}{$\begin{array}{l}\text { MAIN } \\
\text { CHANNEL } \\
\text { SLOPE } \\
\text { (FT/MI) }\end{array}$} & \multirow[b]{2}{*}{$\begin{array}{l}\text { STREAM } \\
\text { LENGTH } \\
\text { (MI) }\end{array}$} & \multirow{2}{*}{$\begin{array}{l}\text { MEAN } \\
\text { BASIN } \\
\text { ELEVA- } \\
\text { TION } \\
\text { (FT) }\end{array}$} & \multirow[b]{2}{*}{$\begin{array}{l}\text { FORESTED } \\
\text { AREA } \\
\text { (PERCENT) }\end{array}$} & \multirow[b]{2}{*}{$\begin{array}{l}\text { SOIL } \\
\text { INDEX }\end{array}$} & \multirow{2}{*}{$\begin{array}{l}\text { MEAN } \\
\text { ANNUAL } \\
\text { PRECIPI- } \\
\text { TATION } \\
\text { (IN) }\end{array}$} & \multicolumn{2}{|c|}{ RAINFALL INTENSITY, 24-HOUR } \\
\hline & & & & & & $\begin{array}{l}\text { 2-YEAR } \\
\text { (IN) }\end{array}$ & $\begin{array}{l}\text { 50-YEAR } \\
\text { (IN) }\end{array}$ \\
\hline 80.9 & 15.3 & 2,800 & 0.3 & 3.0 & 11.2 & 2.1 & 4.4 \\
\hline
\end{tabular}




\section{BIG WASH AT TUCSON, NZ}

LOCATION.--Lat 32.11'10", long 111'00'07", in SW/ANEK sec.27, T.14 S., R.13 E., Pima County, at Mission Road, $0.6 \mathrm{mi}$ north of State Highway 86 , in Tucson.

DRAIMAGE AREA. $--2.94 \mathrm{mi}^{2}$.

ANMUAL PEAK DISCHARGE

\begin{tabular}{cccc}
$\begin{array}{c}\text { WATER } \\
\text { YEAR }\end{array}$ & DATE & $\begin{array}{c}\text { ANNUAL PEAK } \\
\text { DISCHARGE } \\
\text { (FT } 3 / \text { S })\end{array}$ & $\begin{array}{c}\text { DISCHARGE } \\
\text { COOES }\end{array}$ \\
\hline 1965 & $07-10-65$ & 1,000 & ES \\
1966 & $08-12-66$ & 240 & \\
1967 & $07-17-67$ & 50 & \\
1968 & $08-10-68$ & 65 & \\
1969 & $00-00-69$ & 0 & \\
1970 & $07-19-70$ & 11,070 & \\
1971 & $08-17-71$ & 23,000 & \\
1972 & $07-16-72$ & 285 & \\
1973 & $07-00-73$ & 300 & \\
1974 & $00-00-74$ & 0 & \\
1975 & $00-00-75$ & 0 & \\
1976 & $09-25-76$ & 120 & \\
1977 & $00-00-77$ & 0 & \\
1978 & $10-06-77$ & 380 & \\
1979 & $08-12-79$ & 20 & \\
1980 & $09-07-80$ & 3.0 & \\
1981 & $09-18-81$ & 29 & \\
\hline
\end{tabular}

$1_{\text {Highest since } 1963 .}$

Highest since 1920.

MAGNI TUDE AND PROBABILITY OF INSTANTANEOUS PEAK FLOW BASED ON PERIOD OF RECORD 1965-81

DISCHARGE, IN $\mathrm{FT}^{3} / \mathrm{S}$, FOR INDICATED RECURRENCE INTERVAL IN YEARS, AND EXCEEDANCE PROBABILITY, IN PERCENT

\begin{tabular}{|c|c|c|c|c|c|}
\hline$\stackrel{2}{50 x}$ & $\begin{array}{c}5 \\
20 \%\end{array}$ & $\begin{array}{r}10 \\
10 \%\end{array}$ & $\begin{array}{l}25 \\
4 \%\end{array}$ & $\begin{array}{l}50 \nmid \\
2 x\end{array}$ & $\begin{array}{c}100 \nmid \\
1 \%\end{array}$ \\
\hline 63.0 & 390 & 887 & 1,940 & 3,060 & 4,460 \\
\hline $\begin{array}{l}\text { WEIGKTED } \\
\text { MEAN } \\
\text { STANOARD }\end{array}$ & $\begin{array}{l}\text { SKEH } \\
\text { DEV. }\end{array}$ & $\begin{array}{l}(\text { LOGS })= \\
(\text { LOGS })= \\
(\text { LOGS })=\end{array}$ & $\begin{array}{r}-0.62 \\
1.69 \\
1.05\end{array}$ & & \\
\hline
\end{tabular}

+ Reliability of values in column is uncertain, and potential errors are large.

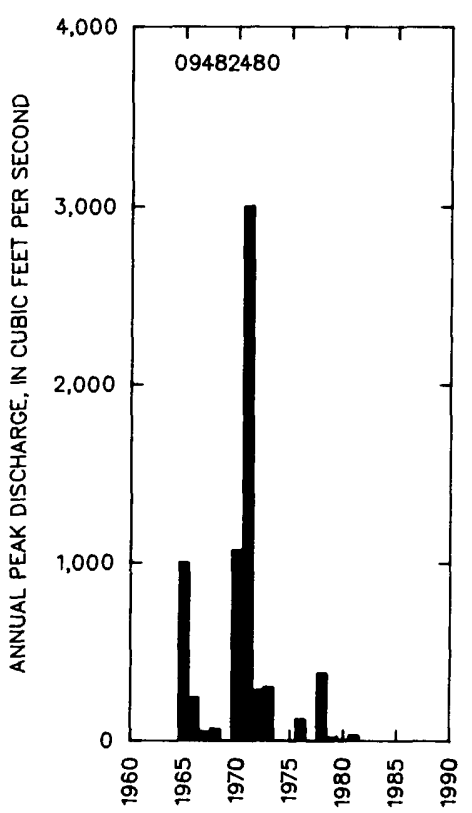

\section{BASIN CHARACTERISTICS}

\begin{tabular}{|c|c|c|c|c|c|c|c|}
\hline MAIN & & $\begin{array}{r}\text { MEAN } \\
\text { BASIN }\end{array}$ & & & $\begin{array}{c}\text { MEAN } \\
\text { ANNUAL }\end{array}$ & RAINFALL II & SITY, 24-HOUR \\
\hline $\begin{array}{l}\text { CHANNEL } \\
\text { SLOPE } \\
\text { (FT/MI) }\end{array}$ & $\begin{array}{c}\text { STREAM } \\
\text { LENGTH } \\
\text { (MI) }\end{array}$ & $\begin{array}{l}\text { ELEVA- } \\
\text { TION } \\
\text { (FT) }\end{array}$ & $\begin{array}{l}\text { FORESTED } \\
\text { AREA } \\
\text { (PERCENT) }\end{array}$ & $\begin{array}{l}\text { SOIL } \\
\text { INDEX }\end{array}$ & $\begin{array}{l}\text { PRECIPI - } \\
\text { TATION } \\
\text { (IN) }\end{array}$ & $\begin{array}{c}\text { 2-YEAR } \\
\text { (IN) }\end{array}$ & $\begin{array}{c}\text { 50-YEAR } \\
\text { (IN) }\end{array}$ \\
\hline 95.2 & 4.9 & 2,850 & 0.0 & 1.0 & 11.0 & 1.9 & 4.4 \\
\hline
\end{tabular}


09482500 SANTA CRUZ RIVER AT TUCSON, AZ

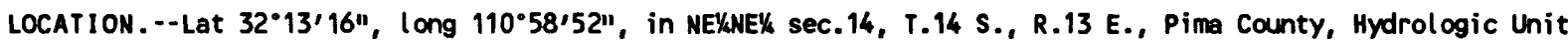
15050301 , on downstream side of center pier of Congress Street Bridge in Tucson.

DRAINAGE AREA. - -2,222 $\mathrm{mi}^{2}$, of which $395 \mathrm{mi}^{2}$ is in Mexico, adjusted for $15.2 \mathrm{mi}^{2}$ of Tucson Arroyo drainage area contributing to this station effective July 1956.

REMARKS.--Irrigation above station of about 26,000 acres, including about 2,300 acres in Mexico, mostly by pumping from ground water. Ground water is also pumped above the station for municipal supply and mining. since October 1969 all flow past station is publ ished, including wastewater when known.

\begin{tabular}{|c|c|c|c|c|c|c|c|}
\hline $\begin{array}{l}\text { WATER } \\
\text { YEAR }\end{array}$ & DATE & $\begin{array}{c}\text { ANNUAAL PEAK } \\
\text { DISCHARGE } \\
\text { (FT } 3 / \mathrm{S})\end{array}$ & $\begin{array}{l}\text { DISCHARGE } \\
\text { COOES }\end{array}$ & $\begin{array}{l}\text { WATER } \\
\text { YEAR }\end{array}$ & DATE & $\begin{array}{c}\text { ANNUAL PEAK } \\
\text { DISCHARGE } \\
\left(\mathrm{FT}^{3} / \mathrm{S}\right)\end{array}$ & $\begin{array}{l}\text { DISCHARGE } \\
\text { CODES }\end{array}$ \\
\hline $\begin{array}{l}1915 \\
1916 \\
1917 \\
1918 \\
1919 \\
1920 \\
1921 \\
1922 \\
1923 \\
1924 \\
1925 \\
1926 \\
1927 \\
1928 \\
1929 \\
1930 \\
1931 \\
1932 \\
1933 \\
1934 \\
1935 \\
1936 \\
1937 \\
1938 \\
1939 \\
1940 \\
1941 \\
1942 \\
1943 \\
1944 \\
1945 \\
1946 \\
1947 \\
1948 \\
1949 \\
1950 \\
1951\end{array}$ & $\begin{array}{l}12-23-14 \\
01-20-16 \\
09-08-17 \\
08-07-18 \\
08-02-19 \\
08-09-20 \\
08-01-21 \\
07-20-22 \\
08-17-23 \\
11-17-23 \\
09-18-25 \\
09-28-26 \\
09-07-27 \\
08-01-28 \\
09-24-29 \\
08-07-30 \\
08-10-31 \\
07-30-32 \\
08-21-33 \\
08-23-34 \\
09-01-35 \\
07-26-36 \\
07-10-37 \\
08-05-38 \\
08-03-39 \\
08-14-40 \\
08-14-41 \\
08-09-42 \\
08-02-43 \\
08-16-44 \\
08-10-45 \\
08-04-46 \\
10-01-46 \\
08-16-48 \\
08-08-49 \\
07-30-50 \\
08-02-51\end{array}$ & $\begin{array}{r}115,000 \\
5,000 \\
7,500 \\
4,900 \\
4,700 \\
1,950 \\
4,000 \\
2,000 \\
1,900 \\
2,050 \\
3,400 \\
11,400 \\
1,950 \\
1,600 \\
10,400 \\
1,770 \\
9,200 \\
4,200 \\
6,100 \\
6,000 \\
10,300 \\
5,400 \\
3,280 \\
9,000 \\
8,000 \\
11,300 \\
2,490 \\
1,670 \\
4,510 \\
6,530 \\
10,800 \\
4,260 \\
2,960 \\
3,860 \\
3,800 \\
9,490 \\
5,020\end{array}$ & & $\begin{array}{l}1952 \\
1953 \\
1954 \\
1955 \\
1956 \\
1957 \\
1958 \\
1959 \\
1960 \\
1961 \\
1962 \\
1963 \\
1964 \\
1965 \\
1966 \\
1967 \\
1968 \\
1969 \\
1970 \\
1971 \\
1972 \\
1973 \\
1974 \\
1975 \\
1976 \\
1977 \\
1978 \\
1979 \\
1980 \\
1981 \\
1984 \\
1985 \\
1986 \\
1987 \\
1988 \\
1989\end{array}$ & $\begin{array}{l}08-16-52 \\
07-15-53 \\
07-24-54 \\
08-03-55 \\
07-29-56 \\
08-31-57 \\
07-29-58 \\
08-20-59 \\
08-10-60 \\
08-23-61 \\
09-26-62 \\
08-26-63 \\
09-10-64 \\
07-16-65 \\
08-19-66 \\
07-17-67 \\
12-20-67 \\
08-06-69 \\
07-20-70 \\
08-17-71 \\
07-15-72 \\
10-19-72 \\
07-08-74 \\
07-12-75 \\
09-25-76 \\
08-15-77 \\
10-10-77 \\
12-19-78 \\
08-13-80 \\
07-27-81 \\
10-02-83 \\
12-28-84 \\
07-21-86 \\
08-02-87 \\
08-23-88 \\
10-20-88\end{array}$ & $\begin{array}{r}3,820 \\
5,900 \\
9,570 \\
10,900 \\
2,610 \\
3,050 \\
6,350 \\
4,420 \\
6,140 \\
16,600 \\
4,980 \\
4,670 \\
13,000 \\
1,190 \\
5,500 \\
5,860 \\
16,100 \\
8,710 \\
8,530 \\
8,000 \\
3,470 \\
4,710 \\
7,930 \\
2,480 \\
7,100 \\
2,660 \\
23,700 \\
13,500 \\
2,760 \\
2,700 \\
252,700 \\
10,000 \\
1,920 \\
1,500 \\
10,700 \\
2,960\end{array}$ & HP \\
\hline
\end{tabular}

1Highest since 1905.

2Highest since 1892.

BASIN CHARACTERISTICS

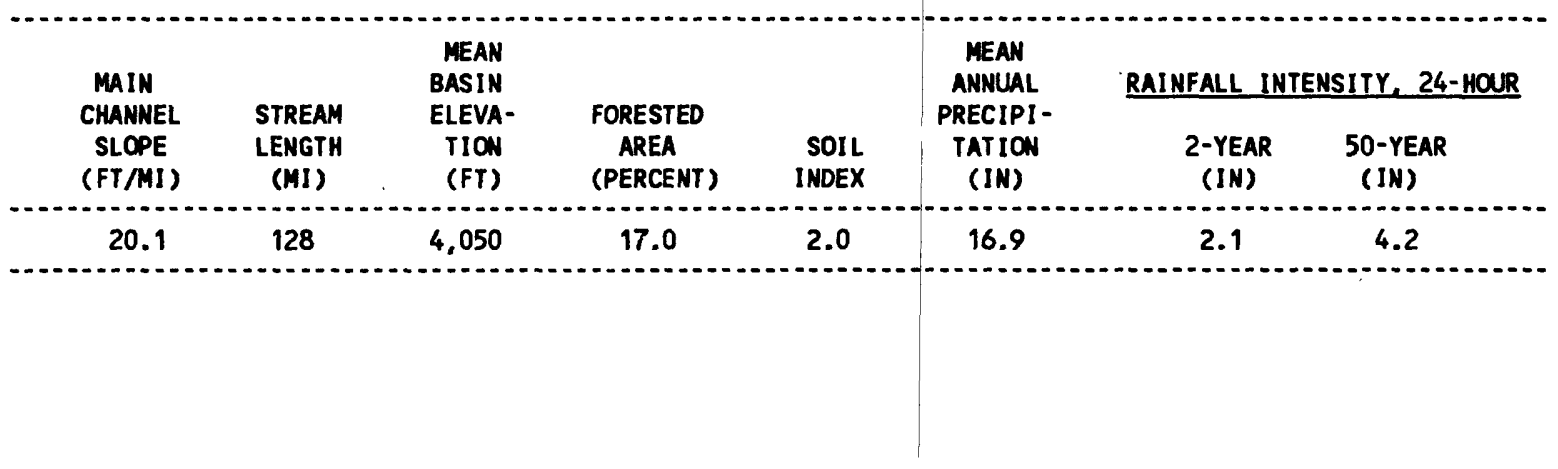


09482500 SANTA CRUZ RIVER AT TUCSON, AZ--Continued

MEAN MONTHLY AND ANMUAL DISCHARgES 1906, 1913, 1915-81

\begin{tabular}{|c|c|c|c|c|c|c|}
\hline MONTH & $\begin{array}{l}\text { MAXIIMU } \\
\left(F^{3} / S\right)\end{array}$ & $\begin{array}{l}\text { MINIMUN } \\
\left(\mathrm{FT}^{3} / \mathrm{S}\right)\end{array}$ & $\begin{array}{c}\text { MEAN } \\
\left\langle\mathrm{FT}^{3} / \mathrm{S}\right)\end{array}$ & $\begin{array}{l}\text { STAN- } \\
\text { DARD } \\
\text { DEVIA- } \\
\text { IION } \\
\text { (FT } 3 / S \text { ) }\end{array}$ & $\begin{array}{l}\text { COEFFI- } \\
\text { CIENT OF } \\
\text { VARI - } \\
\text { ATION }\end{array}$ & $\begin{array}{c}\text { PERCENT } \\
\text { OF } \\
\text { ANNUAL } \\
\text { RUNOFF }\end{array}$ \\
\hline $\begin{array}{l}\text { OCTOBER } \\
\text { NOVEMBER } \\
\text { DECEMBER } \\
\text { JANUARY } \\
\text { FEBRUARY } \\
\text { MARCH } \\
\text { APRIL } \\
\text { MAY } \\
\text { JUNE } \\
\text { JULY } \\
\text { AUGUST } \\
\text { SEPTEMBER }\end{array}$ & $\begin{array}{l}656 \\
215 \\
895 \\
518 \\
202 \\
102 \\
1.7 \\
2.3 \\
25 \\
430 \\
682 \\
312\end{array}$ & $\begin{array}{l}0.00 \\
0.00 \\
0.00 \\
0.00 \\
0.00 \\
0.00 \\
0.00 \\
0.00 \\
0.00 \\
0.00 \\
0.00 \\
0.00\end{array}$ & $\begin{array}{l}13 \\
6.6 \\
36 \\
22 \\
11 \\
4.9 \\
0.11 \\
0.09 \\
1.4 \\
52 \\
95 \\
33\end{array}$ & $\begin{array}{c}79 \\
28 \\
146 \\
82 \\
37 \\
18 \\
0.29 \\
0.34 \\
4.3 \\
71 \\
114 \\
60\end{array}$ & $\begin{array}{l}5.9 \\
4.3 \\
4.1 \\
3.8 \\
3.3 \\
3.6 \\
2.7 \\
3.8 \\
3.1 \\
1.4 \\
1.2 \\
1.8\end{array}$ & $\begin{array}{r}4.9 \\
2.4 \\
13.0 \\
7.8 \\
4.1 \\
1.8 \\
0.0 \\
0.0 \\
0.5 \\
18.8 \\
34.5 \\
12.1\end{array}$ \\
\hline ANNUAL & 112 & 1.3 & 23 & 23 & 0.99 & 100 \\
\hline
\end{tabular}

\begin{abstract}
MAGNITLDE AND PROBABILITY OF INSTANTANEOUS PEAK FLON BASED ON PERIOD OF RECORD 1915-81, 1984-89
\end{abstract}

\begin{tabular}{|c|c|c|c|c|c|}
\hline $\begin{array}{c}2 \\
50 \%\end{array}$ & $\begin{array}{c}5 \\
20 \%\end{array}$ & $\begin{array}{r}10 \\
10 \%\end{array}$ & $\begin{array}{l}25 \\
4 \%\end{array}$ & $\begin{array}{l}50 \\
2 \%\end{array}$ & $\begin{array}{r}100 \\
1 \%\end{array}$ \\
\hline 5,090 & 9,400 & 13,100 & 18,800 & 23,800 & 29,600 \\
\hline $\begin{array}{l}\text { WEIGHTED } \\
\text { MEAN } \\
\text { STANDARD }\end{array}$ & $\begin{array}{l}\text { SKEW } \\
\text { DEV. }\end{array}$ & $\begin{array}{l}(\text { LOGS })=0 \\
(\text { LOGS })=3 \\
(\text { LOGS })=0\end{array}$ & $\begin{array}{l}.15 \\
.71 \\
.31\end{array}$ & & \\
\hline
\end{tabular}

MACNITUDE AND PROBABILITY OF ANMUAL LON FLON BASED ON PERIOD OF RECORD 1916-81

\begin{tabular}{|c|c|c|c|c|c|c|}
\hline \multirow{2}{*}{$\begin{array}{l}\text { PERIOD } \\
\text { (CON- } \\
\text { SECU- } \\
\text { TIVE } \\
\text { DAYS) }\end{array}$} & \multicolumn{6}{|c|}{$\begin{array}{l}\text { DISCHARGE, IN FT }{ }^{3} / \mathrm{S}, \text { FOR INDICATED } \\
\text { RECURRENCE INTERVAL, IN YEARS, AND } \\
\text { NON-EXCEEDANCE PROBABILITY, IN PERCENT }\end{array}$} \\
\hline & $\begin{array}{c}2 \\
50 \%\end{array}$ & $\begin{array}{c}5 \\
20 \%\end{array}$ & $\begin{array}{l}10 \\
10 \%\end{array}$ & $\begin{array}{l}20 \\
5 \%\end{array}$ & $\begin{array}{l}50 \\
2 \%\end{array}$ & $\begin{array}{l}100 \\
1 \%\end{array}$ \\
\hline $\begin{array}{r}1 \\
3 \\
7 \\
14 \\
30 \\
60 \\
90 \\
120 \\
183\end{array}$ & $\begin{array}{l}0.00 \\
0.00 \\
0.12 \\
0.76\end{array}$ & $\begin{array}{l}0.00 \\
0.00 \\
0.00 \\
0.08\end{array}$ & $\begin{array}{l}0.00 \\
0.00 \\
0.00 \\
0.00\end{array}$ & $\begin{array}{l}0.00 \\
0.00 \\
0.00 \\
0.00\end{array}$ & $\begin{array}{l}0.00 \\
0.00 \\
0.00 \\
0.00\end{array}$ & $\begin{array}{l}0.00 \\
0.00 \\
0.00 \\
0.00\end{array}$ \\
\hline
\end{tabular}

MAENITUDE AND PROBABILITY OF ANNUAL HIGH FLON BASED ON PERIOD OF RECORD 1906, 1913, 1915-81

\begin{tabular}{|c|c|c|c|c|c|c|}
\hline \multirow{2}{*}{$\begin{array}{l}\text { PERIOD } \\
\text { (CON- } \\
\text { SECU- } \\
\text { TIVE } \\
\text { DAYS) }\end{array}$} & \multicolumn{6}{|c|}{$\begin{array}{l}\text { DISCHARGE, IN } \mathrm{FT}^{3} / \mathrm{S} \text {, FOR INDICATED } \\
\text { RECURRENCE INTERVAL, IN YEARS, AND } \\
\text { EXCEEDANCE PROBABILITY, IN PERCENT }\end{array}$} \\
\hline & $\begin{array}{c}2 \\
50 \%\end{array}$ & $\begin{array}{c}5 \\
20 \%\end{array}$ & $\begin{array}{l}10 \\
10 \%\end{array}$ & $\begin{array}{l}25 \\
4 \%\end{array}$ & $\begin{array}{l}50 \\
2 \%\end{array}$ & $\begin{array}{r}100 \\
1 \%\end{array}$ \\
\hline $\begin{array}{c}1 \\
3 \\
7 \\
15 \\
30 \\
60 \\
90\end{array}$ & $\begin{array}{r}1,430 \\
714 \\
370 \\
214 \\
133 \\
80 \\
57\end{array}$ & $\begin{array}{r}3,260 \\
1,660 \\
866 \\
491 \\
296 \\
176 \\
124\end{array}$ & $\begin{array}{r}4,900 \\
2,510 \\
1,310 \\
738 \\
438 \\
264 \\
185\end{array}$ & $\begin{array}{r}7,410 \\
3,800 \\
2,010 \\
1,120 \\
655 \\
405 \\
282\end{array}$ & $\begin{array}{r}9,580 \\
4,900 \\
2,610 \\
1,450 \\
842 \\
531 \\
370\end{array}$ & $\begin{array}{r}12,000 \\
6,120 \\
3,290 \\
1,810 \\
1,050 \\
678 \\
472\end{array}$ \\
\hline
\end{tabular}

DURATION TABLE OF DAILY MEAN FLOW FOR PERIOD OF RECORD 1906, 1913, 1915-81

DISCHARGE, IN FT $3 / 5$, WHICH WAS EQUALED OR EXCEEDED FOR INDICATED PERCENT OF TIME

\begin{tabular}{|c|c|c|c|c|c|c|c|c|c|c|c|c|c|c|c|c|}
\hline $1 \%$ & $5 \%$ & $10 \%$ & $15 \%$ & $20 \%$ & $30 x$ & $40 \%$ & $50 \%$ & $60 \%$ & $70 \%$ & $80 \%$ & $90 \%$ & $95 \%$ & $98 \%$ & $99 \%$ & $99.5 \%$ & $99.9 \%$ \\
\hline 539 & 50 & 5.8 & 0.11 & 0.00 & 0.00 & 0.00 & 0.00 & 0.00 & 0.00 & 0.00 & 0.00 & 0.00 & 0.00 & 0.00 & 0.00 & 0.00 \\
\hline
\end{tabular}

$\uparrow$ Reliability of values in colum is uncertain, and potential errors are large. 
09482500 SANTA CRUZ RIVER AT TUCSON, AZ--CONTINUED
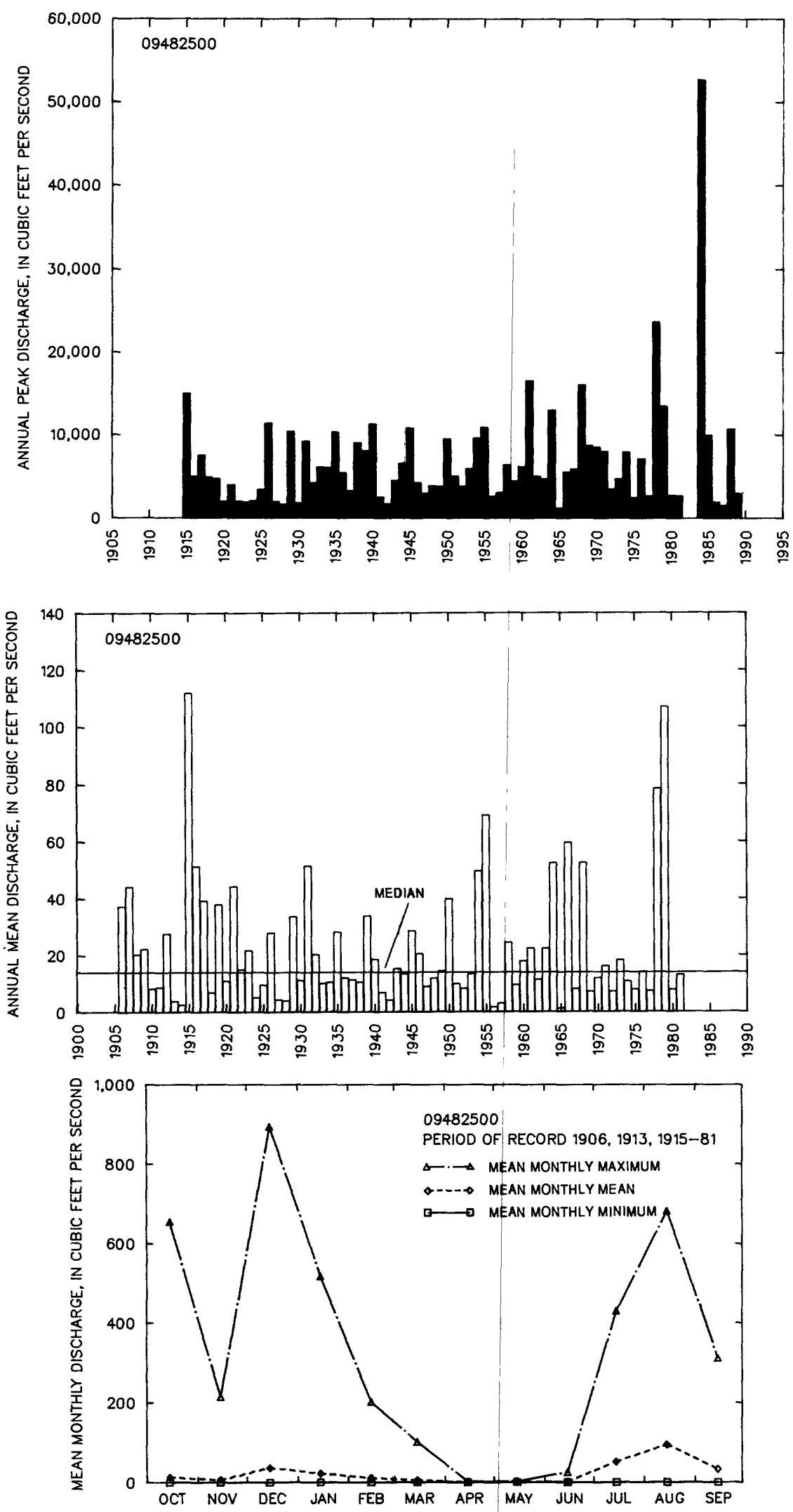
09482950 RAILROAD WASH AT TUCSON, AZ

LOCATION.---Lat 32'12'50", long 11056'45", in NEKSE\% sec.18, T.14 S., R.14 E., Pime County, Hydrologic Unit 15050301, on center of culvert on upstream side of Winsett Street in Tucson. Prior to December 11, 1978, at site $200 \mathrm{ft}$ upstream.

DRAINAGE AREA. $--2.3 \mathrm{mi}^{2}$.

ANNUAL PEAK DISCHARGE

\begin{tabular}{cccc}
$\begin{array}{c}\text { HATER } \\
\text { YEAR }\end{array}$ & DATE & $\begin{array}{c}\text { ANNUAL PEAK } \\
\text { DISCHARGE } \\
\text { (FT } 3 \text { /S) }\end{array}$ & $\begin{array}{c}\text { DISCHARGE } \\
\text { CODES }\end{array}$ \\
\hline 1970 & $07-20-70$ & 642 & C \\
1971 & $07-19-71$ & 1,590 & C \\
1972 & $08-12-72$ & 1,280 & C \\
1973 & $07-27-73$ & 220 & C \\
1974 & $07-18-74$ & 482 & C \\
1976 & $07-11-76$ & 312 & C \\
1977 & $09-10-77$ & 300 & C \\
1978 & $10-06-77$ & 223 & C \\
1979 & $10-21-78$ & 243 & C \\
1980 & $08-23-80$ & 222 & C \\
1981 & $06-25-81$ & 162 & C \\
1982 & $07-25-82$ & 421 & C \\
1983 & $01-29-83$ & 106 & $C$ \\
\hline
\end{tabular}

MAGNITUDE AND PROBABILITY OF INSTANTANEOUS PEAK FLOW BASED ON PERIOD OF RECORD 1970-74, 1976-79, 1981-83

DISCHARGE, IN FT $3 / 5$, FOR INDICATED RECURRENCE INTERVAL

IN YEARS, AND EXCEEDANCE PROBABILITY, IN PERCENT

\begin{tabular}{lccccc}
2 & 5 & 10 & 25 & 50 & 100 \\
$50 \%$ & $20 \%$ & $10 \%$ & $4 \%$ & $2 \%$ & $1 \%$ \\
340 & 666 & 961 & 1,440 & 1,870 & 2,390 \\
\hline MEIGHTED SKEW (LOGS) & 0.19 & & \\
MEAN & $\begin{array}{l}1 \\
\text { (LOGS) }\end{array}$ & 2.54 & & \\
STANDARD DEV. (LOGS) & 0.34 & &
\end{tabular}

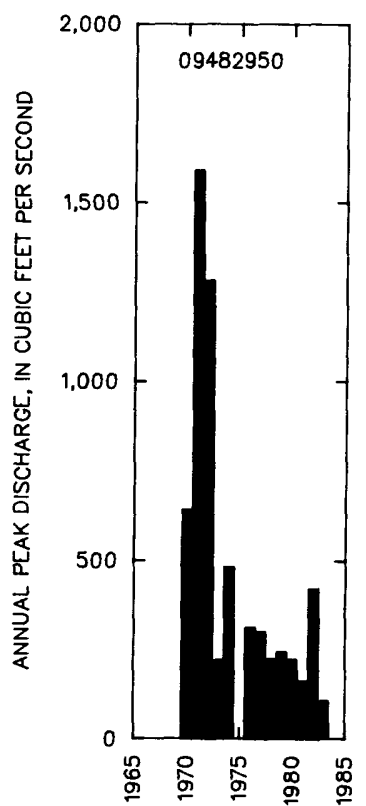

BASIN CHARACTERISTICS

\begin{tabular}{|c|c|c|c|c|c|c|c|}
\hline \multirow{2}{*}{$\begin{array}{l}\text { MAIN } \\
\text { CHANNEL } \\
\text { SLOPE } \\
\text { (FT/MI) }\end{array}$} & \multirow[b]{2}{*}{$\begin{array}{l}\text { STREAM } \\
\text { LENGTH } \\
\text { (MI) }\end{array}$} & \multirow{2}{*}{$\begin{array}{l}\text { MEAN } \\
\text { BASIN } \\
\text { ELEVA- } \\
\text { TION } \\
\text { (FT) }\end{array}$} & \multirow[b]{2}{*}{$\begin{array}{l}\text { FORESTED } \\
\text { AREA } \\
\text { (PERCENT) }\end{array}$} & \multirow[b]{2}{*}{$\begin{array}{l}\text { SOIL } \\
\text { INDEX }\end{array}$} & \multirow{2}{*}{$\begin{array}{l}\text { MEAN } \\
\text { ANNUAL } \\
\text { PRECIPI- } \\
\text { TATION } \\
\text { (IN) }\end{array}$} & \multicolumn{2}{|c|}{ RAINFALL INTENSITY, 24-HOUR } \\
\hline & & & & & & $\begin{array}{c}\text { 2-YEAR } \\
\text { (IN) }\end{array}$ & $\begin{array}{c}\text { 50-YEAR } \\
\text { (IN) }\end{array}$ \\
\hline 0.73 & 2.7 & 2,490 & 0.0 & 1.0 & 11.0 & 1.7 & 4.2 \\
\hline
\end{tabular}


09483000 TUCSON ARROYO AT VINE AVENUE, TUCSON, AZ

LOCATION.--Lat 32'13'00", long 110.56'54", in SW/AEK sec.18, T.14 S., R.14 E., Pima County, Hydrologic Unit 15050301, on right bank at Vine Avenue in Tucson, $0.2 \mathrm{mi}$ downstream from Arroyo Chico.

DRAINAGE AREA.--8.2 $\mathrm{mi}^{2}$ since June 1956. Prior to August 1945, $27.0 \mathrm{mi}^{2}$. See WSP 1733 for history of progressive reduction of drainage area by flood-control diversion structures.

REMARKS.--A flood-control project, at upper end of natural basin, diverts runoff from 3.6 mi into Lakes ide Reservoir (Atterbury), which is in Pantano Wash drainage area. Another flood-control project diverts runoff from 15.2 mi near the upper end of basin into a flood-control detention reservoir in SEK sec.29, T.14 S., R.14 E.., from which reservoir water is released to Julian Wash, which enters Santa Cruz River upstream from Tucson Arroyo. Since October 1969, all flow past the station is published.

ANMUAL PEAK DISCHARGE

\begin{tabular}{|c|c|c|c|}
\hline $\begin{array}{l}\text { HATER } \\
\text { YEAR }\end{array}$ & DATE & $\begin{array}{c}\text { AMIUUAL PEAK } \\
\text { DISCHARGE } \\
\left(F^{3} / S\right)\end{array}$ & $\begin{array}{l}\text { DISCHARGE } \\
\text { CODES }\end{array}$ \\
\hline $\begin{array}{l}1956 \\
1957 \\
1959 \\
1960 \\
1961 \\
1962 \\
1963 \\
1964 \\
1965 \\
1966 \\
1967 \\
1968 \\
1969 \\
1970 \\
1971 \\
1972 \\
1973 \\
1974 \\
1975 \\
1976 \\
1977 \\
1978 \\
1979 \\
1980 \\
1981\end{array}$ & $\begin{array}{l}08-26-56 \\
07-17-57 \\
08-20-59 \\
08-20-60 \\
08-22-61 \\
09-26-62 \\
09-03-63 \\
08-12-64 \\
07-16-65 \\
09-13-66 \\
05-24-67 \\
08-19-68 \\
08-01-69 \\
07-20-70 \\
07-19-71 \\
08-12-72 \\
10-18-72 \\
07-18-74 \\
07-25-75 \\
09-04-76 \\
09-10-77 \\
10-06-77 \\
10-21-78 \\
08-13-80 \\
06-25-81\end{array}$ & $\begin{array}{r}364 \\
716 \\
2,540 \\
609 \\
15,000 \\
1,060 \\
208 \\
1,060 \\
1,220 \\
593 \\
350 \\
644 \\
800 \\
1,550 \\
2,930 \\
2,950 \\
720 \\
332 \\
760 \\
446 \\
1,480 \\
764 \\
1,040 \\
816 \\
746\end{array}$ & $\begin{array}{c}C \\
C \\
C \\
C \\
U R, C \\
C \\
C \\
C \\
C \\
C \\
C \\
C \\
C \\
C \\
C \\
C \\
C \\
C \\
C \\
C \\
C \\
C \\
C \\
C \\
C\end{array}$ \\
\hline
\end{tabular}

$1_{H i g h e s t}$ since 1940.

BASIN CHARACTERISTICS

\begin{tabular}{|c|c|c|c|c|c|c|c|}
\hline MAIN & & $\begin{array}{l}\text { MEAN } \\
\text { BASIN }\end{array}$ & & & $\begin{array}{c}\text { MEAN } \\
\text { ANNUAL }\end{array}$ & RAIMFALL II & SITY, 24-HOUR \\
\hline $\begin{array}{l}\text { CHANNEL } \\
\text { SLOPE } \\
\text { (FT/MI) }\end{array}$ & $\begin{array}{c}\text { STREAM } \\
\text { LENGTH } \\
\text { (MI) }\end{array}$ & $\begin{array}{l}\text { ELEVA- } \\
\text { TION } \\
\text { (FT) }\end{array}$ & $\begin{array}{l}\text { FORESTED } \\
\text { AREA } \\
\text { (PERCENT) }\end{array}$ & $\begin{array}{l}\text { SOIL } \\
\text { INDEX }\end{array}$ & $\begin{array}{l}\text { PRECIPI- } \\
\text { TATION } \\
\text { (IN) }\end{array}$ & $\begin{array}{c}\text { 2-YEAR } \\
\text { (IN) }\end{array}$ & $\begin{array}{c}\text { 50-YEAR } \\
\text { (IN) }\end{array}$ \\
\hline 37.0 & 5.5 & 2,510 & 0.0 & 1.0 & 11.0 & 1.8 & 3.9 \\
\hline
\end{tabular}


09483000 TUCSON ARROYO AT VINE AVE, TUCSON, AZ--Continued.

MEAN MONTHLY AND ANMUAL DISCHARGES 1957-81

\begin{tabular}{|c|c|c|c|c|c|c|}
\hline MONTH & $\begin{array}{l}\operatorname{MAXIMUN} \\
\left(\mathrm{FT}^{3} / \mathrm{S}\right)\end{array}$ & $\begin{array}{l}\operatorname{MINIMUM} \\
\left(F^{3} / S\right)\end{array}$ & $\begin{array}{c}\text { MEAN } \\
\left(F T^{3} / S\right)\end{array}$ & $\begin{array}{l}\text { STAN- } \\
\text { DARD } \\
\text { DEVIA- } \\
\text { TION } \\
\text { (FT } 3 / S)\end{array}$ & $\begin{array}{l}\text { COEFFI- } \\
\text { CIENT OF } \\
\text { VARI- } \\
\text { ATION }\end{array}$ & $\begin{array}{c}\text { PERCENT } \\
\text { OF } \\
\text { ANNUAL } \\
\text { RUNOFF }\end{array}$ \\
\hline $\begin{array}{l}\text { OCTOBER } \\
\text { NOVEMBER } \\
\text { DECEMBER } \\
\text { JANUARY } \\
\text { FEBRUARY } \\
\text { MARCH } \\
\text { APRIL } \\
\text { MAY } \\
\text { JUNE } \\
\text { JULY } \\
\text { AUGUST } \\
\text { SEPTEMBER }\end{array}$ & $\begin{array}{l}8.7 \\
4.4 \\
8.5 \\
3.8 \\
3.8 \\
2.0 \\
0.47 \\
1.0 \\
1.3 \\
4.9 \\
15 \\
5.7\end{array}$ & $\begin{array}{l}0.00 \\
0.00 \\
0.00 \\
0.00 \\
0.00 \\
0.00 \\
0.00 \\
0.00 \\
0.00 \\
0.09 \\
0.00 \\
0.00\end{array}$ & $\begin{array}{l}1.1 \\
0.53 \\
1.1 \\
0.75 \\
0.72 \\
0.47 \\
0.09 \\
0.10 \\
0.12 \\
1.9 \\
2.8 \\
1.1\end{array}$ & $\begin{array}{l}2.0 \\
0.95 \\
2.1 \\
1.1 \\
1.1 \\
0.63 \\
0.13 \\
0.23 \\
0.28 \\
1.3 \\
3.9 \\
1.5\end{array}$ & $\begin{array}{l}1.8 \\
1.8 \\
1.8 \\
1.5 \\
1.5 \\
1.3 \\
1.4 \\
2.2 \\
2.3 \\
0.70 \\
1.4 \\
1.3\end{array}$ & $\begin{array}{r}9.8 \\
4.9 \\
10.5 \\
6.9 \\
6.6 \\
4.4 \\
0.9 \\
1.0 \\
1.1 \\
17.8 \\
25.9 \\
10.4\end{array}$ \\
\hline NNUAL & 1.8 & 0.36 & 0.91 & 0.46 & 0.50 & 100 \\
\hline
\end{tabular}

MagNitUde AND PROBABILITY OF INSTANTANEOUS PEAK FLOH BASED ON PERIOD OF RECORD 1956-81

DISCHARGE, IN $\mathrm{FT}^{3} / \mathrm{S}$, FOR INDICATED RECURRENCE INTERVAL IN YEARS, AND EXCEEDANCE PROBABILITY, IN PERCENT

\begin{tabular}{|c|c|c|c|c|c|}
\hline $\begin{array}{c}2 \\
50 x\end{array}$ & $\begin{array}{c}5 \\
20 \%\end{array}$ & $\begin{array}{r}10 \\
10 \%\end{array}$ & $\begin{array}{l}25 \\
4 \%\end{array}$ & $\begin{array}{l}50 \\
2 \%\end{array}$ & $\begin{array}{c}100 \dagger \\
1 \%\end{array}$ \\
\hline 842 & 1,540 & 2,150 & 3,090 & 3,920 & 4,890 \\
\hline $\begin{array}{l}\text { MEAN } \\
\text { STANDARD }\end{array}$ & $\begin{array}{l}\text { SKEW } \\
\text { DEV. }\end{array}$ & $\begin{array}{l}(\operatorname{LOGS})= \\
(\operatorname{LOGS})= \\
(\operatorname{LOGS})=\end{array}$ & & & \\
\hline
\end{tabular}

MANITUDE AND PROBABILITY OF ANNUAL LON FLON BASED ON PERIOD OF RECORD 1958-81

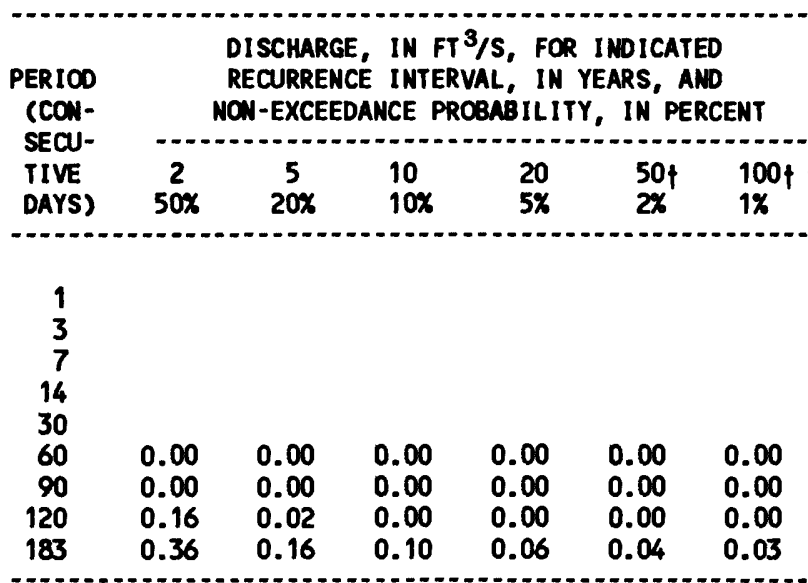

MAGNITUDE AND PROBABILITY OF ANNUAL HIGH FLON BASED ON PERIOD OF RECORD 1957-81

\begin{tabular}{|c|c|c|c|c|c|c|}
\hline \multirow{2}{*}{$\begin{array}{l}\text { PERIOD } \\
\text { (CON- } \\
\text { SECU- } \\
\text { TIVE } \\
\text { DAYS) }\end{array}$} & \multicolumn{6}{|c|}{$\begin{array}{l}\text { DISCHARGE, IN } \mathrm{FT}^{3} / \mathrm{S}, \text { FOR INDICATED } \\
\text { RECURRENCE INTERVAL, IN YEARS, AND } \\
\text { EXCEEDANCE PROBABILITY, IN PERCENT }\end{array}$} \\
\hline & $\stackrel{2}{50 x}$ & $\begin{array}{c}5 \\
20 \%\end{array}$ & $\begin{array}{l}10 \\
10 \%\end{array}$ & $\begin{array}{l}25 \\
4 \%\end{array}$ & $\begin{array}{l}50 \dagger \\
2 \%\end{array}$ & $\begin{array}{c}100 \dagger \\
1 \%\end{array}$ \\
\hline $\begin{array}{r}1 \\
3 \\
7 \\
15 \\
30 \\
60 \\
90\end{array}$ & $\begin{array}{l}67 \\
27 \\
13 \\
7.1 \\
4.5 \\
2.8 \\
2.1\end{array}$ & $\begin{array}{r}125 \\
48 \\
23 \\
13 \\
7.9 \\
4.8 \\
3.6\end{array}$ & $\begin{array}{c}177 \\
68 \\
33 \\
18 \\
11 \\
6.5 \\
4.7\end{array}$ & $\begin{array}{c}262 \\
100 \\
48 \\
25 \\
15 \\
9.0 \\
6.4\end{array}$ & $\begin{array}{c}342 \\
129 \\
62 \\
32 \\
18 \\
11 \\
7.9\end{array}$ & $\begin{array}{c}438 \\
165 \\
78 \\
40 \\
21 \\
14 \\
9.6\end{array}$ \\
\hline
\end{tabular}

DURATION TABLE OF DAILY MEAN FLON FOR PERIOD OF RECORD 1957-81

DISCHARGE, IN FT $3 / 5$, WHICH WAS EQUALED OR EXCEEDED FOR INDICATED PERCENT OF TIME

\begin{tabular}{|c|c|c|c|c|c|c|c|c|c|c|c|c|c|c|c|c|}
\hline $1 \%$ & $5 \%$ & $10 \%$ & $15 \%$ & $20 \%$ & $30 x$ & $40 \%$ & $50 x$ & $60 \%$ & $70 \%$ & $80 \%$ & $90 \%$ & $95 \%$ & $98 \%$ & $99 \%$ & $99.5 \%$ & $99.9 x$ \\
\hline 25 & 2.0 & 0.09 & 0.00 & 0.00 & 0.00 & 0.00 & 0.00 & 0.00 & 0.00 & 0.00 & 0.00 & 0.00 & 0.00 & 0.00 & 0.00 & 0.00 \\
\hline
\end{tabular}

† Reliability of values in column is uncertain, and potential errors are large. 
GILA RIVER BASIN

09483000 TUCSON ARROYO AT VINE AVE, TUCSON, AZ--CONTINUED
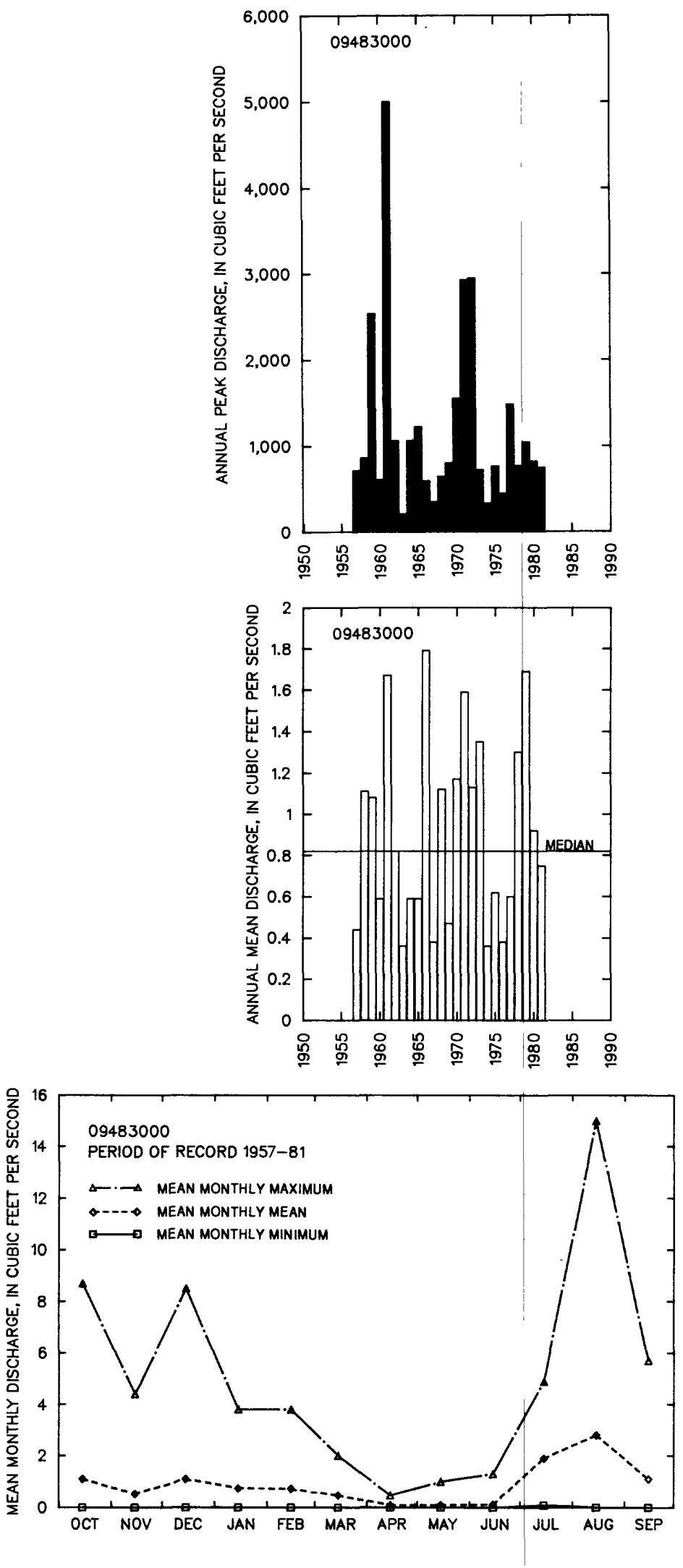
09483010 HIGH SCHOOL WASH AT TUCSON, AZ

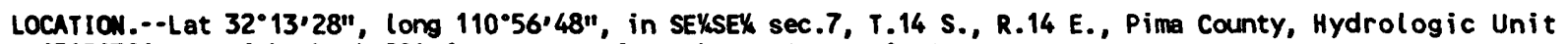
15050301, on right benk $200 \mathrm{ft}$ upstream from Cherry Avenue in Tucson.

DRAIMAGE AREA. $--0.95 \mathrm{mi}^{2}$.

REMARKS.---Entire drainage basin is an urban residential area.

ANNUAL PEAK DISCHARGE

\begin{tabular}{|c|c|c|c|}
\hline $\begin{array}{l}\text { WATER } \\
\text { YEAR }\end{array}$ & DATE & $\begin{array}{l}\text { ANNUAL PEAK } \\
\text { DISCHARGE } \\
\left(\text { FT }^{3} / \mathrm{S}\right)\end{array}$ & $\begin{array}{l}\text { DISCHARGE } \\
\text { CODES }\end{array}$ \\
\hline $\begin{array}{l}1968 \\
1969 \\
1970 \\
1971 \\
1972 \\
1973 \\
1974 \\
1975 \\
1976 \\
1977 \\
1978 \\
1979 \\
1980 \\
1981 \\
1982 \\
1983\end{array}$ & $\begin{array}{l}08-10-68 \\
08-01-69 \\
08-11-70 \\
08-08-71 \\
08-12-72 \\
07-07-73 \\
08-02-74 \\
07-16-75 \\
09-04-76 \\
07-22-77 \\
10-07-77 \\
08-12-79 \\
08-13-80 \\
05-01-81 \\
07-25-82 \\
08-16-83\end{array}$ & $\begin{array}{l}486 \\
341 \\
409 \\
664 \\
800 \\
204 \\
126 \\
195 \\
156 \\
129 \\
178 \\
346 \\
357 \\
85 \\
464 \\
153\end{array}$ & $\begin{array}{l}C \\
C \\
C \\
C \\
C \\
C \\
C \\
C \\
C \\
C \\
C \\
C \\
C \\
C \\
C \\
C\end{array}$ \\
\hline
\end{tabular}

BASIN CHARACTERISTICS

\begin{tabular}{|c|c|c|c|c|c|c|c|}
\hline MAIN & & $\begin{array}{r}\text { MEAN } \\
\text { BASIN }\end{array}$ & & & & RAINFALL I & SITY, 24-HOUR \\
\hline $\begin{array}{l}\text { CHANNEL } \\
\text { SLOPE } \\
\text { (FT/MI) }\end{array}$ & $\begin{array}{c}\text { STREAM } \\
\text { LENGTH } \\
\text { (MI) }\end{array}$ & $\begin{array}{l}\text { ELEVA- } \\
\text { TION } \\
\text { (FT) }\end{array}$ & $\begin{array}{l}\text { FORESTED } \\
\text { AREA } \\
\text { (PERCENT) }\end{array}$ & $\begin{array}{l}\text { SOIL } \\
\text { INDEX }\end{array}$ & $\begin{array}{l}\text { PRECIPI- } \\
\text { TATION } \\
\text { (IN) }\end{array}$ & $\begin{array}{c}\text { 2-YEAR } \\
\text { (IN) }\end{array}$ & $\begin{array}{c}\text { 50-YEAR } \\
\text { (IN) }\end{array}$ \\
\hline 1.11 & 1.6 & 2,460 & 0.0 & 1.0 & 11.0 & 1.7 & 4.2 \\
\hline
\end{tabular}


MEAN MONTHLY AND ANNUAL DISCHARGES 1974-83

\begin{tabular}{|c|c|c|c|c|c|c|}
\hline MONTH & $\begin{array}{l}\operatorname{MAX} \operatorname{Im}_{\left(F T^{3} / S\right)} \\
\end{array}$ & $\begin{array}{l}\text { MINIIMA } \\
\left(F T^{3} / S\right)\end{array}$ & $\begin{array}{c}\text { MEAN } \\
\left(F T^{3} / S\right)\end{array}$ & $\begin{array}{l}\text { DARD } \\
\text { DEVIA- } \\
\text { TION } \\
\left.\text { (FT }{ }^{3} / S\right)\end{array}$ & $\begin{array}{l}\text { COEFFI- } \\
\text { CIENT OF } \\
\text { VARI - } \\
\text { ATION }\end{array}$ & $\begin{array}{c}\text { PERCENT } \\
\text { OF } \\
\text { ANNUAL } \\
\text { RUNOFF }\end{array}$ \\
\hline $\begin{array}{l}\text { OCTOBER } \\
\text { NOVEMBER } \\
\text { DECEMBER } \\
\text { JANUARY } \\
\text { FEBRUARY } \\
\text { MARCH } \\
\text { APRIL } \\
\text { MAY } \\
\text { JUNE } \\
\text { JULY } \\
\text { AUGUST } \\
\text { SEPTEMBER }\end{array}$ & $\begin{array}{l}0.38 \\
0.20 \\
0.35 \\
0.28 \\
0.31 \\
0.26 \\
0.10 \\
0.10 \\
0.09 \\
0.57 \\
0.82 \\
0.78\end{array}$ & $\begin{array}{l}0.00 \\
0.00 \\
0.00 \\
0.00 \\
0.00 \\
0.00 \\
0.00 \\
0.00 \\
0.00 \\
0.04 \\
0.01 \\
0.00\end{array}$ & $\begin{array}{l}0.10 \\
0.05 \\
0.07 \\
0.12 \\
0.07 \\
0.09 \\
0.02 \\
0.02 \\
0.02 \\
0.23 \\
0.27 \\
0.22\end{array}$ & $\begin{array}{l}0.16 \\
0.07 \\
0.11 \\
0.11 \\
0.12 \\
0.07 \\
0.03 \\
0.03 \\
0.03 \\
0.19 \\
0.30 \\
0.24\end{array}$ & $\begin{array}{l}1.5 \\
1.4 \\
1.5 \\
0.92 \\
1.6 \\
0.78 \\
2.0 \\
1.9 \\
1.5 \\
0.81 \\
1.1 \\
1.1\end{array}$ & $\begin{array}{l}8.0 \\
4.0 \\
5.7 \\
9.5 \\
5.6 \\
7.1 \\
1.2 \\
1.4 \\
1.5 \\
17.8 \\
20.9 \\
17.4\end{array}$ \\
\hline ANNUAL & 0.20 & 0.05 & 0.11 & 0.05 & 0.43 & 100 \\
\hline
\end{tabular}

MAGNITUDE AND PROBABILITY OF INSTANTANEQUS PEAK FLOW BASED ON PERIOD OF RECORD 1968-83

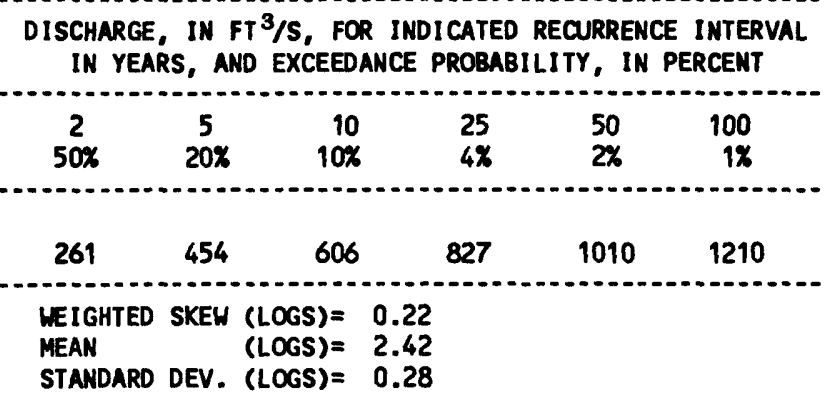

MAGNITLE ANO PROBABILITY OF ANNUAL LOW FLOW BASED ON PERICO OF RECORD 1975-83

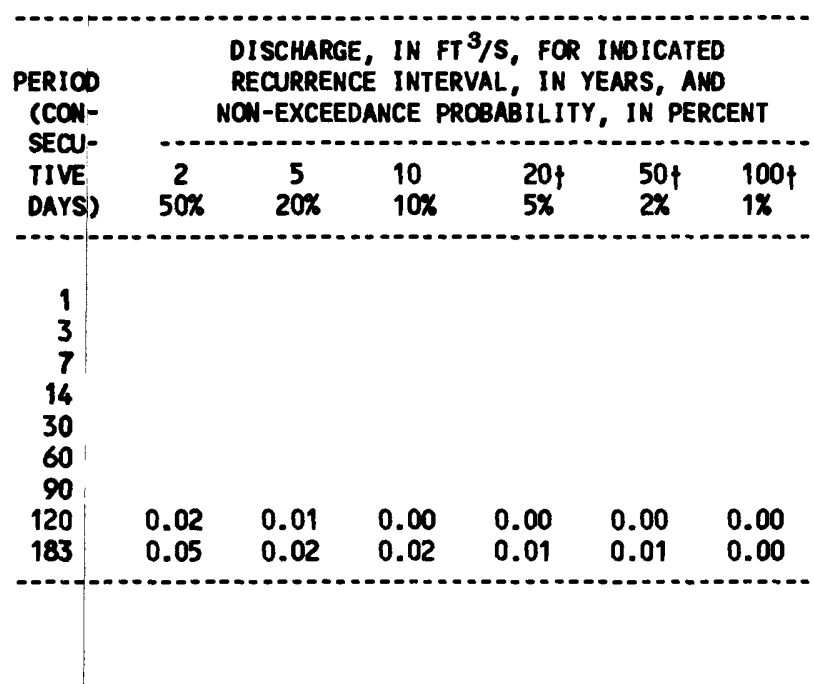

MAGNITLDE AND PROBABILITY OF ANNUAL HIGH FLOH BASED ON PERIOO OF RECORD 1974-83

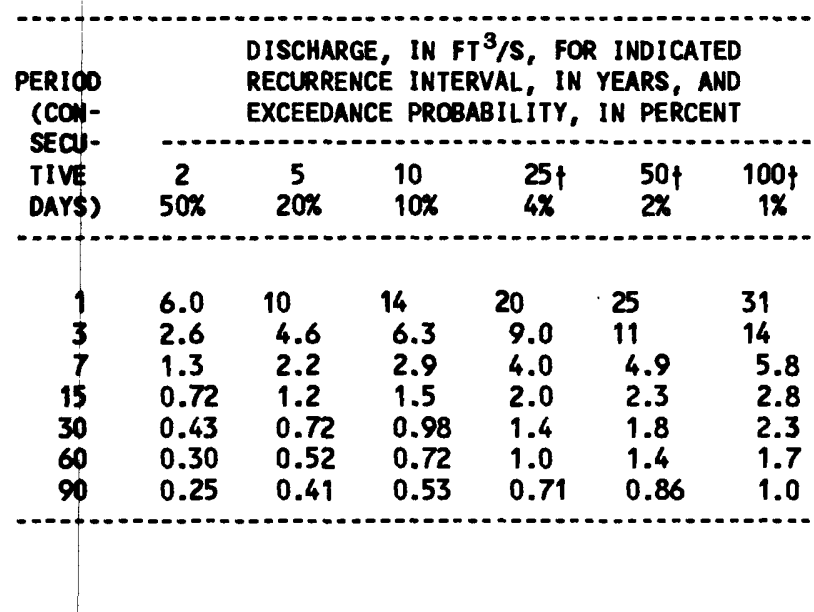

DURATION TABLE OF DAILY MEAN FLON FOR PERIOO OF RECORD 1974-83

DISCHARGE, IN FT ${ }^{3} / \mathrm{S}$, WHICH WAS EQUALED OR EXCEEDED FOR INDICATED PERCENT OF TIME

\begin{tabular}{|c|c|c|c|c|c|c|c|c|c|c|c|c|c|c|c|c|}
\hline $1 x$ & $5 \%$ & $10 \%$ & $15 \%$ & $20 \%$ & $30 \%$ & $40 \%$ & $50 \%$ & $60 \%$ & $70 \%$ & $80 \%$ & $90 \%$ & $95 \%$ & $98 \%$ & $99 \%$ & $99.5 \%$ & $99.9 \%$ \\
\hline 3.0 & 0.35 & 0.00 & 0.00 & 0.00 & 0.00 & 0.00 & 0.00 & 0.00 & 0.00 & 0.00 & 0.00 & 0.00 & 0.00 & 0.00 & 0.00 & 0.00 \\
\hline
\end{tabular}

$\uparrow$ Reliability of values in column is uncertain, and potential errors are large. 
GILA RIVER BASIN

09483010 HIGH SCHOOL WASH AT TUCSON, AZ--CONTINUED
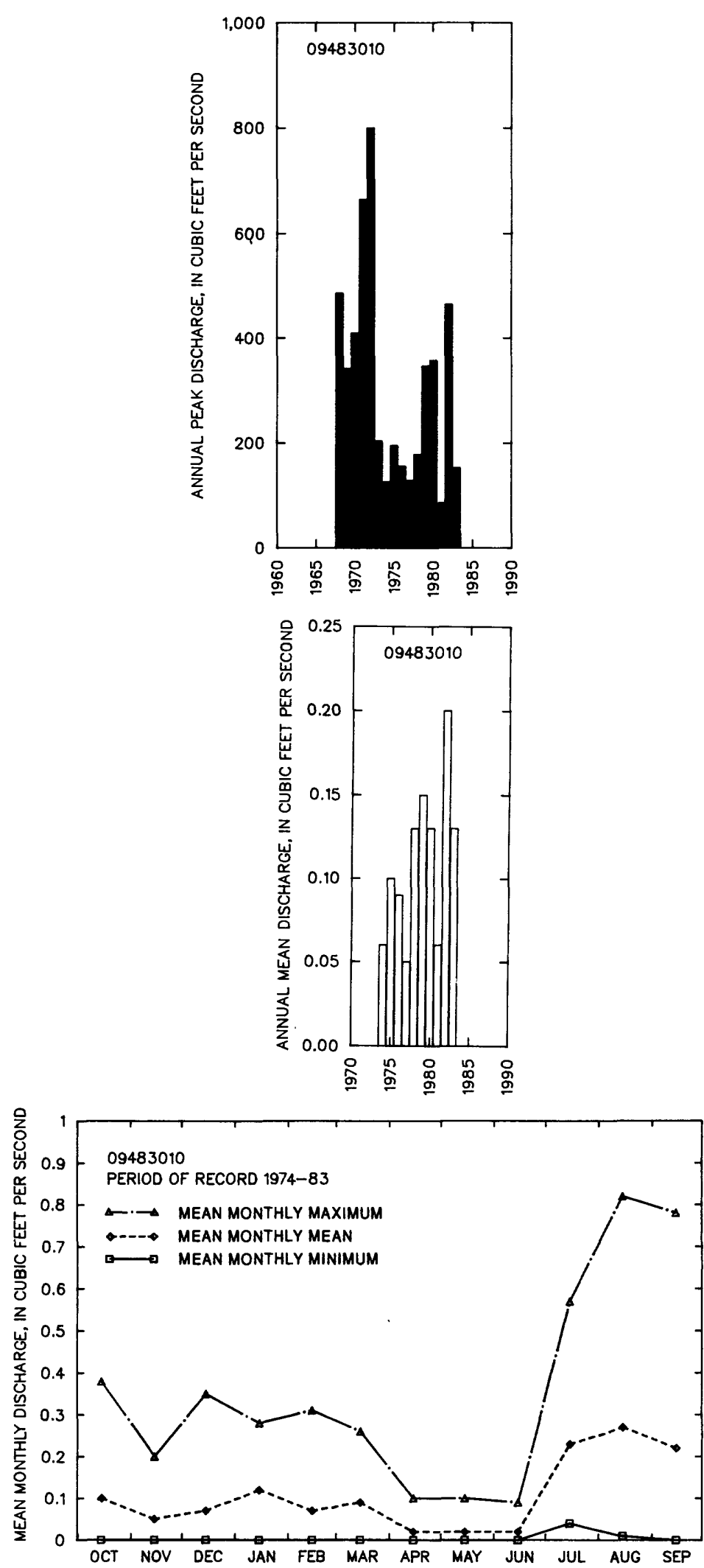
LOCATION.-- Lat 32*13'53", long $111^{\circ} 00^{\prime} 10^{\prime \prime}$, in NWK sec.10, T.14 S., R.13 E., Pima County, Hydrologic Unit 15050301, $0.1 \mathrm{mi}$ west of Silverbell Road, $0.3 \mathrm{mi}$ northwest of St. Mary's Hospital, and $0.4 \mathrm{mi}$ north of Anklam Road at Tucson.

DRAINAGE AREA. $--2.74 \mathrm{mi}^{2}$.

\section{ANNUAL PEAK DISCHARGE}

\begin{tabular}{|c|c|c|c|}
\hline $\begin{array}{l}\text { WATER } \\
\text { YEAR }\end{array}$ & DATE & $\begin{array}{c}\text { ANNUAL PEAK } \\
\text { DISCHARGE } \\
\text { (FT } 3 / \mathrm{S})\end{array}$ & $\begin{array}{l}\text { DISCHARGE } \\
\text { CODES }\end{array}$ \\
\hline $\begin{array}{l}1965 \\
1969 \\
1970 \\
1971 \\
1972 \\
1973 \\
1974 \\
1975 \\
1976 \\
1977 \\
1978 \\
1979 \\
1980 \\
1981\end{array}$ & $\begin{array}{l}07-10-65 \\
08-00-69 \\
07-20-70 \\
08-00-71 \\
00-00-72 \\
07-00-73 \\
07-20-74 \\
10-30-74 \\
09-25-76 \\
01-01-77 \\
10-06-77 \\
07-20-79 \\
08-24-80 \\
07-21-81\end{array}$ & $\begin{array}{c}1560 \\
2365 \\
31,500 \\
1,450 \\
100 \\
115 \\
5.0 \\
10 \\
310 \\
63 \\
290 \\
19 \\
72 \\
22\end{array}$ & $\begin{array}{c}H P, C \\
C \\
C \\
C \\
E S, C \\
C \\
L T, C \\
L T, C \\
C \\
C \\
C \\
C \\
C \\
C\end{array}$ \\
\hline
\end{tabular}

MAGNITUDE AND PROBABILITY OF INSTANTANEQUS PEAK FLOW BASED ON PERICO OF RECORD 1965, 1969-81 IN YEARS, AND EXCEEDANCE PROBABILITY, IN PERCENT

\begin{tabular}{|c|c|c|c|c|c|}
\hline$\stackrel{2}{20 \%}$ & $\begin{array}{c}5 \\
20 \%\end{array}$ & $\begin{array}{r}10 \\
10 \%\end{array}$ & $\begin{array}{l}25 \\
4 \%\end{array}$ & $\begin{array}{l}50 \dagger \\
2 \%\end{array}$ & $\begin{array}{c}100 \nmid \\
1 \%\end{array}$ \\
\hline 90 & 332 & 659 & 1,370 & 2,200 & 3,360 \\
\hline $\begin{array}{l}\text { WEIGHTED } \\
\text { MEAN } \\
\text { STANDARD }\end{array}$ & $\begin{array}{l}\text { SKEW } \\
\text { DEV. }\end{array}$ & $\begin{array}{l}(\text { LOGS })= \\
(\text { LOGS })= \\
(\text { LOGS })=\end{array}$ & $\begin{array}{l}0.01 \\
1.96 \\
0.67\end{array}$ & & \\
\hline
\end{tabular}

$\uparrow$ Reliability of values in colum is uncertain, and potential errors are large.
DISCHARGE, IN $\mathrm{FT}^{3} / \mathrm{S}$, FOR INDICATED RECURRENCE INTERVAL

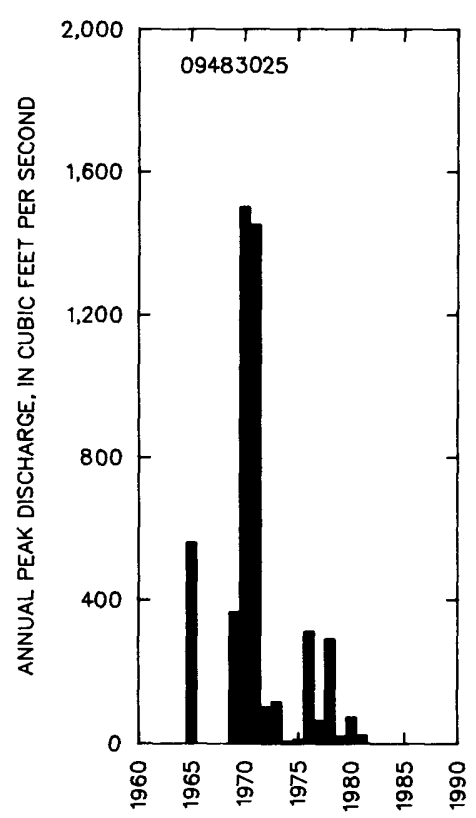

BASIN CHARACTERISTICS

\begin{tabular}{|c|c|c|c|c|c|c|c|}
\hline MAIN & & $\begin{array}{r}\text { MEAN } \\
\text { BASIN }\end{array}$ & & & $\begin{array}{c}\text { MEAN } \\
\text { ANNUAL }\end{array}$ & RAINFALL I & SITY, 24-HOQR \\
\hline $\begin{array}{l}\text { CHANNEL } \\
\text { SLOPE } \\
\text { (FT/MI) }\end{array}$ & $\begin{array}{c}\text { STREAM } \\
\text { LENGTH } \\
\text { (MI) }\end{array}$ & $\begin{array}{l}\text { ELEVA- } \\
\text { TION } \\
\text { (FT) }\end{array}$ & $\begin{array}{l}\text { FORESTED } \\
\text { AREA } \\
\text { (PERCENT) }\end{array}$ & $\begin{array}{l}\text { SOIL } \\
\text { INDEX }\end{array}$ & $\begin{array}{l}\text { PRECIPI- } \\
\text { TATION } \\
\text { (IN) }\end{array}$ & $\begin{array}{l}\text { 2-YEAR } \\
\text { (IN) }\end{array}$ & $\begin{array}{l}\text { 50-YEAR } \\
\text { (IN) }\end{array}$ \\
\hline 44.6 & 3.3 & 2,540 & 0.0 & 1.0 & 11.8 & 1.9 & 4.4 \\
\hline
\end{tabular}


09483030 ANKLAM WASH AT TUCSON, AZ

LOCATION.--Lat 32.13'30", long 111'01'50", in SEK sec.8, T.14 S., R.13 E., Pima County, Hydrologic Unit 15050301, at Anklam Road, 1 mi west of Tucson city limits, and 2 mi west of St. Mary's Hospital.

DRAINAGE AREA. $--2.11 \mathrm{mi}^{2}$.

ANNUAL PEAK DISCHARGE

\begin{tabular}{|c|c|c|c|}
\hline $\begin{array}{l}\text { MATER } \\
\text { YEAR }\end{array}$ & DATE & $\begin{array}{l}\text { ANNUAL PEAK } \\
\text { DISCHARGE } \\
\text { (FT } 3 / \mathrm{S})\end{array}$ & $\begin{array}{l}\text { DISCHARGE } \\
\text { COOES }\end{array}$ \\
\hline $\begin{array}{l}1965 \\
1966 \\
1967 \\
1968 \\
1969 \\
1970 \\
1971 \\
1972 \\
1973 \\
1974 \\
1975 \\
1976 \\
1977 \\
1978 \\
1979 \\
1980 \\
1981\end{array}$ & $\begin{array}{l}07-10-65 \\
12-10-65 \\
00-00-67 \\
10-03-67 \\
08-00-69 \\
07-19-70 \\
08-17-71 \\
09-07-72 \\
07-15-73 \\
00-00-74 \\
10-30-74 \\
09-25-76 \\
01-01-77 \\
07-30-78 \\
01-18-79 \\
08-14-80 \\
08-13-81\end{array}$ & $\begin{array}{c}1,600 \\
30 \\
2.0 \\
50 \\
98 \\
2,000 \\
2,420 \\
75 \\
140 \\
0 \\
160 \\
75 \\
5.0 \\
38 \\
5.0 \\
35 \\
76\end{array}$ & $\begin{array}{l}\text { ES } \\
\text { ES } \\
\text { ES }\end{array}$ \\
\hline
\end{tabular}

MAGNITUDE AND PROBABILITY OF INSTANTANEOUS PEAK FLOW BASED ON PERIOD OF RECORD 1965-81

DISCHARGE, IN $\mathrm{FT}^{3} / \mathrm{S}$, FOR INDICATED RECURRENCE INTERVAL IN YEARS, AND EXCEEDANCE PROBABILITY, IN PERCENT

\begin{tabular}{|c|c|c|c|c|c|}
\hline $\begin{array}{c}2 \dagger \\
50 \%\end{array}$ & $\begin{array}{r}5 \dagger \\
20 \%\end{array}$ & $\begin{array}{c}10 \dagger \\
10 \%\end{array}$ & $\begin{array}{l}25 \uparrow \\
4 \%\end{array}$ & $\begin{array}{l}50 \dagger \\
2 \%\end{array}$ & $\begin{array}{c}100 \dagger \\
1 \%\end{array}$ \\
\hline 75.6 & 362 & 855 & 2,210 & 4,140 & 7,390 \\
\hline $\begin{array}{l}\text { WEIGHTED } \\
\text { MEAN } \\
\text { STANDARD }\end{array}$ & $\begin{array}{l}\text { SKEW } \\
\text { DEV. }\end{array}$ & $\begin{array}{l}(\operatorname{GOS})= \\
(L O G S)= \\
(L O G S)=\end{array}$ & $\begin{array}{l}0.24 \\
1.91 \\
0.78\end{array}$ & & \\
\hline
\end{tabular}

t Reliability of values in column is uncertain, and potential errors are large.

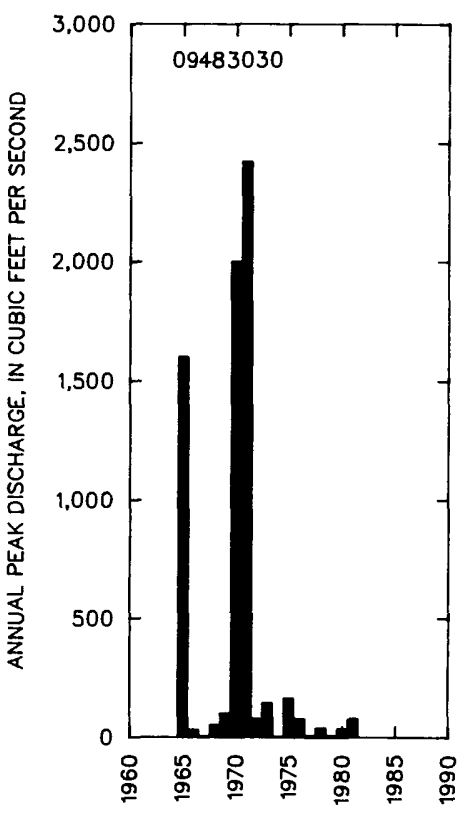


09483040 WEST SPEEDWAY WASH NEAR TUCSON, AZ

LOCATION.--Lat $32^{\circ} 14^{\prime} 20^{\prime \prime}$, Long $11^{\circ} 02^{\prime} 4^{\prime \prime}$, in SEKSE\% sec.6, T.14 S., R.13 E., Pima County, Hydrologic Unit 15050301, at driveway to Power substation off Hest Speedway Road, 2 mi west of Tucson city limits, and 3 mi northwest of St. Mary's Hospital.

DRAINAGE AREA. $-0.46 \mathrm{mi}^{2}$.

ANMUAL PEAK DISCHARGE

\begin{tabular}{|c|c|c|c|}
\hline $\begin{array}{l}\text { WATER } \\
\text { YEAR }\end{array}$ & DATE & $\begin{array}{l}\text { ANNUAL PEAK } \\
\text { DISCHARGE } \\
\text { (FT } 3 / \mathrm{S})\end{array}$ & $\begin{array}{l}\text { DISCHARGE } \\
\text { COOES }\end{array}$ \\
\hline $\begin{array}{l}1965 \\
1966 \\
1967 \\
1968 \\
1969 \\
1970 \\
1971 \\
1972 \\
1973 \\
1974 \\
1975 \\
1976 \\
1977 \\
1978 \\
1979 \\
1980 \\
1981\end{array}$ & $\begin{array}{l}07-10-65 \\
09-13-66 \\
00-00-67 \\
10-03-67 \\
08-08-69 \\
09-04-70 \\
08-20-71 \\
08-12-72 \\
07-00-73 \\
09-14-74 \\
09-07-75 \\
09-25-76 \\
00-00-77 \\
10-06-77 \\
07-20-79 \\
08-24-80 \\
08-13-81\end{array}$ & $\begin{array}{r}224 \\
41 \\
37 \\
44 \\
236 \\
236 \\
144 \\
159 \\
238 \\
15 \\
160 \\
240 \\
10 \\
104 \\
74 \\
86 \\
40\end{array}$ & ES \\
\hline
\end{tabular}

MAGNITUDE AND PROBABILITY OF INSTANTANEOUS PEAK FLOW BASED ON PERIOD OF RECORD 1965-81

DISCHARGE, IN $\mathrm{FT}^{3} / \mathrm{S}$, FOR INDICATED RECURRENCE INTERVAL IN YEARS, AND EXCEEDANCE PROBABILITY, IN PERCENT

\begin{tabular}{|c|c|c|c|c|c|}
\hline $\begin{array}{c}2 \\
50 \%\end{array}$ & $\begin{array}{c}5 \\
20 \%\end{array}$ & $\begin{array}{r}10 \\
10 \%\end{array}$ & $\begin{array}{l}25 \\
4 \%\end{array}$ & $\begin{array}{l}50 \dagger \\
2 \%\end{array}$ & $\begin{array}{c}100 \dagger \\
1 \%\end{array}$ \\
\hline 92.2 & 202 & 291 & 419 & 521 & 627 \\
\hline $\begin{array}{l}\text { WEIGHTED } \\
\text { MEAN } \\
\text { STANDARD }\end{array}$ & $\begin{array}{l}\text { SKEW } \\
\text { DEV. }\end{array}$ & $\begin{array}{l}(\text { LOGS })= \\
(\text { LOGS) }= \\
(\text { LOGS })=\end{array}$ & $\begin{array}{r}-0.05 \\
1.93 \\
0.43\end{array}$ & & \\
\hline
\end{tabular}

† Reliability of values in colum is uncertain, and potential errors are large.

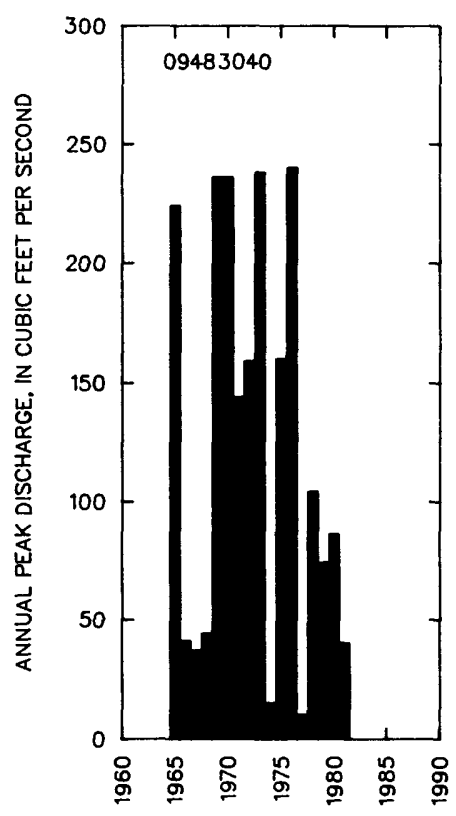

BASIN CHARACTERISTICS

\begin{tabular}{|c|c|c|c|c|c|c|c|}
\hline MAIN & & $\begin{array}{l}\text { MEAN } \\
\text { BASIN }\end{array}$ & & & & RAINFALL I & SITY, 24-HOUR \\
\hline $\begin{array}{l}\text { CHANNEL } \\
\text { SLOPE } \\
\text { (FT/MI) }\end{array}$ & $\begin{array}{l}\text { STREAM } \\
\text { LENGTH } \\
\text { (MI) }\end{array}$ & $\begin{array}{l}\text { ELEVA- } \\
\text { TION } \\
\text { (FT) }\end{array}$ & $\begin{array}{l}\text { FORESTED } \\
\text { AREA } \\
\text { (PERCENT) }\end{array}$ & $\begin{array}{l}\text { SOIL } \\
\text { INDEX }\end{array}$ & $\begin{array}{l}\text { PRECIPI- } \\
\text { TATION } \\
\text { (IN) }\end{array}$ & $\begin{array}{c}\text { 2-YEAR } \\
\text { (IN) }\end{array}$ & $\begin{array}{c}\text { 50-YEAR } \\
\text { (IN) }\end{array}$ \\
\hline 364 & 1.1 & 2,750 & 0.0 & 1.0 & 11.8 & 1.9 & 4.6 \\
\hline
\end{tabular}


09483100 TANQUE VERDE CREEK NEAR TUCSON, AZ

LOCATION.--Lat 32*14\%48", long 110 40'46", in NEYNWH sec.2, T.14 S., R.16 E., Pima County, Hydrologic Unit 15050302, $4.4 \mathrm{mi}$ east of Tanque Verde School, $7.4 \mathrm{mi}$ upstream from Agua Caliente Wash, and $17.5 \mathrm{mi}$ east of city hall in Tucson.

DRAIMAGE AREA. $--43.0 \mathrm{mi}^{2}$.

ANNUAL PEAK DISCHARGE

\begin{tabular}{|c|c|c|c|c|}
\hline $\begin{array}{l}\text { WATER } \\
\text { YEAR }\end{array}$ & $\begin{array}{l}\text { ANNUAL PEAK } \\
\text { DISCHARGE } \\
\left(\mathrm{FT}^{3} / \mathrm{S}\right)\end{array}$ & $\begin{array}{l}\text { WATER } \\
\text { YEAR }\end{array}$ & DATE & $\begin{array}{c}\text { ANMUAL PEAK } \\
\text { DISCHARGE } \\
\left(\mathrm{FT}^{3} / \mathrm{S}\right)\end{array}$ \\
\hline $\begin{array}{l}1960 \\
1961 \\
1962 \\
1963 \\
1964 \\
1965 \\
1966 \\
1967 \\
1968 \\
1969 \\
1970 \\
1971 \\
1972\end{array}$ & $\begin{array}{l}01-11-60 \\
09-08-61 \\
12-16-61 \\
02-11-63 \\
09-10-64 \\
09-04-65 \\
12-22-65 \\
07-16-67 \\
12-20-67 \\
01-15-69 \\
03-02-70 \\
08-21-71 \\
07-16-72\end{array}$ & $\begin{array}{l}1973 \\
1974 \\
1975 \\
1976 \\
1977 \\
1978 \\
1979 \\
1980 \\
1981 \\
1982 \\
1983 \\
1984 \\
1985\end{array}$ & $\begin{array}{l}10-19-72 \\
07-08-74 \\
00-00-75 \\
09-05-76 \\
01-01-77 \\
07-25-78 \\
12-18-78 \\
02-14-80 \\
07-30-81 \\
08-23-82 \\
02-03-83 \\
10-02-83 \\
12-28-84\end{array}$ & $\begin{array}{r}2,120 \\
804 \\
210 \\
300 \\
420 \\
1,280 \\
4,100 \\
1,150 \\
6,700 \\
2,460 \\
1,100 \\
8,600 \\
7,880\end{array}$ \\
\hline
\end{tabular}

BASIN CHARACTERISTICS

\begin{tabular}{|c|c|c|c|c|c|c|c|}
\hline \multirow{2}{*}{$\begin{array}{c}\text { MAIN } \\
\text { CHANNEL } \\
\text { SLOPE } \\
\text { (FT/MI) }\end{array}$} & \multirow[b]{2}{*}{$\begin{array}{l}\text { STREAM } \\
\text { LENGTH } \\
\text { (MI) }\end{array}$} & \multirow{2}{*}{$\begin{array}{l}\text { MEAN } \\
\text { BASIN } \\
\text { ELEVA- } \\
\text { TION } \\
\text { (FT) }\end{array}$} & \multirow[b]{2}{*}{$\begin{array}{l}\text { FORESTED } \\
\text { AREA } \\
\text { (PERCENT) }\end{array}$} & \multirow[b]{2}{*}{$\begin{array}{l}\text { SOIL } \\
\text { INDEX }\end{array}$} & \multirow{2}{*}{$\begin{array}{l}\text { MEAN } \\
\text { ANNUAL } \\
\text { PRECIPI- } \\
\text { TATION } \\
\text { (IN) }\end{array}$} & \multicolumn{2}{|c|}{ RAINFALL INTENSITY, 24-HOUR } \\
\hline & & & & & & $\begin{array}{c}\text { 2-YEAR } \\
\text { (IN) }\end{array}$ & $\begin{array}{c}\text { 50-YEAR } \\
\text { (IN) }\end{array}$ \\
\hline 156 & 11.0 & 4,780 & 21.0 & 1.0 & 17.0 & 2.0 & 4.0 \\
\hline
\end{tabular}


MEAN MONTHLY AND ANNUAL DISCHARGES 1960-74

\begin{tabular}{|c|c|c|c|c|c|c|}
\hline MONTH & $\begin{array}{l}\operatorname{MAXIMUN} \\
\left(F T^{3} / S\right)\end{array}$ & $\begin{array}{l}\text { MINIMUM } \\
\left(F^{3} / S\right)\end{array}$ & $\begin{array}{c}\text { MEAN } \\
\left(F T^{3 / S}\right)\end{array}$ & $\begin{array}{l}\text { STAN- } \\
\text { DARD } \\
\text { DEVIA- } \\
\text { TION } \\
\text { (FT'S/S) }\end{array}$ & $\begin{array}{l}\text { COEFFI- } \\
\text { CIENT OF } \\
\text { VARI - } \\
\text { ATION }\end{array}$ & $\begin{array}{c}\text { PERCENT } \\
\text { OF } \\
\text { ANNUAL } \\
\text { RUNOFF }\end{array}$ \\
\hline $\begin{array}{l}\text { OCTOBER } \\
\text { NOVEMBER } \\
\text { DECEMBER } \\
\text { JANUARY } \\
\text { FEBRUARY } \\
\text { MARCH } \\
\text { APRIL } \\
\text { MAY } \\
\text { JUNE } \\
\text { JULY } \\
\text { AUGUST } \\
\text { SEPTEMBER }\end{array}$ & $\begin{array}{c}44 \\
12 \\
198 \\
94 \\
83 \\
100 \\
19 \\
3.5 \\
0.82 \\
16 \\
46 \\
69\end{array}$ & $\begin{array}{l}0.00 \\
0.00 \\
0.00 \\
0.00 \\
0.00 \\
0.00 \\
0.00 \\
0.00 \\
0.00 \\
0.00 \\
0.00 \\
0.00\end{array}$ & $\begin{array}{l}4.6 \\
2.1 \\
25 \\
15 \\
21 \\
15 \\
3.4 \\
0.31 \\
0.05 \\
3.2 \\
8.2 \\
9.6\end{array}$ & $\begin{array}{l}12 \\
3.4 \\
51 \\
24 \\
31 \\
26 \\
5.2 \\
0.90 \\
0.21 \\
4.8 \\
12 \\
19\end{array}$ & $\begin{array}{l}2.6 \\
1.7 \\
2.1 \\
1.6 \\
1.5 \\
1.7 \\
1.5 \\
2.9 \\
3.9 \\
1.5 \\
1.5 \\
2.0\end{array}$ & $\begin{array}{r}4.3 \\
1.9 \\
23.1 \\
13.8 \\
19.8 \\
14.0 \\
3.2 \\
0.3 \\
0.1 \\
3.0 \\
7.7 \\
9.0\end{array}$ \\
\hline ANNUAL & 32 & 1.1 & 8.9 & 8.5 & 0.96 & 100 \\
\hline
\end{tabular}

MAGNITUDE AND PROBABILITY OF INSTANTANEOUS PEAK FLOW BASED ON PERIOD OF RECORD 1960-85

DISCHARGE, IN $\mathrm{FT}^{3} / \mathrm{S}$, FOR INDICATED RECURRENCE INTERVAL IN YEARS, AND EXCEEDANCE PROBABILITY, IN PERCENT

$\begin{array}{cccccc}2 & 5 & 10 & 25 & 50 & 100 \uparrow \\ 50 \% & 20 \% & 10 \% & 4 \% & 2 \% & 1 \% \\ 1,530 & 3,130 & 4,620 & 7,110 & 9,460 & 12,300\end{array}$

WEIGHTED SKEH (LOGS) $=0.23$

MEAN (LOGS) $=3.20$

STAMDARD DEV. (LOGS) $=0.36$
MAGNITUDE AND PROBABILITY OF ANNUAL LOW FLON BASED ON PERIOO OF RECORD 1961-74

\begin{tabular}{|c|c|c|c|c|c|c|}
\hline \multirow{2}{*}{$\begin{array}{l}\text { PERIOD } \\
\text { (CON- } \\
\text { SECU- } \\
\text { TIVE } \\
\text { OAYS) }\end{array}$} & \multicolumn{6}{|c|}{$\begin{array}{l}\text { DISCHARGE, IN FT } 3 / S \text {, FOR INDICATED } \\
\text { RECURRENCE INTERVAL, IN YEARS, AND } \\
\text { NON-EXCEEDANCE PROBABILITY, IN PERCENT }\end{array}$} \\
\hline & $\begin{array}{c}2 \\
50 \%\end{array}$ & $\begin{array}{c}5 \\
20 \%\end{array}$ & $\begin{array}{l}10 \\
10 \%\end{array}$ & $\begin{array}{l}20 \\
5 x\end{array}$ & $\begin{array}{l}50 \phi \\
2 \%\end{array}$ & $\begin{array}{l}100 \dagger \\
1 x\end{array}$ \\
\hline $\begin{array}{r}1 \\
3 \\
7 \\
14 \\
30 \\
60 \\
90\end{array}$ & & & & & & \\
\hline $\begin{array}{l}120 \\
183\end{array}$ & $\begin{array}{l}0.04 \\
0.40\end{array}$ & $\begin{array}{l}0.00 \\
0.06\end{array}$ & $\begin{array}{l}0.00 \\
0.02\end{array}$ & $\begin{array}{l}0.00 \\
0.01\end{array}$ & $\begin{array}{l}0.00 \\
0.00\end{array}$ & $\begin{array}{l}0.00 \\
0.00\end{array}$ \\
\hline
\end{tabular}

MAGNITUDE AND PROBABILITY OF ANNUAL HIGH FLON BASED ON PERIO0 OF RECORD 1960-74

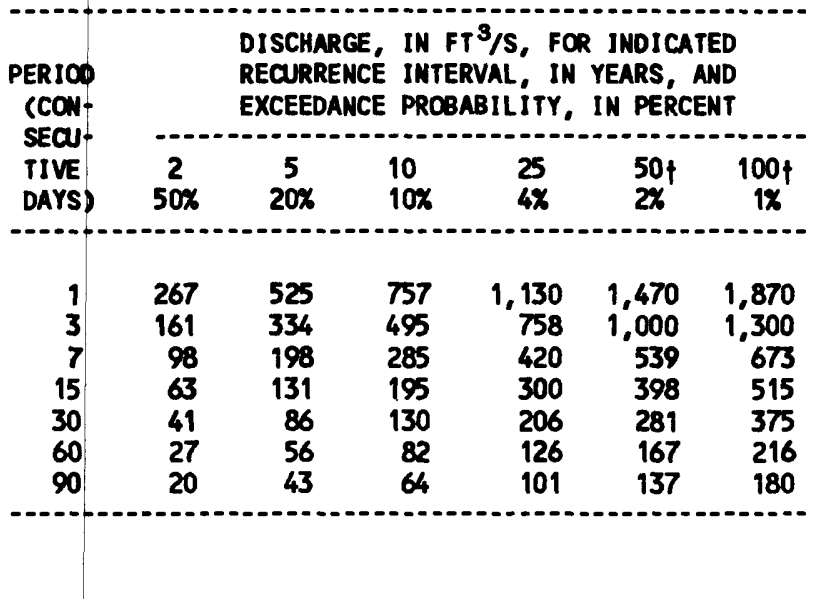

DURATION TABLE OF DAILY MEAN FLOW FOR PERIOD OF RECORD 1960-74

\begin{tabular}{|c|c|c|c|c|c|c|c|c|c|c|c|c|c|c|c|c|}
\hline 181 & 38 & 16 & 8.9 & 5.4 & 1.2 & 0.18 & 0.07 & 0.01 & 0.01 & 0.00 & 0.00 & 0.00 & 0.00 & 0.00 & 0.00 & 0.00 \\
\hline
\end{tabular}

† Reliability of values in colum is uncertain, and potential errors are large. 
09483042 CEMETERY WASH AT TUCSON, AZ

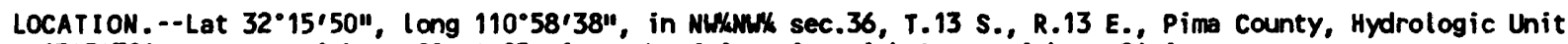
15050301, at U.S. Highway $89,0.25$ mi north of junction with State Highway 84 in Tucson.

DRAIMAGE AREA. $--1.17 \mathrm{mi}^{2}$.

ANIUUAL PEAK DISCHARGE

\begin{tabular}{|c|c|c|c|c|c|c|c|}
\hline $\begin{array}{l}\text { WATER } \\
\text { YEAR }\end{array}$ & DATE & $\begin{array}{l}\text { ANNUAL PEAK } \\
\text { DISCHARGE } \\
\text { (FT } 3 / 5)\end{array}$ & $\begin{array}{c}\text { DISCHARGE } \\
\text { CODES }\end{array}$ & $\begin{array}{l}\text { WATER } \\
\text { YEAR }\end{array}$ & DATE & $\begin{array}{l}\text { ANNUAL PEAK } \\
\text { DISCHARGE } \\
\left(\mathrm{FT}^{3} / \mathrm{S}\right)\end{array}$ & $\begin{array}{l}\text { DISCHARGE } \\
\text { CODES }\end{array}$ \\
\hline $\begin{array}{l}1966 \\
1967 \\
1968 \\
1969 \\
1970 \\
1971 \\
1972 \\
1973 \\
1974 \\
1975 \\
1976 \\
1977\end{array}$ & $\begin{array}{l}08-00-66 \\
07-17-67 \\
08-20-68 \\
11-14-68 \\
08-18-70 \\
08-00-71 \\
08-12-72 \\
07-00-73 \\
09-06-74 \\
07-17-75 \\
09-25-76 \\
09-10-77\end{array}$ & $\begin{array}{l}229 \\
396 \\
600 \\
570 \\
285 \\
100 \\
400 \\
150 \\
580 \\
290 \\
360 \\
205\end{array}$ & $\begin{array}{c}C \\
C \\
C \\
C \\
C \\
E S, C \\
E S, C \\
E S, C \\
C \\
C \\
C \\
C\end{array}$ & $\begin{array}{l}1978 \\
1979 \\
1980 \\
1981 \\
1982 \\
1983 \\
1984 \\
1985 \\
1986 \\
1987 \\
1988 \\
1989\end{array}$ & $\begin{array}{l}07-30-78 \\
08-12-79 \\
08-14-80 \\
04-30-81 \\
08-23-82 \\
08-15-83 \\
10-02-83 \\
00-00-85 \\
07-15-86 \\
02-25-87 \\
08-20-88 \\
07-26-89\end{array}$ & $\begin{array}{l}160 \\
375 \\
225 \\
156 \\
540 \\
209 \\
456 \\
172 \\
264 \\
52 \\
216 \\
262\end{array}$ & $\begin{array}{l}\text { C } \\
\text { C } \\
\text { C } \\
C \\
C \\
C \\
C \\
C \\
C \\
C \\
C \\
C\end{array}$ \\
\hline
\end{tabular}

MAGN1TUDE AND PROBABILITY OF INSTANTANEOUS PEAK FLOH BASED ON PERIOD OF RECORD 1966-89

DISCHARGE, IN FT $3 / 5$, FOR INDICATED RECURRENCE INTERVAL IN YEARS, AND EXCEEDANCE PROBABILITY, IN PERCENT

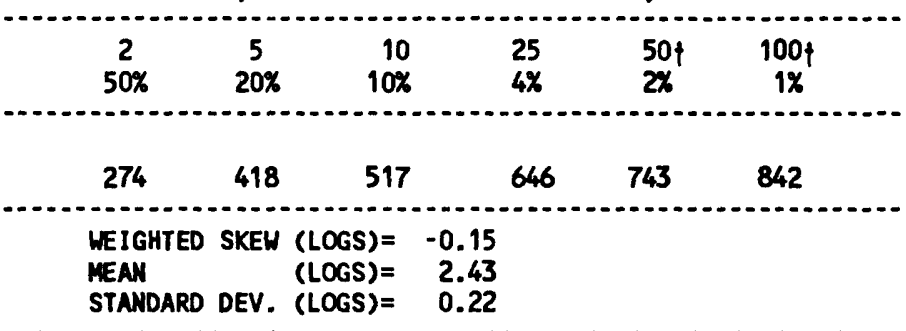

t Reliability of values in colum is uncertain, and potential errors are large.

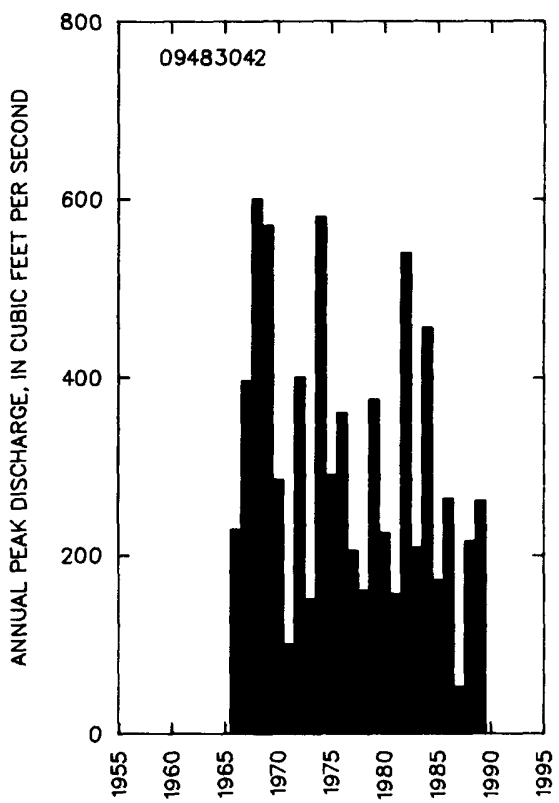

BASIN CHARACTERISTICS

\begin{tabular}{|c|c|c|c|c|c|c|c|}
\hline \multirow{3}{*}{$\begin{array}{l}\text { MAIN } \\
\text { CHANNEL } \\
\text { SLOPE } \\
\text { (FT/MI) }\end{array}$} & \multirow[b]{3}{*}{$\begin{array}{c}\text { STREAM } \\
\text { LENGTH } \\
\text { (MI) }\end{array}$} & \multirow{3}{*}{$\begin{array}{l}\text { MEAN } \\
\text { BASIN } \\
\text { ELEVA- } \\
\text { TION } \\
\text { (FT) }\end{array}$} & \multirow[b]{3}{*}{$\begin{array}{l}\text { FORESTED } \\
\text { AREA } \\
\text { (PERCENT) }\end{array}$} & \multirow[b]{3}{*}{$\begin{array}{l}\text { SOIL } \\
\text { INDEXX }\end{array}$} & \multirow{3}{*}{$\begin{array}{l}\text { MEAN } \\
\text { ANNUAL } \\
\text { PRECIPI- } \\
\text { TATION } \\
\text { (IN) }\end{array}$} & \multirow{2}{*}{\multicolumn{2}{|c|}{ RAINFALL INTENSITY, 24-HOUR }} \\
\hline & & & & & & & \\
\hline & & & & & & $\begin{array}{c}\text { 2-YEAR } \\
\text { (IN) }\end{array}$ & $\begin{array}{l}\text { 50-YEAR } \\
\text { (IN) }\end{array}$ \\
\hline 40.0 & 2.2 & 2,370 & 0.0 & 1.0 & 11.0 & 1.9 & 4.2 \\
\hline
\end{tabular}


09483045 FLOWING WELLS WASH AT TUCSON, AZ

LOCATION.--Lat 32 15'55", long $110^{\circ} 59 \prime 40^{\prime \prime}$, in SWKSWK sec.26, T.13 E., R.13 S., Pima County, Hydrologic Unit 15050301, at intersection of Ft. Lowell Road and Flowing Hells Road in Tucson city limits.

DRAIMAGE AREA. $--3.53 \mathrm{mi}^{2}$.

ANNUAL PEAK DISCHARGE

\begin{tabular}{|c|c|c|c|}
\hline $\begin{array}{l}\text { WATER } \\
\text { YEAR }\end{array}$ & DATE & $\begin{array}{c}\text { ANNUAL PEAK } \\
\text { DISCHARGE } \\
\text { (FT } 3 / S)\end{array}$ & $\begin{array}{l}\text { DISCHARGE } \\
\text { CODES }\end{array}$ \\
\hline $\begin{array}{l}1971 \\
1972 \\
1973 \\
1974 \\
1975 \\
1976 \\
1977 \\
1978 \\
1979 \\
1980 \\
1981 \\
1982 \\
1983 \\
1984 \\
1985 \\
1986 \\
1987 \\
1988 \\
1989\end{array}$ & $\begin{array}{l}08-00-71 \\
08-12-72 \\
00-00-73 \\
09-06-74 \\
07-12-75 \\
07-11-76 \\
09-10-77 \\
07-30-78 \\
08-12-79 \\
02-13-80 \\
04-30-81 \\
08-23-82 \\
08-09-83 \\
07-22-84 \\
00-00-85 \\
07-15-86 \\
02-25-87 \\
08-19-88 \\
07-26-89\end{array}$ & $\begin{array}{r}1,250 \\
870 \\
430 \\
1,150 \\
620 \\
920 \\
225 \\
185 \\
490 \\
330 \\
220 \\
1,470 \\
943 \\
995 \\
356 \\
310 \\
81 \\
438 \\
532\end{array}$ & $\begin{array}{l}C \\
C \\
C \\
C \\
C \\
C \\
C \\
C \\
C \\
C \\
C \\
C \\
C \\
C \\
C \\
C \\
C \\
C \\
C\end{array}$ \\
\hline
\end{tabular}

MAGNITUDE AND PROBABILITY OF INSTANTANEOUS PEAK FLOH BASED ON PERIOD OF RECORD $1971-89$

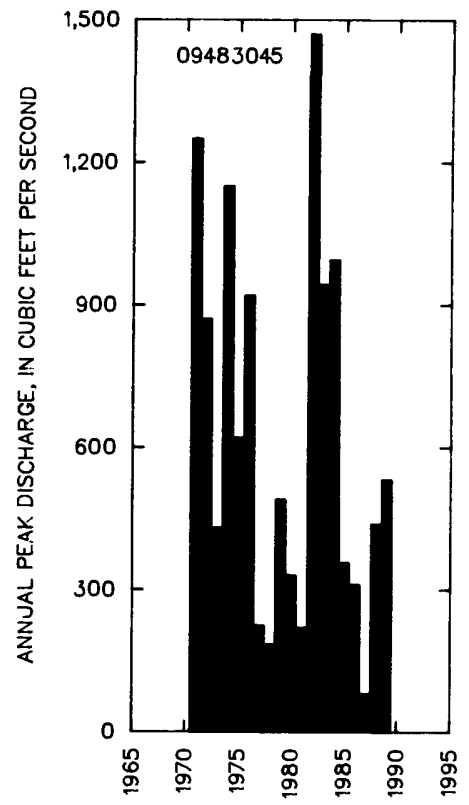

DISCHARGE, IN $\mathrm{FT}^{3} / \mathrm{S}$, FOR INDICATED RECURRENCE INTERVAL IN YEARS, AND EXCEEDANCE PROBABILITY, IN PERCENT

\begin{tabular}{|c|c|c|c|c|c|}
\hline $\begin{array}{c}2 \\
50 \%\end{array}$ & $\underset{20 \%}{5}$ & $\begin{array}{r}10 \\
10 \%\end{array}$ & $\begin{array}{l}25 \\
4 \%\end{array}$ & $\begin{array}{l}50 \phi \\
2 \%\end{array}$ & $\begin{array}{c}100 \dagger \\
1 \%\end{array}$ \\
\hline 524 & 911 & 1,200 & 1,610 & 1,920 & 2,260 \\
\hline $\begin{array}{l}\text { WEIGHTED } \\
\text { MEAN } \\
\text { STANDARD }\end{array}$ & $\begin{array}{l}\text { SKEH } \\
\text { DEV. }\end{array}$ & $\begin{array}{l}(\text { LOGS })= \\
(\text { LOGS) }= \\
(\text { LOGS) }=\end{array}$ & $\begin{array}{r}-0.17 \\
2.71 \\
0.29\end{array}$ & & \\
\hline
\end{tabular}

+ Reliability of values in column is uncertain, and potential errors are large.

BASIN CHARACTERISTICS

\begin{tabular}{|c|c|c|c|c|c|c|c|}
\hline \multirow{3}{*}{$\begin{array}{l}\text { MAIN } \\
\text { CHANNEL } \\
\text { SLOPE } \\
\text { (FT/MI) }\end{array}$} & \multirow[b]{3}{*}{$\begin{array}{l}\text { STREAM } \\
\text { LENGTH } \\
\text { (MI) }\end{array}$} & \multirow{3}{*}{$\begin{array}{l}\text { MEAN } \\
\text { BASIN } \\
\text { ELEVA- } \\
\text { TION } \\
\text { (FT) }\end{array}$} & \multirow[b]{3}{*}{$\begin{array}{l}\text { FORESTED } \\
\text { AREA } \\
\text { (PERCENT) }\end{array}$} & \multirow[b]{3}{*}{$\begin{array}{l}\text { SOIL } \\
\text { INDEX }\end{array}$} & \multirow{3}{*}{$\begin{array}{l}\text { MEAN } \\
\text { ANNUAL } \\
\text { PRECIPI- } \\
\text { TATION } \\
\text { (IN) }\end{array}$} & \multirow{2}{*}{\multicolumn{2}{|c|}{ RAINFALL INTENSITY, 24-HOUR }} \\
\hline & & & & & & & \\
\hline & & & & & & $\begin{array}{c}\text { 2-YEAR } \\
\text { (IN) }\end{array}$ & $\begin{array}{c}\text { 50-YEAR } \\
\text { (IN) }\end{array}$ \\
\hline 32.1 & 4.2 & 2,380 & 0.0 & 1.0 & 11.0 & 1.9 & 4.2 \\
\hline
\end{tabular}


GIL RIVER BASIN

09483100 tandue verde CReEK mear tucson, AZ--Contimued
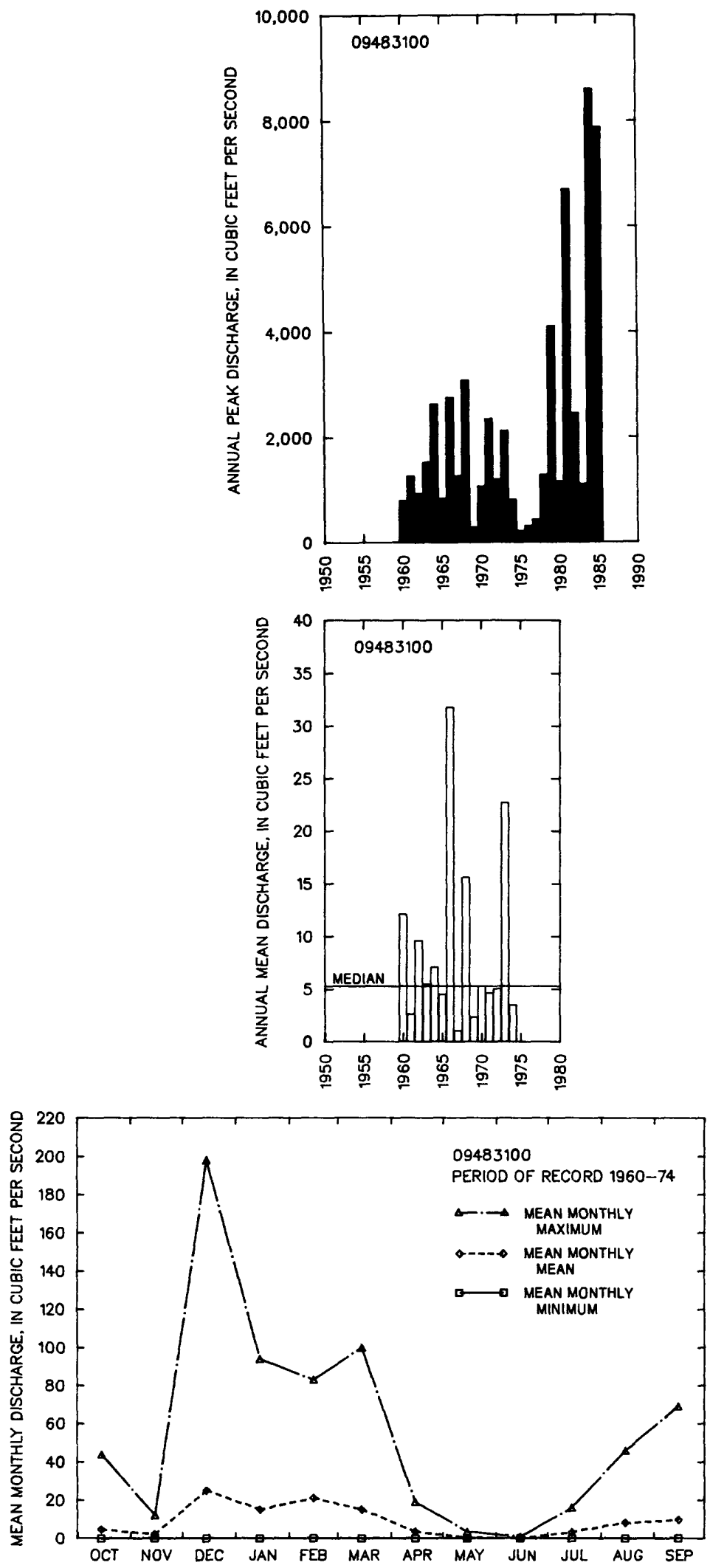
09483200 AQUA CALIEHTE WASH TRIBUTARY NEAR TUCSON, AZ

LOCATION.-- Lat 32*16'07", long $110^{\circ} 44^{\prime} 15^{\prime \prime}$, in SWkSWk sec.29, T.13 S., R.16 E.., Pima County, Hydrologic Unit 15050302, at Soldier Trail, $1.4 \mathrm{mi}$ north of Tanque Verde Road, and 5 mi northeast of Tucson city limits.

DRAINAGE AREA. $--2.04 \mathrm{mi}^{2}$.

ANHUAL PEAK DISCHARGE

\begin{tabular}{|c|c|c|c|}
\hline $\begin{array}{l}\text { WATER } \\
\text { YEAR }\end{array}$ & DATE & $\begin{array}{c}\text { ANNUAL PEAK } \\
\text { DISCHARGE } \\
\left(\mathrm{FT}^{3} / \mathrm{S}\right)\end{array}$ & $\begin{array}{l}\text { DISCHARGE } \\
\text { CODES }\end{array}$ \\
\hline $\begin{array}{l}1965 \\
1966 \\
1967 \\
1968 \\
1969 \\
1970 \\
1971 \\
1972 \\
1973 \\
1974 \\
1975 \\
1976 \\
1977 \\
1978 \\
1979 \\
1980\end{array}$ & $\begin{array}{l}08-00-65 \\
07-19-66 \\
08-00-67 \\
10-03-67 \\
08-00-69 \\
03-02-70 \\
08-19-71 \\
08-00-72 \\
10-00-72 \\
07-07-74 \\
07-25-75 \\
07-17-76 \\
00-00-77 \\
10-06-77 \\
08-12-79 \\
08-13-80\end{array}$ & $\begin{array}{r}86 \\
217 \\
57 \\
44 \\
69 \\
64 \\
430 \\
430 \\
210 \\
10 \\
25 \\
175 \\
240 \\
70 \\
48 \\
76\end{array}$ & LT \\
\hline
\end{tabular}

MAGNITUDE AND PROBABILITY OF INSTANTANEOUS PEAK FLOH BASED ON PERIOD OF RECORD $1965-80$

DISCHARGE, IN $\mathrm{FT}^{3} / \mathrm{S}$, FOR INDICATED RECURRENCE INTERVAL IN YEARS, AND EXCEEDANCE PROBABILITY, IN PERCENT

$\begin{array}{cccccc}5 & 5 & 10 & 25 & 50 \% & 100+ \\ 2 \% & 20 \% & 10 \% & 4 \% & & \\ 1 \%\end{array}$

$\uparrow$ Reliability of values in colum is uncertain, and potential errors are large.

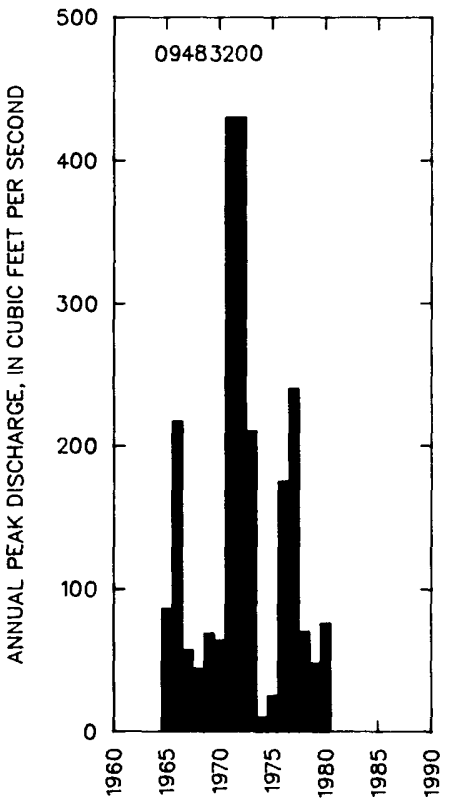

BASIN CHARACTERISTICS

\begin{tabular}{|c|c|c|c|c|c|c|c|}
\hline \multicolumn{5}{|c|}{ MEAN } & \multirow{3}{*}{$\begin{array}{l}\text { ANNUAL } \\
\text { PRECIPI - } \\
\text { TAT ION } \\
\text { (IN) }\end{array}$} & & \\
\hline MAIN & & BASIN & & & & \multicolumn{2}{|c|}{ RAINFALL INTENSITY, 24-HOUR } \\
\hline $\begin{array}{l}\text { CHANNEL } \\
\text { SLOPE } \\
\text { (FT/MI) }\end{array}$ & $\begin{array}{l}\text { STREAM } \\
\text { LENGTH } \\
\text { (MI) }\end{array}$ & $\begin{array}{l}\text { ELEVA- } \\
\text { TION } \\
\text { (FT) }\end{array}$ & $\begin{array}{l}\text { FORESTED } \\
\text { AREA } \\
\text { (PERCENT) }\end{array}$ & $\begin{array}{l}\text { SOIL } \\
\text { INDEX }\end{array}$ & & $\begin{array}{c}\text { 2-YEAR } \\
\text { (IN) }\end{array}$ & $\begin{array}{c}\text { 50-YEAR } \\
\text { (IN) }\end{array}$ \\
\hline 368 & 4.6 & 3,300 & 7.8 & 1.0 & 14.0 & 1.9 & 4.1 \\
\hline
\end{tabular}


09483250 ROB WASH AT TUCSON, AZ

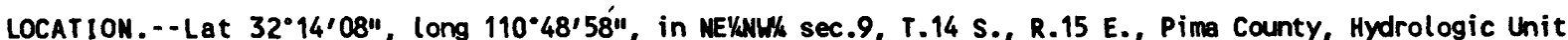
15050302, at Speedway BLvd, $0.4 \mathrm{mi}$ west of Pantano Road, and $1 \mathrm{mi}$ north of East Broadway in Tucson city limits.

DRAINAGE AREA. $--2.08 \mathrm{mi}^{2}$.

ANNUAL PEAK DISCHARGE

\begin{tabular}{|c|c|c|c|}
\hline $\begin{array}{l}\text { WATER } \\
\text { YEAR }\end{array}$ & DATE & $\begin{array}{c}\text { ANNUAL PEAK } \\
\text { DISCHARGE } \\
\left(\mathrm{FT}^{3} / \mathrm{S}\right)\end{array}$ & $\begin{array}{l}\text { DISCHARGE } \\
\text { CODES }\end{array}$ \\
\hline $\begin{array}{l}1971 \\
1972 \\
1973 \\
1974 \\
1975 \\
1976 \\
1977 \\
1978 \\
1979 \\
1980 \\
1981 \\
1982 \\
1983 \\
1984 \\
1985 \\
1986 \\
1987 \\
1988 \\
1989\end{array}$ & $\begin{array}{l}00-00-71 \\
00-00-72 \\
00-00-73 \\
01-00-74 \\
07-12-75 \\
09-25-76 \\
08-01-77 \\
12-28-77 \\
08-12-79 \\
07-26-80 \\
07-19-81 \\
08-23-82 \\
09-23-83 \\
07-16-84 \\
00-00-85 \\
08-24-86 \\
10-10 / 86 \\
08-20-88 \\
07-21-89\end{array}$ & $\begin{array}{r}1,400 \\
600 \\
180 \\
200 \\
400 \\
330 \\
100 \\
50 \\
450 \\
190 \\
305 \\
1,900 \\
156 \\
405 \\
55 \\
277 \\
65 \\
1,300 \\
207\end{array}$ & $\begin{array}{c}E S, C \\
E S, C \\
C \\
C \\
C \\
C \\
C \\
E S, C \\
C \\
C \\
C \\
C \\
C \\
C \\
C \\
C \\
C \\
C \\
C\end{array}$ \\
\hline
\end{tabular}

MAGNITUDE AND PROBABILITY OF INSTANTANEOUS PEAK FLOW BASED ON PERIOD OF RECORD 1971-86

DISCHARGE, IN FT 3 /S, FOR INDICATED RECURRENCE INTERVAL IN YEARS, AND EXCEEDANCE PROBABILITY, IN PERCENT

\begin{tabular}{|c|c|c|c|c|c|}
\hline $\begin{array}{c}2 \\
50 \%\end{array}$ & $\begin{array}{c}5 \\
20 \%\end{array}$ & $\begin{array}{r}10 \\
10 \%\end{array}$ & $\begin{array}{l}25 \\
4 \%\end{array}$ & $\begin{array}{l}50\} \\
2 \%\end{array}$ & $\begin{array}{c}100 \dagger \\
1 \%\end{array}$ \\
\hline 267 & 622 & 973 & 1,580 & 2,160 & 2,870 \\
\hline $\begin{array}{l}\text { WEIGHTED } \\
\text { MEAN } \\
\text { STANDARD }\end{array}$ & $\begin{array}{l}\text { SKEW } \\
\text { DEV. }\end{array}$ & $\begin{array}{l}(\text { LOGS })= \\
(\text { LOGS })= \\
(\text { LOGS })=\end{array}$ & $\begin{array}{l}0.06 \\
2.43 \\
0.43\end{array}$ & & \\
\hline
\end{tabular}

$\uparrow$ Reliability of values in column is uncertain, and potential errors are large.

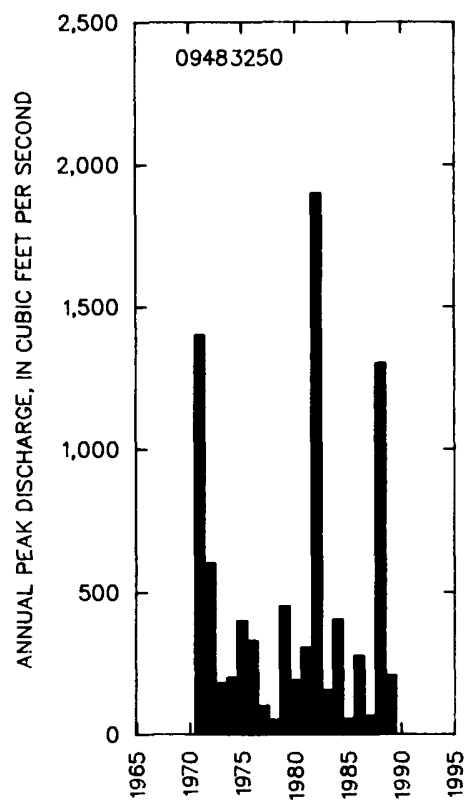

\section{BASIN CHARACTERISTICS}

\begin{tabular}{|c|c|c|c|c|c|c|c|}
\hline MAIN & & $\begin{array}{l}\text { MEAN } \\
\text { BASIN }\end{array}$ & & & $\begin{array}{c}\text { MEAN } \\
\text { ANNUAL }\end{array}$ & RAINFALL II & SITY, 24-HOUR \\
\hline $\begin{array}{c}\text { CHANNEL } \\
\text { SLOPE } \\
\text { (FT/MI) }\end{array}$ & $\begin{array}{l}\text { STREAM } \\
\text { LENGTH } \\
\text { (MI) }\end{array}$ & $\begin{array}{l}\text { ELEVA- } \\
\text { TION } \\
\text { (FT) }\end{array}$ & $\begin{array}{l}\text { FORESTED } \\
\text { AREA } \\
\text { (PERCENT) }\end{array}$ & $\begin{array}{l}\text { SOIL } \\
\text { INDEX }\end{array}$ & $\begin{array}{l}\text { PRECIPI - } \\
\text { TATION } \\
\text { (IN) }\end{array}$ & $\begin{array}{c}\text { 2-YEAR } \\
\text { (IN) }\end{array}$ & $\begin{array}{c}\text { 50-YEAR } \\
\text { (IN) }\end{array}$ \\
\hline 55.6 & 4.7 & 2,710 & 0.0 & 1.0 & 11.0 & 1.9 & 3.6 \\
\hline
\end{tabular}


LOCATION.--Lat 32'19'01", Long 110.48'36", in SEKNEK sec.9, T.13 S., R.15 E., Pima County, Hydrologic Unit 15050302, on right bank 0.5 mi north of Coronado National Forest boundary and 12 mi northeast of city hall in Tucson.

DRAINAGE AREA. $--35.5 \mathrm{mi}^{2}$.

ANMUAL PEAK DISCHARGE

\begin{tabular}{|c|c|c|c|c|c|c|c|}
\hline $\begin{array}{l}\text { HATER } \\
\text { YEAR }\end{array}$ & DATE & $\begin{array}{c}\text { ANMUAL PEAK } \\
\text { DISCHARGE } \\
\left.\text { (FT }{ }^{3} / \mathrm{S}\right)\end{array}$ & $\begin{array}{l}\text { DISCHARGE } \\
\text { CODES }\end{array}$ & $\begin{array}{l}\text { WATER } \\
\text { YEAR }\end{array}$ & DATE & $\begin{array}{c}\text { ANMUAL PEAK } \\
\text { DISCHARGE } \\
\text { (FT } 3 / \mathrm{S})\end{array}$ & $\begin{array}{l}\text { DISCHARGE } \\
\text { CODES }\end{array}$ \\
\hline $\begin{array}{l}1932 \\
1933 \\
1934 \\
1935 \\
1936 \\
1937 \\
1938 \\
1939 \\
1940 \\
1941 \\
1942 \\
1943 \\
1944 \\
1945 \\
1946 \\
1947 \\
1948 \\
1949 \\
1950 \\
1951 \\
1952 \\
1953 \\
1954 \\
1955 \\
1956 \\
1957 \\
1958 \\
1959 \\
1960\end{array}$ & $\begin{array}{l}07-15-32 \\
09-10-33 \\
09-22-34 \\
02-06-35 \\
01-29-36 \\
02-07-37 \\
03-03-38 \\
08-06-39 \\
02-23-40 \\
12-30-40 \\
09-10-42 \\
03-05-43 \\
07-08-44 \\
07-30-45 \\
08-23-46 \\
12-26-46 \\
08-06-48 \\
08-08-49 \\
07-07-50 \\
08-02-51 \\
01-13-52 \\
07-16-53 \\
03-23-54 \\
08-03-55 \\
08-11-56 \\
01-09-57 \\
03-22-58 \\
07-26-59 \\
12-24-59\end{array}$ & $\begin{array}{r}706 \\
510 \\
472 \\
540 \\
500 \\
2,020 \\
3,200 \\
385 \\
904 \\
3,180 \\
449 \\
567 \\
175 \\
916 \\
2,000 \\
227 \\
380 \\
1,430 \\
2,260 \\
750 \\
1,640 \\
861 \\
5,110 \\
2,000 \\
55 \\
2,030 \\
1,500 \\
4,240 \\
1,600\end{array}$ & & $\begin{array}{l}1961 \\
1962 \\
1963 \\
1964 \\
1965 \\
1966 \\
1967 \\
1968 \\
1969 \\
1970 \\
1971 \\
1972 \\
1973 \\
1974 \\
1975 \\
1976 \\
1977 \\
1978 \\
1979 \\
1980 \\
1981 \\
1982 \\
1983 \\
1984 \\
1985 \\
1986 \\
1987 \\
1988 \\
1989\end{array}$ & $\begin{array}{l}08-30-61 \\
09-26-62 \\
08-15-63 \\
09-13-64 \\
02-07-65 \\
08-10-66 \\
07-17-67 \\
12-19-67 \\
01-14-69 \\
09-06-70 \\
08-10-71 \\
10-01-71 \\
10-19-72 \\
07-20-74 \\
00-00-75 \\
09-26-76 \\
07-10-77 \\
03-02-78 \\
12-18-78 \\
02-14-80 \\
07-31-81 \\
08-13-82 \\
02-03-83 \\
10-01-83 \\
12-28-84 \\
02-16-86 \\
08-13-87 \\
08-20-88 \\
08-07-89\end{array}$ & $\begin{array}{r}910 \\
1,010 \\
2,070 \\
1,310 \\
244 \\
6,400 \\
788 \\
2,340 \\
310 \\
7,730 \\
660 \\
1,710 \\
2,750 \\
117 \\
70 \\
580 \\
480 \\
3,160 \\
7,400 \\
2,290 \\
1,420 \\
2,000 \\
1,340 \\
6,500 \\
2,350 \\
910 \\
866 \\
350 \\
350\end{array}$ & LT \\
\hline
\end{tabular}

BASIN CHARACTERISTICS

\begin{tabular}{|c|c|c|c|c|c|c|c|}
\hline \multirow{2}{*}{$\begin{array}{c}\text { MAIN } \\
\text { CHANNEL } \\
\text { SLOPE } \\
\text { (FT/MI) }\end{array}$} & \multirow[b]{2}{*}{$\begin{array}{l}\text { STREAM } \\
\text { LENGTH } \\
\text { (MI) }\end{array}$} & \multirow{2}{*}{$\begin{array}{l}\text { MEAN } \\
\text { BASIN } \\
\text { ELEVA- } \\
\text { TION } \\
\text { (FT) }\end{array}$} & \multirow[b]{2}{*}{$\begin{array}{l}\text { FORESTED } \\
\text { AREA } \\
\text { (PERCENT) }\end{array}$} & \multirow[b]{2}{*}{$\begin{array}{r}\text { SOIL } \\
\text { INDEX }\end{array}$} & \multirow{2}{*}{$\begin{array}{c}\text { MENH } \\
\text { ANNUAL } \\
\text { PRECIPI- } \\
\text { TATION } \\
\text { (IN) }\end{array}$} & \multicolumn{2}{|c|}{ RAINFALL INTENSITY, 24-HOUR } \\
\hline & & & & & & $\begin{array}{c}\text { 2-YEAR } \\
\text { (IN) }\end{array}$ & $\begin{array}{l}\text { 50-YEAR } \\
\text { (IN) }\end{array}$ \\
\hline 482 & 13.0 & 6,300 & 85.0 & 1.0 & 22.6 & 2.1 & 4.3 \\
\hline
\end{tabular}


09484000 SABINO CREEK NEAR TUCSON, AZ--Continued

MEAN MONTHLY AND ANNUAL DISCHARGES 1933-74

\begin{tabular}{|c|c|c|c|c|c|c|}
\hline MONTH & $\begin{array}{l}\operatorname{MAXIMMM} \\
\left(\mathrm{FT}^{3} / \mathrm{S}\right)\end{array}$ & $\begin{array}{l}\text { MINIMUM } \\
\left(F^{3} / S\right)\end{array}$ & $\begin{array}{c}\text { MEAN } \\
\left(F T^{3} / S\right)\end{array}$ & $\begin{array}{l}\text { STAN- } \\
\text { DARD } \\
\text { DEVIA- } \\
\text { TION } \\
\text { (FT } 3 / S)\end{array}$ & $\begin{array}{l}\text { COEFFI- } \\
\text { CIENT OF } \\
\text { VARI- } \\
\text { ATION }\end{array}$ & $\begin{array}{c}\text { PERCENT } \\
\text { OF } \\
\text { ANNUAL } \\
\text { RUNOFF }\end{array}$ \\
\hline $\begin{array}{l}\text { OCTOBER } \\
\text { NONEMBER } \\
\text { DECEMBER } \\
\text { JANUARY } \\
\text { FEBRUARY } \\
\text { MARCH } \\
\text { APRIL } \\
\text { MAY } \\
\text { JUNE } \\
\text { JULY } \\
\text { AUGUST } \\
\text { SEPTEMBER }\end{array}$ & $\begin{array}{c}84 \\
28 \\
217 \\
106 \\
93 \\
120 \\
54 \\
17 \\
5.2 \\
29 \\
70 \\
105\end{array}$ & $\begin{array}{l}0.00 \\
0.00 \\
0.00 \\
0.03 \\
0.02 \\
0.30 \\
0.03 \\
0.00 \\
0.00 \\
0.00 \\
0.09 \\
0.01\end{array}$ & $\begin{array}{c}5.1 \\
3.4 \\
17 \\
16 \\
21 \\
26 \\
9.8 \\
1.8 \\
0.33 \\
4.9 \\
12 \\
9.3\end{array}$ & $\begin{array}{l}15 \\
5.9 \\
38 \\
23 \\
27 \\
31 \\
13 \\
3.4 \\
0.95 \\
7.1 \\
14 \\
22\end{array}$ & $\begin{array}{l}2.9 \\
1.7 \\
2.3 \\
1.5 \\
1.3 \\
1.2 \\
1.3 \\
1.9 \\
2.8 \\
1.4 \\
1.2 \\
2.4\end{array}$ & $\begin{array}{r}4.0 \\
2.7 \\
13.1 \\
12.7 \\
16.5 \\
20.8 \\
7.7 \\
1.5 \\
0.3 \\
3.9 \\
9.4 \\
7.3\end{array}$ \\
\hline NNUAL & 48 & 0.52 & 11 & 9.8 & 0.93 & 100 \\
\hline
\end{tabular}

MAGNITLDE AND PROBABILITY OF INSTANTANEOUS PEAK FLOW BASED ON PERIOD OF RECORD 1932-89

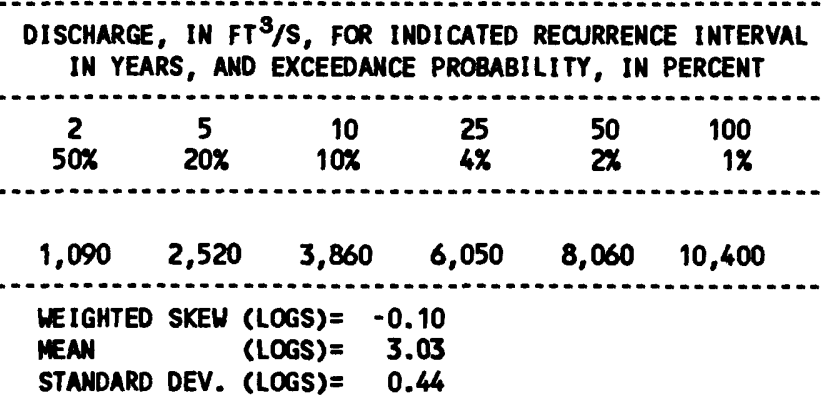

MAGNITUDE AND PROBABILITY OF ANNUAL LON FLON BASED ON PERICD OF RECORD 1934-74

\begin{tabular}{|c|c|c|c|c|c|c|}
\hline \multirow{2}{*}{$\begin{array}{l}\text { PERIOO } \\
\text { (CON- } \\
\text { SECU- } \\
\text { TIVE } \\
\text { DAYS) }\end{array}$} & \multicolumn{6}{|c|}{$\begin{array}{l}\text { DISCHARGE, IN FT }{ }^{3} / S \text {, FOR INDICATED } \\
\text { RECURRENCE INTERVAL, IN YEARS, AND } \\
\text { NON-EXCEEDANCE PROBABILITY, IN PERCENT }\end{array}$} \\
\hline & $\begin{array}{c}2 \\
50 \%\end{array}$ & $\begin{array}{c}5 \\
20 \%\end{array}$ & $\begin{array}{l}10 \\
10 \%\end{array}$ & $\begin{array}{l}20 \\
5 \%\end{array}$ & $\begin{array}{l}50 \\
2 \%\end{array}$ & $\begin{array}{l}100 \uparrow \\
1 \%\end{array}$ \\
\hline $\begin{array}{r}1 \\
3 \\
7 \\
14\end{array}$ & & & & & & \\
\hline $\begin{array}{r}30 \\
60 \\
90 \\
120 \\
183\end{array}$ & $\begin{array}{l}0.00 \\
0.00 \\
0.10 \\
0.63 \\
1.8\end{array}$ & $\begin{array}{l}0.00 \\
0.00 \\
0.00 \\
0.07 \\
0.59\end{array}$ & $\begin{array}{l}0.00 \\
0.00 \\
0.00 \\
0.00 \\
0.28\end{array}$ & $\begin{array}{l}0.00 \\
0.00 \\
0.00 \\
0.00 \\
0.14\end{array}$ & $\begin{array}{l}0.00 \\
0.00 \\
0.00 \\
0.00 \\
0.06\end{array}$ & $\begin{array}{l}0.00 \\
0.00 \\
0.00 \\
0.00 \\
0.03\end{array}$ \\
\hline
\end{tabular}

MAGNITUDE AND PROBABILITY OF ANMUAL HIGH FLOH BASED ON PERICD OF RECORD 1933-74

\begin{tabular}{|c|c|c|c|c|c|c|}
\hline \multirow{2}{*}{$\begin{array}{l}\text { PERIOD } \\
\text { (CON- } \\
\text { SECU- } \\
\text { TIVE } \\
\text { DAYS) }\end{array}$} & & \multicolumn{5}{|c|}{$\begin{array}{l}\text { DISCHARCE, IN } \mathrm{FT}^{3} / \mathrm{S} \text {, FOR INDICATED } \\
\text { RECURRENCE INTERVAL, IN YEARS, AND } \\
\text { EXCEEDANCE PROBABILITY, IN PERCENT }\end{array}$} \\
\hline & $\begin{array}{c}2 \\
50 \%\end{array}$ & $\begin{array}{c}5 \\
20 \%\end{array}$ & $\begin{array}{l}10 \\
10 \%\end{array}$ & $\begin{array}{l}25 \\
4 \%\end{array}$ & $\begin{array}{l}50 \\
2 \%\end{array}$ & $\begin{array}{c}100 \uparrow \\
1 \%\end{array}$ \\
\hline $\begin{array}{r}1 \\
3 \\
7 \\
15 \\
30 \\
60 \\
90\end{array}$ & $\begin{array}{r}269 \\
160 \\
94 \\
60 \\
42 \\
27 \\
21\end{array}$ & $\begin{array}{r}629 \\
366 \\
207 \\
125 \\
86 \\
57 \\
46\end{array}$ & $\begin{array}{r}947 \\
548 \\
301 \\
179 \\
120 \\
79 \\
66\end{array}$ & $\begin{array}{r}1,430 \\
822 \\
437 \\
255 \\
167 \\
110 \\
93\end{array}$ & $\begin{array}{r}1,840 \\
1,060 \\
548 \\
316 \\
204 \\
134 \\
115\end{array}$ & $\begin{array}{r}2,290 \\
1,310 \\
665 \\
381 \\
240 \\
157 \\
137\end{array}$ \\
\hline
\end{tabular}

DURATION TABLE OF DAILY MEAN FLON FOR PERIOD OF RECORD 1933-74

DISCHARGE, IN FT $3 / \mathrm{S}$, WHICH WAS EQUALED OR EXCEEDED FOR INDICATED PERCENT OF TIME

\begin{tabular}{|c|c|c|c|c|c|c|c|c|c|c|c|c|c|c|c|c|}
\hline $1 \%$ & $5 \%$ & $10 \%$ & $15 \%$ & $20 \%$ & $30 \%$ & $40 \%$ & $50 \%$ & $60 \%$ & $70 \%$ & $80 \%$ & $90 \%$ & $95 \%$ & $98 \%$ & $99 \%$ & $99.5 \%$ & $99.9 \%$ \\
\hline 139 & 48 & 26 & 15 & 9.8 & 4.1 & 1.8 & 0.73 & 0.24 & 0.05 & 0.02 & 0.01 & 0.00 & 0.00 & 0.00 & 0.00 & .00 \\
\hline
\end{tabular}

$\uparrow$ Reliability of values in column is uncertain, and potential errors are large. 
09484000 SABINO CREEK NEAR TUCSON, AZ--COnTINUED
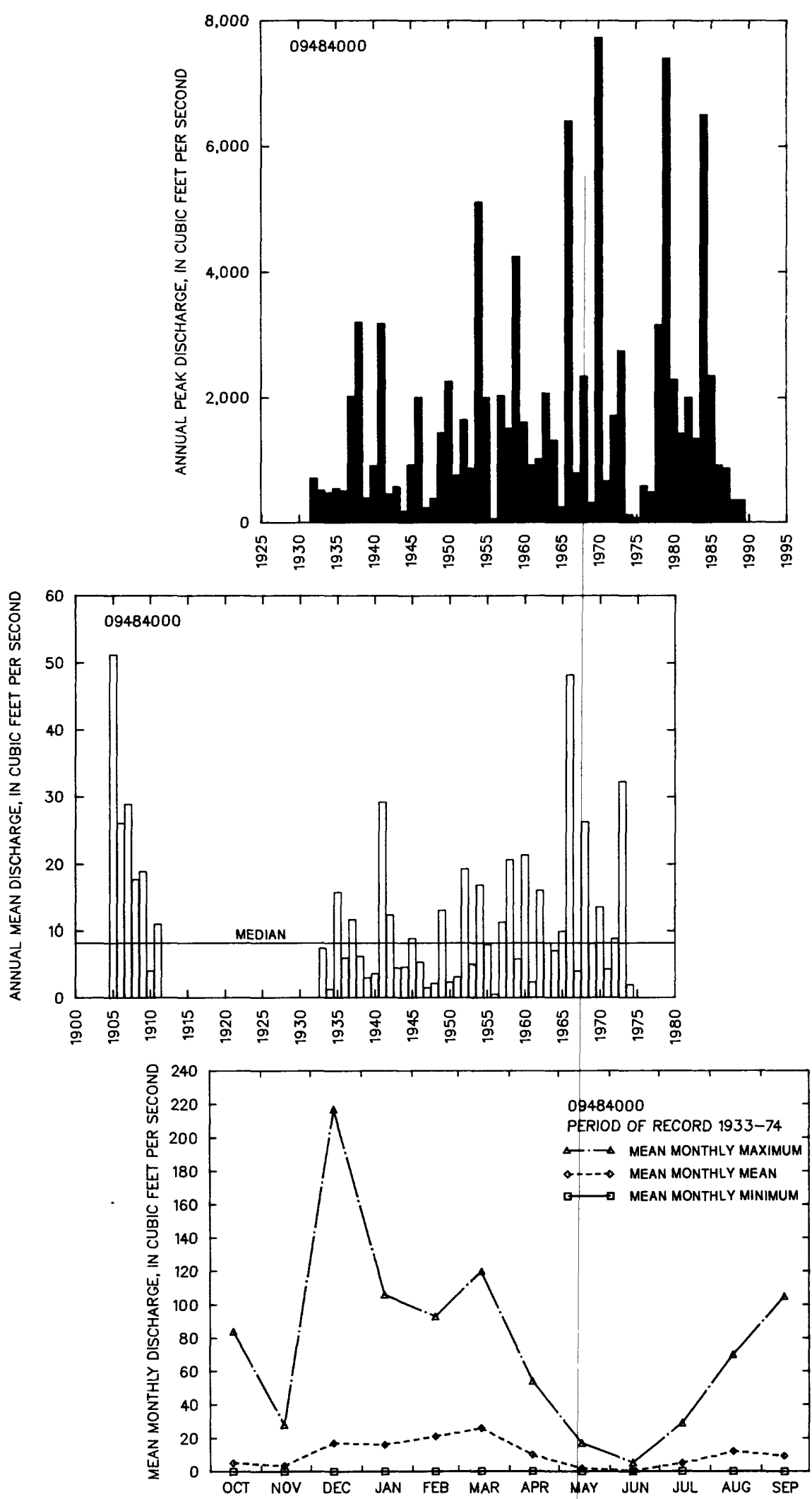
09484200 BEAR CREEK NEAR TUCSON, AZ

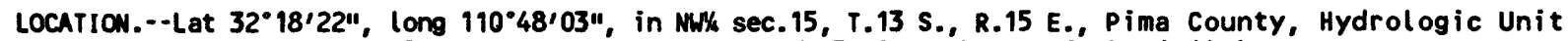
15050302 , on left bank 0.8 mi upstream from mouth and 15 mi northeast of city hall in Tucson.

DRAIMAGE AREA. $--16.3 \mathrm{mi}^{2}$.

ANMUAL PEAK DISCHARGE

\begin{tabular}{|c|c|c|c|}
\hline $\begin{array}{l}\text { WATER } \\
\text { YEAR }\end{array}$ & DATE & $\begin{array}{l}\text { ANNUAL PEAK } \\
\text { DISCHARGE } \\
\left.\text { (FT }{ }^{3} / \mathrm{S}\right)\end{array}$ & $\begin{array}{l}\text { DISCHARGE } \\
\text { CODES }\end{array}$ \\
\hline $\begin{array}{l}1960 \\
1961 \\
1962 \\
1963 \\
1964 \\
1965 \\
1966 \\
1967 \\
1968 \\
1969 \\
1970 \\
1971 \\
1972 \\
1973 \\
1974 \\
1979\end{array}$ & $\begin{array}{l}01-11-60 \\
09-12-61 \\
12-16-61 \\
02-11-63 \\
09-13-64 \\
02-07-65 \\
12-22-65 \\
09-25-67 \\
12-20-67 \\
01-15-69 \\
09-06-70 \\
08-19-71 \\
10-01-71 \\
10-19-72 \\
01-09-74 \\
12-18-78\end{array}$ & $\begin{array}{r}575 \\
53 \\
225 \\
357 \\
433 \\
192 \\
1,150 \\
13 \\
621 \\
214 \\
670 \\
495 \\
247 \\
618 \\
57 \\
1,400\end{array}$ & HP \\
\hline
\end{tabular}

1Highest since 1959.

\section{BASIN CHARACTERISTICS}

\begin{tabular}{|c|c|c|c|c|c|c|c|}
\hline \multirow{2}{*}{$\begin{array}{l}\text { MAIN } \\
\text { CHANNEL } \\
\text { SLOPE } \\
\text { (FT/MI) }\end{array}$} & \multirow[b]{2}{*}{$\begin{array}{c}\text { STREAM } \\
\text { LENGTH } \\
\text { (MI) }\end{array}$} & \multirow{2}{*}{$\begin{array}{l}\text { MEAN } \\
\text { BASIN } \\
\text { ELEVA- } \\
\text { TION } \\
\text { (FT) }\end{array}$} & \multirow[b]{2}{*}{$\begin{array}{l}\text { FORESTED } \\
\text { AREA } \\
\text { (PERCENT) }\end{array}$} & \multicolumn{2}{|r|}{$\begin{array}{c}\text { MEAN } \\
\text { ANNUAL } \\
\text { PRECIPI- }\end{array}$} & \multicolumn{2}{|c|}{ RAINFALL INTENSITY, 24-HOUR } \\
\hline & & & & $\begin{array}{l}\text { SOIL } \\
\text { INDEX }\end{array}$ & $\begin{array}{l}\text { PRECIPI- } \\
\text { TATION } \\
\text { (IN) }\end{array}$ & $\begin{array}{c}\text { 2-YEAR } \\
\text { (IN) }\end{array}$ & $\begin{array}{l}\text { 50-YEAR } \\
\text { (IN) }\end{array}$ \\
\hline 502 & 11.0 & 5,860 & 82.0 & 1.0 & 20.6 & 1.9 & 4.0 \\
\hline
\end{tabular}


MEAN MONTHLY AND ANMUAL DISCHARGES 1960-74

\begin{tabular}{|c|c|c|c|c|c|c|}
\hline MONTH & $\begin{array}{l}\operatorname{MAXIMUM} \\
\left(F^{3} / S\right)\end{array}$ & $\begin{array}{l}\text { MINIMUN } \\
\left(F T^{3} / S\right)\end{array}$ & $\begin{array}{c}\text { MEAN } \\
\left(F T^{3} / S\right)\end{array}$ & $\begin{array}{l}\text { STAN- } \\
\text { DARD } \\
\text { DEVIA- } \\
\text { TION } \\
\text { (FT } \mathbf{3} / \mathbf{S})\end{array}$ & $\begin{array}{l}\text { COEFFI- } \\
\text { CIENT OF } \\
\text { VARI - } \\
\text { ATION }\end{array}$ & $\begin{array}{c}\text { PERCENT } \\
\text { OF } \\
\text { ANNUAL } \\
\text { RUNOFF }\end{array}$ \\
\hline $\begin{array}{l}\text { OCTOBER } \\
\text { NOVEMBER } \\
\text { DECENBER } \\
\text { JANUARY } \\
\text { FEBRUARY } \\
\text { MARCH } \\
\text { APRIL } \\
\text { MAY } \\
\text { JUNE } \\
\text { JULY } \\
\text { AUGUST } \\
\text { SEPTEMBER }\end{array}$ & $\begin{array}{l}27 \\
4.0 \\
89 \\
57 \\
42 \\
41 \\
13 \\
2.6 \\
0.02 \\
7.9 \\
7.4 \\
20\end{array}$ & $\begin{array}{l}0.00 \\
0.00 \\
0.00 \\
0.00 \\
0.00 \\
0.00 \\
0.00 \\
0.00 \\
0.00 \\
0.00 \\
0.00 \\
0.00\end{array}$ & $\begin{array}{l}3.2 \\
1.0 \\
13 \\
10 \\
12 \\
8.8 \\
2.1 \\
0.22 \\
0.00 \\
0.66 \\
1.8 \\
3.6\end{array}$ & $\begin{array}{l}7.4 \\
1.4 \\
23 \\
15 \\
15 \\
12 \\
3.5 \\
0.67 \\
0.01 \\
2.0 \\
2.4 \\
6.7\end{array}$ & $\begin{array}{l}2.3 \\
1.4 \\
1.8 \\
1.5 \\
1.2 \\
1.3 \\
1.7 \\
3.1 \\
3.9 \\
3.1 \\
1.3 \\
1.8\end{array}$ & $\begin{array}{r}5.6 \\
1.8 \\
22.4 \\
18.0 \\
21.8 \\
15.6 \\
3.7 \\
0.4 \\
0.0 \\
1.2 \\
3.2 \\
6.4\end{array}$ \\
\hline INUAL & 16 & 0.14 & 4.7 & 4.6 & 0.99 & 100 \\
\hline
\end{tabular}

MAGNITLDE AND PROBABILITY OF INSTANTANEOUS PEAK FLOW BASED ON PERIOD OF RECORD 1960-74, 1979

DISCHARGE, IN FT $3 / 5$, FOR INDICATED RECURRENCE INTERVAL IN YEARS, AND EXCEEDANCE PROBABILITY, IN PERCENT

\begin{tabular}{lccccc}
2 & 5 & 10 & 25 & $50 \uparrow$ & $100\}$ \\
$50 \%$ & $20 \%$ & $10 \%$ & $4 \%$ & $2 \%$ & $1 \%$ \\
370 & 675 & 917 & 1,260 & 1,550 & 1,850 \\
\hline WEIGHTED SKEW (LOGS) & $=$ & -0.12 & & \\
MEAN & (LOGS) & 2.56 & & \\
STANDARD DEV. (LOGS) & $=0.32$
\end{tabular}

MAGNITUDE AND PROBABILITY OF ANNUAL LOW FLOW BASED ON PERIOD OF RECORD 1961-74

\begin{tabular}{|c|c|c|c|c|c|c|}
\hline \multirow{2}{*}{$\begin{array}{l}\text { PERIOD } \\
\text { (CON- } \\
\text { SEW- } \\
\text { TIVE } \\
\text { DAYS) }\end{array}$} & \multicolumn{6}{|c|}{$\begin{array}{l}\text { DISCHARGE, IN FT \%S, FOR INDICATED } \\
\text { RECURRENCE INTERVAL, IN YEARS, AND } \\
\text { NON-EXCEEDANCE PROBABILITY, IN PERCENT }\end{array}$} \\
\hline & $\begin{array}{c}2 \\
50 \%\end{array}$ & $\begin{array}{c}5 \\
20 \%\end{array}$ & $\begin{array}{l}10 \\
10 \%\end{array}$ & $\begin{array}{l}20 \\
5 \%\end{array}$ & $\begin{array}{l}50 \dagger \\
2 \%\end{array}$ & $\begin{array}{l}100 \dagger \\
1 \%\end{array}$ \\
\hline $\begin{array}{r}1 \\
3 \\
7 \\
14 \\
30 \\
60\end{array}$ & & & & & & \\
\hline $\begin{array}{r}90 \\
120 \\
183\end{array}$ & $\begin{array}{l}0.00 \\
0.00 \\
0.19\end{array}$ & $\begin{array}{l}0.00 \\
0.00 \\
0.00\end{array}$ & $\begin{array}{l}0.00 \\
0.00 \\
0.00\end{array}$ & $\begin{array}{l}0.00 \\
0.00 \\
0.00\end{array}$ & $\begin{array}{l}0.00 \\
0.00 \\
0.00\end{array}$ & $\begin{array}{l}0.00 \\
0.00 \\
0.00\end{array}$ \\
\hline
\end{tabular}

MAGNITUDE AND PROBABILITY OF ANHUAL HIGH FLON BASED ON PERIOD OF RECORD 1960-74

\begin{tabular}{|c|c|c|c|c|c|c|}
\hline \multirow{2}{*}{$\begin{array}{l}\text { PERIOD } \\
\text { (CON- } \\
\text { SECU- } \\
\text { TIVE } \\
\text { DAYS) }\end{array}$} & \multicolumn{6}{|c|}{$\begin{array}{l}\text { DISCHARGE, IN } \mathrm{FT}^{3} / \mathrm{S} \text {, FOR INDICATED } \\
\text { RECURRENCE INTERVAL, IN YEARS, AND } \\
\text { EXCEEDANCE PROBABILITY, IN PERCENT }\end{array}$} \\
\hline & $\begin{array}{c}2 \\
50 \%\end{array}$ & $\begin{array}{c}5 \\
20 \%\end{array}$ & $\begin{array}{l}10 \\
10 \%\end{array}$ & $\begin{array}{l}25 \\
4 \%\end{array}$ & $\begin{array}{l}50 \uparrow \\
2 \%\end{array}$ & $\begin{array}{c}100 \nmid \\
1 \%\end{array}$ \\
\hline $\begin{array}{r}1 \\
3 \\
7 \\
15 \\
30 \\
60 \\
90\end{array}$ & $\begin{array}{c}116 \\
71 \\
43 \\
27 \\
17 \\
11 \\
8.5\end{array}$ & $\begin{array}{r}292 \\
183 \\
108 \\
71 \\
47 \\
33 \\
26\end{array}$ & $\begin{array}{r}429 \\
273 \\
160 \\
107 \\
75 \\
53 \\
43\end{array}$ & $\begin{array}{r}605 \\
392 \\
227 \\
154 \\
114 \\
84 \\
69\end{array}$ & $\begin{array}{r}731 \\
480 \\
274 \\
190 \\
146 \\
110 \\
90\end{array}$ & $\begin{array}{l}849 \\
565 \\
319 \\
223 \\
178 \\
136 \\
112\end{array}$ \\
\hline
\end{tabular}

DURATION TABLE OF DAILY MEAN FLOW FOR PERIOD OF RECORD 1960-74

\begin{tabular}{|c|c|c|c|c|c|c|c|c|c|c|c|c|c|c|c|c|}
\hline $1 \%$ & $5 \%$ & $10 \%$ & $15 \%$ & $20 \%$ & $30 \%$ & $40 \%$ & $50 \%$ & $60 \%$ & $70 \%$ & $80 \%$ & $90 \%$ & $95 \%$ & $98 \%$ & $99 \%$ & $99.5 \%$ & $99.9 \%$ \\
\hline 71 & 25 & 12 & 5.4 & 2.8 & 0.83 & 0.23 & 0.05 & 0.00 & 0.00 & 0.00 & 0.00 & 0.00 & 0.00 & 0.00 & 0.00 & 0.00 \\
\hline
\end{tabular}

f Reliability of values in colum is uncertain, and potential errors are large. 
GIL RIVER BASIM

09484200 BEAR CREEK MEAR TUCSON, AZ--CONTIMUED
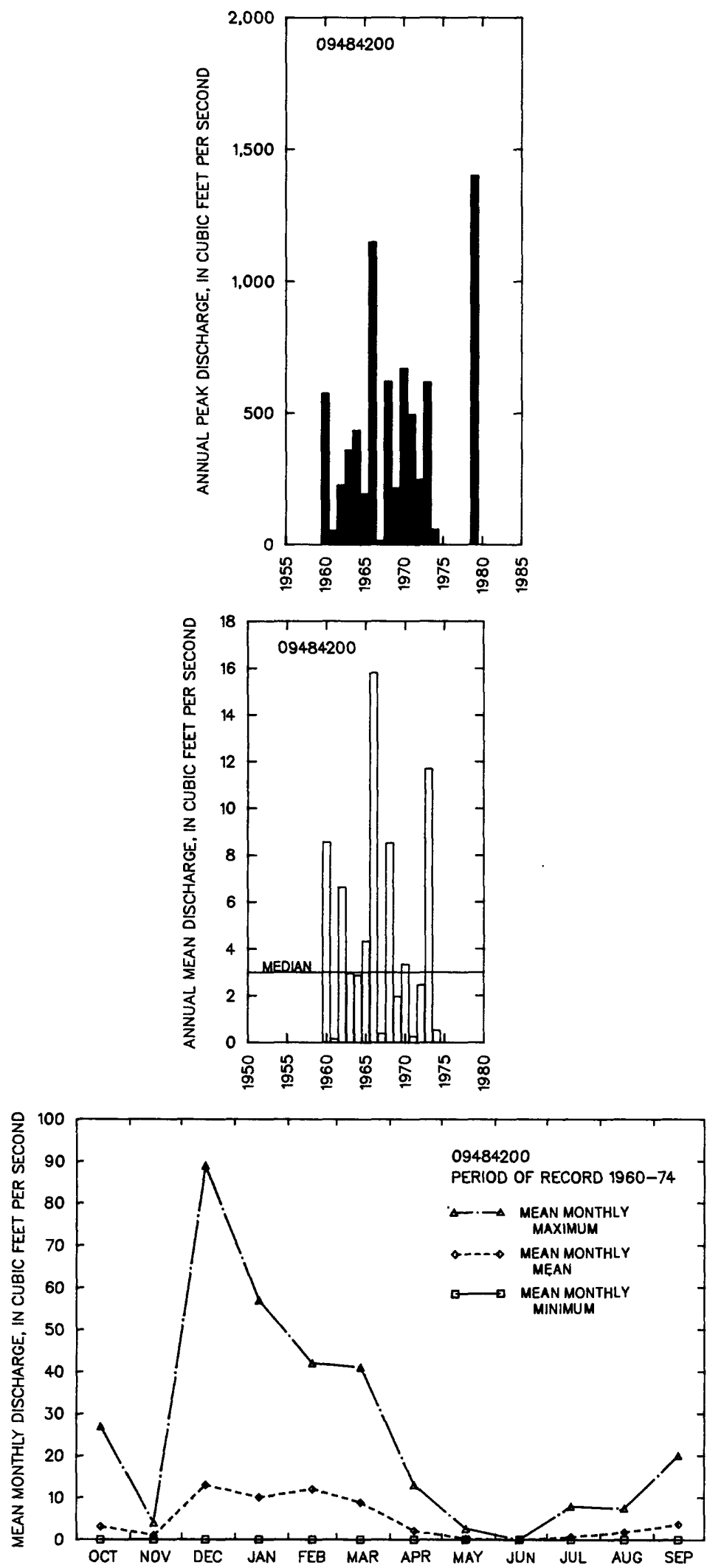
LOCATION.--Lat 32.15'57", long 110.50'27", in SE\%SEK sec.30, T.13 S., R.15 E., Pima County, Hydrologic Unit 15050302, at Sabino Canyon Road, 1 mi downstream from Sabino Creek, and 1.25 mi northeast of Tucs on city limits.

DRAINAGE AREA. $--219 \mathrm{mi}^{2}$.

ANNUAL PEAK DISCHARGE

\begin{tabular}{|c|c|c|c|c|c|c|c|}
\hline $\begin{array}{l}\text { WATER } \\
\text { YEAR }\end{array}$ & DATE & $\begin{array}{l}\text { ANNUAL PEAK } \\
\text { DISCHARGE } \\
\left(\mathrm{FT}^{3} / \mathrm{S}\right)\end{array}$ & $\begin{array}{l}\text { DISCHARGE } \\
\text { COOES }\end{array}$ & $\begin{array}{l}\text { WATER } \\
\text { YEAR }\end{array}$ & DATE & $\begin{array}{l}\text { ANNUAL PEAK } \\
\text { DISCHARGE } \\
\left(\mathrm{FT}^{3} / \mathrm{S}\right)\end{array}$ & $\begin{array}{l}\text { DISCHARGE } \\
\text { CODES }\end{array}$ \\
\hline $\begin{array}{l}1940 \\
1941 \\
1942 \\
1943 \\
1944 \\
1945 \\
1966 \\
1967 \\
1968 \\
1969 \\
1970 \\
1971\end{array}$ & $\begin{array}{l}08-13-40 \\
12-30-40 \\
02-28-42 \\
03-05-43 \\
08-09-44 \\
08-09-45 \\
12-22-65 \\
00-00-67 \\
12-20-67 \\
03-22-69 \\
09-06-70 \\
08-19-71\end{array}$ & $\begin{array}{r}6,400 \\
9,000 \\
639 \\
1,090 \\
825 \\
573 \\
12,200 \\
0 \\
6,300 \\
460 \\
7,340 \\
7,000\end{array}$ & & $\begin{array}{l}1972 \\
1973 \\
1974 \\
1975 \\
1976 \\
1977 \\
1978 \\
1979 \\
1980 \\
1981 \\
1988 \\
1989\end{array}$ & $\begin{array}{l}10-01-71 \\
10-19-72 \\
09-21-74 \\
04-24-75 \\
09-26-76 \\
00-00-77 \\
03-02-78 \\
12-18-78 \\
02-14-80 \\
07-31-81 \\
08-20-88 \\
08-18-89\end{array}$ & $\begin{array}{r}1,240 \\
4,930 \\
420 \\
10 \\
2,020 \\
600 \\
3,880 \\
112,700 \\
1,600 \\
3,500 \\
3,700 \\
2,070\end{array}$ & ES \\
\hline
\end{tabular}

$1_{\text {Highest since } 1940 .}$

MAGNITUDE AND PROBABILITY OF INSTANTANEOUS PEAK FLOW BASED ON PERIOD OF RECORD 1940-45, 1966-81

DISCHARGE, IN FT $3 / 5$, FOR INDICATED RECURRENCE INTERVAL IN YEARS, AND EXCEEDANCE PROBABILITY, IN PERCENT

\begin{tabular}{cccccc}
2 & 5 & 10 & 25 & $50 \uparrow$ & $100 \dagger$ \\
$50 \%$ & $20 \%$ & $10 \%$ & $4 \%$ & $2 \%$ & $1 \%$ \\
1,950 & 5,410 & 9,050 & 15,400 & 21,600 & 29,100 \\
\hline WEIGHTED SKEW (LOGS) & & -0.17 & & \\
MEAN & (LOGS) & 3.27 & & \\
STANDARD DEV. (LOGS) & $=0.54$ & &
\end{tabular}

$\uparrow$ Reliability of values in column is uncertain, and potential errors are large.

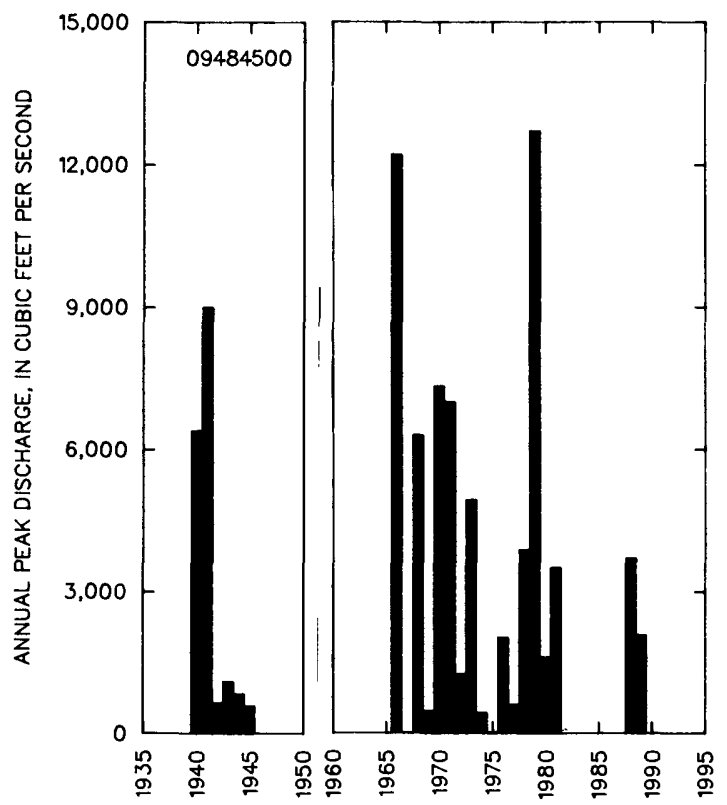

BASIN CHARACTERISTICS

\begin{tabular}{|c|c|c|c|c|c|c|c|}
\hline MAIN & & $\begin{array}{l}\text { MEAN } \\
\text { BASIN }\end{array}$ & & & $\begin{array}{l}\text { MEAN } \\
\text { ANNUAL }\end{array}$ & RAINFALL II & SITY, 24-HOUR \\
\hline $\begin{array}{l}\text { CHANNEL } \\
\text { SLOPE } \\
\text { (FT/MI) }\end{array}$ & $\begin{array}{l}\text { STREAM } \\
\text { LENGTH } \\
\text { (Mi) }\end{array}$ & $\begin{array}{c}\text { ELEVA- } \\
\text { TION } \\
\text { (FT) }\end{array}$ & $\begin{array}{l}\text { FORESTED } \\
\text { AREA } \\
\text { (PERCENT) }\end{array}$ & $\begin{array}{l}\text { SOIL } \\
\text { INDEX }\end{array}$ & $\begin{array}{l}\text { PRECIPI - } \\
\text { TATION } \\
\text { (IN) }\end{array}$ & $\begin{array}{c}\text { 2-YEAR } \\
\text { (IN) }\end{array}$ & $\begin{array}{c}\text { 50-YEAR } \\
\text { (IN) }\end{array}$ \\
\hline 109 & 19.0 & 4,340 & 36.0 & 1.0 & 16.7 & 2.0 & 4.2 \\
\hline
\end{tabular}


09484510 VENTANA CANYON MASH NEAR TUCSON, AZ

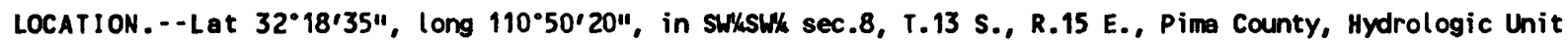
15050302, at Sunrise Drive (Sabino Canyon West Road), $0.5 \mathrm{mi}$ above Esperero Wash, and $4 \mathrm{mi}$ northeast of Tucson city limits.

DRAINAGE AREA. $--6.46 \mathrm{mi}^{2}$.

ANNUAL PEAK DISCHARGE

\begin{tabular}{ccc}
$\begin{array}{l}\text { MATER } \\
\text { YEAR }\end{array}$ & DATE & $\begin{array}{c}\text { ANNUAL PEAK } \\
\text { DISCHARGE } \\
\text { (FT } 3 / \text { S) }\end{array}$ \\
\hline 1965 & $09-08-65$ & 93 \\
1966 & $12-22-65$ & 260 \\
1967 & $10-04-66$ & 21 \\
1968 & $12-20-67$ & 216 \\
1969 & $08-01-69$ & 95 \\
1970 & $09-06-70$ & 180 \\
1971 & $08-19-71$ & 195 \\
1972 & $07-16-72$ & 180 \\
1973 & $10-19-72$ & 125 \\
1974 & $08-02-74$ & 131 \\
1975 & $07-25-75$ & 120 \\
1976 & $09-25-76$ & 195 \\
1977 & $00-00-77$ & 145 \\
1978 & $07-25-78$ & 185 \\
1979 & $12-18-78$ & 234 \\
1980 & $07-13-80$ & 32 \\
1981 & $07-31-81$ & 86 \\
$\ldots . . . \ldots 1$ &
\end{tabular}

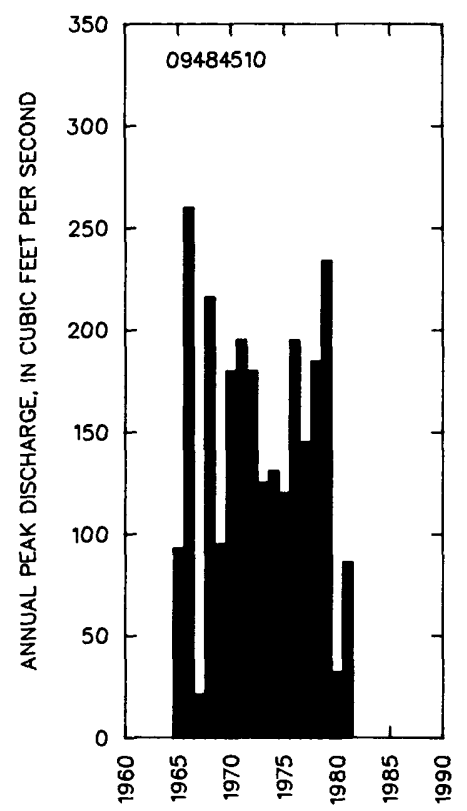

MAGNITUDE AND PROBABILITY OF INSTANTANEOUS PEAK FLON BASED ON PERIOD OF RECORD 1965-81

DISCHARGE, IN $\mathrm{FT}^{3} / \mathrm{S}$, FOR INDICATED RECURRENCE INTERVAL IN YEARS, AND EXCEEDANCE PROBABILITY, IN PERCENT

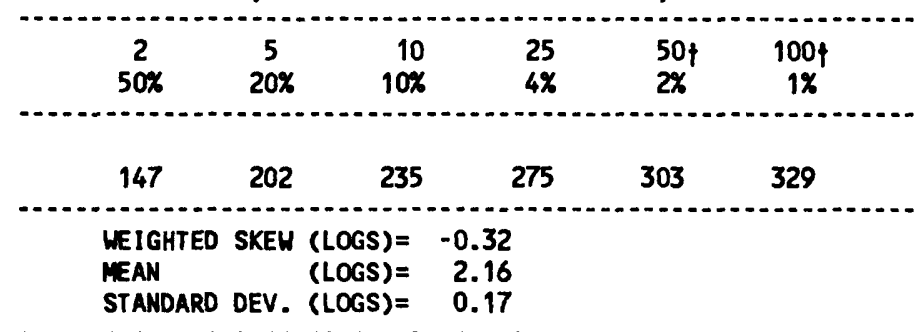

$\uparrow$ Reliability of values in colum is uncertain, and potential errors are large.

BASIN CHARACTERISTICS

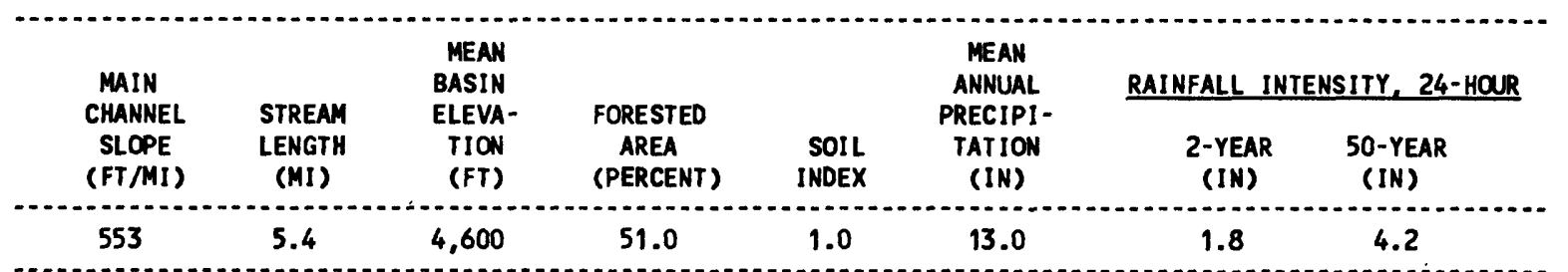




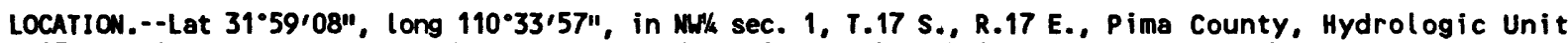
15050302, on downstream end of first pier from right bank of bridge on Interstate Highway 10, and $1.2 \mathrm{mi}$ southeast of Pantano.

DRAIMAGE AREA. $--289 \mathrm{mi}^{2}$.

ANNUAL PEAK DISCHARGE

\begin{tabular}{cccc}
$\begin{array}{c}\text { WATER } \\
\text { YEAR }\end{array}$ & DATE & $\begin{array}{c}\text { ANNUAL PEAK } \\
\text { DISCHARGE } \\
\text { (FT } 3 / \text { S) }\end{array}$ & $\begin{array}{c}\text { DISCHARGE } \\
\text { CODES }\end{array}$ \\
\hline 1958 & $08-11-58$ & 20,000 & ES, HP \\
1968 & $07-26-68$ & 1,870 & \\
1969 & $07-22-69$ & 990 & \\
1970 & $07-20-70$ & 1,770 & \\
1971 & $08-03-71$ & 2,240 & \\
1972 & $09-13-72$ & 1,930 & \\
1973 & $02-22-73$ & 878 \\
1974 & $07-19-74$ & 2,570 & \\
1975 & $09-02-75$ & 1,550 & \\
1976 & $08-10-76$ & 4,650 & \\
1977 & $09-11-77$ & 3,800 & \\
1978 & $10-06-77$ & 900 & \\
1979 & $08-12-79$ & 860 & \\
1980 & $09-07-80$ & 630 \\
1981 & $07-06-81$ & 8,310 & \\
$\ldots$ & &
\end{tabular}

MAGNITUDE AND PROBABILITY OF INSTANTANEOUS PEAK FLOH BASED ON PERIOD OF RECORD 1958, 1968-81

DISCHARGE, IN $\mathrm{FT}^{3} / \mathrm{S}$, FOR INDICATED RECURRENCE INTERVAL IN YEARS, AND EXCEEDANCE PROBABILITY, IN PERCENT

\begin{tabular}{cccccc}
2 & 5 & 10 & 25 & $50 \dagger$ & $100 \uparrow$ \\
$50 \%$ & $20 \%$ & $10 \%$ & $4 \%$ & $2 \%$ & $1 \%$ \\
1,880 & 4,020 & 6,150 & 9,930 & 13,700 & 18,500 \\
\hline MEIGHTED SKEH (LOGS) & 0.36 & & \\
MEAN & (LOGS) & 2.30 & & \\
STANDARD DEV. (LOGS) & 0.37 & &
\end{tabular}

+ Reliability of values in column is uncertain, and potential errors are large.

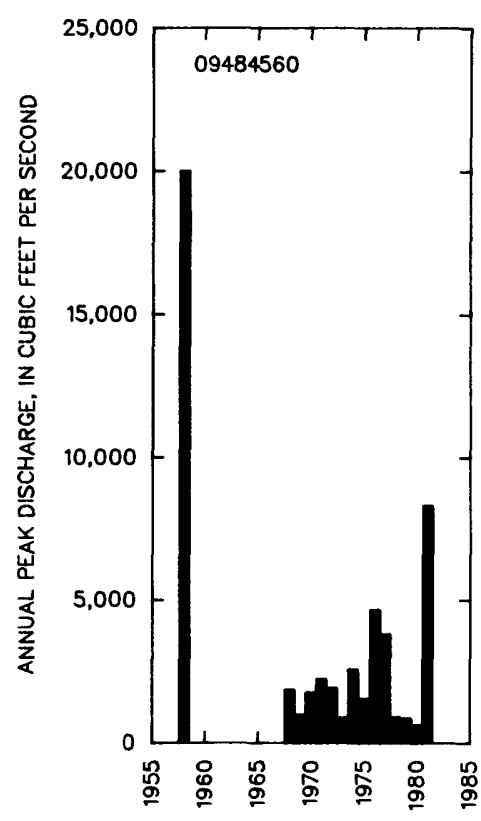

BASIN CHARACTERISTICS

\begin{tabular}{|c|c|c|c|c|c|c|c|}
\hline \multirow{3}{*}{$\begin{array}{c}\text { MAIN } \\
\text { CHANNEL } \\
\text { SLOPE } \\
\text { (FT/MI) }\end{array}$} & \multirow[b]{3}{*}{$\begin{array}{c}\text { STREAM } \\
\text { LENGTH } \\
\text { (MI) }\end{array}$} & \multirow{3}{*}{$\begin{array}{l}\text { MEAN } \\
\text { BASIN } \\
\text { ELEVA- } \\
\text { TION } \\
\text { (FT) }\end{array}$} & \multirow[b]{3}{*}{$\begin{array}{l}\text { FORESTED } \\
\text { AREA } \\
\text { (PERCENT) }\end{array}$} & \multirow[b]{3}{*}{$\begin{array}{l}\text { SOIL } \\
\text { INDEX }\end{array}$} & \multirow{2}{*}{$\begin{array}{l}\text { MEAN } \\
\text { ANNUAL } \\
\text { PRECIPI- }\end{array}$} & \multirow{2}{*}{\multicolumn{2}{|c|}{ RAINFALL INTENSITY, 24-HOUR }} \\
\hline & & & & & & & \\
\hline & & & & & $\begin{array}{l}\text { PRECIPI- } \\
\text { TATION } \\
\text { (IN) }\end{array}$ & $\begin{array}{l}\text { 2-YEAR } \\
\text { (IN) }\end{array}$ & $\begin{array}{l}\text { 50-YEAR } \\
\text { (IN) }\end{array}$ \\
\hline 59.8 & 31.2 & 4,890 & 13.0 & 2.5 & 16.6 & 1.9 & 4.1 \\
\hline
\end{tabular}


09484570 MESCAL ARROYO MEAR PANTANO, AZ

LOCATION. - - Lat 31'59'23", long 110'33'52", in NEYNW/k sec.1, T.17 S., R.17 E., Pima County, Hydrologic Unit 15050302, at county road, $0.25 \mathrm{mi}$ above mouth, and $1.1 \mathrm{mi}$ southeast of Pantano.

DRAIMAGE AREA. $--38.4 \mathrm{mi}^{2}$.

ANMUAL PEAK DISCHARGE

\begin{tabular}{|c|c|c|c|}
\hline $\begin{array}{l}\text { WATER } \\
\text { YEAR }\end{array}$ & DATE & $\begin{array}{l}\text { ANNUAL PEAK } \\
\text { DISCHARGE } \\
\left(F^{3} / S\right)\end{array}$ & $\begin{array}{l}\text { DISCHARGE } \\
\text { CODES }\end{array}$ \\
\hline $\begin{array}{l}1958 \\
1965 \\
1966 \\
1967 \\
1968 \\
1969 \\
1970 \\
1971 \\
1972 \\
1973 \\
1974 \\
1975 \\
1976 \\
1977 \\
1978 \\
1979 \\
1980 \\
1981\end{array}$ & $\begin{array}{l}08-11-58 \\
09-12-65 \\
08-13-66 \\
07-12-67 \\
08-03-68 \\
08-05-69 \\
07-21-70 \\
08-19-71 \\
09-00-72 \\
07-00-73 \\
08-19-74 \\
09-06-75 \\
07-29-76 \\
09-10-77 \\
10-06-77 \\
08-12-79 \\
09-07-80 \\
07-06-81\end{array}$ & $\begin{array}{r}127,000 \\
1,600 \\
1,610 \\
290 \\
430 \\
950 \\
680 \\
6,140 \\
520 \\
320 \\
620 \\
510 \\
385 \\
1,700 \\
2,100 \\
130 \\
15 \\
3,500\end{array}$ & HP \\
\hline
\end{tabular}

1Highest since 1930.

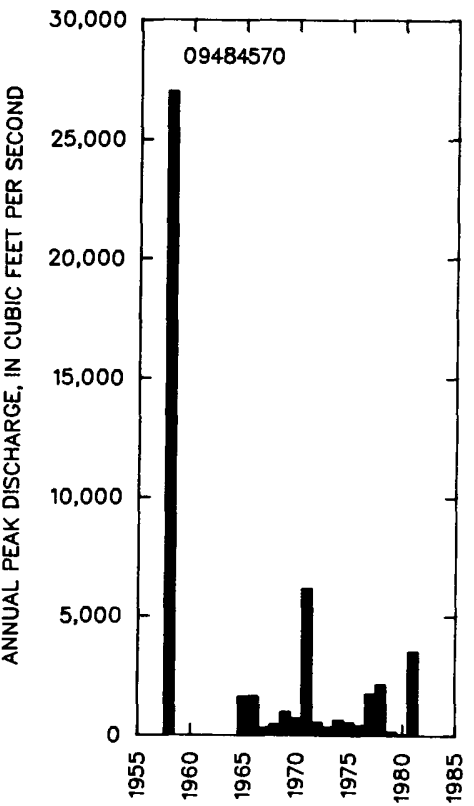

MAGNITUDE AND PROBABILITY OF INSTANTANEQUS PEAK FLOH BASED ON PERICD OF RECORD 1958, 1965-81

DISCHARGE, IN $\mathrm{FT}^{3} / \mathrm{S}$, FOR INDICATED RECURRENCE INTERVAL IN YEARS, AND EXCEEDANCE PROBABILITY, IN PERCENT

\begin{tabular}{|c|c|c|c|c|c|}
\hline $\begin{array}{c}2 \\
50 x\end{array}$ & $\begin{array}{c}5 \\
20 \%\end{array}$ & $\begin{array}{r}10 \\
10 \%\end{array}$ & $\begin{array}{l}25 \\
4 \%\end{array}$ & $\begin{array}{l}50 \dagger \\
2 \%\end{array}$ & $\begin{array}{c}100 \dagger \\
1 \%\end{array}$ \\
\hline 753 & 2,060 & 3,620 & 6,800 & 10,400 & 15,400 \\
\hline $\begin{array}{l}\text { WEIGHTED } \\
\text { MEAN } \\
\text { STANDARD }\end{array}$ & $\begin{array}{l}\text { SKEW } \\
\text { DEV. }\end{array}$ & $\begin{array}{l}\text { OGS) }= \\
O G S)= \\
\text { OGS) }=\end{array}$ & $\begin{array}{l}0.35 \\
2.91 \\
0.50\end{array}$ & & \\
\hline
\end{tabular}

f Reliability of values in column is uncertain, and potential errors are large.

BASIN CHARACTERISTICS

\begin{tabular}{|c|c|c|c|c|c|c|c|}
\hline \multirow{2}{*}{$\begin{array}{l}\text { MAIN } \\
\text { CHANNEL } \\
\text { SLOPE } \\
\text { (FT/MI) }\end{array}$} & \multirow[b]{2}{*}{$\begin{array}{l}\text { STREAM } \\
\text { LENGTH } \\
\text { (MI) }\end{array}$} & \multirow{2}{*}{$\begin{array}{l}\text { MEAN } \\
\text { BASIN } \\
\text { ELEVA- } \\
\text { TION } \\
\text { (FT) }\end{array}$} & \multirow[b]{2}{*}{$\begin{array}{l}\text { FORESTED } \\
\text { AREA } \\
\text { (PERCENT) }\end{array}$} & \multirow[b]{2}{*}{$\begin{array}{l}\text { SOIL } \\
\text { INDEX }\end{array}$} & \multirow{2}{*}{$\begin{array}{l}\text { MEAN } \\
\text { ANNUAL } \\
\text { PRECIPI- } \\
\text { TATION } \\
\text { (IN) }\end{array}$} & \multicolumn{2}{|c|}{ RAINFALL INTENSITY, 24-HOUR } \\
\hline & & & & & & $\begin{array}{l}\text { 2-YEAR } \\
\text { (IN) }\end{array}$ & $\begin{array}{l}\text { 50-YEAR } \\
\text { (IN) }\end{array}$ \\
\hline 82.9 & 11.9 & 4,260 & 0.0 & 1.0 & 15.0 & 1.9 & 4.0 \\
\hline
\end{tabular}


LOCATION.--Lat 31'51'42", long 110"41'25", in SEKSEK sec.15, T.18 S., R.16 E., Pima County, Hydrologic Unit 15050302, at State Highway $83,13 \mathrm{mi}$ north of Sonoita.

DRAINAGE AREA. $--14.1 \mathrm{mi}^{2}$.

ANMUAL PEAK DISCHARGE

\begin{tabular}{|c|c|c|c|}
\hline $\begin{array}{l}\text { WATER } \\
\text { YEAR }\end{array}$ & DATE & $\begin{array}{c}\text { ANNUAL PEAK } \\
\text { DISCHARGE } \\
\text { (FT } 3 / 5)\end{array}$ & $\begin{array}{l}\text { DISCHARGE } \\
\text { CODES }\end{array}$ \\
\hline $\begin{array}{l}1962 \\
1963 \\
1964 \\
1965 \\
1966 \\
1967 \\
1968 \\
1969 \\
1970 \\
1971 \\
1972 \\
1973 \\
1974 \\
1975 \\
1976\end{array}$ & $\begin{array}{l}00-00-62 \\
00-00-63 \\
09-10-64 \\
09-08-65 \\
00-00-66 \\
09-00-67 \\
07-26-68 \\
07-23-69 \\
07-20-70 \\
08-00-71 \\
07-00-72 \\
00-00-73 \\
09-21-74 \\
09-13-75 \\
08-00-76\end{array}$ & $\begin{array}{r}140 \\
145 \\
879 \\
480 \\
260 \\
323 \\
1,600 \\
15 \\
1,350 \\
1,900 \\
240 \\
10 \\
1,350 \\
980 \\
1,100\end{array}$ & LT \\
\hline
\end{tabular}

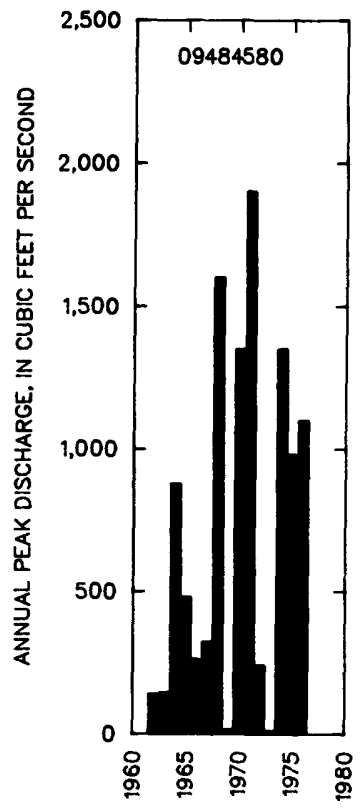

MAGNI TUDE AND PROBABILITY OF INSTANTANEOUS PEAK FLOW BASED ON PERICD OF RECORD 1962-76

DISCHARGE, IN FT $3 / 5$; FOR INDICATED RECURRENCE INTERVAL IN YEARS, AND EXCEEDANCE PROBABILITY, IN PERCENT

\begin{tabular}{|c|c|c|c|c|c|}
\hline $\begin{array}{c}2 \\
50 \%\end{array}$ & $\begin{array}{c}5 \\
20 \%\end{array}$ & $\begin{array}{r}10 \\
10 \%\end{array}$ & $\begin{array}{l}25 \\
4 \%\end{array}$ & $\begin{array}{l}50 \uparrow \\
2 \%\end{array}$ & $\begin{array}{c}100 \nmid \\
1 \%\end{array}$ \\
\hline 504 & 1,190 & 1,810 & 2,760 & 3,580 & 4,480 \\
\hline $\begin{array}{l}\text { WEIGHTED } \\
\text { MEAN } \\
\text { STANDARD }\end{array}$ & $\begin{array}{l}\text { SKEW } \\
\text { DEV. }\end{array}$ & $\begin{array}{l}\text { LOGS) }= \\
(\text { LOGS) }= \\
(\text { LGS }=\end{array}$ & $\begin{array}{r}-0.34 \\
2.68 \\
0.47\end{array}$ & & \\
\hline
\end{tabular}

t Reliability of values in colum is uncertain, and potential errors are large.

BASIN CHARACTERISTICS

\begin{tabular}{|c|c|c|c|c|c|c|c|}
\hline MAIN & & $\begin{array}{l}\text { MEAN } \\
\text { BASIN }\end{array}$ & & & $\begin{array}{l}\text { MEAN } \\
\text { ANNUAL }\end{array}$ & RAINFALL I & SITY, 24-HOUR \\
\hline $\begin{array}{l}\text { CHANNEL } \\
\text { SLOPE } \\
\text { (FT/MI) }\end{array}$ & $\begin{array}{l}\text { STREAN } \\
\text { LENGTH } \\
\text { (MI) }\end{array}$ & $\begin{array}{l}\text { ELEVA- } \\
\text { TION } \\
\text { (FT) }\end{array}$ & $\begin{array}{l}\text { FORESTED } \\
\text { AREA } \\
\text { (PERCENT) }\end{array}$ & $\begin{array}{l}\text { SOIL } \\
\text { INDEX }\end{array}$ & $\begin{array}{l}\text { PRECIPI- } \\
\text { TATION } \\
\text { (IN) }\end{array}$ & $\begin{array}{c}\text { 2-YEAR } \\
\text { (IN) }\end{array}$ & $\begin{array}{c}\text { 50-YEAR } \\
\text { (IN) }\end{array}$ \\
\hline 190 & 5.9 & 5,000 & 0.0 & 3.0 & 16.0 & 1.9 . & 4.1 \\
\hline
\end{tabular}


09484590 DAVIDSON CANYON WASH MEAR VAIL, AZ

LOCATION.--Lat 31'59'37", long 110.38'40", in SWHSE\% sec.31, T.16 S., R.17 E., Hydrologic Unit 15050302, on right bank $0.3 \mathrm{mi}$ upstream from Interstate Highway $10,2.0 \mathrm{mi}$ upstream from mouth, and 5.5 mi southeast of Vail.

DRAINAGE AREA. $--50.5 \mathrm{mi}^{2}$.

ANNUAL PEAK DISCHARGE

\begin{tabular}{ccc}
$\begin{array}{l}\text { MATER } \\
\text { YEAR }\end{array}$ & DATE & $\begin{array}{c}\text { ANNUAL PEAK } \\
\text { DISCHARGE } \\
\text { (FT } 3 / \text { S })\end{array}$ \\
\hline 1968 & $07-26-68$ & $.3,040$ \\
1969 & $08-05-69$ & 587 \\
1970 & $07-20-70$ & 6,860 \\
971 & $08-10-71$ & 1,490 \\
1972 & $09-07-72$ & 1,320 \\
1973 & $10-19-72$ & 28 \\
1974 & $09-21-74$ & 1,460 \\
1975 & $07-08-75$ & 708 \\
1976 & $07-12-76$ & 3,550 \\
1977 & $09-10-77$ & 2,400 \\
1978 & $10-06-77$ & 3,040 \\
1979 & $08-15-79$ & 105 \\
1980 & $09-07-80$ & 1,740 \\
1981 & $07-27-81$ & 4,480 \\
$\ldots$
\end{tabular}

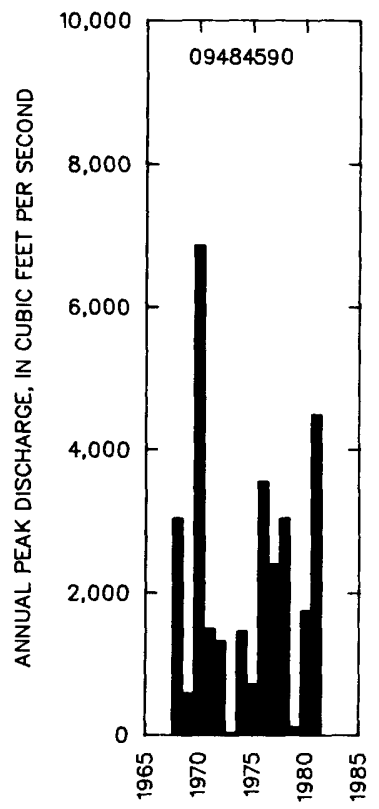

MAGNITUDE AND PROBABILITY OF INSTANTANEQUS PEAK FLOW BASED ON PERIOO OF RECORD 1968-81

DISCHARGE, IN $\mathrm{FT}^{3} / \mathrm{S}$, FOR INDICATED RECURRENCE INTERVAL IN YEARS, AND EXCEEDANCE PROBABILITY, IN PERCENT

\begin{tabular}{|c|c|c|c|c|c|}
\hline $\begin{array}{c}2 \\
50 \%\end{array}$ & $\begin{array}{c}5 \\
20 \%\end{array}$ & $\begin{array}{r}10 \\
10 \%\end{array}$ & $\begin{array}{l}25 \\
4 \%\end{array}$ & $\begin{array}{l}50\} \\
2 \%\end{array}$ & $\begin{array}{c}100 \nmid \\
1 \%\end{array}$ \\
\hline 1,900 & 3,430 & 4,640 & 6,380 & 7,800 & 9,340 \\
\hline $\begin{array}{l}\text { WEIGHTED } \\
\text { MEAN } \\
\text { STANDARD }\end{array}$ & $\begin{array}{l}\text { SKEW } \\
\text { DEV. }\end{array}$ & $\begin{array}{l}(\text { LOGS })= \\
(\text { LOGS })= \\
(\text { LOGS })=\end{array}$ & $\begin{array}{r}-0.11 \\
3.27 \\
0.31\end{array}$ & & \\
\hline
\end{tabular}

t Reliability of values in colum is uncertain, and potential errors are large.

BASIN CHARACTERISTICS

\begin{tabular}{|c|c|c|c|c|c|c|c|}
\hline MIN & & $\begin{array}{r}\text { MEAN } \\
\text { BASIN }\end{array}$ & & & $\begin{array}{l}\text { MEAN } \\
\text { AMNUAL }\end{array}$ & RAINFALL I & SITY, $24-H O U R$ \\
\hline $\begin{array}{c}\text { CHANNEL } \\
\text { SLOPE } \\
\text { (FT/MI) }\end{array}$ & $\begin{array}{c}\text { STREAM } \\
\text { LENGTH } \\
\text { (MI) }\end{array}$ & $\begin{array}{l}\text { ELEVA- } \\
\text { TION } \\
\text { (FT) }\end{array}$ & $\begin{array}{l}\text { FORESTED } \\
\text { AREA } \\
\text { (PERCENT) }\end{array}$ & $\begin{array}{l}\text { SOIL } \\
\text { INDEX }\end{array}$ & $\begin{array}{l}\text { PRECIPI - } \\
\text { TATION } \\
\text { (IN) }\end{array}$ & $\begin{array}{l}\text { 2-YEAR } \\
\text { (IN) }\end{array}$ & $\begin{array}{l}\text { 50-YEAR } \\
\text { (IN) }\end{array}$ \\
\hline 86.2 & 13.6 & 4,340 & 0.0 & 1.0 & 14.9 & 1.9 & 4.1 \\
\hline
\end{tabular}




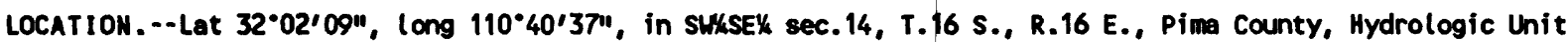
15050302, $60 \mathrm{ft}$ upstream from dam, $2.2 \mathrm{mi}$ southeast of Vail, and $20 \mathrm{mi}$ southeast of city hall in Tucson.

DRAIMACE AREA. $--457 \mathrm{mi}^{2}$.

ANMUAL PEAK DISCHARGE

\begin{tabular}{|c|c|c|c|c|c|c|c|}
\hline $\begin{array}{l}\text { WATER } \\
\text { YEAR }\end{array}$ & DATE & $\begin{array}{l}\text { ANNUAL PEAK } \\
\text { DISCHARGE } \\
\left(\mathrm{FT}^{3} / \mathrm{S}\right)\end{array}$ & $\begin{array}{l}\text { DISCHARGE } \\
\text { CODES }\end{array}$ & $\begin{array}{l}\text { WATER } \\
\text { YEAR }\end{array}$ & DATE & $\begin{array}{l}\text { ANIUAL PEAK } \\
\text { DISCHARGE } \\
\left(F^{3} / S\right)\end{array}$ & $\begin{array}{l}\text { DISCHARGE } \\
\text { CODES }\end{array}$ \\
\hline $\begin{array}{l}1958 \\
1959 \\
1960 \\
1961 \\
1962 \\
1963 \\
1964 \\
1965 \\
1966 \\
1967 \\
1968 \\
1969 \\
1970 \\
1971 \\
1972 \\
1973\end{array}$ & $\begin{array}{l}08-11-18 \\
08-17-59 \\
08-09-60 \\
08-28-61 \\
09-26-62 \\
08-25-63 \\
09-10-64 \\
09-12-65 \\
08-13-66 \\
08-18-67 \\
12-20-67 \\
08-05-69 \\
07-20-70 \\
08-19-71 \\
09-07-72 \\
10-04-72\end{array}$ & $\begin{array}{r}138,000 \\
9,310 \\
7,300 \\
5,280 \\
1,500 \\
9,700 \\
9,960 \\
5,880 \\
7,410 \\
7,680 \\
2,640 \\
857 \\
6,850 \\
8,700 \\
1,460 \\
371\end{array}$ & $E S, H P$ & $\begin{array}{l}1974 \\
1975 \\
1976 \\
1977 \\
1978 \\
1979 \\
1980 \\
1981 \\
1982 \\
1983 \\
1984 \\
1985 \\
1986 \\
1987 \\
1988 \\
1989\end{array}$ & $\begin{array}{l}07-20-74 \\
09-02-75 \\
07-25-76 \\
09-10-77 \\
10-06-77 \\
12-18-78 \\
09-07-80 \\
09-22-81 \\
08-23-82 \\
08-03-83 \\
10-02-83 \\
08-20-85 \\
08-17-86 \\
09-24-87 \\
07-29-88 \\
07-21-89\end{array}$ & $\begin{array}{r}1,780 \\
1,200 \\
5,200 \\
1,600 \\
1,300 \\
790 \\
1,300 \\
13,000 \\
3,400 \\
1,840 \\
12,000 \\
363 \\
1,020 \\
1,370 \\
7,420 \\
803\end{array}$ & \\
\hline
\end{tabular}

Highest since 1930.

\section{BASIN CHARACTERISTICS}

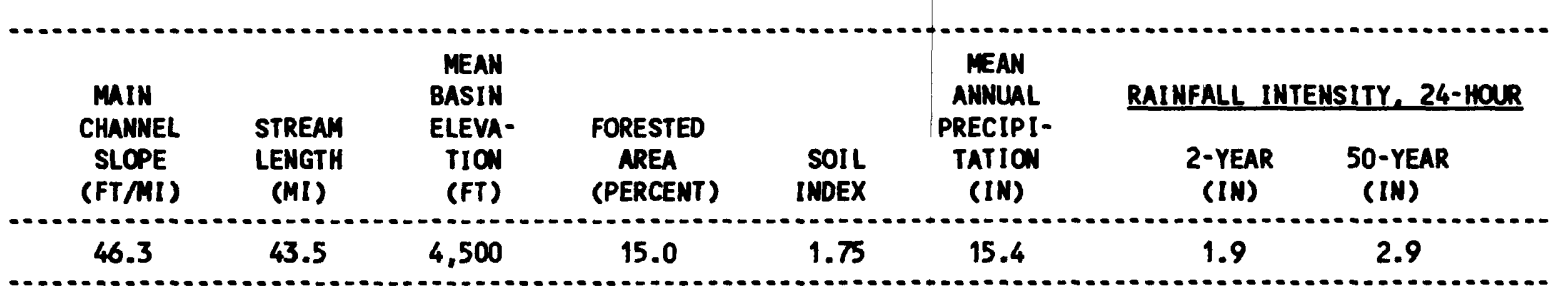


09484600 PANTANO WASH MEAR VAIL, AZ--Continued

MEAN MONTHLY AND ANMUAL DISCHARGES $1960-74$

\begin{tabular}{|c|c|c|c|c|c|c|}
\hline MONTH & $\begin{array}{l}\operatorname{MAx} \lim _{\left(\mathrm{FT}^{3} / \mathrm{S}\right)} \\
\end{array}$ & $\underset{\left(F T^{3} / S\right)}{\operatorname{MINImM}}$ & $\begin{array}{c}\text { MEAN } \\
\left(F T^{3 / S}\right)\end{array}$ & $\begin{array}{l}\text { STAN- } \\
\text { DARD } \\
\text { DEVIA- } \\
\text { TION } \\
\text { (FT } 3 / S)\end{array}$ & $\begin{array}{l}\text { COEFF I- } \\
\text { CIENT OF } \\
\text { VARI - } \\
\text { ATIOH }\end{array}$ & $\begin{array}{c}\text { PERCENT } \\
\text { OF } \\
\text { ANNUAL } \\
\text { RUNOFF }\end{array}$ \\
\hline $\begin{array}{l}\text { OCTOBER } \\
\text { NOVEMBER } \\
\text { DECEMBER } \\
\text { JANUARY } \\
\text { FEBRUARY } \\
\text { MARCH } \\
\text { APRIL } \\
\text { MAY } \\
\text { JUNE } \\
\text { JULY } \\
\text { AUGUST } \\
\text { SEPTEMBER }\end{array}$ & $\begin{array}{c}6.7 \\
3.0 \\
50 \\
18 \\
36 \\
18 \\
5.2 \\
2.0 \\
2.6 \\
50 \\
93 \\
105\end{array}$ & $\begin{array}{l}0.10 \\
0.10 \\
0.10 \\
0.10 \\
0.10 \\
0.12 \\
0.32 \\
0.19 \\
0.07 \\
2.4 \\
0.52 \\
0.16\end{array}$ & $\begin{array}{l}2.4 \\
1.4 \\
7.8 \\
3.1 \\
5.0 \\
3.2 \\
1.8 \\
1.2 \\
1.1 \\
13 \\
25 \\
15\end{array}$ & $\begin{array}{l}2.1 \\
0.76 \\
16 \\
4.2 \\
9.3 \\
4.4 \\
1.2 \\
0.48 \\
0.64 \\
13 \\
30 \\
25\end{array}$ & $\begin{array}{l}0.88 \\
0.53 \\
2.0 \\
1.4 \\
1.8 \\
1.4 \\
0.65 \\
0.39 \\
0.60 \\
1.0 \\
1.2 \\
1.7\end{array}$ & $\begin{array}{r}3.0 \\
1.8 \\
9.8 \\
3.8 \\
6.3 \\
3.9 \\
2.3 \\
1.5 \\
1.3 \\
16.0 \\
31.6 \\
18.6\end{array}$ \\
\hline ANNUAL & 13 & 2.3 & 6.7 & 3.8 & 0.56 & 100 \\
\hline
\end{tabular}

MAGNitUde AND PROBABILITY OF INSTANTANEOUS PEAK FLON BASED ON PERIOD OF RECORD 1958-89

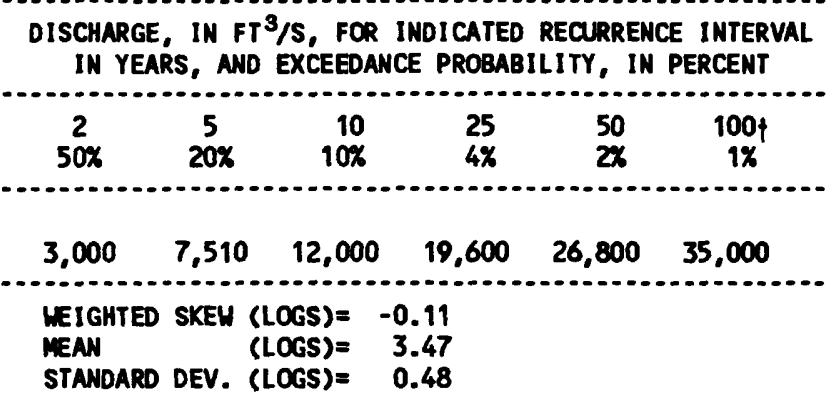

MAGNITLDE ANO PROBABILITY OF ANNUAL LOW FLOW BASED ON PERIOD OF RECORD 1960-74

\begin{tabular}{|c|c|c|c|c|c|c|}
\hline \multirow{2}{*}{$\begin{array}{l}\text { PERIOD } \\
\text { (CON- } \\
\text { SECU- } \\
\text { TIVE } \\
\text { DAYS) }\end{array}$} & \multicolumn{6}{|c|}{$\begin{array}{l}\text { DISCHARGE, IN FT }{ }^{3} / \mathrm{S}, \text { FOR INDICATED } \\
\text { RECURRENCE INTERVAL, IN YEARS, AND } \\
\text { NON-EXCEEDANCE PROBABILITY, IN PERCENT }\end{array}$} \\
\hline & $\stackrel{2}{50 \%}$ & $\begin{array}{c}5 \\
20 \%\end{array}$ & $\begin{array}{l}10 \\
10 \%\end{array}$ & $\begin{array}{l}20 \\
5 \%\end{array}$ & $\begin{array}{l}50\} \\
2 \%\end{array}$ & $\begin{array}{l}100 \uparrow \\
1 \%\end{array}$ \\
\hline $\begin{array}{r}1 \\
3 \\
7 \\
14 \\
30 \\
60 \\
90 \\
120 \\
183\end{array}$ & $\begin{array}{l}0.42 \\
0.45 \\
0.53 \\
0.62 \\
0.70 \\
0.86 \\
1.2 \\
1.8 \\
2.4\end{array}$ & $\begin{array}{l}0.14 \\
0.14 \\
0.16 \\
0.26 \\
0.33 \\
0.43 \\
0.62 \\
0.75 \\
0.90\end{array}$ & $\begin{array}{l}0.00 \\
0.00 \\
0.00 \\
0.00 \\
0.21 \\
0.27 \\
0.37 \\
0.41 \\
0.47\end{array}$ & $\begin{array}{l}0.00 \\
0.00 \\
0.00 \\
0.00 \\
0.13 \\
0.17 \\
0.22 \\
0.24 \\
0.25\end{array}$ & $\begin{array}{l}0.00 \\
0.00 \\
0.00 \\
0.00 \\
0.07 \\
0.09 \\
0.11 \\
0.11 \\
0.11\end{array}$ & $\begin{array}{l}0.00 \\
0.00 \\
0.00 \\
0.00 \\
0.05 \\
0.06 \\
0.06 \\
0.07 \\
0.07\end{array}$ \\
\hline
\end{tabular}

MAGNITUDE AND PROBABILITY OF ANNUAL HIGH FLON BASED ON PERIOD OF RECORD 1960-74

\begin{tabular}{|c|c|c|c|c|c|c|}
\hline \multirow{2}{*}{$\begin{array}{l}\text { PERIOD } \\
\text { (CON- } \\
\text { SECU- } \\
\text { TIVE } \\
\text { DAYS) }\end{array}$} & \multicolumn{6}{|c|}{$\begin{array}{l}\text { DISCHARGE, IN } \mathrm{FT}^{3} / \mathrm{S} \text {, FOR INDICATED } \\
\text { RECURRENCE INTERVAL, IN YEARS, AND } \\
\text { EXCEEDANCE PROBABILITY, IN PERCENT }\end{array}$} \\
\hline & $\begin{array}{c}2 \\
50 x\end{array}$ & $\begin{array}{c}5 \\
20 \%\end{array}$ & $\begin{array}{l}10 \\
10 \%\end{array}$ & $\begin{array}{l}25 \\
4 \%\end{array}$ & $\begin{array}{l}50 \uparrow \\
2 x\end{array}$ & $\underset{1 \%}{100 \dagger}$ \\
\hline $\begin{array}{r}1 \\
3 \\
7 \\
15 \\
30 \\
60 \\
90\end{array}$ & $\begin{array}{r}350 \\
172 \\
88 \\
53 \\
35 \\
22 \\
16\end{array}$ & $\begin{array}{r}757 \\
370 \\
192 \\
112 \\
69 \\
42 \\
30\end{array}$ & $\begin{array}{r}1,150 \\
546 \\
285 \\
162 \\
96 \\
58 \\
41\end{array}$ & $\begin{array}{r}1,830 \\
819 \\
431 \\
236 \\
131 \\
80 \\
56\end{array}$ & $\begin{array}{r}2,480 \\
1,060 \\
559 \\
298 \\
159 \\
98 \\
67\end{array}$ & $\begin{array}{r}3,290 \\
1,330 \\
705 \\
365 \\
187 \\
116 \\
79\end{array}$ \\
\hline
\end{tabular}

DURATION TABLE OF DAILY MEAN FLON FOR PERIOD OF RECORD 1960-74

DISCHARGE, IN FT $3 / 5$, WHICH HAS EQUALED OR EXCEEDED FOR INDICATED PERCENT OF TIME

\begin{tabular}{|c|c|c|c|c|c|c|c|c|c|c|c|c|c|c|c|}
\hline $5 \%$ & $10 \%$ & $15 \%$ & $20 \%$ & $30 \%$ & $40 \%$ & $50 \%$ & $60 \%$ & $70 \%$ & $80 \%$ & $90 \%$ & $95 \%$ & $98 \%$ & $99 \%$ & $99.5 \%$ & $99.9 \%$ \\
\hline 17 & 4.2 & 3.1 & 2.6 & 2.0 & 1.7 & 1.5 & 1.3 & 1.0 & 0.81 & 0.44 & 0.13 & 0.11 & 0.10 & 0.05 & 0.0 \\
\hline
\end{tabular}

f Reliability of values in colum is uncertain, and potential errors are large. 
GILA RIVER BASIN

09484600 PANTANO WASH NEAR VAIL, AZ--CONTINUED
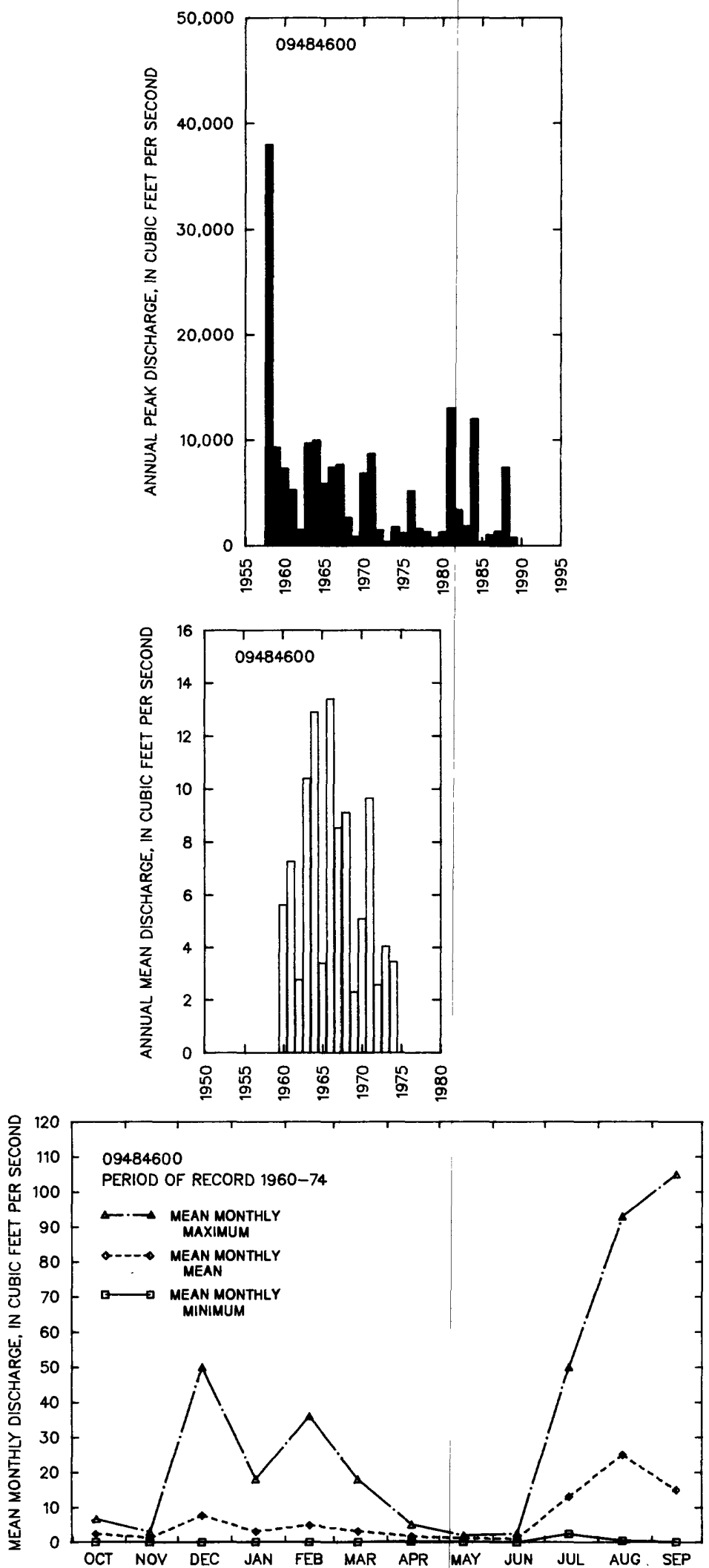
09485000 RINCON CREEK NEAR TUCSON, AZ

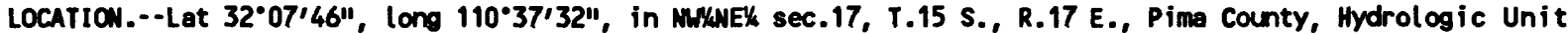
15050302, 9 mi upstram from mouth and 22 mi southeast of city hall' in Tucsón.

DRAIMAGE AREA. $--44.8 \mathrm{mi}^{2}$.

ANMUAL PEAK DISCHARGE

\begin{tabular}{|c|c|c|c|c|c|}
\hline $\begin{array}{l}\text { WATER } \\
\text { YEAR }\end{array}$ & DATE & $\begin{array}{c}\text { ANNUAL PEAK } \\
\text { DISCHARGE } \\
\left(F^{3} / S\right)\end{array}$ & $\begin{array}{l}\text { WATER } \\
\text { YEAR }\end{array}$ & DATE & $\begin{array}{c}\text { ANINAL PEAK } \\
\text { DISCHARGE } \\
\left(F^{3} / S\right)\end{array}$ \\
\hline $\begin{array}{l}1953 \\
1954 \\
1955 \\
1956 \\
1957 \\
1958 \\
1959 \\
1960 \\
1961 \\
1962 \\
1963 \\
1964 \\
1965 \\
1966 \\
1967 \\
1968 \\
1969 \\
1970 \\
1971\end{array}$ & $\begin{array}{l}07-30-53 \\
08-19-54 \\
08-03-55 \\
07-20-56 \\
01-09-57 \\
03-22-58 \\
10-21-58 \\
01-12-60 \\
08-22-61 \\
01-24-62 \\
08-25-63 \\
09-23-64 \\
08-18-65 \\
12-22-65 \\
08-13-67 \\
02-12-68 \\
09-06-69 \\
08-01-70 \\
08-19-71\end{array}$ & $\begin{array}{r}194 \\
2,160 \\
8,250 \\
150 \\
3,570 \\
492 \\
5,220 \\
747 \\
2,600 \\
227 \\
3,420 \\
948 \\
311 \\
3,100 \\
157 \\
1,860 \\
548 \\
1,200 \\
9,660\end{array}$ & $\begin{array}{l}1972 \\
1973 \\
1974 \\
1975 \\
1976 \\
1977 \\
1978 \\
1979 \\
1980 \\
1981 \\
1982 \\
1983 \\
1984 \\
1985 \\
1986 \\
1987 \\
1988 \\
1989\end{array}$ & $\begin{array}{l}07-16-72 \\
10-19-72 \\
08-01-74 \\
09-02-75 \\
00-00-76 \\
01-00-77 \\
01-15-78 \\
12-18-78 \\
02-14-80 \\
08-01-81 \\
08-23-82 \\
01-30-83 \\
10-02-83 \\
01-26-85 \\
07-15-86 \\
12-07-86 \\
08-02-88 \\
07-25-89\end{array}$ & $\begin{array}{r}360 \\
1,440 \\
664 \\
340 \\
230 \\
127 \\
2,440 \\
4,890 \\
586 \\
236 \\
1,800 \\
688 \\
5,640 \\
647 \\
1,170 \\
535 \\
2,640 \\
88\end{array}$ \\
\hline
\end{tabular}

\section{BASIN CHARACTERISTICS}

\begin{tabular}{|c|c|c|c|c|c|c|c|}
\hline \multirow{2}{*}{$\begin{array}{l}\text { MAIN } \\
\text { CHANNEL } \\
\text { SLOPE } \\
\text { (FT/MI) }\end{array}$} & \multirow[b]{2}{*}{$\begin{array}{l}\text { STREAM } \\
\text { LENGTH } \\
\text { (MI) }\end{array}$} & \multirow{2}{*}{$\begin{array}{l}\text { MEAN } \\
\text { BASIN } \\
\text { ELEVA- } \\
\text { TION } \\
\text { (FT) }\end{array}$} & \multirow[b]{2}{*}{$\begin{array}{l}\text { FORESTED } \\
\text { AREA } \\
\text { (PERCENT) }\end{array}$} & \multirow[b]{2}{*}{$\begin{array}{l}\text { SOIL } \\
\text { INDEX }\end{array}$} & \multirow{2}{*}{$\begin{array}{l}\text { MEAN } \\
\text { ANNUAL } \\
\text { PRECIPI- } \\
\text { TATION } \\
\text { (IN) }\end{array}$} & \multicolumn{2}{|c|}{ RAINFALL INTENSITY, 24-HOUR } \\
\hline & & & & & & $\begin{array}{l}\text { 2-YEAR } \\
\text { (IN) }\end{array}$ & $\begin{array}{l}\text { 50-YEAR } \\
\text { (IN) }\end{array}$ \\
\hline 612 & 9.0 & 4,850 & 57.0 & 1.09 & 19.2 & 2.1 & 4.2 \\
\hline
\end{tabular}


MEAN MONTHLY AND ANMUAL DISCHARGES $1953-74$

\begin{tabular}{|c|c|c|c|c|c|c|}
\hline MONTH & $\begin{array}{l}\text { MAXIMUN } \\
\left(F^{3} / S\right)\end{array}$ & $\begin{array}{l}\text { MINIMUN } \\
\left(\mathrm{FT}^{3} / \mathrm{S}\right)\end{array}$ & $\begin{array}{c}\text { MEAN } \\
\left(F^{3} / S\right)\end{array}$ & $\begin{array}{l}\text { STAN- } \\
\text { DARD } \\
\text { DEVIA- } \\
\text { TION } \\
\text { (FT'3/S) }\end{array}$ & $\begin{array}{l}\text { COEFFI - } \\
\text { CIENT OF } \\
\text { VARI - } \\
\text { ATION }\end{array}$ & $\begin{array}{c}\text { PERCENT } \\
\text { OF } \\
\text { ANNUAL } \\
\text { RUNOFF }\end{array}$ \\
\hline $\begin{array}{l}\text { OCTOBER } \\
\text { NOVEMBER } \\
\text { DECEMBER } \\
\text { JAMUARY } \\
\text { FEBRUARY } \\
\text { MARCH } \\
\text { APRIL } \\
\text { MAY } \\
\text { JUNE } \\
\text { JULY } \\
\text { AUGUST } \\
\text { SEPTEMBER }\end{array}$ & $\begin{array}{c}23 \\
3.8 \\
130 \\
63 \\
75 \\
74 \\
18 \\
2.0 \\
1.5 \\
13 \\
64 \\
19\end{array}$ & $\begin{array}{l}0.00 \\
0.00 \\
0.00 \\
0.00 \\
0.00 \\
0.00 \\
0.00 \\
0.00 \\
0.00 \\
0.00 \\
0.00 \\
0.00\end{array}$ & $\begin{array}{c}2.1 \\
0.59 \\
9.5 \\
8.3 \\
12 \\
10 \\
2.4 \\
0.16 \\
0.08 \\
1.1 \\
12 \\
3.8\end{array}$ & $\begin{array}{c}5.7 \\
1.2 \\
28 \\
16 \\
23 \\
18 \\
4.7 \\
0.42 \\
0.32 \\
2.7 \\
18 \\
6.3\end{array}$ & $\begin{array}{l}2.7 \\
2.0 \\
2.9 \\
2.0 \\
1.9 \\
1.8 \\
2.0 \\
2.6 \\
3.8 \\
2.5 \\
1.5 \\
1.7\end{array}$ & $\begin{array}{r}3.4 \\
0.9 \\
15.3 \\
13.3 \\
18.8 \\
16.7 \\
3.8 \\
0.3 \\
0.1 \\
1.8 \\
19.5 \\
6.1\end{array}$ \\
\hline NNUAL & 24 & 0.07 & 5.2 & 5.8 & 1.1 & 100 \\
\hline
\end{tabular}

MAGNITUDE ANO PROBABILITY OF INSTANTANEOUS PEAK FLOH BASED ON PERICO OF RECCRD 1953-89

DISCHARGE, IN $\mathrm{FT}^{3} / \mathrm{S}$, FOR INDICATED RECURRENCE INTERVAL IN YEARS, ANO EXCEEDANCE PROBABILITY, IN PERCENT

\begin{tabular}{lccccc}
2 & 5 & 10 & 25 & 50 & $100 \uparrow$ \\
$50 \%$ & $20 \%$ & $10 \%$ & $4 \%$ & $2 \%$ & $1 \%$ \\
926 & 2,690 & 4,670 & 8,390 & 12,200 & 17,100 \\
\hline MEIGHTED SKEW (LOGS) & 0.04 & & & \\
MENW & (LOGS) & 2.96 \\
STANDARD DEV. (LOGS) & $=0.55$
\end{tabular}

MACNITUDE ND PROBABILITY OF ANNUAL LOW FLOH BASED ON PERIOD OF RECORD 1954-74

\begin{tabular}{|c|c|c|c|c|c|c|}
\hline \multirow{2}{*}{$\begin{array}{l}\text { PERIOO } \\
\text { (CON- } \\
\text { SECU- } \\
\text { TIVE } \\
\text { DAYS) }\end{array}$} & \multicolumn{6}{|c|}{$\begin{array}{l}\text { DISCHARGE, IN } \mathrm{FT}^{3} / \mathrm{S} \text {, FOR INDICATED } \\
\text { RECURRENCE INTERVAL, IN YEARS, AND } \\
\text { NOW-EXCEEDANCE PRCBABILITY, IN PERCENT }\end{array}$} \\
\hline & $\begin{array}{c}2 \\
50 \%\end{array}$ & $\begin{array}{c}5 \\
20 \%\end{array}$ & $\begin{array}{l}10 \\
10 \%\end{array}$ & $\begin{array}{l}20 \\
5 \%\end{array}$ & $\begin{array}{l}50 \gamma \\
2 x\end{array}$ & $\begin{array}{l}100 \uparrow \\
1 \%\end{array}$ \\
\hline $\begin{array}{c}1 \\
3 \\
7 \\
14 \\
30 \\
60 \\
90\end{array}$ & & & & & & \\
\hline $\begin{array}{l}120 \\
183\end{array}$ & $\begin{array}{l}0.00 \\
0.15\end{array}$ & $\begin{array}{l}0.00 \\
0.00\end{array}$ & $\begin{array}{l}0.00 \\
0.00\end{array}$ & $\begin{array}{l}0.00 \\
0.00\end{array}$ & $\begin{array}{l}0.00 \\
0.00\end{array}$ & $\begin{array}{l}0.00 \\
0.00\end{array}$ \\
\hline
\end{tabular}

MAENITUDE AND PROBABILITY OF ANNUAL HIGH FLOW BASED ON PERIOD OF RECORD 1953-74

\begin{tabular}{|c|c|c|c|c|c|c|}
\hline $\begin{array}{l}\text { PERIOD } \\
\text { (CON- } \\
\text { SECU- }\end{array}$ & & $\begin{array}{l}\text { DISCHA } \\
\text { RECURR } \\
\text { EXCEED } \\
\text { E. }\end{array}$ & $\begin{array}{l}\text { IN } \\
\text { E INT } \\
\text { E PRC }\end{array}$ & $\begin{array}{l}\text { AS, } \\
\text { AL, I } \\
\text { ILITY }\end{array}$ & $\begin{array}{l}\text { INDIC } \\
\text { YEARS, } \\
\text { IN PER }\end{array}$ & \\
\hline $\begin{array}{l}\text { TIVE } \\
\text { DAYS) }\end{array}$ & $\stackrel{2}{2}$ & $\begin{array}{c}5 \\
20 \%\end{array}$ & $\begin{array}{l}10 \\
10 \%\end{array}$ & $\begin{array}{l}25 \\
4 x\end{array}$ & $\begin{array}{l}50 \nmid \\
2 \%\end{array}$ & $\begin{array}{c}100 \dagger \\
1 \%\end{array}$ \\
\hline $\begin{array}{r}1 \\
3 \\
7 \\
15 \\
30 \\
60 \\
90\end{array}$ & $\begin{array}{r}177 \\
101 \\
63 \\
39 \\
24 \\
15 \\
11\end{array}$ & $\begin{array}{r}505 \\
285 \\
163 \\
100 \\
66 \\
41 \\
30\end{array}$ & $\begin{array}{r}808 \\
443 \\
233 \\
139 \\
97 \\
61 \\
46\end{array}$ & $\begin{array}{r}1,260 \\
657 \\
311 \\
180 \\
133 \\
84 \\
65\end{array}$ & $\begin{array}{r}1,630 \\
818 \\
360 \\
203 \\
156 \\
99 \\
77\end{array}$ & $\begin{array}{r}2,020 \\
973 \\
399 \\
221 \\
175 \\
112 \\
88\end{array}$ \\
\hline
\end{tabular}

duRATION TABLE OF DAILY MEAN FLON FOR PERIOO OF RECORD 1953-74 DISCHARGE, IN $\mathrm{FT}^{3} / \mathrm{s}$, WHICH WAS EQUALED OR EXCEEDED FOR IMDICATED PERCENT OF TIME

\begin{tabular}{|c|c|c|c|c|c|c|c|c|c|c|c|c|c|c|c|c|}
\hline $1 x$ & $5 \%$ & $10 \%$ & $15 \%$ & $20 \%$ & $30 \%$ & $40 \%$ & $50 \%$ & $60 \%$ & $70 \%$ & $80 \%$ & $90 x$ & $95 \%$ & $98 \%$ & $99 \%$ & $99.5 \%$ & $99.9 \%$ \\
\hline or & 24 & 9.0 & 3.3 & 1.4 & 0.21 & 0.01 & 0.01 & 0.01 & 0.00 & 0.00 & 0.00 & 0.00 & 0.00 & 0.00 & 0.00 & 0.00 \\
\hline
\end{tabular}


GILA RIVER BASIM

09485000 RINCON CREEK MEAR TUCSON, AZ--CONTIMUED
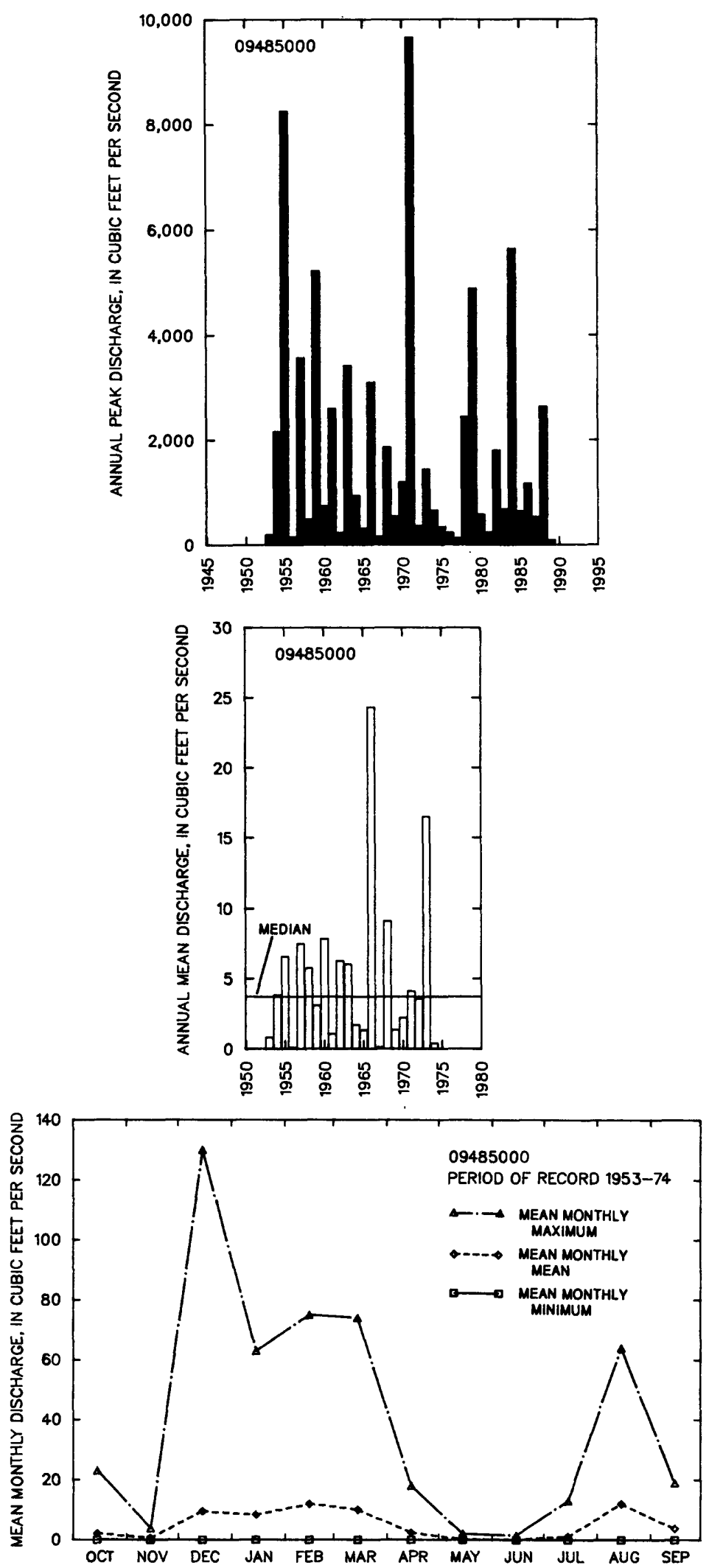
09485100 SAGUARO CORNERS WASH NEAR TUCSON, AZ

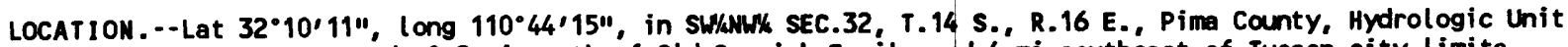
15050302, at Freeman Road, $0.9 \mathrm{mi}$ south of Old Spanish Trail, and $4 \mathrm{mi}$ southeast of Tucson city limits.

DRAINAGE AREA. $-0.17 \mathrm{mi}^{2}$.

ANNUAL PEAK DISCHARGE

\begin{tabular}{lccc}
$\begin{array}{l}\text { MATER } \\
\text { YEAR }\end{array}$ & DATE & $\begin{array}{c}\text { ANNUAL PEAK } \\
\text { DISCHARGE } \\
\left.\text { (FT } 3^{3} / \mathrm{S}\right)\end{array}$ & $\begin{array}{c}\text { DISCHARGE } \\
\text { CODES }\end{array}$ \\
\hline 1965 & $09-12-65$ & 29 & UR \\
1966 & $09-12-66$ & 23 & UR \\
1967 & $07-17-67$ & 33 & UR \\
1968 & $08-00-68$ & 49 & UR \\
1969 & $09-09-69$ & 28 & UR \\
1970 & $07-20-70$ & 29 & UR \\
1971 & $08-00-71$ & 30 & UR \\
1972 & $08-12-72$ & 4.4 & UR \\
1973 & $08-00-73$ & 10 & UR \\
1974 & $00-00-74$ & 0 & UR \\
1974 & 0 & &
\end{tabular}

MAGNI TUDE AND PROBABILITY OF INSTANTANEOUS PEAK FLON BASED ON PERIOD OF RECORD 1965-74

DISCHARGE, IN FT $3 / 5$, FOR INDICATED RECURRENCE INTERVAL IN YEARS, AND EXCEEDANCE PROBABILITY, IN PERCENT

\begin{tabular}{cccccc}
2 & 5 & 10 & $25 \uparrow$ & $50 \uparrow$ & $100 \uparrow$ \\
$50 \%$ & $20 \%$ & $10 \%$ & $4 \%$ & $2 \%$ & $1 \%$ \\
27.4 & 34.4 & 39.1 & 44.8 & 49.1 & 53.4 \\
\hline WEIGHTED SKEW (LOGS) & 0.21 & & \\
MEAN & $\begin{array}{l}\text { (LOGS) } \\
\text { STANDARD DEV. (LOGS) }\end{array}$ & 1.44 & 0.11 & &
\end{tabular}

f Reliability of values in column is uncertain, and potential errors are large.

BASIN CHARACTERISTICS

\begin{tabular}{|c|c|c|c|c|c|c|c|}
\hline MAIN & & $\begin{array}{l}\text { MEAN } \\
\text { BASIN }\end{array}$ & & & $\begin{array}{l}\text { MEAN } \\
\text { ANNUAL }\end{array}$ & RAINFALL II & SITY, 24-HOUR \\
\hline $\begin{array}{l}\text { CHANNEL } \\
\text { SLOPE } \\
\text { (FT/MI) }\end{array}$ & $\begin{array}{l}\text { STREAM } \\
\text { LENGTH } \\
\text { (MI) }\end{array}$ & $\begin{array}{l}\text { ELEVA- } \\
\text { TION } \\
\text { (FT) }\end{array}$ & $\begin{array}{l}\text { FORESTED } \\
\text { AREA } \\
\text { (PERCENT) }\end{array}$ & $\begin{array}{l}\text { SOIL } \\
\text { INDEX }\end{array}$ & $\begin{array}{l}\text { PRECIPI - } \\
\text { TATION } \\
\text { (IN) }\end{array}$ & $\begin{array}{c}\text { 2-YEAR } \\
\text { (IN) }\end{array}$ & $\begin{array}{c}\text { 50-YEAR } \\
\text { (IN) }\end{array}$ \\
\hline 117 & 0.4 & 3,040 & 0.0 & 1.0 & 12.0 & 1.8 & 4.0 \\
\hline
\end{tabular}


09485500 PANTANO MASH MEAR tUCSON, AZ

LOCATION.--Lat 32.14'57", long110 $50^{\circ} 53^{\prime \prime}$, in NWHEY sec.6, T.14 S., R.15 E., Pima County, Hydrologic Unit 15050302, at Tanque Verde Road $0.7 \mathrm{mi}$ northeast of Tucson city limits, and $1.75 \mathrm{mi}$ above mouth.

DRAINAGE AREA. - -602 $\mathrm{mi}^{2}$.

ANNUAL PEAK DISCHARGE

\begin{tabular}{lccc}
$\begin{array}{c}\text { MATER } \\
\text { YEAR }\end{array}$ & DATE & $\begin{array}{c}\text { ANMUAL PEAK } \\
\text { DISCHARGE } \\
\text { (FT } 3 / \text { S) }\end{array}$ & $\begin{array}{c}\text { DISCHARGE } \\
\text { CODES }\end{array}$ \\
\hline 1940 & $08-13-40$ & 9,200 & HP \\
1958 & $08-12-58$ & 120,000 & HP \\
1965 & $08-18-65$ & 250 & \\
1966 & $08-13-66$ & 2,820 & \\
1967 & $07-12-67$ & 4,120 & \\
1968 & $12-20-67$ & 2,420 & \\
1969 & $08-05-69$ & 1,250 & \\
1970 & $07-20-70$ & 6,480 & \\
1971 & $08-20-71$ & 212,800 & \\
1972 & $09-07-72$ & 180 & \\
1973 & $10-19-72$ & 500 & ES \\
1974 & $07-20-74$ & 600 & ES \\
1975 & $07-16-75$ & 3,490 & \\
1976 & $08-10-76$ & 3,080 & \\
1979 & $00-00-79$ & 1,530 & \\
1980 & $00-00-80$ & 1,000 & \\
1981 & $00-00-81$ & 9,700 & \\
1984 & $83-10-01$ & 11,000 & HP
\end{tabular}

$1_{\text {Highest since } 1930 .}$

2Highest since 1958.

MAGNITUDE AND PROBABILITY OF INSTANTANEOUS PEAK FLOW BASED ON PERIOD OF RECORD 1940, 1958, 1965-76, 1979-81, 1984

DISCHARGE, IN $\mathrm{FT}^{3} / \mathrm{S}$, FOR INDICATED RECURRENCE INTERVAL IN YEARS, AND EXCEEDANCE PROBABILITY, IN PERCENT

\begin{tabular}{|c|c|c|c|c|c|}
\hline $\begin{array}{c}2 \\
50 \%\end{array}$ & $\begin{array}{c}5 \\
20 \%\end{array}$ & $\begin{array}{r}10 \\
10 \%\end{array}$ & $\begin{array}{l}25 \\
4 \%\end{array}$ & $\begin{array}{l}50 \dagger \\
2 \%\end{array}$ & $\begin{array}{c}100 \dagger \\
1 \%\end{array}$ \\
\hline 1,720 & 4,620 & 7,540 & 12,500 & 17.100 & 22,600 \\
\hline $\begin{array}{l}\text { WEIGHTED } \\
\text { MEAN } \\
\text { STANDARD }\end{array}$ & $\begin{array}{l}\text { SKEW } \\
\text { DEV. }\end{array}$ & $\begin{array}{l}\text { OGS })= \\
O G S)= \\
O G S)=\end{array}$ & $\begin{array}{r}-0.22 \\
3.22 \\
0.53\end{array}$ & & \\
\hline
\end{tabular}

i Reliability of values in column is uncertain, and potential errors are large.

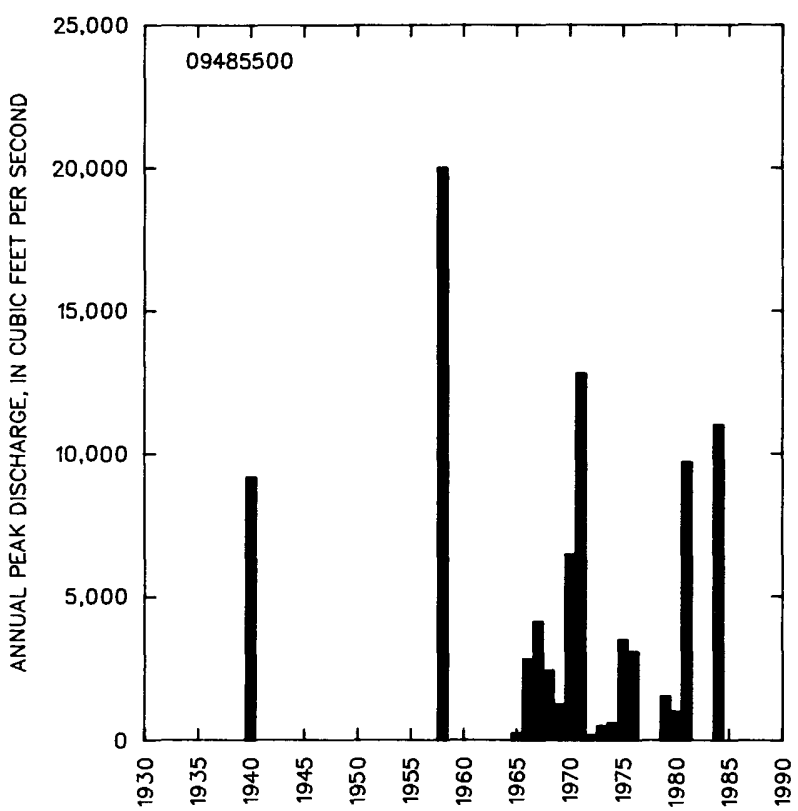

BASIN CHARACTERISTICS

\begin{tabular}{|c|c|c|c|c|c|c|c|}
\hline MAIN & & $\begin{array}{r}\text { MEAN } \\
\text { BASIN }\end{array}$ & & & $\begin{array}{c}\text { MEAN } \\
\text { ANNUAL }\end{array}$ & RAINFALL II & SITY, 24-HOUR \\
\hline $\begin{array}{c}\text { CHANNEL } \\
\text { SLOPE } \\
\text { (FT/MI) }\end{array}$ & $\begin{array}{l}\text { STREAM } \\
\text { LENGTH } \\
\text { (MI) }\end{array}$ & $\begin{array}{c}\text { ELEVA- } \\
\text { TION } \\
\text { (FT) }\end{array}$ & $\begin{array}{l}\text { FORESTED } \\
\text { AREA } \\
\text { (PERCENT) }\end{array}$ & $\begin{array}{r}\text { SOIL } \\
\text { INDEX }\end{array}$ & $\begin{array}{l}\text { PRECIPI- } \\
\text { TATION } \\
\text { (IN) }\end{array}$ & $\begin{array}{c}\text { 2-YEAR } \\
\text { (IN) }\end{array}$ & $\begin{array}{c}\text { 50-YEAR } \\
\text { (IN) }\end{array}$ \\
\hline 56.4 & 54.4 & 4,560 & 16.0 & 1.1 & 17.1 & 1.9 & 4.1 \\
\hline
\end{tabular}


LOCATION.--Lat 32.14'37", long 110:53'05", in SEXNWH sec.2, T.14 S., R.14 E., Pime County, Hydrologic Unit 15050302, on right bank $150 \mathrm{ft}$ downstream from Pime street in Tucson.

DRAIMAGE AREA. $--2.72 \mathrm{mi}^{2}$.

REMARKS.--Entire drainage basin is an urban, residential area.

ANIUAL PEAK DISCHARGE

\begin{tabular}{|c|c|c|c|}
\hline $\begin{array}{l}\text { WATER } \\
\text { YEAR }\end{array}$ & DATE & $\begin{array}{l}\text { ANNUAL PEAK } \\
\text { DISCHARGE } \\
\left(\mathrm{FT}^{3} / \mathrm{S}\right)\end{array}$ & $\begin{array}{l}\text { DISCHARGE } \\
\text { CODES }\end{array}$ \\
\hline $\begin{array}{l}1966 \\
1968 \\
1969 \\
1970 \\
1971 \\
1972 \\
1973 \\
1974 \\
1975 \\
1976 \\
1977 \\
1978 \\
1979 \\
1980 \\
1981 \\
1982 \\
1983\end{array}$ & $\begin{array}{l}07-19-66 \\
08-19-68 \\
08-05-69 \\
08-11-70 \\
08-17-71 \\
08-12-72 \\
07-07-73 \\
07-18-74 \\
07-16-75 \\
09-25-76 \\
09-10-77 \\
09-21-78 \\
08-12-79 \\
08-13-80 \\
06-25-81 \\
09-11-82 \\
11-30-82\end{array}$ & $\begin{array}{r}658 \\
310 \\
265 \\
594 \\
11,210 \\
940 \\
121 \\
264 \\
134 \\
342 \\
220 \\
661 \\
647 \\
595 \\
330 \\
836 \\
157\end{array}$ & $\begin{array}{l}H P, C \\
C \\
C \\
C \\
C \\
C \\
C \\
C \\
C \\
C \\
C \\
C \\
C \\
C \\
C \\
C \\
C\end{array}$ \\
\hline
\end{tabular}

IHighest since 1963.

MAGNITUDE AND PROBABILITY OF INSTANTANEOUS PEAK FLON BASED ON PERIOD OF RECORD 1966, 1968-83

DISCHARGE, IN $\mathrm{FT}^{3} / \mathrm{S}$, FOR INDICATED RECURRENCE INTERVAL IN YEARS, AND EXCEEDANCE PROBABILITY, IN PERCENT

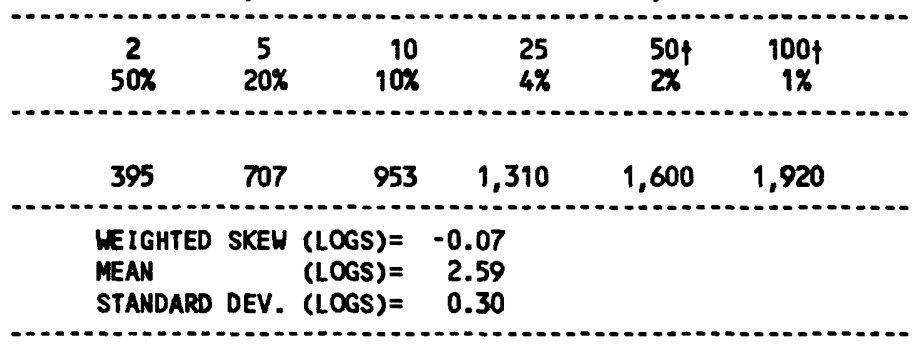

† Reliability of values in column is uncertain, and potential errors are large.

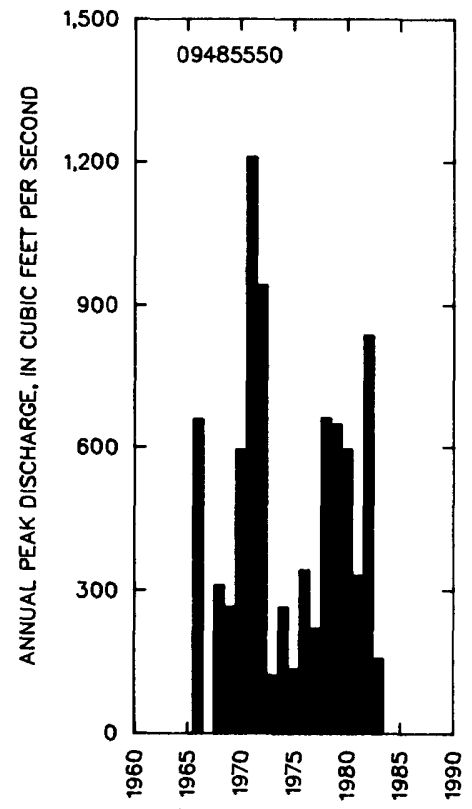

BASIN CHARACTERISTICS

\begin{tabular}{|c|c|c|c|c|c|c|c|}
\hline & & MEAN & & & MEAN & & \\
\hline MAIN & & BASIN & & & ANNUAL & RAINFALL I & SITY, 24-HOUR \\
\hline $\begin{array}{l}\text { CFANREL } \\
\text { SLOPE } \\
\text { (FT/MI) }\end{array}$ & $\begin{array}{l}\text { LENGTH } \\
\text { (MI) }\end{array}$ & $\begin{array}{l}\text { TION } \\
\text { (FT) }\end{array}$ & $\begin{array}{l}\text { AREA } \\
\text { (PERCENT) }\end{array}$ & $\begin{array}{l}\text { SOIL } \\
\text { INDEX }\end{array}$ & $\begin{array}{c}\text { TATION } \\
\text { (IN) }\end{array}$ & $\begin{array}{c}\text { 2-YEAR } \\
\text { (IN) }\end{array}$ & $\begin{array}{l}\text { 50-YEAR } \\
\text { (IN) }\end{array}$ \\
\hline 0.77 & 5.54 & 2,560 & 0.0 & 1.0 & 11.0 & 1.7 & 4.2 \\
\hline
\end{tabular}


09485570 ALAMO WASH AT TUCSON, AZ

LOCATION.--Lat 32.15'31", long 110.53'01", in SEXSEXawk, sec.35, T.13 S., R.14 E.., Pima County, Hydrologic Unit 15050302, $270 \mathrm{ft}$ downstream from Glem Street, 0.5 mi east of the intersection of Glenn Street and Swan Road in Tucson.

DRAIMAGE AREA. $--9.58 \mathrm{ml}^{2}$.

ANNUAL PEAK DISCHARGE

\begin{tabular}{|c|c|c|c|}
\hline $\begin{array}{l}\text { WATER } \\
\text { YEAR }\end{array}$ & DATE & $\begin{array}{c}\text { ANNUAL PEAK } \\
\text { DISCHARGE } \\
\left(\mathrm{FT}^{3} / \mathrm{S}\right)\end{array}$ & $\begin{array}{l}\text { DI SCHARGE } \\
\text { CODES }\end{array}$ \\
\hline $\begin{array}{l}1976 \\
1977 \\
1979 \\
1980 \\
1981 \\
1982 \\
1983 \\
1984 \\
1986 \\
1987 \\
1988 \\
1989\end{array}$ & $\begin{array}{l}09-25-76 \\
09-10-77 \\
08-12-79 \\
08-13-80 \\
06-25-81 \\
08-23-82 \\
09-23-83 \\
07-16-84 \\
07-21-86 \\
07-26-87 \\
08-20-88 \\
07-26-89\end{array}$ & $\begin{array}{r}3,200 \\
2,500 \\
1,890 \\
820 \\
800 \\
3,310 \\
714 \\
2,280 \\
2,340 \\
432 \\
4,000 \\
853\end{array}$ & $\begin{array}{l}C \\
C \\
c \\
C \\
C \\
C \\
C \\
C \\
C \\
C \\
C \\
C\end{array}$ \\
\hline
\end{tabular}

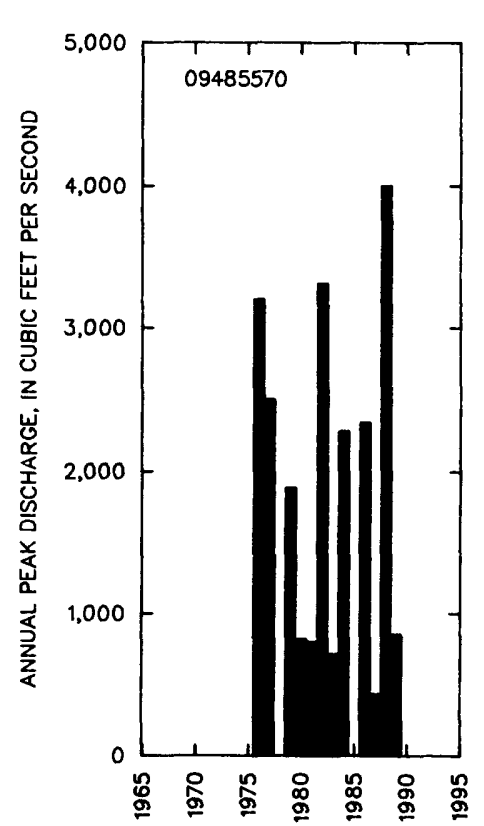

MagNitUde AND PROBABILITY OF INSTANTANEQUS PEAK FLOW BASED ON PERIOD OF RECORD 1976-89

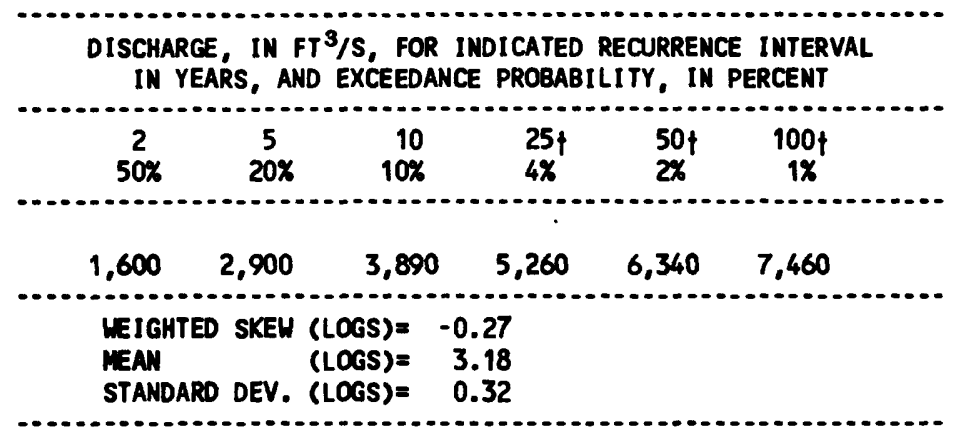

feliability of values in colum is uncertain, and potential errors are large.

BASIN CHARACTERISTICS

\begin{tabular}{|c|c|c|c|c|c|c|c|}
\hline \multirow{2}{*}{$\begin{array}{l}\text { MAIN } \\
\text { CHAMMEL } \\
\text { SLOPE } \\
\text { (FT/MI) }\end{array}$} & \multirow[b]{2}{*}{$\begin{array}{c}\text { STREAM } \\
\text { LENGTH } \\
\text { (MI) }\end{array}$} & \multirow{2}{*}{$\begin{array}{l}\text { MEAN } \\
\text { BASIN } \\
\text { ELEVA- } \\
\text { TION } \\
\text { (FT) }\end{array}$} & \multirow[b]{2}{*}{$\begin{array}{l}\text { FORESTED } \\
\text { AREA } \\
\text { (PERCENT) }\end{array}$} & \multirow[b]{2}{*}{$\begin{array}{l}\text { SOIL } \\
\text { INDEX }\end{array}$} & \multirow{2}{*}{$\begin{array}{l}\text { MEAN } \\
\text { ANNUAL } \\
\text { PRECIPI- } \\
\text { TATION } \\
\text { (IN) }\end{array}$} & \multicolumn{2}{|c|}{ RAINFALL INTENSITY, 24-HOQR } \\
\hline & & & & & & $\begin{array}{l}\text { 2-YEAR } \\
\text { (IN) }\end{array}$ & $\begin{array}{c}\text { 50-YEAR } \\
\text { (IN) }\end{array}$ \\
\hline 46.2 & 6.40 & 2,590 & 0.0 & 1.0 & 11.0 & 3.8 & 1.6 \\
\hline
\end{tabular}




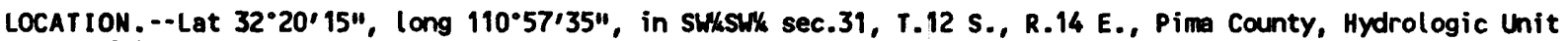
15050302, at Ina Road, and 4 mi north of Tucson city limits.

DRAINAGE AREA. $--4.93 \mathrm{mi}^{2}$.

ANIUUAL PEAK DISCHARGE

\begin{tabular}{|c|c|c|c|}
\hline $\begin{array}{l}\text { WATER } \\
\text { YEAR }\end{array}$ & DATE & $\begin{array}{c}\text { ANNUAL PEAK } \\
\text { DISCHARGE } \\
\left.\text { ( } \mathrm{FT}^{3} / \mathrm{S}\right)\end{array}$ & $\begin{array}{l}\text { DISCHARGE } \\
\text { CODES }\end{array}$ \\
\hline $\begin{array}{l}1964 \\
1965 \\
1966 \\
1967 \\
1968 \\
1969 \\
1970 \\
1971 \\
1972 \\
1973 \\
1974 \\
1975 \\
1976 \\
1977 \\
1978 \\
1979 \\
1980 \\
1981 \\
1984\end{array}$ & $\begin{array}{l}09-06-64 \\
00-00-65 \\
12-22-65 \\
07-17-67 \\
08-06-68 \\
09-06-69 \\
00-00-70 \\
08-12-71 \\
09-01-72 \\
10-19-72 \\
09-07-74 \\
10-30-74 \\
09-26-76 \\
01-00-77 \\
07-26-78 \\
12-18-78 \\
09-26-80 \\
05-01-81 \\
10-01-83\end{array}$ & $\begin{array}{c}195 \\
120 \\
125 \\
65 \\
50 \\
2.0 \\
80 \\
117 \\
170 \\
195 \\
5.0 \\
10 \\
2.0 \\
10 \\
300 \\
100 \\
30 \\
5.0 \\
1460\end{array}$ & $\begin{array}{l}\text { LT } \\
\text { LT } \\
\text { ES } \\
\text { ES }\end{array}$ \\
\hline
\end{tabular}

1Highest since 1964.

MAGNITUDE AND PROBABILITY OF INSTANTANEOUS PEAK FLON BASED ON PERICD OF RECORD 1964-81, 1984

DISCHARGE, IN $\mathrm{FT}^{3} / \mathrm{S}$, FOR INDICATED RECURRENCE INTERVAL IN YEARS, AND EXCEEDANCE PROBABILITY, IN PERCENT

\begin{tabular}{|c|c|c|c|c|c|}
\hline $\begin{array}{c}2 \\
50 \%\end{array}$ & $\begin{array}{c}5 \\
20 \%\end{array}$ & $\begin{array}{r}10 \\
10 \%\end{array}$ & $\begin{array}{l}25 \\
4 \%\end{array}$ & $\begin{array}{l}50 \gamma \\
2 \%\end{array}$ & $\begin{array}{c}100 \dagger \\
1 \%\end{array}$ \\
\hline 74.2 & 177 & 269 & 407 & 524 & 652 \\
\hline $\begin{array}{l}\text { WEIGHTED } \\
\text { MEAN } \\
\text { STANDARD }\end{array}$ & $\begin{array}{l}\text { SKEW } \\
\text { DEV. }\end{array}$ & $\begin{array}{l}(\text { LOGS })= \\
(\text { LOGS })= \\
(\text { LOGS })=\end{array}$ & $\begin{array}{r}-0.39 \\
1.84 \\
0.48\end{array}$ & & \\
\hline
\end{tabular}

t Reliability of values in colum is uncertain, and potential errors are large.

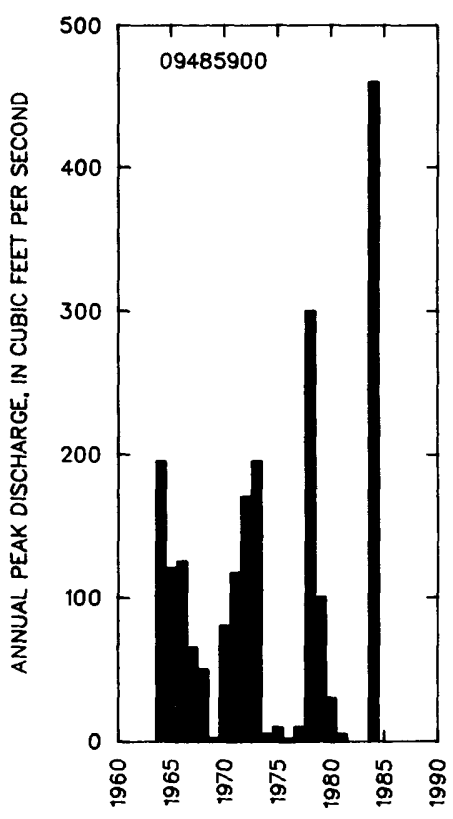

BASIN CHARACTERISTICS

\begin{tabular}{|c|c|c|c|c|c|c|c|}
\hline \multirow{3}{*}{$\begin{array}{l}\text { MAIN } \\
\text { CHANNEL } \\
\text { SLOPE } \\
\text { (FT/MI) }\end{array}$} & \multirow[b]{3}{*}{$\begin{array}{l}\text { STREAM } \\
\text { LENGTH } \\
\text { (MI) }\end{array}$} & \multirow{3}{*}{$\begin{array}{l}\text { MEAN } \\
\text { BASIN } \\
\text { ELEVA- } \\
\text { TION } \\
\text { (FT) }\end{array}$} & \multirow[b]{3}{*}{$\begin{array}{l}\text { FORESTED } \\
\text { AREA } \\
\text { (PERCENT) }\end{array}$} & \multirow[b]{3}{*}{$\begin{array}{l}\text { SOIL } \\
\text { INDEX }\end{array}$} & \multirow{3}{*}{$\begin{array}{l}\text { MEAN } \\
\text { ANNUAL } \\
\text { PRECIPI- } \\
\text { TATION } \\
\text { (IN) }\end{array}$} & \multirow{2}{*}{\multicolumn{2}{|c|}{ RAINFALL INTENSITY, 24-HOUR }} \\
\hline & & & & & & & \\
\hline & & & & & & $\begin{array}{l}\text { 2-YEAR } \\
\text { (IN) }\end{array}$ & $\begin{array}{l}\text { 50-YEAR } \\
\text { (IN) }\end{array}$ \\
\hline 533 & 5.5 & 4,430 & 18.0 & 1.0 & 16.0 & 1.9 & 4.5 \\
\hline
\end{tabular}




\section{GERONIMO WASH NEAR TUCSON, AZ}

LOCATION.--Lat 32'19'56", long 110'56'37", in SEXNEX sec.6, T.13 S., R.14 E., Pima County, Hydrologic Unit 15050302, at Skyline Drive, 0.4 mi southeast of Ina Road, and 3.5 mi north of Tucson city limits.

DRAINAGE AREA. $--2.15 \mathrm{mi}^{2}$.

ANIUAL PEAK DISCHARGE

\begin{tabular}{cccc}
$\begin{array}{c}\text { HATER } \\
\text { YEAR }\end{array}$ & DATE & $\begin{array}{c}\text { ANNUAL PEAK } \\
\text { DISCHARGE } \\
\text { (FT } 3 / \text { S) }\end{array}$ & $\begin{array}{c}\text { DISCHARGE } \\
\text { CODES }\end{array}$ \\
\hline 1964 & $09-06-64$ & 445 & \\
1965 & $08-02-65$ & 135 & \\
1966 & $12-22-65$ & 65 & \\
1967 & $07-17-67$ & 139 & \\
1968 & $08-10-68$ & 120 & \\
1969 & $09-06-69$ & 2.0 & ES \\
1970 & $09-00-70$ & 95 & \\
1971 & $08-12-71$ & 705 & \\
1972 & $09-01-72$ & 385 & \\
1973 & $10-00-72$ & 195 & \\
1974 & $07-19-74$ & 10 & \\
1975 & $10-29-74$ & 35 & \\
1976 & $09-26-76$ & 90 & \\
1977 & $09-10-77$ & 80 & \\
1978 & $07-26-78$ & 225 & \\
1979 & $08-12-79$ & 370 & \\
1980 & $08-13-80$ & 65 & \\
1981 & $07-10-81$ & 4.0 & \\
\hline$\ldots \ldots . \ldots 1$ & &
\end{tabular}

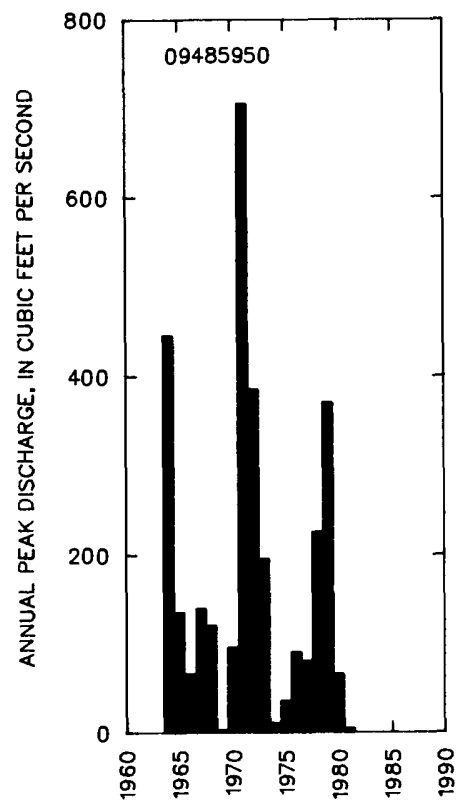

MAGNITUDE AND PROBABILITY OF INSTANTANEOUS PEAK FLON BASED ON PERIOD OF RECORD 1964-81

DISCHARGE, IN $\mathrm{FT}^{3} / \mathrm{S}$, FOR INDICATED RECURRENCE INTERVAL IN YEARS, AND EXCEEDANCE PROBABILITY, IN PERCENT

\begin{tabular}{|c|c|c|c|c|c|}
\hline$\underset{50 \%}{2}$ & $\begin{array}{r}5 . \\
20 \%\end{array}$ & $\begin{array}{r}10 \\
10 \%\end{array}$ & $\begin{array}{l}25 \\
4 \%\end{array}$ & $\begin{array}{l}50 \nmid \\
2 \%\end{array}$ & $\begin{array}{c}100 \nmid \\
1 \%\end{array}$ \\
\hline 118 & 271 & 414 & 643 & 850 & 1,090 \\
\hline $\begin{array}{l}\text { WEIG } \\
\text { MEAN } \\
\text { STAN }\end{array}$ & SKEW & $\begin{array}{l}(\text { LOGS })= \\
(\text { LOGS }= \\
(\text { LOGS })=\end{array}$ & $\begin{array}{r}-0.14 \\
2.06 \\
0.44\end{array}$ & & \\
\hline
\end{tabular}

f Reliability of values in column is uncertain, and potential errors are large.

\section{BASIN CHARACTERISTICS}

\begin{tabular}{|c|c|c|c|c|c|c|c|}
\hline \multirow{3}{*}{$\begin{array}{l}\text { MAIN } \\
\text { CHANNEL } \\
\text { SLOPE } \\
\text { (FT/MI) }\end{array}$} & \multirow[b]{3}{*}{$\begin{array}{c}\text { STREAM } \\
\text { LENGTH } \\
\text { (MI) }\end{array}$} & \multirow{3}{*}{$\begin{array}{l}\text { MEAN } \\
\text { BASIN } \\
\text { ELEVA- } \\
\text { TION } \\
\text { (FT) }\end{array}$} & \multirow[b]{3}{*}{$\begin{array}{l}\text { FORESTED } \\
\text { AREA } \\
\text { (PERCENT) }\end{array}$} & \multirow[b]{3}{*}{$\begin{array}{l}\text { SOIL } \\
\text { INDEX }\end{array}$} & \multirow{2}{*}{$\begin{array}{c}\text { MEAN } \\
\text { ANNUAL } \\
\text { PRECIPI- }\end{array}$} & \multirow{2}{*}{\multicolumn{2}{|c|}{ RAINFALL INTENSITY, 24-HOUR }} \\
\hline & & & & & & & \\
\hline & & & & & $\begin{array}{l}\text { PRECIPI- } \\
\text { TATION } \\
\text { (IN) }\end{array}$ & $\begin{array}{c}\text { 2-YEAR } \\
\text { (IN) }\end{array}$ & $\begin{array}{c}\text { 50-YEAR } \\
\text { (IN) }\end{array}$ \\
\hline 699 & 3.6 & 3,600 & 0.0 & 1.0 & 15.0 & 1.9 & 4.4 \\
\hline
\end{tabular}


LOCATION. --Lat 32.17'41", long 110.59'00", in SWKSEX sec.14, T.13 S., R.13 E., Pima County, Hydrologic Unit 15050302, on right bank $600 \mathrm{ft}$ downstream from Pima Wash, 1,800 ft downstream from U.S. Highway $89,5 \mathrm{mi}$ above mouth, and $\mathbf{5 . 4} \mathrm{mi}$ north of city hall in rucson.

DRAINAGE AREA. $--918 \mathrm{mi}^{2}$.

ANNUAL PEAK DISCHARGE

\begin{tabular}{|c|c|c|c|c|c|c|c|}
\hline $\begin{array}{l}\text { WATER } \\
\text { YEAR }\end{array}$ & DATE & $\begin{array}{c}\text { ANNUAL PEAK } \\
\text { DISCHARGE } \\
\left(\mathrm{FT}^{3} / \mathrm{S}\right)\end{array}$ & $\begin{array}{l}\text { DISCHARGE } \\
\text { COOES }\end{array}$ & $\begin{array}{l}\text { WATER } \\
\text { YEAR }\end{array}$ & DATE & $\begin{array}{c}\text { ANIUAL PEAK } \\
\text { DISCHARGE } \\
\left(\mathrm{FT}^{3} / \mathrm{S}\right)\end{array}$ & $\begin{array}{l}\text { DISCHARGE } \\
\text { COOES }\end{array}$ \\
\hline $\begin{array}{l}1915 \\
1916 \\
1917 \\
1918 \\
1919 \\
1920 \\
1921 \\
1922 \\
1923 \\
1924 \\
1925 \\
1926 \\
1927 \\
1928 \\
1929 \\
1930 \\
1931 \\
1932 \\
1933 \\
1934 \\
1935 \\
1936 \\
1937 \\
1938 \\
1939 \\
1940 \\
1941 \\
1942 \\
1943 \\
1944 \\
1945 \\
1946 \\
1947 \\
1948\end{array}$ & $\begin{array}{l}12-23-14 \\
01-19-16 \\
08-11-17 \\
03-01-18 \\
07-27-19 \\
02-21-20 \\
07-31-21 \\
08-09-22 \\
08-26-23 \\
12-26-23 \\
09-17-25 \\
09-27-26 \\
09-12-27 \\
08-01-28 \\
09-23-29 \\
08-08-30 \\
08-10-31 \\
07-29-32 \\
09-10-33 \\
07-17-34 \\
08-31-35 \\
08-17-36 \\
08-17-37 \\
03-04-38 \\
08-03-39 \\
08-13-40 \\
12-31-40 \\
09-14-42 \\
08-15-43 \\
08-09-44 \\
08-10-45 \\
08-31-46 \\
08-15-47 \\
09-26-48\end{array}$ & $\begin{array}{r}17,000 \\
7,620 \\
10,000 \\
5,300 \\
9,250 \\
7,800 \\
16,000 \\
3,250 \\
4,000 \\
1,980 \\
3,500 \\
1,750 \\
2,200 \\
4,500 \\
24,000 \\
4,600 \\
7,200 \\
7,200 \\
4,400 \\
3,000 \\
13,400 \\
4,500 \\
2,980 \\
3,000 \\
9,710 \\
13,200 \\
9,900 \\
1,600 \\
3,850 \\
4,100 \\
7,000 \\
4,160 \\
7,660 \\
779\end{array}$ & · & $\begin{array}{l}1949 \\
1950 \\
1951 \\
1952 \\
1953 \\
1954 \\
1955 \\
1956 \\
1957 \\
1958 \\
1959 \\
1960 \\
1961 \\
1962 \\
1963 \\
1964 \\
1965 \\
1966 \\
1967 \\
1968 \\
1969 \\
1970 \\
1971 \\
1972 \\
1973 \\
1974 \\
1975 \\
1976 \\
1977 \\
1978 \\
1979 \\
1980 \\
1981 \\
1984\end{array}$ & $\begin{array}{l}09-15-49 \\
07-30-50 \\
07-25-51 \\
11-11-51 \\
07-16-53 \\
07-24-54 \\
07-21-55 \\
07-29-56 \\
01-09-57 \\
08-12-58 \\
08-17-59 \\
01-12-60 \\
07-22-61 \\
09-26-62 \\
08-26-63 \\
09-10-64 \\
09-12-65 \\
12-22-65 \\
08-19-67 \\
02-12-68 \\
08-05-69 \\
09-06-70 \\
08-20-71 \\
08-12-72 \\
10-20-72 \\
08-02-74 \\
07-16-75 \\
09-25-76 \\
09-05-77 \\
03-02-78 \\
00-00-79 \\
00-00-80 \\
00-00-81 \\
10-02-83\end{array}$ & $\begin{array}{r}1,640 \\
9,490 \\
9,500 \\
1,630 \\
5,470 \\
7,680 \\
8,070 \\
2,050 \\
4,500 \\
8,930 \\
7,710 \\
3,610 \\
4,140 \\
2,690 \\
7,640 \\
9,420 \\
754 \\
12,400 \\
3,100 \\
7,740 \\
2,220 \\
7,000 \\
9,290 \\
1,820 \\
5,160 \\
1,440 \\
2,270 \\
9,400 \\
1,200 \\
7,500 \\
16,400 \\
2,300 \\
4,600 \\
129,700\end{array}$ & ES \\
\hline
\end{tabular}

IHighest since 1915.

BASIN CHARACTERISTICS

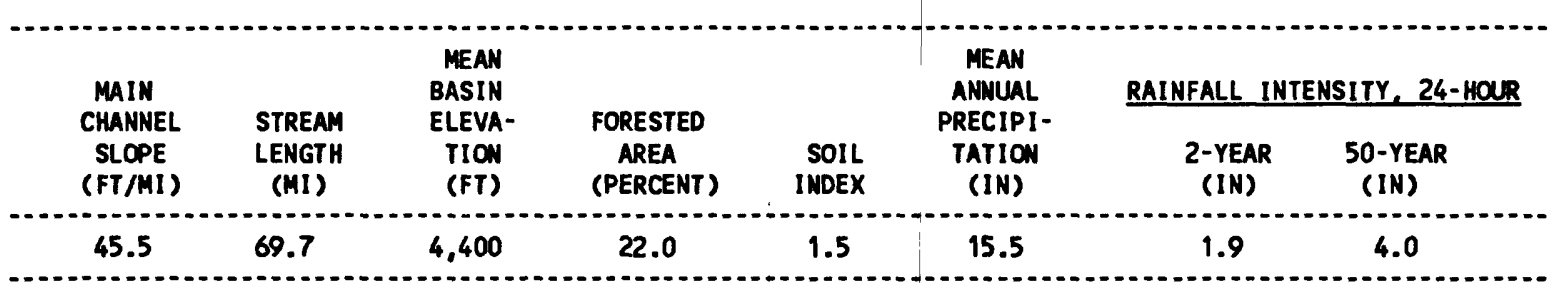


MEAN MONTHLY AND ANMUAL DISCHAREES 1914, 1916-75

\begin{tabular}{|c|c|c|c|c|c|c|}
\hline MONTH & $\begin{array}{l}\operatorname{MAXIMUM} \\
\left(F T^{3} / S\right)\end{array}$ & $\begin{array}{l}\text { MINIMUM } \\
\left(F T^{3} / S\right)\end{array}$ & $\begin{array}{c}\text { MEAN } \\
\left(F T^{3} / S\right)\end{array}$ & $\begin{array}{l}\text { STAN- } \\
\text { DARD } \\
\text { DEVIA- } \\
\text { TION } \\
\left(\mathrm{FT}^{3} / \mathrm{S}\right)\end{array}$ & $\begin{array}{l}\text { COEFFI- } \\
\text { CIENT OF } \\
\text { VARI - } \\
\text { ATION }\end{array}$ & $\begin{array}{c}\text { PERCENT } \\
\text { OF } \\
\text { ANNUAL } \\
\text { RUNOFF }\end{array}$ \\
\hline $\begin{array}{l}\text { OCTOBER } \\
\text { NOVEMBER } \\
\text { OECENBER } \\
\text { JANUARY } \\
\text { FEBRUARY } \\
\text { MARCH } \\
\text { APRIL } \\
\text { MAY } \\
\text { JUNE } \\
\text { JULY } \\
\text { AUCUST } \\
\text { SEPTEMBER }\end{array}$ & $\begin{array}{c}116 \\
40 \\
556 \\
603 \\
203 \\
183 \\
13 \\
69 \\
9.7 \\
500 \\
263 \\
302\end{array}$ & $\begin{array}{l}0.00 \\
0.00 \\
0.00 \\
0.00 \\
0.00 \\
0.00 \\
0.00 \\
0.00 \\
0.00 \\
0.00 \\
0.00 \\
0.00\end{array}$ & $\begin{array}{l}2.8 \\
2.0 \\
18 \\
18 \\
21 \\
17 \\
0.89 \\
1.1 \\
0.54 \\
29 \\
37 \\
17\end{array}$ & $\begin{array}{l}15 \\
7.5 \\
77 \\
80 \\
46 \\
37 \\
2.8 \\
8.8 \\
1.9 \\
84 \\
49 \\
44\end{array}$ & $\begin{array}{l}5.3 \\
3.8 \\
4.2 \\
4.5 \\
2.2 \\
2.2 \\
3.1 \\
7.8 \\
3.5 \\
2.9 \\
1.3 \\
2.7\end{array}$ & $\begin{array}{r}1.7 \\
1.2 \\
11.2 \\
10.9 \\
12.6 \\
10.3 \\
0.5 \\
0.7 \\
0.3 \\
17.7 \\
22.7 \\
10.1\end{array}$ \\
\hline ANNUAL & 74 & 0.43 & 14 & 17 & 1.2 & 100 \\
\hline
\end{tabular}

magnI TUDE ANO PROBABILITY OF InSTANTANEOUS PEAK FLON BASED ON PERIOD OF RECORD 1915-81, 1984

DISCHARGE, IN $\mathrm{FT}^{3} / \mathrm{S}$, FOR INDICATED RECURRENCE INTERVAL IN YEARS, AND EXCEEDANCE PROBABILITY, IN PERCENT

\begin{tabular}{lccccc}
2 & 5 & 10 & 25 & 50 & 100 \\
$50 \%$ & $20 \%$ & $10 \%$ & $4 \%$ & $2 \%$ & $1 \%$ \\
5,120 & 9,530 & 13,100 & 18,400 & 22,800 & 27,700 \\
\hline WEIGHTED SKEW (LOGS) & & -0.07 & & \\
MEAN & (LOGS) & 3.70 & & \\
STANDARD DEV. (LOGS) & $=0.32$
\end{tabular}

DURATION TABLE OF DAILY MEAN FLON FOR PERICD OF RECORD 1914, 1916-75
MAGNITUDE AND PROBABILITY OF ANHUAL LON FLON BASED ON PERIOD OF RECORD 1915, 1917-75

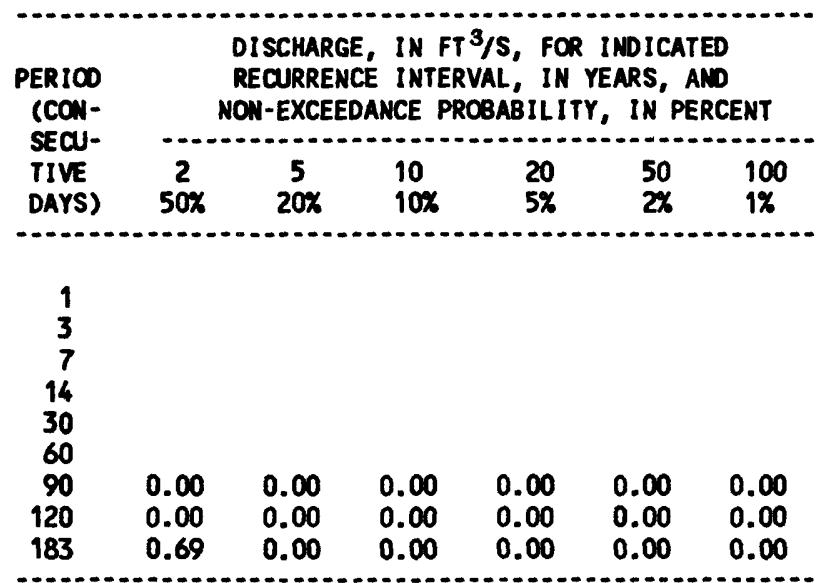

MAGNITUDE AND PROBABILITY OF ANNUAL HIGH FLOH BASED ON PERIOD OF RECORD 1914, 1916-75

\begin{tabular}{|c|c|c|c|c|c|c|}
\hline $\begin{array}{l}\text { PERICO } \\
\text { CCON- } \\
\text { SECU- }\end{array}$ & & $\begin{array}{l}\text { DISCHAR } \\
\text { RECURRE } \\
\text { EXCEED }\end{array}$ & $\begin{array}{l}\text { IN } \\
\text { E INTE } \\
\text { PROE }\end{array}$ & $\begin{array}{l}3 / S, \\
\text { VAL, } \\
\text { BILITY }\end{array}$ & $\begin{array}{l}\text { INDIC } \\
\text { YEARS, }\end{array}$ & \\
\hline $\begin{array}{l}\text { TIVE } \\
\text { DAYS) }\end{array}$ & $\begin{array}{c}2 \\
50 x\end{array}$ & $\begin{array}{c}5 \\
20 \%\end{array}$ & $\begin{array}{l}10 \\
10 \%\end{array}$ & $\begin{array}{l}25 \\
4 \%\end{array}$ & $\begin{array}{l}50 \\
2 \%\end{array}$ & $\begin{array}{r}100 \\
1 \%\end{array}$ \\
\hline $\begin{array}{r}1 \\
3 \\
7 \\
15 \\
30 \\
60 \\
90\end{array}$ & $\begin{array}{r}863 \\
380 \\
186 \\
104 \\
62 \\
36 \\
25\end{array}$ & $\begin{array}{r}2,020 \\
999 \\
493 \\
280 \\
166 \\
94 \\
68\end{array}$ & $\begin{array}{r}3,040 \\
1,630 \\
811 \\
464 \\
275 \\
154 \\
112\end{array}$ & $\begin{array}{r}4,560 \\
2,700 \\
1,370 \\
786 \\
463 \\
258 \\
190\end{array}$ & $\begin{array}{r}5,840 \\
3,730 \\
1,910 \\
1,100 \\
645 \\
357 \\
266\end{array}$ & $\begin{array}{r}7,220 \\
4,960 \\
2,570 \\
1,480 \\
866 \\
476 \\
360\end{array}$ \\
\hline
\end{tabular}

DISCHARGE, IN FT $3 / 5$, UHICH WAS EQUALED OR EXCEEDED FOR INDICATED PERCENT OF TIME

\begin{tabular}{|c|c|c|c|c|c|c|c|c|c|c|c|c|c|c|c|c|}
\hline $1 x$ & $5 \%$ & $10 x$ & $15 x$ & $20 \%$ & $30 \%$ & $40 \%$ & $50 x$ & $60 x$ & $70 \%$ & $80 \%$ & $90 \%$ & $95 \%$ & $98 \%$ & $99 \%$ & $99.5 \%$ & $99.9 \%$ \\
\hline 30 & 23 & 0.01 & 0.01 & 0.01 & 0.01 & 0.01 & 0.01 & 0.00 & 0.00 & 0.00 & 0.00 & 0.00 & 0.00 & 0.00 & 0.00 & .00 \\
\hline
\end{tabular}

† Reliability of values in column is uncertain, and potential errors are large. 
09486000 RILLITO CREEK NEAR TUCSON, AZ--CONTINUED
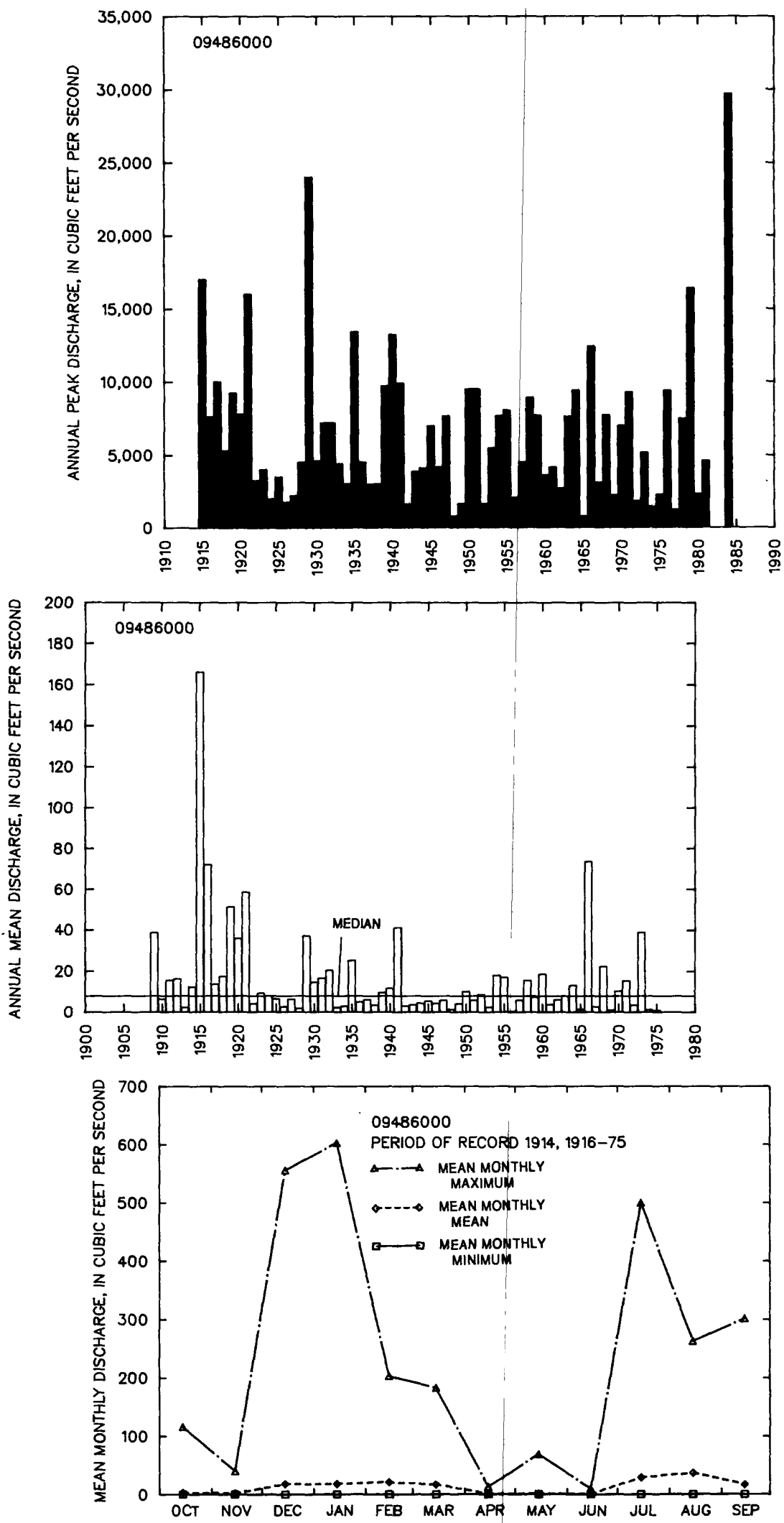
09486300 CANADA DEL ORO NEAR TUCSON, NZ

LOCATION.--Lat 32.22'27", long $111^{\circ} 00^{\prime} 31^{\prime \prime}$, in SW/2NW' sec.22, T.12 S., R.13 E., Pima County, Hydrologic Unit 15050301 , on right bank at upstream side of Overton Road, 4.7 mi upstream from mouth, and 10.5 mi north of city hall in Tucson.

DRAINAGE AREA. $--250 \mathrm{mi}^{2}$.

REMARKS. - -Lago del Oro-capacity 9,400 acre-ft-16 mi upstream, has contained no storage since May 4, 1971 , as gates were opened by court order; however, peak flows are regulated while passing through the lake.

ANNUAL PEAK DISCHARGE

\begin{tabular}{|c|c|c|c|}
\hline $\begin{array}{l}\text { WATER } \\
\text { YEAR }\end{array}$ & DATE & $\begin{array}{c}\text { ANNUAL PEAK } \\
\text { DISCHARGE } \\
\left(F^{3} / S\right)\end{array}$ & $\begin{array}{l}\text { DISCHARGE } \\
\text { COOES }\end{array}$ \\
\hline $\begin{array}{l}1959 \\
1961 \\
1964 \\
1966 \\
1967 \\
1968 \\
1969 \\
1970 \\
1971 \\
1972 \\
1973 \\
1974 \\
1975 \\
1976 \\
1977 \\
1978 \\
1979 \\
1980 \\
1981 \\
1984\end{array}$ & $\begin{array}{l}07-21-59 \\
09-01-61 \\
09-10-64 \\
12-22-65 \\
08-05-67 \\
12-20-67 \\
07-22-69 \\
08-18-70 \\
08-17-71 \\
08-12-72 \\
10-19-72 \\
07-20-74 \\
09-04-75 \\
09-05-76 \\
08-09-77 \\
01-16-78 \\
11-25-78 \\
07-19-80 \\
07-25-81 \\
10-01-83\end{array}$ & $\begin{array}{r}117,000 \\
12,000 \\
8,000 \\
2,290 \\
652 \\
213,900 \\
454 \\
1,930 \\
4,200 \\
728 \\
3,750 \\
7,700 \\
454 \\
2,220 \\
4,500 \\
2,070 \\
1,380 \\
4,240 \\
5,900 \\
6,600\end{array}$ & $\begin{array}{l}\text { ES, HP } \\
\text { ES, HP } \\
\text { ES, HP }\end{array}$ \\
\hline
\end{tabular}

BASIN CHARACTERISTICS

\begin{tabular}{|c|c|c|c|c|c|c|c|}
\hline \multirow{3}{*}{$\begin{array}{l}\text { MAIN } \\
\text { CHANNEL } \\
\text { SLOPE } \\
\text { (FT/MI) }\end{array}$} & \multicolumn{3}{|c|}{ MEAN } & \multicolumn{3}{|c|}{ MEAN } & \multirow[b]{2}{*}{ 24-HOUR } \\
\hline & & BASIN & & & ANNUAL & RAINFALL II & \\
\hline & $\begin{array}{l}\text { STREAM } \\
\text { LENGTH } \\
\text { (MI) }\end{array}$ & $\begin{array}{c}\text { ELEVA- } \\
\text { TION } \\
\text { (FT) }\end{array}$ & $\begin{array}{l}\text { FORESTED } \\
\text { AREA } \\
\text { (PERCENT) }\end{array}$ & $\begin{array}{l}\text { SOIL } \\
\text { INDEX }\end{array}$ & $\begin{array}{l}\text { PRECIPI- } \\
\text { TATION } \\
\text { (IN) }\end{array}$ & $\begin{array}{l}\text { 2-YEAR } \\
\text { (IN) }\end{array}$ & $\begin{array}{l}\text { 50-YEAR } \\
\text { (IN) }\end{array}$ \\
\hline 108 & 28.4 & 4,000 & 21.0 & 2.0 & 16.4 & 2.0 & 4.7 \\
\hline
\end{tabular}


MEAN MONTHLY AND ANNUAL DISCHARGES 1966-78

\begin{tabular}{|c|c|c|c|c|c|c|}
\hline MONTH & $\begin{array}{l}\max _{\left(F T^{3} / S\right)} \\
\left(F^{\prime}\right)\end{array}$ & $\begin{array}{l}\operatorname{MINIMUM} \\
\left(\mathrm{FT}^{3} / \mathrm{S}\right)\end{array}$ & $\begin{array}{c}\text { MEAN } \\
\left(F T^{3} / S\right)\end{array}$ & $\begin{array}{l}\text { STAN- } \\
\text { DAPD } \\
\text { DEVIA- } \\
\text { TION } \\
\left(F T^{3} / S\right)\end{array}$ & $\begin{array}{l}\text { COEFFI - } \\
\text { CIENT OF } \\
\text { VARI - } \\
\text { ATION }\end{array}$ & $\begin{array}{c}\text { PERCENT } \\
\text { OF } \\
\text { ANHUAL } \\
\text { RUNOFF }\end{array}$ \\
\hline $\begin{array}{l}\text { OCTOBER } \\
\text { NOVEMBER } \\
\text { DECEMBER } \\
\text { JANUARY } \\
\text { FEBRUARY } \\
\text { MARCH } \\
\text { APRIL } \\
\text { MAY } \\
\text { JUNE } \\
\text { JULY } \\
\text { AUGUST } \\
\text { SEPTEMBER }\end{array}$ & $\begin{array}{l}19 \\
0.00 \\
88 \\
6.2 \\
2.5 \\
5.9 \\
0.00 \\
0.00 \\
0.00 \\
13 \\
30 \\
14\end{array}$ & $\begin{array}{l}0.00 \\
0.00 \\
0.00 \\
0.00 \\
0.00 \\
0.00 \\
0.00 \\
0.00 \\
0.00 \\
0.00 \\
0.00 \\
0.00\end{array}$ & $\begin{array}{l}2.0 \\
0.00 \\
9.8 \\
0.48 \\
0.34 \\
0.47 \\
0.00 \\
0.00 \\
0.00 \\
1.2 \\
3.5 \\
2.2\end{array}$ & $\begin{array}{l}5.5 \\
0.00 \\
26 \\
1.7 \\
0.79 \\
1.7 \\
0.00 \\
0.00 \\
0.00 \\
3.6 \\
8.3 \\
3.9\end{array}$ & $\begin{array}{l}2.7 \\
2.6 \\
3.6 \\
2.3 \\
3.5\end{array}$ & $\begin{array}{r}10.0 \\
0.0 \\
49.1 \\
2.4 \\
1.7 \\
2.4 \\
0.0 \\
0.0 \\
0.0 \\
6.2 \\
17.4 \\
10.9\end{array}$ \\
\hline ANNUAL & 7.5 & 0.06 & 1.7 & 2.0 & 1.2 & 100 \\
\hline
\end{tabular}

MAGNI TUDE AND PROBABILITY OF INSTANTANEOUS PEAK FLOW BASED ON PERIOD OF RECORD 1959, 1961, 1966-81, 1984

\begin{tabular}{|c|c|c|c|c|c|}
\hline $\begin{array}{c}2 \\
50 \%\end{array}$ & $\underset{20 \%}{5}$ & $\begin{array}{r}10 \\
10 \%\end{array}$ & $\begin{array}{l}25 \\
4 x\end{array}$ & $\begin{array}{l}50 \dagger \\
2 \%\end{array}$ & $\begin{array}{c}100 \nmid \\
1 \%\end{array}$ \\
\hline 2,650 & 6,150 & 9,340 & 14,400 & 18,800 & 23,900 \\
\hline $\begin{array}{l}\text { MEIGHTED } \\
\text { MEAN } \\
\text { STANDARD }\end{array}$ & $\begin{array}{l}\text { SKEW } \\
\text { DEV. }\end{array}$ & $\begin{array}{l}(\text { LOGS })=- \\
(\text { LOGS })= \\
(\text { LOGS })=\end{array}$ & $\begin{array}{r}-0.22 \\
3.41 \\
0.45\end{array}$ & & . \\
\hline
\end{tabular}

MANITLDE AND PROBABILITY OF ANMUAL LOW FLON BASED ON PERIOD OF RECORD 1967-78

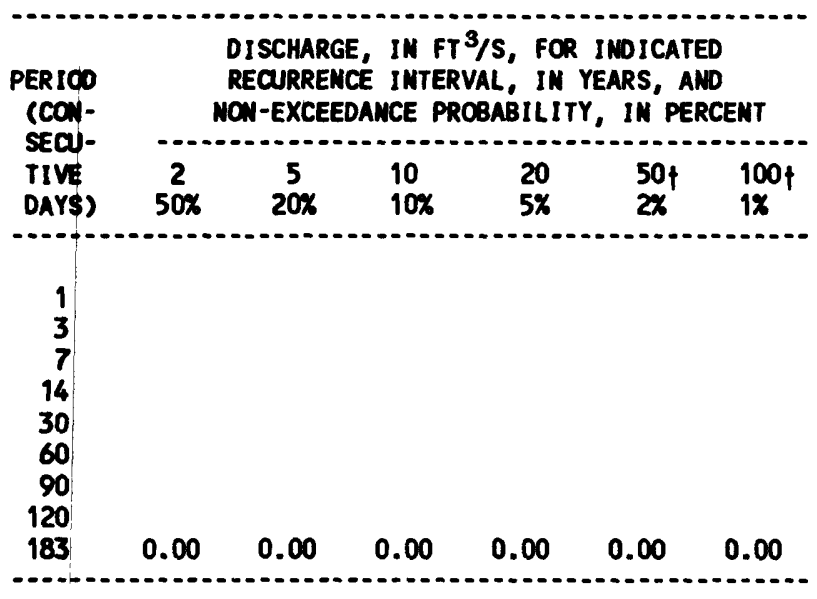

MAGNITLDE AND PROBABILITY OF ANNUAL HIGH FLOW BASED ON PERIOD OF RECORD 1966-78

\begin{tabular}{|c|c|c|c|c|c|c|}
\hline \multirow{2}{*}{$\begin{array}{l}\text { PERIOD } \\
\text { (CON- } \\
\text { SEQU- } \\
\text { TIVE } \\
\text { DAYS) }\end{array}$} & \multicolumn{6}{|c|}{$\begin{array}{l}\text { DISCHARGE, IN } \text { FT }^{3} / S \text {, FOR INDICATED } \\
\text { RECURRENCE INTERVAL, IN YEARS, AND } \\
\text { EXCEEDANCE PROBABILITY, IN PERCENT }\end{array}$} \\
\hline & $\begin{array}{c}2 \\
50 \%\end{array}$ & $\begin{array}{c}5 \\
20 \%\end{array}$ & $\begin{array}{l}10 \\
10 \%\end{array}$ & $\begin{array}{l}25 \\
4 x\end{array}$ & $\begin{array}{l}50 f \\
2 \%\end{array}$ & $\underset{1 \%}{100 \dagger}$ \\
\hline $\begin{array}{r}1 \\
3 \\
7 \\
15 \\
30 \\
60 \\
90\end{array}$ & $\begin{array}{c}140 \\
57 \\
27 \\
13 \\
7.7 \\
4.6 \\
3.2\end{array}$ & $\begin{array}{r}526 \\
232 \\
109 \\
54 \\
29 \\
16 \\
11\end{array}$ & $\begin{array}{r}1,030 \\
468 \\
217 \\
108 \\
55 \\
29 \\
19\end{array}$ & $\begin{array}{r}2,100 \\
963 \\
440 \\
219 \\
105 \\
51 \\
33\end{array}$ & $\begin{array}{r}3,300 \\
1,520 \\
684 \\
339 \\
155 \\
72 \\
47\end{array}$ & $\begin{array}{r}4,940 \\
2,260 \\
1,010 \\
497 \\
216 \\
97 \\
63\end{array}$ \\
\hline
\end{tabular}

DURATION TABLE OF DAILY MEAN FLON FOR PERIOD OF RECORD 1966-78

DISCHARGE, IN FT $3 / 5$, WHICH WAS EQUALED OR EXCEEDED FOR INDICATED PERCENT OF TIME

\begin{tabular}{|c|c|c|c|c|c|c|c|c|c|c|c|c|c|c|c|c|}
\hline $1 \%$ & $5 x$ & $10 x$ & $15 \%$ & $20 \%$ & $30 \%$ & $40 \%$ & $50 \%$ & $60 \%$ & $70 x$ & $80 \%$ & $90 \%$ & $95 x$ & $98 \%$ & $99 \%$ & $99.5 \%$ & $99.9 \%$ \\
\hline 15 & 0.00 & 0.00 & 0.00 & 0.00 & 0.00 & 0.00 & 0.00 & 0.00 & 0.00 & 0.00 & 0.00 & 0.00 & 0.00 & 0.00 & 0.00 & 0.00 \\
\hline
\end{tabular}

$\uparrow$ Reliability of values in colum is uncertain, and potential errors are large. 
GILA RIVER BASIN

09486300 CANADA DEL ORO MEAR tUCSON, AZ--CONTIMUED
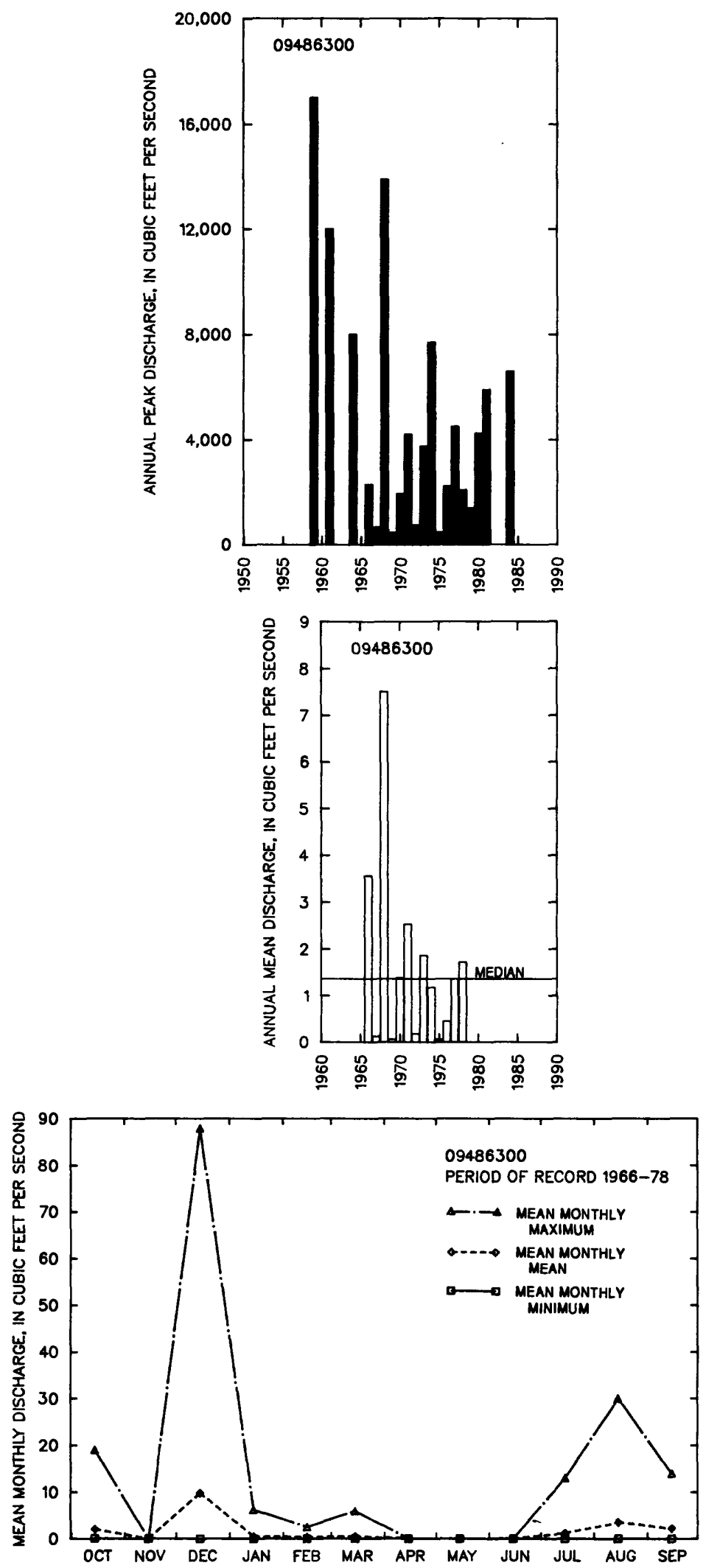
LOCATION.--Lat 32.21'04", Long 111'05'38", in WWHWh sec.35, T.12 s., R.12 E., Pima County, Hydrologic Unit 15050302 , on downstream side of right bridge pier $0.5 \mathrm{mi}$ southwest of Cortaro, $2.6 \mathrm{mi}$ downstream from Canada del Oro, and 3.7 mi downstream from Rilli to Creek.

DRAINACE AREA. $--3,503 \mathrm{mi}^{2}$, of which $395 \mathrm{mi}^{2}$ is in Mexico.

REMARKS.--Many diversions above station, mostly by pumping from ground water, for irrigation of about 34,000 acres. Wastewater from irrigation and from sewage-disposal plants is included in flow past station in water years 1951, 1952, and 1970-82.

ANIUAL PEAK DISCHARGE

\begin{tabular}{|c|c|c|c|c|c|c|c|}
\hline $\begin{array}{l}\text { WATER } \\
\text { YEAR }\end{array}$ & DATE & $\begin{array}{l}\text { ANNUAL PEAK } \\
\text { DISCHARGE } \\
\text { (FT } 3 / S)\end{array}$ & $\begin{array}{l}\text { DISCHARGE } \\
\text { CODES }\end{array}$ & $\begin{array}{l}\text { WATER } \\
\text { YEAR }\end{array}$ & DATE & $\begin{array}{c}\text { ANNUAL PEAK } \\
\text { DI SCHARGE } \\
\left(\mathrm{FT}^{3} / \mathrm{S}\right)\end{array}$ & $\begin{array}{l}\text { DISCHARGE } \\
\text { COOES }\end{array}$ \\
\hline $\begin{array}{l}1940 \\
1941 \\
1942 \\
1943 \\
1944 \\
1945 \\
1946 \\
1947 \\
1950 \\
1951 \\
1952 \\
1953 \\
1954 \\
1955 \\
1956 \\
1957 \\
1958 \\
1959 \\
1960 \\
1961 \\
1962 \\
1963\end{array}$ & $\begin{array}{l}08-14-40 \\
12-31-40 \\
08-09-42 \\
09-24-43 \\
08-16-44 \\
08-10-45 \\
08-04-46 \\
08-15-47 \\
07-30-50 \\
07-25-51 \\
08-14-52 \\
07-14-53 \\
07-24-54 \\
08-03-55 \\
07-29-56 \\
09-01-57 \\
08-12-58 \\
08-20-59 \\
08-11-60 \\
08-23-61 \\
09-26-62 \\
08-26-63\end{array}$ & $\begin{array}{r}117,000 \\
7,800 \\
1,550 \\
5,500 \\
5,650 \\
14,000 \\
4,440 \\
7,500 \\
12,900 \\
6,820 \\
6,100 \\
10,800 \\
9,150 \\
16,600 \\
3,150 \\
4,400 \\
7,890 \\
8,000 \\
6,420 \\
14,700 \\
11,200 \\
7,240\end{array}$ & & $\begin{array}{l}1964 \\
1965 \\
1966 \\
1967 \\
1968 \\
1969 \\
1970 \\
1971 \\
1977 \\
1973 \\
1974 \\
1975 \\
1976 \\
1977 \\
1978 \\
1979 \\
1980 \\
1981 \\
1982 \\
1983 \\
1984 \\
1985\end{array}$ & $\begin{array}{l}09-10-64 \\
07-16-65 \\
12-22-65 \\
07-17-67 \\
12-21-67 \\
08-06-69 \\
07-20-70 \\
08-20-71 \\
08-12-72 \\
10-19-72 \\
07-08-74 \\
07-12-75 \\
09-25-76 \\
09-10-77 \\
10-10-77 \\
12-18-78 \\
07-19-80 \\
09-22-81 \\
08-23-82 \\
02-04-83 \\
10-02-83 \\
12-28-84\end{array}$ & $\begin{array}{r}15,900 \\
2,710 \\
16,800 \\
5,740 \\
15,800 \\
8,400 \\
11,200 \\
9,100 \\
7,050 \\
9,000 \\
11,700 \\
5,200 \\
10,600 \\
4,700 \\
23,000 \\
18,800 \\
2,650 \\
4,310 \\
13,300 \\
7,620 \\
265,000 \\
13,000\end{array}$ & HP \\
\hline
\end{tabular}

I Highest since 1935 .

2Highest since 1914 .

BASIN CHARACTERISTICS

\begin{tabular}{|c|c|c|c|c|c|c|c|}
\hline MAIN & & $\begin{array}{r}\text { MEAN } \\
\text { BASIN }\end{array}$ & & & $\begin{array}{l}\text { MEAN } \\
\text { ANNUAL }\end{array}$ & RAINFALL II & SITY, 24-HOUR \\
\hline $\begin{array}{l}\text { CHANNEL } \\
\text { SLOPE } \\
\text { (FT/MI) }\end{array}$ & $\begin{array}{l}\text { STREAM } \\
\text { LENGTH } \\
\text { (MI) }\end{array}$ & $\begin{array}{l}\text { ELEVA- } \\
\text { TION } \\
\text { (FT) }\end{array}$ & $\begin{array}{l}\text { FORESTED } \\
\text { AREA } \\
\text { (PERCENT) }\end{array}$ & $\begin{array}{l}\text { SOIL } \\
\text { INDEX }\end{array}$ & $\begin{array}{l}\text { PRECIPI - } \\
\text { TATION } \\
\text { (IN) }\end{array}$ & $\begin{array}{c}\text { 2-YEAR } \\
\text { (IN) }\end{array}$ & $\begin{array}{c}\text { 50-YEAR } \\
\text { (IN) }\end{array}$ \\
\hline 20.3 & 140 & 4,000 & 18.0 & 1.8 & 16.3 & 2.0 & 4.2 \\
\hline
\end{tabular}


09486500 SANTA CRUZ RIVER AT CORTARO, AZ--Continued

MEAN MONTHLY AND ANMUAL DISCHARGES 1940-46, 1951-82

\begin{tabular}{|c|c|c|c|c|c|c|}
\hline MONTH & $\begin{array}{l}\operatorname{MAX} \operatorname{ImMM}_{3} \\
(\mathrm{FT} 3 / \mathrm{S})\end{array}$ & $\begin{array}{l}\text { MINIMUM } \\
\left(\mathrm{FT}^{3} / \mathrm{S}\right)\end{array}$ & $\begin{array}{c}\text { MEAN } \\
\left(F T^{3} / S\right)\end{array}$ & $\begin{array}{l}\text { STAN- } \\
\text { DARD } \\
\text { DEVIA- } \\
\text { TION } \\
\text { (FT } 3 / S)\end{array}$ & $\begin{array}{l}\text { COEFFI - } \\
\text { CIENT OF } \\
\text { VARI - } \\
\text { ATION }\end{array}$ & $\begin{array}{c}\text { PERCENT } \\
\text { OF } \\
\text { ANNUAL } \\
\text { RUNOFF }\end{array}$ \\
\hline $\begin{array}{l}\text { OCTOBER } \\
\text { NOVEMBER } \\
\text { DECEMBER } \\
\text { JANUARY } \\
\text { FEBRUARY } \\
\text { MARCH } \\
\text { APRIL } \\
\text { MAY } \\
\text { JUNE } \\
\text { JULY } \\
\text { AUGUST } \\
\text { SEPTEMBER }\end{array}$ & $\begin{array}{r}744 \\
168 \\
1,040 \\
756 \\
192 \\
496 \\
53 \\
48 \\
44 \\
393 \\
868 \\
358\end{array}$ & $\begin{array}{l}0.00 \\
0.00 \\
0.00 \\
0.00 \\
0.00 \\
0.00 \\
0.00 \\
0.00 \\
0.00 \\
1.7 \\
2.0 \\
0.00\end{array}$ & $\begin{array}{c}39 \\
17 \\
85 \\
45 \\
32 \\
34 \\
10 \\
9.8 \\
12 \\
77 \\
131 \\
54\end{array}$ & $\begin{array}{r}122 \\
31 \\
233 \\
125 \\
50 \\
83 \\
17 \\
16 \\
16 \\
84 \\
150 \\
71\end{array}$ & $\begin{array}{l}3.2 \\
1.8 \\
2.7 \\
2.8 \\
1.5 \\
2.4 \\
1.6 \\
1.6 \\
1.4 \\
1.1 \\
1.1 \\
1.3\end{array}$ & $\begin{array}{r}7.1 \\
3.1 \\
15.6 \\
8.2 \\
5.9 \\
6.3 \\
1.9 \\
1.8 \\
2.1 \\
14.1 \\
23.9 \\
10.0\end{array}$ \\
\hline INUAL & 198 & 2.6 & 46 & 41 & 0.89 & 100 \\
\hline
\end{tabular}

MAGNITLOE AND PROBABILITY OF INSTANTANEOUS PEAK FLON BASED ON PERIOD OF RECORD 1940-47, 1950-85

DISCHARGE, IN $\mathrm{FT}^{3} / \mathrm{S}$, FOR INDICATED RECURRENCE INTERVAL IN YEARS, AND EXCEEDANCE PROBABILITY, IN PERCENT

\begin{tabular}{lccccc}
2 & 5 & 10 & 25 & 50 & $100 \dagger$ \\
$50 \%$ & $20 \%$ & $10 \%$ & $4 \%$ & $2 \%$ & $1 \%$ \\
8,390 & 13,900 & 18,100 & 24,300 & 29,400 & 35,000 \\
\hline MEIGHTED SKEW (LOGS) & $=0.12$ & & & \\
MEAN & (LOGS) & 3.93 & & & \\
STANDARD DEV. (LOGS) & $=0.25$ &
\end{tabular}

MAGNITLDE AND PROBABILITY OF ANNUAL LON FLON BASED ON PERIOD OF RECORD 1941-47, 1952-82

\begin{tabular}{|c|c|c|c|c|c|c|}
\hline \multirow{2}{*}{$\begin{array}{l}\text { PERIOD } \\
\text { (CON- } \\
\text { SECU- } \\
\text { TIVE } \\
\text { DAYS) }\end{array}$} & \multicolumn{6}{|c|}{$\begin{array}{l}\text { DISCHARGE, IN } \mathrm{FT}^{3} / \mathrm{S} \text {, FOR INDICATED } \\
\text { RECURRENCE INTERVAL, IN YEARS, AND } \\
\text { NON-EXCEEDANCE PROBABILITY, IN PERCENT }\end{array}$} \\
\hline & $\underset{50 \%}{2}$ & $\underset{20 \%}{5}$ & $\begin{array}{l}10 \\
10 \%\end{array}$ & $\begin{array}{l}20 \\
5 \%\end{array}$ & $\begin{array}{l}50 \\
2 \%\end{array}$ & $\begin{array}{l}100 \dagger \\
1 \%\end{array}$ \\
\hline $\begin{array}{r}1 \\
3 \\
7 \\
14 \\
30 \\
60 \\
90 \\
120 \\
183\end{array}$ & $\begin{array}{l}0.00 \\
0.00 \\
0.00 \\
0.00 \\
0.00 \\
0.00 \\
0.03 \\
2.2 \\
8.0\end{array}$ & $\begin{array}{l}0.00 \\
0.00 \\
0.00 \\
0.00 \\
0.00 \\
0.00 \\
0.00 \\
0.00 \\
1.1\end{array}$ & $\begin{array}{l}0.00 \\
0.00 \\
0.00 \\
0.00 \\
0.00 \\
0.00 \\
0.00 \\
0.00 \\
0.26\end{array}$ & $\begin{array}{l}0.00 \\
0.00 \\
0.00 \\
0.00 \\
0.00 \\
0.00 \\
0.00 \\
0.00 \\
0.05\end{array}$ & $\begin{array}{l}0.00 \\
0.00 \\
0.00 \\
0.00 \\
0.00 \\
0.00 \\
0.00 \\
0.00 \\
0.00\end{array}$ & $\begin{array}{l}0.00 \\
0.00 \\
0.00 \\
0.00 \\
0.00 \\
0.00 \\
0.00 \\
0.00 \\
0.00\end{array}$ \\
\hline
\end{tabular}

MAGNITLDE AND PROBABILITY OF ANNUAL HIGH FLON BASED ON PERIOD OF RECORD 1940-46, 1951-82

\begin{tabular}{|c|c|c|c|c|c|c|}
\hline \multirow{2}{*}{$\begin{array}{l}\text { PERIOD } \\
\text { (CON- } \\
\text { SECU- } \\
\text { TIVE } \\
\text { DAYS) }\end{array}$} & & \multicolumn{5}{|c|}{$\begin{array}{l}\text { DISCHARGE, IN FT } 3 / S \text {, FOR INDICATED } \\
\text { RECURRENCE INTERVAL, IN YEARS, AND } \\
\text { EXCEEDANCE PROBABILITY, IN PERCENT }\end{array}$} \\
\hline & $\begin{array}{c}2 \\
50 \%\end{array}$ & $\begin{array}{c}5 \\
20 \%\end{array}$ & $\begin{array}{l}10 \\
10 \%\end{array}$ & $\begin{array}{l}25 \\
4 \%\end{array}$ & $\begin{array}{l}50 \\
2 \%\end{array}$ & $\begin{array}{c}100 \uparrow \\
1 \%\end{array}$ \\
\hline $\begin{array}{r}1 \\
3 \\
7 \\
15 \\
30 \\
60 \\
90\end{array}$ & $\begin{array}{r}2,070 \\
1,050 \\
560 \\
332 \\
212 \\
133 \\
98\end{array}$ & $\begin{array}{r}4,710 \\
2,420 \\
1,270 \\
727 \\
448 \\
275 \\
203\end{array}$ & $\begin{array}{r}7,170 \\
3,710 \\
1,910 \\
1,060 \\
636 \\
386 \\
281\end{array}$ & $\begin{array}{r}11,100 \\
5,830 \\
2,910 \\
1,540 \\
899 \\
537 \\
384\end{array}$ & $\begin{array}{r}14,700 \\
7,790 \\
3,780 \\
1,940 \\
1,110 \\
655 \\
461\end{array}$ & $\begin{array}{r}18,900 \\
10,100 \\
4,760 \\
2,370 \\
1,320 \\
774 \\
537\end{array}$ \\
\hline
\end{tabular}

DURATION TABLE OF DAILY MEAN FLON FOR PERIOD OF RECORD 1940-46, 1951-82

DISCHARGE, IN FT $3 / 5$, WHICH WAS EQUALED OR EXCEEDED FOR INDICATED PERCENT OF TIME

\begin{tabular}{|c|c|c|c|c|c|c|c|c|c|c|c|c|c|c|c|c|}
\hline $1 \%$ & $5 \%$ & $10 \%$ & $15 \%$ & $20 \%$ & $30 \%$ & $40 \%$ & $50 \%$ & $60 \%$ & $70 \%$ & $80 \%$ & $90 \%$ & $95 \%$ & $98 \%$ & $99 \%$ & $99.5 \%$ & $99.9 \%$ \\
\hline 43 & 105 & 57 & 46 & 39 & 23 & 1.9 & 0.00 & 0.00 & 0.00 & 0.00 & 0.00 & 0.00 & 0.00 & 0.00 & 0.00 & . \\
\hline
\end{tabular}

$\uparrow$ Reliability of values in column is uncertain, and potential errors are large. 
09486500 SANTA CRUZ RIVER AT CORTARO, AZ--CONTINued
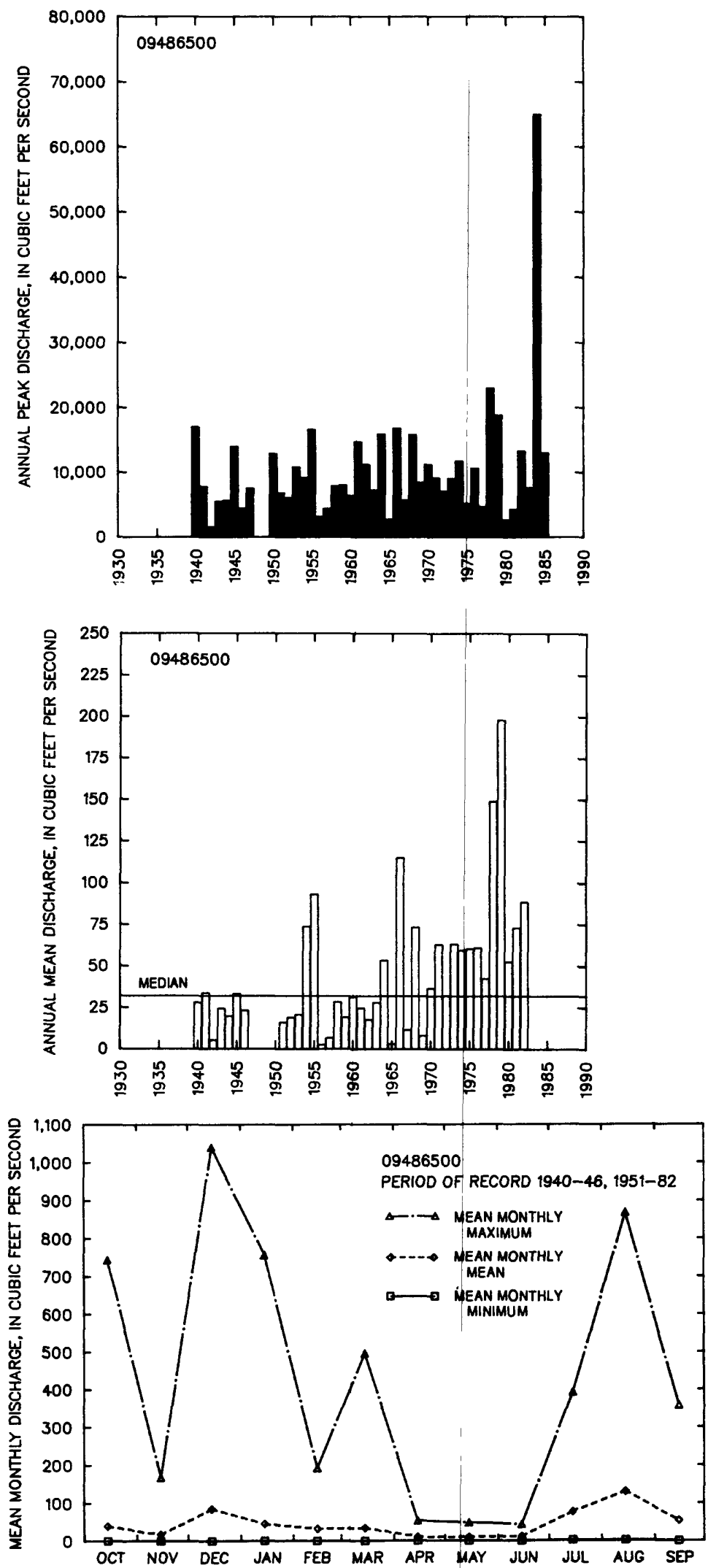
09486700 CHILTEPINES WASH MEAR SASABE, NZ

LOCATION.--Lat 31'49'08", long 111'26'16", in NEYSEK sec.32, T.18 S., R.9 E., Pima County, Hydrologic Unit 15050304, at State Highway 286, 24 mi north of Sasabe.

DRAINAGE AREA. $--7.13 \mathrm{mi}^{2}$, contributing drainage area not determined.

AMNUAL PEAK DISCHAREE

\begin{tabular}{ccc}
$\begin{array}{c}\text { WATER } \\
\text { YEAR }\end{array}$ & DATE & $\begin{array}{c}\text { ANNUAL PEAK } \\
\text { DISCHARGE } \\
\text { (FT } 3 / \text { S) }\end{array}$ \\
\hline 1963 & $08-05-63$ & 189 \\
1964 & $09-10-64$ & 560 \\
1965 & $09-15-65$ & 85 \\
1966 & $08-19-66$ & 158 \\
1967 & $00-00-67$ & 182 \\
1968 & $00-00-68$ & 53 \\
1969 & $00-00-69$ & 118 \\
1970 & $09-04-70$ & 67 \\
1971 & $08-03-71$ & 230 \\
1972 & $08-00-72$ & 100 \\
1973 & $07-15-73$ & 108 \\
1974 & $08-04-74$ & 182 \\
1975 & $09-04-75$ & 182 \\
$\ldots$
\end{tabular}

MAGNITUDE AND PROBABILITY OF INSTANTANEOUS PEAK FLOW BASED ON PERIOD OF RECORD

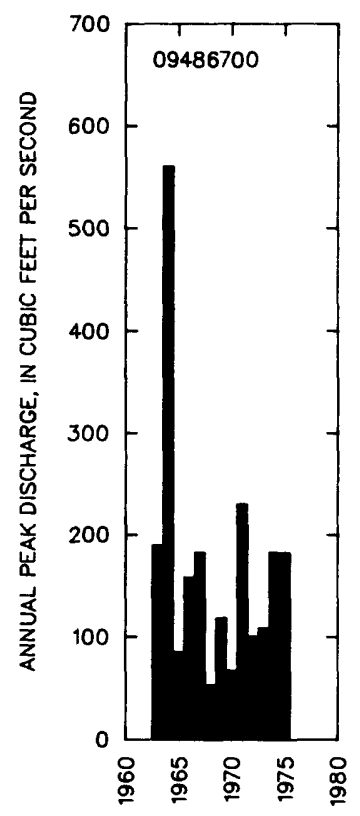

DISCHARGE, IN $\mathrm{FT}^{3} / \mathrm{S}$, FOR INDICATED RECURRENCE INTERVAL IN YEARS, AND EXCEEDANCE PROBABILITY, IN PERCENT

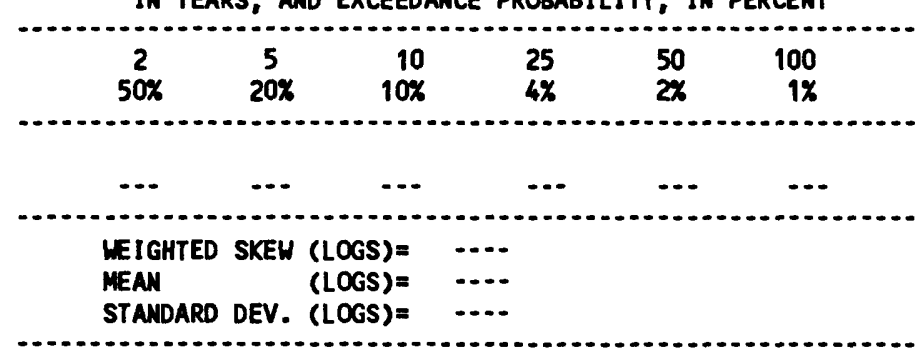

BASIN CHARACTERISTICS

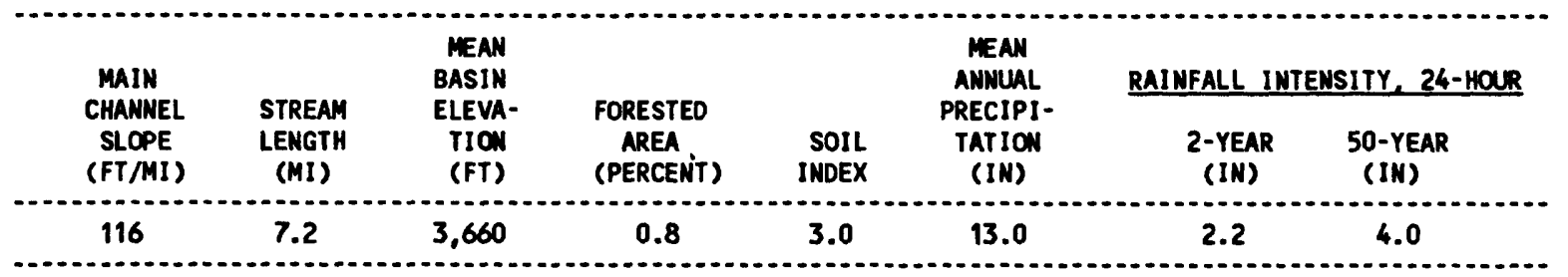


09486800 ALTAR WASH NEAR THREE POINTS, AZ

LOCATION.---Lat 31.50'10", long 111.24'11", in SEYNEK sec.27, T.18 S., R.9 E., Pima County, Hydrol ogic Unit 15050304 , on left abutment of former highway bridge, 0.1 mi downstream from Chiltipines Wash, $0.2 \mathrm{mi}$ upstream from bridge on State Highway 286, and 18 mi south of Three Points.

DRAIMAGE AREA. $--465 \mathrm{mi}^{2}$.

ANMUAL PEAK DISCHARGE

\begin{tabular}{ccc}
$\begin{array}{l}\text { WATER } \\
\text { YEAR }\end{array}$ & DATE & $\begin{array}{c}\text { ANNUAL PEAK } \\
\text { DISCHARGE } \\
\text { (FT } 3 / \text { S) }\end{array}$ \\
\hline 1966 & $08-10-66$ & 10,700 \\
1967 & $07-15-67$ & 2,360 \\
1968 & $08-02-68$ & 3,430 \\
1969 & $07-18-69$ & 3,060 \\
1970 & $09-04-70$ & 122,000 \\
1971 & $08-03-71$ & 4,220 \\
1972 & $07-15-72$ & 3,360 \\
1973 & $07-14-73$ & 2,130 \\
1974 & $08-04-74$ & 9,200 \\
1975 & $08-08-75$ & 9,700 \\
1976 & $08-22-76$ & 7,000 \\
1977 & $07-00-77$ & 4,500 \\
1978 & $10-06-77$ & 10,100 \\
1979 & $11-25-78$ & 1,480 \\
1980 & $08-13-80$ & 1,400 \\
\hline$\ldots$
\end{tabular}

$1_{H i g h e s t}$ since 1940 .

MAGNITUDE AND PROBABILITY OF INSTANTANEOUS PEAK FLOW BASED ON PERIOD OF RECORD 1966-80

DISCHARGE, IN $\mathrm{FT}^{3} / \mathrm{S}$, FOR INDICATED RECURRENCE INTERVAL IN YEARS, AND EXCEEDANCE PROBABILITY, IN PERCENT

\begin{tabular}{|c|c|c|c|c|c|}
\hline $\begin{array}{c}2 \\
50 \%\end{array}$ & $\begin{array}{c}5 \\
20 x\end{array}$ & $\begin{array}{r}10 \\
10 \%\end{array}$ & $\begin{array}{l}25 \\
4 x\end{array}$ & $\begin{array}{l}50 \dagger \\
2 \%\end{array}$ & $\begin{array}{c}100 \nmid \\
1 \%\end{array}$ \\
\hline 4,300 & 7,920 & 10,900 & 15,400 & 19,300 & 23,600 \\
\hline $\begin{array}{l}\text { WEIGHTED } \\
\text { MEAN } \\
\text { STANDARD }\end{array}$ & $\begin{array}{l}\text { SKEU } \\
\text { DEV. }\end{array}$ & $\begin{array}{l}(\text { LOGS })= \\
(\text { LOGS })= \\
(\text { LOGS })=\end{array}$ & $\begin{array}{l}0.03 \\
3.64 \\
0.31\end{array}$ & & \\
\hline
\end{tabular}

$\uparrow$ Reliability of values in column is uncertain, and potential errors are large.

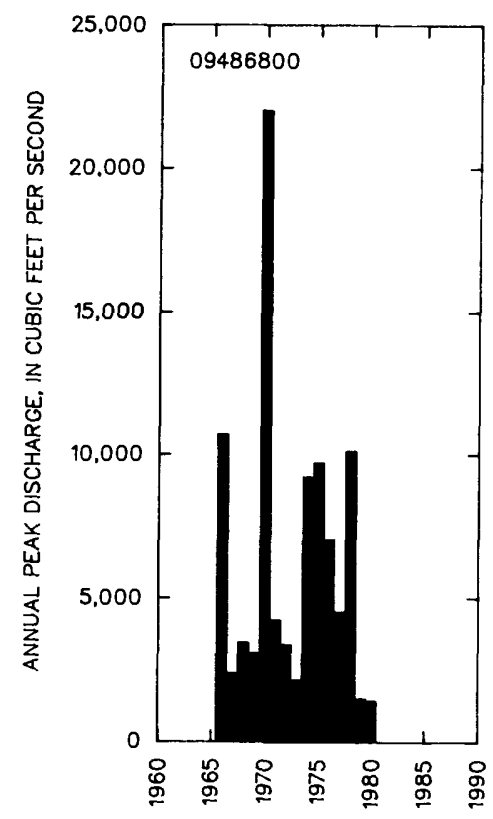

BASIN CHARACTERISTICS

\begin{tabular}{|c|c|c|c|c|c|c|c|}
\hline MAIN & & $\begin{array}{l}\text { MEAN } \\
\text { BASIN }\end{array}$ & & & $\begin{array}{l}\text { MEAN } \\
\text { ANNUAL }\end{array}$ & RAINFALL IN & SITY, 24-HOUR \\
\hline $\begin{array}{l}\text { CHANNEL } \\
\text { SLOPE } \\
\text { (FT/MI) }\end{array}$ & $\begin{array}{c}\text { STREAM } \\
\text { LENGTH } \\
\text { (MI) }\end{array}$ & $\begin{array}{l}\text { ELEVA- } \\
\text { TION } \\
\text { (FT) }\end{array}$ & $\begin{array}{l}\text { FORESTED } \\
\text { AREA } \\
\text { (PERCENT) }\end{array}$ & $\begin{array}{l}\text { SOIL } \\
\text { INDEX }\end{array}$ & $\begin{array}{l}\text { PRECIPI - } \\
\text { TATION } \\
\text { (IN) }\end{array}$ & $\begin{array}{l}\text { 2-YEAR } \\
\text { (IN) }\end{array}$ & $\begin{array}{c}\text { 50-YEAR } \\
\text { (IN) }\end{array}$ \\
\hline 74.1 & 32.4 & 3,920 & 6.5 & 2.0 & 15.6 & 2.2 & 5.0 \\
\hline
\end{tabular}


09487000 BRALLEY WASH MEAR THREE POINTS, $A Z$

LOCATION.--Lat 32 04'32", long $111^{\circ} 20^{\prime} 15^{\prime \prime}$, in NEKSEK sec.32, T.15 S., R.10 E., Pima County, Hydrologic Unit 15050304, at State HIghway 86, $1.5 \mathrm{mi}$ west of Three Points (Robles Junction), and $23 \mathrm{mi}$ west of Tucson.

DRAINAGE AREA. -- $776 \mathrm{mi}^{2}$.

ANIUAL PEAK DISCHARGE

\begin{tabular}{|c|c|c|c|}
\hline $\begin{array}{l}\text { WATER } \\
\text { YEAR }\end{array}$ & DATE & $\begin{array}{c}\text { ANMUAL PEAK } \\
\text { DISCHARGE } \\
\text { (FT } 3 / S)\end{array}$ & $\begin{array}{l}\text { DISCHARGE } \\
\text { COOES }\end{array}$ \\
\hline $\begin{array}{l}1940 \\
1962 \\
1966 \\
1967 \\
1968 \\
1969 \\
1970 \\
1971 \\
1972 \\
1973 \\
1974 \\
1975 \\
1976 \\
1977 \\
1978 \\
1979 \\
1980 \\
1981 \\
1984\end{array}$ & $\begin{array}{l}08-14-40 \\
09-26-62 \\
12-24-65 \\
07-17-67 \\
12-21-67 \\
07-18-69 \\
09-04-70 \\
08-03-71 \\
07-15-72 \\
07-14-73 \\
08-04-74 \\
08-00-75 \\
09-05-76 \\
07-26-77 \\
10-06-77 \\
11-25-78 \\
08-13-80 \\
07-13-81 \\
10-01-83\end{array}$ & $\begin{array}{r}13,000 \\
113,000 \\
6,600 \\
2,250 \\
1,950 \\
2,250 \\
1,3,700 \\
4,830 \\
3,300 \\
3,060 \\
6,910 \\
5,750 \\
3,600 \\
1,400 \\
7,300 \\
3,600 \\
1,900 \\
4,400 \\
19,100\end{array}$ & $\begin{array}{c}\text { ES, HP } \\
\text { HP } \\
\text { DF }\end{array}$ \\
\hline
\end{tabular}

1Highest since 1955.

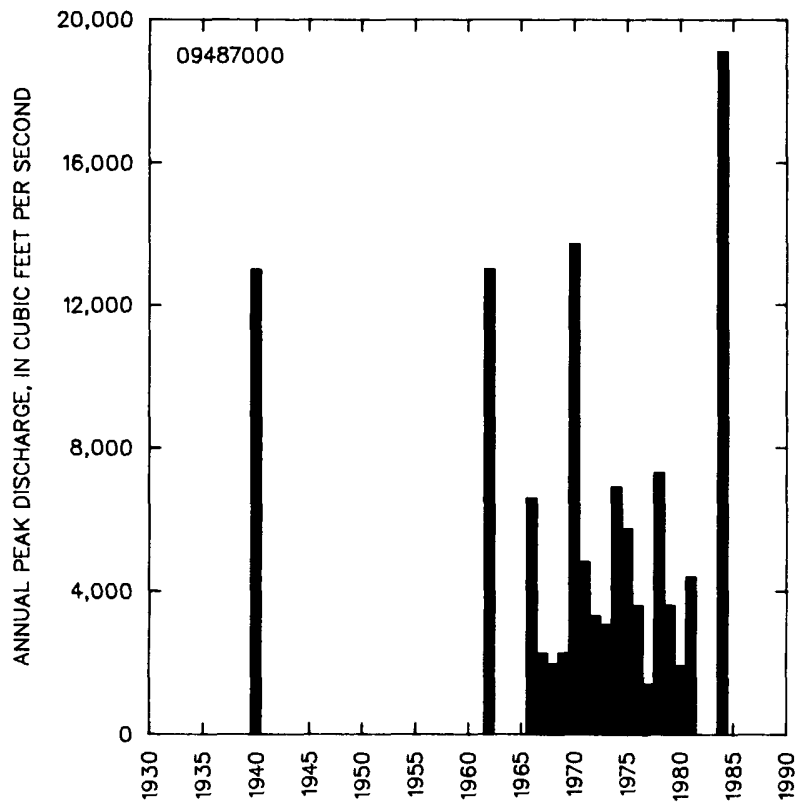

MAGNITUDE AND PROBABILITY OF INSTANTANEOUS PEAK FLOU BASED ON PERIOD OF RECORD 1967-81, 1984

DISCHARGE, IN FT $3 / 5$, FOR INDICATED RECURRENCE INTERVAL IN YEARS, AND EXCEEDANCE PROBABILITY, IN PERCENT

\begin{tabular}{|c|c|c|c|c|c|}
\hline $\begin{array}{c}2 \\
50 \%\end{array}$ & $\begin{array}{c}5 \\
20 \%\end{array}$ & $\begin{array}{r}10 \\
10 \%\end{array}$ & $\begin{array}{l}25 \\
4 \%\end{array}$ & $\begin{array}{l}50 \dagger \\
2 \%\end{array}$ & $\begin{array}{c}100 \dagger \\
1 \%\end{array}$ \\
\hline 3,660 & 6,400 & $8, \pi 50$ & 12,400 & 15,700 & 19,500 \\
\hline $\begin{array}{l}\text { WEIGHTED } \\
\text { MEAN } \\
\text { STANDARD }\end{array}$ & $\begin{array}{l}\text { SKEW } \\
\text { DEV. }\end{array}$ & $\begin{array}{l}(\operatorname{LOGS})= \\
(\text { LOGS })= \\
(\text { LOGS })=\end{array}$ & $\begin{array}{l}0.34 \\
3.58 \\
0.28\end{array}$ & & \\
\hline
\end{tabular}

f Reliability of values in column is uncertain, and potential errors are large.

BASIN CHARACTERISTICS

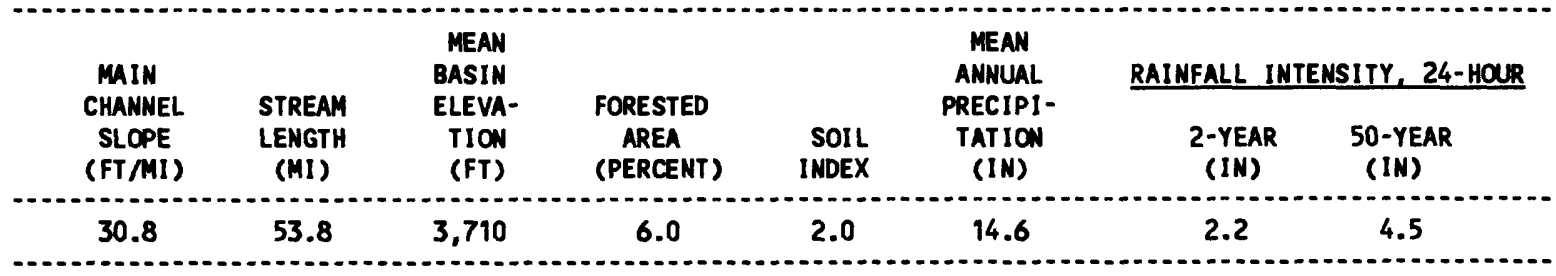


LOCATION.--Lat 32'07'25", long 111'19'45", in SEXNH sec.16, T.15 S., R.10 E., Pima County, Hydrologic Unit 15050304, 3.4 mi north of Three Points.

DRAINAGE AREA. $--11.9 \mathrm{mi}^{2}$.

ANNUAL PEAK DISCHARGE

\begin{tabular}{|c|c|c|c|}
\hline $\begin{array}{l}\text { HATER } \\
\text { YEAR }\end{array}$ & DATE & $\begin{array}{l}\text { ANNUAL PEAK } \\
\text { DISCHARGE } \\
\left(\mathrm{FT}^{3} / \mathrm{S}\right)\end{array}$ & $\begin{array}{l}\text { DISCHARGE } \\
\text { CODES }\end{array}$ \\
\hline $\begin{array}{l}1962 \\
1968 \\
1969 \\
1970 \\
1971 \\
1972 \\
1973 \\
1974 \\
1975 \\
1976 \\
1977 \\
1978 \\
1979 \\
1980 \\
1981\end{array}$ & $\begin{array}{l}09-26-62 \\
08-00-68 \\
08-16-69 \\
00-00-70 \\
00-00-71 \\
00-00-72 \\
00-00-73 \\
00-00-74 \\
08-00-75 \\
09-25-76 \\
00-00-77 \\
10-06-77 \\
08-15-79 \\
06-30-80 \\
09-05-81\end{array}$ & $\begin{array}{r}1,800 \\
450 \\
388 \\
700 \\
1,440 \\
310 \\
1,500 \\
335 \\
1,150 \\
2,230 \\
0 \\
2,500 \\
566 \\
893 \\
1,150\end{array}$ & HP \\
\hline
\end{tabular}

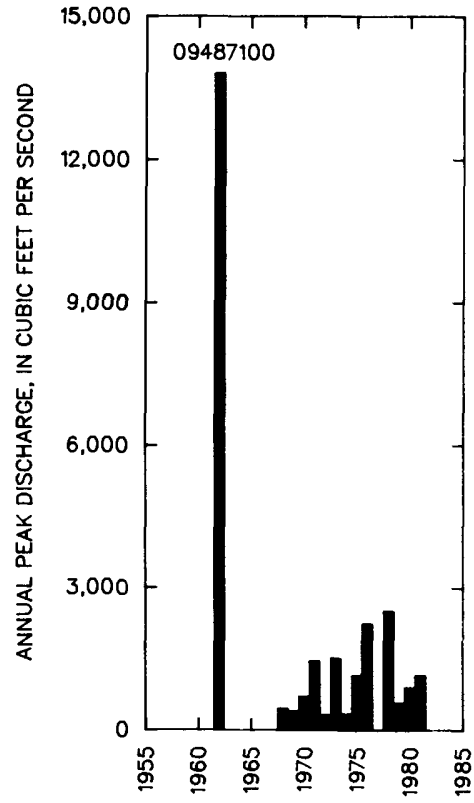

MAGNI TUDE AND PROBABILITY OF INSTANTANEOUS PEAK FLOH BASED ON PERIOD OF RECORD 1962, 1968-81

DISCHARGE, IN $\mathrm{FT}^{3} / \mathrm{S}$, FOR INDICATED RECURRENCE INTERVAL IN YEARS, AND EXCEEDANCE PROBABILITY, IN PERCENT

\begin{tabular}{|c|c|c|c|c|c|}
\hline $\begin{array}{c}2 \\
50 x\end{array}$ & $\underset{20 \%}{5}$ & $\begin{array}{r}10 \\
10 \%\end{array}$ & $\begin{array}{l}25 \\
4 \%\end{array}$ & $\begin{array}{l}50 \dagger \\
24\end{array}$ & $\begin{array}{c}100 \uparrow \\
1 \times\end{array}$ \\
\hline 77 & 1,450 & 2,010 & 2,860 & 3,600 & 4,440 \\
\hline $\begin{array}{l}\text { WEIGH } \\
\text { MEAN } \\
\text { STAND }\end{array}$ & $\begin{array}{l}\text { SKEH } \\
\text { DEV. }\end{array}$ & $\begin{array}{l}\text { OGS) }= \\
\text { OGS) }= \\
\text { OGS) }=\end{array}$ & $\begin{array}{l}0.05 \\
2.89 \\
0.32\end{array}$ & & \\
\hline
\end{tabular}

f Reliability of values in column is uncertain, and potential errors are large.

BASIN CHARACTERISTICS

\begin{tabular}{|c|c|c|c|c|c|c|c|}
\hline \multirow{2}{*}{$\begin{array}{l}\text { MAIN } \\
\text { CHANNEL } \\
\text { SLOPE } \\
\text { (FT/MI) }\end{array}$} & \multirow[b]{2}{*}{$\begin{array}{l}\text { STREAM } \\
\text { LENGTH } \\
\text { (MI) }\end{array}$} & \multirow{2}{*}{$\begin{array}{l}\text { MEAN } \\
\text { BASIN } \\
\text { ELEVA- } \\
\text { TION } \\
\text { (FT) }\end{array}$} & \multirow[b]{2}{*}{$\begin{array}{l}\text { FORESTED } \\
\text { AREA } \\
\text { (PERCENT) }\end{array}$} & \multirow[b]{2}{*}{$\begin{array}{l}\text { SOIL } \\
\text { INDEX }\end{array}$} & \multirow{2}{*}{$\begin{array}{l}\text { MEAN } \\
\text { ANNUAL } \\
\text { PRECIPI- } \\
\text { TATION } \\
\text { (IN) }\end{array}$} & \multicolumn{2}{|c|}{ RAINFALL INTENSITY, 24-HOUR } \\
\hline & & & & & & $\begin{array}{l}\text { 2-YEAR } \\
\text { (IN) }\end{array}$ & $\begin{array}{l}\text { 50-YEAR } \\
\text { (IN) }\end{array}$ \\
\hline 112 & 5.9 & 2,800 & 0.0 & 3.0 & 13.0 & 2.1 & 4.7 \\
\hline
\end{tabular}


09487140 SAN JOAQUIN HASH NEAR TUCSON, AZ

LOCATION.--Lat 32*10'07", long 111.07'58", in NEYSEY sec.32, T.14 S., R.12 E., Pima County, Hydrologic Unit 15050301, 1.1 mi northwest of the intersection of San Joaquin Road and the Tucson-Ajo Highway.

DRAIMAGE AREA. $--0.45 \mathrm{mi}^{2}$.

ANMUAL PEAK DISChaRGE

\begin{tabular}{ccc}
$\begin{array}{c}\text { WATER } \\
\text { YEAR }\end{array}$ & DATE & $\begin{array}{c}\text { ANNUAL PEAK } \\
\text { DISCHARGE } \\
\text { (FT } 3 / \text { S) }\end{array}$ \\
\hline 1969 & $08-02-69$ & 102 \\
1970 & $07-19-70$ & 487 \\
1971 & $08-17-71$ & 370 \\
1972 & $10-17-71$ & 190 \\
1973 & $07-00-73$ & 115 \\
1974 & $07-00-74$ & 135 \\
1975 & $08-20-75$ & 60 \\
1976 & $09-25-76$ & 480 \\
1977 & $07-22-77$ & 220 \\
1978 & $01-15-78$ & 127 \\
1979 & $11-24-78$ & 230 \\
1980 & $00-00-80$ & 0 \\
1981 & $07-28-81$ & 520 \\
$\ldots \ldots$
\end{tabular}

MAGNITUDE AND PROBABILITY OF INSTANTANEOUS PEAK FLON BASED ON PERIOD OF RECORD 1969-81

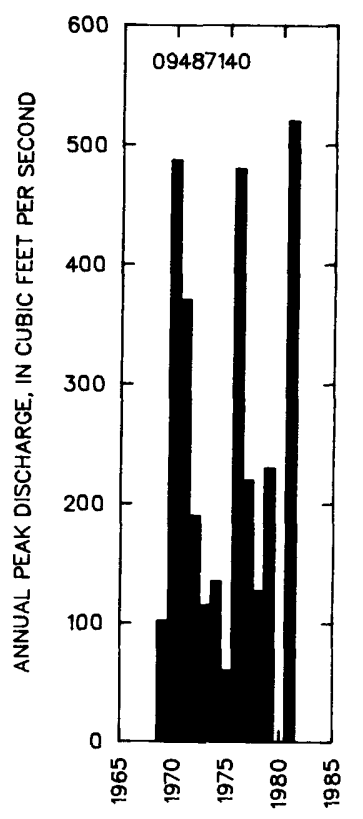

DISCHARGE, IN $\mathrm{FT}^{3} / \mathrm{S}$, FOR INDICATED RECURRENCE INTERVAL IN YEARS, AND EXCEEDANCE PROBABILITY, IN PERCENT

\begin{tabular}{|c|c|c|c|c|c|}
\hline$\stackrel{2}{50 \%}$ & $\underset{20 x}{5}$ & $\begin{array}{r}10 \\
10 \%\end{array}$ & $\begin{array}{l}25 \\
4 x\end{array}$ & $\begin{array}{l}50 t \\
2 \%\end{array}$ & $\begin{array}{c}100 \\
1 X\end{array}$ \\
\hline 191 & 356 & 486 & 672 & 824 & 987 \\
\hline $\begin{array}{l}\text { WEIGHTED } \\
\text { MEAN } \\
\text { STANDARD }\end{array}$ & $\begin{array}{l}\text { SKEH } \\
\text { DEV. }\end{array}$ & $\begin{array}{l}(\text { LOGS })= \\
(\text { LOGS })= \\
(\text { LOGS })=\end{array}$ & $\begin{array}{r}-0.17 \\
2.27 \\
0.33\end{array}$ & & \\
\hline
\end{tabular}

+ Reliability of values in colum is uncertain, and potential errors are large.

BASIN CHARACTERISTICS

\begin{tabular}{|c|c|c|c|c|c|c|c|}
\hline MAIN & & $\begin{array}{l}\text { MEAN } \\
\text { BASIN }\end{array}$ & & & $\begin{array}{l}\text { MEAN } \\
\text { ANNUAL }\end{array}$ & RAINFALL II & SITY, 24-HOUR \\
\hline $\begin{array}{l}\text { CHANNEL } \\
\text { SLOPE } \\
\text { (FT/MI) }\end{array}$ & $\begin{array}{l}\text { STREAM } \\
\text { LENGTH } \\
\text { (MI) }\end{array}$ & $\begin{array}{l}\text { ELEVA- } \\
\text { TION } \\
\text { (FT) }\end{array}$ & $\begin{array}{l}\text { FORESTED } \\
\text { AREA } \\
\text { (PERCENT) }\end{array}$ & $\begin{array}{l}\text { SOIL } \\
\text { INDEX }\end{array}$ & $\begin{array}{l}\text { PRECIPI - } \\
\text { TATION } \\
\text { (IN) }\end{array}$ & $\begin{array}{c}\text { 2-YEAR } \\
\text { (IN) }\end{array}$ & $\begin{array}{l}\text { 50-YEAR } \\
\text { (IN) }\end{array}$ \\
\hline 69.3 & 2.5 & 2,530 & 0.0 & 3.0 & 11.0 & 2.1 & 4.7 \\
\hline
\end{tabular}




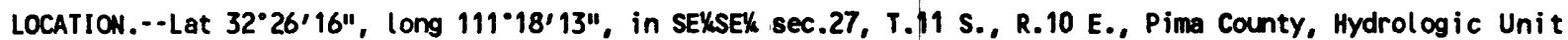
15050304, at Trico Road, 0.75 mi dounstream from confluence of Brawley Wash and China Draw, 3 mi upstream from Blanco Wash, and 5 mi southwest of Marana.

DRAINAGE AREA. $--1,170 \mathrm{mi}^{2}$.

\section{ANNUAL PEAK DISCHARGE}

\begin{tabular}{|c|c|c|c|}
\hline $\begin{array}{l}\text { WATER } \\
\text { YEAR }\end{array}$ & DATE & $\begin{array}{c}\text { ANNUAL PEAK } \\
\text { DISCHARGE } \\
\left(F^{3} / S\right)\end{array}$ & $\begin{array}{l}\text { DISCHARGE } \\
\text { COOES }\end{array}$ \\
\hline $\begin{array}{l}1962 \\
1966 \\
1967 \\
1968 \\
1969 \\
1970 \\
1971 \\
1972 \\
1973 \\
1974 \\
1975 \\
1976 \\
1977 \\
1978 \\
1984\end{array}$ & $\begin{array}{l}09-26-62 \\
00-00-66 \\
07-17-67 \\
12-20-67 \\
09-09-69 \\
09-05-70 \\
08-18-71 \\
08-00-72 \\
10-19-72 \\
07-08-74 \\
08-09-75 \\
09-25-76 \\
00-00-77 \\
10-06-77 \\
10-02-83\end{array}$ & $\begin{array}{r}132,000 \\
2,500 \\
80 \\
1,000 \\
105 \\
24,490 \\
1,770 \\
2,750 \\
1,910 \\
630 \\
260 \\
1,950 \\
900 \\
2,400 \\
12,500\end{array}$ & HP \\
\hline
\end{tabular}

1Highest since 1885 .

$2 \mathrm{Highest}$ since 1963.

MAGNITUDE AND PROBABILITY OF INSTANTANEOUS PEAK FLOW BASED ON PERIOD OF RECORD 1962, 1966-78, 1984

DISCHARGE, IN $\mathrm{FT}^{3} / \mathrm{S}$, FOR INDICATED RECURRENCE INTERVAL IN YEARS, AND EXCEEDANCE PROBABILITY, IN PERCENT

\begin{tabular}{|c|c|c|c|c|c|}
\hline $\begin{array}{c}2 \\
50 \%\end{array}$ & $\underset{20 \%}{5}$ & $\begin{array}{r}10 \\
10 \%\end{array}$ & $\begin{array}{l}25 \\
4 \%\end{array}$ & $\begin{array}{l}50 t \\
2 \%\end{array}$ & $\begin{array}{c}100 \dagger \\
18\end{array}$ \\
\hline 1,140 & 3,090 & 4,900 & 7,670 & 10,000 & 12,500 \\
\hline $\begin{array}{l}\text { WEIGHTED } \\
\text { MEAN } \\
\text { STANDARD }\end{array}$ & $\begin{array}{l}\text { SKEW } \\
\text { DEV. }\end{array}$ & $\begin{array}{l}(\text { LOGS })= \\
(\text { LOGS })= \\
(\text { LOGS })=\end{array}$ & $\begin{array}{r}-0.52 \\
3.01 \\
0.56\end{array}$ & & \\
\hline
\end{tabular}

+ Reliability of values in column is uncertain, and potential errors are large.

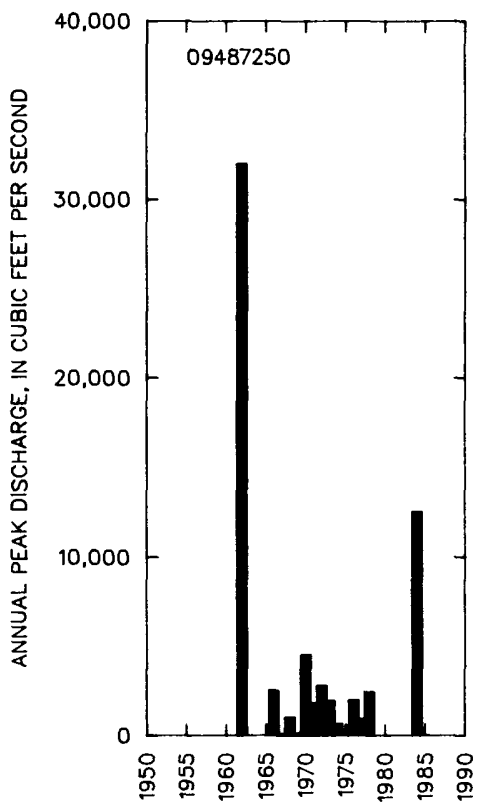

BASIN CHARACTERISTICS

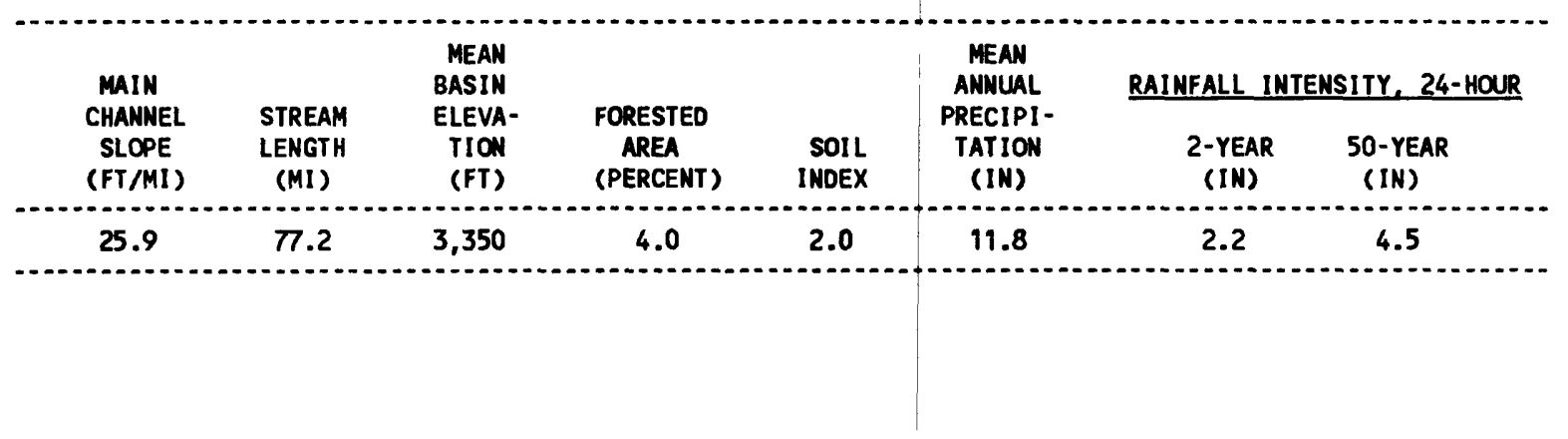


09487400 QUIJOTOA WASH TRIBUTARY NEAR QUI JOTOA, AZ

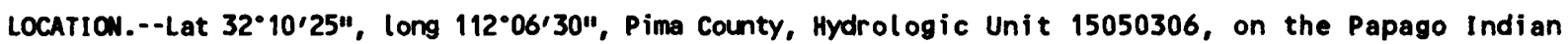
Reservation, at the Quijotoa-Casa Grande Road, and 1.1 mi north of Qui jotoa.

DRAINAGE AREA. $--2.44 \mathrm{mi}^{2}$.

ANMUAL PEAK DISCHARGE

\begin{tabular}{|c|c|c|c|}
\hline $\begin{array}{l}\text { WATER } \\
\text { YEAR }\end{array}$ & DATE & $\begin{array}{l}\text { ANNUAL PEAK } \\
\text { DISCHARGE } \\
\text { (FT } 3 / S \text { ) }\end{array}$ & $\begin{array}{l}\text { DISCHARGE } \\
\text { CODES }\end{array}$ \\
\hline $\begin{array}{l}1963 \\
1964 \\
1965 \\
1966 \\
1967 \\
1968 \\
1969 \\
1970 \\
1971 \\
1972 \\
1973 \\
1974 \\
1975\end{array}$ & $\begin{array}{l}00-00-63 \\
07-24-64 \\
00-00-65 \\
08-00-66 \\
00-00-67 \\
12-00-67 \\
08-05-69 \\
08-00-70 \\
00-00-71 \\
07-00-72 \\
08-17-73 \\
09-26-74 \\
08-26-75\end{array}$ & $\begin{array}{c}127 \\
715 \\
0 \\
225 \\
0 \\
5.0 \\
5.0 \\
200 \\
370 \\
190 \\
20 \\
420 \\
470\end{array}$ & $\begin{array}{l}\text { LT } \\
\text { LT }\end{array}$ \\
\hline
\end{tabular}

MAGNITUDE AND PROBABILITY OF INSTANTANEOUS PEAK FLOW BASED ON PERIOD OF RECORD 1963-75

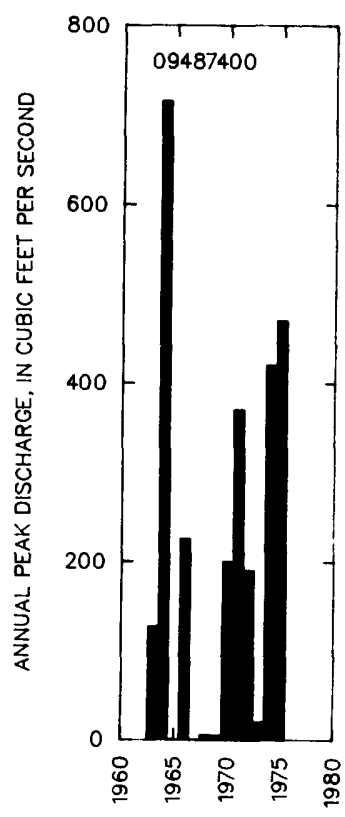

DISCHARGE, IN $\mathrm{FT}^{3} / \mathrm{S}$, FOR INDICATED RECURRENCE INTERYAL IN YEARS, AND EXCEEDANCE PROBABILITY, IN PERCENT

\begin{tabular}{lccccc}
2 & 5 & 10 & 25 & $50 \uparrow$ & $100 \uparrow$ \\
$50 \%$ & $20 \%$ & $10 \%$ & $4 \%$ & $2 \%$ & $1 \%$ \\
168 & 370 & 546 & 813 & 1,040 & 1,300 \\
\hline WEIGHTED SKEH (LOGS) & & -0.26 & & \\
MEAN & (LOGS) & 2.21 & & \\
STANDARD DEV. (LOGS) & & 0.42 & &
\end{tabular}

+ Reliability of values in colum is uncertain, and potential errors are large.

BASIN CHARACTERISTICS

\begin{tabular}{|c|c|c|c|c|c|c|c|}
\hline \multirow{2}{*}{$\begin{array}{l}\text { MAIN } \\
\text { CHANWEL } \\
\text { SLOPE } \\
\text { (FT/MI) }\end{array}$} & \multirow[b]{2}{*}{$\begin{array}{l}\text { STREAM } \\
\text { LENGTH } \\
\text { (MI) }\end{array}$} & \multirow{2}{*}{$\begin{array}{l}\text { MEAN } \\
\text { BASIN } \\
\text { ELEVA- } \\
\text { TION } \\
\text { (FT) }\end{array}$} & \multirow[b]{2}{*}{$\begin{array}{l}\text { FORESTED } \\
\text { AREA } \\
\text { (PERCENT) }\end{array}$} & \multirow[b]{2}{*}{$\begin{array}{l}\text { SOIL } \\
\text { INDEX }\end{array}$} & \multirow{2}{*}{$\begin{array}{l}\text { MEAN } \\
\text { ANNUAL } \\
\text { PRECIPI- } \\
\text { TATION } \\
\text { (IN) }\end{array}$} & \multicolumn{2}{|c|}{ RAINFALL INTENSITY, 24-HOUR } \\
\hline & & & & & & $\begin{array}{c}\text { 2-YEAR } \\
\text { (IN) }\end{array}$ & $\begin{array}{l}\text { 50-YEAR } \\
\text { (IN) }\end{array}$ \\
\hline 88.9 & 3.6 & 2,800 & 0.0 & 1.0 & 10.1 & 2.1 & 4.9 \\
\hline
\end{tabular}


09488500 SANTA ROSA WASH MEAR VAIVA VO, NEAR SELLS, AZ

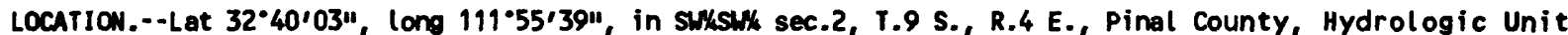
15050306, in Papago Indian Reservation, on right bank about $1 \mathrm{mi}$ downstream from Tat Momol ikot Dam, $3.3 \mathrm{mi}$ south of Vaiva Vo, $10 \mathrm{mi}$ southwest of Chuichu, $12 \mathrm{mi}$ downstream from Gu Komelik and $52 \mathrm{mi}$ north of Sells. Beginning July 1974, floodflows are regulated by Lake St. Clair, formed by Tat Momolikot Danm-total capacity 384,000 acre-ft.

DRAIMAGE AREA.--1,782 $\mathrm{mi}^{2}$.

ANNUAL PEAK DISCHARGE

\begin{tabular}{|c|c|c|c|c|c|c|c|}
\hline $\begin{array}{l}\text { WATER } \\
\text { YEAR }\end{array}$ & DATE & $\begin{array}{c}\text { ANHUAL PEAK } \\
\text { DISCHARGE } \\
\left(F T^{3} / S\right)\end{array}$ & $\begin{array}{l}\text { DISCHARGE } \\
\text { CODES }\end{array}$ & $\begin{array}{l}\text { WATER } \\
\text { YEAR }\end{array}$ & DATE & $\begin{array}{c}\text { ANIUAL PEAK } \\
\text { DISCHARGE } \\
\left(F T^{3} / S\right)\end{array}$ & $\begin{array}{l}\text { DI SCHARGE } \\
\text { CODES }\end{array}$ \\
\hline $\begin{array}{l}1955 \\
1956 \\
1957 \\
1958 \\
1959 \\
1960 \\
1961 \\
1962 \\
1963 \\
1964 \\
1965 \\
1966 \\
1967 \\
1968\end{array}$ & $\begin{array}{l}08-08-55 \\
07-24-56 \\
08-12-57 \\
11-01-57 \\
07-13-59 \\
07-30-60 \\
07-27-61 \\
09-27-62 \\
09-14-63 \\
07-25-64 \\
09-04-65 \\
09-14-66 \\
06-26-67 \\
07-28-68\end{array}$ & $\begin{array}{r}1,150 \\
740 \\
492 \\
10,000 \\
4,120 \\
805 \\
892 \\
153,100 \\
4,180 \\
6,760 \\
433 \\
1,820 \\
302 \\
840\end{array}$ & & $\begin{array}{l}1969 \\
1970 \\
1971 \\
1972 \\
1973 \\
1974 \\
1975 \\
1976 \\
1977 \\
1978 \\
1979 \\
1980 \\
1984\end{array}$ & $\begin{array}{l}08-08-69 \\
08-10-70 \\
08-04-71 \\
08-14-72 \\
10-21-72 \\
08-02-74 \\
07-17-75 \\
09-25-76 \\
07-17-77 \\
02-13-78 \\
01-17-79 \\
08-24-80 \\
10-04-83\end{array}$ & $\begin{array}{r}514 \\
865 \\
6,110 \\
410 \\
762 \\
364 \\
580 \\
390 \\
291 \\
66 \\
51 \\
105 \\
1,890\end{array}$ & $\begin{array}{l}\text { KR } \\
\text { KR } \\
\text { KR } \\
\text { KR } \\
\text { KR } \\
\text { KR } \\
\text { KR } \\
\text { HP, KR }\end{array}$ \\
\hline
\end{tabular}

IHighest since 1885 .

Magni TUDE AND PROBABILITY OF INSTANTANEQUS PEAK FLON BASED ON PERIOD OF RECORD 1955-74

DISCHARGE, IN $\mathrm{FT}^{3} / \mathrm{S}$, FOR INDICATED RECURRENCE INTERVAL IN YEARS, AND EXCEEDANCE PROBABILITY, IN PERCENT

\begin{tabular}{|c|c|c|c|c|c|}
\hline $\begin{array}{c}2 \\
50 \%\end{array}$ & $\begin{array}{c}5 \\
20 \%\end{array}$ & $\begin{array}{r}10 \\
10 \%\end{array}$ & $\begin{array}{l}25 \\
4 \%\end{array}$ & $\begin{array}{l}50 \dagger \\
2 \%\end{array}$ & $\begin{array}{c}100 \dagger \\
1 \%\end{array}$ \\
\hline 808 & 3,160 & 6,250 & 12,600 & 19,700 & 29,000 \\
\hline $\begin{array}{l}\text { WEIGHTED } \\
\text { MEAN } \\
\text { STANDARD }\end{array}$ & $\begin{array}{l}\text { SKEW } \\
\text { DEV. }\end{array}$ & $\begin{array}{l}\text { LOGS) }= \\
(\text { LOGS) }= \\
(\text { LOGS }=\end{array}$ & $\begin{array}{r}-0.20 \\
2.88 \\
0.72\end{array}$ & & \\
\hline
\end{tabular}

† Reliability of values in column is uncertain, and potential errors are large.

BASIN CHARACTERISTICS

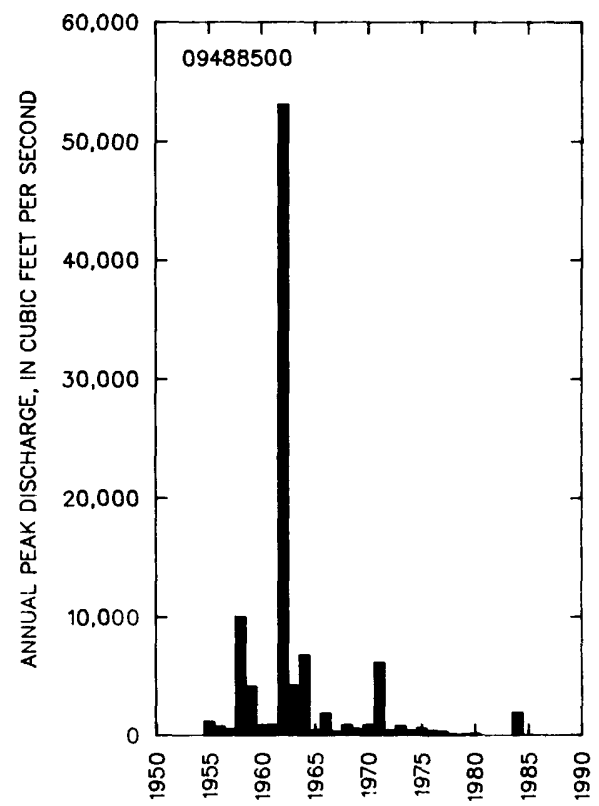

\begin{tabular}{|c|c|c|c|c|c|c|c|}
\hline \multirow{2}{*}{$\begin{array}{l}\text { MAIN } \\
\text { CHANHEL } \\
\text { SLOPE } \\
\text { (FT/MI) }\end{array}$} & \multirow[b]{2}{*}{$\begin{array}{c}\text { STREAM } \\
\text { LENGTH } \\
\text { (MI) }\end{array}$} & \multirow{2}{*}{$\begin{array}{l}\text { MEAN } \\
\text { BASIN } \\
\text { ELEVA- } \\
\text { TION } \\
\text { (FT) }\end{array}$} & \multirow[b]{2}{*}{$\begin{array}{l}\text { FORESTED } \\
\text { AREA } \\
\text { (PERCENT) }\end{array}$} & \multirow[b]{2}{*}{$\begin{array}{l}\text { SOIL } \\
\text { INDEX }\end{array}$} & \multirow{2}{*}{$\begin{array}{c}\text { MEAN } \\
\text { ANNUAL } \\
\text { PRECIPI- } \\
\text { TATION } \\
\text { (IN) }\end{array}$} & \multicolumn{2}{|c|}{ RAINFALL INTENSITY, 24-HOQR } \\
\hline & & & & & & $\begin{array}{l}\text { 2-YEAR } \\
\text { (IN) }\end{array}$ & $\begin{array}{l}\text { 50-YEAR } \\
\text { (IN) }\end{array}$ \\
\hline 25.5 & 55.0 & 2,340 & 0.3 & 2.0 & 10.2 & 1.9 & 4.3 \\
\hline
\end{tabular}


09488600 SILVER REEF WASH MEAR CASA GRANDE, AZ

LOCATION.--Lat 32.40'56", long 111.50'03", in SWKSEK sec.34, T.8 S., R.5 E., Pinal County, Hydrologic Unit 15050306, at Quijotoa-Casa Grande Road, $14 \mathrm{mi}$ southwest of Casa Grande.

DRAINAGE AREA. $--12.8 \mathrm{mi}^{2}$.

ANMUAL PEAK DISCHARGE

\begin{tabular}{|c|c|c|c|}
\hline $\begin{array}{l}\text { MATER } \\
\text { YEAR }\end{array}$ & DATE & $\begin{array}{c}\text { ANNUAL PEAK } \\
\text { DISCHARGE } \\
\text { (FT } 3 / \mathrm{S})\end{array}$ & $\begin{array}{l}\text { DISCHARGE } \\
\text { COOES }\end{array}$ \\
\hline $\begin{array}{l}1950 \\
1963 \\
1964 \\
1965 \\
1966 \\
1967 \\
1968 \\
1969 \\
1970 \\
1971 \\
1972 \\
1973 \\
1974 \\
1975\end{array}$ & $\begin{array}{l}00-00-50 \\
08-21-63 \\
08-12-64 \\
09-00-65 \\
12-00-65 \\
00-00-67 \\
12-19-67 \\
08-11-69 \\
00-00-70 \\
08-03-71 \\
08-12-72 \\
00-00-73 \\
09-00-74 \\
10-28-74\end{array}$ & $\begin{array}{r}(1) \\
662 \\
1,170 \\
100 \\
600 \\
135 \\
490 \\
165 \\
630 \\
1,400 \\
90 \\
100 \\
60 \\
160\end{array}$ & HP \\
\hline
\end{tabular}

Discharge unknown.

MAGNITUDE AND PROBABILITY OF INSTANTANEOUS PEAK FLON

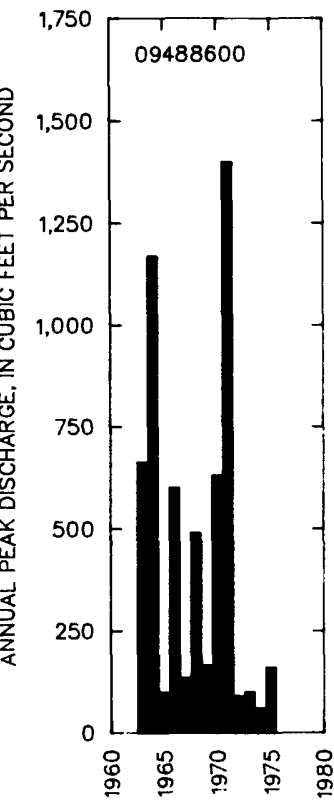
BASED ON PERIOD OF RECORD 1963-75

DISCHARGE, IN $\mathrm{FT}^{3} / \mathrm{S}$, FOR INDICATED RECURRENCE INTERVAL IN YEARS, AND EXCEEDANCE PROBABILITY, IN PERCENT

\begin{tabular}{|c|c|c|c|c|c|}
\hline $\begin{array}{c}2 \\
50 \%\end{array}$ & $\begin{array}{c}5 \\
20 \%\end{array}$ & $\begin{array}{r}10 \\
10 \%\end{array}$ & $\begin{array}{l}25 \\
4 x\end{array}$ & $\begin{array}{l}50 \dagger \\
2 x\end{array}$ & $\begin{array}{c}100 \nmid \\
18\end{array}$ \\
\hline 268 & 663 & 1,070 & 1,780 & 2,480 & 3,340 \\
\hline $\begin{array}{l}\text { WEIGHTED } \\
\text { MEAN } \\
\text { STANDARD }\end{array}$ & $\begin{array}{l}\text { SKEW } \\
\text { DEV. }\end{array}$ & $\begin{array}{l}\text { LOGS) }= \\
\text { LOGS) }= \\
\text { LOGS) }=\end{array}$ & $\begin{array}{l}0.03 \\
2.43 \\
0.47\end{array}$ & & \\
\hline
\end{tabular}

f Reliability of values in colum is uncertain, and potential errors are large.

BASIN CHARACTERISTICS

\begin{tabular}{|c|c|c|c|c|c|c|c|}
\hline \multirow{2}{*}{$\begin{array}{c}\text { MAIN } \\
\text { CHANNEL } \\
\text { SLOPE } \\
\text { (FT/MI) }\end{array}$} & \multirow[b]{2}{*}{$\begin{array}{l}\text { STREAM } \\
\text { LENGTH } \\
\text { (MI) }\end{array}$} & \multirow{2}{*}{$\begin{array}{l}\text { MEAN } \\
\text { BASIN } \\
\text { ELEVA- } \\
\text { TION } \\
\text { (FT) }\end{array}$} & \multirow[b]{2}{*}{$\begin{array}{l}\text { FORESTED } \\
\text { AREA } \\
\text { (PERCENT) }\end{array}$} & \multirow[b]{2}{*}{$\begin{array}{l}\text { SOIL } \\
\text { INDEXX }\end{array}$} & \multirow{2}{*}{$\begin{array}{l}\text { MEAN } \\
\text { ANNUAL } \\
\text { PRECIPI- } \\
\text { TATION } \\
\text { (IN) }\end{array}$} & \multicolumn{2}{|c|}{ RAINFALL INTENSITY, 24-HOUR } \\
\hline & & & & & & $\begin{array}{c}\text { 2-YEAR } \\
\text { (IN) }\end{array}$ & $\begin{array}{l}\text { 50-YEAR } \\
\text { (IN) }\end{array}$ \\
\hline 67.4 & 8.6 & 1,620 & 0.0 & 3.0 & 8.5 & 1.6 & 4.1 \\
\hline
\end{tabular}


LOCATION.--Lat 33'13'56", long 112'10'08", in NEXNEK sec.29, T.2 S., R.2 E., Pinal County, Hydrologic Unit 15050303, in Gila River Indian Reservation, on downstrean side of highway bridge, 3.4 mi upstream from mouth, $4.3 \mathrm{mi}$ south of Komatke, and $9 \mathrm{mi}$ south of Laveen.

DRAINAGE AREA. $--8,581 \mathrm{mi}^{2}$.

REMARKS.--Many diversions above station, mostly by pumping from ground water for municipal uses and for irrigation of about 240,000 acres, not including San Carlos Project. Much of the low flow passing this station is drainage and wasteway return from irrigated lands upstream and pumpage from ground water.

\begin{tabular}{|c|c|c|c|c|c|c|c|}
\hline $\begin{array}{l}\text { WATER } \\
\text { YEAR }\end{array}$ & DATE & $\begin{array}{c}\text { ANNUAL PEAK } \\
\text { DISCHARGE } \\
\left.\text { (FT }{ }^{3} / \mathrm{S}\right)\end{array}$ & $\begin{array}{l}\text { DISCHARGE } \\
\text { CODES }\end{array}$ & $\begin{array}{l}\text { WATER } \\
\text { YEAR }\end{array}$ & DATE & $\begin{array}{c}\text { ANNUAL PEAK } \\
\text { DISCHARGE } \\
\left(\mathrm{FT}^{3} / \mathrm{S}\right)\end{array}$ & $\begin{array}{l}\text { DISCHARGE } \\
\text { CODES }\end{array}$ \\
\hline $\begin{array}{l}1940 \\
1941 \\
1942 \\
1943 \\
1944 \\
1945 \\
1946 \\
1948 \\
1949 \\
1950 \\
1951 \\
1952 \\
1953 \\
1954 \\
1955 \\
1956 \\
1957 \\
1958 \\
1959 \\
1960 \\
1961 \\
1962 \\
1963 \\
1964 \\
1965\end{array}$ & $\begin{array}{l}09-18-40 \\
03-15-41 \\
07-15-42 \\
09-28-43 \\
02-25-44 \\
08-11-45 \\
09-21-46 \\
08-07-48 \\
09-17-49 \\
08-11-50 \\
08-28-51 \\
08-15-52 \\
07-17-53 \\
08-09-54 \\
08-10-55 \\
01-30-56 \\
08-20-57 \\
11-03-57 \\
08-12-59 \\
01-15-60 \\
08-15-61 \\
09-29-62 \\
08-17-63 \\
08-14-64 \\
06-23-65\end{array}$ & $\begin{array}{r}1,200 \\
1,580 \\
1,890 \\
1,200 \\
217 \\
1,200 \\
5,020 \\
1,200 \\
1,780 \\
685 \\
5,060 \\
1,860 \\
555 \\
726 \\
2,180 \\
90 \\
1,040 \\
3,360 \\
3,010 \\
707 \\
547 \\
9,200 \\
608 \\
2,520 \\
309\end{array}$ & $\begin{array}{l}\text { UR } \\
\text { UR } \\
\text { UR } \\
\text { UR } \\
\text { UR } \\
\text { UR } \\
\text { UR } \\
\text { UR } \\
\text { UR } \\
\text { UR } \\
\text { UR } \\
\text { UR } \\
\text { UR } \\
\text { UR } \\
\text { UR } \\
\text { UR } \\
\text { UR } \\
\text { UR } \\
\text { UR } \\
\text { UR } \\
\text { UR } \\
\text { UR } \\
\text { UR } \\
\text { UR } \\
\text { UR }\end{array}$ & $\begin{array}{l}1966 \\
1967 \\
1968 \\
1969 \\
1970 \\
1971 \\
1972 \\
1973 \\
1974 \\
1975 \\
1976 \\
1977 \\
1978 \\
1979 \\
1980 \\
1981 \\
1982 \\
1983 \\
1984 \\
1985 \\
1986 \\
1987 \\
1988 \\
1989\end{array}$ & $\begin{array}{l}12-26-65 \\
09-06-67 \\
12-23-67 \\
11-14-68 \\
09-09-70 \\
08-22-71 \\
08-07-72 \\
10-22-72 \\
07-20-74 \\
07-14-75 \\
09-25-76 \\
10-23-76 \\
10-13-77 \\
12-22-78 \\
02-20-80 \\
07-16-81 \\
09-15-82 \\
03-08-83 \\
10-04-83 \\
12-31-84 \\
07-21-86 \\
02-25-87 \\
08-27-88 \\
10-15-88\end{array}$ & $\begin{array}{r}2,940 \\
448 \\
3,820 \\
152 \\
1,010 \\
2,440 \\
112 \\
1,650 \\
144 \\
203 \\
583 \\
472 \\
2,010 \\
4,120 \\
115 \\
368 \\
751 \\
1,910 \\
33,000 \\
2,030 \\
456 \\
110 \\
310 \\
688\end{array}$ & $\begin{array}{l}\text { UR } \\
\text { UR } \\
\text { UR } \\
\text { UR } \\
\text { UR } \\
\text { UR } \\
\text { UR } \\
\text { UR } \\
\text { KR } \\
\text { KR } \\
\text { KR } \\
\text { KR } \\
\text { KR } \\
\text { KR } \\
\text { KR } \\
\text { KR } \\
\text { KR } \\
\text { KR } \\
\text { KR } \\
\text { KR } \\
\text { KR } \\
\text { KR } \\
\text { KR } \\
\text { KR }\end{array}$ \\
\hline
\end{tabular}

BASIN CHARACTERISTICS

\begin{tabular}{|c|c|c|c|c|c|c|c|}
\hline MAIN & & $\begin{array}{r}\text { MEAN } \\
\text { BASIN }\end{array}$ & & & $\begin{array}{l}\text { MEAN } \\
\text { ANNUAL }\end{array}$ & RAINFALL I & SITY, 24-HOUR \\
\hline $\begin{array}{l}\text { CHANNEL } \\
\text { SLOPE } \\
\text { (FT/MI) }\end{array}$ & $\begin{array}{l}\text { STREAM } \\
\text { LENGTH } \\
\text { (MI) }\end{array}$ & $\begin{array}{l}\text { ELEVA- } \\
\text { TION } \\
\text { (FT) }\end{array}$ & $\begin{array}{l}\text { FORESTED } \\
\text { AREA } \\
\text { (PERCENT) }\end{array}$ & $\begin{array}{l}\text { SOIL } \\
\text { IMDEX }\end{array}$ & $\begin{array}{l}\text { PRECIPI - } \\
\text { TATION } \\
\text { (IN) }\end{array}$ & $\begin{array}{l}\text { 2-YEAR } \\
\text { (IN) }\end{array}$ & $\begin{array}{l}\text { 50-YEAR } \\
\text { (IN) }\end{array}$ \\
\hline 15.2 & 241 & 3,060 & 7.8 & 2.0 & 13.0 & 1.9 & 4.2 \\
\hline
\end{tabular}


09489000 SANTA CRUZ RIVER MEAR LAVEen, AZ--Continued

MEAN MONTHLY AND ANMUAL DISCHARGES $1975-89$

\begin{tabular}{|c|c|c|c|c|c|c|}
\hline MONTH & $\begin{array}{l}\left.\operatorname{MAX} \operatorname{ImMN}_{(\mathrm{M}} \mathrm{F}^{3} / \mathrm{S}\right)\end{array}$ & $\begin{array}{l}\text { MINIMUM } \\
\left(\mathrm{FT}^{3} / \mathrm{S}\right)\end{array}$ & $\begin{array}{c}\text { MEAN } \\
\left(F T^{3} / S\right)\end{array}$ & $\begin{array}{l}\text { STAN- } \\
\text { DARD } \\
\text { DEVIA- } \\
\text { TION } \\
\left(\mathrm{FT}^{3} / \mathrm{S}\right)\end{array}$ & $\begin{array}{l}\text { COEFFI- } \\
\text { CIENT OF } \\
\text { VARI- } \\
\text { ATION }\end{array}$ & $\begin{array}{c}\text { PERCENT } \\
\text { OF } \\
\text { ANNUAL } \\
\text { RUNOFF }\end{array}$ \\
\hline $\begin{array}{l}\text { OCTOBER } \\
\text { NOVEMBER } \\
\text { DECEMBER } \\
\text { JANUARY } \\
\text { FEBRUARY } \\
\text { MARCH } \\
\text { APRIL } \\
\text { MAY } \\
\text { JUNE } \\
\text { JULY } \\
\text { AUGUST } \\
\text { SEPTEMBER }\end{array}$ & $\begin{array}{c}1,810 \\
26 \\
248 \\
455 \\
186 \\
160 \\
6.6 \\
6.8 \\
2.3 \\
41 \\
129 \\
53\end{array}$ & $\begin{array}{l}0.00 \\
0.00 \\
0.00 \\
0.00 \\
0.00 \\
0.00 \\
0.00 \\
0.00 \\
0.00 \\
0.00 \\
0.00 \\
0.00\end{array}$ & $\begin{array}{c}131 \\
2.4 \\
27 \\
43 \\
23 \\
19 \\
0.95 \\
0.72 \\
0.17 \\
5.7 \\
16 \\
12\end{array}$ & $\begin{array}{c}466 \\
6.5 \\
66 \\
118 \\
49 \\
46 \\
1.7 \\
1.8 \\
0.59 \\
11 \\
33 \\
18\end{array}$ & $\begin{array}{l}3.6 \\
2.7 \\
2.4 \\
2.8 \\
2.1 \\
2.5 \\
1.8 \\
2.5 \\
3.5 \\
1.9 \\
2.0 \\
1.5\end{array}$ & $\begin{array}{r}46.7 \\
0.9 \\
9.8 \\
15.2 \\
8.2 \\
6.6 \\
0.3 \\
0.3 \\
0.1 \\
2.0 \\
5.8 \\
4.1\end{array}$ \\
\hline NNUAL & 170 & 0.47 & 24 & 45 & 1.9 & 100 \\
\hline
\end{tabular}

MAGNITUDE AND PROBABILITY OF INSTANTANEOUS PEAK FLOW BASED ON PERIOD OF RECORD

DISCHARGE, IN FT 3 /S, FOR INDICATED RECURRENCE INTERVAL IN YEARS, AND EXCEEDANCE PROBABILITY, IN PERCENT

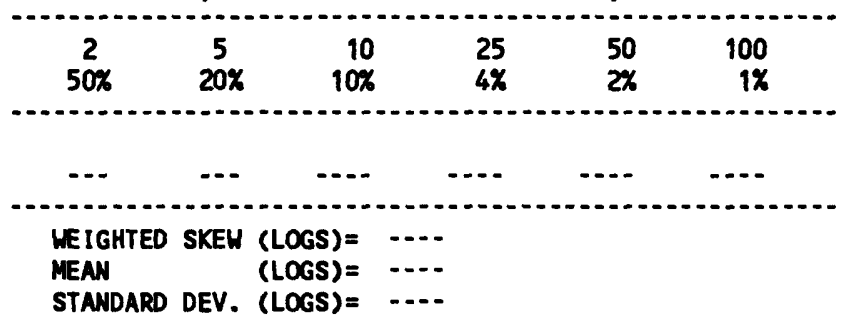

MAGNITLOE AND PROBABILITY OF ANMUAL LON FLOW BASED ON PERIOD OF RECORD 1976-89

\begin{tabular}{|c|c|c|c|c|c|c|}
\hline \multirow{2}{*}{$\begin{array}{l}\text { PERIOD } \\
\text { (CON- } \\
\text { SECU- } \\
\text { TIVE } \\
\text { DAYS) }\end{array}$} & \multicolumn{6}{|c|}{$\begin{array}{l}\text { DISCHARGE, IN FT J/S, FOR INDICATED } \\
\text { RECURRENCE INTERVAL, IN YEARS, AND } \\
\text { NON-EXCEEDANCE PROBABILITY, IN PERCENT }\end{array}$} \\
\hline & $\begin{array}{c}2 \\
50 \%\end{array}$ & $\underset{20 \%}{5}$ & $\begin{array}{l}10 \\
10 \%\end{array}$ & $\begin{array}{l}20 \\
5 x\end{array}$ & $\begin{array}{l}50 \phi \\
2 \%\end{array}$ & $\begin{array}{l}100 t \\
18\end{array}$ \\
\hline $\begin{array}{r}1 \\
3 \\
7 \\
14 \\
30 \\
60\end{array}$ & & & & & & \\
\hline $\begin{array}{r}90 \\
120 \\
183\end{array}$ & $\begin{array}{l}0.00 \\
0.00 \\
1.4\end{array}$ & $\begin{array}{l}0.00 \\
0.00 \\
0.22\end{array}$ & $\begin{array}{l}0.00 \\
0.00 \\
0.07\end{array}$ & $\begin{array}{l}0.00 \\
0.00 \\
0.03\end{array}$ & $\begin{array}{l}0.00 \\
0.00 \\
0.01\end{array}$ & $\begin{array}{l}0.00 \\
0.00 \\
0.00\end{array}$ \\
\hline
\end{tabular}

MAGNITUDE AND PROBABILITY OF ANMUAL HIGH FLOW BASED ON PERIOD OF RECORD $1975-89$

\begin{tabular}{|c|c|c|c|c|c|c|}
\hline \multirow{2}{*}{$\begin{array}{l}\text { PERIOD } \\
\text { (CON- } \\
\text { SECU- } \\
\text { TIVE } \\
\text { DAYS) }\end{array}$} & & \multicolumn{5}{|c|}{$\begin{array}{l}\text { DISCHARGE, IN } \mathrm{FT}^{3} / \mathrm{S} \text {, FOR INDICATED } \\
\text { RECURRENCE INTERVAL, IN YEARS, AND } \\
\text { EXCEEDANCE PROBABILITY, IN PERCENT }\end{array}$} \\
\hline & $\stackrel{2}{50 \%}$ & $\begin{array}{c}5 \\
20 \%\end{array}$ & $\begin{array}{l}10 \\
10 \%\end{array}$ & $\begin{array}{l}25 \\
4 x\end{array}$ & $\begin{array}{l}50 \dagger \\
2 x\end{array}$ & $\begin{array}{c}100\} \\
1 \%\end{array}$ \\
\hline $\begin{array}{l}1 \\
3 \\
7 \\
15 \\
30 \\
60 \\
90\end{array}$ & $\begin{array}{r}359 \\
203 \\
111 \\
58 \\
35 \\
24 \\
17\end{array}$ & $\begin{array}{r}1,620 \\
1,070 \\
558 \\
294 \\
179 \\
121 \\
84\end{array}$ & $\begin{array}{l}4,050 \\
2,930 \\
1,480 \\
778 \\
463 \\
307 \\
209\end{array}$ & $\begin{array}{r}12,000 \\
9,560 \\
4,660 \\
2,420 \\
1,380 \\
869 \\
584\end{array}$ & $\begin{array}{r}25,500 \\
21,800 \\
10,400 \\
5,340 \\
2,940 \\
1,760 \\
1,170\end{array}$ & $\begin{array}{l}52, \\
47, \\
22, \\
11, \\
5, \\
3, \\
2,\end{array}$ \\
\hline
\end{tabular}

DURATION TABLE OF DAILY MEAN FLOW FOR PERIOD OF RECORD 1975-89

DISCHARGE, IN FT $3 / 5$, WHICH WAS EQUALED OR EXCEEDED FOR INDICATED PERCENT OF TIME

\begin{tabular}{|c|c|c|c|c|c|c|c|c|c|c|c|c|c|c|c|c|}
\hline $1 \%$ & $5 \%$ & $10 \%$ & $15 \%$ & $20 \%$ & $30 \%$ & $40 \%$ & $50 \%$ & $60 \%$ & $70 \%$ & $80 \%$ & $90 \%$ & $95 \%$ & $98 \%$ & $99 \%$ & $99.5 \%$ & $99.9 \%$ \\
\hline 03 & 28 & 7.0 & 3.4 & 1.8 & 0.27 & 0.00 & 0.00 & 0.00 & 0.00 & 0.00 & 0.00 & 0.00 & 0.00 & 0.00 & 0.00 & 0.0 \\
\hline
\end{tabular}

$\uparrow$ Reliability of values in column is uncertain, and potential errors are large. 
09489000 SANTA CRUZ RIVER MEAR LAVEEN, AZ-CONTINUED
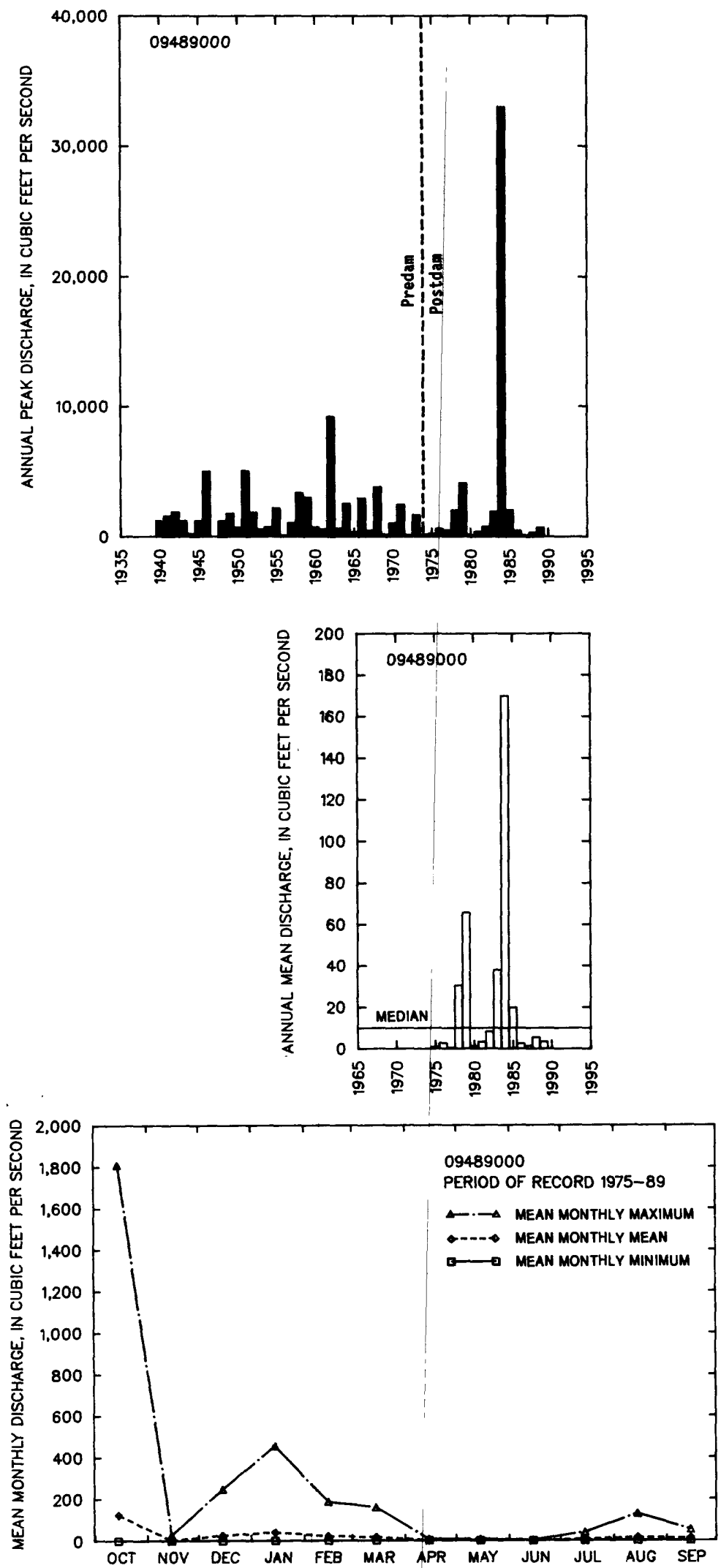
09489070 MORTH FORK OF EAST FORK BLACK RIVER NEAR ALPINE, AZ

LOCATION. - Lat 33'54'11", long 109'19'20", in SW/AEK sec.19, T.6 N., R.29 E. (unsurveyed), Apache County, Hydrologic Unit 15060101, in Apache National Forest, on right bank $1.4 \mathrm{mi}$ downstream from Crosby Crossing and 12 mi northwest of Alpine.

DRAINAGE AREA. $--38.1 \mathrm{mi}^{2}$.

REMARKS.--Minor storage at headwaters for recreation and stock purposes; the largest is 8 ig Lake. No diversions above station.

AMNUAL PEAK DISCHARGE

\begin{tabular}{ccc}
$\begin{array}{c}\text { MATER } \\
\text { YEAR }\end{array}$ & DATE & $\begin{array}{c}\text { ANNUAL PEAK } \\
\text { DISCHARGE } \\
\text { (FT } 3 / \text { S) }\end{array}$ \\
\hline 1966 & $04-03-66$ & 556 \\
1967 & $08-10-67$ & 27 \\
1968 & $04-15-68$ & 515 \\
1969 & $04-06-69$ & 366 \\
1970 & $04-06-70$ & 142 \\
1971 & $03-12-71$ & 39 \\
1972 & $10-25-71$ & 218 \\
1973 & $04-17-73$ & 1,070 \\
1974 & $03-29-74$ & 77 \\
1975 & $04-25-75$ & 577 \\
1976 & $04-05-76$ & 283 \\
1977 & $04-08-77$ & 332 \\
1978 & $03-31-78$ & 383 \\
$\ldots$
\end{tabular}

BASIN CHARACTERISTICS

\begin{tabular}{|c|c|c|c|c|c|c|c|}
\hline \multirow{2}{*}{$\begin{array}{l}\text { MAIN } \\
\text { CHANNEL } \\
\text { SLOPE } \\
\text { (FT/MI) }\end{array}$} & \multirow[b]{2}{*}{$\begin{array}{c}\text { STREAM } \\
\text { LENGTH } \\
\text { (MI) }\end{array}$} & \multirow{2}{*}{$\begin{array}{l}\text { MEAN } \\
\text { BASIN } \\
\text { ELEVA- } \\
\text { TION } \\
\text { (FT) }\end{array}$} & \multirow[b]{2}{*}{$\begin{array}{c}\text { FORESTED } \\
\text { AREA } \\
\text { (PERCENT) }\end{array}$} & \multirow[b]{2}{*}{$\begin{array}{l}\text { SOIL } \\
\text { INDEX }\end{array}$} & \multirow{2}{*}{$\begin{array}{l}\text { MEAN } \\
\text { ANNULL } \\
\text { PRECIPI- } \\
\text { TATION } \\
\text { (IN) }\end{array}$} & \multicolumn{2}{|c|}{ RAINFALL INTENSITY, 24-HOUR } \\
\hline & & & & & & $\begin{array}{c}\text { 2-YEAR } \\
\text { (IN) }\end{array}$ & $\begin{array}{l}\text { 50-YEAR } \\
\text { (IN) }\end{array}$ \\
\hline 48.8 & 10.1 & 9,060 & 24.0 & 3.0 & 27.5 & 2.4 & 4.4 \\
\hline
\end{tabular}


MEAN MONTHLY AND ANNUAL DISCHARGES 1966-78

\begin{tabular}{|c|c|c|c|c|c|c|}
\hline MONTH & $\begin{array}{l}\operatorname{MAXIMUN} \\
\left(F T^{3} / S\right)\end{array}$ & $\begin{array}{l}\text { MINIMUM } \\
\left(F T^{3} / S\right)\end{array}$ & $\begin{array}{c}\text { MEAN } \\
\left(F T^{3} / S\right)\end{array}$ & $\begin{array}{l}\text { STAN- } \\
\text { DARD } \\
\text { DEVIA- } \\
\text { TION } \\
\left(F^{3} / S\right)\end{array}$ & $\begin{array}{l}\text { COEFFI- } \\
\text { CIENT OF } \\
\text { VARI - } \\
\text { ATION }\end{array}$ & $\begin{array}{c}\text { PERCENT } \\
\text { OF } \\
\text { ANNUAL } \\
\text { RUNOFF }\end{array}$ \\
\hline $\begin{array}{l}\text { OCTOBER } \\
\text { NOVEMBER } \\
\text { DECEMBER } \\
\text { JANUARY } \\
\text { FEBRUARY } \\
\text { MARCH } \\
\text { APRIL } \\
\text { MAY } \\
\text { JUNE } \\
\text { JULY } \\
\text { AUGUST } \\
\text { SEPTEMBER }\end{array}$ & $\begin{array}{c}33 \\
8.7 \\
16 \\
13 \\
15 \\
103 \\
362 \\
134 \\
9.8 \\
4.7 \\
13 \\
13\end{array}$ & $\begin{array}{l}0.83 \\
0.67 \\
0.33 \\
0.20 \\
0.20 \\
2.4 \\
1.2 \\
0.49 \\
0.29 \\
0.41 \\
0.56 \\
0.38\end{array}$ & $\begin{array}{l}5.8 \\
3.0 \\
2.5 \\
1.9 \\
2.7 \\
23 \\
83 \\
21 \\
2.0 \\
1.8 \\
3.9 \\
3.0\end{array}$ & $\begin{array}{c}9.9 \\
2.9 \\
4.2 \\
3.3 \\
4.1 \\
29 \\
102 \\
37 \\
2.5 \\
1.2 \\
3.9 \\
3.5\end{array}$ & $\begin{array}{l}1.7 \\
0.97 \\
1.7 \\
1.7 \\
1.5 \\
1.2 \\
1.2 \\
1.8 \\
1.2 \\
0.69 \\
1.0 \\
1.2\end{array}$ & $\begin{array}{r}3.8 \\
1.9 \\
1.6 \\
1.3 \\
1.8 \\
15.1 \\
54.0 \\
13.5 \\
1.3 \\
1.1 \\
2.5 \\
2.0\end{array}$ \\
\hline WUAL & 50 & 1.2 & 13 & 13 & 1.0 & 100 \\
\hline
\end{tabular}

MAGNITUDE AND PROBABILITY OF INSTANTANEOUS PEAK FLON BASED ON PERIOD OF RECORD 1966-78

DISCHARGE, IN $\mathrm{FT}^{3} / \mathrm{S}$, FOR INDICATED RECURRENCE INTERVAL IN YEARS, AND EXCEEDANCE PROBABILITY, IN PERCENT

\begin{tabular}{lccccc}
2 & 5 & 10 & 25 & $50 \dagger$ & $100 \dagger$ \\
$50 \%$ & $20 \%$ & $10 \%$ & $4 \%$ & $2 \%$ & $1 \%$ \\
306 & 553 & 741 & 1,000 & 1,210 & 1,420 \\
\hline MEIGHTED SKEU (LOGS) & $=$ & -0.24 & & \\
MEAN & (LOGS) & 2.47 & & \\
STANDARD DEV. (LOGS) & $=0.32$
\end{tabular}

MAGNITUDE AND PROBABILITY OF ANNUAL LON FLON BASED ON PERIOD OF RECORD 1967-78

\begin{tabular}{|c|c|c|c|c|c|c|}
\hline \multirow{2}{*}{$\begin{array}{l}\text { PERIOO } \\
\text { (CON- } \\
\text { SEQN- } \\
\text { TIVE } \\
\text { DAYS) }\end{array}$} & \multicolumn{6}{|c|}{$\begin{array}{l}\text { DISCHARGE, IN FT } 3 / 5 \text {, FOR INDICATED } \\
\text { RECURRENCE INTERVAL, IN YEARS, AND } \\
\text { NON-EXCEEDANCE PROBABILITY, IN PERCENT }\end{array}$} \\
\hline & $\begin{array}{c}2 \\
50 \%\end{array}$ & $\begin{array}{c}5 \\
20 \%\end{array}$ & $\begin{array}{l}10 \\
10 \%\end{array}$ & $\begin{array}{l}20 \\
5 \%\end{array}$ & $\begin{array}{l}50 \phi \\
2 x\end{array}$ & $\begin{array}{l}100+ \\
1 \%\end{array}$ \\
\hline $\begin{array}{r}1 \\
3 \\
7 \\
14 \\
30 \\
60 \\
90 \\
120 \\
183\end{array}$ & $\begin{array}{l}0.37 \\
0.39 \\
0.40 \\
0.42 \\
0.47 \\
0.55 \\
0.62 \\
0.66 \\
0.96\end{array}$ & $\begin{array}{l}0.24 \\
0.25 \\
0.27 \\
0.29 \\
0.31 \\
0.36 \\
0.40 \\
0.46 \\
0.75\end{array}$ & $\begin{array}{l}0.20 \\
0.21 \\
0.22 \\
0.24 \\
0.25 \\
0.28 \\
0.31 \\
0.41 \\
0.70\end{array}$ & $\begin{array}{l}0.17 \\
0.17 \\
0.19 \\
0.21 \\
0.22 \\
0.23 \\
0.25 \\
0.38 \\
0.68\end{array}$ & $\begin{array}{l}0.14 \\
0.14 \\
0.16 \\
0.18 \\
0.18 \\
0.19 \\
0.20 \\
0.36 \\
0.66\end{array}$ & $\begin{array}{l}0.13 \\
0.13 \\
0.15 \\
0.16 \\
0.16 \\
0.16 \\
0.18 \\
0.35 \\
0.66\end{array}$ \\
\hline
\end{tabular}

MACNITUDE AND PROBABILITY OF ANNUAL HIGH FLON BASED ON PERIOD OF RECORD 1966-78

\begin{tabular}{|c|c|c|c|c|c|c|}
\hline \multirow{2}{*}{$\begin{array}{l}\text { PERIOD } \\
\text { (CON- } \\
\text { SECU- } \\
\text { TIVE } \\
\text { DAYS) }\end{array}$} & & \multicolumn{5}{|c|}{$\begin{array}{l}\text { OISCHARCE, IN } \mathrm{FT}^{3} / \mathrm{S} \text {, FOR INDICATED } \\
\text { RECURRENCE INTERVAL, IN YEARS, AND } \\
\text { EXCEEDANCE PROBABILITY, IN PERCENT }\end{array}$} \\
\hline & ${ }_{50 \%}^{2}$ & $\begin{array}{c}5 \\
20 \%\end{array}$ & $\begin{array}{l}10 \\
10 x\end{array}$ & $\begin{array}{l}25 \\
4 \%\end{array}$ & $\begin{array}{l}50 \dagger \\
2 \%\end{array}$ & $\begin{array}{c}100 \nmid \\
1 \%\end{array}$ \\
\hline $\begin{array}{l}1 \\
3 \\
7 \\
15 \\
30 \\
60 \\
90\end{array}$ & $\begin{array}{r}150 \\
130 \\
105 \\
76 \\
52 \\
34 \\
26\end{array}$ & $\begin{array}{r}380 \\
340 \\
286 \\
217 \\
157 \\
98 \\
71\end{array}$ & $\begin{array}{l}592 \\
539 \\
462 \\
362 \\
269 \\
164 \\
115\end{array}$ & $\begin{array}{l}916 \\
858 \\
751 \\
607 \\
465 \\
277 \\
186\end{array}$ & $\begin{array}{r}1,190 \\
1,140 \\
1,010 \\
833 \\
654 \\
384 \\
250\end{array}$ & $\begin{array}{r}1,500 \\
1,460 \\
1,310 \\
1,100 \\
880 \\
509 \\
321\end{array}$ \\
\hline
\end{tabular}

DURATION TABLE OF DAILY MEAN FLON FOR PERIOD OF RECORD 1966-78

DISCHARGE, IN $\mathrm{FT}^{3} / \mathrm{S}$, WHICH WAS EQUALED OR EXCEEDED FOR INDICATED PERCENT OF TIME

\begin{tabular}{|c|c|c|c|c|c|c|c|c|c|c|c|c|c|c|c|c|}
\hline $1 \%$ & $5 \%$ & $10 \%$ & $15 \%$ & $20 \%$ & $30 x$ & $40 \%$ & $50 x$ & $60 \%$ & $70 x$ & $80 \%$ & $90 \%$ & $95 \%$ & $98 \%$ & $99 \%$ & $99.5 \%$ & $99.9 \%$ \\
\hline 253 & 53 & 22 & 12 & 6.7 & 3.4 & 2.2 & 1.5 & 1.2 & 0.91 & 0.66 & 0.46 & 0.33 & 0.26 & 0.23 & 0.21 & .2 \\
\hline
\end{tabular}

f Reliability of values in colum is uncertain, and potential errors are large. 
GILA RIVER BASIN

09489070 NORTH FORK OF EAST FORK BLACK RIVER NEAR ALPINE, AZ--CONTIMUED
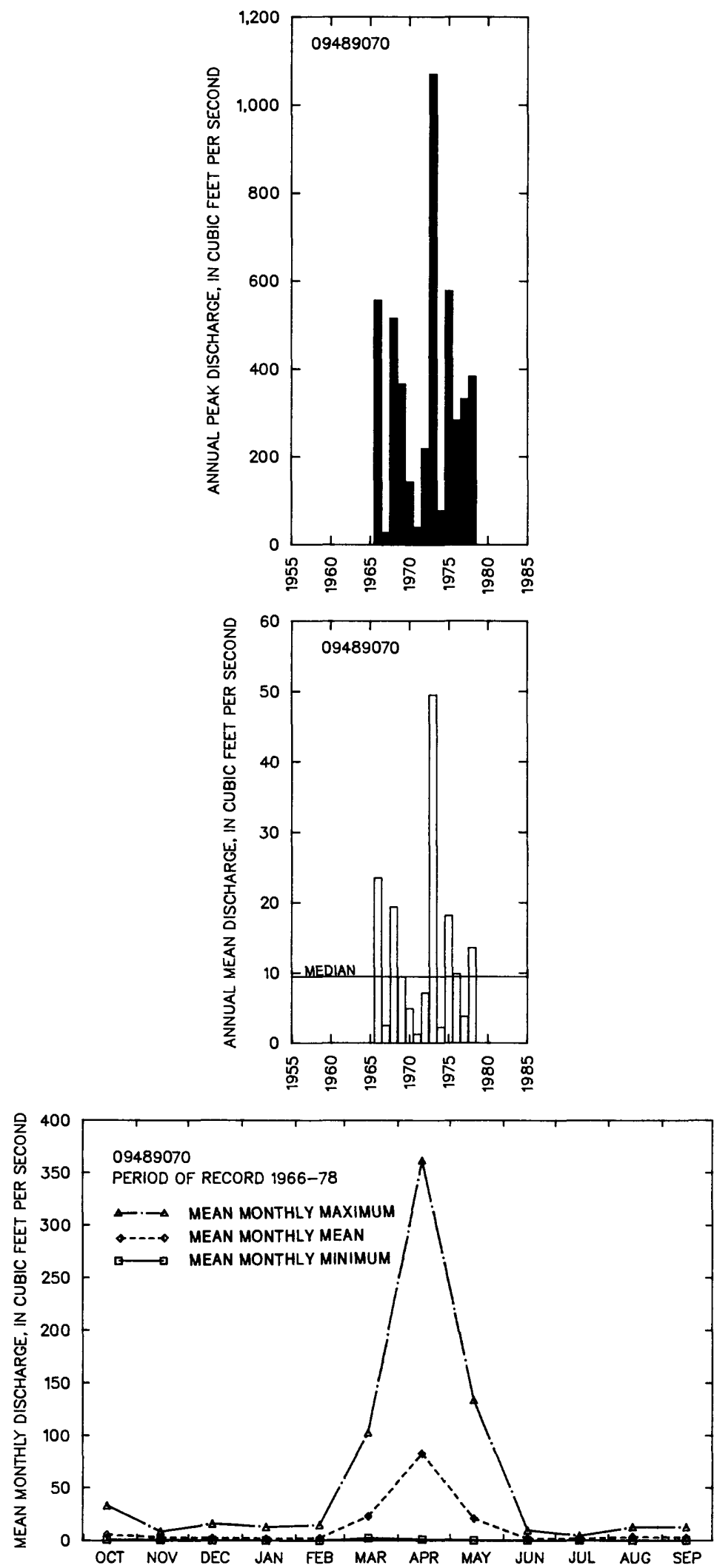
LOCATION. - - Lat 33·38'58", Long 109・17'04", Greenlee County, at U.S. Highway 666, 2.7 mi northeast of Hamagan Meadow.

DRAINACE AREA. $-1.61 \mathrm{mi}^{2}$.

AMNUAL PEAK DISCHAREE

\begin{tabular}{|c|c|c|}
\hline $\begin{array}{l}\text { WATER } \\
\text { YEAR }\end{array}$ & DATE & $\begin{array}{c}\text { ANNUAL PEAK } \\
\text { DISCHARGE } \\
\left(\mathrm{FT}^{3} / \mathrm{S}\right)\end{array}$ \\
\hline $\begin{array}{l}1964 \\
1965 \\
1966 \\
1967 \\
1968 \\
1969 \\
1970 \\
1971 \\
1972 \\
1973 \\
1974 \\
1975 \\
1976\end{array}$ & $\begin{array}{l}09-21-64 \\
04-22-65 \\
04-04-66 \\
08-11-67 \\
04-00-68 \\
09-03-69 \\
04-00-70 \\
09-30-71 \\
10-25-71 \\
10-19-72 \\
04-24-74 \\
09-00-75 \\
08-00-76\end{array}$ & $\begin{array}{l}10 \\
20 \\
20 \\
16 \\
19 \\
19 \\
11 \\
14 \\
12 \\
70 \\
1.0 \\
48 \\
2.0\end{array}$ \\
\hline
\end{tabular}

MAGNITUDE AND PROBABILITY OF INSTANTANEOUS PEAK FLOW BASED ON PERIOD OF RECORD 1964-76

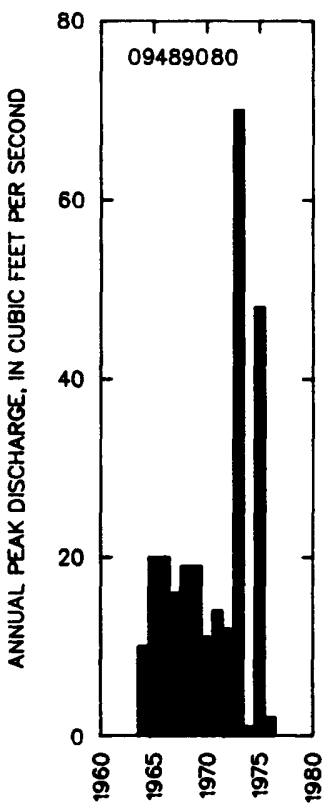

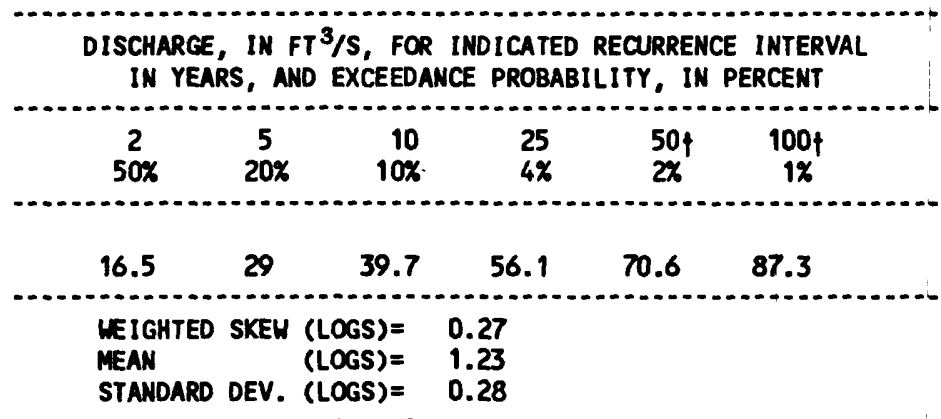

t Reliability of values in colum is uncertain, and potential errors are large.

BASIN CHARACTERISTICS

\begin{tabular}{|c|c|c|c|c|c|c|c|}
\hline MAIN & & $\begin{array}{r}\text { MEAN } \\
\text { BASIN }\end{array}$ & & & & RAINFALL I & SITY, 24-HOUR \\
\hline $\begin{array}{l}\text { CHANNEL } \\
\text { SLOPE } \\
\text { (FTMI) }\end{array}$ & $\begin{array}{c}\text { STREAM } \\
\text { LENGTH } \\
\text { (MI) }\end{array}$ & $\begin{array}{l}\text { ELEVA- } \\
\text { TION } \\
\text { (FT) }\end{array}$ & $\begin{array}{l}\text { FORESTED } \\
\text { AREA } \\
\text { (PERCENT) }\end{array}$ & $\begin{array}{l}\text { SOIL } \\
\text { INDEX }\end{array}$ & $\begin{array}{l}\text { PRECIPI- } \\
\text { TATION } \\
\text { (IN) }\end{array}$ & $\begin{array}{c}\text { 2-YEAR } \\
\text { (IN) }\end{array}$ & $\begin{array}{c}\text { 50-YEAR } \\
\text { (IN) }\end{array}$ \\
\hline 68.6 & 2.0 & 9,160 & 90.0 & 3.0 & 30.0 & 2.4 & 4.0 \\
\hline
\end{tabular}


09489100 BLACK RIVER NEAR MAVERICK, AZ

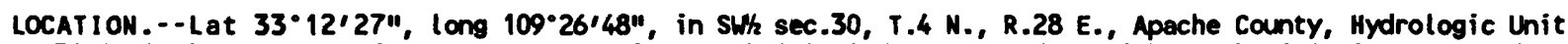
15060101, in Apache National Forest, on right bank 1.0 mi dounstrean from Fish Creek, $1.1 \mathrm{mi}$ upstream from Conkl in Creek, and $6 \mathrm{mi}$ southeast of Maverick.

DRAIMAGE AREA. $--315 \mathrm{mi}^{2}$.

REMARKS.--Minor storage for recreational and stock purposes near headwaters. No diversion above station.

ANIUAL PEAK OISCHARGE

\begin{tabular}{|c|c|c|c|}
\hline $\begin{array}{l}\text { WATER } \\
\text { YEAR }\end{array}$ & DATE & $\begin{array}{c}\text { ANNUAL PEAK } \\
\text { OISCHARGE } \\
\left(F T^{3} / S\right)\end{array}$ & $\begin{array}{l}\text { DISCHARGE } \\
\text { COOES }\end{array}$ \\
\hline $\begin{array}{l}1963 \\
1964 \\
1965 \\
1966 \\
1967 \\
1968 \\
1969 \\
1970 \\
1971 \\
1972 \\
1973 \\
1974 \\
1975 \\
1976 \\
1977 \\
1978 \\
1979 \\
1980 \\
1982 \\
1984\end{array}$ & $\begin{array}{l}09-10-63 \\
09-15-64 \\
04-21-65 \\
04-02-66 \\
08-12-67 \\
04-16-68 \\
04-07-69 \\
09-06-70 \\
08-29-71 \\
10-24-71 \\
10-20-72 \\
03-31-74 \\
03-08-75 \\
04-05-76 \\
04-10-77 \\
03-01-78 \\
12-18-78 \\
04-21-80 \\
04-13-82 \\
10-02-83\end{array}$ & $\begin{array}{r}911 \\
946 \\
2,010 \\
2,300 \\
1,040 \\
1,890 \\
1,740 \\
402 \\
580 \\
2,910 \\
11,100 \\
342 \\
2,360 \\
714 \\
700 \\
2,390 \\
10,300 \\
3,400 \\
1,550 \\
1,000\end{array}$ & HP \\
\hline
\end{tabular}

$1_{\text {Highest since } 1954 .}$

BASIN CHARACTERISTICS

\begin{tabular}{|c|c|c|c|c|c|c|c|}
\hline \multirow{2}{*}{$\begin{array}{l}\text { MAIN } \\
\text { CHANNEL } \\
\text { SLOPE } \\
\text { (FTMI) }\end{array}$} & \multirow[b]{2}{*}{$\begin{array}{c}\text { STRENM } \\
\text { LENGTH } \\
\text { (MI) }\end{array}$} & \multirow{2}{*}{$\begin{array}{l}\text { MEAN } \\
\text { BASIN } \\
\text { ELEVA- } \\
\text { TION } \\
\text { (FT) }\end{array}$} & \multirow[b]{2}{*}{$\begin{array}{l}\text { FORESTED } \\
\text { AREA } \\
\text { (PERCENT) }\end{array}$} & \multirow{2}{*}{\multicolumn{2}{|c|}{$\begin{array}{l}\text { MEAN } \\
\text { ANNUAL } \\
\text { PRECIPI- } \\
\text { TATION } \\
\text { (IN) }\end{array}$}} & \multicolumn{2}{|c|}{ RAINFALL INTENSITY, 24-HOUR } \\
\hline & & & & & & $\begin{array}{c}\text { 2-YEAR } \\
\text { (IN) }\end{array}$ & $\begin{array}{l}\text { 50-YEAR } \\
\text { (IN) }\end{array}$ \\
\hline 69.4 & 38.4 & 8,700 & 82.0 & 3.0 & 27.2 & 2.4 & 4.8 \\
\hline
\end{tabular}


MEAN MONTHLY AMD ANNUAL DISCHARGES 1963-82

\begin{tabular}{|c|c|c|c|c|c|c|}
\hline MONTH & $\begin{array}{l}\operatorname{MAXIMUM} \\
\left(F T^{3} / S\right)\end{array}$ & $\begin{array}{l}\text { MINIMUN } \\
\left(F^{3} / S\right)\end{array}$ & $\begin{array}{c}\text { MEAN } \\
\left(F T^{3} / S\right)\end{array}$ & $\begin{array}{l}\text { STAN- } \\
\text { DARD } \\
\text { DEVIA- } \\
\text { TION } \\
\left(F^{3} / S\right)\end{array}$ & $\begin{array}{l}\text { COEFFI - } \\
\text { CIENT OF } \\
\text { VARI - } \\
\text { ATION }\end{array}$ & $\begin{array}{c}\text { PERCENT } \\
\text { OF } \\
\text { ANNUAL } \\
\text { RUNOFF }\end{array}$ \\
\hline $\begin{array}{l}\text { OCTOBER } \\
\text { NOVEMBER } \\
\text { DECEMBER } \\
\text { JANUARY } \\
\text { FEBRUARY } \\
\text { MARCH } \\
\text { APRIL } \\
\text { MAY } \\
\text { JUNE } \\
\text { JULY } \\
\text { AUGUST } \\
\text { SEPTEMBER }\end{array}$ & $\begin{array}{r}726 \\
219 \\
609 \\
205 \\
290 \\
934 \\
1,480 \\
1,330 \\
147 \\
107 \\
224 \\
274\end{array}$ & $\begin{array}{l}20 \\
18 \\
15 \\
18 \\
21 \\
44 \\
32 \\
22 \\
17 \\
21 \\
24 \\
21\end{array}$ & $\begin{array}{r}91 \\
60 \\
72 \\
61 \\
99 \\
307 \\
559 \\
224 \\
45 \\
38 \\
66 \\
72\end{array}$ & $\begin{array}{r}173 \\
62 \\
134 \\
60 \\
86 \\
262 \\
462 \\
309 \\
37 \\
22 \\
44 \\
70\end{array}$ & $\begin{array}{l}1.9 \\
1.0 \\
1.9 \\
0.99 \\
0.87 \\
0.85 \\
0.83 \\
1.4 \\
0.82 \\
0.58 \\
0.68 \\
0.97\end{array}$ & $\begin{array}{r}5.4 \\
3.6 \\
4.2 \\
3.6 \\
5.8 \\
18.1 \\
33.0 \\
13.2 \\
2.6 \\
2.2 \\
3.9 \\
4.3\end{array}$ \\
\hline WNUAL & 392 & 37 & 141 & 98 & 0.70 & 100 \\
\hline
\end{tabular}

MACNITLDE AND PROBABILITY OF ANNUAL LOW FLOH BASED ON PERIOD OF RECORD $1964-82$

\begin{tabular}{|c|c|c|c|c|c|c|}
\hline \multirow{2}{*}{$\begin{array}{l}\text { PERIOD } \\
\text { (CON- } \\
\text { SECU- } \\
\text { TIVE } \\
\text { DAYS) }\end{array}$} & \multicolumn{6}{|c|}{$\begin{array}{l}\text { DISCHARGE, IN FT } 3 / S \text {, FOR INDICATED } \\
\text { RECURRENCE INTERVAL, IN YEARS, AND } \\
\text { NON-EXCEEDANCE PROBABILITY, IN PERCENT }\end{array}$} \\
\hline & $\frac{2}{50 \%}$ & $\begin{array}{c}5 \\
20 \%\end{array}$ & $\begin{array}{l}10 \\
10 \%\end{array}$ & $\begin{array}{l}20 \\
5 \%\end{array}$ & $\begin{array}{l}50 \nmid \\
2 \%\end{array}$ & $\begin{array}{l}100 t \\
1 \%\end{array}$ \\
\hline $\begin{array}{r}1 \\
3 \\
7 \\
14 \\
30 \\
60 \\
90 \\
120 \\
183\end{array}$ & $\begin{array}{l}14 \\
15 \\
16 \\
17 \\
19 \\
21 \\
23 \\
25 \\
35\end{array}$ & $\begin{array}{l}12 \\
13 \\
14 \\
15 \\
17 \\
19 \\
20 \\
21 \\
27\end{array}$ & $\begin{array}{l}11 \\
12 \\
13 \\
14 \\
16 \\
18 \\
19 \\
20 \\
24\end{array}$ & $\begin{array}{l}10 \\
12 \\
12 \\
14 \\
15 \\
17 \\
18 \\
19 \\
21\end{array}$ & $\begin{array}{c}9.3 \\
11 \\
11 \\
13 \\
14 \\
16 \\
17 \\
18 \\
20\end{array}$ & $\begin{array}{l}8 . \\
11 \\
11 \\
13 \\
14 \\
16 \\
16 \\
18 \\
18\end{array}$ \\
\hline
\end{tabular}

MAGNITLDE AND PROBABILITY OF ANNUAL HIGH FLOW BASED ON PERIOD OF RECORD 1963-82

\begin{tabular}{|c|c|c|c|c|c|c|}
\hline $\begin{array}{r}\text { PERIOD } \\
\text { (CON- } \\
\text { SECU- }\end{array}$ & & \multicolumn{5}{|c|}{$\begin{array}{l}\text { DISCHARGE, IN FT } 3 \text { /S, FOR INDICATED } \\
\text { RECURRENCE INTERVAL, IN YEARS, AND } \\
\text { EXCEEDANCE PROBABILITY, IN PERCENT }\end{array}$} \\
\hline $\begin{array}{l}\text { TIVE } \\
\text { DAYS) }\end{array}$ & $\begin{array}{c}2 \\
50 \%\end{array}$ & $\begin{array}{c}5 \\
20 \%\end{array}$ & $\begin{array}{l}10 \\
10 \%\end{array}$ & $\begin{array}{l}25 \\
4 \%\end{array}$ & $\begin{array}{l}50 \uparrow \\
2 \%\end{array}$ & \\
\hline $\begin{array}{r}1 \\
3 \\
7 \\
15 \\
30 \\
60 \\
90\end{array}$ & $\begin{array}{r}1,030 \\
925 \\
791 \\
647 \\
512 \\
373 \\
294\end{array}$ & $\begin{array}{r}2,220 \\
1,900 \\
1,510 \\
1,270 \\
1,040 \\
757 \\
597\end{array}$ & $\begin{array}{r}3,380 \\
2,770 \\
2,080 \\
1,780 \\
1,490 \\
1,080 \\
848\end{array}$ & $\begin{array}{l}5,350 \\
4,140 \\
2,890 \\
2,520 \\
2,170 \\
1,560 \\
1,220\end{array}$ & $\begin{array}{l}7,250 \\
5,360 \\
3,550 \\
3,140 \\
2,750 \\
1,960 \\
1,520\end{array}$ & \\
\hline
\end{tabular}

DURATION TABLE OF DAILY MEAN FLOW FOR PERICO OF RECORD 1963-82

DISCHARGE, IN FT $3 / 5$, WHICH WAS EQUALED OR EXCEEDED FOR INDICATED PERCENT OF TIME

\begin{tabular}{|ccccccccccccccccc}
\hline $1 \%$ & $5 \%$ & $10 \%$ & $15 \%$ & $20 \%$ & $30 \%$ & $40 \%$ & $50 \%$ & $60 \%$ & $70 \%$ & $80 \%$ & $90 \%$ & $95 \%$ & $98 \%$ & $99 \%$ & $99.5 \%$ & $99.9 \%$ \\
\hline 1,600 & 633 & 354 & 224 & 154 & 84 & 54 & 40 & 31 & 27 & 24 & 20 & 18 & 16 & 15 & 13 & 11 \\
\hline
\end{tabular}

† Reliability of values in column is uncertain, and potential errors are large. 
GILA RIVER BASIN

09489100 BLACK RIVER NEAR MAVERICK, AZ--CONTIMUED
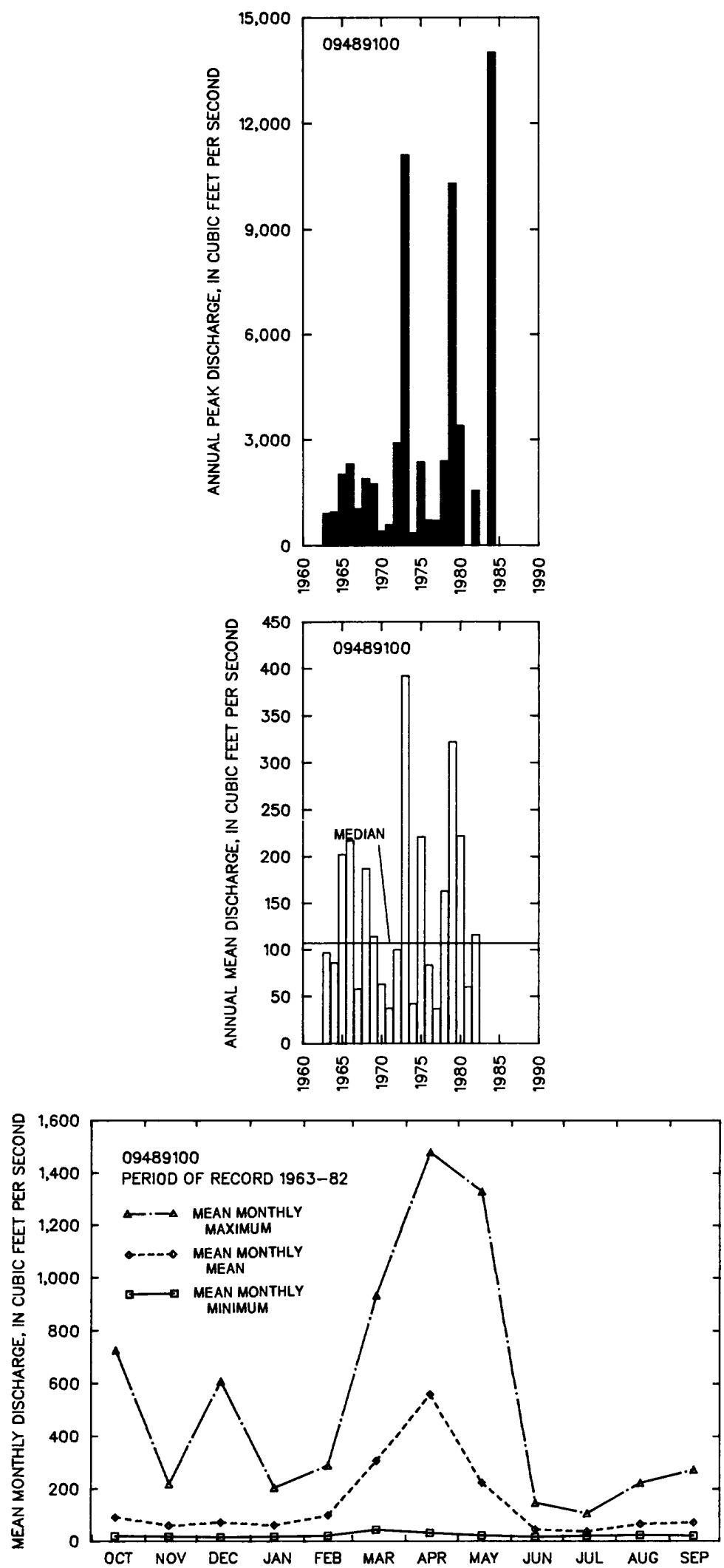
09489200 PACHETA CREEK AT MAVERICK, AZ

LOCATION.--Lat 33"44'23", long 109'32'24", at corner of secs.28, 29, 32, 33, T.4 N., R.27 E. (unsurveyed), Apache County. Hydrologic Unit 15060101, in Fort Apache Indian Reservation, on left bank 0.5 mi southeast of Maverick.

DRAIMAGE AREA. $--14.8 \mathrm{mi}^{2}$.

\begin{tabular}{|c|c|c|}
\hline \multicolumn{3}{|c|}{ AMNUAL PEAK DISCHARFE } \\
\hline $\begin{array}{l}\text { MATER } \\
\text { YEAR }\end{array}$ & DATE & $\begin{array}{c}\text { AMMUAL PEAK } \\
\text { DISCHARGE } \\
\text { (FT } 3 / 5)\end{array}$ \\
\hline $\begin{array}{l}1958 \\
1959 \\
1960 \\
1961 \\
1962 \\
1963 \\
1964 \\
1965 \\
1966 \\
1967 \\
1968 \\
1969 \\
1970 \\
1971 \\
1972 \\
1973 \\
1974 \\
1975 \\
1976 \\
1977 \\
1978 \\
1979 \\
1980\end{array}$ & $\begin{array}{l}04-22-58 \\
10-06-58 \\
03-21-60 \\
08-08-61 \\
04-09-62 \\
08-19-63 \\
08-14-64 \\
04-23-65 \\
03-22-66 \\
08-27-67 \\
04-15-68 \\
04-06-69 \\
04-11-70 \\
09-30-71 \\
10-24-71 \\
05-13-73 \\
08-05-74 \\
04-25-75 \\
04-10-76 \\
08-11-77 \\
03-30-78 \\
12-18-78 \\
04-21-80\end{array}$ & $\begin{array}{r}312 \\
140 \\
102 \\
18 \\
179 \\
118 \\
95 \\
128 \\
145 \\
60 \\
120 \\
122 \\
71 \\
39 \\
69 \\
323 \\
39 \\
132 \\
47 \\
45 \\
173 \\
224 \\
158\end{array}$ \\
\hline
\end{tabular}

BASIN CHARACTERISTICS

\begin{tabular}{|c|c|c|c|c|c|c|c|}
\hline \multirow{2}{*}{$\begin{array}{c}\text { MIIN } \\
\text { CHANNEL } \\
\text { SLOPE } \\
\text { (FT/MI) }\end{array}$} & \multirow[b]{2}{*}{$\begin{array}{l}\text { STREAM } \\
\text { LENGTH } \\
\text { (MI) }\end{array}$} & \multirow{2}{*}{$\begin{array}{l}\text { MEAN } \\
\text { BASIN } \\
\text { ELEVA- } \\
\text { TION } \\
\text { (FT) }\end{array}$} & \multirow[b]{2}{*}{$\begin{array}{l}\text { FORESTED } \\
\text { AREA } \\
\text { (PERCENT) }\end{array}$} & \multirow[b]{2}{*}{$\begin{array}{l}\text { SOIL } \\
\text { INDEX }\end{array}$} & \multirow{2}{*}{$\begin{array}{l}\text { MEAN } \\
\text { ANWUAL } \\
\text { PRECIPI- } \\
\text { TATION } \\
\text { (IN) }\end{array}$} & \multicolumn{2}{|c|}{ RAINFALL INTENSITY, 24-HOUR } \\
\hline & & & & & & $\begin{array}{c}\text { 2-YEAR } \\
\text { (IN) }\end{array}$ & $\begin{array}{c}\text { 50-YEAR } \\
\text { (IN) }\end{array}$ \\
\hline 160 & 14.2 & 8,810 & 88.0 & 3.0 & 30.3 & 2.2 & 5.2 \\
\hline
\end{tabular}


MEAN MONTHLY AND ANNUAL DISCHARGES 1958-80

\begin{tabular}{|c|c|c|c|c|c|c|}
\hline MONTH & $\begin{array}{l}\operatorname{MaXIMMM} \\
\left(F T^{3} / S\right)\end{array}$ & $\begin{array}{l}\text { MINIIMUA } \\
\left(F T^{3} / S\right)\end{array}$ & $\underset{\left(F T^{3 / S}\right)}{\operatorname{MEAN}}$ & $\begin{array}{l}\text { STAN- } \\
\text { DARD } \\
\text { DEVIA- } \\
\text { TION } \\
\text { (FT } 3 / S)\end{array}$ & $\begin{array}{l}\text { COEFF I- } \\
\text { CIENT OF } \\
\text { VARI - } \\
\text { ATION }\end{array}$ & $\begin{array}{c}\text { PERCENT } \\
\text { OF } \\
\text { ANNUAL } \\
\text { RUNOFF }\end{array}$ \\
\hline $\begin{array}{l}\text { OCTOBER } \\
\text { NOVEMBER } \\
\text { DECEMBER } \\
\text { JANUARY } \\
\text { FEBRUARY } \\
\text { MARCH } \\
\text { APRIL } \\
\text { MAY } \\
\text { JUNE } \\
\text { JULY } \\
\text { AUCUST } \\
\text { SEPTEMBER }\end{array}$ & $\begin{array}{c}24 \\
12 \\
27 \\
15 \\
14 \\
61 \\
102 \\
131 \\
19 \\
6.4 \\
12 \\
15\end{array}$ & $\begin{array}{l}0.53 \\
0.35 \\
0.68 \\
0.59 \\
0.59 \\
1.6 \\
1.5 \\
0.50 \\
0.27 \\
0.25 \\
0.37 \\
0.33\end{array}$ & $\begin{array}{l}3.3 \\
2.5 \\
3.3 \\
3.3 \\
4.2 \\
17 \\
44 \\
21 \\
3.4 \\
2.0 \\
2.6 \\
3.3\end{array}$ & $\begin{array}{l}5.2 \\
2.5 \\
5.7 \\
4.3 \\
4.0 \\
17 \\
36 \\
30 \\
4.6 \\
1.5 \\
2.2 \\
3.7\end{array}$ & $\begin{array}{l}1.6 \\
1.0 \\
1.7 \\
1.3 \\
0.94 \\
1.0 \\
0.82 \\
1.4 \\
1.3 \\
0.76 \\
0.87 \\
1.1\end{array}$ & $\begin{array}{r}3.0 \\
2.2 \\
3.0 \\
3.0 \\
3.8 \\
15.3 \\
39.8 \\
19.5 \\
3.1 \\
1.8 \\
2.3 \\
3.0\end{array}$ \\
\hline ANNUAL & 28 & 0.96 & 9.1 & 7.0 & 0.76 & 100 \\
\hline
\end{tabular}

MACNITLDE AND PROBABILITY OF ANNUAL LON FLON BASED ON PERIOD OF RECORD 1959-80

\begin{tabular}{|c|c|c|c|c|c|c|}
\hline \multirow{2}{*}{$\begin{array}{l}\text { PERIOD } \\
\text { (CON- } \\
\text { SECU- } \\
\text { TIVE } \\
\text { DAYS) }\end{array}$} & \multicolumn{6}{|c|}{$\begin{array}{l}\text { DISCHARGE, IN } \mathrm{FT}^{3} / \mathrm{S}, \text { FOR INDICATED } \\
\text { RECURRENCE INTERVAL, IN YEARS, AND } \\
\text { NON-EXCEEDANCE PROBABILITY, IN PERCENT }\end{array}$} \\
\hline & $\underset{50 \%}{2}$ & $\begin{array}{c}5 \\
20 \%\end{array}$ & $\begin{array}{l}10 \\
10 \%\end{array}$ & $\begin{array}{l}20 \\
5 \%\end{array}$ & $\begin{array}{l}50 \dagger \\
2 \%\end{array}$ & $\begin{array}{l}100 \dagger \\
\mathbf{1 \%}\end{array}$ \\
\hline $\begin{array}{r}1 \\
3 \\
7 \\
14 \\
30 \\
60 \\
90 \\
120 \\
183\end{array}$ & $\begin{array}{l}0.89 \\
0.89 \\
0.92 \\
0.95 \\
0.99 \\
1.1 \\
1.2 \\
1.4 \\
1.6\end{array}$ & $\begin{array}{l}0.50 \\
0.50 \\
0.52 \\
0.55 \\
0.61 \\
0.69 \\
0.77 \\
0.86 \\
0.95\end{array}$ & $\begin{array}{l}0.34 \\
0.34 \\
0.35 \\
0.38 \\
0.43 \\
0.50 \\
0.57 \\
0.63 \\
0.70\end{array}$ & $\begin{array}{l}0.23 \\
0.23 \\
0.24 \\
0.26 \\
0.31 \\
0.37 \\
0.42 \\
0.47 \\
0.54\end{array}$ & $\begin{array}{l}0.14 \\
0.14 \\
0.14 \\
0.16 \\
0.20 \\
0.25 \\
0.28 \\
0.32 \\
0.39\end{array}$ & $\begin{array}{l}0.10 \\
0.10 \\
0.10 \\
0.11 \\
0.14 \\
0.18 \\
0.21 \\
0.24 \\
0.32\end{array}$ \\
\hline
\end{tabular}

MAGNITUDE AND PROBABILITY OF ANNUAL HIGH FLON BASED ON PERIOD OF RECORD 1958-80

\begin{tabular}{|c|c|c|c|c|c|c|}
\hline \multirow{2}{*}{$\begin{array}{l}\text { PERIOD } \\
\text { (CON- } \\
\text { SECU- } \\
\text { TIVE } \\
\text { DAYS) }\end{array}$} & & \multicolumn{5}{|c|}{$\begin{array}{l}\text { DISCHARGE, IN } F^{3} / S \text {, FOR INDICATED } \\
\text { RECURRENCE INTERVAL, IN YEARS, AND } \\
\text { EXCEEDANCE PROBABILITY, IN PERCENT }\end{array}$} \\
\hline & $\begin{array}{c}2 \\
50 \%\end{array}$ & $\begin{array}{c}5 \\
20 \%\end{array}$ & $\begin{array}{l}10 \\
10 \%\end{array}$ & $\begin{array}{l}25 \\
4 \%\end{array}$ & $\begin{array}{l}50 \uparrow \\
2 \%\end{array}$ & $\begin{array}{c}100 \dagger \\
1 \%\end{array}$ \\
\hline $\begin{array}{r}1 \\
3 \\
7 \\
15 \\
30 \\
60 \\
90\end{array}$ & $\begin{array}{l}73 \\
66 \\
58 \\
48 \\
38 \\
26 \\
20\end{array}$ & $\begin{array}{r}146 \\
139 \\
127 \\
109 \\
89 \\
63 \\
47\end{array}$ & $\begin{array}{r}199 \\
191 \\
176 \\
155 \\
131 \\
94 \\
70\end{array}$ & $\begin{array}{l}265 \\
254 \\
235 \\
213 \\
187 \\
139 \\
103\end{array}$ & $\begin{array}{l}312 \\
298 \\
275 \\
255 \\
230 \\
175 \\
129\end{array}$ & $\begin{array}{l}356 \\
339 \\
312 \\
294 \\
273 \\
212 \\
157\end{array}$ \\
\hline
\end{tabular}

DURATION TABLE OF DAILY MEAN FLON FOR PERIOD OF RECORD 1958-80 DISCHARGE, IN FT $3 / 5$, WHICH WAS EQUALED OR EXCEEDED FOR INDICATED PERCENT OF TIME

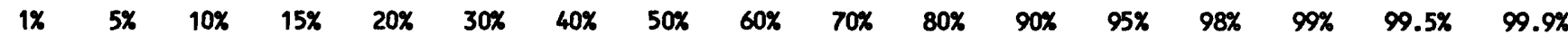

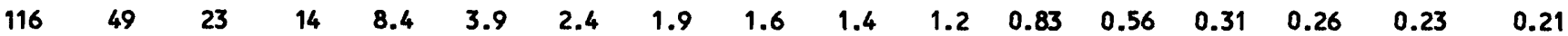

$\uparrow$ Reliability of values in colum is uncertain, and potential errors are large. 
09489200 PACHETA CREEK AT MAVERICK, AZ--CONTINUED
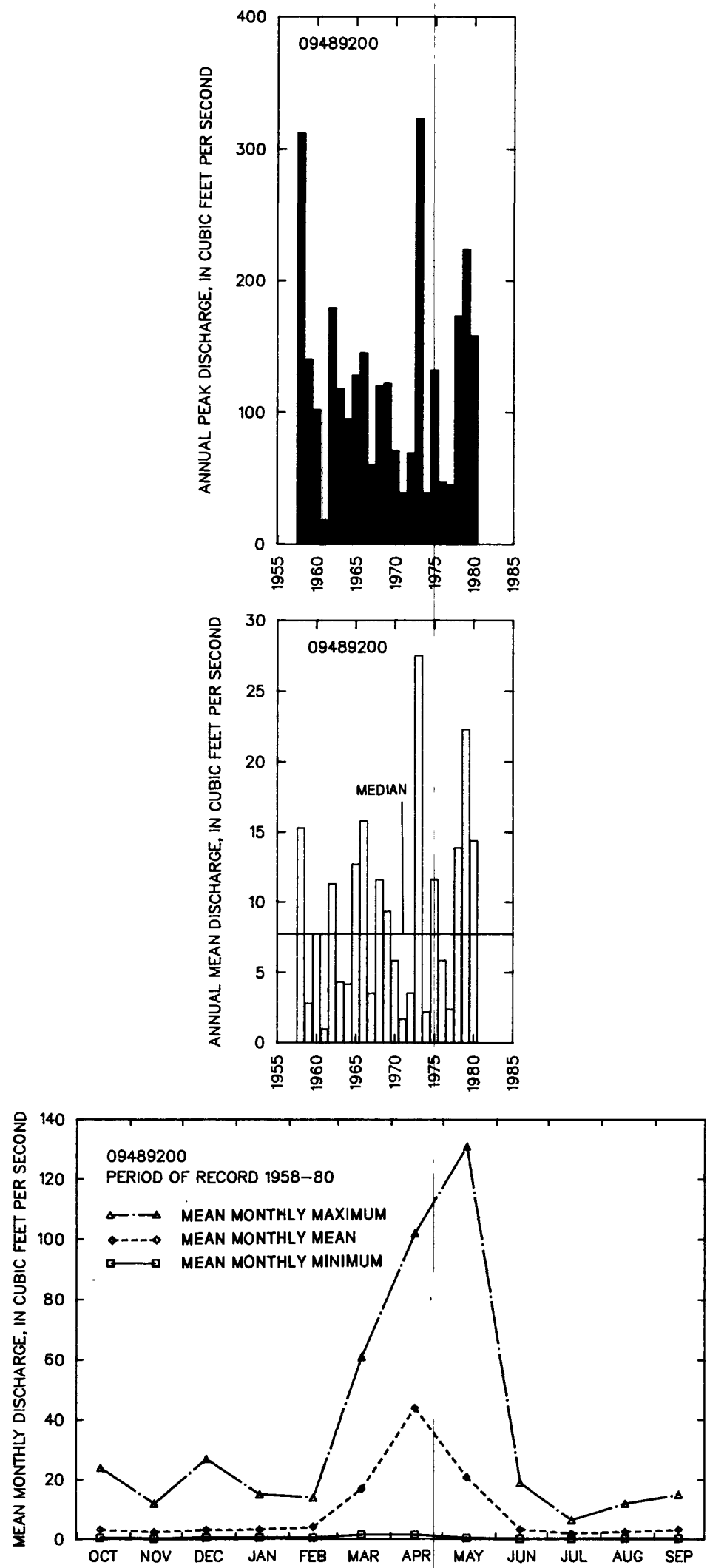
09489499 BLACK RIVER ABOVE HILLON CREEK DIVERSION, NEAR POINT OF PINES, AZ

LOCATION.--Lat 33.28'36", Long 109.45'48", in Wh sec.32, T.2 N., R.25 E. (unsurveyed), Graham County, Hydrologic Unit 15060101, in San Carlos Indian Reservation on left bank 0.9 mi downstream from Phelps Dodge Corporation pumping plant, 1.3 mi downstream from Freezeout Creek, 8 mi northwest of Point of Pines, and 63 mi upstream from confluence with thite River.

DRAINAGE AREA. $--560 \mathrm{mi}^{2}$.

ANNUAL PEAK DISCHARGE

\begin{tabular}{|c|c|c|c|c|c|}
\hline $\begin{array}{l}\text { WATER } \\
\text { YEAR }\end{array}$ & DATE & $\begin{array}{l}\text { ANNUAL PEAK } \\
\text { DISCHARGE } \\
\text { (FT } 3 / \mathrm{S})\end{array}$ & $\begin{array}{l}\text { WATER } \\
\text { YEAR }\end{array}$ & DATE & $\begin{array}{c}\text { ANNUAL PEAK } \\
\text { DISCHARGE } \\
\left(\mathrm{FT}^{3} / \mathrm{S}\right)\end{array}$ \\
\hline $\begin{array}{l}1954 \\
1955 \\
1956 \\
1957 \\
1958 \\
1959 \\
1960 \\
1961 \\
1962 \\
1963 \\
1964 \\
1965 \\
1966 \\
1967 \\
1968 \\
1969 \\
1970 \\
1971\end{array}$ & $\begin{array}{l}03-23-54 \\
08-21-55 \\
03-20-56 \\
08-26-57 \\
04-23-58 \\
08-19-59 \\
03-14-60 \\
04-04-61 \\
04-11-62 \\
08-29-63 \\
10-20-63 \\
04-22-65 \\
12-30-65 \\
08-13-67 \\
04-16-68 \\
04-07-69 \\
04-12-70 \\
08-21-71\end{array}$ & $\begin{array}{r}5,000 \\
1,310 \\
642 \\
2,060 \\
4,590 \\
4,820 \\
1,820 \\
495 \\
2,950 \\
1,720 \\
1,110 \\
2,640 \\
6,380 \\
1,330 \\
2,440 \\
2,010 \\
479 \\
542\end{array}$ & $\begin{array}{l}1972 \\
1973 \\
1974 \\
1975 \\
1976 \\
1977 \\
1978 \\
1979 \\
1980 \\
1981 \\
1982 \\
1983 \\
1984 \\
1985 \\
1986 \\
1987 \\
1988 \\
1989\end{array}$ & $\begin{array}{l}10-25-71 \\
10-19-72 \\
08-02-74 \\
03-09-75 \\
04-10-76 \\
04-10-77 \\
03-01-78 \\
12-19-78 \\
02-15-80 \\
04-14-81 \\
04-13-82 \\
04-26-83 \\
10-02-83 \\
03-12-85 \\
04-03-86 \\
04-18-87 \\
09-01-88 \\
08-05-89\end{array}$ & $\begin{array}{r}3,210 \\
17,900 \\
404 \\
2,840 \\
782 \\
610 \\
5,980 \\
12,400 \\
6,640 \\
820 \\
1,750 \\
3,020 \\
17,300 \\
7,440 \\
1,460 \\
2,530 \\
2,360 \\
1,140\end{array}$ \\
\hline
\end{tabular}

BASIN CHARACTERISTICS

\begin{tabular}{|c|c|c|c|c|c|c|c|}
\hline \multirow{2}{*}{$\begin{array}{l}\text { MAIN } \\
\text { CHANNEL } \\
\text { SLOPE } \\
\text { (FT/MI) }\end{array}$} & \multirow[b]{2}{*}{$\begin{array}{c}\text { STREAM } \\
\text { LENGTH } \\
\text { (MI) }\end{array}$} & \multirow{2}{*}{$\begin{array}{l}\text { MEAN } \\
\text { BASIN } \\
\text { ELEVA- } \\
\text { TION } \\
\text { (FT) }\end{array}$} & \multirow[b]{2}{*}{$\begin{array}{l}\text { FORESTED } \\
\text { AREA } \\
\text { (PERCENT) }\end{array}$} & \multirow[b]{2}{*}{$\begin{array}{l}\text { SOIL } \\
\text { INDEX }\end{array}$} & \multirow{2}{*}{$\begin{array}{l}\text { MEAN } \\
\text { ANNUAL } \\
\text { PRECIPI - } \\
\text { TATION } \\
\text { (IN) }\end{array}$} & \multicolumn{2}{|c|}{ RAINFALL INTENSITY, 24-HOUR } \\
\hline & & & & & & $\begin{array}{c}\text { 2-YंEAR } \\
\text { (IN) }\end{array}$ & $\begin{array}{l}\text { 50-YEAR } \\
\text { (IN) }\end{array}$ \\
\hline 51.1 & 69.2 & 8,000 & 86.0 & 2.9 & 25.3 & 2.3 & 4.4 \\
\hline
\end{tabular}


09489499 BLACK RIVER ABOVE HILLOW CREEK DIVERSION, MEAR POINT OF PINES, AZ--Cont inued

MEAN MONTHLY AND ANNUAL DISCHARGES $1954-89$

\begin{tabular}{|c|c|c|c|c|c|c|}
\hline MONTH & $\begin{array}{l}\operatorname{maxIm}_{\left(\mathrm{FT}^{3} / \mathrm{S}\right)} \\
\end{array}$ & $\begin{array}{l}\operatorname{MINIMUN} \\
\left(\mathrm{FT}^{3} / \mathrm{S}\right)\end{array}$ & $\begin{array}{c}\text { MEAN } \\
\left(F^{3} \mathbf{3} / S\right)\end{array}$ & $\begin{array}{l}\text { STAN- } \\
\text { DARD } \\
\text { DEVIA- } \\
\text { TION } \\
\text { (FT } 3 / S)\end{array}$ & $\begin{array}{l}\text { COEFFI - } \\
\text { CIENT OF } \\
\text { VARI - } \\
\text { ATION }\end{array}$ & $\begin{array}{c}\text { PERCENT } \\
\text { OF } \\
\text { ANNUAL } \\
\text { RUNOFF }\end{array}$ \\
\hline $\begin{array}{l}\text { OCTOBER } \\
\text { NOVEMBER } \\
\text { DECEMBER } \\
\text { JANUARY } \\
\text { FEBRUARY } \\
\text { MARCH } \\
\text { APRIL } \\
\text { MAY } \\
\text { JUNE } \\
\text { JULY } \\
\text { AUEUST } \\
\text { SEPTEMBER }\end{array}$ & $\begin{array}{r}1,220 \\
380 \\
924 \\
518 \\
1,050 \\
1,880 \\
2,270 \\
1,960 \\
267 \\
135 \\
387 \\
385\end{array}$ & $\begin{array}{l}28 \\
33 \\
25 \\
30 \\
37 \\
71 \\
59 \\
38 \\
25 \\
27 \\
34 \\
25\end{array}$ & $\begin{array}{r}140 \\
97 \\
130 \\
124 \\
226 \\
543 \\
766 \\
322 \\
76 \\
58 \\
122 \\
105\end{array}$ & $\begin{array}{r}247 \\
84 \\
185 \\
122 \\
223 \\
457 \\
664 \\
400 \\
63 \\
24 \\
97 \\
89\end{array}$ & $\begin{array}{l}1.8 \\
0.86 \\
1.4 \\
0.98 \\
0.99 \\
0.84 \\
0.87 \\
1.2 \\
0.83 \\
0.42 \\
0.80 \\
0.85\end{array}$ & $\begin{array}{r}5.2 \\
3.6 \\
4.8 \\
4.6 \\
8.3 \\
20.0 \\
28.3 \\
11.9 \\
2.8 \\
2.1 \\
4.5 \\
3.9\end{array}$ \\
\hline ANMUAL & 624 & 60 & 225 & 154 & 0.68 & 100 \\
\hline
\end{tabular}

MAGNITUDE AND PROBABILITY OF INSTANTANEOUS PEAK FLON BASED ON PERIOD OF RECORD 1958-89

DISCHARGE, IN $\mathrm{FT}^{3} / \mathrm{S}$, FOR INDICATED RECURRENCE INTERVAL IN YEARS, AND EXCEEDANCE PROBABILITY, IN PERCENT

\begin{tabular}{|c|c|c|c|c|c|}
\hline$\stackrel{2}{50 x}$ & $\begin{array}{c}5 \\
20 \%\end{array}$ & $\begin{array}{r}10 \\
10 \%\end{array}$ & $\begin{array}{l}25 \\
4 \%\end{array}$ & $\begin{array}{l}50 \\
2 x\end{array}$ & $\begin{array}{c}100 \dagger \\
1 \%\end{array}$ \\
\hline 2,190 & 5,150 & 8,130 & 13,300 & 18,300 & 24,500 \\
\hline $\begin{array}{l}\text { MEAN } \\
\text { STANDARD }\end{array}$ & DEV. & $\begin{array}{l}(\operatorname{LOGS})= \\
(\operatorname{LOGS})= \\
(\operatorname{LOCS})=\end{array}$ & $\begin{array}{l}.09 \\
.35 \\
.44\end{array}$ & & \\
\hline
\end{tabular}

\begin{tabular}{c|ccccc} 
MACNITUDE AND PROBABILITY OF ANNUAL LON FLON \\
BASED ON PERIOD OF RECORD 1955-89
\end{tabular}

MACNITUDE AND PROBABILITY OF ANMUAL HIGH FLON BASED ON PERIOD OF RECORD $1954-89$

\begin{tabular}{|c|c|c|c|c|c|c|}
\hline \multirow{2}{*}{$\begin{array}{l}\text { PERIOO } \\
\text { (CON- } \\
\text { SECH- } \\
\text { TIVE } \\
\text { DAYS) }\end{array}$} & & \multicolumn{5}{|c|}{$\begin{array}{l}\text { DISCHARGE, IN FT } 3 / S \text {, FOR INDICATED } \\
\text { RECURRENCE INTERVAL, IN YEARS, AND } \\
\text { EXCEEDANCE PROBABILITY, IN PERCENT }\end{array}$} \\
\hline & $\begin{array}{c}2 \\
50 \%\end{array}$ & $\begin{array}{c}5 \\
20 \%\end{array}$ & $\begin{array}{l}10 \\
10 \%\end{array}$ & $\begin{array}{l}25 \\
4 \%\end{array}$ & $\begin{array}{l}50 \\
2 x\end{array}$ & $\begin{array}{c}100 \nmid \\
1 \%\end{array}$ \\
\hline $\begin{array}{l}1 \\
3 \\
7 \\
15 \\
30 \\
60 \\
90\end{array}$ & $\begin{array}{r}1,590 \\
1,390 \\
1,170 \\
948 \\
747 \\
549 \\
438\end{array}$ & $\begin{array}{r}3,490 \\
2,850 \\
2,240 \\
1,810 \\
1,460 \\
1,100 \\
891\end{array}$ & $\begin{array}{l}5,280 \\
4,110 \\
3,090 \\
2,490 \\
2,050 \\
1,570 \\
1,280\end{array}$ & $\begin{array}{l}8,210 \\
6,000 \\
4,290 \\
3,460 \\
2,920 \\
2,260 \\
1,850\end{array}$ & $\begin{array}{r}10,900 \\
7,630 \\
5,250 \\
4,250 \\
3,650 \\
2,860 \\
2,350\end{array}$ & $\begin{array}{r}14,100 \\
9,440 \\
6,260 \\
5,090 \\
4,450 \\
3,510 \\
2,890\end{array}$ \\
\hline
\end{tabular}

DURATION TABLE OF DAILY MEAN FLON FOR PERIOD OF RECORD 1954-89

DISCHARGE, IN FT $3 / \mathrm{S}$, WHICH WAS EQUALED OR EXCEEDED FOR INDICATED PERCENT OF TIME

\begin{tabular}{|c|c|c|c|c|c|c|c|c|c|c|c|c|c|c|c|c|}
\hline $1 \%$ & $5 \%$ & $10 \%$ & $15 \%$ & $20 \%$ & $30 x$ & $40 \%$ & $50 \%$ & $60 \%$ & $70 \%$ & $80 \%$ & $90 \%$ & $95 \%$ & $98 \%$ & $99 \%$ & $99.5 \%$ & $99.9 \%$ \\
\hline 2,180 & 996 & 566 & 359 & 258 & 152 & 100 & 73 & 58 & 49 & 43 & 36 & 31 & 26 & 24 & 23 & 20 \\
\hline
\end{tabular}

$\uparrow$ Reliability of values in colum is uncertain, and potential errors are large. 
GILA RIVER BASIN

09489499 BLACK RIVER ABOVE WILLOW CREEK DIVERSION, MEAR POINT OF PIMES, AZ--CONTINUED
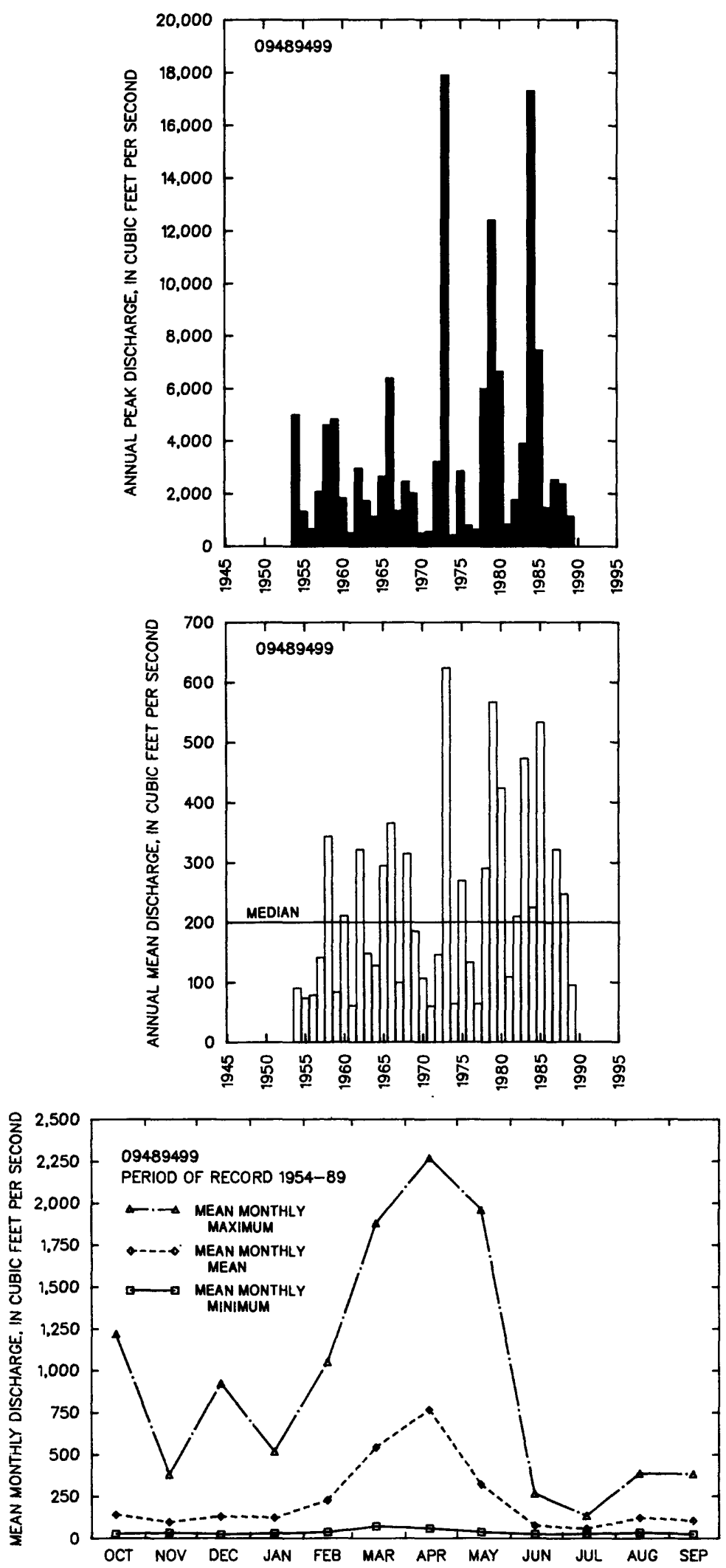
09489700 BIG BONITO CREEK NEAR FORT APACHE, AZ

LOCATION.--Lat 33.40'02", long 109.50'46", in NE\% sec.28, T.4 N., R.24 E. (unsurveyed), Apache County, Hydrologic Unit 15060101, in Fort Apache Indian Reservation, near right bank on downstream side of pier of highway bridge, $1.9 \mathrm{mi}$ upstream from Tonto Creek, $3.7 \mathrm{mi}$ southeast of Chino Springs, and 12 mi southeast of Fort Apache.

DRAINAGE AREA. $--119 \mathrm{mi}^{2}$.

ANMUAL PEAK DISCHARGE

\begin{tabular}{|c|c|c|c|c|}
\hline $\begin{array}{l}\text { WATER } \\
\text { YEAR }\end{array}$ & $\begin{array}{cc} & \text { ANNUAL PEAK } \\
& \text { DISCHARGE } \\
\text { DATE } & \left(F^{3} / S\right)\end{array}$ & $\begin{array}{l}\text { WATER } \\
\text { YEAR }\end{array}$ & DATE & $\begin{array}{l}\text { ANNUAL PEAK } \\
\text { DISCHARGE } \\
\left(F^{3} / S\right)\end{array}$ \\
\hline $\begin{array}{l}1958 \\
1959 \\
1960 \\
1961 \\
1962 \\
1963 \\
1964 \\
1965 \\
1966 \\
1967 \\
1968 \\
1969\end{array}$ & $\begin{array}{l}03-22-58 \\
08-15-59 \\
03-27-60 \\
04-06-61 \\
04-17-62 \\
08-26-63 \\
08-14-64 \\
01-08-65 \\
12-30-65 \\
08-12-67 \\
04-16-68 \\
04-01-69\end{array}$ & $\begin{array}{l}1970 \\
1971 \\
1972 \\
1973 \\
1974 \\
1975 \\
1976 \\
1977 \\
1978 \\
1979 \\
1980 \\
1981\end{array}$ & $\begin{array}{l}09-06-70 \\
09-01-71 \\
12-26-71 \\
10-20-72 \\
08-02-74 \\
04-26-75 \\
02-10-76 \\
08-19-77 \\
03-03-78 \\
12-18-78 \\
02-15-80 \\
04-01-81\end{array}$ & $\begin{array}{r}560 \\
312 \\
1,090 \\
1,870 \\
194 \\
453 \\
194 \\
243 \\
12,870 \\
14,510 \\
3,440 \\
153\end{array}$ \\
\hline
\end{tabular}

1Highest since 1952.

BASIN CHARACTERISTICS

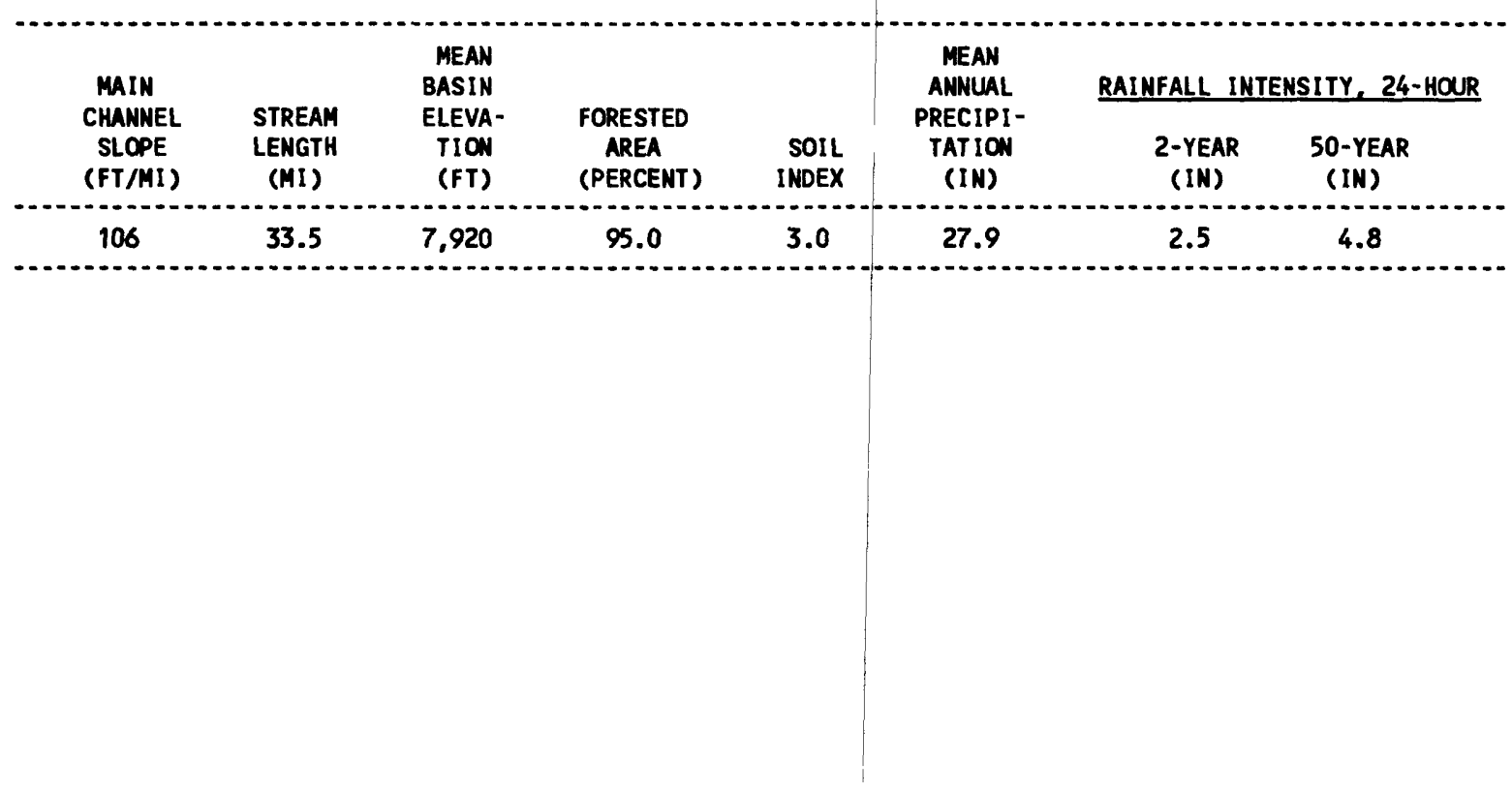


09489700 BIG BONITO CREEK MEAR FORT APACHE, AZ--Continued

MEAN MONTHLY AND ANMUAL DISCHARGES 1958-80

\begin{tabular}{|c|c|c|c|c|c|c|}
\hline MONTH & $\begin{array}{l}\operatorname{Max} 1 \min \\
\left(F^{3} / S\right)\end{array}$ & $\begin{array}{l}\operatorname{MINIMUM} \\
\left(F T^{3} / S\right)\end{array}$ & $\begin{array}{c}\text { MEAN } \\
\left(F T^{3} / S\right)\end{array}$ & $\begin{array}{l}\text { STAN- } \\
\text { DARD } \\
\text { DEVIA- } \\
\text { TION } \\
\left(F^{3} / S\right)\end{array}$ & $\begin{array}{l}\text { COEFFI- } \\
\text { CIENT OF } \\
\text { VARI - } \\
\text { ATION }\end{array}$ & $\begin{array}{c}\text { PERCENT } \\
\text { OF } \\
\text { ANNUAL } \\
\text { RUNOFF }\end{array}$ \\
\hline $\begin{array}{l}\text { OCTCBER } \\
\text { NONEMBER } \\
\text { DECEMBER } \\
\text { JANUARY } \\
\text { FEBRUARY } \\
\text { MARCH } \\
\text { APRIL } \\
\text { MAY } \\
\text { JUNE } \\
\text { JULY } \\
\text { AUGUST } \\
\text { SEPTEMBER }\end{array}$ & $\begin{array}{r}157 \\
69 \\
251 \\
115 \\
316 \\
521 \\
540 \\
610 \\
148 \\
50 \\
122 \\
112\end{array}$ & $\begin{array}{l}9.2 \\
10 \\
11 \\
11 \\
10 \\
21 \\
23 \\
11 \\
6.3 \\
6.5 \\
7.8 \\
7.0\end{array}$ & $\begin{array}{r}30 \\
28 \\
39 \\
40 \\
65 \\
133 \\
224 \\
138 \\
34 \\
20 \\
40 \\
31\end{array}$ & $\begin{array}{r}40 \\
19 \\
57 \\
35 \\
68 \\
119 \\
168 \\
149 \\
39 \\
11 \\
29 \\
26\end{array}$ & $\begin{array}{l}1.3 \\
0.71 \\
1.5 \\
0.86 \\
1.0 \\
0.90 \\
0.75 \\
1.1 \\
1.1 \\
0.56 \\
0.73 \\
0.83\end{array}$ & $\begin{array}{r}3.7 \\
3.3 \\
4.8 \\
4.9 \\
7.9 \\
16.2 \\
27.2 \\
16.8 \\
4.1 \\
2.4 \\
4.9 \\
3.8\end{array}$ \\
\hline ANNUAL & 167 & 17 & 69 & 43 & 0.62 & 100 \\
\hline
\end{tabular}

MAGNITUDE AND PROBABILITY OF INSTANTANEOUS PEAK FLON BASED ON PERIOD OF RECORD 1958-81

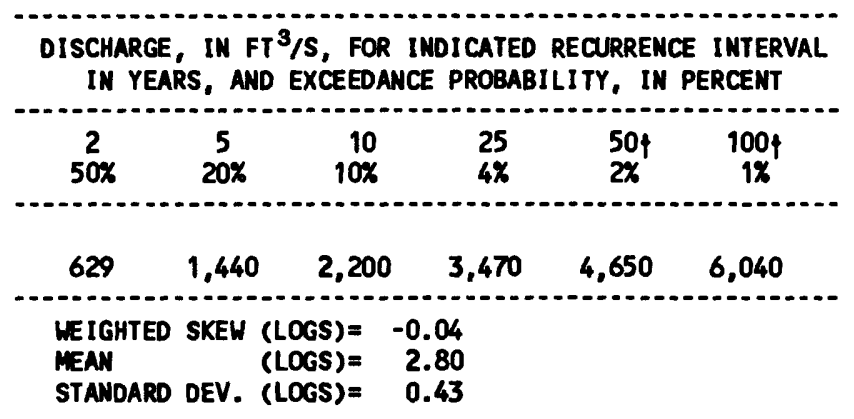

MAGNITUDE AND PROBABILITY OF ANMUAL LON FLON BASED ON PER100 OF RECORD 1959-81

\begin{tabular}{|c|c|c|c|c|c|c|}
\hline \multirow{2}{*}{$\begin{array}{l}\text { PERIOD } \\
\text { (CON- } \\
\text { SECU- } \\
\text { TIVE } \\
\text { DAYS) }\end{array}$} & \multicolumn{6}{|c|}{$\begin{array}{l}\text { DISCHARGE, IN FT }{ }^{3} / S \text {, FOR INDICATED } \\
\text { RECURRENCE INTERVAL, IN YEARS, AND } \\
\text { NON-EXCEEDANCE PROBAB ILITY, IN PERCENT }\end{array}$} \\
\hline & $\begin{array}{c}2 \\
50 x\end{array}$ & $\begin{array}{c}5 \\
20 \%\end{array}$ & $\begin{array}{l}10 \\
10 \%\end{array}$ & $\begin{array}{l}20 \\
5 \%\end{array}$ & $\begin{array}{l}50 \nmid \\
2 x\end{array}$ & $\begin{array}{l}100 \nmid \\
1 \%\end{array}$ \\
\hline $\begin{array}{r}1 \\
3 \\
7 \\
14 \\
30 \\
60 \\
90 \\
120 \\
183\end{array}$ & $\begin{array}{c}6.2 \\
6.7 \\
7.2 \\
7.8 \\
9.0 \\
11 \\
13 \\
14 \\
19\end{array}$ & $\begin{array}{c}4.8 \\
5.3 \\
5.6 \\
6.3 \\
7.3 \\
9.0 \\
10 \\
11 \\
14\end{array}$ & $\begin{array}{c}4.2 \\
4.6 \\
4.9 \\
5.6 \\
6.4 \\
8.0 \\
9.3 \\
10 \\
12\end{array}$ & $\begin{array}{r}3.8 \\
4.1 \\
4.3 \\
5.0 \\
5.8 \\
7.1 \\
8.6 \\
9.7 \\
11\end{array}$ & $\begin{array}{l}3.4 \\
3.7 \\
3.8 \\
4.5 \\
5.1 \\
6.3 \\
7.8 \\
9.3 \\
9.4\end{array}$ & $\begin{array}{l}3.1 \\
3.4 \\
3.5 \\
4.1 \\
4.7 \\
5.7 \\
7.3 \\
9.0 \\
8.7\end{array}$ \\
\hline
\end{tabular}

MAGNITLDE AND PROBABILITY OF AMNUAL HIGH FLON BASED ON PERIOO OF RECORD 1958-80

\begin{tabular}{|c|c|c|c|c|c|c|}
\hline \multirow{2}{*}{$\begin{array}{l}\text { PERIOD } \\
\text { (CON- } \\
\text { SECU- } \\
\text { TIVE } \\
\text { DAYS) }\end{array}$} & \multicolumn{6}{|c|}{$\begin{array}{l}\text { DISCHARGE, IN } \mathrm{FT}^{3} / \mathrm{S} \text {, FOR INDICATED } \\
\text { RECURRENCE INTERVAL, IN YEARS, AND } \\
\text { EXCEEDANCE PROBABILITY, IN PERCENT }\end{array}$} \\
\hline & $\begin{array}{c}2 \\
50 \%\end{array}$ & $\begin{array}{c}5 \\
20 \%\end{array}$ & $\begin{array}{l}10 \\
10 \%\end{array}$ & $\begin{array}{l}25 \\
4 \%\end{array}$ & $\begin{array}{l}50 \nmid \\
2 \%\end{array}$ & $\begin{array}{c}100 \nmid \\
1 \%\end{array}$ \\
\hline $\begin{array}{c}1 \\
3 \\
7 \\
15 \\
30 \\
60 \\
90\end{array}$ & $\begin{array}{l}453 \\
391 \\
328 \\
269 \\
219 \\
172 \\
140\end{array}$ & $\begin{array}{l}969 \\
791 \\
623 \\
503 \\
416 \\
330 \\
271\end{array}$ & $\begin{array}{r}1,440 \\
1,140 \\
859 \\
684 \\
576 \\
456 \\
375\end{array}$ & $\begin{array}{r}2,190 \\
1,670 \\
1,190 \\
937 \\
806 \\
638 \\
520\end{array}$ & $\begin{array}{r}2,860 \\
2,130 \\
1,470 \\
1,140 \\
997 \\
786 \\
638\end{array}$ & $\begin{array}{r}3,640 \\
2,650 \\
1,760 \\
1,350 \\
1,200 \\
945 \\
761\end{array}$ \\
\hline
\end{tabular}

DURATION TABLE OF DAILY MEAN FLON FOR PERICO OF RECORD 1958-80

DISCHARGE, IN FT $3 / 5$, WHICH WAS EQUALED OR EXCEEDED FOR IMOICATED PERCENT OF TIME

\begin{tabular}{|c|c|c|c|c|c|c|c|c|c|c|c|c|c|c|c|c|}
\hline $1 \%$ & $5 \%$ & $10 \%$ & $15 \%$ & $20 \%$ & $30 \%$ & $40 \%$ & $50 \%$ & $60 \%$ & $70 \%$ & $80 \%$ & $90 \%$ & $95 \%$ & $98 \%$ & $99 \%$ & $99.5 \%$ & $99.9 \%$ \\
\hline 597 & 293 & 177 & 122 & 87 & 53 & 34 & 24 & 18 & 15 & 12 & 9.9 & 8.1 & 6.4 & 5.6 & 5.1 & 4. \\
\hline
\end{tabular}

f Reliability of values in colum is uncertain, and potential errors are large. 
GILA RIVER BASIN

09489700 BIG BOHITO CREEK NEAR FORT APACHE, AZ--CONTIMUEd
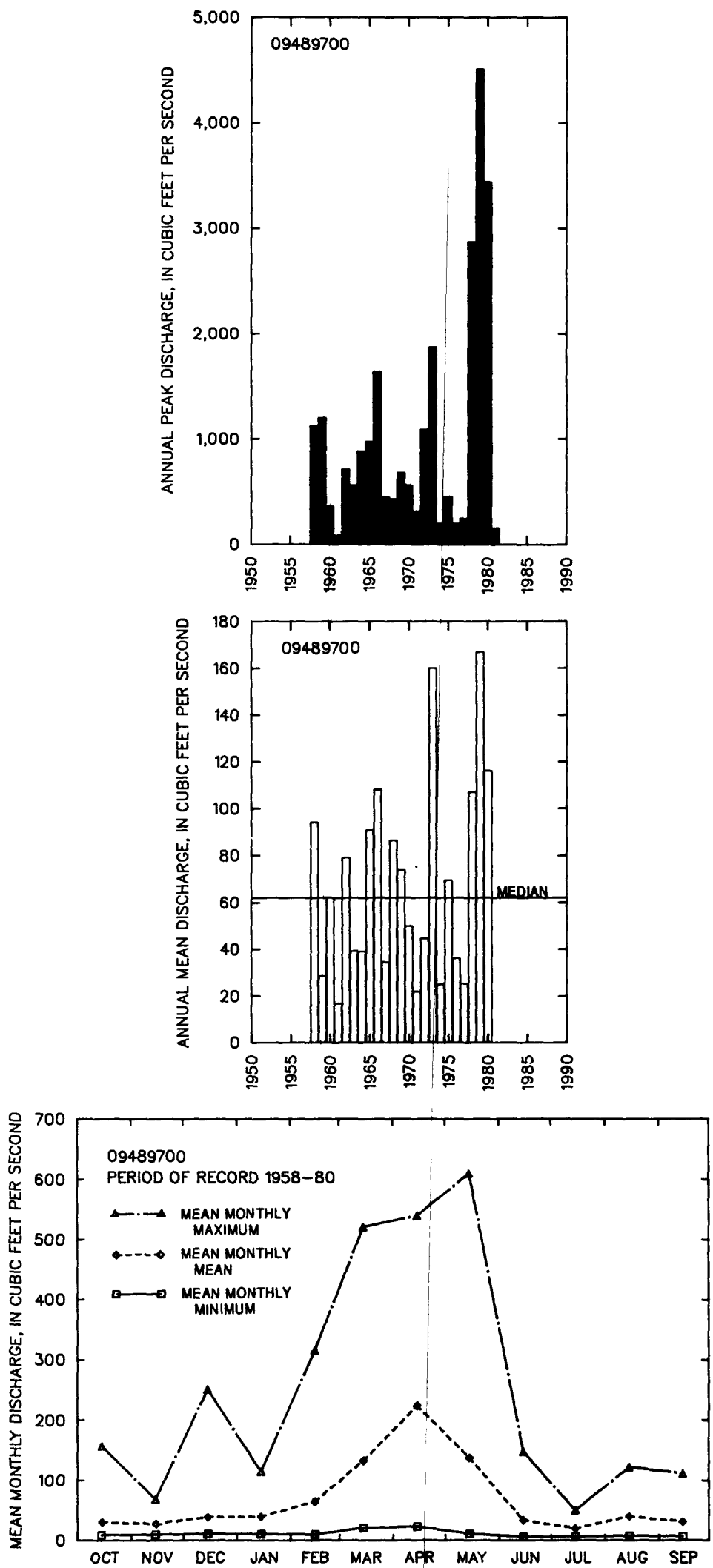
09490500 BLACK RIVER NEAR FORT APACHE, AZ

LOCATION.--Lat 33.42'46", long 110'12'40", in NWK sec.12, T.4 N., R.20 E. (unsurveyed), Gila County, Hydrologic Unit 15060101, on downstream side of first pier from right on highway bridge, $5 \mathrm{mi}$ upstream from confluence with thite River and $14 \mathrm{mi}$ west of Fort Apache.

DRAINACE AREA. $--1,232 \mathrm{mi}^{2}$.

REMARKS. - - One transbas in diversion for industrial and municipal use (see record of Willow Creek diversion from Black River, near Morenci). Negligible storage in several small recreational lakes.

ANIUAL PEAK DISCHARGE

\begin{tabular}{|c|c|c|c|c|c|c|c|}
\hline $\begin{array}{l}\text { WATER } \\
\text { YEAR }\end{array}$ & DATE & $\begin{array}{l}\text { ANNUAL PEAK } \\
\text { DI SCHARGE } \\
\text { (FT } 3 / 5)\end{array}$ & $\begin{array}{l}\text { DISCHARGE } \\
\text { COOES }\end{array}$ & $\begin{array}{l}\text { WATER } \\
\text { YEAR }\end{array}$ & DATE & $\begin{array}{c}\text { ANNUAL PEAK } \\
\text { DISCHAREE } \\
\text { (FT } 3 / S \text { ) }\end{array}$ & $\begin{array}{l}\text { DISCHARGE } \\
\text { CODES }\end{array}$ \\
\hline $\begin{array}{l}1915 \\
1916 \\
1937 \\
1941 \\
1952 \\
1958 \\
1959 \\
1960 \\
1961 \\
1962 \\
1963 \\
1964 \\
1965 \\
1966 \\
1967 \\
1968 \\
1969 \\
1970 \\
1971\end{array}$ & $\begin{array}{l}12-20-14 \\
01-19-16 \\
02-07-37 \\
03-14-41 \\
01-14-52 \\
03-22-58 \\
08-18-59 \\
12-26-59 \\
09-14-61 \\
01-25-62 \\
02-10-63 \\
08-15-64 \\
01-08-65 \\
12-30-65 \\
08-11-67 \\
01-28-68 \\
01-22-69 \\
04-13-70 \\
08-19-71\end{array}$ & $\begin{array}{r}18,000 \\
150,000 \\
235,000 \\
335,000 \\
435,000 \\
12,900 \\
8,300 \\
12,900 \\
914 \\
4,920 \\
5,580 \\
2,280 \\
8,180 \\
24,800 \\
2,870 \\
7,010 \\
3,860 \\
675 \\
1,780\end{array}$ & $\begin{array}{l}\text { ES, HP } \\
\text { ES, HP } \\
\text { ES, HP } \\
\text { ES, HP }\end{array}$ & $\begin{array}{l}1972 \\
1973 \\
1974 \\
1975 \\
1976 \\
1977 \\
1978 \\
1979 \\
1980 \\
1981 \\
1982 \\
1983 \\
1984 \\
1985 \\
1986 \\
1987 \\
1988 \\
1989\end{array}$ & $\begin{array}{l}12-26-71 \\
10-20-72 \\
03-22-74 \\
03-09-75 \\
02-11-76 \\
08-18-77 \\
03-02-78 \\
12-18-78 \\
02-15-80 \\
04-14-81 \\
02-11-82 \\
01-30-83 \\
10-02-83 \\
12-28-84 \\
02-16-86 \\
12-07-86 \\
09-01-88 \\
03-12-89\end{array}$ & $\begin{array}{r}10,500 \\
28,400 \\
574 \\
4,360 \\
1,560 \\
1,030 \\
533,200 \\
640,200 \\
40,000 \\
1,260 \\
10,800 \\
12,000 \\
44,200 \\
21,400 \\
12,600 \\
7,140 \\
8,790 \\
948\end{array}$ & \\
\hline
\end{tabular}

1Highest since 1906 .

2Highest since 1916.

3ighest since 1937.
Highest since 1941.

$5_{\text {Highest since } 1952 .}$

$6_{\text {Highest since } 1916 .}$

BASIN CHARACTERISTICS

\begin{tabular}{|c|c|c|c|c|c|c|c|}
\hline \multirow{2}{*}{$\begin{array}{c}\text { MAIN } \\
\text { CHANNEL } \\
\text { SLOPE } \\
\text { (FT/MI) }\end{array}$} & \multirow[b]{2}{*}{$\begin{array}{l}\text { STREAM } \\
\text { LENGTH } \\
\text { (MI) }\end{array}$} & \multirow{2}{*}{$\begin{array}{l}\text { MEAN } \\
\text { BASIN } \\
\text { ELEVA- } \\
\text { TION } \\
\text { (FT) }\end{array}$} & \multirow[b]{2}{*}{$\begin{array}{l}\text { FORESTED } \\
\text { AREA } \\
\text { (PERCENT) }\end{array}$} & \multirow[b]{2}{*}{$\begin{array}{l}\text { SOIL } \\
\text { INDEX }\end{array}$} & $\begin{array}{c}\text { MEAN } \\
\text { ANNUAL } \\
\text { PRECIPI- }\end{array}$ & \multicolumn{2}{|c|}{ RAINFALL INTENSITY, 24-HOUR } \\
\hline & & & & & $\begin{array}{l}\text { PRECIPI - } \\
\text { TATION } \\
\text { (IN) }\end{array}$ & $\begin{array}{c}\text { 2-YEAR } \\
\text { (IN) }\end{array}$ & $\begin{array}{c}\text { 50-YEAR } \\
\text { (IN) }\end{array}$ \\
\hline 36.2 & 120 & 7,200 & 81.0 & 3.0 & 23.4 & 2.2 & 4.2 \\
\hline
\end{tabular}


MEAN MONTHLY AND ANNUAL DISCHARGES 1915, $1958-89$

\begin{tabular}{|c|c|c|c|c|c|c|}
\hline MONTH & $\begin{array}{l}\operatorname{MAXIMUN} \\
\left(F T^{3} / S\right)\end{array}$ & $\begin{array}{l}\text { MINIMUN } \\
\left(F T^{3} / S\right)\end{array}$ & $\begin{array}{c}\text { MEAN } \\
\left(F T^{3} / S\right)\end{array}$ & $\begin{array}{l}\text { STAN- } \\
\text { DARD } \\
\text { DEVIA- } \\
\text { TION } \\
\text { (FT } 3 / S \text { ) }\end{array}$ & $\begin{array}{l}\text { COEFFI - } \\
\text { CIENT OF } \\
\text { VARI - } \\
\text { ATION }\end{array}$ & $\begin{array}{c}\text { PERCENT } \\
\text { OF } \\
\text { ANNUAL } \\
\text { RUNOFF }\end{array}$ \\
\hline $\begin{array}{l}\text { OCTOBER } \\
\text { NOVEMBER } \\
\text { DECEMBER } \\
\text { JANUARY } \\
\text { FEBRUARY } \\
\text { MARCH } \\
\text { APRIL } \\
\text { MAY } \\
\text { JUNE } \\
\text { JULY } \\
\text { AUGUST } \\
\text { SEPTEMBER }\end{array}$ & $\begin{array}{r}2,730 \\
565 \\
2,450 \\
1,070 \\
3,150 \\
3,860 \\
4,420 \\
3,110 \\
448 \\
763 \\
659 \\
650\end{array}$ & $\begin{array}{l}31 \\
37 \\
38 \\
37 \\
57 \\
90 \\
75 \\
39 \\
17 \\
30 \\
35 \\
31\end{array}$ & $\begin{array}{r}260 \\
155 \\
413 \\
338 \\
592 \\
1,040 \\
1,250 \\
546 \\
114 \\
91 \\
195 \\
149\end{array}$ & $\begin{array}{r}554 \\
144 \\
643 \\
331 \\
635 \\
926 \\
1,060 \\
651 \\
118 \\
125 \\
176 \\
145\end{array}$ & $\begin{array}{l}2.1 \\
0.93 \\
1.6 \\
0.98 \\
1.1 \\
0.89 \\
0.85 \\
1.2 \\
1.0 \\
1.4 \\
0.90 \\
0.97\end{array}$ & $\begin{array}{r}5.1 \\
3.0 \\
8.0 \\
6.6 \\
11.5 \\
20.2 \\
24.3 \\
10.6 \\
2.2 \\
1.8 \\
3.8 \\
2.9\end{array}$ \\
\hline ANMUAL & 1,200 & 78 & 428 & 310 & 0.72 & 100 \\
\hline
\end{tabular}

MAGNITUDE AND PROBABILITY OF INSTANTANEOUS PEAK FLON BASED ON PERIOD OF RECORD 1958-89

DISCHARGE, IN $\mathrm{FT}^{3} / \mathrm{S}$, FOR INDICATED RECURRENCE INTERVAL IN YEARS, AND EXCEEDANCE PROBABILITY, IN PERCENT

\begin{tabular}{lcccccc}
2 & 5 & 10 & 25 & 50 & $100 \uparrow$ \\
$50 \%$ & $20 \%$ & $10 \%$ & $4 \%$ & $2 \%$ & $1 \%$ \\
6,360 & 18,100 & 30,500 & 52,100 & 72,900 & 97,900 \\
\hline WEIGHTED SKEH (LOGS) & $=$ & -0.22 & & \\
MEAN & (LOGS) & 3.78 & & \\
STANDARD DEV. (LOGS) & $=0.56$ & &
\end{tabular}

MAGITLDE AND PROBABILITY OF ANNUAL LOM FLON BASED ON PERIOD OF RECORD 1915, 1959-89

\begin{tabular}{|c|c|c|c|c|c|c|}
\hline \multirow{2}{*}{$\begin{array}{l}\text { PERIOD } \\
\text { (CON- } \\
\text { SECU- } \\
\text { TIVE } \\
\text { DAYS) }\end{array}$} & \multicolumn{6}{|c|}{$\begin{array}{l}\text { DISCHARGE, IN } \mathrm{FT}^{3} / \mathrm{S}, \text { FOR INDICATED } \\
\text { RECURRENCE INTERVAL, IN YEARS, AND } \\
\text { NON-EXCEEDANCE PROBABILITY, IN PERCENT }\end{array}$} \\
\hline & $\begin{array}{c}2 \\
50 \%\end{array}$ & $\begin{array}{c}5 \\
20 \%\end{array}$ & $\begin{array}{l}10 \\
10 \%\end{array}$ & $\begin{array}{l}20 \\
5 \%\end{array}$ & $\begin{array}{l}50 \\
2 x\end{array}$ & $\begin{array}{l}100 t \\
1 \%\end{array}$ \\
\hline $\begin{array}{r}1 \\
3 \\
7 \\
14 \\
30 \\
60 \\
90 \\
120 \\
183\end{array}$ & $\begin{array}{l}25 \\
26 \\
28 \\
31 \\
35 \\
43 \\
53 \\
63 \\
83\end{array}$ & $\begin{array}{l}17 \\
19 \\
20 \\
22 \\
26 \\
32 \\
39 \\
45 \\
57\end{array}$ & $\begin{array}{l}15 \\
16 \\
17 \\
19 \\
22 \\
29 \\
34 \\
39 \\
50\end{array}$ & $\begin{array}{l}13 \\
14 \\
15 \\
17 \\
19 \\
26 \\
31 \\
35 \\
46\end{array}$ & $\begin{array}{l}11 \\
12 \\
13 \\
15 \\
17 \\
24 \\
28 \\
31 \\
42\end{array}$ & $\begin{array}{c}9.9 \\
12 \\
12 \\
14 \\
16 \\
23 \\
26 \\
29 \\
41\end{array}$ \\
\hline
\end{tabular}

MACNITUDE AND PROBABILITY OF ANNUAL HIGH FLON BASED ON PERICD OF RECORD 1915, 1958-89

\begin{tabular}{|c|c|c|c|c|c|c|}
\hline \multirow{2}{*}{$\begin{array}{l}\text { PERIDO } \\
\text { (CON- } \\
\text { SEQU- } \\
\text { TIVE } \\
\text { DAYS) }\end{array}$} & & \multicolumn{5}{|c|}{$\begin{array}{l}\text { DISCHARGE, IN } \mathrm{FT}^{3} / \mathrm{S} \text {, FOR INDICATED } \\
\text { RECURRENCE INTERVAL, IN YEARS, AND } \\
\text { EXCEEDANCE PROBABILITY, IN PERCENT }\end{array}$} \\
\hline & $\begin{array}{c}2 \\
50 \%\end{array}$ & $\begin{array}{c}5 \\
20 x\end{array}$ & $\begin{array}{l}10 \\
10 \%\end{array}$ & $\begin{array}{l}25 \\
4 \%\end{array}$ & $\begin{array}{l}50 \\
2 x\end{array}$ & $\begin{array}{c}100 \dagger \\
1 \%\end{array}$ \\
\hline $\begin{array}{l}1 \\
3 \\
7 \\
15 \\
30 \\
60 \\
90\end{array}$ & $\begin{array}{l}3,880 \\
2,970 \\
2,190 \\
1,720 \\
1,330 \\
1,010 \\
840\end{array}$ & $\begin{array}{r}10,700 \\
7,440 \\
4,820 \\
3,490 \\
2,610 \\
2,030 \\
1,730\end{array}$ & $\begin{array}{r}18,100 \\
11,900 \\
7,170 \\
4,930 \\
3,620 \\
2,850 \\
2,430\end{array}$ & $\begin{array}{r}31,400 \\
19,700 \\
10,800 \\
7,000 \\
5,020 \\
3,980 \\
3,390\end{array}$ & $\begin{array}{r}44,800 \\
27,100 \\
14,000 \\
8,690 \\
6,140 \\
4,890 \\
4,160\end{array}$ & $\begin{array}{r}61,500 \\
36,200 \\
17,600 \\
10,500 \\
7,310 \\
5,840 \\
4,950\end{array}$ \\
\hline
\end{tabular}

DURATION TABLE OF DAILY MEAN FLON FOR PERICD OF RECORD 1915, 1958-89

DISCHARGE, IN FT $3 / 5$, WHICH WAS EQUALED OR EXCEEDED FOR INDICATED PERCENT OF TIME

\begin{tabular}{|c|c|c|c|c|c|c|c|c|c|c|c|c|c|c|c|c|}
\hline $1 \%$ & $5 \%$ & $10 \%$ & $15 \%$ & $20 \%$ & $30 \%$ & $40 \%$ & $50 \%$ & $60 \%$ & $70 x$ & $80 \%$ & $90 \%$ & $95 \%$ & $98 \%$ & $99 \%$ & $99.5 \%$ & $99.9 \%$ \\
\hline 4,050 & 1,870 & 1,180 & 767 & 508 & 273 & 166 & 113 & 84 & 66 & 52 & 39 & 31 & 24 & 21 & 18 & 13 \\
\hline
\end{tabular}

† Reliability of values in colum is uncertain, and potential errors are large. 
GILA RIVER BASIN

09490500 BLACK RIVER NEAR FORT APACHE, AZ--CONTINUEd
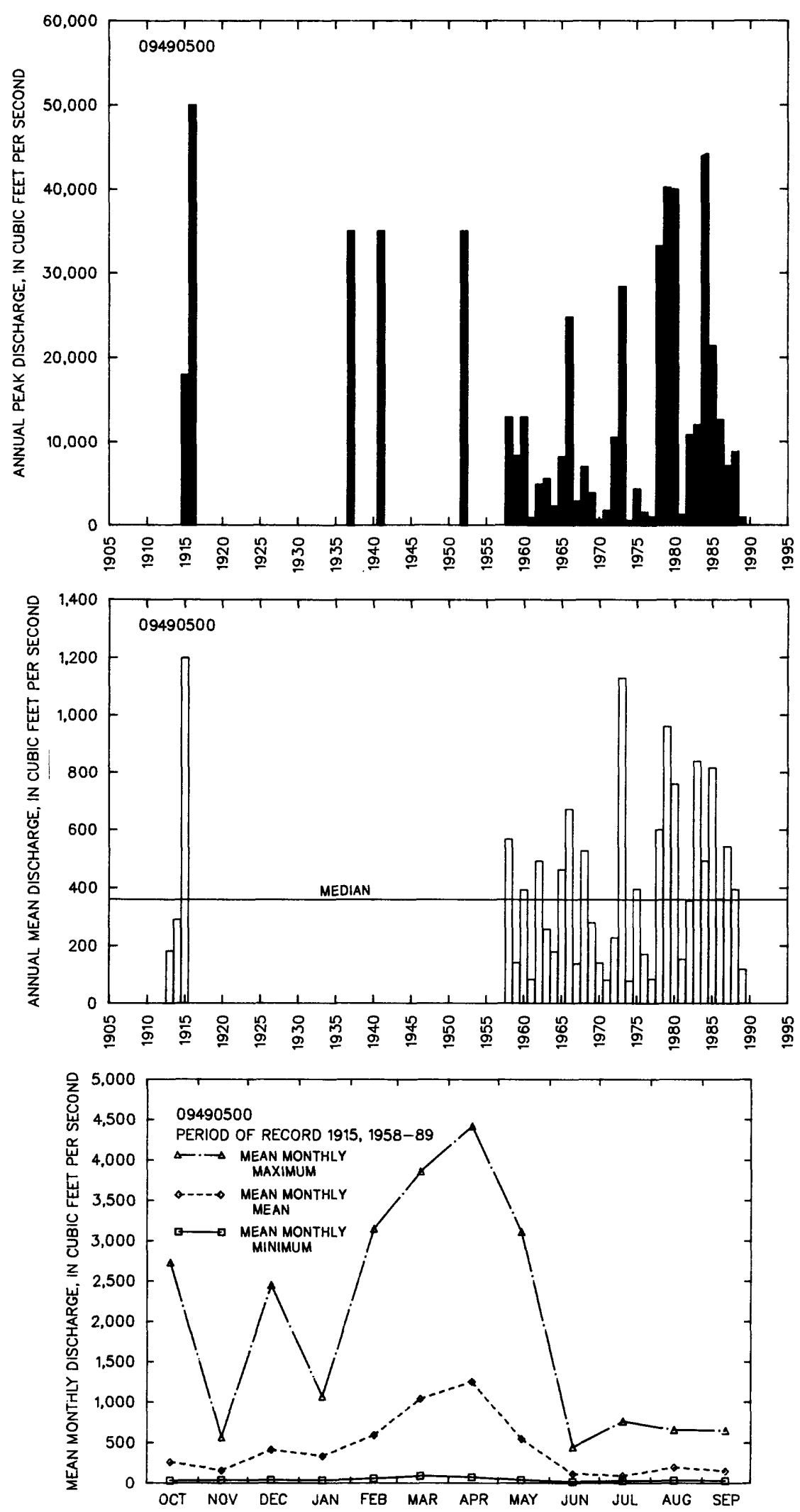
09490800 NORTH FORK WHITE RIVER MEAR GREER, AZ

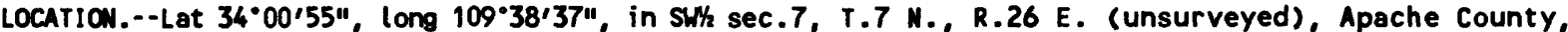
Hydrologic Unit 15060102, in Fort Apache Indian Reservation, on right bank $300 \mathrm{ft}$ upstream from Bear and Cienega Creek and $11 \mathrm{mi}$ west of Greer.
\end{abstract}

DRAIMAGE AREA. $--40.2 \mathrm{mi}^{2}$.

ANNUAL PEAK DISCHARCE

\begin{tabular}{ccc}
$\begin{array}{l}\text { WATER } \\
\text { YEAR }\end{array}$ & DATE & $\begin{array}{c}\text { ANNUAL PEAK } \\
\text { DISCHARGE } \\
\text { (FT } 3 / 5 \text { ) }\end{array}$ \\
\hline 1966 & $04-02-66$ & 299 \\
1967 & $03-09-67$ & 194 \\
1968 & $04-15-68$ & 183 \\
1969 & $04-06-69$ & 177 \\
1970 & $04-10-70$ & 242 \\
1971 & $09-30-71$ & 150 \\
1972 & $10-01-71$ & 162 \\
1973 & $04-28-73$ & 510 \\
1974 & $03-30-74$ & 81 \\
1975 & $05-15-75$ & 157 \\
1976 & $04-09-76$ & 139 \\
1977 & $04-09-77$ & 205 \\
1978 & $03-30-78$ & 153
\end{tabular}

BASIN CHARACTERISTICS

\begin{tabular}{|c|c|c|c|c|c|c|c|}
\hline MIN & & $\begin{array}{r}\text { MEAN } \\
\text { BASIN }\end{array}$ & & & $\begin{array}{c}\text { MEAN } \\
\text { ANNUAL }\end{array}$ & RAINFALL IN & SITY, 24-HOUR \\
\hline $\begin{array}{c}\text { CHANNEL } \\
\text { SLCPE } \\
\text { (FT/MI) }\end{array}$ & $\begin{array}{l}\text { STREAM } \\
\text { LENGTH } \\
\text { (MI) }\end{array}$ & $\begin{array}{l}\text { ELEVA- } \\
\text { TION } \\
\text { (FT) }\end{array}$ & $\begin{array}{l}\text { FORESTED } \\
\text { AREA } \\
\text { (PERCENT) }\end{array}$ & $\begin{array}{l}\text { SOIL } \\
\text { INDEX }\end{array}$ & $\begin{array}{l}\text { PRECIPI- } \\
\text { TATION } \\
\text { (IN) }\end{array}$ & $\begin{array}{c}\text { 2-YEAR } \\
\text { (IN) }\end{array}$ & $\begin{array}{l}\text { 50-YEAR } \\
\text { (IN) }\end{array}$ \\
\hline 216 & 10.1 & 9,520 & 74.0 & 3.0 & 34.2 & 2.9 & 5.5 \\
\hline
\end{tabular}


0\%490800 NORTH FORK UHITE RIVER NEAR GREER, AZ--Continued

MEAN MONTHLY AND ANMUAL DISCHARGES 1966-78

\begin{tabular}{|c|c|c|c|c|c|c|}
\hline MONTH & 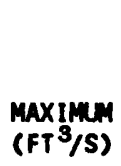 & $\begin{array}{l}\operatorname{MINIMUN} \\
\left(F T^{3} / S\right)\end{array}$ & $\begin{array}{c}\text { MEAN } \\
\left(F T^{3} / S\right)\end{array}$ & $\begin{array}{l}\text { STAN- } \\
\text { DARD } \\
\text { DEVIA- } \\
\text { TION } \\
\text { (FT } 3 / S)\end{array}$ & $\begin{array}{l}\text { COEFFI- } \\
\text { CIENT OF } \\
\text { VARI - } \\
\text { ATION }\end{array}$ & $\begin{array}{c}\text { PERCENT } \\
\text { OF } \\
\text { ANNUAL } \\
\text { RUNOFF }\end{array}$ \\
\hline $\begin{array}{l}\text { OCTOBER } \\
\text { NOVEMBER } \\
\text { DECEMBER } \\
\text { JANUARY } \\
\text { FEBRUARY } \\
\text { MARCH } \\
\text { APRIL } \\
\text { MAY } \\
\text { JUNE } \\
\text { JULY } \\
\text { AUGUST } \\
\text { SEPTEMBER }\end{array}$ & $\begin{array}{r}54 \\
27 \\
25 \\
19 \\
21 \\
54 \\
97 \\
233 \\
152 \\
44 \\
47 \\
43\end{array}$ & $\begin{array}{l}8.7 \\
6.6 \\
6.1 \\
6.0 \\
6.0 \\
9.8 \\
17 \\
14 \\
7.9 \\
8.4 \\
9.9 \\
9.0\end{array}$ & $\begin{array}{l}20 \\
13 \\
11 \\
9.6 \\
10 \\
21 \\
52 \\
63 \\
39 \\
17 \\
20 \\
18\end{array}$ & $\begin{array}{c}15 \\
7.4 \\
5.3 \\
3.3 \\
3.7 \\
13 \\
28 \\
57 \\
39 \\
9.5 \\
9.9 \\
10\end{array}$ & $\begin{array}{l}0.76 \\
0.55 \\
0.49 \\
0.35 \\
0.35 \\
0.62 \\
0.53 \\
0.90 \\
0.98 \\
0.55 \\
0.49 \\
0.57\end{array}$ & $\begin{array}{r}6.7 \\
4.5 \\
3.7 \\
3.3 \\
3.5 \\
7.0 \\
17.6 \\
21.4 \\
13.3 \\
5.9 \\
6.9 \\
6.2\end{array}$ \\
\hline ANNUAL & 57 & 13 & 25 & 12 & 0.47 & 100 \\
\hline
\end{tabular}

MAGNi TUDE AND PROBABILITY OF INSTANTAMEOUS PEAK FLON BASED ON PERIOD OF RECORD 1966-78

DISCHARGE, IN $\mathrm{FT}^{3} / \mathrm{S}$, FOR INDICATED RECURRENCE INTERVAL IN YEARS, AND EXCEEDANCE PROBABILITY, IN PERCENT

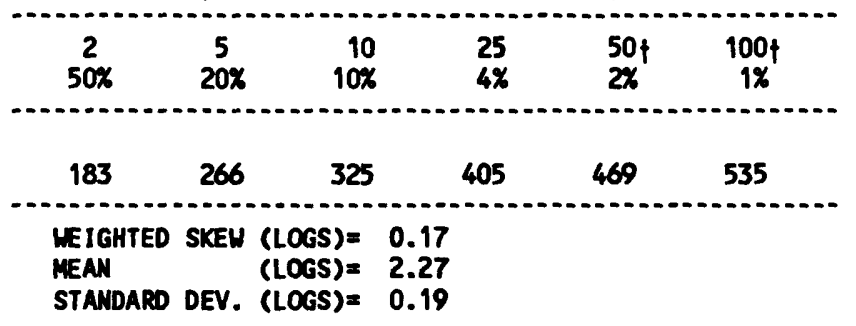

MAENITUDE AND PROBABILITY OF ANNUAL LOW FLON BASED ON PERIOD OF RECORD 1967-78

\begin{tabular}{|c|c|c|c|c|c|c|}
\hline \multirow{2}{*}{$\begin{array}{l}\text { PERIOD } \\
\text { (CON- } \\
\text { SECU- } \\
\text { TIVE } \\
\text { DAYS) }\end{array}$} & \multicolumn{2}{|c|}{$\begin{array}{l}\text { DISCHARGE, II } \\
\text { RECURRENCE II } \\
\text { MON-EXCEEDANC }\end{array}$} & \multicolumn{4}{|c|}{$\begin{array}{l}\text { IN } \text { FT }^{3} / \mathrm{S} \text {, FOR INDICATED } \\
\text { INTERVAL, IN YEARS, AND } \\
\text { CE PROBABILITY, IN PERCENT }\end{array}$} \\
\hline & $\begin{array}{c}2 \\
50 \%\end{array}$ & $\begin{array}{c}5 \\
20 \%\end{array}$ & $\begin{array}{l}10 \\
10 \%\end{array}$ & $\begin{array}{l}20 \\
5 \%\end{array}$ & $\begin{array}{l}50 \uparrow \\
2 \%\end{array}$ & $\begin{array}{l}100 \uparrow \\
1 x\end{array}$ \\
\hline $\begin{array}{r}1 \\
3 \\
7 \\
14 \\
30 \\
60 \\
90 \\
120 \\
183\end{array}$ & $\begin{array}{c}6.4 \\
6.5 \\
6.7 \\
6.8 \\
7.6 \\
8.1 \\
8.6 \\
8.9 \\
11\end{array}$ & $\begin{array}{l}5.3 \\
5.5 \\
5.8 \\
6.1 \\
6.9 \\
7.3 \\
7.6 \\
8.0 \\
9.5\end{array}$ & $\begin{array}{l}4.8 \\
5.0 \\
5.3 \\
5.7 \\
6.5 \\
6.8 \\
7.0 \\
7.6 \\
9.1\end{array}$ & $\begin{array}{l}4.3 \\
4.6 \\
4.9 \\
5.4 \\
6.1 \\
6.4 \\
6.5 \\
7.4 \\
8.8\end{array}$ & $\begin{array}{l}3.9 \\
4.2 \\
4.5 \\
5.1 \\
5.8 \\
5.9 \\
5.9 \\
7.0 \\
8.5\end{array}$ & $\begin{array}{l}3.6 \\
4.0 \\
4.3 \\
4.9 \\
5.5 \\
5.5 \\
5.5 \\
6.8 \\
8.3\end{array}$ \\
\hline
\end{tabular}

MAGNITUDE AND PROBABILITY OF ANNUAL HIGH FLON BASED ON PERIOD OF RECORD 1966-78

\begin{tabular}{|c|c|c|c|c|c|c|}
\hline \multirow{2}{*}{$\begin{array}{l}\text { PERIOD } \\
\text { (CON- } \\
\text { SEOU- } \\
\text { TIVE } \\
\text { DAYS) }\end{array}$} & \multicolumn{6}{|c|}{$\begin{array}{l}\text { DISCHARGE, IN FT }{ }^{3} / S, \text { FOR INDICATED } \\
\text { RECURRENCE INTERVAL; IN YEARS, AND } \\
\text { EXCEEDANCE PROBABILITY, IN PERCENT }\end{array}$} \\
\hline & $\begin{array}{c}2 \\
50 \%\end{array}$ & $\begin{array}{c}5 \\
20 \%\end{array}$ & $\begin{array}{l}10 \\
10 \%\end{array}$ & $\begin{array}{l}25 \\
4 \%\end{array}$ & $\begin{array}{l}50 \phi \\
2 \%\end{array}$ & $\begin{array}{c}100 \nmid \\
1 \%\end{array}$ \\
\hline $\begin{array}{r}1 \\
3 \\
7 \\
15 \\
30 \\
60 \\
90\end{array}$ & $\begin{array}{r}113 \\
98 \\
84 \\
73 \\
64 \\
55 \\
47\end{array}$ & $\begin{array}{r}172 \\
155 \\
137 \\
121 \\
107 \\
93 \\
79\end{array}$ & $\begin{array}{l}221 \\
202 \\
181 \\
159 \\
141 \\
126 \\
104\end{array}$ & $\begin{array}{l}295 \\
274 \\
249 \\
216 \\
192 \\
175 \\
142\end{array}$ & $\begin{array}{l}360 \\
338 \\
308 \\
265 \\
235 \\
218 \\
175\end{array}$ & $\begin{array}{l}434 \\
412 \\
377 \\
321 \\
283 \\
268 \\
211\end{array}$ \\
\hline
\end{tabular}

DURATION TABLE OF DAILY MEAN FLON FOR PERIOD OF RECORD 1966-78 DISCHARGE, IN FT 3 /S, WHICH WAS EQUALED OR EXCEEDED FOR INDICATED PERCENT OF TIME

\begin{tabular}{|c|c|c|c|c|c|c|c|c|c|c|c|c|c|c|c|c|}
\hline $1 \%$ & $5 \%$ & $10 \%$ & $15 \%$ & $20 \%$ & $30 \%$ & $40 \%$ & $50 \%$ & $60 \%$ & $70 \%$ & $80 \%$ & $90 \%$ & $95 \%$ & $98 \%$ & $99 \%$ & $99.5 \%$ & $99.9 \%$ \\
\hline 193 & 79 & 59 & 42 & 32 & 22 & 17 & 14 & 12 & 10 & 8.9 & 7.9 & 7.2 & 6.4 & 6.0 & 5.3 & 4.7 \\
\hline
\end{tabular}

† Reliability of values in colum is uncertain, and potential errors are large. 
GILA RIVER BASIM

09490800 NORTH FORK WHITE RIVER NEAR GREER, AZ--CONTINUED
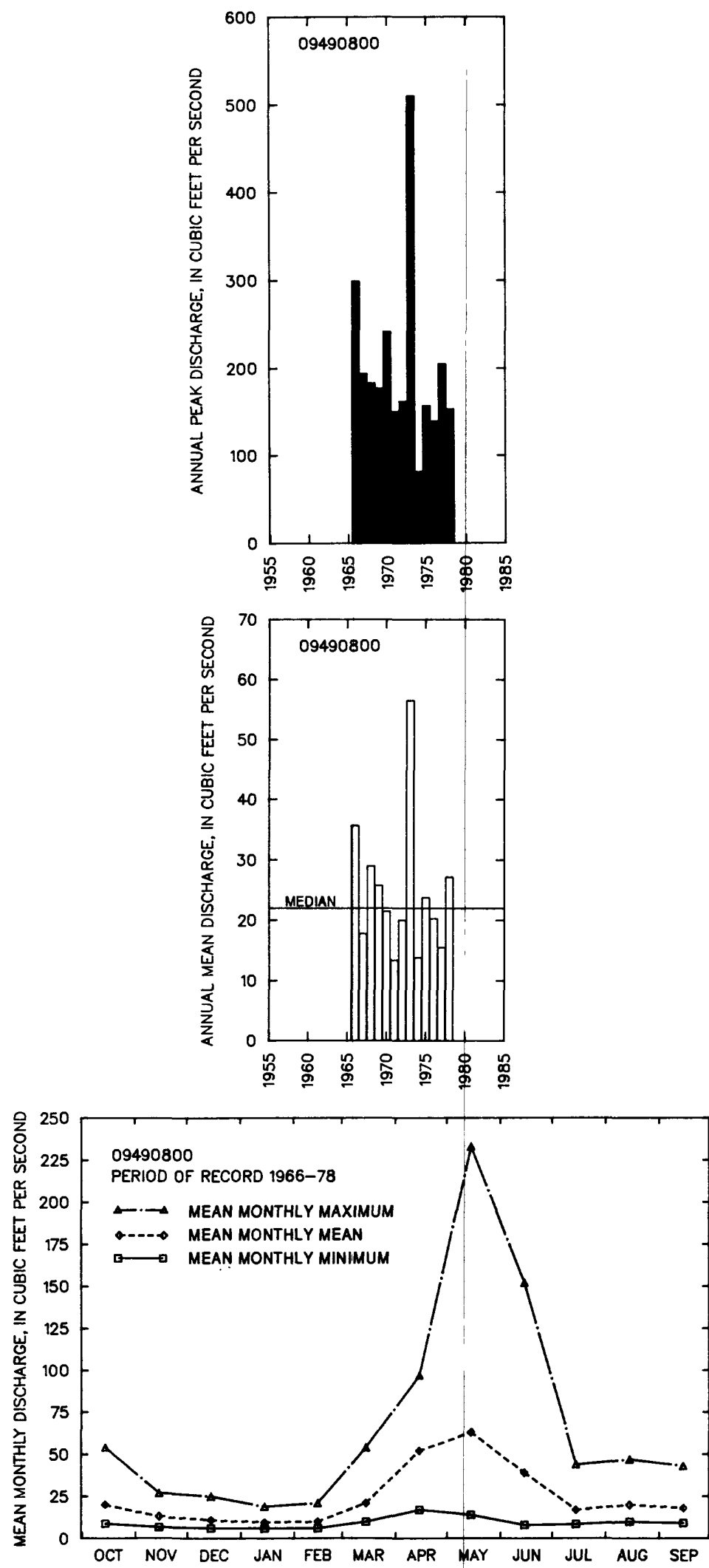
09491000 NORTH FORK WHITE RIVER MEAR MCNARY, AZ

LOCATION.--Lat 34.02'47', long 109.44'02", in Ek sec.31, T.8 N., R.25 E. (unsurveyed), Apache County, Hydrologic Unit 15060102, in Fort Apache Indian Reservation, on left bank 1.9 mi downstream from Paradise Creek and $7 \mathrm{mi}$ southeast of McNary.

DRAINAGE AREA. $--78.2 \mathrm{mi}^{2}$.

REMARKS. - -No storage above station. Water diverted about 5 mi upstream from station for use at McNary.

ANNUAL PEAK DISCHARGE

\begin{tabular}{|c|c|c|c|c|c|c|c|}
\hline $\begin{array}{l}\text { WATER } \\
\text { YEAR }\end{array}$ & DATE & $\begin{array}{l}\text { ANNUAL PEAK } \\
\text { DISCHARGE } \\
\left.\text { (FT }{ }^{3} / \mathrm{S}\right)\end{array}$ & $\begin{array}{l}\text { DISCHARGE } \\
\text { CODES }\end{array}$ & $\begin{array}{l}\text { WATER } \\
\text { YEAR }\end{array}$ & DATE & $\begin{array}{l}\text { ANNUAL PEAK } \\
\text { DISCHARGE } \\
\left(\mathrm{FT}^{3} / \mathrm{S}\right)\end{array}$ & $\begin{array}{l}\text { DISCHARGE } \\
\text { CODES }\end{array}$ \\
\hline $\begin{array}{l}1946 \\
1948 \\
1949 \\
1950 \\
1951 \\
1952 \\
1953 \\
1954 \\
1955 \\
1956 \\
1957 \\
1958 \\
1959 \\
1960 \\
1961 \\
1962 \\
1963 \\
1964 \\
1965 \\
1966\end{array}$ & $\begin{array}{l}09-19-46 \\
04-16-48 \\
04-15-49 \\
03-00-50 \\
08-28-51 \\
04-06-52 \\
03-29-53 \\
03-23-54 \\
00-00-55 \\
00-00-56 \\
08-24-57 \\
04-22-58 \\
10-05-58 \\
03-26-60 \\
04-05-61 \\
04-16-62 \\
09-10-63 \\
04-12-64 \\
04-23-65 \\
04-03-66\end{array}$ & $\begin{array}{r}1,290 \\
1,120 \\
656 \\
188 \\
167 \\
748 \\
152 \\
304 \\
145 \\
170 \\
729 \\
1,230 \\
148 \\
390 \\
248 \\
680 \\
385 \\
444 \\
791 \\
512\end{array}$ & & $\begin{array}{l}1967 \\
1968 \\
1969 \\
1970 \\
1971 \\
1972 \\
1973 \\
1974 \\
1975 \\
1976 \\
1977 \\
1978 \\
1979 \\
1980 \\
1981 \\
1982 \\
1983 \\
1984 \\
1985\end{array}$ & $\begin{array}{l}08-11-67 \\
04-15-68 \\
04-06-69 \\
04-10-70 \\
09-30-71 \\
10-24-71 \\
04-28-73 \\
03-30-74 \\
05-15-75 \\
05-21-76 \\
04-09-77 \\
03-31-78 \\
12-18-78 \\
06-09-80 \\
04-13-81 \\
04-12-82 \\
06-01-83 \\
10-02-83 \\
03-12-85\end{array}$ & $\begin{array}{r}271 \\
351 \\
393 \\
310 \\
257 \\
352 \\
1,000 \\
140 \\
350 \\
184 \\
316 \\
455 \\
1,060 \\
273 \\
397 \\
505 \\
552 \\
2,310 \\
754\end{array}$ & ES \\
\hline
\end{tabular}

BASIN CHARACTERISTICS

\begin{tabular}{|c|c|c|c|c|c|c|c|}
\hline MAIN & & $\begin{array}{l}\text { MEAN } \\
\text { BASIN }\end{array}$ & & & $\begin{array}{c}\text { MEAN } \\
\text { ANNUAL }\end{array}$ & RAINFALL II & SITY, 24-HOUR \\
\hline $\begin{array}{l}\text { CHANNEL } \\
\text { SLOPE } \\
\text { (FT/MI) }\end{array}$ & $\begin{array}{l}\text { STREAM } \\
\text { LENGTH } \\
\text { (MI) }\end{array}$ & $\begin{array}{l}\text { ELEVA- } \\
\text { TION } \\
\text { (FT) }\end{array}$ & $\begin{array}{l}\text { FORESTED } \\
\text { AREA } \\
\text { (PERCENT) }\end{array}$ & $\begin{array}{l}\text { SOIL } \\
\text { INDEX }\end{array}$ & $\begin{array}{l}\text { PRECIPI- } \\
\text { TATION } \\
\text { (IN) }\end{array}$ & $\begin{array}{c}\text { 2-YEAR } \\
\text { (IN) }\end{array}$ & $\begin{array}{l}\text { 50-YEAR } \\
\text { (IN) }\end{array}$ \\
\hline 153 & 18.5 & 9,320 & 79.7 & 3.0 & 32.2 & 2.9 & 5.5 \\
\hline
\end{tabular}


MEAN MONTHLY AND ANMUAL DISCHARges 1946, 1951-54, 1958-85

\begin{tabular}{|c|c|c|c|c|c|c|}
\hline MONTH & 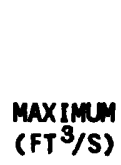 & $\begin{array}{l}\text { MINIMUN } \\
\left(F^{3} / S\right)\end{array}$ & $\begin{array}{c}\text { MEAN } \\
\left(\mathrm{FT}^{3} / \mathrm{S}\right)\end{array}$ & $\begin{array}{l}\text { STAN- } \\
\text { DARD } \\
\text { DEVIA- } \\
\text { TION } \\
\text { (FT } 3 / S)\end{array}$ & $\begin{array}{l}\text { COEFFI- } \\
\text { CIENT OF } \\
\text { VARI - } \\
\text { ATION }\end{array}$ & $\begin{array}{c}\text { PERCENT } \\
\text { OF } \\
\text { ANYUA } \\
\text { RLNOFF }\end{array}$ \\
\hline $\begin{array}{l}\text { OCTOBER } \\
\text { MOVEMBER } \\
\text { DECEMBER } \\
\text { JANUARY } \\
\text { FEBRUARY } \\
\text { MARCH } \\
\text { APRIL } \\
\text { MYY } \\
\text { JUNE } \\
\text { JULY } \\
\text { AUGUST } \\
\text { SEPTEMBER }\end{array}$ & $\begin{array}{r}213 \\
49 \\
98 \\
78 \\
41 \\
170 \\
282 \\
454 \\
293 \\
80 \\
82 \\
123\end{array}$ & $\begin{array}{c}9.4 \\
8.4 \\
7.5 \\
6.4 \\
8.7 \\
14 \\
28 \\
17 \\
10 \\
10 \\
14 \\
9.5\end{array}$ & $\begin{array}{r}31 \\
21 \\
21 \\
20 \\
19 \\
45 \\
127 \\
134 \\
72 \\
27 \\
33 \\
33\end{array}$ & $\begin{array}{c}39 \\
10 \\
17 \\
15 \\
7.7 \\
33 \\
79 \\
104 \\
72 \\
17 \\
15 \\
25\end{array}$ & $\begin{array}{l}1.3 \\
0.48 \\
0.81 \\
0.72 \\
0.40 \\
0.74 \\
0.62 \\
0.78 \\
0.99 \\
0.62 \\
0.47 \\
0.74\end{array}$ & $\begin{array}{r}5.2 \\
3.6 \\
3.7 \\
3.5 \\
3.3 \\
7.7 \\
21.7 \\
23.0 \\
12.4 \\
4.7 \\
5.6 \\
5.7\end{array}$ \\
\hline NNUAL & 108 & 16 & 49 & 25 & 0.51 & 100 \\
\hline
\end{tabular}

MAGNITUDE AND PROBABILITY OF IMSTANTANEOUS PEAK FLOW BASED ON PERIOD OF RECORD 1946, 1948-85

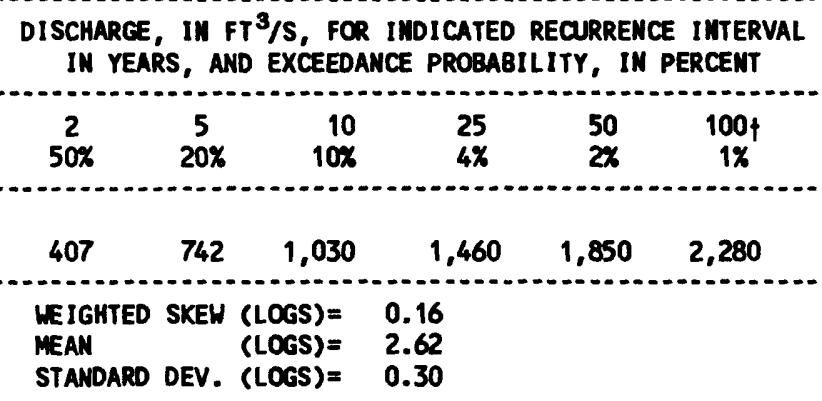

\begin{tabular}{|c|c|c|c|c|c|c|}
\hline \multirow{2}{*}{$\begin{array}{l}\text { PERIOD } \\
\text { (CON- } \\
\text { SECU- } \\
\text { TIVE } \\
\text { DAYS) }\end{array}$} & \multicolumn{6}{|c|}{$\begin{array}{l}\text { DISCHARGE, IN } \mathrm{FT}^{3} / \mathrm{S} \text {, FOR INDICATED } \\
\text { RECWRRENCE INTERVAL, IN YEARS, AND } \\
\text { MON-EXCEEDANCE PROBABILITY, IN PERCENT }\end{array}$} \\
\hline & $\begin{array}{c}2 \\
50 \%\end{array}$ & $\begin{array}{c}5 \\
20 \%\end{array}$ & $\begin{array}{l}10 \\
10 \%\end{array}$ & $\begin{array}{l}20 \\
5 \%\end{array}$ & $\begin{array}{l}50 \\
2 \%\end{array}$ & $\begin{array}{l}100 \dagger \\
1 \%\end{array}$ \\
\hline $\begin{array}{r}7 \\
14 \\
50 \\
60 \\
90 \\
120 \\
183\end{array}$ & $\begin{array}{l}9.8 \\
10 \\
10 \\
11 \\
12 \\
13 \\
14 \\
16 \\
18\end{array}$ & $\begin{array}{c}7.8 \\
8.0 \\
8.2 \\
8.7 \\
9.6 \\
11 \\
12 \\
12 \\
14\end{array}$ & $\begin{array}{c}7.1 \\
7.2 \\
7.4 \\
7.8 \\
8.7 \\
9.7 \\
11 \\
11 \\
13\end{array}$ & $\begin{array}{c}6.6 \\
6.8 \\
6.8 \\
7.2 \\
8.1 \\
9.0 \\
9.9 \\
10 \\
12\end{array}$ & $\begin{array}{c}6.2 \\
6.3 \\
6.3 \\
6.6 \\
7.5 \\
8.4 \\
9.2 \\
9.7 \\
11\end{array}$ & $\begin{array}{c}6.0 \\
6.1 \\
6.1 \\
6.3 \\
7.2 \\
8.0 \\
8.8 \\
9.3 \\
11\end{array}$ \\
\hline
\end{tabular}

MMENITUDE AND PRCBABILITY OF AMMUAL HIGH FLON BASED ON PERIOD OF RECORD 1946, 1951-54, 1958-85

\begin{tabular}{|c|c|c|c|c|c|c|}
\hline $\begin{array}{l}\text { PERICD } \\
\text { (cON- } \\
\text { sECU- }\end{array}$ & & $\begin{array}{l}\text { DISCH } \\
\text { RECURI } \\
\text { EXCEEL }\end{array}$ & E IN & $\begin{array}{l}/ S \text {, FO } \\
\text { AL, IN } \\
\text { ILITY, }\end{array}$ & $\begin{array}{l}\text { INDICA } \\
\text { YEARS, } \\
\text { II PERC }\end{array}$ & \\
\hline $\begin{array}{l}\text { TIVE } \\
\text { DAYS) }\end{array}$ & $\begin{array}{c}2 \\
50 x\end{array}$ & $\begin{array}{c}5 \\
20 \%\end{array}$ & $\begin{array}{l}10 \\
10 \%\end{array}$ & $\begin{array}{l}25 \\
4 x\end{array}$ & $\begin{array}{l}50 \\
2 x\end{array}$ & $\begin{array}{c}100 \dagger \\
1 x\end{array}$ \\
\hline $\begin{array}{r}1 \\
3 \\
7 \\
15 \\
30 \\
60 \\
90\end{array}$ & $\begin{array}{r}294 \\
254 \\
216 \\
178 \\
147 \\
121 \\
99\end{array}$ & $\begin{array}{l}542 \\
458 \\
377 \\
309 \\
258 \\
214 \\
175\end{array}$ & $\begin{array}{l}766 \\
624 \\
495 \\
402 \\
340 \\
286 \\
233\end{array}$ & $\begin{array}{r}1.130 \\
868 \\
652 \\
524 \\
449 \\
384 \\
314\end{array}$ & $\begin{array}{r}1,460 \\
1,070 \\
774 \\
616 \\
534 \\
461 \\
378\end{array}$ & $\begin{array}{r}1,860 \\
1,300 \\
899 \\
708 \\
621 \\
543 \\
447\end{array}$ \\
\hline
\end{tabular}

DURATION TABLE OF DAILY MEAN FLOW FOR PERIOD OF RECORD 1946, 1951-54, 1958-85
DISCHARGE, IN FT $3 / 5$, WHICH WAS EQUALED OR EXCEEDED FOR INDICATED PERCENT OF TIME

\begin{tabular}{|c|c|c|c|c|c|c|c|c|c|c|c|c|c|c|c|c|}
\hline 388 & 189 & 121 & 77 & 58 & 40 & 30 & 23 & 20 & 17 & 15 & 12 & 10 & 8.4 & 7.6 & 6.7 & 5.9 \\
\hline
\end{tabular}


GILA RIVER BASIN

09491000 MORTH FORK HHITE RIVER MEAR MCMARY, AZ--CONTIMUED
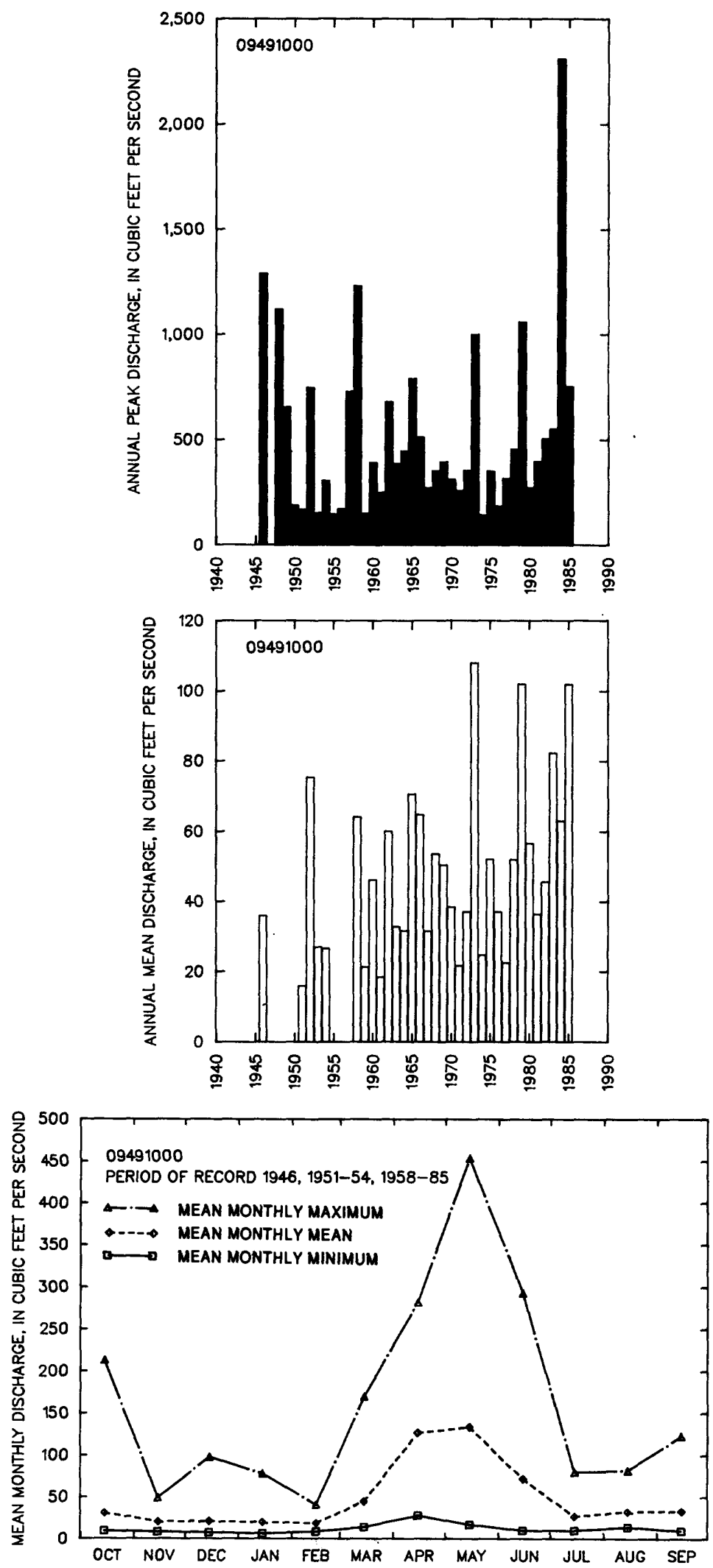
404

\section{GILA RIVER BASIN}

09491800 NORTH FORK WHITE RIVER TRIBUTARY NEAR WHITERIVER, AZ

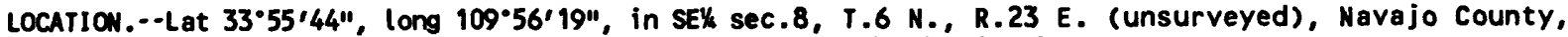
Hydrologic Unit 15060102, at State Highway 73, 6.5 mi north of initeriver.

DRAIMAGE AREA. $--2.27 \mathrm{mi}^{2}$.

ANMUAL PEAK DISCHARGE

\begin{tabular}{|c|c|c|c|}
\hline $\begin{array}{l}\text { WATER } \\
\text { YEAR }\end{array}$ & DATE & $\begin{array}{c}\text { ANNUAL PEAK } \\
\text { DISCHARGE } \\
\left(F^{3} / S\right)\end{array}$ & $\begin{array}{l}\text { DISCHARCE } \\
\text { COOES }\end{array}$ \\
\hline $\begin{array}{l}1965 \\
1966 \\
1967 \\
1968 \\
1969 \\
1970 \\
1971 \\
1972 \\
1973 \\
1974 \\
1975\end{array}$ & $\begin{array}{l}00-00-65 \\
12-22-65 \\
00-00-67 \\
11-00-67 \\
00-00-69 \\
00-00-70 \\
08-00-71 \\
00-00-72 \\
10-19-72 \\
00-00-74 \\
07-00-75\end{array}$ & $\begin{array}{c}120 \\
24 \\
0 \\
0.1 \\
0 \\
0 \\
110 \\
0 \\
25 \\
0 \\
56\end{array}$ & LT \\
\hline
\end{tabular}

MAGNITUDE AND PROBABILITY OF INSTANTANEOUS PEAK FLOW BASED ON PERIOD OF RECORD

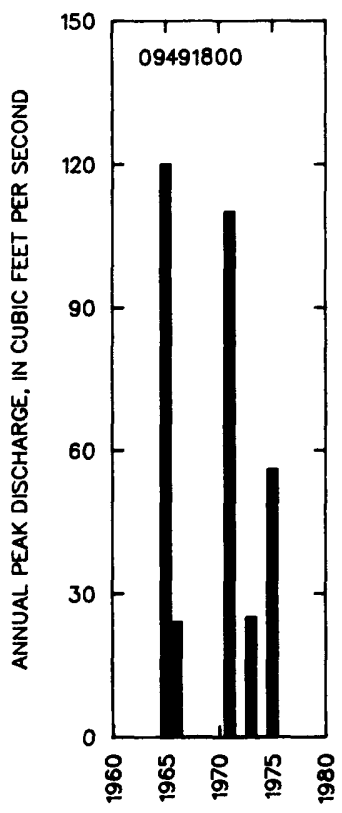

DISCHARCE, IN $\mathrm{FT}^{3} / \mathrm{S}$, FOR INDICATED RECURRENCE INTERVAL IN YEARS, AND EXCEEDANCE PROBABILITY, IN PERCENT

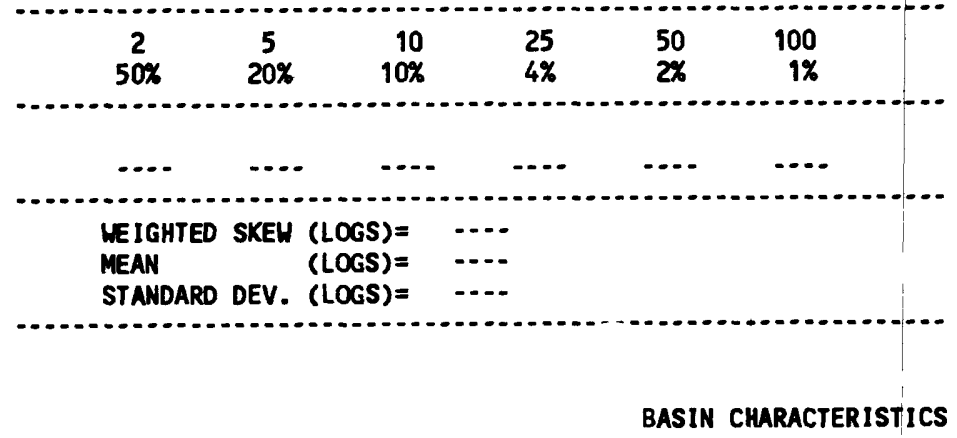

\begin{tabular}{|c|c|c|c|c|c|c|c|}
\hline MAIN & & $\begin{array}{l}\text { MEAN } \\
\text { BASIN }\end{array}$ & & & & RAINFALL I & SITY, 24-HOUR \\
\hline $\begin{array}{l}\text { CHANNEL } \\
\text { SLOPE } \\
\text { (FT/MI) }\end{array}$ & $\begin{array}{c}\text { STREAM } \\
\text { LENGTH } \\
\text { (MI) }\end{array}$ & $\begin{array}{l}\text { ELEVA- } \\
\text { TION } \\
\text { (FT) }\end{array}$ & $\begin{array}{l}\text { FORESTED } \\
\text { AREA } \\
\text { (PERCENT) }\end{array}$ & $\begin{array}{l}\text { SOIL } \\
\text { INDEX }\end{array}$ & $\begin{array}{l}\text { PRECIPI- } \\
\text { TATION } \\
\text { (IN) }\end{array}$ & $\begin{array}{c}\text { 2-YEAR } \\
\text { (IN) }\end{array}$ & $\begin{array}{l}\text { 50-YEAR } \\
\text { (IN) }\end{array}$ \\
\hline 272 & 3.6 & 6,290 & 99.0 & 3.0 & 20.5 & 2.1 & 4.2 \\
\hline
\end{tabular}


09492400 EAST FORK WHITE RIVER NEAR FORT APACHE, NZ

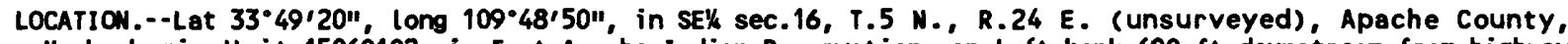
Hydrologic Unit 15060102, in Fort Apache Indian Reservation, on left bank $600 \mathrm{ft}$ downstream from highway bridge, $0.1 \mathrm{mi}$ upstream from Rock Creek and $10 \mathrm{mi}$ east of Fort Apache.

DRAINAGE AREA. $--38.8 \mathrm{mi}^{2}$.

ANNUAL PEAK DISCHARGE

\begin{tabular}{|c|c|c|c|c|c|c|c|}
\hline $\begin{array}{l}\text { WATER } \\
\text { YEAR }\end{array}$ & DATE & $\begin{array}{l}\text { ANNUAL PEAK } \\
\text { DISCHARGE } \\
\text { (FT } 3 / \mathrm{S} \text { ) }\end{array}$ & $\begin{array}{l}\text { DISCHARGE } \\
\text { COOES }\end{array}$ & $\begin{array}{l}\text { WATER } \\
\text { YEAR }\end{array}$ & DATE & $\begin{array}{l}\text { ANNUAL PEAK } \\
\text { DISCHARGE } \\
\left(F^{3} / S\right)\end{array}$ & $\begin{array}{l}\text { DISCHARGE } \\
\text { CODES }\end{array}$ \\
\hline $\begin{array}{l}1958 \\
1959 \\
1960 \\
1961 \\
1962 \\
1963 \\
1964 \\
1965 \\
1966 \\
1967 \\
1968 \\
1969 \\
1970 \\
1971 \\
1972 \\
1973\end{array}$ & $\begin{array}{l}04-22-58 \\
10-06-58 \\
05-13-60 \\
08-17-61 \\
05-12-62 \\
08-30-63 \\
08-09-64 \\
05-02-65 \\
11-25-65 \\
08-03-67 \\
08-05-68 \\
05-21-69 \\
09-06-70 \\
09-01-71 \\
10-01-71 \\
10-20-72\end{array}$ & $\begin{array}{r}411 \\
330 \\
207 \\
663 \\
300 \\
116 \\
83 \\
204 \\
270 \\
758 \\
352 \\
194 \\
396 \\
205 \\
266 \\
732\end{array}$ & ES & $\begin{array}{l}1974 \\
1975 \\
1976 \\
1977 \\
1978 \\
1979 \\
1980 \\
1981 \\
1982 \\
1983 \\
1984 \\
1985 \\
1986 \\
1987 \\
1988 \\
1989\end{array}$ & $\begin{array}{l}05-15-74 \\
05-16-75 \\
07-30-76 \\
08-16-77 \\
03-01-78 \\
12-18-78 \\
05-22-80 \\
05-03-81 \\
05-02-82 \\
06-01-83 \\
10-01-83 \\
03-12-85 \\
07-16-86 \\
04-17-87 \\
04-28-88 \\
03-14-89\end{array}$ & $\begin{array}{r}89 \\
270 \\
166 \\
122 \\
318 \\
751 \\
372 \\
167 \\
283 \\
388 \\
2,700 \\
481 \\
154 \\
235 \\
211 \\
122\end{array}$ & \\
\hline
\end{tabular}

BASIN CHARACTERISTICS

\begin{tabular}{|c|c|c|c|c|c|c|c|}
\hline \multirow{2}{*}{$\begin{array}{l}\text { MAIN } \\
\text { CHANNEL } \\
\text { SLOPE } \\
\text { (FT/MI) }\end{array}$} & \multicolumn{3}{|c|}{ MEAN } & & $\begin{array}{c}\text { MEAN } \\
\text { ANNUAL }\end{array}$ & \multicolumn{2}{|c|}{ RAINFALL INTENSITY, 24-HOUR } \\
\hline & $\begin{array}{l}\text { STREAM } \\
\text { LENGTH } \\
\text { (MI) }\end{array}$ & $\begin{array}{l}\text { ELEVA- } \\
\text { TION } \\
\text { (FT) }\end{array}$ & $\begin{array}{l}\text { FORESTED } \\
\text { AREA } \\
\text { (PERCENT) }\end{array}$ & $\begin{array}{l}\text { SOIL } \\
\text { INDEX }\end{array}$ & $\begin{array}{l}\text { PRECIPI - } \\
\text { TATION } \\
\text { (IN) }\end{array}$ & $\begin{array}{c}\text { 2-YEAR } \\
\text { (IN) }\end{array}$ & $\begin{array}{l}\text { 50-YEAR } \\
\text { (IN) }\end{array}$ \\
\hline 239 & 17.9 & 8,580 & 96.0 & 3.0 & 31.2 & 2.8 & 5.6 \\
\hline
\end{tabular}


09492400 EAST FORK WHITE RIVER NEAR FORT APACHE, AZ--Continued

MEAN MONTHLY AND ANNUAL DISCHARGES $1958-89$

\begin{tabular}{|c|c|c|c|c|c|c|}
\hline MONTH & $\begin{array}{l}\operatorname{MAX} 1 \mathrm{IMN} \\
\left(\mathrm{FT}^{3} / \mathrm{S}\right)\end{array}$ & $\begin{array}{l}\text { MINIMUM } \\
\left(F^{3} / S\right)\end{array}$ & $\begin{array}{c}\text { MEAN } \\
\left(F T^{3} / S\right)\end{array}$ & $\begin{array}{l}\text { STAN- } \\
\text { DARD } \\
\text { DEVIA- } \\
\text { TION } \\
\text { (FT3/S) }\end{array}$ & $\begin{array}{l}\text { COEFFI- } \\
\text { CIENT OF } \\
\text { VARI - } \\
\text { ATION }\end{array}$ & $\begin{array}{c}\text { PERCENT } \\
\text { OF } \\
\text { ANNUAL } \\
\text { RUNOFF }\end{array}$ \\
\hline $\begin{array}{l}\text { OCTOBER } \\
\text { NOVEMBER } \\
\text { DECEMBER } \\
\text { JANUARY } \\
\text { FEBRUARY } \\
\text { MARCH } \\
\text { APRIL } \\
\text { MAY } \\
\text { JUNE } \\
\text { JULY } \\
\text { AUGUST } \\
\text { SEPTEMBER }\end{array}$ & $\begin{array}{r}128 \\
44 \\
57 \\
34 \\
66 \\
103 \\
182 \\
284 \\
172 \\
46 \\
71 \\
66\end{array}$ & $\begin{array}{c}8.7 \\
8.2 \\
7.8 \\
7.7 \\
7.8 \\
9.9 \\
19 \\
13 \\
6.2 \\
7.7 \\
11 \\
6.9\end{array}$ & $\begin{array}{r}25 \\
17 \\
17 \\
16 \\
21 \\
39 \\
82 \\
103 \\
49 \\
20 \\
28 \\
24\end{array}$ & $\begin{array}{c}27 \\
9.2 \\
11 \\
7.7 \\
12 \\
23 \\
43 \\
68 \\
49 \\
11 \\
15 \\
14\end{array}$ & $\begin{array}{l}1.1 \\
0.53 \\
0.66 \\
0.49 \\
0.57 \\
0.60 \\
0.52 \\
0.66 \\
1.0 \\
0.55 \\
0.53 \\
0.57\end{array}$ & $\begin{array}{r}5.7 \\
3.9 \\
3.8 \\
3.5 \\
4.7 \\
8.8 \\
18.6 \\
23.3 \\
11.2 \\
4.5 \\
6.5 \\
5.4\end{array}$ \\
\hline ANUAL & 72 & 15 & 37 & 16 & 0.43 & 100 \\
\hline
\end{tabular}

MAGNITLDE AND PROBABILITY OF INSTANTAMEOUS PEAK FLON BASED ON PERIOD OF RECORD 1958-89

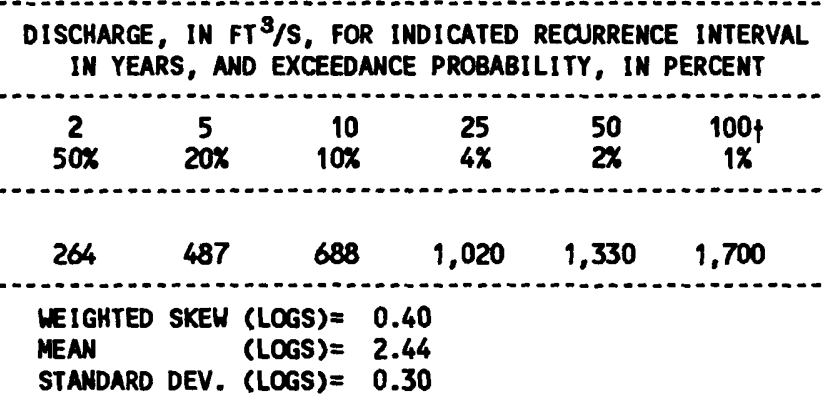

MANITLDE ANO PROBABILITY OF ANMUAL LOW FLOW BASED ON PERIOD OF RECORD 1959-89

\begin{tabular}{|c|c|c|c|c|c|c|}
\hline \multirow{2}{*}{$\begin{array}{l}\text { PERICD } \\
\text { (CON- } \\
\text { SECU- } \\
\text { TIVE } \\
\text { DAYS) }\end{array}$} & \multicolumn{6}{|c|}{$\begin{array}{l}\text { DISCHARGE, IN FT } \text { FT, FOR INDICATED }^{3} \text { RECURRENCE INTERVAL, IN YEARS, AND } \\
\text { MON-EXCEEDANCE PROBABILITY, IN PERCENT }\end{array}$} \\
\hline & $\stackrel{2}{50 \%}$ & $\begin{array}{c}5 \\
20 x\end{array}$ & $\begin{array}{l}10 \\
10 \%\end{array}$ & $\begin{array}{l}20 \\
5 \%\end{array}$ & $\begin{array}{l}50 \\
2 x\end{array}$ & $\begin{array}{l}100 \uparrow \\
1 \%\end{array}$ \\
\hline $\begin{array}{r}1 \\
3 \\
7 \\
14 \\
30 \\
60 \\
90 \\
120 \\
183\end{array}$ & $\begin{array}{c}6.7 \\
7.1 \\
7.7 \\
8.2 \\
9.0 \\
9.7 \\
11 \\
12 \\
15\end{array}$ & $\begin{array}{r}5.4 \\
5.9 \\
6.3 \\
6.8 \\
7.5 \\
8.2 \\
9.0 \\
9.9 \\
12\end{array}$ & $\begin{array}{c}4.9 \\
5.4 \\
5.8 \\
6.4 \\
7.0 \\
7.7 \\
8.3 \\
9.0 \\
10\end{array}$ & $\begin{array}{l}4.6 \\
5.2 \\
5.5 \\
6.1 \\
6.7 \\
7.4 \\
7.9 \\
8.4 \\
9.7\end{array}$ & $\begin{array}{l}4.4 \\
5.0 \\
5.2 \\
5.8 \\
6.4 \\
7.2 \\
7.5 \\
7.8 \\
9.0\end{array}$ & $\begin{array}{l}4.3 \\
4.9 \\
5.0 \\
5.6 \\
6.3 \\
7.1 \\
7.3 \\
7.4 \\
8.6\end{array}$ \\
\hline
\end{tabular}

MAENITUDE AND PROBABILITY OF ANNUAL HIGH FLON BASED ON PERIOO OF RECORD 1958-89

\begin{tabular}{|c|c|c|c|c|c|c|}
\hline \multirow{2}{*}{$\begin{array}{l}\text { PERIOO } \\
\text { (CON- } \\
\text { SECU- } \\
\text { TIVE } \\
\text { DAYS) }\end{array}$} & \multicolumn{6}{|c|}{$\begin{array}{l}\text { DISCHARGE, IN } \mathrm{FT}^{3} / \mathrm{S} \text {, FOR INDICATED } \\
\text { RECURRENCE INTERVAL, IN YEARS, AND } \\
\text { EXCEEDANCE PROBABILITY, IN PERCENT }\end{array}$} \\
\hline & $\begin{array}{c}2 \\
50 \%\end{array}$ & $\begin{array}{c}5 \\
20 \%\end{array}$ & $\begin{array}{l}10 \\
10 \%\end{array}$ & $\begin{array}{l}25 \\
4 \%\end{array}$ & $\begin{array}{l}50 \\
2 \%\end{array}$ & $\underset{1 \%}{100} \uparrow$ \\
\hline $\begin{array}{l}1 \\
3 \\
7 \\
15 \\
30 \\
60 \\
90\end{array}$ & $\begin{array}{r}187 \\
167 \\
148 \\
129 \\
111 \\
92 \\
75\end{array}$ & $\begin{array}{l}342 \\
279 \\
234 \\
198 \\
170 \\
146 \\
121\end{array}$ & $\begin{array}{l}481 \\
368 \\
294 \\
244 \\
211 \\
184 \\
153\end{array}$ & $\begin{array}{l}707 \\
496 \\
374 \\
303 \\
264 \\
235 \\
195\end{array}$ & $\begin{array}{l}917 \\
604 \\
435 \\
346 \\
303 \\
274 \\
226\end{array}$ & $\begin{array}{r}1,170 \\
723 \\
498 \\
389 \\
343 \\
314 \\
259\end{array}$ \\
\hline
\end{tabular}

DURATION TABLE OF DAILY MEAN FLON FOR PERIOD OF RECORD 1958-89 DISCHARGE, IN $\mathrm{FT}^{3} / \mathrm{S}$, HHICH WAS EQUALED OR EXCEEDED FOR INDICATED PERCENT OF TIME

\begin{tabular}{|c|c|c|c|c|c|c|c|c|c|c|c|c|c|c|c|c|}
\hline $1 \%$ & $5 \%$ & $10 \%$ & $15 \%$ & $20 \%$ & $30 \%$ & $40 \%$ & $50 \%$ & $60 \%$ & $70 x$ & $80 \%$ & $90 \%$ & $95 \%$ & $98 \%$ & $99 \%$ & $99.5 \%$ & $99.9 \%$ \\
\hline 237 & 131 & 91 & 63 & 49 & 33 & 25 & 20 & 16 & 13 & 11 & 9.0 & 8.0 & 7.0 & 6.5 & 5.9 & 5.0 \\
\hline
\end{tabular}

$\uparrow$ Reliability of values in colum is uncertain, and potential errors are large. 
GILA RIVER BASIN

09492400 EAST FORK HHITE RIVER NEAR FORT APACHE, AZ--CONTIMUED
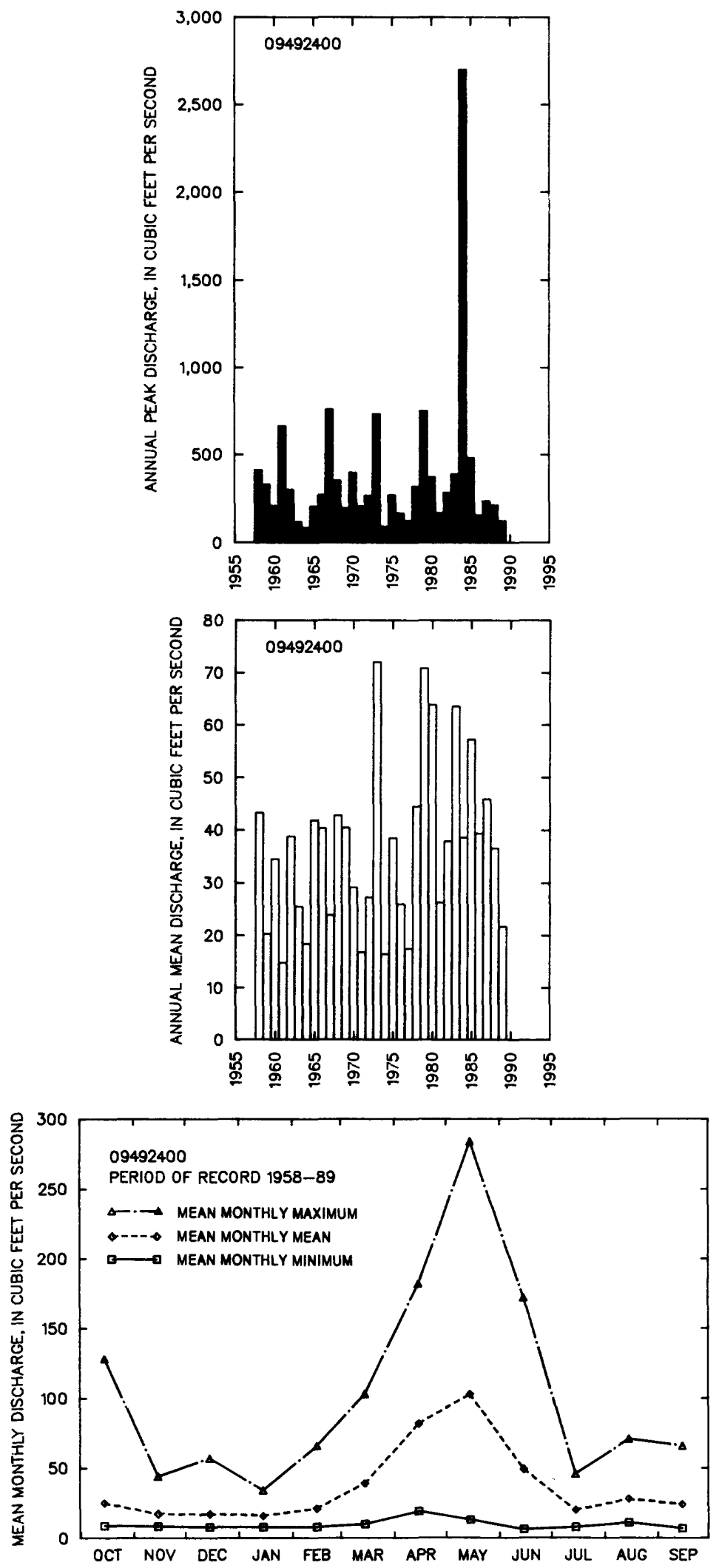
09494000 WHITE RIVER NEAR FORT APACHE, AZ

LOCATION.--Lat 33.44'11", long 110.09'58", in SEK sec.32, T.4 N., R.21 E. (unsurveyed) Gila County, Hydrologic Unit 15060102, in Fort Apache Indian Reservation, on right bank 2,200 ft downstream from highway bridge, $4.5 \mathrm{mi}$ upstream from confluence with Black River, and $11 \mathrm{mi}$ west of Fort Apache.

DRAINAGE AREA. - - $632 \mathrm{mi}^{2}$.

REMARKS.--Small diversions above station for irrigation of about 1,460 acres. Negligible storage above station in several small recreational lakes.

ANMUAL PEAK DISCHARge

\begin{tabular}{|c|c|c|c|c|}
\hline $\begin{array}{l}\text { WATER } \\
\text { YEAR }\end{array}$ & $\begin{array}{cc} & \text { ANNUAL PEAK } \\
& \text { DISCHARGE } \\
\text { DATE } & \left(F^{3} / S\right)\end{array}$ & $\begin{array}{l}\text { WATER } \\
\text { YEAR }\end{array}$ & DATE & $\begin{array}{l}\text { ANMUAL PEAK } \\
\text { DISCHARGE } \\
\left(\mathrm{FT}^{3} / \mathrm{S}\right)\end{array}$ \\
\hline $\begin{array}{l}1958 \\
1959 \\
1960 \\
1961 \\
1962 \\
1963 \\
1964 \\
1965 \\
1966 \\
1967 \\
1968 \\
1969 \\
1970 \\
1971 \\
1972 \\
1973\end{array}$ & $\begin{array}{l}03-22-58 \\
07-28-59 \\
12-26-59 \\
08-29-61 \\
04-16-62 \\
08-26-63 \\
07-25-64 \\
07-28-65 \\
12-30-65 \\
07-22-67 \\
04-16-68 \\
04-07-69 \\
08-13-70 \\
08-12-71 \\
12-26-71 \\
04-29-73\end{array}$ & $\begin{array}{l}1974 \\
1975 \\
1976 \\
1977 \\
1978 \\
1979 \\
1980 \\
1981 \\
1982 \\
1983 \\
1984 \\
1985 \\
1986 \\
1987 \\
1988 \\
1989\end{array}$ & $\begin{array}{l}08-01-74 \\
04-27-75 \\
07-14-76 \\
07-24-77 \\
03-01-78 \\
12-18-78 \\
02-15-80 \\
08-31-81 \\
03-13-82 \\
04-26-83 \\
10-02-83 \\
03-12-85 \\
08-27-86 \\
04-18-87 \\
08-31-88 \\
03-14-89\end{array}$ & $\begin{array}{r}3,110 \\
1,930 \\
2,220 \\
1,980 \\
6,590 \\
14,600 \\
8,160 \\
1,240 \\
2,130 \\
1,870 \\
9,410 \\
8,900 \\
3,780 \\
2,000 \\
1,590 \\
688\end{array}$ \\
\hline
\end{tabular}

BASIN CHARACTERISTICS

\begin{tabular}{|c|c|c|c|c|c|c|c|}
\hline MIN & & $\begin{array}{l}\text { MEAN } \\
\text { BASIN }\end{array}$ & & & & RAINFALL IN & SITY, 24-HOUR \\
\hline $\begin{array}{l}\text { CHANNEL } \\
\text { SLOPE } \\
\text { (FT/MI) }\end{array}$ & $\begin{array}{l}\text { STREAM } \\
\text { LENGTH } \\
\text { (MI) }\end{array}$ & $\begin{array}{l}\text { ELEVA- } \\
\text { TION } \\
\text { (FT) }\end{array}$ & $\begin{array}{l}\text { FORESTED } \\
\text { AREA } \\
\text { (PERCENT) }\end{array}$ & $\begin{array}{l}\text { SOIL } \\
\text { INDEX }\end{array}$ & $\begin{array}{l}\text { PRECIPI - } \\
\text { TATION } \\
\text { (IN) }\end{array}$ & $\begin{array}{c}\text { 2-YEAR } \\
\text { (IN) }\end{array}$ & $\begin{array}{l}\text { 50-YEAR } \\
\text { (IN) }\end{array}$ \\
\hline 76.8 & 62.5 & 7,400 & 83.0 & 3.0 & 25.4 & 2.3 & 4.6 \\
\hline
\end{tabular}


MEAN MONTHLY AND ANMUAL DISCHARGES 1958-89

\begin{tabular}{|c|c|c|c|c|c|c|}
\hline MONTH & $\begin{array}{l}\operatorname{MAX} \operatorname{Imm}_{3} \\
\left(\mathrm{FT}^{3} / \mathrm{S}\right)\end{array}$ & $\begin{array}{l}\text { MINIMUM } \\
\left(F^{3} / S\right)\end{array}$ & $\begin{array}{c}\text { MEAN } \\
\left(F T^{3} / S\right)\end{array}$ & $\begin{array}{l}\text { STAN- } \\
\text { DARD } \\
\text { DEVIA- } \\
\text { TION } \\
\left(F^{3} / S\right)\end{array}$ & $\begin{array}{l}\text { COEFFI- } \\
\text { CIENT OF } \\
\text { VARI - } \\
\text { ATION }\end{array}$ & $\begin{array}{c}\text { PERCENT } \\
\text { OF } \\
\text { ANNUAL } \\
\text { RLNOFI }\end{array}$ \\
\hline $\begin{array}{l}\text { OCTOBER } \\
\text { NOVEMBER } \\
\text { DECEMBER } \\
\text { JANUARY } \\
\text { FEBRUARY } \\
\text { MARCH } \\
\text { APRIL } \\
\text { MAY } \\
\text { JUWE } \\
\text { JULY } \\
\text { AUGUST } \\
\text { SEPTEMBER }\end{array}$ & $\begin{array}{r}774 \\
218 \\
715 \\
333 \\
787 \\
1,160 \\
1,450 \\
2,070 \\
602 \\
187 \\
388 \\
293\end{array}$ & $\begin{array}{l}31 \\
35 \\
35 \\
32 \\
33 \\
49 \\
77 \\
31 \\
10 \\
3.9 \\
27 \\
19\end{array}$ & $\begin{array}{r}123 \\
90 \\
128 \\
113 \\
166 \\
354 \\
610 \\
467 \\
164 \\
76 \\
125 \\
105\end{array}$ & $\begin{array}{r}163 \\
57 \\
154 \\
84 \\
146 \\
276 \\
403 \\
430 \\
170 \\
47 \\
76 \\
73\end{array}$ & $\begin{array}{l}1.3 \\
0.63 \\
1.2 \\
0.75 \\
0.88 \\
0.78 \\
0.66 \\
0.92 \\
1.0 \\
0.62 \\
0.61 \\
0.69\end{array}$ & $\begin{array}{r}4.9 \\
3.6 \\
5.1 \\
4.5 \\
6.6 \\
14.0 \\
24.2 \\
18.5 \\
6.5 \\
3.0 \\
5.0 \\
4.2\end{array}$ \\
\hline NMUAL & 486 & 54 & 210 & 120 & 0.57 & 100 \\
\hline
\end{tabular}

MAGNITUDE AND PROBABILITY OF INSTANTANEOUS PEAK FLOW BASED ON PERIOD OF RECORD

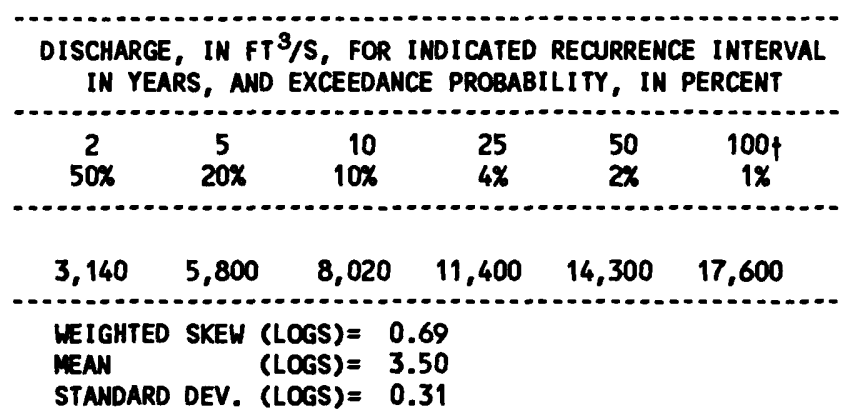

MAGNITUE AND PROBABILITY OF ANNUAL LON FLOW BASED ON PERIOD OF RECORD 1959-89

\begin{tabular}{|c|c|c|c|c|c|c|}
\hline \multirow{2}{*}{$\begin{array}{l}\text { PERIOD } \\
\text { (CON- } \\
\text { SECU- } \\
\text { TIVE } \\
\text { DAYS) }\end{array}$} & \multicolumn{6}{|c|}{$\begin{array}{l}\text { DISCHARGE, IN FT /S, FOR INDICATED } \\
\text { RECURRENCE INTERVAL, IN YEARS, AND } \\
\text { NOW-EXCEEDANCE PROBABILITY, IN PERCENT }\end{array}$} \\
\hline & $\begin{array}{c}2 \\
50 \%\end{array}$ & $\begin{array}{c}5 \\
20 \%\end{array}$ & $\begin{array}{l}10 \\
10 x\end{array}$ & $\begin{array}{l}20 \\
5 \%\end{array}$ & $\begin{array}{l}50 \\
2 \%\end{array}$ & $\begin{array}{l}100 \uparrow \\
\mathbf{1 x}\end{array}$ \\
\hline $\begin{array}{r}1 \\
3 \\
7 \\
14 \\
30 \\
60 \\
90 \\
120 \\
183\end{array}$ & $\begin{array}{l}0.00 \\
0.00 \\
29 \\
32 \\
35 \\
42 \\
47 \\
54 \\
69\end{array}$ & $\begin{array}{l}0.00 \\
0.00 \\
11 \\
14 \\
18 \\
25 \\
33 \\
39 \\
49\end{array}$ & $\begin{array}{l}0.00 \\
0.00 \\
5.7 \\
7.8 \\
12 \\
19 \\
28 \\
34 \\
42\end{array}$ & $\begin{array}{l}000 \\
0.00 \\
2.9 \\
4.5 \\
7.8 \\
15 \\
25 \\
31 \\
38\end{array}$ & $\begin{array}{c}0.00 \\
0.00 \\
1.2 \\
2.2 \\
4.7 \\
11 \\
22 \\
28 \\
35\end{array}$ & $\begin{array}{l}0.00 \\
0.00 \\
0.58 \\
1.3 \\
3.3 \\
8.9 \\
21 \\
27 \\
33\end{array}$ \\
\hline
\end{tabular}

MAGNITUDE AND PROBABILITY OF ANMUAL HIGH FLON BASED ON PERIOD OF RECORD 1958-89

\begin{tabular}{|c|c|c|c|c|c|c|}
\hline \multirow{2}{*}{$\begin{array}{l}\text { PERIOD } \\
\text { (CON- } \\
\text { SECU- } \\
\text { TIVE } \\
\text { DAYS) }\end{array}$} & & \multicolumn{5}{|c|}{$\begin{array}{l}\text { DISCHARGE, IN } \mathrm{FT}^{3} / \mathrm{S} \text {, FOR INDICATED } \\
\text { RECURRENCE INTERVAL, IN YEARS, AND } \\
\text { EXCEEDANCE PROBABILITY, IN PERCENT }\end{array}$} \\
\hline & $\begin{array}{c}2 \\
50 \%\end{array}$ & $\begin{array}{c}5 \\
20 \%\end{array}$ & $\begin{array}{l}10 \\
10 \%\end{array}$ & $\begin{array}{l}25 \\
4 \%\end{array}$ & $\begin{array}{l}50 \\
2 \%\end{array}$ & $\begin{array}{c}100_{\dagger} \\
1 \%\end{array}$ \\
\hline $\begin{array}{r}1 \\
3 \\
7 \\
15 \\
30 \\
60 \\
90\end{array}$ & $\begin{array}{r}1,380 \\
1,160 \\
960 \\
795 \\
651 \\
513 \\
426\end{array}$ & $\begin{array}{r}2,770 \\
2,200 \\
1,700 \\
1,370 \\
1,130 \\
903 \\
757\end{array}$ & $\begin{array}{r}4,080 \\
3,100 \\
2,260 \\
1,790 \\
1,490 \\
1,190 \\
998\end{array}$ & $\begin{array}{l}6,280 \\
4,500 \\
3,040 \\
2,360 \\
1,990 \\
1,590 \\
1,320\end{array}$ & $\begin{array}{l}8,370 \\
5,740 \\
3,660 \\
2,800 \\
2,380 \\
1,900 \\
1,560\end{array}$ & $\begin{array}{r}10,900 \\
7,160 \\
4,320 \\
3,250 \\
2,780 \\
2,220 \\
1,810\end{array}$ \\
\hline
\end{tabular}

DURATION TABLE OF DAILY MEAN FLOW FOR PERIOD OF RECORD 1958-89 DISCHARGE, IN FT $3 / \mathrm{S}$, WHICH WAS EQUALED OR EXCEEDED FOR IMDICATED PERCENT OF TIME

\begin{tabular}{|c|c|c|c|c|c|c|c|c|c|c|c|c|c|c|c|c|}
\hline $1 \%$ & $5 \%$ & $10 \%$ & $15 \%$ & $20 \%$ & $30 \%$ & $40 \%$ & $50 \%$ & $60 \%$ & $70 \%$ & $80 \%$ & $90 \%$ & $95 \%$ & $98 \%$ & $99 \%$ & $99.5 \%$ & $99.9 \%$ \\
\hline 1,580 & 808 & 539 & 391 & 289 & 182 & 127 & 95 & 72 & 56 & 46 & 34 & 26 & 15 & 10 & 7.7 & 2.0 \\
\hline
\end{tabular}

$\uparrow$ Reliability of values in colum is uncertain, and potential errors are large. 
09494000 MITE RIVER NEAR FORT APACHE, AZ--CONTIMUED
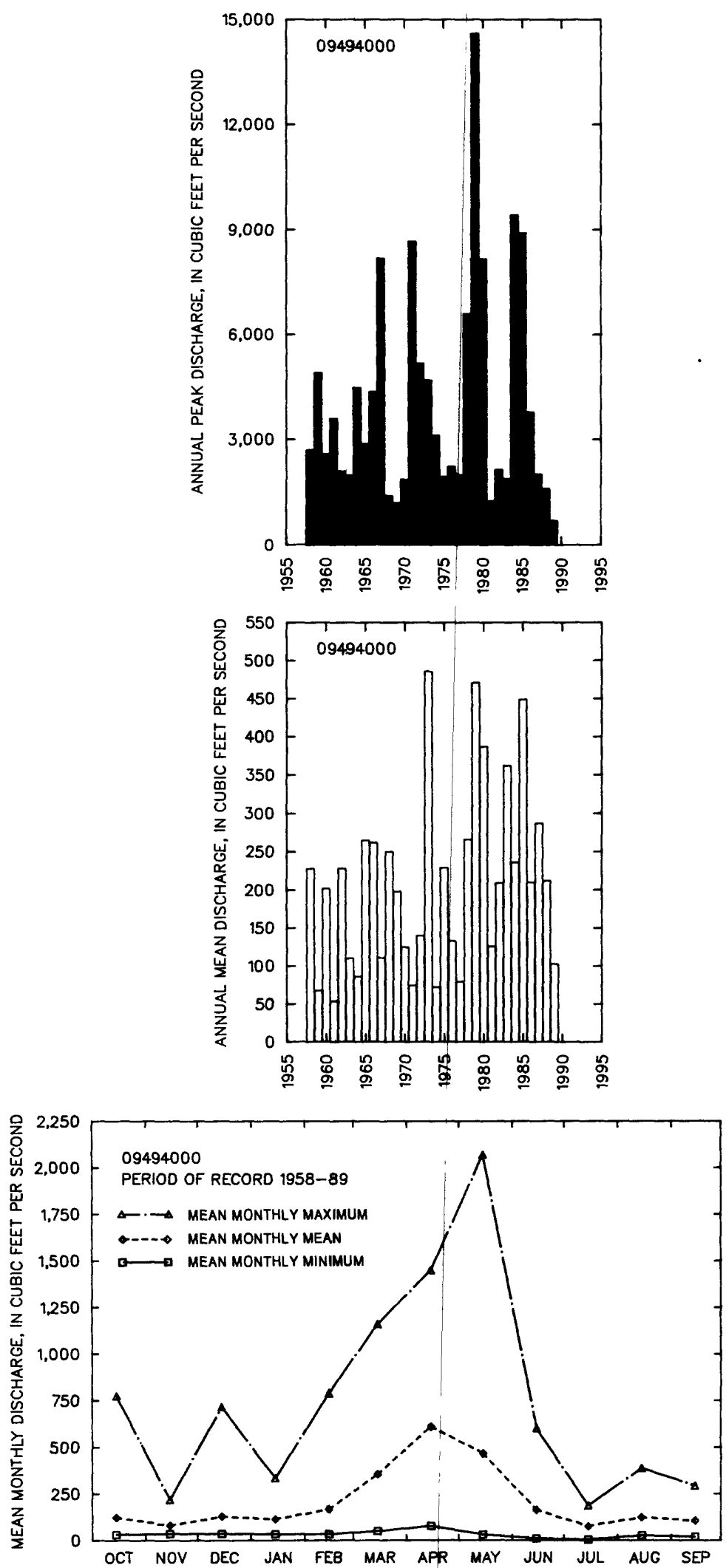
09494300 CARRIZO CREEK ABOVE CORDUROY CREEK, NEAR SHOW LOW, AZ

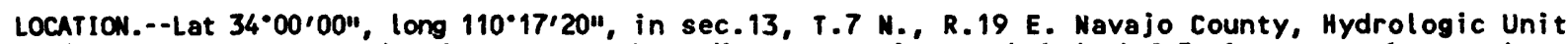
15060104, (unsurveyéd), in Fort Apache Indian Reservation, on left benk 0.5 mi upstrean from Corduroy Creek and $23 \mathrm{mi}$ southwest of Show Low.

DRAIMAGE AREA. $--225 \mathrm{mi}^{2}$.

\begin{tabular}{|c|c|c|}
\hline $\begin{array}{l}\text { WATER } \\
\text { YEAR }\end{array}$ & DATE & $\begin{array}{c}\text { ANNUAL PEAK } \\
\text { DISCHARGE } \\
\left(F^{3} / S\right)\end{array}$ \\
\hline $\begin{array}{l}1954 \\
1955 \\
1956 \\
1957 \\
1958 \\
1959 \\
1960 \\
1961 \\
1962 \\
1963 \\
1964 \\
1965 \\
1966 \\
1967\end{array}$ & $\begin{array}{l}07-09-54 \\
08-18-55 \\
08-14-56 \\
08-31-57 \\
09-04-58 \\
08-19-59 \\
01-11-60 \\
09-06-61 \\
02-13-62 \\
08-26-63 \\
07-21-64 \\
01-07-65 \\
12-30-65 \\
12-08-66\end{array}$ & $\begin{array}{r}2,760 \\
1,850 \\
2,470 \\
935 \\
2,870 \\
1,240 \\
3,260 \\
694 \\
340 \\
3,040 \\
1,860 \\
2,360 \\
10,000 \\
158\end{array}$ \\
\hline
\end{tabular}

\section{BASIN CHARACTERISTICS}

\begin{tabular}{|c|c|c|c|c|c|c|c|}
\hline \multirow{2}{*}{$\begin{array}{l}\text { MAIN } \\
\text { CHANNEL } \\
\text { SLOPE } \\
\text { (FTMI) }\end{array}$} & \multirow[b]{2}{*}{$\begin{array}{c}\text { STREAM } \\
\text { LENGTH } \\
\text { (MI) }\end{array}$} & \multirow{2}{*}{$\begin{array}{l}\text { MEAN } \\
\text { BASIN } \\
\text { ELEVA- } \\
\text { TION } \\
\text { (FT) }\end{array}$} & \multirow[b]{2}{*}{$\begin{array}{l}\text { FORESTED } \\
\text { AREA } \\
\text { (PERCENT) }\end{array}$} & \multirow[b]{2}{*}{$\begin{array}{l}\text { SOIL } \\
\text { INDEX }\end{array}$} & $\begin{array}{c}\text { MEAN } \\
\text { ANNUAL } \\
\text { PRECIPI- }\end{array}$ & \multicolumn{2}{|c|}{ RAINFALL INTENSITY, 24-HOUR } \\
\hline & & & & & $\begin{array}{l}\text { PRECIPI - } \\
\text { TATION } \\
\text { (IN) }\end{array}$ & $\begin{array}{c}\text { 2-YEAR } \\
\text { (IN) }\end{array}$ & $\begin{array}{l}\text { 50-YEAR } \\
\text { (IN) }\end{array}$ \\
\hline 64.9 & 35.0 & 6,370 & 97.0 & 3.0 & 22.5 & 2.3 & 4.8 \\
\hline
\end{tabular}


MONTHLY AMD ANIUAL MEAN DISCHARGES 1954-66

\begin{tabular}{|c|c|c|c|c|c|c|}
\hline MONTH & $\begin{array}{l}\operatorname{MAXIMNM} \\
\left(F T^{3} / S\right)\end{array}$ & $\underset{\left(\mathrm{FT}^{3} / \mathrm{S}\right)}{\operatorname{MINIMN}}$ & $\begin{array}{c}\text { MEAN } \\
\left(F T^{3} / S\right)\end{array}$ & $\begin{array}{l}\text { STAN- } \\
\text { DARD } \\
\text { DEVIA- } \\
\text { TION } \\
\text { (FT } 3 / S \text { S) }\end{array}$ & $\begin{array}{l}\text { COEFFI- } \\
\text { CIENT OF } \\
\text { VARI - } \\
\text { ATION }\end{array}$ & $\begin{array}{c}\text { PERCENT } \\
\text { OF } \\
\text { ANNUAL } \\
\text { RUNOFF }\end{array}$ \\
\hline $\begin{array}{l}\text { OCTOBER } \\
\text { MOVEMBER } \\
\text { DECEMBER } \\
\text { JANUARY } \\
\text { FEBRUARY } \\
\text { MARCH } \\
\text { APRIL } \\
\text { MAY } \\
\text { JUNE } \\
\text { JULY } \\
\text { AUCUST } \\
\text { SEPTEMBER }\end{array}$ & $\begin{array}{l}6.8 \\
54 \\
301 \\
135 \\
46 \\
94 \\
44 \\
8.8 \\
3.5 \\
9.7 \\
31 \\
10\end{array}$ & $\begin{array}{l}0.12 \\
0.87 \\
2.0 \\
3.5 \\
3.5 \\
3.8 \\
3.2 \\
1.3 \\
0.01 \\
0.00 \\
0.00 \\
0.00\end{array}$ & $\begin{array}{l}2.8 \\
7.8 \\
35 \\
25 \\
15 \\
29 \\
12 \\
4.1 \\
1.2 \\
2.0 \\
6.4 \\
3.1\end{array}$ & $\begin{array}{l}2.2 \\
14 \\
85 \\
39 \\
14 \\
30 \\
12 \\
2.7 \\
1.3 \\
2.9 \\
8.3 \\
3.4\end{array}$ & $\begin{array}{l}0.77 \\
1.8 \\
2.4 \\
1.6 \\
0.94 \\
1.0 \\
1.0 \\
0.65 \\
1.1 \\
1.4 \\
1.3 \\
1.1\end{array}$ & $\begin{array}{r}2.0 \\
5.5 \\
24.6 \\
17.5 \\
10.3 \\
20.1 \\
8.2 \\
2.9 \\
0.8 \\
1.4 \\
4.5 \\
2.2\end{array}$ \\
\hline ANAUAL & 40 & 3.1 & 12 & 13 & 1.1 & 100 \\
\hline
\end{tabular}

MAGNITUDE AND PROBABILITY OF INSTANTANEOUS PEAK FLON BASED ON PERIOD OF RECORD 1954-67

DISCHAREE, IN $\mathrm{FT}^{3} / \mathrm{S}$, FOR INDICATED RECURRENCE INTERVAL IN YEARS, AND EXCEEDANCE PROBABILITY, IN PERCENT

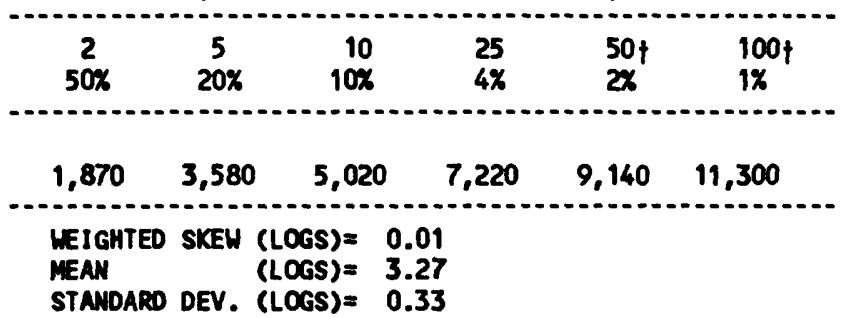

MAGNITUDE AND PROBABILITY OF AMMUAL LOH FLOM BASED ON PERIOD OF RECORD 1955-67

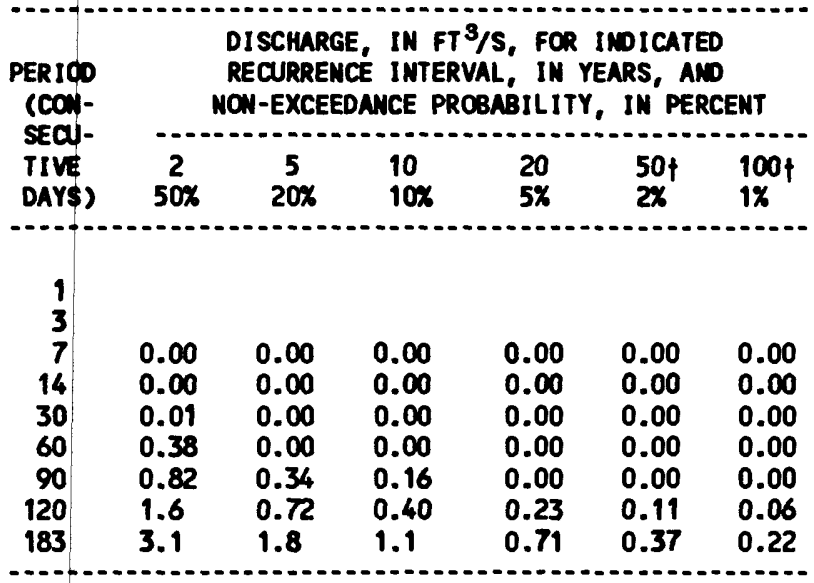

MAGNITUDE ND PROBABILITY OF ANNUAL HIGH FLON BASED ON PERIOD OF RECORD 1954-66

\begin{tabular}{|c|c|c|c|c|c|c|}
\hline \multirow{2}{*}{$\begin{array}{l}\text { PERIOD } \\
\text { (CON- } \\
\text { SEQU- } \\
\text { TIVE } \\
\text { DAYS) }\end{array}$} & \multicolumn{6}{|c|}{$\begin{array}{l}\text { DISCHARCE, IN } \text { FT }^{3} / \mathrm{S} \text {, FOR INDICATED } \\
\text { RECURRENCE INTERVAL, IN YEARS, AND } \\
\text { EXCEEDANCE PROBABILITY, IN PERCENT }\end{array}$} \\
\hline & $\stackrel{2}{50 \%}$ & $\begin{array}{c}5 \\
20 x\end{array}$ & $\begin{array}{l}10 \\
10 \%\end{array}$ & $\begin{array}{l}25 \\
4 \%\end{array}$ & $\begin{array}{l}50 \dagger \\
2 x\end{array}$ & $\begin{array}{c}100 \dagger \\
1 \%\end{array}$ \\
\hline $\begin{array}{r}1 \\
3 \\
7 \\
15 \\
30 \\
60 \\
90\end{array}$ & $\begin{array}{r}269 \\
144 \\
83 \\
51 \\
33 \\
21 \\
16\end{array}$ & $\begin{array}{l}918 \\
511 \\
267 \\
153 \\
97 \\
61 \\
46\end{array}$ & $\begin{array}{r}1,800 \\
1,020 \\
503 \\
279 \\
179 \\
109 \\
85\end{array}$ & $\begin{array}{r}3,760 \\
2,160 \\
1,010 \\
538 \\
359 \\
213 \\
169\end{array}$ & $\begin{array}{r}6,140 \\
3,540 \\
1,590 \\
834 \\
574 \\
334 \\
271\end{array}$ & $\begin{array}{r}9,620 \\
5,570 \\
2,430 \\
1,250 \\
889 \\
507 \\
421\end{array}$ \\
\hline
\end{tabular}

DURATION TABLE OF DAILY MEAN FLON FOR PERIOD OF RECORD 1954-66 DISCHARGE, IN FT $3 / 5$, WHICH WAS EQUALED OR EXCEEDED FOR INOICATED PERCENT OF TIME

\begin{tabular}{|c|c|c|c|c|c|c|c|c|c|c|c|c|c|c|c|c|}
\hline 18 & $5 x$ & $10 x$ & $15 \%$ & $20 \%$ & $30 \%$ & $40 \%$ & $50 \%$ & $60 x$ & $70 x$ & $80 \%$ & $90 \%$ & $95 \%$ & $98 \%$ & $99 x$ & $99.5 x$ & $99.9 \%$ \\
\hline 144 & 37 & 17 & 9.7 & 7.0 & 5.4 & 4.4 & 3.7 & 2.8 & 1.7 & 0.63 & 0.00 & 0.00 & 0.00 & 0.00 & 0.00 & 0.00 \\
\hline
\end{tabular}

† Reliability of values in colum is uncertain, and potential errors are large. 
GILA RIVER BASIN

09494300 CARRIZO CREEK ABOVE CORDUROY CREEK, NEAR SHOW LOW, AZ--CONTINUED
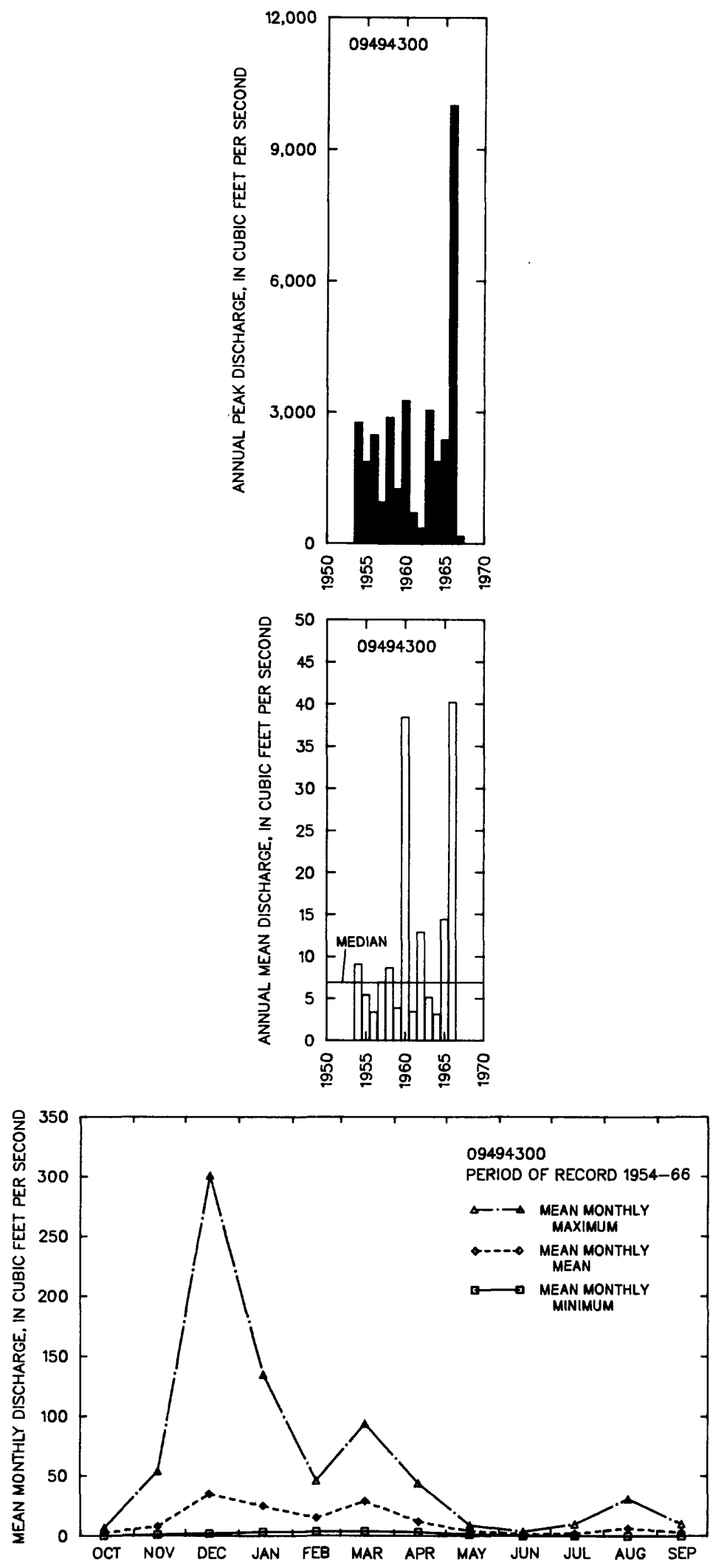
09496000 CORDUROY CREEK MEAR MOUTH, NEAR SHOW LOW, AZ

LOCATION.--Lat 34'01'06", long 110'14'30", in sec.8, T.7 N., R.20 E. (unsurveyed), Navajo County, Hydrologic Unit 15060104, in Fort Apache Indian Reservation, on right bank $4 \mathrm{mi}$ upstream from mouth and $20 \mathrm{mi}$ southwest of Show Low.

DRAIMAGE AREA. $--203 \mathrm{mi}^{2}$.

\section{ANIUAL PEAK DISCHARGE}

\begin{tabular}{|c|c|c|c|c|}
\hline $\begin{array}{l}\text { MATER } \\
\text { YEAR }\end{array}$ & $\begin{array}{cc} & \text { ANNUAL PEAK } \\
& \text { DISCHARGE } \\
\text { DATE } & \left(F^{3} / S\right)\end{array}$ & $\begin{array}{l}\text { WATER } \\
\text { YEAR }\end{array}$ & DATE & $\begin{array}{l}\text { ANNUAL PEAK } \\
\text { DISCHARGE } \\
\text { (FT } 3 / \mathrm{S})\end{array}$ \\
\hline $\begin{array}{l}1952 \\
1953 \\
1954 \\
1955 \\
1956 \\
1957 \\
1958 \\
1959 \\
1960 \\
1961 \\
1962 \\
1963\end{array}$ & $\begin{array}{l}01-18-52 \\
07-29-53 \\
03-23-54 \\
08-07-55 \\
08-17-56 \\
08-02-57 \\
03-22-58 \\
08-19-59 \\
12-25-59 \\
08-22-61 \\
02-13-62 \\
09-09-63\end{array}$ & $\begin{array}{l}1964 \\
1965 \\
1966 \\
1967 \\
1968 \\
1969 \\
1970 \\
1971 \\
1972 \\
1973 \\
1974 \\
1975\end{array}$ & $\begin{array}{l}07-30-64 \\
01-07-65 \\
12-30-65 \\
07-29-67 \\
01-28-68 \\
01-27-69 \\
08-09-70 \\
08-13-71 \\
12-26-71 \\
10-20-72 \\
03-21-74 \\
04-12-75\end{array}$ & $\begin{array}{r}402 \\
4,510 \\
10,900 \\
505 \\
902 \\
504 \\
38 \\
366 \\
8,500 \\
7,600 \\
50 \\
348\end{array}$ \\
\hline
\end{tabular}

\section{BASIN CHARACTERISTICS}

\begin{tabular}{|c|c|c|c|c|c|c|c|}
\hline MaIN & & $\begin{array}{l}\text { MEAN } \\
\text { BASIN }\end{array}$ & & & $\begin{array}{l}\text { MEAN } \\
\text { ANNUAL }\end{array}$ & RAINFALL II & SITY, 24-HOUR \\
\hline $\begin{array}{l}\text { CHANWEL } \\
\text { SLOPE } \\
\text { (FT/MI) }\end{array}$ & $\begin{array}{c}\text { STREAM } \\
\text { LENGTH } \\
\text { (MI) }\end{array}$ & $\begin{array}{l}\text { ELEVA- } \\
\text { TION } \\
\text { (FT) }\end{array}$ & $\begin{array}{l}\text { FORESTED } \\
\text { AREA } \\
\text { (PERCENT) }\end{array}$ & $\begin{array}{l}\text { SOIL } \\
\text { INDEX }\end{array}$ & $\begin{array}{l}\text { PRECIPI - } \\
\text { TATION } \\
\text { (IN) }\end{array}$ & $\begin{array}{c}\text { 2-YEAR } \\
\text { (IN) }\end{array}$ & $\begin{array}{c}\text { 50-YEAR } \\
\text { (IN) }\end{array}$ \\
\hline 71.2 & 31.5 & 6,370 & 93.0 & 3.0 & 21.7 & 2.1 & 4.5 \\
\hline
\end{tabular}


GILA RIVER BASIN

09496000 COROUROY CREEK MEAR MOUTH, NEAR SHOW LOW, AZ--Cont inuEd

MONTHLY AND ANMUAL MEAN DISCHARGES 1952-75

\begin{tabular}{|c|c|c|c|c|c|c|}
\hline MONTH' & $\begin{array}{l}\operatorname{MaxIMUM} \\
\left(\mathrm{FT}^{3} / \mathrm{S}\right)\end{array}$ & $\begin{array}{l}\text { MININUM } \\
\left(\mathrm{FT}^{3} / \mathrm{S}\right)\end{array}$ & $\begin{array}{c}\text { MEAN } \\
\left(\mathrm{FT}^{3} / \mathrm{S}\right)\end{array}$ & $\begin{array}{l}\text { STAN- } \\
\text { DARD } \\
\text { DEVIA- } \\
\text { TION } \\
\text { (FT'S) }\end{array}$ & $\begin{array}{l}\text { COEFFI- } \\
\text { CIENT OF } \\
\text { VARI- } \\
\text { ATION }\end{array}$ & $\begin{array}{c}\text { PERCENT } \\
\text { OF } \\
\text { ANNUAL } \\
\text { RUNOFF }\end{array}$ \\
\hline $\begin{array}{l}\text { OCTOBER } \\
\text { NOVEMBER } \\
\text { DECEMBER } \\
\text { JANUARY } \\
\text { FEBRUARY } \\
\text { MARCH } \\
\text { APRIL } \\
\text { MAY } \\
\text { JUNE } \\
\text { JULY } \\
\text { AUGUST } \\
\text { SEPTEMBER }\end{array}$ & $\begin{array}{r}161 \\
94 \\
347 \\
434 \\
260 \\
429 \\
191 \\
72 \\
28 \\
31 \\
24 \\
18\end{array}$ & $\begin{array}{l}1.6 \\
1.8 \\
1.2 \\
1.8 \\
2.0 \\
2.0 \\
1.8 \\
1.3 \\
1.3 \\
1.4 \\
1.6 \\
1.5\end{array}$ & $\begin{array}{l}13 \\
11 \\
35 \\
45 \\
40 \\
65 \\
27 \\
12 \\
7.8 \\
7.8 \\
7.5 \\
3.6\end{array}$ & $\begin{array}{l}36 \\
24 \\
80 \\
94 \\
72 \\
91 \\
43 \\
16 \\
9.2 \\
8.8 \\
6.4 \\
3.5\end{array}$ & $\begin{array}{l}2.8 \\
2.2 \\
2.3 \\
2.1 \\
1.8 \\
1.4 \\
1.6 \\
1.4 \\
1.2 \\
1.1 \\
0.85 \\
0.98\end{array}$ & $\begin{array}{r}4.6 \\
4.0 \\
12.7 \\
16.3 \\
14.7 \\
23.9 \\
9.8 \\
4.3 \\
2.8 \\
2.8 \\
2.7 \\
1.3\end{array}$ \\
\hline ANNUAL & 115 & 2.3 & 23 & 27 & 1.2 & 100 \\
\hline
\end{tabular}

MAGNITUDE AND PROBABILITY OF INSTANTANEOUS PEAK FLOW BASED ON PERIOD OF RECORD 1952-75

\begin{tabular}{|c|c|c|c|c|c|}
\hline $\begin{array}{c}2 \\
50 \%\end{array}$ & $\begin{array}{c}5 \\
20 \%\end{array}$ & $\begin{array}{r}10 \\
10 \%\end{array}$ & $\begin{array}{l}25 \\
4 \%\end{array}$ & $\begin{array}{l}50 \dagger \\
2 \%\end{array}$ & $\begin{array}{c}100 \dagger \\
1 \%\end{array}$ \\
\hline 1,070 & 3,650 & 6,980 & 14,000 & 22,000 & 33,200 \\
\hline $\begin{array}{l}\text { WEIGHTED } \\
\text { MEAN } \\
\text { STANDARD }\end{array}$ & $\begin{array}{l}\text { SKEW } \\
\text { DEV. }\end{array}$ & $\begin{array}{l}(L O G S)= \\
(L O G S)= \\
(L O G S)=\end{array}$ & $\begin{array}{l}.05 \\
.03 \\
.63\end{array}$ & & \\
\hline
\end{tabular}

MMGNITUDE AND PROBABILITY OF ANMUAL LON FLON BASED ON PERIOD OF RECORD 1953-75

\begin{tabular}{|c|c|c|c|c|c|c|}
\hline \multirow{2}{*}{$\begin{array}{l}\text { PERIOD } \\
\text { (CON- } \\
\text { SECU- } \\
\text { TIVE } \\
\text { DAYS) }\end{array}$} & \multicolumn{6}{|c|}{$\begin{array}{l}\text { DISCHARGE, IN FT } 3 / S \text {, FOR INDICATED } \\
\text { RECURRENCE INTERVAL, IN YEARS, AND } \\
\text { MON-EXCEEDANCE PRCBABILITY, IN PERCENT }\end{array}$} \\
\hline & $\stackrel{2}{20 \%}$ & $\begin{array}{c}5 \\
20 \%\end{array}$ & $\begin{array}{l}10 \\
10 \%\end{array}$ & $\begin{array}{l}20 \\
5 x\end{array}$ & $\begin{array}{l}50 \dagger \\
2 \%\end{array}$ & $\begin{array}{l}100 \dagger \\
1 \%\end{array}$ \\
\hline $\begin{array}{r}1 \\
3 \\
7 \\
14 \\
30 \\
60 \\
90 \\
120 \\
183\end{array}$ & $\begin{array}{l}1.3 \\
1.3 \\
1.3 \\
1.4 \\
1.6 \\
1.7 \\
1.9 \\
2.1 \\
2.4\end{array}$ & $\begin{array}{l}1.0 \\
1.0 \\
1.1 \\
1.2 \\
1.3 \\
1.5 \\
1.7 \\
1.8 \\
2.0\end{array}$ & $\begin{array}{l}0.90 \\
0.91 \\
0.95 \\
1.0 \\
1.2 \\
1.4 \\
1.6 \\
1.7 \\
1.9\end{array}$ & $\begin{array}{l}0.80 \\
0.81 \\
0.85 \\
0.94 \\
1.1 \\
1.3 \\
1.5 \\
1.7 \\
1.8\end{array}$ & $\begin{array}{l}0.70 \\
0.69 \\
0.74 \\
0.84 \\
0.98 \\
1.2 \\
1.5 \\
1.6 \\
1.8\end{array}$ & $\begin{array}{l}0.63 \\
0.62 \\
0.67 \\
0.77 \\
0.90 \\
1.1 \\
1.4 \\
1.5 \\
1.8\end{array}$ \\
\hline
\end{tabular}

MAGNITLDE AND PROBABILITY OF ANMUAL HIGH FLOH BASED ON PERIOD OF RECORD 1952-75

\begin{tabular}{|c|c|c|c|c|c|c|}
\hline \multirow{2}{*}{$\begin{array}{l}\text { PERIOD } \\
\text { (COW- } \\
\text { SECW- } \\
\text { TIVE } \\
\text { DAYS) }\end{array}$} & \multicolumn{4}{|c|}{$\begin{array}{l}\text { DISCHARGE, IN } \mathrm{FT}^{3} / \mathrm{S}, \text { FO } \\
\text { RECURRENCE INTERVAL, IN } \\
\text { EXCEEDANCE PROBABILITY, }\end{array}$} & \multicolumn{2}{|c|}{$\begin{array}{l}\text { INDICATED } \\
\text { YEARS, AND } \\
\text { IN PERCENT }\end{array}$} \\
\hline & $\begin{array}{c}2 \\
50 \%\end{array}$ & $\begin{array}{c}5 \\
20 \%\end{array}$ & $\begin{array}{l}10 \\
10 \%\end{array}$ & $\begin{array}{l}25 \\
4 \%\end{array}$ & $\begin{array}{l}50 \dagger \\
2 \%\end{array}$ & $\begin{array}{c}100 \dagger \\
1 \%\end{array}$ \\
\hline $\begin{array}{c}1 \\
3 \\
7 \\
15 \\
30 \\
60 \\
90\end{array}$ & $\begin{array}{r}287 \\
179 \\
110 \\
71 \\
49 \\
34 \\
27\end{array}$ & $\begin{array}{r}1,290 \\
745 \\
441 \\
270 \\
186 \\
123 \\
98\end{array}$ & $\begin{array}{r}2,830 \\
1,540 \\
893 \\
532 \\
368 \\
240 \\
191\end{array}$ & $\begin{array}{r}6,510 \\
3,280 \\
1,860 \\
1,080 \\
756 \\
482 \\
388\end{array}$ & $\begin{array}{r}11,200 \\
5,310 \\
2,950 \\
1,700 \\
1,200 \\
754 \\
612\end{array}$ & $\begin{array}{r}18,100 \\
8,130 \\
4,460 \\
2,540 \\
1,800 \\
1,120 \\
919\end{array}$ \\
\hline
\end{tabular}

DURATION TABLE OF DAILY MEAN FLON FOR PERIOD OF RECORD 1952-75

DISCMARGE, IN FT ${ }^{3} / \mathrm{S}$, WHICH WAS EQUALED OR EXCEEDED FOR INDICATED PERCENT OF TIME

\begin{tabular}{|c|c|c|c|c|c|c|c|c|c|c|c|c|c|c|c|c|}
\hline $1 \%$ & $5 \%$ & $10 \%$ & $15 \%$ & $20 \%$ & $30 \%$ & $40 \%$ & $50 x$ & $60 \%$ & $70 \%$ & $80 \%$ & $90 \%$ & $95 \%$ & $98 \%$ & $99 \%$ & $99.5 \%$ & $99.9 \%$ \\
\hline 364 & 80 & 35 & 26 & 20 & 7.6 & 3.2 & 2.6 & 2.3 & 2.1 & 1.8 & 1.6 & 1.4 & 1.2 & 1.1 & 0.98 & 0.7 \\
\hline
\end{tabular}

† Reliability of values in colum is uncertain, and potential errors are large. 
09496000 CORDUROY CREEK MEAR MOUTH, MEAR SHOW LOW, AZ--CONTIMUED
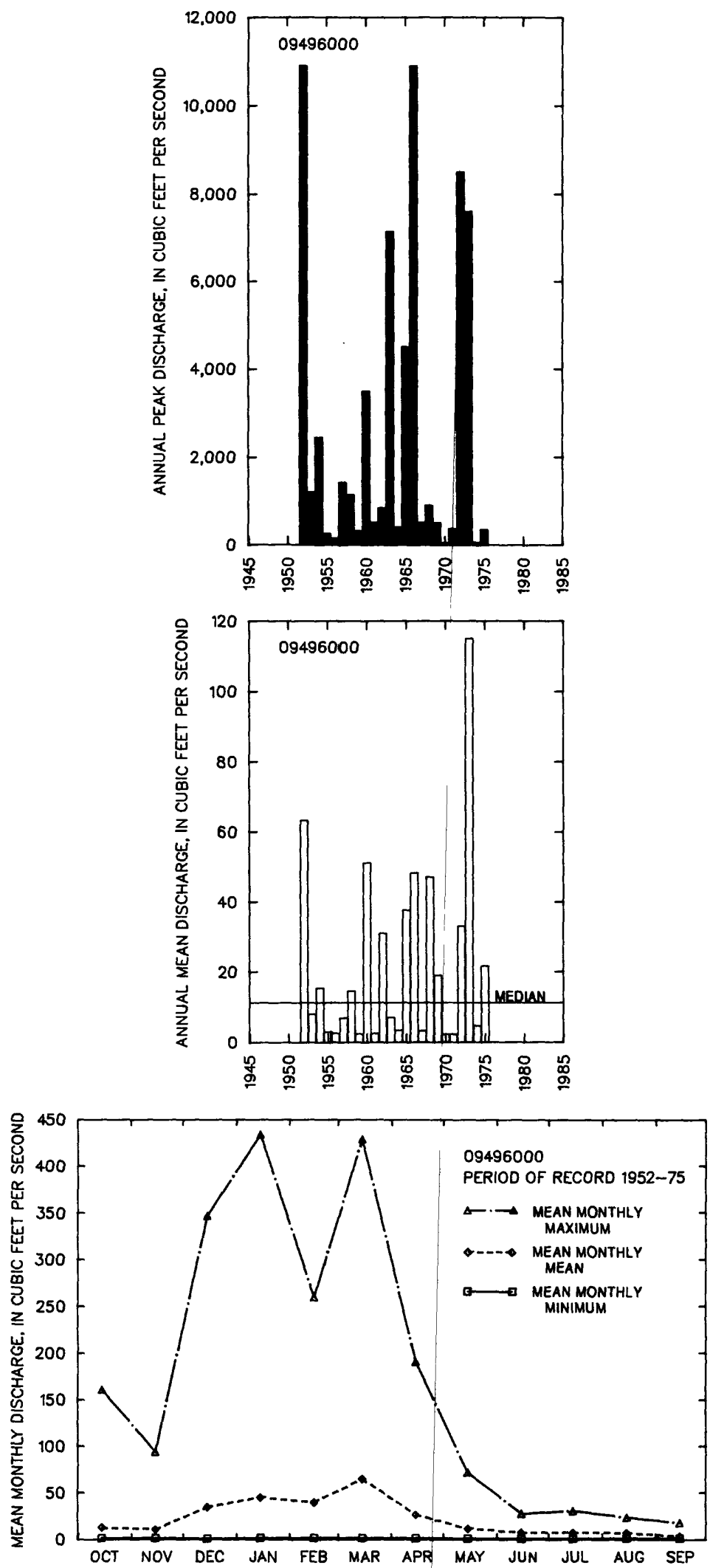
09496500 CARRIZO CREEX MEAR SHON LOH, AZ

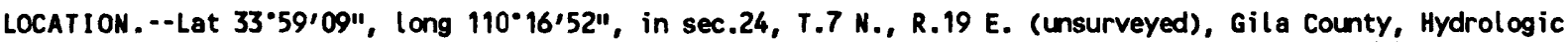
Unit 15060104, in Fort Apache Indian Reservation, on right bank $500 \mathrm{ft}$ upstream from bridge on $U$.S. Highway 60, $1 \mathrm{mi}$ downstream from Corduroy Creek, $23 \mathrm{mi}$ southwest of Show Low, and $24 \mathrm{mi}$ upstream from mouth. Prior to June 1976 at site on bridge pier $400 \mathrm{ft}$ downstream.

DRAINAGE AREA. $--439 \mathrm{mi}^{2}$.

REMARKS.--Diversions for irrigation above station of less than 300 acres. Records include transbasin diversion from Show Low Creek. (See station 09495000.)

ANIUUAL PEAK DISCHARGE

\begin{tabular}{|c|c|c|c|c|c|c|c|}
\hline $\begin{array}{l}\text { WATER } \\
\text { YEAR }\end{array}$ & DATE & $\begin{array}{l}\text { ANNUAL PEAK } \\
\text { DISCHARGE } \\
\text { (FT } 3 / \mathrm{S})\end{array}$ & $\begin{array}{l}\text { DISCHARGE } \\
\text { COOES }\end{array}$ & $\begin{array}{l}\text { HATER } \\
\text { YEAR }\end{array}$ & DATE & $\begin{array}{c}\text { ANNUAL PEAK } \\
\text { DISCHARGE } \\
\left(\mathrm{FT}^{3} / \mathrm{S}\right)\end{array}$ & $\begin{array}{l}\text { DISCHARGE } \\
\text { CODES }\end{array}$ \\
\hline $\begin{array}{l}1951 \\
1952 \\
1953 \\
1954 \\
1955 \\
1956 \\
1957 \\
1958 \\
1959 \\
1960 \\
1961 \\
1962 \\
1963 \\
1964 \\
1965 \\
1966 \\
1967 \\
1968 \\
1969 \\
1970\end{array}$ & $\begin{array}{l}08-28-51 \\
01-18-52 \\
07-29-53 \\
03-23-54 \\
08-18-55 \\
08-14-56 \\
08-02-57 \\
09-04-58 \\
08-19-59 \\
01-11-60 \\
09-06-61 \\
02-13-62 \\
09-09-63 \\
07-21-64 \\
01-07-65 \\
12-30-65 \\
08-09-67 \\
02-14-68 \\
01-27-69 \\
09-06-70\end{array}$ & $\begin{array}{r}3,260 \\
20,500 \\
3,200 \\
3,910 \\
2,060 \\
2,400 \\
1,360 \\
2,920 \\
1,560 \\
6,980 \\
900 \\
1,200 \\
10,000 \\
2,000 \\
6,000 \\
23,000 \\
2,590 \\
1,070 \\
1,060 \\
1,960\end{array}$ & $\begin{array}{l}\text { ES } \\
\text { ES } \\
\text { ES } \\
\text { ES } \\
\text { ES }\end{array}$ & $\begin{array}{l}1971 \\
1972 \\
1973 \\
1974 \\
1975 \\
1976 \\
1977 \\
1978 \\
1979 \\
1980 \\
1981 \\
1982 \\
1983 \\
1984 \\
1985 \\
1986 \\
1987 \\
1988 \\
1989\end{array}$ & $\begin{array}{l}09-29-71 \\
12-26-71 \\
10-19-72 \\
08-03-74 \\
10-29-74 \\
02-09-76 \\
08-11-77 \\
03-01-78 \\
12-18-78 \\
01-30-80 \\
08-08-81 \\
08-11-82 \\
03-24-83 \\
10-01-83 \\
12-27-84 \\
08-08-86 \\
03-07-87 \\
02-03-88 \\
08-18-89\end{array}$ & $\begin{array}{r}2,000 \\
11,200 \\
12,400 \\
160 \\
726 \\
4,220 \\
5,060 \\
12,700 \\
19,400 \\
2,880 \\
1,420 \\
2,250 \\
2,060 \\
3,580 \\
12,800 \\
2,830 \\
763 \\
3,650 \\
600\end{array}$ & \\
\hline
\end{tabular}

\section{BASIN CHARACTERISTICS}

\begin{tabular}{|c|c|c|c|c|c|c|c|}
\hline \multirow{2}{*}{$\begin{array}{l}\text { MAIN } \\
\text { CHANNEL } \\
\text { SLOPE } \\
\text { (FT/MI) }\end{array}$} & \multirow[b]{2}{*}{$\begin{array}{c}\text { STREAM } \\
\text { LENGTH } \\
\text { (MI) }\end{array}$} & \multirow{2}{*}{$\begin{array}{l}\text { MEAN } \\
\text { BASIN } \\
\text { ELEVA- } \\
\text { TION } \\
\text { (FT) }\end{array}$} & \multirow[b]{2}{*}{$\begin{array}{l}\text { FORESTED } \\
\text { AREA } \\
\text { (PERCENT) }\end{array}$} & \multirow[b]{2}{*}{$\begin{array}{l}\text { SOIL } \\
\text { INDEX }\end{array}$} & \multirow{2}{*}{$\begin{array}{l}\text { MEAN } \\
\text { ANNUAL } \\
\text { PRECIPI - } \\
\text { TATION } \\
\text { (IN) }\end{array}$} & \multicolumn{2}{|c|}{ RAINFALL INTENSITY, 24-HOUR } \\
\hline & & & & & & $\begin{array}{c}\text { 2-YEAR } \\
\text { (IN) }\end{array}$ & $\begin{array}{l}\text { 50-YEAR } \\
\text { (IN) }\end{array}$ \\
\hline 61.8 & 36.7 & 6,320 & 95.0 & 3.0 & 22.0 & 2.2 & 4.6 \\
\hline
\end{tabular}


MEAN MONTHLY AND ANMUAL DISCHARGES 1952-60, 1968-75, 1978-89

\begin{tabular}{|c|c|c|c|c|c|c|}
\hline MONTH & $\begin{array}{l}\left.\operatorname{MAX} \operatorname{Imm}_{(\mathrm{FT}} / \mathrm{S}\right) \\
\end{array}$ & $\begin{array}{l}\text { MINIMUN } \\
\left(\mathrm{FT}^{3} / \mathrm{S}\right)\end{array}$ & $\begin{array}{c}\text { MEAN } \\
\left(F T^{3} / S\right)\end{array}$ & $\begin{array}{l}\text { DARD } \\
\text { DEVIA- } \\
\text { TION } \\
\left(\mathrm{FT}^{3} / \mathrm{S}\right)\end{array}$ & $\begin{array}{l}\text { COEFFI- } \\
\text { CIENT OF } \\
\text { VARI- } \\
\text { ATION }\end{array}$ & $\begin{array}{c}\text { PERCENT } \\
\text { OF } \\
\text { ALMUAL } \\
\text { RUHOF F }\end{array}$ \\
\hline $\begin{array}{l}\text { OCTOBER } \\
\text { NOVEMBER } \\
\text { DECEMBER } \\
\text { JANUARY } \\
\text { FEBRUARY } \\
\text { MARCH } \\
\text { APRIL } \\
\text { MAY } \\
\text { JUNE } \\
\text { JULY } \\
\text { AUGUST } \\
\text { SEPTEMBER }\end{array}$ & $\begin{array}{l}397 \\
147 \\
762 \\
758 \\
965 \\
698 \\
350 \\
154 \\
41 \\
41 \\
42 \\
30\end{array}$ & $\begin{array}{l}1.6 \\
2.5 \\
3.9 \\
5.4 \\
6.3 \\
6.1 \\
5.3 \\
2.4 \\
0.87 \\
1.3 \\
3.2 \\
0.91\end{array}$ & $\begin{array}{r}35 \\
25 \\
84 \\
81 \\
120 \\
157 \\
55 \\
22 \\
13 \\
14 \\
18 \\
11\end{array}$ & $\begin{array}{c}83 \\
37 \\
164 \\
154 \\
199 \\
182 \\
77 \\
29 \\
12 \\
12 \\
11 \\
8.8\end{array}$ & $\begin{array}{l}2.4 \\
1.5 \\
2.0 \\
1.9 \\
1.7 \\
1.2 \\
1.4 \\
1.3 \\
0.92 \\
0.87 \\
0.61 \\
0.80\end{array}$ & $\begin{array}{r}5.5 \\
4.0 \\
13.2 \\
12.8 \\
18.9 \\
24.7 \\
8.7 \\
3.4 \\
2.0 \\
2.2 \\
2.8 \\
1.7\end{array}$ \\
\hline ANNUAL & 201 & 5.8 & 53 & 53 & 1.0 & 100 \\
\hline
\end{tabular}

MAGNITUDE AND PROBABILITY OF INSTANTANEOUS PEAK FLOW BASED ON PERIOD OF RECORD 1951-89

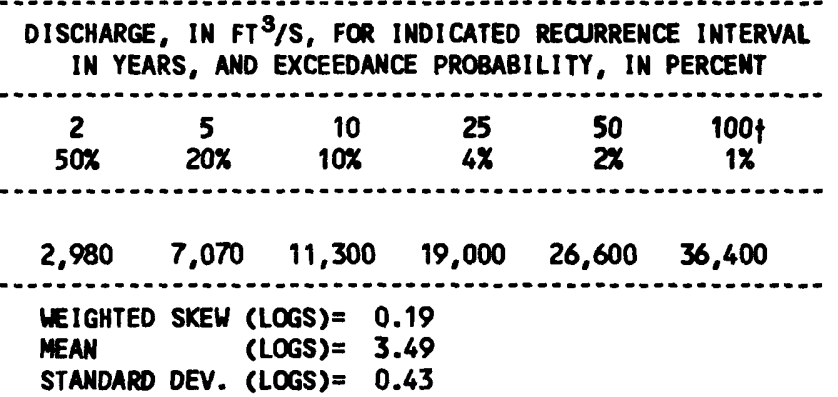

MACNITUDE AND PROBABILITY OF ANNUAL LOW FLOW BASED ON PERIDD OF RECORD 1953-61, 1969-75, 1979-89

\begin{tabular}{|c|c|c|c|c|c|c|}
\hline \multirow{2}{*}{$\begin{array}{l}\text { PERIOD } \\
\text { (CON- } \\
\text { SEOU- } \\
\text { TIVE } \\
\text { DNYS) }\end{array}$} & \multicolumn{6}{|c|}{$\begin{array}{l}\text { DISCHARGE, IN FT 3/S, FOR INDICATED } \\
\text { RECURRENCE INTERVAL, IN YEARS, AND } \\
\text { NON-EXCEEDANCE PROBABILITY, IN PERCENT }\end{array}$} \\
\hline & $\stackrel{2}{20 \%}$ & $\begin{array}{c}5 \\
20 \%\end{array}$ & $\begin{array}{l}10 \\
10 \%\end{array}$ & $\begin{array}{l}20 \\
5 \%\end{array}$ & $\begin{array}{l}50 \\
2 \%\end{array}$ & $\begin{array}{l}100 \dagger \\
1 \%\end{array}$ \\
\hline $\begin{array}{r}1 \\
3 \\
7 \\
14 \\
30 \\
60 \\
90 \\
120 \\
183\end{array}$ & $\begin{array}{l}1.6 \\
1.7 \\
1.9 \\
2.2 \\
3.0 \\
4.5 \\
5.7 \\
6.7 \\
8.8\end{array}$ & $\begin{array}{l}0.67 \\
0.74 \\
0.87 \\
1.0 \\
1.4 \\
2.3 \\
3.2 \\
4.0 \\
5.8\end{array}$ & $\begin{array}{l}0.42 \\
0.49 \\
0.59 \\
0.71 \\
0.96 \\
1.6 \\
2.3 \\
3.0 \\
4.9\end{array}$ & $\begin{array}{l}0.29 \\
0.34 \\
0.43 \\
0.52 \\
0.69 \\
1.1 \\
1.7 \\
2.4 \\
4.2\end{array}$ & $\begin{array}{l}0.19 \\
0.23 \\
0.30 \\
0.36 \\
0.48 \\
0.76 \\
1.3 \\
1.9 \\
3.7\end{array}$ & $\begin{array}{l}0.14 \\
0.18 \\
0.24 \\
0.29 \\
0.37 \\
0.59 \\
1.0 \\
1.6 \\
3.3\end{array}$ \\
\hline
\end{tabular}

MACNITUDE AND PROBABILITY OF ANNUAL HIGH FLON BASED ON PERICD OF RECORD 1952-60, 1968-75, 1978-89

\begin{tabular}{|c|c|c|c|c|c|c|}
\hline \multirow{2}{*}{$\begin{array}{l}\text { PERIOD } \\
\text { (CON- } \\
\text { SECU- } \\
\text { TIVE } \\
\text { DAYS) }\end{array}$} & \multicolumn{6}{|c|}{$\begin{array}{l}\text { DISCHARCE, IN } \mathrm{FT}^{3} / \mathrm{S}, \text { FOR INDICATED } \\
\text { RECURRENCE INTERVAL, IN YEARS, AND } \\
\text { EXCEEDANCE PROBABILITY, IN PERCENT }\end{array}$} \\
\hline & $\stackrel{2}{50 \%}$ & $\begin{array}{c}5 \\
20 \%\end{array}$ & $\begin{array}{l}10 \\
10 \%\end{array}$ & $\begin{array}{l}25 \\
4 \%\end{array}$ & $\begin{array}{l}50 \\
2 \%\end{array}$ & $\begin{array}{c}100 \nmid \\
1 \%\end{array}$ \\
\hline $\begin{array}{c}1 \\
3 \\
7 \\
15 \\
30 \\
60\end{array}$ & $\begin{array}{r}870 \\
590 \\
367 \\
225 \\
151 \\
105 \\
84\end{array}$ & $\begin{array}{r}2,900 \\
1,920 \\
1,130 \\
661 \\
427 \\
287 \\
233\end{array}$ & $\begin{array}{r}5,460 \\
3,470 \\
2,000 \\
1,140 \\
723 \\
475 \\
387\end{array}$ & $\begin{array}{r}10,800 \\
6,400 \\
3,620 \\
2,000 \\
1,250 \\
800 \\
652\end{array}$ & $\begin{array}{r}16,700 \\
9,410 \\
5,260 \\
2,860 \\
1,770 \\
1,110 \\
903\end{array}$ & $\begin{array}{r}24,800 \\
13,200 \\
7,310 \\
3,930 \\
2,410 \\
1,480 \\
1,200\end{array}$ \\
\hline
\end{tabular}

DURATION TABLE OF DAILY MEAN FLON FOR PERICD OF RECORD 1952-60, 1968-75, 1978-89 DISCHARGE, IN FT $3 / 5$, WHICH WAS EQUALED OR EXCEEDED FOR INDICATED PERCENT OF TIME

\begin{tabular}{|c|c|c|c|c|c|c|c|c|c|c|c|c|c|c|c|c|}
\hline $1 x$ & $5 \%$ & $10 \%$ & $15 \%$ & $20 \%$ & $30 \%$ & $40 x$ & $50 \%$ & $60 x$ & $70 x$ & $80 \%$ & $90 \%$ & $95 \%$ & $98 \%$ & $99 \%$ & $99.5 \%$ & $99.9 \%$ \\
\hline 39 & 204 & 83 & 49 & 36 & 26 & 18 & 12 & 8.2 & 6.3 & 4.8 & 2.6 & 1.5 & 0.96 & 0.74 & 0.56 & 0.41 \\
\hline
\end{tabular}


GIL RIVER BASIN

09496500 CARRIZO CREEK MEAR SHOW LOW, AZ--CONTINUED
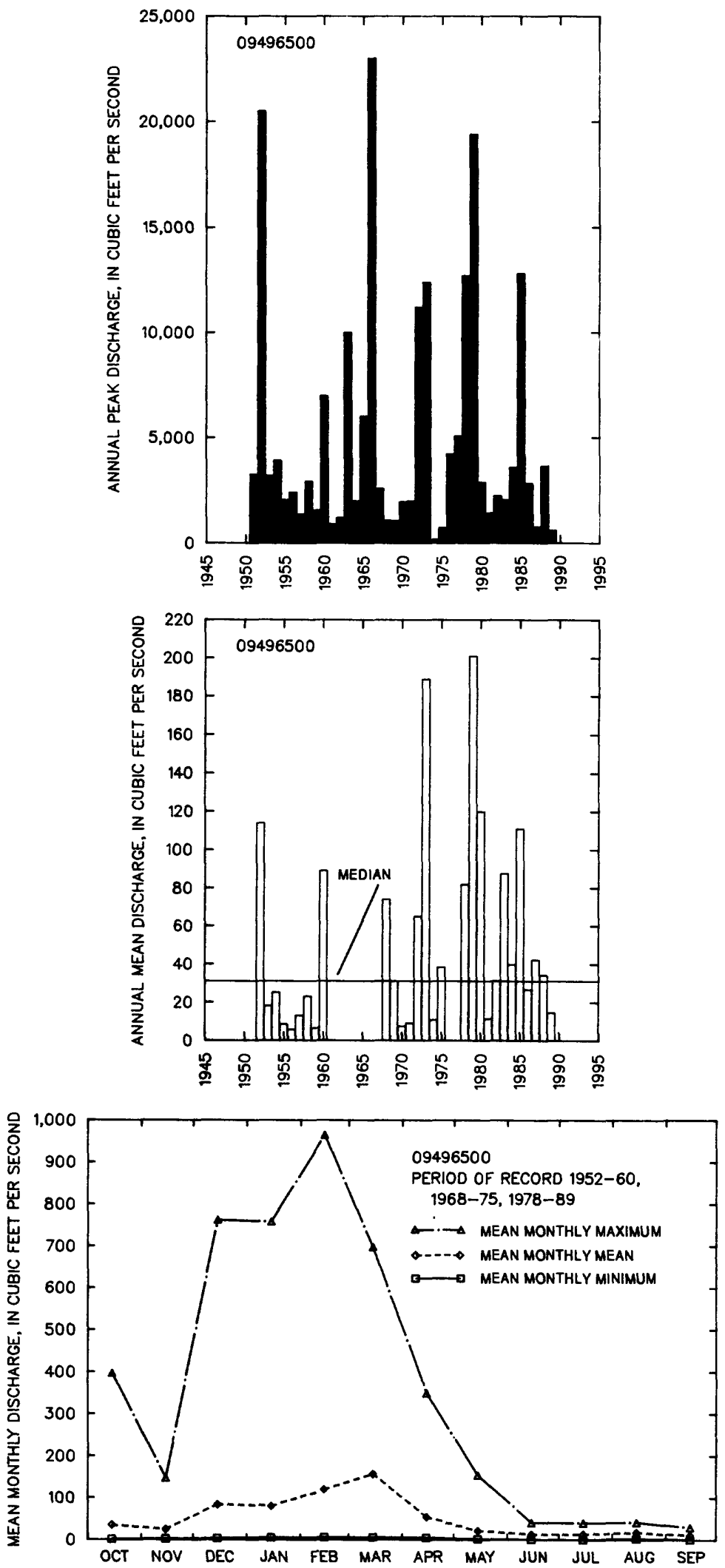
09496600 Cibecue nO. 1, tRibutary tO CARRIZO CREEK, NEAR SHOW LOW, AZ

LOCATION.--Lat 33.59'28", long 110.19'27", in NWK sec.22, T.7 N., R.19 E. (unsurveyed), Gila County, Hydrologic Unit 15060104, in Fort Apache Indian Reservation, on an unnamed tributary to Carrizo Creek, on Cibecue Ridge, $3.0 \mathrm{mi}$ upstrean from mouth of main stem, and 25 mi southwest of Show Low.

DRAINAGE AREA. $--0.10 \mathrm{mi}^{2}$.

ANMUAL PEAK DISCHAREE

\begin{tabular}{|c|c|c|c|}
\hline $\begin{array}{l}\text { WATER } \\
\text { YEAR }\end{array}$ & DATE & $\begin{array}{c}\text { ANMUAL PEAK } \\
\text { DISCHARGE } \\
\text { (FT } 3 / S)\end{array}$ & $\begin{array}{l}\text { DISCHARGE } \\
\text { CODES }\end{array}$ \\
\hline $\begin{array}{l}1958 \\
1959 \\
1960 \\
1961 \\
1962 \\
1963 \\
1964 \\
1965 \\
1966 \\
1967 \\
1968 \\
1969 \\
1970 \\
1971\end{array}$ & $\begin{array}{l}09-04-58 \\
08-17-59 \\
10-29-59 \\
08-18-61 \\
07-26-62 \\
08-26-63 \\
07-31-64 \\
09-03-65 \\
07-23-66 \\
07-27-67 \\
08-09-68 \\
08-02-69 \\
07-23-70 \\
08-15-71\end{array}$ & $\begin{array}{c}2 / 4 \\
39 \\
8.3 \\
16 \\
75 \\
127 \\
134 \\
38.3 \\
76.5 \\
165 \\
27.2 \\
61 \\
15.9 \\
39.5\end{array}$ & ES \\
\hline
\end{tabular}

BASIN CHARACTERISTICS

\begin{tabular}{|c|c|c|c|c|c|c|c|}
\hline MAIN & & $\begin{array}{l}\text { MEAN } \\
\text { BASIN }\end{array}$ & & & & RAIMFALL II & SITY, 24-HOUR \\
\hline $\begin{array}{l}\text { CHANNEL } \\
\text { SLOPE } \\
\text { (FT/MI) }\end{array}$ & $\begin{array}{c}\text { STREAM } \\
\text { LENGTH } \\
\text { (MI) }\end{array}$ & $\begin{array}{l}\text { ELEVA- } \\
\text { TION } \\
\text { (FT) }\end{array}$ & $\begin{array}{l}\text { FORESTED } \\
\text { AREA } \\
\text { (PERCENT) }\end{array}$ & $\begin{array}{l}\text { SOIL } \\
\text { INDEX }\end{array}$ & $\begin{array}{l}\text { PRECIPI- } \\
\text { TATION } \\
\text { (IN) }\end{array}$ & $\begin{array}{c}\text { 2-YEAR } \\
\text { (IN) }\end{array}$ & $\begin{array}{l}\text { 50-YEAR } \\
\text { (IN) }\end{array}$ \\
\hline 364 & 0.30 & 5,390 & 100 & 3.0 & 18.0 & 1.9 & 4.1 \\
\hline
\end{tabular}


09496600 CIBECUE No. 1 TRIBUTARY TO CARRIZO CREEK, NEAR SHOW LOW, AZ--cont inued

MEAN MONTHLY AND ANNUAL DISCHARGES 1959-71

\begin{tabular}{|c|c|c|c|c|c|c|}
\hline MONTH & $\begin{array}{l}\operatorname{MAXIMUN} \\
\text { (FT } 3 / S)\end{array}$ & $\begin{array}{l}\text { MINIMUN } \\
\left.\text { (FT }^{3} / S\right)\end{array}$ & $\begin{array}{c}\text { MEAN } \\
\left(F T^{3} / S\right)\end{array}$ & $\begin{array}{l}\text { STAN- } \\
\text { DARD } \\
\text { DEVIA- } \\
\text { TION } \\
\text { (FT } 3 / S)\end{array}$ & $\begin{array}{l}\text { COEFFI- } \\
\text { CIENT OF } \\
\text { VARI - } \\
\text { ATION }\end{array}$ & $\begin{array}{c}\text { PERCENT } \\
\text { OF } \\
\text { ANNUAL } \\
\text { RUNOFF }\end{array}$ \\
\hline $\begin{array}{l}\text { OCTOBER } \\
\text { NOVEMBER } \\
\text { DECEMBER } \\
\text { JANUARY } \\
\text { FEBRUARY } \\
\text { MARCH } \\
\text { APRIL } \\
\text { MAY } \\
\text { JUNE } \\
\text { JULY } \\
\text { AUCUST } \\
\text { SEPTEMBER }\end{array}$ & $\begin{array}{l}0.05 \\
0.01 \\
0.07 \\
0.00 \\
0.00 \\
0.00 \\
0.00 \\
0.00 \\
0.00 \\
0.27 \\
0.13 \\
0.06\end{array}$ & $\begin{array}{l}0.00 \\
0.00 \\
0.00 \\
0.00 \\
0.00 \\
0.00 \\
0.00 \\
0.00 \\
0.00 \\
0.00 \\
0.00 \\
0.00\end{array}$ & $\begin{array}{l}0.01 \\
0.00 \\
0.01 \\
0.00 \\
0.00 \\
0.00 \\
0.00 \\
0.00 \\
0.00 \\
0.04 \\
0.04 \\
0.02\end{array}$ & $\begin{array}{l}0.02 \\
0.01 \\
0.02 \\
0.00 \\
0.00 \\
0.00 \\
0.00 \\
0.00 \\
0.00 \\
0.08 \\
0.04 \\
0.02\end{array}$ & $\begin{array}{l}1.6 \\
1.1 \\
2.4\end{array}$ & $\begin{array}{r}9.5 \\
3.6 \\
6.5 \\
0.0 \\
0.0 \\
0.0 \\
0.0 \\
0.0 \\
0.0 \\
34.5 \\
32.1 \\
13.7\end{array}$ \\
\hline ANNCAL & 0.03 & 0.00 & 0.01 & 0.01 & 1.1 & 100 \\
\hline
\end{tabular}

MAGNITUDE AND PROBABILITY OF INSTANTANEOUS PEAK FLOW BASED ON PERIOD OF RECORD 1958-71

DISCHARGE, IN $\mathrm{FT}^{3} / \mathrm{S}$, FOR INDICATED RECURRENCE INTERVAL IN YEARS, AND EXCEEDANCE PROBABILITY, IN PERCENT

\begin{tabular}{|c|c|c|c|c|c|}
\hline$\stackrel{2}{50 \%}$ & $\begin{array}{c}5 \\
20 \%\end{array}$ & $\begin{array}{r}10 \\
10 \%\end{array}$ & $\begin{array}{l}25 \\
4 \%\end{array}$ & $\begin{array}{l}50 \gamma \\
2 \%\end{array}$ & $\begin{array}{l}100 t \\
1 \%\end{array}$ \\
\hline 44 & 92 & 133 & 195 & 248 & 307 \\
\hline $\begin{array}{l}\text { WEIGHTED } \\
\text { MEAN } \\
\text { STANDARD }\end{array}$ & $\begin{array}{l}\text { SKEH } \\
\text { DEV. }\end{array}$ & $\begin{array}{l}(\text { LOGS })= \\
(\text { LOGS })= \\
(\text { LOGS })=\end{array}$ & $\begin{array}{r}-0.17 \\
1.64 \\
0.40\end{array}$ & & \\
\hline
\end{tabular}

DURATION TABLE OF DAILY MEAN FLON FOR PERIOD OF RECORD 1959-71
MAGNITLDE AND PROBABILITY OF ANMUAL LON FLON BASED ON PERIOD OF RECORD 1960-71

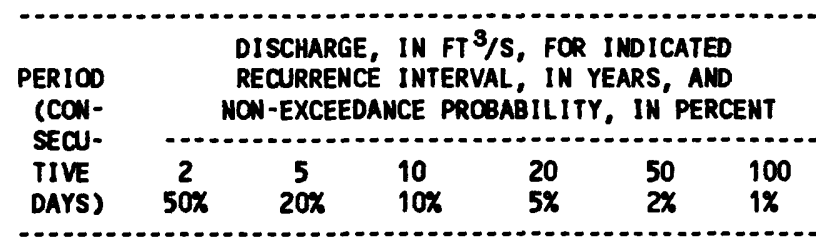

MMGNITLDE AND PROBABILITY OF ANNUAL HIGH FLOH BASED ON PERIOD OF RECORD 1959-71

\begin{tabular}{|c|c|c|c|c|c|c|}
\hline $\begin{array}{l}\text { PERIOD } \\
\text { (CON- } \\
\text { SECU- }\end{array}$ & & $\begin{array}{l}\text { DISCH } \\
\text { RECUR } \\
\text { EXCED }\end{array}$ & $\begin{array}{c}\text { CE I } \\
\text { CE P }\end{array}$ & $\begin{array}{l}\text { /S, } \\
A L \text {, }\end{array}$ & $\begin{array}{l}\text { INDIC } \\
\text { YEARS, } \\
\text { IN PER }\end{array}$ & \\
\hline $\begin{array}{l}\text { TIVE } \\
\text { DAYS) }\end{array}$ & $\begin{array}{c}2 \\
50 \%\end{array}$ & $\begin{array}{c}5 \\
20 \%\end{array}$ & $\begin{array}{l}10 \\
10 \%\end{array}$ & $\begin{array}{l}25 \\
4 \%\end{array}$ & $\begin{array}{l}50 t \\
2 \%\end{array}$ & $\begin{array}{c}100 \phi \\
1 \%\end{array}$ \\
\hline $\begin{array}{r}1 \\
3 \\
7 \\
15 \\
30 \\
60 \\
90\end{array}$ & $\begin{array}{l}1.08 \\
0.41 \\
0.22 \\
0.12 \\
0.07 \\
0.04 \\
0.03\end{array}$ & $\begin{array}{l}1.93 \\
0.75 \\
0.41 \\
0.24 \\
0.13 \\
0.07 \\
0.05\end{array}$ & $\begin{array}{l}2.63 \\
1.02 \\
0.56 \\
0.35 \\
0.20 \\
0.11 \\
0.08\end{array}$ & $\begin{array}{l}3.67 \\
1.39 \\
0.78 \\
0.54 \\
0.32 \\
0.17 \\
0.12\end{array}$ & $\begin{array}{l}4.55 \\
1.69 \\
0.96 \\
0.73 \\
0.44 \\
0.24 \\
0.17\end{array}$ & $\begin{array}{l}5.54 \\
2.02 \\
1.15 \\
0.97 \\
0.60 \\
0.33 \\
0.23\end{array}$ \\
\hline
\end{tabular}

DISCHARGE, IN FT $3 / 5$, WHICH WAS EQUALED OR EXCEEDED FOR INDICATED PERCENT OF TIME

\begin{tabular}{|c|c|c|c|c|c|c|c|c|c|c|c|c|c|c|c|c|}
\hline $1 \%$ & $5 \%$ & $10 \%$ & $15 \%$ & $20 \%$ & $30 \%$ & $40 \%$ & $50 \%$ & $60 \%$ & $70 \%$ & $80 \%$ & $90 \%$ & $95 \%$ & $98 x$ & $99 \%$ & $99.5 \%$ & $99.9 \%$ \\
\hline 3 & 0.00 & 0.00 & 0.00 & 0.00 & 0.00 & 0.00 & 0.00 & 0.00 & 0.00 & 0.00 & 0.00 & 0.00 & 0.00 & 0.00 & 0.00 & 0.0 \\
\hline
\end{tabular}

† Reliability of values in colum is uncertain, and potential errors are large. 
GILA RIVER BASIM

09496600 CIBECUE NO. 1 tRIBUTARY TO CARRIZO CREEK, NEAR SHOW'LOW, AZ--CONTIMUEd
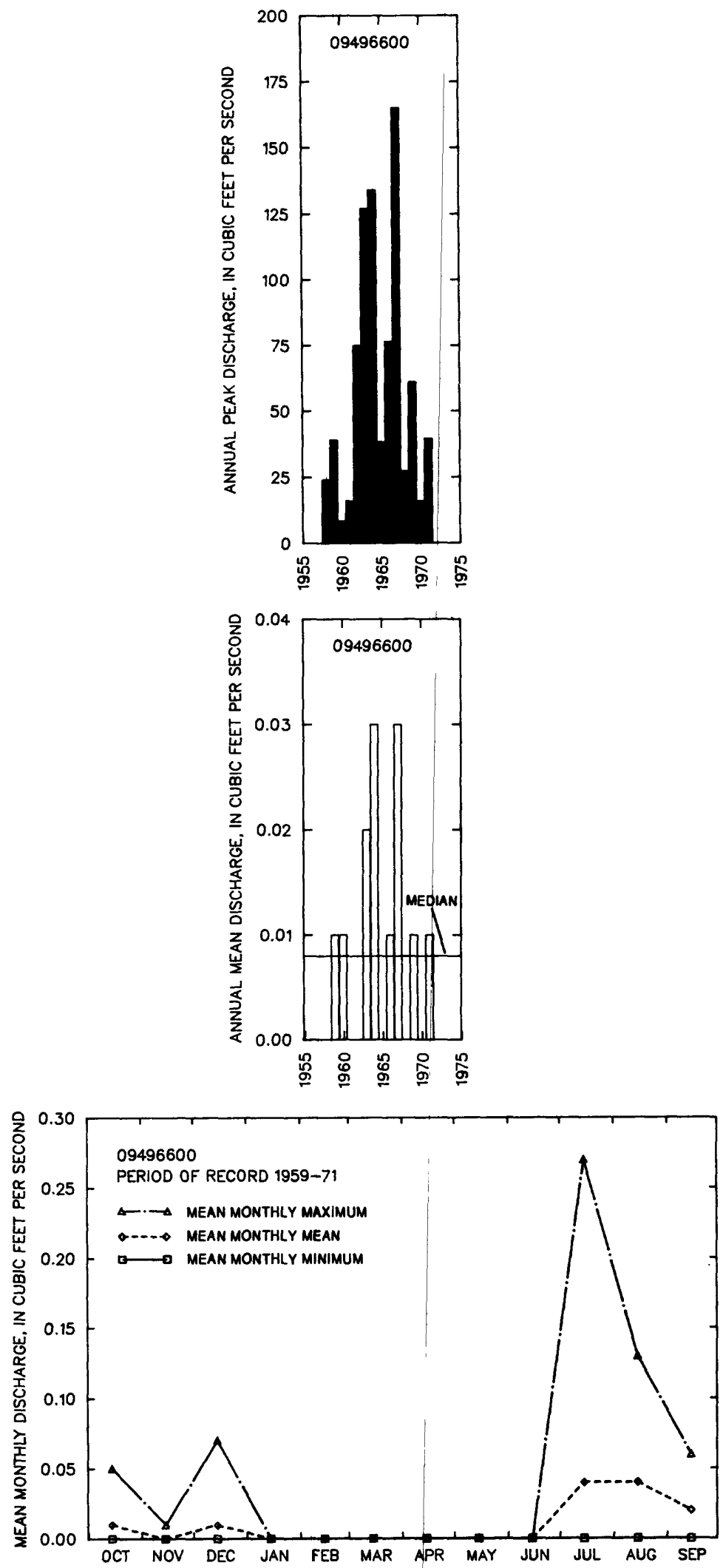
09496700 CIBECUE NO. 2, tRIBUtARY TO CARRIZO CREEK, MEAR SHOW LOW, AZ

LOCATION.-- Lat 33.59'17", long 110.18'38", in MEX sec.22, T.7 N., R.19 E. (unsurveyed), Gila County, Hydrologic Unit 15060104, in Fort Apache Indian Reservation, on an umamed tributary to Carrizo Creek, on Cibecue Ridge, 2.0 mi upstream from mouth of main stem and 25 mi southwest of Show Low.

DRAINAGE AREA. - $-0.07 \mathrm{mi}^{2}$.

\begin{tabular}{ccc}
\multicolumn{3}{c}{ AMNULL PEAK DISCHARGE } \\
$\begin{array}{c}\text { WATER } \\
\text { YEAR }\end{array}$ & DATE & $\begin{array}{c}\text { ANMUAL PEAK } \\
\text { DISCHARGE } \\
\text { (FT } 3 / \text { S) }\end{array}$ \\
\hline 1958 & $09-04-58$ & 30 \\
1959 & $08-19-59$ & 34 \\
1960 & $12-25-59$ & 11 \\
1961 & $09-06-61$ & 25 \\
1962 & $07-29-62$ & 75 \\
1963 & $08-20-63$ & 120 \\
1964 & $07-26-64$ & 66.2 \\
1965 & $09-03-65$ & 95.5 \\
1966 & $09-13-66$ & 26.8 \\
1967 & $07-27-67$ & 48.7 \\
1968 & $08-09-68$ & 22.3 \\
1969 & $07-28-69$ & 45.2 \\
1970 & $08-09-70$ & 39.2 \\
1971 & $08-12-71$ & 50.8 \\
$\ldots$
\end{tabular}

BASIN CHARACTERISTICS

\begin{tabular}{|c|c|c|c|c|c|c|c|}
\hline \multirow{2}{*}{$\begin{array}{l}\text { MAIN } \\
\text { CHANNEL } \\
\text { SLOPE } \\
\text { (FT/MI) }\end{array}$} & \multirow[b]{2}{*}{$\begin{array}{l}\text { STREAM } \\
\text { LENGTH } \\
\text { (MI) }\end{array}$} & \multirow{2}{*}{$\begin{array}{l}\text { MEAN } \\
\text { BASIN } \\
\text { ELEVA- } \\
\text { TION } \\
\text { (FT) }\end{array}$} & \multirow[b]{2}{*}{$\begin{array}{l}\text { FORESTED } \\
\text { NREA } \\
\text { (PERCENT) }\end{array}$} & \multirow[b]{2}{*}{$\begin{array}{l}\text { SOIL } \\
\text { INDEX }\end{array}$} & \multirow{2}{*}{$\begin{array}{l}\text { MEAN } \\
\text { ANNUAL } \\
\text { PRECIPI- } \\
\text { TATION } \\
\text { (IN) }\end{array}$} & \multicolumn{2}{|c|}{ RAINFALL INTENSITY, 24-HOUR } \\
\hline & & & & & & $\begin{array}{c}\text { 2-YEAR } \\
\text { (IN) }\end{array}$ & $\begin{array}{l}\text { 50-YEAR } \\
\text { (IN) }\end{array}$ \\
\hline 200.0 & 0.40 & 5,240 & 100.0 & 3.0 & 18.0 & 2.0 & 4.1 \\
\hline
\end{tabular}


09496700 CIBECUE No. 2 TRIBUTARY TO CARRIZO CREEK, NEAR SHOW LOW, AZ--Continued

MEAN MONTHLY AND ANMUAL DISCHARGES 1959-71

\begin{tabular}{|c|c|c|c|c|c|c|}
\hline MONTH & 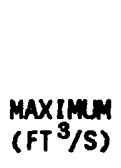 & $\begin{array}{l}\text { MINIMUM } \\
\left(\mathrm{FT}^{3} / \mathrm{S}\right)\end{array}$ & $\begin{array}{c}\text { MEAN } \\
\left(F T^{3} / S\right)\end{array}$ & $\begin{array}{c}\text { STAN- } \\
\text { DARD } \\
\text { DEVIA- } \\
\text { TION } \\
\left(\mathrm{FT}^{3} / \mathrm{S}\right)\end{array}$ & $\begin{array}{l}\text { COEFFI - } \\
\text { CIENT OF } \\
\text { VARI - } \\
\text { ATION }\end{array}$ & $\begin{array}{c}\text { PERCENT } \\
\text { OF } \\
\text { ANNUAL } \\
\text { RUNOFF }\end{array}$ \\
\hline $\begin{array}{l}\text { OCTOBER } \\
\text { NOVEMBER } \\
\text { DECEMBER } \\
\text { JANUARY } \\
\text { FEBRUARY } \\
\text { MARCH } \\
\text { APRIL } \\
\text { MAY } \\
\text { JUNE } \\
\text { JULY } \\
\text { AUGUST } \\
\text { SEPTEMBER }\end{array}$ & $\begin{array}{l}0.05 \\
0.01 \\
0.09 \\
0.03 \\
0.00 \\
0.01 \\
0.00 \\
0.00 \\
0.00 \\
0.13 \\
0.21 \\
0.06\end{array}$ & $\begin{array}{l}0.00 \\
0.00 \\
0.00 \\
0.00 \\
0.00 \\
0.00 \\
0.00 \\
0.00 \\
0.00 \\
0.00 \\
0.00 \\
0.00\end{array}$ & $\begin{array}{l}0.01 \\
0.00 \\
0.01 \\
0.00 \\
0.00 \\
0.00 \\
0.00 \\
0.00 \\
0.00 \\
0.02 \\
0.04 \\
0.02\end{array}$ & $\begin{array}{l}0.01 \\
0.00 \\
0.03 \\
0.01 \\
0.00 \\
0.00 \\
0.00 \\
0.00 \\
0.00 \\
0.04 \\
0.06 \\
0.02\end{array}$ & $\begin{array}{l}1.6 \\
1.6 \\
2.2 \\
2.8 \\
\\
3.6\end{array}$ & $\begin{array}{r}9.0 \\
3.0 \\
11.9 \\
3.0 \\
0.0 \\
0.7 \\
0.0 \\
0.0 \\
0.0 \\
18.7 \\
36.6 \\
17.2\end{array}$ \\
\hline ANNUAL & 0.03 & 0.00 & 0.01 & 0.01 & 0.93 & 100 \\
\hline
\end{tabular}

MAGNITUDE AND PROBABILITY OF INSTANTANEOUS PEAK FLON BASED ON PERIOD OF RECORD 1958-71

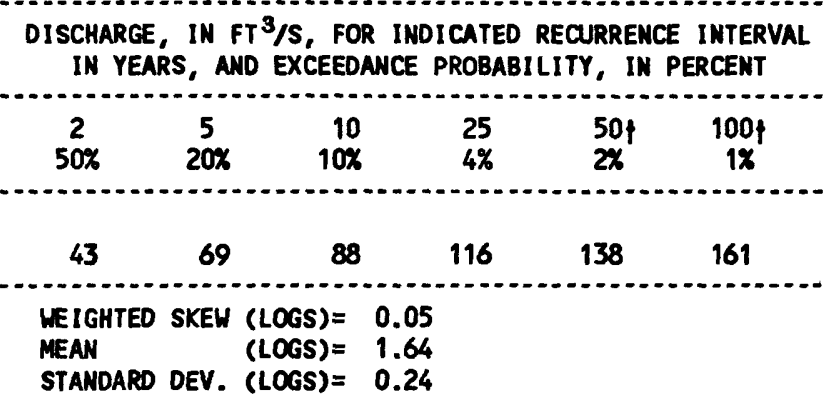

MaGitUde AND PROBABILITY OF ANNUAL LOW FLOW BASED ON PERIOD OF RECORD 1960-71

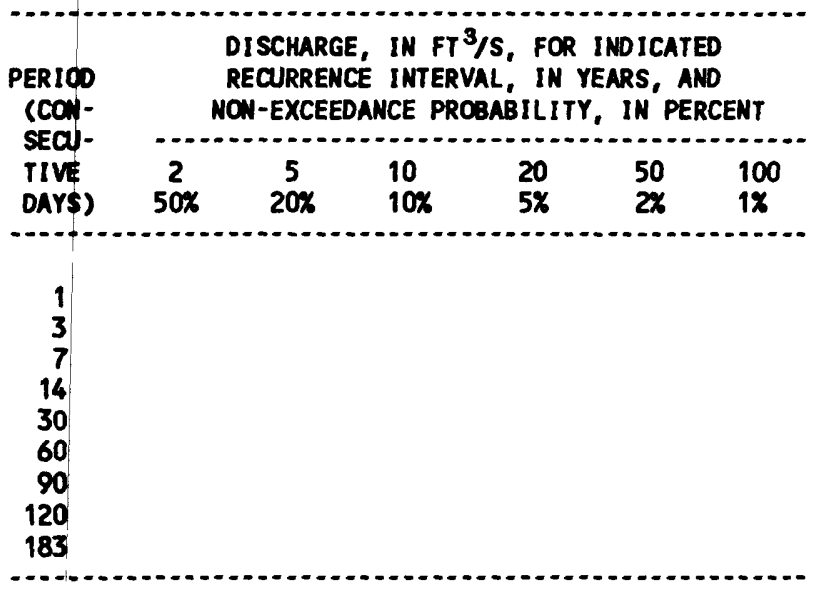

MAGNITLDE AND PROBABILITY OF ANNUAL HIGH FLON BASED ON PERIOD OF RECORD 1959-71

\begin{tabular}{|c|c|c|c|c|c|c|}
\hline \multirow{2}{*}{$\begin{array}{l}\text { PERTOD } \\
\text { (COW- } \\
\text { SECU- } \\
\text { TIVE } \\
\text { DAYS) }\end{array}$} & & \multicolumn{5}{|c|}{$\begin{array}{l}\text { DISCHARCE, IN FT } \\
\text { RECURRENCE INTERVAL, FOR INDICATED } \\
\text { EXCEEDANCE PROBABILITY, IN PERCENT }\end{array}$} \\
\hline & $\begin{array}{c}2 \\
50 \%\end{array}$ & $\begin{array}{c}5 \\
20 \%\end{array}$ & $\begin{array}{l}10 \\
10 \%\end{array}$ & $\begin{array}{l}25 \\
4 \%\end{array}$ & $\begin{array}{l}50 \nmid \\
2 \%\end{array}$ & $\begin{array}{c}100 t \\
1 \mathrm{x}\end{array}$ \\
\hline $\begin{array}{l}1 \\
3 \\
7 \\
15 \\
30 \\
60 \\
90\end{array}$ & $\begin{array}{l}0.77 \\
0.32 \\
0.16 \\
0.09 \\
0.06 \\
0.03 \\
0.03\end{array}$ & $\begin{array}{l}1.27 \\
0.52 \\
0.29 \\
0.18 \\
0.10 \\
0.06 \\
0.05\end{array}$ & $\begin{array}{l}1.70 \\
0.67 \\
0.41 \\
0.25 \\
0.15 \\
0.09 \\
0.06\end{array}$ & $\begin{array}{l}2.38 \\
0.89 \\
0.59 \\
0.35 \\
0.22 \\
0.13 \\
0.10\end{array}$ & $\begin{array}{l}2.99 \\
1.08 \\
0.76 \\
0.44 \\
0.29 \\
0.17 \\
0.13\end{array}$ & $\begin{array}{l}3.71 \\
1.28 \\
0.95 \\
0.55 \\
0.37 \\
0.22 \\
0.18\end{array}$ \\
\hline
\end{tabular}

DURATION TABLE OF DAILY MEAN FLON FOR PERIOD OF RECORD 1959-71 DISCHARGE, IN FT $3 / 5$, WHICH WAS EQUALED OR EXCEEDED FOR INDICATED PERCENT OF TIME

$\begin{array}{ccccccccccccccccc}1 \% & 5 \% & 10 \% & 15 \% & 20 \% & 30 \% & 40 \% & 50 \% & 60 \% & 70 \% & 80 \% & 90 \% & 95 \% & 98 \% & 99 \% & 99.5 \% & 99.9 \% \\ 0.29 & 0.00 & 0.00 & 0.00 & 0.00 & 0.00 & 0.00 & 0.00 & 0.00 & 0.00 & 0.00 & 0.00 & 0.00 & 0.00 & 0.00 & 0.00 & 0.00\end{array}$

$\uparrow$ Reliability of values in colum is uncertain, and potential errors are large. 


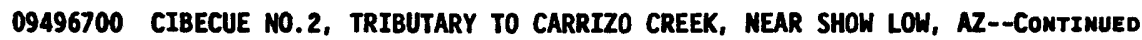
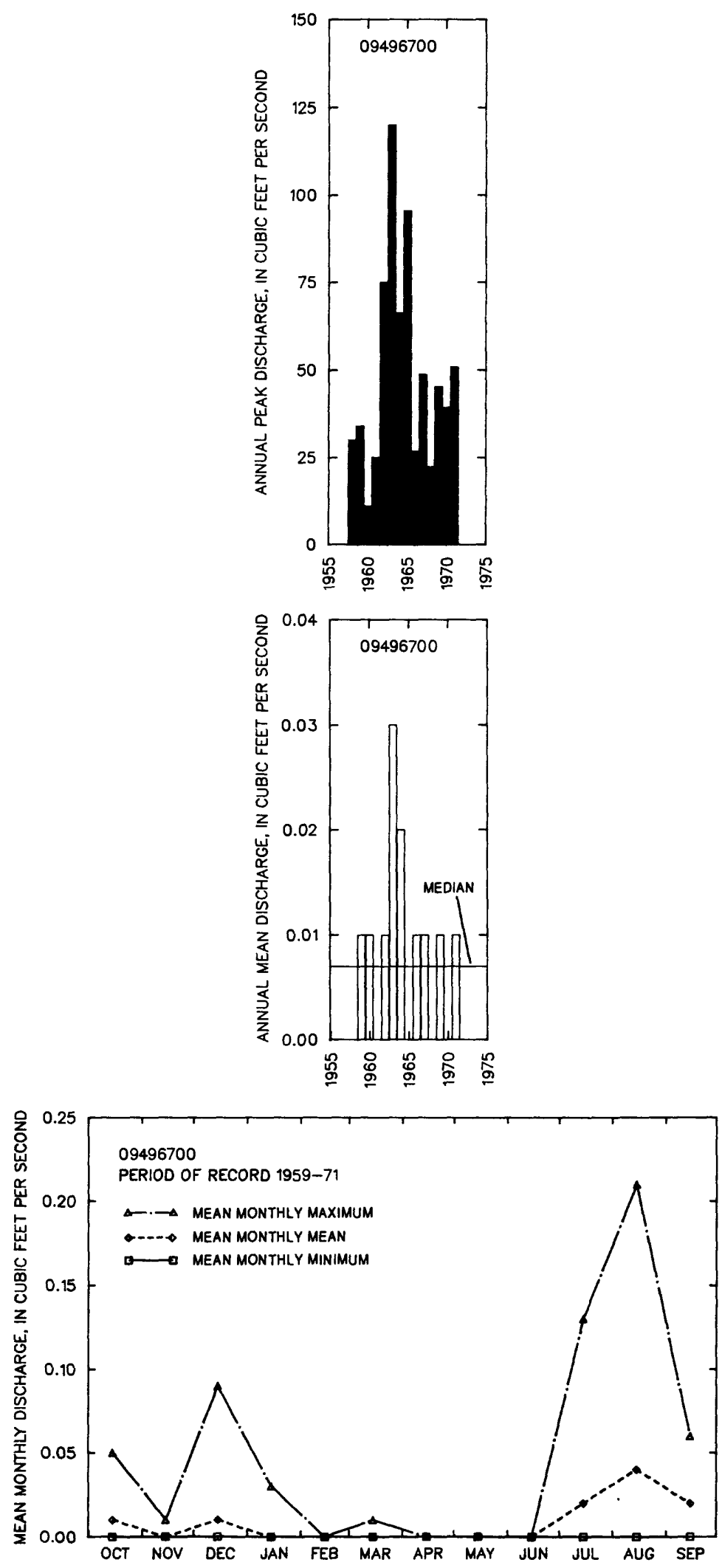
09496800 CARRIZO CREEK TRIBUTARY MEAR SHOW LOW, AZ

LOCATION.--Lat 33.57'16", long 110'19'53", Gila County, Hydrologic Unit 15060104, at U.S. Highway 60, 28 mi southwest of Show Low.

DRAINAGE AREA. $--4.63 \mathrm{mi}^{2}$, of which $2.08 \mathrm{mi}^{2}$ is noncontributing.

ANNUAL PEAK DISCHARGE

\begin{tabular}{ccc}
$\begin{array}{l}\text { MATER } \\
\text { YEAR }\end{array}$ & DATE & $\begin{array}{c}\text { ANNUAL PEAK } \\
\text { DISCHARGE } \\
\text { (FT } 3 / \text { S) }\end{array}$ \\
\hline 1963 & $09-09-63$ & 655 \\
1964 & $07-31-64$ & 1,260 \\
1965 & $09-03-65$ & 286 \\
1966 & $07-24-66$ & 112 \\
1967 & $07-27-67$ & 1,090 \\
1968 & $08-09-68$ & 200 \\
1969 & $11-14-68$ & 150 \\
1970 & $08-04-70$ & 290 \\
1971 & $08-00-71$ & 930 \\
1972 & $00-00-72$ & 0 \\
1973 & $10-19-72$ & 150 \\
1974 & $07-19-74$ & 750 \\
1975 & $10-29-74$ & 130 \\
1976 & $00-00-76$ & 100 \\
\hline
\end{tabular}

MAGNITUDE AND PROBABILITY OF INSTANTANEOUS PEAK FLON BASED ON PERIOD OF RECORD 1963-76

DISCHARGE, IN $\mathrm{FT}^{3} / \mathrm{S}$, FOR INDICATED RECURRENCE INTERVAL IN YEARS, AND EXCEEDANCE PROBABILITY, IN PERCENT

\begin{tabular}{|c|c|c|c|c|c|}
\hline $\begin{array}{c}2 \\
50 x\end{array}$ & $\begin{array}{c}5 \\
20 \%\end{array}$ & $\begin{array}{r}10 \\
10 \%\end{array}$ & $\begin{array}{l}25 \\
4 \%\end{array}$ & $\begin{array}{l}50 \dagger \\
2 x\end{array}$ & $\underset{1 \times}{100}+$ \\
\hline 287 & 660 & 1,020 & 1,620 & 2,180 & 2,850 \\
\hline $\begin{array}{l}\text { WEIGH } \\
\text { MEAN } \\
\text { STAND }\end{array}$ & SKEH & $\begin{array}{l}(\text { LOGS })= \\
(\text { LOGS) }= \\
(\text { LOGS) }=\end{array}$ & $\begin{array}{r}-0.00 \\
2.46 \\
0.43\end{array}$ & & \\
\hline
\end{tabular}

$\uparrow$ Reliability of values in colum is uncertain, and potential errors are large.

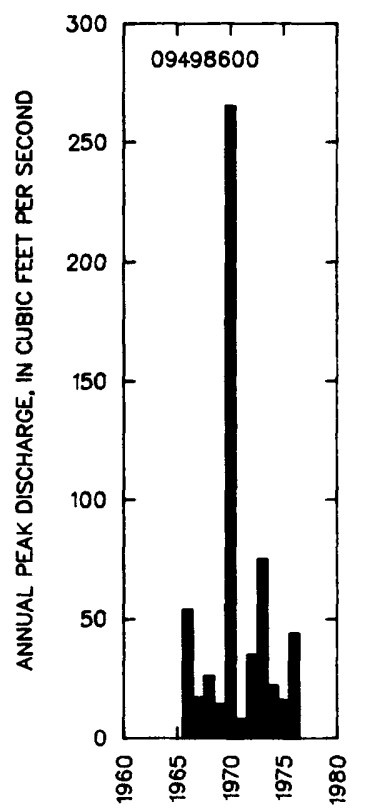

BASIN CHARACTERISTICS

\begin{tabular}{|c|c|c|c|c|c|c|c|}
\hline MAIN & & $\begin{array}{l}\text { MEAN } \\
\text { BASIN }\end{array}$ & & & $\begin{array}{c}\text { MEAN } \\
\text { AMNULAL }\end{array}$ & RAINFALL II & SITY, 24-HOUR \\
\hline $\begin{array}{l}\text { CHANNEL } \\
\text { SLOPE } \\
\text { (FT/MI) }\end{array}$ & $\begin{array}{l}\text { STREAM } \\
\text { LENGTH } \\
\text { (MI) }\end{array}$ & $\begin{array}{l}\text { ELEVA- } \\
\text { TION } \\
\text { (FT) }\end{array}$ & $\begin{array}{l}\text { FORESTED } \\
\text { AREA } \\
\text { (PERCENT) }\end{array}$ & $\begin{array}{l}\text { SOIL } \\
\text { INDEX }\end{array}$ & $\begin{array}{l}\text { PRECIPI- } \\
\text { TATION } \\
\text { (IN) }\end{array}$ & $\begin{array}{c}\text { 2-YEAR } \\
\text { (IN) }\end{array}$ & $\begin{array}{c}\text { 50-YEAR } \\
\text { (IN) }\end{array}$ \\
\hline 306 & 1.7 & 5,810 & 90.0 & 3.0 & 20.0 & 1.9 & 4.2 \\
\hline
\end{tabular}


09497500 SALT RIVER NEAR CHRYSOTILE, AZ

LOCATION.--Lat 33'47'53", long 110.29'57", in sec.25, T.5 N., R.17 E. (unsurveyed), Gila County, Hydrologic Unit 15060103, in San Carlos Indian Reservation, on left bank 1,200 ft upstream from bridge on U.S. Highway $60,5.7 \mathrm{mi}$ northeast of Chrysotile, $8 \mathrm{mi}$ upstream from Cibecue Creek, and $33 \mathrm{mi}$ downstream from confluence of Black and thite Rivers.

DRAIMAGE AREA. $--2,849 \mathrm{mi}^{2}$.

REMARKS. - Several diversions for irrigation above station of about 3,100 acres, one diversion into the basin (record of Forestdale Creek diversion from Show Low Creek, near Show LOW), and one diversion out of the besin (see record of Willow Creek diversion from Black River, near Morenci).

ANMUAL PEAK DISCHARGE

\begin{tabular}{|c|c|c|c|c|c|c|c|}
\hline $\begin{array}{l}\text { WATER } \\
\text { YEAR }\end{array}$ & DATE & $\begin{array}{l}\text { ANNUAL PEAK } \\
\text { DISCHARGE } \\
\text { (FT } 3 / S)\end{array}$ & $\begin{array}{l}\text { DISCHARGE } \\
\text { CODES }\end{array}$ & $\begin{array}{l}\text { HATER } \\
\text { YEAR }\end{array}$ & DATE & $\begin{array}{l}\text { ANNUAL PEAK } \\
\text { DISCHARGE } \\
\left(F^{3} / S\right)\end{array}$ & $\begin{array}{l}\text { DISCHARGE } \\
\text { CODES }\end{array}$ \\
\hline $\begin{array}{l}1916 \\
1925 \\
1926 \\
1927 \\
1928 \\
1929 \\
1930 \\
1931 \\
1932 \\
1933 \\
1934 \\
1935 \\
1936 \\
1937 \\
1938 \\
1939 \\
1940 \\
1941 \\
1942 \\
1943 \\
1944 \\
1945 \\
1946 \\
1947 \\
1948 \\
1949 \\
1950 \\
1951 \\
1952 \\
1953 \\
1954 \\
1955 \\
1956\end{array}$ & $\begin{array}{l}01-19-16 \\
03-08-25 \\
04-06-26 \\
02-17-27 \\
07-21-28 \\
09-23-29 \\
08-11-30 \\
02-15-31 \\
02-10-32 \\
02-28-33 \\
08-20-34 \\
04-09-35 \\
02-17-36 \\
02-07-37 \\
03-04-38 \\
04-05-39 \\
08-15-40 \\
03-14-41 \\
01-13-42 \\
03-05-43 \\
10-19-43 \\
03-27-45 \\
09-19-46 \\
09-18-47 \\
04-12-48 \\
01-14-49 \\
07-21-50 \\
08-29-51 \\
01-14-52 \\
07-30-53 \\
03-23-54 \\
08-23-55 \\
01-29-56\end{array}$ & $\begin{array}{r}17,000 \\
6,930 \\
13,600 \\
19,900 \\
1,670 \\
11,500 \\
11,700 \\
7,400 \\
40,000 \\
2,880 \\
3,850 \\
15,700 \\
13,200 \\
52,900 \\
19,000 \\
8,530 \\
6,300 \\
52,200 \\
5,380 \\
12,800 \\
2,380 \\
4,450 \\
9,600 \\
8,160 \\
5,730 \\
14,200 \\
2,500 \\
5,150 \\
51,500 \\
3,680 \\
28,700 \\
8,820 \\
1,640\end{array}$ & HP & $\begin{array}{l}1957 \\
1958 \\
1959 \\
1960 \\
1961 \\
1962 \\
1963 \\
1964 \\
1965 \\
1966 \\
1967 \\
1968 \\
1969 \\
1970 \\
1971 \\
1972 \\
1973 \\
1974 \\
1975 \\
1976 \\
1977 \\
1978 \\
1979 \\
1980 \\
1981 \\
1982 \\
1983 \\
1984 \\
1985 \\
1986 \\
1987 \\
1988 \\
1989\end{array}$ & $\begin{array}{l}08-02-57 \\
03-22-58 \\
08-20-59 \\
12-26-59 \\
08-30-61 \\
01-25-62 \\
02-11-63 \\
07-26-64 \\
01-08-65 \\
12-30-65 \\
08-12-67 \\
01-28-68 \\
10-04-68 \\
09-06-70 \\
08-13-71 \\
12-26-71 \\
10-20-72 \\
08-06-74 \\
10-29-74 \\
02-10-76 \\
07-23-77 \\
03-02-78 \\
12-18-78 \\
02-15-80 \\
04-14-81 \\
02-11-82 \\
03-25-83 \\
10-02-83 \\
12-28-84 \\
02-16-86 \\
12-08-86 \\
09-02-88 \\
03-12-89\end{array}$ & $\begin{array}{r}3,760 \\
19,700 \\
7,290 \\
26,200 \\
2,130 \\
5,630 \\
6,220 \\
2,780 \\
15,800 \\
41,100 \\
5,060 \\
8,730 \\
4,940 \\
5,000 \\
20,400 \\
23,300 \\
42,100 \\
1,680 \\
7,080 \\
6,070 \\
3,760 \\
46,700 \\
270,400 \\
58,300 \\
2,060 \\
13,200 \\
15,700 \\
56,600 \\
34,600 \\
14,000 \\
8,370 \\
10,600 \\
1,740\end{array}$ & \\
\hline
\end{tabular}

1Highest since 1906.

$2 \mathrm{Highest}$ since 1916.

BASIN CHARACTERISTICS

\begin{tabular}{|c|c|c|c|c|c|c|c|}
\hline \multirow{2}{*}{$\begin{array}{l}\text { MAIN } \\
\text { CHANNEL } \\
\text { SLOPE } \\
\text { (FT/MI) }\end{array}$} & \multirow[b]{2}{*}{$\begin{array}{c}\text { STREAM } \\
\text { LENGTH } \\
\text { (MI) }\end{array}$} & \multirow{2}{*}{$\begin{array}{l}\text { MEAN } \\
\text { BASIN } \\
\text { ELEVA- } \\
\text { TION } \\
\text { (FT) }\end{array}$} & \multirow[b]{2}{*}{$\begin{array}{l}\text { FORESTED } \\
\text { AREA } \\
\text { (PERCENT) }\end{array}$} & \multirow[b]{2}{*}{$\begin{array}{l}\text { SOIL } \\
\text { INDEX }\end{array}$} & \multirow{2}{*}{$\begin{array}{l}\text { MEAN } \\
\text { ANNUAL } \\
\text { PRECIPI- } \\
\text { TATION } \\
\text { (IN) }\end{array}$} & \multicolumn{2}{|c|}{ RAINFALL INTENSITY, 24-HOUR } \\
\hline & & & & & & $\begin{array}{c}\text { 2-YEAR } \\
\text { (IN) }\end{array}$ & $\begin{array}{l}\text { 50-YEAR } \\
\text { (IN) }\end{array}$ \\
\hline 31.9 & 155 & 6,730 & 81.0 & 3.0 & 22.8 & 2.2 & 4.4 \\
\hline
\end{tabular}




\section{GILA RIVER BASIN}

09497500 SALT RIVER NEAR CHRYSOTILE, AZ--Cont inued

MEAN MONTHLY AND ANNUAL DISCHARGES 1925-89

\begin{tabular}{|c|c|c|c|c|c|c|}
\hline MONTH & $\begin{array}{l}\operatorname{MAX} \operatorname{IIMM}_{(\mathrm{M})} \\
(\mathrm{FT} / \mathrm{S})\end{array}$ & $\begin{array}{l}\text { MINIMUM } \\
\left(F^{3} / S\right)\end{array}$ & $\begin{array}{c}\text { MEAN } \\
\left(F T^{3} / S\right)\end{array}$ & $\begin{array}{l}\text { STAN- } \\
\text { DARD } \\
\text { DEVIA- } \\
\text { TION } \\
\left.\text { (FT }{ }^{3} / S\right)\end{array}$ & $\begin{array}{l}\text { COEFFI - } \\
\text { CIENT OF } \\
\text { VARI - } \\
\text { ATION }\end{array}$ & $\begin{array}{c}\text { PERCENT } \\
\text { OF } \\
\text { ANNUAL } \\
\text { RUNOFF }\end{array}$ \\
\hline $\begin{array}{l}\text { OCTOBER } \\
\text { NOVEMBER } \\
\text { DECEMBER } \\
\text { JANUARY } \\
\text { FEBRUARY } \\
\text { MARCH } \\
\text { APRIL } \\
\text { MAY } \\
\text { JUNE } \\
\text { JULY } \\
\text { AUGUST } \\
\text { SEPTEMBER }\end{array}$ & $\begin{array}{l}3,780 \\
1,300 \\
3,980 \\
4,250 \\
6,180 \\
6,030 \\
4,850 \\
5,070 \\
1,190 \\
547 \\
1,250 \\
1,180\end{array}$ & $\begin{array}{r}79 \\
112 \\
113 \\
130 \\
145 \\
187 \\
181 \\
106 \\
74 \\
91 \\
135 \\
69\end{array}$ & $\begin{array}{r}358 \\
270 \\
498 \\
545 \\
851 \\
1,430 \\
1,740 \\
929 \\
315 \\
225 \\
410 \\
343\end{array}$ & $\begin{array}{r}586 \\
209 \\
786 \\
707 \\
1,010 \\
1,200 \\
1,280 \\
936 \\
257 \\
103 \\
237 \\
255\end{array}$ & $\begin{array}{l}1.6 \\
0.77 \\
1.6 \\
1.3 \\
1.2 \\
0.84 \\
0.74 \\
1.0 \\
0.82 \\
0.46 \\
0.58 \\
0.74\end{array}$ & $\begin{array}{r}4.5 \\
3.4 \\
6.3 \\
6.9 \\
10.8 \\
18.1 \\
22.0 \\
11.7 \\
4.0 \\
2.8 \\
5.2 \\
4.3\end{array}$ \\
\hline NUAL & 2,010 & 185 & 658 & 430 & 0.65 & 100 \\
\hline
\end{tabular}

MAGNITLDE AND PROBABILITY OF ANNUAL LOW FLOW BASED ON PERIOD OF RECORD 1926-89

\begin{tabular}{|c|c|c|c|c|c|c|}
\hline \multirow{2}{*}{$\begin{array}{l}\text { PERIOD } \\
\text { (CON- } \\
\text { SECU- } \\
\text { TIVE } \\
\text { DAYS) }\end{array}$} & \multicolumn{6}{|c|}{$\begin{array}{l}\text { DISCHARGE, IN FT } 3 / S \text {, FOR INDICATED } \\
\text { RECURRENCE INTERVAL, IN YEARS, AND } \\
\text { NON-EXCEEDANCE PROBABILITY, IN PERCENT }\end{array}$} \\
\hline & $\stackrel{2}{20 \%}$ & $\begin{array}{c}5 \\
20 \%\end{array}$ & $\begin{array}{l}10 \\
10 \%\end{array}$ & $\begin{array}{l}20 \\
5 x\end{array}$ & $\begin{array}{l}50 \\
2 x\end{array}$ & $\begin{array}{l}100 \\
1 x\end{array}$ \\
\hline $\begin{array}{r}1 \\
3 \\
7 \\
14 \\
30 \\
60 \\
90 \\
120 \\
183\end{array}$ & $\begin{array}{l}102 \\
105 \\
109 \\
117 \\
129 \\
148 \\
164 \\
179 \\
217\end{array}$ & $\begin{array}{r}77 \\
79 \\
82 \\
88 \\
98 \\
113 \\
129 \\
142 \\
165\end{array}$ & $\begin{array}{r}67 \\
68 \\
71 \\
76 \\
85 \\
100 \\
117 \\
129 \\
148\end{array}$ & $\begin{array}{r}60 \\
61 \\
63 \\
68 \\
76 \\
91 \\
108 \\
121 \\
138\end{array}$ & $\begin{array}{r}52 \\
53 \\
56 \\
59 \\
68 \\
82 \\
100 \\
113 \\
129\end{array}$ & $\begin{array}{r}48 \\
48 \\
51 \\
54 \\
62 \\
77 \\
95 \\
110 \\
125\end{array}$ \\
\hline
\end{tabular}

MAGNITLOE AND PROBABILITY OF ANNUAL HIGH FLON BASED ON PERIOD OF RECORD 1925-89

\begin{tabular}{|c|c|c|c|c|c|c|}
\hline \multirow{2}{*}{$\begin{array}{l}\text { PERIOD } \\
\text { (CON- } \\
\text { SECU- } \\
\text { TIVE } \\
\text { DAYS) }\end{array}$} & \multicolumn{6}{|c|}{$\begin{array}{l}\text { DISCHARGE, IN FT }{ }^{3} / \mathrm{S}, \text { FOR INDICATED } \\
\text { RECURRENCE INTERVAL, IN YEARS, AND } \\
\text { EXCEEDANCE PROBABILITY, IN PERCENT }\end{array}$} \\
\hline & $\stackrel{2}{50 \%}$ & $\begin{array}{c}5 \\
20 \%\end{array}$ & $\begin{array}{l}10 \\
10 \%\end{array}$ & $\begin{array}{l}25 \\
4 \%\end{array}$ & $\begin{array}{l}50 \\
2 x\end{array}$ & $\begin{array}{r}100 \\
1 \times\end{array}$ \\
\hline $\begin{array}{r}1 \\
3 \\
7 \\
15 \\
30 \\
60 \\
90\end{array}$ & $\begin{array}{l}5,600 \\
4,260 \\
3,080 \\
2,360 \\
1,860 \\
1,430 \\
1,200\end{array}$ & $\begin{array}{r}14,100 \\
9,800 \\
6,330 \\
4,480 \\
3,390 \\
2,630 \\
2,250\end{array}$ & $\begin{array}{r}23,000 \\
15,400 \\
9,350 \\
6,270 \\
4,610 \\
3,610 \\
3,110\end{array}$ & $\begin{array}{r}39,300 \\
25,400 \\
14,300 \\
9,000 \\
6,340 \\
5,040 \\
4,380\end{array}$ & $\begin{array}{r}55,900 \\
35,300 \\
19,000 \\
11,400 \\
7,770 \\
6,230 \\
5,450\end{array}$ & $\begin{array}{r}76, \\
47, \\
24, \\
14, \\
9, \\
7, \\
6,\end{array}$ \\
\hline
\end{tabular}

DURATION TABLE OF DAILY MEAN FLON FOR PERIOD OF RECORD 1925-89

DISCHARGE, IN FT $3 / \mathrm{S}$, WHICH WAS EQUALED OR EXCEEDED FOR INDICATED PERCENT OF TIME

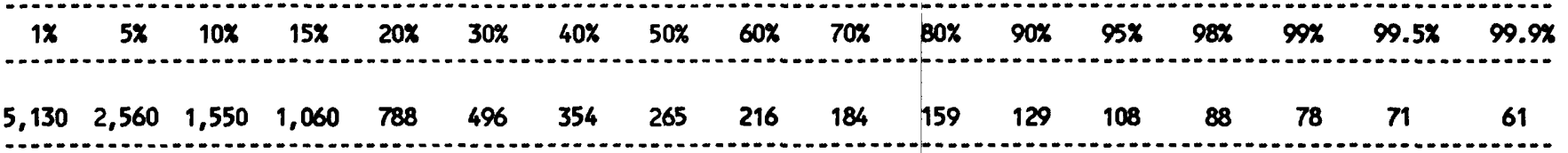


GILA RIVER BASIN

09497500 SALT RIVER NEAR CHRYSOTILE, AZ--CONTIMUEd
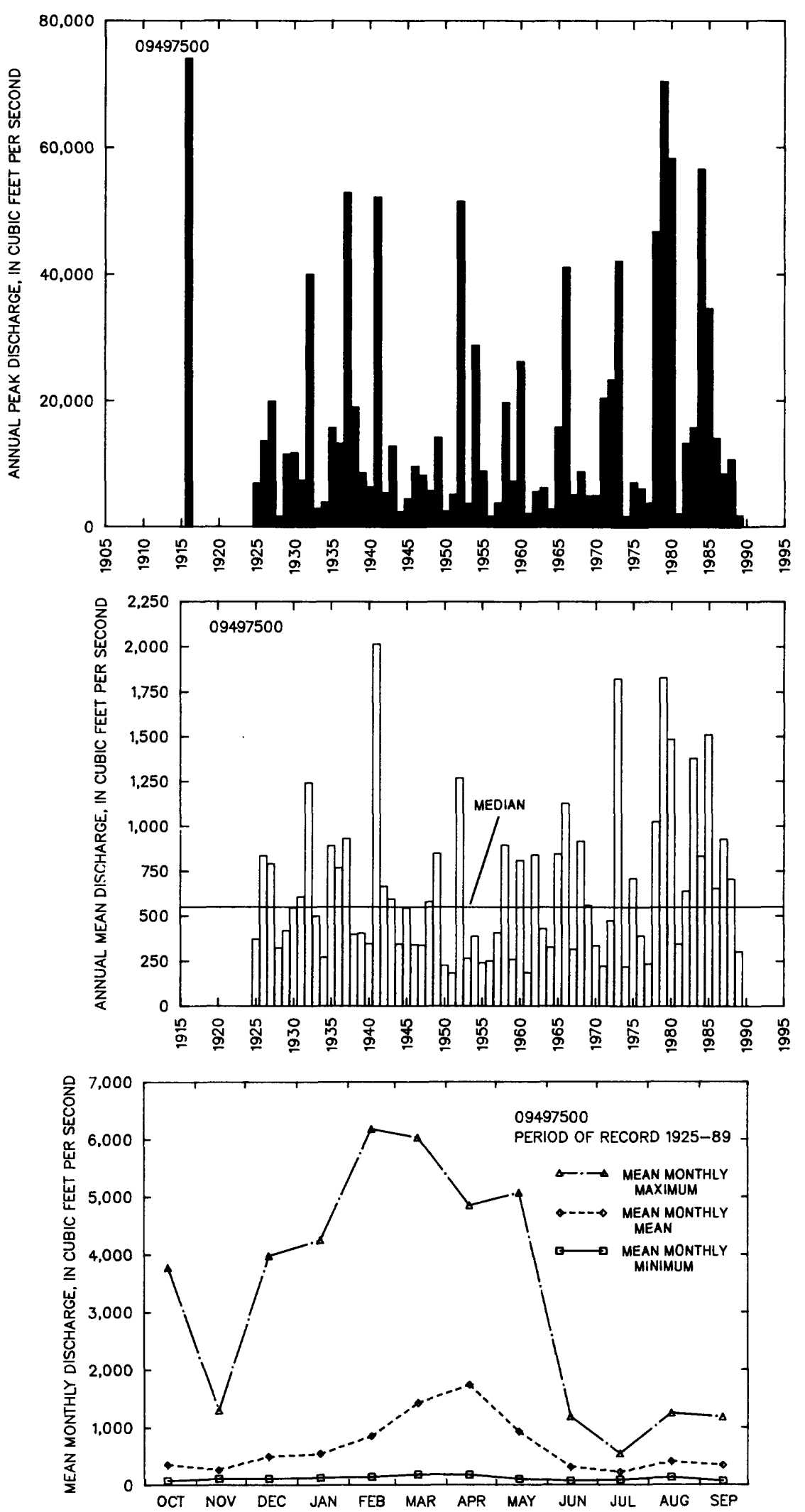
09497800 CIBECUE CREEK NEAR CHRYSOTILE, AZ

LOCATION.--Lat 33.50'35", long 110'33'25", in E sec.8, T.5 N., R.17 E. (unsurveyed), Gila County, Hydrologic Unit 15060103, in Fort Apache Indian Reservation, on right bank $0.5 \mathrm{mi}$ upstream from mouth and $7 \mathrm{mi}$ north of Chrysotile.

DRAIMAGE AREA. $--295 \mathrm{mi}^{2}$.

REMARKS.--Small diversions for irrigation near the village of Cibecue.

AMMUAL PEAK DISCHAREE

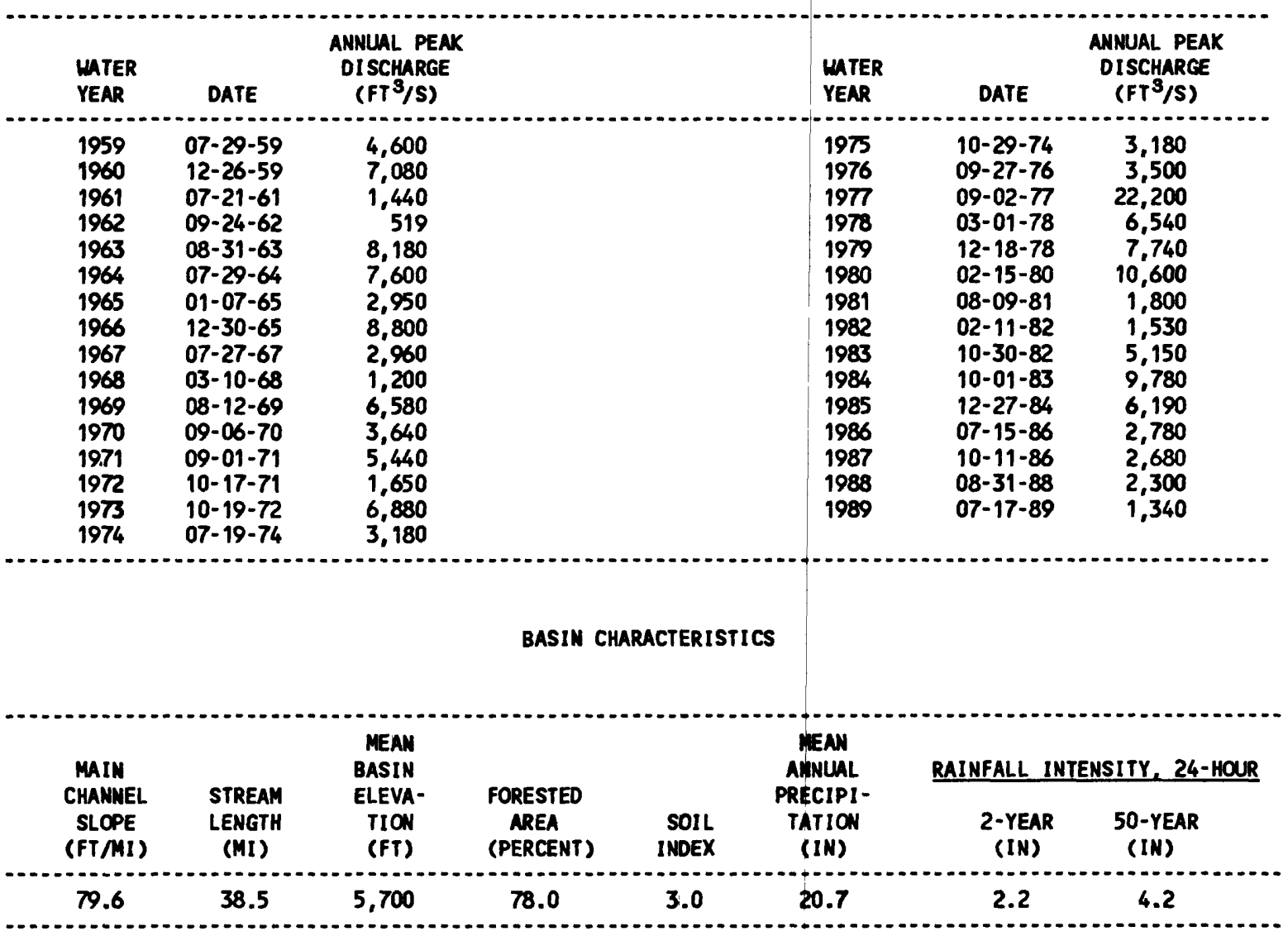


09497800 CIBECUE CREEK MEAR CHRYSOTILE, AZ--COntinued

MEAN MONTHLY AND AMMUAL DISCHAREES $1960-89$

\begin{tabular}{|c|c|c|c|c|c|c|}
\hline MONTH & $\begin{array}{l}\operatorname{Max} \operatorname{mim}^{3} \\
\left(\mathrm{FT}^{3} / \mathrm{S}\right)\end{array}$ & $\begin{array}{l}\operatorname{MINIMU} \\
\left(\mathrm{FT}^{3} / \mathrm{S}\right)\end{array}$ & $\begin{array}{c}\text { MEAN } \\
\left(F^{3} / S\right)\end{array}$ & $\begin{array}{l}\text { STAN- } \\
\text { DARD } \\
\text { DEVIA- } \\
\text { TION } \\
\left(F T^{3} / S\right)\end{array}$ & $\begin{array}{l}\text { COEFFI- } \\
\text { CIENT OF } \\
\text { YARI- } \\
\text { ATION }\end{array}$ & $\begin{array}{c}\text { PERCENT } \\
\text { OF } \\
\text { MinuAL } \\
\text { RUwOFF }\end{array}$ \\
\hline $\begin{array}{l}\text { OCTOBER } \\
\text { NOVEMBER } \\
\text { DECEMBER } \\
\text { JANUARY } \\
\text { FEBRUARY } \\
\text { MARCH } \\
\text { APRIL } \\
\text { MAY } \\
\text { JUNE } \\
\text { JULY } \\
\text { AUGUST } \\
\text { SEPTEMBER }\end{array}$ & $\begin{array}{r}277 \\
186 \\
368 \\
209 \\
550 \\
477 \\
274 \\
131 \\
40 \\
69 \\
106 \\
85\end{array}$ & $\begin{array}{l}11 \\
9.1 \\
11 \\
11 \\
11 \\
12 \\
11 \\
5.6 \\
5.0 \\
6.6 \\
13 \\
13\end{array}$ & $\begin{array}{r}39 \\
30 \\
62 \\
48 \\
74 \\
102 \\
60 \\
26 \\
15 \\
25 \\
36 \\
32\end{array}$ & $\begin{array}{c}53 \\
32 \\
84 \\
48 \\
102 \\
117 \\
62 \\
25 \\
8.4 \\
13 \\
20 \\
19\end{array}$ & $\begin{array}{l}1.3 \\
1.1 \\
1.3 \\
1.0 \\
1.4 \\
1.2 \\
1.0 \\
0.97 \\
0.58 \\
0.54 \\
0.57 \\
0.61\end{array}$ & $\begin{array}{r}7.2 \\
5.5 \\
11.3 \\
8.8 \\
13.5 \\
18.6 \\
10.9 \\
4.7 \\
2.6 \\
4.5 \\
6.6 \\
5.8\end{array}$ \\
\hline Al & 133 & 16 & 46 & 31 & 0.67 & 100 \\
\hline
\end{tabular}

MAGNITLDE AND PROBABILITY OF ANNUAL LON FLON BASED ON PERIOD OF RECORD 1961-89

\begin{tabular}{|c|c|c|c|c|c|c|}
\hline \multirow{2}{*}{$\begin{array}{l}\text { PERIOD } \\
\text { (CON- } \\
\text { SECU- } \\
\text { TIVE } \\
\text { DAYS) }\end{array}$} & \multicolumn{6}{|c|}{$\begin{array}{l}\text { DISCHARGE, IN } \mathrm{FT}^{3} / \mathrm{S} \text {, FOR INDICATED } \\
\text { RECURRENCE INTERVAL, IN YEARS, AND } \\
\text { NON-EXCEEDANCE PROBABILITY, IN PERCENT }\end{array}$} \\
\hline & $\begin{array}{c}2 \\
50 \%\end{array}$ & $\begin{array}{c}5 \\
20 \%\end{array}$ & $\begin{array}{l}10 \\
10 \%\end{array}$ & $\begin{array}{l}20 \\
5 \%\end{array}$ & $\begin{array}{l}50 \\
2 \%\end{array}$ & $\begin{array}{l}100 \nmid \\
1 \%\end{array}$ \\
\hline $\begin{array}{r}1 \\
3 \\
7 \\
14 \\
30 \\
60 \\
90 \\
120 \\
183\end{array}$ & $\begin{array}{c}8.7 \\
8.8 \\
9.1 \\
9.6 \\
10 \\
12 \\
14 \\
17 \\
20\end{array}$ & $\begin{array}{l}5.9 \\
6.0 \\
6.3 \\
6.7 \\
7.3 \\
8.5 \\
10 \\
12 \\
15\end{array}$ & $\begin{array}{l}4.9 \\
5.0 \\
5.2 \\
5.6 \\
6.1 \\
7.0 \\
8.3 \\
11 \\
14\end{array}$ & $\begin{array}{r}4.2 \\
4.2 \\
4.5 \\
4.8 \\
5.2 \\
5.9 \\
7.1 \\
9.1 \\
12\end{array}$ & $\begin{array}{r}3.5 \\
3.6 \\
3.8 \\
4.1 \\
4.4 \\
4.8 \\
5.9 \\
7.7 \\
11\end{array}$ & $\begin{array}{r}3.4 \\
3.7 \\
3.9 \\
4.2 \\
5.2 \\
6.8 \\
11\end{array}$ \\
\hline
\end{tabular}

MAGNITLDE AND PROBABILITY OF ANNUAL HIGH FLO BASED ON PERIOD OF RECORD 1960-89

\begin{tabular}{|c|c|c|c|c|c|c|}
\hline \multirow{2}{*}{$\begin{array}{l}\text { PERIOD } \\
\text { (CON- } \\
\text { SECU- } \\
\text { TIVE } \\
\text { DAYS) }\end{array}$} & & \multicolumn{5}{|c|}{$\begin{array}{l}\text { DISCHARGE, IN } \mathrm{FT}^{3} / \mathrm{S} \text {, FOR INDICATED } \\
\text { RECURRENCE INTERVAL, IN YEARS, AND } \\
\text { EXCEEDANCE PROBABILITY, IN PERCENT }\end{array}$} \\
\hline & $\stackrel{2}{50 \%}$ & $\begin{array}{c}5 \\
20 \%\end{array}$ & $\begin{array}{l}10 \\
10 \%\end{array}$ & $\begin{array}{l}25 \\
4 \%\end{array}$ & $\begin{array}{l}50 \\
2 \%\end{array}$ & $\begin{array}{c}100 \nmid \\
1 \%\end{array}$ \\
\hline $\begin{array}{c}1 \\
3 \\
7 \\
15 \\
30 \\
60 \\
90\end{array}$ & $\begin{array}{r}761 \\
415 \\
242 \\
159 \\
115 \\
86 \\
72\end{array}$ & $\begin{array}{r}1,750 \\
924 \\
521 \\
334 \\
234 \\
168 \\
140\end{array}$ & $\begin{array}{r}2,760 \\
1,450 \\
804 \\
510 \\
352 \\
244 \\
203\end{array}$ & $\begin{array}{r}4,590 \\
2,400 \\
1,310 \\
824 \\
556 \\
369 \\
307\end{array}$ & $\begin{array}{r}6,450 \\
3,360 \\
1,820 \\
1,140 \\
757 \\
488 \\
405\end{array}$ & $\begin{array}{r}8,810 \\
4,600 \\
2,470 \\
1,550 \\
1,010 \\
632 \\
523\end{array}$ \\
\hline
\end{tabular}

DURATION TABLE OF DAILY MEAN FLON FOR PERIOD OF RECORD 1960-89

OISCHARGE, IN FT $3 / 5$, WHICH WAS ECUALED OR EXCEEDED FOR INDICATED PERCENT OF TIME

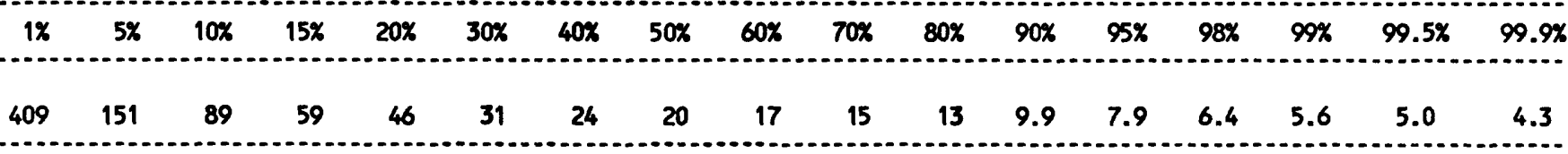

$\uparrow$ Reliability of values in colum is uncertain, and potential errors are large. 
GILA RIVER BASIN

09497800 CIBECUE CREEK NEAR CHRYSOTILE, AZ--CONTINUED
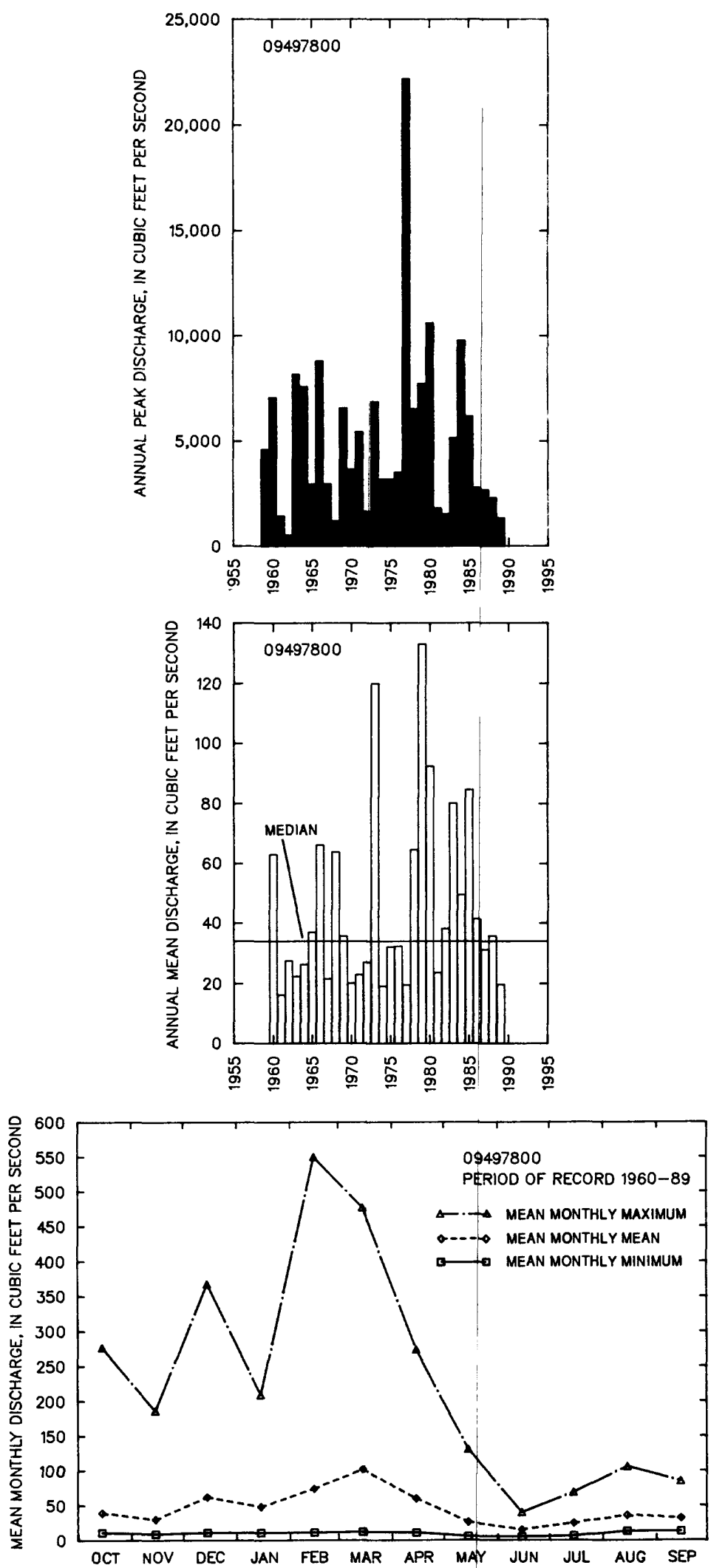
09497900 CHERRY CREEK NEAR YOUNG, AZ

LOCATION.--Lat 34.04'58", long 110'55'25", in SEYNEK sec.32, T.9 N., R.14 E., Gila County, Hydrologic Unit 15060103, on left bank 0.3 mi downstream from Deadman Canyon and 2 mi southeast of Young.

DRAINAGE AREA. $--62.1 \mathrm{mi}^{2}$.

ANNUAL PEAK DISCHARGE

\begin{tabular}{ccc}
$\begin{array}{c}\text { WATER } \\
\text { YEAR }\end{array}$ & DATE & $\begin{array}{c}\text { ANNUAL PEAK } \\
\text { DISCHARGE } \\
\text { (FT } 3 / \text { S) }\end{array}$ \\
\hline 1963 & $08-22-63$ & 2,700 \\
1964 & $07-30-64$ & 266 \\
1965 & $08-17-65$ & 3,280 \\
1966 & $12-22-65$ & 3,400 \\
1967 & $07-31-67$ & 2,670 \\
1968 & $01-28-68$ & 800 \\
1969 & $01-26-69$ & 616 \\
1970 & $09-05-70$ & 3,100 \\
1971 & $07-17-71$ & 920 \\
1972 & $10-24-71$ & 765 \\
1973 & $10-19-72$ & 7,290 \\
1974 & $08-02-74$ & 950 \\
1975 & $07-22-75$ & 258 \\
1976 & $02-09-76$ & 2,300 \\
1977 & $09-02-77$ & 530 \\
1978 & $03-01-78$ & 2,480 \\
\hline$\ldots$
\end{tabular}

BASIN CHARACTERISTICS

\begin{tabular}{|c|c|c|c|c|c|c|c|}
\hline \multirow{3}{*}{$\begin{array}{l}\text { MAIN } \\
\text { CHANNEL } \\
\text { SLOPE } \\
\text { (FT/MI) }\end{array}$} & \multirow[b]{3}{*}{$\begin{array}{c}\text { STREAM } \\
\text { LENGTH } \\
\text { (MI) }\end{array}$} & \multirow{3}{*}{$\begin{array}{l}\text { MEAN } \\
\text { BASIN } \\
\text { ELEVA- } \\
\text { TION } \\
\text { (FT) }\end{array}$} & \multirow[b]{3}{*}{$\begin{array}{l}\text { FORESTED } \\
\text { AREA } \\
\text { (PERCENT) }\end{array}$} & \multirow[b]{3}{*}{$\begin{array}{l}\text { SOIL } \\
\text { INDEX }\end{array}$} & \multirow{2}{*}{$\begin{array}{c}\text { MEAN } \\
\text { ANNUAL } \\
\text { PRECIPI- }\end{array}$} & \multirow{2}{*}{\multicolumn{2}{|c|}{ RAINFALL INTENSITY, 24-HOUR }} \\
\hline & & & & & & & \\
\hline & & & & & $\begin{array}{l}\text { PRECIPI- } \\
\text { TATION } \\
\text { (IN) }\end{array}$ & $\begin{array}{c}\text { 2-YEAR } \\
\text { (IN) }\end{array}$ & $\begin{array}{l}\text { 50-YEAR } \\
\text { (IN) }\end{array}$ \\
\hline 106 & 18.6 & 6,030 & 75.0 & 3.0 & 24.8 & 2.7 & 5.5 \\
\hline
\end{tabular}


MEAN MONTHLY AND ANIUAL DISCHARGES 1966-78, 1980-88

\begin{tabular}{|c|c|c|c|c|c|c|}
\hline MONTH & $\begin{array}{l}\operatorname{Max} I M M \\
\left(F T^{3} / S\right)\end{array}$ & $\begin{array}{l}\text { MINIMUN } \\
\left(\mathrm{FT}^{3} / \mathrm{S}\right)\end{array}$ & $\begin{array}{c}\text { MEAN } \\
\left(\mathrm{FT}^{3} / \mathrm{S}\right)\end{array}$ & $\begin{array}{l}\text { STAN- } \\
\text { DARD } \\
\text { DEVIA- } \\
\text { TION } \\
\text { (FT } 3 / S)\end{array}$ & $\begin{array}{l}\text { COEFFI- } \\
\text { CIENT OF } \\
\text { VARI - } \\
\text { ATION }\end{array}$ & $\begin{array}{c}\text { PERCENT } \\
\text { OF } \\
\text { ANMUAL } \\
\text { RUNOFF }\end{array}$ \\
\hline $\begin{array}{l}\text { OCTOBER } \\
\text { NOVEMBER } \\
\text { DECEMBER } \\
\text { JANUARY } \\
\text { FEBRUARY } \\
\text { MARCH } \\
\text { APRIL } \\
\text { MAY } \\
\text { JUNE } \\
\text { JULY } \\
\text { AUGUST } \\
\text { SEPTEMBER }\end{array}$ & $\begin{array}{l}296 \\
101 \\
537 \\
179 \\
568 \\
423 \\
195 \\
66 \\
18 \\
23 \\
85 \\
151\end{array}$ & $\begin{array}{l}4.6 \\
4.5 \\
4.8 \\
6.7 \\
6.0 \\
6.1 \\
5.3 \\
4.9 \\
4.4 \\
5.6 \\
5.5 \\
3.6\end{array}$ & $\begin{array}{l}30 \\
19 \\
67 \\
43 \\
98 \\
96 \\
30 \\
13 \\
7.7 \\
9.9 \\
17 \\
18\end{array}$ & $\begin{array}{c}64 \\
23 \\
125 \\
46 \\
133 \\
126 \\
42 \\
13 \\
3.2 \\
4.4 \\
17 \\
30\end{array}$ & $\begin{array}{l}2.1 \\
1.2 \\
1.9 \\
1.1 \\
1.4 \\
1.3 \\
1.4 \\
0.99 \\
0.42 \\
0.44 \\
0.95 \\
1.7\end{array}$ & $\begin{array}{r}6.7 \\
4.1 \\
15.0 \\
9.6 \\
21.7 \\
21.4 \\
6.7 \\
2.9 \\
1.7 \\
2.2 \\
3.9 \\
4.0\end{array}$ \\
\hline NHUAL & 130 & 8.2 & 37 & 31 & 0.84 & 100 \\
\hline
\end{tabular}

MGNITUDE AND PROBABILITY OF INSTANTANEOUS PEAK FLOW BASED ON 21 YEARS OF RECORD

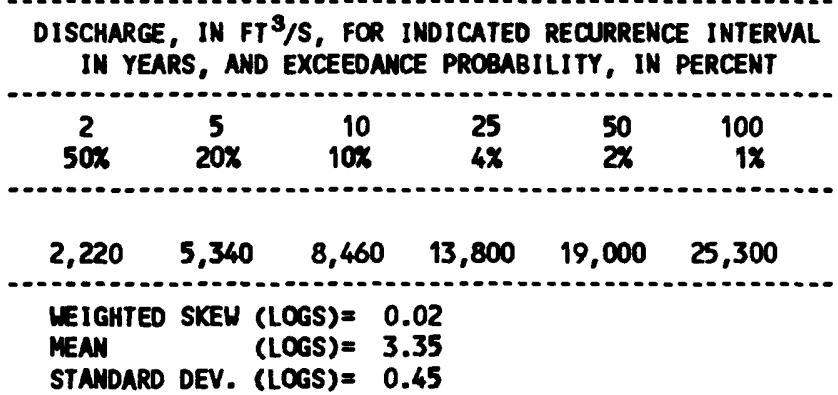

MAEITLDE AND PROBABILITY OF ANMUAL LOW FLOW BASED ON PERICD OF RECORD 1967-78, 1981-89

\begin{tabular}{|c|c|c|c|c|c|c|}
\hline \multirow{2}{*}{$\begin{array}{l}\text { PERIOD } \\
\text { (CON- } \\
\text { SECU- } \\
\text { TIVE } \\
\text { DAYS) }\end{array}$} & \multicolumn{6}{|c|}{$\begin{array}{l}\text { DISCHARGE, IN FT } 3 / \mathrm{S}, \text { FOR INDICATED } \\
\text { RECURRENCE INTERVAL, IN YEARS, AND } \\
\text { NON-EXCEEDANCE PROBABILITY, IN PERCENT }\end{array}$} \\
\hline & $\begin{array}{c}2 \\
50 \%\end{array}$ & $\begin{array}{c}5 \\
20 \%\end{array}$ & $\begin{array}{l}10 \\
10 \%\end{array}$ & $\begin{array}{l}20 \\
5 \%\end{array}$ & $\begin{array}{l}50 \dagger \\
2 \%\end{array}$ & $\begin{array}{l}100 \uparrow \\
1 x\end{array}$ \\
\hline $\begin{array}{r}1 \\
3 \\
7 \\
14 \\
30 \\
60 \\
90 \\
120 \\
183\end{array}$ & $\begin{array}{l}5.2 \\
5.4 \\
5.5 \\
5.6 \\
6.0 \\
6.5 \\
7.1 \\
7.6 \\
9.5\end{array}$ & $\begin{array}{l}4.2 \\
4.4 \\
4.5 \\
4.6 \\
5.0 \\
5.3 \\
5.7 \\
6.4 \\
7.5\end{array}$ & $\begin{array}{l}3.8 \\
4.0 \\
4.1 \\
4.3 \\
4.6 \\
4.8 \\
5.2 \\
5.9 \\
6.7\end{array}$ & $\begin{array}{l}3.6 \\
3.8 \\
3.8 \\
4.0 \\
4.2 \\
4.5 \\
4.8 \\
5.5 \\
6.2\end{array}$ & $\begin{array}{l}3.3 \\
3.5 \\
3.6 \\
3.7 \\
3.9 \\
4.1 \\
4.3 \\
5.1 \\
5.7\end{array}$ & $\begin{array}{l}3.1 \\
3.3 \\
3.4 \\
3.5 \\
3.7 \\
3.9 \\
4.1 \\
4.9 \\
5.4\end{array}$ \\
\hline
\end{tabular}

MEUITLDE NDO PROBABILITY OF ANHUAL HIGH FLOW BASED ON PERICD OF RECORD 1966-78, 1980-88

\begin{tabular}{|c|c|c|c|c|c|c|}
\hline \multirow{2}{*}{$\begin{array}{l}\text { PERIOD } \\
\text { (CON- } \\
\text { SECW- } \\
\text { TIVE } \\
\text { DAYS) }\end{array}$} & & \multicolumn{5}{|c|}{$\begin{array}{l}\text { DISCHARCE, IN } \mathrm{FT}^{3} / \mathrm{S} \text {, FOR INDICATED } \\
\text { RECURRENCE INTERVAL, IN YEARS, AND } \\
\text { EXCEEDANCE PROBABILITY, IN PERCENT }\end{array}$} \\
\hline & $\stackrel{2}{20 x}$ & $\underset{20 x}{5}$ & $\begin{array}{l}10 \\
10 x\end{array}$ & $\begin{array}{l}25 \\
4 x\end{array}$ & $\begin{array}{l}50 \dagger \\
2 \%\end{array}$ & $\begin{array}{c}100 \dagger \\
18\end{array}$ \\
\hline $\begin{array}{l}1 \\
3 \\
7 \\
15 \\
30 \\
60 \\
90\end{array}$ & $\begin{array}{r}765 \\
508 \\
320 \\
200 \\
129 \\
88 \\
68\end{array}$ & $\begin{array}{r}2,180 \\
1,310 \\
773 \\
474 \\
304 \\
205 \\
155\end{array}$ & $\begin{array}{r}3,610 \\
2,040 \\
1,170 \\
720 \\
467 \\
315 \\
237\end{array}$ & $\begin{array}{r}6,010 \\
3,150 \\
1,760 \\
1,090 \\
727 \\
494 \\
370\end{array}$ & $\begin{array}{r}8,210 \\
4,080 \\
2,250 \\
1,420 \\
961 \\
656 \\
491\end{array}$ & $\begin{array}{r}10,700 \\
5,070 \\
2,760 \\
1,770 \\
1,230 \\
845 \\
632\end{array}$ \\
\hline
\end{tabular}

DURATION table OF DAILY MEAN FLOW FOR PERIOD OF RECORd 1966-78, 1980-88 OISCHARGE, IN FT $3 / \mathrm{S}$, HHICH MAS EQUALED OR EXCEEDED FOR INDJCATED PERCENT OF TIME

\begin{tabular}{|c|c|c|c|c|c|c|c|c|c|c|c|c|c|c|c|c|}
\hline $1 x$ & $5 x$ & $10 x$ & $15 \%$ & $20 \%$ & $30 \%$ & $40 \%$ & $50 x$ & $60 \%$ & $70 x$ & $80 \%$ & $90 \%$ & $95 x$ & $98 \%$ & $99 \%$ & $99.5 x$ & $99.9 \%$ \\
\hline 446 & 141 & 62 & 37 & 25 & 15 & 11 & 9.3 & 8.0 & 7.2 & 6.3 & 5.4 & 4.8 & 4.3 & 4.1 & 4.0 & 3.0 \\
\hline
\end{tabular}


GILA RIVER BASIN

09497900 CHERRY CREEK MEAR YOUNG, AZ--CONTIMUED
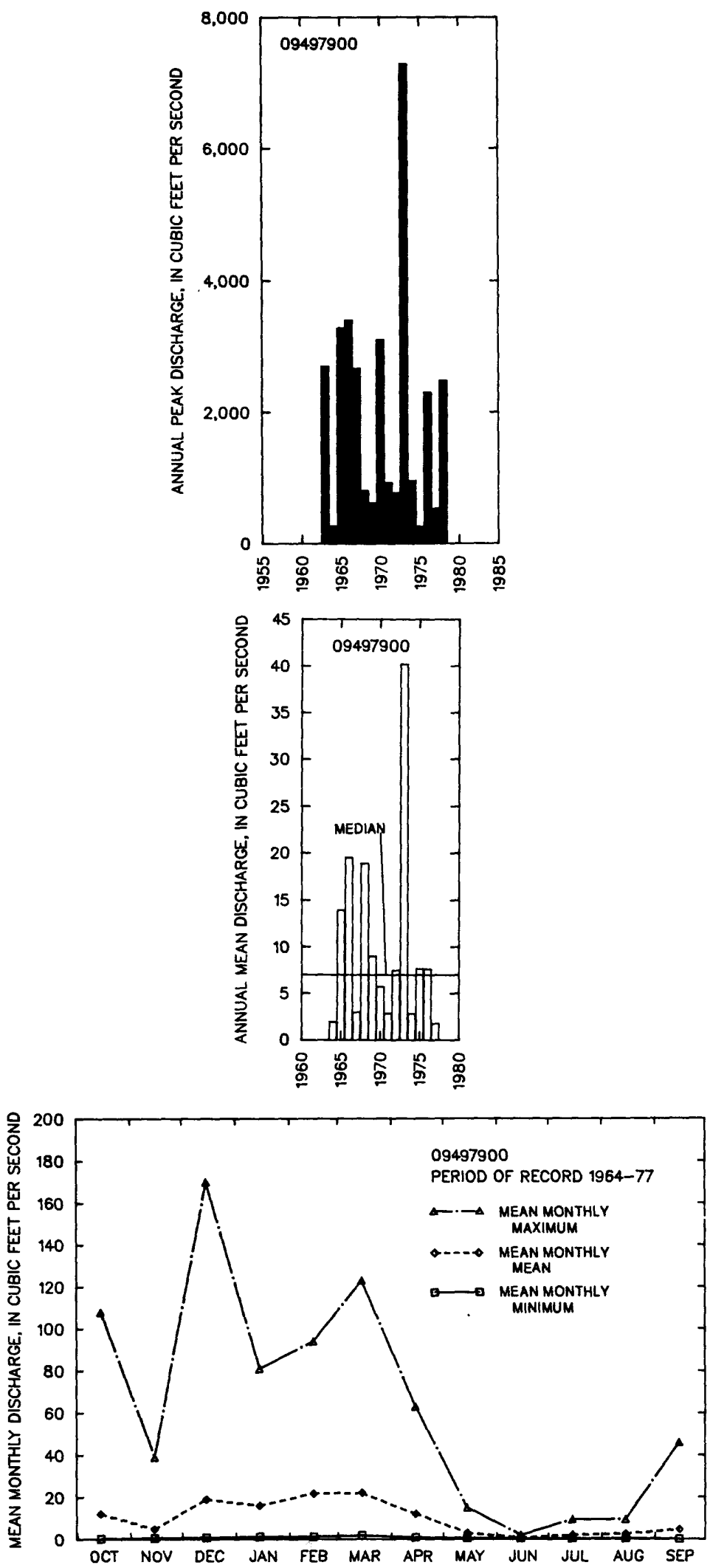
LOCATION.--Lat 33'49'40", long 110'51'20", in SWh sec.30, T.6 N., R.15 E. (unsurveyed), Gila County, Hydrologic Unit 15060103, in Tonto National Forest, on right bank 0.2 mi upstream from Devils Chasm, 13 mi upstream from mouth, and $30 \mathrm{mi}$ north of Globe. Prior to January 17, 1979, on left bank at site $125 \mathrm{ft}$ downstream.

DRAINAGE AREA. $--200 \mathrm{mi}^{2}$.

ANMUAL PEAK DISCHARGE

\begin{tabular}{|c|c|c|}
\hline $\begin{array}{l}\text { WATER } \\
\text { YEAR }\end{array}$ & DATE & $\begin{array}{c}\text { ANNUALL PEAK } \\
\text { DISCHARGE } \\
\left(F^{3} / S\right)\end{array}$ \\
\hline $\begin{array}{l}1966 \\
1967 \\
1968 \\
1969 \\
1970 \\
1971 \\
1972 \\
1973 \\
1974 \\
1975 \\
1976 \\
1977 \\
1978 \\
1979 \\
1980 \\
1981 \\
1982 \\
1983 \\
1984 \\
1985 \\
1986 \\
1987 \\
1988 \\
1989\end{array}$ & $\begin{array}{l}12-22-65 \\
08-06-67 \\
01-28-68 \\
01-26-69 \\
09-06-70 \\
08-19-71 \\
10-24-71 \\
10-19-72 \\
08-06-74 \\
10-24-74 \\
02-09-76 \\
09-11-77 \\
03-01-78 \\
01-17-79 \\
02-15-80 \\
07-17-81 \\
03-13-82 \\
12-01-82 \\
10-01-83 \\
12-27-84 \\
11-30-85 \\
03-05-87 \\
08-31-88 \\
02-05-89\end{array}$ & $\begin{array}{r}6,620 \\
3,600 \\
1,490 \\
928 \\
4,300 \\
1,260 \\
1,010 \\
8,300 \\
596 \\
715 \\
3,820 \\
408 \\
5,370 \\
115,700 \\
13,500 \\
151 \\
1,920 \\
2,800 \\
1,620 \\
8,970 \\
1,690 \\
358 \\
5,170 \\
563\end{array}$ \\
\hline
\end{tabular}

$1_{H i g h e s t}$ since 1960.

BASIN CHARACTERISTICS

\begin{tabular}{|c|c|c|c|c|c|c|c|}
\hline \multirow{3}{*}{$\begin{array}{l}\text { MAIN } \\
\text { CHANNEL } \\
\text { SLOPE } \\
\text { (FT/MI) }\end{array}$} & \multirow[b]{3}{*}{$\begin{array}{c}\text { STREAM } \\
\text { LENGTH } \\
\text { (MI) }\end{array}$} & \multirow{3}{*}{$\begin{array}{l}\text { MEAN } \\
\text { BASIN } \\
\text { ELEVA- } \\
\text { TION } \\
\text { (FT) }\end{array}$} & \multirow[b]{3}{*}{$\begin{array}{l}\text { FORESTED } \\
\text { AREA } \\
\text { (PERCENT) }\end{array}$} & \multirow[b]{3}{*}{$\begin{array}{l}\text { SOIL } \\
\text { INDEX }\end{array}$} & \multirow{3}{*}{$\begin{array}{l}\text { MEAN } \\
\text { ANNUAL } \\
\text { PRECIPI- } \\
\text { TATION } \\
\text { (IN) }\end{array}$} & \multirow{2}{*}{\multicolumn{2}{|c|}{ RAINFALL INTENSITY, 24-HOUR }} \\
\hline & & & & & & & \\
\hline & & & & & & $\begin{array}{c}\text { 2-YEAR } \\
\text { (IN) }\end{array}$ & $\begin{array}{l}\text { 50-YEAR } \\
\text { (IN) }\end{array}$ \\
\hline 87.9 & 36.4 & 5,600 & 81.0 & 2.9 & 24.0 & 2.6 & 5.0 \\
\hline
\end{tabular}


GILA RIVER BASIN

09497980 CHERRY CREEK NEAR GLOBE, AZ--Cont inued

MEAN MONTHLY AND ANMUAL DISCHARGES 1966-78, 1980-88

\begin{tabular}{|c|c|c|c|c|c|c|}
\hline MONTH & $\begin{array}{l}\operatorname{MAXIMUM} \\
\left(F^{3} / S\right)\end{array}$ & $\begin{array}{l}\operatorname{MINIMMM} \\
\left(F T^{3} / S\right)\end{array}$ & $\begin{array}{c}\text { MEAN } \\
\left(F T^{3} / S\right)\end{array}$ & $\begin{array}{l}\text { STAN- } \\
\text { DARD } \\
\text { DEVIA- } \\
\text { TION } \\
\text { (FT } 3 / S)\end{array}$ & $\begin{array}{l}\text { COEFFI - } \\
\text { CIENT OF } \\
\text { VARI - } \\
\text { ATION }\end{array}$ & $\begin{array}{c}\text { PERCENT } \\
\text { OF } \\
\text { ANNUAL } \\
\text { RUNOFF }\end{array}$ \\
\hline $\begin{array}{l}\text { OCTOBER } \\
\text { NOVEMBER } \\
\text { DECEMBER } \\
\text { JANUARY } \\
\text { FEBRUARY } \\
\text { MARCH } \\
\text { APRIL } \\
\text { MAY } \\
\text { JUNE } \\
\text { JULY } \\
\text { AUGUST } \\
\text { SEPTEMBER }\end{array}$ & $\begin{array}{r}296 \\
101 \\
537 \\
179 \\
568 \\
423 \\
195 \\
66 \\
18 \\
23 \\
85 \\
151\end{array}$ & $\begin{array}{l}4.6 \\
4.5 \\
4.8 \\
6.7 \\
6.0 \\
6.1 \\
5.3 \\
4.9 \\
4.4 \\
5.6 \\
5.5 \\
3.6\end{array}$ & $\begin{array}{l}30 \\
19 \\
67 \\
43 \\
98 \\
96 \\
30 \\
13 \\
7.7 \\
9.9 \\
17 \\
18\end{array}$ & $\begin{array}{c}64 \\
23 \\
125 \\
46 \\
133 \\
126 \\
42 \\
13 \\
3.2 \\
4.4 \\
17 \\
30\end{array}$ & $\begin{array}{l}2.1 \\
1.2 \\
1.9 \\
1.1 \\
1.4 \\
1.3 \\
1.4 \\
0.99 \\
0.42 \\
0.44 \\
0.95 \\
1.7\end{array}$ & $\begin{array}{r}6.7 \\
4.1 \\
15.0 \\
9.6 \\
21.7 \\
21.4 \\
6.7 \\
2.9 \\
1.7 \\
2.2 \\
3.9 \\
4.0\end{array}$ \\
\hline ANNUAL & 130 & 8.2 & 37 & 31 & 0.84 & 100 \\
\hline
\end{tabular}

MAGNITUDE AND PROBABILITY OF INSTANTANEOUS PEAK FLON BASED ON PERIOD OF RECORD 1966-89

DISCHARGE, IN $\mathrm{FT}^{3} / \mathrm{S}$, FOR INDICATED RECURRENCE INTERVAL IN YEARS, AND EXCEEDANCE PROBABILITY, IN PERCENT

\begin{tabular}{|c|c|c|c|c|c|}
\hline$\stackrel{2}{50 x}$ & $\underset{20 \%}{5}$ & $\begin{array}{r}10 \\
10 \%\end{array}$ & $\begin{array}{l}25 \\
4 \%\end{array}$ & $\begin{array}{l}50 \dagger \\
2 \%\end{array}$ & $\begin{array}{c}100 \dagger \\
1 \%\end{array}$ \\
\hline 2,150 & 5,480 & 8,850 & 14,700 & 20,200 & 27,000 \\
\hline $\begin{array}{l}\text { WEIGH } \\
\text { MEAN } \\
\text { STAND }\end{array}$ & SKEW & $\begin{array}{l}(x)= \\
(S S)= \\
((S)=\end{array}$ & $\begin{array}{l}09 \\
32 \\
49\end{array}$ & & \\
\hline
\end{tabular}

MAGNITUDE AND PROBABILITY OF ANNUAL LON FLOH BASED ON PERIOD OF RECORD 1967-78, 1981-89

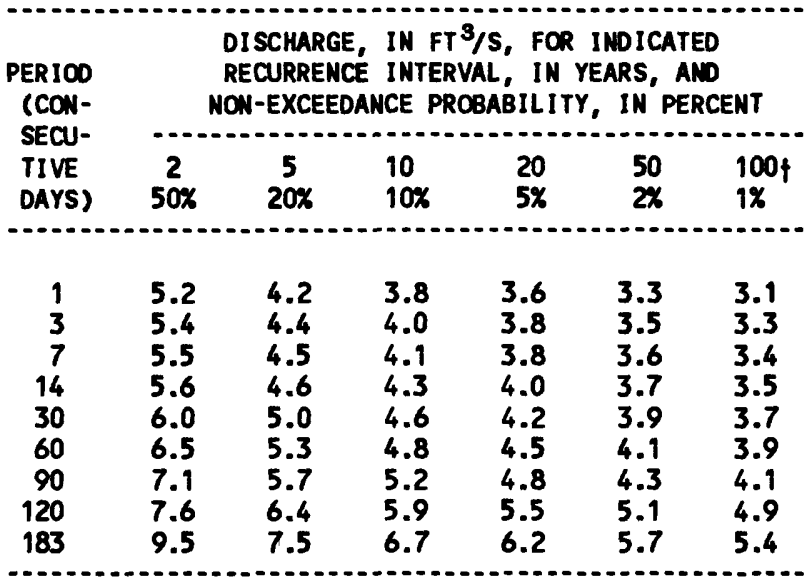

MAGNITUDE AND PROBABILITY OF ANNUAL HIGH FLOW BASED ON PERIOD OF RECORD 1966-78, 1980-88

\begin{tabular}{|c|c|c|c|c|c|c|}
\hline $\begin{array}{l}\text { PERIOD } \\
\text { (CON- } \\
\text { CECH }\end{array}$ & & $\begin{array}{l}\text { DISCHA } \\
\text { RECURR } \\
\text { EXCEED }\end{array}$ & $\begin{array}{ll}E, & \text { IN } \\
\text { CE INT } \\
\text { CE PRO }\end{array}$ & $\begin{array}{l}\text { /S, F( } \\
\text { AL, II } \\
\text { ILITY }\end{array}$ & $\begin{array}{l}\text { YEAR } \\
\text { IN P }\end{array}$ & VT \\
\hline $\begin{array}{l}\text { TIVE } \\
\text { DAYS) }\end{array}$ & $\begin{array}{c}2 \\
50 x\end{array}$ & $\begin{array}{c}5 \\
20 \%\end{array}$ & $\begin{array}{l}10 \\
10 \%\end{array}$ & $\begin{array}{l}25 \\
4 x\end{array}$ & $\begin{array}{l}50 \\
2 x\end{array}$ & $\begin{array}{c}100\} \\
1 \%\end{array}$ \\
\hline $\begin{array}{r}1 \\
3 \\
7 \\
15 \\
30 \\
60 \\
90\end{array}$ & $\begin{array}{r}765 \\
508 \\
320 \\
200 \\
129 \\
88 \\
68\end{array}$ & $\begin{array}{r}2,180 \\
1,310 \\
773 \\
474 \\
304 \\
205 \\
155\end{array}$ & $\begin{array}{r}3,610 \\
2,040 \\
1,170 \\
720 \\
467 \\
315 \\
237\end{array}$ & $\begin{array}{r}6,010 \\
3,150 \\
1,760 \\
1,090 \\
727 \\
494 \\
370\end{array}$ & $\begin{array}{l}8,210 \\
4,080 \\
2,250 \\
1,420 \\
961 \\
656 \\
491\end{array}$ & $\begin{array}{r}10,700 \\
5,070 \\
2,760 \\
1,770 \\
1,230 \\
845 \\
632\end{array}$ \\
\hline
\end{tabular}

DURATION TABLE OF DAILY MEAN FLON FOR PERICD OF RECORD 1966-78, 1980-88

DISCHARGE, IN $\mathrm{FT}^{3} / \mathrm{s}$, WHICH WAS EQUALED OR EXCEEDED FOR INDICATED PERCENT OF TIME

\begin{tabular}{|c|c|c|c|c|c|c|c|c|c|c|c|c|c|c|c|c|}
\hline $1 \%$ & $5 \%$ & $10 \%$ & $15 \%$ & $20 \%$ & $30 \%$ & $40 \%$ & $50 x$ & $60 \%$ & $70 \%$ & $80 \%$ & $90 \%$ & $95 \%$ & $98 \%$ & $99 \%$ & $99.5 \%$ & $99.9 \%$ \\
\hline 546 & 141 & 62 & 37 & 25 & 15 & 11 & 9.3 & 8.0 & 7.2 & 6.3 & 5.4 & 4.8 & 4.3 & 4.1 & 4.0 & 3.0 \\
\hline
\end{tabular}

+ Reliability of values in colum is uncertain, and potential errors are large. 

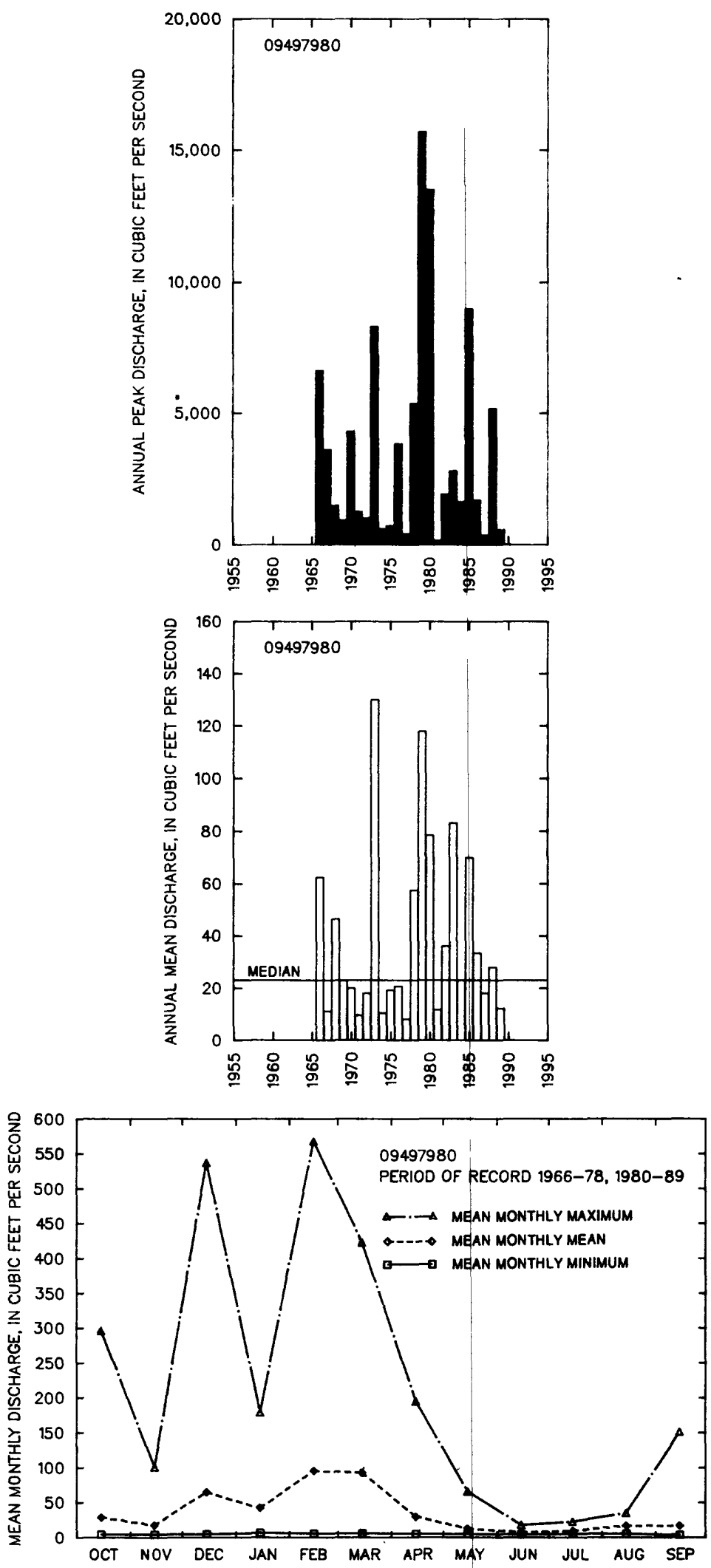


\section{SALT RIVER MEAR ROOSEVELT, AZ}

LOCATION.--Lat 33'37'10", long 110.55'15", in SEXNEX sec.9, T.3 N., R.14 E. (unsurveyed), Gila County, Hydrologic Unit 15060103, in Tonto National Forest on left bank $100 \mathrm{ft}$ downstream from bridge on State Highway 288, $0.3 \mathrm{mi}$ downstream from Pinal Creek, 1 mi upstream from diversion dam for power canal, $14 \mathrm{mi}$ east of village of Roosevelt, and $17 \mathrm{mi}$ upstream from Roosevelt Dam.

DRAIMAGE AREA. $--4,306 \mathrm{mi}^{2}$.

REMARKS.--Several small diversions for irrigation of about 4,000 acres above station and two transbasin diversions above station, one into basin from Show Low Creek and one out of basin to Willow Creek. Records show inflow to Roosevelt Lake. Tonto Creek also contributes to Roosevelt Lake.

ANMULL PEAK DISCHARGE

\begin{tabular}{|c|c|c|c|c|c|c|c|}
\hline $\begin{array}{l}\text { MATER } \\
\text { YEAR }\end{array}$ & DATE & $\begin{array}{c}\text { ANMUAL PEAK } \\
\text { DISCHARGE } \\
\text { (FT } 3 / S)\end{array}$ & $\begin{array}{l}\text { DISCHARGE } \\
\text { CODES }\end{array}$ & $\begin{array}{l}\text { WATER } \\
\text { YEAR }\end{array}$ & DATE & $\begin{array}{l}\text { ANIUUAL PEAK } \\
\text { DISCHARGE } \\
\left.\text { (FT }^{3} / \mathrm{S}\right)\end{array}$ & $\begin{array}{l}\text { DISCHARGE } \\
\text { CODES }\end{array}$ \\
\hline $\begin{array}{l}1388 \\
1916 \\
1924 \\
1925 \\
1926 \\
1927 \\
1928 \\
1929 \\
1930 \\
1931 \\
1932 \\
1933 \\
1934 \\
1935 \\
1936 \\
1937 \\
1938 \\
1939 \\
1940 \\
1941 \\
1942 \\
1943 \\
1944 \\
1945 \\
1946 \\
1947 \\
1948 \\
1949 \\
1950 \\
1951 \\
1952 \\
1953 \\
1954 \\
1955\end{array}$ & $\begin{array}{l}01-19-16 \\
12-28-23 \\
03-09-25 \\
04-07-26 \\
02-18-27 \\
02-05-28 \\
09-23-29 \\
03-17-30 \\
02-15-31 \\
02-10-32 \\
02-28-33 \\
08-04-34 \\
04-09-35 \\
02-17-36 \\
02-07-37 \\
03-04-38 \\
04-05-39 \\
07-16-40 \\
03-14-41 \\
01-13-42 \\
03-05-43 \\
09-26-44 \\
03-27-45 \\
09-19-46 \\
09-19-47 \\
04-13-48 \\
01-14-49 \\
07-21-50 \\
08-28-51 \\
01-18-52 \\
03-09-53 \\
03-23-54 \\
08-24-55\end{array}$ & $\begin{array}{r}1160,000 \\
100,000 \\
43,000 \\
9,000 \\
21,000 \\
40,000 \\
2,600 \\
15,000 \\
8,300 \\
22,000 \\
57,000 \\
4,200 \\
5,500 \\
15,200 \\
13,800 \\
88,000 \\
24,100 \\
9,050 \\
4,610 \\
211,, 000 \\
5,140 \\
16,500 \\
4,560 \\
5,450 \\
15,100 \\
6,170 \\
5,960 \\
15,500 \\
5,930 \\
27,600 \\
111,000 \\
4,320 \\
40,800 \\
8,640\end{array}$ & $\begin{array}{l}\text { PF } \\
\text { HP }\end{array}$ & $\begin{array}{l}1956 \\
1957 \\
1958 \\
1959 \\
1960 \\
1961 \\
1962 \\
1963 \\
1964 \\
1965 \\
1966 \\
1967 \\
1968 \\
1969 \\
1970 \\
1971 \\
1972 \\
1973 \\
1974 \\
1975 \\
1976 \\
1977 \\
1978 \\
1979 \\
1980 \\
1981 \\
1982 \\
1983 \\
1984 \\
1985 \\
1986 \\
1987 \\
1988 \\
1989\end{array}$ & $\begin{array}{l}01-29-56 \\
01-10-57 \\
03-23-58 \\
08-20-59 \\
12-26-59 \\
07-28-61 \\
01-25-62 \\
08-31-63 \\
09-15-64 \\
01-08-65 \\
12-23-65 \\
08-06-67 \\
12-20-67 \\
01-26-69 \\
09-06-70 \\
08-13-71 \\
12-27-71 \\
10-20-72 \\
07-20-74 \\
10-29-74 \\
02-10-76 \\
09-03-77 \\
03-02-78 \\
12-19-78 \\
02-15-80 \\
04-15-81 \\
02-12-82 \\
03-25-83 \\
10-02-83 \\
12-28-84 \\
02-16-86 \\
03-05-87 \\
09-01-88 \\
03-13-89\end{array}$ & $\begin{array}{r}1,460 \\
6,720 \\
24,000 \\
12,100 \\
78,200 \\
2,590 \\
8,540 \\
31,300 \\
3,620 \\
20,400 \\
68,800 \\
5,600 \\
17,200 \\
6,100 \\
17,300 \\
12,800 \\
30,200 \\
70,000 \\
1,500 \\
10,100 \\
16,000 \\
10,200 \\
89,400 \\
95,800 \\
99,000 \\
2,550 \\
15,200 \\
17,600 \\
59,800 \\
46,600 \\
13,300 \\
7,560 \\
11,000 \\
2,040\end{array}$ & \\
\hline
\end{tabular}

Partridge and Baker (1987).

2 Highest since 1906.

BASIN CHARACTERISTICS

\begin{tabular}{|c|c|c|c|c|c|c|c|}
\hline \multirow{2}{*}{$\begin{array}{l}\text { MAIN } \\
\text { CHANNEL } \\
\text { SLOPE } \\
\text { (FT/MI) }\end{array}$} & \multirow[b]{2}{*}{$\begin{array}{c}\text { STREAM } \\
\text { LENGTH } \\
\text { (MI) }\end{array}$} & \multirow{2}{*}{$\begin{array}{l}\text { MEAN } \\
\text { BASIN } \\
\text { ELEVA- } \\
\text { TION } \\
\text { (FT) }\end{array}$} & \multirow[b]{2}{*}{$\begin{array}{l}\text { FORESTED } \\
\text { AREA } \\
\text { (PERCENT) }\end{array}$} & \multirow[b]{2}{*}{$\begin{array}{l}\text { SOIL } \\
\text { INDEX }\end{array}$} & \multirow{2}{*}{$\begin{array}{l}\text { MEAN } \\
\text { ANWULL } \\
\text { PRECIPI- } \\
\text { TATION } \\
\text { (IN) }\end{array}$} & \multicolumn{2}{|c|}{ RAINFALL INTENSITY, 24-HOUR } \\
\hline & & & & & & $\begin{array}{c}\text { 2-YEAR } \\
\text { (IN) }\end{array}$ & $\begin{array}{c}\text { 50-YEAR } \\
\text { (IN) }\end{array}$ \\
\hline 23.3 & 206 & 6,190 & 71.0 & 2.8 & 22.0 & 2.3 & 4.4 \\
\hline
\end{tabular}


MEAN MONTHLY AND ANMUAL DISCHARGES 1914-89

\begin{tabular}{|c|c|c|c|c|c|c|}
\hline MONTH & $\begin{array}{l}\operatorname{MAXIMUN} \\
\left(\mathrm{FT}^{3} / \mathrm{S}\right)\end{array}$ & $\begin{array}{c}\operatorname{MINIMMN} \\
\left(F T^{3} / S\right)\end{array}$ & $\begin{array}{c}\text { MEAN } \\
\left(F T^{3} / S\right)\end{array}$ & $\begin{array}{l}\text { STAN- } \\
\text { DARD } \\
\text { DEVIA- } \\
\text { TION } \\
\left(F T^{3} / S\right)\end{array}$ & $\begin{array}{l}\text { COEFFI- } \\
\text { CIENT OF } \\
\text { VARI - } \\
\text { ATION }\end{array}$ & $\begin{array}{c}\text { PERCENT } \\
\text { OF } \\
\text { ANNUAL } \\
\text { RUNOFF }\end{array}$ \\
\hline $\begin{array}{l}\text { OCTOBER } \\
\text { NOVEMBER } \\
\text { DECEMBER } \\
\text { JANUARY } \\
\text { FEBRUARY } \\
\text { MARCH } \\
\text { APRIL } \\
\text { MAY } \\
\text { JUNE } \\
\text { JULY } \\
\text { AUGUST } \\
\text { SEPTEMBER }\end{array}$ & $\begin{array}{r}4,830 \\
2,150 \\
6,330 \\
16,000 \\
9,070 \\
10,400 \\
6,280 \\
5,930 \\
1,370 \\
3,280 \\
3,610 \\
1,850\end{array}$ & $\begin{array}{r}86 \\
122 \\
127 \\
161 \\
168 \\
220 \\
212 \\
127 \\
79 \\
78 \\
151 \\
78\end{array}$ & $\begin{array}{r}461 \\
380 \\
786 \\
982 \\
1,360 \\
1,960 \\
2,040 \\
1,050 \\
367 \\
341 \\
599 \\
460\end{array}$ & $\begin{array}{r}782 \\
361 \\
1,270 \\
2,020 \\
1,760 \\
1,920 \\
1,550 \\
1,050 \\
299 \\
390 \\
482 \\
349\end{array}$ & $\begin{array}{l}1.7 \\
0.95 \\
1.6 \\
2.1 \\
1.3 \\
0.98 \\
0.76 \\
1.0 \\
0.81 \\
1.2 \\
0.80 \\
0.76\end{array}$ & $\begin{array}{r}4.3 \\
3.5 \\
7.3 \\
9.1 \\
12.6 \\
18.2 \\
18.9 \\
9.7 \\
3.4 \\
3.2 \\
5.6 \\
4.3\end{array}$ \\
\hline ANNUAL & 3,250 & 236 & 896 & 653 & 0.73 & 100 \\
\hline
\end{tabular}

MagntTUDE AND PROBABILITY OF INSTANTANEOUS PEAK FLON BASED ON PERIOD OF RECORD 1388, 1924-89

DISCHARGE, IN $\mathrm{FT}^{3} / \mathrm{S}$, FOR INDICATED RECURRENCE INTERVAL IN YEARS, AND EXCEEDANCE PROBABILITY, IN PERCENT

\begin{tabular}{cccccc}
2 & 5 & 10 & 25 & 50 & 100 \\
$50 \%$ & $20 \%$ & $10 \%$ & $4 \%$ & $2 \%$ & $1 \%$ \\
\hline
\end{tabular}

$\begin{array}{llllll}13,800 & 36,000 & 60,000 & 104,000 & 150,000 & 208,000\end{array}$

WEIGHTED SKEN (LOGS) $=0.11$

MEAN (LOGS) $=4.15$

STANDARD DEV. (LOGS) $=0.48$
MAGNITUDE AND PROBABILITY OF ANNUAL LON FLON BASED ON PERIOO OF RECORD $1915-89$

\begin{tabular}{|c|c|c|c|c|c|c|}
\hline \multirow{2}{*}{$\begin{array}{l}\text { PERICD } \\
\text { (COA- }- \\
\text { SECU- } \\
\text { TIVE } \\
\text { DAYS) }\end{array}$} & \multicolumn{6}{|c|}{$\begin{array}{l}\text { DISCHARGE, IN FT } 3 / S \text {, FOR INDICATED } \\
\text { RECURRENCE INTERVAL, IN YEARS, AND } \\
\text { NON-EXCEEDANCE PROBABILITY, IN PERCENT }\end{array}$} \\
\hline & $\begin{array}{c}2 \\
50 \%\end{array}$ & $\begin{array}{c}5 \\
20 \%\end{array}$ & $\begin{array}{l}10 \\
10 \%\end{array}$ & $\begin{array}{l}20 \\
5 \%\end{array}$ & $\begin{array}{l}50 \\
2 \%\end{array}$ & $\begin{array}{l}100 \\
1 \%\end{array}$ \\
\hline $\begin{array}{r}1 \\
3 \\
7 \\
14 \\
30 \\
60 \\
90 \\
120 \\
183\end{array}$ & $\begin{array}{l}128 \\
130 \\
135 \\
144 \\
161 \\
188 \\
213 \\
234 \\
288\end{array}$ & $\begin{array}{r}93 \\
95 \\
99 \\
105 \\
116 \\
138 \\
160 \\
177 \\
210\end{array}$ & $\begin{array}{r}79 \\
81 \\
83 \\
88 \\
98 \\
117 \\
140 \\
157 \\
184\end{array}$ & $\begin{array}{r}69 \\
70 \\
72 \\
76 \\
85 \\
103 \\
126 \\
144 \\
168\end{array}$ & $\begin{array}{r}59 \\
60 \\
62 \\
65 \\
72 \\
89 \\
112 \\
133 \\
154\end{array}$ & $\begin{array}{r}53 \\
54 \\
56 \\
58 \\
65 \\
81 \\
104 \\
126 \\
146\end{array}$ \\
\hline
\end{tabular}

MaNITUDE AND PROBABILITY OF ANNUAL HIGH FLON BASED ON PERIOO OF RECORD 1914-89

\begin{tabular}{|c|c|c|c|c|c|c|}
\hline $\begin{array}{r}\text { PERIOD } \\
\text { (CON- } \\
\text { SECU- }\end{array}$ & & $\begin{array}{l}\text { DISCHA } \\
\text { RECURRE } \\
\text { EXCEEDA }\end{array}$ & $\begin{array}{l}\text { GE, IN F } \\
\text { NCE INTE } \\
\text { NCE PROB }\end{array}$ & $\begin{array}{l}\text { S/S, FC } \\
\text { IAL, II } \\
\text { ILITY, }\end{array}$ & $\begin{array}{l}\text { R INDICA } \\
\text { YEARS, } \\
\text { IN PERCE }\end{array}$ & $\begin{array}{l}\text { TED } \\
\text { AND } \\
\text { ENT }\end{array}$ \\
\hline $\begin{array}{l}\text { TIVE } \\
\text { DAYS) }\end{array}$ & $\begin{array}{c}2 \\
50 \%\end{array}$ & $\begin{array}{c}5 \\
20 \%\end{array}$ & $\begin{array}{l}10 \\
10 \%\end{array}$ & $\begin{array}{l}25 \\
4 \%\end{array}$ & $\begin{array}{l}50 \\
2 x\end{array}$ & $\begin{array}{r}100 \\
1 \%\end{array}$ \\
\hline $\begin{array}{l}1 \\
3 \\
7 \\
15 \\
30 \\
60 \\
90\end{array}$ & $\begin{array}{l}9,410 \\
6,770 \\
4,590 \\
3,200 \\
2,440 \\
1,850 \\
1,540\end{array}$ & $\begin{array}{r}25,000 \\
16,900 \\
10,300 \\
6,610 \\
4,750 \\
3,550 \\
3,010\end{array}$ & $\begin{array}{r}41,700 \\
27,600 \\
16,000 \\
9,850 \\
6,790 \\
5,020 \\
4,310\end{array}$ & $\begin{array}{r}72,300 \\
47,300 \\
26,000 \\
15,300 \\
10,000 \\
7,310 \\
6,370\end{array}$ & $\begin{array}{r}103,000 \\
67,400 \\
35,800 \\
20,500 \\
12,900 \\
9,350 \\
8,220\end{array}$ & $\begin{array}{r}142 \\
93 \\
48 \\
26 \\
16 \\
11 \\
10\end{array}$ \\
\hline
\end{tabular}

DURATION TABLE OF DAILY MEAN FLON FOR PERIOO OF RECORD 1914-89

\begin{tabular}{|c|c|c|c|c|c|c|c|c|c|c|c|c|c|c|c|c|}
\hline $1 \%$ & $5 \%$ & $10 \%$ & $15 \%$ & $20 \%$ & $30 \%$ & $40 \%$ & $50 \%$ & $60 \%$ & $70 \%$ & $80 \%$ & $90 \%$ & $95 \%$ & $98 \%$ & $99 \%$ & $99.5 \%$ & $99.9 \%$ \\
\hline .100 & 3,360 & 2,040 & 1,380 & 1,010 & 643 & 456 & 343 & 276 & 235 & 198 & 157 & 128 & 102 & 90 & 80 & 66 \\
\hline
\end{tabular}


0949B500 SALT RIVER NEAR ROOSEVELT, AZ--CONTINUED
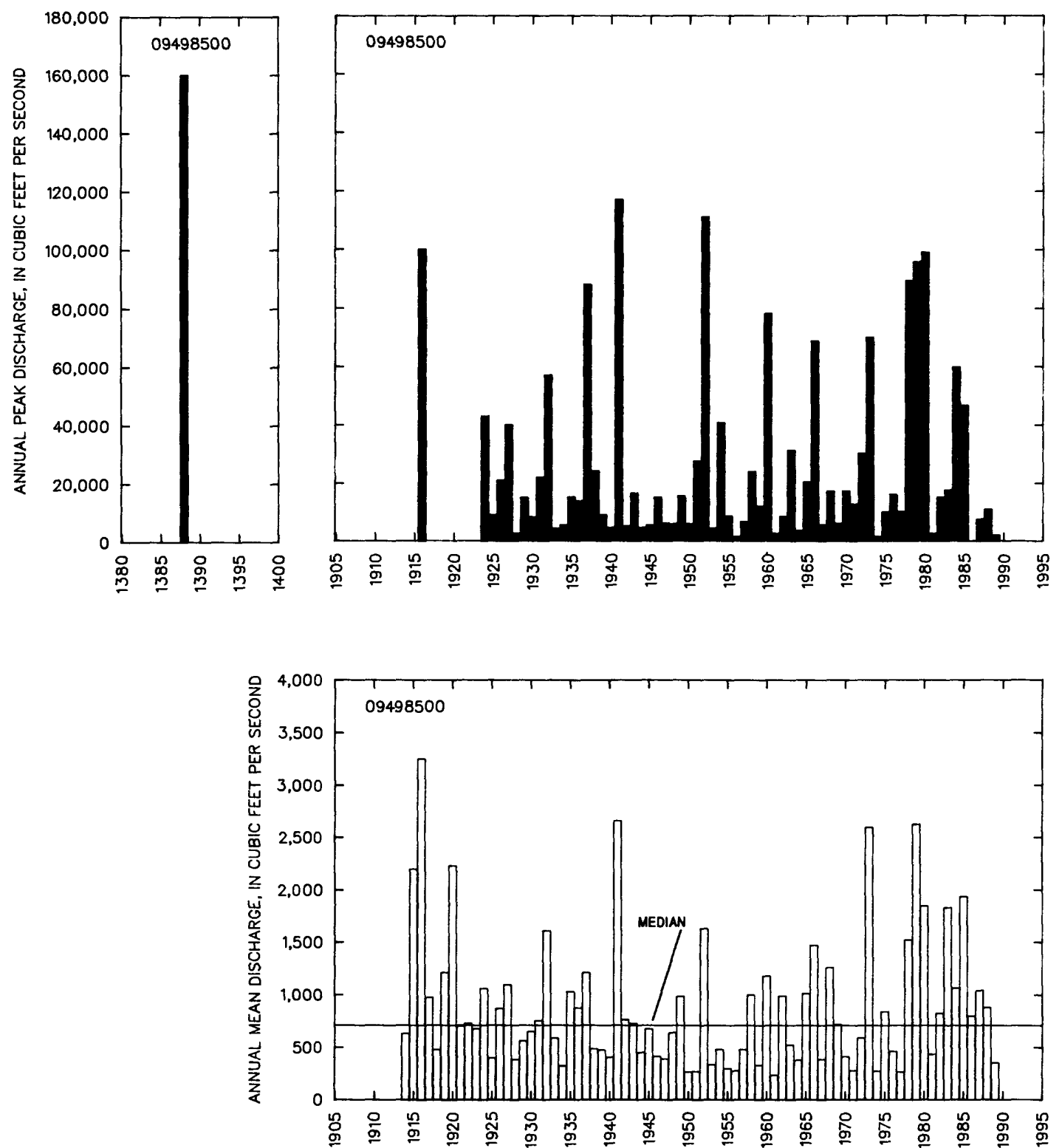
09498500 SALT RIVER MEAR ROOSEVELT, AZ--CONTINUED
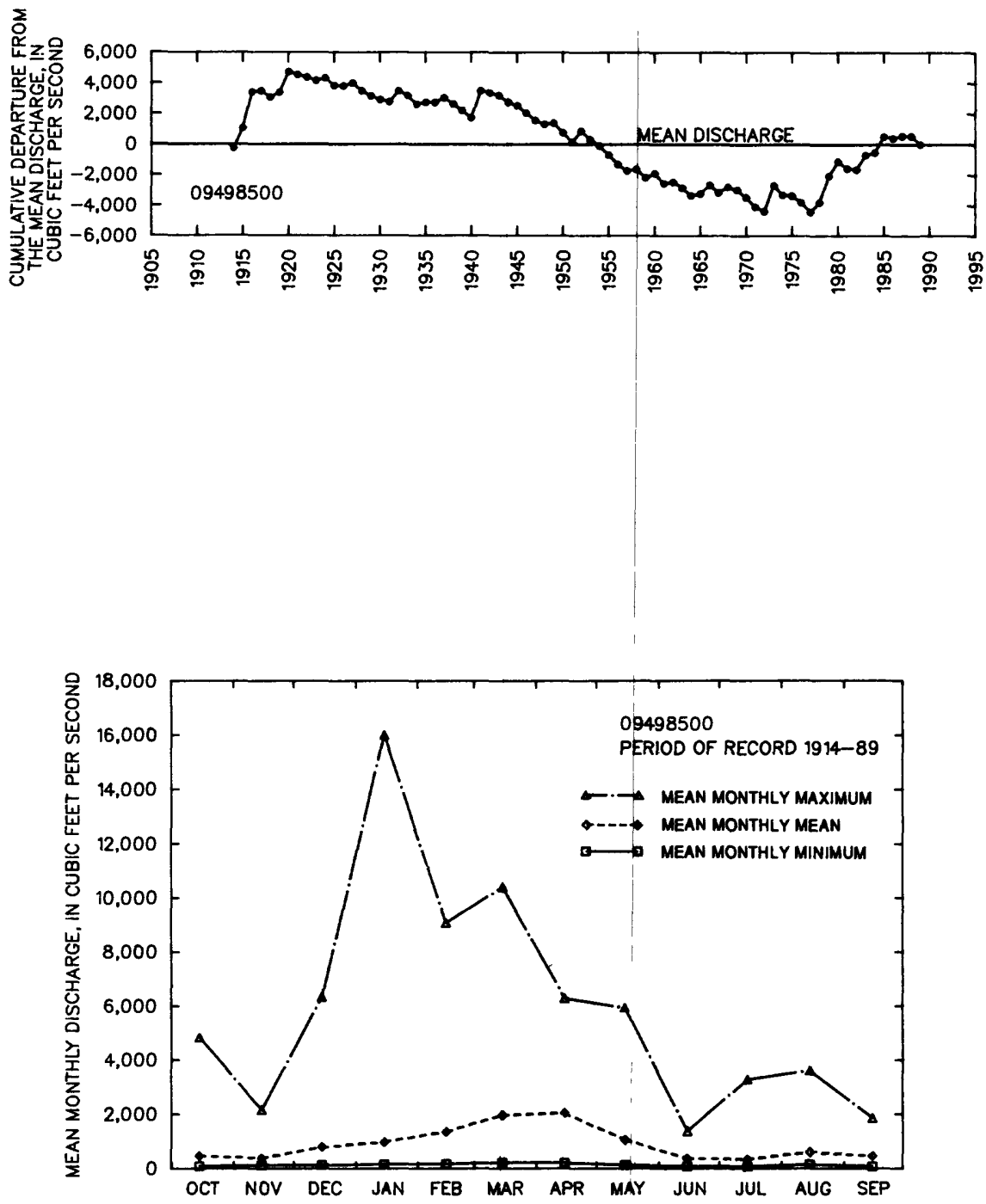
09498600 CHRISTOPHER CREEK TRIBUTARY MEAR KOHL'S RANCH, AZ

LOCATION.--Lat 34'19'20", long 111'04'00", in NEKSEK sec.22, T.11 N., R.12 E., Gila County, Hydrologic Unit 15060105, at State Highway $160,1.8 \mathrm{mi}$ east of $\mathrm{Kchl}$ 's Ranch, and $15.5 \mathrm{mi}$ northeast of Payson.

DRAIMAGE AREA. $-0.66 \mathrm{mi}^{2}$.

ANNUAL PEAK DISCHARGE

\begin{tabular}{ccc}
$\begin{array}{l}\text { WATER } \\
\text { YEAR }\end{array}$ & DATE & $\begin{array}{c}\text { ANNUAL PEAK } \\
\text { DISCHARGE } \\
\text { (FT } 3 / \text { S) }\end{array}$ \\
\hline 1966 & $12-22-65$ & 54.0 \\
1967 & $00-00-67$ & 17.0 \\
1968 & $08-10-68$ & 26.0 \\
1969 & $01-26-69$ & 14.0 \\
1970 & $09-05-70$ & 265 \\
1971 & $08-00-71$ & 8.0 \\
1972 & $08-06-72$ & 35.0 \\
1973 & $10-19-72$ & 75.0 \\
1974 & $08-05-74$ & 22.0 \\
1975 & $07-00-75$ & 16.0 \\
1976 & $02-09-76$ & 44.0 \\
\hline$\ldots$
\end{tabular}

MAGNITUDE AND PROBABILITY OF INSTANTANEOUS PEAK FLOW BASED ON PERIOD OF RECORD 1966-76

DISCHARGE, IN $\mathrm{FT}^{3} / \mathrm{S}$, FOR INDICATED RECURRENCE INTERVAL IN YEARS, AND EXCEEDANCE PROBABILITY, IN PERCENT

\begin{tabular}{|c|c|c|c|c|c|}
\hline$\stackrel{2}{50 \%}$ & $\begin{array}{c}5 \\
20 \%\end{array}$ & $\begin{array}{r}10 \\
10 \%\end{array}$ & $\begin{array}{l}25 \dagger \\
4 \%\end{array}$ & $\begin{array}{l}50 \uparrow \\
2 \%\end{array}$ & $\begin{array}{c}100 \uparrow \\
1 \%\end{array}$ \\
\hline 30.2 & 69.5 & 110 & 182 & 256 & 348 \\
\hline $\begin{array}{l}\text { WEIGHTED } \\
\text { MEAN } \\
\text { STANDARD }\end{array}$ & $\begin{array}{l}\text { SKEW } \\
\text { DEV. }\end{array}$ & $\begin{array}{l}(\text { LOGS })= \\
(\text { LOGS) }= \\
(\text { LOGS) }=\end{array}$ & $\begin{array}{l}0.24 \\
1.50 \\
0.42\end{array}$ & & \\
\hline
\end{tabular}

$\uparrow$ Reliability of values in colum is uncertain, and potential errors are large.

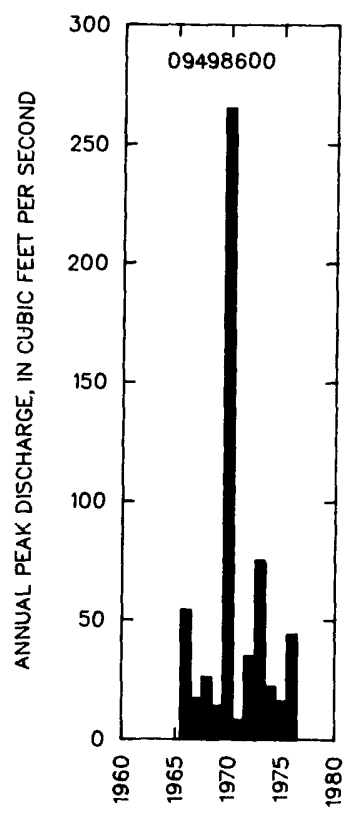

BASIN CHARACTERISTICS

\begin{tabular}{|c|c|c|c|c|c|c|c|}
\hline \multirow{2}{*}{$\begin{array}{l}\text { MAIN } \\
\text { CHANNEL } \\
\text { SLOPE } \\
\text { (FT/MI) }\end{array}$} & \multirow[b]{2}{*}{$\begin{array}{l}\text { STREAM } \\
\text { LENGTH } \\
\text { (MI) }\end{array}$} & \multirow{2}{*}{$\begin{array}{l}\text { MEAN } \\
\text { BASIN } \\
\text { ELEVA- } \\
\text { TION } \\
\text { (FT) }\end{array}$} & \multirow[b]{2}{*}{$\begin{array}{l}\text { FORESTED } \\
\text { AREA } \\
\text { (PERCENT) }\end{array}$} & \multirow[b]{2}{*}{$\begin{array}{l}\text { SOIL } \\
\text { INDEX }\end{array}$} & \multirow{2}{*}{$\begin{array}{l}\text { MEAN } \\
\text { ANNUAL } \\
\text { PRECIPI- } \\
\text { TATION } \\
\text { (IN) }\end{array}$} & \multicolumn{2}{|c|}{ RAINFALL INTENSITY, 24-HOUR } \\
\hline & & & & & & $\begin{array}{c}\text { 2-YEAR } \\
\text { (IN) }\end{array}$ & $\begin{array}{l}\text { 50-YEAR } \\
\text { (IN) }\end{array}$ \\
\hline 510 & 1.7 & 6,080 & 73.0 & 3.0 & 29.0 & 3.5 & 6.0 \\
\hline
\end{tabular}




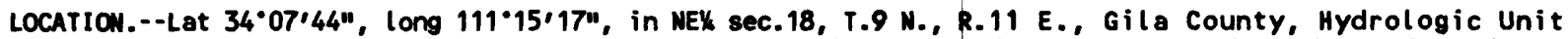
15060105, in Tonto National Forest, on left benk 0.2 mi upstrean from Houston Creek, and 1.5 mi northeast of Gisela.

DRAIMAGE AREA. $--430 \mathrm{mi}^{2}$.

\begin{tabular}{ccc}
\multicolumn{3}{c}{ ANNUAL PEAK DISCHARGE } \\
$\begin{array}{c}\text { WATER } \\
\text { YEAR }\end{array}$ & $\begin{array}{c}\text { DATE } \\
\text { ANNUAL PEAK } \\
\text { DISCHARGE } \\
\text { (FT } 3 / \text { S) }\end{array}$ \\
\hline 1965 & $01-07-65$ & 12,600 \\
1966 & $12-22-65$ & 30,000 \\
1967 & $12-07-66$ & 8,280 \\
1968 & $01-28-68$ & 14,800 \\
1969 & $01-26-69$ & 10,100 \\
1970 & $09-05-70$ & 38,000 \\
1971 & $08-19-71$ & 3,300 \\
1972 & $10-17-71$ & 2,750 \\
1973 & $10-19-72$ & 26,500 \\
1974 & $08-06-74$ & 2,400 \\
1975 & $10-29-74$ & 1,860 \\
$\ldots$
\end{tabular}

\section{BASIN CHARACTERISTICS}

\begin{tabular}{|c|c|c|c|c|c|c|c|}
\hline \multirow{2}{*}{$\begin{array}{l}\text { MAIN } \\
\text { CHANNEL } \\
\text { SLOPE } \\
\text { (FT/MI) }\end{array}$} & \multirow[b]{2}{*}{$\begin{array}{c}\text { STREAM } \\
\text { LENGTH } \\
\text { (MI) }\end{array}$} & \multirow{2}{*}{$\begin{array}{l}\text { MEAN } \\
\text { BASIN } \\
\text { ELEVA- } \\
\text { TION } \\
\text { (FT) }\end{array}$} & \multirow[b]{2}{*}{$\begin{array}{l}\text { FORESTED } \\
\text { AREA } \\
\text { (PERCENT) }\end{array}$} & \multirow[b]{2}{*}{$\begin{array}{l}\text { SOIL } \\
\text { INDEX }\end{array}$} & \multirow{2}{*}{$\begin{array}{l}\text { MEAN } \\
\text { ANNUAL } \\
\text { PRECIPI- } \\
\text { TATION } \\
\text { (IN) }\end{array}$} & \multicolumn{2}{|c|}{ RAINFALL INTENSITY, 24-HOUR } \\
\hline & & & & & & $\begin{array}{c}\text { 2-YEAR } \\
\text { (IN) }\end{array}$ & $\begin{array}{l}\text { 50-YEAR } \\
\text { (IN) }\end{array}$ \\
\hline 126 & 29.6 & 5,810 & 79.0 & 3.0 & 24.7 & 2.8 & 5.5 \\
\hline
\end{tabular}


09498800 TONTO CREEK NEAR GISELA, AZ--Continued

MEAN MONTHLY AND ANMUAL DISCHARGES 1966-75

\begin{tabular}{|c|c|c|c|c|c|c|}
\hline MONTH & 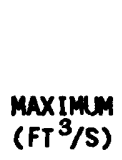 & $\begin{array}{l}\text { MINIMMM } \\
\left.\text { (FT }^{3} / S\right)\end{array}$ & $\begin{array}{c}\text { MEAN } \\
\left(F T^{3} / S\right)\end{array}$ & $\begin{array}{l}\text { STAN- } \\
\text { DARD } \\
\text { DEVIA- } \\
\text { IION } \\
\left(\text { FT }^{3} / S\right)\end{array}$ & $\begin{array}{l}\text { COEFFI- } \\
\text { CIENT OF } \\
\text { VARI - } \\
\text { ATION }\end{array}$ & $\begin{array}{c}\text { PERCENT } \\
\text { OF } \\
\text { ANNUAL } \\
\text { RUNOFF }\end{array}$ \\
\hline $\begin{array}{l}\text { OCTOBER } \\
\text { NOVEMBER } \\
\text { DECEMBER } \\
\text { JANUURY } \\
\text { FEBRUARY } \\
\text { MARCH } \\
\text { APRIL } \\
\text { MAY } \\
\text { JUNE } \\
\text { JULY } \\
\text { AUGUST } \\
\text { SEPTEEMER }\end{array}$ & $\begin{array}{r}761 \\
326 \\
1,970 \\
602 \\
753 \\
1,160 \\
568 \\
235 \\
39 \\
49 \\
103 \\
481\end{array}$ & $\begin{array}{l}7.8 \\
11 \\
16 \\
15 \\
15 \\
15 \\
11 \\
6.8 \\
3.3 \\
8.3 \\
6.7 \\
8.1\end{array}$ & $\begin{array}{r}118 \\
67 \\
344 \\
182 \\
168 \\
242 \\
132 \\
46 \\
14 \\
22 \\
40 \\
64\end{array}$ & $\begin{array}{c}238 \\
97 \\
603 \\
227 \\
248 \\
343 \\
186 \\
68 \\
9.6 \\
13 \\
30 \\
147\end{array}$ & $\begin{array}{l}2.0 \\
1.5 \\
1.8 \\
1.2 \\
1.5 \\
1.4 \\
1.4 \\
1.5 \\
0.68 \\
0.59 \\
0.77 \\
2.3\end{array}$ & $\begin{array}{r}8.2 \\
4.6 \\
23.9 \\
12.7 \\
11.7 \\
16.8 \\
9.2 \\
3.2 \\
1.0 \\
1.5 \\
2.7 \\
4.5\end{array}$ \\
\hline ANNUAL & 377 & 24 & 120 & 112 & 0.93 & 100 \\
\hline
\end{tabular}

MENITLDE AND PROBABILITY OF ANMUAL LOW FLOW BASED ON PERIOD OF RECORD 1966-75

\begin{tabular}{|c|c|c|c|c|c|c|}
\hline \multirow{2}{*}{$\begin{array}{l}\text { PERIOD } \\
\text { (CON- } \\
\text { SECU- } \\
\text { TIVE } \\
\text { DAYS) }\end{array}$} & \multicolumn{6}{|c|}{$\begin{array}{l}\text { DISCHARGE, IN } \mathrm{FT}^{3} / \mathrm{S}, \text { FOR INDICATED } \\
\text { RECURRENCE INTERVAL, IN YEARS, AND } \\
\text { NON-EXCEEDANCE PROBABILITY, IN PERCENT }\end{array}$} \\
\hline & $\begin{array}{c}2 \\
50 \%\end{array}$ & $\begin{array}{c}5 \\
20 \%\end{array}$ & $\begin{array}{l}10 \\
10 \%\end{array}$ & $\begin{array}{l}20 \\
5 x\end{array}$ & $\begin{array}{l}50 \dagger \\
2 x\end{array}$ & $\begin{array}{l}100+ \\
1 \%\end{array}$ \\
\hline $\begin{array}{r}1 \\
3 \\
7 \\
14 \\
30 \\
60 \\
90 \\
120 \\
183\end{array}$ & $\begin{array}{l}5.7 \\
5.8 \\
6.1 \\
6.8 \\
8.0 \\
9.6 \\
13 \\
15 \\
20\end{array}$ & $\begin{array}{c}3.4 \\
3.6 \\
3.8 \\
4.2 \\
5.1 \\
6.6 \\
9.2 \\
11 \\
15\end{array}$ & $\begin{array}{r}2.5 \\
2.6 \\
2.8 \\
3.0 \\
3.6 \\
5.0 \\
7.4 \\
9.2 \\
12\end{array}$ & $\begin{array}{r}1.9 \\
2.0 \\
2.1 \\
2.3 \\
2.6 \\
3.9 \\
6.1 \\
7.7 \\
10\end{array}$ & $\begin{array}{l}1.3 \\
1.4 \\
1.5 \\
1.5 \\
1.7 \\
2.7 \\
4.6 \\
6.2 \\
8.4\end{array}$ & $\begin{array}{l}1.0 \\
1.1 \\
1.1 \\
1.2 \\
1.2 \\
2.1 \\
3.8 \\
5.3 \\
7.1\end{array}$ \\
\hline
\end{tabular}

MAGNITUDE AND PROBABILITY OF ANNULL HIGH FLON BASED ON PERIOD OF RECORD 1966-75

\begin{tabular}{|c|c|c|c|c|c|c|}
\hline \multirow{2}{*}{$\begin{array}{l}\text { PERIOD } \\
\text { (CON- } \\
\text { SECU- } \\
\text { TIVE } \\
\text { DAYS) }\end{array}$} & & \multicolumn{5}{|c|}{$\begin{array}{l}\text { DISCHARGE, IN } \mathrm{FT}^{3} / \mathrm{S}, \text { FOR INDICATED } \\
\text { RECURRENCE INTERVAL, IN YEARS, AND } \\
\text { EXCEEDANCE PROBABILITY, IN PERCENT }\end{array}$} \\
\hline & $\stackrel{2}{20 x}$ & $\begin{array}{c}5 \\
20 \%\end{array}$ & $\begin{array}{l}10 \\
10 \%\end{array}$ & $\begin{array}{l}25 \uparrow \\
4 \%\end{array}$ & $\begin{array}{l}50 \uparrow \\
2 \%\end{array}$ & 10 \\
\hline $\begin{array}{l}1 \\
3 \\
7 \\
15 \\
30 \\
60 \\
90\end{array}$ & $\begin{array}{l}3,400 \\
2,090 \\
1,160 \\
703 \\
436 \\
294 \\
234\end{array}$ & $\begin{array}{r}8,140 \\
4,690 \\
2,360 \\
1,420 \\
962 \\
682 \\
531\end{array}$ & $\begin{array}{r}12,400 \\
6,930 \\
3,290 \\
2,050 \\
1,480 \\
1,060 \\
814\end{array}$ & $\begin{array}{r}18,900 \\
10,300 \\
4,570 \\
3,020 \\
2,380 \\
1,720 \\
1,280\end{array}$ & $\begin{array}{r}24,400 \\
13,100 \\
5,580 \\
3,880 \\
3,250 \\
2,350 \\
1,720\end{array}$ & $\begin{array}{r}30, \\
16, \\
6, \\
4, \\
4, \\
3, \\
2,\end{array}$ \\
\hline
\end{tabular}

DURATION TABLE OF DAILY MEAN FLON FOR PERIOD OF RECORD 1966-75

DISCHARGE, IN FT $3 / 5$, WHICH WAS EQUALED OR EXCEEDED FOR IMDICATED PERCENT OF TIME

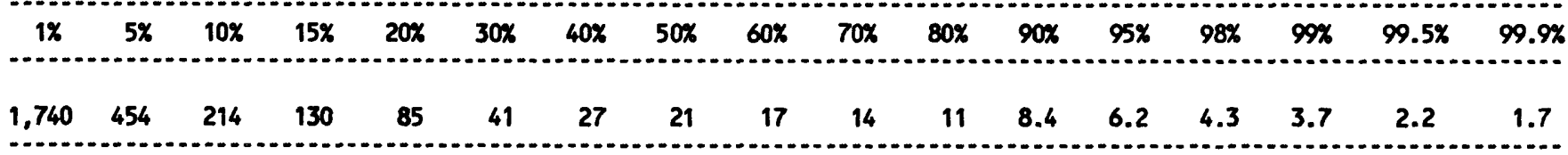

† Reliability of values in colum is uncertain, and potential errors are large. 
GIL RIVER BASIM

09498800 TONTO CREEX NENR GISELA, AZ--CONTIMUED
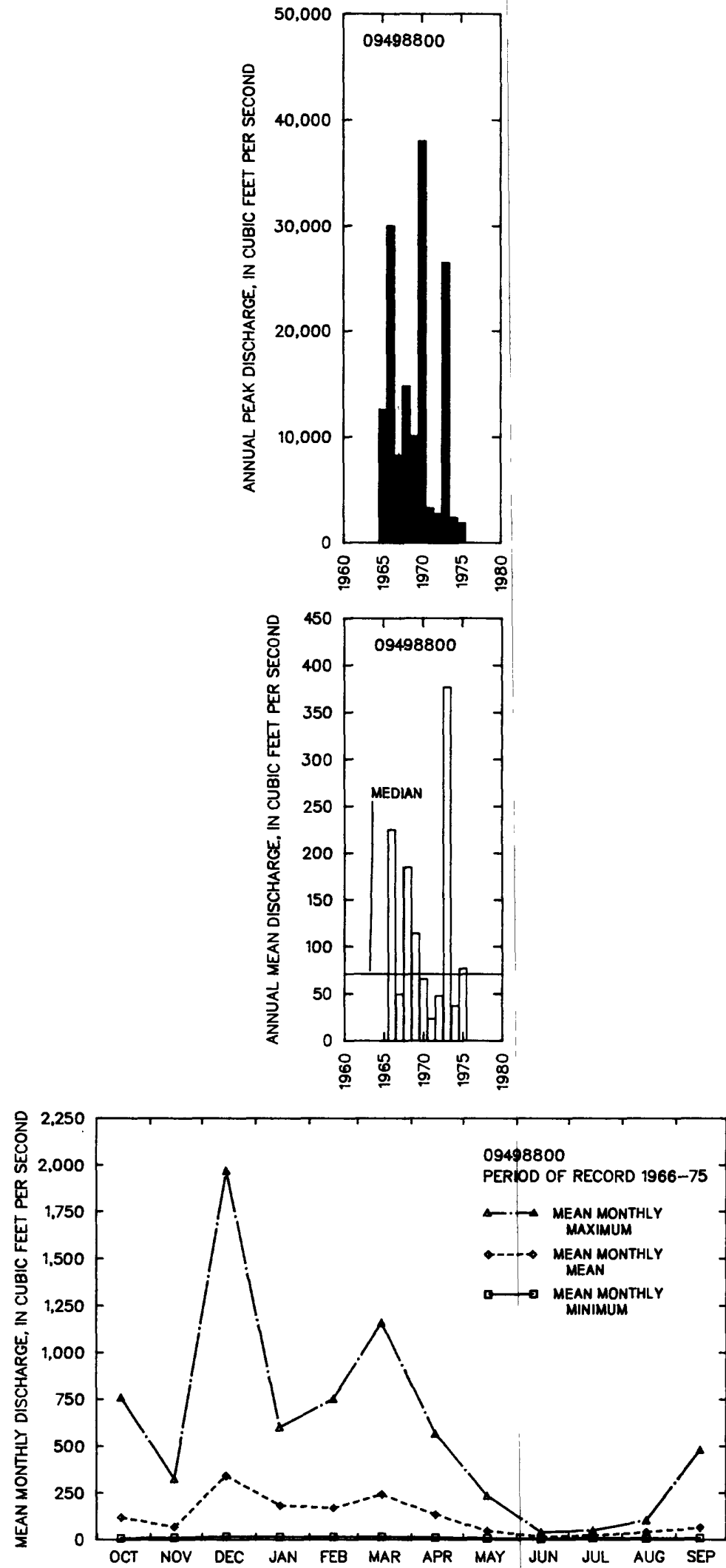
09498870 RYE CREEK NEAR GISELA, AZ

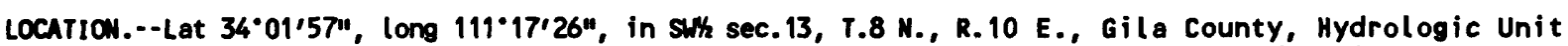
15060105, in Tonto National Forest, on right bank, $0.5 \mathrm{mi}$ upstream fron mouth, $0.8 \mathrm{mi}$ downstream from bridge on county road, and $4.8 \mathrm{mi}$ south of Gisela.

DRAINAGE AREA. $--122 \mathrm{mi}^{2}$.

ANNUAL PEAK DISCHARGE

\begin{tabular}{|c|c|c|c|}
\hline $\begin{array}{l}\text { WATER } \\
\text { YEAR }\end{array}$ & DATE & $\begin{array}{c}\text { ANMUUAL PEAK } \\
\text { DISCHARGE } \\
\left(F^{3} / \mathrm{S}\right)\end{array}$ & $\begin{array}{l}\text { DISCHARGE } \\
\text { CODES }\end{array}$ \\
\hline $\begin{array}{l}1963 \\
1966 \\
1967 \\
1968 \\
1969 \\
1970 \\
1971 \\
1972 \\
1973 \\
1974 \\
1975 \\
1976 \\
1977 \\
1978 \\
1979 \\
1980 \\
1981 \\
1982 \\
1983 \\
1984 \\
1985\end{array}$ & $\begin{array}{l}08-22-63 \\
12-22-65 \\
08-09-67 \\
12-19-67 \\
07-25-69 \\
09-05-70 \\
08-19-71 \\
09-02-72 \\
10-07-72 \\
07-07-74 \\
07-08-75 \\
02-09-76 \\
08-15-77 \\
03-02-78 \\
01-17-79 \\
02-19-80 \\
08-01-81 \\
08-11-82 \\
09-30-83 \\
09-10-84 \\
12-27-84\end{array}$ & $\begin{array}{r}10,000 \\
18,130 \\
5,290 \\
2,520 \\
2,080 \\
244,400 \\
810 \\
1,350 \\
4,250 \\
1,450 \\
1,020 \\
2,700 \\
3,020 \\
8,220 \\
5,230 \\
4,550 \\
1,530 \\
5,220 \\
4,280 \\
1,710 \\
2,300\end{array}$ & ES, HP \\
\hline
\end{tabular}

BASIN CHARACTERISTICS

\begin{tabular}{|c|c|c|c|c|c|c|c|}
\hline \multirow{3}{*}{$\begin{array}{l}\text { MAIN } \\
\text { CHANNEL } \\
\text { SLOPE } \\
\text { (FT/MI) }\end{array}$} & \multirow[b]{3}{*}{$\begin{array}{l}\text { STREAM } \\
\text { LENGTH } \\
\text { (MI) }\end{array}$} & \multirow{3}{*}{$\begin{array}{l}\text { MEAN } \\
\text { BASIN } \\
\text { ELEVA- } \\
\text { TION } \\
\text { (FT) }\end{array}$} & \multirow[b]{3}{*}{$\begin{array}{l}\text { FORESTED } \\
\text { AREA } \\
\text { (PERCENT) }\end{array}$} & \multirow{2}{*}{\multicolumn{2}{|c|}{$\begin{array}{c}\text { MEAN } \\
\text { ANNUAL } \\
\text { PRECIPI- }\end{array}$}} & \multirow{2}{*}{\multicolumn{2}{|c|}{ RAINFALL INTENSITY, 24-HORR }} \\
\hline & & & & & & & \\
\hline & & & & $\begin{array}{l}\text { SOIL } \\
\text { INDEX }\end{array}$ & $\begin{array}{l}\text { PRECIPI- } \\
\text { TATION } \\
\text { (IN) }\end{array}$ & $\begin{array}{c}\text { 2-YEAR } \\
\text { (IN) }\end{array}$ & $\begin{array}{l}\text { 50-YEAR } \\
\text { (IN) }\end{array}$ \\
\hline 91.4 & 15.6 & 4,390 & 21.0 & 3.0 & 24.2 & 2.8 & 5.0 \\
\hline
\end{tabular}


MEAN MONTHLY AND ANNUAL DISCHARGES 1967-85

\begin{tabular}{|c|c|c|c|c|c|c|}
\hline MONTH & $\begin{array}{l}\text { MAXIMUN } \\
(F T 3 / S)\end{array}$ & $\begin{array}{l}\operatorname{MINIMUN} \\
\left(\mathrm{FT}^{3} / \mathrm{S}\right)\end{array}$ & $\begin{array}{c}\text { MEAN } \\
\left(\mathrm{FT}^{3} / \mathrm{S}\right)\end{array}$ & $\begin{array}{l}\text { STAN- } \\
\text { DARD } \\
\text { DEVIA- } \\
\text { TION } \\
\text { (FT } 3 / S)\end{array}$ & $\begin{array}{l}\text { COEFFI - } \\
\text { CIENT OF } \\
\text { VARI - } \\
\text { ATION }\end{array}$ & $\begin{array}{c}\text { PERCENT } \\
\text { OF } \\
\text { ANNUAL } \\
\text { RUNOFF }\end{array}$ \\
\hline $\begin{array}{l}\text { OCTOBER } \\
\text { NOVEMBER } \\
\text { DECEMBER } \\
\text { JANUARY } \\
\text { FEBRUARY } \\
\text { MARCH } \\
\text { APRIL } \\
\text { MAY } \\
\text { JUNE } \\
\text { JULY } \\
\text { AUCUST } \\
\text { SEPTEMBER }\end{array}$ & $\begin{array}{c}89 \\
71 \\
171 \\
222 \\
495 \\
608 \\
94 \\
18 \\
6.5 \\
12 \\
22 \\
97\end{array}$ & $\begin{array}{l}0.74 \\
0.69 \\
0.71 \\
1.0 \\
1.0 \\
1.2 \\
1.3 \\
0.99 \\
0.81 \\
0.63 \\
1.0 \\
1.1\end{array}$ & $\begin{array}{c}10 \\
11 \\
36 \\
41 \\
80 \\
90 \\
22 \\
6.3 \\
3.2 \\
4.5 \\
7.1 \\
11\end{array}$ & $\begin{array}{c}21 \\
21 \\
55 \\
61 \\
121 \\
148 \\
27 \\
5.3 \\
1.8 \\
2.7 \\
5.6 \\
22\end{array}$ & $\begin{array}{l}2.0 \\
1.9 \\
1.5 \\
1.5 \\
1.5 \\
1.7 \\
1.2 \\
0.84 \\
0.56 \\
0.60 \\
0.78 \\
2.1\end{array}$ & $\begin{array}{r}3.2 \\
3.4 \\
11.3 \\
12.7 \\
24.7 \\
27.9 \\
6.9 \\
2.0 \\
1.0 \\
1.4 \\
2.2 \\
3.3\end{array}$ \\
\hline NNUAL & 77 & 1.6 & 27 & 27 & 1.0 & 100 \\
\hline
\end{tabular}

MAGNITLDE AMD PROBABILITY OF INSTANTANEOUS PEAK FLON BASED ON PERIOD OF RECORD 1963, 1966-85

\begin{tabular}{|c|c|c|c|c|c|}
\hline$\stackrel{2}{2}$ & $\begin{array}{c}5 \\
20 \%\end{array}$ & $\begin{array}{r}10 \\
10 \%\end{array}$ & $\begin{array}{l}25 \\
4 \%\end{array}$ & $\begin{array}{l}50 \dagger \\
2 \%\end{array}$ & $\begin{array}{c}100 \dagger \\
1 \%\end{array}$ \\
\hline 2,850 & 6,100 & 9,700 & 16,800 & 24,600 & 35,400 \\
\hline
\end{tabular}

WEIGHTED SKEW (LOGS) $=0.79$

MEAN (LOGS) $=3.50$

STANDARD DEV. (LOGS) $=0.36$
MAEITUDE AND PROBABILITY OF ANMUAL LON FLON BASED ON PERIOD OF RECORD 1967-85

\begin{tabular}{|c|c|c|c|c|c|c|}
\hline \multirow{2}{*}{$\begin{array}{l}\text { PERIOD } \\
\text { (CON- } \\
\text { SECU- } \\
\text { TIVE } \\
\text { DAYS) }\end{array}$} & \multicolumn{6}{|c|}{$\begin{array}{l}\text { DISCHARGE, IN } \mathrm{FT}^{3} / \mathrm{S} \text {, FOR INDICATED } \\
\text { RECURRENCE INTERVAL, IN YEARS, AND } \\
\text { MON-EXCEEDANCE PROBABILITY, IN PERCENT }\end{array}$} \\
\hline & $\begin{array}{c}2 \\
50 \%\end{array}$ & $\begin{array}{c}5 \\
20 \%\end{array}$ & $\begin{array}{l}10 \\
10 \%\end{array}$ & $\begin{array}{l}20 \\
5 \%\end{array}$ & $\begin{array}{l}50 \dagger \\
2 \%\end{array}$ & $\begin{array}{l}100 \dagger \\
1 \%\end{array}$ \\
\hline $\begin{array}{r}1 \\
3 \\
7 \\
14 \\
30 \\
60 \\
90 \\
120 \\
183\end{array}$ & $\begin{array}{l}0.96 \\
0.98 \\
1.0 \\
1.1 \\
1.2 . \\
1.5 \\
1.7 \\
2.1 \\
2.8\end{array}$ & $\begin{array}{l}0.53 \\
0.56 \\
0.62 \\
0.72 \\
0.82 \\
1.0 \\
1.2 \\
1.3 \\
1.8\end{array}$ & $\begin{array}{l}0.37 \\
0.41 \\
0.47 \\
0.57 \\
0.66 \\
0.82 \\
0.97 \\
1.1 \\
1.5\end{array}$ & $\begin{array}{l}0.27 \\
0.31 \\
0.38 \\
0.48 \\
0.55 \\
0.70 \\
0.81 \\
0.89 \\
1.3\end{array}$ & $\begin{array}{l}0.18 \\
0.22 \\
0.29 \\
0.38 \\
0.45 \\
0.58 \\
0.66 \\
0.72 \\
1.1\end{array}$ & $\begin{array}{l}0.14 \\
0.18 \\
0.24 \\
0.33 \\
0.40 \\
0.51 \\
0.57 \\
0.63 \\
1.0\end{array}$ \\
\hline
\end{tabular}

MAGNITLOE AND PROBABILITY OF ANMUAL HIGH FLOH BASED ON PERIOD OF RECORD 1967-85

\begin{tabular}{|c|c|c|c|c|c|c|}
\hline $\begin{array}{l}\text { PERIOD } \\
\text { (CON- } \\
\text { QECI- }\end{array}$ & & $\begin{array}{l}\text { DISCHA } \\
\text { RECURR } \\
\text { EXCEED }\end{array}$ & $\begin{array}{l}\text { IN } \\
\text { E INT } \\
\text { E PRO }\end{array}$ & $\begin{array}{l}\text { 3/S, } \\
\text { VAL, II } \\
\text { BILITY }\end{array}$ & $\begin{array}{l}\text { INDIC } \\
\text { YEARS, } \\
\text { IN PER }\end{array}$ & \\
\hline $\begin{array}{l}\text { TIVE } \\
\text { DAYS) }\end{array}$ & $\begin{array}{c}2 \\
50 \%\end{array}$ & $\begin{array}{c}5 \\
20 \%\end{array}$ & $\begin{array}{l}10 \\
10 \%\end{array}$ & $\begin{array}{l}25 \\
4 \%\end{array}$ & $\begin{array}{l}50 \dagger \\
2 \%\end{array}$ & $\begin{array}{c}100 \dagger \\
1 \%\end{array}$ \\
\hline $\begin{array}{r}1 \\
3 \\
7 \\
15 \\
30 \\
60 \\
90\end{array}$ & $\begin{array}{r}534 \\
289 \\
169 \\
101 \\
66 \\
46 \\
36\end{array}$ & $\begin{array}{r}1,620 \\
967 \\
616 \\
376 \\
240 \\
170 \\
132\end{array}$ & $\begin{array}{r}2.790 \\
1.730 \\
1.140 \\
706 \\
441 \\
318 \\
247\end{array}$ & $\begin{array}{r}4,890 \\
3,110 \\
2,110 \\
1,330 \\
806 \\
596 \\
467\end{array}$ & $\begin{array}{r}6,940 \\
4,460 \\
3,070 \\
1,950 \\
1,160 \\
874 \\
690\end{array}$ & $\begin{array}{r}9,420 \\
6,090 \\
4,230 \\
2,720 \\
1,590 \\
1,220 \\
968\end{array}$ \\
\hline
\end{tabular}

DURATION TABLE OF DAILY MEAN FLON FOR PERICO OF RECORD 1967-85

DISCHARGE, IN FT $3 / \mathrm{S}$, WHICH WAS EQUALED OR EXCEEDED FOR INDICATED PERCENT OF TIME

\begin{tabular}{|c|c|c|c|c|c|c|c|c|c|c|c|c|c|c|c|c|}
\hline $1 \%$ & $5 \%$ & $10 \%$ & $15 \%$ & $20 \%$ & $30 \%$ & $40 \%$ & $50 \%$ & $60 \%$ & $70 x$ & $80 \%$ & $90 \%$ & $95 \%$ & $98 \%$ & $99 \%$ & $99.5 \%$ & $99.9 \%$ \\
\hline 422 & 111 & 49 & 22 & 11 & 5.0 & 3.6 & 2.7 & 2.1 & 1.8 & 1.5 & 1.1 & 0.82 & 0.60 & 0.54 & 0.51 & .3 \\
\hline
\end{tabular}

$\uparrow$ Reliability of values in column is uncertain, and potential errors are large. 
GILA RIVER BASIM

09498870 RYE CREEK NEAR GISELA, AZ--CONTIMUED
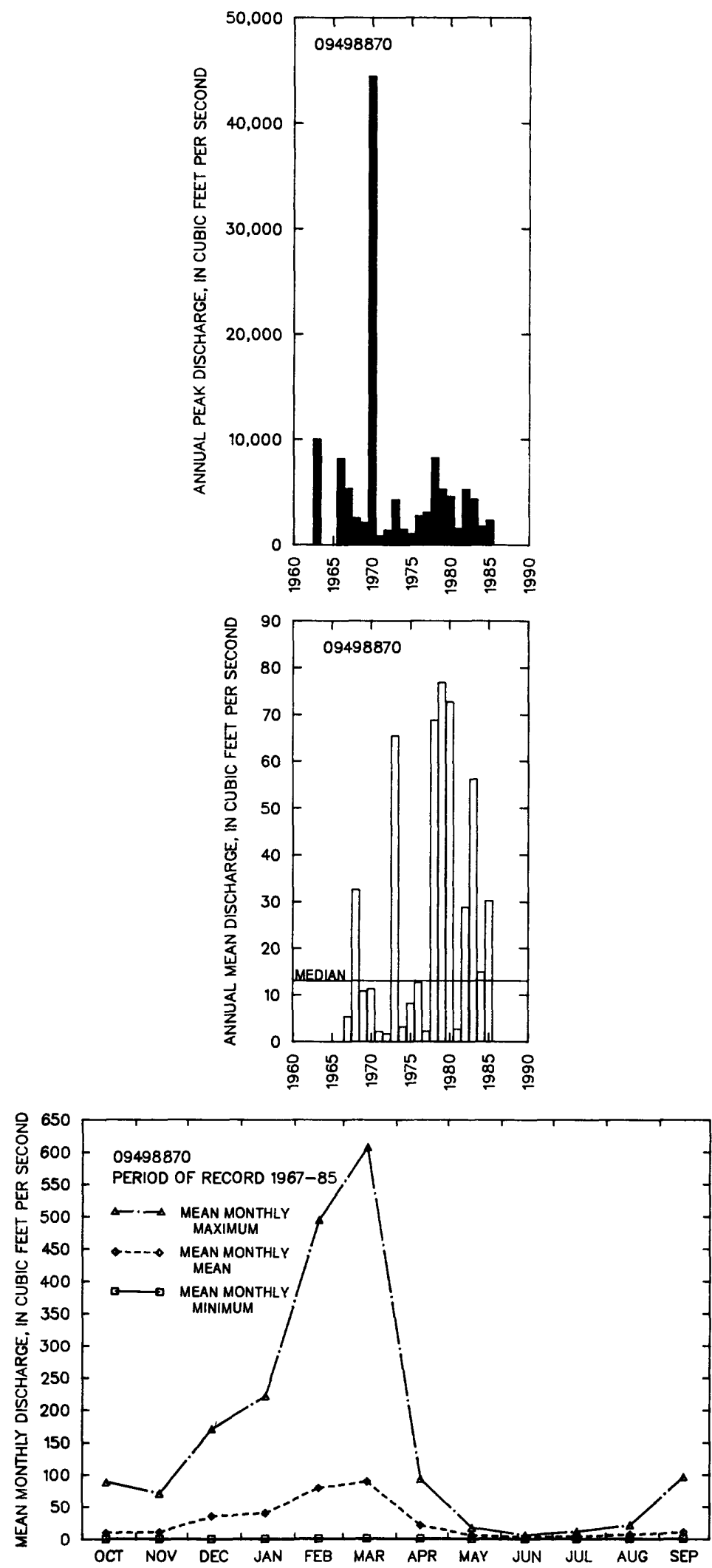
LOCATION.-- Lat 34'00'10", Long 111.21'30", in SWK sec.29, T.8 N., R.10 E., Gila County, Hydrologic Unit 15060105, at State Highway 87, 16 mi south of Payson.

DRAIMAGE AREA. $--6.44 \mathrm{mi}^{2}$.

ANMUAL PEAK DISCHARGE

\begin{tabular}{|c|c|c|c|}
\hline $\begin{array}{l}\text { WATER } \\
\text { YEAR }\end{array}$ & DATE & $\begin{array}{c}\text { ANNUAL PEAK } \\
\text { DISCHARGE } \\
\text { (FT } 3 / S)\end{array}$ & $\begin{array}{l}\text { DISCHARGE } \\
\text { CODES }\end{array}$ \\
\hline $\begin{array}{l}1963 \\
1964 \\
1965 \\
1966 \\
1967 \\
1968 \\
1969 \\
1970 \\
1971 \\
1972 \\
1973 \\
1974 \\
1975 \\
1976 \\
1979\end{array}$ & $\begin{array}{l}08-22-63 \\
07-15-64 \\
01-07-65 \\
12-22-65 \\
08-05-67 \\
12-19-67 \\
00-00-69 \\
09-05-70 \\
08-19-71 \\
06-22-72 \\
10-06-72 \\
01-08-74 \\
10-29-74 \\
02-09-76 \\
12-18-78\end{array}$ & $\begin{array}{r}1,370 \\
163 \\
215 \\
500 \\
510 \\
620 \\
15 \\
2,800 \\
125 \\
160 \\
515 \\
50 \\
12 \\
375 \\
1,120\end{array}$ & $\begin{array}{l}\text { ES } \\
\text { HP }\end{array}$ \\
\hline
\end{tabular}

IHighest since 1970 .

MAGNITUDE AND PROBABILITY OF INSTANTANEOUS PEAK FLOW BASED ON PERICD OF RECORD 1963-76, 1979

DISCHARGE, IN $\mathrm{FT}^{3} / \mathrm{S}$, FOR INDICATED RECURRENCE INTERVAL

IN YEARS, AND EXCEEDANCE PROBABILITY, IN PERCENT

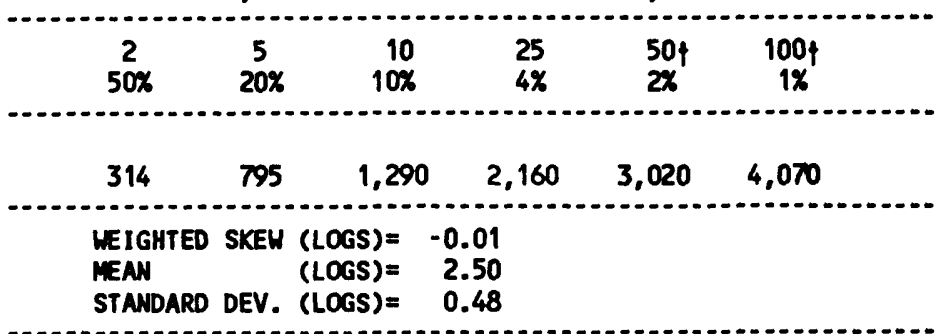

t Reliability of values in column is uncertain, and potential errors are large.

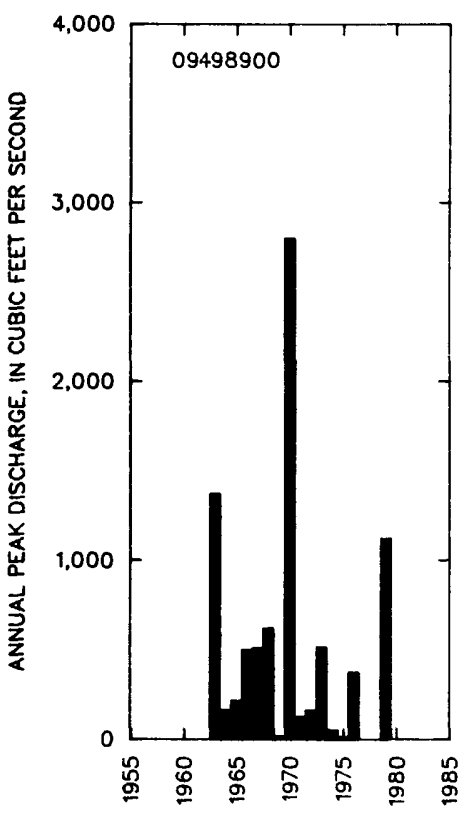

BASIN CHARACTERISTICS

\begin{tabular}{|c|c|c|c|c|c|c|c|}
\hline MAIN & & $\begin{array}{l}\text { MEAN } \\
\text { BASIN }\end{array}$ & & & $\begin{array}{l}\text { MEAN } \\
\text { ANMUAL }\end{array}$ & RAINFALL II & SITY, 24-HOUR \\
\hline $\begin{array}{c}\text { CHANNEL } \\
\text { SLOPE } \\
\text { (FT/MI) }\end{array}$ & $\begin{array}{l}\text { STREAM } \\
\text { LENGTH } \\
\text { (MI) }\end{array}$ & $\begin{array}{l}\text { ELEVA- } \\
\text { TION } \\
\text { (FT) }\end{array}$ & $\begin{array}{l}\text { FORESTED } \\
\text { AREA } \\
\text { (PERCENT) }\end{array}$ & $\begin{array}{l}\text { SOIL } \\
\text { INDEX }\end{array}$ & $\begin{array}{l}\text { PRECIPI - } \\
\text { TATION } \\
\text { (IN) }\end{array}$ & $\begin{array}{c}\text { 2-YEAR } \\
\text { (IN) }\end{array}$ & $\begin{array}{c}\text { 50-YEAR } \\
\text { (IN) }\end{array}$ \\
\hline 295 & 4.4 & 4,590 & 6.5 & 3.0 & 21.0 & 2.9 & 5.5 \\
\hline
\end{tabular}


09499000 TONTO CREEK ABOVE GUN CREEK, NEAR ROOSEVELT, AZ

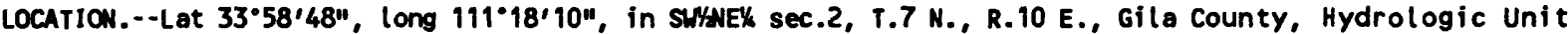
15060105 , in Tonto National forest, on left bank $600 \mathrm{ft}$ upstream from Gun Creek, 17 mi upstream from high-water line of Roosevelt Lake, and $24 \mathrm{mi}$ nor thwest of Roosevelt.

DRAIMAGE AREA. $--675 \mathrm{mi}^{2}$.

REMARKS.--Small diversions above station for irrigation.

ANNUAL PEAK DISCHARGE

\begin{tabular}{|c|c|c|c|c|c|c|c|}
\hline $\begin{array}{l}\text { WATER } \\
\text { YEAR }\end{array}$ & DATE & $\begin{array}{c}\text { ANNUAL PEAK } \\
\text { DISCHARGE } \\
\left(F^{3} / S\right)\end{array}$ & $\begin{array}{l}\text { DISCHARGE } \\
\text { COOES }\end{array}$ & $\begin{array}{l}\text { WATER } \\
\text { YEAR }\end{array}$ & DATE & $\begin{array}{c}\text { ANMUAL PEAK } \\
\text { DISCHARGE } \\
\left(\mathrm{FT}^{3} / \mathrm{S}\right)\end{array}$ & $\begin{array}{l}\text { DISCHARGE } \\
\text { CODES }\end{array}$ \\
\hline $\begin{array}{l}1941 \\
1942 \\
1943 \\
1944 \\
1945 \\
1946 \\
1947 \\
1948 \\
1949 \\
1950 \\
1951 \\
1952 \\
1953 \\
1954 \\
1955 \\
1956 \\
1957 \\
1958 \\
1959 \\
1960 \\
1961 \\
1962 \\
1963 \\
1964 \\
1965\end{array}$ & $\begin{array}{l}03-14-41 \\
12-11-41 \\
03-05-43 \\
02-24-44 \\
08-11-45 \\
09-18-46 \\
12-28-46 \\
07-26-48 \\
01-13-49 \\
07-16-50 \\
08-28-51 \\
01-18-52 \\
07-30-53 \\
03-23-54 \\
08-06-55 \\
07-18-56 \\
01-09-57 \\
03-22-58 \\
08-19-59 \\
12-26-59 \\
09-08-61 \\
09-06-62 \\
08-22-63 \\
07-30-64 \\
01-07-65\end{array}$ & $\begin{array}{r}32,000 \\
1,250 \\
15,800 \\
2,990 \\
5,320 \\
10,200 \\
7,130 \\
3,240 \\
9,890 \\
5,500 \\
31,100 \\
45,400 \\
2,620 \\
8,100 \\
15,200 \\
2,330 \\
15,000 \\
10,600 \\
11,100 \\
25,200 \\
12,900 \\
3,000 \\
19,700 \\
12,000 \\
12,900\end{array}$ & & $\begin{array}{l}1966 \\
1967 \\
1968 \\
1969 \\
1970 \\
1971 \\
1972 \\
1973 \\
1974 \\
1975 \\
1976 \\
1977 \\
1978 \\
1979 \\
1980 \\
1981 \\
1982 \\
1983 \\
1984 \\
1985 \\
1986 \\
1987 \\
1988 \\
1989\end{array}$ & $\begin{array}{l}12-22-65 \\
12-07-66 \\
12-19-67 \\
01-26-69 \\
09-05-70 \\
09-09-71 \\
12-26-71 \\
10-19-72 \\
08-06-74 \\
10-29-74 \\
02-09-76 \\
08-15-77 \\
03-02-78 \\
12-18-78 \\
02-15-80 \\
08-08-81 \\
02-11-82 \\
11-30-82 \\
10-01-83 \\
12-27-84 \\
11-30-85 \\
08-03-87 \\
02-03-88 \\
02-05-89\end{array}$ & $\begin{array}{r}44,700 \\
7,550 \\
19,700 \\
10,600 \\
53,000 \\
5,280 \\
2,600 \\
39,800 \\
3,800 \\
2,020 \\
34,900 \\
2,820 \\
57,200 \\
38,700 \\
161,400 \\
4,420 \\
18,000 \\
32,800 \\
24,400 \\
43,300 \\
10,900 \\
4,460 \\
23,900 \\
6,950\end{array}$ & ES \\
\hline
\end{tabular}

IHighest since 1708, O'Conner and others.

\section{BASIN CHARACTERISTICS}

\begin{tabular}{|c|c|c|c|c|c|c|c|}
\hline \multirow{3}{*}{$\begin{array}{l}\text { MAIN } \\
\text { CHANNEL } \\
\text { SLOPE } \\
\text { (FT/MI) }\end{array}$} & \multirow[b]{3}{*}{$\begin{array}{c}\text { STREAM } \\
\text { LENGTH } \\
\text { (MI) }\end{array}$} & \multirow{3}{*}{$\begin{array}{l}\text { MEAN } \\
\text { BASIN } \\
\text { ELEVA- } \\
\text { TION } \\
\text { (FT) }\end{array}$} & \multirow[b]{3}{*}{$\begin{array}{l}\text { FORESTED } \\
\text { AREA } \\
\text { (PERCENT) }\end{array}$} & \multirow[b]{3}{*}{$\begin{array}{l}\text { SOIL } \\
\text { INDEX }\end{array}$} & \multirow{3}{*}{$\begin{array}{l}\text { MEAN } \\
\text { ANNUAL } \\
\text { PRECIPI- } \\
\text { TATION } \\
\text { (IN) }\end{array}$} & \multirow{2}{*}{\multicolumn{2}{|c|}{ RAINFALL INTENSITY, 24-HOUR }} \\
\hline & & & & & & & \\
\hline & & & & & & $\begin{array}{c}\text { 2-YEAR } \\
\text { (IN) }\end{array}$ & $\begin{array}{c}\text { 50-YEAR } \\
\text { (IN) }\end{array}$ \\
\hline 88.4 & 48.3 & 5,020 & 65.0 & 3.0 & 23.9 & 2.8 & 5.4 \\
\hline
\end{tabular}


MEAN MONTHLY ANO AMNUAL DISChARGES $1942-89$

\begin{tabular}{|c|c|c|c|c|c|c|}
\hline MONTH & 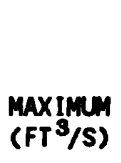 & $\begin{array}{l}\text { MINIMUN } \\
\left(F T^{3} / S\right)\end{array}$ & $\begin{array}{c}\text { MEAN } \\
\left(F T^{3} / S\right)\end{array}$ & $\begin{array}{l}\text { STAN- } \\
\text { DARD } \\
\text { DEVIA- } \\
\text { TION } \\
\left(F^{3} / S\right)\end{array}$ & $\begin{array}{l}\text { COEFFI- } \\
\text { CIENT OF } \\
\text { VARI - } \\
\text { ATION }\end{array}$ & $\begin{array}{c}\text { PERCENT } \\
\text { OF } \\
\text { ANNUAL } \\
\text { RUNOFF }\end{array}$ \\
\hline $\begin{array}{l}\text { OCTOBER } \\
\text { MOVEMBER } \\
\text { DECEMBER } \\
\text { JANUARY } \\
\text { FEBRUARY } \\
\text { MARCH } \\
\text { APRIL } \\
\text { MAY } \\
\text { JUNE } \\
\text { JULY } \\
\text { AUGUST } \\
\text { SEPTEMBER }\end{array}$ & $\begin{array}{r}1,050 \\
438 \\
2,330 \\
1,520 \\
4,190 \\
4,160 \\
709 \\
285 \\
95 \\
207 \\
1,090 \\
626\end{array}$ & $\begin{array}{c}1.5 \\
6.5 \\
9.9 \\
18 \\
13 \\
12 \\
9.0 \\
4.4 \\
0.33 \\
0.35 \\
4.5 \\
0.78\end{array}$ & $\begin{array}{r}68 \\
75 \\
266 \\
285 \\
338 \\
444 \\
148 \\
41 \\
13 \\
23 \\
100 \\
47\end{array}$ & $\begin{array}{r}171 \\
115 \\
507 \\
399 \\
653 \\
697 \\
176 \\
49 \\
16 \\
30 \\
195 \\
104\end{array}$ & $\begin{array}{l}2.5 \\
1.5 \\
1.9 \\
1.4 \\
1.9 \\
1.6 \\
1.2 \\
1.2 \\
1.2 \\
1.3 \\
2.0 \\
2.2\end{array}$ & $\begin{array}{r}3.7 \\
4.0 \\
14.4 \\
15.4 \\
18.3 \\
24.0 \\
8.0 \\
2.2 \\
0.7 \\
1.2 \\
5.4 \\
2.6\end{array}$ \\
\hline ANMUAL & 595 & 22 & 154 & 151 & 0.99 & 100 \\
\hline
\end{tabular}

MAGNI TLDE AND PROBABILITY OF INSTANTANEOUS PEAK FLOW BASED ON PERIOD OF RECORD 1941-89

DISCHAREE, IN $\mathrm{FT}^{3} / \mathrm{S}$, FOR INDICATED RECURRENCE INTERVAL IN YEARS, AND EXCEEDANCE PROBABILITY, IN PERCENT

$\begin{array}{cccccc}2 & 5 & 10 & 25 & 50 & 100 \% \\ 50 \% & 20 \% & 10 \% & 4 \% & 2 \% & 1 \%\end{array}$

\section{$11,200 \quad 25,700 \quad 39,000 \quad 60,100 \quad 79,100 \quad 101,000$}

WEIGHTED SKEW (LOGS) $=-0.16$

MEAN (LOGS) $=4.04$

STANDARD DEV. (LOGS) $=0.44$
MMENITUDE AND PROBABILITY OF ANNUAL LOW FLOW BASED ON PERIOD OF RECORD 1942-89

\begin{tabular}{|c|c|c|c|c|c|c|}
\hline \multirow{2}{*}{$\begin{array}{l}\text { PERIOD } \\
\text { (CON- } \\
\text { SECU- } \\
\text { TIVE } \\
\text { DAYS) }\end{array}$} & \multicolumn{6}{|c|}{$\begin{array}{l}\text { DISCHARGE, IN FT } 3 / \text { S, FOR INDICATED } \\
\text { RECURRENCE INTERVAL, IN YEARS, AND } \\
\text { MON-EXCEEDANCE PROBABILITY, IN PERCENT }\end{array}$} \\
\hline & ${ }_{50 \%}^{2}$ & $\begin{array}{c}5 \\
20 \%\end{array}$ & $\begin{array}{l}10 \\
10 \%\end{array}$ & $\begin{array}{l}20 \\
5 \%\end{array}$ & $\begin{array}{l}50 \\
2 \%\end{array}$ & $\begin{array}{l}100 \dagger \\
1 \%\end{array}$ \\
\hline $\begin{array}{r}1 \\
3 \\
7 \\
14 \\
30 \\
60 \\
90 \\
120 \\
183\end{array}$ & $\begin{array}{c}0.00 \\
0.00 \\
0.00 \\
0.00 \\
0.00 \\
6.9 \\
11 \\
14 \\
21\end{array}$ & $\begin{array}{l}0.00 \\
0.00 \\
0.00 \\
0.00 \\
0.00 \\
2.9 \\
6.2 \\
9.3 \\
13\end{array}$ & $\begin{array}{c}0.00 \\
0.00 \\
0.00 \\
0.00 \\
0.00 \\
1.7 \\
4.6 \\
7.3 \\
11\end{array}$ & $\begin{array}{c}0.00 \\
0.00 \\
0.00 \\
0.00 \\
0.00 \\
1.0 \\
3.6 \\
6.0 \\
10\end{array}$ & $\begin{array}{l}0.00 \\
0.00 \\
0.00 \\
0.00 \\
0.00 \\
0.59 \\
2.7 \\
4.8 \\
9.0\end{array}$ & $\begin{array}{l}0.00 \\
0.00 \\
0.00 \\
0.00 \\
0.00 \\
0.39 \\
2.2 \\
4.1 \\
8.5\end{array}$ \\
\hline
\end{tabular}

MANITLDE AND PROBABILITY OF ANMUAL HIGH FLOW BASED ON PERIOD OF RECORD $1942-89$

\begin{tabular}{|c|c|c|c|c|c|c|}
\hline \multirow{2}{*}{$\begin{array}{l}\text { PERIOD } \\
\text { (CON- } \\
\text { SECU- } \\
\text { TIVE } \\
\text { DAYS) }\end{array}$} & \multicolumn{6}{|c|}{$\begin{array}{l}\text { DISCHARGE, IN } \mathrm{FT}^{3} / \mathrm{S} \text {, FOR INDICATED } \\
\text { RECURRENCE INTERVAL, IN YEARS, AND } \\
\text { EXCEEDANCE PROBABILITY, IN PERCENT }\end{array}$} \\
\hline & $\begin{array}{c}2 \\
50 \%\end{array}$ & $\begin{array}{c}5 \\
20 \%\end{array}$ & $\begin{array}{l}10 \\
10 \%\end{array}$ & $\begin{array}{l}25 \\
4 \%\end{array}$ & $\begin{array}{l}50 \\
2 X\end{array}$ & $\begin{array}{c}100 \\
18\end{array}$ \\
\hline $\begin{array}{r}1 \\
3 \\
7 \\
15 \\
30 \\
60 \\
90\end{array}$ & $\begin{array}{r}3,960 \\
2,360 \\
1,390 \\
844 \\
568 \\
371 \\
284\end{array}$ & $\begin{array}{r}10,800 \\
6,220 \\
3,420 \\
1,970 \\
1,330 \\
884 \\
678\end{array}$ & $\begin{array}{r}17,800 \\
10,100 \\
5,370 \\
3,010 \\
2,060 \\
1,380 \\
1,060\end{array}$ & $\begin{array}{r}29,600 \\
16,800 \\
8,570 \\
4,680 \\
3,220 \\
2,210 \\
1,710\end{array}$ & $\begin{array}{r}40,600 \\
23,000 \\
11,500 \\
6,180 \\
4,280 \\
2,980 \\
2,330\end{array}$ & $\begin{array}{l}53, \\
30, \\
15, \\
7, \\
5, \\
3, \\
3,\end{array}$ \\
\hline
\end{tabular}

DURATION TABLE OF DAILY MEAN FLON FOR PERIOD OF RECORD 1942-89 DISCHARGE, IN FT $3 / \mathrm{S}$, WHICH UAS EQUALED OR EXCEEDED FOR INDICATED PERCENT OF TIME

\begin{tabular}{|c|c|c|c|c|c|c|c|c|c|c|c|c|c|c|c|c|}
\hline $1 \%$ & $5 \%$ & $10 \%$ & $15 \%$ & $20 x$ & $30 \%$ & $40 \%$ & $50 \%$ & $60 \%$ & $70 \%$ & $80 \%$ & $90 \%$ & $95 \%$ & $98 \%$ & $99 x$ & $99.5 \%$ & $99.9 \%$ \\
\hline 450 & 565 & 252 & 147 & 97 & 48 & 31 & 24 & 18 & 14 & 9.0 & 4.5 & 1.9 & 0.18 & 0.00 & 0.00 & .00 \\
\hline
\end{tabular}

Reliability of values in colum is uncertain, and potential errors are large. 
GIUA RIVER BASIN

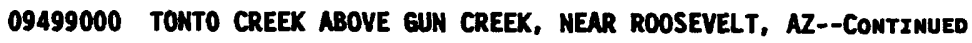
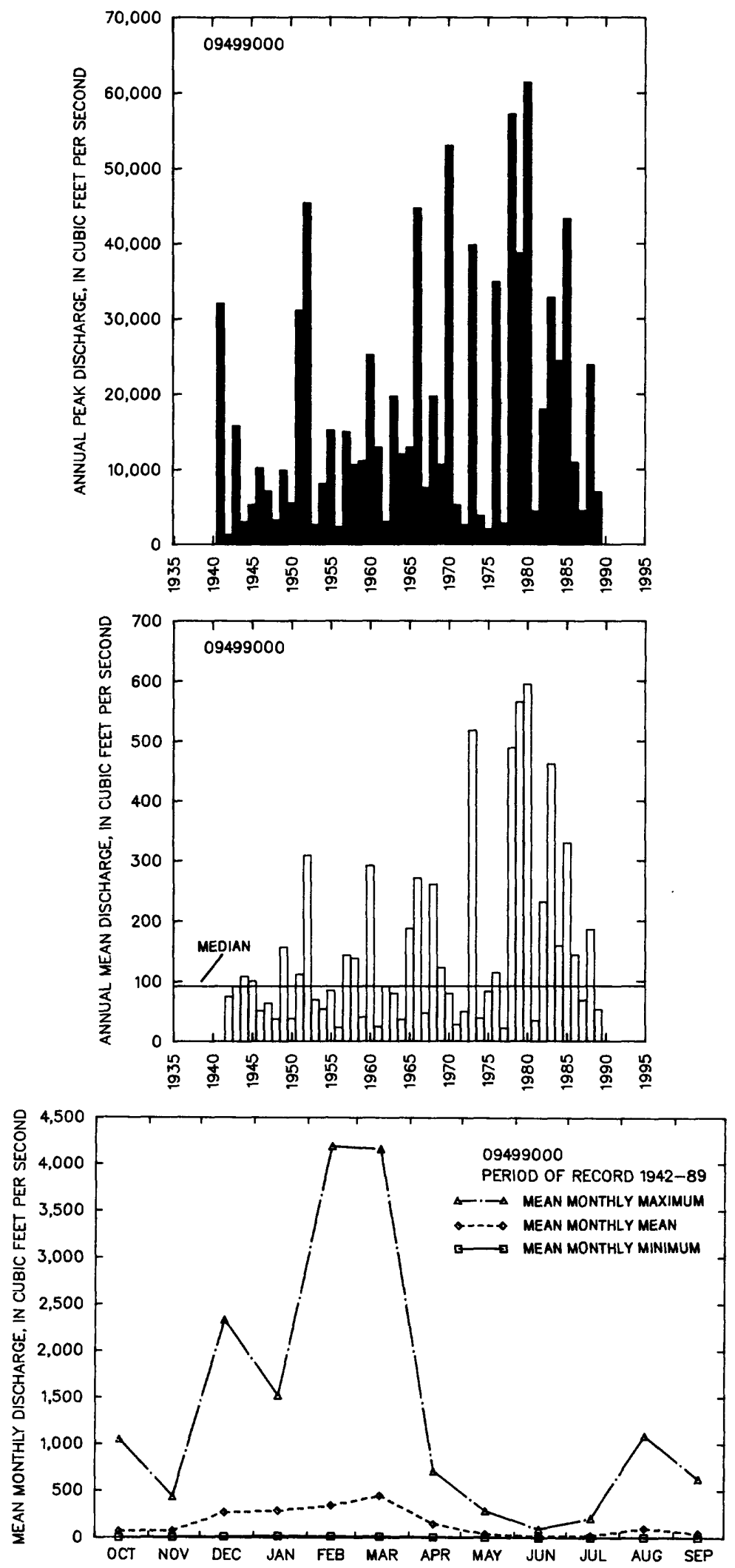


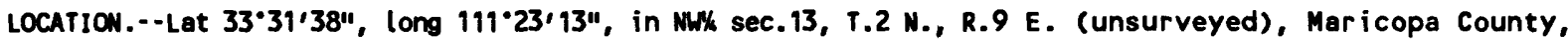
Hydrologic Unit 15060106, $600 \mathrm{ft}$ upstream from State Highway 88 and Tortilla Flat Store, and $3.7 \mathrm{mi}$ southeast of Mormon Flat Dam.

DRAINAGE AREA. $--24.3 \mathrm{mi}^{2}$.

ANMUAL PEAK DISCHARGE

\begin{tabular}{|c|c|c|c|}
\hline $\begin{array}{l}\text { WATER } \\
\text { YEAR }\end{array}$ & DATE & $\begin{array}{c}\text { ANNUAL PEAK } \\
\text { DISCHARGE } \\
\left(F^{3} / S\right)\end{array}$ & $\begin{array}{l}\text { DISCHARGE } \\
\text { CODES }\end{array}$ \\
\hline $\begin{array}{l}1966 \\
1967 \\
1968 \\
1969 \\
1970 \\
1971 \\
1972 \\
1973 \\
1974 \\
1975 \\
1976 \\
1977 \\
1978 \\
1979 \\
1980 \\
1981 \\
1982 \\
1983\end{array}$ & $\begin{array}{l}09-13-66 \\
08-18-67 \\
12-19-67 \\
11-00-68 \\
09-05-70 \\
09-01-71 \\
08-00-72 \\
10-19-72 \\
01-08-74 \\
10-29-74 \\
09-25-76 \\
08-16-77 \\
03-02-78 \\
12-18-78 \\
02-15-80 \\
07-28-81 \\
03-13-82 \\
09-30-83\end{array}$ & $\begin{array}{r}16,660 \\
975 \\
2,000 \\
2,000 \\
5,700 \\
17,500 \\
600 \\
6,000 \\
150 \\
775 \\
160 \\
3,800 \\
3,000 \\
4,400 \\
4,250 \\
520 \\
910 \\
3,800\end{array}$ & LT \\
\hline
\end{tabular}

1Highest since 1941 .

MAGNITUDE AND PROBABILITY OF INSTANTANEOUS PEAK FLON BASED ON PERICD OF RECORD 1966-83

DISCHARGE, IN $\mathrm{FT}^{3} / \mathrm{S}$, FOR INDICATED RECURRENCE INTERVAL IN YEARS, AND EXCEEDANCE PROBABILITY, IN PERCENT

\begin{tabular}{|c|c|c|c|c|c|}
\hline $\begin{array}{c}2 \\
50 \%\end{array}$ & $\begin{array}{c}5 \\
20 \%\end{array}$ & $\begin{array}{r}10 \\
10 \%\end{array}$ & $\begin{array}{l}25 \\
4 \%\end{array}$ & $\begin{array}{l}50 \dagger \\
2 \%\end{array}$ & $\begin{array}{c}100 \dagger \\
1 \%\end{array}$ \\
\hline 1,960 & 4,290 & 6,250 & 9,090 & 11,400 & 13,900 \\
\hline $\begin{array}{l}\text { WEIGHTED } \\
\text { MEAN } \\
\text { STANDARD }\end{array}$ & $\begin{array}{l}\text { SKEW ? } \\
\text { DEV. }\end{array}$ & $\begin{array}{l}\text { LOGS) }=- \\
(O G S)= \\
(O G S)=.\end{array}$ & $\begin{array}{r}-0.39 \\
3.26 \\
0.43\end{array}$ & & \\
\hline
\end{tabular}

f Reliability of values in column is uncertain, and potential errors are large.

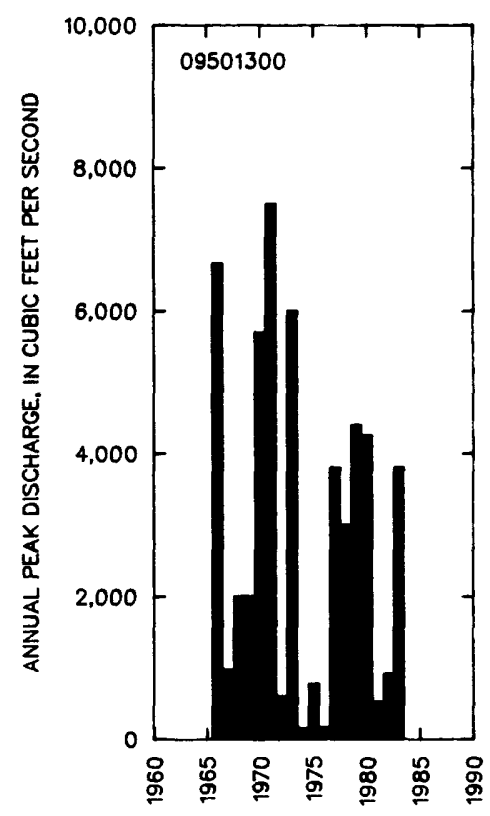

\section{BASIN CHARACTERISTICS}

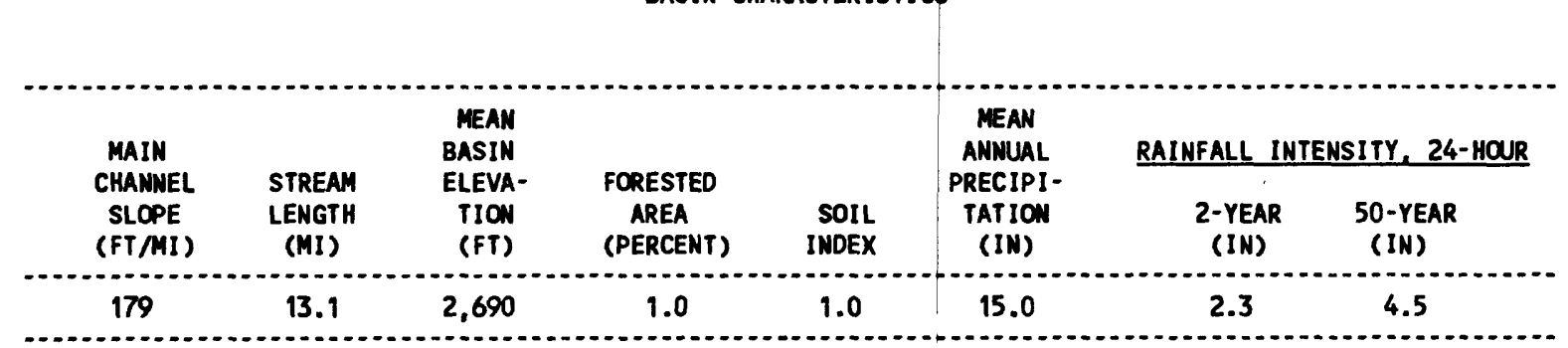


09502700 CROOKTON MASH MEAR SELIGMAN, AZ

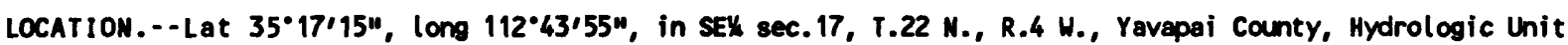
15060201 , at U.S. Highway 66, 9 mi east of Seligman, and 15 mi west of Ashfork.

DRAINAGE AREA. $--6.01 \mathrm{mi}^{2}$.

ANMUAL PEAK DISCHARGE

\begin{tabular}{|c|c|c|c|}
\hline $\begin{array}{l}\text { WMTER } \\
\text { YEAR }\end{array}$ & DATE & $\begin{array}{l}\text { ANNUAL PEAK } \\
\text { DISCHARGE } \\
\text { (FT } 3 / \mathrm{S})\end{array}$ & $\begin{array}{l}\text { DISCHARGE } \\
\text { CODES }\end{array}$ \\
\hline $\begin{array}{l}1963 \\
1964 \\
1965 \\
1966 \\
1967 \\
1968 \\
1969 \\
1970 \\
1971 \\
1972 \\
1973 \\
1974 \\
1975 \\
1976 \\
1978 \\
1979 \\
1980\end{array}$ & $\begin{array}{l}00-00-63 \\
08-01-64 \\
00-00-65 \\
00-00-66 \\
09-00-67 \\
00-00-68 \\
00-00-69 \\
09-05-70 \\
08-18-71 \\
00-00-72 \\
00-00-73 \\
00-00-74 \\
00-00-75 \\
00-00-76 \\
03-01-78 \\
12-18-78 \\
02-19-80\end{array}$ & $\begin{array}{c}1.0 \\
168 \\
1.0 \\
1.0 \\
3.0 \\
1.0 \\
0 \\
92 \\
477 \\
2.0 \\
10 \\
0 \\
0 \\
6.5 \\
1480 \\
125 \\
240\end{array}$ & $\begin{array}{l}\text { LT } \\
\text { LT } \\
\text { LT } \\
\text { LT } \\
\text { LT }\end{array}$ \\
\hline
\end{tabular}

Highest since 1964 .

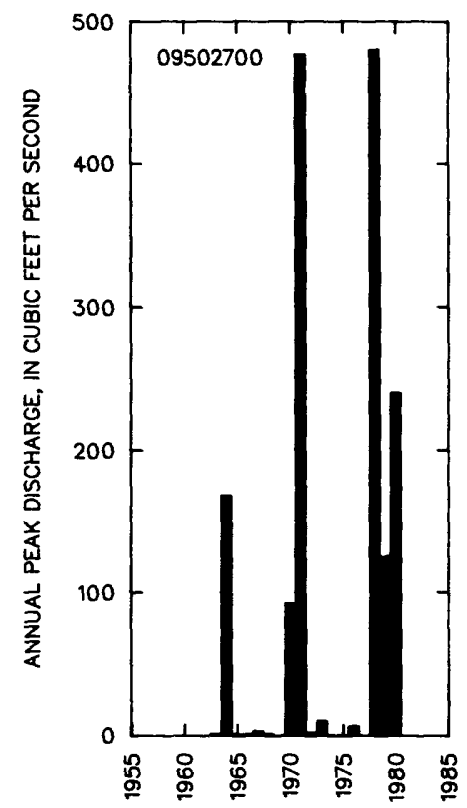

MAGNITUDE AND PROBABILITY OF INSTANTANEOUS PEAK FLON BASED ON PERIOD OF RECORD 1963-76, 1978-80

DISCHARCE, IN FT $3 / 5$, FOR INDICATED RECURREMCE INTERVAL IN YEARS, AND EXCEEDANCE PROBABILITY, IN PERCENT

\begin{tabular}{|c|c|c|c|c|c|}
\hline $\begin{array}{c}2 \\
50 \%\end{array}$ & $\begin{array}{c}5 \\
20 \%\end{array}$ & $\begin{array}{r}10 \\
10 \%\end{array}$ & $\begin{array}{l}25 \\
4 \%\end{array}$ & $\begin{array}{l}50\} \\
2 x\end{array}$ & $\begin{array}{c}100 f \\
1 x\end{array}$ \\
\hline 7.2 & 86.2 & 310 & 1,200 & 2,870 & 6,250 \\
\hline $\begin{array}{l}\text { WEIGHTED } \\
\text { MEAN } \\
\text { STANDARD }\end{array}$ & $\begin{array}{l}\text { SKEW } \\
\text { DEV. }\end{array}$ & $\begin{array}{l}(\text { LOGS })= \\
(\text { LOGS) }= \\
(\text { LOGS })=\end{array}$ & $\begin{array}{r}-0.05 \\
0.85 \\
1.29\end{array}$ & & \\
\hline
\end{tabular}

f Reliability of values in colum is uncertain, and potential errors are large.

BASIN CHARACTERISTICS

\begin{tabular}{|c|c|c|c|c|c|c|c|}
\hline \multirow{3}{*}{$\begin{array}{l}\text { MAIN } \\
\text { CHANNEL } \\
\text { SLOPE } \\
\text { (FTMI) }\end{array}$} & \multirow[b]{3}{*}{$\begin{array}{l}\text { STREAM } \\
\text { LENGTH } \\
\text { (MI) }\end{array}$} & \multirow{3}{*}{$\begin{array}{l}\text { MEAN } \\
\text { BASIN } \\
\text { ELEVA- } \\
\text { TION } \\
\text { (FT) }\end{array}$} & \multirow[b]{3}{*}{$\begin{array}{l}\text { FORESTED } \\
\text { AREA } \\
\text { (PERCENT) }\end{array}$} & \multirow[b]{3}{*}{$\begin{array}{c}\text { SOIL } \\
\text { INDEX }\end{array}$} & \multirow{3}{*}{$\begin{array}{l}\text { MEAN } \\
\text { ANNUAL } \\
\text { PRECIPI- } \\
\text { TATION } \\
\text { (IN) }\end{array}$} & \multirow{2}{*}{\multicolumn{2}{|c|}{ RAINFALL INTENSITY, 24-HOUR }} \\
\hline & & & & & & & \\
\hline & & & & & & $\begin{array}{c}\text { 2-YEAR } \\
\text { (IN) }\end{array}$ & $\begin{array}{c}\text { 50-YEAR } \\
\text { (IN) }\end{array}$ \\
\hline 111 & 4.8 & 5,970 & 27.0 & 3.0 & 15.5 & 1.7 & 3.5 \\
\hline
\end{tabular}


09502800 HILliamson VALLEY waSh NEAR PAULDEN, $2 Z$

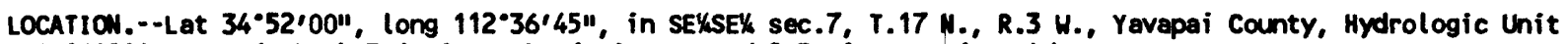
15060201, on left bank $3.6 \mathrm{mi}$ north of simmons and $8.5 \mathrm{mi}$ west of Paulden.

DRAIMAGE AREA. $--255 \mathrm{mi}^{2}$.

\begin{tabular}{|c|c|c|}
\hline $\begin{array}{l}\text { WATER } \\
\text { YEAR }\end{array}$ & DATE & $\begin{array}{r}\text { ANNUAL } \\
\text { DEAS } \\
\text { DCHARGE } \\
\text { (FT } 3 / S)\end{array}$ \\
\hline $\begin{array}{l}1965 \\
1966 \\
1967 \\
1968 \\
1969 \\
1970 \\
1971 \\
1972 \\
1973 \\
1974 \\
1975 \\
1976 \\
1977 \\
1978 \\
1979 \\
1980 \\
1981 \\
1982 \\
1983 \\
1984 \\
1985\end{array}$ & $\begin{array}{l}04-10-65 \\
12-30-65 \\
12-07-66 \\
01-28-68 \\
02-26-69 \\
08-19-70 \\
08-23-71 \\
08-12-72 \\
10-19-72 \\
09-27-74 \\
11-02-74 \\
02-09-76 \\
09-12-77 \\
03-01-78 \\
12-18-78 \\
02-20-80 \\
08-08-81 \\
02-11-82 \\
09-23-83 \\
10-05-83 \\
12-27-84\end{array}$ & $\begin{array}{r}820 \\
3,630 \\
1,710 \\
2,120 \\
400 \\
445 \\
465 \\
254 \\
1,940 \\
570 \\
112 \\
3,910 \\
1,300 \\
7,490 \\
4,890 \\
10,100 \\
137 \\
572 \\
14,800 \\
1,280 \\
2,780\end{array}$ \\
\hline
\end{tabular}

BASIN CHARACTERISTICS

\begin{tabular}{|c|c|c|c|c|c|c|c|}
\hline \multirow{2}{*}{$\begin{array}{l}\text { MIN } \\
\text { CHANEL } \\
\text { SLOPE } \\
\text { (FT/MI) }\end{array}$} & \multirow[b]{2}{*}{$\begin{array}{l}\text { STREAM } \\
\text { LENGTH } \\
\text { (MI) }\end{array}$} & \multirow{2}{*}{$\begin{array}{l}\text { MEAN } \\
\text { BASIN } \\
\text { ELEVA- } \\
\text { TION } \\
\text { (FT) }\end{array}$} & \multirow[b]{2}{*}{$\begin{array}{l}\text { FORESTED } \\
\text { AREA } \\
\text { (PERCENT) }\end{array}$} & \multirow[b]{2}{*}{$\begin{array}{l}\text { SOIL } \\
\text { INDEX }\end{array}$} & \multirow{2}{*}{$\begin{array}{l}\text { MEAN } \\
\text { ANNUAL } \\
\text { PRECIPI- } \\
\text { TATION } \\
\text { (IN) }\end{array}$} & \multicolumn{2}{|c|}{ RAINFALL INTENSITY, 24-HOUR } \\
\hline & & & & & & $\begin{array}{c}\text { 2-YEAR } \\
\text { (IN) }\end{array}$ & $\begin{array}{l}\text { 50-YEAR } \\
\text { (IN) }\end{array}$ \\
\hline 48.6 & 19.2 & 5,120 & 42.0 & 2.0 & 17.3 & 2.1 & 4.0 \\
\hline
\end{tabular}


GILA RIVER BASIN

09502800 WILLIAMSON VALLEY HASH NEAR PAULDEN, AZ--Continued

MEAN MONTHLY AND ANNUAL DISCHARGES 1966-85

\begin{tabular}{|c|c|c|c|c|c|c|}
\hline MONTH & $\begin{array}{l}\text { MAXIMUM } \\
\left(F T^{3} / S\right)\end{array}$ & $\begin{array}{l}\text { MINIMUN } \\
\left(F^{3} / S\right)\end{array}$ & $\begin{array}{c}\text { MEAN } \\
\left(F^{3} / S\right)\end{array}$ & $\begin{array}{l}\text { STAN- } \\
\text { DARD } \\
\text { DEVIA- } \\
\text { TION } \\
\left(F T^{3} / S\right)\end{array}$ & $\begin{array}{l}\text { COEFFI- } \\
\text { CIENT OF } \\
\text { VARI - } \\
\text { ATION }\end{array}$ & $\begin{array}{c}\text { PERCENT } \\
\text { OF } \\
\text { ANNUAL } \\
\text { RUNOFF }\end{array}$ \\
\hline $\begin{array}{l}\text { OCTOBER } \\
\text { NOVEMBER } \\
\text { DECEMBER } \\
\text { JANUARY } \\
\text { FEBRUARY } \\
\text { MARCH } \\
\text { APRIL } \\
\text { MAY } \\
\text { JUNE } \\
\text { JULY } \\
\text { AUGUST } \\
\text { SEPTEMBER }\end{array}$ & $\begin{array}{c}77 \\
28 \\
185 \\
175 \\
513 \\
381 \\
40 \\
3.7 \\
2.1 \\
3.7 \\
15 \\
233\end{array}$ & $\begin{array}{l}0.00 \\
0.49 \\
0.93 \\
1.8 \\
1.6 \\
1.3 \\
0.99 \\
0.00 \\
0.00 \\
0.02 \\
0.32 \\
0.03\end{array}$ & $\begin{array}{l}6.7 \\
5.0 \\
26 \\
21 \\
58 \\
48 \\
5.6 \\
1.5 \\
0.66 \\
0.88 \\
3.4 \\
14\end{array}$ & $\begin{array}{c}18 \\
6.9 \\
49 \\
41 \\
116 \\
94 \\
9.7 \\
0.99 \\
0.68 \\
0.92 \\
4.7 \\
52\end{array}$ & $\begin{array}{l}2.7 \\
1.4 \\
1.9 \\
2.0 \\
2.0 \\
2.0 \\
1.7 \\
0.66 \\
1.0 \\
1.0 \\
1.4 \\
3.8\end{array}$ & $\begin{array}{r}3.5 \\
2.6 \\
13.8 \\
10.9 \\
30.4 \\
25.2 \\
3.0 \\
0.8 \\
0.3 \\
0.5 \\
1.8 \\
7.2\end{array}$ \\
\hline & 6 & 1.6 & 16 & 18 & 1.1 & 100 \\
\hline
\end{tabular}

MAGNITUDE AND PROBABILITY OF INSTANTANEOUS PEAK FLON BASED ON PERIOD OF RECORD 1965-85

DISCHARGE, IN FT $3 / 5$, FOR INDICATED RECURRENCE INTERVAL IN YEARS, AND EXCEEDANCE PROBABILITY, IN PERCENT

\begin{tabular}{|c|c|c|c|c|c|}
\hline $\begin{array}{c}2 \\
50 \%\end{array}$ & $\begin{array}{c}5 \\
20 x\end{array}$ & $\begin{array}{r}10 \\
10 \%\end{array}$ & $\begin{array}{l}25 \\
4 \%\end{array}$ & $\begin{array}{l}50 \uparrow \\
2 \%\end{array}$ & $\underset{1 \times}{100 \dagger}$ \\
\hline 1,310 & 4,080 & 7,360 & 13,700 & 20,400 & 29,200 \\
\hline $\begin{array}{l}\text { WEIGHTED } \\
\text { MEAN } \\
\text { STANDARD }\end{array}$ & $\begin{array}{l}\text { SKEH } \\
\text { DEV. }\end{array}$ & $\begin{array}{l}\text { OGS)= } \\
\text { OGS)= } \\
\text { OGS) }=\end{array}$ & $\begin{array}{l}0.05 \\
3.11 \\
0.59\end{array}$ & & \\
\hline
\end{tabular}

MACNITUDE AND PROBABILITY OF ANNUAL LON FLON BASED ON PERIOO OF RECORD 1966-85

\begin{tabular}{|c|c|c|c|c|c|c|}
\hline \multirow{2}{*}{$\begin{array}{l}\text { PERIOD } \\
\text { (CON- } \\
\text { SECU- } \\
\text { TIVE } \\
\text { DAYS) }\end{array}$} & \multicolumn{6}{|c|}{$\begin{array}{l}\text { DISCHARGE, IN FT } 3 \text { /S, FOR INDICATED } \\
\text { RECURRENCE INTERVAL, IN YEARS, AND } \\
\text { NON-EXCEEDANCE PROBABILITY, IN PERCENT }\end{array}$} \\
\hline & $\stackrel{2}{20 \%}$ & $\begin{array}{c}5 \\
20 \%\end{array}$ & $\begin{array}{l}10 \\
10 \%\end{array}$ & $\begin{array}{l}20 \\
5 \%\end{array}$ & $\begin{array}{l}50\} \\
2 x\end{array}$ & $\begin{array}{l}100 \dagger \\
1 \%\end{array}$ \\
\hline $\begin{array}{r}1 \\
3 \\
7 \\
14 \\
30 \\
60 \\
90 \\
120 \\
183\end{array}$ & $\begin{array}{l}0.00 \\
0.00 \\
0.00 \\
0.00 \\
0.15 \\
0.33 \\
0.56 \\
0.73 \\
1.3\end{array}$ & $\begin{array}{l}0.00 \\
0.00 \\
0.00 \\
0.00 \\
0.00 \\
0.04 \\
0.20 \\
0.34 \\
0.52\end{array}$ & $\begin{array}{l}0.00 \\
0.00 \\
0.00 \\
0.00 \\
0.00 \\
0.00 \\
0.09 \\
0.22 \\
0.31\end{array}$ & $\begin{array}{l}0.00 \\
0.00 \\
0.00 \\
0.00 \\
0.00 \\
0.00 \\
0.00 \\
0.14 \\
0.20\end{array}$ & $\begin{array}{l}0.00 \\
0.00 \\
0.00 \\
0.00 \\
0.00 \\
0.00 \\
0.00 \\
0.08 \\
0.12\end{array}$ & $\begin{array}{l}0.00 \\
0.00 \\
0.00 \\
0.00 \\
0.00 \\
0.00 \\
0.00 \\
0.06 \\
0.08\end{array}$ \\
\hline
\end{tabular}

MACNITLDE AND PROBABILITY OF ANNUAL HIGH FLOU BASED ON PERIOD OF RECORD 1966-85

\begin{tabular}{|c|c|c|c|c|c|c|}
\hline \multirow{2}{*}{$\begin{array}{l}\text { PERIOD } \\
\text { (CON- } \\
\text { SECU- } \\
\text { TIVE } \\
\text { DAYS) }\end{array}$} & \multicolumn{6}{|c|}{$\begin{array}{l}\text { DISCHARGE, IN } \mathrm{FT}^{3} / \mathrm{S} \text {, FOR INDICATED } \\
\text { RECURRENCE INTERVAL, IN YEARS, AND } \\
\text { EXCEEDANCE PROBABILITY, IN PERCENT }\end{array}$} \\
\hline & $\stackrel{2}{50 \%}$ & $\begin{array}{c}5 \\
20 \%\end{array}$ & $\begin{array}{l}10 \\
10 \%\end{array}$ & $\begin{array}{l}25 \\
4 \%\end{array}$ & $\begin{array}{l}50 \dagger \\
2 \%\end{array}$ & $\begin{array}{c}100 \nmid \\
1 \%\end{array}$ \\
\hline $\begin{array}{r}1 \\
3 \\
7 \\
15 \\
30 \\
60 \\
90\end{array}$ & $\begin{array}{r}487 \\
251 \\
130 \\
73 \\
44 \\
28 \\
20\end{array}$ & $\begin{array}{r}1,950 \\
1,020 \\
538 \\
293 \\
171 \\
102 \\
71\end{array}$ & $\begin{array}{r}3,690 \\
1,950 \\
1,070 \\
580 \\
341 \\
200 \\
137\end{array}$ & $\begin{array}{r}6,870 \\
3,680 \\
2,160 \\
1,170 \\
696 \\
409 \\
279\end{array}$ & $\begin{array}{r}9,950 \\
5,360 \\
3,320 \\
1,800 \\
1,090 \\
650 \\
446\end{array}$ & $\begin{array}{r}13,600 \\
7,370 \\
4,810 \\
2,630 \\
1,640 \\
986 \\
681\end{array}$ \\
\hline
\end{tabular}

DURATION TABLE OF DAILY MEAN FLON FOR PERIOD OF RECORD 1966-85

DISCHARGE, IN FT $3 / 5$, WHICH WAS EQUALED OR EXCEEDED FOR INDICATED PERCENT OF TIME

\begin{tabular}{|c|c|c|c|c|c|c|c|c|c|c|c|c|c|c|c|c|}
\hline $1 \%$ & $5 \%$ & $10 \%$ & $15 \%$ & $20 \%$ & $30 \%$ & $40 \%$ & $50 \%$ & $60 \%$ & $70 \%$ & $80 \%$ & $90 \%$ & $95 \%$ & $98 \%$ & $99 \%$ & $99.5 \%$ & $99.9 \%$ \\
\hline 257 & 34 & 7.7 & 4.9 & 4.0 & 3.0 & 2.3 & 1.9 & 1.5 & 1.0 & 0.54 & 0.13 & 0.00 & 0.00 & 0.00 & 0.00 & 0.00 \\
\hline
\end{tabular}

$\uparrow$ Reliability of values in colum is uncertain, and potential errors are large. 
09502800 milliamsON VALLEY WASH MEAR PAULDEN, aZ--CONTIMUEd
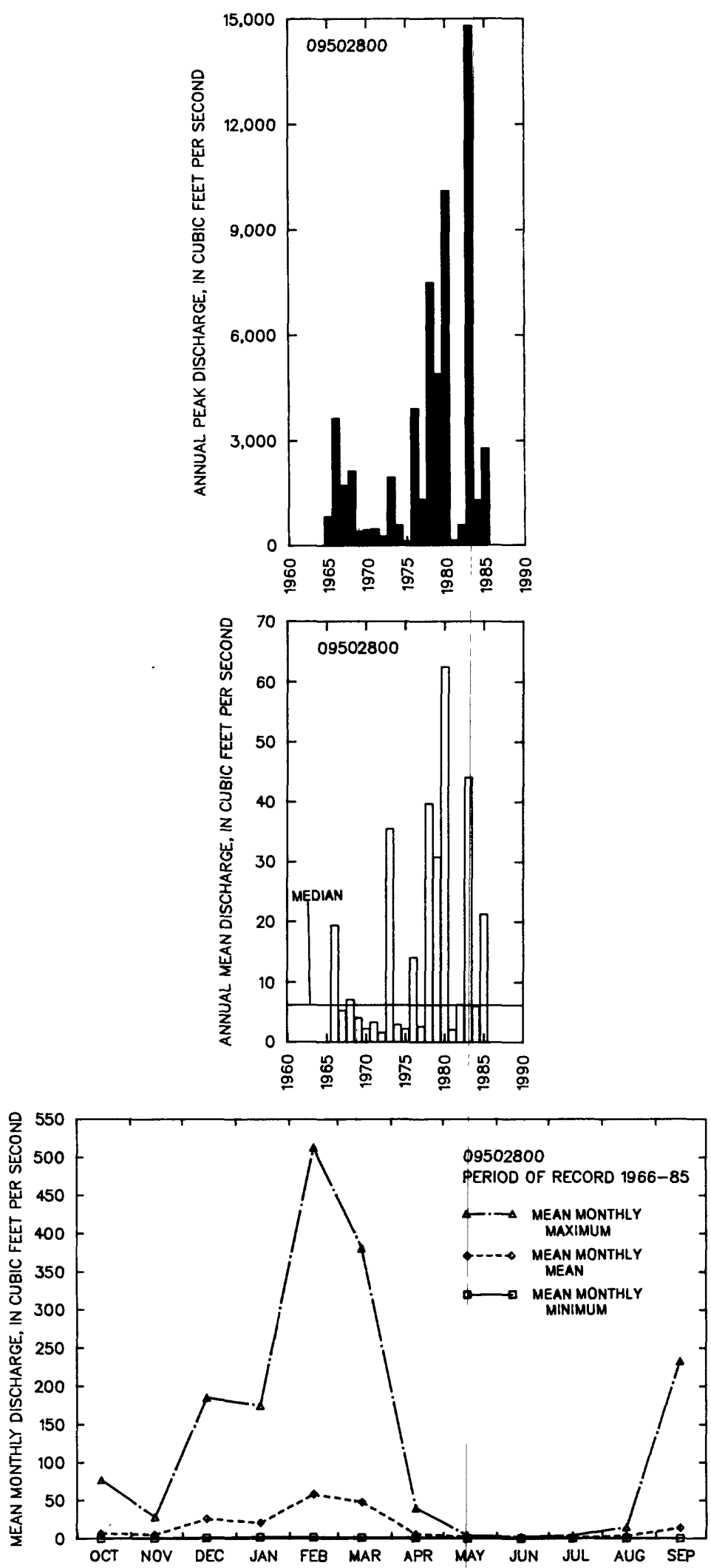
09503000 gRANITE CREEK MEAR PRESCOTt, AZ

LOCATION.--Lat 34.34', long 112.27', in swk sec.26, T.14 N., R.2 W. (unsurveyed), Yavapai County, Hydrologic Unit 15060202, at bridge on the U.S. Highway 89, 2 mi north of Prescott and 4.5 mi upstream from Willow Creek.

DRAINAGE AREA. $--36.3 \mathrm{mi}^{2}$.

ANMUAL PEAK DISCHARGE

\begin{tabular}{|c|c|c|c|}
\hline $\begin{array}{l}\text { WATER } \\
\text { YEAR }\end{array}$ & DATE & $\begin{array}{l}\text { ANNUAL PEAK } \\
\text { DISCHARGE } \\
\text { (FT } 3 / S)\end{array}$ & $\begin{array}{l}\text { DISCHARGE } \\
\text { CODES }\end{array}$ \\
\hline $\begin{array}{l}1933 \\
1934 \\
1935 \\
1936 \\
1937 \\
1938 \\
1939 \\
1940 \\
1941 \\
1942 \\
1943 \\
1944 \\
1945 \\
1946 \\
1947 \\
1963 \\
1966\end{array}$ & $\begin{array}{l}09-07-33 \\
08-30-34 \\
08-30-35 \\
09-11-36 \\
02-07-37 \\
03-03-38 \\
08-04-39 \\
09-29-40 \\
03-01-41 \\
08-17-42 \\
08-28-43 \\
03-14-44 \\
08-10-45 \\
07-20-46 \\
07-21-47 \\
08-19-63 \\
12-00-65\end{array}$ & $\begin{array}{r}230 \\
450 \\
600 \\
500 \\
2,900 \\
2,400 \\
638 \\
83 \\
1,530 \\
1,110 \\
1,780 \\
297 \\
2,200 \\
899 \\
251 \\
16,660 \\
1,500\end{array}$ & $\begin{array}{l}\text { HP } \\
\text { HP }\end{array}$ \\
\hline
\end{tabular}

$1_{\text {Highest since } 1932 .}$

BASIN CHARACTERISTICS

\begin{tabular}{|c|c|c|c|c|c|c|c|}
\hline \multirow{3}{*}{$\begin{array}{l}\text { MAIN } \\
\text { CHANNEL } \\
\text { SLOPE } \\
\text { (FTMI) }\end{array}$} & \multirow[b]{3}{*}{$\begin{array}{c}\text { STREAM } \\
\text { LENGTH } \\
\text { (MI) }\end{array}$} & \multirow{3}{*}{$\begin{array}{l}\text { MEAN } \\
\text { BASIN } \\
\text { ELEVA- } \\
\text { TION } \\
\text { (FT) }\end{array}$} & \multirow[b]{3}{*}{$\begin{array}{l}\text { FORESTED } \\
\text { AREA } \\
\text { (PERCENT) }\end{array}$} & \multirow[b]{3}{*}{$\begin{array}{l}\text { SOIL } \\
\text { INDEX }\end{array}$} & \multirow{3}{*}{$\begin{array}{l}\text { MEAN } \\
\text { ANNUAL } \\
\text { PRECIPI- } \\
\text { TATION } \\
\text { (IN) }\end{array}$} & \multirow{2}{*}{\multicolumn{2}{|c|}{ RAINFALL INTENSITY, 24-HOQR }} \\
\hline & & & & & & & \\
\hline & & & & & & $\begin{array}{c}\text { 2-YEAR } \\
\text { (IN) }\end{array}$ & $\begin{array}{l}\text { 50-YEAR } \\
\text { (IN) }\end{array}$ \\
\hline 104 & 7.3 & 5,900 & 73.0 & 1.0 & 22.1 & 2.2 & 4.5 \\
\hline
\end{tabular}


MEAN MONTHLY AND ANNUAL DISCHARGES 1933-47

\begin{tabular}{|c|c|c|c|c|c|c|}
\hline MONTH & $\begin{array}{l}\operatorname{MAXIMUN} \\
\left(F T^{3} / S\right)\end{array}$ & $\begin{array}{l}\operatorname{MINIMUN} \\
\left(\mathrm{FT}^{3} / \mathrm{S}\right)\end{array}$ & $\begin{array}{c}\text { MEAN } \\
\left(F T^{3} / S\right)\end{array}$ & $\begin{array}{l}\text { STAN- } \\
\text { DARD } \\
\text { DEVIA- } \\
\text { TION } \\
\text { (FT } 3 / S)\end{array}$ & $\begin{array}{l}\text { COEFFI- } \\
\text { CIENT OF } \\
\text { VARI- } \\
\text { ATION }\end{array}$ & $\begin{array}{c}\text { PERCENT } \\
\text { OF } \\
\text { ANNUAL } \\
\text { RUNOFF }\end{array}$ \\
\hline $\begin{array}{l}\text { OCTOBER } \\
\text { NOVEMBER } \\
\text { DECEMBER } \\
\text { JANUARY } \\
\text { FEBRUARY } \\
\text { MARCH } \\
\text { APRIL } \\
\text { MAY } \\
\text { JUNE } \\
\text { JULY } \\
\text { AUGUST } \\
\text { SEPTEMBER }\end{array}$ & $\begin{array}{c}7.3 \\
2.8 \\
33 \\
35 \\
159 \\
79 \\
67 \\
7.0 \\
1.2 \\
2.4 \\
8.3 \\
12\end{array}$ & $\begin{array}{l}0.00 \\
0.00 \\
0.00 \\
0.00 \\
0.00 \\
0.00 \\
0.00 \\
0.00 \\
0.00 \\
0.00 \\
0.00 \\
0.00\end{array}$ & $\begin{array}{l}0.71 \\
0.44 \\
3.2 \\
3.8 \\
19 \\
25 \\
8.4 \\
0.90 \\
0.19 \\
0.76 \\
2.7 \\
1.3\end{array}$ & $\begin{array}{l}1.9 \\
0.91 \\
8.4 \\
9.0 \\
41 \\
31 \\
17 \\
1.8 \\
0.33 \\
0.77 \\
2.7 \\
3.0\end{array}$ & $\begin{array}{l}2.7 \\
2.1 \\
2.6 \\
2.4 \\
2.1 \\
1.2 \\
2.0 \\
2.0 \\
1.7 \\
1.0 \\
0.97 \\
2.2\end{array}$ & $\begin{array}{r}1.1 \\
0.7 \\
4.8 \\
5.7 \\
28.8 \\
37.7 \\
12.6 \\
1.3 \\
0.3 \\
1.1 \\
4.0 \\
2.0\end{array}$ \\
\hline INUAL & 24 & 0.37 & 5.5 & 7.0 & 1.3 & 100 \\
\hline
\end{tabular}

MAGNITLDE AND PROBABILITY OF INSTANTANEOUS PEAK FLOW BASED ON PERIOD OF RECORD 1933-47, 1963, 1966

DISCHARGE, IN $\mathrm{FT}^{3} / \mathrm{S}$, FOR INDICATED RECURRENCE INTERVAL IN YEARS, AND EXCEEDANCE PROBABILITY, IN PERCENT

\begin{tabular}{|c|c|c|c|c|c|}
\hline$\stackrel{2}{50 \%}$ & $\begin{array}{c}5 \\
20 \%\end{array}$ & $\begin{array}{r}10 \\
10 \%\end{array}$ & $\begin{array}{l}25 \\
4 \%\end{array}$ & $\begin{array}{l}50 \dagger \\
2 \%\end{array}$ & $\begin{array}{c}100 \nmid \\
1 \%\end{array}$ \\
\hline 841 & 1,850 & 2,790 & 4,300 & 5,690 & 7,310 \\
\hline $\begin{array}{l}\text { MEIGHTED } \\
\text { MEAN } \\
\text { STANDARD }\end{array}$ & $\begin{array}{l}\text { SKEW } \\
\text { DEV. }\end{array}$ & $\begin{array}{l}(\text { LOGS })= \\
(\text { LOGS) }= \\
(\text { LOGS })=\end{array}$ & $\begin{array}{r}-0.03 \\
2.92 \\
0.41\end{array}$ & & \\
\hline
\end{tabular}

MACNITLDE AND PROBABILITY OF ANNUAL LON FLOH BASED ON PERIOD OF RECORD 1934-47

\begin{tabular}{|c|c|c|c|c|c|c|}
\hline \multirow{2}{*}{$\begin{array}{l}\text { PERICD } \\
\text { (CON- } \\
\text { SECW- } \\
\text { TIVE } \\
\text { DAYS) }\end{array}$} & \multicolumn{6}{|c|}{$\begin{array}{l}\text { DISCHARGE, IN } \mathrm{FT}^{3} / \mathrm{S} \text {, FOR INDICATED } \\
\text { RECURRENCE INTERVAL, IN YEARS, AND } \\
\text { NON-EXCEEDANCE PROBABILITY, IN PERCENT }\end{array}$} \\
\hline & $\begin{array}{c}2 \\
50 \%\end{array}$ & $\begin{array}{c}5 \\
20 \%\end{array}$ & $\begin{array}{l}10 \\
10 \%\end{array}$ & $\begin{array}{l}20 \\
5 x\end{array}$ & $\begin{array}{l}50 \dagger \\
2 x\end{array}$ & $\begin{array}{l}100 t \\
1 x\end{array}$ \\
\hline $\begin{array}{r}1 \\
3 \\
7 \\
14 \\
30 \\
60 \\
90 \\
120 \\
183\end{array}$ & $\begin{array}{l}0.00 \\
0.02 \\
0.08 \\
0.58\end{array}$ & $\begin{array}{l}0.00 \\
0.00 \\
0.00 \\
0.16\end{array}$ & $\begin{array}{l}0.00 \\
0.00 \\
0.00 \\
0.05\end{array}$ & $\begin{array}{l}0.00 \\
0.00 \\
0.00 \\
0.00\end{array}$ & $\begin{array}{l}0.00 \\
0.00 \\
0.00 \\
0.00\end{array}$ & $\begin{array}{l}0.00 \\
0.00 \\
0.00 \\
0.00\end{array}$ \\
\hline
\end{tabular}

MAGNITLDE AND PROBABILITY OF ANNUAL HIGH FLOH BASED ON PERIOD OF RECORD 1933-47

\begin{tabular}{|c|c|c|c|c|c|c|}
\hline $\begin{array}{l}\text { PERIOD } \\
\text { (CON- } \\
\text { SECU- }\end{array}$ & & $\begin{array}{l}\text { ISCHA } \\
\text { RECURR } \\
\text { EXCEED }\end{array}$ & $\begin{array}{l}\text { IN } \\
\text { IN } \\
\text { PR }\end{array}$ & $\begin{array}{l}\text { /S, F } \\
\text { AL, II } \\
\text { ILITY }\end{array}$ & $\begin{array}{l}\text { IND } \\
\text { YEAR } \\
\text { IN P }\end{array}$ & $\begin{array}{l}\text { דע } \\
\text { ד }\end{array}$ \\
\hline $\begin{array}{l}\text { TIVE } \\
\text { DAYS) }\end{array}$ & $\begin{array}{c}2 \\
50 \%\end{array}$ & $\begin{array}{c}5 \\
20 \%\end{array}$ & $\begin{array}{l}10 \\
10 \%\end{array}$ & $\begin{array}{l}25 \\
4 x\end{array}$ & $\begin{array}{l}50 t \\
2 x\end{array}$ & $\begin{array}{c}100 \uparrow \\
1 x\end{array}$ \\
\hline $\begin{array}{r}1 \\
3 \\
7 \\
15 \\
30 \\
60 \\
90\end{array}$ & $\begin{array}{c}103 \\
62 \\
42 \\
27 \\
18 \\
11 \\
8.3\end{array}$ & $\begin{array}{r}328 \\
193 \\
118 \\
80 \\
52 \\
33 \\
25\end{array}$ & $\begin{array}{r}660 \\
372 \\
214 \\
148 \\
96 \\
62 \\
46\end{array}$ & $\begin{array}{r}1,490 \\
783 \\
415 \\
299 \\
192 \\
127 \\
92\end{array}$ & $\begin{array}{r}2,640 \\
1,300 \\
650 \\
484 \\
308 \\
207 \\
150\end{array}$ & $\begin{array}{r}4,540 \\
2,090 \\
987 \\
757 \\
477 \\
327 \\
235\end{array}$ \\
\hline
\end{tabular}

DURATION TABLE OF DAILY MEAN FLON FOR PERIOD OF RECORD 1933-47

DISCHARGE, IN FT $3 / 5$, WHICH WAS EQUALED OR EXCEEDED FOR INOICATED PERCENT OF TIME

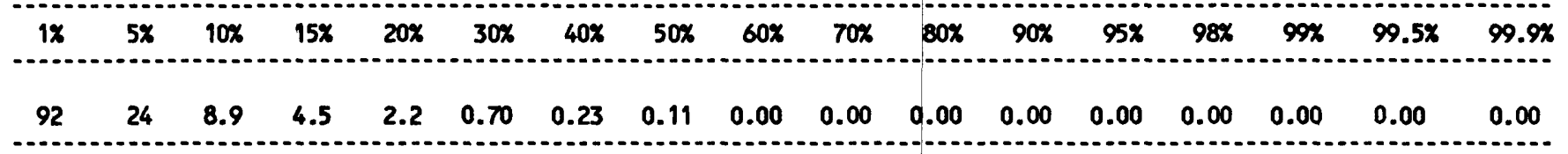

f Reliability of values in colum is uncertain, and potential errors are large. 
GILA RIVER BASIM

09503000 GRANITE CREEK NEAR PRESCOTt, AZ--CONTIMUED
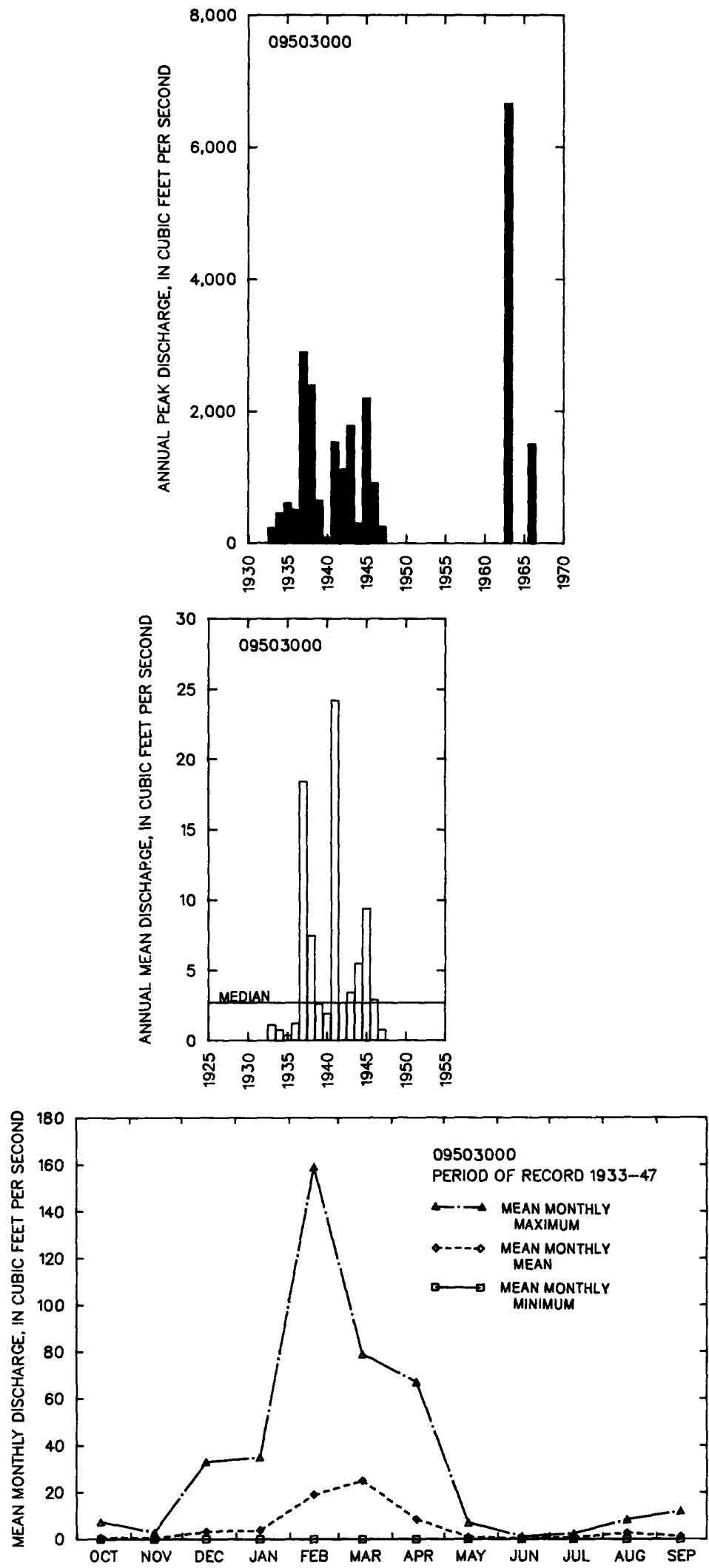


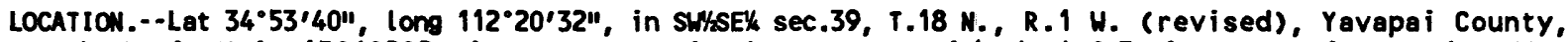
Hydrologic Unit 15060202, in Prescott National Forest, on right bank 0.3 mi upstream from Verde Valley Ranch, $7 \mathrm{mi}$ east of Paulden, $8 \mathrm{mi}$ upstream from Hell Canyon, $8 \mathrm{mi}$ downstream from Granite Creek, and $10 \mathrm{mi}$ downstream from Sull ivan Lake.

DRAImAGe AREA.--2,507 $\mathrm{mi}^{2}$, (includes $357 \mathrm{mi}^{2}$ in Aubrey Valley Playa, a closed basin).

REMARKS.--Diversions and storage above station for irrigation and municipal use.

ANIUAL PEAK DISCHARGE

\begin{tabular}{|c|c|c|c|c|c|}
\hline $\begin{array}{l}\text { WATER } \\
\text { YEAR }\end{array}$ & DATE & $\begin{array}{l}\text { ANNUAL PEAK } \\
\text { DISCHARGE } \\
\text { (FT } 3 / S)\end{array}$ & $\begin{array}{l}\text { WATER } \\
\text { YEAR }\end{array}$ & DATE & $\begin{array}{l}\text { ANMUAL PEAK } \\
\text { DISCHARGE } \\
\left(F^{3} / S\right)\end{array}$ \\
\hline $\begin{array}{l}1963 \\
1964 \\
1965 \\
1966 \\
1967 \\
1968 \\
1969 \\
1970 \\
1971 \\
1972 \\
1973 \\
1974 \\
1975 \\
1976\end{array}$ & $\begin{array}{l}08-25-63 \\
08-05-64 \\
04-10-65 \\
12-30-65 \\
12-07-66 \\
01-28-68 \\
07-26-69 \\
08-19-70 \\
08-13-71 \\
08-08-72 \\
10-20-72 \\
09-05-74 \\
07-09-75 \\
02-09-76\end{array}$ & $\begin{array}{r}710 \\
1,270 \\
685 \\
6,130 \\
1,250 \\
1,800 \\
465 \\
705 \\
2,270 \\
1,620 \\
3,040 \\
270 \\
73 \\
4,340\end{array}$ & $\begin{array}{l}1977 \\
1978 \\
1979 \\
1980 \\
1981 \\
1982 \\
1983 \\
1984 \\
1985 \\
1986 \\
1987 \\
1988 \\
1989\end{array}$ & $\begin{array}{l}09-12-77 \\
03-01-78 \\
12-19-78 \\
02-20-80 \\
08-09-81 \\
03-16-82 \\
09-24-83 \\
09-01-84 \\
12-28-84 \\
11-30-85 \\
08-12-87 \\
04-26-88 \\
07-08-89\end{array}$ & $\begin{array}{r}1,290 \\
8,080 \\
5,700 \\
15,700 \\
195 \\
541 \\
15,600 \\
3,650 \\
2,390 \\
1,460 \\
217 \\
342 \\
263\end{array}$ \\
\hline
\end{tabular}

\section{BASIN CHARACTERISTICS}

\begin{tabular}{|c|c|c|c|c|c|c|c|}
\hline \multirow{2}{*}{$\begin{array}{c}\text { MAIN } \\
\text { CHANNEL } \\
\text { SLOPE } \\
\text { (FT/MI) }\end{array}$} & \multirow[b]{2}{*}{$\begin{array}{l}\text { STREAM } \\
\text { LENGTH } \\
\text { (MI) }\end{array}$} & \multirow{2}{*}{$\begin{array}{l}\text { MEAN } \\
\text { BASIN } \\
\text { ELEVA- } \\
\text { TION } \\
\text { (FT) }\end{array}$} & \multirow[b]{2}{*}{$\begin{array}{l}\text { FORESTED } \\
\text { AREA } \\
\text { (PERCENT) }\end{array}$} & \multirow[b]{2}{*}{$\begin{array}{l}\text { SOIL } \\
\text { INDEX }\end{array}$} & \multirow{2}{*}{$\begin{array}{l}\text { MEAN } \\
\text { AMNUALL } \\
\text { PRECIPI- } \\
\text { TATION } \\
\text { (IN) }\end{array}$} & \multicolumn{2}{|c|}{ RAINFALL INTENSITY, 24-HOUR } \\
\hline & & & & & & $\begin{array}{c}\text { 2-YEAR } \\
\text { (IN) }\end{array}$ & $\begin{array}{l}\text { 50-YEAR } \\
\text { (IN) }\end{array}$ \\
\hline 23.8 & 78.4 & 5,410 & 60.0 & 2.8 & 16.3 & 1.9 & 3.8 \\
\hline
\end{tabular}


09503700 VERDE RIVER MEAR PAULDEN, AZ--Continued

MEAN MONTHLY AND ANNUAL DISCHARGES 1964-89

\begin{tabular}{|c|c|c|c|c|c|c|}
\hline MONTH & $\underset{\left(F T^{3} / S\right)}{\operatorname{MaxIMM}}$ & $\underset{\left(F^{3} / S\right)}{\operatorname{MINIMM}}$ & $\underset{\left(F^{3} / S\right)}{\text { MEAN }}$ & $\begin{array}{l}\text { STAN- } \\
\text { DARD } \\
\text { DEVIA- } \\
\text { TION } \\
\left(F^{3} / S\right)\end{array}$ & $\begin{array}{l}\text { COEFFI- } \\
\text { CIENT OF } \\
\text { VARI- } \\
\text { ATION }\end{array}$ & $\begin{array}{c}\text { PERCENT } \\
\text { OF } \\
\text { ANNUAL } \\
\text { RUNOFF }\end{array}$ \\
\hline $\begin{array}{l}\text { OCTOBER } \\
\text { NOVEMBER } \\
\text { DECEMBER } \\
\text { JANUARY } \\
\text { FEBRUARY } \\
\text { MARCH } \\
\text { APRIL } \\
\text { MAY } \\
\text { JUNE } \\
\text { JULY } \\
\text { AUGUST } \\
\text { SEPTEMBER }\end{array}$ & $\begin{array}{r}200 \\
44 \\
295 \\
232 \\
1,310 \\
669 \\
155 \\
31 \\
27 \\
35 \\
81 \\
440\end{array}$ & $\begin{array}{l}19 \\
20 \\
22 \\
22 \\
20 \\
19 \\
21 \\
16 \\
20 \\
21 \\
23 \\
20\end{array}$ & $\begin{array}{l}33 \\
27 \\
48 \\
40 \\
92 \\
79 \\
35 \\
25 \\
24 \\
26 \\
31 \\
42\end{array}$ & $\begin{array}{c}37 \\
5.7 \\
64 \\
44 \\
251 \\
141 \\
28 \\
2.9 \\
2.0 \\
3.3 \\
13 \\
81\end{array}$ & $\begin{array}{l}1.1 \\
0.21 \\
1.3 \\
1.1 \\
2.7 \\
1.8 \\
0.82 \\
0.12 \\
0.09 \\
0.13 \\
0.42 \\
2.0\end{array}$ & $\begin{array}{r}6.6 \\
5.4 \\
9.5 \\
8.0 \\
18.3 \\
15.8 \\
6.9 \\
4.9 \\
4.8 \\
5.1 \\
6.3 \\
8.3\end{array}$ \\
\hline ANNUALL & 147 & 24 & 42 & 28 & 0.68 & 100 \\
\hline
\end{tabular}

MAGNITUDE AND PROBABILITY OF INSTANTANEQUS PEAK FLON BASED ON PERIOD OF RECORD 1963-89

DISCHARGE, IN $\mathrm{FT}^{3} / \mathrm{S}$, FOR INDICATED RECURRENCE INTERVAL IN YEARS, AND EXCEEDANCE PROBABILITY, IN PERCENT

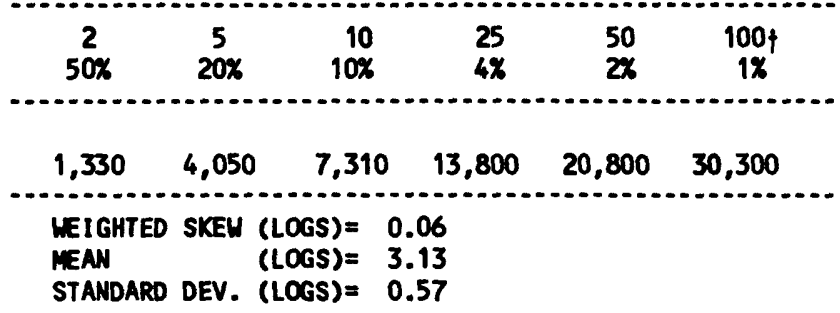

MAGNITUDE AND PROBABILITY OF ANNUAL LOW FLOW BASED ON PERIOD OF RECORD 1965-89

\begin{tabular}{|c|c|c|c|c|c|c|}
\hline \multirow{2}{*}{$\begin{array}{l}\text { PERIOD } \\
\text { (CON- } \\
\text { SECU- } \\
\text { TIVE } \\
\text { DAYS) }\end{array}$} & \multicolumn{6}{|c|}{$\begin{array}{l}\text { DISCHARGE, IN FT } 3 / S \text {, FOR INDICATED } \\
\text { RECURRENCE INTERVAL, IN YEARS, AND } \\
\text { MON-EXCEEDANCE PROBABILITY, IN PERCENT }\end{array}$} \\
\hline & $\begin{array}{c}2 \\
50 \%\end{array}$ & $\begin{array}{c}5 \\
20 \%\end{array}$ & $\begin{array}{l}10 \\
10 \%\end{array}$ & $\begin{array}{l}20 \\
5 \%\end{array}$ & $\begin{array}{l}50 \\
2 \%\end{array}$ & $\begin{array}{l}100 t \\
1 \%\end{array}$ \\
\hline $\begin{array}{r}1 \\
3 \\
7 \\
14 \\
30 \\
60 \\
90 \\
120 \\
183\end{array}$ & $\begin{array}{l}22 \\
22 \\
22 \\
22 \\
22 \\
23 \\
23 \\
24 \\
24\end{array}$ & $\begin{array}{l}19 \\
19 \\
20 \\
20 \\
20 \\
21 \\
22 \\
22 \\
23\end{array}$ & $\begin{array}{l}18 \\
18 \\
18 \\
19 \\
19 \\
20 \\
21 \\
21 \\
23\end{array}$ & $\begin{array}{l}17 \\
17 \\
17 \\
17 \\
18 \\
19 \\
20 \\
21 \\
22\end{array}$ & $\begin{array}{l}15 \\
16 \\
16 \\
16 \\
17 \\
18 \\
19 \\
20 \\
22\end{array}$ & $\begin{array}{l}14 \\
15 \\
15 \\
15 \\
16 \\
18 \\
19 \\
20 \\
22\end{array}$ \\
\hline
\end{tabular}

MAGNITUDE AND PROBABILITY OF ANMUAL HIGH FLON BASED ON PERIOO OF RECORD 1964-89

\begin{tabular}{|c|c|c|c|c|c|c|}
\hline $\begin{array}{l}\text { PERIOD } \\
\text { (CON- } \\
\text { SECU- }\end{array}$ & & $\begin{array}{l}\text { DISCHA } \\
\text { RECURRE } \\
\text { EXCEED }\end{array}$ & $\begin{array}{l}\text { E IN } \\
\text { E IN } \\
\text { E PRC } \\
0 .\end{array}$ & $\begin{array}{l}3 / S, F C \\
\text { AL, IN } \\
\text { ILITY, }\end{array}$ & $\mathrm{YE}$ & \\
\hline $\begin{array}{l}\text { TIVE } \\
\text { DAYS) }\end{array}$ & $\begin{array}{c}2 \\
50 \%\end{array}$ & $\begin{array}{c}5 \\
20 \%\end{array}$ & $\begin{array}{l}10 \\
10 \%\end{array}$ & $\begin{array}{l}25 \\
4 \%\end{array}$ & $\begin{array}{l}50 \\
2 x\end{array}$ & $\begin{array}{c}100\} \\
18\end{array}$ \\
\hline $\begin{array}{r}1 \\
3 \\
7 \\
15 \\
30 \\
60 \\
90\end{array}$ & $\begin{array}{r}488 \\
309 \\
181 \\
114 \\
78 \\
56 \\
47\end{array}$ & $\begin{array}{r}1,770 \\
1,110 \\
601 \\
346 \\
211 \\
131 \\
100\end{array}$ & $\begin{array}{r}3,540 \\
2,230 \\
1,210 \\
677 \\
395 \\
228 \\
165\end{array}$ & $\begin{array}{r}7,560 \\
4,870 \\
2,680 \\
1,490 \\
843 \\
450 \\
307\end{array}$ & $\begin{array}{r}12,500 \\
8,180 \\
4,630 \\
2,570 \\
1,450 \\
733 \\
481\end{array}$ & $\begin{array}{r}19,700 \\
13,200 \\
7,720 \\
4,330 \\
2,430 \\
1,180 \\
747\end{array}$ \\
\hline
\end{tabular}

DURATION TABLE OF DAILY MEAN FLOM FOR PERIOD OF RECORD 1964-89

DISCHARGE, IN FT $3 / 5$, WHICH WAS EQUALED OR EXCEEDED FOR INDICATED PERCENT OF TIME

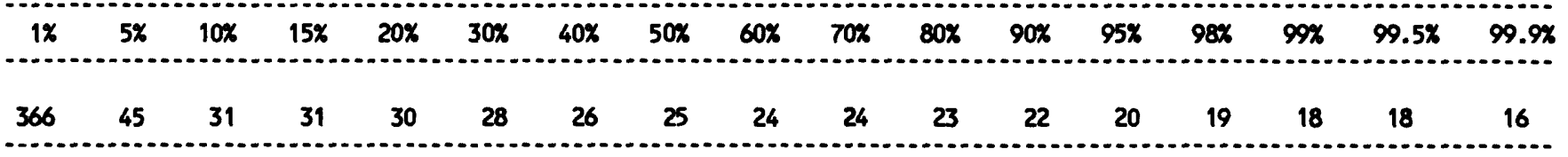

$\uparrow$ Reliability of values in colum is uncertain, and potential errors are large. 
GILA RIVER BASIN

09503700 VERDE RIVER NEAR PAULOEN, AZ--CONTINUED
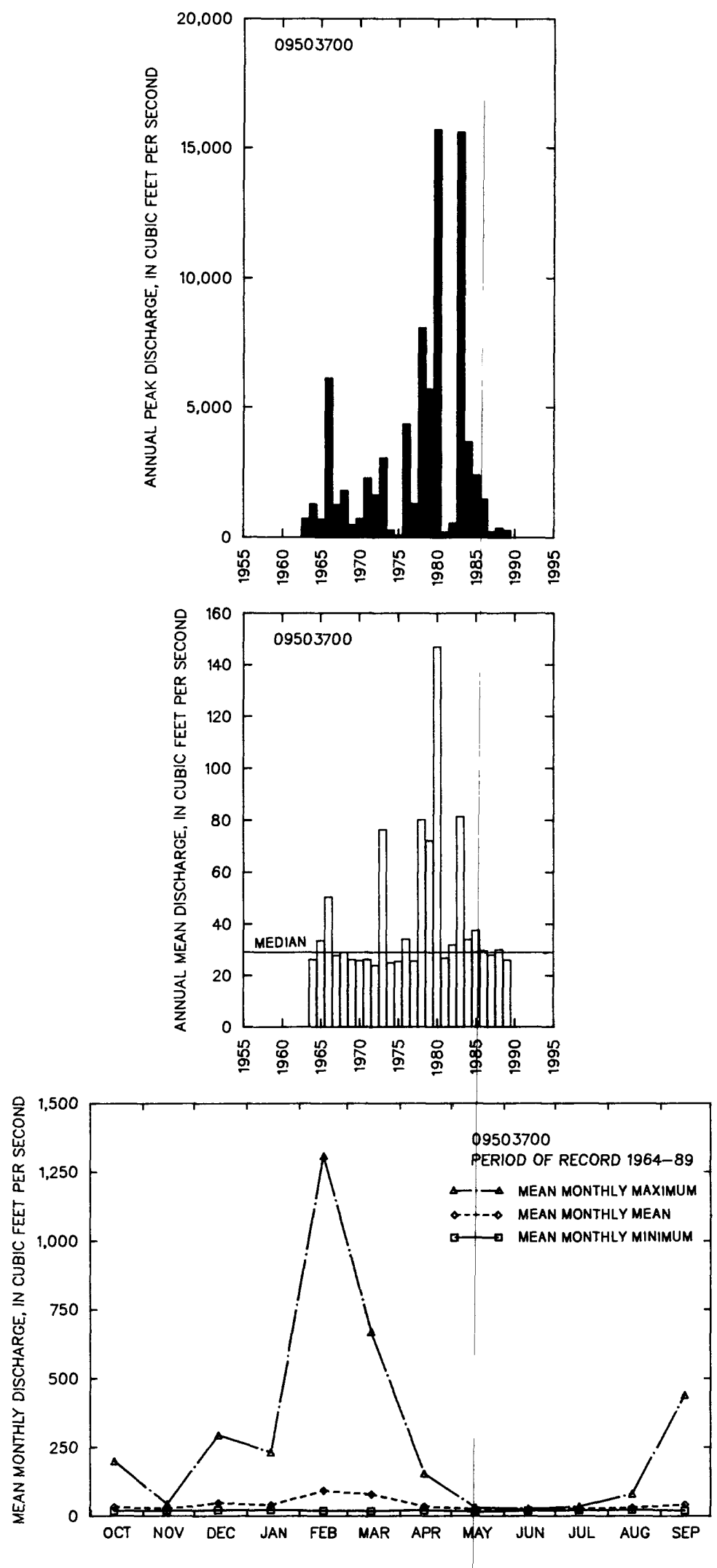
09503720 HELL CANYON MEAR HILLIAMS, AZ

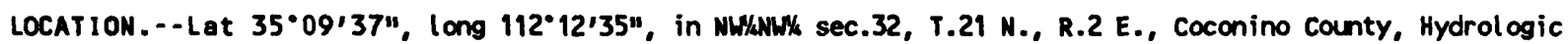
Unit 15060202, in Kaibab National Forest, on right bank 6 mi south of Williams.

DRAINAGE AREA. $--14.9 \mathrm{mi}^{2}$.

AMHUAL PEAK DISCHARGE

\begin{tabular}{ccc}
$\begin{array}{c}\text { MATER } \\
\text { YEAR }\end{array}$ & DATE & $\begin{array}{c}\text { AMNUAL PEAK } \\
\text { DISCHARGE } \\
\text { (FT 3/S) }\end{array}$ \\
\hline 1966 & $11-25-65$ & 1,080 \\
1967 & $12-06-66$ & 955 \\
1968 & $02-24-68$ & 139 \\
1969 & $01-25-69$ & 955 \\
1970 & $03-15-70$ & 91 \\
1971 & $08-04-71$ & 133 \\
1972 & $12-26-71$ & 910 \\
1973 & $10-19-72$ & 960 \\
1974 & $00-00-74$ & 0 \\
1975 & $00-00-75$ & 108 \\
1976 & $00-00-76$ & 250 \\
1978 & $03-01-78$ & 19.080 \\
1979 & $12-18-78$ & 220 \\
\hline$\ldots$
\end{tabular}

Highest since 1966.

MAGNITUDE AND PROBABILITY OF INSTANTAMEOUS PEAK FLOW BASED ON PERIOD OF RECORD 1966-76, 1978-79

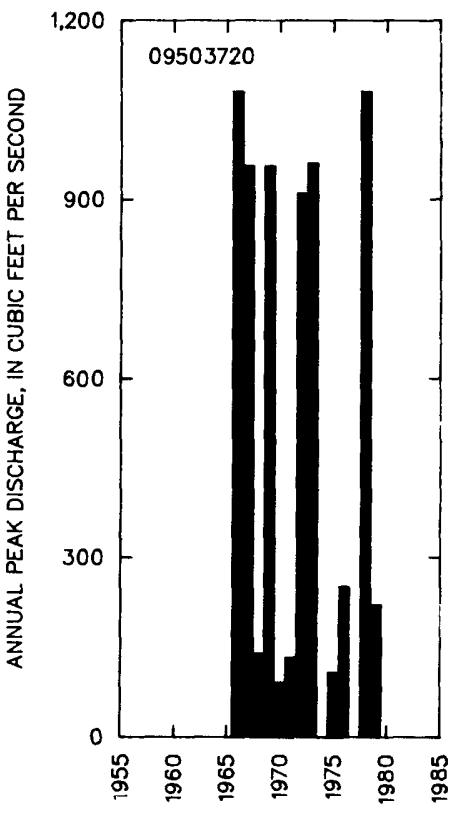

DISCHARGE, IN $\mathrm{FT}^{3} / \mathrm{S}$, FOR IMDICATED RECURRENCE INTERVAL IN YEARS, AND EXCEEDANCE PROBABILITY, IN PERCENT

$\begin{array}{lccccc}2 & 5 & 10 & 25 & 50 \uparrow & 100 \uparrow \\ 1 \% & 20 \% & 10 \% & 4 \% & 2 \% & 1 \% \\ 346 & 862 & 1,360 & 2,190 & 2,960 & 3,860\end{array}$

† Reliability of values in column is uncertain, and potential errors are large.

BASIN CHARACTERISTICS

\begin{tabular}{|c|c|c|c|c|c|c|c|}
\hline \multirow{2}{*}{$\begin{array}{c}\text { MIN } \\
\text { CHAMNEL } \\
\text { SLOPE } \\
\text { (FT/MI) }\end{array}$} & \multirow[b]{2}{*}{$\begin{array}{l}\text { STREAM } \\
\text { LENGTH } \\
\text { (MI) }\end{array}$} & \multicolumn{2}{|l|}{ MEAN } & \multicolumn{2}{|r|}{ MEAN } & \multicolumn{2}{|c|}{ RAINFALL INTENSITY, 24-HOUR } \\
\hline & & $\begin{array}{l}\text { ELEVA- } \\
\text { TION } \\
\text { (FT) }\end{array}$ & $\begin{array}{l}\text { FORESTED } \\
\text { AREA } \\
\text { (PERCENT) }\end{array}$ & $\begin{array}{l}\text { SOIL } \\
\text { INDEX }\end{array}$ & $\begin{array}{l}\text { PRECIPI- } \\
\text { TAT ION } \\
\text { (IN) }\end{array}$ & $\begin{array}{l}\text { 2-YEAR } \\
\text { (IN) }\end{array}$ & $\begin{array}{c}\text { 50-YEAR } \\
\text { (IN) }\end{array}$ \\
\hline 47.8 & 5.3 & 7,110 & 88.0 & 3.0 & 24.1 & 2.3 & 4.2 \\
\hline
\end{tabular}


09503740 HELL CANYON TRIBUTARY MEAR ASHFORK, AZ

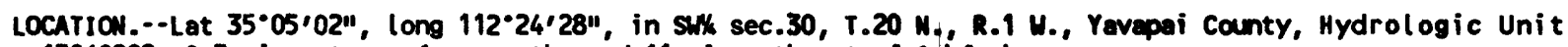
15060202, $0.5 \mathrm{mi}$ upstream from mouth, and $11 \mathrm{mi}$ southeast of Ashfork.

DRAIMAGE AREA. $--0.75 \mathrm{mi}^{2}$.

ANMULAL PEAK DISCHARGE

\begin{tabular}{|c|c|c|c|}
\hline $\begin{array}{l}\text { MATER } \\
\text { YEAR }\end{array}$ & DATE & $\begin{array}{l}\text { ANNUAL PEAK } \\
\text { DISCHARGE } \\
\text { (FT } 3 / S)\end{array}$ & $\begin{array}{l}\text { DISCHARGE } \\
\text { CODES }\end{array}$ \\
\hline $\begin{array}{l}1969 \\
1970 \\
1971 \\
1972 \\
1973 \\
1974 \\
1975 \\
1976 \\
1978 \\
1980\end{array}$ & $\begin{array}{l}00-00-69 \\
09-04-70 \\
00-00-71 \\
04-00-72 \\
10-19-72 \\
00-00-74 \\
00-00-75 \\
02-09-76 \\
03-01-78 \\
02-19-80\end{array}$ & $\begin{array}{c}84 \\
4.0 \\
52 \\
4.0 \\
10 \\
0 \\
0 \\
10 \\
124 \\
20\end{array}$ & $\begin{array}{l}\text { HP } \\
\text { HP }\end{array}$ \\
\hline
\end{tabular}

Highest since 1971.

MAGNITUDE AND PROBABILITY OF INSTANTANEOUS PEAK FLOW BASED ON PERICD OF RECORD 1969-76, 1978, 1980

DISCHARGE, IN $\mathrm{FT}^{3} / \mathrm{S}$, FOR INDICATED RECURRENCE INTERVAL IN YEARS, AND EXCEEDANCE PROBABILITY, IN PERCENT

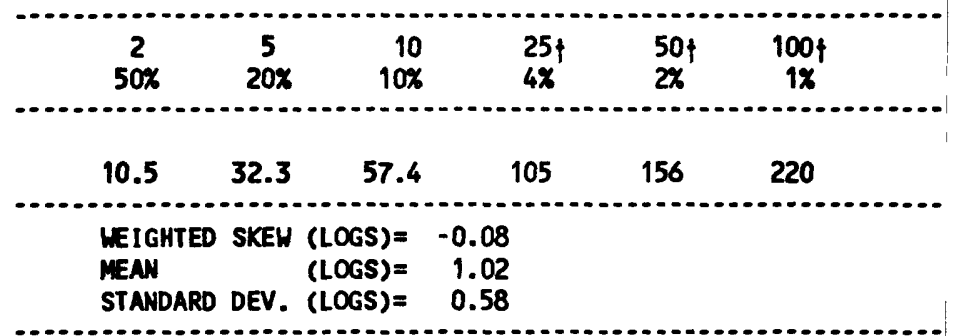

f Reliability of values in column is uncertain, and potential errors are large.

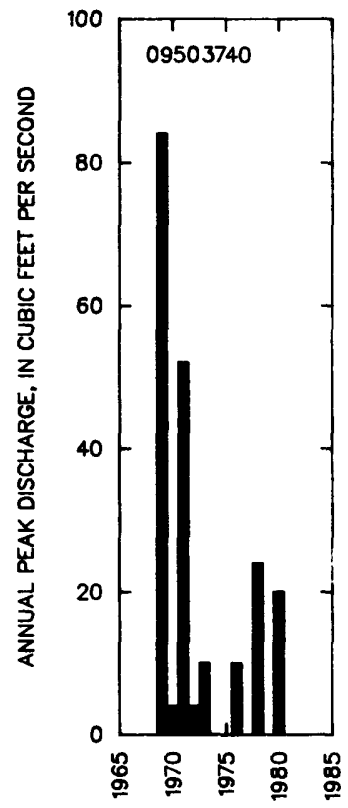

\begin{tabular}{|c|c|c|c|c|c|c|c|}
\hline \multicolumn{8}{|c|}{ BASIN CHARACTERISTICS } \\
\hline MAIN & & $\begin{array}{l}\text { MEAN } \\
\text { BASIN }\end{array}$ & & & $\begin{array}{c}\text { MEAN } \\
\text { ANMUAL }\end{array}$ & RAINFALL I & SITY, 24-HOUR \\
\hline $\begin{array}{l}\text { SLOPE } \\
\text { (FT/MI) }\end{array}$ & $\begin{array}{l}\text { LENGTH } \\
\text { (MI) }\end{array}$ & $\begin{array}{l}\text { TION } \\
\text { (FT) }\end{array}$ & $\begin{array}{l}\text { AREA } \\
\text { (PERCENT) }\end{array}$ & $\begin{array}{l}\text { SOIL } \\
\text { INDEX }\end{array}$ & $\begin{array}{l}\text { TATION } \\
\text { (IN) }\end{array}$ & $\begin{array}{l}\text { 2-YEAR } \\
\text { (IN) }\end{array}$ & $\begin{array}{l}\text { 50-YEAR } \\
\text { (IN) }\end{array}$ \\
\hline 78.4 & 1.7 & 5,180 & 91.0 & 3.0 & 17.2 & 1.7 & 3.8 \\
\hline
\end{tabular}


09503750 LIMESTONE CANYON MEAR PAULDEN, AZ

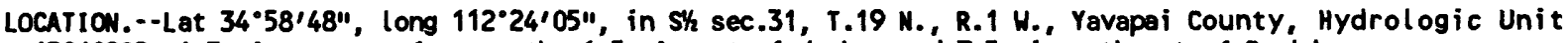
15060202, $1.3 \mathrm{mi}$ upstream from mouth, $1.5 \mathrm{mi}$ west of drake, and $7.5 \mathrm{mi}$ nor theast of Paulden.

DRAIMAGE AREA. $--14.5 \mathrm{mi}^{2}$.

\section{ANMUAL PEAK DISCHARGE}

\begin{tabular}{|c|c|c|c|}
\hline $\begin{array}{l}\text { WATER } \\
\text { YEAR }\end{array}$ & DATE & $\begin{array}{c}\text { ANNUAL PEAK } \\
\text { DISCHARGE } \\
\text { (FT }^{3} / \mathrm{S} \text { ) }\end{array}$ & $\begin{array}{l}\text { DISCHARGE } \\
\text { CODES }\end{array}$ \\
\hline $\begin{array}{l}1969 \\
1970 \\
1971 \\
1972 \\
1973 \\
1974 \\
1975 \\
1976 \\
1978 \\
1979 \\
1980\end{array}$ & $\begin{array}{l}00-00-69 \\
09-04-70 \\
08-12-71 \\
08-12-72 \\
10-07-72 \\
07-20-74 \\
11-02-74 \\
00-00-76 \\
03-01-78 \\
12-18-78 \\
02-14-80\end{array}$ & $\begin{array}{c}1,100 \\
10 \\
4,100 \\
470 \\
275 \\
70 \\
125 \\
1.0 \\
1580 \\
200 \\
500\end{array}$ & ES \\
\hline
\end{tabular}

${ }^{1}$ Highest since 1971.

MAGNI TUDE AND PROBABILITY OF INSTANTANEOUS PEAK FLON BASED ON PERICD OF RECORD 1969-76, 1978-80

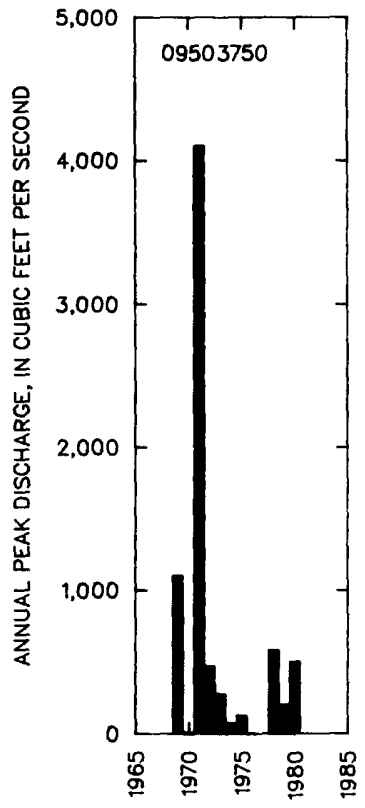

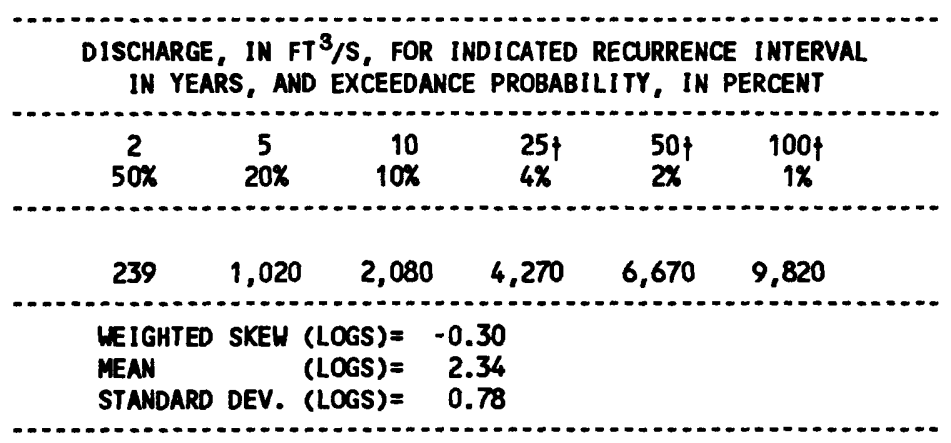

f Reliability of values in column is uncertain, and potential errors are large.

BASIN CHARACTERISTICS

\begin{tabular}{|c|c|c|c|c|c|c|c|}
\hline MAIN & & $\begin{array}{l}\text { MEAN } \\
\text { BASIN }\end{array}$ & & & $\begin{array}{l}\text { MEAN } \\
\text { ANNUAL }\end{array}$ & RAINFALL II & SITY, 24-HOUR \\
\hline $\begin{array}{l}\text { CHANNEL } \\
\text { SLOPE } \\
\text { (FT/MI) }\end{array}$ & $\begin{array}{l}\text { STREAM } \\
\text { LENGTH } \\
\text { (MI) }\end{array}$ & $\begin{array}{l}\text { ELEVA- } \\
\text { TION } \\
\text { (FT) }\end{array}$ & $\begin{array}{l}\text { FORESTED } \\
\text { AREA } \\
\text { (PERCENT) }\end{array}$ & $\begin{array}{l}\text { SOIL } \\
\text { INDEX }\end{array}$ & $\begin{array}{l}\text { PRECIPI - } \\
\text { TATION } \\
\text { (IN) }\end{array}$ & $\begin{array}{c}\text { 2-YEAR } \\
\text { (IN) }\end{array}$ & $\begin{array}{l}\text { 50-YEAR } \\
\text { (IN) }\end{array}$ \\
\hline 87.3 & 8.4 & 5,310 & 100 & 3.0 & 15.5 & 1.8 & 3.8 \\
\hline
\end{tabular}


09503800 VOLUNTEER MASH MEAR BELLEMONT, AZ

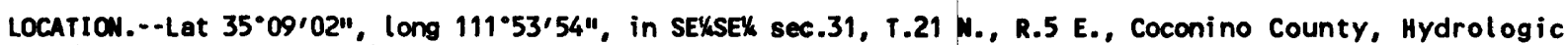
Unit 15060202, in Kaibab National Forest, in Navajo Army Depot military reservation, on right bank 7 mi southwest of Bellemont, and $14 \mathrm{mi}$ west of Flagstaff.

DRAIMAGE AREA. $--131 \mathrm{mi}^{2}$, of which $6.93 \mathrm{mi}^{2}$ is noncontributing.

ANNUAL PEAK DISCHARGE

\begin{tabular}{ccc}
$\begin{array}{c}\text { WATER } \\
\text { YEAR }\end{array}$ & DATE & $\begin{array}{c}\text { ANNUAL PEAK } \\
\text { DISCHARGE } \\
\text { (FT } 3 / \text { S) }\end{array}$ \\
\hline 1966 & $03-12-66$ & 660 \\
1967 & $12-07-66$ & 1,430 \\
1968 & $02-24-68$ & 632 \\
1969 & $01-26-69$ & 447 \\
1970 & $04-04-70$ & 96 \\
1971 & $00-00-71$ & 0 \\
1972 & $12-26-71$ & 1,050 \\
1973 & $10-19-72$ & 1,100 \\
1974 & $00-00-74$ & 0 \\
1975 & $00-00-75$ & 49 \\
1976 & $00-00-76$ & 180 \\
1978 & $03-01-78$ & 12,300 \\
1979 & $12-18-78$ & 100 \\
1980 & $02-19-80$ & 1,160 \\
$\ldots$
\end{tabular}

1Highest since 1965.

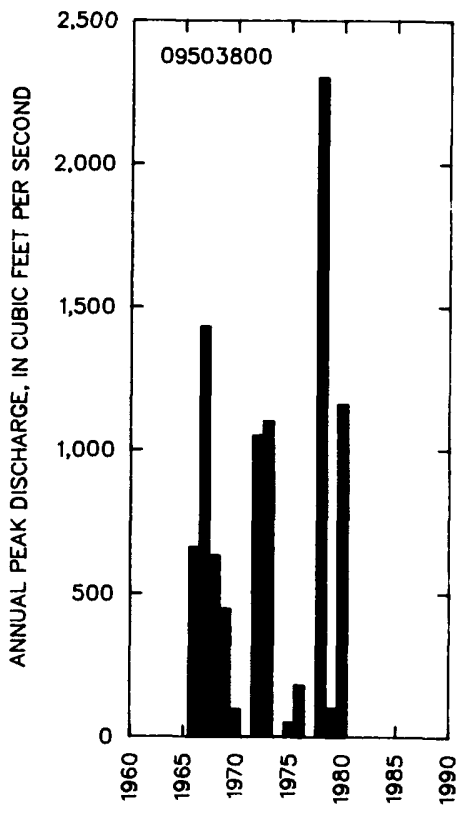

MAGNITUDE AND PROBABILITY OF INSTANTANEOUS PEAK FLON BASED ON PERIOD OF RECORD 1966-80

DISCHARGE, IN $\mathrm{FT}^{3} / \mathrm{S}$, FOR INDICATED RECURRENCE INTERVAL IN YEARS, AND EXCEEDANCE PROBABILITY, IN PERCENT

$\begin{array}{lccccc}2 & 5 & 10 & 25 & 50 \uparrow & 100 \uparrow \\ 2 \% & 20 \% & 10 \% & 4 \% & 1 \%\end{array}$

+ Reliability of values in colum is uncertain, and potential errors are large.

BASIN CHARACTERISTICS

\begin{tabular}{|c|c|c|c|c|c|c|c|}
\hline \multirow{2}{*}{$\begin{array}{l}\text { MAIN } \\
\text { CHANNEL } \\
\text { SLOPE } \\
\text { (FT/MI) }\end{array}$} & \multirow[b]{2}{*}{$\begin{array}{l}\text { STREAM } \\
\text { LENGTH } \\
\text { (MI) }\end{array}$} & \multirow{2}{*}{$\begin{array}{l}\text { MEAN } \\
\text { BASIN } \\
\text { ELEVA- } \\
\text { TION } \\
\text { (FT) }\end{array}$} & \multirow[b]{2}{*}{$\begin{array}{l}\text { FORESTED } \\
\text { AREA } \\
\text { (PERCENT) }\end{array}$} & \multirow[b]{2}{*}{$\begin{array}{l}\text { SOIL } \\
\text { INDEX }\end{array}$} & \multirow{2}{*}{$\begin{array}{l}\text { MEN } \\
\text { ANMUAL } \\
\text { PRECIPI- } \\
\text { TATION } \\
\text { (IN) }\end{array}$} & \multicolumn{2}{|c|}{ RAINFALL INTENSITY, 24-HOUR } \\
\hline & & & & & & $\begin{array}{c}\text { 2-YEAR } \\
\text { (IN) }\end{array}$ & $\begin{array}{c}\text { 50-YEAR } \\
\text { (IN) }\end{array}$ \\
\hline 56.6 & 20.0 & 7,620 & 76.0 & 3.0 & 25.7 & 2.3 & 4.2 \\
\hline
\end{tabular}


09504000 VERDE RIVER NEAR CLARKDale, AZ

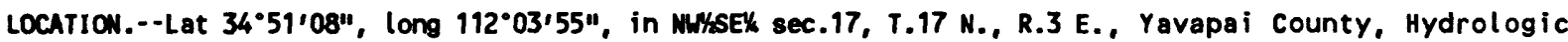
Unit 15060202, in Prescott National Forest, on left bank 1.7 mi downstream from Sycamore Creek and $5.6 \mathrm{mi}$ north of clarkdale.

DRAINAGE AREA.--3,503 $\mathrm{mi}^{2}$, of which $364 \mathrm{mi}^{2}$ is noncontributing, including $359 \mathrm{mi}^{2}$ in Aubrey Valley Playa, a closed basin.

ANNUAL PEAK DISCHARGE

\begin{tabular}{|c|c|c|c|c|c|c|c|}
\hline $\begin{array}{l}\text { WATER } \\
\text { YEAR }\end{array}$ & DATE & $\begin{array}{c}\text { ANNUAL PEAK } \\
\text { DISCHARGE } \\
\left.\text { (FT }{ }^{3} / \mathrm{S}\right)\end{array}$ & $\begin{array}{l}\text { DISCHARGE } \\
\text { CODES }\end{array}$ & $\begin{array}{l}\text { WATER } \\
\text { YEAR }\end{array}$ & DATE & $\begin{array}{c}\text { ANNUAL PEAK } \\
\text { DISCHARGE } \\
\left(\mathrm{FT}^{\mathbf{3}} / \mathrm{S}\right)\end{array}$ & $\begin{array}{l}\text { DISCHARGE } \\
\text { CODES }\end{array}$ \\
\hline $\begin{array}{l}1916 \\
1918 \\
1920 \\
1966 \\
1967 \\
1968 \\
1969 \\
1970 \\
1971 \\
1972 \\
1973 \\
1974 \\
1975 \\
1976\end{array}$ & $\begin{array}{l}01-18-16 \\
03-08-18 \\
02-21-20 \\
12-10-65 \\
12-06-66 \\
01-28-68 \\
01-25-69 \\
09-06-70 \\
07-31-71 \\
12-26-71 \\
10-19-72 \\
09-26-74 \\
03-20-75 \\
02-09-76\end{array}$ & $\begin{array}{r}6,860 \\
35,500 \\
150,600 \\
12,900 \\
22,500 \\
1,630 \\
14,800 \\
717 \\
3,930 \\
7,540 \\
14,000 \\
3,960 \\
1,560 \\
18,000\end{array}$ & $\begin{array}{l}\text { HP } \\
\text { HP } \\
\text { HP }\end{array}$ & $\begin{array}{l}1977 \\
1978 \\
1979 \\
1980 \\
1981 \\
1982 \\
1983 \\
1984 \\
1985 \\
1986 \\
1987 \\
1988 \\
1989\end{array}$ & $\begin{array}{l}08-10-77 \\
03-01-78 \\
12-18-78 \\
02-15-80 \\
09-23-81 \\
03-12-82 \\
09-24-83 \\
09-02-84 \\
12-28-84 \\
11-30-85 \\
03-08-87 \\
11-01-87 \\
10-14-88\end{array}$ & $\begin{array}{r}2,660 \\
25,000 \\
19,900 \\
30,100 \\
1,150 \\
15,720 \\
14,400 \\
4,010 \\
4,760 \\
5,880 \\
1,620 \\
8,810 \\
461\end{array}$ & \\
\hline
\end{tabular}

IHighest since 1906.

BASIN CHARACTERISTICS

\begin{tabular}{|c|c|c|c|c|c|c|c|}
\hline \multirow{2}{*}{$\begin{array}{l}\text { MIN } \\
\text { CHANNEL } \\
\text { SLOPE } \\
\text { (FT/MI) }\end{array}$} & \multirow[b]{2}{*}{$\begin{array}{l}\text { STREAM } \\
\text { LENGTH } \\
\text { (MI) }\end{array}$} & \multirow{2}{*}{$\begin{array}{l}\text { MEAN } \\
\text { BASIN } \\
\text { ELEVA- } \\
\text { TION } \\
\text { (FT) }\end{array}$} & \multirow[b]{2}{*}{$\begin{array}{l}\text { FORESTED } \\
\text { AREA } \\
\text { (PERCENT) }\end{array}$} & \multirow[b]{2}{*}{$\begin{array}{l}\text { SOIL } \\
\text { INDEX }\end{array}$} & \multirow{2}{*}{$\begin{array}{l}\text { MEAN } \\
\text { ANNUAL } \\
\text { PRECIPI- } \\
\text { TATION } \\
\text { (IN) }\end{array}$} & \multicolumn{2}{|c|}{ RAINFALL INTENSITY, 24-HOUR } \\
\hline & & & & & & $\begin{array}{c}\text { 2-YEAR } \\
\text { (IN) }\end{array}$ & $\begin{array}{l}\text { 50-YEAR } \\
\text { (IN) }\end{array}$ \\
\hline 22.9 & 115 & 5,490 & 73.0 & 2.9 & 19.1 & 2.0 & 4.0 \\
\hline
\end{tabular}


MEAN MONTHLY AND ANNUAL DISCHARGES 1916, 1918-20, 1966-89

\begin{tabular}{|c|c|c|c|c|c|c|}
\hline MONTH & $\begin{array}{l}\operatorname{MAXIMUN} \\
\left(F T^{3} / S\right)\end{array}$ & $\begin{array}{l}\text { MINIMUM } \\
\left(\mathrm{FT}^{3} / \mathrm{S}\right)\end{array}$ & $\begin{array}{c}\text { MEAN } \\
\left(F T^{3} / S\right)\end{array}$ & $\begin{array}{l}\text { STAN- } \\
\text { DARD } \\
\text { DEVIA- } \\
\text { TION } \\
\left(F T^{3} / S\right)\end{array}$ & $\begin{array}{l}\text { COEFFI- } \\
\text { CIENT OF } \\
\text { VARI - } \\
\text { ATION }\end{array}$ & $\begin{array}{c}\text { PERCENT } \\
\text { OF } \\
\text { ANNUAL } \\
\text { RUWOFF }\end{array}$ \\
\hline $\begin{array}{l}\text { OCTOBER } \\
\text { NONEMBER } \\
\text { DECEMBER } \\
\text { JANUARY } \\
\text { FEBRUARY } \\
\text { MARCH } \\
\text { APRIL } \\
\text { MAY } \\
\text { JUNE } \\
\text { JULY } \\
\text { AUGUST } \\
\text { SEPTEMBER }\end{array}$ & $\begin{array}{r}1,080 \\
736 \\
1,030 \\
578 \\
3,490 \\
2,760 \\
1,520 \\
355 \\
91 \\
670 \\
201 \\
670\end{array}$ & $\begin{array}{l}68 \\
70 \\
75 \\
73 \\
74 \\
73 \\
69 \\
69 \\
62 \\
64 \\
74 \\
66\end{array}$ & $\begin{array}{r}128 \\
143 \\
229 \\
154 \\
444 \\
528 \\
197 \\
91 \\
76 \\
110 \\
103 \\
109\end{array}$ & $\begin{array}{c}193 \\
144 \\
282 \\
142 \\
756 \\
607 \\
281 \\
52 \\
7.0 \\
111 \\
30 \\
111\end{array}$ & $\begin{array}{l}1.5 \\
1.0 \\
1.2 \\
0.92 \\
1.7 \\
1.2 \\
1.4 \\
0.58 \\
0.09 \\
1.0 \\
0.29 \\
1.0\end{array}$ & $\begin{array}{r}5.5 \\
6.2 \\
9.9 \\
6.7 \\
19.2 \\
22.9 \\
8.5 \\
3.9 \\
3.3 \\
4.7 \\
4.5 \\
4.7\end{array}$ \\
\hline ANNUAL & 448 & 82 & 192 & 112 & 0.59 & 100 \\
\hline
\end{tabular}

MAGNITUDE AND PROBABILITY OF INSTANTANEOUS PEAK FLOH BASED ON PERIOD OF RECORD 1916, 1918, 1920, 1966-89

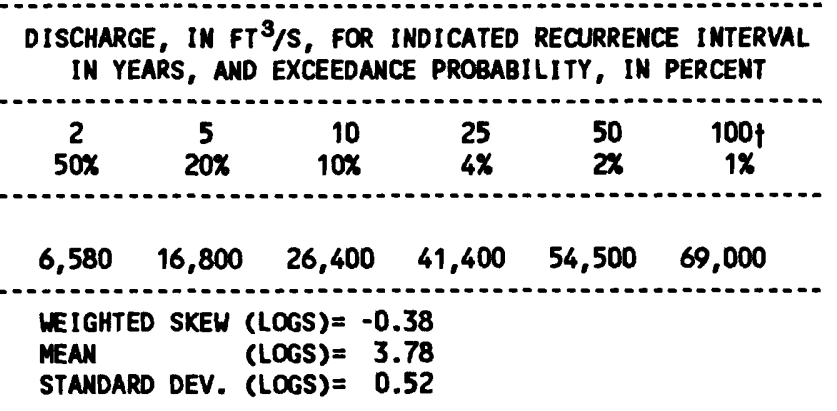

MANITLDE AND PROBABILITY OF ANNUAL LOM FLOH BASED ON PERIOD OF RECORD 1919-21, 1967-89

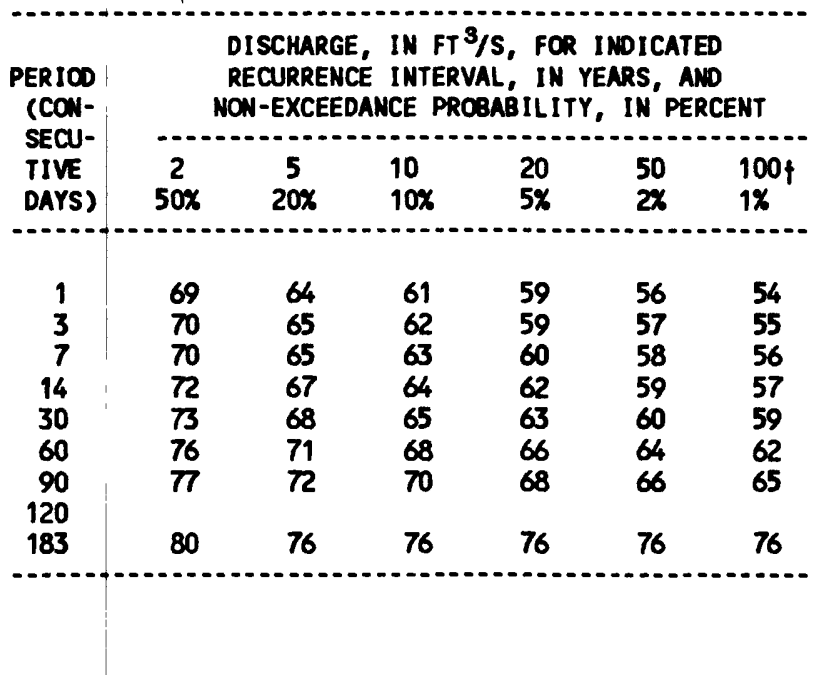

MGNITLDE AND PROBABILITY OF ANNUAL HIGH FLOW BASED ON PERICD OF RECORD 1916, 1918-20, 1966-89

\begin{tabular}{|c|c|c|c|c|c|c|}
\hline $\begin{array}{l}\text { PERIOD } \\
\text { (CON- } \\
\text { SECU- }\end{array}$ & & $\begin{array}{l}\text { DISCHA } \\
\text { RECURR } \\
\text { EXCEED }\end{array}$ & $\begin{array}{l}\text { GE, IN F } \\
\text { NCE INTE } \\
\text { NCE PROB }\end{array}$ & $3 / 5, F$ & $\begin{array}{l}\text { R INDIC } \\
\text { YEARS, } \\
\text { IN PERC }\end{array}$ & $\begin{array}{l}\text { TED } \\
\text { AND } \\
\text { ENT }\end{array}$ \\
\hline $\begin{array}{l}\text { TIVE } \\
\text { DAYS) }\end{array}$ & $\begin{array}{c}2 \\
50 x\end{array}$ & $\begin{array}{c}5 \\
20 x\end{array}$ & $\begin{array}{l}10 \\
10 \%\end{array}$ & $\begin{array}{l}25 \\
4 \%\end{array}$ & $\begin{array}{l}50 \\
2 x\end{array}$ & $\begin{array}{c}100 \dagger \\
1 \%\end{array}$ \\
\hline $\begin{array}{r}1 \\
3 \\
7 \\
15 \\
30 \\
60 \\
90\end{array}$ & $\begin{array}{r}3,370 \\
2,100 \\
1,330 \\
859 \\
583 \\
399 \\
323\end{array}$ & $\begin{array}{r}10,200 \\
5,980 \\
3,730 \\
2,170 \\
1,370 \\
882 \\
668\end{array}$ & $\begin{array}{r}17,100 \\
9,800 \\
6,100 \\
3,410 \\
2,110 \\
1,330 \\
975\end{array}$ & $\begin{array}{r}28,300 \\
15,900 \\
10,000 \\
5,390 \\
3,280 \\
2,040 \\
1,460\end{array}$ & $\begin{array}{r}38,400 \\
21,300 \\
13,500 \\
7,150 \\
4,320 \\
2,690 \\
1,890\end{array}$ & $\begin{array}{r}49,700 \\
27,300 \\
17,500 \\
9,140 \\
5,520 \\
3,450 \\
2,390\end{array}$ \\
\hline
\end{tabular}

DURATION TABLE OF DAILY MEAN FLOW FOR PERIOD OF RECORD 1916, 1918-20, 1966-89 DISCHARGE, IN FT $3 / 5$, HHICH WAS EQUALED OR EXCEEDED FOR INDICATED PERCENT OF TIME

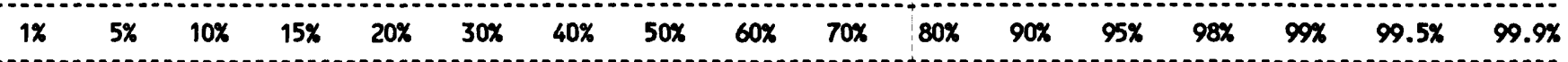

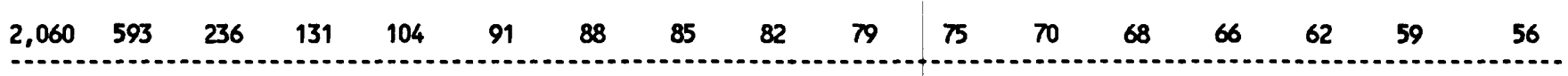


GILA RIVER BASIN

09504000 VERDE RIVER MEAR CLARKDALE, AZ--CONTIMUEd
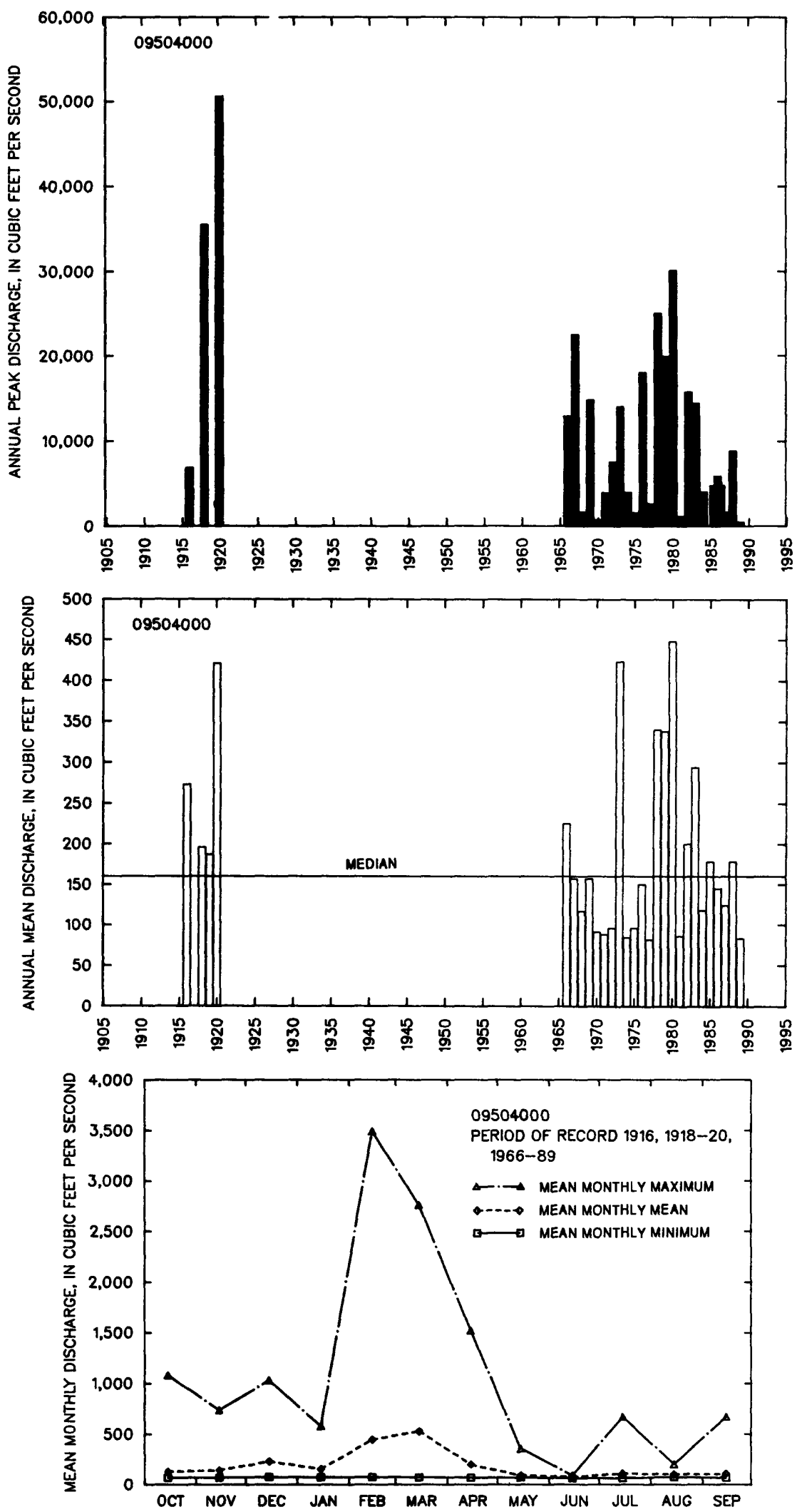


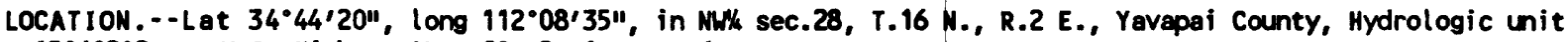
15060202, at U.S. Highway ALt. 89, 2 mi west of Jerome.

DRAINAGE AREA. $--0.85 \mathrm{mi}^{2}$.

ANMUAL PEAK DISCHARGE

\begin{tabular}{lccc}
$\begin{array}{c}\text { UATER } \\
\text { YEAR }\end{array}$ & DATE & $\begin{array}{c}\text { ANNUAL PEAK } \\
\text { DISCHARGE } \\
\text { (FT } 3 / \text { S) }\end{array}$ & $\begin{array}{c}\text { DISCHARGE } \\
\text { CODES }\end{array}$ \\
\hline 1963 & $00-00-63$ & 500 & ES, HP \\
\hline 1964 & $08-10-64$ & 25 & ES \\
1965 & $04-19-65$ & 7.0 & ES \\
1966 & $09-14-66$ & 25 & ES \\
1967 & $00-00-67$ & 0 & \\
1968 & $02-14-68$ & 1.0 & \\
1969 & $07-27-69$ & 0.5 & ES \\
1970 & $09-05-70$ & 100 & ES \\
1971 & $00-00-71$ & 0 & \\
1972 & $00-00-72$ & 0 & \\
1973 & $10-07-72$ & 90 & \\
1974 & $00-00-74$ & 0 & \\
1975 & $00-00-75$ & 0 & \\
1976 & $00-00-76$ & 0 & \\
1977 & $00-00-77$ & 9.0 & LT \\
1978 & $00-00-78$ & 9.0 & LT \\
1979 & $00-00-79$ & 9.0 & LT \\
1980 & $02-00-80$ & 10 & \\
\hline
\end{tabular}

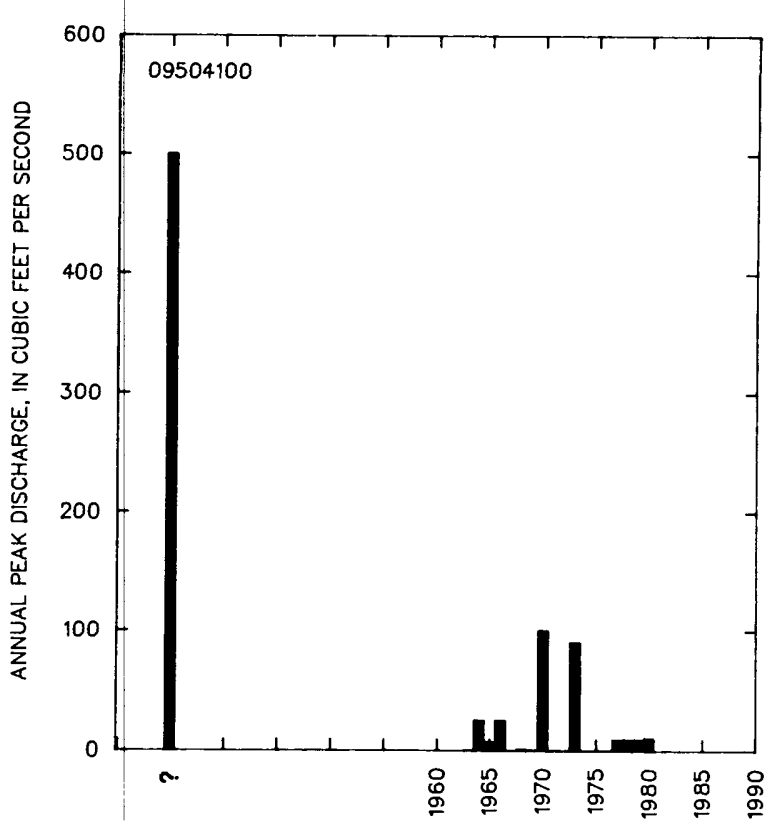

1Highest since 1935, year of occurrence unknown.

MAGNITUDE AND PROBABILITY OF INSTANTANEOUS PEAK FLOU BASED ON PERIOD OF RECORD 1935, 1963-80

DISCHARGE, IN $\mathrm{FT}^{3} / \mathrm{S}$, FOR INDICATED RECURRENCE INTERVAL

IN YEARS, AND EXCEEDANCE PROBABILITY, IN PERCENT

\begin{tabular}{|c|c|c|c|c|c|}
\hline $\begin{array}{c}2 \\
50 \%\end{array}$ & $\begin{array}{c}5 \\
20 \%\end{array}$ & $\begin{array}{r}10 \\
10 \%\end{array}$ & $\begin{array}{l}25 \\
4 \%\end{array}$ & $\begin{array}{l}50 \nmid \\
2 \%\end{array}$ & $\begin{array}{c}100 \nmid \\
1 \%\end{array}$ \\
\hline 2.6 & 23.5 & 66.3 & 183 & 335 & 561 \\
\hline $\begin{array}{l}\text { WEIGHTED } \\
\text { MEAN } \\
\text { STANDARD }\end{array}$ & $\begin{array}{l}\text { SKEW } \\
\text { DEV. }\end{array}$ & $\begin{array}{l}(\text { LOGS })= \\
(\text { LOGS })= \\
(\text { LOGS })=\end{array}$ & $\begin{array}{r}-0.49 \\
0.31 \\
1.24\end{array}$ & & \\
\hline
\end{tabular}

+ Reliability of values in column is uncertain, and potential errors are large.

BASIN CHARACTERISTICS

\begin{tabular}{|c|c|c|c|c|c|c|c|}
\hline \multirow{3}{*}{$\begin{array}{l}\text { MAIN } \\
\text { CHANNEL } \\
\text { SLOPE } \\
\text { (FT/MI) }\end{array}$} & \multirow[b]{3}{*}{$\begin{array}{c}\text { STREAM } \\
\text { LENGTH } \\
\text { (MI) }\end{array}$} & \multirow{3}{*}{$\begin{array}{l}\text { MEAN } \\
\text { BASIN } \\
\text { ELEVA- } \\
\text { TION } \\
\text { (FT) }\end{array}$} & \multirow[b]{3}{*}{$\begin{array}{l}\text { FORESTED } \\
\text { AREA } \\
\text { (PERCENT) }\end{array}$} & \multirow[b]{3}{*}{$\begin{array}{r}\text { SOIL } \\
\text { INDEX }\end{array}$} & \multirow{2}{*}{$\begin{array}{l}\text { MEAN } \\
\text { ANNUAL } \\
\text { PRECIPI- }\end{array}$} & \multirow{2}{*}{\multicolumn{2}{|c|}{ RAINFALL INTENSITY, 24-HOUR }} \\
\hline & & & & & & & \\
\hline & & & & & $\begin{array}{l}\text { PRECIPI - } \\
\text { TATION } \\
\text { (IN) }\end{array}$ & $\begin{array}{c}\text { 2-YEAR } \\
\text { (IN) }\end{array}$ & $\begin{array}{c}\text { 50-YEAR } \\
\text { (IN) }\end{array}$ \\
\hline 1,270 & 1.6 & 7,050 & 97.0 & 3.0 & 22.0 & 2.3 & 4.2 \\
\hline
\end{tabular}


09504400 MUIDS CAWYON TRIBUTARY NEAR SEDONA, AZ

LOCATION.--Lat 34.55'20", long 111'38'40", in SWk sec.22, T.18 N., R.7 E., Coconino County, Hydrologic Unit 15060202, at State Highway 79, $7 \mathrm{mi}$ northeast of Sedona.

DRAIMACE AREA. $--1.15 \mathrm{mi}^{2}$.

ANIUAL PEAK DISCHARGE

\begin{tabular}{|c|c|c|c|}
\hline $\begin{array}{l}\text { MATER } \\
\text { YEAR }\end{array}$ & DATE & $\begin{array}{l}\text { ANWUAL PEAK } \\
\text { DISCHARGE } \\
\text { (FT } 3 / \mathrm{S} \text { ) }\end{array}$ & $\begin{array}{l}\text { DISCHAREE } \\
\text { COOES }\end{array}$ \\
\hline $\begin{array}{l}1964 \\
1965 \\
1966 \\
1967 \\
1968 \\
1969 \\
1970 \\
1971 \\
1972 \\
1973 \\
1974 \\
1975 \\
1976 \\
1977 \\
1979 \\
1980\end{array}$ & $\begin{array}{l}07-00-64 \\
09-03-65 \\
11-25-65 \\
12-06-66 \\
02-00-68 \\
01-25-69 \\
09-05-70 \\
00-00-71 \\
06-05-72 \\
10-07-72 \\
04-02-74 \\
04-00-75 \\
00-00-76 \\
00-00-77 \\
12-18-78 \\
02-00-80\end{array}$ & $\begin{array}{c}1.0 \\
222 \\
222 \\
192 \\
14 \\
181 \\
705 \\
1.0 \\
44 \\
90 \\
20 \\
19 \\
114 \\
18 \\
1275 \\
180\end{array}$ & ES \\
\hline
\end{tabular}

Highest since 1970.

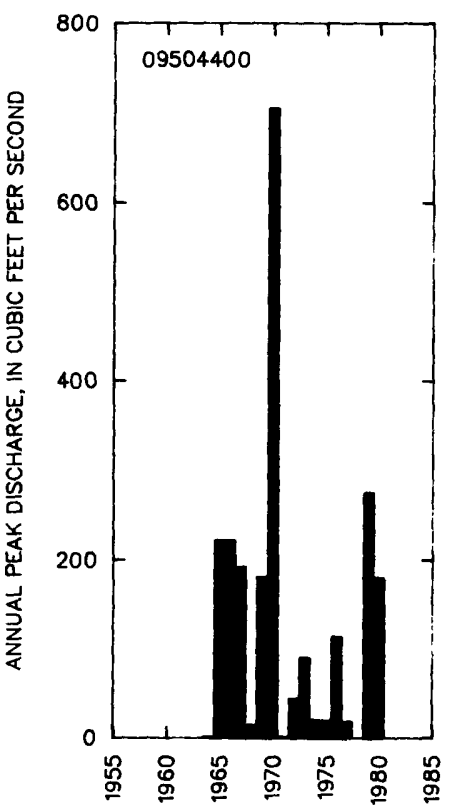

MAGNITUDE AND PROBABILITY OF INSTANTANECUS PEAK FLON BASED ON PERIDO OF RECORD 1964-77, 1979-80

DISCHARGE, IN $\mathrm{FT}^{3} / \mathrm{S}$, FOR INDICATED RECURRENCE INTERVAL IN YEARS, AND EXCEEDANCE PROBABILITY, IN PERCENT

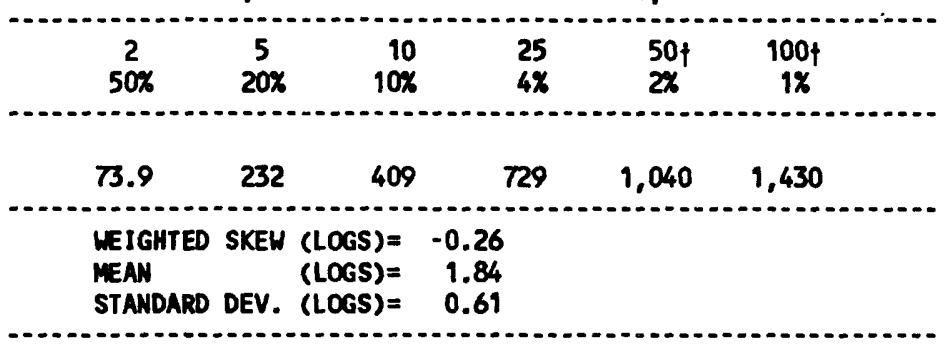

$\uparrow$ Reliability of values in column is uncertain, and potential errors are large.

BASIN CHARACTERISTICS

\begin{tabular}{|c|c|c|c|c|c|c|c|}
\hline \multirow{2}{*}{$\begin{array}{l}\text { MAIN } \\
\text { CHANHEL } \\
\text { SLOPE } \\
\text { (FTMI) }\end{array}$} & \multirow[b]{2}{*}{$\begin{array}{l}\text { STREAM } \\
\text { LENGTH } \\
\text { (MI) }\end{array}$} & \multirow{2}{*}{$\begin{array}{l}\text { MEAN } \\
\text { BASIN } \\
\text { ELEVA- } \\
\text { TION } \\
\text { (FT) }\end{array}$} & \multirow[b]{2}{*}{$\begin{array}{l}\text { FORESTED } \\
\text { AREA } \\
\text { (PERCENT) }\end{array}$} & \multirow[b]{2}{*}{$\begin{array}{l}\text { SOIL } \\
\text { INDEX }\end{array}$} & \multirow{2}{*}{$\begin{array}{l}\text { MEAN } \\
\text { ANNUAL } \\
\text { PRECIPI- } \\
\text { TATION } \\
\text { (IN) }\end{array}$} & \multicolumn{2}{|c|}{ RAINFALL INTENSITY, 24-HOUR } \\
\hline & & & & & & $\begin{array}{c}\text { 2-YEAR } \\
\text { (IN) }\end{array}$ & $\begin{array}{l}\text { 50-YEAR } \\
\text { (IN) }\end{array}$ \\
\hline 269 & 2.2 & 6,880 & 98.0 & 3.0 & 26.0 & 2.8 & 5.5 \\
\hline
\end{tabular}




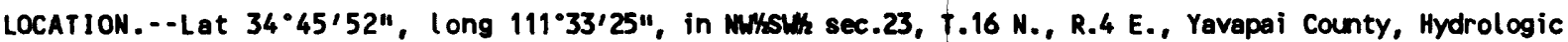
Unit 15060202, on right bank $250 \mathrm{ft}$ downstream from county highway bridge, $0.2 \mathrm{mi}$ upstream from Page Springs, $4 \mathrm{mi}$ northeast of Cornville, and $15 \mathrm{mi}$ upstream from mouth. Prior to March 18, 1981, at site 250 ft upstrean.

DRAINAGE AREA. $--355 \mathrm{mi}^{2}$.

REMARKS.--Numerous diversions above and below station for irrigation.

\section{ANMUAL PEAK DISCHAREE}

\begin{tabular}{|c|c|c|c|c|c|c|c|}
\hline $\begin{array}{l}\text { WATER } \\
\text { YEAR }\end{array}$ & DATE & $\begin{array}{c}\text { ANNUAL PEAK } \\
\text { DISCHARGE } \\
\left(F^{3} / S\right)\end{array}$ & $\begin{array}{l}\text { DISCHARGE } \\
\text { CODES }\end{array}$ & $\begin{array}{l}\text { WATER } \\
\text { YEAR }\end{array}$ & DATE & $\begin{array}{l}\text { ANMUAL PEAK } \\
\text { DISCHARGE } \\
\left(\mathrm{FT}^{3} / \mathrm{S}\right)\end{array}$ & $\begin{array}{l}\text { DISCHARGE } \\
\text { CODES }\end{array}$ \\
\hline $\begin{array}{l}1938 \\
1941 \\
1942 \\
1943 \\
1944 \\
1945 \\
1946 \\
1948 \\
1949 \\
1950 \\
1951 \\
1952 \\
1953 \\
1954 \\
1955 \\
1956 \\
1957 \\
1958 \\
1959 \\
1960 \\
1961 \\
1962 \\
1963 \\
1964 \\
1965\end{array}$ & $\begin{array}{l}03-03-38 \\
03-14-41 \\
10-13-41 \\
03-10-43 \\
04-06-44 \\
07-30-45 \\
00-00-46 \\
07-26-48 \\
09-09-49 \\
10-19-49 \\
08-29-51 \\
12-30-51 \\
07-14-53 \\
03-23-54 \\
08-23-55 \\
08-17-56 \\
01-10-57 \\
11-03-57 \\
08-05-59 \\
12-25-59 \\
07-31-61 \\
02-12-62 \\
08-17-63 \\
08-14-64 \\
04-04-65\end{array}$ & $\begin{array}{r}(1) \\
5,280 \\
2,580 \\
3,640 \\
2,180 \\
6,020 \\
1,200 \\
605 \\
2,260 \\
6,400 \\
3,440 \\
17,200 \\
858 \\
7,850 \\
6,400 \\
675 \\
5,150 \\
9,620 \\
3,750 \\
4,340 \\
4,340 \\
7,280 \\
990 \\
10,300 \\
3,090\end{array}$ & MP & $\begin{array}{l}1966 \\
1967 \\
1968 \\
1969 \\
1970 \\
1971 \\
1972 \\
1973 \\
1974 \\
1975 \\
1976 \\
1977 \\
1978 \\
1979 \\
1980 \\
1981 \\
1982 \\
1983 \\
1984 \\
1985 \\
1986 \\
1987 \\
1988 \\
1989\end{array}$ & $\begin{array}{l}11-25-65 \\
12-06-66 \\
02-26-68 \\
01-25-69 \\
09-05-70 \\
08-27-71 \\
12-26-71 \\
10-19-72 \\
07-07-74 \\
07-14-75 \\
02-09-76 \\
07-18-77 \\
03-01-78 \\
12-19-78 \\
02-19-80 \\
08-12-81 \\
03-12-82 \\
11-30-82 \\
12-27-83 \\
12-27-84 \\
11-30-85 \\
10-11-86 \\
11-01-87 \\
07-09-89\end{array}$ & $\begin{array}{r}17,600 \\
19,200 \\
816 \\
15,800 \\
224,700 \\
4,050 \\
4,020 \\
8,790 \\
3,220 \\
4,820 \\
12,500 \\
415 \\
17,400 \\
225,100 \\
26,400 \\
830 \\
13,000 \\
14,100 \\
5,730 \\
3,070 \\
6,480 \\
3,300 \\
7,640 \\
1,470\end{array}$ & \\
\hline
\end{tabular}

BASIN CHARACTERISTICS

\begin{tabular}{|c|c|c|c|c|c|c|c|}
\hline MAIN & & $\begin{array}{l}\text { MEAN } \\
\text { BASIN }\end{array}$ & & & $\begin{array}{c}\text { MEAN } \\
\text { ANNUAL }\end{array}$ & RAINFALL I & SITY, 24-HOUR \\
\hline $\begin{array}{l}\text { CHANNEL } \\
\text { SLOPE } \\
\text { (FT/MI) }\end{array}$ & $\begin{array}{l}\text { STREAM } \\
\text { LENGTH } \\
\text { (MI) }\end{array}$ & $\begin{array}{l}\text { ELEVA- } \\
\text { TION } \\
\text { (FT) }\end{array}$ & $\begin{array}{l}\text { FORESTED } \\
\text { AREA } \\
\text { (PERCENT) }\end{array}$ & $\begin{array}{l}\text { SOIL } \\
\text { INDEX }\end{array}$ & $\begin{array}{l}\text { PRECIPI - } \\
\text { TATION } \\
\text { (IN) }\end{array}$ & $\begin{array}{c}\text { 2-YEAR } \\
\text { (IN) }\end{array}$ & $\begin{array}{l}\text { 50-YEAR } \\
\text { (IN) }\end{array}$ \\
\hline 85.0 & 40.8 & 6,200 & 66.0 & 2.7 & 22.6 & 2.4 & 4.7 \\
\hline
\end{tabular}


GILA RIVER BASIN

09504500 OAK CREEK NEAR CORNVILLE, AZ--Continued

MEAN MONTHLY AND ANNUAL DISCHARGES 1941-45, 1949-89

\begin{tabular}{|c|c|c|c|c|c|c|}
\hline MONTH & $\begin{array}{l}\operatorname{MAXIMTH} \\
\left(\mathrm{FT}^{3} / \mathrm{S}\right)\end{array}$ & $\begin{array}{l}\text { MINIMUM } \\
\left(\mathrm{FT}^{3} / \mathrm{S}\right)\end{array}$ & $\begin{array}{c}\text { MEAN } \\
\left(F T^{3} / S\right)\end{array}$ & $\begin{array}{l}\text { STAN- } \\
\text { DARD } \\
\text { DEVIA- } \\
\text { TION } \\
\text { (FT } 3 / S \text { ) }\end{array}$ & $\begin{array}{l}\text { COEFFI- } \\
\text { CIENT OF } \\
\text { VARI- } \\
\text { ATION }\end{array}$ & $\begin{array}{c}\text { PERCENT } \\
\text { OF } \\
\text { ANNUAL } \\
\text { RUNOFF }\end{array}$ \\
\hline $\begin{array}{l}\text { OCTOBER } \\
\text { NOVEMBER } \\
\text { DECEMBER } \\
\text { JANUARY } \\
\text { FEBRUARY } \\
\text { MARCH } \\
\text { APRIL } \\
\text { MAY } \\
\text { JUNE } \\
\text { JULY } \\
\text { AUGUST } \\
\text { SEPTEMBER }\end{array}$ & $\begin{array}{r}571 \\
450 \\
881 \\
529 \\
1,390 \\
1,320 \\
1,100 \\
216 \\
58 \\
41 \\
91 \\
373\end{array}$ & $\begin{array}{l}20 \\
29 \\
31 \\
34 \\
32 \\
29 \\
26 \\
17 \\
14 \\
14 \\
13 \\
15\end{array}$ & $\begin{array}{r}51 \\
69 \\
122 \\
82 \\
166 \\
246 \\
178 \\
34 \\
21 \\
25 \\
35 \\
42\end{array}$ & $\begin{array}{c}83 \\
86 \\
184 \\
94 \\
230 \\
244 \\
215 \\
30 \\
7.0 \\
7.6 \\
15 \\
54\end{array}$ & $\begin{array}{l}1.6 \\
1.2 \\
1.5 \\
1.2 \\
1.4 \\
0.99 \\
1.2 \\
0.87 \\
0.34 \\
0.31 \\
0.44 \\
1.3\end{array}$ & $\begin{array}{r}4.8 \\
6.5 \\
11.4 \\
7.6 \\
15.5 \\
23.0 \\
16.7 \\
3.2 \\
1.9 \\
2.3 \\
3.3 \\
3.9\end{array}$ \\
\hline ANNUAL & 240 & 30 & 89 & 54 & 0.60 & 100 \\
\hline
\end{tabular}

MAGNITUDE AND PROBABILITY OF INSTANTANEQUS PEAK FLOW BASED ON PERIOD OF RECORD 1941-46, 1948-89

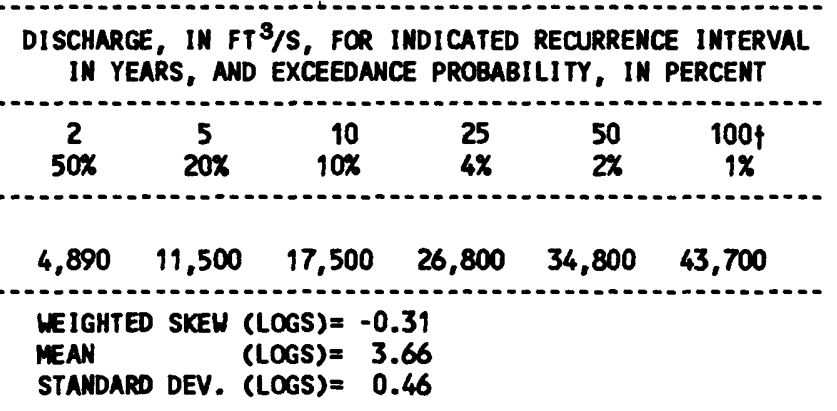

MACNITLDE AND PROBABILITY OF ANNUAL LOW FLOW BASED ON PERIOD OF RECORD 1942-45, 1950-89

\begin{tabular}{|c|c|c|c|c|c|c|}
\hline \multirow{2}{*}{$\begin{array}{l}\text { PERIOD } \\
\text { (CON- } \\
\text { SECU- }- \\
\text { TIVE } \\
\text { DAYS) }\end{array}$} & \multicolumn{6}{|c|}{$\begin{array}{l}\text { DISCHARGE, IN } \mathrm{FT}^{3} / \mathrm{S} \text {, FOR INDICATED } \\
\text { RECURRENCE INTERVAL, IN YEARS, AND } \\
\text { NON-EXCEEDANCE PROBABILITY, IN PERCENT }\end{array}$} \\
\hline & $\begin{array}{c}2 \\
50 \%\end{array}$ & $\begin{array}{c}5 \\
20 \%\end{array}$ & $\begin{array}{l}10 \\
10 \%\end{array}$ & $\begin{array}{l}20 \\
5 \%\end{array}$ & $\begin{array}{l}50 \\
2 \%\end{array}$ & $\begin{array}{l}100 \dagger \\
1 \%\end{array}$ \\
\hline $\begin{array}{r}1 \\
3 \\
7 \\
14 \\
30 \\
60 \\
90 \\
120 \\
183\end{array}$ & $\begin{array}{l}14 \\
15 \\
15 \\
16 \\
17 \\
19 \\
21 \\
24 \\
28\end{array}$ & $\begin{array}{l}12 \\
12 \\
13 \\
14 \\
15 \\
17 \\
19 \\
21 \\
24\end{array}$ & $\begin{array}{l}11 \\
11 \\
12 \\
13 \\
14 \\
16 \\
17 \\
20 \\
22\end{array}$ & $\begin{array}{c}9.8 \\
10 \\
11 \\
12 \\
13 \\
15 \\
16 \\
19 \\
21\end{array}$ & $\begin{array}{c}8.8 \\
9.2 \\
10 \\
11 \\
13 \\
14 \\
15 \\
17 \\
20\end{array}$ & $\begin{array}{c}8.2 \\
8.5 \\
9.8 \\
11 \\
12 \\
14 \\
14 \\
17 \\
19\end{array}$ \\
\hline
\end{tabular}

MAGNITLDE AND PROBABILITY OF ANKUAL HIGH FLON BASED ON PERIOD OF RECORD 1941-45, 1949-89

\begin{tabular}{|c|c|c|c|c|c|c|}
\hline \multirow{2}{*}{$\begin{array}{l}\text { PERIOD } \\
\text { (CON- } \\
\text { SECU- } \\
\text { TIVE } \\
\text { DAYS) }\end{array}$} & \multicolumn{6}{|c|}{$\begin{array}{l}\text { DISCHARGE, IN FT } 3 / \mathrm{S} \text {, FOR INDICATED } \\
\text { RECURRENCE INTERVAL, IN YEARS, AND } \\
\text { EXCEEDANCE PROBABILITY, IN PERCENT }\end{array}$} \\
\hline & $\begin{array}{c}2 \\
50 \%\end{array}$ & $\begin{array}{c}5 \\
20 \%\end{array}$ & $\begin{array}{l}10 \\
10 \%\end{array}$ & $\begin{array}{l}25 \\
4 \%\end{array}$ & $\begin{array}{l}50 \\
2 \%\end{array}$ & $\begin{array}{c}100 \uparrow \\
1 \%\end{array}$ \\
\hline $\begin{array}{r}1 \\
3 \\
7 \\
15 \\
30 \\
60 \\
90\end{array}$ & $\begin{array}{r}1,700 \\
1,100 \\
708 \\
463 \\
317 \\
214 \\
171\end{array}$ & $\begin{array}{r}4,830 \\
2,880 \\
1,710 \\
1,020 \\
673 \\
445 \\
342\end{array}$ & $\begin{array}{r}8,050 \\
4,510 \\
2,560 \\
1,460 \\
952 \\
635 \\
481\end{array}$ & $\begin{array}{r}13,500 \\
7,000 \\
3,790 \\
2,050 \\
1,330 \\
907 \\
682\end{array}$ & $\begin{array}{r}18,700 \\
9,120 \\
4,780 \\
2,510 \\
1,630 \\
1,130 \\
847\end{array}$ & $\begin{array}{r}24,700 \\
11,400 \\
5,820 \\
2,970 \\
1,930 \\
1,360 \\
1,020\end{array}$ \\
\hline
\end{tabular}

DURATION TABLE OF DAILY MEAN FLOW FOR PERIOD OF RECORD 1941-45, 1949-89

DISCHARGE, IN FT $3 / 5$, WHICH WAS EQUALED OR EXCEEDED FOR INDICATED PERCENT OF TIME

\begin{tabular}{|c|c|c|c|c|c|c|c|c|c|c|c|c|c|c|c|c|}
\hline $1 \%$ & $5 \%$ & $10 \%$ & $15 \%$ & $20 \%$ & $30 \%$ & $40 \%$ & $50 \%$ & $60 \%$ & $70 \%$ & $80 \%$ & $90 \%$ & $95 \%$ & $98 \%$ & $99 \%$ & $99.5 \%$ & $99.9 x$ \\
\hline 1,060 & 335 & 146 & 81 & 56 & 42 & 36 & 33 & 29 & 25 & 22 & 19 & 17 & 15 & 14 & 13 & 10 \\
\hline
\end{tabular}

f Reliability of values in colum is uncertain, and potential errors are large. 
09504500 OAK CREEK NEAR CORNVILLE, AZ--CONTIMUED
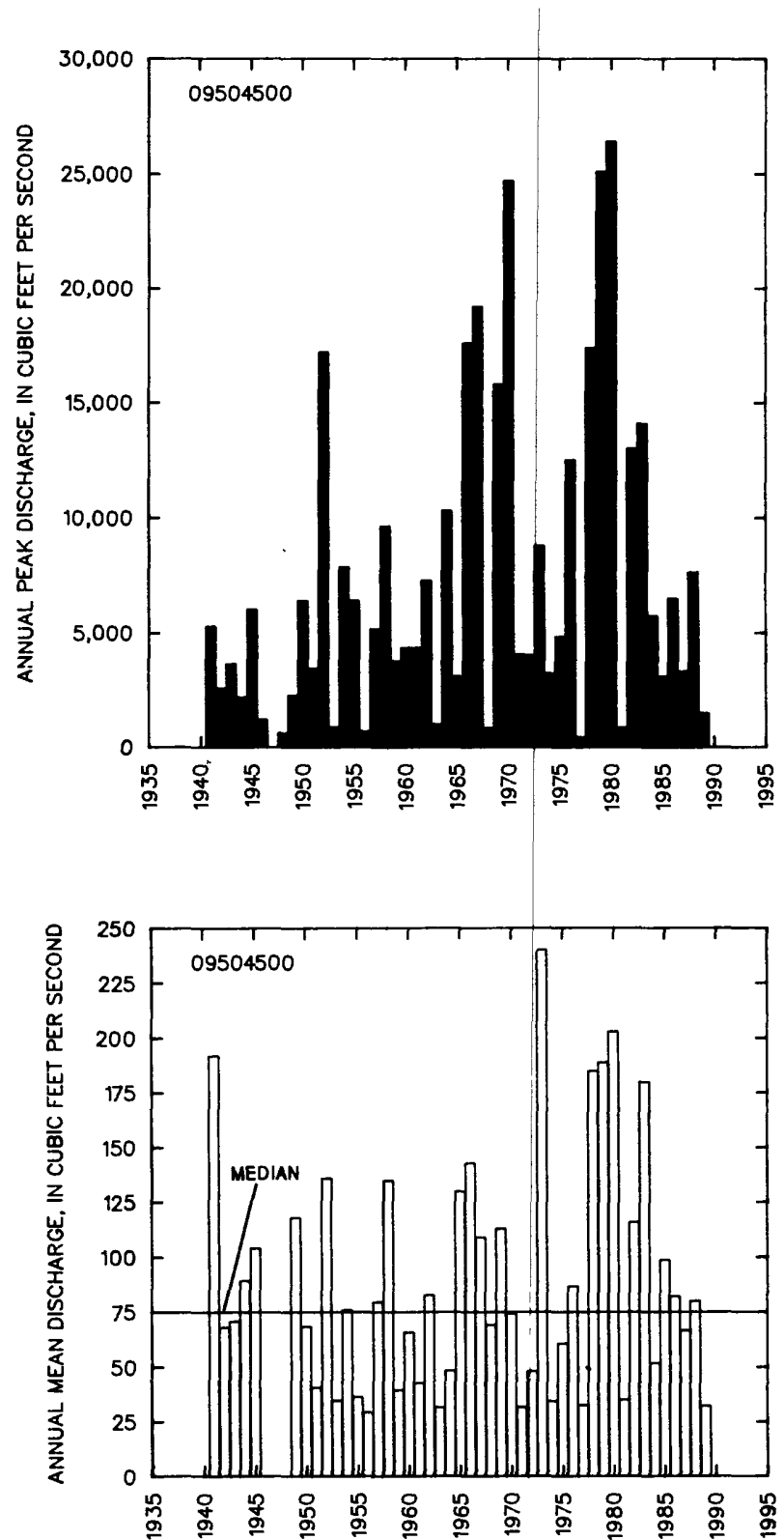
09504500 OAK CREEX NENR CORNITLLE, AZ--CONTIMUED
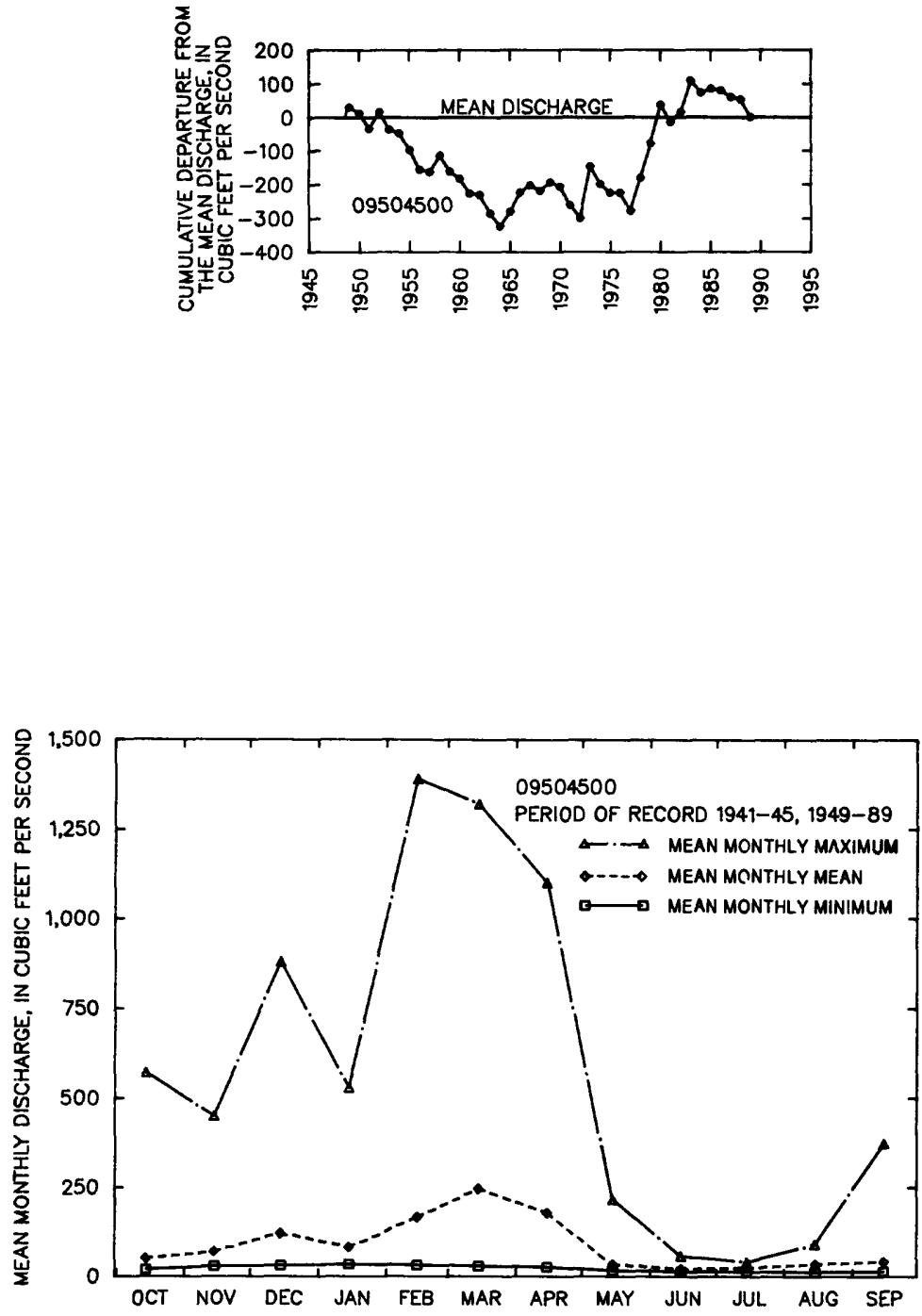
09504800 OAK CREEK TRIBUTARY NEAR CORNVILLE, AZ

LOCATION.--Lat 34'42'45", long 111.52'50", in NWK sec.12, T.15 N., R.4 E., Yavapai County, Hydrologic Unit 15060202, at county road, 2.5 mi east of Cornville.

DRAINAGE AREA. $-0.048 \mathrm{mi}^{2}$.

ANNUAL PEAK DISCHARGE

\begin{tabular}{cccc}
$\begin{array}{c}\text { UATER } \\
\text { YEAR }\end{array}$ & DATE & $\begin{array}{c}\text { ANNUAL PEAK } \\
\text { DISCHARGE } \\
\text { (FT } 3 / \text { /S) }\end{array}$ & $\begin{array}{c}\text { DISCHARGE } \\
\text { CODES }\end{array}$ \\
\hline 1963 & $09-09-63$ & 19 & \\
1964 & $07-26-64$ & 47 & \\
1965 & $08-00-65$ & 3.0 & ES \\
1966 & $00-00-66$ & 0 & \\
1967 & $08-00-67$ & 18 & \\
1968 & $00-00-68$ & 1.0 & LT \\
1969 & $08-08-69$ & 53 & \\
1970 & $09-05-70$ & 47 & LT \\
1971 & $09-29-71$ & 1.0 & LT \\
1972 & $00-00-72$ & 0.6 & LT \\
1973 & $10-07-72$ & 5.0 & ES \\
1974 & $08-00-74$ & 1.0 & HP \\
1975 & $11-02-74$ & 1.0 & \\
1976 & $00-00-76$ & 3.7 & 124 \\
1980 & $02-14-80$ & 124 &
\end{tabular}

$i_{H i g h e s t}$ since 1970.

MAGNITUDE AND PROBABILITY OF INSTANTANEOUS PEAK FLON BASED ON PERICD OF RECORD 1963-76, 1980

DISCHARGE, IN $\mathrm{FT}^{3} / \mathrm{S}$, FOR INDICATED RECURRENCE INTERVAL IN YEARS, AND EXCEEDANCE PROBABILITY, IN PERCENT

\begin{tabular}{|c|c|c|c|c|c|}
\hline $\begin{array}{c}2 \\
50 \%\end{array}$ & $\begin{array}{c}5 \\
20 \%\end{array}$ & $\begin{array}{r}10 \\
10 \%\end{array}$ & $\begin{array}{l}25 \\
4 \%\end{array}$ & $\begin{array}{l}50 \nmid \\
2 \%\end{array}$ & $\begin{array}{r}100 \\
1 \%\end{array}$ \\
\hline 4.1 & 25.9 & 61.7 & 144 & 240 & 369 \\
\hline $\begin{array}{l}\text { MEAN } \\
\text { STAND }\end{array}$ & DEVE. & $\begin{array}{l}(\text { LOGS })= \\
(\text { LOGS })=\end{array}$ & $\begin{array}{r}-0.48 \\
0.52 \\
1.04\end{array}$ & & \\
\hline
\end{tabular}

f Reliability of values in colum is uncertain, and potential errors are large.

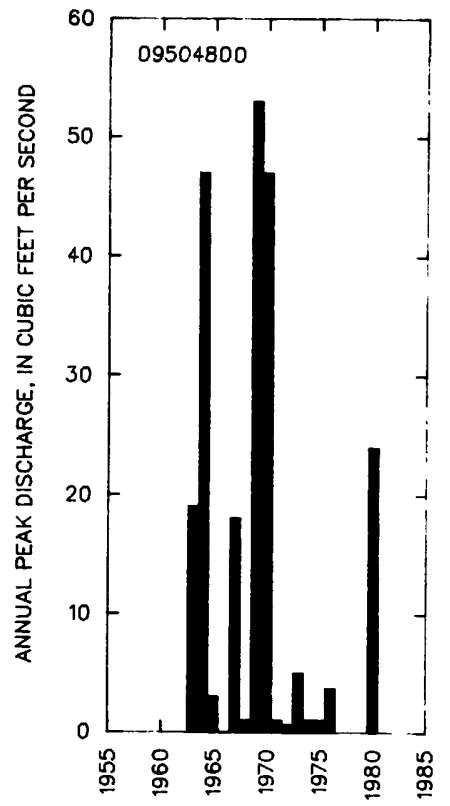

\section{BASIN CHARACTERISTICS}

\begin{tabular}{|c|c|c|c|c|c|c|c|}
\hline MAIN & & $\begin{array}{l}\text { MEAN } \\
\text { BASIN }\end{array}$ & & & $\begin{array}{c}\text { MEAN } \\
\text { ANNUAL }\end{array}$ & RAINFALL II & SITY, 24-HOQR \\
\hline $\begin{array}{l}\text { CHANNEL } \\
\text { SLOPE } \\
\text { (FT/MI) }\end{array}$ & $\begin{array}{l}\text { STREAM } \\
\text { LENGTH } \\
\text { (MI) }\end{array}$ & $\begin{array}{l}\text { ELEVA- } \\
\text { TION } \\
\text { (FT) }\end{array}$ & $\begin{array}{l}\text { FORESTED } \\
\text { AREA } \\
\text { (PERCENT) }\end{array}$ & $\begin{array}{l}\text { SOIL } \\
\text { INDEX }\end{array}$ & $\begin{array}{l}\text { PRECIPI - } \\
\text { TATION } \\
\text { (IN) }\end{array}$ & $\begin{array}{c}\text { 2-YEAR } \\
\text { (IN) }\end{array}$ & $\begin{array}{l}\text { 50-YEAR } \\
\text { (IN) }\end{array}$ \\
\hline 65.0 & 0.41 & 3,570 & 0.0 & 1.0 & 12.4 & 1.7 & 4.0 \\
\hline
\end{tabular}


09505200 WET BEAVER CREEK NEAR RIMROCK, AZ

LOCATION.--Lat 34*40'29", Long 111\%40'17", in MWHSW sec.24, T.15 N., R.6 E., Yavapai County, Hydrologic Unit 15060202, in Coconino National Forest, on right bank $4.5 \mathrm{mi}$ nor theast of Rimrock and $5.7 \mathrm{mi}$ upstream from Red Tank Draw.

DRAIMAGE AREA. $--111 \mathrm{mi}^{2}$.

ANMUAL PEAK DISCMARGE

\begin{tabular}{|c|c|c|c|c|}
\hline $\begin{array}{l}\text { WATER } \\
\text { YEAR }\end{array}$ & $\begin{array}{cc}\text { ANNUAL PEAK } \\
\text { DISCHARGE } \\
\text { DATE } \\
\left(\mathrm{FT}^{3} / \mathrm{S}\right)\end{array}$ & $\begin{array}{l}\text { WATER } \\
\text { YEAR }\end{array}$ & DATE & $\begin{array}{l}\text { ANMUAL PEAK } \\
\text { DISCHARGE } \\
\left(\mathrm{FT}^{3} / \mathrm{S}\right)\end{array}$ \\
\hline $\begin{array}{l}1962 \\
1963 \\
1964 \\
1965 \\
1966 \\
1967 \\
1968 \\
1969 \\
1970 \\
1971 \\
1972 \\
1973 \\
1974 \\
1975\end{array}$ & $\begin{array}{l}02-12-62 \\
08-27-63 \\
08-06-64 \\
01-06-65 \\
11-25-65 \\
07-31-67 \\
03-10-68 \\
01-25-69 \\
09-05-70 \\
09-01-71 \\
07-16-72 \\
10-19-72 \\
03-18-74 \\
04-13-75\end{array}$ & $\begin{array}{l}1976 \\
1977 \\
1978 \\
1979 \\
1980 \\
1981 \\
1982 \\
1983 \\
1984 \\
1985 \\
1986 \\
1987 \\
1988 \\
1989\end{array}$ & $\begin{array}{l}02-09-76 \\
04-07-77 \\
03-01-78 \\
12-18-78 \\
02-19-80 \\
04-05-81 \\
03-12-82 \\
11-30-82 \\
12-27-83 \\
12-27-84 \\
02-18-86 \\
03-18-87 \\
02-03-88 \\
03-29-89\end{array}$ & $\begin{array}{r}6,880 \\
155 \\
4,360 \\
7,560 \\
10,900 \\
368 \\
6,880 \\
5,480 \\
2,740 \\
3,960 \\
710 \\
1,180 \\
3,900 \\
285\end{array}$ \\
\hline
\end{tabular}

BASIN CHARACTERISTICS

\begin{tabular}{|c|c|c|c|c|c|c|c|}
\hline \multirow{2}{*}{$\begin{array}{l}\text { MAIN } \\
\text { CHANNEL } \\
\text { SLOPE } \\
\text { (FT/MI) }\end{array}$} & \multirow[b]{2}{*}{$\begin{array}{c}\text { STREAM } \\
\text { LENGTH } \\
\text { (MI) }\end{array}$} & \multirow{2}{*}{$\begin{array}{l}\text { MEAN } \\
\text { BASIN } \\
\text { ELEVA- } \\
\text { TION } \\
\text { (FT) }\end{array}$} & \multirow[b]{2}{*}{$\begin{array}{l}\text { FORESTED } \\
\text { AREA } \\
\text { (PERCENT) }\end{array}$} & \multirow[b]{2}{*}{$\begin{array}{l}\text { SOIL } \\
\text { INDEX }\end{array}$} & \multirow{2}{*}{$\begin{array}{l}\text { MEAN } \\
\text { ANNUAL } \\
\text { PRECIPI- } \\
\text { TATION } \\
\text { (IN) }\end{array}$} & \multicolumn{2}{|c|}{ RAINFALL INTENSITY, 24-HOUR } \\
\hline & & & & & & $\begin{array}{c}\text { 2-YEAR } \\
\text { (IN) }\end{array}$ & $\begin{array}{l}\text { 50-YEAR } \\
\text { (IN) }\end{array}$ \\
\hline 131 & 30.1 & 6,410 & 35.0 & 3.0 & 24.8 & 2.5 & 5.1 \\
\hline
\end{tabular}


MEAN MONTHLY AND ANMUAL DISCHARGES $1962-82$

\begin{tabular}{|c|c|c|c|c|c|c|}
\hline MONTH & 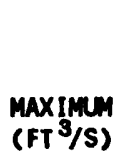 & $\begin{array}{l}\operatorname{MINIMUN} \\
\left(\mathrm{FT}^{3} / \mathrm{S}\right)\end{array}$ & $\begin{array}{c}\text { MEAN } \\
\left.\text { (FT }{ }^{3} / S\right)\end{array}$ & $\begin{array}{c}\text { STAN- } \\
\text { DARD } \\
\text { DEVIA- } \\
\text { TION } \\
\text { (FT } 3 / S)\end{array}$ & $\begin{array}{l}\text { COEFFI - } \\
\text { CIENT OF } \\
\text { VARI - } \\
\text { ATION }\end{array}$ & $\begin{array}{c}\text { PERCENT } \\
\text { OF } \\
\text { ANNUAL } \\
\text { RUNOFF }\end{array}$ \\
\hline $\begin{array}{l}\text { OCTOBER } \\
\text { NOVEMBER } \\
\text { DECEMBER } \\
\text { JANUARY } \\
\text { FEBRUARY } \\
\text { MARCH } \\
\text { APRIL } \\
\text { MAY } \\
\text { JUNE } \\
\text { JULY } \\
\text { AUGUST } \\
\text { SEPTEMBER }\end{array}$ & $\begin{array}{c}231 \\
128 \\
253 \\
149 \\
438 \\
500 \\
433 \\
109 \\
9.9 \\
21 \\
29 \\
82\end{array}$ & $\begin{array}{l}6.5 \\
6.8 \\
6.3 \\
7.1 \\
7.1 \\
7.3 \\
6.9 \\
6.3 \\
6.0 \\
6.3 \\
6.3 \\
6.2\end{array}$ & $\begin{array}{c}19 \\
18 \\
43 \\
34 \\
75 \\
105 \\
82 \\
13 \\
7.1 \\
8.8 \\
9.5 \\
12\end{array}$ & $\begin{array}{c}49 \\
29 \\
76 \\
45 \\
105 \\
115 \\
103 \\
22 \\
0.82 \\
4.4 \\
5.6 \\
17\end{array}$ & $\begin{array}{l}2.6 \\
1.6 \\
1.8 \\
1.3 \\
1.4 \\
1.1 \\
1.3 \\
1.7 \\
0.11 \\
0.50 \\
0.59 \\
1.4\end{array}$ & $\begin{array}{r}4.4 \\
4.1 \\
10.1 \\
7.9 \\
17.6 \\
24.7 \\
19.2 \\
3.1 \\
1.7 \\
2.1 \\
2.2 \\
2.8\end{array}$ \\
\hline ANNUAL & 103 & 7.7 & 35 & 26 & 0.73 & 100 \\
\hline
\end{tabular}

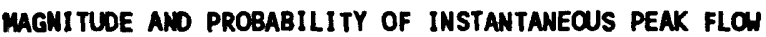
BASED ON PERIOD OF RECORD $1962-89$

DISCHARGE, IN $\mathrm{FT}^{3} / \mathrm{S}$, FOR INDICATED RECURRENCE INTERVAL IN YEARS, AND EXCEEDANCE PROBABILITY, IN PERCENT

\begin{tabular}{lccccc}
2 & 5 & 10 & 25 & 50 & $100 \nmid$ \\
$50 \%$ & $20 \%$ & $10 \%$ & $4 \times$ & $2 \%$ & $1 \times$ \\
$3,030 \quad 6,100$ & 8,410 & 11,500 & 13,800 & 16,100 \\
\hline MEIGHTED SKEW (LOGS) & & -0.54 & & \\
MEAN & (LOGS) & 3.44 & & \\
STANDARD DEV. (LOGS) & $=0.40$
\end{tabular}

MACNITUDE AND PROBABILITY OF ANNUAL LON FLON BASED ON PERIOD OF RECORD 1963-82

\begin{tabular}{|c|c|c|c|c|c|c|}
\hline \multirow{2}{*}{$\begin{array}{l}\text { PERIOO } \\
\text { (CON- } \\
\text { SECU- } \\
\text { TIVE } \\
\text { DAYS) }\end{array}$} & \multicolumn{6}{|c|}{$\begin{array}{l}\text { DISCHARGE, IN FT } 3 / S \text {, FOR INDICATED } \\
\text { RECURRENCE INTERVAL, IN YEARS, AND } \\
\text { NON-EXCEEDANCE PROBAB ILITY, IN PERCENT }\end{array}$} \\
\hline & $\begin{array}{c}2 \\
50 x\end{array}$ & $\begin{array}{c}5 \\
20 x\end{array}$ & $\begin{array}{l}10 \\
10 x\end{array}$ & $\begin{array}{l}20 \\
5 x\end{array}$ & $\begin{array}{l}50 \uparrow \\
2 \%\end{array}$ & $\begin{array}{l}100 f \\
1 x\end{array}$ \\
\hline $\begin{array}{r}1 \\
3 \\
7 \\
14 \\
30 \\
60 \\
90 \\
120 \\
183\end{array}$ & $\begin{array}{l}6.3 \\
6.3 \\
6.4 \\
6.4 \\
6.6 \\
6.7 \\
6.7 \\
6.8 \\
7.6\end{array}$ & $\begin{array}{l}5.9 \\
6.0 \\
6.1 \\
6.1 \\
6.2 \\
6.4 \\
6.5 \\
6.6 \\
6.8\end{array}$ & $\begin{array}{l}5.8 \\
5.8 \\
5.9 \\
5.9 \\
6.1 \\
6.2 \\
6.4 \\
6.5 \\
6.5\end{array}$ & $\begin{array}{l}5.6 \\
5.7 \\
5.8 \\
5.8 \\
5.9 \\
6.1 \\
6.4 \\
6.5 \\
6.5\end{array}$ & $\begin{array}{l}5.5 \\
5.6 \\
5.6 \\
5.7 \\
5.8 \\
5.9 \\
6.4 \\
6.5 \\
6.5\end{array}$ & $\begin{array}{l}5.4 \\
5.5 \\
5.5 \\
5.6 \\
5.6 \\
5.8 \\
6.4 \\
6.5 \\
6.5\end{array}$ \\
\hline
\end{tabular}

MMENITUDE AND PROBABILITY OF ANNUAL HIGH FLON BASED ON PERIOD OF RECORD 1962-82

\begin{tabular}{|c|c|c|c|c|c|c|}
\hline \multirow{2}{*}{$\begin{array}{l}\text { PERICO } \\
\text { (CON- } \\
\text { SECU- } \\
\text { TIVE } \\
\text { DAYS) }\end{array}$} & \multicolumn{6}{|c|}{$\begin{array}{l}\text { DISCHARGE, IN FT }{ }^{3} / S \text {, FOR INDICATED } \\
\text { RECURRENCE INTERVAL, IN YEARS, AND } \\
\text { EXCEEDANCE PROBABILITY, IN PERCENT }\end{array}$} \\
\hline & $\begin{array}{c}2 \\
50 \%\end{array}$ & $\underset{20 x}{5}$ & $\begin{array}{l}10 \\
10 \%\end{array}$ & $\begin{array}{l}25 \\
4 X\end{array}$ & $\begin{array}{l}50 f \\
2 x\end{array}$ & $\begin{array}{c}100 \nmid \\
1 x\end{array}$ \\
\hline $\begin{array}{c}1 \\
3 \\
7 \\
15 \\
30 \\
60 \\
90\end{array}$ & $\begin{array}{r}940 \\
602 \\
361 \\
227 \\
143 \\
93 \\
73\end{array}$ & $\begin{array}{r}2,470 \\
1,360 \\
791 \\
480 \\
319 \\
213 \\
167\end{array}$ & $\begin{array}{r}3,850 \\
1,940 \\
1,110 \\
654 \\
452 \\
311 \\
244\end{array}$ & $\begin{array}{r}5,890 \\
2,690 \\
1,510 \\
861 \\
628 \\
445 \\
355\end{array}$ & $\begin{array}{r}7,570 \\
3,230 \\
1,800 \\
999 \\
757 \\
549 \\
443\end{array}$ & $\begin{array}{r}9,340 \\
3,760 \\
2,080 \\
1,120 \\
882 \\
654 \\
534\end{array}$ \\
\hline
\end{tabular}

DURATION TABLE OF DAILY MEAN FLOM FOR PERIOD OF RECORD 1962-82

DISCHARGE, IN FT $3 / \mathrm{s}$, WHICH WAS EQUALED OR EXCEEDED FOR INDICATED PERCENT OF TIME

\begin{tabular}{|c|c|c|c|c|c|c|c|c|c|c|c|c|c|c|c|c|}
\hline $1 x$ & $5 \%$ & $10 \%$ & $15 x$ & $20 \%$ & $30 x$ & $40 \%$ & $50 \%$ & $60 x$ & $70 \%$ & $80 x$ & $90 x$ & $95 \%$ & $98 \%$ & $99 \%$ & $99.5 x$ & $99.9 \%$ \\
\hline 471 & 157 & 68 & 25 & 12 & 8.2 & 7.9 & 7.7 & 7.4 & 7.2 & 6.9 & 6.4 & 6.0 & 5.8 & 5.7 & 5.6 & 5.6 \\
\hline
\end{tabular}

+ Reliability of values in colum is uncertain, and potential errors are large. 
GILA RIVER BASIN

09505200 WET BEAVER CREEK MEAR RIMROCK, AZ--CONTIMUED
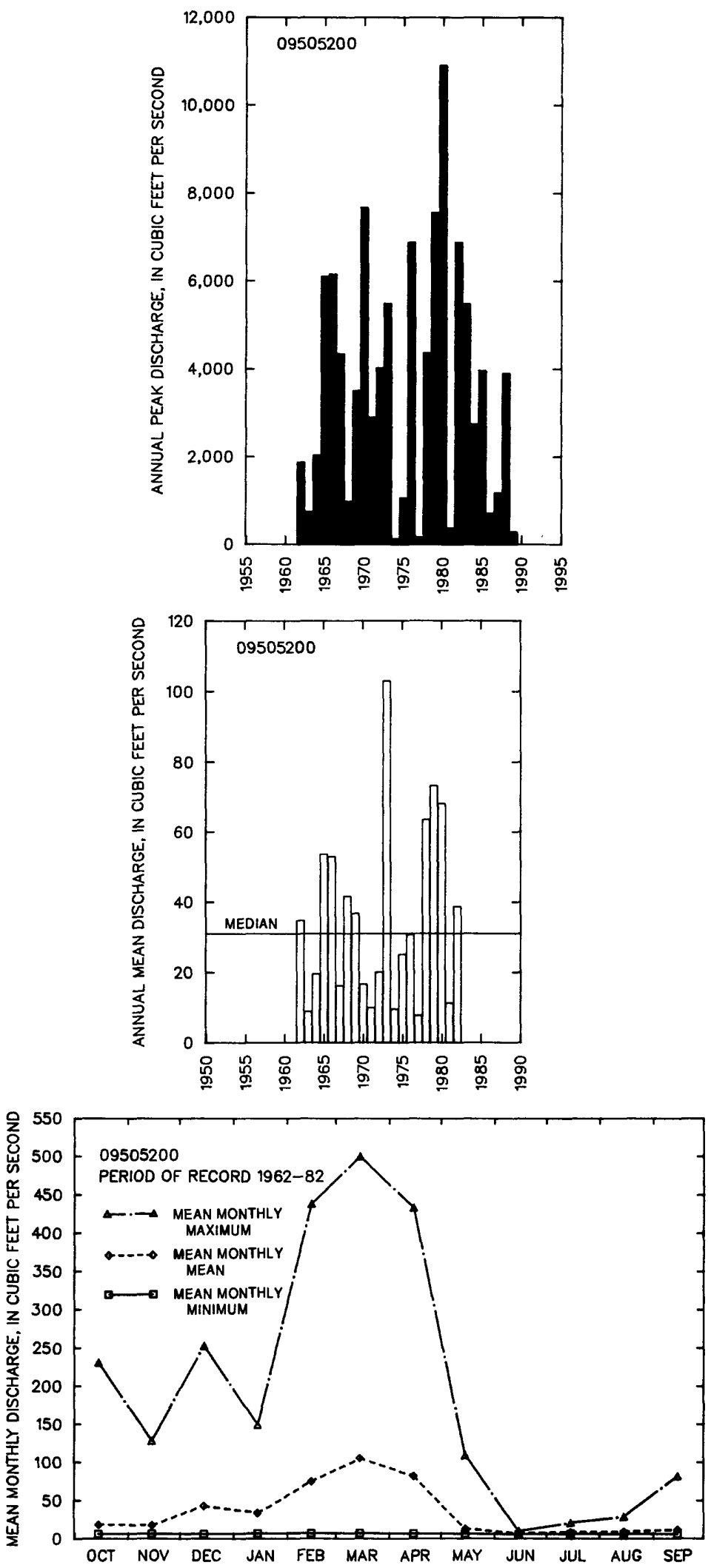
09505220 ROCKY GULCH MEAR RIMPOCK, AZ

LOCATION.--Lat 34.44'49", long 111.29'38", in SEYNWH sec.27, T.16 N, R.8 E., Coconino County, Hydrologic Unit 15060202, in Coconino National Forest, on right bank, on headwaters of Rocky Gulch, and 7 mi northwest of Rimrock.

DRAIHAGE AREA. $--1.40 \mathrm{mi}^{2}$.

REMARKS.--Prior to October 1985 station operated by the U.S. Forest service.

ANIUAL PEAK DISCHARGE

\begin{tabular}{|c|c|c|c|c|c|}
\hline $\begin{array}{l}\text { HATER } \\
\text { YEAR }\end{array}$ & DATE & $\begin{array}{l}\text { NUAL PEAK } \\
\text { DISCHARGE } \\
\text { (FT } 3 / S \text { ) }\end{array}$ & $\begin{array}{l}\text { WATER } \\
\text { YEAR }\end{array}$ & DATE & $\begin{array}{l}\text { ANMUAL PEAK } \\
\text { DISCCHARGE } \\
\left(\mathrm{FT}^{3} / \mathrm{S}\right)\end{array}$ \\
\hline $\begin{array}{l}1960 \\
1961 \\
1962 \\
1963 \\
1964 \\
1965 \\
1966 \\
1967 \\
1968 \\
1969 \\
1970 \\
1971 \\
1972 \\
1973\end{array}$ & $\begin{array}{l}00-00-60 \\
00-00-61 \\
00-00-62 \\
08-11-63 \\
03-31-64 \\
01-06-65 \\
11-25-65 \\
07-31-67 \\
02-24-68 \\
01-25-69 \\
09-05-70 \\
00-00-71 \\
00-00-72 \\
00-00-73\end{array}$ & $\begin{array}{c}22 \\
19 \\
19 \\
12 \\
28 \\
82 \\
147 \\
363 \\
13 \\
162 \\
1,550 \\
8.1 \\
69 \\
121\end{array}$ & $\begin{array}{l}1974 \\
1975 \\
1976 \\
1977 \\
1978 \\
1979 \\
1980 \\
1981 \\
1982 \\
1986 \\
1987 \\
1988 \\
1989\end{array}$ & $\begin{array}{l}00-00-74 \\
00-00-75 \\
02-09-76 \\
04-05-77 \\
03-02-78 \\
12-18-78 \\
02-14-80 \\
04-05-81 \\
03-12-82 \\
04-02-86 \\
03-09-87 \\
04-25-88 \\
03-28-89\end{array}$ & $\begin{array}{c}8.1 \\
27 \\
45.5 \\
5.8 \\
98.2 \\
166 \\
179 \\
15.8 \\
154 \\
24 \\
7.9 \\
48 \\
6.5\end{array}$ \\
\hline
\end{tabular}

MAGNI TUDE AND PROBABILITY OF INSTANTANEOUS PEAK FLON BASED ON PERIOD OF RECORD

DISCHARGE, IN $\mathrm{FT}^{3} / \mathrm{S}$, FOR INDICATED RECURRENCE INTERVAL IN YEARS, AND EXCEEDANCE PROBABILITY, IN PERCENT

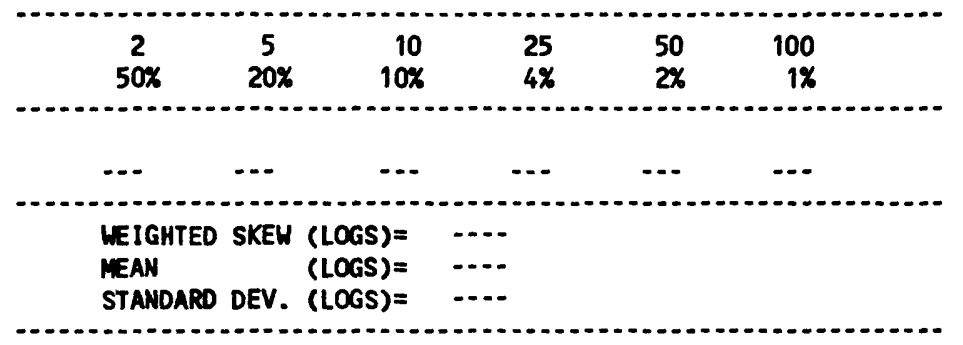

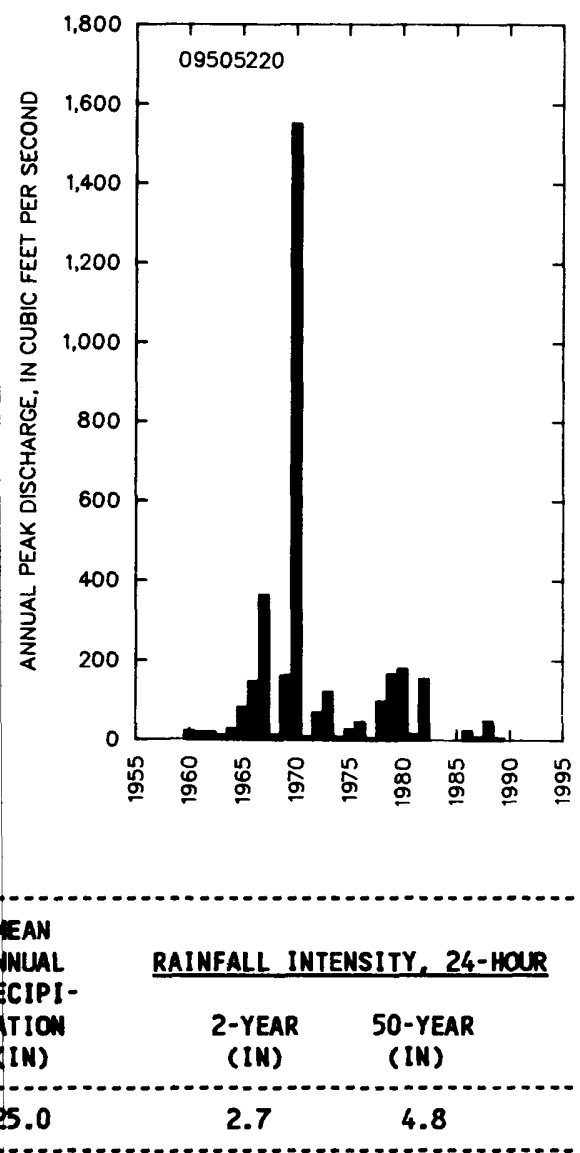


09505250 RED TANK DRAH NEAR RIMROCK, AZ

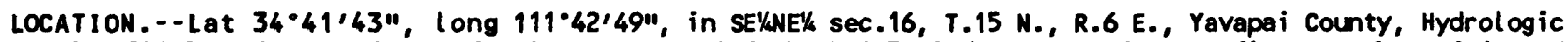
Unit 15060202, in Coconino National Forest, on left bank $2.5 \mathrm{mi}$ dounstream from confluence of Rarick and Mull ican Canyons, and $3.5 \mathrm{mi}$ northeast of Rimrock.

DRAINAGE AREA. $--48.0 \mathrm{mi}^{2}$.

ANNUAL PEAK DISCHARGE

\begin{tabular}{ccc}
$\begin{array}{l}\text { WATER } \\
\text { YEAR }\end{array}$ & DATE & $\begin{array}{c}\text { ANNUAL PEAK } \\
\text { DI SCHARGE } \\
\text { (FT } 3 / \text { S) }\end{array}$ \\
\hline 1958 & $03-22-58$ & 1,280 \\
1959 & $02-17-59$ & 113 \\
1960 & $12-25-59$ & 1,230 \\
1961 & $03-31-61$ & 457 \\
1962 & $02-08-62$ & 620 \\
1963 & $03-22-63$ & 12 \\
1964 & $08-02-64$ & 1,970 \\
1965 & $04-04-65$ & 1,440 \\
1966 & $11-25-65$ & 2,010 \\
1967 & $12-07-66$ & 425 \\
1968 & $02-14-68$ & 327 \\
1969 & $01-25-69$ & 1,650 \\
1970 & $09-05-70$ & 10,500 \\
1971 & $10-03-70$ & 12 \\
1972 & $12-26-71$ & 745 \\
1973 & $10-19-72$ & 2,720 \\
1974 & $01-21-74$ & 34 \\
1975 & $04-13-75$ & 407 \\
1976 & $02-09-76$ & 1,800 \\
1977 & $04-06-77$ & 16 \\
1978 & $02-23-78$ & 441 \\
\hline...$\ldots$ & &
\end{tabular}

BASIN CHARACTERISTICS

\begin{tabular}{|c|c|c|c|c|c|c|c|}
\hline \multirow{2}{*}{$\begin{array}{l}\text { MAIN } \\
\text { CHANNEL } \\
\text { SLOPE } \\
\text { (FT MI) }\end{array}$} & \multirow[b]{2}{*}{$\begin{array}{c}\text { STREAM } \\
\text { LENGTH } \\
\text { (MI) }\end{array}$} & \multirow{2}{*}{$\begin{array}{l}\text { MEAN } \\
\text { BASIN } \\
\text { ELEVA- } \\
\text { TION } \\
\text { (FT) }\end{array}$} & \multirow[b]{2}{*}{$\begin{array}{l}\text { FORESTED } \\
\text { AREA } \\
\text { (PERCENT) }\end{array}$} & \multirow[b]{2}{*}{$\begin{array}{l}\text { SOIL } \\
\text { INDEX }\end{array}$} & \multirow{2}{*}{$\begin{array}{l}\text { MEAN } \\
\text { ANNUAL } \\
\text { PRECIPI- } \\
\text { TATION } \\
\text { (IN) }\end{array}$} & \multicolumn{2}{|c|}{ RAINFALL INTENSITY, 24-HOUR } \\
\hline & & & & & & $\begin{array}{c}\text { 2-YEAR } \\
\text { (IN) }\end{array}$ & $\begin{array}{l}\text { 50-YEAR } \\
\text { (IN) }\end{array}$ \\
\hline 183 & 19.3 & 5,910 & 23.0 & 3.0 & 21.6 & 2.4 & 4.8 \\
\hline
\end{tabular}


MEAN MONTHLY AND ANMUAL DISCHARGES 1958-78

\begin{tabular}{|c|c|c|c|c|c|c|}
\hline MONTH & $\begin{array}{l}\operatorname{Max} \operatorname{IMMN}_{\mathrm{M}} \\
\left(\mathrm{FT}^{3} / \mathrm{S}\right)\end{array}$ & $\begin{array}{l}\operatorname{MINIMUM} \\
\left(\mathrm{FT}^{3} / \mathrm{S}\right)\end{array}$ & $\begin{array}{c}\text { MEAN } \\
\left(F^{3} / S\right)\end{array}$ & $\begin{array}{l}\text { STAN- } \\
\text { DARD } \\
\text { DEVIA- } \\
\text { TION } \\
\text { (FT } 3 / S)\end{array}$ & $\begin{array}{l}\text { COEFFI- } \\
\text { CIENT OF } \\
\text { VARI - } \\
\text { ATION }\end{array}$ & $\begin{array}{c}\text { PERCENT } \\
\text { OF } \\
\text { ANNUAL } \\
\text { RUNOFF }\end{array}$ \\
\hline $\begin{array}{l}\text { OCTOBER } \\
\text { NOVEMBER } \\
\text { DECEMBER } \\
\text { JANUARY } \\
\text { FEBRUARY } \\
\text { MARCH } \\
\text { APRIL } \\
\text { MAY } \\
\text { JUNE } \\
\text { JULY } \\
\text { AUGUST } \\
\text { SEPTEMBER }\end{array}$ & $\begin{array}{c}80 \\
41 \\
104 \\
46 \\
79 \\
161 \\
110 \\
3.7 \\
0.05 \\
1.5 \\
8.8 \\
62\end{array}$ & $\begin{array}{l}0.00 \\
0.00 \\
0.00 \\
0.00 \\
0.00 \\
0.02 \\
0.00 \\
0.00 \\
0.00 \\
0.00 \\
0.00 \\
0.00\end{array}$ & $\begin{array}{c}4.2 \\
4.4 \\
10 \\
7.0 \\
16 \\
27 \\
14 \\
0.25 \\
0.01 \\
0.07 \\
0.50 \\
3.4\end{array}$ & $\begin{array}{l}17 \\
12 \\
25 \\
13 \\
23 \\
42 \\
30 \\
0.82 \\
0.01 \\
0.32 \\
1.9 \\
14\end{array}$ & $\begin{array}{l}4.1 \\
2.6 \\
2.4 \\
1.9 \\
1.4 \\
1.6 \\
2.2 \\
3.3 \\
2.7 \\
4.6 \\
3.9 \\
4.0\end{array}$ & $\begin{array}{r}4.9 \\
5.1 \\
11.8 \\
8.0 \\
18.5 \\
31.0 \\
16.0 \\
0.3 \\
0.0 \\
0.1 \\
0.6 \\
3.8\end{array}$ \\
\hline NNUAL & 37 & 0.04 & 7.2 & 9.1 & 1.3 & 100 \\
\hline
\end{tabular}

MAGNITUDE AND PROBABILITY OF INSTANTANEOUS PEAK FLON BASED ON PERIOD OF RECCRD 1958-78

DISCHARCE, IN FT $3 / \mathrm{S}$, FOR INDICATED RECURRENCE INTERVAL IN YEARS, AND EXCEEDANCE PROBABILITY, IN PERCENT

\begin{tabular}{|c|c|c|c|c|c|}
\hline $\begin{array}{c}2 \\
50 x\end{array}$ & $\underset{20 \%}{5}$ & $\begin{array}{r}10 \\
10 \%\end{array}$ & $\begin{array}{l}25 \\
4 \%\end{array}$ & $\begin{array}{l}50\} \\
2 x\end{array}$ & $\begin{array}{c}100 \nmid \\
1 \%\end{array}$ \\
\hline 724 & 1,860 & 3,090 & 5,410 & 7,810 & 10,900 \\
\hline $\begin{array}{l}\text { MEIGHTED } \\
\text { MEAN } \\
\text { STANDARD }\end{array}$ & $\begin{array}{l}\text { SKEW } \\
\text { DEV. }\end{array}$ & $\begin{array}{l}\text { LOGS }= \\
(\text { LGS })= \\
(\text { LGS })=\end{array}$ & & & \\
\hline
\end{tabular}

MENITUDE AND PROBABILITY OF ANMUAL LON FLON BASED ON PERICD OF RECORD 1959-78

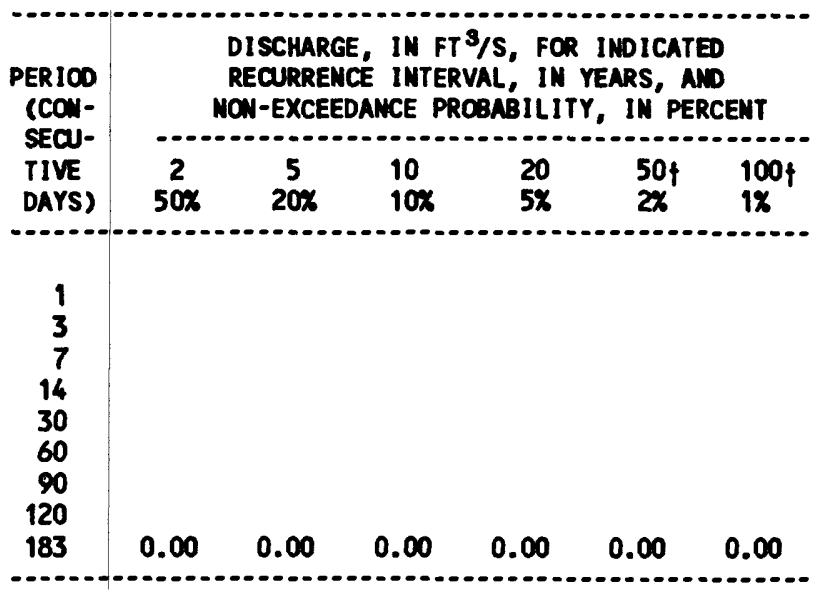

MAGNITUDE NNO PROBABILITY OF AMNUAL HIGH FLOU BASED ON PERIOD OF RECORD 1958-78

\begin{tabular}{|c|c|c|c|c|c|c|}
\hline \multirow{2}{*}{$\begin{array}{l}\text { PERIOD } \\
\text { (CON- } \\
\text { SECU- } \\
\text { TIVE } \\
\text { DAYS) }\end{array}$} & \multicolumn{6}{|c|}{$\begin{array}{l}\text { DISCHARCE, IN FT } 3 / \mathrm{S} \text {, FOR INDICATED } \\
\text { RECURRENCE INTERVAL, IN YEARS, NND } \\
\text { EXCEEDANCE PROBABILITY, IN PERCENT }\end{array}$} \\
\hline & $\begin{array}{c}2 \\
50 \%\end{array}$ & $\begin{array}{c}5 \\
20 \%\end{array}$ & $\begin{array}{l}10 \\
10 x\end{array}$ & $\begin{array}{l}25 \\
4 \%\end{array}$ & $\begin{array}{l}50 \% \\
2 \%\end{array}$ & $\begin{array}{c}100 f \\
1 x\end{array}$ \\
\hline $\begin{array}{r}1 \\
3 \\
7 \\
15 \\
30 \\
60 \\
90\end{array}$ & $\begin{array}{r}208 \\
129 \\
75 \\
45 \\
26 \\
16 \\
12\end{array}$ & $\begin{array}{r}755 \\
424 \\
247 \\
151 \\
96 \\
61 \\
46\end{array}$ & $\begin{array}{r}1,310 \\
691 \\
400 \\
247 \\
164 \\
109 \\
82\end{array}$ & $\begin{array}{r}2,170 \\
1,060 \\
606 \\
378 \\
267 \\
184 \\
140\end{array}$ & $\begin{array}{r}2,880 \\
1,330 \\
755 \\
474 \\
349 \\
248 \\
189\end{array}$ & $\begin{array}{r}3,620 \\
1,590 \\
894 \\
564 \\
430 \\
314 \\
240\end{array}$ \\
\hline
\end{tabular}

DURATION TABLE OF DAILY MEAN FLOW FOR PERIOO OF RECORD 1958-78

DISCHARGE, IN FT $3 / 5$, WHICH WAS EQUALED OR EXCEEDED FOR INDICATED PERCENT OF TIME

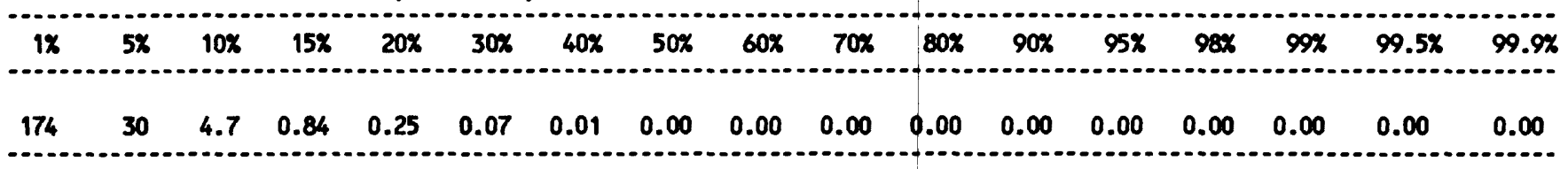

f Reliability of values in column is uncertain, and potential errors are large. 
GILA RIVER BASIN

09505250 RED tANK DRAW MEAR RIMROCK, AZ--CONTIMUED
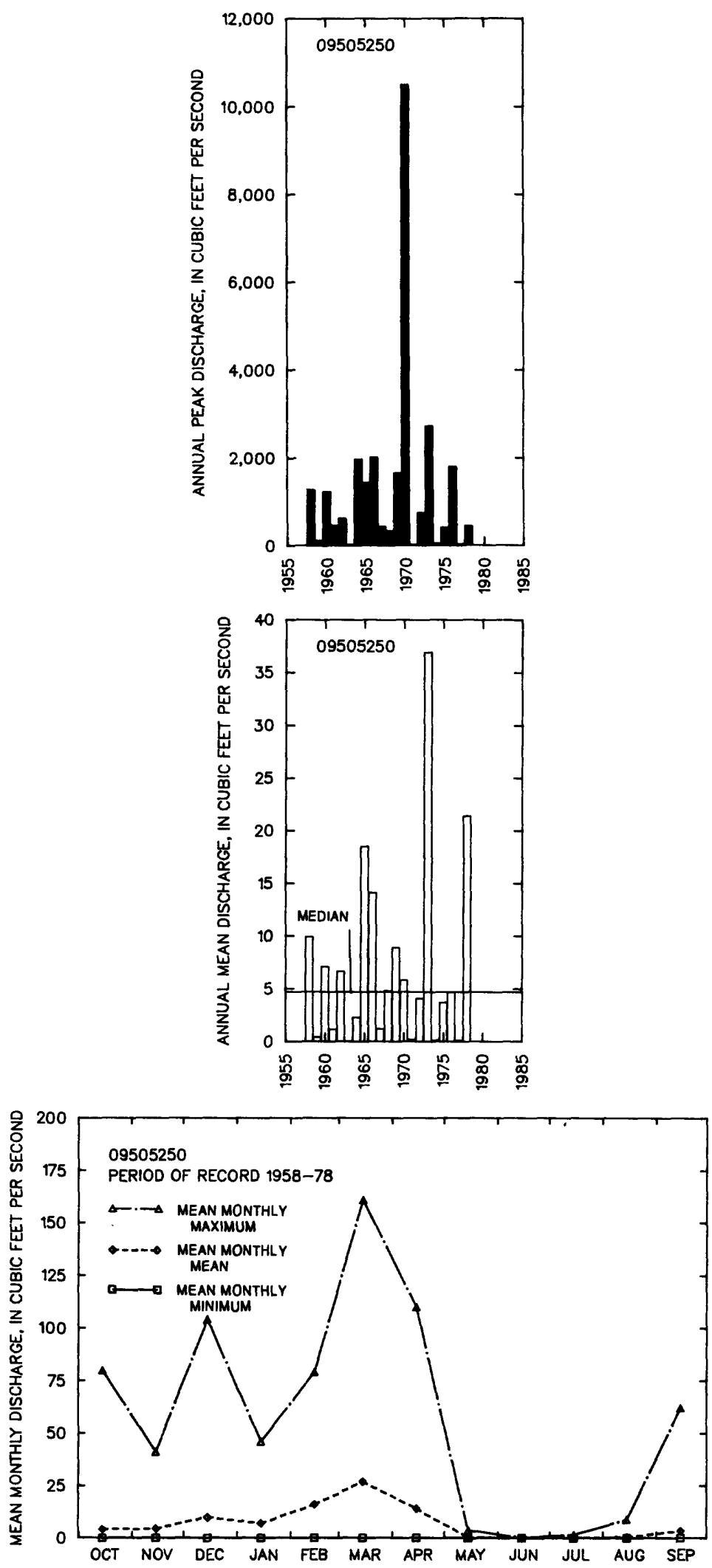
09505300 RATtLesmake CANYON MEAR RIMROCK, AZ

LOCATION.--Lat 34'46'01", Long'111 40'23", in MHKSWH sec.24, T.16 N., R.6 E., Yavapai County, Hydrologic Unit 15060202, in Coconino National Forest, on left benk $2.6 \mathrm{mi}$ upstream from mouth, 7 mi northeast of Beaver Creek Ranger Station, and 9 mi northeast of Rimrock.

DRAINAGE AREA. $--24.6 \mathrm{mi} 2$.

ANNUAL PEAK DISCHARge

\begin{tabular}{|c|c|c|c|c|c|}
\hline $\begin{array}{l}\text { WATER } \\
\text { YEAR }\end{array}$ & DATE & $\begin{array}{l}\text { ANNUAL PEAK } \\
\text { DISCHARGE } \\
\text { (FT } 3 / S)\end{array}$ & $\begin{array}{l}\text { WATER } \\
\text { YEAR }\end{array}$ & DATE & $\begin{array}{l}\text { ANNUAL PEAK } \\
\text { DISCHARGE } \\
\left(\mathrm{FT}^{3} / \mathrm{S}\right)\end{array}$ \\
\hline $\begin{array}{l}1958 \\
1959 \\
1960 \\
1961 \\
1962 \\
1963 \\
1964 \\
1965 \\
1966 \\
1967 \\
1968 \\
1969\end{array}$ & $\begin{array}{l}09-12-58 \\
02-17-59 \\
12-25-59 \\
09-17-61 \\
02-12-62 \\
03-23-63 \\
03-30-64 \\
01-06-65 \\
12-30-65 \\
12-07-66 \\
01-28-68 \\
01-25-69\end{array}$ & $\begin{array}{r}1,050 \\
119 \\
590 \\
384 \\
775 \\
18 \\
288 \\
1,430 \\
1,880 \\
1,240 \\
306 \\
2,160\end{array}$ & $\begin{array}{l}1970 \\
1971 \\
1972 \\
1973 \\
1974 \\
1975 \\
1976 \\
1977 \\
1978 \\
1979 \\
1980\end{array}$ & $\begin{array}{l}09-05-70 \\
09-01-71 \\
12-26-71 \\
12-28-72 \\
04-03-74 \\
04-13-75 \\
02-09-76 \\
04-06-77 \\
03-01-78 \\
03-08-79 \\
02-14-80\end{array}$ & $\begin{array}{r}3,590 \\
741 \\
675 \\
1,500 \\
52 \\
311 \\
1,200 \\
69 \\
1,610 \\
2,850 \\
4,000\end{array}$ \\
\hline
\end{tabular}

BASIN CHARACTERISTICS

\begin{tabular}{|c|c|c|c|c|c|c|c|}
\hline \multirow{3}{*}{$\begin{array}{l}\text { MAIN } \\
\text { CHANNEL } \\
\text { SLOPE } \\
\text { (FT/MI) }\end{array}$} & \multirow[b]{3}{*}{$\begin{array}{l}\text { STREAM } \\
\text { LENGTH } \\
\text { (MI) }\end{array}$} & \multirow{3}{*}{$\begin{array}{l}\text { MEAN } \\
\text { BASIN } \\
\text { ELEVA- } \\
\text { TION } \\
\text { (FT) }\end{array}$} & \multirow[b]{3}{*}{$\begin{array}{l}\text { FORESTED } \\
\text { AREA } \\
\text { (PERCENT) }\end{array}$} & \multirow[b]{3}{*}{$\begin{array}{l}\text { SOIL } \\
\text { INDEX }\end{array}$} & \multirow{3}{*}{$\begin{array}{l}\text { MEAN } \\
\text { ANNUAL } \\
\text { PRECIPI - } \\
\text { TATION } \\
\text { (IN) }\end{array}$} & \multirow{2}{*}{\multicolumn{2}{|c|}{ RAINFALL INTENSITY, 24-HOUR }} \\
\hline & & & & & & & \\
\hline & & & & & & $\begin{array}{c}\text { 2-YEAR } \\
\text { (IN) }\end{array}$ & $\begin{array}{l}\text { 50-YEAR } \\
\text { (IN) }\end{array}$ \\
\hline 174 & 15.5 & 6,560 & 33.0 & 3.0 & 22.8 & 2.5 & 5.1 \\
\hline
\end{tabular}


09505300 RATtLESNAKE CANYON MEAR RIMROCK, AZ--Continued

MEAN MONTHLY AND ANNULL DISCHARGES 1958-80

\begin{tabular}{|c|c|c|c|c|c|c|}
\hline MONTH & $\begin{array}{l}\operatorname{MAXIMMN}_{\left(\mathrm{FT}^{3} / \mathrm{S}\right)} \\
\end{array}$ & $\begin{array}{l}\text { MINIMUM } \\
\left(\mathrm{FT}^{3} / \mathrm{S}\right)\end{array}$ & $\begin{array}{c}\text { MEAN } \\
\left(F^{3} / S\right)\end{array}$ & $\begin{array}{l}\text { STAN- } \\
\text { DARD } \\
\text { DEVIA- } \\
\text { TION } \\
\text { (FT'/S) }\end{array}$ & $\begin{array}{l}\text { COEFFI- } \\
\text { CIENT OF } \\
\text { VARI - } \\
\text { ATION }\end{array}$ & $\begin{array}{c}\text { PERCENT } \\
\text { OF } \\
\text { ANMULL } \\
\text { RUNOFF }\end{array}$ \\
\hline $\begin{array}{l}\text { OCTOBER } \\
\text { NOVEMBER } \\
\text { DECEMBER } \\
\text { JANUARY } \\
\text { FEBRUARY } \\
\text { MARCH } \\
\text { APRIL } \\
\text { MAY } \\
\text { JUNE } \\
\text { JULY } \\
\text { AUGUST } \\
\text { SEPTEMBER }\end{array}$ & $\begin{array}{l}60 \\
42 \\
86 \\
78 \\
165 \\
135 \\
116 \\
37 \\
0.01 \\
0.28 \\
0.88 \\
29\end{array}$ & $\begin{array}{l}0.00 \\
0.00 \\
0.00 \\
0.00 \\
0.00 \\
0.00 \\
0.00 \\
0.00 \\
0.00 \\
0.00 \\
0.00 \\
0.00\end{array}$ & $\begin{array}{l}2.8 \\
4.2 \\
12 \\
12 \\
21 \\
31 \\
22 \\
2.1 \\
0.00 \\
0.02 \\
0.10 \\
1.7\end{array}$ & $\begin{array}{l}12 \\
10 \\
25 \\
23 \\
36 \\
32 \\
33 \\
7.7 \\
0.00 \\
0.06 \\
0.24 \\
6.1\end{array}$ & $\begin{array}{l}4.5 \\
2.5 \\
2.1 \\
1.9 \\
1.7 \\
1.0 \\
1.5 \\
3.7 \\
3.3 \\
3.3 \\
2.3 \\
3.6\end{array}$ & $\begin{array}{r}2.5 \\
3.9 \\
10.8 \\
10.7 \\
19.6 \\
28.6 \\
20.2 \\
1.9 \\
0.0 \\
0.0 \\
0.1 \\
1.6\end{array}$ \\
\hline ANMUALL & 30 & 0.14 & 9.0 & 9.3 & 1.0 & 100 \\
\hline
\end{tabular}

MAGNI TUDE AND PROBABILITY OF INSTANTANEOUS PEAK FLON BASED ON PERIOD OF RECORD 1958-80

DISCHARGE, IN $\mathrm{FT}^{3} / \mathrm{S}$, FOR INDICATED RECURRENCE INTERVAL IN YEARS, AND EXCEEDANCE PROBABILITY, IN PERCENT

\begin{tabular}{lccccc}
2 & 5 & 10 & 25 & $50 \%$ & $100 \uparrow$ \\
$50 \%$ & $20 \%$ & $10 \%$ & $4 \%$ & $2 \%$ & $1 \%$ \\
872 & 1,880 & 2,750 & 4,030 & 5,110 & 6,290 \\
\hline WEIGHTED SKEW (LOGS) & $=$ & -0.29 & & \\
MEAN & (LOGS) & 2.92 & & \\
STANDARD DEV. (LOGS) & $=0.42$ &
\end{tabular}

MGNITUDE AND PROBABILITY OF ANMUAL LON FLON BASED ON PERIOD OF RECORD 1959-80

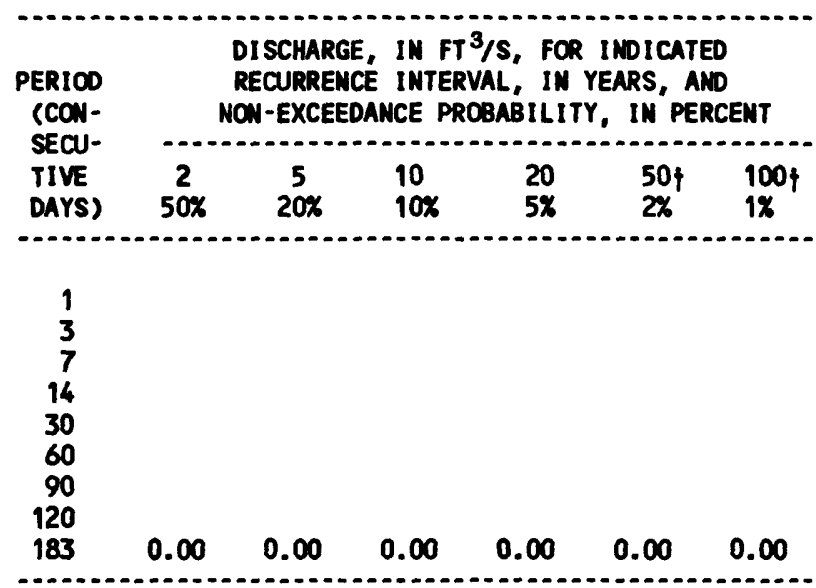

MMGNITUDE AND PROBABILITY OF ANMUAL HIGH FLOH BASED ON PERIOD OF RECORD 1958-80

\begin{tabular}{|c|c|c|c|c|c|c|}
\hline \multirow{2}{*}{$\begin{array}{l}\text { PERIOD } \\
\text { (CON- } \\
\text { SECU- } \\
\text { TIVE } \\
\text { DAYS) }\end{array}$} & \multicolumn{6}{|c|}{$\begin{array}{l}\text { DISCHARGE, IN } \mathrm{FT}^{3} / \mathrm{S} \text {, FOR INDICATED } \\
\text { RECURRENCE INTERVAL, IN YEARS, AND } \\
\text { EXCEEDANCE PROBABILITY, IN PERCENT }\end{array}$} \\
\hline & $\stackrel{2}{50 \%}$ & $\begin{array}{c}5 \\
20 \%\end{array}$ & $\begin{array}{l}10 \\
10 \%\end{array}$ & $\begin{array}{l}25 \\
4 \%\end{array}$ & $\begin{array}{l}50 \dagger \\
2 \%\end{array}$ & $\begin{array}{c}100\} \\
1 \%\end{array}$ \\
\hline $\begin{array}{r}1 \\
3 \\
7 \\
15 \\
30 \\
60 \\
90\end{array}$ & $\begin{array}{r}264 \\
155 \\
98 \\
61 \\
39 \\
24 \\
18\end{array}$ & $\begin{array}{r}731 \\
403 \\
240 \\
144 \\
95 \\
66 \\
53\end{array}$ & $\begin{array}{r}1,160 \\
622 \\
355 \\
206 \\
140 \\
102 \\
84\end{array}$ & $\begin{array}{r}1,790 \\
944 \\
510 \\
284 \\
197 \\
153 \\
129\end{array}$ & $\begin{array}{r}2,320 \\
1,210 \\
628 \\
339 \\
238 \\
192 \\
165\end{array}$ & $\begin{array}{r}2,870 \\
1,480 \\
743 \\
391 \\
278 \\
230 \\
200\end{array}$ \\
\hline
\end{tabular}

DURATION TABLE OF DAILY MEAN FLON FOR PERIOD OF RECORO $1958-80$

DISCHARGE, IN FT $3 / 5$, WHICH WAS EQUALED OR EXCEEDED FOR INDICATED PERCENT OF TIME

\begin{tabular}{|c|c|c|c|c|c|c|c|c|c|c|c|c|c|c|c|c|}
\hline $1 \%$ & $5 \%$ & $10 \%$ & $15 \%$ & $20 \%$ & $30 \%$ & $40 \%$ & $50 \%$ & $60 \%$ & $70 \%$ & $80 \%$ & $90 \%$ & $95 \%$ & $98 \%$ & $99 \%$ & $99.5 \%$ & $99.9 \%$ \\
\hline 155 & 51 & 21 & 6.7 & 0.91 & 0.02 & 0.00 & 0.00 & 0.00 & 0.00 & 0.00 & 0.00 & 0.00 & 0.00 & 0.00 & 0.00 & 0.00 \\
\hline
\end{tabular}

f Reliability of values in column is uncertain, and potential errors are large. 
09505300 RATTLESMAKE CANYON MEAR RIMROCK, AZ--CONTIMUED
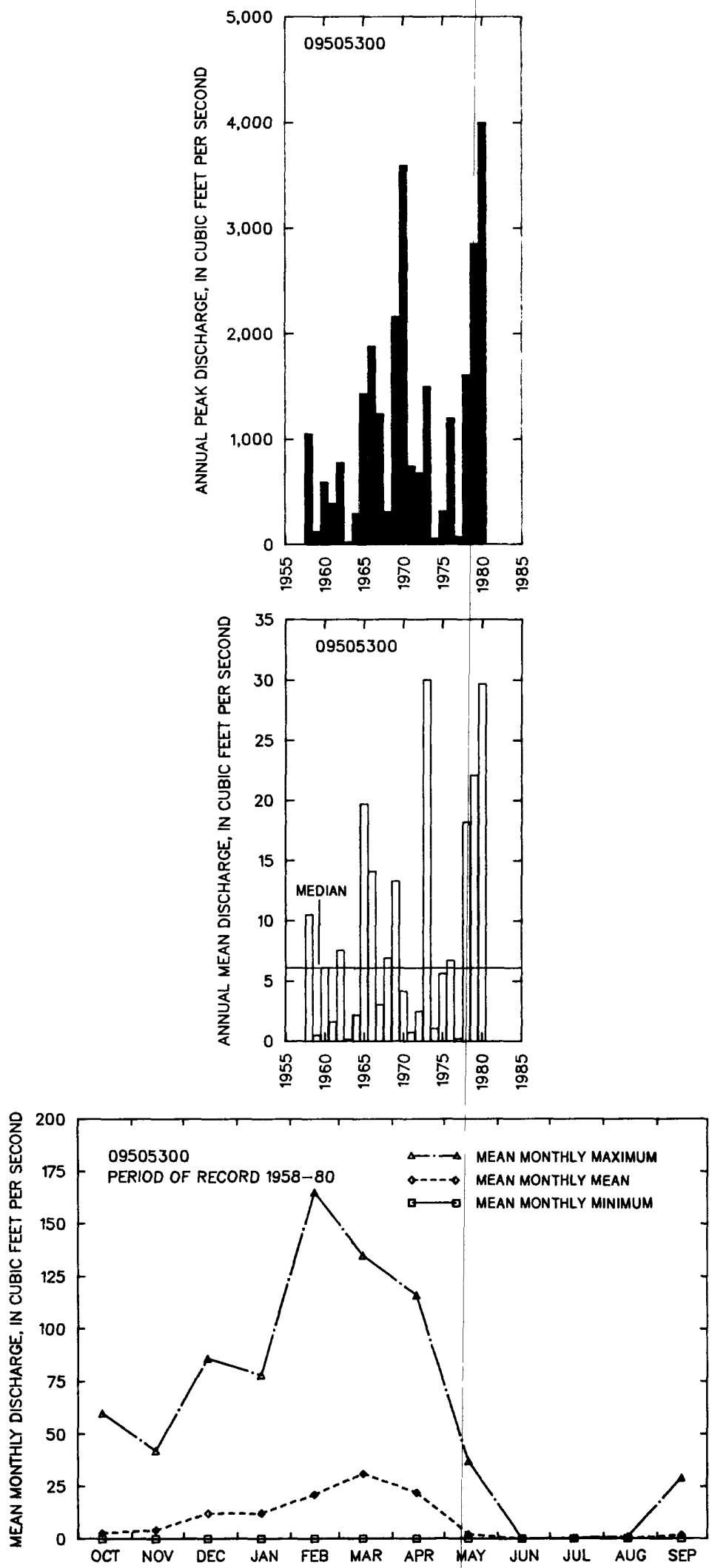
09505350 DRY BEAVER CREEK NEAR RIMROCK, AZ

LOCATION.--Lat 34\%43'43", long 111“46'30", in NEWWWh sec.1, T.15 N., R.5 E., Yavapai County, Hydrologic Unit 15060202 , in Coconino National Forest, on left upstream abutment of abandoned highway bridge, $400 \mathrm{ft}$ upstream from present State Highway 179 and 5.5 mi north of Rimrock.

DRAINAGE AREA. $--142 \mathrm{mi}^{2}$.

ANMUAL PEAK DISCHARGE

\begin{tabular}{|c|c|c|c|c|}
\hline $\begin{array}{l}\text { WATER } \\
\text { YEAR }\end{array}$ & $\begin{array}{cc} & \text { ANNUAL PEAK } \\
\text { DISCHARGE } \\
\text { DATE } \\
\left(F^{3} / \mathrm{S}\right)\end{array}$ & $\begin{array}{l}\text { WATER } \\
\text { YEAR }\end{array}$ & DATE & $\begin{array}{l}\text { ANNUAL PEAK } \\
\text { DISCHARGE } \\
\text { (FT } 3 / S)\end{array}$ \\
\hline $\begin{array}{l}1961 \\
1962 \\
1963 \\
1964 \\
1965 \\
1966 \\
1967 \\
1968 \\
1969 \\
1970 \\
1971 \\
1972 \\
1973 \\
1974 \\
1975\end{array}$ & $\begin{array}{l}07-14-61 \\
02-12-62 \\
08-17-63 \\
03-30-64 \\
01-06-65 \\
11-23-65 \\
12-07-66 \\
02-11-68 \\
01-25-69 \\
09-05-70 \\
09-01-71 \\
12-26-71 \\
12-28-72 \\
04-03-74 \\
04-14-75\end{array}$ & $\begin{array}{l}1976 \\
1977 \\
1978 \\
1979 \\
1980 \\
1981 \\
1982 \\
1983 \\
1984 \\
1985 \\
1986 \\
1987 \\
1988 \\
1989\end{array}$ & $\begin{array}{l}02-09-76 \\
04-07-77 \\
03-01-78 \\
12-18-78 \\
02-14-80 \\
08-11-81 \\
03-12-82 \\
11-30-82 \\
12-04-83 \\
12-27-84 \\
11-30-85 \\
03-09-87 \\
04-25-88 \\
03-29-89\end{array}$ & $\begin{array}{r}7,020 \\
304 \\
8,410 \\
24,200 \\
18,600 \\
1,250 \\
7,790 \\
8,190 \\
5,780 \\
4,250 \\
4,340 \\
1,160 \\
2,650 \\
404\end{array}$ \\
\hline
\end{tabular}

BASIN CHARACTERISTICS

\begin{tabular}{|c|c|c|c|c|c|c|c|}
\hline MAIN & & $\begin{array}{l}\text { MEAN } \\
\text { BASIN }\end{array}$ & & & $\begin{array}{c}\text { MEAN } \\
\text { ANNUAL }\end{array}$ & RAINFALL II & SITY, 24-HOUR \\
\hline $\begin{array}{l}\text { CHANNEL } \\
\text { SLOPE } \\
\text { (FT/MI) }\end{array}$ & $\begin{array}{l}\text { STREAM } \\
\text { LENGTH } \\
\text { (MI) }\end{array}$ & $\begin{array}{l}\text { ELEVA- } \\
\text { TION } \\
\text { (FT) }\end{array}$ & $\begin{array}{l}\text { FORESTED } \\
\text { AREA } \\
\text { (PERCENT) }\end{array}$ & $\begin{array}{l}\text { SOIL } \\
\text { INDEX }\end{array}$ & $\begin{array}{l}\text { PRECIPI- } \\
\text { TATION } \\
\text { (IN) }\end{array}$ & $\begin{array}{c}\text { 2-YEAR } \\
\text { (IN) }\end{array}$ & $\begin{array}{l}\text { 50-YEAR } \\
\text { (IN) }\end{array}$ \\
\hline 137 & 32.5 & 6,220 & 56.0 & 2.8 & 23.1 & 2.5 & 5.1 \\
\hline
\end{tabular}


MEAN MONTHLY AND ANNUAL DISCHARGES 1961-89

\begin{tabular}{|c|c|c|c|c|c|c|}
\hline MONTH & $\begin{array}{l}\operatorname{MAXIMUN} \\
\left(F^{3} / S\right)\end{array}$ & $\begin{array}{l}\operatorname{MINIMUN} \\
\left(F T^{3} / S\right)\end{array}$ & $\begin{array}{c}\text { MEAN } \\
\left(F T^{3} / S\right)\end{array}$ & $\begin{array}{l}\text { STAN- } \\
\text { DARD } \\
\text { DEVIA- } \\
\text { TION } \\
\text { (FT'3/S) }\end{array}$ & $\begin{array}{l}\text { COEFFI - } \\
\text { CIENT OF } \\
\text { VARI - } \\
\text { ATION }\end{array}$ & $\begin{array}{c}\text { PERCENT } \\
\text { OF } \\
\text { ANNUAL } \\
\text { RUNOFF }\end{array}$ \\
\hline $\begin{array}{l}\text { OCTOBER } \\
\text { NOVEMBER } \\
\text { DECENBER } \\
\text { JANUARY } \\
\text { FEBRUARY } \\
\text { MARCH } \\
\text { APRIL } \\
\text { MAY } \\
\text { JUNE } \\
\text { JULY } \\
\text { AUGUST } \\
\text { SEPTEMBER }\end{array}$ & $\begin{array}{c}246 \\
251 \\
602 \\
384 \\
850 \\
678 \\
598 \\
208 \\
0.17 \\
2.5 \\
12 \\
224\end{array}$ & $\begin{array}{l}0.00 \\
0.00 \\
0.00 \\
0.00 \\
0.00 \\
0.00 \\
0.00 \\
0.00 \\
0.00 \\
0.00 \\
0.00 \\
0.00\end{array}$ & $\begin{array}{c}12 \\
23 \\
76 \\
44 \\
108 \\
153 \\
118 \\
10 \\
0.01 \\
0.18 \\
1.2 \\
14\end{array}$ & $\begin{array}{c}46 \\
56 \\
146 \\
93 \\
172 \\
163 \\
145 \\
39 \\
0.03 \\
0.49 \\
2.6 \\
51\end{array}$ & $\begin{array}{l}4.0 \\
2.4 \\
1.9 \\
2.1 \\
1.6 \\
1.1 \\
1.2 \\
3.8 \\
4.4 \\
2.7 \\
2.2 \\
3.6\end{array}$ & $\begin{array}{r}2.1 \\
4.2 \\
13.6 \\
7.9 \\
19.3 \\
27.3 \\
21.0 \\
1.8 \\
0.0 \\
0.0 \\
0.2 \\
2.6\end{array}$ \\
\hline ANNUAL & 139 & 1.1 & 46 & 42 & 0.91 & 100 \\
\hline
\end{tabular}

MAGNITUDE AND PROBABILITY OF INSTANTANEOUS PEAK FLOW BASED ON PERIOD OF RECORD 1961-89

\begin{tabular}{|c|c|c|c|c|c|}
\hline$\stackrel{2}{2}$ & $\begin{array}{c}5 \\
20 \%\end{array}$ & $\begin{array}{r}10 \\
10 \%\end{array}$ & $\begin{array}{l}25 \\
4 x\end{array}$ & $\begin{array}{l}50 \\
2 \%\end{array}$ & $\underset{1 \times}{100}+$ \\
\hline 4,170 & 9,690 & 14,800 & 22,800 & 30,000 & 38,200 \\
\hline \multicolumn{6}{|c|}{$\begin{array}{ll}\text { WEIGHTED SKEW (LOGS) }= & -0.20 \\
\text { MEAN } & \text { (LOGS) }=3.60 \\
\text { STANDARD DEV. (LOGS) }= & 0.45\end{array}$} \\
\hline
\end{tabular}

MACNITUDE AND PROBABILITY OF ANMUAL LON FLON BASED ON PERIOD OF RECORD 1962-89

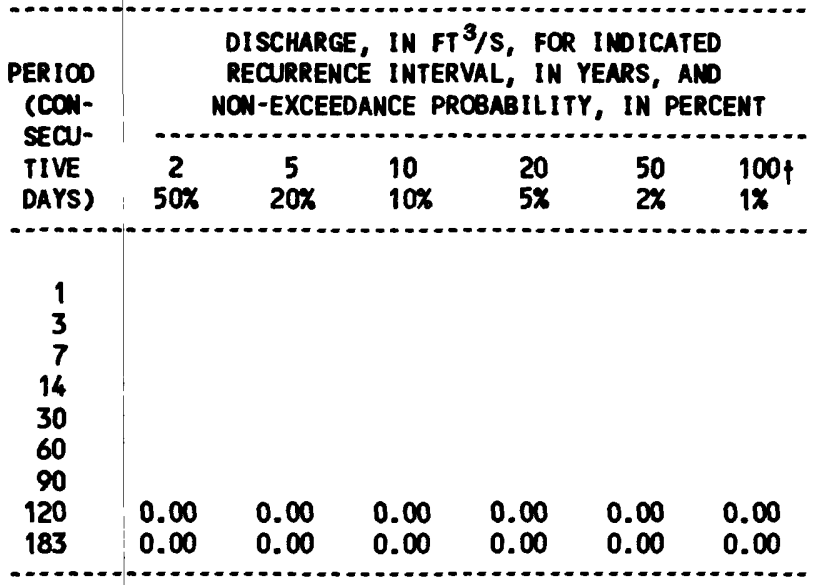

MAEITUDE AND PROBABILITY OF ANNUAL HIGH FLON BASED ON PERIOD OF RECORD 1961-89

\begin{tabular}{|c|c|c|c|c|c|c|}
\hline \multirow{2}{*}{$\begin{array}{l}\text { PERIOD } \\
\text { (CON- } \\
\text { SECU- } \\
\text { TIVE } \\
\text { DAYS) }\end{array}$} & \multicolumn{6}{|c|}{$\begin{array}{l}\text { DISCHARGE, IN FT } 3 / S \text {, FOR INDICATED } \\
\text { RECURRENCE INTERVAL, IN YEARS, AND } \\
\text { EXCEEDANCE PROBABILITY, IN PERCENT }\end{array}$} \\
\hline & $\begin{array}{c}2 \\
50 \%\end{array}$ & $\begin{array}{c}5 \\
20 \%\end{array}$ & $\begin{array}{l}10 \\
10 \%\end{array}$ & $\begin{array}{l}25 \\
4 x\end{array}$ & $\begin{array}{l}50 \\
2 \%\end{array}$ & $\underset{1 \mathrm{X}}{100 \dagger}$ \\
\hline $\begin{array}{r}1 \\
3 \\
7 \\
15 \\
30 \\
60 \\
90\end{array}$ & $\begin{array}{r}1,370 \\
904 \\
580 \\
369 \\
241 \\
153 \\
116\end{array}$ & $\begin{array}{r}3,840 \\
2,230 \\
1,280 \\
745 \\
499 \\
343 \\
270\end{array}$ & $\begin{array}{l}6,320 \\
3,370 \\
1,800 \\
983 \\
659 \\
470 \\
376\end{array}$ & $\begin{array}{r}10,400 \\
5,010 \\
2,430 \\
1,250 \\
831 \\
613 \\
497\end{array}$ & $\begin{array}{r}14,100 \\
6,330 \\
2,880 \\
1,410 \\
934 \\
702 \\
575\end{array}$ & $\begin{array}{r}18,400 \\
7,690 \\
3,290 \\
1,550 \\
1,020 \\
778 \\
641\end{array}$ \\
\hline
\end{tabular}

DURATION TABLE OF DAILY MEAN FLON FOR PERIOD OF RECORD 1961-89 DISCHARGE, IN FT $3 / 5$, WHICH WAS EQUALED OR EXCEEDED FOR INDICATED PERCENT OF TIME

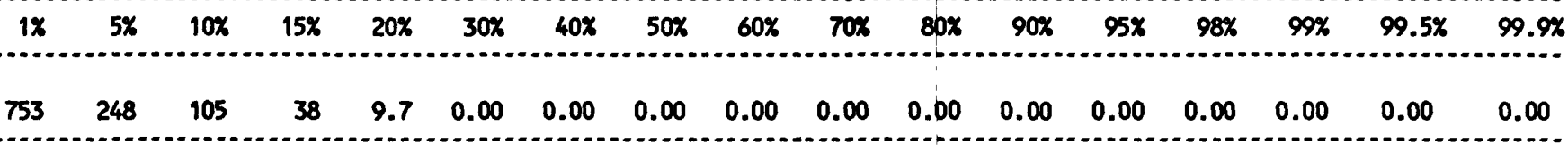

† Reliability of values in colum is uncertain, and potential errors are large. 
GILA RIVER BASIN

09505350 ORY BEAVER CREEK MEAR RIMROCK, AZ--CONTINUEO
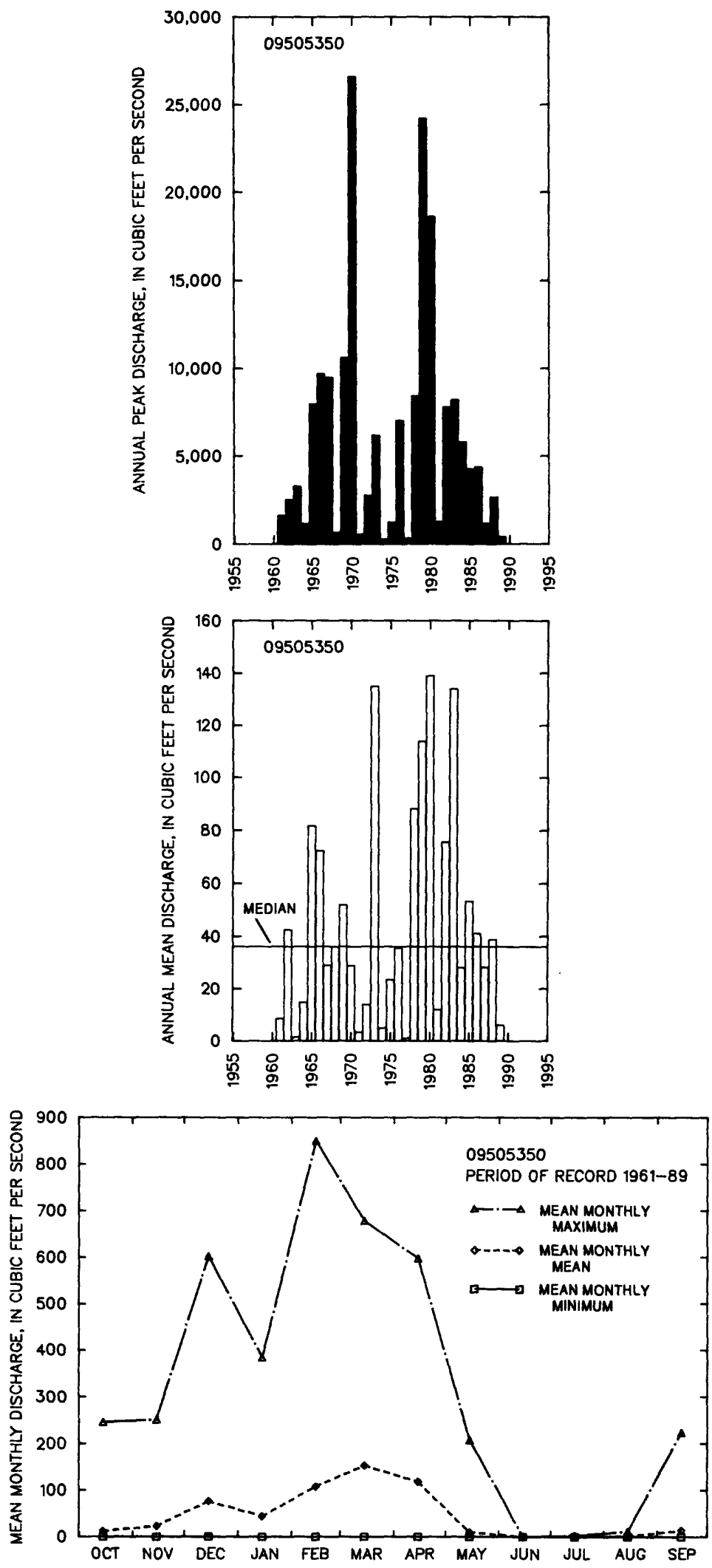
09505550 VERDE RIVER BELOH CAMP VERDE, AZ

LOCATION.--Lat 34'33'02", long 111'51'02", in SWHAWh sec.5, T.13 N., R.5 E., Yavapai County, Hydrologic Unit 15060203, on downstream side of bridge on county highway, $0.5 \mathrm{mi}$ southeast of Camp Verde, and $2.2 \mathrm{mi}$ downstrean from Beaver Creek.

DRAINAGE AREA. $--4,653 \mathrm{mi}^{2}$, of which $365 \mathrm{mi}^{2}$ is noncontributing (including $357 \mathrm{mi}^{2}$ in Aubrey Valley Playa, a closed basin).

REMARKS.--About 10,000 acres above station are irrigated by surface water and ground water.

AMMUAL PEAK DISCHARGE

\begin{tabular}{lccc}
$\begin{array}{c}\text { UATER } \\
\text { YEAR }\end{array}$ & DATE & $\begin{array}{c}\text { ANMUAL PEAK } \\
\text { DISCHARGE } \\
\text { (FT 3/S) }\end{array}$ & $\begin{array}{c}\text { DISCHARGE } \\
\text { CODES }\end{array}$ \\
\hline 1970 & $09-05-70$ & 43,000 & HP \\
1972 & $12-26-71$ & 15,800 & \\
1973 & $10-20-72$ & 40,600 & \\
1974 & $07-08-74$ & 2,200 & \\
1975 & $04-15-73$ & 3,280 & \\
1976 & $02-09-76$ & 30,100 & \\
1977 & $08-23-77$ & 3,490 & \\
1978 & $03-01-78$ & 41,000 & \\
1979 & $12-19-78$ & 55,000 & \\
1980 & $02-15-80$ & 50,900 & \\
\hline
\end{tabular}

MAGNITUDE AND PROBABILITY OF INSTANTANEOUS PEAK FLOW BASED ON PERIOD OF RECORD

DISCHARGE, IN $\mathrm{FT}^{3} / \mathrm{S}$, FOR INDICATED RECURRENCE INTERVAL IN YEARS, AND EXCEEDANCE PROBABILITY, IN PERCENT

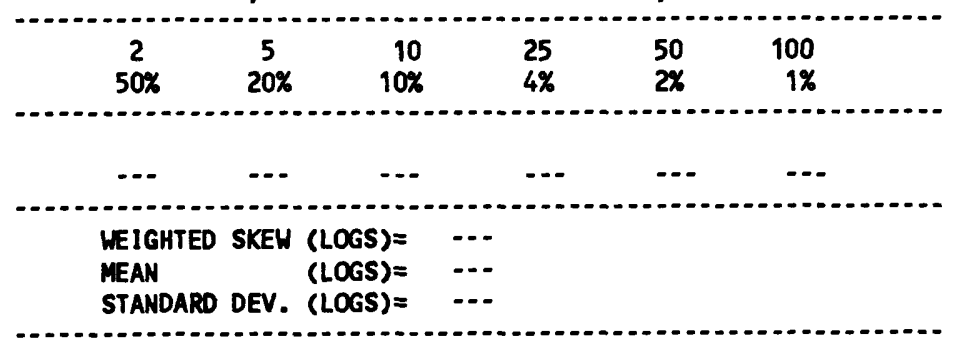

BASIN CHARACTERISTICS

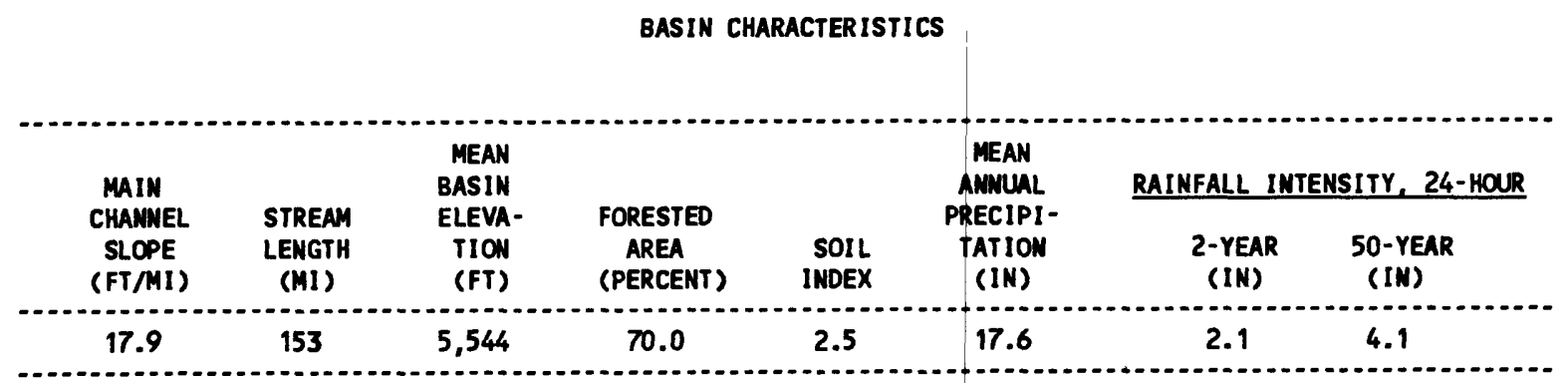

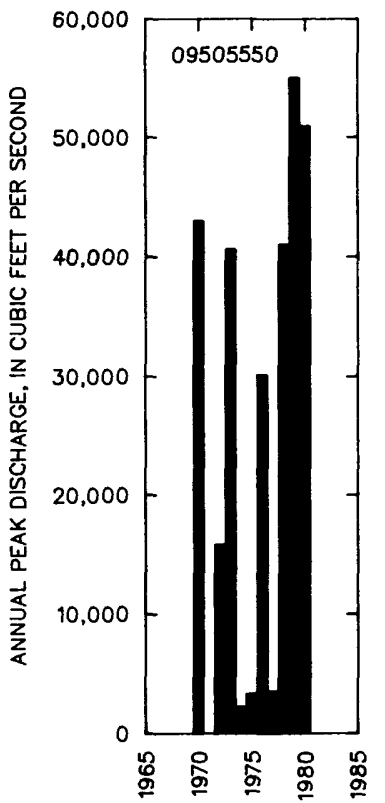


09505600 DIRTY NECK CANYON NEAR CLINTS WELL, AZ

LOCATION.--Lat 34'30'45", long 111'21'30", in NK sec.23, T.13 N., R.9 E., Coconino County, Hydrologic Unit 15060203, at State Highway 87, $4 \mathrm{mi}$ southwest of Clints Hell, and $18 \mathrm{mi}$ north of Payson.

DRAIMAGE AREA. $--3.42 \mathrm{mi}^{2}$.

ANIUAL PEAK DISCHARGE

\begin{tabular}{|c|c|c|c|}
\hline $\begin{array}{l}\text { WATER } \\
\text { YEAR }\end{array}$ & DATE & $\begin{array}{c}\text { ANNUAL PEAK } \\
\text { DISCHARGE } \\
\left(\mathrm{FT}^{3} / \mathrm{S}\right)\end{array}$ & $\begin{array}{l}\text { DISCHARCE } \\
\text { CODES }\end{array}$ \\
\hline $\begin{array}{l}1965 \\
1966 \\
1967 \\
1968 \\
1969 \\
1970 \\
1971 \\
1972 \\
1973 \\
1974 \\
1975 \\
1979\end{array}$ & $\begin{array}{l}01-06-65 \\
12-30-65 \\
12-06-66 \\
00-00-68 \\
01-25-69 \\
09-05-70 \\
00-00-71 \\
12-26-71 \\
10-19-72 \\
00-00-74 \\
00-00-75 \\
12-18-78\end{array}$ & $\begin{array}{c}85 \\
115 \\
45 \\
18 \\
68 \\
210 \\
1.0 \\
84 \\
210 \\
0 \\
20 \\
1200\end{array}$ & LT \\
\hline
\end{tabular}

IHighest since 1972.

MAGNI TUDE AND PROBABILITY OF INSTANTANEOUS PEAK FLOW BASED ON PERICD OF RECORD 1965-75, 1979

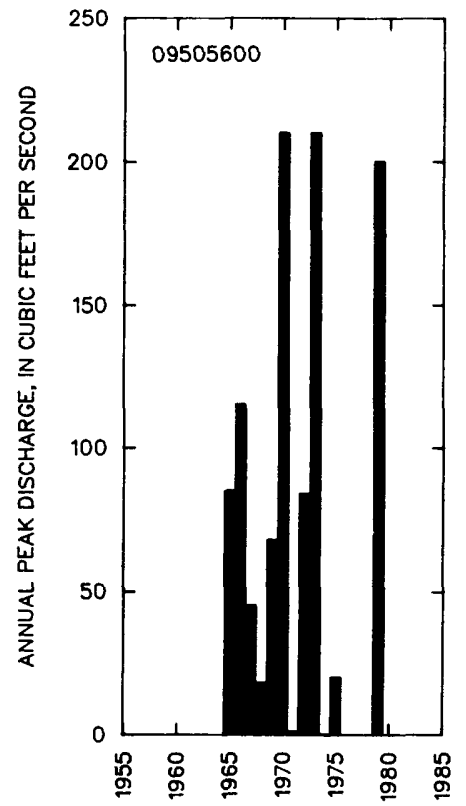

DISCHARGE, IN $\mathrm{FT}^{3} / \mathrm{S}$, FOR INDICATED RECURRENCE INTERVAL IN YEARS, AND EXCEEDANCE PROBABILITY, IN PERCENT

\begin{tabular}{lccccc}
2 & 5 & 10 & $25 \dagger$ & $50 \dagger$ & $100 \dagger$ \\
$50 \%$ & $20 \%$ & $10 \%$ & $4 \%$ & $2 \%$ & $1 \%$ \\
62.7 & 151 & 231 & 353 & 458 & 573 \\
\hline WEIGHTED SKEW (LOGS) & -0.37 & & \\
MEAN & (LOGS) & 1.77 & & \\
STANDARD DEV. (LOGS) & 0.48 & &
\end{tabular}

f Reliability of values in column is uncertain, and potential errors are large.

BASIN CHARACTERISTICS

\begin{tabular}{|c|c|c|c|c|c|c|c|}
\hline \multirow{2}{*}{$\begin{array}{l}\text { MAIN } \\
\text { CHANNEL } \\
\text { SLOPE } \\
\text { (FT/MI) }\end{array}$} & \multirow[b]{2}{*}{$\begin{array}{l}\text { STREAM } \\
\text { LENGTH } \\
\text { (MI) }\end{array}$} & \multirow{2}{*}{$\begin{array}{l}\text { MEAN } \\
\text { BASIN } \\
\text { ELEVA- } \\
\text { TION } \\
\text { (FT) }\end{array}$} & \multirow[b]{2}{*}{$\begin{array}{l}\text { FORESTED } \\
\text { AREA } \\
\text { (PERCENT) }\end{array}$} & \multirow[b]{2}{*}{$\begin{array}{l}\text { SOIL } \\
\text { INDEXX }\end{array}$} & \multirow{2}{*}{$\begin{array}{l}\text { MEAN } \\
\text { ANNUAL } \\
\text { PRECIPI- } \\
\text { TATION } \\
\text { (IN) }\end{array}$} & \multicolumn{2}{|c|}{ RAINFALL INTENSITY, 24-HOUR } \\
\hline & & & & & & $\begin{array}{c}\text { 2-YEAR } \\
\text { (IN) }\end{array}$ & $\begin{array}{c}\text { 50-YEAR } \\
\text { (IN) }\end{array}$ \\
\hline 190 & 3.4 & 7,140 & 99.0 & 3.0 & 26.0 & 2.7 & 4.7 \\
\hline
\end{tabular}


09505800 WEST CLEAR CREEK NEAR CAMP VERDE, AZ

LOCATION.--Lat 34"32'191", long 111'41'36", in NWAWW sec.11, T.13 N., R.6 E., Yavapai County, Hydrologic Unit 15060203, in Coconino National Forest, on left bank at Bull Pen Ranch, 11 mi upstream from mouth, and 9 mi east of Camp Verde.

DRAINAGE AREA. $--241 \mathrm{mi}^{2}$.

\begin{tabular}{|c|c|c|}
\hline \multicolumn{3}{|c|}{ ANMUAL PEAK DISCHARGE } \\
\hline $\begin{array}{l}\text { WATER } \\
\text { YEAR }\end{array}$ & DATE & $\begin{array}{c}\text { ANNUALL PEAK } \\
\text { DISCHARGE } \\
\text { (FT } 3 / S)\end{array}$ \\
\hline $\begin{array}{l}1965 \\
1966 \\
1967 \\
1968 \\
1969 \\
1970 \\
1971 \\
1972 \\
1973 \\
1974 \\
1975 \\
1976 \\
1977 \\
1978 \\
1979 \\
1980 \\
1981 \\
1982 \\
1983 \\
1984 \\
1985 \\
1986 \\
1987 \\
1988 \\
1989\end{array}$ & $\begin{array}{l}01-06-65 \\
12-30-65 \\
12-07-66 \\
02-26-68 \\
01-26-69 \\
09-05-70 \\
09-02-71 \\
12-26-71 \\
10-19-72 \\
01-21-74 \\
04-15-75 \\
02-09-76 \\
07-26-77 \\
03-01-78 \\
12-18-78 \\
02-19-80 \\
08-12-81 \\
03-12-82 \\
11-30-82 \\
12-27-83 \\
12-27-84 \\
03-12-86 \\
03-18-87 \\
08-29-88 \\
03-08-89\end{array}$ & $\begin{array}{r}6,510 \\
6,330 \\
2,670 \\
1,300 \\
3,870 \\
1,050 \\
1,550 \\
6,660 \\
11,300 \\
308 \\
2,730 \\
8,130 \\
101 \\
13,800 \\
22,400 \\
15,100 \\
801 \\
9,890 \\
6,700 \\
3,630 \\
5,140 \\
885 \\
2,110 \\
6,540 \\
446\end{array}$ \\
\hline
\end{tabular}

BASIN CHARACTERISTICS

\begin{tabular}{|c|c|c|c|c|c|c|c|}
\hline MaIN & & $\begin{array}{l}\text { MEAN } \\
\text { BASIN }\end{array}$ & & & $\begin{array}{c}\text { MEAN } \\
\text { ANNUAL }\end{array}$ & RAINFALL II & SITY, 24-HOUR \\
\hline $\begin{array}{l}\text { CHANNEL } \\
\text { SLOPE } \\
\text { (FT/MI) }\end{array}$ & $\begin{array}{l}\text { STREAM } \\
\text { LENGTH } \\
\text { (MI) }\end{array}$ & $\begin{array}{l}\text { ELEVA- } \\
\text { TION } \\
\text { (FT) }\end{array}$ & $\begin{array}{l}\text { FORESTED } \\
\text { AREA } \\
\text { (PERCENT) }\end{array}$ & $\begin{array}{l}\text { SOIL } \\
\text { INDEX }\end{array}$ & $\begin{array}{l}\text { PRECIPI- } \\
\text { TATION } \\
\text { (IN) }\end{array}$ & $\begin{array}{c}\text { 2-YEAR } \\
\text { (IN) }\end{array}$ & $\begin{array}{l}\text { 50-YEAR } \\
\text { (IN) }\end{array}$ \\
\hline 112 & 34.4 & 6,680 & 78.0 & 3.0 & 23.4 & 2.6 & 4.8 \\
\hline
\end{tabular}


09505800 WEST CLEAR CREEK MEAR CAN VERDE, AZ--Continued

MEAN MONTHLY AND ANNUAL DISCHARGES $1966-89$

\begin{tabular}{|c|c|c|c|c|c|c|}
\hline MONTH & $\begin{array}{l}\operatorname{MAX} I M U N \\
\left(F T^{3} / S\right)\end{array}$ & $\begin{array}{l}\operatorname{MINIMUM} \\
\left(F T^{3} / S\right)\end{array}$ & $\begin{array}{c}\text { MEAN } \\
\left(F T^{3} / S\right)\end{array}$ & $\begin{array}{l}\text { STAN- } \\
\text { DARD } \\
\text { DEVIA- } \\
\text { TION } \\
\left(\mathrm{FT}^{3} / \mathrm{S}\right)\end{array}$ & $\begin{array}{l}\text { COEFFI- } \\
\text { CIENT OF } \\
\text { VARI- } \\
\text { ATION }\end{array}$ & $\begin{array}{c}\text { PERCENT } \\
\text { OF } \\
\text { ANNUAL } \\
\text { RUNOF F }\end{array}$ \\
\hline $\begin{array}{l}\text { OCTOBER } \\
\text { NOVEMBER } \\
\text { DECEMBER } \\
\text { JANUARY } \\
\text { FEBRUARY } \\
\text { MARCH } \\
\text { APRIL } \\
\text { MAY } \\
\text { JUNE } \\
\text { JULY } \\
\text { AUGUST } \\
\text { SEPTEMBER }\end{array}$ & $\begin{array}{r}458 \\
110 \\
758 \\
255 \\
956 \\
886 \\
923 \\
157 \\
25 \\
33 \\
51 \\
113\end{array}$ & $\begin{array}{l}14 \\
15 \\
16 \\
16 \\
15 \\
15 \\
15 \\
15 \\
15 \\
13 \\
14 \\
14 \\
14\end{array}$ & $\begin{array}{r}39 \\
31 \\
109 \\
53 \\
145 \\
208 \\
117 \\
28 \\
16 \\
18 \\
20 \\
22\end{array}$ & $\begin{array}{c}90 \\
27 \\
172 \\
63 \\
207 \\
224 \\
189 \\
29 \\
2.9 \\
4.4 \\
8.6 \\
20\end{array}$ & $\begin{array}{l}2.3 \\
0.87 \\
1.6 \\
1.2 \\
1.4 \\
1.1 \\
1.6 \\
1.0 \\
0.18 \\
0.24 \\
0.43 \\
0.89\end{array}$ & $\begin{array}{r}4.9 \\
3.9 \\
13.5 \\
6.6 \\
18.0 \\
25.8 \\
14.5 \\
3.4 \\
2.0 \\
2.2 \\
2.5 \\
2.8\end{array}$ \\
\hline ANMUAL & 199 & 16 & 67 & 50 & 0.74 & 100 \\
\hline
\end{tabular}

MAGNITUDE ANO PROBABILITY OF INSTANTANEQUS PEAK FLOW BASED ON PERIOD OF RECORD 1965-89

DISCHARGE, IN $\mathrm{FT}^{3} / \mathrm{S}$, FOR INDICATED RECURRENCE INTERVAL

IN YEARS, AND EXCEEDANCE PROBABILITY, IN PERCENT

\begin{tabular}{|c|c|c|c|c|c|}
\hline $\begin{array}{c}2 \\
50 \%\end{array}$ & $\begin{array}{c}5 \\
20 \%\end{array}$ & $\begin{array}{r}10 \\
10 \%\end{array}$ & $\begin{array}{l}25 \\
4 \%\end{array}$ & $\begin{array}{l}50 \dagger \\
2 \%\end{array}$ & $\begin{array}{c}100\} \\
1 \times\end{array}$ \\
\hline 4,430 & 9,280 & 13,400 & 19,400 & 24,500 & 30,000 \\
\hline $\begin{array}{l}\text { WEIGHTED } \\
\text { MEAN } \\
\text { STANDARD }\end{array}$ & $\begin{array}{l}\text { SKEW } \\
\text { DEV. }\end{array}$ & $\begin{array}{l}\text { LOGS) }=-( \\
(\mathbf{O G S})= \\
\text { LOGS) }=\end{array}$ & & & \\
\hline
\end{tabular}

MAGNITUDE AND PROBABILITY OF AMNUAL LOW FLOW BASED ON PERIOO OF RECORD 1966-89

\begin{tabular}{|c|c|c|c|c|c|c|}
\hline \multirow{2}{*}{$\begin{array}{l}\text { PERIOD } \\
\text { (CON- } \\
\text { SECU- } \\
\text { TIVE } \\
\text { DAYS) }\end{array}$} & \multicolumn{6}{|c|}{$\begin{array}{l}\text { OISCHARGE, IN FT } 3 / 5 \text {, FOR INDICATED } \\
\text { RECURRENCE INTERVAL, IN YEARS, AND } \\
\text { NON-EXCEEDANCE PROBABILITY, IN PERCENT }\end{array}$} \\
\hline & $\begin{array}{c}2 \\
50 \%\end{array}$ & $\begin{array}{c}5 \\
20 \%\end{array}$ & $\begin{array}{l}10 \\
10 \%\end{array}$ & $\begin{array}{l}20 \\
5 \%\end{array}$ & $\begin{array}{l}50 \uparrow \\
2 \%\end{array}$ & $\begin{array}{l}100 \dagger \\
1 \%\end{array}$ \\
\hline $\begin{array}{r}1 \\
3 \\
7 \\
14 \\
30 \\
60 \\
90 \\
120 \\
183\end{array}$ & $\begin{array}{l}13 \\
13 \\
13 \\
14 \\
14 \\
15 \\
16 \\
16 \\
17\end{array}$ & $\begin{array}{l}12 \\
12 \\
12 \\
13 \\
13 \\
14 \\
15 \\
15 \\
16\end{array}$ & $\begin{array}{l}12 \\
12 \\
12 \\
12 \\
13 \\
13 \\
14 \\
15 \\
16\end{array}$ & $\begin{array}{l}11 \\
11 \\
12 \\
12 \\
12 \\
13 \\
14 \\
14 \\
16\end{array}$ & $\begin{array}{l}11 \\
11 \\
11 \\
12 \\
12 \\
13 \\
13 \\
14 \\
16\end{array}$ & $\begin{array}{l}11 \\
11 \\
11 \\
11 \\
12 \\
13 \\
13 \\
14 \\
16\end{array}$ \\
\hline
\end{tabular}

MAGNITUDE AND PROBABILITY OF ANNUAL HIGH FLOW BASED ON PERIOD OF RECORD 1966-89

\begin{tabular}{|c|c|c|c|c|c|c|}
\hline \multirow{2}{*}{$\begin{array}{l}\text { PERIOD } \\
\text { (CON- } \\
\text { SECU- } \\
\text { TIVE } \\
\text { DAYS) }\end{array}$} & \multicolumn{6}{|c|}{$\begin{array}{l}\text { DISCHARGE, IN } \mathrm{FT}^{3} / \mathrm{S} \text {, FOR INDICATED } \\
\text { RECURRENCE INTERVAL, IN YEARS, AND } \\
\text { EXCEEDANCE PROBABILITY, IN PERCENT }\end{array}$} \\
\hline & $\begin{array}{c}2 \\
50 \%\end{array}$ & $\begin{array}{c}5 \\
20 \%\end{array}$ & $\begin{array}{l}10 \\
10 \%\end{array}$ & $\begin{array}{l}25 \\
4 \%\end{array}$ & $\begin{array}{l}50\} \\
2 x\end{array}$ & $\begin{array}{c}100 \nmid \\
1 \%\end{array}$ \\
\hline $\begin{array}{l}1 \\
3 \\
7 \\
15 \\
30 \\
60 \\
90\end{array}$ & $\begin{array}{r}1,560 \\
941 \\
567 \\
350 \\
230 \\
155 \\
128\end{array}$ & $\begin{array}{r}4,510 \\
2,600 \\
1,550 \\
911 \\
586 \\
378 \\
301\end{array}$ & $\begin{array}{r}7,260 \\
4,120 \\
2,440 \\
1,410 \\
902 \\
574 \\
452\end{array}$ & $\begin{array}{r}11,400 \\
6,390 \\
3,760 \\
2,140 \\
1,370 \\
866 \\
674\end{array}$ & $\begin{array}{r}14,800 \\
8,250 \\
4,850 \\
2,730 \\
1,760 \\
1,110 \\
859\end{array}$ & $\begin{array}{r}18,400 \\
10,200 \\
5,980 \\
3,350 \\
2,180 \\
1,370 \\
1,060\end{array}$ \\
\hline
\end{tabular}

DURATION TABLE OF DAILY MEAN FLOW FOR PERIOO OF RECORD 1966-89 DISCHARGE, IN FT $3 / \mathrm{S}$, UHICH WAS EQUALED OR EXCEEDED FOR INOICATED PERCENT OF TIME

\begin{tabular}{|c|c|c|c|c|c|c|c|c|c|c|c|c|c|c|c|c|}
\hline $1 x$ & $5 x$ & $10 x$ & $15 \%$ & $20 \%$ & $30 \%$ & $40 \%$ & $50 \%$ & $60 \%$ & $70 \%$ & $80 \%$ & $90 \%$ & $95 \%$ & $98 \%$ & $99 \%$ & $99.5 x$ & $99.9 \%$ \\
\hline 887 & 255 & 108 & 51 & 32 & 24 & 20 & 19 & 18 & 17 & 16 & 14 & 14 & 13 & 13 & 12 & 11 \\
\hline
\end{tabular}

$\uparrow$ Reliability of values in colum is uncertain, and potential errors are large. 
GILA RIVER BASIN

09505800 WEST CLEAR CREEK NEAR CAMP VERDE, AZ--CONTINUED
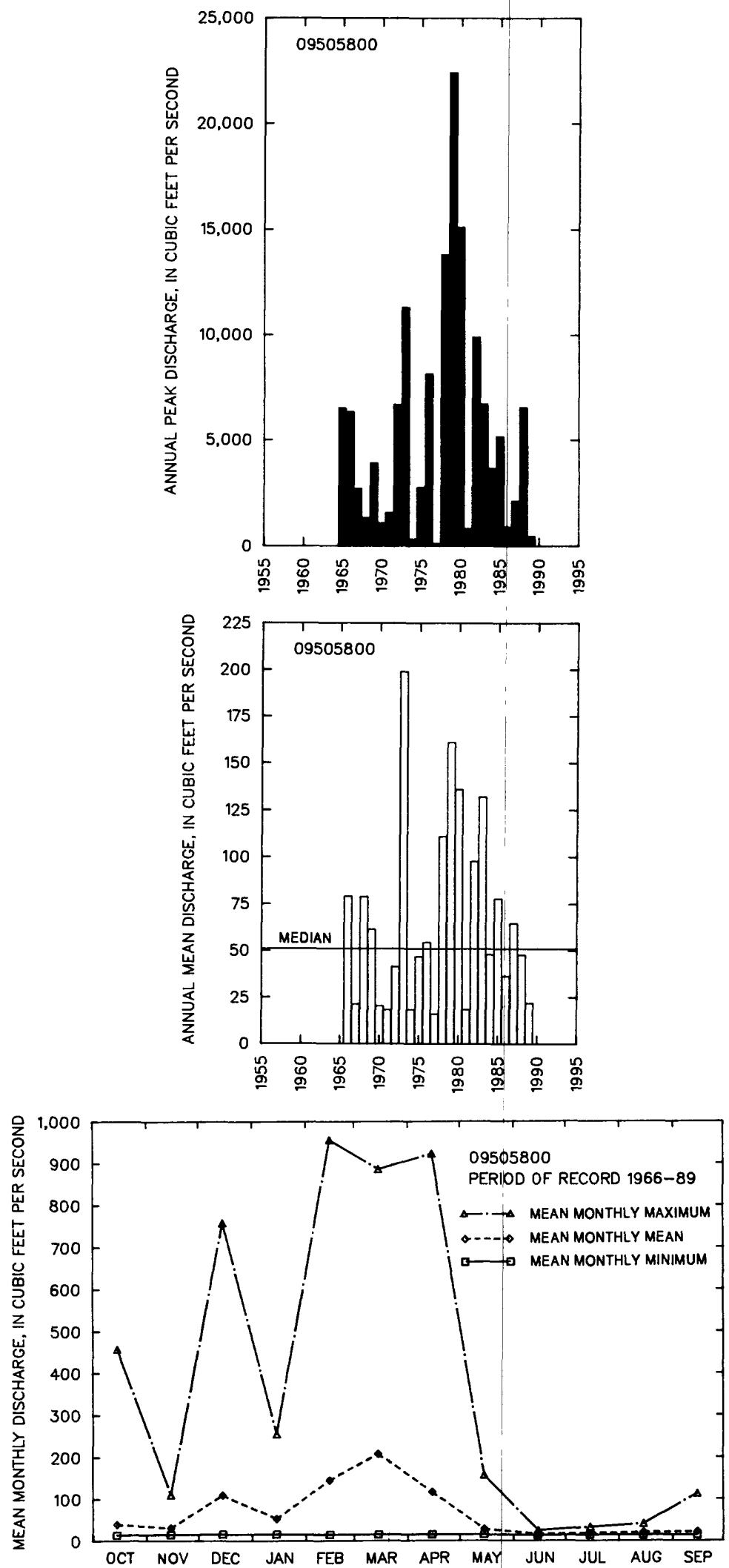
09505900 COTTONWOOD WASH NEAR CAMP VERDE, AZ

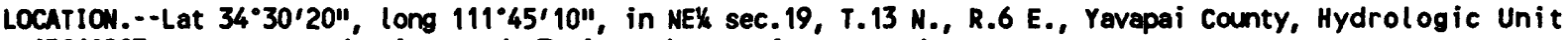
15060203, at Camp Verde-Pine road, $7 \mathrm{mi}$ southeast of Camp Verde.

DRAIMAGE AREA- $-0.64 \mathrm{mi}^{2}$.

aNIUAL PEAK DISCHARGE

\begin{tabular}{|c|c|c|c|}
\hline $\begin{array}{l}\text { MATER } \\
\text { YEAR }\end{array}$ & DATE & $\begin{array}{l}\text { ANNUAL PEAK } \\
\text { DISCHARGE } \\
\text { (FT } 3 / S)\end{array}$ & $\begin{array}{l}\text { DISCHARGE } \\
\text { CODES }\end{array}$ \\
\hline $\begin{array}{l}1964 \\
1965 \\
1966 \\
1967 \\
1968 \\
1969 \\
1970 \\
1971 \\
1972 \\
1973 \\
1974 \\
1975 \\
1976 \\
1979\end{array}$ & $\begin{array}{l}00-00-64 \\
09-18-65 \\
07-29-66 \\
09-00-67 \\
00-00-68 \\
08-00-69 \\
08-14-70 \\
09-29-71 \\
09-29-72 \\
10-19-72 \\
08-00-74 \\
11-02-74 \\
00-00-76 \\
12-18-78\end{array}$ & $\begin{array}{c}250 \\
10 \\
48 \\
36 \\
1.0 \\
4.0 \\
10 \\
195 \\
17 \\
75 \\
15 \\
5.0 \\
17 \\
180\end{array}$ & $\begin{array}{l}\text { ES } \\
\text { LT } \\
\text { ES } \\
\text { ES }\end{array}$ \\
\hline
\end{tabular}

IHighest since 1972.

MAGNITUDE AND PROBABILITY OF InSTANTANEQUS PEAK FLOW BASED ON PERICD OF RECORD 1964-76, 1979

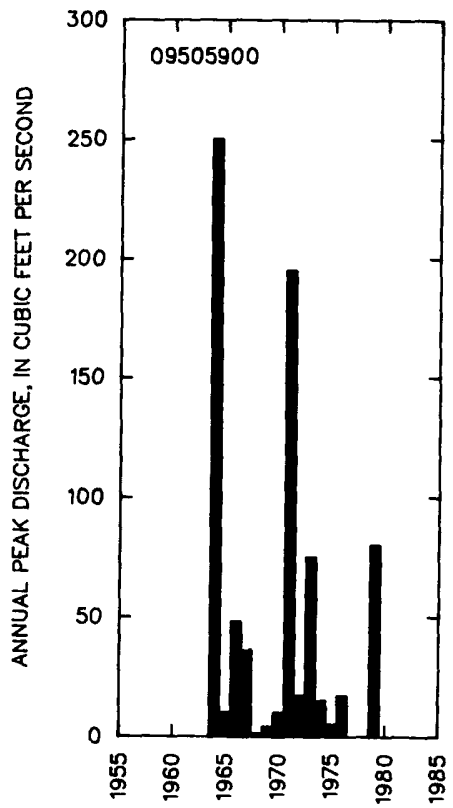

DISCHARGE, IN $\mathrm{FT}^{3} / \mathrm{S}$, FOR INDICATED RECURRENCE INTERVAL IN YEARS, AND EXCEEDANCE PROBABILITY, IN PERCENT

\begin{tabular}{|c|c|c|c|c|c|}
\hline $\begin{array}{c}2 \\
50 \%\end{array}$ & $\begin{array}{c}5 \\
20 \%\end{array}$ & $\begin{array}{r}10 \\
10 \%\end{array}$ & $\begin{array}{l}25 \\
4 \%\end{array}$ & $\begin{array}{l}50 \dagger \\
2 \%\end{array}$ & $\begin{array}{c}100 \dagger \\
1 \%\end{array}$ \\
\hline 23.4 & 75.9 & 141 & 273 & 420 & 619 \\
\hline $\begin{array}{l}\text { WEIGHTED } \\
\text { MEAN } \\
\text { STANDARD }\end{array}$ & $\begin{array}{l}\text { SKEW } \\
\text { DEV. }\end{array}$ & $\begin{array}{l}(\text { LOGS })= \\
(\text { LOGS })= \\
(\text { LOGS })=\end{array}$ & $\begin{array}{l}0.03 \\
1.37 \\
0.61\end{array}$ & & \\
\hline
\end{tabular}

f Reliability of values in column is uncertain, and potential errors are large.

BASIN CHARACTERISTICS

\begin{tabular}{|c|c|c|c|c|c|c|c|}
\hline \multirow{3}{*}{$\begin{array}{l}\text { MAIN } \\
\text { CHANNEL } \\
\text { SLOPE } \\
\text { (FTMI) }\end{array}$} & \multirow[b]{3}{*}{$\begin{array}{c}\text { STREAM } \\
\text { LENGTH } \\
\text { (MI) }\end{array}$} & \multirow{3}{*}{$\begin{array}{l}\text { MEAN } \\
\text { BASIN } \\
\text { ELEVA- } \\
\text { TION } \\
\text { (FT) }\end{array}$} & \multirow[b]{3}{*}{$\begin{array}{l}\text { FORESTED } \\
\text { AREA } \\
\text { (PERCENT) }\end{array}$} & \multirow[b]{3}{*}{$\begin{array}{l}\text { SOIL } \\
\text { INDEX }\end{array}$} & \multirow{3}{*}{$\begin{array}{l}\text { MEAN } \\
\text { ANNUAL } \\
\text { PRECIPI- } \\
\text { TATION } \\
\text { (IN) }\end{array}$} & & \\
\hline & & & & & & \multicolumn{2}{|c|}{ RAINFALL INTENSITY, 24-HOUR } \\
\hline & & & & & & $\begin{array}{l}\text { 2-YEAR } \\
\text { (IN) }\end{array}$ & $\begin{array}{l}\text { 50-YEAR } \\
\text { (IN) }\end{array}$ \\
\hline 385 & 1.1 & 3,540 & 0.0 & 1.0 & 14.5 & 2.1 & 4.1 \\
\hline
\end{tabular}


09506000 VERDE RIVER NEAR CAMP VERDE, AZ

LOCATION.--Water-stage recorder, lat 34'27', long 111.47', in sec.1, T.12 N., R.5 E., Yavapai County, Hydrologic Unit 15060203, (unsurveyed), a short distance downstream from Camp Verde dam site, 750 feet upstream from Chasm Creek, and $9 \mathrm{mi}$ southeast of Camp Verde.

DRAINAGE AREA. - -5,010 $\mathrm{mi}^{2}$ of which $365 \mathrm{mi}^{2}$ is noncontributing (including $357 \mathrm{mi}^{2}$ in Aubrey Valley Playa, a closed basin).

ANNUAL PEAK DISCHARGE

\begin{tabular}{ccc}
$\begin{array}{l}\text { UATER } \\
\text { YEAR }\end{array}$ & DATE & $\begin{array}{c}\text { ANNUAL PEAK } \\
\text { DISCHARGE } \\
\text { (FT } 3 / \text { S) }\end{array}$ \\
\hline 1934 & $07-17-34$ & 5,500 \\
1935 & $04-09-35$ & 11,500 \\
1936 & $02-24-36$ & 6,820 \\
1937 & $02-07-37$ & 41,700 \\
1938 & $03-03-38$ & 97,000 \\
1939 & $09-13-39$ & 16,100 \\
1940 & $08-04-40$ & 7,560 \\
1941 & $03-14-41$ & 30,000 \\
1942 & $10-13-41$ & 6,080 \\
1943 & $03-05-43$ & 11,600 \\
1944 & $03-14-44$ & 5,160 \\
1945 & $03-16-45$ & 8,380 \\
1989 & $03-08-89$ & 777 \\
$\ldots$
\end{tabular}

BASIN CHARACTERISTICS

\begin{tabular}{|c|c|c|c|c|c|c|c|}
\hline MAIN & & $\begin{array}{r}\text { MEAN } \\
\text { BASIN }\end{array}$ & & & $\begin{array}{l}\text { MEAN } \\
\text { ANNUAL }\end{array}$ & RAINFALL IN & SITY, 24-HOUR \\
\hline $\begin{array}{l}\text { CHANNEL } \\
\text { SLOPE } \\
\text { (FT/MI) }\end{array}$ & $\begin{array}{l}\text { STREAM } \\
\text { LENGTH } \\
\text { (MI) }\end{array}$ & $\begin{array}{l}\text { ELEVA- } \\
\text { TION } \\
\text { (FT) }\end{array}$ & $\begin{array}{l}\text { FORESTED } \\
\text { AREA } \\
\text { (PERCENT) }\end{array}$ & $\begin{array}{l}\text { SOIL } \\
\text { INDEX }\end{array}$ & $\begin{array}{l}\text { PRECIPI- } \\
\text { TATION } \\
\text { (IN) }\end{array}$ & $\begin{array}{c}\text { 2-YEAR } \\
\text { (IN) }\end{array}$ & $\begin{array}{l}\text { 50-YEAR } \\
\text { (IN) }\end{array}$ \\
\hline 17.9 & 168 & 5,560 & 70.0 & 2.5 & 17.6 & 2.1 & 4.1 \\
\hline
\end{tabular}


09506000 VERDE RIVER MEAR CANP VERDE, AZ--Continued

MEAN MONTHLY AND ANNUAL DISCHARGES 1935-45, 1989

\begin{tabular}{|c|c|c|c|c|c|c|}
\hline MONTH' & $\begin{array}{l}\operatorname{MAX} \operatorname{Imun}_{3} \\
(\mathrm{FT} / \mathrm{S})\end{array}$ & $\begin{array}{l}\text { MINIMUM } \\
\left(F^{3} / S\right)\end{array}$ & $\begin{array}{c}\text { MEAN } \\
\left(F T^{3} / S\right)\end{array}$ & $\begin{array}{l}\text { STAN- } \\
\text { DARD } \\
\text { DEVIA- } \\
\text { TION } \\
\text { (FT } 3 / S)\end{array}$ & $\begin{array}{l}\text { COEFFI- } \\
\text { CIENT OF } \\
\text { VARI - } \\
\text { ATION }\end{array}$ & $\begin{array}{c}\text { PERCENT } \\
\text { OF } \\
\text { ANNUAL } \\
\text { RUNOFF }\end{array}$ \\
\hline $\begin{array}{l}\text { OCTOBER } \\
\text { NOVEMBER } \\
\text { DECEMBER } \\
\text { JANUARY } \\
\text { FEBRUARY } \\
\text { MARCH } \\
\text { APRIL } \\
\text { MAY } \\
\text { JUNE } \\
\text { JULY } \\
\text { AUGUST } \\
\text { SEPTEMBER }\end{array}$ & $\begin{array}{r}551 \\
339 \\
1,350 \\
819 \\
4,400 \\
4,030 \\
3,050 \\
337 \\
114 \\
209 \\
416 \\
1,150\end{array}$ & $\begin{array}{r}138 \\
169 \\
199 \\
198 \\
221 \\
280 \\
126 \\
85 \\
61 \\
65 \\
114 \\
83\end{array}$ & $\begin{array}{r}221 \\
212 \\
321 \\
324 \\
1,030 \\
1,570 \\
815 \\
139 \\
84 \\
114 \\
220 \\
265\end{array}$ & $\begin{array}{r}136 \\
53 \\
325 \\
199 \\
1,270 \\
1,170 \\
862 \\
74 \\
15 \\
42 \\
92 \\
290\end{array}$ & $\begin{array}{l}0.61 \\
0.25 \\
1.0 \\
0.62 \\
1.2 \\
0.74 \\
1.1 \\
0.53 \\
0.18 \\
0.37 \\
0.42 \\
1.1\end{array}$ & $\begin{array}{r}4.2 \\
4.0 \\
6.0 \\
6.1 \\
19.4 \\
29.6 \\
15.3 \\
2.6 \\
1.6 \\
2.1 \\
4.1 \\
5.0\end{array}$ \\
\hline ANWUAL & 1,060 & 159 & 439 & 257 & 0.58 & 100 \\
\hline
\end{tabular}

\section{MAGNITLDE AND PROBABILITY OF INSTAMTANEOUS PEAK FLOW BASED ON PERICD OF RECORD 1934-45, 1989}

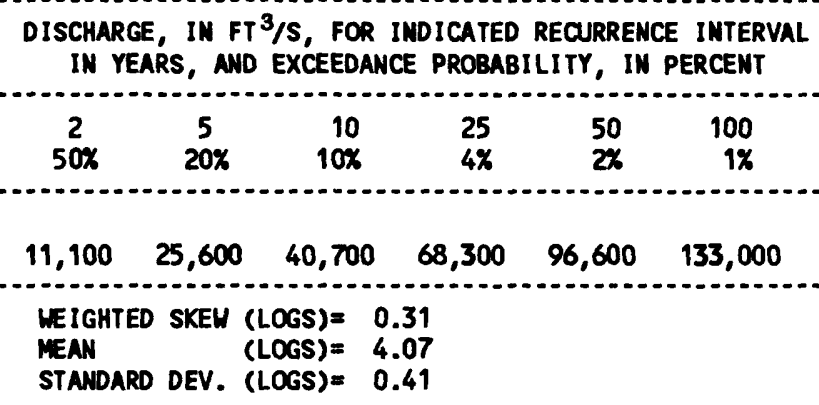

MAEITLOE AND PROBABILITY OF ANNUAL LON FLON BASED ON PERIOD OF RECORD 1935-45

\begin{tabular}{|c|c|c|c|c|c|c|}
\hline \multirow{2}{*}{$\begin{array}{l}\text { PERIOD } \\
\text { (CON- } \\
\text { SECU- } \\
\text { TIVE } \\
\text { DAYS) }\end{array}$} & \multicolumn{6}{|c|}{$\begin{array}{l}\text { DISCHARGE, IN } \mathrm{FT}^{3} / \mathrm{S} \text {, FOR INDICATED } \\
\text { RECURRENCE INTERVAL, IN YEARS, AND } \\
\text { NON-EXCEEDANCE PROBABILITY, IN PERCENT }\end{array}$} \\
\hline & $\begin{array}{c}2 \\
50 \%\end{array}$ & $\begin{array}{c}5 \\
20 \%\end{array}$ & $\begin{array}{l}10 \\
10 \%\end{array}$ & $\begin{array}{l}20 \\
5 \%\end{array}$ & $\begin{array}{l}50 \nmid \\
2 x\end{array}$ & $\begin{array}{l}100 \nmid \\
1 x\end{array}$ \\
\hline $\begin{array}{r}1 \\
3 \\
7 \\
14 \\
30 \\
60 \\
90 \\
120 \\
183\end{array}$ & $\begin{array}{r}61 \\
64 \\
67 \\
70 \\
76 \\
84 \\
93 \\
112 \\
158\end{array}$ & $\begin{array}{r}52 \\
54 \\
57 \\
60 \\
66 \\
75 \\
82 \\
100 \\
130\end{array}$ & $\begin{array}{r}48 \\
49 \\
52 \\
56 \\
62 \\
72 \\
78 \\
95 \\
120\end{array}$ & $\begin{array}{r}45 \\
46 \\
48 \\
52 \\
59 \\
70 \\
76 \\
92 \\
113\end{array}$ & $\begin{array}{r}42 \\
42 \\
43 \\
49 \\
56 \\
68 \\
74 \\
88 \\
107\end{array}$ & $\begin{array}{r}40 \\
39 \\
41 \\
46 \\
54 \\
66 \\
72 \\
87 \\
104\end{array}$ \\
\hline
\end{tabular}

MAGITLDE AND PROBABILITY OF ANMUAL HIGH FLON BASED ON PERIOD OF RECORD 1935-45, 1989

\begin{tabular}{|c|c|c|c|c|c|c|}
\hline \multirow{2}{*}{$\begin{array}{l}\text { PERIOD } \\
\text { (CON- } \\
\text { SECU- } \\
\text { TIVE } \\
\text { DAYS) }\end{array}$} & \multicolumn{6}{|c|}{$\begin{array}{l}\text { DISCHARGE, IN } \mathrm{FT}^{3} / \mathrm{S}, \text { FOR INDICATED } \\
\text { RECURRENCE INTERVAL, IN YEARS, AND } \\
\text { EXCEEDANCE PROBABILITY, IN PERCENT }\end{array}$} \\
\hline & $\begin{array}{c}2 \\
50 \%\end{array}$ & $\begin{array}{c}5 \\
20 \%\end{array}$ & $\begin{array}{l}10 \\
10 \%\end{array}$ & $\begin{array}{l}25 \nmid \\
4 \%\end{array}$ & $\begin{array}{l}50 \dagger \\
2 x\end{array}$ & $\underset{1 \%}{100 \nmid}$ \\
\hline $\begin{array}{l}1 \\
3 \\
7 \\
15 \\
30 \\
60 \\
90\end{array}$ & $\begin{array}{r}6,760 \\
4,550 \\
3,090 \\
2,130 \\
1,660 \\
1,170 \\
895\end{array}$ & $\begin{array}{r}16,000 \\
11,000 \\
6,750 \\
4,410 \\
3,150 \\
2,240 \\
1,690\end{array}$ & $\begin{array}{r}24,200 \\
17,200 \\
9,950 \\
6,430 \\
4,320 \\
3,150 \\
2,370\end{array}$ & $\begin{array}{r}36,600 \\
27,400 \\
14,900 \\
9,610 \\
5,970 \\
4,510 \\
3,430\end{array}$ & $\begin{array}{r}47,100 \\
36,900 \\
19,100 \\
12,400 \\
7,310 \\
5,680 \\
4,380\end{array}$ & $\begin{array}{r}58,600 \\
48,100 \\
23,800 \\
15,700 \\
8,720 \\
6,990 \\
5,460\end{array}$ \\
\hline
\end{tabular}

DURATION TABLE OF DAILY MEAN FLON FOR PERIOD OF RECORD 1935-45, 1989

DISCHARGE, IN FT $3 / 5$, WHICH WAS EQUALED OR EXCEEDED FOR INDICATED PERCENT OF TIME

\begin{tabular}{|c|c|c|c|c|c|c|c|c|c|c|c|c|c|c|c|c|}
\hline $1 x$ & $5 x$ & $10 \%$ & $15 x$ & $20 x$ & $30 \%$ & $40 x$ & $50 \%$ & $60 \%$ & $70 \%$ & $80 \%$ & $90 \%$ & $95 x$ & $98 \%$ & $99 \%$ & $99.5 \%$ & $99.9 \%$ \\
\hline 8,880 & 1,580 & 837 & 494 & 332 & 246 & 214 & 189 & 163 & 129 & 104 & 84 & 72 & 62 & 55 & 51 & 44 \\
\hline
\end{tabular}

\footnotetext{
f Reliability of values in column is uncertain, and potential errors are large.
} 
GILA RIVER bASIN

09506000 VERDE RIVER MEAR CAMP VERDE, AZ--CONTINUED
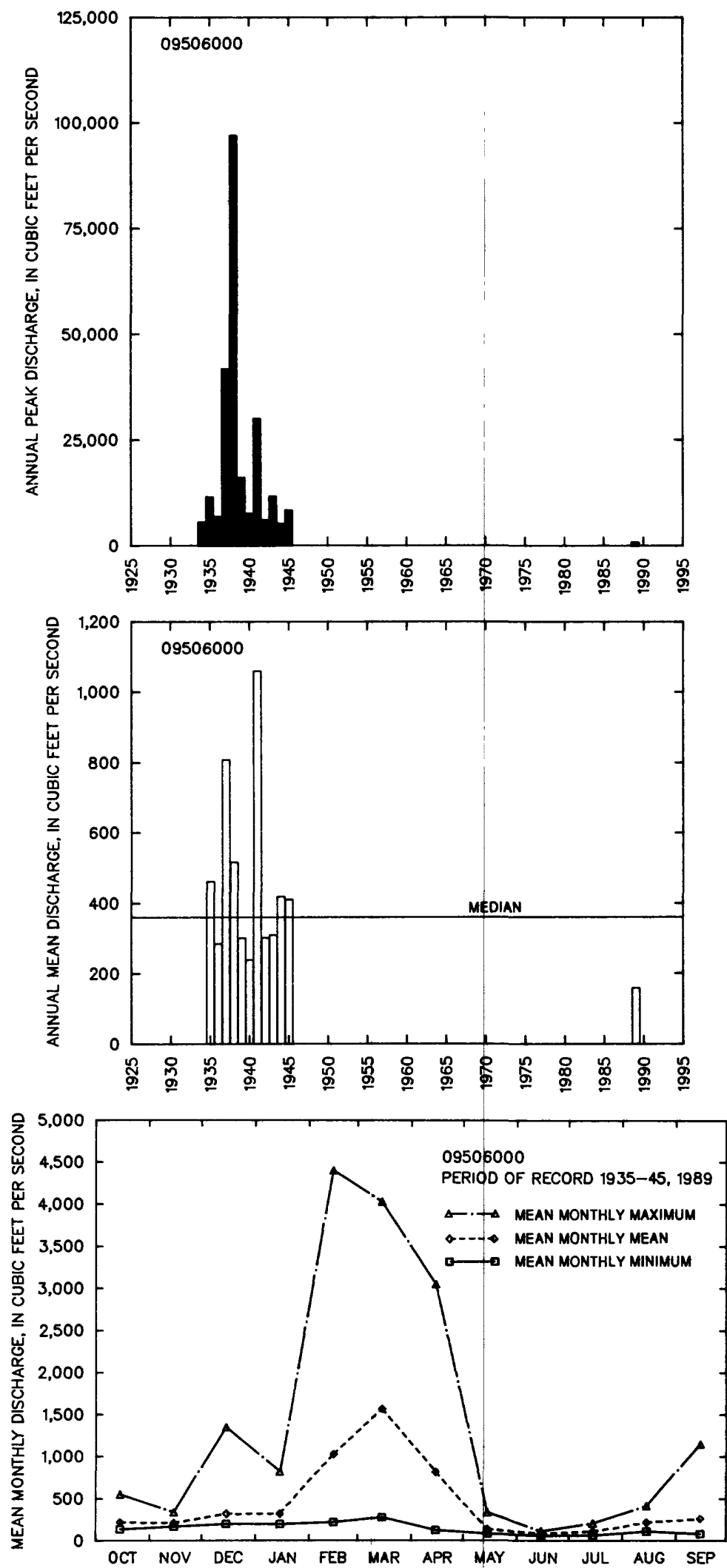
09507600 EAST VERDE RIVER NEAR PINE, AZ

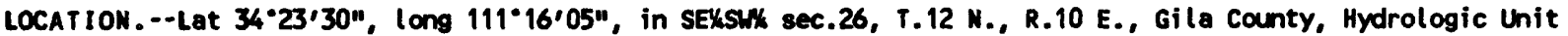
15060203, on right bank $0.8 \mathrm{mi}$ upstream from Dude Creek, $2.7 \mathrm{mi}$ south of Washington Park, and $10 \mathrm{mi}$ east of Pine.

DRAIMAGE AREA. $--6.34 \mathrm{mi}^{2}$.

ANMUAL PEAK DISCHARGE

\begin{tabular}{|c|c|c|c|}
\hline $\begin{array}{l}\text { WATER } \\
\text { YEAR }\end{array}$ & DATE & $\begin{array}{c}\text { ANIUAL PEAK } \\
\text { DISCHARGE } \\
\left(\mathrm{FT}^{3} / \mathrm{S}\right)\end{array}$ & $\begin{array}{l}\text { DISCHARGE } \\
\text { CODES }\end{array}$ \\
\hline $\begin{array}{l}1962 \\
1963 \\
1964 \\
1965 \\
1966 \\
1967 \\
1968 \\
1969 \\
1970 \\
1971 \\
1972 \\
1973 \\
1974\end{array}$ & $\begin{array}{l}02-13-62 \\
09-11-63 \\
08-04-64 \\
01-06-65 \\
12-30-65 \\
07-31-67 \\
08-02-68 \\
01-25-69 \\
09-05-70 \\
08-28-71 \\
12-26-71 \\
10-19-72 \\
07-21-74\end{array}$ & $\begin{array}{r}38 \\
264 \\
143 \\
127 \\
960 \\
1,350 \\
330 \\
298 \\
2,820 \\
99 \\
60 \\
2,700 \\
120\end{array}$ & ES \\
\hline
\end{tabular}

BASIN CHARACTERISTICS

\begin{tabular}{|c|c|c|c|c|c|c|c|}
\hline \multirow{2}{*}{$\begin{array}{c}\text { MAIN } \\
\text { CHANNEL } \\
\text { SLOPE } \\
\text { (FT/MI) }\end{array}$} & \multirow[b]{2}{*}{$\begin{array}{l}\text { STREAM } \\
\text { LENGTH } \\
\text { (MI) }\end{array}$} & \multirow{2}{*}{$\begin{array}{l}\text { MEAN } \\
\text { BASIN } \\
\text { ELEVA- } \\
\text { TION } \\
\text { (FT) }\end{array}$} & \multirow[b]{2}{*}{$\begin{array}{l}\text { FORESTED } \\
\text { AREA } \\
\text { (PERCENT) }\end{array}$} & \multirow[b]{2}{*}{$\begin{array}{l}\text { SOIL } \\
\text { INDEX }\end{array}$} & \multirow{2}{*}{$\begin{array}{l}\text { MEAN } \\
\text { ANNUAL } \\
\text { PRECIPI- }- \\
\text { TATION } \\
\text { (IN) }\end{array}$} & \multicolumn{2}{|c|}{ RAINFALL INTENSITY, 24-HOUR } \\
\hline & & & & & & $\begin{array}{l}\text { 2-YEAR } \\
\text { (IN) }\end{array}$ & $\begin{array}{l}\text { 50-YEAR } \\
\text { (IN) }\end{array}$ \\
\hline 303 & 4.4 & 6,430 & 99.0 & 3.0 & 30.0 & 2.6 & 5.0 \\
\hline
\end{tabular}


MEAN MONTHLY AND ANNUAL DISCHARGES 1962-71

\begin{tabular}{|c|c|c|c|c|c|c|}
\hline MONTH & $\begin{array}{l}\text { MAXIMUN } \\
\left(F T^{3} / S\right)\end{array}$ & $\begin{array}{l}\text { MINIMUM } \\
\left(F T^{3} / S\right)\end{array}$ & $\begin{array}{c}\text { MEAN } \\
\left(\mathrm{FT}^{3 / S}\right)\end{array}$ & $\begin{array}{l}\text { STAN- } \\
\text { DARD } \\
\text { DEVIA- } \\
\text { TION } \\
\text { (FT } 3 / S)\end{array}$ & $\begin{array}{l}\text { COEFFI- } \\
\text { CIENT OF } \\
\text { VARI - } \\
\text { ATION }\end{array}$ & $\begin{array}{c}\text { PERCENT } \\
\text { OF } \\
\text { ANMUAL } \\
\text { RUNOFF }\end{array}$ \\
\hline $\begin{array}{l}\text { OCTOBER } \\
\text { NOVEMBER } \\
\text { DECEMBER } \\
\text { JANUARY } \\
\text { FEBRUARY } \\
\text { MARCH } \\
\text { APRIL } \\
\text { MAY } \\
\text { JUNE } \\
\text { JULY } \\
\text { AUGUST } \\
\text { SEPTEMBER }\end{array}$ & $\begin{array}{l}29 \\
29 \\
28 \\
28 \\
33 \\
36 \\
38 \\
33 \\
29 \\
29 \\
30 \\
28\end{array}$ & $\begin{array}{l}0.49 \\
0.69 \\
0.59 \\
0.60 \\
0.62 \\
1.3 \\
0.84 \\
0.29 \\
0.10 \\
0.11 \\
0.04 \\
0.24\end{array}$ & $\begin{array}{l}8.8 \\
9.2 \\
8.8 \\
10 \\
12 \\
15 \\
18 \\
16 \\
12 \\
11 \\
11 \\
12\end{array}$ & $\begin{array}{l}13 \\
12 \\
12 \\
11 \\
12 \\
13 \\
13 \\
14 \\
13 \\
13 \\
12 \\
12\end{array}$ & $\begin{array}{l}1.4 \\
1.3 \\
1.4 \\
1.1 \\
0.98 \\
0.85 \\
0.76 \\
0.86 \\
1.1 \\
1.2 \\
1.1 \\
0.99\end{array}$ & $\begin{array}{r}6.1 \\
6.4 \\
6.1 \\
7.0 \\
8.7 \\
10.3 \\
12.3 \\
11.3 \\
8.1 \\
7.6 \\
7.6 \\
8.3\end{array}$ \\
\hline WNUAL & 26 & 0.73 & 12 & 9.3 & 0.78 & 100 \\
\hline
\end{tabular}

MAGNITUDE AND PROBABILITY OF INSTANTANEOUS PEAK FLOW BASED ON PERIOD OF RECORD 1962-74

DISCHARGE, IN $\mathrm{FT}^{3} / \mathrm{S}$, FOR INDICATED RECURRENCE INTERVAL IN YEARS, AND EXCEEDANCE PROBABILITY, IN PERCENT

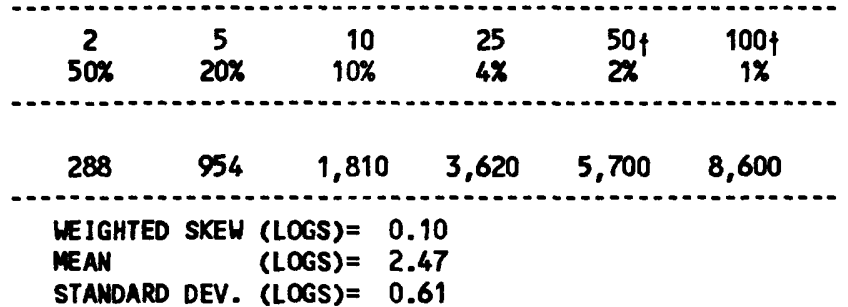

MAGNITUE AND PROBABILITY OF ANNUAL LON FLOW BASED ON PERIOD OF RECORD 1963-71

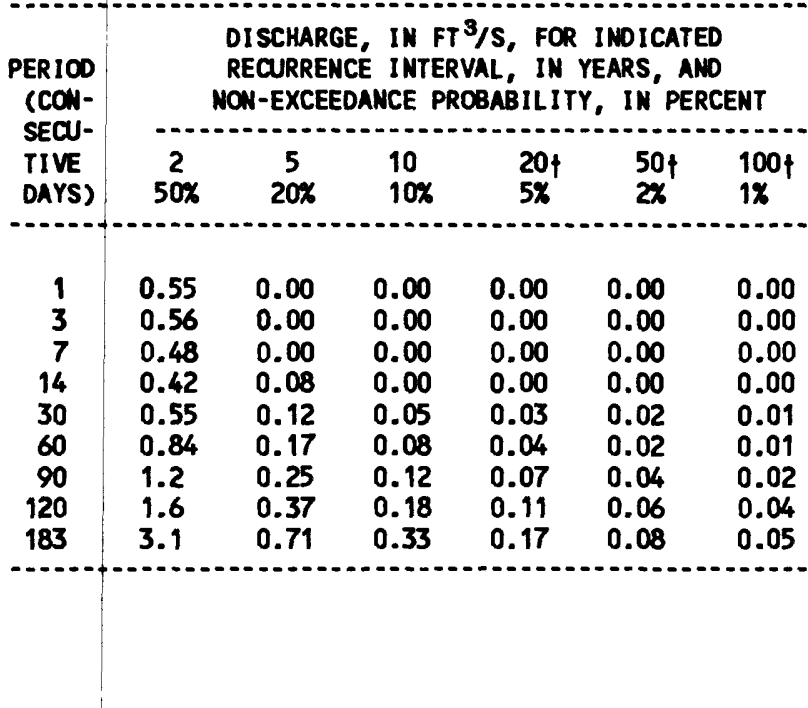

MAGNITUDE AND PROBABILITY OF AMNUAL HIGH FLON BASED ON PERIOD OF RECORD 1962-71

\begin{tabular}{|c|c|c|c|c|c|c|}
\hline \multirow{2}{*}{$\begin{array}{l}\text { PERIOD } \\
\text { (CON- } \\
\text { SECU- } \\
\text { TIVE } \\
\text { DAYS) }\end{array}$} & \multicolumn{6}{|c|}{$\begin{array}{l}\text { DISCHARGE, IN FT } 3 / S \text {, FOR INDICATED } \\
\text { RECURRENCE INTERVAL, IN YEARS, AND } \\
\text { EXCEEDANCE PROBABILITY, IN PERCENT }\end{array}$} \\
\hline & $\begin{array}{c}2 \\
50 \%\end{array}$ & $\begin{array}{c}5 \\
20 \%\end{array}$ & $\begin{array}{l}10 \\
10 \%\end{array}$ & $\begin{array}{l}25 \dagger \\
4 \%\end{array}$ & $\begin{array}{l}50 \nmid \\
2 \%\end{array}$ & $\begin{array}{c}100 \dagger \\
1 \%\end{array}$ \\
\hline $\begin{array}{r}1 \\
3 \\
7 \\
15 \\
30 \\
60 \\
90\end{array}$ & $\begin{array}{l}57 \\
41 \\
28 \\
23 \\
20 \\
17 \\
15\end{array}$ & $\begin{array}{r}145 \\
95 \\
57 \\
46 \\
41 \\
37 \\
36\end{array}$ & $\begin{array}{r}224 \\
134 \\
73 \\
58 \\
53 \\
50 \\
51\end{array}$ & $\begin{array}{r}346 \\
180 \\
88 \\
70 \\
65 \\
64 \\
68\end{array}$ & $\begin{array}{r}450 \\
211 \\
96 \\
76 \\
71 \\
72 \\
79\end{array}$ & $\begin{array}{r}563 \\
239 \\
102 \\
80 \\
77 \\
78 \\
88\end{array}$ \\
\hline
\end{tabular}

DURATION TABLE OF DAILY MEAN FLON FOR PERIOD OF RECORD 1962-71

DISCHARGE, IN FT $3 / 5$, WHICH WAS EQUALED OR EXCEEDED FOR INDICATED PERCENT OF TIME

\begin{tabular}{|c|c|c|c|c|c|c|c|c|c|c|c|c|c|c|c|c|}
\hline $1 \%$ & $5 \%$ & $10 \%$ & $15 \%$ & $20 \%$ & $30 \%$ & $40 \%$ & $50 \%$ & $60 \%$ & $70 x$ & $80 \%$ & $90 \%$ & $95 \%$ & $98 \%$ & $99 \%$ & $99.5 \%$ & $99.9 \%$ \\
\hline 42 & 35 & 32 & 29 & 28 & 25 & 9.5 & 2.8 & 1.2 & 0.78 & 0.64 & 0.47 & 0.22 & 0.11 & 0.10 & 0.00 & 0.0 \\
\hline
\end{tabular}

$\uparrow$ Reliability of values in colum is uncertain, and potential errors are large. 
GILA RIVER BASIN

09507600 EAST VERDE RIVER NEAR PINE, AZ--CONTINUED
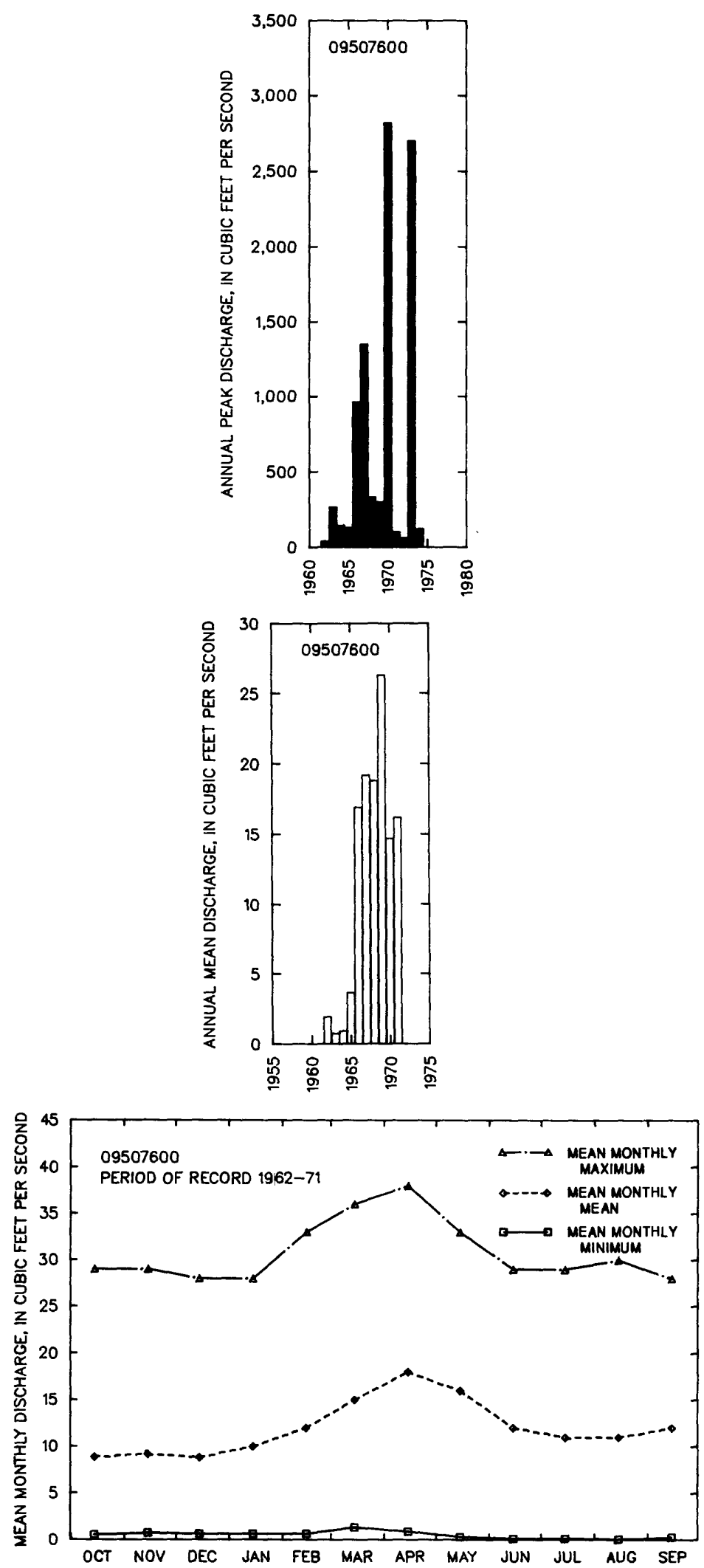
09507700 WEBBER CREEK ABOVE WEST FORK WEBBER CREEK, NEAR PINE, AZ

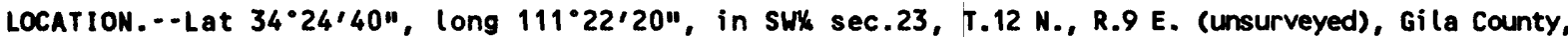
Hydrologic Unit 15060203, in Tonto National Forest, on left bank 0.2 mi upstrean from West Fork, and 4.9 mi northeast of Pine.
\end{abstract}

DRAIMAGE AREA. $--4.79 \mathrm{mi}^{2}$.

\begin{tabular}{ccc}
\multicolumn{3}{c}{ ANNUAL PEAK DISCHARGE } \\
$\begin{array}{c}\text { MATER } \\
\text { YEAR }\end{array}$ & \multicolumn{2}{c}{$\begin{array}{c}\text { ANNUAL PATE } \\
\text { DISCHARGE } \\
\text { (FT } 3 / \text { S) }\end{array}$} \\
\hline 1959 & $08-24-59$ & 21 \\
1960 & $12-25-59$ & 84 \\
1961 & $09-13-61$ & 399 \\
1962 & $04-08-62$ & 32 \\
1963 & $08-22-63$ & 19 \\
1964 & $08-08-64$ & 126 \\
1965 & $01-07-65$ & 148 \\
1966 & $12-30-65$ & 366 \\
1967 & $12-07-66$ & 153 \\
1968 & $04-01-68$ & 32 \\
1969 & $01-26-69$ & 134 \\
1970 & $09-05-70$ & 1,220 \\
1971 & $08-25-71$ & 26 \\
1972 & $12-26-71$ & 50 \\
1973 & $10-19-72$ & 686 \\
1974 & $01-21-74$ & 12 \\
$\ldots$
\end{tabular}

BASIN CHARACTERISTICS

\begin{tabular}{|c|c|c|c|c|c|c|c|}
\hline MAIN & & & & & $\begin{array}{l}\text { MEAN } \\
\text { ANNUAL }\end{array}$ & RAINFALL II & SITY, 24-HOUR \\
\hline $\begin{array}{l}\text { CHANNEL } \\
\text { SLOPE } \\
\text { (FT/MI) }\end{array}$ & $\begin{array}{l}\text { STREAM } \\
\text { LENGTH } \\
\text { (MI) }\end{array}$ & $\begin{array}{l}\text { ELEVA- } \\
\text { TION } \\
\text { (FT) }\end{array}$ & $\begin{array}{l}\text { FORESTED } \\
\text { AREA } \\
\text { (PERCENT) }\end{array}$ & $\begin{array}{l}\text { SOIL } \\
\text { INDEX }\end{array}$ & $\begin{array}{l}\text { PRECIPI- } \\
\text { TATION } \\
\text { (IN) }\end{array}$ & $\begin{array}{c}\text { 2-YEAR } \\
\text { (IN) }\end{array}$ & $\begin{array}{l}\text { 50-YEAR } \\
\text { (IN) }\end{array}$ \\
\hline 634 & 3.8 & 6,980 & 100 & 3.0 & 27.5 & 2.8 & 5.2 \\
\hline
\end{tabular}


09507700 IEBbER CREEK ABOVE WEST FORK WEBBER CREEK, MEAR PINE, AZ--Continued

MEAN MONTHLY AND ANMUAL DISCHARGES 1960-74

\begin{tabular}{|c|c|c|c|c|c|c|}
\hline MONTH & $\begin{array}{l}\operatorname{MAXIMUN} \\
\left(F T^{3} / S\right)\end{array}$ & $\begin{array}{l}\text { MINIMUM } \\
\left(F T^{3} / S\right)\end{array}$ & $\begin{array}{c}\text { MEAN } \\
\left(F T^{3} / S\right)\end{array}$ & $\begin{array}{l}\text { STAN- } \\
\text { DARD } \\
\text { DEVIA- } \\
\text { TIQN } \\
\text { (FT } 3 / S)\end{array}$ & $\begin{array}{l}\text { COEFFI - } \\
\text { CIENT OF } \\
\text { VARI - } \\
\text { ATION }\end{array}$ & $\begin{array}{c}\text { PERCENT } \\
\text { OF } \\
\text { ANNUAL } \\
\text { RUNOFF }\end{array}$ \\
\hline $\begin{array}{l}\text { OCTOBER } \\
\text { NOVEMBER } \\
\text { DECEMBER } \\
\text { JAMUARY } \\
\text { FEBRUARY } \\
\text { MARCH } \\
\text { APRIL } \\
\text { MAY } \\
\text { JUNE } \\
\text { JULY } \\
\text { AUGUST } \\
\text { SEPTEMBER }\end{array}$ & $\begin{array}{l}26 \\
4.6 \\
16 \\
11 \\
8.4 \\
15 \\
29 \\
21 \\
1.3 \\
0.53 \\
1.2 \\
8.8\end{array}$ & $\begin{array}{l}0.25 \\
0.31 \\
0.32 \\
0.51 \\
0.48 \\
0.52 \\
0.50 \\
0.43 \\
0.18 \\
0.16 \\
0.31 \\
0.24\end{array}$ & $\begin{array}{l}2.2 \\
1.1 \\
2.8 \\
3.0 \\
2.6 \\
5.4 \\
7.7 \\
2.7 \\
0.53 \\
0.33 \\
0.62 \\
1.1\end{array}$ & $\begin{array}{l}6.7 \\
1.3 \\
4.1 \\
3.4 \\
2.5 \\
5.1 \\
9.2 \\
5.2 \\
0.35 \\
0.11 \\
0.34 \\
2.2\end{array}$ & $\begin{array}{l}3.0 \\
1.2 \\
1.5 \\
1.1 \\
0.99 \\
0.95 \\
1.2 \\
2.0 \\
0.65 \\
0.33 \\
0.56 \\
1.9\end{array}$ & $\begin{array}{r}7.4 \\
3.7 \\
9.2 \\
10.0 \\
8.5 \\
17.9 \\
25.6 \\
8.9 \\
1.8 \\
1.1 \\
2.1 \\
3.8\end{array}$ \\
\hline ANNUAL & 9.1 & 0.61 & 2.5 & 2.3 & 0.92 & 100 \\
\hline
\end{tabular}

MAGITUDE AND PROBABILITY OF ANNUAL LON FLON BASED ON PERIOD OF RECORD 1961-74

\begin{tabular}{|c|c|c|c|c|c|c|}
\hline \multirow{2}{*}{$\begin{array}{l}\text { PERIOD } \\
\text { (CON- } \\
\text { SECU- } \\
\text { TIVE } \\
\text { DAYS) }\end{array}$} & \multicolumn{6}{|c|}{$\begin{array}{l}\text { DISCHARGE, IN } \mathrm{FT}^{3} / \mathrm{S} \text {, FOR INDICATED } \\
\text { RECURRENCE INTERVAL, IN YEARS, AND } \\
\text { NON-EXCEEDANCE PROBAB ILITY, IN PERCENT }\end{array}$} \\
\hline & $\begin{array}{c}2 \\
50 \%\end{array}$ & $\begin{array}{c}5 \\
20 \%\end{array}$ & $\begin{array}{l}10 \\
10 \%\end{array}$ & $\begin{array}{l}20 \\
5 \%\end{array}$ & $\begin{array}{l}50 \dagger \\
2 \%\end{array}$ & $\begin{array}{l}100 \dagger \\
18\end{array}$ \\
\hline $\begin{array}{r}1 \\
3 \\
7 \\
14 \\
30 \\
60 \\
90 \\
120 \\
183\end{array}$ & $\begin{array}{l}0.19 \\
0.20 \\
0.21 \\
0.22 \\
0.25 \\
0.30 \\
0.34 \\
0.39 \\
0.50\end{array}$ & $\begin{array}{l}0.15 \\
0.16 \\
0.16 \\
0.18 \\
0.21 \\
0.25 \\
0.29 \\
0.32 \\
0.39\end{array}$ & $\begin{array}{l}0.13 \\
0.13 \\
0.14 \\
0.15 \\
0.19 \\
0.23 \\
0.26 \\
0.29 \\
0.35\end{array}$ & $\begin{array}{l}0.12 \\
0.12 \\
0.12 \\
0.14 \\
0.17 \\
0.21 \\
0.24 \\
0.26 \\
0.31\end{array}$ & $\begin{array}{l}0.10 \\
0.10 \\
0.10 \\
0.12 \\
0.16 \\
0.20 \\
0.22 \\
0.24 \\
0.28\end{array}$ & $\begin{array}{l}0.09 \\
0.09 \\
0.09 \\
0.11 \\
0.15 \\
0.19 \\
0.21 \\
0.22 \\
0.25\end{array}$ \\
\hline
\end{tabular}

MAGNITUDE AND PROBABILITY OF ANNUAL HIGH FLOU BASED ON PERIOD OF RECORD 1960-74

\begin{tabular}{|c|c|c|c|c|c|c|}
\hline \multirow{2}{*}{$\begin{array}{l}\text { PERIOD } \\
\text { (CON- } \\
\text { SECU- } \\
\text { TIVE } \\
\text { DAYS) }\end{array}$} & \multicolumn{6}{|c|}{$\begin{array}{l}\text { DISCHARGE, IN FT3/S, FOR INDICATED } \\
\text { RECURRENCE INTERVAL, IN YEARS, AND } \\
\text { EXCEEDANCE PROBABILITY, IN PERCENT }\end{array}$} \\
\hline & $\begin{array}{c}2 \\
50 x\end{array}$ & $\begin{array}{c}5 \\
20 \%\end{array}$ & $\begin{array}{l}10 \\
10 \%\end{array}$ & $\begin{array}{l}25 \\
4 \%\end{array}$ & $\begin{array}{l}50 \nmid \\
2 \%\end{array}$ & $\begin{array}{c}100 \dagger \\
1 \%\end{array}$ \\
\hline $\begin{array}{r}1 \\
3 \\
7 \\
15 \\
30 \\
60 \\
90\end{array}$ & $\begin{array}{l}39 \\
27 \\
18 \\
12 \\
8.2 \\
5.1 \\
4.1\end{array}$ & $\begin{array}{c}117 \\
70 \\
43 \\
27 \\
19 \\
12 \\
9.8\end{array}$ & $\begin{array}{r}200 \\
110 \\
61 \\
38 \\
28 \\
19 \\
15\end{array}$ & $\begin{array}{r}343 \\
171 \\
85 \\
51 \\
42 \\
30 \\
25\end{array}$ & $\begin{array}{r}479 \\
224 \\
103 \\
61 \\
53 \\
40 \\
33\end{array}$ & $\begin{array}{r}640 \\
282 \\
120 \\
71 \\
66 \\
52 \\
44\end{array}$ \\
\hline
\end{tabular}

MAGITLDE AND PROBABILITY OF INSTANTANEOUS PEAK FLON BASED ON PERIOD OF RECORD 1959-74

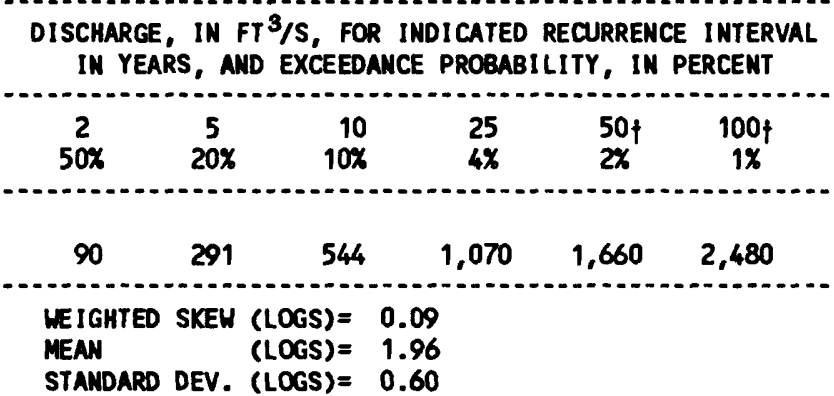

DURATION TABLE OF DAILY MEAN FLON FOR PERIOO OF RECORD 1960-74 DISCHARGE, IN $\mathrm{FT}^{3} / \mathrm{S}$, HHICH WAS EQUALED OR EXCEEDED FOR INDICATED PERCENT OF TIME

\begin{tabular}{|c|c|c|c|c|c|c|c|c|c|c|c|c|c|c|c|c|}
\hline $1 \%$ & $5 \%$ & $10 \%$ & $15 \%$ & $20 \%$ & $30 x$ & $40 \%$ & $50 \%$ & $60 \%$ & $70 \%$ & $80 \%$ & $90 \%$ & $95 \%$ & $98 \%$ & $99 \%$ & $99.5 \%$ & $99.9 \%$ \\
\hline 31 & 11 & 4.8 & 3.2 & 2.4 & 1.1 & 0.77 & 0.60 & 0.53 & 0.46 & 0.36 & 0.27 & 0.2 & 0.20 & 0.1 & 0.14 & \\
\hline
\end{tabular}

† Reliability of values in column is uncertain, and potential errors are large. 
GILA RIVER BASIN

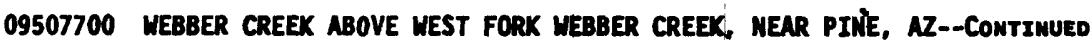
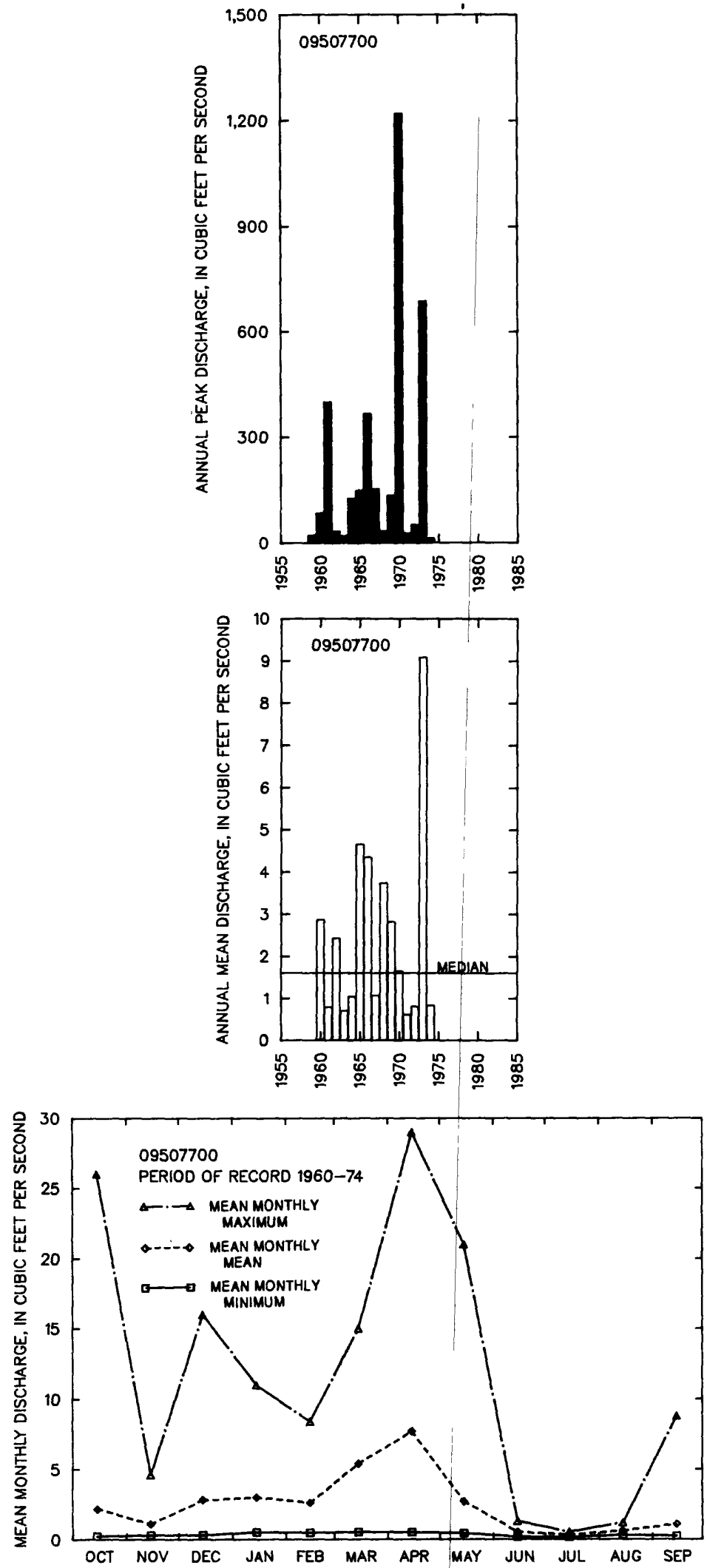
09507980 EAST VERDE RIVER NEAR CHILDS, AZ

LOCATION.--Lat 34'17'00", long $111^{\circ} 38^{\prime} 50^{\prime \prime}$, in sec.21, T.11 N., R.7 E. (unsurveyed), Gila County Hydrologic Unit 15060203, in Tonto National Forest, on left bank $1.3 \mathrm{mi}$ upstrean from mouth, and 6 mi southeast of Childs.

DRAIMAGE AREA. $--328 \mathrm{mi}^{2}$.

REMARKS.--Since September 30, 1965, records include transbasin diversions from East Clear Creek to headwaters of East Verde River.

ANNUAL PEAK DISCHARGE

\begin{tabular}{|c|c|c|c|c|c|}
\hline $\begin{array}{l}\text { WATER } \\
\text { YEAR }\end{array}$ & DATE & $\begin{array}{l}\text { ANNUAL PEAK } \\
\text { DISCHARGE } \\
\left(F^{3} / \mathrm{S}\right)\end{array}$ & $\begin{array}{l}\text { WATER } \\
\text { YEAR }\end{array}$ & DATE & $\begin{array}{c}\text { ANINAL PEAK } \\
\text { DISCHARGE } \\
\left(\mathrm{FT}^{3} / \mathrm{S}\right)\end{array}$ \\
\hline $\begin{array}{l}1961 \\
1962 \\
1963 \\
1964 \\
1965 \\
1966 \\
1968 \\
1969 \\
1970 \\
1971 \\
1972 \\
1973 \\
1974 \\
1975\end{array}$ & $\begin{array}{l}09-09-61 \\
03-22-62 \\
08-22-63 \\
09-13-64 \\
01-06-65 \\
12-22-65 \\
12-19-67 \\
01-26-69 \\
09-05-70 \\
08-11-71 \\
08-11-72 \\
10-19-72 \\
01-21-74 \\
04-11-75\end{array}$ & $\begin{array}{r}1,340 \\
540 \\
11,400 \\
1,280 \\
5,980 \\
17,000 \\
1,410 \\
6,100 \\
23,500 \\
931 \\
740 \\
10,000 \\
802 \\
814\end{array}$ & $\begin{array}{l}1976 \\
1977 \\
1978 \\
1979 \\
1980 \\
1981 \\
1982 \\
1983 \\
1984 \\
1985 \\
1986 \\
1987 \\
1988 \\
1989\end{array}$ & $\begin{array}{l}02-09-76 \\
08-17-77 \\
03-01-78 \\
01-17-79 \\
02-20-80 \\
09-01-81 \\
02-11-82 \\
11-30-82 \\
12-27-83 \\
12-27-84 \\
11-26-85 \\
03-05-87 \\
02-03-88 \\
02-05-89\end{array}$ & $\begin{array}{r}11,400 \\
502 \\
15,000 \\
11,600 \\
14,100 \\
617 \\
4,510 \\
6,250 \\
1,690 \\
5,570 \\
1,760 \\
1,030 \\
4,000 \\
1,750\end{array}$ \\
\hline
\end{tabular}

BASIN CHARACTERISTICS

\begin{tabular}{|c|c|c|c|c|c|c|c|}
\hline MAIN & & $\begin{array}{l}\text { MEAN } \\
\text { BASIN }\end{array}$ & & & $\begin{array}{l}\text { MEAN } \\
\text { ANNUAL }\end{array}$ & RAINFALL II & SITY, 24-HOUR \\
\hline $\begin{array}{l}\text { CHANNEL } \\
\text { SLOPE } \\
\text { (FT/MI) }\end{array}$ & $\begin{array}{c}\text { STREAM } \\
\text { LENGTH } \\
\text { (MI) }\end{array}$ & $\begin{array}{l}\text { ELEVA- } \\
\text { TION } \\
\text { (FT) }\end{array}$ & $\begin{array}{l}\text { FORESTED } \\
\text { AREA } \\
\text { (PERCENT) }\end{array}$ & $\begin{array}{l}\text { SOIL } \\
\text { INDEX }\end{array}$ & $\begin{array}{l}\text { PRECIPI- } \\
\text { TATION } \\
\text { (IN) }\end{array}$ & $\begin{array}{c}\text { 2-YEAR } \\
\text { (IN) }\end{array}$ & $\begin{array}{c}\text { 50-YEAR } \\
\text { (IN) }\end{array}$ \\
\hline 91.6 & 32.0 & 5,140 & 50.0 & 2.8 & 24.7 & 2.7 & 5.0 \\
\hline
\end{tabular}


MEAN MONTHLY AND ANNUAL DISCHARGES $1968-89$

\begin{tabular}{|c|c|c|c|c|c|c|}
\hline MONTH & $\begin{array}{l}\operatorname{MAXIMUM} \\
\left(F T^{3} / S\right)\end{array}$ & $\begin{array}{l}\text { MINIMUM } \\
\left(\mathrm{FT}^{3} / \mathrm{S}\right)\end{array}$ & $\begin{array}{c}\text { MEAN } \\
\left(F T^{3} / S\right)\end{array}$ & $\begin{array}{l}\text { STAN- } \\
\text { DARD } \\
\text { DEVIA- } \\
\text { TION } \\
\text { (FT } 3 / S)\end{array}$ & $\begin{array}{l}\text { COEFFI - } \\
\text { CIENT OF } \\
\text { VARI - } \\
\text { ATION }\end{array}$ & $\begin{array}{c}\text { PERCENT } \\
\text { OF } \\
\text { ANNUAL } \\
\text { RUNOFF }\end{array}$ \\
\hline $\begin{array}{l}\text { OCTOBER } \\
\text { NOVEMBER } \\
\text { DECEMBER } \\
\text { JANUARY } \\
\text { FEBRUARY } \\
\text { MARCH } \\
\text { APRIL } \\
\text { MAY } \\
\text { JUNE } \\
\text { JULY } \\
\text { AUGUST } \\
\text { SEPTEMBER }\end{array}$ & $\begin{array}{r}308 \\
157 \\
443 \\
409 \\
1,150 \\
968 \\
371 \\
115 \\
49 \\
51 \\
77 \\
282\end{array}$ & $\begin{array}{c}1.3 \\
2.4 \\
4.4 \\
6.7 \\
5.8 \\
6.3 \\
9.6 \\
12 \\
1.7 \\
0.48 \\
7.4 \\
0.73\end{array}$ & $\begin{array}{r}39 \\
41 \\
78 \\
92 \\
177 \\
183 \\
87 \\
37 \\
24 \\
26 \\
32 \\
39\end{array}$ & $\begin{array}{r}61 \\
38 \\
117 \\
116 \\
254 \\
236 \\
87 \\
23 \\
14 \\
14 \\
18 \\
56\end{array}$ & $\begin{array}{l}1.6 \\
0.93 \\
1.5 \\
1.3 \\
1.4 \\
1.3 \\
1.0 \\
0.63 \\
0.57 \\
0.55 \\
0.56 \\
1.5\end{array}$ & $\begin{array}{r}4.6 \\
4.8 \\
9.1 \\
10.8 \\
20.7 \\
21.4 \\
10.1 \\
4.3 \\
2.8 \\
3.0 \\
3.8 \\
4.6\end{array}$ \\
\hline ANNUAL & 185 & 14 & 71 & 56 & 0.79 & 100 \\
\hline
\end{tabular}

MAGNITUDE AND PROBABILITY OF INSTANTANEOUS PEAK FLOW BASED ON PERIOD OF RECORD 1961-66, 1968-89

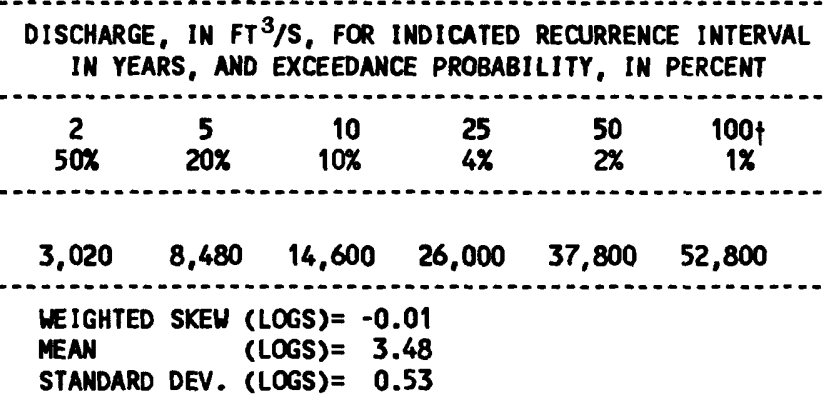

MAGNITLOE AND PROBABILITY OF ANNUAL LOH FLOM BASED ON PERIOD OF RECORD 1969-89

\begin{tabular}{|c|c|c|c|c|c|c|}
\hline \multirow{2}{*}{$\begin{array}{l}\text { PERIOD } \\
\text { (CON- } \\
\text { SECU- } \\
\text { TIVE } \\
\text { DAYS) }\end{array}$} & \multicolumn{6}{|c|}{$\begin{array}{l}\text { DISCHARGE, IN } \mathrm{FT}^{3} / \mathrm{S}, \text { FOR INDICATED } \\
\text { RECURRENCE INTERVAL, IN YEARS, AND } \\
\text { NON-EXCEEDANCE PROBABILITY, IN PERCENT }\end{array}$} \\
\hline & $\stackrel{2}{50 \%}$ & $\begin{array}{c}5 \\
20 \%\end{array}$ & $\begin{array}{l}10 \\
10 \%\end{array}$ & $\begin{array}{l}20 \\
5 x\end{array}$ & $\begin{array}{l}50 \nmid \\
2 x\end{array}$ & $\begin{array}{l}100 \uparrow \\
1 \%\end{array}$ \\
\hline $\begin{array}{r}1 \\
3 \\
7 \\
14 \\
30 \\
60 \\
90 \\
120 \\
183\end{array}$ & $\begin{array}{c}5.3 \\
5.6 \\
6.4 \\
7.4 \\
9.9 \\
12 \\
15 \\
18 \\
23\end{array}$ & $\begin{array}{c}1.7 \\
1.8 \\
2.0 \\
2.4 \\
3.4 \\
4.9 \\
7.5 \\
9.4 \\
13\end{array}$ & $\begin{array}{l}0.81 \\
0.84 \\
0.93 \\
1.1 \\
1.7 \\
2.6 \\
4.9 \\
6.2 \\
9.7\end{array}$ & $\begin{array}{l}0.41 \\
0.42 \\
0.45 \\
0.55 \\
0.87 \\
1.5 \\
3.3 \\
4.2 \\
7.1\end{array}$ & $\begin{array}{l}0.17 \\
0.17 \\
0.18 \\
0.22 \\
0.38 \\
0.73 \\
2.0 \\
2.6 \\
4.9\end{array}$ & $\begin{array}{l}0.09 \\
0.09 \\
0.09 \\
0.11 \\
0.20 \\
0.43 \\
1.5 \\
1.9 \\
3.8\end{array}$ \\
\hline
\end{tabular}

MAGNITUDE AND PROBABILITY OF ANNUAL HIGH FLON BASED ON PER IOD OF RECORD $1968-89$

\begin{tabular}{|c|c|c|c|c|c|c|}
\hline \multirow{2}{*}{$\begin{array}{l}\text { PERIOD } \\
\text { (CON- } \\
\text { SECU- } \\
\text { TIVE } \\
\text { DAYS) }\end{array}$} & \multicolumn{6}{|c|}{$\begin{array}{l}\text { DISCHARGE, IN } \mathrm{FT}^{3} / \mathrm{S}, \text { FOR INDICATED } \\
\text { RECURRENCE INTERVAL, IN YEARS, AND } \\
\text { EXCEEDANCE PROBABILITY, IN PERCENT }\end{array}$} \\
\hline & $\begin{array}{c}2 \\
50 \%\end{array}$ & $\begin{array}{c}5 \\
20 x\end{array}$ & $\begin{array}{l}10 \\
10 \%\end{array}$ & $\begin{array}{l}25 \\
4 \%\end{array}$ & $\begin{array}{l}50 \nmid \\
2 x\end{array}$ & $\underset{1 \%}{100 \nmid}$ \\
\hline $\begin{array}{r}1 \\
3 \\
7 \\
15 \\
30 \\
60 \\
90\end{array}$ & $\begin{array}{r}1.240 \\
759 \\
458 \\
284 \\
197 \\
138 \\
113\end{array}$ & $\begin{array}{r}3,590 \\
2,180 \\
1,320 \\
760 \\
492 \\
333 \\
261\end{array}$ & $\begin{array}{r}6,010 \\
3,630 \\
2,190 \\
1,230 \\
778 \\
529 \\
410\end{array}$ & $\begin{array}{r}10,100 \\
6,070 \\
3,630 \\
2,010 \\
1,250 \\
868 \\
670\end{array}$ & $\begin{array}{r}14,000 \\
8,330 \\
4,950 \\
2,720 \\
1,690 \\
1,200 \\
924\end{array}$ & $\begin{array}{r}18,600 \\
11,000 \\
6,460 \\
3,540 \\
2,200 \\
1,600 \\
1,240\end{array}$ \\
\hline
\end{tabular}

DURATION TABLE OF DAILY MEAN FLON FOR PERIOD OF RECORD 1968-89

DISCHARGE, IN FT ${ }^{3} / \mathrm{S}$, WHICH WAS EQUALED OR EXCEEDED FOR INDICATED PERCENT OF TIME

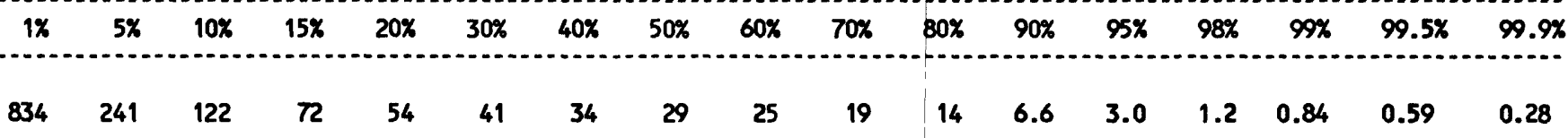

$\uparrow$ Reliability of values in colum is uncertain, and potential errors are large. 
GILA RIVER BASIN

09507980 EAST VERDE RIVER NEAR CHILDS, AZ--CONTINUED
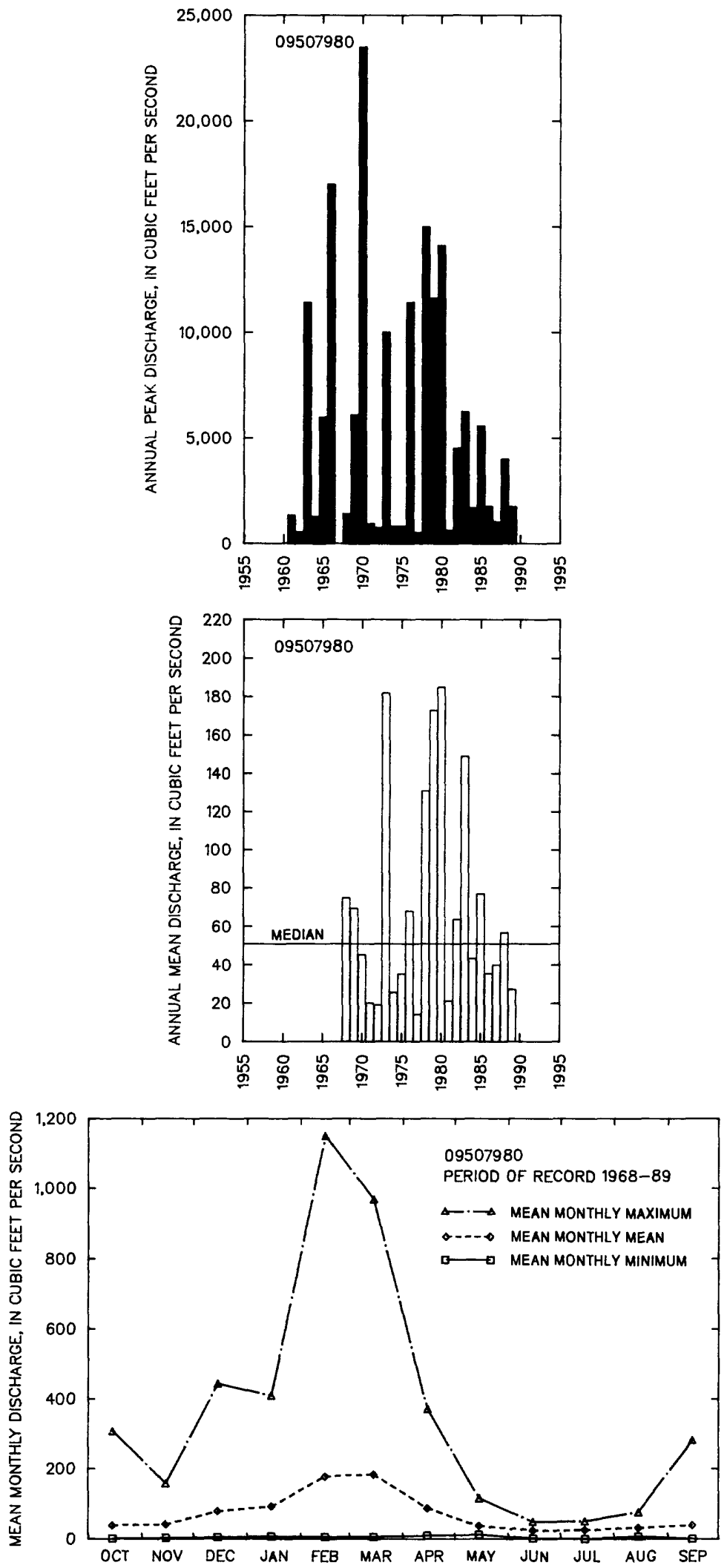
09508300 MET BOTTOM CREEK NEAR CHILDS, AZ

(Hydrologic bench mark station)

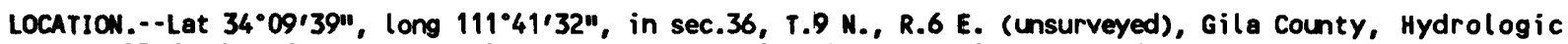
Unit 15060203, in Tonto National Forest, on right bank $1.4 \mathrm{mi}$ upstream from mouth, and $13 \mathrm{mi}$ south of childs.

DRAIMAGE AREA. $--36.4 \mathrm{mi}^{2}$.

REMARKS. - - A cumulative departure from the annual mean discharge graph is included because this station is a hydrlogic benchmark station, not because of a long period of record.

ANMUAL PEAK DISCHARGE

\begin{tabular}{|c|c|c|}
\hline $\begin{array}{l}\text { WATER } \\
\text { YEAR }\end{array}$ & DATE & $\begin{array}{l}\text { ANMUAL PEAK } \\
\text { DISCHARGE } \\
\text { (FT } 3 / S)\end{array}$ \\
\hline $\begin{array}{l}1968 \\
1969 \\
1970 \\
1971 \\
1972 \\
1973 \\
1974 \\
1975 \\
1976 \\
1977 \\
1978 \\
1979 \\
1980 \\
1981 \\
1982 \\
1983 \\
1984 \\
1985 \\
1986 \\
1987 \\
1988 \\
1989\end{array}$ & $\begin{array}{l}12-19-67 \\
01-26-69 \\
09-05-70 \\
08-03-71 \\
12-26-71 \\
10-19-72 \\
01-09-74 \\
11-02-74 \\
02-09-76 \\
01-03-77 \\
03-02-78 \\
12-18-78 \\
02-19-80 \\
03-08-81 \\
02-11-82 \\
11-30-82 \\
12-04-83 \\
12-27-84 \\
11-26-85 \\
03-04-87 \\
02-03-88 \\
02-05-89\end{array}$ & $\begin{array}{r}5,220 \\
535 \\
5,600 \\
158 \\
80 \\
3,700 \\
744 \\
684 \\
5,940 \\
52 \\
6,660 \\
6,680 \\
6,830 \\
122 \\
1,650 \\
3,220 \\
768 \\
2,090 \\
1,260 \\
522 \\
1,840 \\
851\end{array}$ \\
\hline
\end{tabular}

\section{BASIN CHARACTERISTICS}

\begin{tabular}{|c|c|c|c|c|c|c|c|}
\hline \multirow{2}{*}{$\begin{array}{l}\text { MAIN } \\
\text { CHANNEL } \\
\text { SLOPE } \\
\text { (FT/MI) }\end{array}$} & \multirow[b]{2}{*}{$\begin{array}{l}\text { STREAM } \\
\text { LENGTH } \\
\text { (MI) }\end{array}$} & \multirow{2}{*}{$\begin{array}{l}\text { MEAN } \\
\text { BASIN } \\
\text { ELEVA- } \\
\text { TION } \\
\text { (FT) }\end{array}$} & \multirow[b]{2}{*}{$\begin{array}{l}\text { FORESTED } \\
\text { AREA } \\
\text { (PERCENT) }\end{array}$} & \multirow[b]{2}{*}{$\begin{array}{l}\text { SOIL } \\
\text { INDEX }\end{array}$} & \multirow{2}{*}{$\begin{array}{l}\text { MEAN } \\
\text { ANNULAL } \\
\text { PRECIPI- } \\
\text { TATION } \\
\text { (IN) }\end{array}$} & \multicolumn{2}{|c|}{ RAINFALL INTENSITY, 24-HOUR } \\
\hline & & & & & & $\begin{array}{c}\text { 2-YEAR } \\
\text { (IN) }\end{array}$ & $\begin{array}{l}\text { 50-YEAR } \\
\text { (IN) }\end{array}$ \\
\hline 210 & 17.6 & 4,810 & 68.0 & 1.0 & 25.0 & 2.7 & 5.5 \\
\hline
\end{tabular}


09508300 WET BOTTOM CREEK NEAR CHILDS, AZ--Cont inued

MEAN MONTHLY AND ANNUAL DISCHARGES 1968-89

\begin{tabular}{|c|c|c|c|c|c|c|}
\hline MONTH & $\begin{array}{l}\operatorname{MAXIMUN} \\
\left(F T^{3} / S\right)\end{array}$ & $\begin{array}{l}\operatorname{MINIMUN} \\
\left(\mathrm{FT}^{3} / \mathrm{S}\right)\end{array}$ & $\begin{array}{c}\text { MEAN } \\
\left(F T^{3} / S\right)\end{array}$ & $\begin{array}{l}\text { STAN- } \\
\text { DARD } \\
\text { DEVIA- } \\
\text { TION } \\
\text { (FT'/S) }\end{array}$ & $\begin{array}{l}\text { COEFFI- } \\
\text { CIENT OF } \\
\text { VARI - } \\
\text { ATION }\end{array}$ & $\begin{array}{c}\text { PERCENT } \\
\text { OF } \\
\text { ANNUAL } \\
\text { RUNOFF }\end{array}$ \\
\hline $\begin{array}{l}\text { OCTOBER } \\
\text { NOVEMBER } \\
\text { DECEMBER } \\
\text { JANUARY } \\
\text { FEBRUARY } \\
\text { MARCH } \\
\text { APRIL } \\
\text { MAY } \\
\text { JUNE } \\
\text { JULY } \\
\text { AUGUST } \\
\text { SEPTEMBER }\end{array}$ & $\begin{array}{c}103 \\
52 \\
111 \\
129 \\
345 \\
321 \\
38 \\
2.1 \\
0.55 \\
12 \\
31 \\
27\end{array}$ & $\begin{array}{l}0.01 \\
0.17 \\
0.28 \\
0.26 \\
0.58 \\
0.29 \\
0.09 \\
0.00 \\
0.00 \\
0.00 \\
0.00 \\
0.00\end{array}$ & $\begin{array}{l}6.6 \\
9.6 \\
25 \\
31 \\
46 \\
45 \\
9.0 \\
0.63 \\
0.09 \\
1.1 \\
3.6 \\
3.2\end{array}$ & $\begin{array}{l}22 \\
14 \\
39 \\
36 \\
76 \\
72 \\
12 \\
0.65 \\
0.14 \\
2.8 \\
7.5 \\
6.4\end{array}$ & $\begin{array}{l}3.3 \\
1.5 \\
1.6 \\
1.2 \\
1.6 \\
1.6 \\
1.3 \\
1.0 \\
1.6 \\
2.6 \\
2.1 \\
2.0\end{array}$ & $\begin{array}{r}3.7 \\
5.3 \\
13.8 \\
17.3 \\
25.6 \\
24.7 \\
4.9 \\
0.3 \\
0.0 \\
0.6 \\
2.0 \\
1.8\end{array}$ \\
\hline ANNUAL & 41 & 0.45 & 15 & 13 & 0.89 & 100 \\
\hline
\end{tabular}

MAGNITUDE ANO PROBABILITY OF INSTANTANEOUS PEAK FLOW BASED ON PER IOD OF RECORD 1968-89

DISCHARGE, IN $\mathrm{FT}^{3} / \mathrm{S}$, FOR INDICATED RECURRENCE INTERVAL IN YEARS, AND EXCEEDANCE PROBABILITY, IN PERCENT

\begin{tabular}{|c|c|c|c|c|c|}
\hline$\stackrel{2}{50 x}$ & $\begin{array}{c}5 \\
20 \%\end{array}$ & $\begin{array}{r}10 \\
10 x\end{array}$ & $\begin{array}{l}25 \\
4 x\end{array}$ & $\begin{array}{l}50 \dagger \\
2 \%\end{array}$ & $\begin{array}{c}100 \dagger \\
1 \%\end{array}$ \\
\hline 1,570 & 4,040 & 6,470 & 10,500 & 14,200 & 18,500 \\
\hline $\begin{array}{l}\text { MEIGHT } \\
\text { MEAN } \\
\text { STANDD }\end{array}$ & SKEW & $\begin{array}{l}(G S)=-( \\
(G S)= \\
(G S)=\end{array}$ & & & \\
\hline
\end{tabular}

MGNITLDE AND PROBABILITY OF ANNUAL LON FLON BASED ON PERIOD OF RECORD 1969-89

\begin{tabular}{|c|c|c|c|c|c|c|}
\hline \multirow{2}{*}{$\begin{array}{l}\text { PERIOD } \\
\text { (CON- } \\
\text { SECU- } \\
\text { TIVE } \\
\text { DAYS) }\end{array}$} & \multicolumn{6}{|c|}{$\begin{array}{l}\text { DISCHARGE, IN FT } 3 / S \text {, FOR INDICATED } \\
\text { RECURRENCE INTERVAL, IN YEARS, AND } \\
\text { NON-EXCEEDANCE PROBABILITY, IN PERCENT }\end{array}$} \\
\hline & $\begin{array}{c}2 \\
50 \%\end{array}$ & $\begin{array}{c}5 \\
20 x\end{array}$ & $\begin{array}{l}10 \\
10 x\end{array}$ & $\begin{array}{l}20 \\
5 \%\end{array}$ & $\begin{array}{l}50 \nmid \\
2 \%\end{array}$ & $\begin{array}{l}100 \dagger \\
1 \%\end{array}$ \\
\hline $\begin{array}{r}1 \\
3 \\
7 \\
14\end{array}$ & & & & & & \\
\hline $\begin{array}{r}30 \\
60 \\
90 \\
120 \\
183\end{array}$ & $\begin{array}{l}0.00 \\
0.00 \\
0.00 \\
0.00 \\
0.56\end{array}$ & $\begin{array}{l}0.00 \\
0.00 \\
0.00 \\
0.00 \\
0.12\end{array}$ & $\begin{array}{l}0.00 \\
0.00 \\
0.00 \\
0.00 \\
0.05\end{array}$ & $\begin{array}{l}0.00 \\
0.00 \\
0.00 \\
0.00 \\
0.02\end{array}$ & $\begin{array}{l}0.00 \\
0.00 \\
0.00 \\
0.00 \\
0.01\end{array}$ & $\begin{array}{l}0.00 \\
0.00 \\
0.00 \\
0.00 \\
0.00\end{array}$ \\
\hline
\end{tabular}

MAEITUDE AND PROBABILITY OF ANNUAL HIGH FLON BASED ON PERIOD OF RECORD 1968-89

\begin{tabular}{|c|c|c|c|c|c|c|}
\hline \multirow{2}{*}{$\begin{array}{l}\text { PERIOD } \\
\text { (CON- } \\
\text { SECU- } \\
\text { TIVE } \\
\text { DAYS) }\end{array}$} & \multicolumn{6}{|c|}{$\begin{array}{l}\text { DISCHARGE, IN } \mathrm{FT}^{3} / \mathrm{S}, \text { FOR INDICATED } \\
\text { RECURRENCE INTERVAL, IN YEARS, AND } \\
\text { EXCEEDANCE PROBABILITY, IN PERCENT }\end{array}$} \\
\hline & $\begin{array}{c}2 \\
50 x\end{array}$ & $\begin{array}{c}5 \\
20 x\end{array}$ & $\begin{array}{l}10 \\
10 \%\end{array}$ & $\begin{array}{l}25 \\
4 \%\end{array}$ & $\begin{array}{l}50 \dagger \\
2 \%\end{array}$ & $\begin{array}{c}100 \dagger \\
1 \%\end{array}$ \\
\hline $\begin{array}{r}1 \\
3 \\
7 \\
15 \\
30 \\
60 \\
90\end{array}$ & $\begin{array}{r}510 \\
309 \\
190 \\
108 \\
64 \\
42 \\
31\end{array}$ & $\begin{array}{r}1,460 \\
810 \\
482 \\
269 \\
160 \\
111 \\
82\end{array}$ & $\begin{array}{r}2,230 \\
1,170 \\
677 \\
380 \\
232 \\
166 \\
124\end{array}$ & $\begin{array}{r}3,240 \\
1,570 \\
888 \\
507 \\
321 \\
239 \\
181\end{array}$ & $\begin{array}{r}3,960 \\
1,820 \\
1,010 \\
585 \\
381 \\
292 \\
223\end{array}$ & $\begin{array}{r}4,620 \\
2,030 \\
1,110 \\
651 \\
436 \\
342 \\
264\end{array}$ \\
\hline
\end{tabular}

DURATION TABLE OF DAILY MEAN FLON FOR PERIOD OF RECORD 1968-89

DISCHARGE, IN $\mathrm{FT}^{3} / \mathrm{S}$, WHICH WAS EQUALED OR EXCEEDED FOR INDICATED PERCENT OF TIME

\begin{tabular}{|c|c|c|c|c|c|c|c|c|c|c|c|c|c|c|c|c|}
\hline $1 \%$ & $5 x$ & $10 \%$ & $15 \%$ & $20 \%$ & $30 x$ & $40 \%$ & $50 \%$ & $60 \%$ & $70 \%$ & $80 \%$ & $90 \%$ & $95 \%$ & $98 \%$ & $99 \%$ & $99.5 \%$ & $99.9 \%$ \\
\hline 270 & 59 & 22 & 12 & 6.8 & 2.1 & 0.88 & 0.53 & 0.32 & 0.16 & 0.05 & 0.00 & 0.00 & 0.00 & 0.00 & 0.00 & 0.00 \\
\hline
\end{tabular}

f Reliability of values in column is uncertain, and potential errors are large. 
09508300 WET BOTTOM CREEK MEAR CHILDS, AZ--CONTIMUED
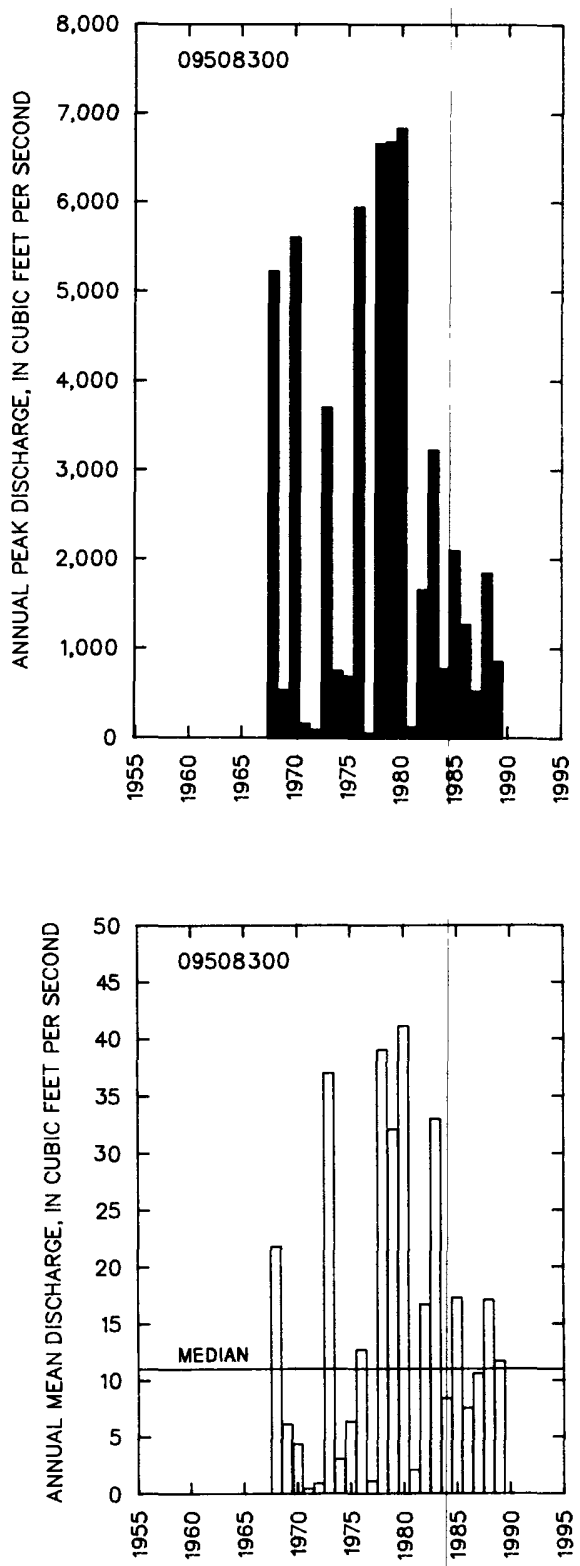
09508300 WET BOTTOM CREEK NEAR CHILDS, AZ--CONTInUEd
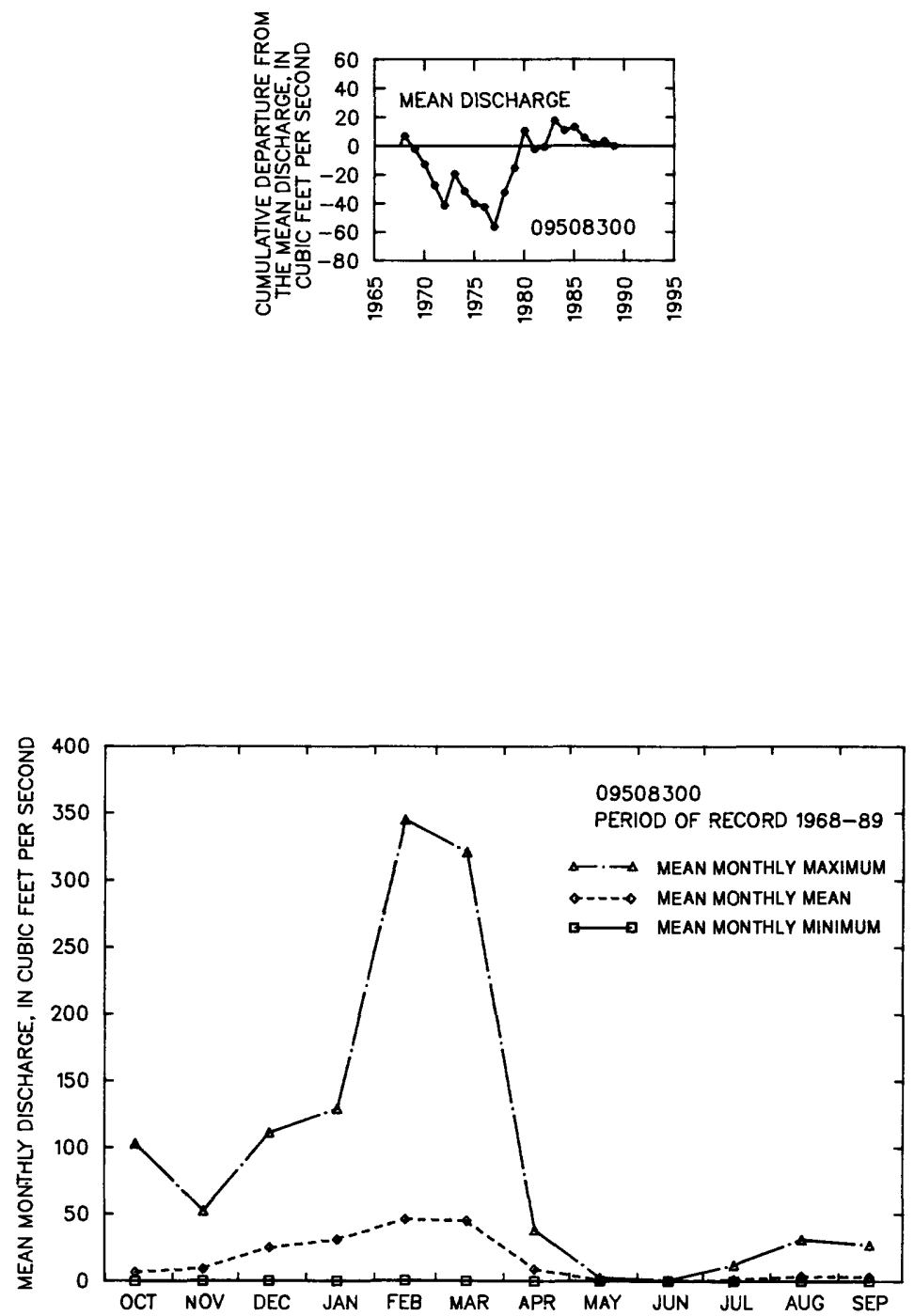


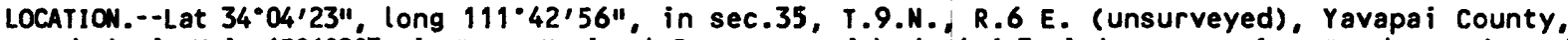
Hydrologic Unit 15060203, in Tonto National Forest, on right bank 1.3 mi downstream from Tangle Creek, and 9 mi upstream from Horseshoe Dam.

DRAINAGE AREA. $-5,859 \mathrm{mi}^{2}$, of which $365 \mathrm{mi}^{2}$ is noncontributing including $357 \mathrm{mi}^{2}$ in Aubrey Valley Playa, a closed basin.

REMARKS.-- About 12,500 acres above station are irrigated by surface water and ground water. Low flow slightly regulated by powerplant $32 \mathrm{mi}$ above station, using water from fossil Creek. This station is above all major reservoirs on Verde River.

\begin{tabular}{|c|c|c|c|c|c|c|c|}
\hline \multicolumn{8}{|c|}{ ANNUAL PEAK DISCHARGE } \\
\hline $\begin{array}{l}\text { WATER } \\
\text { YEAR }\end{array}$ & DATE & $\begin{array}{c}\text { ANNUAL PEAK } \\
\text { DISCHARGE } \\
\left(\mathrm{FT}^{3} / \mathrm{S}\right)\end{array}$ & $\begin{array}{l}\text { DISCHARGE } \\
\text { CODES }\end{array}$ & $\begin{array}{l}\text { WATER } \\
\text { YEAR }\end{array}$ & DATE & $\begin{array}{l}\text { ANNUAL PEAK } \\
\text { DISCHARGE } \\
\left(\mathrm{FT}^{3} / \mathrm{S}\right)\end{array}$ & $\begin{array}{l}\text { DISCHARGE } \\
\text { CODES }\end{array}$ \\
\hline $\begin{array}{l}1000 \\
1760 \\
1891 \\
1906 \\
1916 \\
1920 \\
1925 \\
1926 \\
1927 \\
1928 \\
1929 \\
1930 \\
1931 \\
1932 \\
1933 \\
1934 \\
1935 \\
1936 \\
1937 \\
1938 \\
1939 \\
1940 \\
1941 \\
1942 \\
1943 \\
1944 \\
1945 \\
1946 \\
1947 \\
1948 \\
1949 \\
1950 \\
1951 \\
1952 \\
1953 \\
1954\end{array}$ & $\begin{array}{l}00-00-00 \\
00-00-00 \\
02-24-91 \\
11-27-05 \\
01-20-16 \\
02-22-20 \\
09-17-25 \\
04-06-26 \\
02-17-27 \\
02-05-28 \\
04-05-29 \\
08-09-30 \\
02-14-31 \\
02-09-32 \\
03-13-33 \\
08-25-34 \\
02-07-35 \\
02-24-36 \\
02-07-37 \\
03-04-38 \\
09-14-39 \\
02-27-40 \\
03-14-41 \\
10-14-41 \\
08-14-43 \\
03-14-44 \\
03-16-45 \\
04-08-46 \\
09-19-47 \\
03-25-48 \\
01-13-49 \\
10-19-49 \\
08-30-51 \\
12-31-51 \\
08-29-53 \\
03-23-54\end{array}$ & $\begin{array}{r}1180,000 \\
1_{130,000} \\
2_{150,000} \\
396,000 \\
68,900 \\
49,, 000 \\
20,000 \\
32,000 \\
70,000 \\
14,000 \\
26,000 \\
8,100 \\
34,000 \\
53,000 \\
1,660 \\
3,300 \\
14,300 \\
12,000 \\
63,000 \\
3100,000 \\
17,700 \\
5,020 \\
43,800 \\
3,510 \\
16,600 \\
7,530 \\
9,710 \\
8,660 \\
11,500 \\
2,560 \\
11,000 \\
9,330 \\
16,400 \\
81,600 \\
6,390 \\
19,700\end{array}$ & $\begin{array}{c}E S, P F \\
E S, P F \\
E S, H P \\
E S, H P \\
E S, H P \\
E S, H P \\
E S \\
E S \\
E S \\
E S \\
E S \\
E S \\
E S \\
E S \\
E S \\
E S \\
E S \\
E S \\
E S \\
E S \\
E S \\
E S \\
E S \\
E S \\
E S \\
E S \\
E S\end{array}$ & \begin{tabular}{l|}
1955 \\
1956 \\
1957 \\
1958 \\
1959 \\
1960 \\
1961 \\
1962 \\
1963 \\
1964 \\
1965 \\
1966 \\
1967 \\
1968 \\
1969 \\
1970 \\
1971 \\
1972 \\
1973 \\
1974 \\
1975 \\
1976 \\
1977 \\
1978 \\
1979 \\
1980 \\
1981 \\
1982 \\
1983 \\
1984 \\
1985 \\
1986 \\
1987 \\
1988 \\
1989
\end{tabular} & $\begin{array}{l}08-23-55 \\
07-31-56 \\
01-10-57 \\
03-23-58 \\
08-17-59 \\
12-26-59 \\
08-23-61 \\
02-13-62 \\
08-22-63 \\
08-27-64 \\
01-07-65 \\
12-22-65 \\
12-07-66 \\
12-19-67 \\
01-26-69 \\
09-06-70 \\
08-03-71 \\
12-27-71 \\
10-20-72 \\
08-02-74 \\
04-15-75 \\
02-10-76 \\
08-24-77 \\
03-01-78 \\
12-19-78 \\
02-15-80 \\
04-06-81 \\
03-12-82 \\
12-23-82 \\
10-01-83 \\
12-28-84 \\
11-30-85 \\
03-10-87 \\
02-03-88 \\
02-05-89\end{array}$ & $\begin{array}{r}11,600 \\
12,800 \\
14,500 \\
21,100 \\
6,060 \\
23,400 \\
2,800 \\
13,300 \\
18,900 \\
6,910 \\
25,700 \\
39,300 \\
53,000 \\
32,600 \\
45,800 \\
61,900 \\
3,030 \\
21,100 \\
63,400 \\
1,500 \\
5,420 \\
39,900 \\
1,620 \\
91,400 \\
94,000 \\
94,800 \\
2,030 \\
42,100 \\
22,400 \\
27,200 \\
19,300 \\
10,300 \\
5,000 \\
19,800 \\
2,670\end{array}$ & \\
\hline
\end{tabular}

IEly and Baker (1985).

2 Highest since 1888.
3 Highest since 1891 .

4 Highest since 1906.

BASIN CHARACTERISTICS

\begin{tabular}{|c|c|c|c|c|c|c|c|}
\hline \multirow{3}{*}{$\begin{array}{l}\text { MAIN } \\
\text { CHANNEL } \\
\text { SLOPE } \\
\text { (FT/MI) }\end{array}$} & \multirow[b]{3}{*}{$\begin{array}{c}\text { STREAM } \\
\text { LENGTH } \\
\text { (MI) }\end{array}$} & \multirow{2}{*}{\multicolumn{2}{|c|}{$\begin{array}{l}\text { MEAN } \\
\text { BASIN }\end{array}$}} & \multicolumn{2}{|r|}{ MEAN } & \multirow{2}{*}{\multicolumn{2}{|c|}{ RAINFALL INTENSITY, 24-HOUR }} \\
\hline & & & & & ANNUAL & & \\
\hline & & $\begin{array}{l}\text { ELEVA- } \\
\text { TION } \\
\text { (FT) }\end{array}$ & $\begin{array}{l}\text { FORESTED } \\
\text { AREA } \\
\text { (PERCENT) }\end{array}$ & $\begin{array}{l}\text { SOIL } \\
\text { INDEX }\end{array}$ & $\begin{array}{l}\text { PRECIPI- } \\
\text { TATION } \\
\text { (IN) }\end{array}$ & $\begin{array}{c}\text { 2-YEAR } \\
\text { (IN) }\end{array}$ & $\begin{array}{l}\text { 50-YEAR } \\
\text { (IN) }\end{array}$ \\
\hline 16.2 & 209 & 5,470 & 67.0 & 2.4 & 18.4 & 2.1 & 4.2 \\
\hline
\end{tabular}


09508500 VERDE RIVER 8ELOW TANGLE CREEK ABOVE hORSESHOE DAM, AZ--Continued

MEAN MONTHLY AND ANMLAL DISCHARGES 1946-89

\begin{tabular}{|c|c|c|c|c|c|c|}
\hline MONTH & $\begin{array}{l}\operatorname{MAXIMMM} \\
\left(F T^{3} / S\right)\end{array}$ & $\underset{\left(F^{3} / S\right)}{\operatorname{MINIMUM}}$ & $\begin{array}{c}\text { MEAN } \\
\left(F T^{3 / S}\right)\end{array}$ & $\begin{array}{l}\text { STAN- } \\
\text { DARD } \\
\text { DEVIA- } \\
\text { TION } \\
\text { (FT'S) }\end{array}$ & $\begin{array}{l}\text { COEFFI- } \\
\text { CIENT OF } \\
\text { VARI - } \\
\text { ATION }\end{array}$ & $\begin{array}{c}\text { PERCENT } \\
\text { OF } \\
\text { ANNUAL } \\
\text { RUNOF F }\end{array}$ \\
\hline $\begin{array}{l}\text { OCTOBER } \\
\text { NOVEMBER } \\
\text { DECEMBER } \\
\text { JANUARY } \\
\text { FEBRUARY } \\
\text { MARCH } \\
\text { APRIL } \\
\text { MAY } \\
\text { JUNE } \\
\text { JULY } \\
\text { AUGUST } \\
\text { SEPTEMBER }\end{array}$ & $\begin{array}{r}4,190 \\
1,380 \\
4,640 \\
2,710 \\
11,000 \\
10,400 \\
5,640 \\
1,320 \\
316 \\
430 \\
1,180 \\
1,460\end{array}$ & $\begin{array}{r}155 \\
192 \\
227 \\
224 \\
220 \\
194 \\
155 \\
113 \\
83 \\
76 \\
127 \\
99\end{array}$ & $\begin{array}{r}353 \\
383 \\
803 \\
655 \\
1,060 \\
1,460 \\
878 \\
219 \\
134 \\
181 \\
334 \\
271\end{array}$ & $\begin{array}{r}622 \\
315 \\
1,080 \\
639 \\
1,720 \\
1,830 \\
1,090 \\
186 \\
43 \\
73 \\
215 \\
225\end{array}$ & $\begin{array}{l}1.8 \\
0.82 \\
1.3 \\
0.98 \\
1.6 \\
1.3 \\
1.2 \\
0.85 \\
0.32 \\
0.41 \\
0.64 \\
0.83\end{array}$ & $\begin{array}{r}5.2 \\
5.7 \\
11.9 \\
9.7 \\
15.8 \\
21.7 \\
13.0 \\
3.3 \\
2.0 \\
2.7 \\
5.0 \\
4.0\end{array}$ \\
\hline ANNUAL & 1,710 & 189 & 559 & 382 & 0.68 & 100 \\
\hline
\end{tabular}

MAGNITUDE AND PROBABILITY OF INSTANTANEOUS PEAK FLOW BASED ON PERIOD OF RECORD 1000, 1925-89

DISCHARGE, IN $\mathrm{FT}^{3} / \mathrm{S}$, FOR INDICATED RECURRENCE INTERVAL IN YEARS, AND EXCEEDANCE PROBABILITY, IN PERCENT

\begin{tabular}{lccccc}
2 & 5 & 10 & 25 & 50 & 100 \\
$50 \%$ & $20 \%$ & $10 \%$ & $4 \%$ & $2 \%$ & $1 \%$ \\
16,000 & 39,400 & 61,300 & 96,500 & 128,000 & 164,000 \\
\hline WEIGHTED SKEW (LOGS) & $=0.26$ & & & \\
MEAN & (LOGS) & 4.18 & 4.18 & & \\
STANDARD DEV. (LOGS) & $=0.48$
\end{tabular}

MACNITUDE AND PROBABILITY OF ANNUAL LON FLON BASED ON PERIOD OF RECORD 1947-89

\begin{tabular}{|c|c|c|c|c|c|c|}
\hline \multirow{2}{*}{$\begin{array}{l}\text { PERIOD } \\
\text { (CON- } \\
\text { SECU- } \\
\text { TIVE } \\
\text { DAYS) }\end{array}$} & \multicolumn{6}{|c|}{$\begin{array}{l}\text { DISCHARGE, IN } \mathrm{FT}^{3} / \mathrm{S} \text {, FOR INDICATED } \\
\text { RECURRENCE INTERVAL, IN YEARS, AND } \\
\text { MON-EXCEEDANCE PROBABILITY, IN PERCENT }\end{array}$} \\
\hline & $\stackrel{2}{50 \%}$ & $\begin{array}{c}5 \\
20 \%\end{array}$ & $\begin{array}{l}10 \\
10 \%\end{array}$ & $\begin{array}{l}20 \\
5 \%\end{array}$ & $\begin{array}{l}50 \\
2 \%\end{array}$ & $\begin{array}{l}100 t \\
1 \%\end{array}$ \\
\hline $\begin{array}{r}1 \\
3 \\
7 \\
14 \\
30 \\
60 \\
90 \\
120 \\
183\end{array}$ & $\begin{array}{r}90 \\
93 \\
97 \\
102 \\
110 \\
127 \\
145 \\
173 \\
197\end{array}$ & $\begin{array}{r}74 \\
77 \\
80 \\
84 \\
91 \\
105 \\
121 \\
146 \\
172\end{array}$ & $\begin{array}{r}68 \\
71 \\
74 \\
77 \\
83 \\
96 \\
110 \\
132 \\
165\end{array}$ & $\begin{array}{r}64 \\
66 \\
69 \\
72 \\
77 \\
89 \\
102 \\
120 \\
161\end{array}$ & $\begin{array}{r}59 \\
62 \\
64 \\
67 \\
71 \\
81 \\
93 \\
108 \\
158\end{array}$ & $\begin{array}{r}57 \\
59 \\
61 \\
63 \\
67 \\
77 \\
88 \\
99 \\
157\end{array}$ \\
\hline
\end{tabular}

MACNITUDE AND PROBABILITY OF ANNUAL HIGH FLOM BASED ON PERIOD OF RECORD 1946-89

\begin{tabular}{|c|c|c|c|c|c|c|}
\hline \multirow{2}{*}{$\begin{array}{l}\text { PERIOD } \\
\text { (CON- } \\
\text { SECU- } \\
\text { TIVE } \\
\text { DAYS) }\end{array}$} & & \multicolumn{5}{|c|}{$\begin{array}{l}\text { DISCHARCE, IN } \mathrm{FT}^{3} / \mathrm{S} \text {, FOR INDICATED } \\
\text { RECURRENCE INTERVAL, IN YEARS, AND } \\
\text { EXCEEDANCE PROBABILITY, IN PERCENT }\end{array}$} \\
\hline & $\begin{array}{c}2 \\
50 \%\end{array}$ & $\begin{array}{c}5 \\
20 \%\end{array}$ & $\begin{array}{l}10 \\
10 \%\end{array}$ & $\begin{array}{l}25 \\
4 \%\end{array}$ & $\begin{array}{l}50 \\
2 x\end{array}$ & $\begin{array}{c}100\} \\
1 \%\end{array}$ \\
\hline $\begin{array}{r}1 \\
3 \\
7 \\
15 \\
30 \\
60 \\
90\end{array}$ & $\begin{array}{r}8,220 \\
5,660 \\
3,630 \\
2,420 \\
1,680 \\
1,150 \\
951\end{array}$ & $\begin{array}{r}23,100 \\
15,000 \\
8,960 \\
5,500 \\
3,620 \\
2,430 \\
1,960\end{array}$ & $\begin{array}{r}38,700 \\
24,300 \\
14,100 \\
8,320 \\
5,390 \\
3,640 \\
2,890\end{array}$ & $\begin{array}{r}65,900 \\
39,900 \\
22,300 \\
12,800 \\
8,190 \\
5,630 \\
4,430\end{array}$ & $\begin{array}{r}92,000 \\
54,400 \\
29,900 \\
16,800 \\
10,700 \\
7,510 \\
5,860\end{array}$ & $\begin{array}{r}123,000 \\
71,500 \\
38,500 \\
21,300 \\
13,600 \\
9,760 \\
7,570\end{array}$ \\
\hline
\end{tabular}

DURATION TABLE OF DAILY MEAN FLOW FOR PERIOD OF RECORD 1946-89 DISCHARGE, IN FT $3 / 5$, WHICH WAS EQUALED OR EXCEEDED FOR INDICATED PERCENT OF TIME

\begin{tabular}{|c|c|c|c|c|c|c|c|c|c|c|c|c|c|c|c|c|}
\hline $1 \%$ & $5 \%$ & $10 \%$ & $15 \%$ & $20 \%$ & $30 \%$ & $40 \%$ & $50 \%$ & $60 \%$ & $70 \%$ & $80 \%$ & $90 \%$ & $95 \%$ & $98 \%$ & $99 \%$ & $99.5 \%$ & $99.9 \%$ \\
\hline$a$ & 2,020 & 917 & 558 & 408 & 309 & 264 & 238 & 211 & 180 & 151 & 120 & 103 & 87 & 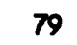 & 75 & 04 \\
\hline
\end{tabular}

I Reliability of values in colum is uncertain, and potential errors are large. 
09508500 VERDE RIVER BELOW TANGLE CREEK, ABOVE HORSESHOE DAM, AZ--CONTIMUEd
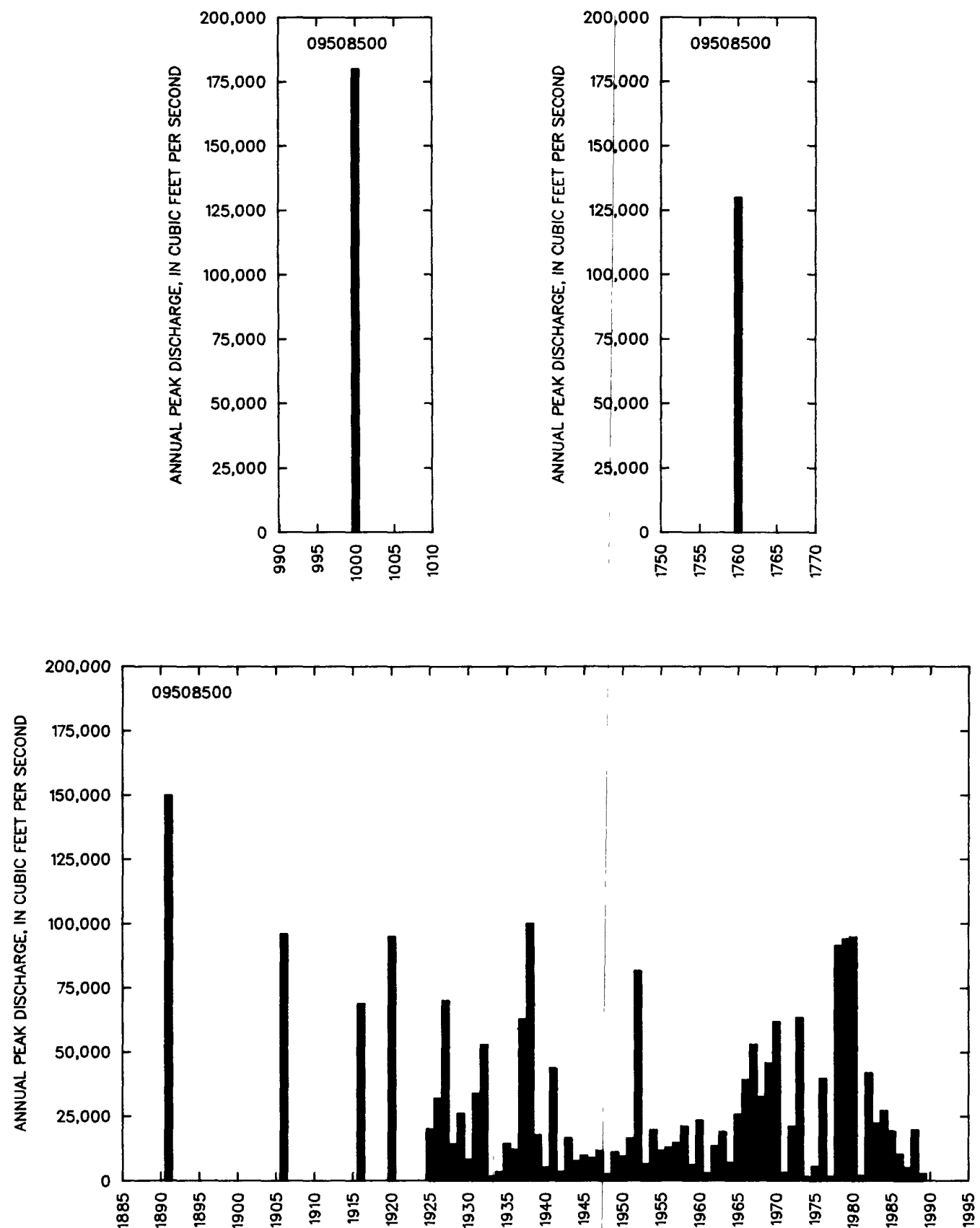
09508500 VERDE RIVER BelOW TANGLE CREeK, ABOVE hORSESHOE DAM, AZ--CONTINued
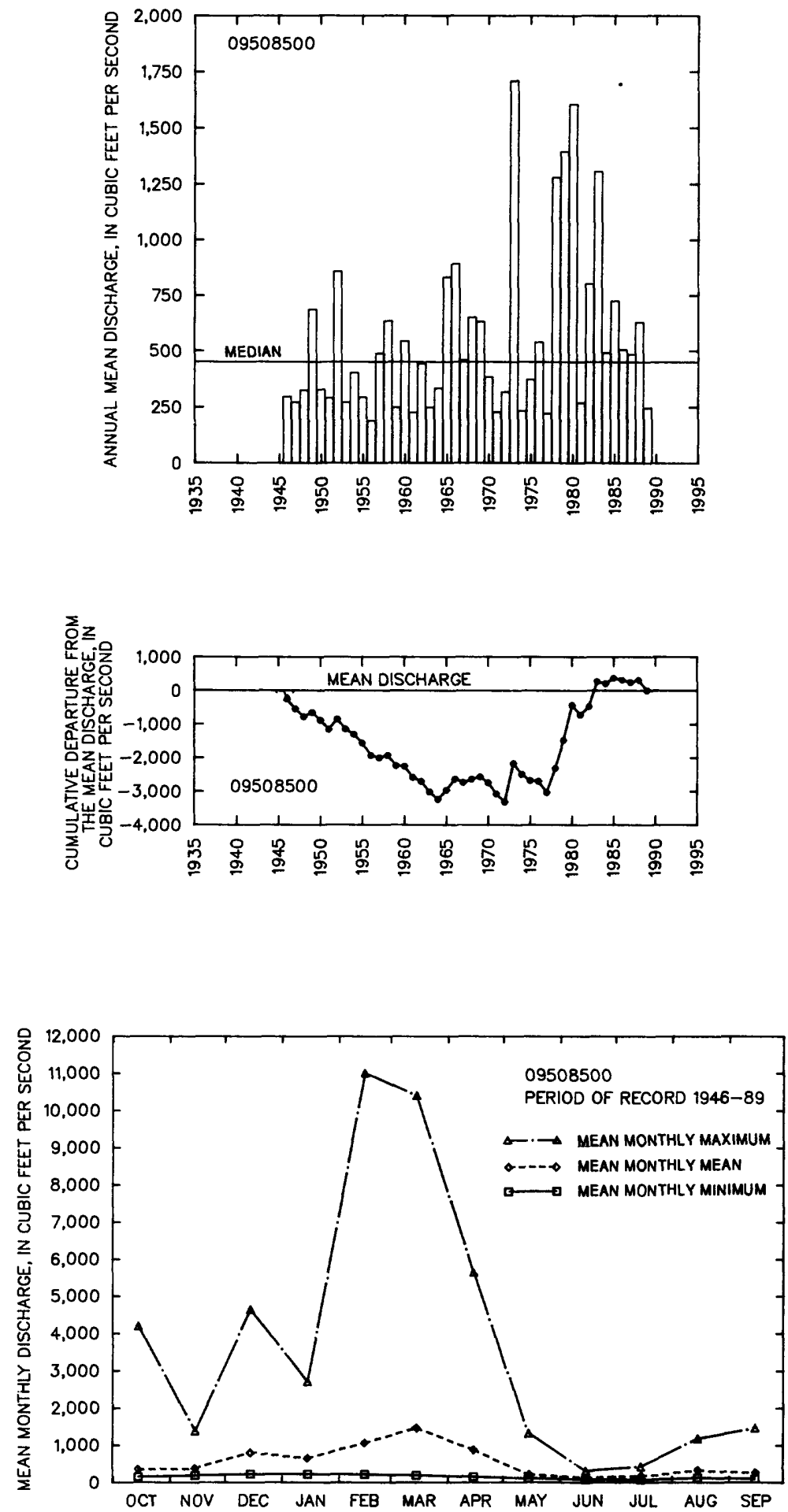
09510070 WEST FORK SYCAMORE CREEK ABOVE MCFARLAND CANYON, MEAR SUNFLONER, AZ

LOCATION.-- Lat 33.57'38", long $1111^{\circ} 29^{\prime} 12^{\prime \prime}$, in SEKSW/2 sec.12, T.7 N., R.8 E. (unsurveyed), Maricopa County, Hydrologic Unit 15060203, in Tonto National Forest, on left benk 0.2 mi upstream from McFarland Canyon, and $6.8 \mathrm{mi}$ north of Sunflower.

DRAINAGE AREA. $--4.58 \mathrm{mi}^{2}$.

\begin{tabular}{lcc}
\multicolumn{3}{c}{ ANMUAL PEAK DISCHAREE } \\
$\begin{array}{l}\text { WATER } \\
\text { YEAR }\end{array}$ & DATE & $\begin{array}{c}\text { ANNUAL PEAK } \\
\text { DISCHARGE } \\
\text { (FT } 3 / \text { S) }\end{array}$ \\
\hline 1966 & $12-22-65$ & 1430 \\
1967 & $12-07-66$ & 13 \\
1968 & $12-19-67$ & 152 \\
1969 & $02-25-69$ & 10 \\
1970 & $09-05-70$ & 1,700 \\
1971 & $11-30-70$ & 0.3 \\
1972 & $06-22-72$ & 0.3 \\
1973 & $10-07-72$ & 185 \\
1974 & $08-05-74$ & 6.6 \\
1978 & $03-01-78$ & 2720 \\
1983 & $11-30-82$ & 178 \\
1984 & $10-01-83$ & 21 \\
1985 & $12-27-84$ & 97 \\
1986 & $11-30-85$ & 12 \\
\hline 1 Highest & since 1959. & \\
\hline Highest & since 1970. &
\end{tabular}

BASIN CHARACTERISTICS

\begin{tabular}{|c|c|c|c|c|c|c|c|}
\hline MAIN & & $\begin{array}{r}\text { MEAN } \\
\text { BASIN }\end{array}$ & & & $\begin{array}{l}\text { MEAN } \\
\text { ANNUAL }\end{array}$ & RAINFALL II & SITY, 24-HOUR \\
\hline $\begin{array}{l}\text { CHANNEL } \\
\text { SLOPE } \\
\text { (FT/MI) }\end{array}$ & $\begin{array}{l}\text { STREAM } \\
\text { LENGTH } \\
\text { (MI) }\end{array}$ & $\begin{array}{l}\text { ELEVA- } \\
\text { TION } \\
\text { (FT) }\end{array}$ & $\begin{array}{l}\text { FORESTED } \\
\text { AREA } \\
\text { (PERCENT) }\end{array}$ & $\begin{array}{l}\text { SOIL } \\
\text { INDEX }\end{array}$ & $\begin{array}{l}\text { PRECIPI- } \\
\text { TATION } \\
\text { (IN) }\end{array}$ & $\begin{array}{c}\text { 2-YEAR } \\
\text { (IN) }\end{array}$ & $\begin{array}{c}\text { 50-YEAR } \\
\text { (IN) }\end{array}$ \\
\hline 260 & 3.8 & 5,430 & 1.3 & 3.0 & 24.5 & 3.0 & 5.5 \\
\hline
\end{tabular}


09510070 WEST FORK SYCAMORE CREEK ABOVE MCFARLAND CANYON, MEAR SUNFLOUER AZ--CONt inUEd

MEAN MONTHLY AND ANNUAL DISCHARGES 1966-74, 1983-85

\begin{tabular}{|c|c|c|c|c|c|c|}
\hline MONTH ' & $\begin{array}{l}\operatorname{MAXIMUM} \\
\left(F T^{3} / S\right)\end{array}$ & $\begin{array}{l}\operatorname{MINIMU} \\
\left(F T^{3} / S\right)\end{array}$ & $\begin{array}{c}\text { MEAN } \\
\left(F T^{3} / S\right)\end{array}$ & $\begin{array}{l}\text { STAN- } \\
\text { DARD } \\
\text { DEVIA- } \\
\text { TION } \\
\text { (FT } 3 \text { /S) }\end{array}$ & $\begin{array}{l}\text { COEFFI - } \\
\text { CIENT OF } \\
\text { VARI - } \\
\text { ATION }\end{array}$ & $\begin{array}{c}\text { PERCENT } \\
\text { OF } \\
\text { ANNUAL } \\
\text { RUNOFF }\end{array}$ \\
\hline $\begin{array}{l}\text { OCTOBER } \\
\text { NONEMBER } \\
\text { DECEMBER } \\
\text { JANUARY } \\
\text { FEBRUARY } \\
\text { MARCH } \\
\text { APRIL } \\
\text { MAY } \\
\text { JUNE } \\
\text { JULY } \\
\text { AUGUST } \\
\text { SEPTEMBER }\end{array}$ & $\begin{array}{c}4.3 \\
2.7 \\
17 \\
7.1 \\
13 \\
12 \\
6.6 \\
1.3 \\
0.39 \\
0.12 \\
0.10 \\
5.5\end{array}$ & $\begin{array}{l}0.00 \\
0.00 \\
0.00 \\
0.01 \\
0.04 \\
0.04 \\
0.03 \\
0.01 \\
0.00 \\
0.00 \\
0.00 \\
0.00\end{array}$ & $\begin{array}{l}0.53 \\
0.44 \\
3.4 \\
1.9 \\
3.2 \\
2.8 \\
1.1 \\
0.32 \\
0.07 \\
0.02 \\
0.02 \\
0.48\end{array}$ & $\begin{array}{l}1.2 \\
0.84 \\
4.9 \\
2.1 \\
4.4 \\
4.3 \\
1.9 \\
0.44 \\
0.12 \\
0.04 \\
0.03 \\
1.6\end{array}$ & $\begin{array}{l}2.4 \\
1.9 \\
1.5 \\
1.1 \\
1.4 \\
1.5 \\
1.7 \\
1.4 \\
1.5 \\
1.9 \\
1.5 \\
3.3\end{array}$ & $\begin{array}{r}3.7 \\
3.1 \\
23.7 \\
13.4 \\
22.4 \\
19.6 \\
7.6 \\
2.3 \\
0.5 \\
0.1 \\
0.1 \\
3.4\end{array}$ \\
\hline NNUAL & 3.6 & 0.02 & 1.2 & 1.3 & 1.1 & 100 \\
\hline
\end{tabular}

ManitUde AND PROBABILITY OF INSTANTANEOUS PEAK FLOW BASED ON PERICD OF RECORD 1966-74, 1978, 1983-86

DISCHARCE, IN $\mathrm{FT}^{3} / \mathrm{S}$, FOR INDICATED RECURRENCE INTERVAL IN YEARS, AND EXCEEDANCE PROBABILITY, IN PERCENT

\begin{tabular}{|c|c|c|c|c|c|}
\hline $\begin{array}{c}2 \\
50 \%\end{array}$ & $\begin{array}{c}5 \\
20 x\end{array}$ & $\begin{array}{r}10 \\
10 \%\end{array}$ & $\begin{array}{l}25 \\
4 \%\end{array}$ & $\begin{array}{l}50 \dagger \\
2 \%\end{array}$ & $\begin{array}{c}100 \dagger \\
1 x\end{array}$ \\
\hline 36 & 268 & 702 & 1,840 & 3,330 & 5,530 \\
\hline $\begin{array}{l}\text { WEIGHTED } \\
\text { MEAN } \\
\text { STANDARD }\end{array}$ & $\begin{array}{l}\text { SKEW } \\
\text { DEV. }\end{array}$ & $\begin{array}{l}(\text { LOGS })= \\
(\text { LOGS }= \\
(\text { LOGS })=\end{array}$ & $\begin{array}{r}-0.37 \\
1.49 \\
1.10\end{array}$ & & \\
\hline
\end{tabular}

DURATION TABLE OF DAILY MEAN FLON FOR PERICO OF RECORD 1966-74, 1983-85
MANITLOE AND PROBABILITY OF ANMUAL LON FLON BASED ON PERIOD OF RECORD 1967-74, 1984-86

\begin{tabular}{|c|c|c|c|c|c|c|}
\hline \multirow{2}{*}{$\begin{array}{l}\text { PERIOD } \\
\text { (CON- } \\
\text { SECU- } \\
\text { TIVE } \\
\text { DAYS) }\end{array}$} & \multicolumn{6}{|c|}{$\begin{array}{l}\text { DISCHARGE, IN FT }{ }^{3} / S \text {, FOR INDICATED } \\
\text { RECURRENCE INTERVAL, IN YEARS, AND } \\
\text { MON-EXCEEDANCE PROBABILITY, IN PERCENT }\end{array}$} \\
\hline & $\begin{array}{c}2 \\
50 \%\end{array}$ & $\begin{array}{c}5 \\
20 \%\end{array}$ & $\begin{array}{l}10 \\
10 \%\end{array}$ & $\begin{array}{l}20 \\
5 \%\end{array}$ & $\begin{array}{l}50 \dagger \\
2 x\end{array}$ & $\begin{array}{l}100 \dagger \\
1 \%\end{array}$ \\
\hline $\begin{array}{r}1 \\
3 \\
7 \\
14 \\
30 \\
60\end{array}$ & & & & & & \\
\hline $\begin{array}{r}90 \\
120 \\
183\end{array}$ & $\begin{array}{l}0.00 \\
0.01 \\
0.02\end{array}$ & $\begin{array}{l}0.00 \\
0.00 \\
0.00\end{array}$ & $\begin{array}{l}0.00 \\
0.00 \\
0.00\end{array}$ & $\begin{array}{l}0.00 \\
0.00 \\
0.00\end{array}$ & $\begin{array}{l}0.00 \\
0.00 \\
0.00\end{array}$ & $\begin{array}{l}0.00 \\
0.00 \\
0.00\end{array}$ \\
\hline
\end{tabular}

MMENITLDE AND PROBABILITY OF ANMUAL HIGH FLON BASED ON PERICO OF RECORD 1966-74, 1983-85

\begin{tabular}{|c|c|c|c|c|c|c|}
\hline \multirow{2}{*}{$\begin{array}{l}\text { PERICO } \\
\text { (CON- } \\
\text { SECU- } \\
\text { TIVE } \\
\text { DAYS) }\end{array}$} & \multicolumn{6}{|c|}{$\begin{array}{l}\text { DISCHARGE, IN FT JS, FOR INDICATED } \\
\text { RECURRENCE INTERVAL, IN YEARS, AND } \\
\text { EXCEEDANCE PROBABILITY, IN PERCENT }\end{array}$} \\
\hline & $\stackrel{2}{50 \%}$ & $\begin{array}{c}5 \\
20 \%\end{array}$ & $\begin{array}{l}10 \\
10 \%\end{array}$ & $\begin{array}{l}25 \nmid \\
4 \%\end{array}$ & $\begin{array}{l}50 \uparrow \\
2 \%\end{array}$ & $\begin{array}{c}100 \nmid \\
1 \times\end{array}$ \\
\hline $\begin{array}{r}1 \\
3 \\
7 \\
15 \\
30 \\
60 \\
90\end{array}$ & $\begin{array}{l}17 \\
11 \\
7.2 \\
4.6 \\
3.3 \\
2.3 \\
1.8\end{array}$ & $\begin{array}{c}85 \\
51 \\
29 \\
18 \\
12 \\
8.8 \\
6.7\end{array}$ & $\begin{array}{r}160 \\
91 \\
49 \\
32 \\
21 \\
16 \\
12\end{array}$ & $\begin{array}{r}270 \\
145 \\
76 \\
51 \\
35 \\
28 \\
20\end{array}$ & $\begin{array}{r}352 \\
183 \\
94 \\
66 \\
45 \\
38 \\
27\end{array}$ & $\begin{array}{r}429 \\
217 \\
111 \\
80 \\
55 \\
49 \\
35\end{array}$ \\
\hline
\end{tabular}

DISCHARGE, IN FT $3 / \mathrm{S}$, WHICH WAS EQUALED OR EXCEEDED FOR INDICATED PERCENT OF TIME

\begin{tabular}{|c|c|c|c|c|c|c|c|c|c|c|c|c|c|c|c|c|}
\hline $1 \%$ & $5 \%$ & $10 x$ & $15 \%$ & $20 x$ & $30 \%$ & $40 \%$ & $50 \%$ & $60 \%$ & $70 \%$ & $80 \%$ & $90 \%$ & $95 x$ & $98 \%$ & $99 \%$ & $99.5 \%$ & $99.9 \%$ \\
\hline 21 & 5.3 & 2.4 & 1.5 & 0.93 & 0.25 & 0.12 & 0.07 & 0.03 & 0.02 & 0.00 & 0.00 & 0.00 & 0.00 & 0.00 & 0.00 & 0.00 \\
\hline
\end{tabular}

f Reliability of values in colum is uncertain, and potential errors are large. 

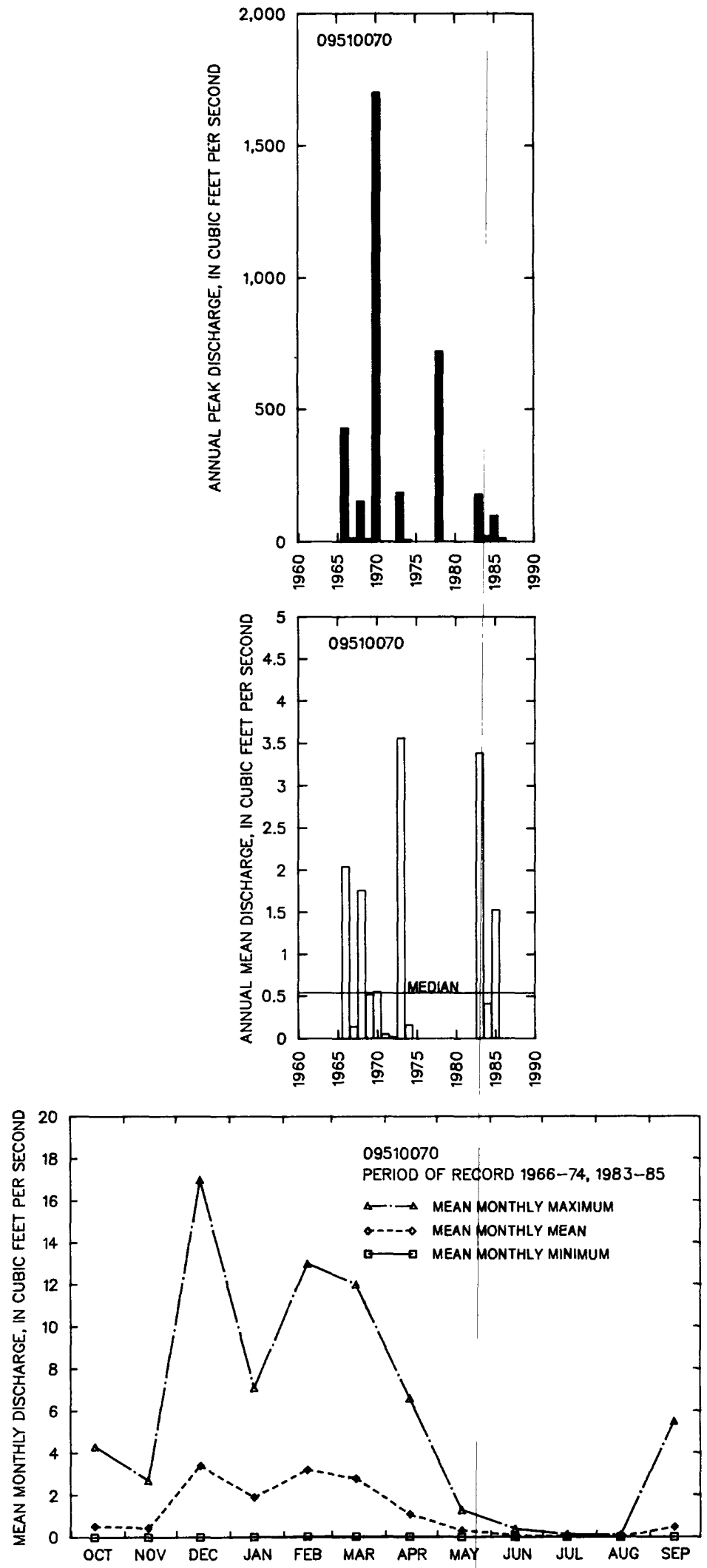
09510080 MEST FORK SYCAMORE CREEK MEAR SUNFLONER, AZ

LOCATION.-- Lat 33.56'45", long $111 \cdot 29$ '05", in SEK sec.13, T.7 N., R.8 E. (unsurveyed), Maricopo Canty, Hydrologic Unit 15060203, in Tonto National Forest, on right bank 1.2 mi upstream from confluence with East Fork, and 5.7 mi north of Sunflower.

DRALNAGE AREA. $--9.8 \mathrm{mi}^{2}$.

ANNUAL PEAK DISCHARGE

\begin{tabular}{|c|c|c|c|}
\hline $\begin{array}{l}\text { WATER } \\
\text { YEAR }\end{array}$ & DATE & $\begin{array}{c}\text { ANNUAL PEAK } \\
\text { DISCHARGE } \\
\left(F^{3} / S\right)\end{array}$ & $\begin{array}{l}\text { DISCHARGE } \\
\text { CODES }\end{array}$ \\
\hline $\begin{array}{l}1962 \\
1963 \\
1964 \\
1965 \\
1966 \\
1967 \\
1968 \\
1969 \\
1970 \\
1971 \\
1972 \\
1973 \\
1974 \\
1978 \\
1979\end{array}$ & $\begin{array}{l}01-25-62 \\
02-11-63 \\
03-24-64 \\
04-10-65 \\
12-22-65 \\
12-07-66 \\
12-19-67 \\
02-25-69 \\
09-05-70 \\
12-22-70 \\
06-22-72 \\
10-07-72 \\
01-09-74 \\
03-02-78 \\
01-17-79\end{array}$ & $\begin{array}{c}52 \\
116 \\
5.6 \\
90 \\
1698 \\
18 \\
364 \\
25 \\
13,480 \\
1.2 \\
4.4 \\
448 \\
30 \\
660 \\
463\end{array}$ & $\begin{array}{l}\mathrm{HP} \\
\mathrm{HP}\end{array}$ \\
\hline
\end{tabular}

$1_{H i g h e s t}$ since 1959.

\section{BASIN CHARACTERISTICS}

\begin{tabular}{|c|c|c|c|c|c|c|c|}
\hline \multirow{2}{*}{$\begin{array}{l}\text { MAIN } \\
\text { CHANNEL } \\
\text { SLOPE } \\
\text { (FT/MI) }\end{array}$} & \multirow[b]{2}{*}{$\begin{array}{l}\text { STREAM } \\
\text { LENGTH } \\
\text { (MI) }\end{array}$} & \multirow{2}{*}{$\begin{array}{c}\text { MEAN } \\
\text { BASIN } \\
\text { ELEVA- } \\
\text { TION } \\
\text { (FT) }\end{array}$} & \multirow[b]{2}{*}{$\begin{array}{l}\text { FORESTED } \\
\text { AREA } \\
\text { (PERCENT) }\end{array}$} & \multirow[b]{2}{*}{$\begin{array}{l}\text { SOIL } \\
\text { IMDEX }\end{array}$} & \multirow{2}{*}{$\begin{array}{l}\text { MEAN } \\
\text { ANNUAL } \\
\text { PRECIPI- } \\
\text { TATION } \\
\text { (IN) }\end{array}$} & \multicolumn{2}{|c|}{ RAINFALL INTENSITY, 24-HOUR } \\
\hline & & & & & & $\begin{array}{c}\text { 2-YEAR } \\
\text { (IN) }\end{array}$ & $\begin{array}{c}\text { 50-YEAR } \\
\text { (IN) }\end{array}$ \\
\hline 353 & 3.9 & 5,260 & 0.8 & 3.0 & 24.5 & 2.9 & 5.5 \\
\hline
\end{tabular}


MEAN MONTHLY AND ANMUAL DISCHARGES 1962-74

\begin{tabular}{|c|c|c|c|c|c|c|}
\hline MONTH & $\begin{array}{l}\operatorname{MAXIMUN} \\
\left(\mathrm{FT}^{3} / \mathrm{S}\right)\end{array}$ & $\begin{array}{l}\text { MINIMUN } \\
\left(F^{3} / S\right)\end{array}$ & $\begin{array}{c}\text { MEAN } \\
\left.\text { (FT }{ }^{3} / S\right)\end{array}$ & $\begin{array}{c}\text { STAN- } \\
\text { DARD } \\
\text { DEVIA- } \\
\text { TION } \\
\text { (FT } 3 / S)\end{array}$ & $\begin{array}{l}\text { COEFFI - } \\
\text { CIENT OF } \\
\text { VARI - } \\
\text { ATION }\end{array}$ & $\begin{array}{c}\text { PERCENT } \\
\text { OF } \\
\text { ANNUAL } \\
\text { RUNOFF }\end{array}$ \\
\hline $\begin{array}{l}\text { OCTOBER } \\
\text { NOVEMBER } \\
\text { DECEMBER } \\
\text { JANUARY } \\
\text { FEBRUARY } \\
\text { MARCH } \\
\text { APRIL } \\
\text { MAY } \\
\text { JUWE } \\
\text { JULY } \\
\text { AUGUST } \\
\text { SEPTEMBER }\end{array}$ & $\begin{array}{l}14 \\
8.0 \\
33 \\
21 \\
21 \\
32 \\
16 \\
2.1 \\
0.55 \\
0.15 \\
5.5 \\
11\end{array}$ & $\begin{array}{l}0.00 \\
0.00 \\
0.01 \\
0.03 \\
0.05 \\
0.08 \\
0.04 \\
0.02 \\
0.01 \\
0.00 \\
0.00 \\
0.00\end{array}$ & $\begin{array}{l}1.1 \\
0.70 \\
4.7 \\
3.4 \\
4.6 \\
5.4 \\
2.8 \\
0.36 \\
0.07 \\
0.02 \\
0.44 \\
1.1\end{array}$ & $\begin{array}{l}3.8 \\
2.2 \\
9.7 \\
5.8 \\
7.0 \\
8.8 \\
5.5 \\
0.55 \\
0.15 \\
0.04 \\
1.5 \\
3.1\end{array}$ & $\begin{array}{l}3.5 \\
3.2 \\
2.1 \\
1.7 \\
1.5 \\
1.6 \\
2.0 \\
1.5 \\
2.0 \\
2.3 \\
3.4 \\
2.9\end{array}$ & $\begin{array}{r}4.4 \\
2.8 \\
19.1 \\
13.7 \\
18.5 \\
22.0 \\
11.4 \\
1.5 \\
0.3 \\
0.1 \\
1.8 \\
4.3\end{array}$ \\
\hline ANNUAL & 8.9 & 0.04 & 2.0 & 2.6 & 1.3 & 100 \\
\hline
\end{tabular}

MAGNITUDE AND PROBABILITY OF INSTANTANEOUS PEAK FLOW BASED ON PERIOD OF RECORD 1962-74, 1978-79

DISCHARGE, IN $\mathrm{FT}^{3} / \mathrm{S}$, FOR INDICATED RECURRENCE INTERVAL IN YEARS, AND EXCEEDANCE PROBABILITY, IN PERCENT

\begin{tabular}{|c|c|c|c|c|c|}
\hline $\begin{array}{c}2 \\
50 x\end{array}$ & $\begin{array}{c}5 \\
20 \%\end{array}$ & $\begin{array}{r}10 \\
10 \%\end{array}$ & $\begin{array}{l}25 \\
4 x\end{array}$ & $\begin{array}{l}50 \phi \\
2 \%\end{array}$ & $\begin{array}{c}100\} \\
1 x\end{array}$ \\
\hline 101 & 519 & 1,190 & 2,840 & 4,920 & 8,030 \\
\hline $\begin{array}{l}\text { WEIGHTED } \\
\text { MEAN } \\
\text { STANDARD }\end{array}$ & $\begin{array}{l}\text { SKEW } \\
\text { DEV. }\end{array}$ & $\begin{array}{l}(\text { LOGS })= \\
(\text { LOGS) }= \\
(\text { LOGS) }=\end{array}$ & $\begin{array}{r}-0.13 \\
1.99 \\
0.86\end{array}$ & & \\
\hline
\end{tabular}

MANITUDE AND PROBABILITY OF ANNUAL LOW FLON BASED ON PERIOD OF RECORD 1963-74

\begin{tabular}{|c|c|c|c|c|c|c|}
\hline \multirow{2}{*}{$\begin{array}{l}\text { PERIOD } \\
\text { (CON- } \\
\text { SECW- } \\
\text { TIVE } \\
\text { DAYSD }\end{array}$} & \multicolumn{6}{|c|}{$\begin{array}{l}\text { DISCHARGE, IN FT }{ }^{3} / S \text {, FOR INDICATED } \\
\text { RECURRENCE INTERVAL, IN YEARS, AND } \\
\text { NON-EXCEEDANCE PROBABILITY, IN PERCENT }\end{array}$} \\
\hline & $\begin{array}{c}2 \\
50 x\end{array}$ & $\begin{array}{c}5 \\
20 \%\end{array}$ & $\begin{array}{l}10 \\
10 \%\end{array}$ & $\begin{array}{l}20 \\
5 \%\end{array}$ & $\begin{array}{l}50 \dagger \\
2 \%\end{array}$ & $\begin{array}{l}100 \dagger \\
1 \%\end{array}$ \\
\hline $\begin{array}{r}1 \\
3 \\
7 \\
14 \\
30 \\
60\end{array}$ & & & & & & \\
\hline $\begin{array}{r}90 \\
120 \\
183\end{array}$ & $\begin{array}{l}0.00 \\
0.00 \\
0.02\end{array}$ & $\begin{array}{l}0.00 \\
0.00 \\
0.00\end{array}$ & $\begin{array}{l}0.00 \\
0.00 \\
0.00\end{array}$ & $\begin{array}{l}0.00 \\
0.00 \\
0.00\end{array}$ & $\begin{array}{l}0.00 \\
0.00 \\
0.00\end{array}$ & $\begin{array}{l}0.00 \\
0.00 \\
0.00\end{array}$ \\
\hline
\end{tabular}

MAGNITLDE AND PROBABILITY OF ANNUAL HIGH FLOH BASED ON PERIOD OF RECORD 1962-74

\begin{tabular}{|c|c|c|c|c|c|c|}
\hline \multirow{2}{*}{$\begin{array}{l}\text { PERIOD } \\
\text { (CON- } \\
\text { SECU- } \\
\text { TIVE } \\
\text { DAYS) }\end{array}$} & \multicolumn{6}{|c|}{$\begin{array}{l}\text { DISCHARGE, IN } \mathrm{FT}^{3} / \mathrm{S} \text {, FOR INDICATED } \\
\text { RECURRENCE INTERVAL, IN YEARS, AND } \\
\text { EXCEEDANCE PROBABILITY, IN PERCENT }\end{array}$} \\
\hline & $\stackrel{2}{2}$ & $\begin{array}{c}5 \\
20 x\end{array}$ & $\begin{array}{l}10 \\
10 \%\end{array}$ & $\begin{array}{l}25 \uparrow \\
4 x\end{array}$ & $\begin{array}{l}50 \dagger \\
2 x\end{array}$ & $\begin{array}{c}100 \dagger \\
1 x\end{array}$ \\
\hline $\begin{array}{r}1 \\
3 \\
7 \\
15 \\
30 \\
60 \\
90\end{array}$ & $\begin{array}{c}29 \\
19 \\
12 \\
8.0 \\
5.6 \\
3.6 \\
2.7\end{array}$ & $\begin{array}{r}140 \\
82 \\
50 \\
32 \\
23 \\
15 \\
11\end{array}$ & $\begin{array}{r}270 \\
149 \\
89 \\
59 \\
43 \\
29 \\
21\end{array}$ & $\begin{array}{r}489 \\
251 \\
148 \\
100 \\
78 \\
56 \\
40\end{array}$ & $\begin{array}{r}677 \\
332 \\
194 \\
135 \\
110 \\
82 \\
59\end{array}$ & $\begin{array}{r}877 \\
412 \\
239 \\
171 \\
145 \\
114 \\
83\end{array}$ \\
\hline
\end{tabular}

DURATION TABLE OF DAILY MEAN FLOW FOR PERIOD OF RECORD 1962-74

DISCHARGE, IN FT $3 / 5$, WHICH WAS EQUALED OR EXCEEDED FOR INDICATED PERCENT OF TIME

\begin{tabular}{|c|c|c|c|c|c|c|c|c|c|c|c|c|c|c|c|c|}
\hline $1 \%$ & $5 \%$ & $10 \%$ & $15 x$ & $20 \%$ & $30 \%$ & $40 \%$ & $50 \%$ & $60 \%$ & $70 \%$ & $80 \%$ & $90 \%$ & $95 \%$ & $98 \%$ & $99 \%$ & $99.5 x$ & $99.9 \%$ \\
\hline 39 & 9.3 & 3.1 & 1.7 & 0.79 & 0.31 & 0.15 & 0.07 & 0.03 & 0.02 & 0.00 & 0.00 & 0.00 & 0.00 & 0.00 & 0.00 & 0.00 \\
\hline
\end{tabular}

$\uparrow$ Reliability of values in colum is uncertain, and potential errors are large. 
GILA RIVER BASIM

09510080 WEST FORK SYCAMORE CREEK NEAR SUNFLOWER, AZ--CONTIMUED
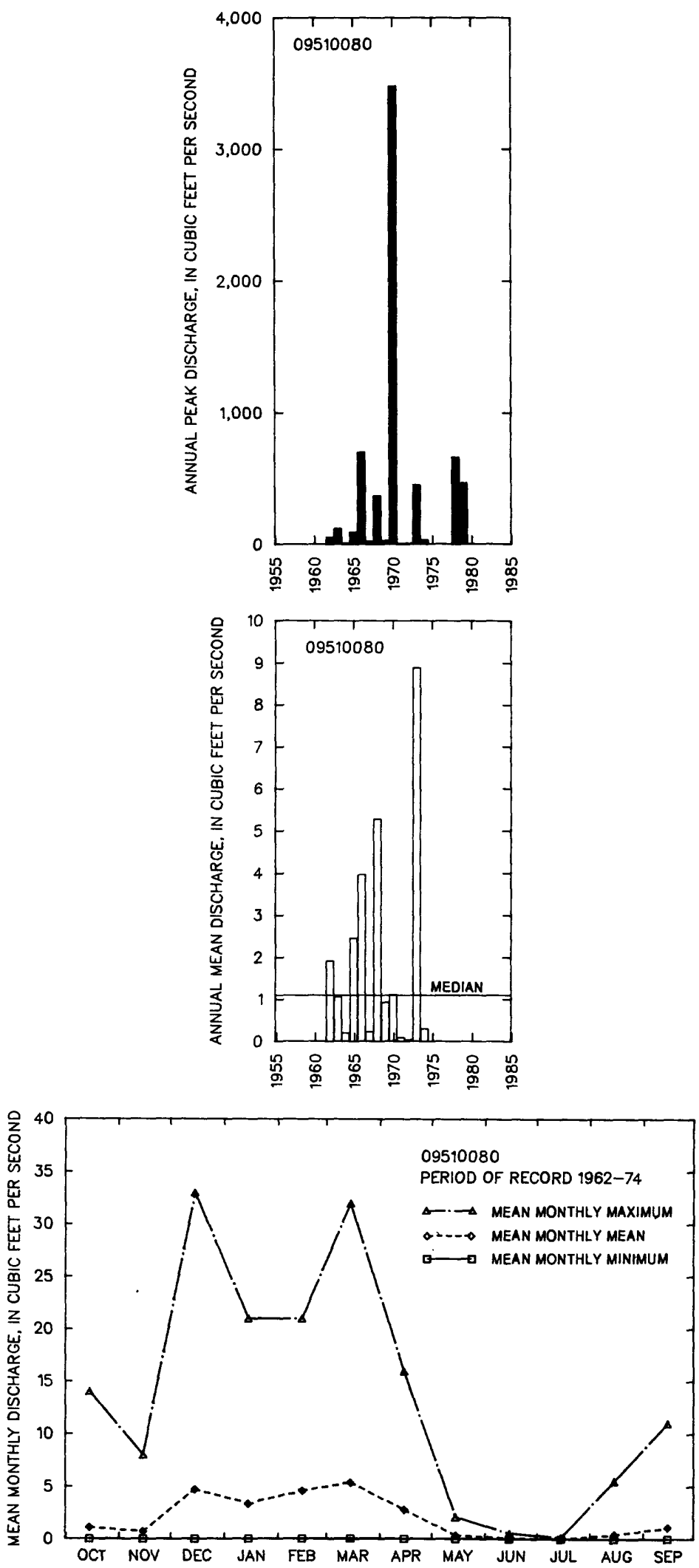
09510100 EAST FORK SYCAMORE CREEK NEAR SUNFLONER, AZ

LOCATION.--Lat 33.56'58", long 111'27'39", in NEKSEK sec. 18, T.7 N., R.9 E., Maricopa County, Hydrol ogic Unit 15060203, in Tonto National Forest, on left bank 1.7 mi upstream from confluence with West Fork, and $6.0 \mathrm{mi}$ north of sunflower.

DRAINAGE AREA. $--4.49 \mathrm{mi}^{2}$.

ANNUAL PEAK DISCHARGE

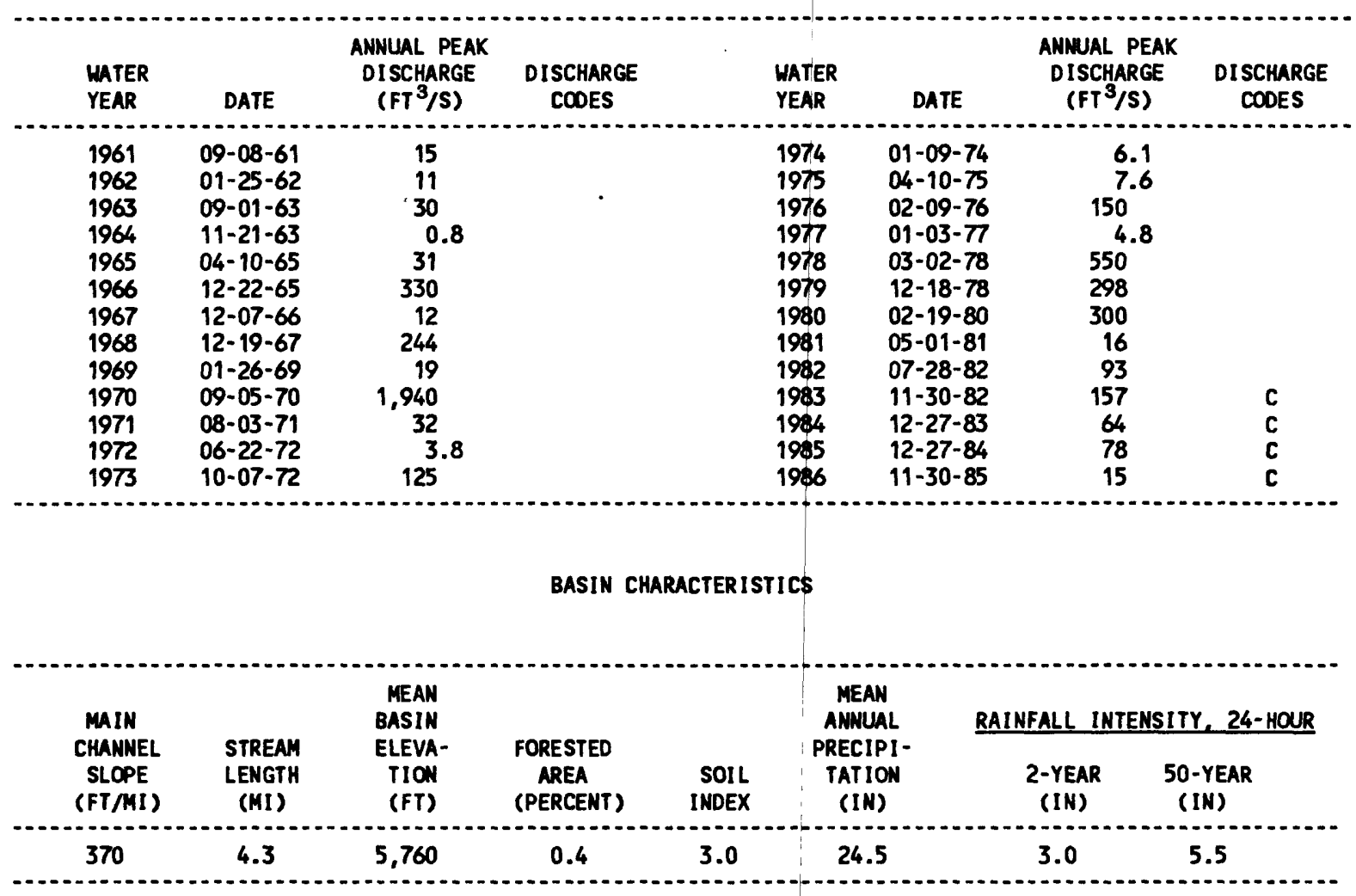


GILA RIVER BASIN

09510100 EAST FORK SYCAMORE CREEK NEAR SUNFLONER, AZ--Continued

MEAN MONTHLY AND ANNUAL DISCHARGES 1966-85

\begin{tabular}{|c|c|c|c|c|c|c|}
\hline MONTH & $\begin{array}{l}\operatorname{MAXIMUN} \\
(F T 3 / S)\end{array}$ & $\begin{array}{l}\text { MINIMUM } \\
\left(F^{3} / S\right)\end{array}$ & $\begin{array}{c}\text { MEAN } \\
\left(F T^{3} / S\right)\end{array}$ & $\begin{array}{l}\text { STAN- } \\
\text { DARD } \\
\text { DEVIA- } \\
\text { TION } \\
\text { (FT } 3 / S \text { S) }\end{array}$ & $\begin{array}{l}\text { COEFFI- } \\
\text { CIENT OF } \\
\text { VARI - } \\
\text { ATION }\end{array}$ & $\begin{array}{c}\text { PERCENT } \\
\text { OF } \\
\text { ANNUAL } \\
\text { RUNOFF }\end{array}$ \\
\hline $\begin{array}{l}\text { OCTOBER } \\
\text { NOVEMBER } \\
\text { DECEMBER } \\
\text { JANUARY } \\
\text { FEBRUARY } \\
\text { MARCH } \\
\text { APRIL } \\
\text { MAY } \\
\text { JUNE } \\
\text { JULY } \\
\text { AUGUST } \\
\text { SEPTEMBER }\end{array}$ & $\begin{array}{l}3.7 \\
1.7 \\
16 \\
11 \\
24 \\
20 \\
5.5 \\
1.3 \\
0.40 \\
0.30 \\
0.27 \\
5.3\end{array}$ & $\begin{array}{l}0.00 \\
0.00 \\
0.00 \\
0.01 \\
0.01 \\
0.01 \\
0.01 \\
0.00 \\
0.00 \\
0.00 \\
0.00 \\
0.00\end{array}$ & $\begin{array}{l}0.25 \\
0.23 \\
2.1 \\
1.9 \\
3.5 \\
3.4 \\
1.1 \\
0.33 \\
0.08 \\
0.04 \\
0.05 \\
0.30\end{array}$ & $\begin{array}{l}0.85 \\
0.50 \\
4.0 \\
2.9 \\
5.8 \\
5.5 \\
1.4 \\
0.42 \\
0.13 \\
0.07 \\
0.08 \\
1.2\end{array}$ & $\begin{array}{l}3.4 \\
2.2 \\
1.9 \\
1.5 \\
1.7 \\
1.6 \\
1.3 \\
1.3 \\
1.6 \\
1.7 \\
1.6 \\
3.9\end{array}$ & $\begin{array}{r}1.9 \\
1.7 \\
16.2 \\
14.3 \\
26.3 \\
25.5 \\
8.0 \\
2.5 \\
0.6 \\
0.3 \\
0.4 \\
2.3\end{array}$ \\
\hline NNUAL & 3.3 & 0.01 & 1.1 & 1.2 & 1.1 & 100 \\
\hline
\end{tabular}

MAGNITLDE AND PROBABILITY OF INSTANTANEOUS PEAK FLOW BASED ON PERIOD OF RECORD 1961-86

DISCHARGE, IN $\mathrm{FT}^{3} / \mathrm{S}$, FOR INDICATED RECURRENCE INTERVAL IN YEARS, AND EXCEEDANCE PROBABILITY, IN PERCENT

\begin{tabular}{lccccc}
2 & 5 & 10 & 25 & $50 \dagger$ & $100 \dagger$ \\
$50 \%$ & $20 \%$ & $10 \%$ & $4 \%$ & $2 \%$ & $1 \%$ \\
43 & 196 & 428 & 978 & 1,660 & 2,670 \\
\hline UEIGHTED SKEW (LOGS) & & -0.05 & & \\
MEAN & (LOES) & 1.63 & & \\
STANDARD DEV. (LOGS) & 0.79 & &
\end{tabular}

DURATION TABLE OF DAILY MEAN FLOW FOR PERIOD OF RECORD 1966-85
MAGNITLDE AND PROBABILITY OF ANNUAL LOW FLOW BASED ON PERIOD OF RECORD 1967-86

\begin{tabular}{|c|c|c|c|c|c|c|}
\hline \multirow{2}{*}{$\begin{array}{l}\text { PERIOD } \\
\text { (CON- } \\
\text { SECU- } \\
\text { TIVE } \\
\text { DAYS) }\end{array}$} & \multicolumn{6}{|c|}{$\begin{array}{l}\text { DISCHARGE, IN FT \%S, FOR INDICATED } \\
\text { RECURRENCE INTERVAL, IN YEARS, AND } \\
\text { NON-EXCEEDANCE PROBABILIITY, IN PERCENT }\end{array}$} \\
\hline & $\begin{array}{c}2 \\
50 \%\end{array}$ & $\begin{array}{c}5 \\
20 \%\end{array}$ & $\begin{array}{l}10 \\
10 \%\end{array}$ & $\begin{array}{l}20 \\
5 \%\end{array}$ & $\begin{array}{l}50 \nmid \\
2 x\end{array}$ & $\begin{array}{l}100 \uparrow \\
1 \%\end{array}$ \\
\hline $\begin{array}{r}1 \\
3 \\
7 \\
14 \\
30 \\
60 \\
90 \\
120 \\
183\end{array}$ & $\begin{array}{l}0.00 \\
0.00 \\
0.00 \\
0.00 \\
0.00 \\
0.00 \\
0.00 \\
0.00 \\
0.02\end{array}$ & $\begin{array}{l}0.00 \\
0.00 \\
0.00 \\
0.00 \\
0.00 \\
0.00 \\
0.00 \\
0.00 \\
0.00\end{array}$ & $\begin{array}{l}0.00 \\
0.00 \\
0.00 \\
0.00 \\
0.00 \\
0.00 \\
0.00 \\
0.00 \\
0.00\end{array}$ & $\begin{array}{l}0.00 \\
0.00 \\
0.00 \\
0.00 \\
0.00 \\
0.00 \\
0.00 \\
0.00 \\
0.00\end{array}$ & $\begin{array}{l}0.00 \\
0.00 \\
0.00 \\
0.00 \\
0.00 \\
0.00 \\
0.00 \\
0.00 \\
0.00\end{array}$ & $\begin{array}{l}0.00 \\
0.00 \\
0.00 \\
0.00 \\
0.00 \\
0.00 \\
0.00 \\
0.00 \\
0.00\end{array}$ \\
\hline
\end{tabular}

MAGNITLDE AND PROBABILITY OF ANNUAL HIGH FLOW BASED ON PERIOD OF RECORD 1966-85

\begin{tabular}{|c|c|c|c|c|c|c|}
\hline \multirow{2}{*}{$\begin{array}{l}\text { PERIOD } \\
\text { (CON- } \\
\text { SECU- } \\
\text { TIVE } \\
\text { DAYS) }\end{array}$} & \multicolumn{6}{|c|}{$\begin{array}{l}\text { DISCHARGE, IN } \mathrm{FT}^{3} / \mathrm{S}, \text { FOR INDICATED } \\
\text { RECURRENCE INTERVAL, IN YEARS, AND } \\
\text { EXCEEDANCE PROBABILITY, IN PERCENT }\end{array}$} \\
\hline & $\begin{array}{c}2 \\
50 \%\end{array}$ & $\begin{array}{c}5 \\
20 \%\end{array}$ & $\begin{array}{l}10 \\
10 \%\end{array}$ & $\begin{array}{l}25 \\
4 \%\end{array}$ & $\begin{array}{l}50 \dagger \\
2 x\end{array}$ & $\begin{array}{c}100\} \\
1 \%\end{array}$ \\
\hline $\begin{array}{r}1 \\
3 \\
7 \\
15 \\
30 \\
60 \\
90\end{array}$ & $\begin{array}{l}20 \\
11 \\
6.6 \\
4.0 \\
2.7 \\
1.9 \\
1.5\end{array}$ & $\begin{array}{l}85 \\
54 \\
32 \\
20 \\
13 \\
8.8 \\
6.6\end{array}$ & $\begin{array}{r}164 \\
105 \\
63 \\
39 \\
25 \\
17 \\
12\end{array}$ & $\begin{array}{r}306 \\
197 \\
118 \\
73 \\
45 \\
31 \\
22\end{array}$ & $\begin{array}{r}441 \\
281 \\
168 \\
104 \\
62 \\
44 \\
31\end{array}$ & $\begin{array}{r}596 \\
376 \\
225 \\
138 \\
80 \\
57 \\
40\end{array}$ \\
\hline
\end{tabular}
DISCHARGE, IN FT $3 / \mathrm{S}$, WHICH WAS EQUALED OR EXCEEDED FOR IMDICATED PERCENT OF TIME

\begin{tabular}{|c|c|c|c|c|c|c|c|c|c|c|c|c|c|c|c|c|}
\hline $1 \%$ & $5 \%$ & $10 \%$ & $15 \%$ & $20 \%$ & $30 \%$ & $40 \%$ & $50 \%$ & $60 \%$ & $70 \%$ & $80 \%$ & $90 \%$ & $95 \%$ & $98 \%$ & $99 \%$ & $99.5 \%$ & $99.9 \%$ \\
\hline 21 & 4.2 & 1.8 & 0.92 & 0.56 & 0.17 & 0.08 & 0.04 & 0.02 & 0.01 & 0.00 & 0.00 & 0.00 & 0.00 & 0.00 & 0.00 & 0.00 \\
\hline
\end{tabular}


GILA RIVER BASIM

09510100 EAST FORK SYCANDE CREEX MEAR SUNFLOWER, AZ--CONTIMUED
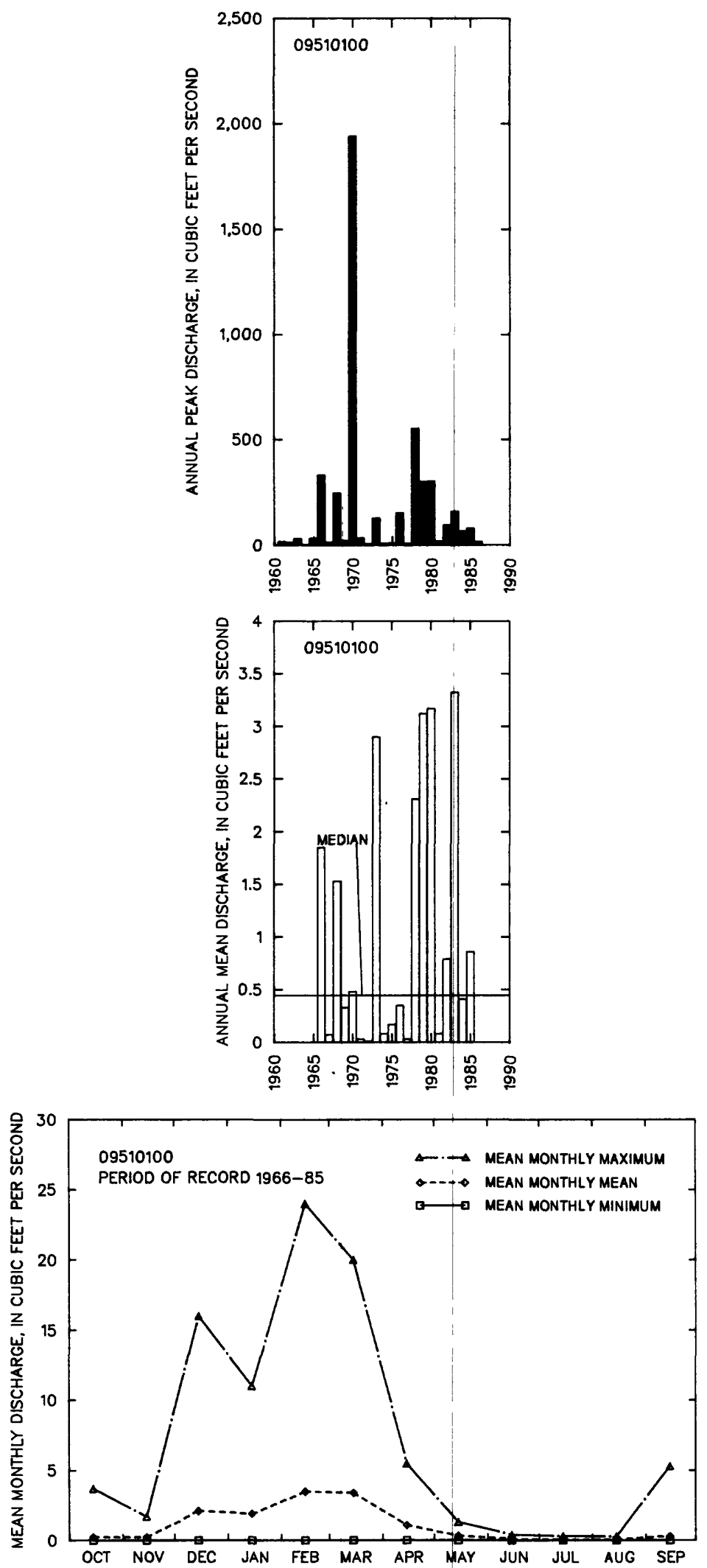
09510150 SYCNDRE CREEK NEAR SUNFLONER, AZ

LOCATION.--Lat 33.51'05", Long 111.27'09", in NEX sec.20, T.6 N., R.9 E., Maricopa County, Hydrologic Unit 15060203, in Tonto National Forest, on right benk 1.1 mi upstream from Boulder Creek, $1.2 \mathrm{mi}$ north of Crabtree Butte, and $1.2 \mathrm{mi}$ southeast of sunflower.

DRAIMAGE AREA. $--52.3 \mathrm{mi}^{2}$.

AMMUAL PEAK DISCHARGE

\begin{tabular}{ccc}
$\begin{array}{c}\text { WATER } \\
\text { YEAR }\end{array}$ & DATE & $\begin{array}{c}\text { ANNUAL PEAK } \\
\text { DISCHARGE } \\
\text { (FT } 3 / \text { S) }\end{array}$ \\
\hline 1962 & $12-16-61$ & 325 \\
1963 & $02-11-63$ & 1,120 \\
1964 & $08-12-64$ & 286 \\
1965 & $04-10-65$ & 762 \\
1966 & $12-22-65$ & 4,800 \\
1967 & $09-06-67$ & 550 \\
1968 & $12-19-67$ & 7,650 \\
1969 & $01-25-69$ & 142 \\
1970 & $09-05-70$ & 16,100 \\
1971 & $08-03-71$ & 395 \\
1972 & $08-04-72$ & 2,350 \\
1973 & $10-07-72$ & 3,810 \\
1974 & $08-05-74$ & 355 \\
1975 & $03-15-75$ & 69 \\
1976 & $02-09-76$ & 6,000 \\
$\ldots$
\end{tabular}

\section{BASIN CHARACTERISTICS}

\begin{tabular}{|c|c|c|c|c|c|c|c|}
\hline \multirow{3}{*}{$\begin{array}{l}\text { MAIN } \\
\text { CHANNEL } \\
\text { SLOPE } \\
\text { (FT/MI) }\end{array}$} & \multirow[b]{3}{*}{$\begin{array}{l}\text { STREAM } \\
\text { LENGTH } \\
\text { (MI) }\end{array}$} & \multirow{3}{*}{$\begin{array}{l}\text { MEAN } \\
\text { BASIN } \\
\text { ELEVA- } \\
\text { TION } \\
\text { (FT) }\end{array}$} & \multirow[b]{3}{*}{$\begin{array}{l}\text { FORESTED } \\
\text { AREA } \\
\text { (PERCENT) }\end{array}$} & \multirow[b]{3}{*}{$\begin{array}{l}\text { SOIL } \\
\text { INDEX }\end{array}$} & \multirow{3}{*}{$\begin{array}{l}\text { MEAN } \\
\text { ANNUAL } \\
\text { PRECIPI- } \\
\text { TATION } \\
\text { (IN) }\end{array}$} & \multirow{2}{*}{\multicolumn{2}{|c|}{ RAINFALL INTENSITY, 24-HOUR }} \\
\hline & & & & & & & \\
\hline & & & & & & $\begin{array}{c}\text { 2-YEAR } \\
\text { (IW) }\end{array}$ & $\begin{array}{l}\text { 50-YEAR } \\
\text { (IN) }\end{array}$ \\
\hline 58.6 & 12.4 & 4,260 & 0.6 & 3.0 & 23.5 & 3.0 & 5.5 \\
\hline
\end{tabular}


MEAN MONTHLY AND ANNUAL DISCHARGES $1962-76$

\begin{tabular}{|c|c|c|c|c|c|c|}
\hline MONTH & $\begin{array}{l}\operatorname{MAXIMUN} \\
\left(F T^{3} / S\right)\end{array}$ & $\begin{array}{l}\operatorname{MINIMUN} \\
\left(\mathrm{FT}^{3} / \mathrm{S}\right)\end{array}$ & $\begin{array}{c}\text { MEAN } \\
\left(F T^{3} / S\right)\end{array}$ & $\begin{array}{l}\text { STAN- } \\
\text { DARD } \\
\text { DEVIA- } \\
\text { TION } \\
\left(F^{3} / S\right)\end{array}$ & $\begin{array}{l}\text { COEFFI - } \\
\text { CIENT OF } \\
\text { VARI - } \\
\text { ATION }\end{array}$ & $\begin{array}{c}\text { PERCENT } \\
\text { OF } \\
\text { ANNUAL } \\
\text { RUNOFF }\end{array}$ \\
\hline $\begin{array}{l}\text { OCTOBER } \\
\text { NOVEMBER } \\
\text { DECEMBER } \\
\text { JANUARY } \\
\text { FEBRUARY } \\
\text { MARCH } \\
\text { APRIL } \\
\text { MAY } \\
\text { JUNE } \\
\text { JULY } \\
\text { AUGUST } \\
\text { SEPTEMBER }\end{array}$ & $\begin{array}{c}62 \\
22 \\
175 \\
39 \\
86 \\
124 \\
55 \\
14 \\
3.7 \\
3.5 \\
11 \\
42\end{array}$ & $\begin{array}{l}0.00 \\
0.10 \\
0.25 \\
0.32 \\
0.38 \\
0.29 \\
0.28 \\
0.21 \\
0.13 \\
0.01 \\
0.04 \\
0.00\end{array}$ & $\begin{array}{c}4.4 \\
2.7 \\
24 \\
8.5 \\
19 \\
16 \\
9.6 \\
2.1 \\
0.89 \\
0.57 \\
1.7 \\
3.4\end{array}$ & $\begin{array}{l}16 \\
6.1 \\
52 \\
11 \\
27 \\
32 \\
17 \\
3.3 \\
1.1 \\
0.91 \\
3.0 \\
11\end{array}$ & $\begin{array}{l}3.6 \\
2.3 \\
2.2 \\
1.3 \\
1.5 \\
2.0 \\
1.7 \\
1.6 \\
1.3 \\
1.6 \\
1.8 \\
3.1\end{array}$ & $\begin{array}{r}4.7 \\
2.9 \\
26.0 \\
9.2 \\
20.1 \\
17.5 \\
10.4 \\
2.3 \\
1.0 \\
0.6 \\
1.8 \\
3.7\end{array}$ \\
\hline INUA & 34 & .52 & 7.7 & 9.5 & 1.2 & 100 \\
\hline
\end{tabular}

MAGNITUDE AND PROBABILITY OF INSTANTANEOUS PEAK FLOW BASED ON PERIOD OF RECORD 1962-76

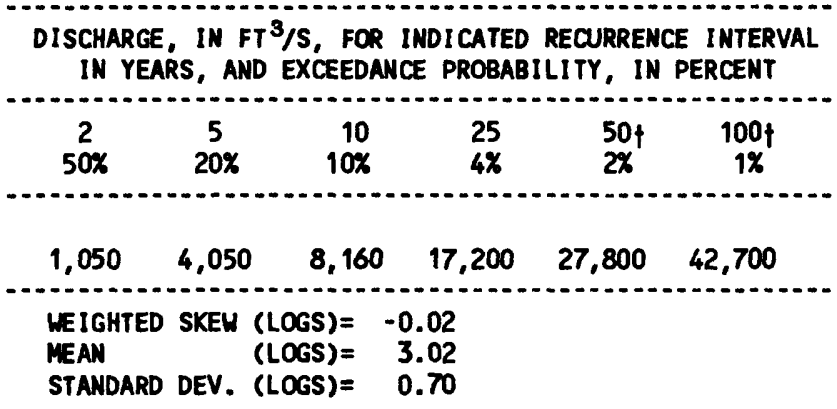

MACNITUDE AND PROBABILITY OF ANNUAL LOW FLOW BASED ON PERIOD OF RECORD 1963-76

\begin{tabular}{|c|c|c|c|c|c|c|}
\hline \multirow{2}{*}{$\begin{array}{l}\text { PERIOD } \\
\text { (CON- } \\
\text { SECU- } \\
\text { TIVE } \\
\text { DAYS) }\end{array}$} & \multicolumn{6}{|c|}{$\begin{array}{l}\text { DISCHARGE, IN } \mathrm{FT}^{3} / \mathrm{S} \text {, FOR INDICATED } \\
\text { RECURRENCE INTERVAL, IN YEARS, AND } \\
\text { NON-EXCEEDANCE PROBABILITY, IN PERCENT }\end{array}$} \\
\hline & $\begin{array}{c}2 \\
50 x\end{array}$ & $\begin{array}{c}5 \\
20 \%\end{array}$ & $\begin{array}{l}10 \\
10 \%\end{array}$ & $\begin{array}{l}20 \\
5 \%\end{array}$ & $\begin{array}{l}50 \phi \\
2 \%\end{array}$ & $\begin{array}{l}100 \nmid \\
1 \%\end{array}$ \\
\hline $\begin{array}{r}1 \\
3 \\
7 \\
14 \\
30 \\
60 \\
90 \\
120 \\
183\end{array}$ & $\begin{array}{l}0.04 \\
0.05 \\
0.05 \\
0.07 \\
0.08 \\
0.12 \\
0.19 \\
0.26 \\
0.40\end{array}$ & $\begin{array}{l}0.00 \\
0.00 \\
0.00 \\
0.00 \\
0.00 \\
0.06 \\
0.10 \\
0.14 \\
0.26\end{array}$ & $\begin{array}{l}0.00 \\
0.00 \\
0.00 \\
0.00 \\
0.00 \\
0.04 \\
0.07 \\
0.11 \\
0.22\end{array}$ & $\begin{array}{l}0.00 \\
0.00 \\
0.00 \\
0.00 \\
0.00 \\
0.02 \\
0.06 \\
0.08 \\
0.19\end{array}$ & $\begin{array}{l}0.00 \\
0.00 \\
0.00 \\
0.00 \\
0.00 \\
0.02 \\
0.05 \\
0.07 \\
0.17\end{array}$ & $\begin{array}{l}0.00 \\
0.00 \\
0.00 \\
0.00 \\
0.00 \\
0.01 \\
0.04 \\
0.06 \\
0.16\end{array}$ \\
\hline
\end{tabular}

MACNITUDE AND PROBABILITY OF ANNUAL HIGH FLOW BASED ON PERIOD OF RECORD 1962-76

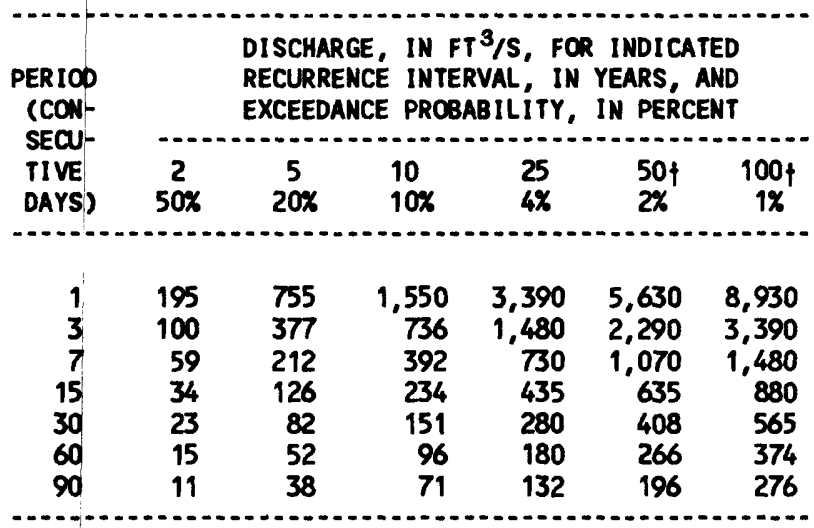

DURATION TABLE OF DAILY MEAN FLON FOR PERIOD OF RECORD 1962-76

DISCHARGE, IN $\mathrm{FT}^{3} / \mathrm{S}$, WHICH WAS EQUALED OR EXCEEDED FOR INDICATED PERCENT OF TIME

\begin{tabular}{|c|c|c|c|c|c|c|c|c|c|c|c|c|c|c|c|c|}
\hline $1 \%$ & $5 \%$ & $10 \%$ & $15 \%$ & $20 \%$ & $30 \%$ & $40 \%$ & $50 \%$ & $60 \%$ & $70 x$ & $80 \%$ & $90 \%$ & $95 \%$ & $98 \%$ & $99 \%$ & $99.5 \%$ & $99.9 \%$ \\
\hline 139 & 29 & 9.4 & 4.8 & 2.9 & 1.3 & 0.74 & 0.52 & 0.37 & 0.22 & 0.16 & 0.09 & 0.05 & 0.00 & 0.00 & 0.00 & 0.0 \\
\hline
\end{tabular}

† Reliability of values in column is uncertain, and potential errors are large. 
GILA RIVER BASIN

09510150 SYCAMORE CREEK NEAR SUNFLOWER, AZ--CONTIMUED
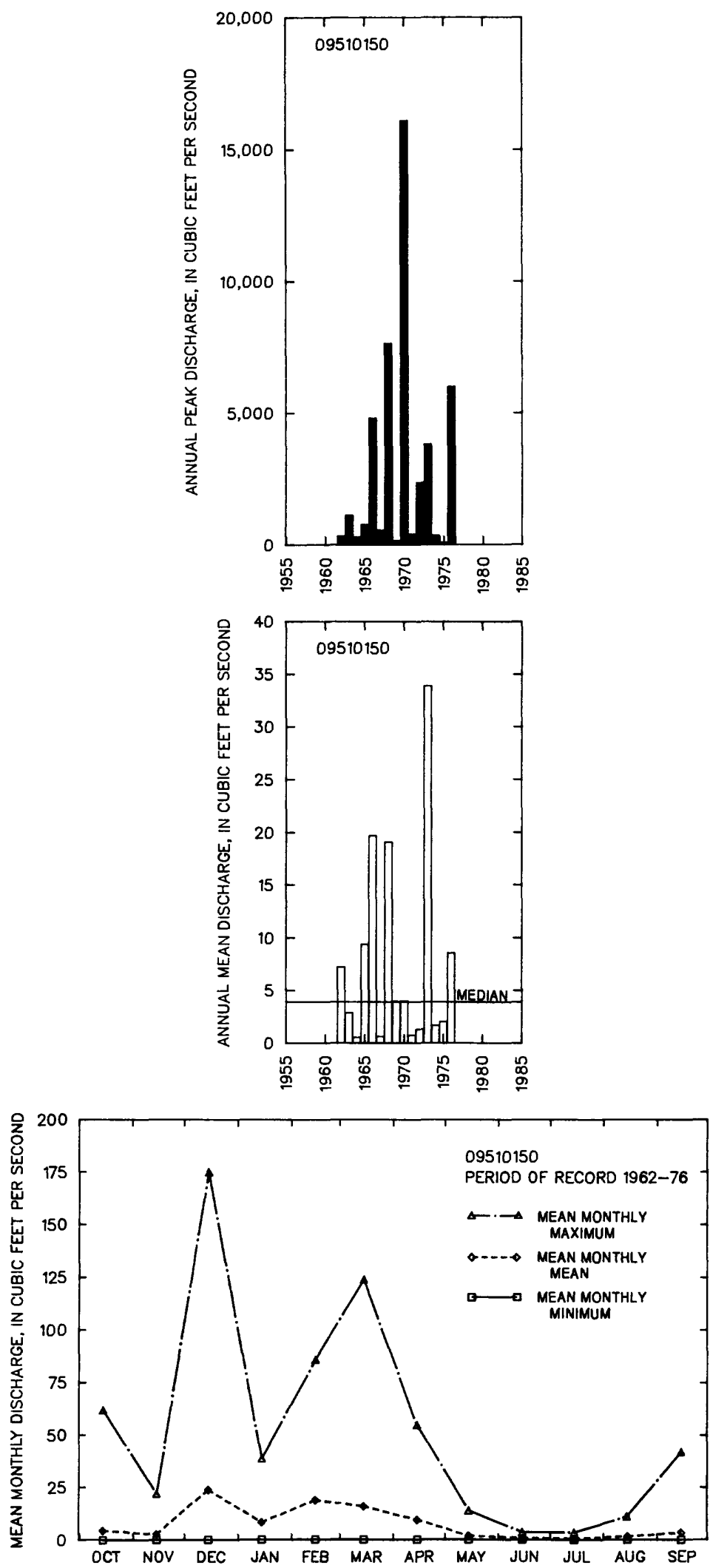
LOCATION.--Lat 33'45'35", long 111'29'44", in SWK sec.24, T.5 N., R.8 E., Maricopa County, Hydrologic Unit 15060203, on right bank at upstream side of culvert of state Highway 87, 0.5 mi upstream from mouth, and 7 mi south of sunflower.

DRAINAGE AREA. $--2.6 \mathrm{mi}^{2}$.

AMNUAL PEAK DISCHARGE

\begin{tabular}{|c|c|c|c|}
\hline $\begin{array}{l}\text { WATER } \\
\text { YEAR }\end{array}$ & DATE & $\begin{array}{l}\text { ANNUAL PEAK } \\
\text { DISCHARGE } \\
\left(F^{3} / \mathrm{S}\right)\end{array}$ & $\begin{array}{l}\text { DISCHARGE } \\
\text { CODES }\end{array}$ \\
\hline $\begin{array}{l}1963 \\
1964 \\
1965 \\
1966 \\
1967 \\
1968 \\
1969 \\
1970 \\
1971 \\
1972 \\
1973 \\
1974 \\
1975 \\
1976 \\
1977 \\
1978 \\
1979\end{array}$ & $\begin{array}{l}08-16-63 \\
08-02-64 \\
01-07-65 \\
12-22-65 \\
12-07-66 \\
12-18-67 \\
01-27-69 \\
09-05-70 \\
08-19-71 \\
06-22-72 \\
10-19-72 \\
08-08-74 \\
10-29-74 \\
09-26-76 \\
08-16-77 \\
03-02-78 \\
12-18-78\end{array}$ & $\begin{array}{r}391 \\
216 \\
51 \\
167 \\
26 \\
221 \\
26 \\
136 \\
68 \\
67 \\
336 \\
31 \\
31 \\
252 \\
269 \\
402 \\
134\end{array}$ & \\
\hline
\end{tabular}

MAGNITUDE AND PROBABILITY OF INSTANTANEOUS PEAK FLON BASED ON PERIOD OF RECORD $1963-79$

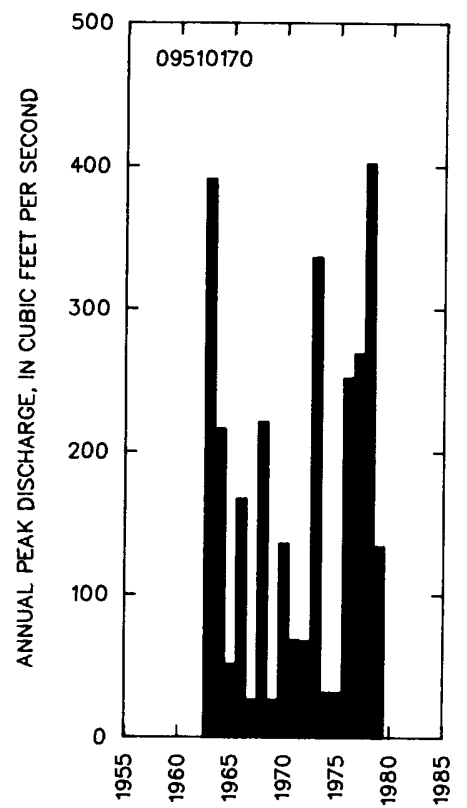

DISCHARGE, IN FT 3 /S, FOR INDICATED RECURRENCE INTERVAL

IN YEARS, AND EXCEEDANCE PROBABILITY, IN PERCENT

$\begin{array}{lccccc}2 & 5 & 10 & 25 & 50 \uparrow & 100 \uparrow \\ 50 \% & 20 \% & 10 \% & 4 \% & 2 \% \\ 1 \% & & & \\ 117 & 262 & 390 & 588 & 759 & 950\end{array}$

+ Reliability of values in column is uncertain, and potential errors are large.

BASIN CHARACTERISTICS

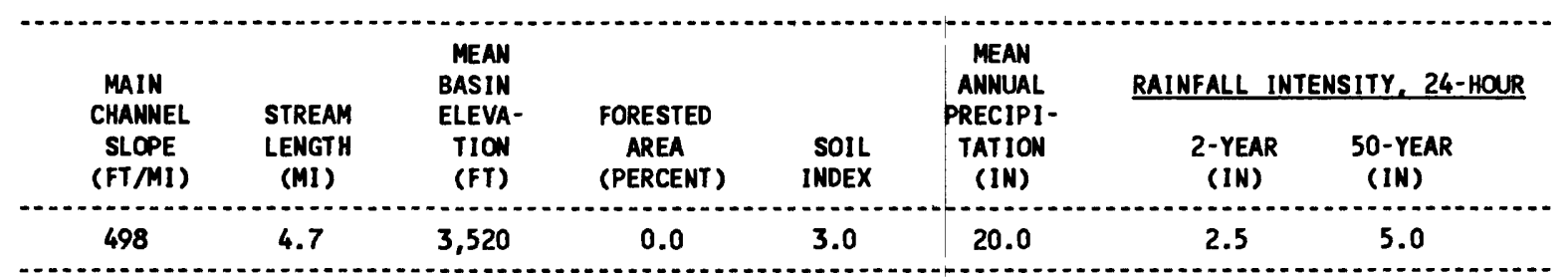


09510180 ROCK CREEK NEAR SUNFLOUER, AZ

LOCATION. - - Lat 33\%43'49", long 111'30'28", in SEK sec.35, T.5 N., R.8 E., Maricopa County, Hydrologic Unit 15060203, on left bank $300 \mathrm{ft}$ upstream from culvert on State Highway $87,0.3$ mi upstream from mouth, and $10 \mathrm{mi}$ south of sunflower.

DRAINAGE AREA. $--15.2 \mathrm{mi}^{2}$.

ANMUAL PEAK DISCHARGE

\begin{tabular}{ccc}
$\begin{array}{l}\text { HATER } \\
\text { YEAR }\end{array}$ & DATE & $\begin{array}{c}\text { ANNUAL PEAK } \\
\text { DISCHARGE } \\
\text { (FT 3/S) }\end{array}$ \\
\hline 1963 & $08-16-63$ & 262 \\
1964 & $08-01-64$ & 916 \\
1965 & $01-07-65$ & 175 \\
1966 & $12-22-65$ & 1,900 \\
1967 & $07-16-67$ & 570 \\
1968 & $12-19-67$ & 1,230 \\
1969 & $01-27-69$ & 43 \\
1970 & $09-05-70$ & 1,540 \\
1971 & $08-19-71$ & 924 \\
1972 & $06-22-72$ & 151 \\
\hline & &
\end{tabular}

MAGNITUDE AND PROBABILITY OF INSTANTANEOUS PEAK FLON BASED ON PERIOD OF RECORD 1963-72

DISCHARGE, IN $\mathrm{FT}^{3} / \mathrm{S}$, FOR INDICATED RECURRENCE INTERVAL IN YEARS, AND EXCEEDANCE PROBABILITY, IN PERCENT

\begin{tabular}{|c|c|c|c|c|c|}
\hline$\stackrel{2}{50 \%}$ & $\underset{20 \%}{5}$ & $\begin{array}{r}10 \\
10 \%\end{array}$ & $\begin{array}{l}25 \uparrow \\
4 \%\end{array}$ & $\begin{array}{l}50 \uparrow \\
2 \%\end{array}$ & $\begin{array}{c}100 \dagger \\
1 \%\end{array}$ \\
\hline 507 & 1,340 & 2,130 & 3,400 & 4,530 & 5,790 \\
\hline $\begin{array}{l}\text { MEIGH } \\
\text { MEAN } \\
\text { STAND }\end{array}$ & $\begin{array}{l}\text { SKEW } \\
\text { DEV. }\end{array}$ & $\begin{array}{l}\text { OGS })= \\
\text { OGS }= \\
\text { OGS }=\end{array}$ & $\begin{array}{r}-0.38 \\
2.67 \\
0.53\end{array}$ & & \\
\hline
\end{tabular}

f Reliability of values in column is uncertain, and potential errors are large.

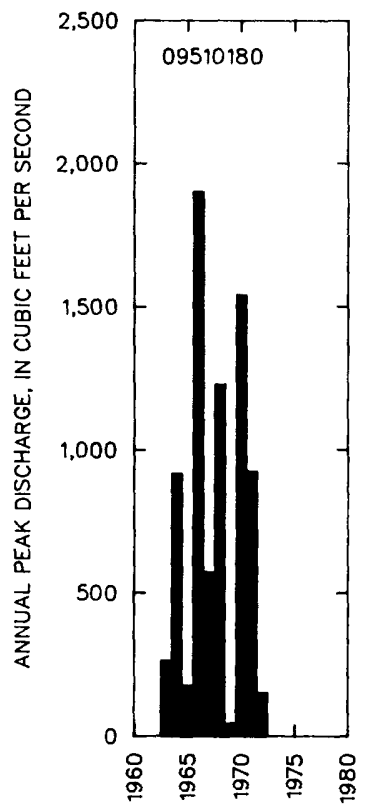

\section{BASIN CHARACTERISTICS}

\begin{tabular}{|c|c|c|c|c|c|c|c|}
\hline MAIN & & $\begin{array}{l}\text { MEAN } \\
\text { BASIN }\end{array}$ & & & $\begin{array}{l}\text { MEAN } \\
\text { ANNUAL }\end{array}$ & RAINFALL I & SITY, 24-HOUR \\
\hline $\begin{array}{c}\text { CHANNEL } \\
\text { SLOPE } \\
\text { (FT/MI) }\end{array}$ & $\begin{array}{l}\text { STREAM } \\
\text { LENGTH } \\
\text { (MI) }\end{array}$ & $\begin{array}{l}\text { ELEVA- } \\
\text { TION } \\
\text { (FT) }\end{array}$ & $\begin{array}{l}\text { FORESTED } \\
\text { AREA } \\
\text { (PERCENT) }\end{array}$ & $\begin{array}{l}\text { SOIL } \\
\text { INDEX }\end{array}$ & $\begin{array}{l}\text { PRECIPI- } \\
\text { TATION } \\
\text { (IN) }\end{array}$ & $\begin{array}{c}\text { 2-YEAR } \\
\text { (IN) }\end{array}$ & $\begin{array}{l}\text { 50-YEAR } \\
\text { (IN) }\end{array}$ \\
\hline 412 & 7.3 & 3,680 & 0.2 & 3.0 & 16.0 & 2.3 & 5.0 \\
\hline
\end{tabular}


09510200 SYCAMORE CREEK NEAR FORT MCDONELL, AZ

LOCATION.--Lat 33.41'39", long $111^{\circ} 32^{\prime 28}$ ", in sec.16, T.4 N., R.8 E. (unsurveyed), Maricopa County, Hydrologic Unit 15060203, in Tonto National Forest, on right benk 0.7 mi southwest of Sugarloaf Mounta in, 9 mi northeast of Fort McDowell, 10 mi upstream from mouth, and 25 mi northeast of Scottsdale.

DRAINAGE AREA. $--164 \mathrm{mi}^{2}$.

ANIUAL PEAK DISCHARGE

\begin{tabular}{|c|c|c|c|c|c|}
\hline $\begin{array}{l}\text { WATER } \\
\text { YEAR }\end{array}$ & DATE & $\begin{array}{l}\text { ANMUAL PEAK } \\
\text { DISCHARGE } \\
\left(\mathrm{FT}^{3} / \mathrm{S}\right)\end{array}$ & $\begin{array}{l}\text { WATER } \\
\text { YEAR }\end{array}$ & DATE & $\begin{array}{l}\text { ANWUAL PEAK } \\
\text { DISCHARGE } \\
\left(\mathrm{FT}^{3} / \mathrm{S}\right)\end{array}$ \\
\hline $\begin{array}{l}1960 \\
1961 \\
1962 \\
1963 \\
1964 \\
1965 \\
1966 \\
1967 \\
1968 \\
1969 \\
1970 \\
1971 \\
1972 \\
1973 \\
1974\end{array}$ & $\begin{array}{l}12-25-59 \\
07-03-61 \\
12-16-61 \\
08-16-63 \\
08-01-64 \\
01-07-65 \\
12-14-65 \\
07-16-67 \\
12-19-67 \\
01-27-69 \\
09-05-70 \\
08-19-71 \\
06-22-72 \\
10-19-72 \\
08-05-74\end{array}$ & $\begin{array}{r}15,800 \\
248 \\
674 \\
2,860 \\
1,060 \\
1,170 \\
668 \\
1,060 \\
9,880 \\
216 \\
124,200 \\
876 \\
1,810 \\
8,540 \\
1,030\end{array}$ & $\begin{array}{l}1975 \\
1976 \\
1977 \\
1978 \\
1979 \\
1980 \\
1981 \\
1982 \\
1983 \\
1984 \\
1985 \\
1986 \\
1987 \\
1988 \\
1989\end{array}$ & $\begin{array}{l}04-11-75 \\
02-09-76 \\
08-16-77 \\
03-02-78 \\
12-18-78 \\
02-15-80 \\
09-23-81 \\
03-14-82 \\
11-30-82 \\
09-02-84 \\
12-27-84 \\
03-17-86 \\
10-11-86 \\
01-18-88 \\
02-05-89\end{array}$ & $\begin{array}{r}188 \\
5,470 \\
6,150 \\
17,900 \\
9,520 \\
10,400 \\
170 \\
1,290 \\
7,440 \\
2,600 \\
2,960 \\
3,000 \\
319 \\
1,410 \\
893\end{array}$ \\
\hline
\end{tabular}

1 Highest since 1959.

BASIN CHARACTERISTICS

\begin{tabular}{|c|c|c|c|c|c|c|c|}
\hline MAIN & & $\begin{array}{l}\text { MEAN } \\
\text { BASIN }\end{array}$ & & & $\begin{array}{l}\text { MEAN } \\
\text { ANNUAL }\end{array}$ & RAINFALL II & SITY, 24-HOUR \\
\hline $\begin{array}{l}\text { CHANNEL } \\
\text { SLOPE } \\
\text { (FT/MI) }\end{array}$ & $\begin{array}{l}\text { STREAM } \\
\text { LENGTH } \\
\text { (MI) }\end{array}$ & $\begin{array}{l}\text { ELEVA- } \\
\text { TIOW } \\
\text { (FT) }\end{array}$ & $\begin{array}{l}\text { FORESTED } \\
\text { AREA } \\
\text { (PERCENT) }\end{array}$ & $\begin{array}{l}\text { SOIL } \\
\text { INDEX }\end{array}$ & $\begin{array}{l}\text { PRECIPI - } \\
\text { TATION } \\
\text { (IN) }\end{array}$ & $\begin{array}{l}\text { 2-YEAR } \\
\text { (IN) }\end{array}$ & $\begin{array}{l}\text { 50-YEAR } \\
\text { (IN) }\end{array}$ \\
\hline 116 & 30.0 & 3,820 & 0.6 & 2.3 & 21.2 & 2.7 & 5.4 \\
\hline
\end{tabular}


09\$10200 SYCAMORE CREEK MEAR FORT MCDOWELL, AZ--COntinued

MEAN MONTHLY AND ANNUAL DISCHARGES 1961-89

\begin{tabular}{|c|c|c|c|c|c|c|}
\hline MONTH & $\begin{array}{l}\operatorname{MAXIMU} \\
\left(\mathrm{FT}^{3} / \mathrm{S}\right)\end{array}$ & $\begin{array}{l}\text { MINIMUM } \\
\left(F^{3} / S\right)\end{array}$ & $\begin{array}{c}\text { MEAN } \\
\left(F T^{3} / S\right)\end{array}$ & $\begin{array}{l}\text { STAN- } \\
\text { DARD } \\
\text { DEVIA- } \\
\text { TION } \\
\left(F^{3} / S\right)\end{array}$ & $\begin{array}{l}\text { COEFFI - } \\
\text { CIENT OF } \\
\text { VARI - } \\
\text { ATION }\end{array}$ & $\begin{array}{c}\text { PERCENT } \\
\text { OF } \\
\text { ANNUAL } \\
\text { RUNOFF }\end{array}$ \\
\hline $\begin{array}{l}\text { OCTOBER } \\
\text { NOVEMBER } \\
\text { DECEMBER } \\
\text { JANUARY } \\
\text { FEBRUARY } \\
\text { MARCH } \\
\text { APRIL } \\
\text { MAY } \\
\text { JUNE } \\
\text { JULY } \\
\text { AUGUST } \\
\text { SEPTEMBER }\end{array}$ & $\begin{array}{c}194 \\
72 \\
426 \\
369 \\
852 \\
881 \\
120 \\
52 \\
21 \\
7.7 \\
26 \\
93\end{array}$ & $\begin{array}{l}0.00 \\
0.00 \\
0.00 \\
0.00 \\
0.10 \\
0.19 \\
0.07 \\
0.00 \\
0.00 \\
0.00 \\
0.00 \\
0.00\end{array}$ & $\begin{array}{l}7.9 \\
7.5 \\
57 \\
40 \\
84 \\
89 \\
24 \\
7.3 \\
2.6 \\
1.8 \\
3.7 \\
5.3\end{array}$ & $\begin{array}{c}36 \\
17 \\
115 \\
73 \\
168 \\
179 \\
36 \\
14 \\
5.1 \\
2.3 \\
6.1 \\
17\end{array}$ & $\begin{array}{l}4.5 \\
2.2 \\
2.0 \\
1.8 \\
2.0 \\
2.0 \\
1.5 \\
1.9 \\
2.0 \\
1.3 \\
1.7 \\
3.2\end{array}$ & $\begin{array}{r}2.4 \\
2.3 \\
17.2 \\
12.0 \\
25.4 \\
27.2 \\
7.3 \\
2.2 \\
0.8 \\
0.5 \\
1.1 \\
1.6\end{array}$ \\
\hline NMUAL & 112 & 0.23 & 27 & 37 & 1.3 & 100 \\
\hline
\end{tabular}

MAGNITLDE AND PROBABILITY OF INSTANTANEOUS PEAK FLOM BASED ON PERIOD OF RECORD 1960-89

\begin{tabular}{|c|c|c|c|c|c|}
\hline$\stackrel{2}{50 x}$ & $\begin{array}{c}5 \\
20 x\end{array}$ & $\begin{array}{r}10 \\
10 \%\end{array}$ & $\begin{array}{l}25 \\
4 \%\end{array}$ & $\begin{array}{l}50 \\
2 \%\end{array}$ & $\begin{array}{c}100 \dagger \\
1 \%\end{array}$ \\
\hline 2,020 & 6,650 & 12,300 & 23,500 & 35,500 & 51,400 \\
\hline $\begin{array}{l}\text { MEIGH } \\
\text { MEAN } \\
\text { STANDA }\end{array}$ & SKEH & $\begin{array}{l}(S)=-( \\
((S)= \\
(G)=\end{array}$ & & & \\
\hline
\end{tabular}

MAGNITUDE AND PROBABILITY OF ANNUAL LOW FLON BASED ON PERIOD OF RECORD 1962-89

\begin{tabular}{|c|c|c|c|c|c|c|}
\hline \multirow{2}{*}{$\begin{array}{l}\text { PERIOD } \\
\text { (CON- } \\
\text { SECU- } \\
\text { TIVE } \\
\text { DAYS) }\end{array}$} & \multicolumn{6}{|c|}{$\begin{array}{l}\text { DISCHARGE, IN } \mathrm{FT}^{3} / \mathrm{S} \text {, FOR INDICATED } \\
\text { RECURRENCE INTERVAL, IN YEARS, AND } \\
\text { NON-EXCEEDANCE PROBABILITY, IN PERCENT }\end{array}$} \\
\hline & $\begin{array}{c}2 \\
50 \%\end{array}$ & $\begin{array}{c}5 \\
20 \%\end{array}$ & $\begin{array}{l}10 \\
10 \%\end{array}$ & $\begin{array}{l}20 \\
5 x\end{array}$ & $\begin{array}{l}50 \\
2 \%\end{array}$ & $\begin{array}{l}100 t \\
1 \times\end{array}$ \\
\hline $\begin{array}{r}1 \\
3 \\
7 \\
14 \\
30 \\
60 \\
90 \\
120 \\
183\end{array}$ & $\begin{array}{l}0.00 \\
0.00 \\
0.00 \\
0.00 \\
0.00 \\
0.00 \\
0.00 \\
0.00 \\
0.00\end{array}$ & $\begin{array}{l}0.00 \\
0.00 \\
0.00 \\
0.00 \\
0.00 \\
0.00 \\
0.00 \\
0.00 \\
0.00\end{array}$ & $\begin{array}{l}0.00 \\
0.00 \\
0.00 \\
0.00 \\
0.00 \\
0.00 \\
0.00 \\
0.00 \\
0.00\end{array}$ & $\begin{array}{l}0.00 \\
0.00 \\
0.00 \\
0.00 \\
0.00 \\
0.00 \\
0.00 \\
0.00 \\
0.00\end{array}$ & $\begin{array}{l}0.00 \\
0.00 \\
0.00 \\
0.00 \\
0.00 \\
0.00 \\
0.00 \\
0.00 \\
0.00\end{array}$ & $\begin{array}{l}0.00 \\
0.00 \\
0.00 \\
0.00 \\
0.00 \\
0.00 \\
0.00 \\
0.00 \\
0.00\end{array}$ \\
\hline
\end{tabular}

MAGNITUDE AND PROBABILITY OF ANMUAL HIGH FLON BASED ON PERIOD OF RECORD 1961-89

\begin{tabular}{|c|c|c|c|c|c|c|}
\hline \multirow{2}{*}{$\begin{array}{l}\text { PERIOD } \\
\text { (CON- } \\
\text { SECU- } \\
\text { TIVE } \\
\text { DAYS) }\end{array}$} & \multicolumn{6}{|c|}{$\begin{array}{l}\text { DISCHARCE, IN FT } 3 / S \text {, FOR INDICATED } \\
\text { RECURRENCE INTERVAL, IN YEARS, AND } \\
\text { EXCEEDANCE PROBABILITY, IN PERCENT }\end{array}$} \\
\hline & $\begin{array}{c}2 \\
50 \%\end{array}$ & $\begin{array}{c}5 \\
20 x\end{array}$ & $\begin{array}{l}10 \\
10 \%\end{array}$ & $\begin{array}{l}25 \\
4 x\end{array}$ & $\begin{array}{l}50 \\
2 \%\end{array}$ & $\underset{1 \%}{100\}}$ \\
\hline $\begin{array}{r}1 \\
3 \\
7 \\
15 \\
30 \\
60 \\
90\end{array}$ & $\begin{array}{l}558 \\
327 \\
189 \\
114 \\
73 \\
47 \\
33\end{array}$ & $\begin{array}{r}2,000 \\
1,160 \\
691 \\
421 \\
272 \\
184 \\
133\end{array}$ & $\begin{array}{r}3,800 \\
2,190 \\
1,310 \\
788 \\
501 \\
347 \\
257\end{array}$ & $\begin{array}{r}7,390 \\
4,220 \\
2,500 \\
1,480 \\
912 \\
642 \\
495\end{array}$ & $\begin{array}{r}11,300 \\
6,350 \\
3,740 \\
2,180 \\
1,300 \\
926 \\
738\end{array}$ & $\begin{array}{l}16, \\
9, \\
5 \\
3\end{array}$ \\
\hline
\end{tabular}

DURATION TABLE OF DAILY MEAN FLON FOR PERIOD OF RECORD 1961-89

DISCHARGE, IN $\mathrm{FT}^{3} / \mathrm{S}$, WHICH WAS EQUALED OR EXCEEDED FOR INDICATED PERCENT OF TIME

\begin{tabular}{|c|c|c|c|c|c|c|c|c|c|c|c|c|c|c|c|c|}
\hline $1 x$ & $5 \%$ & $10 \%$ & $15 \%$ & $20 \%$ & $30 \%$ & $40 \%$ & $50 \%$ & $60 \%$ & $70 \%$ & $80 \%$ & $90 \%$ & $95 \%$ & $98 \%$ & $99 \%$ & $99.5 \%$ & $99.9 \%$ \\
\hline 448 & 105 & 44 & 22 & 9.6 & 3.4 & 1.5 & 0.75 & 0.33 & 0.12 & 0.05 & 0.00 & 0.00 & 0.00 & 0.00 & 0.00 & 0.00 \\
\hline
\end{tabular}

† Reliability of values in column is uncertain, and potential errors are large. 
09510200 SYCAMORE CREEK MEAR FORT MCDOWELL, AZ--CONTIMUED
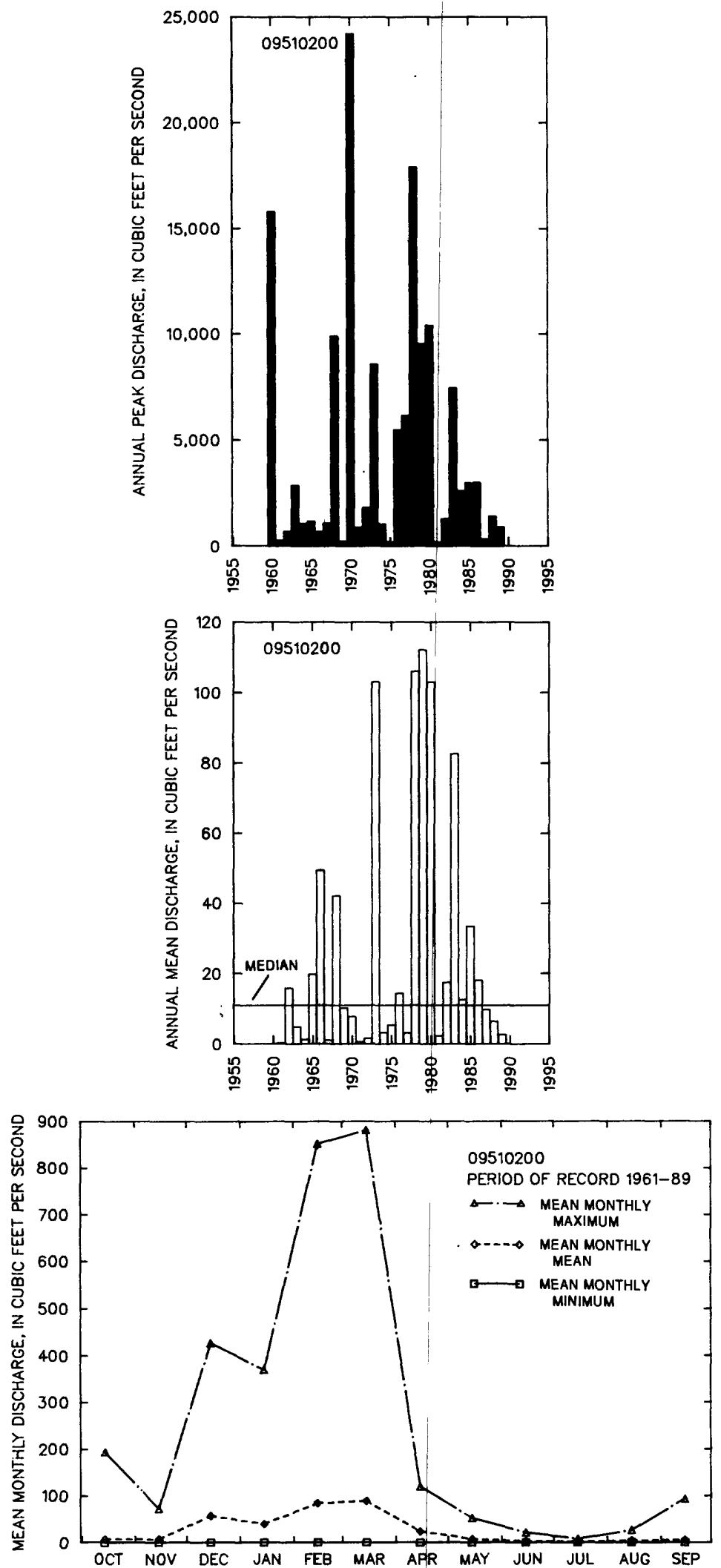
09512100 INDIAN BEND WASH AT SCOTTSDALE, AZ

LOCATION.--Lat 33'32'08", long 111'54'50", in NWHEK sec.11, T.2 N., R.4 E., Maricopa County, Hydrologic Unit 15060106, on right bank $100 \mathrm{ft}$ downstream from Arizona Canal.

DRAIMAGE AREA.--62 $\mathrm{mi}^{2}$ approximately, since October 1975. Prior to October 1975, $139 \mathrm{mi}^{2}$; reduction caused by cutoff of upper portion of basin by Central Arizona Canal and detention dike (also see REMARKS).

REMARKS. - Natural flow of wash affected by urbanization and partly regulated by artificial lakes upstream. Upper portion of basin (about $77 \mathrm{mi}$ ) cut off by Central Arizona Canal and detention dike in October 1975. Release of excess floodwaters may occasionally pass canal into lower portion of besin. Records at present site may include water spilled over emergency spillway along north side of Arizona Canal but do not include water released through the control structure on south side of canal, which enters Indian Bend Wash dounstream from the gage.

MMNUAL PEAK DISCHARGE

\begin{tabular}{|c|c|c|c|c|c|c|c|}
\hline $\begin{array}{l}\text { WATER } \\
\text { YEAR }\end{array}$ & DATE & $\begin{array}{c}\text { ANNUAL PEAK } \\
\text { DISCHARGE } \\
\text { (FT } 3 / \mathrm{S})\end{array}$ & $\begin{array}{l}\text { DISCHARGE } \\
\text { COOES }\end{array}$ & $\begin{array}{l}\text { WATER } \\
\text { YEAR }\end{array}$ & DATE & $\begin{array}{c}\text { ANNUAL PEAK } \\
\text { DISCHARGE } \\
\text { (FT } 3 / S)\end{array}$ & $\begin{array}{l}\text { DISCHARGE } \\
\text { CODES }\end{array}$ \\
\hline $\begin{array}{l}1943 \\
1961 \\
1962 \\
1963 \\
1964 \\
1965 \\
1966 \\
1967 \\
1968 \\
1969 \\
1970 \\
1971\end{array}$ & $\begin{array}{l}08-03-43 \\
09-13-61 \\
00-00-62 \\
07-19-63 \\
10-19-63 \\
02-07-65 \\
09-13-66 \\
07-17-67 \\
12-19-67 \\
00-00-69 \\
09-05-70 \\
08-10-71\end{array}$ & $\begin{array}{r}15,000 \\
745 \\
0 \\
350 \\
328 \\
76 \\
596 \\
248 \\
5,620 \\
0 \\
2,150 \\
85\end{array}$ & $\begin{array}{l}\text { C } \\
\text { C }\end{array}$ & $\begin{array}{l}1972 \\
1973 \\
1974 \\
1975 \\
1976 \\
1977 \\
1978 \\
1979 \\
1980 \\
1981 \\
1983 \\
1984\end{array}$ & $\begin{array}{l}06-22-72 \\
10-19-72 \\
07-31-74 \\
11-03-74 \\
09-25-76 \\
10-23-76 \\
03-02-78 \\
01-17-79 \\
02-15-80 \\
07-30-81 \\
08-16-83 \\
09-02-84\end{array}$ & $\begin{array}{c}121,000 \\
9,600 \\
9.4 \\
20 \\
3,500 \\
140 \\
3,180 \\
252 \\
125 \\
450 \\
3,830 \\
5,000\end{array}$ & $\begin{array}{l}C \\
C \\
C \\
C \\
E S, C \\
C \\
C \\
C \\
C \\
C \\
C \\
C\end{array}$ \\
\hline
\end{tabular}

1Highest since 1922.

MAGNITUDE AND PROBABILITY OF INSTANTANEOUS PEAK FLON BASED ON PERICD OF RECORD 1943, 1961-70

DISCHARGE, IN $\mathrm{FT}^{3} / \mathrm{S}$, FOR INDICATED RECURRENCE INTERVAL IN YEARS, AND EXCEEDANCE PROBABILITY, IN PERCENT

\begin{tabular}{lccccc}
2 & 5 & 10 & 25 & 50 & 100 \\
$50 \%$ & $20 \%$ & $10 \%$ & $4 \%$ & $2 \%$ & $1 \%$ \\
378 & 1,440 & 2,950 & 6,400 & 10,600 & 16,800 \\
\hline MEIGHTED SKEW (LOGS) & 0.10 & & \\
MEAN & $\begin{array}{l}\text { (LOGS) } \\
\text { STANDARD DEV. (LOGS) }\end{array}$ & 2.59 & 0.68 & &
\end{tabular}

$\uparrow$ Reliability of values in column is uncertain, and potential errors are large.

BASIN CHARACTERISTICS

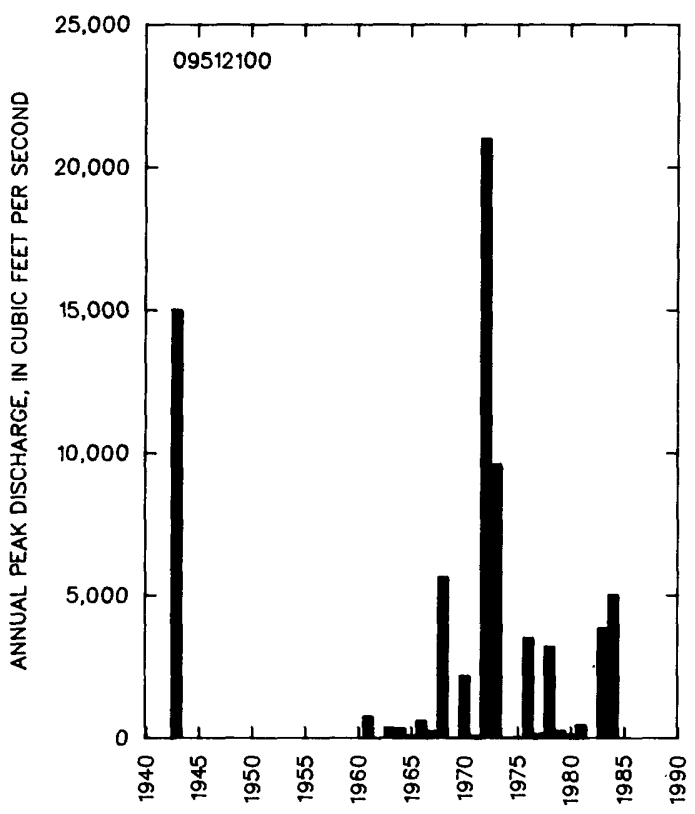

\begin{tabular}{|c|c|c|c|c|c|c|c|}
\hline \multirow{2}{*}{$\begin{array}{l}\text { MAIN } \\
\text { CHANNEL } \\
\text { SLOPE } \\
\text { (FT/MI) }\end{array}$} & \multirow[b]{2}{*}{$\begin{array}{c}\text { STREAM } \\
\text { LENGTH } \\
\text { (MI) }\end{array}$} & \multirow{2}{*}{$\begin{array}{l}\text { MEAN } \\
\text { BASIN } \\
\text { ELEVA- } \\
\text { TION } \\
\text { (FT) }\end{array}$} & \multirow[b]{2}{*}{$\begin{array}{l}\text { FORESTED } \\
\text { AREA } \\
\text { (PERCENT) }\end{array}$} & \multirow[b]{2}{*}{$\begin{array}{l}\text { SOIL } \\
\text { INDEX }\end{array}$} & \multirow{2}{*}{$\begin{array}{l}\text { MEAN } \\
\text { ANNUAL } \\
\text { PRECIPI- } \\
\text { TATION } \\
\text { (IN) }\end{array}$} & \multicolumn{2}{|c|}{ RAINFALL INTENSITY, 24-HOUR } \\
\hline & & & & & & $\begin{array}{c}\text { 2-YEAR } \\
\text { (IN) }\end{array}$ & $\begin{array}{l}\text { 50-YEAR } \\
\text { (IN) }\end{array}$ \\
\hline 60.0 & 23.3 & 1,780 & 0.0 & 2.4 & 10.9 & 1.7 & 3.7 \\
\hline
\end{tabular}




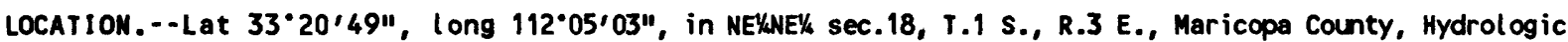
Unit 15060106, in South Mountain Park, on left bank 6.5 mi south of Phoenix main post office.

DRAINAGE AREA. $--1.75 \mathrm{mi}^{2}$.

ANMUAL PEAK DISCHARGE

\begin{tabular}{|c|c|c|c|c|c|c|c|}
\hline $\begin{array}{l}\text { WATER } \\
\text { YEAR }\end{array}$ & DATE & $\begin{array}{l}\text { ANNUAL PEAK } \\
\text { DI SCHARGE } \\
\left.\text { (FT }{ }^{3} / S\right)\end{array}$ & $\begin{array}{l}\text { DISCHARGE } \\
\text { CODES }\end{array}$ & $\begin{array}{l}\text { WATER } \\
\text { YEAR }\end{array}$ & DATE & $\begin{array}{l}\text { ANIUUAL PEAK } \\
\text { DISCHARGE } \\
\left(\mathrm{FT}^{3} / \mathrm{S}\right)\end{array}$ & $\begin{array}{l}\text { DISCHARGE } \\
\text { CODES }\end{array}$ \\
\hline $\begin{array}{l}1961 \\
1962 \\
1963 \\
1964 \\
1965 \\
1966 \\
1967 \\
1968 \\
1969 \\
1970 \\
1971 \\
1972 \\
1973 \\
1974 \\
1975\end{array}$ & $\begin{array}{l}07-22-61 \\
00-00-62 \\
00-00-63 \\
10-19-63 \\
09-04-65 \\
08-18-66 \\
09-03-67 \\
07-30-68 \\
00-00-69 \\
09-05-70 \\
00-00-71 \\
08-12-72 \\
11-11-72 \\
03-20-74 \\
10-29-74\end{array}$ & $\begin{array}{r}370 \\
0 \\
0 \\
530 \\
670 \\
194 \\
12 \\
81 \\
0 \\
77 \\
0 \\
2.0 \\
147 \\
114 \\
3.5\end{array}$ & & $\begin{array}{l}1976 \\
1977 \\
1978 \\
1979 \\
1980 \\
1981 \\
1982 \\
1983 \\
1984 \\
1985 \\
1986 \\
1987 \\
1988 \\
1989\end{array}$ & $\begin{array}{l}09-23-76 \\
10-23-76 \\
12-29-77 \\
00-00-79 \\
00-00-80 \\
00-00-81 \\
10-01-81 \\
11-30-82 \\
07-27-84 \\
07-16-85 \\
00-00-86 \\
00-00-87 \\
11-01-87 \\
10-14-88\end{array}$ & $\begin{array}{c}70 \\
5.0 \\
86 \\
0 \\
0 \\
0 \\
133 \\
44 \\
644 \\
7.0 \\
0 \\
0 \\
94 \\
9.2\end{array}$ & ES \\
\hline
\end{tabular}

BASIN CHARACTERISTICS

\begin{tabular}{|c|c|c|c|c|c|c|c|}
\hline MAIN & & $\begin{array}{l}\text { MEAN } \\
\text { BASIN }\end{array}$ & & & $\begin{array}{l}\text { MEAN } \\
\text { ANNUAL }\end{array}$ & RAINFALL II & SITY, 24-HOUR \\
\hline $\begin{array}{l}\text { CHANMEL } \\
\text { SLOPE } \\
\text { (FT/MI) }\end{array}$ & $\begin{array}{c}\text { STREAM } \\
\text { LENGTH } \\
\text { (MI) }\end{array}$ & $\begin{array}{l}\text { ELEVA- } \\
\text { TION } \\
\text { (FT) }\end{array}$ & $\begin{array}{l}\text { FORESTED } \\
\text { AREA } \\
\text { (PERCENT) }\end{array}$ & $\begin{array}{l}\text { SOIL } \\
\text { INDEX }\end{array}$ & $\begin{array}{l}\text { PRECIPI- } \\
\text { TATION } \\
\text { (IN) }\end{array}$ & $\begin{array}{l}\text { 2-YEAR } \\
\text { (IN) }\end{array}$ & $\begin{array}{c}\text { 50-YEAR } \\
\text { (IN) }\end{array}$ \\
\hline 244 & 2.1 & 1,730 & 0.0 & 1.0 & 9.0 & 1.6 & 3.6 \\
\hline
\end{tabular}


09512200 SALT RIVER tRIBUTARY IN SOUTH MOUNTAIN PARK, AT PHOENIX, NZ--Cont inued

MEAN MONTHLY AND ANNUAL DISCHARGES 1961-89

\begin{tabular}{|c|c|c|c|c|c|c|}
\hline MONTH & $\begin{array}{l}\operatorname{MAXIMUN} \\
\left(F^{3} / S\right)\end{array}$ & $\begin{array}{l}\text { MINIMUN } \\
\left(F^{3} / S\right)\end{array}$ & $\begin{array}{c}\text { MEAN } \\
\left(F T^{3} / S\right)\end{array}$ & $\begin{array}{l}\text { STAN- } \\
\text { DARD } \\
\text { DEVIA- } \\
\text { TION } \\
\left.\text { (FT }{ }^{3} / S\right)\end{array}$ & $\begin{array}{l}\text { COEFFI- } \\
\text { CIENT OF } \\
\text { VARI - } \\
\text { ATION }\end{array}$ & $\begin{array}{c}\text { PERCENT } \\
\text { OF } \\
\text { ANNUAL } \\
\text { RUNOFF }\end{array}$ \\
\hline $\begin{array}{l}\text { OCTOBER } \\
\text { NOVEMBER } \\
\text { OECEMBER } \\
\text { JANUARY } \\
\text { FEBRUARY } \\
\text { MARCH } \\
\text { APRIL } \\
\text { MAY } \\
\text { JUNE } \\
\text { JULY } \\
\text { AUGUST } \\
\text { SEPTEMBER }\end{array}$ & $\begin{array}{l}0.26 \\
0.15 \\
0.03 \\
0.01 \\
0.00 \\
0.07 \\
0.00 \\
0.00 \\
0.01 \\
0.84 \\
0.39 \\
0.27\end{array}$ & $\begin{array}{l}0.00 \\
0.00 \\
0.00 \\
0.00 \\
0.00 \\
0.00 \\
0.00 \\
0.00 \\
0.00 \\
0.00 \\
0.00 \\
0.00\end{array}$ & $\begin{array}{l}0.02 \\
0.01 \\
0.00 \\
0.00 \\
0.00 \\
0.00 \\
0.00 \\
0.00 \\
0.00 \\
0.04 \\
0.02 \\
0.02\end{array}$ & $\begin{array}{l}0.06 \\
0.03 \\
0.01 \\
0.00 \\
0.00 \\
0.01 \\
0.00 \\
0.00 \\
0.00 \\
0.16 \\
0.08 \\
0.07\end{array}$ & $\begin{array}{l}3.2 \\
3.6 \\
3.5 \\
5.4 \\
4.2\end{array}$ & $\begin{array}{r}17.1 \\
7.4 \\
1.5 \\
0.3 \\
0.0 \\
2.6 \\
0.0 \\
0.0 \\
0.3 \\
34.1 \\
16.2 \\
20.6\end{array}$ \\
\hline ANMUAL & 0.07 & 0.00 & 0.01 & 0.02 & 1.9 & 100 \\
\hline
\end{tabular}

MAGNITLE AND PROBABILITY OF INSTANTANEOUS PEAK FLON BASED ON PERIOO OF RECORD 1961-89

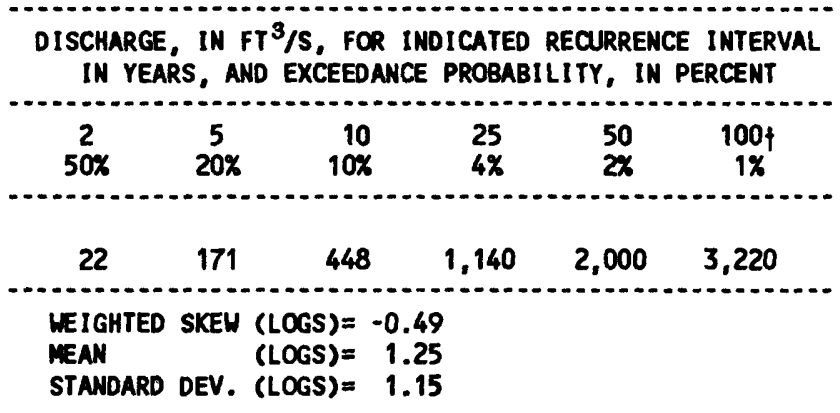

MAGITLDE AND PROBABILITY OF ANMUAL LON FLOH BASED ON PERIOD OF RECORD 1962-89

\begin{tabular}{|c|c|c|c|c|c|c|}
\hline \multirow{2}{*}{$\begin{array}{l}\text { PERIOD } \\
\text { (CON- } \\
\text { SECU- } \\
\text { TIVE } \\
\text { DAYS) }\end{array}$} & \multicolumn{6}{|c|}{$\begin{array}{l}\text { DISCHARGE, IN } \mathrm{FT}^{3} / \mathrm{S} \text {, FOR INDICATED } \\
\text { RECURRENCE INTERVAL, IN YEARS, AND } \\
\text { NON-EXCEEDANCE PROBABILITY, IN PERCENT }\end{array}$} \\
\hline & $\stackrel{2}{20 x}$ & $\begin{array}{c}5 \\
20 x\end{array}$ & $\begin{array}{l}10 \\
10 \%\end{array}$ & $\begin{array}{l}20 \\
5 \%\end{array}$ & $\begin{array}{l}50 \\
2 x\end{array}$ & $\begin{array}{l}10 \\
1 \%\end{array}$ \\
\hline
\end{tabular}

MAGKITUDE AND PROBABILITY OF AMNUAL HIGH FLON BASED ON PERIOD OF RECORD 1961-89

\begin{tabular}{|c|c|c|c|c|c|c|}
\hline \multirow{2}{*}{$\begin{array}{l}\text { PERIOD } \\
\text { (CON- } \\
\text { SECU- } \\
\text { TIVE } \\
\text { DAYS) }\end{array}$} & & \multicolumn{5}{|c|}{$\begin{array}{l}\text { DISCHARGE, IN FT }{ }^{3} / S \text {, FOR INDICATED } \\
\text { RECURRENCE INTERVAL, IN YEARS, AND } \\
\text { EXCEEDANCE PROBABILITY, IN PERCENT }\end{array}$} \\
\hline & $\stackrel{2}{50 x}$ & $\begin{array}{c}5 \\
20 \%\end{array}$ & $\begin{array}{l}10 \\
10 \%\end{array}$ & $\begin{array}{l}25 \\
4 \%\end{array}$ & $\begin{array}{l}50 \\
2 x\end{array}$ & $\begin{array}{c}100 \dagger \\
1 \%\end{array}$ \\
\hline $\begin{array}{r}1 \\
3 \\
7 \\
15 \\
30 \\
60 \\
90\end{array}$ & $\begin{array}{l}0.46 \\
0.17 \\
0.08 \\
0.03 \\
0.01 \\
0.00 \\
0.00\end{array}$ & $\begin{array}{l}3.3 \\
1.2 \\
0.52 \\
0.26 \\
0.15 \\
0.08 \\
0.05\end{array}$ & $\begin{array}{l}7.7 \\
2.7 \\
1.1 \\
0.55 \\
0.29 \\
0.16 \\
0.11\end{array}$ & $\begin{array}{l}16 \\
5.6 \\
2.3 \\
1.1 \\
0.58 \\
0.33 \\
0.22\end{array}$ & $\begin{array}{l}26 \\
8.8 \\
3.5 \\
1.7 \\
0.84 \\
0.50 \\
0.32\end{array}$ & $\begin{array}{l}39 \\
13 \\
5.1 \\
2.4 \\
1.2 \\
0.75 \\
0.47\end{array}$ \\
\hline
\end{tabular}

DURATION TABLE OF DAILY MEAN FLON FOR PERIOD OF RECORD 1961-89

DISCHARGE, IN FT $3 / \mathrm{S}$, WHICH WAS EQUALED OR EXCEEDED FOR INDICATED PERCENT OF TIME

\begin{tabular}{|c|c|c|c|c|c|c|c|c|c|c|c|c|c|c|c|c|}
\hline $1 \%$ & $5 \%$ & $10 x$ & $15 \%$ & $20 \%$ & $30 \%$ & $40 \%$ & $50 \%$ & $60 \%$ & $70 \%$ & $80 \%$ & $90 \%$ & $95 \%$ & $98 \%$ & $99 \%$ & $99.5 \%$ & $99.9 \%$ \\
\hline 0.00 & 0.00 & 0.00 & 0.00 & 0.00 & 0.00 & 0.00 & 0.00 & 0.00 & 0.00 & 0.00 & 0.00 & 0.00 & 0.00 & 0.00 & 0.00 & 0.00 \\
\hline
\end{tabular}

$\uparrow$ Reliability of values in colum is uncertain, and potential errors are large. 

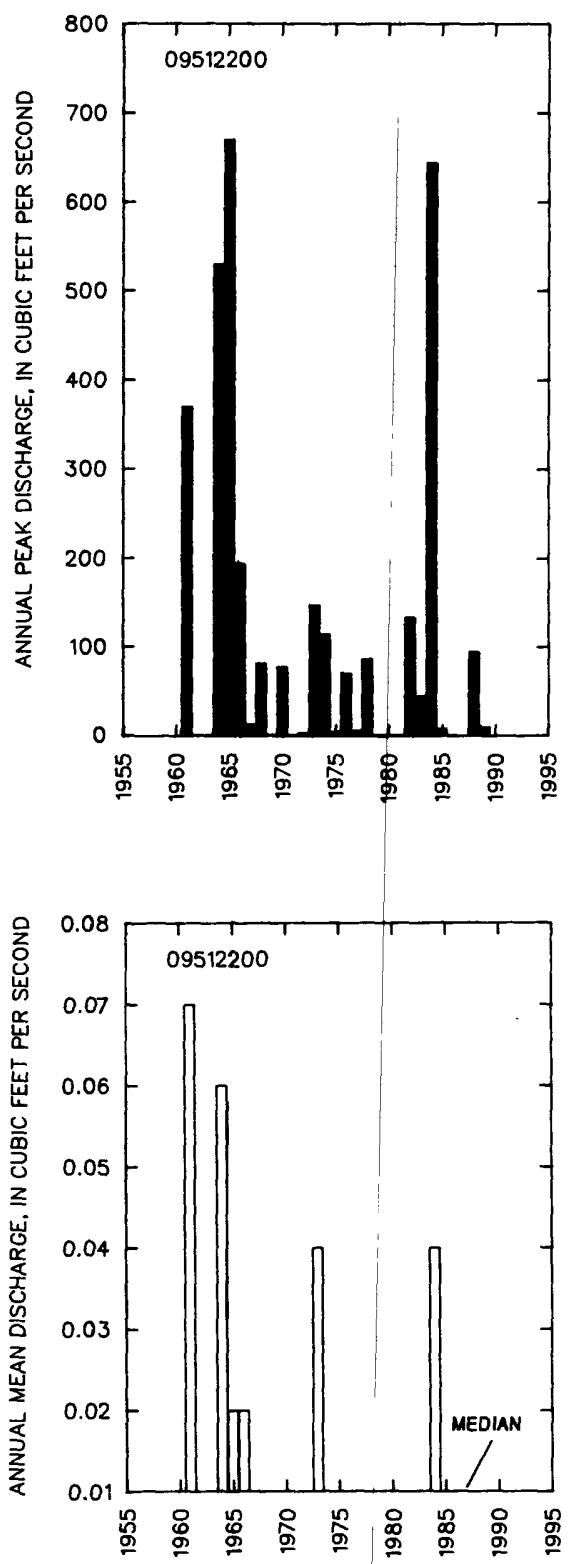
09512200 SALT RIVER tRIBUtARY IN SOUTH MOUNTAIN PARK, AT PHOENIX, AZ--CONTIMUED
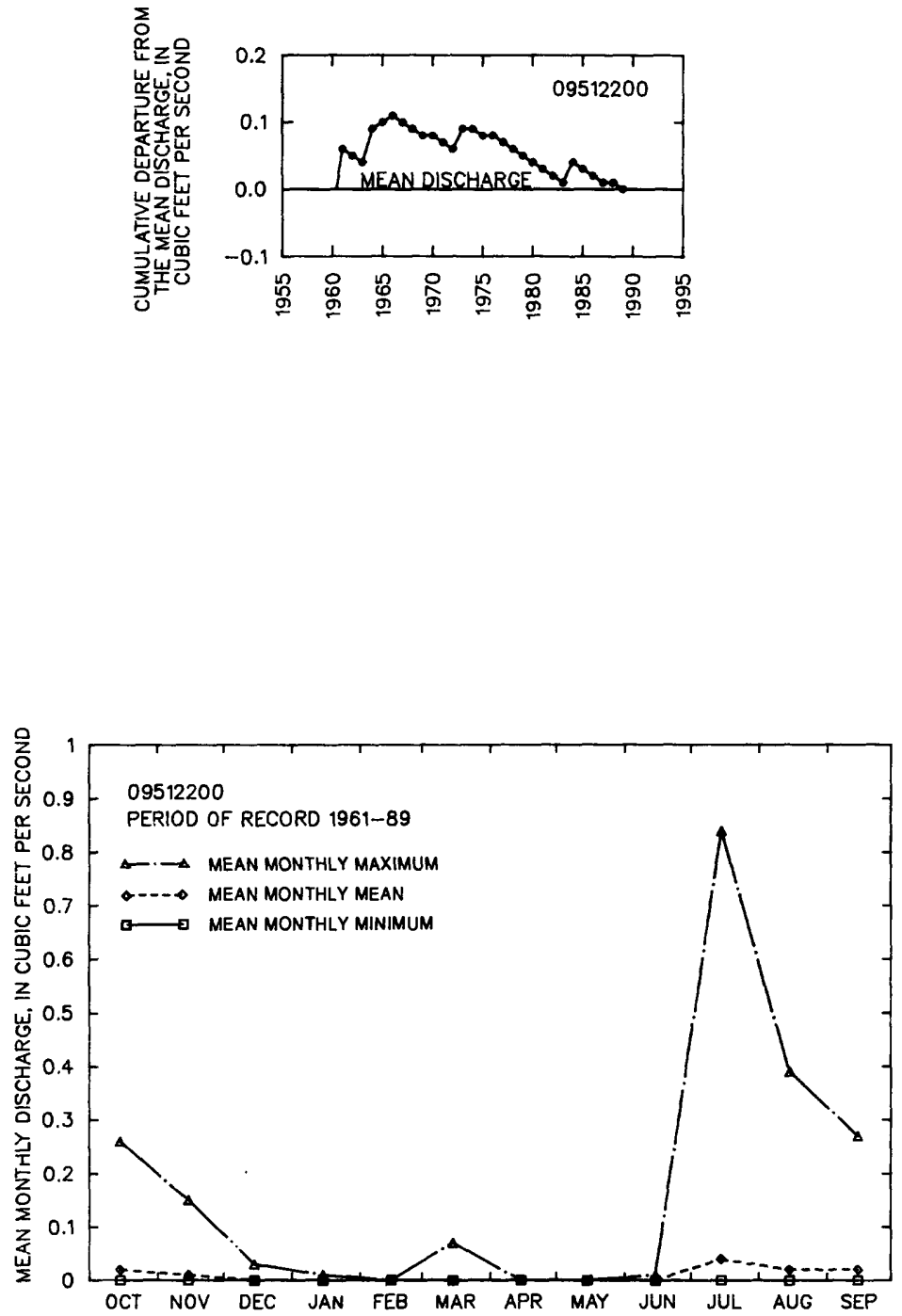


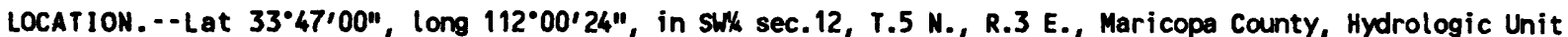
15060106, on left benk, $200 \mathrm{ft}$ upstream from Prescott-to-Mesa transmission line, $5 \mathrm{mi}$ southwest of town of Cave Creek, and 5.0 mi upstream from Cave Creek Dam.

DRAIMAGE AREA. $--121 \mathrm{mi}^{2}$.

ANNUAL PEAK DISCHARGE

\begin{tabular}{|c|c|c|c|c|c|}
\hline $\begin{array}{l}\text { WATER } \\
\text { YEAR }\end{array}$ & DATE & $\begin{array}{c}\text { ANNUAL PEAK } \\
\text { DISCHARGE } \\
\text { (FT } 3 / \mathrm{S})\end{array}$ & $\begin{array}{l}\text { WATER } \\
\text { YEAR }\end{array}$ & DATE & $\begin{array}{l}\text { ANMUALL PEAK } \\
\text { DISCHARGE } \\
\text { (FT } 3 / \mathrm{S})\end{array}$ \\
\hline $\begin{array}{l}1958 \\
1959 \\
1960 \\
1961 \\
1962 \\
1963 \\
1964 \\
1965 \\
1966 \\
1967 \\
1968 \\
1969 \\
1970 \\
1971 \\
1972 \\
1973\end{array}$ & $\begin{array}{l}09-12-58 \\
08-05-59 \\
10-29-59 \\
09-17-61 \\
12-16-61 \\
08-06-63 \\
08-02-64 \\
07-16-65 \\
12-22-65 \\
09-06-67 \\
12-19-67 \\
00-00-69 \\
09-05-70 \\
08-04-71 \\
07-17-72 \\
10-19-72\end{array}$ & $\begin{array}{r}5,680 \\
3,590 \\
8,570 \\
696 \\
280 \\
1,510 \\
3,120 \\
610 \\
6,000 \\
1,800 \\
12,400 \\
0 \\
2,700 \\
364 \\
3,950 \\
3,950\end{array}$ & $\begin{array}{l}1974 \\
1975 \\
1976 \\
1977 \\
1978 \\
1979 \\
1981 \\
1982 \\
1983 \\
1984 \\
1985 \\
1986 \\
1987 \\
1988 \\
1989\end{array}$ & $\begin{array}{l}08-05-74 \\
11-02-74 \\
02-09-76 \\
00-00-77 \\
03-02-78 \\
12-18-78 \\
00-00-81 \\
10-02-81 \\
03-03-83 \\
08-09-84 \\
12-27-84 \\
07-22-86 \\
00-00-87 \\
08-21-88 \\
00-00-89\end{array}$ & $\begin{array}{r}1,390 \\
856 \\
1,260 \\
0 \\
0 \\
7,500 \\
6,900 \\
0 \\
1,200 \\
1,420 \\
148 \\
910 \\
1,350 \\
0 \\
170 \\
0\end{array}$ \\
\hline
\end{tabular}

MAGNITUDE AND PROBABILITY OF INSTANTANEOUS PEAK FLOW BASED ON PERIOD OF RECORD 1958-79, 1981-86

DISCHARGE, IN $\mathrm{FT}^{3} / \mathrm{S}$, FOR INDICATED RECURRENCE INTERVAL IN YEARS, AND EXCEEDANCE PROBABILITY, IN PERCENT

\begin{tabular}{|c|c|c|c|c|c|}
\hline $\begin{array}{c}2 \\
50 \%\end{array}$ & $\begin{array}{c}5 \\
20 \%\end{array}$ & $\begin{array}{r}10 \\
10 \%\end{array}$ & $\begin{array}{l}25 \\
4 \%\end{array}$ & $\begin{array}{l}50 \\
2 \%\end{array}$ & $\begin{array}{c}100 \dagger \\
1 \%\end{array}$ \\
\hline 1,740 & 4,320 & 6,870 & 11,200 & 15,200 & 20,000 \\
\hline $\begin{array}{l}\text { WEIGHTED } \\
\text { MEAN } \\
\text { STANDARD }\end{array}$ & $\begin{array}{l}\text { SKEW } \\
\text { DEV. }\end{array}$ & $\begin{array}{l}\text { OGS) }= \\
O(S)= \\
\text { OGS) }=\end{array}$ & $\begin{array}{r}-0.12 \\
3.23 \\
0.48\end{array}$ & & \\
\hline
\end{tabular}

f Reliability of values in column is uncertain, and potential errors are large.

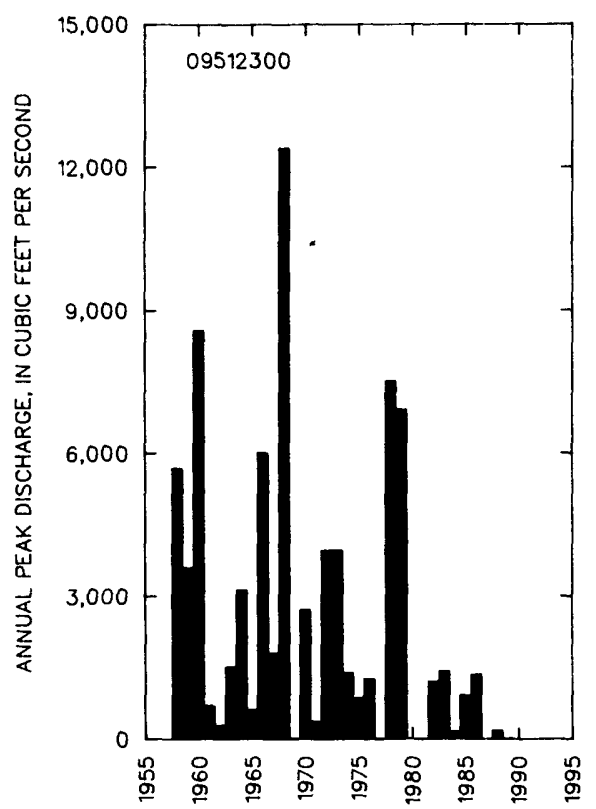

BASIN CHARACTERISTICS

\begin{tabular}{|c|c|c|c|c|c|c|c|}
\hline MAIN & & $\begin{array}{l}\text { MEAN } \\
\text { BASIN }\end{array}$ & & & $\begin{array}{l}\text { MEAN } \\
\text { ANHUAL }\end{array}$ & RAINFALL If & SITY, 24-HOUR \\
\hline $\begin{array}{l}\text { CHANNEL } \\
\text { SLOPE } \\
\text { (FT/MI) }\end{array}$ & $\begin{array}{l}\text { STREAM } \\
\text { LENGTH } \\
\text { (M1) }\end{array}$ & $\begin{array}{l}\text { ELEVA- } \\
\text { TION } \\
\text { (FT) }\end{array}$ & $\begin{array}{l}\text { FORESTED } \\
\text { AREA } \\
\text { (PERCENT) }\end{array}$ & $\begin{array}{l}\text { SOIL } \\
\text { INDEX }\end{array}$ & $\begin{array}{l}\text { PRECIPI - } \\
\text { TATION } \\
\text { (IN) }\end{array}$ & $\begin{array}{c}\text { 2-YEAR } \\
\text { (IN) }\end{array}$ & $\begin{array}{l}\text { 50-YEAR } \\
\text { (IN) }\end{array}$ \\
\hline 123 & 18.4 & 3,470 & 0.1 & 1.17 & 15.7 & 2.3 & 4.4 \\
\hline
\end{tabular}


09512420 LYNX CREEK TRIBUTARY MEAR PRESCOTT, AZ

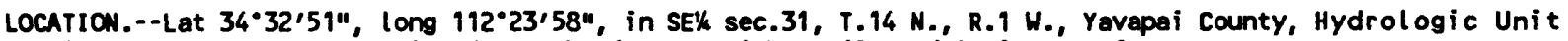
15060202, on Walker Road, $400 \mathrm{ft}$ south of State Highway 69, and $4 \mathrm{mi}$ east of Prescott.

DRAIMAGE AREA. $-0.95 \mathrm{mi}^{2}$.

ANNUAL PEAK DISCHARGE

\begin{tabular}{cccc}
$\begin{array}{l}\text { WATER } \\
\text { YEAR }\end{array}$ & DATE & $\begin{array}{c}\text { ANNLAL PEAK } \\
\text { DISCHARGE } \\
\text { (FT 3/S) }\end{array}$ & $\begin{array}{c}\text { DISCHARGE } \\
\text { CODES }\end{array}$ \\
\hline 1967 & $00-00-67$ & 820 & \\
1968 & $00-00-68$ & 300 & ES \\
1969 & $09-13-69$ & 10 & ES \\
1970 & $09-04-70$ & 205 & \\
1971 & $08-00-71$ & 160 & \\
1972 & $08-00-72$ & 320 & \\
1973 & $10-07-72$ & 130 & \\
1974 & $07-20-74$ & 155 & \\
1975 & $00-00-75$ & 0 & \\
1976 & $02-09-76$ & 12 & \\
\hline
\end{tabular}

MAGNI TUDE AND PROBABILITY OF INSTANTANEOUS PEAK FLOW BASED ON PERIOD OF RECORD 1967-76

DISCHARGE, IN $\mathrm{FT}^{3} / \mathrm{S}$, FOR INDICATED RECURRENCE INTERVAL

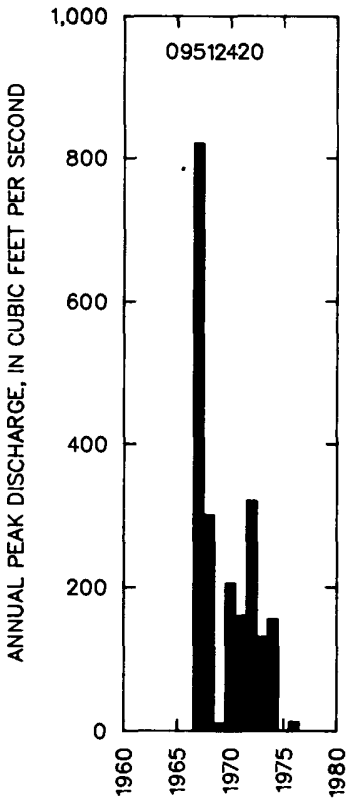
IN YEARS, AND EXCEEDANCE PROBABILITY, IN PERCENT

\begin{tabular}{|c|c|c|c|c|c|}
\hline$\stackrel{2}{2}$ & $\begin{array}{c}5 \\
20 x\end{array}$ & $\begin{array}{r}10 \\
10 \%\end{array}$ & $\begin{array}{l}25 \dagger \\
4 x\end{array}$ & $\begin{array}{l}50\} \\
2 \%\end{array}$ & $\begin{array}{c}100 \nmid \\
1 \%\end{array}$ \\
\hline 106 & 403 & 761 & 1,430 & 2,100 & 2,910 \\
\hline $\begin{array}{l}\text { MEAN } \\
\text { STANDARD }\end{array}$ & $\begin{array}{l}\text { SKEH } \\
\text { DEV. }\end{array}$ & $\begin{array}{l}(\text { LOGS })= \\
(\text { LOGS })= \\
(\text { LOGS })=\end{array}$ & $\begin{array}{r}-0.41 \\
1.97 \\
0.74\end{array}$ & & \\
\hline
\end{tabular}

+ Reliability of values in column is uncertain, and potential errors are large.

\section{BASIN CHARACTERISTICS}

\begin{tabular}{|c|c|c|c|c|c|c|c|}
\hline \multirow{2}{*}{$\begin{array}{l}\text { MAIN } \\
\text { CHANNEL } \\
\text { SLOPE } \\
\text { (FT/MI) }\end{array}$} & \multirow[b]{2}{*}{$\begin{array}{l}\text { STREAM } \\
\text { LENGTH } \\
\text { (MI) }\end{array}$} & \multirow{2}{*}{$\begin{array}{l}\text { MEAN } \\
\text { BASIN } \\
\text { ELEVA- } \\
\text { TION } \\
\text { (FT) }\end{array}$} & \multirow[b]{2}{*}{$\begin{array}{l}\text { FORESTED } \\
\text { AREA } \\
\text { (PERCENT) }\end{array}$} & \multirow[b]{2}{*}{$\begin{array}{l}\text { SOIL } \\
\text { INDEX }\end{array}$} & \multirow{2}{*}{$\begin{array}{l}\text { MEAN } \\
\text { ANNUAL } \\
\text { PRECIPI- } \\
\text { TATION } \\
\text { (IN) }\end{array}$} & \multicolumn{2}{|c|}{ RAINFALL INTENSITY, 24-HOUR } \\
\hline & & & & & & $\begin{array}{c}\text { 2-YEAR } \\
\text { (IN) }\end{array}$ & $\begin{array}{l}\text { 50-YEAR } \\
\text { (IN) }\end{array}$ \\
\hline 101 & 2.2 & 5,900 & 26.0 & 1.0 & 16.0 & 2.1 & 4.4 \\
\hline
\end{tabular}




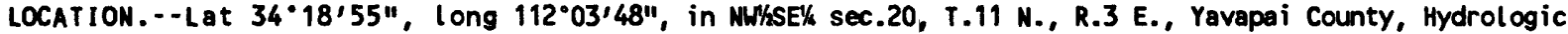
Unit 15070102, on left bank at Sycamore damsite, $700 \mathrm{ft}$ downstream from Big Bug Creek and 12 mi southeast of Mayer.

DRAINAGE AREA. $--585 \mathrm{mi}^{2}$.

REMARKS.--Diversions above station for mining and irrigation of about 600 acres. Perry Canal, which previously headed $300 \mathrm{ft}$ above the gage, was washed out on July 11, 1977, and was not rebuilt.

ANNUAL PEAK DISCHARGE

\begin{tabular}{|c|c|c|c|c|}
\hline $\begin{array}{l}\text { WATER } \\
\text { YEAR }\end{array}$ & $\begin{array}{cc} & \text { ANNUAL PEAK } \\
& \text { DISCHARGE } \\
\text { DATE } & \left(\mathrm{FT}^{3} / \mathrm{S}\right)\end{array}$ & $\begin{array}{l}\text { WATER } \\
\text { YEAR }\end{array}$ & DATE & $\begin{array}{l}\text { ANNUAL PEAK } \\
\text { DISCHARGE } \\
\left(\mathrm{FT}^{3} / \mathrm{S}\right)\end{array}$ \\
\hline $\begin{array}{l}1940 \\
1941 \\
1942 \\
1943 \\
1944 \\
1945 \\
1946 \\
1947 \\
1948 \\
1949 \\
1950 \\
1951 \\
1952 \\
1953 \\
1954 \\
1955 \\
1956 \\
1957 \\
1958 \\
1959 \\
1960 \\
1961 \\
1962 \\
1963 \\
1964\end{array}$ & $\begin{array}{l}06-26-40 \\
03-01-41 \\
08-06-42 \\
09-25-43 \\
09-16-44 \\
07-27-45 \\
07-22-46 \\
08-16-47 \\
08-04-48 \\
01-13-49 \\
07-17-50 \\
08-28-51 \\
01-18-52 \\
07-08-53 \\
09-03-54 \\
08-03-55 \\
07-25-56 \\
08-13-57 \\
06-21-58 \\
08-04-59 \\
08-08-60 \\
07-22-61 \\
09-13-62 \\
08-19-63 \\
07-24-64\end{array}$ & $\begin{array}{l}1965 \\
1966 \\
1967 \\
1968 \\
1969 \\
1970 \\
1971 \\
1972 \\
1973 \\
1974 \\
1975 \\
1976 \\
1977 \\
1978 \\
1979 \\
1980 \\
1981 \\
1982 \\
1983 \\
1984 \\
1985 \\
1986 \\
1987 \\
1988 \\
1989\end{array}$ & $\begin{array}{l}04-04-65 \\
12-22-65 \\
08-19-67 \\
12-19-67 \\
08-07-69 \\
09-05-70 \\
08-25-71 \\
08-12-72 \\
10-07-72 \\
07-20-74 \\
07-27-75 \\
02-09-76 \\
08-23-77 \\
03-01-78 \\
12-18-78 \\
02-19-80 \\
09-23-81 \\
09-10-82 \\
09-23-83 \\
08-14-84 \\
12-27-84 \\
11-26-85 \\
10-11-86 \\
08-29-88 \\
08-18-89\end{array}$ & $\begin{array}{r}7,470 \\
12,100 \\
6,960 \\
3,850 \\
2,490 \\
19,800 \\
7,280 \\
6,800 \\
10,700 \\
740 \\
2,190 \\
9,700 \\
5,480 \\
9,900 \\
18,300 \\
33,100 \\
2,850 \\
3,040 \\
9,940 \\
3,620 \\
2,880 \\
3,970 \\
6,070 \\
25,500 \\
1,280\end{array}$ \\
\hline
\end{tabular}

BASIN CHARACTERISTICS

\begin{tabular}{|c|c|c|c|c|c|c|c|}
\hline \multirow{2}{*}{$\begin{array}{l}\text { MAIN } \\
\text { CHANNEL } \\
\text { SLOPE } \\
\text { (FT/MI) }\end{array}$} & \multirow[b]{2}{*}{$\begin{array}{l}\text { STREAM } \\
\text { LENGTH } \\
\text { (MI) }\end{array}$} & \multirow{2}{*}{$\begin{array}{l}\text { MEAN } \\
\text { BASIN } \\
\text { ELEVA- } \\
\text { TION } \\
\text { (FT) }\end{array}$} & \multirow[b]{2}{*}{$\begin{array}{l}\text { FORESTED } \\
\text { AREA } \\
\text { (PERCENT) }\end{array}$} & \multirow[b]{2}{*}{$\begin{array}{l}\text { SOIL } \\
\text { INDEX }\end{array}$} & \multirow{2}{*}{$\begin{array}{l}\text { MEAN } \\
\text { ANNUAL } \\
\text { PRECIPI- } \\
\text { TATION } \\
\text { (IN) }\end{array}$} & \multicolumn{2}{|c|}{ RAINFALL INTENSITY, 24-HOUR } \\
\hline & & & & & & $\begin{array}{l}\text { 2-YEAR } \\
\text { (IN) }\end{array}$ & $\begin{array}{c}\text { 50-YEAR } \\
\text { (IN) }\end{array}$ \\
\hline 56.9 & 37.5 & 5,000 & 3.4 & 1.3 & 16.7 & 2.1 & 4.3 \\
\hline
\end{tabular}


09512500 ACUA FRIA RIVER MEAR MAYER, AZ--Continued

MEAN MONTHLY AND AMMUAL DISCHARGES 1941-89

\begin{tabular}{|c|c|c|c|c|c|c|}
\hline MONTH & $\begin{array}{l}\operatorname{MAx} \operatorname{ImMN}_{3} \\
(\mathrm{FT} / \mathrm{S})\end{array}$ & $\begin{array}{l}\text { MINIIIUM } \\
\left(F^{3} / S\right)\end{array}$ & $\begin{array}{c}\text { MEAN } \\
\left(\mathrm{FT}^{3} / \mathrm{S}\right)\end{array}$ & $\begin{array}{l}\text { STAN- } \\
\text { DARD } \\
\text { DEVIA- } \\
\text { TION } \\
\left(\mathrm{FT}^{3} / \mathrm{S}\right)\end{array}$ & $\begin{array}{l}\text { COEFFI- } \\
\text { CIENT OF } \\
\text { VARI- } \\
\text { ATION }\end{array}$ & $\begin{array}{c}\text { PERCENT } \\
\text { OF } \\
\text { ANNUAL } \\
\text { RUNOFF }\end{array}$ \\
\hline $\begin{array}{l}\text { OCTOBER } \\
\text { MOVEMBER } \\
\text { DECEMBER } \\
\text { JANUARY } \\
\text { FEBRUARY } \\
\text { MARCH } \\
\text { APRIL } \\
\text { MAY } \\
\text { JUNE } \\
\text { JULY } \\
\text { AUGUST } \\
\text { SEPTEMBER }\end{array}$ & $\begin{array}{r}223 \\
146 \\
453 \\
288 \\
1,180 \\
373 \\
314 \\
20 \\
23 \\
48 \\
244 \\
187\end{array}$ & $\begin{array}{l}0.14 \\
0.10 \\
0.08 \\
0.07 \\
0.02 \\
0.01 \\
0.00 \\
0.03 \\
0.01 \\
0.15 \\
0.31 \\
0.20\end{array}$ & $\begin{array}{l}10 \\
10 \\
34 \\
23 \\
53 \\
46 \\
22 \\
3.1 \\
2.3 \\
12 \\
37 \\
17\end{array}$ & $\begin{array}{c}33 \\
25 \\
87 \\
50 \\
173 \\
83 \\
58 \\
5.1 \\
3.7 \\
13 \\
52 \\
36\end{array}$ & $\begin{array}{l}3.2 \\
2.4 \\
2.6 \\
2.2 \\
3.3 \\
1.8 \\
2.7 \\
1.6 \\
1.7 \\
1.0 \\
1.4 \\
2.1\end{array}$ & $\begin{array}{r}3.7 \\
3.8 \\
12.6 \\
8.5 \\
19.7 \\
17.2 \\
8.0 \\
1.1 \\
0.8 \\
4.5 \\
13.7 \\
6.3\end{array}$ \\
\hline MU & 122 & 1.5 & 22 & 26 & 1.2 & 100 \\
\hline
\end{tabular}

MAGNITUDE AND PROBABILITY OF ANNUAL LOW FLON BASED ON PERIOD OF RECORD 1941-89

\begin{tabular}{|c|c|c|c|c|c|c|}
\hline \multirow{2}{*}{$\begin{array}{l}\text { PERIOD } \\
\text { (CON- } \\
\text { SECU- } \\
\text { TIVE } \\
\text { DAYS) }\end{array}$} & \multicolumn{6}{|c|}{$\begin{array}{l}\text { DISCHARGE, IN } \\
\text { RECURRENCE INTERVAL, IN YEARS, AND } \\
\text { NOW-EXCEEDANCE PROBABILITY, IN PERCENT }\end{array}$} \\
\hline & $\begin{array}{c}2 \\
50 \%\end{array}$ & $\begin{array}{c}5 \\
20 \%\end{array}$ & $\begin{array}{l}10 \\
10 \%\end{array}$ & $\begin{array}{l}20 \\
5 \%\end{array}$ & $\begin{array}{l}50 \\
2 \%\end{array}$ & $\begin{array}{l}100 \uparrow \\
1 \%\end{array}$ \\
\hline $\begin{array}{r}1 \\
3 \\
7 \\
14 \\
30 \\
60 \\
90 \\
120 \\
183\end{array}$ & $\begin{array}{l}0.00 \\
0.00 \\
0.00 \\
0.00 \\
0.00 \\
0.57 \\
0.90 \\
1.9 \\
4.4\end{array}$ & $\begin{array}{l}0.00 \\
0.00 \\
0.00 \\
0.00 \\
0.00 \\
0.19 \\
0.29 \\
0.66 \\
1.6\end{array}$ & $\begin{array}{l}0.00 \\
0.00 \\
0.00 \\
0.00 \\
0.00 \\
0.11 \\
0.16 \\
0.34 \\
0.85\end{array}$ & $\begin{array}{l}0.00 \\
0.00 \\
0.00 \\
0.00 \\
0.00 \\
0.06 \\
0.09 \\
0.19 \\
0.48\end{array}$ & $\begin{array}{l}0.00 \\
0.00 \\
0.00 \\
0.00 \\
0.00 \\
0.03 \\
0.05 \\
0.09 \\
0.24\end{array}$ & $\begin{array}{l}0.00 \\
0.00 \\
0.00 \\
0.00 \\
0.00 \\
0.02 \\
0.03 \\
0.05 \\
0.15\end{array}$ \\
\hline
\end{tabular}

MAGNITLDE AND PROBABILITY OF ANNUAL HIGH FLOH BASED ON PERIOD OF RECORD 1941-89

\begin{tabular}{|c|c|c|c|c|c|c|}
\hline \multirow{2}{*}{$\begin{array}{l}\text { PERIOD } \\
\text { (CON- } \\
\text { SECU- } \\
\text { TIVE } \\
\text { DAYS) }\end{array}$} & \multicolumn{6}{|c|}{$\begin{array}{l}\text { DISCHARGE, IN } \mathrm{FT}^{3} / \mathrm{S} \text {, FOR INDICATED } \\
\text { RECURRENCE INTERVAL, IN YEARS, AND } \\
\text { EXCEEDANCE PROBABILITY, IN PERCENT }\end{array}$} \\
\hline & $\begin{array}{c}2 \\
50 \%\end{array}$ & $\begin{array}{c}5 \\
20 \%\end{array}$ & $\begin{array}{l}10 \\
10 \%\end{array}$ & $\begin{array}{l}25 \\
4 \%\end{array}$ & $\begin{array}{l}50 \\
2 \%\end{array}$ & $\begin{array}{c}100\} \\
1 \%\end{array}$ \\
\hline $\begin{array}{r}1 \\
3 \\
7 \\
15 \\
30 \\
60 \\
90\end{array}$ & $\begin{array}{r}793 \\
388 \\
216 \\
130 \\
83 \\
53 \\
38\end{array}$ & $\begin{array}{r}2,000 \\
998 \\
564 \\
333 \\
211 \\
134 \\
95\end{array}$ & $\begin{array}{r}3,290 \\
1,680 \\
946 \\
549 \\
343 \\
216 \\
155\end{array}$ & $\begin{array}{r}5,670 \\
2,970 \\
1,660 \\
943 \\
574 \\
356 \\
258\end{array}$ & $\begin{array}{r}8,110 \\
4,340 \\
2,390 \\
1,340 \\
799 \\
489 \\
359\end{array}$ & $\begin{array}{r}11,200 \\
6,150 \\
3,350 \\
1,850 \\
1,070 \\
649 \\
483\end{array}$ \\
\hline
\end{tabular}

DURATION TABLE OF DAILY MEAN FLOH FOR PERIOD OF RECORD 1941-89

DISCHARGE, IN FT 3/S, WHICH WAS EQUALED OR EXCEEDED FOR INDICATED PERCENT OF TIME

\begin{tabular}{|c|c|c|c|c|c|c|c|c|c|c|c|c|c|c|c|c|}
\hline $1 \%$ & $5 \%$ & $10 \%$ & $15 \%$ & $20 \%$ & $30 \%$ & $40 \%$ & $50 \%$ & $60 \%$ & $70 \%$ & $80 \%$ & $90 \%$ & $95 \%$ & $98 \%$ & $99 \%$ & $99.5 \%$ & $99.9 \%$ \\
\hline $0 z$ & 70 & 20 & 10 & 6.9 & 4.2 & 2.8 & 1.9 & 1.3 & 0.81 & 0.51 & 0.21 & 0.14 & 0.10 & 0.00 & 0.00 & .0 \\
\hline
\end{tabular}


09512500 AGUA FRIA RIVER NEAR MAYER, AZ--CONTINUEd
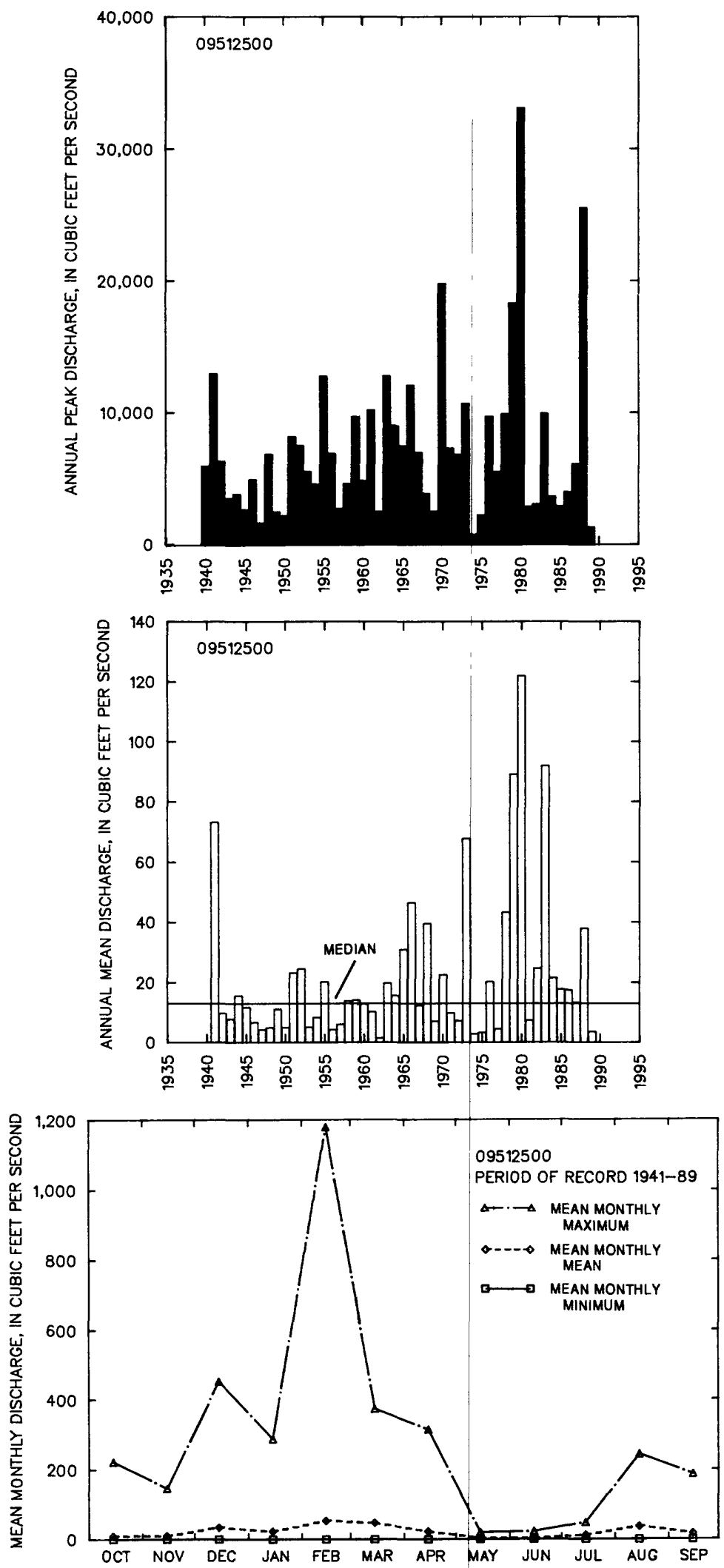
GILA RIVER BASIM

09512600 TURKEY CREEK NEAR CLEATOR, AZ

LOCATIOW.--34'16'56", long 112'12'25", in SWkSW/SEK sec.36, T.11 N., R.1 E (unsurveyed), Yavapai County, Hydrologic Unit 15070102, in Prescott National Forest, on right bank 0.7 mi upstream from Forest Route 259, $1.5 \mathrm{mi}$ east of Cleator, and $9.3 \mathrm{mi}$ south of Mayer.

DRAIMAGE AREA. $--89.4 \mathrm{MI}^{2}$.

ANNUAL PEAK DISCHARGE

\begin{tabular}{lcc}
$\begin{array}{c}\text { WATER } \\
\text { YEAR }\end{array}$ & DATE & $\begin{array}{c}\text { ANNUAL PEAK } \\
\text { DISCHARGE } \\
\text { (FT } 3 / \text { /S) }\end{array}$ \\
\hline 1980 & $02-19-80$ & 5,230 \\
1981 & $07-31-81$ & 127 \\
1982 & $08-23-82$ & 1,260 \\
1983 & $12-09-82$ & 1,840 \\
1984 & $09-10-84$ & 2,260 \\
1985 & $12-27-84$ & 648 \\
1986 & $06-01-86$ & 4,110 \\
1987 & $10-11-86$ & 530 \\
1988 & $08-23-88$ & 1,850 \\
1989 & $12-29-88$ & 1,720 \\
\hline
\end{tabular}

BASIN CHARACTERISTICS

\begin{tabular}{|c|c|c|c|c|c|c|c|}
\hline MAIN & & $\begin{array}{l}\text { MEAN } \\
\text { BASIN }\end{array}$ & & & $\begin{array}{l}\text { MEAN } \\
\text { ANNUAL }\end{array}$ & RAINFALL I & SITY, 24-HOUR \\
\hline $\begin{array}{l}\text { CHANNEL } \\
\text { SLOPE } \\
\text { (FT/MI) }\end{array}$ & $\begin{array}{l}\text { STREAM } \\
\text { LENGTH } \\
\text { (MI) }\end{array}$ & $\begin{array}{l}\text { ELEVA- } \\
\text { TION } \\
\text { (FT) }\end{array}$ & $\begin{array}{l}\text { FORESTED } \\
\text { AREA } \\
\text { (PERCENT) }\end{array}$ & $\begin{array}{l}\text { SOIL } \\
\text { INDEX }\end{array}$ & $\begin{array}{l}\text { PRECIPI- } \\
\text { TATION } \\
\text { (IN) }\end{array}$ & $\begin{array}{c}\text { 2-YEAR } \\
\text { (IN) }\end{array}$ & $\begin{array}{l}\text { 50-YEAR } \\
\text { (IN) }\end{array}$ \\
\hline 122 & 26.7 & 5,360 & 54.0 & 1.0 & 20.2 & 2.2 & 4.4 \\
\hline
\end{tabular}


MEAN MONTHLY AND ANMUAL DISCHARGES $1980-89$

\begin{tabular}{|c|c|c|c|c|c|c|}
\hline MONTH & 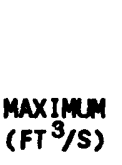 & $\begin{array}{l}\text { MINIMUM } \\
\left(F T^{3} / S\right)\end{array}$ & $\begin{array}{c}\text { MEAN } \\
\left(F T^{3} / S\right)\end{array}$ & $\begin{array}{l}\text { STAN- } \\
\text { DARD } \\
\text { DEVIA- } \\
\text { TIQN } \\
\left(\text { FT }^{3} / S\right)\end{array}$ & $\begin{array}{l}\text { COEFFI- } \\
\text { CIENT OF } \\
\text { VARI - } \\
\text { ATION }\end{array}$ & $\begin{array}{c}\text { PERCENT } \\
\text { OF } \\
\text { ANNUAL } \\
\text { RUNOFF }\end{array}$ \\
\hline $\begin{array}{l}\text { OCTOBER } \\
\text { NONEMBER } \\
\text { DECEMBER } \\
\text { JANUARY } \\
\text { FEBRUARY } \\
\text { MARCH } \\
\text { APRIL } \\
\text { MAY } \\
\text { JUNE } \\
\text { JULY } \\
\text { AUGUST } \\
\text { SEPTEMBER }\end{array}$ & $\begin{array}{c}7.9 \\
15 \\
106 \\
52 \\
420 \\
120 \\
39 \\
14 \\
3.5 \\
8.8 \\
47 \\
12\end{array}$ & $\begin{array}{l}0.00 \\
0.00 \\
0.00 \\
0.00 \\
0.00 \\
0.76 \\
0.42 \\
0.00 \\
0.00 \\
0.00 \\
0.06 \\
0.00\end{array}$ & $\begin{array}{l}1.3 \\
2.5 \\
18 \\
11 \\
61 \\
34 \\
9.8 \\
3.2 \\
0.92 \\
1.3 \\
7.5 \\
2.4\end{array}$ & $\begin{array}{c}2.6 \\
4.6 \\
33 \\
16 \\
130 \\
42 \\
13 \\
4.9 \\
1.3 \\
2.7 \\
15 \\
4.2\end{array}$ & $\begin{array}{l}2.0 \\
1.8 \\
1.9 \\
1.5 \\
2.1 \\
1.2 \\
1.3 \\
1.5 \\
1.4 \\
2.1 \\
1.9 \\
1.7\end{array}$ & $\begin{array}{r}0.9 \\
1.7 \\
11.5 \\
7.1 \\
40.3 \\
22.1 \\
6.4 \\
2.1 \\
0.6 \\
0.8 \\
4.9 \\
1.6\end{array}$ \\
\hline ANMUAL & 47 & 0.26 & 12 & 16 & 1.2 & 100 \\
\hline
\end{tabular}

MAGNITUDE AND PROBABILITY OF INSTANTANEQUS PEAK FLOW BASED ON PERIOD RECORD

DISCHARCE, IN $\mathrm{FT}^{3} / \mathrm{S}$, FOR INDICATED RECURRENCE INTERVAL IN YEARS, AND EXCEEDANCE PROBABILITY, IN PERCENT

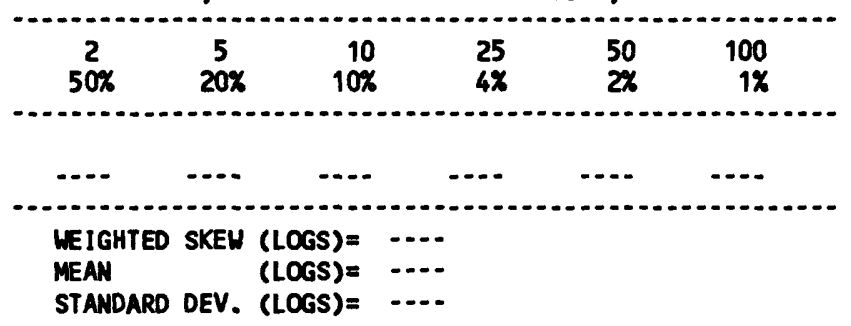

MANITLDE ANO PROBABILITY OF ANNUAL LOW FLOW BASED ON PERIOO OF RECORD 1981-89

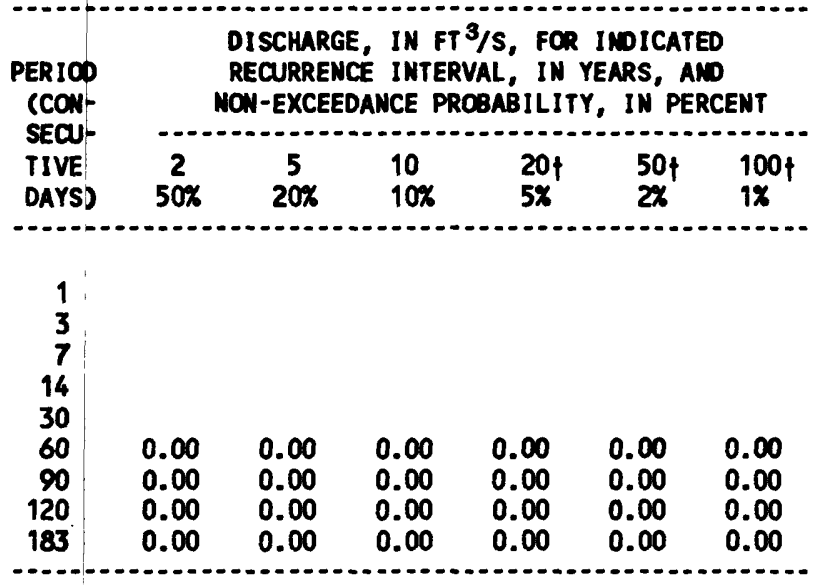

MACNITLDE AND PROBABILITY OF ANNUAL HIGH FLOW BASED ON PERIOO OF RECORD 1980-89

\begin{tabular}{|c|c|c|c|c|c|c|}
\hline \multirow{2}{*}{$\begin{array}{l}\text { PERICO } \\
\text { (CON- } \\
\text { SECU- } \\
\text { TIVE } \\
\text { DAYS) }\end{array}$} & & \multicolumn{5}{|c|}{$\begin{array}{l}\text { DISCHARCE, IN FT3/S, FOR INDICATED } \\
\text { RECURRENCE INTERVAL, IN YEARS, AND } \\
\text { EXCEEDANCE PROBABILITY, IN PERCENT }\end{array}$} \\
\hline & $\begin{array}{c}2 \\
50 x\end{array}$ & $\begin{array}{c}5 \\
20 \%\end{array}$ & $\begin{array}{l}10 \\
10 \%\end{array}$ & $\begin{array}{l}25 \dagger \\
4 \%\end{array}$ & $\begin{array}{l}50 \nmid \\
2 \%\end{array}$ & $\begin{array}{c}100 \uparrow \\
1 \%\end{array}$ \\
\hline $\begin{array}{r}1 \\
3 \\
7 \\
15 \\
30 \\
60 \\
90\end{array}$ & $\begin{array}{r}320 \\
165 \\
89 \\
56 \\
36 \\
23 \\
18\end{array}$ & $\begin{array}{r}776 \\
478 \\
300 \\
196 \\
127 \\
81 \\
62\end{array}$ & $\begin{array}{r}1,120 \\
780 \\
542 \\
355 \\
228 \\
148 \\
111\end{array}$ & $\begin{array}{r}1,530 \\
1,250 \\
984 \\
643 \\
404 \\
267 \\
194\end{array}$ & $\begin{array}{r}1,820 \\
1,660 \\
1,420 \\
923 \\
568 \\
383 \\
272\end{array}$ & $\begin{array}{r}2,080 \\
2,100 \\
1,960 \\
1,260 \\
758 \\
522 \\
361\end{array}$ \\
\hline
\end{tabular}

DURATION TABLE OF DAILY MEAN FLOW FOR PERIOD OF RECCRD 1980-89

DISCHARGE, IN FT $3 / \mathrm{S}$, WHICH WAS EQUALED OR EXCEEDED FOR INDICATED PERCENT OF TIME

\begin{tabular}{|c|c|c|c|c|c|c|c|c|c|c|c|c|c|c|c|c|}
\hline $1 x$ & $5 x$ & $10 x$ & $15 \%$ & $20 \%$ & $30 \%$ & $40 \%$ & $50 \%$ & $60 \%$ & $70 \%$ & $80 x$ & $90 x$ & $95 x$ & $98 \%$ & $99 x$ & $99.5 x$ & $99.9 \%$ \\
\hline 223 & 49 & 23 & 13 & 7.3 & 2.5 & 1.0 & 0.32 & 0.06 & 0.00 & 0.00 & 0.00 & 0.00 & 0.00 & 0.00 & 0.00 & .00 \\
\hline
\end{tabular}

I Reliability of values in column is uncertain, and potential errors are large. 
09512600 tURKEY CREEK NEAR CLEATOR, AZ--CONTIMUEd
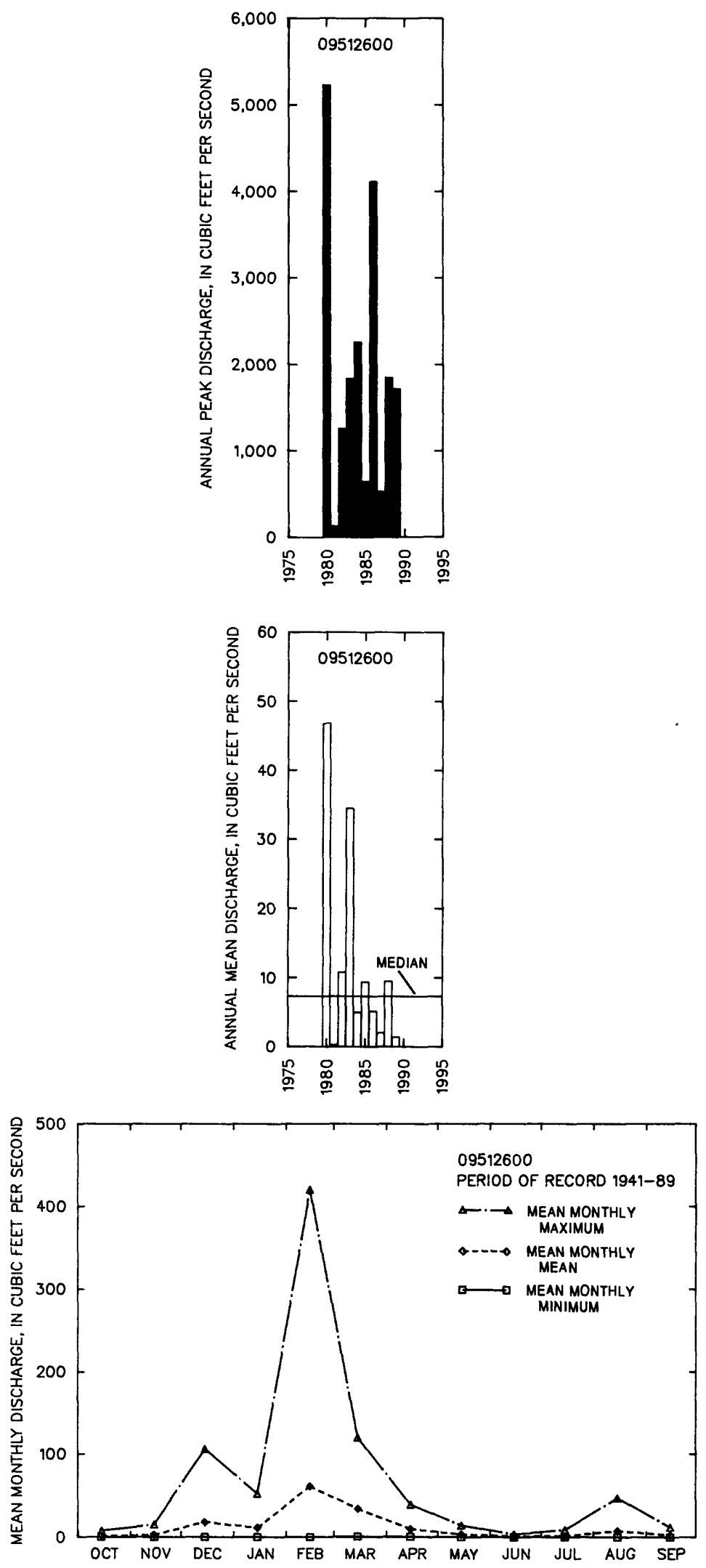
09512700 AGUA FRIA RIVER TRIBUTARY NO. 2 MEAR ROCK SPRINGS, AZ

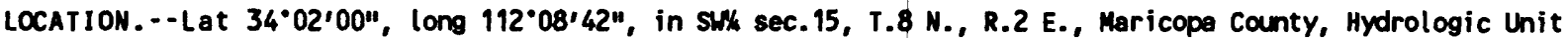
15070102, at State Highway 69, 1 mi south of Rock Springs.

DRAINAGE AREA. $--1.07 \mathrm{mi}^{2}$.

ANIUAL PEAK DISCHARGE

\begin{tabular}{ccc}
$\begin{array}{c}\text { WATER } \\
\text { YEAR }\end{array}$ & DATE & $\begin{array}{c}\text { ANNUAL PEAK } \\
\text { DISCHARGE } \\
\text { (FT 3/S) }\end{array}$ \\
\hline 1963 & $08-16-63$ & 411 \\
1964 & $08-02-64$ & 1,200 \\
1965 & $01-07-65$ & 87 \\
1966 & $09-13-66$ & 812 \\
1967 & $11-08-66$ & 225 \\
1968 & $12-19-67$ & 210 \\
1969 & $09-05-69$ & 400 \\
1970 & $07-21-70$ & 300 \\
1971 & $08-21-71$ & 285 \\
1972 & $07-17-72$ & 140 \\
1973 & $10-07-72$ & 285 \\
1974 & $08-02-74$ & 721 \\
1975 & $07-08-75$ & 175 \\
1976 & $09-26-76$ & 165 \\
1977 & $09-27-77$ & 46 \\
1978 & $03-02-78$ & 920 \\
1979 & $12-18-78$ & 265 \\
1980 & $02-00-80$ & 405 \\
\hline$\ldots$ & & \\
\hline
\end{tabular}

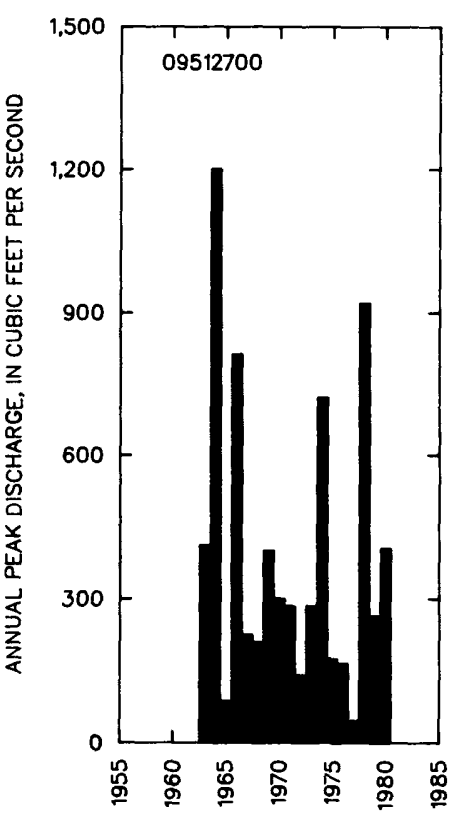

MAGNITUDE AND PROBABILITY OF INSTANTANEOUS PEAK FLOW BASED ON PERIOD OF RECORD 1963-80

DISCHARGE, IN $\mathrm{FT}^{3} / \mathrm{S}$, FOR INDICATED RECURRENCE INTERVAL IN YEARS, AND EXCEEDANCE PROBABILITY, IN PERCENT

\begin{tabular}{|c|c|c|c|c|c|}
\hline$\stackrel{2}{2}$ & $\begin{array}{c}5 \\
20 \%\end{array}$ & $\begin{array}{r}10 \\
10 x\end{array}$ & $\begin{array}{l}25 \\
4 x\end{array}$ & $\begin{array}{l}50 \nmid \\
2 x\end{array}$ & $\begin{array}{c}100 \nmid \\
1 \times\end{array}$ \\
\hline 309 & 565 & 781 & 1,110 & 1,400 & 1,730 \\
\hline $\begin{array}{l}\text { WEIGHTED } \\
\text { MEAN } \\
\text { STANDARD }\end{array}$ & $\begin{array}{l}\text { SKEW } \\
\text { DEV. }\end{array}$ & $\begin{array}{l}(\text { LOGS })= \\
(\text { LOGS })= \\
(\text { LOGS })=\end{array}$ & $\begin{array}{l}0.13 \\
2.50 \\
0.31\end{array}$ & & \\
\hline
\end{tabular}

t Reliability of values in colum is uncertain, and potential errors are large.

BASIN CNARACTERISTICS

\begin{tabular}{|c|c|c|c|c|c|c|c|}
\hline MAIN & & & & & & RAIMFALL I & SITY, 24-HOUR \\
\hline $\begin{array}{l}\text { CHANNEL } \\
\text { SLOPE } \\
\text { (FT/MI) }\end{array}$ & $\begin{array}{c}\text { STREAM } \\
\text { LENGTH } \\
\text { (MI) }\end{array}$ & $\begin{array}{l}\text { ELEVA- } \\
\text { TION } \\
\text { (FT) }\end{array}$ & $\begin{array}{l}\text { FORESTED } \\
\text { AREA } \\
\text { (PERCENT) }\end{array}$ & $\begin{array}{l}\text { SOIL } \\
\text { INDEX }\end{array}$ & $\begin{array}{l}\text { PRECIPI- } \\
\text { TATION } \\
\text { (IN) }\end{array}$ & $\begin{array}{l}\text { 2-YEAR } \\
\text { (IN) }\end{array}$ & $\begin{array}{l}\text { 50-YEAR } \\
\text { (IN) }\end{array}$ \\
\hline 173 & 2.1 & 2,140 & 0.0 & 1.0 & 16.2 & 2.2 & 4.3 \\
\hline
\end{tabular}


09512800 AGUA FRIA RIVER NEAR ROCK SPRINGS, AZ

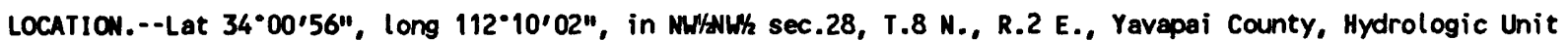
15070102, on right bank 2.5 mi southwest of Rock Springs and $10 \mathrm{mi}$ upstream from Lake Pleasant.

DRAIMAGE AREA. $--1,110 \mathrm{mi}^{2}$, approximately.

ANNUAL PEAK DISCHARGE

\begin{tabular}{|c|c|c|c|}
\hline $\begin{array}{l}\text { WATER } \\
\text { YEAR }\end{array}$ & DATE & $\begin{array}{c}\text { ANIUUAL PEAK } \\
\text { DISCHARGE } \\
\left(\mathrm{FT}^{3} / \mathrm{S}\right)\end{array}$ & $\begin{array}{l}\text { DISCHARGE } \\
\text { CODES }\end{array}$ \\
\hline $\begin{array}{l}1920 \\
1970 \\
1971 \\
1972 \\
1973 \\
1974 \\
1975 \\
1976 \\
1977 \\
1978 \\
1979 \\
1980 \\
1981 \\
1982 \\
1983 \\
1984 \\
1985 \\
1986 \\
1987 \\
1988 \\
1989\end{array}$ & $\begin{array}{l}09-05-70 \\
08-25-71 \\
08-13-72 \\
10-07-72 \\
08-02-74 \\
07-08-75 \\
02-09-76 \\
08-24-77 \\
03-02-78 \\
12-18-78 \\
02-19-80 \\
09-23-81 \\
03-13-82 \\
11-30-82 \\
08-17-84 \\
12-28-84 \\
11-26-85 \\
10-12-86 \\
08-29-88 \\
08-18-89\end{array}$ & $\begin{array}{r}185,000 \\
40,100 \\
3,750 \\
2,620 \\
17,600 \\
1,900 \\
2,490 \\
24,700 \\
2,390 \\
39,500 \\
52,800 \\
59,500 \\
1,020 \\
4,190 \\
10,200 \\
6,860 \\
4,560 \\
3,220 \\
2,160 \\
19,200 \\
562\end{array}$ & HP \\
\hline
\end{tabular}

1Highest since 1891.

BASIN CHARACTERISTICS

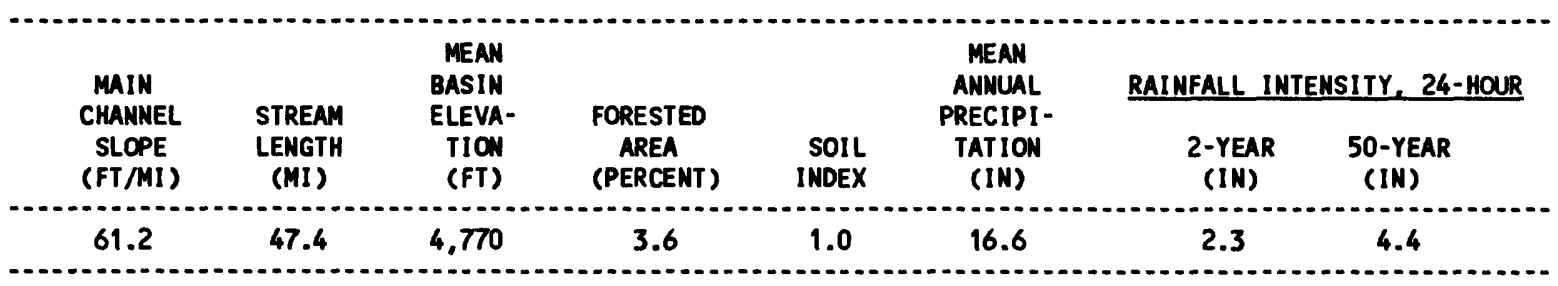


MEAN MONTHLY AND ANNUAL DISCHARGES $1975-89$

\begin{tabular}{|c|c|c|c|c|c|c|}
\hline MONTH & $\begin{array}{l}\operatorname{Max} \operatorname{ImmMM}_{\left(\mathrm{FT}^{3} / \mathrm{S}\right)} \\
\end{array}$ & $\begin{array}{l}\text { MINIMUA } \\
\left(\mathrm{FT}^{3} / \mathrm{S}\right)\end{array}$ & $\begin{array}{c}\text { MEAN } \\
\left(F^{3} / S\right)\end{array}$ & $\begin{array}{l}\text { STAN- } \\
\text { DARD } \\
\text { DEVIA- } \\
\text { TION } \\
\text { (FT } 3 / S)\end{array}$ & $\begin{array}{l}\text { COEFFI- } \\
\text { CIENT OF } \\
\text { VARI - } \\
\text { ATION }\end{array}$ & $\begin{array}{c}\text { PERCENT } \\
\text { OF } \\
\text { ANNUAL } \\
\text { RUNOFF }\end{array}$ \\
\hline $\begin{array}{l}\text { OCTOBER } \\
\text { MOVEMBER } \\
\text { DECEMBER } \\
\text { JANUARY } \\
\text { FEBRUARY } \\
\text { MARCH } \\
\text { APRIL } \\
\text { MAY } \\
\text { JUNE } \\
\text { JULY } \\
\text { AUGUST } \\
\text { SEPTEMBER }\end{array}$ & $\begin{array}{r}69 \\
176 \\
943 \\
751 \\
3,320 \\
1,970 \\
178 \\
71 \\
46 \\
36 \\
164 \\
160\end{array}$ & $\begin{array}{l}0.12 \\
0.11 \\
0.10 \\
0.22 \\
0.66 \\
0.51 \\
0.21 \\
0.08 \\
0.00 \\
0.39 \\
0.35 \\
0.30\end{array}$ & $\begin{array}{c}10 \\
33 \\
130 \\
121 \\
368 \\
283 \\
55 \\
15 \\
6.2 \\
13 \\
29 \\
19\end{array}$ & $\begin{array}{r}18 \\
54 \\
275 \\
220 \\
840 \\
514 \\
59 \\
22 \\
12 \\
12 \\
47 \\
40\end{array}$ & $\begin{array}{l}1.7 \\
1.7 \\
2.1 \\
1.8 \\
2.3 \\
1.8 \\
1.1 \\
1.4 \\
1.9 \\
0.92 \\
1.6 \\
2.1\end{array}$ & $\begin{array}{r}1.0 \\
3.0 \\
12.0 \\
11.2 \\
34.0 \\
26.1 \\
5.1 \\
1.4 \\
0.6 \\
1.2 \\
2.7 \\
1.8\end{array}$ \\
\hline ANNUAL & 355 & 2.6 & 89 & 109 & 1.2 & 100 \\
\hline
\end{tabular}

MAGNITUDE AND PROBABILITY OF INSTANTANEOUS PEAK FLON BASED ON PERIOD OF RECORD 1920, 1970-89

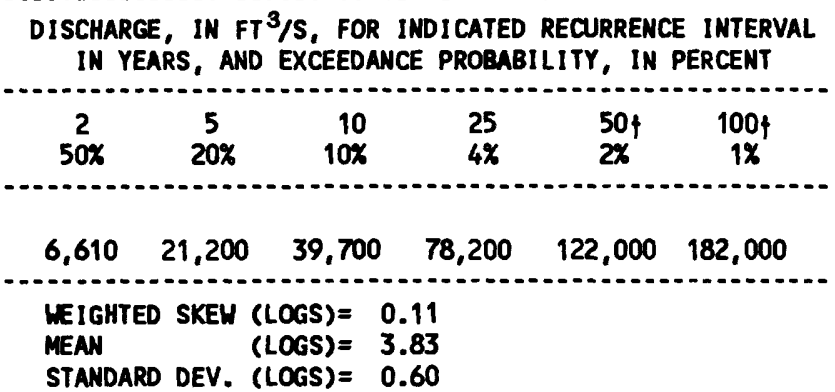

MAENITLDE ANO PROBABILITY OF ANHUAL LON FLON BASED ON PERIOD OF RECORD 1976-89

\begin{tabular}{|c|c|c|c|c|c|c|}
\hline \multirow{2}{*}{$\begin{array}{l}\text { PERIOD } \\
\text { (CON- } \\
\text { SECU- } \\
\text { TIVE } \\
\text { DAYS) }\end{array}$} & \multicolumn{6}{|c|}{$\begin{array}{l}\text { DISCHARGE, IN FT } 3 / 5 \text {, FOR INDICATED } \\
\text { RECURRENCE INTERVAL, IN YEARS, AND } \\
\text { NON-EXCEEDANCE PROBABILITY, IN PERCENT }\end{array}$} \\
\hline & $\stackrel{2}{50 x}$ & $\begin{array}{c}5 \\
20 \%\end{array}$ & $\begin{array}{l}10 \\
10 \%\end{array}$ & $\begin{array}{l}20 \\
5 \%\end{array}$ & $\begin{array}{l}50 \uparrow \\
2 \%\end{array}$ & $\begin{array}{l}100 t \\
1 \%\end{array}$ \\
\hline $\begin{array}{r}1 \\
3 \\
7 \\
14 \\
30 \\
60 \\
90 \\
120 \\
183\end{array}$ & $\begin{array}{l}0.00 \\
0.00 \\
0.00 \\
0.00 \\
0.00 \\
1.7 \\
2.3 \\
4.1 \\
7.2\end{array}$ & $\begin{array}{l}0.00 \\
0.00 \\
0.00 \\
0.00 \\
0.00 \\
0.38 \\
0.61 \\
1.2 \\
2.3\end{array}$ & $\begin{array}{l}0.00 \\
0.00 \\
0.00 \\
0.00 \\
0.00 \\
0.14 \\
0.25 \\
0.55 \\
1.1\end{array}$ & $\begin{array}{l}0.00 \\
0.00 \\
0.00 \\
0.00 \\
0.00 \\
0.05 \\
0.11 \\
0.26 \\
0.53\end{array}$ & $\begin{array}{l}0.00 \\
0.00 \\
0.00 \\
0.00 \\
0.00 \\
0.01 \\
0.04 \\
0.10 \\
0.22\end{array}$ & $\begin{array}{l}0.00 \\
0.00 \\
0.00 \\
0.00 \\
0.00 \\
0.01 \\
0.02 \\
0.05 \\
0.12\end{array}$ \\
\hline
\end{tabular}

MAGNITLDE AND PROBABILITY OF ANNUAL HIGH FLOU BASED ON PERIOO OF RECORD 1975-89

\begin{tabular}{|c|c|c|c|c|c|c|}
\hline \multirow{2}{*}{$\begin{array}{l}\text { PERIOD } \\
\text { (CON- } \\
\text { SECU- } \\
\text { TIVE } \\
\text { DAYYS) }\end{array}$} & \multicolumn{6}{|c|}{$\begin{array}{l}\text { DISCHARGE, IN FT /S, FOR INDICATED } \\
\text { RECURRENCE INTERVAL, IN YEARS, AND } \\
\text { EXCEEDANCE PROBABIL ITY, IN PERCENT }\end{array}$} \\
\hline & $\begin{array}{c}2 \\
50 \%\end{array}$ & $\begin{array}{c}5 \\
20 \%\end{array}$ & $\begin{array}{l}10 \\
10 \%\end{array}$ & $\begin{array}{l}25 \\
4 \%\end{array}$ & $\begin{array}{l}50 \dagger \\
2 \%\end{array}$ & $\begin{array}{c}100 \dagger \\
1 \%\end{array}$ \\
\hline $\begin{array}{l}1 \\
3 \\
7 \\
15 \\
30 \\
60 \\
90\end{array}$ & $\begin{array}{r}1.710 \\
910 \\
562 \\
324 \\
197 \\
132 \\
100\end{array}$ & $\begin{array}{r}7,090 \\
4,170 \\
2,570 \\
1,480 \\
855 \\
561 \\
414\end{array}$ & $\begin{array}{r}14,900 \\
9,130 \\
5,580 \\
3,190 \\
1,820 \\
1,170 \\
851\end{array}$ & $\begin{array}{r}32,700 \\
20,900 \\
12,600 \\
7,090 \\
4,000 \\
2,550 \\
1,800\end{array}$ & $\begin{array}{r}54,400 \\
35,500 \\
21,100 \\
11,700 \\
6,630 \\
4,160 \\
2,900\end{array}$ & $\begin{array}{r}85,800 \\
57,000 \\
33,400 \\
18,300 \\
10,400 \\
6,440 \\
4,410\end{array}$ \\
\hline
\end{tabular}

DURATION TABLE OF DAILY MEAN FLON FOR PERIOD OF RECORD 1975-89

DISCHARGE, IN FT 3/S, WHICH WAS EQUALED OR EXCEEDED FOR INDICATED PERCENT OF TIME

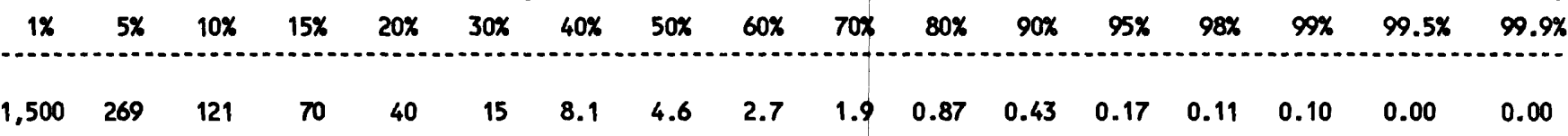

† Reliability of values in colum is uncertain, and potential errors are large. 
GILA RIVER BASIN

09512800 AGUA FRIA RIVER NEAR ROCK SPRINGS, AZ--CONTINUED
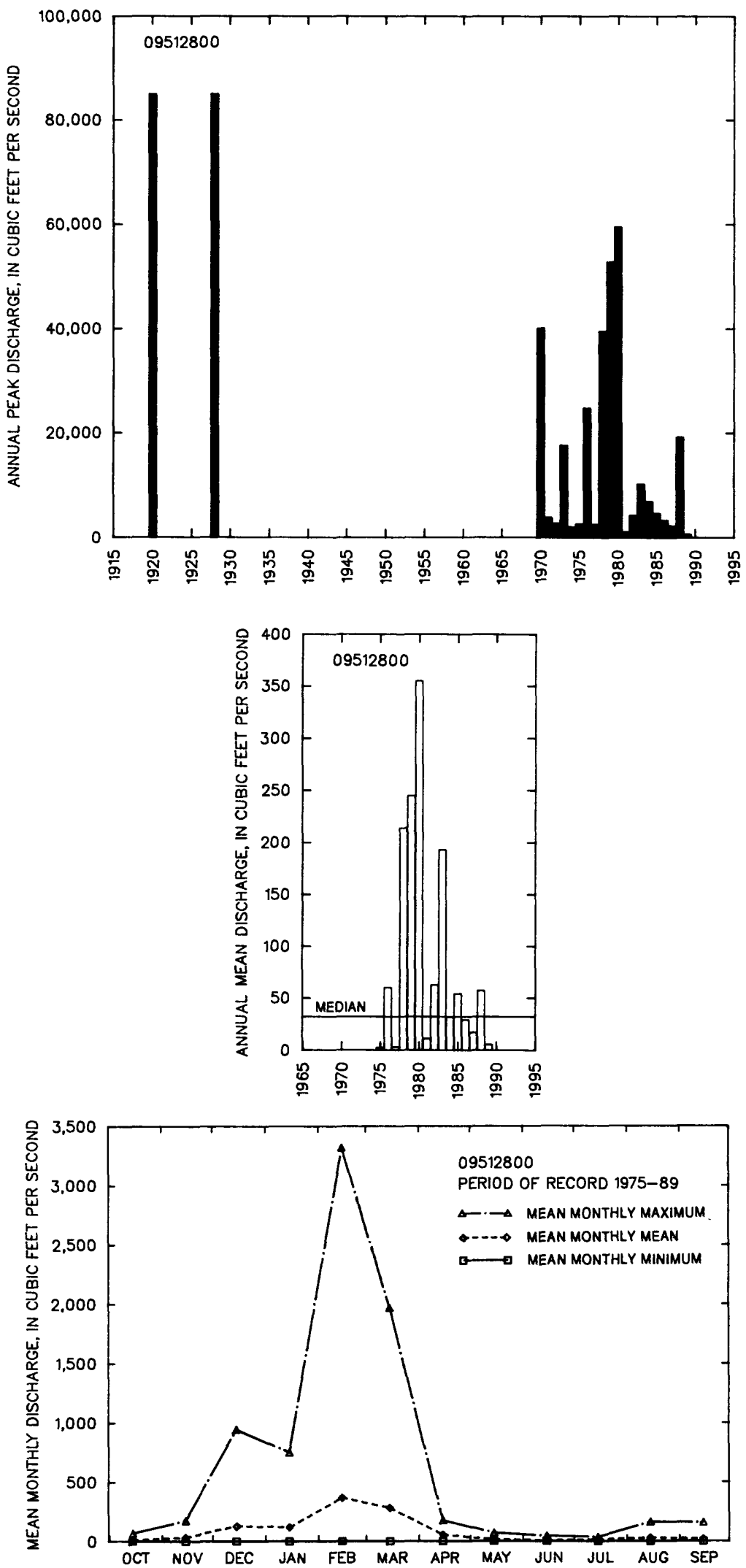
D9513780 NEU RIVER NEAR ROCK SPRINGS, AZ

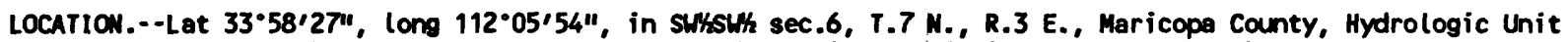
15070102, on right bank $180 \mathrm{ft}$ upstream from road crossing and $6 \mathrm{mi}$ southeast of Rock Springs.

DRAIMAGE AREA. $--67.3 \mathrm{mi}^{2}$.

ANNUAL PEAK DISCHARGE

\begin{tabular}{|c|c|c|c|c|c|}
\hline $\begin{array}{l}\text { WATER } \\
\text { YEAR }\end{array}$ & DATE & $\begin{array}{l}\text { ANNUAL PEAK } \\
\text { DISCHARGE } \\
\text { (FT } 3 / \mathrm{S})\end{array}$ & $\begin{array}{l}\text { WATER } \\
\text { YEAR }\end{array}$ & DATE & $\begin{array}{l}\text { ANNUAL PEAK } \\
\text { DISCHARGE } \\
\text { (FT } 3 / \mathrm{S})\end{array}$ \\
\hline $\begin{array}{l}1962 \\
1963 \\
1964 \\
1965 \\
1966 \\
1967 \\
1968 \\
1969 \\
1970 \\
1971 \\
1972 \\
1973 \\
1974 \\
1975\end{array}$ & $\begin{array}{l}09-28-62 \\
08-16-63 \\
08-02-64 \\
04-04-65 \\
12-22-65 \\
09-06-67 \\
12-19-67 \\
09-05-69 \\
09-05-70 \\
08-03-71 \\
08-12-72 \\
12-28-72 \\
08-05-74 \\
11-01-74\end{array}$ & $\begin{array}{r}1,050 \\
765 \\
4,900 \\
1,510 \\
4,020 \\
245 \\
10,600 \\
1,530 \\
18,600 \\
6,320 \\
231 \\
1,550 \\
68 \\
1,570\end{array}$ & $\begin{array}{l}1976 \\
1977 \\
1978 \\
1979 \\
1980 \\
1981 \\
1982 \\
1983 \\
1984 \\
1985 \\
1986 \\
1987 \\
1988 \\
1989\end{array}$ & $\begin{array}{l}02-09-76 \\
08-16-77 \\
03-02-78 \\
03-28-79 \\
02-19-80 \\
03-06-81 \\
03-15-82 \\
11-30-82 \\
12-27-83 \\
12-27-84 \\
11-26-85 \\
03-03-87 \\
11-01-87 \\
01-05-89\end{array}$ & $\begin{array}{c}3,230 \\
4.0 \\
13,600 \\
6,530 \\
9,350 \\
35 \\
1,760 \\
12,500 \\
692 \\
2,310 \\
3,700 \\
545 \\
4,980 \\
428\end{array}$ \\
\hline
\end{tabular}

BASIN CHARACTERISTICS

\begin{tabular}{|c|c|c|c|c|c|c|c|}
\hline MAIN & & $\begin{array}{l}\text { MEAN } \\
\text { BASIN }\end{array}$ & & & $\begin{array}{l}\text { MEAN } \\
\text { ANNUAL }\end{array}$ & RAINFALL IN & SITY, 24-HOUR \\
\hline $\begin{array}{l}\text { CHANNEL } \\
\text { SLOPE } \\
\text { (FT/MI) }\end{array}$ & $\begin{array}{c}\text { STREAM } \\
\text { LENGTH } \\
\text { (MI) }\end{array}$ & $\begin{array}{l}\text { ELEVA- } \\
\text { TION } \\
\text { (FT) }\end{array}$ & $\begin{array}{l}\text { FORESTED } \\
\text { AREA } \\
\text { (PERCENT) }\end{array}$ & $\begin{array}{l}\text { SOIL } \\
\text { INDEX }\end{array}$ & $\begin{array}{l}\text { PRECIPI- } \\
\text { TATION } \\
\text { (IN) }\end{array}$ & $\begin{array}{c}\text { 2-YEAR } \\
\text { (IN) }\end{array}$ & $\begin{array}{c}\text { 50-YEAR } \\
\text { (IN) }\end{array}$ \\
\hline 140 & 18.6 & 3,970 & 0.2 & 1.0 & 20.0 & 2.4 & 4.6 \\
\hline
\end{tabular}


09513780 MEW RIVER MEAR ROCK SPRIMGS, AZ--Continued

MEAN MONTHLY AND ANMUAL DISCHARGES 1966-89

\begin{tabular}{|c|c|c|c|c|c|c|}
\hline MONTH & $\begin{array}{l}\left.\operatorname{MAX} \operatorname{Immin}_{(\mathrm{FT}} / \mathrm{S}\right) \\
\end{array}$ & $\begin{array}{c}\operatorname{MINIMM} \\
\left(F^{3} / \mathrm{S}\right)\end{array}$ & $\begin{array}{c}\text { MEAN } \\
\left(F T^{3} / S\right)\end{array}$ & $\begin{array}{l}\text { STAN- } \\
\text { DARD } \\
\text { DEVIA- } \\
\text { TION } \\
\left(F T^{3} / S\right)\end{array}$ & $\begin{array}{l}\text { COEFFI- } \\
\text { CIENT OF } \\
\text { VARI - } \\
\text { ATION }\end{array}$ & $\begin{array}{c}\text { PERCENT } \\
\text { OF } \\
\text { ANNUAL } \\
\text { RUNOFF }\end{array}$ \\
\hline $\begin{array}{l}\text { OCTOBER } \\
\text { NOVEMBER } \\
\text { DECEMBER } \\
\text { JANUARY } \\
\text { FEBRUARY } \\
\text { MARCH } \\
\text { APRIL } \\
\text { MAY } \\
\text { JUNE } \\
\text { JULY } \\
\text { AUGUST } \\
\text { SEPTEMBER }\end{array}$ & $\begin{array}{c}32 \\
52 \\
218 \\
180 \\
348 \\
444 \\
26 \\
11 \\
2.2 \\
6.5 \\
15 \\
104\end{array}$ & $\begin{array}{l}0.00 \\
0.00 \\
0.00 \\
0.00 \\
0.00 \\
0.00 \\
0.00 \\
0.00 \\
0.00 \\
0.00 \\
0.00 \\
0.00\end{array}$ & $\begin{array}{l}1.7 \\
7.0 \\
32 \\
21 \\
41 \\
42 \\
4.2 \\
1.2 \\
0.22 \\
0.55 \\
1.5 \\
5.1\end{array}$ & $\begin{array}{l}6.5 \\
13 \\
64 \\
43 \\
80 \\
95 \\
6.7 \\
2.5 \\
0.54 \\
1.4 \\
3.7 \\
21\end{array}$ & $\begin{array}{l}3.9 \\
1.9 \\
2.0 \\
2.0 \\
2.0 \\
2.3 \\
1.6 \\
2.1 \\
2.5 \\
2.6 \\
2.5 \\
4.2\end{array}$ & $\begin{array}{r}1.1 \\
4.4 \\
20.3 \\
13.6 \\
25.9 \\
26.6 \\
2.7 \\
0.8 \\
0.1 \\
0.4 \\
0.9 \\
3.2\end{array}$ \\
\hline ANNUAL & 55 & 0.00 & 13 & 17 & 1.3 & 100 \\
\hline
\end{tabular}

MAGNITLDE AND PROBABILITY OF INSTANTANEOUS PEAK FLON BASED ON PERIOD OF RECORD 1962-89

DISCHARGE, IN $\mathrm{FT}^{3} / \mathrm{S}$, FOR INDICATED RECURRENCE INTERVAL IN YEARS, AND EXCEEDANCE PROBABILITY, IN PERCENT

$\begin{array}{cccccc}2 & 5 & 10 & 25 & 50 & 100 \dagger \\ 50 \% & 20 \% & 10 \% & 4 \% & 2 \% & 1 \%\end{array}$

\section{$2,170 \quad 6,260 \quad 10,600 \quad 18,200 \quad 25,600 \quad 34,600$}

WEIGHTED SKEW (LOGS) $=-0.22$

MEAN (LOGS) $=3.32$

STANDARD DEV. (LOGS) $=0.56$
MAGNITUDE AND PROBABILITY OF ANNUAL LON FLOW BASED ON PERIOD OF RECORD 1967-89

\begin{tabular}{|c|c|c|c|c|c|c|}
\hline \multirow{2}{*}{$\begin{array}{l}\text { PERIOD } \\
\text { (CON- } \\
\text { SECU- } \\
\text { TIVE } \\
\text { DAYS) }\end{array}$} & \multicolumn{6}{|c|}{$\begin{array}{l}\text { DISCHARGE, IN FT } 3 / 5 \text {, FOR INDICATED } \\
\text { RECURRENCE INTERVAL, IN YEARS, AND } \\
\text { NON-EXCEEDANCE PROBABILITY, IN PERCENT }\end{array}$} \\
\hline & $\begin{array}{c}2 \\
50 \%\end{array}$ & $\begin{array}{c}5 \\
20 \%\end{array}$ & $\begin{array}{l}10 \\
10 \%\end{array}$ & $\begin{array}{l}20 \\
5 \%\end{array}$ & $\begin{array}{l}50 \uparrow \\
2 \%\end{array}$ & $\begin{array}{l}100 \uparrow \\
1 \%\end{array}$ \\
\hline $\begin{array}{r}1 \\
3 \\
7 \\
14 \\
30 \\
60\end{array}$ & & & & & & \\
\hline $\begin{array}{r}90 \\
120 \\
183\end{array}$ & $\begin{array}{l}0.00 \\
0.00 \\
0.00\end{array}$ & $\begin{array}{l}0.00 \\
0.00 \\
0.00\end{array}$ & $\begin{array}{l}0.00 \\
0.00 \\
0.00\end{array}$ & $\begin{array}{l}0.00 \\
0.00 \\
0.00\end{array}$ & $\begin{array}{l}0.00 \\
0.00 \\
0.00\end{array}$ & $\begin{array}{l}0.00 \\
0.00 \\
0.00\end{array}$ \\
\hline
\end{tabular}

MAGNITUDE AND PROBABILITY OF ANNUAL HIGH FLON BASED ON PERIOD OF RECORD 1966-89

\begin{tabular}{|c|c|c|c|c|c|c|}
\hline \multirow{2}{*}{$\begin{array}{l}\text { PERIOD } \\
\text { (CON- } \\
\text { SECU- } \\
\text { TIVE } \\
\text { DAYS) }\end{array}$} & \multicolumn{6}{|c|}{$\begin{array}{l}\text { DISCHARGE, IN } \mathrm{FT}^{3} / \mathrm{S} \text {, FOR INDICATED } \\
\text { RECURRENCE INTERVAL, IN YEARS, AND } \\
\text { EXCEEDANCE PROBABILITY, IN PERCENT }\end{array}$} \\
\hline & $\begin{array}{c}2 \\
50 \%\end{array}$ & $\begin{array}{c}5 \\
20 \%\end{array}$ & $\begin{array}{l}10 \\
10 \%\end{array}$ & $\begin{array}{l}25 \\
4 \%\end{array}$ & $\begin{array}{l}50 \uparrow \\
2 \%\end{array}$ & $\begin{array}{c}100 \uparrow \\
1 \%\end{array}$ \\
\hline $\begin{array}{r}1 \\
3 \\
7 \\
15 \\
30 \\
60 \\
90\end{array}$ & $\begin{array}{r}424 \\
208 \\
113 \\
65 \\
40 \\
23 \\
17\end{array}$ & $\begin{array}{r}1,940 \\
962 \\
537 \\
303 \\
178 \\
102 \\
74\end{array}$ & $\begin{array}{r}3,480 \\
1,720 \\
958 \\
530 \\
306 \\
190 \\
136\end{array}$ & $\begin{array}{r}5,690 \\
2,760 \\
1,530 \\
821 \\
466 \\
332 \\
235\end{array}$ & $\begin{array}{r}7,310 \\
3,500 \\
1,920 \\
1,010 \\
570 \\
454 \\
320\end{array}$ & $\begin{array}{r}8,800 \\
4,170 \\
2,270 \\
1,170 \\
655 \\
586 \\
409\end{array}$ \\
\hline
\end{tabular}

DURATION TABLE OF DAILY MEAN FLON FOR PERIOD OF RECORD 1966-89 DISCHARGE, IN FT $3 / \mathrm{S}$, WHICH WAS EQUALED OR EXCEEDED FOR INDICATED PERCENT OF TIME

\begin{tabular}{|c|c|c|c|c|c|c|c|c|c|c|c|c|c|c|c|c|}
\hline $1 x$ & $5 x$ & $10 \%$ & $15 \%$ & $20 \%$ & $30 \%$ & $40 \%$ & $50 \%$ & $60 \%$ & $70 \%$ & $80 \%$ & $90 \%$ & $95 \%$ & $98 \%$ & $99 \%$ & $99.5 \%$ & 99. \\
\hline 36 & 28 & 11 & 5.0 & 2.8 & 0.88 & 0.10 & 0.00 & 0.00 & 0.00 & 0.00 & 0.00 & 0.00 & 0.00 & 0.00 & 0.00 & 0 \\
\hline
\end{tabular}


GIU RIVER BASIN

09513780 NEW RIVER MEAR ROCK SPRIMGS, AZ--CONTINUED
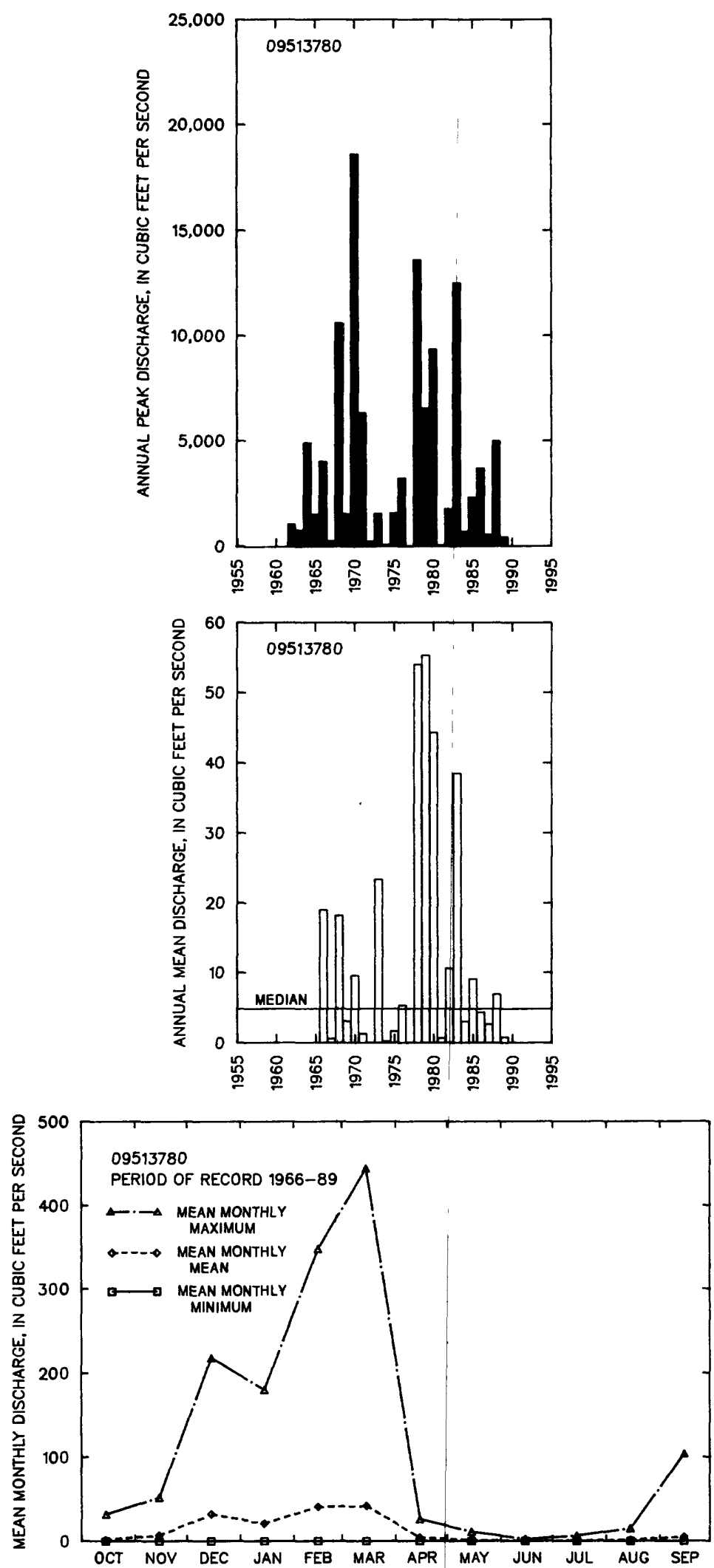
09513800 NEW RIVER AT NEW RIVER, AZ

LOCATION.--Lat 33.54'41", long 112.08'26", in NWHEK sec.34, T.7 N., R.2 E., Maricopa County, Hydrologic Unit 15070102, near center of downstream side of bridge on east frontage road of Interstate Highway 17. $0.5 \mathrm{mi}$ southwest of village of New River, and $10 \mathrm{mi}$ south of Rock Springs.

DRAINAGE AREA. $--83.3 \mathrm{mi}^{2}$.

ANMUAL PEAK DISCHARGE

\begin{tabular}{|c|c|c|c|c|}
\hline $\begin{array}{l}\text { WATER } \\
\text { YEAR }\end{array}$ & $\begin{array}{cc} & \text { ANNUAL PEAK } \\
& \text { DISCHARGE } \\
\text { DATE } & \left(\mathrm{FT}^{3} / \mathrm{S}\right)\end{array}$ & $\begin{array}{l}\text { WATER } \\
\text { YEAR }\end{array}$ & DATE & $\begin{array}{l}\text { ANNUAL PEAK } \\
\text { DISCHARGE } \\
\left(F^{3} / S\right)\end{array}$ \\
\hline $\begin{array}{l}1961 \\
1962 \\
1963 \\
1964 \\
1965 \\
1966 \\
1967 \\
1968 \\
1969 \\
1970 \\
1971\end{array}$ & $\begin{array}{l}07-22-61 \\
09-28-62 \\
08-16-63 \\
08-02-64 \\
04-04-65 \\
12-22-65 \\
08-10-67 \\
12-19-67 \\
09-05-69 \\
09-05-70 \\
08-21-71\end{array}$ & $\begin{array}{l}1972 \\
1973 \\
1974 \\
1975 \\
1976 \\
1977 \\
1978 \\
1979 \\
1980 \\
1981 \\
1982\end{array}$ & $\begin{array}{l}08-12-72 \\
02-11-73 \\
08-05-74 \\
11-02-74 \\
02-09-76 \\
08-17-77 \\
03-02-78 \\
12-18-78 \\
02-19-80 \\
09-23-81 \\
10-01-81\end{array}$ & $\begin{array}{r}525 \\
4,250 \\
49 \\
2,280 \\
7,050 \\
805 \\
18,000 \\
5,560 \\
14,900 \\
20 \\
2,510\end{array}$ \\
\hline
\end{tabular}

BASIN CHARACTERISTICS

\begin{tabular}{|c|c|c|c|c|c|c|c|}
\hline \multirow{2}{*}{$\begin{array}{l}\text { MAIN } \\
\text { CHANNEL } \\
\text { SLOPE } \\
\text { (FT/MI) }\end{array}$} & \multirow[b]{2}{*}{$\begin{array}{l}\text { STREAM } \\
\text { LENGTH } \\
\text { (MI) }\end{array}$} & \multirow{2}{*}{$\begin{array}{l}\text { MEAN } \\
\text { BASIN } \\
\text { ELEVA- } \\
\text { TION } \\
\text { (FT) }\end{array}$} & \multirow[b]{2}{*}{$\begin{array}{l}\text { FORESTED } \\
\text { AREA } \\
\text { (PERCENT) }\end{array}$} & \multirow[b]{2}{*}{$\begin{array}{l}\text { SOIL } \\
\text { INDEX }\end{array}$} & \multirow{2}{*}{$\begin{array}{l}\text { MEAN } \\
\text { ANNUAL } \\
\text { PRECIPI- } \\
\text { TATION } \\
\text { (IN) }\end{array}$} & \multicolumn{2}{|c|}{ RAINFALL INTENSITY, 24-HOUR } \\
\hline & & & & & & $\begin{array}{c}\text { 2-YEAR } \\
\text { (IN) }\end{array}$ & $\begin{array}{c}\text { 50-YEAR } \\
\text { (IN) }\end{array}$ \\
\hline 105 & 25.9 & 3,600 & 0.2 & 1.0 & 19.5 & 2.3 & 4.6 \\
\hline
\end{tabular}


MEAN MONTHLY AND ANMUAL DISCHARGES 1961-82

\begin{tabular}{|c|c|c|c|c|c|c|}
\hline MONTH & $\begin{array}{l}\text { MAXIMUN } \\
\left(F T^{3} / S\right)\end{array}$ & $\begin{array}{l}\text { MINIMUN } \\
\left(F T^{3} / S\right)\end{array}$ & $\begin{array}{c}\text { MEAN } \\
\left(F T^{3} / S\right)\end{array}$ & $\begin{array}{l}\text { DARD } \\
\text { DEVIA- } \\
\text { TION } \\
\text { (FT } 3 / S)\end{array}$ & $\begin{array}{l}\text { COEFFI- } \\
\text { CIENT OF } \\
\text { VARI - } \\
\text { ATION }\end{array}$ & $\begin{array}{c}\text { PERCENT } \\
\text { OF } \\
\text { ANWUAL } \\
\text { RUNOFF }\end{array}$ \\
\hline $\begin{array}{l}\text { OCTOBER } \\
\text { NOVEMBER } \\
\text { DECEMBER } \\
\text { JANUARY } \\
\text { FEBRUARY } \\
\text { MARCH } \\
\text { APRIL } \\
\text { MAY } \\
\text { JUNE } \\
\text { JULY } \\
\text { AUGUST } \\
\text { SEPTEMBER }\end{array}$ & $\begin{array}{c}35 \\
44 \\
207 \\
310 \\
523 \\
443 \\
74 \\
22 \\
0.90 \\
2.9 \\
25 \\
115\end{array}$ & $\begin{array}{l}0.00 \\
0.00 \\
0.00 \\
0.00 \\
0.00 \\
0.00 \\
0.00 \\
0.00 \\
0.00 \\
0.00 \\
0.00 \\
0.00\end{array}$ & $\begin{array}{l}2.1 \\
4.4 \\
28 \\
28 \\
46 \\
40 \\
6.7 \\
1.6 \\
0.11 \\
0.40 \\
3.8 \\
6.3\end{array}$ & $\begin{array}{c}7.5 \\
11 \\
65 \\
73 \\
114 \\
99 \\
16 \\
4.9 \\
0.25 \\
0.77 \\
6.8 \\
24\end{array}$ & $\begin{array}{l}3.5 \\
2.4 \\
2.3 \\
2.6 \\
2.5 \\
2.5 \\
2.4 \\
3.1 \\
2.2 \\
1.9 \\
1.8 \\
3.8\end{array}$ & $\begin{array}{r}1.3 \\
2.6 \\
16.6 \\
16.8 \\
27.4 \\
24.1 \\
4.0 \\
0.9 \\
0.1 \\
0.2 \\
2.3 \\
3.8\end{array}$ \\
\hline MIUAL & 74 & 0.01 & 14 & 21 & 1.5 & 100 \\
\hline
\end{tabular}

MAGNITUDE AND PROBABILITY OF INSTANTANEQUS PEAK FLON BASED ON PERIOD OF RECORD 1961-82

DISCHARGE, IN $\mathrm{FT}^{3} / \mathrm{S}$, FOR INDICATED RECURRENCE INTERVAL IN YEARS, AND EXCEEDANCE PROBABILITY, IN PERCENT

\begin{tabular}{lccccc}
2 & 5 & 10 & 25 & 50 & $100 \dagger$ \\
$50 \%$ & $20 \%$ & $10 \%$ & $4 \%$ & $2 \%$ & $1 \%$ \\
3,150 & 7,880 & 12,600 & 20,600 & 28,300 & 37,500 \\
\hline MEIGHTED SKEW (LOGS) & -0.09 & & \\
MEAN & (LOGS) & 3.49 \\
STANDARO DEV. (LOGS) & $=0.48$
\end{tabular}

MAGNITUDE AND PROBABILITY OF ANNUAL LON FLON BASED ON PERIOD OF RECORD 1962-82

\begin{tabular}{|c|c|c|c|c|c|c|}
\hline \multirow{2}{*}{$\begin{array}{l}\text { PERICD } \\
\text { (CON- } \\
\text { SECU- } \\
\text { TIVE } \\
\text { DAYS) }\end{array}$} & \multicolumn{6}{|c|}{$\begin{array}{l}\text { DISCHARGE, IN } \mathrm{FT}^{3} / \mathrm{S} \text {, FOR INDICATED } \\
\text { RECURRENCE INTERVAL, IN YEARS, AND } \\
\text { MOW-EXCEEDANCE PROBABILITY, IN PERCENT }\end{array}$} \\
\hline & $\begin{array}{c}2 \\
50 \%\end{array}$ & $\begin{array}{c}5 \\
20 \%\end{array}$ & $\begin{array}{l}10 \\
10 \%\end{array}$ & $\begin{array}{l}20 \\
5 \%\end{array}$ & $\begin{array}{l}50 \nmid \\
2 \%\end{array}$ & $\begin{array}{l}100 \dagger \\
1 \%\end{array}$ \\
\hline $\begin{array}{r}1 \\
3 \\
7 \\
14 \\
30 \\
60 \\
90\end{array}$ & & & & & & \\
\hline $\begin{array}{l}120 \\
183\end{array}$ & $\begin{array}{l}0.00 \\
0.18\end{array}$ & $\begin{array}{l}0.00 \\
0.00\end{array}$ & $\begin{array}{l}0.00 \\
0.00\end{array}$ & $\begin{array}{l}0.00 \\
0.00\end{array}$ & $\begin{array}{l}0.00 \\
0.00\end{array}$ & $\begin{array}{l}0.00 \\
0.00\end{array}$ \\
\hline
\end{tabular}

MAGNITUDE AND PROBABILITY OF AMNUAL HIGH FLON BASED ON PERIOD OF RECORD 1961-82

\begin{tabular}{|c|c|c|c|c|c|c|}
\hline \multirow{2}{*}{$\begin{array}{l}\text { PERIOD } \\
\text { (CON- } \\
\text { SECU- } \\
\text { TIVE } \\
\text { DAYS) }\end{array}$} & & \multicolumn{5}{|c|}{$\begin{array}{l}\text { DISCHARGE, IN } \mathrm{FT}^{3} / \mathrm{S} \text {, FOR INDICATED } \\
\text { RECURRENCE INTERVAL, IN YEARS, AND } \\
\text { EXCEEDANCE PROBABILITY, IN PERCENT }\end{array}$} \\
\hline & $\begin{array}{c}2 \\
50 x\end{array}$ & $\begin{array}{c}5 \\
20 \%\end{array}$ & $\begin{array}{l}10 \\
10 \%\end{array}$ & $\begin{array}{l}25 \\
4 \%\end{array}$ & $\begin{array}{l}50 \dagger \\
2 x\end{array}$ & $\underset{1 x}{100 \dagger}$ \\
\hline $\begin{array}{l}1 \\
3 \\
7 \\
15 \\
30 \\
60 \\
90\end{array}$ & $\begin{array}{r}410 \\
179 \\
93 \\
50 \\
28 \\
16 \\
12\end{array}$ & $\begin{array}{r}1,980 \\
969 \\
544 \\
304 \\
174 \\
109 \\
79\end{array}$ & $\begin{array}{r}3,800 \\
1,970 \\
1,150 \\
648 \\
377 \\
243 \\
174\end{array}$ & $\begin{array}{r}6,790 \\
3,730 \\
2,240 \\
1,280 \\
754 \\
499 \\
355\end{array}$ & $\begin{array}{r}9,310 \\
5,310 \\
3,250 \\
1,860 \\
1,100 \\
742 \\
524\end{array}$ & $\begin{array}{r}11,900 \\
7,020 \\
4,360 \\
2,500 \\
1,490 \\
1,020 \\
712\end{array}$ \\
\hline
\end{tabular}

DURATION TABLE OF DAILY MEAN FLON FOR PERIOD OF RECORD 1961-82

DISCHARGE, IN FT $3 / \mathrm{S}$, WHICH WAS EQUALED OR EXCEEDED FOR INDICATED PERCENT OF TIME

\begin{tabular}{|c|c|c|c|c|c|c|c|c|c|c|c|c|c|c|c|c|}
\hline $1 x$ & $5 x$ & $10 x$ & $15 x$ & $20 x$ & $30 \%$ & $40 \%$ & $50 \%$ & $60 x$ & $70 x$ & $80 \%$ & $90 \%$ & $95 \%$ & $98 \%$ & $99 \%$ & $99.5 x$ & $99.9 \%$ \\
\hline 298 & 30 & 7.4 & 1.9 & 0.31 & 0.00 & 0.00 & 0.00 & 0.00 & 0.00 & 0.00 & 0.00 & 0.00 & 0.00 & 0.00 & 0.00 & 0.00 \\
\hline
\end{tabular}

† Reliability of values in column is uncertain, and potential errors are large. 
GIU RIVER BASIN

09513800 NEW RIVER AT NEW RIVER, AZ--CONTINUEd
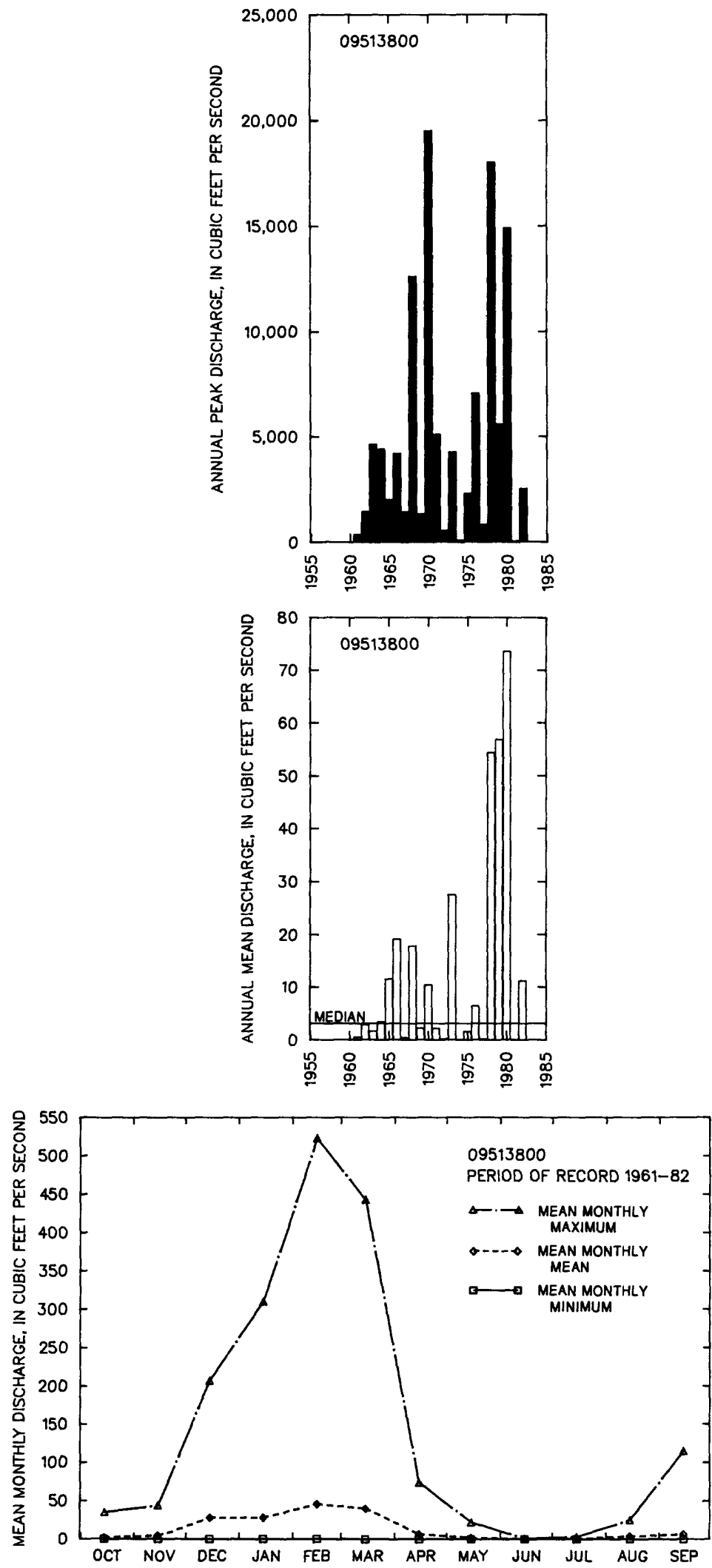
LOCATION.--Lat 33.50'30", Long 112.08'40", in MWK sec.27, T.6 N.., R.2 E., Maricopa County, Hydrologic Unit 15070102, at State Highway 69, $4.5 \mathrm{mi}$ south of New River.

DRAIMAGE AREA. $--11.1 \mathrm{mi}^{2}$.

ANMUAL PEAK DISCHARGE

\begin{tabular}{cccc}
$\begin{array}{c}\text { MATER } \\
\text { YEAR }\end{array}$ & DATE & $\begin{array}{c}\text { ANNUAL PEAK } \\
\text { DISCHARGE } \\
\left.\text { (FT }{ }^{3} / \mathrm{S}\right)\end{array}$ & $\begin{array}{c}\text { DISCHARGE } \\
\text { CODES }\end{array}$ \\
\hline 1960 & $12-25-59$ & 1,850 & \\
1961 & $00-00-61$ & 0 & \\
1962 & $00-00-62$ & 0 & \\
1963 & $08-00-63$ & 270 & \\
1964 & $07-30-64$ & 1,140 & \\
1965 & $04-04-65$ & 70 & ES \\
1966 & $12-22-65$ & 200 & ES \\
1967 & $09-00-67$ & 230 & \\
1968 & $12-19-67$ & 950 & \\
1969 & $00-00-69$ & 0 & \\
1970 & $09-05-70$ & 1,630 & \\
1971 & $08-21-71$ & 1,300 & \\
1972 & $07-17-72$ & 135 & \\
1973 & $10-07-72$ & 1,000 & ES \\
1974 & $09-19-74$ & 150 & \\
1975 & $10-28-74$ & 250 & ES \\
1976 & $08-31-76$ & 64 & \\
1977 & $00-00-77$ & 0 & \\
1978 & $03-02-78$ & 1,400 & \\
1979 & $11-11-78$ & 88 & \\
\hline $19 . \ldots \ldots$ & &
\end{tabular}

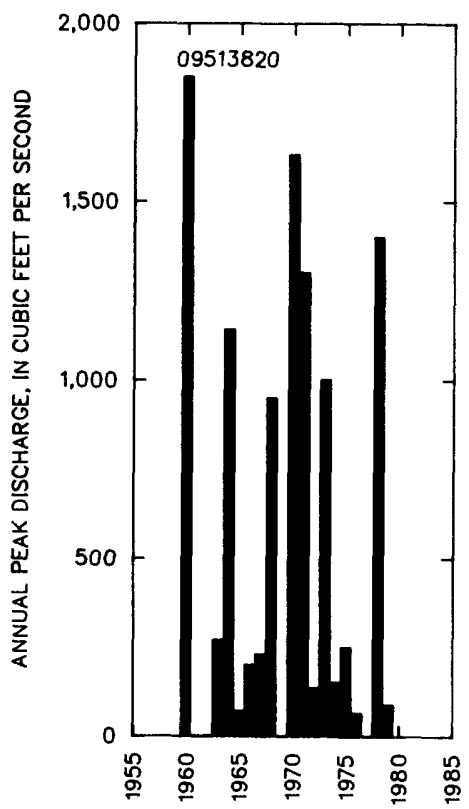

MAGNITUDE AND PROBABILITY OF INSTANTANEOUS PEAK FLON BASED ON PERIOD OF RECORD 1960-79

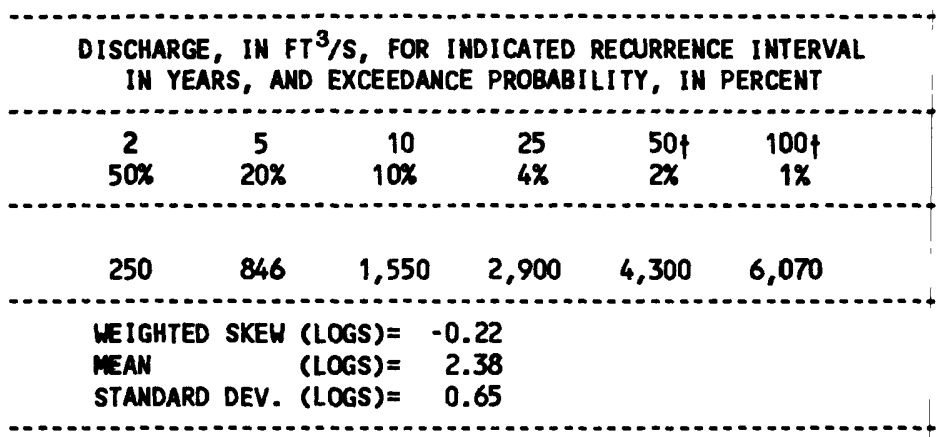

+ Reliability of values in column is uncertain, and potential errors are large.

\section{BASIN CHARACTERISTICS}

\begin{tabular}{|c|c|c|c|c|c|c|c|}
\hline MAIN & & $\begin{array}{l}\text { MEAN } \\
\text { BASIN }\end{array}$ & & & $\begin{array}{c}\text { MEAN } \\
\text { ANMUAL }\end{array}$ & RAINFALL I & SITY, 24-HOUR \\
\hline $\begin{array}{l}\text { CHANNEL } \\
\text { SLOPE } \\
\text { (FT/MI) }\end{array}$ & $\begin{array}{l}\text { STREAM } \\
\text { LENGTH } \\
\text { (MI) }\end{array}$ & $\begin{array}{l}\text { ELEVA- } \\
\text { TION } \\
\text { (FT) }\end{array}$ & $\begin{array}{l}\text { FORESTED } \\
\text { AREA } \\
\text { (PERCENT) }\end{array}$ & $\begin{array}{l}\text { SOIL } \\
\text { INDEX }\end{array}$ & $\begin{array}{l}\text { PRECIPI- } \\
\text { TATION } \\
\text { (IN) }\end{array}$ & $\begin{array}{c}\text { 2-YEAR } \\
\text { (IN) }\end{array}$ & $\begin{array}{l}\text { 50-YEAR } \\
\text { (IN) }\end{array}$ \\
\hline 124 & 4.2 & 1,980 & 0.0 & 1.0 & 11.0 & 1.8 & 4.0 \\
\hline
\end{tabular}


09513835 NEW RIVER AT BELL ROAD, NEAR PEORIA, NZ

LOCATION.--Lat 33'38'18", long 112'14'22", in NEXNEK sec.3, T.3 N., R.1 E., Maricope County, Hydrologic Unit 15070102, on downstream side of bridge at Bell Road, $1.6 \mathrm{mi}$ upstream from Skunk Creek, 3.1 mi north of Peoria, and 9 mi upstream from mouth.

DRAIMAGE AREA. $--185 \mathrm{mi}^{2}$.

\begin{tabular}{|c|c|c|}
\hline $\begin{array}{l}\text { WATER } \\
\text { YEAR }\end{array}$ & DATE & $\begin{array}{c}\text { ANNUAL PEAK } \\
\text { DISCHARGE } \\
\left(F^{3} / S\right)\end{array}$ \\
\hline $\begin{array}{l}1963 \\
1965 \\
1966 \\
1967 \\
1968 \\
1969 \\
1970 \\
1971 \\
1972 \\
1973 \\
1974 \\
1975 \\
1976 \\
1977 \\
1978 \\
1979 \\
1980 \\
1981 \\
1982 \\
1983 \\
1984\end{array}$ & $\begin{array}{l}08-17-63 \\
04-05-65 \\
12-22-65 \\
06-18-67 \\
12-19-67 \\
00-00-69 \\
09-05-70 \\
08-21-71 \\
07-17-72 \\
10-07-72 \\
00-00-74 \\
11-03-74 \\
02-09-76 \\
00-00-77 \\
03-02-78 \\
12-19-78 \\
02-20-80 \\
09-05-81 \\
03-15-82 \\
12-01-82 \\
00-00-84\end{array}$ & $\begin{array}{r}1,550 \\
1,020 \\
4,060 \\
100 \\
14,600 \\
0 \\
11,900 \\
4,800 \\
1,520 \\
2,590 \\
0 \\
257 \\
2,280 \\
0 \\
12,500 \\
8,410 \\
12,100 \\
21 \\
876 \\
4,240 \\
0\end{array}$ \\
\hline
\end{tabular}

BASIN CHARACTERISTICS

\begin{tabular}{|c|c|c|c|c|c|c|c|}
\hline \multirow{3}{*}{$\begin{array}{l}\text { MAIN } \\
\text { CHANNEL } \\
\text { SLOPE } \\
\text { (FT/MI) }\end{array}$} & \multirow[b]{3}{*}{$\begin{array}{c}\text { STREAM } \\
\text { LENGTH } \\
\text { (MI) }\end{array}$} & \multirow{3}{*}{$\begin{array}{c}\text { MEAN } \\
\text { BASIN } \\
\text { ELEVA- } \\
\text { TION } \\
\text { (FT) }\end{array}$} & \multirow[b]{3}{*}{$\begin{array}{l}\text { FORESTED } \\
\text { AREA } \\
\text { (PERCENT) }\end{array}$} & \multirow[b]{3}{*}{$\begin{array}{l}\text { SOIL } \\
\text { INDEX }\end{array}$} & \multirow{3}{*}{$\begin{array}{l}\text { MEAN } \\
\text { ANNUAL } \\
\text { PRECIPI - } \\
\text { TATION } \\
\text { (IN) }\end{array}$} & \multirow{2}{*}{\multicolumn{2}{|c|}{ RAINFALL INTENSITY, 24-HOQR }} \\
\hline & & & & & & & \\
\hline & & & & & & $\begin{array}{c}\text { 2-YEAR } \\
\text { (IN) }\end{array}$ & $\begin{array}{c}\text { 50-YEAR } \\
\text { (IN) }\end{array}$ \\
\hline 64.5 & 38.2 & 2,700 & 0.1 & 1.0 & 15.6 & 1.9 & 4.0 \\
\hline
\end{tabular}


MEAN MONTHLY AND ANNUAL DISCHARGES $1968-84$

\begin{tabular}{|c|c|c|c|c|c|c|}
\hline MONTH & $\begin{array}{l}\operatorname{MAXIMU} \\
(\mathrm{FT} / \mathrm{S} / \mathrm{S})\end{array}$ & $\begin{array}{l}\text { MINIMUM } \\
\left(F T^{3} / S\right)\end{array}$ & $\begin{array}{c}\text { MEAN } \\
\left(F^{3} / S\right)\end{array}$ & $\begin{array}{l}\text { STAN- } \\
\text { DARD } \\
\text { DEVIA- } \\
\text { TION } \\
\text { (FT } 3 / S)\end{array}$ & $\begin{array}{l}\text { COEFFI- } \\
\text { CIENT OF } \\
\text { VARI - } \\
\text { ATION }\end{array}$ & $\begin{array}{c}\text { PERCENT } \\
\text { OF } \\
\text { ANNUAL } \\
\text { RUNOFF }\end{array}$ \\
\hline $\begin{array}{l}\text { OCTOBER } \\
\text { NOVEMBER } \\
\text { DECEMBER } \\
\text { JANUARY } \\
\text { FEBRUARY } \\
\text { MARCH } \\
\text { APRIL } \\
\text { MAY } \\
\text { JUNE } \\
\text { JULY } \\
\text { AUGUST } \\
\text { SEPTEMBER }\end{array}$ & $\begin{array}{c}33 \\
7.9 \\
230 \\
106 \\
491 \\
445 \\
2.6 \\
0.76 \\
0.00 \\
2.7 \\
13 \\
99\end{array}$ & $\begin{array}{l}0.00 \\
0.00 \\
0.00 \\
0.00 \\
0.00 \\
0.00 \\
0.00 \\
0.00 \\
0.00 \\
0.00 \\
0.00 \\
0.00\end{array}$ & $\begin{array}{l}2.2 \\
1.2 \\
29 \\
13 \\
53 \\
38 \\
0.19 \\
0.04 \\
0.00 \\
0.16 \\
0.81 \\
6.0\end{array}$ & $\begin{array}{l}8.0 \\
2.8 \\
67 \\
31 \\
124 \\
108 \\
0.62 \\
0.18 \\
0.00 \\
0.66 \\
3.1 \\
24\end{array}$ & $\begin{array}{l}3.7 \\
2.3 \\
2.3 \\
2.4 \\
2.3 \\
2.8 \\
3.3 \\
4.1 \\
\\
4.1 \\
3.8 \\
4.0\end{array}$ & $\begin{array}{r}1.5 \\
0.8 \\
20.1 \\
8.8 \\
37.3 \\
26.4 \\
0.1 \\
0.0 \\
0.0 \\
0.1 \\
0.6 \\
4.2\end{array}$ \\
\hline IMUAL & 49 & 0.00 & 12 & 16 & 1.4 & 100 \\
\hline
\end{tabular}

MAGNITUDE AND PROBABILITY OF INSTANTANEOUS PEAK FLON BASED ON PERICD OF RECORD 1963, 1965-84

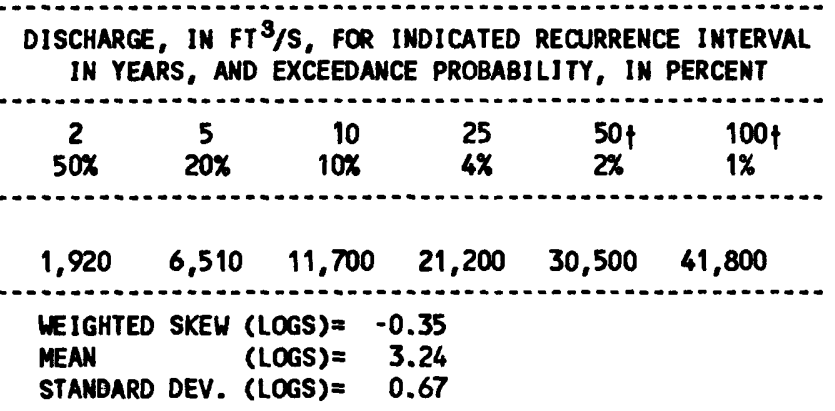

MANITLDE AND PROBABILITY OF ANNUAL LOU FLON BASED ON PERIOD OF RECORD 1969-84

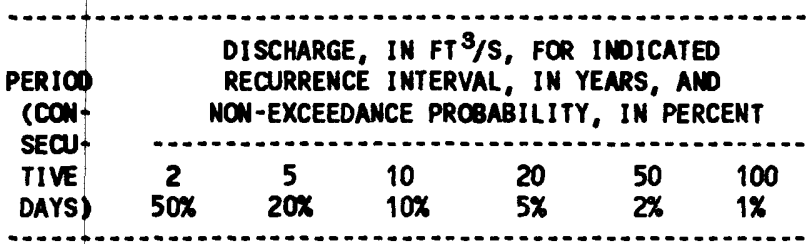

MAENITLDE AND PROBABILITY OF ANNUAL HIGH FLOH BASED ON PERIOD OF RECORD 1968-84

\begin{tabular}{|c|c|c|c|c|c|c|}
\hline \multirow{2}{*}{$\begin{array}{l}\text { PERIOD } \\
\text { (CON- } \\
\text { SECU- } \\
\text { TIVE } \\
\text { DAYS) }\end{array}$} & & \multicolumn{5}{|c|}{$\begin{array}{l}\text { DISCHARGE, IN } \mathrm{FT}^{3} / \mathrm{S}, \text { FOR INDICATED } \\
\text { RECURRENCE INTERVAL, IN YEARS, AND } \\
\text { EXCEEDANCE PROBABILITY, IN PERCENT }\end{array}$} \\
\hline & $\stackrel{2}{50 \%}$ & $\begin{array}{c}5 \\
20 x\end{array}$ & $\begin{array}{l}10 \\
10 \%\end{array}$ & $\begin{array}{l}25 \\
4 \%\end{array}$ & $\begin{array}{l}50 t \\
2 \%\end{array}$ & $\begin{array}{c}100 \nmid \\
1 \%\end{array}$ \\
\hline $\begin{array}{r}1 \\
3 \\
7 \\
15 \\
30 \\
60 \\
90\end{array}$ & $\begin{array}{c}442 \\
189 \\
98 \\
49.0 \\
25.0 \\
13.6 \\
10.7\end{array}$ & $\begin{array}{c}3,040 \\
1,630 \\
922 \\
466 \\
253 \\
147 \\
78.6\end{array}$ & $\begin{array}{r}4,630 \\
2,760 \\
1,600 \\
811 \\
455 \\
270 \\
166\end{array}$ & $\begin{array}{r}5,820 \\
3,800 \\
2,250 \\
1,130 \\
653 \\
396 \\
312\end{array}$ & $\begin{array}{r}6,260 \\
4,270 \\
2,550 \\
1,280 \\
750 \\
459 \\
445\end{array}$ & $\begin{array}{r}6,490 \\
4,560 \\
2,730 \\
1,380 \\
812 \\
501 \\
602\end{array}$ \\
\hline
\end{tabular}

DURATION TABLE OF DAILY MEAN FLON FOR PERIOD OF RECORD 1968-84

DISCHARGE, IN FT $3 / \mathrm{S}$, WHICH WAS EQUALED OR EXCEEDED FOR INDICATED PERCENT OF TIME

\begin{tabular}{|c|c|c|c|c|c|c|c|c|c|c|c|c|c|c|c|c|}
\hline $1 \%$ & $5 \%$ & $10 \%$ & $15 \%$ & $20 \%$ & $30 \%$ & $40 \%$ & $50 \%$ & $60 \%$ & $70 \%$ & $80 \%$ & $90 \%$ & $95 \%$ & $98 \%$ & $99 \%$ & $99.5 \%$ & $99.9 \%$ \\
\hline 213 & 0.00 & 0.00 & 0.00 & 0.00 & 0.00 & 0.00 & 0.00 & 0.00 & 0.00 & 0.00 & 0.00 & 0.00 & 0.00 & 0.00 & 0.00 & 0.00 \\
\hline
\end{tabular}

f Reliability of values in column is uncertain, and potential errors are large. 
GILA RIVER BASIN

09513835 NEW RIVER AT BELL ROAd, NEAR PEORIA, AZ--CONTIMUEd
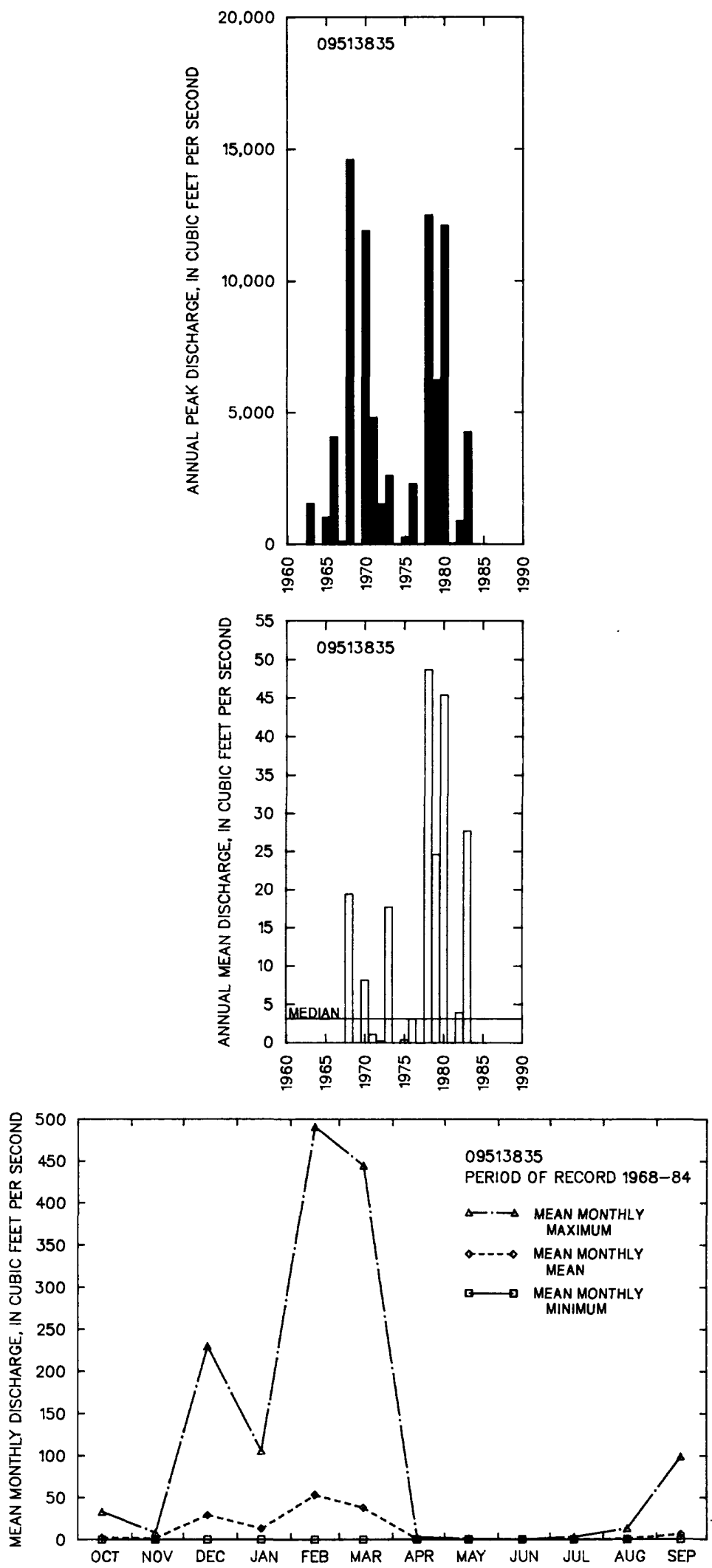
09513860 SKUNK CREEK NEAR PHOENIX, AZ

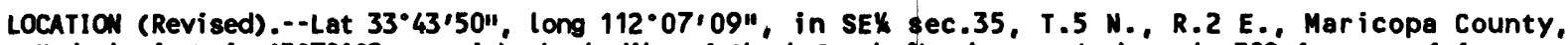
Hydrologic Unit 15070102, on right bank dike of Skunk Creek flood-control channel, $300 \mathrm{ft}$ east of frontage road of Interstate Highway 17, 3 mi north of Adobe, and 20 mi north of city hall in Phoenix. Prior to December 29, 1984, at si te $300 \mathrm{ft}$ dounstream.

DRAJMAGE AREA. $--64.6 \mathrm{mi}^{2}$.

ANNUAL PEAK DISCHARGE

\begin{tabular}{|c|c|c|c|c|c|c|c|}
\hline $\begin{array}{l}\text { MATER } \\
\text { YEAR }\end{array}$ & DATE & $\begin{array}{l}\text { ANNUALL PEAK } \\
\text { DISCHARGE } \\
\text { (FT } 3 / S)\end{array}$ & $\begin{array}{l}\text { DISCHARGE } \\
\text { COOES }\end{array}$ & $\begin{array}{l}\text { WATER } \\
\text { YEAR }\end{array}$ & DATE & $\begin{array}{l}\text { ANNUAL PEAK } \\
\text { DISCHARGE } \\
\text { (FT } 3 / \mathrm{S})\end{array}$ & $\begin{array}{l}\text { DISCHARGE } \\
\text { CODES }\end{array}$ \\
\hline $\begin{array}{l}1960 \\
1961 \\
1962 \\
1963 \\
1964 \\
1965 \\
1966 \\
1967 \\
1968 \\
1969 \\
1970 \\
1971 \\
1972 \\
1973 \\
1974\end{array}$ & $\begin{array}{l}12-25-59 \\
00-00-61 \\
00-00-62 \\
00-00-63 \\
08-01-64 \\
02-07-65 \\
08-18-66 \\
09-02-67 \\
12-19-67 \\
00-00-69 \\
09-05-70 \\
08-21-71 \\
07-17-72 \\
10-06-72 \\
07-21-74\end{array}$ & $\begin{array}{r}9,400 \\
0 \\
175 \\
480 \\
11,500 \\
400 \\
700 \\
950 \\
5,900 \\
0 \\
9,650 \\
4,770 \\
2,380 \\
4,700 \\
300\end{array}$ & $\begin{array}{l}\text { ES } \\
\text { ES }\end{array}$ & $\begin{array}{l}1975 \\
1976 \\
1977 \\
1978 \\
1979 \\
1980 \\
1981 \\
1982 \\
1983 \\
1984 \\
1985 \\
1986 \\
1987 \\
1988 \\
1989\end{array}$ & $\begin{array}{l}10-29-74 \\
07-28-76 \\
01-03-77 \\
03-01-78 \\
01-18-79 \\
02-20-80 \\
07-16-81 \\
10-02-81 \\
11-30-82 \\
09-26-84 \\
01-26-85 \\
07-22-86 \\
10-10-86 \\
11-01-87 \\
01-04-89\end{array}$ & $\begin{array}{r}240 \\
13 \\
70 \\
3,590 \\
600 \\
1,210 \\
311 \\
281 \\
6,170 \\
565 \\
1,320 \\
906 \\
3,440 \\
2,250 \\
1111\end{array}$ & $\begin{array}{l}C \\
C \\
c \\
c \\
c\end{array}$ \\
\hline
\end{tabular}

\section{BASIN CHARACTERISTICS}

\begin{tabular}{|c|c|c|c|c|c|c|c|}
\hline MAIN & & $\begin{array}{r}\text { MEAN } \\
\text { BASIN }\end{array}$ & & & $\begin{array}{l}\text { MEAN } \\
\text { ANNUAL }\end{array}$ & RAIMFALL II & ISITY, 24-HOUR \\
\hline $\begin{array}{l}\text { CHANNEL } \\
\text { SLOPE } \\
\text { (FT/MI) }\end{array}$ & $\begin{array}{l}\text { STREAM } \\
\text { LENGTH } \\
\text { (MI) }\end{array}$ & $\begin{array}{l}\text { ELEVA- } \\
\text { TION } \\
\text { (FT) }\end{array}$ & $\begin{array}{l}\text { FORESTED } \\
\text { AREA } \\
\text { (PERCENT) }\end{array}$ & $\begin{array}{l}\text { SOIL } \\
\text { INDEX }\end{array}$ & $\begin{array}{l}\text { PRECIPI- } \\
\text { TATION } \\
\text { (IN) }\end{array}$ & $\begin{array}{c}\text { 2-YEAR } \\
\text { (IN) }\end{array}$ & $\begin{array}{l}\text { 50-YEAR } \\
\text { (IN) }\end{array}$ \\
\hline 49.2 & 19.7 & 2,180 & 0.0 & 1.0 & 12.2 & 1.9 & 4.2 \\
\hline
\end{tabular}


09513860 SKUNK CREEK NEAR PHOENIX, AZ--Continued

MEAN MONTHLY AND ANNUAL DISCHARGES $1968-89$

\begin{tabular}{|c|c|c|c|c|c|c|}
\hline MONTH & $\begin{array}{l}\operatorname{Max} I \min \\
\left(F T^{3} / S\right)\end{array}$ & $\begin{array}{l}\text { MINIMUN } \\
\left(\mathrm{FT}^{3} / \mathrm{S}\right)\end{array}$ & $\begin{array}{c}\text { MEAN } \\
\left(F T^{3 / S}\right)\end{array}$ & $\begin{array}{l}\text { STAN- } \\
\text { DARD } \\
\text { DEVIA- } \\
\text { TION } \\
\text { (FT } 3 / S)\end{array}$ & $\begin{array}{l}\text { COEFFI- } \\
\text { CIENT OF } \\
\text { VARI- } \\
\text { ATION }\end{array}$ & $\begin{array}{c}\text { PERCENT } \\
\text { OF } \\
\text { ANNUAL } \\
\text { RUNOFF }\end{array}$ \\
\hline $\begin{array}{l}\text { OCTOBER } \\
\text { NOVEMBER } \\
\text { DECEMBER } \\
\text { JANUARY } \\
\text { FEBRUARY } \\
\text { MARCH } \\
\text { APRIL } \\
\text { MAY } \\
\text { JUNE } \\
\text { JULY } \\
\text { AUGUST } \\
\text { SEPTEMBER }\end{array}$ & $\begin{array}{l}26 \\
41 \\
60 \\
15 \\
24 \\
46 \\
0.00 \\
0.03 \\
0.26 \\
6.7 \\
13 \\
43\end{array}$ & $\begin{array}{l}0.00 \\
0.00 \\
0.00 \\
0.00 \\
0.00 \\
0.00 \\
0.00 \\
0.00 \\
0.00 \\
0.00 \\
0.00 \\
0.00\end{array}$ & $\begin{array}{l}2.1 \\
2.6 \\
4.3 \\
1.2 \\
2.0 \\
2.2 \\
0.00 \\
0.00 \\
0.01 \\
0.74 \\
1.3 \\
2.2\end{array}$ & $\begin{array}{c}5.9 \\
8.9 \\
14 \\
3.3 \\
5.9 \\
9.7 \\
0.00 \\
0.01 \\
0.06 \\
1.7 \\
3.3 \\
9.1\end{array}$ & $\begin{array}{l}2.8 \\
3.5 \\
3.3 \\
2.7 \\
3.0 \\
4.5 \\
\\
4.7 \\
4.7 \\
2.3 \\
2.4 \\
4.1\end{array}$ & $\begin{array}{r}11.3 \\
13.8 \\
23.0 \\
6.6 \\
10.6 \\
11.6 \\
0.0 \\
0.0 \\
0.1 \\
4.0 \\
7.2 \\
11.9\end{array}$ \\
\hline NNUAL & 8.6 & 0.00 & 1.5 & 2.3 & 1.5 & 100 \\
\hline
\end{tabular}

MAGNITUDE AND PROBABILITY OF ANNUAL LON FLON BASED ON PERIOD OF RECORD 1969-89

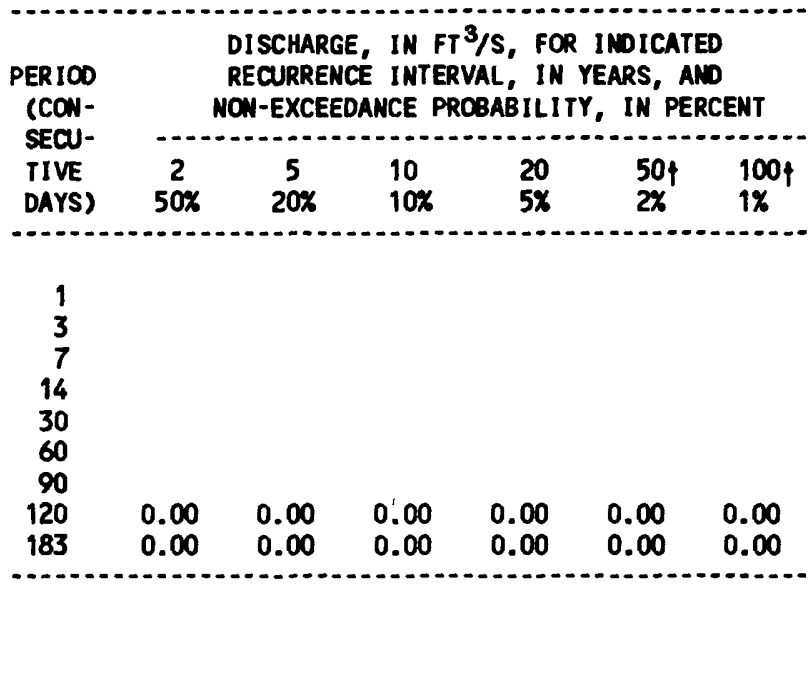

MAGNITUDE AND PROBABILITY OF ANNUAL HIGH FLOW BASED ON PERIOD OF RECORD 1968-89

\begin{tabular}{|c|c|c|c|c|c|c|}
\hline \multirow{2}{*}{$\begin{array}{l}\text { PERIOD } \\
\text { (CON- } \\
\text { SECU- } \\
\text { TIVE } \\
\text { DAYS) }\end{array}$} & \multicolumn{6}{|c|}{$\begin{array}{l}\text { DISCHARGE, IN } \mathrm{FT}^{3} / \mathrm{S} \text {, FOR INDICATED } \\
\text { RECURRENCE INTERVAL, IN YEARS, AND } \\
\text { EXCEEDANCE PROBABILITY, IN PERCENT }\end{array}$} \\
\hline & $\begin{array}{c}2 \\
50 \%\end{array}$ & $\begin{array}{c}5 \\
20 \%\end{array}$ & $\begin{array}{l}10 \\
10 \%\end{array}$ & $\begin{array}{l}25 \\
4 x\end{array}$ & $\begin{array}{l}50 \uparrow \\
2 x\end{array}$ & $\begin{array}{c}100 \nmid \\
1 \%\end{array}$ \\
\hline $\begin{array}{r}1 \\
3 \\
7 \\
15 \\
30 \\
60 \\
90\end{array}$ & $\begin{array}{r}120 \\
47 \\
21 \\
11 \\
5.4 \\
2.8 \\
2.0\end{array}$ & $\begin{array}{c}458 \\
202 \\
91 \\
46 \\
25 \\
13 \\
9.0\end{array}$ & $\begin{array}{r}790 \\
374 \\
169 \\
87 \\
47 \\
26 \\
18\end{array}$ & $\begin{array}{r}1,270 \\
652 \\
292 \\
153 \\
84 \\
49 \\
33\end{array}$ & $\begin{array}{r}1,650 \\
892 \\
397 \\
211 \\
117 \\
70 \\
49\end{array}$ & $\begin{array}{r}2,030 \\
1,150 \\
509 \\
275 \\
153\end{array}$ \\
\hline
\end{tabular}

DURATION TABLE OF DAILY MEAN FLOW FOR PERIOD OF RECORD 1968-89

DISCHARGE, IN FT $3 / \mathrm{S}$, WHICH WAS EQUALED OR EXCEEDED FOR INDICATED PERCENT OF TIME

\begin{tabular}{|c|c|c|c|c|c|c|c|c|c|c|c|c|c|c|c|c|}
\hline $1 \%$ & $5 \%$ & $10 \%$ & $15 \%$ & $20 \%$ & $30 \%$ & $40 \%$ & $50 \%$ & $60 \%$ & $70 \%$ & $80 \%$ & $90 \%$ & $95 \%$ & $98 \%$ & $99 \%$ & $99.5 \%$ & $99.9 \%$ \\
\hline & .00 & 0.00 & 0.00 & 0.00 & 0.00 & 0.00 & 0.00 & 0.00 & 0.00 & 0.00 & 0.00 & 0.00 & 0.00 & 0.00 & 0.00 & 0.0 \\
\hline
\end{tabular}

$\uparrow$ Reliability of values in column is uncertain, and potential errors are large. 
GILA RIVER BASIN

09513860 SKUNK CREEK NEAR PHOENIX, AZ--CONTINUEd
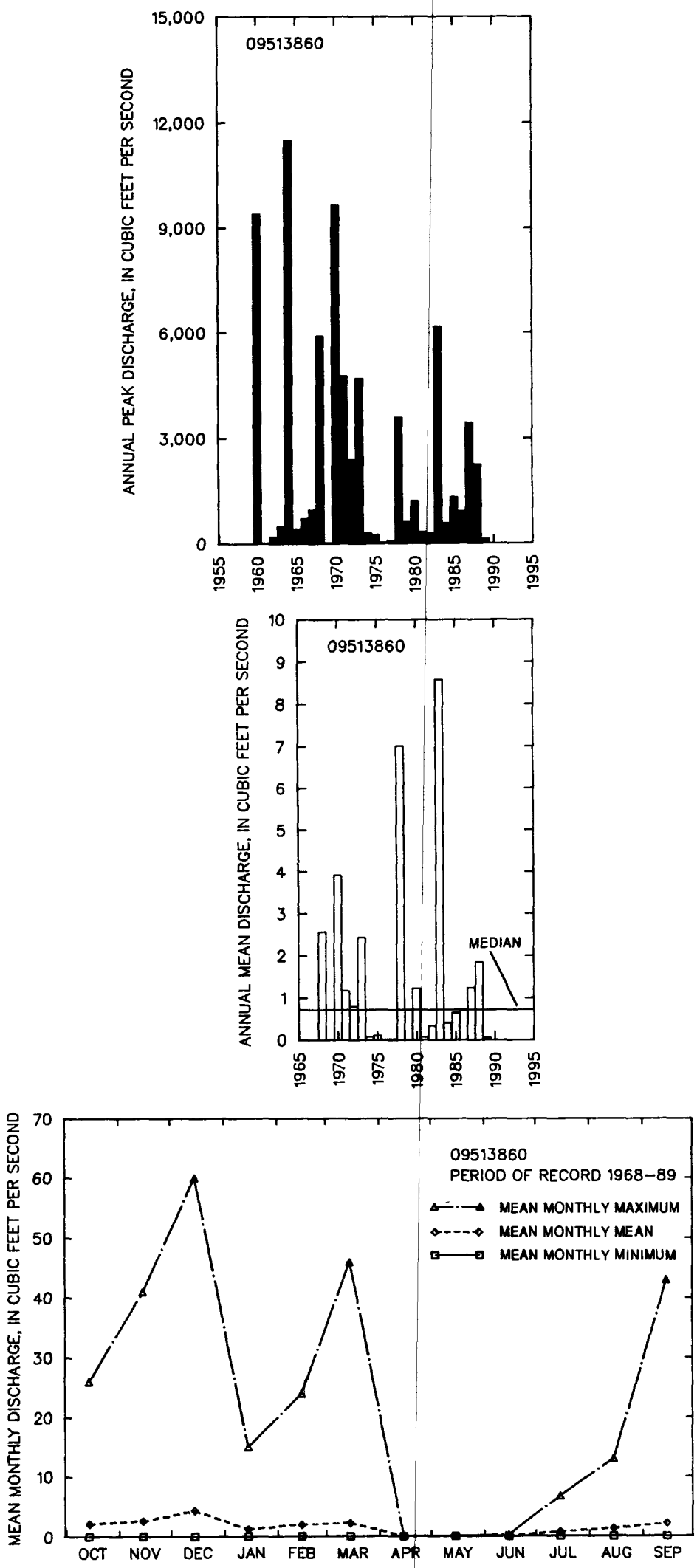
09513890 NEW RIVER AT PEORIA, AZ

LOCATION. --Lat 33'35'43", long 112'15'45", in SEX sec.16, T.3 N., R.1 E., Maricopa County, Hydrologic Unit 15070102, at Grand Avenue, 1.75 mi northwest of Peoria.

DRAIMAGE AREA. $--317 \mathrm{mi}^{2}$.

ANNUAL PEAK DISCHARGE

\begin{tabular}{|c|c|c|c|}
\hline $\begin{array}{l}\text { HATER } \\
\text { YEAR }\end{array}$ & DATE & $\begin{array}{c}\text { ANNUAL PEAK } \\
\text { DISCHARGE } \\
\left(F^{3} / \mathrm{S}\right)\end{array}$ & $\begin{array}{l}\text { DISCHARGE } \\
\text { CODES }\end{array}$ \\
\hline $\begin{array}{l}1943 \\
1960 \\
1961 \\
1962 \\
1963 \\
1964 \\
1965 \\
1966 \\
1967 \\
1968 \\
1969 \\
1970 \\
1971\end{array}$ & $\begin{array}{l}00-00-43 \\
12-25-59 \\
07-22-61 \\
00-00-62 \\
08-17-63 \\
08-01-64 \\
02-07-65 \\
12-23-65 \\
06-18-67 \\
12-19-67 \\
00-00-69 \\
09-05-70 \\
08-21-71\end{array}$ & $\begin{array}{r}38,000 \\
6,400 \\
250 \\
0 \\
1,390 \\
8,300 \\
2,300 \\
4,000 \\
600 \\
20,000 \\
0 \\
20,000 \\
7,430\end{array}$ & HP \\
\hline
\end{tabular}

MAGNITUDE AND PROBABILITY OF INSTANTANEOUS PEAK FLOW BASED ON PERICD OF RECORD 1943, 1960-71

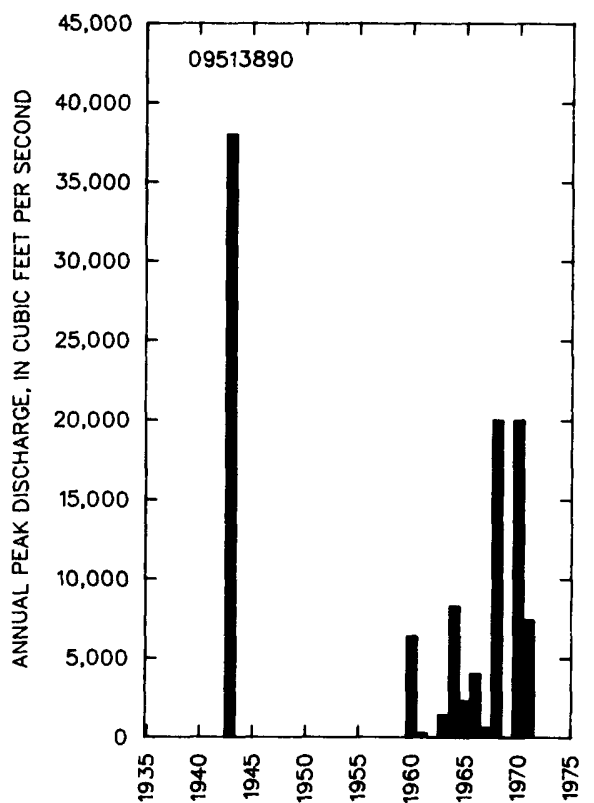

DISCHARGE, IN FT $3 / 5$, FOR INDICATED RECURRENCE INTERYAL IN YEARS, AND EXCEEDANCE PROBABILITY, IN PERCENT

\begin{tabular}{|c|c|c|c|c|c|}
\hline $\begin{array}{c}2 \\
50 \%\end{array}$ & $\begin{array}{c}5 \\
20 \%\end{array}$ & $\begin{array}{r}10 \\
10 \%\end{array}$ & $\begin{array}{l}25 \dagger \\
4 \%\end{array}$ & $\begin{array}{l}50 \nmid \\
2 x\end{array}$ & $\begin{array}{c}100 \dagger \\
1 \%\end{array}$ \\
\hline 3,160 & 11,300 & 20,800 & 38,000 & 54,900 & 75,100 \\
\hline $\begin{array}{l}\text { WEIGHTED } \\
\text { MEAN } \\
\text { STANDARD }\end{array}$ & $\begin{array}{l}\text { SKEW ? } \\
\text { DEV. }\end{array}$ & $\begin{array}{l}\text { LOGS) }=- \\
\text { LOGS }= \\
\text { LOGS }=\end{array}$ & $\begin{array}{r}-0.41 \\
3.45 \\
0.71\end{array}$ & & \\
\hline
\end{tabular}

$\uparrow$ Reliability of values in colum is uncertain, and potential errors are large.

BASIN CHARACTERISTICS

\begin{tabular}{|c|c|c|c|c|c|c|c|}
\hline \multirow{2}{*}{$\begin{array}{c}\text { MAIN } \\
\text { CHANNEL } \\
\text { SLOPE } \\
\text { (FT/MI) }\end{array}$} & \multirow[b]{2}{*}{$\begin{array}{c}\text { STREAM } \\
\text { LENGTH } \\
\text { (MI) }\end{array}$} & \multirow{2}{*}{$\begin{array}{c}\text { MEAN } \\
\text { BASIN } \\
\text { ELEVA- } \\
\text { TION } \\
\text { (FT) }\end{array}$} & \multirow[b]{2}{*}{$\begin{array}{l}\text { FORESTED } \\
\text { AREA } \\
\text { (PERCENT) }\end{array}$} & \multirow[b]{2}{*}{$\begin{array}{l}\text { SOIL } \\
\text { INDEX }\end{array}$} & \multirow{2}{*}{$\begin{array}{l}\text { MEAN } \\
\text { ANNUAL } \\
\text { PRECIPI- } \\
\text { TATION } \\
\text { (IN) }\end{array}$} & \multicolumn{2}{|c|}{ RAINFALL INTENSITY, 24-HOUR } \\
\hline & & & & & & $\begin{array}{c}\text { 2-YEAR } \\
\text { (IN) }\end{array}$ & $\begin{array}{c}\text { 50-YEAR } \\
\text { (IN) }\end{array}$ \\
\hline 65.3 & 44.1 & 2,320 & 0.0 & 1.0 & 13.3 & 1.8 & 3.8 \\
\hline
\end{tabular}




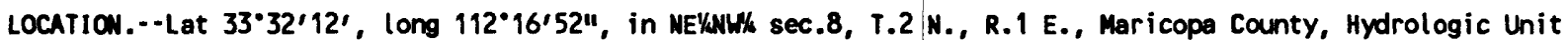
15070102, at Glendale Avenue, 2 mi upstream from mouth, and 6 mi west of Glendale.

DRAINAGE AREA. $--323 \mathrm{mi}^{2}$.

ANNUAL PEAK DISCHARGE

\begin{tabular}{|c|c|c|c|c|c|c|c|}
\hline $\begin{array}{l}\text { WATER } \\
\text { YEAR }\end{array}$ & DATE & $\begin{array}{l}\text { ANNUAL PEAK } \\
\text { DISCHARGE } \\
\text { (FT } 3 / S \text { ) }\end{array}$ & $\begin{array}{l}\text { DISCHARGE } \\
\text { CODES }\end{array}$ & $\begin{array}{l}\text { WATER } \\
\text { YEAR }\end{array}$ & DATE & $\begin{array}{l}\text { ANNUAL PEAK } \\
\text { DISCHARGE } \\
\left(F^{3} / S\right)\end{array}$ & $\begin{array}{l}\text { DISCHARGE } \\
\text { CODES }\end{array}$ \\
\hline $\begin{array}{l}1943 \\
1955 \\
1960 \\
1961 \\
1962 \\
1963 \\
1964 \\
1965 \\
1966 \\
1967 \\
1968\end{array}$ & $\begin{array}{l}08-00-43 \\
07-00-55 \\
12-25-59 \\
00-00-61 \\
00-00-62 \\
08-30-63 \\
08-01-64 \\
01-08-65 \\
12-23-65 \\
00-00-67 \\
12-19-67\end{array}$ & $\begin{array}{r}38,000 \\
12,000 \\
5,500 \\
0 \\
0 \\
690 \\
7,000 \\
1,100 \\
13,000 \\
0 \\
19,800\end{array}$ & $\begin{array}{c}\text { ES, HP } \\
\text { ES, HP } \\
\text { ES }\end{array}$ & $\begin{array}{l}1969 \\
1970 \\
1971 \\
1972 \\
1973 \\
1974 \\
1975 \\
1976 \\
1977 \\
1978 \\
1979\end{array}$ & $\begin{array}{l}00-00-69 \\
09-05-70 \\
08-21-71 \\
07-17-72 \\
10-07-72 \\
08-05-74 \\
10-29-74 \\
09-25-76 \\
10-23-76 \\
03-02-78 \\
12-19-78\end{array}$ & $\begin{array}{c}0.0 \\
19,200 \\
7,000 \\
6,300 \\
8,650 \\
775 \\
490 \\
1,550 \\
168 \\
12,300 \\
3,620\end{array}$ & ES \\
\hline
\end{tabular}

MAGNI TUDE AND PROBABILITY OF INSTANTANEOUS PEAK FLOW BASED ON PERIOD OF RECORD 1943, 1955, 1960-79

DISCHARGE, IN $\mathrm{FT}^{3} / \mathrm{S}$, FOR INDICATED RECURRENCE INTERVAL IN YEARS, AND EXCEEDANCE PROBABILITY, IN PERCENT

\begin{tabular}{cccccc}
2 & 5 & 10 & 25 & $50 \%$ & $100 \dagger$ \\
$50 \%$ & $20 \%$ & $10 \%$ & $4 \%$ & $2 \%$ & $1 \%$ \\
4,000 & 10,900 & 17,500 & 27,900 & 37,000 & 47,100 \\
\hline MEIGHTED SKEW (LOGS) & -0.44 & & \\
MEAN & (LOGS) & 3.56 & & \\
STANDARD DEV. (LOGS) & 0.56 & &
\end{tabular}

† Reliability of values in column is uncertain, and potential errors are large.

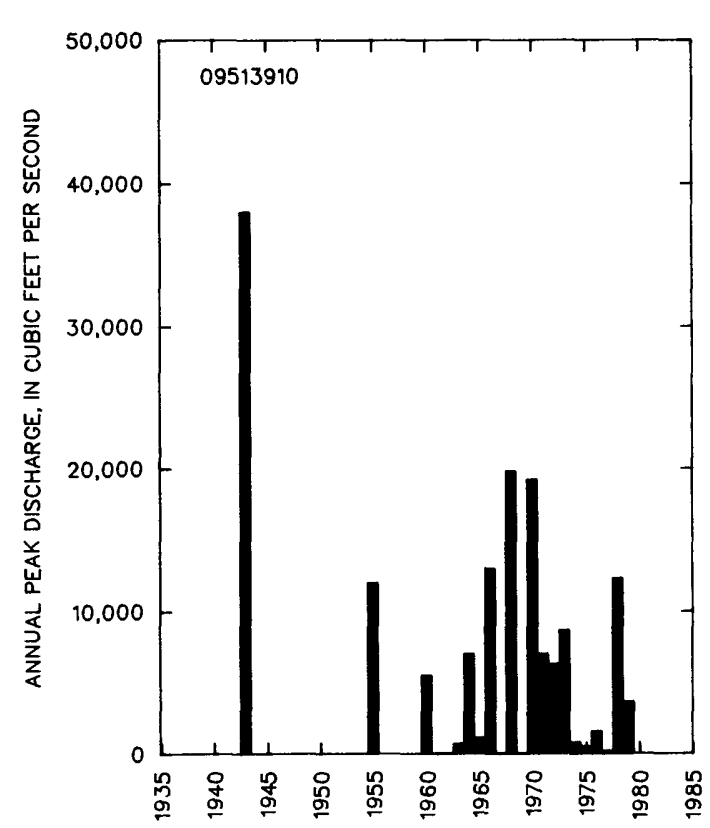

BASIN CHARACTERISTICS

\begin{tabular}{|c|c|c|c|c|c|c|c|}
\hline MAIN & & $\begin{array}{l}\text { MEAN } \\
\text { BASIN }\end{array}$ & & & $\begin{array}{c}\text { MEAN } \\
\text { ANNUAL }\end{array}$ & RAINFALL II & SITY, 24-HOUR \\
\hline $\begin{array}{l}\text { CHANNEL } \\
\text { SLOPE } \\
\text { (FTMI) }\end{array}$ & $\begin{array}{c}\text { STREAM } \\
\text { LENGTH } \\
\text { (MI) }\end{array}$ & $\begin{array}{l}\text { ELEVA- } \\
\text { TION } \\
\text { (FT) }\end{array}$ & $\begin{array}{l}\text { FORESTED } \\
\text { AREA } \\
\text { (PERCENT) }\end{array}$ & $\begin{array}{l}\text { SOIL } \\
\text { INDEX }\end{array}$ & $\begin{array}{l}\text { PRECIPI - } \\
\text { TATION } \\
\text { (IN) }\end{array}$ & $\begin{array}{c}\text { 2-YEAR } \\
\text { (IN) }\end{array}$ & $\begin{array}{c}\text { 50-YEAR } \\
\text { (IN) }\end{array}$ \\
\hline 66.9 & 49.6 & 2,130 & 0.0 & 1.5 & 13.8 & 1.8 & 4.0 \\
\hline
\end{tabular}


09513970 AGUA FRIA RIVER AT AVONDALE, AZ

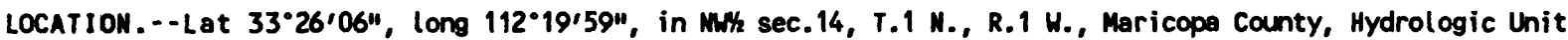
15070102, on downstream side of bridge on U.S. Highway $80,0.5 \mathrm{mi}$ east of Avondale, and $3 \mathrm{mi}$ upstream from mouth.

DRAINAGE AREA.--2,066 $\mathrm{mi}^{2}$, of which 1,433 $\mathrm{mi}^{2}$ above Lake Pleasant is noncontributing except during periods of spill from Waddell Dam. Floodwaters from drainage area of $247 \mathrm{mi}^{2}$ above McMicken Dam may be diverted into Agua fria River basin above station.

REMARKS. - - Flow partly regulated by Lake Pleasant, 35 mi upstream. (See elsewhere in this report.) Records at times may include wastewater from the Arizona Canal of the Salt River Project. Excess floodwater released from McMicken Dam on Trilby Wash may enter Agua Fria River basin above station; this amount. generally is negligible.

ANNUAL PEAK DISCHARGE

\begin{tabular}{|c|c|c|c|c|c|c|c|}
\hline $\begin{array}{l}\text { WATER } \\
\text { YEAR }\end{array}$ & DATE & $\begin{array}{c}\text { ANNUAL PEAK } \\
\text { DISCHARGE } \\
\left(F^{3} / S\right)\end{array}$ & $\begin{array}{l}\text { DISCHARGE } \\
\text { COOES }\end{array}$ & $\begin{array}{l}\text { WATER } \\
\text { YEAR }\end{array}$ & DATE & $\begin{array}{c}\text { ANNUAL PEAK } \\
\text { DISCHARGE } \\
\text { (FT } 3 / S)\end{array}$ & $\begin{array}{l}\text { DISCHARGE } \\
\text { CODES }\end{array}$ \\
\hline $\begin{array}{l}1960 \\
1961 \\
1962 \\
1963 \\
1964 \\
1965 \\
1966 \\
1967 \\
1968 \\
1969 \\
1970 \\
1971\end{array}$ & $\begin{array}{l}12-25-59 \\
00-00-61 \\
00-00-62 \\
08-00-63 \\
08-01-64 \\
04-05-65 \\
12-23-65 \\
00-00-67 \\
12-20-67 \\
00-00-69 \\
08-06-70 \\
08-21-71\end{array}$ & $\begin{array}{r}4,700 \\
0 \\
0 \\
63 \\
3,000 \\
460 \\
800 \\
0 \\
20,000 \\
0 \\
20,600 \\
8,200\end{array}$ & & $\begin{array}{l}1972 \\
1973 \\
1974 \\
1975 \\
1976 \\
1977 \\
1978 \\
1979 \\
1980 \\
1981 \\
1982\end{array}$ & $\begin{array}{l}07-17-72 \\
10-07-72 \\
00-00-74 \\
00-00-75 \\
00-00-76 \\
00-00-77 \\
03-02-78 \\
12-19-78 \\
02-20-80 \\
00-00-81 \\
00-00-82\end{array}$ & $\begin{array}{r}5,180 \\
5,000 \\
0 \\
0 \\
0 \\
0 \\
13,100 \\
29,300 \\
0 \\
0 \\
0\end{array}$ & $\begin{array}{l}\text { UR } \\
\text { UR } \\
C, U R \\
C, U R\end{array}$ \\
\hline
\end{tabular}

BASIN CHARACTERISTICS

\begin{tabular}{|c|c|c|c|c|c|c|c|}
\hline \multirow{3}{*}{$\begin{array}{l}\text { MIN } \\
\text { CHANNEL } \\
\text { SLOPE } \\
\text { (FT/MI) }\end{array}$} & \multirow[b]{3}{*}{$\begin{array}{l}\text { STREAM } \\
\text { LENGTH } \\
\text { (MI) }\end{array}$} & \multirow{3}{*}{$\begin{array}{l}\text { MEAN } \\
\text { BASIN } \\
\text { ELEVA- } \\
\text { TION } \\
\text { (FT) }\end{array}$} & \multirow[b]{3}{*}{$\begin{array}{l}\text { FORESTED } \\
\text { AREA } \\
\text { (PERCENT) }\end{array}$} & \multirow[b]{3}{*}{$\begin{array}{l}\text { SOIL } \\
\text { INDEX }\end{array}$} & \multirow{3}{*}{$\begin{array}{l}\text { MEAN } \\
\text { ANNUAL } \\
\text { PRECIPI- } \\
\text { TATION } \\
\text { (IN) }\end{array}$} & \multirow{2}{*}{\multicolumn{2}{|c|}{ RAINFALL INTENSITY, 24-HOUR }} \\
\hline & & & & & & & \\
\hline & & & & & & $\begin{array}{c}\text { 2-YEAR } \\
\text { (IN) }\end{array}$ & $\begin{array}{l}\text { 50-YEAR } \\
\text { (IN) }\end{array}$ \\
\hline 38.7 & 96.4 & 3,010 & 0.0 & 1.0 & 16.3 & 1.7 & 4.2 \\
\hline
\end{tabular}


MEAN MONTHLY AND ANIUUL DISCHARGES 1968-72, 1974-82

\begin{tabular}{|c|c|c|c|c|c|c|}
\hline MONTH & $\begin{array}{l}\operatorname{MAXIMUN} \\
\left(F^{3} / S\right)\end{array}$ & $\begin{array}{l}\text { MINIMUM } \\
\left.\text { (FT }^{3} / S\right)\end{array}$ & $\begin{array}{c}\text { MEAN } \\
\left(F T^{3} / S\right)\end{array}$ & $\begin{array}{l}\text { STAN- } \\
\text { DARD } \\
\text { DEVIA- } \\
\text { TION } \\
\text { (FT } 3 / S)\end{array}$ & $\begin{array}{l}\text { COEFFI- } \\
\text { CIENT OF } \\
\text { VARI - } \\
\text { ATION }\end{array}$ & $\begin{array}{c}\text { PERCENT } \\
\text { OF } \\
\text { ANNUAL } \\
\text { RUNOFF }\end{array}$ \\
\hline $\begin{array}{l}\text { OCTOBER } \\
\text { NOVEMBER } \\
\text { DECEMBER } \\
\text { JANUARY } \\
\text { FEBRUARY } \\
\text { MARCH } \\
\text { APRIL } \\
\text { MAY } \\
\text { JUNE } \\
\text { JULY } \\
\text { AUGUST } \\
\text { SEPTEMBER }\end{array}$ & $\begin{array}{c}0.00 \\
0.00 \\
520 \\
518 \\
2,900 \\
810 \\
0.00 \\
0.00 \\
1.1 \\
15 \\
24 \\
133\end{array}$ & $\begin{array}{l}0.00 \\
0.00 \\
0.00 \\
0.00 \\
0.00 \\
0.00 \\
0.00 \\
0.00 \\
0.00 \\
0.00 \\
0.00 \\
0.00\end{array}$ & $\begin{array}{c}0.00 \\
0.00 \\
54 \\
42 \\
212 \\
68 \\
0.00 \\
0.00 \\
0.08 \\
1.00 \\
1.7 \\
9.5\end{array}$ & $\begin{array}{c}0.00 \\
0.00 \\
148 \\
138 \\
773 \\
217 \\
0.00 \\
0.00 \\
0.30 \\
3.9 \\
6.4 \\
36\end{array}$ & $\begin{array}{l}2.8 \\
3.3 \\
3.6 \\
3.2\end{array}$ & $\begin{array}{r}0.0 \\
0.0 \\
13.9 \\
10.9 \\
54.6 \\
17.4 \\
0.0 \\
0.0 \\
0.0 \\
0.3 \\
0.4 \\
2.4\end{array}$ \\
\hline ANNUAL & 232 & 0.00 & 32 & 66 & 2.1 & 100 \\
\hline
\end{tabular}

MAGNITLDE AND PROBABILITY OF INSTANTANEOUS PEAK FLOH BASED ON PERICD OF RECORD 1960-82

DISCHAREE, IN $\mathrm{FT}^{3} / \mathrm{S}$, FOR INDICATED RECURRENCE INTERVAL IN YEARS, AND EXCEEDANCE PROBABILITY, IN PERCENT

\begin{tabular}{lccccc}
2 & 5 & 10 & 25 & 50 & 100 \\
$50 \%$ & $20 \%$ & $10 \%$ & $4 \%$ & $2 \%$ & $1 \%$ \\
3,400 & 9,300 & 15,000 & 26,000 & 37,000 & 49,000 \\
\hline MEIGHTED SKEW (LOGS) & $=$ & $\ldots$ & & & \\
MEAN \\
STANDARD DEV. (LOGS) & $=$ & $\ldots$ & &
\end{tabular}

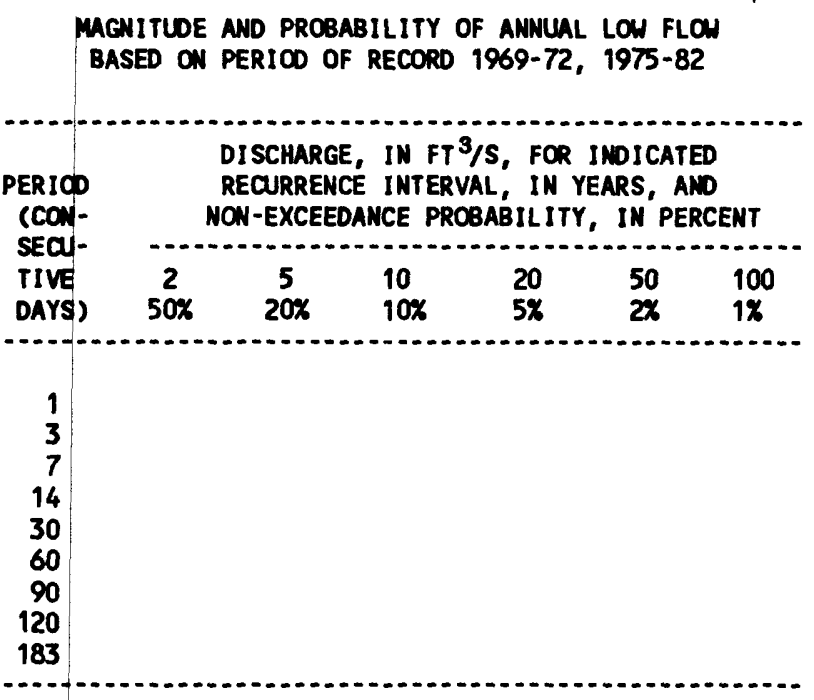

MAGNITUDE AND PROBABILITY OF ANNUAL HIGH FLOW BASED ON PERIOD OF RECORD 1968-72, 1974-82

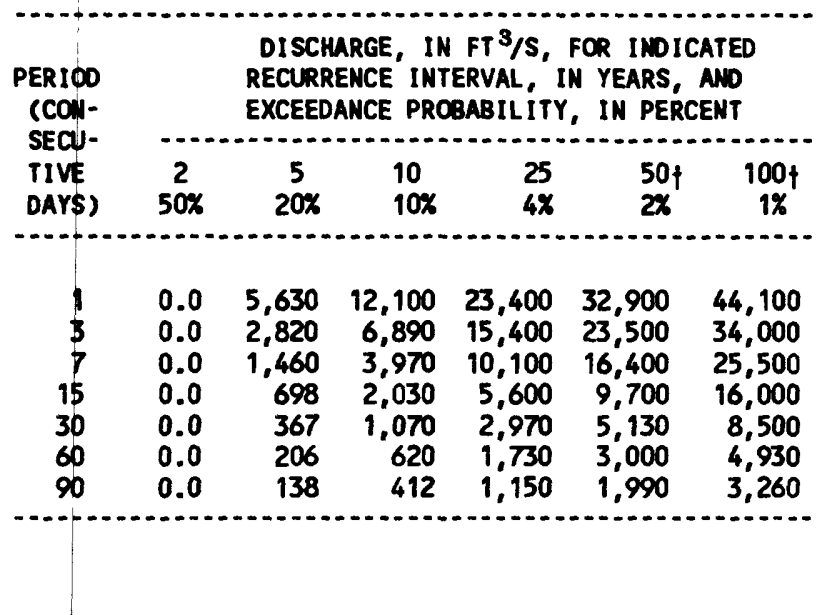

DURATION TABLE OF DAILY MEAN FLON FOR PERIOD OF RECORD 1968-72, 1974-82

\begin{tabular}{|c|c|c|c|c|c|c|c|c|c|c|c|c|c|c|c|c|}
\hline $1 \%$ & $5 \%$ & $10 \%$ & $15 \%$ & $20 \%$ & $30 \%$ & $40 \%$ & $50 \%$ & $60 \%$ & $70 \%$ & $80 \%$ & $90 \%$ & $95 \%$ & $98 \%$ & $99 \%$ & $99.5 \%$ & $99.9 \%$ \\
\hline 98 & 4.6 & 4.4 & 4.1 & 3.9 & 3.4 & 2.9 & 2.4 & 1.9 & 1.5 & 0.97 & 0.49 & 0.24 & 0.10 & 0.05 & 0.02 & 0.00 \\
\hline
\end{tabular}

f Reliability of values in colum is uncertain, and potential errors are large. 
GIU RIVER BASIM

09513970 heuA fRIA RIVEr AT AVONDALE, AZ--CONTIMUed
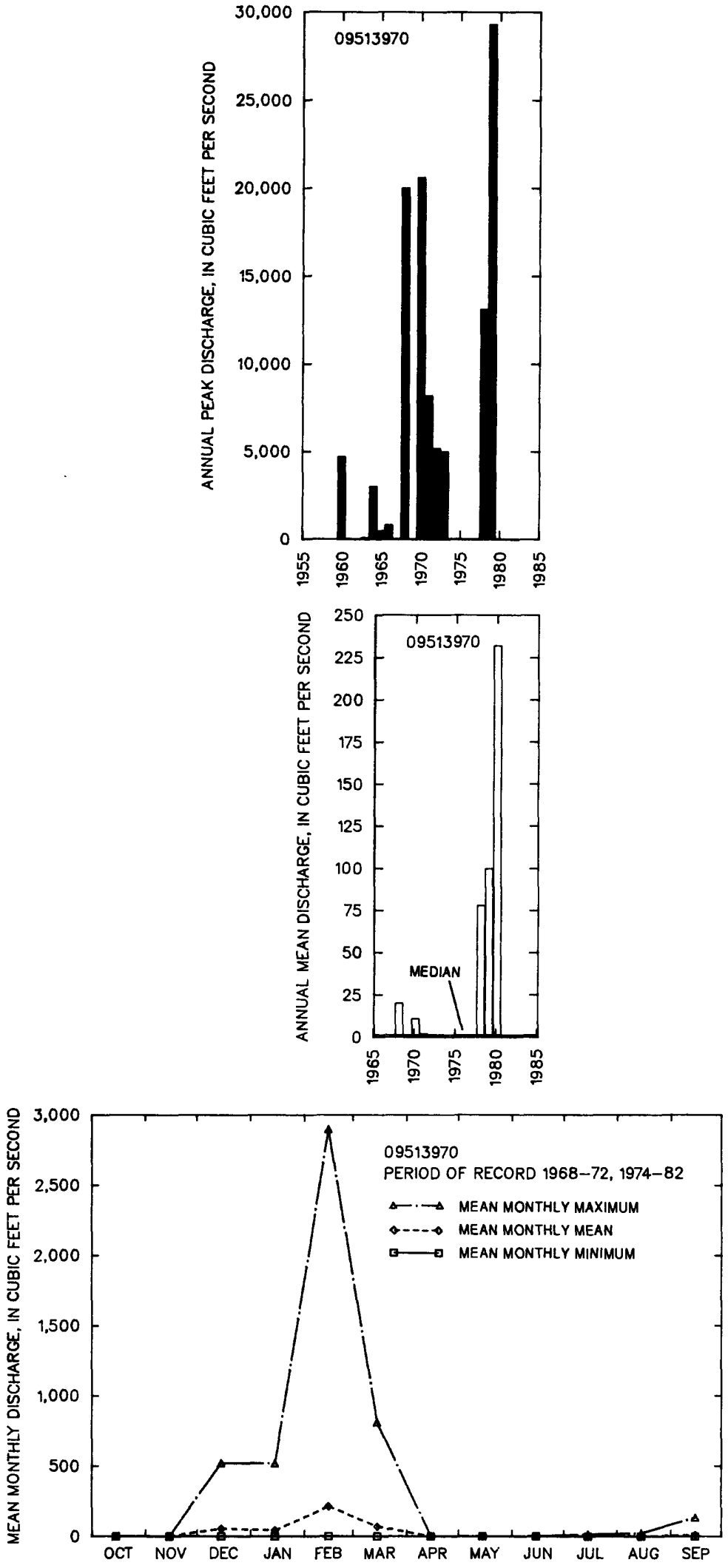
09514200 HATERMAN UASH MEAR BUCKEYE, AZ

LOCATION.--Lat 33.19.49", Long 112.30'33", in SWANEK sec.24, T.1 S., R.3 W., Maricopa County, Hydrologic Unit 15070101, $2.4 \mathrm{mi}$ above mouth, $5.2 \mathrm{mi}$ southeast of Buckeye.

DRAINAGE AREA. $--420 \mathrm{mi}^{2}$.

ANMUAL PEAK DISCHARGE

\begin{tabular}{|c|c|c|c|c|c|c|c|}
\hline \multicolumn{5}{|c|}{ ANNUAL PEAK } & \multicolumn{3}{|c|}{ ANNUAL PEAK } \\
\hline $\begin{array}{l}\text { WATER } \\
\text { YEAR }\end{array}$ & DATE & $\begin{array}{l}\text { DISCHARGE } \\
\left(\mathrm{FT}^{3} / \mathrm{S}\right)\end{array}$ & $\begin{array}{l}\text { DISCHARGE } \\
\text { CCDES }\end{array}$ & $\begin{array}{l}\text { WATER } \\
\text { YEAR }\end{array}$ & DATE & $\begin{array}{c}\text { DISCHARGE } \\
\left(\mathrm{FT}^{3} / \mathrm{S}\right)\end{array}$ & $\begin{array}{l}\text { DISCHARGE } \\
\text { CODES }\end{array}$ \\
\hline $\begin{array}{l}1964 \\
1965 \\
1966 \\
1967 \\
1968 \\
1969 \\
1970 \\
1971 \\
1972 \\
1973 \\
1974 \\
1975 \\
1976\end{array}$ & $\begin{array}{l}09-13-64 \\
08-00-65 \\
09-13-66 \\
09-03-67 \\
12-15-67 \\
08-29-69 \\
08-09-70 \\
08-11-71 \\
08-00-72 \\
00-00-73 \\
09-03-74 \\
10-28-74 \\
09-26-76\end{array}$ & $\begin{array}{r}2,680 \\
1,200 \\
5,560 \\
6,300 \\
560 \\
400 \\
1,600 \\
2,080 \\
2,000 \\
0 \\
100 \\
1,200 \\
1,180\end{array}$ & ES & $\begin{array}{l}1977 \\
1978 \\
1980 \\
1981 \\
1982 \\
1983 \\
1984 \\
1985 \\
1986 \\
1987 \\
1988 \\
1989\end{array}$ & $\begin{array}{l}10-23-76 \\
08-04-78 \\
02-15-80 \\
00-00-81 \\
09-27-82 \\
12-10-82 \\
09-02-84 \\
12-28-84 \\
07-22-86 \\
00-00-87 \\
12-17-87 \\
00-00-89\end{array}$ & $\begin{array}{r}740 \\
1,150 \\
2,220 \\
0 \\
1,660 \\
985 \\
3,520 \\
950 \\
1,500 \\
0 \\
1,430 \\
402\end{array}$ & \\
\hline
\end{tabular}

MAGMITUDE AND PROBABILITY OF INSTANTANEOUS PEAK FLON BASED ON PERIOD OF RECORD 1964-78, 1980-89

DISCHARGE, IN $\mathrm{FT}^{3} / \mathrm{S}$, FOR INDICATED RECURRENCE INTERVAL IN YEARS, AND EXCEEDANCE PROBABILITY, IN PERCENT

$\begin{array}{cccccc}2 & 5 & 10 & 25 & 50 \% & 100 \% \\ 2 \% & 20 \% & 10 \% & 4 \% & 1 \% \\ 1,330 & 2,420 & 3,380 & 4,880 & 6,240 & 7,840\end{array}$

t Reliability of values in column is uncertain, and potential errors are large.

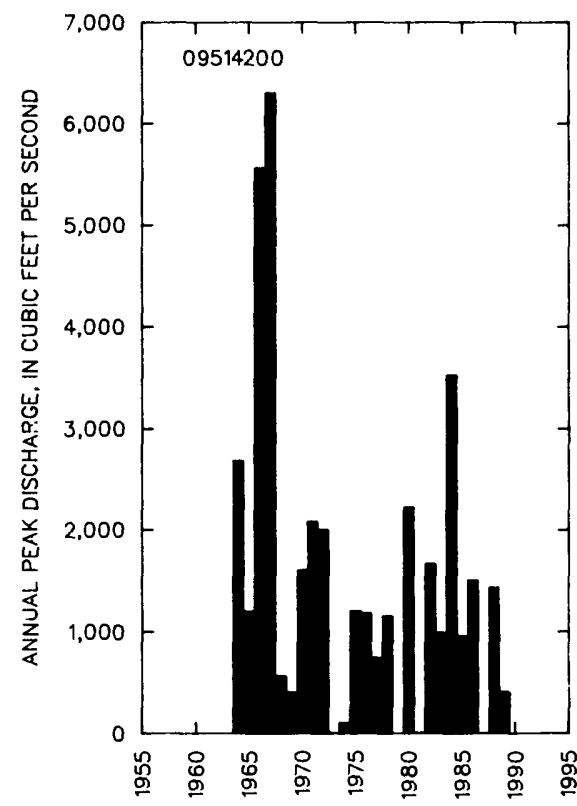

BASIN CHARACTERISTICS

\begin{tabular}{|c|c|c|c|c|c|c|c|}
\hline MAIN & & $\begin{array}{l}\text { MEAN } \\
\text { BASIN }\end{array}$ & & & $\begin{array}{c}\text { MEAN } \\
\text { ANNUAL }\end{array}$ & RAINFALL IN & SITY, 24-HOUR \\
\hline $\begin{array}{l}\text { CHANNEL } \\
\text { SLOPE } \\
\text { (FT/MI) }\end{array}$ & $\begin{array}{l}\text { STREAM } \\
\text { LENGTH } \\
\text { (MI) }\end{array}$ & $\begin{array}{l}\text { ELEVA- } \\
\text { TION } \\
\text { (FT) }\end{array}$ & $\begin{array}{l}\text { FORESTED } \\
\text { AREA } \\
\text { (PERCENT) }\end{array}$ & $\begin{array}{l}\text { SOIL } \\
\text { INDEX }\end{array}$ & $\begin{array}{l}\text { PRECIPI - } \\
\text { TAT ION } \\
\text { (IN) }\end{array}$ & $\begin{array}{c}\text { 2-YEAR } \\
\text { (IN) }\end{array}$ & $\begin{array}{l}\text { 50-YEAR } \\
\text { (IN) }\end{array}$ \\
\hline 21.2 & 37.7 & 1,570 & 0.0 & 2.5 & 9.2 & 1.7 & 3.8 \\
\hline
\end{tabular}


09515500 HASSAYAMPA RIVER AT BOX DAMSITE, NEAR HICKENBURG, AZ

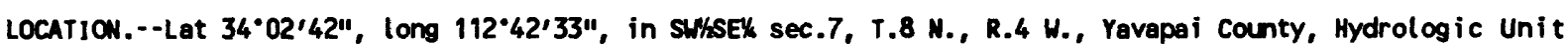
15070103, on right bank at Box damsite, 5.5 mi northeast of Wickenburg.

DRAINAGE AREA. $--417 \mathrm{mi}^{2}$.

REMARKS.--Small diversions for irrigation and mining above station.

ANIUAL PEAK DISCHARGE

\begin{tabular}{|c|c|c|c|c|c|c|c|}
\hline $\begin{array}{l}\text { WATER } \\
\text { YEAR }\end{array}$ & DATE & $\begin{array}{l}\text { ANNUAL PEAK } \\
\text { DISCHARGE } \\
\text { (FT } 3 / \mathrm{S})\end{array}$ & $\begin{array}{l}\text { DISCHARGE } \\
\text { COOES }\end{array}$ & $\begin{array}{r}\text { WATER } \\
\text { YEAR }\end{array}$ & DATE & $\begin{array}{l}\text { ANNUAL PEAK } \\
\text { DISCHARGE } \\
\left.\text { (FT }{ }^{3} / \mathrm{S}\right)\end{array}$ & $\begin{array}{l}\text { DISCHARCE } \\
\text { COOES }\end{array}$ \\
\hline $\begin{array}{l}1925 \\
1927 \\
1937 \\
1938 \\
1946 \\
1947 \\
1948 \\
1949 \\
1950 \\
1951 \\
1952 \\
1953 \\
1954 \\
1955 \\
1956 \\
1957 \\
1958 \\
1959 \\
1960 \\
1961 \\
1962\end{array}$ & $\begin{array}{l}09-19-25 \\
02-16-27 \\
02-07-37 \\
03-03-38 \\
08-11-46 \\
08-08-47 \\
08-05-48 \\
09-26-49 \\
10-18-49 \\
08-29-51 \\
12-30-51 \\
07-18-53 \\
03-23-54 \\
07-23-55 \\
08-18-56 \\
08-10-57 \\
09-05-58 \\
08-24-59 \\
12-26-59 \\
08-19-61 \\
09-21-62\end{array}$ & $\begin{array}{r}25,500 \\
27,100 \\
22,000 \\
10,000 \\
1,710 \\
2,300 \\
5,600 \\
2,910 \\
5,500 \\
127,000 \\
1,590 \\
865 \\
3,090 \\
8,840 \\
1,210 \\
1,980 \\
10,600 \\
5,110 \\
3,210 \\
1,150 \\
1,510\end{array}$ & $\begin{array}{l}\text { HP } \\
\text { HP } \\
\text { HP }\end{array}$ & $\begin{array}{l}1963 \\
1964 \\
1965 \\
1966 \\
1967 \\
1968 \\
1969 \\
1970 \\
1971 \\
1972 \\
1973 \\
1974 \\
1975 \\
1976 \\
1977 \\
1978 \\
1979 \\
1980 \\
1981 \\
1982\end{array}$ & $\begin{array}{l}08-17-63 \\
07-14-64 \\
09-02-65 \\
12-10-65 \\
12-07-66 \\
12-19-67 \\
09-13-69 \\
09-05-70 \\
08-25-71 \\
08-27-72 \\
10-07-72 \\
07-20-74 \\
07-28-75 \\
02-09-76 \\
08-15-77 \\
03-02-78 \\
03-28-79 \\
02-19-80 \\
07-10-81 \\
03-15-82\end{array}$ & $\begin{array}{r}2,150 \\
1,230 \\
9,060 \\
5,560 \\
1,740 \\
11,200 \\
4,630 \\
258,000 \\
556 \\
800 \\
2,600 \\
5,560 \\
154 \\
4,560 \\
315 \\
16,000 \\
9,640 \\
24,900 \\
6,698 \\
2,940\end{array}$ & \\
\hline
\end{tabular}

1 Highest since 1927.

2 Highest since 1890 .

BASIN CHARACTERISTICS

\begin{tabular}{|c|c|c|c|c|c|c|c|}
\hline \multirow{2}{*}{$\begin{array}{l}\text { MAIN } \\
\text { CHANNEL } \\
\text { SLOPE } \\
\text { (FT/MI) }\end{array}$} & \multirow[b]{2}{*}{$\begin{array}{l}\text { STREAM } \\
\text { LENGTH } \\
\text { (MI) }\end{array}$} & \multirow{2}{*}{$\begin{array}{l}\text { MEAN } \\
\text { BASIN } \\
\text { ELEVA- } \\
\text { TION } \\
\text { (FT) }\end{array}$} & \multirow[b]{2}{*}{$\begin{array}{l}\text { FORESTED } \\
\text { AREA } \\
\text { (PERCENT) }\end{array}$} & \multirow[b]{2}{*}{$\begin{array}{l}\text { SOIL } \\
\text { INDEX }\end{array}$} & \multirow{2}{*}{$\begin{array}{l}\text { MEAN } \\
\text { ANNUAL } \\
\text { PRECIPI- } \\
\text { TATION } \\
\text { (IN) }\end{array}$} & \multicolumn{2}{|c|}{ RAINFALL INTENSITY, 24-HOQR } \\
\hline & & & & & & $\begin{array}{l}\text { 2-YEAR } \\
\text { (IN) }\end{array}$ & $\begin{array}{l}\text { 50-YEAR } \\
\text { (IN) }\end{array}$ \\
\hline 71.0 & 45.0 & 4,750 & 9.6 & 1.0 & 19.3 & 2.4 & 4.7 \\
\hline
\end{tabular}


MEAN MONTHLY AND ANMUAL DISCHARGES 1947-82

\begin{tabular}{|c|c|c|c|c|c|c|}
\hline MONTH & $\begin{array}{l}\operatorname{MAX}[\min \\
\left(\mathrm{FT}^{3} / \mathrm{S}\right)\end{array}$ & $\begin{array}{l}\text { MINIMUM } \\
\left(\mathrm{FT}^{3} / \mathrm{S}\right)\end{array}$ & $\underset{\left(F T^{3} / S\right)}{\text { MEAN }}$ & $\begin{array}{l}\text { STAN- } \\
\text { DARD } \\
\text { DEVIA- } \\
\text { TION } \\
\text { (FT } 3 / S)\end{array}$ & $\begin{array}{l}\text { COEFFI- } \\
\text { CIENT OF } \\
\text { VARI - } \\
\text { ATION }\end{array}$ & $\begin{array}{c}\text { PERCENT } \\
\text { OF } \\
\text { ANNUAL } \\
\text { RUNOFF }\end{array}$ \\
\hline $\begin{array}{l}\text { OCTOBER } \\
\text { NOVEMBER } \\
\text { DECEMBER } \\
\text { JANUARY } \\
\text { FEBRUARY } \\
\text { MARCH } \\
\text { APRIL } \\
\text { MAY } \\
\text { JUNE } \\
\text { JULY } \\
\text { AUGUST } \\
\text { SEPTEMBER }\end{array}$ & $\begin{array}{r}50 \\
104 \\
298 \\
365 \\
1,280 \\
1,170 \\
247 \\
77 \\
27 \\
42 \\
372 \\
178\end{array}$ & $\begin{array}{l}0.25 \\
0.21 \\
0.22 \\
0.41 \\
0.26 \\
0.44 \\
0.34 \\
0.03 \\
0.00 \\
0.19 \\
0.33 \\
0.71\end{array}$ & $\begin{array}{c}4.0 \\
7.2 \\
20 \\
28 \\
63 \\
84 \\
34 \\
8.1 \\
3.5 \\
5.9 \\
22 \\
14\end{array}$ & $\begin{array}{c}9.4 \\
20 \\
56 \\
74 \\
214 \\
211 \\
68 \\
16 \\
5.8 \\
8.1 \\
62 \\
34\end{array}$ & $\begin{array}{l}2.3 \\
2.7 \\
2.7 \\
2.6 \\
3.4 \\
2.5 \\
2.0 \\
2.0 \\
1.7 \\
1.4 \\
2.8 \\
2.4\end{array}$ & $\begin{array}{r}1.4 \\
2.4 \\
7.0 \\
9.5 \\
21.5 \\
28.5 \\
11.5 \\
2.7 \\
1.2 \\
2.0 \\
7.5 \\
4.9\end{array}$ \\
\hline ANNUAL & 169 & 1.2 & 24 & 39 & 1.6 & 100 \\
\hline
\end{tabular}

MaGNITUDE AND PROBABILITY OF INSTANTANEOUS PEAK FLON BASED ON PERICD OF RECORD 1925, 1927, 1937-38, 1946-82

DISCHARGE, IN $\mathrm{FT}^{3} / \mathrm{S}$, FOR INDICATED RECURRENCE INTERVAL IN YEARS, AND EXCEEDANCE PROBABILITY, IN PERCENT

$\begin{array}{lccccc}2 & 5 & 10 & 25 & 50 & 100 \uparrow \\ 50 \% & 20 \% & 10 \% & 4 \% & 2 \% & 1 \% \\ 3,180 & 8,480 & 13,900 & 23,300 & 32,270 & 43,000\end{array}$

MACNITLDE AND PROBABILITY OF ANMUAL LOW FLON BASED ON PERIOD OF RECORD 1948-82

\begin{tabular}{|c|c|c|c|c|c|c|}
\hline \multirow{2}{*}{$\begin{array}{l}\text { PER IOD } \\
\text { (CON- } \\
\text { SEQU- } \\
\text { TIVE } \\
\text { DAYS) }\end{array}$} & \multicolumn{6}{|c|}{$\begin{array}{l}\text { DISCHARGE, IN FT } 3 / 5 \text {, FOR INDICATED } \\
\text { RECURRENCE INTERVAL, IN YEARS, AND } \\
\text { NON-EXCEEDANCE PROBABILITY, IN PERCENT }\end{array}$} \\
\hline & $\begin{array}{c}2 \\
50 \%\end{array}$ & $\begin{array}{c}5 \\
20 \%\end{array}$ & $\begin{array}{l}10 \\
10 \%\end{array}$ & $\begin{array}{l}20 \\
5 \%\end{array}$ & $\begin{array}{l}50 \\
2 x\end{array}$ & $\begin{array}{l}100 \dagger \\
1 \%\end{array}$ \\
\hline $\begin{array}{r}1 \\
3 \\
7 \\
14 \\
30 \\
60 \\
90 \\
120 \\
183\end{array}$ & $\begin{array}{l}0.63 \\
0.69 \\
0.76 \\
0.88 \\
1.1 \\
1.3 \\
1.6 \\
1.8 \\
2.5\end{array}$ & $\begin{array}{l}0.28 \\
0.32 \\
0.36 \\
0.42 \\
0.55 \\
0.76 \\
0.81 \\
0.97 \\
1.4\end{array}$ & $\begin{array}{l}0.16 \\
0.19 \\
0.21 \\
0.25 \\
0.35 \\
0.52 \\
0.48 \\
0.67 \\
1.0\end{array}$ & $\begin{array}{l}0.08 \\
0.10 \\
0.11 \\
0.13 \\
0.20 \\
0.33 \\
0.29 \\
0.49 \\
0.84\end{array}$ & $\begin{array}{l}0.00 \\
0.00 \\
0.00 \\
0.00 \\
0.00 \\
0.00 \\
0.15 \\
0.32 \\
0.67\end{array}$ & $\begin{array}{l}0.00 \\
0.00 \\
0.00 \\
0.00 \\
0.00 \\
0.00 \\
0.09 \\
0.25 \\
0.58\end{array}$ \\
\hline
\end{tabular}

MAGNITLDE AND PROBABILITY OF ANNUAL HIGH FLON BASED ON PERIOD OF RECORD 1947-82

\begin{tabular}{|c|c|c|c|c|c|c|}
\hline \multirow{2}{*}{$\begin{array}{l}\text { PERIOD } \\
\text { (CON- } \\
\text { SECU- } \\
\text { TIVE } \\
\text { DAYS) }\end{array}$} & \multicolumn{6}{|c|}{$\begin{array}{l}\text { DISCHARGE, IN } \mathrm{FT}^{3} / \mathrm{S} \text {, FOR INDICATED } \\
\text { RECURRENCE INTERVAL, IN YEARS, AND } \\
\text { EXCEEDANCE PROBABILITY, IN PERCENT }\end{array}$} \\
\hline & $\underset{50 \%}{2}$ & $\begin{array}{c}5 \\
20 \%\end{array}$ & $\begin{array}{l}10 \\
10 x\end{array}$ & $\begin{array}{l}25 \\
4 \%\end{array}$ & $\begin{array}{l}50 \\
2 \%\end{array}$ & $\begin{array}{c}100\} \\
1 \%\end{array}$ \\
\hline $\begin{array}{r}1 \\
3 \\
7 \\
15 \\
30 \\
60 \\
90\end{array}$ & $\begin{array}{r}598 \\
271 \\
142 \\
83 \\
52 \\
32 \\
24\end{array}$ & $\begin{array}{r}2,010 \\
975 \\
540 \\
335 \\
208 \\
124 \\
93\end{array}$ & $\begin{array}{l}3,680 \\
1,900 \\
1,090 \\
704 \\
441 \\
262 \\
199\end{array}$ & $\begin{array}{r}6,880 \\
3,850 \\
2,330 \\
1,580 \\
1,010 \\
602 \\
462\end{array}$ & $\begin{array}{r}10,200 \\
6,070 \\
3,810 \\
2,680 \\
1,740 \\
1,050 \\
808\end{array}$ & $\begin{array}{l}2, \\
1,\end{array}$ \\
\hline
\end{tabular}

DURATION TABLE OF DAILY MEAN FLON FOR PERICD OF RECORD 1947-82

DISCHARGE, IN FT $3 / 5$, WHICH WAS EQUALED OR EXCEEDED FOR INDICATED PERCENT OF TIME

\begin{tabular}{|c|c|c|c|c|c|c|c|c|c|c|c|c|c|c|c|c|}
\hline $1 \%$ & $5 \%$ & $10 \%$ & $15 \%$ & $20 \%$ & $30 \%$ & $40 \%$ & $50 \%$ & $60 \%$ & $70 x$ & $80 \%$ & $90 \%$ & $95 \%$ & $98 \%$ & $99 \%$ & $99.5 \%$ & $99.9 \%$ \\
\hline 404 & 83 & 27 & 12 & 5.6 & 3.1 & 2.3 & 1.9 & 1.7 & 1.5 & 1.2 & 0.67 & 0.41 & 0.24 & 0.12 & 0.00 & .0 \\
\hline
\end{tabular}

† Reliability of values in column is uncertain, and potential errors are large. 
GILA RIVER BASIN

09515500 HASSAYAMPA RIVER AT BOX DAMSITE, NEAR WICKENBURG, AZ--CONTINUED
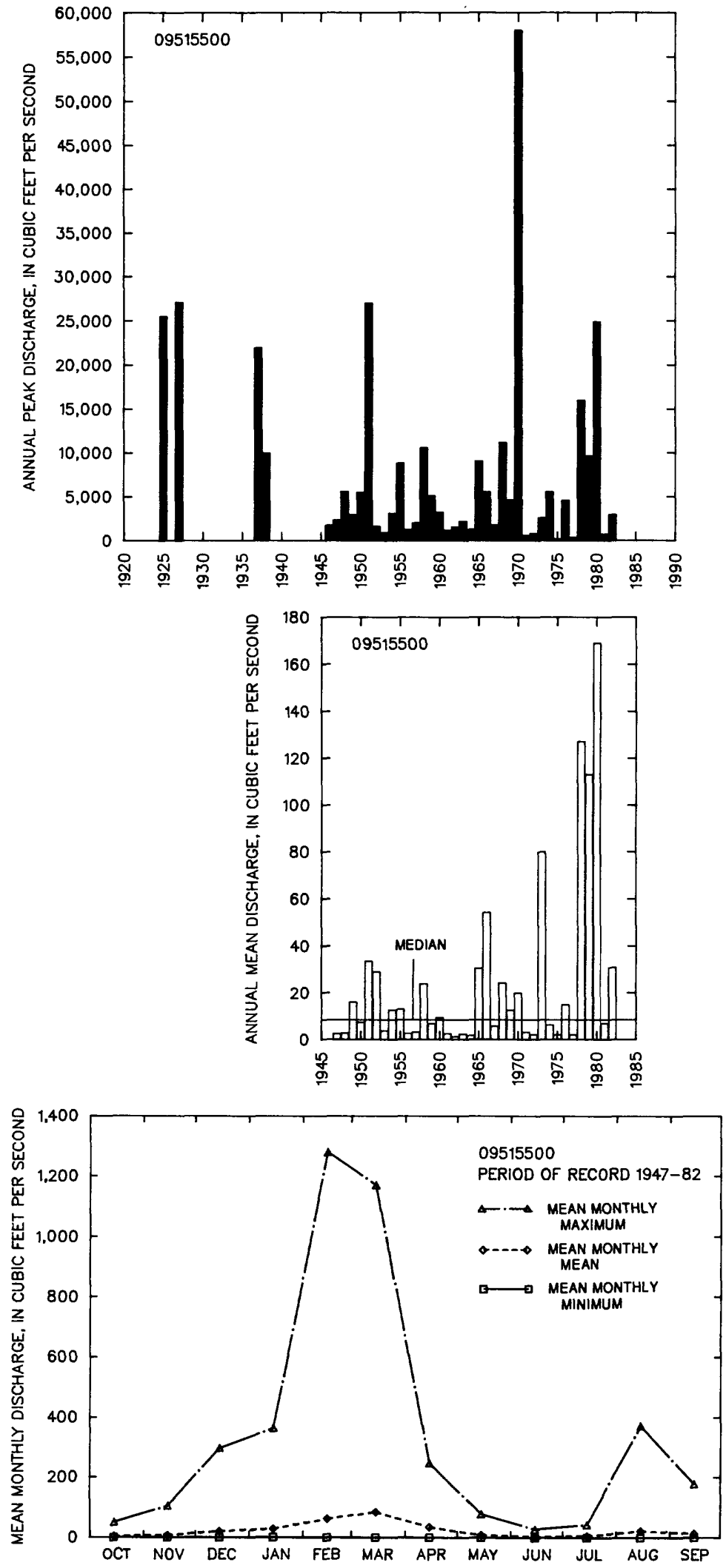
09515800 HARTMAN WASH MEAR HICKENBURG, AZ

LOCATION. - - Lat 33'57'46", Long 112"49'40", in SEX sec.12, T.7 N., R.6 H., Maricopa County, Hydrologic Unit 15070103 , at U.S. Highway $60,5.7 \mathrm{mi}$ west of Wickenburg.

DRAINAGE AREA. $-5.57 \mathrm{mi}^{2}$.

ANINUAL PEAK DISCHARGE

\begin{tabular}{|c|c|c|c|}
\hline $\begin{array}{l}\text { WATER } \\
\text { YEAR }\end{array}$ & DATE & $\begin{array}{c}\text { AHNUAL PEAK } \\
\text { DISCHARGE } \\
\text { (FT } 3 / 5)\end{array}$ & $\begin{array}{l}\text { DISCHARGE } \\
\text { COOES }\end{array}$ \\
\hline $\begin{array}{l}1964 \\
1965 \\
1966 \\
1967 \\
1968 \\
1969 \\
1970 \\
1971 \\
1972 \\
1973 \\
1974 \\
1975 \\
1976 \\
1977 \\
1978 \\
1979\end{array}$ & $\begin{array}{l}08-23-64 \\
09-04-65 \\
09-13-66 \\
08-14-67 \\
12-19-67 \\
08-00-69 \\
09-05-70 \\
08-19-71 \\
09-03-72 \\
10-07-72 \\
07-30-74 \\
07-13-75 \\
09-25-76 \\
09-27-77 \\
01-17-78 \\
11-11-78\end{array}$ & $\begin{array}{c}1,840 \\
50 \\
150 \\
2,600 \\
360 \\
5.0 \\
1,600 \\
1,000 \\
0.5 \\
300 \\
35 \\
100 \\
400 \\
320 \\
60 \\
150\end{array}$ & $\begin{array}{l}\text { ES } \\
\text { ES } \\
\text { ES } \\
\text { ES } \\
\text { ES } \\
\text { ES } \\
\text { ES } \\
\text { ES }\end{array}$ \\
\hline
\end{tabular}

MAGNITUDE AND PROBABILITY OF INSTANTANEOUS PEAK FLOW BASED ON PERIOD OF RECORD 1964-79

DISCHARGE, IN $\mathrm{FT}^{3} / \mathrm{S}$, FOR INDICATED RECURRENCE INTERVAL IN YEARS, AND EXCEEDANCE PROBABILITY, IN PERCENT

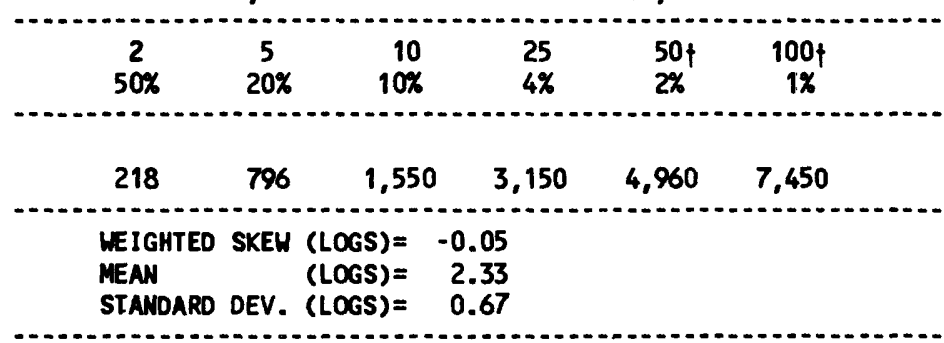

f Reliability of values in column is uncertain, and potential errors are large.

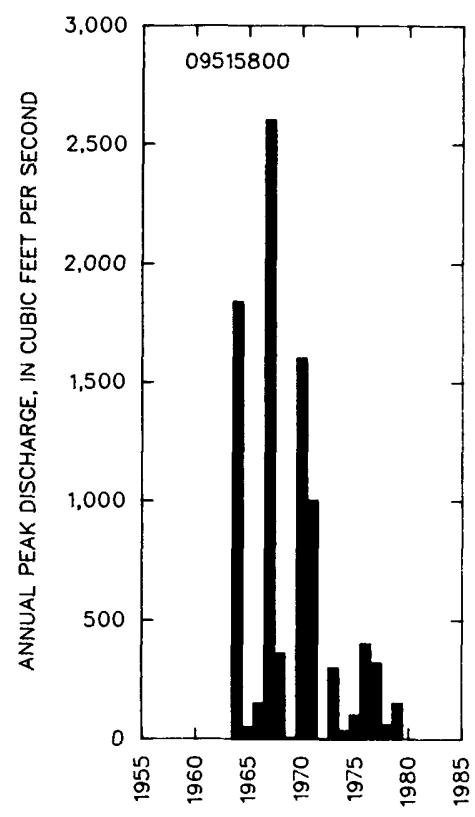

BASIN CHARACTERISTICS

\begin{tabular}{|c|c|c|c|c|c|c|c|}
\hline \multirow{2}{*}{$\begin{array}{c}\text { MAIN } \\
\text { CHANNEL } \\
\text { SLOPE } \\
\text { (FT/MI) }\end{array}$} & \multirow[b]{2}{*}{$\begin{array}{c}\text { STREAM } \\
\text { LEHGTH } \\
\text { (MI) }\end{array}$} & \multirow{2}{*}{$\begin{array}{l}\text { MEAN } \\
\text { BASIN } \\
\text { ELEVA- } \\
\text { TION } \\
\text { (FT) }\end{array}$} & \multirow[b]{2}{*}{$\begin{array}{l}\text { FORESTED } \\
\text { AREA } \\
\text { (PERCENT) }\end{array}$} & \multirow[b]{2}{*}{$\begin{array}{l}\text { SOIL } \\
\text { INDEX }\end{array}$} & \multirow{2}{*}{$\begin{array}{l}\text { MEAN } \\
\text { ANNUAL } \\
\text { PRECIPI- } \\
\text { TATION } \\
\text { (IN) }\end{array}$} & \multicolumn{2}{|c|}{ RAINFALL INTENSITY, 24-HOUR } \\
\hline & & & & & & $\begin{array}{c}\text { 2-YEAR } \\
\text { (IN) }\end{array}$ & $\begin{array}{l}\text { 50-YEAR } \\
\text { (IN) }\end{array}$ \\
\hline 71.6 & 5.4 & 2,690 & 0.0 & 3.0 & 11.0 & 1.6 & 3.8 \\
\hline
\end{tabular}


09516500 HASSAYAMPA RIVER NEAR MORRISTOUN, AZ

LOCATION.--Lat 33'53'06", long 112'39'41", in SWKSEK sec.3, T.6 N., R.4 W., Maricopa County, Hydrologic Unit 15070103, $3.0 \mathrm{mi}$ northwest of Morristown, $7 \mathrm{mi}$ southeast of Wickenburg.

DRAINAGE AREA. $--796 \mathrm{mi}^{2}$.

ANNUAL PEAK DISCHARGE

\begin{tabular}{|c|c|c|c|c|c|c|c|}
\hline $\begin{array}{l}\text { WATER } \\
\text { YEAR }\end{array}$ & DATE & $\begin{array}{c}\text { ANNUAL PEAK } \\
\text { DISCHARGE } \\
\text { (FT } 3 / \mathrm{S})\end{array}$ & $\begin{array}{l}\text { DISCHARGE } \\
\text { CODES }\end{array}$ & $\begin{array}{l}\text { WATER } \\
\text { YEAR }\end{array}$ & DATE & $\begin{array}{l}\text { ANNUAL PEAK } \\
\text { DISCHARGE } \\
\left(\mathrm{FT}^{3} / \mathrm{S}\right)\end{array}$ & $\begin{array}{l}\text { DI SCHARGE } \\
\text { CODES }\end{array}$ \\
\hline $\begin{array}{l}1939 \\
1940 \\
1941 \\
1942 \\
1943 \\
1944 \\
1945 \\
1946 \\
1947 \\
1954 \\
1956 \\
1964 \\
1965 \\
1966 \\
1967 \\
1968 \\
1969 \\
1970\end{array}$ & $\begin{array}{l}09-06-39 \\
02-01-40 \\
03-02-41 \\
08-05-42 \\
08-03-43 \\
08-09-44 \\
08-02-45 \\
09-17-46 \\
08-08-47 \\
00-00-54 \\
00-00-56 \\
07-12-64 \\
09-02-65 \\
09-13-66 \\
09-00-67 \\
12-19-67 \\
09-13-69 \\
09-05-70\end{array}$ & $\begin{array}{r}6,200 \\
160 \\
6,100 \\
100 \\
7,700 \\
3,520 \\
2,200 \\
2,310 \\
6,000 \\
0 \\
0 \\
4,000 \\
9,280 \\
3,210 \\
1,150 \\
4,800 \\
650 \\
147,500\end{array}$ & ES & $\begin{array}{l}1971 \\
1972 \\
1973 \\
1974 \\
1975 \\
1976 \\
1977 \\
1978 \\
1979 \\
1980 \\
1981 \\
1983 \\
1984 \\
1985 \\
1986 \\
1987 \\
1988 \\
1989\end{array}$ & $\begin{array}{l}08-18-71 \\
08-27-72 \\
10-07-72 \\
07-20-74 \\
07-29-75 \\
02-09-76 \\
08-15-77 \\
03-02-78 \\
12-18-78 \\
02-20-80 \\
07-10-81 \\
03-03-83 \\
09-10-84 \\
12-28-84 \\
11-26-85 \\
11-18-86 \\
08-27-88 \\
01-04-89\end{array}$ & $\begin{array}{r}2,000 \\
700 \\
2,000 \\
650 \\
50 \\
800 \\
1,600 \\
18,000 \\
9,600 \\
17,000 \\
4,800 \\
2,520 \\
26,700 \\
848 \\
2,740 \\
714 \\
6,820 \\
1,210\end{array}$ & $\begin{array}{l}\text { ES } \\
\text { LT } \\
\text { ES }\end{array}$ \\
\hline
\end{tabular}

1Highest since 1916.

MAGNI TUDE AND PROBABILITY OF INSTANTANEOUS PEAK FLON BASED ON PERIOD OF RECORD 1939-47, 1964-81, 1983-89

DISCHARGE, IN $\mathrm{FT}^{3} / \mathrm{S}$, FOR INDICATED RECURRENCE INTERVAL IN YEARS, AND EXCEEDANCE PROBABILITY, IN PERCENT

$\begin{array}{cccccc}5 & 5 & 10 & 25 & 50 & 100 \\ 1 \% & 20 \% & 10 \% & 4 \% & 2 \% & 1 \% \\ 2,670 & 7,180 & 12,200 & 21,500 & 31,300 & 43,900\end{array}$

feliability of values in colum is uncertain, and potential errors are large.

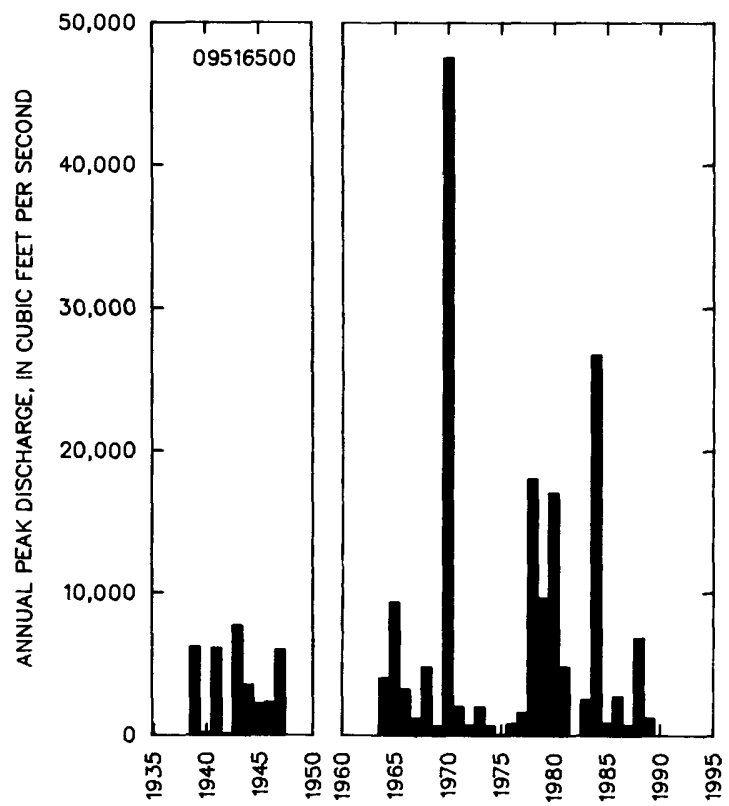

\begin{tabular}{|c|c|c|c|c|c|c|c|}
\hline MAIN & & $\begin{array}{l}\text { MEAN } \\
\text { BASIN }\end{array}$ & & & $\begin{array}{l}\text { MEAN } \\
\text { ANNUAL }\end{array}$ & RAINFALL II & SITY, 24-HOUR \\
\hline $\begin{array}{l}\text { CHANNEL } \\
\text { SLOPE } \\
\text { (FT/MI) }\end{array}$ & $\begin{array}{l}\text { STREAM } \\
\text { LENGTH } \\
\text { (MI) }\end{array}$ & $\begin{array}{l}\text { ELEVA- } \\
\text { TION } \\
\text { (FT) }\end{array}$ & $\begin{array}{l}\text { FORESTED } \\
\text { AREA } \\
\text { (PERCENT) }\end{array}$ & $\begin{array}{l}\text { SOIL } \\
\text { INDEX }\end{array}$ & $\begin{array}{l}\text { PRECIPI - } \\
\text { TATION } \\
\text { (IN) }\end{array}$ & $\begin{array}{c}\text { 2-YEAR } \\
\text { (IN) }\end{array}$ & $\begin{array}{c}\text { 50-YEAR } \\
\text { (IN) }\end{array}$ \\
\hline 84.9 & 58.4 & 3,190 & 5.2 & 1.72 & 16.9 & 2.2 & 4.3 \\
\hline
\end{tabular}




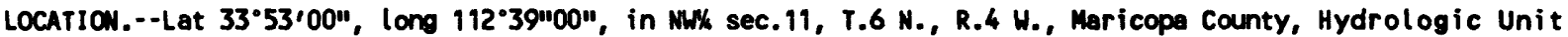
15070103 , at U.S. Highway $60,2.4 \mathrm{mi}$ northwest of Morristown.

DRAINAGE AREA. $--6.31 \mathrm{mi}^{2}$.

ANHUAL PEAK DISCHARGE

\begin{tabular}{|c|c|c|c|}
\hline $\begin{array}{l}\text { WATER } \\
\text { YEAR }\end{array}$ & DATE & $\begin{array}{c}\text { ANNUAL PEAK } \\
\text { OISCHARGE } \\
\text { (FT } 3 / \mathrm{S})\end{array}$ & $\begin{array}{l}\text { DISCHARGE } \\
\text { CODES }\end{array}$ \\
\hline $\begin{array}{l}1960 \\
1963 \\
1964 \\
1965 \\
1966 \\
1967 \\
1968 \\
1969 \\
1970 \\
1971 \\
1972 \\
1973 \\
1974 \\
1975 \\
1976 \\
1977 \\
1978 \\
1979\end{array}$ & $\begin{array}{l}00-00-60 \\
08-26-63 \\
08-26-64 \\
09-02-65 \\
09-13-66 \\
09-00-67 \\
00-00-68 \\
01-15-69 \\
09-05-70 \\
08-20-71 \\
09-00-72 \\
10-00-72 \\
00-00-74 \\
00-00-75 \\
00-00-76 \\
00-00-77 \\
02-22-78 \\
12-18-78\end{array}$ & $\begin{array}{r}1,770 \\
628 \\
2,900 \\
50 \\
1,300 \\
80 \\
550 \\
30 \\
160 \\
250 \\
450 \\
220 \\
0 \\
0 \\
0 \\
0 \\
335 \\
150\end{array}$ & $\begin{array}{l}\text { ES } \\
\text { ES }\end{array}$ \\
\hline
\end{tabular}

Magnitude and PROBABILITY OF INSTANTANEOUS PEAK FLOW BASED ON PERIOD OF RECORD 1960, 1963-79

DISCHARGE, IN $\mathrm{FT}^{3} / \mathrm{S}$, FOR INDICATED RECURRENCE INTERVAL

IN YEARS, AND EXCEEDANCE PROBABILITY, IN PERCENT

\begin{tabular}{|c|c|c|c|c|c|}
\hline $\begin{array}{c}2 \\
50 \%\end{array}$ & $\underset{20 \%}{5}$ & $\begin{array}{r}10 \\
10 \%\end{array}$ & $\begin{array}{l}25 \\
4 \%\end{array}$ & $\begin{array}{l}50 \nmid \\
2 \%\end{array}$ & $\begin{array}{c}100 \nmid \\
1 \%\end{array}$ \\
\hline 194 & 662 & 1,240 & 2,400 & 3,660 & 5,330 \\
\hline $\begin{array}{l}\text { WEIGHTED } \\
\text { MEAN } \\
\text { STANDARD }\end{array}$ & $\begin{array}{l}\text { SKEW } \\
\text { DEV. }\end{array}$ & $\begin{array}{l}\text { (LOGS) }= \\
(\text { LOGS) }= \\
(\text { LOGS })=\end{array}$ & $\begin{array}{r}-0.10 \\
2.28 \\
0.64\end{array}$ & & \\
\hline
\end{tabular}

+ Reliability of values in column is uncertain, and potential errors are large.

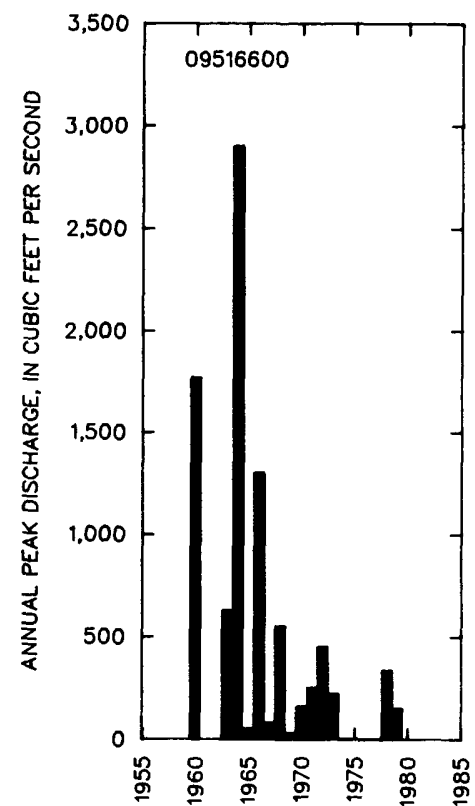

BASIN CHARACTERISTICS

\begin{tabular}{|c|c|c|c|c|c|c|c|}
\hline MAJN & & $\begin{array}{c}\text { MEAN } \\
\text { BASIN }\end{array}$ & & & $\begin{array}{l}\text { MEAN } \\
\text { ANNUAL }\end{array}$ & RAINFALL II & SITY, 24-HOUR \\
\hline $\begin{array}{l}\text { SLOPE } \\
\text { (FTMI) }\end{array}$ & $\begin{array}{l}\text { LENGTH } \\
\text { (MI) }\end{array}$ & $\begin{array}{l}\text { TION } \\
\text { (FT) }\end{array}$ & $\begin{array}{l}\text { AREA } \\
\text { (PERCENT) }\end{array}$ & $\begin{array}{l}\text { SOIL } \\
\text { INDEX }\end{array}$ & $\begin{array}{l}\text { TATION } \\
\text { (IN) }\end{array}$ & $\begin{array}{l}\text { 2-YEAR } \\
\text { (IN) }\end{array}$ & $\begin{array}{c}\text { 50-YEAR } \\
\text { (IN) }\end{array}$ \\
\hline 101 & 6.6 & 2,290 & 0.0 & 3.0 & 12.2 & 1.8 & 3.8 \\
\hline
\end{tabular}


09516800 JACK RABBIT WASH NEAR TONOPAH, AZ

LOCATION.-- Lat 33.39'32", L ong 112"49'40", in NEYNWK sec.25, T.4 N., R.6 W., Maricopa County, Hydrologic Unit 15070103, $100 \mathrm{ft}$ upstream from the Wickenburg-Hassayampa Road, 4.5 mi upstream from Star Wash, and $14 \mathrm{mi}$ northeast of Tonopah.

DRAINAGE AREA. $--137 \mathrm{mi}^{2}$.

ANNUAL PEAK DISCHARGE

\begin{tabular}{|c|c|c|c|}
\hline $\begin{array}{l}\text { WATER } \\
\text { YEAR }\end{array}$ & DATE & $\begin{array}{l}\text { ANNUAL PEAK } \\
\text { DISCHARGE } \\
\left(\mathrm{FT}^{3} / \mathrm{S}\right)\end{array}$ & $\begin{array}{l}\text { DISCHARGE } \\
\text { CODES }\end{array}$ \\
\hline $\begin{array}{l}1964 \\
1965 \\
1966 \\
1967 \\
1968 \\
1969 \\
1970 \\
1971 \\
1972 \\
1973 \\
1974 \\
1975 \\
1976 \\
1977 \\
1978 \\
1979\end{array}$ & $\begin{array}{l}08-26-64 \\
04-04-65 \\
09-13-66 \\
09-03-67 \\
12-19-67 \\
09-13-69 \\
09-05-70 \\
08-17-71 \\
09-18-72 \\
10-07-72 \\
07-07-74 \\
03-11-75 \\
09-25-76 \\
08-16-77 \\
10-06-77 \\
01-18-79\end{array}$ & $\begin{array}{r}2,070 \\
200 \\
200 \\
6,040 \\
105 \\
200 \\
5,000 \\
2,500 \\
100 \\
6,840 \\
75 \\
6.0 \\
2,200 \\
80 \\
650 \\
1,510\end{array}$ & $\begin{array}{l}\text { ES } \\
\text { ES } \\
\text { ES } \\
\text { ES }\end{array}$ \\
\hline
\end{tabular}

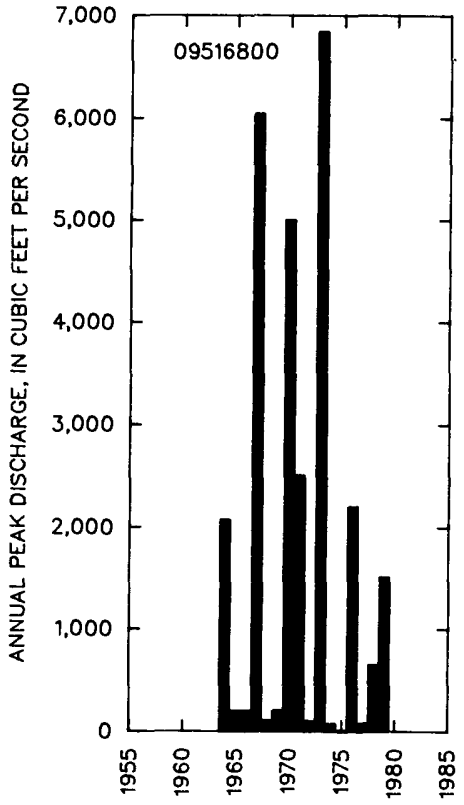

MAGNITUDE AND PROBABILITY OF INSTANTANEOUS PEAK FLON BASED ON PERIOD OF RECORD 1964-79

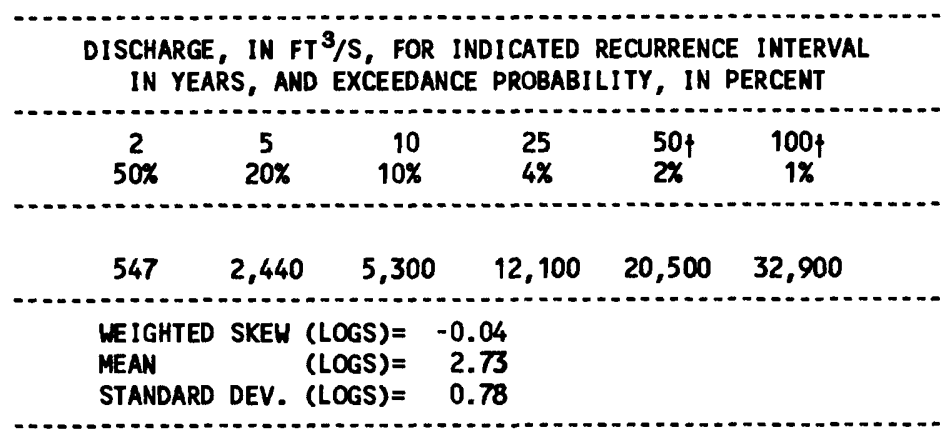

f Reliability of values in column is uncertain, and potential errors are large.

\section{BASIN CHARACTERISTICS}

\begin{tabular}{|c|c|c|c|c|c|c|c|}
\hline \multirow{2}{*}{$\begin{array}{l}\text { MAIN } \\
\text { CHANNEL } \\
\text { SLOPE } \\
\text { (FT/MI) }\end{array}$} & \multirow[b]{2}{*}{$\begin{array}{c}\text { STREAM } \\
\text { LENGTH } \\
\text { (MI) }\end{array}$} & \multirow{2}{*}{$\begin{array}{l}\text { MEAN } \\
\text { BASIN } \\
\text { ELEVA- } \\
\text { TION } \\
\text { (FT) }\end{array}$} & \multirow[b]{2}{*}{$\begin{array}{l}\text { FORESTED } \\
\text { AREA } \\
\text { (PERCENT) }\end{array}$} & \multirow[b]{2}{*}{$\begin{array}{l}\text { SOIL } \\
\text { INDEX }\end{array}$} & \multirow{2}{*}{$\begin{array}{l}\text { MEAN } \\
\text { ANNUAL } \\
\text { PRECIPI- } \\
\text { TATION } \\
\text { (IN) }\end{array}$} & \multicolumn{2}{|c|}{ RAINFALL INTENSITY, 24-HOUR } \\
\hline & & & & & & $\begin{array}{l}\text { 2-YEAR } \\
\text { (IN) }\end{array}$ & $\begin{array}{l}\text { 50-YEAR } \\
\text { (IN) }\end{array}$ \\
\hline 34.4 & 22.5 & 2,260 & 0.0 & 2.5 & 9.2 & 1.5 & 3.7 \\
\hline
\end{tabular}


O9517000 HASSAYAMPA RIVER MEAR ARLIMGTON, AZ

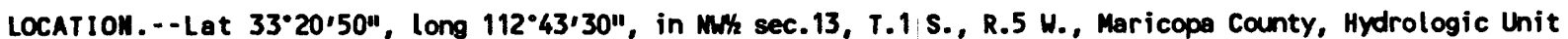
15070104, at former U.S. Highway $80,1.8 \mathrm{mi}$ upstream from mouth and $2.8 \mathrm{mi}$ northeast of Arlington.

DRAINAGE AREA. --1,470 $\mathrm{mi}^{2}$, approximately.

ANMUAL PEAK DISCHARGE

\begin{tabular}{|c|c|c|c|c|c|c|c|}
\hline $\begin{array}{l}\text { MTER } \\
\text { YEAR }\end{array}$ & DATE & $\begin{array}{c}\text { ANNUAL PEAK } \\
\text { DISCHARGE } \\
\text { (FT } 3 / S)\end{array}$ & $\begin{array}{l}\text { DISCHARGE } \\
\text { COOES }\end{array}$ & $\begin{array}{l}\text { MATER } \\
\text { YEAR }\end{array}$ & DATE & $\begin{array}{c}\text { ANMUAL PEAK } \\
\text { DISCHARGE } \\
\text { (FT } 3 / S)\end{array}$ & $\begin{array}{l}\text { DISCHARGE } \\
\text { CODES }\end{array}$ \\
\hline $\begin{array}{l}1961 \\
1962 \\
1963 \\
1964 \\
1965 \\
1966 \\
1967 \\
1968 \\
1969 \\
1970 \\
1971 \\
1972 \\
1973 \\
1974\end{array}$ & $\begin{array}{l}09-11-61 \\
09-06-62 \\
08-00-63 \\
08-14-64 \\
02-07-65 \\
12-10-65 \\
09-05-67 \\
12-20-67 \\
09-15-69 \\
09-05-70 \\
08-11-71 \\
08-12-72 \\
10-07-72 \\
09-00-74\end{array}$ & $\begin{array}{r}50 \\
470 \\
1,930 \\
6,500 \\
3,000 \\
1,600 \\
5,270 \\
4,000 \\
500 \\
139,000 \\
1,230 \\
225 \\
12,300 \\
250\end{array}$ & ES & $\begin{array}{l}1975 \\
1976 \\
1977 \\
1978 \\
1979 \\
1980 \\
1983 \\
1984 \\
1985 \\
1986 \\
1987 \\
1988 \\
1989\end{array}$ & $\begin{array}{l}00-00-75 \\
09-26-76 \\
10-24-76 \\
03-02-78 \\
11-11-78 \\
02-20-80 \\
09-30-83 \\
09-02-84 \\
12-28-84 \\
11-26-85 \\
10-10-86 \\
11-01-87 \\
08-11-89\end{array}$ & $\begin{array}{r}0 \\
13,000 \\
4,300 \\
20,000 \\
3,300 \\
11,200 \\
3,300 \\
2,850 \\
372 \\
2,610 \\
404 \\
2,800 \\
1,510\end{array}$ & . \\
\hline
\end{tabular}

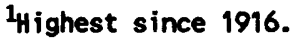

MAGNITUDE AND PROBABILITY OF INSTANTANEOUS PEAK FLOW BASED ON PERIOD OF RECORD 1961-80, 1983-84, 1986-89

DISCHARGE, IN FT $3 / 5$, FOR INDICATED RECURRENCE INTERVAL IN YEARS, AND EXCEEDANCE PROBABILITY, IN PERCENT

$\begin{array}{lccccc}2 & 5 & 10 & 25 & 50 \uparrow & 100 \uparrow \\ 50 \% & 20 \% & 10 \% & 4 \% & 2 \% & 1 \% \\ 2,720 & 7,470 & 12,900 & 23,400 & 34,500 & 49,300\end{array}$

f Reliability of values in colum is uncertain, and potential errors are large.

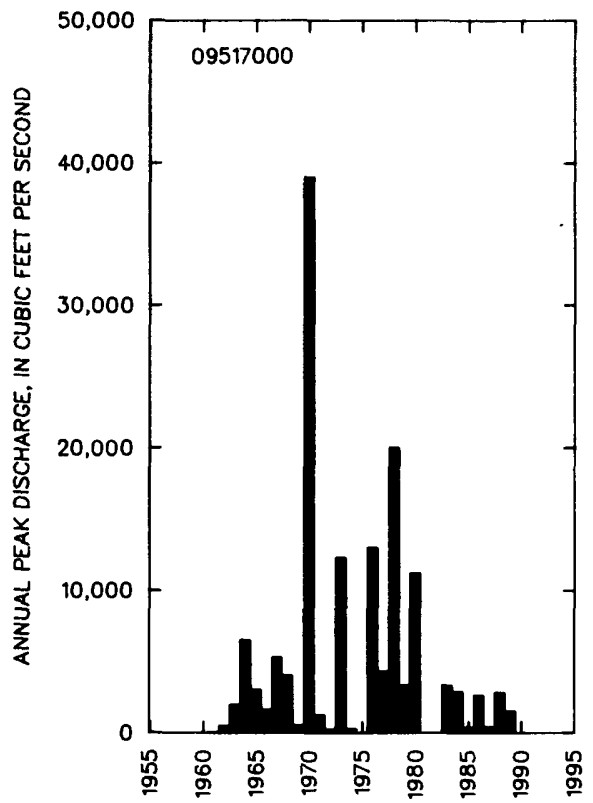

BASIN CHARACTERISTICS

\begin{tabular}{|c|c|c|c|c|c|c|c|}
\hline MAIN & & $\begin{array}{l}\text { MEAN } \\
\text { BASIN }\end{array}$ & & & & RAINFALL IN & SITY, 24-HOUR \\
\hline $\begin{array}{c}\text { CHANNEL } \\
\text { SLOPE } \\
\text { (FT/MI) }\end{array}$ & $\begin{array}{l}\text { STREAM } \\
\text { LENGTH } \\
\text { (MI) }\end{array}$ & $\begin{array}{l}\text { ELEVA- } \\
\text { TION } \\
\text { (FT) }\end{array}$ & $\begin{array}{l}\text { FORESTED } \\
\text { AREA } \\
\text { (PERCENT) }\end{array}$ & $\begin{array}{l}\text { SOIL } \\
\text { INDEXX }\end{array}$ & $\begin{array}{l}\text { PRECIPI- } \\
\text { TATION } \\
\text { (IN) }\end{array}$ & $\begin{array}{c}\text { 2-YEAR } \\
\text { (III) }\end{array}$ & $\begin{array}{l}\text { 50-YEAR } \\
\text { (III) }\end{array}$ \\
\hline 39.9 & 93.6 & 3,010 & 2.7 & 2.0 & 15.9 & 1.9 & 4.0 \\
\hline
\end{tabular}


09517200 CENTENHIAL WASH TRIBUTARY NEAR WENDEN, ARIZ.

LOCATION.- - Lat 33.50'40", Long 113'27'00", in SWMSWk sec.24, T.6 N., R.12 W., Yuma County, Hydrologic Unit 15070104, at U.S. Highway $60,5 \mathrm{mi}$ nor theast of Wenden.

DRAINAGE AREA. $--2.79 \mathrm{mi}^{2}$.

\section{ANMUAL PEAK DISCHARGE}

\begin{tabular}{cccc}
$\begin{array}{c}\text { WATER } \\
\text { YEAR }\end{array}$ & DATE & $\begin{array}{c}\text { ANNUAL PEAK } \\
\text { DISCHARGE } \\
\text { (FT } 3 / \text { S) }\end{array}$ & $\begin{array}{c}\text { DISCHARGE } \\
\text { CODES }\end{array}$ \\
\hline 1963 & $08-16-63$ & 394 & \\
1964 & $08-02-64$ & 30 & ES \\
1965 & $02-07-65$ & 25 & ES \\
1966 & $12-10-65$ & 30 & \\
1967 & $09-02-67$ & 90 & \\
1968 & $00-00-68$ & 320 & \\
1969 & $09-16-69$ & 190 & \\
1970 & $09-05-70$ & 720 & \\
1971 & $08-20-71$ & 170 & \\
1972 & $10-00-71$ & 90 & \\
1973 & $02-11-73$ & 75 & \\
1974 & $07-00-74$ & 330 & \\
1975 & $07-29-75$ & 275 & \\
1976 & $09-25-76$ & 220 & \\
1977 & $00-00-77$ & 0 & \\
1978 & $02-13-78$ & 260 & \\
1979 & $05-21-79$ & 90 & \\
$\ldots$
\end{tabular}

MAGNITUDE AND PROBABILITY OF INSTANTANEOUS PEAK FLOW BASED ON PERIOD OF RECORD 1963-79

DISCHARGE, IN $\mathrm{FT}^{3} / \mathrm{S}$, FOR INDICATED RECURRENCE INTERVAL IN YEARS, AND EXCEEDANCE PROBABILITY, IN PERCENT

\begin{tabular}{|c|c|c|c|c|c|}
\hline$\stackrel{2}{20 \%}$ & $\begin{array}{c}5 \\
20 \%\end{array}$ & $\begin{array}{r}10 \\
10 \%\end{array}$ & $\begin{array}{l}25 \\
4 \%\end{array}$ & $\begin{array}{l}50 \dagger \\
2 \%\end{array}$ & $\begin{array}{c}100 \nmid \\
1 \%\end{array}$ \\
\hline 132 & 312 & 479 & 743 & 977 & 1,240 \\
\hline $\begin{array}{l}\text { WEIGHTED } \\
\text { MEAN } \\
\text { STANDARD }\end{array}$ & $\begin{array}{l}\text { SKEW } \\
\text { DEV. }\end{array}$ & $\begin{array}{l}(\text { LOGS })= \\
(\text { LOGS })= \\
(\text { LOGS })=\end{array}$ & $\begin{array}{r}-0.24 \\
2.10 \\
0.46\end{array}$ & & \\
\hline
\end{tabular}

$\uparrow$ Reliability of values in column is uncertain, and potential errors are large.

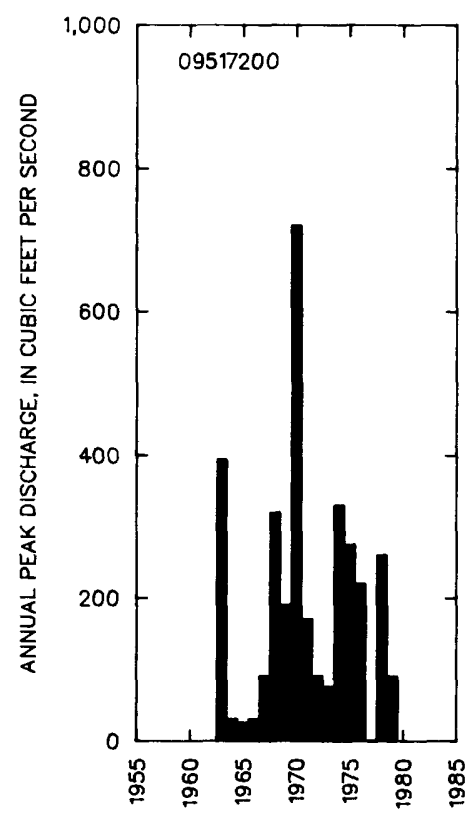

BASIN CHARACTERISTICS

\begin{tabular}{|c|c|c|c|c|c|c|c|}
\hline \multirow{2}{*}{$\begin{array}{l}\text { MAIN } \\
\text { CHANNEL } \\
\text { SLOPE } \\
\text { (FT/MI) }\end{array}$} & \multirow[b]{2}{*}{$\begin{array}{l}\text { STREAM } \\
\text { LENGTH } \\
\text { (MI) }\end{array}$} & \multirow{2}{*}{$\begin{array}{l}\text { MEAN } \\
\text { BASIN } \\
\text { ELEVA- } \\
\text { TION } \\
\text { (FT) }\end{array}$} & \multirow[b]{2}{*}{$\begin{array}{l}\text { FORESTED } \\
\text { AREA } \\
\text { (PERCENT) }\end{array}$} & \multirow[b]{2}{*}{$\begin{array}{l}\text { SOIL } \\
\text { INDEX }\end{array}$} & \multirow{2}{*}{$\begin{array}{l}\text { MEAN } \\
\text { ANNUAL } \\
\text { PRECIPI- } \\
\text { TATION } \\
\text { (IN) }\end{array}$} & \multicolumn{2}{|c|}{ RAINFALL INTENSITY, 24-HOUR } \\
\hline & & & & & & $\begin{array}{l}\text { 2-YEAR } \\
\text { (IN) }\end{array}$ & $\begin{array}{l}\text { 50-YEAR } \\
\text { (IN) }\end{array}$ \\
\hline 193 & 5.4 & 2,480 & 0.0 & 1.0 & 8.0 & 1.6 & 3.7 \\
\hline
\end{tabular}


LOCATION.-- Lat 33.44'30", Long 113'16'43", in SWkSW sec.26, T.5 N., R.10 H., Maricopa County, Hydrologic Unit 15070104, 17 mi south of Aguila.

DRAINAGE AREA. $--85.2 \mathrm{mi}^{2}$.

ANAUAL PEAK DISCHARGE

\begin{tabular}{|c|c|c|c|}
\hline $\begin{array}{l}\text { WATER } \\
\text { YEAR }\end{array}$ & DATE & $\begin{array}{l}\text { ANNUAL PEAK } \\
\text { DISCHARGE } \\
\left(F^{3} / S\right)\end{array}$ & $\begin{array}{l}\text { DISCHARGE } \\
\text { CODES }\end{array}$ \\
\hline $\begin{array}{l}1963 \\
1964 \\
1965 \\
1966 \\
1967 \\
1968 \\
1969 \\
1970 \\
1971 \\
1972 \\
1973 \\
1974 \\
1975 \\
1976 \\
1977 \\
1978 \\
1979\end{array}$ & $\begin{array}{l}08-16-63 \\
10-19-63 \\
08-18-65 \\
09-13-66 \\
08-14-67 \\
12-19-67 \\
09-14-69 \\
08-20-70 \\
08-20-71 \\
08-00-72 \\
10-06-72 \\
08-03-74 \\
07-30-75 \\
09-25-76 \\
08-16-77 \\
03-01-78 \\
12-18-78\end{array}$ & $\begin{array}{r}910 \\
400 \\
1,680 \\
1,450 \\
620 \\
440 \\
441 \\
4,550 \\
2,000 \\
2,770 \\
1,750 \\
45 \\
100 \\
3,000 \\
870 \\
1,400 \\
60\end{array}$ & $\begin{array}{l}\text { ES } \\
\text { ES }\end{array}$ \\
\hline
\end{tabular}

MAGNITUDE AND PROBABILITY OF INSTANTANEOUS PEAK FLON BASED ON PERIOD OF RECORD 1963-79

DISCHARGE, IN $\mathrm{FT}^{3} / \mathrm{S}$, FOR INDICATED RECURRENCE INTERVAL IN YEARS, AND EXCEEDANCE PROBABILITY, IN PERCENT

\begin{tabular}{lccccc}
2 & 5 & 10 & 25 & $50 \dagger$ & $100 \dagger$ \\
$50 \%$ & $20 \%$ & $10 \%$ & $4 \%$ & $2 \%$ & $1 \%$ \\
1,010 & 2,120 & 3,060 & 4,450 & 5,630 & 6,910 \\
\hline MEIGHTED SKEW (LOGS) & -0.25 & & \\
MEAN & (LOGS) & 2.99 & & \\
STANDARD DEV. (LOGS) & 0.40 & &
\end{tabular}

f Reliability of values in colum is uncertain, and potential errors are large.

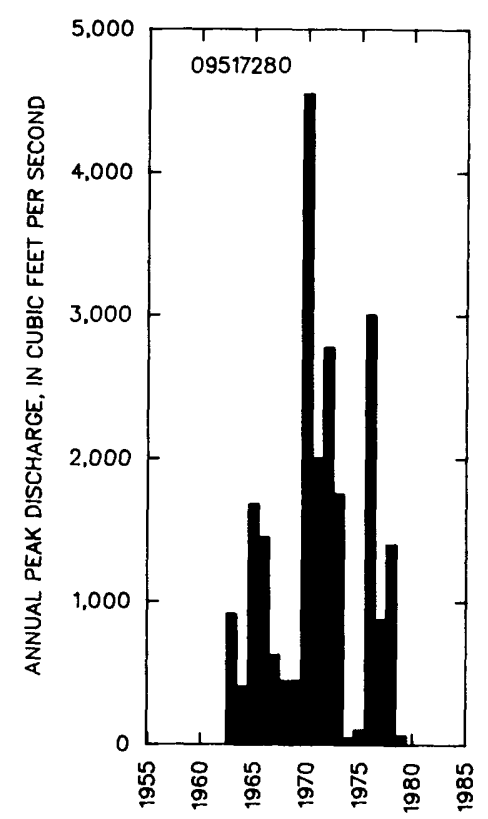

BASIN CHARACTERISTICS

\begin{tabular}{|c|c|c|c|c|c|c|c|}
\hline MIN & & $\begin{array}{l}\text { MEAN } \\
\text { BASIN }\end{array}$ & & & $\begin{array}{c}\text { MEAN } \\
\text { ANNUAL }\end{array}$ & RAINFALL IN & SITY, 24-HOUR \\
\hline $\begin{array}{l}\text { CHANNEL } \\
\text { SLOPE } \\
\text { (FT/MI) }\end{array}$ & $\begin{array}{c}\text { STREAM } \\
\text { LENGTH } \\
\text { (MI) }\end{array}$ & $\begin{array}{l}\text { ELEVA- } \\
\text { TION } \\
\text { (FT) }\end{array}$ & $\begin{array}{l}\text { FORESTED } \\
\text { AREA } \\
\text { (PERCENT) }\end{array}$ & $\begin{array}{l}\text { SOIL } \\
\text { INDEX }\end{array}$ & $\begin{array}{l}\text { PRECIPI - } \\
\text { TATION } \\
\text { (IN) }\end{array}$ & $\begin{array}{l}\text { 2-YEAR } \\
\text { (IN) }\end{array}$ & $\begin{array}{l}\text { 50-YEAR } \\
\text { (IN) }\end{array}$ \\
\hline 35.2 & 15.0 & 2,590 & 0.0 & 1.0 & 9.6 & 1.5 & 3.6 \\
\hline
\end{tabular}


09517400 WINTERS WASH NEAR TONOPAH, AZ

LOCATION.--Lat 33.29'22", Long 112.55'05", in SWHWW sec.30, T.2 N., R.6 H., Maricopa County, Hydrologic Unit 15070104, $0.3 \mathrm{mi}$ dounstream from Airline Road, and $1 \mathrm{mi}$ east of Tonopah.

DRAINAGE AREA. $-47.8 \mathrm{mi}^{2}$.

ANNUAL PEAK DISCHARGE

\begin{tabular}{|c|c|c|c|}
\hline $\begin{array}{l}\text { WATER } \\
\text { YEAR }\end{array}$ & DATE & $\begin{array}{l}\text { ANNUAL PEAK } \\
\text { DISCHARGE } \\
\left(\mathrm{FT}^{3} / \mathrm{S}\right)\end{array}$ & $\begin{array}{l}\text { DISCHARGE } \\
\text { CODES }\end{array}$ \\
\hline $\begin{array}{l}1962 \\
1963 \\
1964 \\
1965 \\
1966 \\
1967 \\
1968 \\
1969 \\
1970 \\
1971 \\
1972 \\
1973 \\
1974 \\
1975 \\
1976 \\
1977 \\
1978 \\
1979\end{array}$ & $\begin{array}{l}09-05-62 \\
09-03-63 \\
08-00-64 \\
02-07-65 \\
12-10-65 \\
09-03-67 \\
12-19-67 \\
11-15-68 \\
09-05-70 \\
08-20-71 \\
08-12-72 \\
10-06-72 \\
03-20-74 \\
10-28-74 \\
09-25-76 \\
08-16-77 \\
03-02-78 \\
12-18-78\end{array}$ & $\begin{array}{r}776 \\
100 \\
850 \\
810 \\
390 \\
900 \\
1,350 \\
960 \\
480 \\
1,000 \\
795 \\
2,100 \\
900 \\
560 \\
3,640 \\
60 \\
1,800 \\
2,100\end{array}$ & ES \\
\hline
\end{tabular}

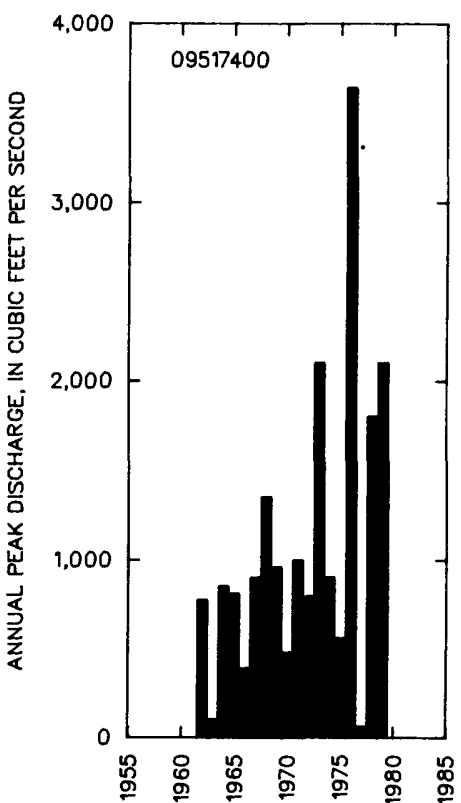

MAGNI TUDE AND PROBABILITY OF INSTANTANEOUS PEAK FLON BASED ON PERIOD OF RECORD 1962-79

DISCHARGE, IN $\mathrm{FT}^{3} / \mathrm{S}$, FOR INDICATED RECURRENCE INTERVAL IN YEARS, AND EXCEEDANCE PROBABILITY, IN PERCENT

$\begin{array}{cccccc}2 & 5 & 10 & 25 & 50 \% & 100 \dagger \\ 50 \% & 20 \% & 10 \% & 4 \% & 2 \% & 1 \% \\ 857 & 1,540 & 2,120 & 2,980 & 3,720 & 4,560\end{array}$

WEIGHTED SKEW (LOGS) $=0.11$

MEAN (LOGS) $=2.94$

STANDARD DEV. (LOGS) $=0.30$

$\uparrow$ Reliability of values in column is uncertain, and potential errors are large.

BASIN CHARACTERISTICS

\begin{tabular}{|c|c|c|c|c|c|c|c|}
\hline MAIN & & $\begin{array}{l}\text { MEAN } \\
\text { BASIN }\end{array}$ & & & $\begin{array}{l}\text { MEAN } \\
\text { ANNUAL }\end{array}$ & RAINFALL IN & SITY, 24-HOUR \\
\hline $\begin{array}{l}\text { CHANAEL } \\
\text { SLOPE } \\
\text { (FT/MI) }\end{array}$ & $\begin{array}{l}\text { LENGTH } \\
\text { (MI) }\end{array}$ & $\begin{array}{l}\text { TION } \\
\text { (FT) }\end{array}$ & $\begin{array}{l}\text { AREA } \\
\text { (PERCENT) }\end{array}$ & $\begin{array}{l}\text { SOIL } \\
\text { INDEX }\end{array}$ & $\begin{array}{l}\text { TATION } \\
\text { (IN) }\end{array}$ & $\begin{array}{l}\text { 2-YEAR } \\
\text { (IN) }\end{array}$ & $\begin{array}{l}\text { 50-YEAR } \\
\text { (IN) }\end{array}$ \\
\hline 83.7 & 18.0 & 1,630 & 0.0 & 1.0 & 9.1 & 1.5 & 3.6 \\
\hline
\end{tabular}


09519600 RAINBON MASH TRIBUTARY MEAR BUCKEYE, AZ

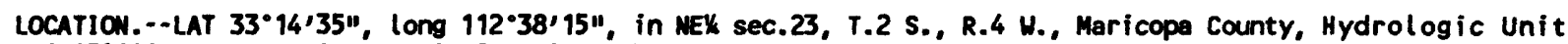
15070101, at U.S. Highway $80,9.5$ mi southwest of Buckeye.

DRAIMACE AREA. $--3.45 \mathrm{mi}^{2}$ of which $1.02 \mathrm{mi}^{2}$ is noncontributing.

ANIUAL PEAK DISCHARGE

\begin{tabular}{lccc}
$\begin{array}{l}\text { HATER } \\
\text { YEAR }\end{array}$ & $\begin{array}{c}\text { DATE } \\
\text { ANMUAL PEAK } \\
\text { DISCHARGE } \\
\text { (FT } 3 / \text { S) }\end{array}$ & $\begin{array}{c}\text { DISCHARGE } \\
\text { COOES }\end{array}$ \\
\hline 1963 & $08-00-63$ & 112 & \\
1964 & $09-13-64$ & 763 & \\
1965 & $02-07-65$ & 120 & \\
1966 & $09-13-66$ & 950 & \\
1967 & $09-03-67$ & 1.430 & \\
1968 & $08-00-68$ & 390 & \\
1969 & $08-29-69$ & 560 & \\
1970 & $08-08-70$ & 810 & \\
1971 & $07-00-71$ & 660 & \\
1972 & $08-00-72$ & 430 & \\
1973 & $11-00-72$ & 150 & \\
1974 & $07-07-74$ & 390 & \\
1975 & $10-28-74$ & 470 & \\
1976 & $09-26-76$ & 660 & \\
1977 & $08-16-77$ & 80 & ES \\
1978 & $08-04-78$ & 240 & ES \\
1979 & $08-12-79$ & 430 & ES \\
\hline
\end{tabular}
BASED ON PERIOD OF RECORD 1963-79

\section{MAGNITUDE AND PROBABILITY OF INSTANTANEQUS PEAK FLOH}

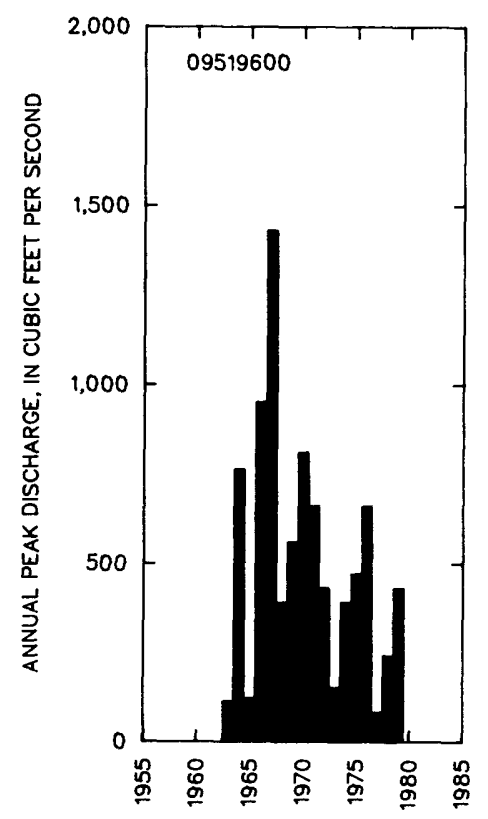

\section{BASED ON PERIOD OF RECORD $1963-79$}

DISCHARGE, IN $F T$ /S, FOR INDICATED RECURRENCE INTERVAL IN YEARS, AND EXCEEDANCE PROBABILITY, IN PERCENT

\begin{tabular}{|c|c|c|c|c|c|}
\hline $\begin{array}{c}2 \\
50 \%\end{array}$ & $\begin{array}{c}5 \\
20 \%\end{array}$ & $\begin{array}{r}10 \\
10 \%\end{array}$ & $\begin{array}{l}25 \\
4 \%\end{array}$ & $\begin{array}{l}50 \dagger \\
2 x\end{array}$ & $\begin{array}{c}100 \uparrow \\
1 \%\end{array}$ \\
\hline 484 & 748 & 945 & 1,220 & 1,440 & 1,670 \\
\hline $\begin{array}{l}\text { WEIGHTED } \\
\text { MEAN } \\
\text { STANDARD }\end{array}$ & DEV. & $\begin{array}{l}(\text { LOGS })= \\
(\text { LOGS })= \\
(\text { LOGS })=\end{array}$ & $\begin{array}{l}0.12 \\
2.69 \\
0.22\end{array}$ & & \\
\hline
\end{tabular}

+ Reliability of values in colum is uncertain, and potential errors are large.

BASIN CHARACTERISTICS

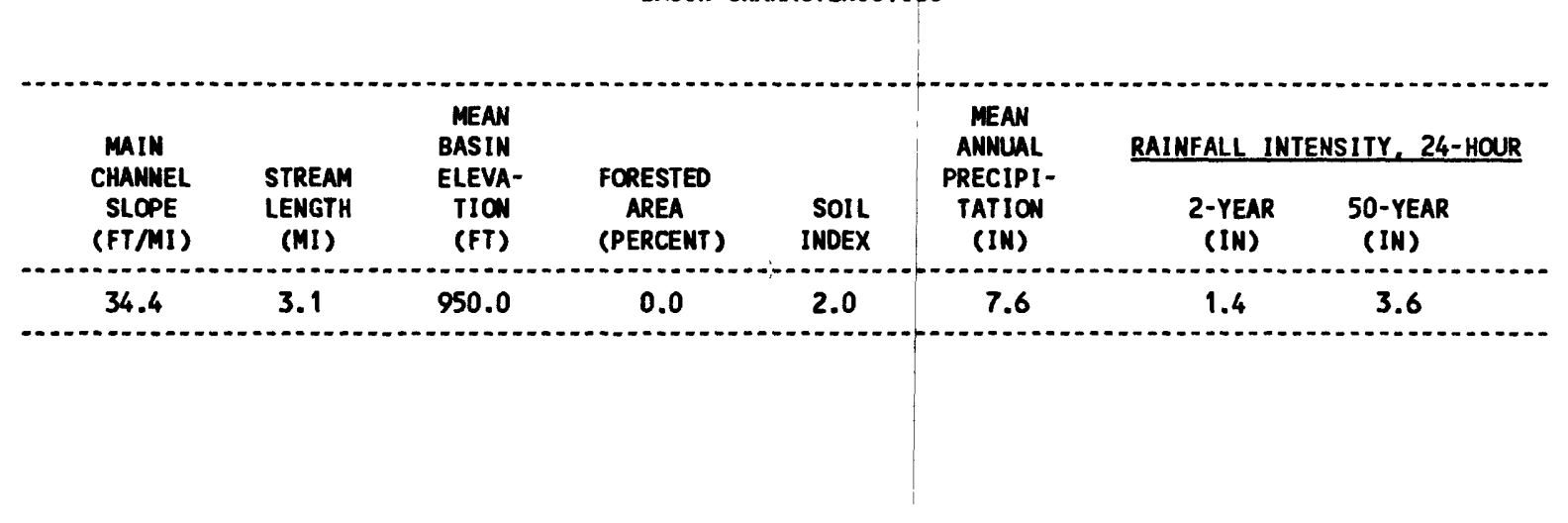


09519750 BENDER WASH MEAR GILA BEND, AZ

LOCATION.--Lat 32.54'25", Long 112.33'05", in MH sec.15, T.6 S., R.3 W., Maricopa County, Hydrologic unit 15070101, along side of Interstate Highway 8, $10 \mathrm{mi}$ southeast of Gila Bend. Prior to Oct. 1, 1966, at site $0.65 \mathrm{mi}$ downstream.

DRAINAGE AREA. $--68.8 \mathrm{mi}^{2}$.

ANIUAL PEAK DISCHARGE

\begin{tabular}{|c|c|c|c|}
\hline $\begin{array}{l}\text { WATER } \\
\text { YEAR }\end{array}$ & DATE & $\begin{array}{c}\text { ANMUAL PEAK } \\
\text { DISCHARGE } \\
\left(\mathrm{FT}^{3} / \mathrm{S}\right)\end{array}$ & $\begin{array}{l}\text { DISCHARGE } \\
\text { CCDES }\end{array}$ \\
\hline $\begin{array}{l}1963 \\
1964 \\
1965 \\
1966 \\
1967 \\
1968 \\
1969 \\
1970 \\
1971 \\
1972 \\
1973 \\
1974 \\
1975 \\
1976 \\
1977 \\
1978 \\
1979\end{array}$ & $\begin{array}{l}08-00-63 \\
00-00-64 \\
00-00-65 \\
12-22-65 \\
09-03-67 \\
10-03-67 \\
08-18-69 \\
08-14-70 \\
08-00-71 \\
06-00-72 \\
07-29-73 \\
08-03-74 \\
08-00-75 \\
09-25-76 \\
09-11-77 \\
00-00-78 \\
01-25-79\end{array}$ & $\begin{array}{r}1,740 \\
1,450 \\
943 \\
20 \\
300 \\
1,010 \\
1,500 \\
100 \\
2,670 \\
1,550 \\
40 \\
1,000 \\
2,290 \\
1,220 \\
45 \\
110 \\
40\end{array}$ & $\begin{array}{l}\text { ES } \\
\text { ES } \\
\text { ES }\end{array}$ \\
\hline
\end{tabular}

MAGNITUDE AND PROBABILITY OF INSTANTANEOUS PEAK FLOW BASED ON PERICD OF RECORD 1963-79

DISCHARGE, IN $\mathrm{FT}^{3} / \mathrm{S}$, FOR INDICATED RECURRENCE INTERVAL IN YEARS, AND EXCEEDANCE PROBABILITY, IN PERCENT

\begin{tabular}{|c|c|c|c|c|c|}
\hline $\begin{array}{c}2 \\
50 \%\end{array}$ & $\begin{array}{c}5 \\
20 \%\end{array}$ & $\begin{array}{r}10 \\
10 \%\end{array}$ & $\begin{array}{l}25 \\
4 \%\end{array}$ & $\begin{array}{l}50 \nmid \\
2 x\end{array}$ & $\begin{array}{c}100 \nmid \\
1 \%\end{array}$ \\
\hline 466 & 1,740 & 3,270 & 6,150 & 9,040 & 12,600 \\
\hline $\begin{array}{l}\text { WEIGHTED } \\
\text { MEAN } \\
\text { STANDARD }\end{array}$ & $\begin{array}{l}\text { SKEW } \\
\text { DEV. }\end{array}$ & $\begin{array}{l}(L O G S)= \\
(L O G S)= \\
(L O G S)=\end{array}$ & $\begin{array}{r}-0.38 \\
2.62 \\
0.72\end{array}$ & & \\
\hline
\end{tabular}

+ Reliability of values in column is uncertain, and potential errors are large.

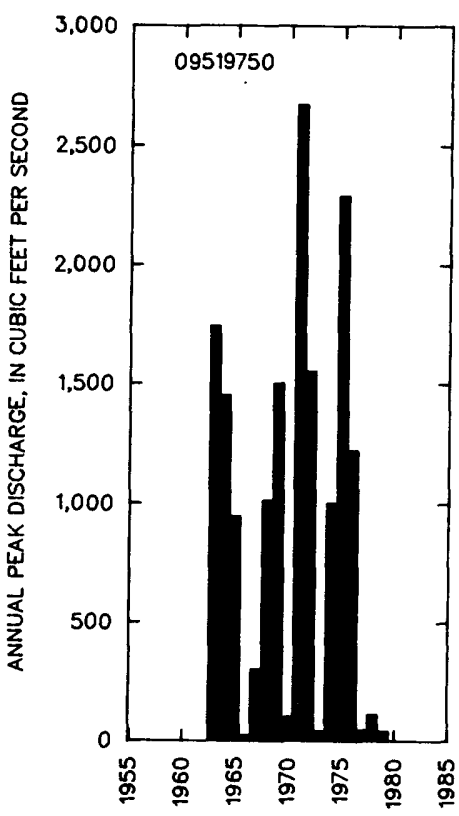


09519760 SAUCEDA WASH NEAR GILA BEND, AZ

LOCATION.--Lat 32'52'14", Long 112\%45'30", in SEKSWK sec.27, T.6 S., R.5 W., Maricopa County, Hydrologic Unit 15070101, at State Highway $85,5.3 \mathrm{mi}$ south of Gila Bend.

DRAINAGE AREA. - - $126 \mathrm{mi}^{2}$ of which $20 \mathrm{mi}^{2}$ also contributes to an adjoining basin.

AMNUAL PEAK DISCHARge

\begin{tabular}{|c|c|c|c|}
\hline $\begin{array}{l}\text { WATER } \\
\text { YEAR }\end{array}$ & DATE & $\begin{array}{l}\text { ANNUAL PEAK } \\
\text { DISCHARGE } \\
\left(\mathrm{FT}^{3} / \mathrm{S}\right)\end{array}$ & $\begin{array}{l}\text { DISCHARGE } \\
\text { COOES }\end{array}$ \\
\hline $\begin{array}{l}1963 \\
1964 \\
1965 \\
1966 \\
1967 \\
1968 \\
1969 \\
1970 \\
1971 \\
1972 \\
1973 \\
1974 \\
1975 \\
1976 \\
1977 \\
1978 \\
1979\end{array}$ & $\begin{array}{l}09-00-63 \\
08-12-64 \\
08-00-65 \\
08-00-66 \\
10-04-66 \\
10-02-67 \\
08-00-69 \\
08-00-70 \\
08-00-71 \\
08-00-72 \\
00-00-73 \\
08-03-74 \\
09-08-75 \\
09-26-76 \\
08-15-77 \\
08-08-78 \\
08-12-79\end{array}$ & $\begin{array}{r}1,100 \\
2,160 \\
55 \\
400 \\
350 \\
840 \\
130 \\
2,850 \\
1,500 \\
630 \\
0 \\
250 \\
2,500 \\
3,150 \\
2,550 \\
180 \\
20\end{array}$ & $\begin{array}{l}\text { ES } \\
\text { ES }\end{array}$ \\
\hline
\end{tabular}

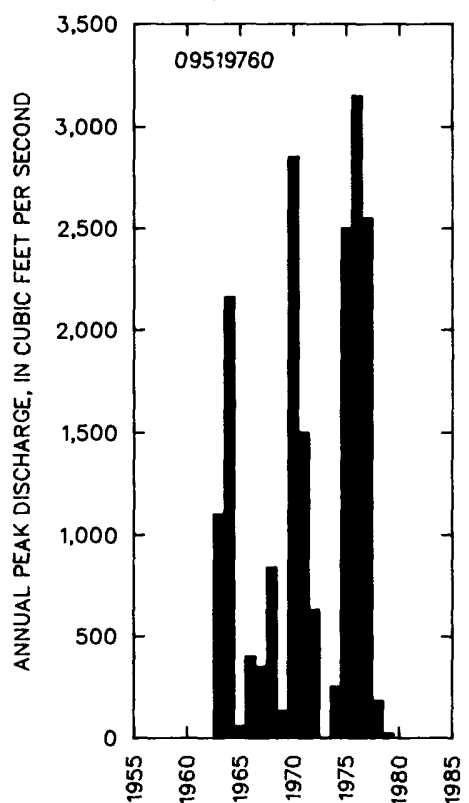

MAGNITUDE AND PROBABILITY OF INSTANTANEOUS PEAK FLOW BASED ON PERICD OF RECORD 1963-79

DISCHARGE, IN $\mathrm{FT}^{3} / \mathrm{S}$, FOR INDICATED RECURRENCE INTERVAL

IN YEARS, AND EXCEEDANCE PROBABILITY, IN PERCENT

\begin{tabular}{|c|c|c|c|c|c|}
\hline$\stackrel{2}{50 \%}$ & $\begin{array}{c}5 \\
20 \%\end{array}$ & $\begin{array}{r}10 \\
10 \%\end{array}$ & $\begin{array}{l}25 \\
4 \%\end{array}$ & $\begin{array}{l}50 \dagger \\
2 \%\end{array}$ & $\begin{array}{c}100 \dagger \\
1 \%\end{array}$ \\
\hline 584 & 1,880 & 3,310 & 5870 & 8,350 & 11,400 \\
\hline $\begin{array}{l}\text { WEIGHTED } \\
\text { MEAN } \\
\text { STANDARD }\end{array}$ & SKEW & $\begin{array}{l}\text { OGS) }= \\
\text { OGS) }= \\
\text { OGS) }=\end{array}$ & $\begin{array}{r}-0.32 \\
2.73 \\
0.63\end{array}$ & & \\
\hline
\end{tabular}

f Reliability of values in column is uncertain, and potent ial errors are large.

BASIN CHARACTERISTICS

\begin{tabular}{|c|c|c|c|c|c|c|c|}
\hline MAIN & & $\begin{array}{l}\text { MEAN } \\
\text { BASIN }\end{array}$ & & & $\begin{array}{c}\text { MEAN } \\
\text { ANNUAL }\end{array}$ & RAINFALL II & SITY, 24-HOUR \\
\hline $\begin{array}{l}\text { CHANNEL } \\
\text { SLOPE } \\
\text { (FT/MI) }\end{array}$ & $\begin{array}{l}\text { STREAM } \\
\text { LENGTH } \\
\text { (MI) }\end{array}$ & $\begin{array}{l}\text { ELEVA- } \\
\text { TION } \\
\text { (FT) }\end{array}$ & $\begin{array}{l}\text { FORESTED } \\
\text { AREA } \\
\text { (PERCENT) }\end{array}$ & $\begin{array}{l}\text { SOIL } \\
\text { INDEX }\end{array}$ & $\begin{array}{l}\text { PRECIPI - } \\
\text { TAT ION } \\
\text { (IN) }\end{array}$ & $\begin{array}{c}\text { 2-YEAR } \\
\text { (IN) }\end{array}$ & $\begin{array}{c}\text { 50-YEAR } \\
\text { (IN) }\end{array}$ \\
\hline 46.7 & 32.5 & 1,980 & 0.0 & 2.0 & 8.2 & 1.5 & 4.0 \\
\hline
\end{tabular}


09519780 HINDMILL WASH NEAR GILA BEND, AZ

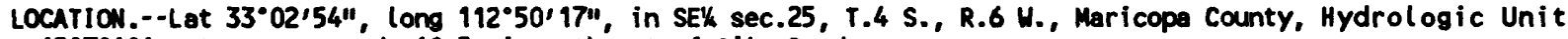
15070101, at county road, 10.5 mi northwest of Gila Bend.

DRAINAGE AREA. $--12.9 \mathrm{mi}^{2}$.

ANNUAL PEAK DISCHARGE

\begin{tabular}{|c|c|c|c|}
\hline $\begin{array}{l}\text { WATER } \\
\text { YEAR }\end{array}$ & DATE & $\begin{array}{c}\text { ANNUAL PEAK } \\
\text { DISCHARGE } \\
\left(F^{3} / S\right)\end{array}$ & $\begin{array}{l}\text { DISCHARGE } \\
\text { CODES }\end{array}$ \\
\hline $\begin{array}{l}1964 \\
1965 \\
1966 \\
1967 \\
1968 \\
1969 \\
1970 \\
1971 \\
1972 \\
1973 \\
1974 \\
1975 \\
1976 \\
1977 \\
1978\end{array}$ & $\begin{array}{l}00-00-64 \\
02-09-65 \\
09-13-66 \\
09-03-67 \\
12-19-67 \\
09-15-69 \\
08-12-70 \\
08-15-71 \\
06-06-72 \\
10-00-72 \\
08-03-74 \\
10-29-74 \\
09-26-76 \\
09-27-77 \\
04-13-78\end{array}$ & $\begin{array}{r}0 \\
10 \\
967 \\
2,510 \\
4,430 \\
150 \\
65 \\
1,850 \\
5.0 \\
60 \\
340 \\
1,900 \\
200 \\
10 \\
20\end{array}$ & $\begin{array}{l}\text { ES } \\
\text { ES } \\
\text { ES } \\
\text { ES } \\
\text { ES } \\
\text { ES }\end{array}$ \\
\hline
\end{tabular}

MAGNITUDE AND PROBABILITY OF INSTANTANEOUS PEAK FLOH BASED ON PERICD OF RECORD 1964-78

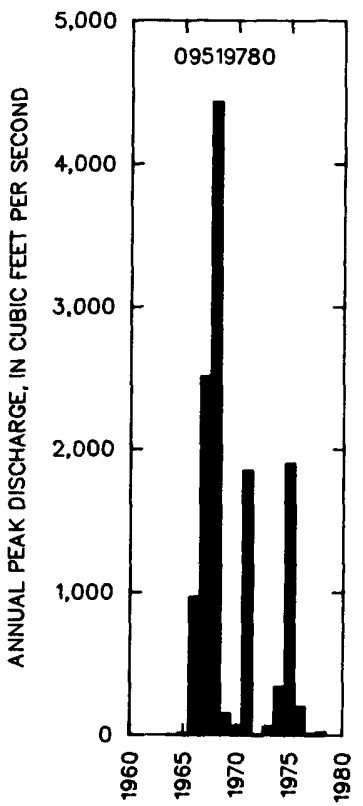

DISCHARGE, IN $\mathrm{FT}^{3} / \mathrm{S}$, FOR INDICATED RECURRENCE INTERVAL IN YEARS, AND EXCEEDANCE PROBABILITY, IN PERCENT

$\begin{array}{lccccc}2 & 5 & 10 & 25 & 50 \dagger & 100 \dagger \\ 50 \% & 20 \% & 10 \% & 4 \% & 2 \% & 1 \% \\ 155 \quad 1,160 & 3,120 & 8,550 & 16,000 & 27,600 \\ \text { MEIGHTED SKEW (LOGS) } & & -0.28 & & \\ \text { MEN } & \text { (LOGS) } & 2.14 & & \\ \text { STAMDARD DEV. (LOGS) } & =1.09\end{array}$

t Reliabllity of values in colum is uncertain, and potential errors are large.

BASIN CHARACTERISTICS

\begin{tabular}{|c|c|c|c|c|c|c|c|}
\hline \multirow{2}{*}{$\begin{array}{l}\text { MIN } \\
\text { CNANHEL } \\
\text { SLOPE } \\
\text { (FT/MI) }\end{array}$} & \multirow[b]{2}{*}{$\begin{array}{c}\text { STREAM } \\
\text { LENGTH } \\
\text { (MI) }\end{array}$} & \multirow{2}{*}{$\begin{array}{l}\text { MEAN } \\
\text { BASIN } \\
\text { ELEVA- } \\
\text { TION } \\
\text { (FT) }\end{array}$} & \multirow[b]{2}{*}{$\begin{array}{c}\text { FORESTED } \\
\text { AREA } \\
\text { (PERCENT) }\end{array}$} & \multirow[b]{2}{*}{$\begin{array}{l}\text { SOIL } \\
\text { INDEX }\end{array}$} & \multirow{2}{*}{$\begin{array}{l}\text { MEAN } \\
\text { ANNUAL } \\
\text { PRECIPI- } \\
\text { TATION } \\
\text { (IN) }\end{array}$} & \multicolumn{2}{|c|}{ BAIMFALL INTEMSITY, 24-HOUR } \\
\hline & & & & & & $\begin{array}{c}\text { 2-YEAR } \\
\text { (IN) }\end{array}$ & $\begin{array}{l}\text { 50-YEAR } \\
\text { (IN) }\end{array}$ \\
\hline 64.4 & 9.1 & 1,050 & 0.0 & 1.0 & 6.1 & 1.3 & 3.6 \\
\hline
\end{tabular}


LOCATION.--Lat 32.50'43", long 113'16'44", in SWK sec.3, T.7 S., R.10 H., Maricopa County, Hydrologic Unit 15070201, at U.S. Highway $80,4.1 \mathrm{mi}$ west of Sentinel.

DRAINAGE AREA. $--8.70 \mathrm{mi}^{2}$.

ANNUAL PEAK DISCHARGE

\begin{tabular}{|c|c|c|c|}
\hline $\begin{array}{l}\text { WATER } \\
\text { YEAR }\end{array}$ & DATE & $\begin{array}{l}\text { ANNUAL PEAK } \\
\text { DISCHARGE } \\
\text { (FT } 3 / S)\end{array}$ & $\begin{array}{l}\text { DISCHARGE } \\
\text { COOES }\end{array}$ \\
\hline $\begin{array}{l}1963 \\
1964 \\
1965 \\
1966 \\
1967 \\
1968 \\
1969 \\
1970 \\
1971 \\
1972 \\
1973 \\
1974 \\
1975 \\
1976 \\
1977 \\
1978 \\
1979\end{array}$ & $\begin{array}{l}08-30-63 \\
10-19-63 \\
01-06-65 \\
12-10-65 \\
09-03-67 \\
12-19-67 \\
08-13-69 \\
08-20-70 \\
08-20-71 \\
06-00-72 \\
11-00-72 \\
08-02-74 \\
07-27-75 \\
07-27-76 \\
08-15-77 \\
08-04-78 \\
01-17-79\end{array}$ & $\begin{array}{r}200 \\
60 \\
12 \\
235 \\
210 \\
1,200 \\
25 \\
30 \\
900 \\
30 \\
100 \\
1,530 \\
30 \\
550 \\
120 \\
560 \\
20\end{array}$ & $\begin{array}{l}\text { ES } \\
\text { ES } \\
\text { ES }\end{array}$ \\
\hline
\end{tabular}

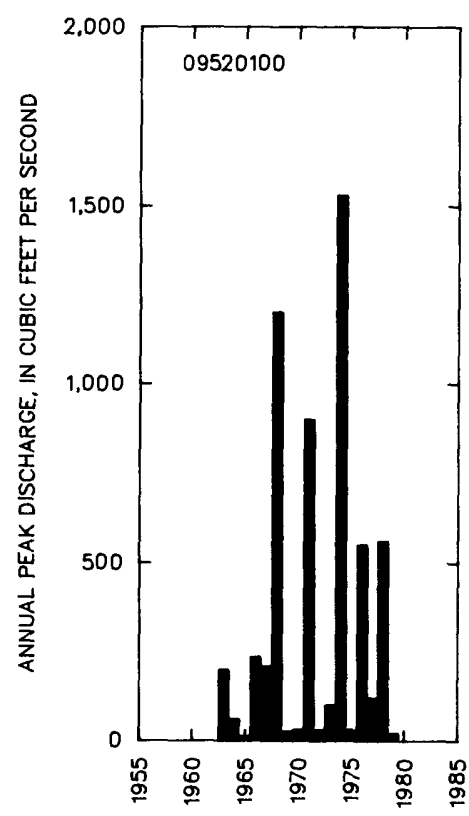

MAGNITUDE AND PROBABILITY OF INSTANTANEOUS PEAK FLOU BASED ON PERIOD OF RECORD 1963-79

DISCHARGE, IN $\mathrm{FT}^{3} / \mathrm{S}$, FOR INDICATED RECURRENCE INTERVAL IN YEARS, AND EXCEEDANCE PROBABILITY, IN PERCENT

\begin{tabular}{|c|c|c|c|c|c|}
\hline $\begin{array}{c}2 \\
50 \%\end{array}$ & $\begin{array}{c}5 \\
20 \%\end{array}$ & $\begin{array}{r}10 \\
10 \%\end{array}$ & $\begin{array}{l}25 \\
4 \%\end{array}$ & $\begin{array}{l}50 \dagger \\
2 \%\end{array}$ & $\begin{array}{c}100 \dagger \\
1 \%\end{array}$ \\
\hline 124 & 468 & 946 & 2,030 & 3,330 & 5,220 \\
\hline $\begin{array}{l}\text { WEIGHTED } \\
\text { MEAN } \\
\text { STANDARD }\end{array}$ & $\begin{array}{l}\text { SKEH } \\
\text { DEV. }\end{array}$ & $\begin{array}{l}(\text { LOGS })= \\
(\text { LOGS })= \\
(\text { LOGS })=\end{array}$ & $\begin{array}{l}0.08 \\
2.10 \\
0.68\end{array}$ & & \\
\hline
\end{tabular}

† Reliability of values in column is uncertain, and potential errors are large.

BASIN CHARACTERISTICS

\begin{tabular}{|c|c|c|c|c|c|c|c|}
\hline \multicolumn{5}{|c|}{ MEAN } & \multirow{2}{*}{$\begin{array}{c}\text { MEAN } \\
\text { ANNUAL } \\
\text { PRECIPI- }\end{array}$} & & \\
\hline MaIN & & BASIN & & & & \multicolumn{2}{|c|}{ RAINFALL INTENSITY, 24-HOUR } \\
\hline $\begin{array}{l}\text { CHANNEL } \\
\text { SLOPE } \\
\text { (FT/MI) }\end{array}$ & $\begin{array}{c}\text { STREAM } \\
\text { LENGTH } \\
\text { (MI) }\end{array}$ & $\begin{array}{l}\text { ELEVA- } \\
\text { TION } \\
\text { (FT) }\end{array}$ & $\begin{array}{l}\text { FORESTED } \\
\text { AREA } \\
\text { (PERCENT) }\end{array}$ & $\begin{array}{l}\text { SOIL } \\
\text { INDEX }\end{array}$ & $\begin{array}{l}\text { PRECIPI- } \\
\text { TATION } \\
\text { (IN) }\end{array}$ & $\begin{array}{l}\text { 2-YEAR } \\
\text { (IN) }\end{array}$ & $\begin{array}{l}\text { 50-YEAR } \\
\text { (IN) }\end{array}$ \\
\hline 56.0 & 5.0 & 674.0 & 0.0 & 1.0 & 5.0 & 1.3 & 3.6 \\
\hline
\end{tabular}


09520110 HOT SHOT ARROYO MEAR AJO, AZ

LOCATION.--Lat 32॰20'49", long $112^{\circ} 48^{\prime} 31^{\prime \prime}$, in SW sec.29, T.12 S., R.5 W., Pima County, Hydrologic Unit 15070202 , at State Highway $85,3 \mathrm{mi}$ southeast of Ajo.

DRAIMAGE AREA. $--0.44 \mathrm{mi}^{2}$.

ANNUAL PEAK DISCHARGE

\begin{tabular}{|c|c|c|c|}
\hline $\begin{array}{l}\text { WATER } \\
\text { YEAR }\end{array}$ & DATE & $\begin{array}{l}\text { ANNUAL PEAK } \\
\text { DISCHARGE } \\
\text { (FT } 3 / S \text { ) }\end{array}$ & $\begin{array}{l}\text { DISCHARGE } \\
\text { CODES }\end{array}$ \\
\hline $\begin{array}{l}1966 \\
1967 \\
1968 \\
1969 \\
1970 \\
1971 \\
1972 \\
1973 \\
1974 \\
1975 \\
1976 \\
1977 \\
1978 \\
1979 \\
1980 \\
1981\end{array}$ & $\begin{array}{l}09-13-66 \\
07-15-67 \\
10-03-67 \\
00-00-69 \\
07-27-70 \\
00-00-71 \\
08-31-72 \\
10-06-72 \\
09-23-74 \\
10-29-74 \\
09-05-76 \\
09-11-77 \\
10-06-77 \\
09-14-79 \\
08-13-80 \\
01-12-81\end{array}$ & $\begin{array}{l}215 \\
206 \\
175 \\
5.0 \\
170 \\
116 \\
92 \\
60 \\
215 \\
110 \\
240 \\
155 \\
150 \\
125 \\
40 \\
72\end{array}$ & ES \\
\hline
\end{tabular}

MAGNITUDE AND PROBABILITY OF INSTANTANEOUS PEAK FLOW BASED ON PERIOD OF RECORD 1966-81

DISCHARGE, IN $\mathrm{FT}^{3} / \mathrm{S}$, FOR INDICATED RECURRENCE INTERVAL

IN YEARS, AND EXCEEDANCE PROBABILITY, IN PERCENT

\begin{tabular}{|c|c|c|c|c|c|}
\hline$\underset{50 \%}{2}$ & $\begin{array}{c}5 \\
20 \%\end{array}$ & $\begin{array}{r}10 \\
10 \%\end{array}$ & $\begin{array}{l}25 \\
4 \%\end{array}$ & $\begin{array}{l}50 \nmid \\
2 x\end{array}$ & $\begin{array}{c}100 \nmid \\
1 \%\end{array}$ \\
\hline 136 & 191 & 226 & 268 & 298 & 327 \\
\hline $\begin{array}{l}\text { WEIGHTED } \\
\text { MEAN } \\
\text { STANDARD }\end{array}$ & $\begin{array}{l}\text { SKEH } \\
\text { DEV. }\end{array}$ & $\begin{array}{l}(\text { LOGS })= \\
(L O G S)= \\
(\text { LOGS) }=\end{array}$ & $\begin{array}{r}-0.28 \\
2.13 \\
0.18\end{array}$ & & \\
\hline
\end{tabular}

+ Reliability of values in column is uncertain, and potential errors are large.

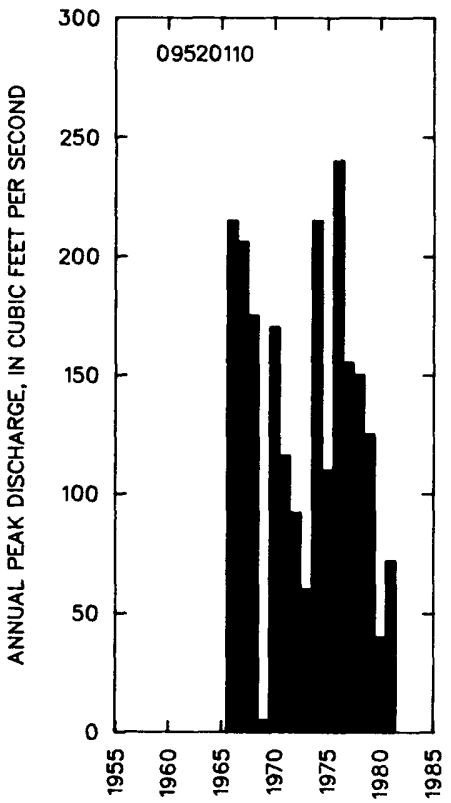


LOCATION.--Lat 32.21'19", long $112 \cdot 49 \cdot 31 \%$, in WHK sec.30, T.12 S., R.5 W., Pima County, Hydrologic Unit 15070202 , at State Highway 85, 2 mi southeast of Ajo.

DRATMACE AREA. $--4.72 \mathrm{mi}^{2}$.

ANNUAL PEAK DISCHARGE

\begin{tabular}{|c|c|c|}
\hline $\begin{array}{l}\text { WATER } \\
\text { YEAR }\end{array}$ & DATE & $\begin{array}{l}\text { ANNUAL PEAK } \\
\text { DISCHARGE } \\
\left(\mathrm{FT}^{3} / \mathrm{S}\right)\end{array}$ \\
\hline $\begin{array}{l}1966 \\
1967 \\
1968 \\
1969 \\
1970 \\
1971 \\
1972 \\
1973 \\
1974 \\
1975 \\
1976 \\
1977 \\
1978 \\
1979 \\
1980 \\
1981\end{array}$ & $\begin{array}{l}09-13-66 \\
09-06-67 \\
07-04-68 \\
08-11-69 \\
08-02-70 \\
08-19-71 \\
10-06-71 \\
10-06-72 \\
09-26-74 \\
10-29-74 \\
08-11-76 \\
07-04-77 \\
10-06-77 \\
11-11-78 \\
08-13-80 \\
08-23-81\end{array}$ & $\begin{array}{r}1,320 \\
1,670 \\
480 \\
480 \\
960 \\
500 \\
450 \\
105 \\
470 \\
270 \\
840 \\
780 \\
1,070 \\
320 \\
150 \\
400\end{array}$ \\
\hline
\end{tabular}

MAGNITUDE AND PROBABILITY OF INSTANTANEOUS PEAK FLOW BASED ON PERIOD OF RECORD 1966-81

DISCHARGE, IN $\mathrm{FT}^{3} / \mathrm{S}$, FOR INDICATED RECURRENCE INTERVAL

IN YEARS, AND EXCEEDANCE PROBABILITY, IN PERCENT

\begin{tabular}{|c|c|c|c|c|c|}
\hline$\stackrel{2}{50 \%}$ & $\begin{array}{c}5 \\
20 \%\end{array}$ & $\begin{array}{r}10 \\
10 \%\end{array}$ & $\begin{array}{l}25 \\
4 \%\end{array}$ & $\begin{array}{l}50 \dagger \\
2 \%\end{array}$ & $\begin{array}{c}100 \dagger \\
1 \%\end{array}$ \\
\hline 550 & 922 & 1,210 & 1,640 & 1,990 & 2,380 \\
\hline $\begin{array}{l}\text { MEIGH } \\
\text { MEAN } \\
\text { STANDI }\end{array}$ & & $\begin{array}{l}\text { OGS) }= \\
\text { OGS) }= \\
\text { OGS) }=\end{array}$ & $\begin{array}{l}0.11 \\
2.75 \\
0.26\end{array}$ & & \\
\hline
\end{tabular}

t Reliability of values in colum is uncertain, and potential errors are large.

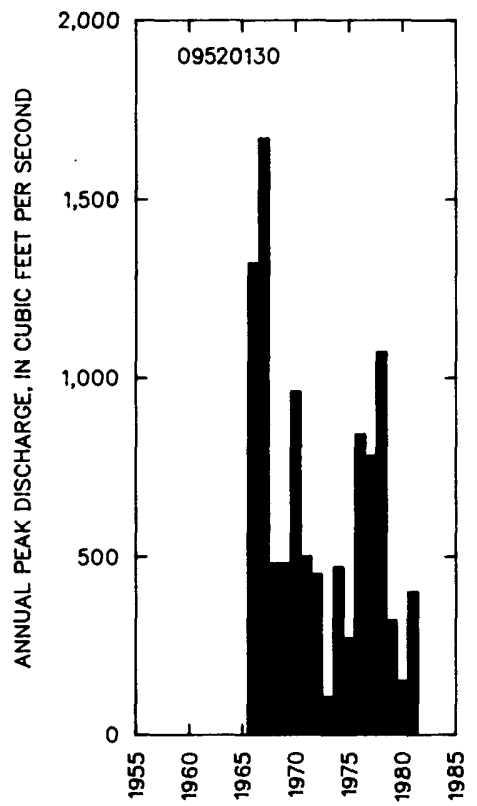

BASIN CHARACTERISTICS

\begin{tabular}{|c|c|c|c|c|c|c|c|}
\hline MAIN & & $\begin{array}{l}\text { MEAN } \\
\text { BASIN }\end{array}$ & & & $\begin{array}{l}\text { MEAN } \\
\text { ANNUAL }\end{array}$ & RAINFALL II & SITY, 24-HOUR \\
\hline $\begin{array}{l}\text { CHANNEL } \\
\text { SLOPE } \\
\text { (FT/MI) }\end{array}$ & $\begin{array}{l}\text { STREAM } \\
\text { LENGTH } \\
\text { (MI) }\end{array}$ & $\begin{array}{l}\text { ELEVA- } \\
\text { TION } \\
\text { (FT) }\end{array}$ & $\begin{array}{l}\text { FORESTED } \\
\text { AREA } \\
\text { (PERCENT) }\end{array}$ & $\begin{array}{l}\text { SOIL } \\
\text { INDEX }\end{array}$ & $\begin{array}{l}\text { PRECIPI- } \\
\text { TATION } \\
\text { (IN) }\end{array}$ & $\begin{array}{c}\text { 2-YEAR } \\
\text { (IN) }\end{array}$ & $\begin{array}{c}\text { 50-YEAR } \\
\text { (IN) }\end{array}$ \\
\hline 71.1 & 6.0 & 1,920 & 0.0 & 3.0 & 8.1 & 1.6 & 4.1 \\
\hline
\end{tabular}


09520160 GIBSON ARROYO AT AJO, AZ

LOCATION.--Lat 32'22'48", long 112.51'40", in MWHSWh sec.14, T.12 S., R.6 W., Pima County, Hydrologic Unit 15070202, at 2 nd Avenue next to rail road tracks in $A j 0$.

DRAINAGE AREA. $--2.18 \mathrm{mi}^{2}$.

ANMUAL PEAK DISCHARGE

\begin{tabular}{cccc}
$\begin{array}{c}\text { WATER } \\
\text { YEAR }\end{array}$ & DATE & $\begin{array}{c}\text { ANNUAL PEAK } \\
\text { DISCHARGE } \\
\text { (FT } 3 / \text { S) }\end{array}$ & $\begin{array}{c}\text { DISCHARGE } \\
\text { CODES }\end{array}$ \\
\hline 1967 & $07-22-67$ & 132 & \\
1968 & $07-04-68$ & 553 & \\
1969 & $08-11-69$ & 306 & \\
1970 & $08-02-70$ & 11,800 & \\
1971 & $08-19-71$ & 10 & LT \\
1972 & $08-00-72$ & 345 & \\
1973 & $08-00-73$ & 240 & \\
1974 & $08-02-74$ & 254 & \\
1975 & $10-29-74$ & 320 & \\
1976 & $09-05-76$ & 340 & \\
1977 & $07-04-77$ & 50 & \\
1978 & $08-11-78$ & 380 & \\
1979 & $08-13-79$ & 270 & \\
1980 & $08-13-80$ & 70 & \\
1981 & $08-23-81$ & 200 & \\
\hline$\ldots$ & & \\
\hline
\end{tabular}

Highest since 1960.

MAGNITUDE AND PROBABILITY OF INSTANTANEOUS PEAK FLON BASED ON PERICD OF. RECORD 1967-81

DISCHARGE, IN $\mathrm{FT}^{3} / \mathrm{S}$, FOR INCICATED RECURRENCE INTERVAL IN YEARS, AND EXCEEDANCE PROBABILITY, IN PERCENT

\begin{tabular}{|c|c|c|c|c|c|}
\hline$\stackrel{2}{50 \%}$ & $\begin{array}{c}5 \\
20 \%\end{array}$ & $\begin{array}{r}10 \\
10 \%\end{array}$ & $\begin{array}{l}25 \\
4 \%\end{array}$ & $\begin{array}{l}50 \dagger \\
2 \%\end{array}$ & $\begin{array}{c}100 \dagger \\
1 \%\end{array}$ \\
\hline 231 & 474 & 686 & 1,010 & 1,300 & 1,620 \\
\hline $\begin{array}{l}\text { WEIGHTED } \\
\text { MEAN } \\
\text { STANDARO }\end{array}$ & $\begin{array}{l}\text { SKEW } \\
\text { DEV. }\end{array}$ & $\begin{array}{l}(\text { LOGS })= \\
(\text { LOGS }= \\
(\text { LOGS }=\end{array}$ & $\begin{array}{r}-0.07 \\
2.36 \\
0.37\end{array}$ & & \\
\hline
\end{tabular}

$\uparrow$ Reliability of values in column is uncertain, and potential errors are large.

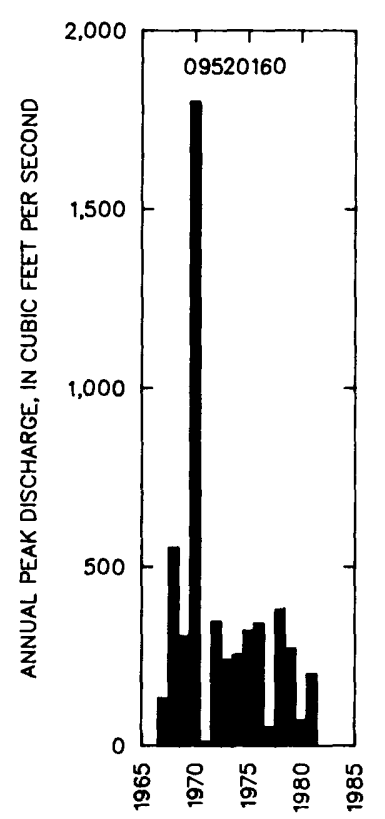

BASIN CHARACTERISTICS

\begin{tabular}{|c|c|c|c|c|c|c|c|}
\hline MAIN & & $\begin{array}{r}\text { MEAN } \\
\text { BASIN }\end{array}$ & & & $\begin{array}{c}\text { MEAN } \\
\text { ANNUAL }\end{array}$ & RAINFALL II & SITY, 24-HOUR \\
\hline $\begin{array}{l}\text { CHANNEL } \\
\text { SLOPE } \\
\text { (FT/MI) }\end{array}$ & $\begin{array}{c}\text { STREAM } \\
\text { LENGTH } \\
\text { (MI) }\end{array}$ & $\begin{array}{l}\text { ELEVA- } \\
\text { TION } \\
\text { (FT) }\end{array}$ & $\begin{array}{l}\text { FORESTED } \\
\text { AREA } \\
\text { (PERCENT) }\end{array}$ & $\begin{array}{l}\text { SOIL } \\
\text { INDEX }\end{array}$ & $\begin{array}{l}\text { PRECIPI- } \\
\text { TATION } \\
\text { (IN) }\end{array}$ & $\begin{array}{c}\text { 2-YEAR } \\
\text { (IN) }\end{array}$ & $\begin{array}{l}\text { 50-YEAR } \\
\text { (IN) }\end{array}$ \\
\hline 171 & 2.8 & 2,100 & 0.0 & 2.0 & 8.1 & 1.7 & 4.1 \\
\hline
\end{tabular}


LOCATION.-- Lat 32.29'58", Long 112.52'50", in SEXNEK sec.4, T.11 S., R.6 H., Pima County, Hydrologic Unit 15070202, on downstream side of bridge on State Highway 85, and $8 \mathrm{mi}$ north of Ajo.

DRAIMAGE AREA. $--243 \mathrm{mi}^{2}$.

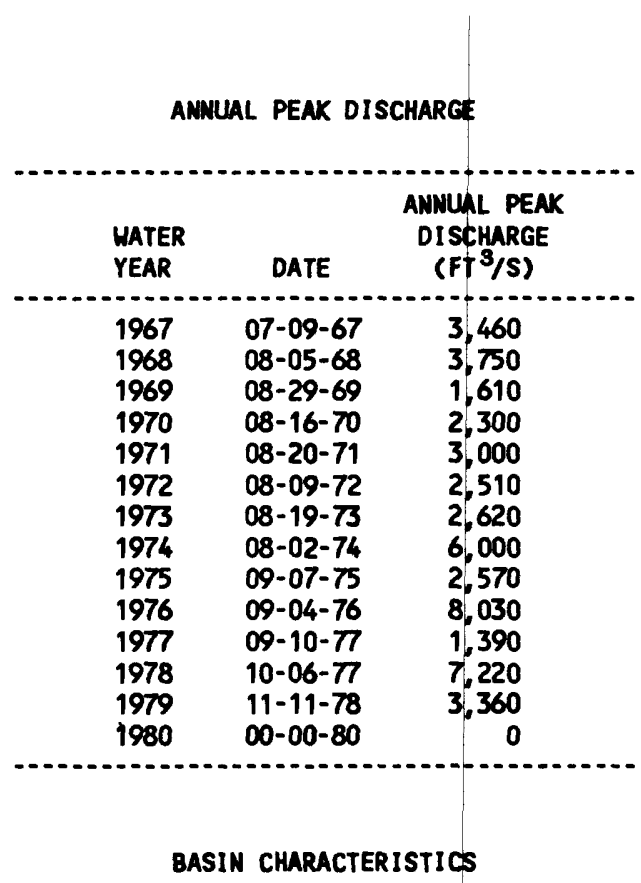

\begin{tabular}{|c|c|c|c|c|c|c|c|}
\hline MAIN & & $\begin{array}{c}\text { MEAN } \\
\text { BASIN }\end{array}$ & & & & RAINFALL I & SITY, 24-HOUR \\
\hline $\begin{array}{l}\text { CHANNEL } \\
\text { SLOPE } \\
\text { (FT/MI) }\end{array}$ & $\begin{array}{l}\text { STREAM } \\
\text { LEWGTH } \\
\text { (MI) }\end{array}$ & $\begin{array}{l}\text { ELEVA- } \\
\text { TION } \\
\text { (FT) }\end{array}$ & $\begin{array}{l}\text { FORESTED } \\
\text { AREA } \\
\text { (PERCENT) }\end{array}$ & $\begin{array}{l}\text { SOIL } \\
\text { INDEX }\end{array}$ & $\begin{array}{l}\text { PRECIPI - } \\
\text { TATION } \\
\text { (IN) }\end{array}$ & $\begin{array}{l}\text { 2-YEAR } \\
\text { (IN) }\end{array}$ & $\begin{array}{l}\text { 50-YEAR } \\
\text { (IN) }\end{array}$ \\
\hline 26.8 & 33.6 & 1,950 & 0.0 & 2.0 & 8.4 & 1.7 & 4.2 \\
\hline
\end{tabular}


09520170 RIO CORNEZ NEAR AJO, AZ--Cont inued

MEAN MONTHLY AND ANNUAL DISCHARGES $1968-78$

\begin{tabular}{|c|c|c|c|c|c|c|}
\hline MONTH & $\begin{array}{l}\left.\max \operatorname{ImMN}_{(\mathrm{FT}} \mathrm{F}^{3} / \mathrm{S}\right)\end{array}$ & $\begin{array}{l}\operatorname{MININMN} \\
\left(\mathrm{FT}^{3} / \mathrm{S}\right)\end{array}$ & $\begin{array}{c}\text { MEAN } \\
\left(F T^{3} / S\right)\end{array}$ & $\begin{array}{l}\text { STAN- } \\
\text { DARD } \\
\text { DEVIA- } \\
\text { TION } \\
\left.\text { (FT }{ }^{3} / S\right)\end{array}$ & $\begin{array}{l}\text { COEFF I- } \\
\text { CIENT OF } \\
\text { VARI - } \\
\text { ATION }\end{array}$ & $\begin{array}{c}\text { PERCENT } \\
\text { OF } \\
\text { ANNUAL } \\
\text { RUNOFF }\end{array}$ \\
\hline $\begin{array}{l}\text { OCTOBER } \\
\text { NOVEMBER } \\
\text { DECEMBER } \\
\text { JANUARY } \\
\text { FEBRUARY } \\
\text { MARCH } \\
\text { APRIL } \\
\text { MAY } \\
\text { JUNE } \\
\text { JULY } \\
\text { AUGUST } \\
\text { SEPTEMBER }\end{array}$ & $\begin{array}{l}41 \\
3.8 \\
2.7 \\
9.0 \\
3.0 \\
39 \\
0.00 \\
8.0 \\
1.2 \\
35 \\
56 \\
89\end{array}$ & $\begin{array}{l}0.00 \\
0.00 \\
0.00 \\
0.00 \\
0.00 \\
0.00 \\
0.00 \\
0.00 \\
0.00 \\
0.00 \\
0.00 \\
0.00\end{array}$ & $\begin{array}{l}4.6 \\
0.64 \\
0.24 \\
0.82 \\
0.27 \\
3.6 \\
0.00 \\
0.73 \\
0.11 \\
6.5 \\
18 \\
14\end{array}$ & $\begin{array}{c}12 \\
1.2 \\
0.80 \\
2.7 \\
0.90 \\
12 \\
0.00 \\
2.4 \\
0.35 \\
11 \\
18 \\
27\end{array}$ & $\begin{array}{l}2.7 \\
1.9 \\
3.3 \\
3.3 \\
3.3 \\
3.3 \\
\\
3.3 \\
3.3 \\
1.7 \\
0.98 \\
1.8\end{array}$ & $\begin{array}{r}9.1 \\
1.3 \\
0.5 \\
1.6 \\
0.5 \\
7.2 \\
0.0 \\
1.5 \\
0.2 \\
13.0 \\
36.5 \\
28.6\end{array}$ \\
\hline MNUAL & 12 & 0.96 & 4.2 & 3.3 & 0.79 & 100 \\
\hline
\end{tabular}

MAGNITLDE AMD PROBABILITY OF INSTANTANEOUS PEAK FLOW BASED ON PERIOD OF RECORD 1967-80

DISCHARGE, IN $\mathrm{FT}^{3} / \mathrm{S}$, FOR INDICATED RECURRENCE INTERVAL IN YEARS, AND EXCEEDANCE PROBABILITY, IN PERCENT

\begin{tabular}{|c|c|c|c|c|c|}
\hline$\stackrel{2}{20 \%}$ & $\underset{20 \%}{5}$ & $\begin{array}{r}10 \\
10 \%\end{array}$ & $\begin{array}{l}25 \\
4 \%\end{array}$ & $\begin{array}{l}50+ \\
2 \%\end{array}$ & $\begin{array}{c}100 \uparrow \\
1 x\end{array}$ \\
\hline 3,000 & 4,850 & 6,280 & 8,310 & 9,980 & 11,800 \\
\hline $\begin{array}{l}\text { WEIGHTED } \\
\text { MEAN } \\
\text { STANDARD }\end{array}$ & $\begin{array}{l}\text { SKEW } \\
\text { DEV. }\end{array}$ & $\begin{array}{l}\text { (LOGS) }= \\
(\text { LOGS }= \\
(\text { LOGS })=\end{array}$ & $\begin{array}{l}0.13 \\
3.48 \\
0.24\end{array}$ & & \\
\hline
\end{tabular}

MAGNITUDE AND PROBABILITY OF ANNUAL LOW FLOW BASED ON PERIOD OF RECORD 1968-78

\begin{tabular}{|c|c|c|c|c|c|c|}
\hline $\begin{array}{l}\text { PER IOD } \\
\text { (CON- } \\
\text { SECU- }\end{array}$ & & $\begin{array}{l}\text { DISCHA } \\
\text { RECWRRE } \\
\text { ON-EXCE }\end{array}$ & $\begin{array}{l}\text { IN } \\
\text { INTE } \\
\text { INCE } \\
\text { W }\end{array}$ & $\begin{array}{l}\text { S, FC } \\
\text { L, II } \\
\text { ABIL }\end{array}$ & $\begin{array}{l}\text { INDICA } \\
\text { EARS, } \\
\text { IN P }\end{array}$ & \\
\hline $\begin{array}{l}\text { TIVE } \\
\text { DAYS) }\end{array}$ & $\begin{array}{c}2 \\
50 x\end{array}$ & $\begin{array}{c}5 \\
20 \%\end{array}$ & $\begin{array}{l}10 \\
10 \%\end{array}$ & $\begin{array}{l}20 \\
5 \%\end{array}$ & $\begin{array}{l}50 \dagger \\
2 \%\end{array}$ & $\begin{array}{l}100 t \\
1 \%\end{array}$ \\
\hline $\begin{array}{r}1 \\
3 \\
7 \\
14 \\
30 \\
60 \\
90 \\
120 \\
183\end{array}$ & 0.18 & 0.00 & 0.00 & 0.00 & 0.00 & 0.00 \\
\hline
\end{tabular}

MAGNITLDE AND PROBABILITY OF ANNUAL HIGH FLON BASED ON PERIOD OF RECORD 1968-78

\begin{tabular}{|c|c|c|c|c|c|c|}
\hline \multirow{2}{*}{$\begin{array}{l}\text { PERIOD } \\
\text { (CON- } \\
\text { SECU- } \\
\text { TIVE } \\
\text { DAYS) }\end{array}$} & \multicolumn{6}{|c|}{$\begin{array}{l}\text { DISCHARGE, IN } \text { FT }^{3} / S \text {, FOR INDICATED } \\
\text { RECURRENCE INTERVAL, IN YEARS, AND } \\
\text { EXCEEDANCE PROBABILITY, IN PERCENT }\end{array}$} \\
\hline & $\begin{array}{c}2 \\
50 \%\end{array}$ & $\begin{array}{c}5 \\
20 \%\end{array}$ & $\begin{array}{l}10 \\
10 \%\end{array}$ & $\begin{array}{l}25 \dagger \\
4 \%\end{array}$ & $\begin{array}{l}50 \dagger \\
2 x\end{array}$ & $\begin{array}{c}100 \dagger \\
1 \%\end{array}$ \\
\hline $\begin{array}{r}1 \\
3 \\
7 \\
15 \\
30 \\
60 \\
90\end{array}$ & $\begin{array}{r}432 \\
228 \\
96 \\
53 \\
30\end{array}$ & $\begin{array}{r}761 \\
396 \\
170 \\
87 \\
53 \\
x\end{array}$ & $\begin{array}{r}972 \\
487 \\
223 \\
108 \\
71 \\
38 \\
30\end{array}$ & $\begin{array}{r}1,220 \\
577 \\
291 \\
132 \\
97 \\
52 \\
45\end{array}$ & $\begin{array}{r}1,380 \\
628 \\
343 \\
148 \\
119 \\
64 \\
60\end{array}$ & $\begin{array}{r}1,530 \\
668 \\
395 \\
162 \\
142 \\
77 \\
77\end{array}$ \\
\hline
\end{tabular}

DURATION TABLE OF DAILY MEAN FLON FOR PERIOD OF RECORD 1968-78

DISCHARGE, IN FT $3 / 5$, WHICH WAS EQUALED OR EXCEEDED FOR INDICATED PERCENT OF TIME

\begin{tabular}{|c|c|c|c|c|c|c|c|c|c|c|c|c|c|c|c|c|}
\hline $1 \%$ & $5 \%$ & $10 \%$ & $15 \%$ & $20 \%$ & $30 x$ & $40 \%$ & $50 \%$ & $60 \%$ & $70 \%$ & $80 \%$ & $90 \%$ & $95 \%$ & $98 \%$ & $99 \%$ & $99.5 \%$ & $99.9 \%$ \\
\hline 101 & 0.01 & 0.01 & 0.01 & 0.01 & 0.01 & 0.01 & 0.00 & 0.00 & 0.00 & 0.00 & 0.00 & 0.00 & 0.00 & 0.00 & 0.00 & 0.00 \\
\hline
\end{tabular}

† Reliability of values in colum is uncertain, and potential errors are large. 
09520170 RIO CORNEZ MEAR MJO, AZ--CONTIMUED
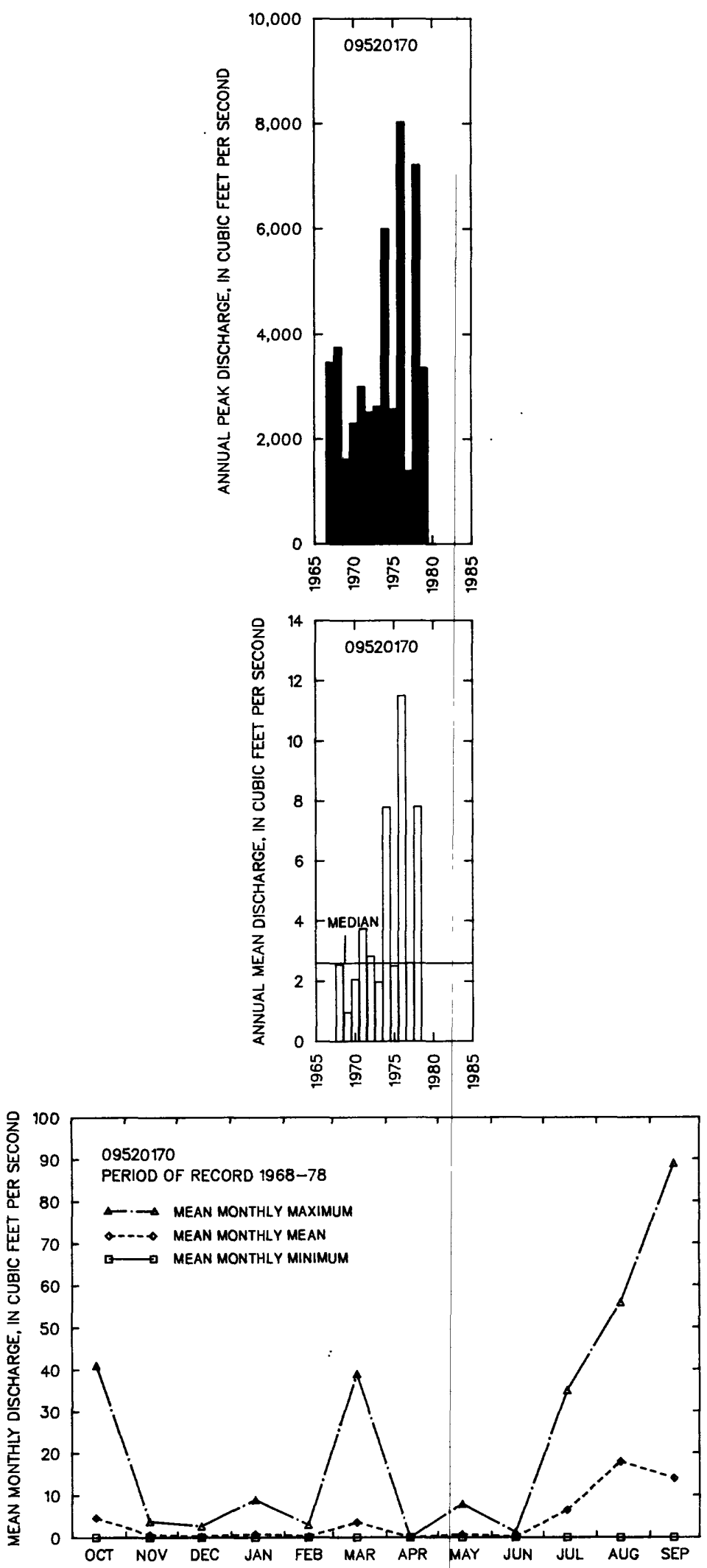
09520200 BLACK GAP WASH NEAR AJO, AZ

LOCATION.-- Lat 32.42'23", long 112.50'43", in MNkNE\% sec.26, T.8 S., R.6 W., Maricopa County, Hydrologic Unit 15070202, at State Highway $85,5.7 \mathrm{mi}$ north of Midway, and $23 \mathrm{mi}$ north of $A j o$.

DRAIMAGE AREA. $--12.1 \mathrm{mi}^{2}$.

ANNUAL PEAK DISCHARGE

\begin{tabular}{|c|c|c|c|}
\hline $\begin{array}{l}\text { WATER } \\
\text { YEAR }\end{array}$ & DATE & $\begin{array}{c}\text { ANNUAL PEAK } \\
\text { DISCHARGE } \\
\text { (FT } 3 / \mathrm{S})\end{array}$ & $\begin{array}{l}\text { DISCHARGE } \\
\text { COOES }\end{array}$ \\
\hline $\begin{array}{l}1962 \\
1963 \\
1964 \\
1965 \\
1966 \\
1967 \\
1968 \\
1969 \\
1970 \\
1971 \\
1972 \\
1973 \\
1974 \\
1975 \\
1976 \\
1977 \\
1978 \\
1979\end{array}$ & $\begin{array}{l}00-00-62 \\
08-06-63 \\
10-19-63 \\
08-00-65 \\
09-13-66 \\
07-14-67 \\
08-00-68 \\
08-14-69 \\
08-20-70 \\
09-30-71 \\
00-00-72 \\
00-00-73 \\
00-00-74 \\
09-08-75 \\
05-04-76 \\
09-11-77 \\
01-15-78 \\
07-20-79\end{array}$ & $\begin{array}{r}499 \\
280 \\
652 \\
770 \\
445 \\
837 \\
309 \\
525 \\
10 \\
735 \\
0 \\
0 \\
0 \\
200 \\
297 \\
578 \\
364 \\
940\end{array}$ & ES \\
\hline
\end{tabular}

MAGNITUDE AND PROBABILITY OF INSTANTANEOUS PEAK FLOW BASED ON PERIOD OF RECORD 1962-79

DISCHARGE, IN $\mathrm{FT}^{3} / \mathrm{S}$, FOR INDICATED RECURRENCE INTERVAL IN YEARS, AND EXCEEDANCE PROBABILITY, IN PERCENT

\begin{tabular}{|c|c|c|c|c|c|}
\hline$\stackrel{2}{20 x}$ & $\begin{array}{c}5 \\
20 \%\end{array}$ & $\begin{array}{r}10 \\
10 x\end{array}$ & $\begin{array}{l}25 \\
4 \%\end{array}$ & $\begin{array}{l}50 \dagger \\
2 \%\end{array}$ & $\begin{array}{c}100 \dagger \\
1 \%\end{array}$ \\
\hline 392 & 672 & 868 & 1,120 & 1,300 & 1,490 \\
\hline $\begin{array}{l}\text { VEIGHTED } \\
\text { MEAN } \\
\text { STANDARD }\end{array}$ & $\begin{array}{l}\text { SKEW } \\
\text { DEV. }\end{array}$ & $\begin{array}{l}(\operatorname{LOGS})= \\
(\operatorname{LOGS})= \\
(\operatorname{LOGS})=\end{array}$ & $\begin{array}{r}-0.43 \\
2.57 \\
0.30\end{array}$ & & \\
\hline
\end{tabular}

f Reliability of values in column is uncertain, and potential errors are large.

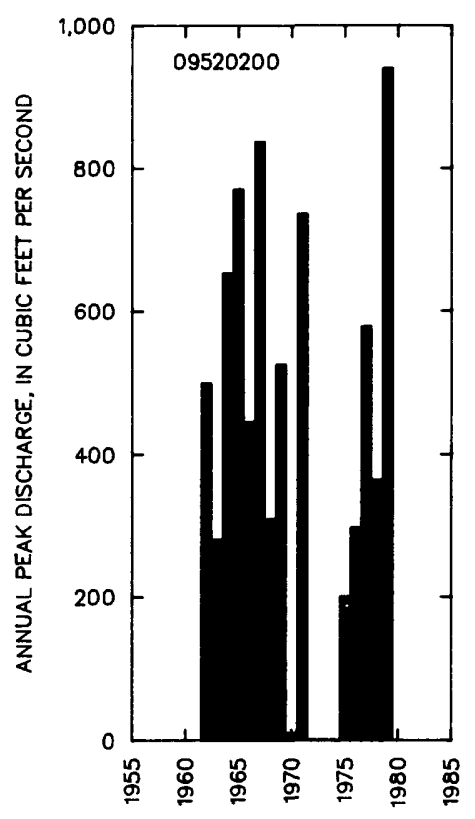

BASIN CHARACTERISTICS

\begin{tabular}{|c|c|c|c|c|c|c|c|}
\hline \multirow{2}{*}{$\begin{array}{c}\text { MAIN } \\
\text { CHANNEL } \\
\text { SLOPE } \\
\text { (FT/MI) }\end{array}$} & \multirow[b]{2}{*}{$\begin{array}{l}\text { STREAM } \\
\text { LENGTH } \\
\text { (MI) }\end{array}$} & \multirow{2}{*}{$\begin{array}{l}\text { MEAN } \\
\text { BASIN } \\
\text { ELEVA- } \\
\text { TION } \\
\text { (FT) }\end{array}$} & \multirow[b]{2}{*}{$\begin{array}{l}\text { FORESTED } \\
\text { AREA } \\
\text { (PERCENT) }\end{array}$} & \multirow{2}{*}{\multicolumn{2}{|c|}{$\begin{array}{l}\text { MEAN } \\
\text { ANNUAL } \\
\text { PRECIPI- } \\
\text { TATION } \\
\text { (IN) }\end{array}$}} & \multicolumn{2}{|c|}{ RAINFALL INTENSITY, 24-HOUR } \\
\hline & & & & & & $\begin{array}{c}\text { 2-YEAR } \\
\text { (IN) }\end{array}$ & $\begin{array}{l}\text { 50-YEAR } \\
\text { (IN) }\end{array}$ \\
\hline 21.8 & 5.5 & 1,280 & 0.0 & 2.0 & 6.7 & 1.5 & 3.9 \\
\hline
\end{tabular}




\section{CRATER RANGE mash MEAR AJO, AZ}

LOCATION.--Lat 32.33'44", Long 112'52'37", in NWANWK sec.15, T.10 S., R.6 H., Maricopa County, Hydrologic Unit 15070202, at State Highway 85, 4.1 mi north of Maricopa-Pima County line, and $13.5 \mathrm{mi}$ north of Ajo.

DRAINAGE AREA. $-1.49 \mathrm{mi}^{2}$.

\section{ANMUAL PEAK DISCHARGE}

\begin{tabular}{|c|c|c|c|}
\hline $\begin{array}{l}\text { WATER } \\
\text { YEAR }\end{array}$ & DATE & $\begin{array}{c}\text { ANNUAL PEAK } \\
\text { OISCHARGE } \\
\left(\mathrm{FT}^{3} / \mathrm{S}\right)\end{array}$ & $\begin{array}{l}\text { DISCHARGE } \\
\text { COOES }\end{array}$ \\
\hline $\begin{array}{l}1963 \\
1964 \\
1965 \\
1966 \\
1967 \\
1968 \\
1969 \\
1970 \\
1971 \\
1972 \\
1973 \\
1974 \\
1975 \\
1976 \\
1977 \\
1978 \\
1979\end{array}$ & $\begin{array}{l}08-06-63 \\
10-19-63 \\
02-06-65 \\
09-13-66 \\
07-15-67 \\
07-00-68 \\
09-04-69 \\
00-00-70 \\
09-00-71 \\
08-12-72 \\
02-22-73 \\
08-04-74 \\
10-00-74 \\
09-24-76 \\
11-15-76 \\
01-15-78 \\
02-20-79\end{array}$ & $\begin{array}{r}267 \\
303 \\
15 \\
50 \\
50 \\
350 \\
590 \\
0 \\
300 \\
20 \\
260 \\
12 \\
175 \\
440 \\
370 \\
65 \\
20\end{array}$ & $\begin{array}{l}\text { ES } \\
\text { ES } \\
\text { ES }\end{array}$ \\
\hline
\end{tabular}

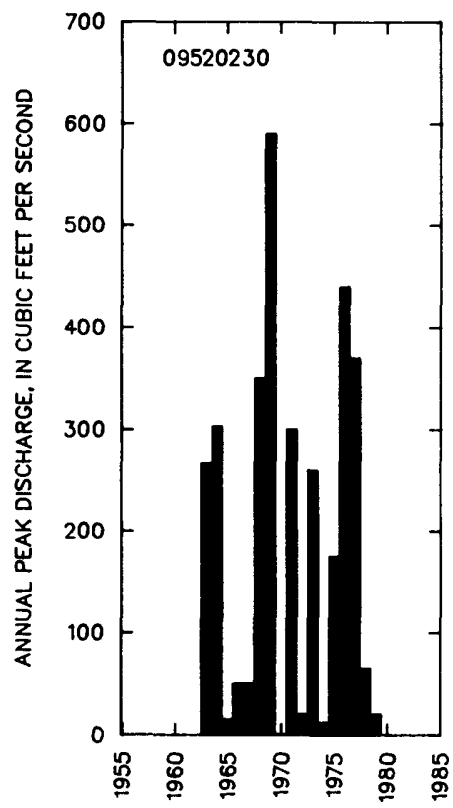

MAGNITUDE AND PROBABILITY OF INSTANTANEOUS PEAK FLOW BASED ON PERIOD OF RECORD 1963-79

DISCHARGE, IN $\mathrm{FT}^{3} / \mathrm{S}$, FOR INDICATED RECURRENCE INTERVAL IN YEARS, AND EXCEEDANCE PROBABILITY, IN PERCENT

\begin{tabular}{|c|c|c|c|c|c|}
\hline $\begin{array}{c}2 \\
50 \%\end{array}$ & $\begin{array}{c}5 \\
20 \%\end{array}$ & $\begin{array}{r}10 \\
10 \%\end{array}$ & $\begin{array}{l}25 \\
4 \%\end{array}$ & $\begin{array}{l}50 \phi \\
2 \%\end{array}$ & $\begin{array}{c}100 \nmid \\
1 \%\end{array}$ \\
\hline 102 & 329 & 587 & 1,060 & 1,540 & 2,130 \\
\hline $\begin{array}{l}\text { MEIGHTED } \\
\text { MEAN } \\
\text { STANDARD }\end{array}$ & $\begin{array}{l}\text { SKEH } \\
\text { DEV. }\end{array}$ & $\begin{array}{l}(\text { LOGS })= \\
(\text { LOGS })= \\
(\text { LOGS })=\end{array}$ & $\begin{array}{r}-0.25 \\
1.98 \\
0.63\end{array}$ & & \\
\hline
\end{tabular}

$\uparrow$ Reliability of values in column is uncertain, and potential errors are large.

\section{BASIN CHARACTERISTICS}

\begin{tabular}{|c|c|c|c|c|c|c|c|}
\hline MAIN & & $\begin{array}{l}\text { MEAN } \\
\text { BASIN }\end{array}$ & & & $\begin{array}{c}\text { MEAN } \\
\text { ANNUAL }\end{array}$ & RAINFALL II & SITY, 24-HOUR \\
\hline $\begin{array}{l}\text { CHANNEL } \\
\text { SLOPE } \\
\text { (FT/MI) }\end{array}$ & $\begin{array}{c}\text { STREAM } \\
\text { LENGTH } \\
\text { (MI) }\end{array}$ & $\begin{array}{l}\text { ELEVA- } \\
\text { TION } \\
\text { (FT) }\end{array}$ & $\begin{array}{l}\text { FORESTED } \\
\text { AREA } \\
\text { (PERCENT) }\end{array}$ & $\begin{array}{l}\text { SOIL } \\
\text { INDEX }\end{array}$ & $\begin{array}{l}\text { PRECIPI - } \\
\text { TATION } \\
\text { (IN) }\end{array}$ & $\begin{array}{c}\text { 2-YEAR } \\
\text { (IN) }\end{array}$ & $\begin{array}{l}\text { 50-YEAR } \\
\text { (IN) }\end{array}$ \\
\hline 69.3 & 2.5 & 1,280 & 0.0 & 1.0 & 6.6 & 1.5 & 3.9 \\
\hline
\end{tabular}


09520300 aLANO HASH TRIBUTARY MEAR AJO, AZ

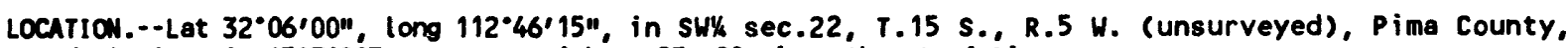
Hydrologic Unit 15070203, at State Highway 85, 20 mi southeast of Ajo.

DRAIMAGE AREA. $--0.90 \mathrm{mi}^{2}$.

ANNUAL PEAK DISCHARGE

\begin{tabular}{|c|c|c|c|c|c|c|c|}
\hline $\begin{array}{l}\text { WATER } \\
\text { YEAR }\end{array}$ & DATE & $\begin{array}{c}\text { ANNUAL PEAK } \\
\text { DISCHARGE } \\
\text { (FT } 3 / S)\end{array}$ & $\begin{array}{l}\text { DISCHARGE } \\
\text { CODES }\end{array}$ & $\begin{array}{l}\text { WATER } \\
\text { YEAR }\end{array}$ & DATE & $\begin{array}{c}\text { ANMUAL PEAK } \\
\text { DISCHARGE } \\
\left(F^{3} / S\right)\end{array}$ & $\begin{array}{l}\text { DISCHARGE } \\
\text { CODES }\end{array}$ \\
\hline $\begin{array}{l}1963 \\
1964 \\
1965 \\
1966 \\
1967 \\
1968 \\
1969 \\
1970 \\
1971 \\
1972 \\
1973 \\
1974 \\
1975\end{array}$ & $\begin{array}{l}08-15-63 \\
09-09-64 \\
10-16-64 \\
00-00-66 \\
08-00-67 \\
08-02-68 \\
08-14-69 \\
08-02-70 \\
00-00-71 \\
08-31-72 \\
08-00-73 \\
00-00-74 \\
09-08-75\end{array}$ & $\begin{array}{c}375 \\
187 \\
74 \\
261 \\
103 \\
74 \\
370 \\
210 \\
5.0 \\
510 \\
150 \\
0 \\
380\end{array}$ & ES & $\begin{array}{l}1976 \\
1978 \\
1979 \\
1980 \\
1982 \\
1983 \\
1984 \\
1985 \\
1986 \\
1987 \\
1988 \\
1989\end{array}$ & $\begin{array}{l}09-25-76 \\
10-06-77 \\
00-00-79 \\
00-00-80 \\
10-01-81 \\
07-21-83 \\
08-00-84 \\
00-00-85 \\
07-21-86 \\
09-23-87 \\
00-00-88 \\
10-14-88\end{array}$ & $\begin{array}{r}230 \\
1135 \\
92 \\
92 \\
104 \\
98 \\
250 \\
0 \\
0 \\
210 \\
240 \\
0 \\
125\end{array}$ & \\
\hline
\end{tabular}

Highest since 1976 .

MAGNITUDE AND PROBABILITY OF INSTANTANEOUS PEAK FLOW BASED ON PERICO OF RECORD 1963-76, 1978-80, 1982-89

DISCHARGE, IN $\mathrm{FT}^{3} / \mathrm{S}$, FOR INDICATED RECURRENCE INTERVAL IN YEARS, AND EXCEEDANCE PROBABILITY, IN PERCENT

\begin{tabular}{|c|c|c|c|c|c|}
\hline $\begin{array}{c}2 \\
50 \%\end{array}$ & $\begin{array}{c}5 \\
20 x\end{array}$ & $\begin{array}{r}10 \\
10 \%\end{array}$ & $\begin{array}{l}25 \\
4 \%\end{array}$ & $\begin{array}{l}50 \\
2 x\end{array}$ & $\begin{array}{c}100 \dagger \\
1 \%\end{array}$ \\
\hline 147 & 260 & 350 & 481 & 590 & 710 \\
\hline $\begin{array}{l}\text { MEIGH } \\
\text { STANDARD }\end{array}$ & $\begin{array}{l}\text { SKEW } \\
\text { DEV. }\end{array}$ & $\begin{array}{l}(\text { LOGS })= \\
(\text { LOGS })= \\
(\text { LOGS })=\end{array}$ & $\begin{array}{l}0.00 \\
2.17 \\
0.29\end{array}$ & & \\
\hline
\end{tabular}

$\uparrow$ Reliability of values in colum is uncertain, and potential errors are large.

BASIN CHARACTERISTICS

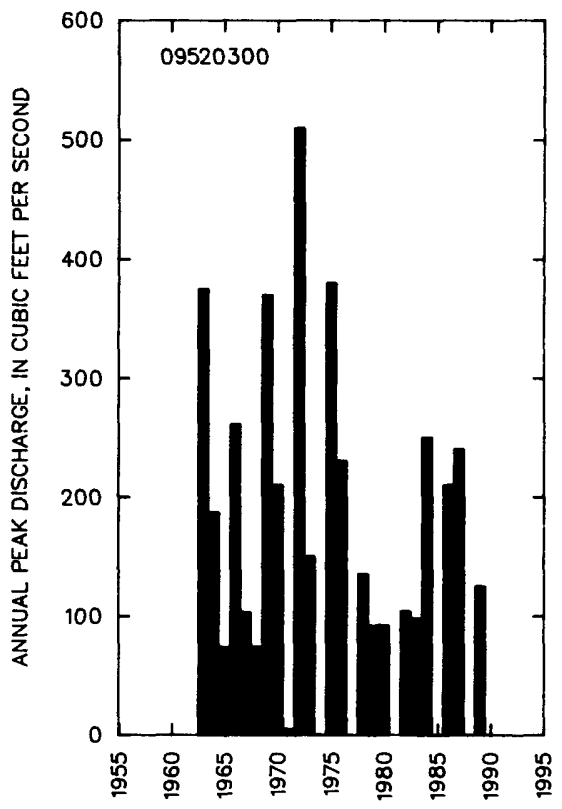

\begin{tabular}{|c|c|c|c|c|c|c|c|}
\hline \multirow{2}{*}{$\begin{array}{l}\text { MAIN } \\
\text { CHANNEL } \\
\text { SLOPE } \\
\text { (FT/MI) }\end{array}$} & \multirow[b]{2}{*}{$\begin{array}{c}\text { STREAM } \\
\text { LENGTH } \\
\text { (MI) }\end{array}$} & \multirow{2}{*}{$\begin{array}{l}\text { MEAN } \\
\text { BASIN } \\
\text { ELEVA- } \\
\text { TION } \\
\text { (FT) }\end{array}$} & \multirow[b]{2}{*}{$\begin{array}{l}\text { FORESTED } \\
\text { AREA } \\
\text { (PERCENT) }\end{array}$} & \multirow[b]{2}{*}{$\begin{array}{l}\text { SOIL } \\
\text { INDEX }\end{array}$} & \multirow{2}{*}{$\begin{array}{l}\text { MEAN } \\
\text { ANNUAL } \\
\text { PRECIPI- } \\
\text { TATION } \\
\text { (IN) }\end{array}$} & \multicolumn{2}{|c|}{ RAINFALL INTENSITY, 24-HOUR } \\
\hline & & & & & & $\begin{array}{c}\text { 2-YEAR } \\
\text { (IN) }\end{array}$ & $\begin{array}{c}\text { 50-YEAR } \\
\text { (IN) }\end{array}$ \\
\hline 64.0 & 2.5 & 2,040 & 0.0 & 2.0 & 9.7 & 1.7 & 4.2 \\
\hline
\end{tabular}




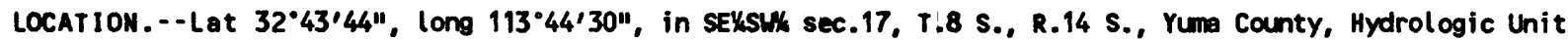
15070203, at Southern Pacific Railroad crossing, 0.6 mi east of Mohank.

DRAINAGE AREA. $--0.09 \mathrm{mi}^{2}$.

ANIUAL PEAK DISCHARGE

\begin{tabular}{cccc}
$\begin{array}{c}\text { WATER } \\
\text { YEAR }\end{array}$ & DATE & $\begin{array}{c}\text { ANMUAL PEAK } \\
\text { DISCHARGE } \\
\text { (FT } 3 / \text { S) }\end{array}$ & $\begin{array}{c}\text { DISCHARGE } \\
\text { CODES }\end{array}$ \\
\hline 1963 & $00-00-63$ & 0 & \\
1964 & $10-17-63$ & 17 & \\
1965 & $04-04-65$ & 34 & \\
1966 & $02-07-66$ & 4 & \\
1967 & $09-02-67$ & 14 & \\
1968 & $00-00-68$ & 58 & \\
1969 & $09-05-69$ & 26 & \\
1970 & $08-01-70$ & 117 & \\
1971 & $09-29-71$ & 20 & \\
1972 & $00-00-72$ & 0 & \\
1973 & $10-06-72$ & 82 & \\
1974 & $07-00-74$ & 1.0 & LT \\
1975 & $09-00-75$ & 10 & LT \\
1976 & $09-25-76$ & 95 & HP \\
1980 & $00-00-80$ & 118 & \\
\hline$\ldots$ & 050 &
\end{tabular}

Highest since 1976.

MAGNI TUDE AND PROBABILITY OF INSTANTANEQUS PEAK FLOW BASED ON PERICD OF RECORD 1963-76, 1980

DISCHARGE, IN $\mathrm{FT}^{3} / \mathrm{s}$, FOR INDICATED RECURRENCE INTERVAL IN YEARS, AND EXCEEDANCE PROBABILITY, IN PERCENT

\begin{tabular}{|c|c|c|c|c|c|}
\hline $\begin{array}{c}2 \\
50 \%\end{array}$ & $\begin{array}{c}5 \\
20 \%\end{array}$ & $\begin{array}{r}10 \\
10 \%\end{array}$ & $\begin{array}{l}25 \\
4 \%\end{array}$ & $\begin{array}{l}50 \nmid \\
2 \%\end{array}$ & $\begin{array}{c}100 \\
1 \%\end{array}$ \\
\hline 20.2 & 52.4 & 85.7 & 145 & 202 & 273 \\
\hline $\begin{array}{l}\text { WEIGHTED } \\
\text { MEAN } \\
\text { STANDARD }\end{array}$ & $\begin{array}{l}\text { SKEW } \\
\text { DEV. }\end{array}$ & $\begin{array}{l}(\text { LOGS })= \\
(\text { LOGS })= \\
(\text { LOGS })=\end{array}$ & $\begin{array}{r}-0.04 \\
1.30 \\
0.50\end{array}$ & & \\
\hline
\end{tabular}

t Reliability of values in colum is uncertain, and potential errors are large.

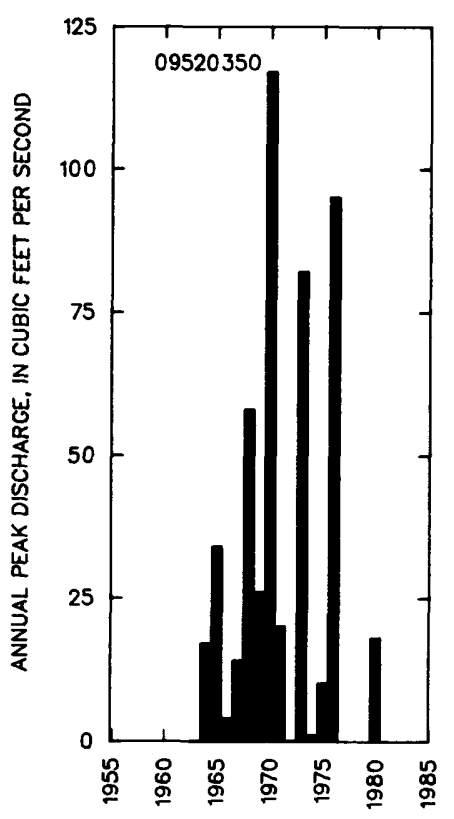

\section{BASIN CHARACTERISTICS}

\begin{tabular}{|c|c|c|c|c|c|c|c|}
\hline MIN & & $\begin{array}{l}\text { MEAN } \\
\text { BASIN }\end{array}$ & & & $\begin{array}{c}\text { MEAN } \\
\text { ANNUAL }\end{array}$ & RAINFALL II & SITY, 24-HOUR \\
\hline $\begin{array}{l}\text { CHANNEL } \\
\text { SLOPE } \\
\text { (FT/MI) }\end{array}$ & $\begin{array}{l}\text { STREAM } \\
\text { LENGTH } \\
\text { (MI) }\end{array}$ & $\begin{array}{l}\text { ELEVA- } \\
\text { TION } \\
\text { (FT) }\end{array}$ & $\begin{array}{l}\text { FORESTED } \\
\text { AREA } \\
\text { (PERCENT) }\end{array}$ & $\begin{array}{l}\text { SOIL } \\
\text { INDEX }\end{array}$ & $\begin{array}{l}\text { PRECIPI - } \\
\text { TATION } \\
\text { (IN) }\end{array}$ & $\begin{array}{c}\text { 2-YEAR } \\
\text { (IN) }\end{array}$ & $\begin{array}{l}\text { 50-YEAR } \\
\text { (IN) }\end{array}$ \\
\hline 707 & 0.49 & 601 & 0.0 & 1.0 & 4.9 & 1.4 & 3.6 \\
\hline
\end{tabular}


09520400 LIGURTA MASH AT LIGURTA, AZ

LOCATION.-- Lat 32.40'33", Long 114'17'38", in MHAwWh sec.2, T.9 S., R.20 H., Yuma County, Hydrologic Unit 15070201, at U.S. Highway 80 at Ligurta, and $9.0 \mathrm{mi}$ west of Well ton.

DRAIMAGE AREA. $--1.99 \mathrm{mi}^{2}$.

\section{ANNUAL PEAK DISCHARGE}

\begin{tabular}{|c|c|c|c|}
\hline $\begin{array}{l}\text { WATER } \\
\text { YEAR }\end{array}$ & DATE & $\begin{array}{l}\text { ANNUAL PEAK } \\
\text { DISCHARGE } \\
\text { (FT } 3 / S)\end{array}$ & $\begin{array}{c}\text { DISCHARGE } \\
\text { COOES }\end{array}$ \\
\hline $\begin{array}{l}1963 \\
1964 \\
1965 \\
1966 \\
1967 \\
1968 \\
1969 \\
1970 \\
1971 \\
1972 \\
1973 \\
1974 \\
1975 \\
1976 \\
1980\end{array}$ & $\begin{array}{l}09-17-63 \\
08-01-64 \\
02-06-65 \\
11-16-65 \\
09-02-67 \\
07-27-68 \\
08-13-69 \\
02-10-70 \\
09-29-71 \\
00-00-72 \\
08-05-73 \\
09-03-74 \\
00-00-75 \\
09-25-76 \\
00-00-80\end{array}$ & $\begin{array}{c}1,590 \\
2.0 \\
195 \\
8.0 \\
194 \\
1,330 \\
58 \\
175 \\
156 \\
0 \\
330 \\
190 \\
0 \\
430 \\
1780\end{array}$ & ES \\
\hline
\end{tabular}

Highest since 1976.

MAGNITUDE AND PROBABILITY OF INSTANTANEOUS PEAK FLOW BASED ON PERICD OF RECORD 1963-76, 1980

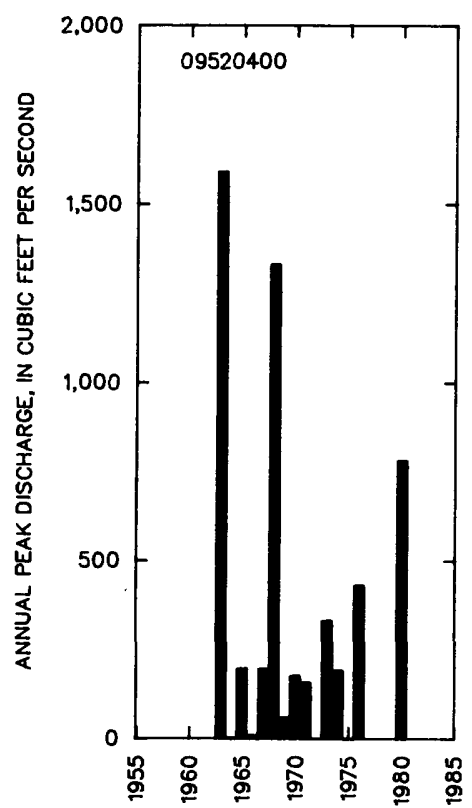

DISCHARGE, IN $\mathrm{FT}^{3} / \mathrm{S}$, FOR INDICATED RECURRENCE INTERVAL IN YEARS, AND EXCEEDANCE PROBABILITY, IN PERCENT

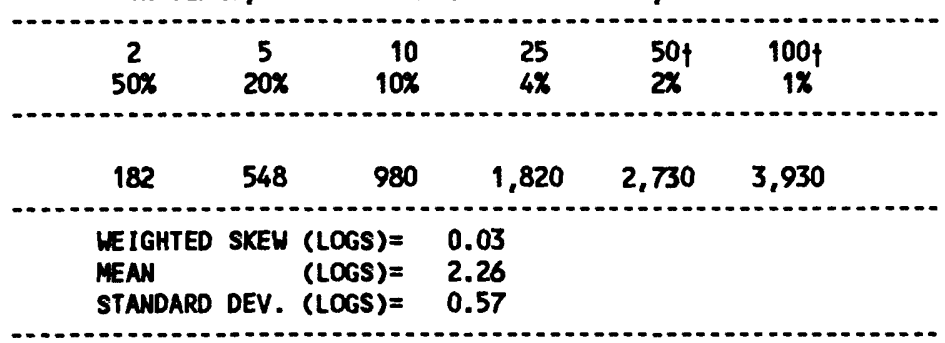

$\uparrow$ Reliability of values in colum is uncertain, and potential errors are large.

BASIN CHARACTERISTICS

\begin{tabular}{|c|c|c|c|c|c|c|c|}
\hline \multirow{2}{*}{$\begin{array}{l}\text { MAIN } \\
\text { CHANNEL } \\
\text { SLOPE } \\
\text { (FT/MI) }\end{array}$} & \multirow[b]{2}{*}{$\begin{array}{l}\text { STREAM } \\
\text { LENGTH } \\
\text { (MI) }\end{array}$} & \multirow{2}{*}{$\begin{array}{l}\text { MEAN } \\
\text { BASIN } \\
\text { ELEVA- } \\
\text { TION } \\
\text { (FT) }\end{array}$} & \multirow[b]{2}{*}{$\begin{array}{l}\text { FORESTED } \\
\text { AREA } \\
\text { (PERCENT) }\end{array}$} & \multirow[b]{2}{*}{$\begin{array}{l}\text { SOIL } \\
\text { INDEX }\end{array}$} & \multirow{2}{*}{$\begin{array}{l}\text { MEAN } \\
\text { ANNUAL } \\
\text { PRECIPI- } \\
\text { TATION } \\
\text { (IN) }\end{array}$} & \multicolumn{2}{|c|}{ RAINFALL INTENSITY, 24-HOUR } \\
\hline & & & & & & $\begin{array}{c}\text { 2-YEAR } \\
\text { (IN) }\end{array}$ & $\begin{array}{l}\text { 50-YEAR } \\
\text { (IN) }\end{array}$ \\
\hline 127 & 2.0 & 395 & 0.0 & 2.0 & 4.0 & 1.4 & 3.6 \\
\hline
\end{tabular}


SAN SIMON WASH BASIN

09535100 SAN SIMON MASH MEAR PISINIMO, AZ

LOCATION.--Lat 32'02'39", long 112'22'13", in SEK sec.9, T.16 S., R.1 W. (unsurveyed), Pima County, Hydrologic Unit 15080101, in Papago Indian Reservation, on the right bank about $100 \mathrm{ft}$ downstream from road, just upstream from Gu Vo Wash, and 3.2 mi west of Pisinimo.

DRAIMAGE AREA. $--569 \mathrm{mi}^{2}$.

\begin{tabular}{|c|c|c|}
\hline $\begin{array}{l}\text { WATER } \\
\text { YEAR }\end{array}$ & DATE & $\begin{array}{c}\text { ANWUAL PEAK } \\
\text { DISCHARGE } \\
\left(F T^{3} / S\right)\end{array}$ \\
\hline $\begin{array}{l}1972 \\
1973 \\
1974 \\
1975 \\
1976 \\
1977 \\
1978 \\
1979 \\
1980 \\
1981 \\
1982 \\
1983 \\
1984 \\
1985 \\
1986 \\
1987 \\
1988 \\
1989\end{array}$ & $\begin{array}{l}08-09-72 \\
10-19-72 \\
07-29-74 \\
09-07-75 \\
09-24-76 \\
08-08-77 \\
09-07-78 \\
11-11-78 \\
08-13-80 \\
07-12-81 \\
08-25-82 \\
09-29-83 \\
08-17-84 \\
07-19-85 \\
07-21-86 \\
08-11-87 \\
08-29-88 \\
10-15-88\end{array}$ & $\begin{array}{r}1,080 \\
1,930 \\
1,370 \\
1,950 \\
12,500 \\
720 \\
473 \\
512 \\
101 \\
2,020 \\
1,780 \\
8,688 \\
8,600 \\
790 \\
943 \\
1,740 \\
1,420\end{array}$ \\
\hline
\end{tabular}

BASIN CHARACTERISTICS

\begin{tabular}{|c|c|c|c|c|c|c|c|}
\hline MAIN & & $\begin{array}{l}\text { MEAN } \\
\text { BASIN }\end{array}$ & & & $\begin{array}{l}\text { MEAN } \\
\text { ANBLLAL }\end{array}$ & RAIMFALL II & SITY, 24-HOUR \\
\hline $\begin{array}{l}\text { CHANNEL } \\
\text { SLOPE } \\
\text { (FT/MI) }\end{array}$ & $\begin{array}{l}\text { STREAM } \\
\text { LENGTH } \\
\text { (MI) }\end{array}$ & $\begin{array}{l}\text { ELEVA- } \\
\text { TION } \\
\text { (FT) }\end{array}$ & $\begin{array}{l}\text { FORESTED } \\
\text { AREA } \\
\text { (PERCENT) }\end{array}$ & $\begin{array}{l}\text { SOIL } \\
\text { INDEX }\end{array}$ & $\begin{array}{l}\text { PRECIPI- } \\
\text { TATION } \\
\text { (IN) }\end{array}$ & $\begin{array}{c}\text { 2-YEAR } \\
\text { (IN) }\end{array}$ & $\begin{array}{l}\text { 50-YEAR } \\
\text { (IN) }\end{array}$ \\
\hline 17.4 & 39.4 & 2,250 & 0.0 & 0.0 & 10.0 & 1.8 & 4.2 \\
\hline
\end{tabular}


SAN SIMON WASH BASIN

09535100 SAN SIMON WASH MEAR PISINIMO, AZ--Continued.

MEAN MONTHLY AND ANNUAL DISCHARGES $1973-89$

\begin{tabular}{|c|c|c|c|c|c|c|}
\hline MONTH & $\begin{array}{l}\operatorname{MAXIMMM} \\
\left(F^{3} / S\right)\end{array}$ & $\begin{array}{l}\operatorname{MINIMMM} \\
\left(F T^{3} / S\right)\end{array}$ & $\begin{array}{c}\text { MEAN } \\
\left(F T^{3} / S\right)\end{array}$ & $\begin{array}{l}\text { STAN- } \\
\text { DARD } \\
\text { DEVIA- } \\
\text { TION } \\
\text { (FT } 3 / S)\end{array}$ & $\begin{array}{l}\text { COEFFI - } \\
\text { CIENT OF } \\
\text { VARI - } \\
\text { ATION }\end{array}$ & $\begin{array}{c}\text { PERCENT } \\
\text { OF } \\
\text { ANMUAL } \\
\text { RUNOFF }\end{array}$ \\
\hline $\begin{array}{l}\text { OCTOBER } \\
\text { MOVEMBER } \\
\text { DECEMBER } \\
\text { JANUARY } \\
\text { FEBRUARY } \\
\text { MARCH } \\
\text { APRIL } \\
\text { MAY } \\
\text { JUNE } \\
\text { JULY } \\
\text { AUGUST } \\
\text { SEPTEMBER }\end{array}$ & $\begin{array}{c}44 \\
14 \\
9.0 \\
8.0 \\
6.6 \\
8.5 \\
0.20 \\
2.0 \\
0.02 \\
40 \\
93 \\
140\end{array}$ & $\begin{array}{l}0.00 \\
0.00 \\
0.00 \\
0.00 \\
0.00 \\
0.00 \\
0.00 \\
0.00 \\
0.00 \\
0.00 \\
0.01 \\
0.00\end{array}$ & $\begin{array}{l}7.3 \\
1.9 \\
0.76 \\
1.3 \\
0.83 \\
1.2 \\
0.02 \\
0.12 \\
0.00 \\
8.8 \\
14 \\
12\end{array}$ & $\begin{array}{c}14 \\
4.0 \\
2.2 \\
2.4 \\
2.1 \\
2.7 \\
0.05 \\
0.48 \\
0.00 \\
10 \\
26 \\
33\end{array}$ & $\begin{array}{l}2.0 \\
2.1 \\
2.8 \\
1.8 \\
2.5 \\
2.3 \\
2.9 \\
4.1 \\
4.1 \\
1.1 \\
1.9 \\
2.8\end{array}$ & $\begin{array}{r}15.2 \\
4.0 \\
1.6 \\
2.7 \\
1.7 \\
2.5 \\
0.0 \\
0.2 \\
0.0 \\
18.3 \\
29.0 \\
24.8\end{array}$ \\
\hline ANNUAL & 15 & 0.13 & 4.0 & 4.1 & 1.0 & 100 \\
\hline
\end{tabular}

MAGNITUDE AND PROBABILITY OF INSTANTAMEOUS PEAK FLOW BASED ON PERIOD OF RECORD 1972-89

DISCHARGE, IN $\mathrm{FT}^{3} / \mathrm{S}$, FOR INDICATED RECURRENCE INTERVAL IN YEARS, AND EXCEEDANCE PROBABILITY, IN PERCENT

\begin{tabular}{lccccc}
2 & 5 & 10 & 25 & $50\}$ & $100 \nmid$ \\
$50 \%$ & $20 \%$ & $10 \%$ & $4 \%$ & $2 \%$ & $1 \%$ \\
1,220 & 2,770 & 4,430 & 7,540 & 10,800 & 15,200 \\
\hline MEIGHTED SKEW (LOGS) & $=0.46$ & & \\
MEAN & (LOGS) & 3.12 \\
STANDARD DEV. (LOGS) & $=0.40$
\end{tabular}

MAGNITUDE AMD PROBABILITY OF AMMUAL LON FLON BASED ON PERIOD OF RECORD 1973-89

\begin{tabular}{|c|c|c|c|c|c|c|}
\hline \multirow{2}{*}{$\begin{array}{l}\text { PERIOD } \\
\text { (CON- } \\
\text { SECU- } \\
\text { TIVE } \\
\text { DAYS) }\end{array}$} & \multicolumn{6}{|c|}{$\begin{array}{l}\text { DISCHARGE, IN FT } 3 / S \text {, FOR INDICATED } \\
\text { RECURRENCE INTERVAL, IN YEARS, AND } \\
\text { MON-EXCEEDANCE PROBABILITY, IN PERCENT }\end{array}$} \\
\hline & $\begin{array}{c}2 \\
50 \%\end{array}$ & $\begin{array}{c}5 \\
20 \%\end{array}$ & $\begin{array}{l}10 \\
10 \%\end{array}$ & $\begin{array}{l}20 \\
5 \%\end{array}$ & $\begin{array}{l}50 \nmid \\
2 \%\end{array}$ & $\begin{array}{l}100 \dagger \\
1 \%\end{array}$ \\
\hline $\begin{array}{r}1 \\
3 \\
7 \\
14 \\
30 \\
60\end{array}$ & & & & & & \\
\hline $\begin{array}{r}90 \\
120 \\
183\end{array}$ & $\begin{array}{l}0.00 \\
0.00 \\
0.00\end{array}$ & $\begin{array}{l}0.00 \\
0.00 \\
0.00\end{array}$ & $\begin{array}{l}0.00 \\
0.00 \\
0.00\end{array}$ & $\begin{array}{l}0.00 \\
0.00 \\
0.00\end{array}$ & $\begin{array}{l}0.00 \\
0.00 \\
0.00\end{array}$ & $\begin{array}{l}0.00 \\
0.00 \\
0.00\end{array}$ \\
\hline
\end{tabular}

MAGNITUDE AND PROBABILITY OF ANNUAL HIGH FLOW BASED ON PERIOD OF RECORD 1973-89

\begin{tabular}{|c|c|c|c|c|c|c|}
\hline \multirow{2}{*}{$\begin{array}{l}\text { PERIOD } \\
\text { (CON- } \\
\text { SECU- } \\
\text { TIVE } \\
\text { DAYS) }\end{array}$} & \multicolumn{6}{|c|}{$\begin{array}{l}\text { DISCHARGE, IN FT } 3 / S \text {, FOR INDICATED } \\
\text { RECURRENCE INTERVAL, IN YEARS, AND } \\
\text { EXCEEDANCE PROBABILITY, IN PERCENT }\end{array}$} \\
\hline & $\begin{array}{c}2 \\
50 x\end{array}$ & $\begin{array}{c}5 \\
20 \%\end{array}$ & $\begin{array}{l}10 \\
10 \%\end{array}$ & $\begin{array}{l}25 \\
4 \%\end{array}$ & $\begin{array}{l}50 \nmid \\
2 \%\end{array}$ & $\begin{array}{c}100 \nmid \\
1 \%\end{array}$ \\
\hline $\begin{array}{r}1 \\
3 \\
7 \\
15 \\
30 \\
60 \\
90\end{array}$ & $\begin{array}{r}375 \\
163 \\
75 \\
38 \\
22 \\
14 \\
10\end{array}$ & $\begin{array}{r}938 \\
414 \\
188 \\
93 \\
51 \\
31 \\
22\end{array}$ & $\begin{array}{r}1,490 \\
655 \\
293 \\
141 \\
73 \\
43 \\
30\end{array}$ & $\begin{array}{r}2,420 \\
1,050 \\
458 \\
212 \\
101 \\
57 \\
38\end{array}$ & $\begin{array}{r}3,290 \\
1,400 \\
602 \\
270 \\
122 \\
67 \\
43\end{array}$ & $\begin{array}{r}4,320 \\
1,800 \\
763 \\
331 \\
141 \\
76 \\
48\end{array}$ \\
\hline
\end{tabular}

DURATION TABLE OF DAILY MEAN FLON FOR PERIOD OF RECORD 1973-89

DISCHARGE, IN FT $3 / \mathrm{S}$, WHICH WAS EQUALED OR EXCEEDED FOR INDICATED PERCENT OF TIME

\begin{tabular}{|c|c|c|c|c|c|c|c|c|c|c|c|c|c|c|c|c|}
\hline $1 \%$ & $5 \%$ & $10 x$ & $15 \%$ & $20 \%$ & $30 \%$ & $40 \%$ & $50 \%$ & $60 \%$ & $70 \%$ & $80 \%$ & $90 \%$ & $95 \%$ & $98 \%$ & $99 \%$ & $99.5 \%$ & $99.9 \%$ \\
\hline 85 & 1.1 & 0.00 & 0.00 & 0.00 & 0.00 & 0.00 & 0.00 & 0.00 & 0.00 & 0.00 & 0.00 & 0.00 & 0.00 & 0.00 & 0.00 & .00 \\
\hline
\end{tabular}

† Reliability of values in column is uncertain, and potential errors are large. 
09535100 SAN SIMON WASH NEAR PISINIMO, AZ--CONTINUED
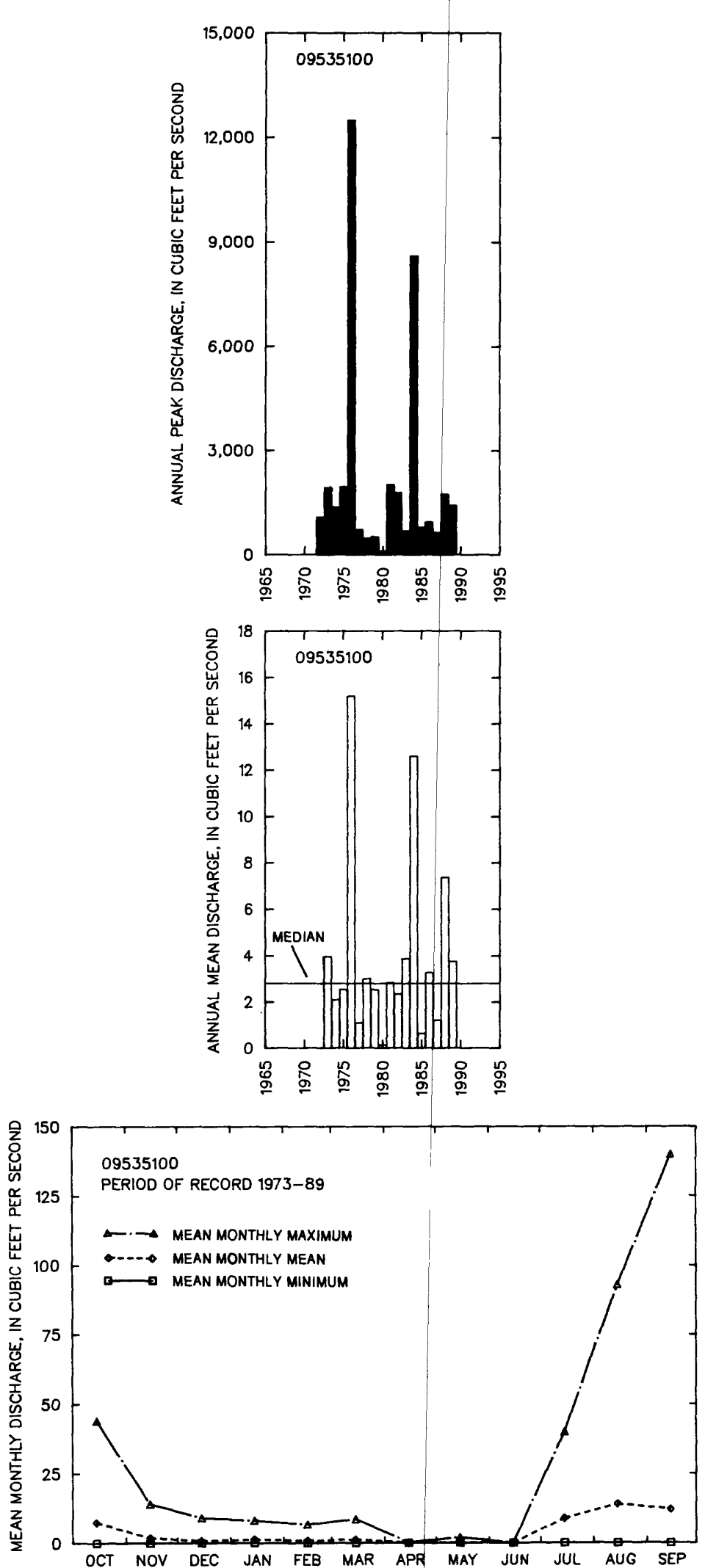
09535200 LITTLE TUCSON WASH AT SELLS, AZ

LOCATION.-- Lat 31'54'55", long 111'52'42", in SEX sec.25, T.17 S., R.4 E., Pima County, Hydrologic Unit 15080101, at Sells.

DRAINAGE AREA. $--26.8 \mathrm{mi}^{2}$ contributing drainage area not determined.

ANMUAL PEAK DISCHARGE

\begin{tabular}{ccc}
$\begin{array}{c}\text { WATER } \\
\text { YEAR }\end{array}$ & DATE & $\begin{array}{c}\text { ANMUAL PEAK } \\
\text { DISCHARGE } \\
\text { (FT } 3 / \text { S) }\end{array}$ \\
\hline 1962 & $09-26-62$ & 2,740 \\
1963 & $00-00-63$ & 1,770 \\
1964 & $07-29-64$ & 2,210 \\
1965 & $08-11-65$ & 1,130 \\
1966 & $09-13-66$ & 2,800 \\
1967 & $08-07-67$ & 1,690 \\
1968 & $12-19-67$ & 770 \\
1969 & $07-22-69$ & 2,510 \\
1970 & $09-06-70$ & 1,520 \\
1971 & $08-19-71$ & 2,080 \\
1972 & $08-00-72$ & 220 \\
1973 & $10-18-72$ & 2,760 \\
1974 & $09-22-74$ & 1,500 \\
1975 & $09-05-75$ & 2,040 \\
1976 & $00-00-76$ & 790 \\
$\ldots \ldots \ldots$ & $\ldots$
\end{tabular}

MAGNITUDE AND PROBABILITY OF INSTANTANEOUS PEAK FLOW BASED ON PERIOD OF RECORD

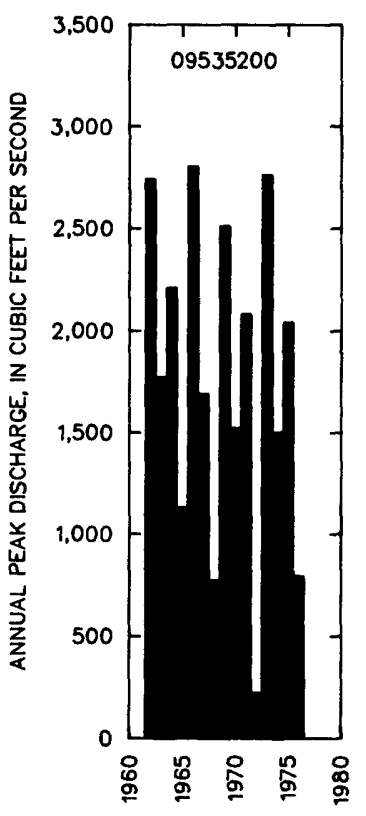

DISCHARGE, IN $\mathrm{FT}^{3} / \mathrm{S}$, FOR INDICATED RECURRENCE INTERYAL

IN YEARS, AND EXCEEDANCE PROBABILITY, IN PERCENT

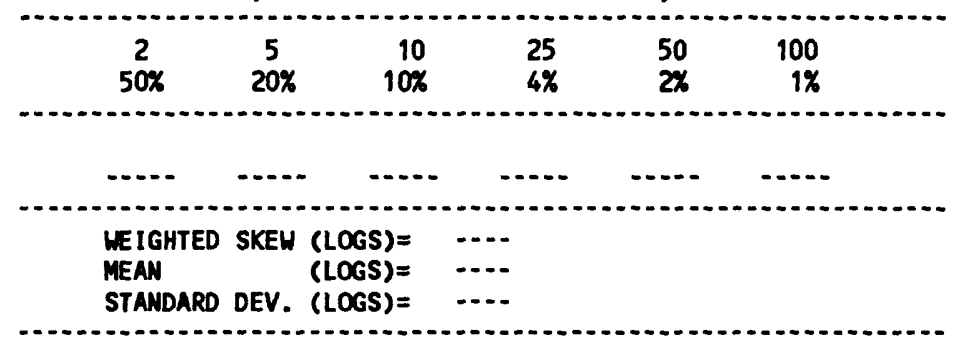

BASIN CHARACTERISTICS

\begin{tabular}{|c|c|c|c|c|c|c|c|}
\hline MAIN & & $\begin{array}{l}\text { MEAN } \\
\text { BASIN }\end{array}$ & & & $\begin{array}{c}\text { MEAN } \\
\text { ANNUAL }\end{array}$ & RAINFALL II & SITY, 24-HOUR \\
\hline $\begin{array}{l}\text { CHANNEL } \\
\text { SLOPE } \\
\text { (FT/MI) }\end{array}$ & $\begin{array}{l}\text { STREAM } \\
\text { LENGTH } \\
\text { (MI) }\end{array}$ & $\begin{array}{l}\text { ELEVA- } \\
\text { TION } \\
\text { (FT) }\end{array}$ & $\begin{array}{l}\text { FORESTED } \\
\text { AREA } \\
\text { (PERCENT) }\end{array}$ & $\begin{array}{l}\text { SOIL } \\
\text { INDEX }\end{array}$ & $\begin{array}{l}\text { PRECIPI - } \\
\text { TATION } \\
\text { (IN) }\end{array}$ & $\begin{array}{c}\text { 2-YEAR } \\
\text { (IN) }\end{array}$ & $\begin{array}{l}\text { 50-YEAR } \\
\text { (IN) }\end{array}$ \\
\hline 49.9 & 10.2 & 2,560 & 0.0 & 3.0 & 11.8 & 2.1 & 4.6 \\
\hline
\end{tabular}


SAN SIMON MASH BASIN

09535300 VAMORL WASH AT KOA VO, AZ

LOCATION.--Lat 31'57'04", long 112"20'50", in NW/2 sec.14, T.17 S., R.1 W (unsurveyed), Pima County, Hydrologic Unit 15080101, in Papago Indian Reservation, on right benk 200 ft downstream from road crossing, 0.6 mi south of Kom Vo (Santa Cruz village) and 5 mi upstream from mouth.

DRAinAGE AREA. $-1,250 \mathrm{mi}^{2}$, approximately, of which about $250 \mathrm{mi}^{2}$ is in Mexico.

ANNCAL PEAK DISCHARCE

\begin{tabular}{|c|c|c|}
\hline $\begin{array}{l}\text { WATER } \\
\text { YEAR }\end{array}$ & DATE & $\begin{array}{c}\text { ANNLAL PEAK } \\
\text { DISCHARGE } \\
\left(F^{3} / \mathrm{S}\right)\end{array}$ \\
\hline $\begin{array}{l}1972 \\
1973 \\
1974 \\
1975 \\
1976 \\
1977 \\
1978 \\
1979 \\
1980 \\
1981 \\
1982 \\
1983 \\
1984 \\
1985 \\
1986 \\
1987 \\
1988 \\
1989\end{array}$ & $\begin{array}{l}08-10-72 \\
10-20-72 \\
09-22-74 \\
09-00-75 \\
09-26-76 \\
08-14-77 \\
08-13-78 \\
01-17-79 \\
08-15-80 \\
09-05-81 \\
08-26-82 \\
07-23-83 \\
10-03-83 \\
07-19-85 \\
08-29-86 \\
07-31-87 \\
08-29-88 \\
07-28-89\end{array}$ & $\begin{array}{r}214 \\
1,880 \\
684 \\
751 \\
1,650 \\
325 \\
808 \\
575 \\
469 \\
769 \\
576 \\
982 \\
10,400 \\
630 \\
960 \\
762 \\
768 \\
453\end{array}$ \\
\hline
\end{tabular}

BASIN CHARACTERISTICS

\begin{tabular}{|c|c|c|c|c|c|c|c|}
\hline \multirow{2}{*}{$\begin{array}{l}\text { MIN } \\
\text { CHANNEL } \\
\text { SLOPE } \\
\text { (FTMI) }\end{array}$} & \multirow[b]{2}{*}{$\begin{array}{c}\text { STREAM } \\
\text { LENGTH } \\
\text { (MI) }\end{array}$} & \multirow{2}{*}{$\begin{array}{l}\text { MEAN } \\
\text { BASIN } \\
\text { ELEVA- } \\
\text { TION } \\
\text { (FT) }\end{array}$} & \multirow[b]{2}{*}{$\begin{array}{l}\text { FORESTED } \\
\text { AREA } \\
\text { (PERCENT) }\end{array}$} & \multirow[b]{2}{*}{$\begin{array}{l}\text { SOIL } \\
\text { INDEX }\end{array}$} & \multirow{2}{*}{$\begin{array}{l}\text { MEAN } \\
\text { ANNUAL } \\
\text { PRECIPI- } \\
\text { TATION } \\
\text { (IN) }\end{array}$} & \multicolumn{2}{|c|}{ RAINFALL INTENSITY, 24-HOLR } \\
\hline & & & & & & $\begin{array}{l}\text { 2-YEAR } \\
\text { (IN) }\end{array}$ & $\begin{array}{c}\text { 50-YEAR } \\
\text { (IN) }\end{array}$ \\
\hline 14.1 & 64.4 & 2,699 & 1.6 & 0.0 & 12.5 & 2.2 & 4.5 \\
\hline
\end{tabular}


SAN SIMON WASH BASIN

09535300 VAMORI WASH AT KOM VO, AZ--Continued.

MEAN MONTHLY AND ANMUAL DISCHARGES 1973-89

\begin{tabular}{|c|c|c|c|c|c|c|}
\hline MONTH & $\begin{array}{l}\operatorname{MAXIMUN} \\
\left(F T^{3} / S\right)\end{array}$ & $\begin{array}{l}\operatorname{MINIMM} \\
\left(\mathrm{FT}^{3} / \mathrm{S}\right)\end{array}$ & $\begin{array}{c}\text { MEAN } \\
\left(F T^{3} / S\right)\end{array}$ & $\begin{array}{l}\text { DARD } \\
\text { DEVIA- } \\
\text { TION } \\
\text { (FT } 3 / S)\end{array}$ & $\begin{array}{l}\text { COEFFI- } \\
\text { CIENT OF } \\
\text { VARI - } \\
\text { ATION }\end{array}$ & $\begin{array}{c}\text { PERCENT } \\
\text { OF } \\
\text { ANNUAL } \\
\text { RUNOFF }\end{array}$ \\
\hline $\begin{array}{l}\text { OCTOBER } \\
\text { NOVEMBER } \\
\text { DECEMBER } \\
\text { JANUARY } \\
\text { FEBRUARY } \\
\text { MARCH } \\
\text { APRIL } \\
\text { MAY } \\
\text { JUNE } \\
\text { JULY } \\
\text { AUGUST } \\
\text { SEPTEMBER }\end{array}$ & $\begin{array}{c}463 \\
37 \\
26 \\
41 \\
33 \\
28 \\
0.49 \\
0.49 \\
0.07 \\
46 \\
106 \\
103\end{array}$ & $\begin{array}{l}0.00 \\
0.00 \\
0.00 \\
0.00 \\
0.00 \\
0.00 \\
0.00 \\
0.00 \\
0.00 \\
0.00 \\
0.73 \\
0.00\end{array}$ & $\begin{array}{l}37 \\
4.6 \\
3.5 \\
7.8 \\
4.6 \\
2.9 \\
0.03 \\
0.06 \\
0.00 \\
16 \\
32 \\
16\end{array}$ & $\begin{array}{c}112 \\
11 \\
6.7 \\
15 \\
11 \\
7.2 \\
0.12 \\
0.15 \\
0.02 \\
14 \\
28 \\
25\end{array}$ & $\begin{array}{l}3.0 \\
2.3 \\
1.9 \\
1.9 \\
2.3 \\
2.5 \\
4.0 \\
2.4 \\
4.1 \\
0.88 \\
0.88 \\
1.5\end{array}$ & $\begin{array}{r}29.7 \\
3.7 \\
2.8 \\
6.2 \\
3.7 \\
2.3 \\
0.0 \\
0.0 \\
0.0 \\
12.9 \\
25.9 \\
12.7\end{array}$ \\
\hline ANNUAL & 52 & 0.97 & 10 & 12 & 1.1 & 100 \\
\hline
\end{tabular}

MAGNITUDE AND PROBABILITY OF IMSTANTANEOUS PEAK FLOW BASED ON PERIOD OF RECORD

DISCHARGE, IN $\mathrm{FT}^{3} / \mathrm{S}$, FOR INDICATED RECURRENCE INTERVAL IN YEARS, AND EXCEEDANCE PROBABILITY, IN PERCENT

\begin{tabular}{|c|c|c|c|c|c|}
\hline $\begin{array}{c}2 \\
50 \%\end{array}$ & $\begin{array}{c}5 \\
20 \%\end{array}$ & $\begin{array}{r}10 \\
10 \%\end{array}$ & $\begin{array}{l}25 \\
4 \%\end{array}$ & $\begin{array}{l}50 \dagger \\
2 \%\end{array}$ & $\begin{array}{c}100 \nmid \\
1 \%\end{array}$ \\
\hline 745 & 1,550 & 2,360 & 3,820 & 5,320 & 7,250 \\
\hline $\begin{array}{l}\text { VEIGHTED } \\
\text { MEAN } \\
\text { STANDARD }\end{array}$ & $\begin{array}{l}\text { SKEW } \\
\text { DEV. }\end{array}$ & $\begin{array}{l}\text { OGS) }= \\
\text { OGS) }= \\
\text { OGS) }=\end{array}$ & & & \\
\hline
\end{tabular}

MAEITUDE AND PROBABILITY OF AMNUAL LON FLON BASED ON PERIOD OF RECORD 1973-89

\begin{tabular}{|c|c|c|c|c|c|c|}
\hline $\begin{array}{l}\text { PERIOD } \\
\text { (CON- } \\
\text { SECU- }\end{array}$ & & $\begin{array}{l}\text { 1 SCHAI } \\
\text { ECURR } \\
\text { N-EXC } \\
\end{array}$ & $\begin{array}{l}\text { IN } \\
\text { INT } \\
\text { ANCE }\end{array}$ & $\begin{array}{l}\text { /S, FC } \\
\text { AL, II } \\
\text { BABIL }\end{array}$ & $\begin{array}{l}\text { INDICA } \\
\text { EARS, } \\
\text { IN P }\end{array}$ & CENT \\
\hline $\begin{array}{l}\text { TIVE } \\
\text { DAYS) }\end{array}$ & $\begin{array}{c}2 \\
50 \%\end{array}$ & $\begin{array}{c}5 \\
20 \%\end{array}$ & $\begin{array}{l}10 \\
10 \%\end{array}$ & $\begin{array}{l}20 \\
5 \%\end{array}$ & $\begin{array}{l}50 \nmid \\
2 x\end{array}$ & $\begin{array}{l}100 t \\
1 \%\end{array}$ \\
\hline $\begin{array}{r}1 \\
3 \\
7 \\
14 \\
30 \\
60 \\
90 \\
120 \\
183\end{array}$ & $\begin{array}{l}0.00 \\
0.00 \\
0.00\end{array}$ & $\begin{array}{l}0.00 \\
0.00 \\
0.00\end{array}$ & $\begin{array}{l}0.00 \\
0.00 \\
0.00\end{array}$ & $\begin{array}{l}0.00 \\
0.00 \\
0.00\end{array}$ & $\begin{array}{l}0.00 \\
0.00 \\
0.00\end{array}$ & $\begin{array}{l}0.00 \\
0.00 \\
0.00\end{array}$ \\
\hline
\end{tabular}

MAGNITLDE AND PROBABILITY OF AMMUAL HIGH FLON BASED ON PERIOD OF RECORD $1973-89$

\begin{tabular}{|c|c|c|c|c|c|c|}
\hline \multirow{2}{*}{$\begin{array}{l}\text { PERIOD } \\
\text { (CON- } \\
\text { SECU- } \\
\text { TIVE } \\
\text { DAYS) }\end{array}$} & & \multicolumn{5}{|c|}{$\begin{array}{l}\text { DISCHARGE, IN FT }{ }^{3} / S, \text { FOR INDICATED } \\
\text { RECURRENCE INTERVAL, IN YEARS, AND } \\
\text { EXCEEDANCE PROBABILITY, IN PERCENT }\end{array}$} \\
\hline & $\begin{array}{c}2 \\
50 \%\end{array}$ & $\begin{array}{c}5 \\
20 \%\end{array}$ & $\begin{array}{l}10 \\
10 \%\end{array}$ & $\begin{array}{l}25 \\
4 \%\end{array}$ & $\begin{array}{l}50 \dagger \\
2 \%\end{array}$ & $\begin{array}{c}100 \dagger \\
1 x\end{array}$ \\
\hline $\begin{array}{r}1 \\
3 \\
7 \\
15 \\
30 \\
60 \\
90\end{array}$ & $\begin{array}{r}359 \\
232 \\
122 \\
67 \\
45 \\
32 \\
24\end{array}$ & $\begin{array}{r}954 \\
622 \\
304 \\
161 \\
103 \\
70 \\
51\end{array}$ & $\begin{array}{r}1,790 \\
1,140 \\
545 \\
277 \\
164 \\
105 \\
74\end{array}$ & $\begin{array}{r}3,860 \\
2,330 \\
1,100 \\
526 \\
277 \\
158 \\
107\end{array}$ & $\begin{array}{r}6,700 \\
3,850 \\
1,820 \\
826 \\
393 \\
206 \\
135\end{array}$ & $\begin{array}{r}11,400 \\
6,220 \\
2,960 \\
1,270 \\
545 \\
259 \\
166\end{array}$ \\
\hline
\end{tabular}

DURATION TABLE OF DAILY MEAN FLON FOR PERIOD OF RECORD 1973-89

DISCHARGE, IN FT $3 / 5$, WHICH WAS EQUALED OR EXCEEDED FOR INDICATED PERCENT OF TINE

\begin{tabular}{|c|c|c|c|c|c|c|c|c|c|c|c|c|c|c|c|c|}
\hline $1 \%$ & $5 \%$ & $10 \%$ & $15 \%$ & $20 \%$ & $30 \%$ & $40 \%$ & $50 \%$ & $60 \%$ & $70 \%$ & $80 \%$ & $90 \%$ & $95 \%$ & $98 \%$ & $99 \%$ & $99.5 \%$ & $99.9 \%$ \\
\hline 248 & 32 & 4.9 & 0.00 & 0.00 & 0.00 & 0.00 & 0.00 & 0.00 & 0.00 & 0.00 & 0.00 & 0.00 & 0.00 & 0.00 & 0.00 & 0.00 \\
\hline
\end{tabular}

f Reliability of values in colum is uncertain, and potential errors are large. 


\section{VNMORI WASH AT KON VO, NZ--CONTINUED}
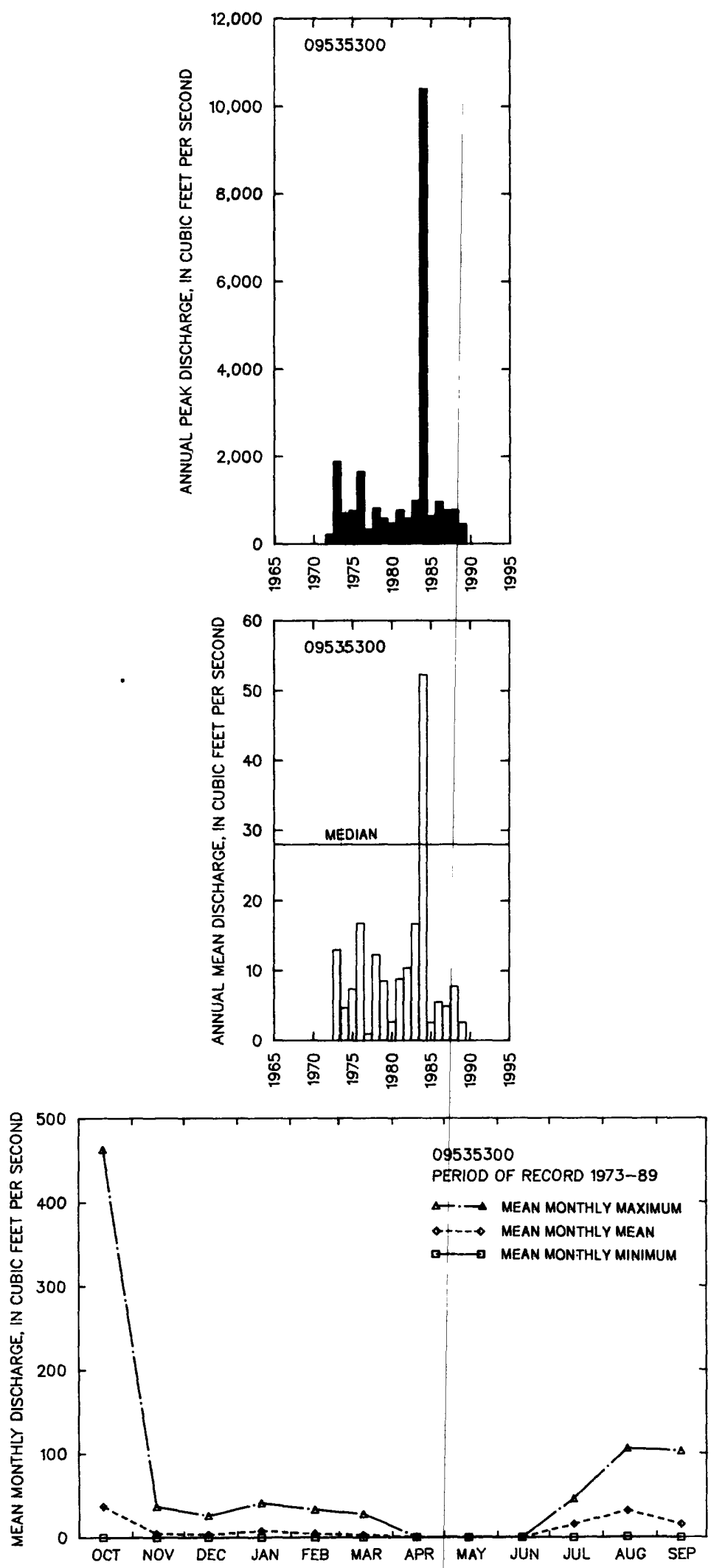
09536100 PITCHFORK CANYON TRIBUTARY MEAR FORT GRANT, AZ

LOCATION.--Lat 32.35'20", long 109.54'40", in SEK sec.5, T.10 S., R.24 E., Graham County, Hydrologic Unit 15050201, at State Highway 266, 3 mi southeast of fort Grant.

DRAIMAGE AREA. $--0.81 \mathrm{mi}^{2}$.

ANIUAL PEAK DISCHARGE

\begin{tabular}{|c|c|c|c|}
\hline $\begin{array}{l}\text { WATER } \\
\text { YEAR }\end{array}$ & DATE & $\begin{array}{c}\text { ANNUAL PEAK } \\
\text { DISCHARGE } \\
\left(\mathrm{FT}^{3} / \mathrm{S}\right)\end{array}$ & $\begin{array}{l}\text { DISCHARGE } \\
\text { CODES }\end{array}$ \\
\hline $\begin{array}{l}1963 \\
1964 \\
1965 \\
1966 \\
1967 \\
1968 \\
1969 \\
1970 \\
1971 \\
1972 \\
1973 \\
1974 \\
1975 \\
1976\end{array}$ & $\begin{array}{l}00-00-63 \\
07-24-64 \\
08-15-65 \\
08-07-66 \\
08-00-67 \\
08-20-68 \\
00-00-69 \\
00-00-70 \\
09-08-71 \\
08-26-72 \\
10-15-72 \\
07-16-74 \\
00-00-75 \\
00-00-76\end{array}$ & $\begin{array}{r}10 \\
354 \\
375 \\
40 \\
200 \\
60 \\
180 \\
0 \\
320 \\
130 \\
135 \\
120 \\
0 \\
190\end{array}$ & LT \\
\hline
\end{tabular}

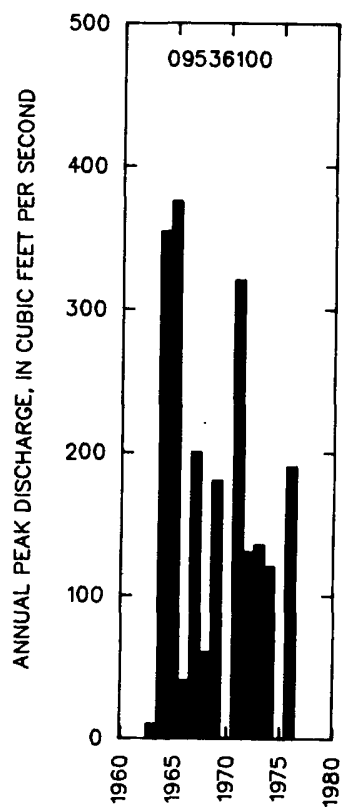

MAGNITUDE AND PROBABILITY OF INSTANTANEOUS PEAK FLOW BASED ON PERIOD OF RECORD 1963-76

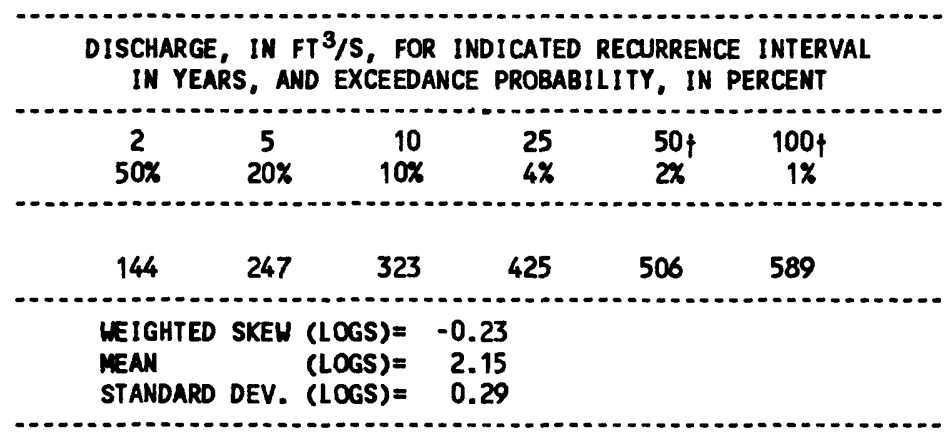

+ Reliability of values in column is uncertain, and potential errors are large.

BASIN CHARACTERISTICS

\begin{tabular}{|c|c|c|c|c|c|c|c|}
\hline \multirow{3}{*}{$\begin{array}{l}\text { MAIN } \\
\text { CHANNEL } \\
\text { SLOPE } \\
\text { (FT/MI) }\end{array}$} & \multirow[b]{3}{*}{$\begin{array}{c}\text { STREAM } \\
\text { LENGTH } \\
\text { (MI) }\end{array}$} & \multirow{3}{*}{$\begin{array}{c}\text { MEAN } \\
\text { BASIN } \\
\text { ELEVA- } \\
\text { TION } \\
\text { (FT) }\end{array}$} & \multirow[b]{3}{*}{$\begin{array}{l}\text { FORESTED } \\
\text { AREA } \\
\text { (PERCENT) }\end{array}$} & \multirow[b]{3}{*}{$\begin{array}{l}\text { SOIL } \\
\text { INDEX }\end{array}$} & \multirow{2}{*}{$\begin{array}{c}\text { MEAN } \\
\text { ANNUAL } \\
\text { PRECIPI- }\end{array}$} & \multirow{2}{*}{\multicolumn{2}{|c|}{ RAINFALL INTENSITY, 24-HOUR }} \\
\hline & & & & & & & \\
\hline & & & & & $\begin{array}{l}\text { PRECIPI - } \\
\text { TATION } \\
\text { (IN) }\end{array}$ & $\begin{array}{c}\text { 2-YEAR } \\
\text { (IN) }\end{array}$ & $\begin{array}{c}\text { 50-YEAR } \\
\text { (IN) }\end{array}$ \\
\hline 459 & 1.8 & 5,210 & 0.0 & 3.0 & 15.0 & 2.1 & 3.8 \\
\hline
\end{tabular}




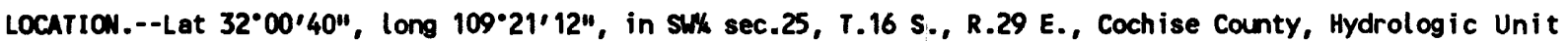
15050201, at main road through Chiricahua National Monument, $0.4 \mathrm{mi}$ north of ranger station, and $19 \mathrm{mi}$ southeast of Dos Cabezas.

DRAINAGE AREA. $--0.65 \mathrm{mi}^{2}$.

ANIUUAL PEAK DISCHARGE

\begin{tabular}{|c|c|c|c|}
\hline $\begin{array}{l}\text { WATER } \\
\text { YEAR }\end{array}$ & DATE & $\begin{array}{l}\text { ANNUAL PEAK } \\
\text { DISCHARGE } \\
\text { (FT } 3 / S)\end{array}$ & $\begin{array}{l}\text { DISCHARGE } \\
\text { CODES }\end{array}$ \\
\hline $\begin{array}{l}1963 \\
1964 \\
1965 \\
1966 \\
1967 \\
1968 \\
1969 \\
1970 \\
1971 \\
1972 \\
1973 \\
1974 \\
1975 \\
1976\end{array}$ & $\begin{array}{l}08-00-63 \\
08-14-64 \\
00-00-65 \\
08-18-66 \\
07-26-67 \\
00-00-68 \\
07-15-69 \\
00-00-70 \\
08-19-71 \\
10-25-71 \\
02-21-73 \\
07-07-74 \\
07-19-75 \\
00-00-76\end{array}$ & $\begin{array}{c}94 \\
61 \\
0 \\
32 \\
108 \\
0 \\
191 \\
0 \\
130 \\
17 \\
4.0 \\
120 \\
80 \\
30\end{array}$ & ES \\
\hline
\end{tabular}

MAGNITUDE AND PROBABILITY OF INSTANTANEOUS PEAK FLON BASED ON PERICD OF RECORD 1963-76

DISCHARGE, IN FT $3 / 5$, FOR INDICATED RECURRENCE INTERVAL IN YEARS, AND EXCEEDANCE PROBABILITT, IN PERCENT

\begin{tabular}{|c|c|c|c|c|c|}
\hline$\stackrel{2}{50 \%}$ & $\begin{array}{c}5 \\
20 \%\end{array}$ & $\begin{array}{r}10 \\
10 \%\end{array}$ & $\begin{array}{l}25 \\
4 \%\end{array}$ & $\begin{array}{l}50 \uparrow \\
2 \%\end{array}$ & $\begin{array}{c}100\} \\
1 x\end{array}$ \\
\hline 44.9 & 113 & 172 & 261 & 335 & 413 \\
\hline $\begin{array}{l}\text { WEIGHTED } \\
\text { MEAN } \\
\text { STANDARD }\end{array}$ & $\begin{array}{l}\text { SKEW } \\
\text { DEV. }\end{array}$ & $\begin{array}{l}(\text { LOGS })= \\
(\text { LOGS })= \\
(\text { LOGS })=\end{array}$ & $\begin{array}{r}-0.51 \\
1.61 \\
0.52\end{array}$ & & \\
\hline
\end{tabular}

+ Reliability of values in colum is uncertain, and potential errors are large.

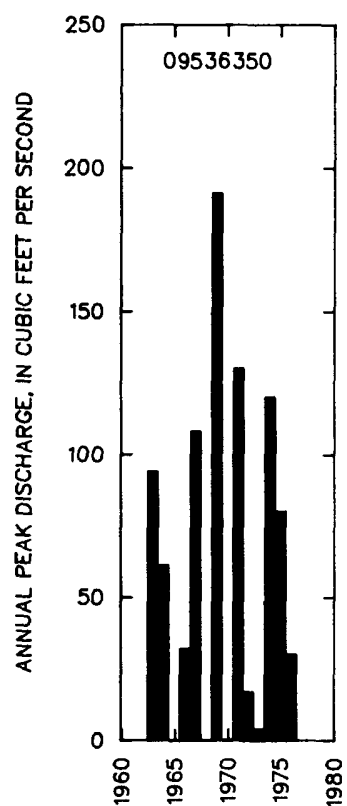

\section{BASIN CHARACTERISTICS}

\begin{tabular}{|c|c|c|c|c|c|c|c|}
\hline MAIN & & $\begin{array}{l}\text { MEAN } \\
\text { BASIN }\end{array}$ & & & $\begin{array}{l}\text { MEAN } \\
\text { ANNUAL }\end{array}$ & RAINFALL I & SITY, 24-HOUR \\
\hline $\begin{array}{l}\text { CHANNEL } \\
\text { SLOPE } \\
\text { (FT/MI) }\end{array}$ & $\begin{array}{c}\text { STREAM } \\
\text { LENGTH } \\
\text { (MI) }\end{array}$ & $\begin{array}{l}\text { ELEVA- } \\
\text { TION } \\
\text { (FT) }\end{array}$ & $\begin{array}{l}\text { FORESTED } \\
\text { AREA } \\
\text { (PERCENT) }\end{array}$ & $\begin{array}{l}\text { SOIL } \\
\text { INDEX }\end{array}$ & $\begin{array}{l}\text { PRECIPI - } \\
\text { TATION } \\
\text { (IN) }\end{array}$ & $\begin{array}{c}\text { 2-YEAR } \\
\text { (IN) }\end{array}$ & $\begin{array}{l}\text { 50-YEAR } \\
\text { (IN) }\end{array}$ \\
\hline 1,040 & 1.7 & 6,280 & 100 & 1.0 & 18.0 & 2.2 & 4.4 \\
\hline
\end{tabular}


WHITE MATERDRAH BASIN

09537200 LESLIE CREEK NEAR MCNEAL, AZ

LOCATION.--Lat $31^{\circ} 35^{\prime} 24^{\prime \prime}$, long 109'30'30", in SEYNEK sec.20, T.21 S., R.28 E., Cochise County, Hydrologic Unit 15080301, on right bank $10 \mathrm{k}$ : east of McNeal.

DRAINAGE AREA. - - $79.1 \mathrm{mi}^{2}$.

\begin{tabular}{|c|c|c|}
\hline $\begin{array}{l}\text { WATER } \\
\text { YEAR }\end{array}$ & DATE & $\begin{array}{c}\text { ANNUAL PEAK } \\
\text { DISCHARGE } \\
\text { (FT } 3 / S)\end{array}$ \\
\hline $\begin{array}{l}1970 \\
1971 \\
1972 \\
1973 \\
1974 \\
1975 \\
1976 \\
1977 \\
1982 \\
1983 \\
1984 \\
1985 \\
1986 \\
1987 \\
1988 \\
1989\end{array}$ & $\begin{array}{l}08-10-70 \\
08-12-71 \\
07-15-72 \\
10-20-72 \\
07-20-74 \\
07-23-75 \\
10-21-75 \\
08-08-77 \\
08-15-82 \\
02-04-83 \\
07-21-84 \\
10-03-84 \\
08-18-86 \\
08-05 / 87 \\
07-20 / 88 \\
08-06 / 89\end{array}$ & $\begin{array}{c}345 \\
1,760 \\
314 \\
255 \\
162 \\
132 \\
1.0 \\
563 \\
30 \\
322 \\
4.600 \\
709 \\
658 \\
307 \\
250 \\
71\end{array}$ \\
\hline
\end{tabular}

BASIN CHARACTERISTICS

\begin{tabular}{|c|c|c|c|c|c|c|c|}
\hline \multirow{3}{*}{$\begin{array}{l}\text { MAIN } \\
\text { CHANNEL } \\
\text { SLOPE } \\
\text { (FT/MI) }\end{array}$} & \multirow[b]{3}{*}{$\begin{array}{l}\text { STREAM } \\
\text { LENGTH } \\
\text { (MI) }\end{array}$} & \multirow{3}{*}{$\begin{array}{l}\text { MEAN } \\
\text { BASIN } \\
\text { ELEVA- } \\
\text { TION } \\
\text { (FT) }\end{array}$} & \multirow[b]{3}{*}{$\begin{array}{l}\text { FORESTED } \\
\text { AREA } \\
\text { (PERCENT) }\end{array}$} & \multirow{2}{*}{\multicolumn{2}{|c|}{$\begin{array}{c}\text { MEAN } \\
\text { ANNUAL } \\
\text { PRECIPI- }\end{array}$}} & \multirow{2}{*}{\multicolumn{2}{|c|}{ RAINFALL INTENSITY, 24-HOUR }} \\
\hline & & & & & & & \\
\hline & & & & $\begin{array}{l}\text { SOIL } \\
\text { INDEX }\end{array}$ & $\begin{array}{l}\text { PRECIPI - } \\
\text { TATION } \\
\text { (IN) }\end{array}$ & $\begin{array}{l}\text { 2-YEAR } \\
\text { (IN) }\end{array}$ & $\begin{array}{l}\text { 50-YEAR } \\
\text { (IN) }\end{array}$ \\
\hline 62.1 & 14.5 & 5,360 & 30.0 & 2.0 & 18.0 & 2.0 & 4.0 \\
\hline
\end{tabular}


MEAN MONTHLY AND ANMUAL DISCHARGES 1970-77, 1983-89

\begin{tabular}{|c|c|c|c|c|c|c|}
\hline MONTH & $\begin{array}{l}\operatorname{MAXIMUH} \\
\left(F T^{3} / S\right)\end{array}$ & $\begin{array}{l}\text { MINIMUM } \\
\left(F T^{3} / S\right)\end{array}$ & $\begin{array}{c}\text { MEAN } \\
\left(F T^{3} / S\right)\end{array}$ & $\begin{array}{l}\text { STAN- } \\
\text { DARD } \\
\text { DEVIA- } \\
\text { TION } \\
\left(F T^{3} / S\right)\end{array}$ & $\begin{array}{l}\text { COEFFI- } \\
\text { CIENT OF } \\
\text { VARI- } \\
\text { ATION }\end{array}$ & $\begin{array}{c}\text { PERCENT } \\
\text { OF } \\
\text { ANNUAL } \\
\text { RUNOFF }\end{array}$ \\
\hline $\begin{array}{l}\text { OCTOBER } \\
\text { NONEMBER } \\
\text { DECEMBER } \\
\text { JANUARY } \\
\text { FEBRUARY } \\
\text { MARCH } \\
\text { APRIL } \\
\text { MAY } \\
\text { JUNE } \\
\text { JULY } \\
\text { AUGUST } \\
\text { SEPTEMBER }\end{array}$ & $\begin{array}{l}31 \\
1.8 \\
1.8 \\
2.1 \\
3.2 \\
1.6 \\
1.7 \\
1.4 \\
1.2 \\
26 \\
17 \\
4.9\end{array}$ & $\begin{array}{l}0.00 \\
0.00 \\
0.02 \\
0.02 \\
0.02 \\
0.02 \\
0.00 \\
0.00 \\
0.00 \\
0.00 \\
0.00 \\
0.00\end{array}$ & $\begin{array}{l}3.4 \\
0.84 \\
0.75 \\
0.72 \\
0.77 \\
0.55 \\
0.53 \\
0.45 \\
0.38 \\
2.5 \\
3.2 \\
1.0\end{array}$ & $\begin{array}{l}7.8 \\
0.63 \\
0.59 \\
0.65 \\
0.82 \\
0.46 \\
0.49 \\
0.43 \\
0.37 \\
6.6 \\
4.5 \\
1.3\end{array}$ & $\begin{array}{l}2.3 \\
0.75 \\
0.78 \\
0.90 \\
1.1 \\
0.83 \\
0.93 \\
0.95 \\
0.97 \\
2.7 \\
1.4 \\
1.3\end{array}$ & $\begin{array}{r}22.7 \\
5.6 \\
5.0 \\
4.8 \\
5.1 \\
3.7 \\
3.5 \\
3.0 \\
2.5 \\
16.4 \\
21.0 \\
6.7\end{array}$ \\
\hline ANNUAL & 6.6 & 0.07 & 1.3 & 1.6 & 1.3 & 100 \\
\hline
\end{tabular}

MAGNITUDE AND PROBABILITY OF INSTANTANEOUS PEAK FLOW BASED ON PERIOD OF RECORD 1970-77, 1982-89

DISCHARGE, IN $\mathrm{FT}^{3} / \mathrm{S}$, FOR INDICATED RECURRENCE INTERVAL IN YEARS, AND EXCEEDANCE PROBABILITY, IN PERCENT

\begin{tabular}{lccccc}
52 & 5 & 10 & 25 & 504 & $\begin{array}{c}100\} \\
1 \%\end{array}$ \\
$50 \%$ & $20 \%$ & $10 \%$ & $4 \%$ & $2 \%$ & $1 \%$ \\
449 & 1,360 & 2,440 & 4,560 & 6,850 & 9,880 \\
\hline WEIGHTED SKEW (LOGS) & $=0.09$ & & \\
MEAN & (LOGS) & $=2.50$ \\
STANOARD DEV. (LOGS) & $=0.57$
\end{tabular}

MIGNITUDE AND PROBABILITY OF ANHUAL LOW FLOW BASED ON PERIOD OF RECORD 1971-77, 1984-89

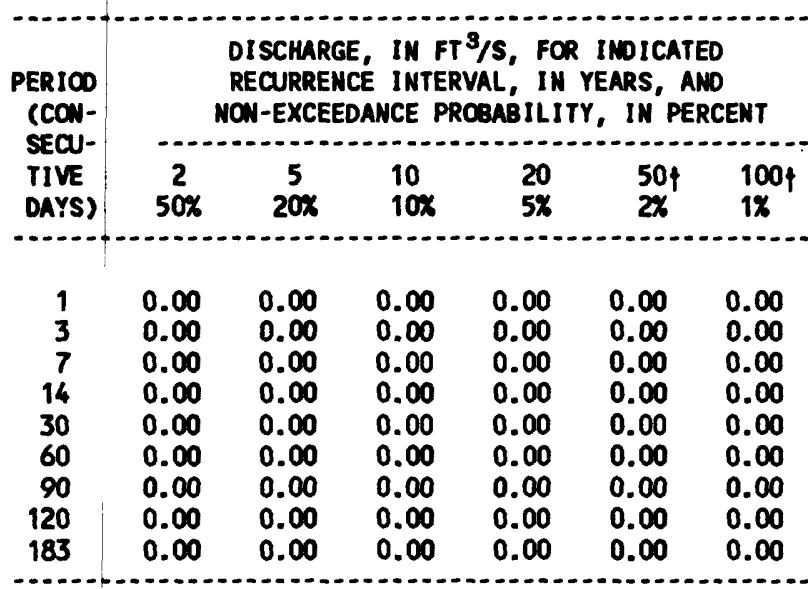

MAGNITUDE AND PROBABILITY OF ANMUAL HIGH FLOH BASED ON PERICO OF RECORD 1970-77, 1983-89

\begin{tabular}{|c|c|c|c|c|c|c|}
\hline \multirow{2}{*}{$\begin{array}{l}\text { PERIOD } \\
\text { (CON- } \\
\text { SECU- } \\
\text { TIVE } \\
\text { DAYS) }\end{array}$} & \multicolumn{6}{|c|}{$\begin{array}{l}\text { DISCHARCE, IN FT }{ }^{3} / S \text {, FOR INOICATED } \\
\text { RECURRENCE INTERVAL, IN YEARS, AND } \\
\text { EXCEEDANCE PROBABILITY, IN PERCENT }\end{array}$} \\
\hline & $\stackrel{2}{50 x}$ & $\begin{array}{c}5 \\
20 x\end{array}$ & $\begin{array}{l}10 \\
10 x\end{array}$ & $\begin{array}{l}25 \\
4 \%\end{array}$ & $\begin{array}{l}50\} \\
22\end{array}$ & $\begin{array}{c}100 \nmid \\
1 \%\end{array}$ \\
\hline $\begin{array}{r}1 \\
3 \\
7 \\
15 \\
30 \\
60 \\
90\end{array}$ & $\begin{array}{r}52 \\
20 \\
8.7 \\
5.0 \\
3.0 \\
1.9 \\
1.5\end{array}$ & $\begin{array}{c}171 \\
70 \\
30 \\
16 \\
8.9 \\
5.1 \\
3.8\end{array}$ & $\begin{array}{c}261 \\
117 \\
52 \\
27 \\
15 \\
8.6 \\
6.2\end{array}$ & $\begin{array}{r}362 \\
184 \\
88 \\
47 \\
27 \\
15 \\
10\end{array}$ & $\begin{array}{r}423 \\
235 \\
120 \\
65 \\
39 \\
21 \\
15\end{array}$ & $\begin{array}{r}471 \\
284 \\
156 \\
87 \\
53 \\
28 \\
20\end{array}$ \\
\hline
\end{tabular}

DURATION TABLE OF DAILY MEAN FLON FOR PERICD OF RECORD 1970-77, 1983-89

DISCHARGE, IN $\mathrm{FT}^{3} / \mathrm{S}$, WHICH WAS EQUALED OR EXCEEDED FOR IMDICATED PERCENT OF TIME

\begin{tabular}{|c|c|c|c|c|c|c|c|c|c|c|c|c|c|c|c|c|}
\hline $1 \%$ & $5 \%$ & $10 \%$ & $15 \%$ & $20 \%$ & $30 x$ & $40 x$ & $50 \%$ & $60 \%$ & $70 \%$ & $80 \%$ & $90 x$ & $95 \%$ & $98 \%$ & $99 \%$ & $99.5 \%$ & $99.9 x$ \\
\hline 8.9 & 1.8 & 1.6 & 1.4 & 1.1 & 0.80 & 0.62 & 0.48 & 0.33 & 0.21 & 0.14 & 0.05 & 0.00 & 0.00 & 0.00 & 0.00 & 0.00 \\
\hline
\end{tabular}

+ Reliability of values in colum is uncertain, and potential errors are large. 
WHITE WATERDRAW BASIN

09537200 LESLIE CREEX NEAR MCNEAL, AZ--CONTINUEd
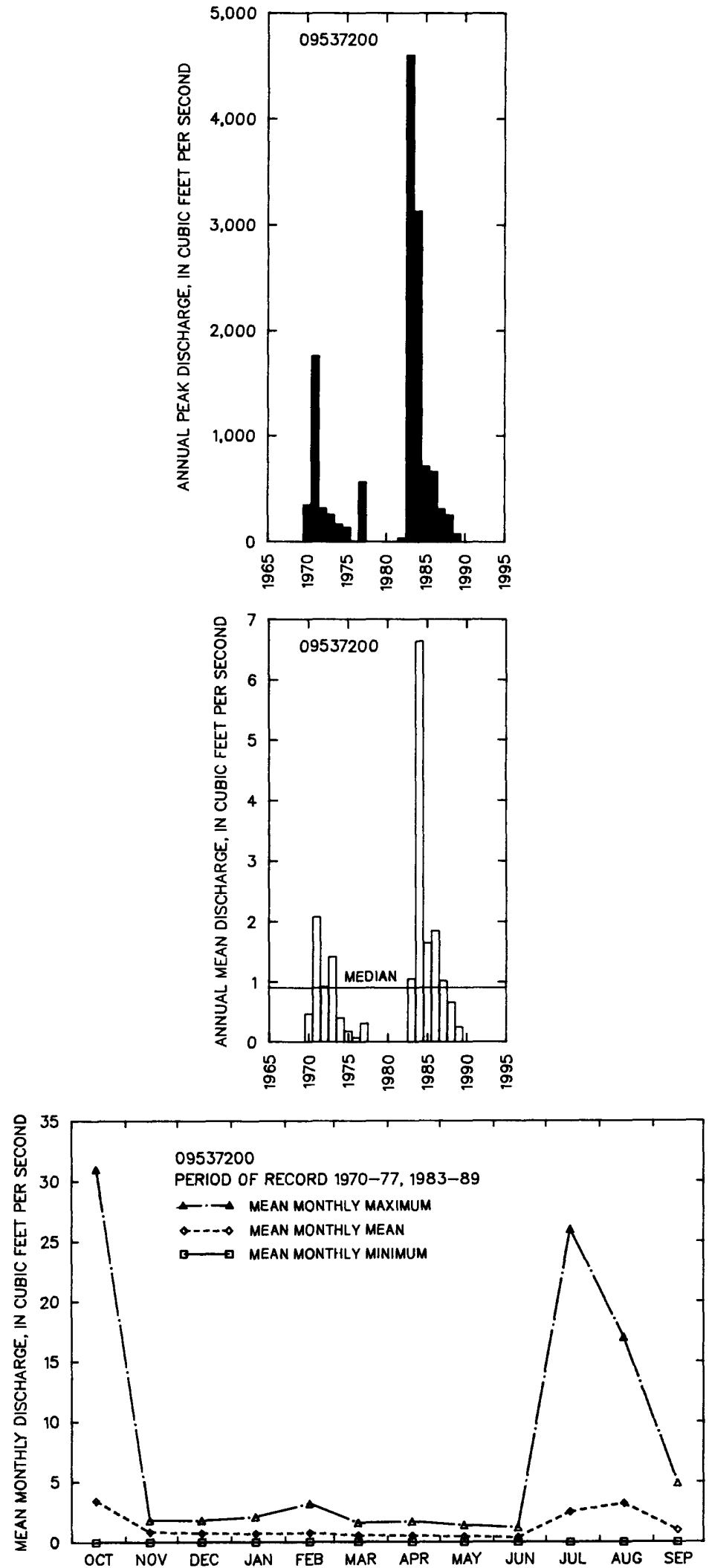


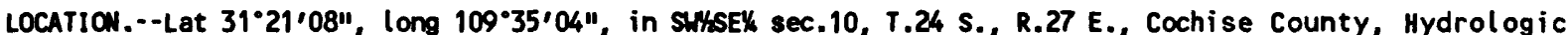
Unit 15080301, on downstream side of pier of bridge on U.S. Highway 80, 1.5 mi upstream from international boundary and $2 \mathrm{mi}$ west of Douglas.

DRAINAGE AREA. $--1,023 \mathrm{mi}^{2}$.

REMARKS.--Irrigation of about 40,000 acres above station in 1978, by pumping from ground water. Whitewater Draw discharges into Gulf of California through Rio Yaqui in Mexico. Records show flow at international boundary except for smelter wastewater, which enters stream below station.

Records furnished by International Boundary and Water Commission 1983-89.

ANMULL PEAK DISCHARGE

\begin{tabular}{|c|c|c|c|c|c|c|c|}
\hline $\begin{array}{l}\text { WATER } \\
\text { YEAR }\end{array}$ & DATE & $\begin{array}{l}\text { ANNUAL PEAK } \\
\text { DISCHARGE } \\
\text { (FT } 3 / S \text { ) }\end{array}$ & $\begin{array}{l}\text { DISCHARGE } \\
\text { CODES }\end{array}$ & $\begin{array}{l}\text { WATER } \\
\text { YEAR }\end{array}$ & DATE & $\begin{array}{c}\text { ANIUAL PEAK } \\
\text { DISCHARGE } \\
\left(\mathrm{FT}^{3} / \mathrm{S}\right)\end{array}$ & $\begin{array}{l}\text { DISCHARGE } \\
\text { CODES }\end{array}$ \\
\hline $\begin{array}{l}1916 \\
1917 \\
1918 \\
1919 \\
1920 \\
1930 \\
1931 \\
1932 \\
1933 \\
1934 \\
1935 \\
1936 \\
1937 \\
1938 \\
1939 \\
1940 \\
1941 \\
1942 \\
1943 \\
1944 \\
1945 \\
1946 \\
1947 \\
1948 \\
1949 \\
1950 \\
1951 \\
1952 \\
1953 \\
1954 \\
1955 \\
1956 \\
1957\end{array}$ & $\begin{array}{l}07-11-16 \\
08-09-17 \\
07-15-18 \\
07-27-19 \\
11-23-19 \\
09-07-30 \\
08-10-31 \\
07-31-32 \\
09-20-33 \\
08-00-34 \\
09-01-35 \\
09-11-36 \\
08-19-37 \\
08-07-38 \\
08-05-39 \\
06-24-40 \\
09-29-41 \\
09-13-42 \\
06-30-43 \\
08-16-44 \\
07-31-45 \\
10-09-45 \\
07-08-47 \\
07-22-48 \\
07-18-49 \\
07-19-50 \\
08-20-51 \\
06-02-52 \\
07-07-53 \\
08-09-54 \\
08-07-55 \\
08-27-56 \\
07-24-57\end{array}$ & $\begin{array}{r}1,600 \\
720 \\
1,050 \\
4,050 \\
3,400 \\
1,700 \\
3,450 \\
1,800 \\
1,730 \\
3,100 \\
2,900 \\
2,000 \\
2,770 \\
1,990 \\
2,690 \\
2,750 \\
2,750 \\
2,300 \\
2,750 \\
2,190 \\
3,100 \\
1,440 \\
1,580 \\
3,170 \\
1,790 \\
3,400 \\
1,230 \\
1,670 \\
2,950 \\
3,680 \\
5,060 \\
2,720\end{array}$ & ES & $\begin{array}{l}1958 \\
1959 \\
1960 \\
1961 \\
1962 \\
1963 \\
1964 \\
1965 \\
1966 \\
1967 \\
1968 \\
1969 \\
1970 \\
1971 \\
1972 \\
1973 \\
1974 \\
1975 \\
1976 \\
1977 \\
1978 \\
1979 \\
1980 \\
1981 \\
1982 \\
1983 \\
1984 \\
1985 \\
1986 \\
1987 \\
1988 \\
1989\end{array}$ & $\begin{array}{l}09-23-58 \\
07-27-59 \\
07-31-60 \\
07-29-61 \\
07-28-62 \\
08-01-63 \\
07-31-64 \\
09-04-65 \\
07-29-66 \\
08-05-67 \\
09-01-68 \\
08-25-69 \\
08-17-70 \\
08-11-71 \\
08-13-72 \\
07-11-73 \\
08-02-74 \\
07-23-75 \\
07-24-76 \\
08-19-77 \\
10-09-77 \\
07-20-79 \\
08-13-80 \\
07-19-81 \\
08-30-82 \\
07-24-83 \\
10-01-83 \\
09-29-85 \\
08-18-86 \\
08-05-87 \\
08-26-88 \\
10-16-88\end{array}$ & $\begin{array}{r}1,280 \\
2,760 \\
676 \\
1,380 \\
687 \\
1,260 \\
1,370 \\
1,500 \\
3,760 \\
2,930 \\
1,280 \\
1,130 \\
2,260 \\
1,700 \\
2,540 \\
800 \\
936 \\
1,020 \\
654 \\
625 \\
3,020 \\
1,100 \\
467 \\
753 \\
542 \\
170 \\
891 \\
1,420 \\
1,540 \\
381 \\
172 \\
95\end{array}$ & \\
\hline
\end{tabular}

BASIN CHARACTERISTICS

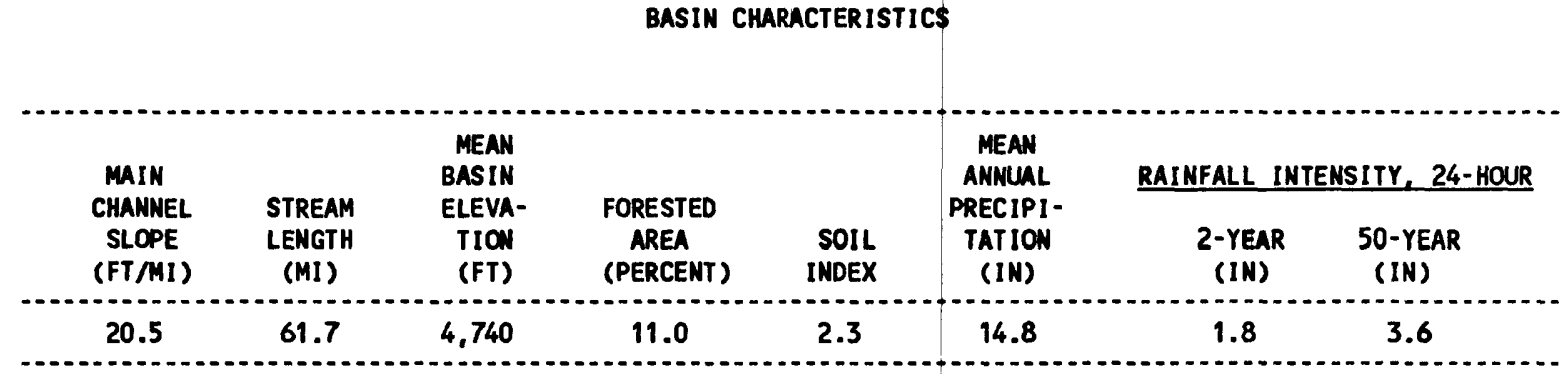


SULPHUR SPRING VALLEY

WHITEWATER DRAW BASIN

09537500 MHITEHATER DRAW NEAR DOUGLAS, AZ--Continued

MEAN MONTHLY AND ANMUAL DISChARGES 1919, 1931-33, 1936-46, 1949-82

MAGNITLDE ANO PROBABILITY OF ANNUAL LOW FLOH BASED ON PERICD OF RECORD 1932-33, 1937-47, 1949-82

\begin{tabular}{|c|c|c|c|c|c|c|}
\hline MONTH & $\begin{array}{l}\operatorname{MAX}[M U N \\
\left(F T^{3} / S\right)\end{array}$ & $\begin{array}{l}\text { MINIMUM } \\
\text { (FT } 3 / S)\end{array}$ & $\begin{array}{c}\text { MEAN } \\
\left(F T^{3} / S\right)\end{array}$ & $\begin{array}{l}\text { STAN- } \\
\text { DARO } \\
\text { DEVIA- } \\
\text { TION } \\
\text { (FT } 3 / S)\end{array}$ & $\begin{array}{l}\text { COEFFI - } \\
\text { CIENT OF } \\
\text { VARI - } \\
\text { ATION }\end{array}$ & $\begin{array}{c}\text { PERCENT } \\
\text { OF } \\
\text { ANNUAL } \\
\text { RUNOFF }\end{array}$ \\
\hline $\begin{array}{l}\text { OCTOBER } \\
\text { NOVEMBER } \\
\text { DECEMBER } \\
\text { JANUARY } \\
\text { FEBRUARY } \\
\text { MARCH } \\
\text { APRIL } \\
\text { MAY } \\
\text { JUNE } \\
\text { JULY } \\
\text { AUGUST } \\
\text { SEPTEMBER }\end{array}$ & $\begin{array}{c}99 \\
9.9 \\
38 \\
7.3 \\
9.1 \\
4.8 \\
2.9 \\
2.2 \\
27 \\
342 \\
235 \\
53\end{array}$ & $\begin{array}{l}0.00 \\
0.00 \\
0.00 \\
0.00 \\
0.00 \\
0.00 \\
0.00 \\
0.00 \\
0.00 \\
0.00 \\
0.00 \\
0.00\end{array}$ & $\begin{array}{l}4.9 \\
0.85 \\
2.0 \\
0.66 \\
0.55 \\
0.49 \\
0.38 \\
0.27 \\
2.1 \\
38 \\
48 \\
13\end{array}$ & $\begin{array}{l}15 \\
1.7 \\
6.0 \\
1.2 \\
1.3 \\
0.79 \\
0.55 \\
0.44 \\
5.9 \\
55 \\
58 \\
14\end{array}$ & $\begin{array}{l}3.1 \\
2.0 \\
2.9 \\
1.8 \\
2.4 \\
1.6 \\
1.5 \\
1.6 \\
2.8 \\
1.5 \\
1.2 \\
1.1\end{array}$ & $\begin{array}{l}4.4 \\
0.8 \\
1.8 \\
0.6 \\
0.5 \\
0.4 \\
0.3 \\
0.2 \\
1.9 \\
34.2 \\
43.3 \\
11.3\end{array}$ \\
\hline WNUAL & 33 & 0.32 & 9.3 & 6.9 & 0.75 & 100 \\
\hline
\end{tabular}

\begin{tabular}{|c|c|c|c|c|c|c|}
\hline \multirow{2}{*}{$\begin{array}{l}\text { PERICD } \\
\text { (CON- } \\
\text { SECU- } \\
\text { TIVE } \\
\text { DAYS) }\end{array}$} & \multicolumn{6}{|c|}{$\begin{array}{l}\text { DISCHARGE, IN FT } 3 / S \text {, FOR INDICATED } \\
\text { RECURRENCE INTERVAL, IN YEARS, AND } \\
\text { NOW-EXCEEDANCE PROBABILITY, IN PERCENT }\end{array}$} \\
\hline & $\begin{array}{c}2 \\
50 \%\end{array}$ & $\begin{array}{c}5 \\
20 x\end{array}$ & $\begin{array}{l}10 \\
10 \%\end{array}$ & $\begin{array}{l}20 \\
5 \%\end{array}$ & $\begin{array}{l}50 \dagger \\
2 \%\end{array}$ & $\begin{array}{l}100 \nmid \\
1 \%\end{array}$ \\
\hline $\begin{array}{r}1 \\
3 \\
7 \\
14 \\
30 \\
60 \\
90 \\
120 \\
183\end{array}$ & $\begin{array}{l}0.00 \\
0.00 \\
0.00 \\
0.00 \\
0.00 \\
0.02 \\
0.06 \\
0.25 \\
0.52\end{array}$ & $\begin{array}{l}0.00 \\
0.00 \\
0.00 \\
0.00 \\
0.00 \\
0.00 \\
0.00 \\
0.00 \\
0.10\end{array}$ & $\begin{array}{l}0.00 \\
0.00 \\
0.00 \\
0.00 \\
0.00 \\
0.00 \\
0.00 \\
0.00 \\
0.00\end{array}$ & $\begin{array}{l}0.00 \\
0.00 \\
0.00 \\
0.00 \\
0.00 \\
0.00 \\
0.00 \\
0.00 \\
0.00\end{array}$ & $\begin{array}{l}0.00 \\
0.00 \\
0.00 \\
0.00 \\
0.00 \\
0.00 \\
0.00 \\
0.00 \\
0.00\end{array}$ & $\begin{array}{l}0.00 \\
0.00 \\
0.00 \\
0.00 \\
0.00 \\
0.00 \\
0.00 \\
0.00 \\
0.00\end{array}$ \\
\hline
\end{tabular}

MAGNITUDE AND PROBABILITY OF INSTANTANEOUS PEAK FLOH BASED ON PERIOD OF RECORD 1916-20, 1930-89

DISCHARGE, IN $\mathrm{FT}^{3} / \mathrm{S}$, FOR INDICATED RECURRENCE INTERVAL IN YEARS, AND EXCEEDANCE PROBABILITY, IN PERCENT

\begin{tabular}{lccccc}
5 & 5 & 10 & 25 & 50 & 100 \\
$50 \%$ & $20 \%$ & $10 \%$ & $4 \%$ & $2 \%$ & $1 \%$ \\
1,640 & 2,840 & 3,620 & 4,540 & 5,170 & 5,750 \\
\hline MEIGHTED SKEH (LOGS) & $=$ & -0.70 & & \\
MEAN & (LOGS) & 3.17 & & \\
STANDARD DEV. (LOGS) & $=0.32$ & &
\end{tabular}

MAGNITLDE AND PROBABILITY OF ANNUAL HIGH FLOU BASED ON PERICD OF RECORD 1919, 1931-33, 1936-46, 1949-82

\begin{tabular}{|c|c|c|c|c|c|c|}
\hline \multirow{2}{*}{$\begin{array}{l}\text { PERIOD } \\
\text { (CON- } \\
\text { SECU- } \\
\text { TIVE } \\
\text { DAYS) }\end{array}$} & \multicolumn{6}{|c|}{$\begin{array}{l}\text { OISCHARGE, IN FT } 3 / S \text {, FOR INDICATEO } \\
\text { RECURRENCE INTERVAL, IN YEARS, AND } \\
\text { EXCEEDANCE PROBABILITY, IN PERCENT }\end{array}$} \\
\hline & $\stackrel{2}{2}$ & $\begin{array}{c}5 \\
20 \%\end{array}$ & $\begin{array}{l}10 \\
10 \%\end{array}$ & $\begin{array}{l}25 \\
4 \%\end{array}$ & $\begin{array}{l}50 \nmid \\
2 x\end{array}$ & $\begin{array}{c}100 \dagger \\
1 \times\end{array}$ \\
\hline $\begin{array}{r}1 \\
3 \\
7 \\
15 \\
30 \\
60 \\
90\end{array}$ & $\begin{array}{r}623 \\
327 \\
176 \\
102 \\
63 \\
39 \\
29\end{array}$ & $\begin{array}{r}1,020 \\
574 \\
328 \\
198 \\
129 \\
76 \\
54\end{array}$ & $\begin{array}{r}1,290 \\
740 \\
437 \\
269 \\
181 \\
101 \\
70\end{array}$ & $\begin{array}{r}1,600 \\
945 \\
579 \\
362 \\
253 \\
133 \\
89\end{array}$ & $\begin{array}{r}1,820 \\
1,090 \\
684 \\
433 \\
310 \\
156 \\
101\end{array}$ & $\begin{array}{r}2,030 \\
1,230 \\
788 \\
503 \\
370 \\
177 \\
112\end{array}$ \\
\hline
\end{tabular}

DURATION TABLE OF DAILY MEAN FLOW FOR PERICD OF RECORD 1919, 1931-33, 1936-46, 1949-82

OISCHARGE, IN FT $3 / 5$, WHICH WAS EQUALED OR EXCEEDED FOR INDICATED PERCENT OF TIME

\begin{tabular}{|c|c|c|c|c|c|c|c|c|c|c|c|c|c|c|c|c|}
\hline $1 \%$ & $5 \%$ & $10 \%$ & $15 \%$ & $20 \%$ & $30 \%$ & $40 \%$ & $50 \%$ & $60 \%$ & $70 \%$ & $80 \%$ & $90 \%$ & $95 \%$ & $98 \%$ & $99 \%$ & $99.5 \%$ & $99.9 \%$ \\
\hline 248 & 22 & 3.4 & 1.4 & 1.0 & 0.66 & 0.44 & 0.25 & 0.11 & 0.01 & 0.01 & 0.00 & 0.00 & 0.00 & 0.00 & 0.00 & 0.00 \\
\hline
\end{tabular}

† Reliability of values in colum is uncertain, and potential errors are large. 
WHITEWATER DRAW BASIN

09537500 WHITEWATER DRAW MEAR DOUGLAS, AZ--CONTINUED
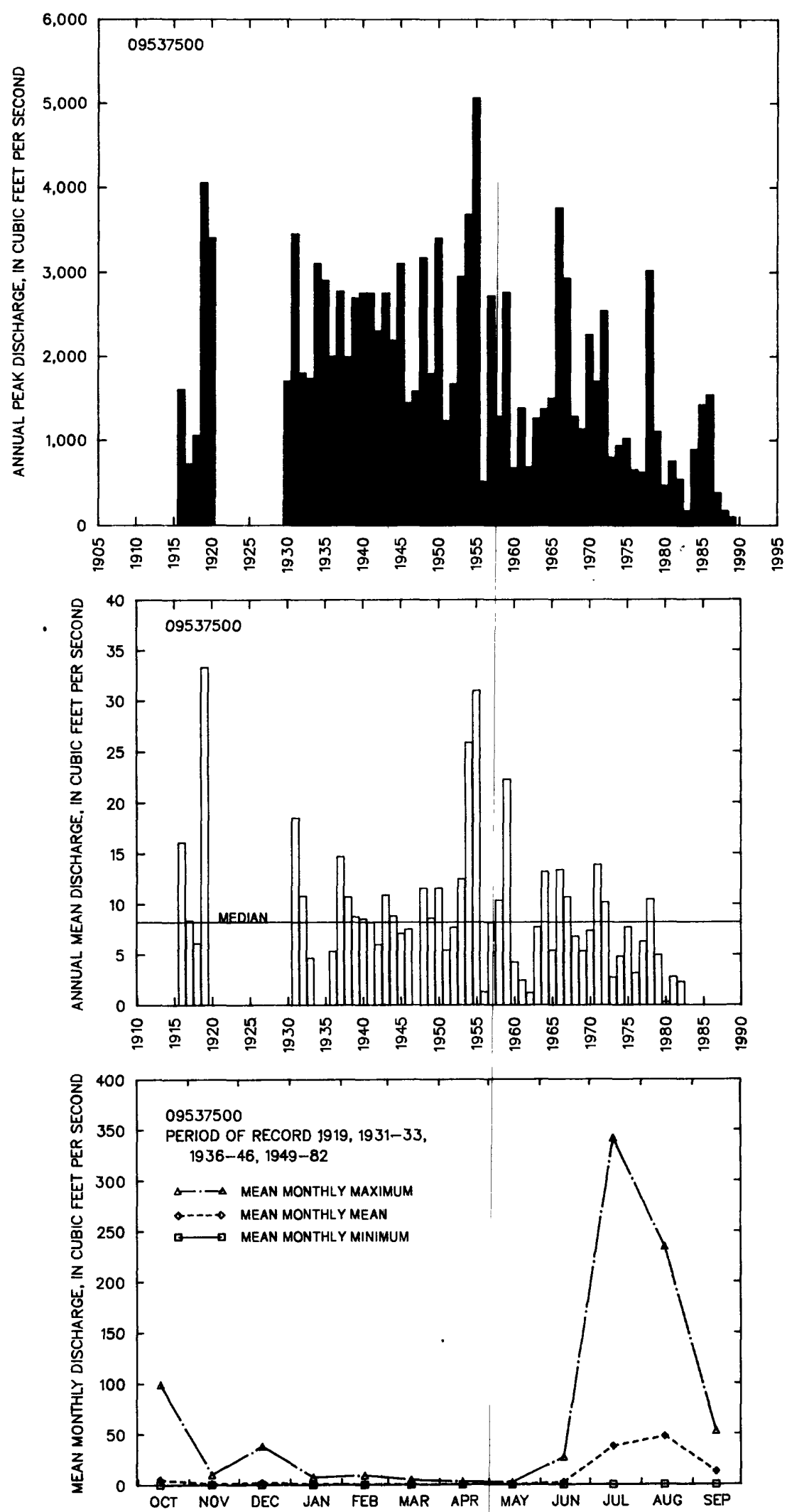